\title{
A NOVEL PROCESS TO USE SALT CAVERNS TO RECEIVE SHIP BORNE LNG
}

DOE AwARD NumBer: DE-FC26-02NT41653

\section{FINAL REPORT}

August 2005

I. Examine and Evaluate a Process to Use Salt Caverns in

THE RECEIPT OF SHIP BORNE LNG

II. Field Test and Full Scale Design of Critical Components of a Salt Cavern Based lng Receiving Terminal

\author{
BY \\ MiChAEL M. MCCALL \\ WILLIAM M. BISHOP \\ Marcus KREKEL \\ JAMES F. DAVIS \\ D. BRAXTON SCHERZ
}

CONVERSION GAS IMPORTS, L.P.

2929 BRIARPARK SUITE 220

HOUSTON, TEXAS 77042

WWW.CONVERSIONGAS.COM 


\begin{tabular}{|l|l|l|l|}
\hline Customer: & $\begin{array}{l}\text { The United States Department of Energy } \\
\text { National Energy Technology Laboratory }\end{array}$ & $\begin{array}{l}\text { Date of Issue: } \\
2005\end{array}$ & \\
\hline $\begin{array}{l}\text { Document } \\
\text { Title: }\end{array}$ & Document Register and Executive Summaries & $\begin{array}{l}\text { Version: } \\
3.0\end{array}$ & Page 2 of 12 \\
\hline
\end{tabular}

\section{DISCLAIMER}

"This report was prepared as an account of work sponsored by an agency of the United States Government. Neither the United States Government nor any agency thereof, nor any of their employees, makes any warranty, express or implied, or assumes any legal liability or responsibility for the accuracy, completeness, or usefulness of any information, apparatus, product, or process disclosed, or represents that its use would not infringe privately owned rights. Reference herein to any specific commercial product, process, or service by trade name, trademark, manufacturer, or otherwise does not necessarily constitute or imply its endorsement, recommendation, or favoring by the United States government or any agency thereof. The views and opinions of authors expressed herein do not necessarily state or reflect those of the United States Government or any agency thereof." 


\begin{tabular}{|l|l|l|l|}
\hline Customer: & $\begin{array}{l}\text { The United States Department of Energy } \\
\text { National Energy Technology Laboratory }\end{array}$ & $\begin{array}{l}\text { Date of Issue: } \\
2005\end{array}$ \\
\hline $\begin{array}{l}\text { Document } \\
\text { Title: }\end{array}$ & Document Register and Executive Summaries & $\begin{array}{l}\text { Version: } \\
3.0\end{array}$ & Page 3 of 12 \\
\hline
\end{tabular}

TABLE OF CONTENTS

1. ABSTRACT

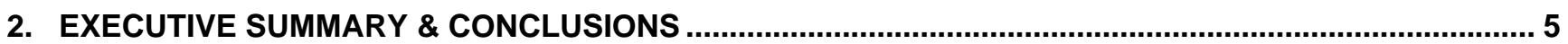

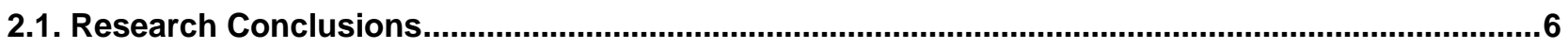

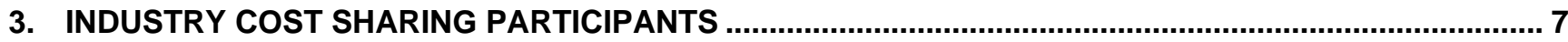

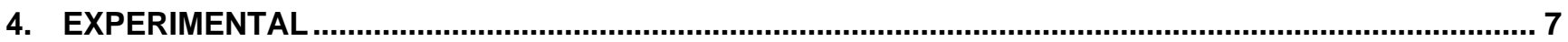

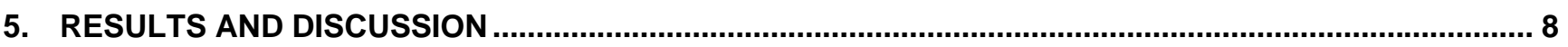

5.1. Integrated Offshore LNG Facility \& Cavern Design (Tab 2)..............................................

5.2. Salt Caverns Provide Secure, Inexpensive Storage (Included in Tab 2)...........................10

5.3. Offshore Mooring Design and Wave Tank Tests (Tab 3) ...............................................10

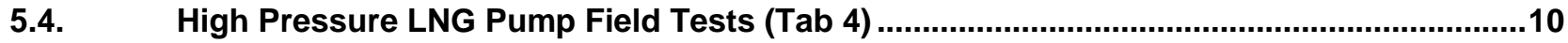

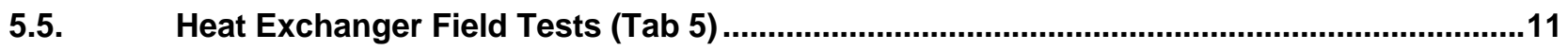

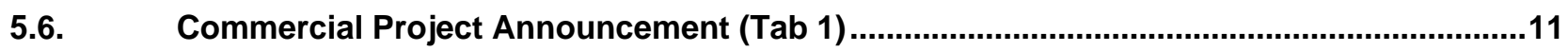

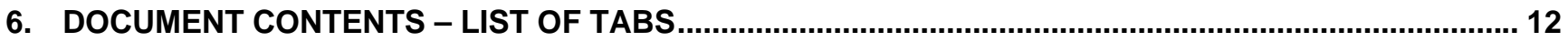




\begin{tabular}{|l|l|l|l|}
\hline Customer: & $\begin{array}{l}\text { The United States Department of Energy } \\
\text { National Energy Technology Laboratory }\end{array}$ & $\begin{array}{l}\text { Date of Issue: } \\
2005\end{array}$ & \\
\hline $\begin{array}{l}\text { Document } \\
\text { Title: }\end{array}$ & Document Register and Executive Summaries & $\begin{array}{l}\text { Version: } \\
3.0\end{array}$ & Page 4 of 12 \\
\hline
\end{tabular}

\section{ABSTRACT}

This cooperative research project validates use of man made salt caverns to receive and store the cargoes of LNG ships in lieu of large liquid LNG tanks. Salt caverns will not tolerate direct injection of LNG because it is a cryogenic liquid, too cold for contact with salt. This research confirmed the technical processes and the economic benefits of pressuring the LNG up to dense phase, warming it to salt compatible temperatures and then directly injecting the dense phase gas into salt caverns for storage.

The use of salt caverns to store natural gas sourced from LNG imports, particularly when located offshore, provides a highly secure, large scale and lower cost import facility as an alternative to tank based LNG import terminals. This design can unload a ship in the same time as unloading at a tank based terminal. The Strategic Petroleum Reserve uses man made salt caverns to securely store large quantities of crude oil. Similarly, this project describes a novel application of salt cavern gas storage technologies used for the first time in conjunction with LNG receiving. The energy industry uses man made salt caverns to store an array of gases and liquids but has never used man made salt caverns directly in the importation of LNG.

This project has adapted and expanded the field of salt cavern storage technology and combined it with novel equipment and processes to accommodate LNG importation. The salt cavern based LNG receiving terminal described in the project can be located onshore or offshore, but the focus of the design and cost estimates has been on an offshore location, away from congested channels and ports. The salt cavern based terminal can provide large volumes of gas storage, high deliverability from storage, and is simplified in operation compared to tank based LNG terminals.

Phase I of this project included mathematical modeling that proved a salt cavern based receiving terminal could be built at lower capital cost, and would have significantly higher delivery capacity, shorter construction time, and be much more secure than a conventional liquid tank based terminal. Operating costs of a salt cavern terminal are lower than tank based terminals because "boil off" is eliminated and maintenance costs of caverns are lower than LNG tanks.

Phase II included the development of offshore mooring designs, wave tank tests, high pressure LNG pump field tests, heat exchanger field tests, and development of a model offshore LNG facility and cavern design. Engineers designed a model facility, prepared equipment lists, and confirmed capital and operating costs. In addition, vendors quoted fabrication and installation costs, confirming that an offshore salt cavern based LNG terminal would have lower capital and operating costs than a similarly sized offshore tank based terminal. Salt cavern storage is infinitely more secure than surface storage tanks, far less susceptible to accidents or purposeful damage, and much more acceptable to the community.

More than thirty industry participants provided cost sharing, technical expertise, and guidance in the conduct and evaluation of the field tests, facility design and operating and cost estimates. Their close participation has accelerated the industry's acceptance of the conclusions of this research. The industry participants also developed and submitted several alternative designs for offshore mooring and for high pressure LNG heat exchangers in addition to those that were field tested in this project. HNG Storage, a developer, owner, and operator of natural gas storage facilities, and a participant in the DOE research has announced they will lead the development of the first offshore salt cavern based LNG import facility. Which will be called the Freedom LNG Terminal. It will be located offshore Louisiana, and is expected to be jointly developed with other members of the research group yet to be named. An offshore port license application is scheduled to be filed by fourth quarter 2005 and the terminal could be operational by 2009 . This terminal allows the large volume importation of LNG without disrupting coastal port operations by being offshore, out of sight of land. 


\begin{tabular}{|l|l|l|l|}
\hline Customer: & $\begin{array}{l}\text { The United States Department of Energy } \\
\text { National Energy Technology Laboratory }\end{array}$ & $\begin{array}{l}\text { Date of Issue: } \\
2005\end{array}$ \\
\hline $\begin{array}{l}\text { Document } \\
\text { Title: }\end{array}$ & Document Register and Executive Summaries & $\begin{array}{l}\text { Version: } \\
3.0\end{array}$ & Page $\mathbf{5}$ of 12 \\
\hline
\end{tabular}

\section{EXECUTIVE SUMMARY \& CONCLUSIONS}

The goal of this U.S. Department of Energy cooperative research project is to define, describe, validate, and move to commercial application, a novel process to use salt caverns to receive and store the cargoes of LNG ships. Called the Bishop Process ${ }^{\mathrm{TM}}$ this includes receiving LNG from a ship or tank, pumping the LNG up to cavern injection pressures, warming it to cavern compatible temperatures, and injecting the warmed vapor directly into salt caverns for storage, and distribution to the pipeline network. The industry participants in the research (Para 3), include firms involved in natural gas and LNG production, transportation, distribution, storage, marketing, engineering, environmental sciences, marine facilities, risk and hazard assessment, and earth sciences. These participants provided about one third of the funding for this project and significant expertise in the development and execution of the field tests and design of the prototype facilities. Most importantly, the industry participants raised the questions and presented the issues representative of the energy industry which were addressed and answered in the field tests and analyses.

Phase I (Tab 16) of this project entailed document research and mathematical analyses of salt cavern design, heat exchangers, LNG pumps, marine facilities, potential site evaluations, and preliminary facility cost estimates. It concluded that the critical components of cavern design, LNG pumps and heat exchangers, marine mooring and LNG transfer systems and potential high volume locations, were feasible but needed further development to answer the skeptics in industry before commercial acceptance would be achieved.

Phase II included field tests, at full scale where possible, of the critical components and the number of industry participants grew from three companies in Phase I to over thirty in Phase II. Field tests of the mooring system, the high pressure LNG pumps, and a high capacity, high efficiency, water warmed heat exchanger have been successfully completed providing technical validations of the science behind the concepts. The components were then incorporated into an integrated LNG terminal design and costs and operating characteristics of the model offshore facility were developed.

This project was a successful collaborative effort between government and industry. It focused on proving that an alternative to tank based LNG terminals could be moved from research concept to commercial application in a short time frame. It involved several very different technical fields ranging from naval architecture to rock mechanics, from centrifugal pump design to heat exchange, from offshore platform design to gas storage cavern operations. This research project proved that salt cavern based LNG receiving facilities can provide a very secure, very flexible, economically advantaged alternative to tank based terminals. It also indicated that locating such facilities in the Gulf of Mexico could reduce port congestion and reduce the security concerns of coastal communities related to increasing volumes of LNG importation.

There are an array of laws and regulations that govern the use of federal lands, the development of offshore port facilities, and the acquisition of licenses, leases, permits, easements, and other necessary authorities for a commercial development as described in this project. It was beyond the scope of the project to define a clear path forward through the implementing agencies. It is apparent, however, that without a clear path forward, the significant funds necessary to accomplish a commercial development will not be committed. The offshore project contemplates the creation of salt caverns for storage not the production of the mineral 


\begin{tabular}{|l|l|l|l|}
\hline Customer: & $\begin{array}{l}\text { The United States Department of Energy } \\
\text { National Energy Technology Laboratory }\end{array}$ & $\begin{array}{l}\text { Date of Issue: } \\
2005\end{array}$ \\
\hline $\begin{array}{l}\text { Document } \\
\text { Title: }\end{array}$ & Document Register and Executive Summaries & $\begin{array}{l}\text { Version: } \\
3.0\end{array}$ & Page 6 of 12 \\
\hline
\end{tabular}

salt, it contemplates the storage of imported gas in these caverns not domestic production, it contemplates the operation of platforms and pipelines for import terminal operations, not domestic production. In short, this is a concept that has achieved technical validation and can provide a significant increase in the nation's energy infrastructure but may be delayed in implementation because it doesn't fit the more familiar pattern of oil and gas leases on the Outer Continental Shelf.

\subsection{Research Conclusions}

This project concludes that a salt cavern based receiving terminal could be built in a shorter construction time, at larger scale, with lower unit capital cost, lower unit operating costs, and be much more secure than a conventional liquid tank based terminal. There is a significant body of knowledge and practice concerning natural gas storage in salt caverns, and there is a considerable body of knowledge and practice in handling LNG, but this is the first attempt to directly combine the two technologies. Salt cavern storage is infinitely more secure than surface storage tanks, far less susceptible to accidents or purposeful damage, and more acceptable to the community. Salt cavern gas storage currently provides an important element in the country's natural gas logistical network; this report concludes it will also play an important role in a direct application to LNG importation.

Rigorous analyses of the field test results, vetting of the conclusions by the industry participants, and incorporation of the lessons learned in improved or "optimized" designs have accelerated commercial development directly arising from this body of work. The replacement of large volume liquid storage LNG storage tanks with gas storage in man made salt caverns makes the terminal process design and operation simpler than those normally seen in the LNG industry. A salt cavern based terminal, with permits in hand, could be constructed in about 2.5 years, a considerably shorter construction time than that required for tank based designs located either onshore or offshore.

More than two dozen potential sites were identified that combine salt formations suitable for storage, located near multiple pipelines for large take away capacity and navigable water. The sites are about evenly split between onshore salt formation locations and offshore salt formation locations. This research reveals that because of the convergence of pipeline capacities and salt formations that a few very large capacity salt cavern based receiving terminals could provide a significant portion of the U.S.'s future LNG import needs (Tab 16). 


\begin{tabular}{|l|l|l|l|}
\hline Customer: & $\begin{array}{l}\text { The United States Department of Energy } \\
\text { National Energy Technology Laboratory }\end{array}$ & $\begin{array}{l}\text { Date of Issue: } \\
2005\end{array}$ & \\
\hline $\begin{array}{l}\text { Document } \\
\text { Title: }\end{array}$ & Document Register and Executive Summaries & $\begin{array}{l}\text { Version: } \\
3.0\end{array}$ & Page 7 of 12 \\
\hline
\end{tabular}

\section{INDUSTRY COST SHARING PARTICIPANTS}

\begin{tabular}{|l|l|}
\hline ABS & FMC \\
\hline AGL Resources. & Heogh LNG \\
\hline AMEC Paragon & HNG Storage \\
\hline Arthur D. Little & International LNG Association \\
\hline Bluewater Offshore & Marathon \\
\hline BP & Marsh USA \\
\hline Carter Cryogenics & Mustang Engineering \\
\hline Charles River Associates & Nikkiso Cryo \\
\hline D Braxton \& Associates & Northstar Industries \\
\hline DNV & PB Energy Storage Services \\
\hline Dominion Resources & Remora Technology \\
\hline Ebara & RRS Engineering \\
\hline Ecology \& Environment, Inc. & SBM \\
\hline Encana & Texas Brine \\
\hline ExxonMobil & Tennessee Gas Pipeline/ El Paso \\
\hline FLUOR & Tulane/Entergy Energy Institute \\
\hline
\end{tabular}

\section{EXPERIMENTAL}

The test protocols for the conduct of the field tests, data gathering, and computational requirements for the analysis of each field test followed industry practices for that particular field. These are discussed separately in each of the tabs for each test. All aspects of the conduct of each field test were reviewed and approved by both the industry participants and the NETL.

The field test of a high pressure LNG pump was conducted on the factory test stand, using LNG at Ebara's manufacturing facilities in Nevada. The pump tested was being prepared for delivery to a customer outside the US. Ebara designed a test protocol that would demonstrate discharge pressures in excess of 2,000psi, a benchmark for cavern injection pressures. The tests were conducted successfully without incident, observed by several of the project's industry participants and confirming performance data was recorded. 


\begin{tabular}{|l|l|l|l|}
\hline Customer: & $\begin{array}{l}\text { The United States Department of Energy } \\
\text { National Energy Technology Laboratory }\end{array}$ & $\begin{array}{l}\text { Date of Issue: } \\
\mathbf{2 0 0 5}\end{array}$ & Page $\mathbf{8}$ of 12 \\
\hline $\begin{array}{l}\text { Document } \\
\text { Title: }\end{array}$ & Document Register and Executive Summaries & $\begin{array}{l}\text { Version: } \\
\mathbf{3 . 0}\end{array}$ & \\
\hline
\end{tabular}

The high pressure LNG heat exchanger was constructed at an AGL Resources LNG peak shaving plant in Cherokee County, Georgia. The site had large quantities of water and LNG, room for equipment and a highly experienced and capable staff. After consultation with the DOE it was determined that the test LNG heat exchanger would be built at full scale, tested at maximum rates, and performance recorded across a broad combination of flow rates and temperatures. This was a broader testing program than originally envisioned but conclusively proved the concept of heat exchange in the dense phase. At the same time an unusual cold spell during the testing allowed for full throttle performance and provided large quantities of gas for consumers in the Southeast US. The testing program was observed by a number of the industry participants and more than 50 persons attended a performance review and test conclusion meeting at the site following the testing program.

Bluewater's LNG offshore mooring system, called the "Big Sweep", was wave tank model tested at the Canadian Marine Research Center in St. Johns, Newfoundland, Canada. The testing program is common for marine designs for ships hulls, semi submersible oil rigs, offshore platforms, gravity based structures and other marine equipment. In this case it mimicked the sea states for the shallow areas of the Gulf of Mexico both for standard weather conditions of winds and waves and for hurricane survival conditions. The model constructed was the standard 1/40 scale so the LNG ship model pictured in the tests was about 8 meters long representing a scale model of an LNG ship which would be over 300 meters long. During parts of the testing program the winds, waves, and currents were moving in the same direction but at varying velocities, then their directions and velocities were varied relative to one another to represent the full gamut of sea conditions. Data recording is done by an array of electronic sensors and then subjected to appropriate analyses. Emergency break off conditions were simulated and evaluated in addition to more normal mooring conditions. The tests were observed by several industry participants and the results presented to the entire group at meetings in Houston upon completion. This testing program clearly proved that a successful method exists to moor an LNG ship at sea in the Gulf of Mexico.

\section{RESULTS AND DISCUSSION}

Technological change in the energy sector is a long and difficult process. Change requires large investments, and failure has serious consequences. Generally change only occurs in response to a crisis, i.e. "something needs to be fixed", or to implement improvements that are immediate and obvious, i.e., "a better mousetrap". LNG importation into the US has elements of both motivations. The US needs to significantly expand its ability to import natural gas, and to develop more economical, more secure, and larger scale alternatives to the traditional tank based terminal. (Tab 15)

This report describes an economically advantaged import terminal design using salt caverns rather than LNG tanks. The economic advantages come primarily from the significantly lower costs of salt cavern gas storage compared to LNG tank storage, and the larger scale of storage and deliverability that can be achieved using caverns. Generally, anything done offshore costs more to build and operate than its onshore alternative. This project concludes that an offshore salt cavern based LNG terminal can be built at a unit cost competitive with onshore tank based terminals and at less expense than offshore tank based alternatives. (Tab 2) 


\begin{tabular}{|l|l|l|l|}
\hline Customer: & $\begin{array}{l}\text { The United States Department of Energy } \\
\text { National Energy Technology Laboratory }\end{array}$ & $\begin{array}{l}\text { Date of Issue: } \\
2005\end{array}$ \\
\hline $\begin{array}{l}\text { Document } \\
\text { Title: }\end{array}$ & Document Register and Executive Summaries & $\begin{array}{l}\text { Version: } \\
3.0\end{array}$ & Page $\mathbf{9}$ of 12 \\
\hline
\end{tabular}

The environmental advantages of natural gas over other fossil fuels or as a feedstock to hydrogen are well known and are responsible for the projected growth in natural gas demand. (Tab 15). The terminal described in this project immediately converts the incoming LNG into natural gas upon unloading and stores it as gas. The elimination of LNG storage also eliminates "boil off" from LNG storage tanks which requires energy intensive compression or reliquefaction. Using seawater as a warmant this terminal has significantly lower operating costs than a tank based terminal using submerged combustion vaporizers. Compared to tank based terminals using submerged combustion vaporizers this is more than $\$ 1$ million per day worth of gas that will go to customers rather than be consumed at the terminals if imports reach 15Bcf/Day. This project describes a seawater warming system using a closed loop for biocidal treatments that is believed to maintain the economy of seawater warming while mitigating and reducing ichthyoplankton mortality (Tab 5). In addition, an ambient air LNG warming system is described (Tab 10) that materially reduces the amount of gas consumed in vaporization and uses no water.

Energy security is a broad topic that includes availability of supply, protection of facilities, avoidance of disruption, logistical alternatives and much more. Cavern storage is fundamentally more secure than any surface alternative. North American Aerospace Defense Headquarters in Cheyenne Mountain and the Strategic Petroleum Reserve share the security of thousands of feet of rock overburden. A salt cavern LNG terminal would have those same characteristics. The offshore facilities described in Tab 2 uses multiple caverns, each cavern independent from another. A platform design could segregate pump and vaporization trains to achieve the same redundancy with the process equipment. Large gas volumes stored under pressure in caverns, ready to be dispatched to the pipeline provides operating flexibility. In a tank based terminal, the storage is generally so small that the delay of even a few days of a ship could disrupt gas dispatch. Early arrival of a ship without sufficient tank capacity to receive it is another potential scheduling problem. Cavern gas storage equivalent to 5, 10, or even 20 times the cargo capacity of an LNG ship decouples the storage from the ships' arrivals and can compensate for all types of marine delays.

\subsection{Integrated Offshore LNG Facility \& Cavern Design (Tab 2)}

The final product of the research project is the integration of the test results into the design, engineering, and cost analyses on the construction and operation of a salt cavern based offshore LNG receiving terminal. We concluded that this is a technically valid concept, and that it requires lower unit capital and operating costs, and is a secure method of receiving imported LNG, storing it as gas and distributing it to the nation by the existing natural gas pipeline grid. Further, the results confirm that salt cavern based LNG receiving facilities could be built at sea in the Gulf of Mexico and the ships would thus never enter into congested US navigable channels or ports, significantly reducing the NIMBY effect encountered by land based LNG tank terminals. The placement of process equipment, power generation, control rooms, and crew quarters on platforms characterizes this facility as being much closer in design and operation to the 3,000+ oil and gas production facilities in the Gulf of Mexico than to the five LNG terminals in America. 


\begin{tabular}{|l|l|l|l|}
\hline Customer: & $\begin{array}{l}\text { The United States Department of Energy } \\
\text { National Energy Technology Laboratory }\end{array}$ & $\begin{array}{l}\text { Date of Issue: } \\
2005\end{array}$ \\
\hline $\begin{array}{l}\text { Document } \\
\text { Title: }\end{array}$ & Document Register and Executive Summaries & $\begin{array}{l}\text { Version: } \\
3.0\end{array}$ & Page 10 of 12 \\
\hline
\end{tabular}

\subsection{Salt Caverns Provide Secure, Inexpensive Storage (Included in Tab 2)}

Man-made salt caverns are an integral part of the energy infrastructure of the United States. The entire Strategic Petroleum Reserve, totaling 700 million barrels of crude oil is stored in salt caverns on the Gulf Coast. Private industry stores hydrogen, natural gas, natural gas liquids, olefins, refined products, and crude oil in salt caverns in the US and Canada. Solution miners create caverns to precise size, shape and operational requirements by injecting fresh or seawater into the salt formation thus dissolving the salt and creating a man made cavern.

Salt caverns provide about five (5\%) percent of the natural gas storage capacity in the United States, but none of these caverns are associated with the LNG receiving terminals currently in operation. Salt caverns can deliver gas at high rates to pipelines which is important in natural gas distribution and confirmed by this project as important in LNG receiving.

Salt formations will not tolerate direct injection of LNG because of the low temperatures but this research confirmed methods that would allow their use in LNG receiving by pumping the LNG up to cavern injection pressures with pumps and warming the LNG to salt compatible temperatures. Unlike the design of this study, the opposite is true in natural gas storage in salt caverns which requires compressors to create injection pressures thereby heating the gas which must then be cooled by heat exchangers before it can be injected into salt caverns.

\subsection{Offshore Mooring Design and Wave Tank Tests (Tab 3)}

Offshore mooring and transfer of crude oil is a well established practice for over 40 years with an excellent safety and environmental record. Building on this body of experience, Bluewater Offshore designed and model tested a mooring system for offshore transfer of LNG during April 19 - April 30, 2004. The wave tank testing concluded that the designs were adequate for sea states encountered in the Gulf of Mexico and would survive hurricane conditions. This confirmation that an LNG ship could be moored at sea and the product unloaded is important to reducing the risks and disruption to port and channel operations as the numbers of LNG ships calling on America increases. LNG import requirements of 15 Bcf/Day are the equivalent of 2000 or more LNG ship port calls per year. Each LNG ship arrival and port departure involves heightened security, and exclusion zones disruptive to commercial and recreational marine transportation. Moving most of those port calls to offshore ports will materially ease coastal community security concerns and mainland port and harbor congestion. Bluewater's system transfers the LNG to a nearby platform containing the process equipment, power, pumps, heat exchanger, measurement, salt cavern wellheads, etc. Other systems by SBM, FMC, OPE, and Remora (Tabs 6-9) have been submitted as part of the research.

\subsection{High Pressure LNG Pump Field Tests (Tab 4)}

LNG pumps in common use are of multistage centrifugal design. Those used in terminals receive LNG from the storage tanks at atmospheric pressures and discharge at pipeline pressures. To achieve direct cavern 


\begin{tabular}{|l|l|l|l|}
\hline Customer: & $\begin{array}{l}\text { The United States Department of Energy } \\
\text { National Energy Technology Laboratory }\end{array}$ & $\begin{array}{l}\text { Date of Issue: } \\
2005\end{array}$ \\
\hline $\begin{array}{l}\text { Document } \\
\text { Title: }\end{array}$ & Document Register and Executive Summaries & $\begin{array}{l}\text { Version: } \\
3.0\end{array}$ & Page 11 of 12 \\
\hline
\end{tabular}

injection pumps must be capable of achieving discharge pressures in excess of 2000psi. New designs with greater capability were developed by Ebara, Nikkiso Cryogenics, and Carter, three of the largest LNG pump manufacturers. Field tests have confirmed the designs and operating characteristics of these machines. It is important to use pumps for the liquid instead of compressing gas because of the energy efficiencies that result. Using pumps to achieve cavern injection pressures saves about $80 \%$ of the energy required for this work.

\subsection{Heat Exchanger Field Tests (Tab 5)}

At the commencement of this project there was no high capacity, LNG heat exchangers in operation or in design at pressures suitable for cavern injection. Therefore, we developed a new pipe-in-pipe design incorporating a cryogenic LNG pipe inside a water warmant pipe. In Phase I this design was extensively mathematically modeled. In Phase II there was more modeling and in addition a prototype was designed and constructed by Northstar Industries for field testing. This serial number 1 Bishop Process ${ }^{\mathrm{TM}}$ Heat Exchanger was field tested April 12-16, 2004, at full scale, at the AGL Resources LNG Plant near Canton, Georgia. Tests were performed at varying LNG rates, varying warmant water ratios, and varying water temperatures. Flow rates as high as $160 \mathrm{MMcf} /$ Day were tested in this prototype. Multiple units will allow the warming of the LNG simultaneous with cargo unloading at standard rates.

The field test results indicated some significant improvements compared to the mathematical predictions and important design changes which will improve operations in commercial applications.

\subsection{Commercial Project Announcement (Tab 1)}

HNG Storage, a developer, owner, and operator of natural gas storage facilities, and a participant in the DOE research has announced they will lead the development of the first offshore salt cavern based LNG import facility. Called the Freedom LNG Terminal, it will be located offshore Louisiana, and is expected to be jointly developed with other members of the research group yet to be named. An offshore port license application is scheduled to be filed by fourth quarter 2005 and the terminal could be operational in 2009. Offshore, out of sight of land, with large volume gas storage below the sea bed, this may be the ultimate cure for the NIMBY effect and allow the large volume importation of LNG without disrupting the coastal port operations.

\subsection{Related Studies}

There was significant industry interest in this project which resulted in additions to the work not originally in the work plan. For example, while wave tank testing was conducted on the Bluewater "Big Sweep" offshore LNG mooring systems, other competent systems were presented to the industry group by, SBM, Remora, FMC, and OPE (Tabs 6-9 respectively) and are included in this final report. An ambient air high pressure heat exchanger design and a comparative analysis of various heat exchangers were submitted by AMEC Paragon in Tabs 10 \& 12. Subsea cryogenic LNG pipeline designs were submitted by OPE and ITP in Tab 


\begin{tabular}{|l|l|l|l|}
\hline Customer: & $\begin{array}{l}\text { The United States Department of Energy } \\
\text { National Energy Technology Laboratory }\end{array}$ & $\begin{array}{l}\text { Date of Issue: } \\
2005\end{array}$ \\
\hline $\begin{array}{l}\text { Document } \\
\text { Title: }\end{array}$ & Document Register and Executive Summaries & $\begin{array}{l}\text { Version: } \\
3.0\end{array}$ & Page 12 of 12 \\
\hline
\end{tabular}

12. An Ichthyoplankton study for the model facility in Vermilion block 179 was conducted by Environment and Ecology and included as Tab 13. A very informative and well done study on the broad implications of increased LNG importation was provided by the Entergy-Tulane Energy Institute - "LNG Imports and Their Impact on the State Regional, and National Economies and included as Tab 15.

These related studies, additive to the original scope of this project, are indicative of the interest of industry in this topic and the cooperative nature of the work conducted.

\section{DOCUMENT CONTENTS - LIST OF TABS}

\begin{tabular}{|l|l|}
\hline \multicolumn{2}{|l|}{} \\
\hline Tab 01 & Closeout Meeting Presentations (March 8, 2005) \\
\hline Tab 02 & Integrated Offshore LNG Facility \& Cavern Design \\
\hline Tab 03 & Offshore Mooring Design and Wave Tank Tests \\
\hline \hline Tab 04 & High Pressure LNG Pump Field Tests \\
\hline Tab 05 & Heat Exchanger Field Tests \\
\hline Tab 05 Attachment & Field Test Data (Excel File Available by Request) \\
\hline \hline Tab 06 & Offshore Mooring Design - SBM \\
\hline Tab 07 & Offshore Mooring Design- Remora Technologies \\
\hline Tab 08 & Offshore Mooring Design- FMC \\
\hline Tab 09 & Offshore Mooring Design - OPE \\
\hline Tab 10 & Ambient Air Heat Exchanger Regasification \\
\hline Tab 11 & Subsea Cryogenic Pipeline - OPE and ITP-InTerPipe \\
\hline Tab 12 & Heat Exchanger/Vaporizer Comparisons \\
\hline Tab 13 & Ichthyoplankton Study \\
\hline \hline Tab 14 & Contract Documents (Objectives, Scope \& Tasks) \\
\hline \hline Tab 15 16 & On the State Regional, and National Economies" \\
\hline
\end{tabular}


Novel Process to use Salt Caverns

to Receive Ship Borne LNG

DE-FC26-02NT41653

Final Report Presentation

March 8, 2005

Natjonal Energy Jechnology Laboratory

Morgantown, WV

MJichael IYJ. IMcCall

Conversion Gas Jmports, L.P. 


\section{Novel Process to use Salt Caverns to Receive Ship Borne LNG DISCLAIMER}

- "This report was prepared as an account of work sponsored by an agency of the United States Government. Neither the United States Government nor any agency thereof, nor any of their employees, makes any warranty, express or implied, or assumes any legal liability or responsibility for the accuracy, completeness, or usefulness of any information, apparatus, product, or process disclosed, or represents that its use would not infiringe privately owned rights. Reference herein to any specific commercjal product, process, or service by trade name, trademark, manufacturer, or otherwise does not necessarily constitute or imply its endorsement, recommendation, or favoring by the United States government or any agency thereof. The views and opinions of authors expressed herein do not necessarily state or reflect those of the United States Government or any agency thereof." 


\section{Novel Process to use Salt Caverns to Receive Ship Borne LNG AGENDA}

- Introduction

- Objectjves

- Offshore Terminal

- Mooring Jests

- LNG PUInp Јest's

- Heat Exchanger 『ests

- Freedom LNG Jerminal

- summary
James Ammer DOE

Mike Mccall

James Davis

Max Krekel

Braxtion Scherz DB\&A

Willian Bishop CGI

Crajg raylor

MJjke MJcCal]
CGI

AMECParagon

Bluewater

HNG LNG

CGI 


\section{CGI $I_{L P}$}

\section{Cooperative $R \& D \rightarrow$ Accelerate Commercial Application DOE (\$1.9MM) + Industry Participants (\$1.1MM)}

- ABS

- AGL Resources

- AMEC Paragon

- Arthur D. Littile

- Bluewater Offshore

- BP

- Carter Cryogenics

- Charles River Associates

- Det Norske Veritas

- Dominion Resources

- Ebara

- Ecology \& Environment Inc.

- EnCana

- ExxonMobil

- Fluor
- FMC SOFEC

- Heogh LNG

- HNG Storage

- Intit' LNG Assoc (ILNGA)

- Marathon

- Marsh USA

- Nikkiso Cryo

- Northstar

- PB Energy Storage Services

- Remora Technology

- RRS Engjineering

- SBM

- Texas Brine

- Tenn Gas Pipe/ El Paso

- Tulane University 


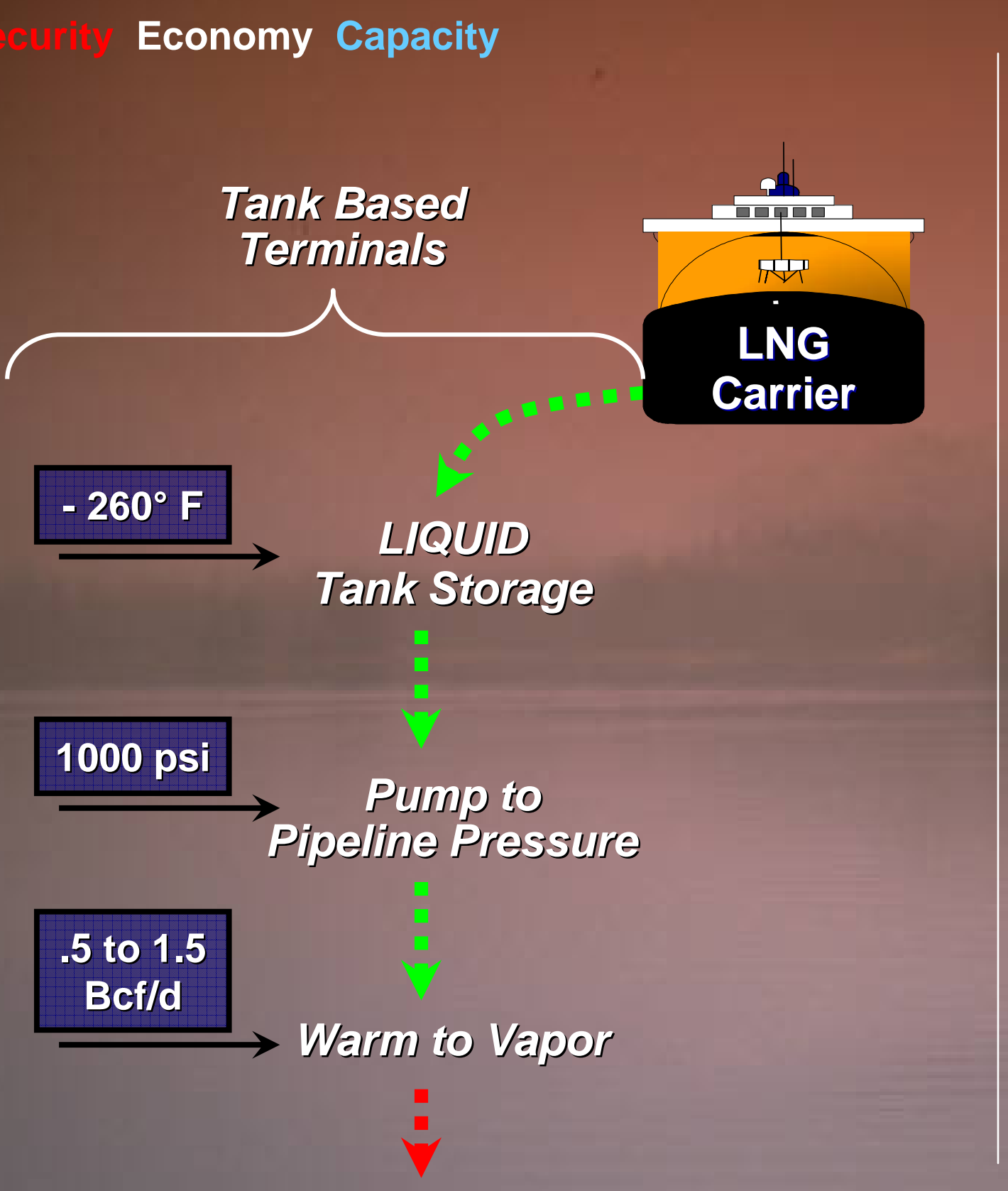

$\mathrm{CGI}_{L \mathrm{p}}$

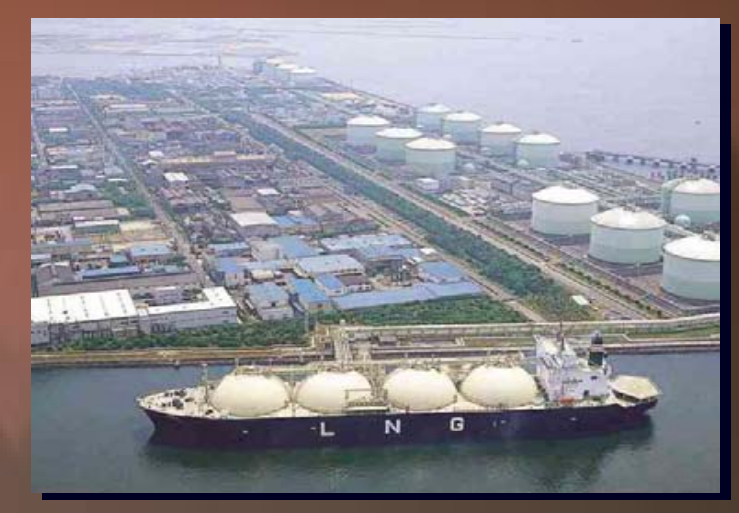

\section{Tank-Based LNG} Terminals

- Surface Tank Storage

- LNG Inventory

- Sendout Limited by Vaporizer Capacity

- Visually Intimidating 


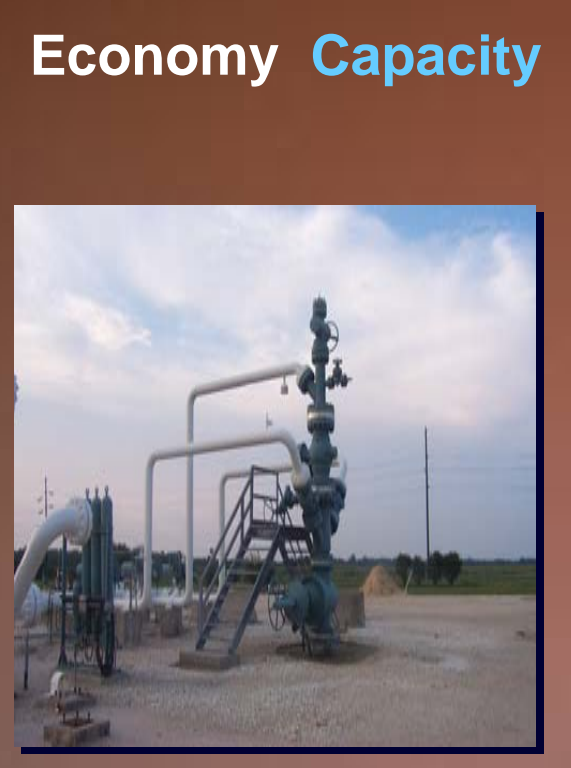

Salt Cavern LNG Terminals

- Underground = Maximum Security

- Gas Inventory

- Peak Sendout Limited Only by Pijpelines

- Visually Insignjificant
$\mathrm{CGI}_{L P}$

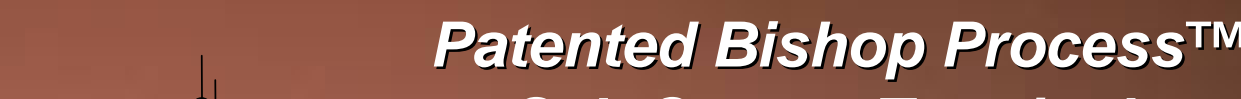
Salt Cavern Terminals

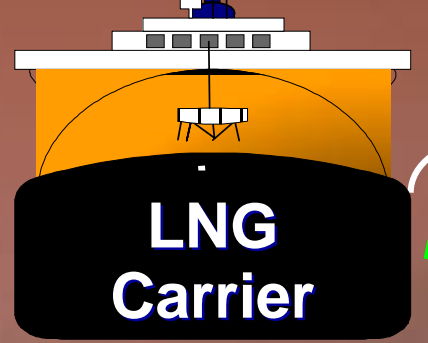

Offshore Mooring $>2000$ psi $>+40 \mathrm{~F}$ LNG PUMps Heat Exchanger

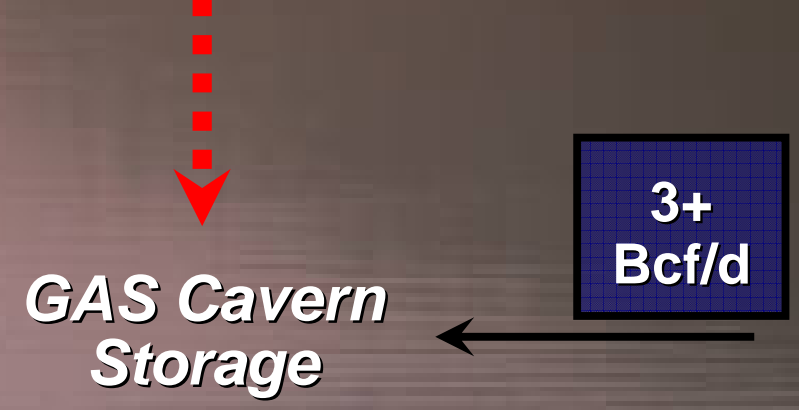




\section{Phase I Studies Showed Promise (April 2003)}

- Rock Mechanics Showed Caverns OK

- Offishore Mooring Feasible

- LNG Pumps Could Provide Injection Pressures

- Hi-Cap, Hi-Pressure Heat Exchangers Possible

- Offishore Salti Formations \& Pipelines Available

- Preliminary Costs Looked Good 
Novel Technology CombinationsMaking LNG Access Safer, Cheaper, Faster ...

"The Bishop Process"

if proved successful,

has the potential to significantly increase world LNG trade and provide a highly secure, economical and flexible way to expand LNG imports and augment the natijon's energy supply...

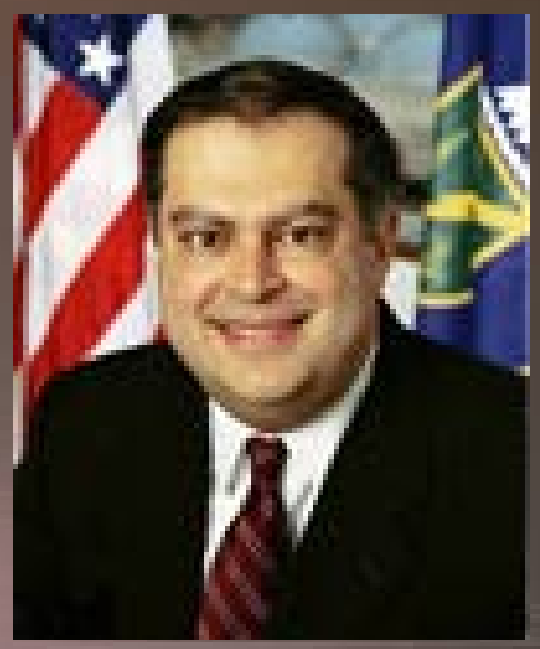

Spencer Abraham

Spencer Abraham

U.S. Secretary of Energy

July 22, 2003 
Salt Caverns to Receive LNG

Phase II- Answer Skeptics, Move Towards

$\mathrm{CGI}_{\mathrm{LP}}$

Commercial Development

\section{Project Objectives}

VTask: Model Test Offshore Mooring System

V Task: Field Test High Pressure LNG Pump

VTask: Field Test Heat Exchanger

\section{Desigju Initegratied Ternininal}

\section{(Engjineering, Operatijons \& Costs)}




\section{Model Tests}

\section{Model Basin Test Program}

\section{Pictures:}

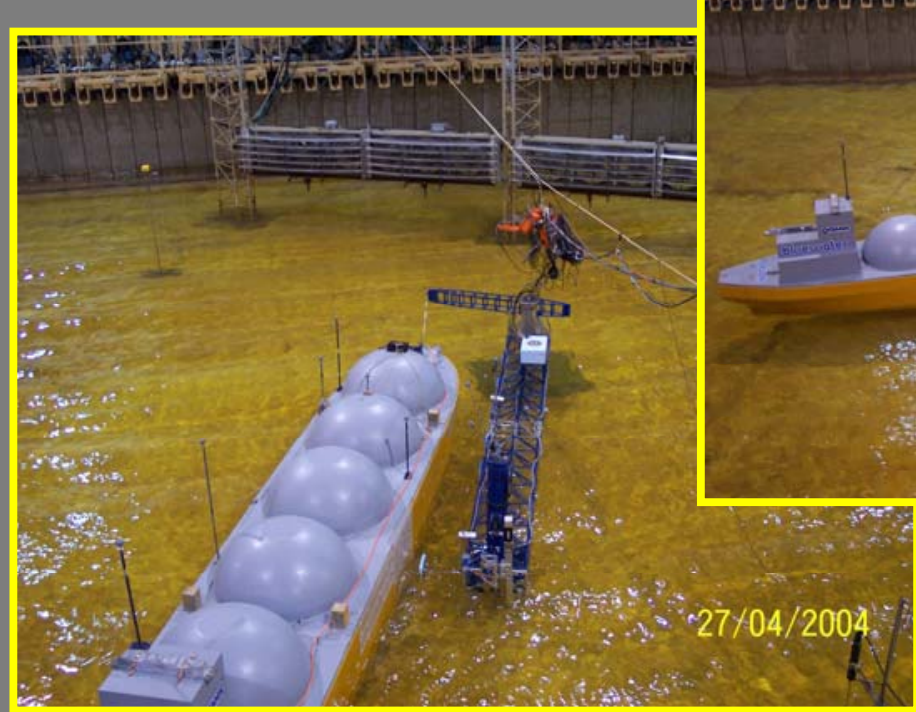

Operational Waves 
Ebara \& Nikkiso Cryo High-Pressure LNG Pumps CGI $\underline{\text { Successfully }}$ Tested $\rightarrow$ Alternate Designs Proposed
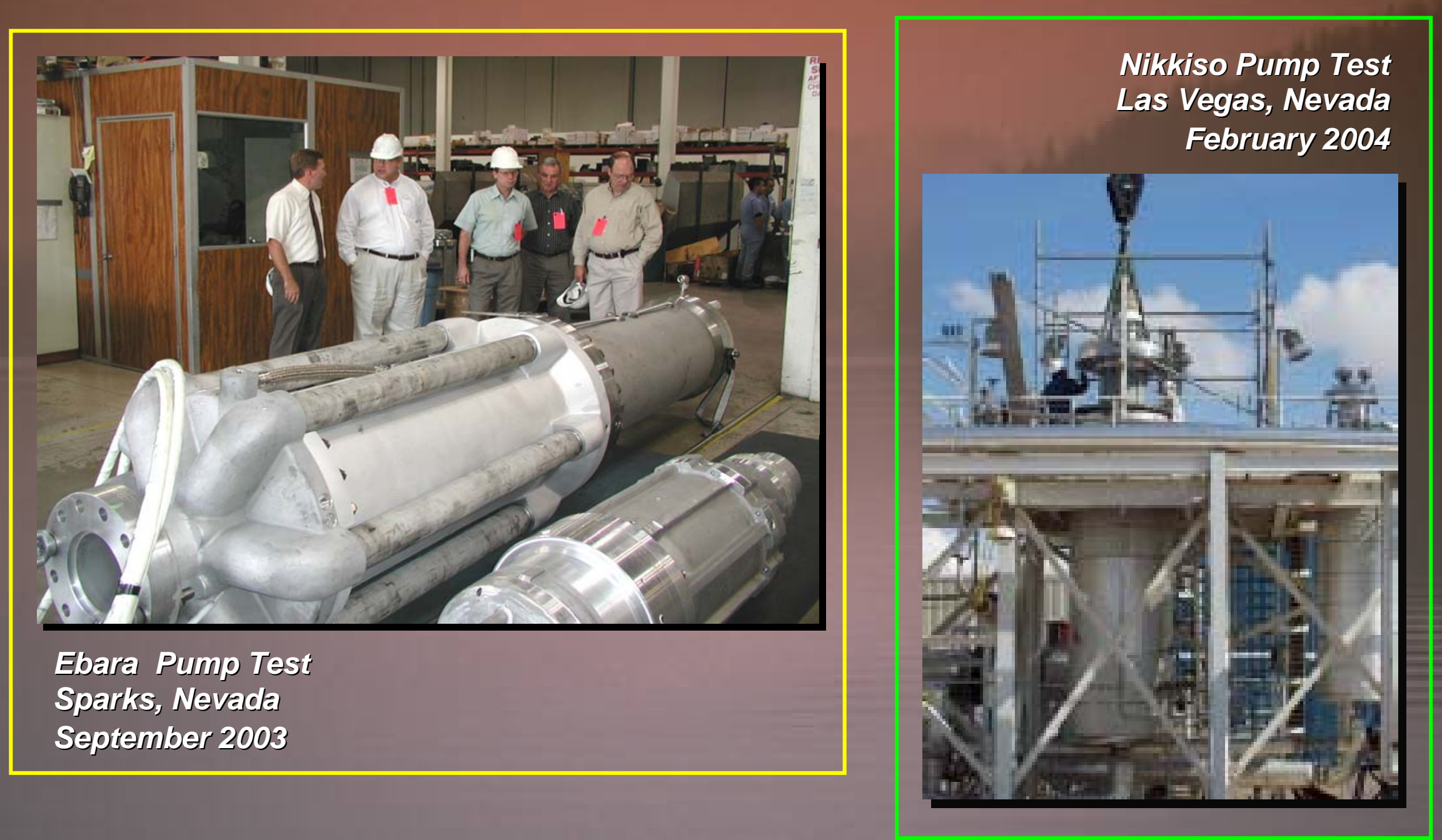


\section{High Capacity-High Pressure Heat Exchanger Successfully Tested $\rightarrow$ April 2004}
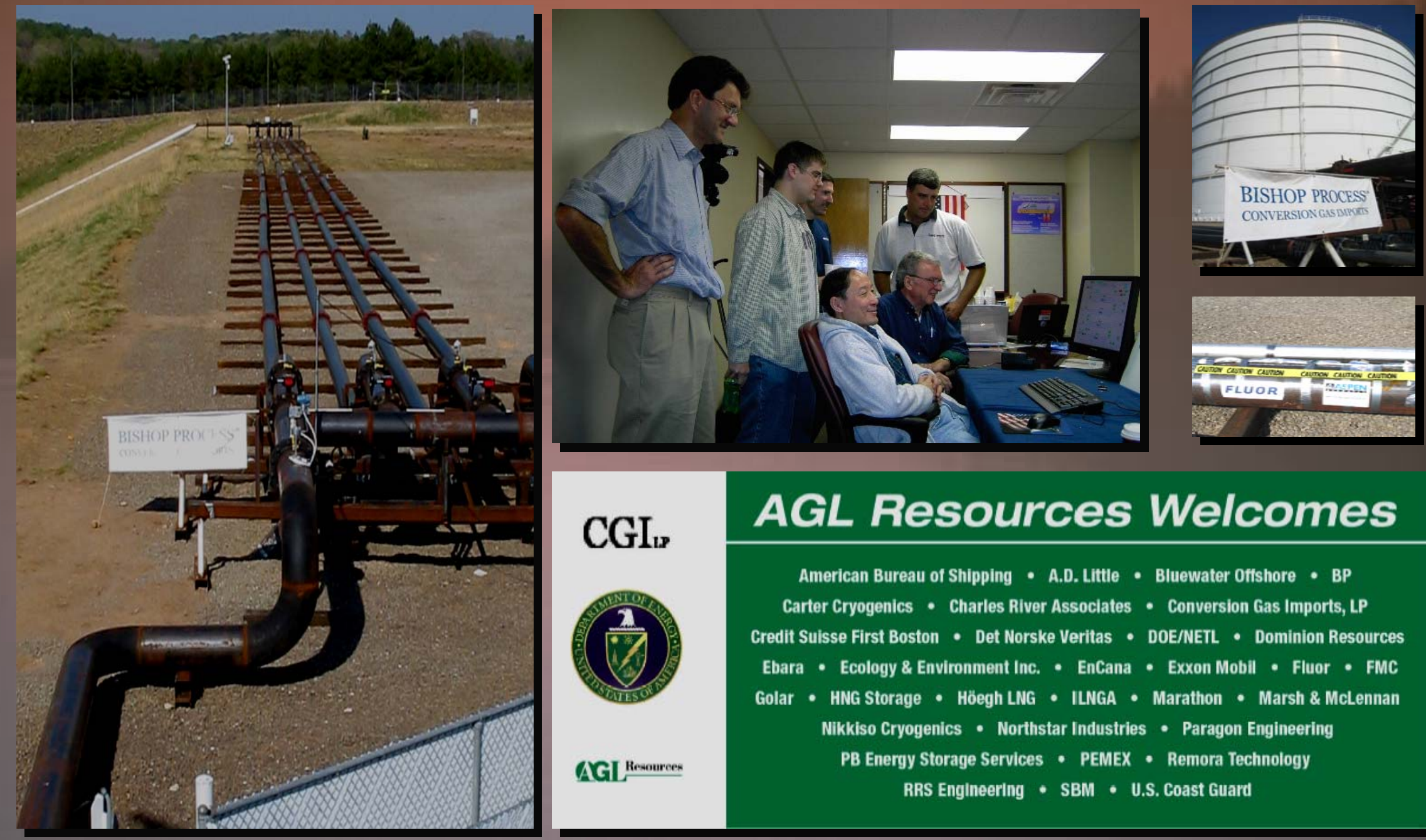

Security Economy Cajpacjty 


\section{Offshore Terminal Design- Dec 2004}

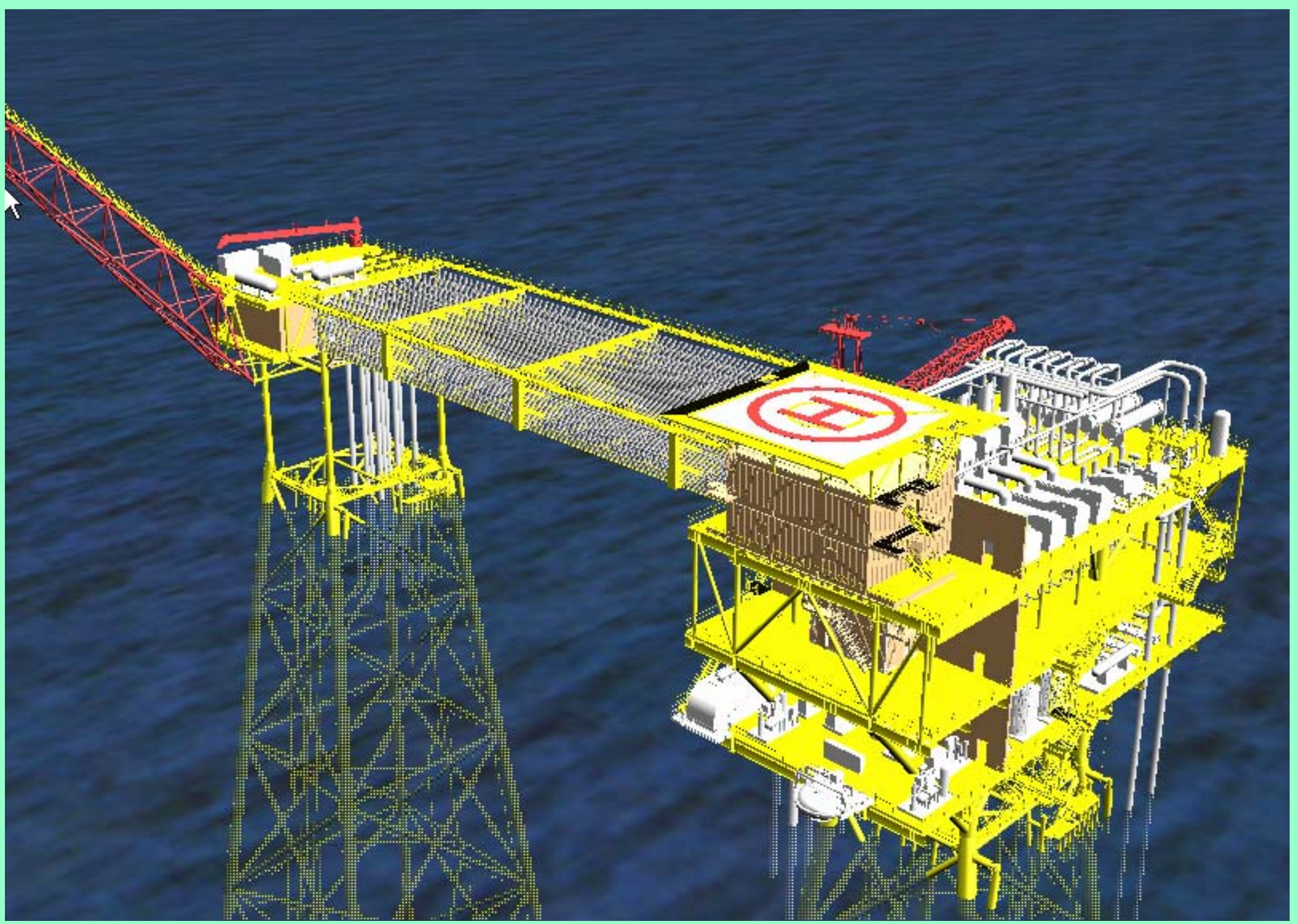




\title{
Freedom LNG Terminal
}

\section{Project Overview}

\section{The Freedom LNG Terminal \\ A New Standard For LNG Receiving Terminals}

\author{
Craig Taylor \\ President \\ HNG Storage Company
}


The Bishop Process TM Salt Cavern Based LNG Receiving Terminal

- Field Tests Confirm Science

- Engineering Design Confirms Costs

- Offshore/Cavern Storage Solves Nimby, Security \&. Port Congestion Problems

- First Commercjal Project will Include MJultijple Jnolustify Pajticjpants firom Group 
Novel Process to use Salt Caverns to Receive Ship Borne LNG

Project Summary

- Tasks Completed On Time and On (Revised) Budget

- Defines an Advantaged Alternative to Tank Based Terminals

- Brings Economy of Scale, Security of Underground Storage, \& Simplicity of Cavern Operations to LNG Industiry 
Salt Cavern Based LNG Receiving

$\mathrm{CGI}_{L P}$ Makes 15 Bcf/D a Real Possibilitity

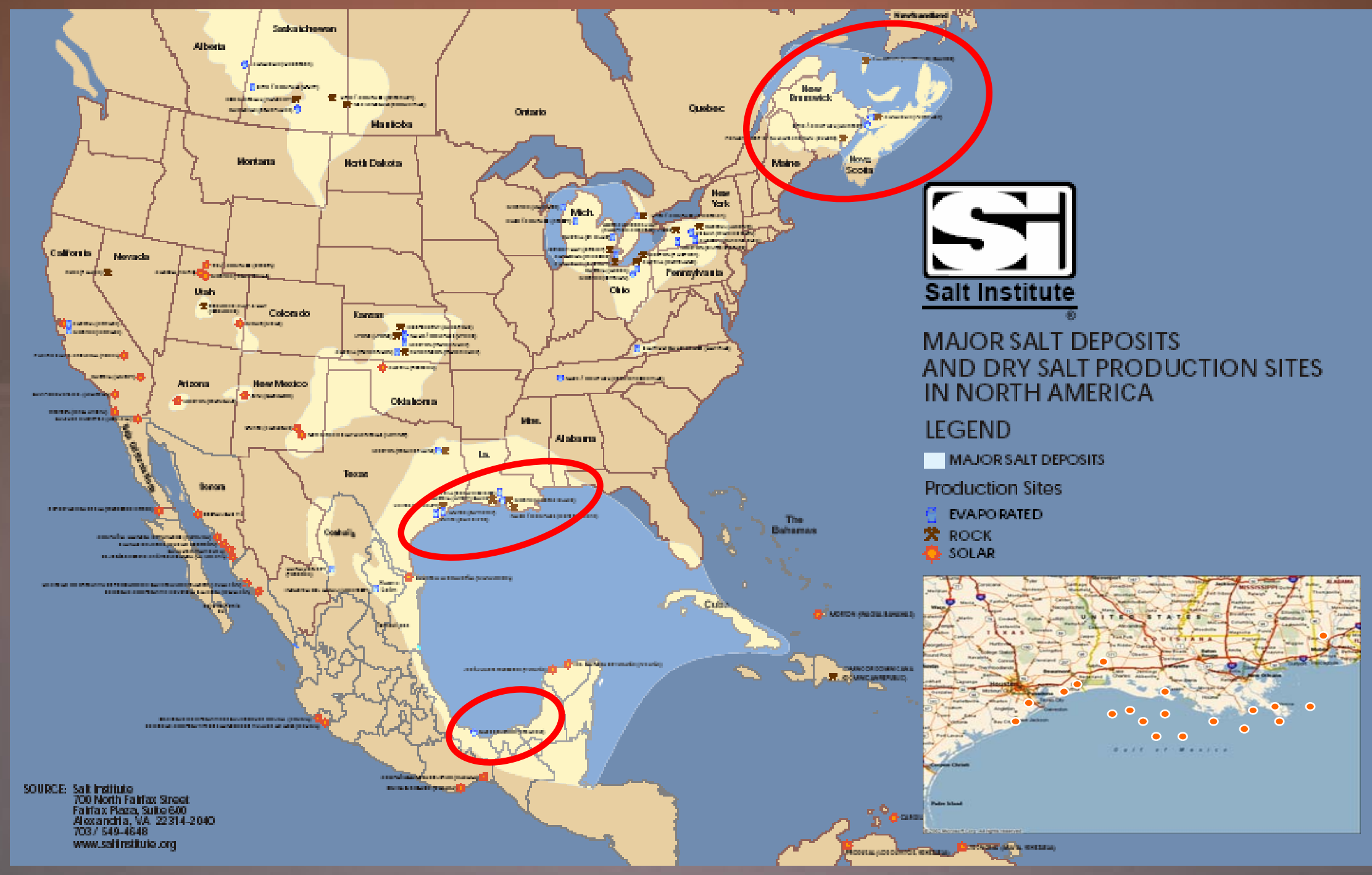




\section{Salt Cavern Based LNG Receiving Terminals Import LNG and Export US Technology}

Atlantic Canada
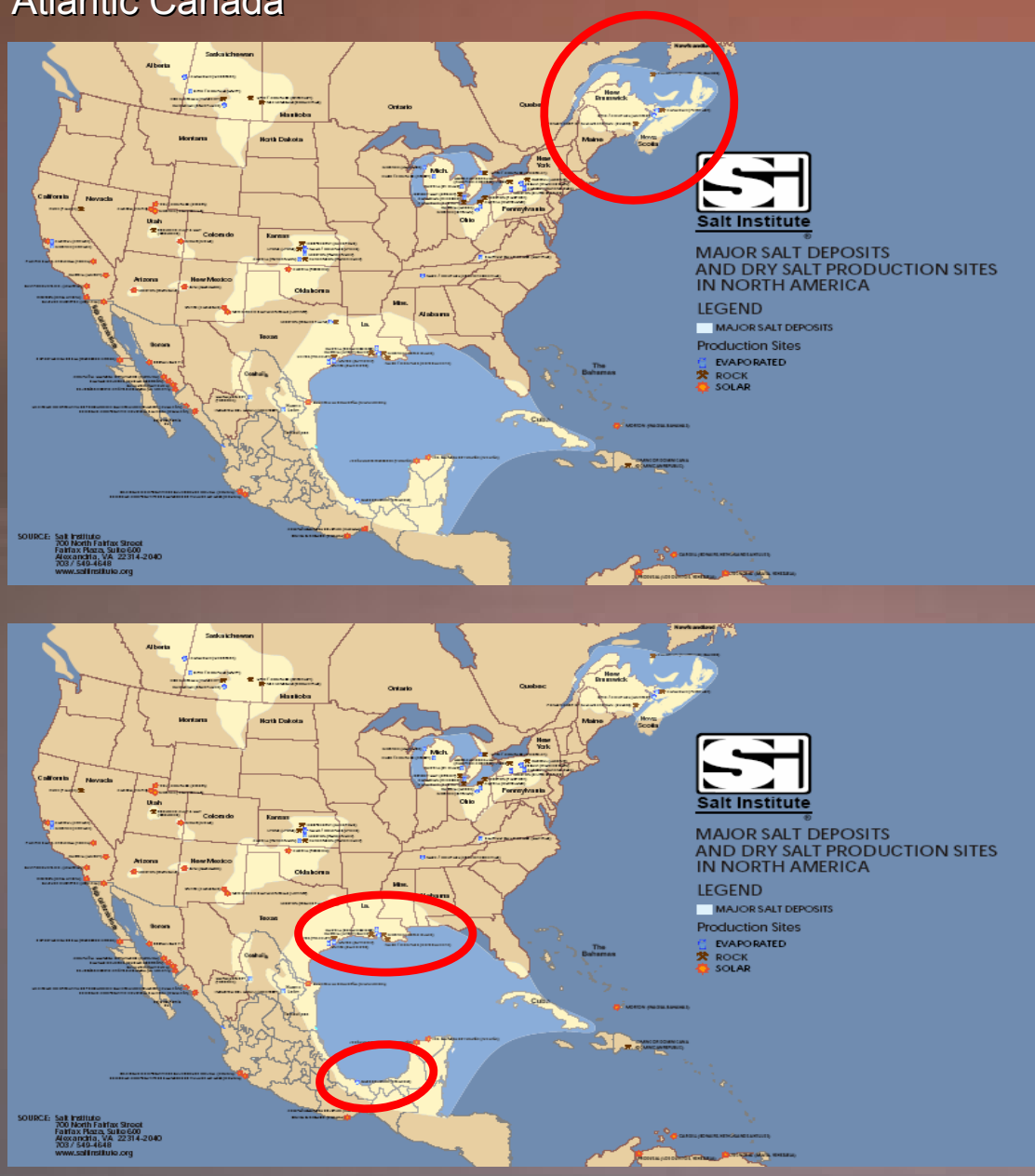

Gulf of Mexico (US \& Mexico)
Europe
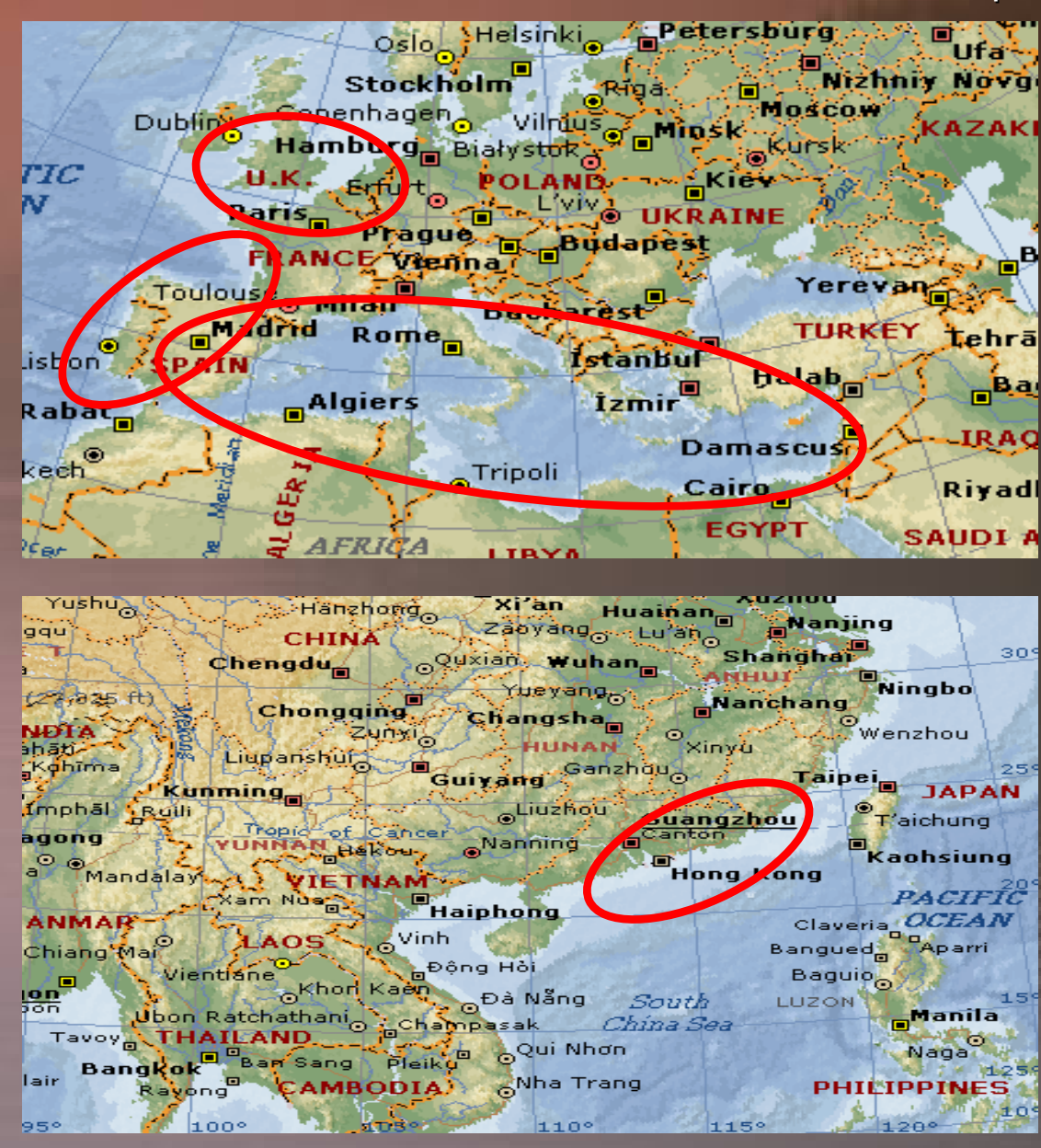

China 


\section{Offshore LNG terminals \\ tin}

Presentation to

U.S. Department of Energy

National Energy Technology Laboratory

Morgantown, March $8^{\text {th }}, 2005$ 


\section{Introduction}

Production \& Terminals for LNG moving offshore $\rightarrow$ Need for offshore LNG transfer systems

- High system availability

- Weathervaning system

- Robust cryogenic flow path

- Suitable for 'open' terminals, i.e.

- Vessels of opportunity, transfer at existing man. as well as 'dedicated' terminals

- Dedicated vessels with bow loading facilities 
Task III has been split up in 3 parts:

A. Overall system design

- Basis of Design

- Field Lay-out study

- HSSE assessment

B. Mooring Terminal

- Lay-out, Structural analysis

- Mooring analysis, incl. model testing program

- LNG transfer systems, Utility systems,...

C. Re-gas, Injection \& send-out facilities

- Performed by Paragon Engineering Services 
Import terminal c/w re-gas and salt dome storage - Vermilion 179

- Water depth $100 \mathrm{ft}$. / unlimited salt

- Location $47 \mathrm{Nm}$ offshore Louisiana

- Send-out to three gathering systems

- Bluewater, Sea Robin, Texas Eastern

- Nominal capacity 2.0 bcfd, peak 2.5 bcfd

- LNG carrier 125,000 m³ (option 200,000 m³)

- Terminal will unload $4 \sim 6$ LNG carriers / week 


\section{Part 'A' - Terminal Lay-out}

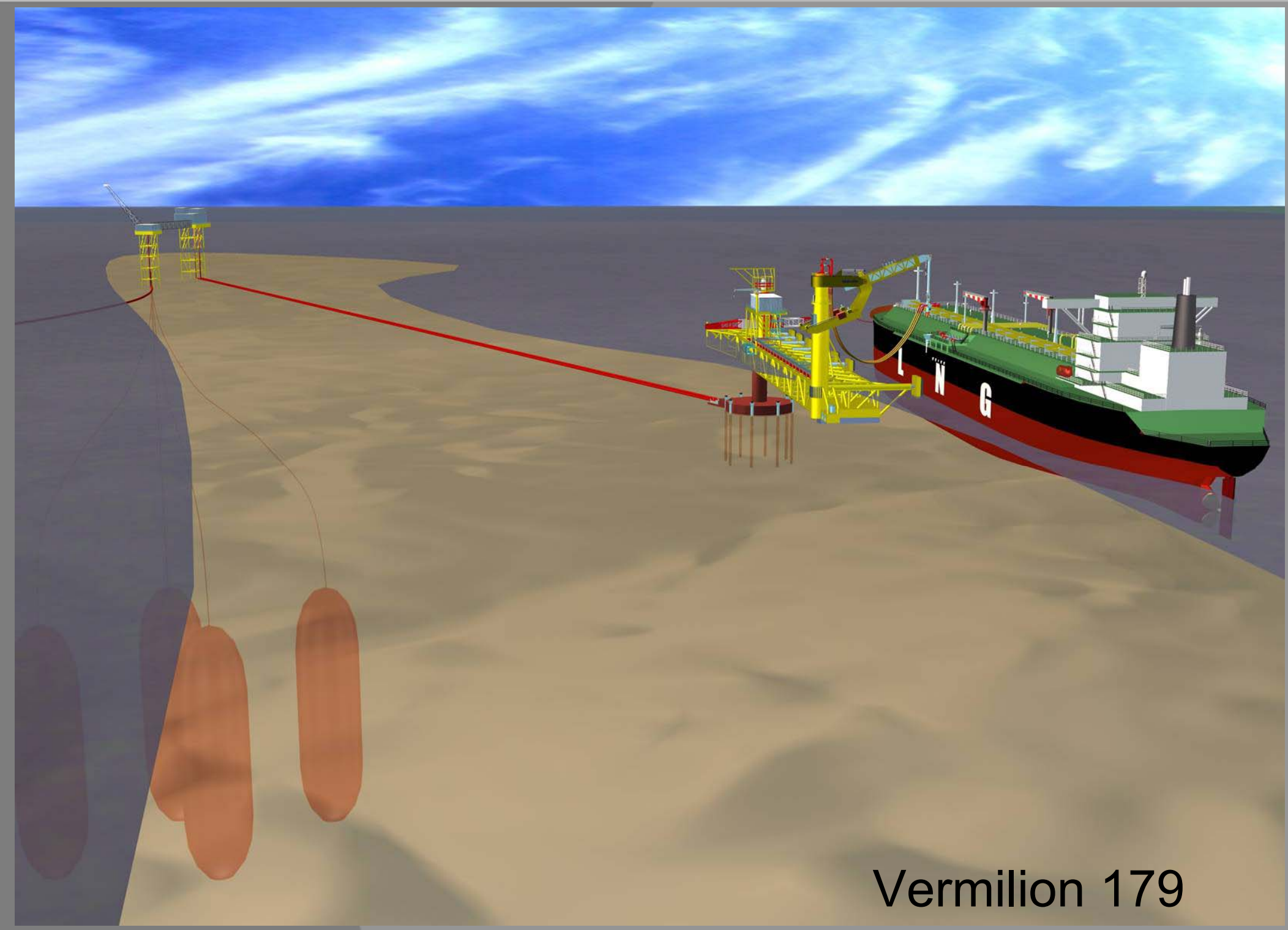




\section{bluewater}

\section{Part 'A' - Terminal Location}

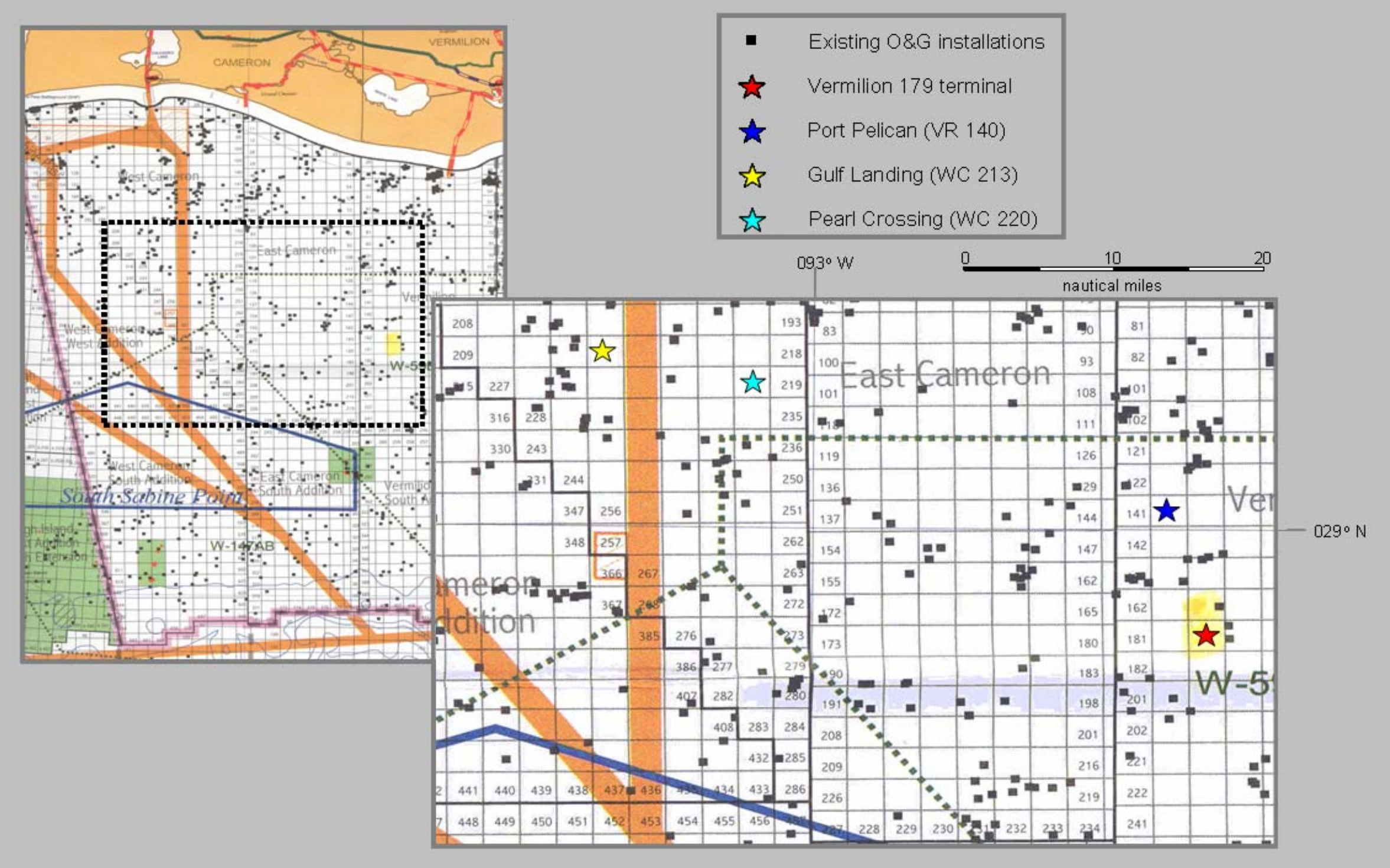


Conceptual design of Mooring Terminal:

- Lay-out, Structural analysis

- Model basin testing program

ModeltestsIModel Tests BW Big Sweep.ppt

- Dynamic Positioning (DP) system

DP ThrustersIThruster System.ppt

- LNG transfer system

LNG transferlLNG transfer.ppt

- Product system

Product systemlProduct system. ppt 


\section{LNG Transfer system}

LNG transfer system based on technology Developed by 'Amplitude LNG'

- Partners in group are:

- Eurodim: conceptual design and engineering

- KSB-Amri: supply connection system

- Technip: supply of cryogenic hose

- System \& components in qualification stage

- Type approval by Bureau Veritas

- Supporting companies are Total, Gaz de France, BP, CVX, ENI, Leif Hoegh LNG,.. 


\section{LNG transfer}

\section{Amplitude-LNG Loading System Main Principles}

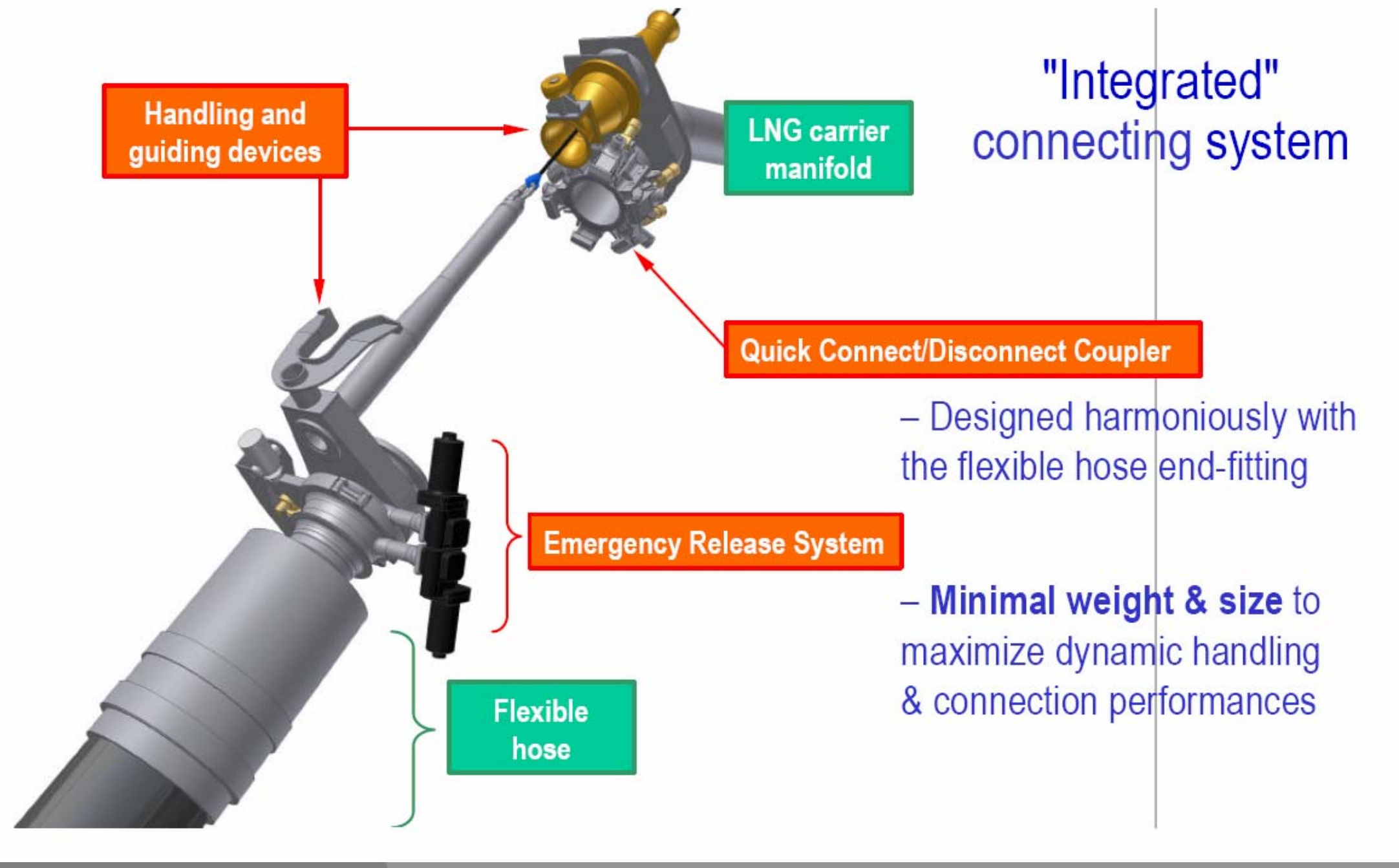




\section{bluewater}

Power by People

\section{Big Sweep - hose arrangement}

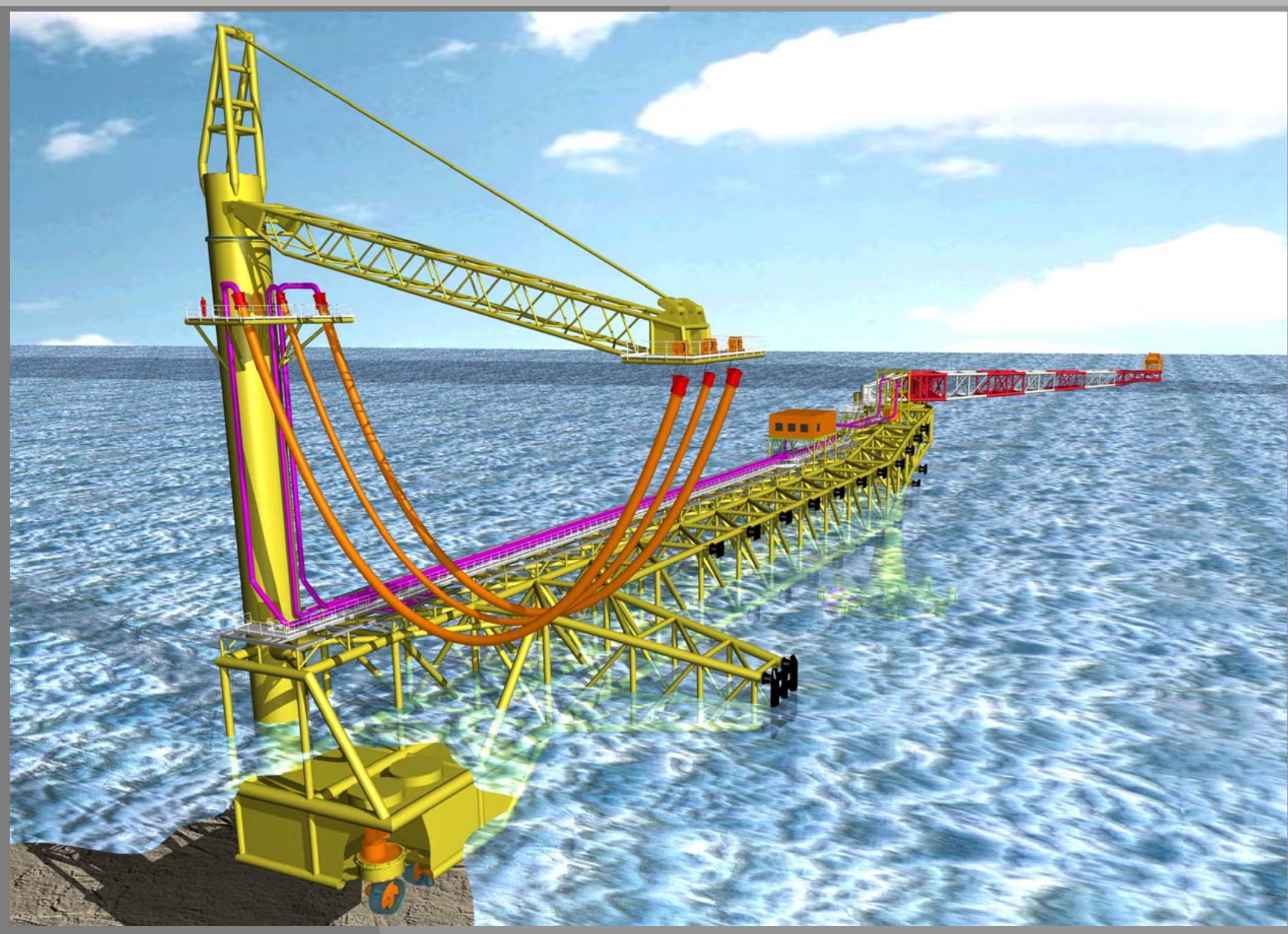




\section{Further developments}

- Bluewater development work

- Continue with dynamic hose analyses

- Contact ship owners \& operators on vessel mod's

- Cryogenic hose qualification

- Technip (Amplitude JIP)

- Amnitec (formerly Senior Flexonics)

- BPP / Dantech (BHP's composite technology)

- Nexan Kabelmetal's CRYODYN ${ }^{\circledR}(\mathrm{OCL}$ JIP)

- Amplitude LNG

- JIP \& pilot installation at Gaz de France's Montoir terminal 


\section{Model Tests}

\section{Model Basin Tests to verify system for:}

- Survivability in 'Extreme Hurricane Conditions'

- Structural loads w/o LNG carrier

- Operability in 'Normal Operating Conditions'

- Hawser loads, DP thrust requirements

- Overall behavior, relative motions

- Characteristics in 'Calibration Conditions'

- Regular waves to verify and/or calibrate analytical models 


$\begin{array}{ll}\text { Specifications: } & \\ \text { Length } & 75 \mathrm{~m} \\ \text { Width } & 32 \mathrm{~m} \\ \text { Max. Water Depth } & 3.2 \mathrm{~m} \\ \text { Wave Making System (power) } & 1800 \mathrm{~kW} \\ \text { Max. Wave Height (regular waves) } & 1 \mathrm{~m} \\ \text { Max. Sig. Wave Height (irregular waves) } & 0.5 \mathrm{~m} \\ \text { Range of Wavelengths } & 0.5 \mathrm{~m} \text { to } 20 \mathrm{~m} \\ \text { Articulation of Waves (modes) } & \text { Happer, Piston, } \\ & \text { Combination } \\ \text { Wave Spectra } & \text { Regular, Irregular, } \\ & \text { Bi-modal, } \\ & \text { Multi-directional } \\ \text { Current Speed } & \text { Water-depth } \\ & \text { Dependent } \\ & (0.2 \mathrm{~m} / \mathrm{sec} \text { at } \\ \text { Average Wind Velocity } & 2 \mathrm{~m} \text { depth) } \\ & 11 \mathrm{~m} / \mathrm{sec} \text { at } 1 \mathrm{~m} \text { from Fan; } \\ \text { Turbulent Wind Spectrum Mean Speed } & 5 \mathrm{~m} / \mathrm{sec} \text { at } 5 \mathrm{~m} \text { from Fan } \\ & 12 \mathrm{~m} / \mathrm{sec} \\ \text { Wind Spectra } & \text { American Petroleum } \\ & \text { Institute Standard, } \\ & \text { Norwegian Petroleum } \\ & \text { Directorate Standard, } \\ & \text { Other Industry } \\ \text { Optical Tracking System Accuracy } & \text { Standards } \\ \text { Moored Models } & \\ \text { Free-running Models } & \pm 1 \mathrm{~mm} \\ & \pm 5 \mathrm{~mm} \\ & \end{array}$
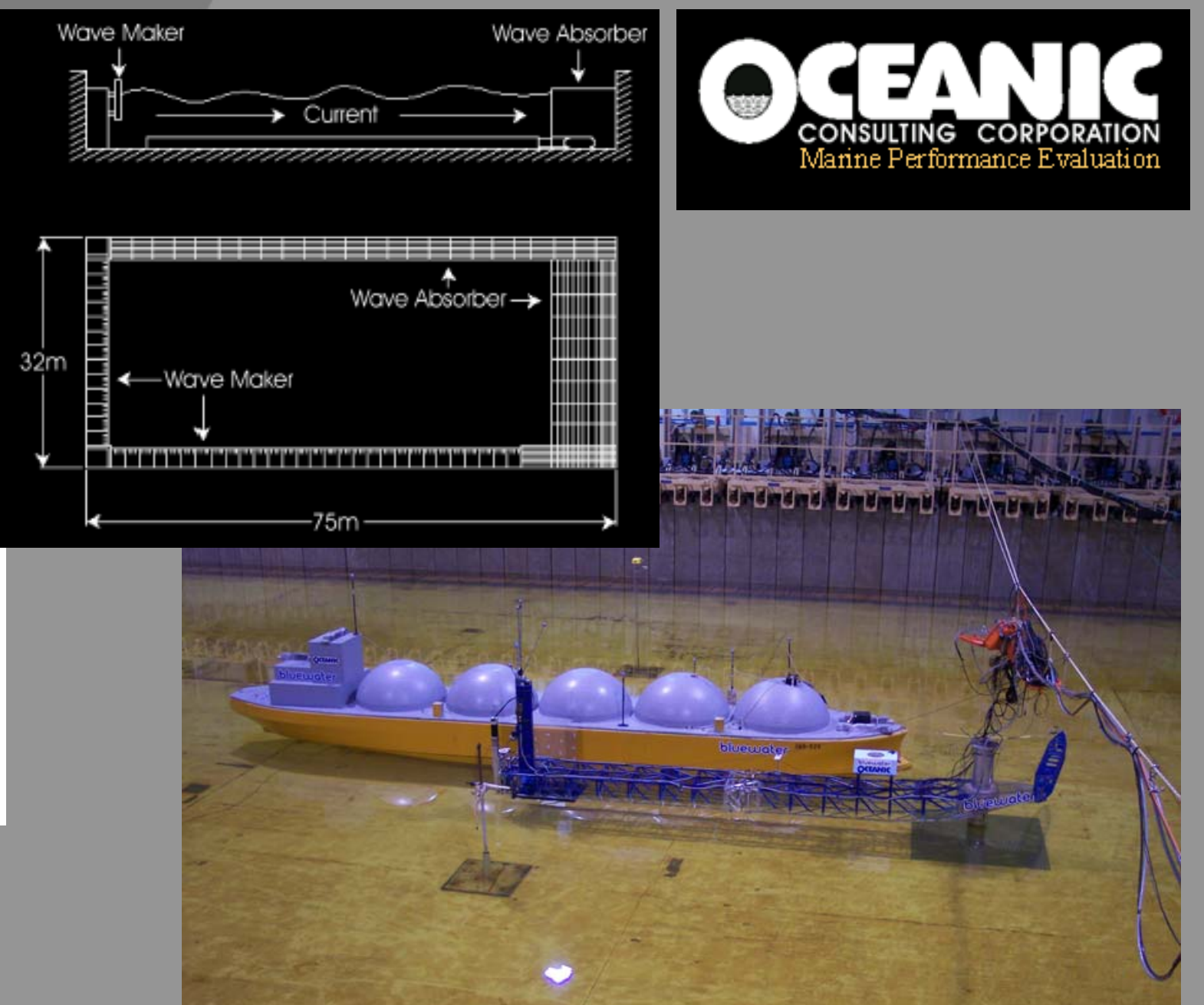


\section{Model Tests}

\section{Model Basin Tests - Measurements:}

- Tower Loads $\left(F_{x}, F_{y}, F_{z}, M_{x}\right)$

- Bending and Torsion moment in arm

- Motions of Buoyancy Column and Arm rotations

- LNG Carrier motions and Relative motions Arm-Carrier

- Vertical loads on Buoyancy Tank

- Relative wave heights along Arm

- Thrust force of DP System

- Hawser tension

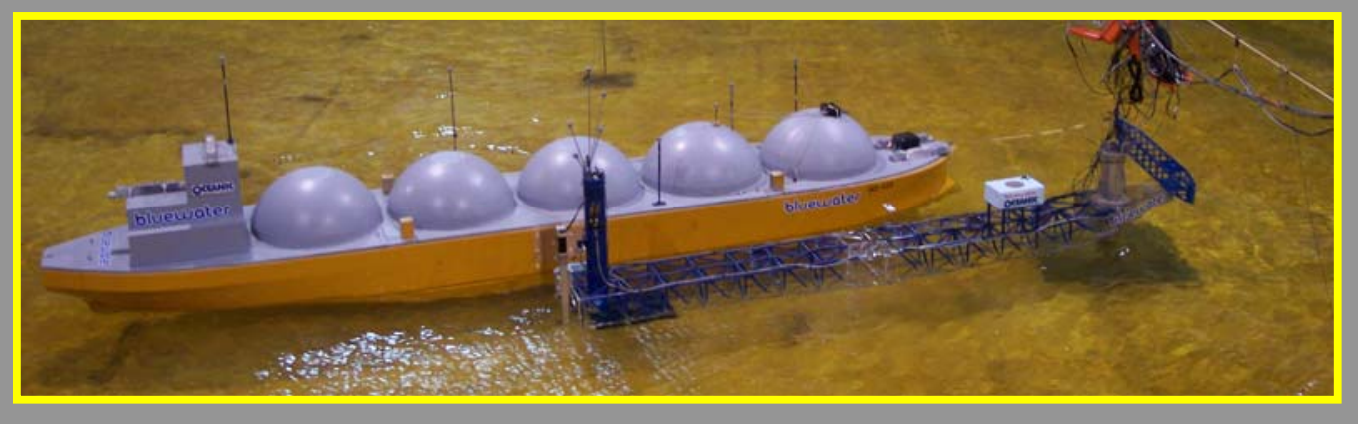




\section{Model Tests}

\section{Model Basin Tests - Callibration:}

- Regular Wave Tests

- Periods from 8 - $25 \mathrm{~s}$

- Different wave heights (4 m, $10 \mathrm{~m}$ and $17 \mathrm{~m}$ )

- With and Without current

- Pitch Decay

- Current Tests

- Arm at different angle with respect to current

- Rotation of arm by DP/Thruster system 


\section{Model Tests}

Model Basin Tests - Survival:

- Metocean Data selected from API (RP 2A)

- Current Velocity : $2.1 \mathrm{kn}(=1 \mathrm{~m} / \mathrm{s})$

-Wave Height : $H_{\max }=17 \mathrm{~m} \quad\left(H_{\mathrm{s}}=9.35 \mathrm{~m}\right)$

-Wind Velocity : not modeled

- Collinear and Cross Current Tests 


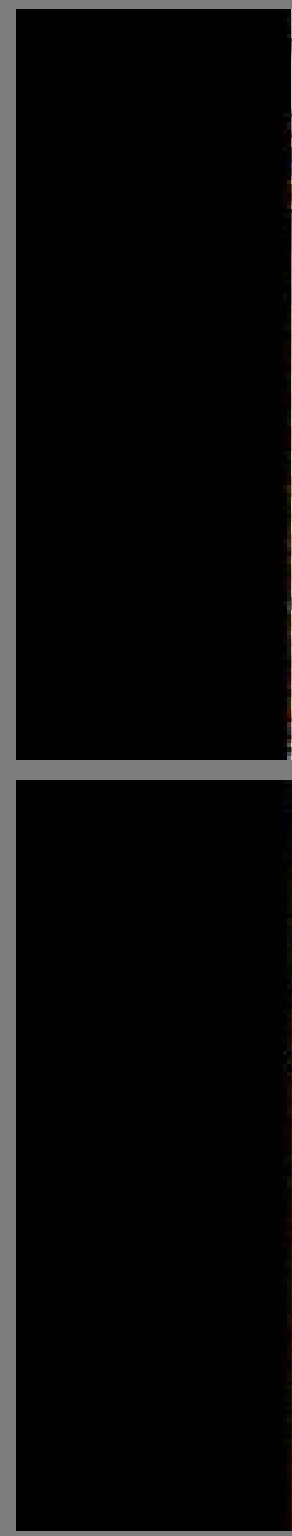

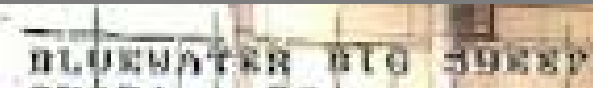
7.tet-m-ast

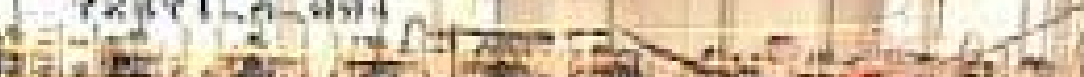

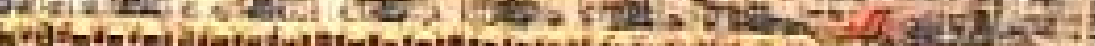

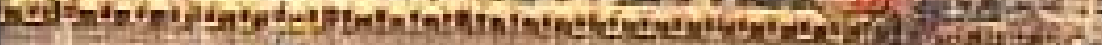

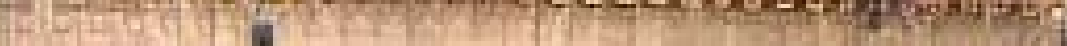
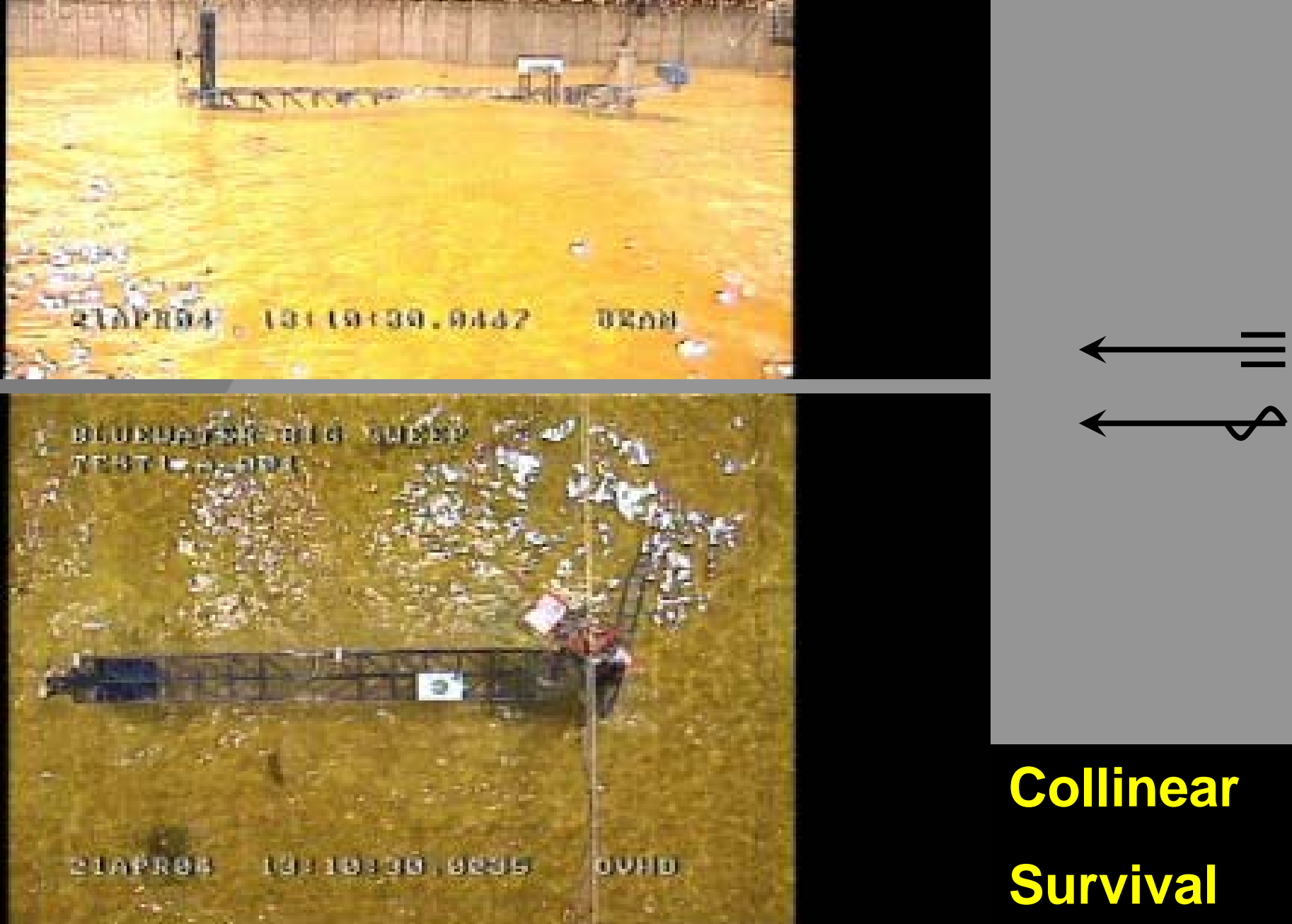

\section{Collinear}

Survival 


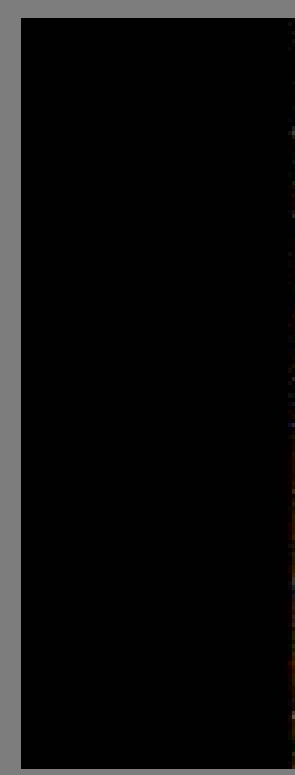

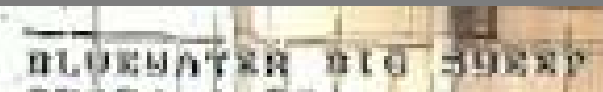
7xacs-a-9a 4

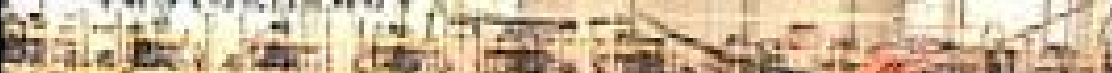

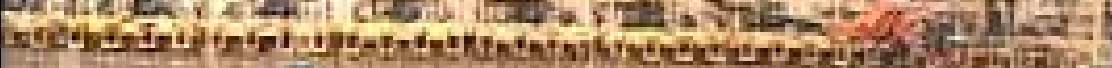
ant

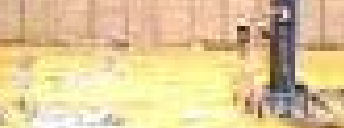
Winting

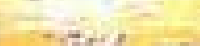

10.74

$\rightarrow \mathrm{T}=$ 724hinga

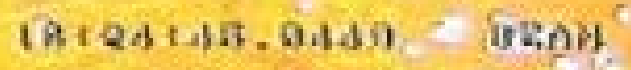
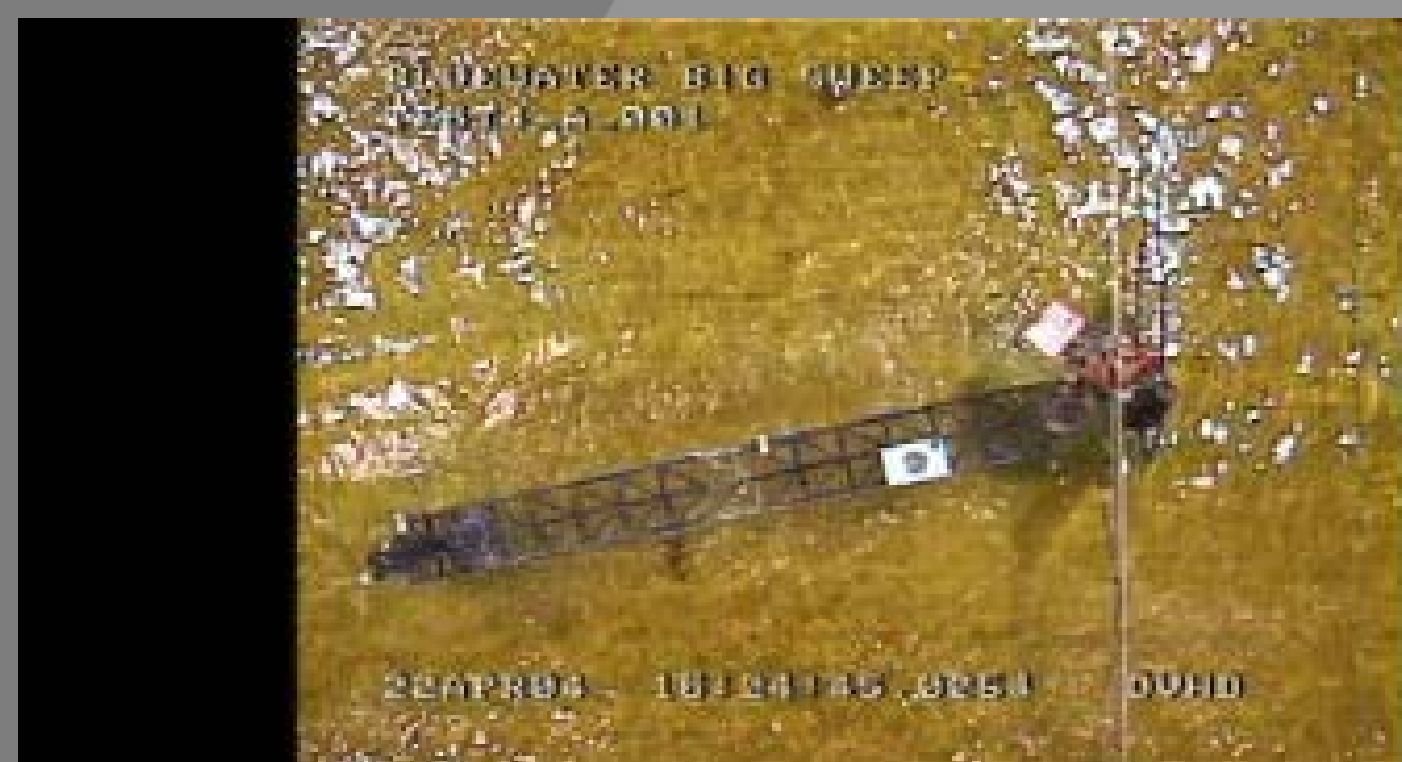

Cross current Survival 


\section{Model Tests}

\section{Model Basin Tests - Operational:}

- Metocean Data selected from 'Buoy Data' and 'Industry sources'

-Approx. 1-year storm

$$
\mathrm{H}_{\mathrm{s}}=4.3 \mathrm{~m}
$$

- Approx. 98\% non-occurrence level

$$
\mathrm{H}_{\mathrm{s}}=3.0 \mathrm{~m}
$$

- Collinear and Oblique and Cross Current Tests

- 1 Tanker Loading condition 


\section{Model Basin Tests - Operational:}

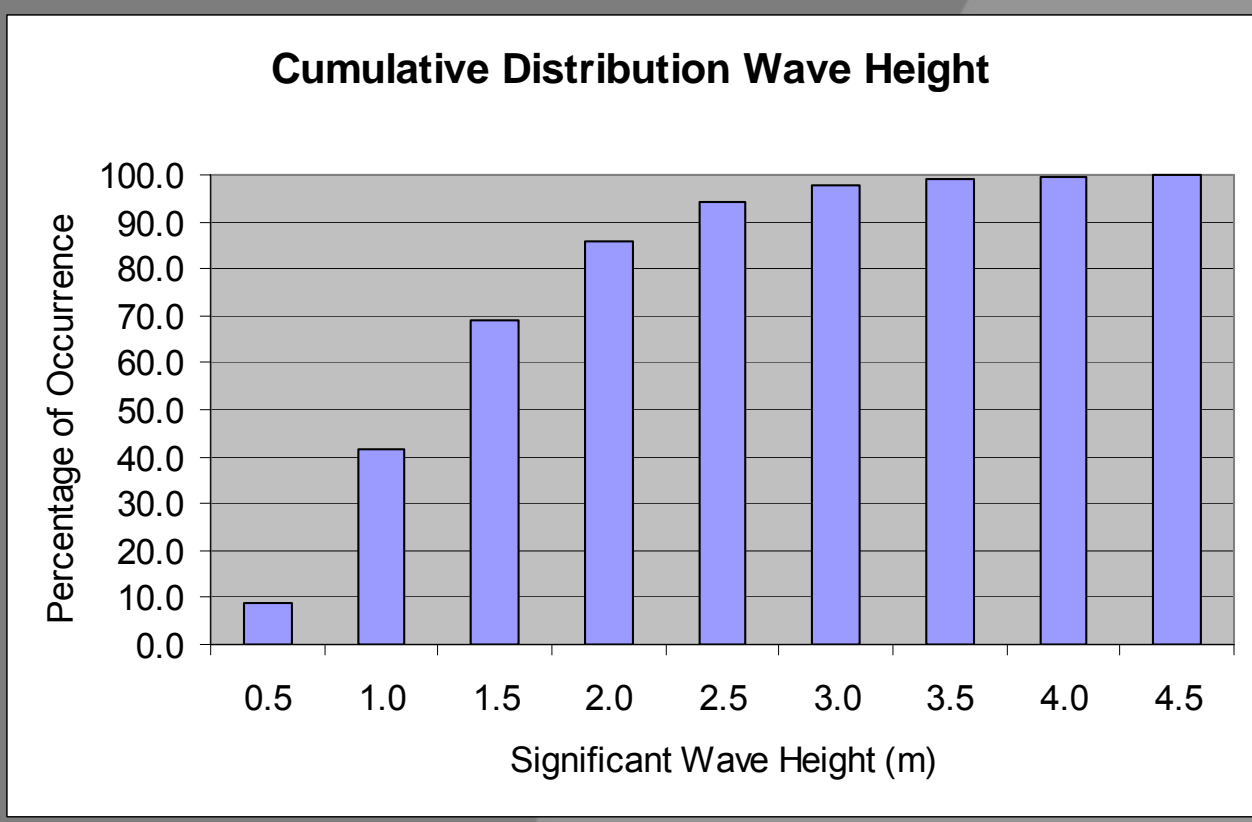

\section{Wave Direction Distribution}

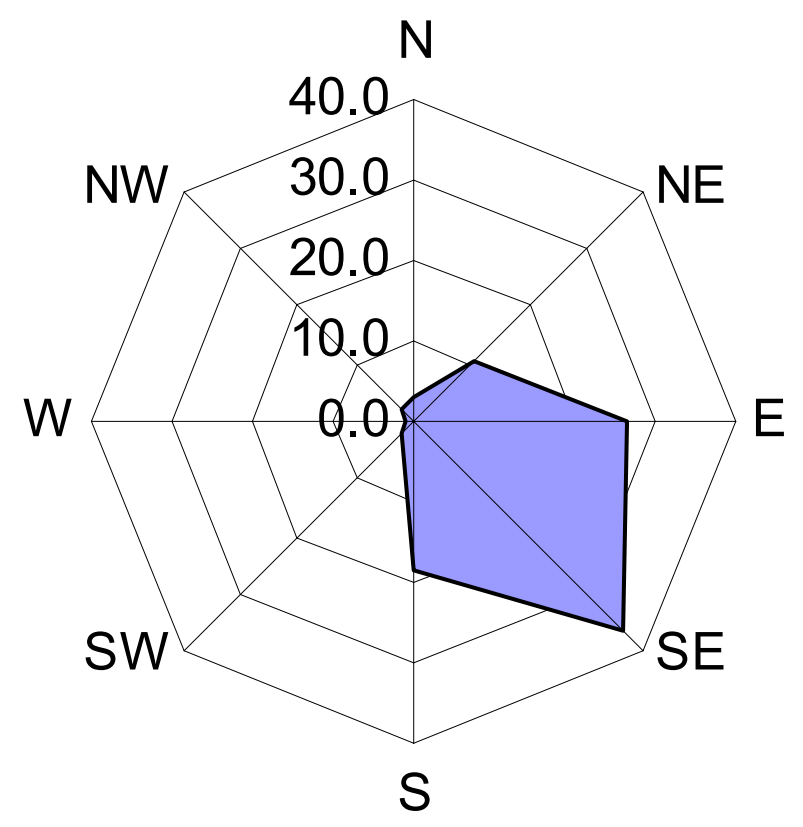




\section{Model Basin Tests - Operational:}

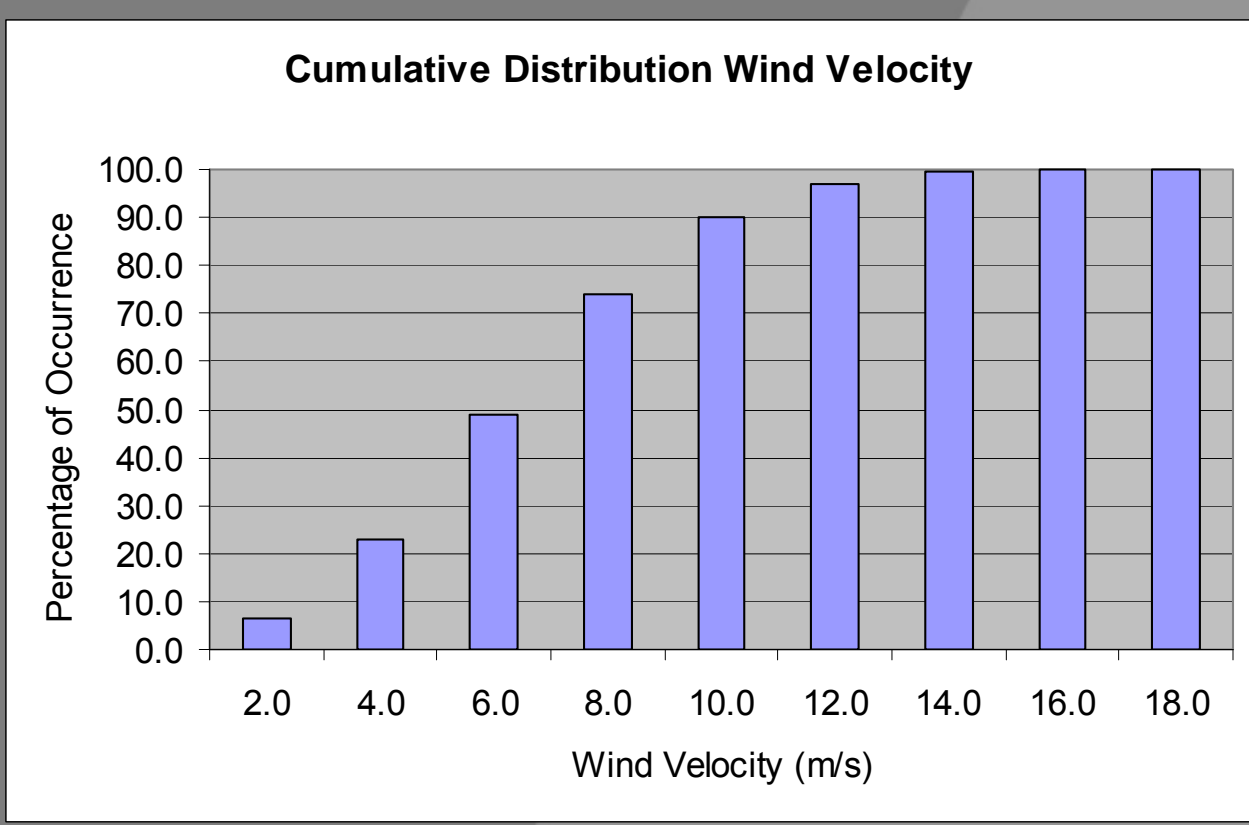

\section{Wind Direction Distribution}

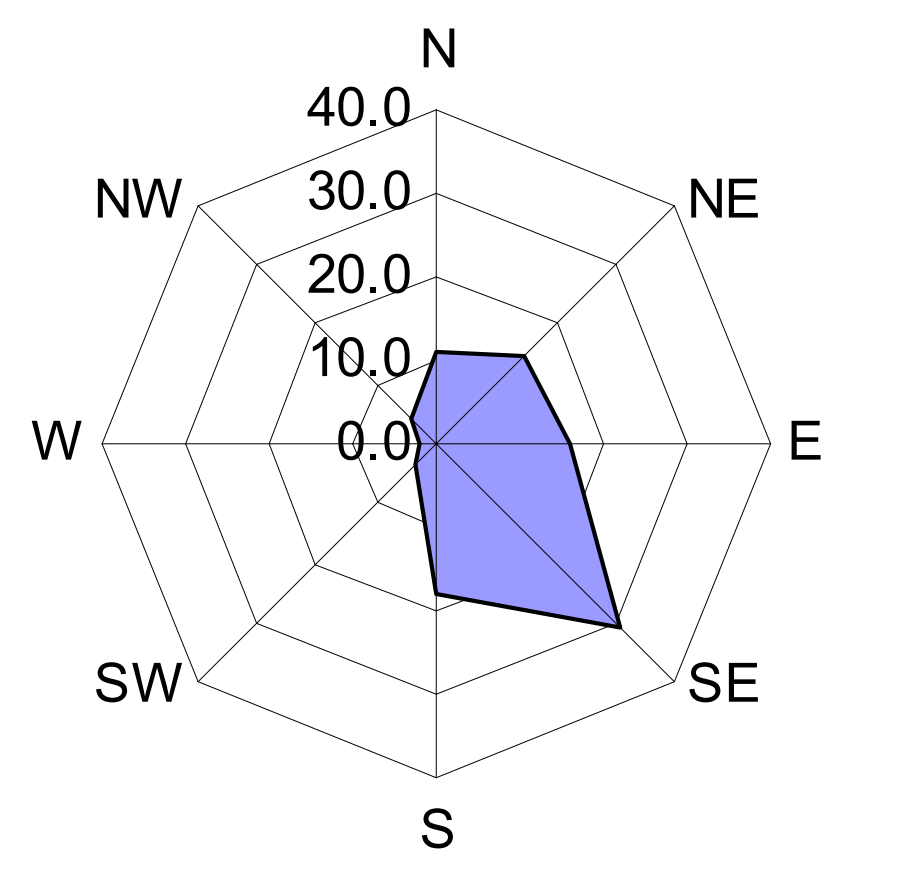




\section{Model Tests}

\section{Model Basin Tests - Operational:}

- Environmental Combinations

- Prevailing directions for wind, wave and current

- Large relative angles can occur though

- Following combinations have been tested
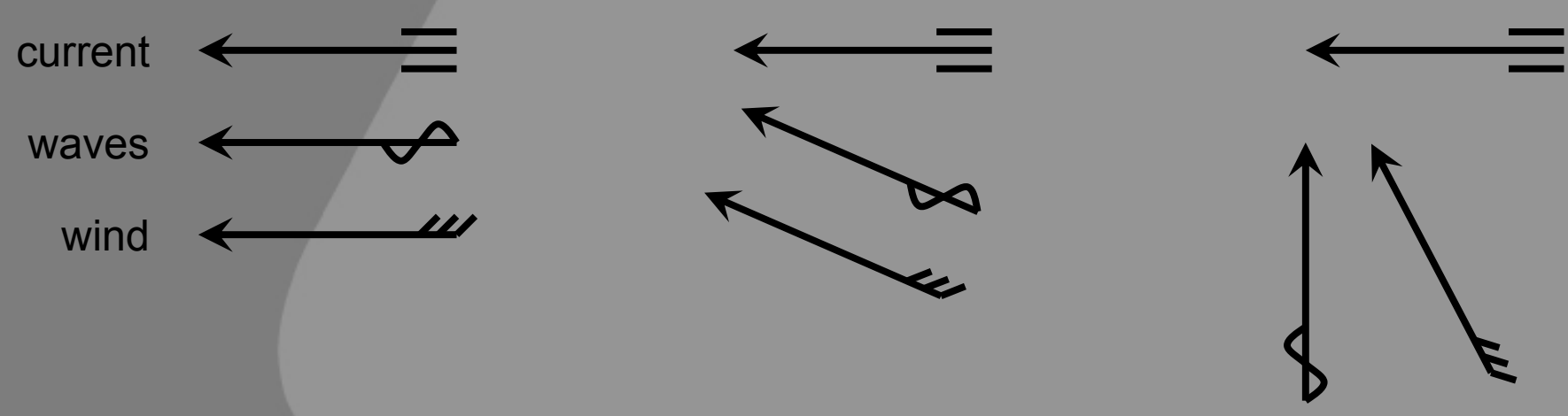


\section{Model Tests}

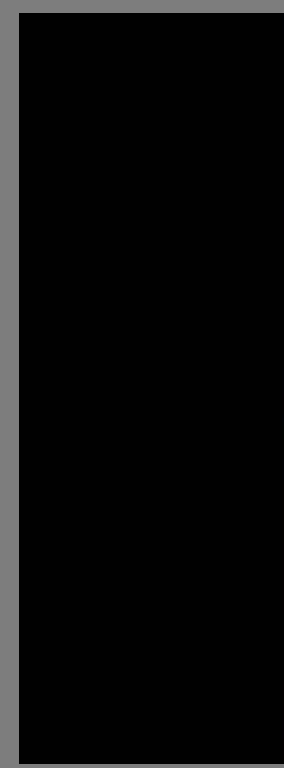

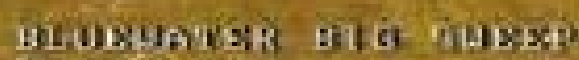

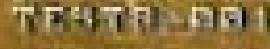
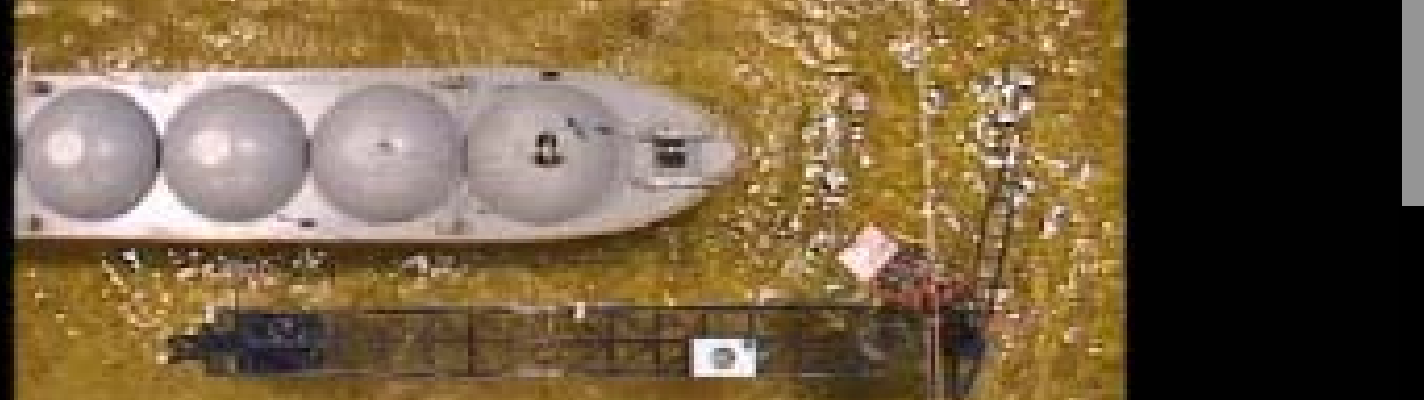

Collinear

Operational

$H_{s}=4.3 \mathrm{~m}$

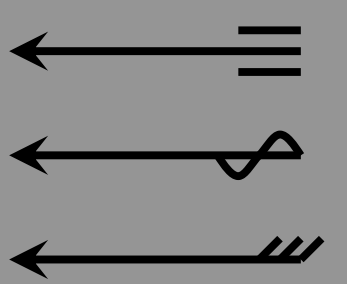




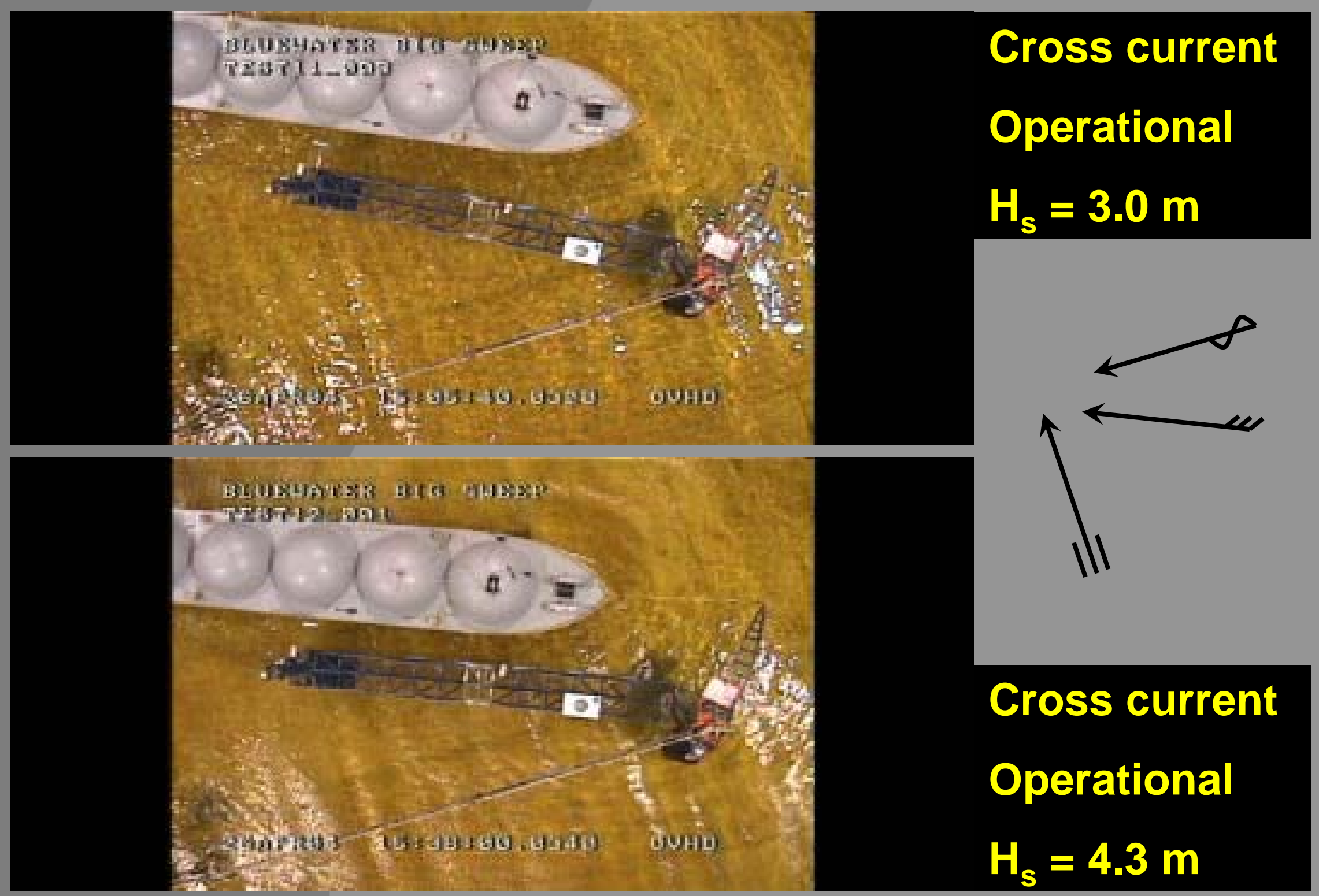




\section{Model Tests}

\section{Model Basin Tests - Results:}

- Survival Loads are well within design limits

- Operational $3 \mathrm{~m}$ sea-states are fully operable

- Operational $4.3 \mathrm{~m}$ sea-states are 'doable' for certain combinations of wind, wave \& current

- Configuration proved 'fail to safe' in hawser and DP failure cases 


\section{Model Basin Test Program - Pictures:}

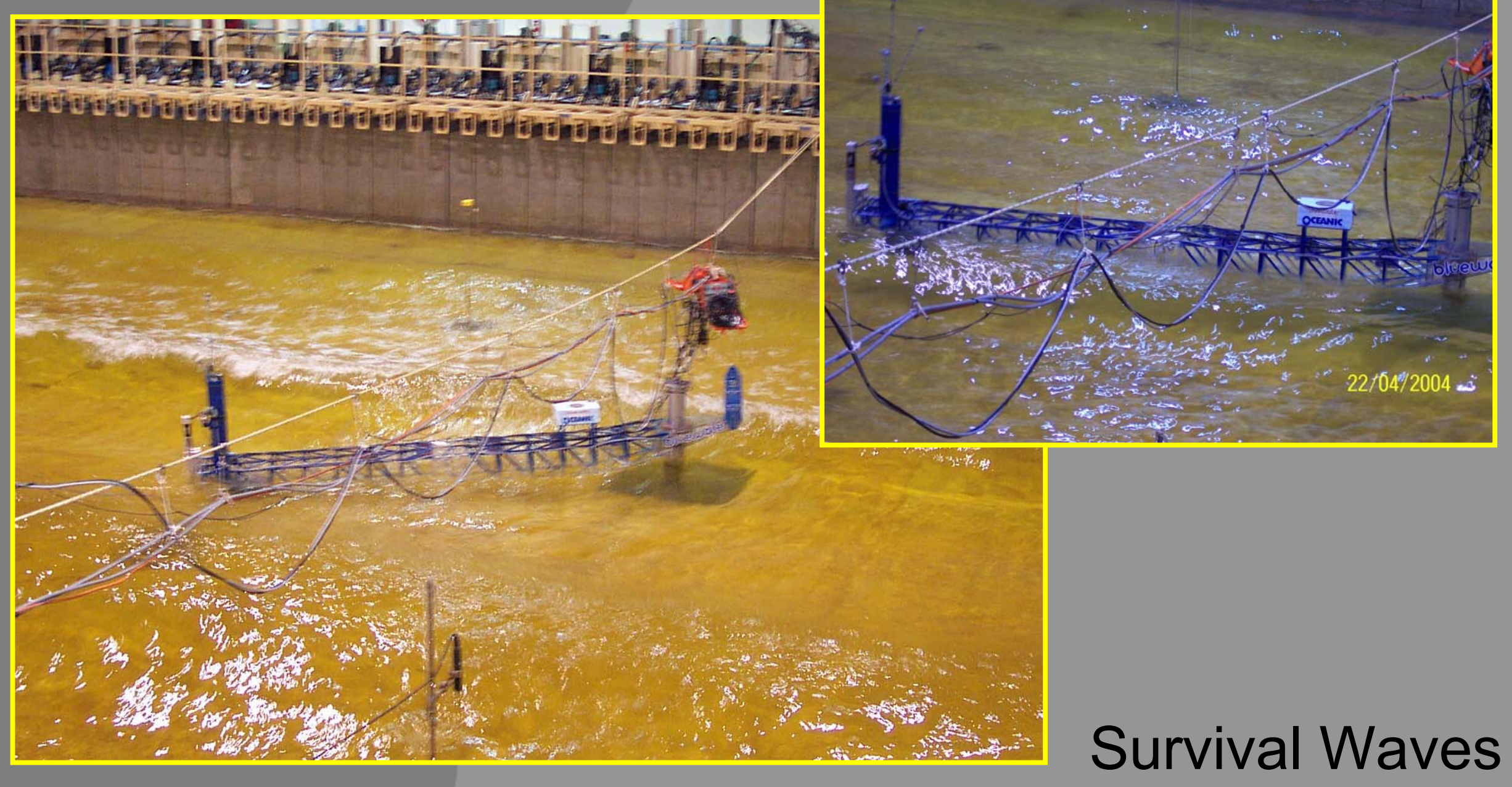




\section{Model Basin Test Program - Pictures:}

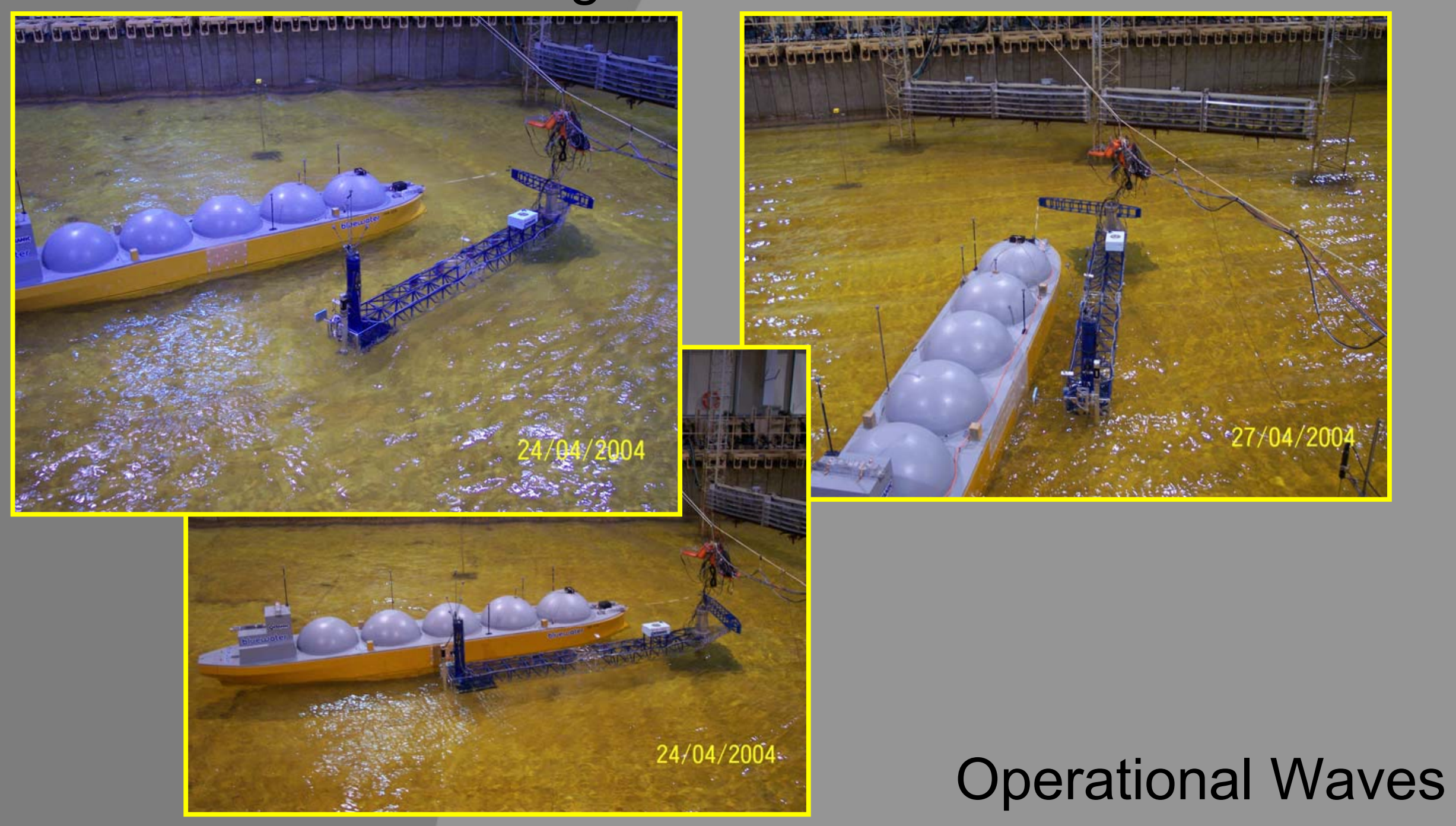




\section{Model Tests}

\section{Final report by Oceanic Consulting:}

"Throughout the tests, general observations showed that the arm and tanker would prove adequate for this type of mooring arrangement."

\section{And}

"Overall, nothing observed during the tests indicates that such a setup will not be able to operate in the conditions tested." 


\section{Heat Exchanger Field Test}

AGL Resources

Cherokee LNG Plant

DOE Final Report Presentation

March 8, 2005 


\section{Purpose of Tests}

- Prior to this new design, no exchanger existed that allowed pressures and flow rates required for direct cavern injection into salt caverns

- The Cherokee LNG plant provided the facilities for a full scale test

- No LNG tests of any type had provided heat transfer data at these flow rates, pressures, and temperatures. 


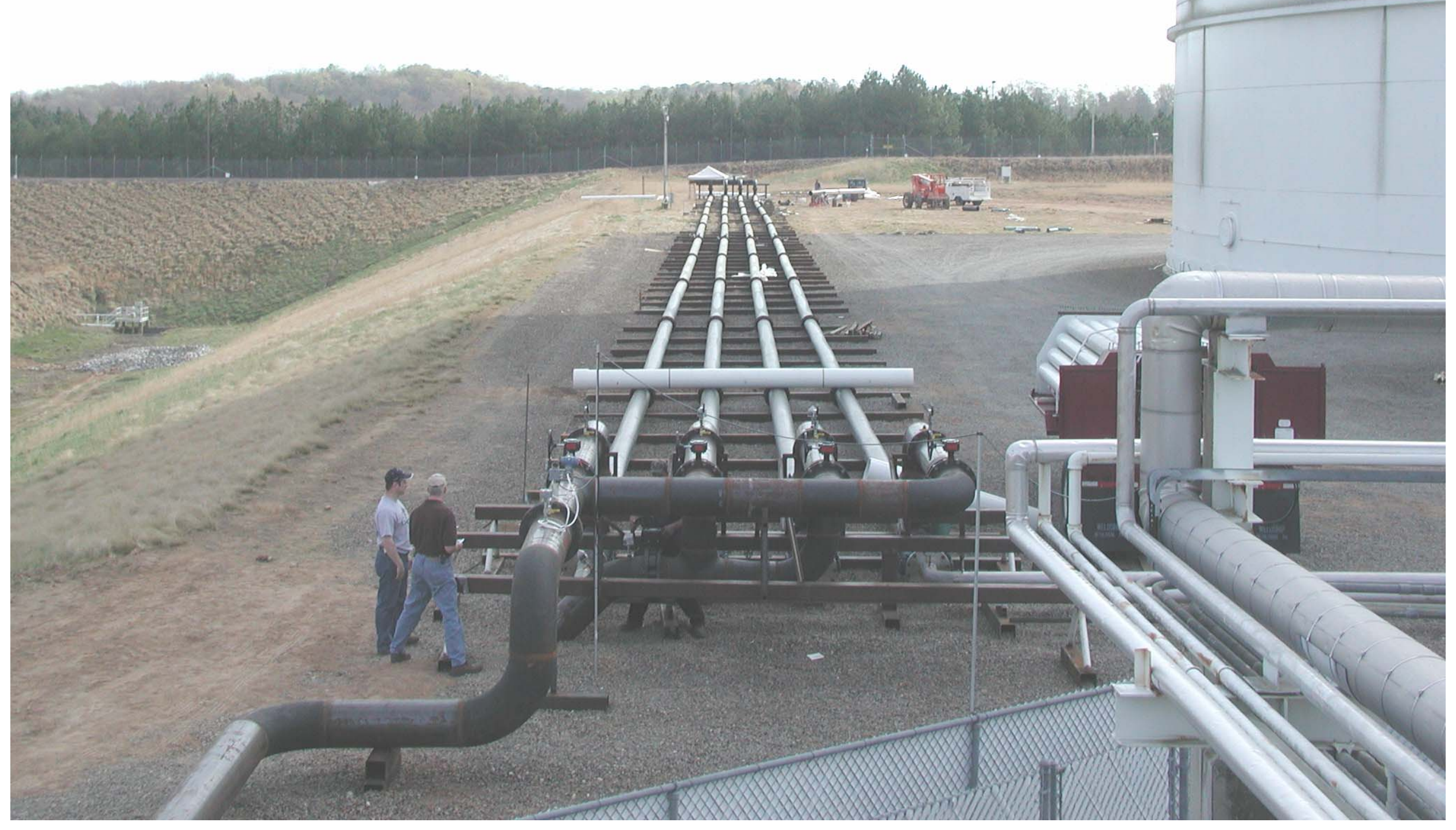




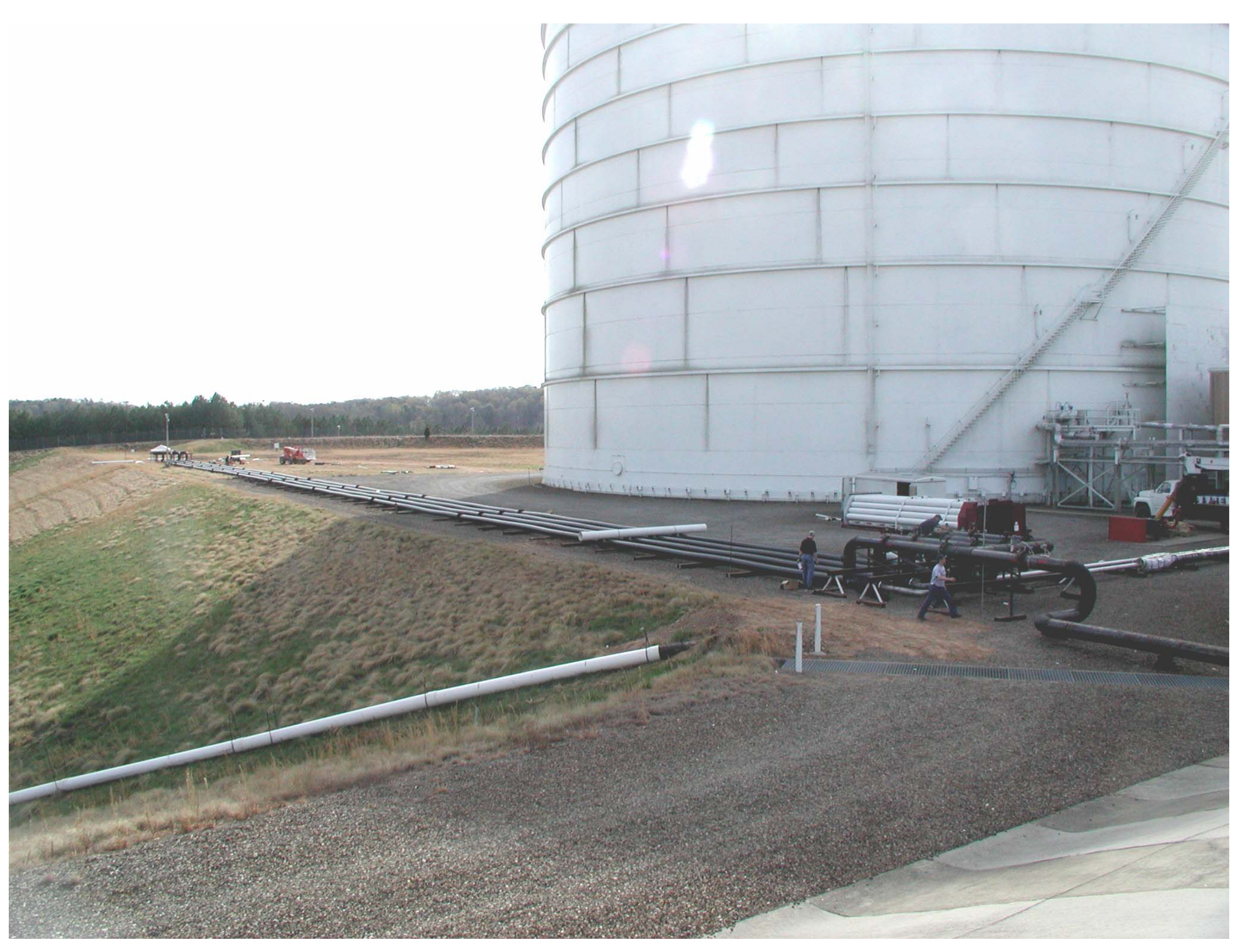




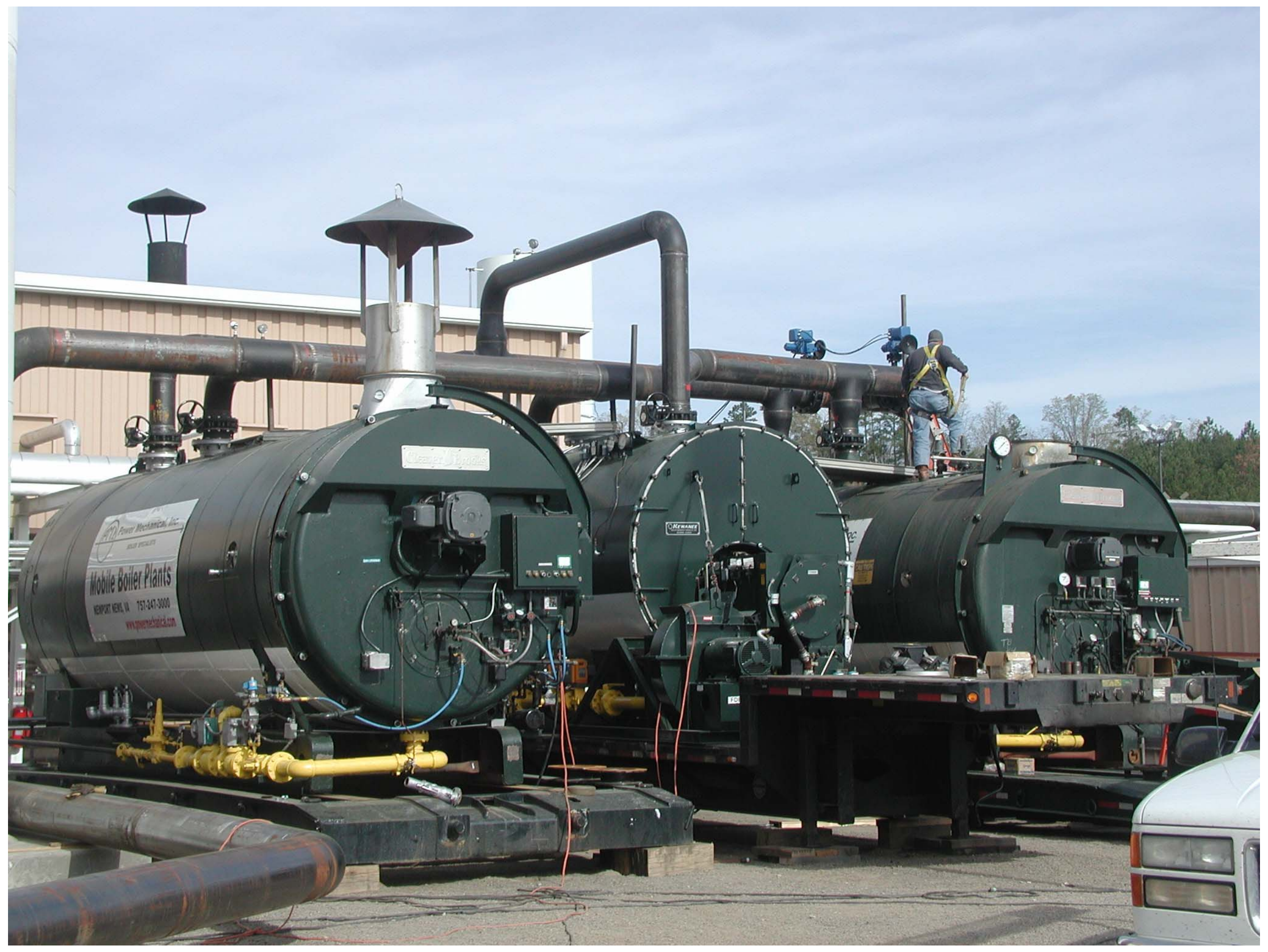




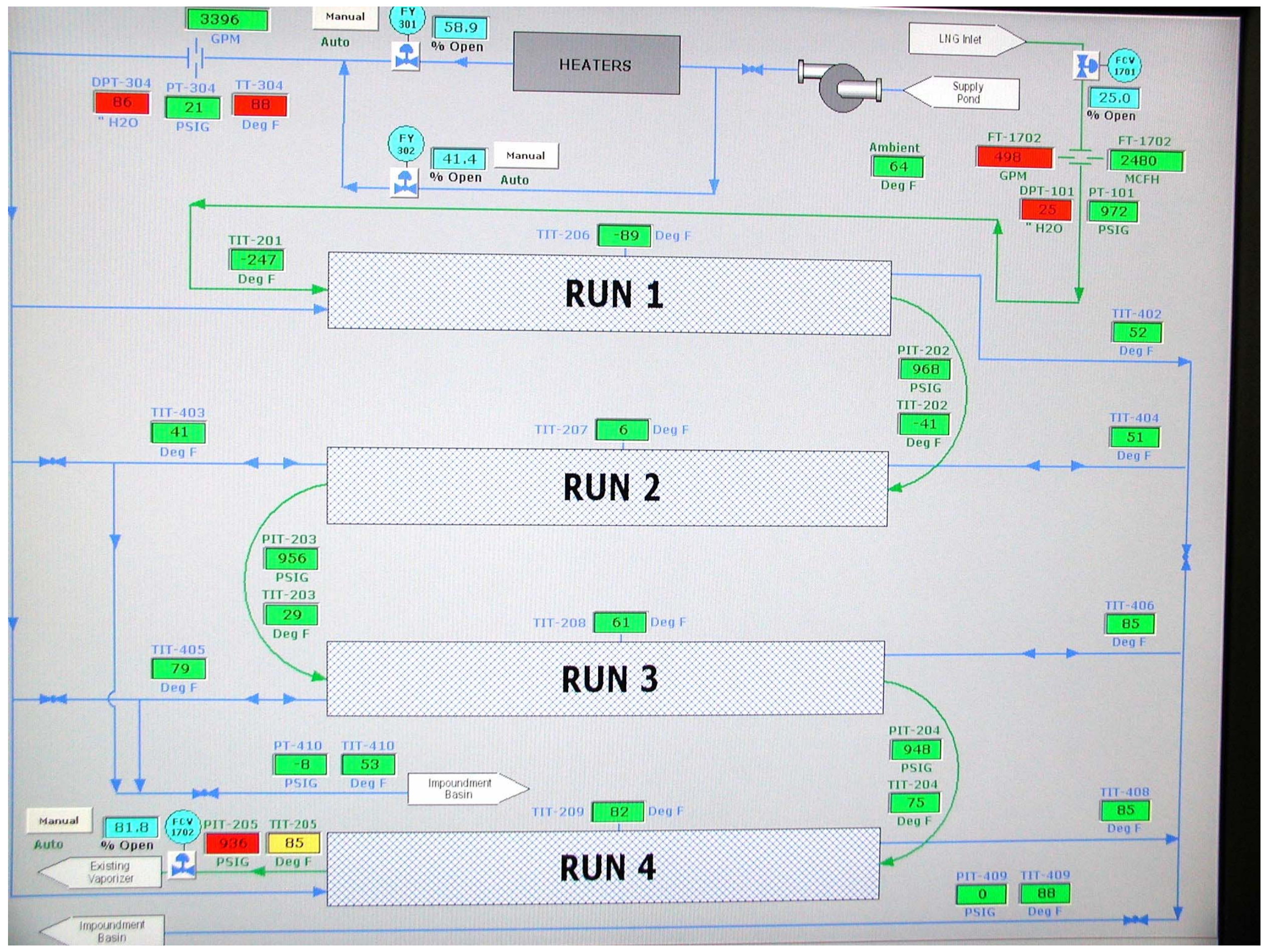




\section{Heat Exchanger Field Test Results}

- The test was successful

- Severe tests that should have blocked, flowed freely

- Calculations indicate most ice removed by flow, confirmed by measurements

- Higher than predicted heat transfer

- Ice measurements appear reasonably accurate - matched by simulations

- Tests provided a wide range of conditions 


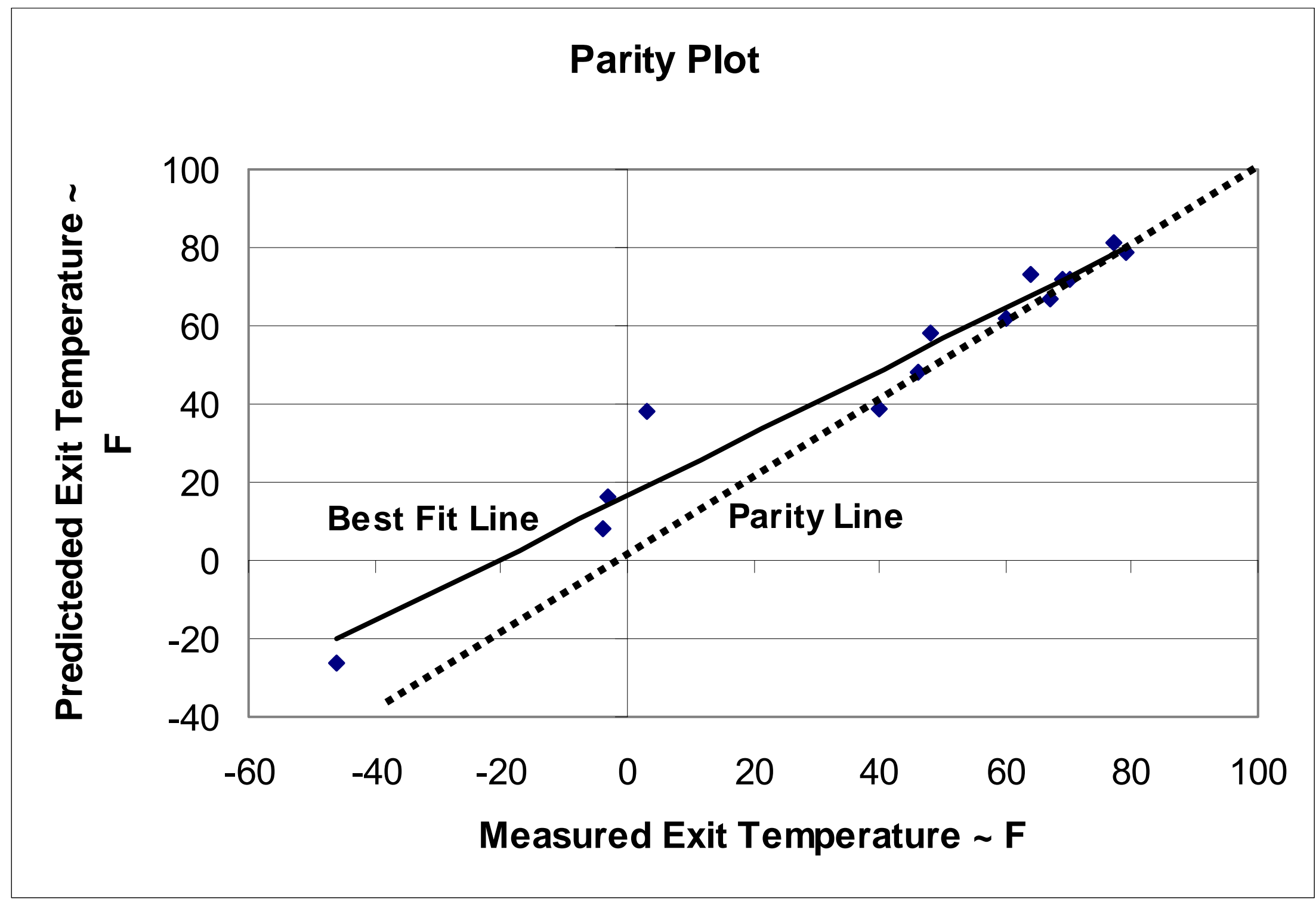




\section{Heat Exchanger As Tested}

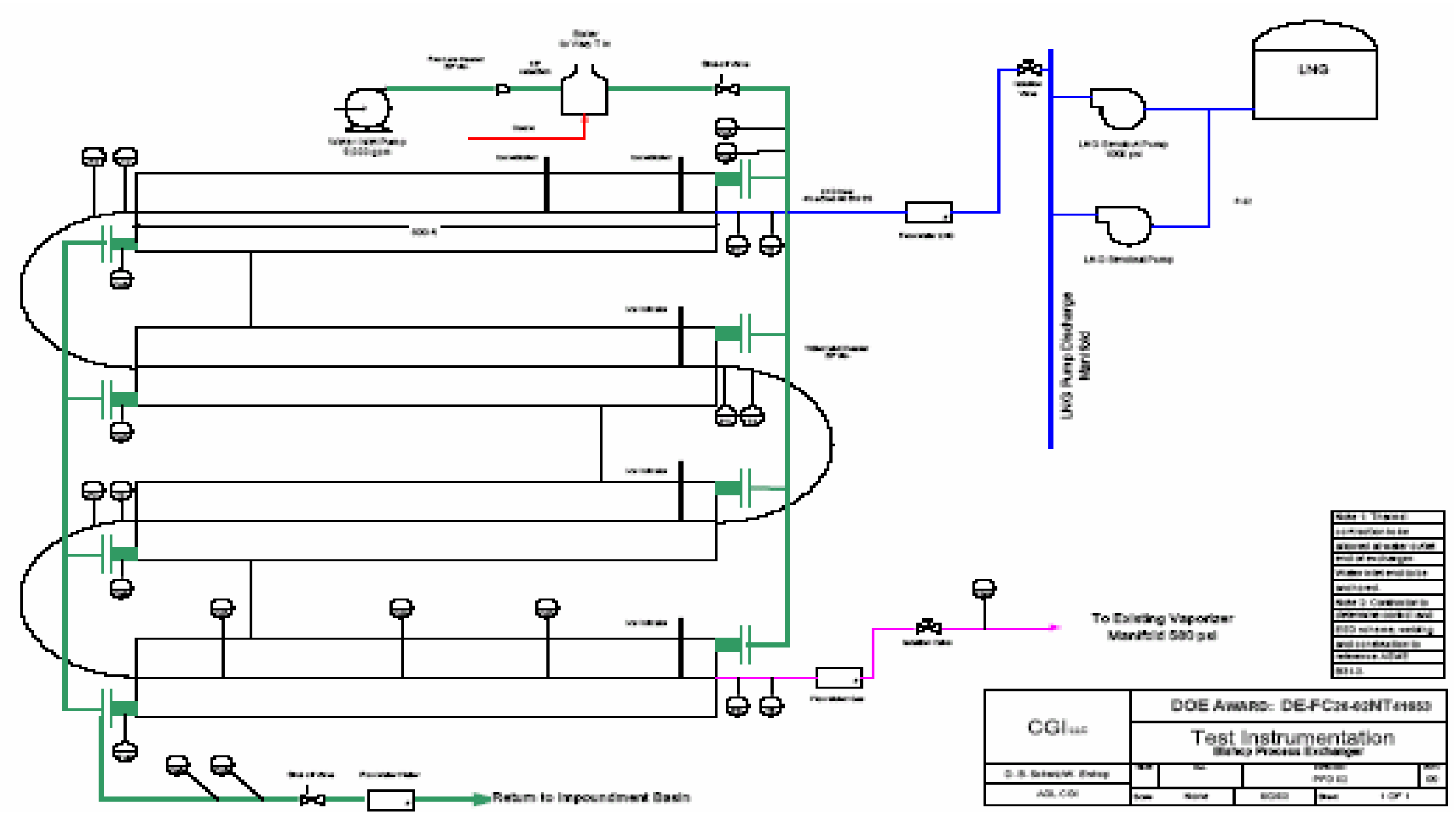




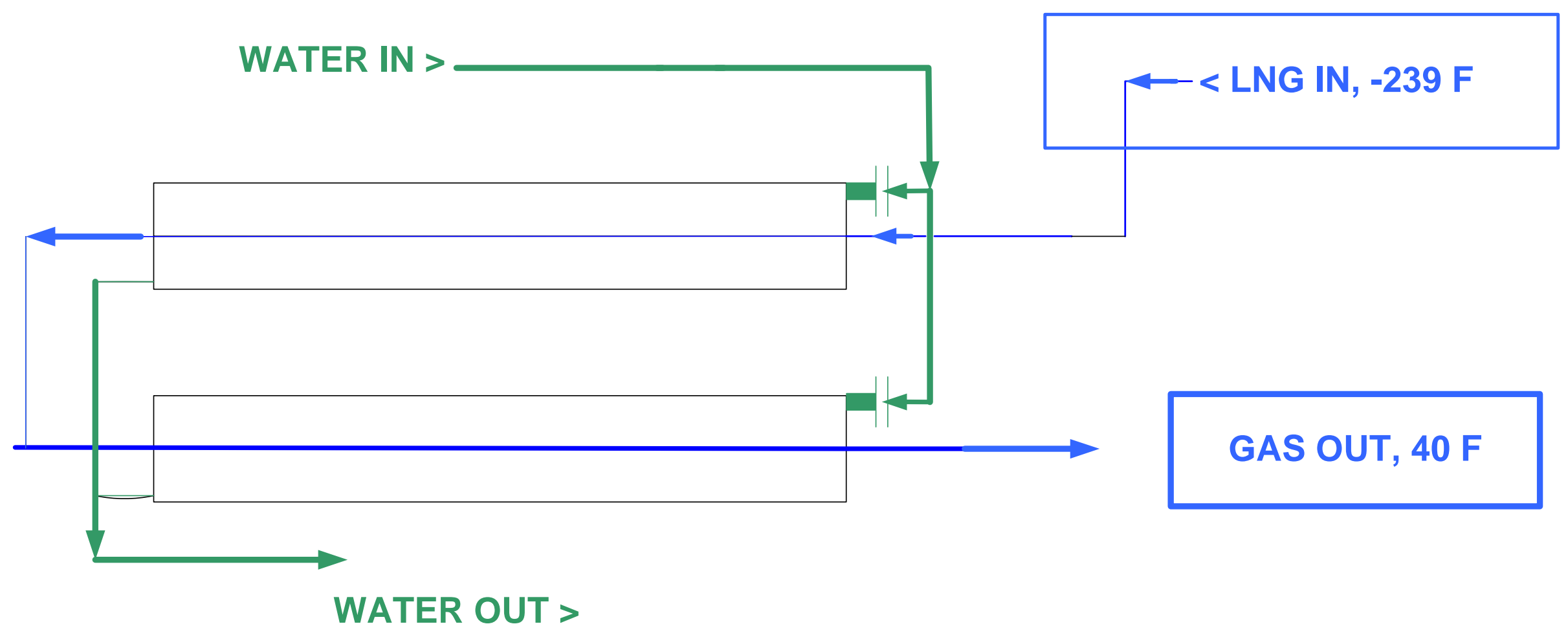

\author{
270' per leg \\ $75 \mathrm{~m} 3 / \mathrm{hr}$ \\ 4.5" cryo OD \\ 9" warmant ID, delta T 12F \\ wall $\mathrm{t}=0.14$ " \\ delta $p$ LNG $\sim 10$ psi, water $\sim 25$ psi
}




\section{New "Optimized" Exchanger Design-Cryo Pipe}

- Reduced cryo radius from $65 / 8$ " to $4 \frac{1}{2}$ "

- Wall thickness reduced by $47 \%$ to 0.14 "

- New metal selection Inconel 27-7MO

- Length increases from 2000' to 2160'

- Cryo weight decreased by $50 \%$ 


\section{New "Optimized" Exchanger Design-Warmant Pipe \& Water}

- ID reduced from 11.5" to 9.0"

- Weight per foot reduced from 21.0 to 12.4

- Water weight reduced by $26 \%$

- Total weight reduction per $300 \mathrm{~m}^{3} / \mathrm{hr}$ exchanger $=45,682 \mathrm{lbs}=34 \%$ 


\section{Advantages of the Bishop Process Heat Exchanger vs. Shell and Tube}

- Closed loop flush system

- Easily repairable offshore or on site.

- Fully drainable between uses. Allows exposure to air

- Constructed on site by local labor.

- Fully variable flow rates, turndown.

- Can tolerate a high degree of turbidity, foreign matter.

- Can handle warmant fluid very close to the warmant freezing point.

- Can't freeze on flow stoppage or power outage.

- Overall very robust technology \& lower costs 


\section{Seawater Warming Biota Problem}

- NOAA assumes $100 \%$ biota kill

- Seawater warming possibly not permitted

- CGI biota protection approach

- Closed Loop Flush system > zero biocide

- Low damage pumps: vanes, screws, lobes

- Low warmant velocity, $10 \mathrm{fps}=7 \mathrm{mph}$

- Bulk temperature drop: $12^{\circ} \mathrm{F}$

- Biota not affected by cryo wall temperature 
Flow in exchanger annulus

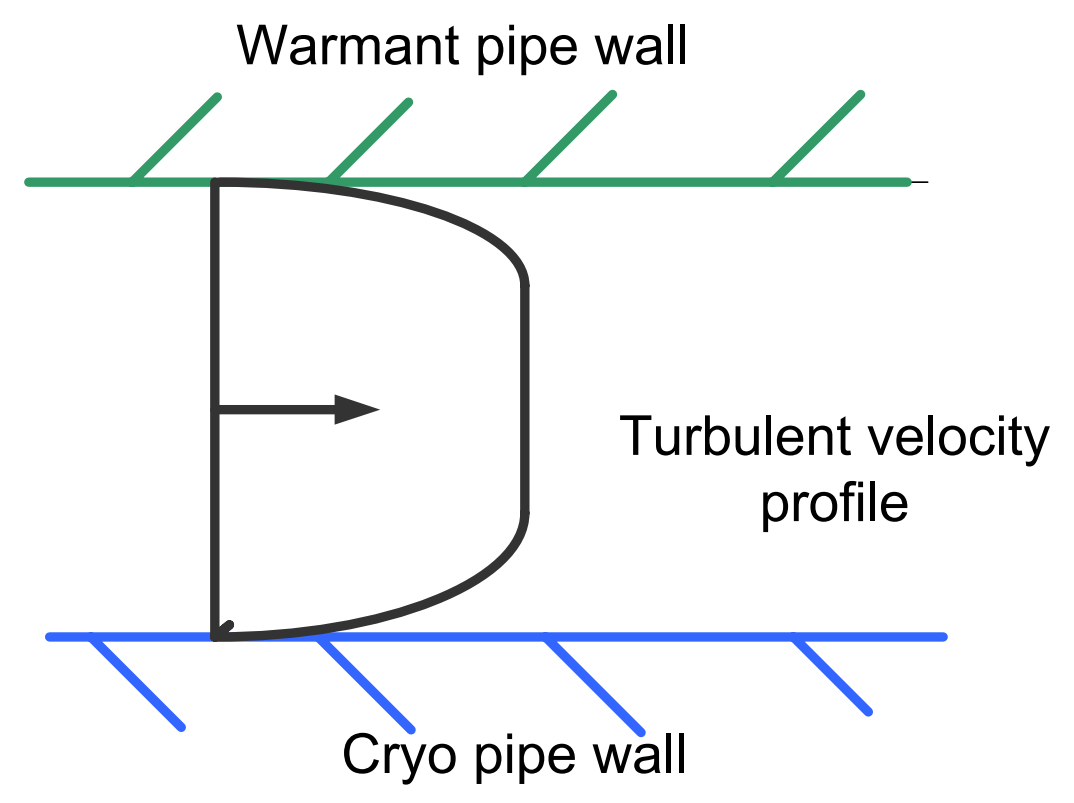

Biota have neutral buoyancy and high viscosity, follow path of least resistance, remain in center of flow, experience only the 12 degree drop 


\section{Consequences of Seawater Warming}

- Less air pollution

- Lower capital cost

- Increased gas delivery

- Gas use saving of approximately $1.3 \%$

- $\$ 6$ gas \& 1 BCFD, savings $=\$ 78,000 /$ day

- Saved gas/year at $1 \mathrm{BCFD}=4.7 \mathrm{BCF}$ 


\section{BRAXTON \\ C I A T E S}

\section{Task 2.0}

\section{Field Test High}

Pressure LNG Pump 


\section{Qualified Vendors}

\section{Ebara International Corporation - Cryodynamics Division}

Nikkiso Cryo Corporation 


\section{Ebara Pump Assembly}
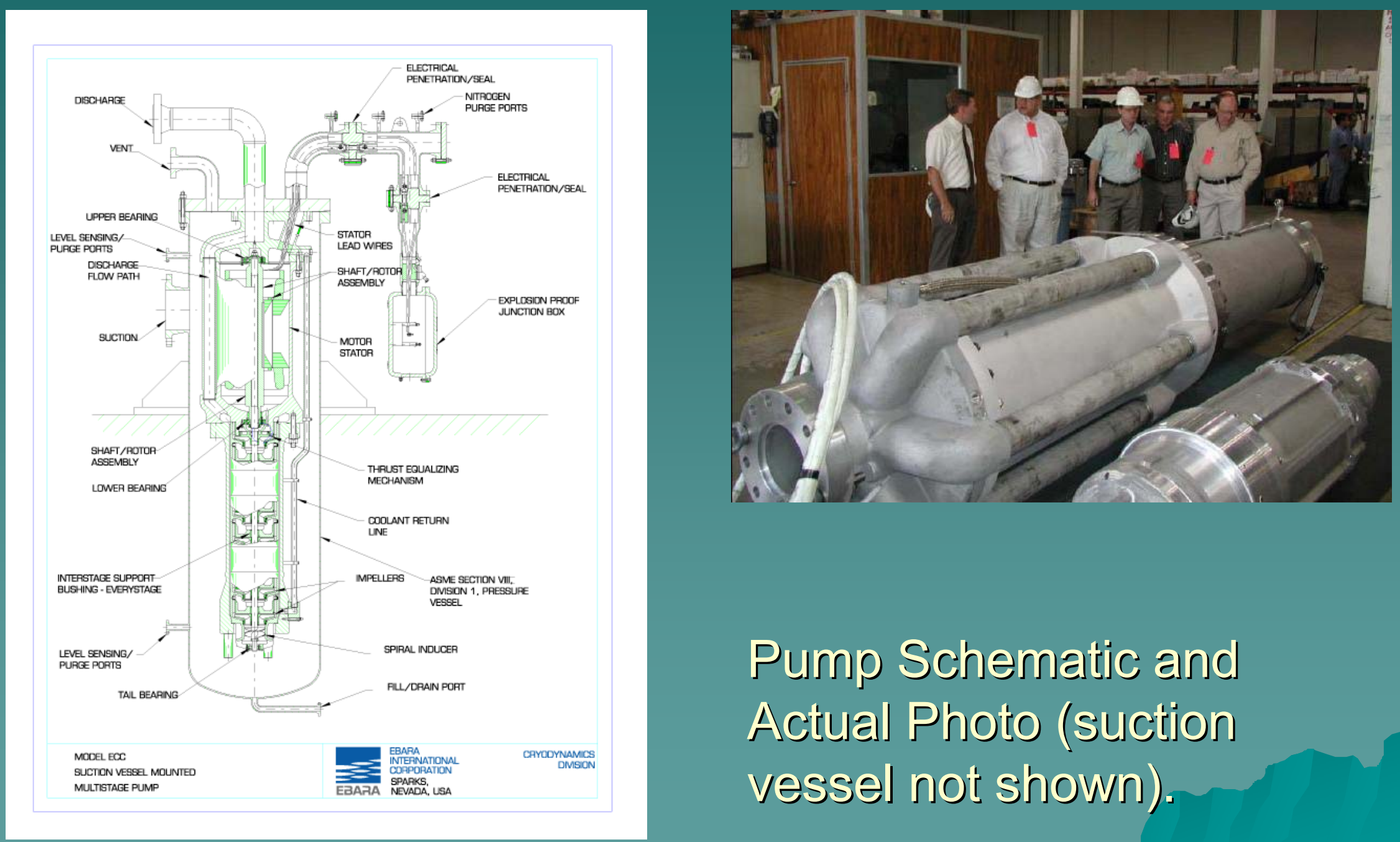

Pump Schematjc and Actual Photo (suctjon vessel not shown). 


\section{Ebara Pump Performance Test}

- This proposal provides for the testing of one Model 8ECC-15-6, LNG submerged motor pump to demonstrate that pumps in excess of 2000 psi could be manufactured using existing technology

- Ebara to use a pump that is currently being manufactured for operational use

The test will be conducted in LNG

The test will consist of operation of the 8ECC-1516 pump at several flow rates and pressures to demonstrate the proper function of the pump and it's various features.

- The pump will be fully instrumented to verify flow, pressure, power, voltage, frequency, vibration level, input and output temperature

- The pump will be tested at five points at flow rates from 0 flow (shut-off') to maximum flow (120\% of rated flow). One NPSH test will also be performed at rated flow.

, Results of the testing will be recorded, with a full Test Report issued affer the compilation of all test data. 


\section{Ebara Pump Test Facility}

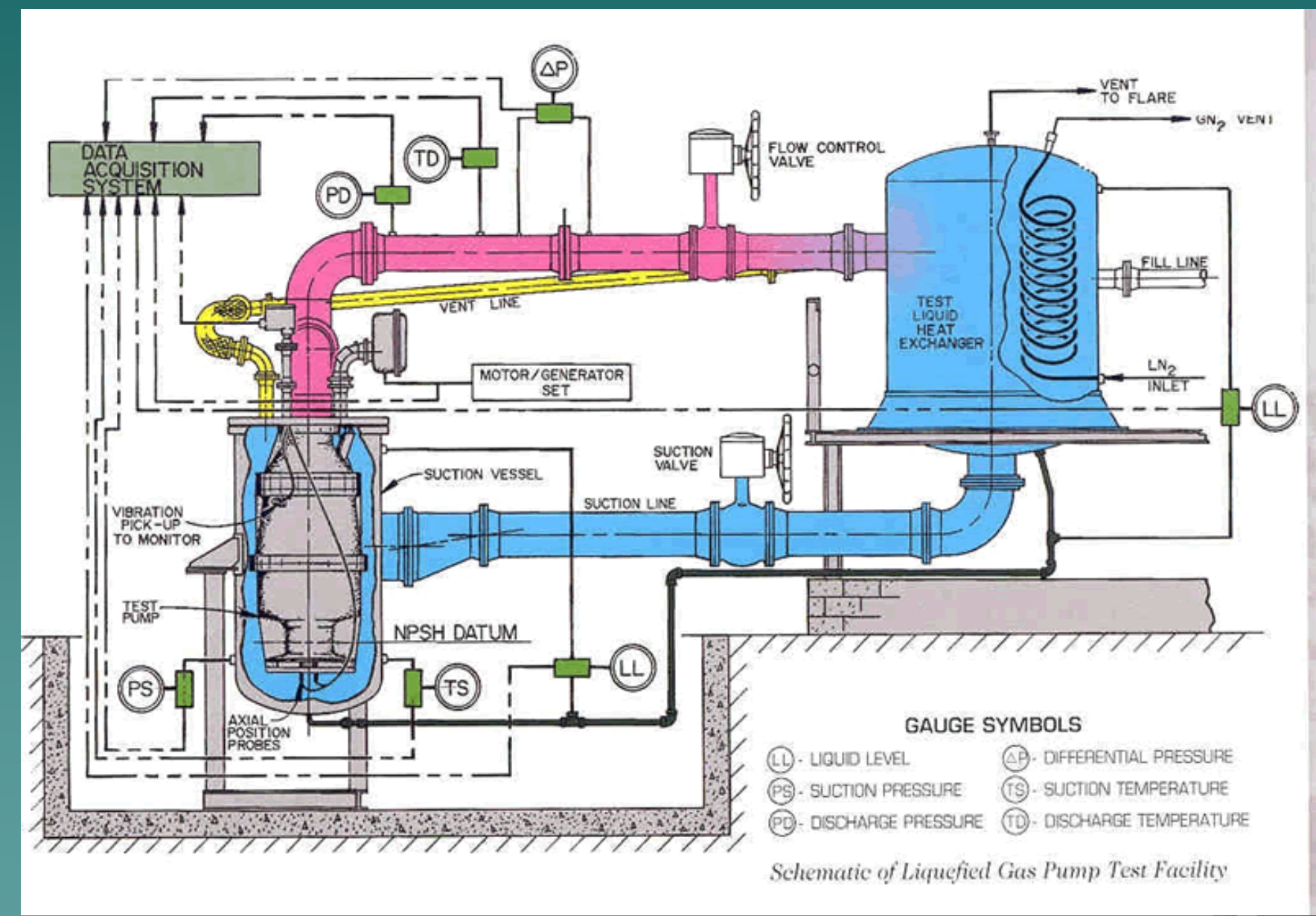




\section{Ebara Pump Test Facility}

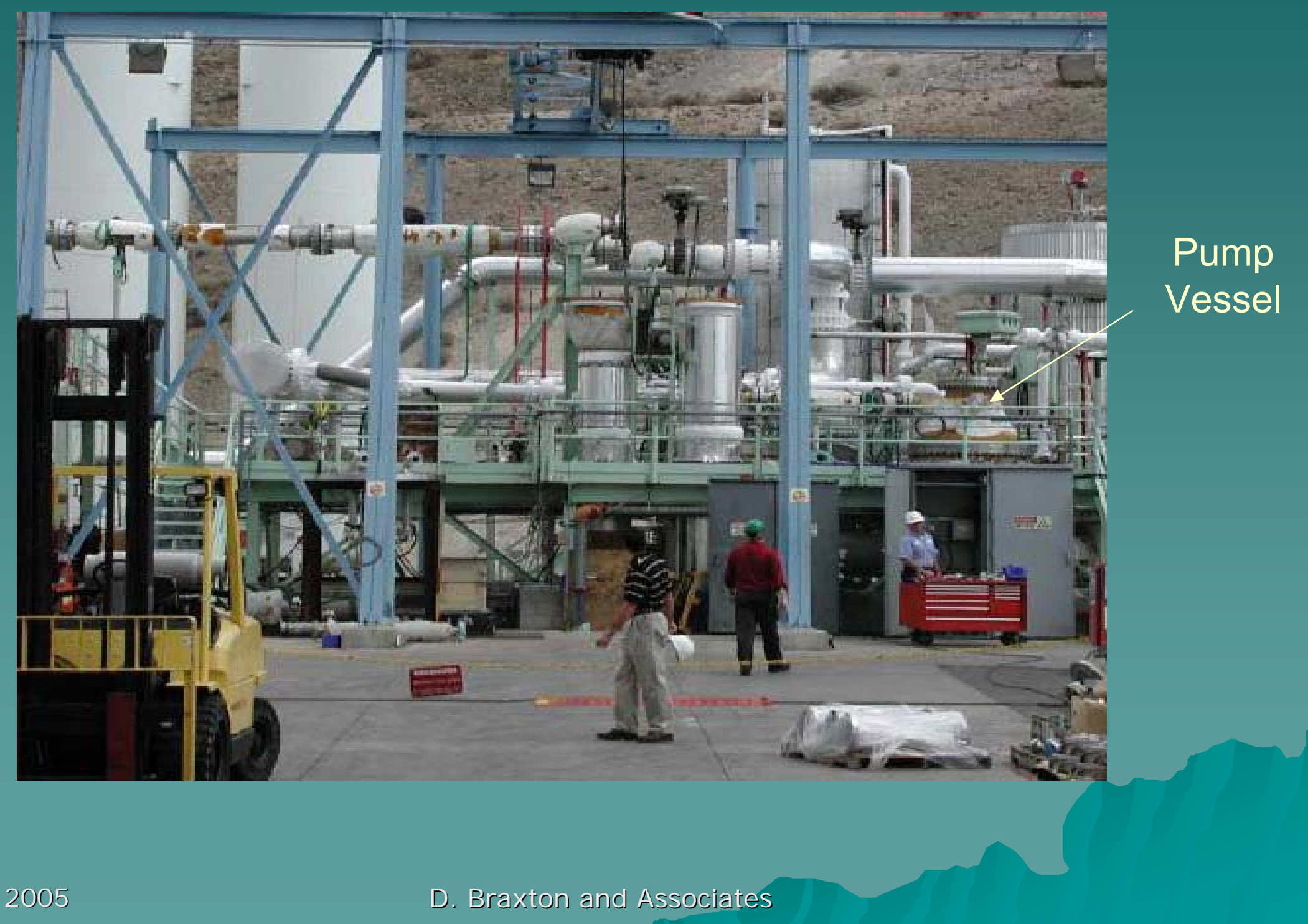




\section{Ebara Test Pump Specifications}

Pump Tested: Model 8ECC-1516

$\checkmark 8$ inch discharge

$\checkmark 16$ stages

-15" nominal impeller

$50 \mathrm{HZ}$ (motor is also designed to operate at 60 $\mathrm{Hz})$

Rated Speed: 2960 RPM

Rated Flow: $475 \mathrm{m3} / \mathrm{hr}$

Rated Head: 2120 meters, or 1325 psi at .44 specific gravity

- Rated Motor Power: 2000 kw or 2680 hp

- Code: API 610 modified for cryogenic requirements 


\section{Ebara Performance Results}

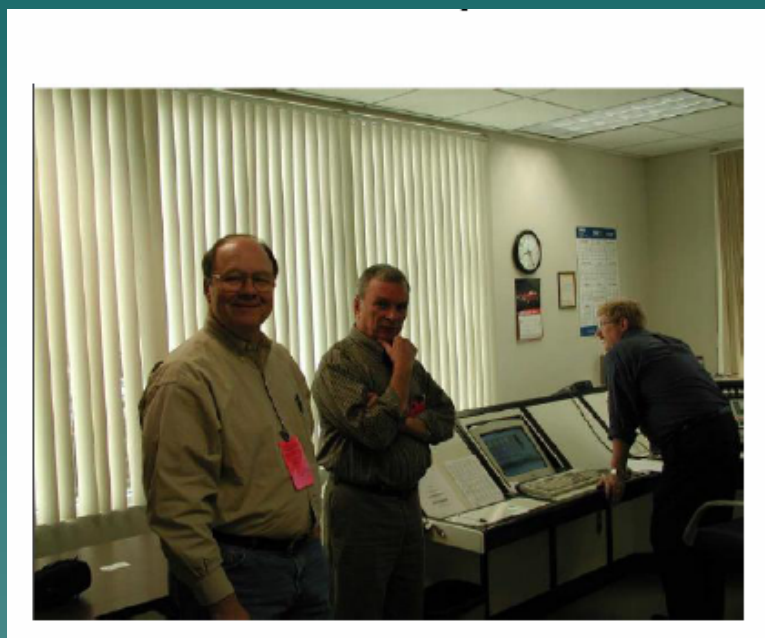

$\mathrm{LNG} \mathrm{SG}=0.4252$

Electric Freq $(\mathrm{Hz}) \quad \sim$ motor speed $(\mathrm{rpm}) \quad$ Dis Pres (psia)

\begin{tabular}{|c|c|c|c|}
\hline \multirow{2}{*}{$\begin{array}{l}\text { Flow rate } \\
\left(\mathrm{m}^{\wedge} 3 / \mathrm{hr}\right)\end{array}$} & 47.5 & 2812 & 1700 \\
\hline & 48.5 & 2871 & 1752 \\
\hline \multirow[t]{5}{*}{307} & 49.5 & 2930 & 1760 \\
\hline & 50 & 2960 & 1780 \\
\hline & 51 & 3019 & 1860 \\
\hline & 51.5 & 3049 & 1940 \\
\hline & 51.8 & 3067 & 1970 \\
\hline \multirow{2}{*}{240} & 52 & 3078 & 2005 \\
\hline & 52.5 & 3108 & 2050 \\
\hline
\end{tabular}

Note: The motor speeds are approximate, assumed slip $=1.3 \%$ (a) $50 \mathrm{~Hz}$ the motor shaft is turning a $2960 \mathrm{rpm}$

Note: the flow rate was reduced to operate within the power limits of the electric motor, discharge pressure at $2960 \mathrm{rpm}$ is greater than design because the operating point is closer to shut-off than the design operating point. 


\section{Ebara Cavern HP Pump Design}

Rated PSI - 2,353

\begin{tabular}{|c|c|c|c|}
\hline \multicolumn{3}{|l|}{ Pump Model } & 6ECC-1518 \\
\hline \multicolumn{3}{|l|}{ Number of Stages } & 18 \\
\hline \multicolumn{3}{|l|}{ Liquid } & LNG \\
\hline \multirow{2}{*}{ Operating Temperature } & $\left({ }^{\circ} \mathrm{C}\right)$ & & -160 \\
\hline & & & 0.45 \\
\hline Specific Gravity & $\left(\mathrm{m}^{3} / \mathrm{hr}\right)$ & & 330 \\
\hline B.E.P. Flow & $\left(\mathrm{m}^{3} / \mathrm{hr}\right)$ & & 308 \\
\hline Minimum Continuous Flow & $\left(\mathrm{m}^{3} / \mathrm{hr}\right)$ & & 108 \\
\hline \multirow[t]{2}{*}{ Differential Head: } & (m) & & 3756.0 \\
\hline & (m) & (see Note 1) & 3887.9 \\
\hline Shutoff & (m) & & 4608.0 \\
\hline Rated Flow & (m) & (see Note 2) & 1.67 \\
\hline Efficiency: & $(\%)$ & & 64.6 \\
\hline B.E.P. & (\%) & & 64.9 \\
\hline Power Required: Rated & $(\mathrm{kW})$ & & 2351.9 \\
\hline B.E.P. & $(\mathrm{kW})$ & & 2261.1 \\
\hline Maximum & $(\mathrm{kW})$ & (see Note 3) & 2580.7 \\
\hline Shutoff & $(\mathrm{kW})$ & & 1023.0 \\
\hline Rated Rotational Speed (Calculated) & (rpm) & & 3560 \\
\hline Vibration Level & & IN & API 610 \\
\hline Maximum Differential Pressure & $(\mathrm{kg} / \mathrm{cm}$ & & 207 \\
\hline
\end{tabular}




\section{Ebara Cavern HP Motor Design}

Rated Horsepower - 3,500

\section{MOTOR DATA SHEET-QUOTATION, HIGH FLOW}

Pump Model Number

Manufacturer

Motor Rating

Voltage

Frequency

Number of Poles

Synchronous Speed

Current:

Full Load (100\% Volts)

Starting $(100 \%$ Volts $)$

Insulation Class

$(\mathrm{kW})$

(V)

$(H Z)$

(rpm)

(amps)

(amps)

6ECC-1518

EIC/EMD

2610

6600

60

2

3600

Winding Type

Winding Special Treatment

Metallic Parts Treatment

Starting Method

Starting Time (Calculated)

Rotor Type

$\begin{array}{cl} & \text { F } \\ & \text { Random Wound } \\ \text { Epoxy Dbl Vac Press Impregnation } & \text { Hot Varnish Dip } \\ & \text { Direct On Line } \\ \text { (sec) } & 1.2 \\ \text { Squirrel Cage With Aluminum Bars }\end{array}$




\section{Ebara Cavern HP Pump Curve}

\section{Estimated Pump Characteristic Curve - Pump Engineering}

LIQUID : LNG @ - $160 \mathrm{C}$

SPECIFIC GRAVITY : 0.45

IMPELLER DIA. (min/rated/max) : $285 / 340.75 / 406 \mathrm{~mm}$

RATED FLOW : $300 \mathrm{~m} 3 / \mathrm{h}$

RATED HEAD : $3437 \mathrm{~m}$

ELECTRICAL DATA : $60 \mathrm{~Hz} / 6600 \mathrm{~V} / 2$ Pole (3600 RPM) / 3 Phase

PROJECT : LNG Receiving Terminal PUMP MODEL : 6ECC-1516

ITEM NO. : Case \# 2, Medium Flow CUSTOMER : CGI
DOC. NO. : C-QUS-3124-2

REVISION : N/C

DATE : May 29/03

PREPARED BY : N/A

APPROVED BY : J. Goodrich Jr.

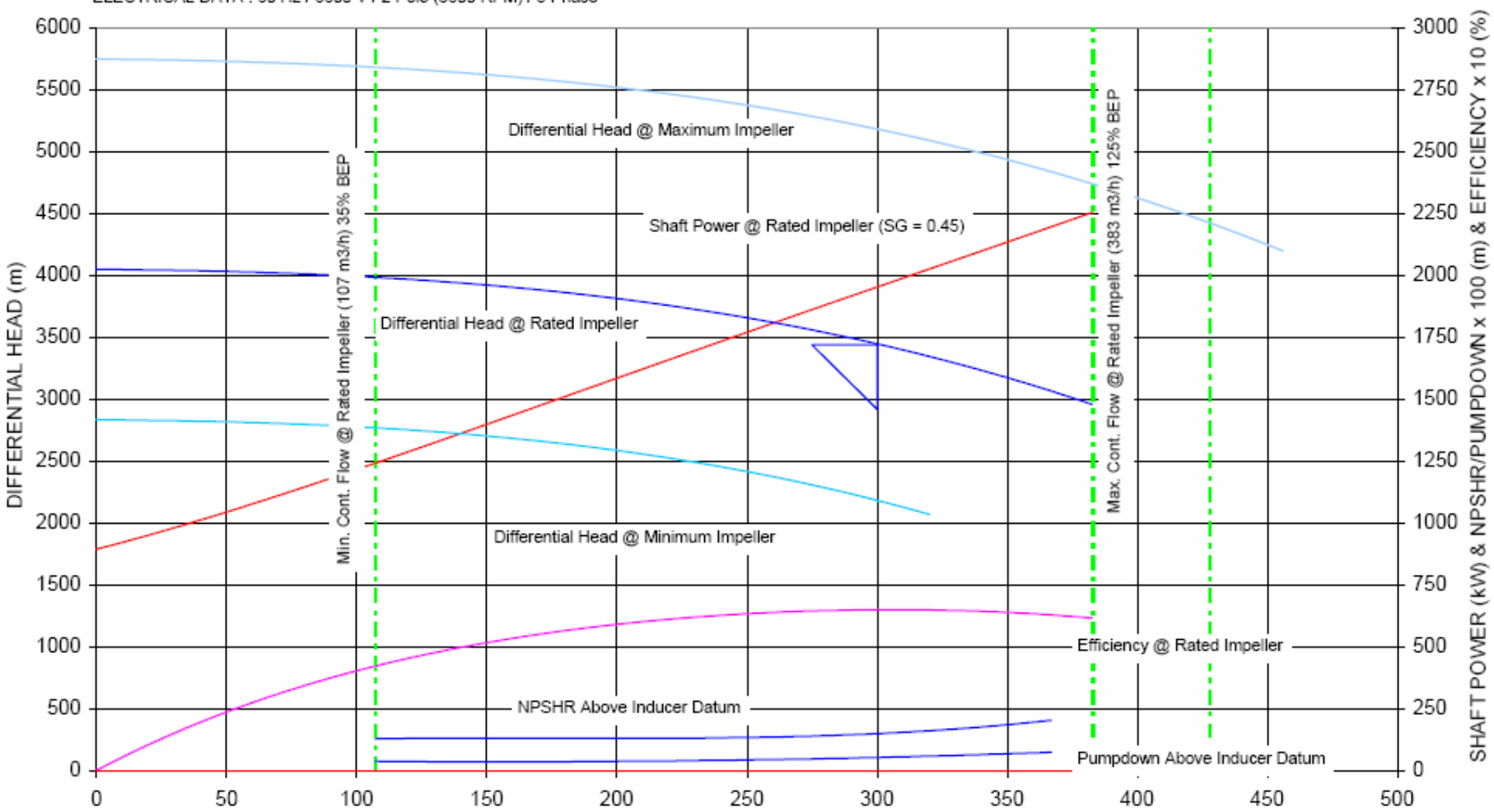




\section{Nikkiso Test Stand}

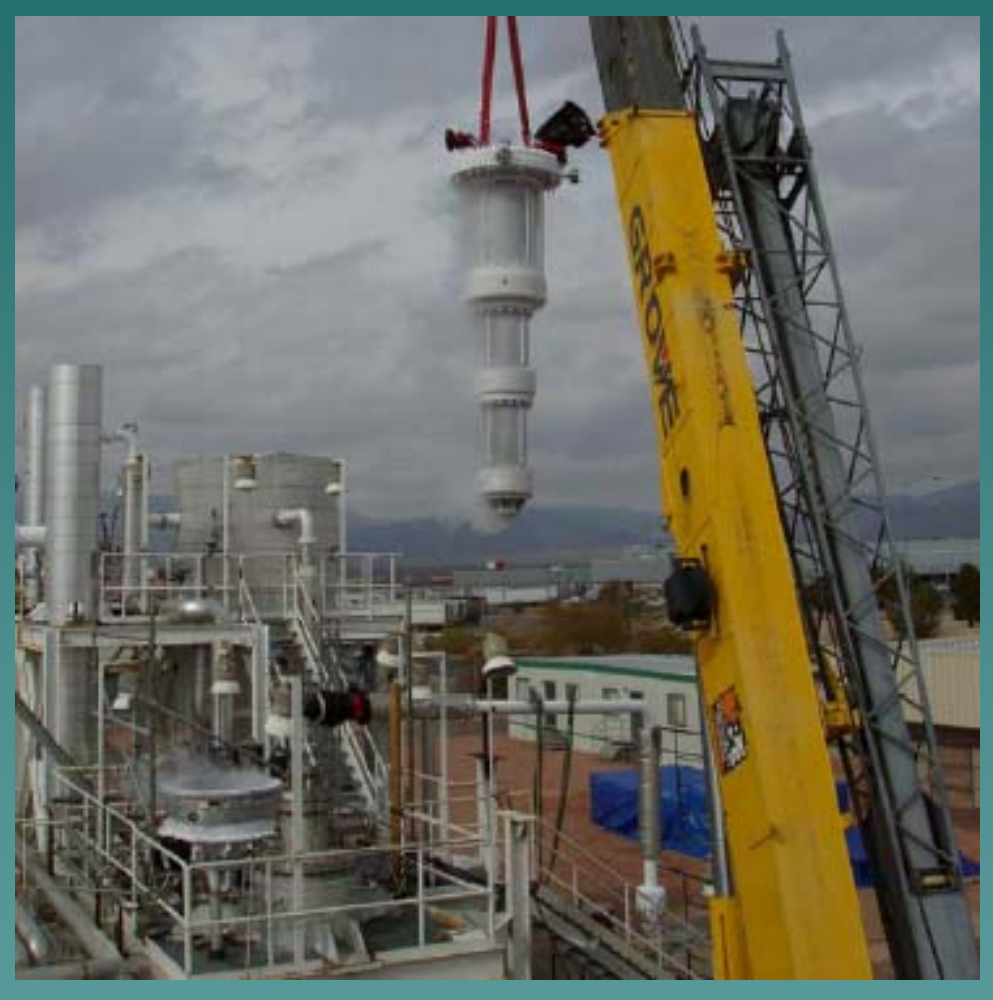

Pump Extraction from Test Stand

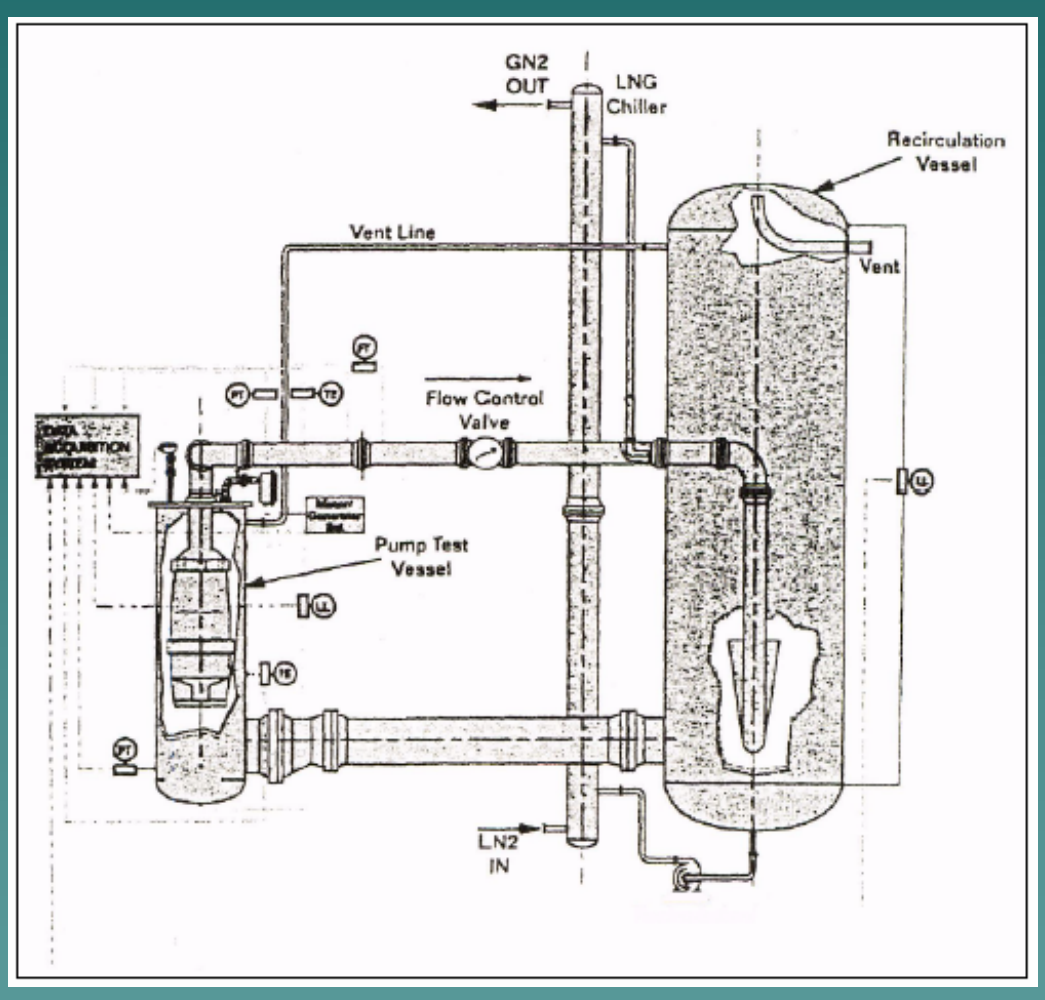

Test Stand Schematic 


\section{Nikkiso Pump Assembly}

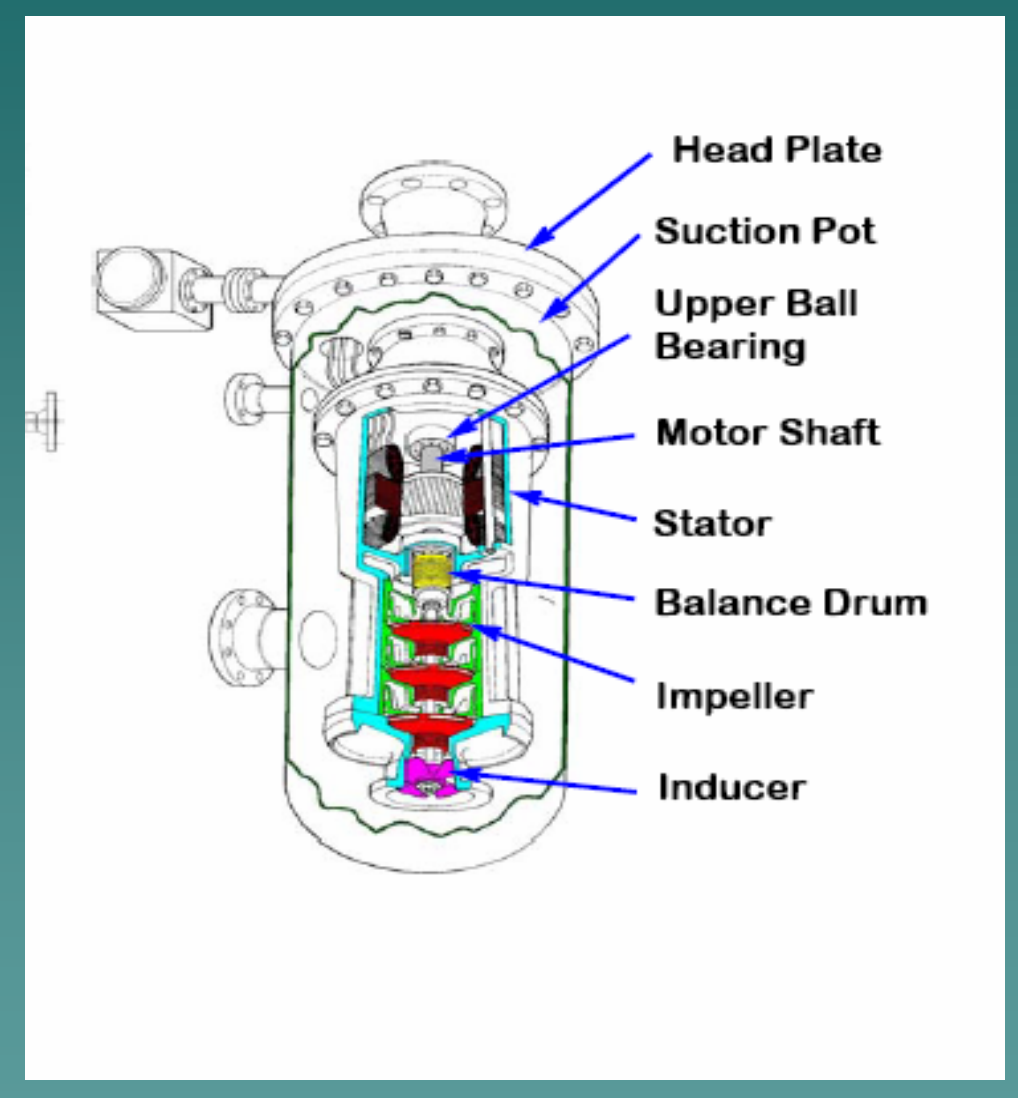

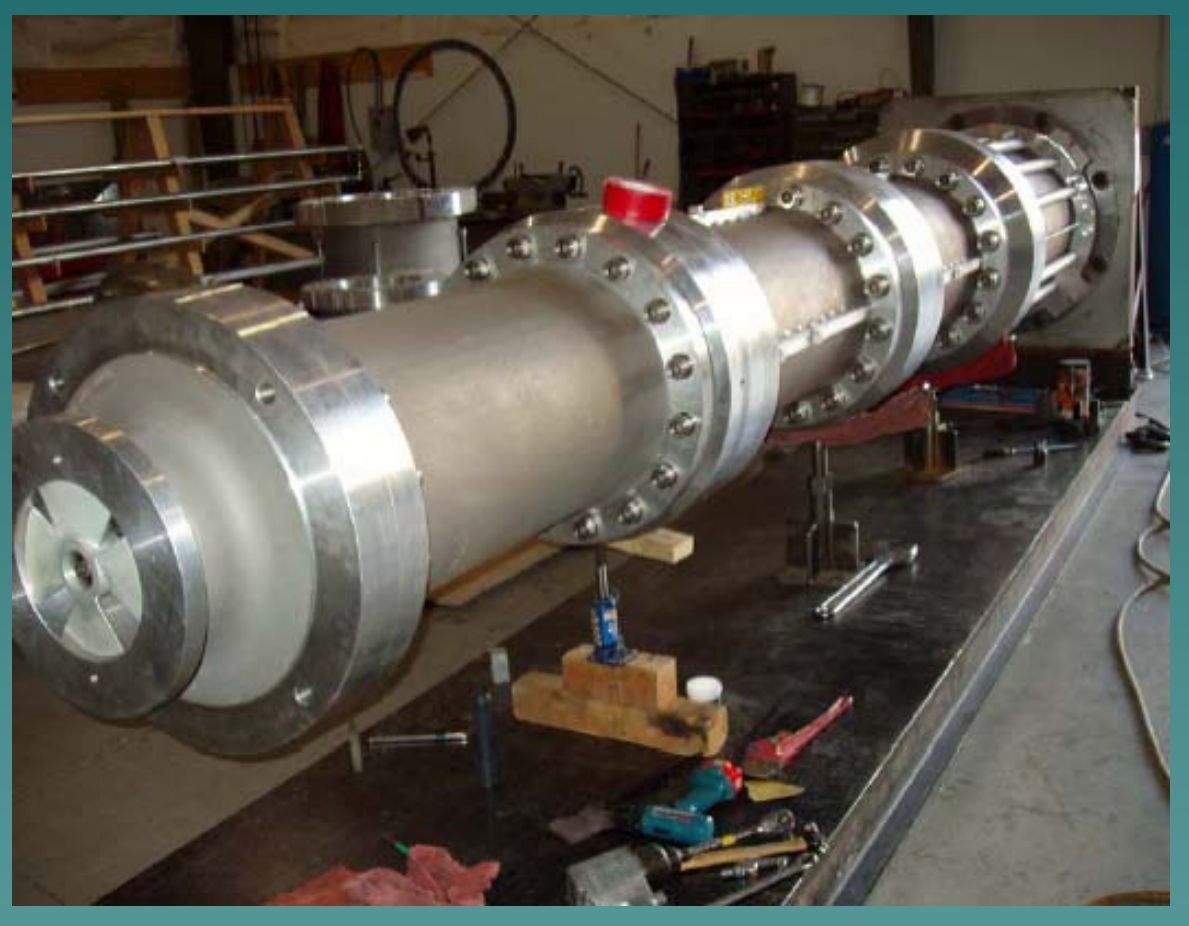

Pump Schematic and Actual Photo (suction vessel not shown). 


\section{Nikkiso Test Pump Specifications}

Pump Tested: Model 60788L12-P1100F

$\checkmark 6$ inch discharge

$\checkmark 12$ stages

12.5 inch nominal impeller

$\checkmark 60 \mathrm{HZ}$

Rated Speed: 3600

- Rated Flow: 205 m3/hr

Rated Head: 2370 meters (2,110 psi)

- Rated Motor Power: 1015.4 kW (1,361 hp)

- Code: API 610 modified for cryogenic requirements 


\section{Nikkiso Test Pump Results}

TEST PROCEDURE: NIKKISO Dos. No.: DEJ62E12A-04

\begin{tabular}{|c|c|c|c|c|c|}
\hline Parameters & $\begin{array}{l}\text { Ref. } \\
\text { No }\end{array}$ & $\begin{array}{l}\text { Spec Sheet ? } \\
\text { Description }\end{array}$ & Acceptance Critena & Result & Conclusion \\
\hline Ratod Head & 7.0 & $2370 \mathrm{~m}$ & $\begin{array}{l}\text { Msximum } 2417,4 \mathrm{~m} \text { Minimum } \\
2322.6 \mathrm{~m}\end{array}$ & $\begin{array}{l}2325.5 \mathrm{~m}\left[207,4 \mathrm{~m}^{3} \mathrm{~h}\right. \\
1336.3 \mathrm{~m}\left[205 \mathrm{~m}^{3} / \mathrm{h}\right][ \\
\text { Projocted J }\end{array}$ & Acceptable \\
\hline Head $̧$ Strat off & 7.0 & $2600 \mathrm{~m}$ & $\begin{array}{l}\text { Meximum } 2730.0 \mathrm{~m} \mathrm{Mrimum} \\
2470.0 \mathrm{~m}\end{array}$ & $2590.8 \mathrm{~m} @ 10.9 \mathrm{~m}^{3} / \mathrm{h}$ & Acceptsble \\
\hline Shaft Raicd Power (Ouiput) & 7.0 & $9830 \mathrm{~kW}$ & $<10275 \mathrm{~kW} / 2$ Custocrer SpG=0 5 & $\begin{array}{l}1022.5 \mathrm{~kW} @ 207.4 \\
. \mathrm{m} \% \\
1015.4 \mathrm{sW} @ 205 \mathrm{~m}^{3} / \mathrm{h} \\
\text { Projotted }\end{array}$ & Acceptable \\
\hline Vitration & 8.0 & Velocity at Overall & $\begin{array}{l}<5.0 \mathrm{~mm} / \mathrm{s} \mathrm{R} / \mathrm{S} \\
\left(184.5-225.5 \mathrm{~m}^{3} / \mathrm{h}\right)\end{array}$ & Refer to test resced & Acceptable \\
\hline Noise messurement & 9.0 & & & $\begin{array}{l}86 \mathrm{dBA} \\
\text { (Back ground: } 68 \mathrm{dAA})\end{array}$ & Fer infortrion \\
\hline NPSH test & 10.0 & $00 \mathrm{~m}(\mathrm{a} 200 \mathrm{~m} 3 \mathrm{~h}$ (Note) & $\angle 3 \%$ head down & $-0.38 \%$ & Acceptable \\
\hline Durem Alene & $11 n$ & & & תOtm Nines & Der infonmution \\
\hline Throst balance confinuation & 12.0 & - & Shsft is in up position & Refer to lest rcoend & Acceptable \\
\hline Startig current messurcment & - & $902 A$ & $<1082.4(=902\lceil A 1 X 12)$ & $\begin{array}{l}\text { Starting current: } 902 \mathrm{~A} \\
\text { Volage Dopp: } 33 \%\end{array}$ & Acceptible \\
\hline
\end{tabular}




\section{Nikkiso Test Pump Results}

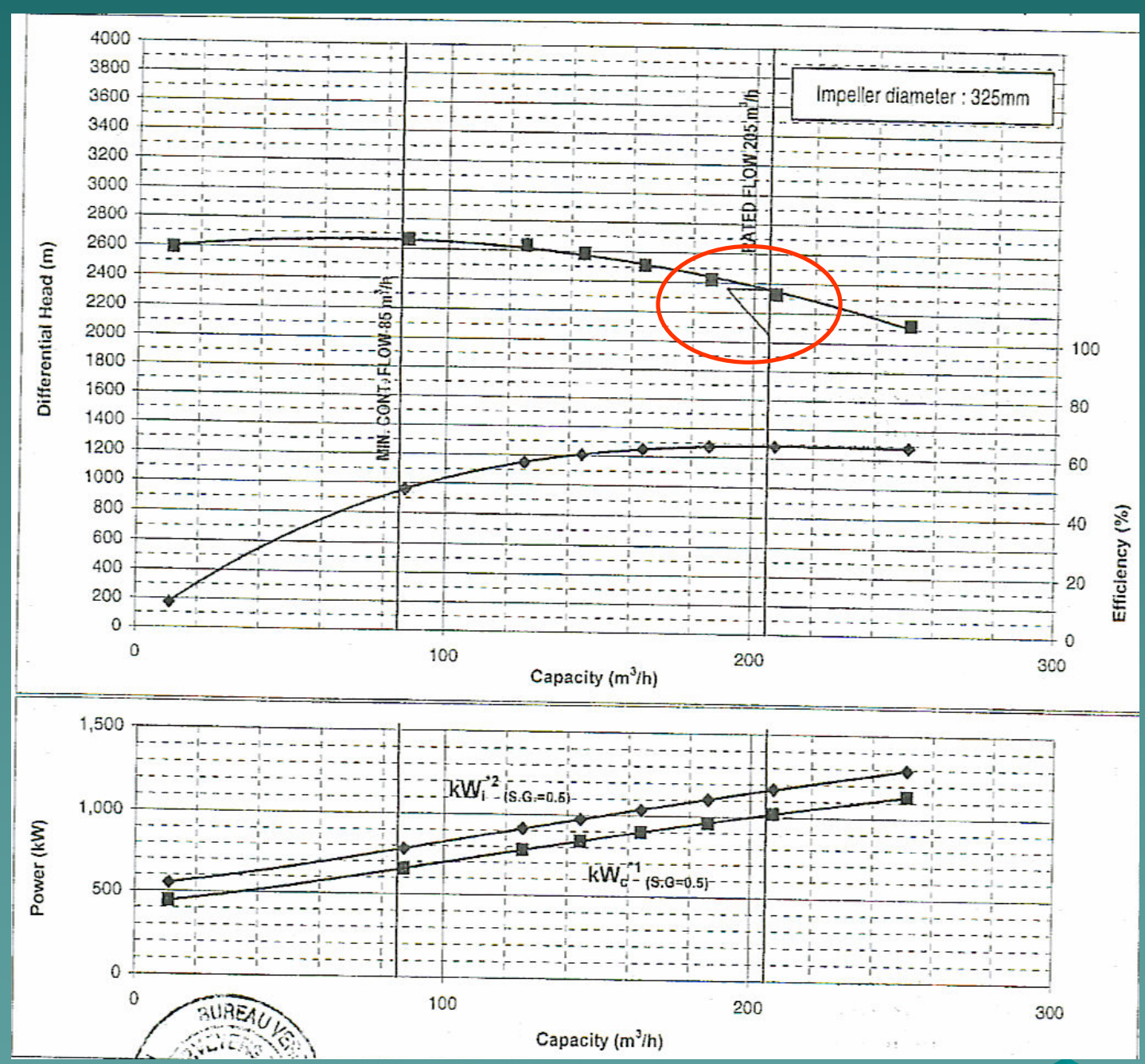




\section{LNG HP Pump Development}

$\checkmark$ In mid 2003 two types of LNG pumps designed for high pressure operation were nearing completion, one at Ebara and one at Nikkiso

$\checkmark$ Both manufacturers have offered to build cavern compatible pumps with rated:

- Flows in the range of 330-350 m3/hr,

- Pressures of 2,350 psi

- Horsepower of 3,500

, The Tests Reflect Current State of the Art 


\title{
Vermilion 179 LNG Receiving Terminal
}

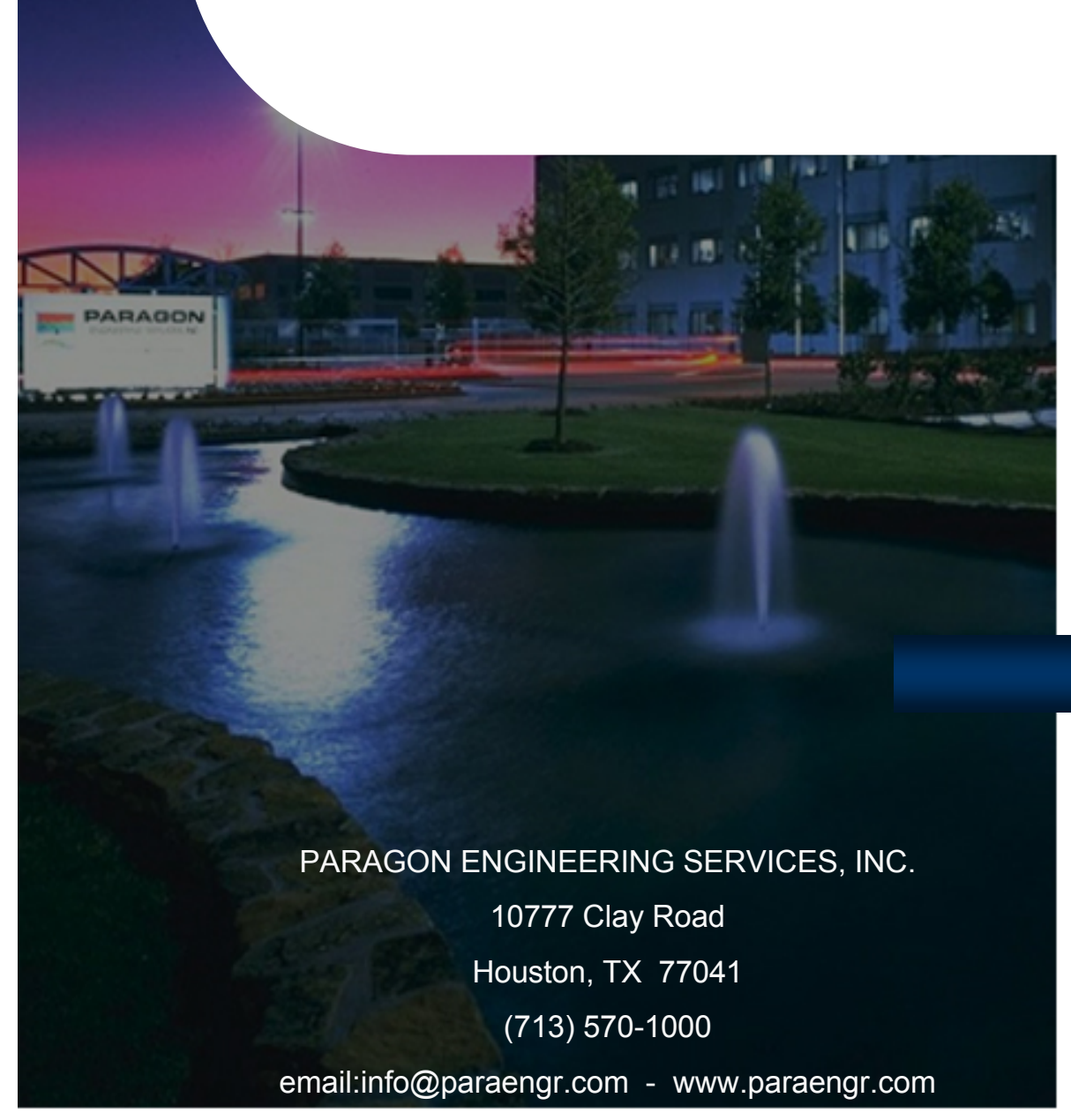

\author{
Presentation to: \\ National Energy \\ Technology \\ Laboratory
}

March 8, 2005 


\section{Agenda}

> Overview Paragon Engineering Services

$>$ Review of the Vermilion 179 Facility

> Define Major Systems \& Design Basis

$>$ Walk Through of Operations

$>$ Preliminary Schedule

$>$ Cost review

$>$ Alternatives \& Optimization

$>$ Questions \& Answers 


\section{Business Segments Served}

> Conventional Offshore Oil \& Gas

> Floating Oil \& Gas Facilities

$>$ Large FEED Projects

> Marine Pipelines

> Deepwater Subsea

> Onshore Oil \& Gas

> Onshore Pipeline

> LPG Fractionation, Storage

> LNG Regas Terminals

$>\mathrm{CNG}$ and GTL
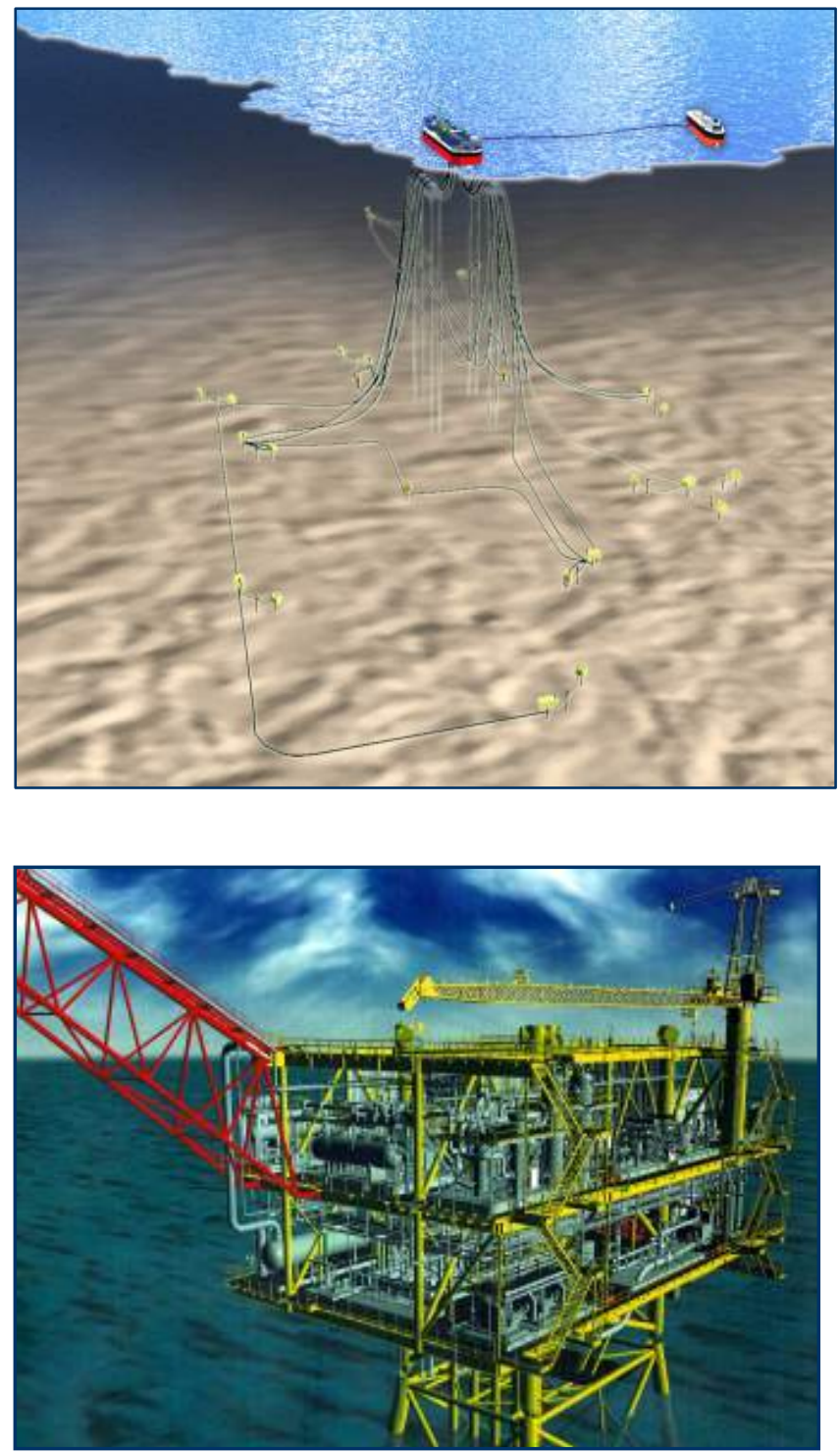


\section{The Bishop Process ${ }^{\mathrm{TM}}$}

> The Bishop Process ${ }^{\mathrm{TM}}$ - the process in which LNG is unloaded from a carrier - in shallow or deep water at typical rates, pumped to pressure and immediately vaporized in the dense-phase. This dense-phase gas is then injected into salt caverns for storage and subsequent / concurrent send-out to pipelines.

$>$ The hydrocarbon is stored as a gas vs. as a cryogenic liquid making it immediately deliverable to the market.....

> The novel and innovative process together with the large volume, low-cost storage capability of salt caverns creates the potential to implement a true "Energy Terminal". 


\section{Vermilion 179 LNG Receiving Terminal}

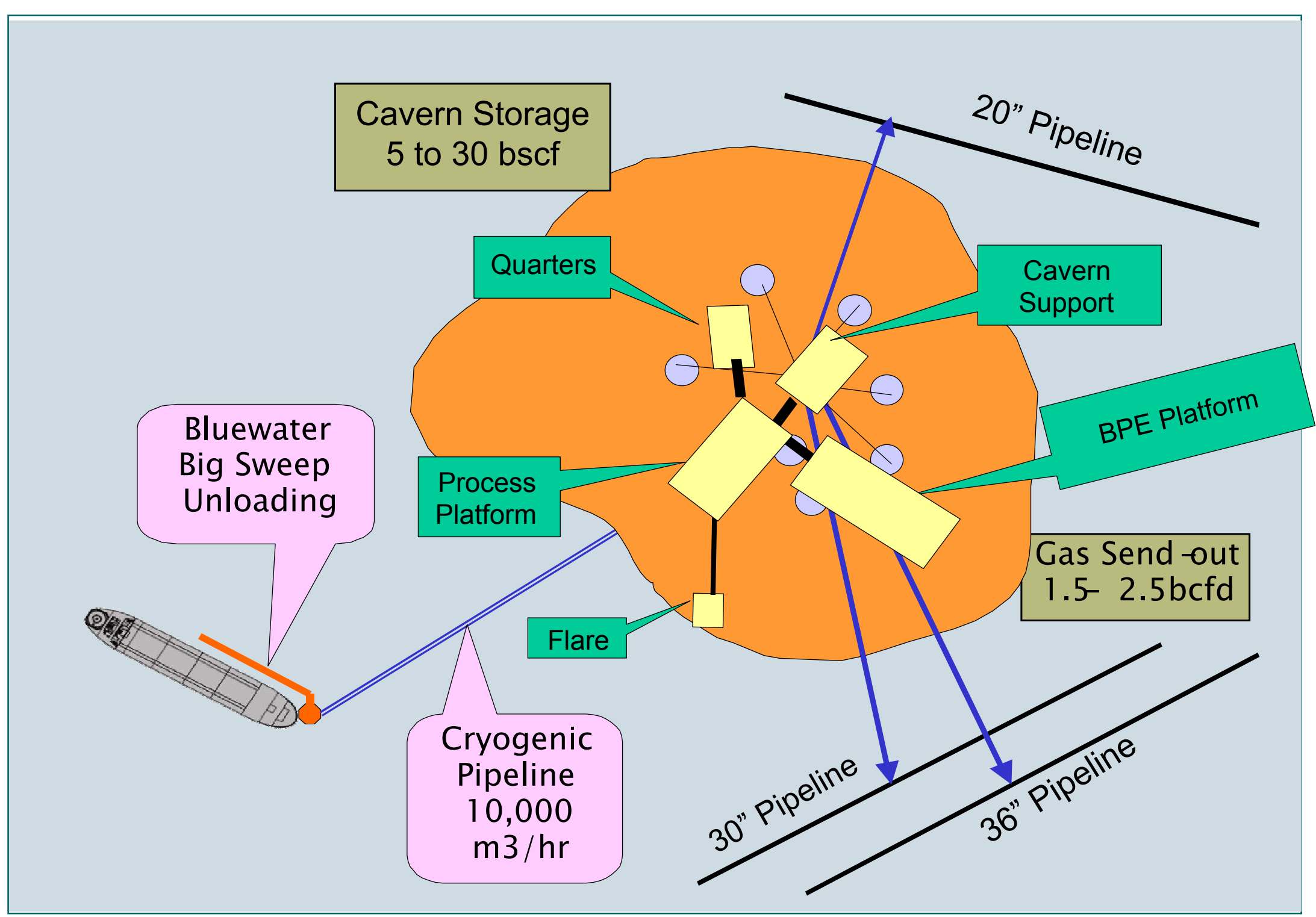




\section{Design Philosophy}

$>$ Safe Design Meeting all Codes

> Functional Design that Will Work

> Major Technical Issues Resolved

$>$ Proven Systems \& Equipment

$>$ Technical Validations Accomplished by Field Test

> Typical Offshore Fabrication and Installation

Not optimized - Opportunities Identified 


\section{Basis of Design Summary}

\begin{tabular}{|l|l|}
\hline \multicolumn{1}{|c|}{ KEY FACTORS } & \multicolumn{1}{c|}{ VALUE } \\
\hline Offload Rate & $10,000 \mathrm{~m} 3 / \mathrm{hr}$ \\
\hline Sendout rate & $\begin{array}{l}2.0 \mathrm{bcfd} \text { annual } \\
\text { average }\end{array}$ \\
\hline Gas Storage Capacity & 10 bcf working volume \\
\hline Cavern MOAP & 2000 psig \\
\hline Number of Caverns & 7 uncompensated \\
\hline Range of Gas Send-out Flow & 1.5 to 2.5 bcfd \\
\hline Vaporizing Medium & Seawater \\
\hline
\end{tabular}




\section{What Has Changed During Study?}

> Full Awareness of Safety Issues

> LNG Offload Rate: 8,000 to $10,000 \mathrm{~m}^{3} / \mathrm{hr}$

$>$ Knowledge Gained from Field Tests

- Water Flow Rate per Exchanger

- Pressure Drop

- Temperature Profile

- LNG pump performance

> Incorporate Offshore Fabrication, Installation and Operation Procedures

> Bishop Exchanger Metallurgy, Size, Length 


\section{Design Challenges}

> Power Generation and Process Design to Support LNG Offload Rate

> Variable Cavern Pressure - 1100 to 2000 psig

> Variability in Gas Send-out -1.5 to 2.5 bcfd

$>$ Transition - Ship Unloading to Pipeline Send-out \& Cavern Injection and then Cavern Withdraw to Pipeline Send-out 


\section{Major Systems}

> Mooring \& Unloading System

$>$ LNG Cryogenic Pipeline

> Process Platform

$>$ Bishop Process ${ }^{\mathrm{TM}}$ Exchanger Platform

> Cavern Support Platform

> Quarters Platform

$>$ Flare Platform

> Cavern Drilling \& Development

> Gas Send-out Pipelines 


\section{LNG Mooring \& Offloading}

> Bluewater Offshore

> "Big Sweep" Single Point Mooring

> 10,000 m3/hr offload capacity

> Vapor Recovery for Ship

> Interconnect with marine LNG pipelines

> Model Basin Tested

> ABS "Approval in Principle" to be Pursued

> All LNG Carrier Sizes
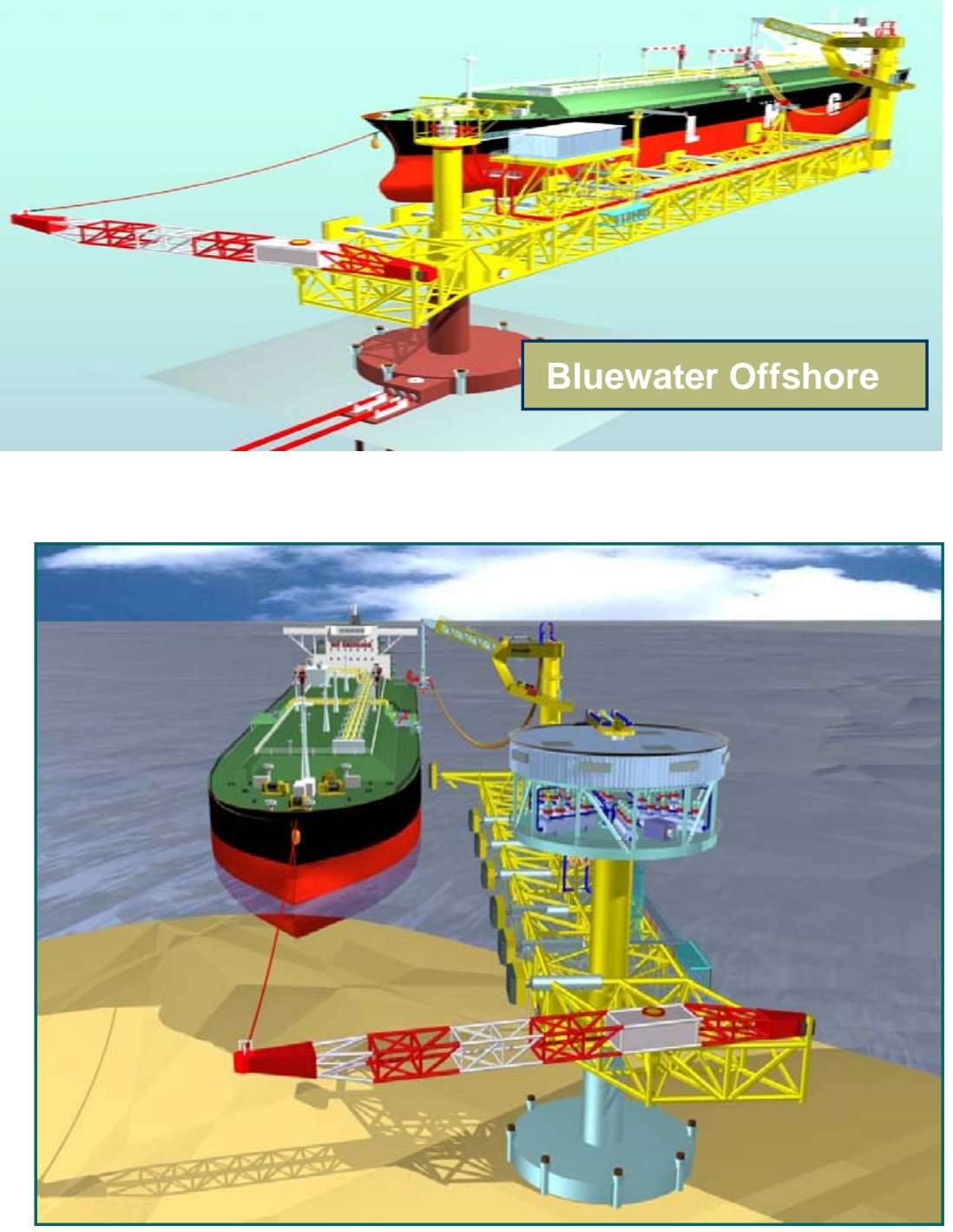

Photo Courtesy of Bluewater Offshore 


\section{LNG Marine Pipeline}

$>2 \times 24$ inch Pipe-in-Pipe-in-Pipe

$>$ Low U Value $=0.03 \mathrm{Btu} / \mathrm{hr}-\mathrm{ft}^{2}{ }^{\circ}{ }^{\circ} \mathrm{F}$

$>$ Robust \& Rugged Design by ITP InTerPipe

$>$ Install with Normal Equipment

$>$ Lay Barge or Tow-Out
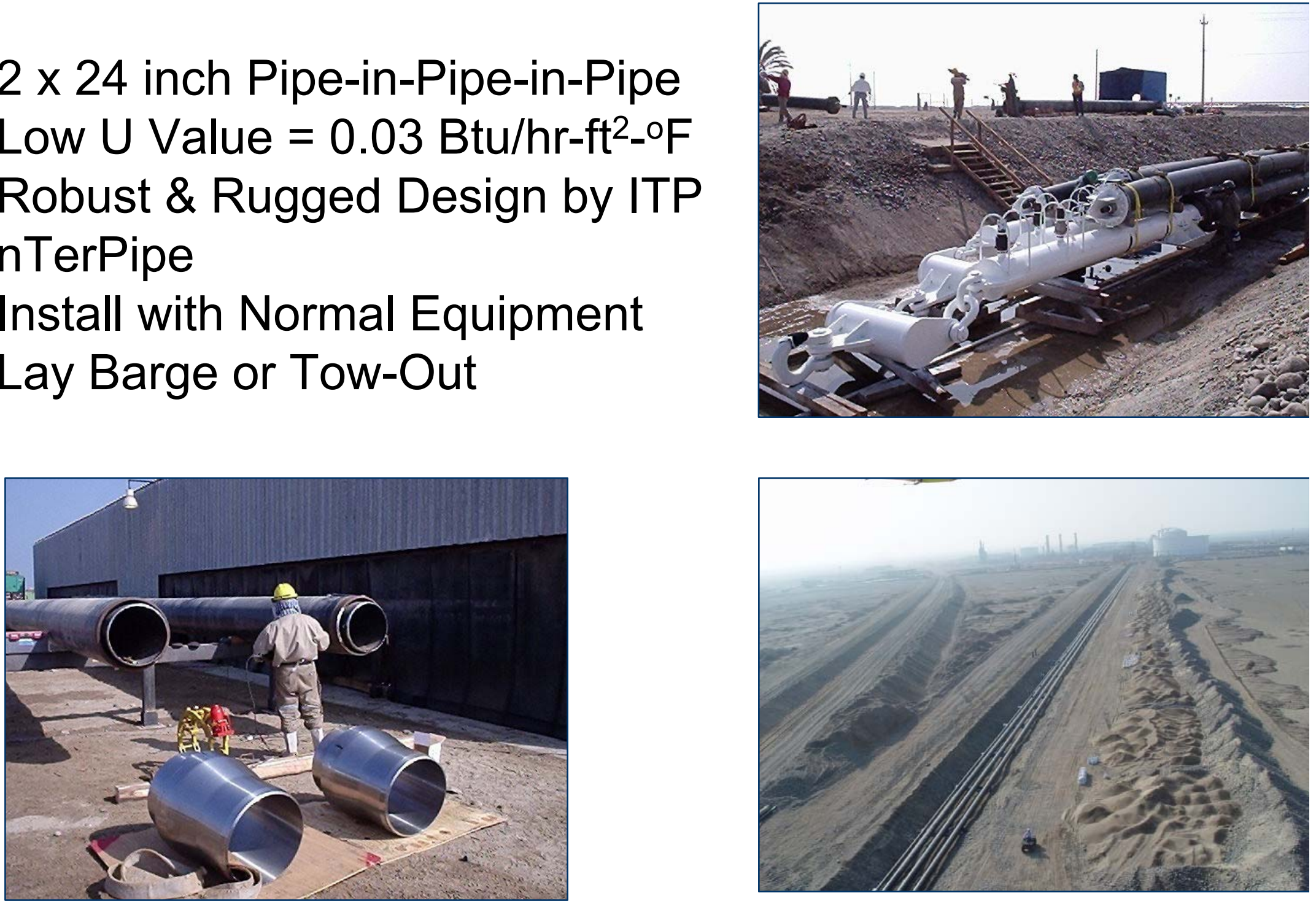


\section{Platform Overview}

\begin{tabular}{|l|l|}
\hline Process (8 Leg) & $\begin{array}{l}\text { 80+ Mw Power generation; 26 LNG } \\
\text { pumps; Control Room; Waste Heat } \\
\text { Recovery }\end{array}$ \\
\hline $\begin{array}{l}\text { Bishop Process } \\
\text { Exchanger (8 Leg) }\end{array}$ & $\begin{array}{l}\text { 36 BPE units with manifold; Seawater } \\
\text { pumps }\end{array}$ \\
\hline Cavern Support (8 Leg) & $\begin{array}{l}\text { 7 Dry Trees; Dehydration; Leaching } \\
\text { Pumps; Cavern Metering; Custody } \\
\text { Transfer }\end{array}$ \\
\hline Quarters (4 Leg) & 30 man Quarters; Associated Utilities \\
\hline Flare (Tripod) & 500 mm scfd flare \\
\hline
\end{tabular}




\section{Gulf Coast Salt Dome}
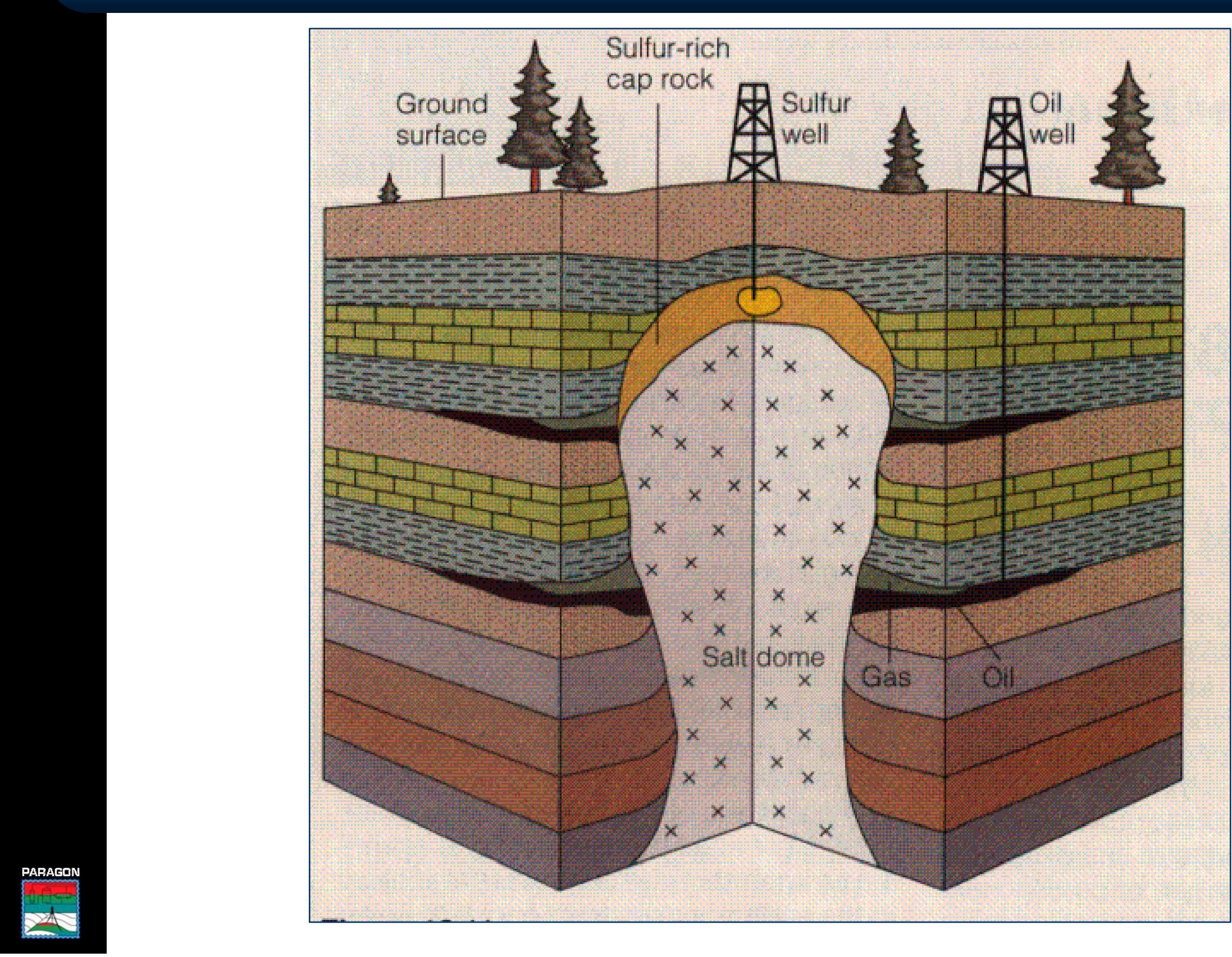


\section{Cavern Layout Pattern \& Spacing}

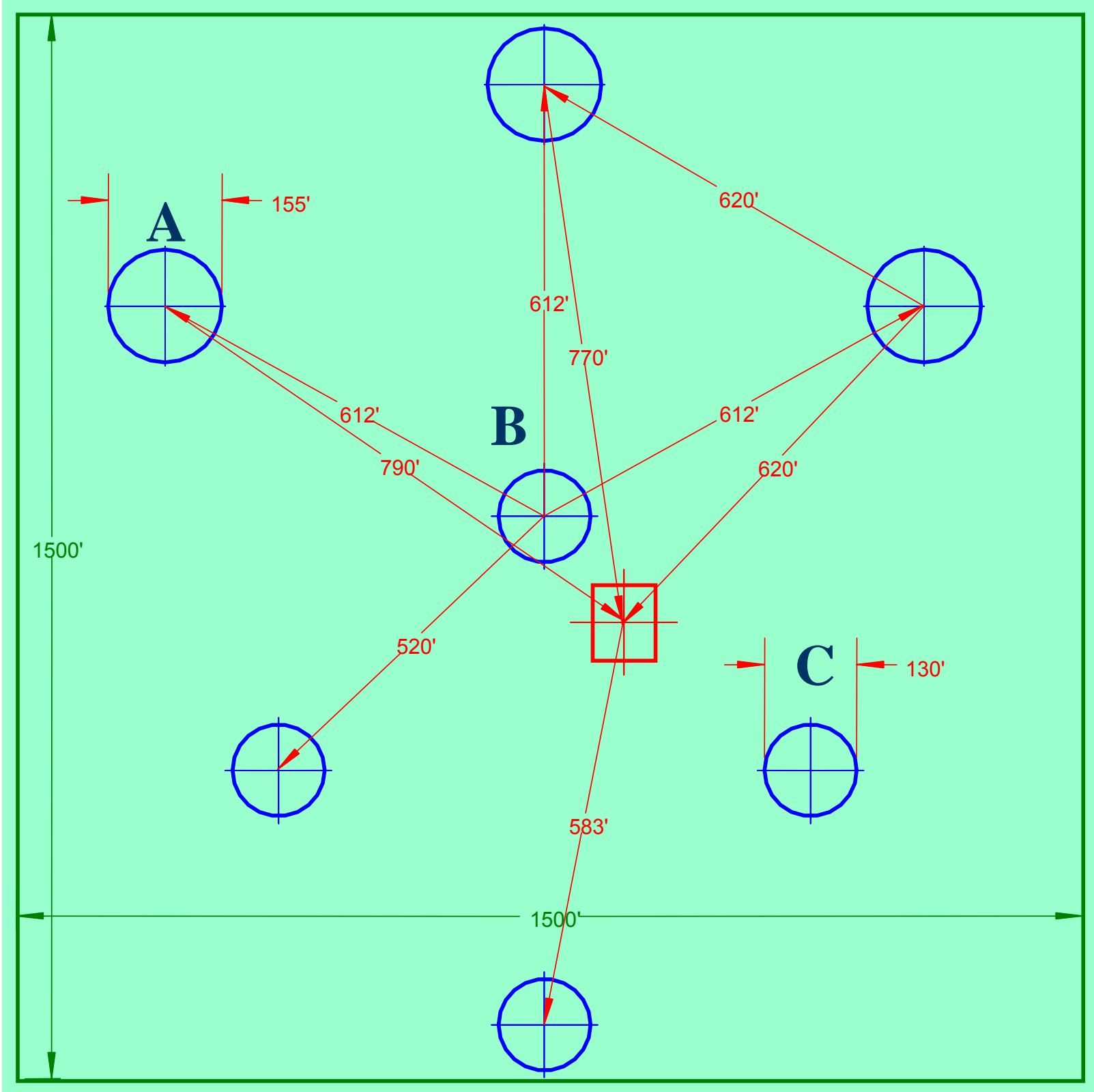




\section{Cavern Design}

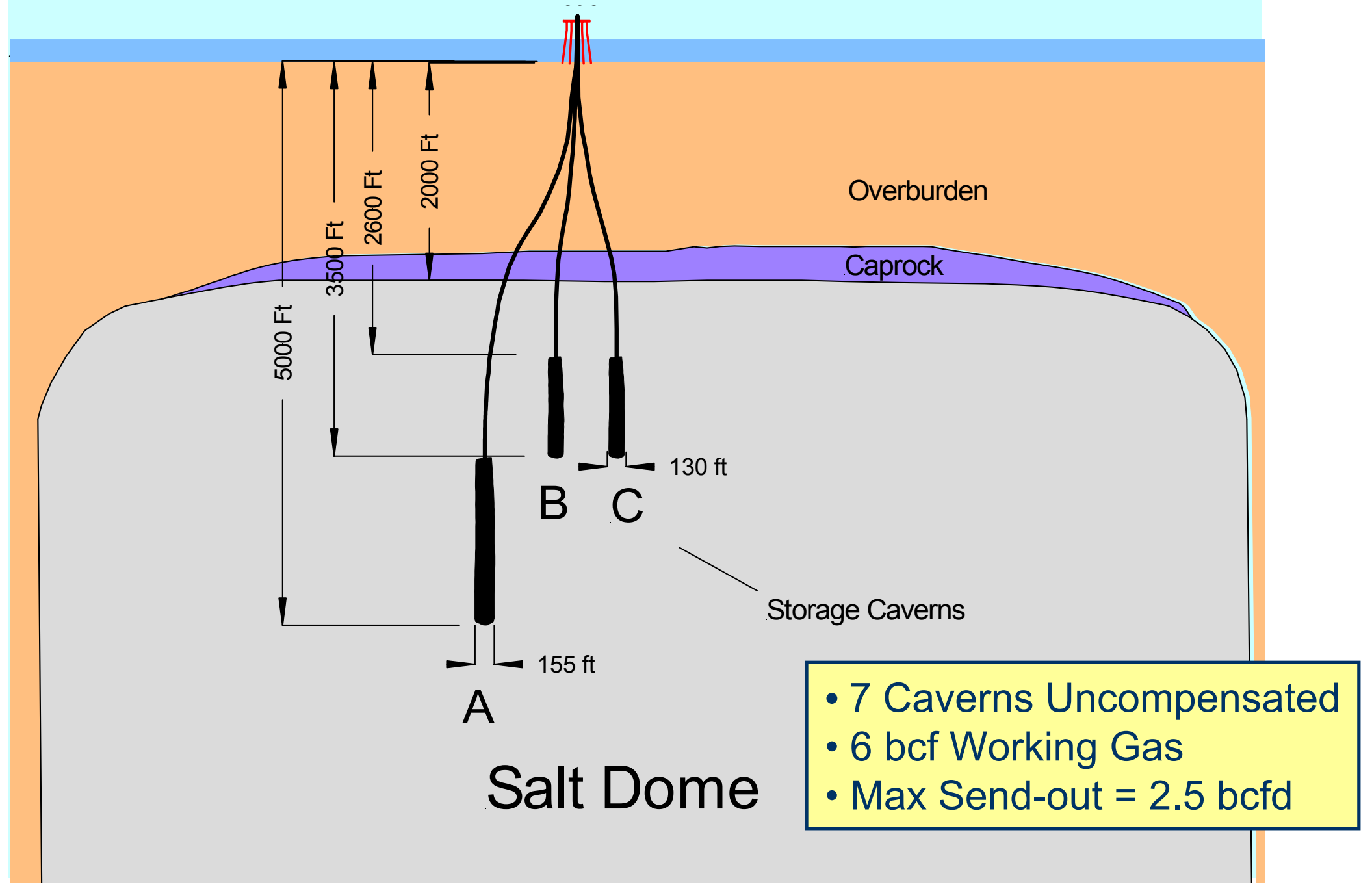




\section{Gas Send-out Pipelines}

> Three Pipelines to Tie-in Points on Existing Gas Pipelines

> Custody Transfer Stations on Cavern Support Platform

> 20 inch, 30 inch and 36 inch Lines

> Assumed 1100 Operating Pressure - ANSI 600 rated

> Assumed 10 Miles with 2 Crossings Each Line

Conventional Gulf of Mexico Pipelines 


\section{Vermilion 179 LNG Receiving Terminal}

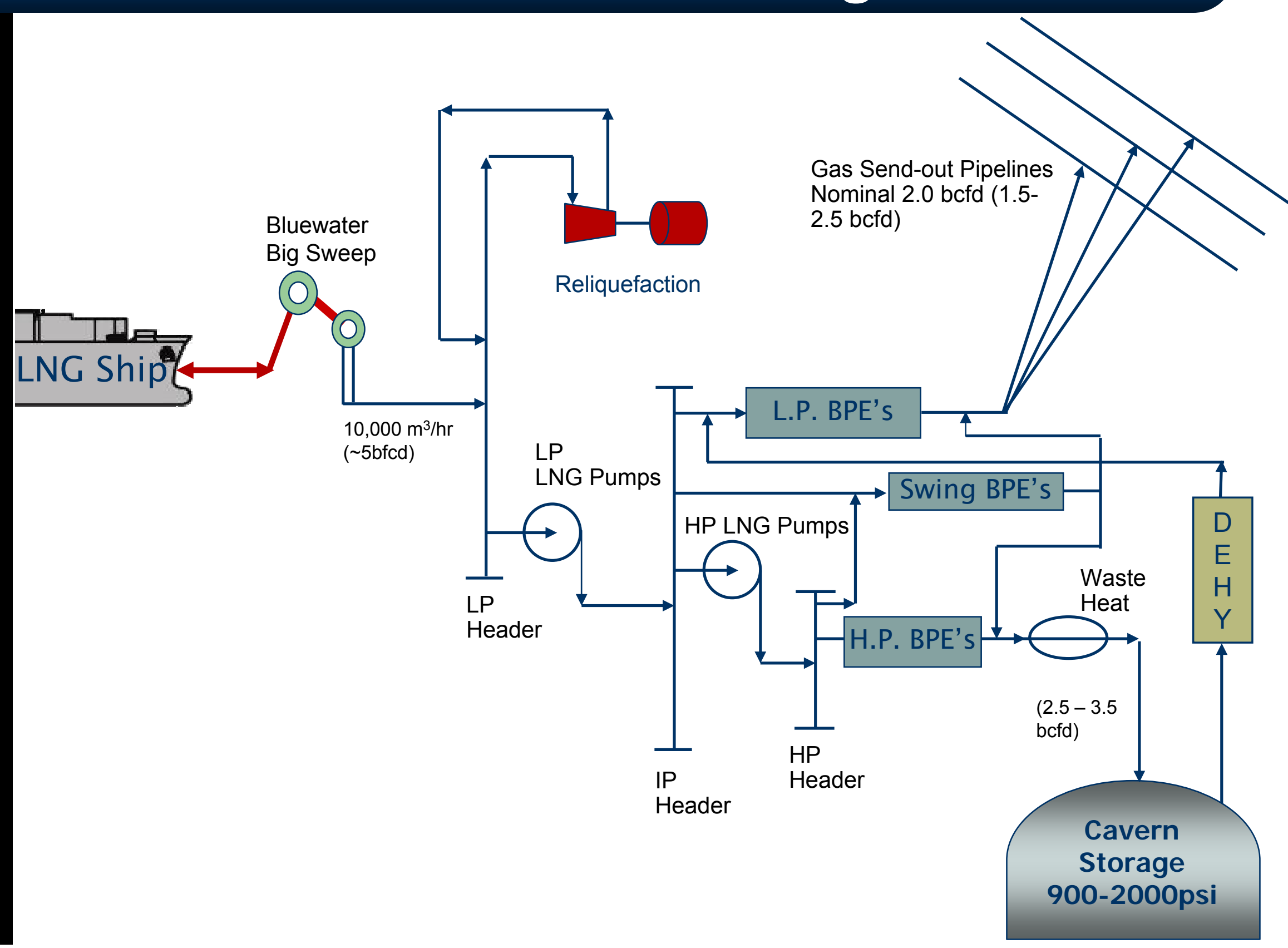




\section{Transition}

> Operation changes at ship offload initiation and completion

$>$ Critical factor in design and layout

$>$ Shift from cavern send-out to cavern injection

$>$ Smooth transition for pipeline send-out

> Utilizes "Swing exchangers" 


\section{Schedule}

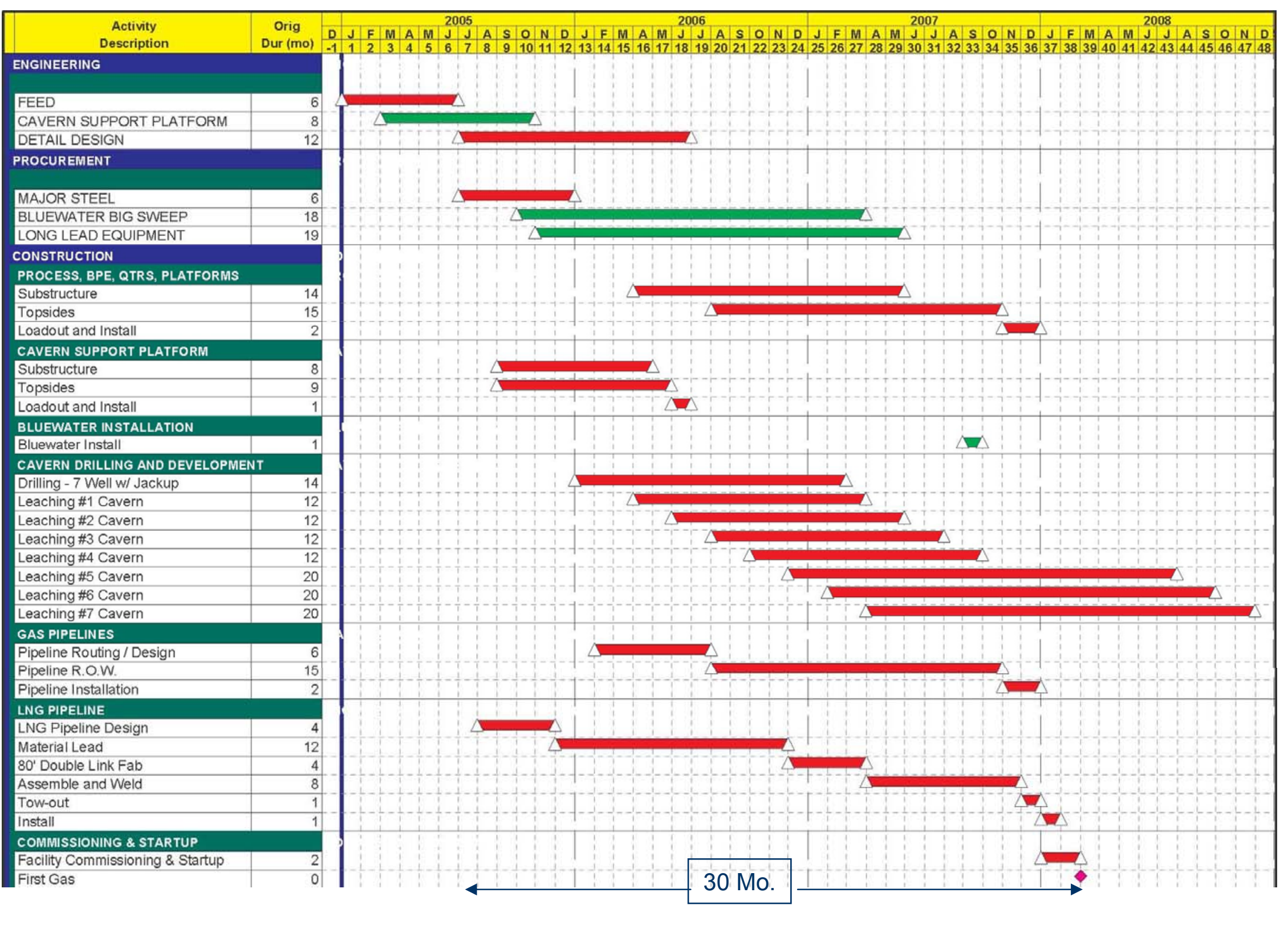




\section{Basis for Cost Estimate}

> HYSYS Model

> Preliminary PFDs

> Sized Equipment List

$>$ Load List

> Electrical One Lines

> Platform Layouts 


\section{Cost Estimate Methodology}

> LNG Mooring/Unloading - Cost Directly from Bluewater

$>$ LNG Pipelines - Material Cost by Vendor \& Installation Estimated by PES

> Major Equipment - 95\% by Vendor Quote \& Remainder by Past Projects

> Fabrication - Today's Steel Prices and Unit Rates from Gulf Coast Fabricator

- Weights Estimated by PES from Past Projects

> Installation - Based upon Derrick Barge day rates * PES Estimated Durations

> Hook-Up \& Commissioning - Based upon Estimated Crew Size \& Day Rate for Barge

> Cavern Drilling - Development - Cost Directly from PB Energy

> Project Management/Engineering Cost - Percentage of Total

> Estimate Accuracy $\pm 30 \%$ 


\section{Cost Summary}

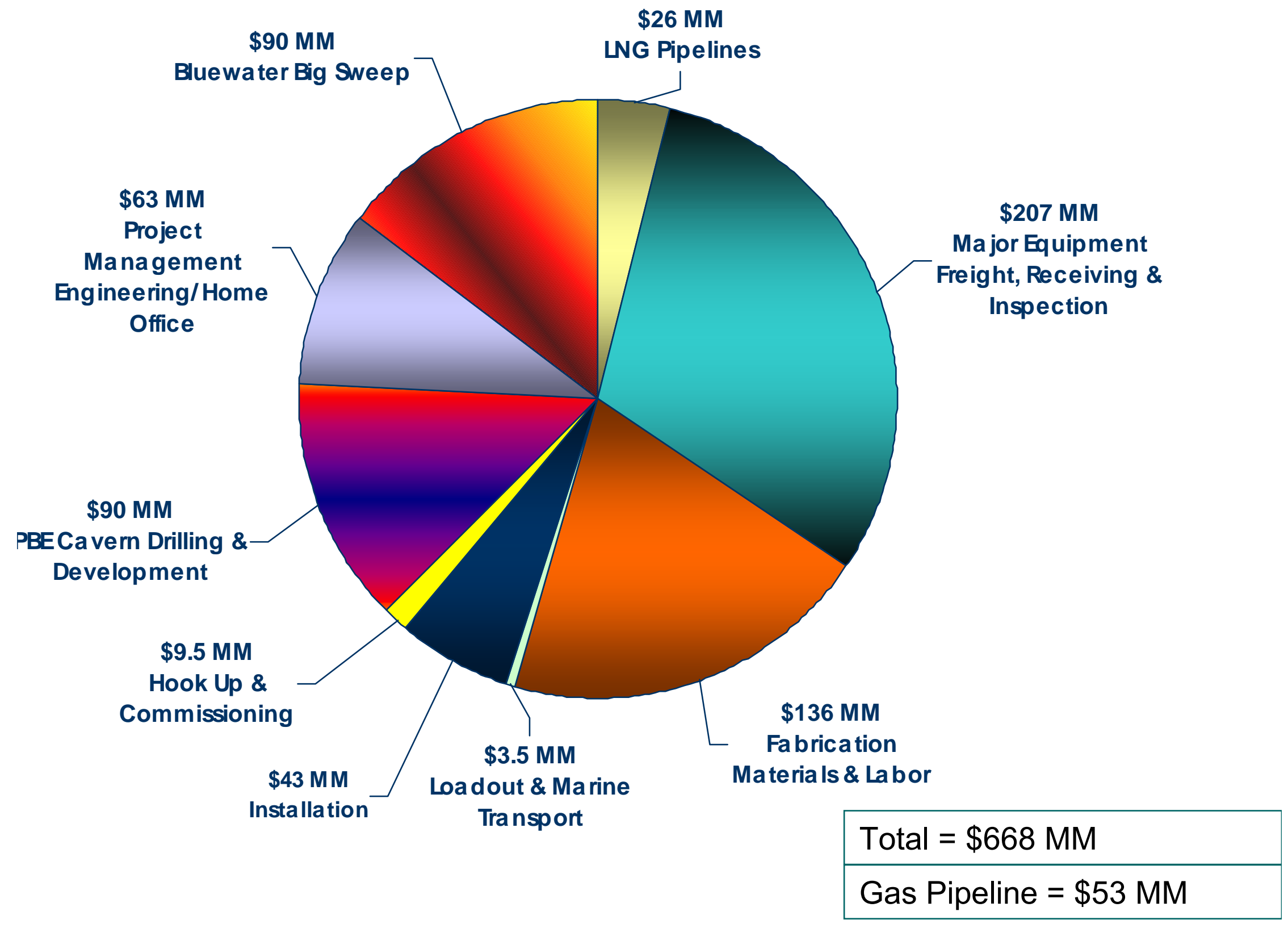




\section{System Cost Summary}

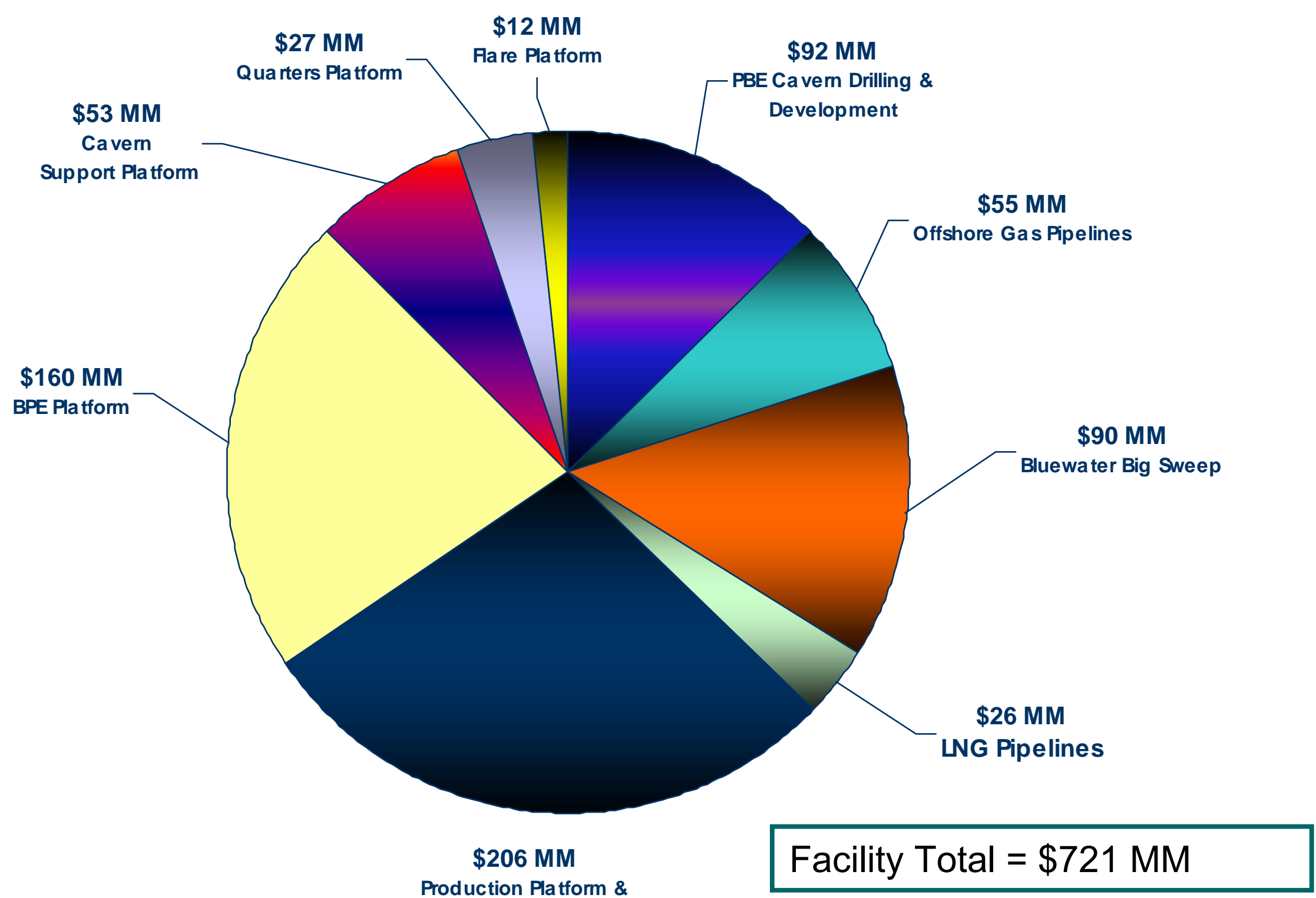

Production Platform \&

Bridges 


\section{Bluewater Offshore Big Sweep Costs}

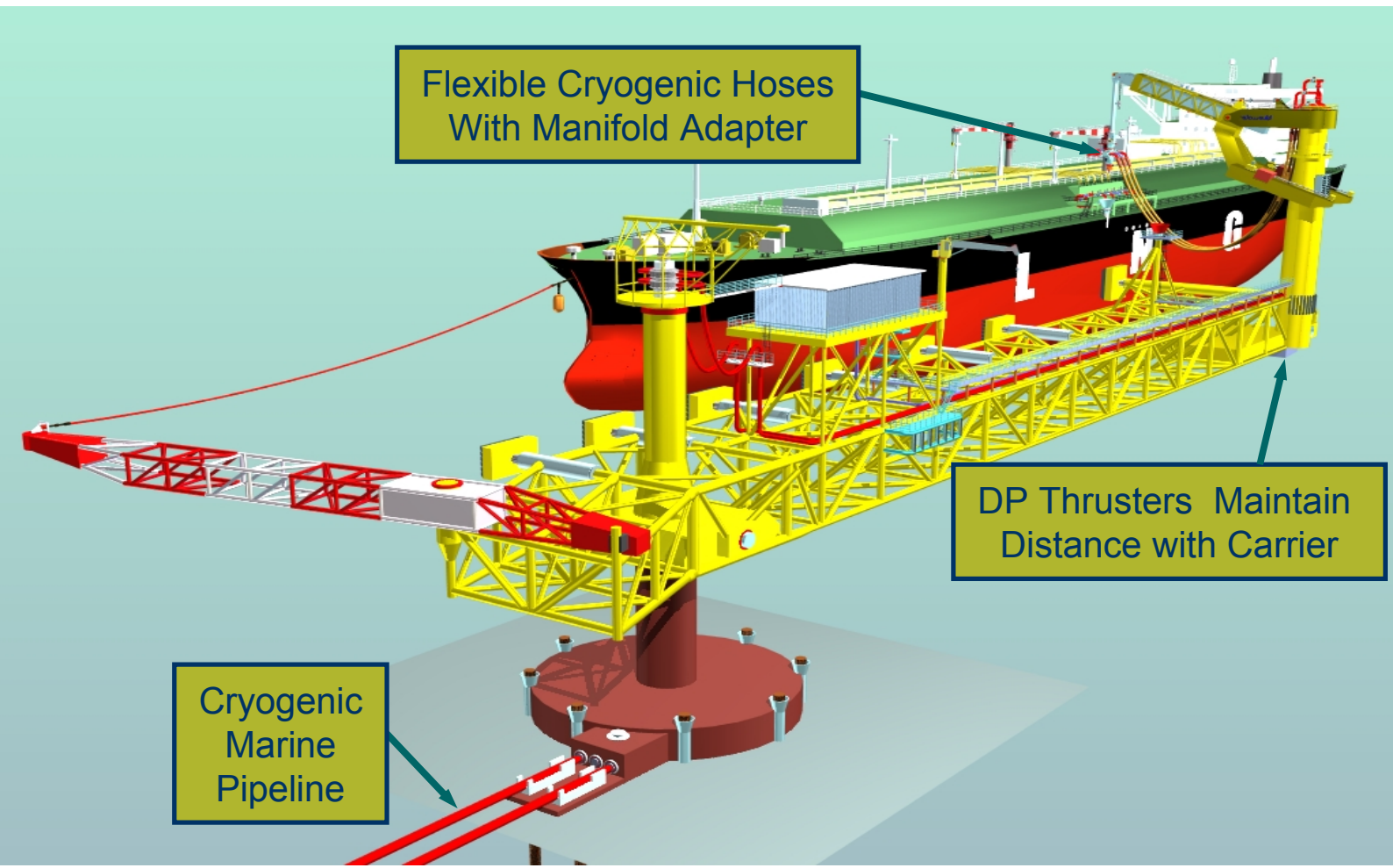

Big Sweep Equipment \& Fabrication Cost

$\$ 80 \mathrm{MM}$

Installation Cost

$\$ 10 \mathrm{MM}$

Total

$\$ 90 \mathrm{MM}$ 


\section{LNG Pipeline Cost}

(2) 24" Pipe-in-Pipe-in-Pipe

6400’ Plus (2) Risers

Material Cost

$\$ 17 \mathrm{MM}$

Installation Cost

$\$ 9 \mathrm{MM}$

Total Cost

$\$ 26 \mathrm{MM}$ 


\section{Process Platform Costs}

Major Equipment

$\$ 105 \mathrm{MM}$

Fabrication Materials \& Labor

$\$ 55.5 \mathrm{MM}$

Loadout, Transport \& Installation $\quad \$ 18.7 \mathrm{MM}$

Project Management/Engineering $\underline{26.8 \mathrm{MM}}$

Total

$\$ 206 \mathrm{MM}$ 


\section{BPE Platform Costs}

Major Equipment

Fabrication Materials \& Labor

Loadout Transport \& Installation

Project

Management/Engineering

Total
$\$ 76.1 \mathrm{MM}$

$\$ 50.5 \mathrm{MM}$

$\$ 12.6 \mathrm{MM}$

$\$ 20.9 \mathrm{MM}$

$\$ 160.1 \mathrm{MM}$ 


\section{Cavern Support Platform Costs}

Major Equipment

Fabrication Materials \& Labor

Loadout Transport \& Installation

Project Management/Engineering

Total
$\$ 13.4 \mathrm{MM}$

$\$ 20.1 \mathrm{MM}$

$\$ 12.5 \mathrm{MM}$

$\$ 6.9 \mathrm{MM}$

$\$ 52.9 \mathrm{MM}$ 


\section{Quarters Platform Costs}

Major Equipment

$\$ 10.9 \mathrm{MM}$

Fabrication Materials \& Labor

$\$ 6.0 \mathrm{MM}$

Loadout Transport \& Installation

$\$ 6.9 \mathrm{MM}$

Project Management/Engineering

$\$ 3.6 \mathrm{MM}$

Total

$\$ 27.4 \mathrm{MM}$ 


\section{Flare Platform Costs}

Major Equipment

Fabrication Materials \& Labor

Loadout Transport \& Installation

Project Management/Engineering

Total
$\$ 1.3 \mathrm{MM}$

$\$ 4.2 \mathrm{MM}$

$\$ 4.9 \mathrm{MM}$

$\$ 1.6 \mathrm{MM}$

$\$ 12.0 \mathrm{MM}$ 


\section{PB Cavern Drilling \& Development Costs}

Drilling

Developing the Cavern

Project Management

Total
$\$ 70 \mathrm{MM}$

$\$ 20 \mathrm{MM}$

$\$ 2 \mathrm{MM}$

$\$ 92 \mathrm{MM}$ 


\section{Offshore Gas Pipeline Costs}

36" Pipeline

30" Pipeline

20" Pipeline

Project Management/Engineering

Total

Materials

Installation

Materials

Installation

Materials

Installation
$\$ 11.8 \mathrm{MM}$

$\$ 8.5 \mathrm{MM}$

$\$ 7.6 \mathrm{MM}$

$\$ 8.5 \mathrm{MM}$

$\$ 4.3 \mathrm{MM}$

$\$ 7.2 \mathrm{MM}$

$\$ 7.0 \mathrm{MM}$

$\$ 54.9 \mathrm{MM}$ 


\section{Alternatives \& Options}

> Mooring \& Unloading Systems

$>$ Optimum Offload Rate vs. Berth Time

$>$ Vaporizer Options

- BPE vs. SCV vs. Ambient Air

> Cavern Design \& Operation

- MAOP; Number of Wells and Size; Compensated or Noncompensated

> Cavern Well Dry Tree Minimal Structure

> Blending/Segregation by LNG/Gas Composition

$>$ Storage Capacity and Send-out Rate

> Accommodation of CNG 


\section{Offload Rate vs. Capital Cost}

Offshore Energy Terminal Cost v. LNG Offload Rate

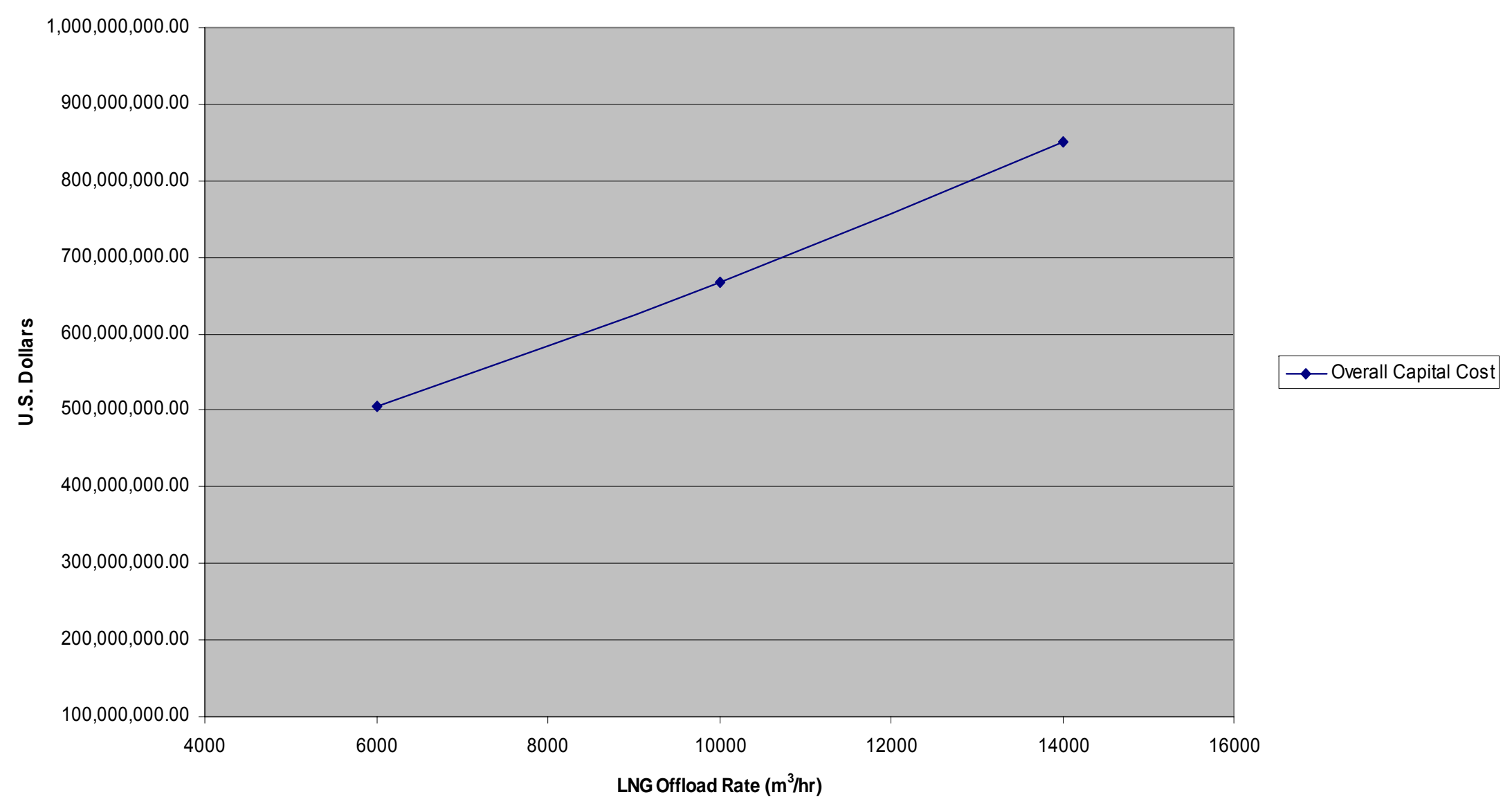




\section{Summary}

> Simple and Robust Design

$>$ Platforms, Piping and Pipelines

$>$ Ready for Implementation

> Opportunities to Optimize

\section{Energy Terminal}




\title{
Freedom LNG Terminal
}

\section{Project Overview}

March 8, 2005

\section{The Freedom LNG Terminal}

A New Standard For LNG Receiving Terminals

\author{
Craig Taylor \\ President \\ HNG Storage, LP
}




\section{Another Terminal ... Are You Crazy?}

$\checkmark$ Many planned terminals... but few needed

$\checkmark$ Resource owners, not developers - real decision makers

$\checkmark$ Freedom LNG is a better mousetrap!

- Economics: Cost competitive with shore-based terminals

- Constructability: Common Gulf Coast fabrication

- Security: No visible tanks; no ships in tight river channels

- Gas Industry Friendly: Large scale, cavern based 


\section{Project Objectives}

$\checkmark$ Create the most economical LNG import terminal on Gulf Coast - to compete economically with on-shore terminal proposals but offering benefits of being offshore

$\checkmark$ Demonstrate enough positive benefits to attract LNG suppliers to use the terminal 


\section{Goal: Avoid Negative Aspects of Other Terminals}

$\square$ Permitting risk - current and future

$\square$ NIMBY concerns

$\square$ Security risk for terminals, ships

$\square$ Low ship productivity due to harbor constraints Value of offloaded cargo tightly coupled to daily market price

$\square$ High port "political" costs, including taxes

$\square$ High capital, operating, and energy costs

$\square$ Limited pipeline grid access 


\section{Solution \# 1 - Move Offshore}

- Much better security than onshore locations

- Improved ship productivity

- Physical isolation from NIMBY concerns

- Potential access to water for warming LNG

- Access to large, unutilized salt domes

- Access to multiple underutilized gathering pipelines 


\section{Solution \#2 - Salt Cavern Storage}

- Large storage capacity decouples ship offloading from gas market demand and price volatility

- Large capacity storage converts "interruptible" gas to "firm" gas

- Multiple caverns reduce storage risk

- Multiple caverns allows blending of different BTU gases 


\section{Solution \#3 - High Throughput}

- Multiple docks increase ship productivity

- Multiple pipeline connections increase market optionality and thus value of gas

- Salt cavern storage has superior economies of scale 


\section{Terminal Location}

$\checkmark$ Offshore Central Louisiana

$\checkmark$ Adjacent to offshore salt dome

$\checkmark$ Adjacent to existing gathering pipelines

$\checkmark$ Adjacent to existing ship fairway 


\section{Terminal Overview}

$\checkmark \quad$ Initial storage $9 \mathrm{Bcf}$; continuously expand to $30+$ Bcf

$\checkmark \quad$ Multiple pipeline connections across mulfiple markets

$\checkmark \quad$ Design sendout:

- 1-1/2 Bcf/d at startup

- $3 \mathrm{Bcf} / \mathrm{d}$ after 2 nd year 


\section{Construction Schedule}

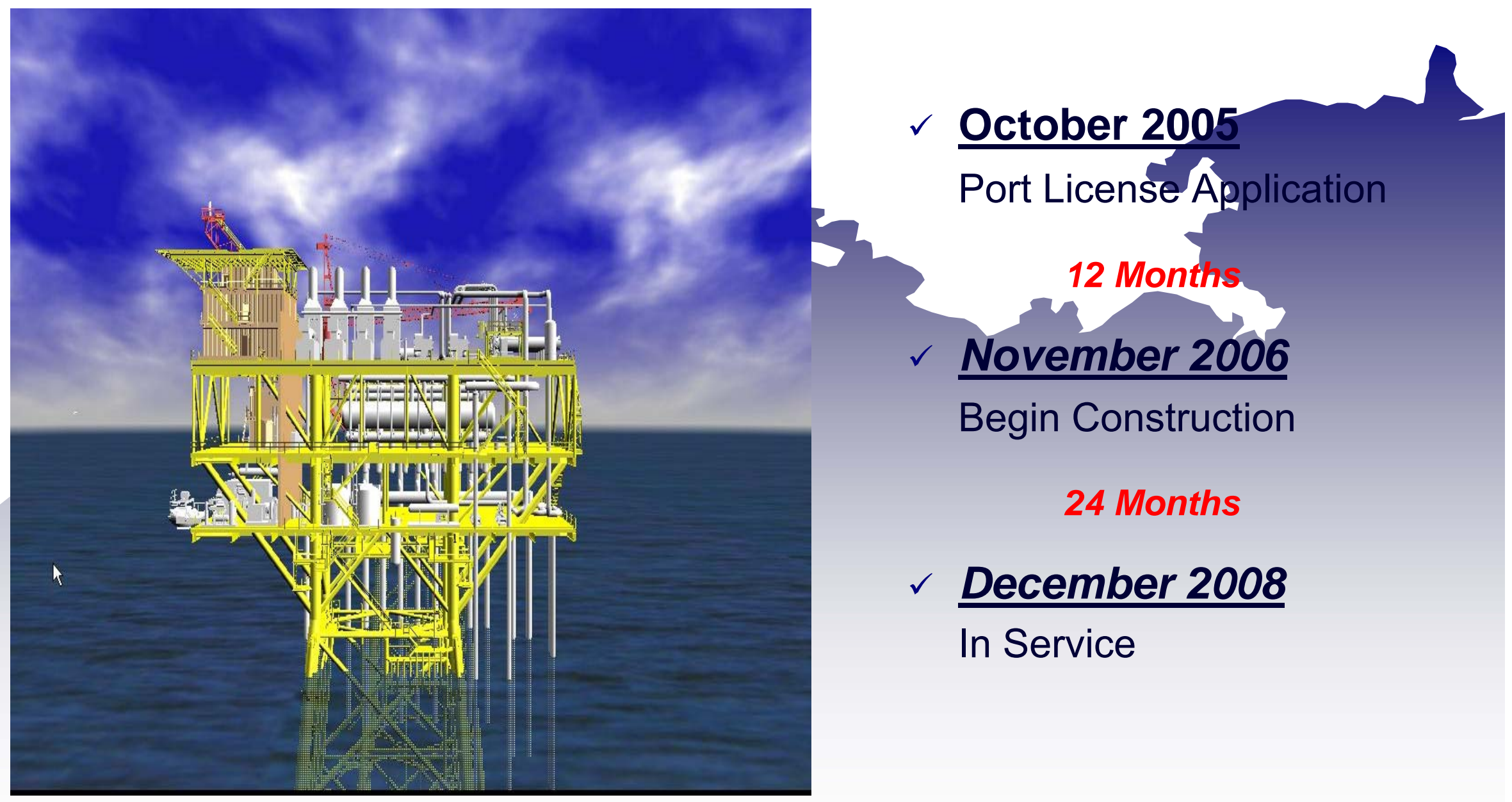

Freedom LNG Terminal 


\section{Where Are We in Project?}

$\checkmark \quad$ Hired Paragon to perform optimizing and pre-FEED engineering which:

$\checkmark$ Optimized Bishop Process

$\checkmark$ Confirmed expected cost benefits

$\checkmark \quad$ Negotiating with funding partners for development stage

$\checkmark \quad$ Deepwater port license application by Fall 2005 


\section{TAB 2}

\section{TABLE OF CONTENTS}

\section{PART 1 - FUNCTIONAL SPECIFICATION \& EXECUTIVE SUMMARY}

Section A - Objective and Scope of Report

$\mathrm{Pg} 3$

Section B - Executive Summary

$\mathrm{Pg} 4$

Section C - Department of Energy Study

$\mathrm{Pg} 6$

Section D - Functional Specifications

$\mathrm{Pg} 7$

Section E - Deliverables for Study

$\operatorname{Pg} 13$

\section{PART 2 - BASIS OF DESIGN for OFFSHORE INSTALLATION}

Section A - Overview of Offshore project

Section B - Facility Cost Estimate Summary

Section C - Basis of Design

System 1 - LNG Offloading System

System 2 - Marine LNG Transfer Pipeline

System 3 - Process Platform

System 4 - Bishop Process Exchanger

System 5 - Cavern Support Platform

System 6 - Quarters Platform

System 7 - Flare Platform

System 8 - Storage Cavern Development

System 9 - Sendout Pipeline
$\mathrm{Pg} 3$

$\mathrm{Pg} 7$

$\mathrm{Pg} 9$

$\mathrm{Pg} 9$

$\mathrm{Pg} 13$

$\mathrm{Pg} 20$

$\mathrm{Pg} 31$

$\mathrm{Pg} 36$

$\mathrm{Pg} 43$

$\mathrm{Pg} 45$

$\mathrm{Pg} 47$

$\mathrm{Pg} 48$

$\operatorname{Pg} 49$

$\mathrm{Pg} 55$

$\mathrm{Pg} 60$

$\mathrm{Pg} 63$

Section D - Safety Systems \& Overpressure Protection

Section E - Operating \& Maintenance Philosophy

Section F - Options and Alternatives

Section G - Appendices

Appendix 1 - Layout \& Drawings

Appendix 2 - Process Flow Diagrams

Appendix 3 - Equipment List

Appendix 4-Utility Summary

Appendix 5-Pump Curves

Appendix 6 - Cost Estimate

Appendix 7 - Bluewater Offshore Big Sweep System

Appendix 8 - PB Storage Cavern Drilling \& Development

Appendix 9 - Schedule 
Department of Energy, National Energy Technology Laboratory

Cooperative Agreement DE-FC-O2NT 41653

Amendment No. A002

Entitled

"EXAMINE AND EVALUATE A PROCESS TO USE SALT CAVERNS TO RECEIVE SHIP BORNE LIQUEFIED NATURAL GAS (LNG) / FIELD TEST AND FULL SCALE DESIGN OF CRITICAL COMPONENTS OF A SALT CAVERN LNG RECEIVING TERMINAL - PHASE 2"

\author{
PART 1 \\ FINAL REPORT \\ FUNCTIONAL SPECIFICATION \& \\ EXECUTIVE SUMMARY \\ OF THE \\ BISHOP PROCESS ${ }^{\mathrm{TM}}$ \\ FOR \\ OFFSHORE INSTALLATION \\ Prepared By \\ Paragon Engineering Services, Inc \\ March 30, 2005
}




\begin{tabular}{|c|c|c|}
\hline PARAGON & PART 1 VERMILION 179 & Date: 10/21/04 \\
\cline { 2 - 3 } & & Page 3 of 14 \\
\cline { 2 - 3 } & & Revision: B B \\
\hline
\end{tabular}

\section{SECTION A - OBJECTIVE AND SCOPE OF REPORT}

\section{OBJECTIVE}

This report presents the conclusions and findings of a design effort to complete the activities as outlined in Task 3 of the Cooperative Agreement described in Part 1, Section C. Task 3.1-3.4 incorporates the Bishop Process Exchanger into a fully functional LNG receiving terminal located offshore at a site typified by Vermilion 179. The design effort represented in this report describes the mooring and LNG transfer systems, process requirements, sub-sea cavern designs, projected costs, and operating characteristics for an offshore location.

The overall objective of this study is a workable and safe facility design utilizing the Bishop Process Exchanger (BPE) technology in an offshore application. This work scope concludes with a preliminary Basis of Design for the exchanger along with the platforms, pipelines and salt caverns for Vermilion 179. This Basis of Design incorporates the collective thought of experienced personnel at several companies. However, the body of work is not represented as being optimal. Promising alternatives are captured and listed for future consideration. This report contains information from multiple participants with the primary lead organizations being:

- $\quad$ Conversion Gas Imports, LLC - provides the overall program directorship and functions as the liaison with the Department of Energy. They provide the technical and functional objectives for the facility.

- $\quad$ Paragon Engineering Services, Inc. - provides marine pipeline, offshore structure and topsides designs, LNG process design, capital cost estimate and overall project integration services.

- Bluewater Offshore - provides the technical and economic information related to the LNG carrier mooring and offloading system - the "Big Sweep@" technology.

- $\quad$ P B Energy - provides the design of the salt cavern gas storage system and the associated cost estimate 


\begin{tabular}{|c|c|c|}
\hline PARAGON & PART 1 VERMILION 179 & Date: 10/21/04 \\
\cline { 2 - 3 } & & Page 4 of 14 \\
\cline { 2 - 3 } & & Revision: B \\
\hline
\end{tabular}

\section{SECTION B - EXECUTIVE SUMMARY}

\section{$\underline{B A C K G R O U N D}$}

The unique and heretofore unknown combination of gas storage in man made salt caverns with LNG importation presents the possibility for LNG receiving terminals with very large storage capacities and large gas send out flow rate. In particular, the use of salt formations for cavern development and LNG receiving in the Gulf of Mexico has the potential for offshore facilities combining easy ship access, large storage, and very large send out to the gas pipeline grid. This report describes such a facility, its components, capabilities, and operating characteristics as well as an overview of some of the design decisions made during the preparation of the Basis of Design.

There are more than forty LNG receiving terminals in the world. They are the same basic design, differing mostly in size. They consist of a dock to moor an LNG ship, cryogenic loading arms for the product transfer, cryogenic liquid (LNG) storage tanks, LNG pumps capable of achieving pipeline pressures, and some form of heat exchangers to vaporize the LNG and to warm the gas to pipeline compatible temperatures as it leaves the facility. This basic design has not changed since its introduction in Japan where more than half of the world's LNG terminals exist. Significant scale increases have been introduced into the world's LNG business in baseload liquefaction and shipping. Offshore salt cavern based terminals can provide the corresponding scale increases needed in LNG receiving terminals with storage capacity and send-out volumes far exceeding the tank based terminal model.

\section{Salt Caverns Provide High Volume Storage at Low Cost}

Man-made salt caverns are an integral part of the energy infrastructure of the United States. The entire strategic petroleum reserve, totaling more than 600 million barrels of crude oil is stored in salt caverns on the Gulf Coast. In addition, there are more than 600 million barrels of products owned by private industry including hydrogen, natural gas, natural gas liquids, olefins, refined products, and crude oil stored in salt caverns in the US and Canada. This high-deliverability storage is a critical logistical link between the natural gas, gas processing, petrochemical, and refining industries. Salt cavern storage is a technology that is well known, well developed, and very acceptable to the community, highly secure, and low cost. Salt caverns, thousands of feet below the Earth's surface, are the most secure method known to store hydrocarbon substances such as natural gas liquids, crude oil and natural gas.

Salt caverns provide about five $(5 \%)$ percent of the natural gas storage capacity in the United States, but about fifteen (15\%) percent of the deliverability of natural gas into the gas grid. This $3: 1$ ratio illustrates the high deliverability nature of natural gas storage in salt caverns, and demonstrates their fundamental value in LNG receiving and natural gas distribution. Salt cavern natural gas storage is characterized as having high utilization with frequent 'turns' meaning that injection and withdrawal cycles occur as often as 10 times in a year.

Salt does not tolerate direct injection of LNG because its low temperatures adversely affect the salt formation. Therefore, integrating salt cavern storage with LNG terminal operation requires 


\begin{tabular}{|c|c|c|}
\hline PARAGON & PART 1 VERMILION 179 & Date: 10/21/04 \\
\cline { 2 - 3 } & & Page 5 of 14 \\
\cline { 2 - 3 } & & Revision: B \\
\hline
\end{tabular}

that the LNG first be vaporized at high pressure 69 to 206.8 bar (1000 to 3000 psig) and then stored as a dense phase gas in the cavern.

The technical and economic advantages of salt cavern storage apply whether the LNG is unloaded at dockside or in open water. The unique capability to handle high volume gas flow rates matches well with the need for LNG tankers to unload quickly at rates from 8,000 - 14,000 cubic meters of LNG per hour (an equivalent flow rate of 4 to 7 billion cubic feet per day of gas). Similarly, these caverns exhibit high-deliverability when customers of the pipelines connected to the cavern need the gas. The reaction time to turn from low flow rate to full flow is on the order of 30 minutes making caverns ideal for highly variable loads and for back-filling interruptible sources.

Salt cavern applications for LNG receiving are ideal in today's political climate where protection against hostile acts is an important consideration of any industrial facility.

In summary, the concept of integrating salt cavern storage with LNG terminal facilities is technically feasible with current proven technology. The concept has excellent potential to improve the overall economics for importing and handling LNG in the United States. There are currently no known technical issues that would hinder or prevent full-scale commercialization of this concept.

\section{Alternative LNG Transfer Technologies}

The work described herein for the offshore location has as its LNG unloading and transfer system the Bluewater Offshore Big Sweep system. It should be noted that there are at least three other fully capable LNG unloading and transfer technologies available to perform this vital function. These other technologies include:

- Remora HiLoad

- FMC SOFEC Floating \& Weathervaning Platform

- $\quad$ SBM IMODCO

Each of these technologies has its own advantages and limitations and all of these technologies are ready for implementation.

\section{Alternative Locations}

The work performed in this Study has utilized the bathymetric and metocean data as well as pipeline interconnect distances of the Vermilion 179 site. The Bishop Process ${ }^{\mathrm{TM}}$ is readily adaptable to other offshore locations in shallower and deeper water as well as a land-based site. These locations should be the subject of future studies. 


\begin{tabular}{|c|c|c|}
\hline PARAGON & PART 1 VERMILION 179 & Date: 10/21/04 \\
\cline { 2 - 3 } & & Page 6 of 14 \\
\cline { 2 - 3 } & & Revision: B B \\
\hline
\end{tabular}

\section{SECTION C - DEPARTMENT OF ENERGY STUDY}

\section{Department of Energy Cooperative Research Study}

In 2002, the U.S. Department of Energy (DOE), through the National Energy Technology Laboratory (NETL) recognized the potential for the study and development of salt cavern storage for large volumes of gas and awarded a Cooperative Research Agreement to Conversion Gas Imports, LLC for a comprehensive analysis of the critical components involved in the 'Bishop Process $^{\mathrm{TM}}$ ' that offered lower cost, larger storage volumes, higher gas send-out rates and shorter construction time than traditional land based LNG receiving terminals. The goal of the DOE's Cooperative Research program is to move technology from concept to commercialization as rapidly as possible using industry's joint financial participation with the DOE to fund the process and provide technical and operating expertise. Joining in the funding and design support for the first stage of research was BP America, Bluewater Offshore, and HNG Storage.

The NETL has awarded Conversion Gas Imports, LLC the authorization to proceed with and complete Phase 2 of the Cooperative Agreement. This portion of the Study reflects the work done on Task 3.1 and 3.3 as defined below.

Task 3. Conceptual Design, Engineering, Evaluation, and Model Test of an Offshore LNG Receiving and Product Transfer System.

\section{Subtask 3.1 Conceptual Design and Engineering of an Offshore LNG Import and Gas Storage Terminal \\ The project team shall develop an overall system design, expanding the work done in the previous research, using Vermilion Block 179 as the site basis. This shall include the basis of design, field lay out, health, safety, security, and environmental (HSSE) assessments, and a system cost estimate.}

\section{Subtask 3.2 LNG Ship Mooring Terminal Design and Model Basin Test}

This Subtask was performed in 2 qtr 2004 by Bluewater Offshore and is reported in detail in a separate document. A summary is proved herein.

\section{Subtask 3.3 LNG Regasification, Cavern/Pipeline Injection and Send-Out Platform Design \\ The project team shall develop the platform lay-out, LNG and vapor return systems, Regasification systems, platform utility systems, injection, conditioning and send out systems, and the structural design of the platform necessary to contain them.}

\section{Subtask 3.4 Topical Report}

At the request of the COR, the project team shall prepare a topical report on Subtasks 3.1 3.3. 


\begin{tabular}{|c|c|c|}
\hline PARAGON & PART 1 VERMILION 179 & Date: 10/21/04 \\
\cline { 2 - 3 } & & Page 7 of 14 \\
\cline { 2 - 3 } & & Revision: B \\
\hline
\end{tabular}

\section{SECTION D - FUNCTIONAL SPECIFICATIONS}

\section{INTRODUCTION}

The concept of a Functional Specification is to convey the functions that a facility must perform to achieve project business objectives. It addresses the question "What must this facility be capable of accomplishing?" It may also prescribe specific information if that requirement is prerequisite for functionality. The Functional Specification is general in nature allowing flexibility in terms of specific implementation and design. It is well suited for the first-of-a-kind design basis of an emerging technology.

\section{INITIAL REQUIREMENTS}

Several requirements have been set for this Study. They are:

a. The location is deemed to be on Vermilion 179. This site would be used to establish all metocean and bathymetric data required to complete this Study. This site is considered typical of an offshore location utilizing this process.

b. For this Study, the mooring and offloading system will be the "Big Sweep (" system offered by Bluewater Offshore. Alternative mooring and unloading systems are available.

c. The Offshore LNG receiving Terminal will utilize the Bishop Process ${ }^{\mathrm{TM}}$ as described elsewhere within this document. This means the LNG is offloaded and immediately pressurized to an operating pressure whereupon it is warmed to a temperature suitable for injection into salt cavern storage. A portion of the pressurized, warmed gas may by-pass the caverns and be sent directly to send-out pipelines to market.

d. It will incorporate the Bishop Process Exchanger ${ }^{\mathrm{TM}}$ as the warming process (vaporization). Alternative LNG exchangers are available.

e. It will utilize one or more salt caverns leached into an adjacent salt dome suitable for storage. Between LNG Carrier unload operations; the gas stored within the caverns will service the send-out requirements.

f. One or more existing gas pipelines in the Gulf of Mexico, having excess transmission capacity, will be connected to the LNG terminal. These pipelines are deemed for this Study to be operating at a nominal pressure of 69 bar (1000 psig). This in turn causes the operating pressure at the battery limit of the facility to be a nominal 76 bar (1100 psig). 


\begin{tabular}{|c|c|c|}
\hline PARAGON & PART 1 VERMILION 179 & Date: 10/21/04 \\
\cline { 2 - 3 } & & Page 8 of 14 \\
\cline { 2 - 3 } & & Revision: B \\
\hline
\end{tabular}

\section{MAJOR FUNCTIONS}

The entire offshore Bishop Process ${ }^{\mathrm{TM}}$ facility must perform the following functions:

a. LNG carrier mooring - the LNG carrier approaches the mooring site in open water, is moored and the LNG is offloaded. The offloaded ship then debarks for its return run.

b. LNG offloading method and LNG transfer from the offloading point to the processing (pressurizing \& warming) function- this may be a short transfer distance aboard a floating facility or to a platform or it may require a longer distance transmission to optimize the ship mooring near navigation fairlanes while maintaining the proximity of the facility to the salt cavern and to the send-out pipelines.

c. LNG Process - pressurizing and warming - Commercially available LNG pumps capable of achieving the operating pressures for the facility will be utilized. The LNG will then be warmed to at least $4.4^{\circ} \mathrm{C}$ (40 degree $\mathrm{F}$ ) using commercially available exchangers. These exchangers could utilize water only for the heat medium or some combination of water and fired heater.

d. Cavern storage - one or more salt caverns will be utilized to store the warmed gas until required for send-out to the pipelines. The numbers and sizes of each cavern to be determined in FEED. The mode of operation may be compensated or un-compensated.

e. Gas Send-out - gas will be metered for send-out into one or more pipelines at a temperature of at least $4.4^{\circ} \mathrm{C}$ (40 degree $\mathrm{F}$ ). The send-out pressure required at the facility is dictated by assurance of contracted flow at the interconnect point.

\section{A. MOORING SYSTEM}

The specifications for an offshore LNG carrier mooring system are as follows:

- The mooring system should not require mooring modifications to an LNG carrier with the single exception of being able to moor at a single point mooring - bow hawsers.

- The mooring system should enable mooring operations in sea states of 3-meters (9.8 ft) significant wave height, which represents $98 \%$ of the Gulf of Mexico sea states.

- The preferred embodiment is a weather-vaning mooring to maximize calculated terminal availability.

- There will not be LNG carrier bunkering or provisioning services from the facility.

- Navigation aides and markers will be part of the mooring system.

- The mooring will accommodate LNG carriers up to $200,000+\mathrm{m}^{3}\left(7.06 \mathrm{~mm} \mathrm{ft}^{3}\right)$ capacity. 


\begin{tabular}{|c|c|c|}
\hline PARAGON & PART 1 VERMILION 179 & Date: 10/21/04 \\
\cline { 2 - 3 } & & Page 9 of 14 \\
\cline { 2 - 3 } & & Revision: B \\
\hline
\end{tabular}

\section{B. LNG UNLOADING and TRANSFER LINES}

The LNG unloading system will provide the means to get the LNG off the ship. Transfer piping will be the means to move the LNG to subsequent stages of the facility above the water line. The cryogenic marine pipeline will move the LNG under the water. This marine pipeline could be utilized for designs incorporating a centralized LNG Process arrangement in which the mooring / unloading facility is at a distance from the Process facility. This distance may be up to $7 \mathrm{~km}(4.3 \mathrm{mi})$ enabling the best balance of ship navigation and mooring access together with the best proximity of the process facility to the gas storage caverns and pipelines.

\section{Unloading}

- The unloading system should not require modifications to the LNG carrier in the form of bow or stern manifolds or special purpose piping that would be used only for this specific terminal. Simple manifold adapters, those that can be readily manipulated during the hookup procedure or a universal adapter accommodating this terminal's special requirement but not affecting connections with the majority of global terminals, are acceptable.

- The unloading system will utilize procedures to eliminate vapor entrapment in the initial flows of LNG from the ship and will provide for venting of vapors prior to the flow entering the pipeline or transfer system.

- The unloading system should be proven technology for LNG transfer. This may be traditional unloading arms or cryogenic flexibles.

- Piping aboard the unloading system will have its own venting system designed to meet the requirements

- The cryogenic piping insulation will be high efficiency with a $U$-value of no greater than $0.17 \mathrm{w} / \mathrm{m}^{2}{ }^{\circ} \mathrm{C}\left(0.03 \mathrm{Btu} / \mathrm{ft}^{2}-\mathrm{hr}-{ }^{\circ} \mathrm{F}\right)$ on straight-run piping.

- The ship vapor recovery / replacement system should be self-contained on the unloading system. This avoids the need to use cavern gas for ship requirements.

- The unloading system will meet all MMS, USCG and code requirements for safety, emergency shutdown and emergency breakaway.

\section{LNG Transfer Lines and Fittings}

LNG transfer lines and fittings aboard the mooring or process facility will be capable of the following:

- The MAOP will be 8 bar prior to the LNG pumps

- The insulation target is $0.17 \mathrm{w} / \mathrm{m}^{2}{ }^{\circ} \mathrm{C}\left(0.03 \mathrm{Btu} / \mathrm{hr}-\mathrm{ft}^{2}{ }^{\circ} \mathrm{F}\right)$

- The piping and fittings following the LNG pumps will be designed for cyclic duty from ambient to cryogenic temperatures and atmospheric pressure to the MAOP - up to ANSI 900. 


\begin{tabular}{|c|c|c|}
\hline PARAGON & PART 1 VERMILION 179 & Date: 10/21/04 \\
\cline { 2 - 3 } & & Page 10 of 14 \\
\cline { 2 - 3 } & & Revision: B \\
\hline
\end{tabular}

\section{LNG Cryogenic Pipeline}

The mooring location is ideally situated near fair-lanes and open navigation water. The facility may be more economically situated closer to the salt caverns and the send-out pipelines. LNG can be transferred up to $7 \mathrm{~km}(4.3 \mathrm{mi})$ by means of cryogenic marine pipelines of the pipe-inpipe-in-pipe configuration

- The marine LNG transfer pipeline spans from the Bluewater Offshore's Big Sweep@ riser hung from the cryogenic swivel, through the elbow connector spool-piece to the marine pipeline to the Process Platform riser terminating at the LNG inlet header on the Process Platform.

- The length of the marine pipeline must provide at least 1 nautical mile between the mooring site and the Process Platform to assure ship maneuvering and safety.

- The LNG carrier unloading pumps will provide 7.5 bar (108.8 psig) pressure at the inlet to the LNG transfer line.

- The transfer rate must be at least $10,000 \mathrm{~m} 3 / \mathrm{hr}$ (8.5 MM CFD) with a pressure drop of less than 2 bar (29 psig).

- The pipeline will have isolation valves at the mooring and a valve on the connector between the two lines. These will be in cryogenic service.

- Pressure relief will be taken at the process platform.

- The lines must be capable of LNG recirculation

- There will be capability to: 1) purge the pipelines of cryogenic materials and 2) inert the pipeline making it free of flammable gas.

- The transfer line thermal performance requirement is governed by the more restrictive of the two following conditions:

o No vapor permitted in the transfer line during tanker unloading.

o Minimal LNG re-circulation required between ship offloading to maintain the temperature of the pipeline such that vapor is not formed.

\section{PROCESS FACILITY - PRESSURIZING \& WARMING}

The Process facility will be located on one or more platforms or upon a floating facility. The facility must provide the following functions:

- Capability to receive LNG as listed in the table below: 


\begin{tabular}{|c|c|c|}
\hline PARAGON & PART 1 VERMILION 179 & Date: 10/21/04 \\
\cline { 2 - 2 } & & Page 11 of 14 \\
\cline { 2 - 3 } & & Revision: B \\
\hline
\end{tabular}

\begin{tabular}{|c|c|}
\hline Factor & Value \\
\hline Tanker Capacity & Up to $200,000 \mathrm{~m}^{3}$ \\
\hline LNG Temperature & $-126.7^{\circ} \mathrm{C}\left(-260^{\circ} \mathrm{F}\right)$ \\
\hline LNG Unloading Rate & $10,000 \mathrm{~m}^{3} / \mathrm{hr}$ \\
\hline Gas Sendout Rate & 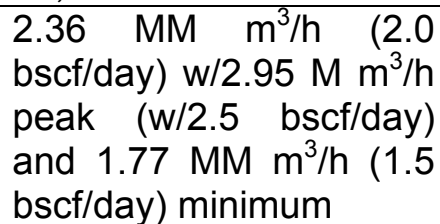 \\
\hline Unloading Frequency & Every 48 hours \\
\hline
\end{tabular}

- Capability to meet nominal average pipeline send-out of $2.36 \mathrm{MM} \mathrm{m}^{3} / \mathrm{h}$ (2 bscf/day) with a minimum of $1.77 \times 10^{6} \mathrm{~m}^{3} / \mathrm{h}(1.5 \mathrm{bscf} /$ day $)$ and a peak of $2.95 \times 10^{6} \mathrm{~m}^{3} / \mathrm{h}(2.5 \mathrm{bscf} /$ day $)$.

- Capability to provide cavern gas injection flow rate up to $4.13 \mathrm{MM} \mathrm{m}^{3} / \mathrm{h}(3.5 \mathrm{bscf} /$ day $)$ at cavern pressures ranging from 76 to 138 bar (1100 to 2000 psig) (uncompensated mode)

- LNG pumps to process up to $10,000 \mathrm{~m} 3 / \mathrm{hr}$ at the pressures mandated by the storage caverns

- Seawater pumps providing warmant to vaporize $10,000 \mathrm{~m} 3 / \mathrm{hr}$ LNG to $40^{\circ} \mathrm{F}$ or better

- The BPE exchanger

- Reliquefaction unit as required to preclude need for gas compressors

- Primary and emergency power generation \& utilities for the entire complex. Must be selfsupporting and capable of 'black start'

- Main control room for the entire facility; communications room

- Utilities such as potable water, sanitation, waste handling, instrument air, nitrogen for inerting.

- Quarters for 2 shifts of operations and maintenance personnel plus catering personnel and guests

- Maintenance shop, helipad, workboat access.

- Meet all applicable safety codes;

- Safety systems; fire suppression systems; flame and gas detection; lifeboats; ESD system.

- Flaring and / or emergency pressure relief (including cold vent) 


\begin{tabular}{|c|c|c|}
\hline PARAGON & PART 1 VERMILION 179 & Date: 10/21/04 \\
\cline { 2 - 2 } & & Page 12 of 14 \\
\cline { 2 - 3 } & & Revision: B \\
\hline
\end{tabular}

\section{CAVERN STORAGE}

Cavern storage is comprised of one or more caverns leached into a salt dome accessible via pipeline from the main processing facility. The dome need not be immediately adjacent to the mooring nor the gas pipeline. However, economics - not technology - will drive the proximity of the caverns to the facility and the pipelines. Cavern storage will include the following:

- Metering of the gas into and out of each cavern.

- Capability to isolate each cavern.

- The numbers and sizes of caverns will be determined by the peak send-out rate, the LNG offload rate, the interval between ship unloading and the need to store gas above the volume needed to serve pipeline contracts.

- Minimum gas injection temperature will be $4.4^{\circ} \mathrm{C}\left(40^{\circ} \mathrm{F}\right)$.

- Minimum gas withdraw temperature at the wellhead will be $4.4^{\circ} \mathrm{C}\left(40^{\circ} \mathrm{F}\right)$.

- Minimum gas storage pressure is set by the design of the caverns and the requirement to use the cavern pressure to deliver the contracted volume at the pipeline connection point.

- At this time, the maximum design pressure is ANSI 900 with a cavern MAOP of 138 bar (2000 psig).

- Maximum gas injection rate and withdraw rate is set by the cavern well design.

\section{E. GAS SEND-OUT}

The gas send-out utilizes the gas pressure of the storage caverns to move contracted gas into one or more send-out pipelines.

- The nominal daily gas send-out rate is set based upon long-term send out contracts. For this Study this value is $2.36 \times 10^{6} \mathrm{~m}^{3} / \mathrm{h}$ ( 2 bscf/day).

- Variability of this nominal rate can accommodate peak situations and shut-in scenarios but the annual send-out (avg daily rate $\times 365.3$ ) is a constant. The variability for this Study is from 1.77 $x 10^{6}$ to $2.95 \times 10^{6} \mathrm{~m}^{3} / \mathrm{h}(1.5$ to $2.5 \mathrm{bscf} /$ day $)$.

- The send-out gas must meet pipeline specifications for HC dew point, Btu content and water content.

- Metering and custody transfer is required for each pipeline. 


\begin{tabular}{|c|c|c|}
\hline PARAGON & PART 1 VERMILION 179 & Date: 10/21/04 \\
\cline { 2 - 3 } & & Page 13 of 14 \\
\cline { 2 - 3 } & & Revision: B \\
\hline
\end{tabular}

\section{SECTION E - DELIVERABLES FOR STUDY}

Task 3 requires specific information to be prepared to complete the definition of the BPE and the full operation facility at an offshore site typified by Vermillion 179. The items in Table represent the deliverables to be prepared or created to achieve the necessary level of definition.

TABLE

\begin{tabular}{|c|c|c|}
\hline DELIVERABLE & COMMENT & REFERENCE \\
\hline $\begin{array}{l}\text { Functional Specification } \\
\text { w/ PFD for Vermilion }\end{array}$ & LNG pumps, BPE, Power, Seawater pumps & $\begin{array}{l}\text { Part 2, Section C } \\
\text { and Part 3, } \\
\text { Section C }\end{array}$ \\
\hline $\begin{array}{l}\text { Process Platform } \\
\text { General Arrangements }\end{array}$ & $\begin{array}{l}\text { General arrangement w/ preliminary HFE and } \\
\text { safety assessment }\end{array}$ & $\begin{array}{l}\text { Part 2, Section C, } \\
\text { System } 3\end{array}$ \\
\hline $\begin{array}{l}\text { Cavern Support } \\
\text { Platform General } \\
\text { Arrangement }\end{array}$ & Tie ins to exchanger support, dehydration, flare & $\begin{array}{l}\text { Part 2, Section C, } \\
\text { System } 5\end{array}$ \\
\hline $\begin{array}{l}\text { Major equipment - size, } \\
\text { weight, utility needs; } \\
\text { power generation, crew } \\
\text { quarters }\end{array}$ & $\begin{array}{l}\text { Self-sufficient for power, water, and sanitation as } \\
\text { per any manned platform. }\end{array}$ & \\
\hline $\begin{array}{l}\text { Bishop Process } \\
\text { Exchanger } \\
\text { configuration, structure, } \\
\text { access, operability, } \\
\text { maintainability }\end{array}$ & $\begin{array}{l}\text { Design for } 300 \mathrm{~m}^{3} / \mathrm{hr} \text { LNG per exchanger. Assign } \\
\text { LP units for continuous direct pipeline sendout of } \\
1.77 \times 10^{6} \mathrm{~m}^{3} / \mathrm{h}(1.5 \mathrm{bcfd}) \text {. Assign HP units for } \\
\text { cavern injection at } 2.95 \times 10^{6} \mathrm{~m}^{3} / \mathrm{h}(2.5 \mathrm{bcfd}) \text {. The } \\
\text { cavern injection pressures range from } 76-138 \text { bar } \\
\text { ( } 1100-2000 \mathrm{psig}) \text {. Assign additional BPE units to } \\
\text { accommodate } 1.18 \times 10^{6} \mathrm{~m}^{3} / \mathrm{h}(1 \mathrm{bcfd}) \text { of either } \\
\text { direct send-out or cavern injection. BPE may be } \\
\text { used for send-out gas re-heat to counter J-T } \\
\text { effect. }\end{array}$ & $\begin{array}{l}\text { Part 2, Section C, } \\
\text { System } 4\end{array}$ \\
\hline $\begin{array}{l}\text { Cryogenic LNG Pumps } \\
\text { w/ headers }\end{array}$ & $\begin{array}{l}\text { Provide pump system to meet pipeline send-out } \\
\text { requirements at } 76 \text { bar ( } 1100 \text { psig) and to provide } \\
\text { volume and flow to meet cavern injection } \\
\text { requirements at } 76-138 \text { bar }(1100-2000 \text { psig). }\end{array}$ & $\begin{array}{l}\text { Part 2, Section C, } \\
\text { System } 3\end{array}$ \\
\hline $\begin{array}{l}\text { Seawater System, Inlet } \\
\text { and Outlet Structure } \\
\text { Definition, Impact } \\
\text { Assessment of Heat } \\
\text { Loss in Discharge }\end{array}$ & $\begin{array}{l}\text { Determine allowable temperature change for } \\
\text { discharge. Design inlet screens/structures and } \\
\text { outlet diffusers to meet regulations based upon } \\
\text { worst case BPE loading. Define seawater pumps } \\
\text { and manifolding requirements. }\end{array}$ & $\begin{array}{l}\text { Part 2, Section C, } \\
\text { System } 3\end{array}$ \\
\hline
\end{tabular}




\begin{tabular}{|c|c|c|}
\hline PARAGON & PART 1 VERMILION 179 & Date: 10/21/04 \\
\cline { 2 - 2 } & & Page 14 of 14 \\
\cline { 2 - 3 } & & Revision: B \\
\hline
\end{tabular}

\begin{tabular}{|c|c|c|}
\hline $\begin{array}{l}\text { Export pipeline straight- } \\
\text { line routing, crossing } \\
\text { identification, Closed } \\
\text { approach tie-in points } \\
\text { defined }\end{array}$ & $\begin{array}{l}\text { Provide platform-based flange tie-in and } \\
\text { control/metering to three major gathering lines } \\
\text { (e.g. Blue Water, Sea Robin \& Texas Eastern), } \\
\text { straight-line routing to point of nearest approach } \\
\text { and crossing identification for cost estimate. }\end{array}$ & $\begin{array}{l}\text { Part 2, System C, } \\
\text { System } 6\end{array}$ \\
\hline $\begin{array}{l}\text { Safety systems, safe } \\
\text { haven, egress, } \\
\text { evacuation, quarters, } \\
\text { control room }\end{array}$ & $\begin{array}{l}\text { Written description of safety systems including } \\
\text { overview of emergency procedures and } \\
\text { evacuation as needed to meet code. }\end{array}$ & Part 2, Section D \\
\hline $\begin{array}{l}\text { Overview of Project } \\
\text { Execution Plan }\end{array}$ & $\begin{array}{l}\text { Pipeline installation, cavern development, BPE } \\
\text { fabrication and installation, platform fabrication } \\
\text { and installation. }\end{array}$ & Part 2, Section E \\
\hline $\begin{array}{l}\text { Standards, } \\
\text { specifications, codes, } \\
\text { materials of construction }\end{array}$ & $\begin{array}{l}\text { Initial listing of applicable codes, standards and } \\
\text { specs and reason for use - Include in BOD where } \\
\text { practicable. }\end{array}$ & $\begin{array}{l}\text { Part 2, Section F, } \\
\text { Appendix } 7\end{array}$ \\
\hline $\begin{array}{l}\text { Conceptual Cost } \\
\text { Estimate }\end{array}$ & $\begin{array}{l}\text { Using information at hand, provide a preliminary } \\
\text { cost estimate for the Vermilion }\end{array}$ & Part 2, Section B \\
\hline Vapor Return System & Small unit on Big Sweep@ for Vermilion 179 & \\
\hline $\begin{array}{l}\text { Cryogenic Marine } \\
\text { Pipeline }\end{array}$ & $\begin{array}{l}\mathrm{U}=0.17 \mathrm{w} / \mathrm{m}^{2}{ }^{\circ} \mathrm{C}\left(0.03 \mathrm{Btu} / \mathrm{hr}^{-} \mathrm{ft}^{2}-{ }^{\circ} \mathrm{F}\right)(\text { ITP pipe-in- } \\
\text { pipe-in-pipe })\end{array}$ & $\begin{array}{l}\text { Part 2, Section C, } \\
\text { System } 2\end{array}$ \\
\hline Mooring System & $\begin{array}{l}\text { Single Point Mooring - Bluewater Offshore Big } \\
\text { Sweep@ }\end{array}$ & $\begin{array}{l}\text { Part 2, Section C, } \\
\text { System } 1\end{array}$ \\
\hline LNG Unloading System & Bluewater Offshore Big Sweep@ & $\begin{array}{l}\text { Part 2, Section C, } \\
\text { System } 1\end{array}$ \\
\hline $\begin{array}{l}\text { Salt Cavern Drilling and } \\
\text { Development }\end{array}$ & P B Energy Report & $\begin{array}{l}\text { Part 2, Section C, } \\
\text { System } 7\end{array}$ \\
\hline $\begin{array}{l}\text { Preliminary Operations } \\
\text { Overview }\end{array}$ & Vermilion 179 facility operations overview & Part 2, Section E \\
\hline
\end{tabular}


Department of Energy, National Energy Technology Laboratory

Cooperative Agreement DE-FC-O2NT 41653

Amendment No. A002

Entitled

"EXAMINE AND EVALUATE A PROCESS TO USE SALT CAVERNS TO RECEIVE SHIP BORNE LIQUEFIED NATURAL GAS (LNG) / FIELD TEST AND FULL SCALE DESIGN OF CRITICAL COMPONENTS OF A SALT CAVERN LNG RECEIVING TERMINAL - PHASE 2"

\author{
PART 2 \\ FINAL REPORT \\ BASIS OF DESIGN \\ OF THE \\ BISHOP PROCESS $^{T M}$ \\ FOR \\ OFFSHORE INSTALLATION
}

DOCUMENT No. A3122-05.03

Revision A 


\title{
TABLE OF CONTENTS FOR PART 2
}

\author{
SECTION A OVERVIEW OF OFFSHORE PROJECT \\ SECTION B FACILITY COST ESTIMATE SUMMARY \\ SECTION C BASIS OF DESIGN \\ System 1 LNG Offloading System \\ System 2 Marine LNG Transfer Pipeline \\ System 3 Process Platform \\ System 4 Bishop Process ${ }^{\mathrm{TM}}$ Exchanger Platform \\ System 5 Cavern Support Platform \\ System 6 Quarters Platform \\ System 7 Flare Platform \\ System 8 Storage Cavern Drilling \& Development \\ System 9 Send-out Pipelines
}

\section{SECTION D SAFETY SYSTEMS \& OVERPRESSURE PROTECTION \\ SECTION E OPERATING AND MAINTENANCE PHILOSOPHY \\ SECTION F OPTIONS AND ALTERNATIVES \\ SECTION G APPENDICES}

Appendix 1 - Layout and Drawings

Appendix 2 - PFD

Appendix 3 - Equipment List

Appendix 4 - Utility Summary

Appendix 5 - Pump Curves

Appendix 6 - Cost Estimate

Appendix 7 - Bluewater Offshore Big Sweep System

Appendix 8 - P B Energy Storage Cavern Drilling \& Development 


\section{SECTION A - OVERVIEW OF OFFSHORE PROJECT}

\section{INTRODUCTION}

The use of salt caverns for storage of hydrocarbon liquids and gases is a well established proven technology. The U.S. Strategic Petroleum Reserve relies heavily upon salt cavern storage for its $600+$ million barrels of oil. A multi-participant study, sponsored in part by the National Energy Technology Laboratory of the U.S. Department of Energy and in part by participant contributions, is focused upon commercializing the Bishop Process ${ }^{T M}$ for the receiving of LNG, warming to a dense phase fluid, storage of that fluid in salt caverns with subsequent send-out of natural gas to one or more existing and / or purpose-built pipeline(s) to market.

In Part 1 of the Study Report, an overview of the Bishop Process ${ }^{\mathrm{TM}}$ is provided as well as a description of the Department of Energy sponsorship of the development work through the National Energy Technology Laboratory. Within Part 1 is an Executive Summary and a Functional Specification for the implementation of the Bishop Process ${ }^{\mathrm{TM}}$ at a generic offshore location. The Functional Specification defines what the facility must be capable of doing - system by system - to achieve its business objective. Part 1 contains a listing of the Project Study Deliverables to be created as a product of this study effort.

Part 2 of the Study - this document - provides the Basis of Design that is a more detailed description of how the functionality specified in Part 1 will be met for a selected site. Vermilion 179 is chosen as being representative of that offshore location. The Basis of Design is the source of data upon which the cost estimate is based.

\section{THE BISHOP PROCESS ${ }^{\mathrm{TM}}$}

The patented Bishop Process ${ }^{\mathrm{TM}}$ can be simply described as the process of unloading an LNG carrier with immediate pumping to operating pressures and warming that pressurized LNG to its final temperature prior to injection into a salt cavern for storage. This occurs as a continual flow of hydrocarbon for the duration of the LNG carrier offloading, and during which the LNG and the fluid is maintained in the dense phase. In one variation of this process a portion of the LNG offloaded is concurrently pressurized, warmed and sent directly to pipelines for transfer to markets. Between LNG carrier unloading operations, the fluid stored in the cavern is released into the pipelines.

\section{Heat Exchanger}

Any heat exchanger may be used with the Bishop Process ${ }^{\mathrm{TM}}$. To take full advantage of the salt cavern's unique volume and cost capability, a rugged, low cost, high flow rate heater is needed to warm the LNG as it is offloaded for immediate injection into the cavern or into a send-out pipeline. Warming the $L N G$ from a nominal minus $(-) 162^{\circ} \mathrm{C}\left(260^{\circ} \mathrm{F}\right)$ up to a cavern gas injection temperature of $>4^{\circ} \mathrm{C}\left(40^{\circ} \mathrm{F}\right)$ requires a specially designed process unit - a vaporizer that can operate at send-out pressures varying from 76 to 138 bar (1100 to $2000 \mathrm{psi}$ ) to accommodate both pipeline and cavern requirements. The patented Bishop Process ${ }^{\mathrm{TM}}$ Exchanger (BPE) is an enabling vaporizer technology that has been selected for application in Gulf of Mexico shallow water locations such as 
Vermilion 179 in 30 meters (100 ft.) of water. The Bishop Process ${ }^{\mathrm{TM}}$. Exchanger (BPE) is a simple, modular pipe-in-pipe design to warm up to 300 cubic meters of LNG per hour at maximum available operating pressures up to 138 bar (2000 psi) (ANSI 900) into about 6.5 million standard cubic feet per hour (156 million $\mathrm{std}_{\mathrm{ft}}^{3} /$ day equivalent flow rate) of natural gas.

Each BPE is made of $27-7 \mathrm{MO}(27 \%$ nickel, $7 \%$ molybdenum) alloy for the cryogenic pipe and HDPE for the outer shell. The individual BPE units will be fabricated, inspected, and hydro-tested in shop conditions to reduce costs and assure long service life.

\section{$\underline{B P E}$ Complex (LNG pumps and Bishop Process Exchangers $^{\text {TM }}$ )}

All of the equipment, including the BPE and high-pressure LNG pumps, have been proven in fullscale tests for both offshore and land-based implementation. The LNG pumps have been proven "in kind" as part of other LNG transport and offloading concepts that utilize shipboard vaporizers and pumps. The BPE complex (pumps and exchangers) can be tailored to match a specific location and operating requirements such as the specific cavern pressure operating range and storage capacity, as well as for the pipeline send-out flow rate and pressure. For example, if the pipeline pressures are below 90 bar (1300 psi), a low pressure BPE can be designed with ANSI 600, 102 bar (1480 psi) specifications supplied by cryogenic pumps readily available from several manufacturers. For injection into un-compensated salt caverns at pressures varying from 76 to 138 bar (1100 to 2000 psi) (depending upon how much gas is currently stored), a high pressure BPE will be designed with ANSI 900, 153 bar (2220 psi) ratings. Higher-pressure operation with ANSI 1500 (3705 psi) is possible with increases in costs for all valves, piping, flanges and pumps. For this Basis of Design, all Bishop Process ${ }^{\mathrm{TM}}$ Exchangers will be identical ANSI 900 rated units.

Paragon Engineering Services, Inc. has modeled the LNG pump configurations required to work against this variable pressure of un-compensated caverns at the required flow-rates. By linking multiple BPE's into a common high-pressure header, currently available LNG pumps can satisfy the pressure range from 76 bar (1100 psi) to a Maximum Allowable Operating Pressure (MAOP) of 138 barg (2000 psig). The offloading flow rate target (nominally 10,000 m3/hr.) to offload an LNG tanker in the allotted time frame is set for a cavern pressure of 122 barg (1775 psig). At lower pressures the flow will be higher than at the higher pressures but the average should be at the target.

\section{Vermilion 179}

The Vermilion 179 site has been selected as typical of an offshore Gulf of Mexico location and will be used to establish site-specific geotechnical and metocean data for the Basis of Design. The site is adjacent to a known salt dome suitable for cavern development, near multiple existing marine gas pipelines. Shipping fairways nearby provide access by LNG tankers.

The Vermilion 179 facility is comprised of five (5) fixed platforms encompassing nine (9) major systems that will be described in detail in Section $\mathrm{C}$. These systems are:

- An LNG ship offshore mooring and offloading system,

- A marine cryogenic transfer pipeline system,

- A Process Platform supporting the multiple cryogenic pumps for pressurizing the LNG

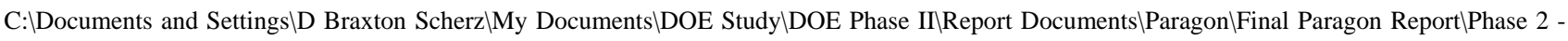
Basis of Design - Final.doc 
- The Bishop Process Exchanger ${ }^{\mathrm{TM}}$ Platform upon which the LNG is warmed (vaporized) to $>40^{\circ} \mathrm{F}$ while in the dense phase,

- A Cavern Support Platform system with units for injecting, storing, and extracting pressurized dense phase fluid from a salt cavern,

- A Flare Platform

- A Quarters Platform for the operations staff,

- Salt Cavern Drilling \& Development, and

- A marine gas pipeline system to distribute the gas to shore markets

\section{Vermilion 179 LNG Receiving Terminal}

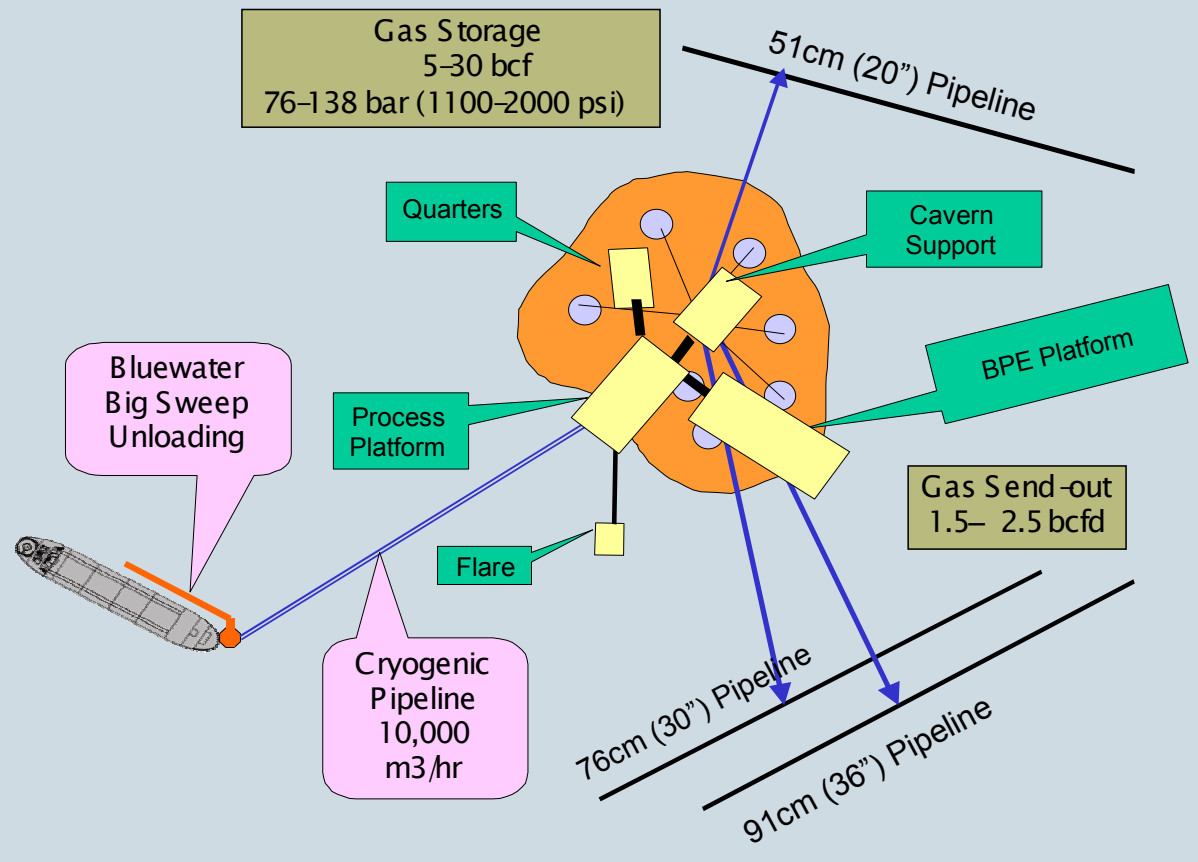

For this particular embodiment of the Bishop Process ${ }^{T M}$, the Vermilion 179 facility will receive LNG carriers up to $200,000 \mathrm{~m}^{3}$ that will be offloaded at $10,000 \mathrm{~m}^{3}$ per hour using Bluewater Offshore Technology's Big Sweep@). The LNG will be vaporized using the Bishop Process ${ }^{\mathrm{TM}}$ Exchanger with the gas being sent directly to the pipeline and concurrently to a salt cavern gas storage complex. These caverns will be created within a nearby salt dome to create large volume, low-cost storage. The average gas send-out rate for this facility into the pipelines is $57 \mathrm{~mm} \mathrm{~m}^{3} /$ day $(2.0 \mathrm{bscf} /$ day $)$ with a peak send-out of $71.5 \mathrm{~mm} \mathrm{~m} /$ day $\left(2.5 \mathrm{bscf} /\right.$ day) and a minimum of $42.9 \mathrm{~mm} \mathrm{~m}^{3} / \mathrm{day}(1.5 \mathrm{bscf} / \mathrm{day})$. During LNG carrier unloading, the flow rate of gas into the caverns ranges from $71.5 \mathrm{~mm} \mathrm{~m}^{3} /$ day (2.5 bscf/day) to $100 \mathrm{~mm} \mathrm{~m}^{3} /$ day (3.5 bscf/day). 


\section{PREPARATION of the BASIS OF DESIGN}

The Basis of Design defines how to satisfy the Functional Specification using a specific site as the example. This work is more quantitative and involves considerable engineering and modeling. The best description of the extent of engineering design performed to date is that of a pre-FEED. It is general in nature and there are still optimizations that need to be done. It is "A HOW", not "THE HOW". It is NOT a detailed design and a facility should not be designed on this document without further front-end engineering and detailed design work being performed for a specific site, for a specific client at a specific time and according to the regulations and laws in effect at that time.

The applicable Codes and Standards from ABS, AGA, ANSI, API, ASME, CFR 33, 40 \& 46, NFPA, and ANSI were used to prepare this document and would be used for the FEED and detailed design of this facility.

The document represents a safe and workable design but one that may not be optimized. To the extent possible, alternatives have been identified for future consideration. The intent has been to provide sufficient explanation of the recommended basis that a knowledgeable person or design firm could make adjustments deemed necessary. The cost estimate accuracy is deemed to be +/$30 \%$. 


\section{SECTION B - FACILITY COST ESTIMATE SUMMARY}

\section{BASIS OF THE COST ESTIMATE}

The Vermilion 179 Cost Estimate is based upon a HYSYS process model of the facility in both shipunloading mode and in cavern gas send-out mode. Preliminary PFD's were developed based upon this model and modified to accommodate the functionality required for the operational transition between these two modes.

All major equipment and major process piping (including all cryogenic piping) was sized for the most demanding operating condition. Once the process equipment was sized, power generation requirement was determined enabling electrical one-line drawings and a load list were developed

The above information was used to develop platform layouts and the overall facility arrangement. Safety requirements influenced the layout as did the incorporation of operations and maintenance functions. Further, the anticipation for ease of installation was factored into the final layouts and arrangements.

Using the basis above and the methodology described below, the overall accuracy of the cost estimate is taken to be $+/-30 \%$. The total cost of the project contains no provisions for contingency, license fees, interest during construction, Owner's costs, site lease costs, permitting costs, taxes or other fees.

\section{COST ESTIMATE METHODOLOGY}

The cost estimates for the Bluewater Big Sweep LNG Mooring and Unloading system and for the Cavern Drilling and Development system were provided on a "Vendor supplied and installed" basis without the same level of detail as for the platforms and pipelines. The Cost Estimate for the major platforms and all pipelines was prepared in a "Project Cost Account" format as listed below:

- $\quad$ LNG Marine Pipeline - material costs were provided by the vendor (ITP) on a cost per unit length basis for vendor provided $12 \mathrm{~m}$ (40 ft.) lengths delivered to the marshalling site. Installation costs were estimated by Paragon Engineering using a lay barge installation at current Fall 2004 day rates. The estimated installation time was determined from recent and current pipeline projects in the Gulf of Mexico with the estimated welding time tripled to account for the pipe-in-pipe-in-pipe configuration.

- $\quad$ Major Equipment - Written, e-mail, and verbal quotes were obtained for $95+\%$ of all sized equipment. The remainder was estimated based upon recent project work of similar duty. All costs were checked against current and recent project experience.

- Fabrication Materials and Labor - The cost estimate utilized current Fall 2004 steel prices and labor unit rates quoted from a major Gulf Coast Fabricator.

- Installation Equipment and Labor - Paragon utilized quoted derrick barge day rates and estimated durations based upon similar projects in the Gulf of Mexico to establish the cost to install the five platforms and interconnecting bridges. 
- Gas Send-out Pipelines - Material cost for each of the three send-out pipelines was estimated using current Fall 2004 steel prices. Installation costs were estimated by Paragon Engineering using a lay barge installation at current Fall 2004 day rates. The estimated installation time was determined from recent and current pipeline projects in the Gulf of Mexico. Since the location of actual tie-in could not be determined, the length of each of the three pipelines was assumed to be 16 kilometers (10 miles) with two crossings each. The size of each pipeline was sized by Paragon to meet the required volumetric flowrate.

- Hookup \& Commissioning - The day rate for the required quarters barge was estimated by Paragon from current Gulf of Mexico projects with the duration estimated based upon Paragon's recent and current experience.

- $\quad$ Project Management \& Engineering - These two cost elements were estimated using industry-accepted percentages of the total project cost.

\section{DETAILED COST ESTIMATE}

A Summary of the Capital Costs is provided below. A more detailed estimate is provided in Appendix 6.

\begin{tabular}{|c|c|c|c|c|c|c|}
\hline $\begin{array}{c}\text { Description } \\
\text { LNG Mooring \& } \\
\text { Unloading }\end{array}$ & $\begin{array}{c}\text { Total } \\
\text { Cost }\end{array}$ & $\begin{array}{c}\text { Process } \\
\text { Platform \& } \\
\text { Bridges }\end{array}$ & $\begin{array}{c}\text { BPE } \\
\text { Platform }\end{array}$ & $\begin{array}{c}\text { Cavern } \\
\text { Support } \\
\text { Platform }\end{array}$ & $\begin{array}{c}\text { Quarters } \\
\text { Platform }\end{array}$ & $\begin{array}{c}\text { Flare } \\
\text { Platform }\end{array}$ \\
\hline LNG Pipeline & $\$ 26 \mathrm{~mm}$ & N/A & N/A & N/A & N/A & N/A \\
\hline $\begin{array}{c}\text { Major Equipment } \\
\begin{array}{c}\text { Fabrication Materials } \\
\text { \& Labor }\end{array}\end{array}$ & $\$ 207 \mathrm{~mm}$ & $\$ 105 \mathrm{~mm}$ & $\$ 76.1 \mathrm{~mm}$ & $\$ 13.4 \mathrm{~mm}$ & $\$ 10.9 \mathrm{~mm}$ & $\$ 1.3 \mathrm{~mm}$ \\
\hline $\begin{array}{c}\text { Loadout, Transport \& } \\
\text { Installation }\end{array}$ & $\$ 56 \mathrm{~mm}$ & $\$ 18.7 \mathrm{~mm}$ & $\$ 12.6 \mathrm{~mm}$ & $\$ 12.5 \mathrm{~mm}$ & $\$ 6.9 \mathrm{~mm}$ & $\$ 4.9 \mathrm{~mm}$ \\
\hline $\begin{array}{c}\text { Project Management } \\
\text { \& Engineering }\end{array}$ & $\$ 63 \mathrm{~mm}$ & $\$ 26.8 \mathrm{~mm}$ & $\$ 20.9 \mathrm{~mm}$ & $\$ 6.9 \mathrm{~mm}$ & $\$ 3.6 \mathrm{~mm}$ & $\$ 1.6 \mathrm{~mm}$ \\
\hline $\begin{array}{c}\text { Cavern Drilling \& } \\
\text { Development }\end{array}$ & $\$ 90 \mathrm{~mm}$ & N/A & N/A & N/A & N/A & N/A \\
\hline $\begin{array}{c}\text { Gas Send-out } \\
\text { Pipeline }\end{array}$ & $\$ 53 \mathrm{~mm}$ & N/A & N/A & N/A & N/A & N/A \\
\hline \begin{tabular}{c} 
TOTAL \\
\hline
\end{tabular} & $\$ 721 \mathrm{~mm}$ & $\$ 206 \mathbf{m m}$ & $\$ 160.1 \mathrm{~mm}$ & $\$ 52.9 \mathrm{~mm}$ & $\$ 27.4 \mathrm{~mm}$ & $\mathbf{\$ 1 2} \mathrm{mm}$ \\
\hline
\end{tabular}




\section{SECTION C - BASIS OF DESIGN}

\section{SYSTEM 1 - LNG OFFLOADING SYSTEM}

\section{OVERVIEW}

For the Vermilion site in 30m (100 ft.) (nominal) water the Bluewater Offshore Technologies' "Big Sweep@" Mooring and Unloading System has been included within this Basis of Design.

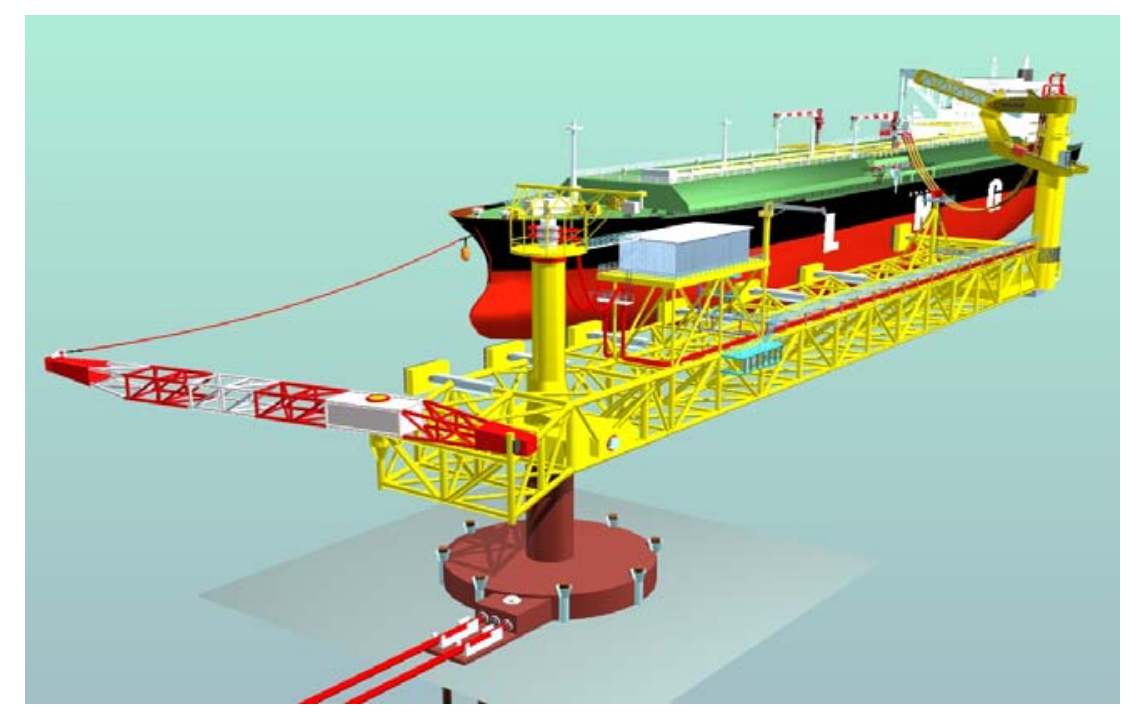

The Big Sweep(C) is a mooring and offshore LNG transfer system that provides high system availability, and suitability for non-dedicated vessels. The design shown above, developed for operation in the Gulf of Mexico, is a shallow water version of the deep water Big Sweep@ system. Key components of the Big Sweep@ include:

(a) a monopod structure with a swivel deck piled to the seabed,

(b) a rigid-truss arm, suspended from the monopod,

(c) a mooring outrigger at the forward end; its aft end terminating in buoyant column,

(d) an LNG Cryogenic Transfer System, starting at the LNG carrier's manifold and ending at seafloor at the monopod structure where it connects to the cryogenic marine pipeline.

(e) system to generate gas vapor for return to the LNG carrier

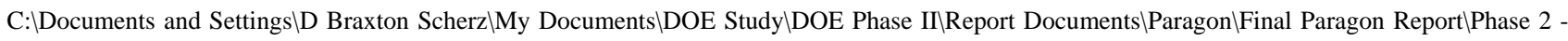


This design calls for the LNG carrier to hook-up to the mooring outrigger fitted on the forward end of the truss arm by means of a bow hawser. Most notable is the low wave profile making this unit very stable in many sea states. The overall length of the rigid arm is such that the buoyant column is positioned nominally near the mid-ship cargo manifold of the LNG carrier. By adjusting the length of the mooring hawser, the carrier's cargo manifold can be lined up to the offloading station for vessel sizes ranging from $125,000 \mathrm{~m}^{3}$ to $200,000 \mathrm{~m}^{3}$ storage. The Big Sweep@ loading arm is normally trailing downwind of the monopod but can be temporarily "parked" away from the LNG carrier's line of approach, with its thrusters. In this position the entire loading arm assembly cannot be damaged by a failed mooring approach of the LNG tanker.

A custom-design quick connect and disconnect manifold will be fitted forward of the LNG carrier's existing mid-ship manifold. This will be piped up with removable spool pieces and allow use of the existing manifold at conventional terminals. Flexible cryogenic jumpers, suspended from a manipulator, are connected to the skid onboard the LNG carrier and will enable up to $12,000 \mathrm{~m}^{3} / \mathrm{hr}$. to transfer. The normally unmanned manipulator is remotely operated from the Process Platform and allows connect / disconnect of the LNG flow path without manual intervention. A marine cryogenic pipeline transfers the LNG to the Process Platform.

Power is provided (approximately $1.8 \mathrm{~km}$ distant) via a marine power cable and control via a fiber optic umbilical - both from the Process Platform.

The Bluewater Offshore "Big Sweep" LNG mooring and unloading facility, as configured for the Vermilion 179 terminal facility, provides a single-point and weathervane mooring of LNG carriers up to $200,000 \mathrm{~m} 3$ capacity. Its capacity to transfer LNG from the ship to a subsea cryogenic marine pipeline is up to $12,000 \mathrm{~m}^{3} / \mathrm{hr}$. The nominal design flow rate for Vermilion 179 is $10,000 \mathrm{~m} 3 / \mathrm{hr}$. The pipeline is expected to be about $1830 \mathrm{~km}$. (6,000 ft.) long. The mooring system consists of a mooring pylon (for use in shallow water) and a traversing trestle arm providing unloading hoses at the ship's midpoint manifold. Power, control systems and alarm systems will be connected between the Big Sweep and the Process Platform in addition to the fluid flow of LNG.

\section{UNIT 1 - SHIP OFFLOADING PIPING}

The offloading hoses are sized at $51 \mathrm{~cm}$ (20 inches). The LNG transport lines are dual $51 \mathrm{~cm}(20$ inches) insulated pipes to the monopod swivel. Further specifications and design of the offloading piping / hoses are provided within Appendix 7.

\section{UNIT 2 - SHIP VAPOR RECOVERY SYSTEM}

The vapor return for the LNG tanker will be provided by a small vaporizer unit located on the Big Sweep. This unit utilizes a slip-stream of the $10,000 \mathrm{~m} 3 / \mathrm{hr}$. LNG flow and warms it to approximately $-157^{\circ} \mathrm{C}\left(-250^{\circ} \mathrm{F}\right)$ for return to the ship at $<0.14$ barg $(2 \mathrm{psig})$. The units include small LNG pumps, a separator vessel, a $200 \mathrm{~m}^{3} / \mathrm{hr}$.. seawater pump, and a small seawater based shell and tube exchanger. Instruments for pressure, flow, and temperature will interface with both a local control panel and the main control panel on the Process Platform. Antifoulant will be provided via tote tanks to the Big Sweep. Further detail can be found in Appendix 7.

C: $\backslash$ Documents and Settings $\backslash D$ Braxton Scherz $\backslash$ My Documents $\backslash$ DOE Study $\backslash$ DOE Phase II $\backslash$ Report Documents $\backslash$ Paragon $\backslash$ Final Paragon Report $\backslash$ Phase 2 - 


\section{UNIT 3 - UTILITIES AND CONTROLS}

Electrical Umbilical - All power to the Big Sweep@, except for some battery backup for emergency shutdown and emergency lighting / alarm power during outages will be supplied at the proper voltages from the Process Platform. At this time the design calls for $6 \mathrm{~mW}$ of peak power at 13.8 Kv. An emergency shutdown battery backup will be provided aboard the Big Sweep@ by Bluewater. A detailed description of the electrical system can be found in narrative and in diagram form within Appendix 7.

Control I Alarm Umbilical - There will be provision for dedicated alarm circuits both to and from the Big Sweep(C). Four levels of alarms are provided separate from the ESD system. These four levels will interface with alarm panels at each location and will cause action to be taken in the respective control systems. The ESD system will be a separate circuit with a redundant path other than hard wiring in the umbilical - such as wireless.

Control functions to valves, pumps, etc will be provided via dual and redundant coaxial cable to the Big Sweep(c) control system. The Big Sweep(C) is envisioned to have a remote operator's panel and a PLC for local control and operation. The umbilical will link this controller to the main Control room on the platform. It is expected that the Big Sweep@ $\subseteq$ will be unmanned during operations and that Big Sweep operations will be controlled from the Process Platform.

Hydraulic Power Pack - In lieu of instrument air, all Big Sweep@ control functions and actuators will utilize hydraulic power from an electrically driven packaged system.

\section{UNIT 4 - SAFETY SYSTEMS}

Bluewater Offshore has provided extensive instrumentation, monitoring and safety systems for the Big Sweep@. These are described in detail within Appendix 7.

\section{UNIT 5 - LNG PIPELINE INTERFACE}

The transfer of LNG at $10,000 \mathrm{~m} 3 / \mathrm{hr}$. will require a pressure of 7.5 bar at the inlet to the pipeline interface. The preferred interface embodiment will have all cryogenic valves above the water line within the mooring pylon or at its top. It is envisioned that a single riser will be hung from the top of the mooring pylon to a flanged connection within the base of the pylon. A cryogenic elbow spoolpiece will be installed as a connection riser with the horizontal cryopipe. The procedures and methods for such installation and connections are to be established with Bluewater, Paragon, and the selected cryogenic pipeline vendor. More detail can be found in Appendix 2 and Appendix 7.

The riser top end will terminate at the swivel. Prior to that swivel ("down pipe" toward the platform) will be the isolation valve for the pipeline. Upstream of the swivel, it is expected that there will be an isolation valve(s) for the Bluewater system.

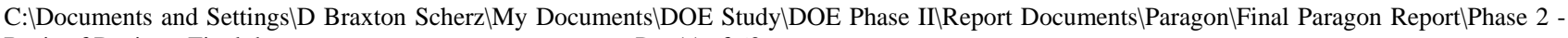
Basis of Design - Final.doc 


\section{Recirculation System}

Big Sweep@ LNG piping is to be insulated with high efficiency insulation $U<0.28 \mathrm{~W} / \mathrm{m}^{2}{ }^{\circ} \mathrm{C}(0.05$ Btu/ft. ${ }^{2 \circ} \mathrm{F}$-hr.) such as provided by ITP or Logstor. This greatly reduces the boil-off generated by ambient heat gain in the interval between ship arrivals. Please refer to Appendix 7.

In this Functional Specification, a small recirculation flow from the Process Platform will provide LNG flow through the pylon and swivel, through the Big Sweep cryogenic lines up to the base of the cryogenic unloading hoses and return to the Process Platform.

At the pipeline, Paragon plans to use two $61 \mathrm{~cm}$ (24-inch) lines with a jumper link just below the isolation valves. Please refer to the PFD in Appendix 2 for more details. 


\section{SYSTEM 2 - MARINE LNG TRANSFER PIPELINE}

\section{A. SYSTEM OVERVIEW}

For the purpose of the Vermilion 179 Study, Bluewater's shallow water version of the Big Sweep(C) LNG transfer system (ref: System 1) will be utilized as the "source" of the LNG. As a single point mooring (SPM), the LNG carrier will be allowed to weathervane about the SPM to reduce the influence of wind, waves and currents on the ship's motion. As mentioned above, the availability of the terminal is enhanced with the weathervaning capability. Thus, the SPM must be some distance - for this Study we are assuming $1951 \mathrm{~m}$ (6,400 ft.) from the Process Platform to allow safe ship maneuvering and mooring.

The interface point between the SPM and the cryogenic marine pipeline is at the interface point with the cryogenic riser. The design basis specifies an unloading rate of $10,000 \mathrm{~m}^{3} / \mathrm{hr}$. requiring $2 \mathrm{x}$ $61 \mathrm{~cm}$ (24 inch) lines to meet pressure drop objectives. Paragon's flow assurance analysis based its calculations on the information listed in Table 2.1.

\section{B. BASIS OF DESIGN}

TABLE 2.1 - Transfer Pipeline Basis of Design

\begin{tabular}{|c|c|}
\hline LNG Flow rate & 10,000 m³/hr. @7.5 bar \\
\hline Temperature at Inlet & $-159^{\circ} \mathrm{C}\left(-255^{\circ} \mathrm{F}\right)$ \\
\hline Pressure at Inlet & 7.5 bar nominal \\
\hline Number of Pipes & 2 \\
\hline Diameter of Cryogenic Pipes (O.D.) & $61 \mathrm{~cm}(24 \mathrm{in})$. \\
\hline Wall Thickness & $1.59 \mathrm{~cm}(0.625$ in. $)$ per API 5L \\
\hline Depth of Water & 33.5 meters (110 ft.) \\
\hline Max Allowable Temperature Gain in Pipeline & $5.6^{\circ} \mathrm{C}\left(10^{\circ} \mathrm{F}\right)$ \\
\hline Head Loss @ 10,000 m3/hr.. & 2.14 barg (31 psig) \\
\hline U Value - OHTC of Pipe & $0.17 \mathrm{~W} / \mathrm{m}^{2 \circ} \mathrm{C}\left(0.03 \mathrm{Btu} / \mathrm{hr} . \mathrm{ft}^{2}{ }^{2}{ }^{\circ} \mathrm{F}\right)$ \\
\hline $\begin{array}{l}\text { Effective OHTC for Entire Transfer System } \\
\text { including valves, swivel, etc. }\end{array}$ & $0.28 \mathrm{~W} / \mathrm{m}^{2 \circ} \mathrm{C}\left(0.05 \mathrm{Btu} / \mathrm{hr} . \mathrm{ft}^{2}{ }^{2}{ }^{\circ} \mathrm{F}\right)$ \\
\hline Seawater Temperature - max & $26.7^{\circ} \mathrm{C}\left(80^{\circ} \mathrm{F}\right) @$ bottom \\
\hline Maximum Allowable Operating Pressure & 10.3 barg (150 psig) - ANSI 150 \\
\hline Specific Gravity of LNG & 0.454 with range of $0.45-0.47$ \\
\hline Heat Capacity of LNG & $1.94 \mathrm{KJ} / \mathrm{kg}^{\circ} \mathrm{C}\left(0.464 \mathrm{Btu} / \mathrm{lb} . /{ }^{\circ} \mathrm{F}\right)$ \\
\hline Heat of Vaporization of LNG & $\begin{array}{l}444.2 \mathrm{KJ} / \mathrm{kg} \text { with range of } 434.9-451.2 \mathrm{KJ} / \mathrm{kg}(191 \mathrm{Btu} / \mathrm{lb} .) \text { with } \\
\text { range of } 187-194 \mathrm{Btu} / \mathrm{lb} .)\end{array}$ \\
\hline
\end{tabular}


TABLE 2.1 - Transfer Pipeline Basis of Design (CONTINUED)

\begin{tabular}{|l|l|}
\hline Duty Cycle & $\begin{array}{l}\text { LNG transfer for } 16 \text { hours; } 18 \text { hours before next transfer; pipeline } \\
\text { will remain flooded with LNG }\end{array}$ \\
\hline Viscosity of LNG & $14 \mathrm{cp} @-171^{\circ} \mathrm{C}\left(-276{ }^{\circ} \mathrm{F}\right)$ (methane) \\
\hline Line Pipe Roughness & $0.0046 \mathrm{~cm}(0.0018$ in. $)($ mean $)$ \\
\hline Length of pipe & $\begin{array}{l}2,042 \mathrm{~m}(6,700 \mathrm{ft} .) \\
\text { (including risers and unloading system) }\end{array}$ \\
\hline Minimum Delivery Pressure & $\begin{array}{l}3.1 \text { bar }(45 \text { psia) to maintain dense phase at LNG Pump Inlet } \\
\text { Header }\end{array}$ \\
\hline LNG Composition & Reference Table 2.3 \\
\hline Venting / Pressure Relief & $\begin{array}{l}\text { Vent \& Pressure Relief located at top of Process Platform riser; set } \\
\text { at } 110 \text { psig; vent sized for boil-off rate due to heat gain through } \\
\text { insulation. }\end{array}$ \\
\hline Cryogenic Valves & $\begin{array}{l}3 \times 61 \mathrm{~cm}(24 \text { in.) valves at Big Sweep } \odot-2 \text { isolation and } 1 \text { for } \\
\text { crossover line }\end{array}$ \\
\hline
\end{tabular}

\section{ANALYSIS OF THE DESIGN}

\section{Critical Design Factor}

During the analysis of the undersea piping, it was discovered that the overriding event that defines the insulation requirements was the "down time" - that is the time between ships. When the ships are unloading, the LNG flowrate is such that any heat pick-up is below measurement thresholds. The addition of heat is not unwanted as long as it does not cause two-phase flow in these undersea pipes. It is the heat gain between unloading operations that sets the insulation requirement (ref: Table 2.2).

\section{Methane Calculations}

Use of wet insulation $U=5.68 \mathrm{~W} / \mathrm{m}^{2 \circ} \mathrm{C}\left(1.0 \mathrm{Btu} / \mathrm{ft} .{ }^{2-} \mathrm{hr} .{ }^{\circ}{ }^{\circ} \mathrm{F}\right)$ on this pipe would create about 97 MMscfd of boil-off due to heat gain. Capturing this volume of gas and compressing to either sendout or cavern pressure would require dedicated compression capacity not otherwise needed. At this boil-off rate, the entire contents of the undersea pipe would vaporize in about 13 hours at which time the temperature of the pipe would quickly warm toward ambient. This in turn would create a cool-down problem at the next ship's arrival and unload. Furthermore, it would create a routine venting / flaring capability not required for any other purpose.

TABLE 2.2

Percent Methane Boiloff During Idle Time

\begin{tabular}{|c|c|c|}
\hline $\begin{array}{c}\text { IDLE TIME BETWEEN SHIPS } \\
\text { (hours) }\end{array}$ & $\begin{array}{c}\text { WET INSULATION } \\
\text { \% Vaporized } \\
\left(\mathrm{U}=5.68 \mathrm{~W} / \mathrm{m}^{2 \circ} \mathrm{C}\right)\end{array}$ & $\begin{array}{c}\text { DRY INSULATION } \\
\text { \% Vaporized } \\
\left(\mathrm{U}=0.568 \mathrm{~W} / \mathrm{m}^{2 \circ} \mathrm{C}\right)\end{array}$ \\
\hline 12 & $97 \%$ & $9.0 \%$ \\
\hline 24 & $100 \%$ & $19.5 \%$ \\
\hline 72 & $100 \%$ (ambient) & $58.5 \%$ \\
\hline
\end{tabular}

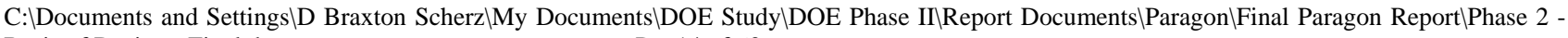


Interestingly, the calculation for the maximum allowable $U$ factor that would prevent vapor forming during unloading is $U=5.85 \mathrm{~W} / \mathrm{m}^{2 \circ} \mathrm{C}\left(1.03 \mathrm{Btu} / \mathrm{hr}\right.$. $\left.-\mathrm{ft}^{2}{ }^{2}{ }^{\circ} \mathrm{F}\right)$ - above this value of $U$ we would expect bubbles to form during the unloading. A summer-cycle of higher seawater temperature could create a serious operations problem of eliminating the entrained bubbles prior to the LNG pumps. While $U$ $=5.68 \mathrm{~W} / \mathrm{m}^{2 \circ} \mathrm{C}\left(1.0 \mathrm{Btu} / \mathrm{hr} . \mathrm{ft}^{2}{ }^{2}{ }^{\circ} \mathrm{F}\right)$ will work, it is borderline and the compression / re-liquefaction operations cost is significant on a life-cycle cost basis.

\section{High Efficiency Cryogenic Insulation}

High efficiency insulation with an Overall Heat Transfer Coefficient (OHTC) of $U=0.17 \mathrm{~W} / \mathrm{m}^{2 \circ} \mathrm{C}$ $\left(0.03 \mathrm{Btu} / \mathrm{ft} .{ }^{2-} \mathrm{hr} .{ }^{\circ} \mathrm{F}\right)$ is available and is currently being installed in shallow sub-sea applications for LPG hydrocarbon liquids at $-40^{\circ} \mathrm{C}\left(-40^{\circ} \mathrm{F}\right)$. Ongoing development and testing of this insulation technology for application with LNG is underway due in part to strong industry demand for such piping.

Marine cryogenic pipelines with $U=0.17 \mathrm{~W} / \mathrm{m}^{2 \circ} \mathrm{C}\left(0.03 \mathrm{Btu} / \mathrm{ft} .^{2}-\mathrm{hr} .{ }^{\circ}{ }^{\circ} \mathrm{F}\right)$ or better (such as those offered by ITP) are being specified for use with several international LNG baseload liquefaction plants. Prior to any implementation at Vermilion 179, cryogenic marine pipelines will have been installed and proven at multiple locations. Therefore, it is reasonable to assume its first use within a few years and therefore the Basis of Design calls for high-efficiency insulation without being specific as to the exact manufacturer or physical form of the insulation itself.

\section{Vermilion LNG Chemical Composition}

While the figures in Table 2.2 reflect pure methane behavior, Vermilion 179 may experience LNG sourced from multiple locations. LNG composition does affect the bubble point. The analysis is complete for three LNG compositions: a lean source such as Trinidad, a rich source such as from Qatar, and a middle ground composition typical of Nigeria sources. This Study has selected the middle ground of Nigerian LNG as the basis for design. These three compositions are listed in Table 2.3.

The initial thermo-hydraulic calculation was performed using pure methane properties (ref. Table 2.2). The design is confirmed for Vermilion using three LNG compositions:

TABLE 2.3

\begin{tabular}{|c|c|c|c|}
\hline Component & Trinidad (mol\%) & $\begin{array}{c}\text { Nigeria (mol\%) } \\
\text { (Design Basis) }\end{array}$ & Qatar (mol\%) \\
\hline N2 & 0.05 & 0.14 & 0.09 \\
\hline C1 & 94.75 & 89.34 & 89.07 \\
\hline C2 & 3.55 & 5.32 & 7.67 \\
\hline C3 & 0.92 & 3.36 & 2.92 \\
\hline IC4 & 0.34 & 0.73 & 0.24 \\
\hline
\end{tabular}

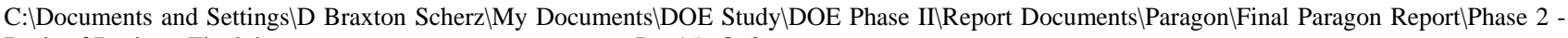
Basis of Design - Final.doc 
TABLE 2.3 (continued)

\begin{tabular}{|c|c|c|c|}
\hline NC4 & 0.34 & 1.10 & 0.10 \\
\hline IC5 & 0.02 & 0.01 & 0.0 \\
\hline NC5 & 0.01 & 0.0 & 0.0 \\
\hline
\end{tabular}

Based on the above high efficiency $\mathrm{OHTC}$ of $0.17 \mathrm{~W} / \mathrm{m}^{2 \circ} \mathrm{C}\left(0.03 \mathrm{Btu} / \mathrm{hr} . \mathrm{ft}^{2}{ }^{2}{ }^{\circ} \mathrm{F}\right)$, Table 2.4 below provides the percentage of the LNG that would vaporize without any recirculation as a function of the idle period (no recirculation) between two successive LNG unloading operations. NOTE - the boil-off rate of traditional wet insulation $\left(\mathrm{OHTC}=5.68 \mathrm{~W} / \mathrm{m}^{2 \circ} \mathrm{C}\left(1.0 \mathrm{Btu} / \mathrm{hr} .-\mathrm{ft} .{ }^{2}-\mathrm{hr} .{ }^{\circ} \mathrm{F}\right)\right)$ would vaporize all LNG in the line within 15 hours.

TABLE 2.4

Percent LNG Boil-off

\begin{tabular}{|c|c|c|c|c|}
\hline Idle for (hr.) & Pure Methane & Trinidad & Nigeria & Qatar \\
\hline 12 & $13.0 \%$ & $14.2 \%$ & $13.6 \%$ & $13.3 \%$ \\
\hline 24 & $26.0 \%$ & $28.4 \%$ & $27.2 \%$ & $26.6 \%$ \\
\hline 72 & $78.1 \%$ & $85.1 \%$ & $81.6 \%$ & $79.7 \%$ \\
\hline \multirow{2}{*}{} & Percent increase & $9 \%$ & $5 \%$ & $2 \%$ \\
\hline
\end{tabular}

Two $61 \mathrm{~cm}$ (24 in.) pipes were selected as the Basis of Design, which will enable recirculation of LNG between ship arrivals. The actual cost of recirculation and some LNG reliquefaction is considered an acceptable operations cost, as it will preclude thermal cycling of the pipe and fittings. This recirculation will encompass the sub-sea pipes, the LNG pumps and most of the Bluewater unloading system and will reduce the time for cool-down prior to LNG transfer. A small liquefier on the Process Platform will provide make-up LNG.

\section{Hydraulic Design Calculations}

Maximum velocity and pressure drop criteria must be met.

\section{LNG Data}

TABLE 2.5

\begin{tabular}{|c|c|c|c|c|}
\hline Characteristics & Pure Methane & Trinidad & Nigeria & Qatar \\
\hline Specific Gravity & 0.45 to 0.47 & 0.432 & 0.454 & 0.470 \\
\hline Viscosity (cP) & 0.14 & 0.14 & 0.17 & 0.19 \\
\hline $\begin{array}{c}\text { Heat of vaporization } \\
\text { (KJ/kg/BTU/lb.) }\end{array}$ & $511.7 / 220$ & $450 / 193.5$ & $444.5 / 191.1$ & $436.3 / 187.6$ \\
\hline
\end{tabular}

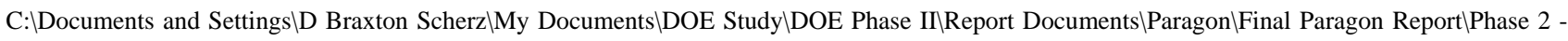
Basis of Design - Final.doc 


\section{Maximum Velocity}

- Objective is to minimize surge and corrosion/erosion.

- The criterion is taken as $V_{e}=\frac{C}{\sqrt{\rho}}$ where:

$\mathrm{V}_{\mathrm{e}}=$ fluid erosional velocity, $\mathrm{ft} / \mathrm{s}$

$\mathrm{C}=$ empirical constant, 100 for continuous service

" $\rho "$ = density at flowing pressure and temperature in $\mathrm{lb} / \mathrm{ft}^{3}$

- The resultant calculation yields $=\mathrm{V}_{\mathrm{e}}=18.5 \mathrm{ft} / \mathrm{s}$

- The minimum internal diameter of either of the two lines is therefore:

$$
\begin{aligned}
& d=\sqrt{\frac{2 Q_{v}}{\pi V_{e}}} \\
& Q v=\text { volumetric flowrate } \mathrm{ft}^{3} / \mathrm{s} \\
& " \mathrm{~d} "=\text { minimum internal diameter } \mathrm{ft} \\
& " \mathrm{~d} "=1.64 \mathrm{ft} \quad(19.7 " \text { ID }) \\
& " \mathrm{~d} "=0.5 \mathrm{~m} \quad(50 \mathrm{~cm} \mathrm{ID)})
\end{aligned}
$$

- The erosional velocity criterion leads to a $61 \mathrm{~cm}$ (24 in.)OD minimum.

\section{Head Loss}

The minimum assumed available transfer pressure produced by the LNG tanker pumps is 8 bar $=$ 117 psig. Flow losses through the Big Sweep(C) will give us 7.5 bar $=110$ psig at the inlet to the cryogenic pipeline.

- Based on the Colebrook equation the frictional head losses are 2.14 bar (31 psi) for two $61 \mathrm{~cm}$ (24 in.) lines.

\section{Wall Thickness (WT)}

The wall thickness of the $61 \mathrm{~cm}$ (24 in.) line, calculated based on pressure containment, is low. For installation purpose, a maximum $\mathrm{D} / \mathrm{t}$ ratio of about 40 is considered, which would lead to a $1.59 \mathrm{~cm}$ (0.625 in.) WT as the next API $5 \mathrm{~L}$ standard size. 


\section{Allowable Temperature Gain to Preclude Vapor Phase (Bubbles) During Unloading}

In accordance with the pure methane Molier diagram, at atmospheric pressure the temperature at which the liquid phase and vapor phase are in equilibrium is $162^{\circ} \mathrm{C}\left(-260^{\circ} \mathrm{F}\right)$, which correspond to the LNG inside of the tanker. The tanker offloading pumps increase the pressure to 8 barg (117 psig), putting the LNG into the dense phase. Friction losses and heat gain in the Big Sweep@ yields 7.5 bar and $-159^{\circ} \mathrm{C}\left(-255^{\circ} \mathrm{F}\right)$ at the pipeline inlet. Flow in the two $61 \mathrm{~cm}(24 \mathrm{in}$.) LNG line at the design flowrate of $5000 \mathrm{~m}^{3} / \mathrm{hr}$.. each will reduce the pressure by 2.41 barg (35 psig) to 5.17 barg (75 psig) at the inlet to the LNG pump suction header At this pressure the first bubble of vapor appears at a temperature of $-140^{\circ} \mathrm{C}\left(-220^{\circ} \mathrm{F}\right)$.

Therefore it is acceptable to tolerate a temperature increase of $19.4^{\circ} \mathrm{C}\left(35^{\circ} \mathrm{F}\right)$ within the line prior to LNG pump entry.

This $19.4^{\circ} \mathrm{C}\left(35^{\circ} \mathrm{F}\right)$ difference must account for:

- The heat gained through insulation, taken as $1.11^{\circ} \mathrm{C}\left(2^{\circ} \mathrm{F}\right)$

- The temperature gained in the pump, taken as $1.11^{\circ} \mathrm{C}\left(2^{\circ} \mathrm{F}\right)$

- An allowance for additional heat losses in other areas of the LNG transfer system on the Big Sweep(

- An allowance for LNG line field joints, valves, and the cryogenic swivel

- An allowance for uncertainties on the LNG composition

However, in order to remain on the safe side, the temperature gain selected as design criterion for insulation is $5.56^{\circ} \mathrm{C}\left(10^{\circ} \mathrm{F}\right)$. This is to be associated with the minimum steady flowrate of 5000 $\mathrm{m}^{3} / \mathrm{hr}$.. within each of the two pipes.

\section{General Comments}

Based upon this analysis, it is demonstrated that:

- Steady state offloading conditions are not governing the Overall Heat Transfer Coefficient (OHTC); rather, it is the idle time between unloading operations.

- Recirculation of LNG is not required to maintain the loading line at low temperature during the idle period between two offloading operations as long as the effective overall $\mathrm{HTC}$ is = $0.28 \mathrm{~W} / \mathrm{m}^{2 \circ} \mathrm{C}\left(0.05 \mathrm{Btu} / \mathrm{hr}^{\circ}-\mathrm{ft}^{2}{ }^{2}{ }^{\circ} \mathrm{F}\right)$, and the idle time does not exceed 72 hours.

- Under idle conditions between two offloading operations, an $\mathrm{OHTC}$ of $0.17 \mathrm{~W} / \mathrm{m}^{2 \circ} \mathrm{C}(0.03 \mathrm{Btu} / \mathrm{hr}$.$\left.\mathrm{ft}^{2}{ }^{2}{ }^{\circ} \mathrm{F}\right)$ reduces the size of the condensing (reliquefaction) unit associated with the recirculation package.

- Thermal calculations performed using PVTsim conclude that boil-off rate is quite sensitive to chemical composition of the LNG. Sizing of reliquefaction must be based upon actual project composition. 
- Each of the two dual LNG lines will be $61 \mathrm{~cm}(24$ in.) with an Overall Heat Transfer Coefficient $(\mathrm{OHTC})$ of $0.17 \mathrm{~W} / \mathrm{m}^{2 \circ} \mathrm{C}\left(0.03 \mathrm{Btu} / \mathrm{ft} .^{2}-\mathrm{hr} .{ }^{\circ}{ }^{\circ} \mathrm{F}\right)$. The effective overall coefficient is estimated at 0.28 (0.05) including the effect of valves and fittings. 


\section{Receiving \& Production Profile}

The Process Platform will support the LNG receiving characteristics listed in Table 3.1

TABLE 3.1

LNG Receiving Requirements

\begin{tabular}{|c|c|}
\hline Factor & Value \\
\hline Tanker Capacity & Up to $200,000 \mathrm{~m}^{3}$ capacity \\
\hline LNG Temperature @ Platform & $-157^{\circ} \mathrm{C}\left(-250^{\circ} \mathrm{F}\right)$ \\
\hline LNG Unloading Rate & $10,000 \mathrm{~m}^{3} / \mathrm{hr} .$. \\
\hline Minimum Pressure of LNG at Platform & 5.17 barg $(75 \mathrm{psig})$ \\
\hline Unloading Frequency - maximum & Ship arrives every 48 hours \\
\hline
\end{tabular}

The Vermilion facility will always be sending a minimum flowrate of $1.5 \mathrm{bscf} /$ day to the pipeline. Normal operations provide $2.0 \mathrm{bscf} /$ day and the peak is $2.5 \mathrm{bscf} /$ day. These scenarios are defined in Table 3.2. If an LNG ship is unloading, the pipeline sendout requirement will be met via direct vaporization through the LNG pumps and BPE bypassing the caverns. The remainder of the LNG offloaded is warmed for cavern injection.

TABLE 3.2

Vermilion 179 Production Scenarios While Offloading LNG

\begin{tabular}{|c|c|c|c|c|c|c|c|c|c|}
\hline $\begin{array}{l}\text { Production } \\
\text { Scenario }\end{array}$ & $\begin{array}{l}\text { Offload } \\
\text { Rate - } \\
\text { Equivalent } \\
\text { Gas } \\
\text { Production } \\
\text { (Bscfd) }\end{array}$ & $\begin{array}{c}\text { LNG } \\
\text { Arrival } \\
\text { Press.@ } \\
\text { Platform } \\
\text { barg I } \\
\text { (psig) }\end{array}$ & $\begin{array}{l}\text { LNG } \\
\text { Arrival } \\
\text { Temp. } \\
\left({ }^{\circ} \mathrm{C} /{ }^{\circ} \mathrm{F}\right)\end{array}$ & $\begin{array}{l}\text { Gas to } \\
\text { Storage } \\
\text { Cavern } \\
\text { (Bscfd) }\end{array}$ & $\begin{array}{c}\text { Storage } \\
\text { Cavern } \\
\text { Pressure } \\
\text { (barg/psig) }\end{array}$ & $\begin{array}{c}\text { Send } \\
\text { Out Gas } \\
\text { to } \\
\text { Pipeline } \\
\text { (Bscfd) }\end{array}$ & $\begin{array}{l}\text { Send Out } \\
\text { Pressure } \\
\text { @ Platform } \\
\text { (barg } \\
\text { Ipsig) }\end{array}$ & $\begin{array}{l}\text { Send Out } \\
\text { Gas Temp. } \\
\text { @ Platform } \\
\left.{ }^{\circ} \mathrm{C} /{ }^{\circ} \mathrm{F}\right)\end{array}$ & $\begin{array}{c}\text { Minimum } \\
\text { Pressure } \\
\text { @ Pipeline } \\
\text { Tie-In } \\
\text { (barg I } \\
\text { psig) }\end{array}$ \\
\hline $\begin{array}{l}\text { Nominal } \\
\text { Operation }\end{array}$ & 5.0 & $5.17 / 75$ & $\begin{array}{c}-159 /- \\
254\end{array}$ & 3.0 & $\begin{array}{c}76-138 / \\
1100-2000\end{array}$ & 2.0 & $76 / 1100$ & $4.4 / 40$ & $69 / 1000$ \\
\hline $\begin{array}{l}\text { Max Gas to } \\
\text { Pipeline }\end{array}$ & 5.0 & $5.17 / 75$ & $\begin{array}{c}-159 \text { / - } \\
254\end{array}$ & 2.5 & $\begin{array}{c}76-138 / \\
1100-2000\end{array}$ & 2.5 & $76 / 1100$ & $4.4 / 40$ & $69 / 1000$ \\
\hline $\begin{array}{l}\text { Max Gas to } \\
\text { Storage }\end{array}$ & 5.0 & $5.17 / 75$ & $\begin{array}{c}-159 / \text { - } \\
254\end{array}$ & 3.5 & $\begin{array}{c}76-138 / \\
1100-2000\end{array}$ & 1.5 & $76 / 1100$ & $\begin{array}{c}18.3-21.1 / \\
65-70\end{array}$ & $69 / 1000$ \\
\hline
\end{tabular}




\section{SYSTEM 3 - PROCESS PLATFORM}

\section{A. SYSTEM OVERVIEW}

LNG is offloaded at the mooring and LNG offloading system (System 1) and flows to the Process Platform via two $61 \mathrm{~cm}$ (24 in.) cryogenic pipelines (System 2). Once on the main processing platform, the LNG will enter an LNG pump suction header for distribution to individual $1^{\text {st }}$. Stage LNG pumps. Any vapor will be taken off the top of the header and re-liquified. The $1^{\text {st }}$ Stage LNG pumps will discharge into an intermediate pressure header at a pressure nominally at 75.8 barg (1100 psig). This intermediate header serves two functions: 1 ) as the suction header to the $2^{\text {nd }}$ Stage LNG pumps, and 2) as the LNG supply header to the pipeline vaporizers (Low Pressure BPE) that operate at 75.8 barg (1100 psig) providing immediate send-out to pipelines. The outlet of the $2^{\text {nd }}$ Stage LNG pumps discharge into the high pressure (HP) LNG header to be vaporized for injection into the salt cavern. This HP header operates at cavern pressure that can range from 75.8 barg (1100 psig) up to 138 barg (2000 psig) MAOP.

The Process Platform provides the required $80+\mathrm{MW}$ of electrical power to the entire facility from three LM6000 (3 x 50\%) gas turbine generators. Waste heat recovery units on each turbine provide additional heat to gas entering the caverns.

A simplified process schematic is depicted in Figure 3-1 (detailed layouts and PFD's are provided in Appendix 1 and 2).

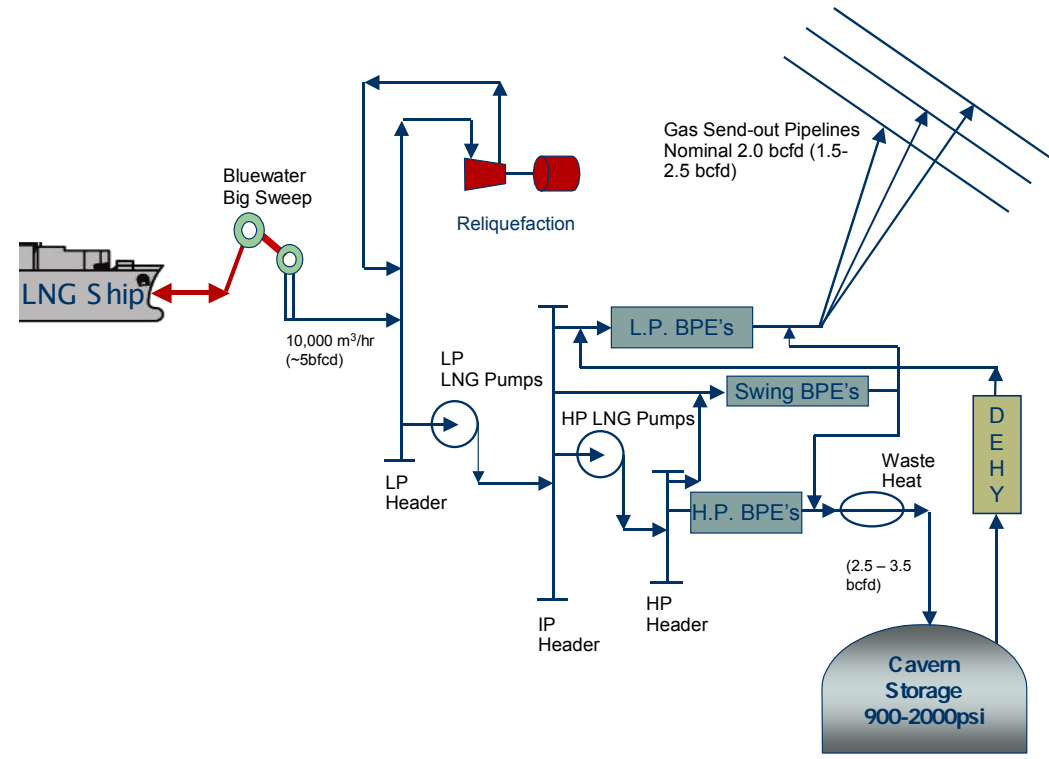

Figure 3.1

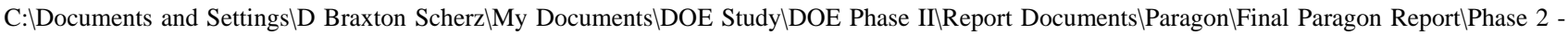
Basis of Design - Final.doc 


\section{B. BASIS OF DESIGN}

The Process Platform as specified for the Vermilion 179 location is comprised of many units each of which is designed to support the overall facility. Each of the units is presented below with their respective technical information. All major systems are assumed to be spared in an N+1 fashion.

\section{UNIT 1 - RISERS AND INTERFACES}

The Process Platform is fitted with the following risers:

\section{a. LNG Risers}

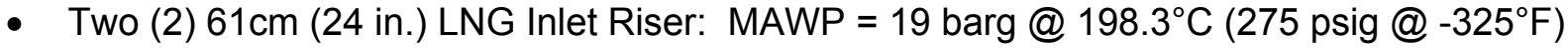

- $\quad$ Normal operating pressure range 5.17-6.89 barg (75-100 psig).

- Venting at the top of both risers - sized to meet expected boil-off due to natural heat gain

b. Power, Control and ESD Umbilical to SPM - Bluewater Big Sweep@

- 6.0 MW peak @13.8 KV max

- Two (2) redundant marine cables from Process Platform laid coaxially with LNG Pipelines

- ESD system interconnect with SPM system will be wire cable

- Control cable for SPM will be fiber optic

C. Power, Control and ESD Cable via Interconnecting Bridges

- Cavern Support Platform

- Quarters Platform

- BPE Platform

- Flare Platform

- ESD system interconnect will be wire cable

- Control cable will be fiber optic

d. Major Headers and Piping via Interconnecting Bridges

- $61 \mathrm{~cm}$ (24 in.) LP LNG header to the BPE Platform

- $76 \mathrm{~cm}$ (30 in.) HP LNG header to the BPE Platform

- $91 \mathrm{~cm}$ (36 in.) LP Gas header from the BPE Platform

- $\quad 91 \mathrm{~cm}$ (36 in.) HP Gas Header from the BPE Platform 
- $91 \mathrm{~cm}$ (36 in.) LP and $91 \mathrm{~cm}$ (36 in.) HP Gas Headers to and from the Cavern Support Platform

- Utility headers to all platforms

\section{UNIT 2 - CRYOGENIC UNITS}

a. LNG Suction Header: this header receives the LNG from the dual cryogenic marine pipelines and provides the inlet suction to the $1^{\text {st }}$ Stage LNG pumps. This $91 \mathrm{~cm}$ (36 in.) header operates at a nominal pressure of 7 bar.

b. $1^{\text {st }}$ Stage LNG Pumps: These fixed-speed pumps take suction from the LNG suction header and discharge at 76 barg (1100 psig) (max) into the intermediate pressure header. This discharge / header pressure is controlled within a narrow range of $+/-1.4$ barg $(20$ psig). Each pump is equipped with a minimum flow control to protect from damage.

c. Intermediate Pressure (IP) Header: This $91 \mathrm{~cm}$ (36 in.) header provides LNG distribution to the suction side of the $2^{\text {nd }}$ Stage LNG pumps and to the inlet header of the Pipeline Bishop Process $^{\mathrm{TM}}$ Exchangers (BPE).

d. $2^{\text {nd }}$ Stage LNG Pumps: These variable frequency drive pumps provide LNG to the Cavern BPE units at the cavern operating pressure that can range from 76 barg (1110 psig) to 138 barg (2000 psig) MAOP. Each pump is equipped with a minimum flow control to protect from damage. 
TABLE 3- 6

LNG PUMP

\begin{tabular}{|c|c|}
\hline FACTOR & VALUE \\
\hline Model \& Make & Ebara $8 E C C-1510$ or equivalent \\
\hline Duty & $\begin{array}{c}\text { Cyclic operation from } 1 \text { bar to full discharge pressure } \\
3 \text { times per week. All pumps will remain at cryogenic } \\
\text { temperatures in normal terminal operation }\end{array}$ \\
\hline Number of Pumps & $\begin{array}{c}161^{\text {st }} \text { Stage fixed speed pumps; } 10 \text { VFD } 2^{\text {nd }} \text { stage } \\
\text { pumps including one (1) spare }\end{array}$ \\
\hline Volume Flow Rate per $1^{\text {st }}$ Stage Pump & Design point is 700 m3/hr. @ 76 barg (1100 psig) \\
\hline Motor & $\begin{array}{c}\text { Submerged Can, } 3600 \text { rpm for } 1^{\text {st }} \text { Stage; } 0-3600 \mathrm{rpm} \\
\text { for } 2^{\text {nd }} \text { Stage VFD }\end{array}$ \\
\hline $\begin{array}{l}\text { Outlet Pressure flow rate across } 2^{\text {nd }} \text { Stage } \\
\text { Pump }\end{array}$ & $\begin{array}{c}\text { Variable from } 354 \mathrm{~m}^{3} / \mathrm{hr} \text {. @ } 87.8 \mathrm{barg}(1274 \mathrm{psig}) \\
\text { to } 808 \mathrm{~m} 3 / \mathrm{hr} \text {. @ } 138 \text { barg (2000 psig) }\end{array}$ \\
\hline Code rating for pumps & ANSI 900 \\
\hline Power at Maximum Pressure & $2294 \mathrm{KW}$; starting surge is $6 \mathrm{x}$ \\
\hline Inlet size & $30 \mathrm{~cm}(12$ in. $)$ \\
\hline Outlet Size & $25 \mathrm{~cm}(10 \mathrm{in})$. \\
\hline NPSH maximum & TBD \\
\hline Size & $1.2 \mathrm{~m} \times 4.6 \mathrm{~m}(4 \mathrm{ft} . \times 15 \mathrm{ft})$. \\
\hline Weight & 11,975 kg $(26,400$ lbs. $)$ \\
\hline Flow protection & Included \\
\hline
\end{tabular}

TABLE 3 - 7

QUANTITIES OF PUMPS

\begin{tabular}{|c|c|c|c|c|c|c|c|}
\hline $\begin{array}{l}\text { Operating } \\
\text { Scenario }\end{array}$ & $\begin{array}{c}\text { LNG } \\
\text { Offload } \\
\text { Rate } \\
\left(\mathrm{m}^{3} / \mathrm{hr} .\right) \\
\{\mathrm{A}\} \\
\end{array}$ & $\begin{array}{c}\text { Total Gas } \\
\text { Productio } \\
\text { n } \\
\text { (Bscfd) } \\
\{B\} \\
\end{array}$ & $\begin{array}{c}1^{\text {st }} \text { Stage } \\
\text { Pumps } \\
\text { Required } \\
\{C\}\end{array}$ & $\begin{array}{c}\text { Gas Flow } \\
\text { to } \\
\text { Pipeline } \\
\{D\}\end{array}$ & $\begin{array}{c}\text { Gas } \\
\text { Flow } \\
\text { to } \\
\text { Cavern } \\
\{E\} \\
\end{array}$ & $\begin{array}{c}2^{\text {nd }} \text { Stage } \\
\text { Pumps } \\
\text { Required } \\
\{F\}\end{array}$ & $\begin{array}{c}\text { Total } \\
\text { Number } \\
\text { of } \\
\text { Pumps } \\
\{G\}\end{array}$ \\
\hline $\begin{array}{l}\text { Nominal } \\
\text { Operation } \\
(2 \mathrm{bcfd})\end{array}$ & 10,000 & 5.0 & $\begin{array}{c}\{A\} / 700= \\
15\end{array}$ & 2 bcfd & 3 bcfd & 9 & 24 \\
\hline $\begin{array}{l}\text { Max to Pipeline } \\
\text { @ } 76 \text { barg } \\
\text { (1100 psig) }\end{array}$ & 10,000 & 5.0 & $\begin{array}{c}\{\mathrm{A}\} / 700= \\
15\end{array}$ & $2.5 \mathrm{bcfd}$ & $2.5 \mathrm{bcfd}$ & 7 & 22 \\
\hline $\begin{array}{l}\text { Max to Storage } \\
@ 122 \text { barg } \\
\text { (1775 psig) }\end{array}$ & 10,000 & 5.0 & $\begin{array}{c}\{\mathrm{A}\} / 700= \\
15\end{array}$ & $1.5 \mathrm{bcfd}$ & $3.5 \mathrm{bcfd}$ & 10 & 25 \\
\hline
\end{tabular}

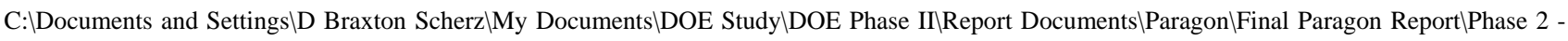
Basis of Design - Final.doc 


\section{e. LNG Recirculation Pumps}

The VFD $2^{\text {nd }}$ Stage pumps will be used to recirculate LNG through the two (2) $61 \mathrm{~cm} \mathrm{(24} \mathrm{in.)}$ LNG lines when no offloading is present to keep the marine pipeline, portions of the Big Sweep@ and the main LNG pumps cold.

\section{UNIT 3 - POWER GENERATION}

a. Maximum Platform Operating Load

Electrical power for the terminal will be located on the Process Platform top deck and will be generated by the units defined below:

- Three GE LM $6000(3 \times 50 \%)$ gas fuel turbine/generator sets with waste heat recovery for normal ship offloading power requirements.

- Two Solar Centaur $40(2 \times 100 \%)$ gas turbine generator sets for general support during the intervals between ship offloading

- One 1,000 KW diesel generator for black start / emergency (essential) requirements.

Power generation will be at $13.8 \mathrm{kV}$. Transformers will be included for power at lower levels (6900V, 480V, 208V, 120V). DC voltage requirements will be by chargers and battery sets.

b. Switchgear/MCC Building equipped with:

- $13.8 \mathrm{kV}$ metal clad switchgear for primary power distribution

- $6.9 \mathrm{kV}$ metal clad switchgear for medium voltage motor control

- 480 Volt Motor control Center (MCC) assemblies for low voltage motor control and power distribution

- Variable Frequency Drives (VFD) for the HP LNG pumps

- Transformers and distribution panel boards for power requirements less than $480 \mathrm{~V}$, such as lighting and various utility loads

- Battery charges and DC distribution panel boards

\section{UNIT 4 - PLATFORM UTILITIES}

a. Utility and Instrument Air Skid

- Instrument Air Compressors, Rotary Screw, Oil Free, 119 kV (200 hp)

- Instrument Air Receiver: 10.3 barg (150 psig) operating pressure

- Capacity: 3 x 50\% @ 587 scfm each 


\section{b. Fuel Gas System:}

\section{Fuel Gas}

The system supplies gas to the following users:

- Air:

Starting air receiver 13.8 barg (200 psig) operating pressure fuel gas heater

- Fuel Gas to:

Power Generator Engines 46.5 barg (675 psig)); max flow = $20.5 \mathrm{mmscfd}$

\section{Fuel Gas Heater}

- $91 \mathrm{~cm}$ (36 in.) OD x 2.4m (8 ft. -0 in.) SS Vertical Vessel

- MAWP 51.7 barg (750 psig) @ $-45.6^{\circ} \mathrm{C}\left(-50^{\circ} \mathrm{F}\right)$

- 41.4 barg $(600 \mathrm{psig})$ Operating pressure @ $4.4^{\circ} \mathrm{C}$ to $22^{\circ} \mathrm{C}\left(40^{\circ} \mathrm{F}\right.$ to $\left.72^{\circ} \mathrm{F}\right)$

\section{c. Diesel System}

Diesel is stored in $27 \mathrm{~m}^{3}$ (7,200 gallon) diesel storage tank. A diesel distribution pump supplies diesel to the crane's onboard engine, diesel driven emergency generator and diesel firewater pump's engine.

- Fuel Storage: 3 days at full power load

\section{UNIT 5 - RELIQUEFACTION SYSTEM}

Packaged reliquefaction system designed for 2 mmscfd of boil off gas at a pressure of 4.14 barg (60 psig). The refrigeration system within the unit is $2-50 \%$ electric motor driven compressor units. The reliquefaction system will include an LNG return pump.

\section{a. Reliquefaction LNG Compressor}

- One 1119 KW (1500 hp) unit

b. Reliquefaction LNG Return Pumps

- $2 \times 100 \%, 14.1 \mathrm{~m}^{3} / \mathrm{hr}$. (62 gpm), $2.24 \mathrm{KW}(3 \mathrm{hp})$

\section{UNIT 6 - BUILDINGS}

The Process Platform includes the MCC/ Electrical building described above and the Control Room, Maintenance Shop, and Warehouse. 
Control Room equipped with the following:

- Platform process control

- Emergency shutdown

- Diesel Generator Black Start control panel

- Solar Turbine Generator control panels

- Sequence control

- Programmable controllers and support devices

- Communications equipment

- LACT control panel

- Vermilion 179 master control station including SPM cavern and sendout (Special remote function is remote control station within the SPM to control its functions during manned operations for ship approach, mooring, LNG manifold hookup, LNG transfer, un-hooking.)

- Fire/gas control system - Panel A (Panel B on Cavern Operations Platform)

NOTE: The synchronizing controls for the LM-6000 generators are located with the generators.

\section{Workshop}

The Workshop is provided for storage of spare parts and equipped with work bench, drill, press, welding sets, grinder, tool rack and shelving, electrical shop.

\section{Maintenance Shop}

The Maintenance Shop is provided for maintenance of the terminal equipment and is equipped with calibration equipment and tools.

\section{UNIT 7 - SAFETY AND LIFE SUPPORT}

Life support equipment will include personnel life jackets, life buoys, life rafts, escape capsule, and fire fighting devices such as hand extinguishers, wheeled extinguishers, hose reels and monitors.

Additional safety information is provided in Section D including the ESD and HIPPS systems.

\section{UNIT 8 - FIRE PROTECTION}

Fire detection will consist of fusible loops, gas, smoke, thermal and flame detectors, reporting to a central control panel. 
The fire suppression system will include:

- Two (2) $100 \% 1136 \mathrm{~m}^{3} / \mathrm{hr}$. (5000 gpm), 10.3 barg (150 psig) discharge firewater pumps - one pump drive electrical and one pump drive diesel / water deluge zones, firewater monitors and hose reels

- $\mathrm{CO}_{2}$ discharge systems (for electrical) generator enclosures

- Two (2) $11.4 \mathrm{~m}^{3} / \mathrm{hr}$. (50 gpm) jockey pumps, 10.3 barg (150 psi) discharge

\section{UNIT 9 - PLATFORM CRANE}

- Two (2) 45 Ton Capacity

- $61 \mathrm{~m}$ (200 ft.) Boom, Lattice Type

- Electric Motor Drive Control Cabin

\section{UNIT 10 - WASTE HEAT RECOVERY SYSTEM}

The process heating system uses Dowtherm or equivalent operating between $176.7^{\circ} \mathrm{C}\left(350^{\circ} \mathrm{F}\right)$ to $65.6^{\circ} \mathrm{C}\left(150^{\circ} \mathrm{F}\right)$ as the heat transfer medium and consists of the following components:

Heat medium tank is equipped with nitrogen blanketing.

Heat Medium Circulation Skid:

- Heat Medium Expansion/Surge Tank :

o Horizontal Vessel

o Operating Conditions $=.68$ barg $(10 \mathrm{psig}) @ 65.5^{\circ} \mathrm{C}\left(150^{\circ} \mathrm{F}\right)$ to $79.4^{\circ} \mathrm{C}\left(175^{\circ} \mathrm{F}\right)$

o Capacity $=22.7 \mathrm{~m}^{3}$ (6000 Gallons)

o Design Conditions = 10.3 barg @ 315.6 $\mathrm{C}(150$ psig @ 600 $\mathrm{F})$

o ASME Section VIII, Division 1

- Heat Medium Circulation Pumps

o $2 \times 100 \%$ Centrifugal Pumps, API 610

o $702.5 \mathrm{~m}^{3} / \mathrm{hr}$. (3093 gpm)

o Operating Conditions $=13.8$ barg $(200$ psig $)$ discharge @ $65.6^{\circ} \mathrm{C}\left(150^{\circ} \mathrm{F}\right)$ to $79.4^{\circ} \mathrm{C}\left(175^{\circ} \mathrm{F}\right)$

o $93.2 \mathrm{KW}(125 \mathrm{hp})$ Electric Motor 
- Heat Medium Filters

o Two (2) 100\% Slipstream (10\%) Charcoal bed Liquid Filter

o $70.4 \mathrm{~m}^{3} / \mathrm{hr}$. (310 gpm)

o $\quad 6.89$ barg $(100 \mathrm{psig}) @ 65.6^{\circ} \mathrm{C}\left(150^{\circ} \mathrm{F}\right)$ to $79.4^{\circ} \mathrm{C}\left(175^{\circ} \mathrm{F}\right)$

o 103 barg $(150 \mathrm{psig}) \mathrm{MAWP} @ 315.6^{\circ} \mathrm{C}\left(600^{\circ} \mathrm{F}\right)$

\section{UNIT 11 - MISCELLANEOUS SYSTEMS}

\section{Slop Oil System}

The platform is equipped with a slop oil tank located at the sub-cellar deck in order to provide for gravity drain from process equipment. The closed drain sump receives process and utility drains which may contain hydrocarbons and any other flammable liquids.

The slop oil tank's gas outlet is connected to the flare scrubber for blanketing in order to prevent air from entering and eventually migrating into the process system.

The system consists of the following components:

Slop Oil Tank:

- MAWP 10.3 barg (150 psig)

- $24.6 \mathrm{~m}^{3}$ (6500 gallon)

Slop Oil Transfer Pumps:

- Two (2) $100 \%$ centrifugal Pumps

- $5.97 \mathrm{KW}(8 \mathrm{hp})$ Electric Motor

- $22.7 \mathrm{~m}^{3} / \mathrm{hr}$. (100 gpm) each @ 6.89 barg (100 psig) with offloading connection to boat landing

- 6.89 barg (100 psig)

\section{Main and Cellar Deck Sump}

This sump collects skid and deck drains (including rain water) from the main and cellar decks. The sump is of the cassion type with hydrocarbon skimming capability. Oil separated in this sump is pumped to the slop oil tank for future reprocessing. The effluent water is discharged overboard from the bottom of the cassion.

\section{Slop Oil Sump}

This sump collects skid and deck drains from the sub-cellar deck. This sump is hanging from the sub-cellar deck in order to provide for gravity drain. 
- Sump

o MAWP 10.3 barg (150 psig)

- Sump Pump

- Deepwell submersible

- $5.68 \mathrm{~m}^{3} / \mathrm{hr}$. $(25 \mathrm{gpm})$

- 3.45 barg (50 psig) Discharge Pressure

\section{Closed Drain Receiver}

Capture liquids from the manual closed drain system. The liquids will be level control dumped to the Slop Oil Sump.

- $4.6 \mathrm{~m}(15 \mathrm{ft}.) \mathrm{s} / \mathrm{s} \times 1.5 \mathrm{~m}(5 \mathrm{ft}$.$) diameter$

- MAWP 10.3 barg (150 psig)

\section{UNIT 12 - PLATFORM STRUCTURE}

Deck Size: three levels - top two levels @ 39.6m x 88.4m (130 ft. x 290 ft.) lower level @ 39.6m x $56.4 \mathrm{~m}$ (130 ft. $\times 185 \mathrm{ft}$ ), $24.4 \mathrm{~m}$ ( $80 \mathrm{ft}$.) deck-leg spacing for 8 legs

Weight: Deck Structure $=3,978$ short tons; Dry Equipment $=3,940$ short tons; Dry Piping $=675$ short tons. Total estimated lift weight $=8,593$ short tons

Weight: Bridge Structure $=961$ short tons; Bridge Piping $=286$ short tons

Jacket Size: 8 pile jacket

Jacket Weight: 1,265 short tons

Piles: $137 \mathrm{~cm}(54 \mathrm{in}$.$) main piles$

Bridges: Process to BPE $=7.62 \mathrm{~m} \times 30.5 \mathrm{~m}(25 \times 100 \mathrm{ft}$. $)-2$ levels;

Process to Cavern Support $=6.1 \times 30.5 \mathrm{~m}(20 \times 100 \mathrm{ft})-$.2 levels;

Process to Flare $=4.6 \mathrm{~m} \times 45.7 \mathrm{~m}(15 \times 150 \mathrm{ft})-$. single level 3 chord (triangular);

Process to Quarters $=6.1 \mathrm{~m} \times 30.5 \mathrm{~m}(20 \times 100 \mathrm{ft}$. $)-$ single level 3 chord. 


\section{SYSTEM 4 - BISHOP PROCESS ${ }^{\mathrm{TM}}$ EXCHANGER PLATFORM}

\section{A. SYSTEM OVERVIEW}

The Bishop Process ${ }^{T M}$ Exchanger Platform receives LNG from the LNG pumps at pressures from 76 barg (1100 psig) up to 138 barg (2000 psig). The Platform includes lift pumps for seawater used as the warmant, Bishop Process Exchanger units and associated piping, valves, and instruments.

The Bishop Process ${ }^{T M}$ Exchangers on this platform provide two functions: 1) to vaporize the LNG for injection into salt cavern storage or for sendout to gas pipelines, 2) for re-warming the gas from the cavern.

The Bishop Process ${ }^{\mathrm{TM}}$ Exchanger is quite simple - basically a pipe-in-pipe heat (cold) exchanger. The $11.4 \mathrm{~cm}$ (4.5 in.) diameter inner cryogenic pipe is made of $27 \%$ nickel $-7 \%$ moly (27-7MO) at an ANSI 900 rating. An outer pipe of $25.4 \mathrm{~cm}$ (10 in.) O.D. wall thickness $2.56 \mathrm{~cm}$ (1.0 in.) is fabricated from HDPE or GRP. Within the annulus, seawater or fresh water is pumped to warm the LNG.

\section{UNIT 1 - BISHOP PROCESS ${ }^{\mathrm{TM}}$ EXCHANGER}

Pipeline (Low Pressure) Bishop Process ${ }^{\mathrm{TM}}$ Exchanger (BPE)

The Pipeline Bishop Exchanger consists of 10 individual pipe-in-pipe exchanger units. Each unit is $91.4 \mathrm{~m}$ (300 ft.) long, $3.35 \mathrm{~m}$ ( $11 \mathrm{ft}$.) tall, and $2.44 \mathrm{~m}$ ( $8 \mathrm{ft}$.) wide. These units are stacked two high on the cellar deck and are spaced for accessibility for maintenance and inspection. Each unit is manifolded to receive LNG from the LP LNG headers. Each unit is also manifolded to receive and return seawater warmant. The gas produced from these LP units is manifolded for direct gas send-out to the pipeline(s) without having been stored in the salt caverns.

\section{Cavern Storage (High Pressure) Bishop Process ${ }^{\mathrm{TM}}$ Exchanger (BPE)}

The Cavern Storage Bishop Exchanger consists of 17 individual pipe-in-pipe exchanger units. Each unit is $91.4 \mathrm{~m}$ (300 ft.) long, $3.35 \mathrm{~m}$ (11 ft.) tall, and $2.44 \mathrm{~m}(8 \mathrm{ft}$.) wide. These units are stacked two high on the main deck and are spaced for accessibility for maintenance and inspection. Each unit is manifolded to receive LNG from the HP LNG headers. Each unit is manifolded to receive and return seawater warmant. The gas produced from these HP units is manifolded to direct the gas to injection into the salt caverns for storage.

\section{Swing (Low and High Pressure) Bishop Process ${ }^{\mathrm{TM}}$ Exchanger (BPE)}

The Swing Bishop Exchanger consists of 9 individual pipe-in-pipe exchanger units. Within the quantity is one spare BPE that can be used for any service. Each unit is $91.4 \mathrm{~m}$ (300 ft.) long, $3.35 \mathrm{~m}$ (11 ft.) tall, and $2.44 \mathrm{~m}(8 \mathrm{ft}$.) wide. These units are stacked two high on the sub-cellar deck and are spaced for accessibility for maintenance and inspection. Each unit is manifolded to receive LNG from either the LP or the HP LNG header. Each unit is also manifolded to receive and return seawater warmant. The gas produced from these Swing units are manifolded such that the gas can be directed either for gas send-out to the pipeline(s) or for injection into the salt caverns for storage.

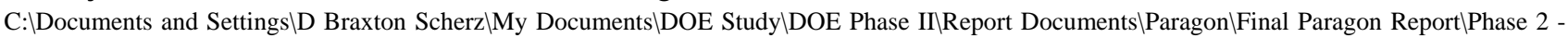
Basis of Design - Final.doc 
All BPE units are identical in design and construction. The design case is based on seawater entering at $18.3^{\circ} \mathrm{C}\left(65^{\circ} \mathrm{F}\right)$ and leaving at no less than $11.7^{\circ} \mathrm{C}\left(53^{\circ} \mathrm{F}\right)$, a $6.6^{\circ} \mathrm{C}\left(12^{\circ} \mathrm{F}\right)$ temperature drop. The LNG flow rate through each BPE is $300 \mathrm{~m} 3 / \mathrm{hr}$. and the water flow rate for each BPE $3,000 \mathrm{~m} 3 / \mathrm{hr}$. The BPE units are designed to ASME VIII Division 2 code and are rated at ANSI 900.

\section{Design Details:}

- $\quad$ Type: Pipe in Pipe

- Design Code: ASME

- $\quad$ Temperature of LNG: $-162^{\circ} \mathrm{C}\left(-260^{\circ} \mathrm{F}\right)$ Liquid to $4.44^{\circ} \mathrm{C}\left(40^{\circ} \mathrm{F}\right)$ gas

- $\quad$ Inlet Temperature of Warrant: $18.3^{\circ} \mathrm{C}\left(65^{\circ} \mathrm{F}\right)$ (seasonal maximum is $26.7^{\circ} \mathrm{C}\left(80^{\circ} \mathrm{F}\right)$

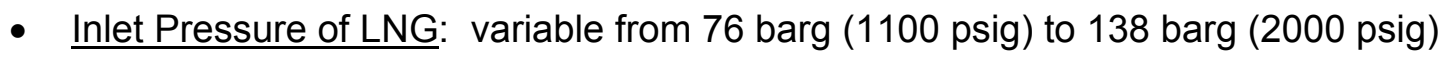

- $\quad$ Cryopipe Material: $27 \%$ nickel; $7 \%$ moly

- $\quad$ Cryopipe dimensions: Nominal $11.4 \mathrm{~cm}$ (4.5 in.)

- $\quad$ Outer pipe Material: FRP or Polymer - nominal $25.4 \mathrm{~cm}$ (10 in.) ID

- Layout: LNG cryopipe is branched into four U-tubes (each carrying $75 \mathrm{~m}^{3} / \mathrm{hr}$.) with warmant in 1 concurrent flow and 1 counter-current flow arrangement. Warmant enters the annulus of each of the two $U$-tube legs at one end and both exit at the other end.

- Unit Weight: 78 short tons per BPE unit

- Dimensions: $91.4 \mathrm{~m}$ (300 ft.) length $\times$ 2.44m (8 ft.) wide and 3.35m (11 ft.) tall outside dimensions (reference Appendix 1).

- Structural Configuration: design structural framework for support of piping and for lifting assembled unit during platform fabrication. Also, to support double stacking of units.

- Piping: manifold inlet to groups of pumps with valves for isolation. Outlet of exchangers manifold into gas transfer header with valves for isolation.

- Gas Warming: must be capable of accepting HP gas from cavern for warming to pipeline pressure after J-T.

- Fabrication: Each unit will be fabricated, inspected, x-rayed, and hydrotested prior to assembly.

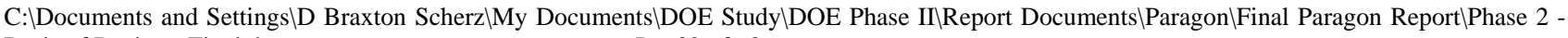




\section{UNIT 2 - SEAWATER (WARMANT) PUMPS \& INLET I OUTLET SUB-SYSTEMS}

a. Seawater Pumps

TABLE 3-5

Seawater Pumps

\begin{tabular}{|c|c|}
\hline FACTOR & VALUE \\
\hline Number of Pumps & 12 including 1 spare \\
\hline Type of Pump & Vertical turbine with $15.2 \mathrm{~m}$ (50 ft.) shaft \\
\hline HP rating at Full Load & $2,237 \mathrm{KW}(3000 \mathrm{hp})$ \\
\hline Capacity at Full Load & $9,278 \mathrm{~m}^{3} / \mathrm{hr} .(40,850 \mathrm{gpm})$ \\
\hline Voltage required & 6,900 Volt, 3-phase \\
\hline Outlet Pressure & $\begin{array}{c}3.45 \text { barg (50 psig) at } 12.2 \mathrm{~m} \text { (40 ft.) above } \\
\text { mean sea level }\end{array}$ \\
\hline Seawater temperature @ inlet & $18.3^{\circ} \mathrm{C}\left(65^{\circ} \mathrm{F}\right)$ minimum \\
\hline Inlet Suction & $12.2 \mathrm{~m}$ (40 ft.) below mean sea level \\
\hline Materials of Construction & N1-AL-Brz \\
\hline Inlet Screens & Meet 316(b) \\
\hline Outlet Diffusers & Meet dispersion requirements \\
\hline $\begin{array}{l}\text { Total flow rate to vaporizers @ } 10,000 \mathrm{~m}^{3} / \mathrm{hr} \text {. } \\
\text { LNG offload rate } \& 6.7^{\circ} \mathrm{C}\left(12^{\circ} \mathrm{F}\right) \text { temperature } \\
\text { drop across vaporizer }\end{array}$ & $100,000 \mathrm{~m}^{3} / \mathrm{hr} .(440,000 \mathrm{gpm})$ \\
\hline Ratio of seawater to LNG & 10:1 \\
\hline
\end{tabular}

\section{Seawater Inlet}

The seawater inlet is designed to meet the provisions of EPA guideline 316 (b), protecting fish and sea life from entrapment or entrainment. A stationary screen structure is preferred versus. a rotating screen due to maintenance. At $78,150 \mathrm{~m}^{3} / \mathrm{hr}$. $\left(46,000 \mathrm{ft}^{3} / \mathrm{min}\right.$.), the screen would need to be about $144 \mathrm{~m}^{2}\left(1550 \mathrm{ft}^{2}\right)$ to achieve a velocity of less than $0.15 \mathrm{~m} / \mathrm{sec}$. $(0.5 \mathrm{ft} . / \mathrm{sec}$.) across the $4 \mathrm{~mm}$ (0.157 in.) mesh screen. Back flushes using systems such as HydroBurst would clear the screens between offloadings. Furthermore, mechanical cleaning will be used when the units are removed for routine maintenance.

Special considerations during design of the intake \& discharge system will avoid any closed loop flow of cold discharge to the inlet.

\section{Seawater Discharge}

The seawater discharge part of the system is designed to maximize eddy currents to disperse the cooled seawater in the diffusing zone. The specific design will achieve the desired temperature differential of $2.78^{\circ} \mathrm{C}\left(5^{\circ} \mathrm{F}\right)$ at the edge of the 100 meter $(328 \mathrm{ft}$.) dispersion zone. 


\section{Biocide and Anti-fouling - Cleaning}

The design objective is to minimize the discharge of any biocide or shock treatment chemicals. The unique nature of the BPE and its intermittent operation gives rise to innovative methods for maintaining heat transfer efficiency with prudent use of biocide. In the Bishop Process ${ }^{\mathrm{TM}}$, the warming is intermittent providing a means to flush the entire seawater system (except for inlet pipes and screens and outlet piping and diffusers) with biocide in a closed system manner.

Biocide - For the Vermilion project design it is planned to prepare and store the biocide on the Process Platform. Between unloading operations, the biocide will be flushed through or even left standing in one or more of the BPE runs. The discharge of the biocide will be captured and stored, refreshed or segregated for removal off the Process Platform by service boat. The amount of storage will be twice the total volume of the BPE warmant system. Once the final sizing of the seawater pumps and intake manifolds are sized, the means to prepare and store the biocide will be defined.

Mechanical Cleaning - For the remainder of the seawater system, the various screens, diffusers, and piping will be periodically removed and high pressure water blasted in the maintenance area as part of routine maintenance functions.

\section{UNIT 3 - CRANE}

- Two (2) 45 Ton Pedestal Cranes

- $61 \mathrm{~m}(200 \mathrm{ft}$.) Boom Lattice type

- Electric Motor Drive Control Cabin

\section{UNIT 4 - PLATFORM STRUCTURE}

- $\quad$ Deck Size: three levels -

o top level @ 32m x 103m (105 x 337.75 ft.);

o middle level @ 30m x 103m (98ft. x 337.75 ft.);

o lower level @ 36.6m x 103m (120ft x $337.75 \mathrm{ft}$.);

o $24.4 \mathrm{~m}$ (80 ft.) deck leg spacing for 8 legs

- Weight: Deck Structure $=4,692$ short tons;

Dry Equipment $=4,378$ short tons;

Dry Piping $=786$ short tons.

Total estimated lift weight $=9,856$ short tons 
- Jacket Size: 8 pile jacket

- Jacket Weight: 1,265 short tons

- Piles: $137 \mathrm{~cm}(54$ in.) main piles 


\section{SYSTEM 5 - CAVERN SUPPORT PLATFORM}

\section{A. SYSTEM OVERVIEW}

The Cavern Support Platform supports the salt cavern operations with dry trees, dehydration, leaching pumps, cavern metering and pipeline custody transfer metering. Gas sent from the BPE Platform is injected into the salt caverns and gas from those caverns is sent-out to the pipelines through the metering stations. All gas movement into and out of the caverns is metered.

\section{B. BASIS OF DESIGN}

\section{UNIT 1: DRY TREES}

Physical space for seven (7) dry trees is provided in a well bay at one end of the platform where they are grouped for access by jack-up rig. The design and specification of these trees is included within the work scope of Cavern Drilling and Development. The costs associated with these trees and associated valves is included within the cost estimate provided to Paragon Engineering by P B Energy Storage.

\section{UNIT 2: BI-DIRECTIONAL CAVERN METERING}

The gas to and from each cavern is metered with a 16 inch ANSI 900 ultrasonic bi-directional meter. Each meter has a data acquisition panel connected to the main terminal control system.

\section{UNIT 3 - CUSTODY TRANSFER METERS}

Each of the send-out pipeline connections has an associated custody transfer station. These $61 \mathrm{~cm}$ (24 in.) ANSI 900 ultrasonic natural gas meters have an integral gas chromatograph and a data acquisition panel connected to the main control system.

\section{UNIT 4 - GAS DEHYDRATION}

A gas treating system may be required on the platform due to water absorption while in the storage cavern. The actual need for this system cannot be predicted with accuracy until after the first several withdrawal cycles so the described system is designed for the worst case. Further study of the necessity of a dehydration system on the platform should be examined further in detail design.

The primary design provides a temporary, smaller dehydration system to be used to dry the caverns during commissioning. This system would be designed to recycle the gas in the cavern. The unit would take gas injected in the cavern at a nominal 68.9 barg (1000 psig) pressure, withdraw saturated gas from the storage cavern, dehydrate the gas and re-inject the now dry gas back into the storage cavern. A small dehydration system and compressor would be needed for a temporary basis for this system. Estimates are for a moderate sized temporary system would require about 30 days to dry one cavern. 
The Glycol regeneration systems purpose is to remove the water from the gas stream. In a compensated cavern environment this will be a necessity. The gas leaving the cavern in a compensated scenario is assumed to be saturated. Due to the flow rate of gas from each cavern it is suggested that the dehydration system be spilt into at least six trains. This should limit the size of the contactors required and allow for flexibility in operation. The gas shall be dehydrated to $3.18 \mathrm{~kg}$ (7 lbs.) water per MMSCFD of gas. Slipstream processing of gas may allow for a smaller sized dehydration unit.

\section{Design:}

- Service

- Application

- Type of Gas

Design Conditions:

- Design Gas Flow

- Design Water Contents

- Exiting Water Contents

- Design Pressure

- Design temperature

Operating Conditions:

- Operating Pressure

- Operating Temperature

- Exiting Gas Pressure

- Exiting Water Contents
Dehydration System

Remove water from Gas

LNG Vapors

\section{1,500.0 MMSCFD}

Saturated @ $32.2^{\circ} \mathrm{C}\left(90^{\circ} \mathrm{F}\right)$

$3.18 \mathrm{~kg}(7 \mathrm{lb}.) / \mathrm{MMSCF}$

149 barg (2160 psig)

$-28.9^{\circ} \mathrm{C}\left(-20^{\circ} \mathrm{F}\right)$ to $93.3^{\circ} \mathrm{C}\left(200^{\circ} \mathrm{F}\right)$

\section{a. GLYCOL ABSORBER}

65.5 barg (950 psig) to 136.5 barg (1980 psig)

$4.44^{\circ} \mathrm{C}\left(40^{\circ} \mathrm{F}\right)$

76 barg (1,100 psig)

$3.18 \mathrm{~kg}$ (7 lb.) / MMSCF

Design:

- Service

- Gas Flow Rate

- Water Flow Rate

- Number in Service
Glycol Dehydration

1,500.0 MMSCFD

Saturated @ $32.2^{\circ} \mathrm{C}\left(90^{\circ} \mathrm{F}\right)$ 
- $\%$ Capacity each

\section{b. GLYCOL FLASH DRUM}

\section{Design:}

- Service

- Gas Flow Rate

- Glycol Flow Rate

- Condensate

- Number in Service

Vessel:

- Quantity

- Diameter

- Length

- Code

\section{c. FILTER}

\section{Design:}

- Service

- Glycol Flow Rate

- Number in Service

- Number in Stand by

- \% Capacity each
$50.0 \%$

Separate gas from Glycol

1.12 MMSCFD

$22.7 \mathrm{~m}^{3} / \mathrm{hr}$. (100 gpm / $\left.3428 \mathrm{BPD}\right)$

$6.62 \mathrm{~m}^{3} / \mathrm{hr}$. / $29.2 \mathrm{gpm} / 1000$ BPD

One (1)

One (1)

$137 \mathrm{~cm}$ (54 in.) OD

$4.57 \mathrm{~m}$ (15 ft.- 0 in.) Seam / Seam

ASME Section VIII, Division 1
Carbon Filters

$18.2 \mathrm{~m}^{3} / \mathrm{hr}$. (80 gpm)

Four (4)

None

$25.0 \%$

Vessel:

- Quantity

Four (4)

- Diameter

$91.4 \mathrm{~cm}$ (36 in.) OD

- Length

$246.4 \mathrm{~cm}$ (97 in.)

- Code 


\section{d. GLYCOL SURGE DRUM}

Design:

- Service

Glycol Storage

- Glycol Flow Rate

$22.7 \mathrm{~m}^{3} / \mathrm{hr}$. (100 gpm / 3428 BPD)

- Number in Service

One (1)

- $\%$ Capacity each

$100.0 \%$

$\underline{\text { Vessel: }}$

- Quantity

One (1)

- Diameter

$152 \mathrm{~cm}$ (60 in.) OD

- Length

$6.1 \mathrm{~m}$ (20 ft.- 0 in.) Seam / Seam

- Code

ASME Section VIII, Division 1

\section{e. GAS/ GLYCOL EXCHANGERS}

Design:

- Service

- Gas Flow Rate

- Glycol Rate

- Code Design

\section{Heat Exchanger Vessel:}

- Quantity

- Type

- Diameter

- Length
Gas Glycol Heat Exchangers

1,500.0 MMSCFD (750 MMSCFD per Exchanger)

18.2-20.9 $\mathrm{m}^{3} / \mathrm{hr}$. (80-92 gpm) Total

$9.08-10.4 \mathrm{~m}^{3} / \mathrm{hr}$. (40-46 gpm) per Exchanger

ASME Section VIII, Div. 1

Two (2)

Shell \& Tube

$76.2 \mathrm{~cm}$ (30 in.) OD

$4.27 \mathrm{~m}$ (14 ft.- 0 in.) Seam / Seam 


\section{f. GLYCOL / GLYCOL EXCHANGERS}

Design:

- Service

Glycol Glycol Heat Exchangers

- Glycol Rate

18.2-20.9 $\mathrm{m}^{3} / \mathrm{hr}$. (80-92 gpm) Total

9.08-10.4 $\mathrm{m}^{3} / \mathrm{hr}$. (40-46 gpm) per Exchanger

- Code Design

ASME Section VIII, Div. 1

\section{g. GLYCOL REBOILER}

Design:

- Service

Boil Water from Glycol

- Glycol Flow Rate

$22.7 \mathrm{~m}^{3} / \mathrm{hr}$. (100 gpm / 3428 BPD)

- Water

93.5kg (42.49 lbs.)/MMSCF (140,217kg (63,735 lbs./Day)

- Number in Service

One (1)

- \% Capacity each

$100.0 \%$

- Duty

$7 \mathrm{MM} \mathrm{Btu} / \mathrm{hr}$.

- Operating Temperature

$193.3^{\circ} \mathrm{C}\left(380^{\circ} \mathrm{F}\right)$

\section{h. GLYCOL STILL COLUMN WITH REFLUX CONDENSER}

Design:

- Service

Glycol Glycol Heat Exchangers

- Heat Duty

$70.3 \mathrm{KW}(240,000 \mathrm{Btu} / \mathrm{hr}$.)

- Code Design

ASME Section VIII, Div. 1

Still Column Vessel:

- Quantity

One (1)

- Type

Packed

- Diameter

$91.4 \mathrm{~cm}$ (36 in.) OD

- Length

7.32m (24 ft.- 0 in.)

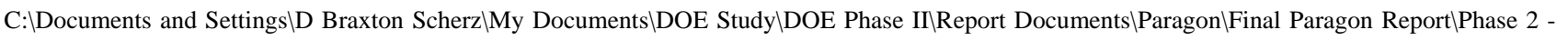




\section{i. GLYCOL CIRCULATION PUMPS}

\section{Design:}

- Service

- Glycol Flow Rate

- Discharge Pressure

- Number in Service

- Number in Stand by

- \% Capacity each

- Operating Temperature
Glycol

$9.08 \mathrm{~m}^{3} / \mathrm{hr}$. (40 gpm)

79.3 barg (1150 psig)

Two (2)

One (1)

$50.0 \%$

$93.3^{\circ} \mathrm{C}\left(200^{\circ} \mathrm{F}\right)$

Pump:

- Type

- Manufacturer

- Model No.

- Rated

- $\quad$ Speed

- Volumetric Efficiency

- Maximum Pressure
Triplex Plunger Type

KERR

KP-3300XPBC

9.08m³/hr. (40 gpm)@ 79.3 barg (1150 psig)

355 RPM

$92 \%$ at $9.08 \mathrm{~m}^{3} / \mathrm{hr}$. (40gpm) @ 79.3 barg (1150 psig)

148.2 barg (2150 psig)

\section{UNIT 5 - LEACHING PUMPS}

The leaching pumps will be used to develop and expand the salt caverns once the initial drilling is completed. The seawater lift pumps provide the inlet flow and pressure to the leaching pumps. The leaching pumps are multi-stage units designed to inject $567.8 \mathrm{~m}^{3} / \mathrm{hr}$. (2,500 gpm) seawater at 76 barg (1100 psig). One pump will be provided for each cavern.

\section{UNIT 6- - PLATFORM CRANE}

- 20 ton capacity

- 36.6m (120 ft.) Lattice Boom

- Electric Motor Drive Control Cabin 


\section{UNIT 7 - CONTROL BUILDING}

- $7.3 \mathrm{~m} \times 6.7 \mathrm{~m} \times 4.6 \mathrm{~m}(24 \mathrm{ft} . \times 22 \mathrm{ft} . \times 15 \mathrm{ft}$.) Control Building

- Safety and Process Controllers

- Fire \& Gas Control Panel

- HMI Monitor and Control Stations

- Field Instrument Terminations

\section{UNIT 8 - PLATFORM STRUCTURE}

- Deck Size: two levels - both levels @ 33.5m x 44.2m (110 ft. x 145 ft.); $12.2 \mathrm{~m}$ x 18.3m (40 ft. x $60 \mathrm{ft}$.) deck leg spacing for 8 legs

- $\quad$ Weight: Deck Structure = 1,496 short tons; Dry Equipment $=651$ short tons; Dry Piping = 254 short tons. Total estimated lift weight $=2,401$ short tons

- Jacket Size: 8 pile jacket

- Jacket Weight: 1,012 short tons

- Piles: $137 \mathrm{~cm}(54$ in.) main piles 


\section{SYSTEM 6 - QUARTERS PLATFORM}

The Quarters Platform will provide accommodations for operations crews, special maintenance crews, and for regular visitors such as the U.S. Coast Guard and the representatives of the shippers and pilots/ mooring masters.

\section{UNIT 1 - TERMINAL OPERATIONS OFFICE}

- Meeting area with tables

- 10 permanent offices

- 6 open area desks

- Computer Server/LAN

- Phone-to-shore

- Office equipment: fax, copier, file cabinets, etc.

\section{UNIT 2 - LIVING QUARTERS I SAFETY SYSTEMS}

Living and dining accommodations for thirty (30) persons, with bedrooms, showers and baths, galley, office and dining/lounge galley, sanitary system, assembly area, recreation room, sleeping quarters, and emergency systems including escape capsule and lifeboats. Quarters include heating, ventilation and air conditioning. Public address (page and alarm system) will be extended into the quarters. Fire, smoke, gas and thermal detection system will be extended into the quarters.

\section{UNIT 3 - COMMUNICATION SERVICES}

The terminal will be equipped with services such as: VHF-FM, CCC-TV, satellite TV, IT equipment, microwave transmission and high-speed broad band communication to shore for computers, voice, data and emergency traffic.

\section{UNIT 4 - HELIDECK}

The helideck is located on top of the Living Quarters and is designed with a $12.2 \mathrm{~m} \times 12.2 \mathrm{~m}(40 \mathrm{ft}$. $\mathrm{x}$ $40 \mathrm{ft}$.) minimum footprint with $1.5 \mathrm{~m}$ ( $5 \mathrm{ft}$.) solid safety shelf. The deck is designed to hold either a $26,400 \mathrm{~kg}(12,000 \mathrm{lb}$.) skid helicopter (Bell 412) or an $24,200 \mathrm{~kg}(11,000 \mathrm{lb}$.) wheeled helicopter (Sikorsky S76). The platform is not equipped with a helicopter refueling station. 


\section{UNIT 5 - POTABLE AND UTILITY WATER SYSTEM}

The potable water system consists of the following major components:

- Potable Water Maker, $0.42 \mathrm{~m}^{3} / \mathrm{hr}$. (1.85 gpm) reverse osmosis

- Potable Water Storage Tank, $15.9 \mathrm{~m}^{3}$ (100 barrels) storage capacity

- Potable Water Distribution Pumps, 2 x 100\%, 22.7m³/hr. (100 gpm) @ 4.48 barg (65 psig) discharge pressure

- Potable Water Pressure Supply Tank, 4.48 barg (65 psig) operating pressure

The utility water system uses potable water for utility applications and consists of the following major components:

- Washdown Pump, 2.27 $\mathrm{m}^{3} / \mathrm{hr}$. (10 gpm) @ 17.2 barg (250 psig) discharge pressure

- Washdown Soap Tank

\section{UNIT 6 - SEWAGE TREATMENT PACKAGE}

A modular pre-packaged unit will provide sanitary sewer capability for the terminal.

\section{UNIT 7 - SHIP PROVISIONS I BUNKERING}

No capability is provided for supplying provisions, fueling, and medical services to the LNG carriers calling at the terminal

\section{UNIT 8 - PLATFORM CRANE}

- 1-20 ton capacity

- $36.6 \mathrm{~m}$ (120 ft.) Lattice Boom

- Electric Motor Drive Control Cabin

\section{UNIT 9 - PLATFORM STRUCTURE}

- $\quad$ Deck Size: two levels - top level @ 22.9m x 24.4m (75 ft. x 80 ft.); lower level @ 15.2m x 19.8m (50 ft. x $65 \mathrm{ft}$.); $12.2 \mathrm{~m}$ (40 ft.) deck leg spacing for 4 legs

- $\quad$ Weight: Deck Structure $=370$ short tons; Dry Equipment $=615$ short tons; Dry Piping $=63$ short tons. Total estimated lift weight $=1,048$ short tons

- Jacket Size: 4 pile jacket

- Jacket Weight: 440 short tons

- $\quad$ Piles: $106.7 \mathrm{~cm}(42$ in.) main piles

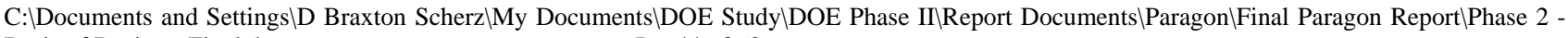




\section{SYSTEM 7 - FLARE PLATFORM}

\section{A. SYSTEM OVERVIEW}

To provide the terminal with the required relief system in the event of abnormal operation, a flare system is provided. The flare size is calculated based upon specific code requirements. The terminal flare will require a separate platform to achieve the required spacing from all other terminal equipment. The calculations that determined the flare sizing are discussed within Section D.

\section{B. BASIS OF DESIGN}

Liquids which drop out in the flare knockout drum are pumped to the closed drain receiver.

\section{UNIT 1: FLARE SYSTEMS}

- Design Capacity $=500$ MMSCFD + $300 \mathrm{~m}^{3}$ LNG

- Flare Scrubber:

- 19 barg (275 psig) MAWP, ASME VIII, Division $1 @-198^{\circ} \mathrm{C}\left(-325^{\circ} \mathrm{F}\right)$

- $\quad$ Flare Header and Tip:

- 500 MMSCFD + 300 m³/hr. LNG @ 3.45 barg (50 psig) Backpressure against most remote PSU

- Non-Air Assist Smokeless Natural Draft Sonic Tip

- Emissivity Factor $=0.1$ or Less

- Designed for cryoservice to $-198^{\circ} \mathrm{C}\left(-325^{\circ} \mathrm{F}\right)$

- Flare Ignition Panel: The flare system ignition method is of the direct sparking type. A minimum of two pilots are continuously lit to provide for ignition of the flare tip. The pilots' flames are monitored by dedicated thermocouples connected to a monitoring and ignition panel, located near the base of the flare, for automatic re-ignition and alarming in the event of pilot flame failure

- $\quad$ Flare Tower: $57.9 \mathrm{~m}$ (190 ft.) structural steel to achieve maximum radiation level of less than $4730 \mathrm{~W} / \mathrm{m}^{2}$ (1500 Btu/hr.-ft. $\left.{ }^{2}\right)$ with a $26.8 \mathrm{~m} / \mathrm{s}(60 \mathrm{mph})$ wind speed directed toward the platform

\section{UNIT 2 - PLATFORM STRUCTURE}

- $\quad$ Deck Size: two levels - top level @ 10.7m x 12.2m (35 ft. x 40 ft.); lower level @ 9.1m x 15.2m (30 ft. x $50 \mathrm{ft}$.); tripod leg configuration

- $\quad$ Weight: Deck Structure $=116$ short tons; Dry Equipment $=58$ short tons; Dry Piping $=25$ short tons; Flare Tower $=154$ short tons. Total estimated lift weight $=199$ short tons 
- $\quad$ Jacket Size: 3 pile jacket

- Jacket Weight: 330 short tons

- Piles: $106.7 \mathrm{~cm}(42$ in.) main piles 


\section{SYSTEM 8 - STORAGE CAVERN DRILLING \& DEVELOPMENT}

\section{A. SYSTEM OVERVIEW}

For the Vermilion 179 site associated with the Study, P. B. Energy Storage Services Inc. was selected to provide details of the design, drilling plan, and development plan for the salt caverns.

Their design calls for seven caverns that will provide up to 6.6 bcf of working gas storage. Each of the caverns has a single well with the dry tree located in the Cavern Support Platform well bay.

The detailed design and cavern information as provided by P. B. Energy Storage Services Inc. can be found within Appendix 8. 


\section{SYSTEM 9 - SEND-OUT PIPELINE}

\section{A. SYSTEM OVERVIEW}

The location of the Vermilion site is adjacent to at least three major gas pipelines that currently are operating at less than full capacity. The desire for multiple send-out pipeline is driven by the volume of gas being provided and the need for redundancy in the event one of the pipelines is unable to accept the volume forecasted for it.

\section{B. CANDIDATE PIPELINE INTERCONNECTS}

Sea Robin $-76.2 \mathrm{~cm}$ (30 in.) line interconnect. Sea Robin has two legs with the eastern leg $66 \mathrm{~cm}-$ $76.2 \mathrm{~cm}$ (26 in. - 30 in.) starting from Ship Shoals through Eugene Island and South Marsh island to the joining with the western leg $76.2 \mathrm{~cm}$ (30 in.) that starts in East Cameron-South addition They meet around Vermilion 148 and the main $91.4 \mathrm{~cm}$ (36 in.) line runs north to the Louisiana shoreline.

Bluewater - 91.4cm (36 in.) line interconnect - Bluewater runs from the West Cameron - south addition up through East Cameron- south addition into Vermilion and to shore at Freshwater City, LA.

Texas Eastern - 50.8cm (20 in.) line interconnect - Texas Eastern runs from Vermilion 187 Westward through Vermilion 179 to a major trunkline interconnect in Cameron 272.

\section{GENERAL COMMENTS}

- Three separate send-out pipelines (laterals) are designed to connect with existing infrastructure pipelines.

- The metering and custody transfer for each resides on the Cavern Support Platform.

- The actual connection with any pipeline is subject to agency approvals.

- The actual interconnect point with any pipeline could not be established for this Study. The Basis of Design assumes a $16.1 \mathrm{~km}$ (10 mile) lateral with two crossings for each lateral.

- The design pressure at the point of interconnection was deemed to be 68.9 barg (1000 psig). 


\section{SECTION D - SAFETY SYSTEMS AND OVERPRESSURE PROTECTION}

\section{LNG HAZARDS RESULT FROM THREE (3) MAIN FACTORS:}

- Its cryogenic temperature

- Its flammability characteristics

- Its dispersion characteristics

\section{LNG HAZARDS:}

LNG is a cryogenic liquid, with a temperature of approximately $-162^{\circ} \mathrm{C}\left(-260^{\circ} \mathrm{F}\right)$. By itself $\mathrm{LNG}$ will neither burn nor explode. However, like other cryogenic liquids LNG can cause freeze burns, and upon prolonged exposure, it can cause more serious injury.

Another hazard of LNG stems from the flammability of vaporized LNG. Each volume of LNG, when vaporized and warmed to ambient temperature, will produce a vapor volume more than 600 times the volume of the LNG. Initially, the vapor will be close to the liquid temperature, and hence heavier than air. As more heat is absorbed from the ambient, and the vapor becomes lighter than air, it will rise and can be carried away by the wind. This results in the so called "vapor cloud". LNG vapors in a $5 \%$ to $15 \%$ (by volume) mixture with air are highly flammable. If a source of ignition is found there is high risk that the flame will propagate towards the evaporating liquid pool and ignite the pool. The ignition of the vapor cloud can cause extensive damage to life and property. Hence, prevention of spills, and provisions to deal with spills in case they were to occur, are major factors in designing safety systems.

\section{SAFETY PROTECTION SYSTEMS}

Protection systems to counter the LNG Hazards can be divided into two categories:

- Passive systems: built -in design features that prevent or minimize the effect of hazardous situations.

- Active systems: measures to detect hazardous situations in a timely manner and provide ways to avoid or minimize damage from these situations. 


\section{SAFETY FEATURE INSTALLATION}

A centralized spill, fire, and combustible gas alarm, and control system will provide input to an information management system. The primary purpose is to provide plant operators with a central facility for monitoring the conditions of accidental spills, fires, and the release of combustible gases. It will also provide the operators with information and a means of responding to emergencies involving these conditions.

The main distributed control system, DCS console, is the physical operator/alarm and control system interface and will be located in the central control room, which is manned 24 hours a day. Various lighted push buttons, digital read outs and annunciates provide the operator with complete monitoring and control capabilities.

Automatic detection devices, manual alarms and audible and visual signaling devices will be strategically located throughout the terminal. Hazard detection and alarm signaling devices will report to the central control room and tie- in to the DCS.

Automatic detection devices will include flame, fire and heat, smoke, low temperature and combustible gas detectors. The hazard detection system will be designed to minimize the time a spill, leak or fire might go undetected by installing multiple and redundant different detectors within the terminal to detect gas, fire, low temperatures and low and/or high operating pressures outside normal operating levels. The detectors will be located to provide warning as quickly as possible. The detector signals are continuously monitored by an online computer in the control room that identifies a hazardous condition within the terminal to alarm and locate the situation for operating personnel.

The following safety and firefighting features will be installed:

a. Spill-collection system will be designed to deflect and prevent LNG spills. The LNG leak detection system is typically designed to detect spills and to shutdown the plant less than two minutes after a spill, and the LNG spill can be contained in the drainage basin area. The LNG spill sump will be designed for removing water and keeping debris free.

b. Fixed high expansion foam protect will be provided in accordance with NFPA-11A.

c. Hydrants approximately 90 meters apart and firewater monitors approximately 60 meters apart to be installed on the firewater main. Isolation valves in the fire water main will be provided.

d. Automatic actuation for the firefighting system will be automatic, actuated by combustible gas detectors and low temperature detectors. 


\section{Emergency Shutdown (ESD) and Emergency Depressurization (EDP) System}

The isolation systems will be located in different areas along with equipment with fire, explosion and toxicity potential risks. An emergency shutdown (ESD) and emergency depressurization (EDP) system will be provided to protect plant personnel, plant equipment and the environment in case of an emergency such as a fire, potential dangerous process upset, or LNG leak. The ESD system will isolate the unit/system where an incident is occurring from the adjacent units/system. The EDP system will reduce the hydrocarbon inventory of the system and it's pressure. Equipment and piping are divided into sections called ESD zones, considering the plot plan and process flow.

The EDP system shall be fail- safe and include a fire sensitive element on the actuator supply for immediate depressuring. The primary design guide is API 521 and the requirements as highlighted in its Performance Standard. EDP valving shall be a fail open, actuated ball or gate valve. LNG process temperature $(-160 \mathrm{C})$ discharges from relief valves shall receive a full review for appropriate materials of construction and possible inclusion in the positive material identification program. Results shall be documented in the subsequent HAZID/HAZOP findings.

\section{OVERPRESSURE PROTECTION}

The relief system will be to provide overpressure protection on all pressure vessels and piping systems. ASME pressure vessel code, API RP 520, API RP 521 and API RP14C provide the principal consensus engineering recommended practice that will be followed. However, these recommended practices allow options that are sometimes conflicting and were developed for onshore plant systems. To reduce PSV and Flare design capacity, a HIPPS (High Integrity Pressure Protection System) concept is utilized.

\section{LNG OFF LOADING SYSTEM}

Relief system will be Bluewater's responsibility.

\section{Marine LNG Pipeline}

The subsea pipeline boil-off gas (BOG) would be generated due to heat gain through its insulation, and that volume flow would be flared or vented. In the event of emergency, the Marine LNG Pipeline would be isolated from the Big Sweep $\odot$ and from the Process Platform. The minimal boiloff gas due to heat gain would be vented or flared.

\section{LNG PUMP DISCHARGE DEADHEAD PROTECTION}

The combined $1^{\text {st }}$ Stage and $2^{\text {nd }}$ Stage LNG pumps take the LNG from the suction header at 4.83 barg (70 psig) and pressure up to 137.9 barg (2000 psig) (Max) for salt cavern storage or to 75.8 barg (1100 psig) (Max) for send out to the pipelines. The $1^{\text {st }}$ Stage (Low-pressure) LNG pump discharge pressure is 75.8 barg (1100 psig) with shut off pressure at 85.8 barg (1245 psig), and the discharge header is ANSI 900 with a MAWP of 151.7 barg (2220 psig). Therefore, no deadhead over-pressure protection for the low-pressure LNG pumps is provided. 
The $2^{\text {nd }}$ Stage (High-pressure) LNG pump discharge pressure is up to 137.9 barg (2000 psig) (MAOP) with shut off pressure at 161.7 barg (2345 psig). These $2^{\text {nd }}$ Stage LNG pumps are connected to a $900 \mathrm{lb}$ ANSI header with a MAWP of 151.7 barg (2220 psig). Therefore a pressure relief is located at the discharge of the $2^{\text {nd }}$ Stage LNG pumps set at 151.7 barg (2220 psig), discharging back into the suction header of the $2^{\text {nd }}$ Stage LNG pumps.

\section{HIGH INTEGRITY PRESSURE PROTECTION SYSTEM (HIPPS)}

Primary overpressure protection for each of the terminal's systems is provided by an emergency shutdown system (ESD) that isolates the system from continued flow upon sensing a high pressure (HP) condition. This essentially isolates each system from another enabling an over-pressure system to be designed specifically for that system.

Secondary overpressure protection is provided by pressure safety valves (CSV's) designed to prevent overpressure within each system. This approach works well for the Marine LNG Pipeline, the combined LNG pumps, storage caverns themselves (each can be isolated) and piping and equipment on the Cavern Support Platform.

For over pressure protection of the Bishop exchanger and header down stream of the LNG pumps the Basis of Design calls for a HIPPS system to be installed. When HIPPS is applied as a pressure protection system, an appropriate Safety Integrity Level (SIL) for each specific HIPPS needs to be developed during the detail-engineering phase of this project. These HIPPS systems are an independent, instrumented shutdown system designed for high reliability, which will provide the secondary level of overpressure protection usually provided by a pressure safety valve (PSV) system. HIPPS uses redundant pressure sensors and control logic to close shutdown valves (SDV's) when the pressure exceeds the normal emergency shutdown pressure. With a HIPPS system PSV, the corresponding relief piping and flare sizing will be significantly reduced in size since they now only needed to size to accommodate SDV leakage/ fire relief requirements.

A high integrity pressure protection system, HIPPS, will be used for emergency shutdown of highpressure LNG pumps and the seawater supply system for effective de-pressurizing of the Bishop Exchangers.

The Vermilion 179 blow-down criteria is to provide depressurizing on all equipment that processes LNG to achieve 6.9 barg (100 psig) or $50 \%$ of the vessel design pressure, which ever is lower, within 15 minutes.

\section{Flare design criteria}

A high-pressure flare system, including a high-pressure flare stack, high-pressure flare knockout drum, and collection system, will be provided. This system will collect relief valve and emergency blow-down discharges from throughout facility. A separate platform will be provided for the flare stack.

C: $\backslash$ Documents and Settings $\backslash D$ Braxton Scherz $\backslash$ My Documents $\backslash$ DOE Study $\backslash$ DOE Phase II $\backslash$ Report Documents $\backslash$ Paragon $\backslash$ Final Paragon Report $\backslash$ Phase 2 Basis of Design - Final.doc 
The flare will be sized to fit the actual inventory of the LNG and the gas that is not sequestered in the caverns or in the pipeline. The LNG delivered to the vaporizer can be isolated at the ship, on the Bluewater SPM and within the pipeline.

API RP 521 Section 3.15 contains extensive guidance relative to relief requirements for external fire. To paraphrase, a pressure relief device adequate for the external fire scenario should be installed for all vessels, heat exchangers, and filters with a liquid inventory that is located with in a potential fire zone. The guidelines are less clear on the treatment of vapor filled equipment that may be subject to thermal failure prior to overpressure. In these cases, other preventive measures such as depressurizing systems may be more appropriate.

The GPSA Engineering data book is referred to for calculating relief requirements in terms of heat input from the fire into a Bishop Heat Exchanger ${ }^{\mathrm{TM}}$ per API 520 as follows:

$$
Q=(21,000)(F)\left(A_{w}\right)^{0.82}
$$

Where:

Q = Heat input, Btu/hr..

$\mathrm{A}_{\mathrm{w}} \quad=$ Total wetted surface area of vessel, sq. $\mathrm{ft}$.

$\mathrm{F}=\quad=$ Environmental factors, bare metal vessel is 1.0 (GPSA, Fig. 5-17)

$\mathrm{Q} / \mathrm{L} \quad=$ LNG evaporation, Ib/hr..

$\mathrm{L}=\quad=$ Latent heat of LNG assumed $504.7 \mathrm{KW} / \mathrm{kg}$ (217 Btu/lb.) to calculate vaporization rate in $\mathrm{lb} / \mathrm{hr}$.)

Estimated surface area of Bishop Heat Exchanger ${ }^{\mathrm{TM}}$ is $9426 \mathrm{~m}^{2}(101,464$ sq. ft.)

A relief requirements in terms of heat input from the fire is calculated for worst case scenario, considering Bishop Heat Exchanger contains 66\% LNG and $34 \%$ vapor.

$$
\begin{aligned}
& A_{w}=66,966 \text { Sq. ft. (wetted area) and } F=1 \\
& A_{w}=6221 m^{2} \\
& Q=(21,000)(F)\left(A_{w}\right)^{0.82}
\end{aligned}
$$

Based on the above formula, the estimated relief requirement in term of heat input from the fire for the Bishop exchanger is 487 MMSCFD.

C: $\backslash$ Documents and Settings $\backslash D$ Braxton Scherz $\backslash$ My Documents $\backslash$ DOE Study $\backslash$ DOE Phase II $\backslash$ Report Documents $\backslash$ Paragon $\backslash$ Final Paragon Report $\backslash$ Phase 2 Basis of Design - Final.doc Pg. 53 of 63 
The flare system is designed with a disposal capacity of 500 MMSCFD capacities. All equipment and vessels with design pressures higher than 19.7 barg (285 psig) and equipped with pressure relief and blow-down valves are connected to this system. The design of the flare boom and flare tip is selected so that the maximum radiation level at the base of the boom does not exceed $4730 \mathrm{~W} / \mathrm{m}^{2}$ (1500 Btu/hr.-ft. $\left.{ }^{2}\right)$ with a $26.8 \mathrm{mls}(60 \mathrm{mph}$ ) wind speed directed toward the platform.

The $57.9 \mathrm{~m}$ (190 ft.) long flare boom and flare tip will be installed on a separate flare platform.

\section{FLARE SCRUBBER:}

The high-pressure flare system includes a flare scrubber. It is a cryogenic pressure vessel designed to entrain liquids from the gas stream in accordance with API 521, based on a liquid droplet size no larger than 400 microns. The vessel design pressure shall be at least 1.5 times the expected backpressure or 10.3 barg (150 psig), whichever is greater. The flare scrubber is sized for one (1) minute based on design inlet rate of the Bishop Heat Exchanger ${ }^{\mathrm{TM}}$, i.e. $166 \mathrm{~m}^{3} / \mathrm{min}$. 


\section{SECTION E - OPERATING AND MAINTENANCE PHILOSOPHY}

\section{OPERATIONS}

\section{New Terminal Design}

The incentive to develop this specific terminal technology is substantial as salt cavern based LNG receiving terminals have material advantages over tank design terminals in greater safety, lower capital and operating costs, far greater volume of storage, rapid response (nominally within 20 minutes) to changes in send-out rate demand at any point from maximum to minimum, increased security, and acceptance by the community. The particular Gulf of Mexico site being referenced Vermilion 179 - has been selected as being typical for the Bishop Process ${ }^{\mathrm{TM}}$ work as it is in shallow water $30.5 \mathrm{~m}$ (100 ft.) about $75.6 \mathrm{~km}$ (47 miles) south of the Louisiana coast and in close proximity to an ideal salt dome formation (top of salt formation is $335.3 \mathrm{~m}$ (1100 ft.) below water surface). Also, it is adjacent to several major gas gathering pipelines.

Major portions of the equipment and systems being incorporated into this design have been well proven in other applications. The unique challenge faced within this design and integration effort is the combination and arrangement into an offshore application. It must again be stated that the work to date is preliminary and an on-going development directed at defining an operational facility that is safe. It is not the intent of the Bishop Process ${ }^{\mathrm{TM}}$ as described herein to be the optimal as each Owner will have its own preferences and Vermilion may not be the actual site.

\section{The Bishop Process ${ }^{\mathrm{TM}}$}

The Bishop Process ${ }^{T M}$ works in a manner different from other LNG receiving terminals. The LNG from the LNG carrier is immediately vaporized either for gas injection into salt cavern storage for future send-out or for concurrent direct gas send-out via pipeline - there is no liquid LNG storage in the Bishop Process ${ }^{T M}$. In this process, the LNG carrier is offloaded through its internal pumps at its normal offload rates of up to $10,000 \mathrm{~m} 3 / \mathrm{hr}$. The discharge LNG flow from the ship is transferred to the $1^{\text {st }}$ Stage LNG pumps that produce an intermediate discharge pressure of a nominal 75.8 barg (1100 psig). The LNG can then travel one of two paths; 1) the intermediate pressure matches the send-out pipeline gas pressure and can be directly vaporized, metered and sent-out; 2) the other LNG path is fed to the inlet of second stage pumps that operate on variable frequency drive systems. These pumps are designed to match the cavern pressure that can vary from 75.8 barg (1100 psig) to 137.9 barg (2000 psig) depending upon the volume of gas stored at any given time.

Both LNG paths pass through a heat exchanger (vaporizer) at high rates, high pressures and low temperatures to be warmed for discharge at cavern and pipeline compatible temperatures, nominally above $4.44^{\circ} \mathrm{C}\left(40^{\circ} \mathrm{F}\right)$. The resulting gas is either directly injected into salt caverns without further compression and/or sent into the pipeline grid. 
The LNG carrier ship is unloaded in the same amount of time as at a conventional cryogenic tank based receiving terminal, but when it leaves, there is very little LNG stored at the site - only enough to keep the cryogenic equipment cold between ship arrivals.

\section{Operating Considerations}

The Bishop Process ${ }^{T M}$ requires a different approach to the day-to-day operation of the facility. The vaporization takes place only during the unloading of the ship - all LNG is immediately vaporized. The LNG pumps and the vaporizers operate only when a ship is unloading - otherwise they are idle. In addition, the power generation required to drive the pumps is active when unloading and idle otherwise.

The $1^{\text {st }}$. Stage LNG pumps receive the LNG from the ship and pressurize to an intermediate value set equal to the pressure required to send out the gas from the terminal into the pipelines - nominal 75.8 barg (1100 psig). Any gas that is to be sent-out to supply the market delivery requirements would first be provided from immediate vaporization. Immediate send-out preempts the need to pump to cavern pressure and then letdown for subsequent send-out. The operations plan is to satisfy the market need first and then put the rest into storage.

The remainder of the vaporized gas is sent to the caverns at a pressure that can range from 75.8 barg to 137.9 barg (1100 psig to 2000 psig). These caverns are operated in an un-compensated mode and thus do not maintain a constant pressure. The lower storage pressure limit is set by the higher of either cavern dynamics (minimal pressure required to maintain cavern integrity) or the lowest pressure needed for send-out. The maximum is set to stay within ANSI 900.

In all operating situations there is a nominal flow of 2 bcfd to the pipelines. At a minimum there is a constant gas flow of 1.5 bcfd delivered to the send-out pipelines with a peak flow of 2.5 bcfd to meet demand. (In fact, the maximum send-out would be dictated by the availability of take-away pipelines. There is no other limiting factor that would preclude send-out rates of $3+$ bcfd).

There are two basic operating scenarios plus the transition between them. These are:

Scenario A: LNG carrier is at the mooring and discharging at the nominal rate of $10,000 \mathrm{~m} 3 / \mathrm{hr}$ with a portion of the vaporized gas going into the caverns and a portion going directly to the pipelines.

Scenario B: No LNG carrier unloading underway and the entire market demand for gas is met by the withdrawal of gas from the cavern

Scenario A - The $1^{\text {st }}$ Stage (LP) pumps produce the pressure required for direct send out once the LNG has been vaporized. Operationally, it is the intent that whenever LNG discharging is in progress, the gas send-out flow requirement will be serviced to the extent possible through direct send-out. In essence, unload, pump to 75.8 barg (1100 psig), warm it up and send it directly to the pipeline - bypassing the cavern. To simplify piping, a fixed number of exchangers are dedicated to satisfy this minimal send out.

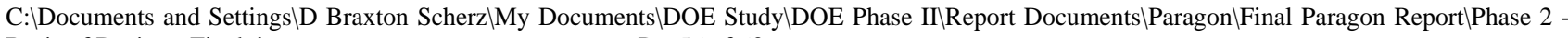
Basis of Design - Final.doc

Pg. 56 of 63 
The remainder of the LNG is pumped to cavern pressure by the $2^{\text {nd }}$ Stage pumps and vaporized prior to injection. These $2^{\text {nd }}$ Stage pumps are equipped with VFD units to accommodate the varying pressure encountered with the uncompensated caverns. The design basis specifies these pumps are able to function with maximum flow to the caverns via the cavern service header with the caverns at the high end of the pressure range - the worst case. The $2^{\text {nd }}$ stage exchangers required for this duty are dedicated. If a minimum of 1.5 MMscfd is going to the pipeline then about 3.5 MMscfd is being injected - but against a cavern pressure that can vary from 75.8 barg (1100 psig) up to 137.9 barg (2000 psig). The VFD units enable the pumps to match the required cavern pressure/flow curve with little efficiency loss.

In recognition that the average send-out is 2 bcfd and could peak at 2.5 bcfd, a portion of the $2^{\text {nd }}$ Stage exchanger outlets are piped to connect to both the send-out header and the cavern header. These units are termed "swing" exchangers providing a variable flow / pressure capability. This matches with the need to switch some of the $2^{\text {nd }}$ Stage (HP) pumps to send-out duty when the demand exceeds the 1.5 bcfd minimum rate with up to an additional $1.0 \mathrm{bcfd}$ provided from several $2^{\text {nd }}$ Stage pumps operating at lower pressure.

In summary, during Scenario $A$ the combination of $1^{\text {st }}$ and $2^{\text {nd }}$ Stage pumps and exchangers provide the flexibility to meet a variable gas send-out in response to market demand as well as the need to inject a varying volume of gas into caverns at varying pressures.

Scenario B - Far less complicated operation than above since the natural pressure of the cavern gas is sufficient to push the gas through the metering and into the pipelines to market. A 6.9 barg (100 psig) pressure differential loss is assumed from the Terminal to the actual trunkline tie-in point. (the actual values are likely to vary from this design point). The gas within the cavern will be at a nominal $15.6^{\circ} \mathrm{C}\left(60^{\circ} \mathrm{F}\right)$ at a pressure ranging from 75.8 barg (1100 psig) to 137.9 barg (2000 psig). No further compression is required. The ability of the cavern to provide gas in response to demand changes is virtually immediate.

There is some capability to re-warm the gas withdrawn from the cavern at high pressure following the $\mathrm{J}$-T valve to assure pipeline temperature requirements are met.

Transition - the current configuration of the cavern service header enables gas either to be going into the caverns (as a group) or to be withdrawn. While each cavern can be isolated, gas injection or withdrawal occurs within one bi-directional header. Thus when a ship arrives and begins offloading, a portion of that LNG is immediately vaporized to satisfy the send-out demand. The cavern send out rate is ramped to zero as the ship unloading rate increases. At this point, the cavern service header is reversed and gas from the ship is injected.

As the ship ends its offloading, the gas flow into the cavern will slow to zero at which time the header will be reversed and gas from the caverns will begin flowing to pick up the send-out demand as the LNG offload continues to drop.

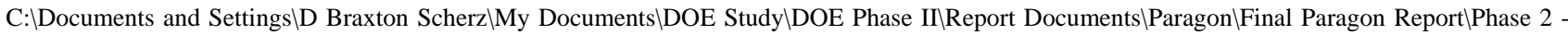
Basis of Design - Final.doc Pg. 57 of 63 
Bi-directional metering for each cavern is provided as well as pressure and temperature gauges. The piping, manifolds and pumps are also monitored for pressure and temperature. LNG meters on the ship, on the unloading mooring system and gas meters at each cavern will augment custody transfer meters for each send-out lateral pipeline.

Cryogenic Idle Mode - Between LNG carrier offloading operations the cryogenic portion of the facility will remain cold with LNG circulated via one of the VFD pumps. At a nominal 2 bcfd send-out a ship should arrive every other day. The marine pipeline, portions of the Big Sweep, the $1^{\text {st }}$ Stage and $2^{\text {nd }}$ Stage pumps along with the interconnected piping will remain cold. A small re-liquefaction unit will capture any boil-off and provide any make-up required. High efficiency insulation will minimize the heat gain during idle time.

\section{Control System}

The control system for the facility will be located on the Process Platform. There will be remote operator stations to access operating information but primary control will be retained at the main panel except for emergency or maintenance situations. The Bluewater Big Sweep will have a local control panel but is expected to be un-manned in normal operation. Mooring, security and cargo transfer personnel would move to the LNG carrier via workboat.

The facility will be designed to maintain continual gas send out to the pipeline from cavern storage in the event of severe weather even while platform is un-manned. Remote telemetry and smart safety systems on the platform will assure safe operations. The emergency scenario is to shut in the facility and close all cavern valves virtually isolating the stored gas from the surface or any pipeline.

\section{MAINTENANCE}

\section{Spare Equipment}

The spare philosophy is essentially an $\mathrm{N}+1$ design basis with spares piped and connected for immediate start-up. This would equate to a $3 \times 50 \%$ or a $4 \times 33 \%$ or a $5 \times 25 \%$ design philosophy. In the instance of the exchangers we have made available several additional Bishop Process Exchangers to fill out the structure vs. adherence to the $\mathrm{N}+1$ basis. In such cases, the actual number of units exceeds the plan basis. These units can be used for increased production if available.

\section{Service On Site}

All equipment is designed to be serviced-in-place except for major overhaul or major failure. Manufacturer recommendations, open access and good safety practices are included within the design basis. Lifting and handling devices will be provided to assure safe maintenance procedures. 
A small staff would be onsite to monitor major equipment and to do routine service functions. Periodic servicing, inspections or repairs would be scheduled and supported by resources from a shore-based service company. A small shop and warehouse for consumable items is provided.

\section{Bishop Process Exchanger Maintenance and Repair}

Unique to the Vermilion site is the Bishop Process Exchanger (BPE). This is essentially a pipe-inpipe arrangement with a metal inner pipe and a polymer (HDPE, FRP) outer pipe. The outer pipe is subject to low pressure from the water flow. The inner pipe may reach 137.9 barg (2000 psig) MAOP and would be cyclic in both pressure and in temperature - from ambient down to $-160^{\circ} \mathrm{C}$ $\left(-256^{\circ} \mathrm{F}\right)$.

Maintenance and repairs are made to the BPE only after all the units have been de-pressured, inerted with nitrogen, and locked-out. The BPE area is a restricted area during normal operations.

The design of the low pressure outer pipe enables repairs to be made simply. The ends of the BPE inner pipe are designed to be removed and the outer pipe can be slid in or out. Small holes or cracks can be sealed with a "clam-shell" type of repair kit. Larger breaks can be cut clean at both ends and the pieces slid together and friction-sealed at the joint. A new piece can be added to the end, then end inner pipe piece is replaced and the unit placed back into operation. This is envisioned as a field repair.

Should there be a pin hole or crack in the inner metal pipe, the leak would be detected by $\mathrm{HC}$ sensors in the cooling water exit and by other temperature and pressure detectors. The outer pipe would be cut out for access to the site. Field repairs could be made as if done to any offshore pipe rack. Welding procedures, training and equipment would be available for on-site repairs. Testing procedures would be implemented before placing the unit into service. The outer pipe would be repaired as above.

\section{Cleaning of Seawater Piping and Equipment.}

The idle time that occurs during routine operations offers many opportunities to do routine maintenance, repairs and to take specific cleaning actions such as flushing the seawater system with biocide in a closed system manner. There will be about 20 hours between ships according to plan. The system is designed for closed circuit flushing of the exchangers and portions of the inlet and outlet piping. The flush would be stored aboard the BPE Platform and would be replenished via shore-based service boat. Mechanical cleaning of the inlet screens would be performed with each screen being brought to the deck - one at a time - and cleaned with HP water in a designated area. The exact method and procedure for cleaning would be defined in detailed engineering. 


\section{SECTION F - OPTIONS AND ALTERNATIVES}

The work described elsewhere within this document was based upon certain input data and information provided to the Study as "given" values. As the course of this work progressed some of these values were changed and a considerable number of optional, alternative and optimizing studies were identified for future consideration. Some of these would have a dramatic impact upon the capital cost estimates, the size of structures and the amount of equipment.

Some of the more significant of these are listed below in no particular order or priority.

\begin{tabular}{|c|c|c|}
\hline ALTERNATIVE & CURRENT BASIS & $\begin{array}{l}\text { QUALITATIVE VALUE OF } \\
\text { FURTHER STUDY }\end{array}$ \\
\hline $\begin{array}{l}\text { Reducing LNG Unloading } \\
\text { Rate from BOD } 10,000 \mathrm{~m} 3 / \mathrm{hr} \\
\text { to } 8,000 \mathrm{~m} 3 / \mathrm{hr}\end{array}$ & $\begin{array}{l}\text { The initial basis for this work started } \\
\text { with } 8,000 \mathrm{~m} 3 / \mathrm{hr} \text { as the offload rate. } \\
\text { In subsequent meetings / } \\
\text { presentations, the feedback was } \\
\text { clearly that } 10,000 \text { is expected. }\end{array}$ & $\begin{array}{l}\text { A straight-line relationship exists } \\
\text { between the capital / operating cost of } \\
\text { the facility and the offload rate. } \\
\text { Reducing the offload rate to } 8,000 \\
\text { m3/hr can save up to } \$ 75 \mathrm{~mm} \text { in } \\
\text { capital cost. The impact may be } \\
\text { incurred demurrage. }\end{array}$ \\
\hline $\begin{array}{l}\text { Assess impact of a two-fold } \\
\text { increase in maximum send- } \\
\text { out rate (to } 4.0 \text { Bcfd) }\end{array}$ & $\begin{array}{l}\text { The current value of } 2 \text { bcf was } \\
\text { selected as being realistic. } \\
\text { Subsequent work has revealed that } \\
\text { once the gas is in the cavern, being } \\
\text { able to deliver more gas can be a } \\
\text { major asset. }\end{array}$ & $\begin{array}{l}\text { The gas sendout capability is limited } \\
\text { only by the ability to interconnect } \\
\text { existing or new pipelines. Each added } \\
\text { bcfd send out would need the } \\
\text { equivalent of a } 36 \text {-inch pipeline. A } \\
\$ 0.05 \text { spike in gas prices would be } \$ \\
50 \mathrm{~mm} \text { possible in one day. If the } \\
\text { additional gas could be delivered. }\end{array}$ \\
\hline $\begin{array}{l}\text { Assess value of heat } \\
\text { integration for off-shore \& } \\
\text { onshore applications }\end{array}$ & $\begin{array}{l}\text { The current source of heat is } \\
\text { seawater that is the lowest cost } \\
\text { approach. Regulations being } \\
\text { promulgated could reduce this } \\
\text { advantage making alternative heat } \\
\text { sources attractive. Heat integration } \\
\text { is one that has been incorporated } \\
\text { into the Vermilion site with Gas } \\
\text { turbine waste heat being captured } \\
\text { for about } 15 \% \text { of the vaporizing } \\
\text { duty. }\end{array}$ & $\begin{array}{l}\text { In rivers and estuaries, water usage } \\
\text { may be severely restricted or } \\
\text { regulated. For any shore location, } \\
\text { seek heat sources from adjacent or } \\
\text { near-by process plants or power } \\
\text { generation. Alternative heat sources } \\
\text { and vaporizer technology may be } \\
\text { attractive in some venues. }\end{array}$ \\
\hline $\begin{array}{l}\text { Preliminary Operations / } \\
\text { Safety Plan }\end{array}$ & $\begin{array}{l}\text { The current preliminary design } \\
\text { basis has been developed in } \\
\text { accordance with the best practices } \\
\text { and according to existing } \\
\text { regulations and codes. There are } \\
\text { many pieces to the overall facility } \\
\text { that must operate in unison and } \\
\text { must operate safely. }\end{array}$ & $\begin{array}{l}\text { Perform a HAZID (hazard } \\
\text { identification) assessment of the } \\
\text { facility commencing with approach of } \\
\text { vessel to unload to embarkation to } \\
\text { arrival of next vessel. The } \\
\text { assessment must include operations } \\
\text { during interval between ships and } \\
\text { anticipated maintenance functions. }\end{array}$ \\
\hline
\end{tabular}

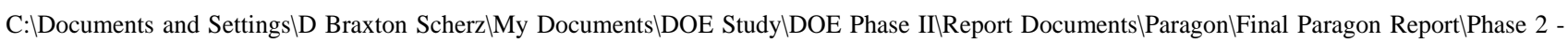
Basis of Design - Final.doc

Pg. 60 of 63 


\begin{tabular}{|c|c|c|}
\hline ALTERNATIVE & CURRENT BASIS & $\begin{array}{l}\text { QUALITATIVE VALUE OF } \\
\text { FURTHER STUDY }\end{array}$ \\
\hline $\begin{array}{l}\text { Operating Efficiency with } \\
\text { Multiple Moorings }\end{array}$ & $\begin{array}{l}\text { The current facility is designed with } \\
\text { a single mooring. This creates a } \\
\text { scenario in which the majority of the } \\
\text { facility is idle between ship arrivals. } \\
\text { With the daily send out (as } \\
\text { averaged over a year) at } 2 \text { bcfd and } \\
\text { with the range from } 1.5 \text { to } 2.5 \text { bcf, a } \\
\text { LNG carrier must arrive every other } \\
\text { day. }\end{array}$ & $\begin{array}{l}\text { Preliminary indications are that for a } \\
\text { single dock the unloading time is } \\
\text { almost overshadowed by the time } \\
\text { required to moor and to embark. } \\
\text { Multiple docks would enable a second } \\
\text { vessel to make transit of channels } \\
\text { and gain clearances while first vessel } \\
\text { is offloading. }\end{array}$ \\
\hline $\begin{array}{l}\text { Use of Idle Time for Seawater } \\
\text { System Cleaning - } \\
\text { Elimination of Biocide } \\
\text { Discharge }\end{array}$ & $\begin{array}{l}\text { The Bishop Process }{ }^{\mathrm{TM}} \text { as defined } \\
\text { within this Study is intermittent in } \\
\text { nature - it operates about half the } \\
\text { time. }\end{array}$ & $\begin{array}{l}\text { Key to seawater usage is keeping the } \\
\text { systems free of fouling activity. } \\
\text { Dosing the water with biocide - } \\
\text { sodium hypochlorite - during } \\
\text { operations usually does this. The } \\
\text { 'batch' nature of the Bishop } \\
\text { Process }{ }^{T M} \text { enables antifouling agent } \\
\text { to be used in a batch mode to flush } \\
\text { the system just upstream of the inlet } \\
\text { screens to just before the outlet } \\
\text { diffuser. The flushing medium would } \\
\text { be maintained in a closed circuit } \\
\text { system with storage aboard the } \\
\text { platform. Replenishment / disposal } \\
\text { would be a service proved by shore- } \\
\text { based service company. One or more } \\
\text { of the systems would be flushed each } \\
\text { offload cycle. The nature of the flush } \\
\text { could be stronger than for an open } \\
\text { cycle. }\end{array}$ \\
\hline $\begin{array}{l}\text { Compatibility with CNG / } \\
\text { associated gas }\end{array}$ & $\begin{array}{l}\text { The current design makes no } \\
\text { special provisions for the LNG } \\
\text { received. CNG or gas from } \\
\text { gathering lines could have sulfur, } \\
\text { CO2, nitrogen, water, C5+ in more } \\
\text { than trace amounts. }\end{array}$ & $\begin{array}{l}\text { Special care must be exercised in } \\
\text { accepting cargoes or gas sources } \\
\text { other than LNG. Depending upon the } \\
\text { send-out pipeline capability and } \\
\text { tariffs, this "outside" gas may be } \\
\text { suitable for storage and send out. } \\
\text { More than a trace of some } \\
\text { contaminants would make much of } \\
\text { the Vermilion facility incompatible. }\end{array}$ \\
\hline $\begin{array}{l}\text { Processing of Rich LNG } \\
\text { Cargos }\end{array}$ & $\begin{array}{l}\text { The current design makes no } \\
\text { special provisions for the LNG } \\
\text { received. It is assumed to be } \\
\text { offshore pipeline quality (HC dew } \\
\text { point). De-hydration is provided for } \\
\text { cavern gas. One or more caverns } \\
\text { could be designated for rich } \\
\text { cargoes to be blended in with } \\
\text { leaner cargoes at send out }\end{array}$ & $\begin{array}{l}\text { Technology exists to process the NGL } \\
\text { (LPG) portion of the cargo while in } \\
\text { liquid form. A separate product } \\
\text { stream(s) would be created but could } \\
\text { easily be sent to market via tanker } \\
\text { calling at one of the docks or by } \\
\text { pipeline. The impact would be another } \\
\text { platform dedicated to the separation } \\
\text { process. }\end{array}$ \\
\hline
\end{tabular}

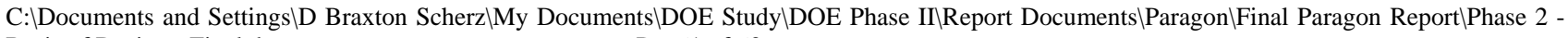
Basis of Design - Final.doc 


\begin{tabular}{|l|l|l|}
\hline \multicolumn{1}{|c|}{ ALTERNATIVE } & \multicolumn{1}{|c|}{ CURRENT BASIS } & \multicolumn{1}{c|}{$\begin{array}{c}\text { QUALITATIVE VALUE OF } \\
\text { FURTHER STUDY }\end{array}$} \\
\hline \multirow{5}{*}{ Cavern Operating Pressure } & $\begin{array}{l}\text { The initial cavern pressure was } \\
\text { 2400 but required ANSI 1500 } \\
\text { ratings for the majority of the facility } \\
\text { - in the original process design. It } \\
\text { was decided that the added cost } \\
\text { was not justified and the caverns } \\
\text { were made bigger with a new } \\
\text { MAOP of 2000 psig. }\end{array}$ & $\begin{array}{l}\text { Analysis of cavern operations vs. the } \\
\text { added cost for the facility should be } \\
\text { studied. Is the added cost more than } \\
\text { offset by improved cavern operations } \\
\text { and better working gas/cushion gas } \\
\text { ratio? Better design of the process } \\
\text { flow might reduce impact of the higher } \\
\text { rating of a portion of the facility }\end{array}$ \\
\hline \multirow{5}{*}{$\begin{array}{l}\text { Location and Proximity of } \\
\text { Mooring, Platforms and } \\
\text { Caverns }\end{array}$} & $\begin{array}{l}\text { "stretch" the LNG pipeline enables } \\
\text { the mooring to be remote to better } \\
\text { suit maneuvering if needed. The } \\
\text { send out pipelines and the pipeline } \\
\text { to the caverns from the platform are } \\
\text { simple GOM pipelines. Vermilion } \\
\text { has everything in close proximity. }\end{array}$ & $\begin{array}{l}\text { component should be based upon } \\
\text { operability as well as capital cost. }\end{array}$ \\
\hline
\end{tabular}




\section{SECTION G - APPENDICES}

APPENDIX 1 - LAYOUT AND DRAWINGS

APPENDIX 2 - PFD

APPENDIX 3 - EQUIPMENT LIST

APPENDIX 4 - UTILITY SUMMARY

APPENDIX 5 - PUMP CURVES

APPENDIX 6 - COST ESTIMATE

APPENDIX 7 - BLUEWATER OFFSHORE BIG SWEEP SYSTEM

APPENDIX 8 - PB ENERGY STORAGE CAVERN DRILLING AND DEVELOPMENT

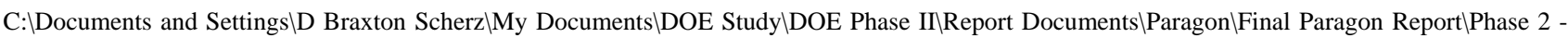




\section{Appendix 1 \\ Layout \& Drawings}




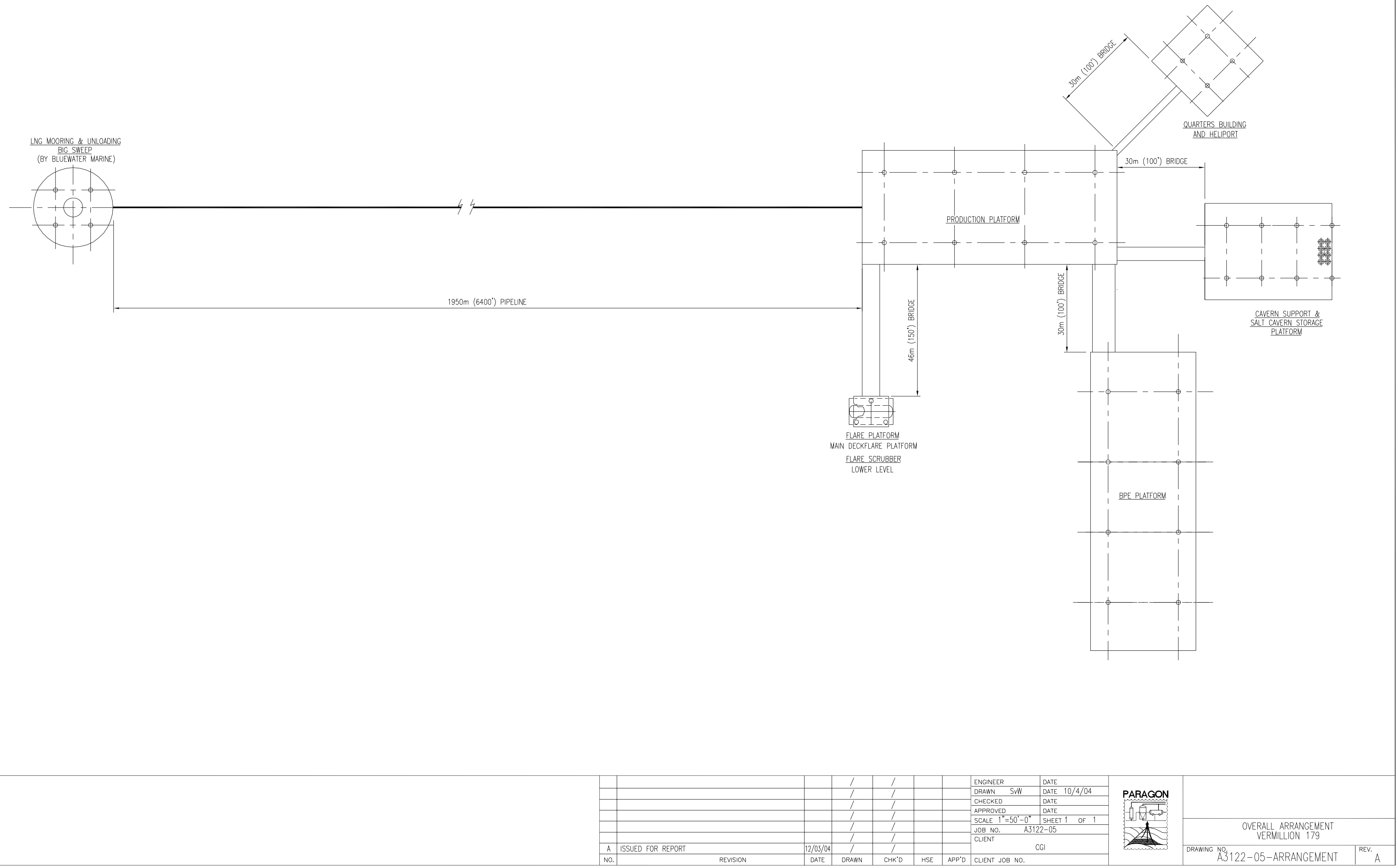



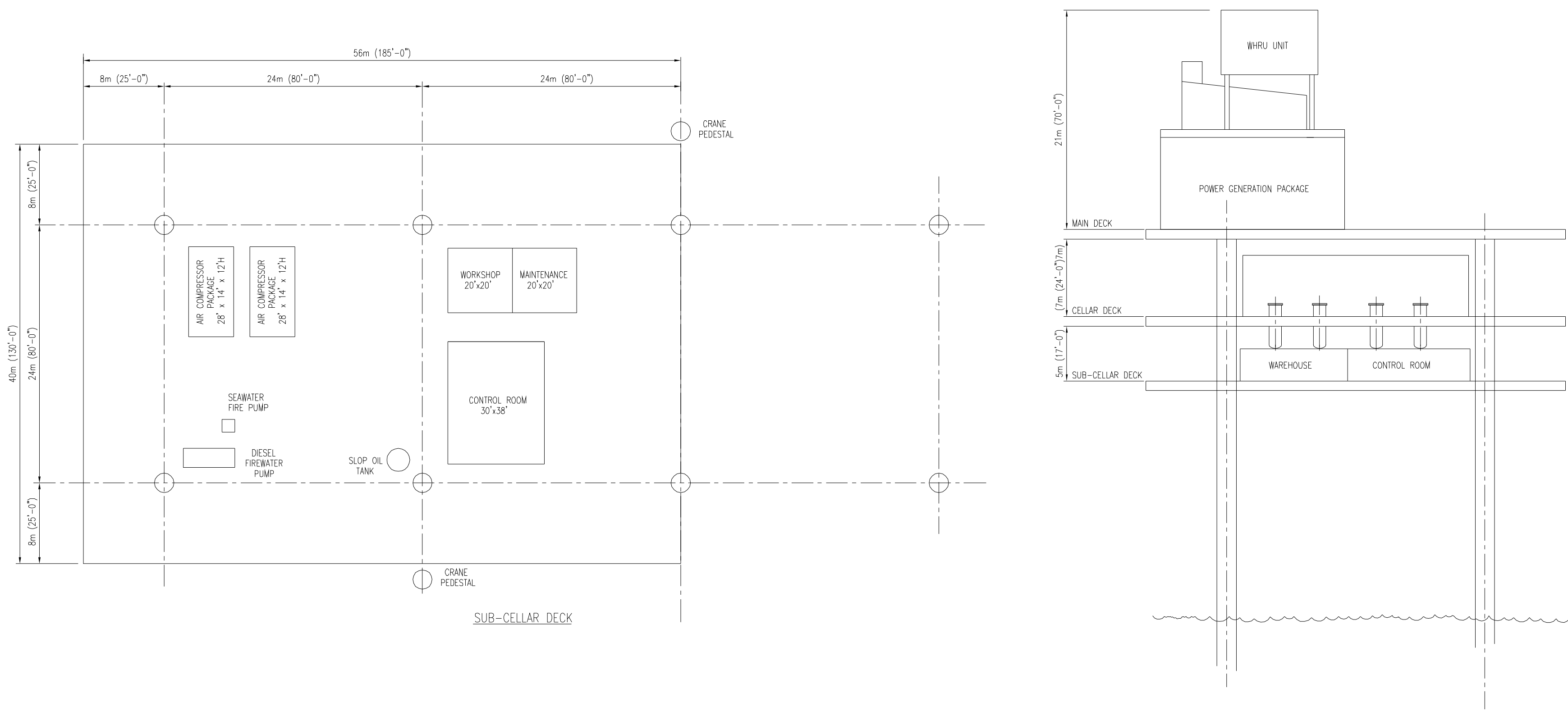


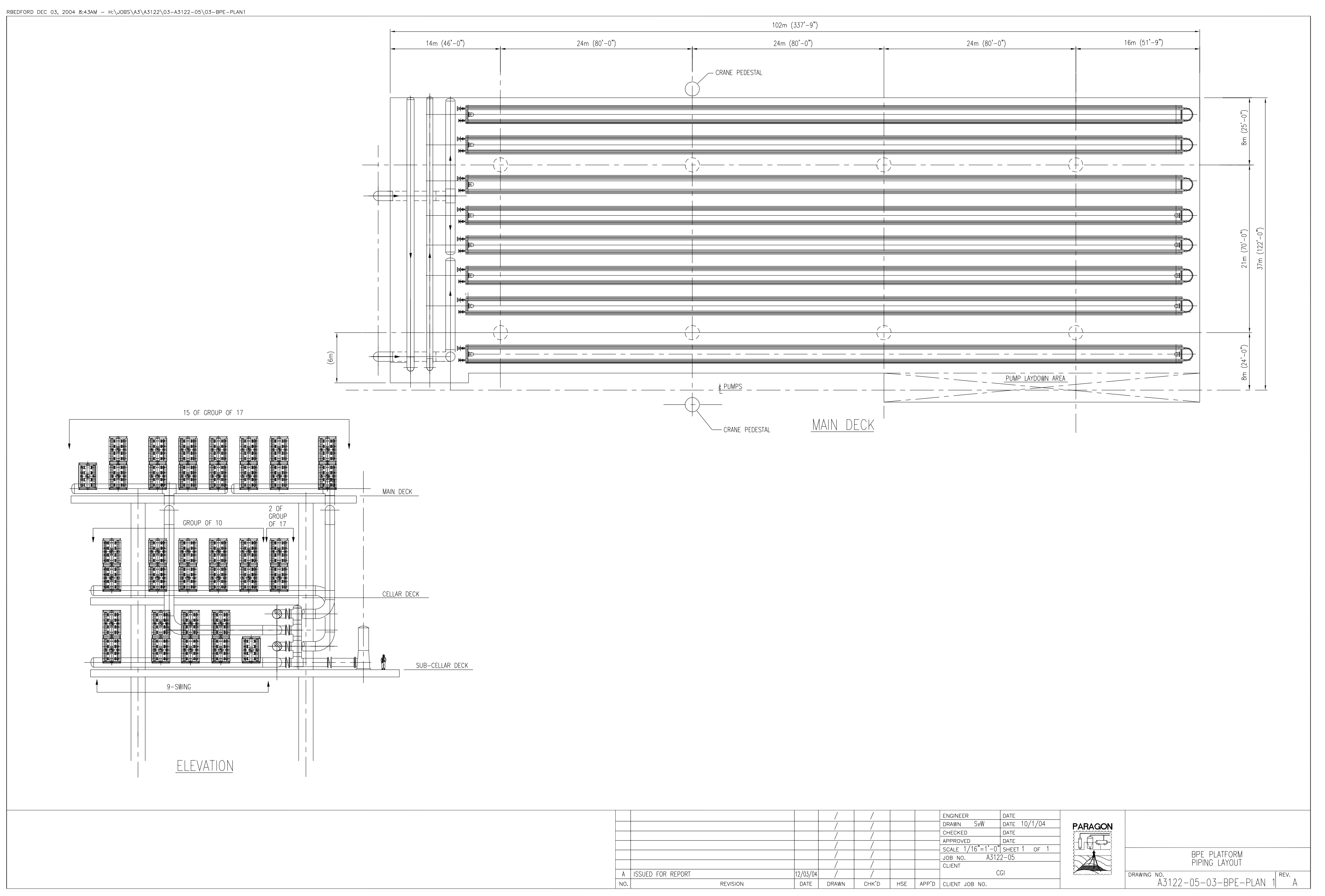




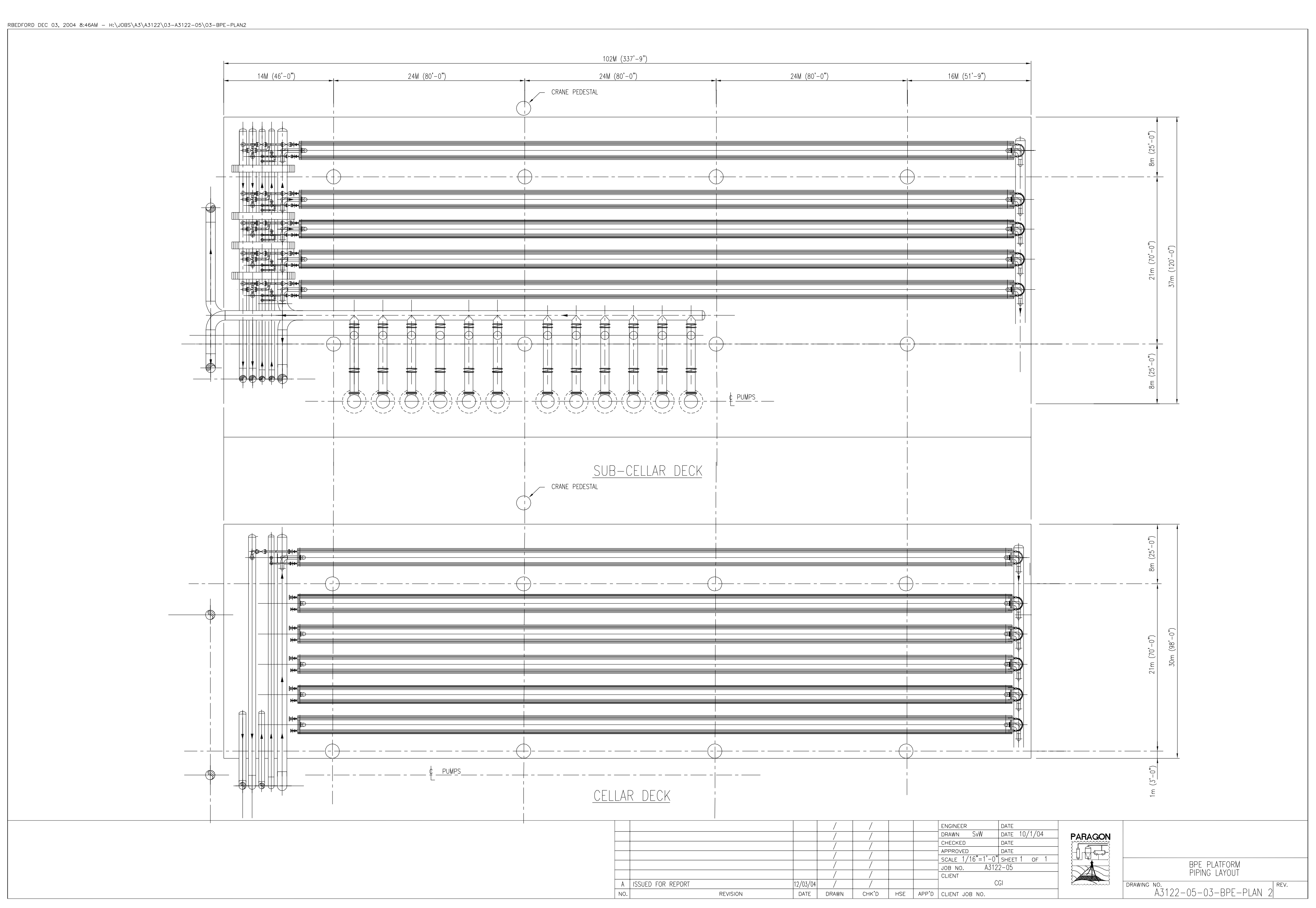



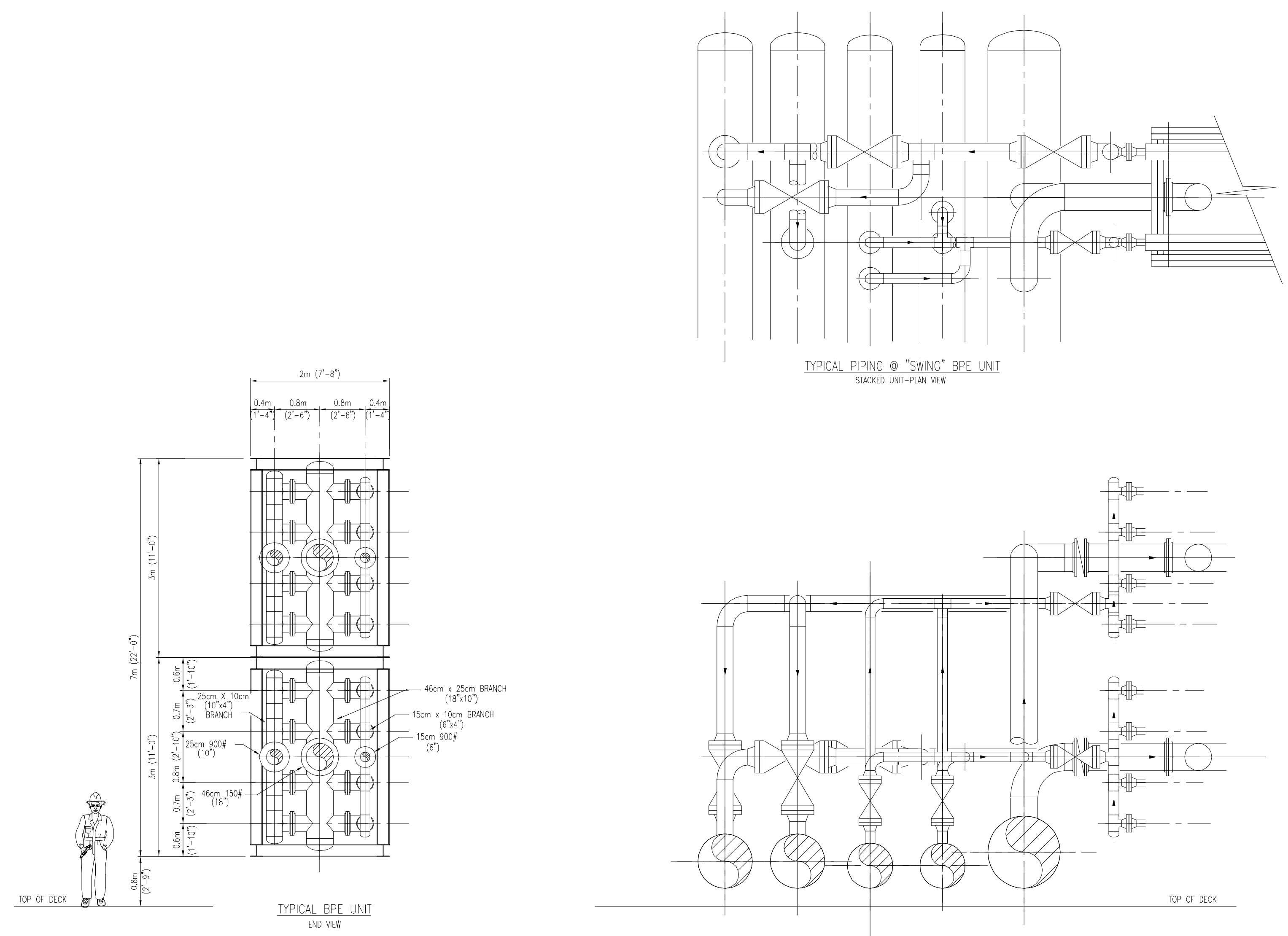

$\frac{\text { TYPICAL PIPING @ "SWIN" BPE UNIT }}{\text { SIACKED UNIT-PAN WEW }}$

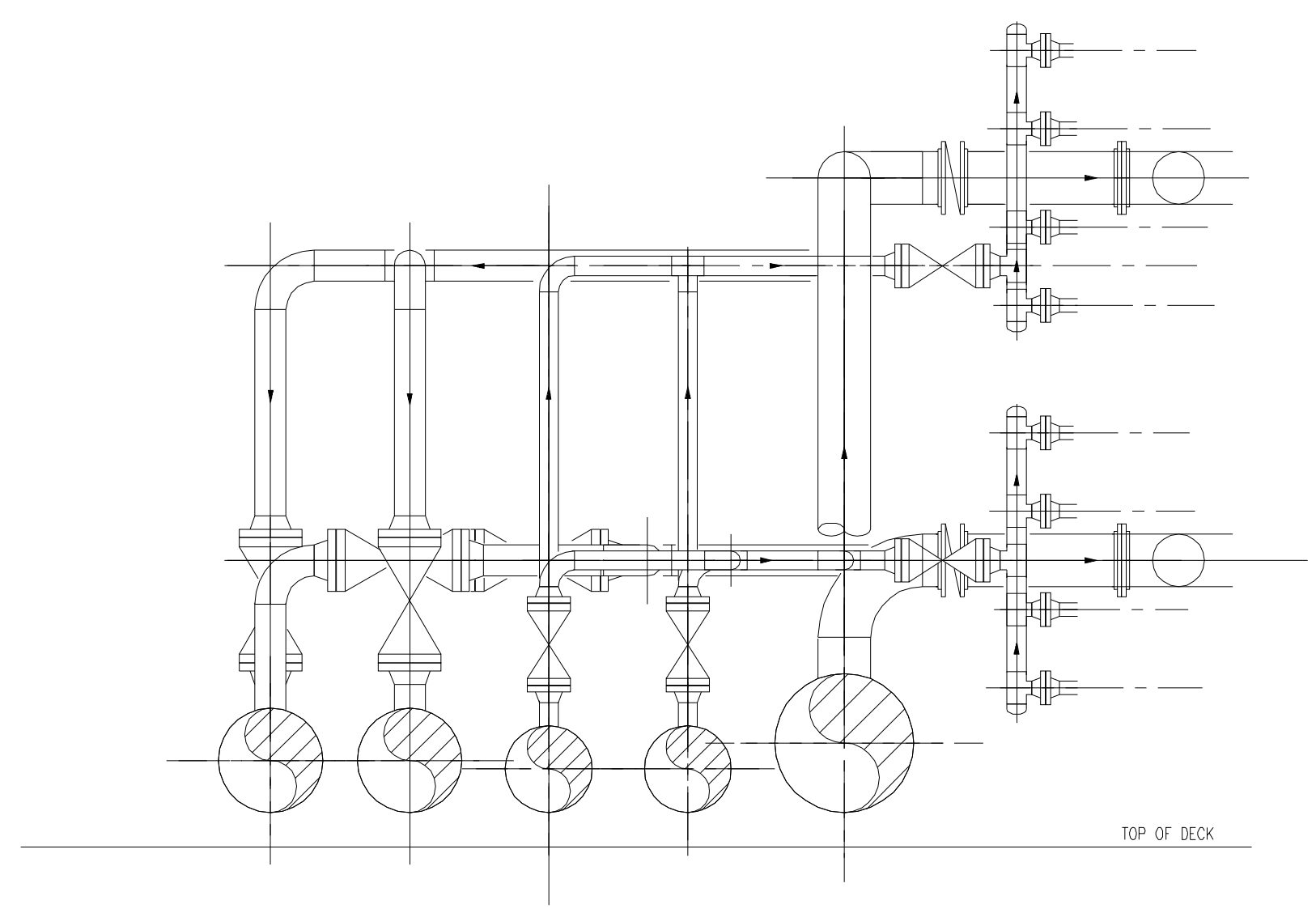



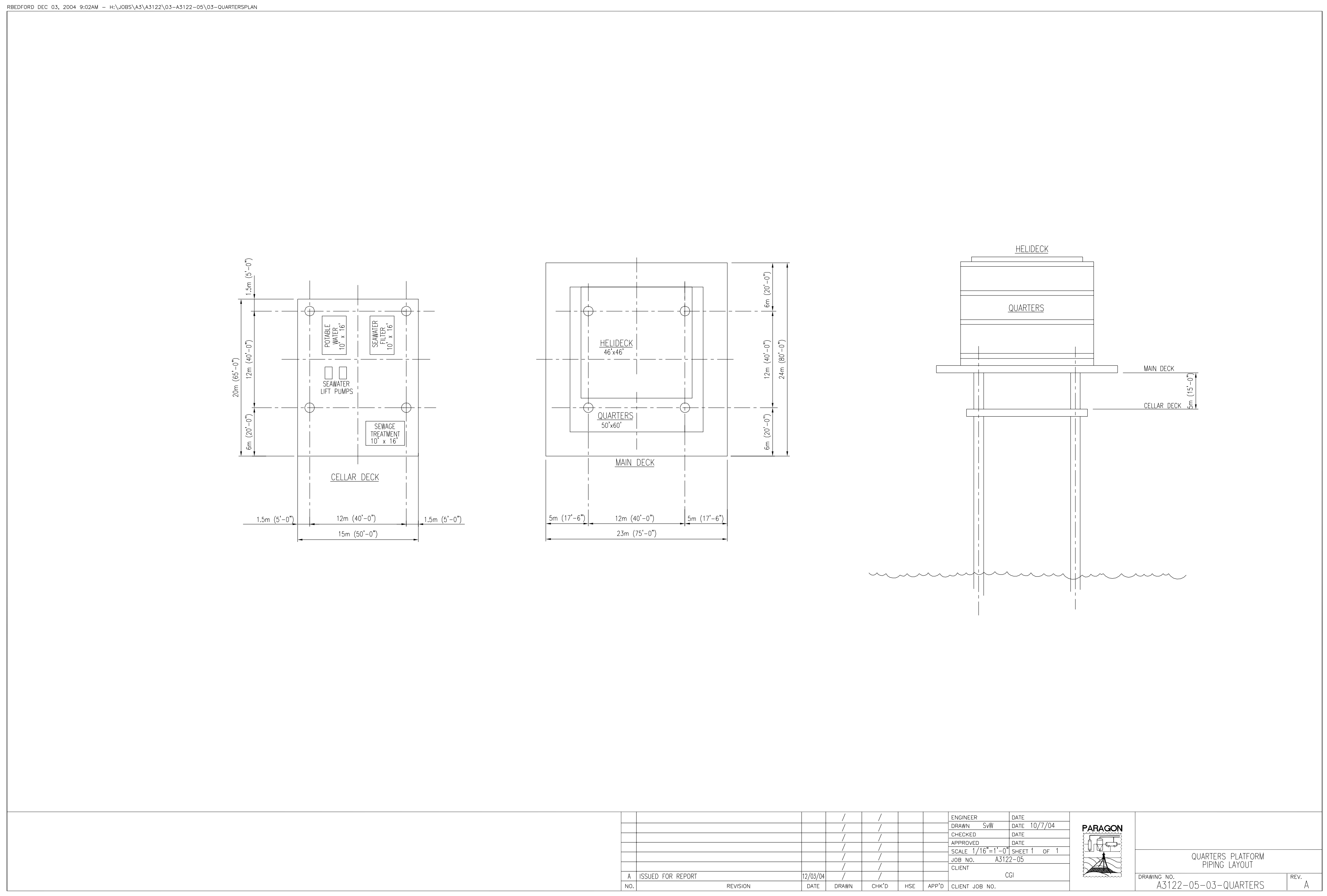


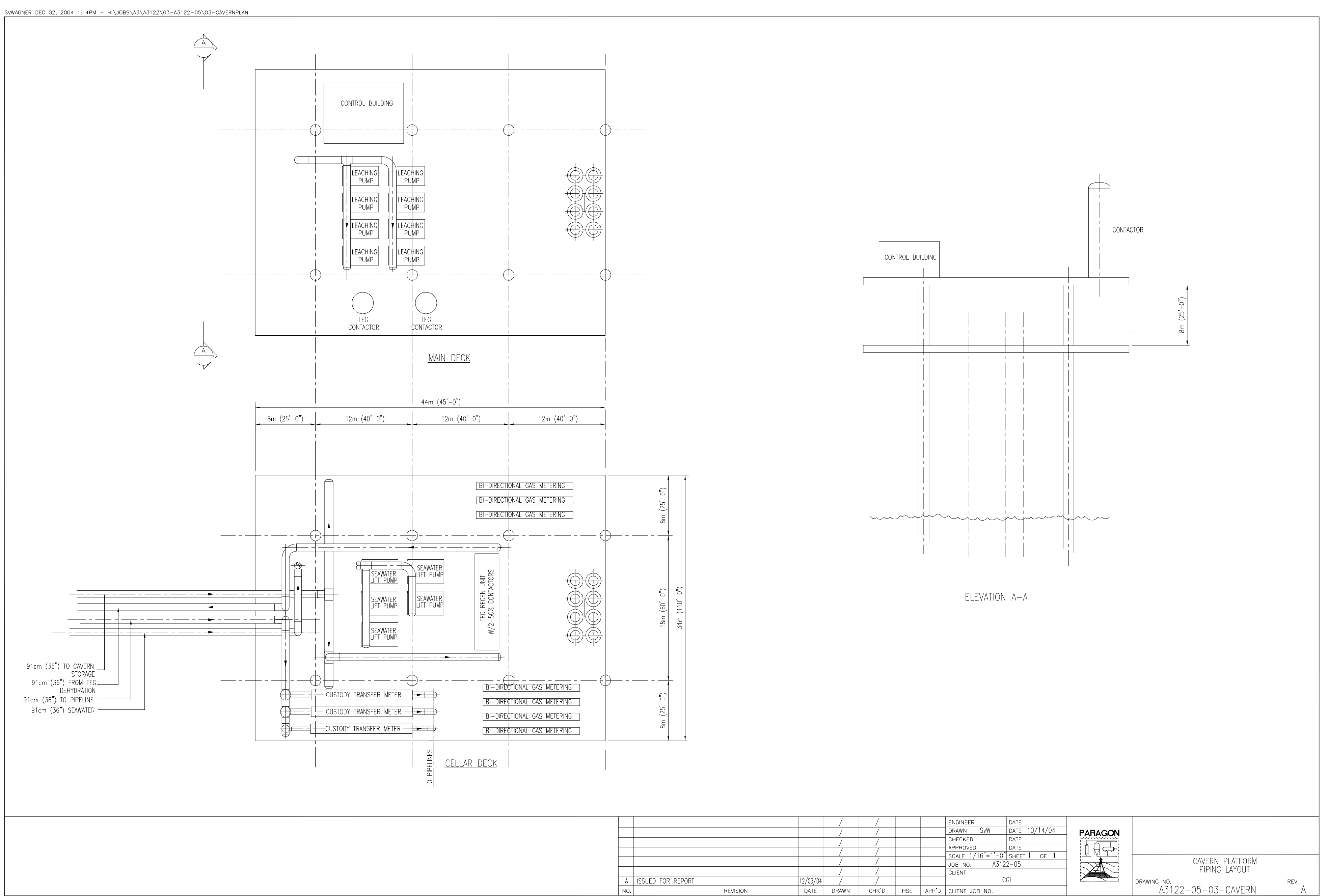


Appendix 2

PFDs 


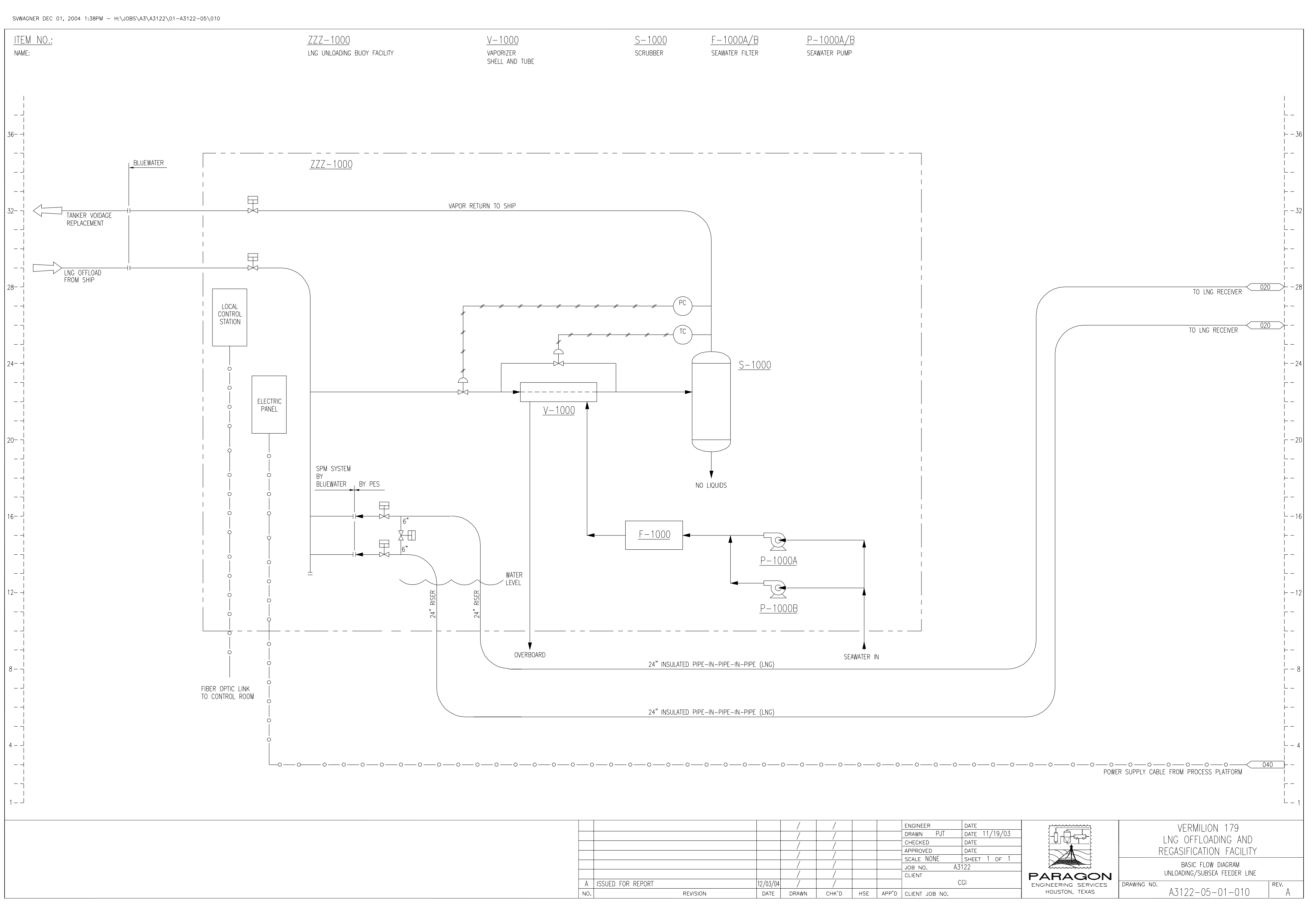




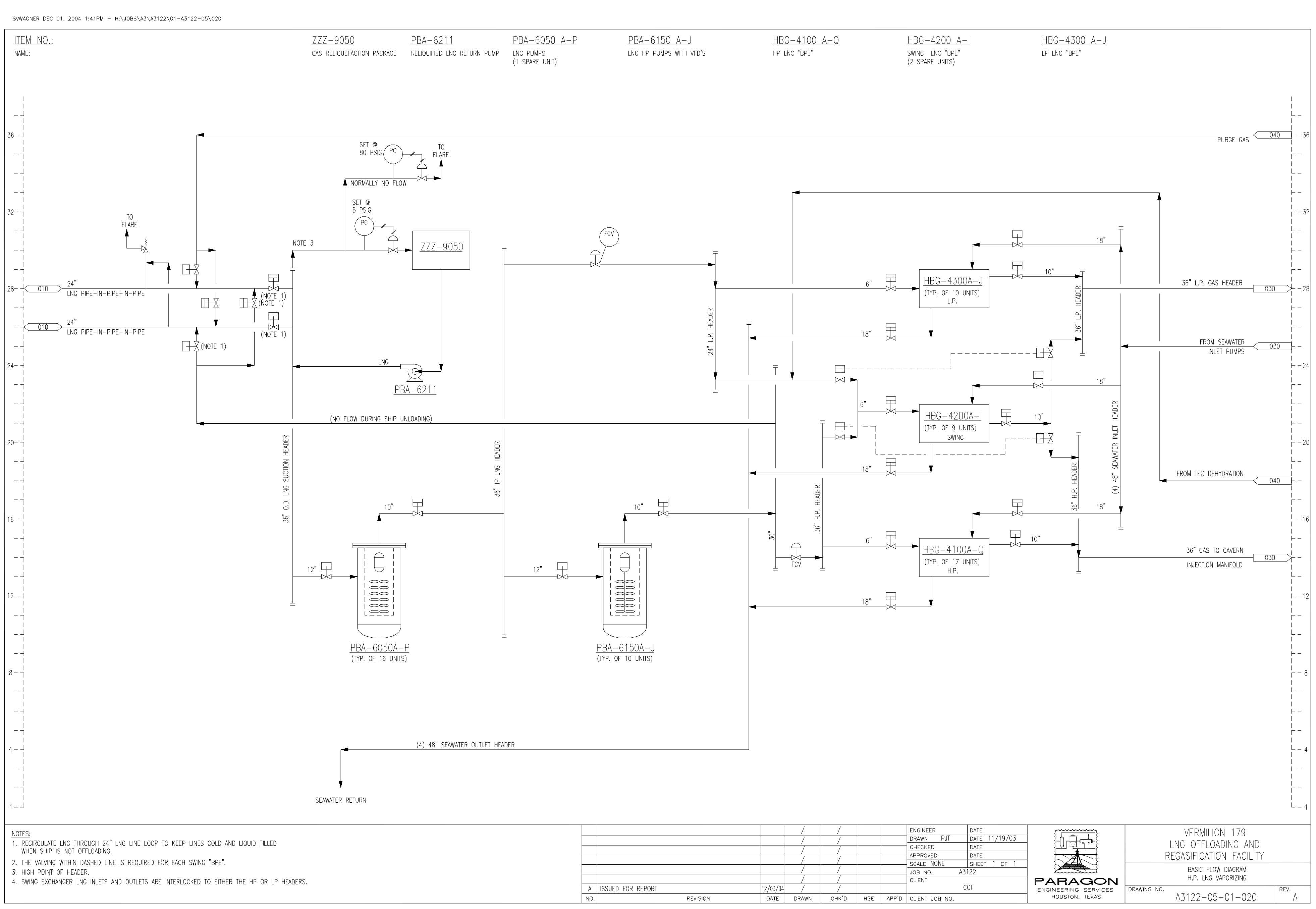




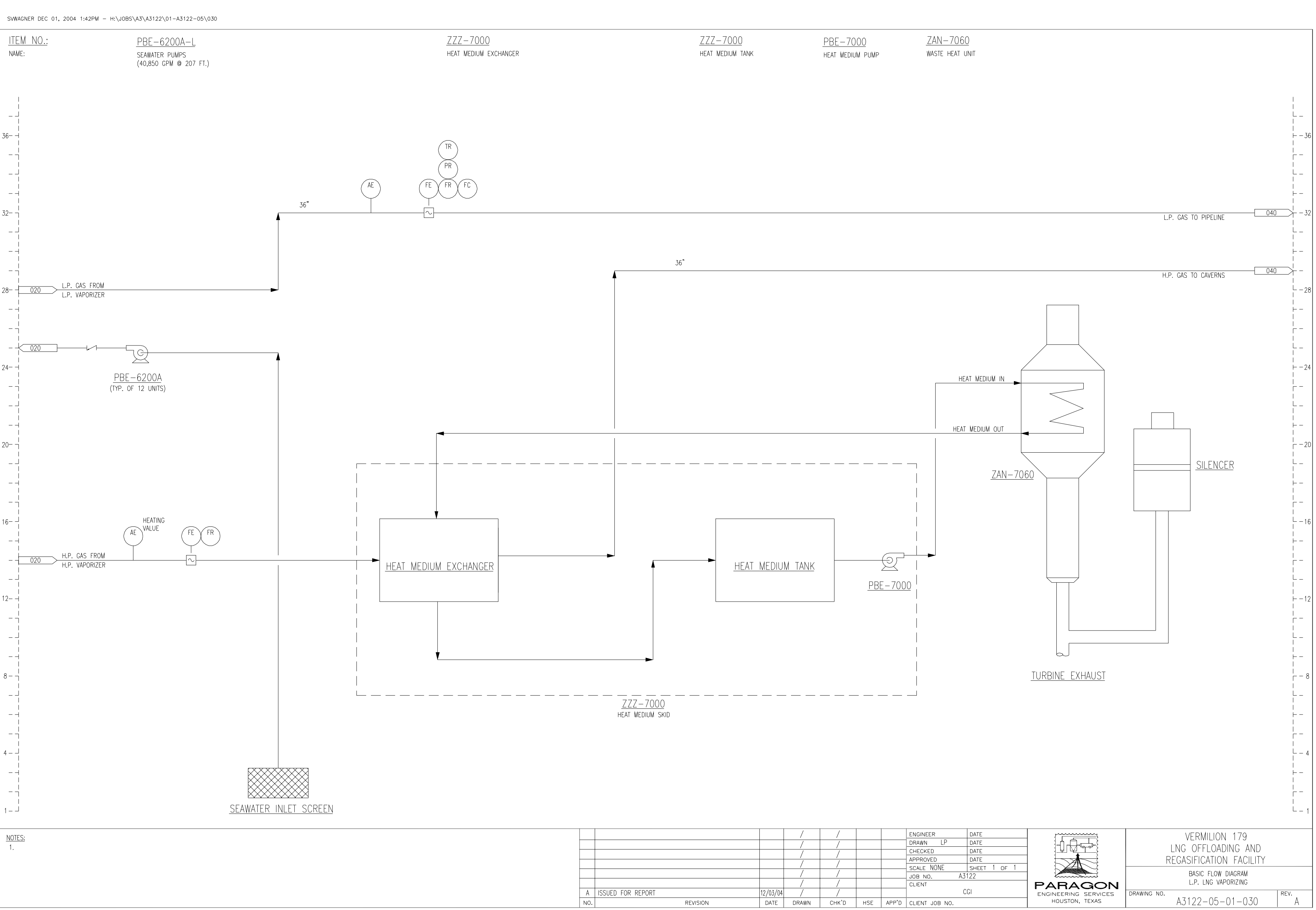




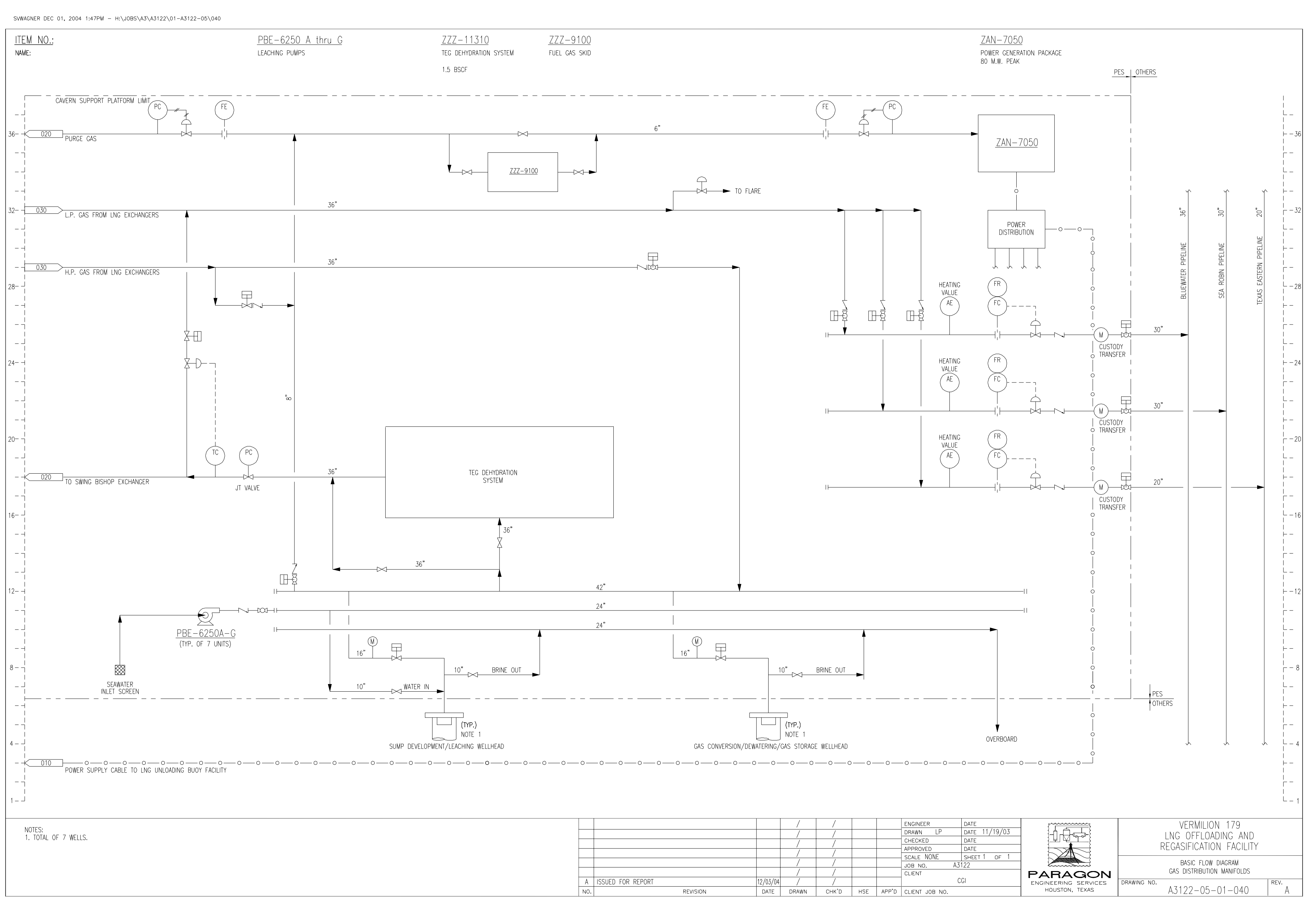


Appendix 3

Equipment List 


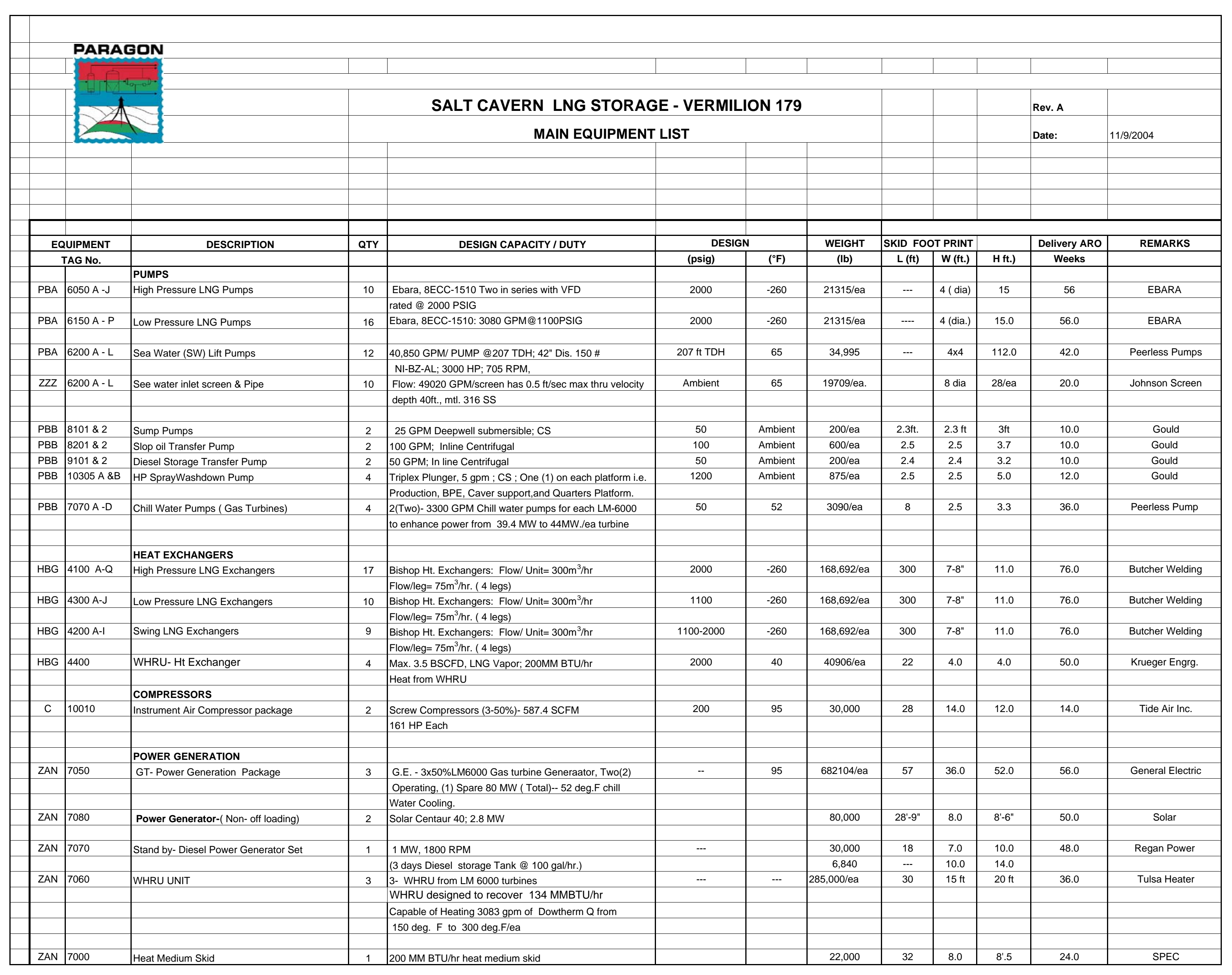




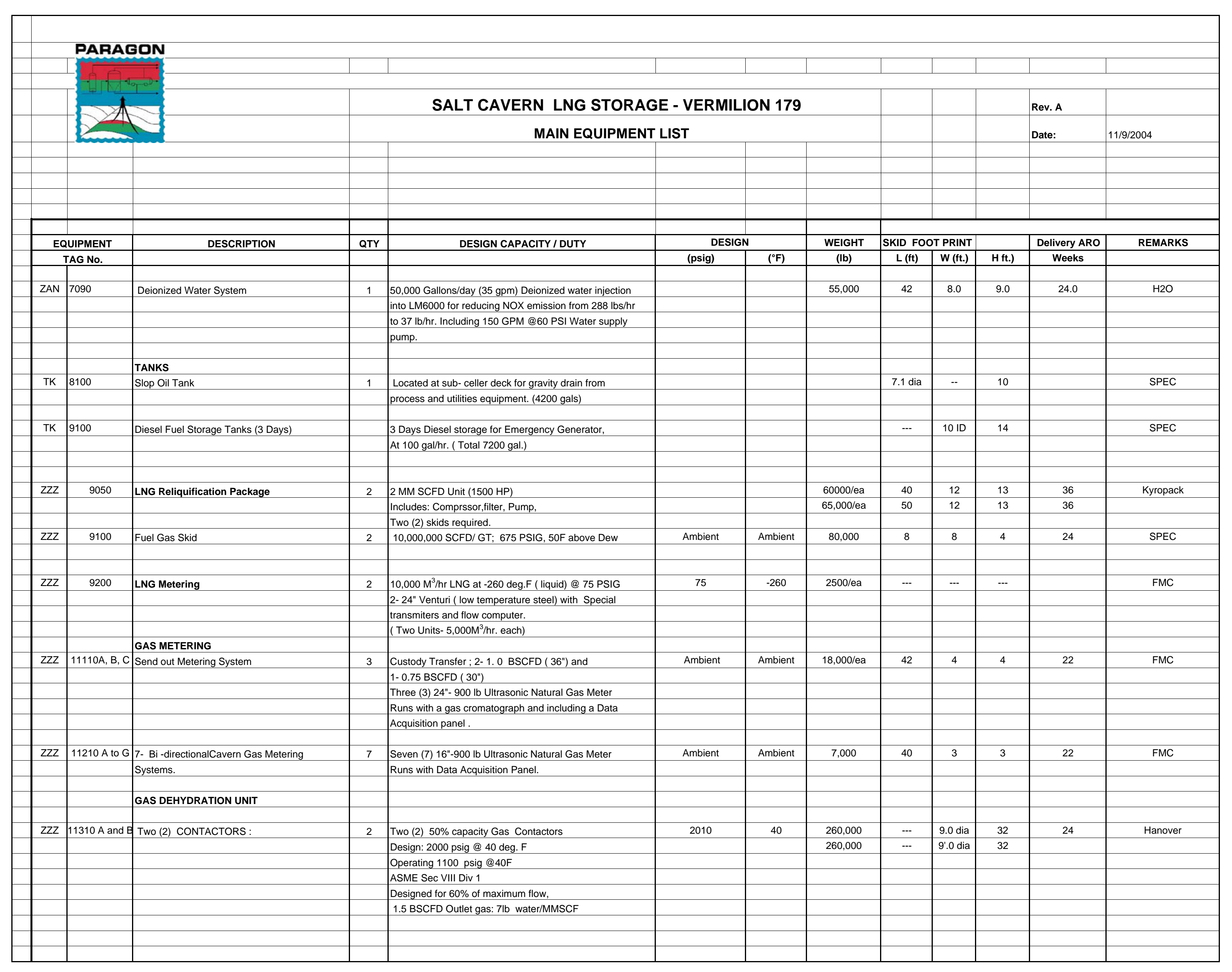




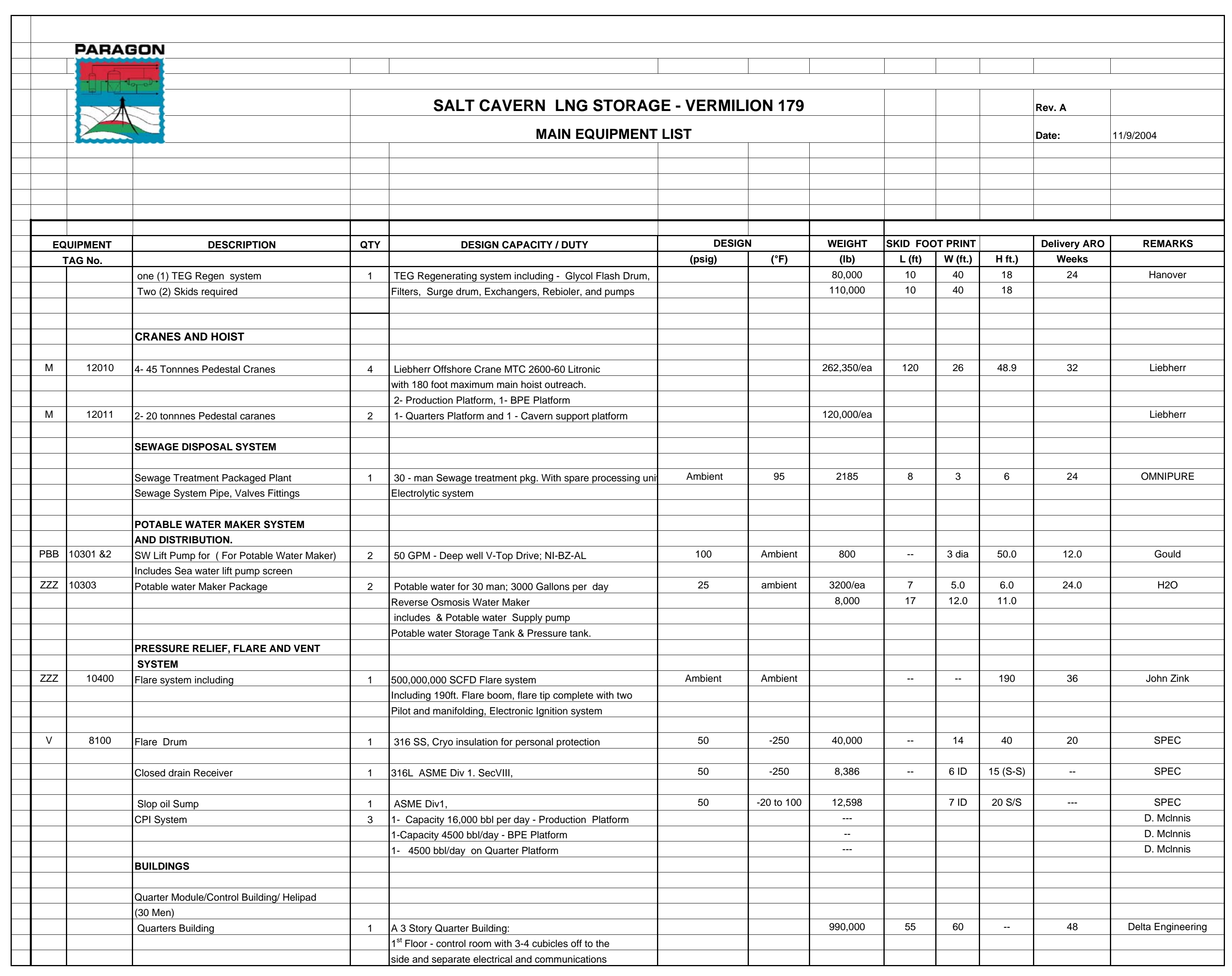




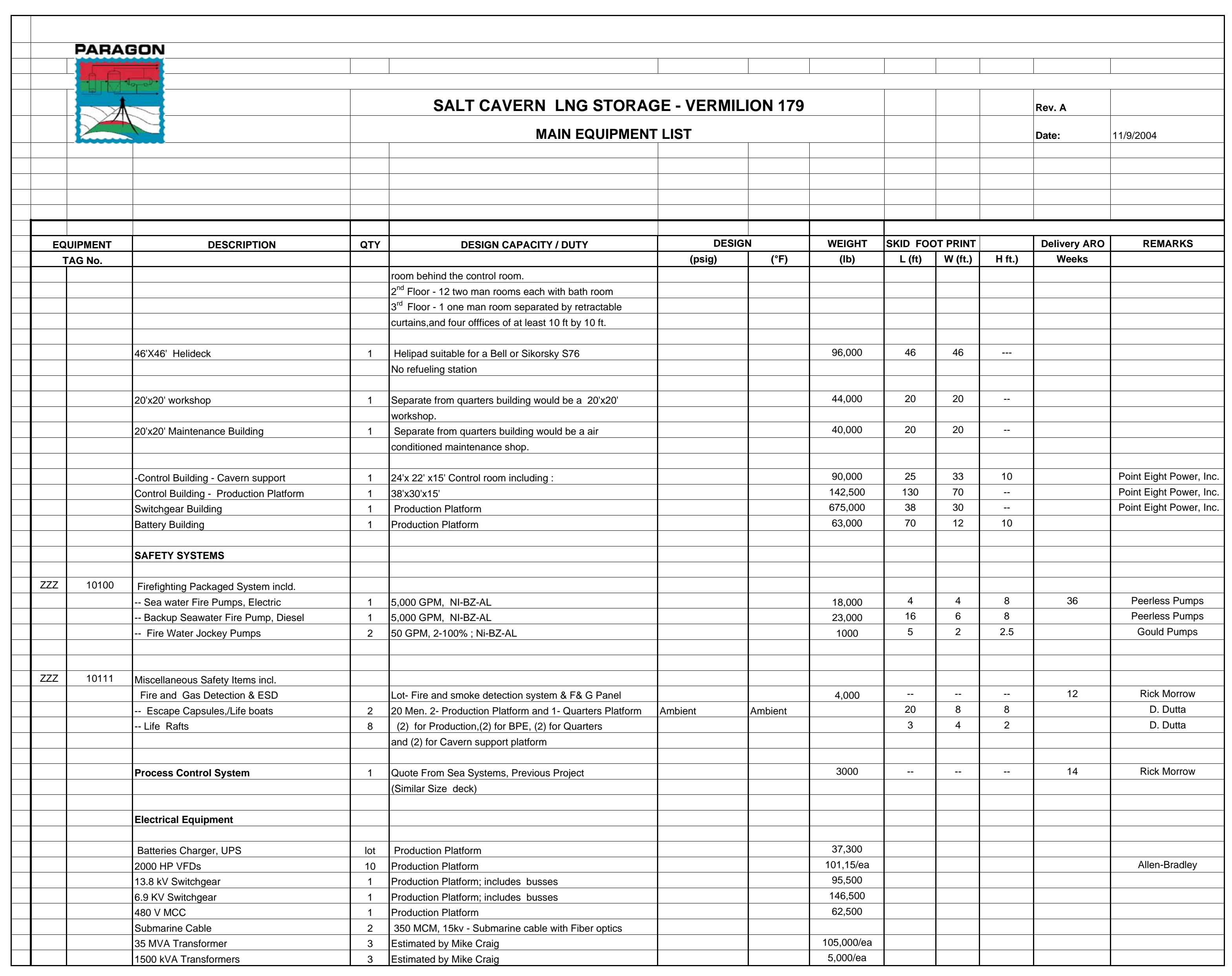




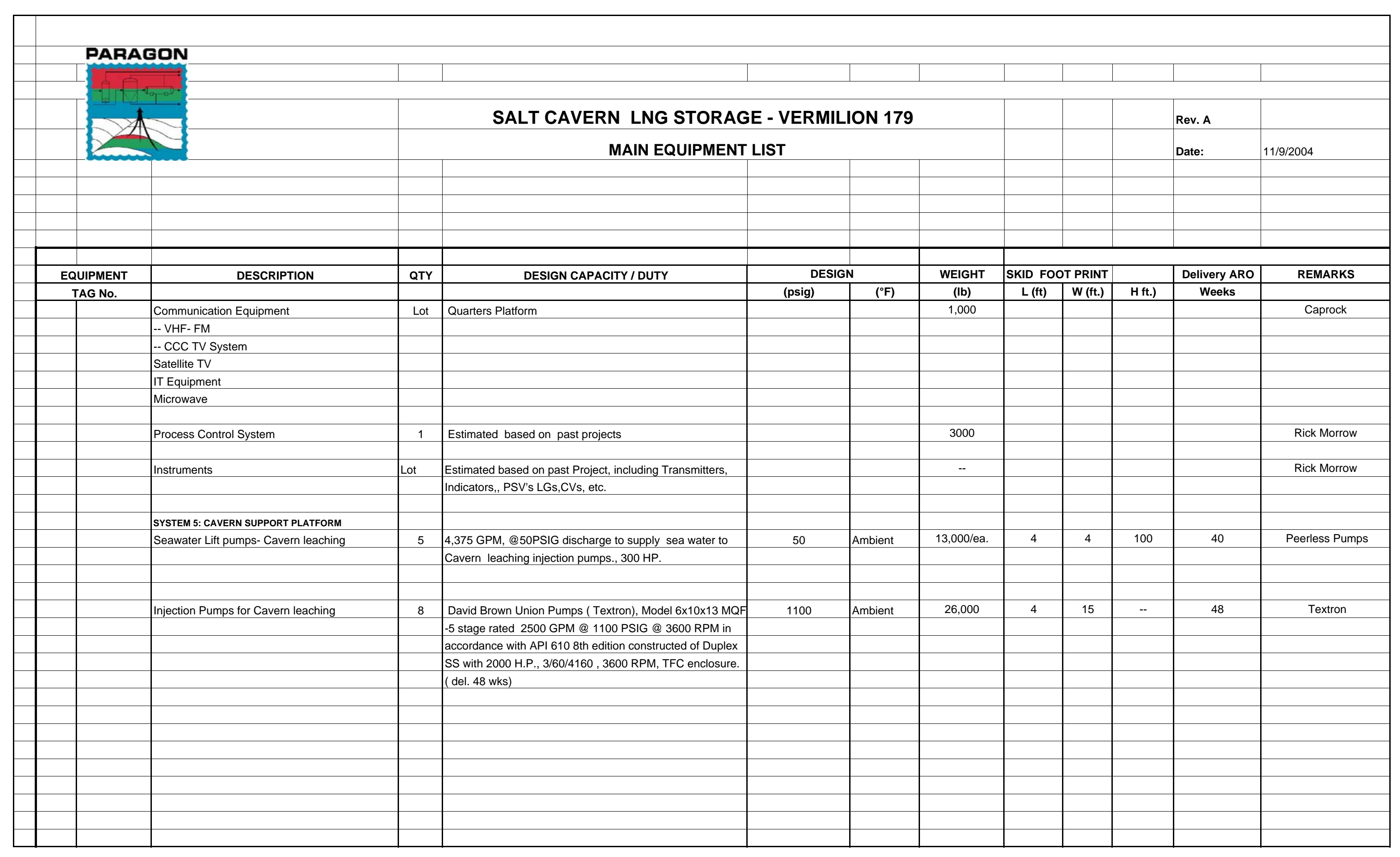


Appendix 4

Utility Summary 


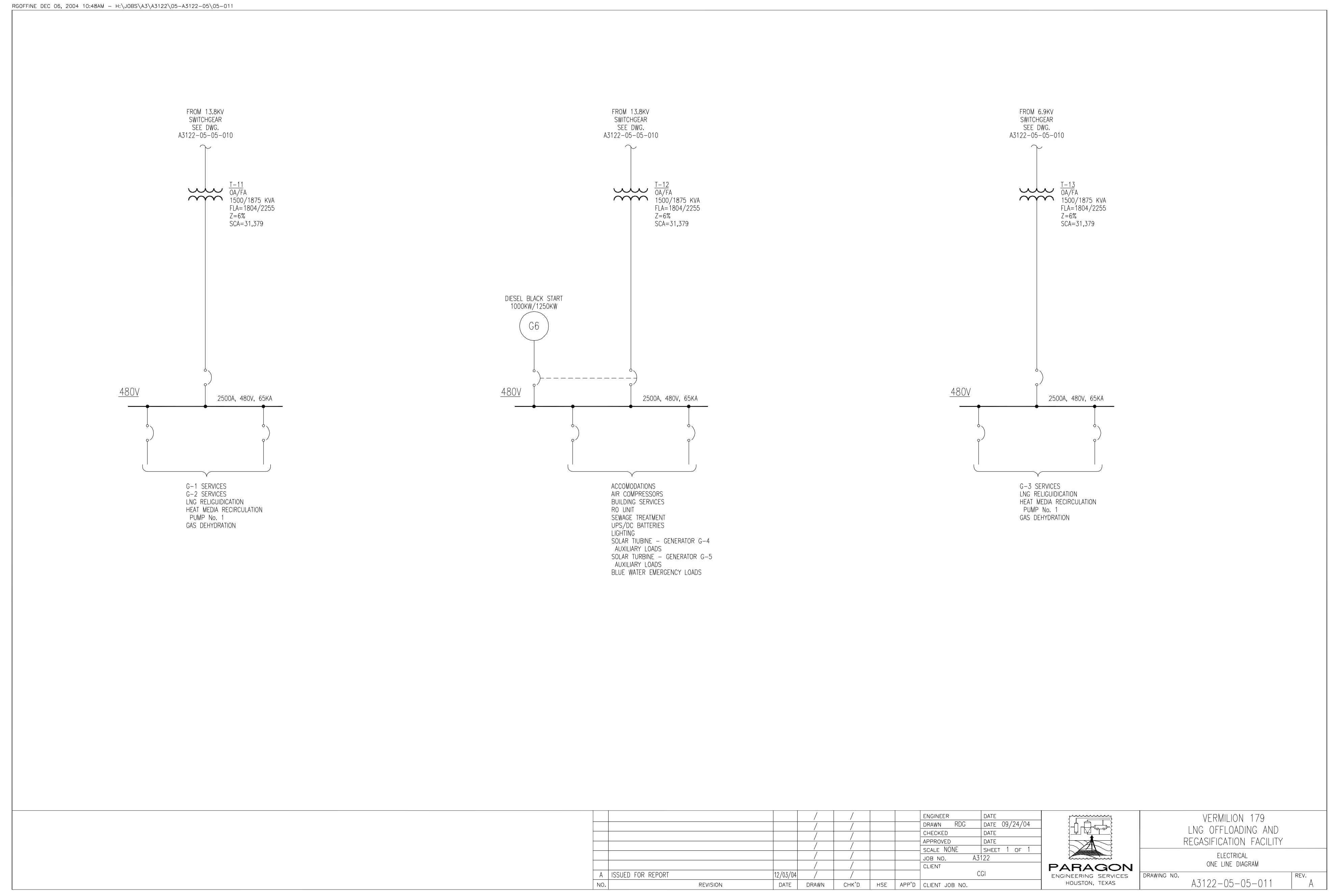




\section{Appendix 5 \\ Pump Curves}




\section{DESCRIPTION OF PUMP CONFIGURATION - PARAGON ENGINEERING \\ Offshore LNG Receiving Terminal - Salt Cavern Storage and Pipeline Feed}

Pump Model: 8ECC-1510

Recommended Equipment: 25 pumps +10 Variable Frequency Drives (VFD)

Rated Point: $700 \mathrm{~m}^{3} / \mathrm{h} @ 1100 \mathrm{psi}(1800 \mathrm{~m}) @ 60 \mathrm{~Hz}$

Motor Rating: $3080 \mathrm{hp}$

Curves Attached: Standard curves and data sheets at $60 \mathrm{~Hz} \&$ VFD Curve

- Pipeline Sendout $\left(3000 \mathrm{~m}^{3} / \mathrm{h}\right.$ @ $\left.1100 \mathrm{psi}\right)$

Can be accomplished using 5 pumps in parallel operating at $\left(600 \mathrm{~m}^{3} / \mathrm{h} @ 1130 \mathrm{psi}\right)$

In order to use identical pumps (same model number and trim), the pressure increases as the operating point is moved from $700 \mathrm{~m}^{3} / \mathrm{h}$ to $600 \mathrm{~m}^{3} / \mathrm{h}$. Also note that a total flow of $2800 \mathrm{~m}^{3} / \mathrm{h}$ (8) $1100 \mathrm{psi}$ can be achieved by operating 4 pumps at $700 \mathrm{~m}^{3} / \mathrm{h}$ and $1100 \mathrm{psi}$ in parallel.

- Cavern Storage $\left(7000 \mathrm{~m}^{3} / \mathrm{h} @ 1100-2000 \mathrm{psi}\right)$

Can be accomplished using 10 pumps in parallel operating at $\left(700 \mathrm{~m}^{3} / \mathrm{h} @ 1100 \mathrm{psi}\right)$, in series with pumps running on VFD's. The table below shows various combinations:

\begin{tabular}{|c|c|c|c|c|c|c|c|c|c|}
\hline & \begin{tabular}{|c|} 
VFD Drive \\
Frequency \\
$(\mathrm{Hz})$
\end{tabular} & \begin{tabular}{|l|} 
No. of \\
VFD \\
Pumps
\end{tabular} & \begin{tabular}{|c|} 
Capacity \\
of VFD \\
Pumps \\
$\left(\mathrm{m}^{3} / \mathrm{h}\right)$
\end{tabular} & \begin{tabular}{|c|} 
Diff. \\
Pressure of \\
VFD Pumps \\
(psi)
\end{tabular} & $\begin{array}{l}\text { No. of } \\
\text { Non- } \\
\text { VFD } \\
\text { Pumps }\end{array}$ & \begin{tabular}{|c|} 
Capacity of \\
Non-VFD \\
Pumps \\
$\left(\mathrm{m}^{3} / \mathrm{h}\right)$
\end{tabular} & $\begin{array}{c}\text { Diff. } \\
\text { Pressure of } \\
\text { Non-VFD } \\
\text { Pumps (psi) }\end{array}$ & $\begin{array}{c}\text { Total Flow } \\
\text { Rate to } \\
\text { Caverns } \\
\left(\mathrm{m}^{3} / \mathrm{h}\right)\end{array}$ & $\begin{array}{c}\text { Total } \\
\text { Discharge } \\
\text { Pressure of } \\
\text { Pumps in } \\
\text { Series (psi) }\end{array}$ \\
\hline & & \pm & & & 10 & 700 & 1100 & 7000 & 1100 \\
\hline & 57 & 9 & 808 & 900 & 10 & 700 & 1100 & 7272 & 2000 \\
\hline 3 & 49.2 & 10 & 700 & 675 & 10 & 700 & 1100 & 7000 & 1775 \\
\hline 4 & 30 & 10 & 425 & 250 & 4 & 700 & 1100 & 4250 & 1350 \\
\hline 5 & 25 & 10 & 354 & 174 & 4 & 700 & 1100 & 3540 & 1274 \\
\hline
\end{tabular}

Note that at lower drive frequencies (Cases $4 \& 5$ ), the total flow rate to the caverns is decreased. In order to obtain additional flow at theses pressures, more pumps with VFD's would be required.

- The number of pumps required when both the maximum Pipeline Sendout and Cavern Storage flow rates are required, is 15 pumps running in parallel at $60 \mathrm{~Hz}$, in series with 10 pumps running on VFD, for a total of 25 pumps (Model No. 8ECC-1510) and 10 VFD's.

- The price for one 8ECC-1510 is $\$ 524,550$.

The extended price for twenty five BECC-15t0 pumps is $\$ 13,113,750$. 


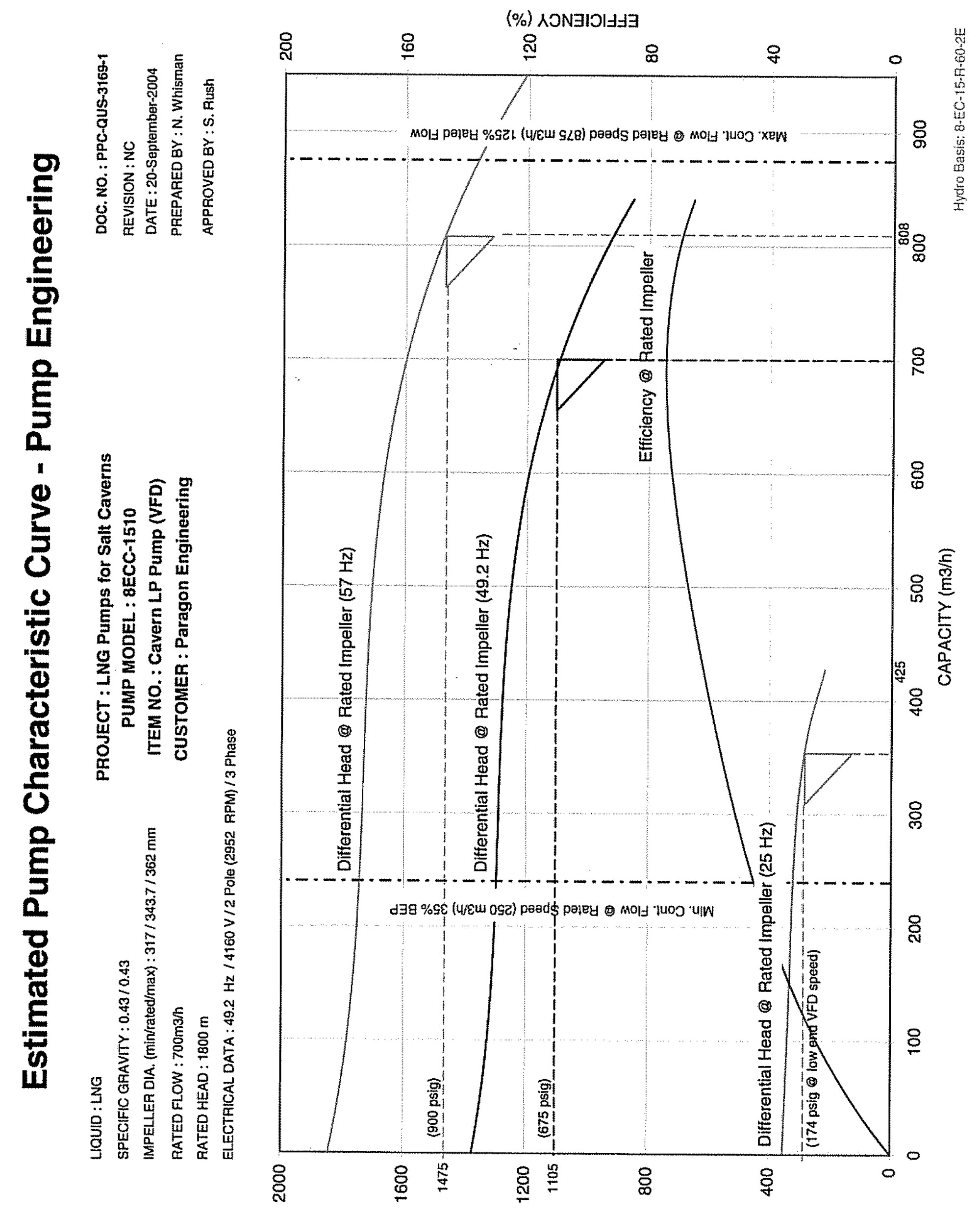

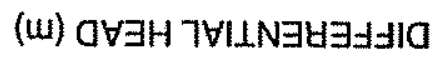




\begin{tabular}{|c|c|c|c|}
\hline CUSTOMEA & \multicolumn{3}{|c|}{ Paragon Engineering } \\
\hline PUMP MODEL NO. & $8 E C C-1510$ & PATED FLOW \& HEAD & $700 \mathrm{~m} 3 \mathrm{~m} \cdot 1800 \mathrm{~m}$ \\
\hline ITEM NO. & Cavem LP Fump & Lovio & LNG $\oplus-162$ deg $C$ \\
\hline PROJECT & LNG Pumps for Sall Caverns & SPECIFIC GRAVITY (SG 18 SG 2) & 0.4380 .43 \\
\hline DOC.No. & PPC.QUS-3169-1 & IMPELLLEA DIA. \{minirated/max\} & $317.00 / 343.70 / 362.00 \mathrm{~mm}$ \\
\hline DATE & $20.50 p \cdot 2004$ & ELECTRICAL DATA & $2297.68 \mathrm{~kW} / 80 \mathrm{~Hz} / 4160 \mathrm{~V} / 3600 \mathrm{RPM} / 3$ Phase \\
\hline
\end{tabular}
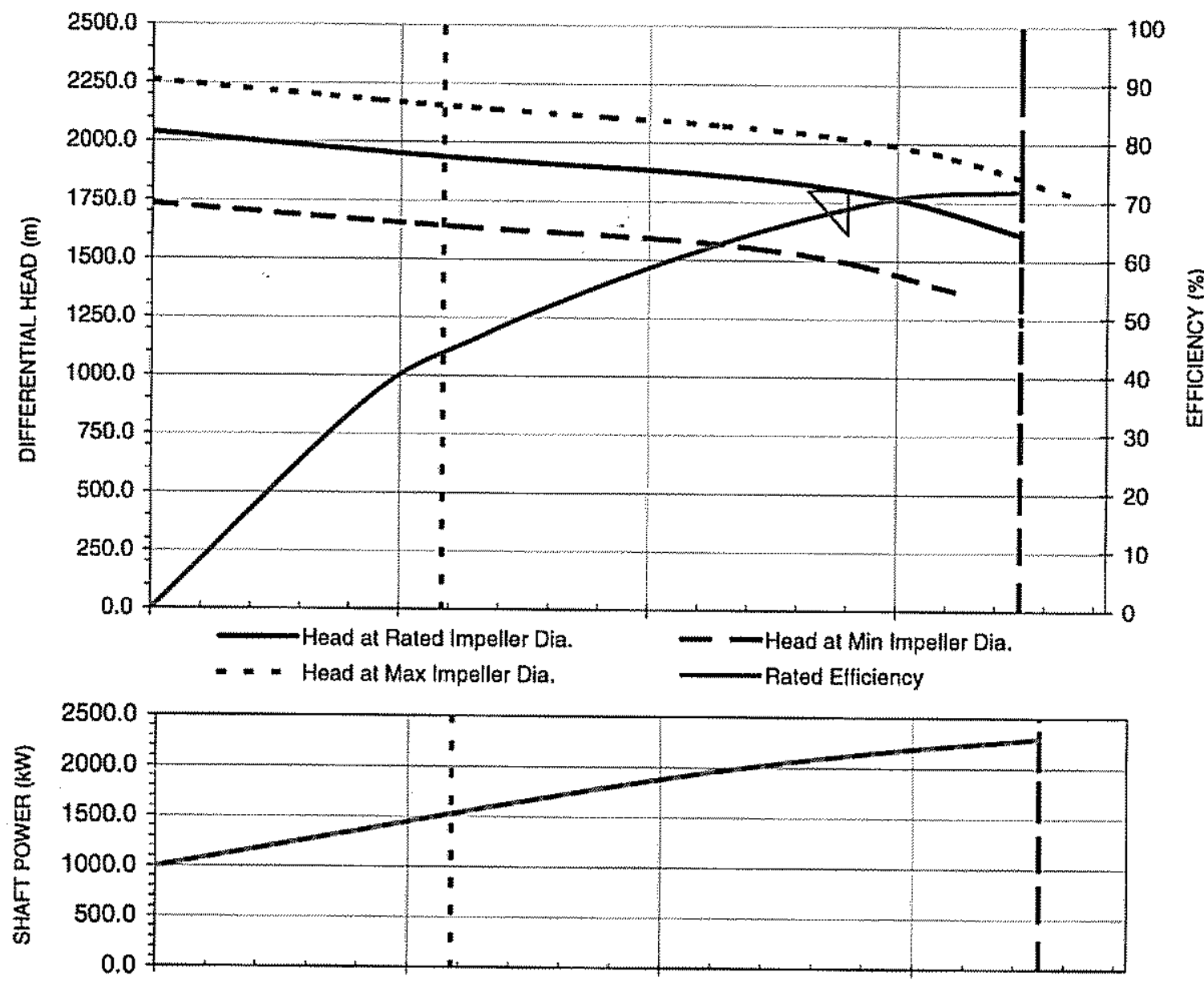

Power SG 1

$-m$ Power SG2

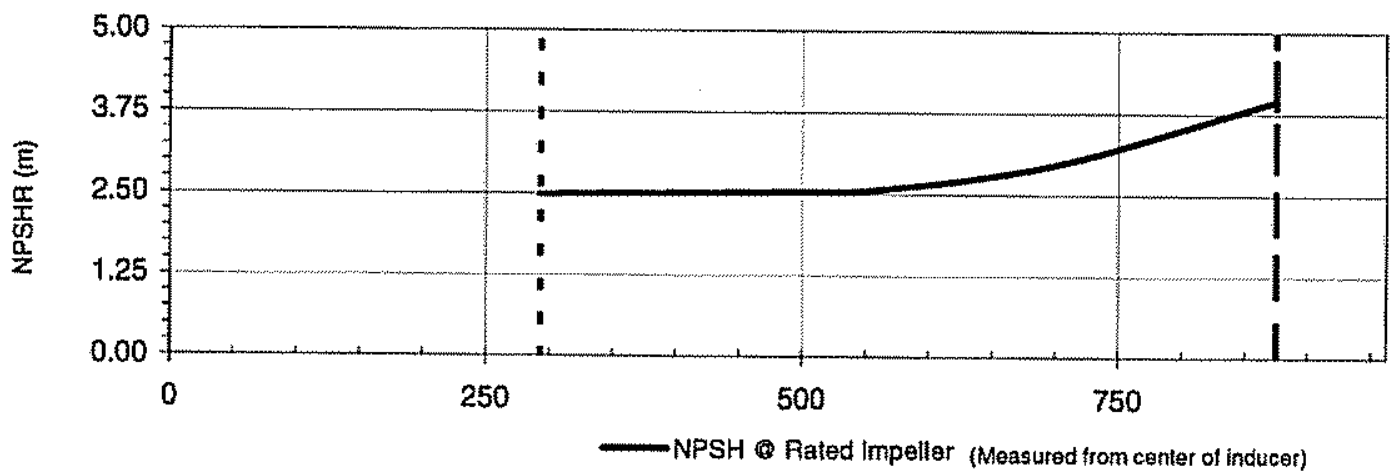

RATED FLOW $\left(\mathrm{m}^{3} / \mathrm{hr}\right)$

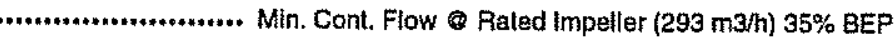

- . - . . Max. Cont. Flow Rated Impeller $(875 \mathrm{~m} 3 / \mathrm{h}) 125 \%$ Rated Flow 


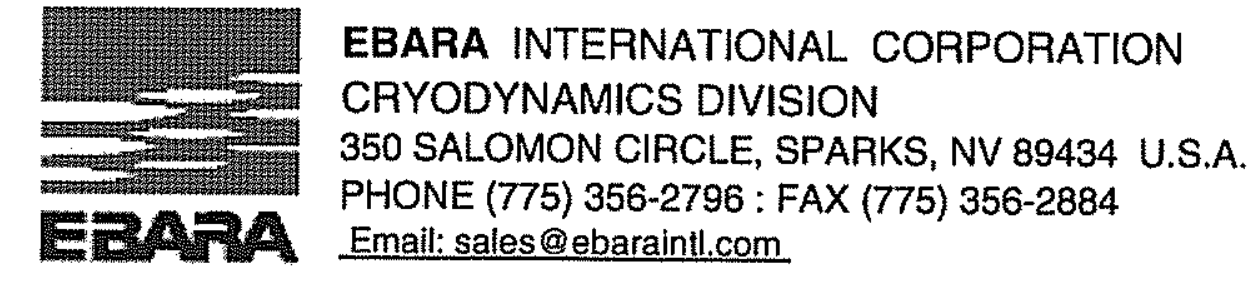

\section{Centrifugal Pump Data Sheet}

Proposal No.: QUS-3169

Item No.: Cavern LP Pump

Operating Conditions

Pump Model No.

8ECC-1510

Number of Stages

10

Liquid Pumped

Operating Temp.

Specific Gravity

Normal $\left({ }^{\circ} \mathrm{C}\right)$

LNG

Capacity:

$-162$

SG2

0.430

Rated Flow (m3/h)

0.430

B.E.P. Flow $(\mathrm{m} 3 / \mathrm{h})$

700.0

Diff Head:

Min. Cont. Flow $(\mathrm{m} 3 / \mathrm{h})$

836.0

Rated (m)

B.E.P. $(m)$

Shutoff $(\mathrm{m})$

Efficiency:

Pated (\%)

B.E.P. $(\%)$

293.0

1800.0

1667.6

2039.5

69.0

NPSHR at Rated Point

(m)

72.1

NPSHR at Min. Cont. Flow

(m)

2.97

(See Note 1)

Power Req'd @:

Rated (kW)

2.49

B.E.P. (kW)

2139.6

Shutoff (kW)

2264.7

Maximum (kW) See Note 2

996.2

Suction Specific Speed

(RPM, m3/h, m)

2294.5

Rotation Speed

(RPM)

41915.5

MAWP

(kg/cm2)

3580

96.5

Construction Details

Impeller Dia:

Pump Type

Impeller Type

Axial Thrust

Discharge Size
Rated (mm)

Minimum (mm)

Maximum (mm)

Imp Rated OD/Max OD

(ANSI)
343.7

317.0

362.0

0.949

Suction Vessel Mounted

Aadial, Closed

Totally Balanced

8 inch $-600 \mathrm{lb}$

Performance Curve No.

PPC-QUS-3169-1

Note 1:

Note 2:

Note 3:
NPSH required above inducer centerline

At $125 \%$ rated flow and specific gravity of 0.43

B.E.P. Means best efficiency point 
EBARA INTERNATIONAL CORPORATION

CRYODYNAMICS DIVISION

350 SALOMON CIRCLE, SPARKS, NV 89434 U.S.A.

PHONE (775) 356-2796: FAX (775) 356-2884

Email: sales@ebaraintl.com

Motor Data Sheet

Proposal No. QUS-3169

Item No.: Cavern LP Pump

Pump Model No.:

$8 E C C-1510$

Driver By

Cryodynamics

Manufacturer

Cryodynamics

Motor Rating

(HP).

3080

Motor Rating

$(k W)$

2297.68

Nominal Voltage

(V)

4160

Frequency

60

Number of Poles

(PPM)

2

Synchronous Speed

3600

Insulation Class

$" F "$

Winding Special Treatment

Epoxy Double Vacuum Pressure Impregnation

Starting Method

Direct-On-Line

Starting Time

(Sec)

1.2

Rotor Type

Squirrel Cage with Aluminum bar

Torque:

Running (Kg-m)

621.0

Starting Current

(Amps)

2417.5

Frame Size

Y5800

Motor Weight

(kg)

2008.1

Bearing, Type, and Designation

Ball, 6300 Series

\begin{tabular}{|l|r|r|r|r|}
\hline & Nameplate Rating & $3 / 4$ & $1 / 2$ & $1 / 4$ \\
\hline Load (kW) & 2297.7 & 1723.3 & 1148.8 & 574.4 \\
\hline Efficiency (\%) & 91.8 & 91.8 & 90.9 & 86.7 \\
\hline Current (Amps) & 371.9 & 280.1 & 193.2 & 113.9 \\
\hline Power Factor & 0.934 & 0.930 & 0.908 & 0.807 \\
\hline
\end{tabular}




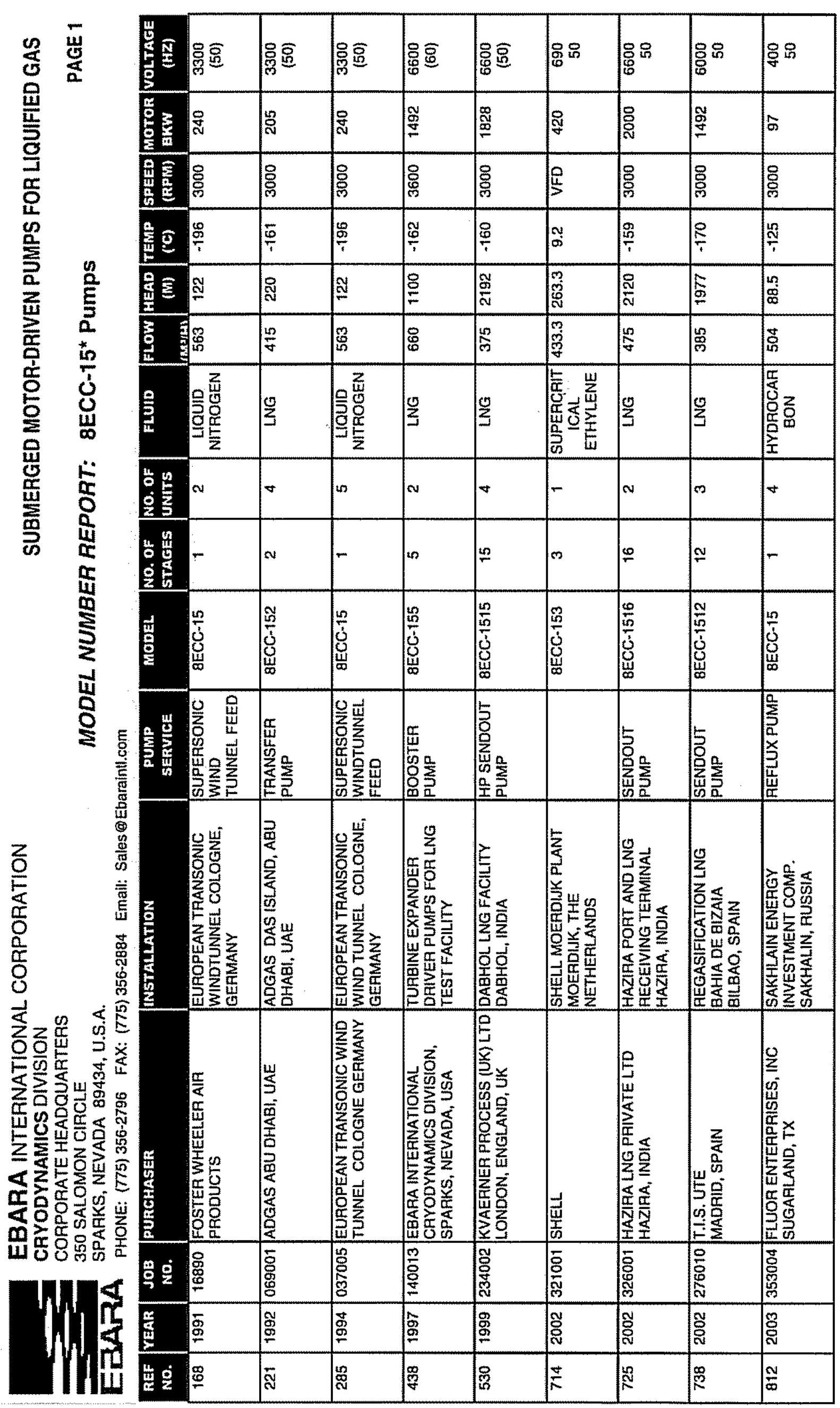

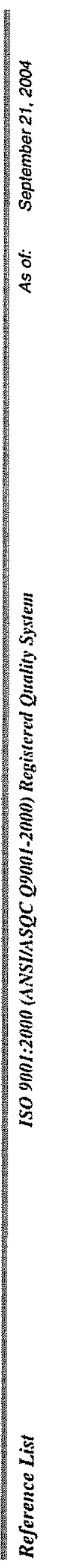




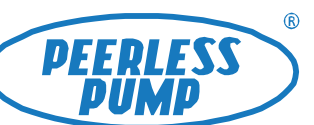

PHOENIX PUM P, INC.

7171 HWY 6 NORTH, SUITE $104 *$ HOUSTON, TX * 77095

J OE BATTSON

Phone 281-345-8700

Fax 281-345-2361

Project :

Quote No. : US-6095-109
Contact :

Phone :

Page No: 1 Date :
Fax :

Monday, September 27, 2004

Item No. : 1

Our Ref. :

US-6095-109

Pump Type : 8196 - ANSI Standard End Suction

Pump Model : Peerless - 8x10-13 XLTP 8196

Your Ref. :

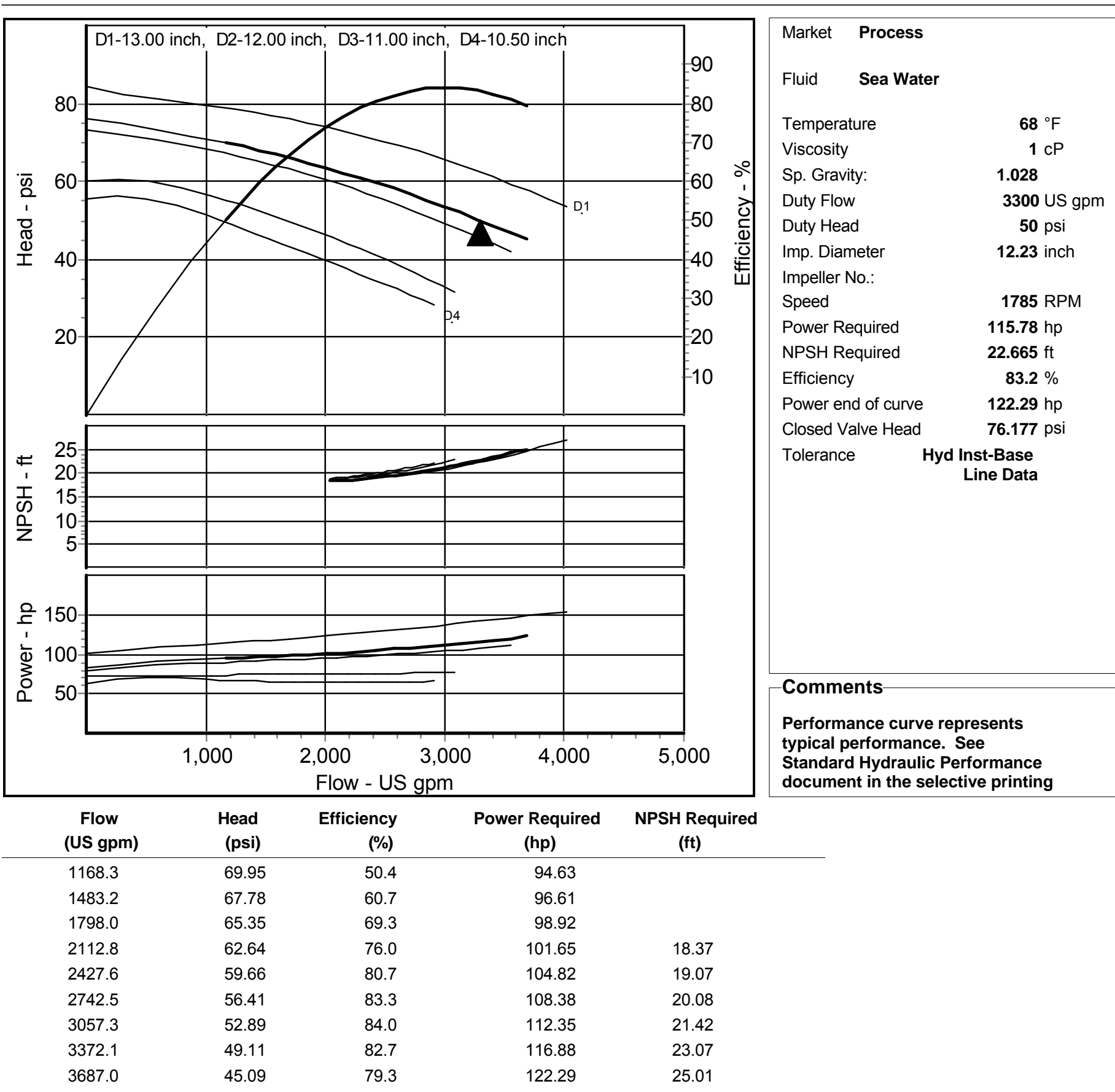


DEEILESS

Sterling Fluid Systems (USA)

P O Box 7026, Indianapolis, Indiana, 46202
Project :

Quote No. : $\quad 4096-818$
Contact :

Phone : $\quad$ Fax :

Page No:1 Date: Wednesday, September 08, 2004

\section{Pump Model: \\ Peerless Vertical - 48HXB 2 Stages}

Nom. Speed:

Market :

Impeller No: 710 RPM, $60 \mathrm{~Hz}$ Electric

Vertical Turbine Pump 2608562 I LC

Material Spec. Group:

V - B: NiAl-Brz; I: NiAI-Brz

Item :

Your Ref. :
Fluid:

Temperature: $\mathbf{7 7} \quad{ }^{\circ} \mathrm{F}$

Viscosity: $\quad 1.009 \mathrm{cP}$

Sp. Gravity: 1.030 (base temp. $68^{\circ} \mathrm{F}$ )

Performance curve according to Hyd Inst-Peerless Std

\begin{tabular}{|c|c|c|}
\hline & & Imp. Dia. (inch) \\
\hline Stage No. & Trim Status & D2-in x D2-out \\
\hline --- & $\mathrm{Fu}$ & ---- \\
\hline --- & Full & $33.75 \times 35.94$ \\
\hline $1-2$ & Trimmed $\mathbf{P}$ & $30.63 \times 32.58$ \\
\hline
\end{tabular}

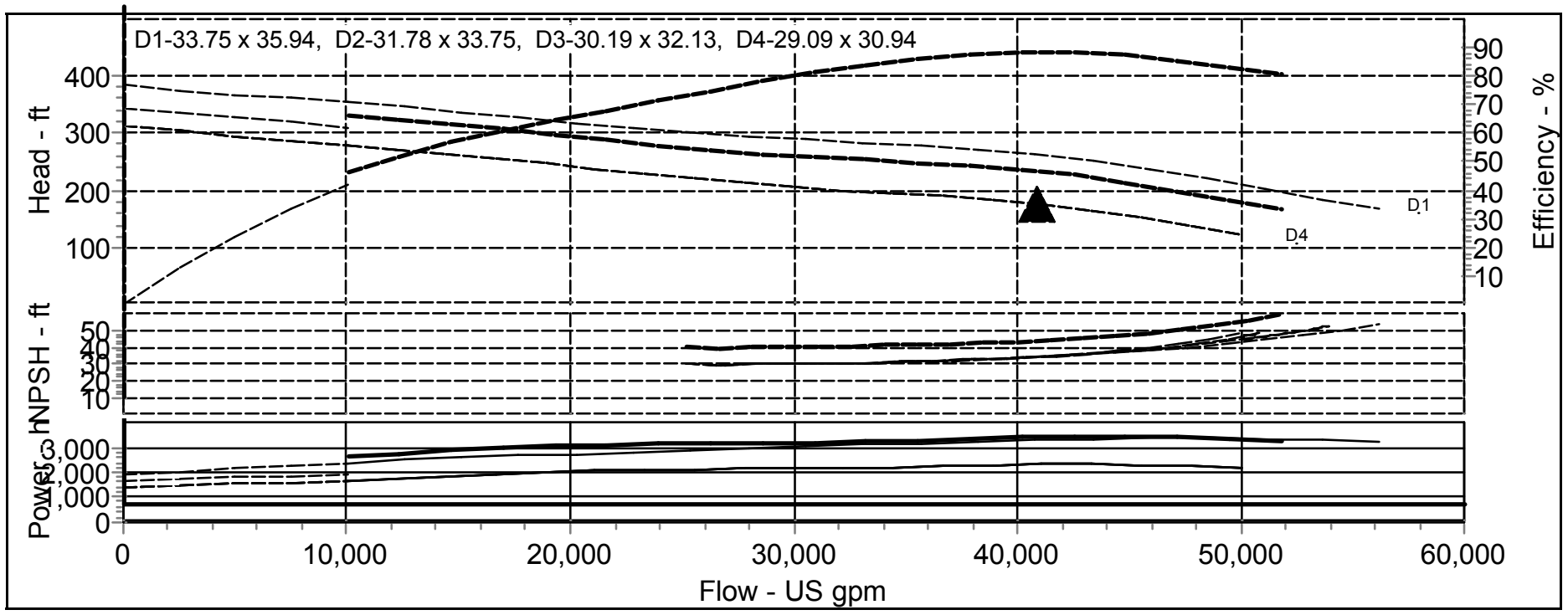

\section{Comments}

Refer to factory for all single point bowl performance guarantees. Pumps must be selected with Hydraulic Institute-Peerless Std. See Std Hydraulic Performance document in RAPID for testing tolerances \& contractual guarantees.

\begin{tabular}{|c|c|c|c|c|c|}
\hline $\begin{array}{c}\text { Flow } \\
\text { (US gpm) }\end{array}$ & $\begin{array}{c}\text { Head } \\
\text { (ft) }\end{array}$ & $\begin{array}{c}\text { Efficiency } \\
(\%)\end{array}$ & $\begin{array}{l}\text { Power Required } \\
\text { (hp) }\end{array}$ & $\begin{array}{l}\text { NPSH Required } \\
\text { (ft) }\end{array}$ & $\begin{array}{c}\text { Thrust } \\
\text { (Ib) }\end{array}$ \\
\hline 0.0 & 343.66 & 0.0 & 1615.6 & & 101561.28 \\
\hline 6473.7 & 322.92 & 29.9 & 1816.9 & & 90459.22 \\
\hline 12947.4 & 299.96 & 49.0 & 2061.2 & & 78977.21 \\
\hline 19421.0 & 275.19 & 60.2 & 2309.1 & & 68233.72 \\
\hline 25894.7 & 250.55 & 69.9 & 2414.3 & 29.99 & 58145.91 \\
\hline 32368.4 & 232.91 & 78.8 & 2489.6 & 30.79 & 49118.11 \\
\hline 38842.1 & 218.74 & 83.6 & 2642.2 & 33.22 & 39092.24 \\
\hline 45315.8 & 189.13 & 82.5 & 2700.5 & 38.20 & 24553.04 \\
\hline 51789.4 & 144.23 & 76.0 & 2555.5 & & 8223.36 \\
\hline
\end{tabular}




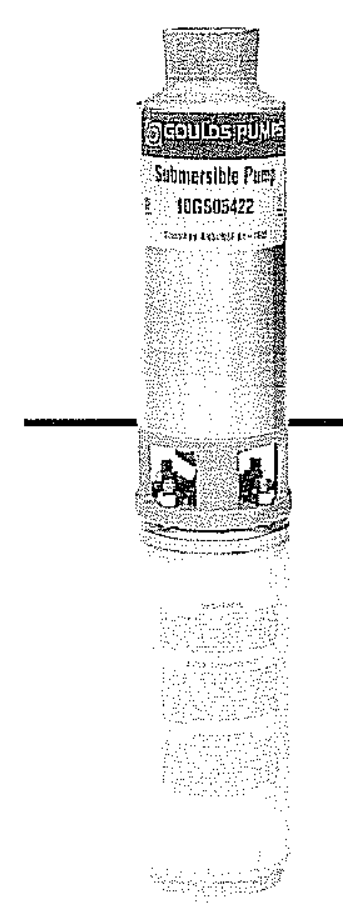

Ifem

MODEL GS

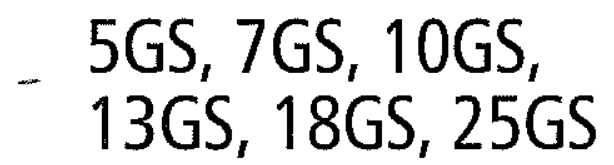

\section{FEATURES}

Powered for Continuous Operation: All ratings are within the working limits of the motor as recommended by the motor manufacturer. Pump can be operated continuously without damage to the motor.

Field Serviceable: Pump can be rebuilt in the field to like new condition with common tools and readily available spare parts. NOTE: The Model GS has left hand casing threads. - Sand Resistant Construction: Field proven over almost four decades, face clearance design and floating impellers for an extremely abrasion resistant configuration.

Stainless Steel Metal Parts: AlSI types 302, 303 and 304 are corrosion resistant, non-toxic and non-leaching.

FDA Compliant Non-Metallic Parts: Impellers, diffusers and bearing spiders are constructed of a glass filled engineered compos-

\section{ORDER NUMBER CODE}

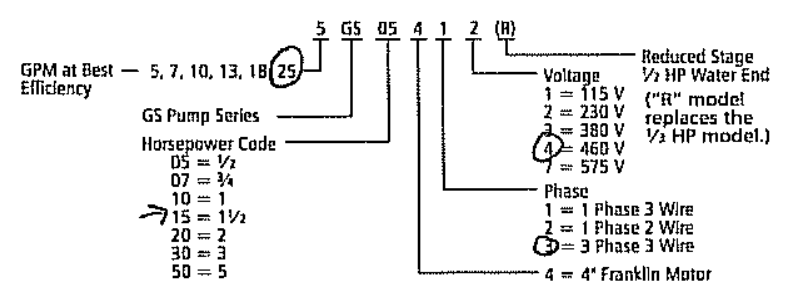

ite. This material is corrosion resistant and non-toxic. space for removal of motor end wrench.

Bowls: Stainless steel for strength and abrasive resistance. and low compression, FDA compliant, BUNA rubber for quiet, efficient operation.

몸 Stainless Steel Casing:

Polished stainless steel is corrosive water.

\section{SPECIFICATIONS}

\begin{tabular}{|c|c|c|c|c|c|c|}
\hline Model & $\begin{array}{c}\text { Flow Range } \\
\text { GPM }\end{array}$ & $\begin{array}{c}\text { Horsepower } \\
\text { Range }\end{array}$ & $\begin{array}{c}\text { Best Eff. } \\
\text { GPM }\end{array}$ & $\begin{array}{l}\text { Discharge } \\
\text { Connection }\end{array}$ & $\begin{array}{l}\text { Minimum } \\
\text { Well Size }\end{array}$ & Rotation(1) \\
\hline $5 G S$ & $1.2-7.5$ & $h-2$ & 5 & $1 \frac{1}{4}$ & $4^{\prime \prime}$ & $\mathrm{CCW}$ \\
\hline $7 G S$ & $1.5-10$ & $1 / 2-3$ & 7 & $1 \frac{1}{4}$ & $4^{\prime \prime}$ & $\mathrm{CCW}$ \\
\hline 10GS & $3-16$ & $1 / 2-5$ & 10 & $11 / 4$ & $4^{\prime \prime}$ & $\mathrm{CCW}$ \\
\hline $13 G 5$ & $4-20$ & $1 / 2-3$ & 13 & $1 \frac{1}{4}$ & $4^{\prime \prime}$ & $\mathrm{CCW}$ \\
\hline 18GS & $6-28$ & $3 / 4-5$ & 18 & $11 / 4$ & $4^{\prime \prime}$ & $\mathrm{CCW}$ \\
\hline $25 G S$ & $8-33$ & $1-5$ & 25 & $11 / 4$ & 4" & $\mathrm{CCW}$ \\
\hline
\end{tabular}

Discharge Head: High profile precision cast 303 stainless steel for superior strength and durability. Cast in loop for safety line. $\mathbf{n}$ Motor Adapter: Precision cast 303 stainless steel is extremely rigid for accurate alignment of liquid end to motor. Generous mounting nuts with regular open-

Check Valve: Built in check valve constructed of stainless steel excellent abrasive resistance and attractive and durable in the most

Hex Shaft Design: Six sided shafts for positive impeller drive.

혀 Shaft Coupling: Exposed for ease of field alignment to motor shaft and to check pump rotation.

믈 Urethane Upper and Middle Bearings: Fluted design for free passage of abrasives and excellent resistance to sand damage.

Franklin Electric Motor:

- Corrosion resistant stainless steel construction through $2 \mathrm{HP}$, stainless steel casing with nickel plated gray iron end bells on motors over 2 HP.

- Built-in surge arrestor is provided on single phase motors through $5 \mathrm{HP}$.

- Stainless steel splined shaft.

- Hermetically sealed windings.

- Replaceable motor lead assembly.

- UL 778 recognized.

- NEMA mounting dimensions.

- Control box is required with 3 wire single phase units.

- Three phase units require a magnetic starter with three leg protection. Magnetic starter and heaters must be ordered separately.

Agency Listings: All complete pump/motor assemblies are UL778 and CSA listed and complies with ANSI/NSF std. 61. All 4" Franklin Electric Motors are UL778 recognized.
"GS" SERIES MATERIALS OF CONSTRUCTION

\begin{tabular}{|l|c|}
\hline Part Name & Material \\
\hline Discharge Head & AISI 30355 \\
\hline Check Valve Poppet & AlSI 30455 \\
\hline Check Valve Seal & BUNA, \\
FDA compliant
\end{tabular}

(1) Used on pumps over 24 stages.

(3) Used on models with 27 stages or larger.

\section{AGENCY LISTINGS}

雨. Canadian Standards Association

(U.) Underwriters Laboratories Classified ANSI/NSF 61-1992 Goulds Pumps is ISO 9001 Registered.

Goulds Pumps

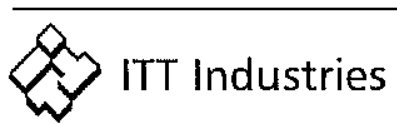




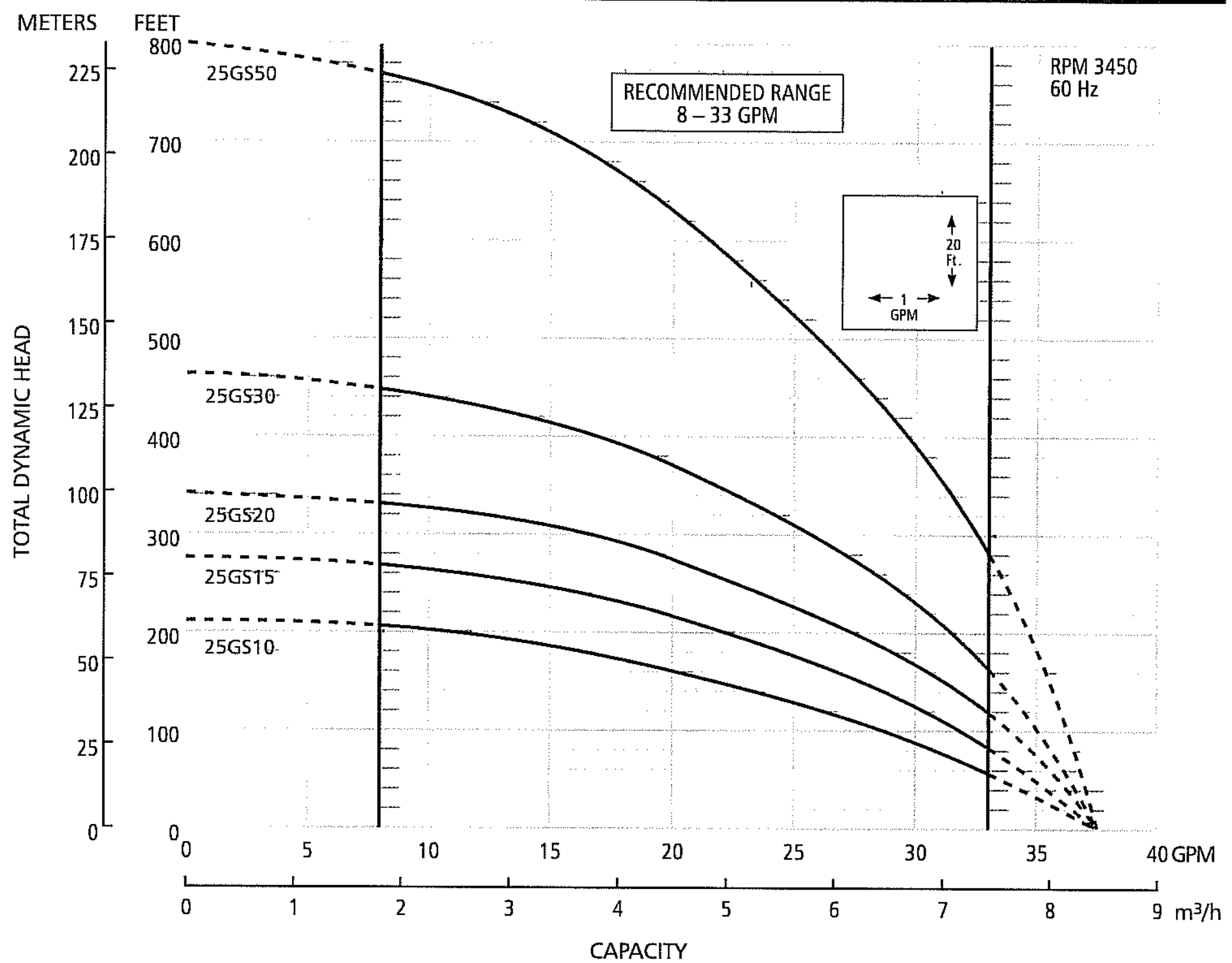

\section{DIMENSIONS AND WEIGHTS}

\begin{tabular}{|l|c|c|c|c|c|c|c|c|c|}
\hline \multirow{2}{*}{ Model } & \multirow{2}{*}{ HP } & \multirow{2}{*}{ Phase } & \multirow{2}{*}{ Stages } & \multicolumn{3}{c|}{ Length (inches) } & \multicolumn{3}{c|}{ Weight (lbs.) } \\
\cline { 5 - 11 } & & & W.E.(2) & Motor & L.0.A.(3) & W.E. & Motor & Total \\
\hline $25 G S 10412,22$ & 1 & 1 & 7 & 12.7 & 11.8 & 24.5 & 7 & 24 & 31 \\
\hline $25 G 515412$ & $11 / 2$ & 1 & 9 & 14.6 & 13.6 & 28.2 & 8 & 28 & 36 \\
\hline $25 G S 15422$ & $11 / 2$ & 1 & 9 & 14.6 & 15.1 & 29.7 & 8 & 31 & 39 \\
\hline $25 G 515432,34$ & $11 / 2$ & 3 & 9 & 14.6 & 11.8 & 26.4 & 8 & 24 & 32 \\
\hline $25 G S 20412$ & 2 & 1 & 11 & 16.5 & 15.1 & 31.6 & 9 & 33 & 42 \\
\hline $25 G 520432,34$ & 2 & 3 & 11 & 16.5 & 13.6 & 30.1 & 9 & 28 & 37 \\
\hline $25 G 530412$ & 3 & 1 & 15 & 20.2 & 19.1 & 39.3 & 11 & 41 & 52 \\
\hline $25 G 530432,34$ & 3 & 3 & 15 & 20.2 & 16.1 & 36.3 & 11 & 35 & 46 \\
\hline $25 G 550412$ & 5 & 1 & 26 & 31.8 & 28.2 & 60.0 & 17 & 70 & 87 \\
\hline $25 G 550432,34$ & 5 & 3 & 26 & 31.8 & 22.2 & 54.0 & 17 & 55 & 72 \\
\hline
\end{tabular}

(2) W.E. = water end or pump without motor.

(3) L.O.A. = length of assembly - complete pump - water end and motor.

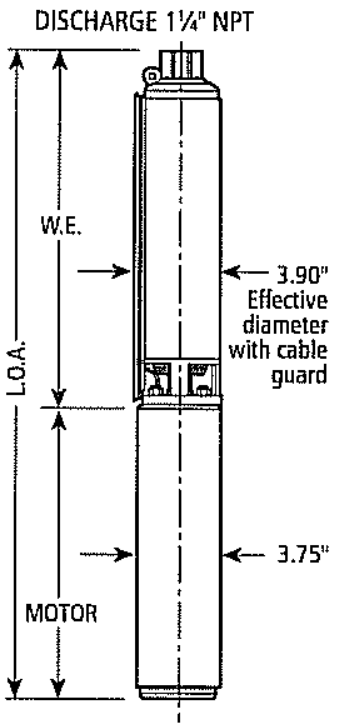




\section{SELECTION CHART}

Horsepower Range $1-5$, Recommended Range $8-33 \mathrm{GPM}, 60 \mathrm{~Hz}$, $3450 \mathrm{RPM}$

\begin{tabular}{|c|c|c|c|c|c|c|c|c|c|c|c|c|c|c|c|c|c|c|c|c|c|c|c|c|c|c|c|c|}
\hline \multirow{2}{*}{$\begin{array}{l}\text { Pump } \\
\text { Model }\end{array}$} & \multirow{2}{*}{ HP } & \multirow{2}{*}{ PSI } & \multicolumn{26}{|c|}{ Depth to Water in Feet/Ratings in GPM (Gallons per Minute) } \\
\hline & & & 20 & 40 & 60 & 80 & 100 & 120 & 140 & 160 & 180 & 200 & 220 & 240 & 260 & 280 & 300 & 340 & 380 & 420 & 460 & 500 & 540 & 580 & 620 & 660 & 700 & 740 \\
\hline \multirow{6}{*}{$25 \mathrm{GS} 10$} & \multirow{6}{*}{1} & 0 & & & 32.8 & 30.8 & 28.6 & 26.2 & 23.5 & 20.0 & 16.2 & 11.0 & & & & & & & & & & & & & & & & \\
\hline & & 20 & 31.8 & 30.0 & 27.5 & 25.2 & 22.0 & 19.0 & 15.0 & 8.0 & & & & & & & & & & & & & & & & & & \\
\hline & & 30 & 29.6 & 27.2 & 25.0 & 21.6 & 18.0 & 14.0 & & & & & & & & & & & & & & & & & & & & \\
\hline & & 40 & 27.1 & 24.9 & 21.5 & 17.9 & 13.9 & & & & & & & & & & & & & & & & & & & & & \\
\hline & & 50 & 24.3 & 21.0 & 17.5 & 13.0 & & & & & & & & & & & & & & & & & & & & & & \\
\hline & & 60 & 20.0 & 16.2 & 11.0 & & & & & & & & & & & & & & & & & & & & & & & \\
\hline \multicolumn{3}{|c|}{ Shut-off PSI } & 82 & 74 & 65 & 56 & 48 & 39 & 30 & 22 & 13 & 4 & & & & & & & & & & & & & & & & \\
\hline \multirow{6}{*}{$25 \mathrm{GS} 15$} & \multirow{6}{*}{$1 \frac{1}{2}$} & 0 & & & & 33.0 & 31.8 & 30.3 & 28.8 & 26.9 & 24.8 & 22.0 & 19.8 & 16.5 & 11.0 & & & & & & & & & & & & & \\
\hline & & 20 & & 32.6 & 31.2 & 29.6 & 28.0 & 26.0 & 23.8 & 21.0 & 18.1 & 14.8 & 8.0 & & & & & & & & & & & & & & & \\
\hline & & 30 & 32.5 & 31.0 & 29.5 & 27.6 & 25.6 & 23.2 & 20.9 & 17.9 & 14.0 & & & & & & & & & & & & & & & & & \\
\hline & & 40 & 30.9 & 29.4 & 27.5 & 25.5 & 23.1 & 20.8 & 17.7 & 13.6 & & & & & & & & & & & & & & & & & & \\
\hline & & 50 & 29.0 & 27.2 & 25.1 & 22.9 & 20.4 & 17.2 & 13.0 & & & & & & & & & & & & & & & & & & & \\
\hline & & 60 & 26.9 & 24.8 & 22.0 & 19.8 & 16.5 & 11.0 & & & & & & & & & & & & & & & & & & & & \\
\hline \multirow{7}{*}{ 25GS20 } & & & 111 & 103 & 94 & 85 & 77 & \begin{tabular}{|l|}
68 \\
\end{tabular} & 59 & 51 & 42 & 33 & 25 & 16 & 7 & & & & & & & & & & & & & \\
\hline & \multirow{6}{*}{2} & 0 & & & & & & 33.0 & 31.8 & 30.4 & 29.0 & 27.4 & 25.7 & 22.6 & 21.5 & 19.3 & 15.4 & & & & & & & & & & & \\
\hline & & 20 & & & & 32.7 & 31.3 & 30.0 & 28.6 & 26.8 & 25.0 & 22.9 & 20.9 & 18.3 & 14.3 & 9.0 & & & & & & & & & & & & \\
\hline & & 30 & & & 32.3 & 31.0 & 29.6 & 28.5 & 26.4 & 24.5 & 22.6 & 20.5 & 18,0 & 14.0 & 8.0 & & & & & & & & & & & & & \\
\hline & & 40 & & & 30.9 & 29.5 & 28.2 & 26.3 & 24.3 & 22.4 & 20.4 & 17.8 & 13.6 & 8.0 & & & & & & & & & & & & & & \\
\hline & & 50 & & 30.5 & 29.4 & 28.0 & 26.0 & 24.1 & 22.1 & 20.0 & 17.2 & 13.2 & & & & & & & & & & & & & & & & \\
\hline & & 60 & 30.4 & 29.0 & 27.4 & 25.7 & 22.6 & 21.5 & 19.3 & 15.4 & 12.2 & & & & & & & & & & & & & & & & & \\
\hline \multicolumn{3}{|c|}{ Shut-off PSI } & 139 & 130 & 121 & 113 & 104 & 95 & 87 & 78 & 69 & 61 & 52 & 43 & 35 & 26 & 17 & & & & & & & & & & & \\
\hline \multirow{6}{*}{$25 \mathrm{GS30}$} & \multirow{6}{*}{3} & 0 & & & & & & & & 33.0 & 32.2 & 31.5 & 30.5 & 29.6 & 28.3 & 27.1 & 25.8 & 22.6 & 19.0 & 14.0 & & & & & & & & \\
\hline & & 20 & & & & & & 32.8 & 32.0 & 31.0 & 30,0 & 29.0 & 27.9 & 26.6 & 25.0 & 23.8 & 21.9 & 20.0 & 12.6 & & & & & & & & & \\
\hline & & 30 & & & & & 32.6 & 31.8 & 30.9 & 30.0 & 28.8 & 27.6 & 26.5 & 24.9 & 23.4 & 21.6 & 19.9 & 15.2 & 8,0 & & & & & & & & & \\
\hline & & 40 & & & & 32.5 & 31.7 & 30.9 & 29.9 & 28.8 & 27.5 & 26.2 & 24.7 & 23.3 & 21.5 & 19.9 & 17,8 & 11.9 & & & & & & & & & & \\
\hline & & 50 & & & 32.3 & 31.6 & 30.8 & 29.8 & 28.5 & 27.3 & 26.0 & 24.5 & 23.0 & 21.2 & 19.5 & 17.4 & 11.5 & & & & & & & & & & & \\
\hline & & 60 & 33.0 & 32.2 & 31.5 & 30.5 & 29.6 & 28.3 & 27.1 & 25.8 & 24.1 & 22.6 & 20.9 & 19.0 & 16.9 & 14.0 & 10.0 & & & & & & & & & & & \\
\hline \multicolumn{3}{|c|}{ Shut-off PSI } & 191 & 183 & 174 & 165 & 157 & 148 & 139 & 131 & 122 & 113 & 105 & 96 & 87 & 79 & 70 & \begin{tabular}{|l|}
53 \\
\end{tabular} & 35 & 18 & & & & & & & & \\
\hline \multirow{6}{*}{$25 G 550$} & & 0 & & & & & & & & & & & & & & 33.0 & 32.5 & 31.5 & 30.2 & 29.0 & 27.6 & 26.02 & 24.22 & $222.4 \sqrt{2}$ & 20.5 & \begin{tabular}{|l|}
18.3 \\
\end{tabular} & 15.8 & 12.0 \\
\hline & & 20 & & & & & & & & & & & & 32.9 & 32.3 & 31.8 & 31.3 & 30.0 & 28.8 & 27.2 & 25.8 & 23.92 & 22.02 & \begin{tabular}{|l|l|}
20.0 & 1 \\
\end{tabular} & 17.8 & \begin{tabular}{|l|}
15.0 \\
\end{tabular} & 11.0 & \\
\hline & 5 & 30 & & & & & & & & & & & 32.8 & 32.2 & 31.8 & 31.2 & 30.5 & 29.3 & 27.9 & 26.4 & 24.8 & 22.92 & 21.0 & \begin{tabular}{|l|l|}
18.9 & \\
\end{tabular} & 16.2 & 13.0 & 8.0 & \\
\hline & & 40 & & & & & & & & & & 32.7 & 32.1 & 31.7 & 31.1 & 30.4 & 29.9 & 28.5 & 27.1 & 25.4 & 23.7 & 21.911 & \begin{tabular}{ll|}
19.9 & 1 \\
\end{tabular} & \begin{tabular}{|l|l|}
17.5 & 1 \\
\end{tabular} & 14.5 & 10.5 & & \\
\hline & & 50 & & & & & & & & & 32.6 & 32.1 & 31.6 & 31.0 & 30.3 & 29.9 & 29.2 & 27.8 & 26.3 & 24.5 & 22.6 & 21.81 & 18.7 & \begin{tabular}{|l|l|}
16.0 & 1 \\
\end{tabular} & 12.7 & & & \\
\hline & & 60 & & & & & & & 33.0 & 32.5 & 32.0 & 31.5 & 30.8 & 30.2 & 29.8 & 29.0 & 28.3 & 26,9 & 25.1 & 23.3 & 21.5 & 19.51 & 17.01 & \begin{tabular}{|l|l|}
14.0 & \\
\end{tabular} & 9.5 & & & \\
\hline Shut-off $P$ & & & & & & & & & 286 & 277 & 268 & 260 & 251 & 242 & 234 & 225 & 216 & 199 & 182 & $165 \mid$ & \begin{tabular}{|l|}
147 \\
\end{tabular} & $\begin{array}{lll}130 & \\
\end{array}$ & $\begin{array}{l}113 \\
\end{array}$ & \begin{tabular}{|l|l}
95 & 7 \\
\end{tabular} & 78 & \begin{tabular}{|l|}
61 \\
\end{tabular} & 43 & 26 \\
\hline
\end{tabular}




\begin{tabular}{|c|c|c|c|c|c|c|c|c|c|}
\hline $\begin{array}{l}\text { Item } \\
\text { No. }\end{array}$ & \multicolumn{2}{|c|}{ Description } & \multicolumn{7}{|c|}{ Current Models (3) } \\
\hline & \multirow{9}{*}{\multicolumn{2}{|c|}{$\begin{array}{l}\text { NUMBER } \\
\text { OF } \\
\text { STAGES }\end{array}$}} & $\mathrm{HP}$ & $5 G 5$ & 7GS & 10GS & $13 \mathrm{GS}$ & $18 G 5$ & $25 G S$ \\
\hline & & & $1 / 2 R$ & 9 & 7 & 5 & - & - & - \\
\hline & & & $1 / 2$ & 12 & 10 & 7 & 5 & - & - \\
\hline & & & $3 / 4$ & 15 & 13 & 10 & 7 & 6 & - \\
\hline & & & 1 & 20 & 17 & 12 & 10 & 8 & 7 \\
\hline & & & $1 \frac{1}{2}$ & 26 (1) & 22 & 17 & 12 & 11 & 9 \\
\hline & & & 2 & $33(2)$ & 27 (1) & 20 & 17 & 14 & 11 \\
\hline & & & 3 & - & $34(2)$ & 27 (2) & 21 & 19 & 15 \\
\hline & & & 5 & - & - & $42(2)$ & - & 30 (2) & 26 (2) \\
\hline $1-4$ & \multicolumn{3}{|c|}{ Discharge head assembly } & $7 K 2077$ & $7 \mathrm{~K} 2077$ & $7 K 2077$ & 712077 & 712077 & $7 \mathrm{~K} 2077$ \\
\hline 2 & \multirow{2}{*}{\multicolumn{3}{|c|}{$\begin{array}{l}\text { Check valve poppet } \\
\text { C.V. seal/seat assembly }\end{array}$}} & $7 \mathrm{~K} 1366$ & $7 \mathrm{~K} 1366$ & $7 \mathrm{~K} 1365$ & $7 \mathrm{~K} 1366$ & $7 \mathrm{k} 1366$ & $7 \mathrm{~K} 1366$ \\
\hline 3 & & & & $7 K 2123$ & $7 K 2123$ & $7 \mathrm{~K} Z 123$ & $7 K 2123$ & $7 K 2123$ & $7 K 2123$ \\
\hline 4 & \multicolumn{3}{|c|}{ C V. retaining ring } & $7 \mathrm{~K} 1364$ & $7 \mathrm{~K} 1364$ & $7 \mathrm{~K} 1364$ & $7 \mathrm{~K} 1364$ & $7 \mathrm{~K} 1364$ & $7 \mathrm{~K} 1364$ \\
\hline 5 & \multicolumn{3}{|c|}{ Bearing spider - upper } & $7 K 1372$ & $7 \mathrm{~K} 1372$ & $7 \mathrm{~K} 1372$ & $7 \mathrm{~K} 1372$ & $7 \times 1372$ & $7 \mathrm{~K} 1372$ \\
\hline 6 & \multirow{2}{*}{\multicolumn{3}{|c|}{\begin{tabular}{|l|} 
Bearing \\
Shaft retaining ring - upper \\
\end{tabular}}} & $7 \mathrm{~K} 1740$ & $7 K 1740$ & $7 \mathrm{~K} 1740$ & $7 \mathrm{~K} 1740$ & $7 \mathrm{K1740}$ & $7 \mathrm{K1740}$ \\
\hline 7 & & & & $7 \mathrm{~K} 817$ & $7 K 817$ & $7 \times 817$ & $7 K 817$ & $7 \mathrm{~K} 817$ & $7 \mathrm{~K} 817$ \\
\hline 8 & & $7 \mathrm{~K} 1750$ & $7 \mathrm{Kg95}$ & $7 \mathrm{~K} 17$ & $7 \mathrm{~K} 17$ & $7 K 20$ & $7 \mathrm{~K} 20$ \\
\hline 9 & \multicolumn{3}{|c|}{ Upthrust washer } & $7 \mathrm{~K} 15$ & $7 \mathrm{~K} 15$ & $7 \mathrm{~K} 15$ & - & $7 \mathrm{~K} 15$ & $7 \mathrm{~K} 15$ \\
\hline 10 & \multicolumn{3}{|c|}{$\begin{array}{l}\text { Impeller } \\
7651 / 2 \mathrm{hp}-11 / 2 \mathrm{hp}\end{array}$} & $7 \mathrm{~K} 1837$ & $7 K 1343$ & $7 K 35$ & $7 K 16$ & $7 \mathrm{~K} 1334$ & $7 \mathrm{~K} 19$ \\
\hline 10 & \begin{tabular}{|l|} 
Impeller \\
7GS 2 and
\end{tabular} & $3 \mathrm{hp}$ & & - & $7 \mathrm{kgg} 4$ & - & - & - & - \\
\hline 11 & Bowl & & & $7 K 1838$ & $7 \mathrm{~K} 478$ & $7 K 478$ & $7 \mathrm{~K} 478$ & $7 \mathrm{KBSB}$ & $7 \mathrm{~K} 18$ \\
\hline $12 A(1)$ & Intermedia & ate shaft & sleeve & $7 \mathrm{~K} 20 \mathrm{9}$ & - & $7 K 209$ & - & $7 \mathrm{~K} 209$ & $7 K 209$ \\
\hline $12 \mathrm{~B}(2)$ & Intermedia & ate shaft & sleeve & (4) & (6) & (4) & - & (6) & - \\
\hline $13 \mathrm{~A} \oplus$ & Intermediat & te bearin & spider & $7 \mathrm{~K} 1371$ & - & - & - & - & - \\
\hline $13 \mathrm{~B}(2)$ & Intermediat & te bearin & spider & $7 K 1989$ & $7 \mathrm{~K} 19 \mathrm{Bg}$ & $7 \times 1989$ & - & $7 \mathrm{~K} 1989$ & $7 \mathrm{~K} 1989$ \\
\hline 14 & Mid bearin & laf 13 & $\& 13 B$ & $7 K 1369$ & $7 \mathrm{~K} 1369$ & $7 K 1369$ & - & $7 \mathrm{~K} 1369$ & $7 \mathrm{~K} 1369$ \\
\hline 15 & Shim & & & $7 \mathrm{~K} 155$ & $7 \mathrm{~K} 155$ & $7 K 155$ & $7 \mathrm{~K} 155$ & $7 \mathrm{~K} 155$ & $7 K 155$ \\
\hline 16 & Lower shaf & ft sleeve & & $7 K 1336$ & $7 \mathrm{~K} 1336$ & $7 \mathrm{~K} 1336$ & $7 \mathrm{~K} 1336$ & $7 \times 1336$ & $7 \times 1336$ \\
\hline 17 & Inlet strain & & & $7 K 1370$ & $7 K 1370$ & $7 K 1370$ & $7 \mathrm{~K} 1370$ & $7 \times 1370$ & $7 \mathrm{~K} 1370$ \\
\hline 18 & Screws - - & able gu: & & $13 \mathrm{Kg} 1$ & $13 \mathrm{KG1}$ & $13 \mathrm{Kg} 1$ & 13KG1 & $13 \mathrm{~K} 91$ & $1 \exists \mathrm{K} 91$ \\
\hline 19 & Hex nust & & & 13K114 & $13 K 114$ & $13 \mathrm{~K} 114$ & $13 K 114$ & $13 K 114$ & $13 \mathrm{~K} 114$ \\
\hline 20 & Motor ada & pter & & $7 K 1363$ & $7 \mathrm{~K} 1363$ & $7 \mathrm{~K} 1363$ & $7 \mathrm{~K} 1363$ & $7 \mathrm{~K} 1363$ & $7 \mathrm{~K} 1363$ \\
\hline 21 & Lower shaf & ft retaini & gg ing & - & $7 \mathrm{~K} 1553$ & $7 \mathrm{~K} 1553$ & - & $7 \mathrm{~K} 1553$ & - \\
\hline 22 & Motor lead & dinsulat & & $7 \mathrm{~K} 1023$ & $7 K 1023$ & $7 \mathrm{~K} 1023$ & $7 K 1023$ & $7 \mathrm{~K} 1023$ & $7 \mathrm{~K} 1023$ \\
\hline 23 & Gasings & & $1 / 2 R$ & $7 K 1968$ & 7K1913 & $7 K 1902$ & - & - & - \\
\hline & & & $1 / 2$ & $7 \mathrm{~K} 1938$ & $7 \mathrm{~K} 1936$ & $7 K 1905$ & $7 \mathrm{~K} 1902$ & - & - \\
\hline & & & $3 / 4$ & $7 \mathrm{~K} 1941$ & $7 \mathrm{~K} 1939$ & $7 \mathrm{~K} 1935$ & $7 \mathrm{~K} 1905$ & $7 \mathrm{~K} 1964$ & - \\
\hline & & & 1 & $7 \mathrm{~K} 1949$ & $7 \mathrm{~K} 1973$ & $7 K 1938$ & $7 \mathrm{~K} 1935$ & $7 K 1935$ & $7 \mathrm{~K} 1914$ \\
\hline & & Upper & $1 / 6$ & $7 K 1954$ & $7 \mathrm{~K} 1951$ & 7 7K1944 & $7 K 1938$ & 7K1939 & $7 \mathrm{~K} 1943$ \\
\hline & & Lower & $1 n$ & - & - & - & - & - & - \\
\hline & & Upper & 2 & $7 \mathrm{~K} 14.53$ & $7 K 1958$ & $7 K 1949$ & $7 K 1944$ & $7 \mathrm{~K} 1945$ & 7 K1941 \\
\hline & & Lower & 2 & $7 K 1452$ & $=$ & - & $=$ & - & - \\
\hline & & Upper & 3 & - & $7 \mathrm{~K} 1973$ & 7K1946 & $7 K 1950$ & $7 \mathrm{~K} 1952$ & $7 \mathrm{~K} 1479$ \\
\hline & & Lower & 3 & - & $7 K 1453$ & 7K1943 & - & - & - \\
\hline & & Upper & 5 & - & - & $7 \mathrm{~K} 1971$ & - & 7K1948 & $7 \mathrm{~K} 1947$ \\
\hline & & Lower & 3 & - & - & $7 \mathrm{~K} 1636$ & - & $7 \mathrm{~K} 1738$ & $7 \mathrm{~K} 1453$ \\
\hline 24 & Shaft & & $1 / 2 R$ & $7 \mathrm{~K} 1033$ & $7 \mathrm{~K} 1361$ & $7 \mathrm{~K} 1358$ & - & - & - \\
\hline & and couplir & & $1 / 2$ & 7111377 & $7 \mathrm{~K} 1376$ & $7 \mathrm{~K} 1360$ & $7 \mathrm{~K} 1358$ & - & - \\
\hline & assemblies & & $3 / 4$ & $7 \mathrm{K1} 381$ & $7 \times 1380$ & $7 \times 1375$ & $7 \mathrm{~K} 1360$ & $7 \mathrm{~K} 1359$ & $=$ \\
\hline & & & 1 & $7 \mathrm{~K} 1458$ & $7 \mathrm{~K} 1384$ & $7 \mathrm{Ki} 377$ & $7 \mathrm{~K} 1375$ & $7 \mathrm{~K} 1375$ & $7 K 1374$ \\
\hline & & Upper & 116 & $7 \mathrm{~K} 1839$ & $7 \mathrm{~K} 1839$ & $7 \mathrm{~K} 1457$ & $7 \times 1377$ & $7 \mathrm{~K} 1380$ & $7 \mathrm{~K} 1378$ \\
\hline & & Lower & $1 / 2$ & - & - & $=$ & - & - & $=$ \\
\hline & & Upper & 7 & $7 \mathrm{~K} 1877$ & $7 \mathrm{~K} 1391$ & $7 \mathrm{~K} 1458$ & 7K1457 & $7 \mathrm{k} 1382$ & $7 \mathrm{~K} 1381$ \\
\hline & & Lower & 2 & $7 \mathrm{~K} 1879$ & - & - & - & - & - \\
\hline & & Upper & 3 & - & $7 \mathrm{~K} 1462$ & $7 \mathrm{~K} 1878$ & $7 K 1386$ & $7 \mathrm{~K} 1387$ & $7 \mathrm{~K} 1385$ \\
\hline & & Lower & 3 & - & $7 K 1213$ & $7 \mathrm{~K} 1880$ & - & - & - \\
\hline & & Upper & 5 & $=$ & - & $7 \mathrm{~K} 1393$ & - & $7 \mathrm{~K} 1736$ & $7 \mathrm{~K} 2212$ \\
\hline & & Lower & & - & - & $7 \times 1221$ & - & $7 \mathrm{~K} 1737$ & $71 \times 2211$ \\
\hline 25 & Cable guar & & $1 / 2 R$ & $7 \mathrm{~K} 1885$ & $7 \mathrm{~K} 1883$ & $7 \times 1881$ & $=$ & - & - \\
\hline & & & $1 / 2$ & $7 \mathrm{K1888}$ & $7 \mathrm{~K} 1886$ & $7 \mathrm{~K} 1883$ & $7 \mathrm{~K} 1881$ & - & - \\
\hline & & & $3 / 4$ & $7 \mathrm{~K} 1890$ & $7 \mathrm{~K} 1889$ & $7 \mathrm{~K} 1886$ & $7 \mathrm{~K} 188 \mathrm{~B}$ & $7 K 1883$ & - \\
\hline & & & 1 & $7 \mathrm{~K} 1917$ & $7 \mathrm{~K} 1916$ & $7 \mathrm{~K} 1888$ & $7 \mathrm{~K} 1886$ & $7 \mathrm{~K} 1886$ & $7 \mathrm{~K} 1886$ \\
\hline & & & $1 \frac{1}{2}$ & $7 \mathrm{~K} 1922$ & $7 K 1919$ & 7K1916 & $7 \mathrm{~K} 1888$ & $7 K 1889$ & $7 \mathrm{~K} 1888$ \\
\hline & & & 2 & $7 \mathrm{~K} 1927$ & $7 K 1924$ & $7 \mathrm{~K} 1917$ & $7 K 1916$ & $7 \mathrm{~K} 1916$ & $7 \mathrm{~K} 1890$ \\
\hline & & & 3 & - & $7 \mathrm{~K} 1929$ & $7 \mathrm{k} 1923$ & 7K1918 & $7 \mathrm{~K} 1920$ & 7K1917 \\
\hline & & & 5 & - & - & 7K1931 & $=$ & $7 \mathrm{~K} 1930$ & $7 \mathrm{~K} 1929$ \\
\hline
\end{tabular}

\section{Repair Parts}

MODEL

GS
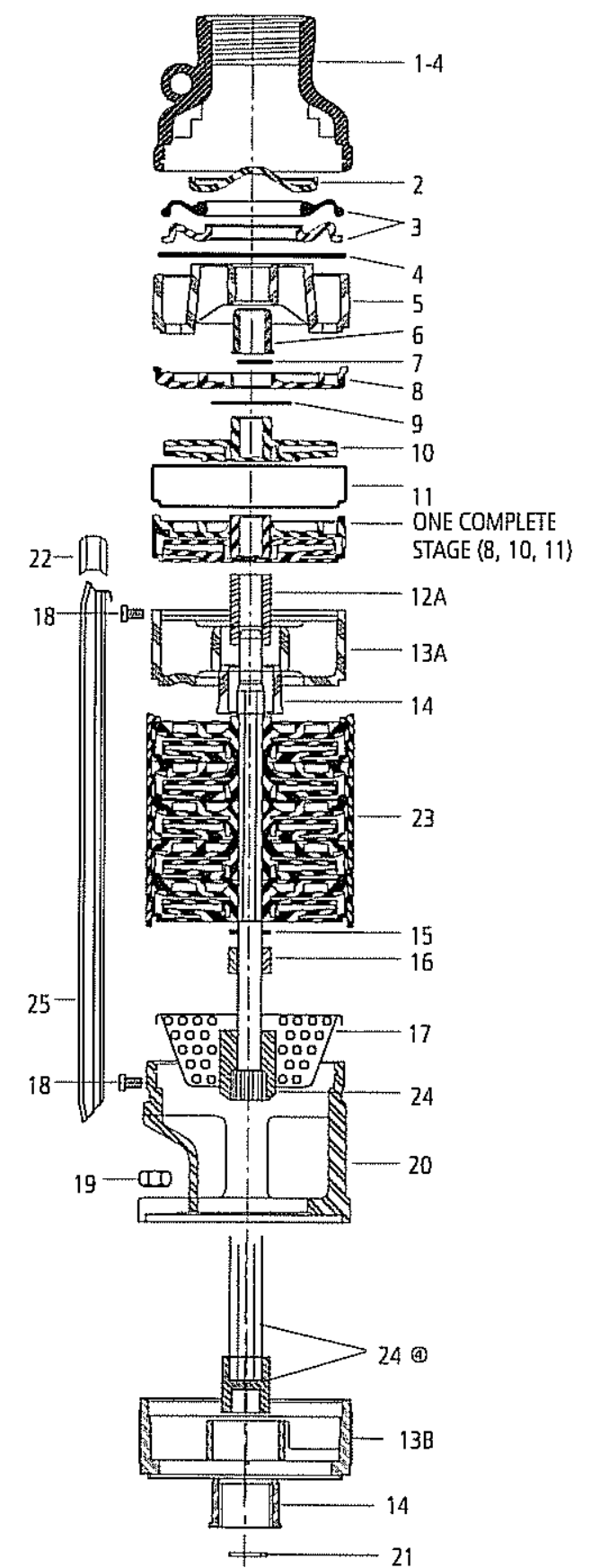

(3) Model has one intermediate bearing spider, order bearing and spider separately.

(2) Modiel has one intermediate bearing spider, a split case design and upper anti lower shaft assemílies.

(7) Current GS pumps are identified by 4 cable guard screws.

(1) Intermediate Shaft Sleeve $7 \mathrm{~K} 1490$ is now a pressed on part of the upper shatt assembly on split case pumps. 


\begin{tabular}{|llllll|}
\hline Model:3996 & Size:1.5X2-10 & Group:MT & $60 \mathrm{~Hz}$ & RPM:3560 & Stages:1 \\
\hline
\end{tabular}

Job/lnqu. No.

Purchaser:

User:

Item/Equip.No:

Issued by: BRIAN SEAY

Service:

Quotation No.

Date:

$10 / 7 / 04$

Order No.

Certified By:

Liquid: Operating Conditions

Temp.: $\quad 70^{\circ} \mathrm{F}$

Sp. Heat:

S.G.Nisc: $\quad 1 / 1 \mathrm{cp}$

Flow: $\quad 100 \mathrm{gpm}$ (US)

TDH:

NPSHa:

Req. solid size:

$\%$ Solids:

Vapor Press:
Actual Pump Eff::

Actual Pump Power:

Mech. Seal Loss:

Dyn. Seal Loss:

Other Power Loss:

Rated Total Power:

Imp. Dia. First 1 Stg

NPSHr:

Shut off Head:

Max. Solids Size:
Pump Performance

$41 \% \quad$ Suction Specific Speed: 7570 (gpm(US) , ft)

$14.7 \mathrm{hp} \quad$ Min. Cont. Stable Flow: $30.5 \mathrm{gpm}$ (US)

0 hp Min. Cont. Thermal Flow:

0 hp

0 hp

$14.7 \mathrm{hp}$

7.625 in

$7.9 \mathrm{ft}$

$284.5 \mathrm{ft}$

0.438 in
Non-Overioading Power: $17 \mathrm{hp}$ Imp. Dia. Addt'l Stg

Mag. Drive Circuit Flow:

Max Drive Power:

Max Drive Temp:

Max Motor Size:

Notes: 1. The Mechanical seal increased drag effect on power and efficiency is not included, unless the correction is shown in the appropriate field above. 2. Magnetic drive eddy current and viscous effect on power and efficiency is not included. 3. Elevated temperature effects on performance are not included.

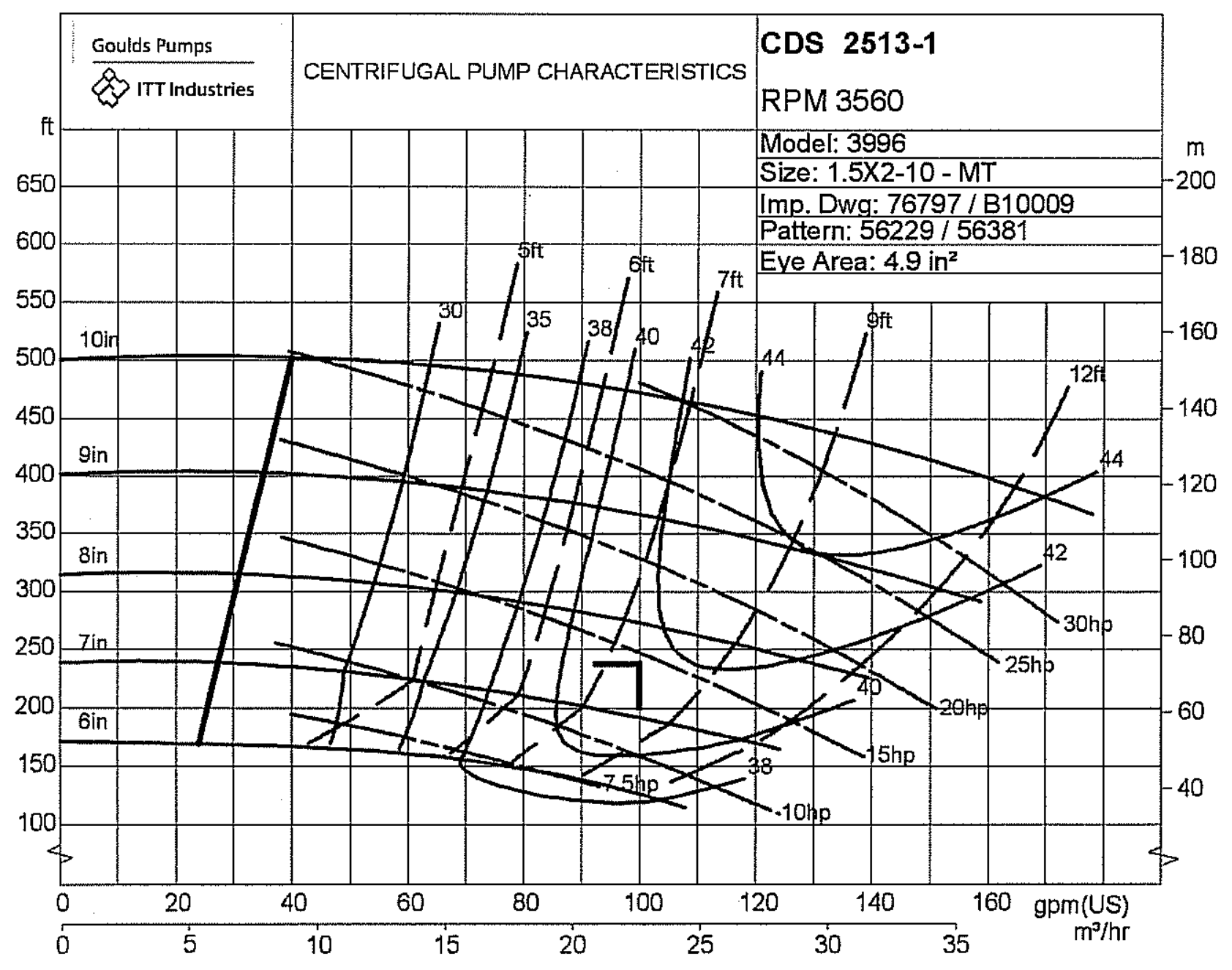




\section{Itom 3}

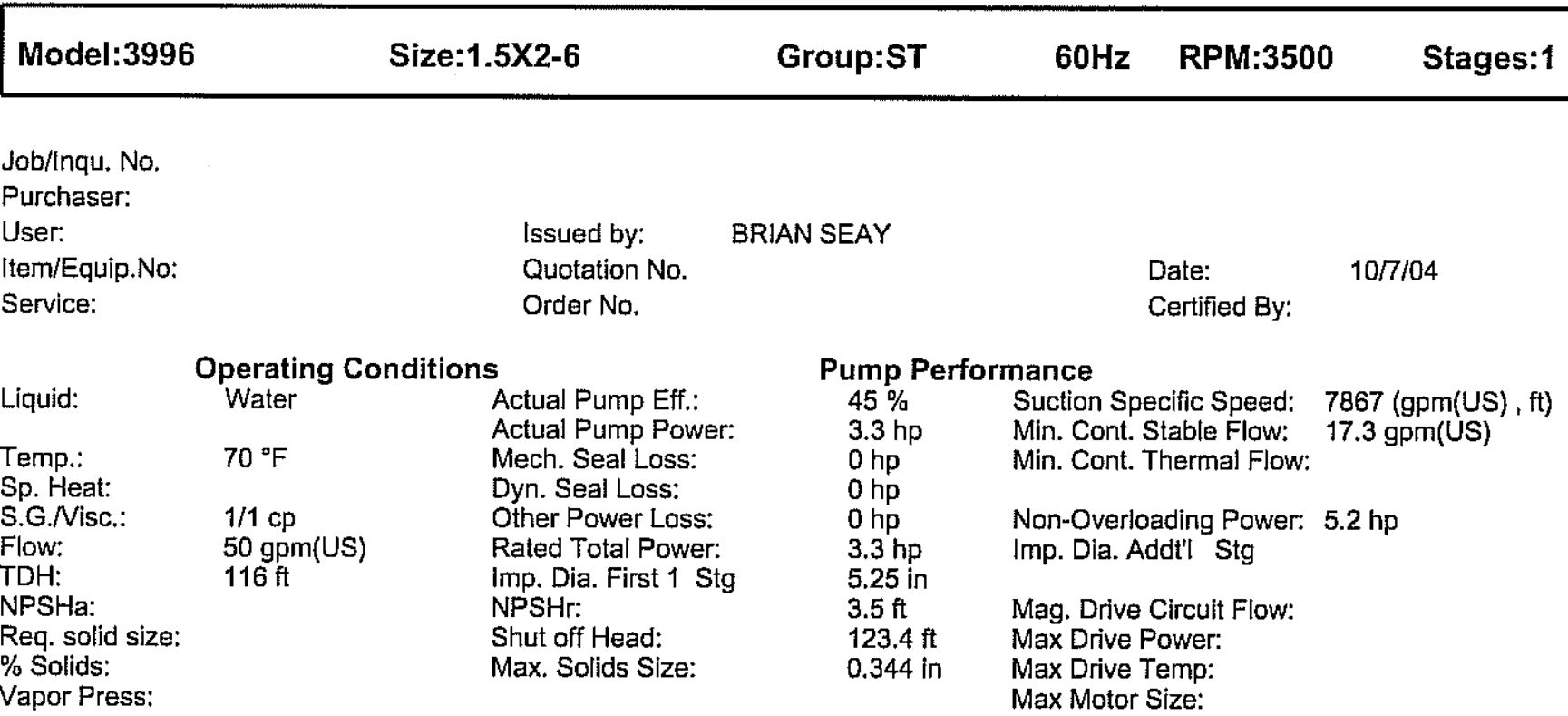

Notes: 1. The Mechanical seal increased drag effect on power and efficiency is not included, unless the correction is shown in the appropriate field above. 2. Magnetic drive eddy current and viscous effect on power and efficiency is not included. 3. Elevated temperature effects on performance are not included.

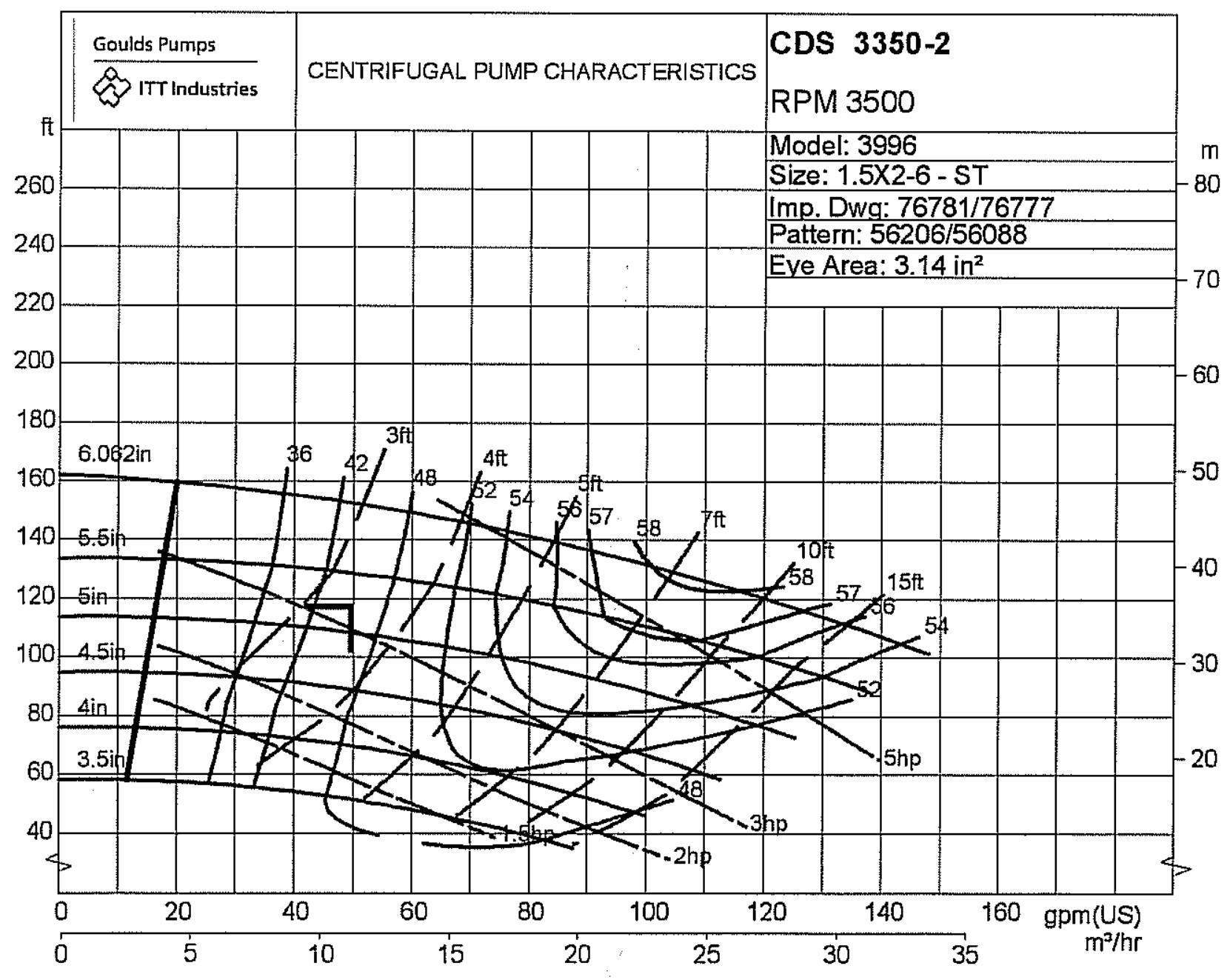




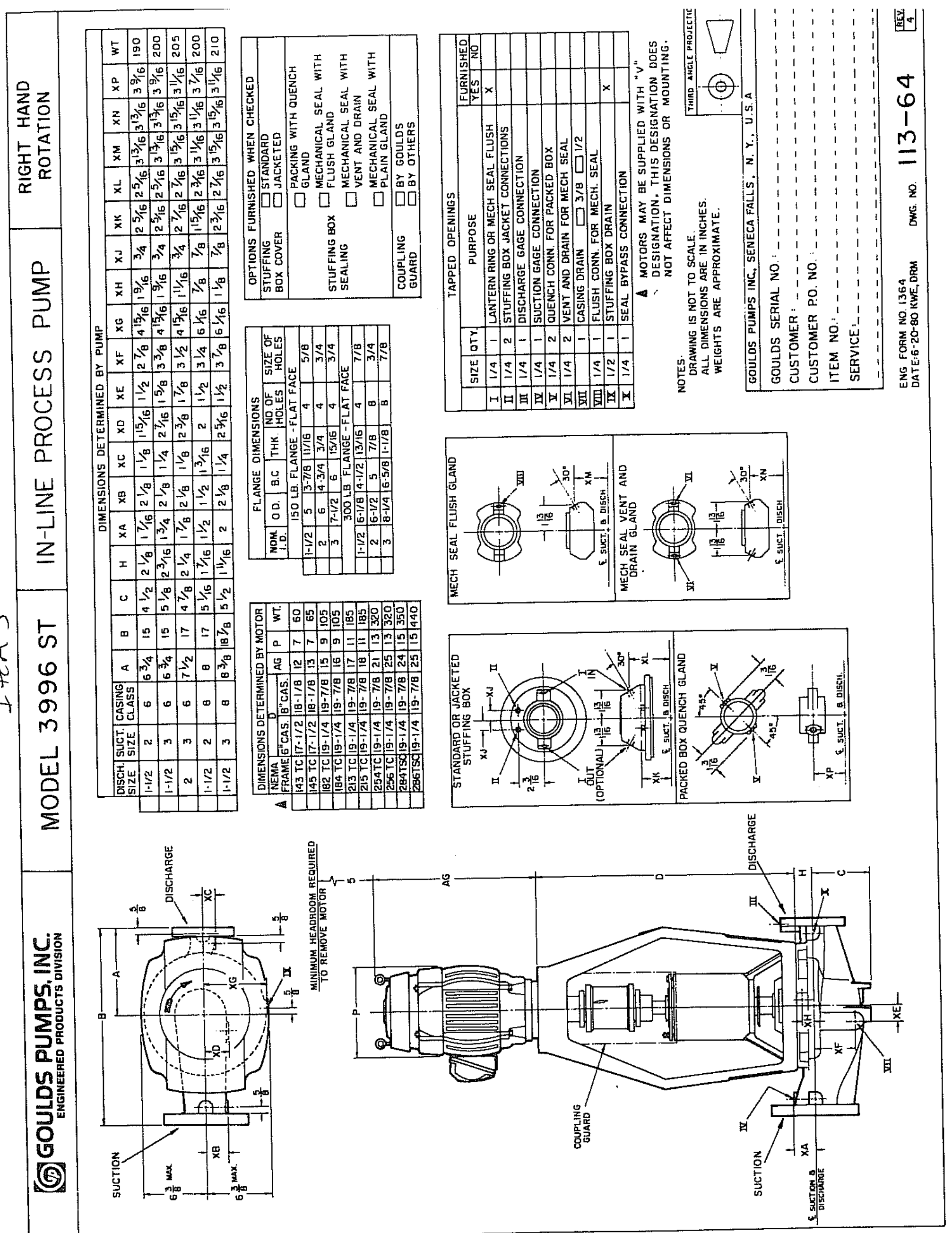



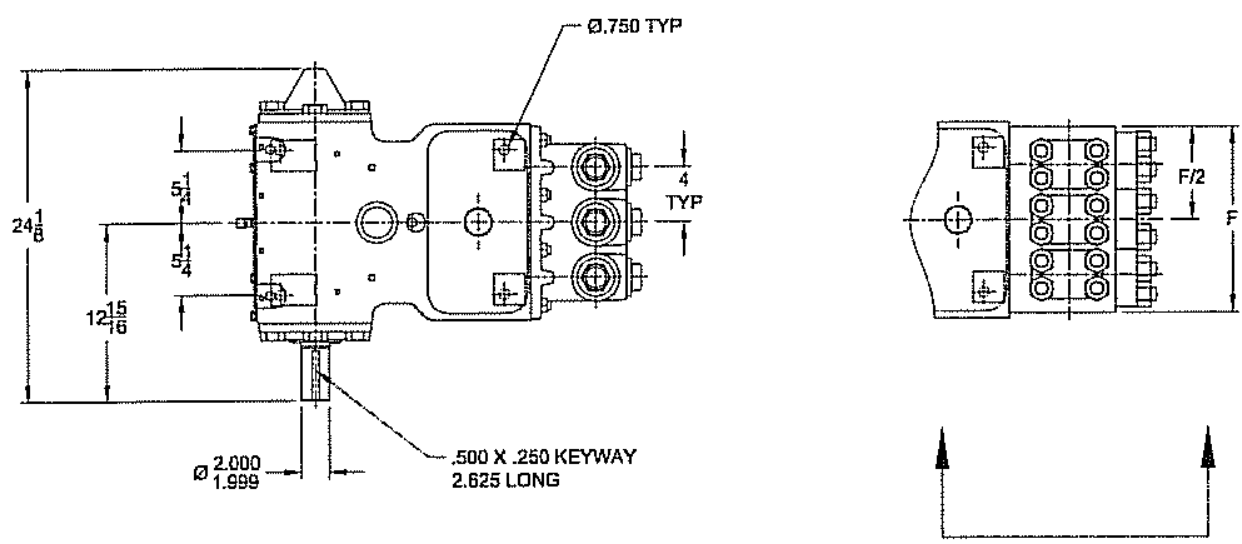

22T-2H ONLY

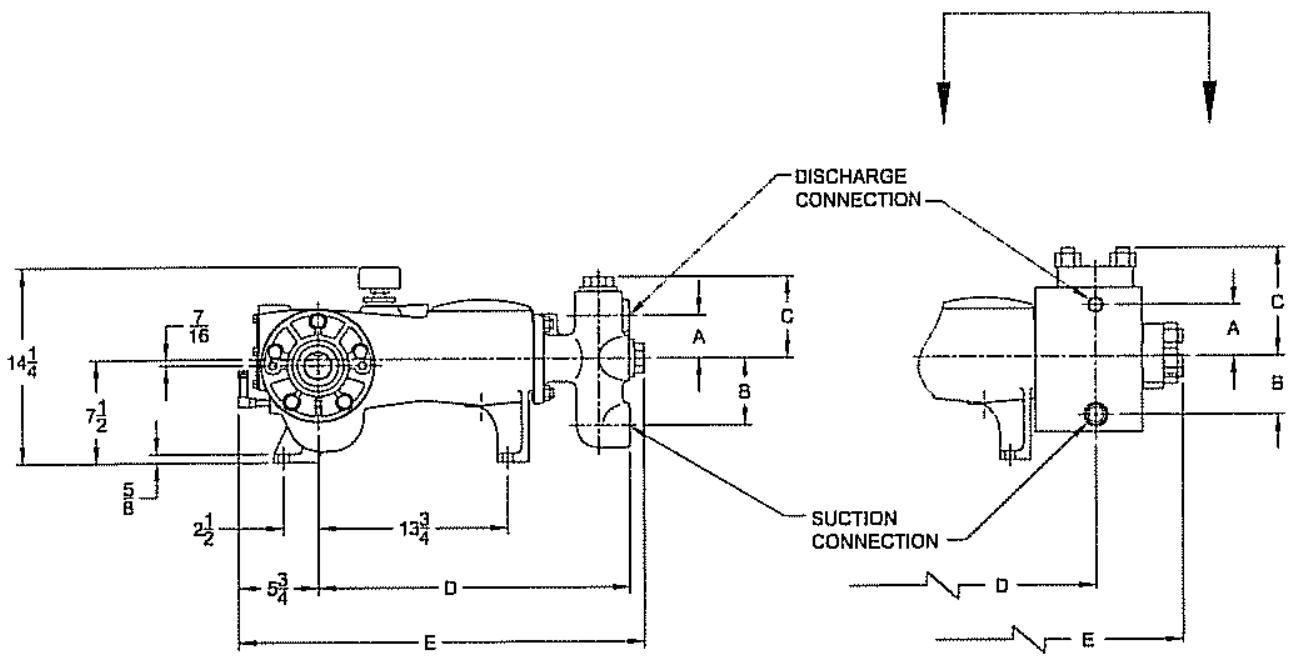

\section{Specififications}

Pump Size:

maximum plunger size $x$ stroke length, in.(mm) $2.000 \times 2.250(50.8 \times 57.15)$

Rated 日HP (kW) at 465 RPM: 22 (17)

Rated plunger load, pounts (kg): 2550 (1157)

Maximum dlscharge pressure: psi ( $\mathrm{kPa}$ )

"L" madel: 1443 (9949)

"M" model: 2565 (17688)

"H" model: 4600 (31716)

Crankshaft extension:

Diameter, in.(mm): 2.000 (50.8)

Length, in.(mm) : 3.875 (98.43)

Keyway width $x$ depth, in.(mm): $1 / 2 \times 1 / 4(12.7 \times 6.35)$

Maximum recommended sheave diameter, in. (mm): 33.5 (850.9)

For larger sizes: Contact Factory

Oil Capacity, gallons (L)

Crankcase: 1-1/4 (4.73)

Weight, pump anly on wood shipplng skids, pounds (kg)

"L" model: 395 (179)

"M" model: 395 (179)

"H" modal: 395 (179)

Standard Materials for Fluid Ends:

"L"' model

Cast Ductile Iron

Cast Nickel-Alumin:um-Bronze

Cast 316 Stainless Steel

Forged/Plate Carbon Steal

"M" model

Gast Ductlle iran

Cast Nickel-Aluminum-Bronze

Cest 316 Stainless Stea

Forged/Plate Carbon Steel

"H" model

Forged 15-5 Stainless Steel
Pump Model

22T-2L

22T-2M

22T-2H
Flange Connections

\begin{tabular}{|c|c|c|c|c|c|c|c}
\hline \multicolumn{2}{c|}{ Flange Connections } & \multicolumn{4}{c|}{ Dimensions (Inches) } \\
\hline Discharge Connection Sizes & Suction Connection Sizes & A & B & C & D & E & F \\
$1(25.4)-111 / 2$ NPT & $2(50.8)-111 / 2$ NPT & $31 / 8$ & $47 / 8$ & $515 / 16$ & $225 / 8$ & $291 / 2$ & $111 / 2$ \\
$1(25.4)-111 / 2$ NPT & $2(50.8)-111 / 2$ NPT & $31 / 8$ & $47 / 8$ & $515 / 16$ & $225 / 8$ & $291 / 2$ & $111 / 2$ \\
$3 / 4(19.1)-14$ NPT & $11 / 4(31,8)-111 / 2$ NPT & $33 / 4$ & $41 / 4$ & $77 / 8$ & 20 & $321 / 8$ & $131 / 2$
\end{tabular}




\section{Performance Data}

\begin{tabular}{|c|c|c|c|c|c|c|c|c|c|c|c|c|c|c|c|c|c|}
\hline \multirow[t]{2}{*}{ PUMP } & \multicolumn{5}{|c|}{ English Units } & \multicolumn{2}{|c|}{$50 \mathrm{RPM}$} & \multicolumn{2}{|c|}{150 RPM } & \multicolumn{2}{|c|}{$200 \mathrm{RPM}$} & \multicolumn{2}{|c|}{$250 \mathrm{RPM}$} & \multicolumn{2}{|c|}{$350 \mathrm{RPM}$} & \multicolumn{2}{|c|}{465 RPM } \\
\hline & $\begin{array}{c}\text { Plunger } \\
\text { Dia. } \\
\text { In. }\end{array}$ & $\begin{array}{l}\text { Plunger } \\
\text { Area } \\
\text { Sq. In. }\end{array}$ & $\begin{array}{l}\text { BPD } \\
\text { per } \\
\text { RPM }\end{array}$ & $\begin{array}{l}\text { GPM } \\
\text { per } \\
\text { FPM }\end{array}$ & $\begin{array}{c}\text { Max. } \\
\text { Press. } \\
\text { PSI }\end{array}$ & BPD & GPM & EPD & GPM & BPD & GPM & BPD & GPM & BPD & GPM & BPD & GPM \\
\hline \multirow[t]{4}{*}{ (T225LS) } & 1.875 & 2.7612 & 2.7663 & 0.6807 & 924 & 139 & 4.0 & 415 & 12.1 & 554 & 16.1 & 692 & 20.2 & 969 & 28.2 & 1287 & 37.5 \\
\hline & 1.750 & 2.4053 & 2.4097 & 0.0703 & 1060 & 121 & 3.5 & 362 & 10.5 & 482 & 14.1 & 603 & 17.6 & 844 & 24.6 & 1121 & 32.7 \\
\hline & 1.625 & 2.0739 & 2.0778 & 0.0606 & 1230 & 104 & 3.0 & 312 & 9.1 & 416 & 12.1 & 520 & 15.2 & 728 & 21.2 & 967 & 28.2 \\
\hline & 1.500 & 1.7671 & 1.7704 & 0.0516 & 1443 & 89 & 2.6 & 266 & 7.7 & 355 & 10.3 & 443 & 12.9 & 620 & 18.1 & 824 & 24.0 \\
\hline & 1.500 & 1.7671 & 1.7704 & 0.0516 & 1443 & 89 & 2.6 & 266 & 7.7 & 355 & 10.3 & 443 & 12.9 & 620 & 18.1 & 824 & 24.0 \\
\hline & 1.375 & 1.4849 & 1.4876 & 0,0434 & 1717 & 75 & 2.2 & 224 & 6.5 & 298 & 8.7 & 372 & 10.8 & 521 & 15.2 & 692 & 20.2 \\
\hline & 1.250 & 1.2272 & 1.2295 & 0.0359 & 2078 & 62 & 1.8 & 185 & 5.4 & 246 & 7.2 & 308 & 9.0 & 431 & 12.6 & 572 & 16.7 \\
\hline & 1.125 & 0.9940 & 0.9959 & 0.0290 & 2565 & 50 & 1.5 & +50 & 4.4 & 200 & 5.8 & 249 & 7.3 & 349 & 10.2 & 464 & 13.5 \\
\hline $22 \mathrm{~T}-2 \mathrm{H}$ & 1.000 & 0.7854 & 0.7869 & 0.0229 & 3247 & 40 & 1.1 & 119 & 3.4 & 158 & 4.6 & 197 & 5.7 & 276 & 8.0 & 366 & 10.7 \\
\hline (T225H) & 0.875 & 0.6013 & 0.6024 & 0.0176 & $424 t$ & 31 & 0.9 & 91 & 2.6 & t21 & 3.5 & 151 & 4.4 & 211 & 6.1 & 281 & 8.2 \\
\hline
\end{tabular}

\begin{tabular}{|c|c|c|c|c|c|c|c|c|c|c|c|c|c|c|c|c|c|}
\hline \multirow[t]{2}{*}{ PUMP } & \multicolumn{5}{|c|}{ Metric Units } & \multicolumn{2}{|c|}{50 RPM } & \multicolumn{2}{|c|}{150 RPM } & \multicolumn{2}{|c|}{200 RPM } & \multicolumn{2}{|c|}{250 RPM } & \multicolumn{2}{|c|}{350 RPM } & \multicolumn{2}{|c|}{465 RPM } \\
\hline & $\begin{array}{c}\text { Plenger } \\
\text { Diz. } \\
\mathrm{cm}\end{array}$ & $\begin{array}{c}\text { Pluriger } \\
\text { Area } \\
\mathrm{cm}^{2}\end{array}$ & $\begin{array}{l}\mathrm{M}^{3} / \mathrm{Hr} \\
\text { per } \\
\text { APM }\end{array}$ & $\begin{array}{l}\text { LSEc. } \\
\text { per } \\
\text { RPM }\end{array}$ & $\begin{array}{l}\text { Max. } \\
\text { Press. } \\
\mathrm{kPa}\end{array}$ & $\mathrm{M} / \mathrm{Hr}$ & U/Sec. & $\mathrm{M}^{3} / \mathrm{Hr}$ & L/Sec. & $M^{3} / \mathrm{Hr}$ & USec. & $\mathrm{M}^{3} / \mathrm{Hr}$ & USSec. & $\mathrm{M}^{1} / \mathrm{Hr}$ & U/Sec. & $\mathrm{M}^{1} / \mathrm{Hr}$ & LSec. \\
\hline 22T-2L & 51 & 20.268 & 0.0208 & 0.0058 & 5596 & 1.04 & 0.29 & 3.13 & 0.87 & 4.17 & 1.16 & 5.21 & 1.45 & 7.30 & 2.03 & 9.69 & 2.69 \\
\hline \multirow[t]{4}{*}{ (17225L.S) } & 48 & 17.814 & 0.0183 & 0.0051 & 6368 & 0.92 & 0.25 & 2.75 & 0.76 & 3.66 & 1,02 & 4.58 & 1.27 & 6.41 & 1.78 & 8.52 & 2.37 \\
\hline & 44 & 15.518 & 0.0160 & 0.0044 & 7310 & 0.80 & 0.22 & 2.39 & 0.67 & 3.19 & 0,89 & 3.99 & 1.11 & 5.59 & 1.55 & 7.42 & 2.06 \\
\hline & 41 & 13.380 & 0.0138 & 0.0038 & 8477 & 0.69 & 0.19 & 2.06 & 0.57 & 2.75 & 0.76 & 3.44 & 0.96 & 4.82 & 1.34 & 6.40 & 1.78 \\
\hline & 38 & 11.401 & 0.0117 & 0.0033 & 9949 & 0.59 & 0.16 & 1.76 & 0.49 & 2.35 & 0.65 & 2.93 & 0.81 & 4.10 & 1.14 & 5.45 & 1.51 \\
\hline $22 T-2 M$ & 44 & 15.518 & 0.0460 & 0.0044 & 7310 & 0.80 & 0.22 & 2.39 & 0.67 & 3.19 & 0.89 & 3.99 & 1.11 & 5.59 & 1.55 & 7.42 & 2.06 \\
\hline \multirow[t]{5}{*}{ (T225M) } & 41 & 13.380 & $0.0+38$ & 0.0038 & 8477 & 0.69 & 0.19 & 2.06 & 0.57 & 2.75 & 0.76 & 3.44 & 0.96 & 4.82 & 1.34 & 6.40 & 1.78 \\
\hline & 38 & 11.401 & 0.0117 & 0.0033 & 9949 & 0.59 & 0.16 & 1.76 & 0.49 & 2.35 & 0.65 & 2.93 & 0.81 & 4.10 & 1.14 & 5.45 & 1.51 \\
\hline & 35 & 9.580 & 0.0099 & 0.0027 & 11840 & 0.49 & 0.14 & 1,48 & 0.41 & 1.97 & 0,55 & 2.46 & 0.68 & 3.45 & 0.96 & 4.58 & 1,27 \\
\hline & 32 & 7.917 & 0.0081 & 0.0023 & 14327 & 0.41 & 0.11 & 1.22 & 0.34 & 1.63 & 0.45 & 2.04 & 0.57 & 2.85 & 0.79 & 3.79 & $t .05$ \\
\hline & 29 & 6.413 & 0.0066 & 0,0018 & 17688 & 0.39 & 0.09 & 0.99 & 0.27 & 1.32 & 0.37 & 1.65 & 0.46 & 2.31 & 0.64 & 3.07 & 0.85 \\
\hline & 25 & 5.067 & 0.0052 & 0.0014 & 22386 & 0.26 & 0.07 & 0.78 & 0.22 & 1.04 & 0.29 & 1.30 & 0.36 & 1.82 & 0.51 & 2.42 & 0.67 \\
\hline \multirow[t]{2}{*}{ (T225H) } & 22 & 3.879 & 0.0040 & 0.0011 & 29239 & 0.20 & 0.06 & 0.60 & 0.17 & 0.80 & 0.22 & 1.00 & 0.28 & 1.40 & 0.39 & 1.86 & 0.52 \\
\hline & 19 & 2.850 & 0.0029 & 0.0008 & 31716 & 0.15 & 0.04 & 0.44 & 0.12 & 0.59 & 0.16 & 0.73 & 0.20 & 1.03 & 0.29 & 1.36 & 0,38 \\
\hline
\end{tabular}

For operation balow 75 RPM, an atxillary lubrication system is required.

Volumetric Rate is based on $100 \%$ Volumeiric Efficiancy. Brake Horsepower/Kilowatts Required is based on 90\% Mechanlical EHiciency.

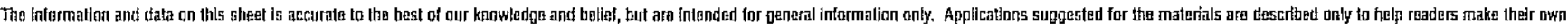

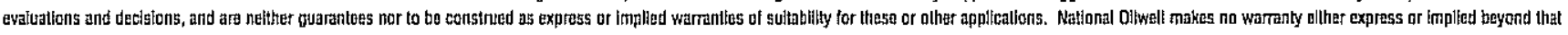
stpulatad In National Gilwell Standard Terms and Concititons of Sale.

\section{Authorized Distributor:}

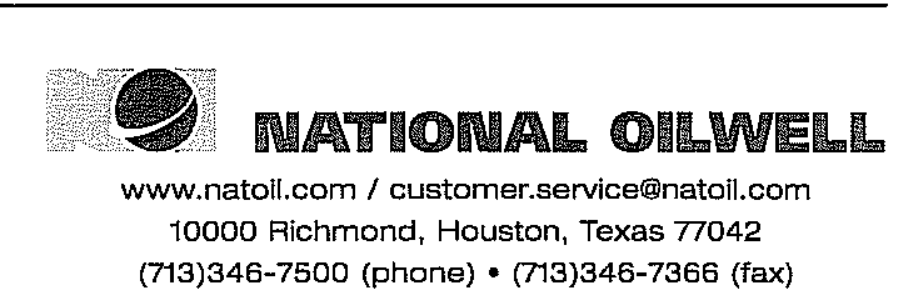


A Full Range of Product Features Una Gama Total de Características del Producto
NPE Product Line Numbering System

Línea de Producto NPE Sistema de Numeración

\section{Superior Materials of}

Construction: Complete AISI 316L

stainless steel liquid handling

components and mounting bracket

for corrosion resistance, quality

appearance, and improved strength and ductility.

High Efficiency Impeller:

Enclosed impeller with unique floating seal ring design maintains maximum efficiencies over the life of the pump without adjustment.

Casing and Adapter Features: Stainless steel construction with NPT threaded, centerline connections, easily accessible vent, prime and drain connections with stainless steel plugs. Optional seal face vent/ flush available.

Mechanical Seal: Standard John Crane Type 21 with carbon versus silicon-carbide faces, Viton elastomers, and 316 stainless metal parts. Optional high temperature and chemical dyty seals available.

Motors: NEMA standerd open dripproof, totally enclosed fan cooled or explosion proof enclosures. Rugged ball bearing design for continuous duty under all operating conditions.

The various versions of the NPE are identified by a product code number on the pump label. This number is also the cotilog number for the pump. The meaning of each digit in the product code number is shown at left.
Materiales Superiores de

Construcción: Componentes completos para manejo de llquidos en acero inoxidable AlSI $3161 \mathrm{y}$ consola para el montaje para resistencia a la corrosión, apariencia de calidad, y fuerza y ductilidad mejoradas.

Impulsor de Eficiencia Superior: El impulsor encerrado con un diseño único de anillo del sello fotante, mantiene sin ajustes, la eficiencia máxima sobre la vida de la bomba.

\section{Caracteristicas de la} Carcasa y del Adaptador: Construcción en acero inoxidable con NPT roscado, conexiones centrales, váhulas de fácil accero, conexiones de cebado y drenaje con enchufes de acero inoxidable. Cara del sello válula/chorro opcional disponible.

\section{Sello Mecánico: Estándar John} Crane Tipo 21 con carbón en contraste con caras de silicóncarbide, elastómeros de Viton, y partes metálicas de acero inoxidable 316. Sellos de alta temperatura y productos quimicos están disponibles.

Motores: Extándar NEMA a prueba de goteo, ventilador totalmente encerrado o recintos a prueba de explosión. Diseño robusto de balineras de bolas para trabajo continuo en todas las condiciones de funcionamiento.

Las diferentes versiones de la NPE se identifican con un número de código del producto en la etiqueta de la bomba. Este número es también el número del catálogo para la bomba. El significado de cada dlgito en el número de código del producto se muestra a la izquierda.

\section{Example Product Code,} Ejemplo Código del Producto

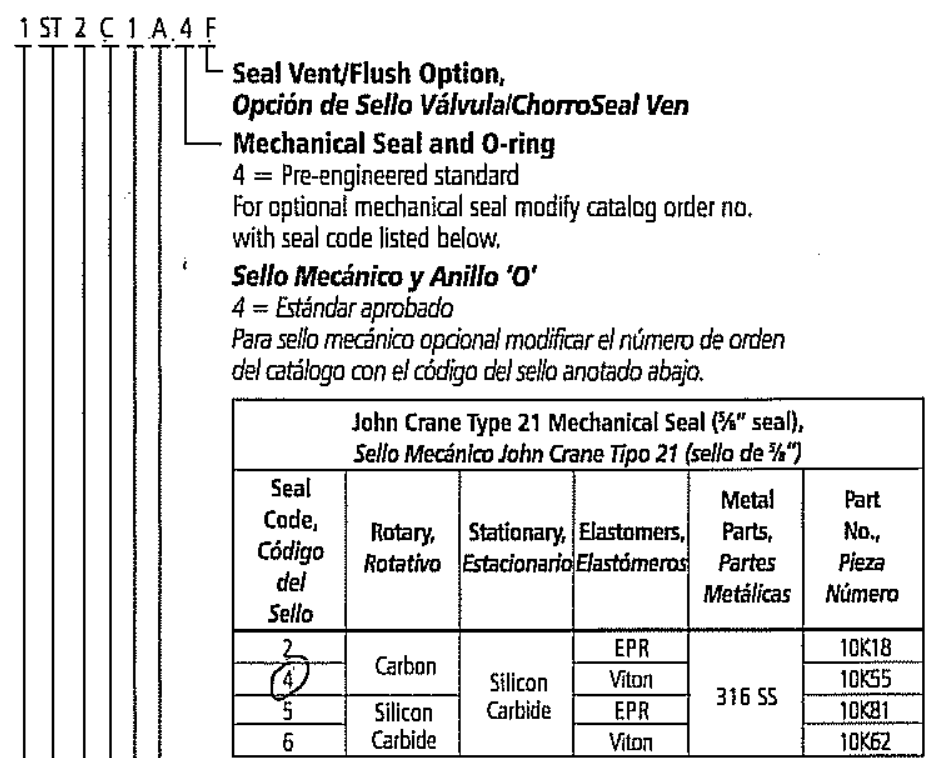

Impeller Option ... No Adder Required

For optional impel!er diameters modify cotalog order no. with impeller code listed. Select optional impeller diameter from pump performance curve.

Código del Impulsor Opcional

Para impulsorer con diämetros opcionales modificar el número de orden del catálogo con el código del impulsor anotado. Eccoger el impul con diämetro opcional de la curva de funcionamiento de la bomba.

\begin{tabular}{|c|c|c|c|}
\hline \multirow{3}{*}{$\begin{array}{l}\text { Impeller Code, } \\
\text { Código del } \\
\text { Impulsor }\end{array}$} & \multicolumn{3}{|c|}{ Pump Size, Jamaño de la Bomba } \\
\hline & $1 \times 11 / 4-6$ & $1 \frac{1}{4} \times 1 \frac{1}{2}-6$ & $11 / 2 \times 2-6$ \\
\hline & Diameter & Diameter & Diameter \\
\hline $\mathrm{K}$ & - & $61 / 4$ & - \\
\hline G & - & $515 / 16$ & $5^{3 / 6}$ \\
\hline $\mathrm{H}$ & - & $51 / 2$ & 5 \\
\hline A & 61/8 & $51 / 4$ & $4 \frac{3}{4}$ \\
\hline B) & $53 / 4$ & $5 / / 5$ & $45 / 4$ \\
\hline C & $53 / 16$ & $4 \%$ & $43 / 8$ \\
\hline $\mathrm{D}$ & $43 / 4$ & $4^{5} /$ & $41 / 16$ \\
\hline $\mathrm{E}$ & $4 / 16$ & $41 / 4$ & $3 \%$ \\
\hline $\mathrm{F}$ & $4 / 114$ & $3 \%$ & - \\
\hline
\end{tabular}

Driver, Conductor

$1=1 \mathrm{PH}_{\mathrm{t}} \mathrm{ODP} \quad 7=3 \mathrm{PH}_{\mathrm{t}} \mathrm{XP}$

$2=3 \mathrm{PH}_{1}, \mathrm{ODP} \quad 8=575 \mathrm{~V}, \mathrm{XP}$

$\exists=575 \mathrm{~V}, \mathrm{ODP} \quad 9=3 \mathrm{PH}, \mathrm{TEFC}$.

$4=1$ PH, TEFC Premium Eff.

(5) 3 PH, TEFC $0=1 \mathrm{PH}, \mathrm{XP}$

$\sigma=575$ V, TEFC

HP Rating, HP Potencia

$\mathrm{C}=1 / 2 \mathrm{HP} \mathrm{E}=1 \mathrm{HP}(\mathrm{G}=2 \mathrm{HP} J=5 \mathrm{HP}$

For frame mounted version, substitute the letters "FRM" in these positions.

$\mathrm{D}=3 / 4 \mathrm{HP} \quad \mathrm{F}=1 \frac{1}{2} \mathrm{HPF}=3 \mathrm{HPP} \quad$ Parala

Driver: Hertz/Pole/RPM,

Conductor: Hercios/Polo/RPM

$1=60 \mathrm{~Hz}, 2$ pole, $3500 \mathrm{RPM}$

$Z=60 \mathrm{~Hz}, 4$ pole, $1750 \mathrm{RPM}$

$3=60 \mathrm{~Hz}, 6$ pole, $1150 \mathrm{RPM}$

$4=50 \mathrm{~Hz}, 2$ pole, $2900 \mathrm{RPM}$

$5=50 \mathrm{~Hz}, 4$ pole, $1450 \mathrm{RPM}$

versión con el amazón montado sustituya las letras "FRM" en estas posiciones.

\section{Material}

(ST) $=$ Stainless steel, Acero inoxidable

Pump Size, Tamaño de la Bomba

Pf $1 \times 1 \frac{1}{4}-6 \quad 2=1 \frac{1}{4} \times 1 \frac{1}{2}-6 \quad 3=1 \frac{1}{2} \times 2-6$ 


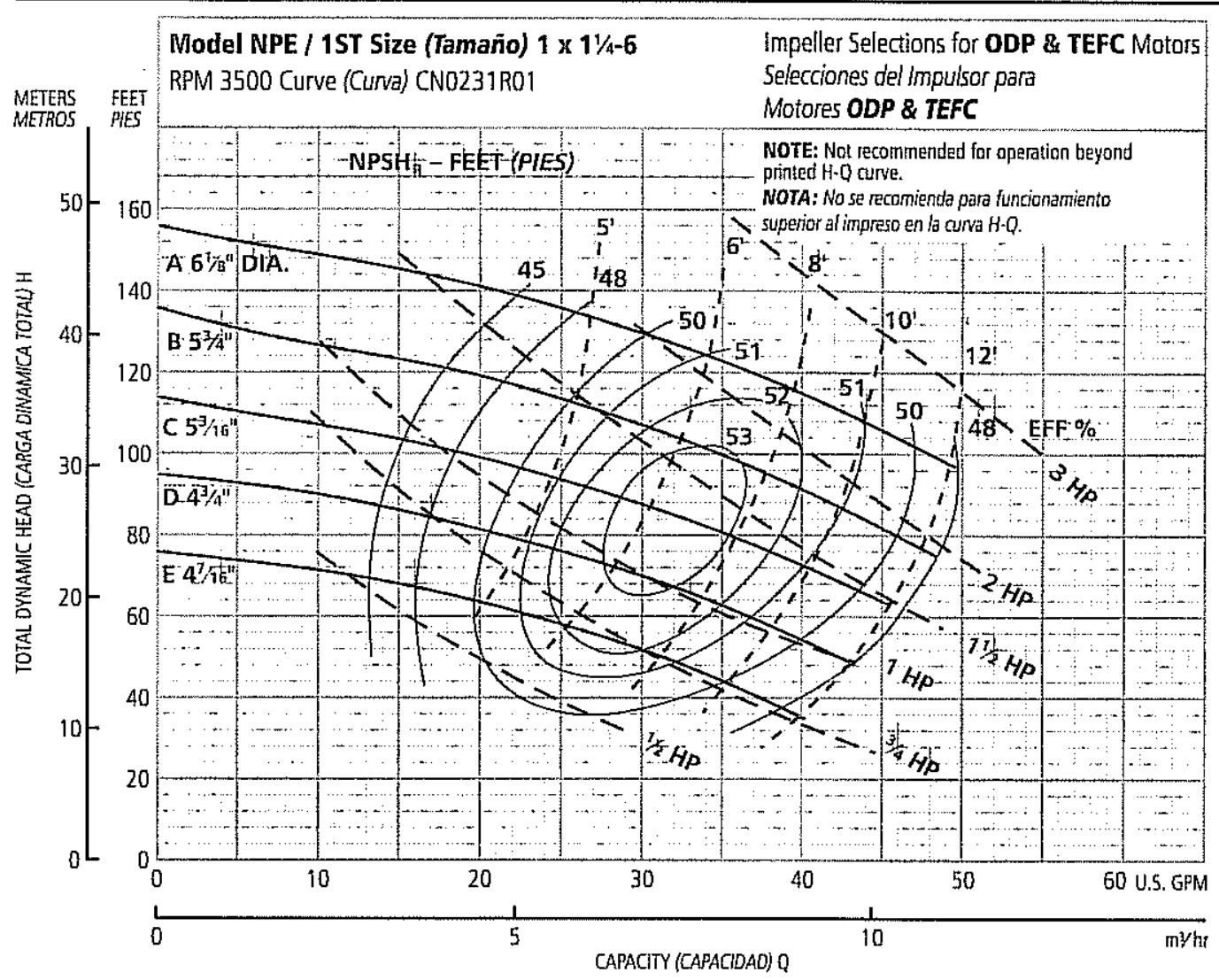

\begin{tabular}{|c|c|c|}
\hline $\begin{array}{c}\text { Ordering } \\
\text { Code, } \\
\text { Código } \\
\text { de Pedido }\end{array}$ & $\begin{array}{c}\text { Standard } \\
\text { HP Rating, } \\
\text { Estándar HP } \\
\text { Potencia }\end{array}$ & $\begin{array}{c}\text { Imp. } \\
\text { Dia. }\end{array}$ \\
\hline E & $1 / 2$ & $4^{7} / 6^{\mathrm{t}}$ \\
\hline $\mathrm{D}$ & $3 / 4$ & $4^{3 / 4}$ \\
\hline C & 1 & $5^{3 / 15}$ \\
\hline B & $11 / 2$ & $5^{3 / 4}$ \\
\hline A & 2 & $6^{1 / 6}$ \\
\hline
\end{tabular}

NOTE: Aithough not recommended, the pump may pass a $1 / 16$ " sphere.

NOTA: Si bien no se

recomienda, la bomba puede pasar una esfera de $1 / 16^{\prime \prime}$.

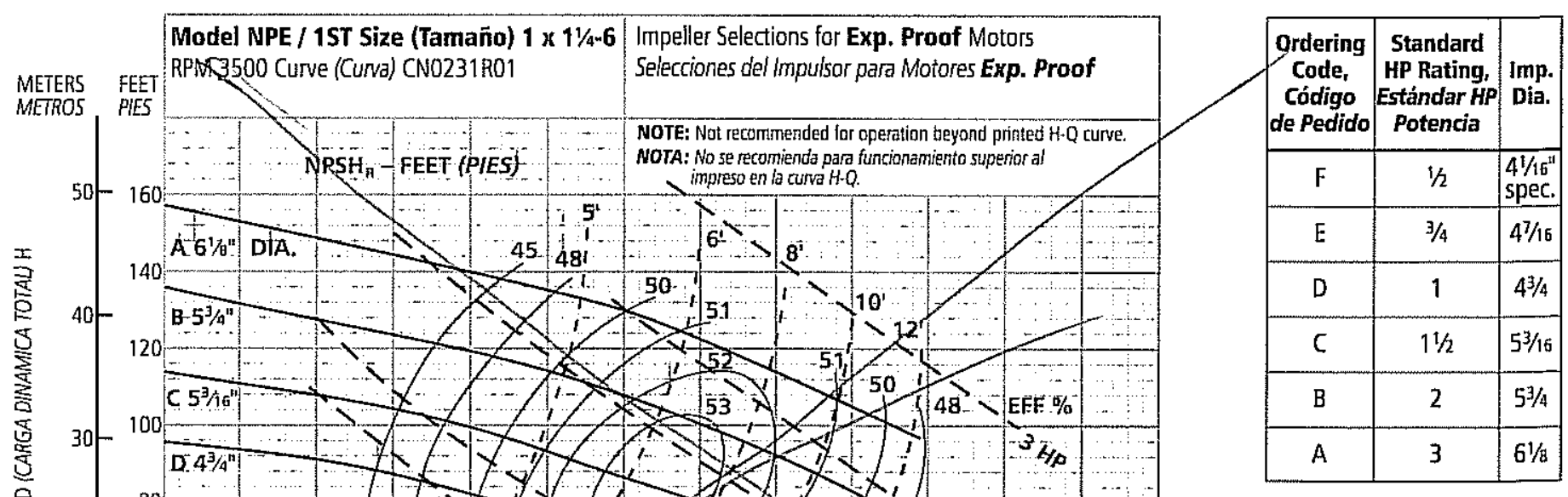

NOTE: Although not recommended, the pump may pass a $1 / 1 s^{\prime \prime}$ sphere, NOTA: Si bien no se recomienda, la bomba puede pasar una effera de $1 / 16^{*}$. 

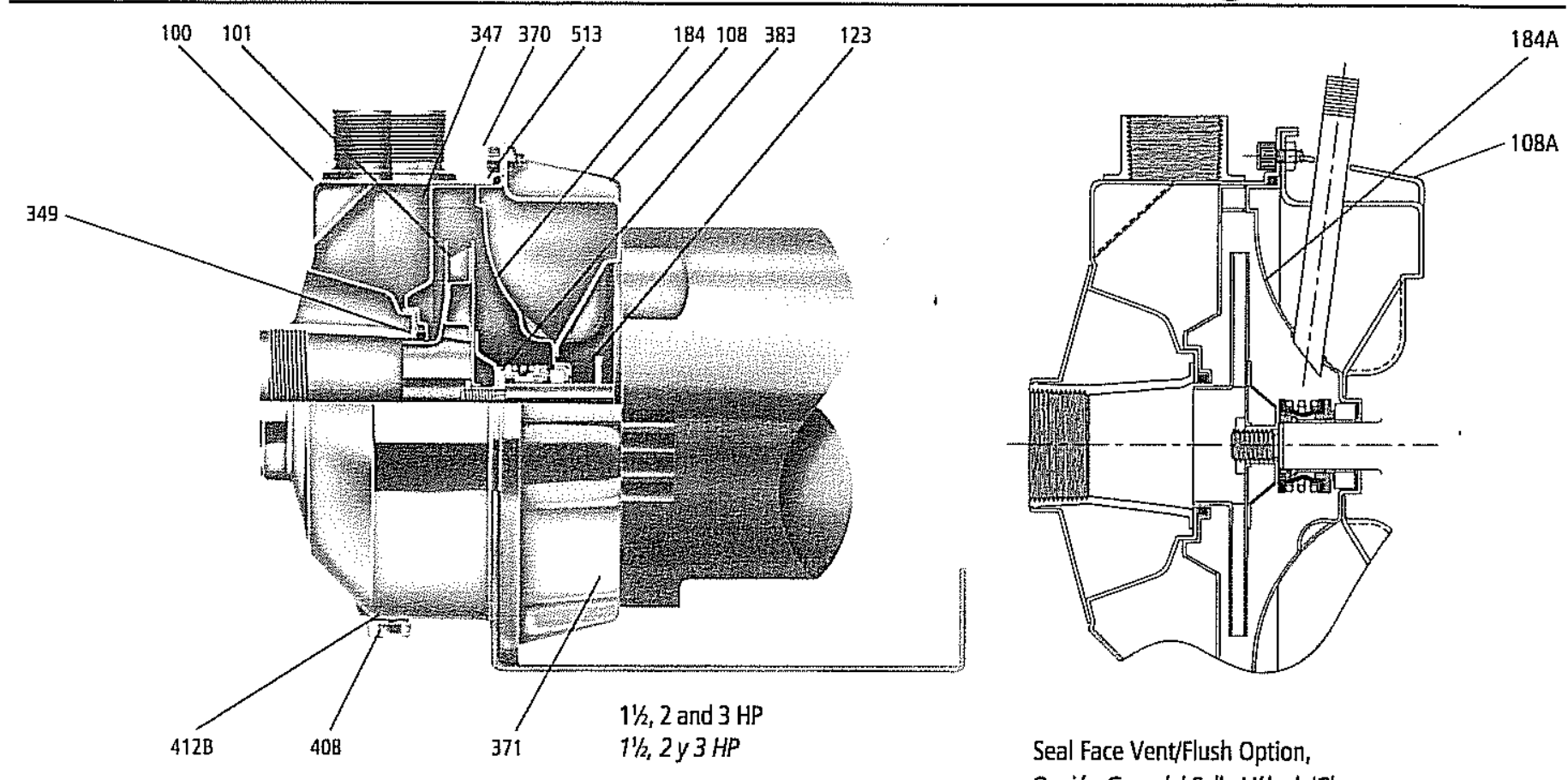

Seal Face Vent/Flush Option, Opción Cara del Sello Válvula/Chorro

\begin{tabular}{|c|c|c|}
\hline $\begin{array}{l}\text { Item No., } \\
\text { Parte No. }\end{array}$ & $\begin{array}{l}\text { Description, } \\
\text { Descripción }\end{array}$ & $\begin{array}{l}\text { Materials, } \\
\text { Materiales }\end{array}$ \\
\hline 100 & Casing, Carcasa & \multirow{4}{*}{$\begin{array}{l}\text { At5l } 316 \mathrm{LSS}, \\
\text { AISI } 316 \mathrm{~L} \text { Acero inoxidable }\end{array}$} \\
\hline 101 & Impeller, Impuisor & \\
\hline 108 & Motor adapter, Adaptador del motor & \\
\hline $108 \mathrm{~A}$ & $\begin{array}{l}\text { Mator adapter seal vertifiusti, } \\
\text { Sello váluila/chorn del adaptador del motor }\end{array}$ & \\
\hline 123 & Deflector, Deflector & BUNA-N \\
\hline 184 & Seal housing, Alojamiento del sello & \multirow{3}{*}{$\begin{array}{l}\text { AlSI 316L SS, } \\
\text { AISI } 316 \text { L Acero inaxidable }\end{array}$} \\
\hline $184 \mathrm{~A}$ & $\begin{array}{l}\text { Seal housing seal vent/llush, } \\
\text { Sello valuila/chorro del alojamiento del sello }\end{array}$ & \\
\hline 347 & Guidevane, Difusor & \\
\hline 349 & Seal ning, guidevane; Anillo del sello, difusor & Viton \\
\hline 370 & $\begin{array}{l}\text { Socket head screws, casing; } \\
\text { Encojes cabezas de tomillos, carasa }\end{array}$ & $\begin{array}{l}\text { AISI } 410 \text { SS, } \\
\text { AISI } 410 \text { Acero inoxidable }\end{array}$ \\
\hline 371 & $\begin{array}{l}\text { Bolls, moter; } \\
\text { Tomillos, motor }\end{array}$ & $\begin{array}{l}\text { Plated steel, } \\
\text { Acero thapeado }\end{array}$ \\
\hline 383 & Mechanical seal, Sello mecánico & *"see chart, ver tabla \\
\hline 408 & $\begin{array}{l}\text { Drain and vent plug, casing; } \\
\text { Enchufes de drenaje y váluta, carcasa }\end{array}$ & $\begin{array}{l}\text { Al51 316L 55, } \\
\text { Al5l } 316 \text { Acero inoxidable }\end{array}$ \\
\hline $412 B$ & $\begin{array}{l}\text { O-ing, drain and vent plug; } \\
\text { Anillo 'O' enchufe de drenaje y válimula }\end{array}$ & \multirow[t]{2}{*}{ Viton } \\
\hline 513 & O-ring, casing; Anillo 'O', carcasa & \\
\hline $\begin{array}{l}\text { Motor } \\
\text { Motor }\end{array}$ & $\begin{array}{l}\text { NEMA standard, 56J llange; } \\
\text { NEMA estándar, brida 56j }\end{array}$ & $-r$ \\
\hline
\end{tabular}

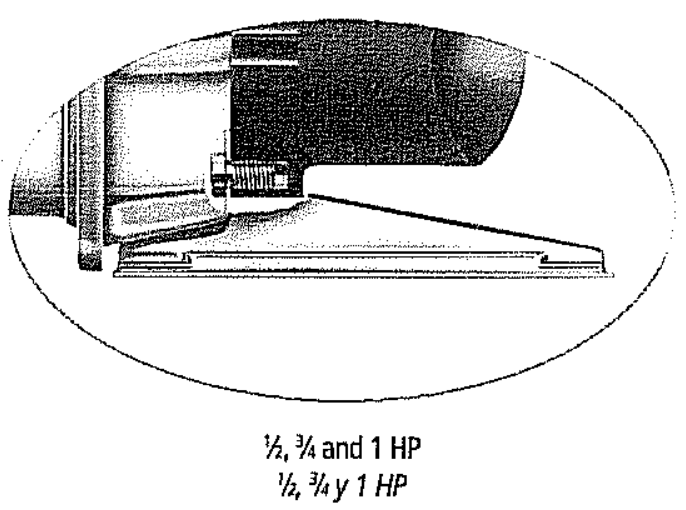

Footed motor for 1750 RPM and 5 HP ODP and TEFC, all explosion proof see page 13.

Motor con pie para 1750 RPM, 5 HP ODP y TEFC; a prueba de explosiones en la página 13. 
Clockurise Rotation Viewed from Drive End

Rotación en Dirección de las Agujas del Reloj Visto desde el Ertremo del Motor

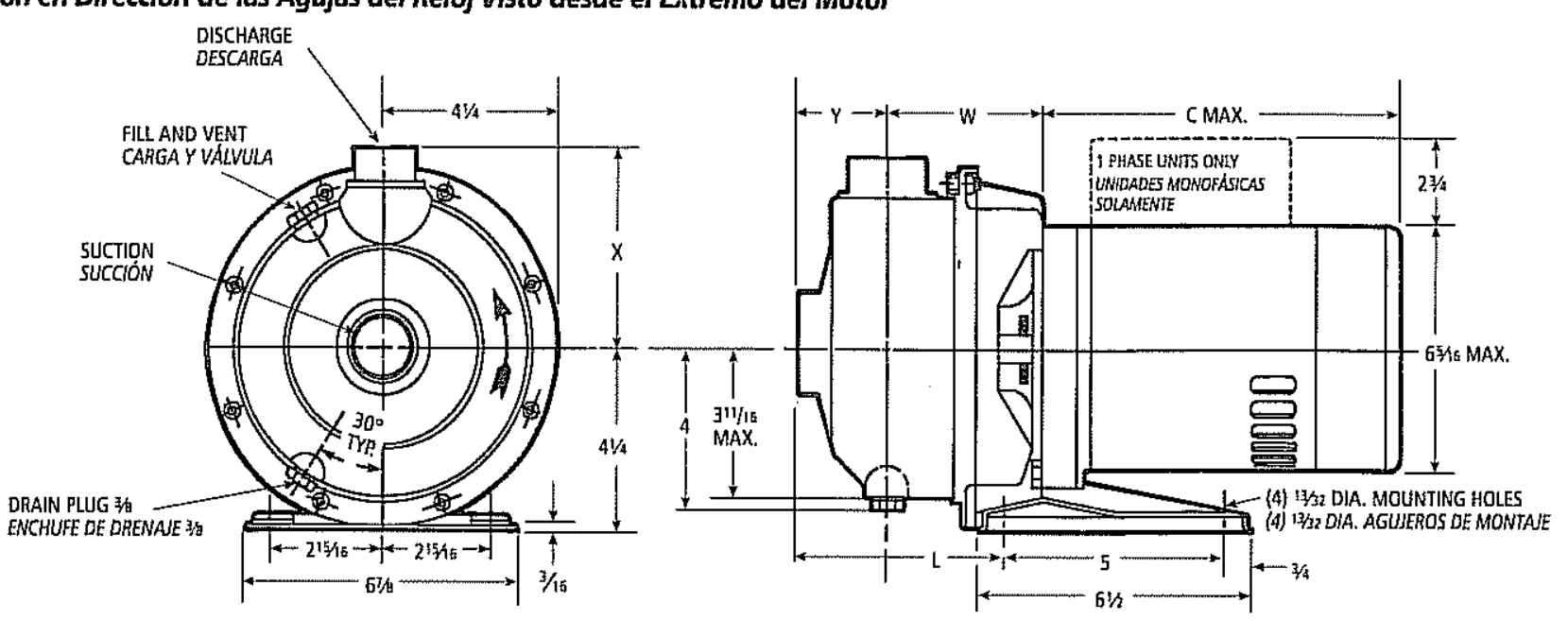

ODP and TEFC $1 / 2,3 / 4$ and $1 \mathrm{HP}$, ODP y TEFC $1 / 2,3 / 4$ y $1 \mathrm{HP}$

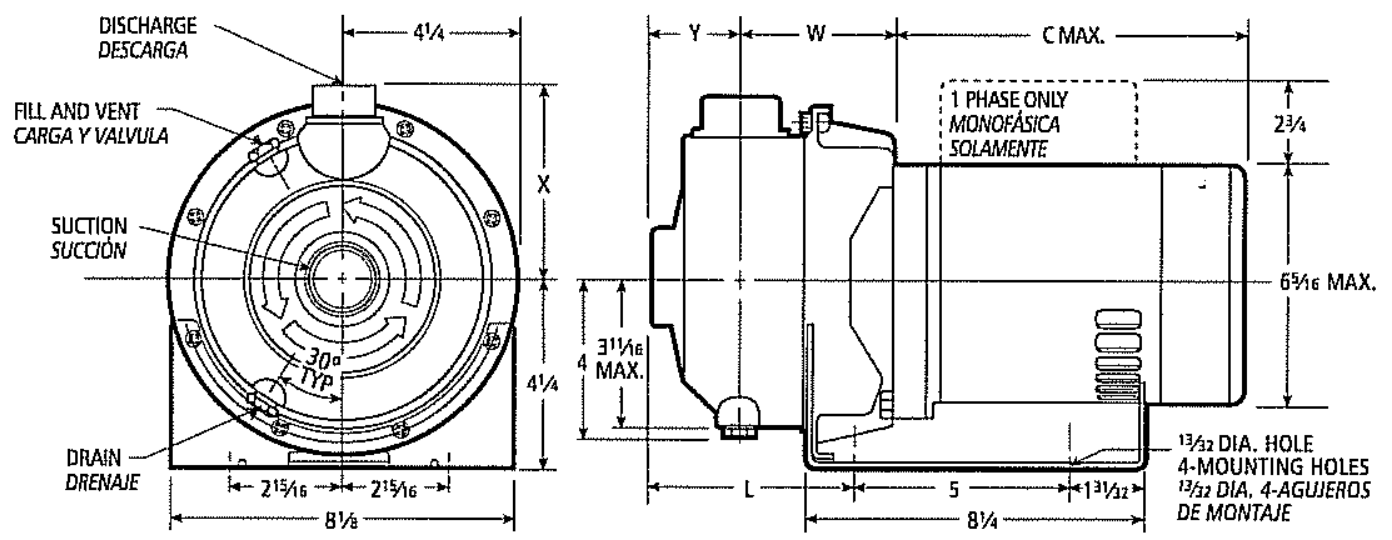

ODP and TEFC $1 \frac{1}{2}, 2$ and 3 HP, ODP y TEFC $1 \frac{1}{2}, 2$ y 3 HP

\section{Specifications}

\section{Especificaciones}

\section{Capacities to:}

$75 \mathrm{GPM}(283 \mathrm{~L} / \mathrm{min})$ at $1750 \mathrm{RPM}$

$150 \mathrm{GPM}$ (550//min) at $3500 \mathrm{RPM}$

\section{Heads to:}

39 feet $(12 \mathrm{~m})$ at $1750 \mathrm{RPM}$

150 feet (46 m) at 3500 RPM

Working pressures to:

$125 \mathrm{PSIG}$ (9 bars)

Maximum temperatures to:

$212^{\circ} \mathrm{F}\left(100^{\circ} \mathrm{C}\right)$ with standard seal or

$250^{\circ} \mathrm{F}\left(121^{\circ} \mathrm{C}\right)$ with optional high

temperature seal.

Direction of rotation:

Clockwise when viewed from motor end.

\section{Motor specifications:}

NEMA 56] frame, 1750 RPM,

$1 / 2$ HP. 3500 RPM $1 / 2$ through 5 HP.

Open drip-proof, totally enclosed

fan-cooled or $2 \mathrm{HP}$ explosion proof enclosures. Stainless steel shaft with ball bearings.

Single phase: Voltage 115/230 ODP and TEFC. (3 HP model $230 \mathrm{~V}$ only) Built-in overload with auto-reset provided.

Three phase: Vottage 208-230/ 460 ODP, TEFC and EX PROOF.

NOTE: For three phase motors, overload protection must be provided in starter unit. Starter and heaters must be ordered separately.

\section{Capacidades:}

75 GPM (283U/min) a 1750 RPM

150 GPM (550U/min) a 3500 RPM

\section{Cargas:}

39 pies (12 m) a 1750 RPM

150 pies $(46 \mathrm{~m})$ a 3500 RPM

Presión de trabajo:

125 PSIG (9 baras)

Temperatura máxima:

$212^{\circ} \%\left(100^{\circ} \mathrm{C}\right)$ con sello estándar o

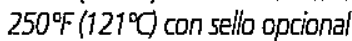
para alta temperatura.

Dirección de rotación:

En dirección de las agujas del reloj visto desde el extremo final del motor.

\section{Motores:}

Armazón 56/ NEMA, 1750 RPM $1 / 2$ HP. 3500 RPM $1 / 2$ a 5 HP.

Cubiertas abiertas resguardadas, totalmente encerradas enfriadas por ventilador o a prueba de explosiones de 2 HP. Eje de acero inoxidable con balineras de bolas.

Monofásicos: Voltaje 115/230 ODP y TEFC. (modelo 3 HP-230 voltios solamente) Se proporciona protección térmica contra sobrecarga construida con reseteo automático.

Trifásicos: Voltaje 208-230/460 ODP, TEFC Y EX PROOF.

NOTA: Para matores trifásicos se debe de proporcionar la protección térmica contra sobrecarga en la unidad de arranque. El arrancador $y$ los calentadores se deben pedir por separado. 
Appendix 6

Cost Estimate 


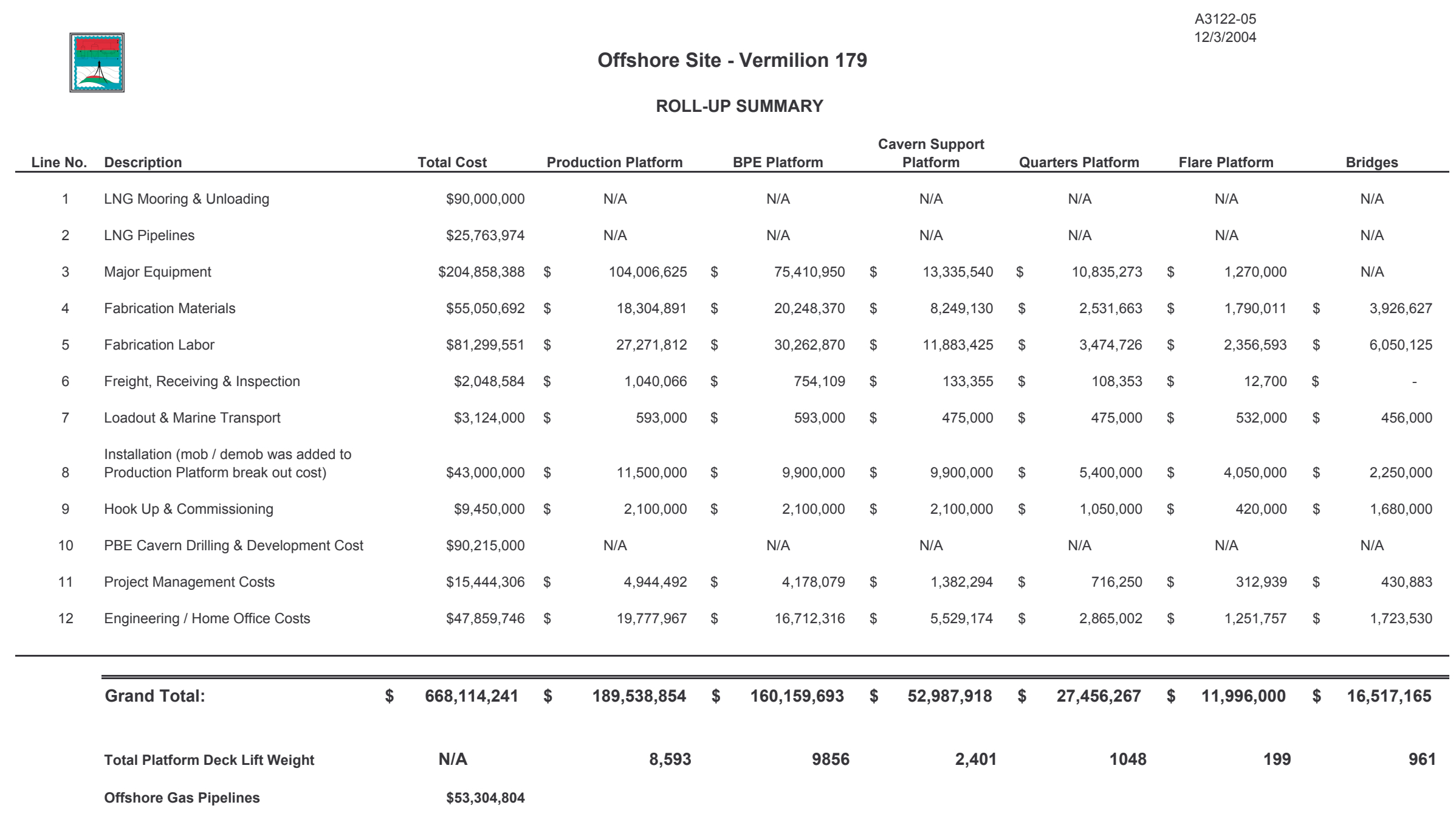




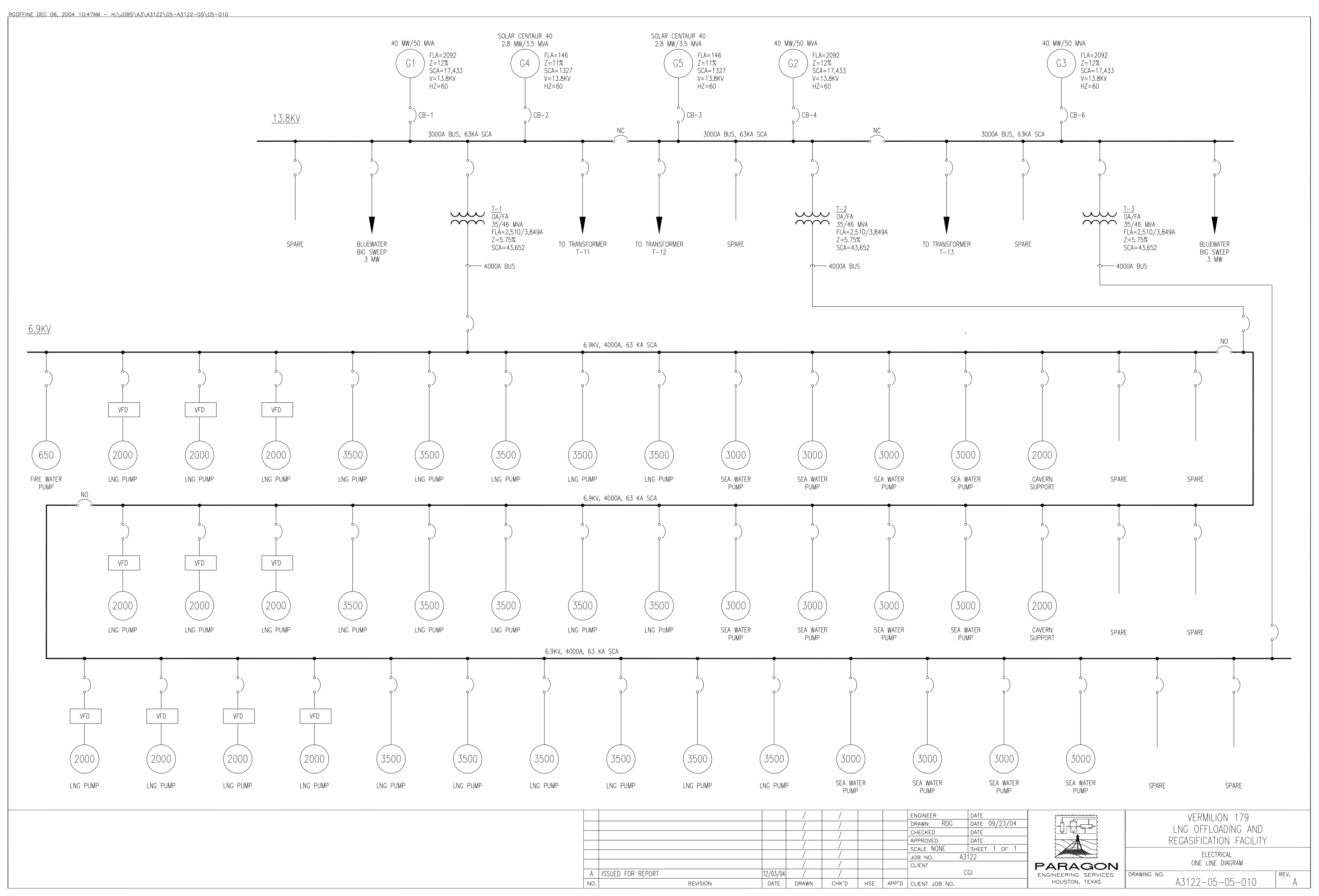


Offshore Site - Vermilion 179

Detailed Cost Estimate Sheet

A3122-05

SYSTEM 1 LNG Offloading System - Bluewater Big Sweep

Cost Estimate by Bluewater

DESCRIPTION

Big Sweep Equipment and Fabrication Costs

Installation Costs

\section{TOTALS}

$\begin{array}{ccc}\text { Quantity } & \text { Unit Cost } & \text { Total Cost } \\ 1 & \$ 80,000,000 & \$ 80,000,000 \\ 1 & \$ 10,000,000 & \$ 10,000,000 \\ & & \\ & & \$ 90,000,000\end{array}$

$\$ 90,000,000$

\section{NOTES}

Paragon received the costs directly from Bluewater and the costs do not include any contingency. 


\section{MARINE PIPELINE PRELIMINARY COST ESTIMATE}

24-INCH, PIPE IN PIPE IN PIPE LNG PIPELINE 6400 FT LONG

Two 24" Pipe in Pipe in Pipe LNG Pipeline (Top of Riser to Top of Riser)

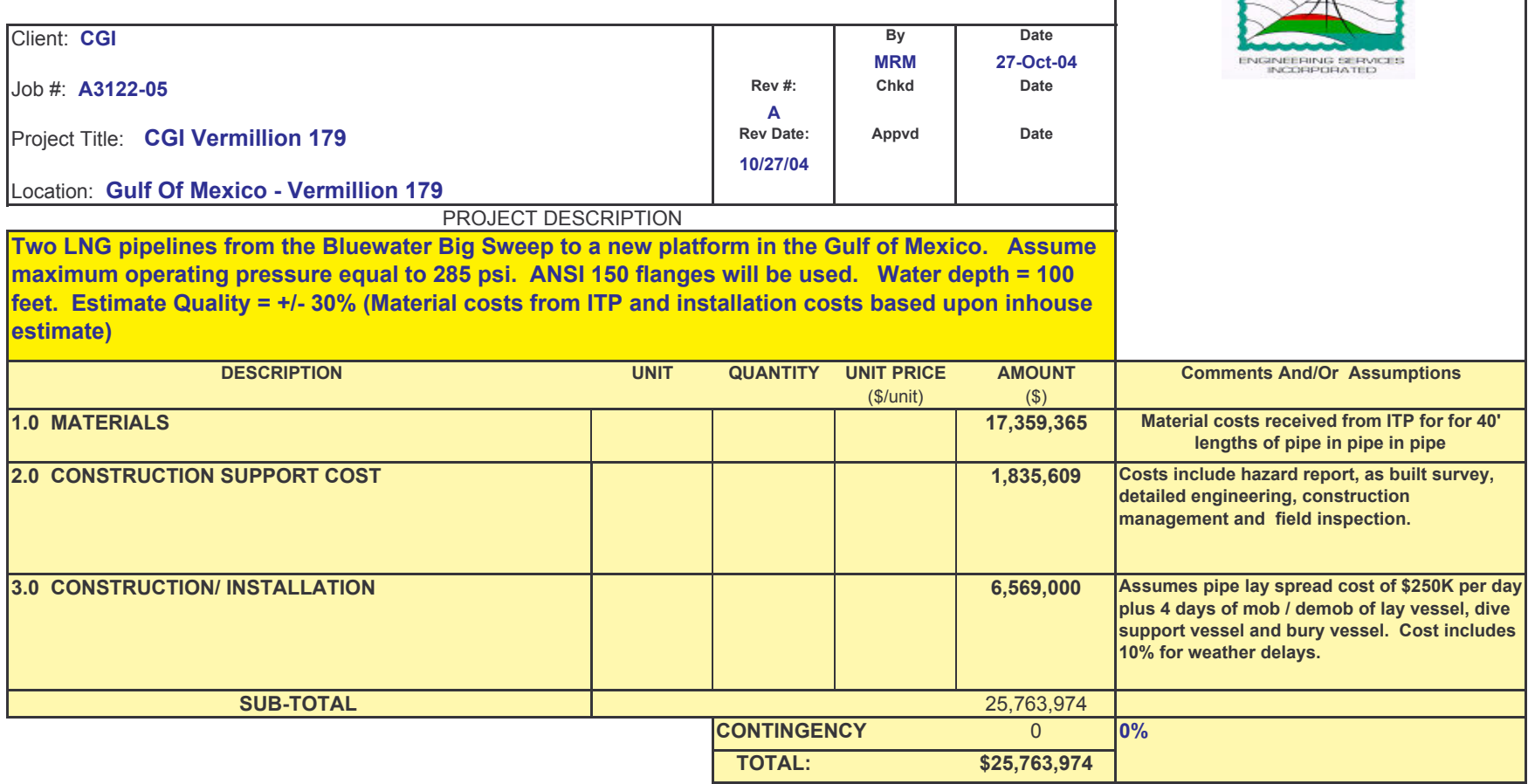


PRODUCTION

\section{PrODTCION}

\begin{tabular}{|c|c|c|}
\hline $\begin{array}{l}C-10010 \\
\text { CBG-4400 }\end{array}$ & $\begin{array}{l}\text { Instrument Air Compressor Package } \\
\text { a }\end{array}$ & Tide Air, Inc. \\
\hline HBG-4400 & $\begin{array}{l}\text { Waste Heat Recovery Unit Heat Exchanger } \\
45 \text { Ton Pedestal Crane }\end{array}$ & Krueger Engineering \\
\hline PBA-6050 A-J & $\begin{array}{l}45 \text { Ton Pedestal Crane } \\
\text { High Pressure LNG Pumps }\end{array}$ & Liebherr \\
\hline PBA-6150 A-P & $\begin{array}{l}\text { Hilgh Pressure LNG Pumps } \\
\text { Low Pressure LNG Pumps }\end{array}$ & $\begin{array}{l}\text { Ebara } \\
\text { Ebara }\end{array}$ \\
\hline PBB-10305A & High Pressure Spray Washdown Pumps & Gould \\
\hline PBB-7070 A-D & Chill Water Pumps & Peerless \\
\hline PBB-8101\&2 & Sump Pumps & Gould \\
\hline PBB- $8201 \& 2$ & Slop Oil Transfer Pump & Gould \\
\hline PBB-9101 \& 2 & Diesel Storage Transfer Pumps & Gould \\
\hline TK-8100 & Slop Oil Tank & SPEC \\
\hline TK-9100 & Diesel Fuel Storage Tanks & SPEC \\
\hline $\mathrm{V}-8200$ & Closed Drain Receiver & SPEC \\
\hline $\mathrm{V}-8300$ & Slop Oil Sump & SPEC \\
\hline ZAN-7000 & Heat Medium Skid & SPEC \\
\hline ZAN-7050 & Gas Turbine Power Generation Package & G.E. \\
\hline ZAN-7060 & Waste Heat Recovery Unit & Tulsa Heater \\
\hline ZAN-7070 & Stand-by Diesel Power Generator Set & Reagan Power \\
\hline ZAN-7080 & Non-Offloading Power Generator & Solar \\
\hline \multirow{7}{*}{$\begin{array}{l}\text { ZAN--1090 } \\
\text { ZZZ-10100 }\end{array}$} & Deionized Water System & $\mathrm{H} 2 \mathrm{O}$, Inc. \\
\hline & Firefighting Package System Including: & \\
\hline & Electric Sea Water Fire Pump & Peerless \\
\hline & Diesel Backup Seawater Fire Pump & Peerless \\
\hline & Firewater Jockey Pumps & Gould \\
\hline & Foam System, Monitors, etc & Past Project \\
\hline & Firefighting Equipment and Deluge Syste & nPast Project \\
\hline \multirow[t]{4}{*}{ ZZZ-10111 } & Miscellaneous Safety Items Including: & \\
\hline & Fire and Gas Detection \& ESD & Past Project \\
\hline & Escape Capsules, Life Boats & Past Project \\
\hline & & $\begin{array}{l}\text { Past Project } \\
\text { Salion }\end{array}$ \\
\hline & LNG Reliquifaction Package - Skid 1 & Salof Refrigeration \\
\hline \multirow{17}{*}{ ZZZ-9100 } & $\begin{array}{l}\text { LNG Reliquifaction Package - Skid } 2 \\
\text { Fuel Gas Skid }\end{array}$ & $\begin{array}{l}\text { Salof Refrigeration } \\
\text { SPEC }\end{array}$ \\
\hline & $\begin{array}{l}\text { Fuel Gas Skid } \\
\text { CPI System }\end{array}$ & Past Project \\
\hline & Demin. Water Pump to GT & Gould \\
\hline & Air-Conditioned Warehouse & Delta \\
\hline & Air-Conditioned Maintenance Building & \\
\hline & Control Building & Past Project \\
\hline & Switchgear Building & Point Eight Power, Inc. \\
\hline & $\begin{array}{l}\text { Battery Building } \\
\text { Batteries Charger, UPS }\end{array}$ & $\begin{array}{l}\text { Point Eight Power, Inc. } \\
\text { Pass Project }\end{array}$ \\
\hline & $\begin{array}{l}2000 \text { hp VFD's } \\
\text { Bates }\end{array}$ & Allen-Bradley \\
\hline & $13.8 \mathrm{kV}$ Switchgear & Point Eight Power, Inc. \\
\hline & $6.9 \mathrm{kV} \mathrm{Switchgear}$ & Point Eight Power, Inc. \\
\hline & $\begin{array}{l}480 \text { V MCC } \\
\text { Submarine Cable }\end{array}$ & $\begin{array}{l}\text { Point Eight Power, Inc. } \\
\text { Past Project }\end{array}$ \\
\hline & 35 MVA Transformers & Past Project \\
\hline & 1500 kVA Transformers & Past Project \\
\hline & Process control System & Past Project \\
\hline & $\begin{array}{c}\text { Valves } \\
\text { dnctruments }\end{array}$ & $\begin{array}{l}\text { Estimate } \\
\text { Fftimato }\end{array}$ \\
\hline & $\begin{array}{l}\text { Instruments } \\
\text { Subtotals: }\end{array}$ & \\
\hline
\end{tabular}

\$780,000.00 Three 50\% Screw Compressors @ 587.4 SCFM and 161 hp
\$560,000.00 Max. 3.5 BSCFD LNG Vapor, 200 MM BTU/hr from W.H.R.U.

$\$ 2,900,000.00$ Lebherr Offshore Crane, MTC 2600-60 Litronic, and 180 ft Max Main Hoist Outreac

$55,245,500.00$ Ebara 8ECC-1510 with Variable Frequency Drives @ 2000psig in Series with L.P. LNG Pumps

$\$ 8,392,800.00$ Ebara 8ECC-1510@ 1100 psig and 3080 gpm

$\$ 12,750.0003000$ gationa Pumps for Gas Turbine Power Augmentation, + 5 MW

$\$ 1,270.0025$ GS Submersible Pump

$\$ 7,790.003996$ 1.5x2-6 DI Inline pump

$\$ 12,680.00 \quad 10 \mathrm{ft}$ Dia. By $11 \mathrm{ft} \mathrm{H}, \mathrm{SA}$ S16 70 (CS)

$\$ 30,000.00$ Three Day Capacity (7200 gal. @ 100gph)

$\$ 55,680.00$ SS $316 \mathrm{~L}$, ASME DIV 1 , sec.VIIII

$\$ 30,000.00$ SA516-70 Carbon stee

$\$ 113,059.00200 \mathrm{MM}$ BTU/hr Skid

$\$ 42,000,000.00$ To

MM BTU/hr - Heats $3083 \mathrm{gpm}$ of Dowtherm Q from $150 \mathrm{~F}$ to $300 \mathrm{~F}$

$\$ 5,000,000,00$ Solar Centaur $40,28 \mathrm{MW}$

$\$ 420,000.0035 \mathrm{gpm}$ Deionized Water Skid for Power Augmentation of G.E. LM6000

$\$ 385,330.005000$ gpm Ni-Bz-Al

$\$ 20,000.0050$ gpm, two $100 \%$, Ni-Bz-A

$\$ 285,000.00$ (4) Monitor Assemblies, 10 Hydrant Hose Rack Assemblies, 9 Foam Eductor units, plus Misc. Extinguishers $\$ 195,000.00$ Deluge Valves, Nozzles, 7 Zone Fusible Plug Panel

$\$ 845,000.00$ Includes Fire \& Gas Detectors, plus F\&G Panel

$\$ 150,000.0020$ Men, $8 \mathrm{ft}$ by $20 \mathrm{ftby} 8 \mathrm{ft}$

33,000,000.002 MMSCFD Unit @ 1500 hp

$\$ 0.0010 \mathrm{MMSCFD} / \mathrm{Gas}$ Turbine

$\$ 85,650.00$

$\$ 61,000.00$

$\$ 484,000.0020 \mathrm{ft}$ by $20 \mathrm{ft}$

$\$ 212,000.0020 \mathrm{ft}$ by $20 \mathrm{ft}$

$\$ 684,000.0038 \mathrm{ft}$ by $30 \mathrm{ft} @ \$ 600 / \mathrm{ft} 2$

$\$ 504,0000012 \mathrm{ft}$ by $70 \mathrm{ft} @ \$ 600 / \mathrm{f} 2$

$\$ 181,550.00$

$2,600,000.00$

$\$ 1,586,891.00$ Weight includes busses

$\$ 387,618.00$ Weight includes busses.

$\$ 1,680,000.00350$ MCM, $15 \mathrm{kV}$, with Fiber Optic

$\$ 1,200,000.00$

$\$ 60,000.00$
$1,500,000.00$ Quote from Sea Systems for Previous Projects (Similar sized deck)

Subtotals: $\quad \quad 0$ 
Line No.

Major Equipmen

\begin{tabular}{|c|c|c|c|c|c|c|c|}
\hline $\begin{array}{c}\text { System } \\
\text { No. }\end{array}$ & Tag No. & Equipment Description & Vendor & Unit Qty. & $\begin{array}{l}\text { Total Weight } \\
\text { (short tons) }\end{array}$ & $\begin{array}{c}\text { Total Estimated } \\
\text { Cost }\end{array}$ & Notes \\
\hline \multicolumn{8}{|c|}{ BPE PLATFORM } \\
\hline & & High Pressure Bishop Exchangers & Butcher's Welding & 17 & 1318 & $\$ 16,059,424.00$ & \\
\hline 4 & HBG-4200 A-I & Swing Bishop Exchangers & Butcher's Welding & 9 & 698 & $\$ 8,502,048.00$ & \\
\hline 4 & HBG-4300 A-J & Low Pressure Bishop Exchangers & Butcher's Welding & 10 & 775 & $\$ 9,446,720.00$ & \\
\hline 4 & PBA-6200 A-L & Sea Water Lift Pumps & Peerless & 12 & 210 & $\$ 14,880,000.00$ & 40850 gpm/pump @ 207 TDH, 42" Discharge, ANSI 150, Ni-Bz-Al, 3000 hp @ 705 RPM \\
\hline 4 & PBB-10305 & High Pressure Spray Washdown Pumps & Gould & 1 & 0 & $\$ 12,750.00$ & National Oil Well 22T-2L Reciprocating Pump Unit \\
\hline 4 & & CPI System & Past Project & 1 & 5 & $\$ 29,000.00$ & 4500 bpd \\
\hline 4 & & Seawater Inlet Screens & Johnson Screens & 10 & 99 & $\$ 1,150,000.00$ & 96 in screen diameter, $316 \mathrm{~L}$ Stainless Steel, 0.125 in slot size and $0.5 \mathrm{ft} / \mathrm{s}$ velocity through slot \\
\hline 4 & & Inlet Screen Hydroburst System & Johnson Screens & 1 & 1 & $\$ 95,000.00$ & 5000 gal tank, compressor/motor assembly, automatic control panel, and valves based on $100 \mathrm{ft}$ of line \\
\hline 4 & & 45 Tonnes Pedestal Crane & Liebherr & 2 & 262 & $\$ 2,900,000.00$ & \\
\hline 4 & & Life Rafts & & 2 & 0 & $\$ 20,000.00$ & \\
\hline 4 & & Valves & Estimate & & 1011 & $\$ 18,725,010.00$ & Includes Cryo Valves, Automated Valves and Manual Valves \\
\hline 4 & & Instrumentation & Estimate & & 0 & $\$ 3,590,997.60$ & Use $5 \%$ of equipment cost for instrument tagged items (ie Transmitters, Indicators, PSVs, LGs, CVs, etc.) \\
\hline \multicolumn{8}{|c|}{ (1) } \\
\hline 4 & & & & Subtotals: & 4378 & $\$ 75,410,949.60$ & \\
\hline \multicolumn{8}{|c|}{ CAVERN SUPPORT } \\
\hline \multicolumn{8}{|c|}{ 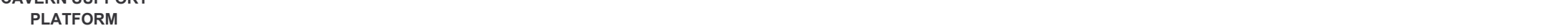 } \\
\hline 5 & PBB-10305 & High Pressure Spray Washdown Pumps & Gould & 1 & 0 & $\$ 12,750.00$ & National Oil Well 22T-2L Reciprocating Pump Unit \\
\hline 5 & ZZZ-11110 A-C & Send-out Metering System & FMC & 3 & 27 & $\$ 1,299,999.00$ & Custody Transfer, 24" 900 lb Ultrasonic Natural Gas Meter with Gas Chromatograph and Data Acquisition Panel \\
\hline 5 & ZZZ-11210 A-G & Bi-Directional Cavern Gas Metering System & FMC & 7 & 25 & $\$ 1,499,995.00$ & $16 " 900$ Ib Ultrasonic Natural Gas Meter with Data Acquisition Panel \\
\hline 5 & & Gas Dehydration Unit & Hanover & 1 & 130 & $\$ 3,100,000.00$ & Two $50 \%$ Contactors, Designed for $60 \%$ of Max. Flow, 1.5 BSCFD Gas and $7 \mathrm{lb} \mathrm{H} 2 \mathrm{O} / \mathrm{MMSCF}$ \\
\hline 5 & & Control Building & Past Projects & 1 & 33 & $\$ 316,800.00$ & $24 \mathrm{ft}$ by $22 \mathrm{ft}$ by $15 \mathrm{ft}$ \\
\hline 5 & & 20 Tonnes Pedestal Crane & Liebherr & 2 & 120 & $\$ 1,600,000.00$ & \\
\hline 5 & & Life Rafts & & & 1 & $\$ 20,000.00$ & \\
\hline 4 & & CPI System & D. Mclnnis & 1 & 5 & $\$ 29,000.00$ & 4500 bpd \\
\hline 5 & & Leaching Seawater lift pump & Peerless Pumps & 5 & 35 & $\$ 425,000.00$ & National Oil Well 22T-2L Reciprocating Pump Unit \\
\hline \multirow{2}{*}{\multicolumn{8}{|c|}{$\$ 2,906,520.00$ Textron model $6 \times 10 \times 13$ MQF -5 Stage, multistage pump to inject Seawater @ 1100 PSIG }} \\
\hline & & & & & & & \\
\hline 5 & & Valves & Estimate & & 172 & $\$ 1,490,450.00$ & \\
\hline 4 & & Instrumentation & Instrumentation & & 172 & $\$ 635,025.70$ & Use $5 \%$ of equipment cost for instrument tagged items (ie Transmitters, Indicators, PSVs, LGs, CVs, etc.) \\
\hline 5 & & Dry Trees & PB Energy & & & $\$ 000,020.10$ & Price is included in PB Energy's Cavern Drilling and Development Costs \\
\hline 5 & & & & Subtotals: & 651 & $\$ 13,335,539.70$ & \\
\hline \multicolumn{8}{|c|}{ QUARTERS } \\
\hline \multicolumn{8}{|c|}{ 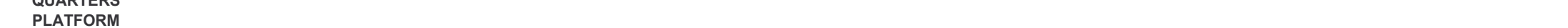 } \\
\hline 6 & PBB-10301 \& 2 & Potable Water Maker Sea Water Lift Pump & Gould & 2 & 1 & $\$ 17,250.00$ & \\
\hline 6 & PBB-10305B & High Pressure Spray Washdown Pumps & Gould & 1 & 0 & $\$ 12,750.00$ & National Oil Well 22T-2L Reciprocating Pump Unit \\
\hline 6 & ZZZ-10303 & Potable Water Maker Package & $\mathrm{H} 2 \mathrm{O}$, Inc. & 2 & 3 & $\$ 186,600.00$ & 3000 GPD @ 100gal/person/day, Reverse Osmosis \\
\hline 6 & & 30 man Quarters Building & Delta & 1 & 495 & $\$ 8,068,500.00$ & $55 \mathrm{ft}$ by $60 \mathrm{ft}, 3$ story $30 \mathrm{man}$ \\
\hline 6 & & Helideck & Delta & 1 & 48 & $\$ 214,173.00$ & $46 \mathrm{ft}$ by $46 \mathrm{ft}$ \\
\hline 6 & & Sewage Treatment Package & OMNIPure & 1 & 2 & $\$ 83,000.00$ & $12 \mathrm{MC}, 9 \mathrm{ft}$ by $3 \mathrm{ft}$ by $6 \mathrm{ft}$ \\
\hline 6 & & Communication Equipment Including: & CapRock & 1 & 1 & $\$ 1,255,000.00$ & Communication Equipment Price from CapRock \\
\hline 6 & & VHF-FM & & 1 & 0 & $\$ 0.00$ & Included above \\
\hline 6 & & CCC TV System & & 1 & 0 & $\$ 0.00$ & Included above \\
\hline 6 & & Satellite TV & & 1 & 0 & $\$ 0.00$ & Included above \\
\hline 6 & & IT Equipment & & 1 & 0 & $\$ 0.00$ & Included above \\
\hline 6 & & Microwave & & 1 & 0 & $\$ 0.00$ & Included above \\
\hline 6 & & CPI System & Past Project & 1 & 0 & $\$ 28,000.00$ & $4300 \mathrm{bpd}$ \\
\hline 6 & & 20 Tonne Pedestal Crane & Liebherr & 1 & 60 & $\$ 800,000.00$ & \\
\hline 6 & & Escape Capsules. Life boat & Past Project & 1 & 4 & $\$ 150,000.00$ & \\
\hline $\begin{array}{l}6 \\
6\end{array}$ & & & Past Project & 2 & $\begin{array}{l}2 \\
0\end{array}$ & $\$ 20,000.00$ & \\
\hline
\end{tabular}


Offshore Site - Vermilion 179

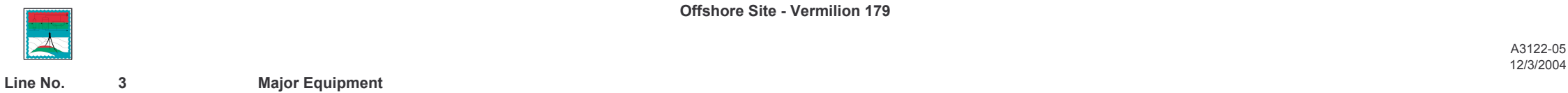

\begin{tabular}{|c|c|c|c|c|c|c|c|}
\hline $\begin{array}{c}\text { System } \\
\text { No. }\end{array}$ & Tag No. & Equipment Description & Vendor & Unit Qty. & $\begin{array}{l}\text { Total Weight } \\
\text { (short tons) }\end{array}$ & $\begin{array}{l}\text { Total Estimated } \\
\text { Cost }\end{array}$ & Notes \\
\hline $\begin{array}{l}6 \\
6\end{array}$ & & & & Subtotals: & 615 & $\$ 10,835,273.00$ & \\
\hline & $\begin{array}{l}\text { Platform } \\
\text { V-8100 }\end{array}$ & $\begin{array}{l}\text { Flare Knockout Drum } \\
\text { Flare boom Tip \& Igniter }\end{array}$ & $\begin{array}{l}\text { SPEC } \\
\text { John Zink }\end{array}$ & $\begin{array}{l}1 \\
1\end{array}$ & $\begin{array}{c}20 \\
2\end{array}$ & $\begin{array}{l}\$ 130,000.00 \\
\$ 260,000.00\end{array}$ & \\
\hline 7 & & Valves & & & 36 & $\$ 880,000.00$ & \\
\hline 7 & & & & Subtotals: & 58 & $\$ 1,270,000.00$ & \\
\hline
\end{tabular}




\section{OFFSHORE SITE VERMILION 179 \\ Conversion Gas Imports Structural Weight Estimate Calculations}

A3122-05

$12 / 3 / 2004$

\begin{tabular}{|c|c|c|c|c|c|c|c|}
\hline Jackets & \# of Legs & Water Depth & $\begin{array}{c}\text { Tons } / \text { Leg } / \mathrm{Ft} \text {. of } \\
\text { Water }\end{array}$ & Short Tons & Design Growth & Short Tons & $\begin{array}{l}\text { Total Weight } \\
\text { Short Tons }\end{array}$ \\
\hline 8-Pile Production & 8 & 110 & 1.25 & 1100 & 0.15 & 165 & 1265 \\
\hline 8-Pile BPE & 8 & 110 & 1.25 & 1100 & 0.15 & 165 & 1265 \\
\hline 8-Pile Cavern Support & 8 & 110 & 1 & 880 & 0.15 & 132 & 1012 \\
\hline Tripod Flare Platform & 3 & 110 & 1 & 330 & & 0 & 330 \\
\hline Quarters & 4 & 110 & 1 & 440 & & 0 & 440 \\
\hline
\end{tabular}

\begin{tabular}{|c|c|c|c|c|c|c|}
\hline Main Piles & Piles & Stickup Distance Ft. & $\begin{array}{c}\text { Estimated } \\
\text { Penetration } \\
\text { Ft. }\end{array}$ & Total Pile Length & Pile Weight Lb/Ft. & $\begin{array}{l}\text { Total Weight } \\
\text { Short Tons }\end{array}$ \\
\hline \multicolumn{7}{|l|}{$\begin{array}{l}(54 " \text { dia. By 1.25" wall)* } \\
\text { (42" dia. By 1." wall) ** }\end{array}$} \\
\hline Production * & 8 & 130 & 300 & 430 & 625 & 1075 \\
\hline $\mathrm{BPE}$ * & 8 & 130 & 300 & 430 & 625 & 1075 \\
\hline Cavern Support * & 8 & 130 & 250 & 380 & 625 & 950 \\
\hline Tripod Flare Platform ** & 3 & 130 & 250 & 380 & 440 & 251 \\
\hline Quarters ** & 4 & 130 & 250 & 380 & 440 & 334 \\
\hline
\end{tabular}




\section{OFFSHORE SITE VERMILION 179 \\ Conversion Gas Imports Structural Weight Estimate Calculations}

A3122-05

$12 / 3 / 2004$

\begin{tabular}{|c|c|c|c|c|c|}
\hline Decks & Deck Length Ft. & Deck Width Ft. & Deck Area $\mathrm{Ft}^{2}$ & Weight @ 80 psf & $\begin{array}{l}\text { Total Weight } \\
\text { Short Tons }\end{array}$ \\
\hline \multicolumn{6}{|l|}{ Production } \\
\hline Main Deck & 290 & 130 & 37700 & 3016000 & 1508 \\
\hline Cellar Deck & 290 & 130 & 37700 & 3016000 & 1508 \\
\hline Subcellar Deck & 185 & 130 & 24050 & 1924000 & 962 \\
\hline Total Production & & & & 7956000 & 3978 \\
\hline \multicolumn{6}{|l|}{ BPE } \\
\hline Main Deck & 340 & 115 & 39100 & 3128000 & 1564 \\
\hline Cellar Deck & 340 & 115 & 39100 & 3128000 & 1564 \\
\hline Subcellar Deck & 340 & 115 & 39100 & 3128000 & 1564 \\
\hline Total BPE & & & & 9384000 & 4692 \\
\hline \multicolumn{6}{|l|}{ Cavern Support } \\
\hline Main Deck & 170 & 110 & 18700 & 1496000 & 748 \\
\hline Cellar Deck & 170 & 110 & 18700 & 1496000 & 748 \\
\hline Subcellar Deck & & & 0 & 0 & 0 \\
\hline Total Cavern Support & & & & 2992000 & 1496 \\
\hline \multicolumn{6}{|l|}{ Flare } \\
\hline Main Deck & 40 & 35 & 1400 & 112000 & 56 \\
\hline Cellar Deck & 50 & 30 & 1500 & 120000 & 60 \\
\hline Subcellar Deck & & & 0 & 0 & 0 \\
\hline Total Flare & & & & 232000 & 116 \\
\hline \multicolumn{6}{|l|}{ Quarters } \\
\hline Main Deck & 80 & 75 & 6000 & 480000 & 240 \\
\hline Cellar Deck & 65 & 50 & 3250 & 260000 & 130 \\
\hline Subcellar Deck & & & 0 & 0 & 0 \\
\hline Total Quarters & & & & 740000 & 370 \\
\hline
\end{tabular}




\section{OFFSHORE SITE VERMILION 179 \\ Conversion Gas Imports Structural Weight Estimate Calculations}

A3122-05

$12 / 3 / 2004$

\begin{tabular}{|c|c|c|c|c|c|c|c|}
\hline Bridges & Bridge Width & Bridge Length & Bridge Area $\mathrm{Ft}^{2}$ & $\begin{array}{l}\text { Number of } \\
\text { Levels }\end{array}$ & Total Area $\mathrm{ft}^{2}$ & Weight @125 psf & $\begin{array}{l}\text { TotalWeight } \\
\text { Short Tons }\end{array}$ \\
\hline Production to BPE & 25 & 100 & 2500 & 2 & 5000 & 625000 & 313 \\
\hline Production to Cavern Support & 20 & 100 & 2000 & 2 & 4000 & 500000 & 250 \\
\hline Production to Quarters & 20 & 100 & 2000 & 1.5 & 3000 & 375000 & 188 \\
\hline Production to Flare & 15 & 150 & 2250 & 1.5 & 3375 & 421875 & 211 \\
\hline Total Bridges & & & & & 15375 & & 961 \\
\hline Flare Tower & Width & Length & Height & & Total S. Tons & \multicolumn{2}{|c|}{ Notes } \\
\hline Flare Tower 190' & 36 & 36 & 194 & & 154 & \multicolumn{2}{|c|}{$\begin{array}{c}\text { Wt. From Previous Project with 194' } \\
\text { tower }\end{array}$} \\
\hline
\end{tabular}




\begin{tabular}{|c|c|c|c|c|c|c|c|c|}
\hline System & Description & Quantity & & Unit Cost & SubTotal & \begin{tabular}{|c|}
$\begin{array}{c}\text { Contingency } \\
\%\end{array}$ \\
\end{tabular} & Total Estimated Cost & Notes \\
\hline \multicolumn{2}{|c|}{ STRUCTURAL STEEL MATERIALS } & Short Tons & & \$/Ton & & & & $\begin{array}{l}\text { Structural Steel costs were estimated based upon } \\
\text { rates obtained from a Gulf Coast Fabricator in } \\
\text { October of 2004. Weights were estimated based } \\
\text { upon past experience. Structural Weights were } \\
\text { calculated on the previous spreadsheet. }\end{array}$ \\
\hline \multicolumn{2}{|c|}{ Production Platform Structural Steel } & & & & & & & 8 leg platform in $110^{\prime}$ of water \\
\hline 3 & Jacket Steel & 1265 & $\$$ & $1,650.00$ & $\$ 2,087,250.00$ & $0 \%$ & $2,087,250.00$ & Use 1 ton per leg per foot of water \\
\hline 3 & Piling Steel & 1075 & $\$$ & $1,200.00$ & $\$ 1,290,000.00$ & $0 \%$ & $1,290,000.00$ & (8) 54" diameter 400' long piles \\
\hline 3 & Deck Steel & 3978 & $\$$ & $2,500.00$ & $\$ 9,945,000.00$ & $0 \%$ & $9,945,000.00$ & 3 levels @ 120' by 260' @ 80 psf steel weight \\
\hline 3 & Boat Landing Steel & 85 & $\$$ & $1,650.00$ & $140,250.00$ & $0 \%$ & $140,250.00$ & (2) $80^{\prime}$ boatlandings \\
\hline 3 & Sub Total & 6403 & & & $\$ 13,462,500.00$ & & $13,462,500.00$ & \\
\hline \multicolumn{2}{|r|}{ BPE Platform Structural Steel } & & & & & & & 8 leg platform in $110^{\prime}$ of water \\
\hline 4 & Jacket Steel & 1265 & $\$$ & $1,650.00$ & $\$ 2,087,250.00$ & $0 \%$ & $2,087,250.00$ & \\
\hline 4 & Piling Steel & 1075 & $\$$ & $1,200.00$ & $\$ 1,290,000.00$ & $0 \%$ & $1,290,000.00$ & \\
\hline 4 & Deck Steel & 4692 & $\$$ & $2,500.00$ & $\$ 11,730,000.00$ & $0 \%$ & $11,730,000.00$ & \\
\hline 4 & Boat Landing Steel & 85 & $\$$ & $1,650.00$ & $\$ \quad 140,250.00$ & $0 \%$ & $140,250.00$ & \\
\hline 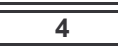 & Sub Total & $\overline{71117}$ & & & $\$ 15,247,500.00$ & & $15,247,500.00$ & \\
\hline \multicolumn{9}{|c|}{ Cavern Support Platform Structural Steel } \\
\hline 5 & Jacket Steel & 1012 & $\$$ & $1,650.00$ & $\$ 1,669,800.00$ & $0 \%$ & $1,669,800.00$ & \\
\hline 5 & Piling Steel & 950 & $\$$ & $1,200.00$ & $\$ 1,140,000.00$ & $0 \%$ & $1,140,000.00$ & \\
\hline 5 & Deck Steel & 1496 & $\$$ & $2,500.00$ & $\$ 3,740,000.00$ & $0 \%$ & $3,740,000.00$ & \\
\hline 5 & Boat Landing Steel & 32 & $\$$ & $1,650.00$ & $52,800.00$ & $0 \%$ & $52,800.00$ & (1) 60 ' boatlanding \\
\hline 5 & Sub Total & 3490 & & & $\$ 6,602,600.00$ & & $6,602,600.00$ & \\
\hline \multicolumn{9}{|c|}{ Quarters Platform Structural Steel } \\
\hline 6 & Jacket Steel & 440 & $\$$ & $1,650.00$ & $726,000.00$ & $0 \%$ & $726,000.00$ & \\
\hline 6 & Piling Steel & 334 & $\$$ & $1,200.00$ & $401,280.00$ & $0 \%$ & $401,280.00$ & \\
\hline 6 & Deck Steel & 370 & $\$$ & $2,500.00$ & $925,000.00$ & $0 \%$ & $925,000.00$ & \\
\hline 6 & Helideck Steel & & $\$$ & $2,500.00$ & - & $0 \%$ & - & $46^{\prime}$ by $46^{\prime}$ Helideck Included in Quarters Cost \\
\hline 6 & Boat Landing Steel & 21 & $\$$ & $1,650.00$ & $34,650.00$ & $0 \%$ & $34,650.00$ & (1) $40^{\prime}$ boatlanding \\
\hline 6 & Sub Total & 1165 & & & $\$ 2,086,930.00$ & & $2,086,930.00$ & \\
\hline \multicolumn{9}{|c|}{ Flare Platform } \\
\hline 7 & Jacket Steel & 330 & $\$$ & $1,650.00$ & $544,500.00$ & $0 \%$ & $544,500.00$ & \\
\hline 7 & Piling Steel & 251 & $\$$ & $1,200.00$ & $300,960.00$ & $0 \%$ & $300,960.00$ & \\
\hline 7 & Deck Steel & 116 & $\$$ & $2,500.00$ & $290,000.00$ & $0 \%$ & $290,000.00$ & \\
\hline 7 & Flare Tower Steel & 154 & $\$$ & $1,650.00$ & $254,100.00$ & $0 \%$ & $254,100.00$ & $\begin{array}{c}\text { Flare tower weight was taken from previous project } \\
\text { with similar size tower. }\end{array}$ \\
\hline 7 & Sub Total & 851 & & & $\$ 1,389,560.00$ & & $1,389,560.00$ & \\
\hline
\end{tabular}


Offshore Site - Vermilion 179

Detailed Cost Estimate Sheet

Line No. 4 Fabrication Materials

A3122-05

$12 / 3 / 2004$

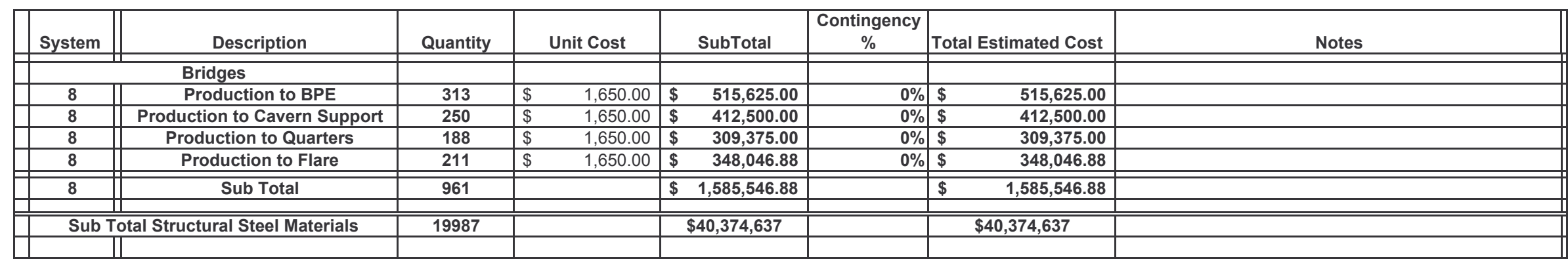


Offshore Site - Vermilion 179

Detailed Cost Estimate Sheet

Line No. 4 Fabrication Materials

A3122-05

$12 / 3 / 2004$

\begin{tabular}{|c|c|c|c|c|c|c|c|c|c|}
\hline System & Description & Quantity & & Unit Cost & & SubTotal & \begin{tabular}{|c|} 
Contingency \\
$\%$ \\
\end{tabular} & Total Estimated Cost & Notes \\
\hline \multicolumn{2}{|r|}{ PIPING MATERIALS } & & & & & & & & $\begin{array}{l}\text { Piping costs were estimated based upon rates } \\
\text { obtained from a Gulf Coast Fabricator in October of } \\
\text { 2004. Weights were estimated based upon past } \\
\text { experience. Stainless steel piping weights were } \\
\text { estimated based upon the platform complex layouts. }\end{array}$ \\
\hline \multicolumn{2}{|r|}{ Production Platform } & & & & & & & & \\
\hline 3 & Carbon Steel & 540 & $\$$ & $3,450.00$ & $\$$ & $1,863,000.00$ & $0 \%$ & $1,863,000.00$ & \\
\hline 3 & Stainless Steel & 120 & $\$$ & $12,000.00$ & $\$$ & $1,440,000.00$ & $0 \%$ & $1,440,000.00$ & \\
\hline 3 & FRP Piping & 15 & $\$$ & $5,000.00$ & $\$$ & $75,000.00$ & $0 \%$ & $75,000.00$ & \\
\hline 3 & Sub Total & 675 & & & $\$$ & $3,378,000.00$ & & $\$ \$ 3,378,000.00$ & \\
\hline \multicolumn{2}{|r|}{ BPE Platform } & & & & & & & & \\
\hline 4 & Carbon Steel & 580 & $\$$ & $3,450.00$ & $\$$ & $2,001,000.00$ & $0 \%$ & $2,001,000.00$ & \\
\hline 4 & Stainless Steel & 50 & $\$$ & $12,000.00$ & $\$$ & $600,000.00$ & $0 \%$ & $600,000.00$ & \\
\hline 4 & FRP Piping & 156 & $\$$ & $5,000.00$ & $\$$ & $780,000.00$ & $0 \%$ & $780,000.00$ & \\
\hline 4 & Sub Total & 786 & & & $\$$ & $3,381,000.00$ & & $\$ 3,381,000.00$ & \\
\hline \multicolumn{2}{|r|}{ Cavern Support Platform } & & & & & & & & \\
\hline 5 & Carbon Steel & 228 & $\$$ & $3,450.00$ & $\$$ & $786,600.00$ & $0 \%$ & $786,600.00$ & \\
\hline 5 & Stainless Steel & 10 & $\$$ & $12,000.00$ & $\$$ & $120,000.00$ & $0 \%$ & $120,000.00$ & \\
\hline 5 & FRP Piping & 16 & $\$$ & $5,000.00$ & $\$$ & $80,000.00$ & $0 \%$ & $80,000.00$ & \\
\hline 5 & Sub Total & 254 & & & $\$$ & $986,600.00$ & & $\$ 986,600.00$ & \\
\hline \multicolumn{2}{|r|}{ Quarters Platform } & & & & & & & & \\
\hline 6 & Carbon Steel & 56 & $\$$ & $3,450.00$ & $\$$ & $193,200.00$ & $0 \%$ & $193,200.00$ & \\
\hline 6 & Stainless Steel & 2 & $\$$ & $12,000.00$ & $\$$ & $24,000.00$ & $0 \%$ & $24,000.00$ & \\
\hline 6 & FRP Piping & 5 & $\$$ & $5,000.00$ & $\$$ & $25,000.00$ & $0 \%$ & $25,000.00$ & \\
\hline 6 & Sub Total & 63 & & & $\$$ & $242,200.00$ & & $\$ 242,200.00$ & \\
\hline \multicolumn{2}{|r|}{ Flare Platform } & & & & & & & & \\
\hline 7 & Carbon Steel & 5 & $\$$ & $3,450.00$ & $\$$ & $17,250.00$ & $0 \%$ & $17,250.00$ & \\
\hline 7 & Stainless Steel & 20 & $\$$ & $12,000.00$ & $\$$ & $240,000.00$ & $0 \%$ & $240,000.00$ & \\
\hline 7 & Sub Total & 25 & & & $\$$ & $257,250.00$ & & $\$ 257,250.00$ & \\
\hline
\end{tabular}


Offshore Site - Vermilion 179

Detailed Cost Estimate Sheet

Line No. 4 Fabrication Materials

A3122-05

$12 / 3 / 2004$

\begin{tabular}{|c|c|c|c|c|c|c|c|c|}
\hline System & Description & Quantity & & Unit Cost & SubTotal & $\begin{array}{c}\text { Contingency } \\
\%\end{array}$ & Total Estimated Cost & Notes \\
\hline \multicolumn{9}{|c|}{ Piping on the Bridges } \\
\hline 8 & Production to BPE & 95 & $\$$ & $9,000.00$ & $855,000.00$ & $0 \%$ & $855,000.00$ & \\
\hline 8 & Production to Cavern Support & 75 & $\$$ & $3,450.00$ & $258,750.00$ & $0 \%$ & $258,750.00$ & \\
\hline 8 & Production to Quarters & 56 & $\$$ & $3,450.00$ & $193,200.00$ & $0 \%$ & $193,200.00$ & \\
\hline 8 & Production to Flare & 60 & $\$$ & $12,000.00$ & $720,000.00$ & $0 \%$ & $720,000.00$ & \\
\hline 8 & Sub Total & 286 & & & $\$ 2,026,950.00$ & & $\$ 2,026,950.00$ & \\
\hline \multicolumn{2}{|r|}{ Sub Total Piping Materials } & 2089 & & & $\$ 10,272,000.00$ & & $\overline{10,272,000.00}$ & \\
\hline & & & & & & & & \\
\hline
\end{tabular}


Offshore Site - Vermilion 179

Detailed Cost Estimate Sheet

Line No. 4 Fabrication Materials

A3122-05

$12 / 3 / 2004$

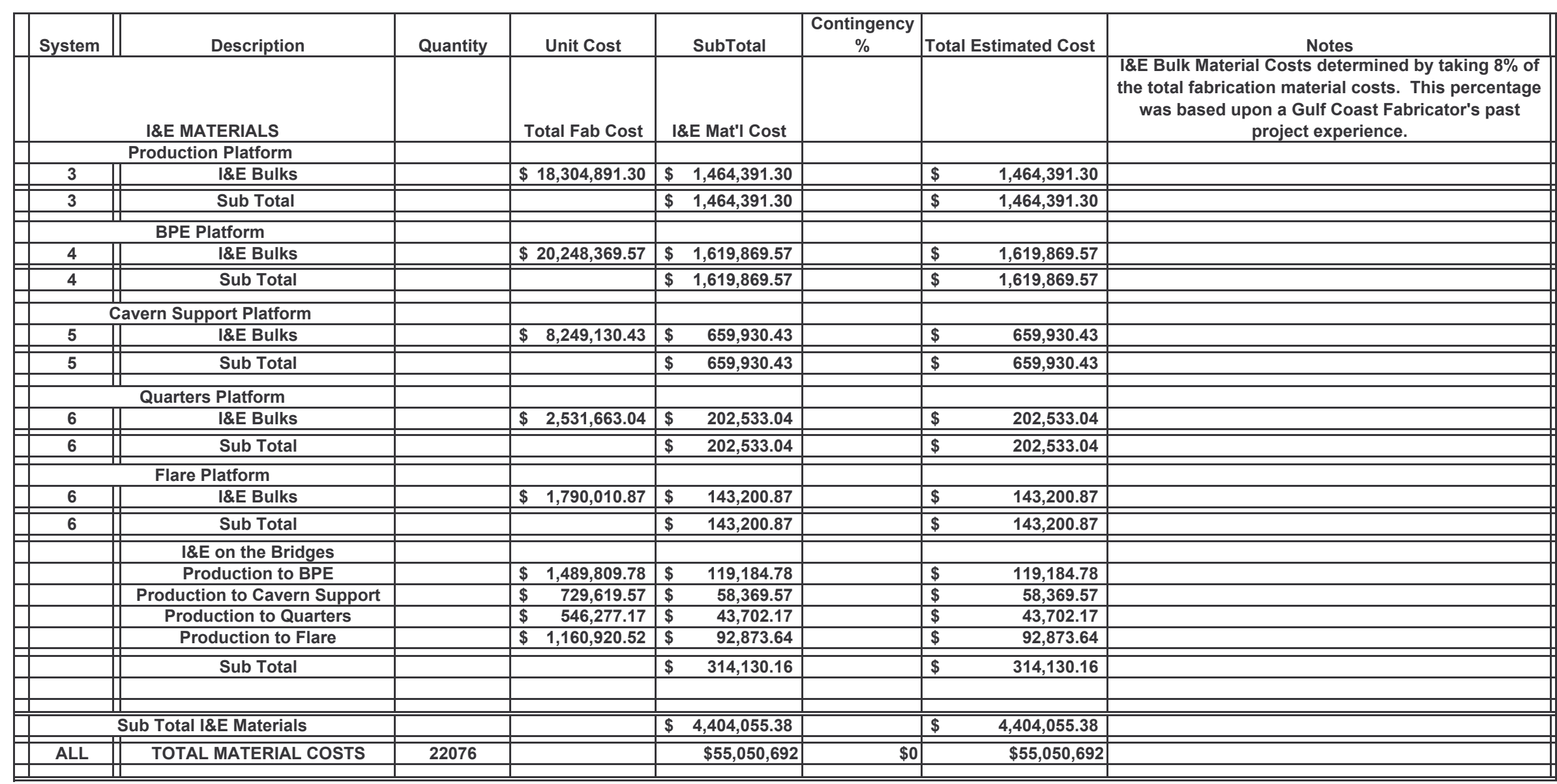


Offshore Site - Vermilion 179

Detailed Cost Estimate Sheet

Line No. 5 Fabrication Labor

A3122-05

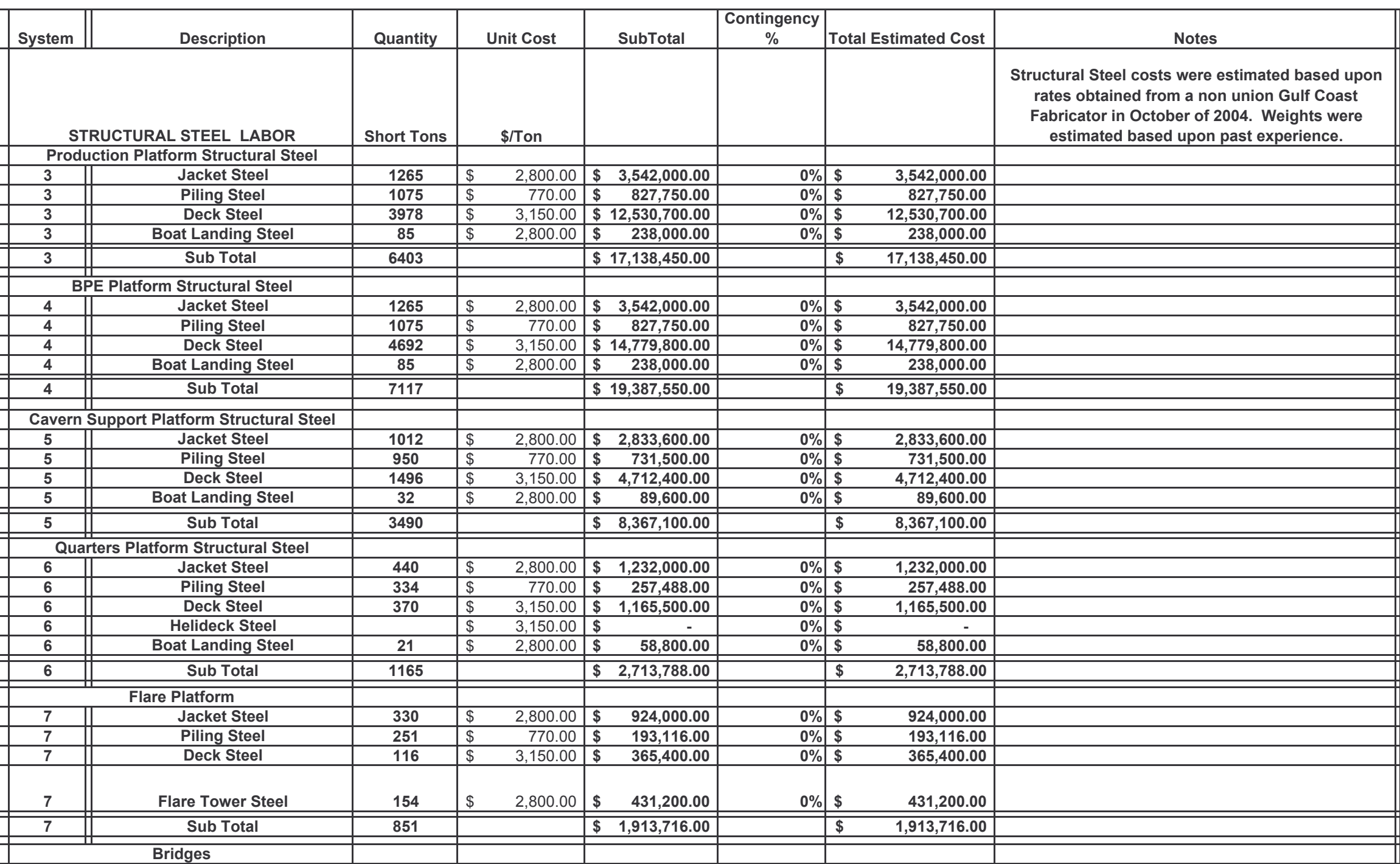


Offshore Site - Vermilion 179

Detailed Cost Estimate Sheet

Line No. 5 Fabrication Labor

A3122-05

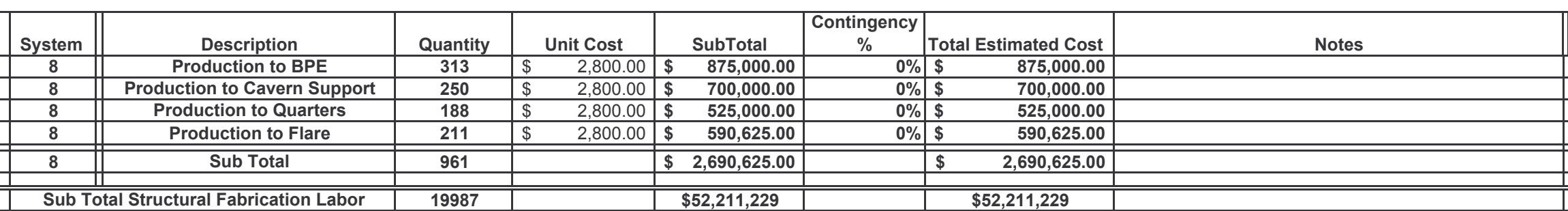


Offshore Site - Vermilion 179

Detailed Cost Estimate Sheet

Line No. 5 Fabrication Labor

A3122-05

\begin{tabular}{|c|c|c|c|c|c|c|c|c|c|}
\hline System & Description & Quantity & \multicolumn{2}{|r|}{ Unit Cost } & & SubTotal & \begin{tabular}{|c|} 
Contingency \\
$\%$
\end{tabular} & Total Estimated Cost & Notes \\
\hline \multicolumn{2}{|c|}{ PIPING PRE-FAB \& ASSEMBLY LABOR } & & & & & & & & $\begin{array}{l}\text { Piping costs were estimated based upon rates } \\
\text { obtained from a Gulf Coast Fabricator in October of } \\
\text { 2004. Weights were estimated based upon past } \\
\text { experience. Stainless steel piping weights were } \\
\text { estimated based upon the platform complex layouts. }\end{array}$ \\
\hline \multicolumn{2}{|c|}{ Production Platform } & & & & & & & & \\
\hline 3 & Carbon Steel & 540 & $\$$ & $9,290.00$ & $\$$ & $5,016,600.00$ & $0 \%$ & $5,016,600.00$ & \\
\hline 3 & Stainless Steel & 120 & $\$$ & $10,700.00$ & $\$$ & $1,284,000.00$ & $0 \%$ & $1,284,000.00$ & \\
\hline 3 & FRP Piping & 15 & $\$$ & $5,000.00$ & $\$$ & $75,000.00$ & $0 \%$ & $75,000.00$ & \\
\hline 3 & Sub Total & & & & $\$$ & $6,375,600.00$ & & $6,375,600.00$ & \\
\hline \multicolumn{2}{|c|}{ BPE Platform } & & & & & & & & \\
\hline 4 & Carbon Steel & 580 & $\$$ & $9,290.00$ & $\$$ & $5,388,200.00$ & $0 \%$ & $5,388,200.00$ & \\
\hline 4 & Stainless Steel & 50 & $\$$ & $10,700.00$ & $\$$ & $535,000.00$ & $0 \%$ & $535,000.00$ & \\
\hline 4 & FRP Piping & 156 & $\$$ & $5,000.00$ & $\$$ & $780,000.00$ & $0 \%$ & $780,000.00$ & \\
\hline 4 & Sub Total & & & & $\$$ & $6,703,200.00$ & & $6,703,200.00$ & \\
\hline \multicolumn{2}{|c|}{ Cavern Support Platform } & & & & & & & & \\
\hline 5 & Carbon Steel & 228 & $\$$ & $9,290.00$ & $\$$ & $2,118,120.00$ & $0 \%$ & $2,118,120.00$ & \\
\hline 5 & Stainless Steel & 10 & $\$$ & $10,700.00$ & $\$$ & $107,000.00$ & $0 \%$ & $107,000.00$ & \\
\hline 5 & FRP Piping & 16 & $\$$ & $5,000.00$ & $\$$ & $80,000.00$ & $0 \%$ & $80,000.00$ & \\
\hline 5 & Sub Total & & & & $\$$ & $2,305,120.00$ & & $2,305,120.00$ & \\
\hline \multicolumn{2}{|c|}{ Quarters Platform } & & & & & & & & \\
\hline 6 & Carbon Steel & 56 & $\$$ & $3,450.00$ & $\$$ & $193,200.00$ & $0 \%$ & $193,200.00$ & \\
\hline 6 & Stainless Steel & 2 & $\$$ & $9,290.00$ & $\$$ & $18,580.00$ & $0 \%$ & $18,580.00$ & \\
\hline 6 & FRP Piping & 5 & $\$$ & $5,000.00$ & $\$$ & $25,000.00$ & $0 \%$ & $25,000.00$ & \\
\hline 6 & Sub Total & & & & $\$$ & $236,780.00$ & & $236,780.00$ & \\
\hline \multicolumn{2}{|c|}{ Flare Platform } & & & & & & & & \\
\hline 7 & Carbon Steel & 5 & $\$$ & $3,450.00$ & $\$$ & $17,250.00$ & $0 \%$ & $17,250.00$ & \\
\hline 7 & Stainless Steel & 20 & $\$$ & $10,700.00$ & $\$$ & $214,000.00$ & $0 \%$ & $214,000.00$ & \\
\hline 7 & Sub Total & & & & $\$$ & $231,250.00$ & & $231,250.00$ & \\
\hline
\end{tabular}


Offshore Site - Vermilion 179

Detailed Cost Estimate Sheet

Line No. 5 Fabrication Labor

A3122-05

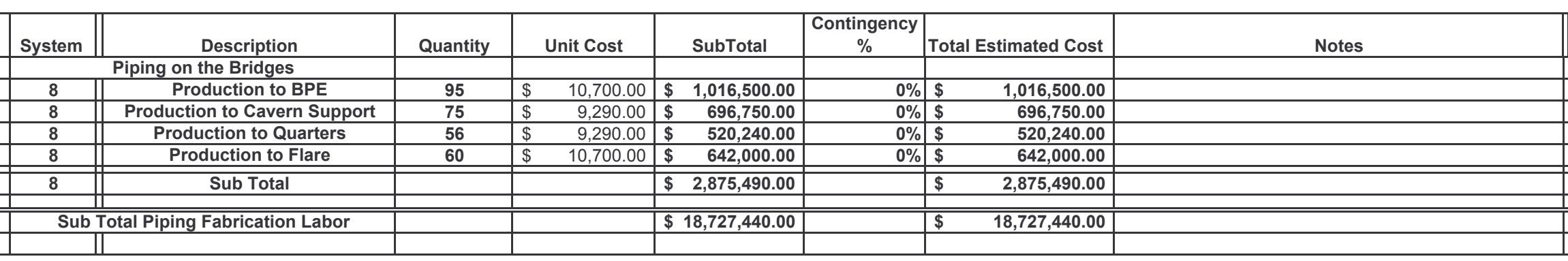


Offshore Site - Vermilion 179

Detailed Cost Estimate Sheet

Line No. 5 Fabrication Labor

A3122-05

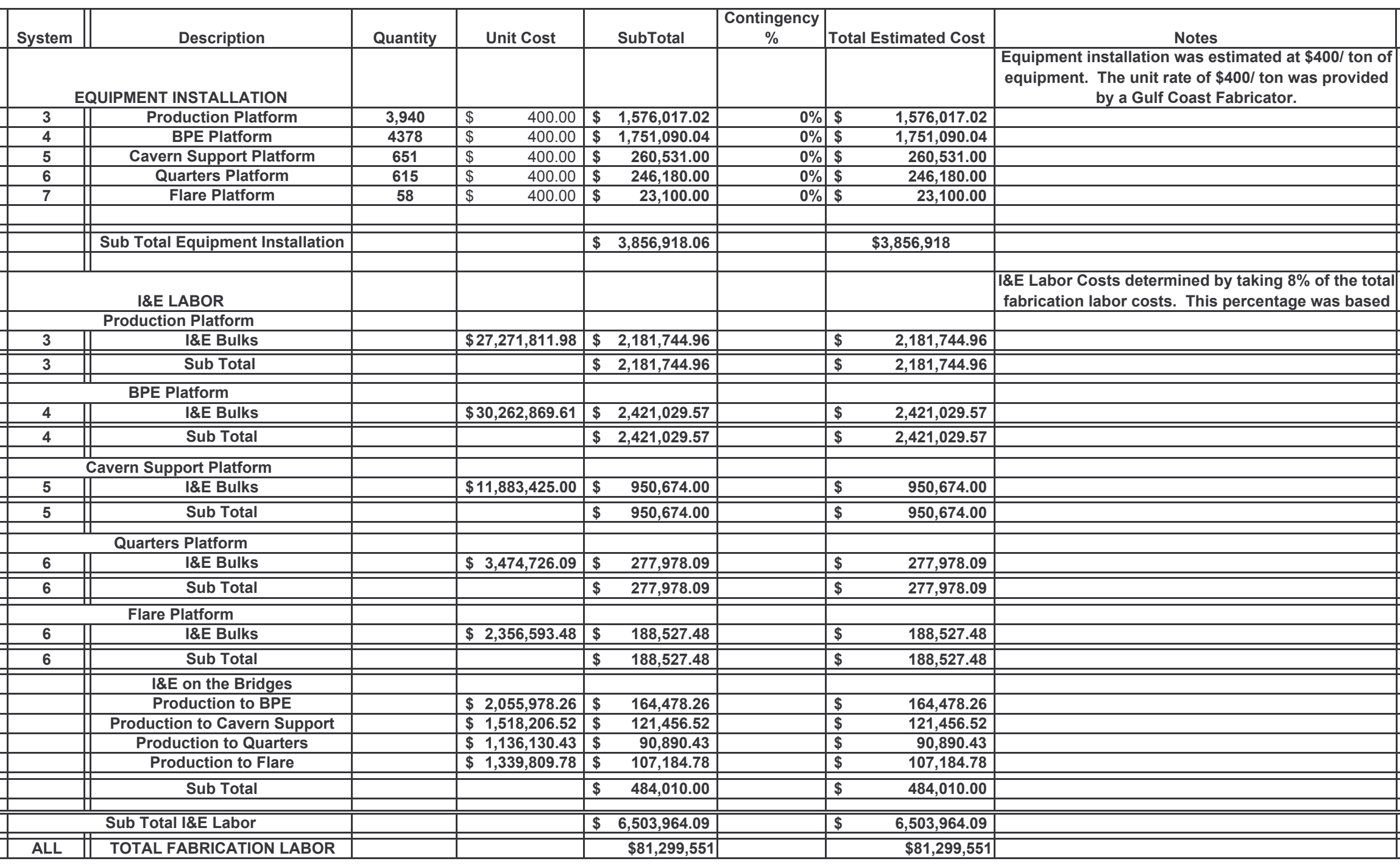


Offshore Site - Vermilion 179

Detailed Cost Estimate Sheet

A3122-05

$12 / 3 / 2004$

Line No. 6 Freight, Receiving \& Inspection

\begin{tabular}{|c|c|c|c|c|}
\hline Description & Equipment Cost & $\begin{array}{c}\text { Freight as \% } \\
\text { of } \\
\text { Equipment } \\
\text { Cost } \\
\end{array}$ & $\begin{array}{c}\text { Freight Total } \\
\text { Cost }\end{array}$ & Notes \\
\hline Freight for Equipment on Production Platform & $\$ 104,006,625$ & $1 \%$ & $\$ 1,040,066$ & \\
\hline Freight for Equipment on BPE Platform & $\$ 75,410,950$ & $1 \%$ & $\$ 754,109$ & \\
\hline Freight for Equipment on Cavern Support Platform & $\$ 13,335,540$ & $1 \%$ & $\$ 133,355$ & \\
\hline Freight for Equipment on Quarters Platform & $\$ 10,835,273$ & $1 \%$ & $\$ 108,353$ & \\
\hline Freight for Equipment on Flare Platform & $\$ 1,270,000$ & $1 \%$ & $\$ 12,700$ & \\
\hline Freight for Equipment on Bridges & & $1 \%$ & $\$ 0$ & \\
\hline Sub-Totals for: Freight, Receiving \& Inspection & & & $\$ 2,048,584$ & \\
\hline TOTALS FOR LINE NO.: & & & $\$ 2,048,584$ & \\
\hline
\end{tabular}


Offshore Site - Vermilion 179

Detailed Cost Estimate Sheet

Line No. 7 Loadout \& Marine Transport

A3122-05

$1 / 3 / 2004$

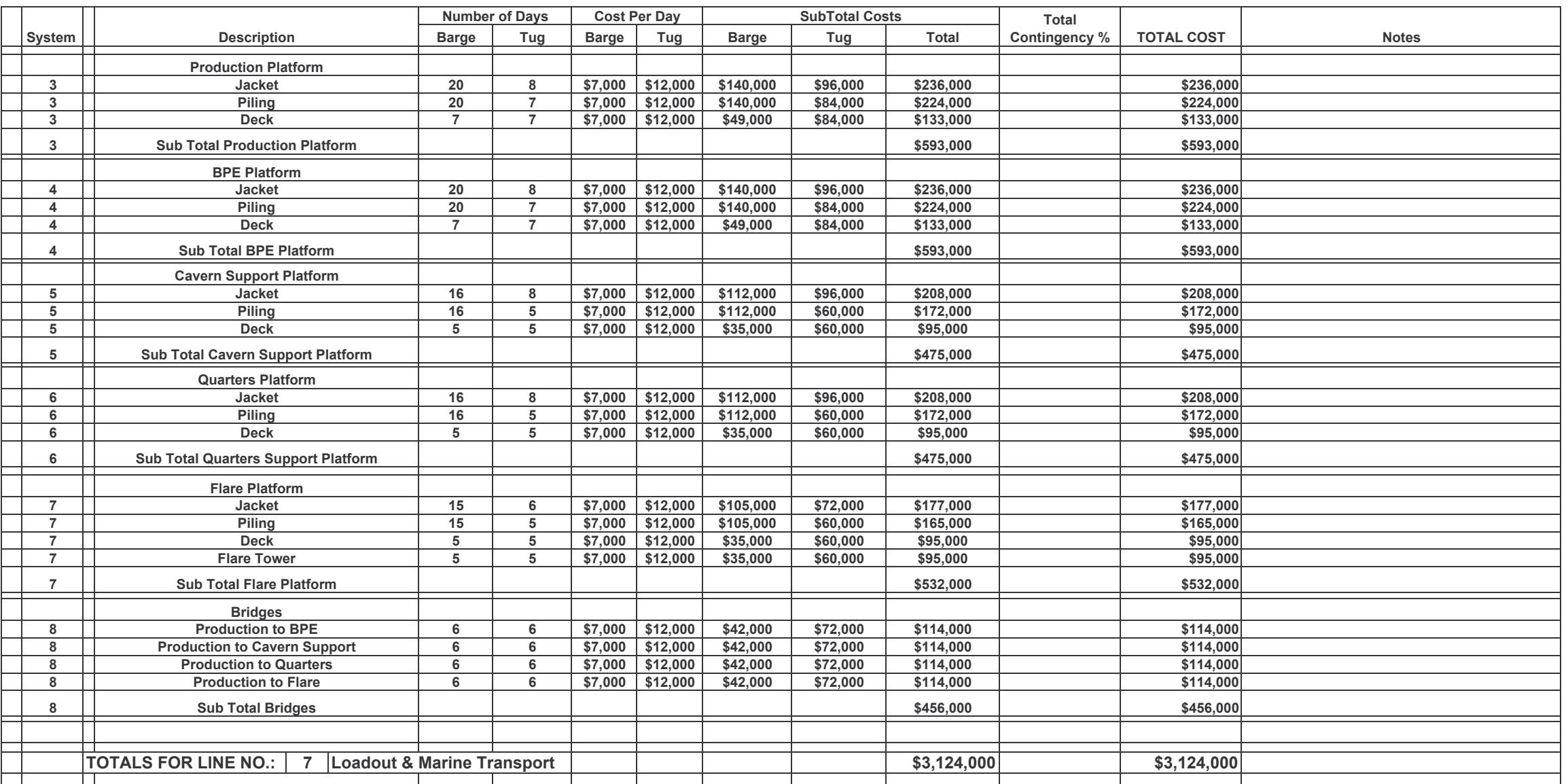


Offshore Site - Vermilion 179

Detailed Cost Estimate Sheet

8 Installation

A3122-05

$12 / 3 / 2004$

\begin{tabular}{|c|c|c|c|c|c|c|c|c|c|}
\hline System & Description & Number of Days & $\begin{array}{c}\text { Cost of Spread Per } \\
\text { Day }\end{array}$ & SubTotal Costs & $\begin{array}{c}\begin{array}{c}\text { Weather Related } \\
\text { Costs }\end{array} \\
\end{array}$ & $\begin{array}{c}\text { Total Cost } \\
\text { Without } \\
\text { Contingency } \\
\end{array}$ & \begin{tabular}{|c|}
$\begin{array}{c}\text { Total } \\
\text { Contingency } \%\end{array}$ \\
\end{tabular} & TOTAL COST & Notes \\
\hline & Production Platform & & & & & & & & \multirow{5}{*}{$\begin{array}{l}\text { Costs based upon the day rate of the Herema's } \\
\text { Thialf Derrick Barge. The number of days were } \\
\text { estimated for the jacket at a day to get set up } \\
\text { and a day to install. The number of days were } \\
\text { estimated for the piling as } 1.5 \text { days per pile } \\
\text { plus } 1.5 \text { days to set up and take down }\end{array}$} \\
\hline 3 & Jacket & 2 & & & & & & & \\
\hline 3 & Piling & 15 & & & 1 & & & & \\
\hline 3 & Deck & 3 & & & 1 & & & & \\
\hline \multirow[t]{2}{*}{3} & Sub Total Production Platform & 20 & $\$ 450,000$ & $\$ 9,000,000$ & $\$ 900,000$ & $\$ 9,900,000$ & & $\$ 9,900,000$ & \\
\hline & BPE Platform & & & & & & & & \multirow{5}{*}{$\begin{array}{c}\text { The number of days were estimated for the } \\
\text { deck as a day to get set up, a day to lift and } \\
\text { install and a day to weldout. }\end{array}$} \\
\hline 4 & Jacket & 2 & & & & & & & \\
\hline 4 & Piling & 15 & & & 1 & & & & \\
\hline 4 & Deck & 3 & & & 1 & & & & \\
\hline \multirow[t]{2}{*}{4} & Sub Total BPE Platform & 20 & $\$ 450,000$ & $\$ 9,000,000$ & $\$ 900,000$ & $\$ 9,900,000$ & & $\$ 9,900,000$ & \\
\hline & Cavern Support Platform & & & & & & & & \multirow{5}{*}{$\begin{array}{l}\text { The bridges were estimated at one day a piece } \\
\text { to set and install. Weather downtime was } \\
\text { assumed at approximately } 10 \% \text { of the time. }\end{array}$} \\
\hline 5 & Jacket & 2 & & & & & & & \\
\hline 5 & Piling & 15 & & & 1 & & & & \\
\hline 5 & Deck & 3 & & & 1 & & & & \\
\hline \multirow[t]{2}{*}{5} & Sub Total Cavern Support Platform & 20 & $\$ 450,000$ & $\$ 9,000,000$ & $\$ 900,000$ & $\$ 9,900,000$ & & $\$ 9,900,000$ & \\
\hline & Quarters Platform & & & & & & & & \\
\hline 6 & Jacket & 2 & & & & & & & \\
\hline 6 & Piling & 6 & & & & & & & \\
\hline 6 & Deck & 3 & & & 1 & & & & \\
\hline \multirow[t]{2}{*}{6} & Sub Total Quarters Support Platform & 11 & $\$ 450,000$ & $\$ 4,950,000$ & $\$ 450,000$ & $\$ 5,400,000$ & & $\$ 5,400,000$ & \\
\hline & Flare Platform & & & & & & & & \\
\hline 7 & Jacket & 2 & & & & & & & \\
\hline 7 & Piling & 4 & & & & & & & \\
\hline 7 & Deck & 1 & & & & & & & \\
\hline 7 & Flare Tower & 1 & & & 1 & & & & \\
\hline \multirow[t]{2}{*}{7} & Sub Total Flare Platform & 8 & $\$ 450,000$ & $\$ 3,600,000$ & $\$ 450,000$ & $\$ 4,050,000$ & & $\$ 4,050,000$ & \\
\hline & Bridges & & & & & & & & \\
\hline 8 & Production to BPE & 1 & & & & & & & \\
\hline 8 & Production to Cavern Support & 1 & & & & & & & \\
\hline 8 & Production to Quarters & 1 & & & & & & & \\
\hline 8 & $\begin{array}{l}\text { Production to Flare } \\
\end{array}$ & 1 & & & 1 & & & & \\
\hline \multirow[t]{2}{*}{8} & Sub Total Bridges & 4 & $\$ 450,000$ & $\$ 1,800,000$ & $\$ 450,000$ & $\$ 2,250,000$ & & $\$ 2,250,000$ & \\
\hline & Mob / Demob & 4 & $\$ 400,000$ & $\$ 1,600,000$ & $\$ 0$ & $\$ 1,600,000$ & & $\$ 1,600,000$ & $\begin{array}{c}\text { Mob / Demob based upon Barge being in Gulf } \\
\text { of Mexico }\end{array}$ \\
\hline & \begin{tabular}{|l|c|l|} 
TOTALS FOR LINE NO.: & $\mathbf{8}$ & Installation \\
\end{tabular} & & & $\$ 38,950,000$ & $\$ 4,050,000$ & $\$ 43,000,000$ & & $\$ 43,000,000$ & \\
\hline
\end{tabular}


Offshore Site - Vermilion 179

Cost Estimate Sheet

8 Hook Up \& Commissioning

\begin{tabular}{|c|c|c|c|c|c|c|c|c|c|c|c|}
\hline \multirow[b]{2}{*}{ System } & \multirow[b]{2}{*}{ Description } & \multicolumn{2}{|c|}{ Number of Days } & \multicolumn{2}{|c|}{ Cost Per Day } & \multicolumn{3}{|c|}{ SubTotal Costs } & \multirow[b]{2}{*}{$\begin{array}{c}\text { Total } \\
\text { Contingency \% }\end{array}$} & \multirow[b]{2}{*}{ TOTAL COST } & \multirow[b]{2}{*}{ Notes } \\
\hline & & Crew & \begin{tabular}{|c|}
$\begin{array}{c}\text { Support } \\
\text { Vessel }\end{array}$ \\
\end{tabular} & Crew & $\begin{array}{l}\text { Support } \\
\text { Vessel }\end{array}$ & Crew & $\begin{array}{l}\begin{array}{c}\text { Support } \\
\text { Vessel }\end{array} \\
\end{array}$ & Total & & & \\
\hline & Production Platform & & & & & & & & & & \\
\hline 3 & Deck & 10 & 10 & $\$ 90,000$ & $\$ 120,000$ & $\$ 900,000$ & $\$ 1,200,000$ & $\$ 2,100,000$ & & $\$ 2,100,000$ & \\
\hline 3 & Sub Total Production Platform & 10 & 10 & & & & & & & $\$ 2,100,000$ & \\
\hline & BPE Platform & & & & & & & & & & \\
\hline 4 & Deck & 10 & 10 & $\$ 90,000$ & $\$ 120,000$ & $\$ 900,000$ & $\$ 1,200,000$ & $\$ 2,100,000$ & & $\$ 2,100,000$ & \\
\hline \multirow[t]{2}{*}{4} & Sub Total BPE Platform & 10 & 10 & & & & & & & $\$ 2,100,000$ & \\
\hline & Cavern Support Platform & & & & & & & & & & \\
\hline 5 & Deck & 10 & 10 & $\$ 90,000$ & $\$ 120,000$ & $\$ 900,000$ & $\$ 1,200,000$ & $\$ 2,100,000$ & & $\$ 2,100,000$ & \\
\hline \multirow[t]{2}{*}{5} & Sub Total Cavern Support Platform & 10 & 10 & & & & & & & $\$ 2,100,000$ & \\
\hline & Quarters Platform & & & & & & & & & & \\
\hline 6 & Deck & 5 & 5 & $\$ 90,000$ & $\$ 120,000$ & $\$ 450,000$ & $\$ \$ 600,000$ & $\$ 1,050,000$ & & $\$ 1,050,000$ & \\
\hline \multirow[t]{2}{*}{6} & Sub Total Quarters Platform & 5 & 5 & & & & & & & $\$ 1,050,000$ & \\
\hline & Flare Platform & & & & & & & & & & \\
\hline 7 & Deck/Flare Tip & 2 & 2 & $\$ 90,000$ & $\$ 120,000$ & $\$ 180,000$ & $\$ 240,000$ & $\$ 420,000$ & & $\$ 420,000$ & \\
\hline \multirow[t]{2}{*}{7} & Sub Total Flare Platform & 2 & 2 & & & & & & & $\$ 420,000$ & \\
\hline & Bridges & & & & & & & & & & \\
\hline 8 & Production to BPE & 2 & 2 & $\$ 90,000$ & $\$ 120,000$ & $\$ 180,000$ & $\$ 240,000$ & $\$ 420,000$ & & $\$ 420,000$ & \\
\hline 8 & Production to Cavern Support & 2 & 2 & $\$ 90,000$ & $\$ 120,000$ & $\$ 180,000$ & 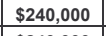 & $\$ 420,000$ & & $\$ 420,000$ & \\
\hline$\frac{8}{8}$ & Production to Quarters & $\frac{2}{2}$ & $\frac{2}{2}$ & $\$ 90,000$ & $\$ 120,000$ & $\$ 180,000$ & $\$ 240,000$ & $\$ 420,000$ & & $\$ 420,000$ & \\
\hline$\frac{8}{8}$ & $\begin{array}{l}\text { Production to Flare } \\
\text { Sub }\end{array}$ & $\frac{2}{8}$ & $\frac{2}{8}$ & $\$ 90,000$ & $\$ 120,000$ & $\$ 180,000$ & 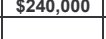 & $\$ 420,000$ & & $\$ 420,000$ & \\
\hline \multirow{2}{*}{8} & Suo toral briages & & & & & & & & & $\$ 1,680,000$ & \\
\hline & TOTALS FOR LINE NO.: & & Hook Up & Comm & ioning & & & $\$ 9,450,000$ & & $\$ 9,450,000$ & \\
\hline
\end{tabular}




\section{MARINE PIPELINE PRELIMINARY COST ESTIMATE}

\section{6-INCH, 10-MILE EXPORT GAS PIPELINE}

One 36" Pipeline (Top of Riser to Subsea-Tie-in)

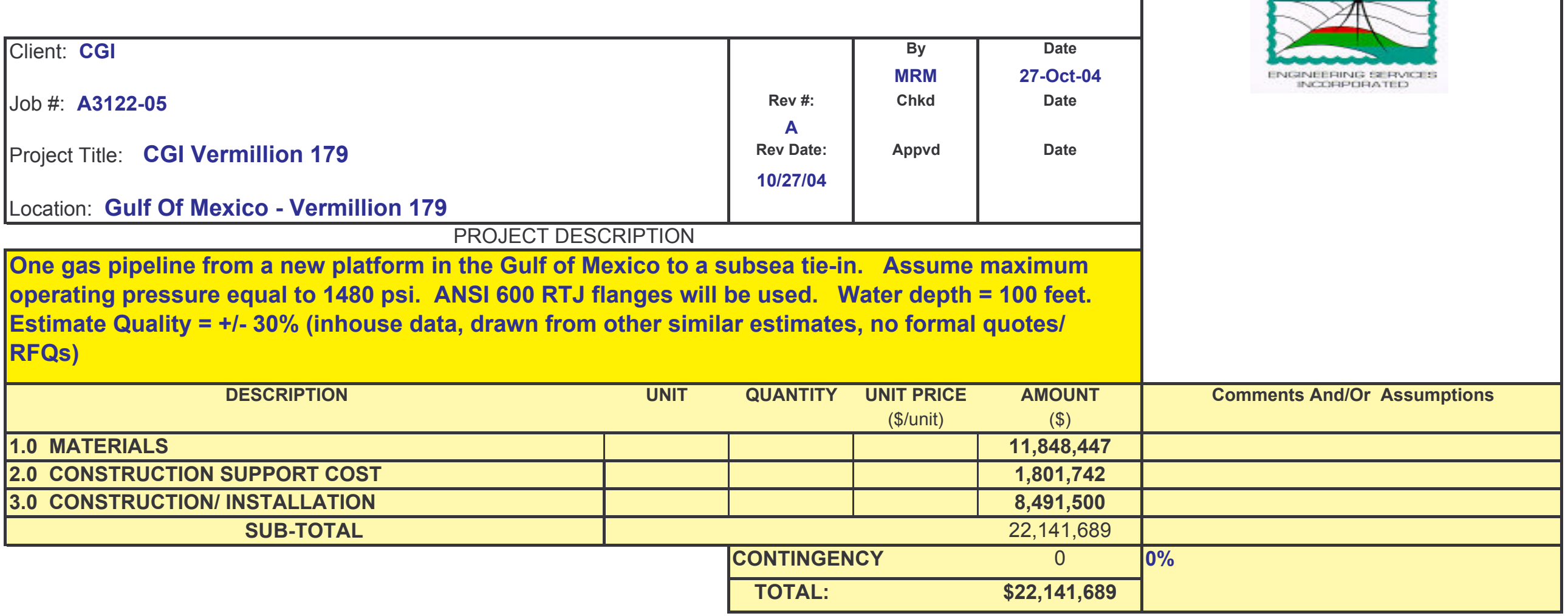




\section{MARINE PIPELINE PRELIMINARY COST ESTIMATE}

30-INCH, 10-MILE EXPORT GAS PIPELINE

One 30" Pipeline (Top of Riser to Subsea-Tie-in)

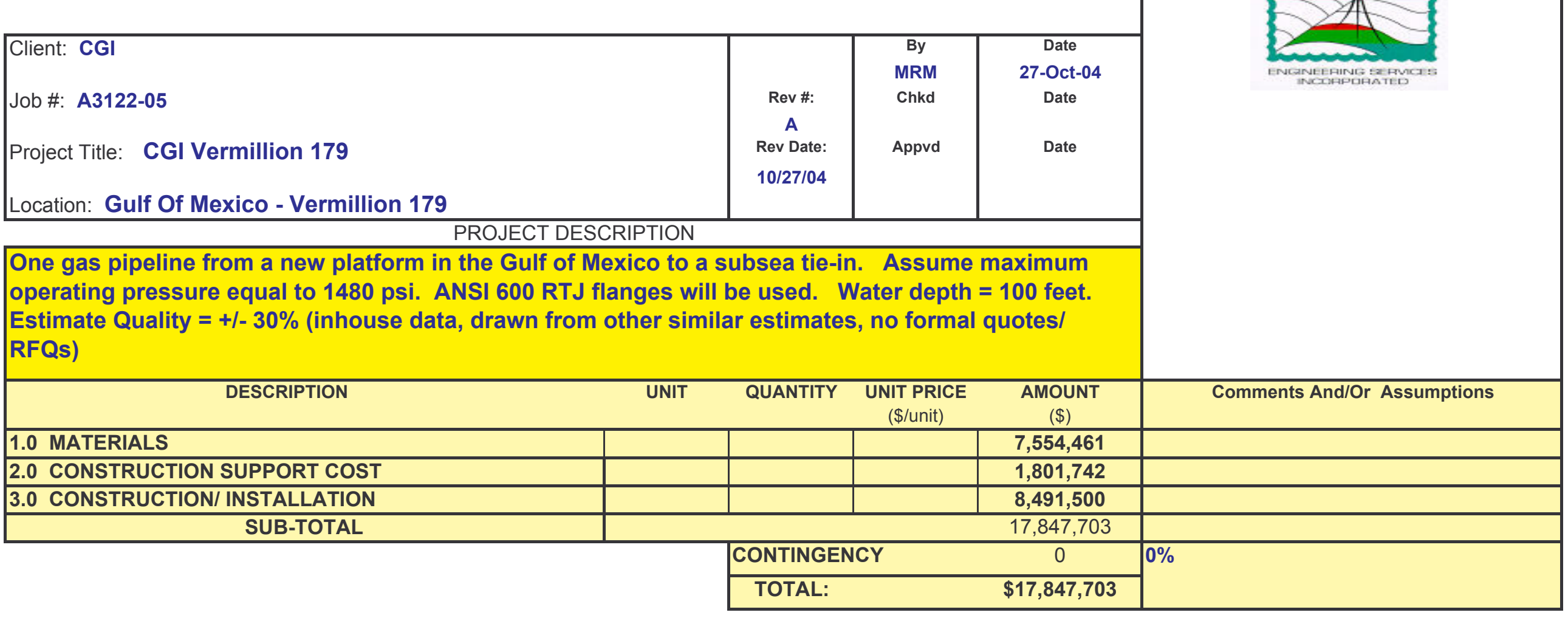




\section{MARINE PIPELINE PRELIMINARY COST ESTIMATE}

\section{0-INCH, 10-MILE EXPORT GAS PIPELINE}

One 20" Pipeline (Top of Riser to Subsea-Tie-in)

\begin{tabular}{|c|c|c|c|c|c|}
\hline $\begin{array}{l}\text { Client: CGI } \\
\text { Job \#: A3122-05 } \\
\text { Project Title: CGI Vermillion } 179 \\
\text { Location: Gulf Of Mexico - Vermillion } 179\end{array}$ & & $\begin{array}{l}\text { Rev \#: } \\
\text { A } \\
\text { Rev Date: } \\
\text { 10/27/04 }\end{array}$ & $\begin{array}{l}\text { By } \\
\text { MRM } \\
\text { Chkd } \\
\text { Apprd }\end{array}$ & $\begin{array}{l}\text { Date } \\
\text { 27-Oct-04 } \\
\text { Date } \\
\text { Date }\end{array}$ & 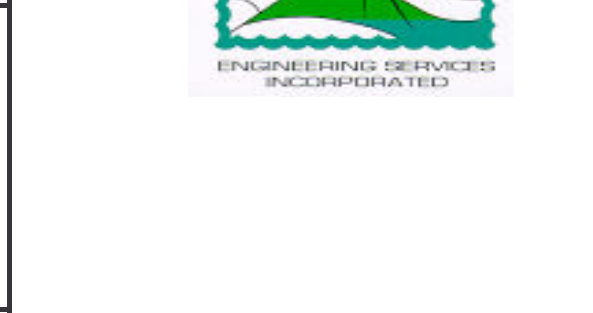 \\
\hline \multicolumn{5}{|c|}{$\begin{array}{l}\text { One gas pipeline from a new platform in the Gulf of Mexico to a subsea tie-in. Assume maximum } \\
\text { operating pressure equal to } 1480 \text { psi. ANSI } 600 \text { RT J flanges will be used. Water depth = } 100 \text { feet. } \\
\text { Estimate Quality = +/- } 30 \% \text { (inhouse data, drawn from other similar estimates, no formal quotes/ } \\
\text { RFQs) }\end{array}$} & \\
\hline DESCRIPTION & UNIT & QUANTITY & $\begin{array}{l}\text { UNIT PRICE } \\
\text { (\$/unit) }\end{array}$ & $\begin{array}{c}\text { AMOUNT } \\
(\$)\end{array}$ & Comments And/Or Assumptions \\
\hline 1.0 MATERIALS & & & & $4,303,670$ & \\
\hline 2.0 CONSTRUCTION SUPPORT COST & & & & $1,801,742$ & \\
\hline 3.0 CONSTRUCTION/INSTALLATION & & & & $7,210,000$ & \\
\hline \multirow{3}{*}{\multicolumn{2}{|c|}{ SUB-TOTAL }} & & & $13,315,412$ & \\
\hline & & CONTINGEI & & 0 & \multirow[t]{2}{*}{$0 \%$} \\
\hline & & TOTAL: & & $\$ 13,315,412$ & \\
\hline
\end{tabular}


Offshore Site - Vermilion 179

Detailed Cost Estimate Sheet

Cost Estimate by PB Energy and Listed Below

$$
\begin{gathered}
\text { DESCRIPTION } \\
\text { Drilling the Wells } \\
\text { Developing the Salt Caverns } \\
\text { Salt Coring Program } \\
\text { Laboratory Testing \& Analysis } \\
\text { Numerical Modeling Program }
\end{gathered}
$$

TOTALS

$\begin{array}{ccc}\text { Quantity } & \text { Unit Cost } & \text { Total Cost } \\ 7 & \$ 10,000,000 & \$ 70,000,000 \\ 7 & \$ 2,857,143 & \$ 20,000,000 \\ 1 & 75000 & \$ 75,000 \\ 1 & 60000 & \$ 60,000 \\ 1 & 80000 & \$ 80,000 \\ & & \$ 90,215,000\end{array}$

NOTES

Paragon received the costs directly from PB Energy and the costs do not include any contingency. 


\section{Appendix 7 \\ BLUEWATER OFFSHORE BIG SWEEP SYSTEM}




\section{Revision Status Sheet}

$\begin{array}{cclc}\text { Rev. } & \text { Date } & \text { Description } & \text { Initiator } \\ \text { A } & \text { 04-Jun-2004 } & \text { Initial issue } & \text { FKRI } \\ \text { B } & \text { 09-July-2004 } & \text { Latest information incorporated } & \text { FKRI }\end{array}$


Doc. No. BIGS-B-100-RP-0001/Rev.in Progress

\section{BI G Sweep Study}

\section{Process System Description}

Doc.No. BIGS-B-100-RP-0001/Rev. in progress

Project No.: 2-6024-3 


\section{Contents}

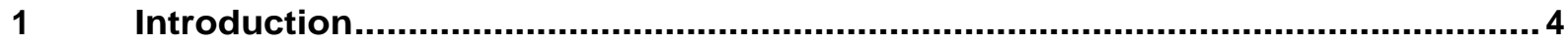

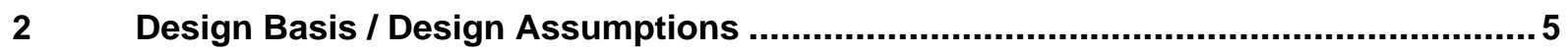

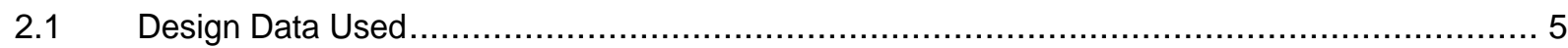

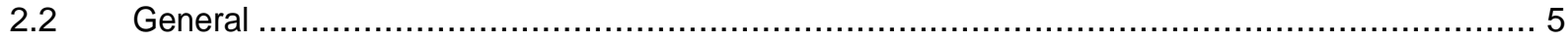

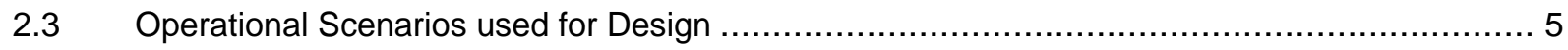

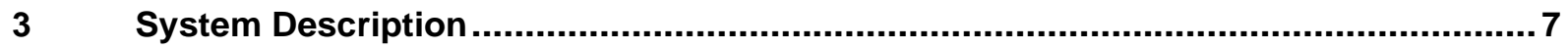

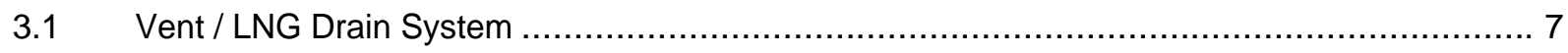

3.1.1 Connection with Vent /Relief Valves .......................................................... 7

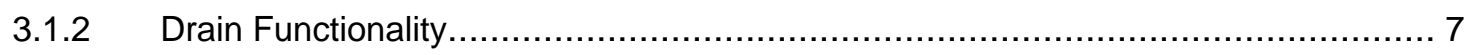

3.1.3 Manual Venting of Recycle Lines ............................................................ 7

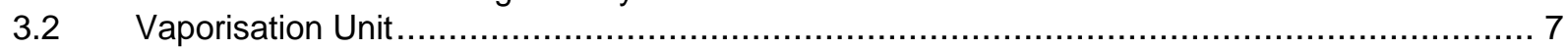

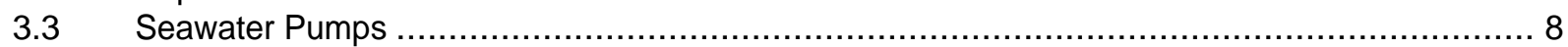

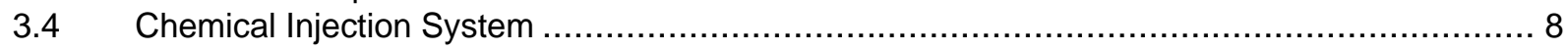

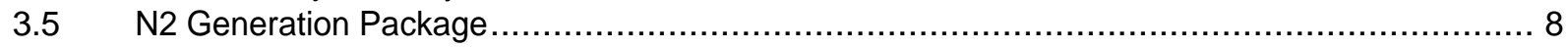

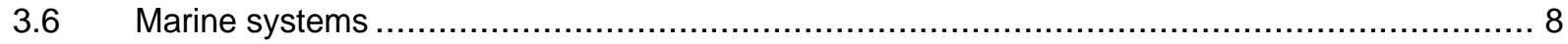

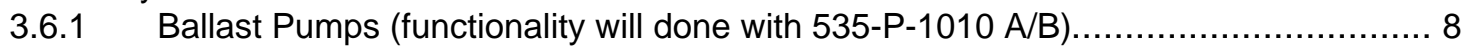

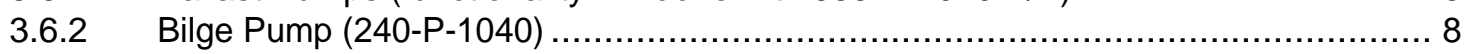

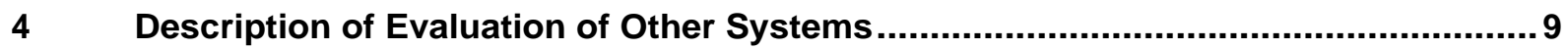

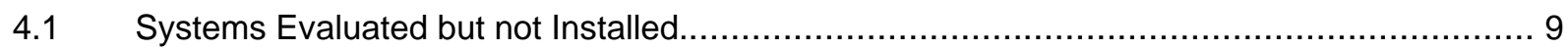

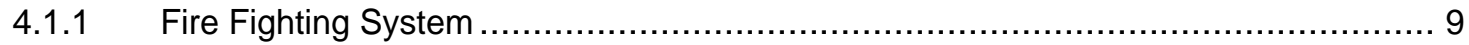

4.1.2 Emergency Power System .................................................................... 9

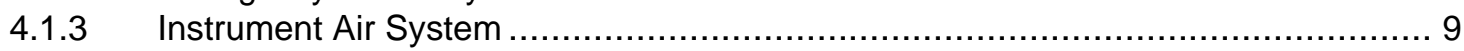

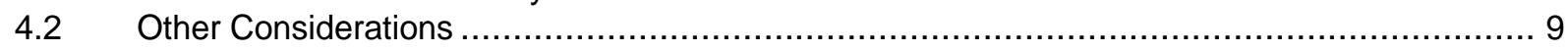

$5 \quad$ References ............................................................................................................ 10 
Doc. No. BIGS-B-100-RP-0001/Rev.in Progress Big Sweep Study - Process System Description

\section{Introduction}

This document describes the process design requirements and assumptions for the Big Sweep. The development of the Big Sweep is in the conceptual phase. This means that this process description reflects the thoughts currently seen as the most likely set-up. Where required, alternative solutions will be presented. A more detailed engineering phase and/or further studies will determine the final selection in such cases. 
Doc. No. BIGS-B-100-RP-0001/Rev.in Progress

\section{Design Basis / Design Assumptions}

\subsection{Design Data Used}

The Big Sweep is an unloading system for LNG. The design capacity of the Big Sweep is $8000 \mathrm{~m} 3 / \mathrm{hr}$ of LNG offloading. Physical properties used for the calculation may be found in the Design Basis, Design philosophies, Functional descriptions and scope of work document (ref. 1).

\subsection{General}

The Big Sweep is an unloading system for LNG (in other words LNG carriers are offloaded). The LNG is transported via the big sweep piping (above sea level), via $2 \times 24$ " lines (buried subsea pipelines), to a process platform. The LNG will be converted to gas at the process platform. The conversion into gas takes place via a so-called Bishop Process Heat Exchanger (BPE). This BPE exchanger (a sort of pipe in pipe exchanger) uses seawater as heating medium for the vaporisation of the LNG. The LNG is then stored in the gaseous phase in salt caverns. The caverns are linked to the gas pool (mainland US).

Two operational scenarios are possible,

- Supply of gas to the gas pool and /or the salt caverns during offloading.

- Supply of gas from out the salt caverns into the gas pool (no LNG carrier offloading).

The subsea piping system is kept cold (to limit LNG vaporisation and to avoid lengthy cool down periods before offloading) during non off-loading conditions by 2 mechanisms;

- Passive, to avoid heat ingress by insulation.

- Active, by transport of the heat absorbed by the LNG via a circulation circuit. The gas developed during this circulation will be knocked -out in a KO drum on the process platform. Knocked out LNG will be re-liquefied to $L N G$. The re-liquefied gas will be added to the circulation circuit to replace the vaporised LNG with liquid. The circulation system will be maintained liquid filled and cold via this procedure.

The circulation will under normal circumstances include the Big Sweep. Isolation of the subsea piping will be done by a manifold ${ }^{1}$ below the swivel (Paragon scope).

\subsection{Operational Scenarios used for Design}

For the Big Sweep the following operational process cases can be foreseen,

Normal operation;

- Offloading conditions. Vapour generation has to be active to be able to replace the offloaded LNG from the LNG carrier with vapour. A vaporisation unit will be installed on the Big Sweep (design of vaporiser is in Paragon scope)

- Transition phase between offloading and circulating (connect/ disconnect and vice versa).

- Circulating conditions. The circulation over the subsea piping will include circulation over the Big Sweep.

\footnotetext{
${ }^{1}$ Location of manifold could also be selected subsea, but the location below the swivel seems to be preferred, as subsea valves are difficult to maintain.
} 
Doc. No. BIGS-B-100-RP-0001/Rev.in Progress

\section{Abnormal operation}

- Emergency conditions ${ }^{2}$ at the process platform, at the LNG carrier or at the Big Sweep might require (partial) isolation of the Big Sweep and the process platform (see also Control philosophy paragraph safeguarding system - ref. 2).

Draining of the LNG content of the Big Sweep into the transport / circulation piping is seen as a safe measure to minimise the inventory. The loading arm will be at ambient temperature after draining and depressurising.

- $\quad$ Start-up after prolonged shutdown (e.g. start of cooling down of piping by circulating over subsea piping and Big Sweep piping, or form a LNG carrier, depending on the availability of LNG).

Additional operation

- The subsea pipeline has to be able to be vented on either end of the pipeline (Paragon to advise for sizing of venting caused by absorbed heat).

\footnotetext{
${ }^{2}$ Process upsets, which will require temporary stop of process are not seen as an abnormal situation
} 
Doc. No. BIGS-B-100-RP-0001/Rev.in Progress Big Sweep Study - Process System Description

\section{System Description}

A PFD (ref. 3) has been prepared for the Big Sweep. This PFD shows the main process layout of the Big Sweep. A very important system will be the vent / relief / LNG drain system. The following line sizes are selected within this phase of the study:

- Transport lines are selected as 20 " lines (in line with the size of the coupling and the hoses).

- The vapour return line is estimated as 16 " (velocity $20 \mathrm{~m} / \mathrm{s}$ ), although smaller sizes could be selected / evaluated.

\subsection{Vent / LNG Drain System}

The Vent / Relief / LNG drain system is set-up to service as a system to vent/relief LNG in a safe manner but also to support emergency draining and/or the manual venting of the subsea pipelines.

\subsubsection{Connection with Vent /Relief Valves}

Closed segments of piping filled with liquid LNG will absorb heat from the environment. This heat will cause vaporisation, resulting in an increase of pressure. Segments like this will be equipped with a relief valve. This relief valve will be connected with the drain/vent vessel (return vapour separator 515-V-1000) via which it will be disposed at a safe location. Vents (e.g. highpoint vents) will also be lined up to this vessel. A LNG vapour blanket (generated by the vaporiser 505-E-1000) will avoid ingress of air/ oxygen into this vessel in case not sufficient is vented.

\subsubsection{Drain Functionality}

The connection of the process platform and the Big Sweep will be supplied with a jump over (location to be determined - Paragon scope). An unusual operation at the process platform, LNG carrier or at the Big Sweep will require the Big Sweep to drain (via purging with LNG generated with the vaporiser 505-E-1000) via the local dummy manifold into the subsea pipeline. The Big sweep can be inerted with $\mathrm{N} 2$ if required after being drained with LNG vapour. An alternative draining method will be draining LNG via the return vapour vaporiser (515-V-1000) which will act as a KO vessel / suction vessel for the return LNG pump (515-P-1000 ABB). This return LNG pump ${ }^{3}$ transfers LNG collected from the Big Sweep into this vessel (under LNG vapour pressure or N2 pressure) into the liquid filled subsea pipeline (via one of the two swivel passes).

\subsubsection{Manual Venting of Recycle Lines}

The subsea pipeline will require to be vented via the Big Sweep. The vent system will be designed for this option (Paragon to advise vent capacity as venting caused by absorbed heat could be size determining for the vent line to safe location).

\subsection{Vaporisation Unit}

This unit will produce gas for the vapour return line to the LNG carrier. This unit will require a gas production of at least $8000^{4} \mathrm{~m} 3 / \mathrm{hr}$ (design rate of the Big Sweep). This vaporiser (505-E-1000) will be using direct seawater (see next paragraph) as a heating medium. Seawater is preferred as heating medium as the risk of freezing of tubes with air-cooling is seen as an operational risk.

\footnotetext{
${ }^{3}$ Pump is currently sized for liquid LNG draining, knocked out during vapor generation ( $23 \mathrm{~m} 3 / \mathrm{hr}$ ).

${ }^{4}$ It is advised to increase the flow of the vapor generator to approx. $110 \%=8800$ to ensure a surplus of gas generation capacity. Paragon based design on $8000 \mathrm{~m} 3 / \mathrm{hr}$ as vendors normally provide overdesign in heaters.
} 
Doc. No. BIGS-B-100-RP-0001/Rev.in Progress

The vaporiser will use a slipstream of the liquid $L N G$ transport line as $L N G$ source. The vaporiser will require a return vapour separator (515-V-1000) and a LNG return pump (515-P-1000 A/B) as part of the vaporisation process (design Paragon). The mentioned separator and pump are combined with the drain vessel/ drain pump functionality as described in \$3.1 Other utilities required are power, nitrogen, relief valve / vent connections, LNG drain connections. The vaporiser delivers vapour for the LNG carrier as well as vapour for drain purposes.

\subsection{Seawater Pumps}

Seawater is required as heating source for the vaporiser (seawater pumps are selected to be 190 $\mathrm{m} 3 / \mathrm{hr}$ - Paragon data sheet ref. 5). The seawater could be used direct or indirect. Direct is an advantage with respect to complexity. Indirect is expected to be advantages for material selection and maintenance. This study uses direct cooling as the basic concept. The centrifugal seawater lift pumps (535-P-1010 A/B) will be placed in an equipment room adjacent to the ballast spaces. This ensures a positive suction head as these ballast vessels are under the waterline. Seawater lift pump suction piping is preliminary sized as 8 " and discharge piping 6".

The seawater lift pump will be combined with the ballast eductor (see §3.6.1). A possible future interfaces / combined operation could be with a fire water systems (if applicable, see chapter 4). Required utilities are chemical dosing (biocide chlorination), power.

\subsection{Chemical Injection System}

Seawater will require chlorination and biocide shock dosing. Intention is to use the supply of chemicals via tote tanks. No chlorination unit is foreseen (unless the quantities will be logistically too large). Dosing pumps (540-P-1020 / 540-P-1030) will be installed.

\subsection{N2 Generation Package}

The piping of the big sweep has to be purged in an emergency situation ${ }^{5}$.

(Partial) Inerting of the Big Sweep will be done after draining in exceptional cases (e.g. maintenance). An estimate of the required N2 capacity will determine the final selection of the required N2 system. No N2 generation is foreseen.

The volume of the Big Sweep is approx. $100 \mathrm{m3}$. A N2 pressure vessel (approx. $5 \mathrm{~m} 3$ at 200 bar) or a liquid N2 storage with vaporiser skid seems to be required for inerting the volume of the Big Sweep. Sectionalising (inerting pipe segments during maintenance) can limit N2 usage, although this will not influence the required N2 skid capacity.

\subsection{Marine systems}

\subsubsection{Ballast Pumps (functionality will done with 535-P-1010 A/B)}

Ballasting is mainly required for maintenance purpose. A content of $1000 \mathrm{~m} 3$ ballast water is estimated to be on board of the Big Sweep. Ballasting will be done with the seawater lift pumps. This will result in ballast clearance time of approx. 5 hours

\subsubsection{Bilge Pump (240-P-1040)}

A bilge pump will be foreseen for the equipment rooms. This will be done via an eductor (in combination with the seawater lift pump) or by a small dedicated pump (capacity approx. $5 \mathrm{~m} 3 / \mathrm{h}$ ).

\footnotetext{
${ }^{5}$ The Big Sweep will only be drained under Emergency shutdown situation, but not under normal process upsets.
} 


\section{Description of Evaluation of Other Systems}

\subsection{Systems Evaluated but not Installed.}

\subsubsection{Fire Fighting System}

The requirement of a fire fighting system is not seen as a necessity to establish a safe operating unloading arm (Current estimate is that a fire fighting system might not be required see ref. 6). Specific coverage will be specified if a fire water system is required. Combination of the seawater lift pump functionality with firewater capacity $(2 \times 100 \%$ or $3 \times 50 \%)$ will be selected in such case. Requirement of a fire fighting system whit area coverage is seen as very unlikely.

\subsubsection{Emergency Power System}

No emergency power system is foreseen. Emergency power will be supplied via a slip ring. An emergency power system will require installation of an emergency diesel with required utilities. Installation of diesel facilities would require installation of a closed drain system in combination with diesel day tank provisions (see also ref. 4). Also fire water system requirements will be influenced by the introduction of a diesel system. Consequences for electrical switchboard are not yet evaluated, but will be present. The emergency slip ring profits from power reliability on the process platform.

\subsubsection{Instrument Air System}

A hydraulic power pack is selected as required / preferential for control purposes (see ref. 2). The electrical sliprings (normal and emergency) will be oil filled or gas purged to ensure that it will be Exd. (Classification required for this application). An instrument air system could be selected if air is selected as purge medium. Special consideration should be given in the next (project) phase, to a black start scenario (e.g. after shut down of the process platform) in case a gas purged slip ring is selected. Three start-up purge options are seen as possible; Air by diesel driven compressor or air purge by bottled air or purging with nitrogen. The next phase should also evaluate selection of an emergency power slipring vs. installation of an emergency diesel generator.

\subsection{Other Considerations}

- Bunkering requirements are not installed / incorporated in the current design. If bunkering is required an evaluation has to be done on the best way forward. Bunkering will have a big influence on the various systems. The swivel might require some extra passes if supply from the process platform will be foreseen. Some extra connection with the LNG carrier will be required. Extra piping across the Big Sweep will be installed. Operation could be influenced depending whether bunkering is allowed during offloading of the LNG carrier. An important factor for the Big Sweep will be introduction of diesel. This will require extra fire fighting requirements and introduction of a closed drain system.

- Extra facilities for maintenance.

- $\quad$ POB facilities (toilet). The scenario currently used is that the facilities of the transport boat are used for the personal present on this unmanned facility. Fresh water if required for emergency will be supplied per tote tank. Toilet facilities will be chemical based in case transport boat is not available.

- Introduction of a closed cooling medium system will result in fresh water requirements. Currently a direct seawater system is selected and no fresh water generation is foreseen. 
Doc. No. BIGS-B-100-RP-0001/Rev.in Progress

\section{$5 \quad$ References}

\begin{tabular}{|c|l|c|l|}
\hline Ref. & Document & Rev & Description \\
\hline 1 & BIGS-G-100-PB-0100 & A & $\begin{array}{l}\text { Design Basis, Design philosophies, Functional descriptions } \\
\text { and scope of work document }\end{array}$ \\
\hline 2 & BIGS-G-100-PB-0100 & A & Control Philosophy (included in ref. document) \\
\hline 3 & BIGS-B-100-DF-0002 & A & PFD - Main Process Big Sweep \\
\hline 4 & BIGS-G-100-PB-0100 & A & Electrical System Description (included in ref. document) \\
\hline 5 & Paragon information & & $\begin{array}{l}\text { PFD and datasheet attached to e-mail to M. Krekel } \\
18 / 05 / 2004\end{array}$ \\
\hline 6 & BIGS-X-600-PH-001 & A & Fire Protection Philosophy \\
\hline
\end{tabular}




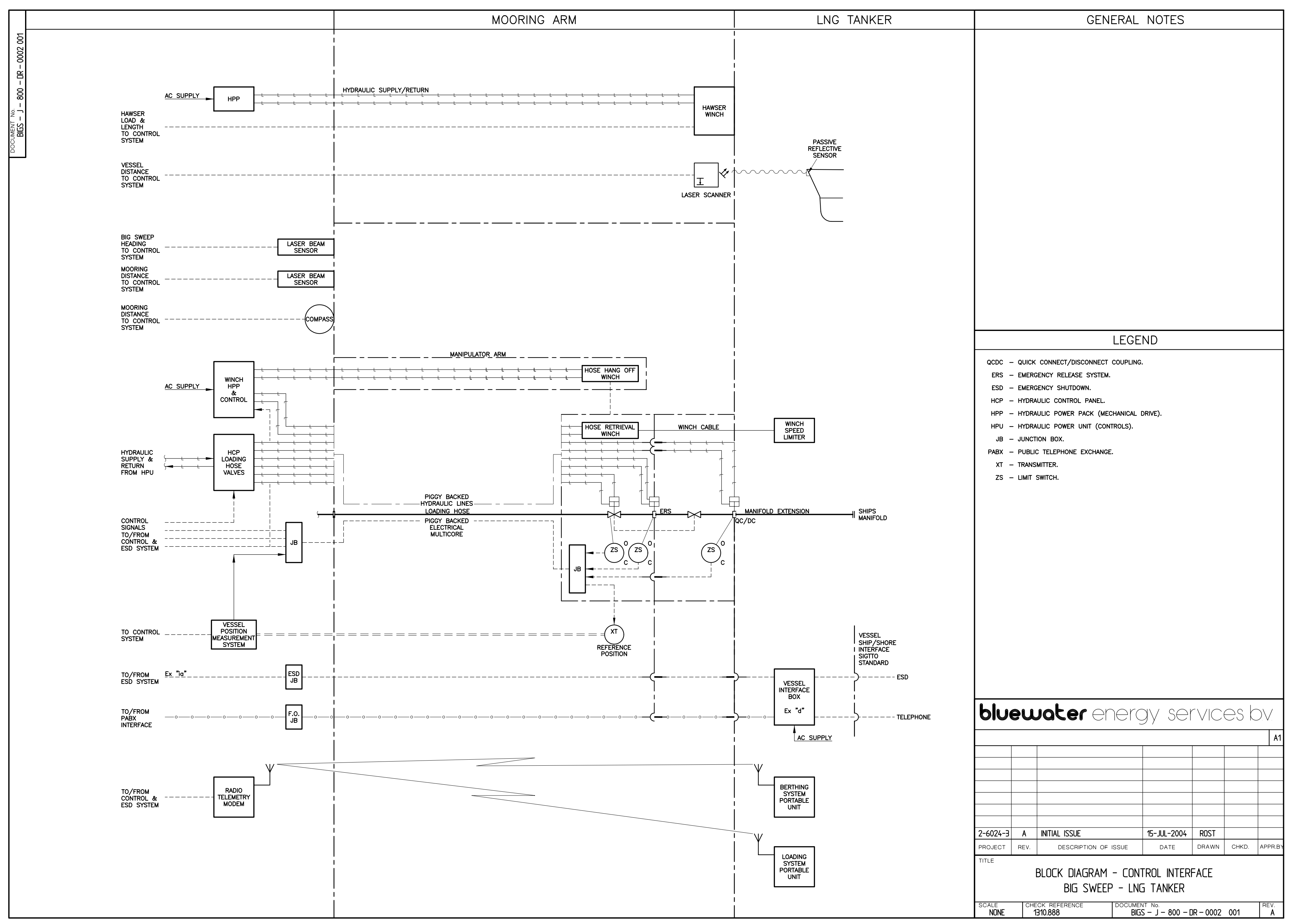




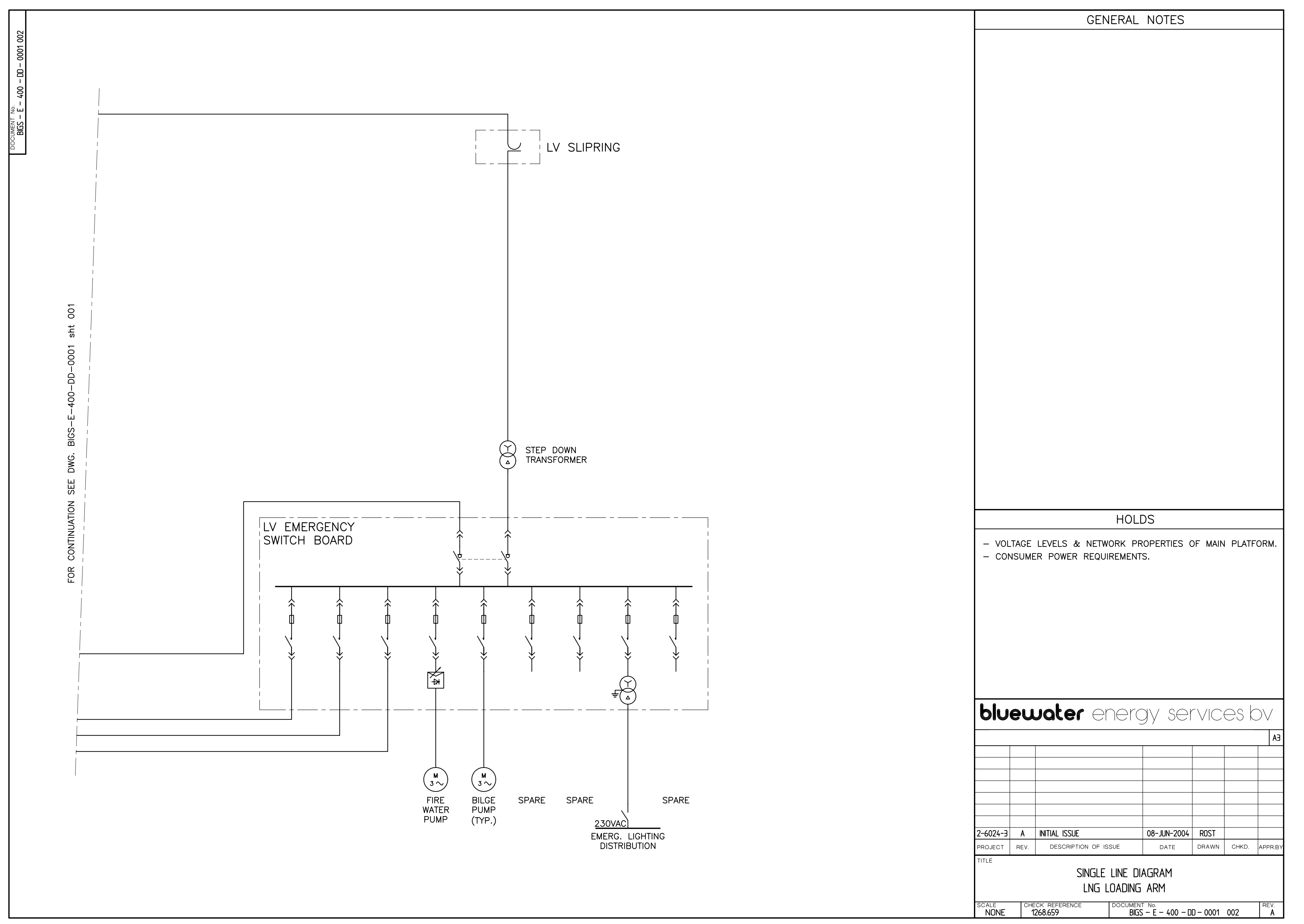




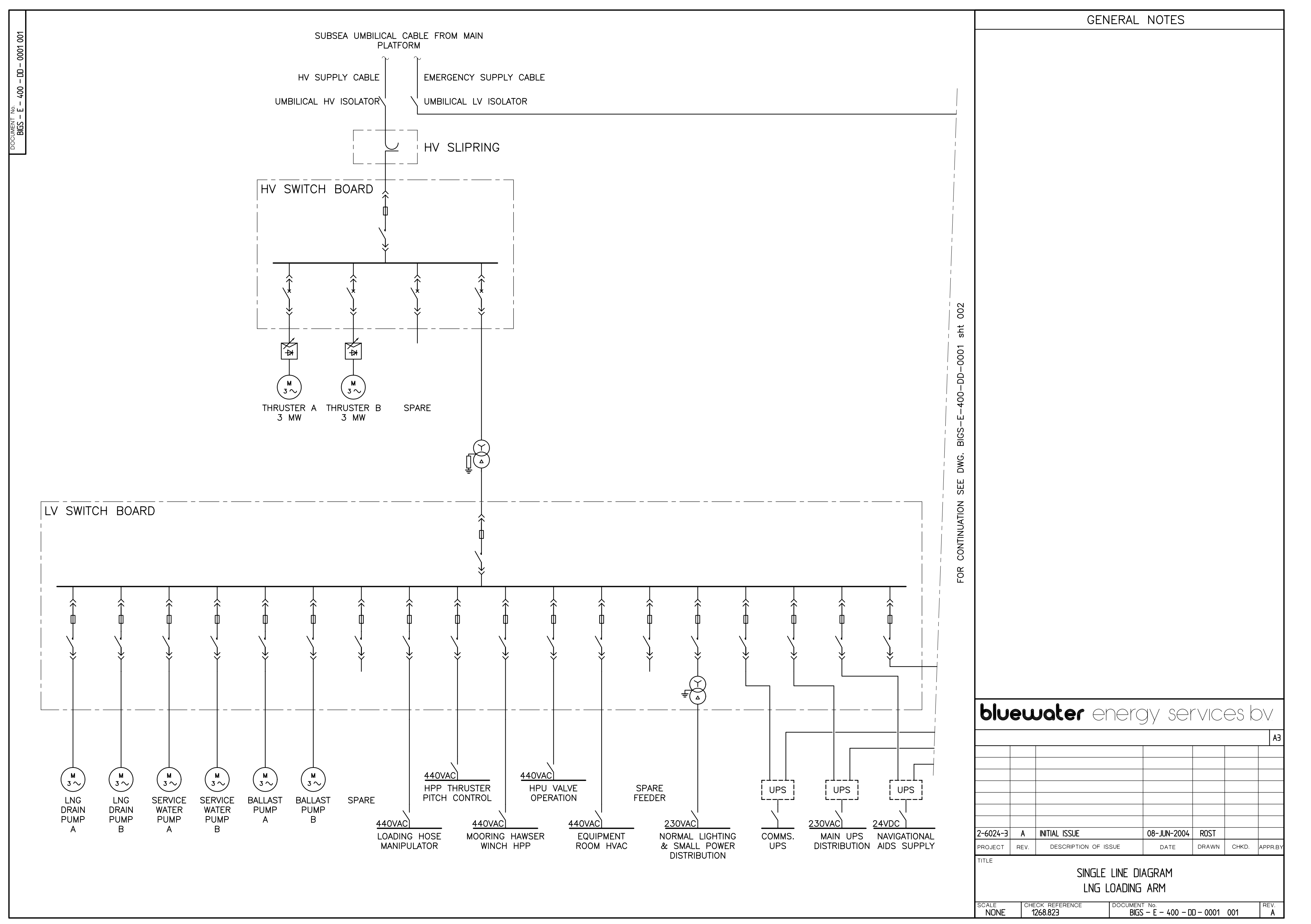




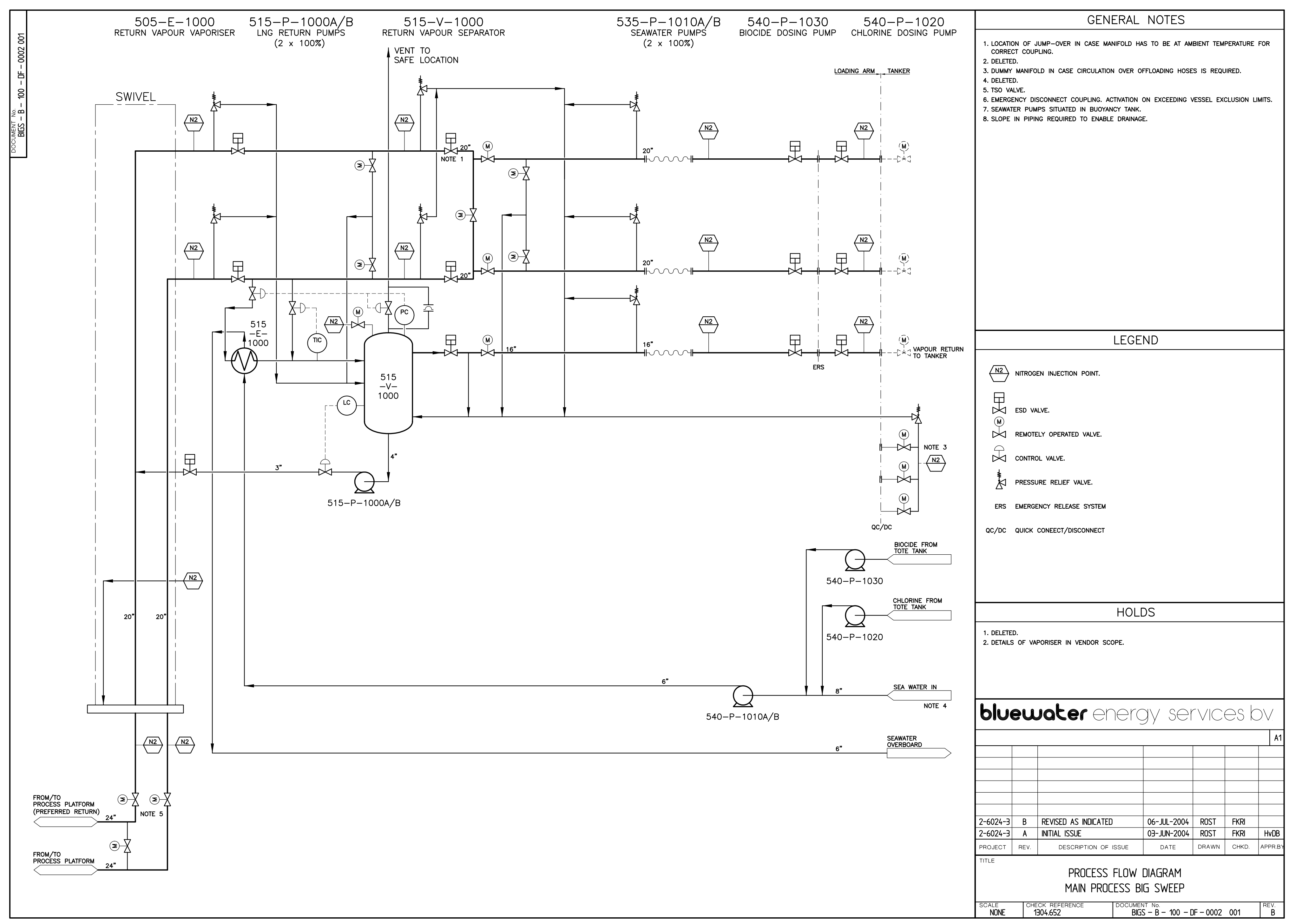




\section{$1.1 \quad$ Electrical system}

\subsubsection{Introduction}

The SPM electrical power system uses power generated on the main platform and transported to the loading facility via an umbilical cable. Thereby the requirement for generators, drivers and utility systems is omitted for a lean concept suitable for unmanned operation. Availability of the electrical supply will be mainly dependent on the power generation equipment redundancy of the main platform.

Voltage levels and frequency and network properties shall be selected similar to the main platform.

\subsubsection{Codes and standards}

The electrical system shall be designed in accordance with regulations and standards as follows:

Code of federal regulations Title 33 Volume

- 2 sections 127.107 (power source), 127.109 (lighting)

National fire protection association (NFPA)

- NFPA 70 National electrical code

- NFPA 59A Standard for production, storage and handling of LNG section 2.3 ventilation of enclosures, section 7.6 electrical equipment, and section 7.7 electrical grounding and bonding

American Bureau of Shipping

- $\quad$ ABS Guide for building and classing facilities on offshore installations

- $\quad$ chapter 4 'fixed installations' section 6 'electrical systems'

- $\quad$ ABS Guide for building and classing offshore LNG terminals, chapter 2, section 2 'Design of gravity based offshore LNG terminals,

- part 13 Hazardous areas,

- part 17 Electrical systems and installations

American Petroleum Institute (API)

- $\quad$ API RP 500/505 for area classification

- $\quad$ API RP 14 F Electrical installations

- $\quad$ API RP 14 FZ in lieu of API RP $14 \mathrm{~F}$ for installations classified by class and zone

- IEC standards may be used as an alternative to API 14F provided they are not less effective and they are applied to the entire system.

\subsubsection{Normal power supply}

The mooring facility will be supplied from the main platform electrical system via a single HV supply through the umbilical cable and electrical slipring. This shall provide power for the thrusters and the LV normal distribution system via HV/LV transformer. Thrusters will be sized approximately $3 \mathrm{MW}(2 * 100 \%)$ and operate under VSD control.

\subsubsection{Emergency power supply}

A LV emergency supply shall be installed in parallel from the emergency distribution system on the main platform through the umbilical and slipring. Step-up / down transformers may be required for optimum umbilical cable sizing. The emergency supply shall power the consumers required to operate under emergency conditions i.e. 
- UPS systems for Navigation lights, communication systems and control ESD and Fire and gas systems

- Emergency and escape lighting

- bilge pumps

- Fire extinguishing system

- fire water pump (if installed)

- Emergency power to Hose disconnect system

Alternatively an emergency generator may be installed on the loading facility. This has however not been selected in order to limit the complexity of the installation and consequent manning requirements.

\subsubsection{UPS systems}

UPS systems will be provided for:

- ESD, fire and gas and control system

- Radio communications

- Aids to navigation systems

Each system sized for individual service duration requirements in accordance with the main platform electrical philosophy. The capacity of the UPS system for aids to navigation shall be minimum 96 hours in accordance with class requirements and regulations.

\subsubsection{Lighting systems}

Lighting systems will be provided for normal, emergency and escape lighting. Normal lighting will be installed in all accessible areas of the facility to provide acceptable lighting levels form normal power supply. Emergency lighting will be installed for lighting at control areas for emergency operation and at equipment required for emergency operation. Escape lighting is required for minimum lighting levels at escape routes. Emergency and escape lighting are supplied from the emergency power distribution board. Escape lighting fixtures will be provided with built in batteries for back up under blackout conditions.

\subsubsection{Navigational Aids}

Class A navigational aids will be provided as required by the US Coast Guard (USCG). These shall comprise radar reflector, marine navigation light (5 NM), foghorn (2 NM) for approval by USCG.

The installation of aeronautical obstruction lights shall be considered.

\subsubsection{Electrical slipring}

The interface between the platform and the loading arm shall be through an umbilical cable, comprising the following:

- HV power cable

- LV emergency power cable

- Multi-pair cable for hardwired safety related signals

- Optical fibre for data communication, CCTV, PA and telephone systems. 
Electrical power and signals shall be transferred to systems on the weathervaning loading arm via a hollow bore slipring assembly around the two path product swivel. All except HV power could alternatively be transferred via a wind-on/off device. The optical signals shall be routed via a cable wind-on/off device. This device will allow for a limited number of full 360 degree rotations of the loading arm in either direction. The environmental conditions are such that a full rotation of the unit is not likely to occur frequently. If required the unit may be reset to its nominal start position between two loading operations by rotation of the arm by thruster power.

\subsubsection{Cable runs}

Cable runs on the loading arm shall be protected from green water impact. Either cables shall be installed in cable trays on an elevated pipe rack or shipbuilder construction practice shall be followed and cables shall be routed in protective piperuns.

Special cable support construction shall be provided at the location where the loading arm is hinged on the swivel tower, allowing flexibility of the cables to a maximum of +1 2 degrees in the vertical plane. It is intended to install standard cables and construct a flexible cable support that will spread the relative movement over a longer distance.

\subsubsection{E\&I equipment rooms}

A container type equipment module shall be installed, providing a conditioned environment for electrical and control equipment. The unit shall be divided in separate rooms for electrical and control equipment, with a common ventilation system. Adequate ventilation with gas detection shall be installed for classification of the rooms as nonhazardous areas. UPS batteries shall be installed in a separate compartment with extract ventilation.

Equipment shall comprise:

- HV switchboard

- $\quad$ Thruster VSDs

- HV/LV transformer

- LV switchboards and distribution panels

- UPS switchgear and rectifiers

- Control system cabinets

- Shutdown and F\&G system cabinet

- Communication systems

- Operator and engineering workstation

- Documentation book shelve

- Office desk

A fire extinguishing system shall be installed for automatic release.

\subsubsection{Hazardous Areas}

Classification of hazardous areas shall be in accordance with API RP 500/505.

The turntable/turret at the mooring tower, the process and utility area, the pipe rack and loading manifold area shall be designed as open and naturally ventilated areas. Rooms containing electrical control equipment shall be provided with adequate ventilation for classification as safe areas.

Electrical equipment shall be selected suitable for the hazardous areas in which they are installed, however all electrical equipment installed in open areas on the SPM shall be suitable for installation in hazardous area classed zone 2 or class 1 division 2 as a minimum. Protection techniques shall be selected in accordance with API RP 14F. 
Ship-SPM interface shall be Ex-i as per SIGTTO recommendation.

\subsection{Control, automation and safeguarding systems}

\subsubsection{Introduction}

The loading terminal is intended to be an unmanned facility, with remote operation from the central control room (CCR) on the main platform. A local control system shall be installed, which shall relay process and equipment data and diagnostics to the main platform for incorporation in the main control system and operation from a common HMI. These controls, completed with integral CCTV, and communication systems will provide an operator interface suitable for reliable remote operation.

\subsubsection{Rules and regulations}

The instrument and control system shall be designed in accordance with regulations and standards for electrical systems and references as follows:

Code of federal regulations Title 33 Volume 2

- 127.201 (fire and gas detection),

- $\quad 127.205$ (emergency shutdown)

- $\quad 127.207$ (Warning alarms)

National fire protection association (NFPA)

- NFPA 70 National electric code

- NFPA 72 National fire alarm code

- $\quad$ NFPA 59A Standard for the production, storage and handling of LNG

- $\quad$ section 2.3 Buildings and Structures

- section 9 Fire Protection, Safety, and Security

American Bureau of Shipping

- $\quad$ ABS Guide for building and classing offshore LNG terminals, chapter 2, section 2 'Design of gravity based offshore LNG terminals

- $\quad$ part 19

- $\quad$ part 21 Instrumentation and Control Systems Safety Systems

- $\quad$ ABS Guide for building and classing facilities on offshore installations 2000

- $\quad$ chapter 4 'Fixed Installations' section 7' Instrumentation \& Control Systems

- chapter 4 'Fixed Installations' section 8' Fire protection and Personnel Safety

- $\quad$ ABS Rules for building and classing steel vessels

- $\quad$ part 5 chapter 8 section 13 Instrumentation

- $\quad$ part 5 chapter 8 section $6 \quad$ Cargo system valving requirements

American Petroleum Institute (API)

- $\quad$ API RP 14C Recommended Practice for Analysis, Design, Installation, and Testing of Basic Surface Safety Systems for Offshore Platforms

- $\quad$ API RP 14F Recommended practice for design and installation of electrical systems for fixed and floating offshore petroleum facilities for unclassified class 1, division 1 and division 2 locations.

- API RP 14G Recommended practice for fire Prevention and control on open type offshore production platforms. 


\subsubsection{Control system architecture}

Local control and monitoring system shall be configured as a subsystem of the main platform control system, using similar hardware and software products in similar configurations for control, safeguarding, fire and gas and HMI. The system will comprise I/O modules, controllers and a workstation in the local control room. The system shall be fully integrated with the platform control system through redundant network communications for system operation, diagnostics, maintenance and configuration activities from the main platform control room. System configuration properties (signal types, field bus application, integration levels, etc.) shall comply with the system definition of the main platform. However, due consideration shall be given to diagnostic data communication for remote maintenance in order to reduce manning requirements and enable classification of the loading facility as 'unmanned'.

It is assumed that the control system will be configured as dedicated units for control and monitoring, safeguarding and fire and gas, all with data communication to the control system for monitoring through the common HMI. Configuration is pending platform system architecture.

Control systems (incl. Fire and gas and ESD systems) will be supplied from a dedicated uninterrupted power supply system, comprising battery back-up and separate supplies from normal and emergency power distribution systems.

\subsubsection{Control locations}

The loading facility will be remotely controlled from the central control room (CCR) on the main platform. Local systems shall be installed in an electrical and instrument control room on the SPM. This shall typically provide a conditioned environment suitable for the electronic equipment. Local operation and engineering workstation shall be provided in this room for back-up operation, maintenance and commissioning activities.

A local control station will be provided at the loading hose end of the SPM. It will comprise controls for local hose handling and thruster operation.

Two portable control units shall be provided for operation of systems from the LNG tanker. They shall be interfaced with the control system via reliable radio telemetry systems.

- A portable control station will be provided as a berthing aid for the marine mooring master. It will be equipped with position monitoring (speed of approach, distance, bearing, etc.), hawser controls (length and load) and loading arm thruster controls.

- Another portable control station will be provided for the cargo-loading master on the tanker. This unit will be equipped with control functions for hose handling equipment and offloading controls.

An interface to the LNG tanker systems at wheelhouse/cargo control room will be provided. It will be based on standard LNG terminal monitoring system. The interface shall comprise ESD commands, and communication links.

\subsubsection{Safeguarding system}

Safeguarding system will be configured for 'Process Shut Down' (PSD), 'Emergency Shut Down' (ESD-1) and 'Emergency disconnect' (ESD-2). It will be designed as a high integrity system with hardwired interface with the main platform Emergency Shutdown (ESD) system. 
Shutdown levels are envisaged for Unit shutdown (USD) and Process shutdown (PSD) as defined in the main platform safeguarding philosophy for shutdown of equipment and process, due to upsets and equipment failures. Furthermore shutdown levels specific for LNG loading apply as described hereafter:

ESD-1: Stop offloading operations in case of (potentially) unsafe conditions. It shall interrupt the loading operations without disconnecting the loading hoses from the tanker. It will be activated on occurrence of the following events:

- Manual from loading master control station on vessel

- Manual from various locations on the vessel

- Manual local (loading end of Big Sweep)

- Manual from CCR

- Manual from local control room (back-up operation)

- Automatic from vessel ESD system in event of power failure, fire detection, etc.

- Automatic from ESD system on Big Sweep in the event of:

- Low pressure hydraulic system for ESD valve actuation

- Low pressure hydraulic system for loading hose manipulator

- ESD system failure

- Activation of ESD-2

- Fire or gas detected

- Process shutdowns (e.g. high pressure/level trip)

Activation of ESD-1 will result in the following shutdown actions:

- Process system isolation on Big Sweep by closure of ESD valves and drainage of product. This action shall be delayed to ensure flow is reduced.

- $\quad$ ESD-1 command to vessel via hardwired ship/shore link:

- Stop off-loading pumps,

- $\quad$ Closure of LNG manifold valves on tanker (closure time to limit surge pressures)

ESD-2: Prevent damage to the loading systems and prevent large LNG spills in case the tanker drifts away from the mooring tower or loading arm. It shall interrupt the loading operations and disconnect the loading hoses from the tanker via the emergency release valves.

It will be activated manually from each of the following locations:

- mooring master control station on vessel

- loading master control station on vessel

- loading end of Big Sweep

- Central Control Room (CCR)

- Local control room (back-up operation)

ESD-2 may be activated automatically in the event of:

- Detection of tanker movement outside operational envelope

Activation of ESD-2 will result in the following shutdown actions:

- $\quad$ Activation of ESD-1

- De-coupling of Emergency Release Valves (ERV). Dry break shall be obtained by closure of upstream and downstream valves prior to disconnection.

Activation of emergency release shall only be effective if the QC/DC couplings of the respective hose are engaged. This shall be signalled by limit switches.

Notes: 
- The effect of fast closure of the ERS valves on the ship's systems must be evaluated for each ship calling at the terminal. A default value for ERS valve closure time of 5 seconds should normally suffice to prevent surge pressures exceeding the design pressure of the ships piping system. If the 5 seconds period is not sufficient, the offload flow rate shall be reduced to lower the potential for surge pressures above the design limit.

- Similarly the closure time of the valves on Big Sweep shall be verified for generation of surge pressures by closing these valves, whilst the ship's pumps are still in operation and the ship's valves are open.

- ESD-1 status on vessel and Big Sweep shall be communicated through an intrinsically safe hardwired interface according SIGTTO standard. The vessel ESD status shall activate the ESD-1 status on Big Sweep, however it shall not activate the ESD-1 output to the vessel to avoid signal lock.

- The activation of ERS valves shall be simultaneous for all three hoses, however it shall only be effective if their respective QC/DC coupling is engaged. Limit switch for QC/DC coupling shall also be a permissive condition for offload operation.

- $\quad$ ESD-1 and ESD-2 commands over telemetry may give rise to spurious shutdowns. These shall not be of 'failsafe' design. The telemetry commands are backed-up with communication channels to CCR from where the command may be issued in case telemetry link is not available. Signalling of ERS activation by limit switch shall set the winch on the manipulator in 'brake' mode.

\subsubsection{Fire and gas detection}

Fire and gas detection systems shall be designed as a sub system of the main platform. As such it will follow the design philosophies for the main platform. Furthermore it shall comply with the referenced codes and standards. The system will activate shutdown and extinguishing actions via the safeguarding system and provide monitoring through the control system HMI.

\subsubsection{Gas detectors}

Fixed sensors that continuously monitor for LNG vapours shall be installed in enclosed or semi enclosed areas where vapour or gas may accumulate, at fresh air inlets of non classified areas, and at locations in open areas near potential leaks from process equipment and piping.

Spot type sensors will be installed in process areas and open path type sensors may cover the extensive area of the pipe routing along the loading arm.

Gas detectors shall meet the requirements and be installed, operated and maintained in accordance with ANSI/ISA S12.13 part I and part II, 'performance requirements combustible gas detectors'. Sensors shall be Explosion proof or flame proof (Ex-d).

Gas sensors shall be provided with two levels of alarm. Sensors shall give an alarm at $20 \%$ LEL ( no more than 25\%) of LEL. Trip and consequent actions shall be initiated at $60 \%$ LEL. (hold; setting 40\% acc. CFR 127.205). 


\subsubsection{Fire detectors}

Fixed sensors for automatic fire detection will be installed such that areas and equipment that have a potential for fire outbreak will be monitored. Automatic detection of fires shall provide an early response by audible and visual alarm at the loading facility and the continuously manned CCR. It will activate the necessary functions through the ESD system. It shall be designed and maintained in accordance with NFPA 72.

Detectors will be selected and installed in accordance with the guidelines of API RP $14 \mathrm{C}$ and API RP 14G and will comprise:

- Fusible plug system with pilot lines covering hydrocarbon process equipment (evaporator, LNG drain pump and vessel), pipelines, swivel and riser pipes (only the zone protected from wave impact) and loading manifolds

- IR flame detection installed in combination with fusible plug detection

- Smoke/heat detection system for control room and electrical equipment rooms.

- Manual alarm call points (MAC). Push buttons to manually activate the general alarm system shall be installed at strategic locations, typically the escape routes from process areas, rooms or work locations.

\subsubsection{General alarm}

An alarm system will be provided for signalling of manual alarm activation (MAC), fire alarm, gas alarm and emergency shutdown. The design of the system shall follow the platform safeguarding philosophy. The system will comprise warning lights throughout the facility and audible alarms via the PA system. A monitoring panel will be provided in the local control room, and in the normally manned CCR.

A flashing or rotating warning light (colour amber, 5000 candelas) and a siren of 125 $\mathrm{dB}(\mathrm{a})$ shall be provided for issue of a warning signal for vessels in the vicinity.

\subsubsection{Control functions}

A single control system shall cover the full scope of control functions as per table below:

\begin{tabular}{|l|l|}
\hline System & Equipment/ functions \\
\hline LNG Process & Pipelines, vaporiser, LNG drain vessel and pumps, etc. \\
\hline Utilities & $\begin{array}{l}\text { Air compressors and nitrogen generator, hydraulic power unit, } \\
\text { service water, chloride injection etc }\end{array}$ \\
\hline Marine systems & Thrusters, Ballast tanks and pumps, bilge system, etc. \\
\hline Mooring system & $\begin{array}{l}\text { Hydraulic power pack, hawser winch control, hawser length } \\
\text { monitoring, hawser load monitoring, emergency hawser } \\
\text { disconnect, Loading arm to Vessel side distance control, etc. }\end{array}$ \\
\hline Electrical system & $\begin{array}{l}\text { HV distribution, LV distribution, emergency power, transformers } \\
\text { and UPS systems Navigational aids, etc }\end{array}$ \\
\hline Subsea pipeline & Manifold valve controls \\
\hline LNG Loading manifold & $\begin{array}{l}\text { Hose manipulator controls, manifold ESD valves Emergency hose } \\
\text { disconnect mechanism, Vessel interface }\end{array}$ \\
\hline
\end{tabular}




\subsubsection{LNG Flow metering}

No metering facilities will be provided on the Big Sweep system. The import vessel shall provide volumes and temperature for discharged LNG, which are used for fiscal/commercial settlements, as for normal receiving terminals. Further fiscal metering including sample system for compositional analysis by gas chromatograph will be performed on the main platform after gasification. Gas flow metering on the loading arm will be limited to vapour return from the vaporiser and the vent gas system.

\subsubsection{Valve operation}

Valves will be hydraulically operated. A hydraulic power unit will be installed in the utility area, providing sufficient capacity for valve operation. Valves in ESD service shall be failsafe spring return. Alternatively valves may be operated pneumatically, however hydraulic operation is preferred in the saline environment close to the seawater surface.

Valve control shall include valves at the riser manifold via a hydraulic swivel, in the process area and at the loading manifold via hoses in piggy back configuration with the loading hoses.

\subsubsection{Control interface Ship-SPM}

The instrument and control interface between Big Sweep and the LNG ships are identified as:

- $\quad$ Berthing system

- Mooring hawser monitoring system

- Big Sweep heading/positioning control system

- $\quad$ Loading hoses/couplings

- Loading hose Manipulator

- ESD signals

- Communications

These interfaces are considered as specific for the Big Sweep project and outlined hereafter.

Loading hoses will be connected to the ships manifold extension. The hose ends are provided with hydraulic operated ESD isolation valves and disconnect mechanism. Hydraulic control lines and cables for electronic sensor feedback signals will be piggybacked with the loading hoses to the SPM.

A ship-SPM communications interface will be provided comprising bi-directional ESD commands, and telephone communication (normal PABX and hotline. The interface cabling will be piggybacked with the offloading hoses from the manifold to the SPM.

At the manifold a connector will be installed for connection to its counterpart in the tanker manifold extension. The connection can be made by the operator or via a connector integral with the LNG hose connector. Cabling shall run from the manifold connector to the ship-shore connectors based on the SIGTTO ship-shore interface standard. A dummy connector with test device shall be provided for verification of the electronic hook-up of the manifold connector to the ship installation. The device shall be plugged into the manifold connector for testing prior to mooring to the SPM. 


\section{Berthing system:}

This system shall provide information relevant to the safe and efficient berthing of the LNG tanker to the Big Sweep installation. The information shall be available at the CCR and on the portable display unit for the mooring master on the tanker.

Information shall comprise:

- Speed of approach

- Distance to mooring arm

- Big Sweep heading

- Current velocity and direction

- Wind velocity and direction

Information from all above-mentioned systems shall be routed to the control system for presentation in the CCR via the common HMI. The information shall be transferred via radio telemetry for display on the portable unit in a graphical format using SCADA/HMI software.

The system shall be based on a standard (Oceantech or equal) berthing system using GPS type position reference systems. Laser scanner (Fanbeam or Cyscan) may be an alternative for the GPS system..

\section{Mooring hawser monitoring system}

The system shall provide monitoring and control of the mooring hawser winch arrangement. It shall comprise the functions of adjustment of the hawser length to suit each individual vessel prior to mooring, monitoring of the mooring load, alarm for high loads and disconnect conditions.

Mooring hawser length and load shall be measured on the mooring hawser winch. Data shall be processed in the control system. In addition, a hawser lifetime calculation program may be used for data processing. The hawser winch shall be remotely controlled for adjustment of the hawser length to suit the vessel properties. Remote monitoring and control of the hawser shall be configured on the control system HMI and the portable display unit for the mooring master with data transfer via radio telemetry.

\section{Big sweep heading / position control system}

The heading of Big Sweep shall be actively controlled to optimise conditions for safe berthing, offloading and disconnect operations.

During berthing and disconnect operations, Big Sweep shall be positioned to a heading that it will not interfere with the vessel manoeuvring.

During offload the heading of Big Sweep shall be controlled to maintain a constant lateral distance between the vessel hull and Big Sweep at the location of the offload hoses. The controlled distance shall be such that distance from fender at the loading end to vessel hull is 3 meters ( $+/-3$ meters) with the vessel positioned in parallel with Big Sweep. 
Measurements will comprise compass for heading and laser beams for distance. The distance measurement will be a system common to shore terminals measuring distance between jetty and hull. However the transmitter cannot be located at the loading hose manifold. Therefore two laser beam type distance measurements shall be installed at some distance along Big Sweep. The first measurement shall measure the distance between the fender and the hull, and the second shall be used to derive the distance at the hose manifold by correction of the measured distance for vessel yaw. Alternatively a laser scanner may be installed.

Signals shall be processed in the control system and adjustments effected through variable pitch thrusters driven by speed controlled electrical motors.

\section{Loading hoses/ couplings}

The loading hose ends will each be equipped with an Emergency Release System (ERS) and a Quick connect/disconnect (QC/DC) coupling.

Instrumentation signals for each of the hoses comprise:

- Switch signal for QC/DC coupling 'Engaged' status

- Hydraulic lines (2 off ) for actuation of QCDC coupling

- $\quad$ Limit switch for signalling of ERS 'Released' status

- Hydraulic lines (2 off) for actuation of ERS valves

- Hydraulic line (1 off) for actuation of ERS coupling

- Limit switch for signalling of ERS valves 'Open' and 'Closed' position

The QC/DC coupling will be a complex piece of equipment with mechanisms for pull-in, release and flange clamp operations. The engaged signal may comprise a combination of switches pending the mechanical design of the device.

Signals to/from the QC/DC couplings shall pass through hydraulic and electric connectors incorporated in the ERS. These shall be arranged in stabbing plates, integral with either part of the ERS, with guiding pins/bushes to protect the connectors in case of emergency release. Electric signals shall be certified Ex-'ia' with connectors certified Ex-'e'.

Vessel position monitoring system shall comprise a laser scanner on the Big Sweep structure and either active or passive targets located on the hose ends.

Signal cables and hydraulic hoses shall be piggy backed along the loading hoses towards the Big Sweep control system. Additional hydraulic lines shall be installed for the supply/return of the pull-in winch on the hose end.

Signals shall be available for indication on the $\mathrm{HMI}$ and serve the following control services:

ERS valves open/closed: Permissive for cargo transfer operation (green line)

QC/DC coupling engaged: Enable emergency release (ESD-2) and, Permissive for cargo transfer operation (green line)

ERS released: $\quad$ Brake hose winch on loading hose manipulator

Position reference: Detect vessel excursion outside operation envelope: generate ESD-1 and/or ESD-2 commands. 


\section{Loading Hose Manipulator}

Loading hoses shall be supported from the manipulator, which is a crane type structure that reaches overhead the vessel extended manifold. Each of the hoses is hang-off the manipulator arm by a steel wire. The steel wires are normally kept under tension by individual winches on the manipulator. In case of an emergency release the winches shall be stopped within fractions of a second in order to fully release the couplings (drop $1 / 2$ meter) and prevent them from dropping into the sea.

Instrumentation signals comprise:

- Taut wire angles (3 off)

- Manipulator arm angle

Taut wire angles shall be measured in the sideways direction relative to the plane of manipulator vertical axis and centre line of manipulator arm.

Signals shall be available for indication on the control system $\mathrm{HMI}$ and serve the following control services:

- Taut wire: Alignment of manipulator and loading hoses

- Manipulator angle: Monitoring only

The manipulator will normally be in neutral position. The manipulator shall be moved in line with the hose manifold as the vessel moves outside the normal operating window to prepare for emergency release operation (ESD-2), whereby the hose, the wire for hose end hang-off and manipulator arm shall be moved into a single plane.

\section{ESD signals}

Emergency shutdown signals shall be exchanged between the vessel ESD system and Big Sweep ESD system. The signals shall comprise ESD command from vessel to Big Sweep and ESD-1 command from Big Sweep to vessel. These signals shall be intrinsically safe Ex-'ia' according SIGTTO standard.

\section{Communications}

Communications interface with the vessel shall comprise:

- Telephone: The main platform telephone network shall extend to the Big Sweep facility. A few extensions shall be made available for the LNG vessel communications.

- Hotline: A dedicated hotline between CCR and the vessel shall be established. This shall also be provided in the control room on Big Sweep for back-up operations.

- VHF radio: A common marine VHF radio transceiver shall be provided in the CCR and the control room on Big Sweep (back-up operations)

- Radio telemetry for data exchange with portable units for mooring master and loading master.

Telephone and ESD communication require a cable link with plug/socket connectors between vessel and Big Sweep. The plug/socket connection shall be located in the manifold area that will be classified as hazardous zone 0 or 1 . Therefor the ESD signals shall be Ex-'ia' and telephone signals shall be routed through a fibre optic link. Connectors shall be incorporated in the ERS of one of the loading hoses and arranged in stabbing plates, integral with either part of the ERS, with guiding pins/bushes to protect the connectors in case of emergency release. 
Connectors will require individual spring loading, as the commonly used mechanical locking devices like fixing screws or lock nuts are not practicable for emergency release.

\subsubsection{CCTV}

Cameras shall be provided for monitoring of the mooring, loading operation and process and utilities equipment area from the central control room. Cameras shall be integrated with the platform CCTV system.

\subsection{Communication systems}

Communication systems shall be installed for co-ordinated loading operations on LNG vessel, loading arm and main platform.

\subsubsection{Rules and regulations}

The communication systems shall be designed in accordance with regulations and standards as generally applicable to the offload unit and the following specific guidelines:

- Code of federal regulations Title 33 Volume 2 section 127.111 (communication)

- National fire protection association (NFPA) NFPA 59A Section 8.8 communications and lighting

\subsubsection{Internal Communication}

The platform Public Address (PA) and Telephone communications systems shall extend to the SPM and loading arm. Public address amplifiers shall be installed in the control room on the loading arm. Furthermore the PA and telephone systems shall be interfaced with the LNG vessel systems via the standard ship-shore interface. The telephone interface shall include normal PABX and hotline.

\subsubsection{External communication}

VHF communication shall be established between the main platform and the tanker with VHF station in the control room on the loading facility for back-up operation.

\subsubsection{Radio Telemetry}

Portable control stations for mooring master and loading master shall communicate with the loading arm control system via radio telemetry. The telemetry systems shall be designed for reliable operation of the facility and due consideration shall be given to failsafe design of ESD actions through the telemetry. 

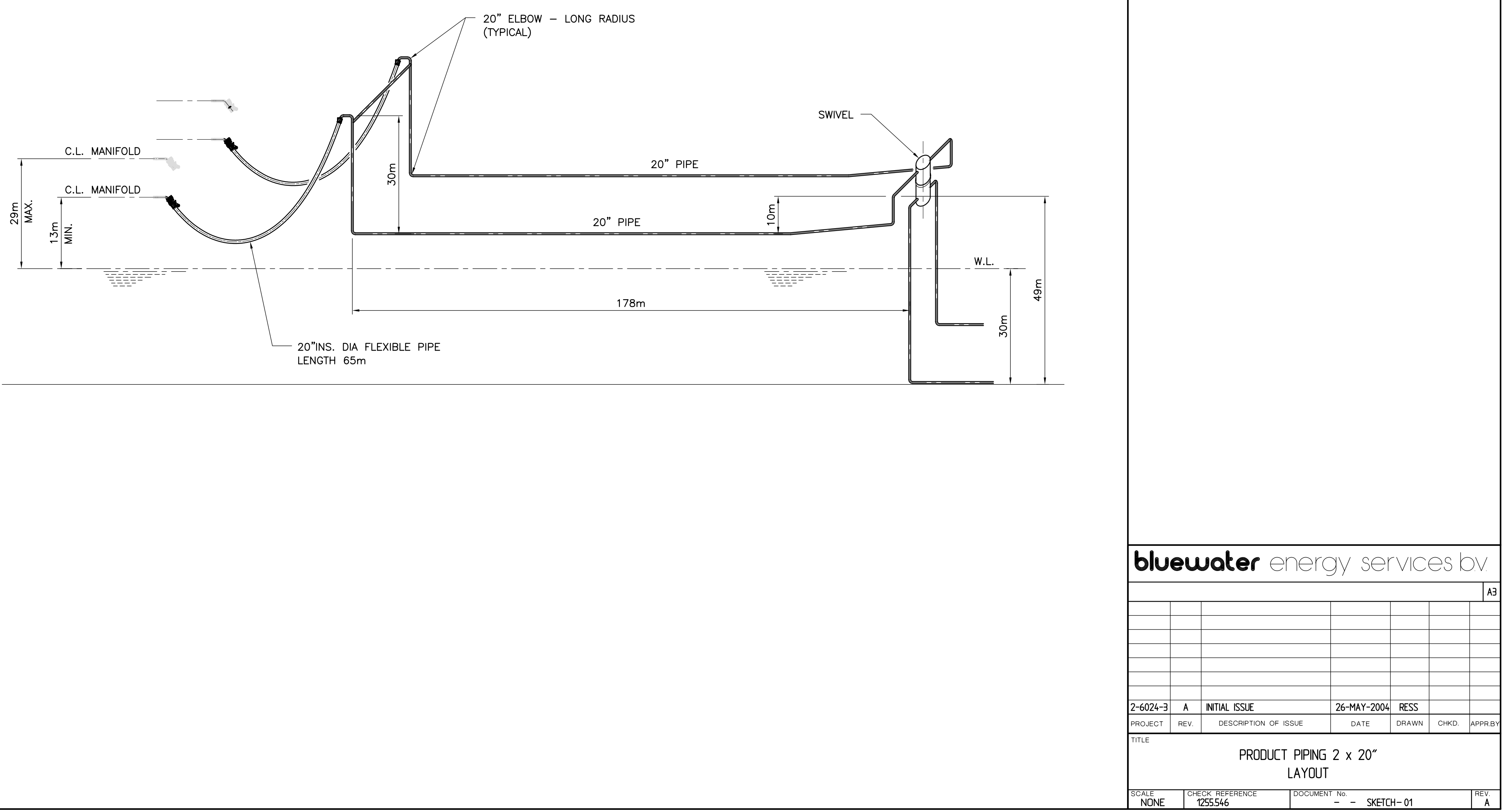


\section{Appendix 8 PB ENERGY STORAGE CAVERN DRILLING AND DEVELOPMENT}


Offshore Natural Gas Storage Caverns Conceptual Design and Cost Estimate

\author{
Prepared for Conversion \\ Gas Imports, L.P., \\ DOE Cooperative Research
}

by

PB Energy Storage Services, Inc.

Houston, TX

Project No. 50543A

June 2004 


\section{Scope of Work}

- Conceptual Cavern Design

- Well Design

- Drilling Plan

- Cavern Development Plan

- Dehydration Requirements

- Rock Mechanics Study Requirements

- Test Well Requirements

- ROM Cost Estimates

- Cavern Operations Concepts 
Agenda

- What are salt domes?

- Salt Cavern Storage

Cavern Concept for an LNG Port

Conclusions

Questions? 


\section{Salt Cavern Storage of Natural Gas is Commercially Viable}

- Solution Mining of salt first started in Europe and Asia about 1000 years ago

- First LPG storage in North America in early 1950's

- First Natural Gas storage in North America in the 1960's

- About 2000 North American storage caverns in salt today (about 200 are Natural Gas) 


\section{Major Salt Deposits in U.S.}

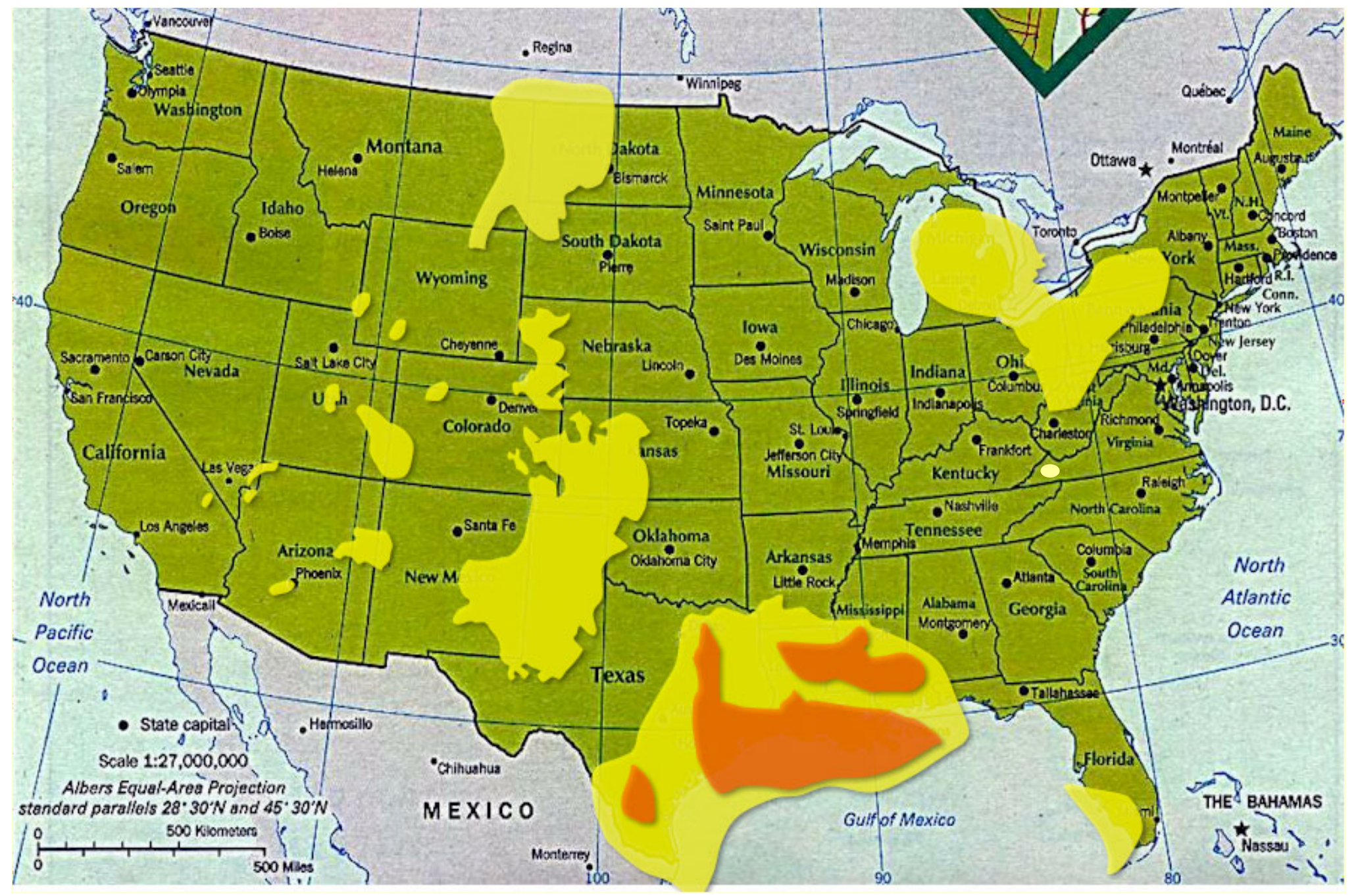

Bedded Salt

Salt Domes 


\section{Gulf Coast Salt Dome}

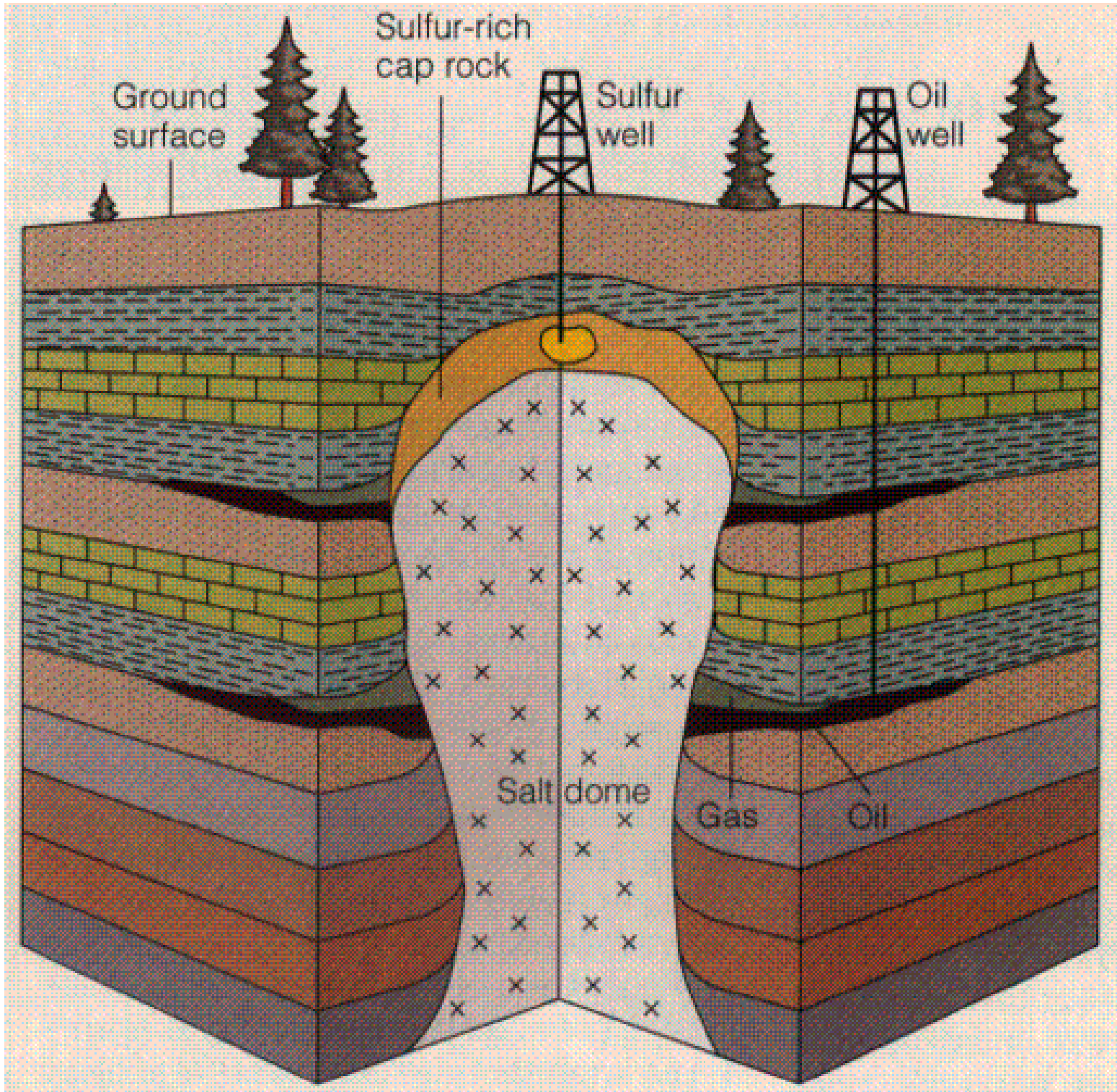

Illustration of the types of mineral utilization on a "typical" Gulf Coast Salt Dome 


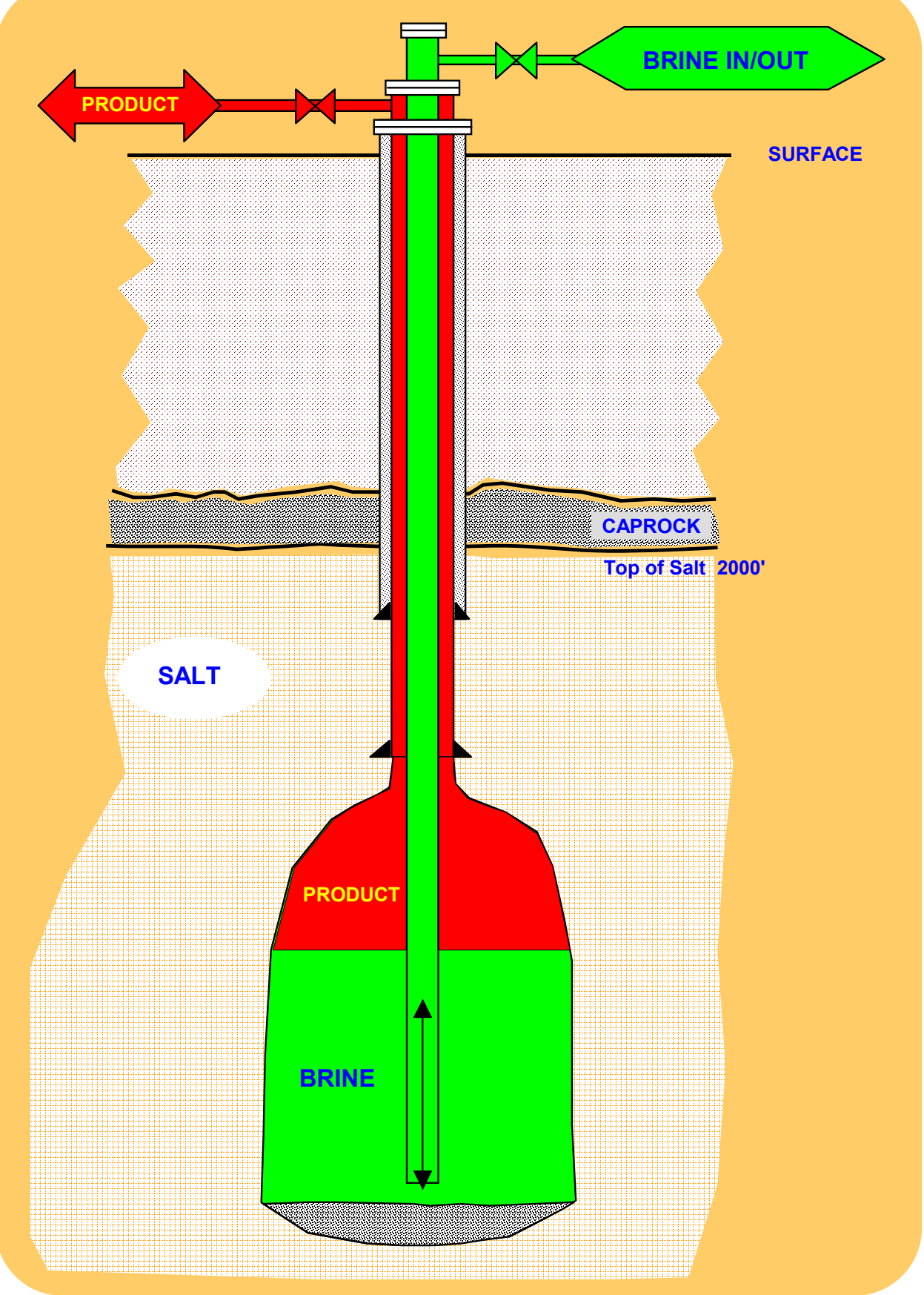

Schematic Illustration of a
“Typical” Liquid Hydrocarbon
Storage Cavern

Product is less dense than brine, and is stored above the brine. Brine is used to displace product out. Brine brought to the surface must be stored, used as feedstock or disposed of. 


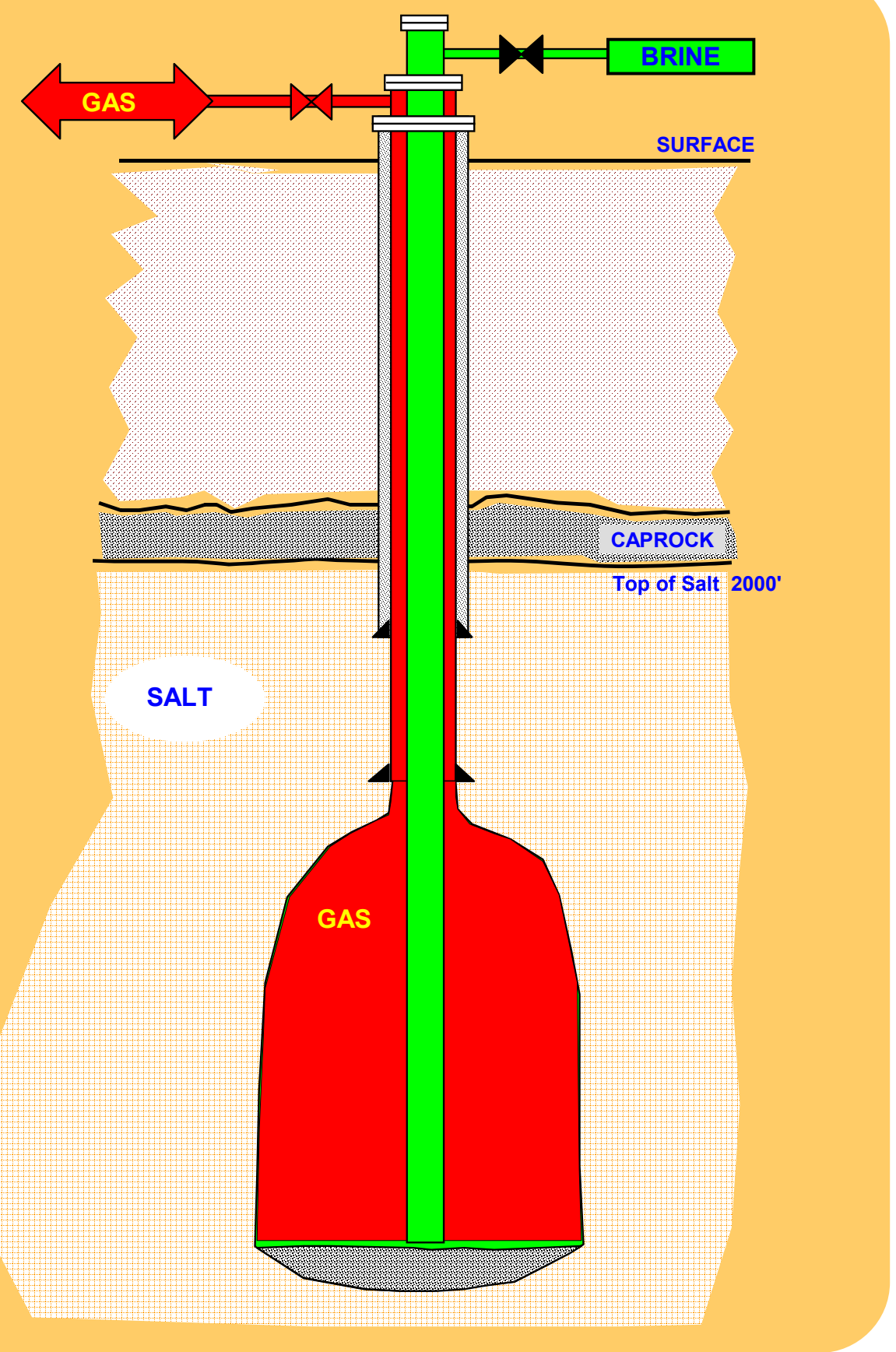

Schematic Illustration of a "Typical" Gas Storage Cavern

Generally, brine is displaced from the cavern by the storage gas. The cavern is then operated as a pressure vessel between a range of operating storage pressures. A minimum gas pressure must be maintained to support the cavern structure. Brine or water can be used to displace the gas on occasion to recover the base gas if the dewatering string is left in tact. 


\section{Louisiana Salt Domes With LPG Storage Caverns}

\begin{tabular}{||l|c|c||}
\hline \multicolumn{1}{|c|}{ Salt Dome } & Parish & $\begin{array}{c}\text { Depth to the Top of } \\
\text { Salt (feet) }\end{array}$ \\
\hline \hline Anse La Butte & St. Martin - Lafayette & 137 \\
\hline Arcadia & Bienville & 1,400 \\
\hline Bayou Choctaw & Iberville & 629 \\
\hline Napoleonville & Assumption & 657 \\
\hline Pine Prairie & Evangeline & 346 \\
\hline Section 28 & St. Martin & 1,181 \\
\hline Sorrento & Ascension & 1,717 \\
\hline Sulphur Mines & Calcasieu & 1,460 \\
\hline Venice & Plaquemines & 1,328 \\
\hline West Hackberry & Cameron & 1,790 \\
\hline \multicolumn{2}{|c|}{ Average } & $\mathbf{1 , 0 6 5}$ \\
\hline
\end{tabular}




\section{Louisiana Salt Domes With Crude Oil Storage Caverns}

\begin{tabular}{||l|c|c|}
\hline \multicolumn{1}{|c|}{ Salt Dome } & Parish & $\begin{array}{c}\text { Depth to the Top of } \\
\text { Salt (feet) }\end{array}$ \\
\hline \hline Bayou Choctaw & Iberville & 629 \\
\hline Clovelly & Lafourche & 1,168 \\
\hline West Hackberry & Cameron & 1,790 \\
\hline \multicolumn{2}{|c|}{ Average } & $\mathbf{1 , 1 9 6}$ \\
\hline
\end{tabular}




\section{Louisiana Salt Domes With Natural Gas Storage Caverns}

\begin{tabular}{||l|c|c||}
\hline \multicolumn{1}{|c|}{ Salt Dome } & Parish & $\begin{array}{c}\text { Depth to the Top of } \\
\text { Salt (feet) }\end{array}$ \\
\hline \hline Bayou Choctaw $^{(\mathrm{a})}$ & Iberville & 629 \\
\hline Jefferson Island & Iberia & 31 \\
\hline Jennings & Acadia & 2,400 \\
\hline Napoleonville $^{(\mathrm{b})}$ & Assumption & 657 \\
\hline Sorrento $^{(\mathrm{c})}$ & Ascension & 1,717 \\
\hline \multicolumn{2}{|c|}{} & $\mathbf{1 , 0 8 7}$ \\
\hline
\end{tabular}


Study Area

\section{Vermillion Area - Block 179}

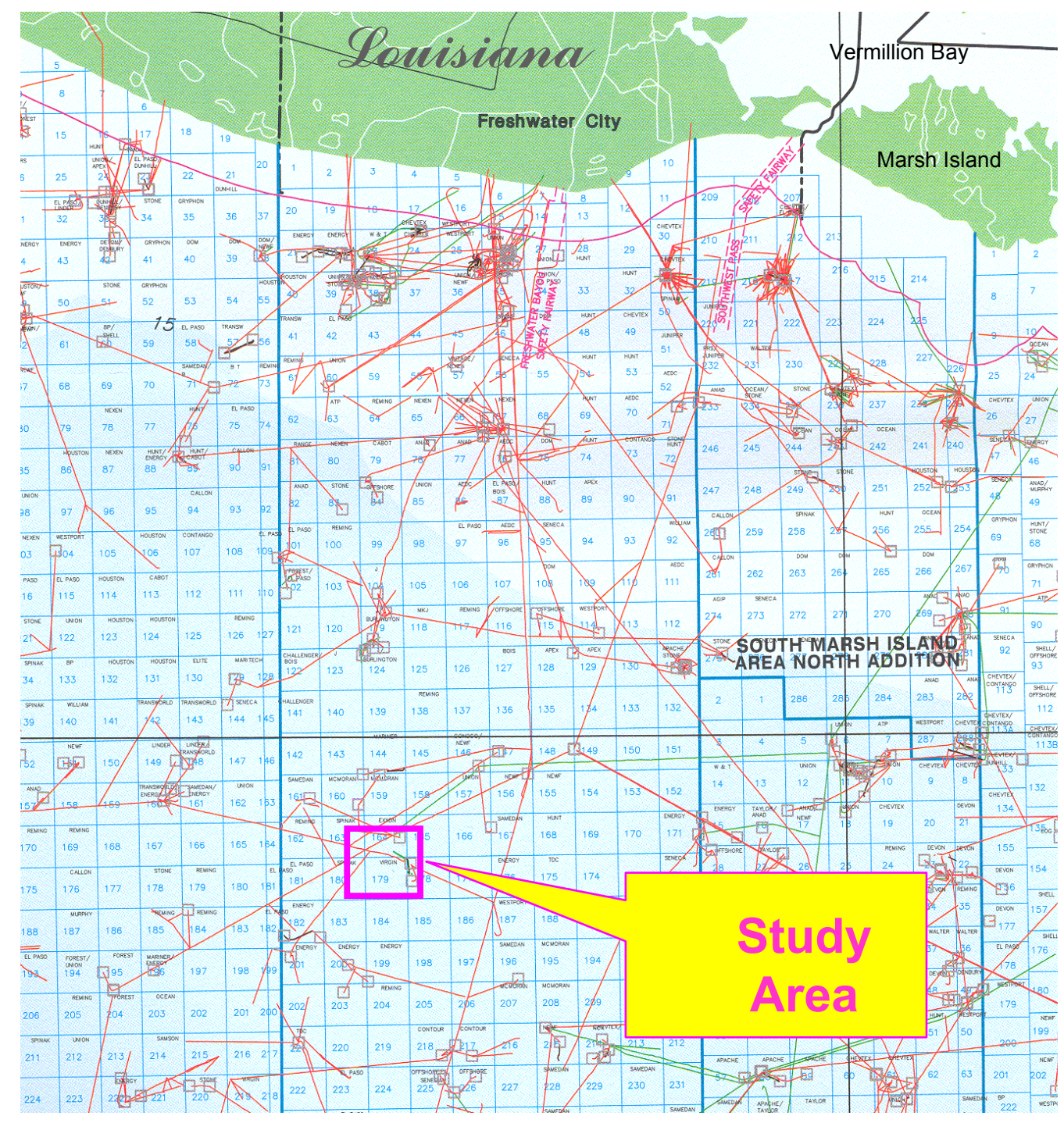




\section{Vermillion Block 179 Salt Dome}

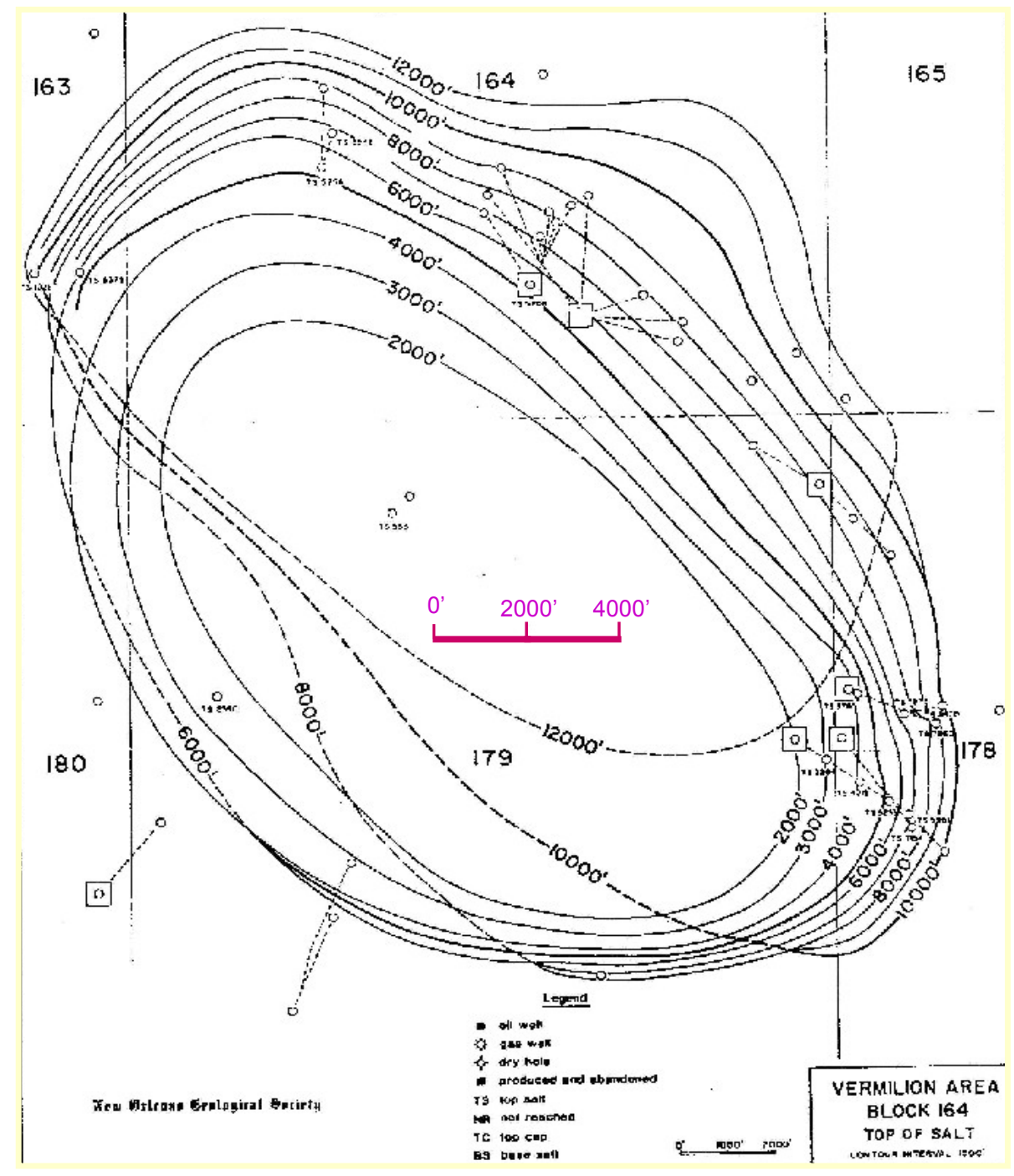




\section{Program for Acquiring and Evaluating Basic Salt Dome Geologic Data}

- Salt Properties of Vermillion 179 are not well defined.

- A small test well may be necessary to develop satisfactory geologic information for a storage well design.

- Some drilling has been done on the subject dome.

- To determine if a test well is necessary, PB ESS proposes a data evaluation program. 


\section{Program for Acquiring and Evaluating Basic Salt Dome Geologic Data}

Conduct a search for geological, geophysical and physical data on the Vermillion 179 Dome and its immediate surroundings. Sources would include client files, PB ESS files, MMS files, Louisiana Department of Natural Resources files, geophysical data brokers, libraries and the internet.

Data could include geological and bathymetric reports, records of any test wells drilled, and the location, dates, types, and owners of any seismic surveys over the dome.

Evaluate the collected data and determine the need for additional investigation work needed to determine if the dome is suitable for gas storage and to determine a suitable facility location on the dome.

Review the seismic (and other) surveys that may have been conducted across the dome and determine if it may be appropriate to license any of the data for study and / or reprocessing. 


\section{Program for Acquiring and Evaluating Basic Salt Dome Geologic Data}

After evaluation of all available existing data, determine with client if a test hole into the salt is necessary for technical or political reasons. A test well would be used to develop "new" information on the depth and characteristics of the salt prior to committing to the first cavern well.

Should it be decided that a test well is required, a detailed design, schedule and cost estimate for the well can be developed. Factors that are considered in planning for a test well include:

Permit requirements

Well location with respect to the storage field.

Type of well (I.e. whether the well will be for test only, or is large enough to be converted to storage service should the findings prove successful.

Well size (diameter), depth and casing program needed for successful coring.

Assessment of rock mechanics plan. (Discussed later)

Geophysical logging program

In hole testing program, if required.

Plugging and abandonment plan, or long term use plan for monitoring or geophysical survey use. 


\section{Cavern Design Basis}

\begin{tabular}{|l|r|l|}
\hline & & \\
\hline Temperatures & 60 & ${ }^{\circ} \mathrm{F}$ \\
\hline Vaporized LNG Injection Temperature & 40 & ${ }^{\circ} \mathrm{F}$ \\
\hline Minimum Design Gas Temperature & & \\
\hline & & \\
\hline Cavern Pressures & 0.85 & Psi/ft \\
\hline$\quad$ Maximum Pressure Gradient @ Casing Shoe & 2000 & Psig \\
\hline Maximum Wellhead Pressure (Injection) & 900 & Psig \\
\hline Minimum Wellhead Pressure (Withdrawal) & & \\
\hline & & \\
\hline Flow Rates & 1.0 & BCFD \\
\hline Maximum injection rate per cavern & 0.7 & BCFD \\
\hline Maximum withdrawal rate per cavern & & \\
\hline & & \\
\hline Volumes (Regular service - per cavern) & 0.55 & BCF \\
\hline Working Gas & 4 & \\
\hline Number of Caverns (Initial) & & \\
\hline & & \\
\hline Volumes (Ship-interrupt service - per cavern) & 1.5 & BCF \\
\hline Working Gas & 3 & \\
\hline$\quad$ Number of Caverns (Initial) &
\end{tabular}




\section{Regular Service Caverns}

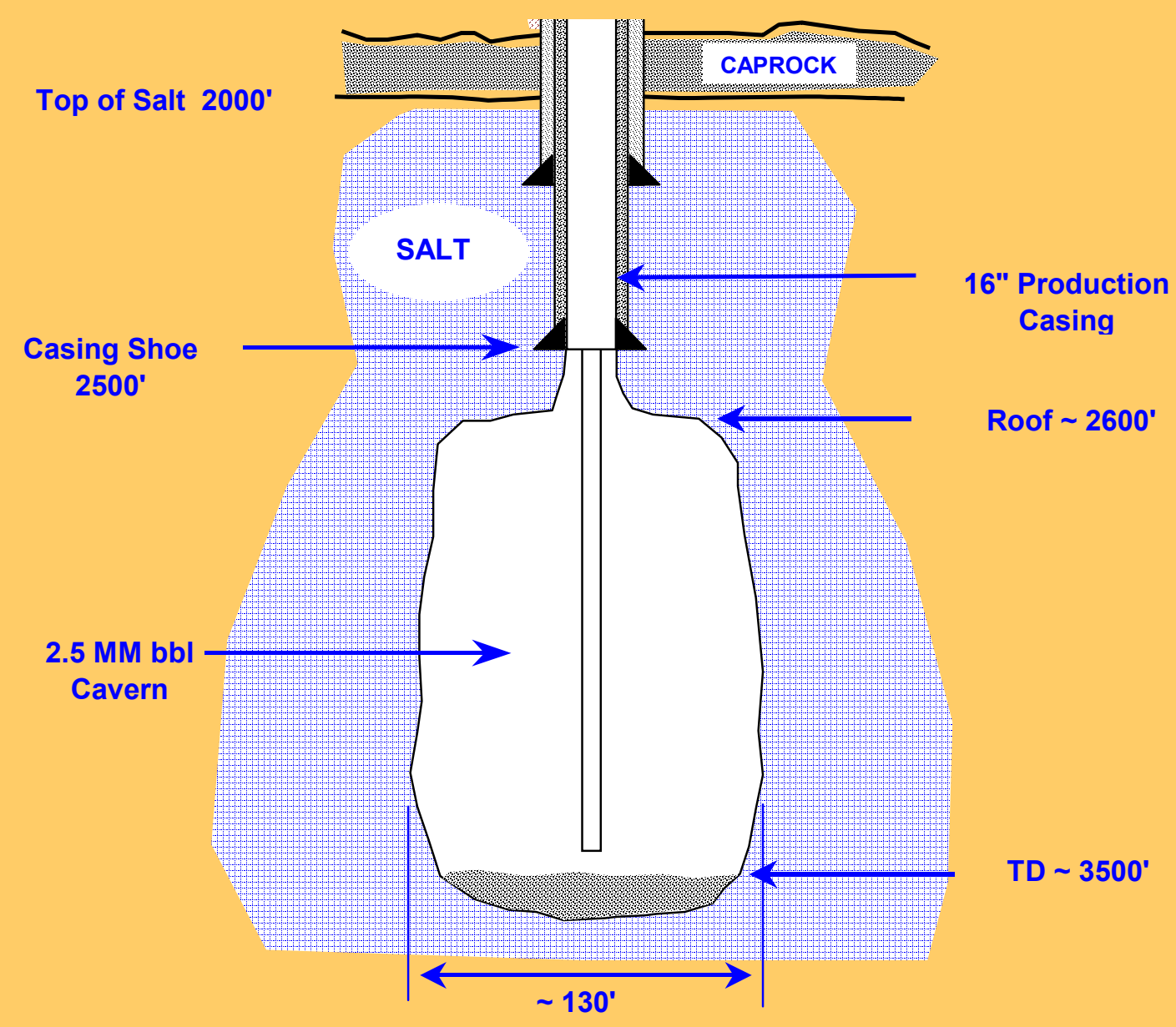




\section{Ship-interrupt Service Caverns}

\section{Approximate Dimensions}

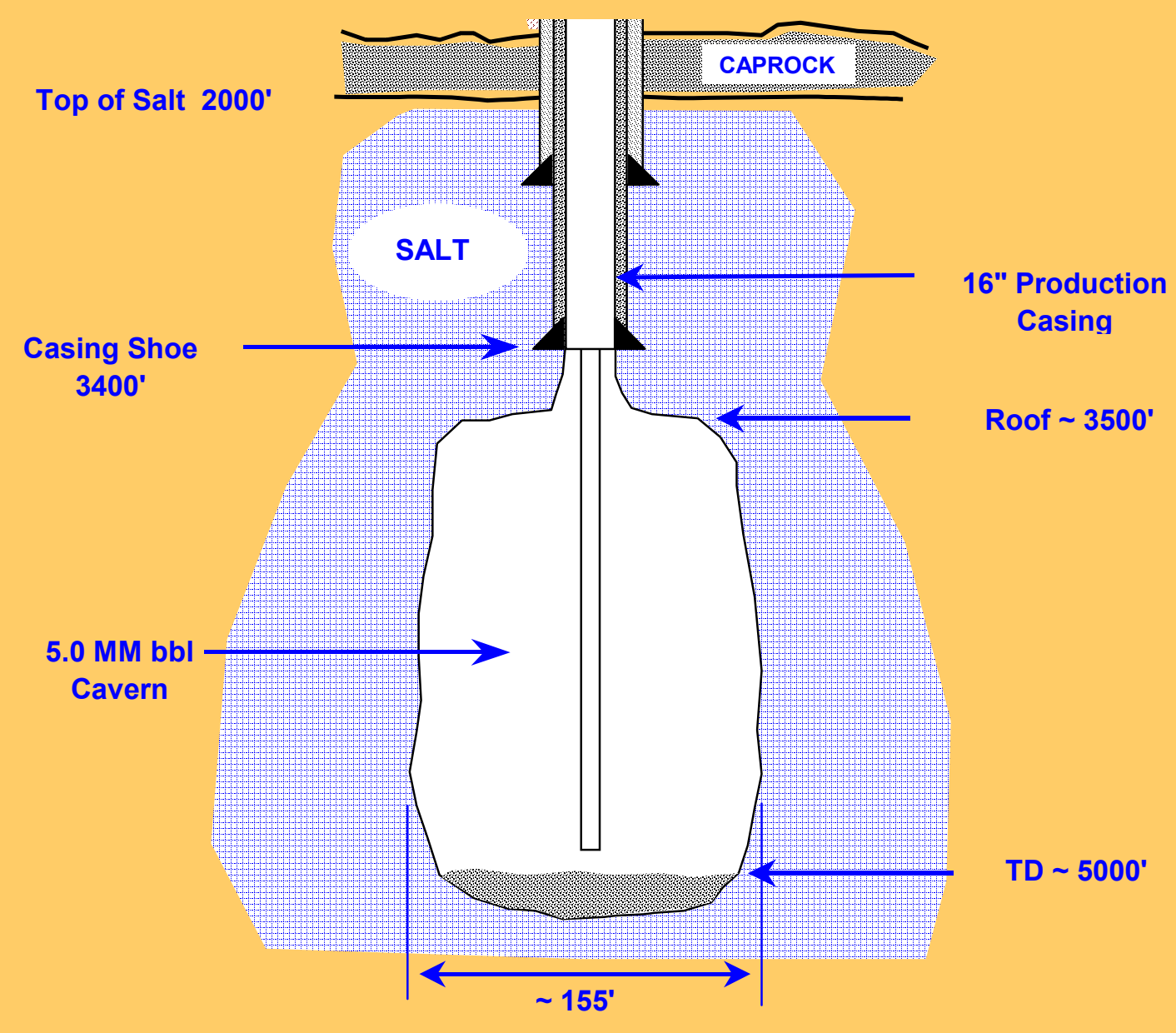




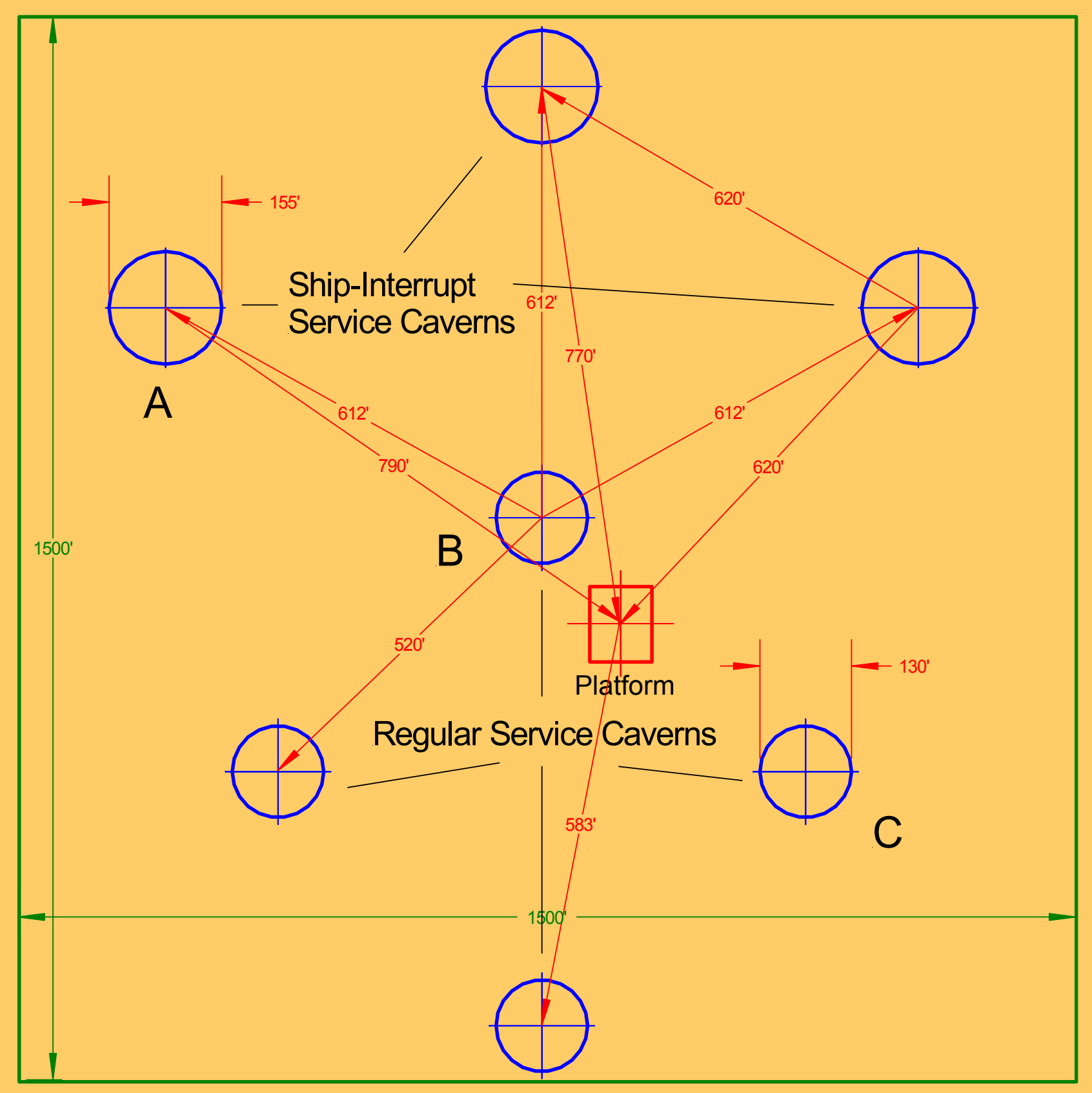

\section{Cavern Layout}

Pillar/Diameter

Ratio $=3.0$ 


\section{Gas Storage Volume Data}

\begin{tabular}{|l|r|l|}
\hline Volumes (Regular service caverns)) & & \\
\hline Working Gas (Per Cavern) & 0.550 & Bscf \\
\hline Cushion Gas (Per Cavern) & 1.604 & Bscf \\
\hline Total Gas (Per Cavern) & 2.154 & Bscf \\
\hline Cavern volume (physical) & 2.500 & MM Bbls. \\
\hline Number of Caverns (Initial) & 4 & \\
\hline Working Gas (Total) & 2.200 & Bscf \\
\hline Cushion Gas (Total) & 6.416 & Bscf \\
\hline Total Gas (Total) & 8.616 & Bscf \\
\hline & & \\
\hline Volumes (Ship-interrupt service caverns) & & \\
\hline Working Gas (Per Cavern) & 1.500 & Bscf \\
\hline Cushion Gas (Per Cavern) & 2.900 & Bscf \\
\hline Total Gas (Per Cavern) & 4.400 & Bscf \\
\hline Cavern volume (physical) & 5.000 & MM Bbls. \\
\hline Number of Caverns (Initial) & 3 & \\
\hline Working Gas (Total) & 4.500 & Bscf \\
\hline Cushion Gas (Total) & 8.700 & Bscf \\
\hline Total Gas (Total) & 13.200 & Bscf \\
\hline
\end{tabular}




\section{Regular Service Cavern Cycle}

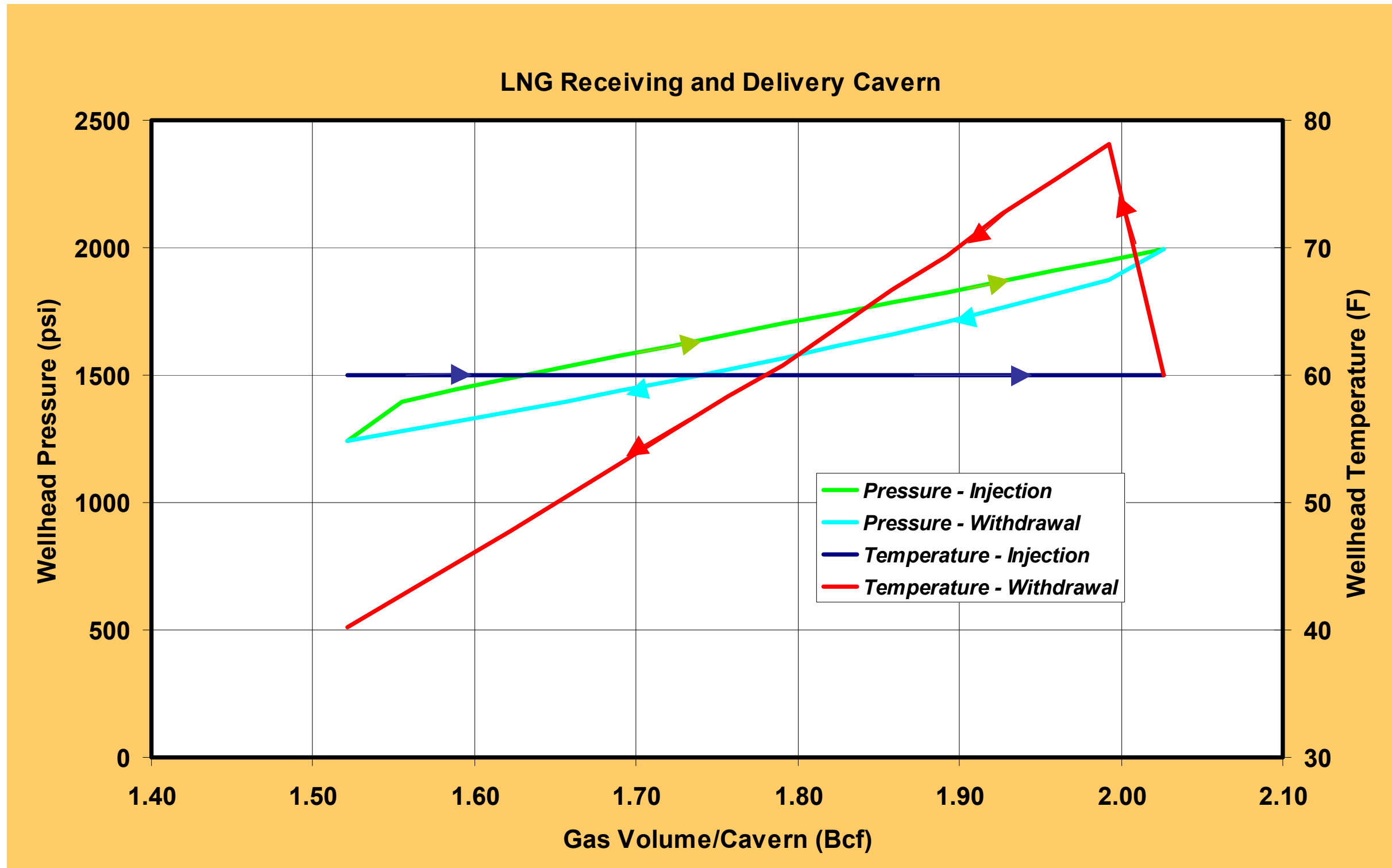




\section{Ship-interrupt Cavern Cycle}

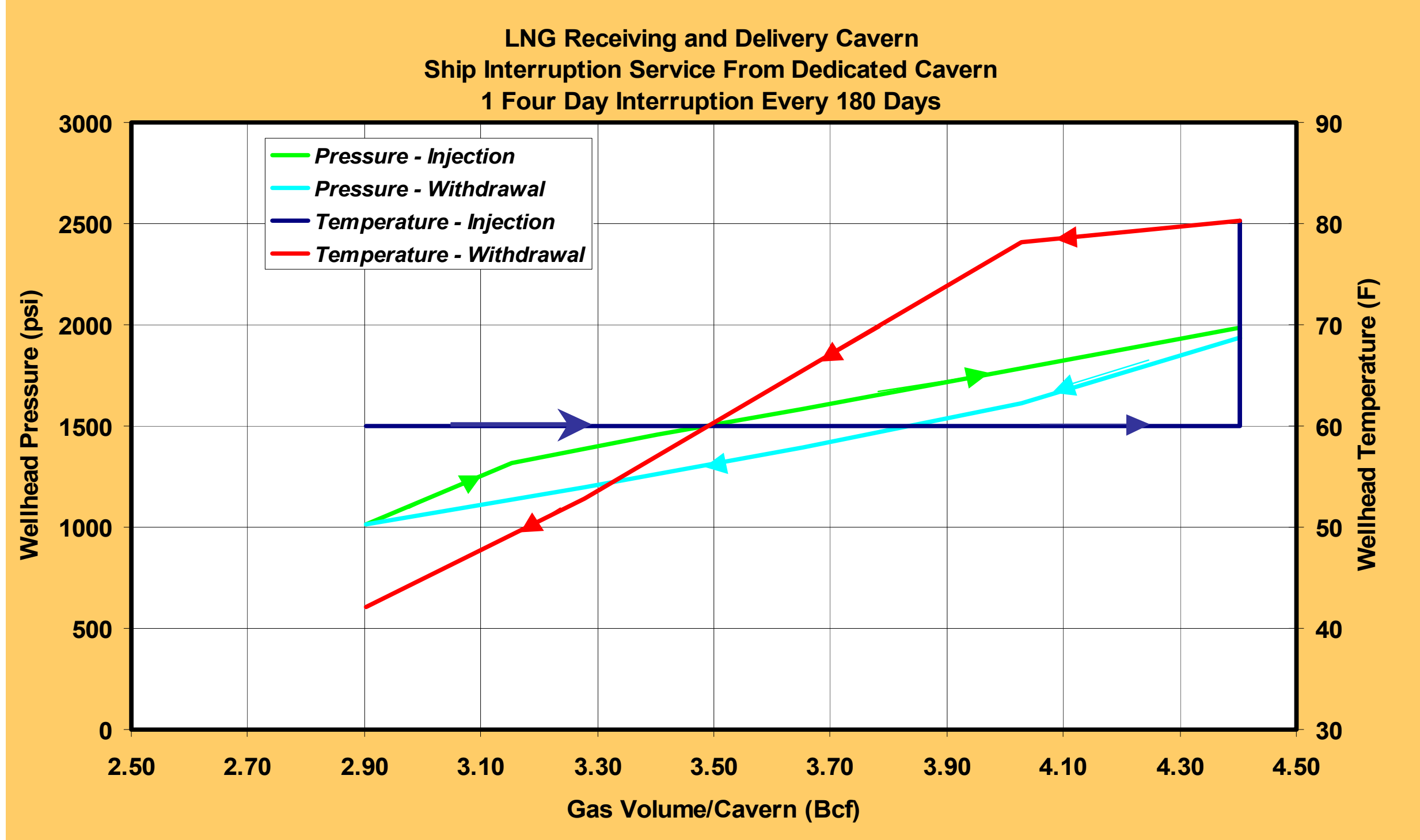




\section{Well Drilling}

- Drilling planned for 7 wells directionally drilled from a single platform. (Stationary or Jack Up Type.)

- 16 " final production casing for each well with dry completion trees.

- Estimated drilling time for "Regular Service Caverns" is 65 days.

- Estimated drilling time for "Ship-Interrupt Caverns is 75 days.

- After drilling, the well is configured for cavern development (leaching of salt dome with seawater).

- 13-3/8" and 8-5/8" leaching strings. 


\section{Well Casing Design}

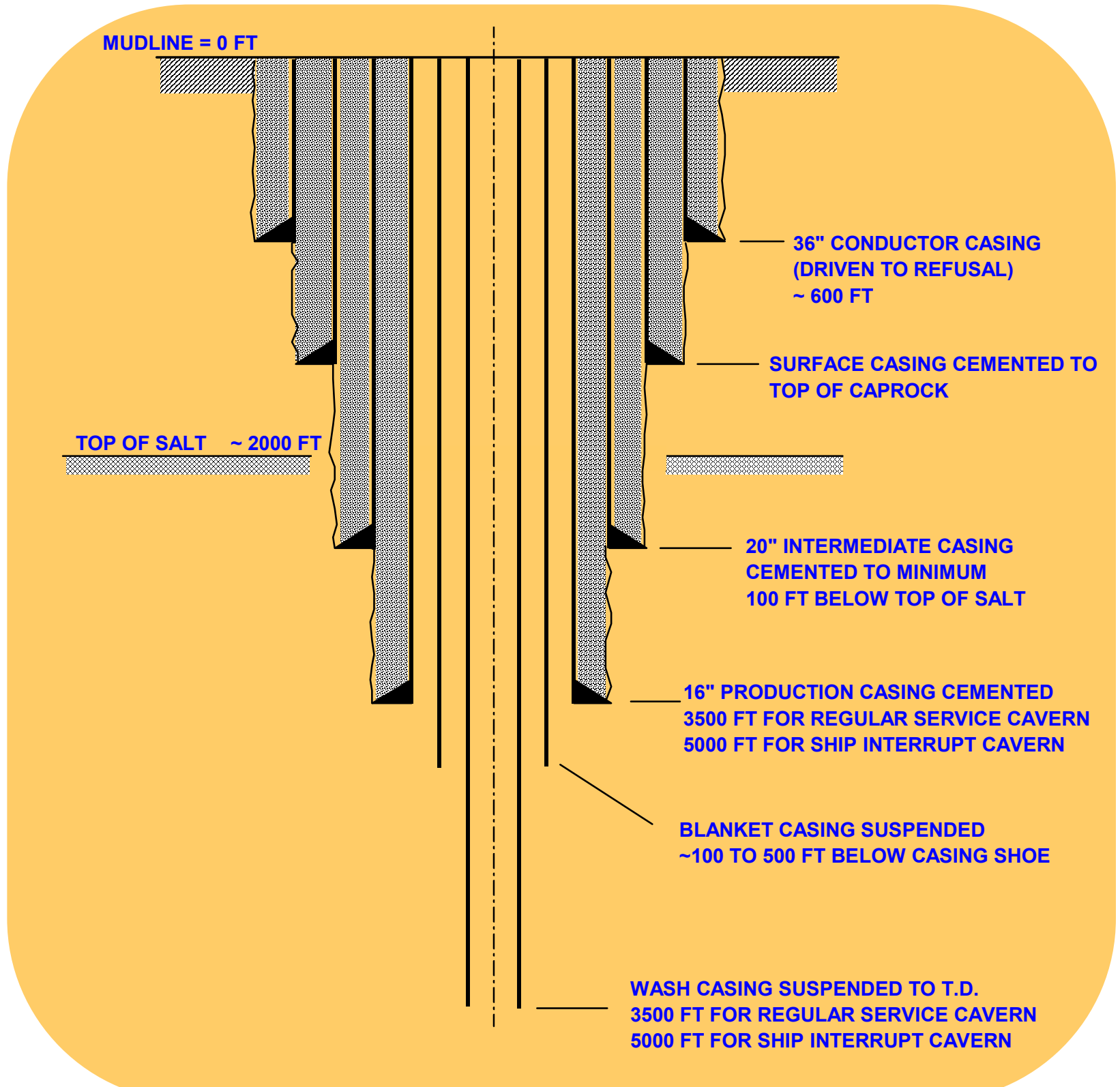

Casing depths will vary from well to well. Four "Base Case" wells have $2500 \mathrm{ft}$. casing shoes. Three deeper "Ship Interruption Case" wells have casing shoes at $3500 \mathrm{ft}$. 
Cavern

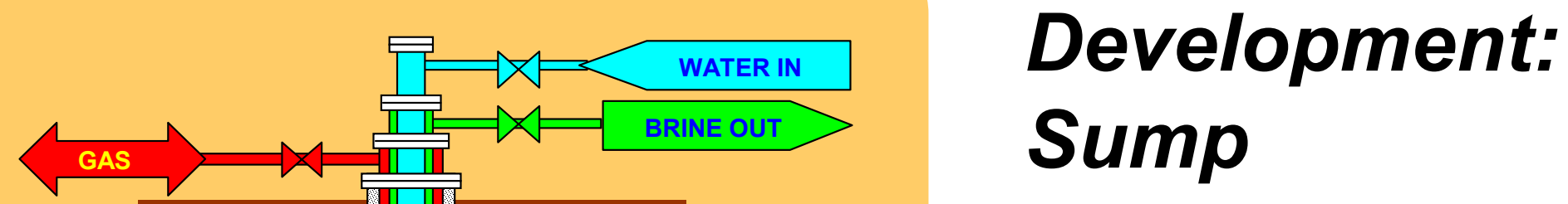

Seawater is injected into the bottom of the cavern through the tubing and brine is withdrawn from the top of the well in the $13-3 / 8$ " x 8-5/8" annulus. Space is developed preferentially in the bottom of the cavern. 


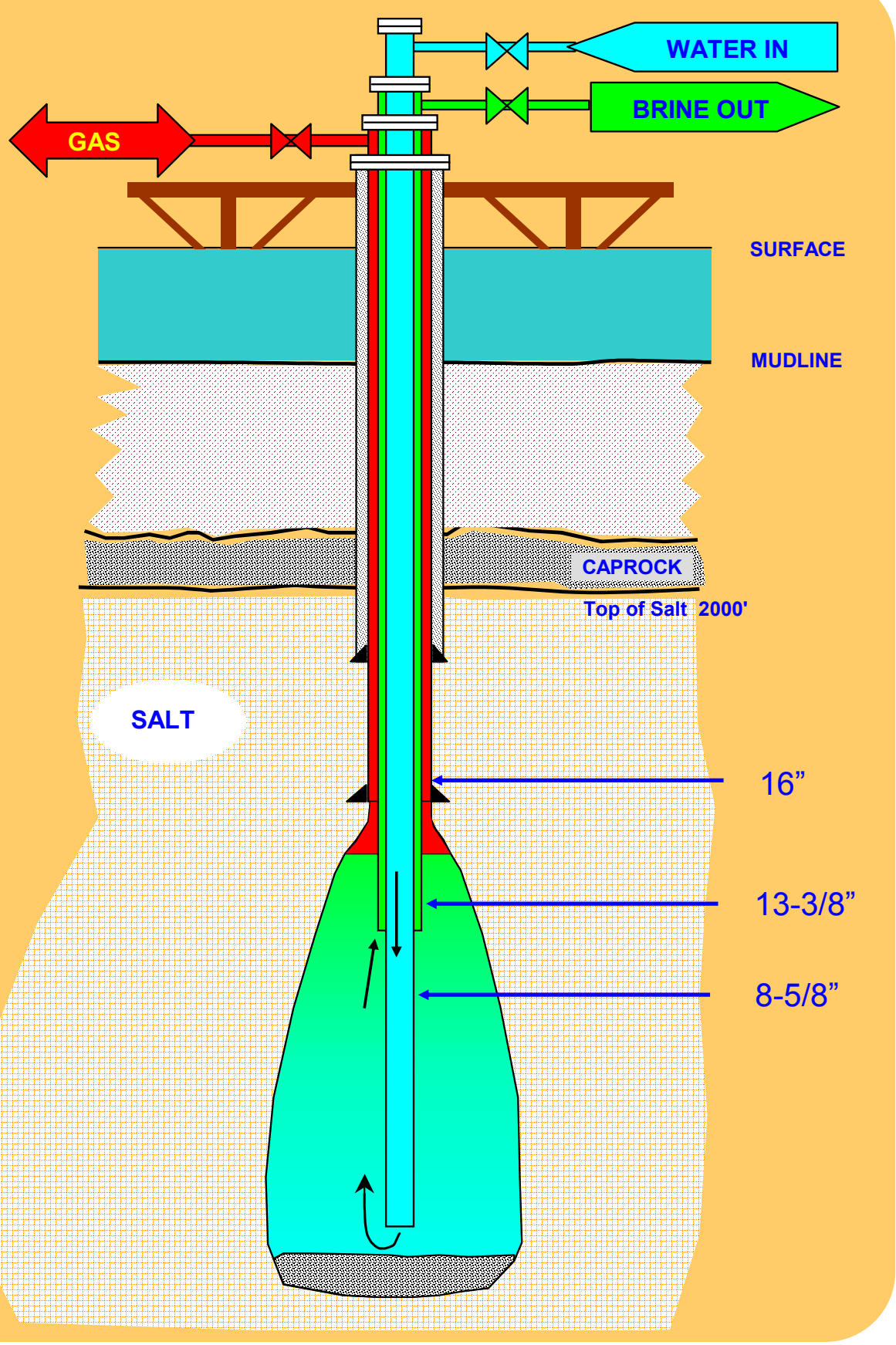

\section{Cavern Development: Direct Flow Leaching}

Seawater injection continues into the bottom of the cavern through the tubing and brine is withdrawn from the top. The blanket is set near the casing shoe. The cavern develops a bottle type shape, wide at the bottom and narrow at the top 


\section{Cavern Development: Leaching Hydraulics}

- Maximum leach rate with 13-3/8" x 8-5/8" hanging strings is typically 2500 gallons/minute.

- The dewatering string in this example is 7-5/8" diameter. Nominal flow at 15 fps velocity is $1750 \mathrm{gpm}$.

- With this configuration, development of a $2.5 \mathrm{MM}$ bbl cavern requires

9 months of leaching plus 1.5 months to dewater.

- Development of a 5.0 MM bbl cavern requires 18 months leaching and 3 months dewatering.

- It is recommended that maximum fluid velocity in the dewatering and leaching strings should be limited to 15 feet per second. 


\section{Hydraulics}

\section{Pressures During Direct Flow Leaching}

CGI Vermillion Block 179 Study

Regular Service Caverns

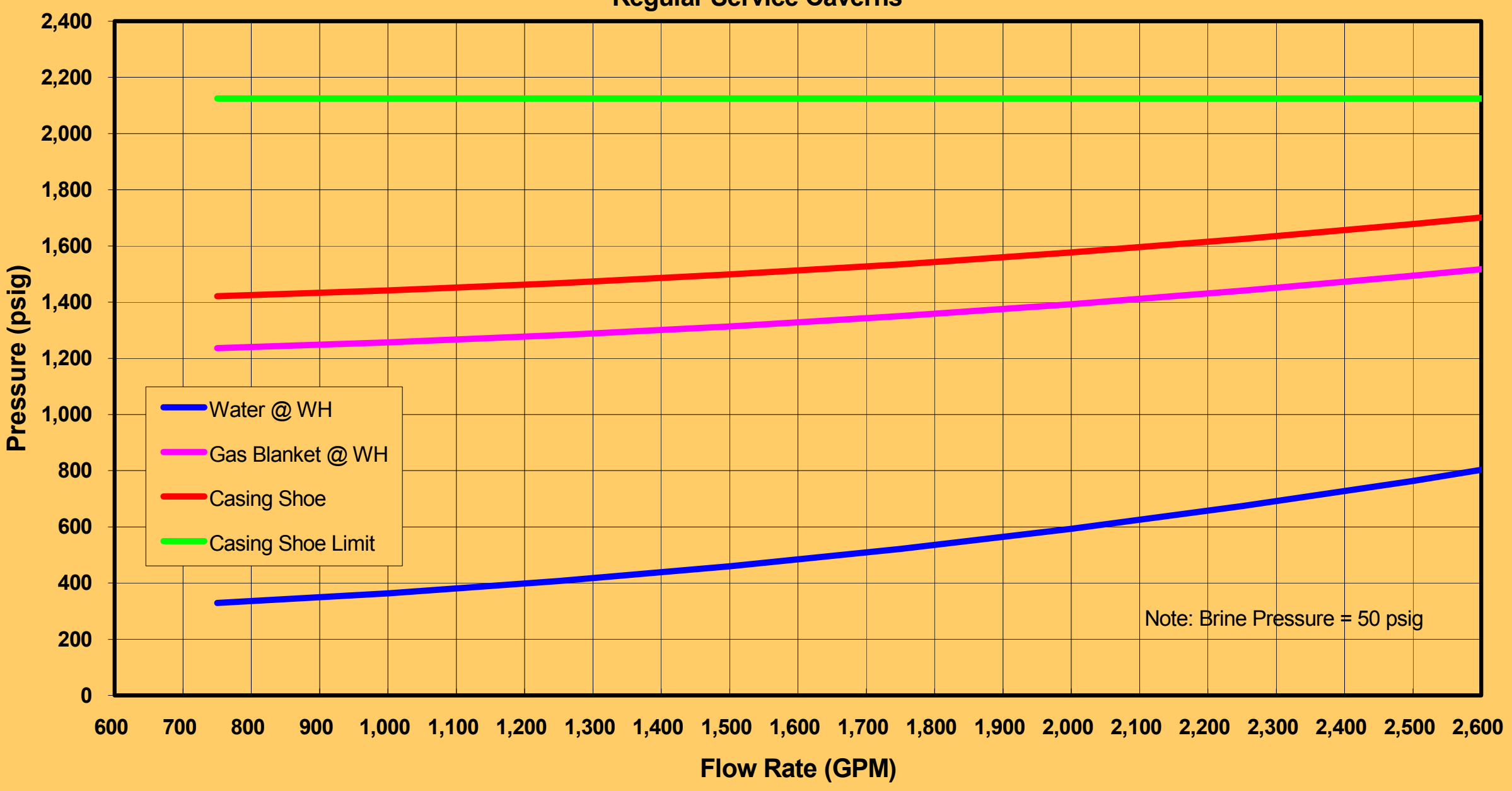




\section{Hydraulics}

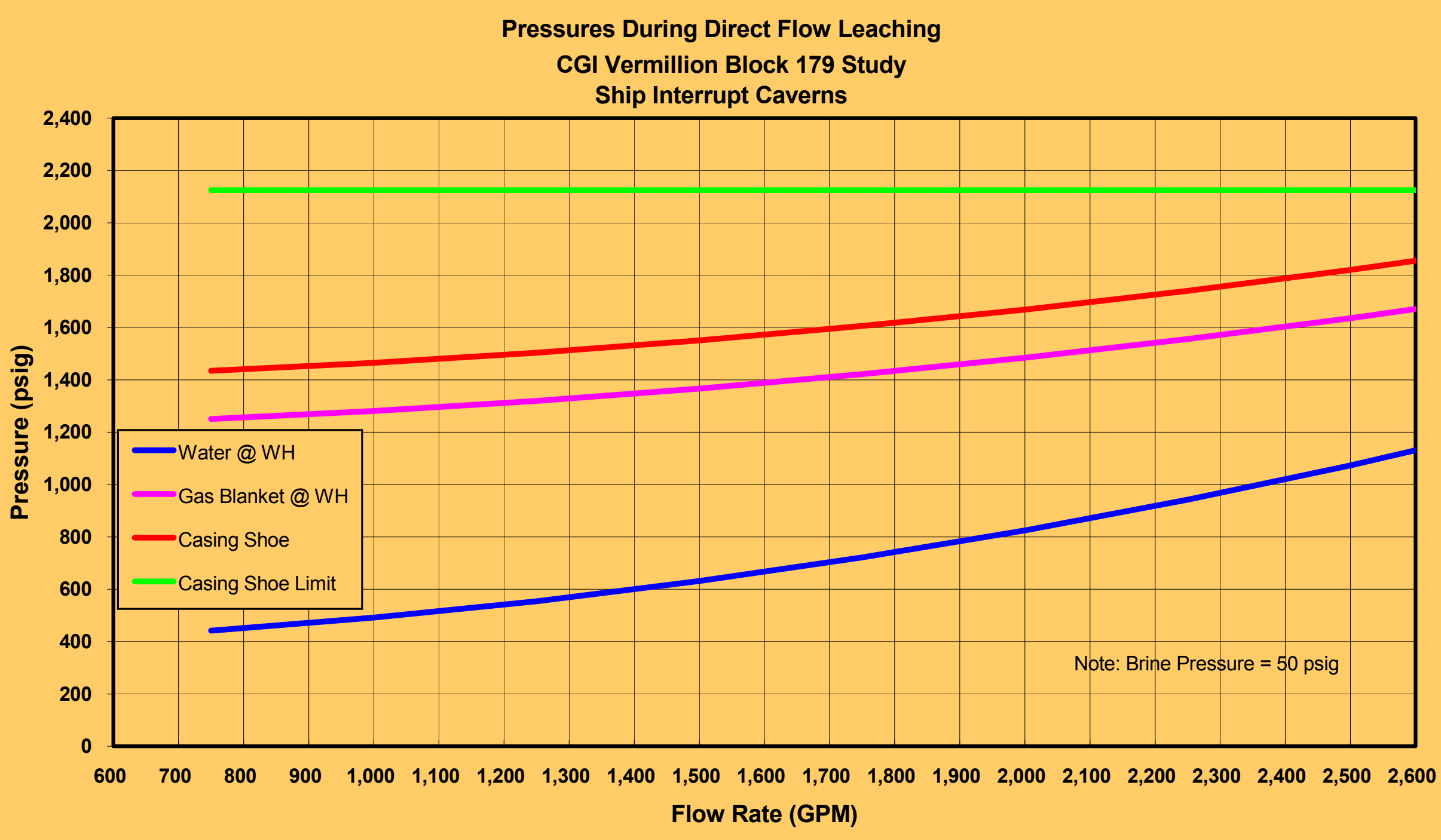




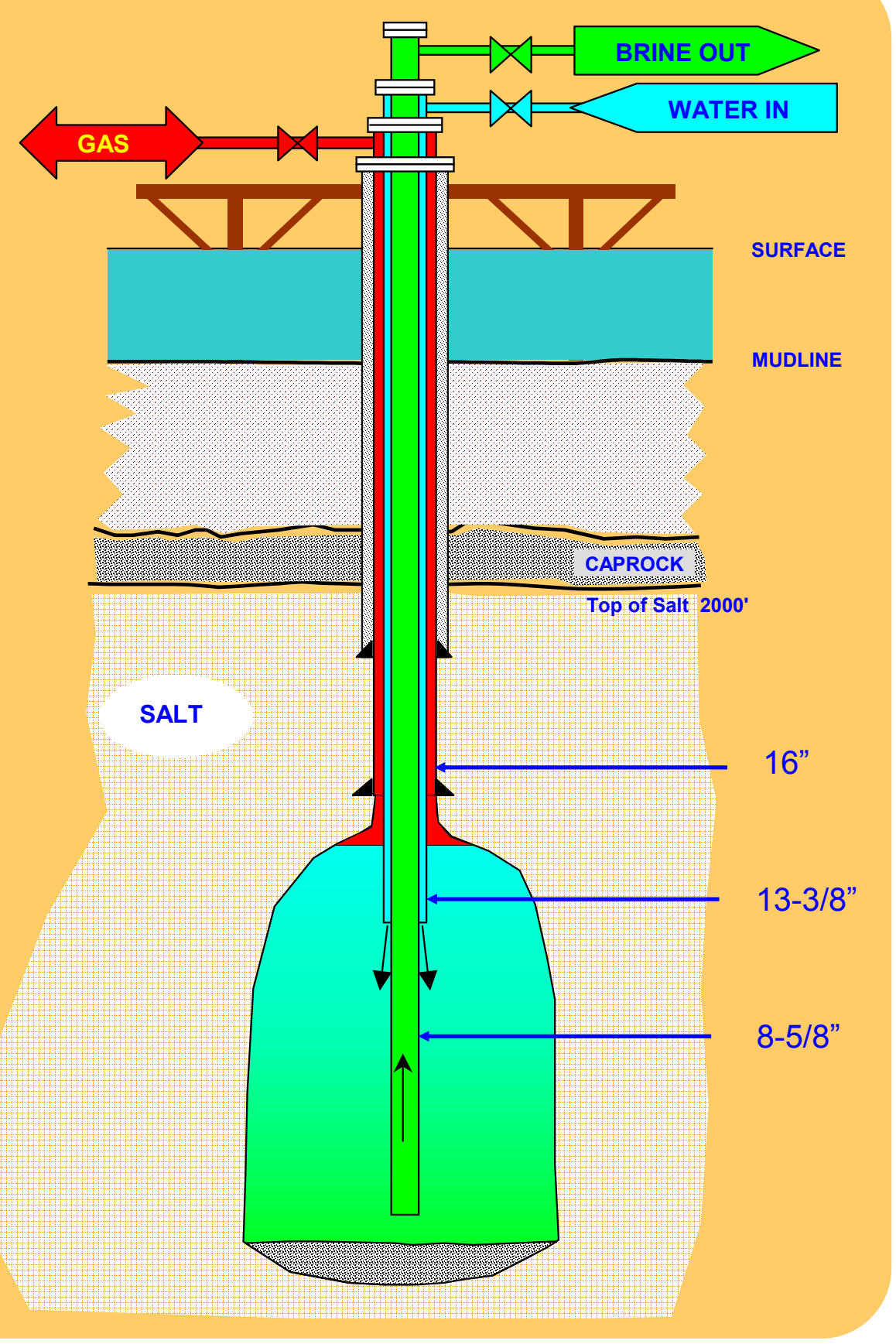

\section{Cavern Development: Reverse Flow Leaching}

Seawater injection is into the top of the cavern through the annulus and brine is withdrawn from the bottom. The blanket is set according to the development plan, usually well below the casing shoe. The blanket depth is adjusted to direct development. Cavern development is near the blanket and the cavern forms a more cylindrical or even a "top heavy" form. 


\section{Hydraulics}

\section{Pressures During Reverse Flow Leaching}

CGI Vermillion Block 179 Study

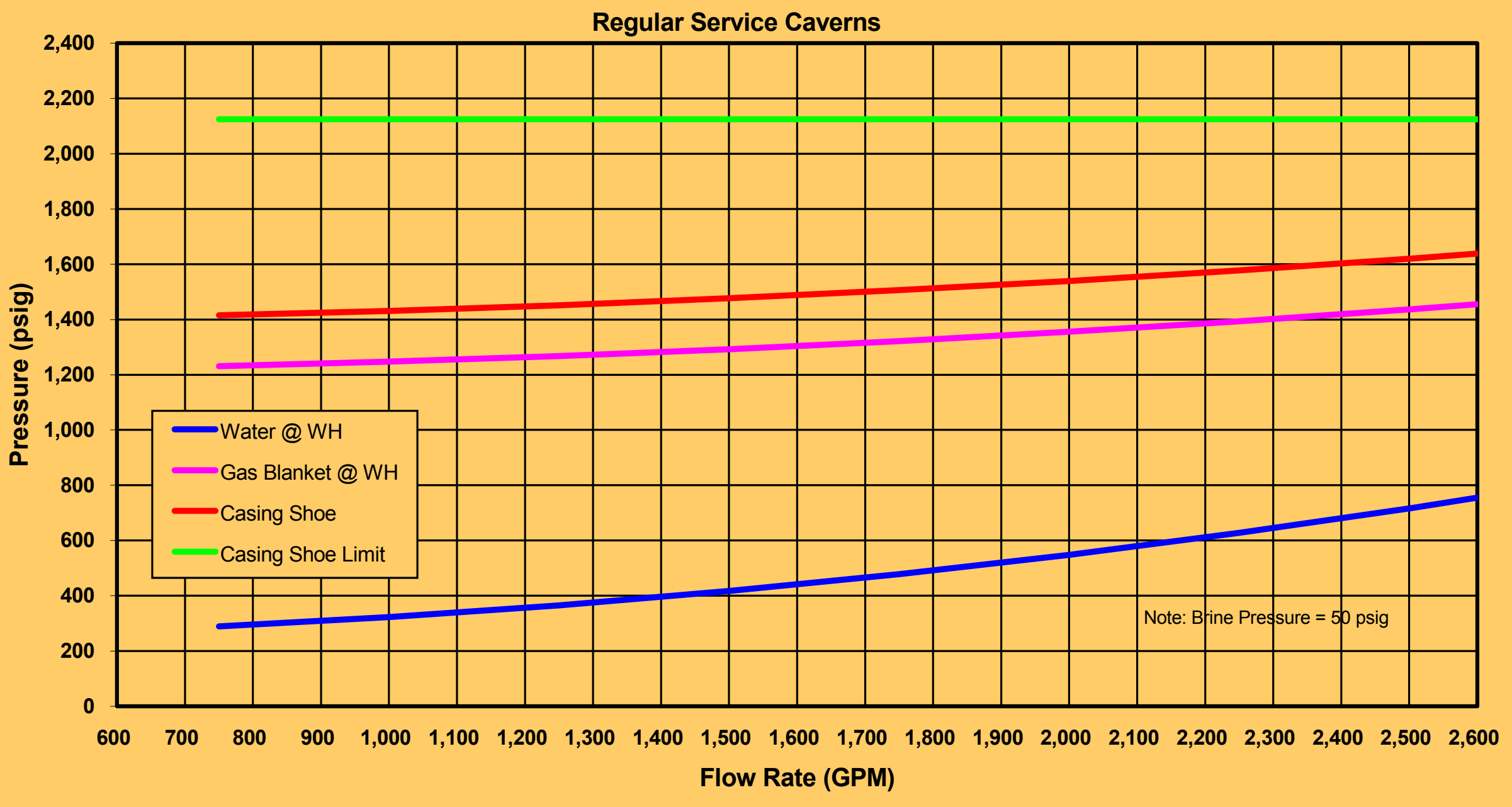




\section{Hydraulics}

Pressures During Reverse Flow Leaching

CGI Vermillion Block 179 Study

Ship Interrupt Caverns

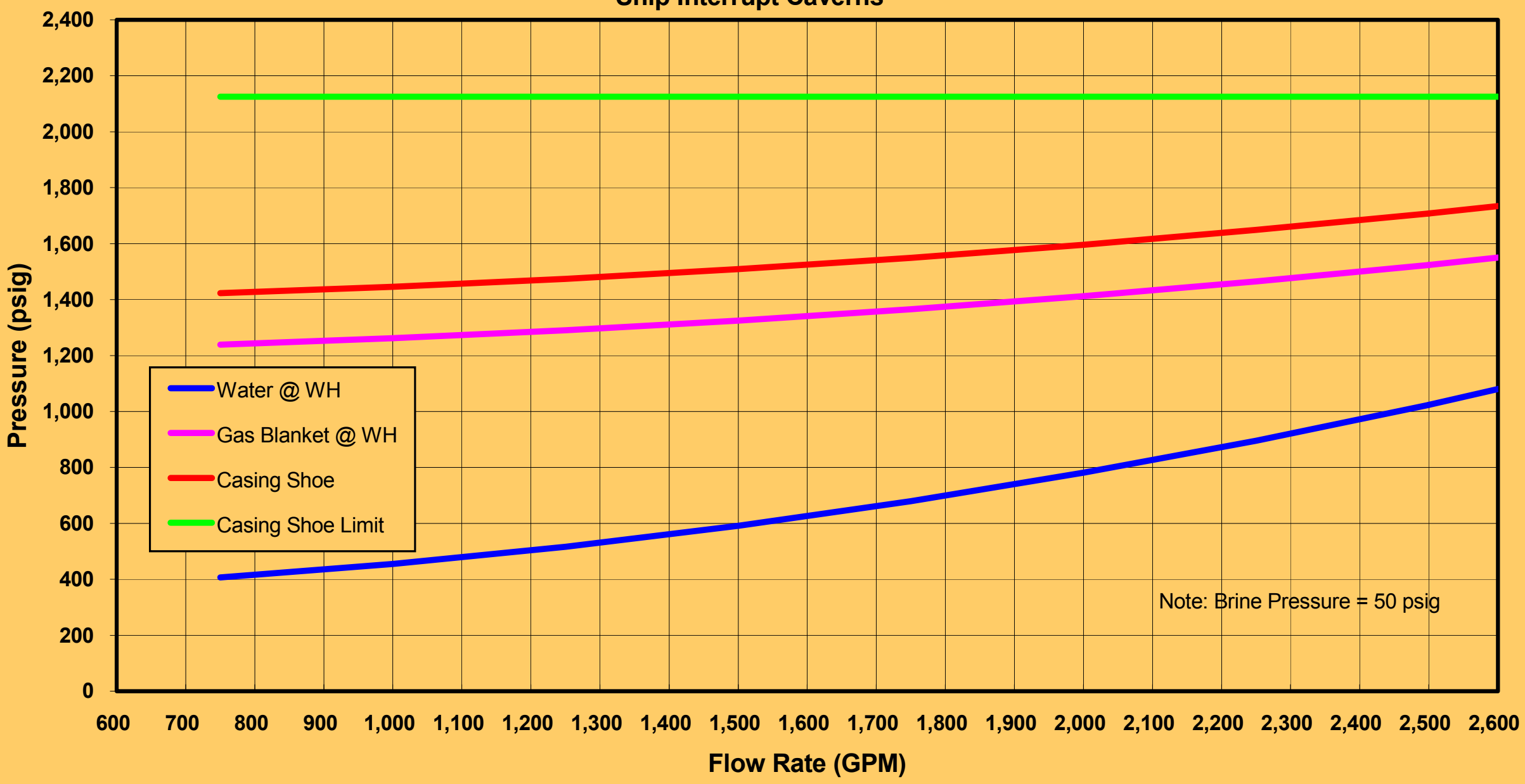




\section{Cavern Development: Leaching Equipment Requirements}

- The use of seawater for leaching will require organism screening, biocide treatment (hypochlorite), and possibly an $\mathrm{O} 2$ scavenger addition such as $\mathrm{SO} 2$.

- Low pressure lift pumps will be needed to feed water to the well injection pumps at less than 100 psig.

- Seawater injection pumps well be required to inject the leaching water into the storage well cavern at pressures of up to 1100 psig for the deeper "Ship Interrupt" caverns, and 800 psig for the "Regular Service" caverns.

- The hydraulic horsepower required for $2500 \mathrm{gpm}$ at these pressures is $\sim 1600$ hp and $\sim 1200 \mathrm{hp}$ respectively. Continuous pressure and flow monitoring equipment is recommended for all well tubulars.

- Brine disposal will be via dispersal at sea. A distribution system may be required for environmental permit purposes.

- Natural gas, nitrogen or diesel fuel is recommended for the blanket material during leaching. Gas compression will be needed if nitrogen or natural gas is used. This equipment can be leased. Nitrogen generators can be leased or purchased. 


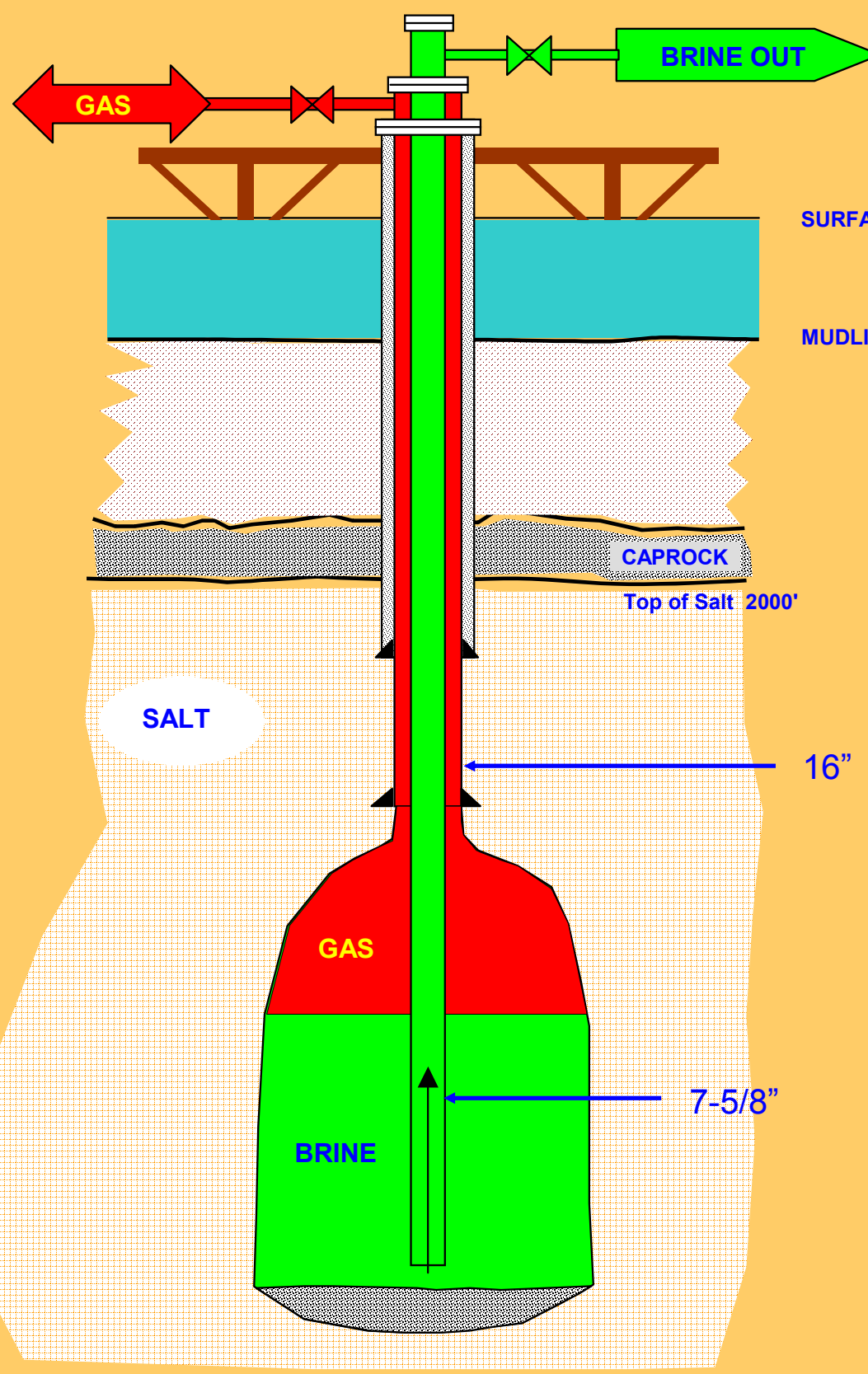

\section{Cavern \\ Conversion and Dewatering}

Once the cavern has reached the required volume, a conversion workover is performed to configure the well for gas storage service. The leaching strings and wellhead are removed, and a gas storage wellhead and a dewatering string are installed. A mechanical integrity test is performed on the cavern, testing the cavern and well system to the maximum allowable operating pressure. When the workover and test are completed, the well is ready for gas storage service. 


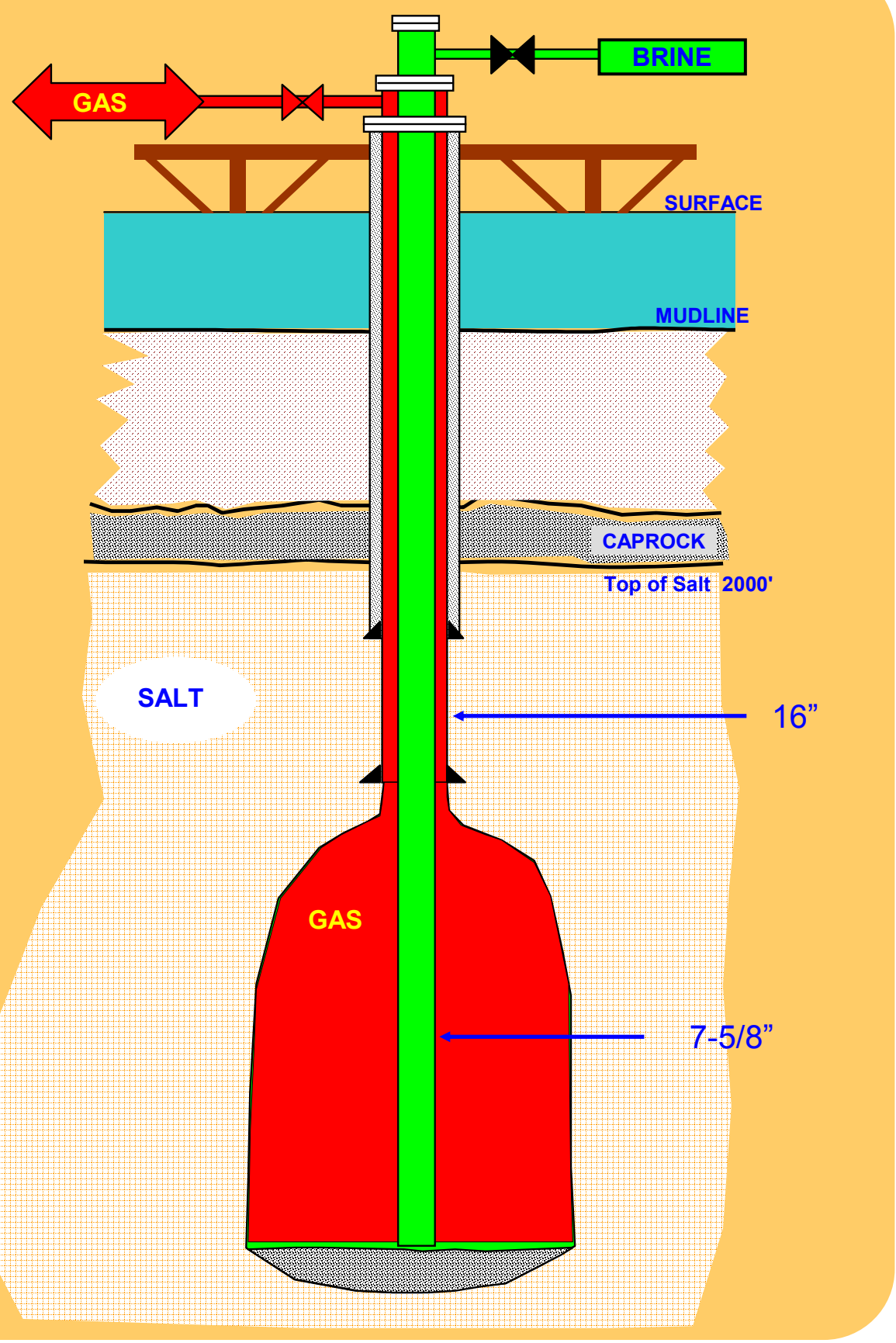

\section{Gas Storage Operations}

Natural Gas is injected into the well, displacing the brine out of the cavern. The rate of dewatering is dependent upon the gas pressure available and the size of the dewatering string. Many factors that require careful consideration by the operator enter into sizing of the dewatering string. The string size will affect future gas operations and possible re-watering and dewatering of the cavern. The need for snubbing out the string for removal, repair or replacement must also be evaluated. 


\section{Compensated Flow Operations Purpose}

- Compensated flow involves displacement of the stored gas volume with seawater or brine while delivering gas from the cavern. Conversely, when receiving gas, brine is displaced from the cavern to the surface via the dewatering tubing.

- The initial dewatering of the cavern is an example of compensated flow operations.

- Many salt caverns that are presently in gas storage service are operated in some form of compensated flow operations on occasions. However, typically gas storage salt caverns are operated in the non-compensated or gas compression/expansion cycle mode.

- Some caverns that are operated in the compensated mode are being solution mined while they are still in gas service. This is referred to as "Solution Mining Under Gas" or SMUG.

- Additionally, some operators will refill their caverns with water, to recover the base gas during high demand periods, or to recover cavern volume that has been lost due to "salt creep". A one-time refill will leach approximately $15 \%$ additional cavern volume. 


\section{Compensated Flow Hydraulics}

- The hydraulics for compensated flow are determined by the configuration of the cavern, the hanging string(s), and the pressure requirements of the fluids.

- The casing shoe must be deep enough to allow adequate gas pressure for brine displacement without exceeding the safety limits of the overburden gradient.

- The following 4 cases illustrate the pressures and flows required for gas and brine when dewatering the caverns specified in this conceptual design.

- Note that some of the brine velocities exceed our recommended maximum of $15 \mathrm{fps}$. This is for illustration purposes only to show brine flows equivalent to the gas flow rate. To achieve these flow rates, it is recommended that a larger brine string be installed.

- The cases illustrated are for brine-full and gas-full caverns 


\section{Dewatering "Regular Service” Wells}

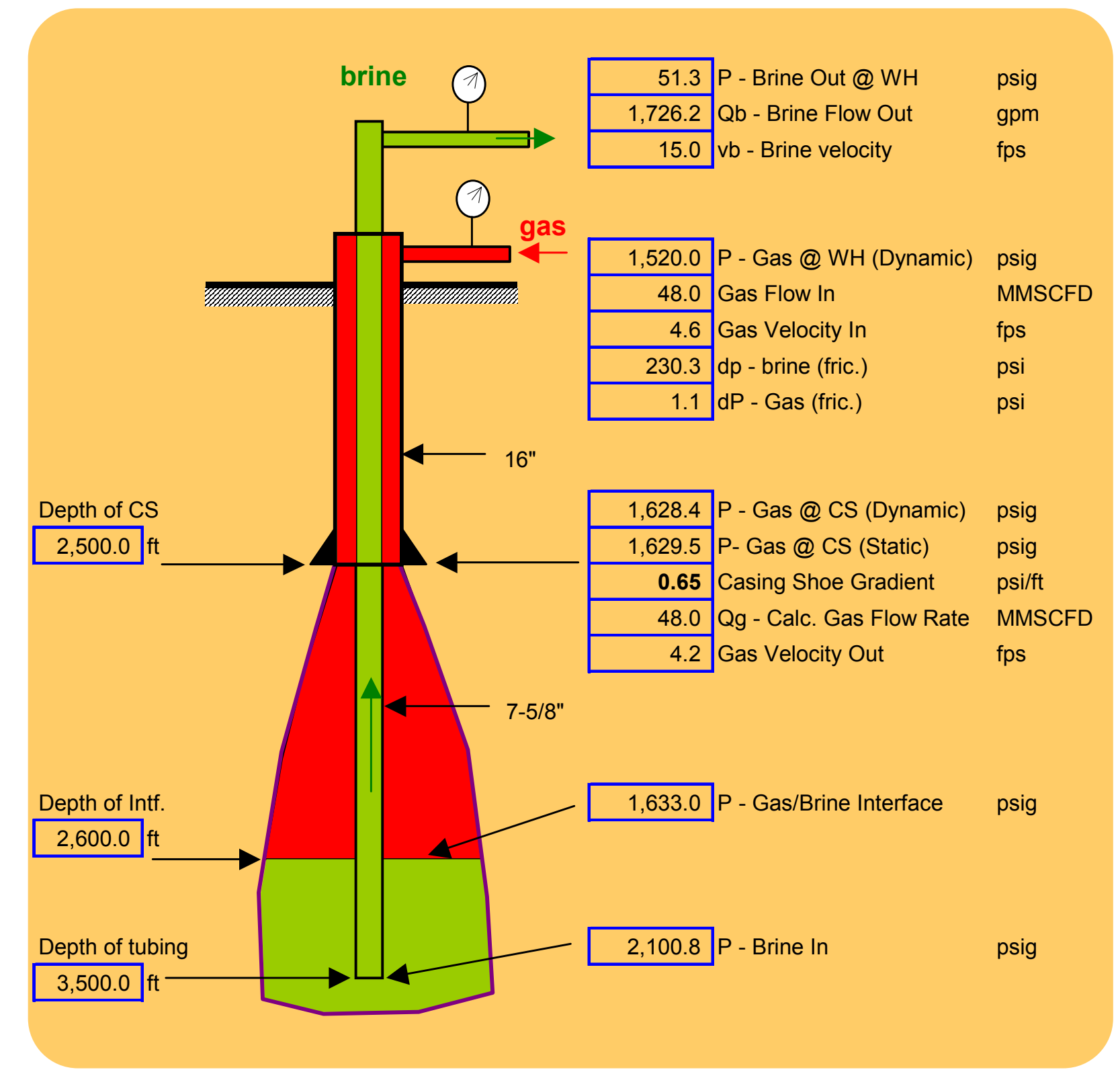

\section{Case 1 \\ Brine Full}

C.S. $=2500 \mathrm{ft}$.

Interface $\mathbf{=} \mathbf{2 6 0 0} \mathrm{ft}$.

Gas Flow In $=48$ MMSCFD

Brine Flow Out $=1726 \mathrm{gpm}$

Brine Velocity $=15 \mathrm{fps}$

WH Brine Press. $=51 \mathrm{psig}$

WH Gas Press. $=1520$ psig 


\section{Dewatering "Regular Service” Wells}

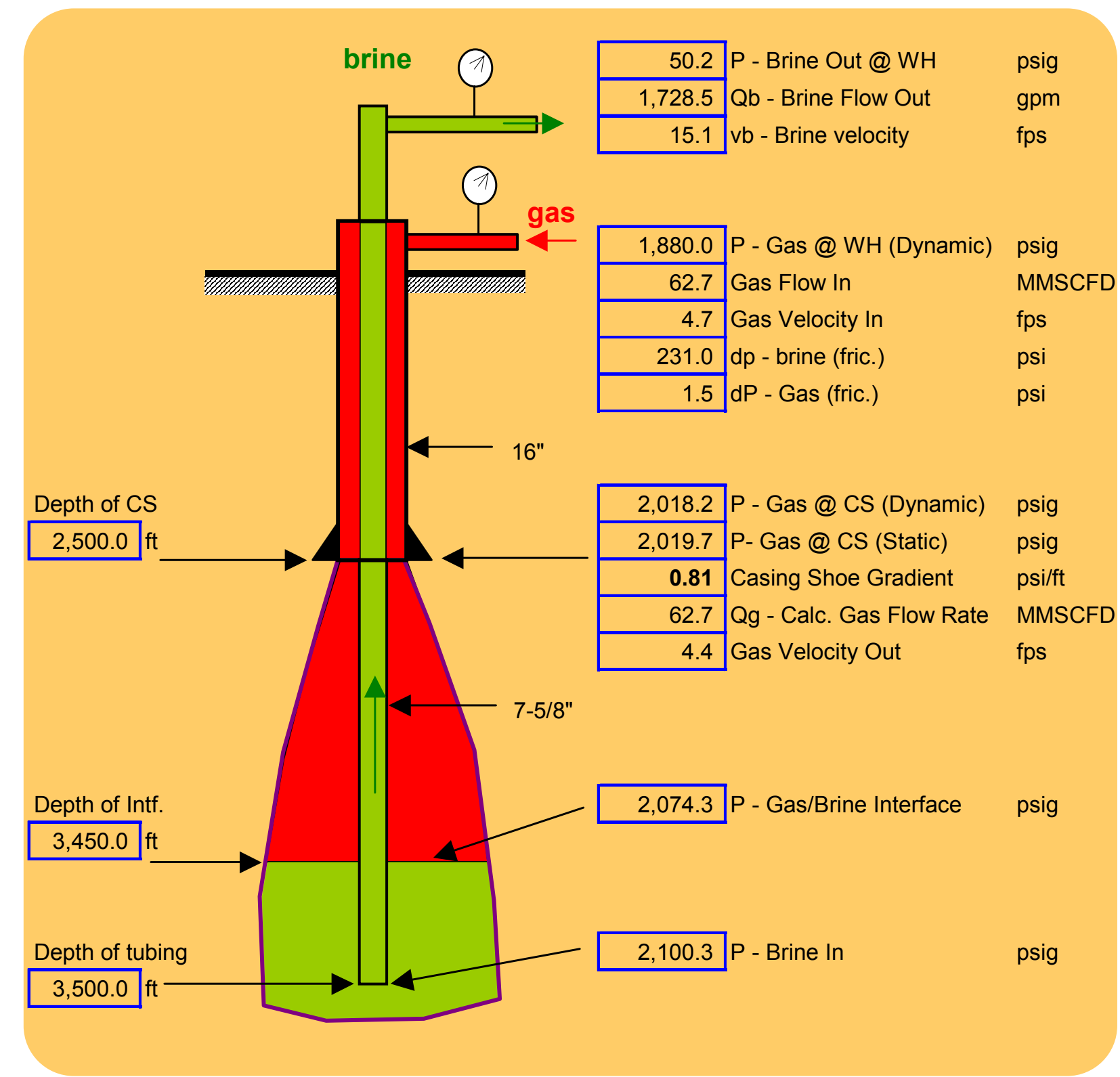

\section{Case 2}

Gas Full

C.S. $=2500 \mathrm{ft}$.

Interface $=\mathbf{3 4 5 0} \mathrm{ft}$.

Gas Flow In= 63 MMSCFD

Brine Flow Out $=1728 \mathrm{gpm}$

Brine Velocity $=15 \mathrm{fps}$

WH Brine Press. $=50$ psig

WH Gas Press. $=1880$ psig 


\section{Dewatering “Interrupt Service” Wells}

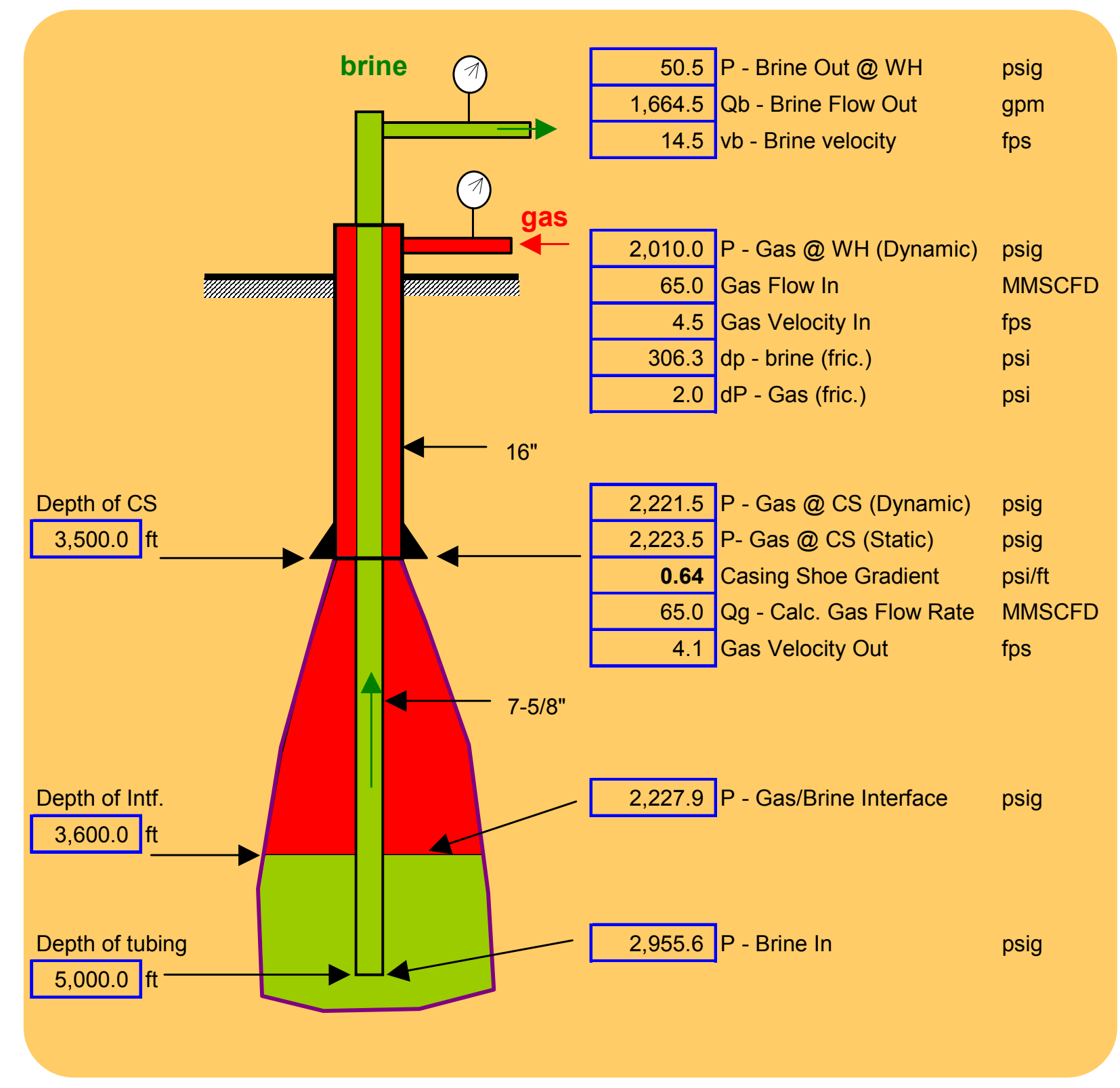

Case 3

Brine Full

C.S. $=3500 \mathrm{ft}$.

Interface $\mathbf{=} \mathbf{3 6 0 0} \mathrm{ft}$.

Gas Flow In $=65$ MMSCFD

Brine Flow Out $=1665 \mathrm{gpm}$

Brine Velocity $=14.5 \mathrm{fps}$

WH Brine Press. $=50$ psig

WH Gas Press. $=2010$ psig

Note: compression required to dewater at this rate. 


\section{Gas Withdrawal with Compensated Flow}

- The calculations for withdrawal of gas from the cavern with compensated flow are complicated by the number of possible operating scenarios, especially $f$ the gas pressure is allowed to vary during withdrawal.

- The examples shown here are snapshots of possible scenarios showing the brine flow required to displace gas at the flow rate and pressure as shown.

- In actual practice the gas pressure could be allowed to fall within specified limits, making the brine requirement somewhat less. However, methods to regulate brine flow must be in place, since the brine pressure will fall to a vacuum if gas is withdrawn too quickly. 


\section{Gas Withdrawal - "Regular Service” Wells (Compensated)}

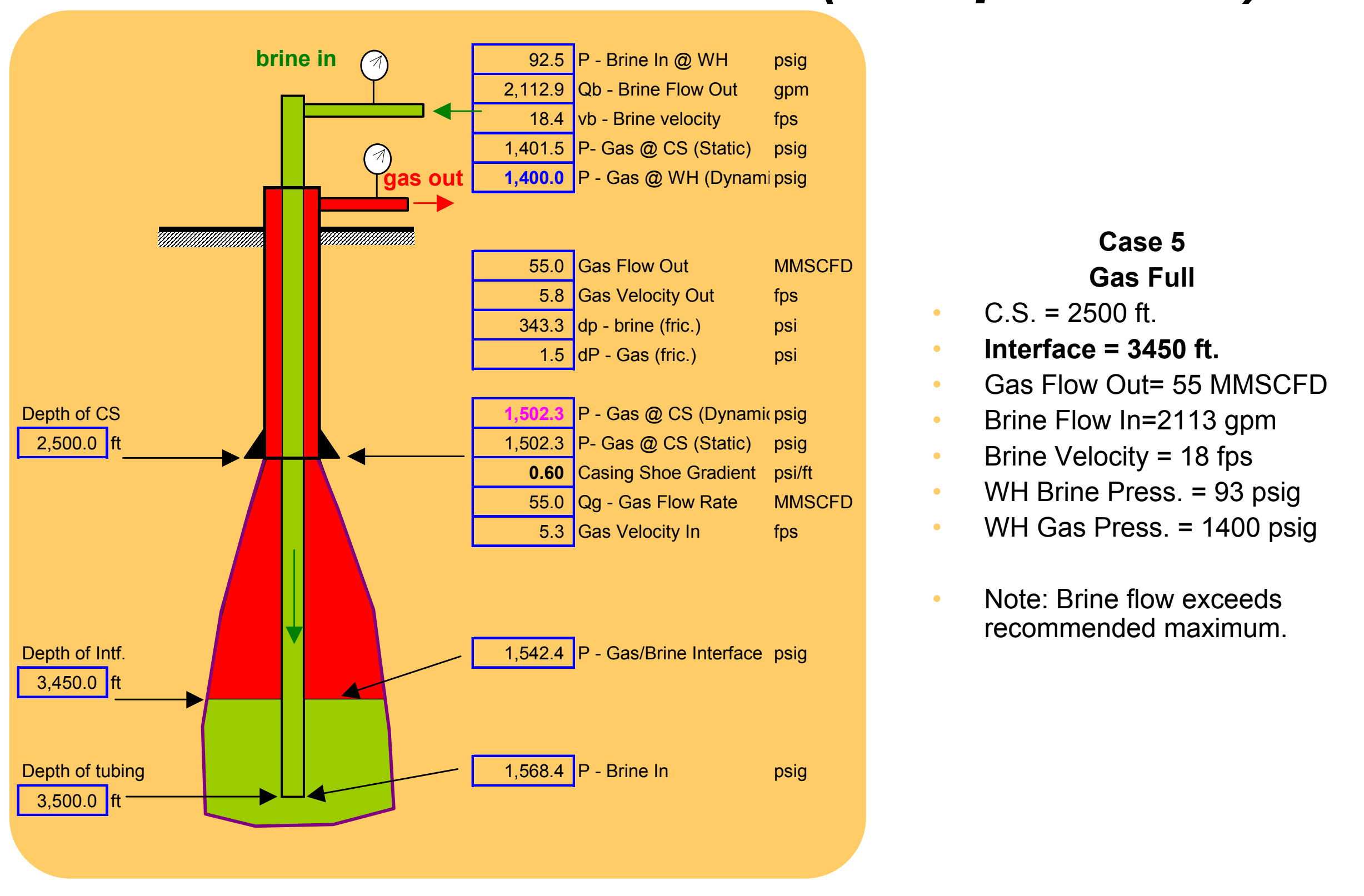




\title{
Gas Withdrawal - "Regular Service” Wells (Compensated)
}

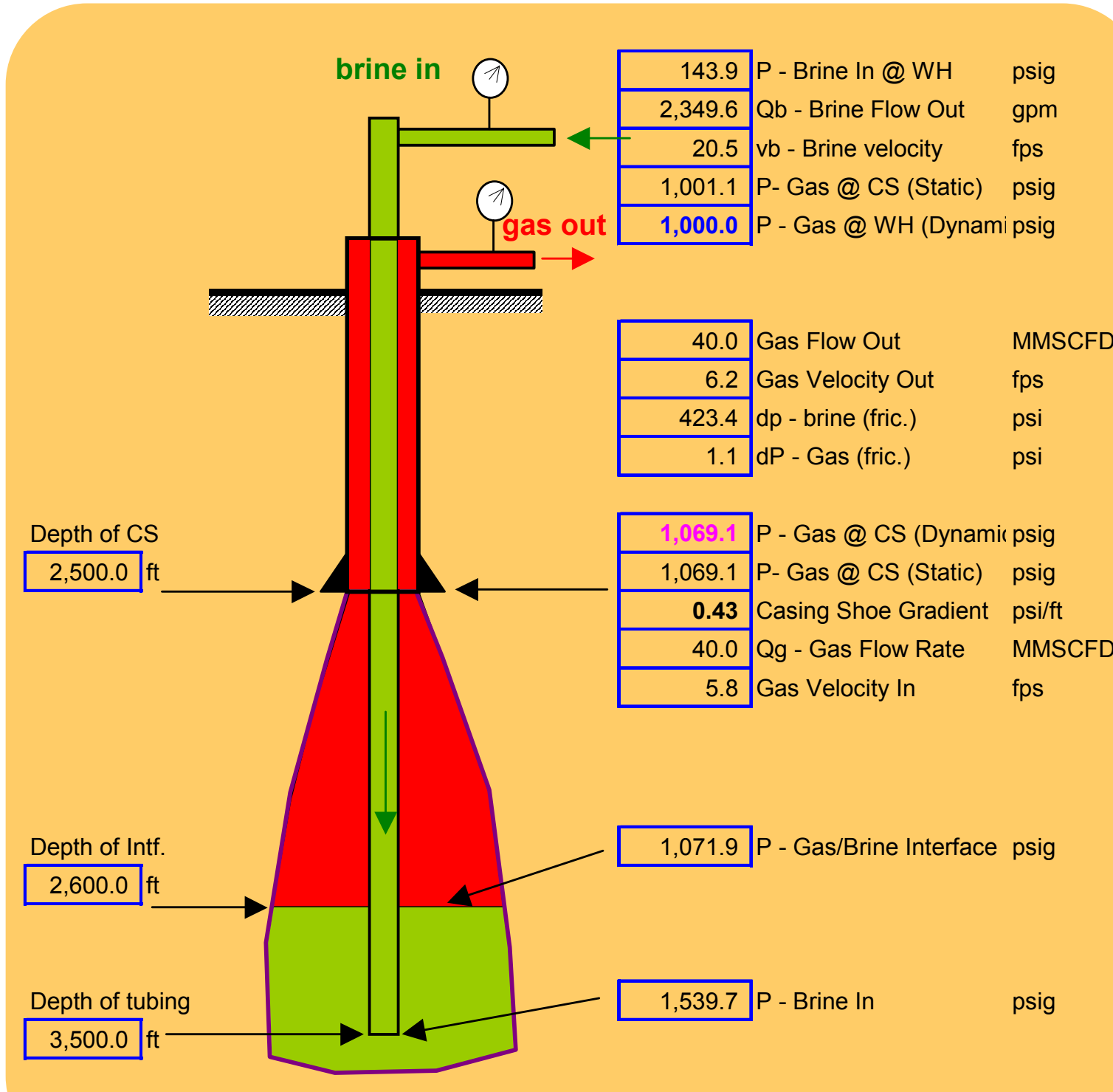

\author{
Case 6 \\ Brine Full \\ C.S. $=2500 \mathrm{ft}$. \\ Interface $=\mathbf{2 6 0 0} \mathbf{f t}$. \\ Gas Flow Out $=40$ MMSCFD \\ Brine Flow In=2350 gpm \\ Brine Velocity $=20.5 \mathrm{fps}$ \\ WH Brine Press. $=144$ psig \\ WH Gas Press. $=1000$ psig
}

Note: Brine flow exceeds recommended maximum. 


\title{
Gas Withdrawal - "Interrupt Service” Wells (Compensated)
}

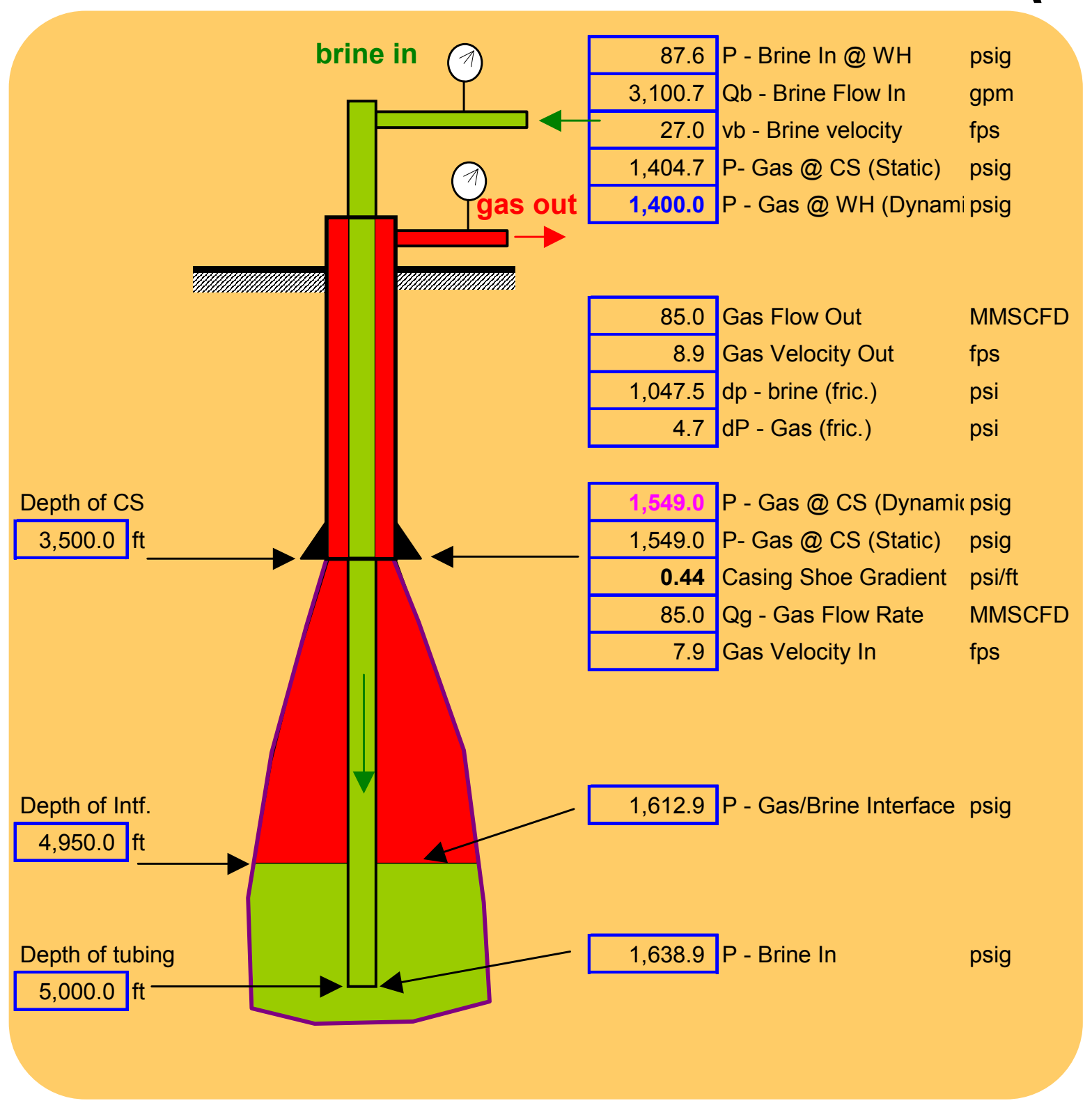

\author{
Case 7 \\ Gas Full \\ C.S. $=3500 \mathrm{ft}$. \\ Interface $=\mathbf{4 9 5 0} \mathrm{ft}$. \\ Gas Flow Out $=85$ MMSCFD \\ Brine Flow In=3100 gpm \\ Brine Velocity $=27.0 \mathrm{fps}$ \\ $\mathrm{WH}$ Brine Press. $=88 \mathrm{psig}$ \\ WH Gas Press. $=1400$ psig
}

Note: Brine flow exceeds recommended maximum. 


\section{Gas Withdrawal - "Interrupt Service” Wells (Compensated)}

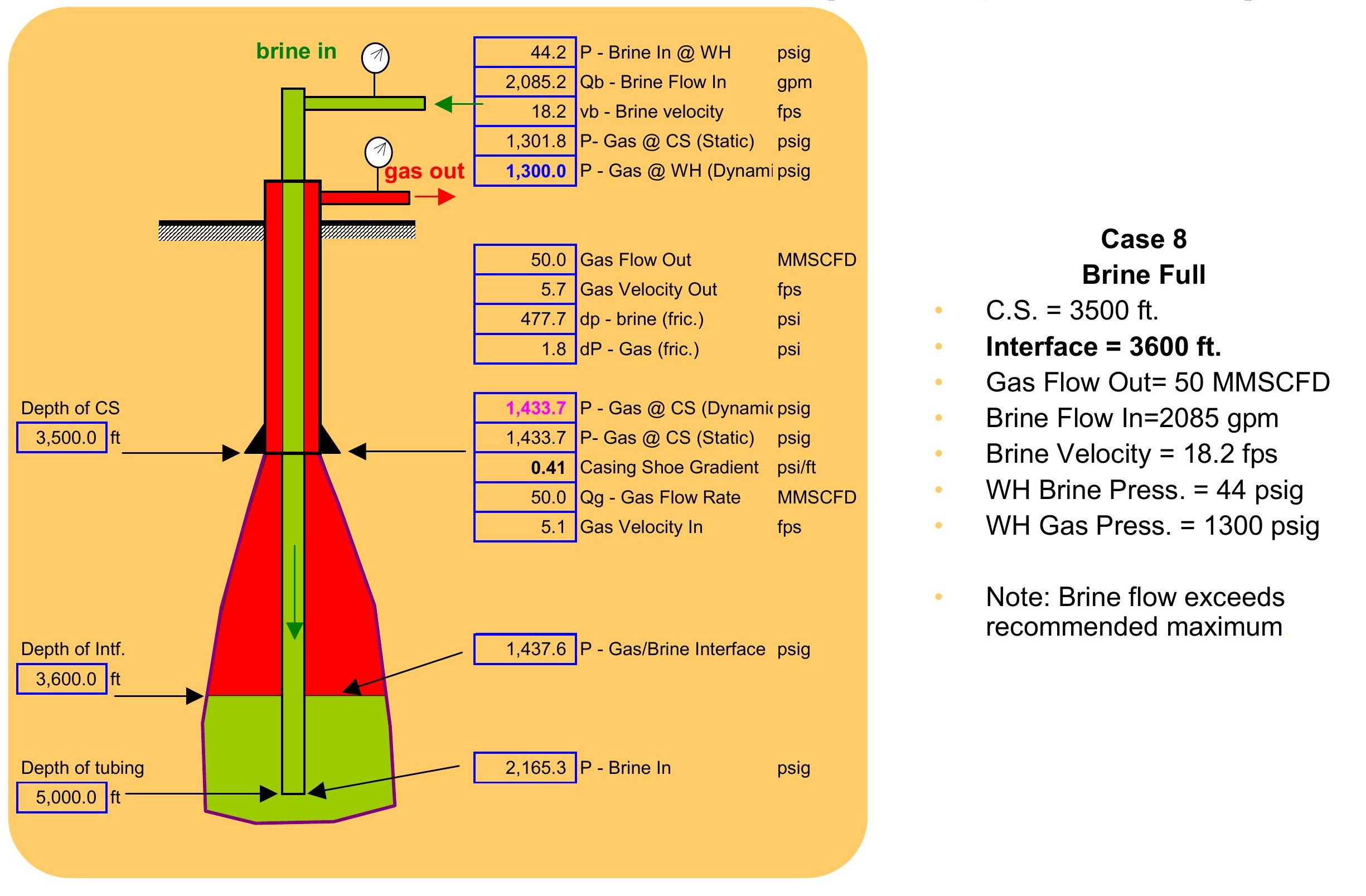




\section{Compensated Gas Withdrawal Summary}

- In order to achieve the conceptual design pipeline delivery rates with compensated flow, the volume of brine or water required to maintain fully compensated caverns will be too high in pressure drop and velocity for the these well sizes.

- Partially compensated flow during gas withdrawal will be more practical on a limited basis, giving consideration for cavern growth and maximum brine velocity.

- Lower flow rates should be expected during withdrawal as the cavern pressure approaches minimums, and brine/water addition is limited by string diameter. 


\section{Gas Dehydration Requirements}

PB ESS provided dehydration concepts for the storage caverns during discussions with CGI and Paragon Engineering Services. Paragon supplied the top-side equipment design and cost estimates.

- PB ESS recommends $100 \%$ dehydration capacity of saturated gas during compensated flow operations and during the initial phase of storage operations.

While, reductions in the level of dehydration required should occur with time, this will be a function of the resulting cavern geometry, operating cycles and maintenance of the caverns.

Re-watering of the caverns for expansion or volume recovery will result in the need for drying saturated gas again. 


\section{Rock Mechanics}

- The rock mechanics analysis is used to define the characteristics of the salt mass that will form the gas caverns.

- The results of the analysis are used to design the depth, size and shape characteristics of the eventual cavern design.

- The rock mechanics program consists of salt core sampling, laboratory analysis, and mathematical modeling of the cavern based on the sampling and analytical work. 


\section{Salt Coring}

- Salt Coring Program is defined prior to drilling

- Several core samples are drawn from various depths near the top, the middle and the bottom of the cavern.

- Samples for testing and analysis must be at least 1 $\mathrm{ft}$. long by 4 in. in diameter.

- Confined Creep test 


\section{Recommended Salt Core Testing}

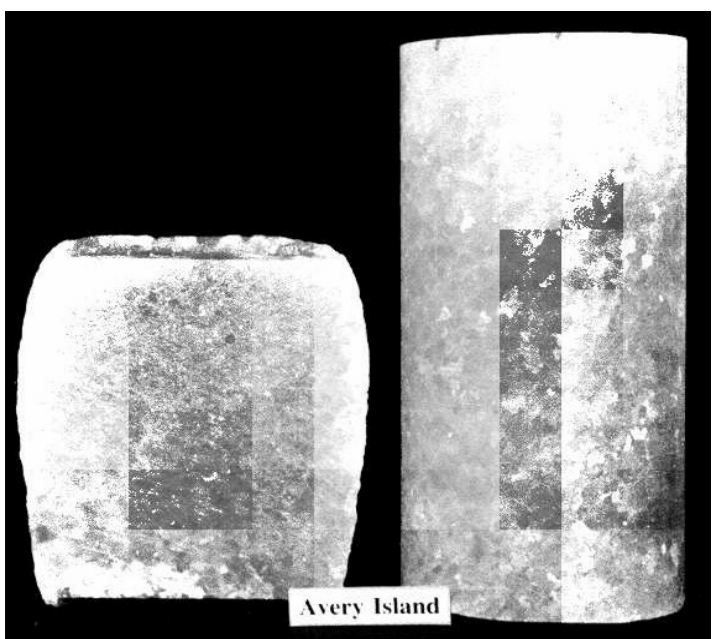

- Unconfined compression test

- Constant mean stress test

- Brazilian indirect tension test

- Confined Creep test 


\section{Unconfined compression test}

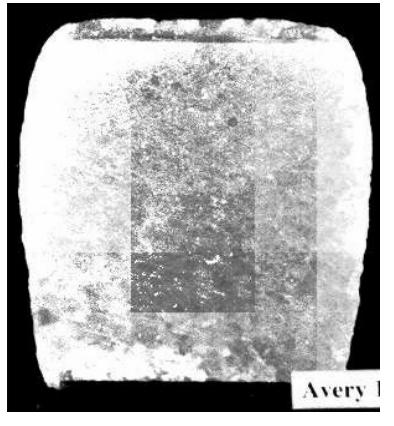

- Determines unconfined compression strength and other strength defining indices of the salt.

- Used for comparing strength of various rock types and of the same rock type from different locations.

- Used in the modeling and design of underground storage caverns. 


\section{Constant mean stress test}
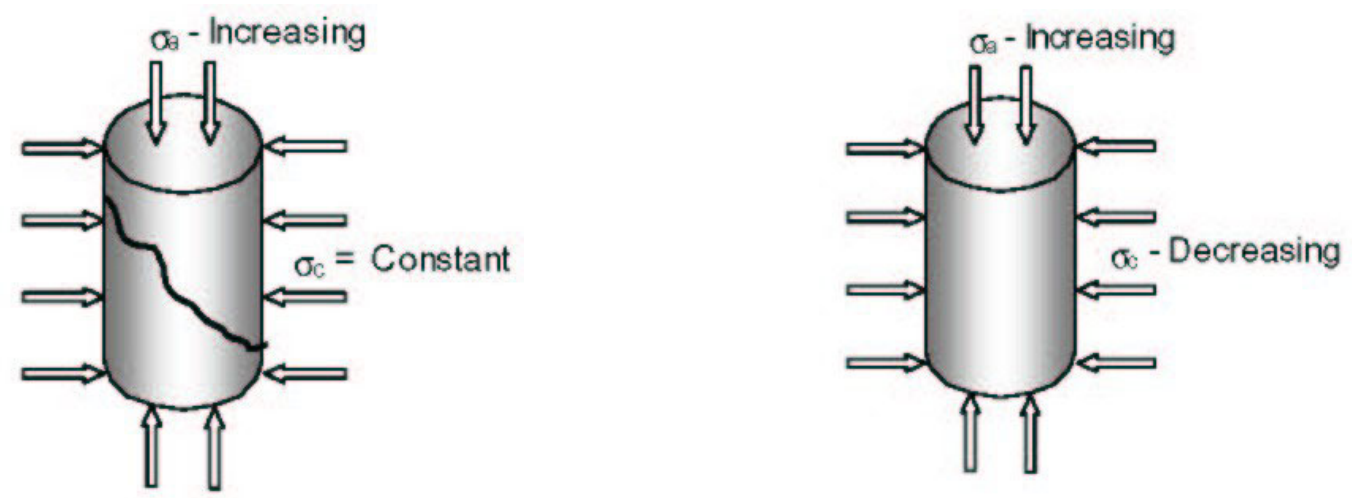

- Used to characterize the dilational behavior of the salt.

- The dilational characteristics of the salt are used directly in the design of the gas storage caverns.

- The criteria is used to determine the caverns minimum allowable gas pressure 


\section{Brazilian indirect tension test}

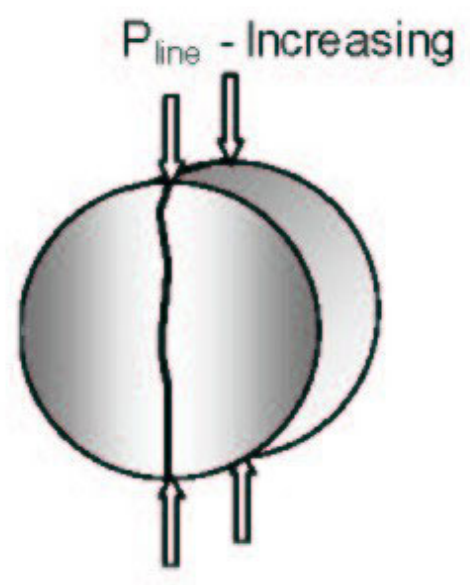

- Used to determine the apparent tensile strength of the salt.

- Helpful in comparing variations in rock strength from one location to another. 


\section{Confined Creep test}

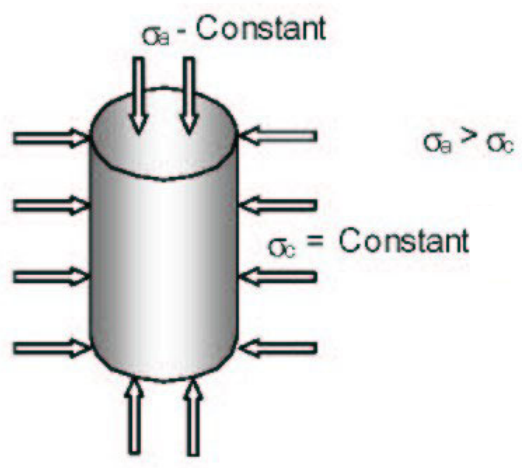

- Used to determine salt deformation with time under a constant stress condition.

- Creep is the principal deformation mechanism in salt surrounding a storage cavern.

- Creep leads to the closure or volume reduction of the cavern with time.

- Useful in comparing different salts. 


\section{Test Results and Analysis}

- Laboratory testing includes a final report detailing specimen preparation, testing activities and results.

- Results are compared to other salt types and industry averages.

- Variations due to salt depth are noted.

- More sophisticated data analysis and numerical modeling for cavern design can be considered. 


\section{Cost Estimate Well Drilling and Completion}

- Well Drilling (7 wells) -

- Development Program -

(Includes conversion workover)

\author{
$\$ 70,000,000$ \\ $\$ 20,000,000$
}




\section{Cost Estimate Rock Mechanics Program}

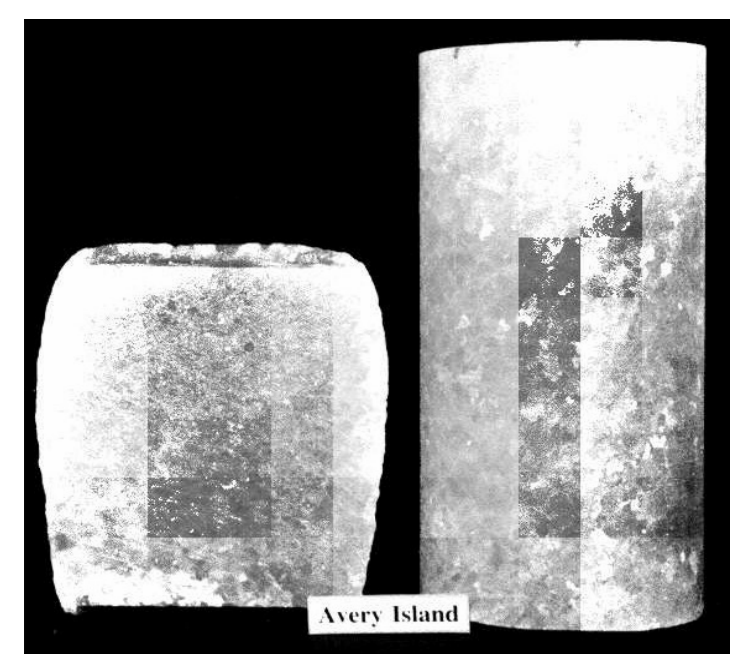

- Salt Coring Program -

$\$ 75,000$

- Laboratory Testing and Analysis -

$\$ 60,000$

- Numerical Modeling Program -

$\$ 80,000$ 


\section{Conclusions}

Components are proven technology

- Max flow rates of 0.5 to $1.0 \mathrm{BCF} /$ day per well are comparable to several existing facilities

- Planned gas temperatures are acceptable

- Directional drilling of cavern wells has been used

- Cavern sizes/shapes/depths comparable to existing gas storage facilities

- Caverns (for brine production) have been created offshore

- Option for compensated flow is done to varying extents at many facilities (reduce or recover cushion gas) 


\section{Conclusions (cont.)}

- Further optimization studies can be performed

- Cavern size/number/depth variations

- Partial compensation

- Larger well tubulars may be possible (would improve hydraulics)

- Wider temperatures may be possible (improves storage volumes) 


\section{Appendix 9 - Schedule}

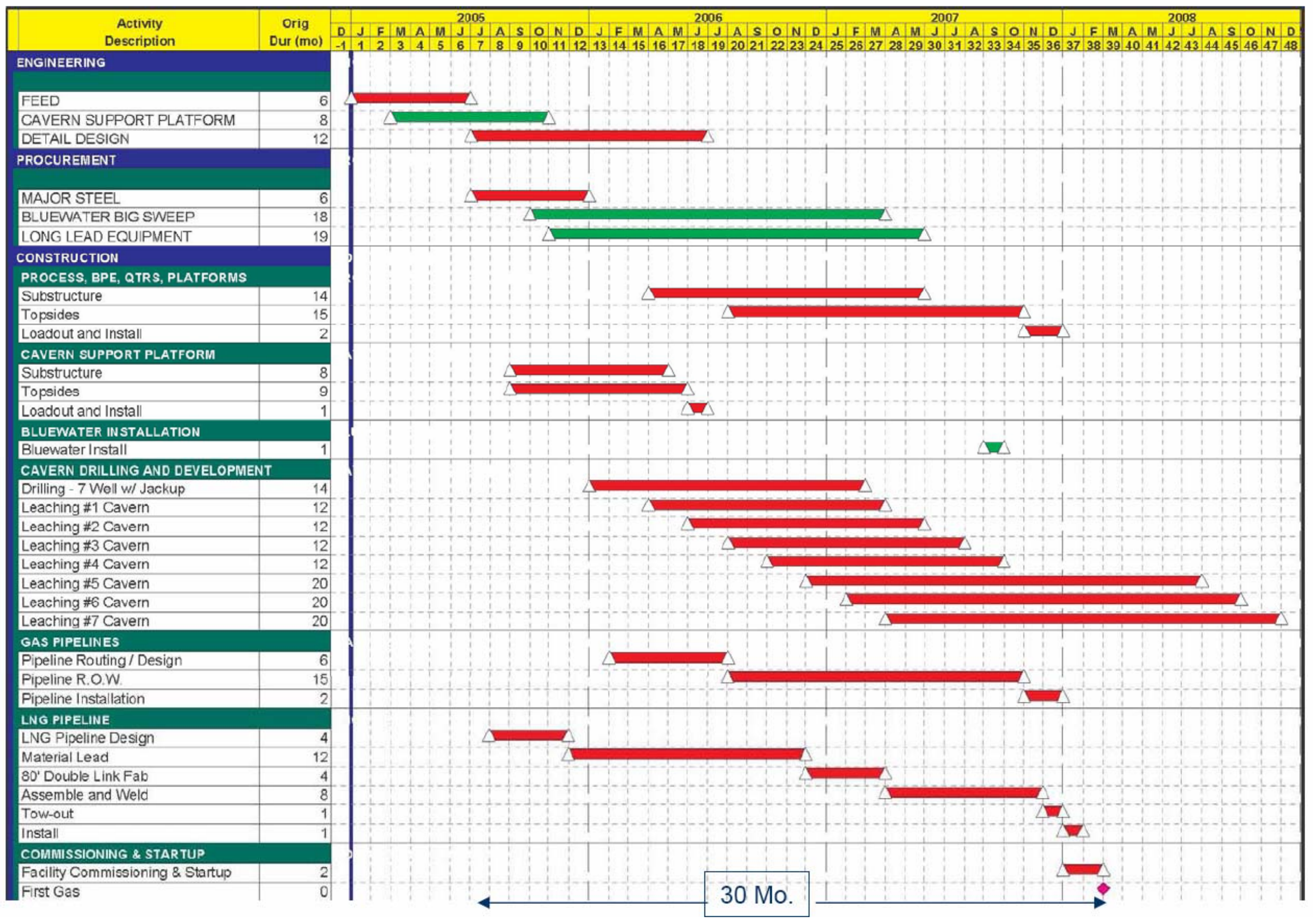




\section{Tab 3}

Offshore Mooring Design \& Wave Tank Tests

Table of Contents

Big Sweep Study

Basis of Design

Operational Philosophy

Offloading Facility Description

Model Tests

Design Load Report

Design-Elements

Pipe Stress Analysis

Intact and Damaged Stability

Sweep Arm Structural Design

Fire Protection Philosophy

Equipment List- Product Transfer

Cost Estimate

Field Layout Workshop

HAZID Study

What-if Analysis Process Flow 


\title{
Big Sweep Study
}

\author{
Basis of Design
}

Doc. No. CGI-G-100-RP-0001 Rev. B

Project. No. 1-0282-0

Bluewater Energy Services B.V.

Marsstraat 33

2132 HR Hoofddorp

The Netherlands

Tel. +31235682800

Fax. +31235652053 


\section{Revision Status Sheet}

\begin{tabular}{|c|c|}
\hline Rev. & Date \\
\hline A & 09 Dec. 200 \\
\hline$R$ & \\
\hline
\end{tabular}

Description

Initiator

Initial Issue

BS

CGI comments included

$B S$

\section{Date}

Checked by

Approved by
July 2005

July 2005
I nitials

HvdB

RU

Y:|1_PROJS|1-0282-0|Doc|G0001 Rev B - Basis of Design.doc 


\section{Table of Contents}

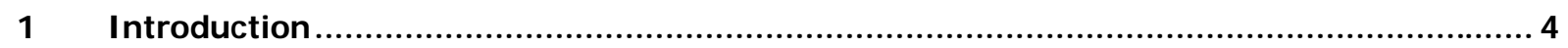

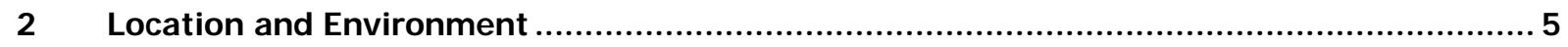

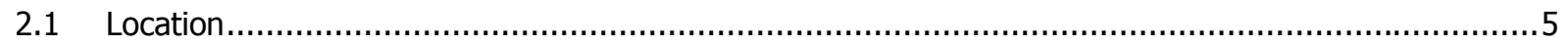

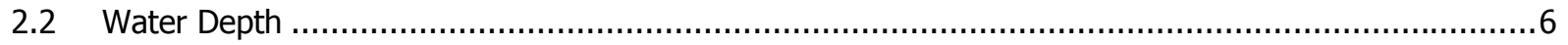

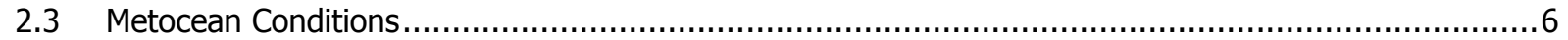

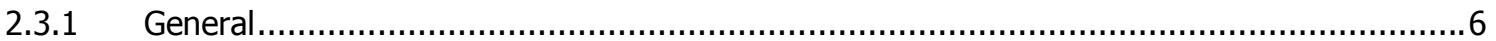

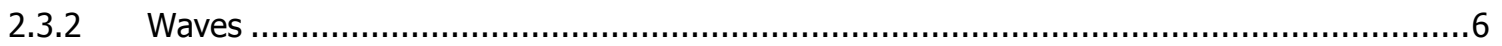

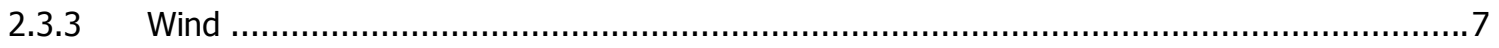

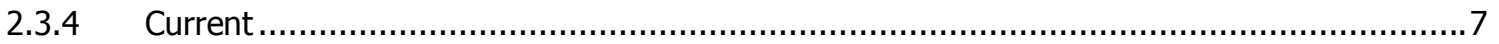

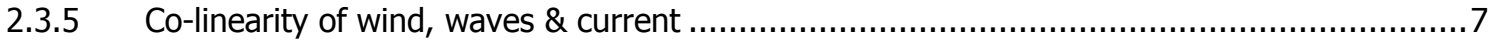

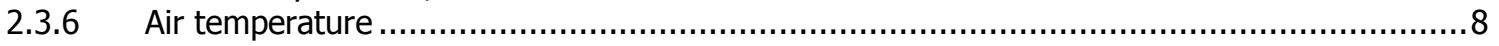

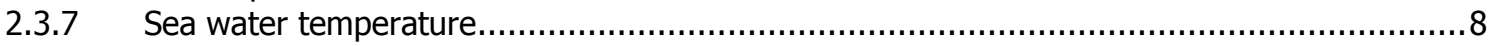

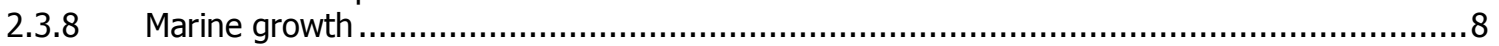

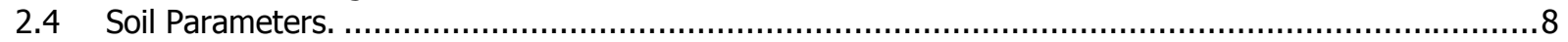

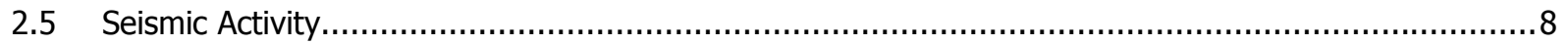

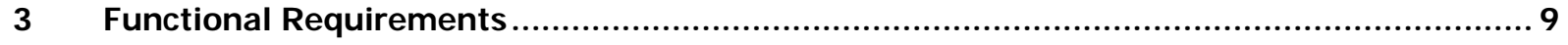

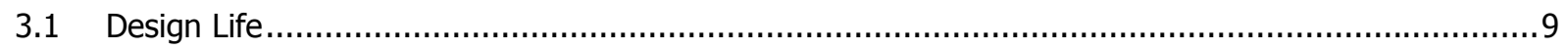

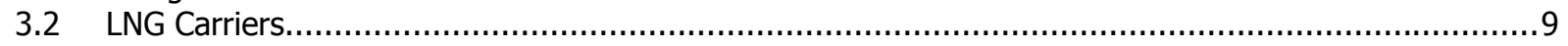

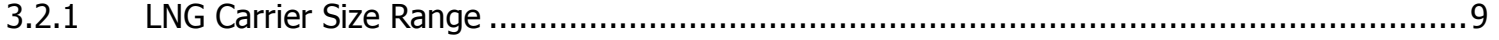

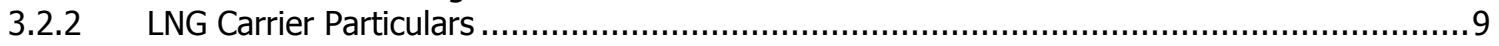

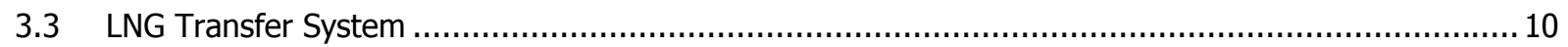

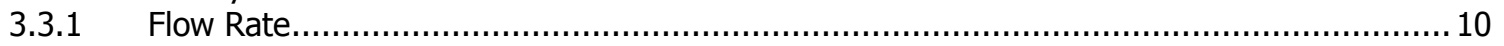

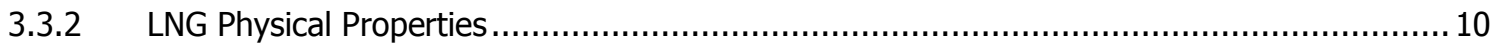

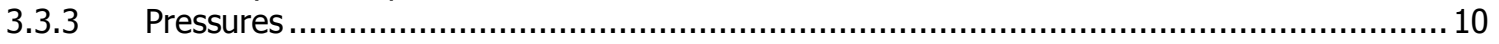

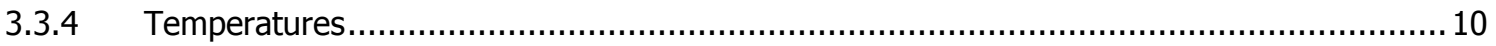

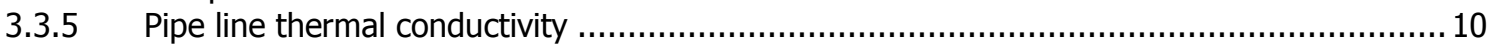

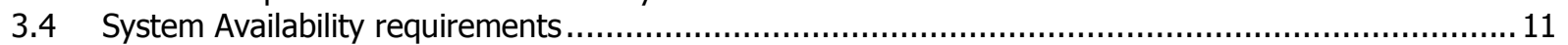

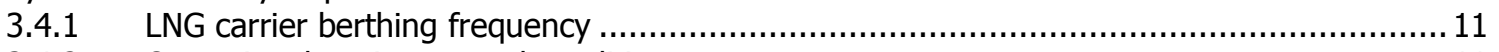

3.4.2 Operational environmental conditions ................................................................... 11

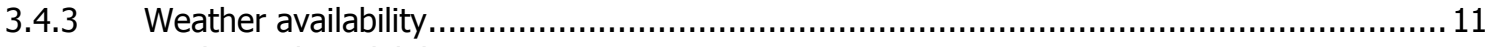

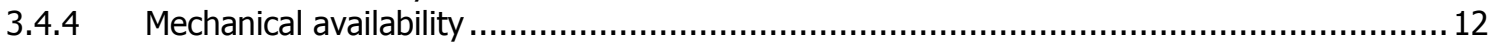

$4 \quad$ Regulatory Compliance and Classification........................................................... 13

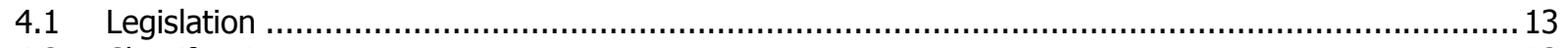

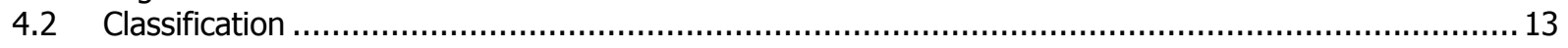

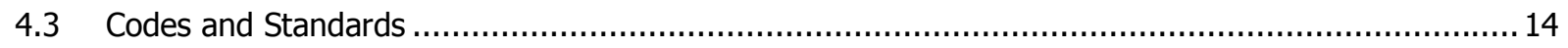

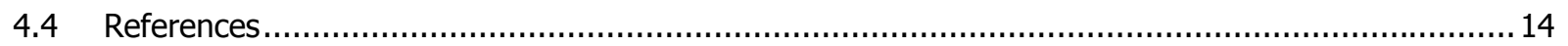

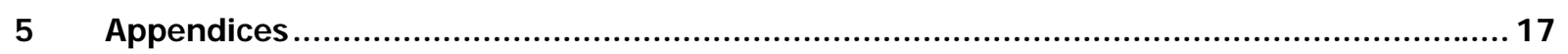

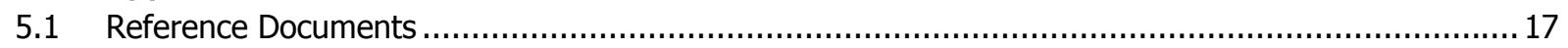

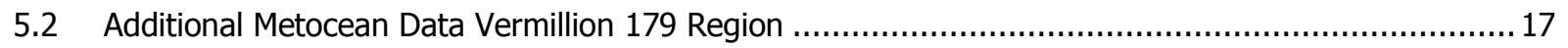

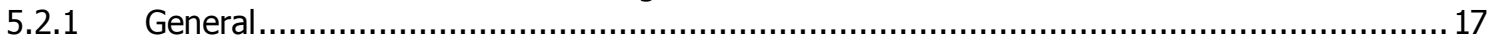

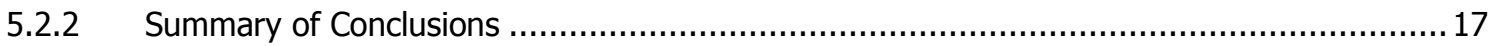

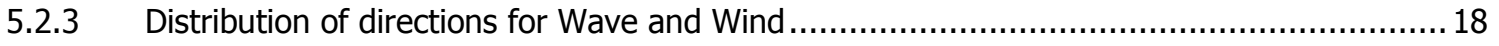

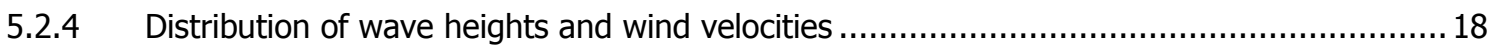

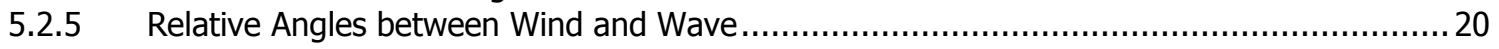

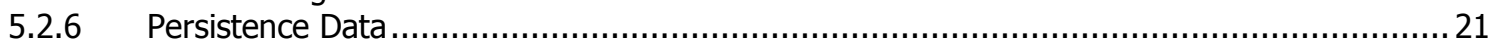

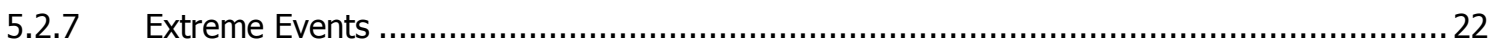

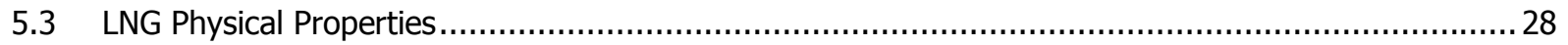

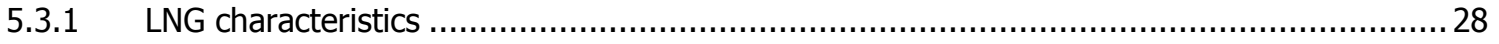

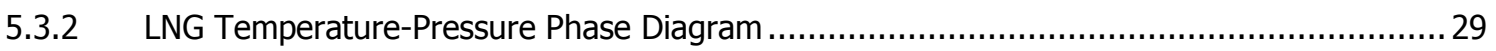

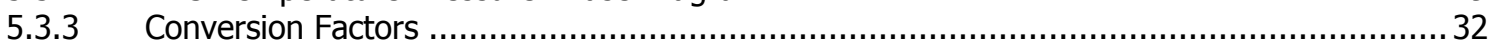




\section{Introduction}

The Big Sweep is a dynamically positioned Single Point Mooring (SPM) facility for offloading LNG from LNG Carriers (LNGC's). Offloading of the cryogenic liquid will take place from the midship manifold of the LNGC. The LNG is transferred via the Big Sweep, through a subsea pipeline to a process platform. At the platform the LNG will be converted to gas by vaporisation. The conversion takes place via a so-called Bishop Process Heat Exchanger (BPE), a special kind of pipe-in-pipe heat exchanger. The BPE uses seawater as the heating medium. Once in the gaseous phase, the gas can be stored in salt caverns or sent into the US gas grid immediately.

The LNG receiving terminal as briefly described above is being conceptually developed by Conversion Gas Imports (CGI) in the context of study awarded by the US Department of Energy. Bluewater Offshore was awarded the subcontract for the conceptual development of the Big Sweep offloading facility.

This document, the Basis of Design, specifies the design requirements of the offloading system. Reference is made to the Operational Philosophy [1] and the Facilities Description [2]. 


\section{Location and Environment}

\subsection{Location}

The planned location of the terminal is Vermilion block 179, 75 kilometres (47 miles) offshore Louisiana.

Geographical co-ordinates:

Latitude: $28^{\circ} 50^{\prime}$ North

Longitude: $92^{\circ} 30^{\prime}$ West

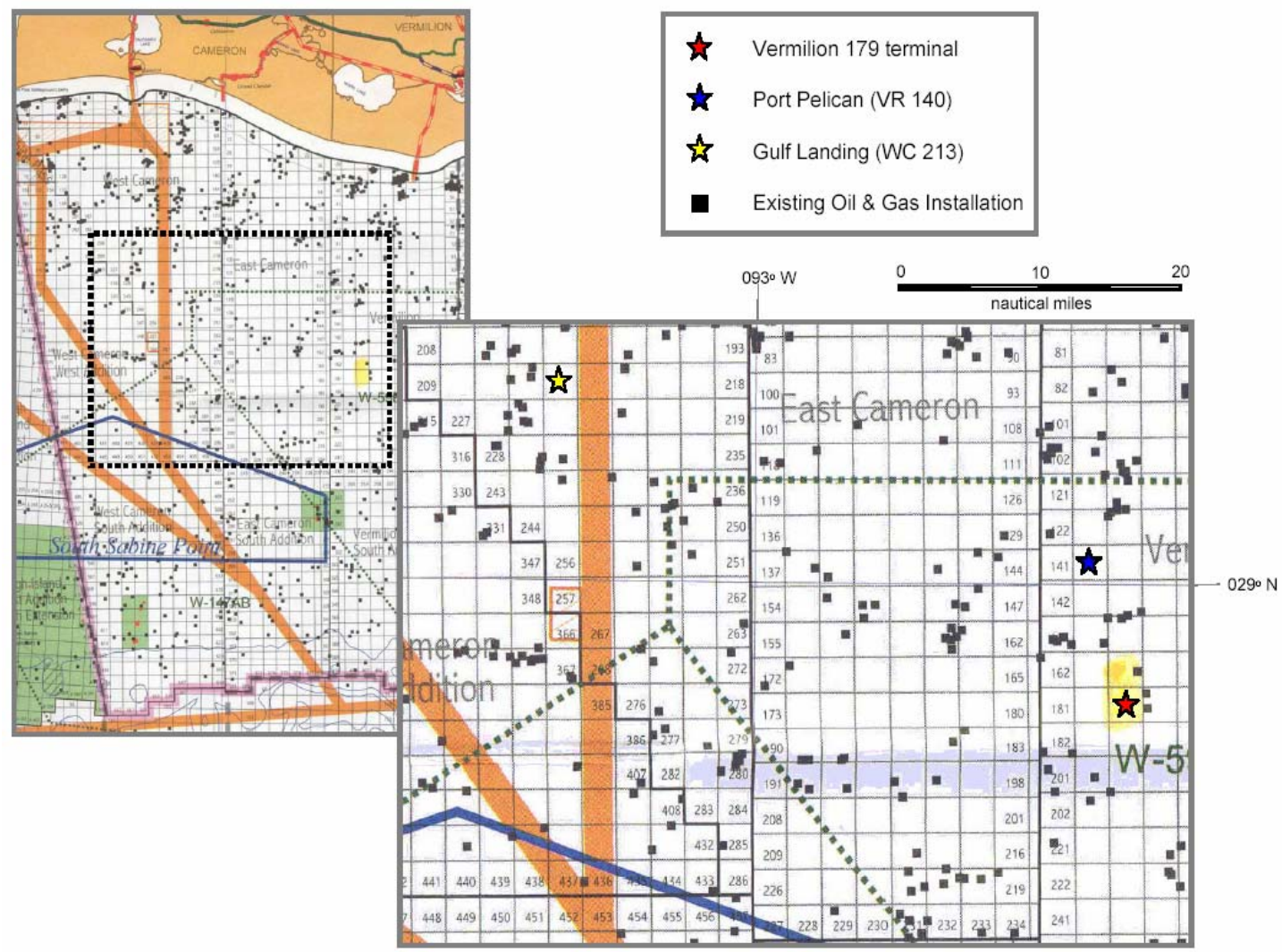




\subsection{Water Depth}

The mean water depth at the site is 30 meter (approx. 100 feet).

Tidal variations have been estimated based on public domain data available from the internet (http://tbone.biol.sc.edu/tide) and from API RP2A

\begin{tabular}{|l|l|l|}
\hline \multicolumn{2}{|l|}{ Water depth and Tidal Variations } & Source \\
\hline Mean water depth & $30 \mathrm{~m}$ & \\
\hline Lowest Astronomical tide & $-0.6 \mathrm{~m}$ & $\underline{\mathrm{http}} / / /$ tbone.biol.sc.edu/tide \\
\hline Highest Astronomical tide & $+1.0 \mathrm{~m}$ & $\underline{\text { http://tbone.biol.sc.edu/tide }}$ \\
\hline Storm tide & $+1.4 \mathrm{~m}$ & API RP2A \\
\hline
\end{tabular}

\subsection{Metocean Conditions}

\subsubsection{General}

For the purpose of the study public domain or in-house available data is analysed to establish a set of environmental design data for the Vermilion block 179 site.

Wave and Wind data have been obtained from the National Data Buoy Centre, Centre of Excellence in Marine Technology (www.ndbc.noaa.gov). The public domain data available comprises amongst others the following from the year 1993:

- Wind speed and direction

- Significant wave height, direction, average and dominant wave period

- $\quad$ Air and Water temperatures

- Atmospheric pressure

Concerning currents, far less data is available in the public domain. Therefore some conservative values have been estimated in consultation with Industry sources.

\subsubsection{Waves}

The following table represents a summary of 'extreme' wave data.

\begin{tabular}{|c|c|c|c|c|c|}
\hline \multicolumn{6}{|l|}{ Extreme Wave Data } \\
\hline Designation & Abbr. & Unit & $\begin{array}{l}98 \% \\
\text { Non-occurrence }\end{array}$ & 1 year & $\begin{array}{l}100 \text { year } \\
\text { Hurricane }\end{array}$ \\
\hline Significant Wave Height & $\mathrm{H}_{\mathrm{s}}$ & $\mathrm{m}$ & 3.0 & 4.3 & 9.35 \\
\hline Spectral Peak Period & $T_{p}$ & $\mathrm{~s}$ & 8.4 & 8.4 & 15.1 \\
\hline Zero Up-crossing Period & $\mathrm{T}_{\mathrm{z}}$ & $\mathrm{s}$ & 6.5 & 6.5 & 11.7 \\
\hline Peak enhancement factor & $\Gamma$ & - & 3.3 & 3.3 & 3.3 \\
\hline Maximum Wave Height & $\mathrm{H}_{\max }$ & $\mathrm{m}$ & 5.6 & 8.1 & 17.4 \\
\hline Period Maximum Wave & $\mathrm{T}_{\max }$ & $\mathrm{s}$ & 7.0 & 9.0 & 14.0 \\
\hline
\end{tabular}




\subsubsection{Wind}

The below values are wind velocities with a different level of occurrence. The Hurricane wind velocity represents the associated wind velocity for the extreme Hurricane waves [Source: API RP $2 \mathrm{~A}]$.

\begin{tabular}{|l|l|l|l|l|l|}
\hline \multicolumn{5}{|l|}{ Extreme Wind Data } \\
\hline Designation & Abbr. & Unit & $\begin{array}{l}98 \% \\
\text { Non-occurrence }\end{array}$ & 1 year & $\begin{array}{l}100 \text { year } \\
\text { Hurricane }\end{array}$ \\
\hline $1 \mathrm{Hr}$ mean & $\mathrm{Vw}, 1 \mathrm{hr}$ & $\mathrm{m} / \mathrm{s}$ & 13.5 & 23.7 & 41.2 \\
\hline 1 Min. mean & $\mathrm{Vw}, 1 \mathrm{~min}$ & $\mathrm{~m} / \mathrm{s}$ & 16.0 & 28.0 & 48.6 \\
\hline 10 Sec. gust & Vw,gust & $\mathrm{m} / \mathrm{s}$ & 17.3 & 30.3 & 52.5 \\
\hline
\end{tabular}

\subsubsection{Current}

For current velocities, the following conservative velocities have been considered at this stage of the design.

\begin{tabular}{|l|l|l|l|}
\hline \multicolumn{4}{|l|}{ Current Data } \\
\hline $\begin{array}{l}\text { Depth below mean water } \\
\text { level }\end{array}$ & Unit & Operational & $\begin{array}{l}100 \text {-year } \\
\text { Hurricane }\end{array}$ \\
\hline Surface & $\mathrm{m} / \mathrm{s}$ & 0.5 & 1.0 \\
\hline $15 \mathrm{~m}$ & $\mathrm{~m} / \mathrm{s}$ & 0.5 & 0.9 \\
\hline Bottom & $\mathrm{m} / \mathrm{s}$ & 0.5 & 0.5 \\
\hline
\end{tabular}

\subsubsection{Co-linearity of wind, waves \& current}

Directions of wind, waves and current do not necessarily coincide in the Gulf of Mexico. Especially the current flow direction is more or less independent from wind and waves. Wind directions can change rather rapidly in the GoM, both during normal weather conditions, but more obvious during Hurricane conditions.

For the design of the Big Sweep terminal, these co-linearity issues are mainly of importance during normal operating conditions, since in those conditions a LNG carrier might be moored to the structure. At this stage insufficient environmental data is available to investigate on the joint occurrences of wave, wind and current. Appendix 5.2 elaborates further on the issue of co-linearity.

The relative angles between wind, wave and current presented in the following table have been considered at this stage.

\begin{tabular}{|c|c|c|c|c|c|c|c|}
\hline \multirow[t]{2}{*}{ Description } & \multicolumn{3}{|c|}{ Magnitude } & \multicolumn{4}{|l|}{ Relative Angle } \\
\hline & $\begin{array}{l}\mathrm{Hs} \\
{[\mathrm{m}]}\end{array}$ & $\begin{array}{l}\mathrm{Vw} \\
{[\mathrm{m} / \mathrm{s}]}\end{array}$ & $\begin{array}{l}\mathrm{Vc} \\
{[\mathrm{m} / \mathrm{s}]}\end{array}$ & [deg] & $\begin{array}{l}\text { Wind - } \\
\text { Wave }\end{array}$ & $\begin{array}{l}\text { Wave - } \\
\text { Current }\end{array}$ & $\begin{array}{l}\text { Wind - } \\
\text { Current }\end{array}$ \\
\hline \multirow{3}{*}{$\begin{array}{l}98 \% \text { Non- } \\
\text { occurrence }\end{array}$} & \multirow[t]{3}{*}{3.0} & \multirow[t]{3}{*}{16.0} & \multirow[t]{3}{*}{0.5} & Collinear & 0 & 0 & 0 \\
\hline & & & & Oblique Current & 0 & 30 & 30 \\
\hline & & & & Cross Current & 30 & 90 & 60 \\
\hline \multirow[t]{3}{*}{ 1-year Storm } & \multirow[t]{3}{*}{4.3} & \multirow[t]{3}{*}{28.0} & \multirow[t]{3}{*}{0.5} & Collinear & 0 & 0 & 0 \\
\hline & & & & Oblique Current & 0 & 30 & 30 \\
\hline & & & & Cross Current & 30 & 90 & 60 \\
\hline
\end{tabular}




\subsubsection{Air temperature}

The following table regarding air temperatures have been derived from records from 1990 through 2003 and are not based on predictions

$\begin{array}{lll}\text { Min } & : & -2 \operatorname{deg} C \\ \text { Average } & : & 22 \operatorname{deg} C \\ \text { Max } & : & 35 \operatorname{deg} C\end{array}$

Monthly statistical data over the same period are available on the National Buoy Data Centre's website (see section 2.3.1 for more details).

\subsubsection{Sea water temperature}

The following table regarding sea water temperatures have been derived from records from 1990 through 2003 and are not based on predictions

$\begin{array}{lll}\text { Min } & : & 9 \operatorname{deg} \text { C } \\ \text { Average } & : & 23 \operatorname{deg} \text { C } \\ \text { Max } & : & 35 \operatorname{deg} \text { C }\end{array}$

Monthly statistical data over the same period are available on the National Buoy Data Centre's website (see section 2.3.1 for more details).

\subsubsection{Marine growth}

The guideline for marine growth thickness in the Gulf of Mexico is 1.5 inch. As per API requirements the marine growth shall be considered over the entire height of the water column up to the Mean Higher High Water (MHHW) level. MHHW shall be taken as the mean water level plus the highest astronomical tide.

\subsection{Soil Parameters.}

A typical Gulf of Mexico soil profile is assumed for the concept design of the foundation.

Soil shear strength profile is taken as: $\mathrm{Su}=4+1.5^{*} \mathrm{Z}[\mathrm{kPa}]$ (with $\mathrm{Z}=$ depth in meters).

\subsection{Seismic Activity}

The Gulf of Mexico can be considered as a zone with low seismic activity, meaning horizontal ground accelerations less than $0.05 \mathrm{~g}$. As a result, no earthquake analysis is required since the design for environmental loading other than earthquake will provide sufficient resistance against potential effects from seismically active zones. [Source: API RP 2A] 


\section{Functional Requirements}

\subsection{Design Life}

The main structure design life shall be 40 years. No major overhauls or main component replacement shall be necessary. Main articulations such as the yaw and pitch bearing shall be designed to allow for the wear that can be expected during this design life.

System components that are subject to normal wear and tear will be replaceable under a maintenance scheme. Such components shall be designed with a design life following normal industry practice.

\subsection{LNG Carriers}

\subsubsection{LNG Carrier Size Range}

The larger size of existing carriers has a storage capacity in the range of 125,000 to $140,000 \mathrm{~m}^{3}$. For the purpose of this study the selection of the main dimensions shall be based on this range.

To meet future increase demand for LNG transport new carrier designs are developed for LNG carriers up to $200,000 \mathrm{~m}^{3}$. The consequences of enabling the reception of these larger carriers shall be considered.

\subsubsection{LNG Carrier Particulars}

The main particulars for typical LNG carriers are presented in the following table.

\begin{tabular}{|l|l|l|l|l|l|}
\hline \multicolumn{6}{|l|}{ LNG Carrier Particulars } \\
\hline Carrier capacity & {$\left[\mathrm{m}^{3}\right]$} & $125,000-140,000$ & 165,000 & 200,000 \\
\hline Type & - & Membrane & Spherical & Membrane & Membrane \\
\hline Length $\left(\mathrm{L}_{\mathrm{pp}}\right)$ & {$[\mathrm{m}]$} & $272-298$ & $268-289$ & 300 & 315 \\
\hline Length $\left(\mathrm{L}_{\mathrm{pp}}\right)$ & {$[\mathrm{m}]$} & $257-276$ & $260-283$ & 286 & 302 \\
\hline Beam & {$[\mathrm{m}]$} & $41-47$ & $41-48$ & 46.0 & 50.0 \\
\hline Depth & {$[\mathrm{m}]$} & $21-31$ & $25-27$ & 26.0 & 27.0 \\
\hline Draft & {$[\mathrm{m}]$} & $10.7-12.3$ & $10.6-12.0$ & 11.5 & 12.0 \\
\hline Displacement & {$[\mathrm{ktonnes}]$} & $90-107$ & $95-115$ & & \\
\hline $\begin{array}{l}\text { Distance Bow to } \\
\text { Midship Manifold }\end{array}$ & {$[\mathrm{m}]$} & $113-145$ & $104-144$ & & \\
\hline
\end{tabular}




\subsection{LNG Transfer System}

\subsubsection{Flow Rate}

The design flow rate is $8,000 \mathrm{~m}^{3} / \mathrm{hr}$. Assuming a constant offloading rate during the entire cargo transfer period, this is sufficient to offload an $125,000 \mathrm{~m}^{3}$ LNG carrier in 16 hours. Process and safety systems will be based on this flow rate of $8,000 \mathrm{~m}^{3} / \mathrm{hr}$.

For the future $200,000 \mathrm{~m}^{3}$ LNG carriers the design flow rate will be $12,000 \mathrm{~m}^{3} / \mathrm{hr}$ LNG. Piping systems will be designed to meet this higher capacity.

Note that the direct re-gasification capacity of the BPE is $10,000 \mathrm{~m}^{3} / \mathrm{h}$.

\subsubsection{LNG Physical Properties}

LNG physical properties are included in Appendix 5.3. Also included are pressure-temperature phase diagrams for the design LNG mixture and typical lean and rich LNG mixtures.

\subsubsection{Pressures}

System operating pressure is defined by the maximum discharge pressure at the LNG Carrier manifold.

Assumed is an operating pressure of 7 bar (100 psi), provided by ship's pumps at the midship manifold @ $15 \mathrm{~m}$ above waterline.

The design pressure for the liquid lines (seawater + LNG), vapour lines and drain lines is 12.1 barg (175 Psig).

\subsubsection{Temperatures}

The design temperatures for the cargo piping are presented in below table:

\begin{tabular}{|l|l|c|c|}
\hline \multirow{2}{*}{ Description } & Operating & \multicolumn{2}{|c|}{ Design } \\
\cline { 3 - 4 } & & Minimum & Maximum \\
\hline LNG lines & $-160^{\circ} \mathrm{C}(-256 \mathrm{~F})$ & $-168^{\circ} \mathrm{C}(-270 \mathrm{~F})$ & $+66^{\circ} \mathrm{C}(150 \mathrm{~F})$ \\
\hline Vapour return & $-110^{\circ} \mathrm{C}$ & $-168^{\circ} \mathrm{C}(-270 \mathrm{~F})$ & $+66^{\circ} \mathrm{C}(150 \mathrm{~F})$ \\
\hline
\end{tabular}

\subsubsection{Pipe line thermal conductivity}

A low Overall Heat Transfer Coefficient (OHTC) is important to minimise boil off in the periods between cargo off loading. High efficiency insulation is available and is proposed for the system.

The design value for the SPM transfer pipeline system will be the same as for the subsea cryogenic line. The cryogenic lines design $\mathrm{U}$-value is $0.57 \mathrm{Wm} \mathrm{W}^{-2} \cdot \mathrm{K}^{-1}\left(0.1 \mathrm{Btu} / \mathrm{ft}^{2} \mathrm{hr}{ }^{\circ} \mathrm{F}\right)$. 


\subsection{System Availability requirements}

\subsubsection{LNG carrier berthing frequency}

The LNG carrier berthing frequency can be calculated from the required nominal send out capacity and the anticipated carrier/parcel size. The nominal send out capacity is set at $2.0 \mathrm{bcfd}$. (The minimum pipeline send out rate is 1.5 bcfd while peak production is $2.5 \mathrm{bcfd}$.) $2.0 \mathrm{bcfd}$ of gas equals $94,000 \mathrm{~m}^{3}$ of liquid a day. Assuming an average carrier size of $135,000 \mathrm{~m}^{3}$ this equals 4.9 carriers a week.

The LNG transfer period without ramp-up time is roughly 16 hours (see section 3.3.1). With ramp-up and ramp down this time is estimated to be between 17.5 and 19.5 hours. A complete berthing cycle is built-up of the phases as indicated in the table below.

\footnotetext{
- Approach (5 NM) \& berthing

- Hook-up, testing \& cool down of product system

- Ramp-up, LNG transfer, ramp down

- Break-up, disconnect \& departure

- Total cycle time
}

- Avg. idle time between offloads with 6 carriers / week

- Avg. idle time between offloads with 4 carriers / week

- Maximum number of carriers / week

\begin{tabular}{llll} 
& & 3.0 & hour \\
& & 1.5 & hour \\
17.5 & to & 19.5 & hour \\
& & 1.0 & hour \\
\hline 23 & to & 25 & hour
\end{tabular}

$\begin{array}{lll}5 & 3 & \text { hour } \\ 19 & 17 & \text { hour } \\ 7.3 & 6.7 & -\end{array}$

To meet the terminal import needs a semi-continuous service is envisaged. The environmental conditions can influence the idle times. Given the high utilisation of the SPM, berthing, transfer and departure operations will be carried out 24 hours per day.

\subsubsection{Operational environmental conditions}

Operational weather limitations are discussed in the Operational Philosophy [1].

\subsubsection{Weather availability}

The Big Sweep is a special form of Single Point Mooring system (SPM). One of the advantages of an SPM is the high weather availability. Based on the weather limits as discussed in the Operational Philosophy [1], the non-availability due to bad weather in the Gulf of Mexico region is assessed to be insignificant. The 1-year storm conditions are still within the operational limits of the system. 


\subsubsection{Mechanical availability}

Mechanical availability of the system is defined as the capacity of the Big Sweep SPM system to moor a LNG Carrier (LNGC), receive and transfer LNG from the LNGC to the seabed pipeline interface and vapour return delivery to achieve LNGC offloading at the system design capacity. The availability shall be achieved when a LNGC is at the terminal.

The mechanical availability requirement depends on various economic factors for the terminal and LNGC. An assessment is beyond the study scope.

A system un-availability of maximum 1 day per year is considered a reasonable target value, which equals an availability of $99.7 \%$.

Non - essential systems availability shall be $95 \%$.

The mechanical availability figures are considered in the study based on engineering judgement. No specific availability assessment will be performed in this study. 


\section{Regulatory Compliance and Classification}

\subsection{Legislation}

The basis for the legal requirements for Big Sweep is the (US) Code of Federal Regulations Title 33 Navigation and Navigable Waters, Parts 148, 149 and 150 related to deep water ports.

\begin{tabular}{|l|l|}
\hline $\begin{array}{l}\text { US Code of Federal Regulations } \\
\begin{array}{l}\text { Coast Guard, Department of } \\
\text { Transportation }\end{array}\end{array}$ & $\begin{array}{l}\text { Title } 33 \text { Navigation and Navigable Waters } \\
\text { Part } 148 \\
\text { Deep Water Ports: General }\end{array}$ \\
\hline $\begin{array}{l}\text { US Code of Federal Regulations } \\
\text { Coast Guard, Department of } \\
\text { Transportation }\end{array}$ & $\begin{array}{l}\text { Title } 33 \text { Navigation and Navigable Waters } \\
\text { Part } 149\end{array}$ \\
\hline $\begin{array}{l}\text { US Code of Federal Regulations Water Ports: Design, Construction and Equipment } \\
\text { Coast Guard, Department of } \\
\text { Transportation }\end{array}$ & $\begin{array}{l}\text { Title } 33 \text { Navigation and Navigable Waters } \\
\text { Part } 150\end{array}$ \\
\hline
\end{tabular}

\subsection{Classification}

\begin{tabular}{|l|l|}
\hline ABS & Guidance Notes on Review and Approval of Novel Concepts \\
\hline ABS & $\begin{array}{l}\text { Guide for Risk Evaluation for the Classification of Marine-related } \\
\text { Facilities }\end{array}$ \\
\hline ABS & $\begin{array}{l}\text { Guide For Building and Classing Offshore LNG Terminals - December } \\
2002\end{array}$ \\
\hline ABS & Rules for Building and Classing Single Point Moorings \\
\hline
\end{tabular}




\subsection{Codes and Standards}

\begin{tabular}{|l|l|}
\hline NFPA 59A & $\begin{array}{l}\text { Standard for Production, Storage and Handling of Liquefied Natural } \\
\text { Gas }\end{array}$ \\
\hline NFPA 70 & National Electrical Code \\
\hline NFPA 72 & National Fire Alarm Code \\
\hline API RP 2A & $\begin{array}{l}\text { Recommended Practice for Planning, Designing and Construction of } \\
\text { Fixed Offshore Platforms }\end{array}$ \\
\hline API RP 14C & $\begin{array}{l}\text { Recommended Practice for Analysis, Design, Installation, and Testing } \\
\text { of Basic Surface Safety Systems for Offshore Platforms }\end{array}$ \\
\hline API RP 14E & $\begin{array}{l}\text { Recommended Practice for Design and Installation of Offshore } \\
\text { Production Platform Piping Systems }\end{array}$ \\
\hline API RP 14 F & $\begin{array}{l}\text { Recommended practice for design and installation of electrical } \\
\text { systems for fixed and floating offshore petroleum facilities for } \\
\text { unclassified class 1, division 1 and division 2 locations }\end{array}$ \\
\hline API RP 14G & $\begin{array}{l}\text { Recommended practice for fire Prevention and control on open type } \\
\text { offshore production platforms }\end{array}$ \\
\hline API RP 500 & $\begin{array}{l}\text { Recommended practice for classification of locations for electrical } \\
\text { installations at petroleum facilities }\end{array}$ \\
\hline API RP 505 & $\begin{array}{l}\text { Recommended practice for classification of locations for electrical } \\
\text { installations at petroleum facilities classified as class I, zone 0, zone 1, } \\
\text { and zone 2 }\end{array}$ \\
\hline
\end{tabular}

\subsection{References}

The following, non-exhaustive, list of documents may be used for guidance or reference.

\begin{tabular}{|l|l|}
\hline $\begin{array}{l}\text { US Code of Federal Regulations } \\
\text { Coast Guard, Department of }\end{array}$ & $\begin{array}{l}\text { Title 33 Navigation and Navigable Waters Part 127 } \\
\text { Waterfront Facilities Handling Liquefied Natural Gas and Liquefied } \\
\text { Hazardous Gas }\end{array}$ \\
\hline European Standard EN 1160 & $\begin{array}{l}\text { Installations and equipment for Liquefied Natural Gas - General } \\
\text { characteristics of Liquefied Natural Gas }\end{array}$ \\
\hline BS EN 1473 & $\begin{array}{l}\text { Installation and equipment for Liquefied natural gas - Design of } \\
\text { onshore Installations }\end{array}$ \\
\hline BS EN 1474 & $\begin{array}{l}\text { Installation and equipment for Liquefied natural gas - Design and } \\
\text { testing of loading / unloading arms }\end{array}$ \\
\hline BS EN 1532 & $\begin{array}{l}\text { Installation and equipment for Liquefied natural gas - Ship to shore } \\
\text { interface }\end{array}$ \\
\hline SIGTTO & $\begin{array}{l}\text { Guidelines for Automatic Cargo Tank Overfill Protection Abroad Gas } \\
\text { Carriers }\end{array}$ \\
\hline SIGTTO & Terminal Incident Questionnaire. \\
\hline SIGTTO & $\begin{array}{l}\text { Index for the International Code for the Construction and Equipment } \\
\text { of Ships Carrying Liquefied Gases in Bulk (IGC Code) - 2nd edition. }\end{array}$ \\
\hline SIGTTO & $\begin{array}{l}\text { Publications Referencing Gas Tanker Cargo Operations - } \\
\text { revised.(Formerly Information Paper No.13) }\end{array}$ \\
\hline SIGTTO & $\begin{array}{l}\text { Recommendations for the Installation of Cargo Strainers on LNG } \\
\text { Carriers - 2nd edition. }\end{array}$ \\
\hline
\end{tabular}




\begin{tabular}{|c|c|}
\hline SIGTTO & $\begin{array}{l}\text { Safe Havens for Disabled Gas Carriers - Information Paper for Those } \\
\text { Seeking a Safe Haven And Those Who May Be Asked To Provide It - } \\
\text { 3rd edition. }\end{array}$ \\
\hline SIGTTO & $\begin{array}{l}\text { Fire Prevention in the Cargo Containment Systems of Liquefied Gas } \\
\text { Carriers in Shipyards. }\end{array}$ \\
\hline SIGTTO & $\begin{array}{l}\text { Training of Terminal Staff involved in Loading and Discharging Gas } \\
\text { Carriers }\end{array}$ \\
\hline SIGTTO & $\begin{array}{l}\text { Safety Aspects of the Marine Transportation and Storage of } \\
\text { Refrigerated Liquefied Fuel Gases - A Review of Current Practice. }\end{array}$ \\
\hline SIGTTO & $\begin{array}{l}\text { Liquefied Gas Industry Book - General Statistics and Information - } \\
\text { LNG, LPG, Ammonia and Chemical Gases with data on Terminals and } \\
\text { Deep-Sea Carriers - 3rd edition (MEMBERS ONLY). }\end{array}$ \\
\hline SIGTTO & LNG Ship Data Book - 2nd edition. \\
\hline SIGTTO & Ignition Hazards Due to Marine Radios \& Radio Transmissions \\
\hline SIGTTO & $\begin{array}{l}\text { LNG Operations in Port Areas: Essential best practices for the } \\
\text { industry. }\end{array}$ \\
\hline SIGTTO & $\begin{array}{l}\text { Crew Safety Standards and Training for Large LNG Carriers: Essential } \\
\text { best practices for the industry. }\end{array}$ \\
\hline SIGTTO & Liquefied Gas Carriers: Your Personal Guide to Safety. \\
\hline SIGTTO & $\begin{array}{l}\text { Liquefied Gas Handling Principles on Ships and in Terminals - 3rd } \\
\text { edition. }\end{array}$ \\
\hline SIGTTO & $\begin{array}{l}\text { Guidelines for Hazard Analysis as an Aid to Management of Safe } \\
\text { Operations in Port. }\end{array}$ \\
\hline SIGTTO & $\begin{array}{l}\text { An Introduction to the Design and Maintenance of Cargo System } \\
\text { Pressure Relief Valves on Board Gas Carriers - 2nd edition. }\end{array}$ \\
\hline SIGTTO & Guidelines for the Alleviation of Excessive Surge Pressures on ESD. \\
\hline SIGTTO & $\begin{array}{l}\text { Recommendations and Guidelines for Linked Ship/Shore Emergency } \\
\text { ShutDown of Liquefied Gas Cargo Transfer. }\end{array}$ \\
\hline SIGTTO & $\begin{array}{l}\text { Accident Prevention - The Use of Hoses and Hard-Arms at Marine } \\
\text { Terminals Handling Liquefied Gases - 2nd edition (Information Paper } \\
\text { No.4). }\end{array}$ \\
\hline SIGTTO & $\begin{array}{l}\text { The Ship/Shore Interface - Communications Necessary for Matching } \\
\text { Ship to Berth (Information Paper No.5). }\end{array}$ \\
\hline SIGTTO & $\begin{array}{l}\text { Human Error and the Environment - Management Systems of the Gas } \\
\text { Industry. }\end{array}$ \\
\hline SIGTTO (ICS, OCIMF \& SIGTTO) & $\begin{array}{l}\text { A Guide to Contingency Planning for Marine Terminals Handling } \\
\text { Liquefied Gases in Bulk - 2nd edition. }\end{array}$ \\
\hline SIGTTO & $\begin{array}{l}\text { Site Selection and Design for LNG Ports and Jetties (Information } \\
\text { Paper No.14). }\end{array}$ \\
\hline SIGTTO & $\begin{array}{l}\text { A Listing of Design Guidelines for Liquefied Gas Terminals } \\
\text { (Referencing Ports and Jetties) (Information Paper No.15). }\end{array}$ \\
\hline SIGTTO & $\begin{array}{l}\text { Ship/Shore Interface - Safe Working Practice for LPG \& Liquefied } \\
\text { Chemical Gas Cargoes (Information Paper No.16). }\end{array}$ \\
\hline SIGTTO & Cargo Fire-fighting on Liquefied Gas Carriers - Study Notes. \\
\hline SIGTTO & A Glossary of Terms Used in Liquefied Gas Shipping. \\
\hline SIGTTO & $\begin{array}{l}\text { A Risk Based Approach for the Evaluation of Fire-fighting Equipment } \\
\text { on Liquefied Gas Jetties. }\end{array}$ \\
\hline
\end{tabular}




\begin{tabular}{|c|c|}
\hline SIGTTO & $\begin{array}{l}\text { Safety in Liquefied Gas Marine Transportation and Terminal } \\
\text { Operations - A Guide to Self Assessment }\end{array}$ \\
\hline SIGTTO/ IACS & $\begin{array}{l}\text { Application of Amendments to Gas Carrier Codes concerning Type C } \\
\text { Tank Loading Limits. }\end{array}$ \\
\hline OCIMF/ SIGTTO & Ship Information Questionnaire for Gas Carriers - 2nd edition. \\
\hline OCIMF/ SIGTTO & $\begin{array}{l}\text { Inspection Guidelines for Ships Carrying Liquefied Gases in Bulk - 2nd } \\
\text { edition. }\end{array}$ \\
\hline OCIMF/ SIGTTO & $\begin{array}{l}\text { Recommendations for Manifolds for Refrigerated Liquefied Natural } \\
\text { Gas Carriers (LNG) - 2nd edition). }\end{array}$ \\
\hline ICS/OCIMF/ SIGTTO & $\begin{array}{l}\text { A Contingency Planning and Crew Response Guide for Gas Carrier } \\
\text { Damage at Sea and in Port Approaches - 3rd edition } 1999 .\end{array}$ \\
\hline ICS/OCIMF/ SIGTTO & $\begin{array}{l}\text { A Guide to Contingency Planning for the Gas Carrier Alongside and } \\
\text { Within Port Limits - 2nd edition. }\end{array}$ \\
\hline OCIMF/ SIGTTO & Ship to Ship Transfer Guide (Liquefied Gases) - 2nd edition. \\
\hline OCIMF/ SIGTTO & Prediction of Wind Loads on Large Liquefied Gas Carriers. \\
\hline OCIMF/ SIGTTO & Ship to Ship Transfer Guide (Petroleum) - 3rd edition. \\
\hline SIGTTO & Cargo Fire-fighting on Liquefied Gas Carriers (video - 2nd edition) \\
\hline SIGTTO & Guidelines for Ship to Shore Access for Gas Carriers. \\
\hline OCIMF & $\begin{array}{l}\text { Safety Guide for Terminals Handling Ships Carrying Liquefied Gases in } \\
\text { Bulk. }\end{array}$ \\
\hline OCIMF & Prediction of Wind and Current Loads on VLCCs. \\
\hline OCIMF & Effective Mooring. \\
\hline OCIMF & Mooring Equipment Guidelines 2nd edition. \\
\hline OCIMF & Marine Terminal Survey Guidelines. \\
\hline ICS & Tanker Safety Guide (Liquefied Gas) 2nd edition. \\
\hline ICS & Safety In Liquefied Gas Tankers. \\
\hline ICS, OCIMF \& IAPH & $\begin{array}{l}\text { International Safety Guide for Oil Tankers and Terminals (ISGOTT) } \\
\text { 4th edition. }\end{array}$ \\
\hline IMO & $\begin{array}{l}\text { International Code for the Construction and Equipment of Ships } \\
\text { Carrying Liquefied Gases in Bulk (IGC Code). }\end{array}$ \\
\hline IMO SOLAS & Consolidated Edition. \\
\hline OCIMF & $\begin{array}{l}\text { Design and Construction Specification for Marine Loading Arms 3rd } \\
\text { edition. }\end{array}$ \\
\hline ICS & Bridge Procedures Guide 3rd edition. \\
\hline BS 6349 & $\begin{array}{l}\text { Maritime Structures Part } 4 \text {. Code of practice for design of fendering } \\
\text { and mooring systems }\end{array}$ \\
\hline OSHA & Occupational Safety \& Health Administration \\
\hline 29 CFR 1910.119 & Process Safety Management of Highly Hazardous Chemicals \\
\hline 49-CFR-193 & LNG Facilities, Federal Safety Standards \\
\hline
\end{tabular}




\section{Appendices}

\subsection{Reference Documents}
Ref Document number
Rev Title
[1]
CGI-G-100-PH-002
A Operational Philosophy
[2]
CGI-G-100-RP-006
A Facilities Description

\subsection{Additional Metocean Data Vermillion 179 Region}

\subsubsection{General}

Environmental Data as available in the public domain has been assessed to establish general environmental design conditions for the Vermilion 179 location in the Gulf of Mexico.

In the following some overall results and conclusions are presented, together with some recorded events that appear to be typical for the location.

Data assessed has been measured at a buoy in the Galveston area in a waterdepth of $15.9 \mathrm{~m}$ and a buoy in the Freeport area in a waterdepth of $82.3 \mathrm{~m}$.

Approximately 11 years of wind velocity and wave height data is available, but the information on the associated directions is limited. Even more limited is the information on current. Basically some general knowledge is available on the current.

Wave height in figures means significant wave height. Wind velocity in graphs is the 8 min. mean velocity. Directions are the directions from which the wave/wind is coming.

\subsubsection{Summary of Conclusions}

The data acquired at the different buoys is very similar, from which it is concluded that the conditions at the Vermilion 179 block in a waterdepth of approximately $30 \mathrm{~m}$ is expected to be similar as well.

Even though there exist an 'official' hurricane season in the Gulf of Mexico which is from June through November, high wind velocities and high waves can occur all year long.

There exist prevailing directions for waves as well as wind. The prevailing directions are from a south easterly direction.

Wind velocity and Wave height seldom become virtually zero. The average wave height throughout the year is approximately $1 \mathrm{~m}$ significant. The average wind velocity varies from 5.8 to $7.4 \mathrm{~m} / \mathrm{s}$ between the two buoys

No clear correlation can be found between wind and wave, both in terms of magnitude and direction. 


\subsubsection{Distribution of directions for Wave and Wind}

The following graphs show the normalized distributions of wave and wind directions. Directions reflected are coming from.

Wave Direction Distribution

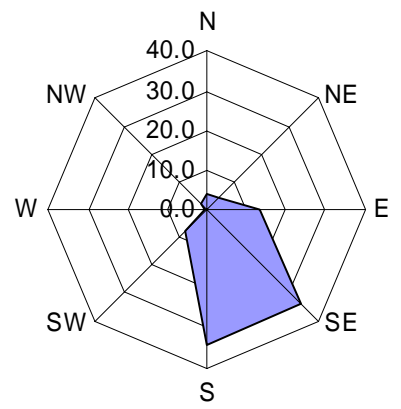

\section{Wind Direction Distribution}

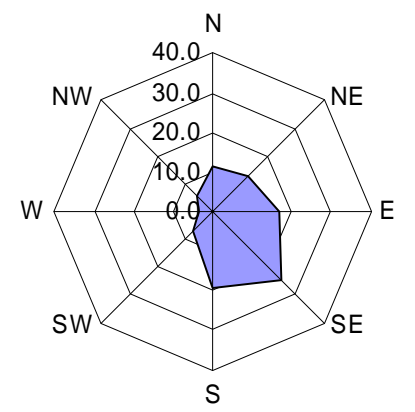

The directional distributions clearly show the prevailing directions, which are a little more concentrated for the waves that for the wind.

\subsubsection{Distribution of wave heights and wind velocities}

The graphs below show the distributions of wave height and wind velocity.
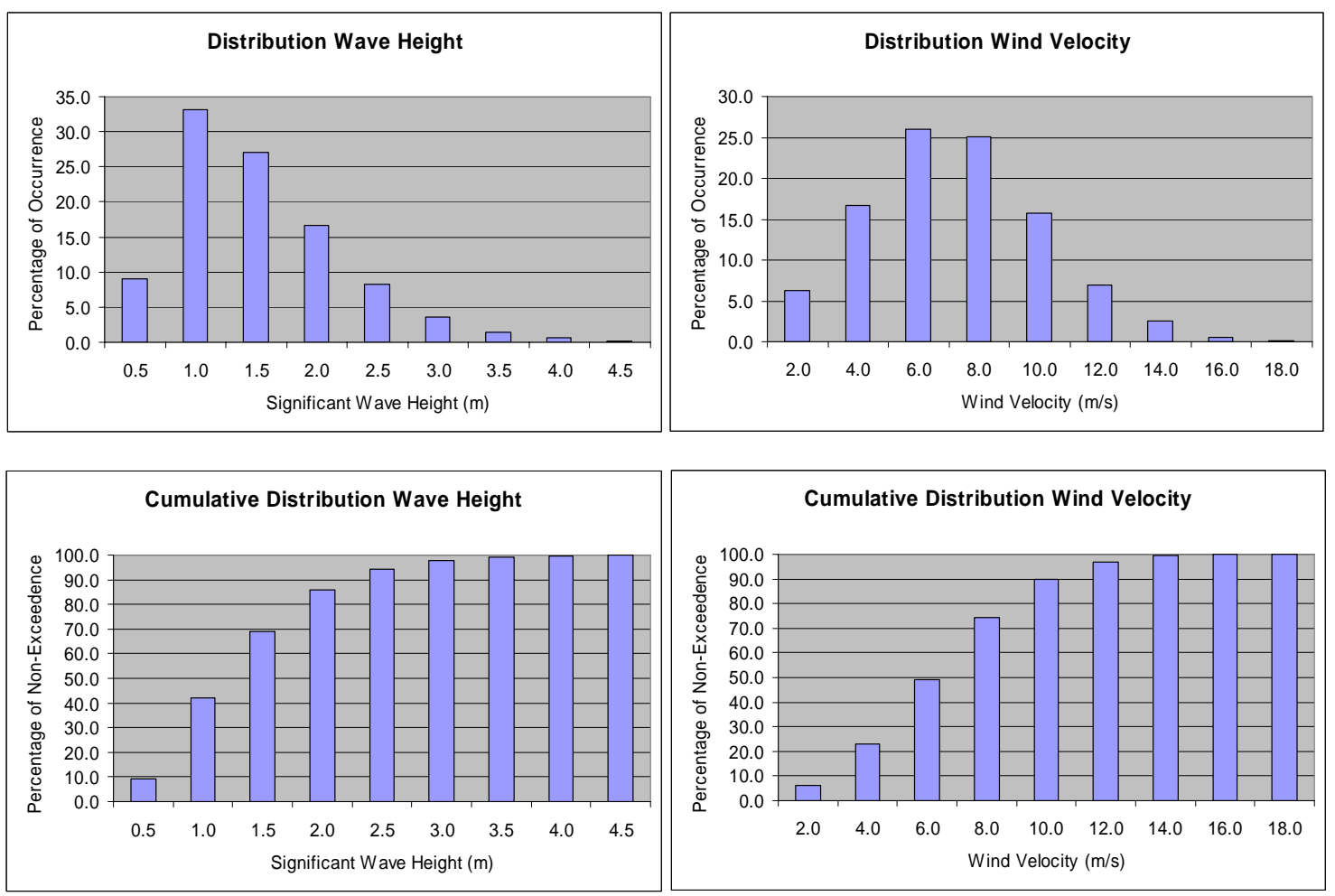
The following graphs are yearly timetraces of wave height and wind velocity. The objectives of these graphs is to show that:

- Although most extreme events occur during hurricane season, extreme events can occur at any time.

- The amount seastates that exceed $3 \mathrm{~m}$ significant is rather limited.

- The average seastate of about $1 \mathrm{~m}$ significant can be observed from the graph.

- Fluctuations in wind velocity are large throughout the year.
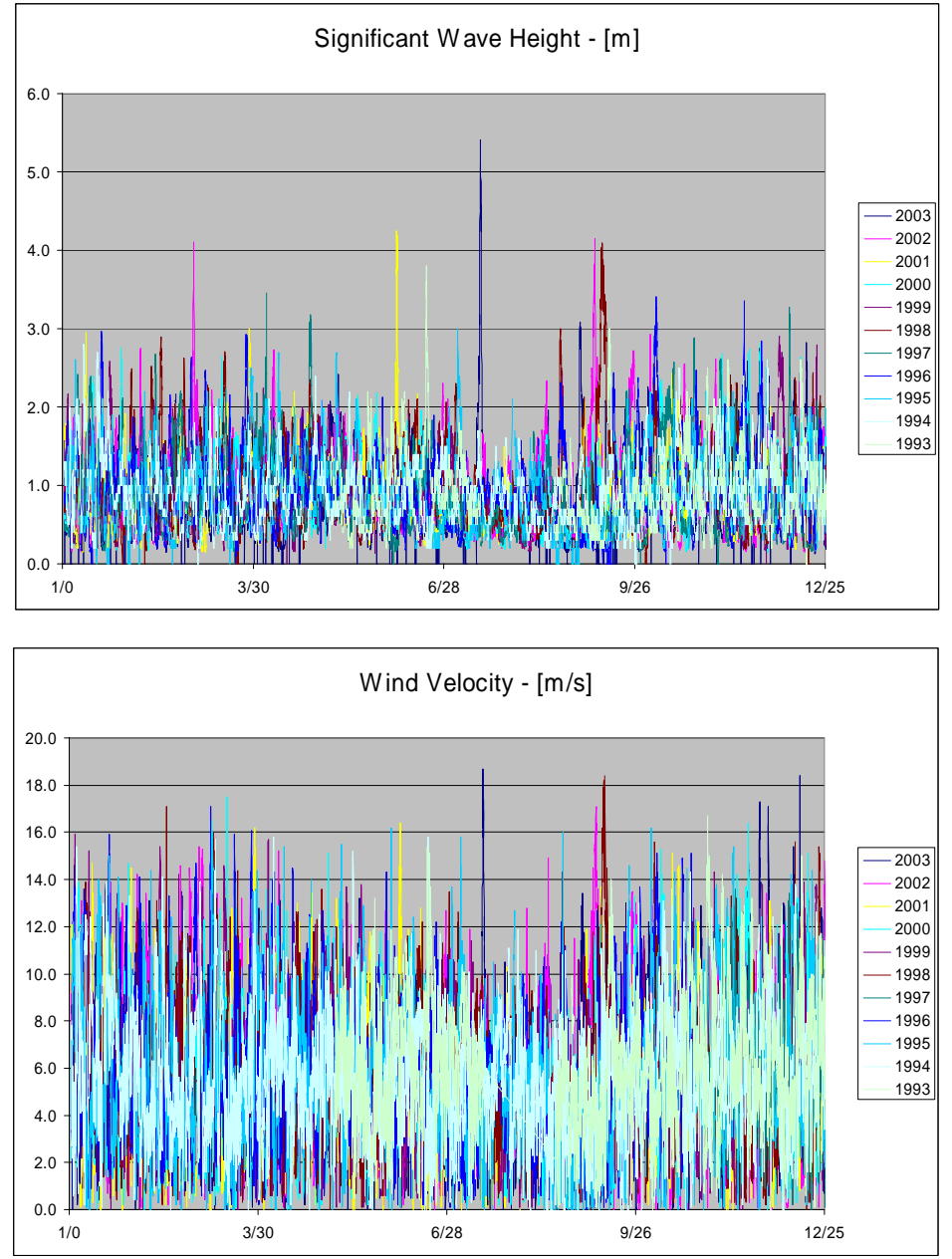


\subsubsection{Relative Angles between Wind and Wave}

The following graphs show the angular difference in wave direction and wind direction for the following conditions:

- $\quad$ All occurrences measured

- $\quad$ Conditions with significant wave height larger than $2.5 \mathrm{~m}$

- Conditions with wind velocities larger than $10 \mathrm{~m} / \mathrm{s}$

- Conditions with wind velocities larger than $10 \mathrm{~m} / \mathrm{s}$ and sign. wave height larger than $2.5 \mathrm{~m}$
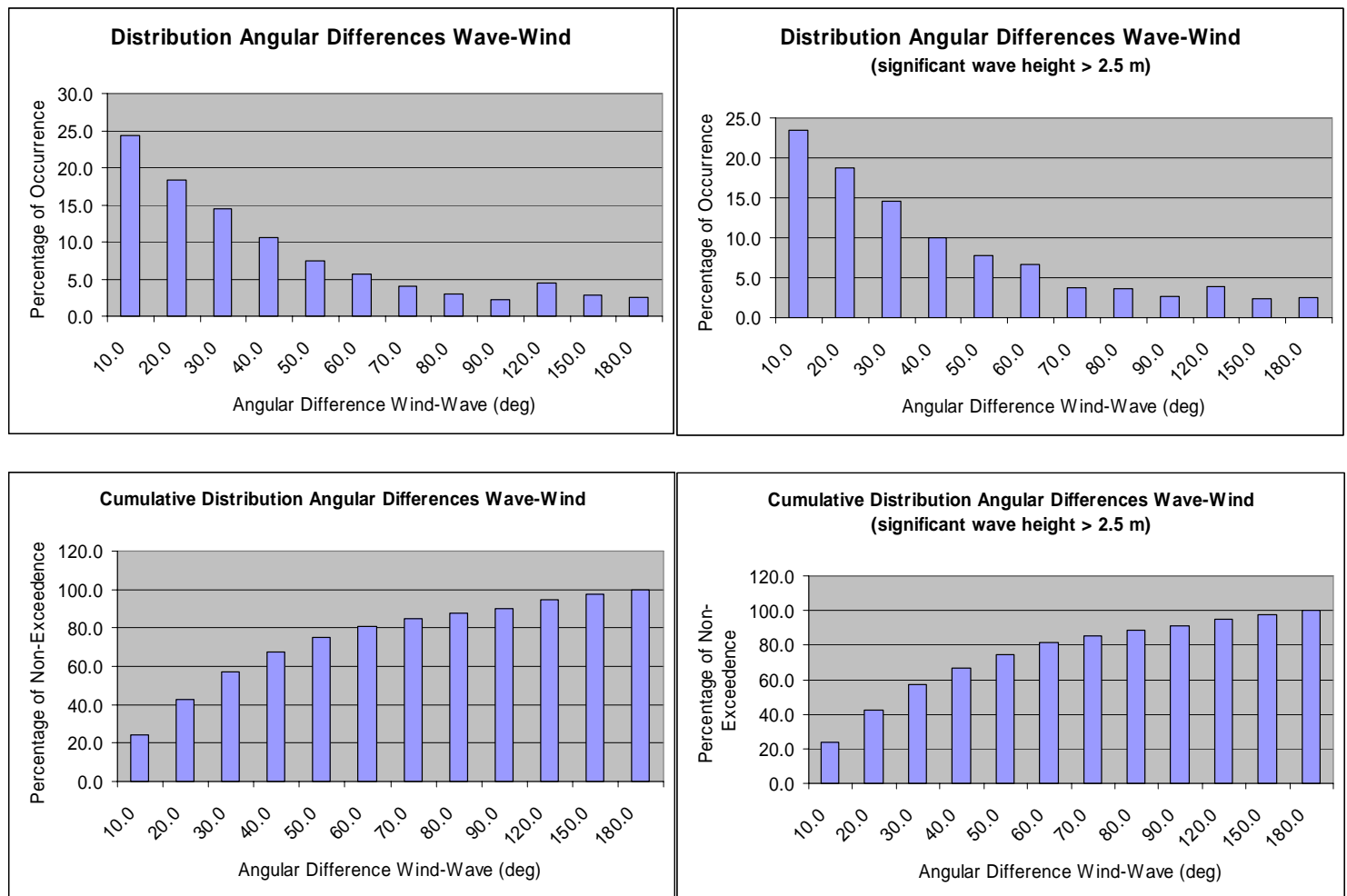

Cumulative Distribution Angular Differences Wave-Wind (significant wave height $>2.5 \mathrm{~m}$ )

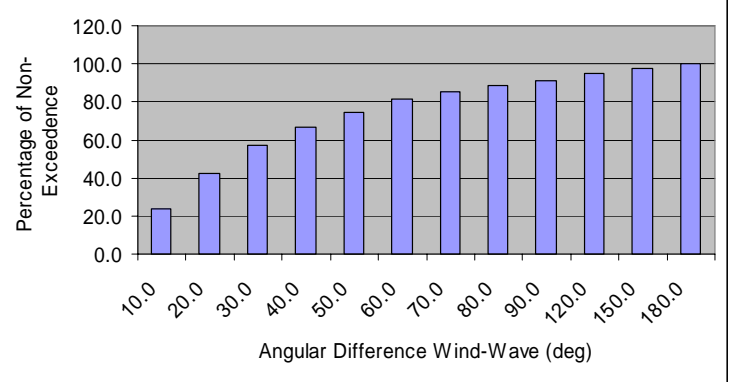



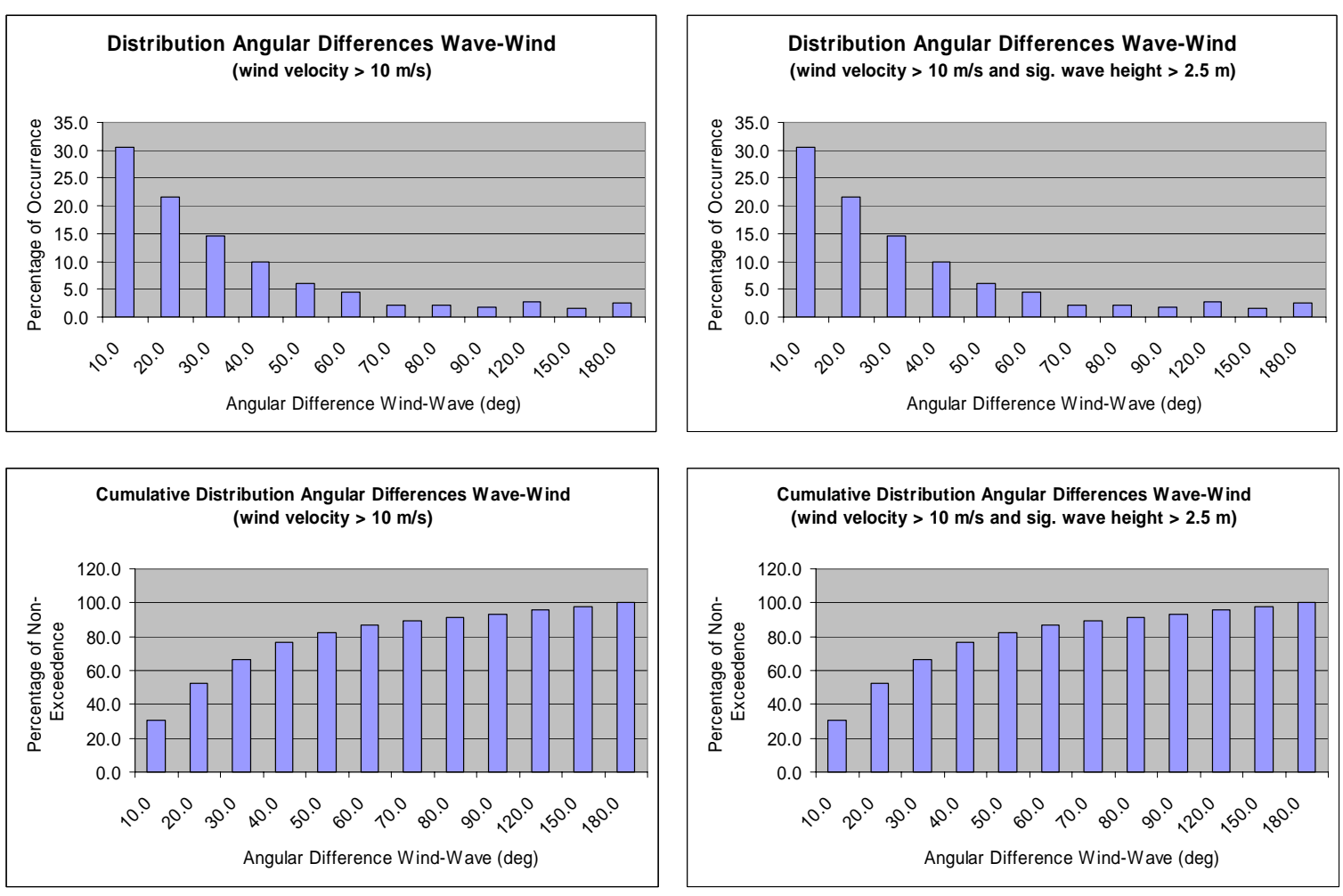

Although a lot of events show relative angles between wave and wind smaller than 40 degrees, there are still about $20 \%$ of the cases that show larger angular differences.

\subsubsection{Persistence Data}

The following table shows the number of measurements where the significant wave height was higher than $2 \mathrm{~m}$ for a period of 2 hours or longer. It is noted that the data points do not 'overlap' meaning events with a different wave height can occur consecutively.

\begin{tabular}{|c|c|c|c|c|}
\hline $\begin{array}{l}\text { Duration } \\
\text { (hrs) }\end{array}$ & $\begin{array}{c}2.0<\mathrm{Hs}<2.5 \\
(\mathrm{~m})\end{array}$ & $\begin{array}{c}2.5<\mathrm{Hs}<3.0 \\
(\mathrm{~m})\end{array}$ & $\begin{array}{c}3.0<\mathrm{Hs}<3.5 \\
(\mathrm{~m})\end{array}$ & $\begin{array}{c}\mathrm{Hs}>3.5 \\
(\mathrm{~m})\end{array}$ \\
\hline 2 & 43 & 11 & 3 & 2 \\
\hline 3 & 47 & 4 & 2 & 1 \\
\hline 4 & 14 & 6 & & 2 \\
\hline 5 & 16 & 1 & & 1 \\
\hline 6 & 15 & 3 & & 1 \\
\hline 7 & 10 & 4 & & \\
\hline 8 & 8 & 3 & & \\
\hline 9 & 3 & 3 & & 1 \\
\hline 10 & 3 & & & \\
\hline 11 & 1 & & 1 & \\
\hline 12 & 1 & & & \\
\hline 13 & & & & \\
\hline 14 & 1 & & & \\
\hline 15 & 1 & 1 & & \\
\hline 16 & & & & \\
\hline 17 & 1 & & & \\
\hline$>18$ & 4 & & & \\
\hline$>24$ & & & & \\
\hline Total & 168 & 36 & 6 & 8 \\
\hline Grand Total & \multicolumn{4}{|c|}{218} \\
\hline
\end{tabular}


It can be seen from the table that only about 50 occurrences have been measured over the last 10 years during which the seastates were higher than $2.5 \mathrm{~m}$ for 2 hours or longer.

The following table shows the number of measurements where the wind velocity was higher than 10 $\mathrm{m} / \mathrm{s}$ for a period of 2 hours or longer. It is noted that the data points do not 'overlap' meaning events with a different wave height can occur consecutively.

\begin{tabular}{|l|c|c|c|}
\hline $\begin{array}{l}\text { Duration } \\
\text { (hrs) }\end{array}$ & $\begin{array}{c}10<\mathrm{Vw}<12 \\
(\mathrm{~m} / \mathrm{s})\end{array}$ & $\begin{array}{c}12<\mathrm{Vw}<15 \\
(\mathrm{~m} / \mathrm{s})\end{array}$ & $\begin{array}{c}\mathrm{Vw}>15 \\
(\mathrm{~m} / \mathrm{s})\end{array}$ \\
\hline 2 & 93 & 51 & 3 \\
\hline 3 & 67 & 17 & 3 \\
\hline 4 & 37 & 16 & 1 \\
\hline 5 & 37 & 6 & 1 \\
\hline 6 & 23 & 7 & \\
\hline 7 & 14 & 2 & \\
\hline 8 & 13 & 1 & \\
\hline 9 & 13 & 1 & \\
\hline 10 & 5 & & \\
\hline 11 & 3 & & \\
\hline 12 & 3 & & \\
\hline 13 & 2 & & \\
\hline 14 & & & \\
\hline 15 & & & \\
\hline 16 & & & \\
\hline 17 & & & \\
\hline$>18$ & & & \\
\hline$>24$ & & & \\
\hline & & & \\
\hline Total & & & \\
\hline Grand \\
Total
\end{tabular}

\subsubsection{Extreme Events}

Because of the lack of especially directional data, it is not possible to determine typical extreme environmental combinations. Below are a number of occurrences that have been registered over the last 10-years. These can give an idea on extreme conditions that can occur in the region. Extreme condition in this sense does not mean survival conditions, but potential critical operational conditions.

From the below events, it can be clearly seen that during 'storms' wave and wind coincide in terms of magnitude growth. The directional data is limited, but from the data available, it can be seen that the wind and waves are not collinear, but directional changes follow the same trend. 
30 ОСТ 1993

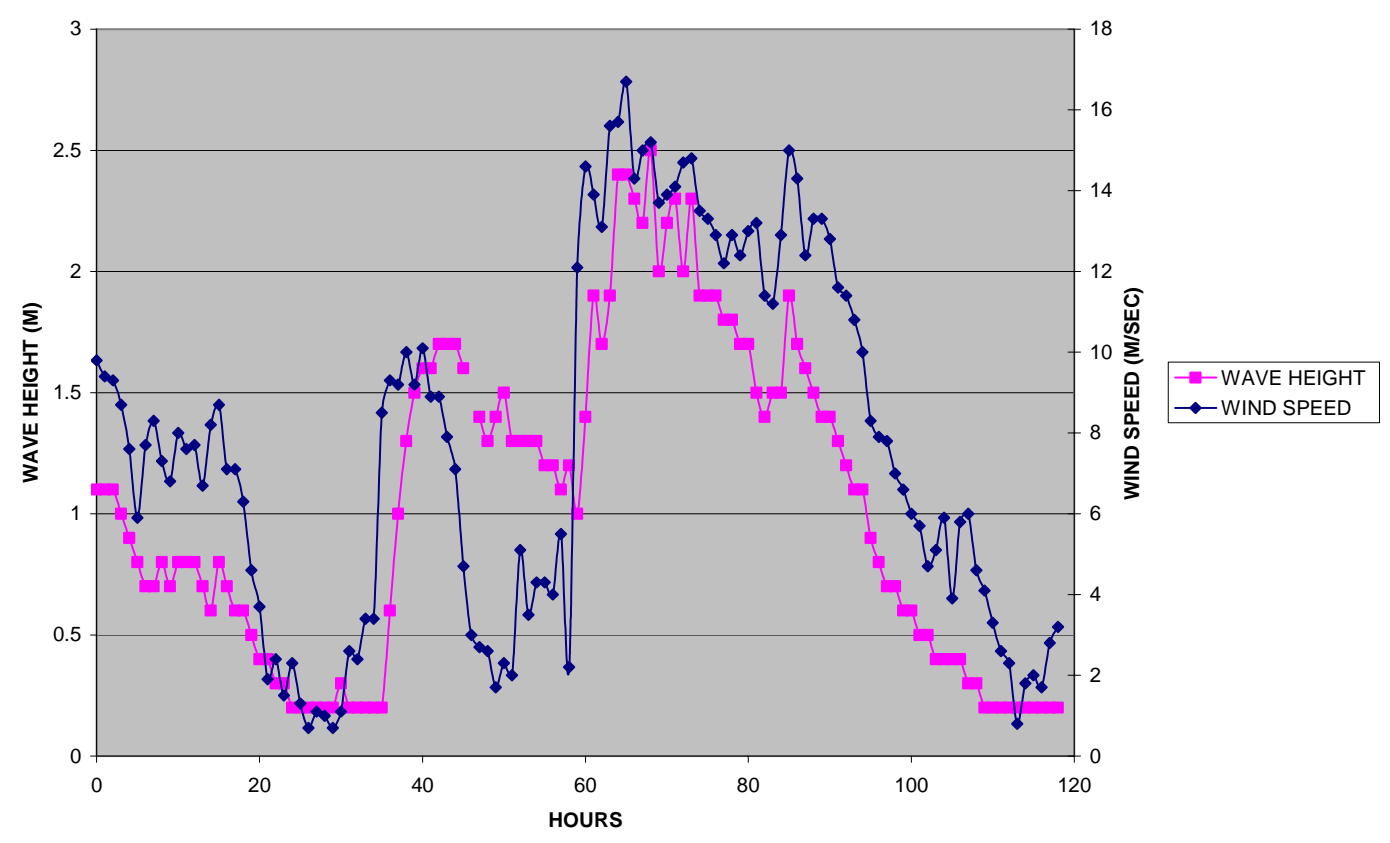

30 OCT 1993

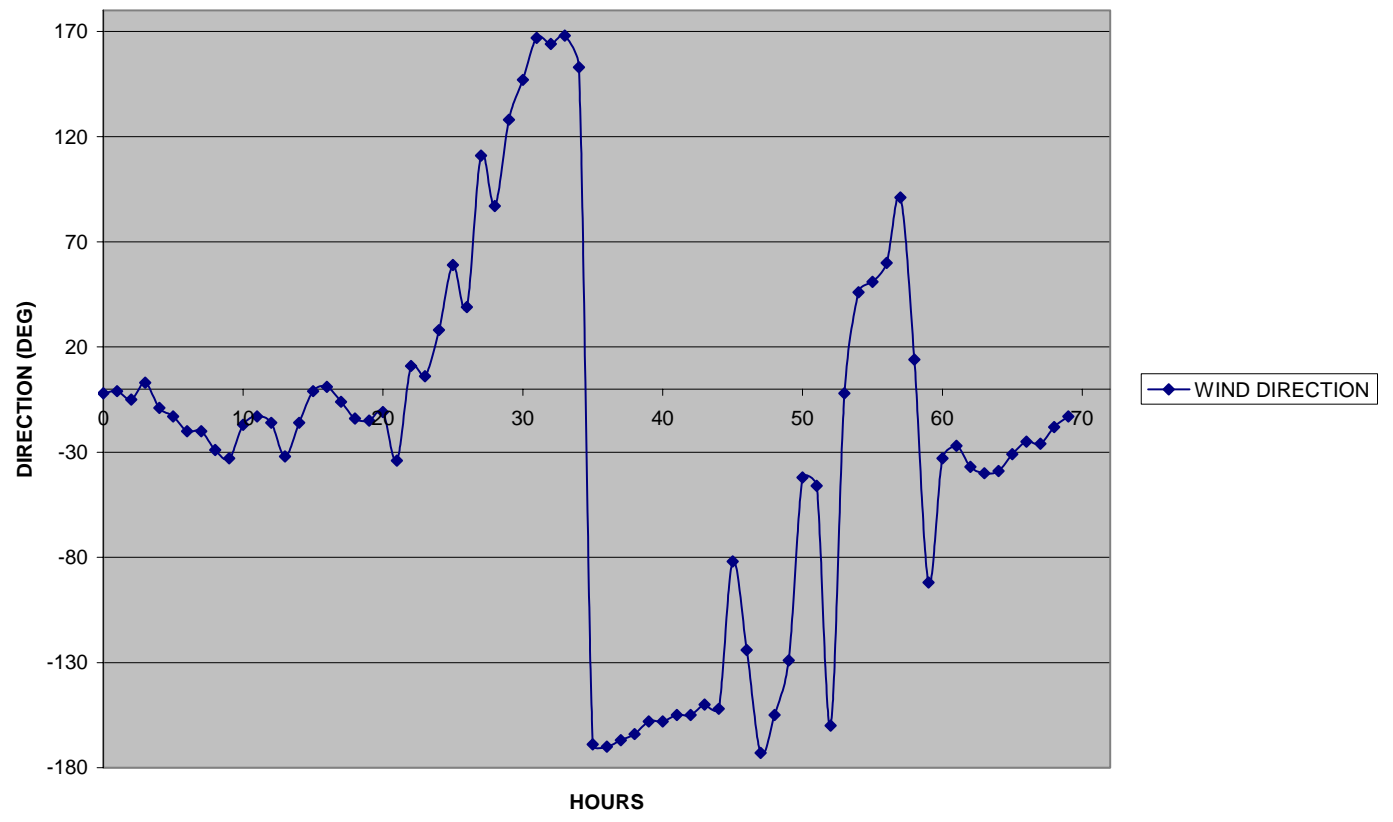




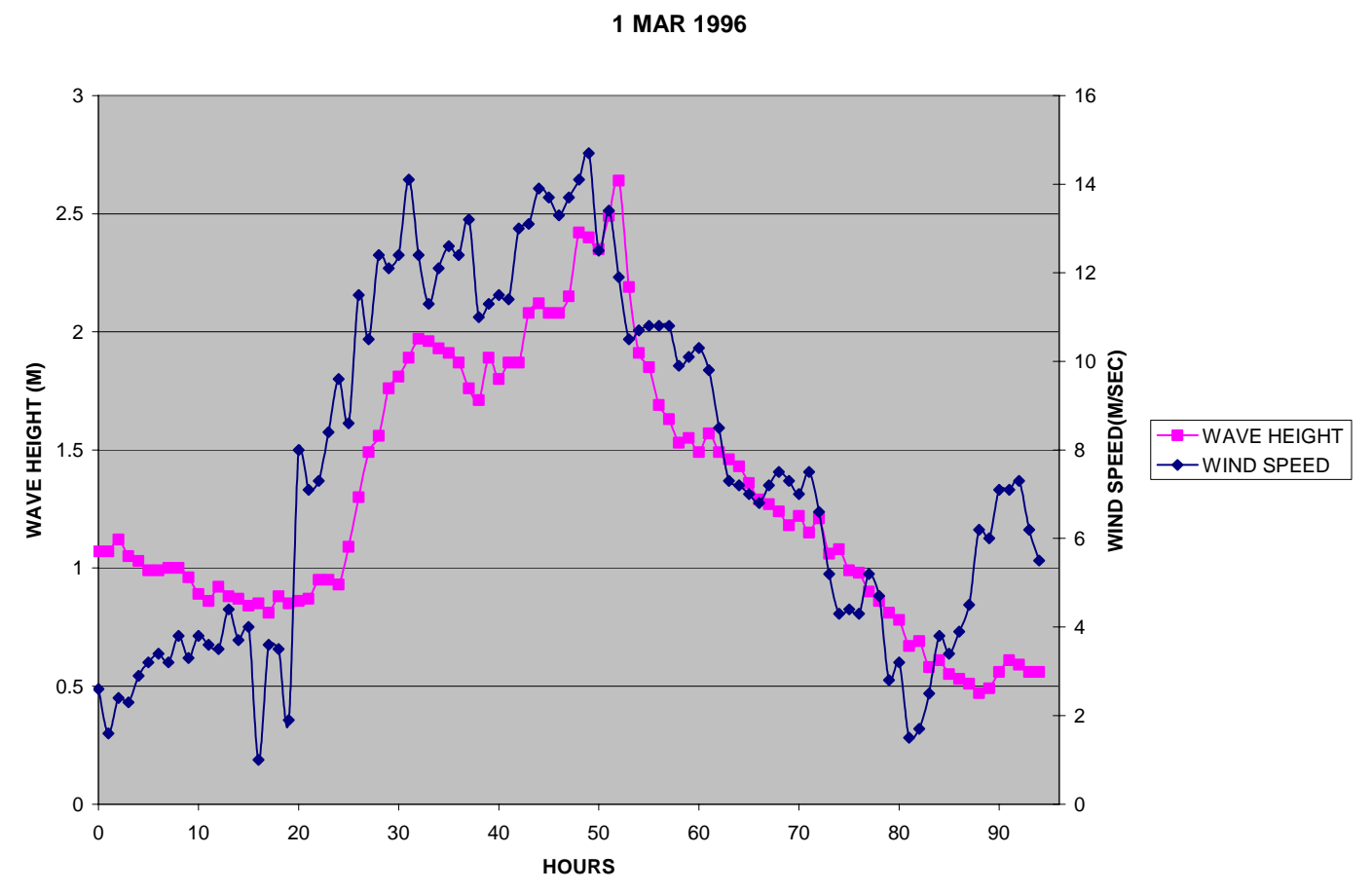

1 MAR 1996

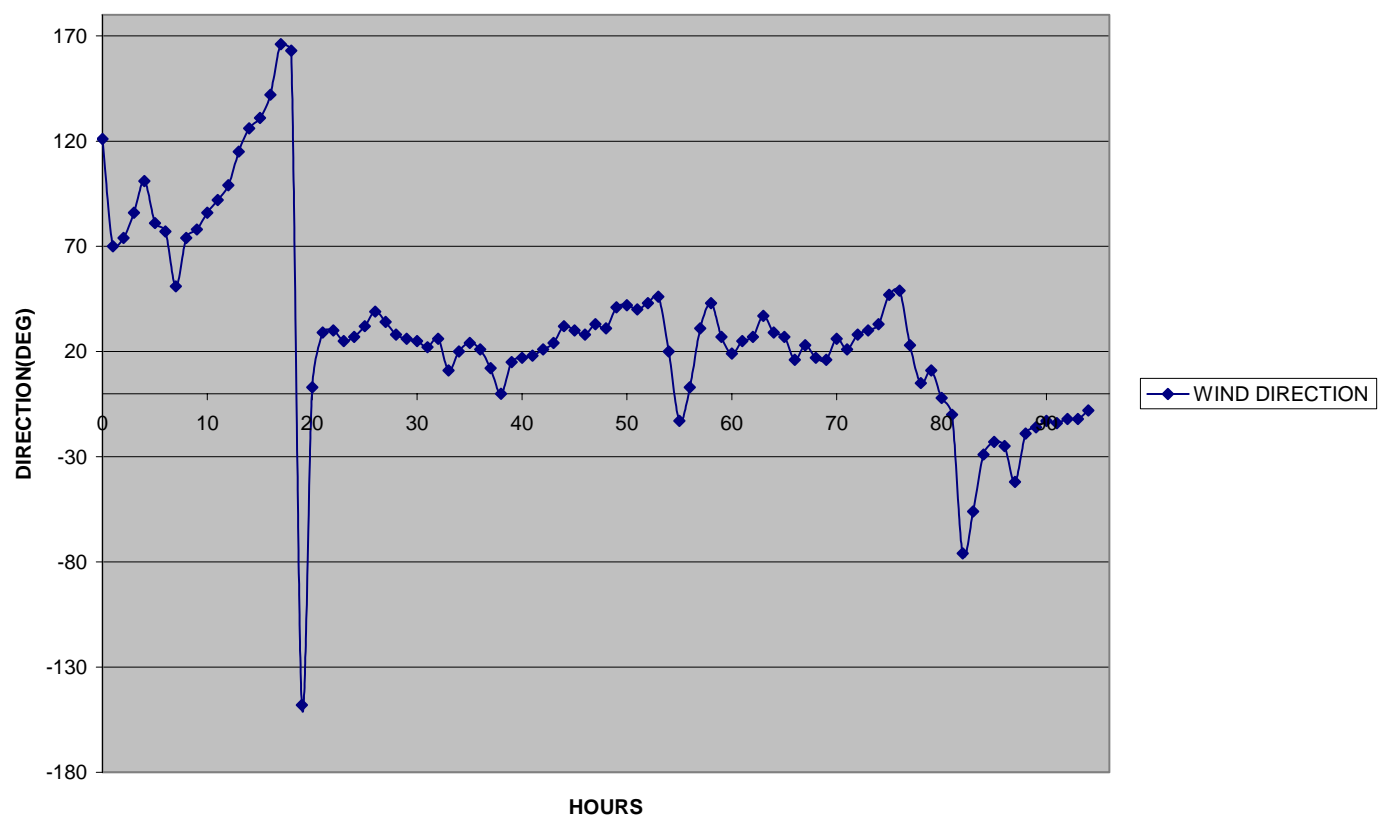




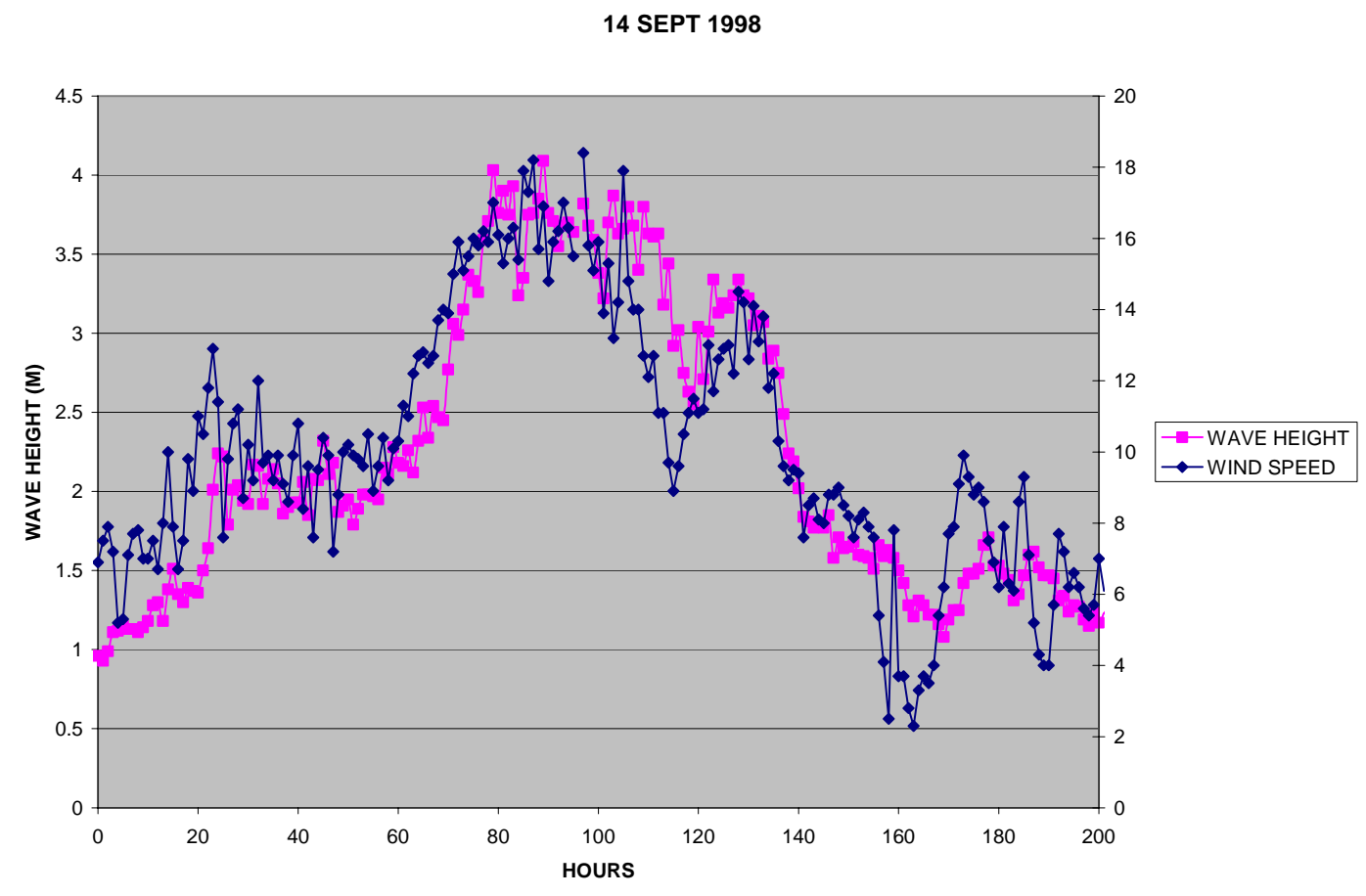

14 SEPT 1998

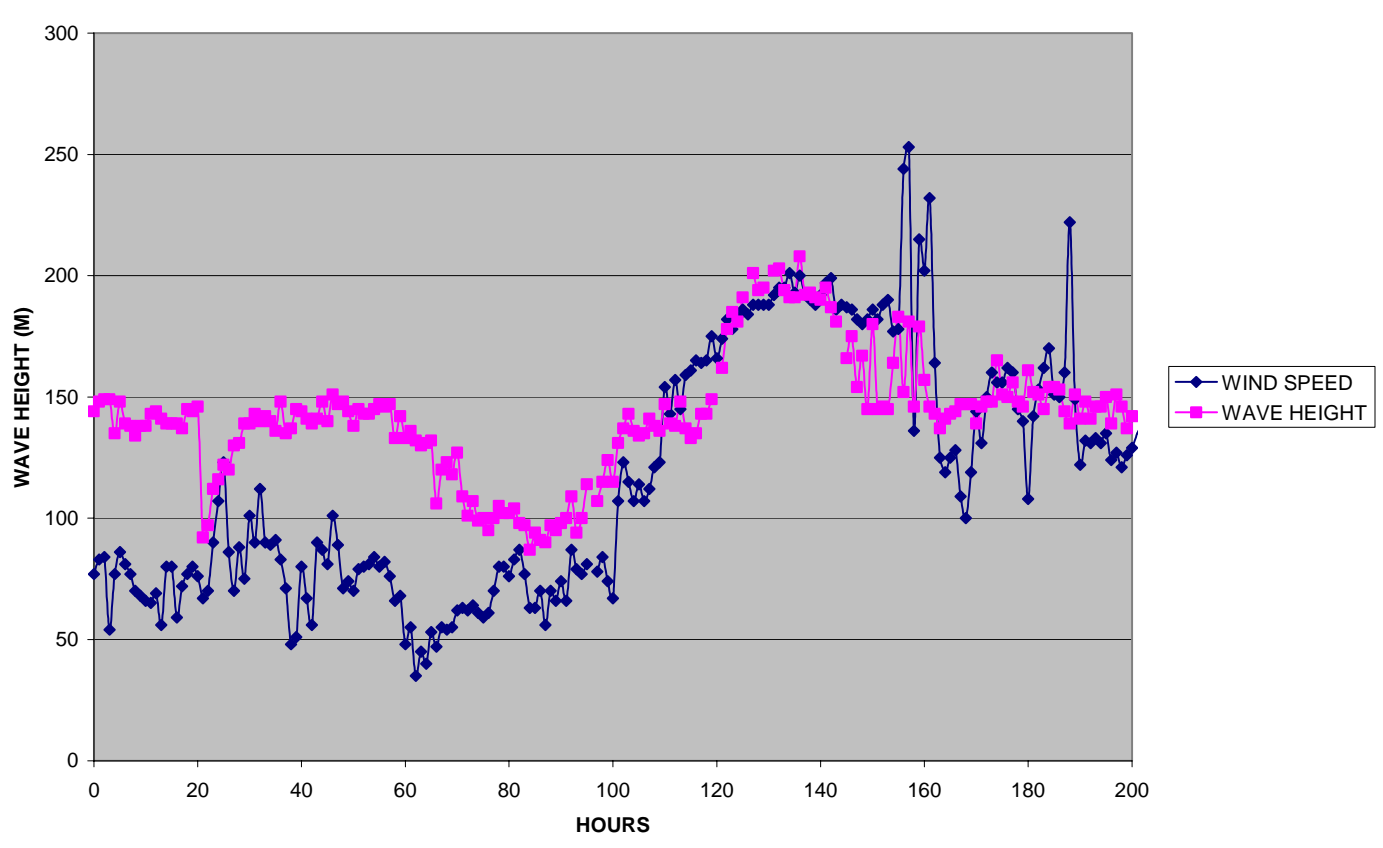


11 JAN 2001

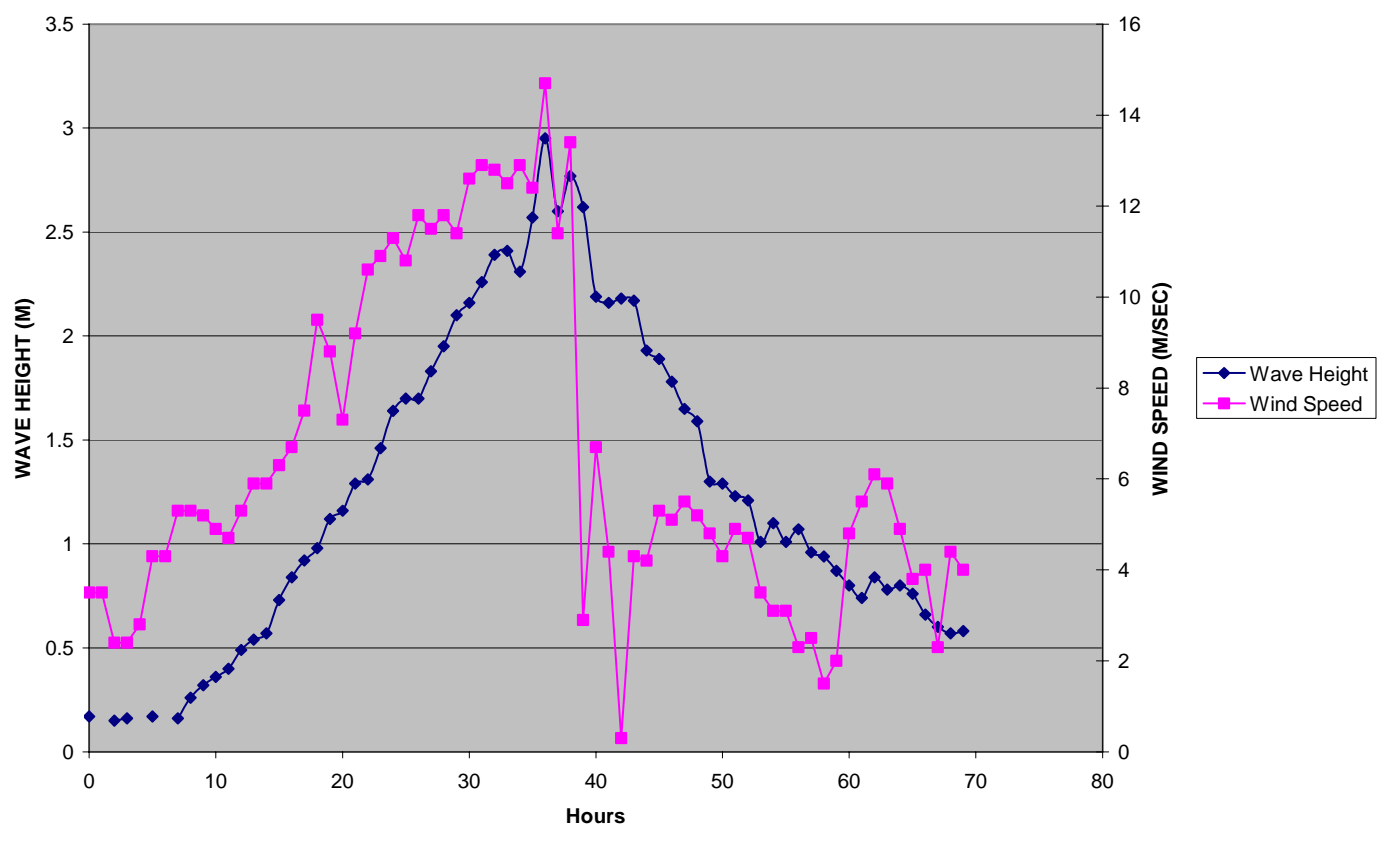

11 JAN 2001

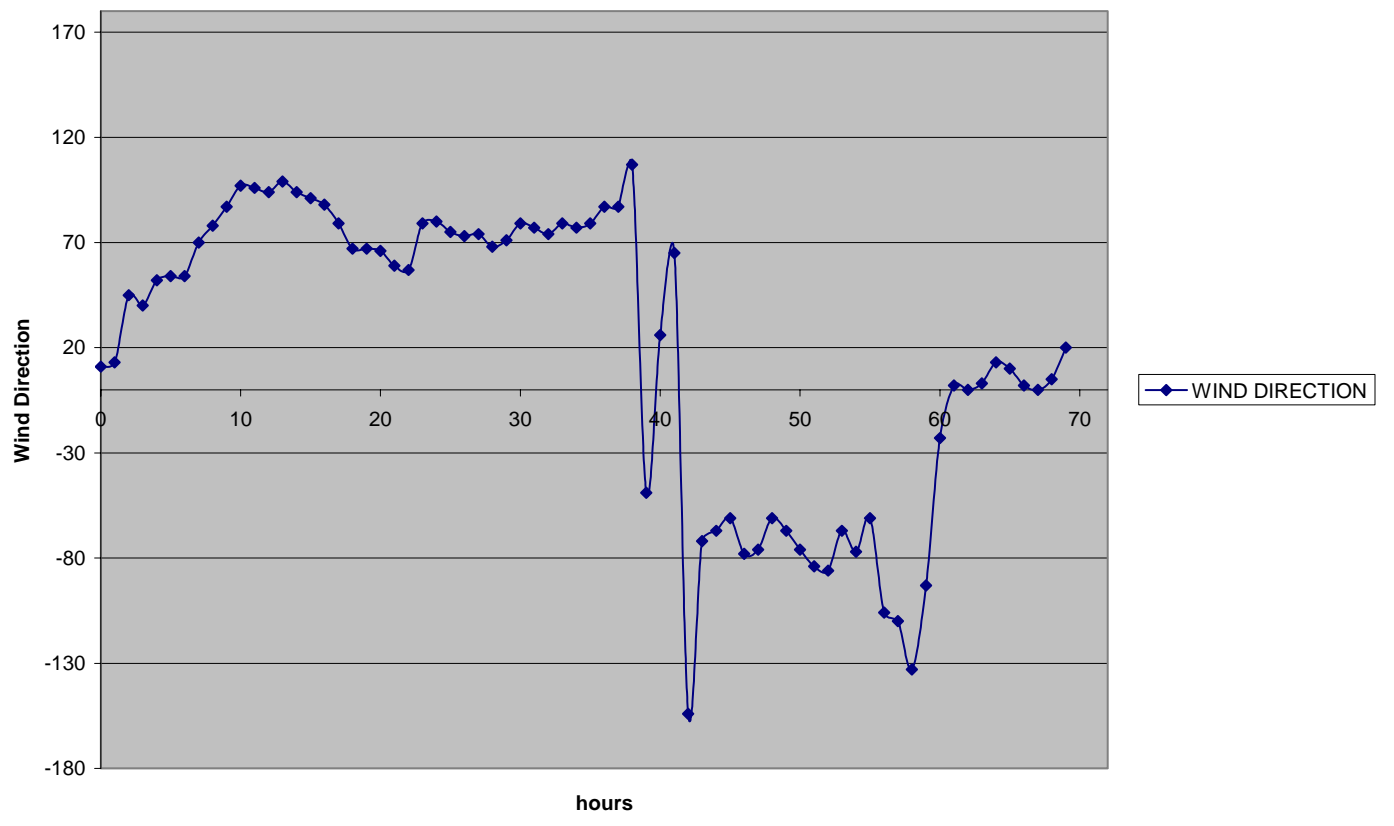


16 JULY 2003

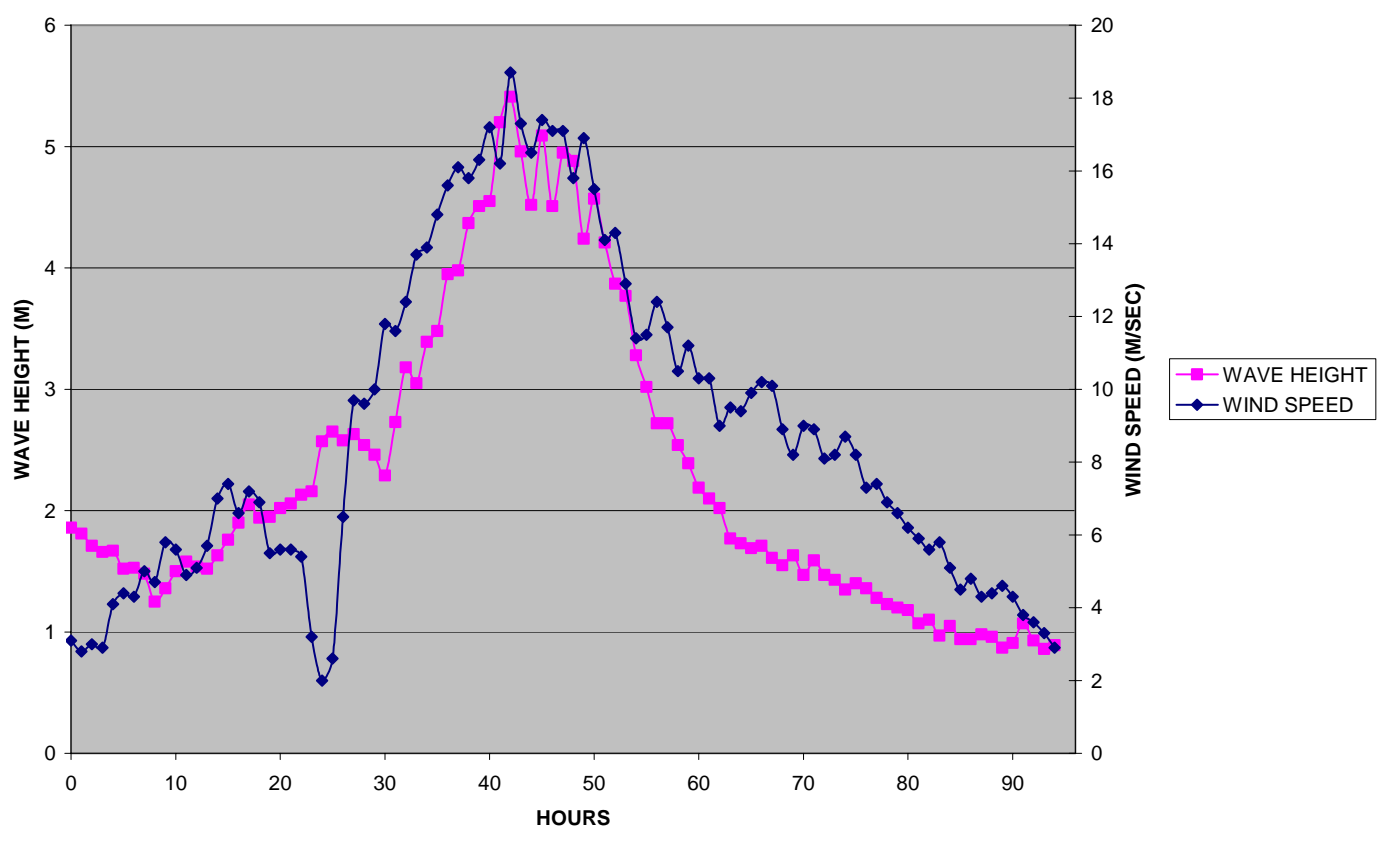

16 JULY 2003

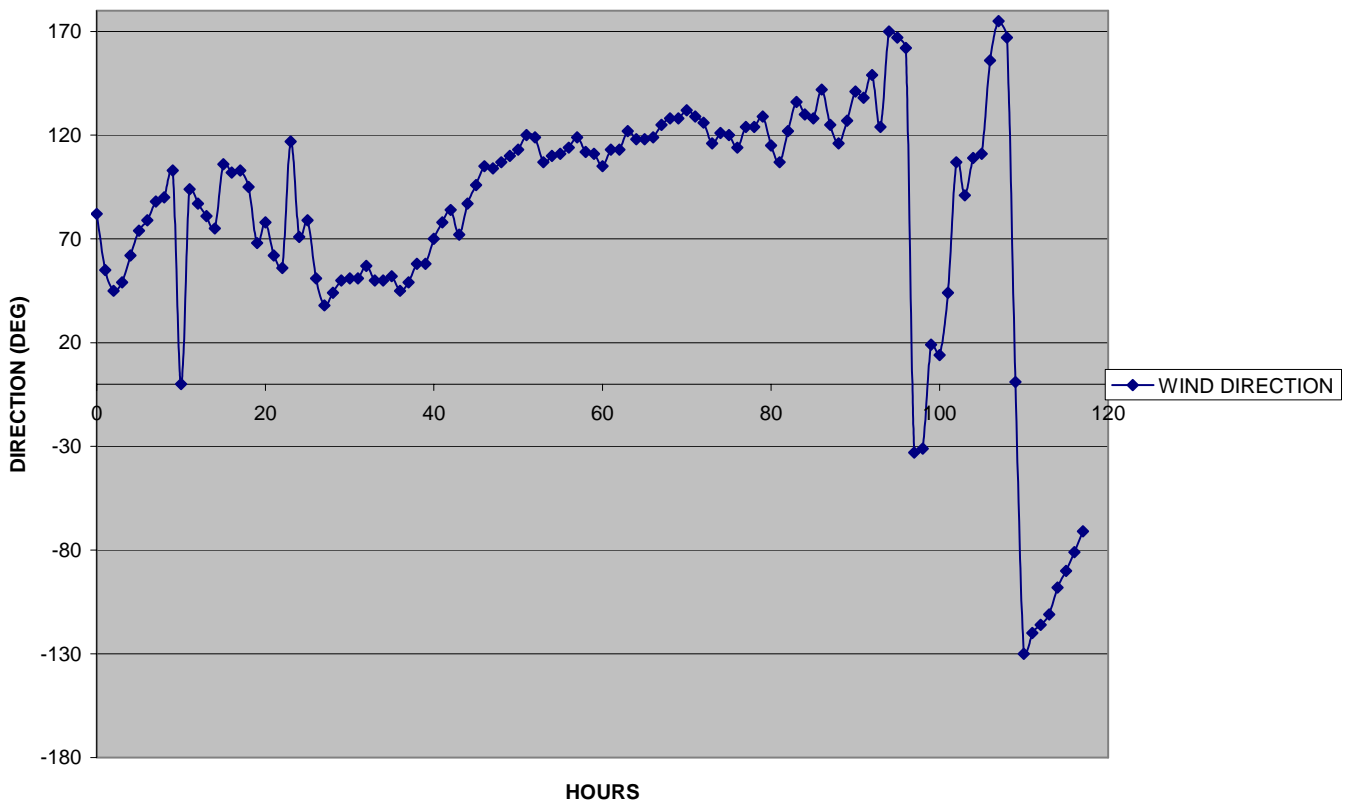




\subsection{LNG Physical Properties}

\subsubsection{LNG characteristics}

The table below presents the design gas compositions for the study.

\begin{tabular}{|l|l|}
\hline Component & Mole \% \\
\hline Nitrogen & 0.00 \\
\hline Carbon dioxide & 0.00 \\
\hline Methane & 85.00 \\
\hline Ethane & 8.00 \\
\hline Propane & 4.00 \\
\hline I - Butane & 1.50 \\
\hline N- Butane & 1.50 \\
\hline IC5 & 0.00 \\
\hline NC5 & 0.00 \\
\hline C6+ & 0.00 \\
\hline Total & 100.00 \\
\hline
\end{tabular}




\subsubsection{LNG Temperature-Pressure Phase Diagram}

The LNG Temperature - Pressure Phase diagram for the design case is presented below. Also Phase diagrams for a rich and a lean composition include for reference. The Big Sweep transfer system is compatible with the different gas compositions.

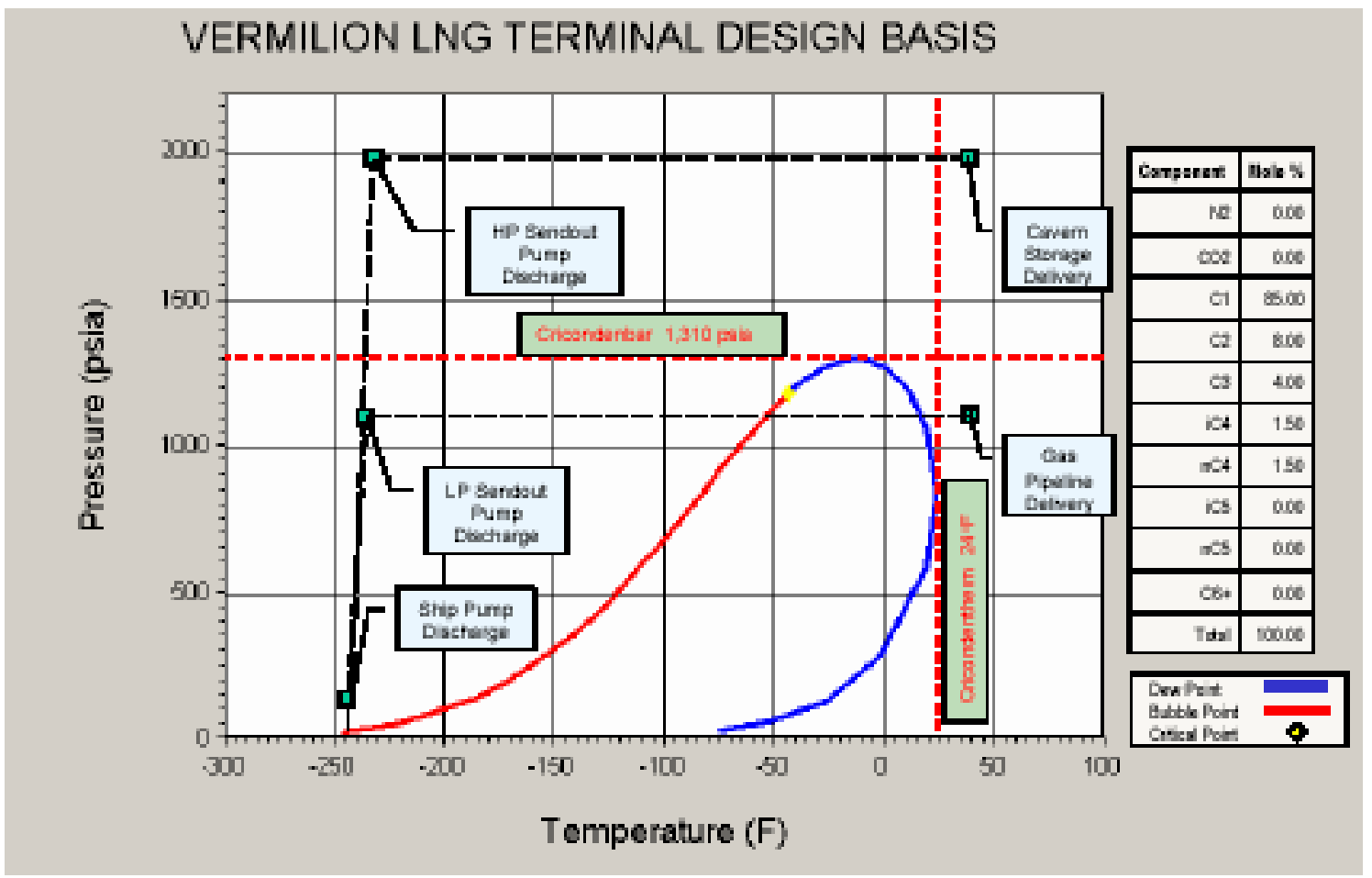

Figure 4.1 Phase diagram Design Case 


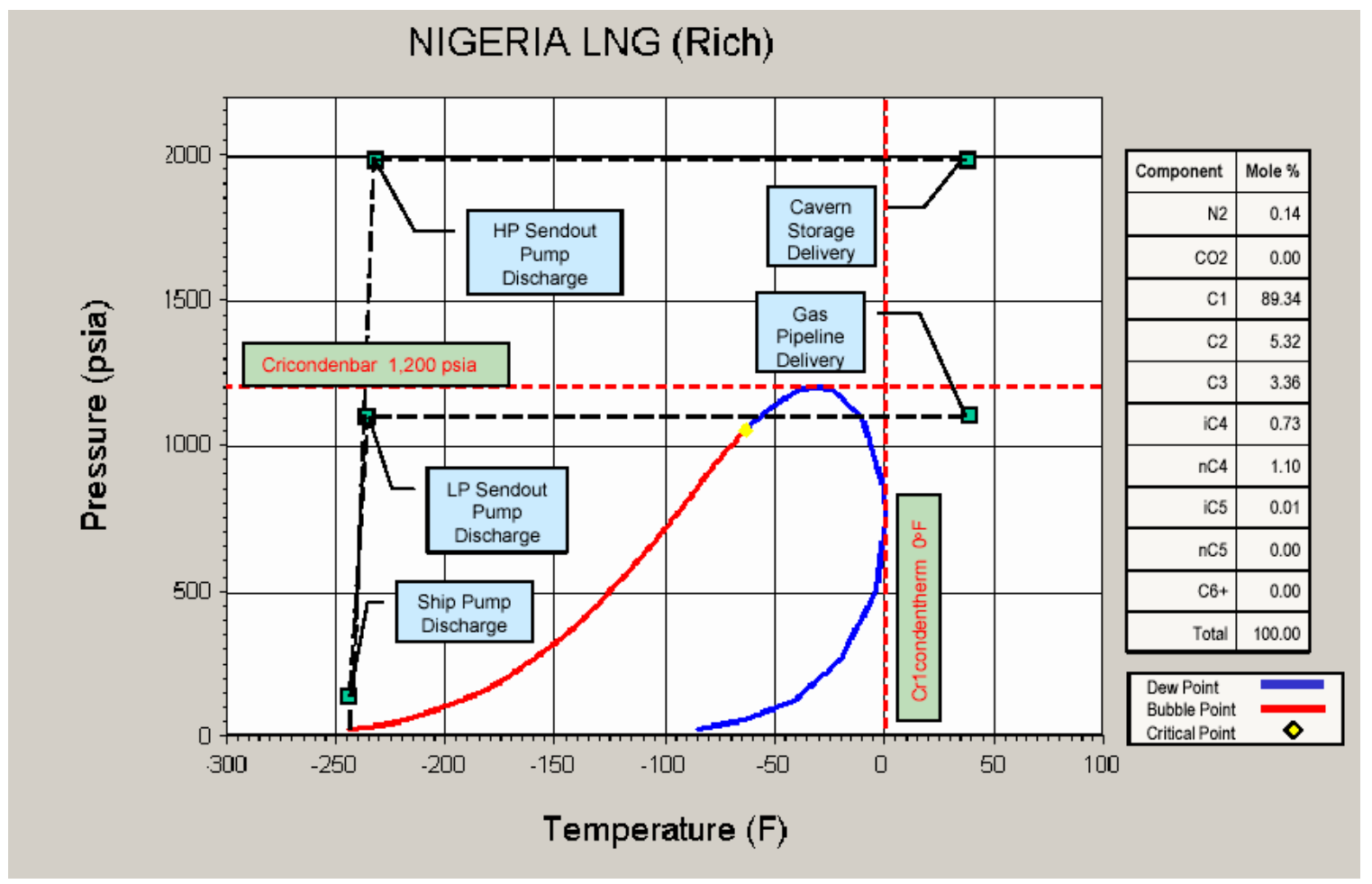

Figure 4.2 Phase diagram Rich gas composition 


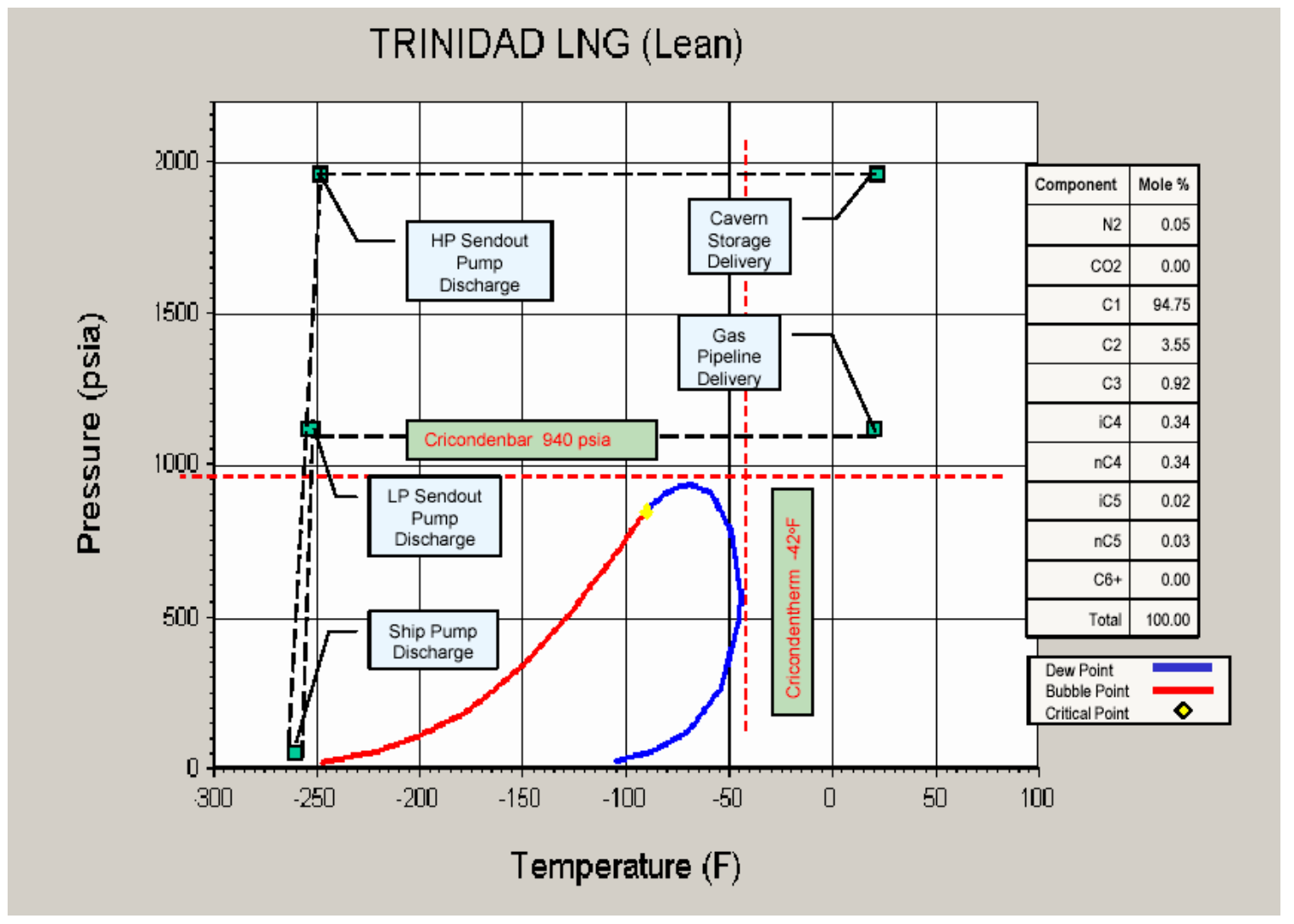

Figure 4.3 Phase diagram Lean gas composition 


\subsubsection{Conversion Factors}

\begin{tabular}{|c|c|c|c|c|c|c|c|}
\hline \multicolumn{8}{|c|}{ LNG conversion factors } \\
\hline tonnes & $\mathrm{m}^{3}$ & $\mathrm{ft}^{3}$ & bbl & Mscf & $\mathrm{nm}^{3}$ & MMBtu & GJ \\
\hline 1.0 & 2.2 & 77.1 & 13.7 & 46.1 & 1,236 & 52 & $\overline{54}$ \\
\hline 0.5 & 1.0 & 35.3 & 6.3 & 21.1 & 566 & 24 & 25 \\
\hline 13.0 & 28.3 & $1,000.0$ & $\overline{178.1}$ & 598.3 & 16,029 & 668 & 705 \\
\hline 72.8 & 159.0 & $5,614.7$ & $1,000.0$ & $3,359.1$ & 89,998 & 3,753 & $\overline{3,959}$ \\
\hline 22.0 & 47.0 & $1,671.0$ & 298.0 & $1,000.0$ & 26,792 & 1,117 & 1,179 \\
\hline 0.8 & 1.8 & 62.4 & 11.1 & 37.3 & 1,000 & 42 & $\overline{44}$ \\
\hline 19.4 & 42.4 & $1,496.1$ & 266.5 & 895.1 & 23,981 & 1,000 & 1,055 \\
\hline 18.4 & 40.2 & $1,418.1$ & $\overline{252.6}$ & 848.4 & 22,730 & 948 & 1,000 \\
\hline \multicolumn{4}{|c|}{ liquid phase } & \multicolumn{2}{|c|}{ gas phase } & \multicolumn{2}{|c|}{ energy } \\
\hline
\end{tabular}

Note 1: The above table present typical values and may vary for different gas compositions. The energy value colomn gives indicative values of a typical Oman LNG.

\section{$\underline{\text { Reference Conditions }}$}

Natural gas quantities are expressed in terms of normal cubic meters $\left(\mathrm{Nm}^{3}\right)$ with reference conditions of $0^{\circ} \mathrm{C}$ and $0.101325 \mathrm{MPa}$ and in terms of standard cubic feet (scf) with reference conditions of $60^{\circ} \mathrm{F}$ and $14.696 \mathrm{psi}$. 


\title{
Big Sweep Study
}

\section{Operational Philosophy}

\section{Doc. No. CGI-G-100-PH-0002 Rev. A}

\author{
Project. No. 1-0282-0
}




\title{
Big Sweep Study
}

\section{Offloading Facility Description}

Doc. No. CGI-G-100-RP-0003 Rev. B

\author{
Project. No. 1-0282-0
}

\author{
Bluewater Energy Services B.V. \\ Marsstraat 33 \\ 2132 HR Hoofddorp \\ The Netherlands \\ Tel. +31235682800 \\ Fax. +31235652053
}




\section{Revision Status Sheet}

Rev. Date

A 19. Nov.2004

B 14. July.2005

\section{Description}

Initial Issue

CGI comments Included
Initiator

BS

$B S$
Date

July 2005

July 2005
I nitials

HvdB

RU

Approved by

Y:|1_PROJS|1-0282-0|Doc|G0003 Rev B - Offloading Facility Description.doc 


\section{Table of Contents}

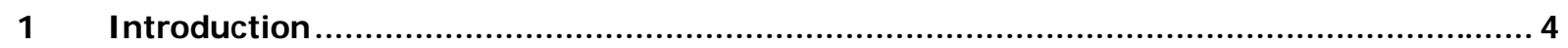

2 Tower

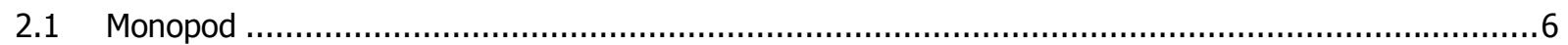

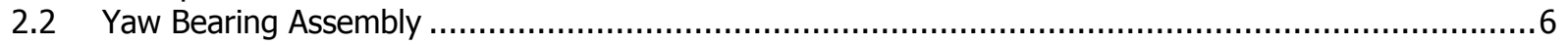

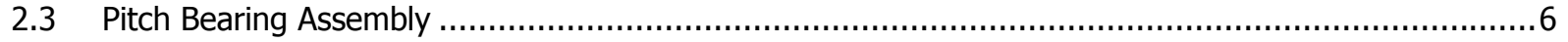

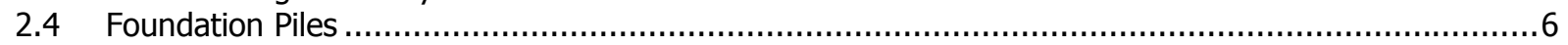

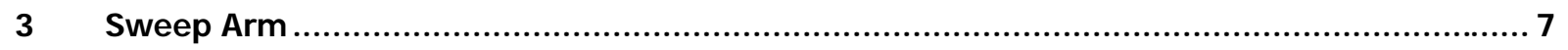

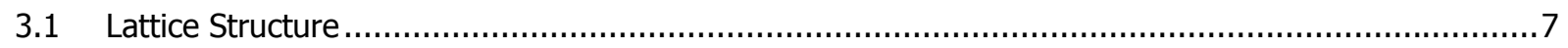

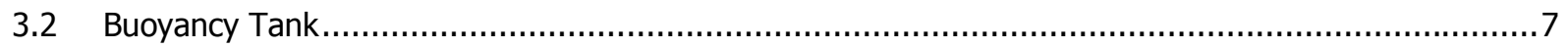

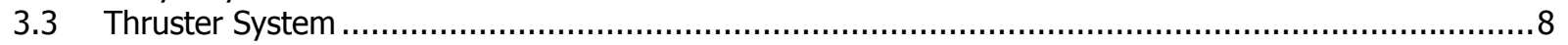

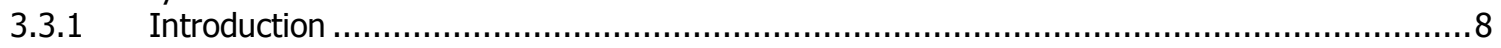

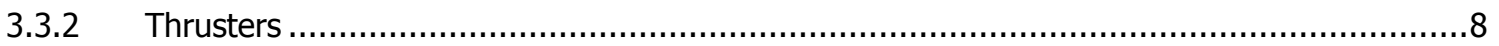

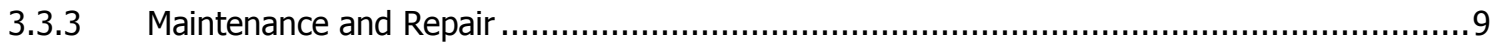

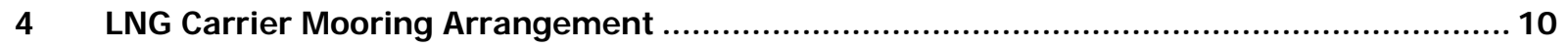

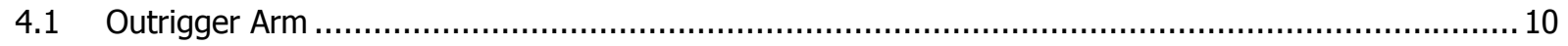

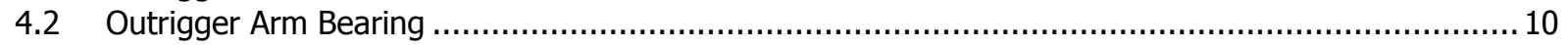

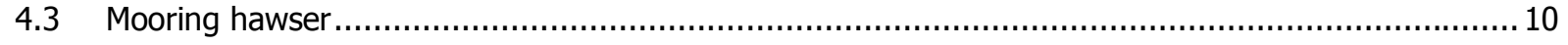

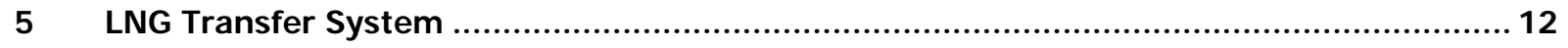

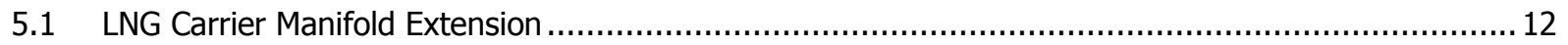

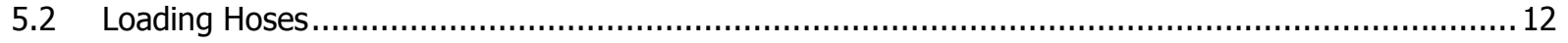

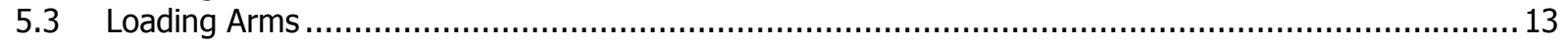

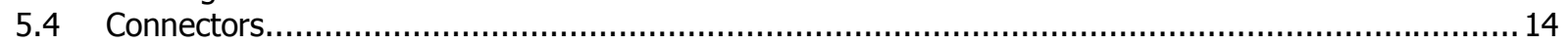

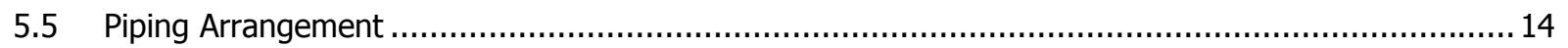

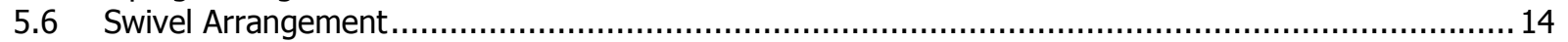

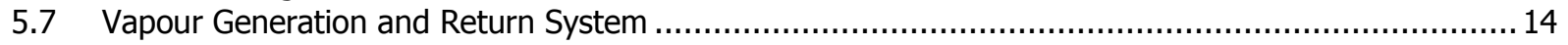

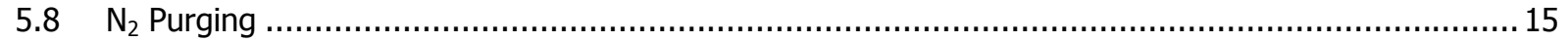

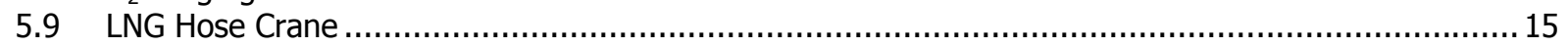

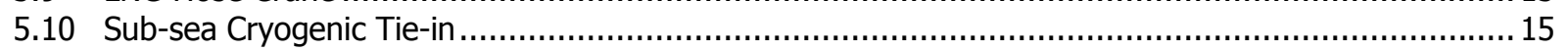

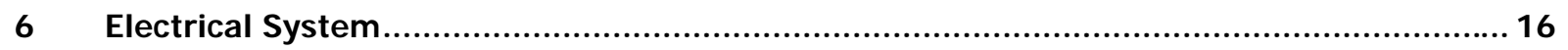

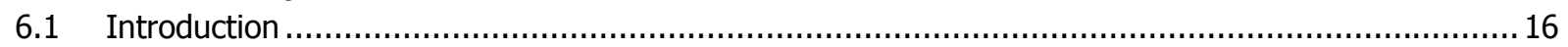

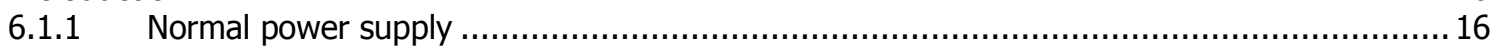

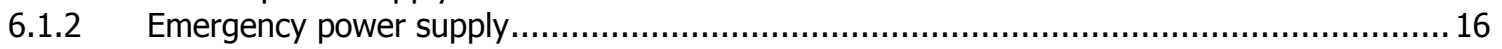

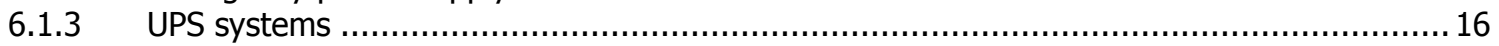

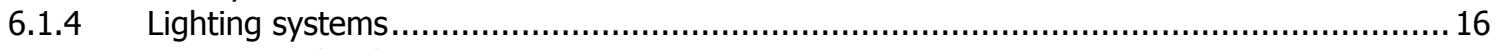

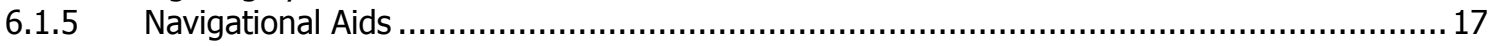

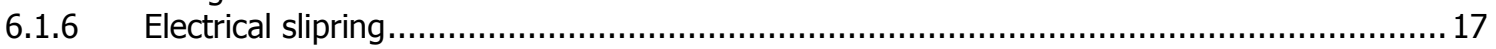

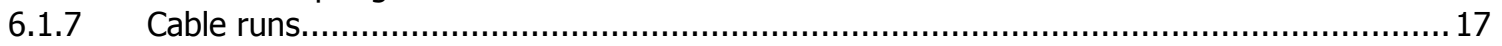

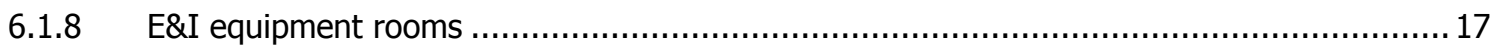

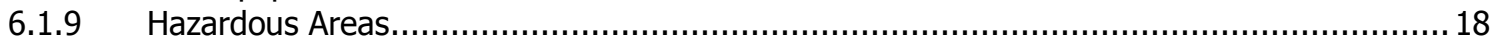

7 Control, Automation and Safeguarding Systems................................................... 19

8 Reference Documents............................................................................................... 20 


\section{Introduction}

The Big Sweep is a facility for offloading LNG from LNG Carriers (LNGC's). The Big Sweep is a Single Point Mooring system that comprises a tower structure that is piled to the sea bed and a weathervaning buoyant arm. The weathervaning buoyant arm supports an LNG transfer system and a mooring arrangement for LNG Carriers. The concept of the Big Sweep can be applied in a variety of arrangements, e.g. in shallow water or deep water, stand alone or installed in tandem with a floating LNG production facility.

This document describes the Big Sweep in an arrangement as it was specifically developed for an LNG receiving terminal in the Gulf of Mexico. The terminal comprises the Big Sweep offloading facility, a subsea cryogenic pipe line to a process facility and storage caverns. The terminal is developed in the context of a study awarded by the US Department of Energy to Conversion Gas Imports (CGI). CGI has subcontracted the development of the offloading facility to Bluewater.

The offloading facility is designed to offload the larger size LNG Carriers $\left(>125.000 \mathrm{~m}^{3}\right)$. Offloading of the cryogenic LNG will take place from the midship manifold of the LNGC. The LNG is transferred via the Big Sweep, through an insulated subsea pipeline to a process facility. At the process facility, located approximately one nautical mile from the Big Sweep, the LNG will be converted to gas by vaporisation. The conversion takes place via a so-called Bishop Process Heat Exchanger (BPE), a special kind of pipe-in-pipe heat exchanger. The BPE uses seawater as heating medium. Once in the gaseous phase, the gas can be stored in salt caverns below the seabed or sent into the US gas grid immediately.

The system is designed for a specific location in the Gulf of Mexico, Vermillion block 179, approximately 75 kilometres offshore Louisiana where the water depth is $30 \mathrm{~m}$. Further details on the location and the environmental conditions are specified in the Basis of Design [1].

This document gives a description of the Big Sweep LNG offloading facility. For operational aspects reference is made to the Operational Philosophy [2].

Figure 1 and drawings [3] and [4] give an overview of the total terminal lay-out; drawings [5], [6] and [7] give a general arrangement of the Big Sweep. 


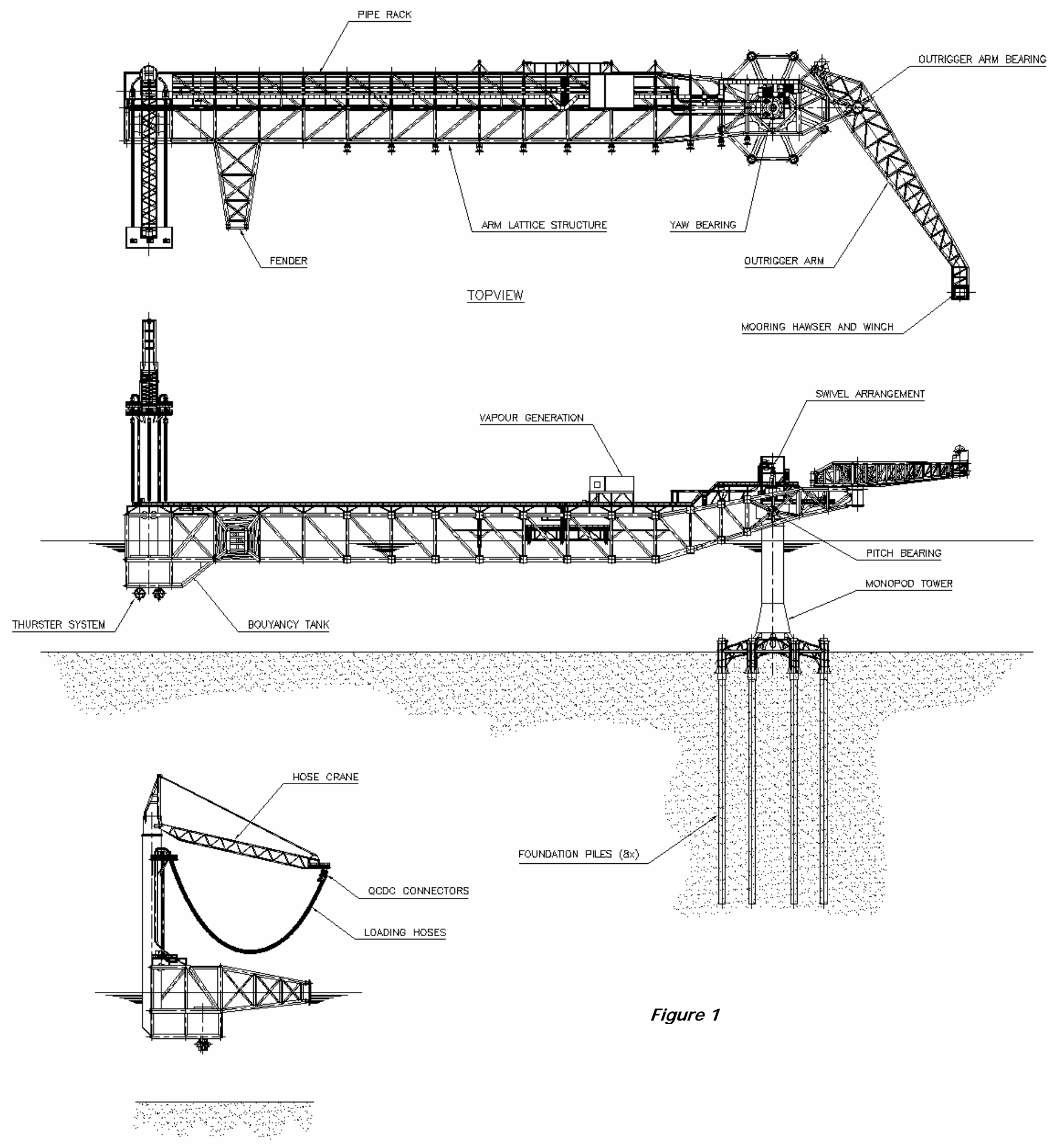




\section{Tower}

\subsection{Monopod}

The single column tower, also called monopod, is the geostatic part of the Big Sweep and is piled to the seabed. The centreline of the column forms the weathervaning axis of the system. The column has a diameter of approximately $5-\mathrm{m}$ and the pitch circle diameter of the piles at the base is approximately $30 \mathrm{~m}$. The LNG flow lines enter the column through penetrations at the base and rise through the column to the swivel stack. The base of the swivel stack is located at approximately $9 \mathrm{~m}$ above the waterline.

At approximately 2-m above the waterline a bolted flanged connection is provided that enables the installation of the lower part of the tower separate from the upper part and the sweep arm.

The column extends up to the yaw bearing at 11-m above the waterline

\subsection{Yaw Bearing Assembly}

The yaw bearing assembly provides a pivoting joint in the horizontal plane and thereby enables weathervaning of the system. The bearing transfers the loads from the sweep arm to the tower column. The bearing is a 3-race roller bearing and enables unlimited rotation.

The bearing is located above water, approximately $12-\mathrm{m}$ above the mean waterline. It is freely accessible for maintenance and inspection. The bearing can be provided with an automatic grease system.

\subsection{Pitch Bearing Assembly}

The pitch bearing provides a pivoting joint in the vertical plane. It allows the sweep arm to follow wave motions and tidal differences. Together with the yaw bearing it makes a universal joint. The pitch bearing assembly consists of two journals supported by plain bearings diametrically positioned about the yaw bearing. The pitch angles in operation are expected to be within $+/-2.5^{\circ}$. The pitch angle clearance for the assembly exceeds $+/-5^{\circ}$.

The journals are steel running against synthetic or self lubricating bronze bearing bushes.

\subsection{Foundation Piles}

The Big Sweep system will be piled to the seabed. Conventional piles will be used with grouted pile to sleeve connection. The diameter of the base, number and diameter of piles are selected to achieve efficient design. A preliminary assessment based on a typical GoM soil profile has resulted in a requirement for $72^{\prime \prime}$ piles with a penetration depth of $63 \mathrm{~m}$. 


\section{Sweep Arm}

\subsection{Lattice Structure}

The sweep arm is a semi-buoyant rigid lattice structure built from tubular members. On one end it is supported by the tower and on the other end by the buoyancy tank.

The arm supports the vaporizer module, pipe rack and the hawser outrigger on the tower end and the hose crane column on the other end. Furthermore the arm is fitted with fenders along the length of the arm and a main fender near the hose crane.

The sweep arm has the following main dimensions:

Cross-section $\quad 18-\mathrm{m}$ wide by $12-\mathrm{m}$ high, 3 upper and 3 lower longitudinal members

Overall length $\quad 200-\mathrm{m}$

System length $\quad 170-\mathrm{m}$ between yaw axis and hose crane column centreline

The tubular members $\mathrm{D} / \mathrm{t}$ ratios are within normal industry practice (i.e. $\mathrm{D} / \mathrm{t}<120$ ) and joints will be designed as simple joints, i.e. no overlapping joints. The material used is common offshore construction steel (typically X52).

The upper plane of the lattice structure is positioned well above the waterline, i.e. the centreline of the upper longitudinal is 7-m above the waterline. As a result the upper plane will only get wetted in storm conditions. The lower plane is situated 5-m below the waterline, resulting in that the members remain submerged in all but extreme storm conditions (Hurricane).

To avoid wave slamming and buoyancy variations as much as possible no (nearly) horizontal members are located near the waterline.

All tubular members are buoyant. The longitudinal members could be designed as one long buoyancy compartment which enables access or divided in multiple watertight compartments.

\subsection{Buoyancy Tank}

The buoyancy tank at the hose crane end provides the required buoyancy and ballast to trim the sweep arm in a horizontal position. The buoyancy tank also houses the thrusters that drive the sweep arm and the seawater pumps that feed the vaporizer with warmant.

The buoyancy tank is $20 \mathrm{~m}$ long, $18 \mathrm{~m}$ wide and $6 \mathrm{~m}$ high. The top of the tank is $5 \mathrm{~m}$ below the waterline.

The buoyancy tank is subdivided in 7 compartments, 2 ballast tanks, 2 thruster rooms, 2 equipment rooms and the crane column. The crane column pierces the waterline.

In normal operations the ballast tanks are filled to such a level that the arm is horizontal. The tanks will not be ballasted or de-ballasted to change draft to suit different tanker manifold positions. Deballasting will only be done when required for inspection or maintenance, e.g. to bring the thruster access hatches above the waterline.

The division in compartments allows the Big Sweep to sustain damage to the buoyancy tank without progressive effects. The arm remains floating with two damaged compartments being flooded.

Access to the buoyancy tank is through the crane column. The compartments are equipped with mechanical ventilation. 


\subsection{Thruster System}

\subsubsection{Introduction}

The sweep arm is provided with a thruster system located at the hose end. The thruster system actively controls the heading of the arm with the following purposes:

- Manoeuvre the arm in a safe position for tanker approach

The tanker will approach the berth while heading into the governing wind \& wave direction. The arm will be located at an angle of about 30 degrees with the tanker providing ample distance between tanker and arm.

- Bring the arm alongside the tanker once the tanker is connected to the hawser Once the connection with the hawser is made, the arm will manoeuvre into the position for offload, alongside the tanker.

- Keep the arm at a controlled distance from the tanker's side while connected Once the arm is alongside the offloading hoses will be connected and the offload starts. During the offload the arm will follow the side shell of the tanker at a controlled distance of approximately $3 \mathrm{~m}$.

- Swing the arm away from the tanker after the offload or after an emergency disconnect Once the offload is finished and the offloading hoses have been disconnected the arm will swing away from the tanker, the hawser will be disconnected and the tanker will sail away astern.

In all of the above situations the thruster system will have to counteract any wind, wave and current loads acting on the arm and, where the arm needs to be accelerated, inertia loads. In addition the thrusters have to compensate for the hawser loads acting on the outrigger (the hawser load causes the Big Sweep to move away from the tanker, pivoting about the axis at the tower).

The control system that is required to keep the arm in position alongside the tanker is similar to a conventional dynamic positioning system as used on DP ships with that difference that the position reference system will be related to the position of the tanker instead of a geo-stationary reference system.

\subsubsection{Thrusters}

The system is equipped with two thrusters each able to $100 \%$ of the maximum required thrust. The two thrusters are located in separate thruster rooms. Each thruster room is equipped with the required utility systems for one thruster. The thrusters and auxiliary equipment are therefore fully redundant. Each thruster is rated for approximately $3 \mathrm{MW}$ each.

The thruster nozzles have a fixed position, directed perpendicular to the arm, each pointing in an opposite direction. Changing the thrust direction will either be done by changing the propeller rotation direction in case of a fixed pitch propeller or by changing the propeller pitch in case of a variable pitch direction.

In operation, with the tanker connected, the thruster system will have to compensate for the hawser load acting on the outrigger. Because this load is always working in the same direction and because this load is the governing contributor to the required thrust, the requested thrust will be mainly towards one direction. By variations of the thrust around the mean level, the system will follow the tanker movements.

A selection for thruster type (variable or fixed pitch) and drive (speed control or constant rpm) will have to be made in a further design stage. 


\subsubsection{Maintenance and Repair}

The thrusters are located in two thruster rooms in the buoyancy tank at the loading end. The hull is accessible for normal maintenance via the hose crane column.

The top of the buoyancy tank is provided with bolted thruster hatches. In case the e-motor or the thruster unit needs to be replaced or removed for repair these hatches can be brought above the waterline by de-ballasting the buoyancy tank (the buoyancy tank is provided with two ballast tanks). The thruster can then be accessed from the top to remove the e-motor. If a whole thruster unit needs to be replaced the thruster room will be flooded first. 


\section{LNG Carrier Mooring Arrangement}

The LNG carrier will be moored to the Big Sweep with a bow hawser arrangement. At the carrier side the hawser will be secured in a stopper arrangement. At the Big Sweep end the hawser is fixed to an outrigger arm. The hawser length is adjustable.

\subsection{Outrigger Arm}

The outrigger arm is a lattice structure that supports the mooring hawser and positions it in front of the bow of the tanker. The outrigger is connected to the sweep arm by means of a vertical hinge situated on the sweep arm near the tower column.

The outrigger arm length is determined such to position the hawser connection point in front of the bow while maintaining sufficient clearance between the Big Sweep arm and the LNG carrier in normal operational conditions.

The vertical hinge is provided to allow the arm to swing out of the way if the LNG carrier overshoots its berthing position. The outrigger fixed in position with a safe release device. The device will break at a when a collision with a tanker occurs. Note that a tanker collision will cause a load in the opposite direction than the normal mooring load.

Further the outrigger arm is provided with a winch arrangement to adjust hawser length to accommodate different tanker sizes. The winch is sized for the mooring loads with the exception of the winch drive system, which is sized to reel in/out the hawser when there is no tanker connected.

The outrigger arm will be designed for a mooring load of $250 \mathrm{t}$.

\subsection{Outrigger Arm Bearing}

The bearing at the vertical hinge is not subjected to rotations under normal operating conditions. It will only require rotating in the exceptional case of a tanker collision. The bearing will be of a friction bearing type.

\subsection{Mooring hawser}

The (floating type) mooring hawser provides the connection between the tanker and the end of the outrigger arm. The mooring hawser length will be adjustable with approximately $45 \mathrm{~m}$ between $60 \mathrm{~m}$ and $105 \mathrm{~m}$ to allow a range of carriers with different manifold to bow forward length unloading at the terminal.

The tanker end of the hawser will be outfitted with end gear as specified by OCIMF for SPM Mooring of Oil tankers.

The outrigger end of the hawser will be spooled on a remotely operated mooring winch. ESD disconnect will be by paying out the complete hawser until the end attachment unlatches from the winch.

In between offloads the rope part of the hawser can be spooled on the winch up to the chafe chain. The chafe chain arrangement remains suspended outboard. 


\section{Mooring system particulars}

\begin{tabular}{|l|l|}
\hline Hawser & effective length, minimum $60 \mathrm{~m}$, extension range $45 \mathrm{~m}$ \\
\hline & material polyester \\
\hline Chafe chain tanker side & $76 \mathrm{~mm}$, chafe chain $\mathrm{B}$, length $9 \mathrm{~m}$ \\
\hline Winch & Winding force $15 \mathrm{t}$, speed $5 \mathrm{~m} / \mathrm{min}$ \\
\hline & Tacho system, brake to hold the mooring load \\
\hline
\end{tabular}




\section{LNG Transfer System}

The battery limits for the LNG transfer system of the Big Sweep are at the LNG carrier existing manifold and at the subsea pipeline interface point at the base of the tower. The LNG transfer system consists of a midship manifold extension, transfer hoses with special connectors suspended from a hose crane and a piping system on the Big Sweep including a fluid swivel.

\subsection{LNG Carrier Manifold Extension}

LNG carriers are provided with a midship manifold for loading and unloading LNG. Loading arms connect to this manifold for in-shore operation. For an offshore transfer with hoses an extension spools need to be added which matches the hose connector arrangement. Alternatively a dedicated manifold can be located next to the standard midship manifold.

The midship manifolds are standardised for LNG carriers and comply with the OCIMF/SIGTTO recommendations. The standard arrangement for the larger LNG carriers comprises typically $2 \times 16^{\prime \prime}$ LNG lines forward and $2 \times 16^{\prime \prime}$ LNG lines aft of a central 16" vapour return line with all flanges typically 3.5 meters inboard.

The LNG carrier will discharge through two $20^{\prime \prime}$ in line spools connected to $16^{\prime \prime}$ manifold connections. The spools are equipped with the matting arrangement for the offshore hose connection system.

Just downstream of the manifold flange the flow line diameter increases to 20 " to minimize the pressure drop.

The vapour return line will have a similar spool with offshore connection system as for the liquid lines.

A concept design is developed for the manifold extension spools. The arrangement does not impede the normal use of the existing manifold. The extension spools have to be fabricated for each carrier visiting the terminal. The spools will be carried onboard and be fitted to the manifold and leak tested before arrival at the terminal.

\subsection{Loading Hoses}

Flexible hoses will be used between the LNG carrier and the Big Sweep system. The cryogenic flexibles are a new development and not yet operational in the diameter necessary for large volume LNG transfer. Qualification test programs are progressing and type approval certification is expected in the near future. At this moment three companies are considered to be able to provide a flexible hose of the required dimensions. These companies are Technip, Dantec and Senior Flexonics.

For the development of the configuration typical hose properties are used of the hose developed by Technip. The Technip hose basically consists of a large number of $\Omega$ shaped bellows forming a flexible hose length. This hose design is expected to give the more conservative design boundary conditions, i.e. the hose is more stiff than the Dantec hose design and similar in stiffness as the Senior Flexonics design.

Alternatively, a design based on loading arms with hard piping arrangement and swivel joints can be considered, see next section. 


\begin{tabular}{|c|c|c|}
\hline \multicolumn{3}{|l|}{ Design Properties Technip LNG Flexible Hose } \\
\hline Parameter & Value & Unit \\
\hline Internal diameter & 500 & $\mathrm{Mm}$ \\
\hline External diameter & 880 & $\mathrm{Mm}$ \\
\hline Mass empty in air & $*)$ & $\mathrm{kg} / \mathrm{m}$ \\
\hline Mass full of LNG in air & $*)$ & $\mathrm{kg} / \mathrm{m}$ \\
\hline Bending stiffness at $-163^{\circ} \mathrm{C}$ & $*)$ & $\mathrm{kN} \cdot \mathrm{m} 2$ \\
\hline Torsional stiffness at $-163^{\circ} \mathrm{C}$ & $*)$ & $\mathrm{kN} . \mathrm{m} 2 / \mathrm{rad}$ \\
\hline Axial stiffness at $-163^{\circ} \mathrm{C}$ & $*)$ & $\mathrm{kN}$ \\
\hline Minimum static bending radius & $*)$ & M \\
\hline Minimum dynamic bending radius & $*)$ & $M$ \\
\hline Maximum torsional deflexion & $*)$ & $\% / \mathrm{m}$ \\
\hline Pressure drop for $100 \mathrm{~m}$ of pipeline & $*)$ & \\
\hline at $2500 \mathrm{~m} 3 / \mathrm{h}$ & $*)$ & Bar \\
\hline at $5000 \mathrm{~m} 3 / \mathrm{h}$ & $*)$ & Bar \\
\hline at $7500 \mathrm{~m} 3 / \mathrm{h}$ & $*)$ & Bar \\
\hline at $10,000 \mathrm{~m} 3 / \mathrm{h}$ & $*)$ & Bar \\
\hline Coefficient of thermal exchange (per meter of pipeline) & *) & $\mathrm{W} / \mathrm{m} \cdot{ }^{\circ} \mathrm{K}$ \\
\hline
\end{tabular}

\subsection{Loading Arms}

Loading arms are normally used on jetties, which are located in sheltered areas. The offshore use of standard jetty loading arm is not feasible because of the more dynamic behaviour of the LNG carrier. Modified loading arm designs with increased structural ruggedness exist but as these loading arms are counter weighted Pantograph constructions they are not particular suitable for offshore dynamic load-motions. The mechanical complexity of loading arms and large number of swivels are a burden for offshore maintenance and high terminal availability.

The excursion envelope of loading arms is limited and does not cater for the full motion envelope. The excursion capacity and dynamic loads would need careful consideration for all operational and emergency scenarios before accepting loading arms as feasible in an offshore environment.

Loading arms will not be considered for the offshore mooring terminal at this stage as flexibles are the preferred solution. 


\subsection{Connectors}

Quick Connect/Disconnect Couplings (QCDC) will be used for the connection of the LNG lines to the LNG carrier midship manifold. These couplings are similar to the couplings used in land based loading arm arrangements and comprise a remotely controlled latch/lock mechanism and a double valve arrangement with hydraulic actuator and emergency release coupling. The couplings are Type Approved. Every line has a separate connector.

Common industry practice for LNG carriers moored to jetty is to connect the QCDC coupling of the loading arm at ambient temperature and cool the couplings until LNG can be introduced and cargo transfer can commence.

\subsection{Piping Arrangement}

Two independent LNG flow paths with $50 \%$ capacity will be maintained over the whole system. During offloading both lines run in parallel flow and in between offloading a crossover at the arm end allows circulation of LNG.

LNG piping runs from the hose support crane at the receiving end over the Big Sweep arm to the tower column mounted swivel. The sweep arm that supports the piping makes small angular pitch motions relative to the tower (see section 2.3). These angular motions need to be catered for either by pipe flexibility, in-line LNG swivels or jumper hoses. The preferred solution is to accommodate the relatively small pitch angles with the flexibility of the piping arrangement to minimise the number of mechanical components in the LNG line. The conceptual piping analysis studied the different arrangements and indicates that rigid piping is feasible although resulting in high piping loads. Careful supporting design and expansion loops should limit the stresses to acceptable levels. An alternative arrangement with jumper hoses or swivels mitigate high pipeline stresses effectively, further evaluation is necessary to conclude on the optimum arrangement.

\subsection{Swivel Arrangement}

A swivel arrangement at the top of the monopod allows LNG transfer from the weathervaning arm to the geostatic section of the lines.

The swivel stack consists of a dual path LNG swivel, an electrical power slip-ring and a swivel for electrical instrument signals and optical signals. Utilities can be added if this should be required.

The vapour return generation unit is located on the arm and does not need a swivel path. For LNG circulation over the arm during the intervals between off loading the two swivel paths are used in counter flow direction while during offloading both flow path run parallel flow.

The swivel arrangement is located above the area exposed to any green water or splash. The swivel arrangement will be rigidly supported on the geostatic tower column.

Depending on the solution selected for the LNG hose system connecting to the LNG carrier mid-ship manifold, in-line swivels could be required to limit hose twist and torque.

\subsection{Vapour Generation and Return System}

While offloading LNG an equal volume of gas needs to be delivered to the carrier to replace the offloaded LNG volume. Therefore a LNG slipstream will be drawn from the main flow and vaporised via a heat exchanger with seawater as a heating medium (warmant). Seawater is preferred as heating medium as the risk of freezing of tubes with air-cooling is seen as an operational risk. The vapour generation system will be located on the sweep arm. Vapour generation in the vicinity of the LNG Carrier gives an economic overall arrangement. 
The vaporiser will require a return vapour separator and a LNG return pump. Utilities required are power, nitrogen, relief valve/vent connections, LNG drain connections. The vaporiser delivers vapour for the LNG carrier as well as vapour for drain/purge purposes.

The seawater (warmant) will be delivered by the seawater lift pumps. These centrifugal pumps will be placed in an equipment room adjacent to the ballast spaces. This ensures a positive suction head as these ballast vessels are under the waterline. Seawater lift pump suction piping is preliminary sized as $8^{\prime \prime}$ and discharge piping 6". The seawater lift pumps will also be used as ballast pumps and will be equipped an eductor for bilge water removal.

The seawater will require chlorination and biocide shock dosing. Intention is to use the supply of chemicals via tote tanks and dosing pumps. No chlorination unit is foreseen.

\section{$5.8 \quad \mathrm{~N}_{2}$ Purging}

In an emergency situation the piping of the Big Sweep requires to be purged with $\mathrm{N}_{2}$. Partial inerting may be required for inspection, maintenance or repair.

The total volume of the piping system is approx. $100 \mathrm{~m}^{3}$. As this is a relatively small volume and because the expected frequency of $\mathrm{N}_{2}$ purging is small a $\mathrm{N}_{2}$ storage system seems a logical choice and no $\mathrm{N}_{2}$ generation is foreseen.

A $\mathrm{N}_{2}$ pressure vessel (approx. $5 \mathrm{~m}^{3}$ at 200 bar) or a liquid $\mathrm{N}_{2}$ storage with vaporiser skid will be required for inerting the entire volume of the Big Sweep piping. Dividing the piping arrangement in sections can limit $\mathrm{N}_{2}$ usage, although this will not influence the required $\mathrm{N}_{2}$ skid capacity.

\subsection{LNG Hose Crane}

LNG will be transferred between the carrier and the Big Sweep with flexible hoses. On one end the hoses are suspended from the hose crane column and the other end either hung-off from the crane boom tip or from the mid-ship manifold extension when a LNG Carrier is connected. Between the hang-off points the hoses will hang in a catenary.

A hose catenary envelope is determined encompassing the operational envelope, the emergency envelope and stowing position.

The boom tip will carry a winch system, which together with the winch mounted on the connector arrangement facilitates pull-in and disconnect handling of the connector. Each transfer hose has a dedicated winch arrangement. A crane slewing mechanism will control the crane boom heading to maintain the boom aligned towards the manifold within an operating window. The crane operating includes normal operation and emergency condition.

\subsection{Sub-sea Cryogenic Tie-in}

The cryogenic pipeline materials and insulation system at the Big Sweep sub-sea part will be preferably of the same design as the sub-sea pipeline. The tie-in arrangement of the sub-sea cryogenic pipelines to the Big Sweep is an interface issue where the sub-sea pipeline design will drive the arrangement layout. Detailed engineering considering installation will be conducted in a later phase when the pipeline design has been established. 


\section{Electrical System}

\subsection{Introduction}

The SPM electrical power system uses power generated on the main platform and transported to the loading facility via an umbilical cable. Thereby the requirement for generators, drivers and utility systems is omitted for a lean concept suitable for unmanned operation. Availability of the electrical supply will be mainly dependent on the power generation equipment redundancy of the main platform.

Voltage levels and frequency and network properties will be selected similar to the main platform.

\subsubsection{Normal power supply}

The mooring facility will be supplied from the main platform electrical system via a single HV supply through the umbilical cable and electrical slipring. This will provide power for the thrusters and the LV normal distribution system via HV/LV transformer. Thrusters will be sized approximately $3 \mathrm{MW}$ (2*100\%) and operate under VSD control.

\subsubsection{Emergency power supply}

A LV emergency supply will be installed in parallel from the emergency distribution system on the main platform through the umbilical and slipring. Step-up/down transformers may be required for optimum umbilical cable sizing. The emergency supply will power the consumers required to operate under emergency conditions i.e.

- UPS systems for Navigation lights, communication systems and control ESD and Fire and gas systems

- Emergency and escape lighting

- $\quad$ Bilge pumps

- $\quad$ Fire extinguishing system

- Emergency power to hose disconnect system

\subsubsection{UPS systems}

UPS systems will be provided for:

- $\quad$ ESD, fire and gas and control system

- $\quad$ Radio communications

- $\quad$ Aids to navigation systems

Each system will be sized for individual service duration requirements in accordance with the main platform electrical philosophy. The capacity of the UPS system for aids to navigation will be minimum 96 hours in accordance with class requirements and regulations.

\subsubsection{Lighting systems}

Lighting systems will be provided for normal, emergency and escape lighting. Normal lighting will be installed in all accessible areas of the facility to provide acceptable lighting levels form normal power supply. Emergency lighting will be installed for lighting at control areas for emergency operation and at equipment required for emergency operation. Escape lighting is required for minimum lighting levels at escape routes. Emergency and escape lighting are supplied from the emergency power distribution board. Escape lighting fixtures will be provided with built in batteries for back up under blackout conditions. 


\subsubsection{Navigational Aids}

Class A navigational aids will be provided as required by the US Coast Guard (USCG). These will comprise radar reflector, marine navigation light (5 NM), foghorn (2 NM) for approval by USCG.

The installation of aeronautical obstruction lights will be considered.

\subsubsection{Electrical slipring}

The interface between the platform and the loading arm will be through an umbilical cable, comprising the following:

- $\quad$ HV power cable

- $\quad$ LV emergency power cable

- Multi-pair cable for hardwired safety related signals

- Optical fibre for data communication, CCTV, PA and telephone systems.

Electrical power and signals will be transferred to systems on the weathervaning loading arm via a hollow bore slipring assembly around the two path product swivel. All except HV power could alternatively be transferred via a wind-on/off device. The optical signals will be routed via a cable wind-on/off device. This device will allow for a limited number of full 360 degree rotations of the loading arm in either direction. The environmental conditions are such that a full rotation of the unit is not likely to occur frequently. If required the unit may be reset to its nominal start position between two loading operations by rotation of the arm by thruster power.

\subsubsection{Cable runs}

Cable runs on the loading arm will be protected from green water impact. Either cables will be installed in cable trays on an elevated pipe rack or shipbuilder construction practice will be followed and cables will be routed in protective cable conduits.

Special cable support construction will be provided at the location where the loading arm is hinged on the swivel tower, allowing flexibility of the cables in the vertical plane. It is intended to install standard cables and construct a flexible cable support that will spread the relative movement over a longer distance.

\subsubsection{E\&l equipment rooms}

A container type equipment module will be installed, providing a conditioned environment for electrical and control equipment. The unit will be divided in separate rooms for electrical and control equipment, with a common ventilation system. Adequate ventilation with gas detection will be installed for classification of the rooms as non-hazardous areas. UPS batteries will be installed in a separate compartment with extract ventilation. 
Equipment will comprise:

- HV switchboard

- Thruster VSDs

- HV/LV transformer

- LV switchboards and distribution panels

- UPS switchgear and rectifiers

- Control system cabinets

- $\quad$ Shutdown and F\&G system cabinet

- Communication systems

- Operator and engineering workstation

- Documentation book shelve

- Office desk

A fire extinguishing system will be installed for automatic release.

\subsubsection{Hazardous Areas}

Classification of hazardous areas will be in accordance with API RP 500/505.

The turntable/turret at the mooring tower, the process and utility area, the pipe rack and loading manifold area will be designed as open and naturally ventilated areas. Rooms containing electrical control equipment will be provided with adequate ventilation for classification as safe areas.

Electrical equipment will be selected suitable for the hazardous areas in which they are installed, however all electrical equipment installed in open areas on the SPM will be suitable for installation in hazardous area classed zone 2 or class 1 division 2 as a minimum. Protection techniques will be selected in accordance with API RP 14F.

Ship-SPM interface will be Ex-ia as per SIGTTO recommendation. 


\section{Control, Automation and Safeguarding Systems}

The loading terminal is intended to be an unmanned facility, with remote operation from the central control room (CCR) on the main platform. A local control system will be installed, which will relay process and equipment data and diagnostics to the main platform for incorporation in the main control system and operation from a common Human Machine Interface. These controls, completed with integral CCTV, and communication systems will provide an operator interface suitable for reliable remote operation.

A description of the control, automation and safeguarding systems is given in the Operational Philosophy [2]. 


\section{Reference Documents}

Ref Document number

[1] CGI-G-100-RP-0001

[2] CGI-G-100-PH-0002

[3] CGI-G-100-DR-0103

[4] CGI-G-100-DR-0104

[5] CGI-G-100-DR-0105

[6] CGI-G-100-DR-0106

[7] CGI-G-100-DR-0107
Rev Title

A Basis of Design

A Operational Philosophy

A Vermillion LNG Terminal, Field lay-out

A Vermillion LNG Terminal, General Arrangement of Mooring Terminal

A Big Sweep General Arrangement, Front View

A Big Sweep General Arrangement, Top View

A Big Sweep General Arrangement, View on Hose Crane End 


\section{Revision Status Sheet}

Rev. Date

A

19. Nov.2004
Description

Initial Issue
Initiator

BS

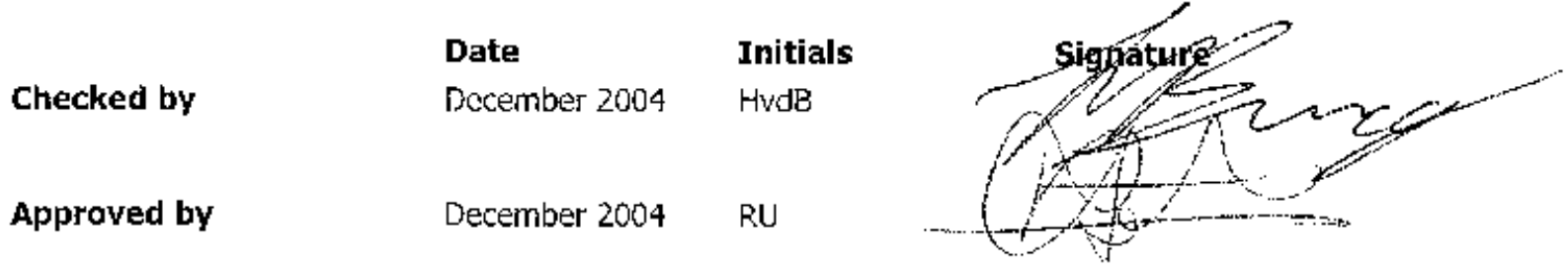

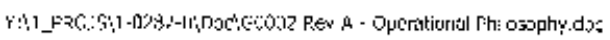




\section{Table of Contents}

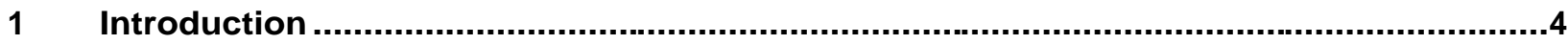

$2 \quad$ Marine Operations Philosophy

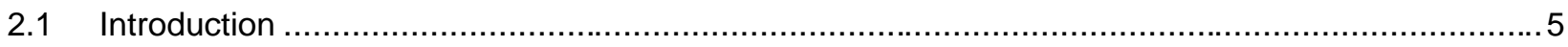

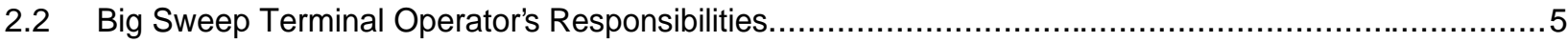

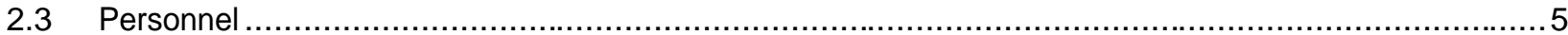

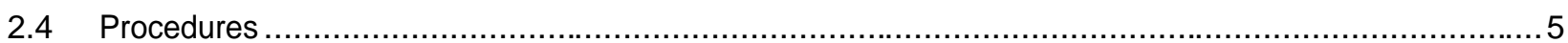

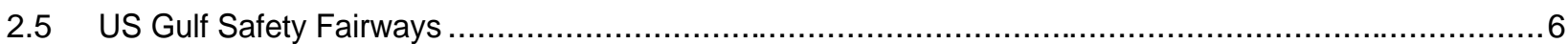

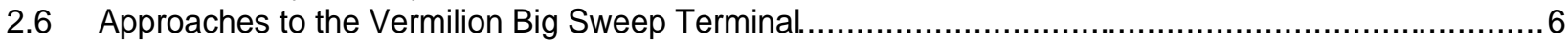

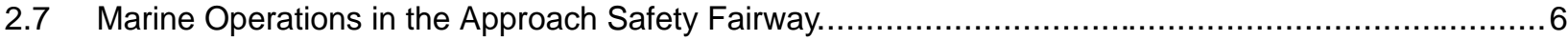

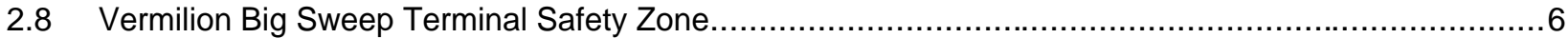

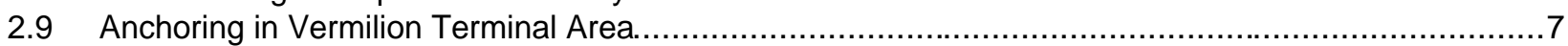

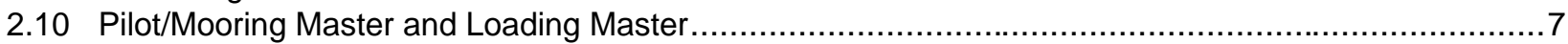

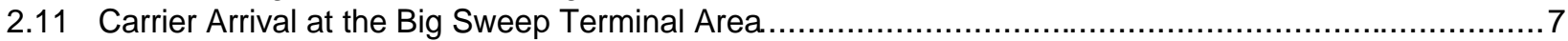

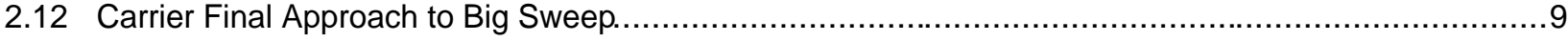

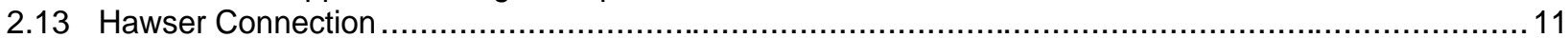

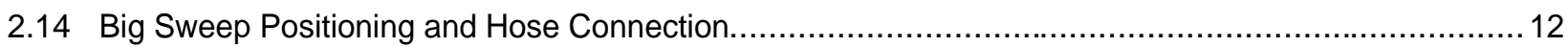

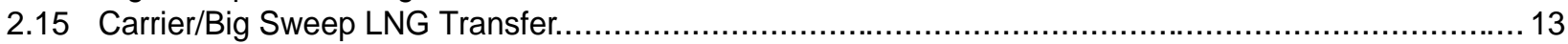

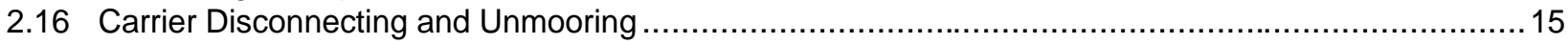

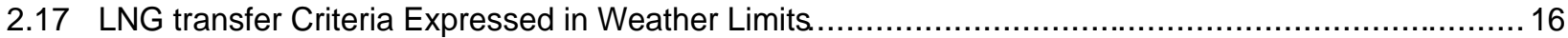

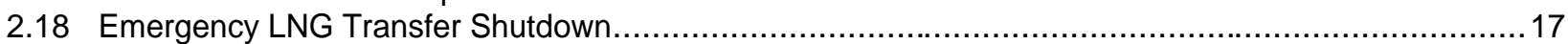

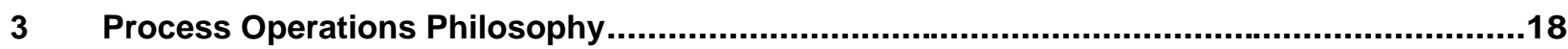

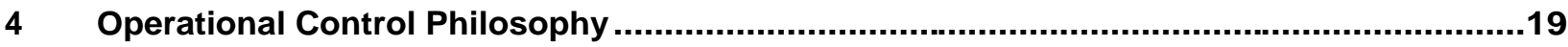

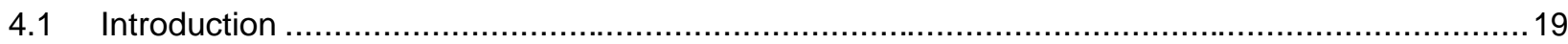

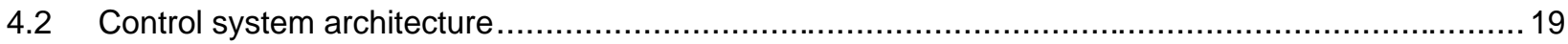

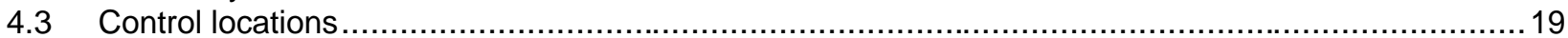

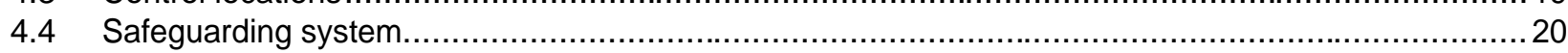

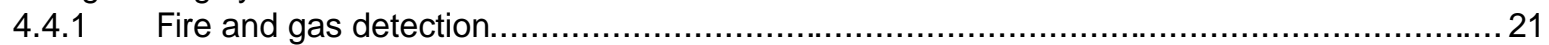

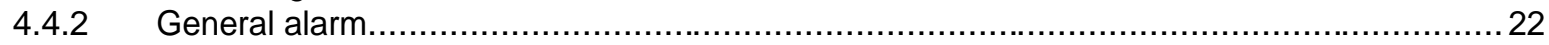

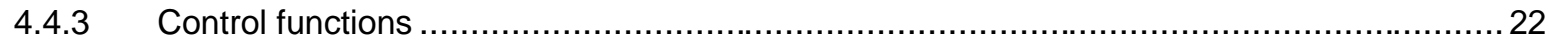

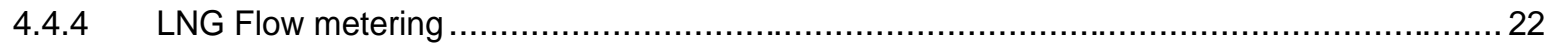

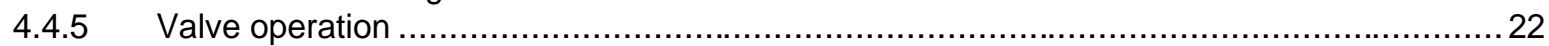

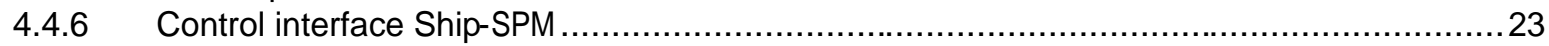

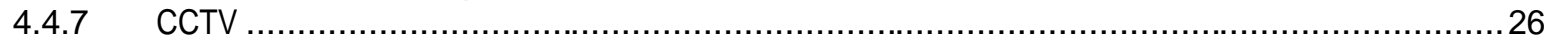

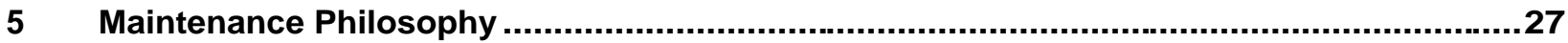




\section{Introduction}

The Big Sweep is a facility for offloading LNG from LNG Carriers (LNGCs). Offloading will take place from the midship manifold of the LNGC. The LNG is transferred via the Big Sweep, through a subsea pipeline to a process platform. At the platform the LNG will be converted to gas by vaporisation. The conversion takes place via a so-called Bishop Process Heat Exchanger (BPE), a special kind of pipe-inpipe heat exchanger. The BPE uses seawater as heating medium. Once in the gaseous phase, the gas can be stored in salt caverns or sent into the US gas grid immediately.

The offloading system has 2 large bore offloading lines and a vapour return line connecting to the LNGC's mid ship manifold. Each line comprises a free hanging flexible hose, a connector with an Emergency Release System (ERS) and a Quick Connect Dis-Connect (QCDC) system. The hoses with the connector are handled with the hose crane.

The flexible hose system with connector requires the hook-up interface flanges to be presented slightly outboard of the carrier hull contour. Therefore, adapter spools have to be mounted to the LNG Carrier's manifold before the carrier moors up to the terminal. The QCDC coupling connects directly to these adapter spools.

Cargo transfer will generally follow the same principles as offloading through loading arms at a jetty mooring. Offloading and further transfer to the platform will be by means of the carrier cargo pumps. The design offloading rate is 8000 to $12000 \mathrm{~m}^{3} / \mathrm{hr}$ which will allow offloading with similar duration as for jetty moored carriers.

The Big Sweep will be designed to operate without any operators on board of the Big Sweep system. Maintenance requirements will be minimised. The overall objective is to have the system accepted by the USCG as unmanned installation. Access onto the Big Sweep for inspection and maintenance will be by means of a boat landing platform. 


\section{Marine Operations Philosophy}

\subsection{Introduction}

The LNG carrier/Big Sweep mooring configuration will be with the LNG carrier positioned alongside but clear of the Big Sweep. The mooring arrangement comprises of one mooring hawser between the bow of the LNG carrier and the Big Sweep Outrigger. The two units usually lie alongside but clear of each other with the headings into the environment. A tug will be present at all times as back-up for the LNG carrier's propulsion and steering systems and to assist in heading control of the LNG carrier. In order to ensure manageable risk levels and to ensure system availability, the Terminal Operator should:

- Take full account of industry guidelines (where applicable).

- Provide competent marine personnel.

The objective of this chapter is to explain how the Big Sweep Terminal operating organisation will perform the management of LNG carrier operations at the Big Sweep Terminal.

\subsection{Big Sweep Terminal Operator's Responsibilities}

It is assumed that the Big Sweep Terminal Operator will conduct and co-ordinate the actual mooring, LNG transfer and unmooring operations for the Big Sweep and discharging LNG carriers, including but not limited to the following:

- Develop a Port and Terminal Rules and Regulations Manual, LNG transfer procedures; establish Big Sweep Safety Zone Boundary and other related items/activities.

- Provide a Mooring Master and Loading Master to supervise and co-ordinate all LNG transfer activities. The Big Sweep Terminal Operator will be responsible to make final decisions to moor and for co-ordinating local operations of the supplied workboat and tugs.

- Develop and maintain custody transfer documentation and the Port Log.

- Schedule and vet discharge of LNG carriers.

- Provide workboat and tugs.

- Provide terminal information and custody transfer procedures to discharging LNG carriers in advance of LNG transfer.

- Co-ordinate and schedule Customs/Immigration inspections and clearances if and where applicable.

\subsection{Personnel}

The Big Sweep Terminal Operator will provide a sufficient number experienced and competent marine personnel, including a mooring master and a Loading Master boarding the LNG carrier to perform the LNG transfer operations.

\subsection{Procedures}

Before the first carrier arrives, procedures will be in place to minimise the risk of injuries to people, damage to the carrier or Big Sweep, or contact between carrier and the Big Sweep. As a minimum, these critical procedures will include:

- $\quad$ LNG carrier approach \& mooring, LNG transfer and departure.

- Standby vessel/tug/workboat control

- Emergency response. 


\subsection{US Gulf Safety Fairways}

Vessel entering US ports along the Gulf Coast use so-called shipping safety fairways and fairway anchorage areas.

These fairways and anchorage areas are established to control the erection of structures therein and to provide safe approaches through oil fields in the Gulf of Mexico to entrances to the major ports along the Gulf Coast. The fairways are 2 nautical miles wide. Fairways and fairway anchorage's are subject to modification in accordance with US Coastguard Regulations (=USCG).

\subsection{Approaches to the Vermilion Big Sweep Terminal}

The nearest safety fairway running along the Vermilion Big Sweep Terminal is the existing Calcasieu Pass Safety Fairway to the West. The shortest distance from this safety fairway to the terminal is 37 nautical miles (68.5 km or 75,000 yards). Along this route, oil fields and associated structures are located. It is envisaged to establish a "Recommended Navigation Route" from the Calcasieu Pass Safety fairway to the Vermilion terminal through these fields in order to provide a safe overall approach corridor to the safety zone of the terminal. This will be done in close co-operation with the appropriate authorities (i.e. USCG). Refer to doc. No. BW-G-100-DG-2001-001 LNG Terminal with Platforms.

A possible route of the new Navigation Route / approach corridor is drafted up such that a minimum possible distance of one nautical mile ( $1852 \mathrm{~m}=2025 \mathrm{yards})$ is granted at either side of the corridor to any structure. In most cases, the passing distances to structures are more than 2 nautical miles.

In case of early arrival of LNG carriers or in case of any other unforeseen circumstance, the LNGcarriers may have to wait and anchor. A fairway anchorage Calcasieu Pass South Anchorage Area is already established by the USCG close to the NW of the entrance of the "new safety fairway/approach corridor".

\subsection{Marine Operations in the Approach Safety Fairway}

When the LNG carrier is about to leave the established Calcasieu Pass Safety fairway, it is envisaged that a tug will escort the LNG carrier through the 37 nautical mile distance approach corridor/new safety fairway.

A rapid and effective response by the tug is dependent on it being proximate to the carrier and the closest position of approach $(=\mathrm{CPA})$ of the LNG carrier to any structure.

The nearest structure is, most of the time, more than 2 miles off. Therefore the tug will escort but not make fast. In this mode, the tug escorts to allow higher cruising speeds of approximately 12 nautical miles per hour.

The purpose of the escort and emergency response tug is to provide emergency assistance to the carrier should a problem develop with the carrier's steering or propulsion systems. The tug will have a towing line on board, suitable for connection at the bow or stern of the carrier. The tug is also fendered to allow pushing directly on the hull of the carrier.

\subsection{Vermilion Big Sweep Terminal Safety Zone}

A dedicated Vermilion Terminal Safety Zone will be established in consultation with the appropriate authorities. The Safety Zone will encompass all Terminal components plus a safe zone for manoeuvring and anchoring. Marker buoys may indicate the boundaries of the zone. Normally, a zone of one nautical mile is required for manoeuvring. 


\subsection{Anchoring in Vermilion Terminal Area}

To the SE of the Vermilion Terminal, a designated 2 nautical miles radius anchorage area inside the anticipated Safety Zone will be established to provide safety and continuity of operations. All vessels are encouraged to utilise this anchorage in unforeseen circumstances but normally, such vessels are proceeding directly to moor to the Big Sweep upon arrival.

Vessels at anchor must maintain engines and propulsion machinery in readiness to clear the marine terminal area under full power on short notice.

\subsection{Pilot/Mooring Master and Loading Master}

The Pilot/Mooring Master and Loading Master fulfil key role positions in managing the entire LNG transfer. Their responsibilities will be described in the Big Sweep Port and Terminal Rules and Regulations Manual. The Terminal Operator will provide two senior experienced marine personnel to serve as Pilot/Mooring Master and Loading Master. Both individuals will board the LNG carriers approximately 5 nautical miles off as per normal deep-sea shipping practices (accommodation ladder) and remain onboard the LNG carrier during the entire mooring and LNG transfer operation.

The Pilot/Mooring Master will be pilot-qualified for handling vessels of the anticipated size of the LNG carriers. He will be experienced in shipboard operations, the manoeuvring and docking of vessels in the class anticipated and the discharge of LNG to the Big Sweep and/or loading and discharge of oil at Single Point Mooring (SPM) facilities.

The Pilot/Mooring Master will be supported by a qualified assistant, the Loading Master, to assist in mooring/unmooring and enable one or the other to maintain constant watch on the LNG carrier and in continuous communication with the Big Sweep Terminal control location.

The Mooring Master/Pilot and Loading Master will board all LNG carriers prior to the LNG carrier's approach to the Big Sweep to brief and advise the LNG carrier's captain and crew of the Big Sweep berthing requirements, the preparation of the LNG carrier to offload LNG, co-ordinate or verify mounting of offshore adapter spool receive the Big Sweep hoses, provide recommended approaches to the Big Sweep, advice on local weather conditions and currents and the effect upon both theBig Sweep and the LNG carrier, and advise the import LNG carrier into berth.

Additional duties of the pilot/mooring master and Loading Master will include:

- the handling by remote control of the Big Sweep functions,

- deployment and co-ordination of tugs and workboat,

- hooking up of the hoses to the LNG carrier manifold

- co-ordination of communications with the Big Sweep and LNG carrier from first boarding through the discharge

- transfer of appropriate documentation transferring care, custody and control of LNG.

\subsection{Carrier Arrival at the Big Sweep Terminal Area}

The Big Sweep will provide the arriving LNG carrier with details of mooring arrangements, hose connection, terminal waiting zone location, port requirements and safety regulations. The message will also request details of the LNG carrier's arrival draught, mooring arrangements, manifold sizes, bow to manifold distance, ballast quantity.

A Big Sweep Terminal Questionnaire will be sent to the LNG carrier, filled in by the Master and returned prior to arrival of the LNG carrier in the field. 
One workboat will be required on location for assistance during (un)mooring; (dis)connecting and LNG transfer of the carrier. It is envisaged two tugs should be available for controlling the LNG carrier's position throughout the approach, mooring up to the Big Sweep and departure and one tug should be available at the stern during LNG transfer.

It is envisaged that these two tugs have multimission capabilities:

- Tug capabilities with a bollard pull of $60 t$ and special fendering for pushing in open water

- Guard vessel duties/standby by vessel duties for the terminal.

- Personnel transfer.

- $\quad$ Fire fighting.

Prior to arrival of the carrier it is essential that a proper line of communication is established between the carrier, the Big Sweep, the tugboats and the workboat.

Once the carrier arrives in the field, the Big Sweep Port and Terminal Rules and Regulations Manual will be handed to the Master of the LNG carrier.

Prior to arriving at the Big Sweep it is essential that the Master and officers of the LNG carrier are made familiar with the area (including such items as structures, installations, pipelines, oil field activities and other restrictions). This will involve study of the Big Sweep Port and Terminal Rules and Regulations Manual and include any inherent limitations relevant to marine operations. The master must also have written emergency and contingency plans available. The Big Sweep Terminal Pilot/Mooring Master will advise the carrier Master. Pilotage should be compulsory.

When manoeuvring in the area, the most recent navigational chart together with the Terminal Area Plan should be available. This Field Plan is a navigational chart of the relevant offshore area. These will show all Big Sweep's installations, buoys and obstructions to surface navigation as well as sub-sea flow-lines, wellheads, anchors, chains and cables.

Communications will be established with the Big Sweep and LNG carrier in accordance with the Big Sweep Port and Terminal Rules and Regulations Manual and confirmation obtained that theBig Sweep is ready to receive the LNG carrier. If the Big Sweep has not confirmed readiness or is out of order at short notice due to an unforeseen circumstance, the LNG carrier may have to wait for further instructions on arrival in the 4 nautical mile diameter ( $=7408$ meters) waiting anchorage which is to the SE well clear of the Big Sweep. See drawing BW-G-100-DG-2001-001.

Some of the aspects to be considered are described in the Big Sweep Port and Terminal Rules and Regulations Manual sub-sections such as testing and or inspection of equipment:

\section{Onboard the Big Sweep:}

Tests and checks should be made to the:

- Portable mooring master's remote control unit.

- Thrusters \& DP equipment.

- Hawser plus its handling arrangement.

- $\quad$ LNG loading equipment including the QC/DC and ERS.

- $\quad$ Systems for emergency shutdown and emergency release (not at each loading).

- Communication equipment. 


\section{On board the LNG carrier:}

Tests and checks should be made to steering gear, main engines, communication equipment, control systems, mooring equipment, LNG pipelines, LNG manifold, fire fighting equipment. The adapter spools need to be connected to the manifold.

The Pilot/Mooring Master and Loading Master will verify that the tests and checks have been carried out on the carrier.

The tests and inspections should be carried out with assistance of checklists (including safety checklists) completed by the carrier Master.

\subsection{Carrier Final Approach to Big Sweep}

\section{Refer to Figure 1 Final Approach}

Before the final approach commences the field Pilot/Mooring Master and the Loading Master together with small equipment (a portable berthing aid unit and a portable Big Sweep control unit) and tools will board the carrier. The Mooring Master advises the carrier Master regarding the approach, manoeuvring and connecting to the Big Sweep.

Prior to the approach, the field Pilot/Mooring Master will formally brief the LNGcarrier Master and officers to ensure they are familiar with the field specific operations.

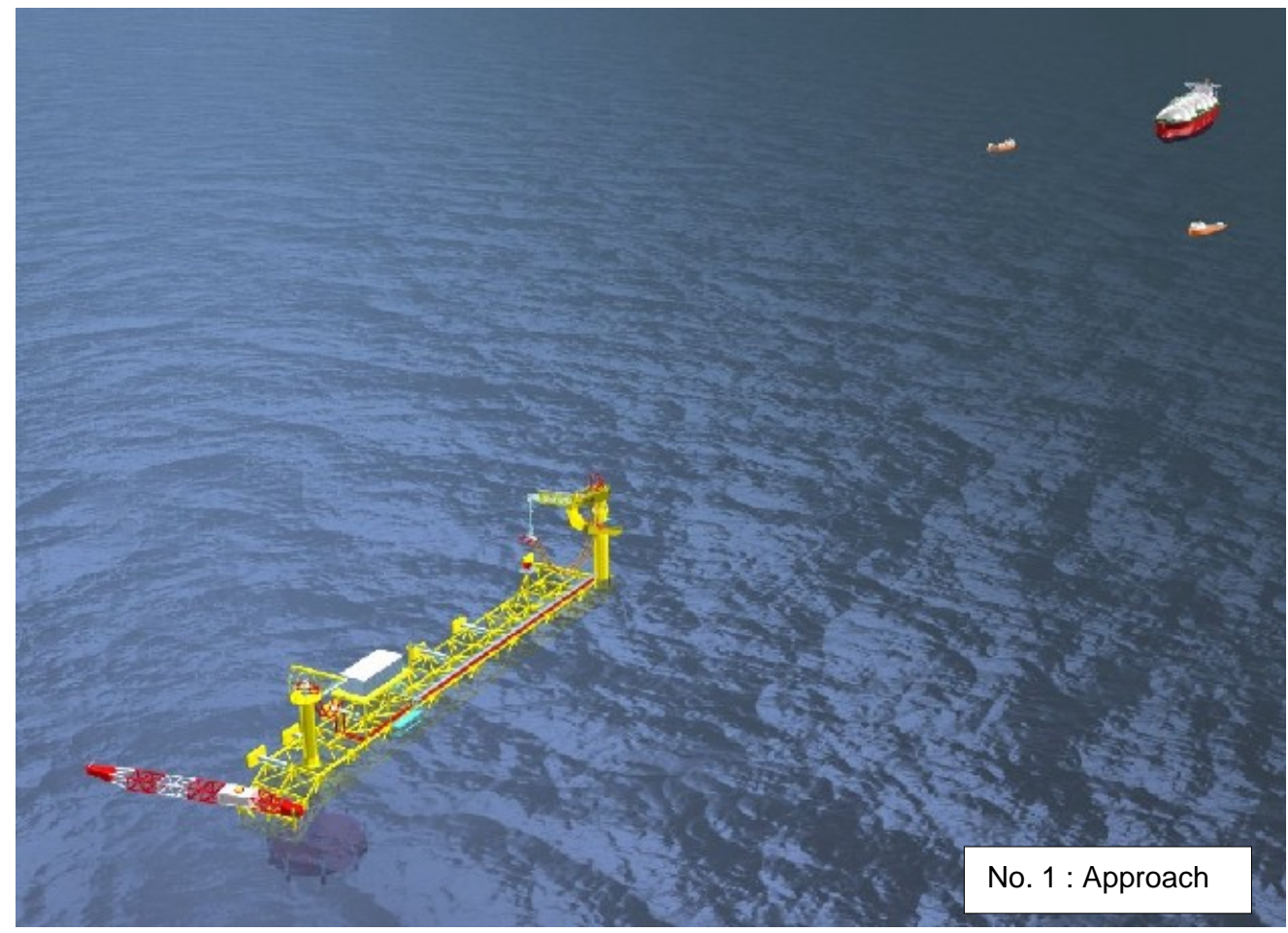

Figure 1 Final Approach 
The tugs will make fast 2-3 nautical miles from the Big Sweep.

The Loading Master will advise the carrier crew on connecting up the tugs to the carrier stern and starboard bow. These tugs will stay connected throughout the approach and mooring operation and will have sufficient bollard pull to handle the carrier safely. A bollard pull of $60 t$ each is envisaged.

The Pilot/Mooring Master continuously monitors the stand off distances from the LNG carrier bow to the Big Sweep outrigger through the information provided by the portable unit.

He will also advise the crew on the preparations for mooring up the carrier to the Big Sweep outrigger and connecting up of the tug to the carrier's starboard bow.

The initial approach heading to the Big Sweep will be determined by the resulting forces of the wind, current, sea and swell and will usually be performed on approximately the same heading as the Big Sweep heading (see figure 1). The approach will be made from the direction in which the carrier can best be handled at very slow speed and can best be held stationary in the water. The final approach starts approximately three miles from the Big Sweep or starts from the waiting anchorage. This manoeuvre will be carried out as slowly as possible, maintaining just sufficient engine power or just sufficient headway to ensure effective steerage. The actual approach speed for each part of the operation depends on previously agreed conditions.

Then the mooring master/pilot will rotate the Big Sweep in a clockwise direction 30 degrees away from the direction of approach of the LNG carrier, with his portable remote control unit. Refer to Figure 1 and Figure 2 and compare the Big Sweep heading in relation to the carrier heading.

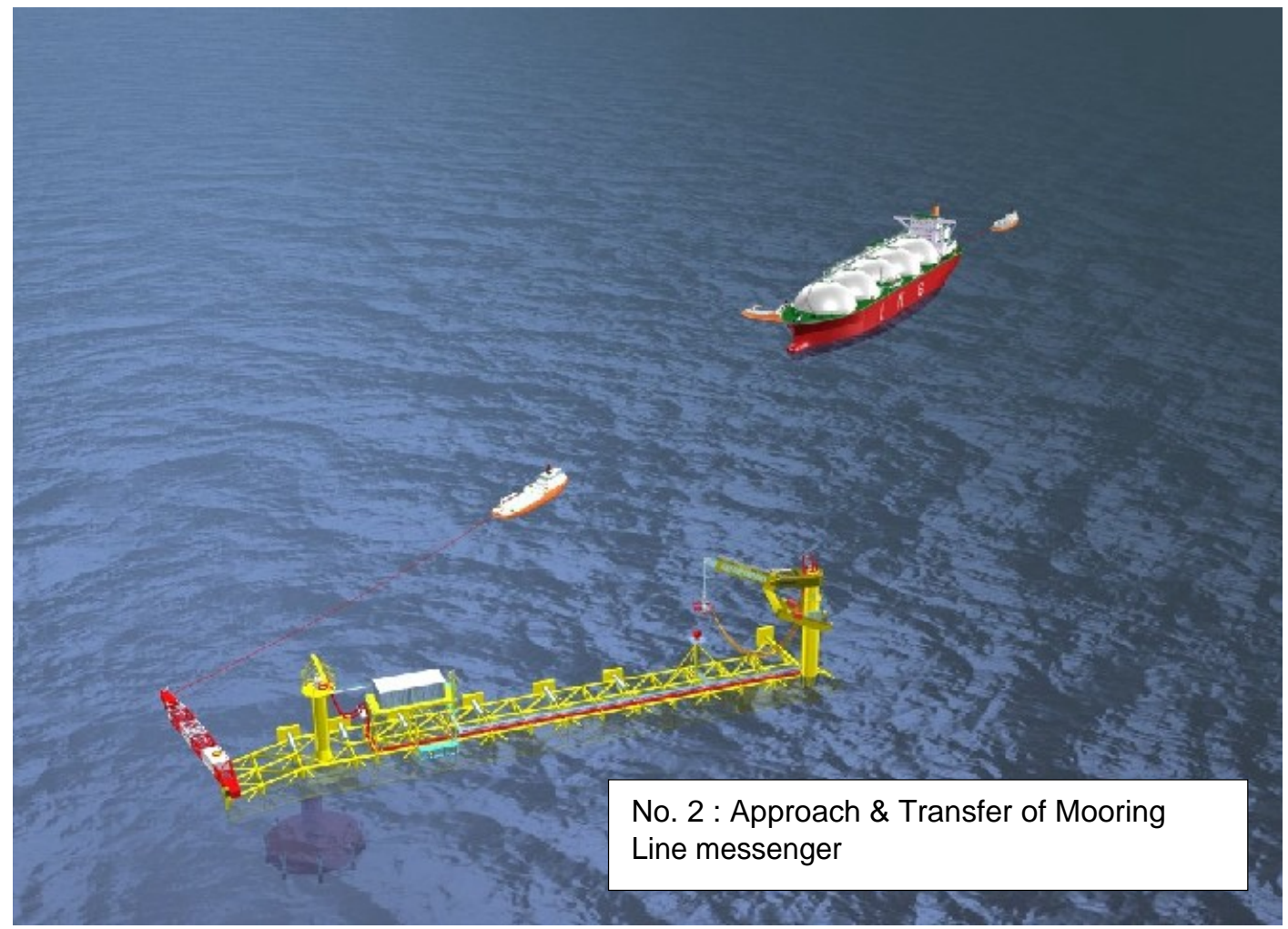

Figure 2 Approach and Transfer of Mooring Line Messenger 
The final approach will only be made once the work-boat and the carrier's forecastle area arrangements are confirmed as being ready and suitable by the Loading Master.

At all times the carrier shall avoid passing within $1000 \mathrm{~m}$ of any other installation located within the field. The use of anchors is not allowed in the Terminal area.

\subsection{Hawser Connection}

A hawser is a large diameter single mooring line with an OCIMF standard chafe chain fitted at the beginning. The chafe chain fits to an OCIMF standard stopper at the bow of thecarrier.

At a convenient safe distance off the Big Sweep, (approx. $400 \mathrm{~m}$ ) the mooring master will advise the carrier master to lower a messenger line through the fairlead, which is to be used for mooring to the hawser. In marginal weather conditions, other methods are available for the transfer of the Big Sweep hawser messenger to the carrier bow (i.e. compressed air line throwing device from the workboat). The workboat will take the messenger line and connect it to theBig Sweep hawser messenger/pick up rope.

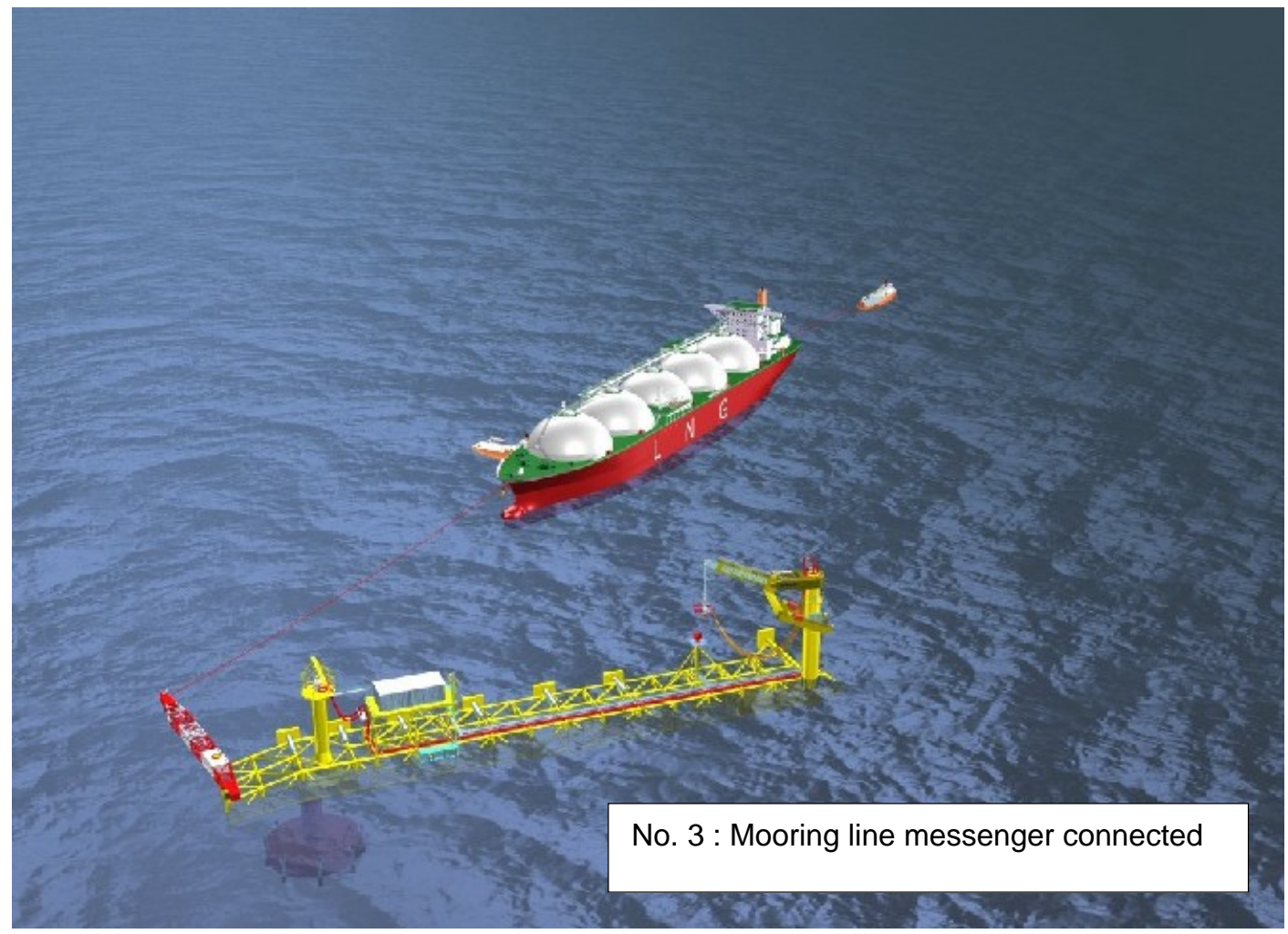

Figure 3 Mooring line messenger connected

When the messenger line has been connected, the carrier will manoeuvre to within $150 \mathrm{~m}$ of the Big Sweep. As soon as the workboat is clear, the messenger will be winched on board the carrier as quickly as possible. The pick-up rope and hawser \& chafe chain will be readily deployed to moor the vessel midship manifold aligned with the LNG transfer system. The pick up rope will be transferred to the winch on the carrier bow and heaved in until the chafing chain passes through the fairlead and reaches the required position. Care should be taken when winching in the pick-up rope to ensure that there is always some slack in the mooring assembly on board. 
Once the chafing chain is in the correct position, it will be secured to the carrier in the chain stopper as expediently as possible and before the mooring comes under tension. When the hawser connection is made, the LNG carrier should be allowed to settle back slowly on the hawser. The tug at stern will take over the steady pull on the hawser. The LNG carrier's engines must remain on stand by and ready for immediate use at all times.

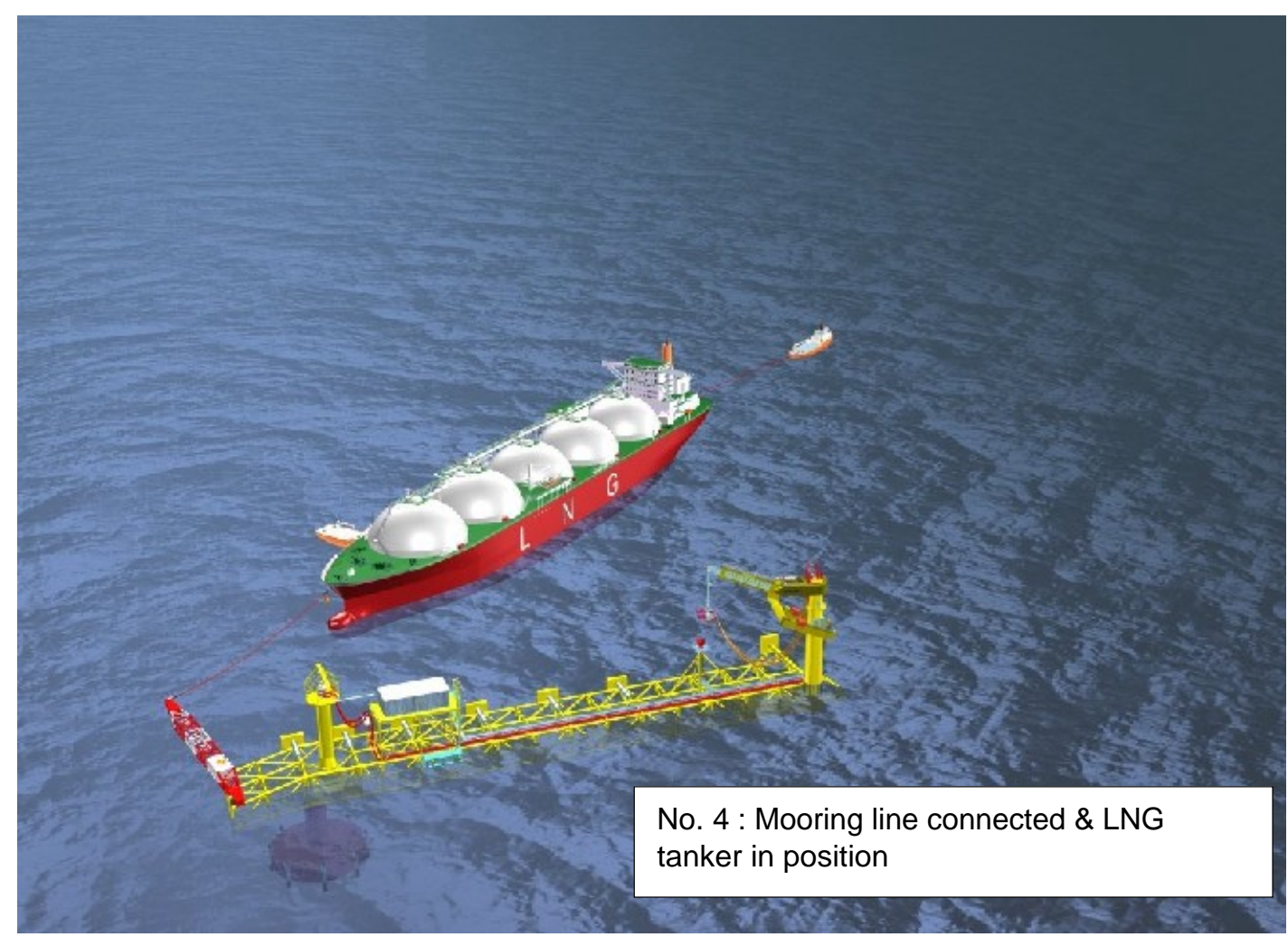

Figure 4 Mooring line connected and LNG carrier in position

\subsection{Big Sweep Positioning and Hose Connection}

Refer to Figure 5 Big Sweep dynamically positioned alongside

After the carrier is securely moored, the Mooring Master will rotate the Big Sweep alongside the hull of the LNG carrier with the use of his portable remote control unit. The Big Sweep will remain approximately 3 meters clear from the hull at all times using its position control system. The position control system controls the thrusters, generating the thrust to maintain the fixed relative position in relation to the carrier hull.

When the Big Sweep is on position control alongside, the tug on the starboard bow can be released.

The connecting of the LNG hoses will be made by the Loading Master by means of the portable unit remote control unit. 


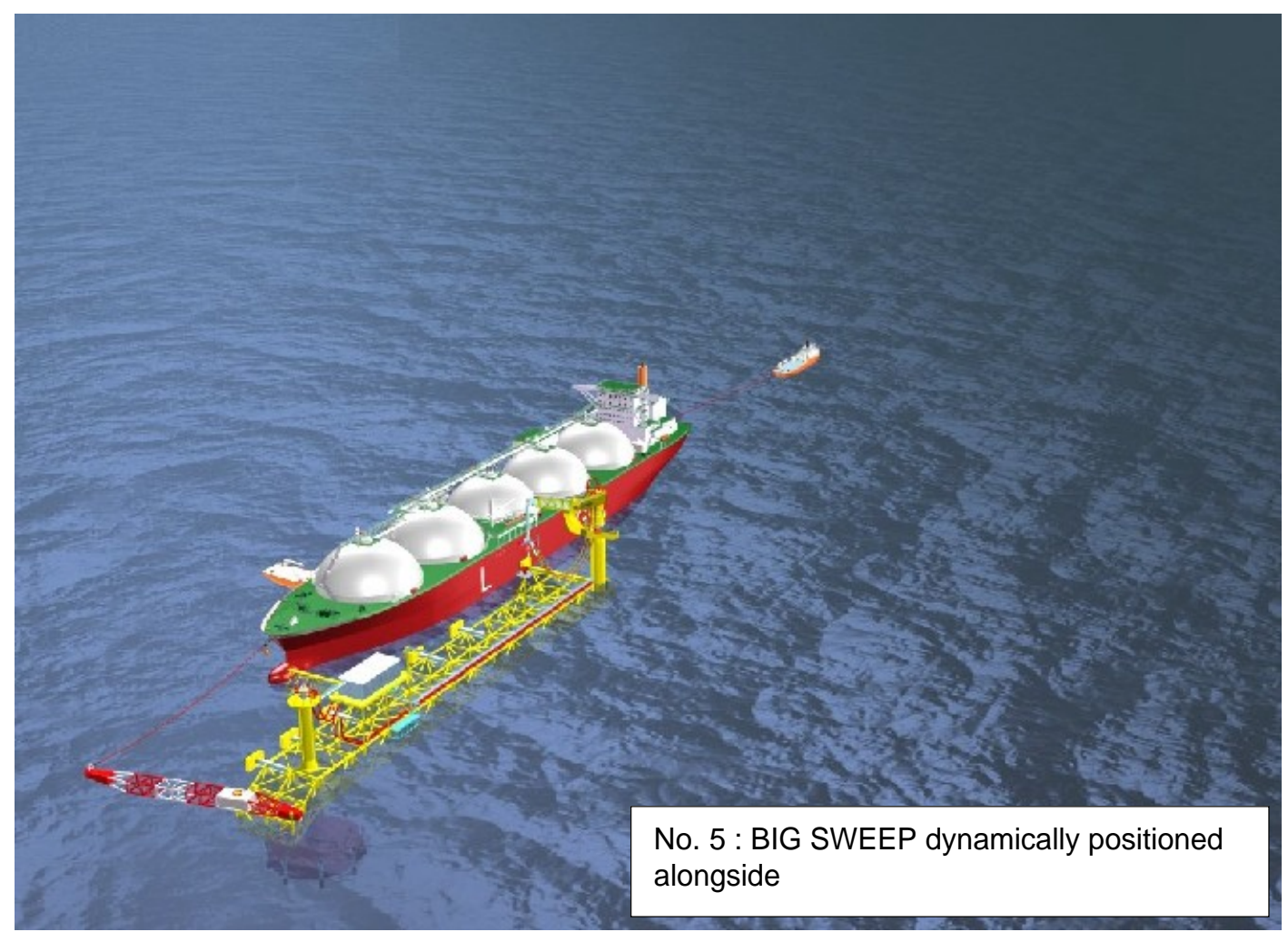

Figure 5 Big Sweep dynamically positioned alongside

\subsection{Carrier/ Big Sweep LNG Transfer}

Refer to Figure 6 Hoses connected and LNG transfer

Whilst the carrier is secured to the Big Sweep, the Pilot/Mooring master will ensure that suitable precautions are taken to monitor the carrier's position relative to the Big Sweep to prevent the carrier from riding up to the Big Sweep outrigger or yawing excessively. 


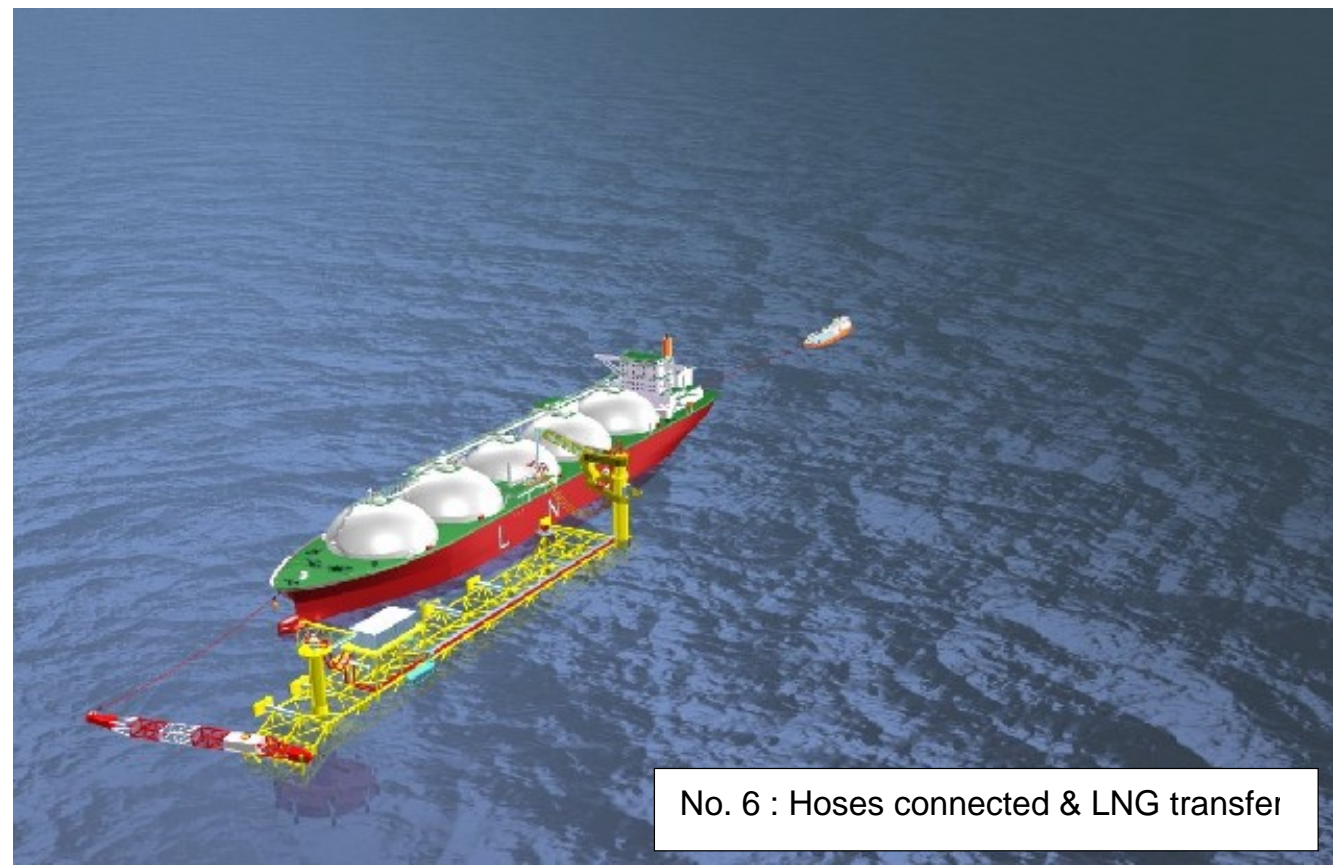

Figure 6 Hoses connected and LNG transfer

During the entire LNG transfer operation, the tug will keep a steady pull on the towing wire (pretension) in order to reduce the risk of the carrier riding into the Big Sweep outrigger as a result of a sudden change in wind and or current condition and in order to keep a stable heading of thecarrier and Big Sweep combination.

Any instructions to the tug by the mooring master to change the heading of the carrier will be automatically followed by a change of heading of theBig Sweep by the position control, maintaining the constant distance.

To continually assess the mooring status of the carrier, the pilot/mooring master will perform the following by means of portable berthing aid equipment:

- Monitor Big Sweep/LNG Carrier distance.

- Monitor hawser tension readings.

- Monitor current/wind.

- Monitor Big Sweep thrusters, position control.

- Monitor difference in angle between Big Sweep heading versus carrier heading.

- Monitor pull and angle of tug.

The basic procedures for LNG handling at Big Sweep are the same as those for a conventional berth. Since good communications are of utmost importance for safe LNG handling, a reliable communications system, including a secondary stand-by system, will be established and tested.

Prior to a carrier arriving to discharge, a proper exchange of information will be made between the Big Sweep and the carrier. This will include a check on the ability of the carrier to comply with the international carrier safety standards.

The discharging plan, a LNG carrier's tank content calculation (before discharging), as well as the arrangements for emergency shut down of cargo operations, will be ageed between the Loading Master and the carrier Master during a pre-transfer conference and recorded in writing. A joint LNG carrier-Big Sweep pumping and valve closing regime will be established and maintained to avoid pressure surges. 
LNG transfer will begin slowly until it has been verified that LNG is reaching the process platform and that the whole system is operating satisfactorily. The hoses and the area around the Big Sweep will be inspected from the LNG carrier midship manifold area for evidence of leakage. When it has been firmly established that the total system is operating correctly, the pumping rate may be increased on the LNG carrier to the maximum rate as specified for the LNG carrier as the case may be.

A member of the LNG carrier crew equipped with radio communications will be continuously on watch on deck. Sufficient crew on the vessel will remain on stand-by to deal with the operation and security of Big Sweep and carrier. At regular intervals the pressure at the manifolds and the quantity of cargo transferred, will be recorded by both the process platform and carrier and the figures compared with each other.

Any marked discrepancy between quantities will be investigated immediately. Upon completion of cargo transfer, it is essential that the carrier's valves remain open until flow has ceased completely. The Loading Master must wait for confirmation from the Big Sweep before directing that the carrier's valves can be closed.

Carrier LNG transfer key administrative data will be collected by he Loading Master on board the carrier and by the Control Room Operator of the Process Platform. The data will include, but not limited to, the following:

- $\quad$ LNG transfer export volumes

- $\quad$ LNG specifications

- Time logs

- $\quad$ Letters of protest

- $\quad$ Notice of readiness

The carrier will provide this data to the Terminal Operator and vice versa, as instructed, via the traditional communication methods. The carrier will make use of any Terminal supplied software to administer and format acceptable to Terminal.

\subsection{Carrier Disconnecting and Unmooring}

A second tug will make fast starboard forward on the carrier. The load will be taken off the hawser, if necessary by an ahead movement on the LNG carrier's engine. The pick-up rope will be heaved tight and the chafing chain let go from the bow. The pick up rope will then be slowly paid out through the fairlead. Whilst the pick-up rope is being lowered, the carrier will come slowly astern until it is clear from the Big Sweep. The hawser will be reeled in by the Big Sweep's hawser reel.

When the carrier is clear, the tug(s) will be disconnected and the workboat will come alongside to receive the ancillary equipment and to disembark the Pilot/Mooring Master and Loading Master. Embarking will take place by accommodation/pilot ladder as is common practice in the shipping industry.

The Big Sweep will be rotated away from the LNG carrier using its thruster system 


\subsection{LNG transfer Criteria Expressed in Weather Limits}

The following assumptions are applicable to the environmental weather window critera (see table):

- Two tugboats of minimum 60 ts bollard pull each are connected up to the carrier stern and/or bow during approach and mooring operation. And one tug at the carrier stern while the LNG carrier is moored to the Big Sweep during LNG transfer.

- Initially it should be considered to perform the approach and connecting up of the LNG carrier in daylight only, until on site experience and adequate additional measures do allow approach and connecting up at night. Unmooring can be performed by night.

- Table is based on operational experience and does not necessarily reflect typical GoM conditions at the Vermilion site.

- A workboat is available for hawser transfer and other duties.

- Hawser loads remain below design loads during LNG transfer.

- A field Pilot/Mooring Master and a Loading Master boarding the carrier prior to berthing.

\begin{tabular}{|c|c|c|}
\hline \multicolumn{3}{|l|}{$\begin{array}{l}\text { Guidance Table } \\
\text { Weather Limits for LNG carriers discharging at Big Sweep }\end{array}$} \\
\hline Weather Criteria & LNG transfer & Connecting \\
\hline $\begin{array}{c}\mathrm{H}_{\text {significant }}[\mathrm{m}] \\
\text { swell / sea }\end{array}$ & 4.5 & 3.5 \\
\hline Current at $-5 \mathrm{~m}[\mathrm{~m} / \mathrm{s}]$ & 1.2 & 0.9 \\
\hline Windspeed in $[\mathrm{m} / \mathrm{s}]$ & 20 & 16 \\
\hline
\end{tabular}

However, the hawser load remains the governing criterion whether to disconnect.

Other environmental restrictions:

If an observed severe squall/thunderstorm within the 10 nautical mile range is observed approaching the Big Sweep area, a controlled LNG transfer stop shall be carried out and carrier disconnection will be considered.

If a changing surface current is observed, close monitoring of current, carrier position and hawser tension shall take place. Increase of pretension of the hawser by increasing the tugboat's pull should be considered.

These values are for guidance only, and the carrier master has the sole right to stop discharging and disconnect at his discretion before such limits are reached, if he feels the safety of his vessel is compromised.

Note:

A mooring analysis has been executed to establish the hawser loads, carrier heading stability and the effect of a tug pulling at the stern of the carrier. Preliminary simulations do indicate that hawser loads are moderate. A single hawser circumference diameter of 21 " will be sufficient for this environment. 


\subsection{Emergency LNG Transfer Shutdown}

If, during LNG transfer the carrier and/or Big Sweep cannot be kept within the safe limits by the tug and/or Big Sweep's position control system, or the hawser cannot be kept under tension by the tug, an emergency LNG transfer shutdown must be initiated and an immediate disconnection should be performed.

If, during LNG transfer the hawser loads increase beyond the extreme limits an emergercy LNG transfer shutdown must be performed.

The LNG transfer emergency shutdown activation button will be situated on theBig Sweep Terminal and on the portable unit on the LNG carrier. Activation of this system gives a sequential alarm to stop the LNG pumps and closure of shut-in valve.

An emergency disconnection of the hoses can be initiated by manual activation.

In order to control pressure surges, the minimum acceptable closing time for the LNG transfer shut-in valve is pre-set in line with standard industry practice.

Emergency response procedures during specific emergency situations while LNG transfer, are described in the Port and Terminal Rules and Regulations Manual. 


\section{Process Operations Philosophy}

The following operational process cases can be distinguished:

\section{Normal operations}

- Offloading conditions

- Vapour generation has to be active to be able to replace the offloaded LNG from the LNG carrier with vapour. A vaporisation unit will be installed on the Big Sweep

- Transition phase between offloading and circulating

- Circulating conditions

- Normally, in between offloads, the inventory of the Big Sweep piping and the subsea piping will be circulated to keep the piping systems at cryogenic conditions (see below).

\section{Abnormal operation}

- Emergency Disconnect

- Emergency conditions at the process platform, the LNG carrier or the Big Sweep might require (partial) isolation of the Big Sweep and the process platform (see also section 4.4). Draining of the LNG content of the Big Sweep into the subsea pipeline can be adopted as a safety measure to minimise the inventory. The loading arm will gradually reach ambient temperature after draining and depressurising.

- $\quad$ Start-up after prolonged shutdown

- Cooling down of the piping system by circulating over the subsea lines and the Big Sweep. LNG could be provided from the platform or from an LNG carrier.

\section{Additional operations}

- $\quad$ The subsea pipeline will be vented and pressure relived from the platform side.

In between offloads the warming of the subsea piping system will be limited in two ways:

- Passively, by applying insulation.

- $\quad$ Actively, by transport of the heat absorbed by the LNG via a circulation circuit. The gas developed during this circulation will be knocked-out in a KO drum on the process platform. Knocked out LNG will be re-liquefied to LNG. The re-liquefied gas will be added to the circulation circuit to replace the vaporised LNG with liquid. The circulation system will be maintained liquid filled and cold via this procedure. The circulation will under normal circumstances include the Big Sweep. However, isolation of the subsea piping from the Big Sweep is possible by a manifold below the swivel. 


\section{Operational Control Philosophy}

\subsection{Introduction}

The loading terminal is intended to be an unmanned facility, with remote operation from the Central Control Room (CCR) on the main platform. A local control system shall be installed, which shall relay process and equipment data and diagnostics to the main platform for incorporation in the main control system and operation from a common Human Machine Interface (HMI). These controls, completed with integral CCTV, and communication systems will provide an operator interface suitable for reliable remote operation.

\subsection{Control system architecture}

Local control and monitoring system shall be configured as a subsystem of the main platform control system, using similar hardware and software products in similar configurations for control, safeguarding, fire and gas and HMl. The system will comprise I/O modules, controllers and a workstation in the local control room. The system shall be fully integrated with the platform control system through redundant network communications for system operation, diagnostics, and maintenance and configuration activities from the main platform control room. System configuration properties (signal types, field bus application, integration levels, etc.) shall comply with the system definition of the main platform. However, due consideration shall be given to diagnostic data communication for remote maintenance in order to reduce manning requirements and enable classification of the loading facility as 'unmanned'.

It is assumed that the control system will be configured as dedicated units for control and monitoring, safeguarding and fire and gas, all with data communication to the control system for monitoring through the common HMI. Configuration is pending platform system architecture.

Control systems (incl. Fire and gas and ESD systems) will be supplied from a dedicated uninterrupted power supply system, comprising battery back-up and separate supplies from normal and emergency power distribution systems.

\subsection{Control locations}

The loading facility will be remotely controlled from the central control room (CCR) on the main platform. Local systems shall be installed in an electrical and instrument control room on the SPM. This shall typically provide a conditioned environment suitable for the electronic equipment. Local operation and engineering workstation shall be provided in this room for back-up operation, maintenance and commissioning activities.

A local control station will be provided at the loading hose end of the SPM. It will comprise controls for local hose handling and thruster operation. 
Two portable control units shall be provided for operation of systems from the LNG carrier. They shall be interfaced with the control system via reliable radio telemetry systems.

- A portable control station will be provided as a berthing aid for the marine mooring master. It will be equipped with position monitoring (speed of approach, distance, bearing, etc.), hawser controls (length and load) and loading arm thruster controls.

- Another portable control station will be provided for the cargo-loading master on the carrier. This unit will be equipped with control functions for hose handling equipment and offloading controls.

An interface to the LNG carrier systems at wheelhouse/cargo control room will be provided. It will be based on standard LNG terminal monitoring system. The interface shall comprise ESD commands, and communication links.

\subsection{Safeguarding system}

Safeguarding system will be configured for 'Process Shut Down' (PSD), 'Emergency Shut Down' (ESD-1) and 'Emergency disconnect' (ESD-2). It will be designed as a high integrity system with hardwired interface with the main platform Emergency Shutdown (ESD) system.

Shutdown levels are envisaged for Unit shutdown (USD) and Process shutdown (PSD) as defined in the main platform safeguarding philosophy for shutdown of equipment and process, due to upsets and equipment failures. Furthermore shutdown levels specific for LNG loading apply as described hereafter:

ESD-1: Stop offloading operations in case of (potentially) unsafe conditions. It shall interrupt the loading operations without disconnecting the loading hoses from the carrier. It will be activated on occurrence of the following events:

- Manual from loading master control station on vessel

- Manual from various locations on the vessel

- Manual local (loading end of Big Sweep)

- Manual from CCR

- Manual from local control room (back-up operation)

- Automatic from vessel ESD system in event of power failure, fire detection, etc.

- Automatic from ESD system on Big Sweep in the event of:

- Detection of carrier movement outside normal operational envelope (ESD-1 limit)

- $\quad$ Activation of ESD-2

- $\quad$ Fire or gas detected

- $\quad$ Process shutdowns (e.g. high pressure/level trip)

- $\quad$ Low pressure hydraulic system for ESD valve actuation

- $\quad$ Low pressure hydraulic system for loading hose manipulator

- $\quad$ ESD system failure

Activation of ESD-1 will result in the following shutdown actions:

- Process system isolation on Big Sweep by closure of ESD valves and drainage of product. This action shall be delayed to ensure flow is reduced.

- $\quad$ ESD-1 command to vessel via hardwired ship/shore link:

- Stop off-loading pumps,

- Closure of LNG manifold valves on carrier (closure time to limit surge pressures)

ESD-2: Prevent damage to the loading systems and prevent large LNG spills in case the carrier drifts away from the mooring tower or loading arm. It shall interrupt the loading operations and disconnect the loading hoses from the carrier via the emergency release valves. 
It will be activated manually from each of the following locations:

- mooring master control station on vessel

- loading master control station on vessel

- $\quad$ loading end of Big Sweep

- Central Control Room (CCR)

- Local control room (back-up operation)

ESD-2 may be activated automatically in the event of:

- Detection of carrier movement outside normal operational envelope (ESD-2 limit)

Activation of ESD-2 will result in the following shutdown actions:

- $\quad$ Activation of ESD-1

- De-coupling of Emergency Release Valves (ERV). Dry break shall be obtained by closure of upstream and downstream valves prior to disconnection.

Activation of emergency release shall only be effective if the QCDC couplings of the respective hose are engaged. Limit switches shall signal this.

Notes:

- The effect of fast closure of the ERS valves on the ship's systems must be evaluated for each ship calling at the terminal. A default value for ERS valve closure time of 5 seconds should normally suffice to prevent surge pressures exceeding the design pressure of the ships piping system. If the 5 seconds period is not sufficient, the offload flow rate shall be reduced to lower the potential for surge pressures above the design limit.

- Similarly the closure time of the valves on Big Sweep shall be verified for generation of surge pressures by closing these valves, whilst the ship's pumps are still in operation and the ship's valves are open.

- ESD-1 status on vessel and Big Sweep shall be communicated through an intrinsically safe hardwired interface according SIGTTO standard. The vessel ESD status shall activate the ESD-1 status on Big Sweep; however it shall not activate the ESD-1 output to the vessel to avoid signal lock.

- The activation of ERS valves shall be simultaneous for all three hoses; however it shall only be effective if their respective QCDC coupling is engaged. Limit switch for QCDC coupling shall also be a permissive condition for offload operation.

- $\quad$ ESD-1 and ESD-2 commands over telemetry may give rise to spurious shutdowns. These shall not be of 'failsafe' design. The telemetry commands are backed-up with communication channels to CCR from where the command may be issued in case telemetry link is not available. Signalling of ERS activation by limit switch shall set the winch on the manipulator in 'brake' mode.

\subsubsection{Fire and gas detection}

Fire and gas detection systems shall be a sub system of the main platform. The system will activate shutdown and extinguishing actions via the safeguarding system and provide monitoring through the control system HMI. 


\subsubsection{General alarm}

An alarm system will be provided for signalling of manual alarm activation (MAC), fire alarm, gas alarm and emergency shutdown. The design of the system shall follow the platform safeguarding philosophy. The system will comprise warning lights throughout the facility and audible alarms via the PA system. A monitoring panel will be provided in the local control room, and in the normallymanned CCR.

A flashing or rotating warning light (colour amber, 5000 candelas) and a siren of $125 \mathrm{~dB}(\mathrm{a})$ shall be provided for issue of a warning signal for vessels in the vicinity.

\subsubsection{Control functions}

A single control system shall cover the full scope of control functions as per table below:

\begin{tabular}{|c|c|}
\hline System & Equipment/functions \\
\hline LNG Process & Pipelines, vaporiser, LNG drain vessel and pumps, etc. \\
\hline Utilities & $\begin{array}{l}\text { Air compressors and nitrogen generator, hydraulic power unit, } \\
\text { service water, chloride injection etc }\end{array}$ \\
\hline Marine systems & Thrusters, Ballast tanks and pumps, bilge system, etc. \\
\hline Mooring system & $\begin{array}{l}\text { Hydraulic power pack, hawser winch control, hawser length } \\
\text { monitoring, hawser load monitoring, emergency hawser } \\
\text { disconnect, Loading arm to Vessel side distance control, etc. }\end{array}$ \\
\hline Electrical system & $\begin{array}{l}\text { HV distribution, LV distribution, emergency power, transformers } \\
\text { and UPS systems Navigational aids, etc }\end{array}$ \\
\hline Subsea pipeline & Manifold valve controls \\
\hline LNG Loading manifold & $\begin{array}{l}\text { Hose manipulator controls, manifold ESD valves Emergency hose } \\
\text { disconnect mechanism, Vessel interface }\end{array}$ \\
\hline
\end{tabular}

\subsubsection{LNG Flow metering}

No metering facilities will be provided on the Big Sweep system. The import vessel shall provide volumes and temperature for discharged LNG, which are used for fiscal/commercial settlements, as for normal receiving terminals. Further fiscal metering including sample system for compositional analysis by gas chromatograph will be performed on the main platform after gasification. Gas flow metering on the loading arm will be limited to vapour return from the vaporiserand the vent gas system.

\subsubsection{Valve operation}

Valves will be hydraulically operated. A hydraulic power unit will be installed in the utility area, providing sufficient capacity for valve operation. Valves in ESD service shall be failsafe spring return. Alternatively valves may be operated pneumatically, however hydraulic operation is preferred in the saline environment close to the seawater surface.

Valve control shall include valves at the riser manifold via a hydraulic swivel, in the process area and at the loading manifold via hoses in piggy back configuration with the loading hoses. 


\subsubsection{Control interface Ship-SPM}

The instrument and control interface between Big Sweep and the LNG ships are identified as:

- $\quad$ Berthing system

- Mooring hawser monitoring system

- Big Sweep heading/positioning control system

- Loading hoses/couplings

- Loading hose Manipulator

- $\quad$ ESD signals

- Communications

These interfaces are considered as specific for the Big Sweep project and outlined hereafter.

Loading hoses will be connected to the ships manifold extension. The hose ends are provided with hydraulic operated ESD isolation valves and disconnect mechanism. Hydraulic control lines and cables for electronic sensor feedback signals will be piggybacked with the loading hoses to the SPM.

A ship-SPM communications interface will be provided comprising bi-directional ESD commands, and telephone communication (normal PABX and hotline. The interface cabling will be piggybacked with the offloading hoses from the manifold to the SPM.

At the manifold a connector will be installed for connection to its counterpart in the carrier manifold extension. The connection can be made by the operator or via a connector integral with the LNG hose connector. Cabling shall run from the manifold connector to the ship-shore connectors based on the SIGTTO ship-shore interface standard. A dummy connector with test device shall be provided for verification of the electronic hook-up of the manifold connector to the ship installation. The device shall be plugged into the manifold connector for testing prior to mooring to the SPM.

\section{Berthing system}

This system shall provide information relevant to the safe and efficient berthing of the LNGcarrier to the Big Sweep installation. The information shall be available at the CCR and on theportable display unit for the mooring master on the carrier.

Information shall comprise:

- Speed of approach

- $\quad$ Distance to mooring arm

- $\quad$ Big Sweep heading

- Current velocity and direction

- Wind velocity and direction

Information from all above-mentioned systems shall be routed to the control system for presentation in the CCR via the common HMI. The information shall be transferred via radio telemetry for display on the portable unit in a graphical format using SCADA/HMI software.

The system shall be based on a standard berthing system using GPS type position reference systems. Laser scanner systems may be an alternative for the GPS system. 


\section{Mooring hawser monitoring system}

The system shall provide monitoring and control of the mooring hawser winch arrangement. It shall comprise the functions of adjustment of the hawser length to suit each individual vessel prior to mooring, monitoring of the mooring load, alarm for high loads and disconnect conditions.

Mooring hawser length and load shall be measured on the mooring hawser winch. Data shall be processed in the control system. In addition, a hawser lifetime calculation program may be used for data processing. The hawser winch shall be remotely controlled for adjustment of the hawser length to suit the vessel properties. Remote monitoring and control of the hawser shall be configured on the control system $\mathrm{HMI}$ and the portable display unit for the mooring master with data transfer via radio telemetry.

\section{Big sweep heading / position control system}

The heading of Big Sweep shall be actively controlled to optimise conditions for safe berthing, offloading and disconnect operations.

During berthing and disconnect operations, Big Sweep shall be positioned to a heading that it will not interfere with the vessel manoeuvring.

During offload the heading of Big Sweep shall be controlled to maintain a constant lateral distance between the vessel hull and Big Sweep at the location of the offload hoses. The controlled distance shall be such that distance from fender at the loading end to vessel hull is 3 meters $(+/-3$ meters) with the vessel positioned in parallel with Big Sweep.

Measurements will comprise compass for heading and laser beams for distance. The distance measurement will be a system common to shore terminals measuring distance between jetty and hull. However the transmitter cannot be located at the loading hose manifold. Therefore two laser beam type distance measurements shall be installed at some distance along Big Sweep. The first measurement shall measure the distance between the fender and the hull, and the second shall be used to derive the distance at the hose manifold by correction of the measured distance for vessel yaw. Alternatively a laser scanner may be installed.

Signals shall be processed in the control system and adjustments effected through variable pitch thrusters driven by speed controlled electrical motors.

\section{Loading hoses/couplings}

The loading hose ends will each be equipped with an Emergency Release System (ERS) and a Quick connect/disconnect (QCDC) coupling.

Instrumentation signals for each of the hoses comprise:

- $\quad$ Switch signal for QCDC coupling 'Engaged' status

- Hydraulic lines (2 off) for actuation of QCDC coupling

- $\quad$ Limit switch for signalling of ERS 'Released' status

- Hydraulic lines (2 off) for actuation of ERS valves

- Hydraulic line (1 off ) for actuation of ERS coupling

- Limit switch for signalling of ERS valves 'Open' and 'Closed' position

The QCDC coupling will be a complex piece of equipment with mechanisms for pull-in, release and flange clamp operations. The engaged signal may comprise a combination of switches pending the mechanical design of the device. 
Signals to/from the QCDC couplings shall pass through hydraulic and electric connectors incorporated in the ERS. These shall be arranged in stabbing plates, integral with either part of the ERS, with guiding pins/bushes to protect the connectors in case of emergency release. Electric signals shall be certified Ex 'ia' with connectors certified Ex-'e'.

Vessel position monitoring system shall comprise a laser scanner on the Big Sweep structure and either active or passive targets located on the hose ends.

Signal cables and hydraulic hoses shall be piggy backed along the loading hoses towards the Big Sweep control system. Additional hydraulic lines shall be installed for the supply/return of the pull-in winch on the hose end.

Signals shall be available for indication on the $\mathrm{HMI}$ and serve the following control services:

ERS valves open/closed: Permissive for cargo transfer operation (green line)

QCDC coupling engaged: Enable emergency release (ESD-2) and, Permissive for cargo transfer operation (green line)

ERS released: $\quad$ Brake hose winch on loading hose manipulator

Position reference: Detect vessel excursion outside operation envelope: generate ESD-1 Loading Hose Manipulator and/or ESD-2 commands.

Loading hoses shall be supported from the manipulator, which is a crane type structure that reaches overhead the vessel extended manifold. Each of the hoses is hang-off the manipulator arm by a steel wire. The steel wires are normally kept under tension by individual winches on the manipulator. In case of an emergency release the winches shall be stopped within fractions of a second after full release of the couplings (drop $1 / 2$ metre) and prevent them fromdropping into the sea.

Instrumentation signals comprise:

- Taut wire angles (3 off)

- Manipulator arm angle

Taut wire angles shall be measured in the sideways direction relative to the plane of manipulator vertical axis and centre line of manipulator arm.

Signals shall be available for indication on the control system HMl and serve the following control services:

- Taut wire: Alignment of manipulator and loading hoses

- Manipulator angle: Monitoring only

The manipulator will normally be in neutral position. The manipulator shall be moved in line with the hose manifold as the vessel moves outside the normal operating window to prepare for emergency release operation (ESD-2), whereby the hose, the wire for hose end hang-off and manipulator arm shall be moved into a single plane.

\section{ESD signals}

Emergency shutdown signals shall be exchanged between the vessel ESD system and Big Sweep ESD system. The signals shall comprise ESD command from vessel to Big Sweep and ESD-1 command from Big Sweep to vessel. These signals shall be intrinsically safe Ex-'ia' according SIGTTO standard. 


\section{Communications}

Communications interface with the vessel shall comprise:

- Telephone: The main platform telephone network shall extend to the Big Sweep facility. A few extensions shall be made available for the LNG vessel communications.

- Hotline: A dedicated hotline between CCR and the vessel shall be established. This shall also be provided in the control room on Big Sweep for back-up operations.

- VHF radio: A common marine VHF radio transceiver shall be provided in the CCR and the control room on Big Sweep (back-up operations)

- Radio telemetry for data exchange with portable units for mooring master and loading master.

Telephone and ESD communication require a cable link with plug/socket connectos between vessel and Big Sweep. The plug/socket connection shall be located in the manifold area that will be classified as hazardous zone 0 or 1 . Therefore the ESD signals shall be Ex-'ia' and telephone signals shall be routed through a fibre optic link. Connectors shall be incorporated in the ERS of one of the loading hoses and arranged in stabbing plates, integral with either part of the ERS, with guiding pins/bushes to protect the connectors in case of emergency release.

\subsubsection{CCTV}

Cameras shall be provided for monitoring of the mooring, loading operation and process and utilities equipment area from the central control room. Cameras shall be integrated with the platform CCTV system. 


\section{Maintenance Philosophy}

To achieve a high mechanical availability the components will be conservatively sized based on established design principles and will be selected from suppliers with proven track records. Non essential systems components will be selected on minimum lifetime cost basis.

It is foreseen that Inspection, Maintenance \& Repair (IMR) will be carried out in annual campaigns driven by the platform shutdown intervals. Routine IMR for minor tasks will be performed in the idle periods between offloadings. An adequate stock of spares shall be kept to facilitate effective operation and minimum repair time.

Inspection and maintenance schedules shall be adopted and records are to be maintained to minimise the occurrence of equipment downtime affecting the availability.

Personnel involved in the system IMR shall receive a familiarisation and maintenance training for the specific equipment on the system.

Normal inspections will remain limited to pre-berthing visual inspections of the mooring equipment (hawser assembly, etc) and the LNG transfer system. 


\title{
Report
}

\section{Model Tests \\ Big Sweep LNG Transfer Terminal}

\author{
Doc. No.: CGI-G-100-RP-0008/Rev. A
}

Project No.: 1-0282-0 


\section{Revision Status Sheet}

Rev.

A

Date

16 July 2004

Description

Initial Issue
Initiator

$R L$

Checked by RU

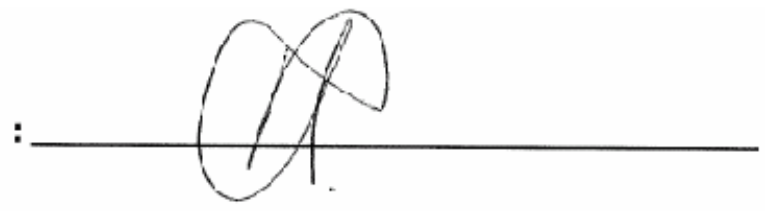

Approved by HVDB

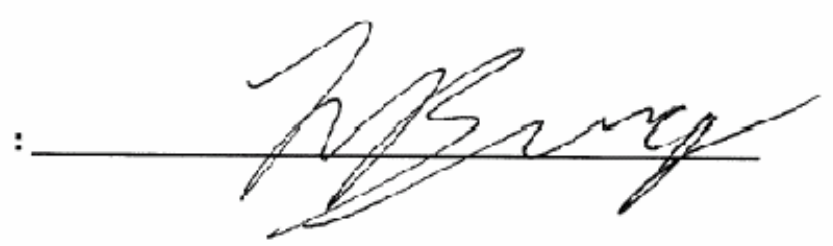




\section{Contents}

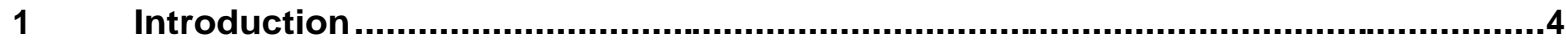

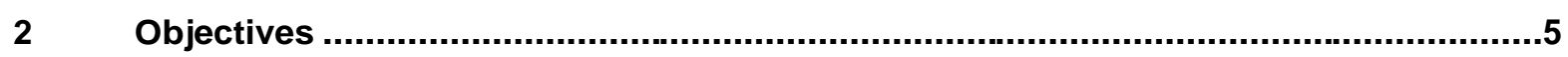

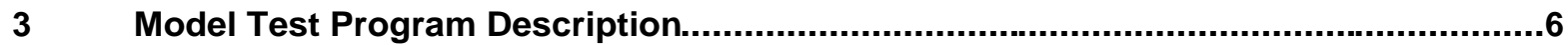

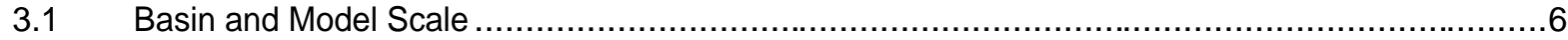

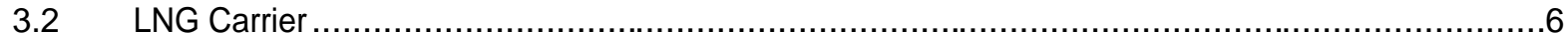

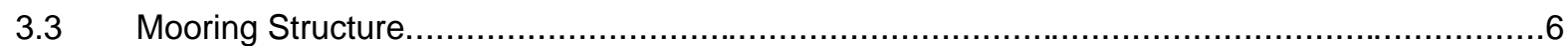

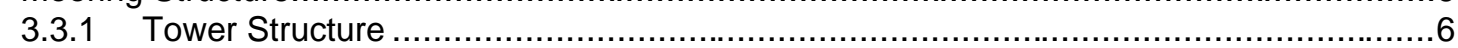

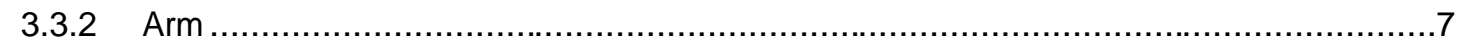

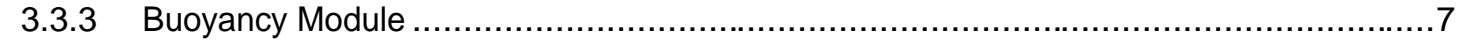

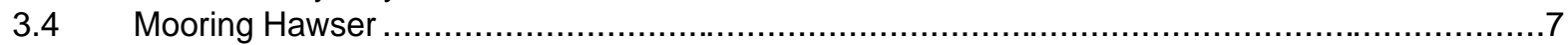

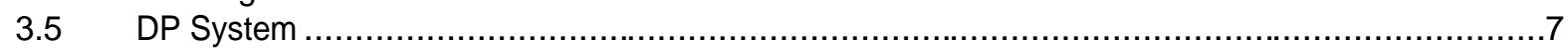

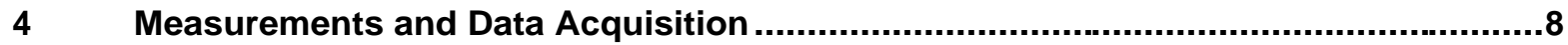

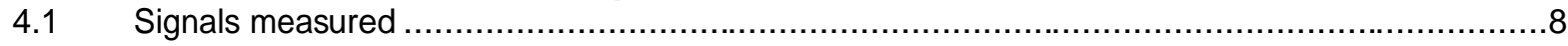

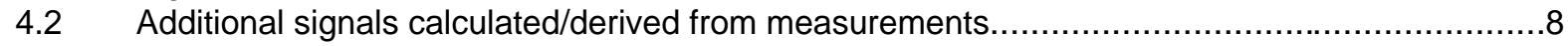

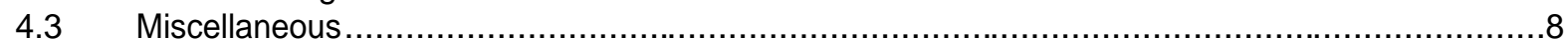

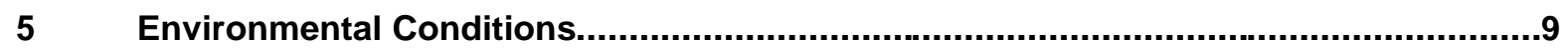

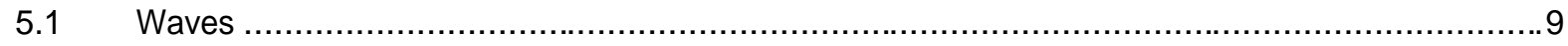

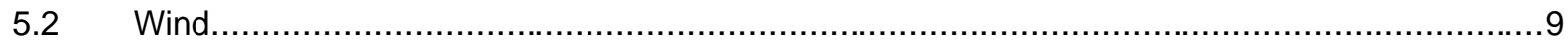

5.3 Current

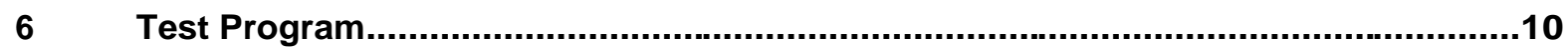

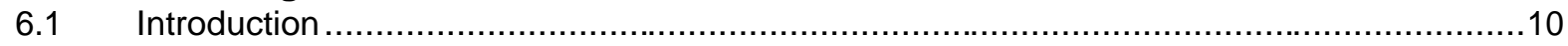

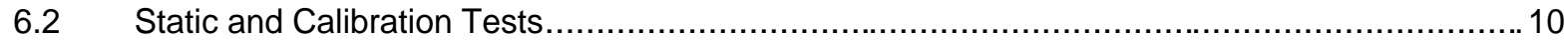

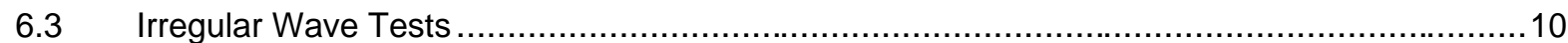

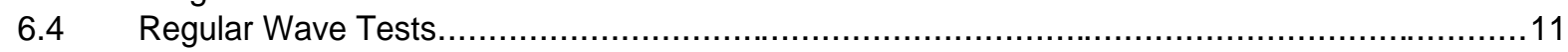

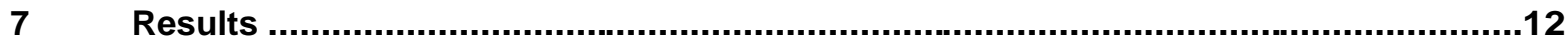

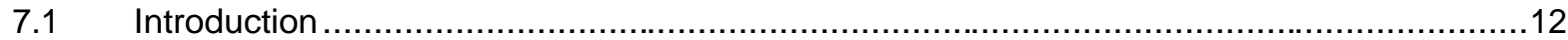

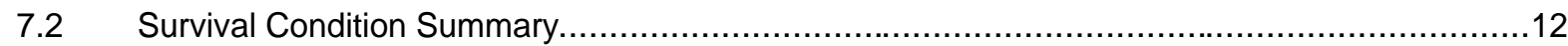

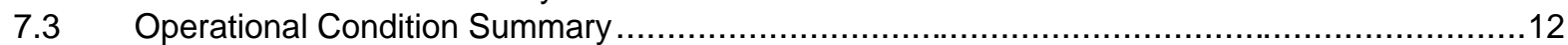

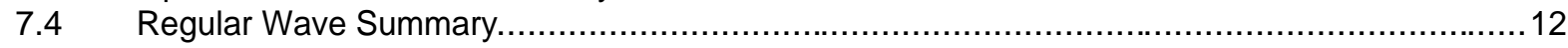

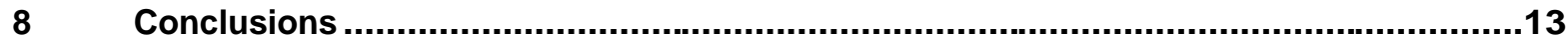

\section{Appendices}

$\begin{array}{ll}\text { A } & \text { General Arrangement Drawing - CGI-G-100-0112-001 } \\ \text { B } & \text { Pictures } \\ \text { C } & \text { Hawser Characteristics }\end{array}$




\section{Introduction}

This document summarizes a model test program and the findings thereof for Bluewater's shallow water Big Sweep system. The Big Sweep system is a concept for offshore LNG transfer between any type of LNG carrier and another facility.

The model test program has been executed as part of a feasibility study, sponsored by DOE/NETL, for an offshore LNG transfer and re-gasification terminal and salt cavern storage of the gas. The LNG transfer terminal will be separated from the re-gasification terminal and the model test series have been executed for the Big Sweep LNG transfer terminal only. The re-gasification terminal, which will be a fixed jacket type of structure, is not treated any further in this report.

The figure on the right shows a possible field lay-out, with the LNG transfer terminal at the foreground.

The terminal is intended for discharging LNG from very large gas carriers (VLGCs). Waterdepth and environmental conditions used in the test series reflect a potential location in the Gulf of Mexico. The environmental conditions at the potential site can be qualified as mild during the majority of time, but hurricanes can result in harsh environmental conditions.

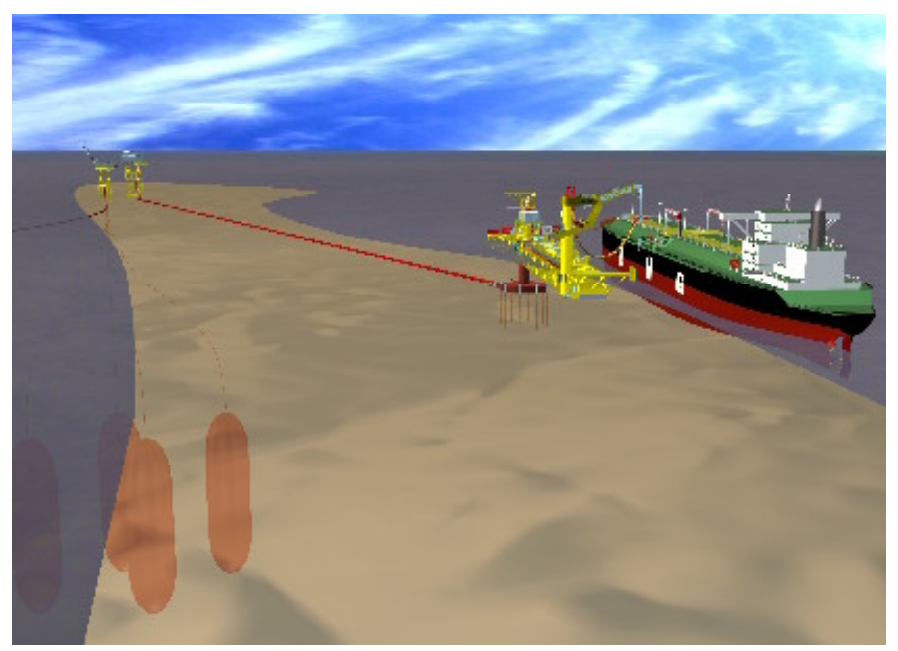

The model tested terminal consists of a monopod structure, piled to the seabed. A rigid truss arm, connected to the monopod on one end and a buoyancy column on the other end. The buoyancy column accommodates a hose manipulator to establish a fluid transfer system between the LNG carrier and the arm. The structural arm is hinged at the tower, to allow pitch motions of the arm (roll motions are constrained). A horizontal bearing allows the complete arm to rotate around the vertical axis of the tower. A DP system on the buoyant end of the arm ensures therelative position of the arm with respect to the LNG carrier's midship manifold. The maximum size of LNG carriers to moor to the terminal will be approximately $138,000 \mathrm{~m}^{3}$ vessels with a typical length of about 285 $\mathrm{m}$. The LNG carriers will moor to the terminal by a bow hawser, connected to a beam on the far end of the truss arm.

As the model test program concerns the hydrodynamic aspects of the structure, the process and LNG aspects are not treated in this document. 


\section{Objectives}

The main objective of the model test program was to prove the feasibility of the system. The waterdepth of about 30 metres and hurricane conditions result in onerous survival conditions during which the loads on the structure can become significant. Also the clearance of the arm with the seabed might become critical and has therefore to be evaluated

During operational conditions, the relative motions between the LNG carrier and the structural arm are of importance. The distance between the two bodies and the dynamics shall remain within certain limitations to safely transfer the LNG. Operational tests allow to assess the operability and to determine the main required characteristics for the DP system.

Finally, test results are used to calibrate numerical software tools, to be able to turther analyse and optimize the configuration.

Prior to the model tests, an initial analysis has been executed to determine the main load levels to be expected in the structure. By doing this, the size and amount of braces can pass a first optimization cycle. Also, the buoyancy element was designed to obtain a favourable natural period of the arm.

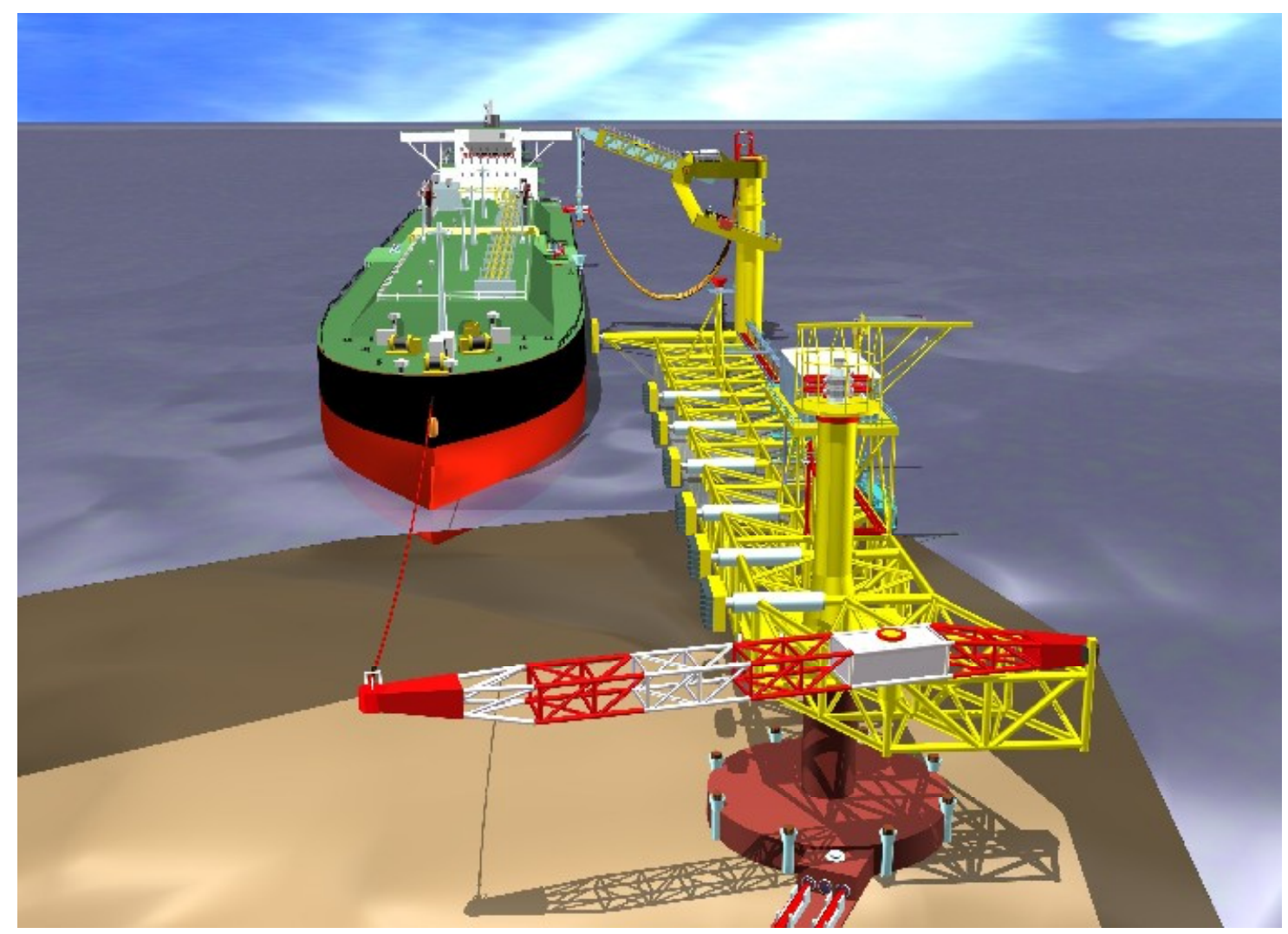




\section{Model Test Program Description}

\subsection{Basin and Model Scale}

The model tests were executed in the Offshore Engineering Basin (OEB) of Oceanic Consulting Corporation in St. John's - Newfoundland, at a scale of 1:40.

Oceanic Consulting Corporation is an alliance of the National Research Council of Canada, Memorial University of Newfoundland and the private sector. The OEB has a working area of approximately $62 \times 26 \mathrm{~m}$ and a waterdepth range of 0.1 to $2.8 \mathrm{~m}$.

\subsection{LNG Carrier}

The largest LNG Carrier to berth at the loading facility will be an approx. $135,000 \mathrm{~m}^{3}$ storage tanker. The terminal will be designed to accommodate tankers of convenience. These will include both membrane as well as spherical tanks. The carriers with the spherical tanks are heavier and have larger wind areas than the membrane tankers. Therefore the spherical type of tanker is considered to be more 'severe' for the design. To prove the feasibility of the terminal design, a typical spherical LNG carrier has been selected for this model test series.

As the design philosophy of the terminal is to be able to receive non-dedicated vessels, a stock model was selected for the model tests that could represent a very large LNG carrier. The main particulars of the tanker tested are presented in the following table.

\begin{tabular}{|l|l|l|}
\hline Designation & Unit & LNG Tanker Model \\
\hline Length (Lpp) & {$[\mathrm{m}]$} & 282.44 \\
\hline Beam & {$[\mathrm{m}]$} & 50.04 \\
\hline Depth & {$[\mathrm{m}]$} & 24.84 \\
\hline Draft & {$[\mathrm{m}]$} & 10.26 \\
\hline Trim & {$[\mathrm{m}]$} & 0 \\
\hline Displacement & {$[$ tonnes] } & 115,449 \\
\hline $\begin{array}{l}\text { LCG (forward of } \\
\text { midship) }\end{array}$ & {$[\mathrm{m}]$} & 10.42 \\
\hline VCG (above keel) & {$[\mathrm{m}]$} & 20.37 \\
\hline GM Lateral & {$[\mathrm{m}]$} & 3.3 \\
\hline Wind area & {$[\mathrm{m} 2]$} & 7,539 \\
& {$[\mathrm{~m} 2]$} & 1,608 \\
\hline
\end{tabular}

\subsection{Mooring Structure}

\subsubsection{Tower Structure}

The tower structure consists of a base that is piled to the ground. A single column penetrates the water surface. On top of the column, a turntable is installed holding amongst others the low pressure cryogenic swivel. The axial bearing for the weathervaning capabilities is located a few meters above the still waterline. A general arrangement drawing of the tower structure is included in Appendix A. 
Doc. No. 1-0282-0/ CGI-G-100-RP-0008/Rev. A Report - Model Tests Big Sweep LNG Transfer Terminal

\subsubsection{Arm}

The arm is a lattice structure. The distance between the centreline of the tower structure and the buoyancy module is $170 \mathrm{~m}$, see Appendix A.

Hinges at the tower side allow pitch motions of the arm. The hinges are located above still water level. The tower structure more or less penetrates the arm structure and on the shorter end of the arm, another (secondary) arm is connected to which the hawser configuration is attached.

The main arm consists of 6 longitudinal members of which the top 3 members are situated above water and the bottom 3 members below the waterline. The longitudinal members are interconnected via horizontal, vertical and diagonal braces. All braces are 2D braces (in plane).

\subsubsection{Buoyancy Module}

The buoyancy module is connected to the far end of the main arm structure. The module holds the fluid transfer system that is connected to the mid-ship manifold of the tanker in reality. This fluid transfer system has not been modelled in the test series other than a component representing the mass and centre of gravity of this.

Besides the column penetrating the water level, a box structure is added underneath the main arm to generate additional buoyancy. The box structure is completely integrated with the structural members of the arm and is fully submerged in the neutral position. Since this box structure generates a considerable amount of added mass, hence influencing the natural period of the system, a series of three box-structures with equal net buoyancy have been tested.

\subsection{Mooring Hawser}

The LNG carriers will moor via a bow hawser to the secondary arm. The total length of the hawser arrangement between bow and arm is $60 \mathrm{~m}$.

\subsection{DP System}

The arm is equipped with a redundant DP system. The thrusters are connected at the outside of the buoyancy column. The thrusters will have a fixed azimuth. Thrust can be delivered perpendicular to the arm in a positive and negative direction. One of the objectives of the model tests was to establish the amount of thrust required. The thruster has therefore been calibrated for the model tests at a relatively high force.

A relatively simple control system has been modelled to actively control the distance between the end of the arm and the LNG carrier's midship manifold. 


\section{Measurements and Data Acquisition}

\subsection{Signals measured}

The following signals have been measured:

- Tanker Motions

- Buoyancy Module Positions

- Tower Loads

- Hawser Tension

- Thrust of DP system

- Bending Moment Arm

- Relative wave motions
Surge, Sway, Heave, Roll, Pitch and Yaw

$X, Y$ and $Z$ and Pitch, Yaw

$\mathrm{Fx}, \mathrm{Fy}, \mathrm{Fz}, \mathrm{Mx}, \mathrm{My}$

Middle of arm

at tower

at bending moment transmitter

at buoyancy module/column

\subsection{Additional signals calculated/derived from measurements}

Besides the main signals measured, the following have been derived from the measurements:

- Accelerations in 6 deg of freedom for the buoyancy column centreline at the top of the column ( $40 \mathrm{~m}$ above 'keel' level)

- $\quad$ Tanker motions at starboard midship manifold ( $145 \mathrm{~m}$ aft bow)

- Combined X, Y signal for tower loads

Horizontal distance between starboard manifold and buoyancy column at centreline

Clearance between bottom of buoyancy box and seabed

\subsection{Miscellaneous}

Tests have been video recorded by above water cameras (side view and overhead view) as well as an underwater camera.

The underwater camera captured the end of the main arm to verify the clearance with the seabed. 


\section{Environmental Conditions}

Two types of environmental conditions have be calibrated and tested. These conditions reflect the maximum operational conditions desired and the 100-year hurricane survival conditions.

\subsection{Waves}

\begin{tabular}{|l|c|c|l|l|l|}
\hline Designation & Abbr. & Unit & $\begin{array}{l}\text { Wave 1 } \\
\text { Operational }\end{array}$ & $\begin{array}{l}\text { Wave 2 } \\
\text { Operational }\end{array}$ & $\begin{array}{l}\text { Wave 3 } \\
\text { Survival * }\end{array}$ \\
\hline Significant Wave Height & $\mathrm{Hs}$ & $\mathrm{m}$ & 4.3 & 3.0 & 9.35 \\
\hline Spectral Peak Period & $\mathrm{Tp}$ & $\mathrm{s}$ & 8.4 & 8.0 & 15.1 \\
\hline Zero Up-crossing Period & $\mathrm{Tz}$ & $\mathrm{s}$ & 6.5 & 6.2 & 11.7 \\
\hline Peak enhancement factor & $?$ & - & 3.3 & 3.3 & 3.3 \\
\hline \multicolumn{7}{|l}{} \\
\hline
\end{tabular}

Wave 1 - Operational represents an approximate 1-year return period wave height

Wave 2 - Operational represents an approximate non-occurrence level of $98 \%$

Wave 3 - Survival represents a 100-year Hurricane event

\subsection{Wind}

Velocity I $28 \quad \mathrm{~m} / \mathrm{s}$ (constant velocity), associated with 'Wave 1 Operational'

Velocity II $16 \quad \mathrm{~m} / \mathrm{s}$ (constant velocity), associated with 'Wave 2 Operational'

Hurricane wind velocities have not been considered as these conditions will only occur without the presence of an LNG carrier and the 'wind area' of the Big Sweep structure has not been modelled properly.

\subsection{Current}

\begin{tabular}{|l|l|l|}
\hline $\begin{array}{l}\text { Depth below } \\
\text { mean water level }\end{array}$ & $\begin{array}{l}\text { Operational } \\
\text { Velocity } \\
\text { [m/s] }\end{array}$ & $\begin{array}{l}\text { Survival } \\
\text { Velocity } \\
\text { [m/s] }\end{array}$ \\
\hline surface & 0.5 & 1.0 \\
\hline bottom & 0.5 & 1.0 \\
\hline
\end{tabular}

Operational velocity represents an approximate 1-year non-occurrence level

Survival velocity represents a hurricanegenerated current 


\section{Test Program}

\subsection{Introduction}

In the following Chapter, the test program is described. The program comprises a few different series, all with specific purposes and objectives.

Static and Calibration tests are executed to obtain specific characteristics of the structures like natural frequencies, damping as well as drag loads at different angles in current.

Irregular wave tests in which the Big Sweep structure is exposed to a combination of wind, current and random generated waves. These types of tests normally last for 3 hours proto-type time. Irregular wave tests have been executed for two different environmental conditions. Hurricane conditions, which govern the structural design and integrity of the Big Sweep configuration. Operational conditions, which will determine the requirements for the DP system and the tanker mooring hawser. Different combinations of wind, current and wave drections have been tested.

Regular wave tests are executed to investigate the response of the Big Sweep structure in waves with different heights and periods. Results of these types of tests are very valuable for calibration of analytical tools.

\subsection{Static and Calibration Tests}

Roll Decay Test Tanker

Pitch Decay Test Arm

Current Test (No vessel)

Rotation Test
1 Tanker loading condition

Executed with each buoyancy box

4 Relative directions to arm

Rotate arm using DP system in still water and in current

\subsection{Irregular Wave Tests}

The following tests have been executed for 3 hour duration on prototype scale.

\begin{tabular}{|l|l|l|l|l|l|}
\hline $\begin{array}{l}\text { Test } \\
\text { No }\end{array}$ & Environment & $\begin{array}{l}\text { LNG } \\
\text { Carrier } \\
\text { Present }\end{array}$ & Hawser & $\begin{array}{l}\text { DP } \\
\text { System }\end{array}$ & Wave \\
\hline 1 & Survival - Collinear & $\mathrm{N}$ & n.a. & Idle & 3 - 3 runs of 3 hrs \\
\hline 2 & Survival - Cross & $\mathrm{N}$ & n.a. & Idle & $3-3$ runs of 3 hrs \\
\hline 3 & Survival - Cross * & $\mathrm{N}$ & n.a. & Idle & 3 \\
\hline & & & & & \\
\hline 4 & Parallel & $\mathrm{Y}$ & intact & Active & 1 \\
\hline 5 & Parallel & $\mathrm{Y}$ & intact & Active & 2 \\
\hline 6 & Cross current & $\mathrm{Y}$ & intact & Active & 1 \\
\hline 7 & Cross current & $\mathrm{Y}$ & intact & Active & 2 \\
\hline
\end{tabular}




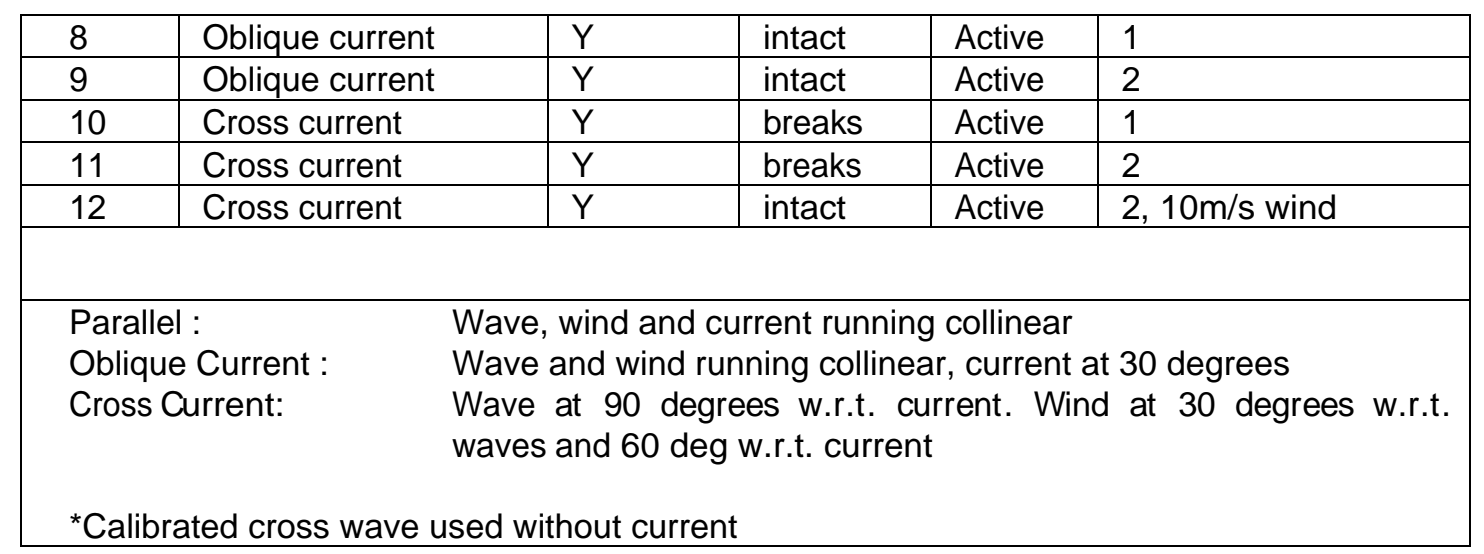

\subsection{Regular Wave Tests}

A number of regular wave tests have been carried out that serve as verification for numerical analysis. All tests were at least 10 regular waves, but continued until stable behaviour was achieved in any case.

\begin{tabular}{|l|l|l|l|}
\hline Test No & Wave Height & Period & Current \\
\hline 1 & 4.0 & 4.0 & - \\
\hline 2 & 4.0 & 6.0 & - \\
\hline 3 & 4.0 & 8.0 & - \\
\hline 4 & 4.0 & 13.0 & - \\
\hline 5 & 4.0 & 15.0 & - \\
\hline 6 & 4.0 & 17.0 & - \\
\hline 7 & 4.0 & 19.0 & \\
\hline 8 & 4.0 & 21.0 & \\
\hline 9 & 4.0 & 25.0 & \\
\hline 10 & 10.0 & 8.0 & \\
\hline 11 & 10.0 & 10.0 & \\
\hline 12 & 10.0 & 13.0 & \\
\hline 13 & 17.4 & 13 & - \\
\hline 14 & 17.4 & 15 & - \\
\hline 15 & 17.4 & 18 & - \\
\hline 16 & 17.4 & 13 & 1.0 \\
\hline 17 & 17.4 & 15 & 1.0 \\
\hline 18 & 17.4 & 18 & 1.0 \\
\hline
\end{tabular}




\section{$7 \quad$ Results}

\subsection{Introduction}

Most results presented in the following sections are of a qualitative nature. Main reasons for this are that the test results serve as a basis for further analysis and development of the Big Sweep and loads should not be reflected as 'final' design loads. There are also a number of scaling effects that need to be taking into account as well as conditions that might be more severe than the actual conditions that might occur at the selected site in the Gulf of Mexico.

\subsection{Survival Condition Summary}

The following observations outline key results form the survival condition tests:

- The maximum tower loads were experienced during the crossed survival condition. The order of magnitude was $20,000 \mathrm{kN}$ horizontal load.

- The maximum range of pitch angle experienced by the arm for collinear survival conditions was 4.8 degrees while for the crossed conditions it was 6.0 degrees.

- Minimum seafloor clearance of about $12 \mathrm{~m}$ occurred

\subsection{Operational Condition Summary}

Key observations made from the operational tests include the following:

- Loads at the tower reached a maximum of $5800 \mathrm{kN}$. Generally, the tower loads decreased as the environment moved from a collinear direction to the crossed direction. This may be due to the sheltering effect the tanker has on the arm in the crossed conditions.

- The maximum hawser load did not exceed $1800 \mathrm{kN}$.

- The relatively simple DP system as modelled proved adequate for controlling the arm and maintaining separation from the tanker for most cases. In operation, a more sophisticated DP control system will be required to fully control the arm-ship separation and further optimize the operations. During hawser break tests, the DP system also proved adequate in moving the arm clear of the tanker.

\subsection{Regular Wave Summary}

During the regular wave tests the following observations were noted:

- The maximum response was found to be approximately $0.300 \mathrm{rad} / \mathrm{sec}$ with a heave RAO of about 2.25.

- The response of the arm appears to be more dependent on wave frequency than on natural frequency of the arm. As such buoyancy box variation did not produce significant shift in maximum arm response. 


\section{Conclusions}

The model tests clearly showed the feasibility of the Big Sweep concept, both in terms of survivability during Hurricane conditions and operability during the vast majority of time in the Gulf of Mexico.

The following quotes have been obtained from the model test report prepared by Oceanic Consulting.

Quotes Oceanic Consulting: "Throughout the tests, general observations showed that the arm and tanker would prove adequate for this type of mooring arrangement."; "Overall, nothing observed during the tests indicates that such a setup will not be able to operate in the conditions tested."

Besides the visual observations, captured by video recording and photos, an enormous amount of data was acquired by measurements. This data is and will be extensively used as input for structural analysis, establishments of functional requirements of sub-systems as well as for calibration of numerical tools to further analyze and develop the Big Sweep. 


\section{Appendix A \\ General Arrangement}


Doc. No. 1-0282-0/ CGI-G-100-RP-0008/Rev. A Report - Model Tests Big Sweep LNG Transfer Terminal

\section{Appendix B Pictures}




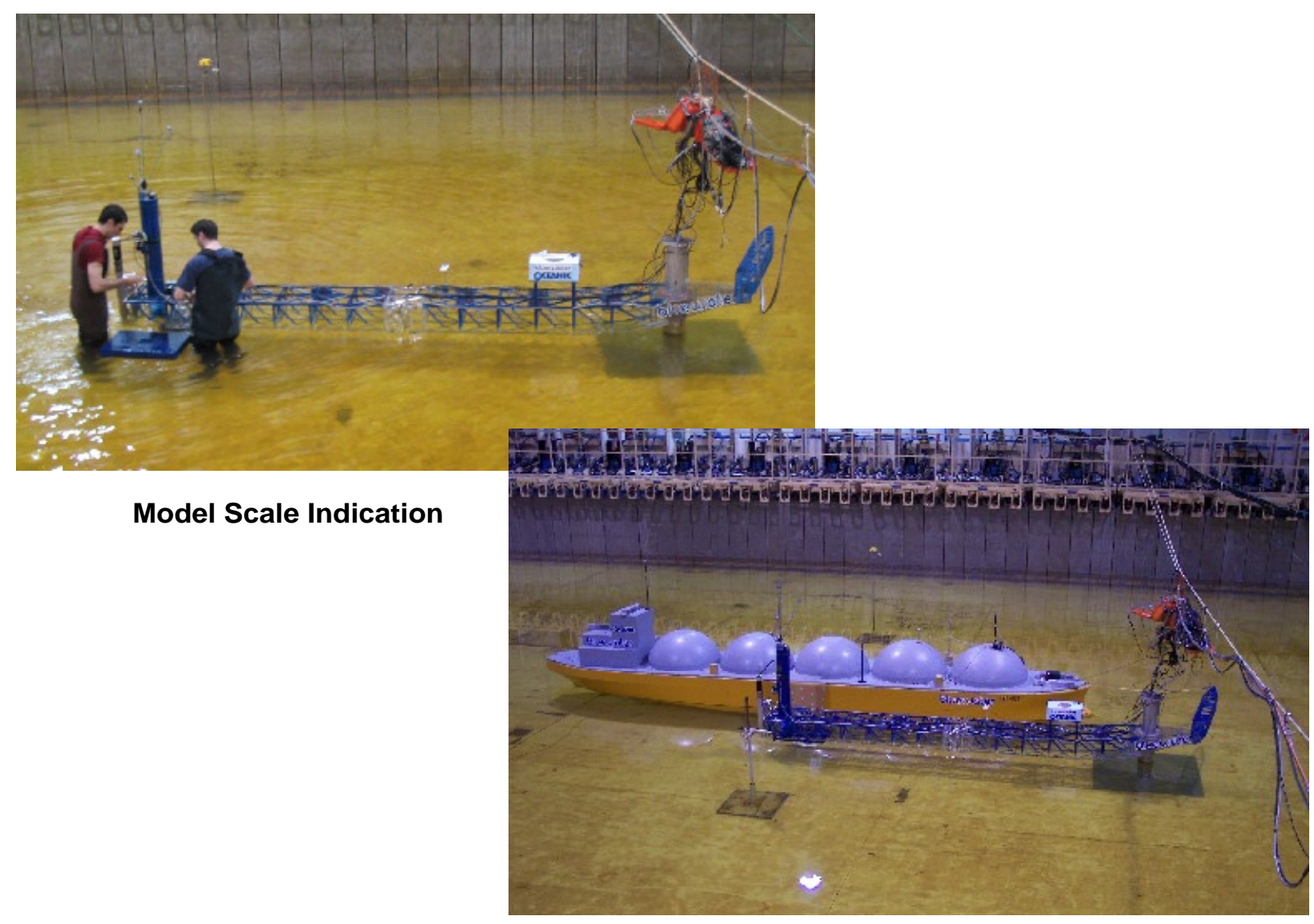

Tanker and Big Sweep in Still Water

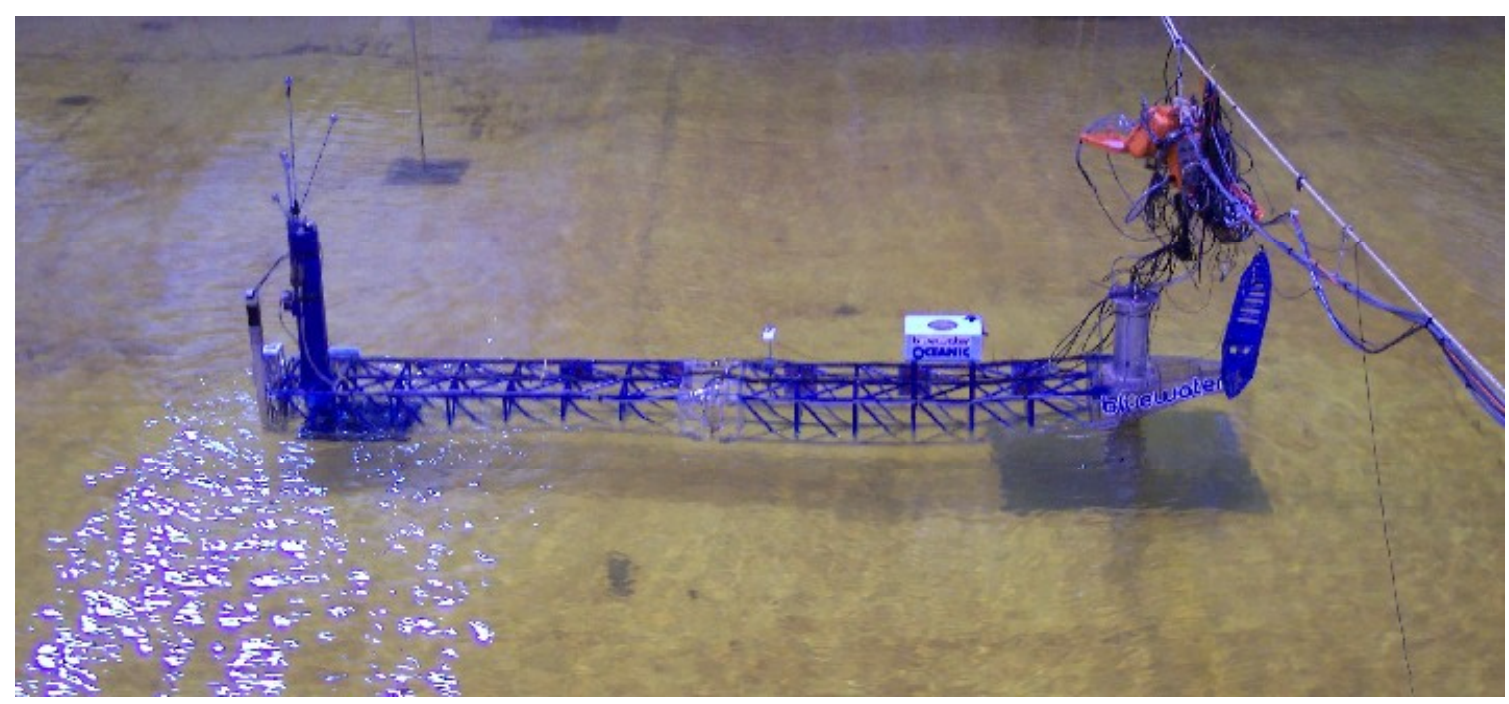

Regular Wave Test $(\mathrm{H}=4 \mathrm{~m})$ 


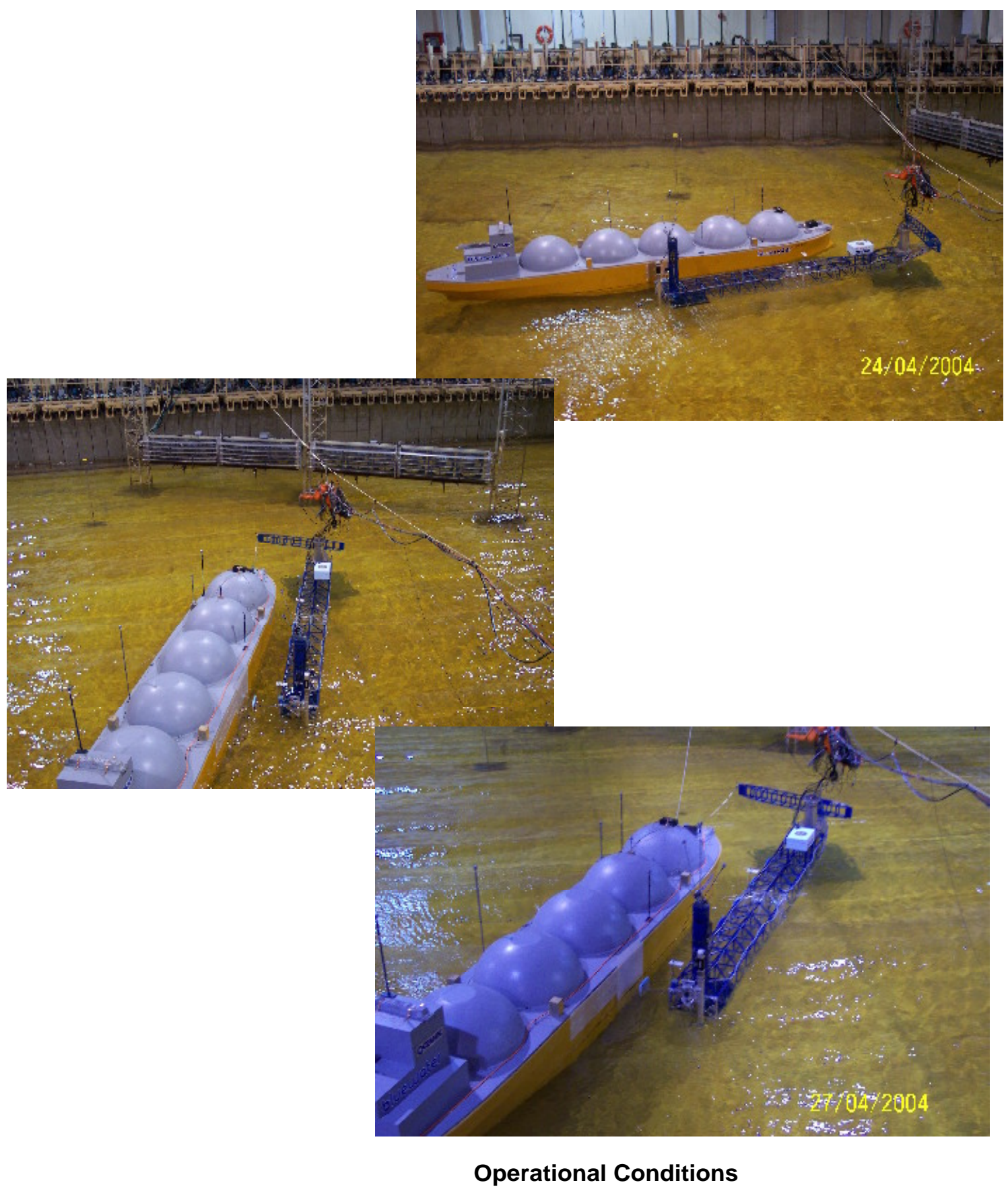


Doc. No. 1-0282-0/ CGI-G-100-RP-0008/Rev. A Report - Model Tests Big Sweep LNG Transfer Terminal

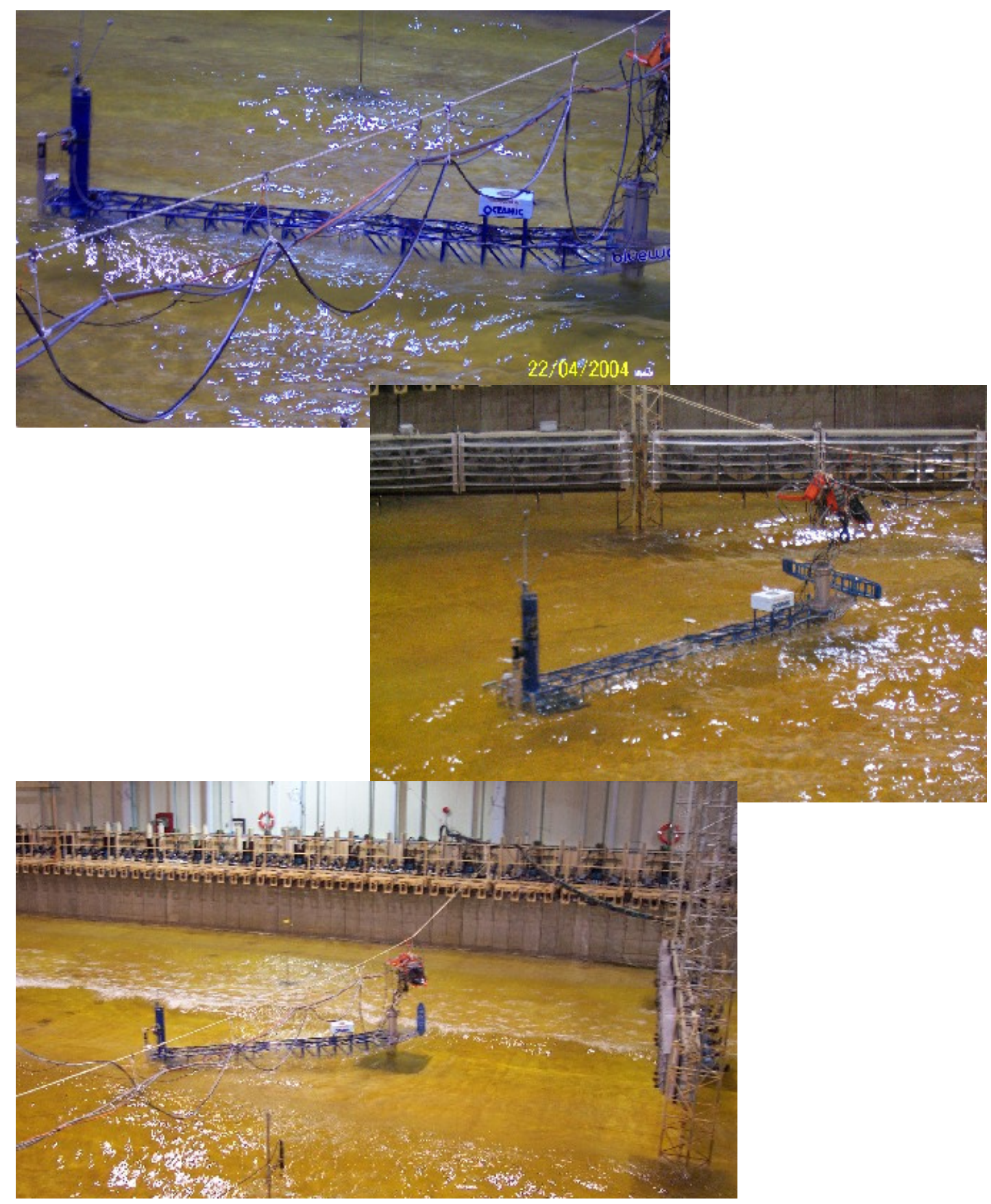

\section{Survival Conditions}




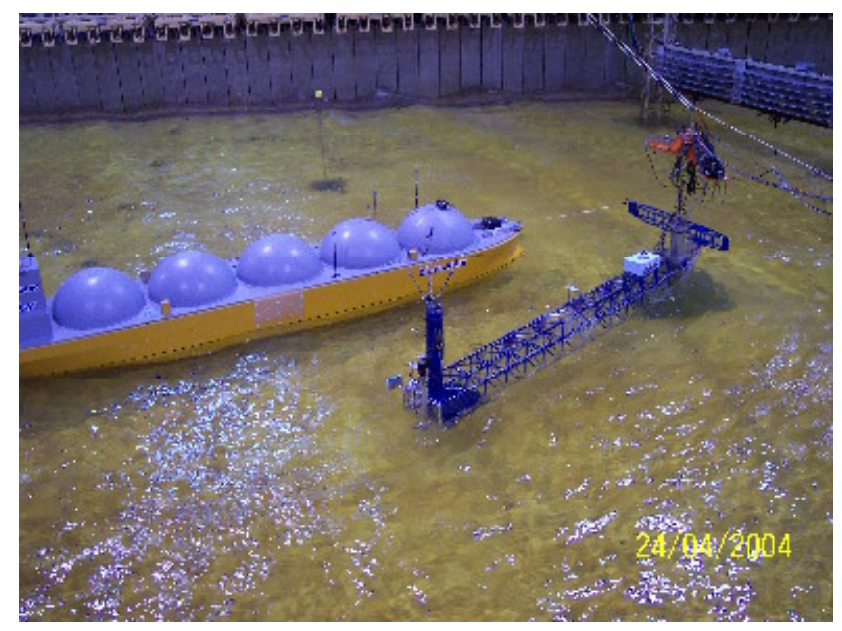

Equilibrium Position after DP failure
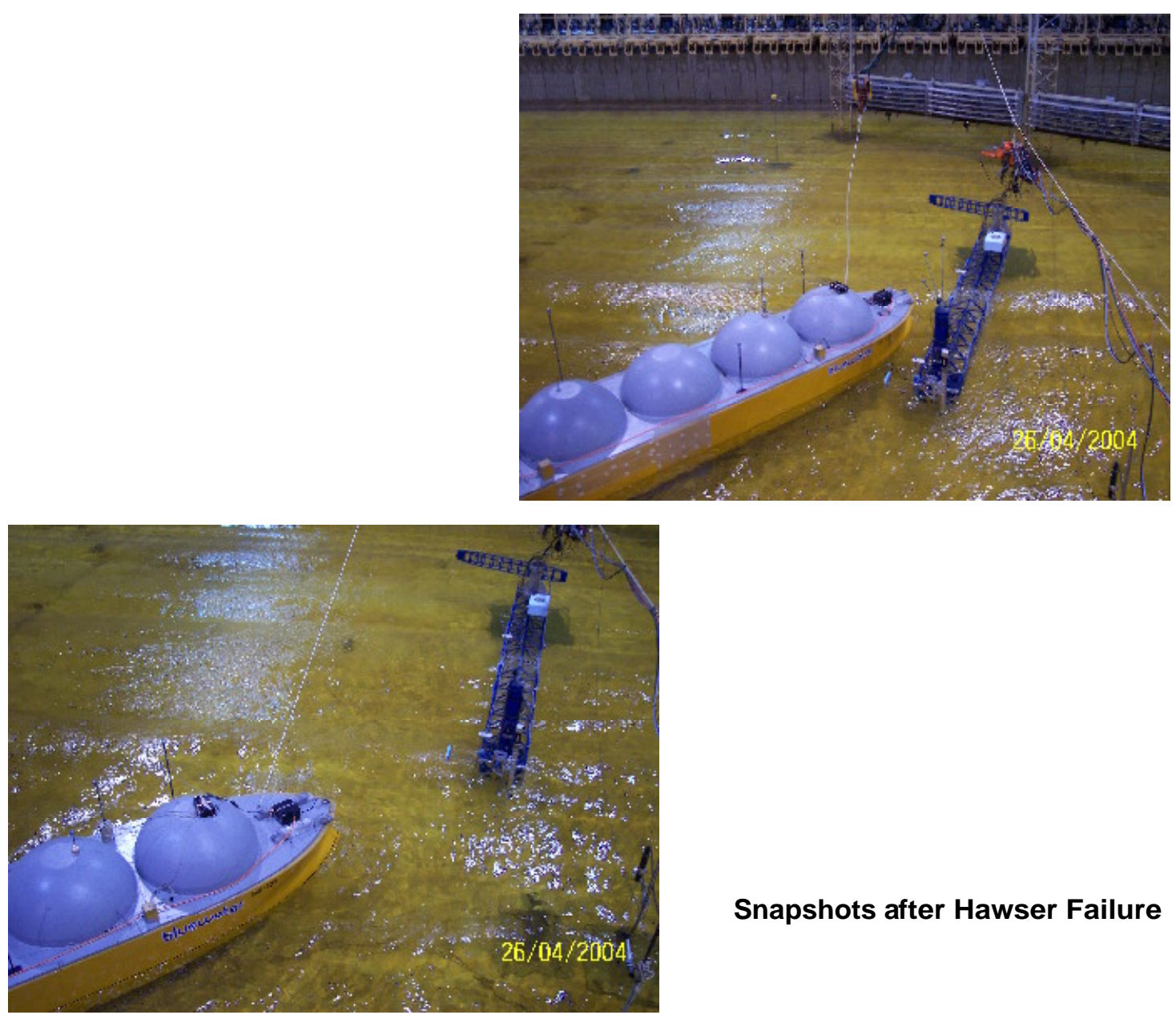

Snapshots after Hawser Failure 


\section{Appendix C \\ Hawser Characteristics}




\section{Hawser Characteristics}

\begin{tabular}{rcr} 
Load & \multicolumn{2}{c}{ Length Elongation } \\
{$[\mathrm{kN}]$} & {$[\mathrm{m}]$} & {$[\mathrm{m}]$} \\
0 & 60.0 & 0.0 \\
225 & 62.5 & 2.5 \\
451 & 63.8 & 3.8 \\
676 & 64.7 & 4.7 \\
902 & 65.5 & 5.5 \\
1127 & 66.2 & 6.2 \\
1352 & 66.8 & 6.8 \\
1578 & 67.2 & 7.2 \\
1803 & 67.7 & 7.7 \\
2028 & 68.1 & 8.1 \\
2254 & 68.5 & 8.5 \\
2479 & 68.8 & 8.8 \\
2705 & 69.1 & 9.1 \\
2930 & 69.3 & 9.3 \\
3155 & 69.5 & 9.5 \\
3381 & 69.7 & 9.7 \\
3606 & 69.9 & 9.9 \\
3831 & 70.1 & 10.1 \\
4057 & 70.2 & 10.2 \\
4282 & 70.3 & 10.3 \\
4508 & 70.4 & 10.4 \\
9015 & 71.7 & 11.7
\end{tabular}




\title{
Report
}

\section{Design Load Report}

\author{
Doc. No. CGI-G-800-RP-0009/Rev. A
}

Project No.: 1-0282-0

Bluewater Energy Services B.V.

Marsstraat 33

2132 HR Hoofddorp

The Netherlands

Tel. +31235682800

Fax. +31235652053 


\section{Revision Status Sheet}

Rev.

Date

A

$17 / 12 / 2004$
Description

Initial Issue
Initiator

SGer
Date

Checked by

Approved by
Initials

RU
December 2004 HVDB

\section{Signature}

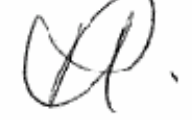

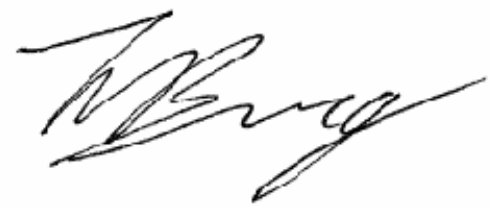




\section{Contents}

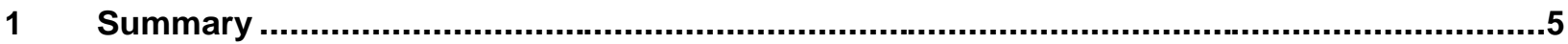

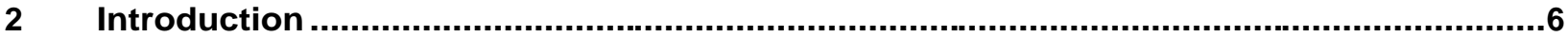

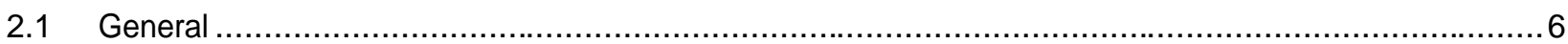

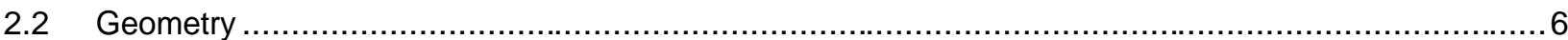

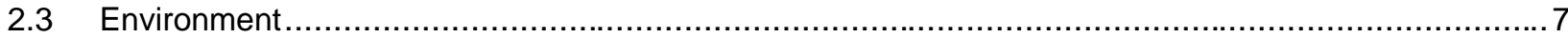

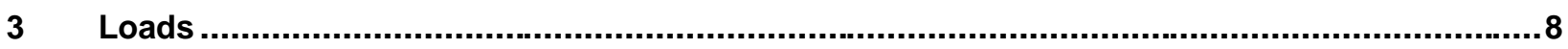

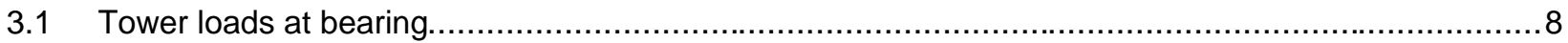

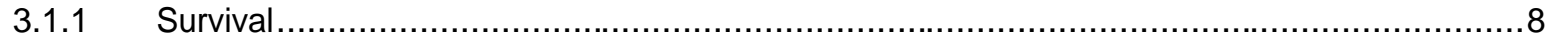

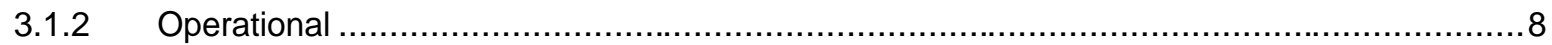

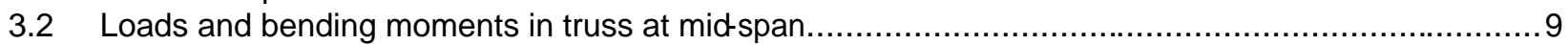

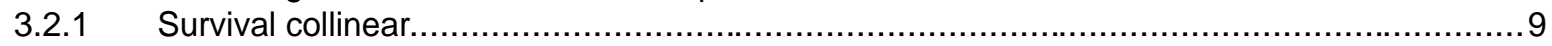

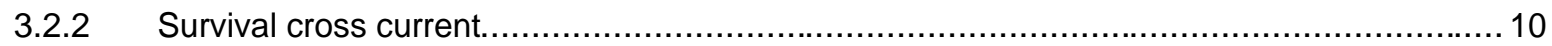

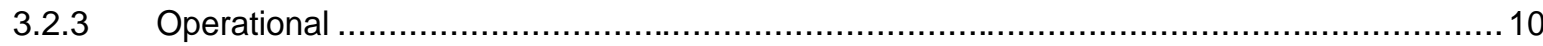

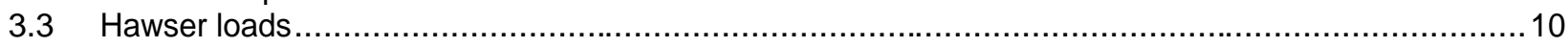

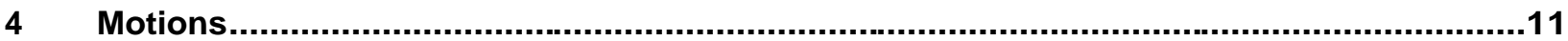

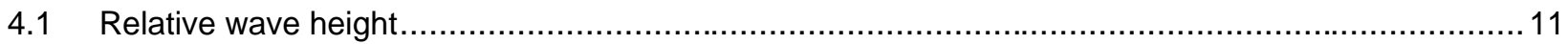

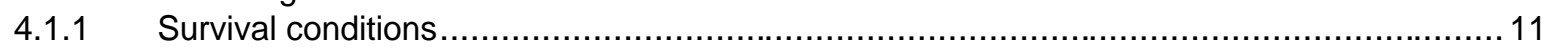

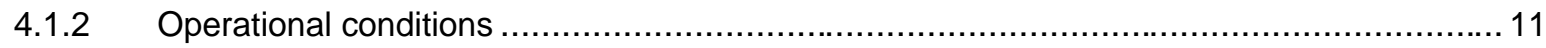

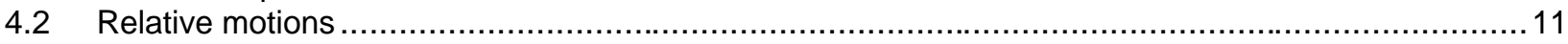

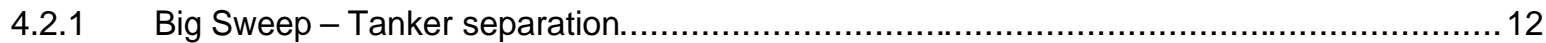

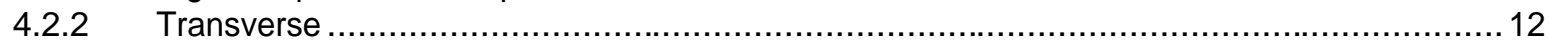

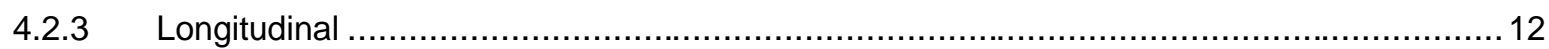

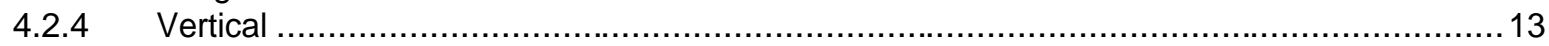

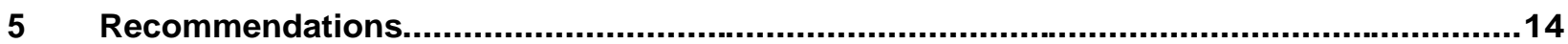




\section{List of Tables}

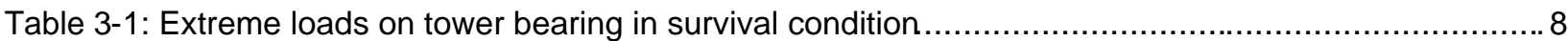

Table 3-2: Extreme roll moments on tower pitch bearing in survival condition.................................... 8

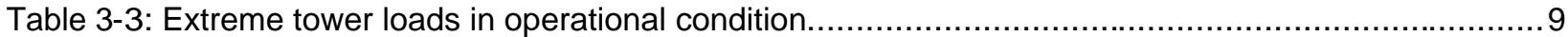

Table 3-4: Extreme roll moments on tower bearing in operational condition...........................................

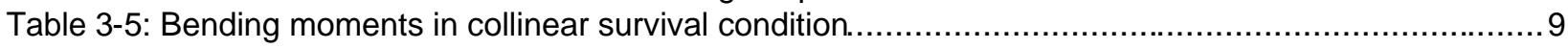

Table 3-6: Bending moments in cross current survival condition................................................... 10

Table 3-7: Typical maximum bending moment in operational condition .............................................. 10

Table 4-1: Calculated extreme relative non-breaking-wave heights in survival conditions........................11

Table 4-2: Extreme relative wave heights in operational conditions................................................. 11

Table 4-3: High frequency extreme arm-ship separation ............................................................ 12

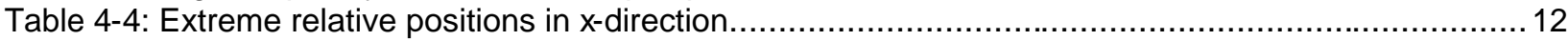

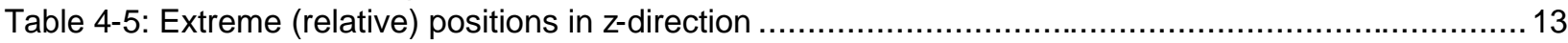




\section{Summary}

Model tests have been performed to evaluate hydrodynamic loading and motion behaviour of the Big Sweep in both regular and irregular waves. Both survival and operational environmental conditions have been modelled with irregular waves, wind and current. The design loads presented in this report are all based on the analysis of the results of these model tests. In this report a summary of either the measured loads or calculated loads, based on the model test results of the Big Sweep in irregular waves, are presented to serve as a basis for further development.

The highest loads and moments generally occur in the survival conditions. Maximum longitudinal bearing loads in the collinear cases are of the same order of magnitude as the transverse loads in the cross current case. The maximum vertical bending moment (about the yaxis) occurs in collinear survival condition. The maximum horizontal bending moment (about the z-axis) in the truss at mid-span has been measured in the cross current condition. In the cross current condition several horizontal maximums have been recorded in $œ$ mbination of high vertical bending moments.

The model test results show a significant possibility of waves rising above the 7-metre freeboard at some parts of the truss in survival conditions. The maximum wave height above the truss at the tower in these conditions is directly related to the height above freeboard of the highest wave modelled. At mid-span some waves will exceed the freeboard, but at the buoyancy column the truss will not be submerged completely.

The hawser loads have shown to be well within the range of anticipated values. The relative motions between the Big Sweep and the LNG vessel have shown to be maintained within the range of motions already taken as basis of design for the concept. 


\section{Introduction}

\subsection{General}

Model tests have been performed on a scale of 1:40 to evaluate the loads and moments on key parts of the concept design of the Big Sweep structure. In this report the survival loads and moments on the mooring tower will be discussed as well as horizontal and vertical bending moments in the truss. The hawser loads and relative motions in operational conditions will also be discussed. These loads, moments and motions will be discussed in fullscale units.

\subsection{Geometry}

The geometry of the Big Sweep as tested has 5 main components from a structural point of view, see Figure 2-1.

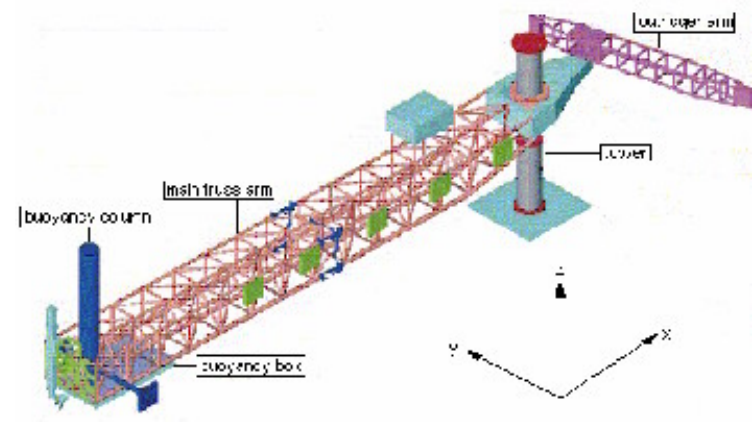

Figure 2-1: Big Sweep as tested

In Figure 2-1 the sign convention as used in the report has been displayed. A usual "right hand" sign convention has been used with $x$ directed to the tower, seen from the buoyancy box, $y$ to portside and $z$ directed upwards. The origin is located at the mean waterline of the centre of the tower. The axis system for loads is tower fixed; meaning $x$ is always in the longitudinal direction of the arm. Note that the model has been tested as a mirrored image of the Big Sweep as designed to be able to perform the tests in the required environmental conditions.

The yaw bearing in the tower has been placed at about 25 meter above the seabed. Above this bearing the loads and moments in the tower have been measured. The pitch bearing is located at the truss connection to the tower. The bending moments in the truss have been measured at mid-span of the main truss arm.

Tension is defined as a positive load. Sagging is defined as a positive bending moment about the y-axis. Tension in the portside longitudinal combined with pressure in the starboard longitudinal (after subtracting the mean loads in the longitudinal members) is defined as a positive bending moment about the z-axis

A 60-meter mooring hawser has been modelled as a tri-linear spring system. Hawser loads have been measured in local hawser direction at the connection with the outrigger arm.

Relative wave heights have been measured at the tower, at mid-span of the truss and at the buoyancy column. Motions of both LNG vessel and Big Sweep arm have been measured by optical tracking 


\subsection{Environment}

The environmental test cases in which the Big Sweep was tested have been chosen to match the harshest operational and survival conditions in the Vermilion block 179 in the Gulf of Mexico.

The survival conditions are based on a 100-year return wave condition. In this condition no vessel will be moored at the Big Sweep and no DP thrust will be delivered.

A number of operational environmental cases are based on the 1-year return storm condition to investigate the maximum operability boundary. Also cases have been selected based on $98 \%$ nonoccurrence levels of wind and waves in the concept design area. Operational conditions have been defined as conditions in which a vessel must be able to remain moored. Modelling the approach of a shuttle tanker towards the Big Sweep was beyond the scope of the tests. 


\section{Loads}

\subsection{Tower loads at bearing}

\subsubsection{Survival}

The maximum tower loads have been observed in the cross current survival condition. The current moves the Big Sweep to a beam wave orientation, which causes the wave loads to have impact at almost the same instant on all members. The maximum double amplitude is almost as high as the sum of minimum and maximum tower loads -see Table 3-1 and Table 3-2- which indicates that wavefrequent hydrodynamic loading causes these high loads. Slamming has been observed during the model tests and can be directly related to the highest tower loads. The presented results of the Tower loads are the most probable maximum values based on the Weibull analysis of model test results

\begin{tabular}{|l|c|c|c|c|}
\hline \multicolumn{5}{|c|}{ Extreme loads on tower bearing } \\
\hline Load & $\begin{array}{c}\text { Mean } \\
{[\mathbf{k N ]}}\end{array}$ & $\begin{array}{c}\text { Minimum } \\
{[\mathbf{k N ]}}\end{array}$ & $\begin{array}{c}\text { Maximum } \\
{[\mathbf{k N}]}\end{array}$ & $\begin{array}{c}\text { Double } \\
\text { Amplitude } \\
{[\mathbf{k N}]}\end{array}$ \\
\hline $\mathrm{Fx}$ & -485 & $-11,900$ & 6,387 & 18,055 \\
\hline $\mathrm{Fy}$ & 211 & $-3,073$ & 18,943 & 22,016 \\
\hline $\mathrm{FH}$ & -755 & $-20,491$ & 3,029 & 22,709 \\
\hline $\mathrm{Fz}$ & $-1,273$ & $-7,021$ & 10,336 & 16,680 \\
\hline
\end{tabular}

Table 3-1: Extreme loads on tower bearing in survival condition

\begin{tabular}{|l|c|c|c|c|}
\hline \multicolumn{5}{|c|}{ Extreme roll moments on tower bearing } \\
\hline Load & $\begin{array}{c}\text { Mean } \\
{[\mathbf{k N m}]}\end{array}$ & $\begin{array}{c}\text { Minimum } \\
{[\mathbf{k N m}]}\end{array}$ & $\begin{array}{c}\text { Maximum } \\
{[\mathbf{k N m}]}\end{array}$ & $\begin{array}{c}\text { Double } \\
\text { Amplitude } \\
\text { [kNm] }\end{array}$ \\
\hline $\mathrm{Mx}$ & $-1,987$ & $-93,547$ & 87,365 & 172,967 \\
\hline
\end{tabular}

Table 3-2: Extreme roll moments on tower pitch bearing in survival condition

\subsubsection{Operational}

Although a vessel is connected to the Big Sweep in relatively harsh operational conditions, the tower loads in operational conditions are significantly lower than in the survival conditions. In operational conditions low frequency wave loads (wave drift loads, acting on the vessel) are relatively larger, compared to the first order wave loads, than in survival conditions. Due to the simplicity of the dynamic positioning (DP) system, contact between the Big Sweep and the vessel during model tests has been observed. In contact, high peaks have been observed in the tower load signal. If contact, e.g. because of DP drop out, can not be precluded, contact loads in this order of magnitude had to be considered possible. The presented maximum operation loads in Table 3-3 and Table 3-4 show however that the loads during contact do not exceed the maximum survival loads. 


\begin{tabular}{|c|c|c|c|c|}
\hline \multicolumn{5}{|c|}{ Extreme horizontal operational loads at tower bearing } \\
\hline Load & $\begin{array}{c}\text { Mean } \\
{[\mathbf{k N}]}\end{array}$ & $\begin{array}{c}\text { Minimum } \\
{[\mathbf{k N}]}\end{array}$ & $\begin{array}{c}\text { Maximum } \\
\text { [kN] }\end{array}$ & $\begin{array}{c}\text { Double } \\
\text { Amplitude } \\
\text { [kN] }\end{array}$ \\
\hline $\mathrm{FH}$ & $-1,622$ & $-5,817$ & 1,879 & 6,990 \\
\hline
\end{tabular}

Table 3-3: Extreme tower loads in operational condition

\begin{tabular}{|l|c|c|c|c|}
\hline \multicolumn{5}{|c|}{ Extreme operational roll moments at tower bearing } \\
\hline Load & $\begin{array}{c}\text { Mean } \\
{[\mathbf{k N m}]}\end{array}$ & $\begin{array}{c}\text { Minimum } \\
{[\mathbf{k N m}]}\end{array}$ & $\begin{array}{c}\text { Maximum } \\
{[\mathbf{k N m}]}\end{array}$ & $\begin{array}{c}\text { Double } \\
\text { Amplitude } \\
\text { [kNm] }\end{array}$ \\
\hline $\mathrm{Mx}$ & -357 & $-35,538$ & 42,132 & 64,182 \\
\hline
\end{tabular}

Table 3-4: Extreme roll moments on tower bearing in operational condition

\subsection{Loads and bending moments in truss at mid-span}

The bending moments in the truss are built up from a static part and a dynamic part. The maximum static bending moment in the truss is of order $200,000 \mathrm{kNm}$ (sagging) and is located at about midspan.

Force transducers on the four longitudinal members of the truss at mid-span have been used to measure the axial loads in the members. From the axial loads in these transducers the total horizontal longitudinal load and the bending moment in two directions can be computed in two directions. Shear loads have not been measured.

\subsubsection{Survival collinear}

The vertical bending moment and longitudinal load are the highest (absolute) in the collinear condition with wave and current coming from the same direction. As can be observed from the time trace extreme vertical bending moment and extreme longitudinal load occurs in some cases simultaneously, see Table 3-5.

\begin{tabular}{|l|c|c|c|c|}
\cline { 2 - 5 } \multicolumn{1}{c|}{} & \multicolumn{4}{c|}{ Extreme survival bending moment } \\
\cline { 2 - 5 } \multicolumn{1}{c|}{} & $\begin{array}{c}\text { Maximum 1 } \\
\text { [kNm] }\end{array}$ & $\begin{array}{c}\text { Maximum 2 } \\
\text { [kNm] }\end{array}$ & $\begin{array}{c}\text { Minimum 1 } \\
\text { [kNm] }\end{array}$ & $\begin{array}{c}\text { Minimum 2 } \\
\text { [kNm] }\end{array}$ \\
\hline Bending Y-moment & 274,004 & 265,241 & $-206,094$ & $-198,124$ \\
\hline Associated Z-moment & 7,696 & 6,523 & 36,911 & 18,334 \\
\hline Associated load Fx & 10,053 & 9,385 & 657 & $-2,960$ \\
\hline
\end{tabular}

Table 3-5: Bending moments in collinear survival condition 


\subsubsection{Survival cross current}

The extreme horizontal transverse loads (all minimum values) occur in the survival cross current condition. In this condition the current drives the truss arm in a position almost perpendicular to the waves. Vertical bending moment and longitudinal load are less than in co-linear conditions, see Table 3-6.

\begin{tabular}{|l|c|c|c|c|}
\cline { 2 - 5 } \multicolumn{1}{c|}{} & \multicolumn{4}{c|}{ Extreme survival bending moment } \\
\cline { 2 - 5 } & $\begin{array}{c}\text { Minimum 1 } \\
\text { [kNm] }\end{array}$ & $\begin{array}{c}\text { Minimum 2 } \\
\text { [kNm] }\end{array}$ & $\begin{array}{c}\text { Minimum 3 } \\
\text { [kNm] }\end{array}$ & $\begin{array}{c}\text { Minimum 4 } \\
\text { [kNm] }\end{array}$ \\
\hline Bending Z-moment & $-487,400$ & $-474,242$ & $-427,255$ & $-175,786$ \\
\hline Associated Y-moment & $-29,592$ & $-179,231$ & $-219,143$ & $-218,867$ \\
\hline Associated load Fx & 2,378 & 434 & 822 & $-2,364$ \\
\hline
\end{tabular}

Table 3-6: Bending moments in cross current survival condition

\subsubsection{Operational}

As can be expected the vertical bending moment, My, is significantly lower in operational conditions than in the above displayed survival conditions. The bending moment in the horizontal plane, $\mathrm{Mz}$, is determined in operational conditions mainly by the hawser and DP loads, survival conditions remain governing however, see Table 3-7.

\begin{tabular}{|c|c|c|}
\hline \multicolumn{3}{|c|}{$\begin{array}{c}\text { Extreme operational bending } \\
\text { moment }\end{array}$} \\
\hline Load & $\begin{array}{c}\text { Minimum } \\
\text { [kNm] }\end{array}$ & $\begin{array}{c}\text { Maximum } \\
\text { [kNm] }\end{array}$ \\
\hline $\mathrm{My}$ & $-67,646$ & 50,378 \\
\hline $\mathrm{Mz}$ & $-69,944$ & 12,290 \\
\hline
\end{tabular}

Table 3-7: Typical maximum bending moment in operational condition

\subsection{Hawser loads}

The operational environmental conditions have been chosen such that high operational uptime can be assured. Standard OCIMF bow hawser stoppers are assumed sufficient to moor the LNG shuttle tankers and to keep the adjustments to these vessels as minimal as possible. The maximum measured hawser load of $1,779 \mathrm{kN}$ confirms this assumption. 


\section{Motions}

\subsection{Relative wave height}

\subsubsection{Survival conditions}

In the survival conditions, several breaking waves have been observed. The presented relative waveheights are considered the maximum non-breaking relative wave-heights, calculated from the measured relative wave-height during the model tests, see Table 4-1. Relative Wave Probe in (RWP in) is located at the tower, RWP mid at the mid-span of the truss and RWP out at the buoyancy column. The freeboard of the truss at the tower is about 10 meters, which results in submergence of the truss at the tower of half a meter. Relative wave heights at the mid-span of the truss are smaller because the truss is somewhat in the shelter of the tower. The truss has a lower freeboard at that point; therefore the wave exceeds the upper longitudinal of the structure up to 1,81 meters. No waves exceed the freeboard of the truss at the buoyancy column.

\begin{tabular}{|l|c|c|}
\hline \multicolumn{2}{|c|}{ Extreme survival relative wave heights } \\
\hline \multicolumn{1}{|c|}{ location } & $\begin{array}{c}\text { Minimum } \\
\text { [m] }\end{array}$ & $\begin{array}{c}\text { Maximum } \\
\text { [m] }\end{array}$ \\
\hline Tower & -6.47 & 10.35 \\
\hline mid-span & -7.28 & 8.81 \\
\hline Buoyancy column & -3.83 & 6.07 \\
\hline
\end{tabular}

Table 4-1: Calculated extreme relative non-breaking-wave heights in survival conditions

\subsubsection{Operational conditions}

In operational conditions only the relative wave heights at the buoyancy column will be discussed. These relative wave heights may be of importance when the flexible transfer pipes have to remain clear of contact with waves. The presented extreme relative wave heights in Table 4-2 have been taken directly from the model test results.

\begin{tabular}{|c|c|}
\hline \multicolumn{2}{|c|}{$\begin{array}{c}\text { Extreme operational relative wave } \\
\text { heights }\end{array}$} \\
\hline \multicolumn{2}{|c|}{ RWP out } \\
\hline $\begin{array}{c}\text { Minimum } \\
\text { [m] }\end{array}$ & $\begin{array}{c}\text { Maximum } \\
\text { [m] }\end{array}$ \\
\hline-2.98 & 5.02 \\
\hline
\end{tabular}

Table 4-2: Extreme relative wave heights in operational conditions

\subsection{Relative motions}

It is noted that the relative motions between Big Sweep and Tanker, discussed in the following sections, do not include any differences in size of the tankers berthing the terminal facility. 


\subsubsection{Big Sweep - Tanker separation}

The horizontal arm-ship separation is both low and high frequency driven. The vertical relative motion is mainly a wave frequent phenomenon. Measured low frequent motions during the model tests have found to be larger than the wave frequent motions. Low frequency transverse motions may be suppressed by dynamic positioning control, in longitudinal direction stern thrust could suppress the low frequent motions.

\subsubsection{Transverse}

Optimising the DP system has not been a scope of the performed model tests. As a consequence, the low frequency arm-ship separation measurements do not provide us with any results for direct use in the design. The high (wave) frequency arm-ship separation can be found in Table 4-3. To what extend the low frequency separation can be minimised depends on the type DP control system.

High frequency extreme transverse Arm-Ship
separation
\begin{tabular}{|c|c|c|c|}
\hline $\begin{array}{c}\text { Mean } \\
\text { [m] }\end{array}$ & $\begin{array}{c}\text { Minimu } \\
\mathbf{m} \\
{[\mathbf{m}]}\end{array}$ & $\begin{array}{c}\text { Maximum } \\
\text { [m] }\end{array}$ & $\begin{array}{c}\text { Double } \\
\text { Amplitude } \\
\text { [m] }\end{array}$ \\
\hline 33 & 31.3 & 34.1 & 2.8 \\
\hline
\end{tabular}

Table 4-3: High frequency extreme arm-ship separation

\subsubsection{Longitudinal}

As substantiated above, low frequency motions in the y-direction from the model tests can be discarded because of the simple DP system during the model tests. Another simplification in the model tests is that the tests have been performed without stern thrust, which will be available in actual operation activities. The absence of stern thrust results in a modest yaw or fishtailing motion in the milder environmental conditions tested.

The relative motions in the longitudinal $x$-direction shown in Table 4-4 still give, apart from this stern thrust influence, a good indication of the actual longitudinal relative motions. Extended analyses will however be needed on the berthing of vessels of variable dimensions, related hawser length and stern thrust.

\begin{tabular}{|c|c|c|}
\hline \multicolumn{3}{|c|}{ Extreme longitudinal envelope } \\
\hline $\begin{array}{c}\text { Minimum } \\
\text { [m] }\end{array}$ & $\begin{array}{c}\text { Maximum } \\
\text { [m] }\end{array}$ & $\begin{array}{c}\text { Envelope } \\
\text { [m] }\end{array}$ \\
\hline 0.25 & 11.03 & 10.78 \\
\hline
\end{tabular}

Table 4-4: Extreme relative positions in $x$-direction 


\subsubsection{Vertical}

The (wave frequency) motions in z-direction of both bodies in operational conditions are small, see Table 4-5.

\begin{tabular}{|l|c|c|c|}
\hline \multicolumn{4}{|c|}{ z-motion } \\
\hline Signal & $\begin{array}{c}\text { Minimum } \\
\text { deviation } \\
{[\mathbf{m}]}\end{array}$ & $\begin{array}{c}\text { Maximum } \\
\text { deviation } \\
{[\mathbf{m}]}\end{array}$ & $\begin{array}{c}\text { Envelope } \\
\text { [m] }\end{array}$ \\
\hline Buoyancy column & -1.97 & 2.53 & \multirow{2}{*}{3.1} \\
\hline Ship manifold & -0.53 & 0.35 & \\
\hline
\end{tabular}

Table 4-5: Extreme (relative) positions in z-direction

It is noted that for the required stroke of the transfer system in vertical directions, also the draft range of the LNG carriers have to be taken into account, as well as the depth variation of the different carriers. 


\section{$5 \quad$ Recommendations}

To obtain a (better) general understanding of the complex hydrodynamic aspects involved in the loads on the Big Sweep a thorough hydrodynamic analysis including a sensitivity study is required. This study should cover the effects of buoyancy box and other member size variation on the loads on the structure.

An analysis should also be performed on the possibilities to suppress low frequency relative motions using a DP system. This analysis should involve a review of available control systems as well as required thrust.

The Big Sweep LNG offloading terminal is designed to berth LNG shuttle tankers of opportunity. This requires mooring analyses on a range of vessels with varying length and displacement. Hawser length variation and stern thrust should be included in these analyses.

The acquisition of site specific metoœan data should give more information about the maximum relative wave height and other aspects involved in the design details. 


\section{Piping Design Philosophy}

Doc. No. CGI-P-840-RP-0001 Rev. A

Project. No. 1-0282-0 


\section{Revision Status Sheet}

Rev.

Date

A

14-07-2004

\section{Description}

Initial Issue
Initiator

JVMA

\section{Date}

December 2004

Initials

Checked by

Approved by
December 2004

HVDB

\section{JWEV}

Y:\1_PROJS\1-0282-0;Doc\P0001 Rev A - Piping Design Philosophy.doc
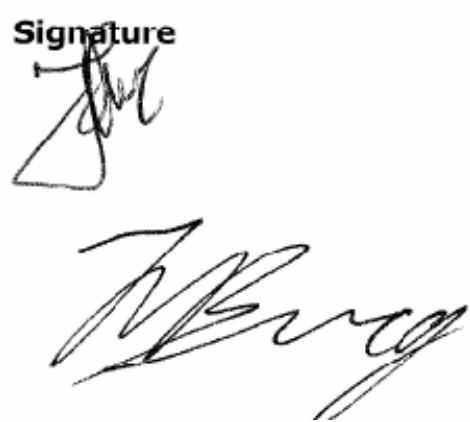


\section{Table of Contents}

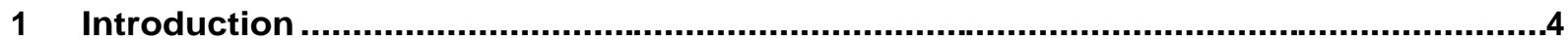

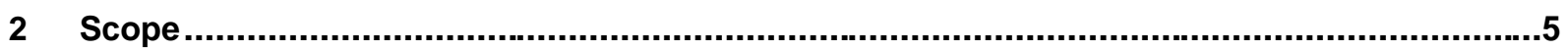

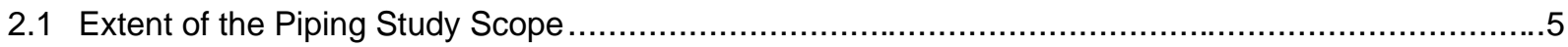

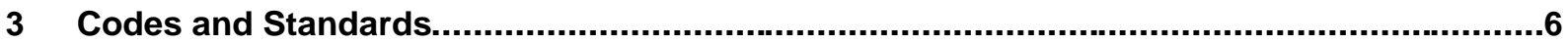

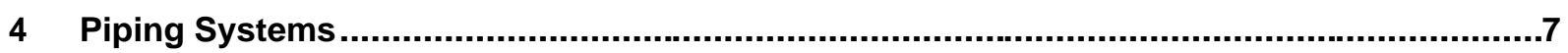

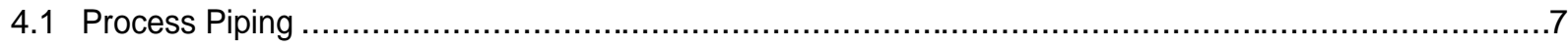

4.1.1 Pressure

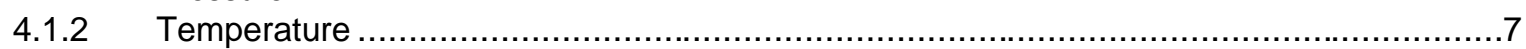

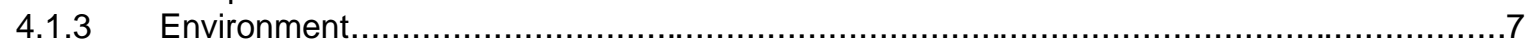

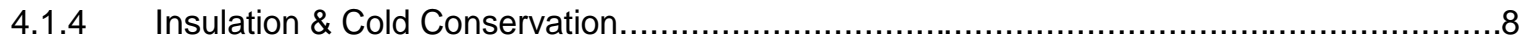

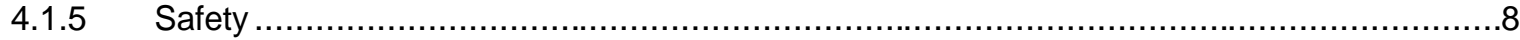

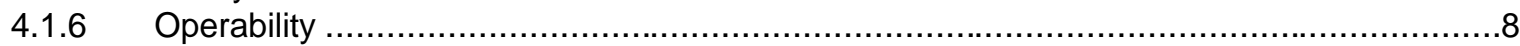

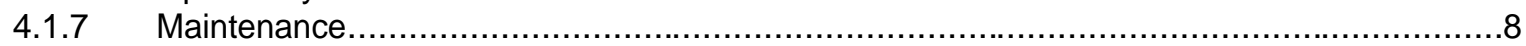

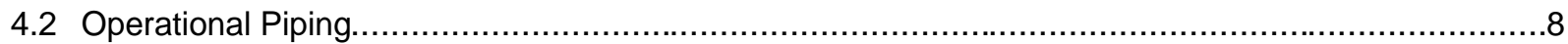

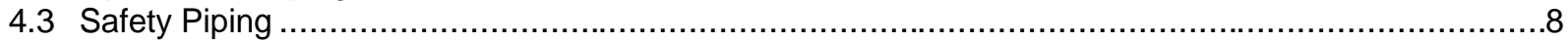

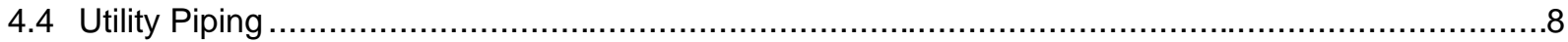

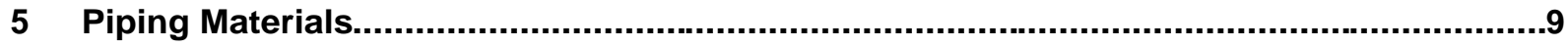

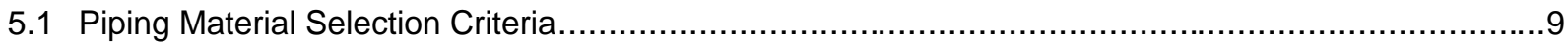

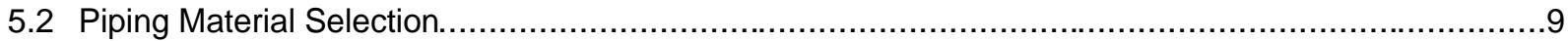

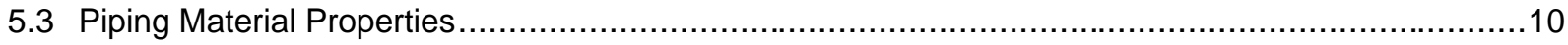

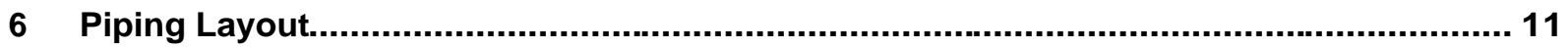

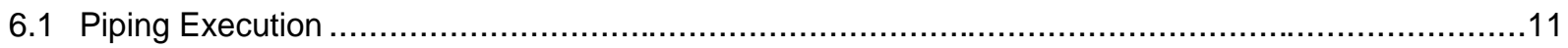

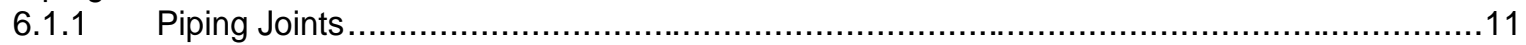

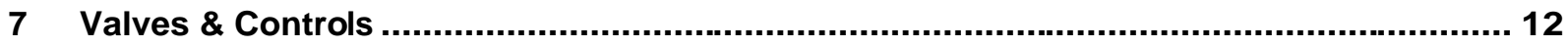

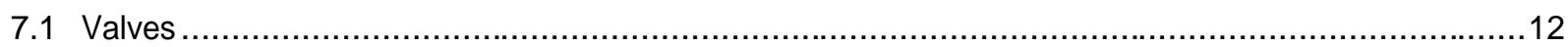

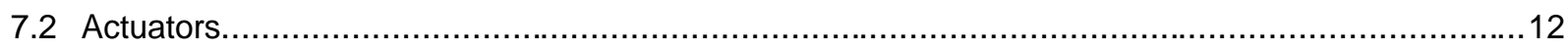

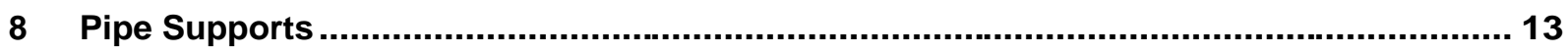

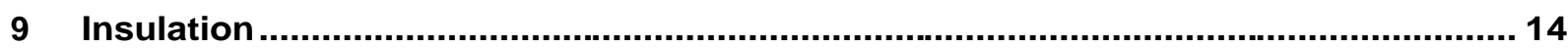

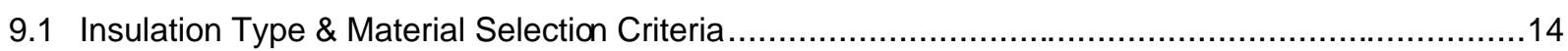

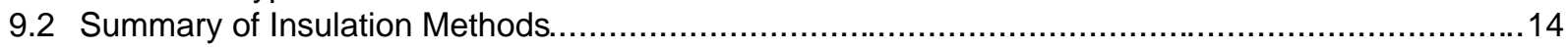

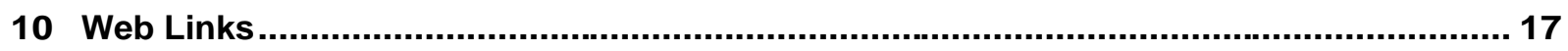

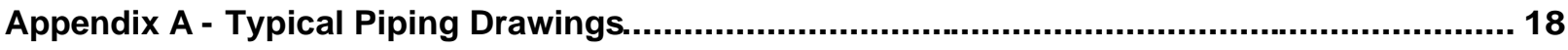

Appendix B - Typical Examples of Cryogenic Valves Cryogenic Pipe Supports Cold Insulation 21 


\section{Introduction}

Bluewater participates, as a subcontractor of Conversion Gas Imports (CGl), in a conceptual design study for an offshore LNG terminal located in the USGulf of Mexico.

A terminal concept for shallow waters was selected for further engineering development. This conceptual design study is further referred to as 'Big Sweep'.

The function of the Big Sweep system is to provide an offshore 'single point' mooring facility for LNG carriers and to facilitate offshore LNG transfer. The system comprises of a piled geo-static tower structure with a hinged and weathervaning arm which includes a loading hose handling station, a tanker mooring arrangement, LNG transfer systems and a vapour return system.

The study project includes a Basis of Design, System Philosophies and gives functional descriptions of the Big Sweep components and systems.

This 'Piping Design Philosophy' summarises a number of options and recommendations for e.g. piping material selection, insulation types, piping execution, layout, etc. 


\section{Scope}

The overall piping scope will include all piping systems that are to be used for LNG transportation, operations, safety and utilities required for the operation of the facility.

The piping scope for LNG transfer on the 'Big Sweep' arrangement is defined between the 'existing' LNG carrier manifold and the sub-sea pipeline connection flanges at the base of the geo-static tower. Modifications and/or extensions to the existing carrier manifold are also considered to be part of the piping scope.

\subsection{Extent of the Piping Study Scope}

The 'piping' involvement in the study for the 'Big Sweep' LNG Offloading will include the following:

- $\quad$ Piping material selection/recommendation for the LNG transportation and Vapour return lines

- Piping insulation type and material selection/recommendation for cryogenic applications (topside)

- Piping insulation selection/recommendation for 'submerged' cryogenic applications, referring to the submerged section of the geo-static tower (HOLD for insulation type selection of the submarine pipelines)

- Definition of a basic piping layout and design basis for transitions to/from the geo-static tower and routing requirements to from the offloading connections at the carrier manifold.

- Preparation of a conceptual pipe stress report with alternative recommendations for taking the pitch of the 'sweep' arm by e.g. deflection of the pipes (see doc. no.CGI-P-840-CA-0101). 


\section{Codes and Standards}

The following Codes and Standards have been considered for the design of the 'Big Sweep' process and utility piping systems:

International Codes

\begin{tabular}{|l|l|}
\hline API RP 14E & $\begin{array}{l}\text { Recommended Practice for Design and Installation of } \\
\text { Offshore Production Platform Piping Systems }\end{array}$ \\
\hline ASME B31.4 & $\begin{array}{l}\text { Pipeline Transportation Systems for Liquid Hydrocarbons } \\
\text { and Other Liquids }\end{array}$ \\
\hline & \\
\hline
\end{tabular}

International Standards

\begin{tabular}{|l|l|}
\hline NFPA 59A - 2001 & $\begin{array}{l}\text { Standard for the Production, Storage and Handling of } \\
\text { Liquefied Natural Gas (LNG) }\end{array}$ \\
\hline ISO 14313 & $\begin{array}{l}\text { Petroleum and Natural Gas Industries - Pipeline } \\
\text { Transportation systems - Pipeline Valves }\end{array}$ \\
\hline ISO 14723 & $\begin{array}{l}\text { Petroleum and Natural Gas Industries - Pipeline } \\
\text { Transportation systems - Subsea Pipeline Valves }\end{array}$ \\
\hline ASME B16.5 & Pipe Flanges and Flanged Fittings - NPS 1/2 through NPS 24 \\
\hline ASME B16.9 & Factory-Made Wrought Steel Buttwelding Fittings \\
\hline ASME B16.10 & Face-to-Face and End-to-End Dimensions of Valves \\
\hline ASME B16.11 & Forged Fittings, Socket Welding and Threaded \\
\hline ASME B16.20 & $\begin{array}{l}\text { Metallic Gaskets for Pipe Flanges - Ring Joint, Spiral-Wound } \\
\text { and Jacketed }\end{array}$ \\
\hline ASME B16.21 & Non-metallic Gaskets for Pipe Flanges \\
\hline ASME B16.34 & Valves - Flanged, Threaded and Welding End \\
\hline ASME B16.47 & Large Diameter Steel Flanges - NPS 26 through NPS 60 \\
\hline ASME B36.10 & Welded and Seamless Wrought Steel Pipe \\
\hline ASME B36.19 & Stainless Steel Pipe \\
\hline & \\
\hline
\end{tabular}




\section{$4 \quad$ Piping Systems}

The 'Big Sweep' facility comprises several piping systems:

- $\quad$ Process (LNG transfer and Vapour return, Seawater, Purge, Drain, etc.)

- Operational (e.g. Ballast system, etc.)

- Safety (Firewater, Foam), if considered required.

- Utilities (Air, Nitrogen, Hydraulic Oil, etc.)

\subsection{Process Piping}

The process piping systems for the transportation and handling of LNG on the 'Big Sweep' facility are the main subject of this study report.

When designing the LNG transfer piping systems, the following aspects shall be taken into account to obtain an operational and maintainable system that suits the requirements of the facility. These criteria are o.a.:

- Pressure

- Temperature fluctuations (LNG transfer and ambient conditions)

- Environmental conditions (Offshore location and weather conditions)

- Insulation type (Cold conservation, environmental suitability)

- Safety

- Operability

- Maintenance (Accessibility of piping, valves and other equipment)

\subsubsection{Pressure}

The LNG transfer system shall be executed as ASME Class 150 rated, based on the LNG transfer pressure of 6 barg. Actual design pressure is subject to the final material and component selection.

\subsubsection{Temperature}

The operational temperature for the $L N G$ handling is set at $-164^{\circ} \mathrm{C}$. The environmental temperature is assumed to be max. $35{ }^{\circ} \mathrm{C}$. The difference in temperatures shall be taken in account in the design of the systems with respect to expansion of the lines when warming up and retraction of the lines when cooling down during operation.

The normal operation of the facility includes the circulation of LNG during the periods that no actual offloading takes place. This to prevent product loss between and at commence of the offloading operations.

\subsubsection{Environment}

The environment in which the 'Big Sweep' will operate is to be considered as an exposed marine environment. Weather and sea conditions shall be taken in account for when designing the piping systems, with respect to e.g.:

- Wave slam (green water)

- Wind (hurricanes, cyclones) 
These considerations shall lead to detailed studies regarding:

- Piping material selection

- Corrosion protection

- Insulation type selection

- Supporting

\subsubsection{Insulation \& Cold Conservation}

The type of insulation that will be applied for cold conservation on the LNG lines will have impact on the piping design philosophy. Criteria that shall be taken into consideration are e.g.:

- External diameter (to be minimised)

- Weight

- Compatibility with piping materials

- $\quad$ Supporting (cold bridges)

- Dissimilar expansion (in case of pipe-in-pipe)

\subsubsection{Safety}

The piping design shall include safety with respect to lay-out and selection of materials.

\subsubsection{Operability}

The piping design shall be such that easy and safe access is provided to valves and equipment that require to be operated.

\subsubsection{Maintenance}

The piping design and overall facility lay-out shall be such that easy and safe access is provided to allow for normal maintenance, inspection and exchange of equipment, valves and instruments.

\subsection{Operational Piping}

Operational piping systems like seawater ballast lines etc are not further detailed in this study report.

\subsection{Safety Piping}

Safety piping systems are limited to seawater Fire-fighting systems (if required) and are not further detailed in this study report.

\subsection{Utility Piping}

Utility piping for normal operation of the facility is excluded from this study report. 


\section{$5 \quad$ Piping Materials}

\subsection{Piping Material Selection Criteria}

The selection of materials that may be used for transportation of Liquefied Natural Gas (LNG) shall be based on the following 'minimal' criteria:

- $\quad$ LNG Transfer Temperature $\left(-164^{\circ} \mathrm{C}\right)$

- Mechanical strength (internal pressure and deflection due to o.a. thermal expansion)

- Chemical resistance (composition of the medium)

- Marine industry practice

- Environmental suitability (marine salt laden atmosphere)

- Conservation (coating, corrosion protection, etc.)

- $\quad$ Ease of Construction/Welding (future extensions, field modifications)

- $\quad$ Availability (e.g. world market for nickel)

- History of similar applications

- Recognised standards

- Weight (minor impact)

- Total installed cost

\subsection{Piping Material Selection}

\section{A333-Gr.8}

This is $9 \% \mathrm{Ni}$ alloy steel with good qualifications for cold applications. It has significant better mechanical properties than stainless steel.

\section{AISI 316(L)}

This is an austenitic stainless steel with excellent qualifications for cold applications. Molybdenum (Mo) gives a higher resistance to general corrosion, pitting and crevice corrosion. 'L' Grade has a lower Carbon content and an improved welding ability. It has also an improved resistance to pitting and crevice corrosion in chloride bearing environments.

\section{Invar 36}

This is a special $36 \% \mathrm{Ni}$ alloy with an extreme low coefficient of linear expansion @ 20-90 ${ }^{\circ} \mathrm{C}(1.7-2.0$ $\left.{ }^{*} 10^{-6} /{ }^{\circ} \mathrm{C}\right)$ compared with the considerable higher figures of e.g. SS316 $\left(15.0{ }^{*} 10^{-6} /{ }^{\circ} \mathrm{C}\right)$ and LTCS $\left(11.0^{*} 10^{-6} /{ }^{\circ} \mathrm{C}\right)$. This implicates that the contraction at LNG transfer temperature is limited to approx. $0.3 \mathrm{~mm} / \mathrm{m}$ and thus limiting the number and size of expansion loops in the piping layout.

Application of Invar $36^{\circledR}$ shall require extensive investigations with respect to e.g. weldability, corrosion resistance and total installed cost. 


\subsection{Piping Material Properties}

Piping Materials (B31.3, Table A-1)

\begin{tabular}{|c|c|c|c|c|c|c|c|}
\hline Standard & $\begin{array}{l}\text { Chem. } \\
\text { Comp. }\end{array}$ & $\begin{array}{c}\text { P or S } \\
\text { Nr. }\end{array}$ & Type & Product & $\begin{array}{l}\text { Temp. } \\
\text { Limit. } \\
{ }^{\circ} \mathbf{C}\left({ }^{\circ} \mathrm{F}\right)\end{array}$ & $\begin{array}{c}\text { Tensile } \\
\mathbf{N} / \mathbf{m m}^{2} \\
\text { (ksi) }\end{array}$ & $\begin{array}{c}\text { Yield } \\
\mathrm{N} / \mathrm{mm}^{2} \text { (ksi) }\end{array}$ \\
\hline \multicolumn{8}{|l|}{$\begin{array}{l}\text { Low \& } \\
\text { Intermediate } \\
\text { Alloys }\end{array}$} \\
\hline ASTM A333-Gr.8 & $9 \mathrm{Ni}$ & $11 \mathrm{~A}$ & $\mathrm{AL}$ & Pipe & $-196(-320)$ & $689(100)$ & $517(75)$ \\
\hline $\begin{array}{l}\text { ASTM A553-Type } \\
1\end{array}$ & $9 \mathrm{Ni}$ & $11 \mathrm{~A}$ & $\mathrm{AL}$ & Plate & $-196(-320)$ & $689(100)$ & $586(85)$ \\
\hline $\begin{array}{l}\text { ASTM A522-Type } \\
1\end{array}$ & $9 \mathrm{Ni}$ & $11 \mathrm{~A}$ & AL & Forging & $-196(-320)$ & $689(100)$ & $517(75)$ \\
\hline ASTM A420-WPL8 & $9 \mathrm{Ni}$ & $11 \mathrm{~A}$ & AL & Fitting & $-196(-320)$ & $785(110)$ & $517(75)$ \\
\hline \multicolumn{8}{|l|}{ Stainless } \\
\hline $\begin{array}{l}\text { ASTM A312- } \\
\text { TP316L }\end{array}$ & $\begin{array}{l}18 \mathrm{Cr}-10 \mathrm{Ni}- \\
2 \mathrm{Mo}\end{array}$ & 8 & AS & Pipe & $-254(-425)$ & $483(70)$ & $172(25)$ \\
\hline ASTM A240-316L & $\begin{array}{l}18 \mathrm{Cr}-10 \mathrm{Ni}- \\
2 \mathrm{Mo}\end{array}$ & 8 & AS & Plate & $-254(-425)$ & $483(70)$ & $172(25)$ \\
\hline ASTM A182-F316L & $\begin{array}{l}18 \mathrm{Cr}-10 \mathrm{Ni}- \\
2 \mathrm{Mo}\end{array}$ & 8 & AS & Forging & $-198(-325)$ & $483(70)$ & $172(25)$ \\
\hline $\begin{array}{l}\text { ASTM A403- } \\
\text { WP316L }\end{array}$ & $\begin{array}{l}18 \mathrm{Cr}-10 \mathrm{Ni}- \\
2 \mathrm{Mo}\end{array}$ & 8 & AS & Fitting & $-254(-425)$ & $483(70)$ & $172(25)$ \\
\hline ASTM A351-CF8M & $\begin{array}{l}18 \mathrm{Cr}-10 \mathrm{Ni}- \\
2 \mathrm{Mo}\end{array}$ & 8 & AS & Casting & $-254(-425)$ & $483(70)$ & $172(25)$ \\
\hline \multicolumn{8}{|l|}{ Bolting } \\
\hline ASTM A320-B8 & & & & Bolts & $-198(-325)$ & $862(125)$ & $689(100)$ \\
\hline ASTM A194-8 & & & & Nuts & $-254(-425)$ & & \\
\hline
\end{tabular}

Piping Materials (Not listed)

\begin{tabular}{|l|l|l|l|l|l|l|l|}
\hline \multicolumn{1}{|c|}{ Standard } & $\begin{array}{c}\text { Chem. } \\
\text { Comp. }\end{array}$ & $\begin{array}{c}\text { P or S } \\
\text { Nr. }\end{array}$ & Type & Product & $\begin{array}{c}\text { Temp. } \\
\text { Limit. } \\
{ }^{\circ} \mathbf{C}\left({ }^{\circ} \mathbf{F}\right)\end{array}$ & $\begin{array}{c}\text { Tensile } \\
\mathbf{N} / \mathbf{m m}^{2} \\
(\mathbf{k s i})\end{array}$ & $\begin{array}{c}\text { Yield } \\
\mathbf{N} / \mathbf{m m}^{2}\end{array}$ \\
\hline High Alloys & & & & & & & \\
\hline Invar $36^{\oplus}$ & $36 \mathrm{Ni}-64 \mathrm{Fe}$ & - & AL & - & & $440(64)$ & $240(35)$ \\
\hline
\end{tabular}

Legend:

AS $=$ Austenitic Stainless Steel

$\mathrm{AL}=\quad$ Low \& Intermediate \& High Alloy 


\section{$6 \quad$ Piping Layout}

The piping on the 'Big Sweep' has basically two main termination points and the system is sub-divided into the geo-static tower part and the dynamic 'sweep' arm.

One termination point is located at seabed level and is connecting the geo-static part of the "Big Sweep' to the sub-sea pipelines to/from the processing platform. Two 24" sub-sea lines are foreseen which will reduce to $2 \times 20$ "before entering the swivel.

The other termination point is the 'dynamic' hose-loading tower that connects the facility to the carrier manifold. Three dynamic connections are foreseen. Two 20" loading connections and one 16" vapour return connection. For the dynamic connections between the carrier manifold and the LNG loading terminal, special cryogenic hoses are foreseen with hydraulic quick connect/disconnectcouplings.

Distinction shall also be made between the 'sub-merged' part of the risers within the geo-static tower, connecting to the 'swivel' and the 'top-side' part between the 'swivel and the carrier manifold.

The LNG transfer between the geo-static tower part and the weathervaning 'sweep' arm is performed by means of a 'two path swivel'.

The 'sweep' arm is hinged to the geo-static tower to allow for an anticipated plus and minus 2.5 degrees movement (pitch) of the arm. The compliant piping, between the arm and the geo-static tower part, shall follow this rotation. The movement of the arm may either be transferred by means of the flexibility of the hard piping (see concept stress report) or alternatively by means of mechanical swivel joints or flexible jumpers.

\subsection{Piping Execution}

\subsubsection{Piping Joints}

LNG piping shall be executed such that potential leak paths are kept to an absolute minimum and should be avoided wherever possible. The type of piping joints shall therefore be carefully selected. Piping joints are o.a.:

- Welded connections (preferred)

- Compact type flange connectors (e.g. Vector/SPO)

- Conventional ASME flanges

- Graylok type clamp connectors 


\section{$7 \quad$ Valves \& Controls}

Valves that are to be used in cryogenic applications (LNG transport, vapour return, blowoff, etc.) shall be of a proven design and shall have a recorded history for similar applications.

\subsection{Valves}

All valves shall be executed with 'vapour chambers' and shall be 'Fire Safe'.

Several types and configurations are available on the cryogenic valve market, eg.:

- Butterfly valves, high performance, double- or triple eccentric metal sealing (preferred for main flow service with reference to size, weight and actuation)

- Ball valves, Full port, Top- or End entry, Metal sealing

- Globe valves (for throttling service, max. 14")

- Gate valves (general utility service, drains)

- Check valves (dual disc, swing, piston)

- Control valves

- Safety Relief valves

- Cryogenic valve suppliers with a track record in LNG offloading are o.a.

- Butterfly, Ball, Gate, Globe \& Check: e.g. Velan, Tyco, Dresser, etc.

\subsection{Actuators}

Actuators may be divided into the following categories:

- $\quad$ Emergency Shut-down service (ESD)

- On/off service (ROV/SDV)

- Control service (PCV/TCV/FCV)

Depending on the available power supply, these actuators may be:

- Hydraulic (single or double acting)

- $\quad$ Electric

Actuators for ESD (Spring Return) and SDV (Double acting) service shall be Hydraulic driven.

Actuators for normal control services may be Electric Motor (preferred) or Hydraulic oil pressure driven. Pneumatic actuators are not recommended for the application, due to a.o. their larger volume and vulnerability to internal corrosion.

[Typical examples of cryogenic valves are given in Appendix 'B'] 


\section{$8 \quad$ Pipe Supports}

Pipe supports shall be carefully selected for their application. Since this report is limited to the LNG loading lines, only typical supports for cryogenic service are referred to.

All supports shall be specifically designed for cryogenic service, to minimise the effect of cold-bridges and transfer of heat from the supporing structural steel into the piping.

In addition to the requirements for cryogenic service, the environmental conditions, e.g. salt water, wave slam and wind force, shall also be taken in account.

Cryogenic pipe supports are required to perform two distinct functions:

1. Supporting the pipe by restraining it against static, dynamic and thermally generated loads.

2. Provide a thermal barrier between the product piping and the supporting steel structure.

For the preliminary design basis, the Cryogenic Pipe Support from 'LISEGA ${ }^{\circledR}$ ' have been considered.

a) High Density Polyurethane moulded shapes are used as the insulating barrier between the outer diameter of the product piping and the steel clamp base that performs the actual support function. Cylindrical components are monolithically moulded in 180 deg. segments with overlap steps being machined to suit the main insulation system. The clamp bases can be executed as weight supports, guides, hangers, etc. (Ref. LISEGA product group 56)

b) Densified Wood (Cold block) is the selected option for those locations in the piping system where a higher load capacity is required (e.g. anchors). (Ref. LISEGA product group 56)

c) The application of sliding supports, for piping that is subject to longitudinal displacements, is recommended over the application of 'roller' type supports. Where required, the sliding type supports may be executed with transverse and/or liftoff restraints.

d) The application of stanchions/trunnions made out of pipe shall be avoided.

[Typical examples of cryogenic pipe supports are given in Appendix 'B'] 


\section{Insulation}

\subsection{Insulation Type \& Material Selection Criteria}

The selection of materials and insulation methods that can be used for insulation of the LNG transportation lines on the 'Big Sweep' offloading terminal shall be based on the following 'minimal' requirements:

- Conductivity, convection and radiation

- Mass (volume)

- Weight

- Environmental suitability (offshore, seawater, cyclones)

- Dissimilar expansion between product line and outer protection

- Safety (fire rating, flame spread, smoke generation, toxicity, etc.)

- $\quad$ Supporting

- Total Installed Cost (Materials and Application)

- Maintenance \& Conservation

\subsection{Summary of Insulation Methods}

In order to minimise the 'boil off' rate of the product over the entire complex (terminal, sub-marine pipelines, platforms, etc.), a product comparison has been performed to evaluate the various insulation systems.

Selected methods and makes for cold conservation of the LNG transportation lines are, in order of preference:

Closed Cell 'rubber' wrapping (e.g. Armaflex ${ }^{\circledR}+$ Arma-Chek $R^{\circledR}$ )

This is a Closed Cell Flexible Elastomer, which is adhesive bonded to the product pipe. External protection against mechanical impact, UV-attack and salt water is obtained by means of a synthetic rubber based (EPDM) protective sheet wrapping. The combination of the closedcell insulation material and the protective sheeting is highly flexible, lightweight and easy to install. The visual appearance is 'grey'. The calculated heat flow at $35^{\circ} \mathrm{C}$ ambient temperature is for a NPS 20 (508 OD) pipe * 194 $\mathrm{W} / \mathrm{m}$ when applying a $50 \mathrm{~mm}$ single layer of Armaflex $^{\circledR}$. A $100 \mathrm{~mm}$ double layer results in a heat flow < $109 \mathrm{~W} / \mathrm{m}$.

\section{Advantages:}

- Thermal Conductivity $=0.033 \mathrm{~W} / \mathrm{mK}\left(0.0184 \mathrm{Btu} / \mathrm{ft} \mathrm{hr}{ }^{\circ} \mathrm{F}\right)$

- Excellent performance concerning 'heat leak'

- $\quad$ No additional vapour barrier required (with stainless steel piping)

- Highly flexible (can take both linear contraction and expansion)

- $\quad$ Light weight (compared with systems that require a jacket pipe or external metal sheeting)

- Flame retardant

- Easy installation in situ

- Seawater and UV resistant

- Low maintenance

- Proven technology on e.g. FPSOs and LNG/LPG carriers 


\section{Disadvantages:}

- None known

Nanoporous Gel (e.g. Aspen Aerogel ${ }^{\mathrm{TM}}$ \& Cabot Nanogel ${ }^{\mathrm{TM}}$ ). These are 'nanoporous' insulation materials that are applied to the product pipe in the shape of blankets. The blankets are wrapped around the pipe and fixed by means of tape or wire straps. Pipe plus wrapping is inserted into an external protection sleeve and centered by means of special cryogenic spacers.

\section{Advantages:}

- $\quad$ Thermal Conductivity $=0.012 \mathrm{~W} / \mathrm{m} . \mathrm{K}\left(0.0067 \mathrm{Btu} / \mathrm{ft} \mathrm{hr}{ }^{\circ} \mathrm{F}\right)$

- Cost effective compared with other pipe-in-pipe (vacuum) systems.

- Reduced volume/mass compared with 'common' insulation systems.

\section{Disadvantages:}

- Relatively 'new' technique.

- Dissimilar expansion of product line and protection sleeve to be taken in account.

- Vapour barrier required

Pipe in Pipe incl. PUR (e.g. Logstor ${ }^{\circledR}+$ HDPE Jacket). A Closed Cell Polyurethane Foam is injected into the annulus between the product pipe and the HDPE Jacket.

\section{Advantage:}

- $\quad$ Thermal Conductivity $=0.03 \mathrm{~W} / \mathrm{m} . \mathrm{K}\left(0.0167 \mathrm{Btu} / \mathrm{ft} \mathrm{hr}{ }^{\circ} \mathrm{F}\right)$

- Excellent performance concerning 'heat leak'

- $\quad$ No cold bridges

- Low maintenance

- Water tight

- UV resistant

- Limited dissimilar expansion of product line and external jacket sleeve due to fully bonded system

\section{Disadvantage:}

- Pre-fabrication of insulated pipe spools

'Static' vacuum piping (pipe-in-pipe); factory manufactured/prefabricated pre-vacuum-pulled piping system.

\section{Advantage:}

- Good performance concerning 'heat leak'

- Low maintenance 


\section{Disadvantage:}

- Relatively 'new' for the size of application

- High cost for first installation

- Dissimilar expansion of product line and external jacket sleeve (internal or external bellows required)

'Dynamic' vacuum piping (pipe-in-pipe), continuous vacuum suction of the annulus between the inner product line and the outer jacket sleeve.

\section{Advantage:}

- Good performance concerning 'heat leak'.

\section{Disadvantage:}

- Maintenance cost for continuous vacuum pumps.

- High cost for first installation.

- Dissimilar expansion of product line and external jacket sleeve (internal or external bellows required)

- Highly depending on vacuum pumps functioning.

Common (e.g. Polystyrene Foam blocks or pre-formed mineral wool shapes) insulation and metal sheeting.

\section{Advantage:}

- Cheap

- Fewer problems with dissimilar expansion.

\section{Disadvantage:}

- $\quad$ Large volume/thickness

- Additional vapour barrier required

- Vulnerable, easily damaged (ingress of seawater, loss of insulation, corrosion)

- Cold bridges

[Typical examples of cryogenic insulation types are given in Appendix 'B'] 


\section{Web Links}

Web Links to referenced Manufacturers/Suppliers:

\section{Insulation;}

iwww.armacell.com

iwww. logstor.com

iwww.vjpipe.com

Valves;

r..........

wwww.velan.com

iwww.tyco-valves.com

'wwww.dresser.cond

Pipe Supports;

iwww.lisega.com

www.pipesupports.com

\section{Compact Flanges;}

wwww.vectorint.co.uk.com 
Doc. No. 1-0282-0/CGI-P-840-RP-0001/ Rev A Big Sweep Study Piping Design Philosophy

\section{Appendix A - Typical Piping Drawings}




\section{Typical Piping Layout near the Swivel}

A.1 - Deflection and elongation transferred by the flexibility of the 'hard' pipng

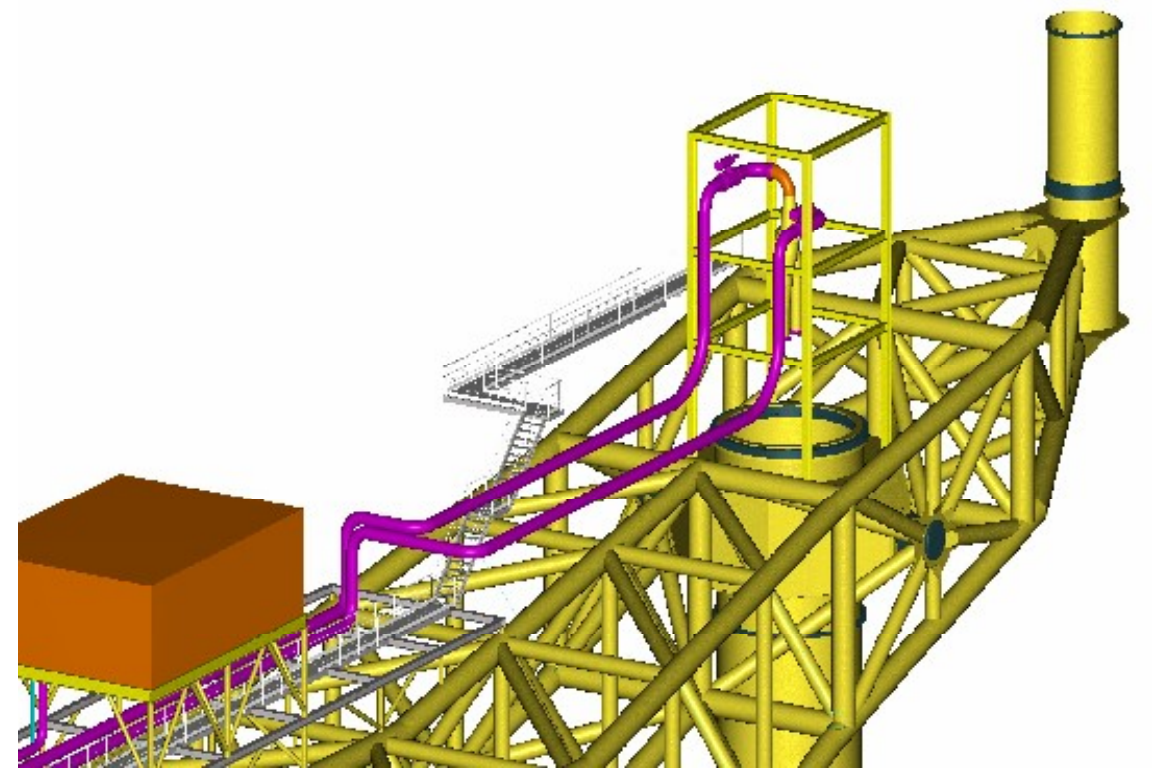

A.2 - Deflection and elongation transferred by mechanical swivel joints

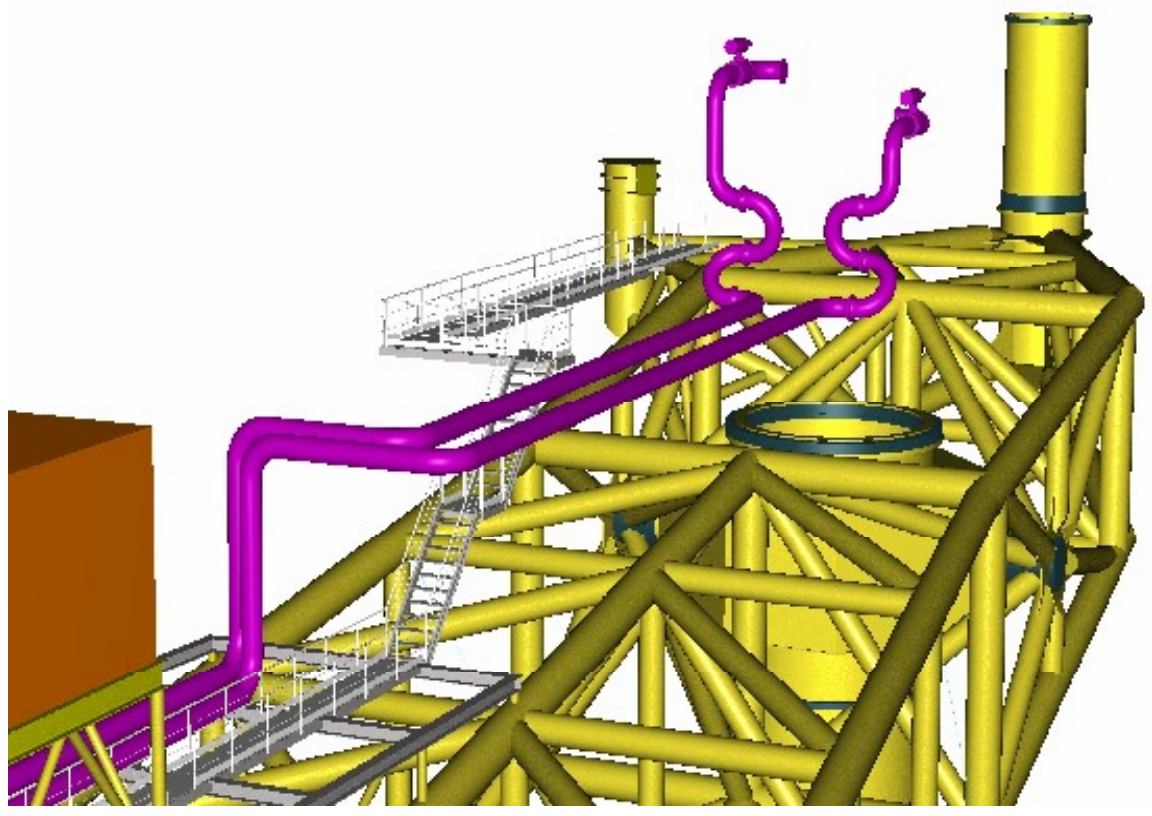


A.3 - Deflection and elongation transferred by means of a 'jumper hose'.

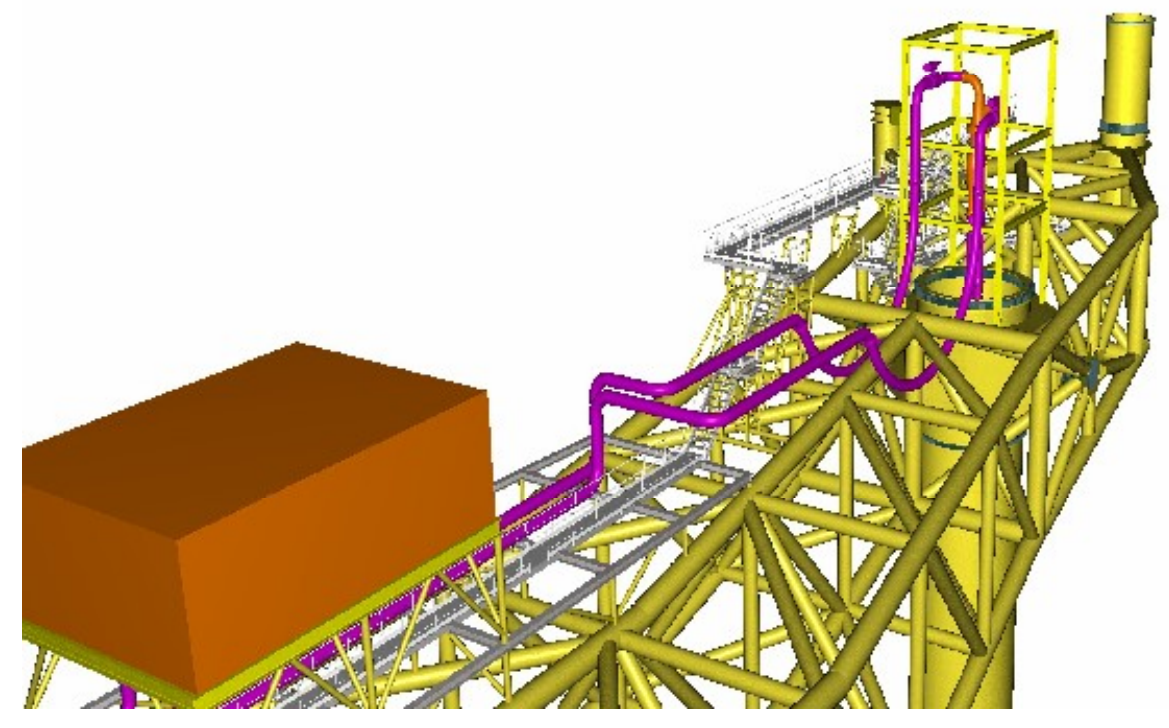




\section{Appendix B - Typical Examples of Cryogenic Valves Cryogenic Pipe Supports Cold Insulation}


Typical examples of Cryogenic valve types

Cryogenic Butterfly valve
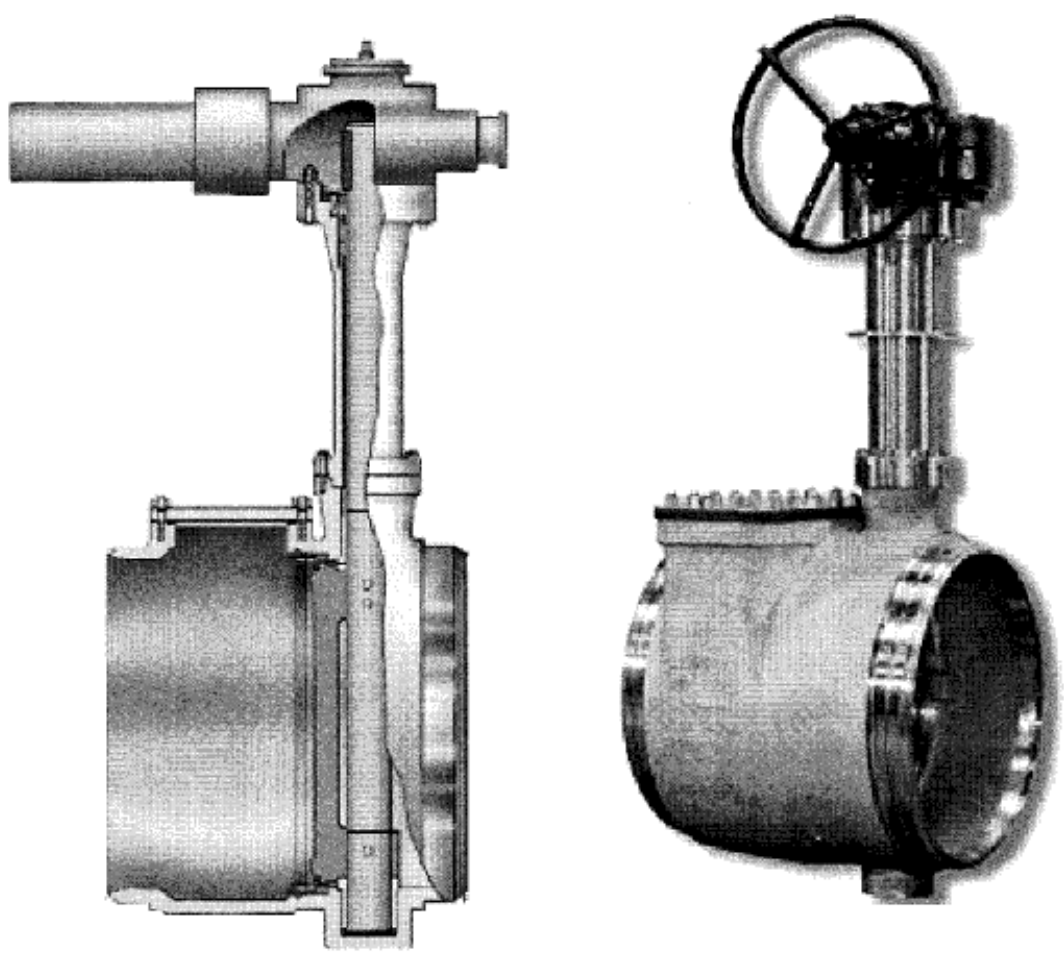

Cryogenic Ball valve

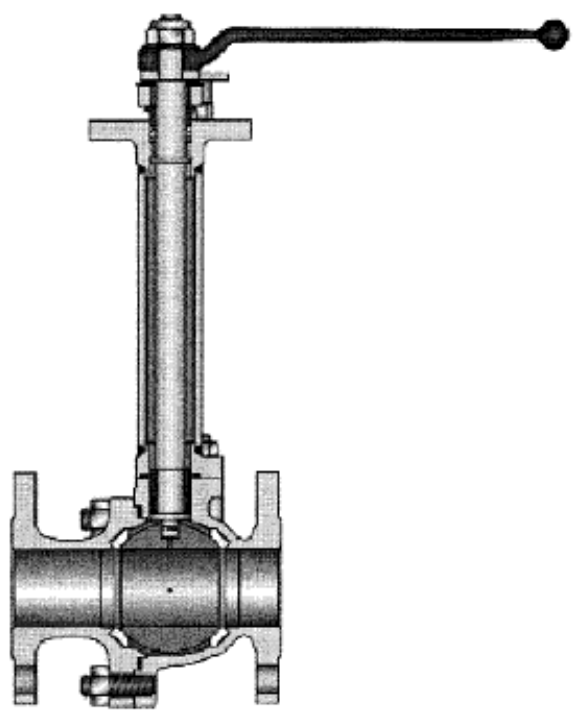

Piping Design Philosophy - Page 22 


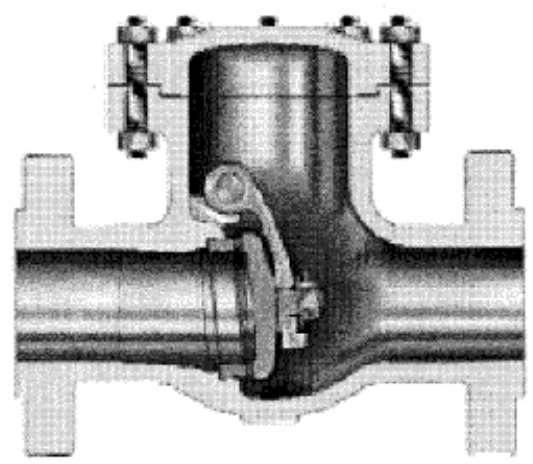

Cryogenic Gate valve $(\mathrm{L})$ \& Globe valve $(\mathrm{R})$
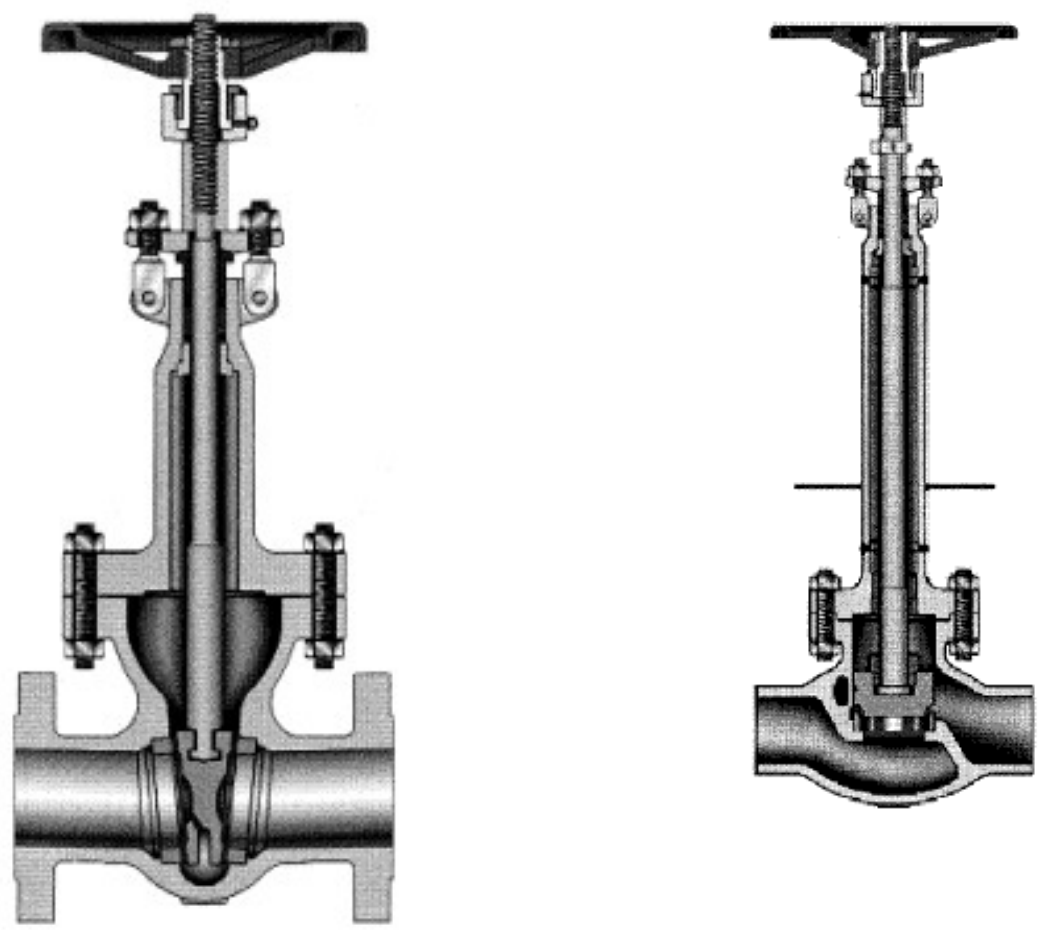


\section{Typical examples of cryogenic pipe supports}

High Density Polyurethane mouldings
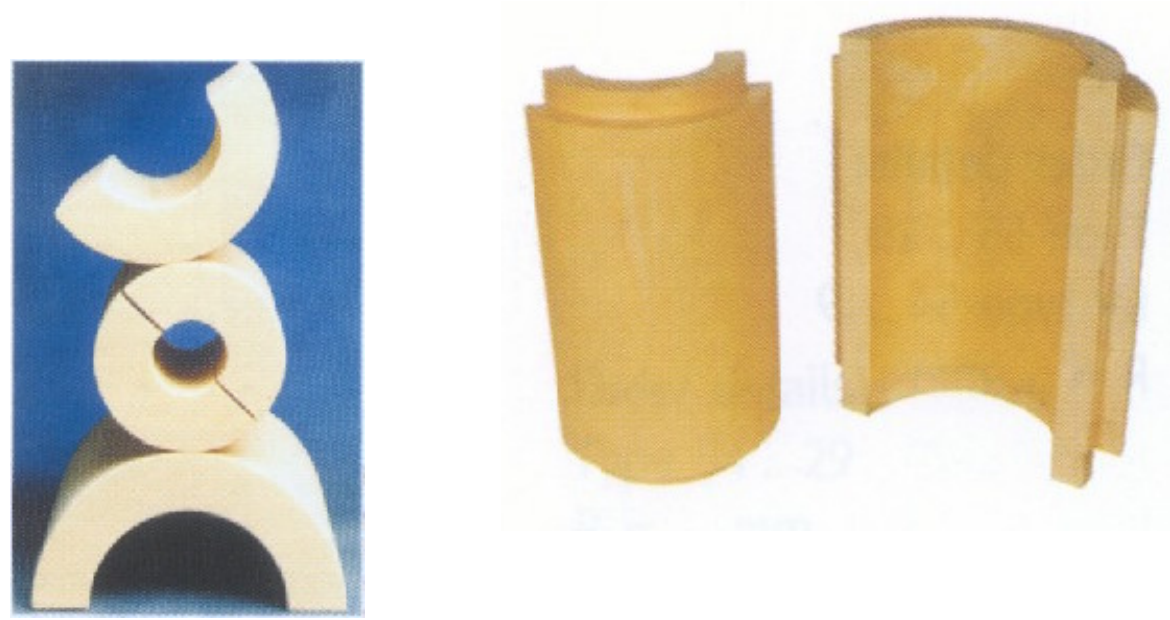

Assemblies
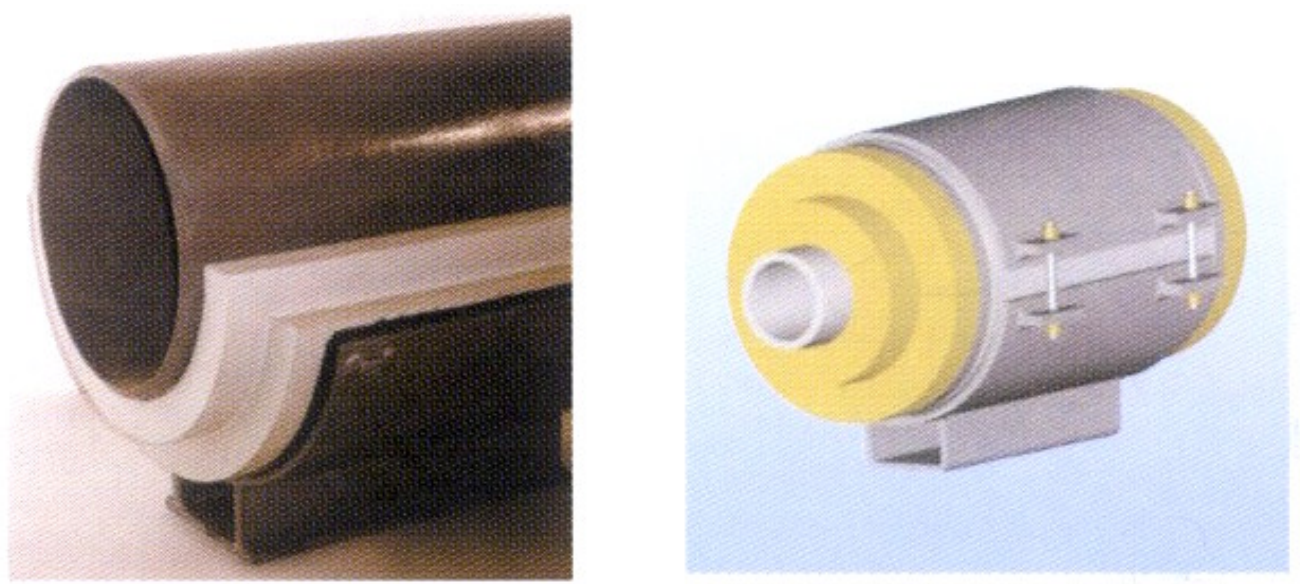


\section{Applications}
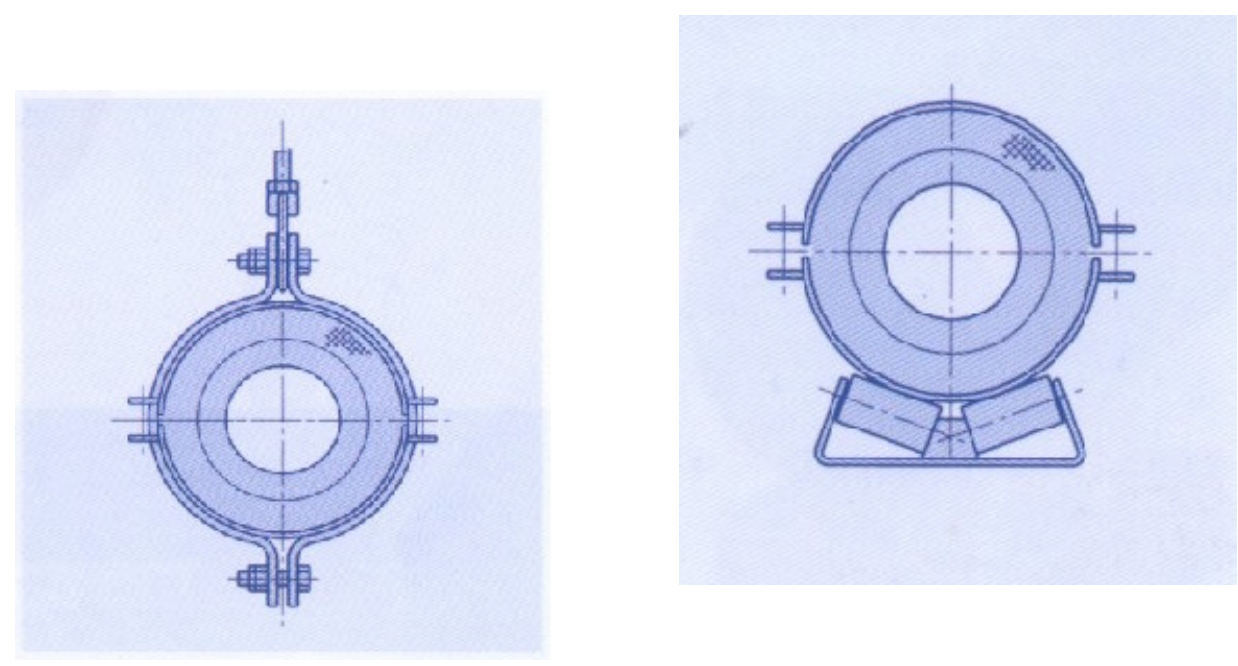

'Cold Block'
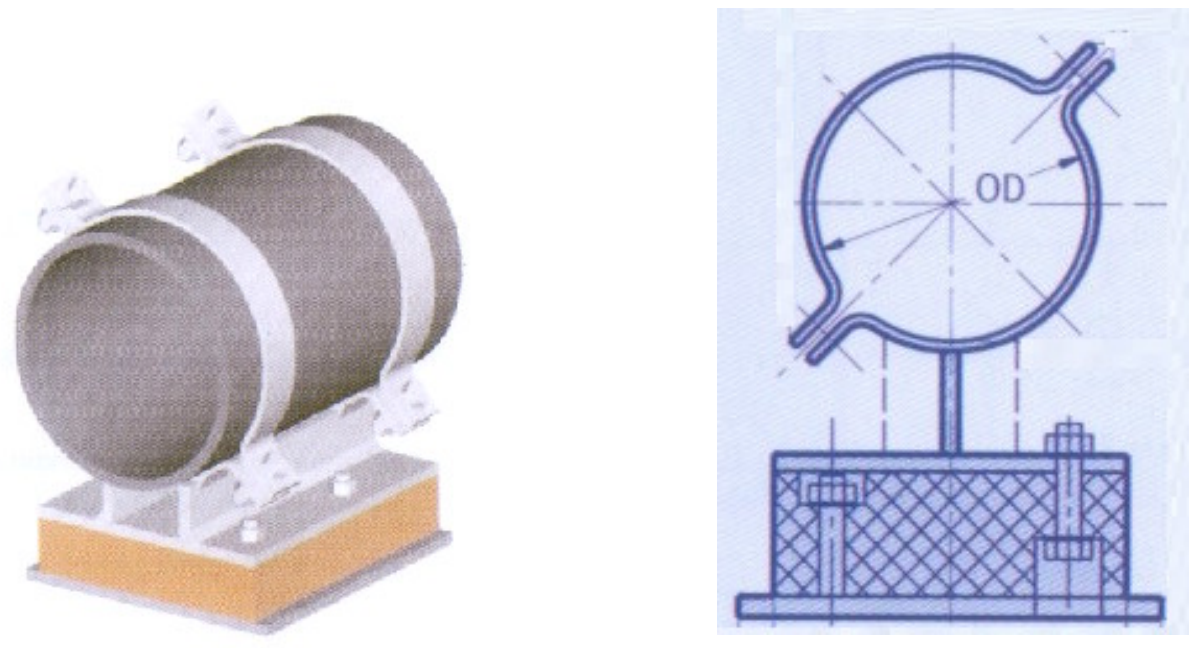
Typical examples of cold conservation/insulation
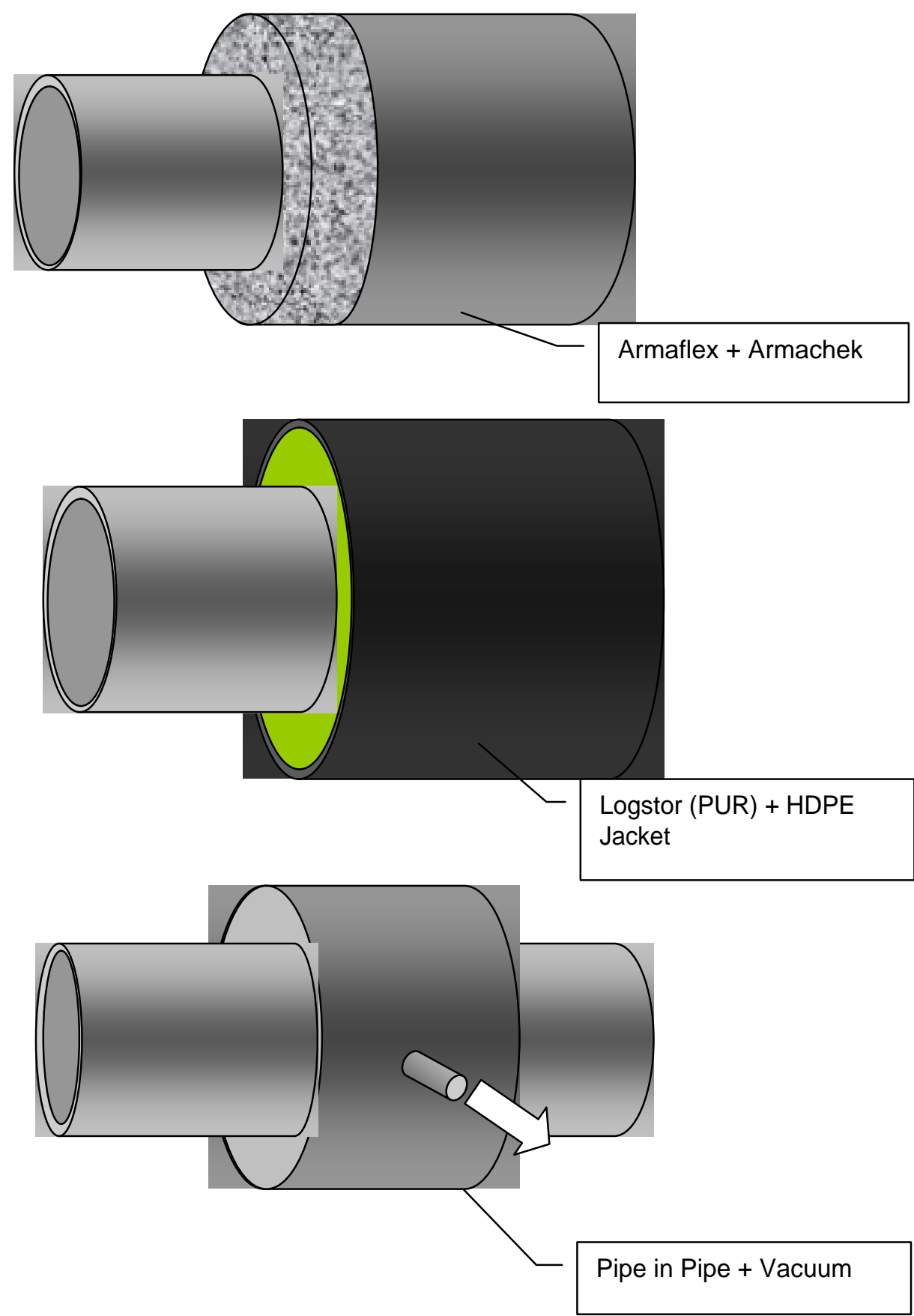


\title{
Calculation
}

\section{Pipe Stress Analysis}

\section{Doc. No. CGI-P-840-CA-0101 Rev. A}

\author{
Project. No. 1-0282-0
}

\author{
Bluewater Energy Services B.V. \\ Marsstraat 33 \\ 2132 HR Hoofddorp \\ The Netherlands \\ Tel. +31235682 800 \\ Fax. +31235652053
}




\section{Revision Status Sheet}

Rev.

$$
\text { Date }
$$

A

09-07-2004

\section{Description}

Initial Issue
Initiator

HK

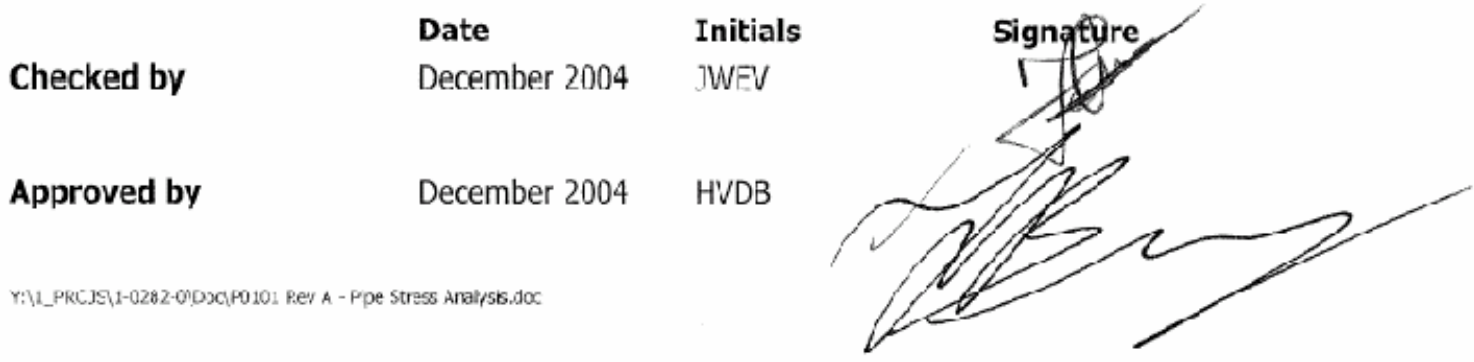

Pipe Stress Analysis - Page 2 


\section{Table of Contents}

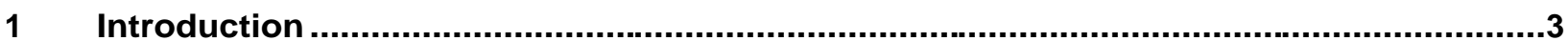

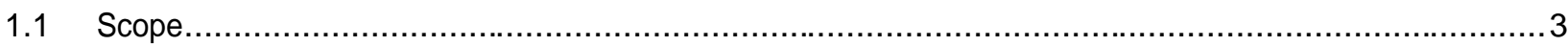

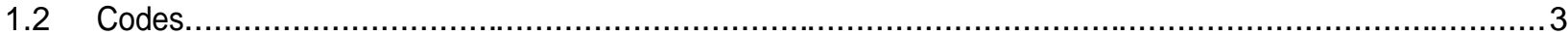

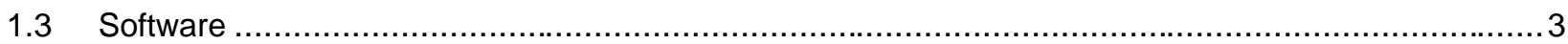

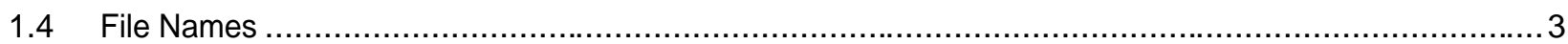

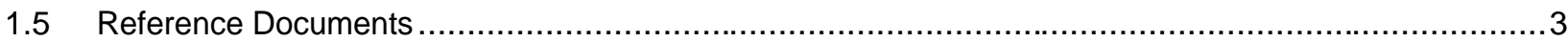

2 Design Data

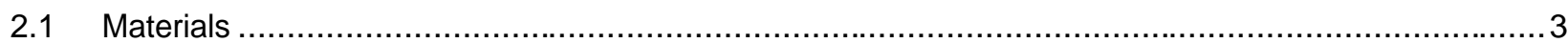

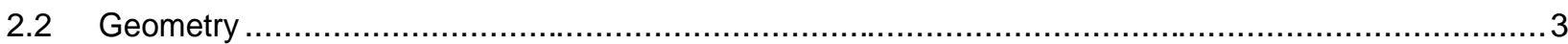

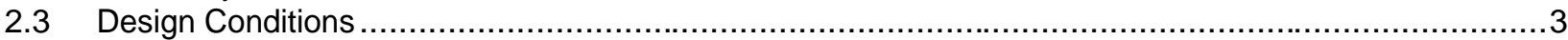

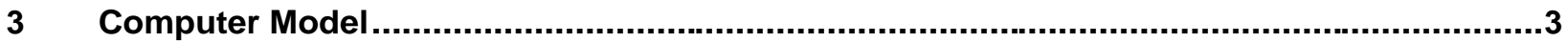

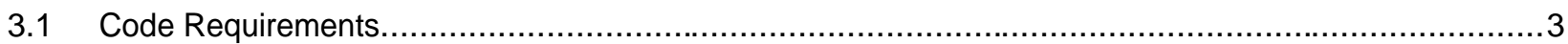

3.2 Fatigue

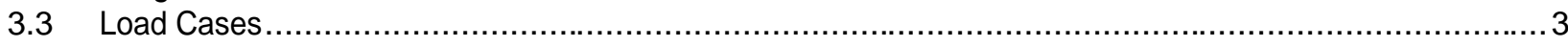

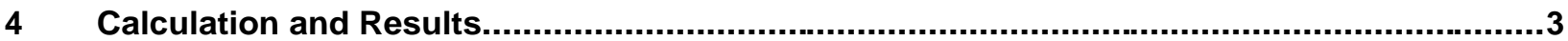

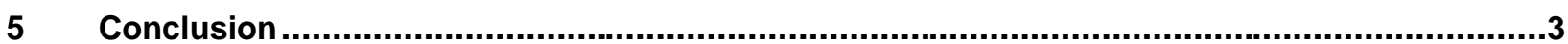




\section{Introduction}

\subsection{Scope}

The LNG offshore facility "Big Sweep" is a development of Bluewater for the Golf of Mexico. This development is part of a large LNG project. The "Big Sweep" concept consists of a fixed tower with a rotating part connected to a hinged rigid floating arm. On this tower a special swivel connects the tower piping with the arm piping. The piping from swivel to armconsists of hard piping.

This calculation describes the principal behaviour of this piping system. In this study three different piping materials are investigated.

These pipe materials are:

- Low Alloy (9Ni) Carbon steel A333 Gr.8 (min . temperature- $196{ }^{\circ} \mathrm{C}$ )

- "INVAR" (36\% Ni) developed for LNG piping for its low coefficient of linear expansion $\left(1.7^{*} 10-6\right.$ $\left.1{ }^{\circ} \mathrm{C}\right)$

- Stainless steel A312 TP316L (min. temperature $-254^{\circ} \mathrm{C}$ ). Coefficient of linear expansion high $\left(15^{\star} 10-6 /{ }^{\circ} \mathrm{C}\right)$

For the SS316L material there is no separate calculation made. Due to the high coefficient of linear expansion and the low allowable stress the piping layout will lead to a large number of expansion loops. The use of SS $316 \mathrm{~L}$ will be the subject of a more detailed study including also commercial aspects.

\subsection{Codes}

The governing code for the design of the piping is:

- $\quad$ ASME B31.4 2002 - Chapter IX Offshore Liquid Pipeline Systems

\subsection{Software}

The following analysis has been carried out using 'Caesar II' version 4.50. This software package is produced by 'Coade / Engineering Physics Software. Inc." Houston, Texas, and is used commonly throughout the industry.

\subsection{File Names}

The CAESAR-II file names used are:

- $\quad$ For A333 Gr.8: BIGS-BOOMPIP-A333-A

- For INVAR: BIGS-BOOMPIP-INVAR-A 


\subsection{Reference Documents}

1. ASME B31.4 - Pipeline Transportation systems for liquid hydrocarbons and other liquids (2002 edition).

2. Piping Design Philosophy: CGI-P-840-RP-0001 / Rev.A

3. Piping Arrangement: CGI-P-840-DR-0100 / Rev.A

When a certain part of the report is being referred to one of the above mentioned documents the number of the relating document is placed between brackets. E.g. [2] 


\section{Design Data}

\subsection{Materials}

The piping consists of two 20" SCH STD pipelines with the following properties:

\begin{tabular}{|c|c|c|c|c|c|}
\hline \multirow{2}{*}{ Material } & \multirow{2}{*}{$\mathbf{S}_{\mathbf{y}}$} & $\mathbf{S}_{\mathbf{t}}$ & $\begin{array}{c}\text { Hoop } \\
\text { Stress }\end{array}$ & $\begin{array}{c}\text { Longitudinal } \\
\text { Stress }\end{array}$ & $\begin{array}{c}\text { Combined } \\
\text { Stress }\end{array}$ \\
\cline { 2 - 6 } & $\mathbf{N} / \mathbf{m m}^{2}$ & $\mathbf{N} / \mathbf{m m}^{2}$ & $\mathbf{N} / \mathbf{m m}^{2}$ & $\mathbf{N} / \mathbf{m m}^{2}$ & $\mathbf{N} / \mathbf{m m}^{2}$ \\
\hline A333 Gr.8 & 517 & 689 & 310 & 413.6 & 465.3 \\
\hline INVAR36 & 240 & 440 & 144 & 192 & 216 \\
\hline $\begin{array}{c}\text { A312- } \\
\text { TP316L }\end{array}$ & 172.4 & 482.6 & 103.4 & 137.9 & 155.1 \\
\hline
\end{tabular}

\begin{tabular}{|c|c|}
\hline Material & $\begin{array}{c}\text { Coefficient of Linear Expansion } \\
\mathbf{m m} / \mathbf{m m} /{ }^{\circ} \mathbf{C}\end{array}$ \\
\hline A333 Gr.8 & $11.0^{*} 10^{-6}$ \\
\hline INVAR36 & $1.7^{*} 10^{-6}$ \\
\hline A312-TP316L & $15.0^{*} 10^{-6}$ \\
\hline
\end{tabular}

\subsection{Geometry}

The Caesar-Il plots in appendix ' $A$ ' reflect the stress model.

\subsection{Design Conditions}

\begin{tabular}{|l|c|}
\hline Design Pressure & ASME Class 150 \\
\hline Hydrostatic Test Pressure & $1.5^{*} \mathrm{P}_{\text {design }}$ \\
\hline Max. Design Temperature & $35^{\circ} \mathrm{C}$ \\
\hline Min. Design Temperature & $-164^{\circ} \mathrm{C}$ \\
\hline Ambient Temperature & $21^{\circ} \mathrm{C}$ \\
\hline Density LNG Liquid & $500 \mathrm{~kg} / \mathrm{m}^{3}$ \\
\hline
\end{tabular}




\section{Arm Hinging:}

In order to reflect the hinging of the arm in the vertical direction due to wave motions a total angle of 5 degree has been taken into account.

This is modelled as $+2.5 \circ$ and $-2.5^{\circ}$

The motions of the arm are introduced as displacements (D1, D2) in the calculation model. The supports are displaced in relation to the distance to the hinge and the hinge angle. The displacements are both in the axial- and vertical direction.

\section{Arm Bending:}

The arm is subject to hogging and sagging due to wave motions. The motions of the arm are introduced as displacements (D3, D4) in the calculation model. The supports are displaced in relation to the bending-curve of the arm, the displacements are both in the axiar and. vertical direction.

\section{Wind Loading:}

Wind load (WIN1), with a wind shape factor of 0.7 , has been applied to that part of the piping that is exposed. The winds speed varies per elevation but for the arm piping a speed of $55 \mathrm{~m} / \mathrm{s}(198 \mathrm{~km} / \mathrm{hr}$ equiv. 100 knots) has been applied in the Z-direction (perpendicular to the pipe).

\section{Insulation}

All piping and piping components are insulated to minimise heat transfer to the LNG liquid. The thickness of this insulation is approximately $100 \mathrm{~mm}$ and is made of a closed cell elastomer. (e.g. Armacell $\left.{ }^{\circledR}\right)$. The density has been set at $70 \mathrm{~kg} / \mathrm{m} 3$.

\section{Acceleration}

The motion of the arm affects all piping and piping components. This vertical motion is taken into account as an acceleration of $0.25 \mathrm{~g}$ downwards. 


\section{Computer Model}

\section{Piping Model:}

The piping model is part of a total study and can therefore deviate from the final layout. This model starts with the swivel on the tower. This swivel can only rotate around the vertical axis. On the swivel two 20" outlet nozzles are connected to the arm piping. The arm piping is completely hard piping with no special provisions for taken into account the hinging of the arm. The piping is running from the tower to the arm by a large (e.g. 5D) bend.

To keep the piping away as far as possible from the tanker, a loop is made. This loop takes also care of a part of the expansion. Further the pipe is running to the end of the arm, about $160 \mathrm{~m}$, where the piping is running up on the loading arm-tower (height approx. $33 \mathrm{~m}$ ) and where a cross-over (not yet modelled) is present to make it possible to circulate the medium (LNG).

In the whole system several valves are placed.

Drains and vents are not modelled.

\section{Node Numbering:}

The models have been built using the following node number ranges:

$10 \quad$ Origin (Swivel rotation point: bearing)

$100-490 \quad$ Most starboard pipeline

$1000-1490 \quad$ Other pipeline

$5000 \quad$ Expansion loops

\section{Supports:}

The supports are of a special cryogenic type and are in general sliding in the pipe direction and are restricted in the horizontal direction. The piping is pinned in the swivel bearing as well as near the connection to the loading hoses to the tanker.

\section{Weights:}

The weights of the pipes and flanges are according the applicable ASME/ANSI standards. The dimensions and weights of the valves and actuators are estimated.

\subsection{Code Requirements}

In order to comply with the requirements of ASME B31.4 [1] it is necessary to construct load cases within CAESAR to satisfy the sustained, occasional and expansion stress conditions. 


\section{(i) Sustained stress :}

Internal pressure Hoop stress:

Calculation of this stress will have been completed during preparation of piping material specification. However during the analysis CAESAR will check that the pipe has sufficient wall thickness in accordance with A402.3.5 (1) of piping code [1]. It will include any specified corrosion allowance together with 12.5 $\%$ mill tolerance.

The hoop stress due to internal pressure shall not exceed $F_{1}{ }^{*} S_{y}\left(F_{1}=0.6\right)$, the piping material allowable stress at maximum metal temperature.

Longitudinal stress:

During the analysis CAESAR will check that the pipe has sufficient wall thickness in accordance with A402.3.5 (2) of piping code [1]. It will include any specified corrosion allowance together with $12.5 \%$ mill tolerance.

The longitudinal stress due to all loads shall not exceed $F_{2}{ }^{*} S_{y}\left(F_{2}=0.8\right)$, the piping material allowable stress at maximum metal temperature.

Combined stress:

During the analysis CAESAR will check that the pipe has sufficient wall thickness in accordance with A402.3.5 (3) of piping code [1]. It will include any specified corrosion allowance together with $12.5 \%$ mill tolerance.

The combined stress due to all loads shall not exceed $F_{3}{ }^{*} S_{y}\left(F_{3}=0.9\right)$, the piping material allowable stress at maximum metal temperature.

\section{(ii) Occasional stress}

See (i)

\section{(iii) Expansion stress}

This is in fact the total displacement stress range $S_{E}$ due to all displacement strains on the piping system. These can be from thermal expansion of piping and/or connecting equipment, deflection of piping restraints and from movements resulting from arm motions.

The B31.4 chapter IX does not perform a code check for expansion stress load cases, so officially there is no need to build those load case combinations within this code.

\subsection{Fatigue}

For this study no fatigue calculations are made. They will be the subject of a more detailed study. 


\subsection{Load Cases}

For the model sustained (SUS), operational (OPE), occasional (OCC), and expansion (EXP) load cases have been build.

In those load cases the following loads have been combined:

$\mathrm{W}=$

$\mathrm{WW}=$

Weight of piping inclusive content (LNG) and insulation

WNC $=$

$\mathrm{P} 1=$

$\mathrm{HP}=$

Weight of piping filled with water and inclusive insulation

Weight of piping no content

$\mathrm{U} 1=$

$\mathrm{T} 1=$

15 bar

$\mathrm{T} 2=$

$\mathrm{T} 3=$

hydrostatic (test) pressure $=1.5^{*}$ design pressure

Uniform loads $=-0.25 \mathrm{~g}$

homogeneous $35^{\circ} \mathrm{C}$

$\mathrm{T} 4=$

$\mathrm{D} 1=$

$\mathrm{D} 2=$

$\mathrm{D} 3=$

$\mathrm{D} 4=$ homogeneous $-164^{\circ} \mathrm{C}$

most starboard pipe line (numbers 100 ) $-164^{\circ} \mathrm{C} /$ other pipe (numbers 1000 ) $35^{\circ} \mathrm{C}$ most starboard pipe line (numbers 1000) - $164^{\circ} \mathrm{C} /$ other pipe (numbers 100) $35^{\circ} \mathrm{C}$ piping displacement $+2.5^{\circ}$ upwards piping displacement -2.5 은 downards

piping displacement due to hogging (upwards)

$\mathrm{WIN} 1=$ piping displacement due to sagging (downwards)

Wind perpendicular to the pipe (-Z-direction) 


\section{The load cases are:}

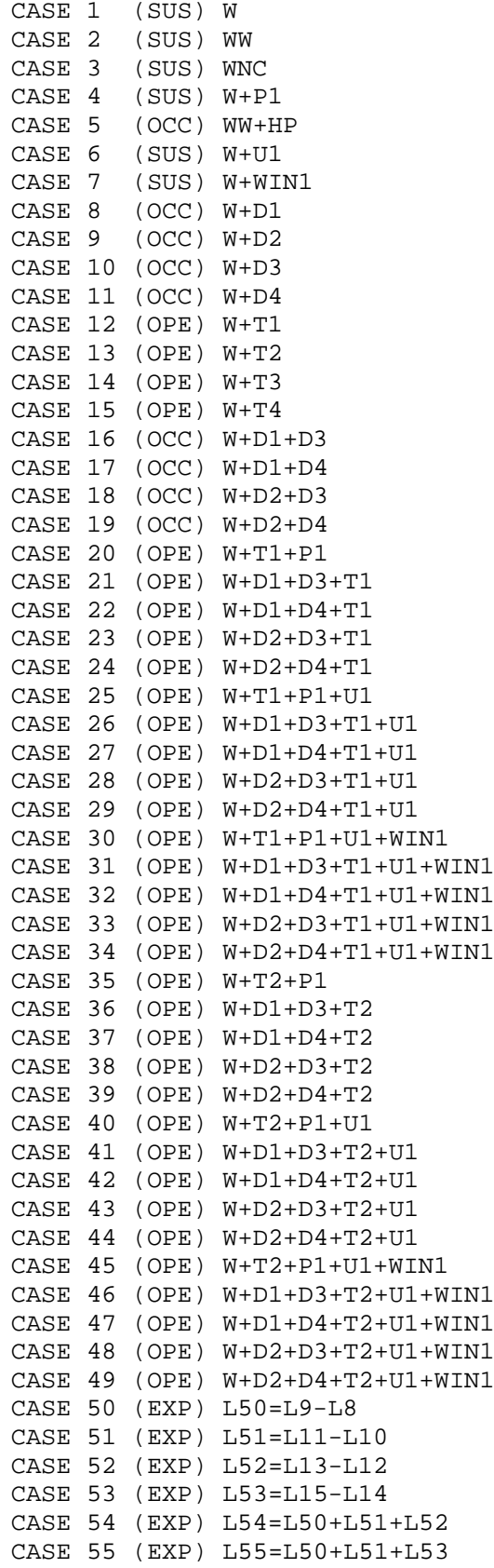




\section{$4 \quad$ Calculation and Results}

The piping model is optimised based on the ASTM A333 Gr.8 material. The results for INVAR36 are presented to compare the effect of this material. If finally the choice will be for INVAR then a certain optimisation will take place.

A summary of the results is given below.

Sustained (SUS), Operational (OPE) and Occasional (OCC) load cases in percentage from the allowable and the Expansion (EXP) load cases in percentage from yield:

\begin{tabular}{|l|c|c|c|c|}
\hline \multirow{2}{*}{ LOAD CASE } & \multicolumn{2}{|c|}{ A 333 Gr.8 } & \multicolumn{2}{c|}{ INVAR36 } \\
\cline { 2 - 5 } & $\begin{array}{c}\text { Location } \\
\text { (Node) }\end{array}$ & $\begin{array}{c}\text { Stress } \\
\text { Location }\end{array}$ & $\begin{array}{c}\text { Stress } \\
\text { (Node) }\end{array}$ & $\%$ \\
\hline CASE 1 (SUS) W & 370 & 18 & 370 & 35 \\
CASE 2 (SUS) WW & 370 & 21 & 370 & 42 \\
CASE 3 (SUS) WNC & 370 & 14 & 370 & 28 \\
CASE 4 (SUS) W+P1 & 370 & 22 & 370 & 44 \\
CASE 5 (OCC) WW+HP & 370 & 27 & 370 & 56 \\
CASE 6 (SUS) W+U1 & 370 & 22 & 370 & 44 \\
CASE 7 (SUS) W+WIN1 & 370 & 22 & 370 & 44 \\
CASE 8 (OCC) W+D1 & 129 & 49 & 129 & 76 \\
CASE 9 (OCC) W+D2 & 128 & 55 & 128 & 87 \\
CASE 10 (OCC) W+D3 & 1295 & 17 & 295 & 29 \\
CASE 11 (OCC) W+D4 & 370 & 35 & 370 & 62 \\
CASE 12 (OPE) W+T1 & 370 & 17 & 370 & 35 \\
CASE 13 (OPE) W+T2 & 370 & 34 & 370 & 40 \\
CASE 14 (OPE) W+T3 & 370 & 34 & 370 & 40 \\
CASE 15 (OPE) W+T4 & 1359 & 28 & 370 & 35 \\
CASE 16 (OCC) W+D1+D3 & 129 & 51 & 129 & 79 \\
CASE 17 (OCC) W+D1+D4 & 129 & 44 & 129 & 68 \\
CASE 18 (OCC) W+D2+D3 & 128 & 54 & 128 & 84 \\
CASE 19 (OCC) W+D2+D4 & 128 & 61 & 128 & 96 \\
CASE 20 (OPE) W+T1+P1 & 370 & 21 & 370 & 44 \\
CASE 24 (OPE) W+D2+D4+T1 & 128 & 61 & 128 & 96 \\
CASE 25 (OPE) W+T1+P1+U1 & 370 & 25 & 370 & 53 \\
CASE 29 (OPE) W+D2+D4+T1+U1 & 128 & 62 & 128 & 98 \\
CASE 30 (OPE) W+T1+P1+U1+WIN1 & 370 & 30 & 370 & 62 \\
CASE 34 (OPE) W+D2+D4+T1+U1+WIN1 & 128 & 62 & 128 & 98 \\
CASE 35 (OPE) W+T2+P1 & 370 & 37 & 370 & 48 \\
CASE 39 (OPE) W+D2+D4+T2 & 128 & 60 & 128 & 95 \\
CASE 40 (OPE) W+T2+P1+U1 & 370 & 41 & 370 & 57 \\
CASE 44 (OPE) W+D2+D4+T2+U1 & 128 & 60 & 128 & 97 \\
CASE 45 (OPE) W+T2+P1+U1+WIN1 & 370 & 45 & 370 & 66 \\
CASE 49 (OPE) W+D2+D4+T2+U1+WIN1 & 128 & 61 & 128 & 98 \\
CASE 50 (EXP) L50=L9-L8 & 129 & 81 & 129 & 126 \\
CASE 51 (EXP) L51=L11-L10 & 370 & 21 & 370 & 33 \\
CASE 52 (EXP) L52=L13-L12 & 359 & 22 & 359 & 8 \\
CASE 53 (EXP) L53=L15-L14 & 359 & 22 & 359 & 8 \\
CASE 54 (EXP) L54=L50+L51+L52 & 129 & 87 & 129 & 136 \\
CASE 55 (EXP) L55=L50+L51+L53 & 128 & 88 & 128 & 135 \\
\hline
\end{tabular}

The program calculates the stresses using Stress Intensification Factors (SF). These are used for bends like node 128 / 129 (SF=1.2), 370 (SF=3.2). This explains the locations in above table. 


\section{Explanation of the stresses:}

- Weight (W) has more influence on the stresses when the allowable is lesser (INVAR)

- $\quad$ Arm hinging (D1, D2) has a large influence on the stresses. For the higher strength material (A333) the stresses are lower.

- The thermal cases 12 to 15 seems not much different but the weight (W) gives more stress for INVAR so actual the thermal stresses are lower for INVAR as was expected.

Displacements:

The difference between the two materials A333 Gr.8 and INVAR is showing in the displacements in Xdirection (axial) at the end of the arm (node 1370) e.g. for case 13 INVAR gives $-57 \mathrm{~mm}$, A333 gives $216 \mathrm{~mm}$.

Nozzle Loads on the swivel:

The nozzle loads are at the highest for the A333 material (about $40-50 \%$ ) with a maximum combined shear force of $93.3 \mathrm{kN}$ and combined bending moment of $42.8 \mathrm{kNm}$.

Swivel bearing loads:

The Swivel bearing loads are given at node 10:

- A333 material: combined shear force $167 \mathrm{kN}$, combined bending moment $217 \mathrm{kNm}$

- INVAR: combined shear force $98 \mathrm{kN}$, combined bending moment $126 \mathrm{kNm}$ 


\section{Conclusion}

Based on the stress results, the ASTM A333 Gr. 8 material seems to be the better choice.

The disadvantage of ASTM A333 Gr.8 and especially ASTM A312-TP316L considering the relative high coefficient of expansion compared to INVAR36, can mostly be accommodated by putting in more expansion loops or even other methods like pipe swivels etc.

Recommendation: In this phase of the study e.g. the cost of the materials is left out. In the next phase this will be picked up because the choice of material can have a substantial impact. 


\section{Report}

\section{Intact and Damaged Stability}

Doc. No. CGI-S-810-CA-0001 Rev. A

Project. No. 1-0282-0 


\section{Revision Status Sheet}

Rev.

$$
\text { Date }
$$

A

30-11-04

\section{Description}

Initial Issue
Initiator

BS
Checked by

Approved by

\section{Date}

December 2004

Initials

CNAT

Decemoer $2004 \quad$ HVDB

Y:L1 PROJS\1-02B2-0100-1S-0001 [ntact and Damagerd Sabilty $d x$

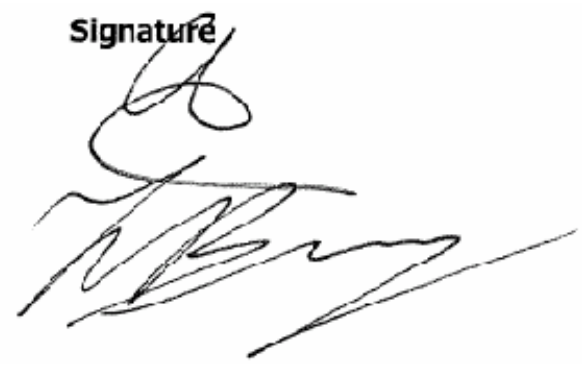




\section{Table of Contents}

1

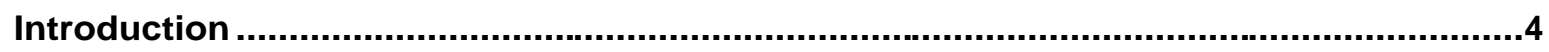

$2 \quad$ Intact Stability .5 


\section{Introduction}

The hinges on the tower and buoyancy support the weight of the sweep arm. The hinges provide the arm with a pitch degree of freedom. Buoyancy is generated by the structural tubular members of the arm; the column supporting the hose crane and the buoyancy tank underneath.

The pitch angle is determined by the weight and buoyancy distribution and the water plane area. The water plane area of the sweep arm, consisting of the vertical members and the column of the hose crane, is relatively small. This results in stable motion behaviour in sea waves.

To further enhance the sea keeping behaviour of the arm, the buoyancy tank is larger than strictly required for buoyancy purposes. To compensate for the surplus in buoyancy, the buoyancytank is fitted with ballast tanks. The arm will be trimmed in a horizontal position by filling the ballast tanks to the required level.

A number of different hydrostatic loading conditions need to be assessed:

- Normal operations

In normal operations the ballast tanks are filled to a certain, fixed level. The ballast system will not be used to enforce draft modifications to control the vertical position of the hose crane.

- Maintenance

Inside the buoyancy tank there are two equipment and two thruster rooms. For routine maintenance access to these rooms is provided via the crane column that pierces the waterline. However, to enable the change-out of large pieces of equipment like e.g. the thruster engines the buoyancy tank is provided with access hatches on top of the buoyancy tank. De-ballasting the buoyancy tanks will be bring these access hatches above the waterline

- $\quad$ Damaged conditions

The buoyancy tank is divided into watertight compartments by bulkheads. In a condition with one of these compartments damaged the remaining compartments need to provide sufficient reserve buoyancy to keep the arm afloat.

A spreadsheet is used to calculate the weight and buoyancy distribution and the resulting equilibrium position of the complete sweep arm in the above conditions. Discussion of the normal operations and maintenance condition is included in the next section under 'Intact Stability'; the damaged conditions are further discussed in section 3, 'Damaged Stability'. 


\section{Intact Stability}

Calculation of weight and buoyancy distribution is done in a spreadsheet.

The system has only one degree of freedom: pitch. This is because the yaw angle is not of interest for hydrostatics and the arm cannot roll. Therefore the equilibrium is determined only by the moment about the hinge axis.

The spreadsheet calculates the individual weight and buoyancy contribution of each truss member. Added to these are the contributions of discrete mass and buoyancy items such as outrigger, the vaporiser module, hose crane and buoyancy tank.

The results of the calculations are included in Appendix A, 'Loading Conditions'.

In normal operations a total ballast weight (seawater) of 592 tons is required to trim the arm in a horizontal position.

When the ballast tanks are completely emptied, the equilibrium position is 2.75 degrees upwards and the buoyancy tank rises with $6.75 \mathrm{~m}$. this sufficient to get the thruster hatches above the waterline to be able to remove the thruster engines.

The thrusters units themselves form an integral part of the tank bottom. To remove them entirely the thruster compartment needs to be flooded. In this condition the arm will have an angle of 1.82 degrees upwards and the rim of the thruster hatches is just above the waterline. 


\section{Damaged Stability}

Buoyancy is provided by the buoyancy tank and the tubular structural members.

The buoyancy tank is sub-divided in 7 watertight compartments:

- Two thruster compartments

- Two equipment compartments

- The hose crane column

- Two ballast tanks

The column, equipment and thruster compartments are accessible via watertight doors. The ballast tanks by means of removable inspection hatches.

The three submerged longitudinal tubular members are assumed to a internally continuously open, creating one buoyancy compartment per member.

Damage stability requirements for SPMs (ABS Rules for Building and Classing Single Point Moorings) demand sufficient reserve buoyancy in a condition with one compartment damaged. If however a watertight bulkhead separating two compartments is damaged (e.g. in a collision) the two compartments will be affected. Therefore, as a worst case, the flooding of two adjacent compartments is taken into account.

Three damaged scenarios have been considered:

- One compartment flooded

- Two compartments flooded

- One compartment and the hose crane column flooded

- One compartment and one longitudinal member over the entire length flooded

In all of the scenarios the ballast tanks are considered filled to the normal operating level.

In all four damaged conditions the arm remains afloat, albeit at a deeper draft. The deepest immersion is found when one compartment and the column are flooded: 3.29 degrees or 9.8-m additional draft at the hose crane column. The total draft (up to the underside of the thrusters) in the worst case is approximately $25-\mathrm{m}$.

When locating vent openings or other items that are to be considered as down flooding points the above maximum damaged draft shall be considered. 


\title{
REPORT
}

\section{Sweep Arm Structural Design}

\author{
Doc. No. CGI-S-810-CA-0002 Rev. A
}

Project. No. 1-0282-0

\author{
Bluewater Energy Services B.V. \\ Marsstraat 33 \\ 2132 HR Hoofddorp \\ The Netherlands \\ Tel. +312356 82800 \\ Fax. +31235652053
}




\section{Revision Status Sheet}

Rev. Date

A 30-11-2004

\section{Description}

Initial Issue
Initiator

BS

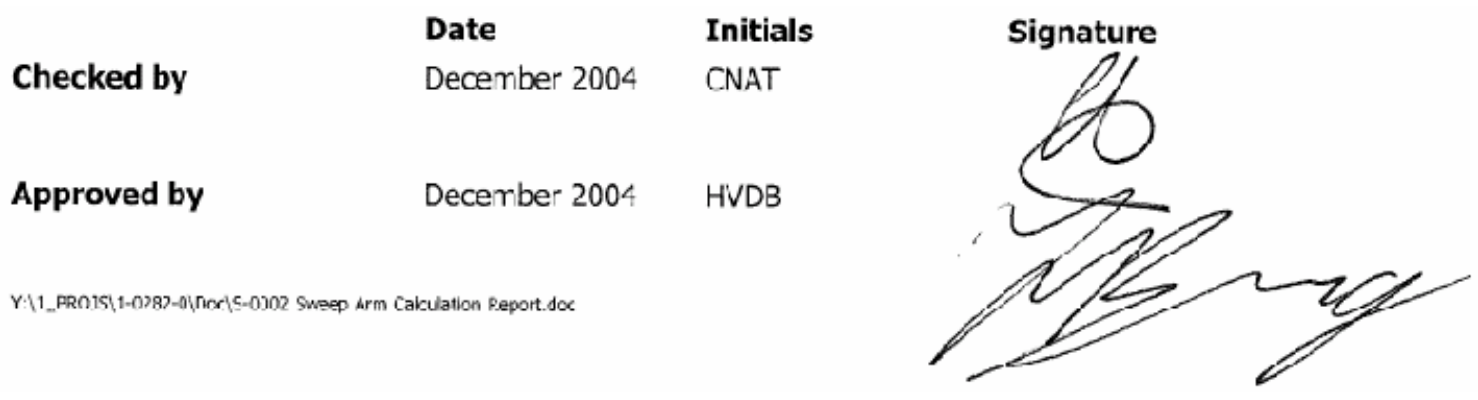




\section{Table of Contents}

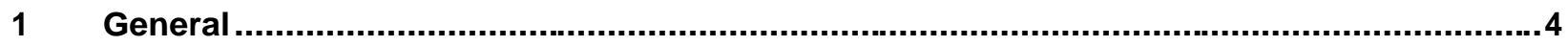

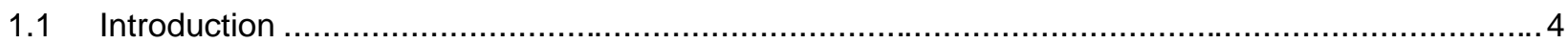

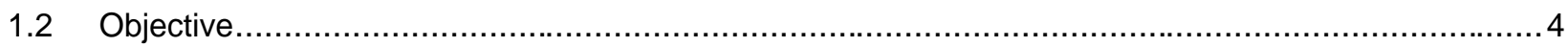

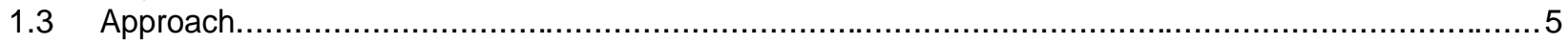

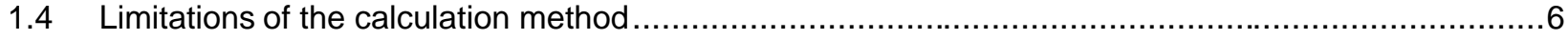

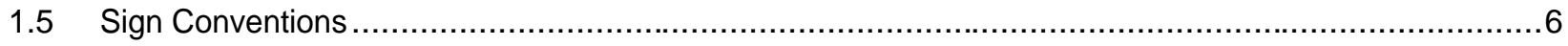

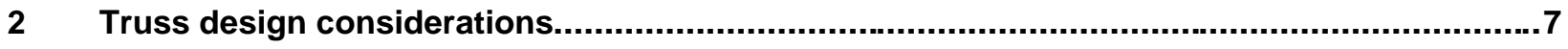

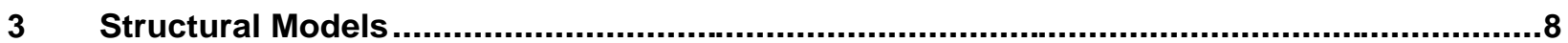

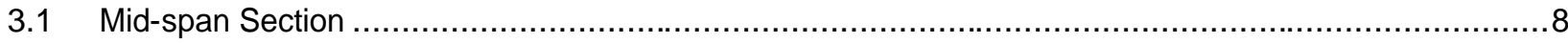

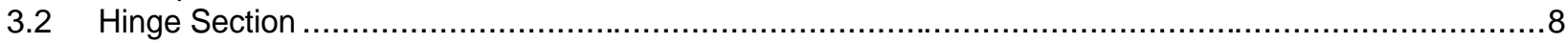

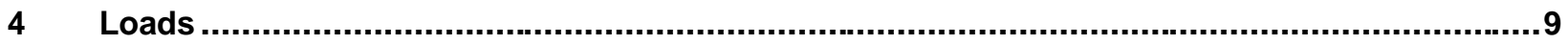

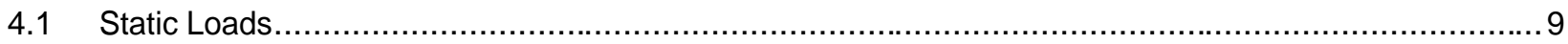

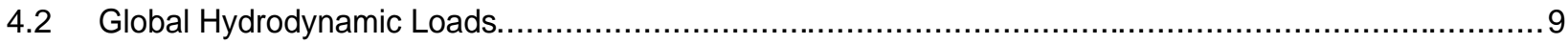

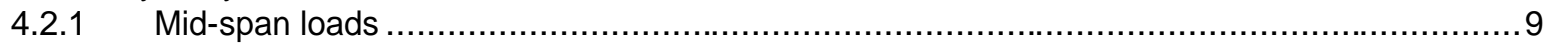

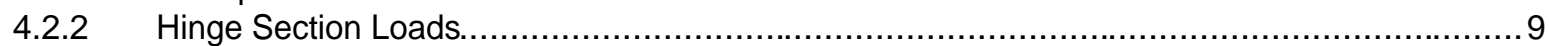

4.39

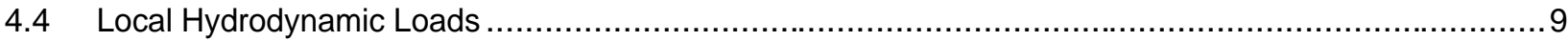

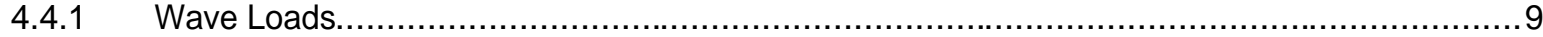

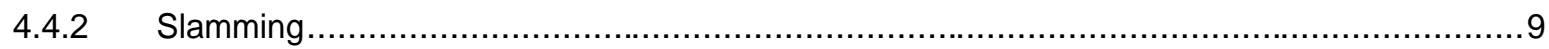

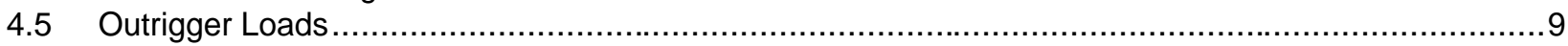

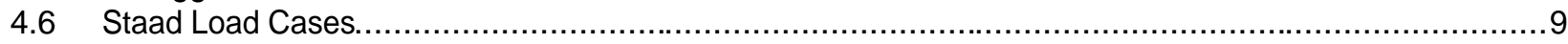

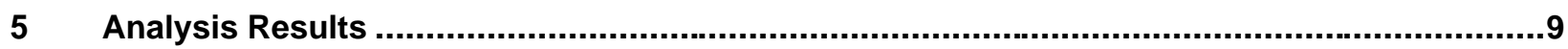

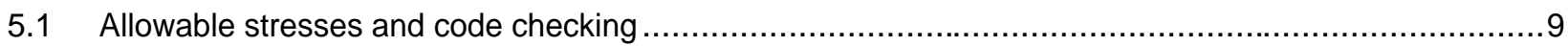

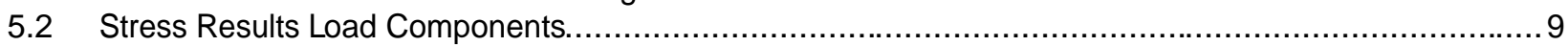

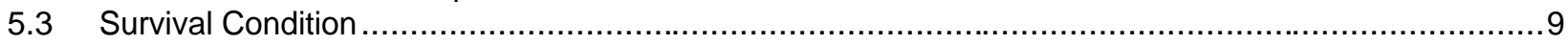

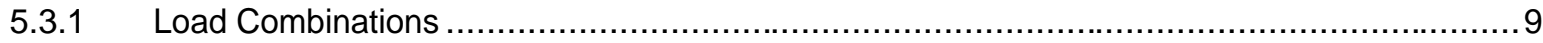

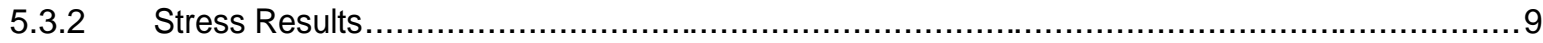

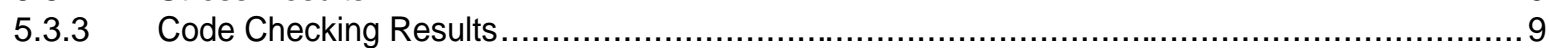

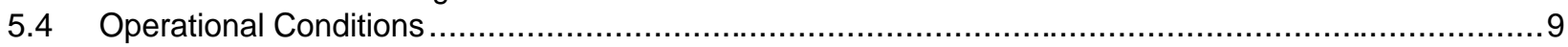

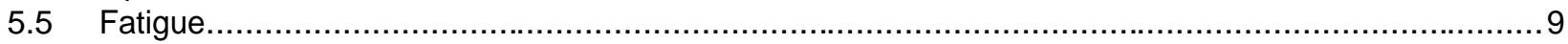

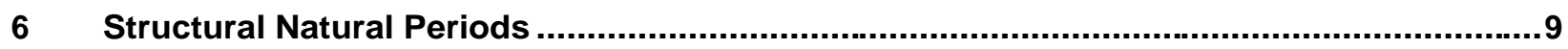

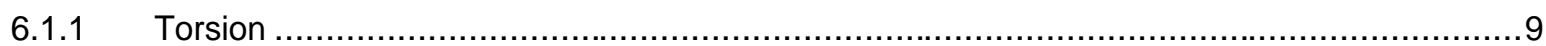

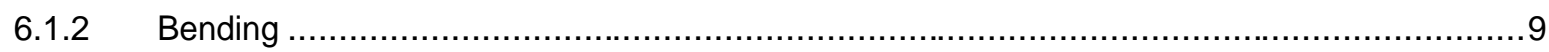

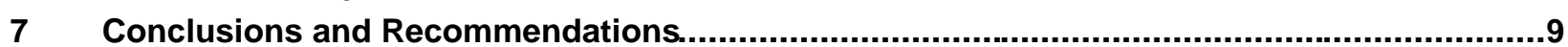

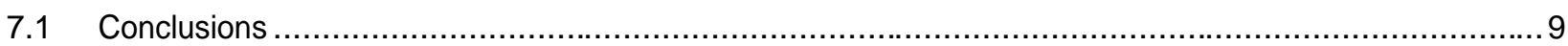

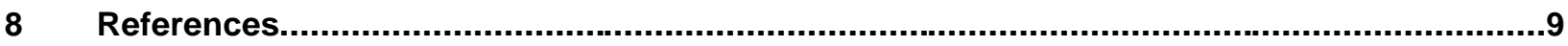




\section{General}

\subsection{Introduction}

One of main components of the Big Sweep is the sweep arm. It is a semi-buoyant rigid lattice structure supported on one end by the tower and on the other end by a buoyancy tank. In addition to the arm the buoyancy tank also supports the hose crane column.

The sweep arm has the following main dimensions:

Cross section $\quad 18-\mathrm{m}$ wide by $12-\mathrm{m}$ high

Overall length 200-m

System length 170-m between weathervaning axis and hose crane column centreline

The arm is constructed from tubular members with diameters ranging from 500 to $1400 \mathrm{~mm}$ and wall thickness of $20 \mathrm{~mm}$ to $40 \mathrm{~mm}$.

The longitudinal members with a wall thickness of 25 are reinforced at the nodes by $35-\mathrm{mm}$ can sections.

At the hinge section the wall thickness of some highly loaded members is $40 \mathrm{~mm}$.

\subsection{Objective}

The objective of this report is to prove feasibility of the sweep on structural aspects. This means the question shall be answered if the chosen geometry and main dimensions and member sizes are fit for purpose. In addition the minimum wall thickness of the various members of a typical cross section will be determined. A total weight estimate of the sweep arm will be made in which all member wall thickness is based on this typical cross-section.

Model tests at a scale 1:40 have been conducted to study the responses of the Big Sweep to environmental loading and the study behaviour of the Big Sweep and LNG Carrier during offloading. The structural arrangement of the sweep arm considered in this report is the same arrangement as in the model tests.

In this report only the design of the main structure of the sweep arm is discussed. The design of other components, such as the outrigger arm and the monopod tower not subject of this report.

No attempt has been made to optimise the geometry with regards to weight and fabrication costs. Optimisation of the geometry will be possible but is beyond the scope of this report: changing the geometry will mean that the results of the model tests can no longer be directly used as design loads, as the loads on the arm are related to this geometry. For optimisation of the geometry direct calculation of the dynamic (global) loads on the arm is required. This direct calculation of the dynamic global loads will be done at a later stage.

However, the stress levels in the structure caused by the different load components will be evaluated and recommendations for the optimisation of the structure will be given based on these stress levels. 


\subsection{Approach}

Two critical locations of the arm have been evaluated: the arm at mid-span and the connection to the tower. A local beam model is made for eachlocation.

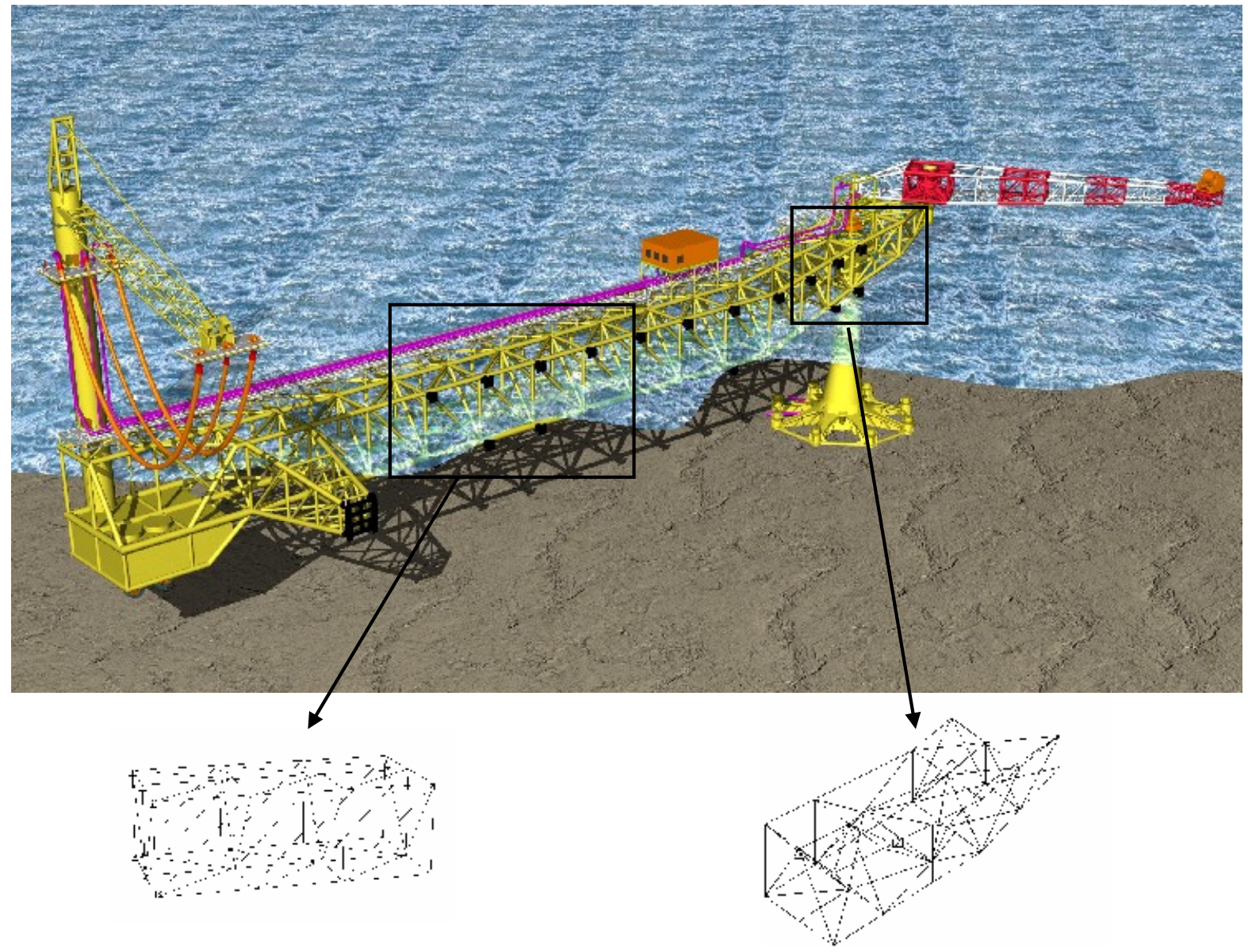

The analysis has the following steps:

1. The beam models are made in STAAD.Pro. STAAD.Pro is a beam finite element software package with extensive code checking possibilities (section 3 )

2. Global still water bending and shear forces are determined along the arm based on the weight and buoyancy distribution (section 4.1)

3. Dynamic (global) loads are obtained from the model tests (section4.2)

4. Local hydrodynamic loads are calculated for each member (section4.3)

5. The global maximum still water and global maximum dynamic loads are applied on the model and combined with the local hydrodynamic member loads

6. The members and joints are code checked according API RP2A [2], including punching shear (results in section 5.1)

7. A simplified fatigue assessment according API [2] is done for a number of selected typical joints (results in section 5.5)

8. In addition to a strength analysis, the structural natural periods for bending and torsion are calculated (section 6) 


\subsection{Limitations of the calculation method}

Although the structure is relatively transparent for wave loading, there is interaction between the arm pitch motion and the drag and inertia loads. The result of this interaction on the motion behaviour and global wave bending loads is captured in the model tests. However this interaction is ignored in the calculation of the local hydrodynamic loads. The significance of the error made while ignoring this interaction is assessed below.

The pitch motions of the arm in survival conditions is typically about 2.5 degrees maximum at a period of approximately 20-s. This results in a maximum velocity of the arm through the water, at a distance of say $150-\mathrm{m}$ from the hinge point, of $2.1 \mathrm{~m} / \mathrm{s}$ and an acceleration of $0.6 \mathrm{~m} / \mathrm{s}^{2}$.

These member velocities are to be compared with the wave particle velocities. To get a feel of these velocities a simple calculation was made with linear wave theory to calculate water particle velocities in the design wave, $\mathrm{H}_{\max } 17.4 \mathrm{~m}$ at a period of $\mathrm{T}_{\max } 14.0 \mathrm{~s}$. This resulted in a maximum horizontal speed velocity of $7.1 \mathrm{~m} / \mathrm{s}$ and a vertical velocity of $3.9 \mathrm{~m} / \mathrm{s}$, both at waterline.

From this, it can be concluded that, in survival conditions, the relative vertical particle velocity is significantly influenced by the pitch motion because the velocities are in the same order of magnitude $(2.1 \mathrm{~m} / \mathrm{s}$ compared to $3.9 \mathrm{~m} / \mathrm{s})$. In addition the added mass effects cannot be ignored either.As a result the local hydrodynamic loads may be significantly over or underestimated.

However, this analysis shows that the stresses due to local hydrodynamic loads are minor compared to the global loads (see section 5.2). It can therefore be concluded that the error made is acceptable.

Another thing that should be considered is the following:

The application of the local hydrodynamic loads is required to assess the effects of local bending of the truss members, but in fact the contribution of these local hydrodynamic loads to the overall bending moment is already included in the overall bending moment.

However, because it cannot be guaranteed that the location where the bending moment is measured in the test is indeed the location of the actual peak of the bending moment, the global bending moment will not be corrected for this effect.

\subsection{Sign Conventions}

For the vertical mid-span bending moment, a moment due to sagging is defined as positive, hogging as negative. 


\section{Truss design considerations}

- The sweep arm is a lattice structure built up form tubular members. Member $D / t$ ratios are within normal industry practice (i.e. $\mathrm{D} / \mathrm{t}<120$ ).

- $\quad$ All joints will be designed as simple joints, i.e. no overlapping joints.

- Common offshore construction steel will be used: material API 5L grade X52 is selected with yield strength of $52 \mathrm{Ksi}$ or $360 \mathrm{Mpa}$.

- $\quad$ API-RP2A Working Stress Design guidelines are followed. No load factors areapplied.

- $\quad$ No (nearly) horizontal members are located near the waterline.

- Horizontal members near the waterline must be avoided for two reasons. The buoyancy of such a member changes from zero to full buoyancy (or the other way around) every time a wave passes which influences the total motion behaviour of the big sweep and has a serious negative effect on the fatigue life of such a member.

- Secondly, horizontal members near the waterline pick up wave slamming loads. In diagonal members these wave slamming loads are less on diagonal members and (almost) absent on vertical members.

- The upper plane of the lattice structure is positioned well above the waterline. The centreline of the upper longitudinals is 7-m above the waterline. As a result the upper plane will only get wetted in storm conditions. The lower plane is situated $5-\mathrm{m}$ below the waterline, resulting in that the members remain submerged in all but extreme storm conditions.

- Welded connections in the splash zone are avoided as much as possible.

- All tubular members are buoyant.

- The longitudinal members may be fitted with bulkheads to divide the longitudinal in multiple compartments. This way a leak will have a minimal effect on buoyancy. Alternatively the longitudinal members may be an internally continuous open structure to enable inspection. 


\section{Structural Models}

\subsection{Mid-span Section}

The model of the mid-span section consists of 3 longitudinal sections of $12 \mathrm{~m}$. Three sections are modelled to minimise the effect of boundary conditions. Only the results of the middle section are considered.

The global wave loads, measured in the model tests, are applied at the right hand nodes of the middle section.

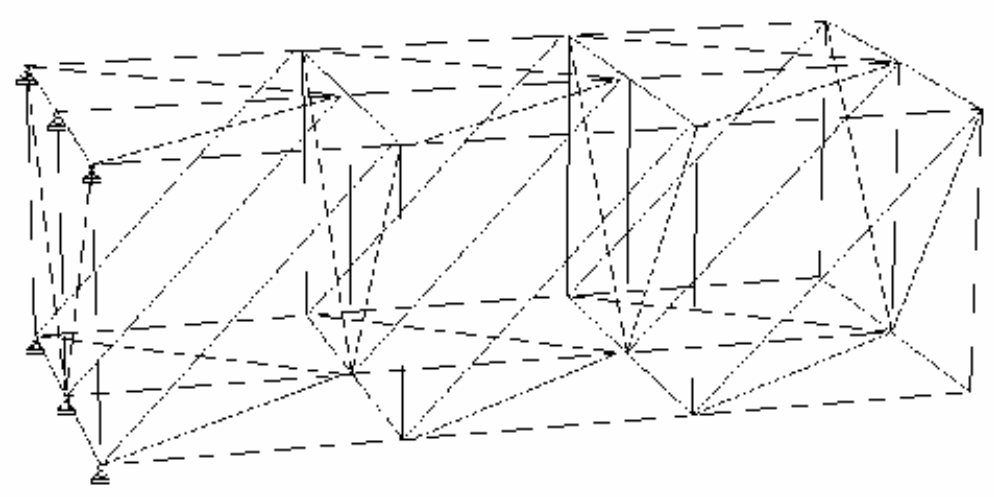

Figure 1 Structural model mid-span section

\subsection{Hinge Section}

Figure 2 Structural model hinge section

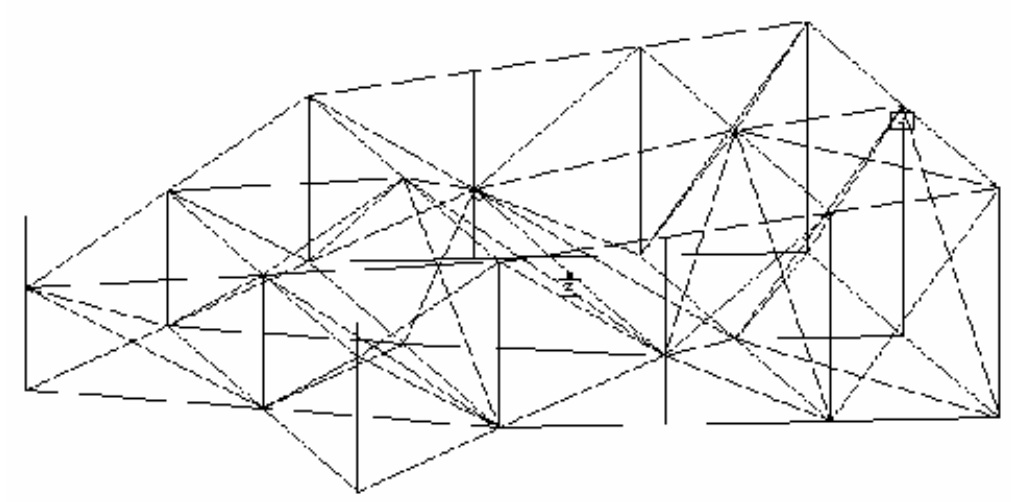




\section{Loads}

\subsection{Static Loads}

Calculation of weight and buoyancy distribution is done in a spreadsheet. The spreadsheet calculates the individual weight and buoyancy of each truss member. Added to these are the contributions of discrete mass and buoyancy items such as outrigger, the vaporiser module and the manipulator column. The results are the global still water shear force and bending moment distributions (see below).

The maximum static bending moment is due to sagging and occurs mid-span, i.e. in de middle between the tower hinge supports and the manipulator column. This sagging moment is approximately 167,000 $\mathrm{kNm}$.

The shear force is at maximum at the hinge supports and equals approximately $7,500 \mathrm{kN}$.

The static load on the hinge supports at the tower is $12,600 \mathrm{kN}$.

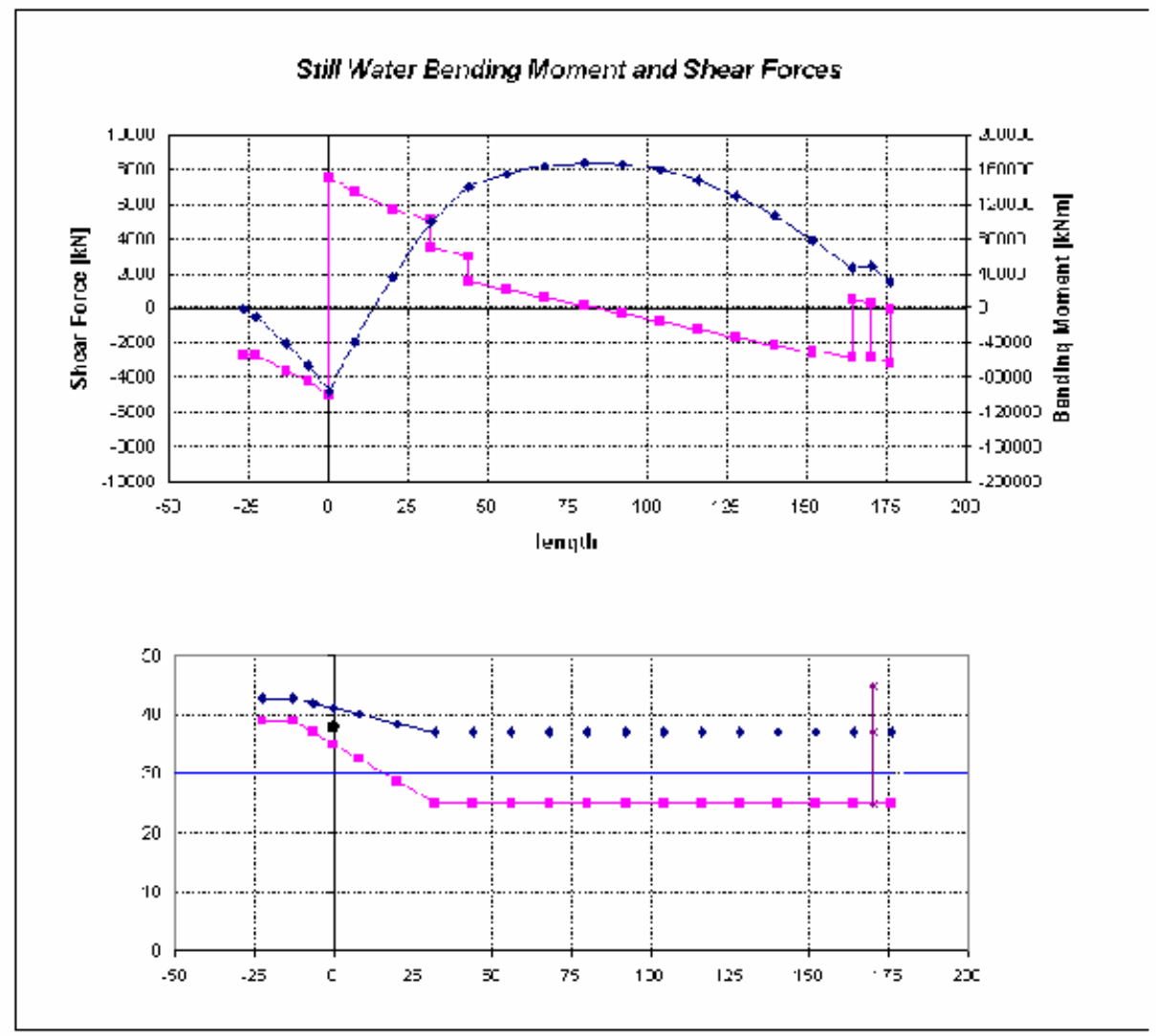




\section{Condition: Normal Operations}

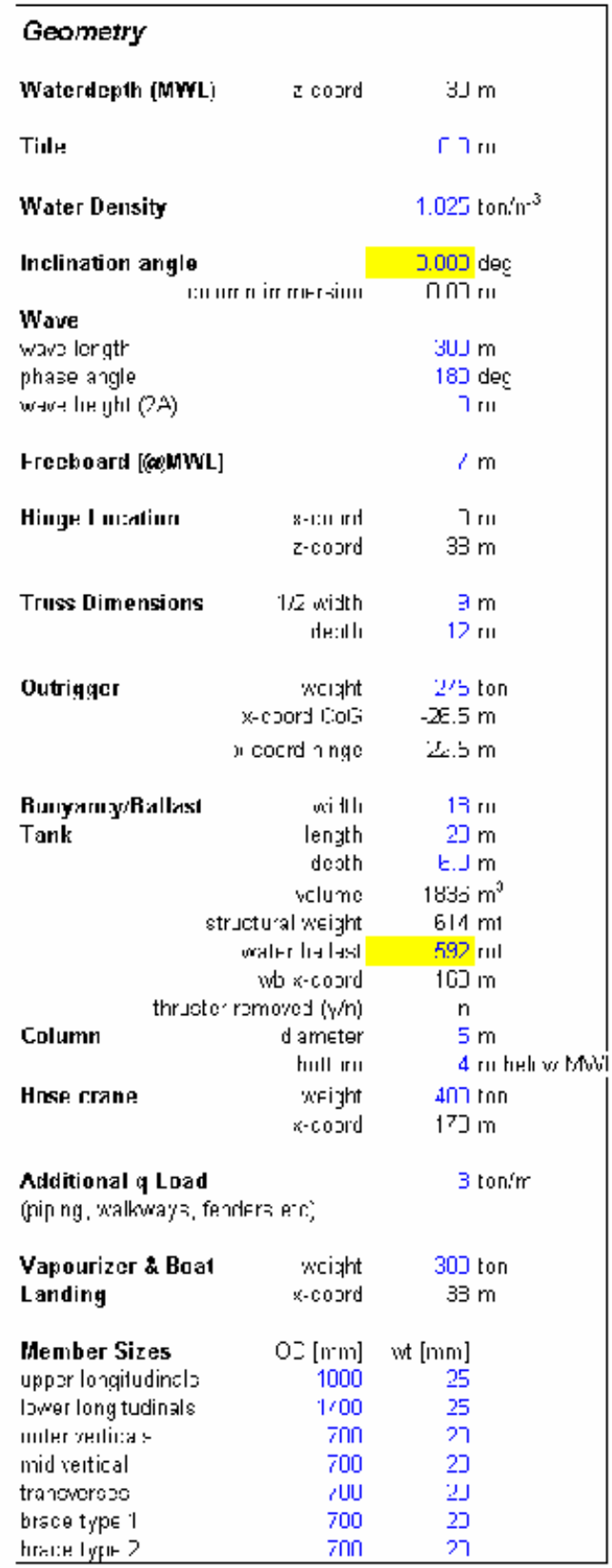

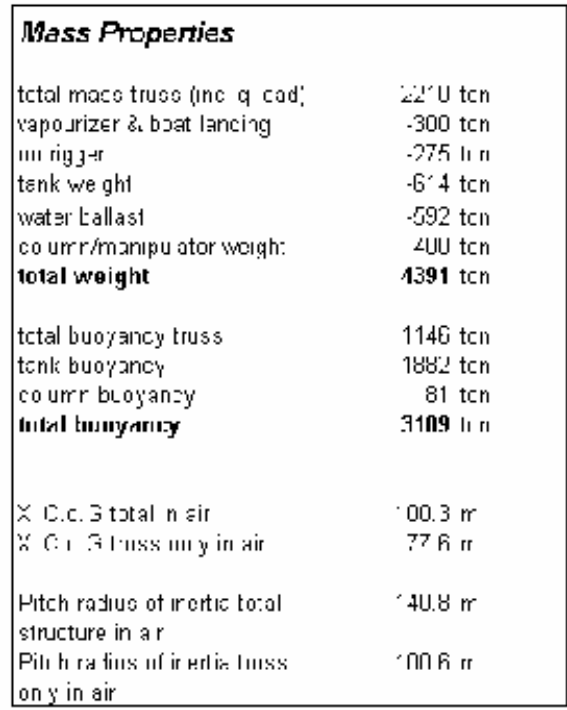

\begin{tabular}{|c|c|}
\hline Reactions & \\
\hline 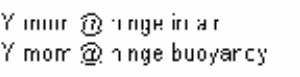 & $\begin{array}{l}-44 \Gamma 3^{\prime} 4 \text { l } r^{+} r^{-1} \\
44\left[3^{\prime} 4 \text { tcn }^{+} m\right.\end{array}$ \\
\hline $\begin{array}{l}\text { Net forc2 a: ccl Jmn } \\
\text { Resction a1 ing }\end{array}$ & $\begin{array}{r}\text { U.U tcn } \\
1283 \text { tcn }\end{array}$ \\
\hline $\begin{array}{l}\text { Voxım.m S'ectiorce Inuec } \\
\text { Wax. Eend rg Momənt - HLss }\end{array}$ & $\begin{array}{c}15 / 8 \mathrm{kN} \\
167245 \mathrm{kNm}\end{array}$ \\
\hline Statir: Steass Cnmaar snn & 2 กิ. $\mathrm{f} \mathrm{N} / \mathrm{mm}^{2}$ \\
\hline (Struct) \atural Periad & 0.40 \\
\hline Herguf apror nd & $7 \mathrm{~h} . .3 \mathrm{~s}$ \\
\hline
\end{tabular}

\subsection{Global Hydrodynamic Loads}

As described above, distinction is made between global and local loads hydrodynamic loads. Global hydrodynamic loads are based on the model tests results described in the design load report [1]. Two different loading conditions, collinear and cross current environmental conditions, are considered. 


\subsubsection{Mid-span loads}

\section{Longitudinal load and bending moment}

The table below gives the relevant mid-span loads derived from the model tests. The vertical bending moment has its peak in the collinear condition, the horizontal bending moment in the cross condition. For the vertical moment in the collinear case the associated horizontal bending moment has been given and vice-versa.

\begin{tabular}{|l|l|l|l|l|l|l|}
\hline \multicolumn{7}{|c|}{ Mid-span loads from model tests } \\
\hline & $\begin{array}{l}\text { Longitudinal load } \\
\text { Fx }-\mathrm{kN}\end{array}$ & \multicolumn{2}{l|}{$\begin{array}{l}\text { Vertical bending moment } \\
\text { My - kNm }\end{array}$} & $\begin{array}{l}\text { transverse bending } \\
\text { moment } \\
\text { Mz - kNm }\end{array}$ \\
\hline & Min & Max & Min & Max & Min & Max \\
\hline Collinear & $-2,960$ & $\mathbf{1 0 , 0 5 3}$ & $-198,124$ & $\mathbf{2 7 4 , 0 0 4}$ & - & $7,696^{1}$ \\
\hline Cross & $-2,364$ & 2,378 & $-29,592^{1}$ & - & $\mathbf{- 4 8 7 , 4 0 0}$ & 136,762 \\
\hline
\end{tabular}

${ }^{1}$ associated

\section{Shear Loads}

Shear loads have not been recorded in the test. An estimate is made for the maximum shear load that may be expected in the truss arm.

Consider the arm to be supported by the hinges at the tower and the buoyancy tank at the columnend. Then, in a (quasi) static case, the bending moment (vertical or horizontal) is at its highest at mid-span and the shear load is zero at this peak of the bending moment (see the graph of static bending moment and shear loads above).

The situation is different if we look at it dynamically and consider the buoyancy tank not as a support but as a member picking up wave load that is counteracted by the inertia of the arm and outrigger. Then the bending moment will peak at the hinge supports and the shear load will not be zero at midspan.

The shear load at mid-span can be estimated from the measured bending moment and an assumed contribution to the total load of the sweep arm members and the buoyancy tank/ hose crane column. It is assumed here that the buoyancy tank/hose crane column cause $25 \%$ of the shear load and the sweep arm members $75 \%$ :

$$
\begin{gathered}
M_{\text {mid-span }}=1 / 4 F_{\text {shear mid-span }} \cdot 1 / 2 L+3 / 4 F_{\text {shear mid-span }} \cdot 1 / 4 L \\
\text { And } \\
F_{\text {shear mid-span }}=16 / 5 \cdot M_{\text {mid-span }} / L
\end{gathered}
$$


With $L=170 \mathrm{~m}$ this results in the following shear loads at midspan:

\begin{tabular}{|l|l|l|l|l|}
\hline \multicolumn{5}{|c|}{ Mid-span shear loads estimate } \\
\hline & \multicolumn{3}{l}{ Horizontal shear load } & \multicolumn{2}{l|}{ Vertical shear load } \\
& Fy - kN & Fy - kN \\
\hline & Min & Max & Min & Max \\
\hline Collinear & - & 695 & $-3,729$ & 5,158 \\
\hline Cross & $-9,175$ & - & $-4,125$ & - \\
\hline
\end{tabular}

\section{Torsion about the longitudinal axis}

Similar to the shear forces, torsion about the longitudinal axis has not been measured at mid-span. Conservatively the same torsion moment as measured at the tower will be assumed at mid-span. In the co-linear condition torsion is negligible.

\begin{tabular}{|l|l|l|}
\hline \multicolumn{2}{|c|}{ Torsion at mid-span estimate } \\
\hline & $\begin{array}{l}\text { Torsion } \\
\text { Mx }-\mathrm{kNm}\end{array}$ \\
\hline & Min & Max \\
\hline Collinear & - & - \\
\hline Cross & $-93,547$ & 87,365 \\
\hline
\end{tabular}

\subsubsection{Hinge Section Loads}

Tower loads are measured with a six component force transducer in the tower column below the hinge and main bearing [1]. The measured loads represent the loads transferred from the truss to the tower and will be applied to the boundary of the hinge section model.

\begin{tabular}{|l|l|l|l|l|l|l|l|l|}
\hline \multicolumn{9}{|c|}{ Hinge loads from model tests } \\
\hline & \multicolumn{2}{|l|}{$\begin{array}{l}\text { Longitudinal load } \\
\text { Fx }-\mathrm{kN}\end{array}$} & \multicolumn{2}{l|}{$\begin{array}{l}\text { Transverse load } \\
\mathrm{Fy}-\mathrm{kN}\end{array}$} & \multicolumn{2}{l|}{$\begin{array}{l}\text { Vertical load } \\
\text { Fz }-\mathrm{kN}\end{array}$} & \multicolumn{2}{l|}{$\begin{array}{l}\text { Torsion moment } \\
\text { Mx }-\mathrm{kNm}\end{array}$} \\
\hline & Min & Max & Min & Max & Min & Max & Min & Max \\
\hline Collinear & $-11,900$ & 6,387 & -800 & 1,159 & $-6,599$ & 8,996 & $-29,549$ & 27,315 \\
\hline Cross & $-8,895$ & 2,810 & $-3,073$ & 18,943 & $-7,021$ & 10,336 & $-93,547$ & 87,365 \\
\hline
\end{tabular}

4.3 


\subsection{Local Hydrodynamic Loads}

\subsubsection{Wave Loads}

Local hydrodynamic loads, drag and added mass are calculated with the Staad.Pro utility 'Offshore Loading Program'.

Based on the properties of the design wave $(\mathrm{H}$ 17.4-m and T 14.0-s) and API-RP2A figure 2.3.1-3 the $12^{\text {th }}$ order Stream function was selected for the calculation of wave forces. A drag coefficient $C_{d}$ of 0.7 and an added mass coefficient $\mathrm{C}_{\mathrm{m}}$ of 2.0 were used.

Wave loads are calculated at angles of 0,30 and 90 degrees with the structure. Local loads under 0 and 30 degrees are combined with the global collinear loads, loads at 90 degrees with the global cross condition loads. A graphical representation of the local hydrodynamic loads at 30 degrees is shown in the figure below.

Current loads are not taken into account. The contribution to the local load is considered minor.

At the hinge section no local hydrodynamic loads are applied.

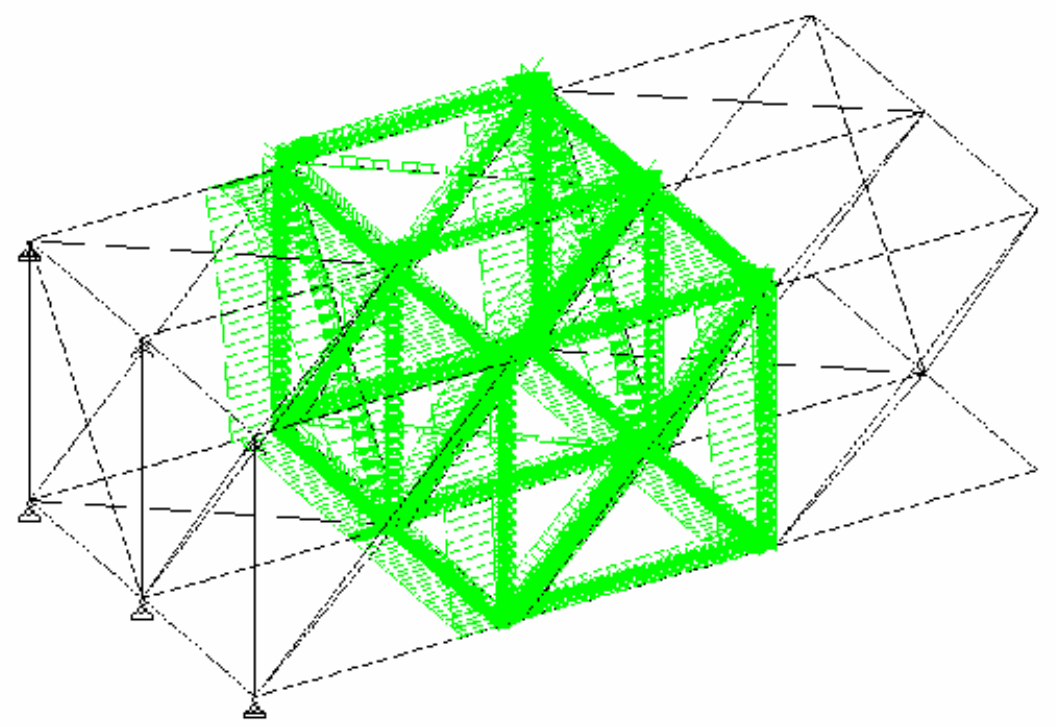

\subsubsection{Slamming}

Local slamming loads are calculated the same way as the normal wave loads taking into account a slamming drag coefficient $C_{s}$ of 5.5. Slamming pressures are calculated with the 17.4-m design wave at angles of 0,30 and 90 degrees with the structure.

(Note: slamming drag coefficient $C_{s}$ should be reduced to 3.5 based on DNV classification note 30.5 and MILLER, B.L. Wave slamming loads on horizontal circular elements of offshore structures) 
In the model tests massive slamming had been observed on the hinge section box structure. This box structure is now changed into a lattice structure built from tubular members. Also the underside of the structure has been raised by approximately $2 \mathrm{~m}$ without changing the location of the hinges. With these measures the effect of slamming loads has been greatly reduced. In this analysis slamming loads on the hinge section are not yet taken into account.

\subsection{Outrigger Loads}

A hawser-mooring load of $2500 \mathrm{kN}$ is taken into account. This load is transferred into point loads at the outrigger rotation point and stopper.

An outrigger weight of $250 \mathrm{mt}$ is assumed and applied at the rotation point.

\subsection{Staad Load Cases}

The following load cases are modelled into staad. In the analysis (see section 5) these load cases are combined in load combinations.

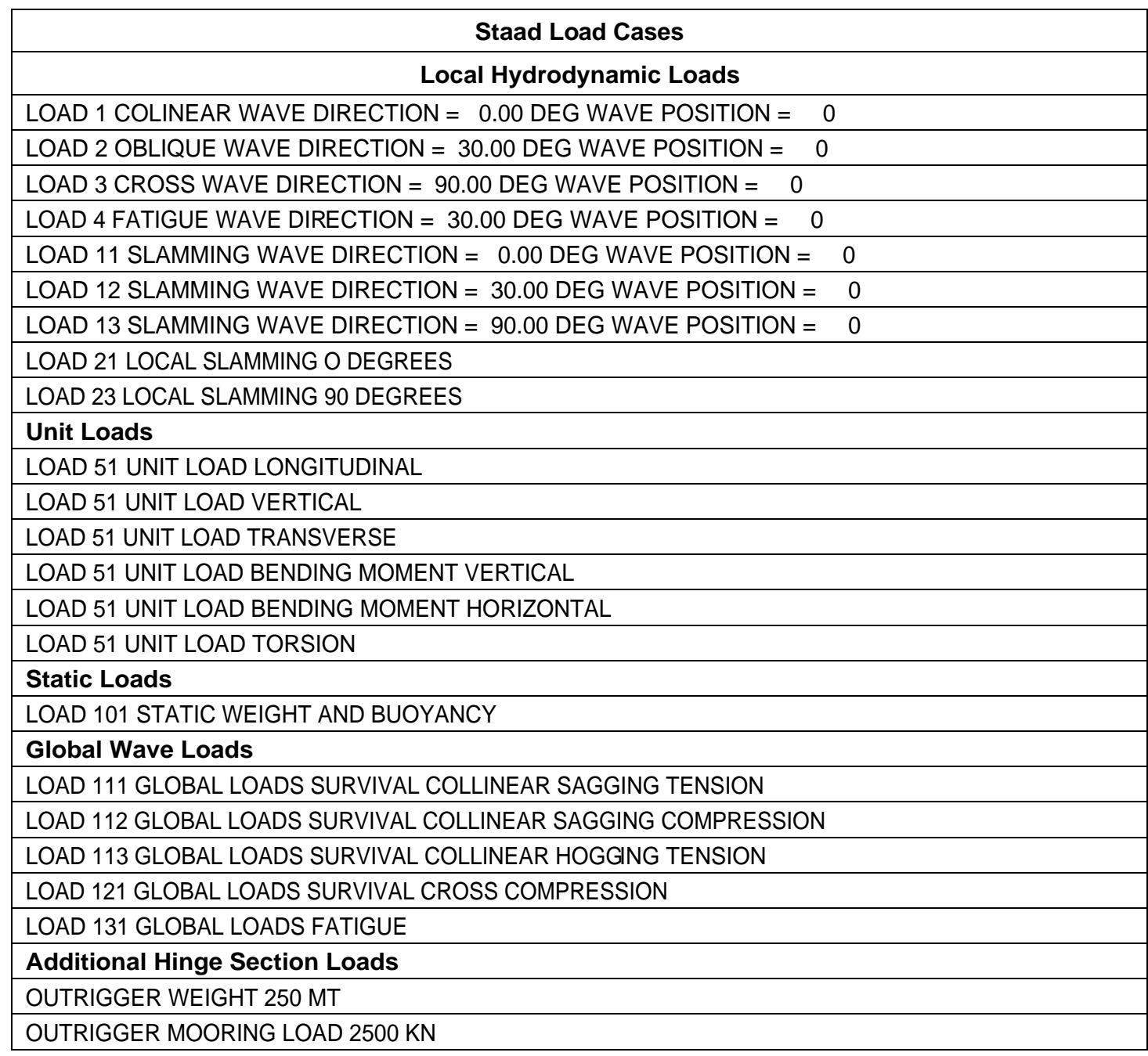




\section{$5 \quad$ Analysis Results}

\subsection{Allowable stresses and code checking}

The structure is designed to comply with API-RP2A [2]. For allowable stresses in members API refers to AISC Allowable Stress Design [3].

Because the design is governed by dynamic loading, the allowable member usage ratio is 1.33 , taking into account the $1 / 3$ stress allowable stress increase for wind induced loading.

A punching shear check according API [2] is done for all nodes. The allowable usage factor is 1.0 .

\subsection{Stress Results Load Components}

To gain understanding of the contribution of the various loads to the stress levels in the structure, the table below gives the stress components in the upper and lower longitudinals caused by the different load components. As can be observed from these results, the contribution of the local hydrodynamic loads is minor.

\begin{tabular}{|l|l|l|l|l|l|}
\hline \multicolumn{7}{|c|}{ Maximum stress levels in upper and lower longitudinals caused by individual load } \\
components \\
\hline Stresses in Mpa & & Upper Longitudinal & Lower Longitudinal \\
\cline { 2 - 7 } & & Outer & Middle & Outer & Middle \\
\hline Local Hydrodynamic & LC1/2/3 & 11 & 8 & 6 & 7 \\
\hline Static & LC 101 & 62 & 61 & 48 & 46 \\
\hline Global wave sag & LC 111/112 & 130 & 131 & 93 & 91 \\
\hline Global wave hog & LC 113 & 112 & 11 & 43 & 42 \\
\hline Global wave cross & LC 121 & 216 & 40 & 171 & 32 \\
\hline
\end{tabular}

\subsection{Survival Condition}

\subsubsection{Load Combinations}

The global static and dynamic loads are combined with the local hydrodynamic member loads. Due to the very local nature of slamming loads they are not combined with global wave loads.

\begin{tabular}{|l|}
\multicolumn{1}{c|}{ Survival Load Combinations } \\
\hline LOAD COMB 200 TOTAL SURVIVAL COLLINEAR SAGGING TENSION \\
\hline LOAD COMB 201 TOTAL SURVIVAL COLLINEAR SAGGING COMPRESSION \\
\hline LOAD COMB 202 TOTAL SURVIVAL COLLINEAR HOGGING TENSION \\
\hline LOAD COMB 203 TOTAL SURVIVAL OBLIQUE SAGGING TENSION \\
\hline LOAD COMB 204 TOTAL SURVIVAL OBLIQUE SAGGING COMPRESSION \\
\hline LOAD COMB 205 TOTAL SURVIVAL OBLIQUE HOGGING TENSION \\
\hline LOAD COMB 210 TOTAL SURVIVAL CROSS COMPRESSION \\
\hline LOAD COMB 211 TOTAL SURVIVAL CROSS NO LOCALLOADS \\
\hline
\end{tabular}


The load combinations result in the following loads on the truss midspan and hinge section (see below). Figures have been rounded off to round numbers to reflect the rough estimate of (some of) the loads.

\begin{tabular}{|l|l|l|l|l|l|l|l|}
\hline \multicolumn{7}{|c|}{ Survival Load Combinations } \\
\hline Loads in KN, KNm & Fx & Fy & Fz & Mx & My & Mz \\
\hline $\begin{array}{l}\text { Mid- } \\
\text { span } \\
\text { Section }\end{array}$ & LC 200/203 & 10,000 & 700 & 5,200 & - & 440,000 & 7,700 \\
\cline { 2 - 9 } & LC 201/204 & $-3,000$ & 700 & 5,200 & - & 440,000 & 7,700 \\
\cline { 2 - 9 } & LC 202/205 & 10,000 & 700 & $-3,800$ & - & $-31,000$ & 7,700 \\
\cline { 2 - 9 } & LC 210 & 2,400 & 3,800 & $-4,100$ & 94,000 & 137,000 & 490,000 \\
\hline $\begin{array}{l}\text { Hinge } \\
\text { Section }\end{array}$ & Collinear & 12,000 & 1,200 & 17,000 & - & - & - \\
\cline { 2 - 8 } & Cross & 8,900 & 19,000 & 18,000 & 94,000 & - & - \\
\hline
\end{tabular}

For simplicity, the hinge section survival collinear wave loads have been combined with the hawser load. The cross condition loads are not combined with the mooring load.

\subsubsection{Stress Results}

\begin{tabular}{|l|l|l|l|l|l|}
\hline \multicolumn{5}{|c|}{ Maximum stress levels in upper and lower longitudinals Load Combinations } \\
\hline \multirow{2}{*}{ Stresses in MPa } & & Upper Longitudinal & \multicolumn{2}{l|}{ Lower Longitudinal } \\
\cline { 2 - 7 } & & Outer & Middle & Outer & Middle \\
\hline Global wave sag & LC 200/203 & 163 & 166 & 144 & 143 \\
\hline Global wave sag & LC 201/204 & 192 & 191 & 126 & 125 \\
\hline Global wave hog & LC 202/205 & 56 & 53 & 19 & 16 \\
\hline Cross & LC 210 & 231 & 48 & 197 & 49 \\
\hline
\end{tabular}

\subsubsection{Code Checking Results}

\section{Mid-span Section}

All usage factors are below allowable, i.e. $<1.33$.

The highest usage factors are observed in the upper longitudinal members and in the cross condition. In the collinear condition all usage factors are below 1. In the cross condition the highest usage factor is 1.18 (see Figure 3: Usage factors Survival Co-linear and Figure 4: Usage factors survival cross)

The highest usage factor as a result of local slamming load is 0.74 . This occurs in the horizontal diagonal bracing in the upper plane, where the water particle velocities are the highest.

All punching shear check usage factors are below 1 .

\section{Hinge Section}

In the collinear cases all usage factors are within allowable limits. High usage factors are found for the cross condition. These high usage factors are caused by the high transverse load in this condition. This transverse load has to be transferred to one single hinge point, as the hinges in the transverse direction can only take compression loads. The maximum usage factors are slightly above the allowable $(5 \%)$ easily mitigated by locally increasing the wall thickness. 


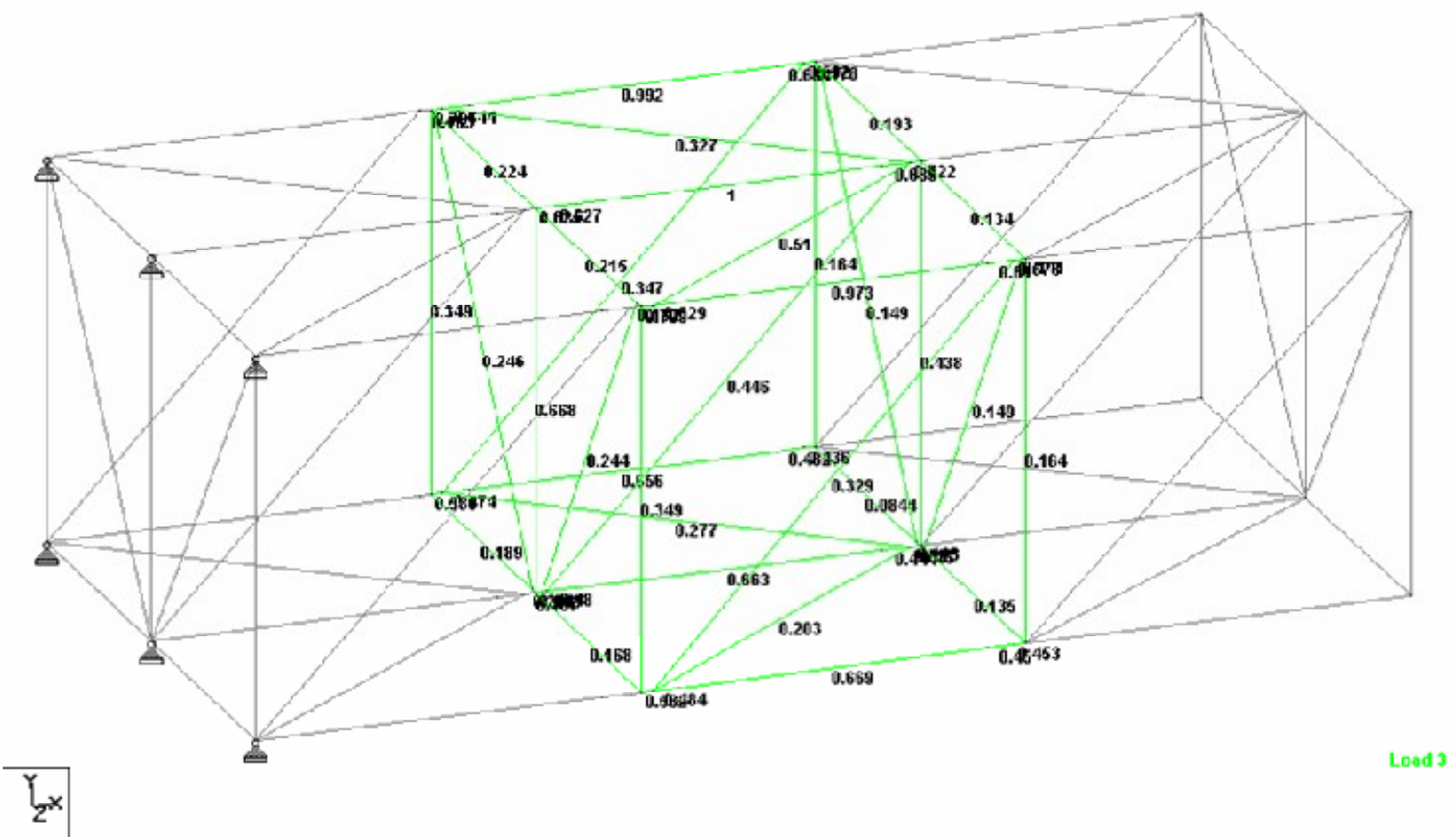

Figure 3: Usage factors Survival Co-linear

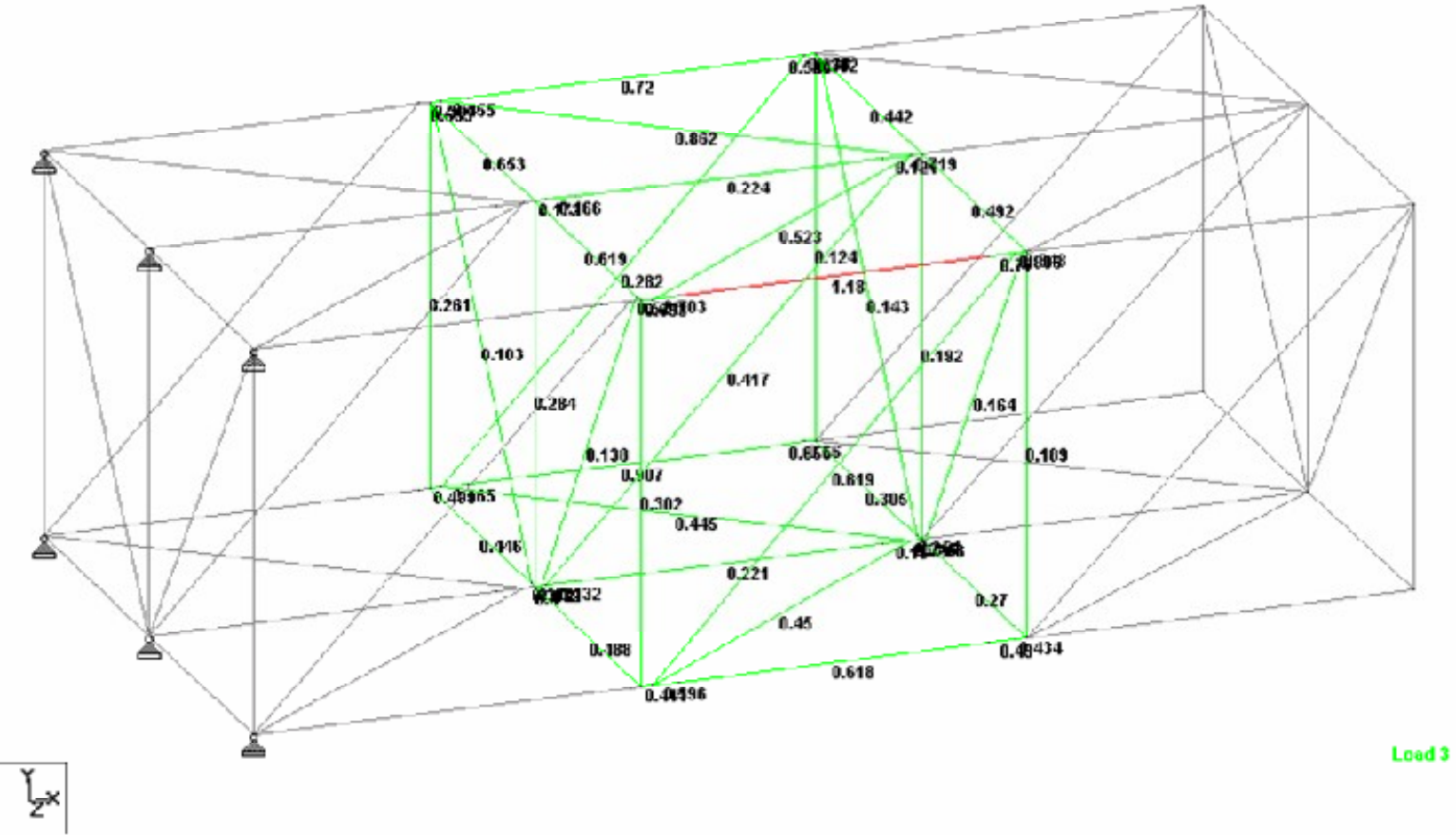

Figure 4: Usage factors survival cross

Sweep Arm Structural Design Report - Page 17 


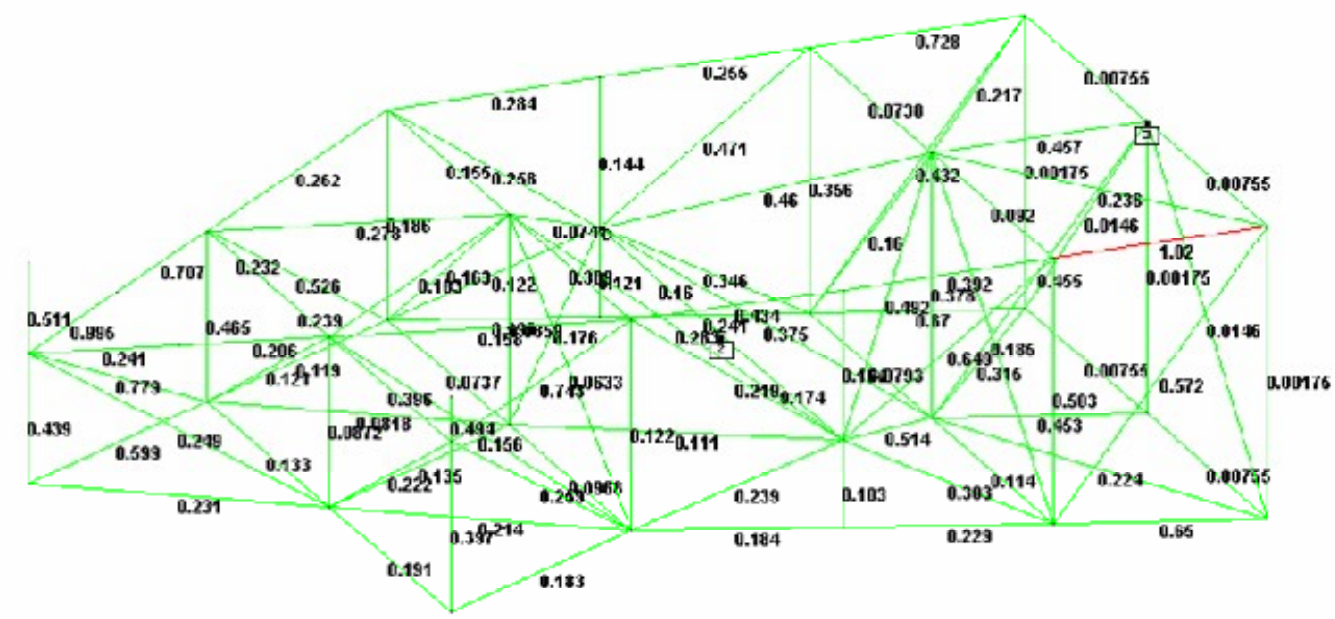

$Y_{-x}$

Figure 5: Usage factors survival collinear

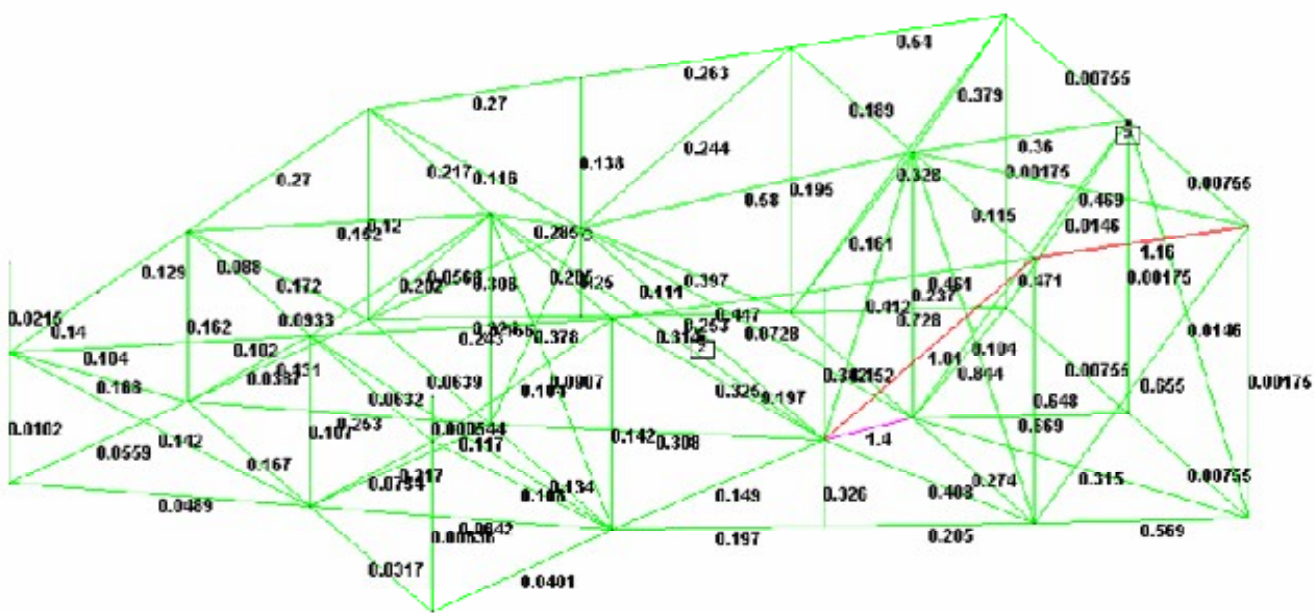

$\mathrm{I}_{\mathrm{E}}$

Figure 6: Usage factors survival cross

Sweep Arm Structural Design Report - Page 18 


\subsection{Operational Conditions}

Operational conditions do not result in governing structural design conditions for the sweep arm.

In the operational conditions, i.e. those conditions up to 1-year storm conditions in which a LNG tanker is connected to the BS, the wave loading on the sweep arm is far less than in 100-year hurricane conditions.

The design codes ([2] and [3]) allow higher stress levels (1/3 stress increase) if the stress is caused by environmental loading. For some designs, when the design is governed by static loads, the static load case is governing because of the lower allowable stress. For the BS this is not the case.

\subsection{Fatigue}

A simplified fatigue assessment according API [2] is done to assess the fatigue life of a number of selected joints. The allowable stresses and the fatigue design wave are based on the API guidelines for the Vermilion site (100 ft. water depth). The fatigue design wave is determined at $52 \mathrm{ft}$ or $16 \mathrm{~m}$ (consequence factor L-2).

The results of the operational tests are used to estimate the maximum double amplitude wave bending moment in the arm resulting from the fatigue design wave. The results from the tests with the waves and current acting under an angle of 30 degrees relative to the current are used. The estimate of the maximum double amplitude bending moment is done by extrapolation.

The horizontal bending moment is not taken into account in this simplified analysis, as it is believed that the horizontal loads play only a minor role in fatigue.

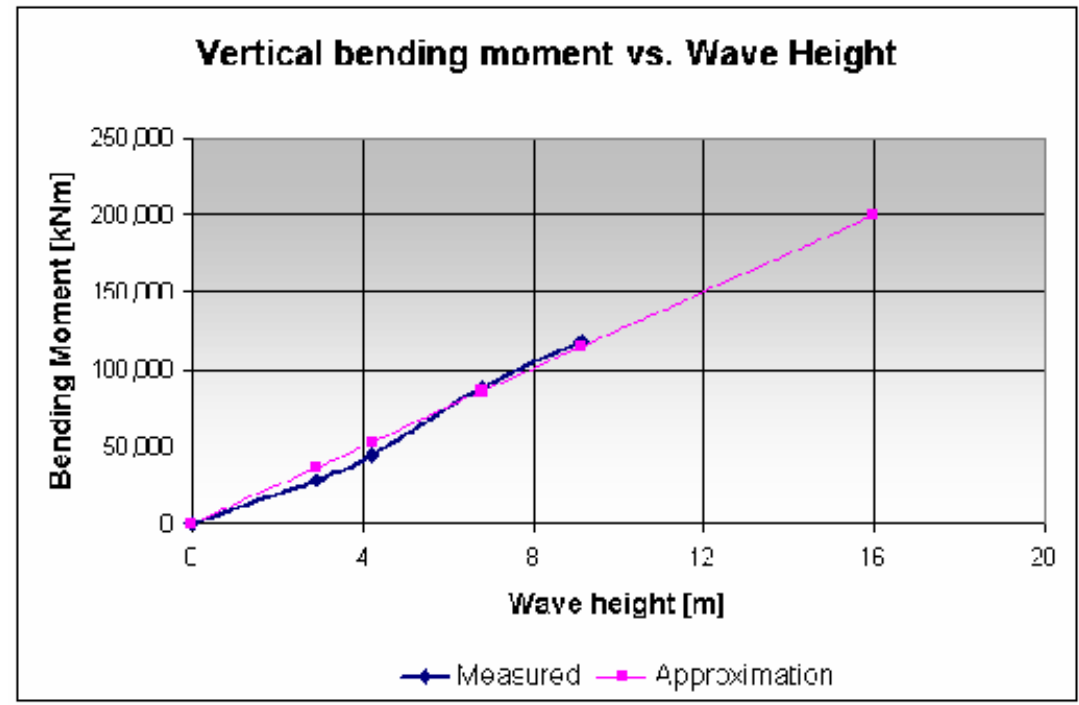

Local hydrodynamic loads from the fatigue design wave are assumed to act under an angle of 30 degrees (oblique). The loads are calculated as described above.

It should be noted that the stress contribution of the local hydrodynamic loads are small compared to the stresses resulting from the global wave bending. 
Allowable hot spot stresses are based on API2A-WSD, figure C5.1-1 (X-curve). For the selection of the curve all members are considered as waterline members, the design fatigue life is taken as 100 years and weld profile control is assumed. From this the allowable fatigue hot spot stress is $47 \mathrm{KSI}$ or 324 $\mathrm{MPa}$.

Hot spot stresses are calculated at four locations for each joint, crown toe, crown heel and two saddle points. Stress concentration factors are calculated with the recommended SCF formulas from table C5.1-1.

All connections have an adequate fatigue life. The maximum calculated usage factor, based on a 100year fatigue design life, and is 0.76 . 


\section{$6 \quad$ Structural Natural Periods}

The structural natural periods for bending and torsion have been assessed. The stiffness (bending and torsion) of a single section of the sweep arm is calculated. From this the stiffness per meter length is determined and the stiffness of the complete truss arm (170-m) is approximated by stiffness per meter time's length.

Mass distribution and mode shapes are described below.

If the natural periods are less than 3 or above 20 seconds, no problems with regards to fatigue due to resonance are expected, as there is little wave energyout with the range of these periods.

\subsubsection{Torsion}

The torsion natural frequency is governed by the torsional stiffness of the arm and the mass of the hose crane and column at a distance from the centre line of the arm. Conservatively the mass of the hose crane is estimated at 250 tons at $40-\mathrm{m}$ above the centre line of the arm. The contribution of the mass of the arm itself to the total (polar) inertia of the system is rather small and can be neglected compared to the contribution of the hose crane.

With the above assumptions the (first) torsion natural period is 1.9 seconds.

If the mass or CoG of the crane reduces the period becomes shorter.

\subsubsection{Bending}

There are two mode shapes that are relevantin relation to the bending natural period. One is where the arm is considered a beam simply supported at two ends (by the hinges and the buoyancy box). The second mode is where the arm is considered hinged at the tower end and free at the other end (the second mode can be considered as half a simply supported beam width a weight in the middle)
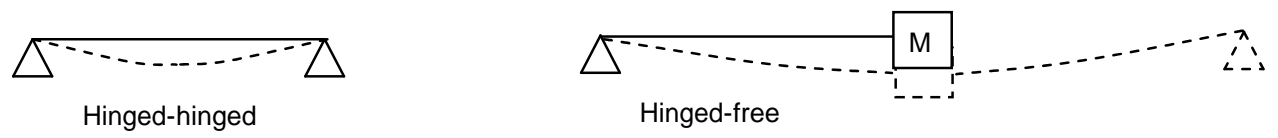

The simply supported beam has a natural frequency of $7.8 \mathrm{rad} / \mathrm{s}$ and a natural period of 0.8 seconds.

The weight considered in the second mode shape is the weight of the distributed weight of the arm plus added mass along the arm and the weight of the buoyancy box, hose crane and added mass of the buoyancy box. Especially this last item, the added mass of the buoyancy box, some 4000 metric tons, is of great influence on the natural frequency of this mode shape: the natural frequency is $0.15 \mathrm{rad} / \mathrm{s}$ and the natural period 42 seconds. As there is little wave energy above 20 seconds period and the period is longer than the natural pitch period of the arm, no problems are to be expected. 
Doc. No. 1-0282-0/CGI-S-810-CA-0002/ Rev A Report - Sweep Arm Structural Design

\section{Conclusions and Recommendations}

\subsection{Conclusions}

The considered loads are conservative: maximum bending moments are combined with a conservatively estimated shear load.

The contribution of the local hydrodynamic loads is minor when compared to the global static and global wave loading.

The chosen geometry of the arm lattice structure, main dimensions and member sizes, appears adequate for the considered loads. Nowhere the usage factors exceed the maximum allowable value. The ratio between the horizontal and vertical main dimensions and is in line with the encountered horizontal and vertical bending moments and shear loads.

The longitudinals (chords) are reinforced at the nodes with can sections.

Structural natural periods are not critical.

Compared to the model tests the hinge section has been changed into a lattice structure to mitigate the effects of slamming loads 
Doc. No. 1-0282-0/CGI-S-810-CA-0002/ Rev A Report - Sweep Arm Structural Design

\section{References}

[1] Design Load Report, BIGS-G-100-RP-0101/Rev.A

[2] API-RP2A, Recommended Practice for planning, designing and construction of fixed offshore platforms, Working Stress Design, Third Edition 1997

[3] AISC, Manual of Steel Construction, Allowable Stress Design, Ninth Edition 1989

[4] DNV, Classification Note 30.5, Environmental Conditions and Environmental Loads, March 2000 


\title{
Philosophy
}

\section{Fire Protection Philosophy}

\section{Doc. No. CGI-G-600-RP-0011 Rev. A}

\section{Project. No. 1-0282-0}

\author{
Bluewater Energy Services B.V. \\ Marsstraat 33 \\ 2132 HR Hoofddorp \\ The Netherlands \\ Tel. +31235682800 \\ Fax. +31235652053
}




\section{Revision Status Sheet}

Rev.

Date

A

14-07-2004
Description

Initial Issue
Initiator

RVVE

\section{Checked by}

Approved by
Date

December 2004

December 2004
Initials

FLIE

HVDB

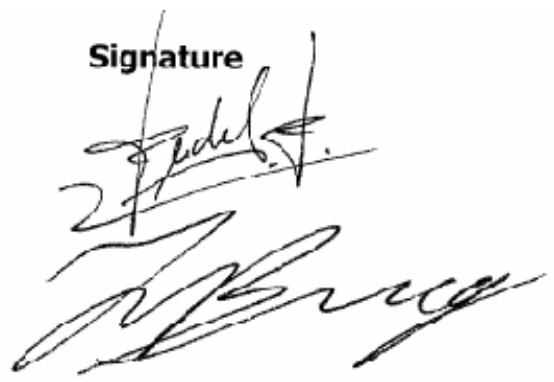




\section{Table of Contents}

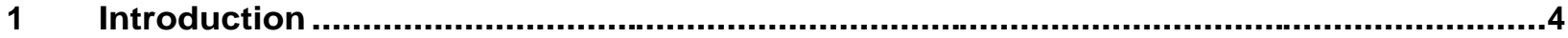

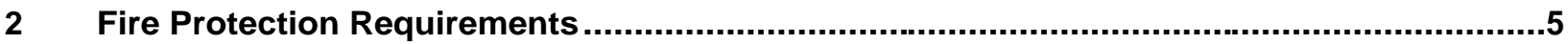

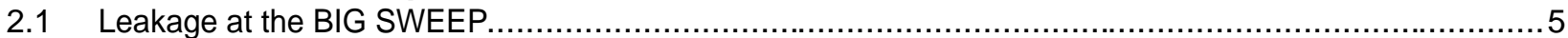

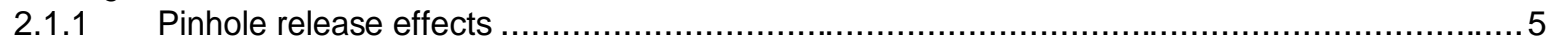

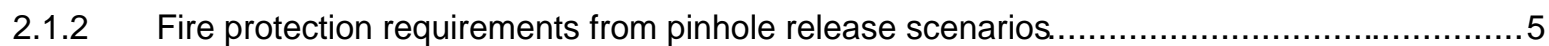

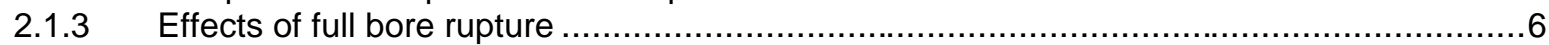

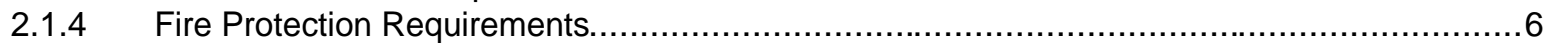

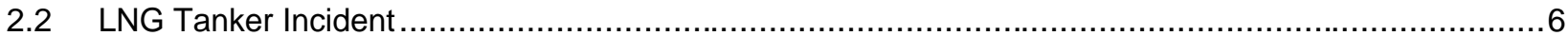

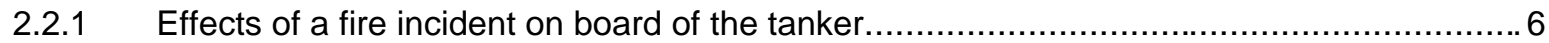

2.2.2 Fire protection requirements for LNG Tanker Fire Incidents......................................

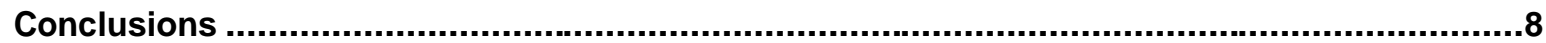




\section{Introduction}

In this document the philosophy for the BIG SWEEP LNG Unloading Arm is described. This document forms part of a package of design documents.

For a short description of the operation of the BIG SWEEP, reference is made to the process narrative (CGI-G-100-PH-0002/Rev. A).

In chapter 2, an overview is given of relevant fire scenarios for the LNG loading arm.

In chapter 3, the philosophy is presented with respect to fire and explosion protection. 


\section{Fire Protection Requirements}

In this chapter, governing fire scenarios are described qualitatively that will form the basis for the requirements for fire protection.

\subsection{Leakage at the BIG SWEEP}

\subsubsection{Pinhole release effects}

A pinhole release from the BIG SWEEP will lead to a two-phase LNG outflow of limited size. The size should be quantified in the project phase. Full vaporisation is to be expected in case of this type of leak scenario. This can result in a very limited size of explosive cloud and, in case of delayed ignition to a minor explosion, or, in case of direct ignition, can lead to a jet flame of limited size.

The effect of the ignition of a small size explosive cloud is negligible. As the structure is fairly open, the build-up of significant overpressures is not to be expected (to be quantified in project phase).

Should direct ignition occur, then the jet flame of limited size would have limited effects. Should the jet flame impinge on piping containing LNG, local hot spots and limited vapour generation in the pipework could be the consequences. When a jet flame would impinge on an ESDV or on a blowdown valve, valve and/or actuator could be rendered inoperative.

\subsubsection{Fire protection requirements from pinhole release scenarios}

From the scenario presented in the previous paragraph, the following requirements can be formulated:

- Prevention of ignition sources: To prevent direct or delayed ignition, the following measures should be implemented:

1. Consequent application of a code for hazardous area classification, and the purchase of equipment suitable for the zones that were defined to prevent ignition from electric equipment;

2. The application of adequate earthing and bonding to prevent the buildup of static electricity;

3. The installation should be normally unmanned, to prevent ignition due to the presence of humans or due to human activities.

4. The use of adequate surface coating to prevent iron corrosion, and to prevent ignition by a pyrite reaction

- $\quad$ Limiting the amount of LNG present during a pinhole leakage by using a drain- and vent system that will empty the BIG SWEEP in an adequate time period (time to be determined in project phase);

- The use of PSV's that are dimensioned for an adequate thermal flux scenario from a small size jet flame to be able to cater for limited vapour generation (dimensioning heat flux to be calculated in project phase)

- Design for overpressure: it should be evaluated in an early project phase whether the BIG SWEEP should be designed to withstand overpressures resulting from an explosion from a pinhole release;

- Prevent the accumulation of hazardous gasses: the installation will be designed such that a maximum degree of natural ventilation is achieved.

- Application of Passive Fire Protection: ESDV's, drain/blow down valves, emergency power supply and PSV's should be protected against jet fire impact by the application of PFP with a rating of $J 30$.

- The use of F\&G detection leading to automatic closure of the ESDV's and shutdown of the loading pumps and activation of the drain system should be applied to limit the duration and effects of the outflow. This should be enabled by an emergency power supply that is available under fire conditions. 


\subsubsection{Effects of full bore rupture}

The occurrence of a full-bore pipe rupture is estimated to be highly unlikely. The least unlikely location is the location of the heat exchangers. This will most likely result in two-phase outflow with rapid vaporisation. Formation of a pool on the loading arm is not considered as a possibility as most of the entire structure will be grated. Sections where a pool can form should be designed to prevent pool formation.

If at a location of the installation a pool of liquid LNG could form, this could result in subsequent failure of structural elements due to embrittlement.

A pool of limited size could form on the sea surface. The vaporisation from a pool on the sea surface will be very rapid, as a consequence of the unlimited size and heat transfer capacity of the water (rapid phase transition). This will result in an explosive cloud of consderable size.

Should direct ignition occur, a large two phase jet flame of a short duration will be the result. Should the jet flame impinge on piping containing LNG, local hot spots and limited vapour generation in the pipework could be the consequences.

When a jet flame would impinge on an ESDV or on a blowdown valve, valve and/or actuator could be rendered inoperative.

Delayed ignition can lead to an explosion or a flash fire leading to stresses on the structure as a consequence of thermal flux or explosion overpressures and damage to instrumentation.

\subsubsection{Fire Protection Requirements}

Additional to the requirements listed in paragraph 3.1.2, the following recommendation should be implemented:

- Locations where a pool of LNG could form should be prevented as much as possible by the use of grating. If this is unavoidable at certain locations, the local application of Passive Fire Protection with an adequate rating should be considered. Furthermore, locations where a liquid LNG pool could form should be protected against subsequent failure due to embrittlement.

- ESDV's, PSV's, emergency power supply and drain/blow down valves should be protected against explosion overpressures in order to keep them operable under explosion and flash fire conditions.

\subsection{LNG Tanker Incident}

\subsubsection{Effects of a fire incident on board of the tanker}

Should a fire incident occur on a LNG tanker, then the loading arm is likely to be subjected to a thermal flux as a consequence of this. A thermal flux can lead to vapour generation within the piping system, and can ultimately lead to pipe rupture and subsequent aggravation of an incident by the release of its inventory.

An explosion on board of the LNG tanker and subsequent missile impact or explosion overpressures to which the loading arm might be subjected is not considered here. 


\subsubsection{Fire protection requirements for LNG Tanker Fire Incidents}

Next to the fire protection measures identified in the previous paragraphs, the following measures should be implemented:

- On confirmed F\&G detection on tanker or on loading arm during loading ops, an automatic closure of the loading arm ESDV's should be initiated, and an automatic quick disconnect between tanker and loading arm should be triggered.

- The PSV's should be dimensioned for thermal flux originating from the tanker. The value for thermal flux should be established in co-operation with the tanker operator.

- $\quad$ The LNG tanker is assumed not to depend on fire fighting capabilities of the BIG SWEEP. 


\section{Conclusions}

In chapter 2, a set of governing fire scenarios was presented. In chapter 3 , based on a set of fire scenarios, a set of recommendations was generated that is specific for the location and operation of the BIG SWEEP.

The recommendations that were formulated in chapter 3 should be implemented in the design. In a project phase, it should be proven to the relevant authorities that an equal or higher level of safety is achieved by implementing the proposed measures.

The supply of firewater is not foreseen at this point in time. Firewater cannot be used to extinguish a LNG fire. For cooling purposes, firewater is not effective due to the low operating temperatures of the $\operatorname{BIG} \operatorname{SWEEP}\left(-160^{\circ} \mathrm{C}\right)$. 


\section{Equipment List}

\section{Product Transfer System}

Doc. No. CGI-100-LQ-0001 Rev. A

Project. No. 1-0282-0

Bluewater Energy Services B.V.

Marsstraat 33

2132 HR Hoofddorp

The Netherlands

Tel. +31235682800

Fax. +31235652053 


\section{Revision Status Sheet}

Rev.

Date

A December 2004
Description

Initial Issue
Initiator

HVDB

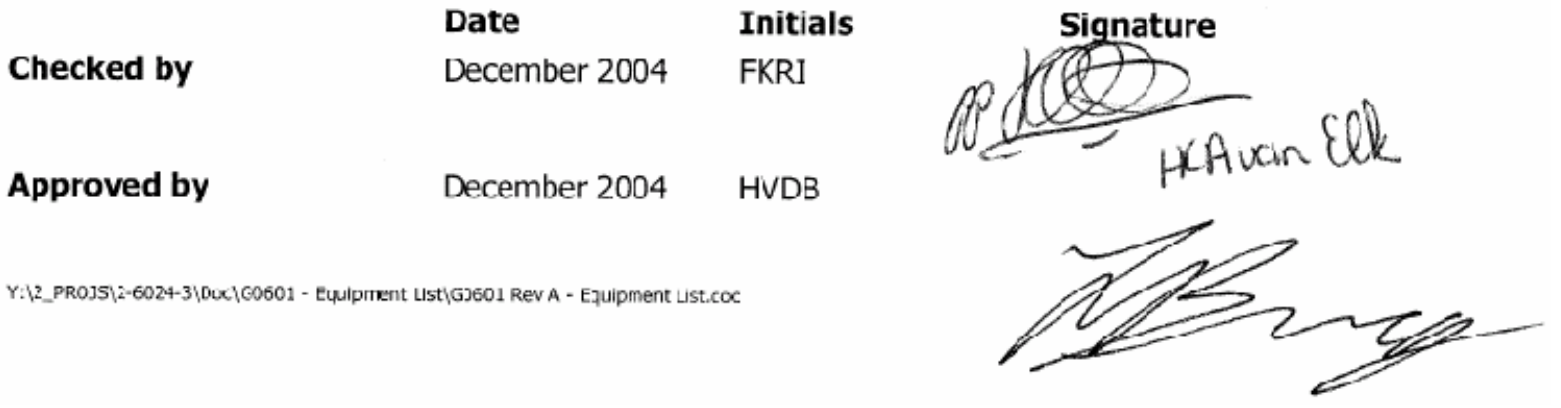

Equipment List - Page 2 


\section{Table of Contents}

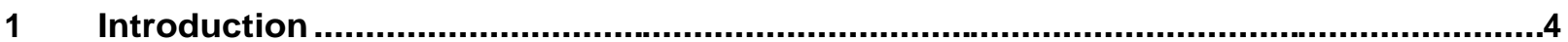

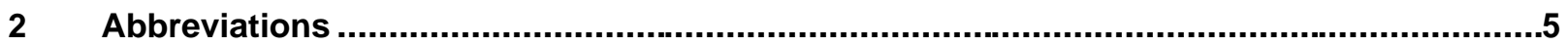

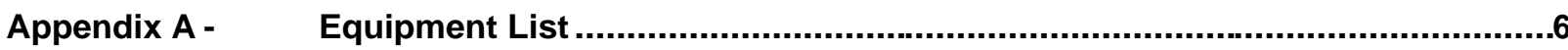


Doc. No. 1-0282-0/CGI-100-LQ-0001/ Rev A Big Sweep - Product Transfer System

\section{Introduction}

The equipment list identifies the main equipment for the LNG import terminal with Big Sweep system.

When engineering progresses in more detail phase, the equipment list will be expanded to include minor equipment, valves, etc. and equipment details. Further specificationwill be added in next issues. 


\section{Abbreviations}

C- Coating and Insulation

E- Electrical

$\mathrm{H}$ - HVAC

$\mathrm{J}$ - Instrumentation

L- Civil

M- Mechanical

P- Piping

S- Structural

T- Telecoms 
Doc. No. 1-0282-0/CGI-100-LQ-0001/ Rev A Big Sweep - Product Transfer System

\section{Appendix A - Equipment List}




\section{Equipment List}

\section{Mechanical \\ and \\ Electrical \& Instrumentation}

Doc. No. CGI-H-300-LQ-0001 Rev. A

Project. No. 1-0282-0 
Doc. No. 1-0282-0/CGI-H-300-LQ-0001/ Rev A Electrical \& Instrumentation - Mechanical and Electrical \& Instrumentation

\section{Revision Status Sheet}

Rev. Date

A
Description

Initial Issue
Initiator

HVDB
Date

Checked by

Approved by

December 2004

Initials

BOVE

HVDB

Y:W__PFOJS'1-0282-OLDoc(H0)01 Rev A - Equipment List,H0001 Rev A - Equipment List.Joc

Signature
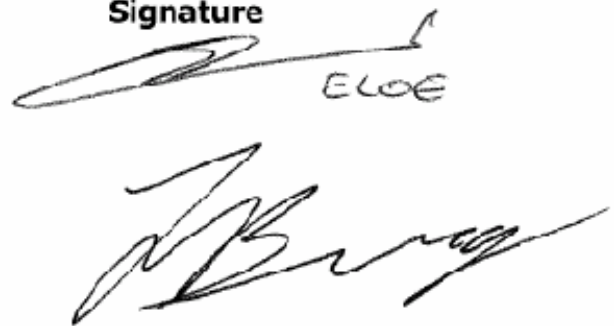


\section{Table of Contents}

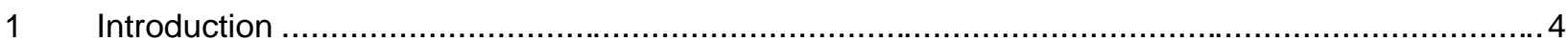

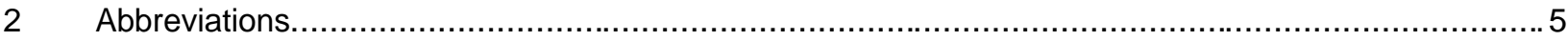

Appendix A -

Equipment List .

6 
Doc. No. 1-0282-0/CGI-H-300-LQ-0001/ Rev A Electrical \& Instrumentation - Mechanical and Electrical \& Instrumentation

\section{Introduction}

The equipment list identifies the main equipment for the LNG import terminal with Big Sweep system.

When engineering progresses in more detail phase, the equipment list will be expanded to include minor equipment, valves, etc. and equipment details. Further specifcation will be added in next issues. 
Doc. No. 1-0282-0/CGI-H-300-LQ-0001/ Rev A Electrical \& Instrumentation - Mechanical and Electrical \& Instrumentation

\section{Abbreviations}

C- Coating and Insulation

E- Electrical

$\mathrm{H}$ - HVAC

$\mathrm{J}$ - Instrumentation

L- Civil

M- Mechanical

P- Piping

S- Structural

T- Telecoms 
Doc. No. 1-0282-0/CGI-H-300-LQ-0001/ Rev A Electrical \& Instrumentation - Mechanical and Electrical \& Instrumentation

\section{Appendix A - Equipment List}




\title{
Report
}

\author{
Cost Estimate
}

\section{Big Sweep LNG Terminal}

\author{
Doc.No. CGI-G-100-RP-0005/Rev. A
}

\author{
Project No.: 1-0282-0
}

Bluewater Energy Services B.V. 


\section{Revision Status Sheet}

$\begin{array}{cc}\text { Rev. } & \text { Date } \\ \text { A } & 29 / 11 / 2004\end{array}$

$\begin{array}{lll} & \text { Date } & \text { Initial } \\ \text { Checked by } & \text { December 20C4 } & \text { HVK } \\ \text { Approved by } & \text { December 20C4 } & \text { JDB }\end{array}$

\section{Description}

Initial Issue
Approved by

December 20c4

JDB
Initiator

HvdB

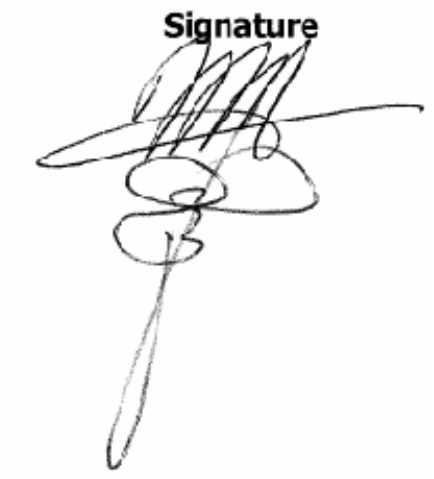




\section{Contents}

\begin{tabular}{|c|c|}
\hline 1 & Summary \\
\hline 2 & Cost Estimate. \\
\hline 2.1 & Scope. \\
\hline 2.2 & Estimating Method \\
\hline 2.3 & Fabrication...................... \\
\hline 2.4 & Offshore Installation........ \\
\hline 2.5 & LNG Carrier................ \\
\hline 2.6 & Currency \\
\hline .7 & 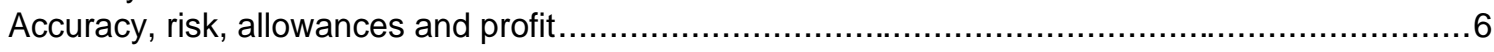 \\
\hline & dices.................................. \\
\hline
\end{tabular}


Doc. No. CGI-G-100-RP-0005/Rev. A Report - Cost estimate Big Sweep LNG Terminal

\section{Summary}

The cost estimate for the Big Sweep LNG terminal is based on the terminal design presented for the Vermilion block 179 location and as further detailed in the Conceptual Design documents part of the study performed for Conversion Gas Imports, LLC.

The terminal CAPEX is estimated for one unit comprising the Big Sweep system engineering, fabrication, transport to site, installation, hook-up and commissioning. The scope boundary for the estimate is at the perimeter of the tower base at the seabed.

The man-hour costs are based on current internal project hourly rates while material and equipment cost are derived from historical data.

The Big Sweep installation is assumed to be part of the terminal installation scope hence assuming cost efficiency in the offshore installation contracting strategy.

The cost estimate breakdown is included in Appendix A. 


\section{Cost Estimate}

\subsection{Scope}

The cost estimate for the Big Sweep terminal assumes a separate contract for the LNG Carrier mooring facility as part of a complete Vermilion terminal development. Main interface scopes are the sea lines and the platforms. The battery limit for the systems design is the seabed perimeter of the base structure. Cost at the Big Sweep side of this battery limit are included in the Big Sweep cost estimate, cost at the sea line side and platform side shall be estimated by the other study partners.

The estimate concerns the terminal design as presented in the study deliverables for Conversion Gas Imports and basically comprises:

- Management and administration

- Design and engineering

- Procurement of equipment

- Fabrication

- Transport of materials

- Installation and hook-up at offshore site

- Commissioning

- Certification and documentation

The estimate for the Big Sweep terminal CAPEX assumes a Lump sum EPIC contract for a single unit.

\subsection{Estimating Method}

The cost estimate uses the project specific design package compiled for the studycomprising the lay-out and arrangement drawings, process PFD's and diagrams and the structural weight report and equipment lists.

Man-hour cost for Project Management and Engineering \& home office cost are based on the internal rates applicable for activities performed at the main office, man-hour construction supervision cost are based on fabrication site assignments.

Cost information for fabrication, transport and Installation is drawn from the Bluewater data base with historical cost information.

This data base is maintained up to date with both as built project data as well as equipment and yard cost enquiry data.

Man-hour costs are estimated for the main disciplines, material and equipment costs are estimated by system. Costs are rolled-up to a breakdown schedule common for the complete Vermillion LNG Terminal.

\subsection{Fabrication}

The fabrication cost for the steel structure is based on Middle East fabrication and transport to the Gulf of Mexico. Fabrication in the US is expected to arrive at a similar cost level as Middle East fabrication including transport cost, further work should however confirm this assumption. 


\subsection{Offshore Installation}

The Vermilion terminal comprises next to the Big Sweep LNG carrier mooring facility, the platforms, caverns and sea lines. The cost estimate for the Big Sweep installation assumes that the contracting strategy for the Vermilion terminal is optimized towards an efficient contracting of the offshore works.

In the Big Sweep installation cost estimate the project cost and marine equipment cost are estimated assuming a single mob and demob for all installation equipment, i.e. only partial costs are taken into account. Furthermore, other task costs are estimated for a joint survey, installation, testing and commissioning program.

\subsection{LNG Carrier}

LNG carrier preparation costs are excluded from the cost estimate. These costs depend heavily on the number of different carrier that will receive an offshore manifold adoption arrangement. The cost associated with the modification will be mainly the vessel day rate for the aggregated duration of the modification work. Should the manifold modification be carried out during a scheduled periodic survey at a shipyard, the modification cost will be significantly less compared to a stand alone modification.

\subsection{Currency}

The cost estimate summary presents a breakdown in US dollars whereas the estimate amounts for approximately equal parts in US dollar value and Euro value. The exchange rate of end November 2004 is used for the conversion of Euro to US dollar values.

\subsection{Accuracy, risk, allowances and profit}

The level of scope definition up on delivery of the study results and the deterministic approach to the cost estimating exercises result in an estimate accuracy for the Big Sweep LNG Terminal scope of work of $+/-25 \%$.

Cost for risks beyond the direct control of the contractor is excluded.

The estimate is based on cost levels in year 2004, future cost escalation is excluded.

The design of the mooring terminal identifies major systems and includes a preliminary sizing of structures, systems and equipment. Minor systems and subsystem are not yet specified. Therefore allowances for a scope growth in the Basic and Detailed Design Phase are included.

The reported cost figures are excluding insurances, profit and taxes. 


\section{Appendices}

Appendix A: Cost Estimate Big Sweep.

.8 
Appendix A: Cost Estimate Big Sweep

\begin{tabular}{|c|c|c|c|}
\hline \multicolumn{2}{|r|}{ Main Scope of Work } & & November 2004 \\
\hline $\begin{array}{l}\text { CBS } \\
\text { Code }\end{array}$ & Description & Remarks & $\begin{array}{r}\text { Cost price } \\
\text { USD }\end{array}$ \\
\hline 1 & LNG Mooring and Offloading & & $17,735,151$ \\
\hline 2 & LNG pipeline & Not included & 0 \\
\hline 3 & Major equipment & & $12,579,422$ \\
\hline 4 & Fabrication Materials & & $7,307,238$ \\
\hline 5 & Fabrication Labor & & $21,107,447$ \\
\hline 6 & Freight, Receiving and Inspection & & $3,904,191$ \\
\hline 7 & Load out and marine operations & & $3,276,063$ \\
\hline 8 & Offshore Installation & & $2,547,839$ \\
\hline 9 & Hook-up \& Commissioning & & 175,656 \\
\hline 10 & Offshore Gas pipelines & Not included & 0 \\
\hline 11 & PBE Cavern Drilling \& development Cost & Not included & 0 \\
\hline 12 & Project Management Costs & & $1,788,713$ \\
\hline \multirow[t]{2}{*}{13} & Engineering \& Home Office Costs & & $9,403,570$ \\
\hline & & TOTAL & $79,825,291$ \\
\hline
\end{tabular}




\title{
Field Layout Workshop
}

\section{For Vermilion 179 LNG Offshore Terminal}

Doc. No. CGI-G-600-RP-0004 Rev. A

Project. No. 1-0282-0

\author{
Bluewater Energy Services B.V. \\ Marsstraat 33 \\ 2132 HR Hoofddorp \\ The Netherlands \\ Tel. +31235682800 \\ Fax. +31235652053
}




\section{Revision Status Sheet}

Rev.

Date

A

14-7-2004
Description

Initial Issue
Initiator

HVDB

\begin{tabular}{|c|c|c|}
\hline & Date & Initials \\
\hline Checked by & December 2004 & FLIE \\
\hline Approved by & December 2004 & HVDB \\
\hline
\end{tabular}

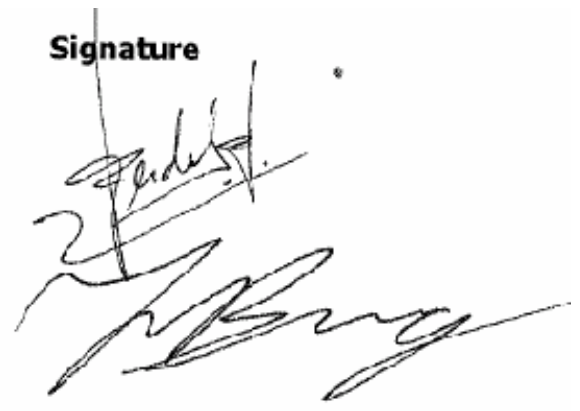




\section{Table of Contents}

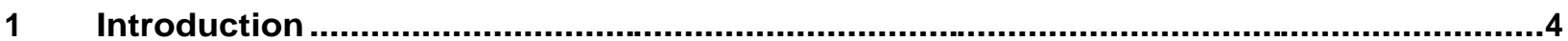

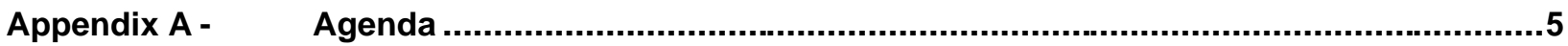

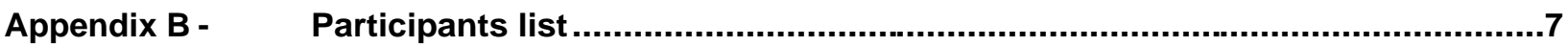

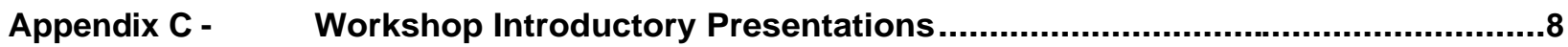

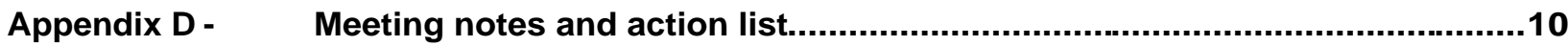




\section{Introduction}

Conversion Gas Imports LC awarded a study sub-contract to Bluewater for - the conceptual design of an offshore LNG receiving terminal - of their Department of Energy's NETL research study on the 'Bishop' process for receipt, re-gasification and salt-dome storage of LNG.

Bluewater organised a workshop at the beginning of the study in a workshop format meeting with a number of industry experts in the respective fields of LNG aspects with the objective that joint efforts will significantly enhance the credibility of the final study result.

As a starting point Bluewater used the 'Vermilion 179' concept described in OTC paper 15301. The base configuration is an LNG Single Point Mooring (SPM) system connected via a subsea pipeline to a re-gas, injection \& send-out platform at $\sim 1$ NM distance.

The goal of the one day workshop is to confirm the overall field layout and workability of the 'Vermilion 179' LNG import terminal, offshore Louisiana. The meeting took place in Houston TX, USA, January $14^{\text {th }}$ 2004.

In this report, the Agenda is presented in Appendix A, the OTC paper, workshop presentations andHIRA introduction are presented in Appendix $C$ and the results of the study are included in Appendix D 
Doc. No. 1-0282-0/CGI-G-600-RP-0004/ Rev A Field Layout Workshop For Vermilion 179 LNG Offshore Terminal

\section{Appendix A - Agenda}


CLIENT: $\quad$ Conversion Gas Imports

PROJECT NO: $\quad 1-0282-0$

PROJECT: $\quad$ BIG SWEEP LNG import terminal

DETAILS: $\quad$ A FIELD LAYOUT WORKSHOP was held to evaluate the concept as presented in OTC paper 15301. The workshop started with a number of presentations on the overall terminal concept and field layout followed by an animation video of the Big Sweep terminal concept. A HIRA session procedure was presented which was the basis for review of the terminal aspects.

MEETING DATES: 15 January 2004

CHAIRMAN: Chris Cassias

TEAM MEMBERS: See appendix B

\section{ACTION RESPONSES TO: HSEQ}

\section{DOCUMENTS STUDIED}

The concept presented in the video animation and the Artist impression drawing included in Appendix C1

Agenda of the meeting:

1. Introduction

2. Description of the Bishop process

3. Terminal location \& field layout

4. Mooring terminal operation

a. Approach to- and departure from site

b. Escort \& support vessel requirements

c. Berthing operations

d. (Emergency-) disconnect operations

5. LNG transfer operations

a. Start-up / shut down of LNG transfer systems (ship to SPM, SPM to regas platform)

b. Process disruption

c. Venting / flaring requirements

6. HAZID session, building on findings \& observations voiced under 4 \& 5 
Doc. No. 1-0282-0/CGI-G-600-RP-0004/ Rev A Field Layout Workshop For Vermilion 179 LNG Offshore Terminal

\section{Appendix B - Participants List}




\section{Appendix C - Workshop Introductory Presentations}


Doc. No. 1-0282-0/CGI-G-600-RP-0004/Rev A Field Layout Workshop For Vermilion 179 LNG Offshore Terminal

\section{Contents}

C1 OTC paper 15301 "Offshore Transfer, Re-Gasification and Salt Dome Storage of LNG

C2 CGI presentation".

"Field Test and Full Scale Design of Critical Components of a Salt Cavern Based LNG Receiving Terminal"

C3 Paragon Presentation "Regas, Injection + sendout Offshore Facilities

C4 Bluewater Presentation "SPM Terminal Lay-out"

C5 Bluewater Presentation "Metocean Criteria"

C6 Bluewater Presentation "HIRA Process"

C6 HIRA LNG Terminal 


\section{Appendix D - Meeting notes and action list}




\title{
OTC 15301
}

\section{Offshore Transfer, Re-Gasification and Salt Dome Storage of LNG}

\author{
J. de Baan / Bluewater Energy Services B.V.; M.H. Krekel, R. Leeuwenburgh / Bluewater Offshore Production Systems \\ (USA), Inc.; M.M. McCall / Conversion Gas Imports, LLC.
}

Copyright 2003, Offshore Technology Conference

This paper was prepared for presentation at the 2003 Offshore Technology Conference held in Houston, Texas, U.S.A., 5-8 May 2003.

This paper was selected for presentation by an OTC Program Committee following review of information contained in an abstract submitted by the author(s). Contents of the paper, as remente con prested to correction by the author(s). The material, as presented, does not necessarily reflect an position of the Offshore Technology Conference or its officers. Electronic reproduction, distribution, or storage of any part of this paper for commercial purposes without the written consent of the Offshore Technology Conference is prohibited. Permission to reproduce in prin is restricted to an abstract of not more than 300 words; illustrations may not be copied. The abstract must contain conspicuous acknowledgment of where and by whom the paper was presented.

\section{Abstract}

The paper describes a design family for 'ship to ship' and 'ship to shore' transfer systems for LNG. The common design philosophy is explained and each configuration is described briefly. Auxiliary systems and equipment are discussed as are operational procedures.

A case study is presented for a near shore LNG terminal, comprising a marine transfer system in combination with a regasification plant and a salt dome storage cavern. The regasification plant and the salt dome storage cavern are treated extensively.

The systems described will greatly advance the implementation of offshore terminals for LNG. Although new, all of the components used are proven and have been applied in LNG terminals and offshore loading systems longtime.

\section{Introduction}

LNG is the fastest growing hydrocarbon fuel; while gas as a primary fuel source is forecast to grow at 3\% in the coming two decades, LNG as a subset is forecast to grow at double that rate over the same period. ${ }^{[1]}$ The development of LNG has been encouraged by the enormous amount of stranded gas, a reduction in gas flaring, an ongoing 'greening' of the energy mix and several price spikes in natural gas prices. These many factors have stimulated growth of $\mathrm{LNG}$ production but also introduce 'commoditization' of LNG because of the substantial new sources of supply.

The U.S. is currently by far the world's largest gas market. Of the current supply $85 \%$ is produced within the US, and $15 \%$ is imported; $98 \%$ from Canada and only $2 \%$ in the form of LNG. Whereas U.S. demand is expected to grow with $2 \%$ per annum, the current U.S. gas production shows an increasing intrinsic decline rate and more newly discovered gas is needed each year to keep up with demand. No excess capacity exists at the wellhead. Current demand for winter heat is greater than storage and production. ${ }^{[2]}$ In order to stabilize price, there is a need for increased storage capacity.
With current producers struggling to maintain production, LNG is likely to capture a portion of the foreseen growth.

Community concerns, congested ports, security and cost considerations are seen to slow the development of significant increases in capacities to receive LNG in the U.S. and Europe. This paper will describe an offshore alternative to moor, unload, store and distribute gas sourced as LNG that has the potential to be faster to build, less expensive, much more secure, and more acceptable to the community than conventional alternatives.

Besides the liquefaction plants and shipping, a few key elements in the gas chain between production and delivery are the loading and offloading operations of the LNG ships, the re-gasification and the temporary storage of $\mathrm{LNG}$ and/or gas.

For the loading of LNG into the tankers and for the offloading thereof, terminals are required. The terminal at the loading side is normally close to the liquefaction plant. Traditionally on the offloading end, the terminal is situated near a temporary storage facility and re-gasification plant. After the LNG has been re-gasified, it is brought into the pipeline network to distribute it to the consumers. On locations with sufficient deepwater close to the coast or in ports, terminals may consist of jetty structures, where tankers can be moored and offloaded with standard midship sideloading arms. The LNG/Gas handling and storage can be done onshore.

In cases where conditions are less favorable due to shallow waters and / or congested shipping situations but also because of political reasons, offshore transfer, re-gasification and temporary storage can be an attractive alternative. Design work done to date shows that the transfer system, regasification and salt cavern based storage options are fully feasible. Again mentioning the U.S., there are numerous possibilities for these applications along the coast line and the design of the three components (transfer system, regasification unit and salt cavern based storage facility) are very flexible in the amount of LNG/gas to be handled.

Salt caverns can be solution mined in far less time and at about one fifth of the cost of constructing cryogenic tanks resulting in significantly lower investment and a shorter construction schedule. The permitting schedule will also be significantly shorter. Overall, these advantages result in a lower CAPEX and OPEX than for conventional terminals. Underground hydrocarbon storage is inherently secure as evidenced by the Strategic Petroleum Reserve's use of salt caverns to store more than $600 \mathrm{MM}$ bbls of crude oil. A salt cavern based LNG receiving terminal can provide far more 
storage capacity and 'send out' capability than a conventional terminal. To support these statements, a case study for a LNG import terminal, re-gasification plant and a storage salt cavern to be located in the Gulf of Mexico is presented in the following, together with the status and an outcome of a recent study executed for the U.S. Department of Energy.

\section{Transfer of LNG offshore}

Given that both production and import of LNG will move more and more offshore, Bluewater recognized a need for a safe, efficient and reliable transfer system. Since there is a wide variance in waterdepth and environmental conditions between the potential sites a whole suite of concepts has been developed to serve each application's specifics, see figure [1]. All concepts share a common philosophy:

High System Availability. The investments made in the LNG production and transport chain are large thus so are the costs associated with downtime of LNG production and / or demurrage of the carriers. High system availability is achieved by using weathervaning mooring systems, a robust flow path and a minimum number of cryogenic mechanical components. All concepts are based upon proven components.

Suitability for Non-Dedicated Vessels. The current market trend indicates that a spot market for LNG is developing. To allow flexible and efficient operation of the terminal facilities, it is essential that vessels of opportunity can be handled. Thus transfer of LNG in all systems takes place at the midship manifold and only a minimum of adaptation of the LNG carrier is required.

Near Shore Terminal. Both for loading of LNG into the tankers and for offloading thereof, terminals are required. For locations with sufficient deep water close to the coast, terminals may consist of jetty structures and breakwaters, where tankers can be moored and offloading can take place via the standard loading arms.

In case the conditions are less favourable due to shallow waters, congested shipping and / or mooring situations, but also because of community acceptance and permitting, offshore terminals are a very attractive alternative. Although such terminals exist - they have been widely used for loading of crude oil and oil products for many years - no offshore terminals for LNG are in use.

The most dominant advantages of LNG offshore terminals are the lower costs for construction and operation, the possibility to locate the terminal in deeper water thereby eliminating the need for dredging and increased availability, safety and reduced voyage time as LNG carriers need not enter and manoeuvre in congested waters.

Based on its long time experience in mooring and offloading systems, Bluewater has developed a series of concepts for LNG terminals based on the premise of safe transfer of LNG offshore to and from non-dedicated tankers in wave heights of up to $\mathrm{H}_{\mathrm{s}}=5.0 \mathrm{~m}$ and flow rates of up to $10,000 \mathrm{~m}^{3} / \mathrm{hr}$. Three near shore concepts were developed:

Medium Waterdepth Terminal. This concept, dubbed 'Big Sweep' consists of three basic elements, see figure [2]:

- A jacket structure with turntable, anchored to the seabed

- A submerged rigid arm, hinged at one end to the jacket turntable and terminating at its other end with a buoyant column, and
- The LNG loading and transfer structure, located on top of the buoyant column.

To allow the vessel and arm to passively 'weathervane' into the most favourable direction with respect to the environment, the turntable is connected to the jacket structure by means of a bearing. This allows the turntable to rotate $360^{\circ}$ with respect to the jacket.

The turntable supports the rigid arm hinges, the cryogenic fluid swivels and the hawser attachment point. Optionally a helicopter deck, control/monitoring room and re-gasification equipment can be mounted.

The rigid arm consists of the following main elements:

- A hinge assembly, which allows the loading arm to pitch and weathervane relative to the jacket structure

- A structural lattice forming a rigid arm, and a

- A buoyant hull section which pierces the waterline and accommodates the LNG offloading equipment.

The overall length of the rigid arm is such that the buoyant column is positioned nominally near the midship cargo manifold of the LNG carrier. By adjusting the length of the mooring hawser the carrier's cargo manifold can be lined up to the offloading station for vessel sizes ranging from large to very large gas carriers.

The buoyant hull is equipped with a thruster system to swing the arm in a safe position during approach of the vessel and in-line with the vessel in the operational mode. A water ballast tank allows draft adjustment of the loading arm to match tanker size and / or drafts.

The standard fluid transfer system consists essentially of 3 Pipe-in-Pipe (PIP) lines. Two lines are dedicated to LNG; either in full flow mode or re-circulation mode. The third line is dedicated for vapour return.

The flow paths cross the weathervaning and pitch hinges between the jacket and the rigid arm. This is achieved with swivels and full metal jumpers which can be easily inspected and serviced.

The loading arm is normally trailing the jacket but can be temporarily 'parked' away from the LNG carrier line of approach, with its own propulsion. In this position the entire loading arm assembly cannot be damaged by a failed mooring approach of the export carrier tanker. Note that offshore tanker mooring to SPM systems is standard marine practice and that a failed approach run very rarely happens. Should the carrier 'brush' against the terminal, this will be a 'low energy' collision which can be accommodated by the fendering.

The LNG carrier moors in tandem with the turntable and once it has secured itself safely and the overall alignment is stable, the loading arm will be deployed from its parked position toward the vessel's manifold.

The hose deployment and loading operation may now be initiated. After completion of the transfer operations all of the steps discussed above are done in reverse order.

Emergency disconnection, such as may follow from e.g. hawser failure or excessive positioning difficulties (e.g. fishtailing) may readily take place by:

- Quick disconnect, allowing for the controlled closure of valves/pumps of the fluid transfer system, but includes all the typical emergency measures as known in normal terminals, and 
- Activating full power on the thrusters to clear the rigid arm away from the export tanker returning it to its temporary parking position, giving wide berth to the LNG carrier.

Due to the relative high mass of the rigid arm, its long length compared to operating wave lengths and the small waterline area of the buoyant column, the heave motions (pitch) of the arm are very small and this has been validated in physical model tests in significant wave heights up to $9.0 \mathrm{~m}$.

Shallow Waterdepth Terminal. Developed from the 'Big Sweep' system, this unit is designed to operate in waterdepths below $40 \mathrm{~m}$, see figure [3]. It allows direct offshore-to-shore transfer of LNG, at rates up to $10,000 \mathrm{~m}^{3} / \mathrm{hr}$ from nondedicated vessels.

Motion characteristics are such that offloading can proceed up to significant wave heights of $3 \mathrm{~m}$, depending on the waterdepth, which may be as little as 15 metres. For extreme survival conditions such as in the Gulf of Mexico, the free-end of the unit is water-ballasted and set temporarily on the seabed.

A self-positioning DP capability allows the unit to follow the LNG carrier manifold when loading or unloading LNG but drives the unit out of the way when the LNG carrier is mooring itself to the turntable on the jacket, thereby avoiding marine hazards.

Re-gasification equipment may be located on the unit for applications without LNG storage e.g. where gas is stored in salt caverns or delivered directly to the shore gas grid.

Offshore Re-Gasification Dock. The concept of a floating dock is not new, however in combination with a reduced displacement and connected to a Single Point Mooring (SPM) system, and also fitted with a simple but redundant Dynamic Positioning (DP) system, it becomes a powerful tool to:

- Berth standard LNG vessels offshore

- Enable unloading LNG through standard marine loading arms

- Allow transfer operation to continue in conditions up to 4 $\mathrm{m}$ significant wave height

- Provide a stable platform for a re-gasification plant

- Allow disconnection from its anchor legs for dry docking for campaign maintenance and / or modifications.

In essence the concept is based on mooring permanently a partly submerged dock, through an articulated rigid arm to a catenary anchor leg buoy, see figure [4].

The articulated rigid arm has been selected because it allows the dock to take up a position of sway and yaw relative to the buoy, when seen from above. Since the concept is based on having transverse propulsion means integrated in the dock, it is quite clear that with an LNG vessel mooring on the hawser messenger wire of the SPM and inching itself up to the buoy, the dock is now able to fully track the path the LNG vessel will follow, including yaw and sway. Hence the dock can simply maintain sideway clearance with the LNG vessel until it surfaces to contact the underside of the hull once it has completed its approach, see figure [5].

The amount of contact force is a function of operating environmental parameters and will be of such magnitude that no relative motions occur between vessel and dock. At all times contact forces are modest and can be easily accepted by the vessel. Effectively, the vessel is now fixed to the SPM through friction only. This in turn allows standard marine loading arms to be employed.

Given the displacement of the dock, a substantial load carrying capacity can be generated to support e.g. a full regasification plant. This allows gas to be exported to shore rather than LNG.

Of particular interest in this sense is the ability of the dock to release itself from the anchor chains and be taken into a harbour/yard environment for any major upgrades or campaign overhauls.

Finally, relocation of the unit to another gas-import location is well feasible.

Export from Production Barge. Currently operators are developing systems for Floating Liquid Natural Gas production and storage (FLNG) ${ }^{[3]}$ Key to successful operation of such systems is safe and reliable means of transfer of LNG to the export vessel.

Current transfer concepts are based upon the traditional side-by-side configuration, or require the export vessel to be equipped with propriety connection equipment. Both factors adversely influence the availability and flexibility of the terminal, and so Bluewater has developed a number of concepts that circumvent these drawbacks.

Tandem Configuration. The 'Big Sweep' concept as previously described can also be deployed from a FLNG unit, see figure [6]. Such a system will enable offshore ship-to-ship transfer of LNG in tandem mode, which will increase the overall availability. The concept has the same components, albeit that a 3-axis joint is provided on the FLNG side of the arm.

The main differences between the two concepts are the motions of the FLNG. These, in combination with the steady arm result, in higher structural loadings.

Operationally, both systems are fully comparable. In nonoperating conditions, the 'Big Sweep' will be parked alongside the FLNG which allows easy access to the buoyant column and the loading arms for Inspection Repair and Maintenance (IRM).

This concept has been physically model tested in the offshore basin of MARIN, The Netherlands. The tests confirmed the workability in sea states up to $5 \mathrm{~m}$ and survival condition of $9 \mathrm{~m}$ significant wave height. Moreover, the station keeping by DP has been verified and showed only modest power levels to maintain a 'follow me' mode.

Side by Side Configuration. Another concept has been developed as a variation on the traditional side-by-side configuration for transfer of LNG, see figure [7]. The key features of this concept are:

- Increase of safe distance between the FLNG barge and the export vessel during transfer operation

- Easier mooring up, fewer mooring lines and less personnel safety issues.

The concept works with a typical (short) low sway / yaw single point mooring type hawser attached to the end of a rigid arm which in turn is mounted on a turntable fitted to the barge. The required mooring elasticity is provided by a gas-hydraulic cylinder at the short end of the rigid arm on the barge.

The arm is able to swing freely forward in case the LNG carrier was to 'nudge' it that way. 
An aft fender arrangement, based on a pivotal support arrangement, is provided near the end of the carrier's flat side shell, assuring that the 'near position' (i.e. bending radius control) of the flexible hose LNG transfer system is never compromised.

Although no model tests have been performed to date, Bluewater believes that safe mooring in conditions up to $3.5 \mathrm{~m}$ significant can be maintained.

Deepwater Remote SPM Dock. When transfer of LNG in side-by-side or tandem mode poses unacceptable operational constraints, export operations to the LNG carrier can be realized via a remote Single Point Moored Dock, see figure [8]. The system will be similar to the offshore dock described previously, but without the re-gasification plant. It will be located at a safe distance from the FLNG unit, typically 1 NM.

Transfer of product from the FLNG unit to the SPM dock will be via submerged full metal PIP lines. The transfer lines will be suspended via short chain sections from the SPM, jumpers forming the final connection to the dock's piping. This effectively decouples the dynamic rotations of the SPM dock from PIP transfer lines, reducing fatigue damage in the latter.

Fluid Handling System. The offloading equipment has been configured as a 'manipulator' from which the free end of either steel articulated loading arms or flexible catenary hoses are suspended. The advantage of this configuration is that it allows combining the free ends ( $3 \mathrm{x} \varnothing 20$ ") into a single assembly, handled by direct mechanical means. Individual hose connections, although technically feasible, would lead to clash potential during high-offset emergency disconnects and also require more manpower in establishing first-line connections. The arrangement of the 'manipulator' is shown in figure [9].

The principle of the manipulator is based on supporting the free end of the flowlines (flexible or rigid) from a tension leg, which maintains a slight vertical tension on the vessel interface while fully accommodating low frequency heave of the 'Big Sweep', and the heave, pitch and roll of the LNG carrier. The tension is generated by a counterweight which is moved in the fore-aft direction as a function of the stroking out of the horizontal boom. A redundant load pin measures actual tension in the tension leg and adjusts automatically the counterweight position.

When the tension leg experiences an angle of tilt, due to relative motions between 'Big Sweep ' and the carrier, such angle is automatically detected and the manipulator horizontal boom length and azimuth angle are automatically adjusted to bring back the angular value below a pre-set value (say $<10^{\circ}$ ). The loads typically experienced by the manipulator assembly are in the same order of magnitude as normal offshore cranes and hence fully practicable. Since high frequency motions have no effect on the positioning demands, power demands are low. Beyond the pre-set limits, the tension leg will automatically initiate disconnect whereby the entire connector part is lifted up and away from the carrier.

The connector in the lower part of the tension leg consists of a structural part and a multi-path flow part. All connectors are made up of standard commercially available components. The structural connector is connected first, the flowpath connectors at that time still having a clearance at their mating faces of about $300 \sim 500 \mathrm{~mm}$. Once the structural connector is secured, the flowpath connectors are stroked out to make up the connection. The structural connector is winched-down against the slight over pull of the tension leg. This allows that the 'first line' connection is made in-phase and avoids impact loads in case of large LNG carrier roll events. All elements of the tension leg and its connectors are designed to fail-safe.

The concept of the 'manipulator' allows significant automation of functions which enhances safety and limits manpower demand.

\section{Case Study: LNG terminal offshore Gulf of Mexico}

The goal of the U.S. Department of Energy cooperative research project, on which this paper's case study is based, is to define, describe, and validate, a process to utilize salt caverns to receive and store the cargoes of LNG ships. The project defines the process as receiving LNG from a ship, pumping the LNG up to cavern injection pressures, warming it to cavern compatible temperatures, injecting the warmed vapor directly into salt caverns for storage, and distribution to the pipeline network. The performance of work under this agreement is based on U.S. Patent 5,511,905, and other U.S. and Foreign pending patent applications. The cost sharing participants in the research study are The National Energy Technology Laboratory (U.S. Department of Energy), BP America Production Company, Bluewater Offshore Production Systems (U.S.A.), Inc., and HNG Storage, L.P.

Initial results indicate that a salt cavern based receiving terminal could be built at about half the capital cost, less than half the operating costs and would have significantly higher delivery capacity, shorter construction time, and be much more secure than a conventional liquid tank based terminal. There is a significant body of knowledge and practice concerning natural gas storage in salt caverns, and there is a considerable body of knowledge and practice in handling LNG, but there has never been any attempt to develop a process whereby the two technologies can be combined. Salt cavern storage is infinitely more secure than surface storage tanks, far less susceptible to accidents or terrorist acts, and much more acceptable to the community.

In particular, validation of the concept of an offshore, Gulf of Mexico, LNG receiving terminal, utilizing salt caverns for storage and the existing comprehensive pipeline system has profound implications for the next generation of LNG terminals. LNG imports are expected to become an increasingly more important part of the U.S. energy supply and the capacities to receive LNG securely, safely, and economically must be expanded. Salt cavern LNG receiving terminals both in onshore and offshore locations can be quickly built and provide additional import capacity into the U.S. exceeding $6 \sim 10 \mathrm{bcf} /$ day in the aggregate.

Conventional Tank Based LNG Receiving Facility. A typical facility will have tank storage capacity for 2 to 3 ships' cargoes or about $5 \sim 8$ bcf at standard conditions $(250,000 \sim$ $380,000 \mathrm{~m}^{3}$ in liquid form). The terminal will always have a LNG inventory in its storage tanks to keep everything cooled down. Typically the high-pressure pumps and vaporizers are the units limiting send-out as the facility can receive a cargo in 24 hours but takes from 3 to 6 days to discharge that volume 
as gas to the pipelines. There are four LNG terminals in the U.S. of this design, one of which is being refurbished. All have announced expansion plans but collectively the expanded terminals fall far short of the projected imports of LNG by 2020. Various alternate designs using cryogenic tank storage on floating vessels, shipboard re-gasification units or gravitybased structures generally take this same model and move it to sea.

LNG cryogenic storage tanks are expensive to build and maintain. Further, the cryogenic tanks are on the surface and present a tempting terrorist target. Several cargoes scheduled to be received after September 11, 2001 were delayed because of security concerns. There is therefore a need for a more secure, more economical, and higher capacity way to receive, store, and distribute LNG imports than has been done in the past.

Salt Cavern Based LNG Receiving Facility. The application of conventional salt cavern storage technology, augmented by new technology in the area of pumps, heat exchangers and facility design, could marry LNG and salt caverns into a highly secure, economical, flexible method to expand the Nation's energy supply.

Two key differences between a salt cavern based facility and a liquid tank based facility are that the caverns can be miles from the ship offloading facilities, and there is limited cryogenic liquid on site absent a ship. In a conventional terminal the liquid storage tanks must be in close proximity to the ship discharge site and considerable inventory is maintained between ships calls.

There are a number of salt formations, both offshore and near shore close to navigable waters where the caverns could be washed and developed into LNG receiving terminals. Salt cavern gas storage facilities have very high deliverability instantaneously available to the pipeline system, far higher than LNG vaporization capacities in conventional LNG terminals.

To illustrate the potential of this concept, a case study for an offshore LNG terminal with salt cavern storage is described in this paper. It consists of a marine terminal, which will receive LNG from the tanker. From there on LNG will be transferred to the injection platform, were it will be re-gasified and injected in the salt storage cavern. The injection platform has a seawater lift system; seawater will be used as warmant for the re-gasification process. Furthermore, the injection platform will accommodate a power generation plant fitted with a Waste Heat Recovery Unit (WHRU) to boost the seawater temperature, and a Living Quarters. Receipt and send-out of gas to the connecting pipelines will be controlled from the injection platform. Typical field lay-out is shown in figure [10].

Critical Elements. The major critical elements revealed in the cooperative research study are:

- Salt formations suitable for cavern development

- A pipeline infrastructure sufficient to carry large volumes of gas to market

- A method to moor and offload an LNG carrier and boost the LNG to storage cavern injection pressures at volumes that allow acceptable ship discharge times

- A heat exchanger design that will economically warm the LNG at high pressure and high volumes
Salt Formations and Storage Location. This case study locates the salt cavern storage facility in Vermilion block 179, a well-known salt formation in water approximately 100 feet deep, see figure [12]. This is sufficient for the drafts of any known and contemplated LNG carrier.

The rights to develop a salt cavern storage facility in U.S. territorial waters are obtained via lease from the Mineral Management Service. Such a lease would be granted on a 'non-interference basis' with any existing or future mineral exploration and production lease on the same blocks. This case study describes the development of six caverns, each initially of $2 \mathrm{MM}$ bbls capacity, but maintaining a wash string in operation so that while in operation and over time they could be continually washed to greater capacities depending on the needs of the operator. These caverns could hold approximately $12 \mathrm{bcf}$ of dense phase natural gas at 2,000 psi and be developed and placed in operation in 12 months. They could be subsequently enlarged to $4 \mathrm{MM}$ bbls each for a total storage capacity of $24 \mathrm{bcf}$ at a subsequent additional cost of less than \$ 2 million. Larger caverns with increased storage capacity are feasible.

In the U.S. there are more than 300 known salt domes and countless acres of salt strata many of which are located in offshore territorial waters. For a cross section of a salt dome refer to figure [13]. Salt domes, 'pillows', or thick salt strata suitable for the development of hydrocarbon storage caverns are also known to exist in other areas of the world including Mexico, Northeast Brazil, Europe, and China. A well can be drilled into the salt formation and fresh water or seawater can be injected through the well into the salt to create a cavern. Salt cavern storage of hydrocarbons is a proven technique that is well established in the oil and gas industry. The drilling program, casing requirements, solution mining techniques, monitoring, logging and testing are all well developed practices. Permitting by the MMS is expected to follow practices used by state agencies that permit these types of facilities presently. Discharge of the saturated brine created by solution mining at sea is currently permitted and practiced in the U.S. and in several other countries where cavern development is practiced. Salt caverns have high send-out capacity, are very secure, and are very inexpensive to create and maintain compared to surface tanks, particularly cryogenic tanks.

When fresh or seawater is injected into a salt formation, it dissolves thus creating brine, which is returned to the surface. The more fresh or seawater that is injected into the salt formation, the larger the cavern becomes. The top of the salt formation found in Vermilion block 179 is at depths of less than 1000 feet and has a horizontal extent of more than one mile. A salt cavern is an elongate chamber that may be up to 1,500 feet in length and have a capacity that varies between 3 $\sim 15 \mathrm{MM}$ bbls. The largest is about $40 \mathrm{MM}$ bbls, in crude oil service in the U.S. Strategic Petroleum Reserve. Each cavern itself needs to be fully surrounded by the salt formation so nothing escapes to the surrounding strata or another cavern. Multiple caverns will typically be formed in a single salt dome.

Presently, there are more than a 1,000 salt caverns being used in the U.S. and Canada to store hydrocarbons. Storage in salt caverns exceeds 1.2 billion bbls of hydrogen, natural gas, 
natural gas liquids, olefins, refined products, and crude oil. In the U.S. the salt cavern storage sites form a logistical connection between the gas, gas liquids, refining and petrochemical industries, resulting in the most comprehensive, efficient energy/processing infrastructure in the world.

Explorationists have known the locations of salt formations in the Gulf of Mexico for some time because of their interest in oil accumulations on the salt dome flanks and sub-salt. The first offshore oil wildcat well drilled in the Gulf of Mexico was drilled on the flanks of a salt formation in the Ship Shoal blocks in the late 1940's. Hydrocarbons do not dissolve or pass through the salt so the outer boundaries of salt formations are known as excellent 'traps' for hydrocarbon accumulations.

The Pipelines. This case study contemplates connecting the salt cavern based LNG receiving facility to three of the largest natural gas systems in the Gulf of Mexico, namely Bluewater, Sea Robin, and Texas Eastern. It is believed that there is 2 bcf / day of available take away capacity in these systems. Looping the connections or extending connections to additional systems could expand on the available capacity.

The Gulf of Mexico has an extensive pipeline network to transport produced oil and gas for processing and distribution. On average, close to $15 \mathrm{bcf} /$ day is moved onshore in this gathering system with estimated additional capacity to be close to $5 \mathrm{bcf} /$ day. This indicates that there is capacity available to move imported LNG from salt cavern storage sites to markets in the existing infrastructure. Over twenty potential sites were evaluated during the DOE research project that combine salt formations suitable for storage cavern development in proximity to existing pipeline capacity. Vermilion block 179 was selected for this case study but there are many attractive sites.

Marine Terminal. For the case study the shallow waterdepth terminal as described earlier in the paper, was selected as the most suitable concept.

Transfer from the ship's manifold to the weathervaning arm will be via two cryogenic flexible hoses supplemented by a vapor return hose. On the fixed jacket structure, a series of high-pressure LNG pumps will be provided to boost the LNG from the ship's discharge pressure of about $50 \mathrm{psi}$ to the storage cavern pressure of $2000 \mathrm{psi}$. A schematic diagram is shown in figure [11]. This arrangement allows the cryogenic hoses and swivels to be of low pressure rating. Power for the pumps will be provided from the injection platform via High Voltage subsea cable. A small re-gasification plant will be provided on the arm to provide vapor return to the LNG carrier.

The high pressure LNG pumps proposed cross no technological barriers from those that are in common use at lower pressures (1400 psi) Limiting factors of the pump's capacity are the power requirements of its drivers which limit each pump to about 2000 horsepower. Unloading rates in the $8,000 \sim 10,000 \mathrm{~m}^{3} / \mathrm{hr}$ can be achieved with multiple pumps and are the design basis for the case study facility.

The LNG will be pumped to the injection platform, located approximately $1 \mathrm{NM}$ away, via two $\varnothing 20$ " PIP cryogenic subsea flowlines. Note that the design of these will be based primarily on (thermal) stress considerations, and not so much on thermal efficiency, as the LNG will be re-gasified.

LNG Heat Exchangers. Conventional designs of heat exchangers can be utilized to warm the resultant high-pressure LNG but capacity limitations and energy consumption dictated a new approach resulting in the patented Bishop Process Heat Exchanger.

The Bishop Process warms LNG using seawater as warmant and stores the resulting dense phase natural gas (DPNG) in a salt cavern, or discharges it to a pipeline or both. The volume ratio of warmant to LNG, the number of warmant injection points and the preheating of the warmant and/or the LNG can be incorporated on a site-specific basis.

To accomplish heat exchange in a horizontal flow configuration, such as the Bishop Process, it is important that the cold fluid be at a temperature and pressure such that it is maintained in the dense or critical phase so that no phase change takes place in the cold fluid during its warming to the desired temperature. This eliminates problems associated with two-phase flow such as stratification, cavitation and vapor lock.

The dense or critical phase is defined as the state of a fluid when it is outside the two-phase envelope of its pressureenthalpy phase diagram. In this condition, there is no distinction between liquid and gas, and density changes on warming are gradual with no change in phase. This allows the heat exchanger of the Bishop Process to reduce or avoid problems with two-phase gas-liquid flows. The effect of confining the fluid to the dense phase is illustrated by an analysis of the densimetric Froude Number F that defines flow regimes for layered or stratified flows:

$$
F=V\left(g D \frac{\Delta \gamma}{\gamma}\right)^{-\left(\frac{1}{2}\right)}
$$

Here $V$ is fluid velocity, $g$ is acceleration due to gravity, $D$ is the pipe diameter, $\gamma$ is the fluid density and $\Delta \gamma$ is the change in fluid density. If $F$ is large, the terms involving stratification in the governing equation of fluid motion dropout of the equation. As a practical example, two-phase flows in enclosed systems generally lose all stratification when the Froude Number rises to a range of from 1 to 2 . In this application the value of the Froude Number ranges in the hundreds which assures complete mixing of any density variations. These high values occur because in dense phase flow, the term $\Delta \gamma / \gamma$ in the equation above is small.

Measurement of the Froude Number occurs downstream of the high-pressure pump systems and in the heat exchangers. Process simulations using HYSIS and the finite element modeling conducted as part of the research project indicate that the heat exchange occurs as predicted, icing is controlled, and energy consumption for the system is significantly lower than that experienced in conventional liquid tank terminals.

Facility Operations. The LNG ship mooring and unloading procedures are described previously in the paper.

The ship's discharged LNG will be presented to the inlet of the high-pressure LNG pumps at around $50 \mathrm{psi}$ and $-260^{\circ} \mathrm{F}$. at rates between 8,000 and $10,000 \mathrm{~m}^{3} / \mathrm{hr}$. The high-pressure 
LNG pumps will boost the LNG to approximately 2,000 psi and discharge to the heat exchangers. The discharge temperatures from the pumps to the heat exchanger would be higher than the inlet temperatures and is considered in the design of the heat exchangers. Seawater would be introduced into the heat exchangers in a counter flow manner and the resultant discharge of dense phase natural gas from the heat exchangers would be at 2,000 psi and design temperatures of plus $40^{\circ} \mathrm{F}$. Cryogenic tolerance and expansion considerations are accommodated by a combination of metallurgy and mechanical design. Generally the volumetric difference between LNG at atmospheric pressure and dense phase natural gas at 2,000 psi and $40^{\circ} \mathrm{F}$ is one to three so there is a velocity increase in the warming process and consideration is given in the piping and cavern design to allow for this expansion.

The dense phase natural gas will be injected directly into the caverns and/or the connecting pipelines with appropriate pressure control as necessary. Upon completion of the cargo unloading the entire cargo parcel will be handled in one time leaving only enough LNG on site on the inlet side of the highpressure pumps to maintain them in a cryogenic state.

The operation of the salt cavern storage caverns, their maintenance and inspection would be identical to those practices in the 100 plus natural gas storage caverns in operation in North America and Europe.

A difference between the operation of salt caverns used in LNG receiving and conventional natural gas storage is the high rates of injection into the caverns compared to most facilities. Conventional natural gas storage in salt caverns use compressors to boost the pressure of inlet gas to cavern injection at rates generally between $0.5 \sim 1 \mathrm{bcf} /$ day. This application would involve injections rates of $3 \sim 4 \mathrm{bcf} /$ day which is accommodated by multiple caverns and wells. A significant energy savings occurs in pumping LNG compared to compressing natural gas. A geo-mechanical temperature and rock mechanic analysis conducted as part of the research project indicate that injections to the caverns and withdrawals from them at the design rates described are within salt tolerances.

\section{Conclusion}

The adaptation of well accepted marine technologies; with equally well-accepted salt cavern storage technologies have the potential to accommodate a significant increase in the world LNG trade. Areas of the world that are projecting significant increases in import requirements of LNG, namely the US, Western Europe, China, and Mexico have a need for new methods for importing, storing and distributing LNG. Offshore terminal locations far from populated areas and congested ports will heighten community acceptance and reduce security concerns. The use of salt caverns can result in an LNG import terminal that compared to a cryogenic tank based terminal is much more secure, is much less expensive to build and operate, and can have both higher storage capacity and higher take away capacity. Northeast Asia has been the major traditional destination of the world's LNG but that is changing. The adoption of the well-developed technologies described in this paper has the potential to accommodate a virtually unlimited increase in LNG imports to the high growth areas of the Americas, Europe, and China.

\section{Acknowledgements}

Grateful acknowledgement is given to the U.S. Department of Energy, its component agencies, the Strategic Gas Center, and the National Energy Technology Laboratory for commissioning the cooperative research agreement under which this work was done, and the funding participants, BP American Production Company, Bluewater Offshore Production Systems (U.S.A.), Inc., and HNG Storage, L.P. who have participated in it. In addition, cooperation and assistance has been provided by the Federal Energy Regulatory Commission, the Mineral Management Service, and the U.S. Coast Guard.

\section{References}

[1] Meryll Lynch: Global Octane - Chapter 9 "Global LNG: a High Growth Market”, 23 October 2002

[2] Stephan Schubarth: "U.S. Gas Market Recent Dynamics", presentation to SPE Houston West Side Study Group, January 2003

[3] F. Faber et al: "Floating LNG Solutions - From Drawing Board to Reality", Paper OTC 14100, presented at the 2002 OTC, Houston 6-9 May 2002. 


\section{LNG Transfer Offshore}

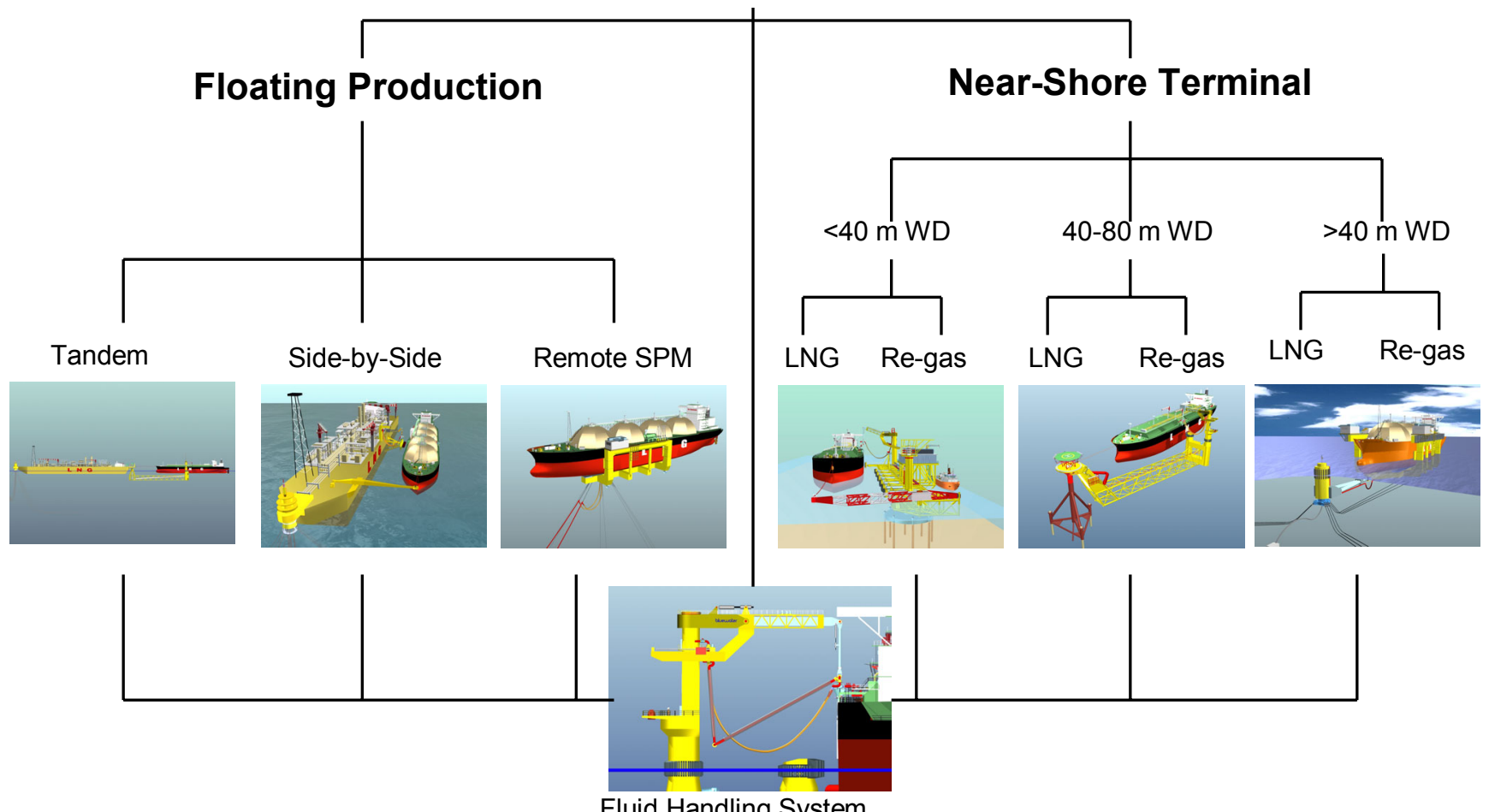

Figure 1: Design Concepts for LNG Transfer
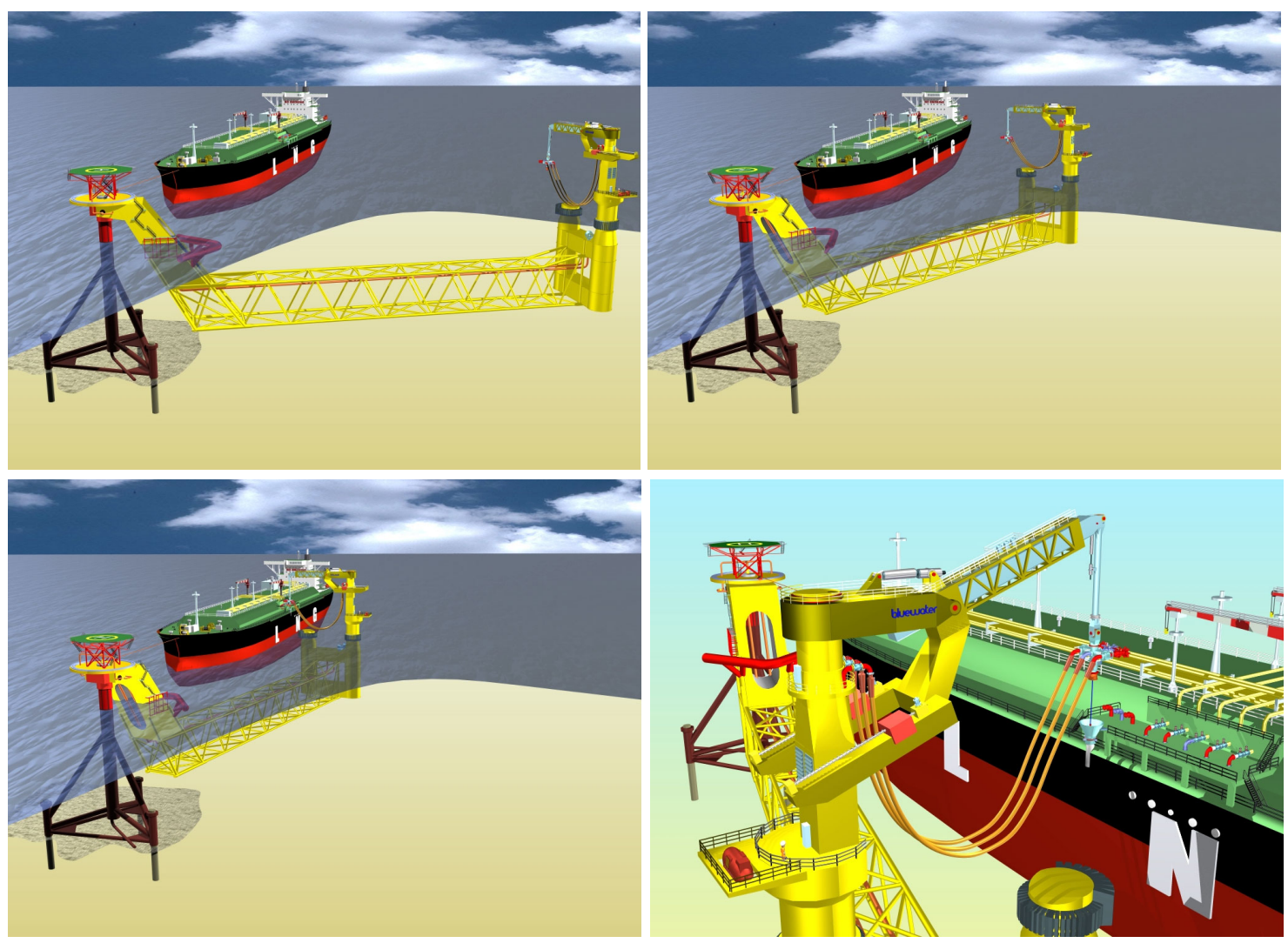

Figure 2: Medium Waterdepth 'Big Sweep' Terminal 

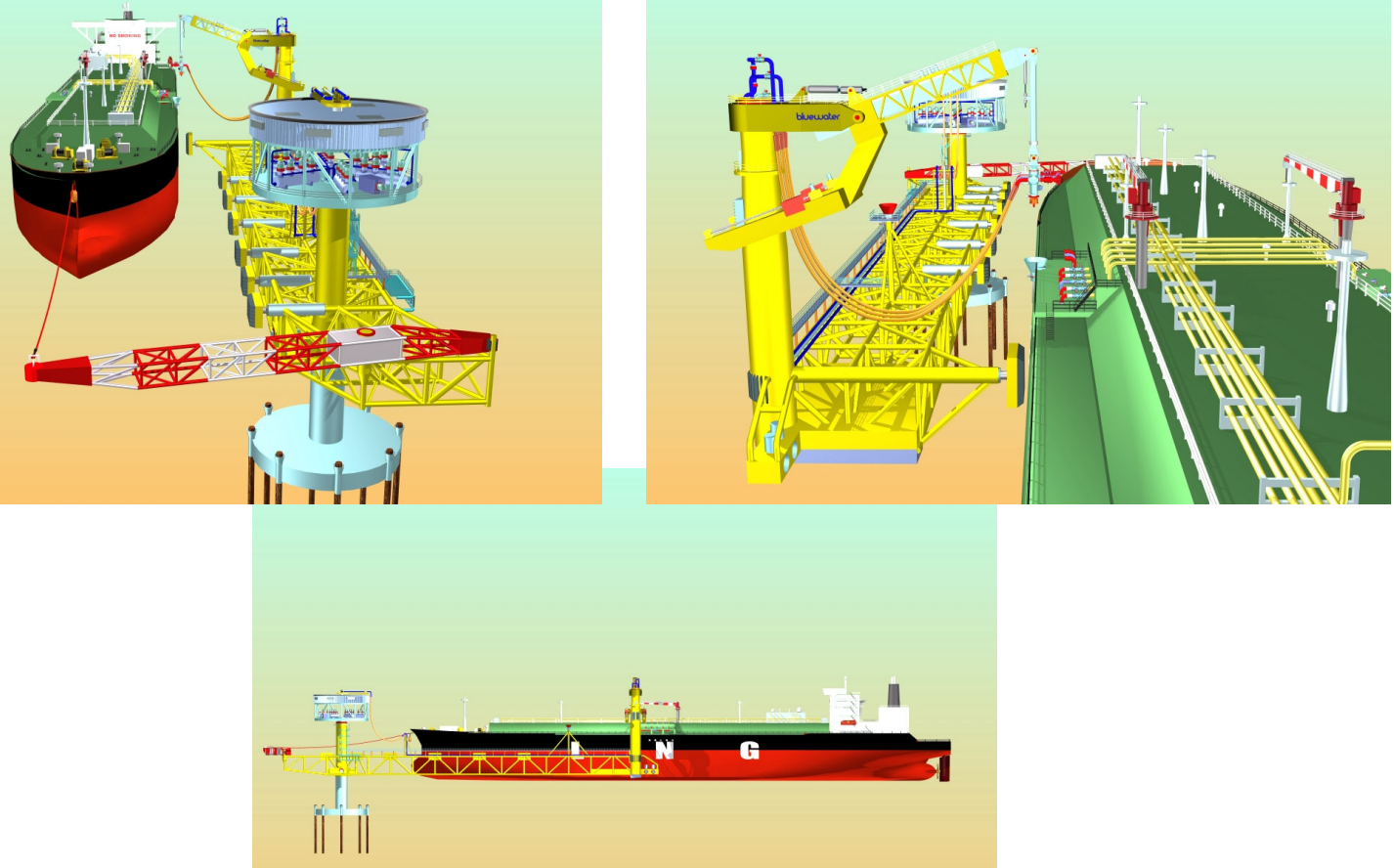

Figure 3: Shallow Waterdepth 'Big Sweep' Terminal

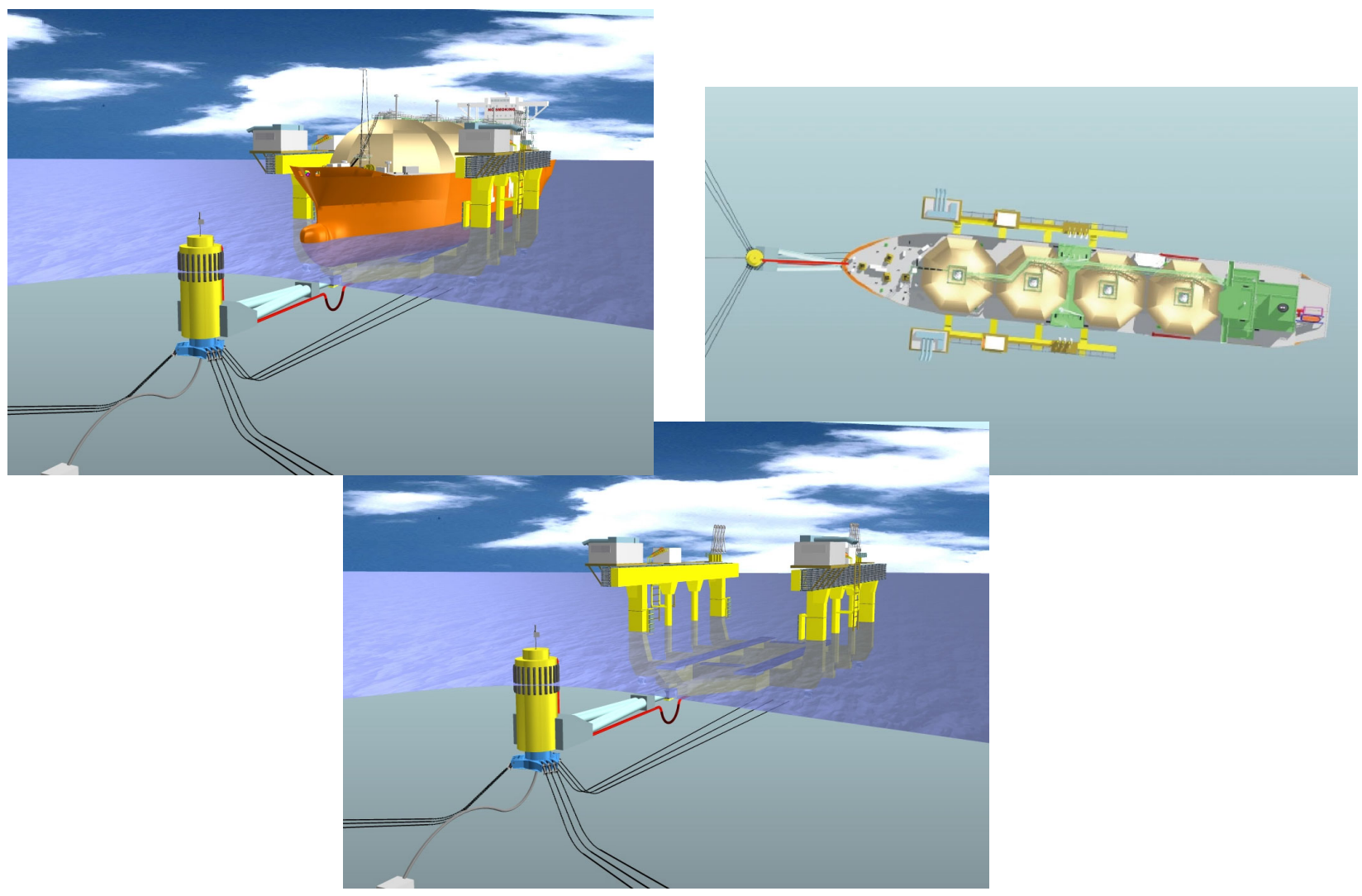

Figure 4: Offshore Re-Gasification Dock 


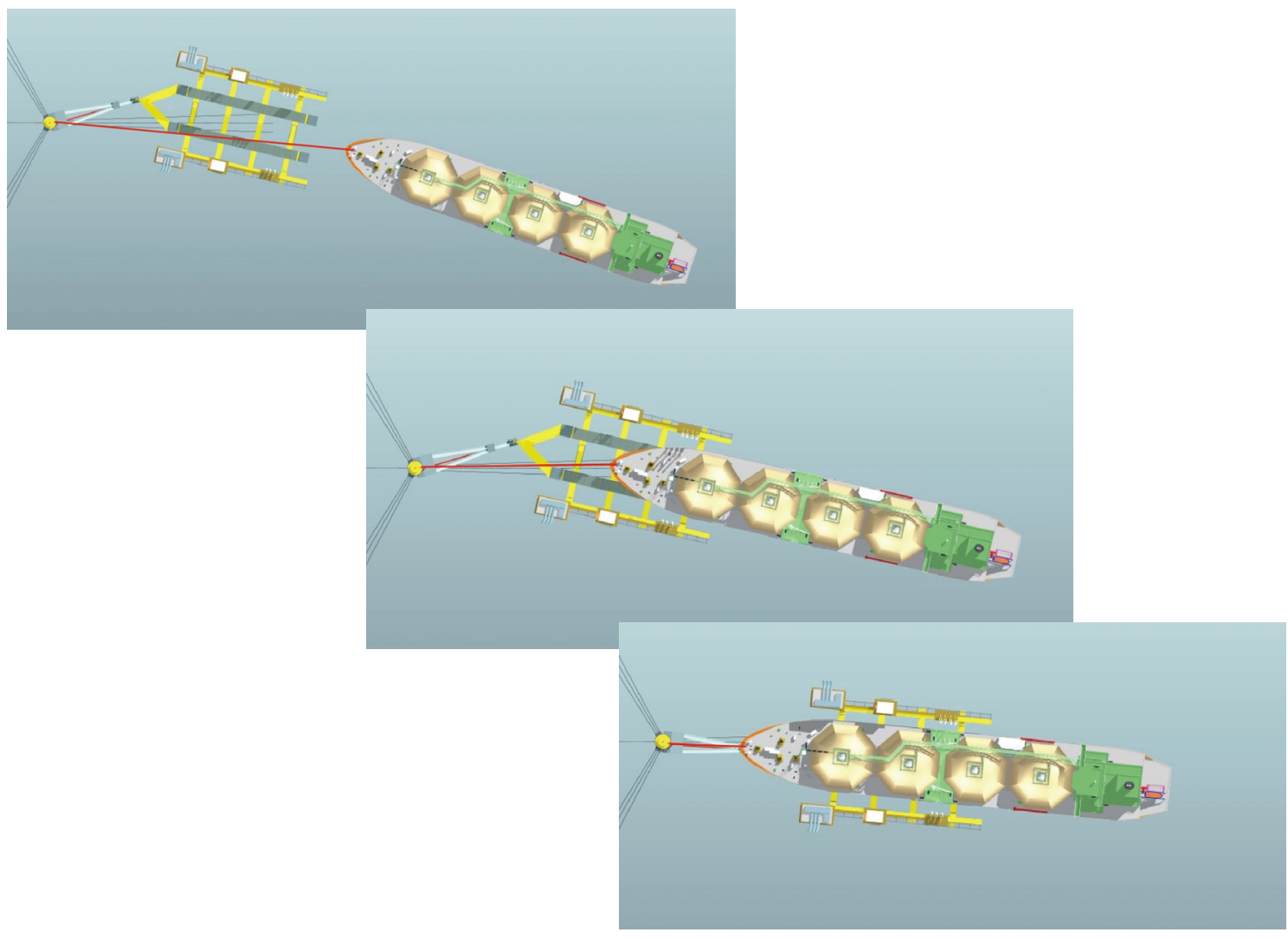

Figure 5: Berthing of LNG Carrier into Offshore Dock
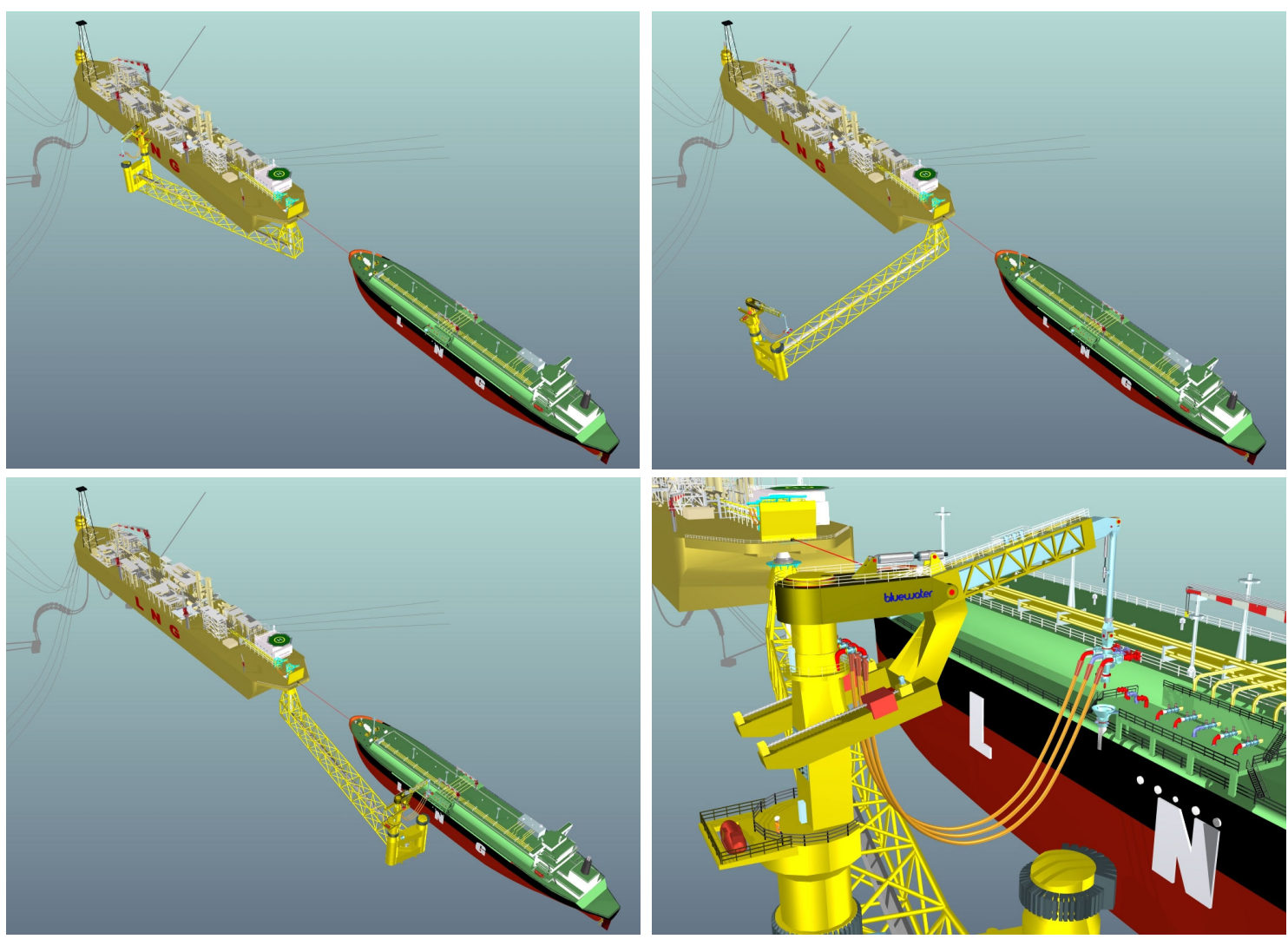

Figure 6: 'Big Sweep' for Tandem Export from FLNG Barge 


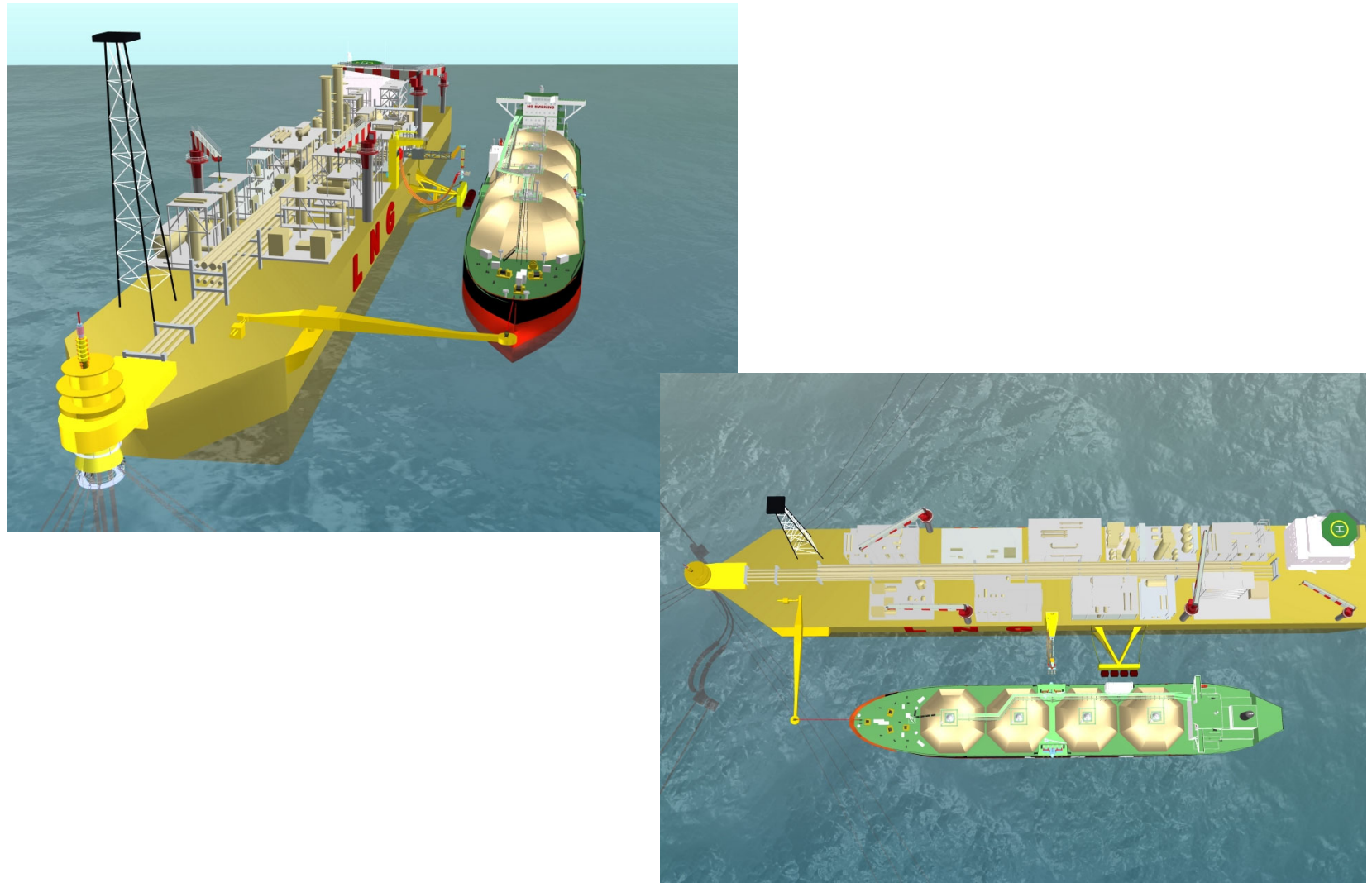

Figure 7: 'Side by Side' Transfer from FLNG Barge

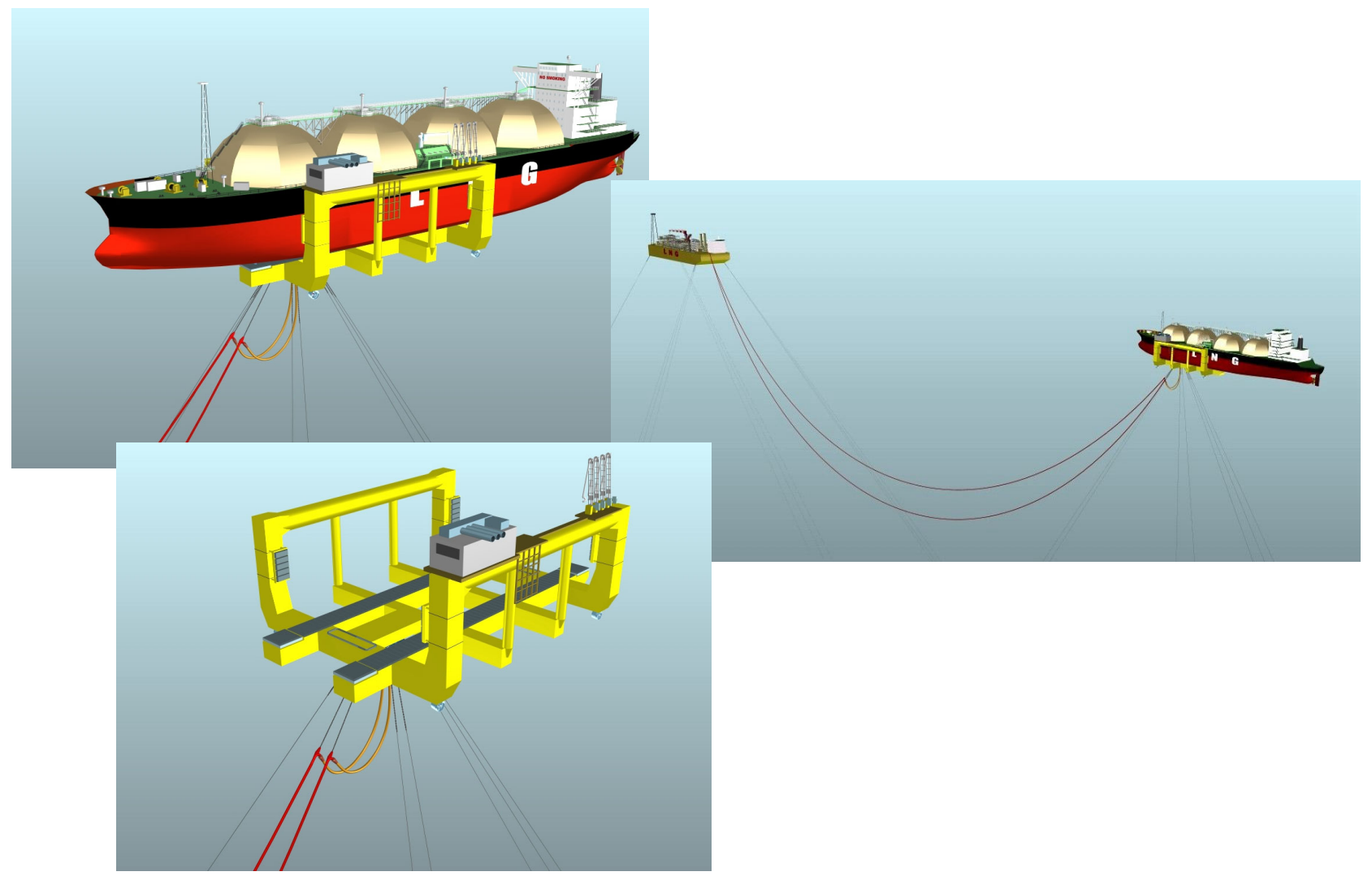

Figure 8: Deepwater Remote SPM Dock 

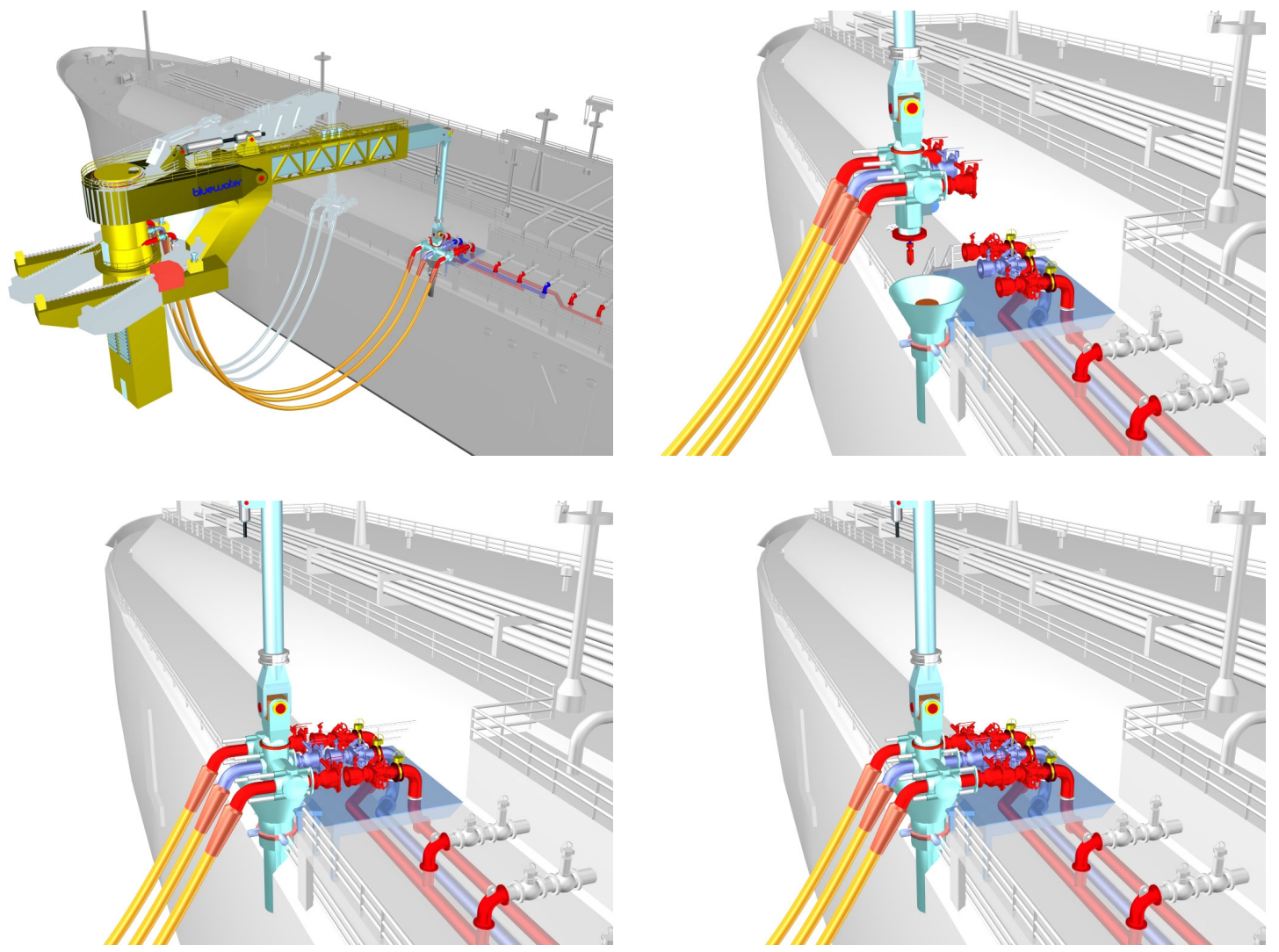

Figure 9: Manipulator for LNG Transfer Hoses

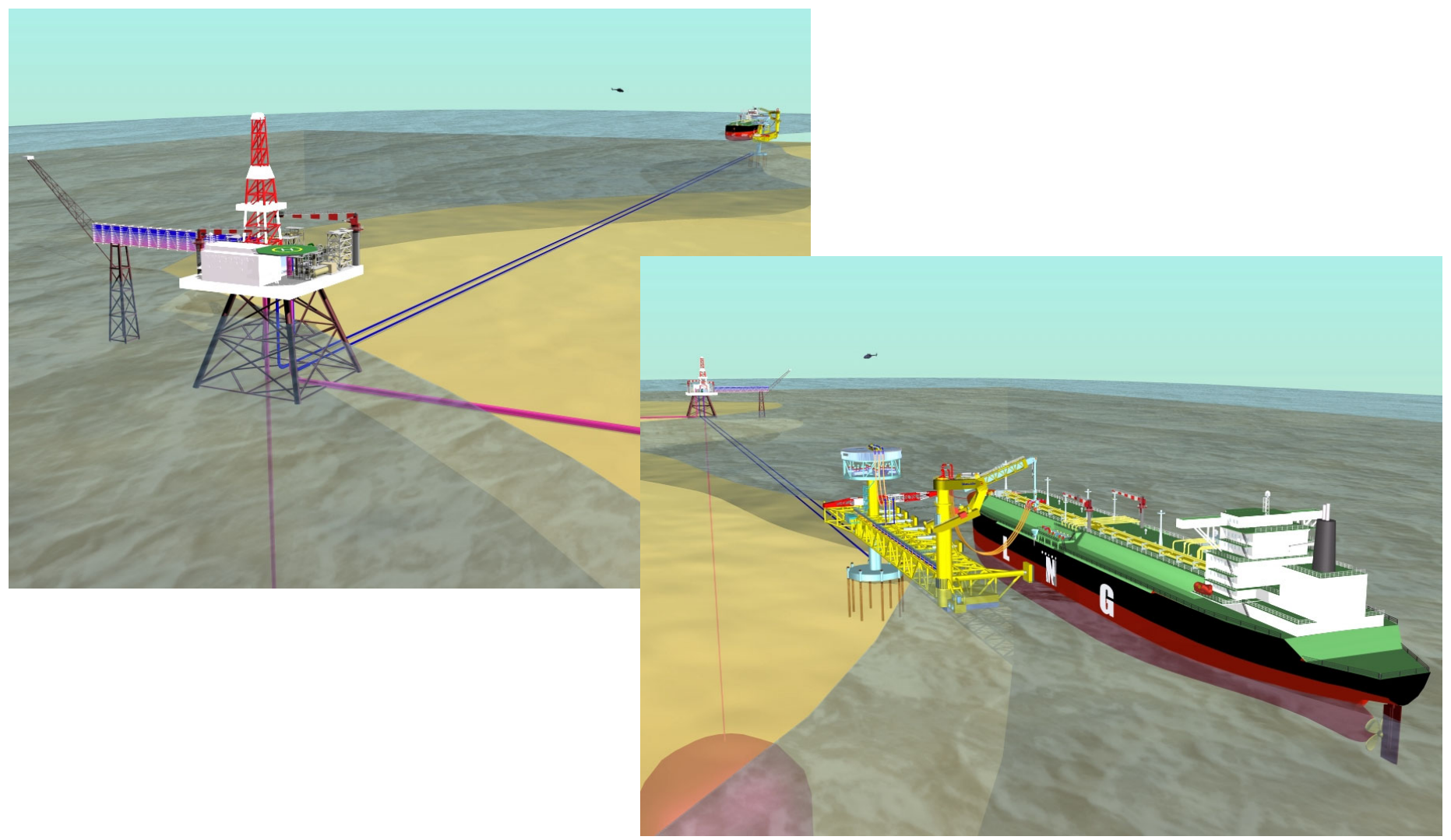




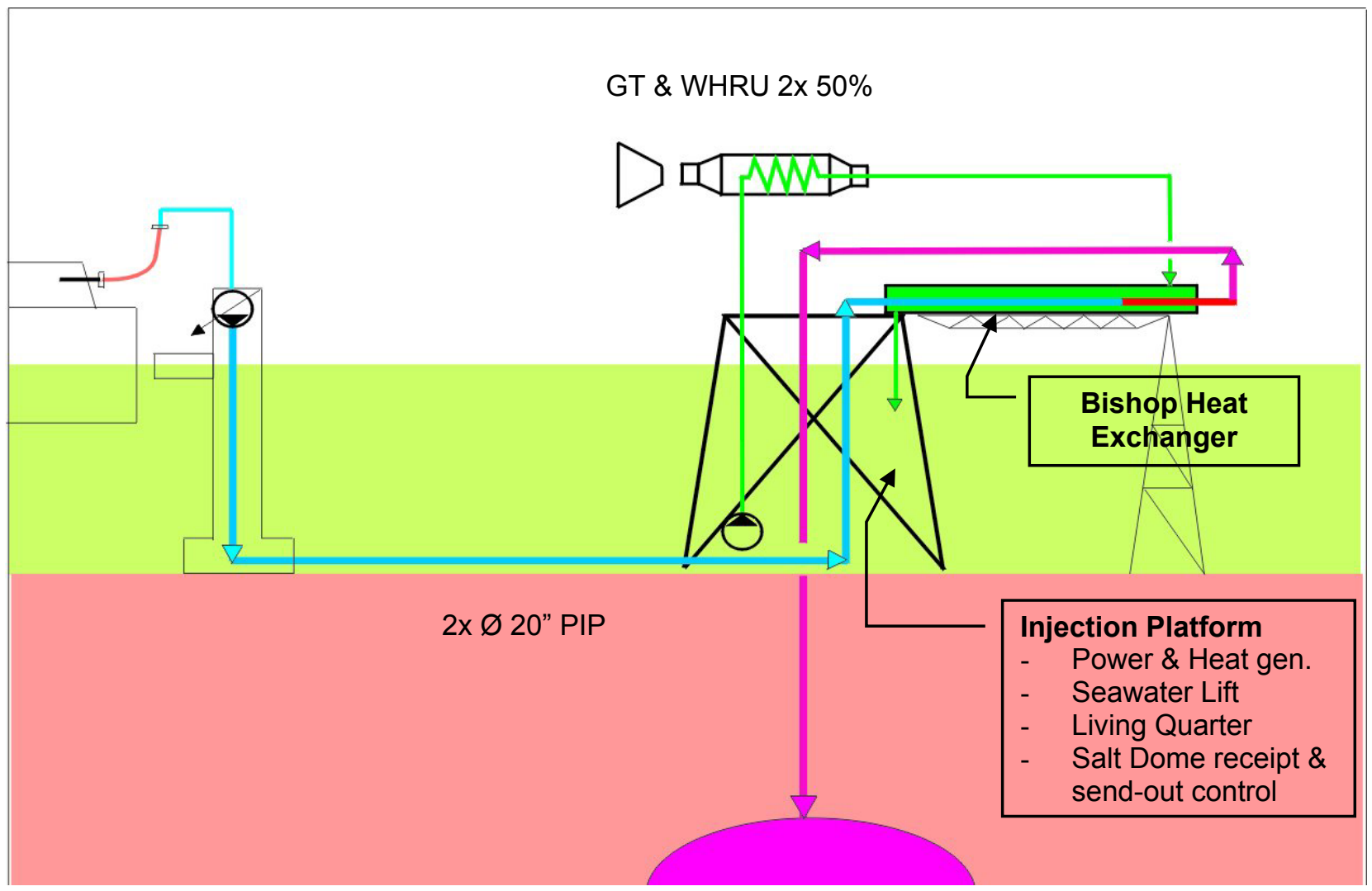

Figure 11: Case Study - Process Schematic for LNG Import Terminal with Salt Cavern Storage

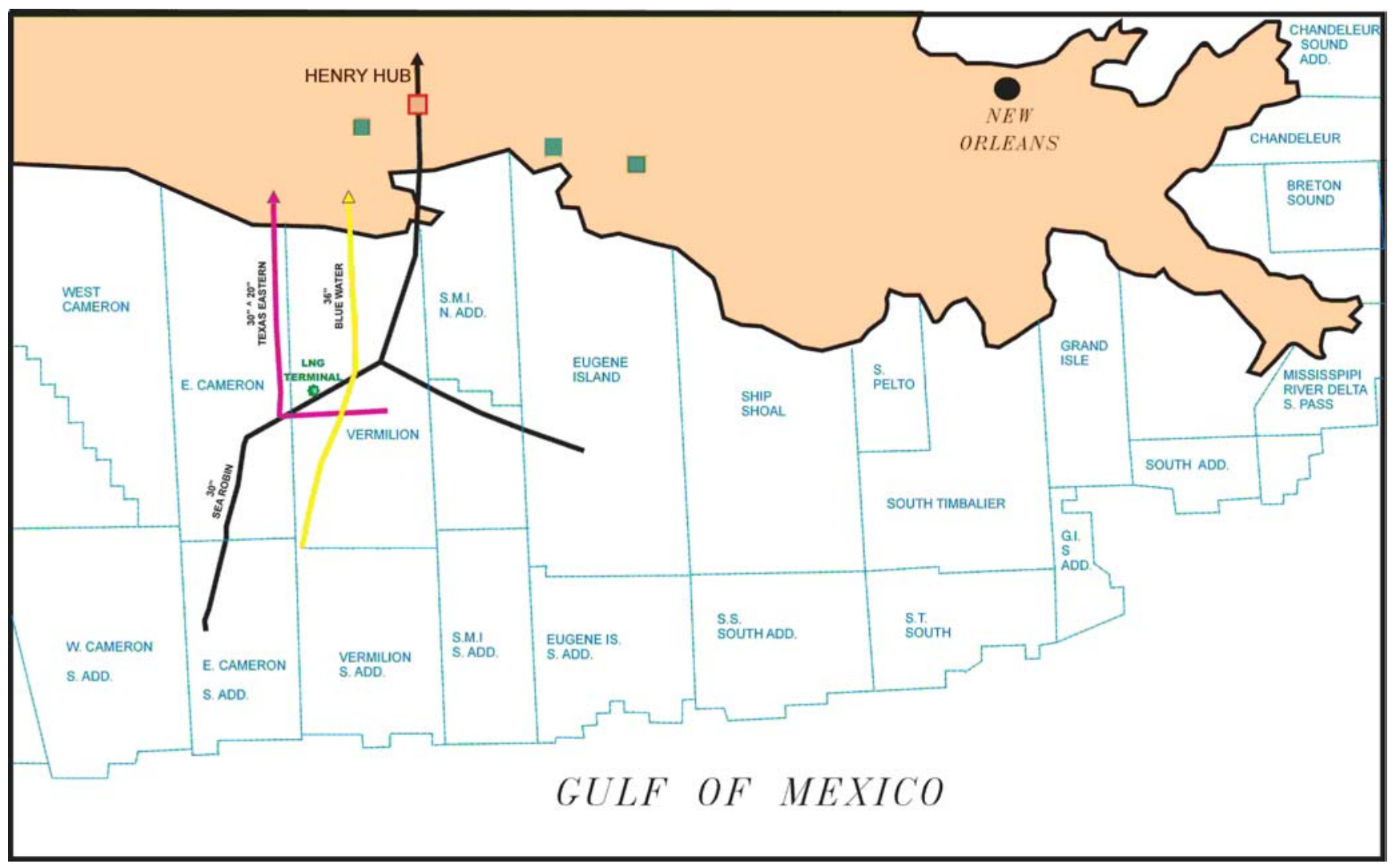

Figure 12: Case Study - Location of LNG Import Terminal - Vermillion Block 179 

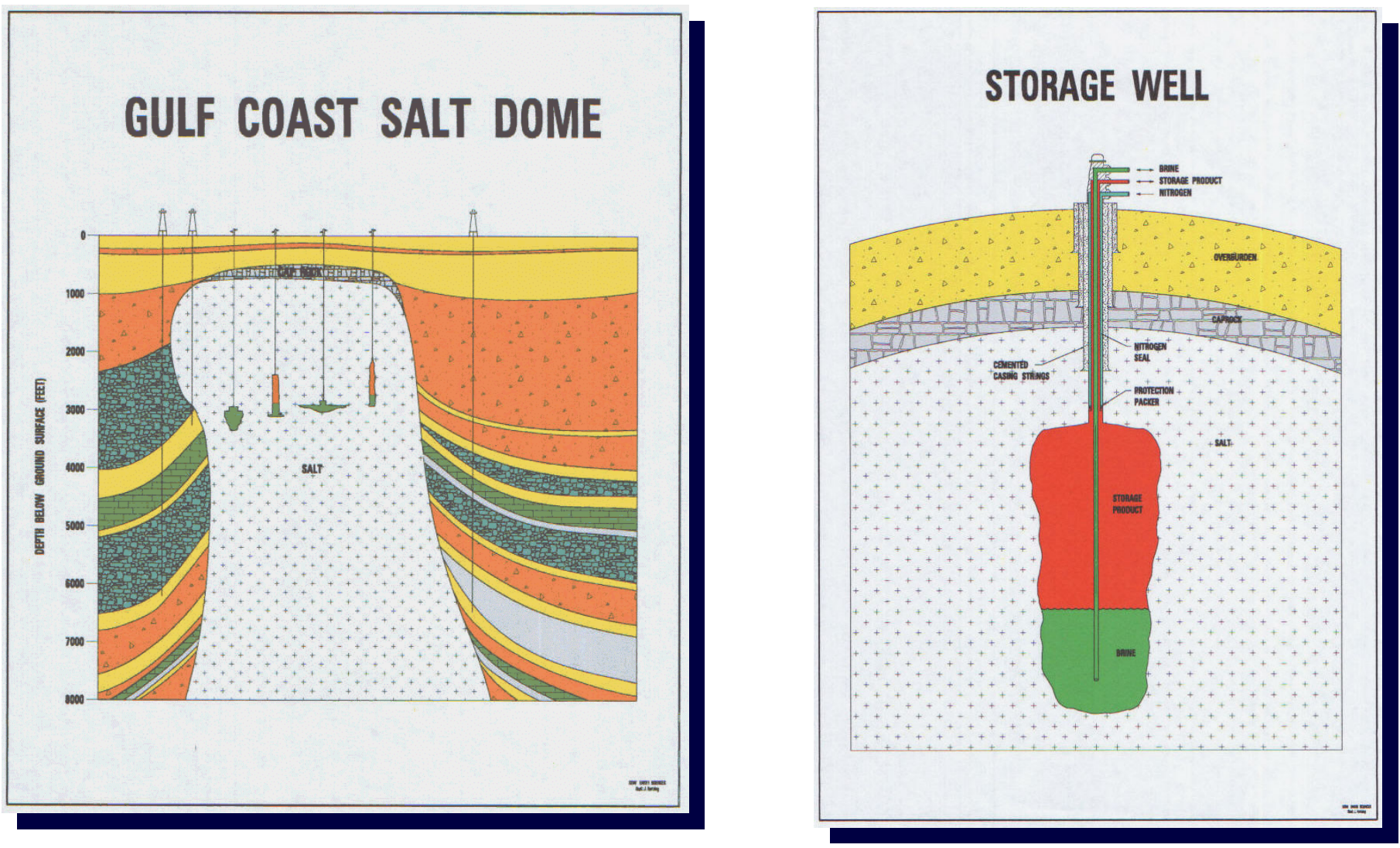

Figure 13: Cross Section over Salt Dome 


\section{FACILITIES}

- Vermilion 179 provides basis for offshore facility

- Shore-based site provides basis for land application of technology 


\section{OPERATING ASSUMPTIONS}

- Continual send-out of 1.5 bcfd minimum

- Maximum send-out of 2.5 bcfd to pipeline

- Caverns are uncompensated with operating range of $1100-2400$ psi

- During ship unloading all LNG is immediately vaporized for direct send-out at 1150 psi or for cavern injection at $1100-2400$ psi.

- Minimum cavern pressure $=1000$ psi

- Multiple caverns arranged into 2 groups 


\section{DESIGN BASIS SUMMARY}

- Vermilion 179 in $100 \mathrm{ft}$. water; $50 \mathrm{mi}$. offshore

- 4 salt caverns of 2-3 bcf capacity @ 2400 psi

- 3 send-out pipelines w/ max of $2.5 \mathrm{bcfd}$

- Range of send-out is $1.5-2.5$ bcfd @ 1150 psi

- LNG unload rate @ 8,000 m3/hr

- Accommodate tankers from 125,000 - 200,000

- Plan ship arrival every other day

- Two platforms - Process \& Cavern Support w/ BPE as bridge spanning gap 


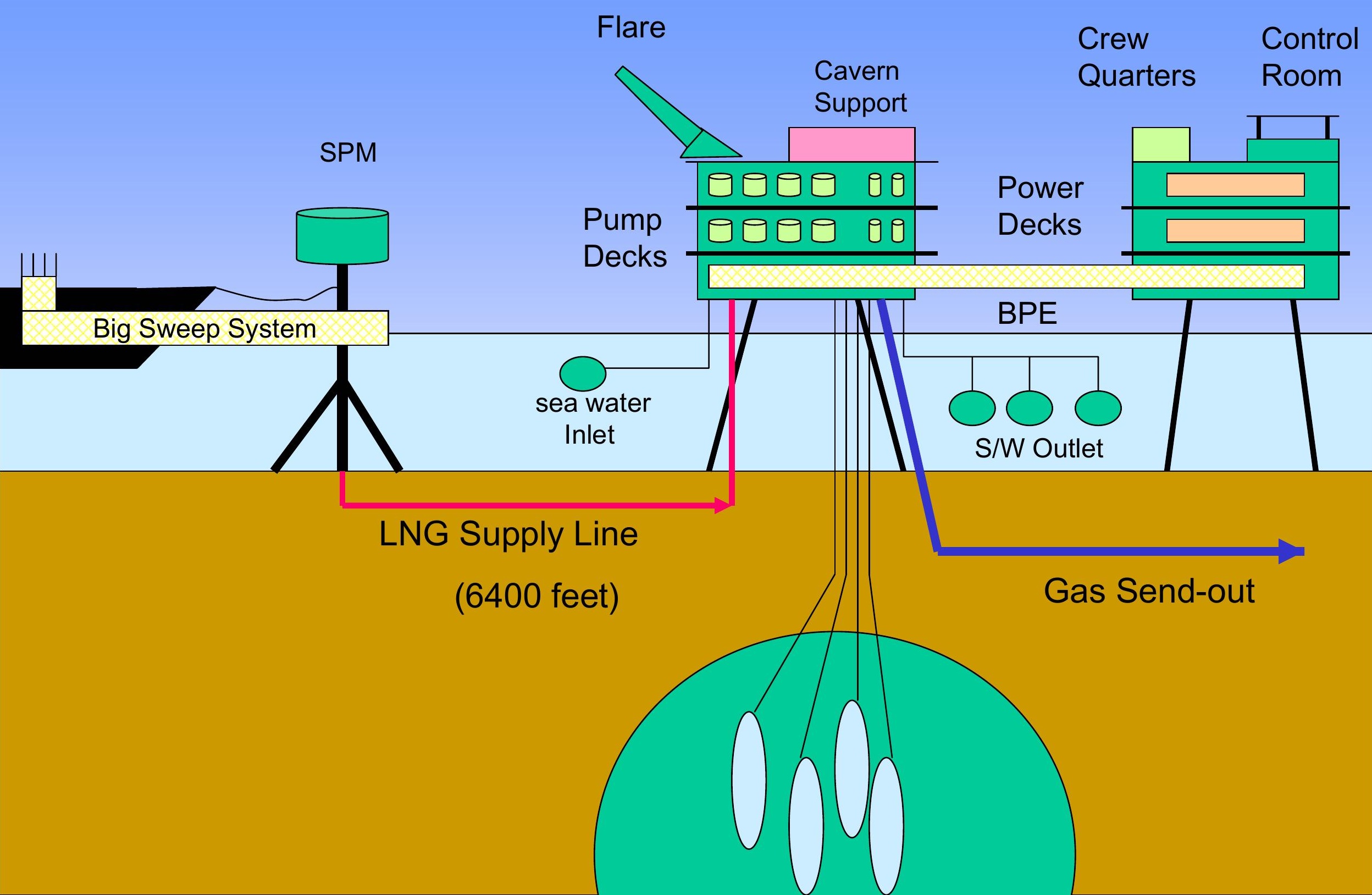




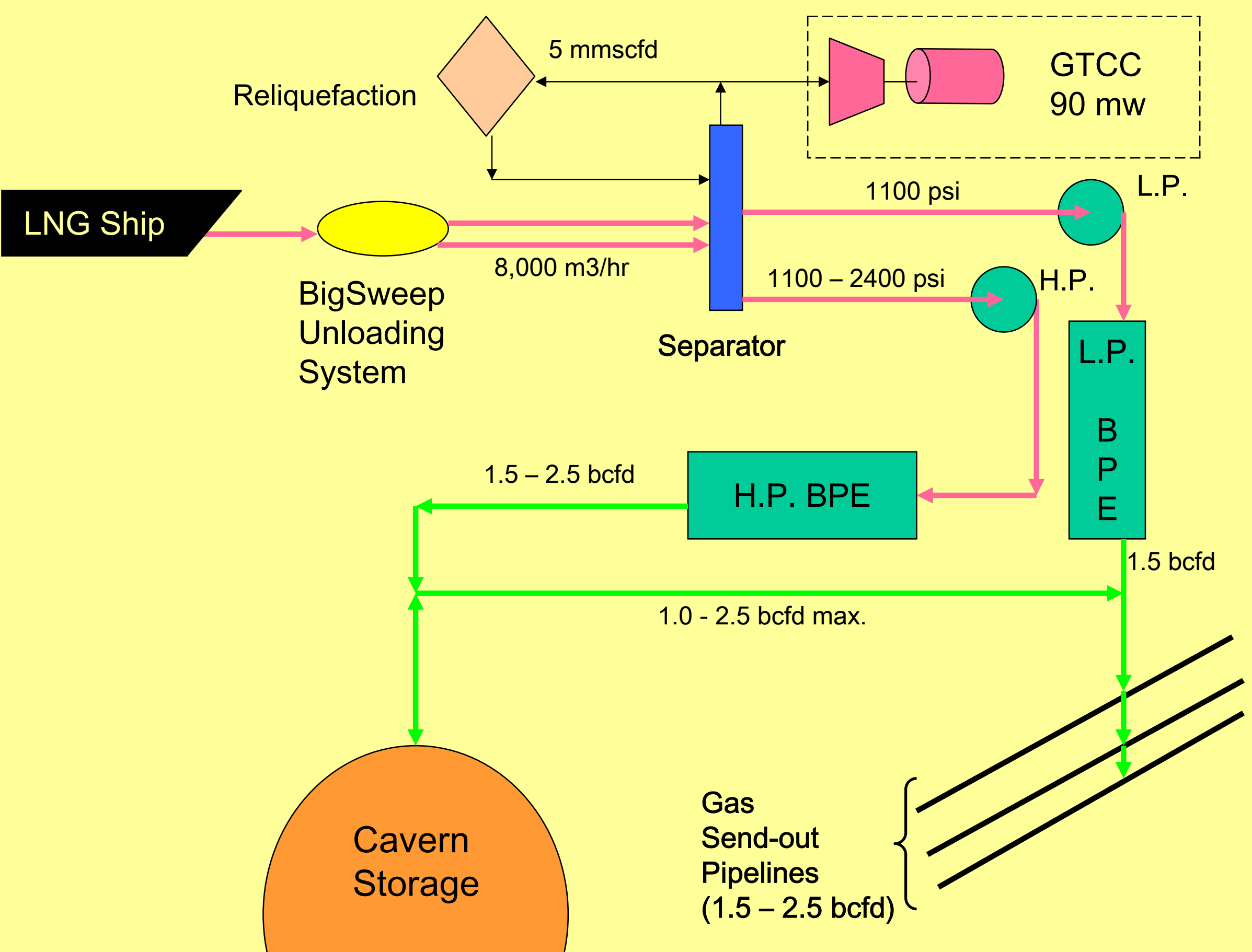




\section{KEY DESIGN CONSIDERATIONS}

- LP LNG pumps and exchangers provide send-out baseload - save money, weight \& op cost.

- All cavern injection must accommodate variable cavern pressures - 1150-2400 psi op. range

- Some HP LNG pumps will be used to augment send-out as required - remainder assigned for cavern injection duty.

- 4-pass Bishop Process Exchanger (BPE) to be used creating a 200-300 ft. long bridge between platforms

- Double 24 inch P-I-P LNG pipeline from SPM - insulation set by duty cycle $\&$ addressing extended downtime. 


\section{OPERATING SCENARIOS}

\section{SCENARIO A - SHIP UNLOADING}

- Direct send-out base load met w/ LP LNG pumps \& exchangers - to max of 1.5 bcfd flow rate @ 1150

- Remainder of send-out demand met via HP LNG pumps to match pressure \& flow

- All other LNG thru HP LNG pumps to cavern @ $1150-2400$ psi

SCENARIO B - NO SHIP UNLOADING

- All send-out demand met from caverns 


\section{MINIMUM SENDOUT DURING UNLOADING $(8,000 \mathrm{~m} 3 / \mathrm{hr})$}

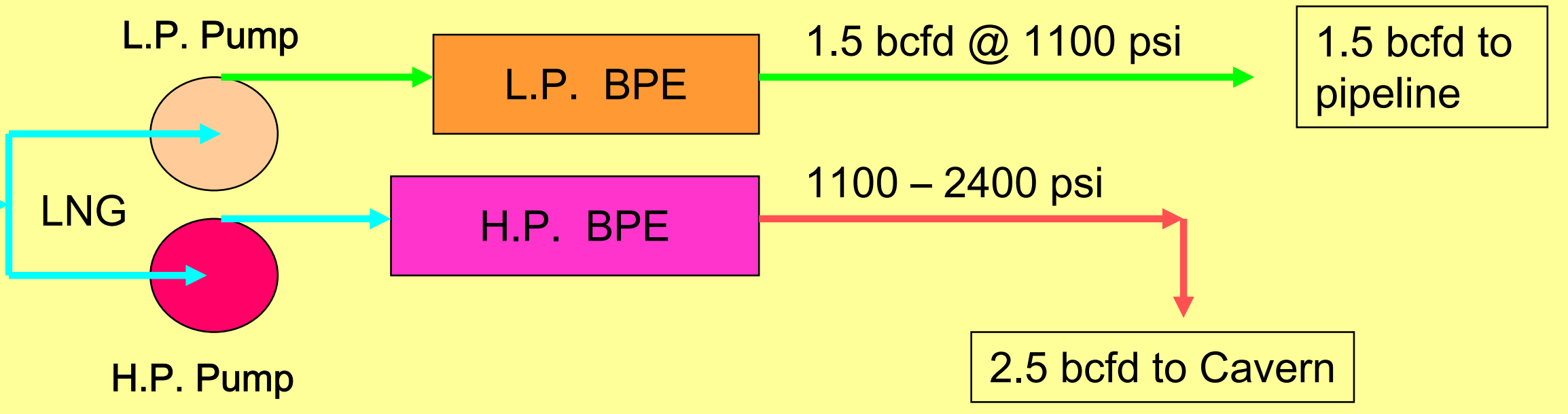

\section{MAXIMUM SENDOUT DURING UNLOADING (8,000 m3 / hr)}

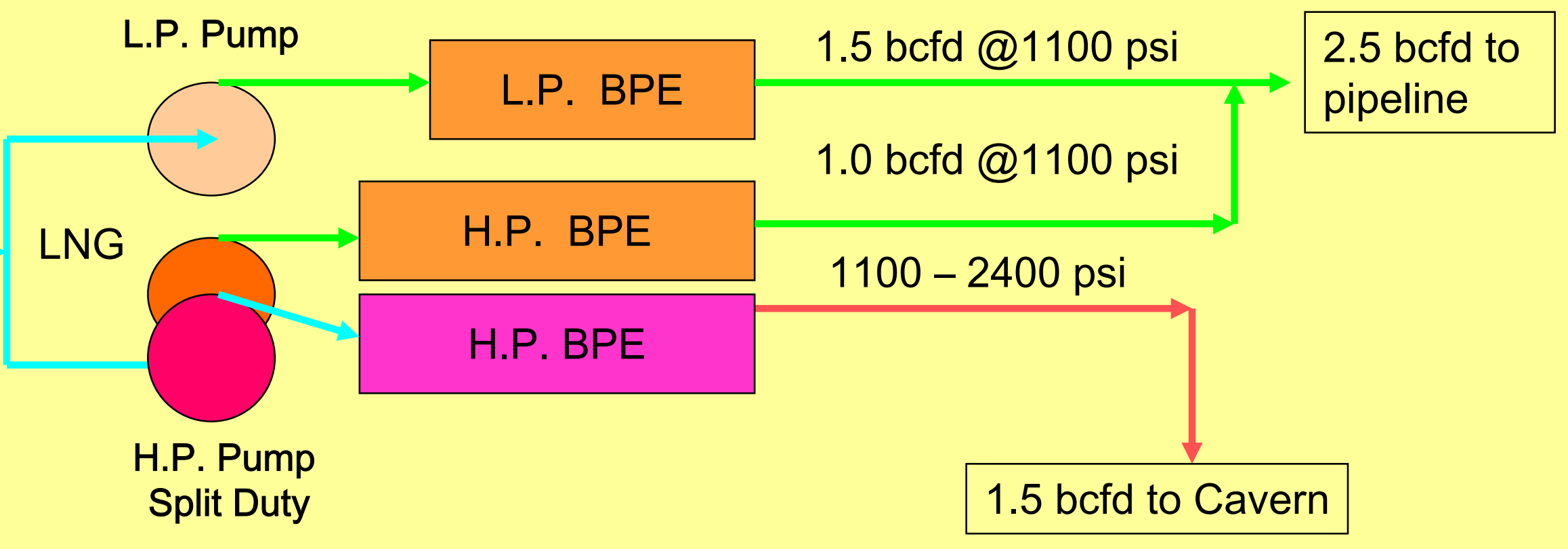




\section{STATUS of TASK 1}

- PFD in final draft

- Preliminary Basis of Design

- LNG Pipeline specifications complete

- Power Generation / Electrical One line drafted

- Mooring Systems Design

- Marine Operations Plan

- Mooring System Modelling - Wave Pool 


\section{TASK 1 - To Be Completed}

- Platform Configuration \& Deck Layout

- Shore-based Layout \& Plot Plan

- Exchanger Design

- Supporting Structure Design

- Equipment Arrangement

- Heat Integration Analysis

- Preliminary Operations Plan

- HAZID review

- Cost Estimate 


\section{OPTIMIZING STUDIES}

- Impact of $12,000 \mathrm{~m} 3 / \mathrm{hr}$ unload rate

- Optimize HP/LP/BPE design

- Assess use of VFD on HP pumps

- Impact of 2-pass BPE layout (i.e. $1000 \mathrm{ft}$ )

- Assess impact of 2X send-out capacity on platforms \& structures

- Assessment of Heat Integration w/ GTCC 


\section{bluewater}

\section{Vermilion 179 LNG Terminal}

HIRA Workshop

14 January 2004 


\section{bluewater}

\section{Sources}

- Operational Criteria :

- Survival Criteria :

-WATERDEPTH : 15 fathoms $=90$ feet 27.4 meters
National Data Buoy Center 10 years of data on waves and wind

API Guidelines

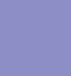




\section{bluewater}

\section{Wave and Wind Directions}

\section{Wave Direction Distribution}

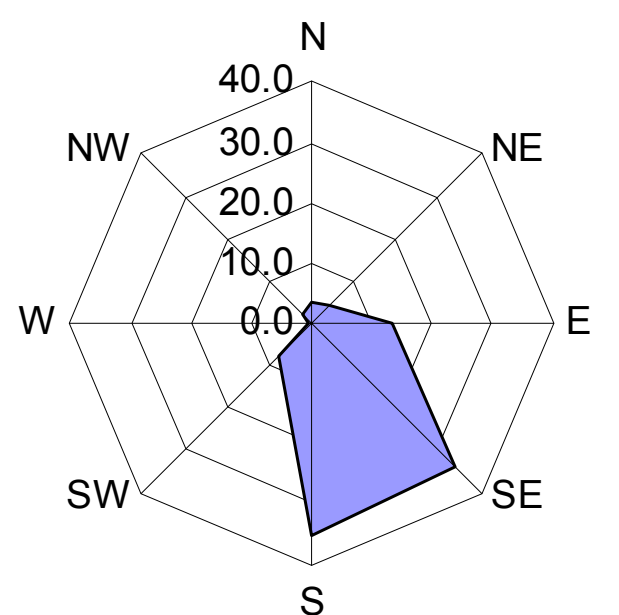

\section{Wind Direction Distribution}

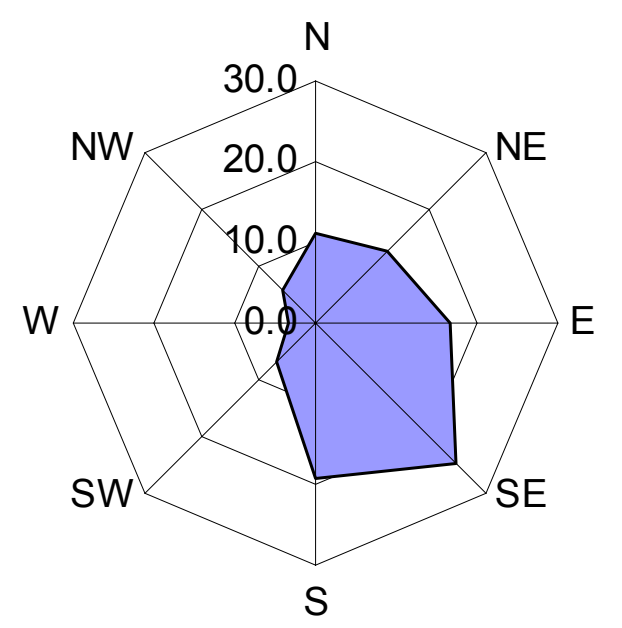




\section{bluewater}

Power by People

\section{Metocean Criteria}

\section{Wave and Wind Directions}

Waves

\begin{tabular}{|c|c|c|}
\hline Sector & \multicolumn{2}{|c|}{ Percentage } \\
\hline $\mathrm{N}$ & 3.7 & \\
\hline $\mathrm{NE}$ & 4.3 & \\
\hline$E$ & 13.5 & \\
\hline SE & 33.4 & $82 \%$ \\
\hline$S$ & 35.3 & \\
\hline SW & 7.2 & \\
\hline W & 0.7 & \\
\hline NW & 2.0 & \\
\hline
\end{tabular}

Wind

\begin{tabular}{|l|l|l|}
\hline Sector & Percentage \\
\hline N & 11.1 & \\
\hline NE & 12.4 & \\
\hline E & 16.8 & $84 \%$ \\
\hline SE & 24.5 & \\
\hline S & 19.2 & \\
\hline SW & 6.7 & \\
\hline W & 3.4 & \\
\hline NW & 5.8 \\
\hline
\end{tabular}




\section{bluewater}

\section{Metocean Criteria}

\section{Relative Angles Wave and Wind}

\begin{tabular}{|l|l|l|}
\hline Angle & Percentage \\
\hline $0-15 \mathrm{deg}$ & 34.0 & \\
\hline $15-30 \mathrm{deg}$ & 23.5 & \\
\hline $30-45 \mathrm{deg}$ & 14.5 & $87 \%$ \\
\hline $45-60 \mathrm{deg}$ & 9.1 & \\
\hline $60-75 \mathrm{deg}$ & 5.7 & \\
\hline $75-90 \mathrm{deg}$ & 3.6 \\
\hline $90-120 \mathrm{deg}$ & 4.4 \\
\hline $120-150 \mathrm{deg}$ & 2.8 \\
\hline $150-180 \mathrm{deg}$ & 2.4 \\
\hline
\end{tabular}




\section{bluewater}

\section{Significant Wave Height}

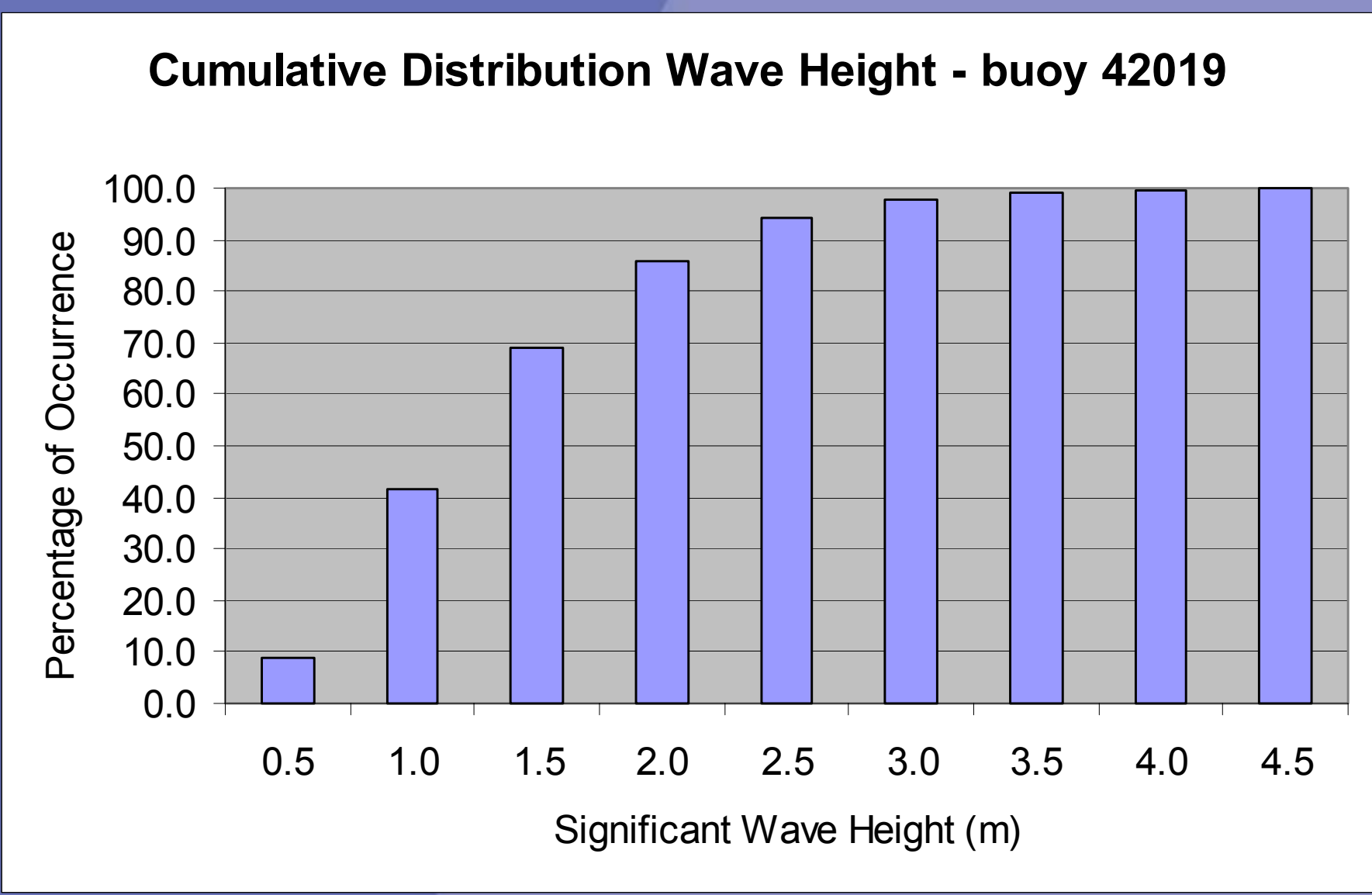




\section{bluewater}

\section{Wind Velocity}

\section{Cumulative Distribution Wind Velocity - buoy 42035}

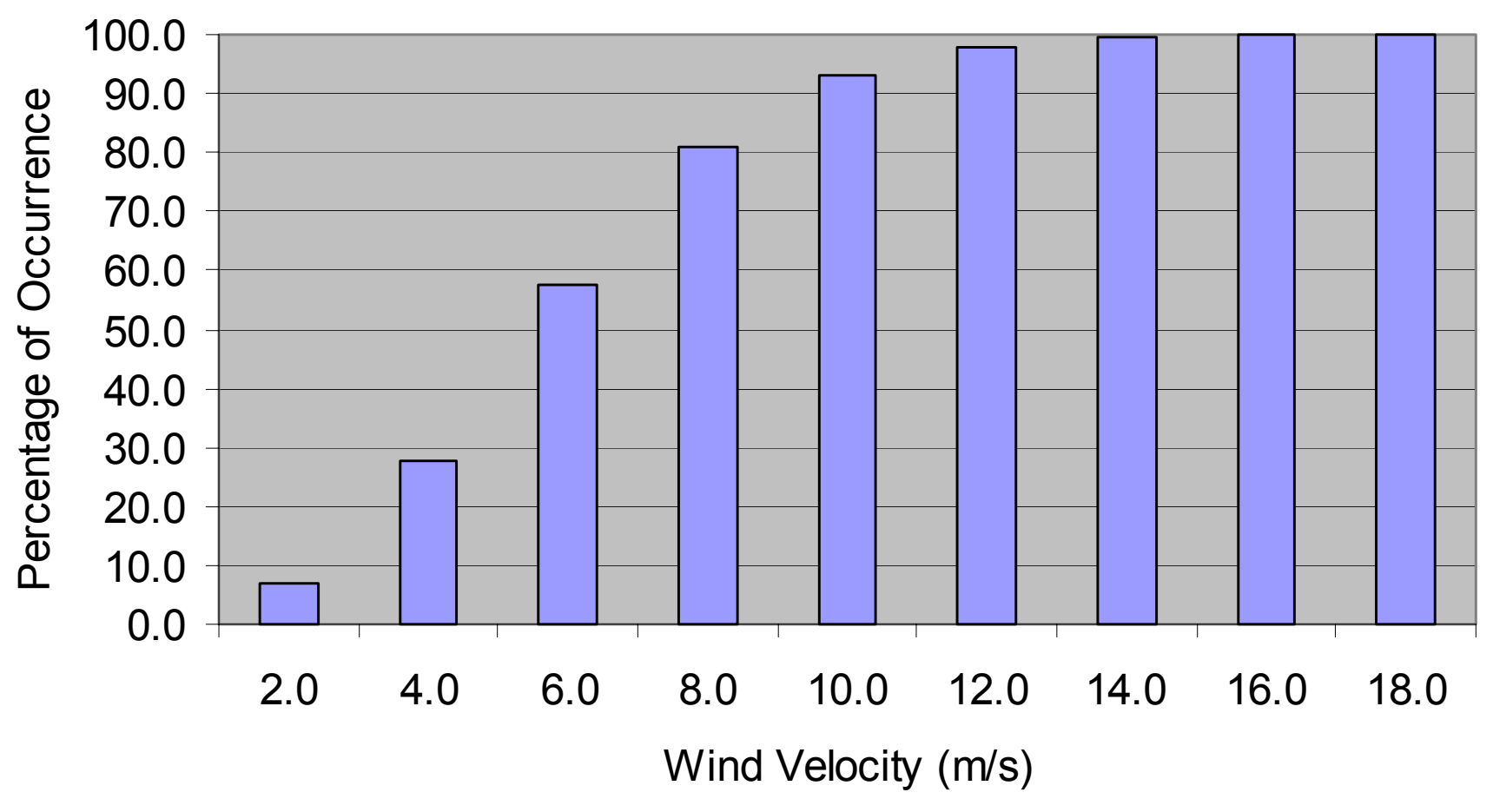




\section{bluewater}

\section{Metocean Criteria}

Survival Conditions (100-yr)

$-H \max : 56 \mathrm{ft}=17.1 \mathrm{~m}$

- Tass.: $13 \mathrm{~s}$

- Direction : Omni-directional, but highest from East

- Vwind : $80 \mathrm{kn}=41.15 \mathrm{~m} / \mathrm{s}$

(1hr. mean)

- Direction : Omni-directional

- Vcurrent : $2.1 \mathrm{kn}=1.1 \mathrm{~m} / \mathrm{s} \quad$ (uniform)

- Direction : East to West 


\section{bluewater}

\section{Metocean Criteria}

Conclusions

- Waves

$98 \%$ lower than $3.0 \mathrm{~m}(10 \mathrm{ft})$

$82 \%$ from $\mathrm{E}, \mathrm{SE}$ or $\mathrm{S}$ sector

- Wind

$98 \%$ lower than $12 \mathrm{~m} / \mathrm{s}$ (27 mph) $84 \%$ from N, NE, E, SE or S sector

- Current

$100 \%$ lower than $1 \mathrm{~m} / \mathrm{s}(2 \mathrm{kn})$

Usually from East to West 
Typical Loads on 135,000 m³ $^{3}$ LNG carrier in ballast condition

- Vwind $=12 \mathrm{~m} / \mathrm{s}$

15 tonnes Head on

75 tonnes Transverse

- Vcurrent $=1 \mathrm{~m} / \mathrm{s} \quad 12$ tonnes Head on

(estimate) 240 tonnes Transverse 


\section{bluewater}

\section{'Vermilion 179' LNG Terminal}

Hazard \& Operability Workshop

14 January 2004 
Vermilion 179 - Terminal Lay-out

Import terminal c/w re-gas and salt dome storage (Bishop process)

Water depth $100 \mathrm{ft}$. / unlimited salt

Location $47 \mathrm{Nm}$ offshore Louisiana

Send-out to three gathering systems

- Bluewater

- Sea Robin

- Texas Eastern 


\section{bluewater}

\section{Power by People}

\section{Vermilion 179 - Terminal Lay-out}

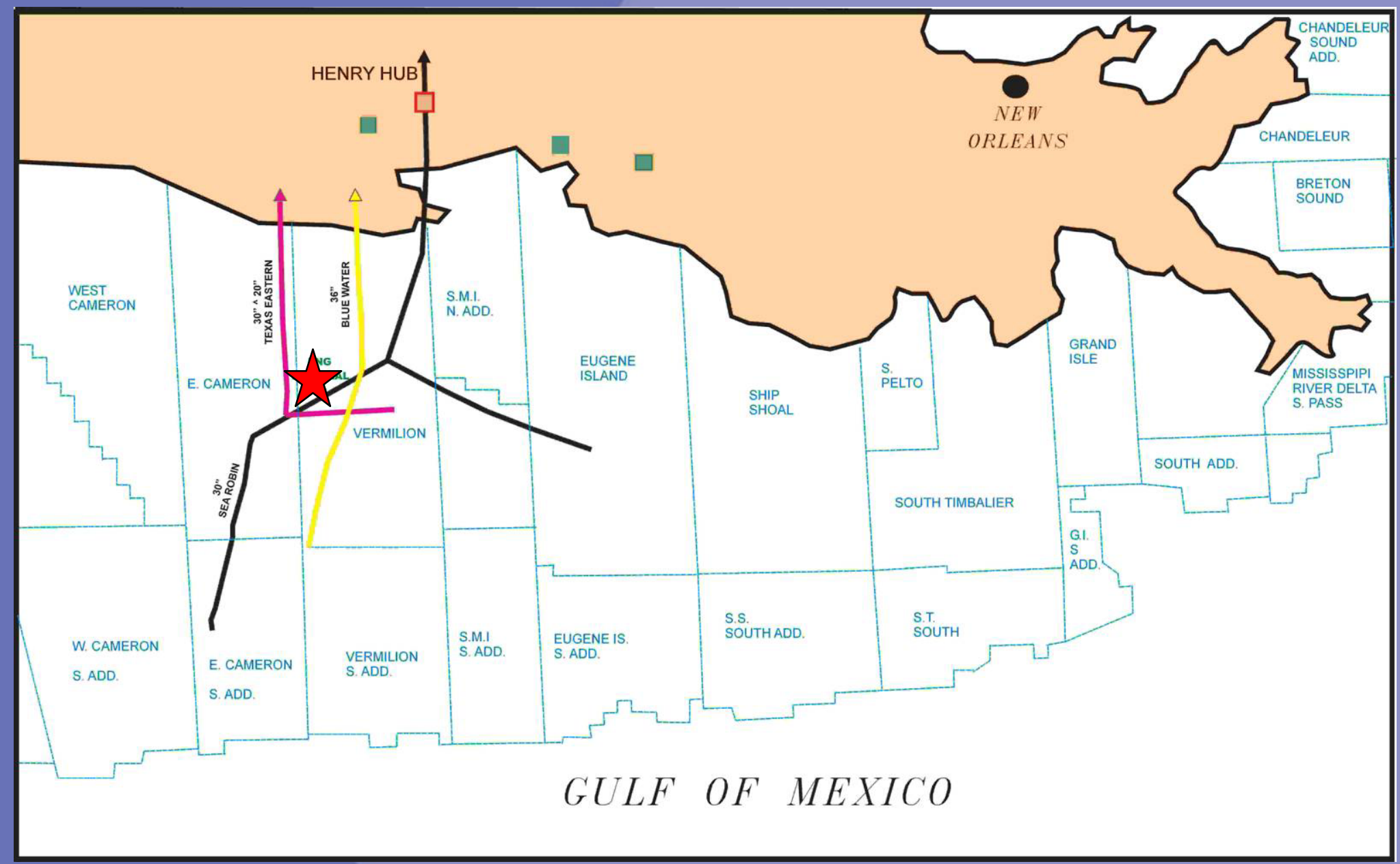




\section{LNG Shipping assumptions}

Mooring terminal

- Base case: 125,000 m³ LNG carrier @ 8,000 m³/hr - Future 200,000 m³ LNG carrier @ 12,000 m³/hr Send-out to grid

- Minimum capacity $1.5 \mathrm{bcfd} \sim 71,000 \mathrm{~m}^{3} \mathrm{LNG} /$ day

- Maximum capacity $2.5 \mathrm{bcfd} \sim 118,000 \mathrm{~m}^{3} \mathrm{LNG} /$ day

- Nominal capacity $2.0 \mathrm{bcfd} \sim 94,000 \mathrm{~m}^{3} \mathrm{LNG} /$ day

Terminal will unload $4 \sim 6$ LNG carriers / week 1 or 2 support tugs depending on LNG carrier cap. 24 hour operation, mooring-up during daylight 


\section{bluewater}

Power by People

\section{Vermilion 179 - Terminal Lay-out}

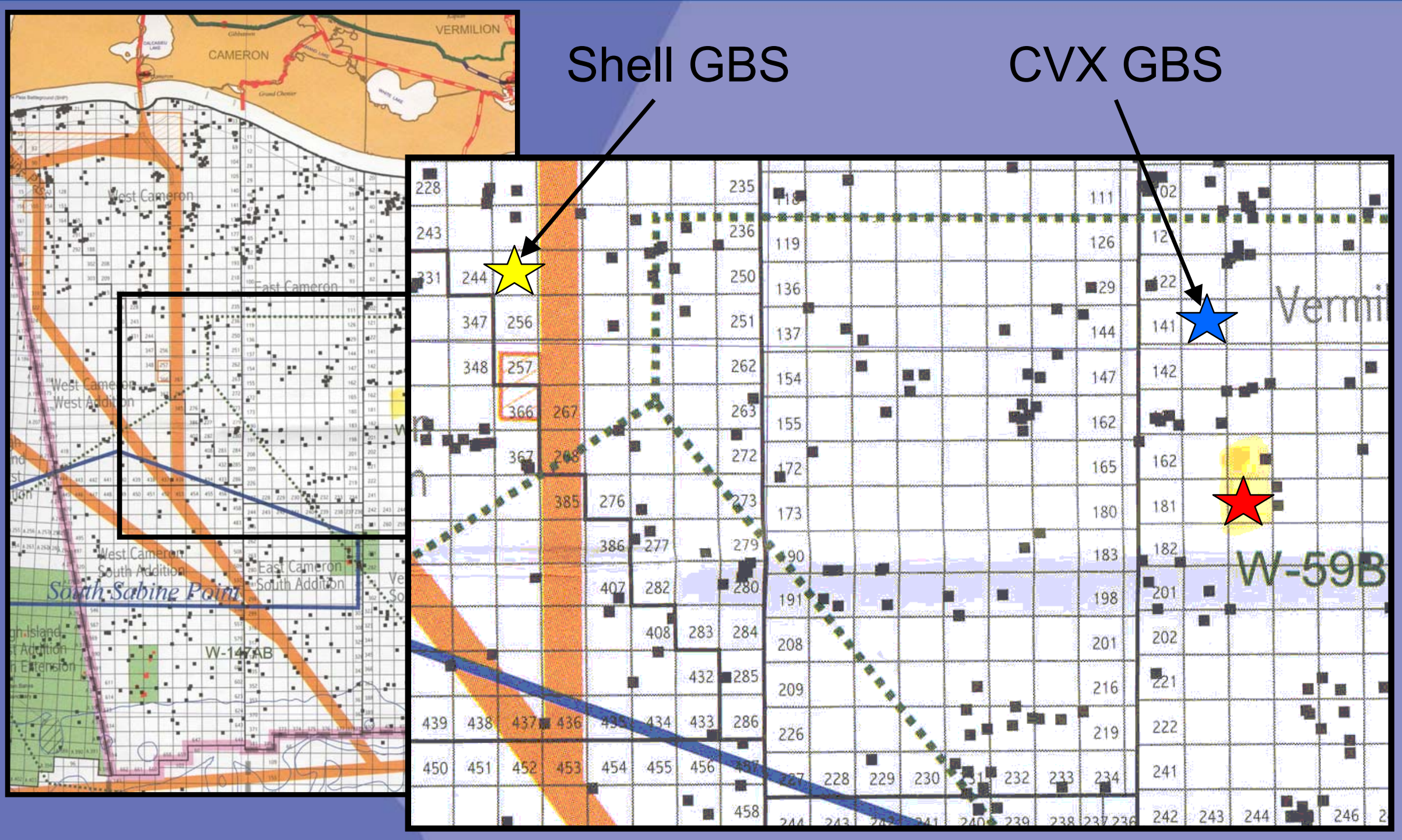




\section{bluewater}

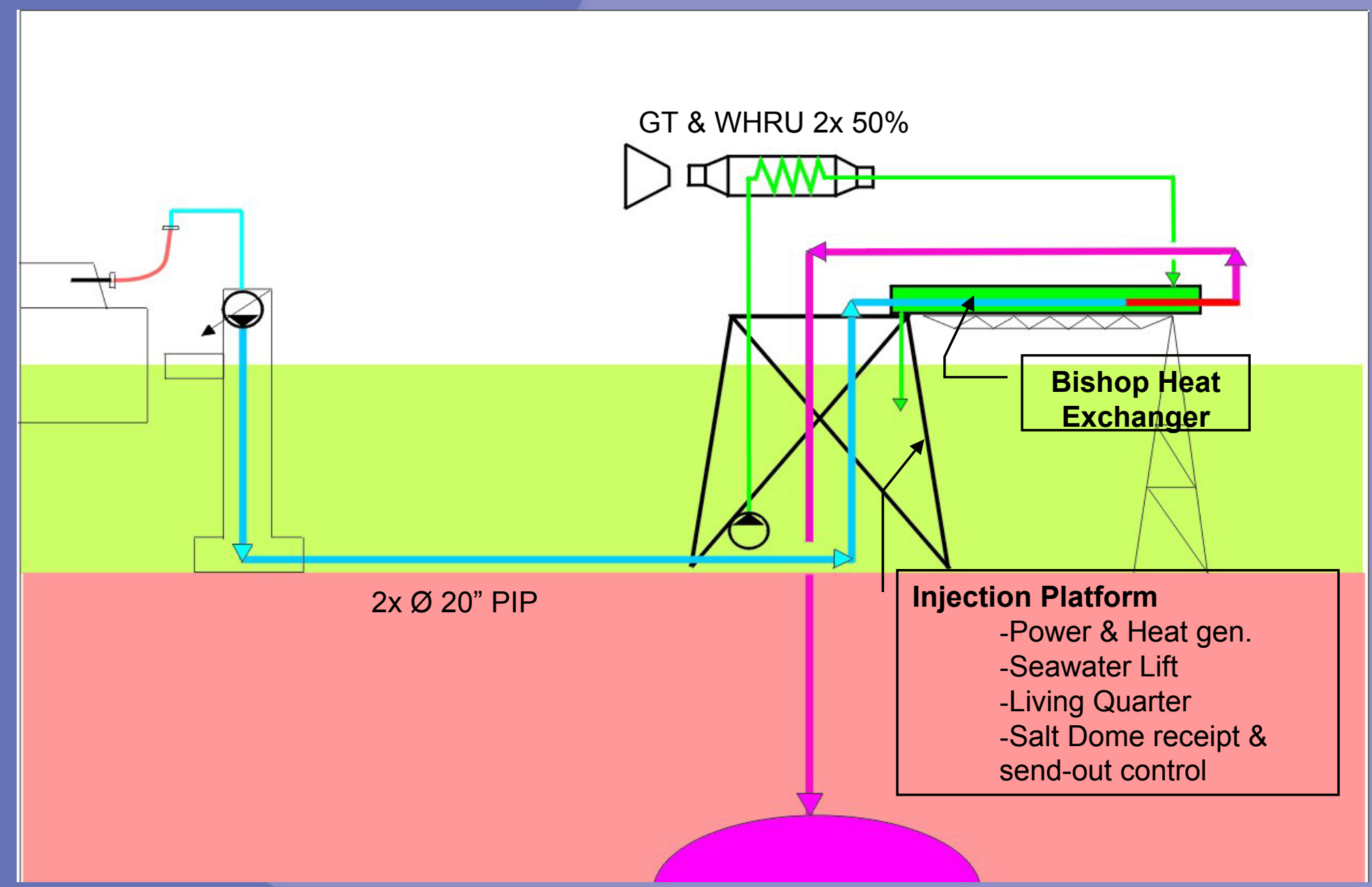




\section{bluewater}

Power by People

\section{Vermilion 179 - Terminal Lay-out}

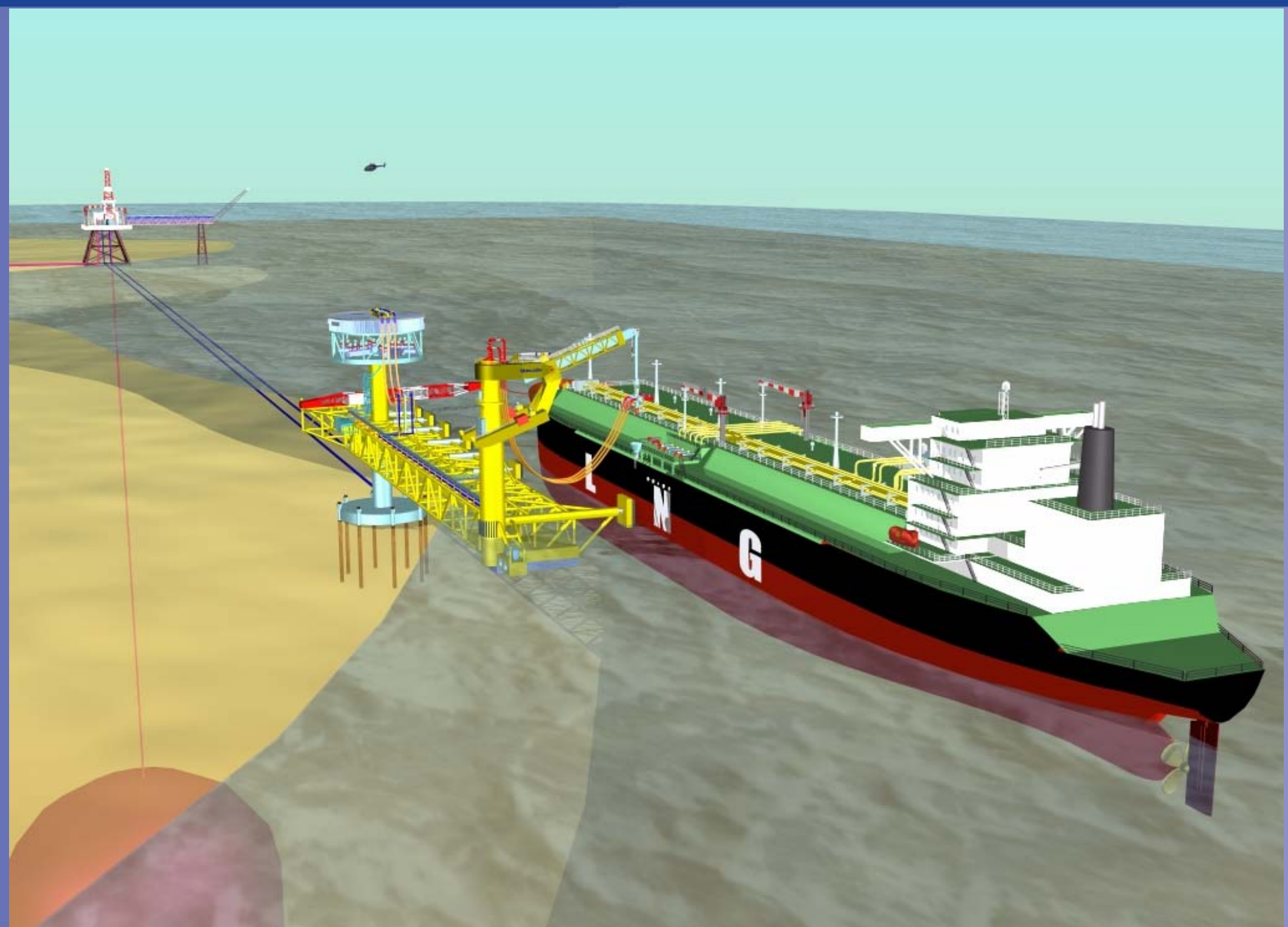




\section{bluewater}

\section{Vermilion 179 - Terminal Lay-out}

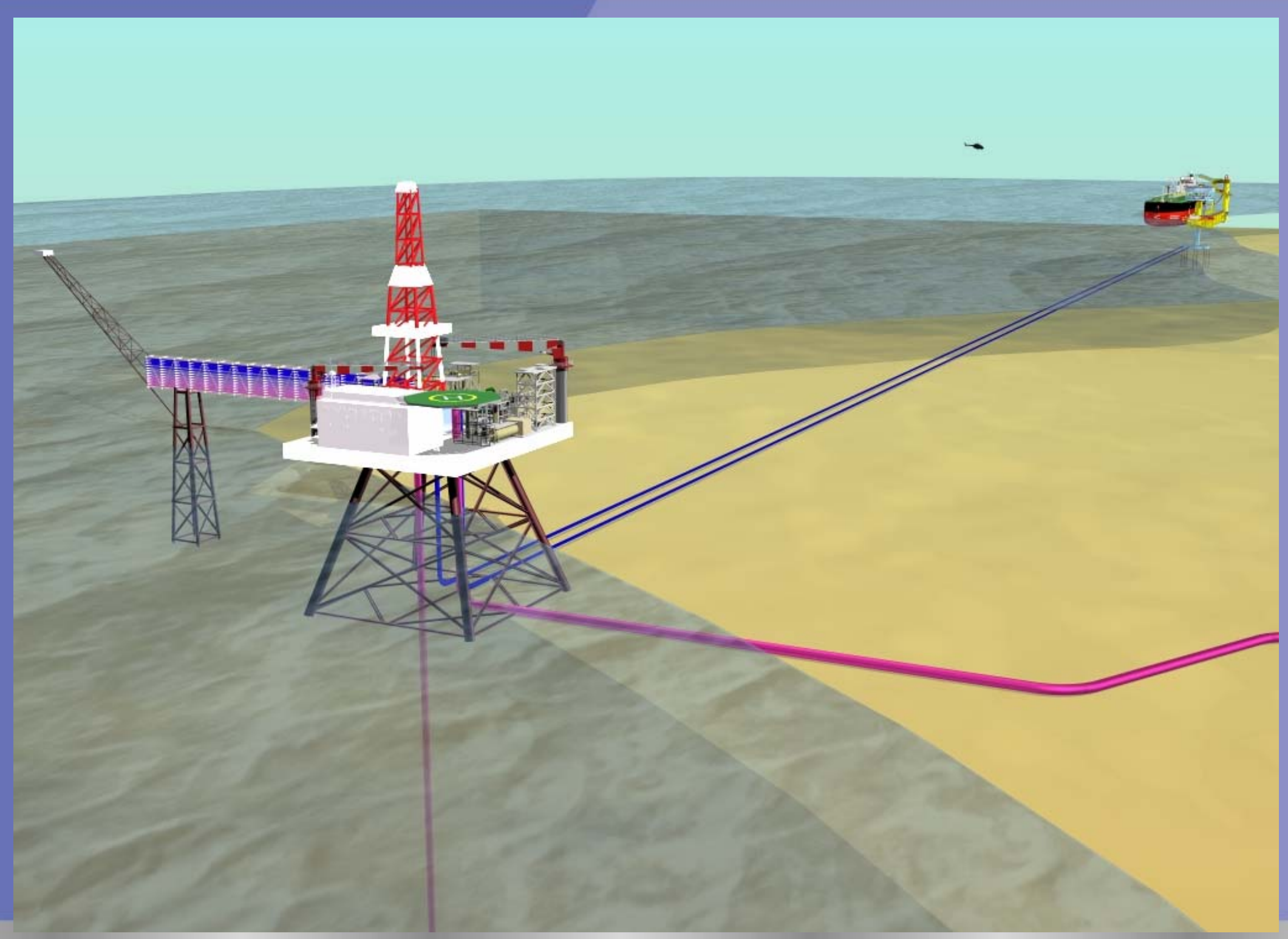




\section{bluewater}

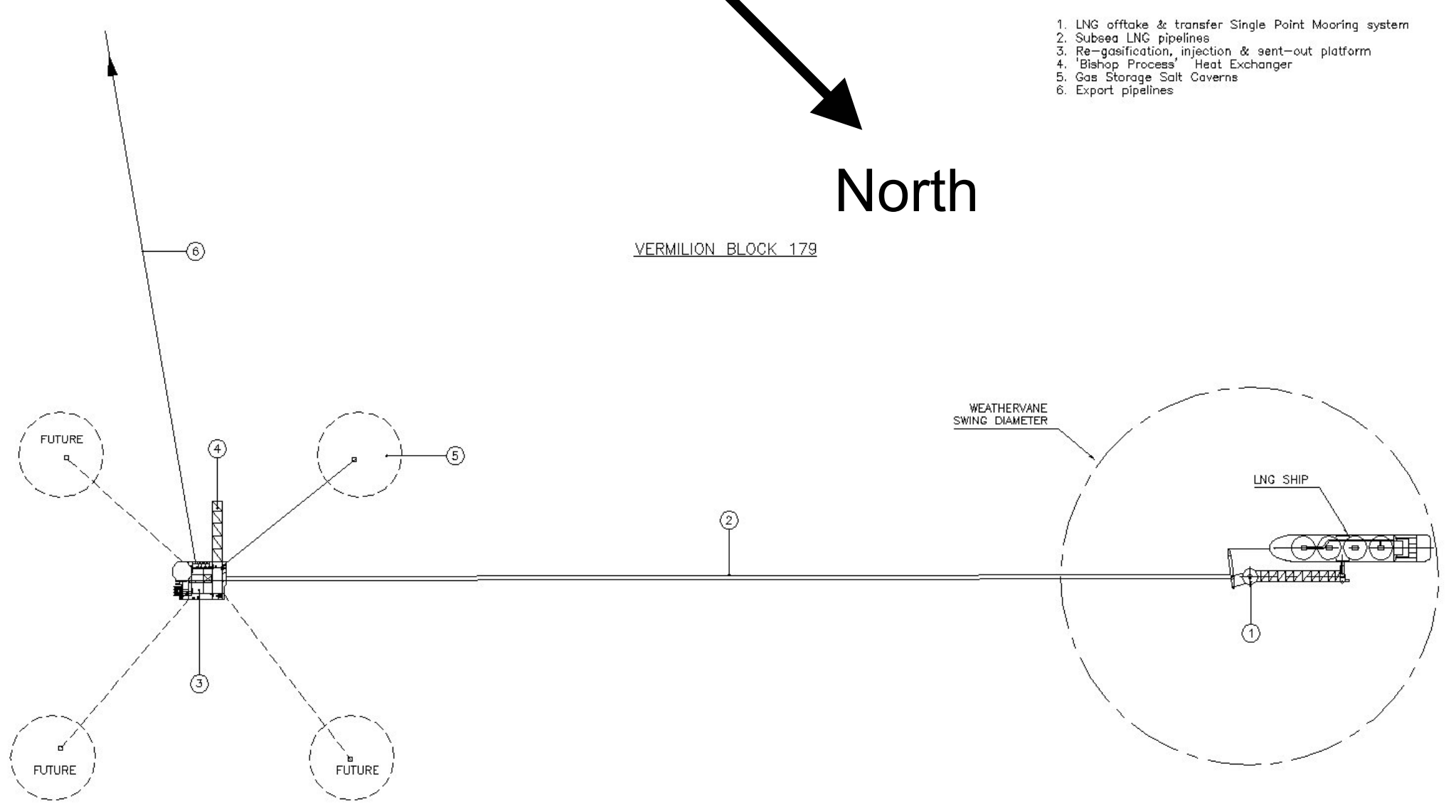




\section{bluewater}

\section{Vermilion 179 LNG Terminal}

HIRA Workshop

14 January 2004 


\section{bluewater}

Hazard

Identification and

Risk

Assessment 


\section{bluewater}

\section{The process}

- Break Down into discreet systems and define boundaries

- Identify Hazard(s)

- Determine Hazard Effects

- Identify Existing Control Measures in Place

- Classify Hazard Severity and Probability of Occurrence

- Identify Additional Control Measure, Action parties

- Assess Residual Risk 


\section{bluewater}

Power by People

\section{Risk Classification Matrix}

\begin{tabular}{|c|c|c|c|c|c|c|c|c|c|c|c|}
\hline \multicolumn{7}{|c|}{ CONSEQUENCE } & \multicolumn{5}{|c|}{ PROBABILITY OF OCCURENCE } \\
\hline \multirow[t]{2}{*}{$\begin{array}{l}\text { Personnel } \\
\text { Injury } \\
\text { (S) }\end{array}$} & \multirow[t]{2}{*}{$\begin{array}{l}\text { Asset } \\
\text { Damage } \\
\$ \\
\text { (A) }\end{array}$} & \multicolumn{2}{|c|}{$\begin{array}{l}\text { Environmental } \\
\text { Damage } \\
\text { (E) }\end{array}$} & \multirow{2}{*}{$\begin{array}{l}\text { Schedule } \\
\text { Delays/ } \\
\text { loss of } \\
\text { Production } \\
\text { (D) }\end{array}$} & \multirow[t]{2}{*}{$\begin{array}{l}\text { Publicity } \\
\text { Damage (M) }\end{array}$} & \multirow[t]{2}{*}{ Severity } & \multirow{2}{*}{$\begin{array}{l}\text { P5 } \\
\text { Probable } \\
>10^{-1} \\
\text { Several } \\
\text { times per } \\
\text { year at our } \\
\text { site/ } \\
\text { location }\end{array}$} & \multirow{2}{*}{\begin{tabular}{|l|}
$\begin{array}{l}\text { P4 } \\
\text { Possible }\end{array}$ \\
$10^{-1}-10^{-2}$ \\
$\begin{array}{l}\text { Several } \\
\text { times per } \\
\text { year in our } \\
\text { company }\end{array}$ \\
\end{tabular}} & \multirow{2}{*}{$\begin{array}{l}\text { P3 } \\
\text { Unlikely } \\
10^{-2}-10^{-3} \\
\text { Incident } \\
\text { has } \\
\text { occurred in } \\
\text { our } \\
\text { company }\end{array}$} & \multirow{2}{*}{ 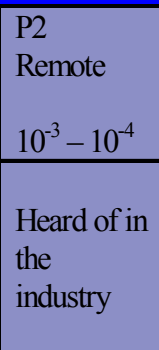 } & \multirow{2}{*}{$\begin{array}{l}\text { P1 } \\
\text { Insignificant } \\
10^{-4}-10^{-5} \\
\text { Never heard of } \\
\text { in the industry }\end{array}$} \\
\hline & & $\begin{array}{l}\text { Oil } \\
\text { (bbls) }\end{array}$ & $\begin{array}{l}\text { Gas } \\
\text { (kgs) }\end{array}$ & & & & & & & & \\
\hline $\begin{array}{l}\text { Catastrophic event with } \\
\text { multiple fatalities from } \\
\text { injury or occupational } \\
\text { illness }\end{array}$ & $>10 \mathrm{M}$ & $>1,000$ & $>10,000$ & $>1$ year & International & 5 & A & A & A & B & $\mathrm{C}$ \\
\hline $\begin{array}{l}\text { Fatalities }(1-3) \text { or } \\
\text { permanent total Disability } \\
\text { from injury or occupational } \\
\text { illness }\end{array}$ & $\begin{array}{l}500 \mathrm{~K}- \\
10 \mathrm{M}\end{array}$ & $100-1,000$ & $\begin{array}{l}1,000- \\
10,000\end{array}$ & 3 months & National & 4 & A & A & B & $\mathrm{C}$ & $\mathrm{C}$ \\
\hline $\begin{array}{l}\text { Major single injury (LTI =3 } \\
\text { days, prolonged work } \\
\text { absence, irreversible health } \\
\text { effects) or multiple injuries }\end{array}$ & $\begin{array}{l}100 \mathrm{~K}- \\
500 \mathrm{~K}\end{array}$ & $10-100$ & $\begin{array}{l}100- \\
1,000\end{array}$ & 30 days & $\begin{array}{l}\text { State / } \\
\text { Regional }\end{array}$ & 3 & A & B & $\mathrm{C}$ & $\mathrm{C}$ & $\mathrm{D}$ \\
\hline $\begin{array}{l}\text { Minor injury or health effect } \\
\text { (including RWC, minor LTI } \\
<3 \text { days, reversible health } \\
\text { effects) which affects work } \\
\text { performance }\end{array}$ & $\begin{array}{l}10 \mathrm{~K}- \\
100 \mathrm{~K}\end{array}$ & $1-10$ & $10-100$ & 7 days & Local & 2 & B & $\mathrm{C}$ & $\mathrm{C}$ & $\mathrm{D}$ & $\mathrm{D}$ \\
\hline $\begin{array}{l}\text { Slight injury or health effect } \\
\text { (including FAC and MTC) } \\
\text { which does not affect work } \\
\text { performance or cause } \\
\text { disability }\end{array}$ & $<10 \mathrm{~K}$ & $<1$ & $<10$ & $<1$ day & Company & 1 & $\mathrm{C}$ & $\mathrm{C}$ & $\mathrm{D}$ & D & $\mathrm{D}$ \\
\hline
\end{tabular}




\section{bluewater}

Power by People

\section{HIRA Worksheet}

\begin{tabular}{|l|l|l|l|l|l|l|l|l|l|l|}
\hline Area & $\begin{array}{l}\text { Hazard } \\
\text { ID }\end{array}$ & Description & Cause & Consequence & $\begin{array}{l}\text { Risk } \\
\text { Ranking }\end{array}$ & Safeguards & $\begin{array}{l}\text { Recommendations } \\
\text { / Summary of } \\
\text { Actions }\end{array}$ & Reference & By & Date \\
\hline (to be studied) & & $\begin{array}{l}\text { Of activity and } \\
\text { of resulting } \\
\text { hazard }\end{array}$ & & & $\begin{array}{l}\text { As per } \\
\text { RCM }\end{array}$ & $\begin{array}{l}\text { What is currently } \\
\text { in place }\end{array}$ & $\begin{array}{l}\text { What else needs to be } \\
\text { put in place }\end{array}$ & $\begin{array}{l}\text { As required, also } \\
\text { to be used also to } \\
\text { establish residual } \\
\text { risk }\end{array}$ & \\
\hline & & & & & & & & & \\
\hline
\end{tabular}




\section{bluewater}

\section{Scope (1 of 3)}

\section{Preliminary Hazard Identification}

- Design

- LNG Offloading System - Big Sweep Truss-type swing arm

- LNG cryogenic Supply Pipeline System

- Processing Platform Structure and Topsides (Electrical Power, Vaporizer Trestle)

- Gas Send-out Pipeline

- Caverns 
- Operations

- Marine Operations (approach, mooring, unmooring, Emergency disconnect)

- LNG Transfer Operations (Pumping)

- LNG Processing (LNG vaporization)

- LNG Storage Operations (transfer to and from Caverns) 


\section{- Safety Systems}

Process integrity

- Fire and Gas Detection

ESD and Blowdown (including Pressure relief systems)

- Safe havens

Egress, evacuation, escape and rescue

- Emergency plan outline

- other 


\section{Appendix D - Meeting notes and action list}




\begin{tabular}{|c|c|c|c|c|c|c|}
\hline 2. Mooring Ops & Reference & Query & Comments & Remarks & Action Required? & Response \\
\hline 2.1 & BOD & $\begin{array}{l}\text { Current vessel size 125,000 m3 @ } 8000 \text { m3/hr @ } 7 \text { bar 45' } \\
\text { above LWL }\end{array}$ & $\begin{array}{l}\text { Existing } 125 \mathrm{~K} \text { are older vessels. Newer vessels are } 135 \text { to } 145 \mathrm{k} . \\
\text { Revisit base case? Most } 125 \text { are dedicated. }\end{array}$ & & $\begin{array}{l}\text { 1. Base case includes various } \\
\text { sizes. }\end{array}$ & \\
\hline $\begin{array}{l}2.2 \\
2.3\end{array}$ & $\begin{array}{l}\text { Operations } \\
\text { Operations }\end{array}$ & $\begin{array}{l}\text { Cycle time } \\
-5 \mathrm{NM} \text { (distance) to securing pick-up buov at LNG carrier }\end{array}$ & & & & \\
\hline 2.4 & Operations & - Start winching in of pick-up rope to securing hawser & $1 \mathrm{hr}$ & & & \\
\hline 2.5 & Operations & $\begin{array}{l}\text { - Swinging in loading arm until loading arm is in 'steady } \\
\text { state' }\end{array}$ & $.5 \mathrm{hr}$ & & & \\
\hline 2.6 & Operations & $\begin{array}{l}\text { - Deploy hose connector to make-up of mechanical } \\
\text { connection to ships manifold }\end{array}$ & $.5 \mathrm{hr}$ & & & \\
\hline 2.7 & Operations & - Cargo transfer & Refer to Cargo Transfer Operations & & & \\
\hline 2.8 & Operations & $\begin{array}{l}\text { - stop pumping to store hose connector onto cradle on } \\
\text { SPM }\end{array}$ & $.5 \mathrm{hr}$ & & & \\
\hline 2.9 & Operations & $\begin{array}{l}\text { - cast off from SPM to departure LNG carrier from } \\
\text { terminal area }\end{array}$ & $.5 \mathrm{hr}$ & & & \\
\hline 2.10 & $\begin{array}{l}\text { Operations / } \\
\text { HSSE }\end{array}$ & Approach speed restrictions & Requires to be developed for $5 \mathrm{~nm}$ to hook-up & $\begin{array}{l}\text { Rule of Thumb: approach } \\
\text { speed in knots is about the } \\
\text { as distance in nm. }\end{array}$ & & \\
\hline 2.11 & $\begin{array}{l}\text { Operations / } \\
\text { HSSE }\end{array}$ & Mooring failure (hawser, tug, etc) & Failure modes to be identified and philosophy to be developed. & & & \\
\hline 2.12 & Operations & Approach & $\begin{array}{l}\text { Vessel can not divert track to both port and starboard in case of } \\
\text { an 'emergency' as the big sweep arm prohibits port track. } \\
\text { Philosophy where to attach tugs shall be considered in light of } \\
\text { this. Example is that it may be more logical to tether a tug to the } \\
\text { sb bow in order to assist is a sb exit track. Note that the normal } \\
\text { configuration of the tugs is one at center fairlead stern and one at } 2 \\
\text { sh bowe }\end{array}$ & $\begin{array}{l}\text { Consider orientation of arm } \\
\text { such that port and sb } \\
\text { escape tracks are possible. } \\
\text { Note that both tugs will } \\
\text { make fast at approximately } \\
2-3 \text { miles distance from }\end{array}$ & 1. Evaluate further BS. & \\
\hline 2.13 & Operations & Control of Big Sweep arm & 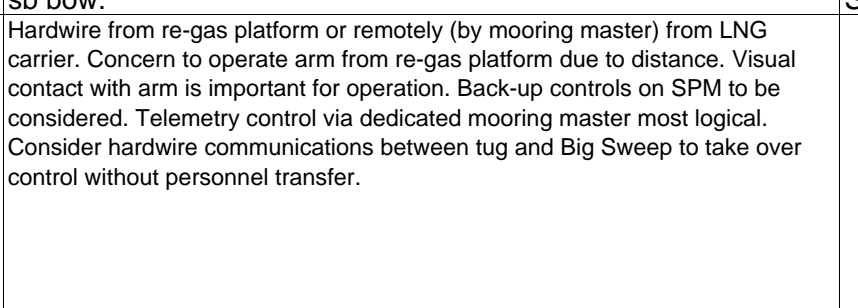 & & $\begin{array}{l}\text { 1. Check implementation of } \\
\text { recommendations. BOVE/HBRU/HVDB }\end{array}$ & 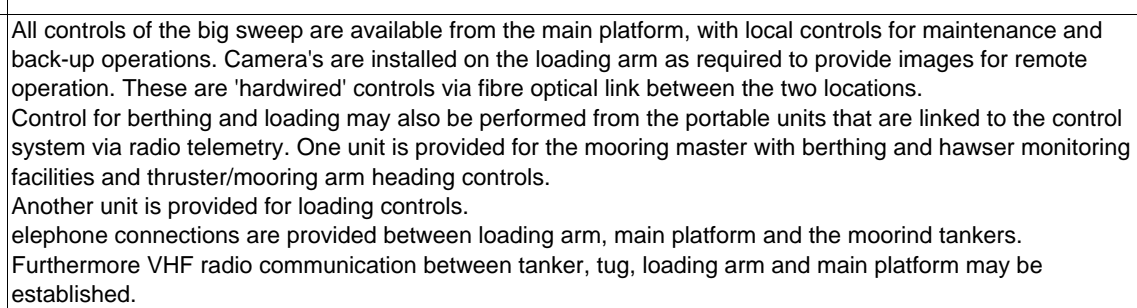 \\
\hline 2.14 & Operations & Pick-up rope length & Normally $400 \mathrm{~m}$ (excl. hawser length) & & $\begin{array}{l}\text { 1. Include in design package } \\
\text { (drawing) }\end{array}$ & \\
\hline 2.15 & Operations & Emergency Disconnect & $\begin{array}{l}\text { Hawser to be released from the tanker releasing the tension } \\
\text { and/or releasing the hawser completely. Design and philosophy to } \\
\text { be developed. }\end{array}$ & & $\begin{array}{l}\text { 1. Check requirements for } \\
\text { Emergency Disconnect BS. }\end{array}$ & \\
\hline 2.16 & Operations & Maintenance (LNG Carrier) & $\begin{array}{l}\text { Restrict maintenance activities on LNG carriers during moored } \\
\text { condition and cargo transfer operations. LNG carrier shall be fully } \\
\text { operational. }\end{array}$ & & & \\
\hline
\end{tabular}




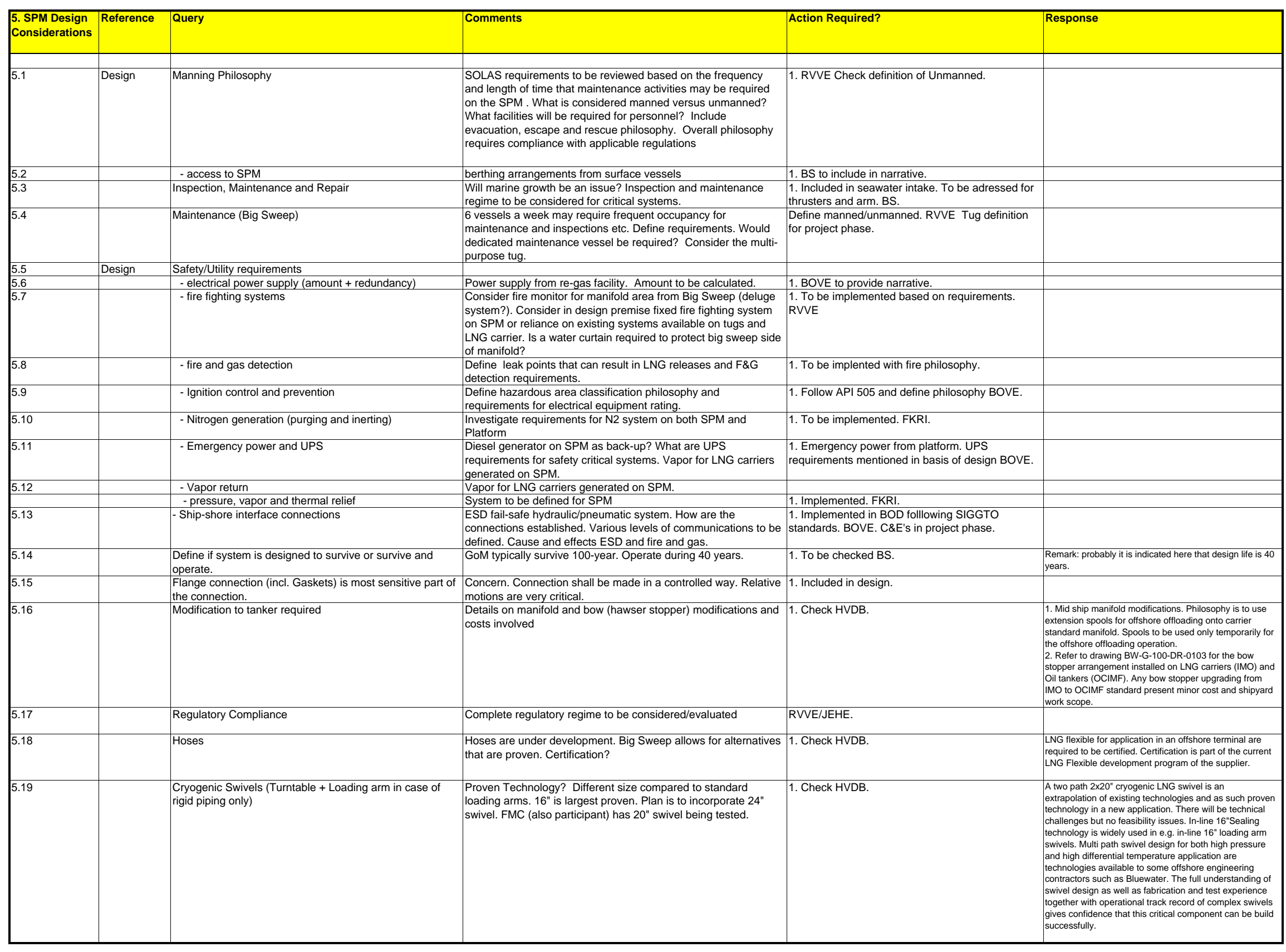




\begin{tabular}{|c|c|c|c|c|c|c|}
\hline 1. Shipping Ops & Reference & Query & Comments & Remarks & Action Required? & Response \\
\hline 1.1 & BOD & $\begin{array}{l}\text { Terminal send-out capacity currently } \\
\text { listed as } 2.0 \text { bcfd nominal, varying } \\
\text { between } 1.5 \text { bcfd min to } 2.5 \text { bcfd } \\
\text { max. However, no duration stated for } \\
\text { 'peak' production }\end{array}$ & $\begin{array}{l}\text { Foreseen send-out durations to be further specified (hours, days, } \\
\text { weeks, months...) Notet that } 1.5 \text { bbfti implies } 70,000 \mathrm{~m} 3 \text { /day or } 4 \\
\text { ships/week and } 2.5 \text { befd implies } 120,000 \mathrm{~m} 3 / \text { day or } 6 \text { ships/week } \\
\text { r. }\end{array}$ & & & \\
\hline 1.2 & BOD & $\begin{array}{l}\text { What is the 'regulariti' of LNG } \\
\text { carriers arrivals? Is an anchorage } \\
\text { area to be provided? Do ships adjust } \\
\text { their speed? }\end{array}$ & $\begin{array}{l}\text { May have implications on discharge vessel cycle time. What } \\
\text { flexibility may be needed in terms of capacity (oftload quicker / } \\
\text { tt turnaround) catching up on backlog. Problem with delaying offload } \\
\text { and increased boil-off resulting in lower planned discharge parcel. } \\
\text { Location, etc to consider achorage availability }\end{array}$ & & $\begin{array}{l}\text { 1. Check against operational procedure. } \\
\text { HBRU }\end{array}$ & \\
\hline 1.3 & BOD & Weather implications & $\begin{array}{l}\text { Consider seasonality with respect to excessive weather and weather } \\
\text { windows. Refers to persistence of weather conditions. Squallls } \\
\text { must be considered and there frequency/severity needs to be } \\
\text { established. }\end{array}$ & & $\begin{array}{l}\text { 1. Available weather data is now being } \\
\text { used for designn. Full weather data not } \\
\text { available yet, project phase. RL. }\end{array}$ & \\
\hline 1.4 & Operations & $\begin{array}{l}\text { Number and capability of escort tugs } \\
\text { required for berthing at the mooring } \\
\text { terminal }\end{array}$ & $\begin{array}{l}\text { s } 2 \text { i in BOD with multi-mission capabilities (SBV for plattorm, guard } \\
\text { vessel duties [Tugs have radarl, personnel transfer, towing, fire } \\
\text { fighting). Bollard pull ( (50 ton mimimum, determine if more is } \\
\text { required to account for example extreme weather, LNG tanker size). } \\
\text { Require special fendering for pushing. }\end{array}$ & & 1 Included in onerational nrocedure & \\
\hline 1.5 & Operations & Tugs & $\begin{array}{l}\text { Stand alone capable for deployment period. Determine how long a } \\
\text { tug is self-supprting. }\end{array}$ & & 1. Included in operational procedure HBRU. & \\
\hline 1.6 & $\begin{array}{l}\text { Operations/ } \\
\text { HSSE }\end{array}$ & Tugs & $\begin{array}{l}\text { Shall tugs serve as a dual purpose SBV for the plattorm or mooring } \\
\text { terminal? }\end{array}$ & & & \\
\hline 1.7 & Operations & Tugs & $\begin{array}{l}\text { What is required in terms of berthing facilities for tugs? Example- } \\
\text { assistance required on the big sweep which may require personnel } \\
\text { transfer. }\end{array}$ & & 1. BS & \\
\hline 1.8 & Operations & $\begin{array}{l}\text { What operations need to be carried } \\
\text { out tin day lilht? (Hook-up, } \\
\text { discharge, disconnect,...) }\end{array}$ & $\begin{array}{l}\text { Permit shall apply for } 24 \text { hour operation. Initial policy will be for } \\
\text { daylight operation tor hook-upp. Initial meaning training perirod. Night } \\
\text { time might have some advantages because of less traffici. }\end{array}$ & & 1. Include in operational procedure HBRU & \\
\hline 1.9 & HSSE & $\begin{array}{l}\text { What are the consequences of } \\
\text { increased number of LNG carrier } \\
\text { operations outwidth the Safety } \\
\text { Fairways }\end{array}$ & Possible involvement with MMS outwith the Deepwater Port License & & & \\
\hline 1.1 & Operations & $\begin{array}{l}\text { What are the environmental } \\
\text { limititions for mooring / unmooring; } \\
\text { cargo transfer; staying moored. } \\
\text { Decision to approach based on } \\
\text { weather forecast etc. }\end{array}$ & $\begin{array}{l}\text { Comparable to oil transfer operatitions. Limitations for hook-up, for } \\
\text { cargo transsere ret. Forecast for hurricanes and tropical storms. } \\
\text { Evacuation plans shall be in place beginning of hurricane season. }\end{array}$ & $\begin{array}{l}\text { To be established during project phase } \\
\text { once detail is known }\end{array}$ & 1, Include in BOD RL/HBRU & \\
\hline 1.11 & Operations & $\begin{array}{l}\text { Cargo sloshing effect, concerns, } \\
\text { issues during discharge }\end{array}$ & $\begin{array}{l}\text { Issue is a problem particularly for membrane systems and requires } \\
\text { further evaluation. }\end{array}$ & $\begin{array}{l}\text { Look into possibilities for heading control } \\
\text { with tug to minimise effects. }\end{array}$ & 1. Include in Operations Document HvdE & $\begin{array}{l}\text { Roll motion issues are not addressed in } \\
\text { this studd ys terminal feasibility nor } \\
\text { availablility is impaired. } \\
\text { Further work has to be performed in a } \\
\text { later stage. } \\
\text { The BOD section } 2.5 \text { elaborates on this } \\
\text { issue. }\end{array}$ \\
\hline 1.12 & Operations & $\begin{array}{l}\text { How and when to get mooring } \\
\text { masters and independent surveyor } \\
\text { on board. } \\
\text { Collision Platform - Ships }\end{array}$ & $\begin{array}{l}\text { Develop in line with security requirements. Point is how to get them } \\
\text { onboard but should be similar to how a pilot normally boards vessel } \\
\text { Collisions are verer rare } \text {. poprox } 4500 \text { plattrors in GoM }\end{array}$ & & & \\
\hline $\begin{array}{l}1.13 \\
1.14\end{array}$ & $\begin{array}{l}\text { HSSE } \\
\text { HSSE }\end{array}$ & $\begin{array}{l}\text { Collision Plattorm - Ships } \\
\text { Shipping safety fairways }\end{array}$ & 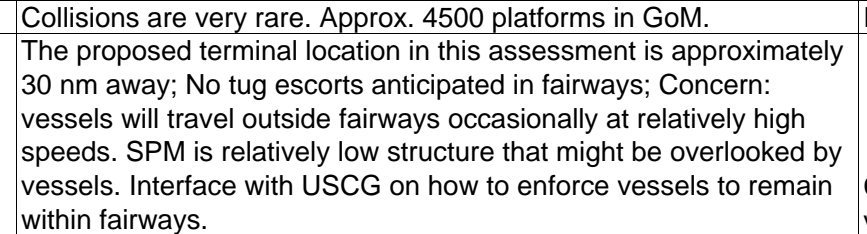 & $\begin{array}{l}\text { Consider to use field tugs as a guard } \\
\text { vessel. }\end{array}$ & $\begin{array}{l}\text { 1. Drawing included in Ops Description } \\
\text { HBRU. }\end{array}$ & \\
\hline 1.15 & & $\begin{array}{l}\text { LNG carrier + tugs escorting in } \\
\text { approach corridor }\end{array}$ & 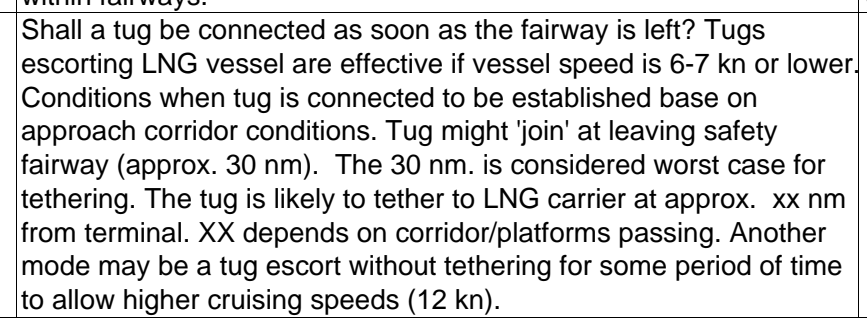 & & 1. Include in Operational Philosophy HBRU & \\
\hline 1.16 & HSSE & Approach corridor & $\begin{array}{l}\text { Interfface with USCG. What nav.aids will be required. There shall be } \\
\text { a moving security zone with the LNG tanker. ISPS is applicable. } \\
\text { Conflicts with existing plattorms? }\end{array}$ & & & \\
\hline 1.17 & HSSE & Safety Zone & 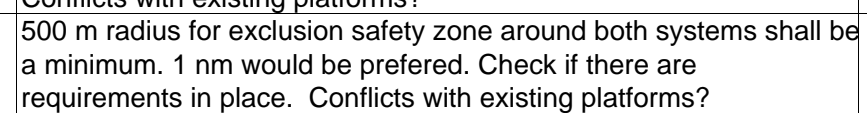 & & 1. See operational Philosophy. HBRU & \\
\hline 1.18 & $\mathrm{RC}$ & Regulatory interfaces & $\begin{array}{l}\text { Interface with USCG, MMS is required to determine what is within } \\
\text { their jurisdiction and what regulations are in place outside } 12 \text { miles } \\
\text { zone of cosstal waters. }\end{array}$ & $\begin{array}{l}\text { Is there a similar MOU as in the UK (HSE } \\
\text { MCA regarding primacy in terms of } \\
\text { responsibility and jurisdiction? }\end{array}$ & $\begin{array}{l}\text { 1. } 33 \text { CFR } 127 \text {. Check what term 'navigable } \\
\text { waters' means. Check with IELE document. }\end{array}$ & \\
\hline 1.19 & Operations & Bunkering & $\begin{array}{l}\text { Could be done at anchorage or bunkering port. Not allowed during } \\
\text { cargo transfer operations. Bunkering may add some extra time to } \\
\text { the } L N G \text { carrier journey time. }\end{array}$ & $\begin{array}{l}\text { Check into the possibility of bunkering at } \\
\text { SPM when not conducting cargo transfer } \\
\text { operations. }\end{array}$ & $\begin{array}{l}\text { 1. Include remark in BOD that bunkering } \\
\text { through Big Sweep not is included in base } \\
\text { case design. }\end{array}$ & \\
\hline
\end{tabular}




\begin{tabular}{|c|c|c|c|c|c|}
\hline $\begin{array}{l}\text { 4. Re-gas, Stor. \& } \\
\text { Send Out Ops }\end{array}$ & Reference & Query & Comments & Action Required? & Response \\
\hline 4.1 & Design & Indvidual lay-outs of platforms & To be discussed at a later stage & & \\
\hline 4.2 & Operations & $\begin{array}{l}\text { Transfer pipe between SPM \& re-gas, injection \& } \\
\text { send-out platform }\end{array}$ & & & \\
\hline 4.3 & & - purging / venting / inerting operations & Details are under development & $\begin{array}{l}\text { 1. Purging venting and inerting only } \\
\text { considered for SPM. Rest is Paragon scope. }\end{array}$ & \\
\hline 4.4 & & - inspection & Piggability? & $\begin{array}{l}\text { 1. No pigging requirements on board SPM } \\
\text { foreseen. }\end{array}$ & \\
\hline 4.5 & & - monitoring & $\begin{array}{l}\text { Monitoring of annulus temperature, pressure, composition for the purpose of } \\
\text { early detection of leaks }\end{array}$ & & \\
\hline 4.6 & Design & Utility systems & Define overall utilities supplied from re-gas to SPM. & 1. Was defined. BOVE. & \\
\hline 4.7 & & $\begin{array}{l}\text { - availability / redundancy of E-power (DP capability } \\
\text { of SPM) }\end{array}$ & Primary E power for SPM supplied from re-gas facility. Back-up to be defined. & 1. Backup in emergency power umbillical. & \\
\hline 4.8 & & Relief system & Thermal pressure relief system to be defined & 1. Included in scope. & \\
\hline 4.9 & & Piping on Cavern \& send-out platform & $\begin{array}{l}\text { Dry trees on platform. Safety valves on sea-bed? Gas cavern storage } \\
\text { technology in an offshore environment is not done previously. Technology from } \\
\text { iil industry expected to be applicable. Monitoring controls on send out laterals } \\
\text { on platform rather than at tie in point. }\end{array}$ & & \\
\hline 4.10 & & Quality of gas & $\begin{array}{l}\text { Monitor compatibility of gas quality in overall gas pipeline infra structure. } \\
\text { (Delivery of gas could be 'downstream' of gas processing facilities because of } \\
\text { higher quality) }\end{array}$ & & \\
\hline 4.11 & & Caverns & Caverns add flexibility on receipt and dispatch of gas. & & \\
\hline
\end{tabular}




\begin{tabular}{|c|c|c|c|c|c|}
\hline \begin{tabular}{|l|} 
6. Overall \\
Facilities Layout
\end{tabular} & Reference & Query & Comments & Action Required? & Response \\
\hline 6.1 & Lay-out & Minimum safe distance between SPM and re-gas platform & $\begin{array}{l}\text { To be studied. Base case is } 1 \mathrm{~nm} \text {. Distance is critical } \\
\text { economically due to the expense of the pipelines }\end{array}$ & Study to be done in project phase. & \\
\hline 6.2 & Lay-out & Relative location of the SPM with respect to the re-gas platform & $\begin{array}{l}\text { To be studied, based on environmental data, approach route of } \\
\text { tanker }\end{array}$ & 1. Check RL / HBRU & \\
\hline 6.3 & Lay-out & Location re-gas platform relative to cavern & Close if preferable, but not required to be on top. & & \\
\hline 6.4 & Lay-out & Location of platform & $\begin{array}{l}\text { Might be more economical/practical by resiting both platform and } \\
\text { SPM towards the safety fairway and/or away from existing } \\
\text { platforms. }\end{array}$ & Project phase. & \\
\hline 6.5 & Lay-out & Minimum safe distance between SPM and other platforms & Related to LNG tanker approach & See marine ops remark. & \\
\hline 6.6 & Lay-out & $\begin{array}{l}\text { Requirements for 'dropped object' protection for the cryogenic } \\
\text { transfer lines between SPM and re-gas platform }\end{array}$ & $\begin{array}{l}\text { Lines will be burried/protected (see below). Regulatory } \\
\text { requirements to be checked. }\end{array}$ & & \\
\hline 6.7 & Philosophy & Isolation & $\begin{array}{l}\text { Philosophy to be determined. What systems are located on what } \\
\text { part of the overall system (SPM, re-gas facility) }\end{array}$ & 1. FKRI to provide narrative. & \\
\hline 6.8 & HSSE & Cryogenic pipeline & $\begin{array}{l}\text { Protection philosophy? Will be concrete coated. Line to be burried } \\
\text { approx. } 3 \text { - } 8 \mathrm{ft} \text {. Study may be required to address dropped } \\
\text { objects. }\end{array}$ & & \\
\hline 6.9 & HSSE & Riser protection & Consider splash zone if applicable & 1. Check HVDB & $\begin{array}{l}\text { The riser will be run through the } \\
\text { central colum of the monopod. The } \\
\text { monopod will protect the riser from } \\
\text { direct wave impact and collission. }\end{array}$ \\
\hline \multicolumn{6}{|l|}{6.10} \\
\hline 6.11 & Design & Mooring system availability & Correlation between demand and weather availability to be plottec & 1. Weather availability per season wi & I be provided. RL. \\
\hline 6.12 & Design & Second mooring system & & & \\
\hline 6.13 & & $\begin{array}{l}\text { - Should the base case be two mooring systems to allow for } \\
\text { availability? }\end{array}$ & $\begin{array}{l}\text { Cost is an implication. Establish availability with respect to } \\
\text { normal operations (e.g., weather). Consider damaged conditions } \\
\text { which may required second mooring system. Cost benefit } \\
\text { analysis based on risk assessment (e.g., identify scenarios) to be } \\
\text { performed. }\end{array}$ & $\begin{array}{l}\text { Beyond CGI study scope. To be } \\
\text { adressed prior to project phase. }\end{array}$ & \\
\hline 6.14 & Design & - Where should an additional SPM be sited? & $\begin{array}{l}\text { Future expansion of terminal; Previously addressed. Plan first } \\
\text { SPM location based on future expansion. Prevailing conditions to } \\
\text { allow approachable path with minimal requirements to go around } \\
\text { mooring system / vessel. }\end{array}$ & 1. Check. HVDB. & $\begin{array}{l}\text { A location for a future terminal is } \\
\text { tentatively indicated on drawing BW- } \\
\text { G-100-DR-0100 sht. } 002 \text { considering } \\
\text { local conditions. A detailed siting } \\
\text { study needs to be performed in case } \\
\text { of a project. }\end{array}$ \\
\hline 6.15 & Layout & Anchorage area & Shall be at least $1 \mathrm{~nm}$ away from configuration. & See ops response $\mathrm{nr} . .$. & \\
\hline 6.16 & Layout & Pipeline routing over salt domes & No particular issues forseen. Normal site surveys have to be done & & \\
\hline 6.17 & Layout & Caverns & Number, availability, size & & \\
\hline 6.18 & Design & Larger Carriers & $\begin{array}{l}\text { Are overall design parameters sized (e.g.pipeline capacities) to } \\
\text { handle larger vessels and transfer rates? }\end{array}$ & & \\
\hline
\end{tabular}




\begin{tabular}{|c|c|c|c|c|c|}
\hline 3. Transfer Ops & Reference & Query & Comments & Action Required? & Response \\
\hline 3.1 & Operations & Cycle time & & & \\
\hline 3.2 & Operations & - hose manipulator connected to start pumping & $\begin{array}{l}\text { Prior to commencement of pumping operations, connections are tested for } \\
\text { gas tightness as well as ESD systems. Standard checklist are also } \\
\text { completed. Cool down time will depend on the characteristics of the overall } \\
\text { system and the extent of what requires to be cooled. Boundaries for cool } \\
\text { down loop require definition. Onshore terminals require approximately } 3 \text { hrs } \\
\text { cool down time (prior to liquid pumping) }\end{array}$ & & 1. Implemented in design. \\
\hline 3.3 & Operations & - ramp-up time to max. pump capacity & $\begin{array}{l}\text { Approximately } 1 \mathrm{hr} \text {. (1 additional pump brougnt online approximately every } \\
10 \text { min.) }\end{array}$ & & \\
\hline 3.4 & Operations & - ramp-up time to max. pump capacity & $\begin{array}{l}\text { Once ramp-up is complete, discharge is relatively constant. Shore practices } \\
\text { are expected to be applicable offshore as well. Weather window is key for } \\
\text { discharge plan. }\end{array}$ & & \\
\hline 3.5 & Operations & - time required for stripping tanks empty & & & \\
\hline $\begin{array}{l}3.6 \\
3.7\end{array}$ & $\begin{array}{l}\text { Operations } \\
\text { Operations }\end{array}$ & $\begin{array}{l}\text { - ramp-down } \\
\text { Start-up of system }\end{array}$ & Approximately $1 \mathrm{hr}$. to ramp down. & & \\
\hline 3.8 & Operations & - initial operations & $\begin{array}{l}\text { Requires purging and cooling of piping and pumps. Mostly likely source of } \\
\text { LNG is from the LNG carrier. (Elba island had about } 3 \text { days before first } \\
\text { cargo transfer.) }\end{array}$ & & \\
\hline 3.9 & Operations & - after prolonged shut down & $\begin{array}{l}\text { LNG is removed from pipelines by passing ambient gas through the system. } \\
\text { Significant time required before operations. Basically the time required will } \\
\text { be equal to the time required for the first operation. Time to be calculated. } \\
\text { Procedures to be defined }\end{array}$ & & \\
\hline 3.10 & Operations & - normal operations & System kept cool up to system boundaries. & $\begin{array}{l}\text { 1. FKRI to be } \\
\text { implemented in } \\
\text { operational narrative }\end{array}$ & \\
\hline 3.11 & Operations & Shut-down of system & & & \\
\hline 3.12 & & - normal shut down & System kept cool up to system boundaries. & & \\
\hline 3.13 & & - emergency disconnect & $\begin{array}{l}\text { ESD system will be present. All pumps will be shut down. Philosophy and } \\
\text { procedures will be developed for disconnection of loading arms and/or } \\
\text { tanker. }\end{array}$ & 1. Implemented: HVDB & $\begin{array}{l}\text { 1. Refer to document BIGS-G-100-PB-0100, } \\
\text { Section } 8.11 \text { [holdl for the Control, Automation } \\
\text { and Safaguarding systems philosophies. } \\
\text { 2. For disconnect philosophy refer to [BIGS-G-100- } \\
\text { PB-0100, Section } 8.11 \text { HoLD] } \\
\text { 3. For loading arm disconnect procedure see } \\
\text { Eurodim drawings } 6096 \text {-DWG-PO } 01 / 09 \text { [HOLD } \\
\text { for BW numbers] }\end{array}$ \\
\hline 3.14 & & - routine / maintenance inspections & Isolate affected areas only. & $\begin{array}{l}\text { 1. Include in } \\
\text { operational narrative } \\
\text { FKRI }\end{array}$ & \\
\hline 3.15 & Operations & Station keeping (Big Sweep) & $\begin{array}{l}\text { Is redundancy of systems equivalent to DP } 1 \text { or DP } 2 \text { required? Wind squall } \\
\text { to be considered/evaluated. }\end{array}$ & $\begin{array}{l}\text { 1. Include in narrative } \\
\text { BS. }\end{array}$ & \\
\hline 3.16 & & Station Keeping (general) & $\begin{array}{l}\text { Special consideration to be given under cross conditions (LNG carrier roll } \\
\text { mitigation). Tug assistance to force heading. If vessel heading is forced } \\
\text { could that create 'conflicts' with the DP system/algorithm? Manual control of } \\
\text { SPM thruster shall be considered as back-up. Wind squall to be } \\
\text { considered/evaluated. }\end{array}$ & $\begin{array}{l}\text { 1. Include in narrative } \\
\mathrm{BS} / \mathrm{BOVE}\end{array}$ & \\
\hline 3.17 & Operations & Cargo Discharge & $\begin{array}{l}\text { Requires standard contingency of authorities to witness transfer (MMS, etc). } \\
\text { Establish constraints wrt personnel }\end{array}$ & & \\
\hline 3.18 & & Cargo Discharge & $\begin{array}{l}\text { Cargo measurement (custody transfer) considering vapour transfer back to } \\
\text { LNG Tanker. Metering prior to caverns. Metering device onboard tanker. } \\
\text { Traditional gas measurement is planned to be installed on platform. Is this } \\
\text { acceptable for custody transfer. Establish what may be acceptable from a } \\
\text { commercial basis. Note that normally measurements are only taken on the } \\
\text { LNG carrier; however, due to the motions offshore it is doubtful that this will } \\
\text { be sufficiently accurate and/or acceptable. }\end{array}$ & $\begin{array}{l}\text { 1. Fiscal metering part } \\
\text { of plattorm scope. } \\
\text { BOVE to provide } \\
\text { reference. }\end{array}$ & \\
\hline
\end{tabular}




\section{Report}

\section{Hazid Study}

Doc. No. CGI-G-600-RP-0010 Rev. A

Project. No. 1-0282-0 


\section{Revision Status Sheet}

Rev. Date

A 14-7-2004
Description

Initial Issue
Initiator

RVVE
Checked by

Date

December 2004

Initials

FLIE

Approved by
December 2004

HVDB

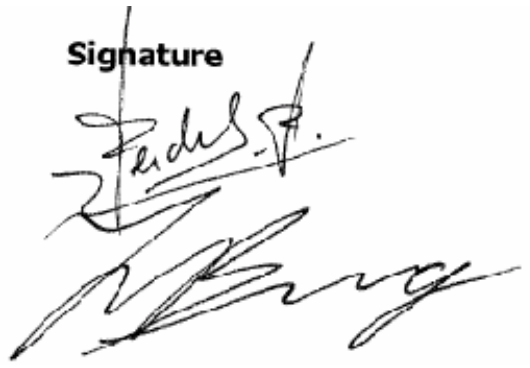




\section{Table of Contents}

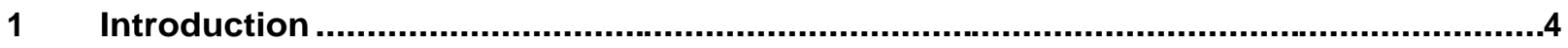

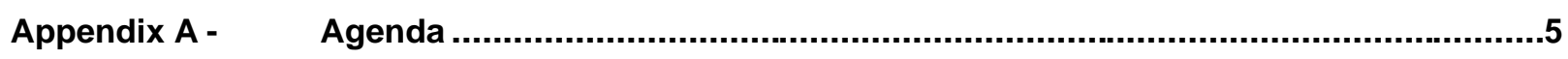

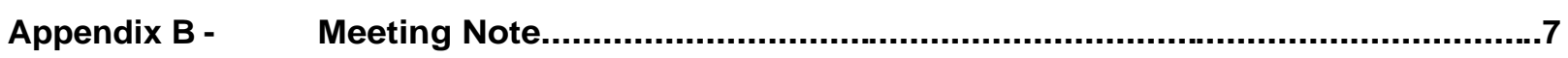

Appendix C - HAZID Action and Response Sheets ................................................. 12

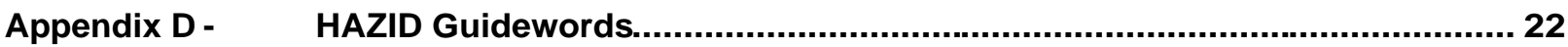




\section{Introduction}

This report forms a part of the Design Package of the concept design for the Big Sweep LNG Unloading Arm. The design was reviewed in a HAZID study

The HAZID was done in accordance with the Bluewater HIRA procedure [Doc. No. BWC-X-100-PR0003/Rev. A].

In this report, the results of the HAZID study are included. In Appendix A, the Agenda is presented. In Appendix B, the Review Notes are presented. In Appendix C, the Action - \& Response Sheets are presented. In appendix D, the HAZID Guide Words are included. 


\section{Appendix A - Agenda}


CLIENT: $\quad$ Bluewater Energy Services B.V.

PROJECT NO: $\quad 1-0282-0$

PROJECT: $\quad$ BIG SWEEP

DETAILS: $\quad$ A coarse HAZID was held to evaluate the concept design as available now. The HAZID followed the Bluewater HAZID procedure. Risk ranking and identification of Safety Critical Elements has not been done, as the design is still in the conceptual stage.

MEETING DATES: 13 July 2004

CHAIRMAN: Roel van Veen

SECRETARY:

TEAM MEMBERS: Henk van der Burg

- HVDB - Project Engineer;

Frank Krieg

- FKRI - Process Engineer;

Benedikt Overtoom

- BOVE - Instrumentation Engineer;

Bart Steuten

- BS - Naval Architect;

Jan de Wever

- JWEV - Piping Engineer;

Hielke Brugts

- HBRU - Operations Support Manager;

Roel van Veen

- RVVE - HSE Engineer/chairman

ACTION RESPONSES TO: RVVE

DOCUMENTS STUDIED

3D General Arrangement Big Sweep. 


\section{Appendix B - Meeting Note}




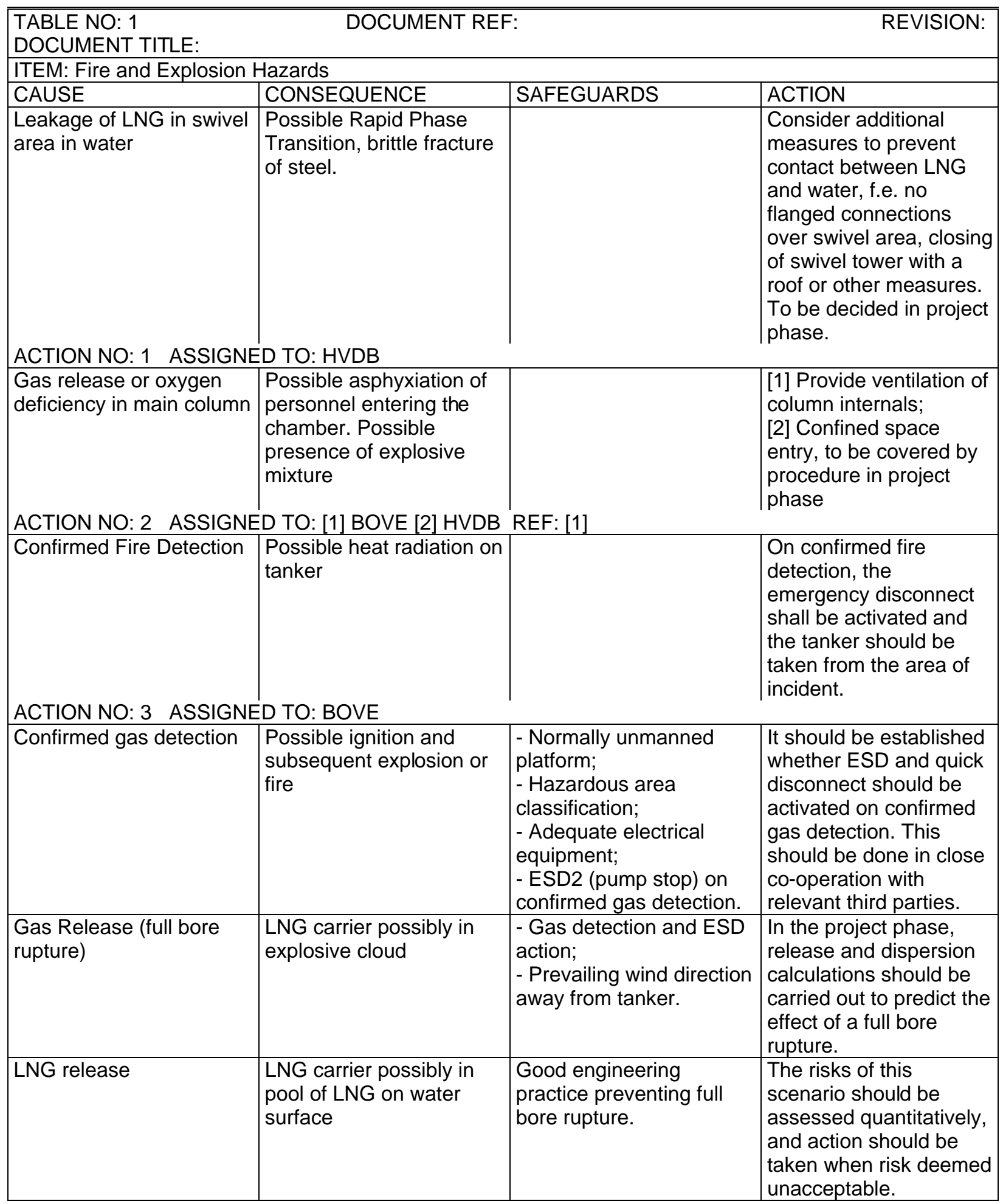


TABLE NO: 1 (continued)

DOCUMENT REF:

ITEM: Fire and Explosion Hazards

\begin{tabular}{|l|l|l|l|}
\hline CAUSE & CONSEQUENCE & SAFEGUARDS & ACTION \\
\hline $\begin{array}{l}\text { Possible ignition of gas } \\
\text { during quick disconnect }\end{array}$ & Explosion/Flashfire & $\begin{array}{l}{[1] \text { It should be }} \\
\text { assessed whether the } \\
\text { materials of the quick } \\
\text { disconnect system } \\
\text { should be spark free } \\
\text { (project phase). } \\
\text { [2] The loading hoses } \\
\text { should be anti-static. }\end{array}$ \\
\hline
\end{tabular}

ACTION NO: 4 ASSIGNED TO: [1] HVDB; [2] HVDB REF: [1]

TABLE NO: 2

DOCUMENT REF:

REVISION:

DOCUMENT TITLE:

ITEM: Process Hazards

\begin{tabular}{|l|l|l|l|}
\hline CAUSE & CONSEQUENCE & SAFEGUARDS & ACTION \\
\hline $\begin{array}{l}\text { Covered adequately in } \\
\text { What If review. }\end{array}$ & & & \\
\hline
\end{tabular}

TABLE NO: 3

DOCUMENT REF:

REVISION:

DOCUMENT TITLE:

ITEM: Utility Systems

\begin{tabular}{|l|l|l|l|}
\hline CAUSE & CONSEQUENCE & SAFEGUARDS & ACTION \\
\hline General Remark & & $\begin{array}{l}{[1] \text { Instrument Air }} \\
\text { system should be } \\
\text { provided to provide } \\
\text { overpressure in slip ring } \\
\text { (Ex-rating); } \\
{[2] \text { The design should }} \\
\text { be re-evaluated when } \\
\text { Instrument Air is } \\
\text { provided. ESDV's could } \\
\text { operate on air, } \\
\text { Emergency Power might } \\
\text { be available as a } \\
\text { consequence of the } \\
\text { presence of a diesel } \\
\text { generator etc. }\end{array}$ \\
\\
ACTION NO: 5 ASSIGNED TO: [1] FKRI [2] FKRI REF: [1] \\
\end{tabular}


ITEM: Maintenance Hazards

\begin{tabular}{|l|l|l|l|}
\hline CAUSE & CONSEQUENCE & SAFEGUARDS & ACTION \\
\hline Access to thruster. & $\begin{array}{l}\text { Thruster change-out } \\
\text { could be difficult to } \\
\text { achieve }\end{array}$ & $\begin{array}{l}\text { Two hatches are provided } \\
\text { on top of the buoyancy } \\
\text { tank. The buoyancy tank } \\
\text { can be de-ballasted to get } \\
\text { the hatches above the } \\
\text { waterline. }\end{array}$ & $\begin{array}{l}\text { In the project phase, a } \\
\text { detailed maintenance } \\
\text { philosophy should be } \\
\text { provided, and } \\
\text { access/egress to } \\
\text { different parts of the BIG } \\
\text { SWEEP should be } \\
\text { assessed in that light. }\end{array}$ \\
\hline
\end{tabular}

ACTION NO: 6 ASSIGNED TO: HVDB

\begin{tabular}{l|l|l|l|}
$\begin{array}{l}\text { Isolation philosophy not } \\
\text { available }\end{array}$ & $\begin{array}{l}\text { Possible difficulties in } \\
\text { achieving proper isolation } \\
\text { of various piping } \\
\text { subsystems. }\end{array}$ & $\begin{array}{l}\text { In the project phase, an } \\
\text { isolation philosophy } \\
\text { should be provided and } \\
\text { the valve configuration } \\
\text { should be checked in } \\
\text { this light. }\end{array}$
\end{tabular}

ACTION NO: 7 ASSIGNED TO: HVDB

General Remark

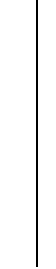

ACTION NO: 8 ASSIGNED TO: HVDB
Consider placing heat exchanger close to hose crane, w.r.t. mechanical handling. To be assessed in project phase.

TABLE NO: 5

DOCUMENT REF:

REVISION:

DOCUMENT TITLE:

ITEM: Construction

\begin{tabular}{|l|l|l|l|}
\hline CAUSE & CONSEQUENCE & SAFEGUARDS & ACTION \\
\hline $\begin{array}{l}\text { Not relevant in this stage } \\
\text { of design. }\end{array}$ & & & \\
\hline
\end{tabular}

TABLE NO: 6

DOCUMENT REF:

REVISION:

DOCUMENT TITLE:

ITEM: Health Hazards

\begin{tabular}{|l|l|l|l|}
\hline CAUSE & CONSEQUENCE & SAFEGUARDS & ACTION \\
\hline Not relevant in this stage. & & & \\
\hline
\end{tabular}


TABLE NO: 7

DOCUMENT REF:

REVISION:

DOCUMENT TITLE:

ITEM: Project implementation issues

\begin{tabular}{|l|l|l|l|}
\hline CAUSE & CONSEQUENCE & SAFEGUARDS & ACTION \\
\hline Not relevant in this stage. & & & \\
\hline
\end{tabular}

TABLE NO: 8

DOCUMENT REF:

REVISION:

DOCUMENT TITLE:

ITEM: Natural and Environmental Hazards

\begin{tabular}{|l|l|l|l|}
\hline CAUSE & CONSEQUENCE & SAFEGUARDS & ACTION \\
\hline Earthquake & $\begin{array}{l}\text { Possible damage to } \\
\text { installation. }\end{array}$ & $\begin{array}{l}\text { Potential for earthquakes } \\
\text { assessed. No potential in } \\
\text { the area. }\end{array}$ & \\
\hline Lightning & $\begin{array}{l}\text { Possible damage to } \\
\text { installation }\end{array}$ & $\begin{array}{l}\text { Provide lightning rod at } \\
\text { highest point. }\end{array}$ \\
\hline
\end{tabular}

TABLE NO: 9

DOCUMENT REF:

REVISION:

DOCUMENT TITLE:

ITEM: Created Hazards

CAUSE

A lot of ship movements

in the area

CONSEQUENCE

SAFEGUARDS

ACTION

for collision/ship impact.

Provide adequate

collision avoidance provisions f.e. RACON transponder, navigation lights etc. To be further studied and identified in project phase. 


\section{Appendix C - HAZID Action and Response Sheets}


HAZID STUDY ACTION AND RESPONSE SHEET

\begin{tabular}{l|l|l|}
\hline \multicolumn{2}{|l|}{ ACTION ON: HVDB } & RESPOND BY: T.B.A. \\
\hline ACTION NO: 1 & MEETING DATES: 13 July 2004 & \\
\hline DOCUMENT REF: & \\
TITLE:
\end{tabular}

ITEM:

(HAZID Table 1)

Fire and Explosion Hazards

CAUSE:

Leakage of LNG in swivel area in water

CONSEQUENCE:

Possible Rapid Phase Transition, brittle fracture of steel.

SAFEGUARDS:

None

ACTION:

Consider additional measures to prevent contact between LNG and water, f.e. no flanged connections over swivel area, closing of swivel tower with a roof or other measures. To be decided in project phase.

RESPONSE: (Action 1) DATED:

\section{SIGNED:}

ENTER YOUR RESPONSE IN THE BOX ABOVE, THEN SIGN AND RETURN TO:

RVVE

NOTES (for use of HAZID Secretary only) 
HAZID STUDY ACTION AND RESPONSE SHEET

\begin{tabular}{|c|c|c|}
\hline \multicolumn{2}{|c|}{ ACTION ON: [1] BOVE [2] HVDB } & RESPOND BY: T.B.A. \\
\hline ACTION NO: 2 & MEETING DATES: 13 July 2004 & \\
\hline
\end{tabular}

ITEM:

(HAZID Table 1)

Fire and Explosion Hazards

CAUSE:

Gas release or oxygen deficiency in main column

CONSEQUENCE:

Possible asphyxiation of personnel entering the chamber. Possible presence of explosive mixture

SAFEGUARDS:

None

ACTION:

YOUR REFERENCE BELOW: [1]

[1] Provide ventilation of column internals;

[2] Confined space entry, to be covered by procedure in project phase

RESPONSE TO REFERENCE [1]: (Action 2)

DATED:

SIGNED:

ENTER YOUR RESPONSE IN THE BOX ABOVE, THEN SIGN AND RETURN TO:

RVVE

NOTES (for use of HAZID Secretary only) 
HAZID STUDY ACTION AND RESPONSE SHEET

\begin{tabular}{|c|c|c|}
\hline \multicolumn{2}{|c|}{ ACTION ON: BOVE } & RESPOND BY: T.B.A. \\
\hline ACTION NO: 3 & MEETING DATES: 13 July 2004 & \\
\hline \multicolumn{3}{|c|}{$\begin{array}{l}\text { DOCUMENT REF: } \\
\text { TITLE: }\end{array}$} \\
\hline \multicolumn{2}{|c|}{$\begin{array}{l}\text { ITEM: } \\
\text { Fire and Explosion Hazards }\end{array}$} & (HAZID Table 1) \\
\hline \multicolumn{3}{|c|}{$\begin{array}{l}\text { CAUSE: } \\
\text { Confirmed Fire Detection }\end{array}$} \\
\hline \multicolumn{3}{|c|}{$\begin{array}{l}\text { CONSEQUENCE: } \\
\text { Possible heat radiation on tanker }\end{array}$} \\
\hline \multicolumn{3}{|l|}{$\begin{array}{l}\text { SAFEGUARDS: } \\
\text { None }\end{array}$} \\
\hline
\end{tabular}

RESPONSE: (Action 3)

DATED:

SIGNED:

ENTER YOUR RESPONSE IN THE BOX ABOVE, THEN SIGN AND RETURN TO:

RVVE

NOTES (for use of HAZID Secretary only) 
HAZID STUDY ACTION AND RESPONSE SHEET

ACTION ON: [1] HVDB; [2] HVDB

RESPOND BY: T.B.A.

\begin{tabular}{l|l} 
ACTION NO: 4 & MEETING DATES: 13 July 2004
\end{tabular}

DOCUMENT REF:

TITLE:

ITEM:

Fire and Explosion Hazards

(HAZID Table 1)

CAUSE:

Possible ignition of gas during quick disconnect

CONSEQUENCE:

Explosion/Flashfire

SAFEGUARDS:

None

ACTION:

YOUR REFERENCE BELOW: [1]

[1] It should be assessed whether the materials of the quick disconnect system should be spark free (project phase).

[2] The loading hoses should be antistatic.

RESPONSE TO REFERENCE [1]: (Action 4) DATED:

SIGNED:

ENTER YOUR RESPONSE IN THE BOX ABOVE, THEN SIGN AND RETURN TO:

RVVE

NOTES (for use of HAZID Secretary only) 
HAZID STUDY ACTION AND RESPONSE SHEET

\begin{tabular}{|c|c|c|}
\hline \multicolumn{2}{|c|}{ ACTION ON: [1] FKRI [2] FKRI } & RESPOND BY: T.B.A. \\
\hline ACTION NO: 5 & \multicolumn{2}{|l|}{ MEETING DATES: 13 July 2004} \\
\hline \multicolumn{3}{|c|}{$\begin{array}{l}\text { DOCUMENT REF: } \\
\text { TITLE: }\end{array}$} \\
\hline \multicolumn{2}{|l|}{$\begin{array}{l}\text { ITEM: } \\
\text { Utility Systems }\end{array}$} & (HAZID Table 3) \\
\hline \multicolumn{3}{|l|}{$\begin{array}{l}\text { CAUSE: } \\
\text { General Remark }\end{array}$} \\
\hline \multicolumn{3}{|l|}{$\begin{array}{l}\text { SAFEGUARDS: } \\
\text { None }\end{array}$} \\
\hline \multicolumn{3}{|c|}{$\begin{array}{l}\text { ACTION: YOUR REFERENCE BELOW: } \\
\text { [1] Instrument Air system should be provided to provide overpressure in slip ring(Ex-rating); } \\
\text { [2] The design should be re-evaluated when Instrument Air is provided. ESDV's could operate on air, } \\
\text { Emergency Power might be available as a consequence of the presence of a diesel generator etc. }\end{array}$} \\
\hline \multicolumn{2}{|c|}{ RESPONSE TO REFERENCE [1]: (Action 5) } & DATED: \\
\hline \multicolumn{3}{|c|}{ SIGNED: } \\
\hline \multicolumn{3}{|c|}{$\begin{array}{l}\text { ENTER YOUR RESPONSE IN THE BOX ABOVE, THEN SIGN AND RETURN TO: } \\
\text { RVVE }\end{array}$} \\
\hline \multicolumn{3}{|c|}{ NOTES (for use of HAZID Secretary only) } \\
\hline
\end{tabular}


HAZID STUDY ACTION AND RESPONSE SHEET

\begin{tabular}{|l|l|}
\hline ACTION ON: HVDB & RESPOND BY: T.B.A. \\
\hline ACTION NO: 6 & MEETING DATES: 13 July 2004 \\
\hline DOCUMENT REF: & \\
TITLE: &
\end{tabular}

ITEM:

(HAZID Table 4)

Maintenance Hazards

CAUSE:

Access to thruster.

CONSEQUENCE:

Thruster change-out could be difficult to achieve

SAFEGUARDS:

Two hatches are provided on top of the buoyancytank. The buoyancy tank can be de-ballasted to get the hatches above the waterline.

ACTION:

In the project phase, a detailed maintenance philosophy should be provided, and access/egress to different parts of the BIG SWEEP should be assessed in that light.

RESPONSE: (Action 6) DATED:

\section{SIGNED:}

ENTER YOUR RESPONSE IN THE BOX ABOVE, THEN SIGN AND RETURN TO:

RVVE

NOTES (for use of HAZID Secretary only) 
HAZID STUDY ACTION AND RESPONSE SHEET

\begin{tabular}{l|l|l|}
\hline \multicolumn{2}{|l|}{ ACTION ON: HVDB } & RESPOND BY: T.B.A. \\
\hline ACTION NO: 7 & MEETING DATES: 13 July 2004 & \\
\hline DOCUMENT REF: & \\
TITLE: &
\end{tabular}

ITEM:

(HAZID Table 4)

Maintenance Hazards

CAUSE:

Isolation philosophy not available

CONSEQUENCE:

Possible difficulties in achieving proper isolation of various piping subsystems.

SAFEGUARDS:

None

ACTION:

In the project phase, an isolation philosophy should be provided and the valve configuration should be checked in this light.

RESPONSE: (Action 7)

DATED:

SIGNED:

ENTER YOUR RESPONSE IN THE BOX ABOVE, THEN SIGN AND RETURN TO:

RVVE

NOTES (for use of HAZID Secretary only) 
HAZID STUDY ACTION AND RESPONSE SHEET

\begin{tabular}{|c|c|c|}
\hline \multicolumn{2}{|c|}{ ACTION ON: HVDB } & RESPOND BY: T.B.A. \\
\hline ACTION NO: 8 & \multicolumn{2}{|l|}{ MEETING DATES: 13 July 2004} \\
\hline \multicolumn{3}{|c|}{$\begin{array}{l}\text { DOCUMENT REF: } \\
\text { TITLE: }\end{array}$} \\
\hline \multicolumn{2}{|c|}{$\begin{array}{l}\text { ITEM: } \\
\text { Maintenance Hazards }\end{array}$} & (HAZID Table 4) \\
\hline \multicolumn{3}{|l|}{$\begin{array}{l}\text { CAUSE: } \\
\text { General Remark }\end{array}$} \\
\hline \multicolumn{3}{|l|}{$\begin{array}{l}\text { SAFEGUARDS: } \\
\text { None }\end{array}$} \\
\hline \multicolumn{3}{|c|}{$\begin{array}{l}\text { ACTION: } \\
\text { Consider placing heat exchanger close to hose crane, w.r.t. mechanical handling. To be assessed in } \\
\text { project phase. }\end{array}$} \\
\hline \multicolumn{2}{|c|}{ RESPONSE: (Action 8) } & DATED: \\
\hline \multicolumn{3}{|r|}{ SIGNED: } \\
\hline \multicolumn{3}{|c|}{$\begin{array}{l}\text { ENTER YOUR RESPONSE IN THE BOX ABOVE, THEN SIGN AND RETURN TO: } \\
\text { RVVE }\end{array}$} \\
\hline \multicolumn{3}{|c|}{ NOTES (for use of HAZID Secretary only) } \\
\hline
\end{tabular}


HAZID STUDY ACTION AND RESPONSE SHEET

\begin{tabular}{|c|c|c|}
\hline \multicolumn{2}{|c|}{ ACTION ON: HVDB } & RESPOND BY: T.B.A. \\
\hline ACTION NO: 9 & \multicolumn{2}{|l|}{ MEETING DATES: 13 July 2004} \\
\hline \multicolumn{3}{|l|}{$\begin{array}{l}\text { DOCUMENT REF: } \\
\text { TITLE: }\end{array}$} \\
\hline \multicolumn{2}{|l|}{$\begin{array}{l}\text { ITEM: } \\
\text { Created Hazards }\end{array}$} & (HAZID Table 9) \\
\hline \multicolumn{3}{|c|}{$\begin{array}{l}\text { CAUSE: } \\
\text { A lot of ship movements in the area }\end{array}$} \\
\hline \multicolumn{3}{|c|}{$\begin{array}{l}\text { CONSEQUENCE: } \\
\text { Relatively high potential for collision/ship impact. }\end{array}$} \\
\hline \multicolumn{3}{|l|}{$\begin{array}{l}\text { SAFEGUARDS: } \\
\text { None }\end{array}$} \\
\hline \multicolumn{3}{|c|}{$\begin{array}{l}\text { ACTION: } \\
\text { Provide adequate collision avoidance provisions f.e. RACON transponder, navigation lights etc. To be } \\
\text { further studied and identified in project phase. }\end{array}$} \\
\hline \multicolumn{2}{|c|}{ RESPONSE: (Action 9) } & DATED: \\
\hline \multicolumn{3}{|r|}{ SIGNED: } \\
\hline \multicolumn{3}{|c|}{$\begin{array}{l}\text { ENTER YOUR RESPONSE IN THE BOX ABOVE, THEN SIGN AND RETURN TO: } \\
\text { RVVE }\end{array}$} \\
\hline NOTES (for use o & AZID Secretary only) & \\
\hline
\end{tabular}




\section{Appendix D - HAZID Guidewords}




\begin{tabular}{|c|c|c|}
\hline \multicolumn{3}{|c|}{ Section A: Facility Hazards } \\
\hline Category & Guide Word & $\begin{array}{c}\text { Expanders } \\
\text { (Examples of guide word application - not } \\
\text { exclusive) }\end{array}$ \\
\hline Layout & $\begin{array}{l}\text { Fire and Explosion } \\
\text { hazards } \\
\text { Process hazards } \\
\text { Utility systems } \\
\text { Maintenance hazards } \\
\text { Construction/existing } \\
\text { facilities }\end{array}$ & \\
\hline \multirow[t]{6}{*}{$\begin{array}{l}\text { Fire and } \\
\text { Explosion } \\
\text { Hazards }\end{array}$} & Stored Flammables & $\begin{array}{l}\text { Improper storage, operator error (release), defect, } \\
\text { impact, fire (mitigation measures include: substitute } \\
\text { non flammable, minimise and separate inventory), gas } \\
\text { based fire, flight systems, hot material release (solid, } \\
\text { liquid, gas) }\end{array}$ \\
\hline & Sources of Ignition & $\begin{array}{l}\text { Electricity, flares, sparks, hot surfaces (mitigation } \\
\text { measures include: identify, remove, separate), hot } \\
\text { work }\end{array}$ \\
\hline & Equipment Layout & $\begin{array}{l}\text { Confinement, escalation following release of explosive } \\
\text { or flammable fluid (operator error, defect, impact } \\
\text { process control failure, corrosion), module (cellulosic) } \\
\text { layout/proximity, engine room, orientation of } \\
\text { equipment, predominant wind direction (mitigation } \\
\text { measures include: reduce degree of confinement, } \\
\text { spacing based on consequence assessment, escalation } \\
\text { barriers) }\end{array}$ \\
\hline & $\begin{array}{l}\text { Toxic fumes and smoke } \\
\text { generation/accumulation }\end{array}$ & $\begin{array}{l}\text { Hydrocarbon release, methanol release, corrosive } \\
\text { chemicals, and lighting. }\end{array}$ \\
\hline & $\begin{array}{l}\text { Fire Protection and } \\
\text { Response }\end{array}$ & $\begin{array}{l}\text { Active/passive insulation, fire/gas detection, } \\
\text { blowdown/relief system philosophy, fire-fighting } \\
\text { facilities }\end{array}$ \\
\hline & Operator Protection & $\begin{array}{l}\text { Means of escape, PPE, communications, emergency } \\
\text { response, plant evacuation }\end{array}$ \\
\hline \multirow[t]{3}{*}{$\begin{array}{l}\text { Process } \\
\text { Hazards }\end{array}$} & Hazardous Materials & $\begin{array}{l}\text { Well fluid (storage), processing equipment, natural } \\
\text { gas, helifuel, steam, bottled gas (e.g. acetylene, } \\
\text { oxygen, halon, } \mathrm{CO}_{2} \text {, nitrogen propane), asbestos, } \\
\text { processed gas, crude oil, condensate, corrosive } \\
\text { chemicals, nitrogen, glycol, methanol, diesel, heavy } \\
\text { fuel oil, high temperature materials, refrigerants, } \\
\text { cryogenic materials. }\end{array}$ \\
\hline & Inventory & $\begin{array}{l}\text { Excess hazardous material (mitigation measures } \\
\text { include: minimise hazardous inventory, alternate } \\
\text { processes and utility systems) }\end{array}$ \\
\hline & Release of inventory & $\begin{array}{l}\text { Excessive process stress, impact (penetration by } \\
\text { foreign object), process control failure, structural } \\
\text { failure, erosion or corrosion (mitigation measures } \\
\text { include recognise and minimise process hazards } \\
\text { during design, inherently safe plant, containment and } \\
\text { recovery measures), offloading operations, production } \\
\text { slow out. }\end{array}$ \\
\hline
\end{tabular}




\begin{tabular}{|c|c|c|}
\hline \multicolumn{3}{|c|}{ Section A: Facility Hazards } \\
\hline \multirow[t]{6}{*}{ Category } & Guide Word & $\begin{array}{c}\text { Expanders } \\
\text { (Examples of guide word application - not } \\
\text { exclusive) }\end{array}$ \\
\hline & Over Pressure & $\begin{array}{l}\text { Offsite sources, process blockage, thermal expansion, } \\
\text { connection of process to utility systems, chemical } \\
\text { reaction }\end{array}$ \\
\hline & Over/under Temperature & $\begin{array}{l}\text { Atmospheric conditions, blowdown, fire, hot surfaces, } \\
\text { chemical reaction }\end{array}$ \\
\hline & Excess/zero Level & $\begin{array}{l}\text { Overfill storage tanks, loss of function in separation } \\
\text { vessels, blow by to downstream vessels }\end{array}$ \\
\hline & $\begin{array}{l}\text { Wrong } \\
\text { Composition/Phase }\end{array}$ & $\begin{array}{l}\text { Offsite contamination, failure of separation process, } \\
\text { build-up of wrong phase (sand, hydrates, etc), toxic } \\
\text { substances }\end{array}$ \\
\hline & Diving Hazards & $\begin{array}{l}\text { Operations control, interface of emergency system, } \\
\text { failure of life support systems, sub surface difficulties, } \\
\text { loss of diving vessel, entrapment. }\end{array}$ \\
\hline \multirow[t]{2}{*}{$\begin{array}{l}\text { Utility } \\
\text { Systems }\end{array}$} & $\begin{array}{l}\text { Firewater Systems } \\
\text { Fuel Gas } \\
\text { Heating Medium } \\
\text { Diesel Fuel } \\
\text { Power Supply } \\
\text { Steam } \\
\text { Drains }\end{array}$ & \\
\hline & $\begin{array}{l}\text { Inert Gas } \\
\text { Waste Storage and } \\
\text { Treatment } \\
\text { Chemical/fuel Storage } \\
\text { Potable Water } \\
\text { Sewerage }\end{array}$ & \\
\hline $\begin{array}{l}\text { Maintenance } \\
\text { Hazards }\end{array}$ & $\begin{array}{l}\text { Access Requirements } \\
\text { Override Necessity } \\
\text { Bypasses Required } \\
\text { Commonality of } \\
\text { Equipment } \\
\text { Heavy Lifting } \\
\text { Requirements } \\
\text { Transport }\end{array}$ & $\begin{array}{l}\text { Processing facilities, engine room, pump rooms, } \\
\text { confined sphere-working, modifications, non ionising } \\
\text { radiation, slips, trips and falls, men over board, } \\
\text { radioactive material, and toxic substances. }\end{array}$ \\
\hline $\begin{array}{l}\text { Construction/ } \\
\text { Existing } \\
\text { Facilities }\end{array}$ & $\begin{array}{l}\text { Tie-ins (shutdown } \\
\text { requirements) } \\
\text { Concurrent Operations } \\
\text { Reuse of Material } \\
\text { Corrosion } \\
\text { Common Equipment } \\
\text { Capacity } \\
\text { Interface - } \\
\text { Shutdown/blowdown/ } \\
\text { ESD } \\
\text { Skid Dimensions (weight } \\
\text { handling/equipment } \\
\text { (congestion) }\end{array}$ & \\
\hline
\end{tabular}




\begin{tabular}{|c|c|c|}
\hline Section A: Facility Hazards \\
\hline Category & \multicolumn{1}{|c|}{ Guide Word } & $\begin{array}{c}\text { Expanders } \\
\text { (Examples of guide word application - not } \\
\text { exclusive) }\end{array}$ \\
$\begin{array}{l}\text { Soil Contamination } \\
\text { (existing facilities) } \\
\text { Mobilisation/ } \\
\text { demobilisation }\end{array}$ & \\
\hline
\end{tabular}

\begin{tabular}{|c|c|c|}
\hline \multicolumn{3}{|c|}{ Section B: Health Hazards } \\
\hline Category & Guide Word & $\begin{array}{c}\text { Expanders } \\
\text { (Examples of guide word application - not } \\
\text { exclusive) }\end{array}$ \\
\hline \multirow[t]{8}{*}{$\begin{array}{l}\text { Health } \\
\text { Hazards }\end{array}$} & Disease Hazards & $\begin{array}{l}\text { Endemic diseases, infection, malarial mosquitoes, } \\
\text { hygiene - personal and/or catering, contaminated } \\
\text { water or foodstuff, social, e.g. AIDS, VD, etc stagnant } \\
\text { water, poor living conditions }\end{array}$ \\
\hline & Asphyxiation hazards & $\begin{array}{l}\text { Asphyxiating atmospheres, failure to use appropriate } \\
\text { PPE, vessel entry, working in confined spaces, smoke, } \\
\text { exhaust }\end{array}$ \\
\hline & Carcinogenic & Chemicals in use \\
\hline & Toxic & $\begin{array}{l}\text { Hazardous atmosphere, asphyxiating atmosphere, } \\
\text { chemicals in use }\end{array}$ \\
\hline & Physical & $\begin{array}{l}\text { Noise, radiation (ionising, e.g. radioactive scale or } \\
\text { non-ionising, e.g. flares, UV, sunlight), ergonomics }\end{array}$ \\
\hline & Mental & Shift patterns \\
\hline & Working Hazards & $\begin{array}{l}\text { Diving, working in water, working at heights, } \\
\text { hazardous equipment, hazardous surfaces, electricity }\end{array}$ \\
\hline & Transport & $\begin{array}{l}\text { Excessive journeys, extreme weather, quality of roads } \\
\text { (mitigation measures include: effective journey } \\
\text { management) }\end{array}$ \\
\hline
\end{tabular}

\begin{tabular}{|c|c|c|}
\hline \multicolumn{3}{|c|}{ Section C: Project Implementation Issues } \\
\hline Category & Guide Word & $\begin{array}{c}\text { Expanders } \\
\text { (Examples of guide word application - not } \\
\text { exclusive) }\end{array}$ \\
\hline $\begin{array}{l}\text { Contracting } \\
\text { Strategy }\end{array}$ & $\begin{array}{l}\text { Prevailing influence } \\
\text { Legislation } \\
\text { External Standards } \\
\text { External Environmental } \\
\text { Constraints }\end{array}$ & $\begin{array}{l}\text { Stability and contractual conditions, contractor } \\
\text { selection constraints } \\
\text { Governmental contracting requirements } \\
\text { Additional engineering and construction standards } \\
\text { Governmental environmental requirements }\end{array}$ \\
\hline $\begin{array}{l}\text { Hazards } \\
\text { Recognition } \\
\text { and } \\
\text { Management }\end{array}$ & $\begin{array}{l}\text { Hazard Studies } \\
\text { HSE Case } \\
\text { Hazards and Effects } \\
\text { Register } \\
\text { Project Controls }\end{array}$ & $\begin{array}{l}\text { HAZOP, FEHA, Explosion Study, QRA, EIA, etc } \\
\text { Quality assurance (change control, interdepartmental } \\
\text { involvement and interfaces) }\end{array}$ \\
\hline Contingency & $\begin{array}{l}\text { Geographical } \\
\text { Infrastructure }\end{array}$ & Plant location, plant layout \\
\hline
\end{tabular}




\begin{tabular}{|c|c|c|}
\hline \multicolumn{3}{|c|}{ Section C: Project Implementation Issues } \\
\hline Category & Guide Word & $\begin{array}{c}\text { Expanders } \\
\text { (Examples of guide word application - not } \\
\text { exclusive) }\end{array}$ \\
\hline & & up support, security/military support, evacuation \\
\hline Competency & $\begin{array}{l}\text { Level of Indigenous } \\
\text { Training } \\
\text { Training Requirements } \\
\text { Level of Technology }\end{array}$ & Quality of local workforce and contractors \\
\hline $\begin{array}{l}\text { Control } \\
\text { Methods/ }\end{array}$ & $\begin{array}{l}\text { Manning/operations } \\
\text { Philosophy }\end{array}$ & $\begin{array}{l}\text { Effect on design, effect on locality (Manned, } \\
\text { unmanned, visited) }\end{array}$ \\
\hline Philosophy & $\begin{array}{l}\text { Operations Concept } \\
\text { Maintenance Philosophy } \\
\text { Control Philosophy } \\
\text { Manning Levels } \\
\text { Emergency Response } \\
\text { Concurrent Operations } \\
\text { Start-up Shutdown }\end{array}$ & $\begin{array}{l}1 \text { train, } x \text {-trains, simplification } \\
\text { Plant/train/equipment item, heavy lifting, access, } \\
\text { override, bypass, commonality of equipment, transport } \\
\text { Appropriate technology, (DCS/local panels) } \\
\text { Accommodation, travel, support requirements. } \\
\text { Consistency with operations and maintenance, etc } \\
\text { philosophies } \\
\text { Isolation, ESD philosophy, blowdown, flaring } \\
\text { requirements } \\
\text { Production, maintenance requirements } \\
\text { Modular or plant wide }\end{array}$ \\
\hline
\end{tabular}

\begin{tabular}{|c|c|c|}
\hline \multicolumn{3}{|c|}{ Section D: External and Environmental hazards } \\
\hline Category & Prompt word & $\begin{array}{c}\text { Expanders } \\
\text { (Examples of guide word application - not } \\
\text { exclusive) }\end{array}$ \\
\hline $\begin{array}{l}\text { Natural and } \\
\text { Environmenta } \\
\text { I Hazards }\end{array}$ & $\begin{array}{l}\text { Climate Extremes } \\
\text { Lightning } \\
\text { Erosion } \\
\text { Seismic Effects } \\
\text { Subsidence }\end{array}$ & $\begin{array}{l}\text { Temperature, waves, currents, wind, dust, ice and } \\
\text { snow (also accumulated), blizzards } \\
\text { Moving and dropped objects, rotating objects, } \\
\text { mechanical equipment's. } \\
\text { Operations outside design, fatigue } \\
\text { Ground slide, structural failure } \\
\text { Ground structure, foundations, reservoir depletion }\end{array}$ \\
\hline $\begin{array}{l}\text { Created } \\
\text { (Man-made) } \\
\text { Hazards }\end{array}$ & $\begin{array}{l}\text { Security Hazards } \\
\text { Terrorist Activity } \\
\text { Aircraft impact } \\
\text { Vessel Impact }\end{array}$ & $\begin{array}{l}\text { Internal and external security threats } \\
\text { Riots, civil disturbance, strikes, military action, } \\
\text { political unrest } \\
\text { Visiting helicopters, passing helicopters, passing } \\
\text { fixed wing aircraft. } \\
\text { Loss of station, mooring failure (mooring lines, } \\
\text { anchor, spider, turret snagging of mooring lines). } \\
\text { Loss of stability, loss of hull integrity, loss of control. } \\
\text { Rig tenders, supply vessels, offloading (shuttle) } \\
\text { tanker, standby vessel, lay barges, not-attendant } \\
\text { vessel, support vessel, diving support vessels, } \\
\text { floating installations, crane barges, bulk oil } \\
\text { transports, tugs, material failure. }\end{array}$ \\
\hline Effect of the & $\begin{array}{l}\text { Geographical - } \\
\text { Infrastructure }\end{array}$ & Location, pipeline routing \\
\hline
\end{tabular}




\begin{tabular}{|c|c|c|}
\hline \multicolumn{3}{|c|}{ Section D: External and Environmental hazards } \\
\hline Category & Prompt word & $\begin{array}{c}\text { Expanders } \\
\text { (Examples of guide word application - not } \\
\text { exclusive) }\end{array}$ \\
\hline $\begin{array}{l}\text { Facility on the } \\
\text { Surroundings }\end{array}$ & $\begin{array}{l}\text { Adjacent Area Use } \\
\text { Proximity to Transport } \\
\text { Corridors } \\
\text { Environmental Issues } \\
\text { Social Issues }\end{array}$ & $\begin{array}{l}\text { Fishing grounds, other installations } \\
\text { Shipping lanes, air line routes, etc } \\
\text { Previous exploration/production campaign on } \\
\text { locations, vulnerable fauna and flora, visual impact } \\
\text { Local population, local attitude, social/cultural areas } \\
\text { of significance }\end{array}$ \\
\hline Infrastructure & $\begin{array}{l}\text { Normal Communications } \\
\text { Communications for } \\
\text { Contingency planning } \\
\text { Supply Support }\end{array}$ & $\begin{array}{l}\text { Road links, air links, water links, radio links } \\
\text { Consumables/spares holding }\end{array}$ \\
\hline $\begin{array}{l}\text { Environmenta } \\
\text { I Damage }\end{array}$ & $\begin{array}{l}\text { Continuous Plant } \\
\text { Discharges to Air } \\
\text { Continuous Plant } \\
\text { Discharges to Water } \\
\text { Emergency/upset } \\
\text { Discharges } \\
\text { Contaminated location } \\
\text { Facility Impact } \\
\text { Waste Disposal Options } \\
\text { Timing of Construction }\end{array}$ & $\begin{array}{l}\text { Flares, vents, fugitive emissions, energy efficiency } \\
\text { Target/legislative requirements, drainage facilities, } \\
\text { oil/water separation } \\
\text { Flares, vents, drainage } \\
\text { Previous use or events } \\
\text { Pipeline routing, environmental impact assessment } \\
\text { Seasons, periods of environmental significance }\end{array}$ \\
\hline
\end{tabular}




\section{Report}

\section{What-if Analysis of Process Flow Diagram}

Doc. No. CGI-G-600-RP-0012 Rev. A

Project. No. 1-0282-0 
Doc. No. 1-0282-0/CGI-G-600-RP-0012/ Rev A Report - What-if Analysis of Process Flow Diagram

\section{Revision Status Sheet}

Rev.

Date

A

19-07-2004
Description

Initial Issue
Initiator

RVVE

$\begin{array}{lll} & \text { Date } & \text { Initials } \\ \text { Checked by } & \text { Decenber 2004 } & \text { FLIE }\end{array}$

Aporoved by
December $2004 \quad$ HVDB

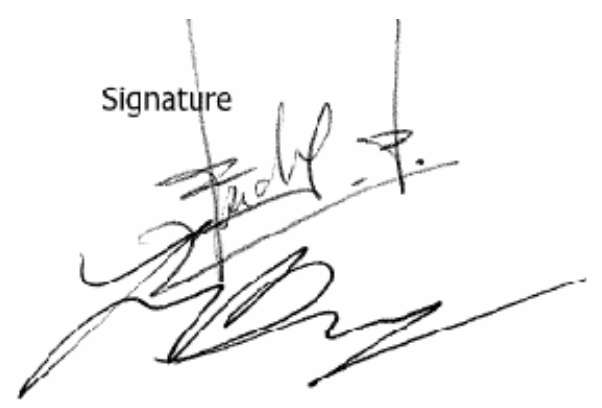




\section{Table of Contents}

1 Introduction . .4

Appendix A -

Agenda .5

Appendix B Review Note. ..7

Appendix C Action and Response Sheets. .13

Appendix D Illustrations. 31 
Doc. No. 1-0282-0/CGI-G-600-RP-0012/ Rev A Report - What-if Analysis of Process Flow Diagram

\section{Introduction}

This report forms a part of the Design Package of the concept design for the Big Sweep LNG Unloading Arm. For the concept design, the first issue of the Process Flow Diagram was reviewed using a What-If brainstorming technique.

In this report, the results of a What If analysis are summarised. In Appendix A, the Agenda is presented. In Appendix B, the Review Notes are presented. In Appendix C, the Action - \& Response Sheets are presented. 
Doc. No. 1-0282-0/CGI-G-600-RP-0012/ Rev A Report - What-if Analysis of Process Flow Diagram

\section{Appendix A - Agenda}


What-If Analysis for Big Sweep

CLIENT: $\quad$ Bluewater Energy Services B.V.

PROJECT NO: $\quad 1-0282-0$

PROJECT: $\quad$ Vermilion

DETAILS: $\quad$ A meeting was held to review the first issue of the Process Flow Diagram BIGS-B-100-DF0002-001/Rev. B for the Big Sweep project. The review was a What If analysis.

MEETING DATES: Thursday 8-7-2004 9:00 - 12:00 hours

CHAIRMAN: Roel van Veen

SECRETARY: Roel van Veen

TEAM MEMBERS: Henk van der Burg - HVDB - Project Engineer;

Frank Krieg - FKRI - Process Engineer;

Rob de Witte - ROWI - Process Engineer (independent);

Benedikt Overtoom - BOVE - Instrumentation Engineer;

Ferry Liem - FLIE - HSE Engineer (independent);

Roel van Veen - RVVE - HSE engineer.

ACTION RESPONSES TO: RVVE

DOCUMENTS STUDIED

Process Flow Diagram Main Process Big Sweep- Doc. No. BIGS-B-100-DF-0002-001/Rev. B dd. 06-JUL-2004 
Doc. No. 1-0282-0/CGI-G-600-RP-0012/ Rev A Report - What-if Analysis of Process Flow Diagram

\section{Appendix B - Review Note}


TABLE NO: 1 DOCUMENT REF: BIGS-B-100-DF-0002-001

DOCUMENT TITLE: PROCESS FLOW DIAGRAM - MAIN PROCESS BIG SWEEP

ITEM: Section 1

Incoming LNG lines from tanker up to and including first 20" ESDV's (after PSV's) and including crossover between lines.

\begin{tabular}{|l|l|l|l|}
\hline CAUSE & CONSEQUENCE & SAFEGUARDS & ACTION \\
\hline General Remark & & $\begin{array}{l}\text { Sloping for main piping } \\
\text { required, to be indicated } \\
\text { on PFD. }\end{array}$ \\
\hline
\end{tabular}

ACTION NO: 1 ASSIGNED TO: FKRI

\begin{tabular}{|c|c|c|c|}
\hline $\begin{array}{l}\text { Temperature High } \\
\text { (section } 1 \text { not precooled } \\
\text { during start of unloading) }\end{array}$ & $\begin{array}{lr}\text { Cooling of piping over } \\
\text { LNG tanker offloading } \\
\text { manifold, } & \text { vapour } \\
\text { generation } & \text { possible, } \\
\text { possible } & \text { pressure } \\
\text { increase. } & \end{array}$ & Details not known. & $\begin{array}{l}\text { It should be verified } \\
\text { whether a procedure is } \\
\text { present on LNG carriers } \\
\text { for this operation, in } \\
\text { order to avoid damage } \\
\text { to tanker. This should } \\
\text { be done in close contact } \\
\text { with a LNG tanker } \\
\text { operator. }\end{array}$ \\
\hline
\end{tabular}

ACTION NO: 2 ASSIGNED TO: HVDB

Temperature high, Temperature stress on

Section 1 not pre-cooled piping materials, possibly during start of offloading. leading to rupture.

[1] Piping materials should be resistant to temperature shock. Temperature gradient in materials to be included in piping calculations. [2] Cooling should be done using a small flow to prevent temperature shock in piping. Procedure to be drafted up in project phase.

ACTION NO: 3 ASSIGNED TO: [1] JWEV [2] HVDB REF: [1] No temperature It cannot be predicted measurement in section when section one has 1. been precooled enough to start unloading.

ACTION NO: 4 ASSIGNED TO: HVDB

\begin{tabular}{|c|c|c|c|}
\hline $\begin{array}{l}\text { Temperature high } \\
\text { section one not precooled } \\
\text { prior to offloading }\end{array}$ & $\begin{array}{l}\text { Possible vapour } \\
\text { generation with pressure } \\
\text { increase. }\end{array}$ & Installed PRV's. & $\begin{array}{l}\text { PRV's to be sized } f \\
\text { vapour generation. } \\
\text { be implemented } \\
\text { project phase. }\end{array}$ \\
\hline
\end{tabular}

ACTION NO: 5 ASSIGNED TO: FKRI

Criteria for transition from precooling to unloading to be defined, and procedure for transition (interface BES/CCR/Tanker operator) to be drafted up in project phase. 
Doc. No. 1-0282-0/CGI-G-600-RP-0012/ Rev A Report - What-if Analysis of Process Flow Diagram

\begin{tabular}{|c|c|c|c|}
\hline \multicolumn{4}{|l|}{$\begin{array}{ll}\text { TABLE NO: } 1 & \text { (continued) } \\
\text { ITEM: Section } 1 & \\
\end{array}$} \\
\hline CAUSE & CONSEQUENCE & SAFEGUARDS & ACTION \\
\hline $\begin{array}{l}\text { Pressure High by } \\
\text { offloading pumps of LNG } \\
\text { carrier }\end{array}$ & Actuation of PRV's & $\begin{array}{l}\text { Selection of Design } \\
\text { Pressure. }\end{array}$ & $\begin{array}{l}\text { The Shut off head of the } \\
\text { offloading pumps and } \\
\text { predicted surge } \\
\text { pressures should be } \\
\text { lower than set points of } \\
\text { PRV's. Set point of } \\
\text { offloading pumps to be } \\
\text { communicated prior to } \\
\text { offloading should be } \\
\text { covered in procedure. } \\
\text { To be resolved in } \\
\text { project phase. }\end{array}$ \\
\hline \multicolumn{4}{|c|}{ ACTION NO: 6 ASSIGNED TO: HVDB } \\
\hline $\begin{array}{l}\text { Pressure surge from } \\
\text { offloading pumps }\end{array}$ & $\begin{array}{l}\text { Possible mechanical } \\
\text { damage }\end{array}$ & & $\begin{array}{llr}\text { Pressure } & \text { Surge } \\
\text { Calculations to } & \text { be } \\
\text { performed based on } \\
\text { offloading r pump } \\
\text { characteristics in project } \\
\text { phase. }\end{array}$ \\
\hline \multicolumn{4}{|c|}{ ACTION NO: 7 ASSIGNED TO: HVDB } \\
\hline Wrong valve configuration & $\begin{array}{l}\text { Open connection to } \\
\text { vapour separator, } \\
\text { overfilling vent pipe, } \\
\text { release of LNG through } \\
\text { vent pipe (depending on } \\
\text { overfill rate). }\end{array}$ & REF: [2] & $\begin{array}{l}\text { [1] LSHH to be installed } \\
\text { on vapour separator } \\
\text { with adequate reliability. } \\
\text { Reliability criterion to be } \\
\text { established in SIL } \\
\text { Classification session in } \\
\text { project phase; } \\
\text { [2] Drain valves to be } \\
\text { interlocked to prevent } \\
\text { wrong valve } \\
\text { configuration. To be } \\
\text { implemented in project } \\
\text { phase. }\end{array}$ \\
\hline & & & \\
\hline
\end{tabular}


Doc. No. 1-0282-0/CGI-G-600-RP-0012/ Rev A Report - What-if Analysis of Process Flow Diagram

TABLE NO: 2 DOCUMENT REF: BIGS-B-100-DF-0002-01

DOCUMENT TITLE: PROCESS FLOW DIAGRAM - MAIN PROCESS BIG SWEEP

REVISION: B

ITEM: Section 2

Offloading lines from 20" ESDV through swivel to subsea pipeline.

\begin{tabular}{|l|l|l|l|}
\hline CAUSE & CONSEQUENCE & SAFEGUARDS & ACTION \\
\hline General remark & & $\begin{array}{l}\text { Remove Note } 2 \text { from } \\
\text { PFD. }\end{array}$
\end{tabular}

ACTION NO: 9 ASSIGNED TO: FKRI

\begin{tabular}{|c|c|c|c|}
\hline Temperature high & No cases identified & & \\
\hline High pressure & $\begin{array}{ll}\begin{array}{l}\text { Possible mechanical } \\
\text { damage }\end{array} & \end{array}$ & $\begin{array}{l}\text { Design Pressure (see } \\
\text { action 6). }\end{array}$ & \\
\hline \multicolumn{4}{|c|}{ ACTION NO: 10 ASSIGNED TO: HVDB } \\
\hline Pressure low & No cases identified & & \\
\hline Wrong valve configuration & $\begin{array}{l}\text { Overfilling of vapour } \\
\text { separator: see previous. }\end{array}$ & & \\
\hline $\begin{array}{l}\text { Leakage over isolation } \\
\text { valves when topsides is } \\
\text { gas freed }\end{array}$ & $\begin{array}{l}\text { Direct contact of topsides } \\
\text { with large LNG inventory } \\
\text { subsea, large and } \\
\text { continued release when } \\
\text { leakage occurring in the } \\
\text { swivel }\end{array}$ & & $\begin{array}{l}\text { [1] MOV's to be TSO; } \\
\text { [2] (post meeting note) } \\
\text { Consider changing } \\
\text { MOV's to ESDV's to } \\
\text { isolate swivel from } \\
\text { subsea pipeline in case } \\
\text { of leakage, following } \\
\text { API 14C paragraph } \\
\text { A.9.3.3. and figure A.9. } \\
\text { Use SIL classification }\end{array}$ \\
\hline
\end{tabular}

ACTION NO: 11 ASSIGNED TO: [1] FKRI [2] FKRI REF: [2]

Rupture in topsides piping Explosive

leading to gas release formation.

and low pressure.

cloud

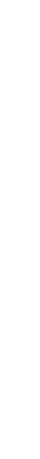

ACTION NO: 12 ASSIGNED TO: [1] HVDB [2] HVDB REF: [1]

[1] Shutdown and draining on confirmed F\&G detection. To be implemented in project phase.

[2] Emergency Disconnect to be activated and LNG tanker to move out of the area of incident. To be studied further in the project phase. 
TABLE NO: 3 DOCUMENT REF: BIG-B-100-DF-0002-001

DOCUMENT TITLE: PROCESS FLOW DIAGRAM- MAIN PROCESS BIG SWEEP

REVISION: B

ITEM: Vapour separator

Off take from 20" main loading line to Heat Exchanger and Vapour Separator including drain pumps and vapour return line

\begin{tabular}{|c|c|c|c|}
\hline CAUSE & CONSEQUENCE & SAFEGUARDS & ACTION \\
\hline $\begin{array}{l}\text { Connection of vapour } \\
\text { return line to offloading } \\
\text { line (wrong line up). Note: } \\
\text { see also action } 8 .\end{array}$ & $\begin{array}{l}\text { No vapour return to ship } \\
\text { possible material damage } \\
\text { on LNG tanker. }\end{array}$ & & $\begin{array}{l}\text { [1] The vapour return } \\
\text { line should be clearly } \\
\text { marked as such to rule } \\
\text { out mistakes. To be } \\
\text { implemented in project } \\
\text { phase \& LNG tanker } \\
\text { operator to be } \\
\text { consulted. } \\
\text { [2] It should be } \\
\text { confirmed by LNG } \\
\text { carrier operator that } \\
\text { LNG carrier has } \\
\text { provisions on board to } \\
\text { cater for no vapour } \\
\text { return scenario }\end{array}$ \\
\hline ACTION NO: 15 ASSIGN & ED TO: [1] HVDB [2] HVDB & REF: [1] & \\
\hline General remark & & & $\begin{array}{l}\text { It should be considered } \\
\text { to route vent pipe along } \\
\text { the crane column. }\end{array}$ \\
\hline
\end{tabular}

ACTION NO: 16 ASSIGNED TO: JWEV

\begin{tabular}{|l|l|l|l|}
\hline Low temperature & $\begin{array}{l}\text { Pump failure during } \\
\text { precooling }\end{array}$ & $\begin{array}{l}\text { Sparing }(2 * 100 \%) \\
\text { recirculation pumps. }\end{array}$ & \\
\hline $\begin{array}{l}\text { High Pressure in vapour } \\
\text { return line }\end{array}$ & $\begin{array}{l}\text { Possible mechanical } \\
\text { damage on LNG carrier }\end{array}$ & $\begin{array}{l}\text { It should be verified that } \\
\text { LNG carrier has PCV to } \\
\text { deal with pressure } \\
\text { fluctuations. To be } \\
\text { confirmed in project } \\
\text { phase. }\end{array}$ \\
\hline
\end{tabular}

ACTION NO: 17 ASSIGNED TO: HVDB

\begin{tabular}{|l|l|l|l|}
\hline $\begin{array}{l}\text { Low level in Vapour } \\
\text { Separator }\end{array}$ & $\begin{array}{l}\text { No adverse } \\
\text { consequences identified. }\end{array}$ & \\
\hline $\begin{array}{l}\text { Piping rupture in Heat } \\
\text { Exchanger }\end{array}$ & $\begin{array}{l}\text { Depending on differences } \\
\text { in operating pressure in } \\
\text { LNG system and } \\
\text { Seawater System release } \\
\text { of LNG to seawater of } \\
\text { release or seawater } \\
\text { system to LNG system, } \\
\text { with its physical } \\
\text { consequences. }\end{array}$ & $\begin{array}{l}\text { Gas detection with } \\
\text { consequent ESD action }\end{array}$ & $\begin{array}{l}\text { Operating pressure of } \\
\text { seawater to be higher or } \\
\text { lower than operating } \\
\text { pressure of LNG } \\
\text { system, depending on } \\
\text { consequences. To be } \\
\text { implemented in project } \\
\text { phase. }\end{array}$ \\
ACTION NO: 18 ASSIGNED TO: HVDB & & \\
\hline
\end{tabular}


Doc. No. 1-0282-0/CGI-G-600-RP-0012/ Rev A Report - What-if Analysis of Process Flow Diagram

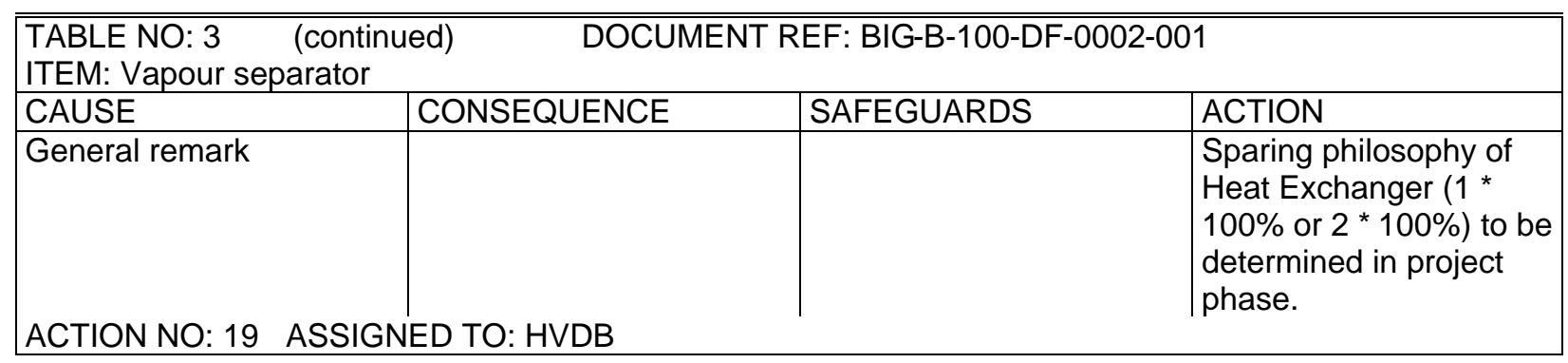


Doc. No. 1-0282-0/CGI-G-600-RP-0012/ Rev A Report - What-if Analysis of Process Flow Diagram

\section{Appendix C - Action and Response Sheets}


HAZOP STUDY ACTION AND RESPONSE SHEET

\begin{tabular}{|l|l|l|}
\hline \multicolumn{2}{|l|}{ ACTION ON: FKRI } & RESPOND BY: 17 JUL 2004 \\
\hline ACTION NO: 1 & MEETING DATES: Thursday 8-7-2004 9:00 - 12:00 hours & REVISION: B \\
\hline $\begin{array}{l}\text { DOCUMENT REF: BIGS-B-100-DF-0002-001 } \\
\text { TITLE: PROCESS FLOW DIAGRAM - MAIN PROCESS BIG SWEEP }\end{array}$ & (Hazop Table 1) \\
\hline $\begin{array}{l}\text { ITEM: } \\
\text { Section 1 }\end{array}$ & \\
\hline $\begin{array}{l}\text { CAUSE: } \\
\text { General Remark }\end{array}$ & \\
\hline $\begin{array}{l}\text { SAFEGUARDS: } \\
\text { None }\end{array}$ & \\
\hline $\begin{array}{l}\text { ACTION: } \\
\text { Sloping for main piping required, to be indicated on PFD. }\end{array}$ & DATED: \\
\hline $\begin{array}{l}\text { RESPONSE: } \\
\text { Corrective action is incorporated on the formal issue of Rev. B of the PFD. }\end{array}$ \\
\\
(*TTAF*)Transferred to Microsoft Word (12 JUL 2004) \\
\hline NOTES (for use of Hazop Secretary only)
\end{tabular}


HAZOP STUDY ACTION AND RESPONSE SHEET

\begin{tabular}{|l|l|l|}
\hline \multicolumn{2}{|l|}{ ACTION ON: HVDB } & RESPOND BY: T.B.A. \\
\hline ACTION NO: 2 & MEETING DATES: Thursday 8-7-2004 9:00 - 12:00 hours & REVISION: B \\
\hline DOCUMENT REF: BIGS-B-100-DF-0002-001 & (Hazop Table 1) \\
TITLE: PROCESS FLOW DIAGRAM - MAIN PROCESS BIG SWEEP & \\
\hline $\begin{array}{l}\text { ITEM: } \\
\text { Section } 1\end{array}$ & \\
\hline $\begin{array}{l}\text { CAUSE: } \\
\text { Temperature High (section 1 not precooled during start of unloading) }\end{array}$ & \\
\hline $\begin{array}{l}\text { CONSEQUENCE: } \\
\text { Cooling of piping over LNG tanker offloading manifold, vapour generation possible, possible pressure } \\
\text { increase. }\end{array}$ \\
\hline $\begin{array}{l}\text { SAFEGUARDS: } \\
\text { Details not known. }\end{array}$ \\
\hline $\begin{array}{l}\text { ACTION: } \\
\text { It should be verified whether a procedure is present on LNG carriers for this operation, in order to avoid } \\
\text { damage to tanker. This should be done in close contact with a LNG tanker operator. }\end{array}$ \\
\hline \hline RESPONSE: (Action 2) \\
\hline \\
\hline $\begin{array}{l}\text { ENTER YOUR RESPONSE IN THE BOXABOVE, THEN SIGN AND RETURN TO: } \\
\text { RVVE }\end{array}$ \\
\hline NOTES (for use of Hazop Secretary only) \\
\hline
\end{tabular}


HAZOP STUDY ACTION AND RESPONSE SHEET

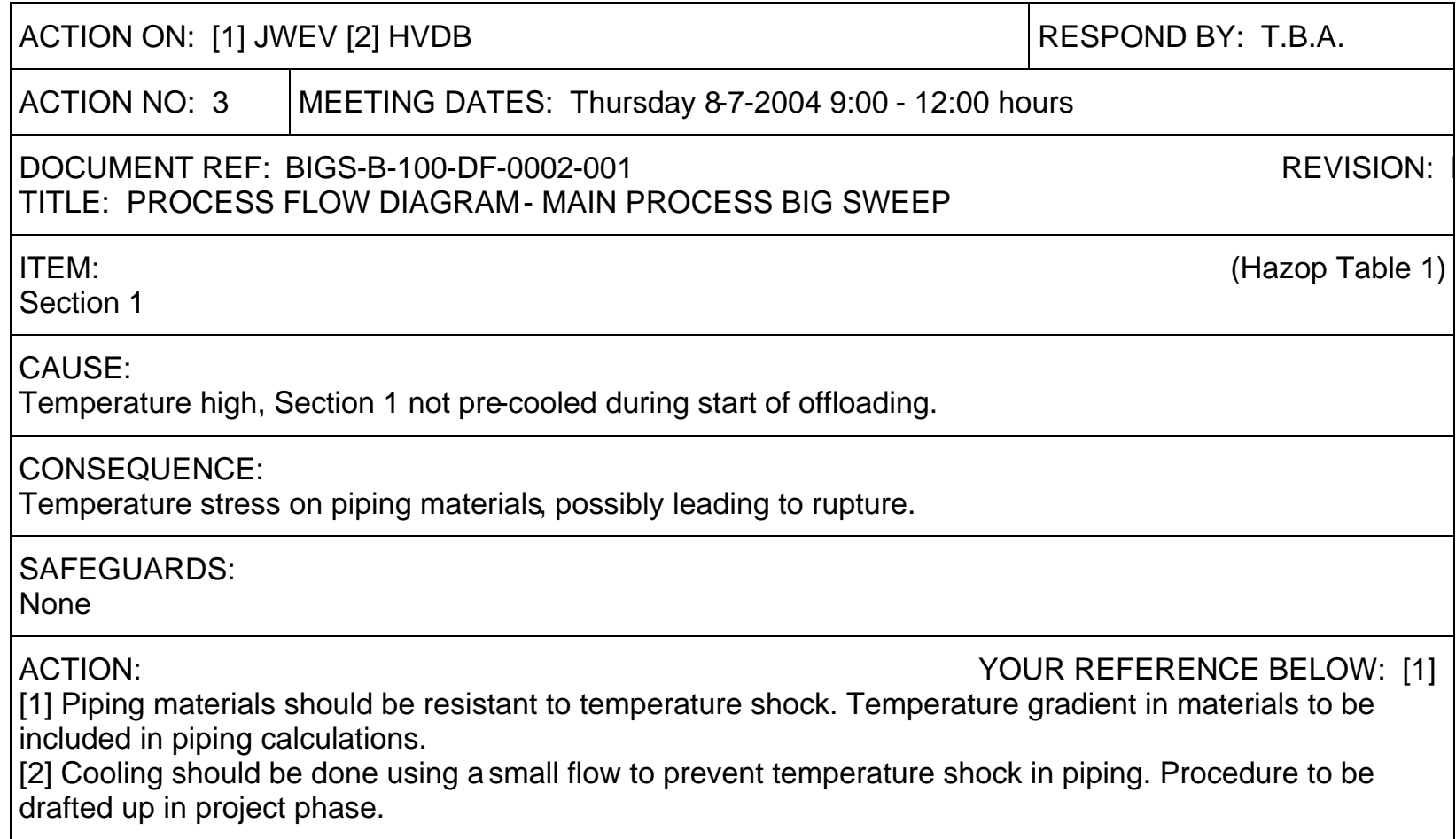

\begin{tabular}{|l|}
\hline \hline RESPONSE TO REFERENCE [1]: (Action 3) DATED: \\
\hline \\
\hline SIGNED: \\
\hline $\begin{array}{l}\text { ENTER YOUR RESPONSE IN THE BOX ABOVE, THEN SIGN AND RETURN TO: } \\
\text { RVVE }\end{array}$ \\
\hline NOTES (for use of Hazop Secretary only) \\
\hline
\end{tabular}


HAZOP STUDY ACTION AND RESPONSE SHEET

\begin{tabular}{|l|l|l|}
\hline \multicolumn{2}{|l|}{ ACTION ON: HVDB } & RESPOND BY: T.B.A. \\
\hline ACTION NO: 4 & MEETING DATES: Thursday 8-7-2004 9:00 - 12:00 hours & \\
\hline $\begin{array}{l}\text { DOCUMENT REF: BIGS-B-100-DF-0002-001 } \\
\text { TITLE: PROCESS FLOW DIAGRAM- MAIN PROCESS BIG SWEEP }\end{array}$ & REVISION: B \\
\hline $\begin{array}{l}\text { ITEM: } \\
\text { Section } 1\end{array}$ & (Hazop Table 1) \\
\hline
\end{tabular}

CAUSE:

No temperature measurement in section 1.

CONSEQUENCE:

It cannot be predicted when section one has been precooled enough to start unloading.

SAFEGUARDS:

None

ACTION:

Criteria for transition from precooling to unloading to be defined, and procedure for transition (interface $\mathrm{BES} / \mathrm{CCR} /$ Tanker operator) to be drafted up in project phase.

RESPONSE: (Action 4) DATED:

\section{SIGNED:}

ENTER YOUR RESPONSE IN THE BOX ABOVE, THEN SIGN AND RETURN TO:

RVVE

NOTES (for use of Hazop Secretary only) 
HAZOP STUDY ACTION AND RESPONSE SHEET

\begin{tabular}{|l|l|l|}
\hline \multicolumn{2}{|l|}{ ACTION ON: FKRI } & RESPOND BY: 17 JUL 2004 \\
\hline ACTION NO: 5 & MEETING DATES: Thursday 8-7-2004 9:00 - 12:00 hours & REVISION: B \\
\hline $\begin{array}{l}\text { DOCUMENT REF: BIGS-B-100-DF-0002-001 } \\
\text { TITLE: PROCESS FLOW DIAGRAM- MAIN PROCESS BIG SWEEP }\end{array}$ & (Hazop Table 1) \\
\hline $\begin{array}{l}\text { ITEM: } \\
\text { Section } 1\end{array}$ & \\
\hline CAUSE: & \\
Temperature high - section one not precooled prior to offloading & \\
\hline $\begin{array}{l}\text { CONSEQUENCE: } \\
\text { Possible vapour generation with pressure increase. }\end{array}$ & \\
\hline $\begin{array}{l}\text { SAFEGUARDS: } \\
\text { Installed PRV's. }\end{array}$ \\
\hline $\begin{array}{l}\text { ACTION: } \\
\text { PRV's to be sized for vapour generation. To be implemented in project phase. }\end{array}$ \\
\hline \hline RESPONSE: (Action 5) \\
\hline
\end{tabular}

No action will be taken in this phase. Consequences will be taken in normal design procedure.

SIGNED:

ENTER YOUR RESPONSE IN THE BOX ABOVE, THEN SIGN AND RETURN TO:

RVVE

NOTES (for use of Hazop Secretary only) 
HAZOP STUDY ACTION AND RESPONSE SHEET

\begin{tabular}{|c|c|c|}
\hline \multicolumn{2}{|c|}{ ACTION ON: HVDB } & RESPOND BY: T.B.A. \\
\hline ACTION NO: 6 & MEETING DATES: Thursday 8-7-2004 9:00 - 12: & ours \\
\hline \multicolumn{2}{|c|}{$\begin{array}{l}\text { DOCUMENT REF: BIGS-B-100-DF-0002-001 } \\
\text { TITLE: PROCESS FLOW DIAGRAM - MAIN PROCESS BIG SWEEP }\end{array}$} & REVISION: B \\
\hline \multicolumn{2}{|l|}{$\begin{array}{l}\text { ITEM: } \\
\text { Section } 1\end{array}$} & (Hazop Table 1) \\
\hline \multicolumn{3}{|c|}{$\begin{array}{l}\text { CAUSE: } \\
\text { Pressure High by offloading pumps of LNG carrier }\end{array}$} \\
\hline \multicolumn{3}{|c|}{$\begin{array}{l}\text { CONSEQUENCE: } \\
\text { Actuation of PRV's }\end{array}$} \\
\hline \multicolumn{3}{|c|}{$\begin{array}{l}\text { SAFEGUARDS: } \\
\text { Selection of Design Pressure. }\end{array}$} \\
\hline
\end{tabular}
procedure. To be resolved in project phase.

RESPONSE: (Action 6) DATED:

SIGNED:

ENTER YOUR RESPONSE IN THE BOX ABOVE, THEN SIGN AND RETURN TO: RVVE

NOTES (for use of Hazop Secretary only) 
HAZOP STUDY ACTION AND RESPONSE SHEET

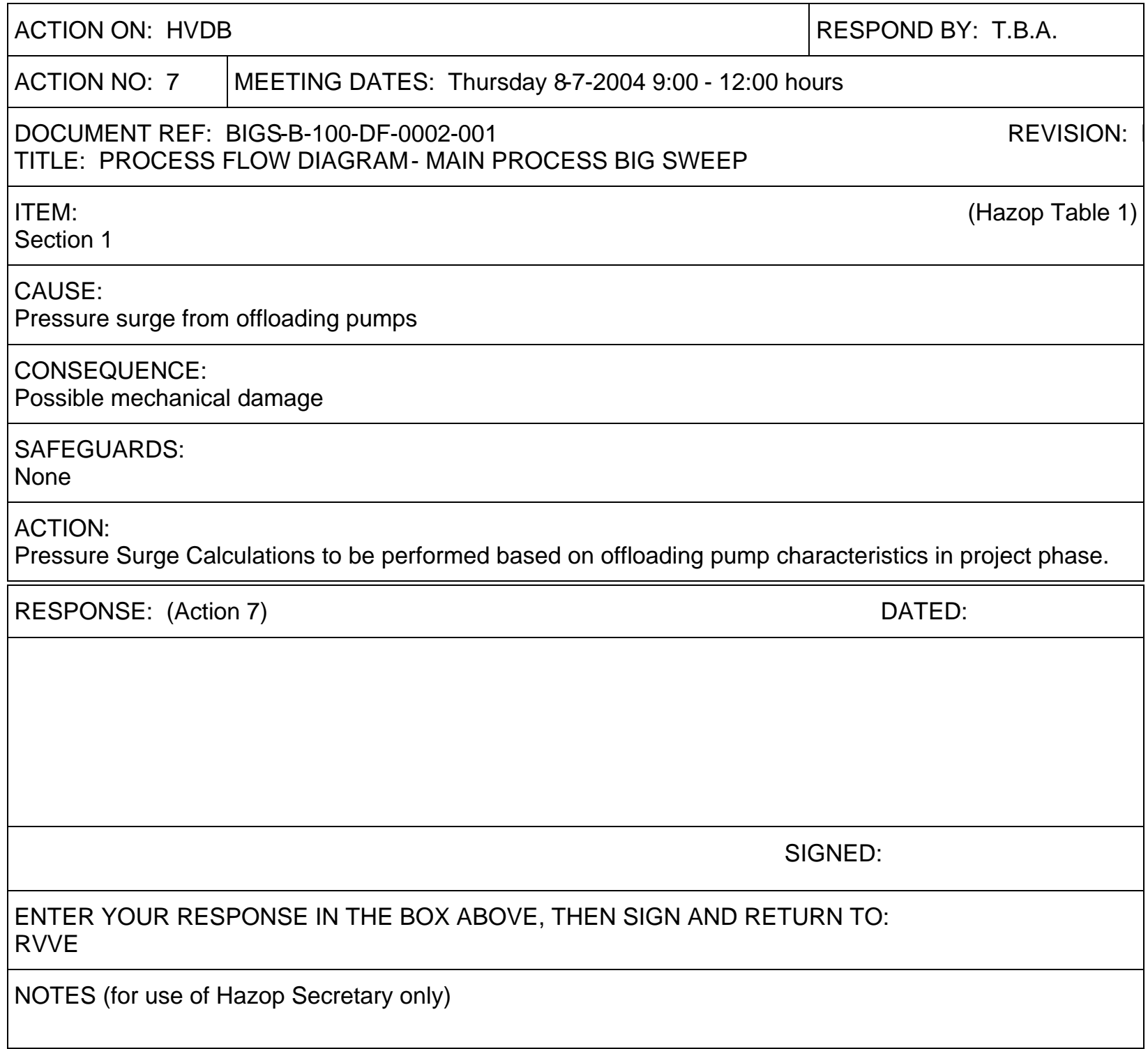


HAZOP STUDY ACTION AND RESPONSE SHEET

\begin{tabular}{|c|c|c|}
\hline \multicolumn{2}{|c|}{ ACTION ON: [1] HVDB [2] HVDB } & RESPOND BY: T.B.A. \\
\hline ACTION NO: 8 & \multicolumn{2}{|c|}{ MEETING DATES: Thursday 8-7-2004 9:00 - 12:00 hours } \\
\hline \multicolumn{2}{|c|}{$\begin{array}{l}\text { DOCUMENT REF: BIGS-B-100-DF-0002-001 } \\
\text { TITLE: PROCESS FLOW DIAGRAM - MAIN PROCESS BIG SWEEP }\end{array}$} & REVISION: B \\
\hline \multicolumn{2}{|l|}{$\begin{array}{l}\text { ITEM: } \\
\text { Section } 1\end{array}$} & (Hazop Table 1) \\
\hline \multicolumn{3}{|c|}{$\begin{array}{l}\text { CAUSE: } \\
\text { Wrong valve configuration }\end{array}$} \\
\hline \multicolumn{3}{|c|}{$\begin{array}{l}\text { CONSEQUENCE: } \\
\text { Open connection to vapour separator, overfilling vent pipe, release of LNG through vent pipe (depending on } \\
\text { overfill rate). }\end{array}$} \\
\hline \multicolumn{2}{|l|}{$\begin{array}{l}\text { SAFEGUARDS: } \\
\text { None }\end{array}$} & \\
\hline
\end{tabular}

[1] LSHH to be installed on vapour separator with adequate reliability. Reliability criterion to be established in SIL Classification session in project phase;

[2] Drain valves to be interlocked to prevent wrong valve configuration. To be implemented in project phase.

RESPONSE TO REFERENCE [2]: (Action 8) DATED:

SIGNED:

ENTER YOUR RESPONSE IN THE BOX ABOVE, THEN SIGN AND RETURN TO:

RVVE

NOTES (for use of Hazop Secretary only) 
HAZOP STUDY ACTION AND RESPONSE SHEET

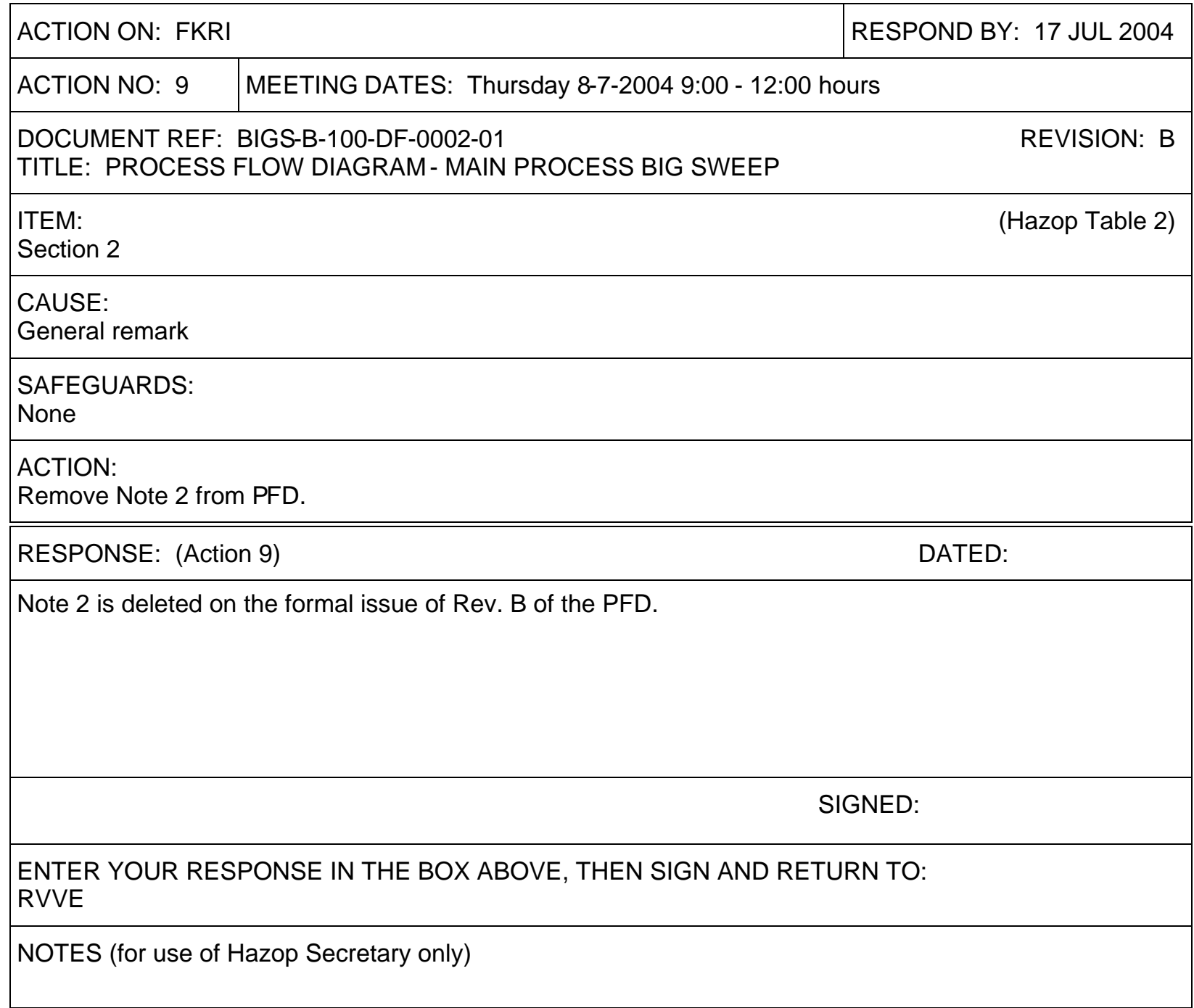


HAZOP STUDY ACTION AND RESPONSE SHEET

ACTION ON: HVDB

ACTION NO: $10 \quad$ MEETING DATES: Thursday 8-7-2004 9:00 - 12:00 hours

DOCUMENT REF: BIGS-B-100-DF-0002-01

TITLE: PROCESS FLOW DIAGRAM - MAIN PROCESS BIG SWEEP

ITEM:

Section 2

CAUSE:

High pressure

CONSEQUENCE:

Possible mechanical damage

SAFEGUARDS:

Design Pressure (see action 6).

ACTION:

RESPONSE: (Action 10)
RESPOND BY: T.B.A.

REVISION: B

(Hazop Table 2)

DATED:

\section{SIGNED:}

ENTER YOUR RESPONSE IN THE BOX ABOVE, THEN SIGN AND RETURN TO: RVVE

NOTES (for use of Hazop Secretary only) 
HAZOP STUDY ACTION AND RESPONSE SHEET

\begin{tabular}{|c|c|c|}
\hline \multicolumn{2}{|c|}{ ACTION ON: [1] FKRI [2] FKRI } & RESPOND BY: T.B.A. \\
\hline ACTION NO: 11 & \multicolumn{2}{|c|}{ MEETING DATES: Thursday 8-7-2004 9:00 - 12:00 hours } \\
\hline \multicolumn{2}{|c|}{$\begin{array}{l}\text { DOCUMENT REF: BIGS-B-100-DF-0002-01 } \\
\text { TITLE: PROCESS FLOW DIAGRAM - MAIN PROCESS BIG SWEEP }\end{array}$} & REVISION: B \\
\hline \multicolumn{3}{|c|}{$\begin{array}{l}\text { ITEM: } \\
\text { Section } 2\end{array}$} \\
\hline \multicolumn{3}{|c|}{$\begin{array}{l}\text { CAUSE: } \\
\text { Leakage over isolation valves when topsides is gas freed }\end{array}$} \\
\hline \multicolumn{3}{|c|}{$\begin{array}{l}\text { CONSEQUENCE: } \\
\text { Direct contact of topsides with large LNG inventory subsea, large and continued release when leakage } \\
\text { occurring in the swivel }\end{array}$} \\
\hline $\begin{array}{l}\text { SAFEGUARDS: } \\
\text { None }\end{array}$ & & \\
\hline
\end{tabular}

ACTION

YOUR REFERENCE BELOW: [2]

MOV's to be TSO;

[2] (post meeting note) Consider changing MOV's to ESDV's to isolate swivel from subsea pipeline in case of leakage, following API 14C paragraph A.9.3.3. and figure A.9. Use SIL classification

RESPONSE TO REFERENCE [2]: (Action 11) DATED:

SIGNED:

ENTER YOUR RESPONSE IN THE BOX ABOVE, THEN SIGN AND RETURN TO:

RVVE

NOTES (for use of Hazop Secretary only) 
HAZOP STUDY ACTION AND RESPONSE SHEET

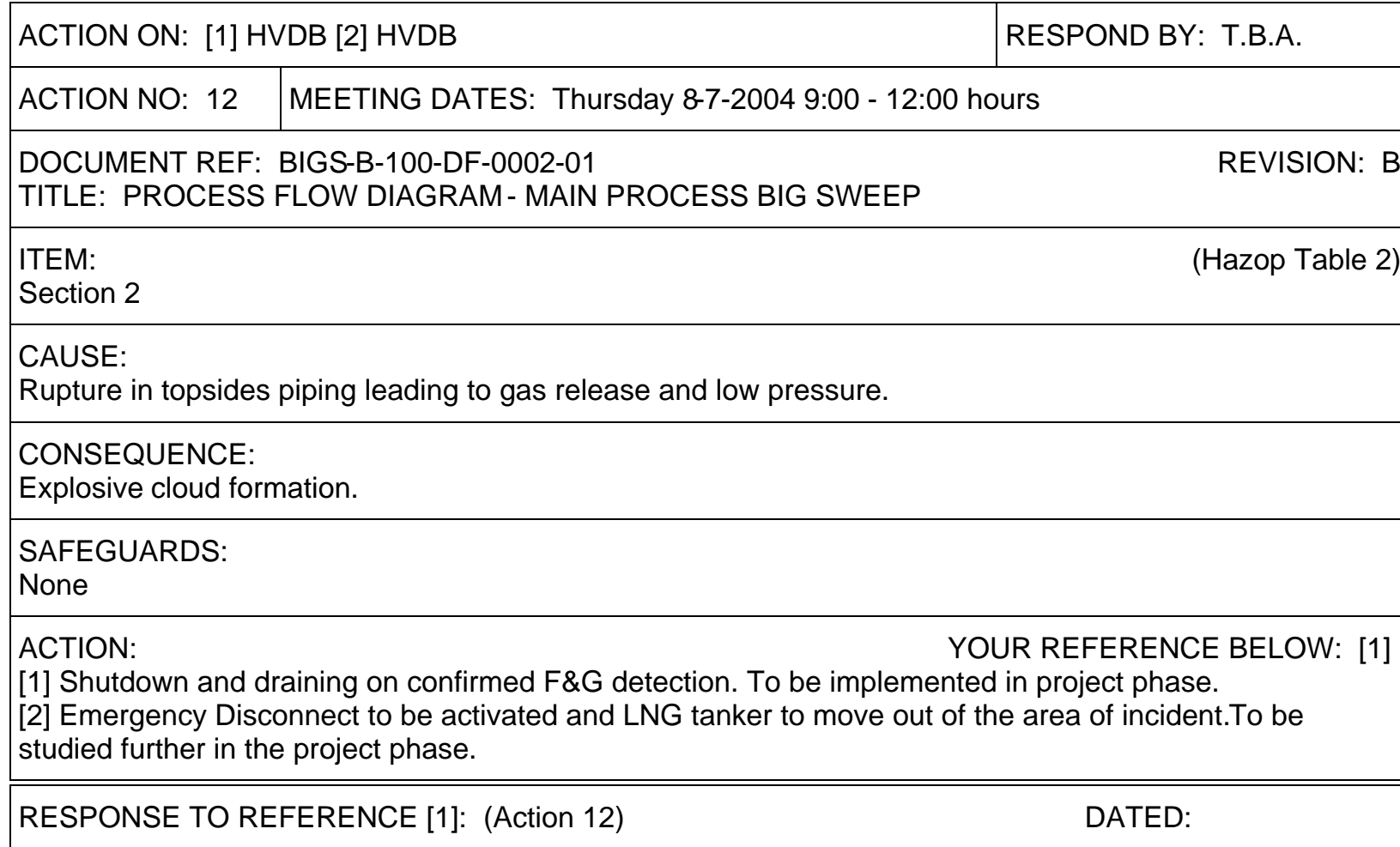

\begin{tabular}{l}
\hline \\
\hline SIGNED: \\
\hline $\begin{array}{l}\text { ENTER YOUR RESPONSE IN THE BOX ABOVE, THEN SIGN AND RETURN TO: } \\
\text { RVVE }\end{array}$ \\
\hline NOTES (for use of Hazop Secretary only)
\end{tabular}


HAZOP STUDY ACTION AND RESPONSE SHEET

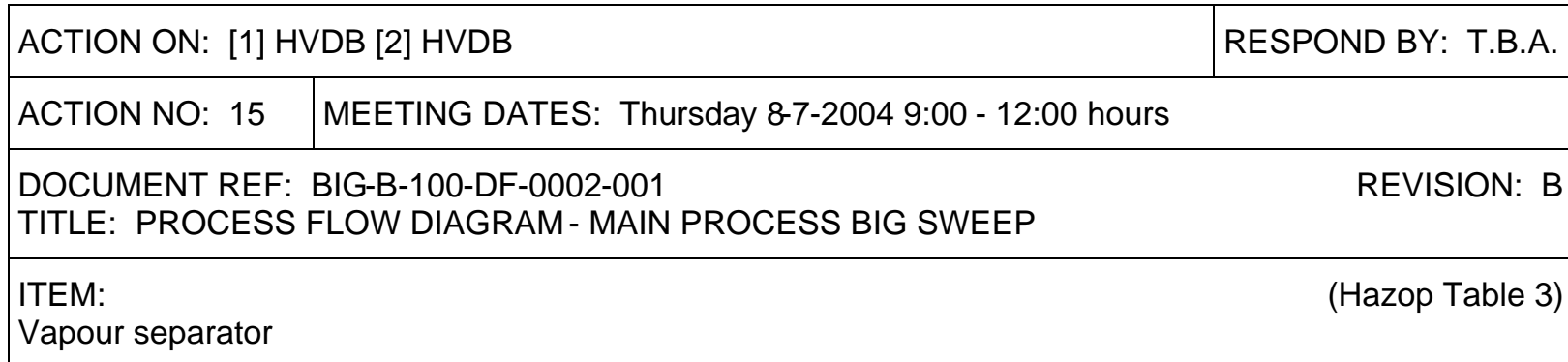

CAUSE:

Connection of vapour return line to offloading ine (wrong line up). Note: see also action 8.

CONSEQUENCE:

No vapour return to ship possible material damage on LNG tanker.

\section{SAFEGUARDS:}

None

ACTION:

YOUR REFERENCE BELOW: [1]

[1] The vapour return line should be clearly marked as such to rule out mstakes. To be implemented in project phase \& LNG tanker operator to be consulted.

[2] It should be confirmed by LNG carrier operator that LNG carrier has provisions on board to cater for no vapour return scenario

RESPONSE TO REFERENCE [1]: (Action 15)

DATED:

\section{SIGNED:}

ENTER YOUR RESPONSE IN THE BOX ABOVE, THEN SIGN AND RETURN TO:

RVVE

NOTES (for use of Hazop Secretary only) 
HAZOP STUDY ACTION AND RESPONSE SHEET

\begin{tabular}{|l|l|l|}
\hline \multicolumn{2}{|l|}{ ACTION ON: JWEV } & RESPOND BY: T.B.A. \\
\hline ACTION NO: 16 & MEETING DATES: Thursday 8-7-2004 9:00 - 12:00 hours & \\
\hline $\begin{array}{l}\text { DOCUMENT REF: BIG-B-100-DF-0002-001 } \\
\text { TITLE: PROCESS FLOW DIAGRAM - MAIN PROCESS BIG SWEEP }\end{array}$ & (Hazop Table 3) \\
\hline $\begin{array}{l}\text { ITEM: } \\
\text { Vapour separator }\end{array}$ & \\
\hline $\begin{array}{l}\text { CAUSE: } \\
\text { General remark }\end{array}$ & \\
\hline $\begin{array}{l}\text { SAFEGUARDS: } \\
\text { None }\end{array}$ & \\
\hline $\begin{array}{l}\text { ACTION: } \\
\text { It should be considered to route vent pipe along the crane column. }\end{array}$ \\
\hline \hline RESPONSE: (Action 16) \\
\hline \\
\hline NOTES (for use of Hazop Secretary only) \\
\hline RVVE \\
\hline
\end{tabular}


HAZOP STUDY ACTION AND RESPONSE SHEET

\begin{tabular}{|c|c|c|}
\hline \multicolumn{2}{|c|}{ ACTION ON: HVDB } & RESPOND BY: T.B.A. \\
\hline ACTION NO: 17 & MEETING DATES: Thursday 8-7-2004 9:00 - 12:00 hours & \\
\hline \multicolumn{2}{|c|}{$\begin{array}{l}\text { DOCUMENT REF: BIG-B-100-DF-0002-001 } \\
\text { TITLE: PROCESS FLOW DIAGRAM - MAIN PROCESS BIG SWEEP }\end{array}$} & REVISION: E \\
\hline
\end{tabular}

CAUSE:

High Pressure in vapour return line

CONSEQUENCE:

Possible mechanical damage on LNG carrier

SAFEGUARDS:

None

ACTION:

It should be verified that LNG carrier has PCV to deal with pressure fluctuations. To be confirmed in project phase.

RESPONSE: (Action 17) DATED:

\section{SIGNED:}

ENTER YOUR RESPONSE IN THE BOX ABOVE, THEN SIGN AND RETURN TO: RVVE

NOTES (for use of Hazop Secretary only) 
HAZOP STUDY ACTION AND RESPONSE SHEET

\begin{tabular}{|l|l|l|}
\hline \multicolumn{2}{|l|}{ ACTION ON: HVDB } & RESPOND BY: T.B.A. \\
\hline ACTION NO: 18 & MEETING DATES: Thursday 8-7-2004 9:00 - 12:00 hours & REVISION: \\
\hline $\begin{array}{l}\text { DOCUMENT REF: BIG-B-100-DF-0002-001 } \\
\text { TITLE: PROCESS FLOW DIAGRAM- MAIN PROCESS BIG SWEEP }\end{array}$ & (Hazop Table 3) \\
\hline $\begin{array}{l}\text { ITEM: } \\
\text { Vapour separator }\end{array}$ & \\
\hline $\begin{array}{l}\text { CAUSE: } \\
\text { Piping rupture in Heat Exchanger }\end{array}$ & \\
\hline $\begin{array}{l}\text { CONSEQUENCE: } \\
\text { Depending on differences in operating pressure in LNG system and Seawater System release of LNG to } \\
\text { seawater of release or seawater system to LNG system, with its physical consequences. }\end{array}$ \\
\hline $\begin{array}{l}\text { SAFEGUARDS: } \\
\text { Gas detection with consequent ESD action }\end{array}$ \\
\hline $\begin{array}{l}\text { ACTION: } \\
\text { Operating pressure of seawater to be higher or lower than operating pressure of LNG system, depending } \\
\text { on consequences. To be implemented in project phase. }\end{array}$ \\
\hline
\end{tabular}
on consequences. To be implemented in project phase.

RESPONSE: (Action 18) DATED:

SIGNED:

ENTER YOUR RESPONSE IN THE BOX ABOVE, THEN SIGN AND RETURN TO:

RVVE

NOTES (for use of Hazop Secretary only) 
HAZOP STUDY ACTION AND RESPONSE SHEET

ACTION ON: HVDB

ACTION NO: 19 MEETING DATES: Thursday 8-7-2004 9:00 - 12:00 hours

DOCUMENT REF: BIG-B-100-DF-0002-001

TITLE: PROCESS FLOW DIAGRAM - MAIN PROCESS BIG SWEEP

ITEM:

Vapour separator

CAUSE:

General remark

SAFEGUARDS:

None

ACTION:

Sparing philosophy of Heat Exchanger ( $1{ }^{*} 100 \%$ or $\left.2{ }^{*} 100 \%\right)$ to be determined in project płase.

RESPONSE: (Action 19)

DATED:

\section{SIGNED:}

ENTER YOUR RESPONSE IN THE BOX ABOVE, THEN SIGN AND RETURN TO:

RVVE

NOTES (for use of Hazop Secretary only) 
Doc. No. 1-0282-0/CGI-G-600-RP-0012/ Rev A Report - What-if Analysis of Process Flow Diagram

\section{Appendix D - Illustrations}




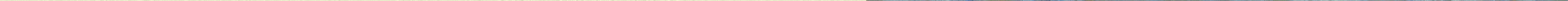




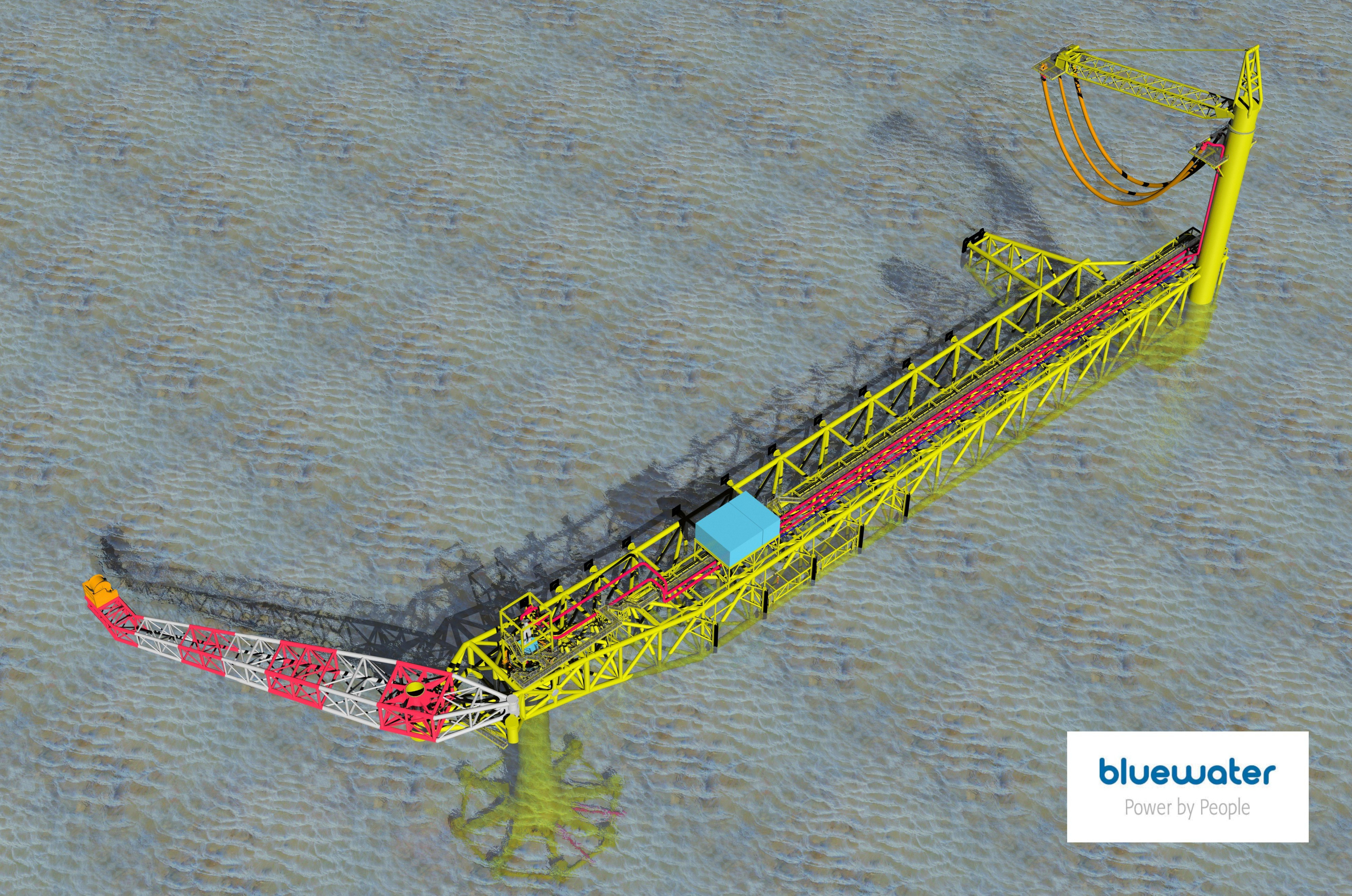




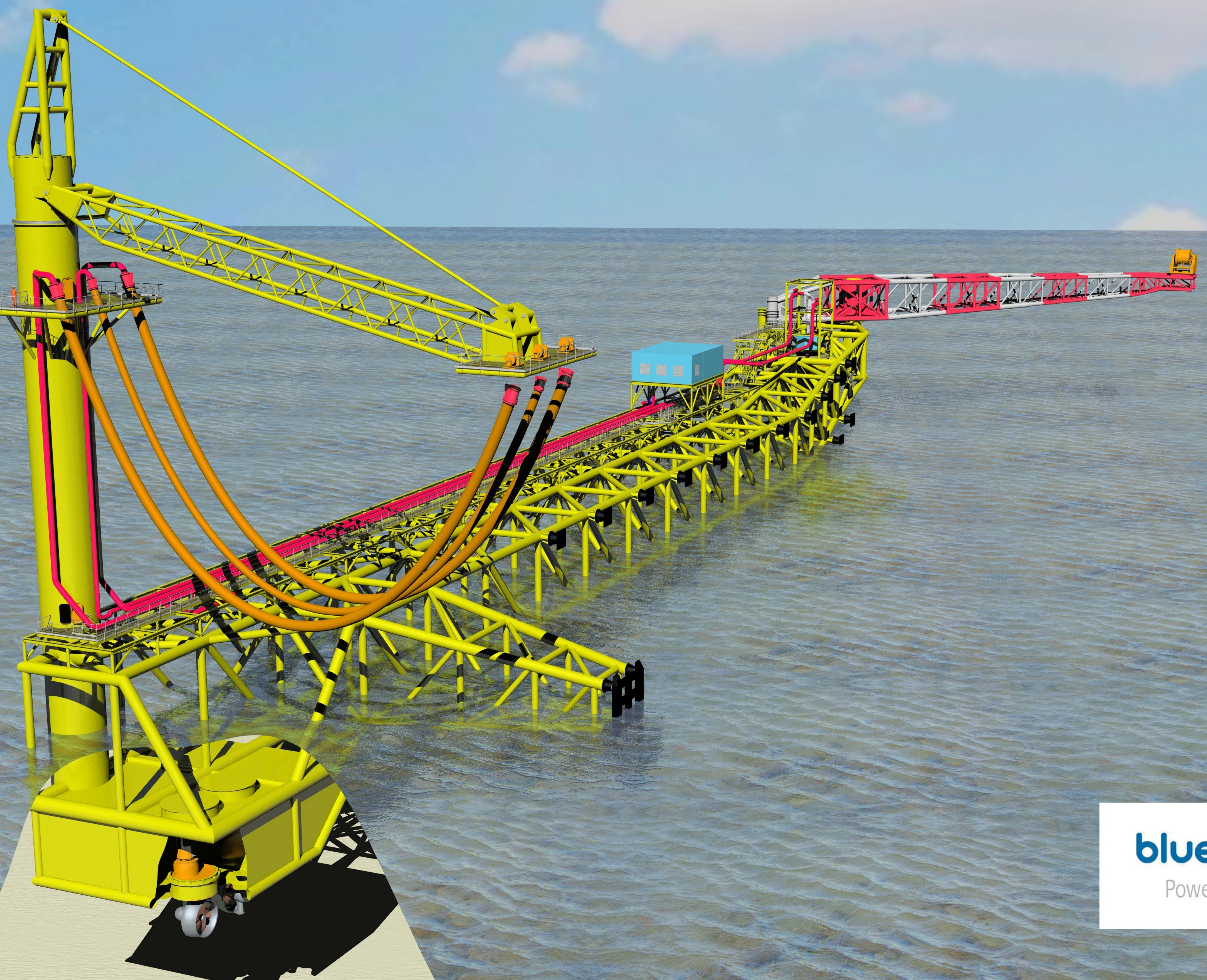


Avis

Natio

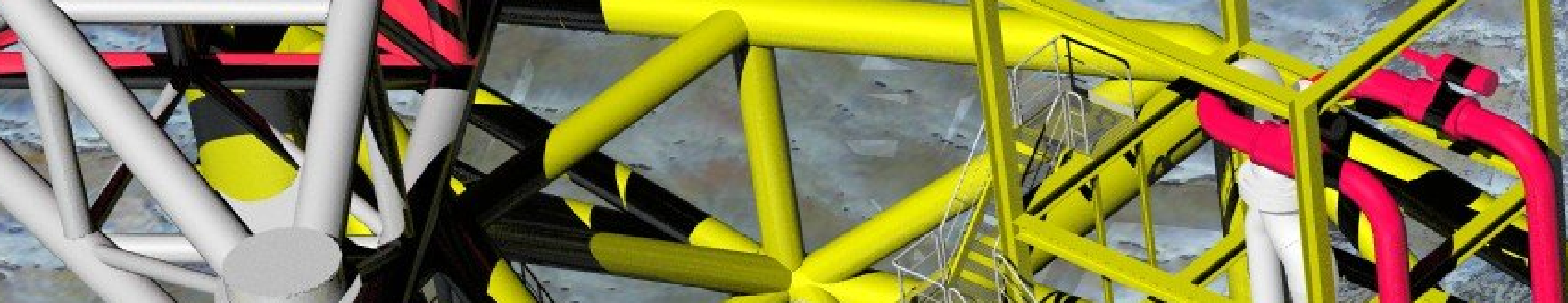

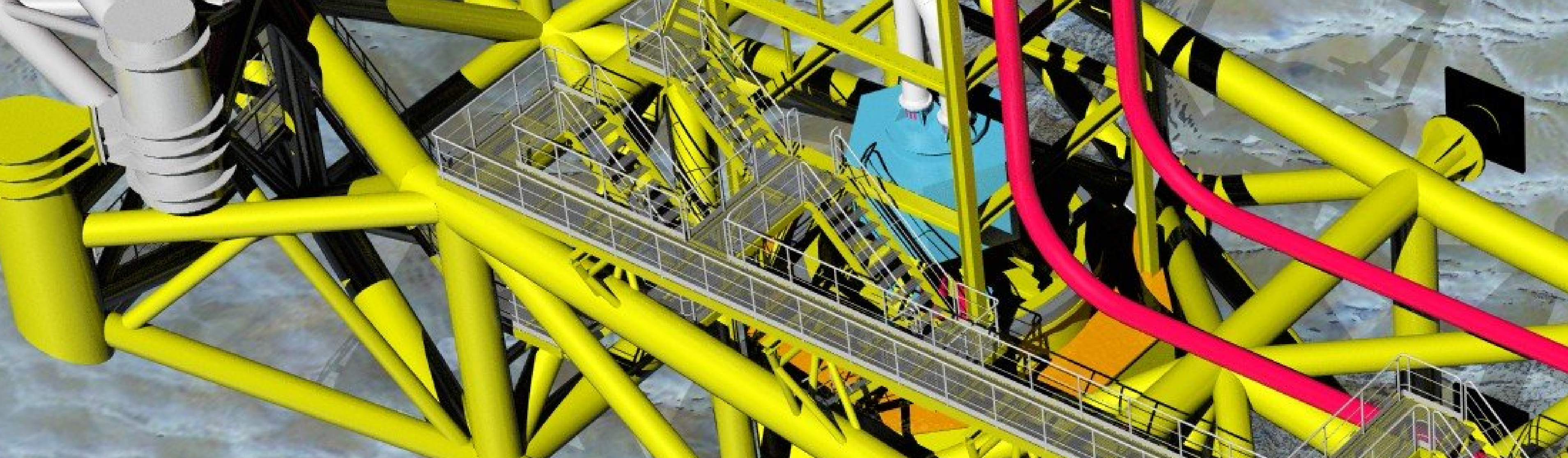

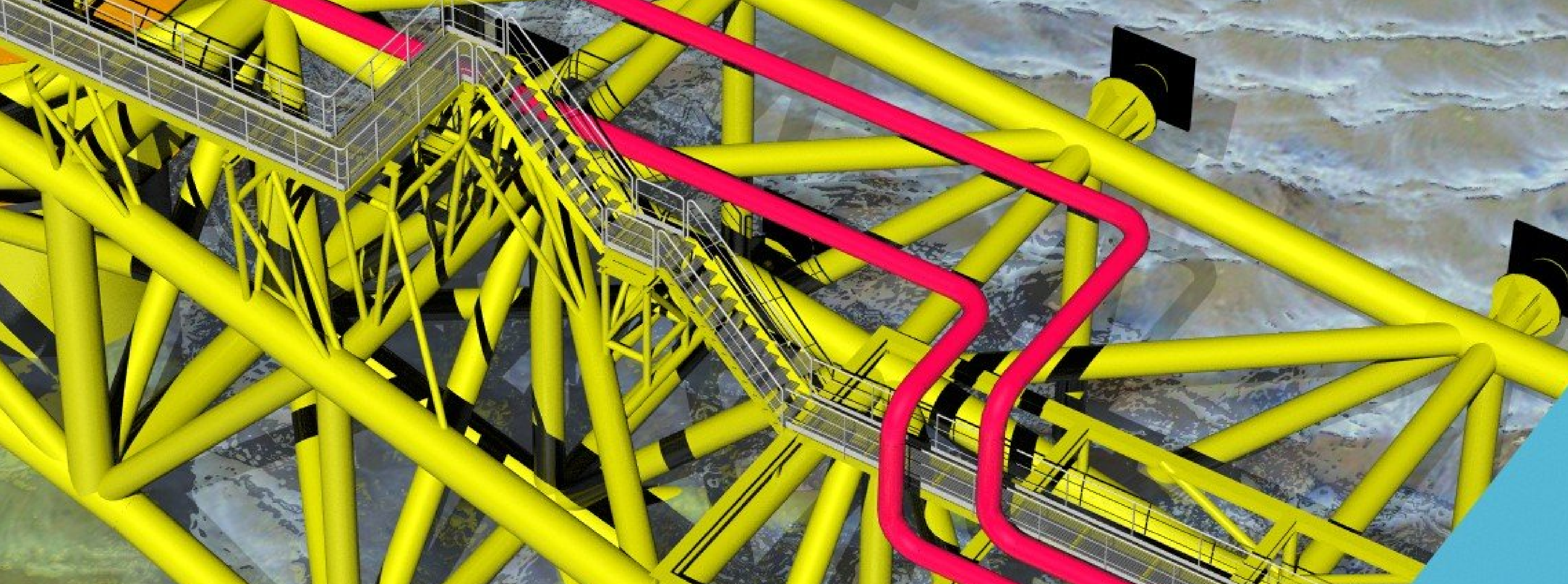

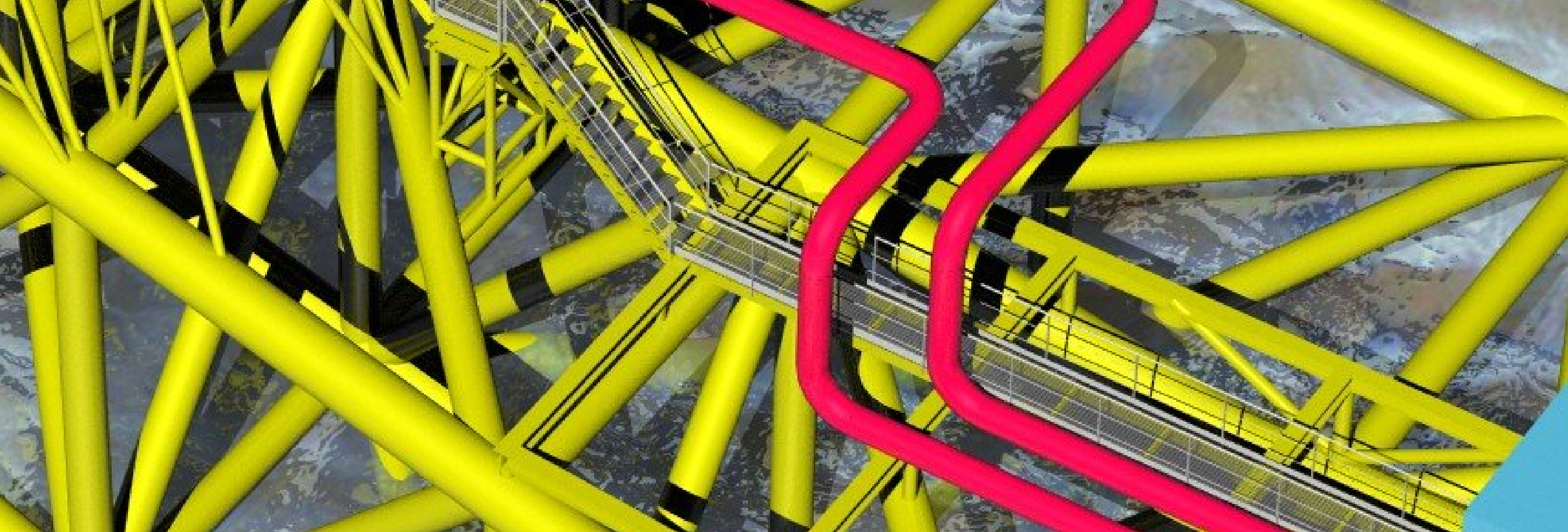

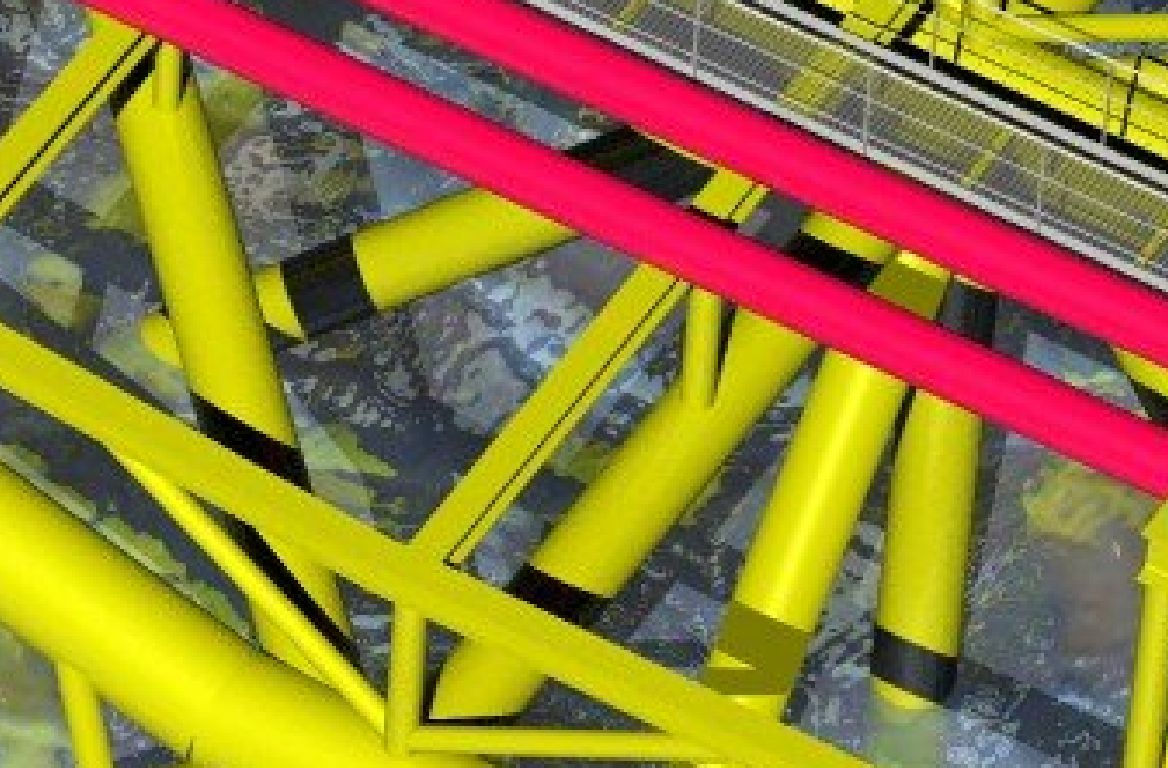

as a

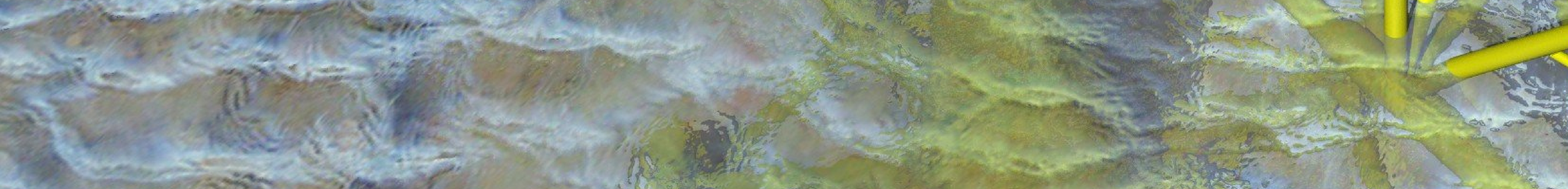
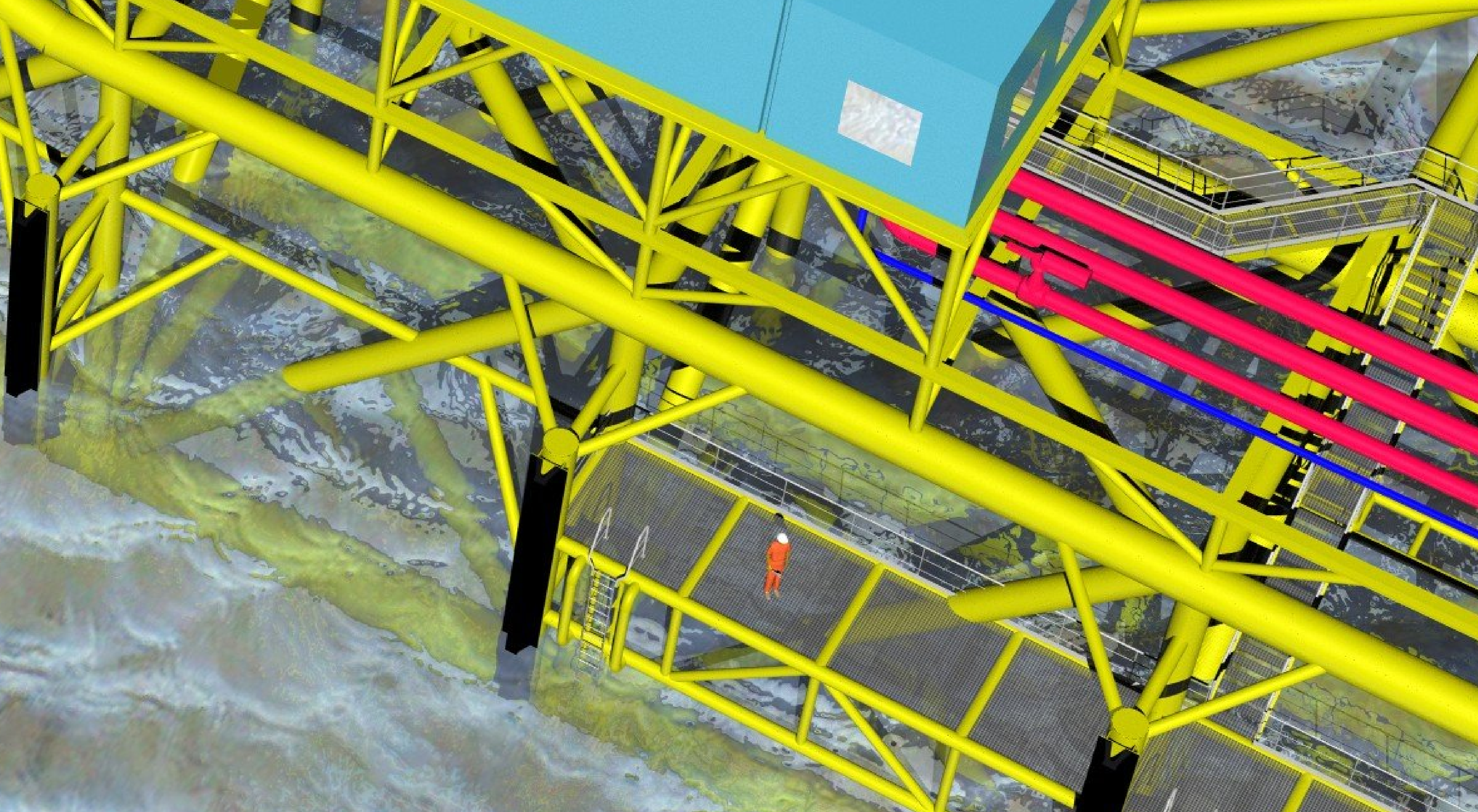

\section{bluewater}

power by people
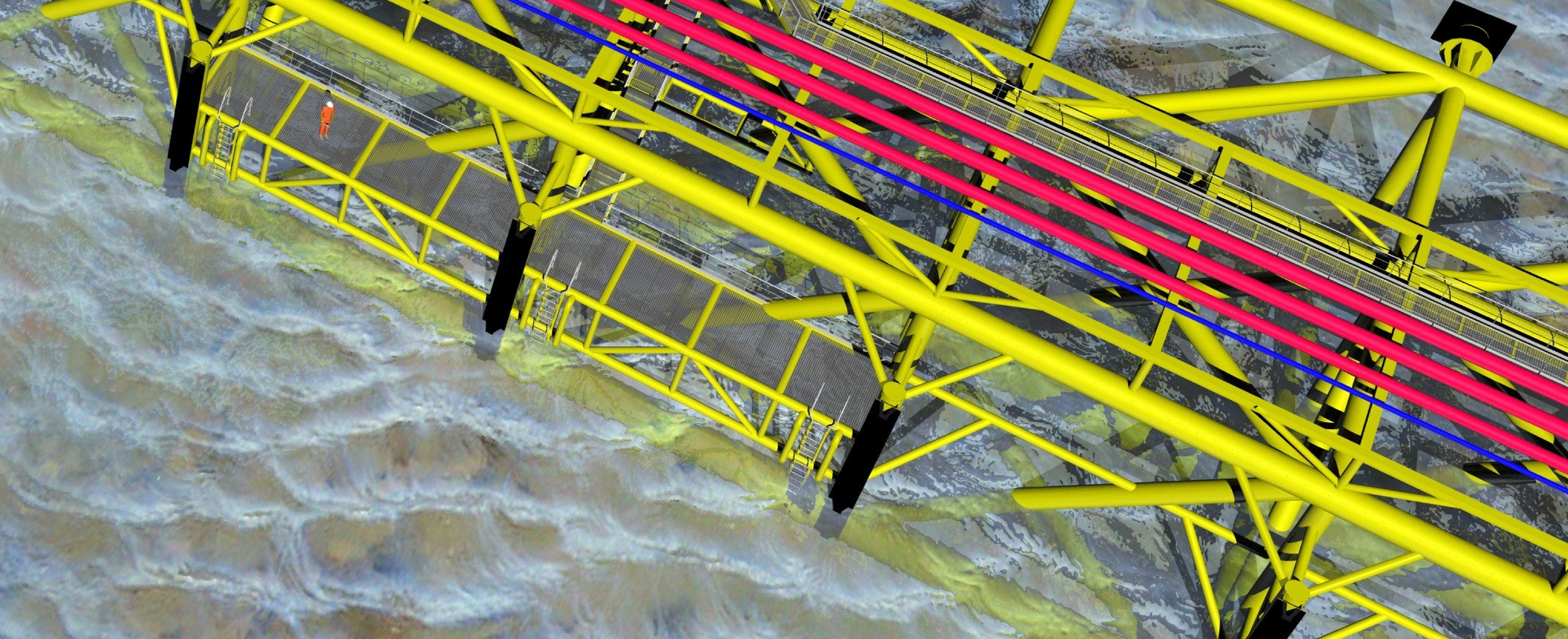

satatis

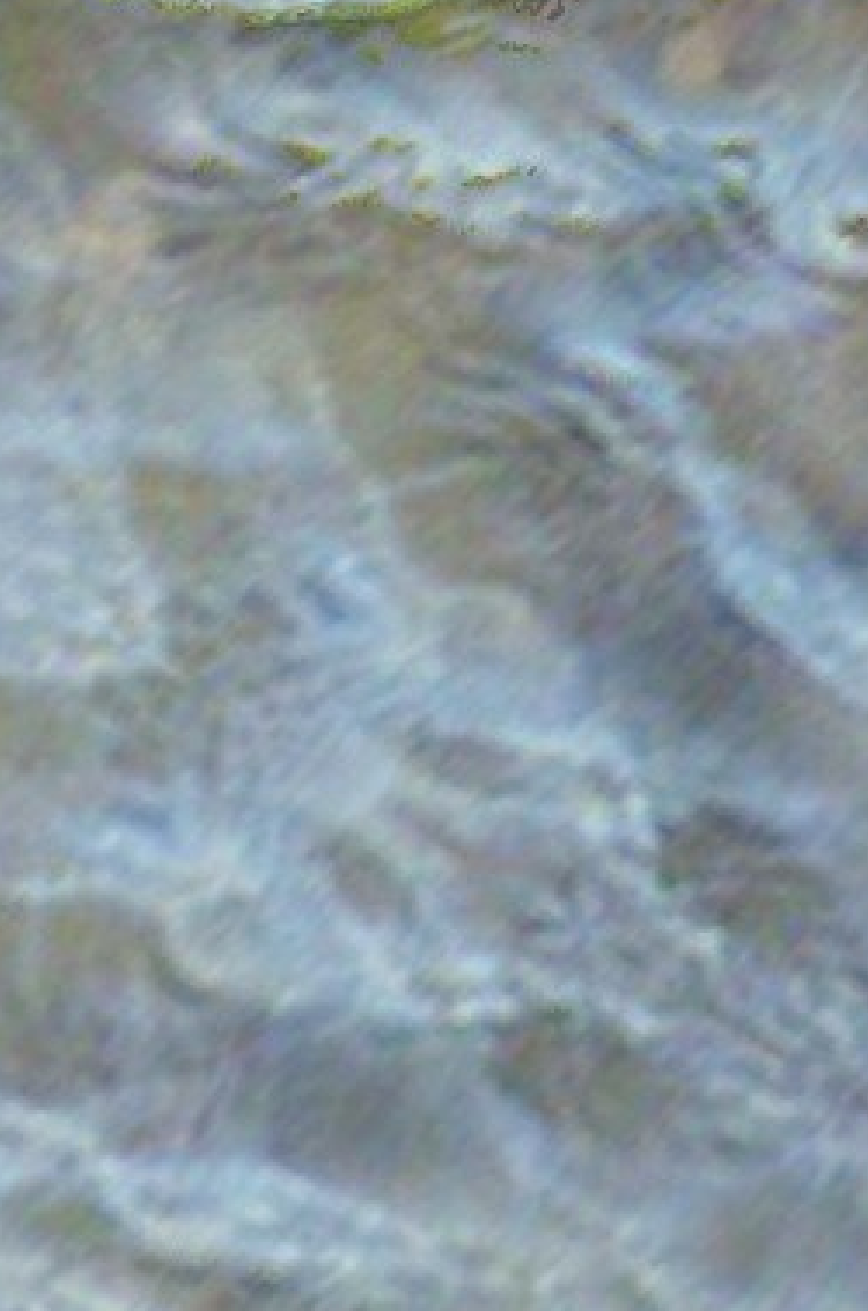

(il) $\rightarrow=5$ 
TAB 4 High Pressure LNG Pump Field Tests

PROPOSAL

TO

CONVERSION GAS IMPORTS, LP

FOR

DEMONSTRATION PERFORMANCE TEST

OF

SUBMERGED MOTOR-DRIVEN

LNG PUMP MODEL 8ECC-1516

SUBMITTED BY:

EBARA INTERNATIONAL CORPORATION

CRYODYNAMICS DIVISION

19 JUNE 2003 
EAARA PHONE (775) 356-2796 : FAX (775) 356-2884 : Email - Sales@ebaraintl.com

\section{SCOPE}

This proposal provides for the testing of one, LNG submerged motor pump model $8 \mathrm{ECC}-1516$, to demonstrate the existing technology for the design and manufacturing of LNG pumps to operate at pressures higher than 2000 psi.

The proposed test will use a pump that is currently being manufactured for operational use (not a prototype). The test will be conducted in LNG at the Ebara International Corporation, Cryodynamics Division, test facility located in Sparks, Nevada.

The test will consist of operation of the 8ECC-1516 pump at several flow rates and pressures to demonstrate the proper function of the pump and it's various features. The pump will be fully instrumented to verify it's operation, with flow, pressure, power, voltage, frequency, vibration level, input and output temperature, all being measured.

The pump will be tested at five points at flow rates from 0 flow (shut-off) to maximum flow ( $120 \%$ of rated flow). One NPSH test will also be performed at rated flow.

Results of the testing will be recorded, with a full Test Report issued after the compilation of all test data.

\section{PUMP MODEL DETAILS ${ }^{\star}$}

EIC Pump Model: 8ECC-1516

Rated Flow: $475 \mathrm{~m}^{3} / \mathrm{h}(2091 \mathrm{gpm})$

Rated Head: 2120 meters (6955 feet)

Rated Discharge Pressure: 144 barg (2088 psig)

Rated Motor Power: 2000 kW (2681 HP)

Electrical Input: $6600 \mathrm{~V} / 3 \mathrm{PH} / 50 \mathrm{~Hz}$

Liquid: LNG

Operating Temperature: $-159^{\circ} \mathrm{C}\left(-254^{\circ} \mathrm{F}\right)$

Liquid Specific Gravity: 0.442

* Note: Please refer to attached drawing $\mathrm{C7000633}$ for General Outline and further details. 
EAARA PHONE (775) 356-2796 : FAX (775) 356-2884 : Email - Sales@ebaraintl.com

\section{PRICING*}

Total Price includes:

- Assembly and Set-up Costs

- Installation of the pump into the test stand

- Inert system and Cool-down

- Performance Test

- Liquids Consumed

- Power costs

- Inert system and removal of pump

- Dis-assembly, drying out and inspection

Price for above: $\$ 62,000$

* Note: Testing to be performed courtesy of EIC. All test costs comprise EIC's contribution to the DOE study. 
EARA PHONE (775) 356-2796 : FAX (775) 356-2884 : Email - Sales@ebaraintl.com

\section{TERMS AND CONDITIONS OF SALE}

Commercial terms

1. The quoted prices are fixed and firm for the delivery period for an order placed within the validity period.

2. Validity of Quotation

The quotation is valid for ninety (90) days from the date of this quotation.

3. Currency - The prices are quoted in USA Dollars.

4. The quotation is submitted for and on the behalf of Ebara International Corporation, Cryodynamics Division, 350 Salomon Circle, Sparks, Nevada USA. Telephone (775) 356-2796, Telefax (775) 356-2884, Email: Sales@ebaraintl.com

5. All payments to be made by wire transfer within 30 days of invoice.

6. Terms of Payment - $100 \%$ on completion.

7. Warranty

No warranty is included or implied for the work scope in this proposal.

8. In no case shall Ebara International Corporation, Cryodynamics Division be liable for indirect, special, consequential incidental damages. 


\section{Meeting Notes \\ CGI and Ebara International \\ Sparks, Nevada \\ September 3 -5, 2003}

\section{Subject:}

DOE Phase II Task 2.0 - High Pressure LNG Pump Field Test

\section{Test Participants:}

Steve Rush - Ebara International Cryodynamics Division - VP Sales and Service Bill Bishop - CGI - VP Engineering Braxton Scherz - CGI - VP Business Development Larry Evans - Blackwell Sanders Peper Martin LLP - Atty. At Law (patents) Steve Persky - Paragon - LNG/LPG Manager

John Walter - ExxonMobil - Upstream Research - Gas and Facilities Division

\section{Pump Tested:}

Model 8ECC-1516

8 inch discharge

16 stages

15” nominal impeller

$50 \mathrm{HZ}$ (motor is also designed to operate at $60 \mathrm{~Hz}$ )

Rated Speed: 2960 RPM

Rated Flow: 475 m3/hr

Rated Head: 2120 meters, or 1325 psi at .44 specific gravity

Rated Motor Power: 2000 kw or 2680 hp

\section{Test Agenda:}

Attached

\section{Summary:}

To demonstrate the viability and practicality of manufacturing high pressure LNG pumps capable of producing cavern compatible injection pressures and flow rates, Ebara International invited CGI to witness a cryogenic pump test at the company's facility located in Sparks Nevada. The cryogenic LNG pump tested is the largest production unit to date and is capable of exceeding pressures of $2200 \mathrm{psi}$. The pump was to be tested at a pressure exceeding 2000 psi.

The group arrived at Ebara's HQ located in Sparks, Nevada. We were invited to listen to Steve Rush's presentation and the pump was readied in the test stand. Mr. Rush 
completed an extended question and answer period which covered the material attached to this summary. Some of the topics addressed were:

1. Use of soft starting or variable frequency drives for these very large motors

2. Bearing life and lubrication

3. pump maintenance and operation

4. API codes used as the design basis (API 610 with additions for cryogenic requirements)

The group toured the cryogenic pump assembly facility after a problem with one of the packaged power units caused another delay. After returning to the office, Steve suggested that we tour the shop in Sparks where Ebara secures the electrical motors for its pumps.

During this tour we were shown the various stages of assembly for the stator and windings. Each part of the process is carefully completed by hand before the motor is assembled and sent to Ebara's shop. The facility was small but dedicated to the rigid specifications that the integrated cryogenic pump requires.

We returned to Ebara's HQ in the late afternoon but Ebara had to accommodate the needs of the purchaser and we waited for an opportunity to witness the test. Due to the long day, Ebara had to shutdown the pump before the extended run test was completed. Steve asked that we return first thing Friday morning to complete our test requirements.

On Friday morning the group arrived and moved to the test stand control room. The pump was restarted without incident or delay. The pump was taken to 50 cycles and produced about 1450 psig with a flow of about $405 \mathrm{~m} 3 / \mathrm{hr}$. The generator speed was increased and the pump approached 2000 psi. The generator speed was bumped to about 53 cycles and the pump produced 2050 psi at about $240 \mathrm{~m} 3 / \mathrm{hr}$ flow. The test was successfully completed.

Ebara will submit the official documentation to CGI for the DOE study after the customers witnesses the second pump test later during the second week of September.

Please see the attached documentation for greater detail.

\section{End of Meeting Notes}




\section{Ebara HP LNG Pump Test September 4-5, 2003}

- Subject:

- DOE Phase II Task 2.0 - High Pressure LNG Pump Field Test

- Test Participants:

- Steve Rush - Ebara International Cryodynamics Division - VP Sales and Service

- Bill Bishop - CGI - VP Engineering

- Braxton Scherz - CGI - VP Business Development

- Larry Evans - Blackwell Sanders Peper Martin LLP - Atty. At Law (patents)

- Steve Persky - Paragon - LNG/LPG Manager

- John Walter - ExxonMobil - Upstream Research - Gas and Facilities Division

- Pump Design:

- Model 8ECC-1516

- 8 inch discharge

- 16 stages

- 15 " nominal impeller

- $50 \mathrm{HZ}$ (motor is also designed to operate at $60 \mathrm{~Hz}$ )

- Rated Speed: 2960 RPM

- Rated Flow: $475 \mathrm{~m} 3 / \mathrm{hr}$

- Rated Head: 2120 meters, or 1325 psi at .44 specific gravity

- Rated Motor Power: 2000 kw or 2680 hp 


\section{2nd HP LNG Pump}

- 2nd pump waiting for testing

- $\quad \sim 17 \mathrm{ft}$ overall length

- Pump increases the temperature of the LNG by 10 degrees C

- Cooling flow from discharge routed thru motor to 2 nd stage impeller suction to avoid cavitation

- Stainless steel bearings lubricated and cooled by the LNG

- Pump is designed for continuous duty

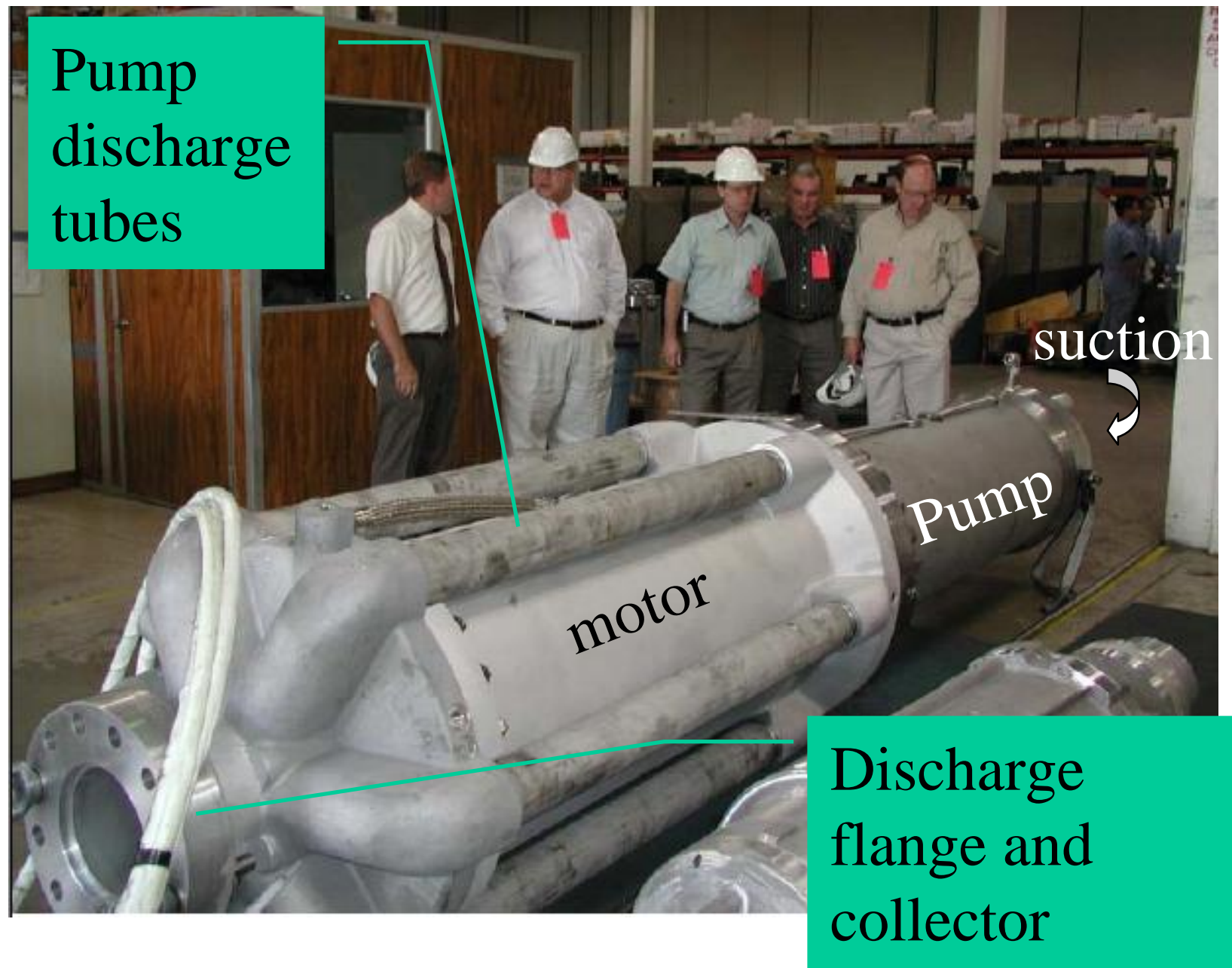




\section{Pump Discharge}

End view of the

pump

discharge and collector

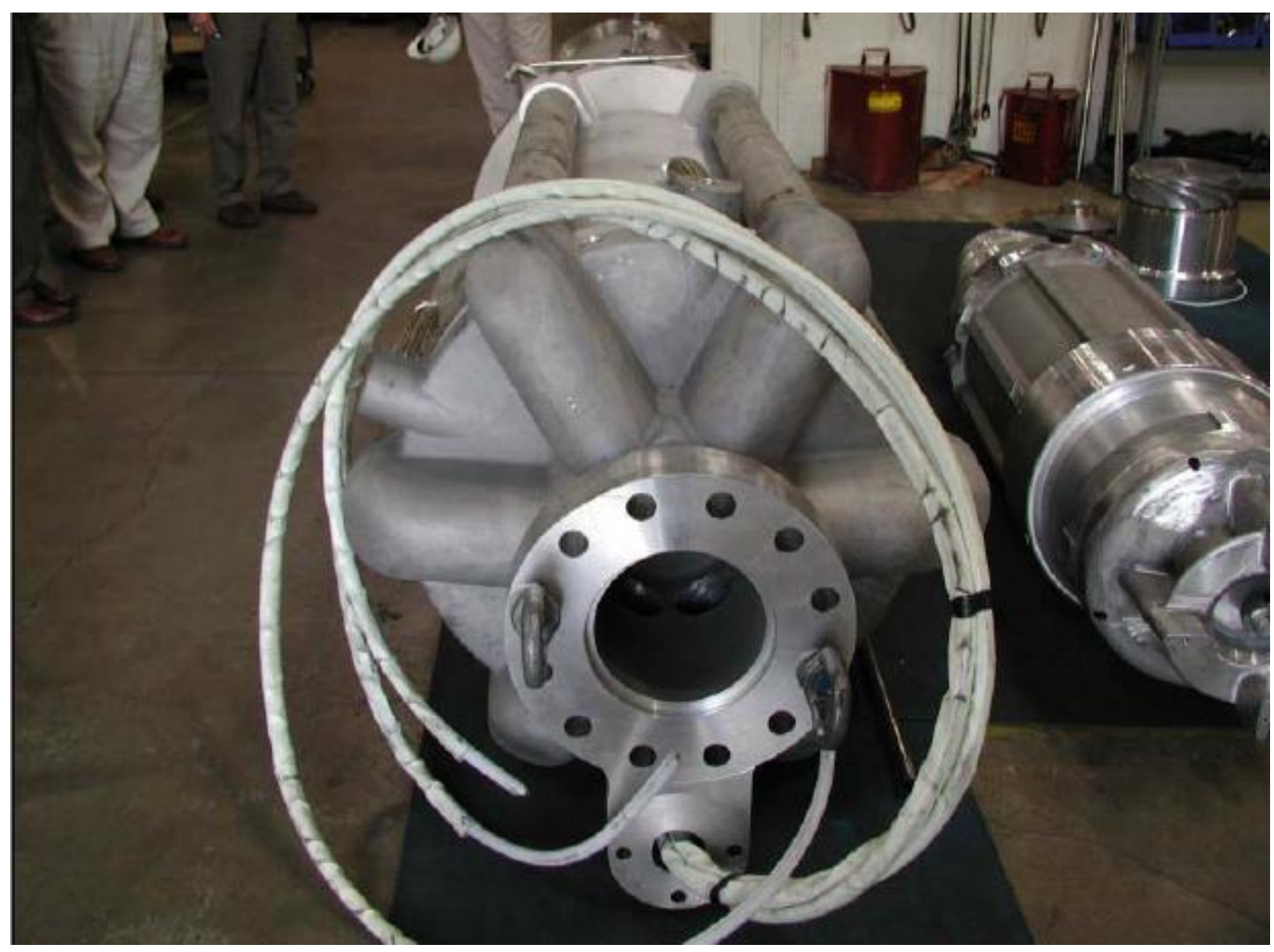




\section{Common Pump and Motor Shaft}

- Pump shaft and motor rotor are machined as a single piece

- (this is not the rotor of the tested pump)

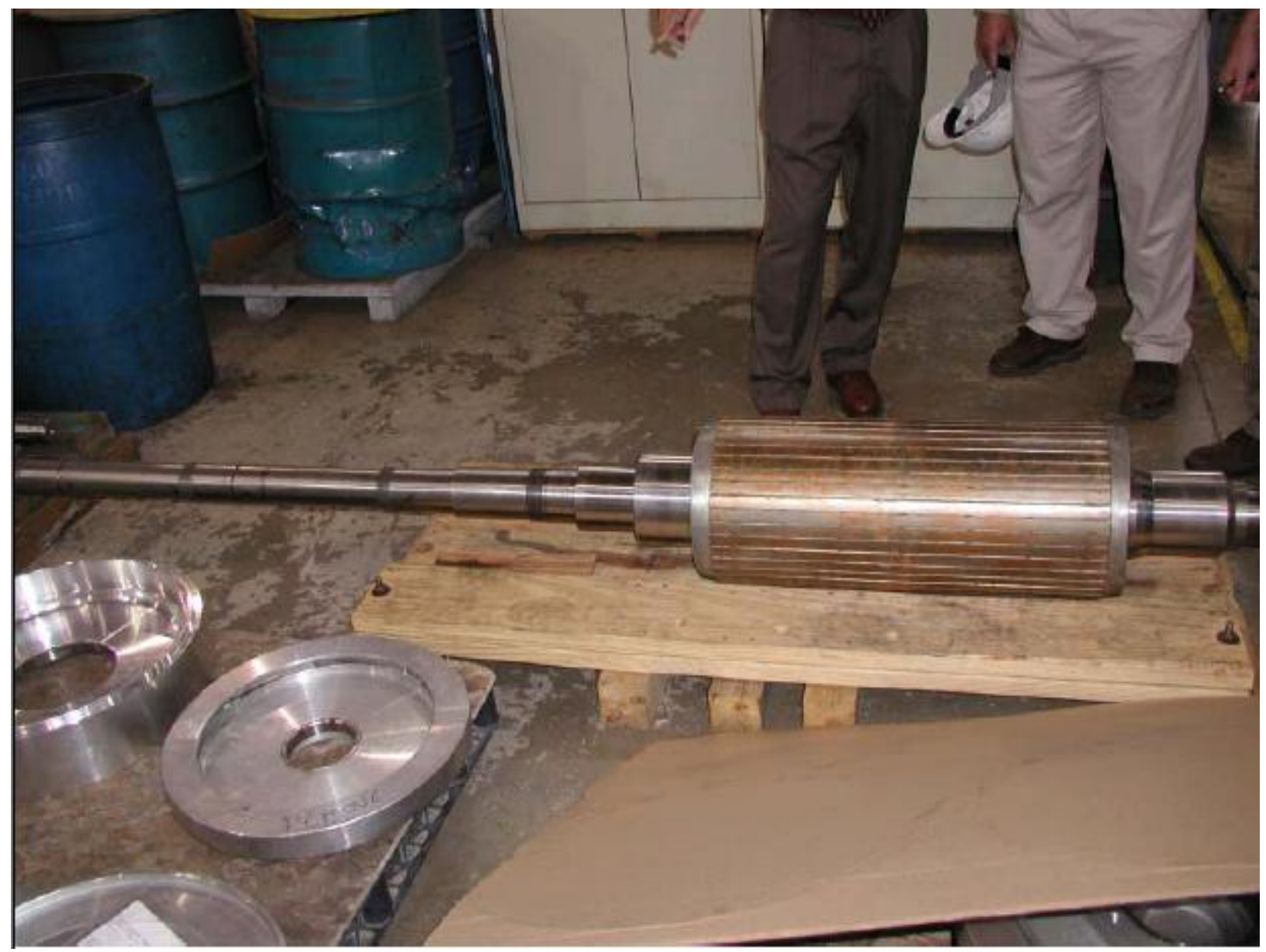




\section{Testing Rig for HP LNG Pump}

$\mathrm{N} 2$ is used to subcool the LNG after dischargi ng from pump

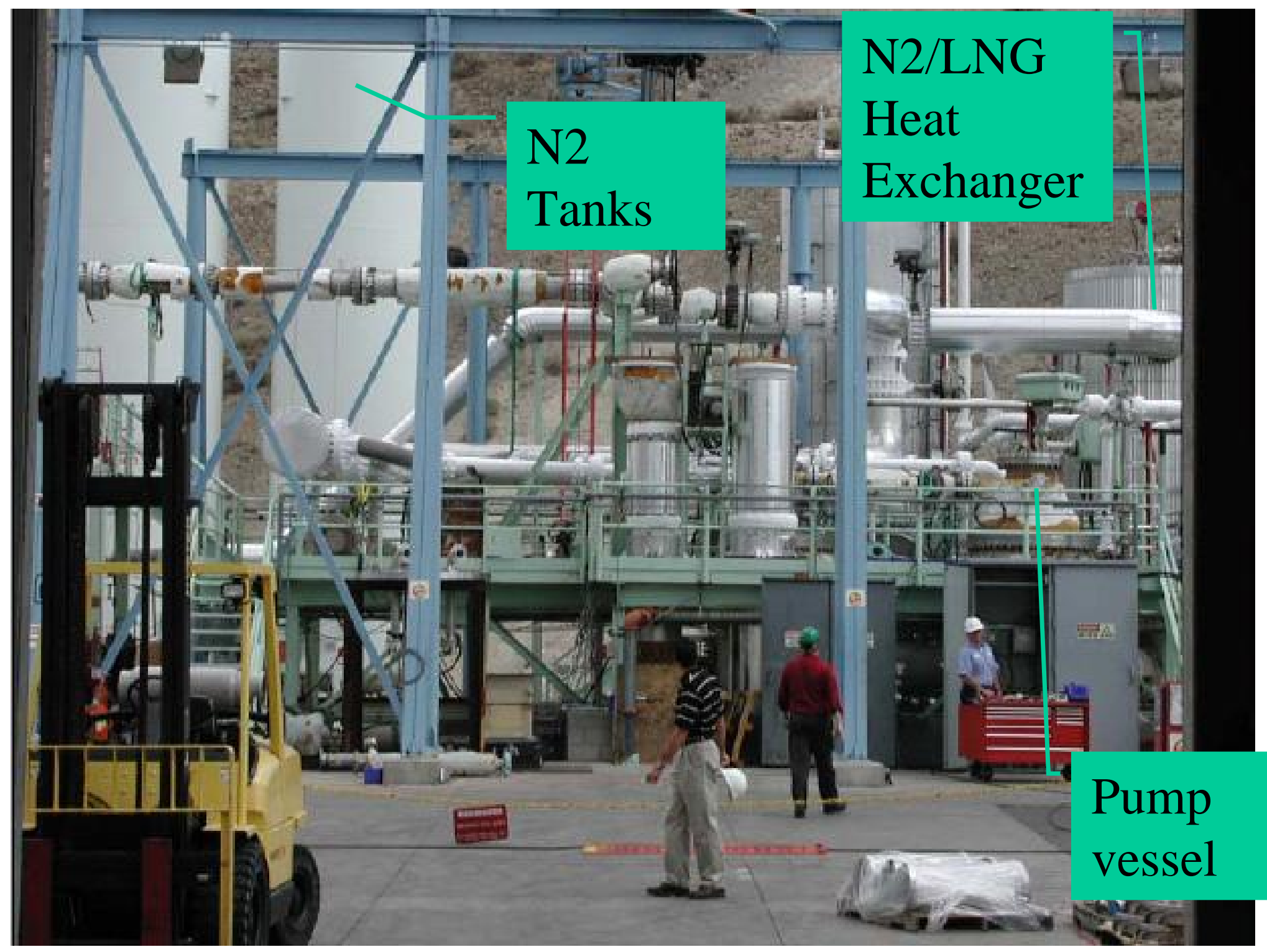


N2 Vent From Heat Exchanger

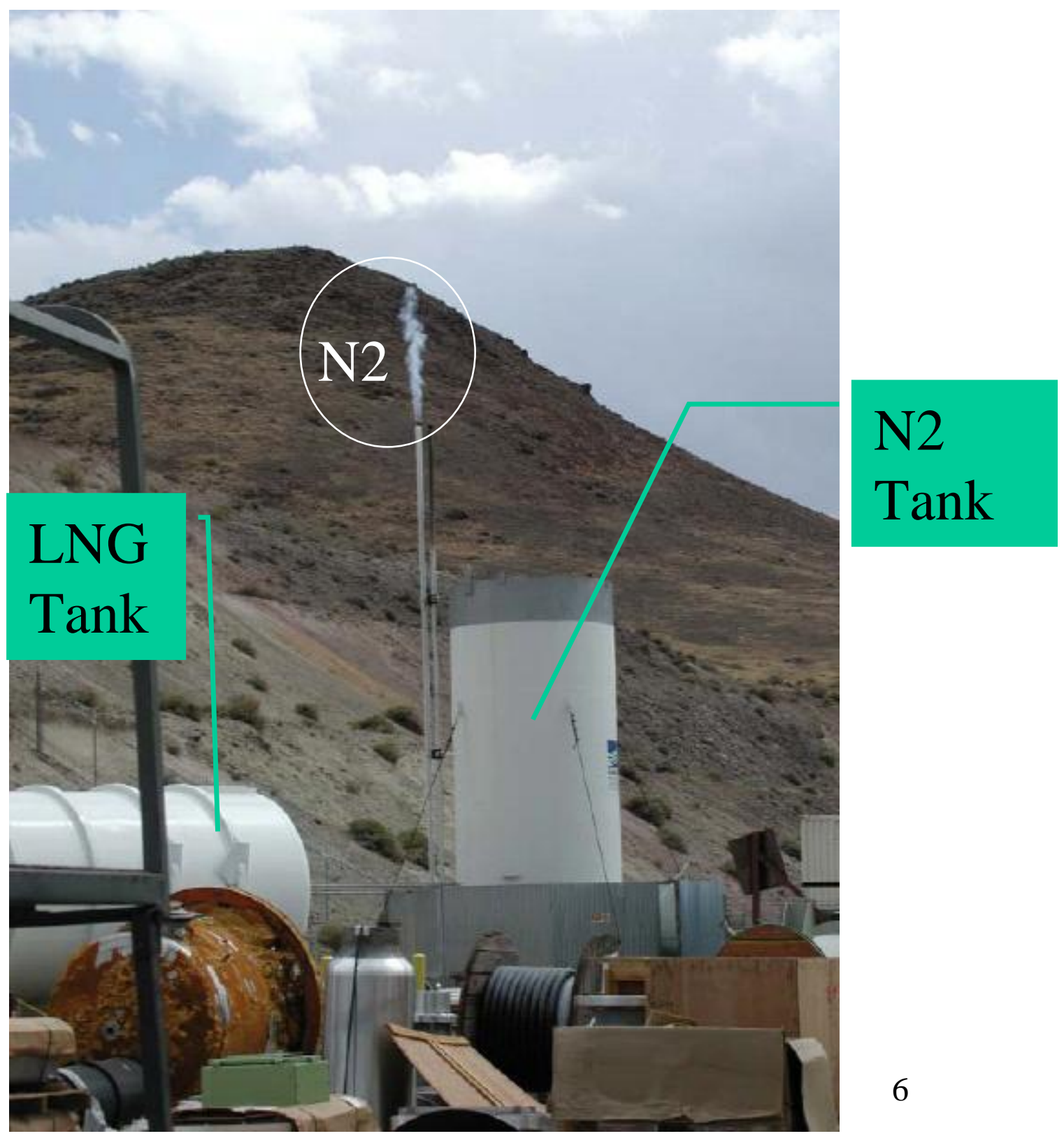




\section{4-Diesel Gen-Sets}

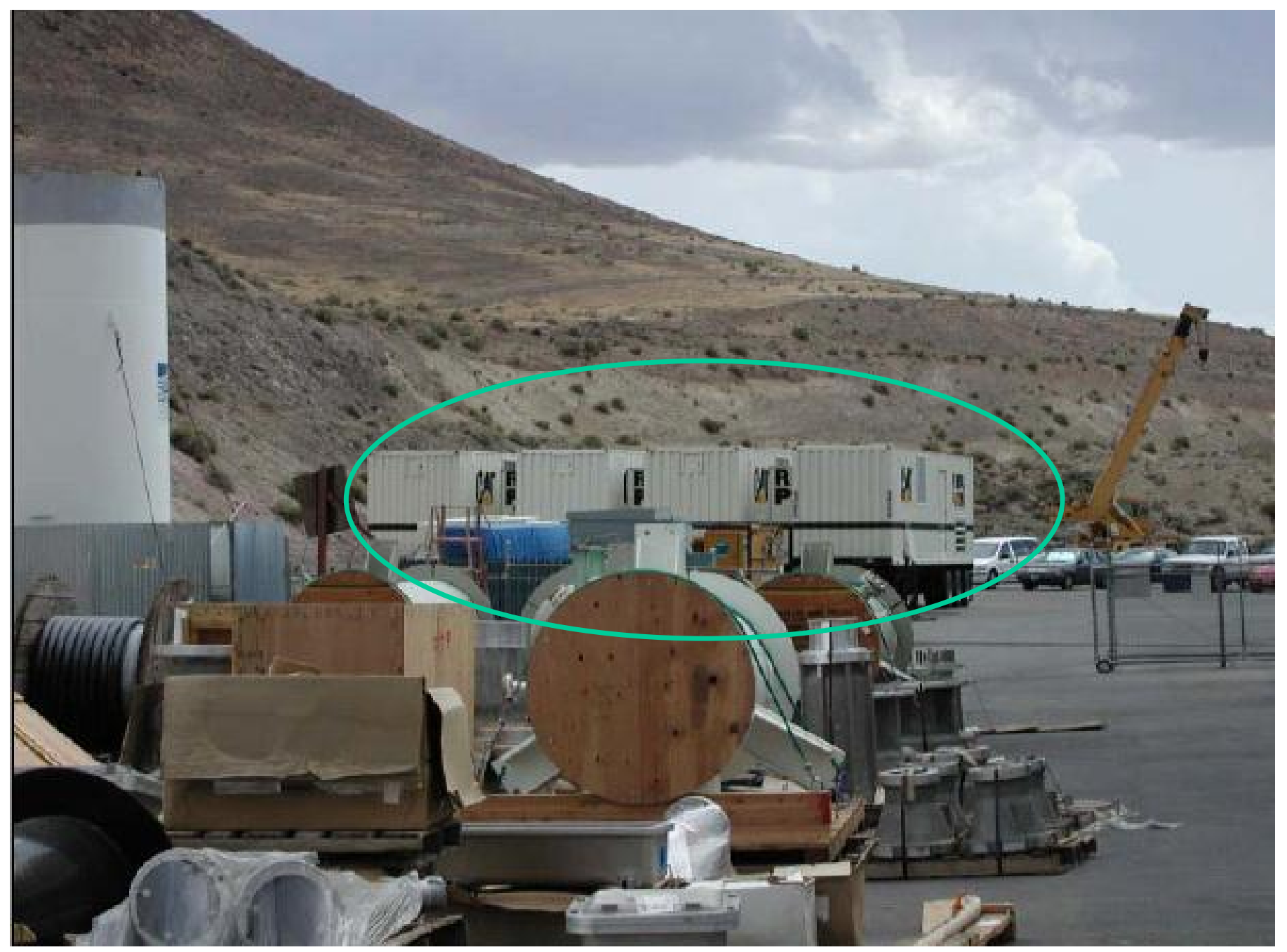




\section{Ebara Motor Stator}

Ebara stacks and winds own motor stators

(Rotors are manufacture d by US Motors)

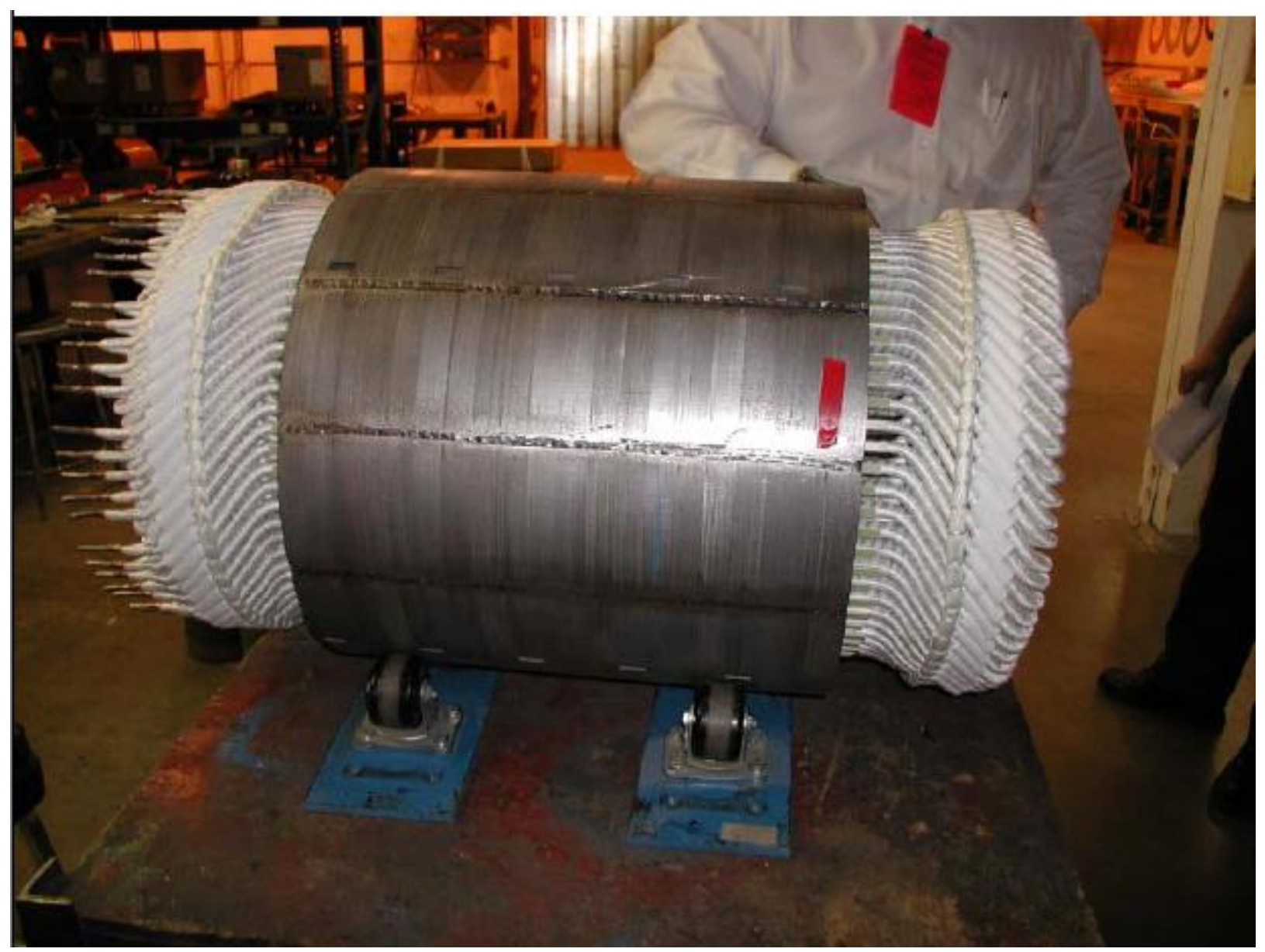




\section{Motor Stator Manufactured by Ebara}

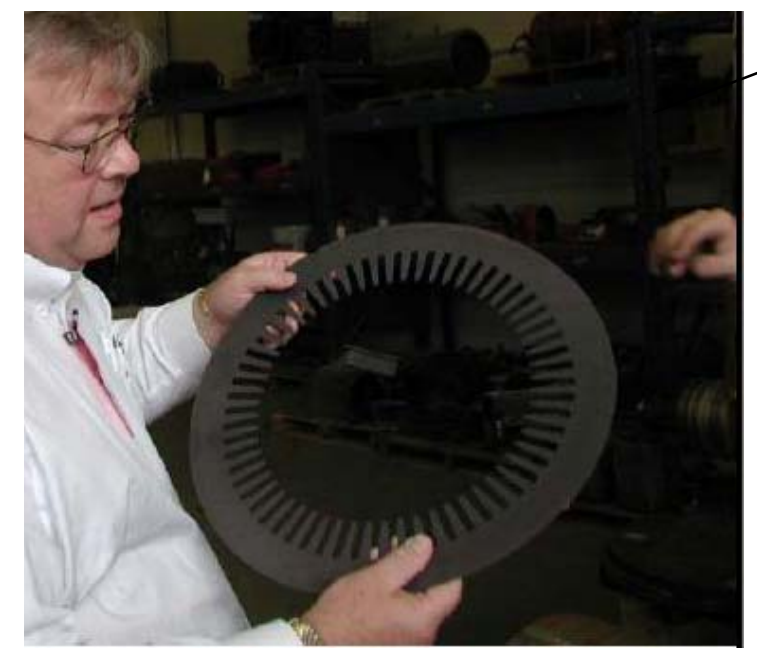

\section{Stator Laminations}
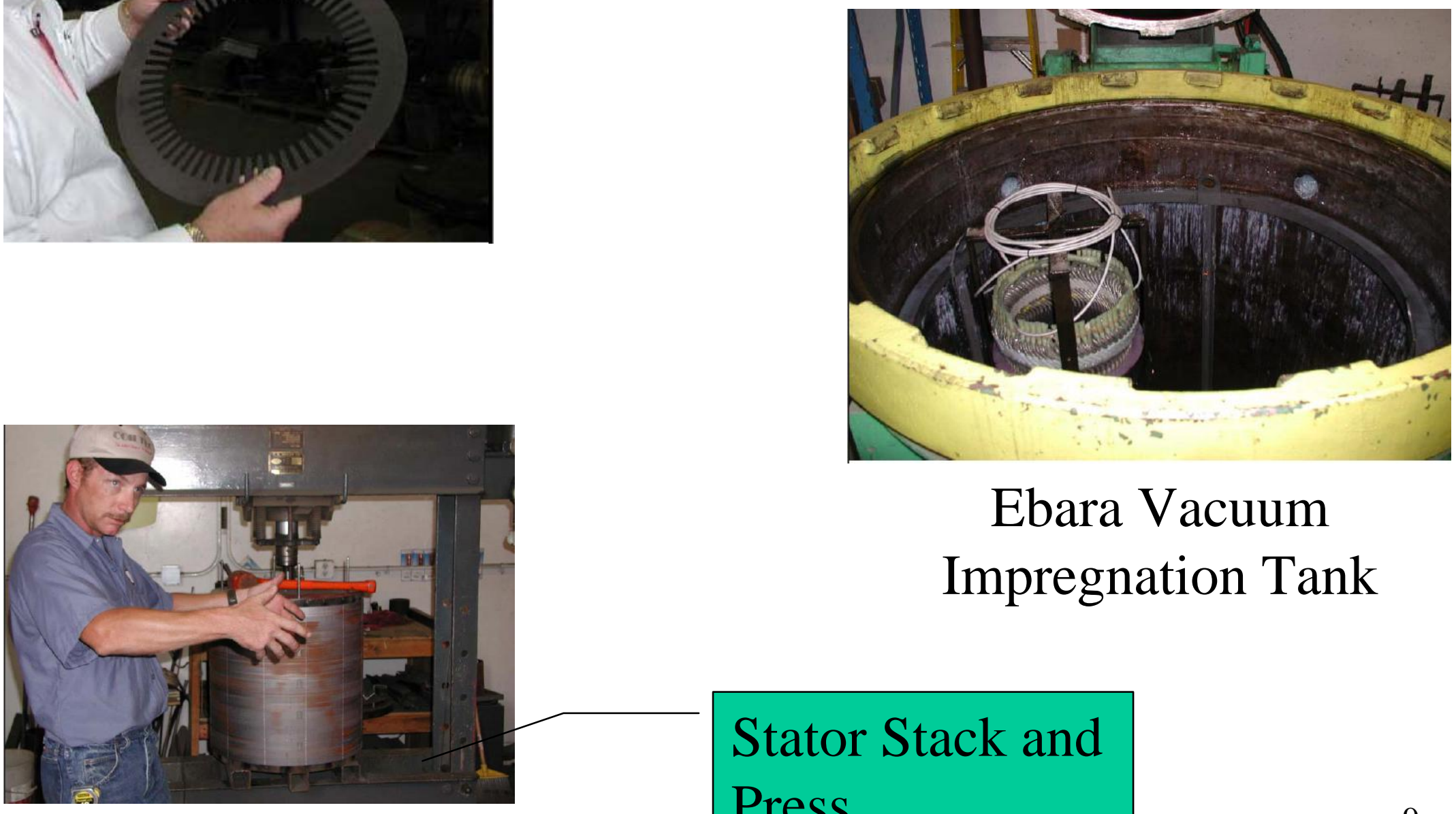

Ebara Vacuum Impregnation Tank

Stator Stack and Press 


\section{Pump Test Results}

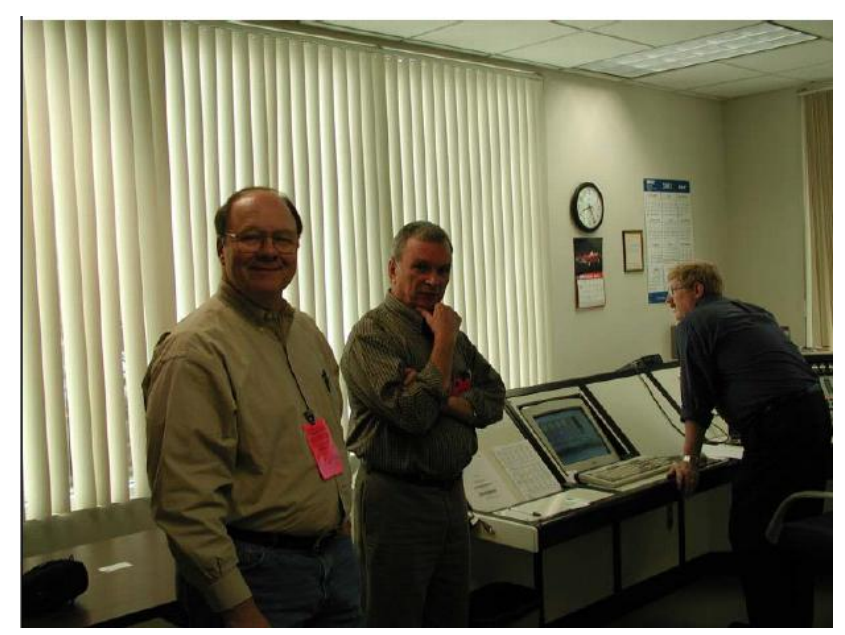

\begin{tabular}{|c|c|c|c|}
\hline & LNG SG $=0.4$ & 252 & \\
\hline & $\begin{array}{l}\text { Electric Freq (Hz) } \\
\text { (psia) }\end{array}$ & $\sim$ motor speed (rpm) & Dis Pres \\
\hline Flow rate & 47.5 & 2812 & 1700 \\
\hline$\left(\mathrm{m}^{\wedge} 3 / \mathrm{hr}\right)$ & 48.5 & 2871 & 1752 \\
\hline 307 & 49.5 & 2930 & 1760 \\
\hline & 50 & 2960 & 1780 \\
\hline & 51 & 3019 & 1860 \\
\hline & 51.5 & 3049 & 1940 \\
\hline & 51.8 & 3067 & 1970 \\
\hline & 52 & 3078 & 2005 \\
\hline & 52.5 & 3108 & 2050 \\
\hline
\end{tabular}

Note: The motor speeds are approximate, assumed slip $=1.3 \%$ @ $50 \mathrm{~Hz}$ the motor shaft is turning a $2960 \mathrm{rpm}$

Note: the flow rate was reduced to operate within the power limits of the electric motor, discharge pressure at $2960 \mathrm{rpm}$ is greater than design because the operating point is closer to shut-off than the design operating point. 
EBARA INTERNATIONAL CORPORATION

CRYODYNAMICSDIVISION

350 SALOMON CIRCLE, SPARKS, NV 89434 U.S.A.

EAAA PHONE (775) 356-2796 : FAX (775) 356-2884

Email: sales@ebaraintl.com or jgoodrich@ebaraintl.com

\begin{tabular}{ll}
\hline \hline & EMAIL TRANSMISSION \\
\hline \hline COMPANY: CGI & FROM: John Goodrich Jr. \\
\hline ATTENTION: D. Braxton Scherz & DATE: 29 May 2003 \\
\hline EMAIL: Ingship@attglobal.net & TOTAL PAGES: \\
\hline COPY: S. Rush - EIC/USA & \\
\hline YOUR REFERENCE: Inquiry of 23 May 03 & REFERENCE: JG.052903.3124.1 \\
\hline SUBJECT: QUS-3124 & \\
\hline \hline
\end{tabular}

Dear Sir,

Thank you for your revised inquiry received 23 May 2003. We now take pleasure in submitting our proposal for your review and consideration in accordance with the attached documentation.

We trust that we have interpreted your requirements correctly, however, should you require any additional information or clarification please do not hesitate to contact us.

Best Regards,

John Goodrich Jr.

Cost Estimating Manager 
WE ARE PLEASED TO SUBMIT THIS BUDGETARY QUOTATION FOR THE FOLLOWING PUMP AND EQUIPMENT IN SUPPORT OF THE SUBJECT APPLICATION.

\section{AA) EQUIPMENT DESCRIPTION}

Pump Model(s) - 6ECC-1514 (low flow), 6ECC-1516 (medium flow), and 6ECC-1518 (high flow)

\section{BB) SCOPE OF SUPPLY AND DATA SHEETS}

The following data sheets and curve(s) are attached:

Pump Data Sheet

Motor Data Sheet

Performance Curve

Submittal Documentation

Special Tools List

\section{CC) PRICES}

Standard Conditions of Sales

Warranty

\section{DD) MATERIALS OF CONSTRUCTION}


TECHNICALAND COMMERCIAL QUOTATION

EQUIPMENT DESCRIPTION, SUCTION VESSEL MOUNTED

\begin{tabular}{|c|c|c|c|}
\hline ITEM NUMBER & $\begin{array}{l}\text { Case \# 1, } \\
\text { Low Flow }\end{array}$ & $\begin{array}{c}\text { Case \# 2, } \\
\text { Medium Flow }\end{array}$ & $\begin{array}{l}\text { Case \# 3, } \\
\text { High Flow }\end{array}$ \\
\hline EIC PUMP MODEL NO. & 6ECC-1514 & 6ECC-1516 & 6ECC-1518 \\
\hline QUANTITY & 1 & 1 & 1 \\
\hline PUMP TYPE & \multicolumn{3}{|c|}{ Suction Vessel Mounted } \\
\hline NO. OF STAGES & Fourteen (14) & Sixteen (16) & Eighteen (18) \\
\hline LIQUID & \multicolumn{3}{|c|}{ LNG } \\
\hline RATED CAPACITY $\left(\mathrm{M}^{3} / \mathrm{H}\right)$ & 270 & 300 & 330 \\
\hline RATED HEAD (M) & 3133 & 3437 & 3756 \\
\hline MOTOR RATING (kW) & 2013.4 & 2274.4 & 2610 \\
\hline LIQUID SP. GR. & \multicolumn{3}{|c|}{0.45} \\
\hline LIQUID TEMP. (Deg C) & \multicolumn{3}{|c|}{-160} \\
\hline ABSORBED / MAX. kW & $1618.5 / 1979.9$ & 1952.4/2254.9 & $2351.9 / 2580.7$ \\
\hline $\begin{array}{l}\text { NPSHR / PUMPDOWN } \\
\text { (ABOVE INDUCER } \\
\text { DATUM) (M) }\end{array}$ & $1.37 / 0.46$ & $1.49 / 0.52$ & $1.67 / 0.59$ \\
\hline M.A.W.P. $\left(\mathrm{kg} / \mathrm{cm}^{2}\right)$ & 160 & 182 & 207 \\
\hline $\begin{array}{l}\text { DISCHARGE NOZZLE } \\
\text { SIZE / RATING }\end{array}$ & \multicolumn{3}{|c|}{6 Inch - $1500 \mathrm{lb}$} \\
\hline PUMP / MOTOR WT. (kg) & 8755 & 8980 & 9210 \\
\hline $\begin{array}{l}\text { ELECTRICAL SUPPLY } \\
\text { (VOLT/HZ/PH) }\end{array}$ & \multicolumn{3}{|c|}{$6600 / 60 / 3$} \\
\hline $\begin{array}{l}\text { NOMINAL O.D. OF } \\
\text { VESSEL }\end{array}$ & \multicolumn{3}{|c|}{$1219.2 \mathrm{~mm}$} \\
\hline
\end{tabular}

ISO 9001:2000 (ANSI/ASQC Q9001-2000) Registered Quality System 


\section{SCOPE OF SUPPLY FOR SUCTION VESSEL MOUNTED PUMPS}

PUMP MODEL AS INDICATED COMPLETE WITH:

1. INTEGRAL ELECTRIC MOTOR.

2. HEADPLATE ASSEMBLY IN STAINLESS STEEL PER THE ASME CODE.

3. SUCTION VESSEL ASSEMBLY IN STAINLESS STEEL PER THE ASME CODE.

4. ELECTRICAL TESTS PER OUR QA MANUAL AND QUALITY PLAN.

5. DUAL ELECTRICAL PENETRATION SEALS.

6. “UL" LISTED ELECTRICAL JUNCTION BOX SUITABLE FOR CLASS 1, DIVISION 1 LOCATIONS.

7. SUPPLY OF MATERIAL CERTIFICATES, DRAWINGS, MANUFACTURING PLAN, TEST PROCEDURE, DOCUMENTATION AND DATA AS DESCRIBED AND/OR REQUIRED.

8. MANUFACTURING AND MATERIAL TESTS.

9. HYDROSTATIC TESTS ON PUMP AND COMPONENTS.

10. PRESERVATION AND OCEAN BOXING.

11. DELIVERY IS 12 MONTHS, EX-WORKS SPARKS, NEVADA FACTORY PER INCOTERMS 2000. 
Pump Model

6ECC-1514

Number of Stages

Liquid

Operating Temperature

Specific Gravity

Capacity: Rated Flow

B.E.P. Flow

Minimum Continuous Flow

Differential Head:

Rated

B.E.P.

Shutoff

NPSHR

Rated Flow

Efficiency: Rated

B.E.P.

Power Required: Rated

B.E.P.

Maximum

Shutoff

$\left({ }^{\circ} \mathrm{C}\right)$

LNG

14

$-160$

0.45

$\left(\mathrm{m}^{3} / \mathrm{hr}\right)$

270

$\left(\mathrm{m}^{3} / \mathrm{hr}\right)$

306

$\left(\mathrm{m}^{3} / \mathrm{hr}\right)$

107

(m)

3133.0

(m) (see Note 1)

3000.4

(m)

(m) (see Note 2)

3552.7

$(\%)$

1.37

64.2

$(\%)$

64.9

$(\mathrm{kW})$

$(\mathrm{kW})$

1618.5

(kW)

(see Note 3)

1733.6

1979.9

(kW)

785.2

(rpm)

3560

Rated Rotational Speed (Calculated)

Vibration Level

Maximum Differential Pressure

$\left(\mathrm{kg} / \mathrm{cm}^{2}\right)$

IN ACCORDANCE WITH API 610

160

\section{CONSTRUCTION DETAILS:}

Impeller Diameter:

$\begin{array}{ll}\text { Rated } & (\mathrm{mm}) \\ \text { Minimum } & (\mathrm{mm}) \\ \text { Maximum } & (\mathrm{mm})\end{array}$

Ratio (Impeller Rated OD / Maximum OD)

Pump Type

Impeller Type

Axial Thrust

Pump/ Motor

Discharge Flange Size

(kg)

(ANSI)

(ANSI)

Suction Flange Size

(ANSI)
341.25

285

406

0.841

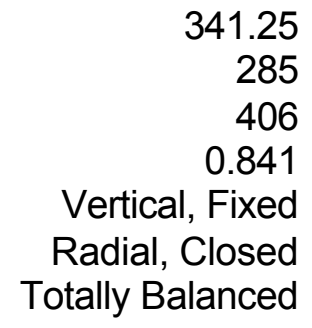

6 Inch - $1500 \mathrm{lb}$

10 Inch - $150 \mathrm{lb}$

4 Inch - 150 lb

NOTE 1: B.E.P. MEANS BEST EFFICIENCY POINT.

NOTE 2: NPSHR DATUM AT INDUCER CENTERLINE.

NOTE 3: AT 120\% OF B.E.P. AND SPECIFIC GRAVITY OF 0.45 . 


\section{MOTOR DATA SHEET - QUOTATION, LOW FLOW}

Pump Model Number

$\begin{array}{ll} & \text { 6ECC-1514 } \\ & \text { EIC / EMD } \\ (\mathrm{kW}) & 2013.4 \\ (\mathrm{~V}) & 6600 \\ (\mathrm{HZ}) & 60 \\ & 2 \\ (\mathrm{rpm}) & 3600 \\ (\mathrm{amps}) & \\ (\mathrm{amps}) & \mathrm{F} \\ & \\ & \\ & \text { Random Wound } \\ \text { Epoxy Dbl Vac Press Impregnation } \\ & \text { Hot Varnish Dip } \\ & \text { Direct On Line } \\ \text { (sec) } & 1.2 \\ \text { Squirrel Cage With Aluminum Bars }\end{array}$

Efficiency:

$$
\begin{aligned}
& \text { 4/4 Load } \\
& \text { 3/4 Load } \\
& \text { 2/4 Load } \\
& \text { 1/4 Load }
\end{aligned}
$$

$89.6 \%$

$88.7 \%$

$85.9 \%$

$77.5 \%$

$\begin{array}{ll}\text { Power Factor: } & 4 / 4 \text { Load } \\ & 3 / 4 \text { Load } \\ & 2 / 4 \text { Load } \\ & 1 / 4 \text { Load }\end{array}$

0.908

0.906

0.886

0.79 .8

Bearing, Type \& Designation

Ball, 6300 Series 
PUMP DATA SHEET - QUOTATION, MEDIUM FLOW

Pump Model

6ECC-1516

Number of Stages

Liquid

Operating Temperature

Specific Gravity

Capacity: Rated Flow

B.E.P. Flow

Minimum Continuous Flow

Differential Head:

Rated

B.E.P.

Shutoff

NPSHR

Rated Flow

Efficiency: Rated

B.E.P.

Power Required: Rated

B.E.P.

Maximum

Shutoff

$\left({ }^{\circ} \mathrm{C}\right)$

ING

$-160$

0.45

$\left(\mathrm{m}^{3} / \mathrm{hr}\right)$

300

$\left(\mathrm{m}^{3} / \mathrm{hr}\right)$

306

$\left(\mathrm{m}^{3} / \mathrm{hr}\right)$

(m)

107

(m) (see Note 1)

3437.0

(m)

(m) (see Note 2)

3416.7

4048.3

1.49

$(\%)$

64.9

$(\%)$

64.9

$(\mathrm{kW})$

$(\mathrm{kW})$

$(\mathrm{kW})$

(kW)

Rated Rotational Speed (Calculated)

Vibration Level

Maximum Differential Pressure

(rpm)

$\left(\mathrm{kg} / \mathrm{cm}^{2}\right)$

1952.4

1974.2

2254.9

893.5

3560

IN ACCORDANCE WITH API 610

182

CONSTRUCTION DETAILS:

Impeller Diameter:

$\begin{array}{ll}\text { Rated } & (\mathrm{mm}) \\ \text { Minimum } & (\mathrm{mm}) \\ \text { Maximum } & (\mathrm{mm})\end{array}$

340.75

285

406

Ratio (Impeller Rated OD / Maximum OD)

0.839

Pump Type

Impeller Type

Axial Thrust

Pump/ Motor

Discharge Flange Size

( $\mathrm{kg})$

Suction Flange Size

(ANSI)

(ANSI)

Vent Flange Size

(ANSI)

Vertical, Fixed

Radial, Closed

Totally Balanced

6 Inch - $1500 \mathrm{lb}$

$10 \mathrm{lnch}-150 \mathrm{lb}$

4 Inch - $150 \mathrm{lb}$

NOTE 1: B.E.P. MEANS BEST EFFICIENCY POINT.

NOTE 2: NPSHR DATUM AT INDUCER CENTERLINE.

NOTE 3: AT 120\% OF B.E.P. AND SPECIFIC GRAVITY OF 0.45.

ISO 9001:2000 (ANSI/ASQC Q9001-2000) Registered Quality System 


\section{MOTOR DATA SHEET-QUOTATION, MEDIUM FLOW}

Pump Model Number

6ECC-1516

Manufacturer

EIC / EMD

Motor Rating

Voltage

$(\mathrm{kW})$

(V)

2274.4

Frequency

$(H Z)$

6600

Number of Poles

60

Synchronous Speed

Current:

Full Load (100\% Volts)

Starting $(100 \%$ Volts $)$

Insulation Class

(rpm)

2

(amps)

(amps)

Winding Type

Winding Special Treatment

Metallic Parts Treatment

Starting Method

Starting Time (Calculated)

Rotor Type

(sec)

3600

F

Random Wound

Epoxy Dbl Vac Press Impregnation

Hot Varnish Dip

Direct On Line

Squirrel Cage With Aluminum Bars

Efficiency:

4/4 Load

3/4 Load

$89.6 \%$

2/4 Load

$88.7 \%$

1/4 Load

$85.9 \%$

$77.5 \%$

Power Factor: $\quad$ 4/4 Load

0.908

3/4 Load

0.906

2/4 Load

0.886

1/4 Load

0.79 .8

Bearing, Type \& Designation

Ball, 6300 Series 
Pump Model

6ECC-1518

Number of Stages

18

Liquid

Operating Temperature

LNG

Specific Gravity

$\left({ }^{\circ} \mathrm{C}\right)$

$-160$

Capacity: Rated Flow

B.E.P. Flow

$\left(\mathrm{m}^{3} / \mathrm{hr}\right)$

0.45

330

$\left(\mathrm{m}^{3} / \mathrm{hr}\right)$

308

Minimum Continuous Flow

$\left(\mathrm{m}^{3} / \mathrm{hr}\right)$

Differential Head:

Rated

(m)

108

B.E.P.

Shutoff

NPSHR

Rated Flow

(m) (see Note 1)

3756.0

(m)

(m) (see Note 2)

3887.9

4608.0

1.67

$(\%)$

64.6

$(\%)$

64.9

Power Required: Rated

B.E.P.

$(\mathrm{kW})$

(kW)

2351.9

2261.1

(kW) (see Note 3)

2580.7

$(\mathrm{kW})$

1023.0

Shutoff

(rpm)

3560

Rated Rotational Speed (Calculated)

Vibration Level

Maximum Differential Pressure

$\left(\mathrm{kg} / \mathrm{cm}^{2}\right)$

IN ACCORDANCE WITH API 610

207

CONSTRUCTION DETAILS:

Impeller Diameter:

$\begin{array}{ll}\text { Rated } & (\mathrm{mm}) \\ \text { Minimum } & (\mathrm{mm}) \\ \text { Maximum } & (\mathrm{mm})\end{array}$

342.75

285

406

Ratio (Impeller Rated OD / Maximum OD)

0.0 .844

Pump Type

Impeller Type

Axial Thrust

Pump/ Motor

Discharge Flange Size

(kg)

(ANSI)

(ANSI)

Suction Flange Size

(ANSI)

Vertical, Fixed

Radial, Closed

Totally Balanced

Vent Flange Size

6 Inch - $1500 \mathrm{lb}$

$10 \mathrm{lnch}-150 \mathrm{lb}$

4 Inch - $150 \mathrm{lb}$

NOTE 1: B.E.P. MEANS BEST EFFICIENCY POINT.

NOTE 2: NPSHR DATUM AT INDUCER CENTERLINE.

NOTE 3: AT 120\% OF B.E.P. AND SPECIFIC GRAVITY OF 0.45.

ISO 9001:2000 (ANSI/ASQC Q9001-2000) Registered Quality System 


\section{MOTOR DATA SHEET - QUOTATION, HIGH FLOW}

Pump Model Number

6ECC-1518

Manufacturer

Motor Rating

Voltage

Frequency

Number of Poles

Synchronous Speed

Current:

Full Load (100\% Volts)

Starting $(100 \%$ Volts $)$

Insulation Class

(kW)

$\mathrm{EIC} / \mathrm{EMD}$

(V)

2610

$(\mathrm{HZ})$

6600

60

(rpm)

2

(amps)

(amps)

3600

Winding Type

Winding Special Treatment

Metallic Parts Treatment

Starting Method

Starting Time (Calculated)

Rotor Type

(sec)

F

Random Wound

Epoxy Dbl Vac Press Impregnation

Hot Varnish Dip

Direct On Line

Squirrel Cage With Aluminum Bars

Efficiency:

4/4 Load

3/4 Load

2/4 Load

1/4 Load

$89.6 \%$

$88.7 \%$

$85.9 \%$

$77.5 \%$

Power Factor: $\quad$ 4/4 Load

0.908

3/4 Load

0.906

2/4 Load

0.886

1/4 Load

0.79 .8

Bearing, Type \& Designation

Ball, 6300 Series 


\section{DRAWINGS, DATA AND DOCUMENTATION}

The following supply of drawings, data and documentation are included in our quoted prices. The drawings/data will be submitted per the schedule as indicated.

\begin{tabular}{|c|c|c|c|}
\hline DESCRIPTION & INITIAL & FINAL & $\begin{array}{l}\text { SUBMITTAL } \\
\text { WEEKS FROM } \\
\text { PO }\end{array}$ \\
\hline (1) General Arrangement Drawing(s) & $3 p$ & $1 r+6 p$ & 6 \\
\hline (2) Assembly Drawing(s) and parts list & $3 p$ & $1 r+6 p$ & 16 \\
\hline (3) Completed Data Sheets (Pump and Motor) & $3 p$ & $6 p$ & 10 \\
\hline $\begin{array}{l}\text { (4) Instruction, Operation \& Maintenance } \\
\text { Manual (IOM) }\end{array}$ & $3 p$ & $6 p$ & 24 \\
\hline (5) Manufacturing Plan/Progress Report(s) & $1 p$ & $\begin{array}{l}\text { (issued } \\
\text { monthly) }\end{array}$ & 6 \\
\hline (6) Manufacturing Data Book (MDB) ${ }^{1}$ & $1 p$ & $6 p$ & $\begin{array}{l}4 \text { weeks after } \\
\text { delivery }\end{array}$ \\
\hline (7) Quality Plan & $3 p$ & $6 p$ & 8 \\
\hline (8) Test Procedure & $3 p$ & $6 p$ & 18 \\
\hline $\begin{array}{l}\text { (9) Suction Vessel Design Calculations } \\
\text { (if applicable) }\end{array}$ & $3 p$ & $6 p$ & 10 \\
\hline (10) Hazardous Area Certificates & $3 p$ & $6 p$ & 24 \\
\hline (11) Performance Test Report & & $6 p$ & $\begin{array}{l}2 \text { weeks after } \\
\text { test }\end{array}$ \\
\hline (12) Weld Procedure, Weld Map & $3 p$ & $6 p$ & 16 \\
\hline (13) Spare Parts Form & $3 p$ & $6 p$ & 12 \\
\hline (14) Document List & $3 p$ & $6 p$ & 4 \\
\hline
\end{tabular}

$r=$ Reproducible $p=$ Print $^{1}$ This may be incorporated in Quality Plan (7) 


\title{
SPECIAL TOOLS
}

One (1) set of the following is included in our offer. This set will adequately provide for all pump requirements;

\author{
Collet Wrenches \\ Shaft Holding Tool \\ Bearing Locknut Wrench \\ TEM Setting Gauge \\ Support Plate Assembly (Retractable Pumps Only) \\ Alignment Pin (Retractable Pumps Only) \\ Weight Scale (Retractable Pumps Only)
}


PRICING

\begin{tabular}{|c|c|c|c|}
\hline ITEMNUMBER & $\begin{array}{l}\text { Case \# 1, } \\
\text { Low Flow }\end{array}$ & $\begin{array}{c}\text { Case \# 2, } \\
\text { Medium Flow }\end{array}$ & $\begin{array}{l}\text { Case \# 3, } \\
\text { High Flow }\end{array}$ \\
\hline EIC PUMP MODEL NO. & 6ECC-1514 & 6ECC-1416 & 6ECC-1518 \\
\hline QUANTITY & 1 & 1 & 1 \\
\hline $\begin{array}{l}\text { PUMP / MOTOR UNIT } \\
\text { ONLY, PRICE EACH US } \\
\text { DOLLARS }\end{array}$ & $\begin{array}{r}\$ 330,000 \\
-20 \% \\
=\$ 264,000\end{array}$ & $\begin{array}{r}\$ 350,000 \\
-20 \% \\
=\$ 280,000\end{array}$ & $\begin{array}{r}\$ 375,000 \\
-20 \% \\
=\$ 300,000\end{array}$ \\
\hline $\begin{array}{l}\text { SUCTION VESSEL / } \\
\text { HEADPLATE / } \\
\text { ELECTRICAL SYSTEM }\end{array}$ & \multicolumn{3}{|c|}{$\$ 96,250-20 \%=\$ 77,000$} \\
\hline $\begin{array}{l}\text { PRICE EACH, FOR EACH } \\
\text { FULL PERFORMANCE } \\
\text { TEST }\end{array}$ & \multicolumn{3}{|c|}{$\$ 15,000-20 \%=\$ 12,000$} \\
\hline \multicolumn{4}{|c|}{$\begin{array}{l}\text { EACH FULL PERFORMANCE TEST INCLUDES THE FOLLOWING: } \\
\text { A) FIVE (5) POINT HEAD VERSUS CAPACITY TEST IN LNG. } \\
\text { B) ONE (1) POINT NPSH TEST AT OR NEAR THE RATED POINT IN LNG. } \\
\text { C) ONE (1) VIBRATION LEVEL READING AT OR NEAR THE RATED POINT. } \\
\text { D) ONE (1) NOISE LEVEL READING AT OR NEAR THE RATED POINT. } \\
\text { E) STARTING CURRENT. } \\
\text { F) DISASSEMBLY INSPECTION AFTER PERFORMANCE TEST. }\end{array}$} \\
\hline
\end{tabular}

ISO 9001:2000 (ANSI/ASQC Q9001-2000) Registered Quality System 


\section{STANDARD TERMS AND CONDITIONS OF SALE}

$\underline{\text { Commercial terms }}$

1. The quoted prices are fixed and firm for the delivery period for an order placed within the validity period.

2. Validity of Quotation

The quotation is valid for ninety (90) days from the date of this quotation.

3. Currency - The prices are quoted in USA Dollars.

4. The quotation is submitted for and on the behalf of Ebara International Corporation, Cryodynamics Division, 350 Salomon Circle, Sparks, Nevada USA. Telephone (775) 356-2796, Telefax (775) 356-2884, Email: Sales@ebaraintl.com

5. All payments to be made as follows, Net cash thirty (30) days after date of Invoice(s) by bank transfer to our account.

6. Terms of Payment

$15 \%$ against submittal of certified elevation drawings

$20 \%$ upon receipt of major castings and motors in our works declaration that parts are for this order.

$65 \%$ on completion of equipment and our readiness to ship.

7. Warranty

Our equipment is covered by our standard warranty terms, see attached.

8. In no case shall Ebara International Corporation, Cryodynamics Division be liable for indirect, special, consequential incidental damages.

9. Delivery period shall commence from receipt of complete purchase order, containing full and clear information for us to commence design work. Drawing approvals to be given within two (2) weeks of submittal by Cryodynamics.

10. Delivery ex-works based on current shopload is 14 months.

11. VAT and Import Duties/Taxes are excluded from our price. 


\section{STANDARD CONDITIONS OF SALE}

(01 January 1995)

These Standard Conditions Of Sale ("Conditions") exclusively define the contractual relationship between Ebara International Corporation ("EIC") ant the Purchaser, and no terms proposed by the Purchaser in conflict with or additional to these Conditions shall become a part of the contract of sale unless expressly accepted in writing by EIC. Any EIC proposal to which these Conditions are attached or referred shall be for information purposes only, and the Purchaser's order is subject to acceptance and acknowledgement by EIC as the supplier of the equipment in accordance with these Conditions.

\section{TERMS OF PAYMENT}

Terms of Payment for any order based on these Conditions shall be included in the EIC proposal of which these Conditions are a part.

\section{PRICE ADJUSTMENT}

The price clauses applicable to the contract of sale of which these Conditions are a part are included in the EIC proposal and are based on the proposed shipping date of the equipment cited. In the event of delays in release to manufacture or in shipment for any reason the contract price shall be adjusted to the price in effect at the time of shipment. Some equipment to be provided hereunder which is not manufactured by EIC ("Other Equipment") may be subject to different pricing adjustment policies than those stated for the EIC manufactured equipment ("EIC Products"), which Other Equipment shall be identified in the Proposal of which these Conditions are a part and which shall be incorporated in the contract. 
EIC warrants for a period of twelve months from the date of initial startup or eighteen months from the date of shipment, whichever shall first occur (the "Warranty Period") the EIC Products to be delivered hereunder against defects in material and workmanship, under normal use and service when used and maintained in accordance with instructions supplied by EIC. This is EIC's sole and exclusive warranty. It applies only to EIC Products and specifically excludes Other Equipment, whether or not such Other Equipment is included in EIC's scope of supply hereunder. Such Other Equipment is warranted only by its manufacturer. If a defect, as defined, appears in EIC Products within the Warranty Period and Purchaser has given EIC immediate written notice of same, EIC will either repair the part, or at it option replace the part, by shipping a similar part F.O.B. EIC's shipping point, or at its option refund an equitable portion of the purchase price. EIC may require the return of the defective part, transportation prepaid, to establish the claim. All costs of removal, reinstallation, field labor, and transportation shall be borne by the Purchaser. No allowance will be made for repairs without EIC's written consent or approval, and the Warranty Period shall not be suspended upon stopping operation for warranty repairs, nor recommence upon completion of the warranty repairs, but shall run continuously from commencement until normal expiration. Repair parts shall carry no greater warranty than the remaining balance of the underlying EIC Product, into which they may be installed, expiring at the same time as said underlying warranty.

Any descriptions of EIC Products or Other Equipment, any specifications, and any samples, models, bulletins, or similar material used in connection with this sale are for the sole purpose of identifying the said Equipment and not to be construed as express or implied warranties. Unless during the warranty period all repairs or replacements of parts or components for EIC Products are with EIC approved parts or components, and all warranty service is performed by EIC or it's authorized distributor or representative, the warranty responsibility of EIC shall immediately terminate.

\section{EIC MAKES NO OTHER WARRANTY OF ANY KIND WHATSOEVER, EXPRESS OR IMPLIED; AND ALL WARRANTIES OF MERCHANTABILITY AND FITNESS FOR A PARTICULAR PURPOSE AND HEREBY DISCLAIMED BY EIC AND EXCLUDED FROM THESE CONDITIONS. The Purchaser's sole and exclusive remedy, whether upon warranty, contract, or tort, including negligence, will be to proceed under this warranty. All liability of EIC shall terminate no later than the expiration of the Warranty Period.}

\section{ii) INSPECTIONS, TESTS}

Any Purchaser inspections or shop testing of EIC Product at EIC's facilities prior to its shipment must be authorized by EIC in writing at least ten (10) days prior to such inspection, and shall be subject to EIC's manufacturing cycle availability and facility security requirements. Field testing of EIC Products may be conducted by Purchaser to confirm mechanical compatibility of the EIC Product and that there has been no damage in transit, but compliance with specifications shall be conclusively established by shop tests at EIC's facilities. 
EIC shall not in any event be liable for special, indirect, incidental or consequential damages, including liquidated damages in any amount. EIC's liability on any claim of any kind, including negligence, for loss or damage arising out of, connected with, or resulting from a contract based on these conditions, or the performance or breach thereof, or the design, manufacture, sale, delivery, resale, installation, technical direction of installation, inspection, repair, operation or use of any EIC Products covered by or furnished hereunder shall in no case exceed the price paid by the Purchaser for the Equipment. EIC also disclaims all liability, whether in contract, tort, warranty or otherwise, to any party other than Purchaser, and EIC's sole responsibilities with respect of Other Equipment furnished hereunder shall be to ensure mechanical compatibility of EIC Equipment with the Other Equipment and to pass through to the Purchaser whatever warranty the Other Equipment manufacturer has provided to EIC.

\section{iv) SHIPPING DATES/FORCE MAJEURE}

Although the time for shipment given herein is of utmost importance it is an approximation estimated from the date of receipt of order with complete manufacturing information and approval of drawings as may be necessary. EIC shall not be liable for any loss or damage for delay or non-delivery due to the acts of civil or military authority, acts of the Purchaser or by reason of "force majeure" which shall be deemed to mean all causes whatsoever not reasonably within the control of EIC, including, but not limited to, acts of God, war, riot or insurrection, blockages, embargoes, sabotage, epidemics, fires, strikes, lockouts or other industrial disturbances, delays of carriers and inabilities to secure materials, labor or manufacturing facilities.

\section{v) PAYMENTS}

Unless otherwise stated in the proposal, the prices quoted are specified in U.S. Dollars and shall be payable to EIC free of all exchange, conversion and collection fees or charges. Pro rated payments shall be made for partial shipments. If shipment is temporarily suspended or postponed at the Purchaser's request, or prevented per paragraph iv), above, then all dates of payments based on date of shipment shall relate instead to the date of completion of manufacture. Letters of credit or other credit instruments established for the Equipment specified herein shall provide for such payment on completion of manufacture where shipment is prevented or postponed under such circumstances. In the event delay in shipment is requested by Purchaser, all costs, and risk of storage and reinspection to make Equipment ready for shipment shall be borne by Purchaser. When in the opinion of EIC the financial condition of Purchaser renders it prudent, EIC may require cash payment or satisfactory security before shipment. Interest at the highest legal rate permitted, not to exceed one and one-half (1 1/2\%) percent per month, will apply to all invoices not paid when due. 
EIC reserves the right to change or modify the design and construction of Equipment and to substitute materials of construction. Such changes, modifications or substitutions, however, shall not affect EIC's commitment to Purchaser to provide Equipment in accordance with specifications as accepted by EIC. If drawings are furnished, they are submitted to show general style and arrangement of the Equipment offered.

\section{vii) CANCELLATION, SUSPENSION, TERMINATION FOR CONVENIENCE OF PURCHASER}

The purchaser may terminate this order for the convenience of the Purchaser at any time upon written notice and payment to EIC of cancellation charges as shall be specified by EIC, which charges may include reasonable anticipated profits and unabsorbed burden costs for EIC. EIC shall use its best efforts to mitigate these latter costs to Purchaser, but shall be under no obligation to act to its overall detriment thereby.

If EIC's performance of the work is delayed for a period of more than three (3) months either by reason of the request or acts of the Purchaser, acts of civil or military authority or by "force majeure", upon removal of the cause of any such delay EIC's performance shall be resumed, delivery will be rescheduled, and the purchase price shall be adjusted to that in effect at the time of resumption of performance, as may then be notified by EIC to Purchaser. If purchaser is unwilling to accept the adjustment price and/or projected delivery date, he may cancel his order by giving written notice thereof to EIC within ten (10) days after EIC's notification. In such event, Purchaser shall be liable for payment of reasonable cancellation charges as specified by EIC, but such charges shall be equitably determined, based on the reason for such termination and EIC's reasonable ability to reutilize such terminated Equipment. In no event EIC be liable hereunder for cover or other consequential damages.

\section{viii) $\quad$ RISK OF LOSS, SECURITY}

The Purchaser shall bear all risk of loss or damage to the Equipment after delivery to EIC's transportation facility at shipping point. Purchaser agrees that EIC shall retain a security interest in the Equipment only until the purchase price has been paid, and the Purchaser agrees to perform all acts necessary and/or required to perfect and assure EIC's security interest.

\section{ix) TAXES, DUTIES, FREIGHT}

The Purchaser shall pay to EIC, in addition to the purchase price, the amount of all Customs duties, fees and charges, Sales, Use, Privilege, Occupation, Excise or other taxes, Federal, state, local or foreign, which EIC may be required to pay in connection with furnishing Equipment or services to the Purchaser. Purchaser shall also be responsible for payment of all transportation charges, including such increases in cost as may be imposed from rate changes between the time of quotation and shipment, and any additional costs required by changes in Purchaser' shipping requirements. 


\section{x) DISPUTES}

The parties shall use their best efforts to resolve any disputes amicably, in realization that costs associated with litigation of differences may be disproportionate to the matter in dispute. Should amicable resolution prove unsuccessful, the parties hereby consent to the jurisdiction of the Nevada Courts and the application of Nevada laws, rules, and regulations in adjudication of any such dispute. By mutual agreement the parties may elect to submit any dispute to binding arbitration in lieu of litigation, in which event such arbitration shall be conducted in Reno or Carson City, Nevada before the American Arbitration Association in accordance with it's Rules of Conciliation and Arbitration and applying the laws of the State of Nevada. Each party shall bear it's own costs of arbitration.

\section{xi) MISCELLANEOUS}

In event any of the Conditions herein is determined to be legally unenforceable, such Condition shall be deemed severed from these Conditions, and the balance shall remain in force and effect. In the event, however, that such severing materially alters the nature of the relationship between the parties hereto, then at the option of EIC the contract of sale of which these Conditions are a part may be terminated for the convenience of EIC, and an equitable adjustment shall be made for any funds previously paid by Purchaser for which Equipment has not yet been shipped.

These Conditions constitute the entire agreement relating to Conditions of Sale between the parties hereto, and all previous negotiations, discussions, and agreements are deemed merged into and superseded by these Conditions. 


\section{WARRANTY}

WARRANTY - Seller warrants that the articles or service delivered under this order are free from defects in labor, material or workmanship.

The warranties given herein are subject to the conditions that the articles covered are properly installed, serviced and maintained by Buyer or its agents, and that the Buyer shall comply in all respects with Seller's instructions as to the installation, service or maintenance of the articles delivered hereunder.

Seller's responsibility is limited to replacing or repairing at its factory, any part or parts which have been returned to Seller which are defective or do not conform to specifications and are covered by these warranties; provided, however, that such parts are returned to Seller within ninety (90) days after such defect is discovered. Freight to and from factory, are to Buyer's account.

The warranty does not cover any costs to Buyer for replacement of parts, adjustments or repairs or any other work unless such charges are agreed and authorized by Seller in writing.

IN NO EVENT SHALL SELLER BE RESPONSIBLE FOR INCIDENTAL, COLLATERAL OR CONSEQUENTIAL DAMAGES.

The responsibility of Seller under this warranty shall terminate upon the expiration of twelve (12) months from the first use of the equipment or eighteen (18) months following shipment (ex-works); whichever occurs first.

THIS WARRANTY IS PROVIDED SPECIFICALLY IN LIEU OF ANY OTHER WARRANTIES, EXPRESSED OR IMPLIED, INCLUDING ANY IMPLIED WARRANTY OF MERCHANTABILITY OR FITNESS FOR A PARTICULAR PURPOSE, ANY OTHER OBLIGATIONS OR LIABILITY ON THE PART OF THE SELLER. 
MATERIALS OF CONSTRUCTION FOR SUCTION VESSEL MOUNTED PUMPS

\begin{tabular}{|c|c|c|}
\hline PUMP & & \\
\hline ITEM & MATERIAL & ASTM SPECIFICATION \\
\hline PUMP CASTINGS & $\begin{array}{l}\text { ALUMINUM ALLOY } \\
\text { A356-T6 }\end{array}$ & B-26 \\
\hline IMPELLER(S) & $\begin{array}{l}\text { ALUMINUM ALLOY } \\
\text { A356-T6 }\end{array}$ & B-26 \\
\hline INDUCER & $\begin{array}{l}\text { ALUMINUM ALLOY } \\
\text { A356-T6 }\end{array}$ & B-26 \\
\hline BEARINGS & $\begin{array}{l}\text { SST 440C WITH } \\
\text { "CRYOLON" BALL } \\
\text { SEPARATORS }\end{array}$ & \\
\hline $\begin{array}{l}\text { IMPELLER WEAR } \\
\text { RINGS }\end{array}$ & BRONZE & B-144 ALLOY 937 \\
\hline HOUSING WEAR RINGS & STAINLESS STEEL & TYPE 304 \\
\hline PUMP/MOTOR SHAFT & STAINLESS STEEL & 15-5 PH / AQUAMET \\
\hline STATOR & $\begin{array}{l}\text { ELECTRICAL STEEL } \\
\text { LAMINATIONS WITH } \\
\text { COPPER WINDINGS } \\
\text { AND DOUBLE VPI } \\
\text { TREATMENT }\end{array}$ & \\
\hline ROTOR & $\begin{array}{l}\text { ELECTRICAL STEEL } \\
\text { LAMINATIONS WITH } \\
\text { ALUMINUM ROTOR } \\
\text { BARS }\end{array}$ & \\
\hline \multicolumn{3}{|l|}{ SUCTION VESSEL } \\
\hline SHELL & STAINLESS STEEL & A 240, TYPE 304 \\
\hline HEAD & STAINLESS STEEL & A 240, TYPE 304 \\
\hline NOZZLES & STAINLESS STEEL & A 312, TYPE 304 \\
\hline FLANGES & $\begin{array}{l}\text { STAINLESS STEEL } \\
\end{array}$ & A 182, TYPE F304 \\
\hline BOLTING & STAINLESS STEEL & A 320, GRADE B8 \\
\hline \multicolumn{3}{|l|}{ HEADPLATE } \\
\hline HEADPLATE & STAINLESS STEEL & A 182, TYPE F304 \\
\hline FLANGES & STAINLESS STEEL & A 182, TYPE F304 \\
\hline
\end{tabular}

ALL CASTINGS TO BE PER CRYODYNAMICS PROCEDURE SPECIFICATION PS-4013, ALUMINUM ALLOY SAND CASTING AND ALUMINUM ASSOCIATION STANDARD AACS-M5-85, QUALITY LEVEL III, FREQUENCY LEVEL 2 FOR PRESSURE CASTINGS AND QUALITY LEVEL V, FREQUENCY LEVEL 2 FOR NON-PRESSURE CASTINGS. 


\section{Estimated Pump Characteristic Curve - Pump Engineering}

LIQUID : LNG @ -160 C

SPECIFIC GRAVITY : 0.45

IMPELLER DIA. (min/rated/max) : 285 / $340.75 / 406$ mm

RATED FLOW : $300 \mathrm{~m} 3 / \mathrm{h}$

RATED HEAD : $3437 \mathrm{~m}$
PROJECT : LNG Receiving Terminal

PUMP MODEL : 6ECC-1516

ITEM NO. : Case \# 2, Medium Flow CUSTOMER : CGI
DOC. NO. : C-QUS-3124-2

REVISION : N/C

DATE : May 29/03

PREPARED BY : N/A

APPROVED BY : J. Goodrich Jr.

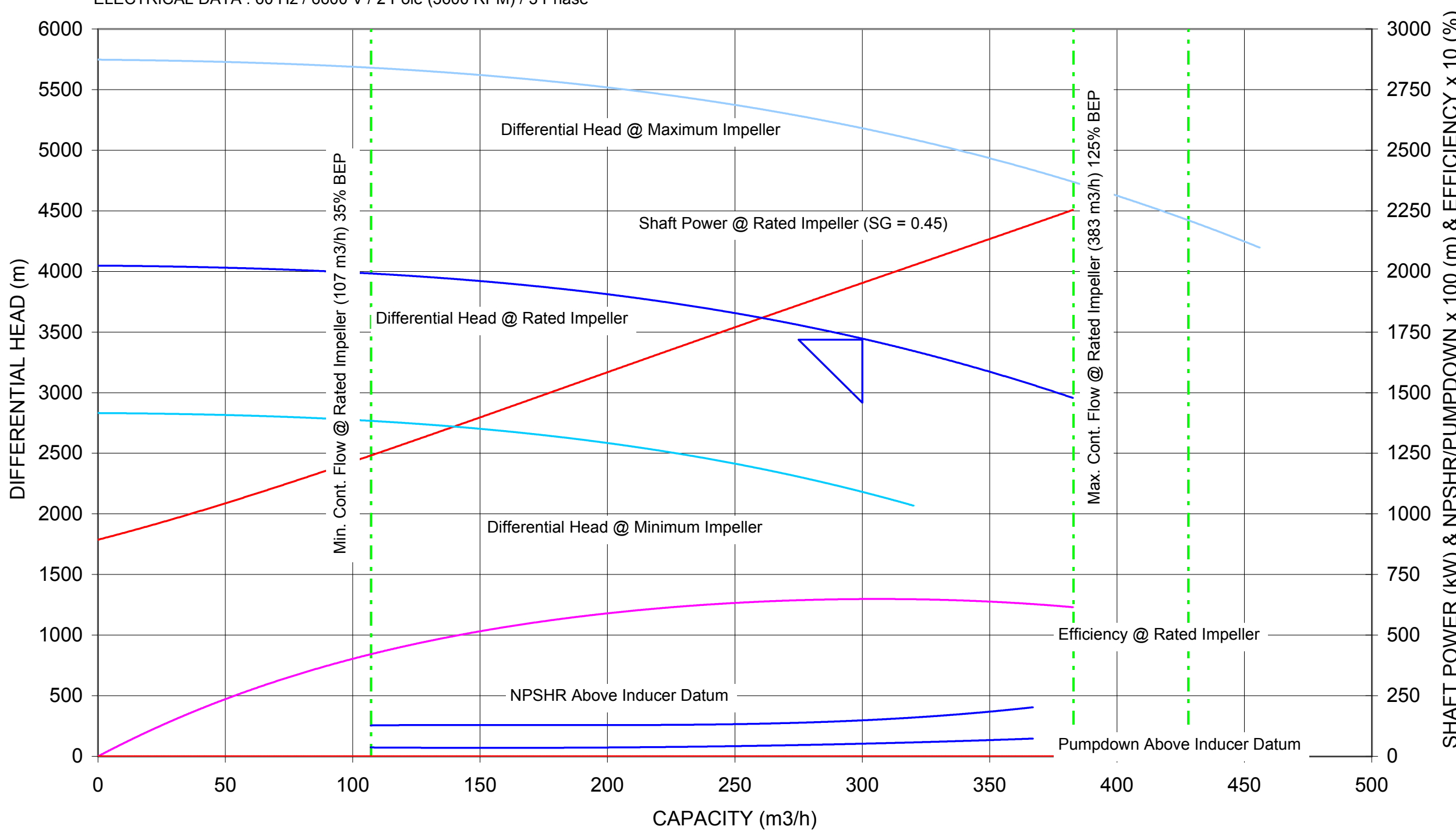

EBARA INTERNATIONAL CORP. - CRYODYNAMICS DIVISION 


\section{Estimated Pump Characteristic Curve - Pump Engineering}

\section{LIQUID : LNG @ -160 C}

SPECIFIC GRAVITY : 0.45

IMPELLER DIA. (min/rated/max) : $285 / 341.25 / 406$ mm

RATED FLOW : $270 \mathrm{~m} 3 / \mathrm{h}$

RATED HEAD : $3133 \mathrm{~m}$

ELECTRICAL DATA : 60 Hz / 6600 V / 2 Pole (3600 RPM) / 3 Phase

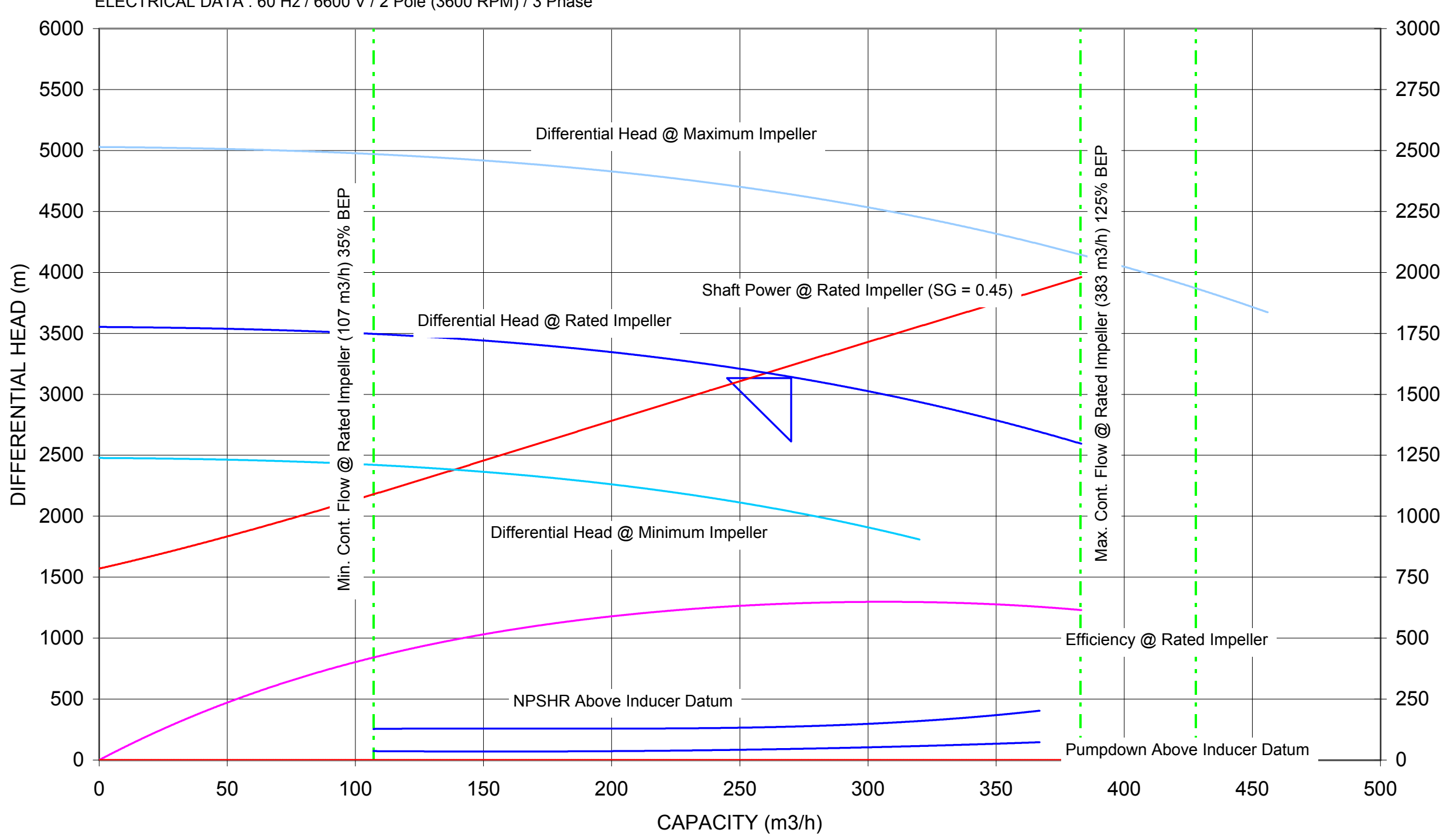

DOC. NO. : C-QUS-3124-1

REVISION : N/C

PREPARED BY : N/A

APPROVED BY : J. Goodrich Jr.
DATE : May 29/03
PUMP MODEL : 6ECC-1514

ITEM NO. : Case \# 1, Low Flow

CUSTOMER : CGI 


\section{Estimated Pump Characteristic Curve - Pump Engineering}

LIQUID : LNG @ -160 C

SPECIFIC GRAVITY : 0.45

IMPELLER DIA. (min/rated/max) : 285 / 342.75 / 406 mm

RATED FLOW : $330 \mathrm{~m} 3 / \mathrm{h}$

RATED HEAD : $3756 \mathrm{~m}$

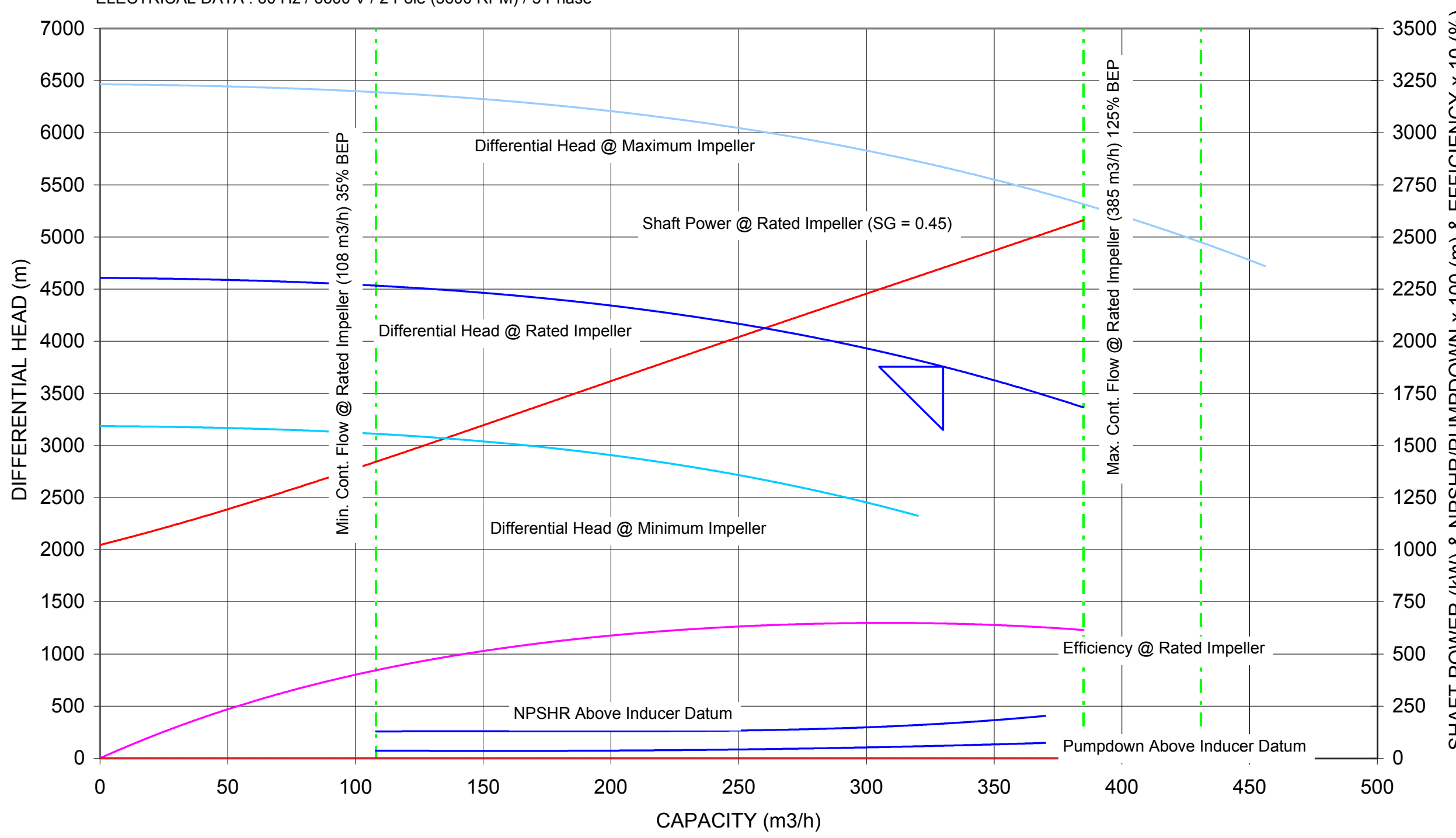

REVISION : N/C

DATE : May 29/03

PREPARED BY : N/A

APPROVED BY : J. Goodrich Jr.
DOC. NO. : C-QUS-3124-3
PUMP MODEL : 6ECC-1518

ITEM NO. : Case \# 3, High Flow

CUSTOMER : CGI 
Nikkiso-Cryo

\section{High Pressure Cryogenic Pumps}




\section{NIKKISO CRYO INCORPORATED}

\section{Company Overview}

History

Nikkiso Co., Ltd. has a long history in the manufacture of specialized rotating machinery including its own developed line of submerged motor cryogenic pumps.

The company has been in the pump business since 1953. Designing and manufacturing products both of its own design as well as under exclusive licensing agreements. Current licensing agreements exist with such well-known companies as Gorman-Rupp Co., Sundstrand Corp., Vetco Gray, and Waltron Corp.

From these beginnings, Nikkiso Co. has become a licensor to Sundstrand Corp., The Boeing Co., and Tae Kwang Industrial Co., Ltd. for proprietary pump designs and other advanced technologies, which it has developed.

Nikkiso's forte and highly regarded reputation for the design and manufacture of pumps and compressors for applications with unique and demanding service requirements is well known in Japan. Nikkiso has supplied pumps for diverse applications in the petrochemical, chemical processing, nuclear power, power generation, and wastewater treatment industries.

It was for these reasons that, in 1982, the J.C. Carter Co. selected Nikkiso as its sole licensee to design and manufacture cryogenic liquefied gas pumps for applications in Japan and Asia.

This strengthened Nikkiso's knowledge, technology and experience in the cryogenic pump area.

In January 1987, ownership of J.C. Carter changed from a public to a privately held corporation. Nikkiso concluded an agreement with the new owners, which granted Nikkiso the exclusive and perpetual rights to all new J.C. Carter pump business worldwide, excluding North America.

Under the terms of this agreement, J.C. Carter subsequently delivered to Nikkiso, all engineering, manufacturing, testing, development, and trouble shooting data developed at J.C. Carter since Mr. Carter's original inception of the submerged motor cryogenic pump design in 1954. In addition, Nikkiso obtained the exclusive right to practice all J.C. Carter U.S. and foreign patents pertaining to submerged motor cryogenic pumps. This was a significant milestone in the cryogenic pumping industry. 
Strengthened by this agreement, Nikkiso has intensified its engineering efforts and commitment to the continued development of technology assuring that this product can be purchased with confidence.

Utilizing superior workmanship and quality control as well as extensive experience in the manufacture of specialized rotating machinery, Nikkiso Co., Ltd., is pleased to offer an improved cryogenic pump design conforming to the highest quality and reliability standards.

To facilitate further development of this business, on January 20, 2000, Nikkiso terminated all agreements with J.C. Carter. These agreements restricted the market territory of new pump supply and offered no opportunity for servicing the replacement pump market. Nikkiso has developed many design improvements and studied numerous existing installations in Japan, which has and continues to be the most developed market for LNG. New hydraulic designs and extended bearing life resulting from improved thrust balancing are some of the examples. This experience can now be transferred to customers worldwide including the United States for new pump supply, maintenance and modification or replacement of existing J.C. Carter pumps. Because of our intimate knowledge of the technology, including possession of all J.C. Carter manufacturing drawings, the modification, repair, inspection and spare parts supply for existing J.C. Carter pumps are now available worldwide.

Also, in January Nikkiso opened an office in London especially for the sale of cryogenic pumps. This office, Nikkiso Cryo Europe, will be responsible for Europe, the Middle East and Africa. This provides Nikkiso with a presence in the UK where many well known engineering companies and low temperature tank builders are located. Nikkiso Cryo Europe, Nikkiso LNG Testing, Inc. and Nikkiso Tokyo form the basis for expanding Nikkiso's cryogenic pump supply and will support Nikkiso's plan for aggressive market development worldwide.

Facilities

\section{Major Plants}

Nikkiso maintains and operates three factories in Japan. The Higashimurayama Plant is located approximately one hour northwest of Tokyo's city center. The Fluid Equipment Factory located here makes pumps and compressors. The plant was built in 1960 as a modern plant, reflecting the philosophies of the founder of the company. As the business has expanded and become more diverse, a ¥3.5 billion expansion of the development and production facilities was recently completed.

The construction included: 
- Construction of a new 7,000 $\mathrm{m}^{2}$ main building

- The addition of $4,700 \mathrm{~m}^{2}$ of factory floor space contained in a new building

- Construction of a new Research \& Development Center opened in January 1999.

Each of Nikkiso's plants is operated under the slogan "Quality Takes Precedence Over All Else". And it is significant to note that Nikkiso was the first Japanese company in the pump manufacturing division of the general machinery category to receive ISO certification.

Fora more detailed description of the plant, please refer to the Higashimurayama Plant brochure in the Appendix of this proposal.

\section{Testing Facilities}

In April 1997 Nikkiso held a ceremony to mark the opening of Nikkiso LNG Testing, Inc. was held in North Las Vegas, NV. The most prominent feature of the facility is that it can service pumps in LNG, which is not possible in Japan. It is the world's largest testing facility of its type with maximum flow capabilities of $3,400 \mathrm{~m} / \mathrm{h}$. Besides providing testing services for pumps, the facility provides testing services to other LNG related industries. One example of these services was a pipeline simulation for Sumitomo Metals. In this test more than 300 channels of instrumentation were used to monitor a 100-meter pipeline that was subjected to a variety of simulated cool down and startup scenarios. The results of these tests are expected to contribute to the validation of Sumitomo's computer simulation that predicts the reaction of cryogenic pipelines under transient conditions.

A detailed description of the testing facility is provided in the following section. 
LNG Pump Testing Facility

\section{OVERVIEW}

The LNG Pump Testing Facility is designed to measure and record the operating characteristics of submerged motor pumps designed and constructed for LNG, propane and other cryogenic hydrocarbon liquids. The facility consists of a cryogenic pump test station where various designs of pumps can be operated to obtain actual pump performance data, a cryogenic storage area and an operations building.

The facility is principally designed for LNG pump testing and the following description is specific to the testing of pumps for LNG service.

Cryogenic test fluids are delivered to the site in road trailers, as either cryogenic liquids at low pressure or as a compressed liquid. Fluid transfer to and from the facility is accomplished by pressure by using pressure building coils or nitrogen gas.

The cryogenic hydrocarbon liquid used as the test media is stored in vessels located on the facility and transferred to the vessels located at the test station. Liquid nitrogen is used to chill the test liquid. The nitrogen removes pump energy and minimizes the venting of the hydrocarbon test liquid. The liquid Nitrogen is also stored on the test facility. Vapor generated during the test procedure may be vented or burned from the discretionary flare. In general, nitrogen and LNG vapor is vented. All other hydrocarbon vapors are flared. The facility also includes a building for control and administrative functions. The building contains a shop area for preparation and service required for assembly, testing and handling of the test pumps.

The facility is designed and constructed in conformance with state and local codes and regulations.

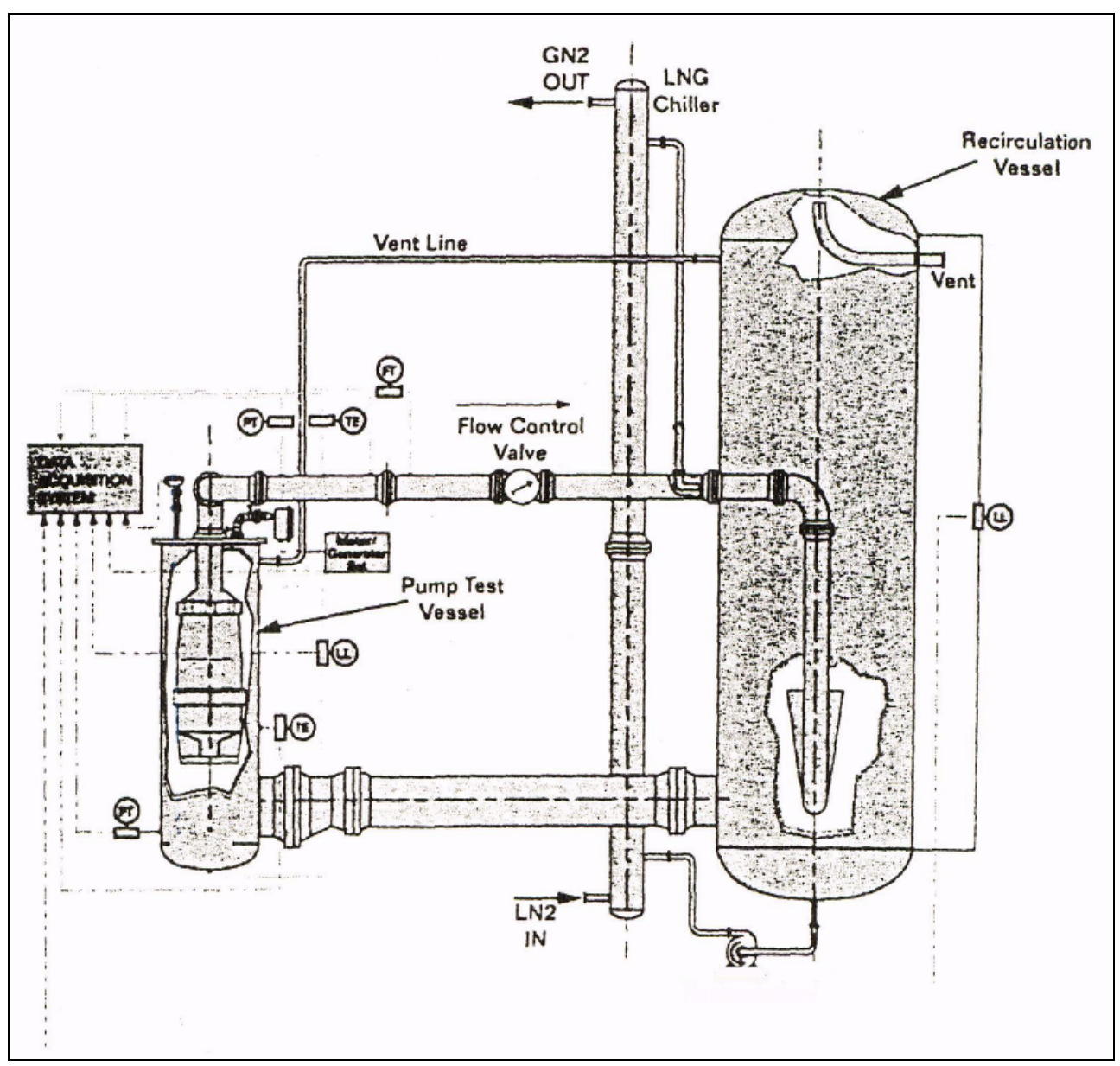




\section{TEST STATION}

The test station contains the pump test loop equipment required for the operation of various designs of submerged motor pumps. The test equipment consists of a Recirculation Vessel, C-300, that functions as the fluid reservoir and liquid head control for the test pump. The pump circulates LNG through a closed loop. The Recirculation Vessel is connected through unrestricted 24" piping to the Test Pump Vessel, C-301, which may be removed and replaced with alternate test vessels. A second pump test vessel, C-303, with 8" suction piping is used for low flow pumps. LNG pumps to be tested are installed in the Pump Test Vessels. LNG discharging from the pump passes through an orifice flow meter run which measures the fluid flow, LNG temperature and pressure. The orifice flanges of each meter run are located for connection to a permanently mounted flow transmitter. Removable flow meter runs are provided to measure the test pump flow over the required range of operation. The size of the meter run and flow control valve are selected in accordance with the flow and head characteristics of the pump. The flow is controlled by throttling the LNG flow downstream of the flow meter before the LNG enters the LNG Recirculation Vessel. Each removable meter run has a flow control valve with positioner. The positioner input to each valve is connected to the local I/P of the flow controller and operated from the control room.

An NPSH/pump down line upstream of the control valve allows test fluid to be returned to the storage vessels in order to lower the level of the recirculation vessel. Each metering run is equipped with a 2" flange connection upstream of the flow control valve that connects to a 2 " valve in the test fluid transfer line. The flanges and valve are 600\# class to allow the same valve to be used for all tests.

The liquid head at the suction of the test pump is controlled by varying the height of LNG in the Recirculation Vessel. This is achieved by transferring LNG to and from LNG storage to obtain the required level in the LNG Recirculation Vessel. Vapor from the LNG pump vessels is vented via 6" piping to the top of the LNG Recirculation Vessel. The heat generated from the pumping energy is removed by circulating LNG through the LNG Chiller, E-300, cooled by liquid nitrogen. The LNG Chiller is designed to remove pumping energy for a 1,000 hp test pump. The chiller design is based on the design of a shell and tube LNG vaporizer. Liquid nitrogen flows upwards through specially designed tubes containing turbulators to promote vaporizing and eliminate surging. LNG flow is on the shell side, co-current with the liquid nitrogen. The shell is designed with an expansion joint to compensate for uneven temperature operation that can occur if the cool down procedure is inadvertently accelerated. Nitrogen vaporized during the chilling process is vented to atmosphere, through either the discretionary flare or the local vent. During pump operation chilled fluid is injected into the pump discharge piping downstream of the flow control valve to mix with the test fluid returning to the recirculation vessel. The cooling effect is designed to remove pump energy and hence condense any flashed LNG vapor. The chilled fluid is injected into the return flow approximately $6 \mathrm{ft}$ below the liquid level of the return pipe, which increases the effective pressure in the liquid to enhance the subcooling effect. The chilling system is designed so that the test fluid may be chilled as it is delivered to the test station from storage, or while it is being circulated in the test loop, prior to, or after, test pump operation. Circulation is by means of Transfer Pumps, P-300 A/B.

\section{TRANSFER PUMPS, P-300 A/B}

Two Transfer Pumps, P-300 A/B are provided to return test fluid from the test station to storage. The pumps are $300 \mathrm{gpm}, 120 \mathrm{ft}$ head designed for LNG service with inducers. Piping to and from the pumps is designed to allow test fluid to be circulated from and to either the Test Pump Vessel or Recirculation Vessel. The system is designed for the pump discharge to flow up through the LNG Chiller co-current with liquid nitrogen. The pumps are intended to be operated separately, one in service and one in standby, however both pumps may be operated at the same time if required. 


\section{RECIRCULATION VESSEL, C-300}

The Recirculation Vessel is designed to provide liquid head for the test pump and to dis-entrain any bubbles that may occur. The diameter, $9 \mathrm{ft}$, is sized to provide an average liquid velocity of less than $0.6 \mathrm{ft} / \mathrm{sec}$ at a flow rate of 15,000 gpm. To enhance the reliquefaction of vapor and eliminate bubbling caused by splashing, the fluid returning to the Recirculation Vessel is introduced below the liquid level. The return pipe projects to the center of the vessel and turns upwards into an enlarged section designed to reduce the velocity to approximately $10 \mathrm{ft} / \mathrm{sec}$ at 15,000 gpm. Discharging the fluid vertically, below the surface calms the fluid and discharges any entrained bubbles to the surface. During test operations where vapor is generated and the circulating fluid is not chilled, the dis-entrainment space above the liquid level prevents significant particulate carry over. The 8" vapor outlet nozzle is ducted from the inside of the vessel head to maximize the dis-entrainment height and further minimize carryover.

The vessel is supported at approximately $25 \mathrm{ft}$, on a steel structure. The structure is designed to flex in the direction of the test pump vessels, while restricting side to side movement. This feature compensates for the contraction and expansion of the piping connecting the Test Pump Vessel and Recirculation Vessel.

\section{OPERATING LEVEL AND DENSITY MEASUREMENT}

The Test Pump Vessels and Recirculation Vessel are equipped with level transmitters that have local gauges from the electronic transmitter and cryogenic site glasses. The cryogenic site glasses allow the actual level of the liquid to be observed at all times. A drain valve connected to the sight glass is used to take test fluid samples. Test fluid is transferred into a dewar flask whose volume and tare weight have been calibrated. The mass of the fluid is measured to determine the density of the test fluid.

\section{SITING}

The test facility is located on a level 4.5 acre site near the northern boundary of N. Las Vegas.

LNG containers, test liquid transfer piping and the test station, are located on LNG Containment drainage systems that are designed to direct a spill to an impoundment. The test station is located at least $50 \mathrm{ft}$. from the nearest building and spill impoundment. LNG and propane storage is located at least $50 \mathrm{ft}$. from the spill impoundment.

\section{SPILL CONTAINMENT AND CONTROL}

Spill trenches and containments are designed to direct liquid spills to a spill impoundment. The trenches, containments and impoundment are made of, or lined with, insulating polymer concrete (I.P.C.) to reduce the vaporization rate of a spill and hence reduce the dispersion distance of a flammable vapor cloud.

The spill impoundment is equipped with a sump pump for water removal. The pump is interlocked with the flammable gas, cryogenic liquid spill and fire detection system to prevent operation in the event of a spill.

The sump pump is designed for $30 \mathrm{gpm}$ to remove the maximum anticipated rain fall of 7"/hr from the spill containment system.

\section{CONTROL ROOM}

Control equipment for the test process and data recording is located in the control room of the operations building. Instrumentation for temperature, pressures and liquid levels is provided to monitor the test operation. Test instrumentation is connected to PC based system with data acquisition and print out capabilities for monitoring and recording test data. Test fluid density can be calculated from either differential head measurement or, accurate mass measurement of a known volume of the test fluid. 


\section{Electrical Power}

Electrical power for the test pump is provided by a diesel driven electric generator located adjacent to the Southwest wall of the shop area and approximately 56 ' from the test station. Utility power for services, lighting and controls is provided from the main service.

\section{Storage Facilities}

The LNG and liquid Nitrogen storage vessels are located approximately 115 ' from the test station. LNG storage pressure is maintained at less than 2 psig during normal operation. LNG is transferred to the LNG Recirculation Vessel by pressurizing the LNG storage vessel using a pressure building coil or Nitrogen vapor. LNG is returned to storage by the LNG Transfer Pumps, P-300A/B, located at the test station or by pressurizing the Test Station with Nitrogen vapor. Spill control and containment is provided by open trenches from the test station and LNG storage area to an impoundment located midway between the test station and LNG storage area. Nitrogen is available from storage as liquid for chilling the test fluid and preceding the test system before transferring the test fluid. Cold nitrogen vapor is used to precool the test pump and recirculation system before liquid nitrogen or test fluid is introduced. Warm nitrogen vapor is available for instrument operation and for purging the test system. A cryogenic vent is provided to dispose of LNG and nitrogen vapor as required. A d utility flare is provided to dispose of hydrocarbon vapors. During testing Nitrogen vapor is generated in the LNG Chiller. LNG and Nitrogen vapor generated due to boil off in the storage vessels is preheated in an ambient heater before venting.

\section{Operations Building}

The operations building is located approximately 55 feet from the test station. The building is 140 ' x 50' and is designed as an operations control building with an shop area of 3000 $\mathrm{ft}^{2}$ that can be expanded for future requirements.

The shop area of the building has a drive through bay that allows LNG pumps and test equipment to be moved to and from the test station and shop area conveniently. A monorail crane is provided to lift the test pumps from and to the transporter and LNG test vessel. 


\section{Predicted Performance of High Pressure LNG Pump 391}

The following data sheets were generated from the predicted, calculated performance of Nikkiso's high pressure LNG pump and will be included as follows. The outline and cross sectional drawings have also been inserted for the reader's reference.

\section{Pump Data Sheets}

CUSTOMER PROJECT No. 2208/18/19/25

PROJECT NAME

LNG 138,000 CBM RV

EQUIPMENT NAME High Pressure Pump

NIKK1SO DOCUMENT No. DEJ62E12A-02

REV. NO.

$\underline{2}$

NIKKISO JOB NO. EJU62E0012A

PUMP DATA SHEET

CUSTOMER: DAEWOO SHIPBUILDING \& MARINE ENGINEERING CO., LTD

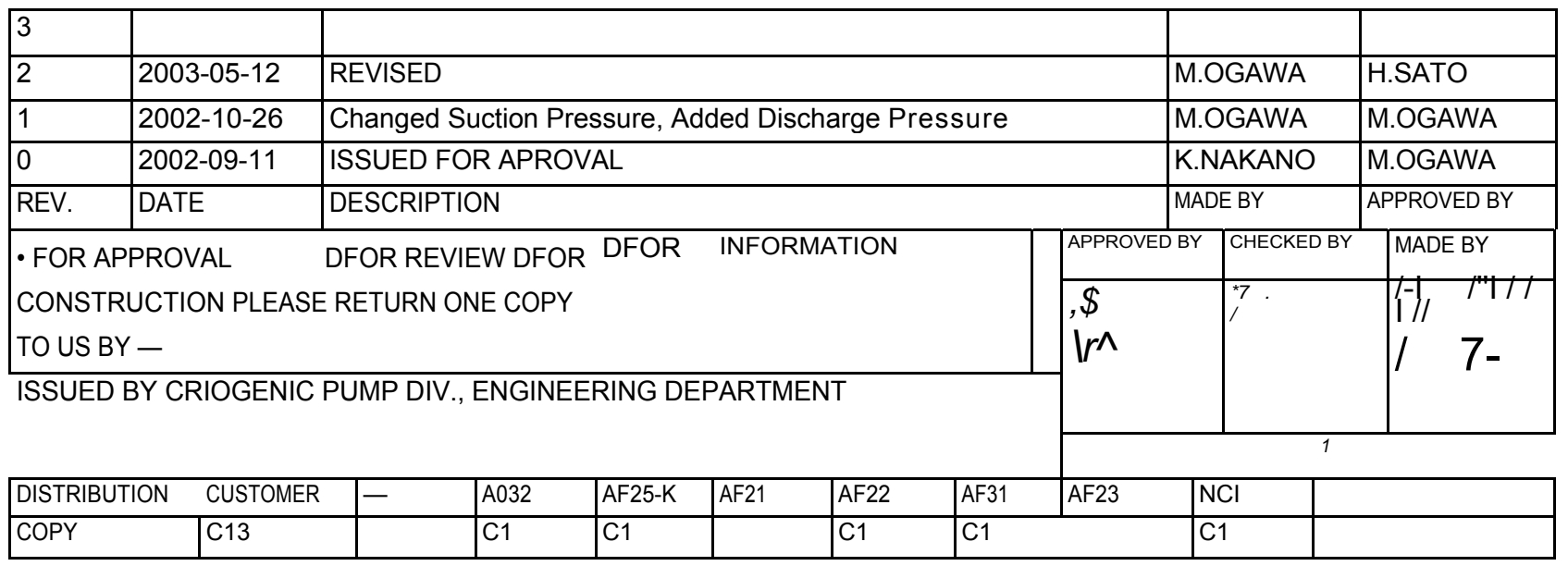

Nikkiso Cryo, Inc. 


\section{NIKKISO CRYOGENIC PUMP DATA SHEET}

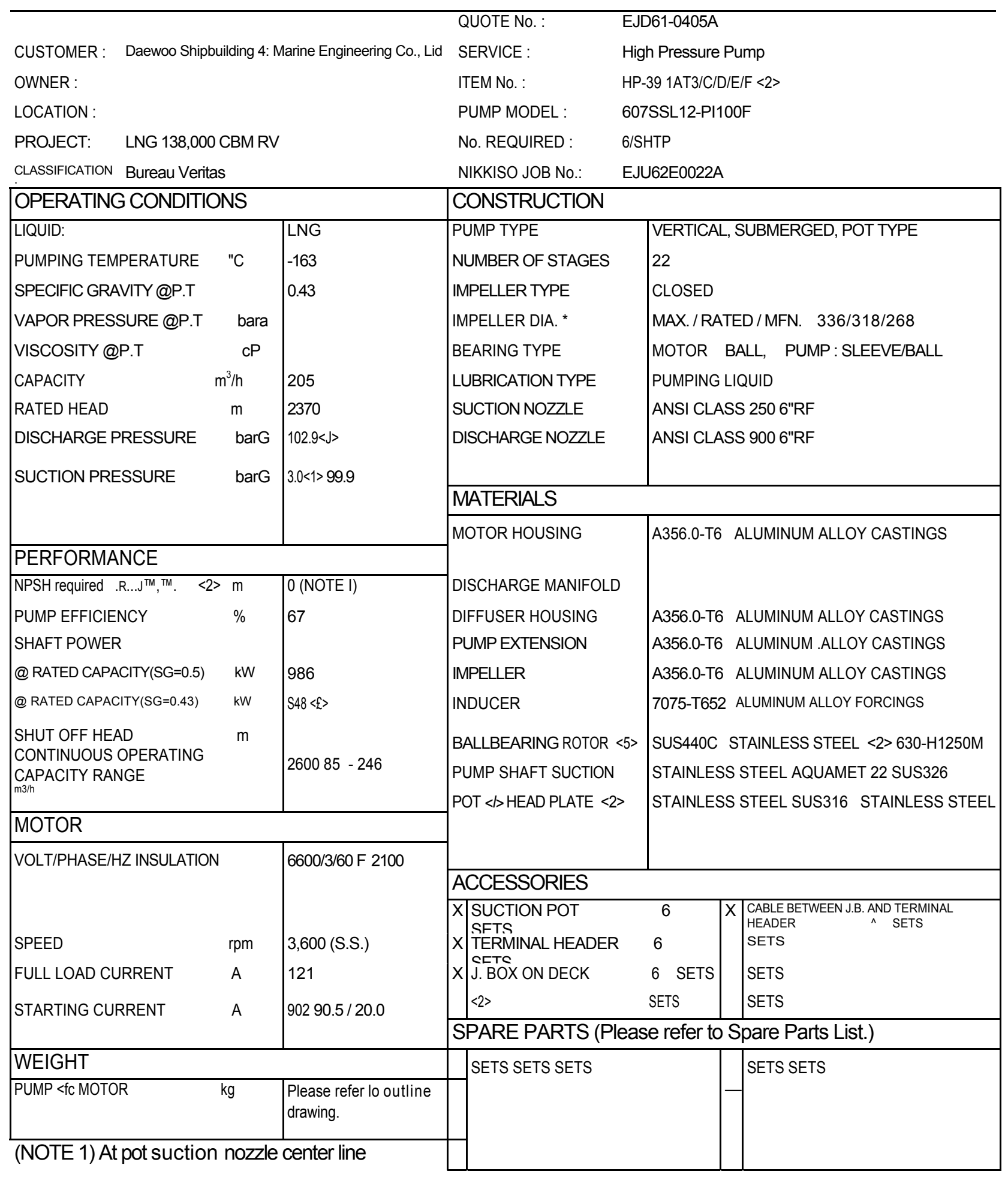

File: Data Sheet and Curve 6078S(Rev.3) 


\section{Predicted Performance Curve}

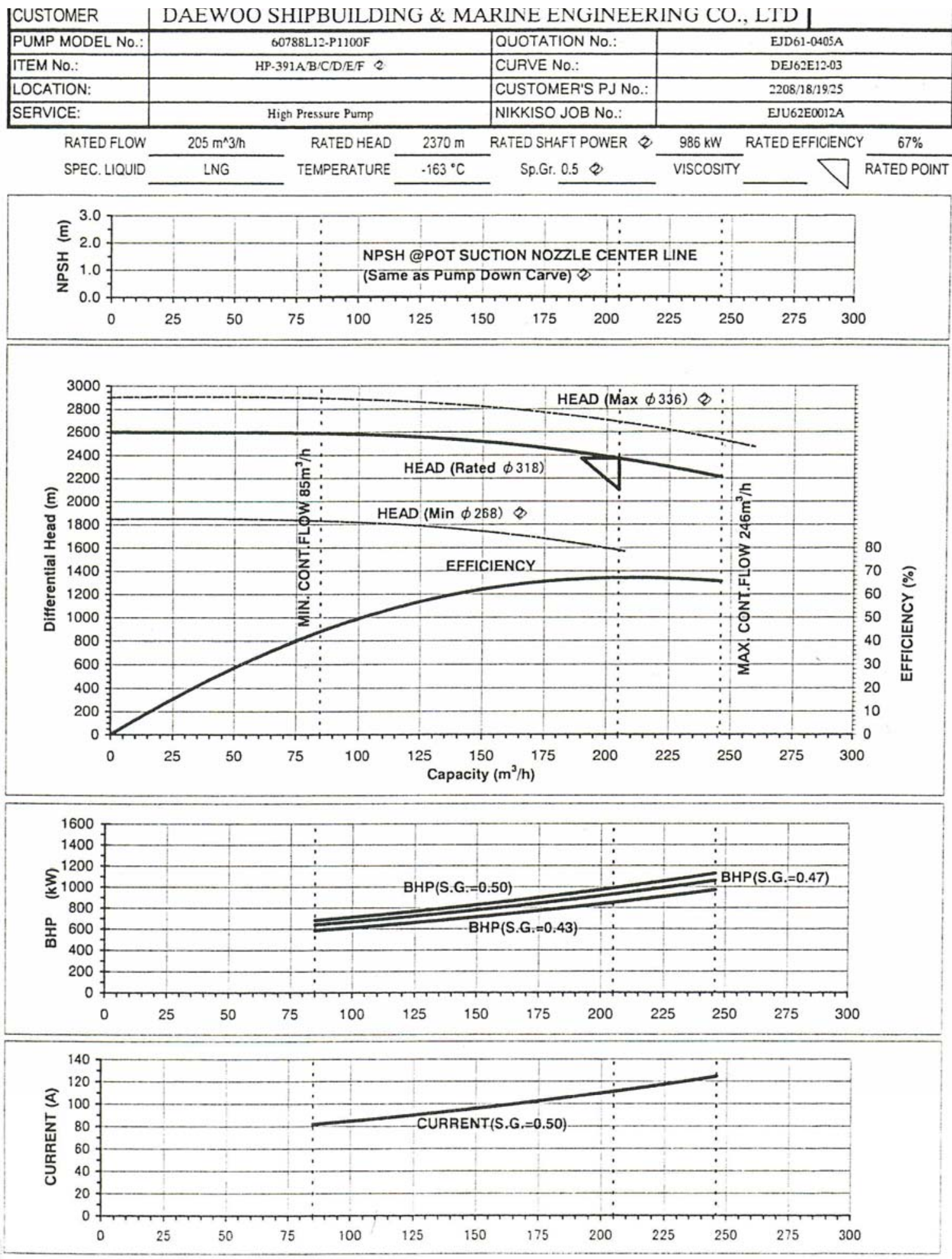

File: Data Sheet and Curve 60788(Rev.2) 
CUSTOMER PROJECT No.

$2208 / 18 / 19 / 25$

PROJECT NAME

EXMAR 138.000 CBM RV

EQUIPMENT NAME

High Pressure Pump
NIKK!SO DOCUMENT No.

REV.NO.

DEJ62E12A-08
EJU62E0012A

REFERENCE NO.

T I T L E :

Motor Performance Curve for HP Pump

CUSTOMER: DAEWOO SHIPBUILDING \& MARINE ENGINEERING CO., LTD

\begin{tabular}{|c|c|l|c|c|}
\hline 3 & & & & \\
\hline 2 & $2003-06-27$ & REVISED TORQE CURVE & M.OGAWA & H.SATO \\
\hline 1 & $2003-05-12$ & ADDED TORQE CURVE & K.N, M.O & H.SATO \\
\hline 0 & $2002-10-07$ & ISSUED FOR APROVAL & M.OGAWA & H.SATO \\
\hline REV. & DATE & DESCRIPTION & MADE BY & APPROVED BY \\
\hline
\end{tabular}

DFOR APPROVAL IFOR CONSTRUCTION

PLEASE RETURN ONE COPY TO US BY -

ISSUED BY CRIOGENIC PUMP DN., ENGINEERING DEPARTMENT

$$
\text { D! }
$$$$
\text { DFOR REVIEW } \square \text { FOR INFORMATION }
$$
COPY

CUSTONER

$-$

\begin{tabular}{|c|c|c|c|}
\hline A.032 & AF25-K & AF21 & AF2 \\
\hline
\end{tabular}

\begin{tabular}{l|c|c|c}
$\mathrm{Cl}$ & $\mathrm{Cl}$ & & $\mathrm{Cl}$
\end{tabular}

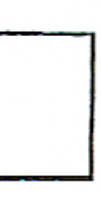

\begin{tabular}{|}
\begin{tabular}{|l|l|l|l|}
\hline Aaproved BY & CHECKED BY & MADE BY \\
\hline & & \\
\hline
\end{tabular} \\
\hline
\end{tabular}




\section{NIKKISO CRYOGENIC PUMP MOTOR EXPECTED PERFORMANCE CURVE}

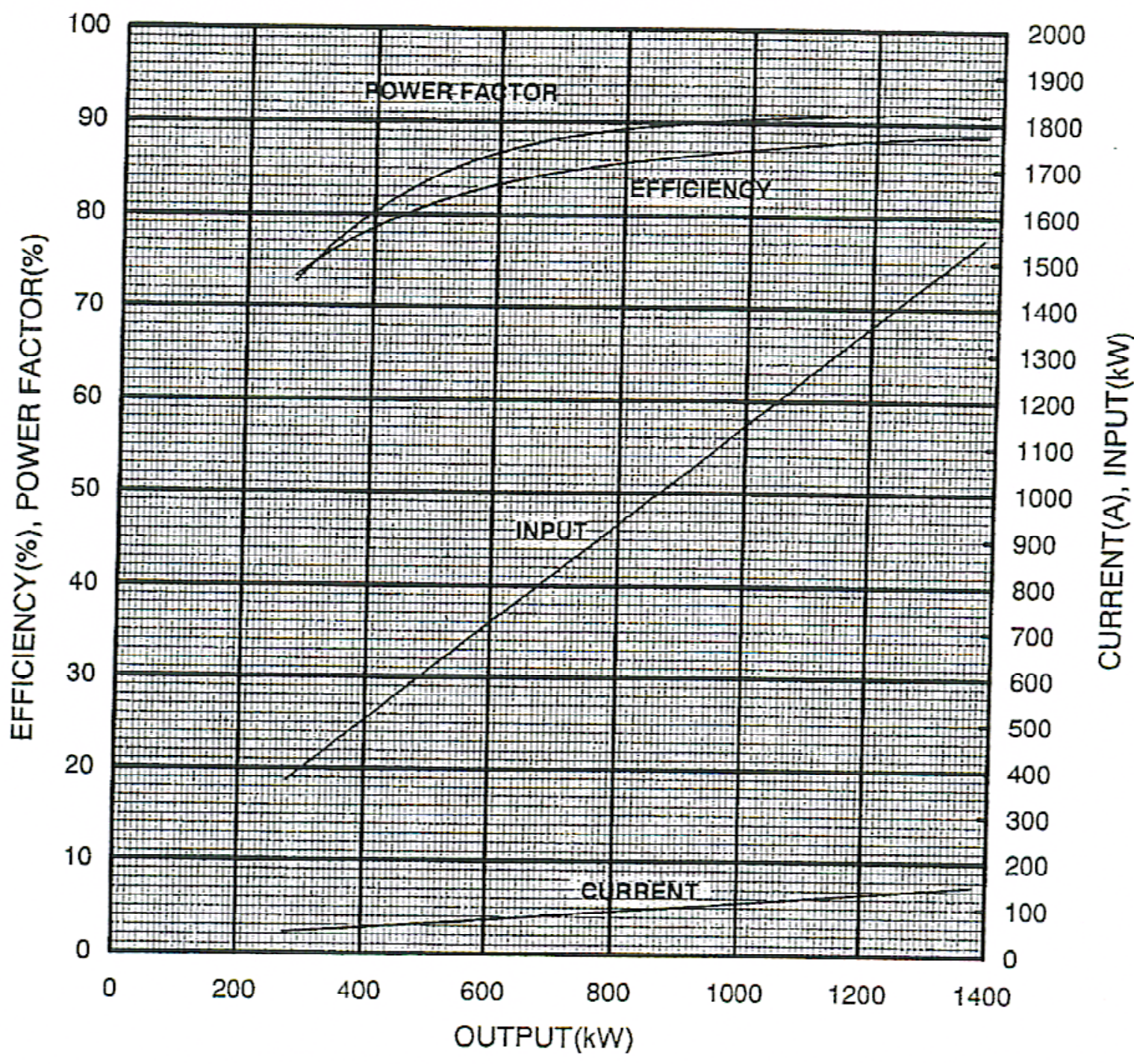

$\begin{array}{lc}\text { FLUID } & \text { LNG } \\ \text { OUTPUT } & 1100 \mathrm{~kW} \\ \text { POLES } & 2 \mathrm{P} \\ \text { FREQ. } & 60 \mathrm{~Hz} \\ \text { VOLT } & 6600 \mathrm{~V}\end{array}$

TEMP. $\quad-163^{\circ} \mathrm{C}$

RATED CURRENT 121A STARTING CURREN $902 A$ 


\section{NIKKISO-CRYOGENIC PUMP SPEED-TORQUE, CURRENT CURVE}

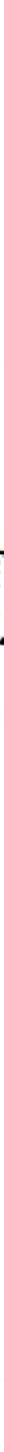

$\begin{array}{lc}\text { FLUID } & \text { LNG } \\ \text { OUTPUT } & 1100 \mathrm{~kW} \\ \text { POLES } & 2 \mathrm{P} \\ \text { FRIQ. } & 60 \mathrm{~Hz} \\ \text { VOLT } & 6600 \mathrm{~V}\end{array}$

TEMP.

$-163^{\circ} \mathrm{C}$

RATED CURRENT

STARTING CURRENT

$121 \mathrm{~A}$

$902 \mathrm{~A}$

STARTING TORQUE

$3350 \mathrm{~N} \cdot \mathrm{m}$

RATED TORQUE $2923 \mathrm{~N} \cdot \mathrm{m}$ 
Pump Cross Section Drawing

The following photos and diagrams have been added to illustrate the assembly of the pump and preparation for insertion into the test stand.

\section{Nikkiso Cryo Pod Mounted Pump}
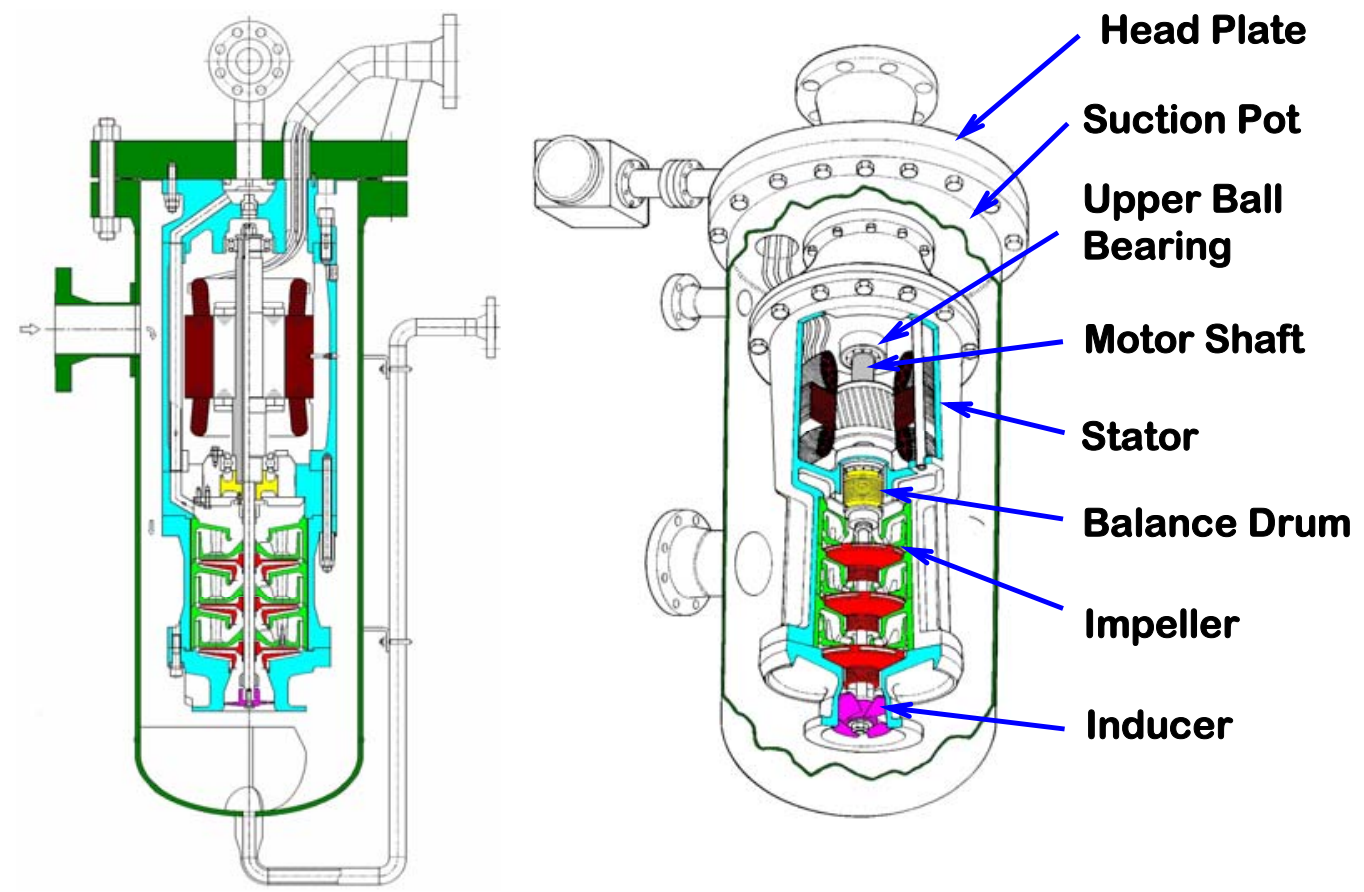


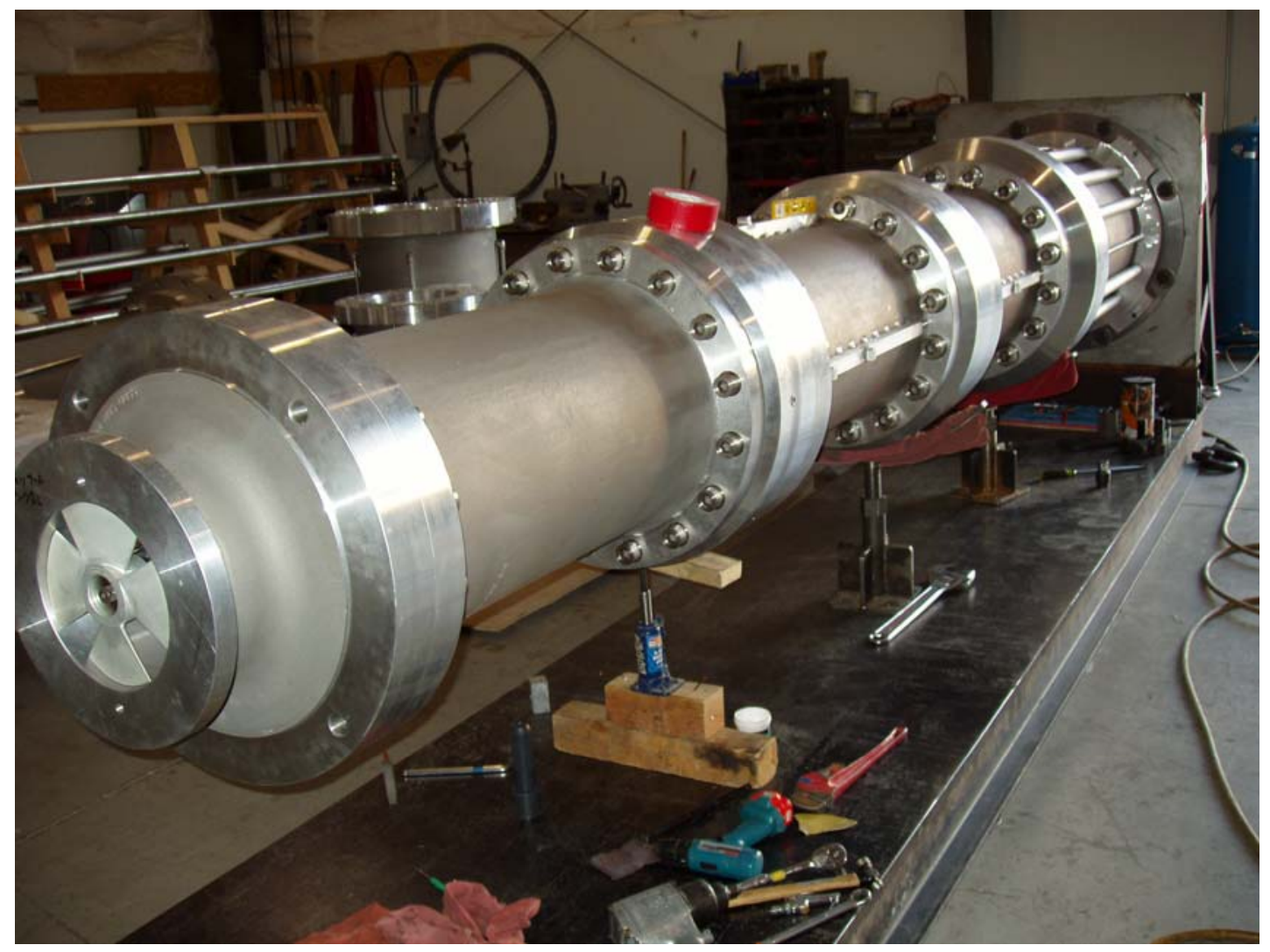

Completed Pump Assembly Ready for Testing

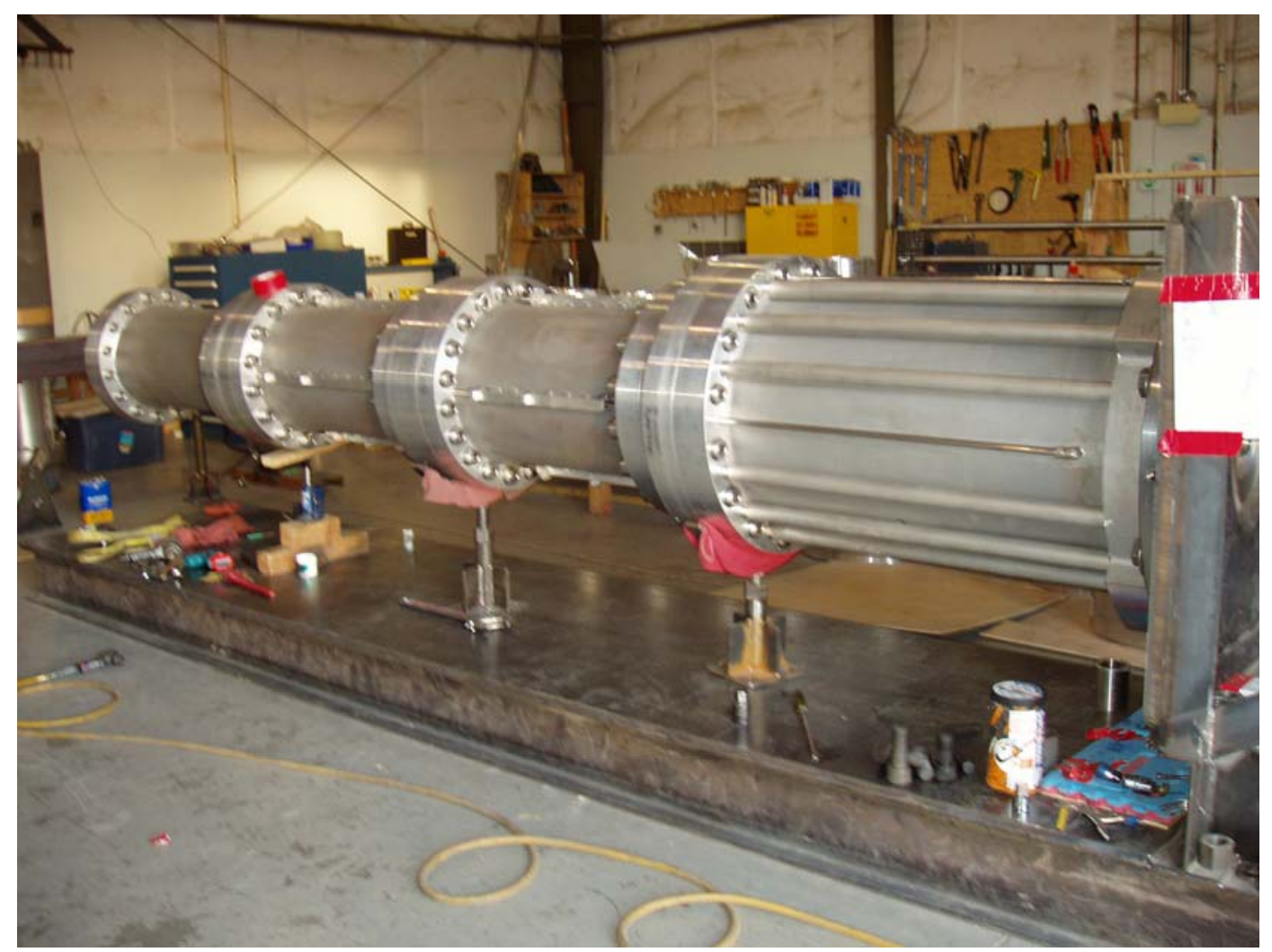




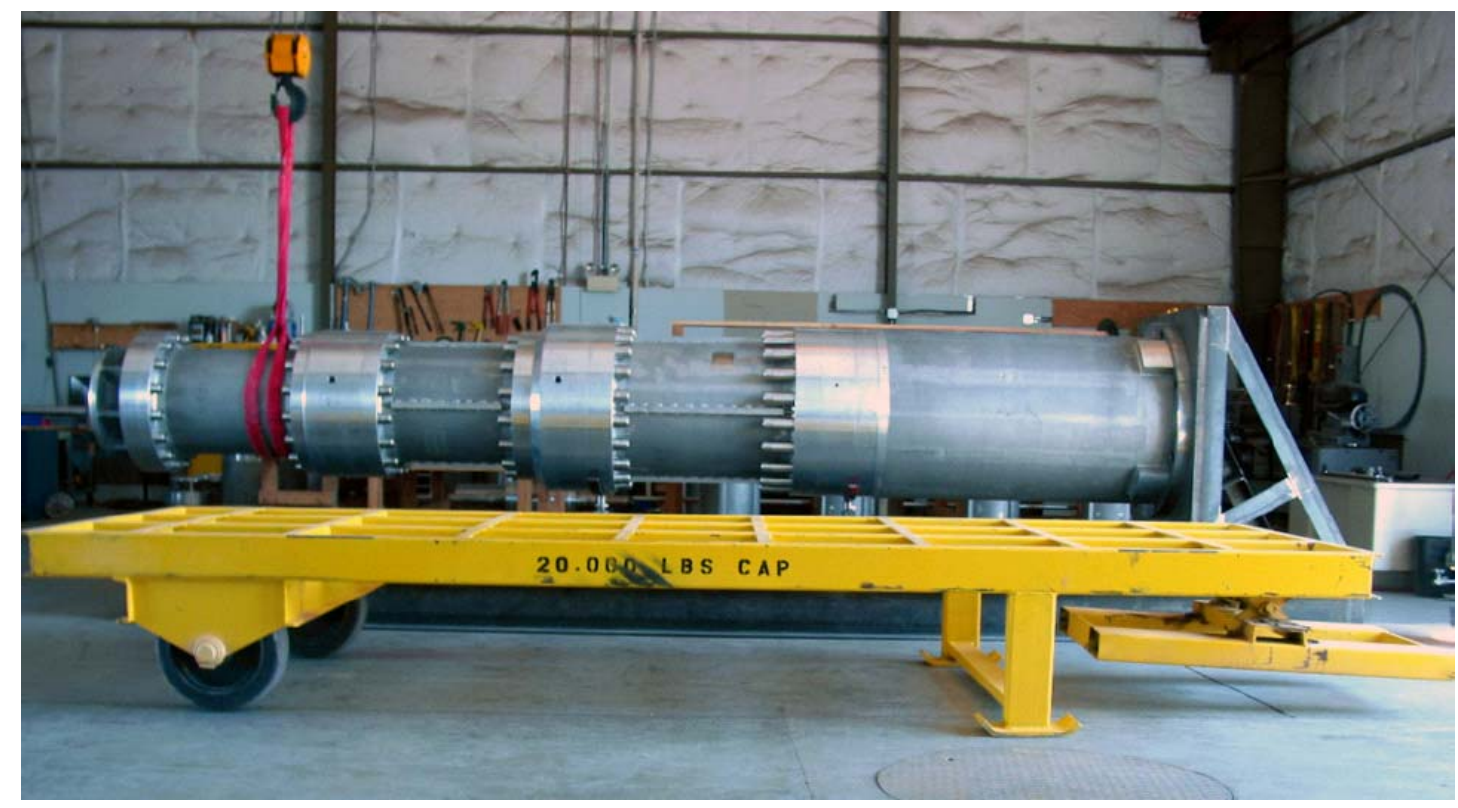

Transport to Test Stand

Detailed Drawings 


\section{Trip Report \\ Nikkiso-Cryo, Inc. High Pressure LNG Pump Test \\ Las Vegas, NV \\ 24 - 26 February 2004}

\section{Summary}

CGI represented by D.B. Scherz arrived at Nikkiso's plant in Las Vegas on 24 February where a total of six large high pressure LNG pumps were to be tested. There was a short delay due to rain. Early in the morning of the $25^{\text {th }}$ the rain stopped and the assembled large high pressure pump was moved to the vertical stand where workers attached the nozzle adapter plate. The completed unit was readied for lift, insertion into the pump reservoir on the test stand, and withdrawal after the test (see photos).

The pump was cooled (a 10 to 12 hour process) and the test was scheduled for the following day. During cooldown, Scherz witnessed the assembly of the next LNG pump to be tested, and discussed pump capacity and start-up power requirements with Mr. Bob Whiting, the inspector for Bureau Veritas. The pump is assembled in two parts and is comprised of staging the shaft with an impeller and its corresponding diffuser, and bolting on the housing in two large sections. Assembly is surprisingly fast taking approximately 1.5 hours, due to the well established procedure.

\section{Pump Test Specifications and Test Results}

Pump Model Number 60788L12-P1100F

\begin{tabular}{|c|c|c|c|c|}
\hline Parameter & Specification & $\begin{array}{c}\text { Acceptance } \\
\text { Criteria }\end{array}$ & Result & Conclusion \\
\hline Rated Head & $2370 \mathrm{~m}$ & $\begin{array}{l}\text { Min } 2322.6 \mathrm{~m} \\
\text { Max 2417.4 m }\end{array}$ & $\begin{array}{c}2325 \text { m @207.4 m3/hr } \\
\text { Projected } \\
2336.3 \text { m @205m3/hr }\end{array}$ & Accept \\
\hline Shut off Head & $2600 \mathrm{~m}$ & $\begin{array}{l}\text { Min } 2470.0 \mathrm{~m} \\
\operatorname{Max} 2730 \mathrm{~m}\end{array}$ & 2590.8 m@10.9 m3/hr & Accept \\
\hline $\begin{array}{c}\text { Shaft Rated } \\
\text { Power (Output) }\end{array}$ & $988.0 \mathrm{~kW}$ & $\begin{array}{c}<1027.5 \text { kW@ } \\
\text { SpGr of } 5.0\end{array}$ & $\begin{array}{c}1022.5 \text { kW @207.4 m3/hr } \\
\text { Projected } \\
1015.4 \text { kW @ 205 m3/hr }\end{array}$ & Accept \\
\hline
\end{tabular}

* $2600 \mathrm{~m}=1812.5 \mathrm{psig}$

\section{Future Growth}

Nikkiso-Cryo has made a decision to move to higher pressure/higher capacity, and therefore higher horsepower pumps. They are currently quoting a pump of $3000 \mathrm{bkW}$ or 4,025 hp up from the previously stated $2500 \mathrm{bkW}$. The test stand at the Las Vegas facility will be decommissioned after the current round of testing, and upgraded to ANSI 1500 to handle pump pressures up to 3,600 psi. Motor testing will begin in Japan to support the higher power required for this next generation pump. LNG sendout pumps exceeding 2400 psi and $400 \mathrm{~m} 3 / \mathrm{hr}$ should be possible in the very near future. The BPE pump 
package in a "Three Pack" arrangement could supply 4 vaporizers and might look similar to the photo on the last page of this report.

\section{End of Summary}
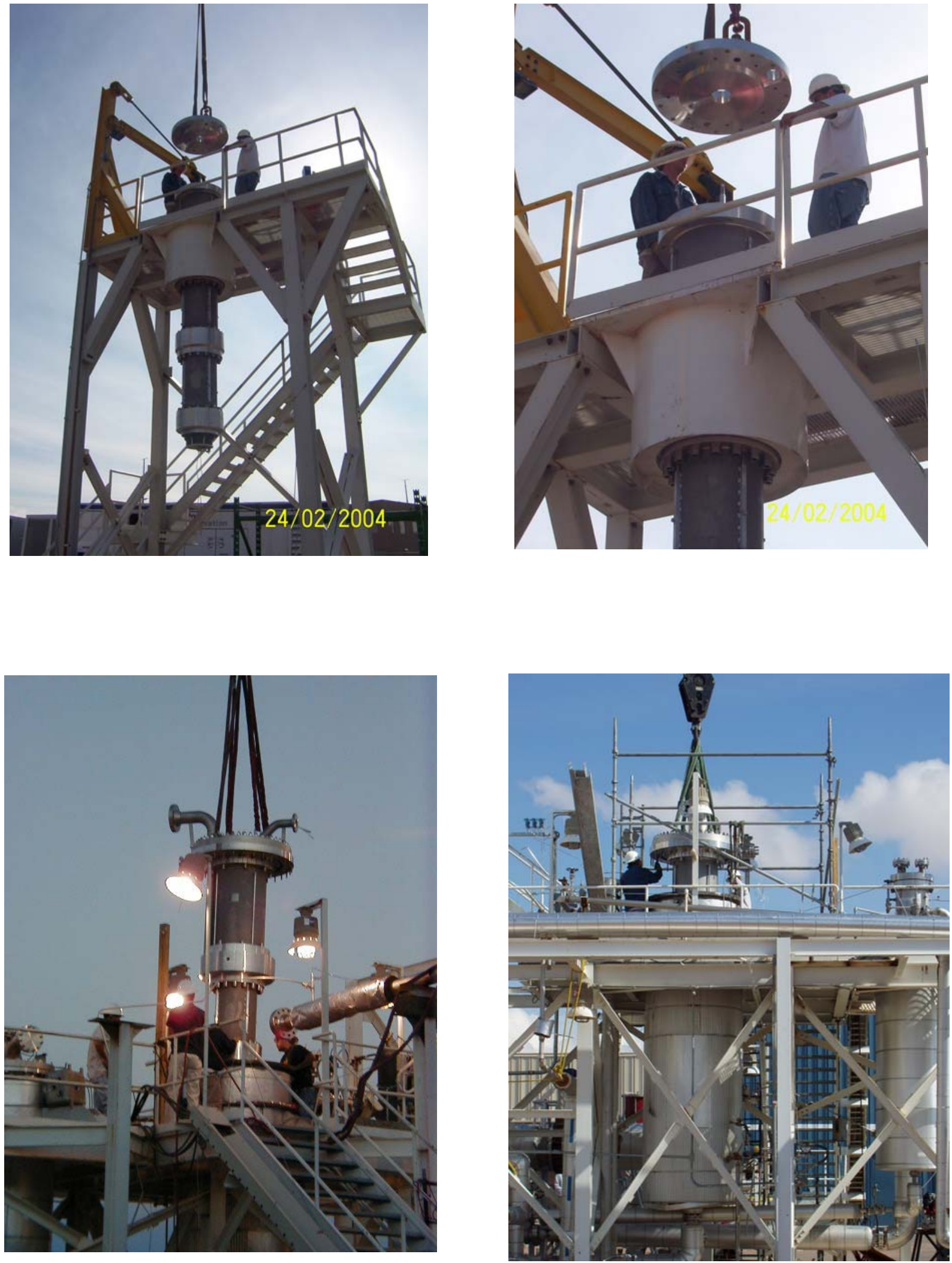

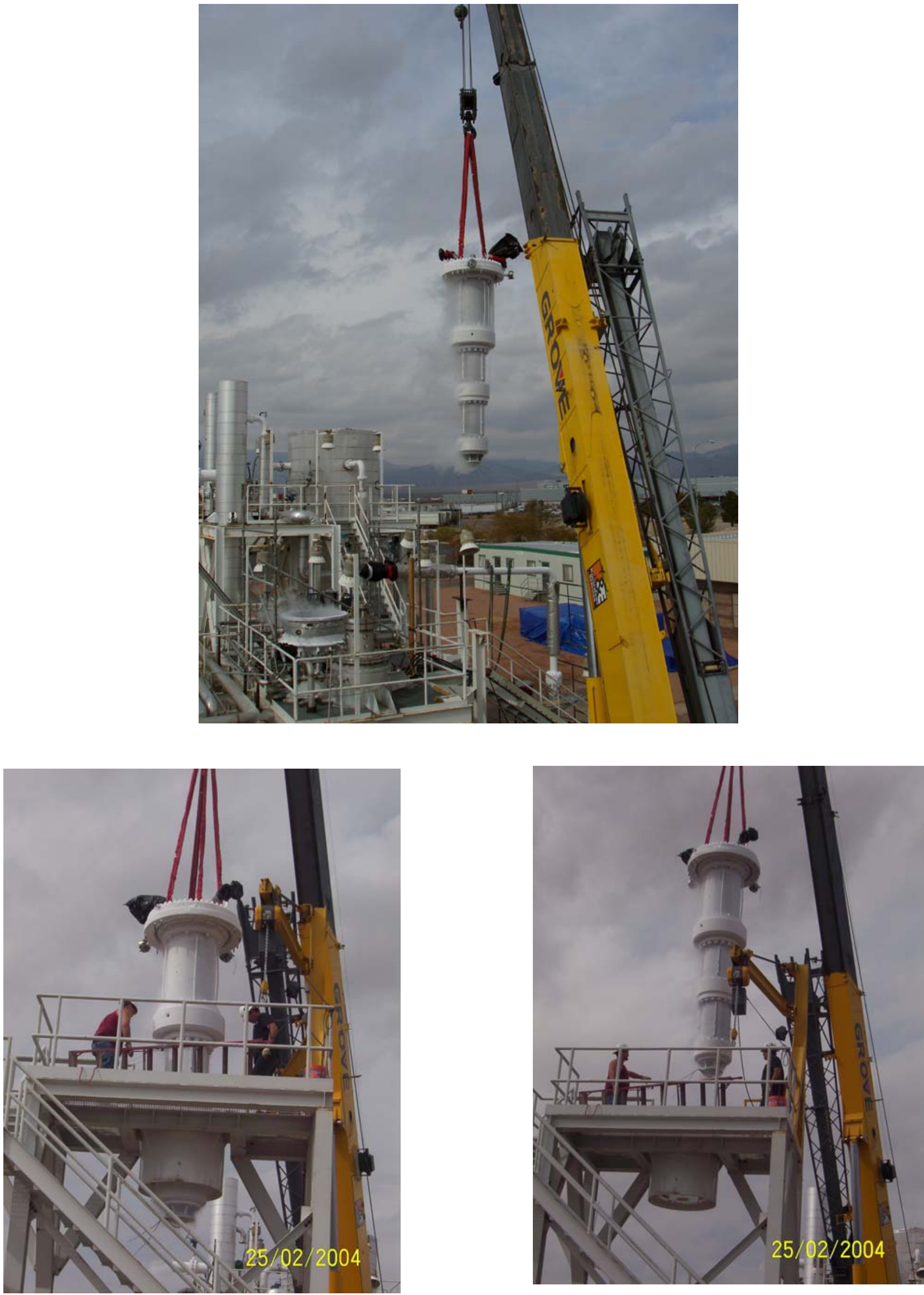


\section{$\underline{\text { High Pressure LNG PUMP Project }}$}

CUSTOMER : Daewoo Shipbuilding \& Marine Engineering Co.. Ltd.

Owner : LNG

Equipment Name : HIGH PRESSURE PUMP

ITEM NO.

: HP-391B

Nikkiso Job No. : EJU62E0013A-2

\section{AGENDA OF WITNESS TEST}

Feburarv 25. 2004

9:30 Performance Test

Q-H Performance

Vibration Measurement

Noise Measurement

Axial Thrust Balance Confirmation Test

NPSH Test

Pump Down Test

Starting Current Measurement

15-0 Interim Test Report of the Performance 


\section{NIKKISO CRYOGENIC PUMP PERFORMANCE TEST SUMMARY}

\begin{tabular}{|l|l|l|l|}
\hline CUSTOMER & DAEWOO SHIPBUILDING \& MARINE ENGINEERING & Test No.: \\
\hline Customer's P/O No.; & 2208/18 & Test Date: & Ol-Mar-04 \\
\hline Nikkiso's Job No.: & EJU62E0013A & Item No.: & HP-391D \\
\hline Location: & - & Pump Model No.: & 60788L12-P1100F \\
\hline Service: & High Pressure Pumps & Serial Mo.: & EJ62E0013A-4 \\
\hline
\end{tabular}

TEST PROCEDURE: NIKKISO Doc. No.: $\quad$ DEJ62E12A-04

\begin{tabular}{|c|c|c|c|c|c|}
\hline Parameters & $\begin{array}{l}\text { Ref. } \\
\text { No }\end{array}$ & $\begin{array}{l}\text { Spec Sheet / } \\
\text { Description }\end{array}$ & Acceptance Criteria & Result & Conclusion \\
\hline Rated Head & 7.0 & $2370 \mathrm{~m}$ & $\begin{array}{l}\text { Maximum } \quad 2417,4 \mathrm{~m} \text { Minimum } \\
2322.6 \mathrm{~m}\end{array}$ & $\begin{array}{l}2325.5 \mathrm{~m} @ 207,4 \mathrm{~m}^{3} / \mathrm{h} \\
\left.1336.3 \mathrm{~m} @ 205 \mathrm{~m}^{3} / \mathrm{h}\right][ \\
\text { Projected J }\end{array}$ & Acceptable \\
\hline Head § Shut off & 7.0 & $2600 \mathrm{~m}$ & $\begin{array}{l}\text { Maximum } \quad 2730.0 \mathrm{~m} \text { Minimum } \\
2470.0 \mathrm{~m}\end{array}$ & $2590.8 \mathrm{~m} @ 10.9 \mathrm{~m}^{3} / \mathrm{h}$ & Acceptable \\
\hline Shaft Rated Power (Output) & 7.0 & $988.0 \mathrm{~kW}$ & $<1027.5$ kW @ Customer SpGr=0.5 & $\begin{array}{l}1022.5 \mathrm{~kW} @ 207.4 \\
. m \% \\
1015,4 \mathrm{~kW} @ 205 \mathrm{~m}^{3} / \mathrm{h} \\
\text { Projected }\end{array}$ & Acceptable \\
\hline Vibration & 8.0 & Velocity at Overall & \begin{tabular}{|l|}
$<5.0 \mathrm{~mm} / \mathrm{s}$ RMS \\
$\left(184.5-225.5 \mathrm{~m}^{3} / \mathrm{h}\right)$
\end{tabular} & Refer to test record & Acceptable \\
\hline Noise measurement & 9.0 & & & $\begin{array}{l}\text { 86dBA } \\
\text { (Back ground: } 68 \mathrm{dBA} \text { ) }\end{array}$ & For information \\
\hline NPSH test & 10.0 & $0.0 \mathrm{~m} @ 205 \mathrm{~m} 3 / \mathrm{h}$ (Note) & $<3 \%$ head down & $-0.38 \%$ & Acceptable \\
\hline Durmn dnrum & $11 n$ & & & $-\cap 01 \mathrm{~m}(\mathrm{~N} n t a)$ & Enrinfnrmntinn \\
\hline Thrust balance confirmation & 12.0 & - & Shaft is in up position & Refer to lest record & Acceptable \\
\hline Starting current measurement & - & $902 \mathrm{~A}$ & $<1082.4(=902[\mathrm{~A}] \mathrm{X} 1.2)$ & $\begin{array}{l}\text { Starting current : } 902 \mathrm{~A} \\
\text { Voltage Drop : } 33 \%\end{array}$ & Acceptable \\
\hline
\end{tabular}

(Note) Datum is suction nozzle inlet center line on actual suction pot. WE HEREBY CERTIFY THAT THIS REPORT IS CORRECT AND TRUE,

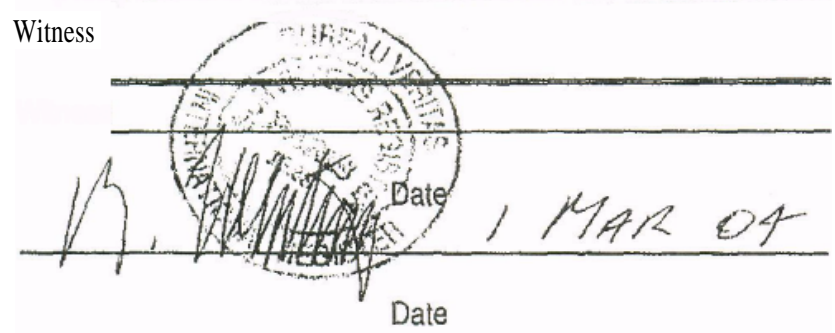
DATE RESULT FLUID EQUIPMENT FACTORY QC DEPARTMENT

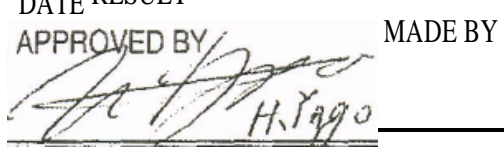
name: EJ62-0013A4-W2 


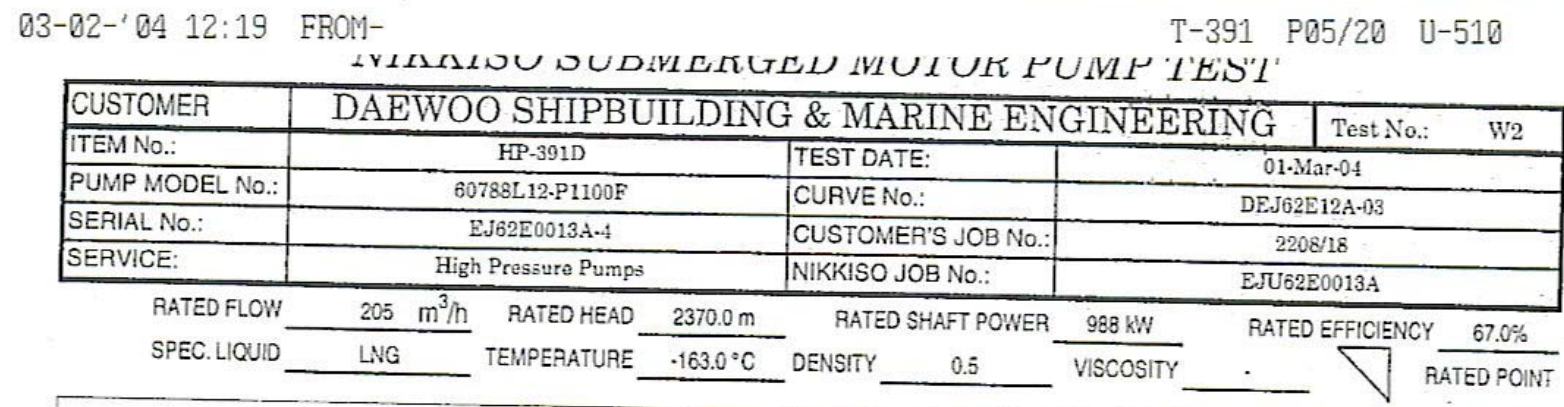

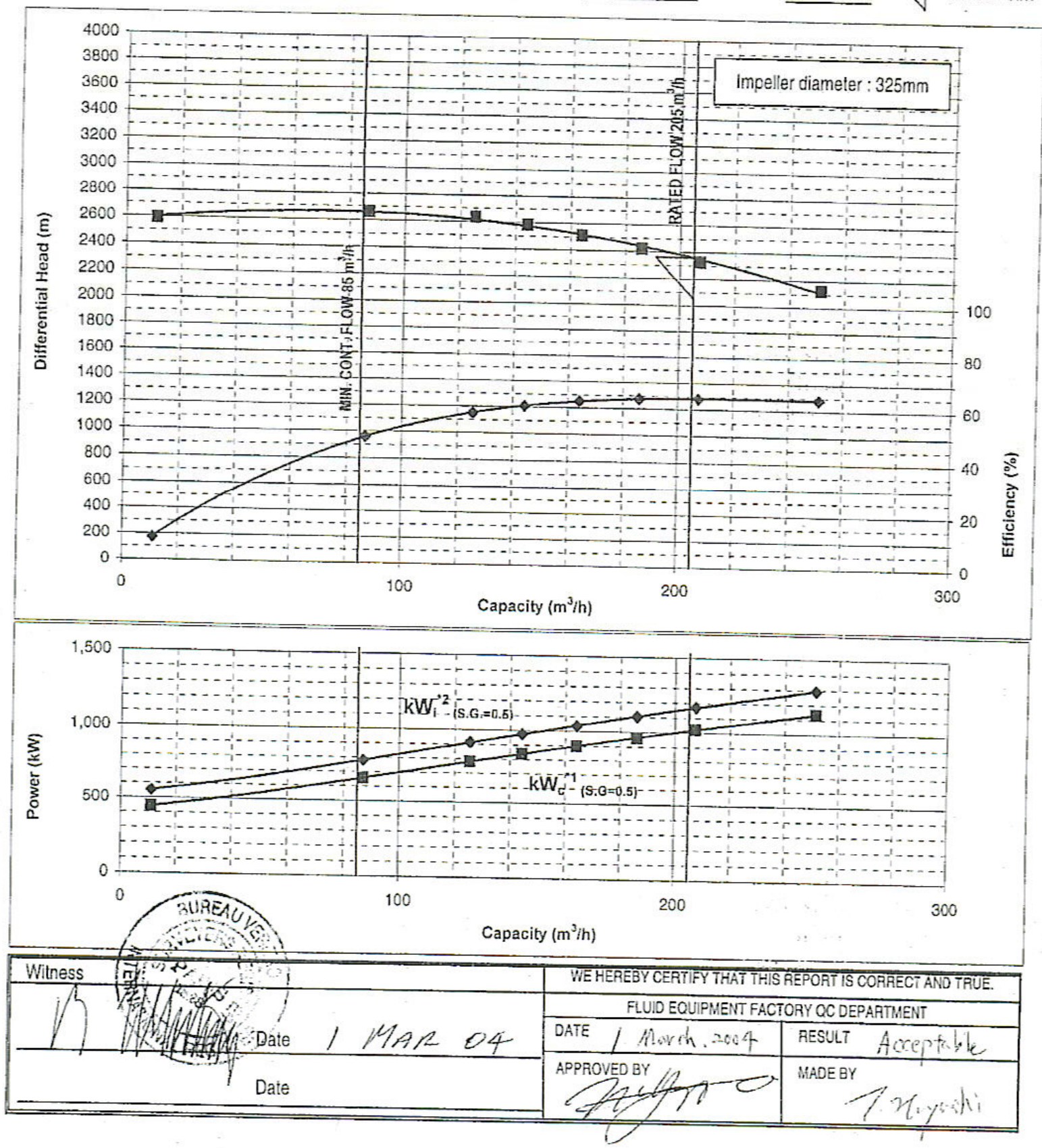

"1 Shaft power (BHP) corrected to Customer SpG.

'2 Input overall power.
Page 1 of 1

Sheet name : Performance Curve (Metric) File name : EJ62-0013A4-W2 
VISUAL INSPECTION ( AFTER PERFORMANCE TEST)

\begin{tabular}{ll|l|l|}
\hline PURCHASER & \\
\hline ITEM No. HP- 391 B & EQUIPMENT NAME & HIGH PRESSURE PUMP \\
\hline MODEL No. 60788L1 2-P110OF & OBJECT OF TEST & FINAL WITNESS \\
\hline SERIAL No. EJ62E0013A-2 & NIKKISO JOB No. & EJU62E0013A \\
\hline
\end{tabular}

Acceptance criteria: The pump shall not indicate any harmful damage to pump operation.

\section{VISUAL CHECK}

\begin{tabular}{|c|c|}
\hline Impellers: & Good \\
\hline Impeller Wear rings: & Good \\
\hline Shaft: & Good \\
\hline Shaft bearings: & Good \\
\hline Ball bearings: & Replace new at Final Assy. \\
\hline Impeller Spacer & Good \\
\hline Baffle Plate & Good \\
\hline \multicolumn{2}{|l|}{ Balance Drum assembly: } \\
\hline Bearing housing & Good \\
\hline Balance drum & Good \\
\hline Motor / Rotor Assembly & Good \\
\hline & Acceptable \\
\hline
\end{tabular}

\section{Conclusion:}

We hereby certify that this report is correct and true.

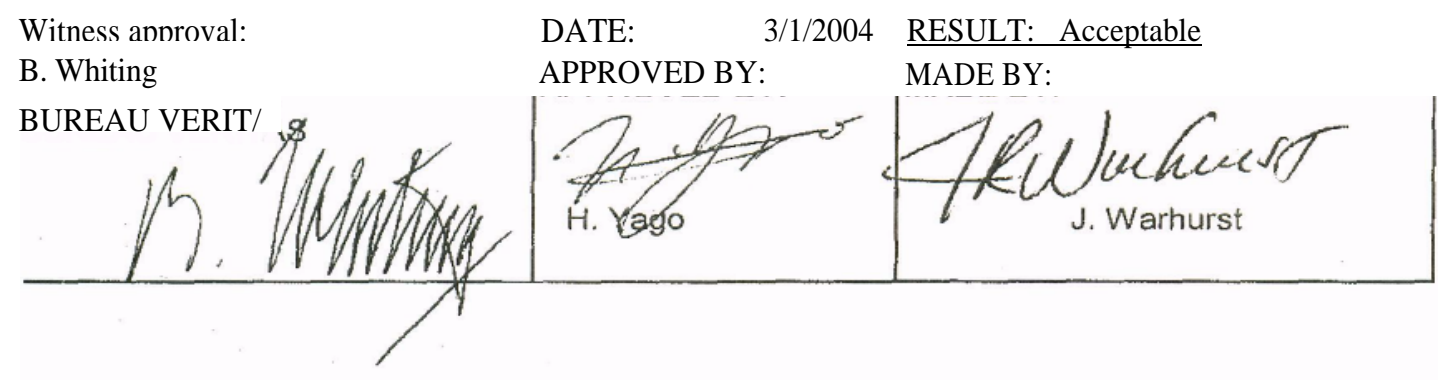




\begin{tabular}{|l|c|l|l|}
\hline Customer: & Department of Energy - NETL & $\begin{array}{l}\text { Date of Issue: } \\
\mathbf{2 0 0 5}\end{array}$ & \\
\hline $\begin{array}{l}\text { Document } \\
\text { Title: }\end{array}$ & TAB 5 Heat Exchanger Field Test & $\begin{array}{l}\text { Version: } \\
\mathbf{2 . 0}\end{array}$ & Page $\mathbf{1}$ of $\mathbf{2 8}$ \\
\hline
\end{tabular}

THE HEAT EXCHANGER TESTS AND RESULTS 


\begin{tabular}{|l|c|l|l|}
\hline Customer: & Department of Energy - NETL & $\begin{array}{l}\text { Date of Issue: } \\
\mathbf{2 0 0 5}\end{array}$ & \\
\hline $\begin{array}{l}\text { Document } \\
\text { Title: }\end{array}$ & Heat Exchanger Field Test & $\begin{array}{l}\text { version: } \\
\mathbf{2 . 0}\end{array}$ & Page $\mathbf{2}$ of $\mathbf{2 8}$ \\
\hline
\end{tabular}

\section{TABLE OF CONTENTS}

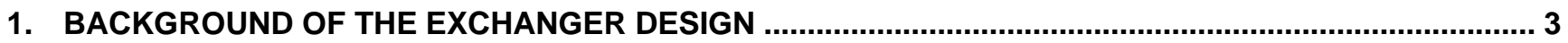

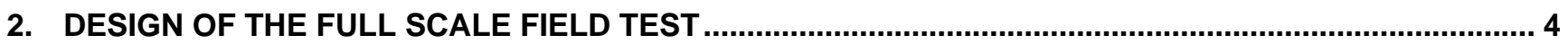

3. COMPOSITION OF THE TEST NATURAL GAS, DENSE PHASE OPERATION ..................................... 6

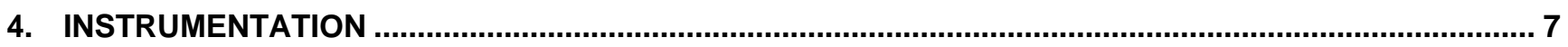

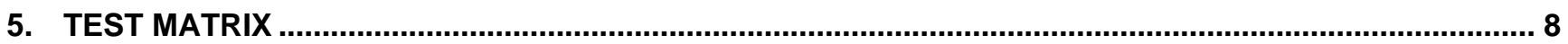

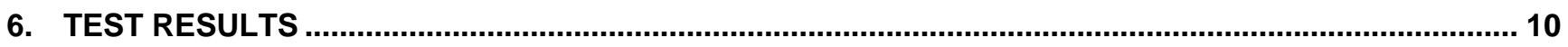

6.1. Table 2. Optimization of Simulation Parameters for April 13, 4-Pass Run ...................... 12

6.2. Table 3. Optimization of Simulation Parameters for April 15, 2-Pass Run ...................... 13

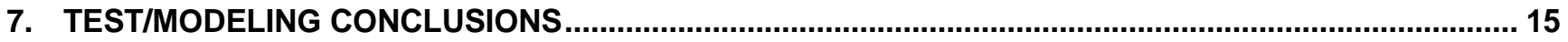

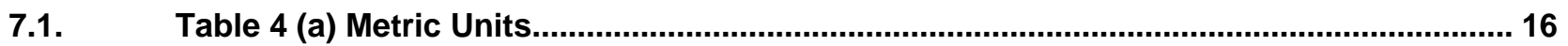

7.1.1. Measured and Predicted LNG Temperature Profiles for Selected Runs ..................... 16

7.2. Table 4 (b) English Units ................................................................................................. 19

7.2.1. Measured and Predicted LNG Temperature Profiles for Selected Runs ................... 19

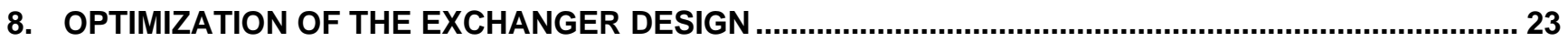

8.1. Fig. 5 Optimized Exchanger Configuration ................................................................. 25

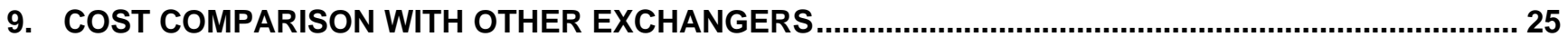

10. ADVANTAGES OF THE BISHOP PROCESS HEAT EXCHANGER VS. SHELL AND TUBE.................. 25

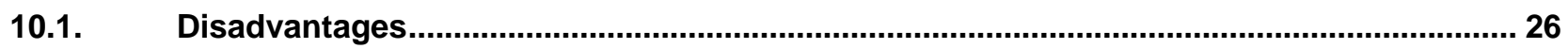

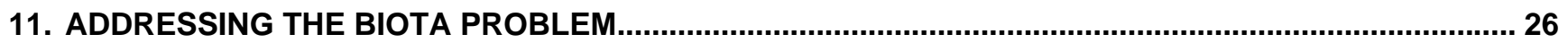

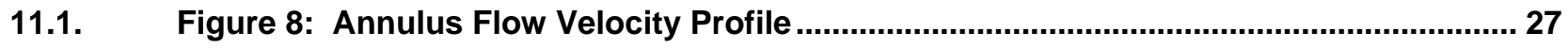




\begin{tabular}{|l|c|l|l|}
\hline Customer: & Department of Energy - NETL & $\begin{array}{l}\text { Date of Issue: } \\
\mathbf{2 0 0 5}\end{array}$ & \\
\hline $\begin{array}{l}\text { Document } \\
\text { Title: }\end{array}$ & Heat Exchanger Field Test & $\begin{array}{l}\text { Version: } \\
\mathbf{2 . 0}\end{array}$ & Page $\mathbf{3}$ of $\mathbf{2 8}$ \\
\hline
\end{tabular}

\section{BACKGROUND OF THE EXCHANGER DESIGN}

The high volume, high pressure heat exchanger was originally conceived as an in-the- well exchanger for gas storage salt caverns that would receive LNG. As the LNG was pumped into a cavern through the center (cryogenic) tubing, brine would be forced back out through the annulus formed by the center tubing and an outer coaxial hanging string, thus forming a counter flow, pipe-in-pipe heat exchanger. Since the LNG expands as it warms in the exchanger the return brine flow can be as much as four times the rate of LNG injection rate, depending on the amount of warming and the length of the exchanger. The exchanger was extensively modeled, Ref. 1, using a commercial computational fluid dynamics code, PHOENIX, but was never tested. This technology is covered in U.S. Patent No. 5,511,905. This in-the-cavern application of the exchanger is very feasible but it requires the use of a brine pond from which brine can be pumped back into the cavern as the previously warmed gas is withdrawn. Brine ponds are expensive ${ }^{1}$ and in some areas may not be allowed or feasible for various reasons. This prompted the development of the surface pipe-in-pipe exchanger. This design would allow the warmant fluid to be varied in any manner desired, rather than being tied to the brine return rate, and of course didn't require the use of brine or a brine pond. Because the surface exchanger would normally be installed horizontally, this required some additional considerations versus the vertical configuration. These are namely that the LNG/gas always be in the dense phase and that the densimetric Froude Number be reasonably high. The dense phase is required so that two-phase flow does not occur in the LNG piping. This would decrease the efficiency and possibly cause slug flow, cavitation, and "water"hammer. The high Froude Number assures that stratification does not occur in the horizontal plane, which would also decrease efficiency.

For the test configuration, the cryogenic pipe diameter was kept close to that which was modeled during the cavern work and the warmant diameter was selected using a code developed specifically for this task by Prof. William Thomson at Washington State Univ. This resulted in a 6 5/8" OD cryo pipe and an 11.5" ID warmant pipe. Optimization of exchanger efficiency and control of warmant use is strongly affected by the annular area between the two pipes and resultant warmant velocity. If the velocity is low, heat transfer will drop, thus requiring a longer exchanger. If the velocity is too high, the pressure drop becomes prohibitive. Similar reasoning applies to the possible use of heat transfer enhancers such as fins or spiral grooving. These techniques will shorten the exchanger but in the long run the cost of the added pressure drop far outweighs the capital savings in a shorter exchanger. The horizontal heat exchanger is covered under U.S. Patent Application No. 10/686,450.

\footnotetext{
${ }^{1}$ But note that with the rising price of natural gas, brine ponds may often cost less than the cushion gas required in an uncompensated cavern.
} 


\begin{tabular}{|l|c|l|l|}
\hline Customer: & Department of Energy - NETL & $\begin{array}{l}\text { Date of Issue: } \\
\mathbf{2 0 0 5}\end{array}$ & \\
\hline $\begin{array}{l}\text { Document } \\
\text { Title: }\end{array}$ & Heat Exchanger Field Test & $\begin{array}{l}\text { Version: } \\
\mathbf{2 . 0}\end{array}$ & Page $\mathbf{4}$ of $\mathbf{2 8}$ \\
\hline
\end{tabular}

\section{DESIGN OF THE FULL SCALE FIELD TEST}

With the help of James Walzel, president of HNG Storage and the management of AGL Resources (formerly Atlanta Gas Light) CGI was granted permission to perform testing at AGL's LNG peak shaving facility in Cherokee County, Georgia. This facility had all of the components necessary for the heat exchanger tests: a million barrel cryogenic LNG storage tank, high (1000psi) pressure LNG pumps, LNG vaporizers, a large fresh water pond for a source of warming water, and connection to a natural gas supply and demand infrastructure. The test was of a single, full-scale exchanger with a nominal throughput capacity of $300 \mathrm{~m} 3 / \mathrm{hr}$. A $10,000 \mathrm{~m} 3 / \mathrm{hr}$ offload rate would require 33 of these in parallel, not counting spares. Northstar Industries constructed the test facility and conducted the tests under CGI's supervision. The exchanger test layout including instrumentation is shown in Fig. 1. Each leg of the exchanger is $152.4 \mathrm{~m} / 500$ ' in length, not counting the $180^{\circ}$ elbow. The four legs constitute 2000' of water-warmed exchanger. The $65 / 8$ " OD cryo was of Schedule $40,316 \mathrm{~L}$ stainless steel with a $0.71 \mathrm{~cm} / 0.280$ " wall thickness. The warmant pipe was nominal 12" HPDE with an ID of $29.2 \mathrm{~cm} / 11.5$ ". The HPDE was chosen because of its toughness, wall smoothness, resistance to scaling and resistance to corrosion. During the tests it performed well and showed negligible contraction and expansion. During warm weather periods it drooped slightly.

As shown in Fig.1, there were four warmant runs, one for each leg of the exchanger. The warmant manifolding was such that the exchanger could be operated either in the 2-pass mode or the 4-pass mode. In the 2-pass mode the warmant would run through two legs of the exchanger before being ejected. In the 4pass, each leg received its own flow of warmant. This resulted in the 4-pass using approximately twice the amount of warmant as the 2-pass, with the warmant dropping only half as much in temperature. This is a desirable flexibility depending on the environmental constraints. The 4-pass may be the preferred technology when natural bodies of water are being used, but the 2-pass may be preferred when the warmant source is a closed system like a pond, less pumping and warmant being required. Additionally the two test configurations provided a wider range of data. A photograph of the test installation is shown in Fig.2.

The testing included variations in the LNG flow rate, starting low and eventually getting to get over the full nominal design rate of $300 \mathrm{~m} 3 / \mathrm{hr}$. The warmant flow rate was also varied as well as the ratio between the two flows. It was intended to vary this ratio between 2.0 and 3.0. The nominal design ratio is 2.5 warmant to LNG. Warmant temperature was also varied. AGL's pond was near $65^{\circ} \mathrm{F}$, depending on the weather, and heaters were installed to allow this to be increased to $85^{\circ} \mathrm{F}$, so that the total test temperature range was between about 65 and $85^{\circ} \mathrm{F}$. A total of three gas fired heaters were used for this purpose. The heaters were rated at 35.2 gigajoules/33.4 MMbtu each. 


\begin{tabular}{|l|c|l|l|}
\hline Customer: & Department of Energy - NETL & $\begin{array}{l}\text { Date of Issue: } \\
\mathbf{2 0 0 5}\end{array}$ & \\
\hline $\begin{array}{l}\text { Document } \\
\text { Title: }\end{array}$ & Heat Exchanger Field Test & $\begin{array}{l}\text { Version: } \\
\mathbf{2 . 0}\end{array}$ & Page $\mathbf{5}$ of $\mathbf{2 8}$ \\
\hline
\end{tabular}

Figure1: Heat Exchanger As Tested

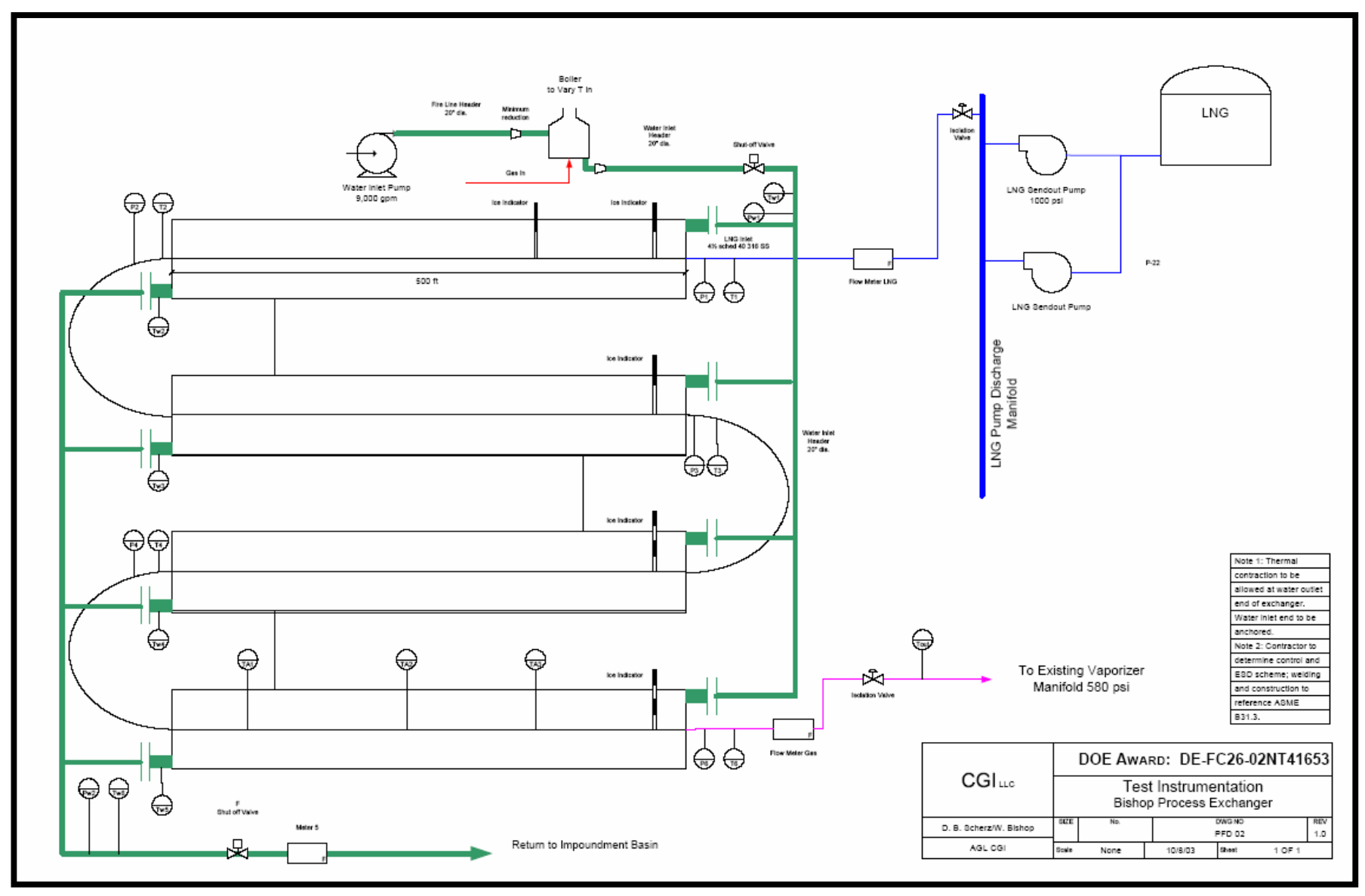




\begin{tabular}{|l|c|l|l|}
\hline Customer: & Department of Energy - NETL & $\begin{array}{l}\text { Date of Issue: } \\
\mathbf{2 0 0 5}\end{array}$ & \\
\hline $\begin{array}{l}\text { Document } \\
\text { Title: }\end{array}$ & Heat Exchanger Field Test & $\begin{array}{l}\text { Version: } \\
\mathbf{2 . 0}\end{array}$ & Page $\mathbf{6}$ of $\mathbf{2 8}$ \\
\hline
\end{tabular}

Figure 2: Photo of Test Installation

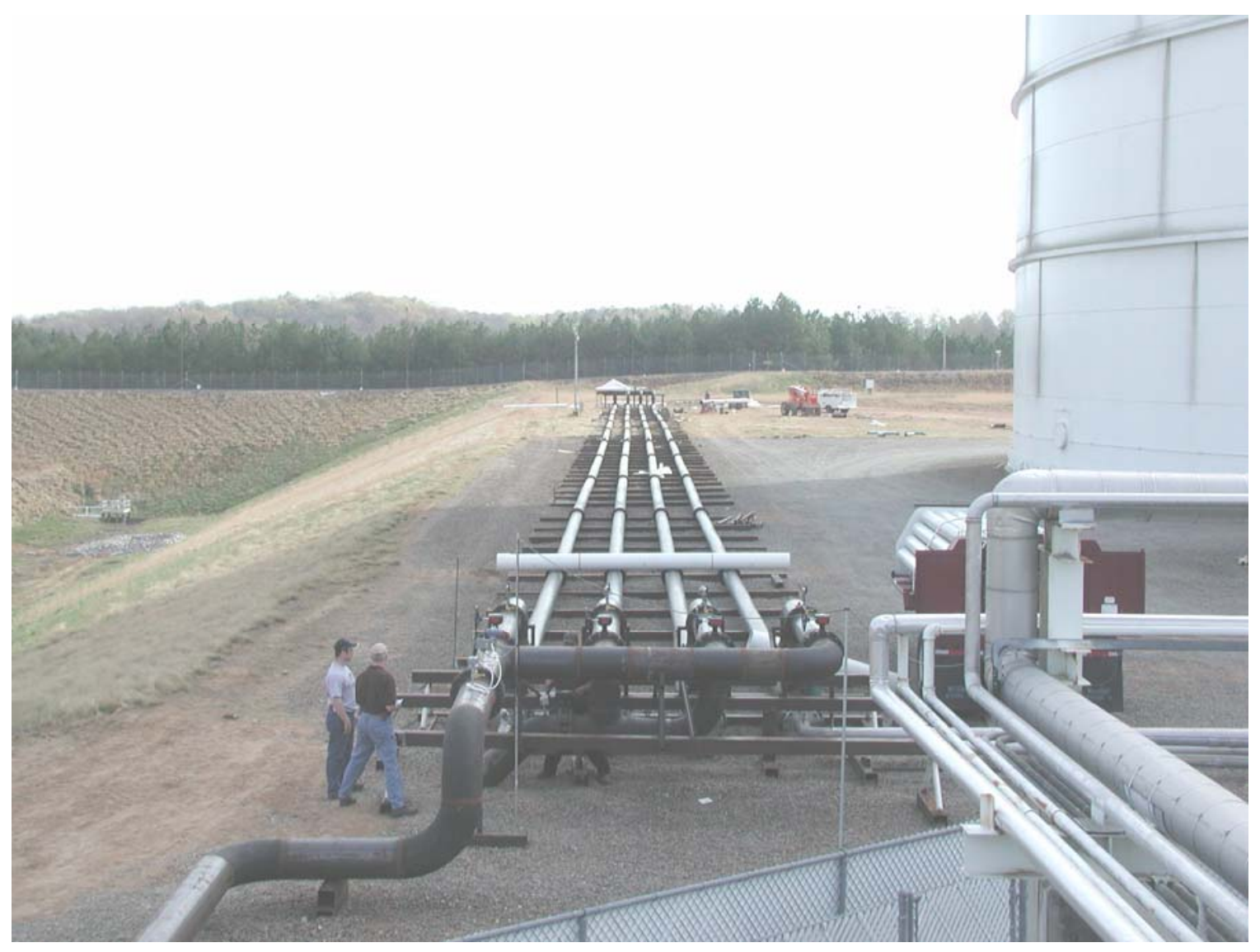

\section{COMPOSITION OF THE TEST NATURAL GAS, DENSE PHASE OPERATION}

Since the exchanger was designed to operate with the LNG/gas in the dense phase, it was important that the pressure exceed the vapor/liquid envelop of the test gas. This was determined by sampling the gas and having it analyzed by a commercial laboratory. The gas analysis in mole $\%$ is as follows:

Methane 95.2223, Ethane 3.8400, Propane 0.7039, I-Butane 0.1017, N-butane 0.0767,

$\mathrm{C}_{5}+$ 0.0182, 0.0088, 0.0113, Carbon Dioxide 0.0470, Nitrogen 0.0113, Total 100.0423

Fig. 3 is a plot of the test dense phase pressure versus temperature along the length of the exchanger during a simulated test at the lowest pressure conditions. This is superimposed above the test gas vapor/liquid dome, which falls about 100psi below the test pressure. Thus the test gas was considered to remain in the dense phase for all of the tests. 


\begin{tabular}{|l|c|l|l|}
\hline Customer: & Department of Energy - NETL & $\begin{array}{l}\text { Date of Issue: } \\
\mathbf{2 0 0 5}\end{array}$ & \\
\hline $\begin{array}{l}\text { Document } \\
\text { Title: }\end{array}$ & Heat Exchanger Field Test & $\begin{array}{l}\text { version: } \\
\mathbf{2 . 0}\end{array}$ & Page $\mathbf{7}$ of $\mathbf{2 8}$ \\
\hline
\end{tabular}

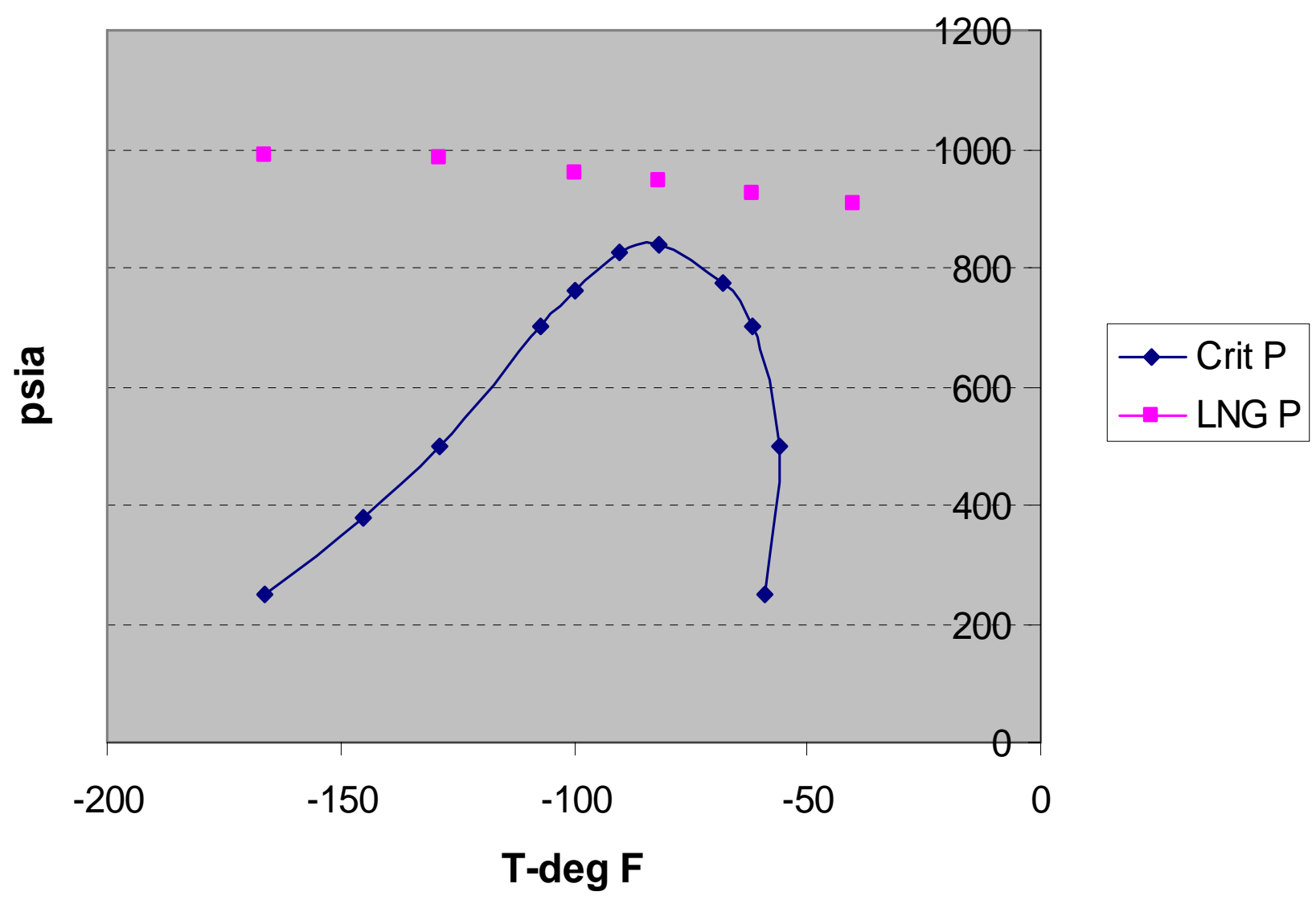

Fig. 3 Test Gas Vapor/Liquid Dome vs. Test Pressure

\section{INSTRUMENTATION}

Temperature and pressure instrumentation points are shown in Fig. 1. Both the LNG and the warmant paths were instrumented and all data recorded continuously. Flow rates were also measured continuously. Ice build-up on the outer surface of the cryo pipe was also measured. This was done by means of a probe inserted through the warmant pipe wall and held in place with a plastic gasket to prevent leaks. The probes were oriented in the horizontal plane, were located near each end of each leg of the exchanger and were operated by hand. Thus not a lot of measurements were made. However, despite this crude approach, the ice measurements agree very well with the results of the model based on the new heat transfer data acquired in the tests. When using the probe, there was no significant vibration noted. All of the test data, except the ice measurements, was relayed live to the test observation room and displayed on an electronic simulation of the heat exchanger system. 


\begin{tabular}{|l|c|l|l|}
\hline Customer: & Department of Energy - NETL & $\begin{array}{l}\text { Date of Issue: } \\
\mathbf{2 0 0 5}\end{array}$ & \\
\hline $\begin{array}{l}\text { Document } \\
\text { Title: }\end{array}$ & Heat Exchanger Field Test & $\begin{array}{l}\text { Version: } \\
\mathbf{2 . 0}\end{array}$ & Page $\mathbf{8}$ of $\mathbf{2 8}$ \\
\hline
\end{tabular}

\section{TEST MATRIX}

The target test matrix is shown below in Table 1. None of these conditions were obtained exactly, as they were meant as approximate goals. The highest LNG flow rate achieved in the tests was in the high $320 \mathrm{~m}^{3} / \mathrm{hr} / 1400 \mathrm{gpm}$ range, approximately $8 \%$ above the target rate. These conditions were not held for as long a period as the lower rates and were not examined in the results shown here. However this is probably valid data and could be analyzed if the need arises. The quality of the correlation obtained probably makes this unnecessary. The primary variable of importance in extending the test conditions is the ratio of warmant to LNG flow rate. This ratio ranged all the way from 1.1 to infinity. In the case of the lower limit, a ratio of water to LNG of 1.1, it was somewhat surprising that the warmant did not freeze to the point of plugging. This is evidence of the very strong effect of the warmant velocity on ice removal from the cryo pipe surface. This will be addressed below in the results section.

Calculations done prior to the test estimated that the thermal response time for the cryo wall and ice formation was on the order of 10-20 seconds. The flow itself took several minutes to stabilize from one test condition to another. With this in mind, test conditions, where possible, were obtained by ramping flows from the previous test to the new test conditions. This saved time and LNG with the total test program taking roughly five days including start-up exercises. 


\begin{tabular}{|l|c|l|l|}
\hline Customer: & Department of Energy - NETL & $\begin{array}{l}\text { Date of Issue: } \\
\mathbf{2 0 0 5}\end{array}$ & \\
\hline $\begin{array}{l}\text { Document } \\
\text { Title: }\end{array}$ & Heat Exchanger Field Test & $\begin{array}{l}\text { Version: } \\
\mathbf{2 . 0}\end{array}$ & Page $\mathbf{9}$ of $\mathbf{2 8}$ \\
\hline
\end{tabular}

Table 1. Heat Exchanger Test Matrix (All LNG injection pressures are at approximately 1000psig)

\begin{tabular}{|c|c|c|c|c|}
\hline $\begin{array}{l}\text { LNG } \\
\mathrm{m}^{3} / \mathrm{hr} \\
(\mathrm{gpm})\end{array}$ & $\begin{array}{l}\text { Water } \mathrm{m}^{3} / \mathrm{hr} \\
\quad(\mathrm{gpm})\end{array}$ & $\begin{array}{l}\text { Temperature } \\
{ }^{\circ} \mathrm{C} \quad\left({ }^{\circ} \mathrm{F}\right)\end{array}$ & $\begin{array}{l}\text { Temperature } \\
{ }^{\circ} \mathrm{C} \quad\left({ }^{\circ} \mathrm{F}\right)\end{array}$ & $\begin{array}{c}\text { Temperature } \\
{ }^{\circ} \mathrm{C} \quad\left({ }^{\circ} \mathrm{F}\right)\end{array}$ \\
\hline $\begin{array}{c}\text { Four pass } \\
\text { tests }\end{array}$ & Per pass/Total & & & \\
\hline \multirow[t]{2}{*}{$\begin{array}{c}185 \\
(800) \\
\end{array}$} & $\begin{array}{l}462(2000) / \\
1845(8000)\end{array}$ & $29 \quad(85)$ & $24 \quad(75)$ & (65) \\
\hline & $\begin{array}{l}370(1600) / \\
1475(6400)\end{array}$ & " & " & " \\
\hline $240(1050)$ & $\begin{array}{l}485(2100) / \\
1940(8400)\end{array}$ & $"$ & " & " \\
\hline \multicolumn{5}{|l|}{$\begin{array}{c}\text { Two pass } \\
\text { tests }\end{array}$} \\
\hline $185(800)$ & $\begin{array}{l}555(2400) / \\
1110(4800) \\
\end{array}$ & " & " & " \\
\hline \multirow[t]{2}{*}{$240(1050)$} & $\begin{array}{l}725(3150) / \\
1455(6300)\end{array}$ & " & " & " \\
\hline & $\begin{array}{l}605(2625) / \\
1210(5250) \\
\end{array}$ & " & “ & $"$ \\
\hline \multirow[t]{3}{*}{$300(1300)$} & $\begin{array}{l}900(3900) / \\
1800(7800)\end{array}$ & " & " & " \\
\hline & $\begin{array}{l}750(3250) / \\
1500(6500)\end{array}$ & " & " & " \\
\hline & $\begin{array}{l}600(2600) / \\
1200(5200)\end{array}$ & $"$ & " & No test \\
\hline
\end{tabular}

\begin{tabular}{|l|l} 
Shut in test & Stop both flows
\end{tabular} 


\begin{tabular}{|l|c|l|l|}
\hline Customer: & Department of Energy - NETL & $\begin{array}{l}\text { Date of Issue: } \\
\mathbf{2 0 0 5}\end{array}$ & \\
\hline $\begin{array}{l}\text { Document } \\
\text { Title: }\end{array}$ & Heat Exchanger Field Test & $\begin{array}{l}\text { Version: } \\
\mathbf{2 . 0}\end{array}$ & Page $\mathbf{1 0}$ of $\mathbf{2 8}$ \\
\hline
\end{tabular}

\section{TEST RESULTS}

There are approximately four days of test flow, much of it continuous. This is contained in the CD that accompanies this report, and also as an attachment to the electronic version. Only the data used to develop and verify the heat transfer correlation will be shown here. The computer code to model the flow was developed by Prof. William Thomson of the Washington State Chemical Engineering Department at Pullman and his Research Assistant, Alexandru Platon. The model uses HYSIS to provide the gas properties and MATLAB to perform the steady-state numerical calculations.

The Bishop Process employs a double pipe heat exchanger designed to operate in a variety of multi-pass configurations, but with the LNG phase remaining above the 2-phase envelope, i.e., in the dense gas phase. For the demonstration tests, both 2-pass and 4-pass configurations were utilized. LNG flow rates examined for purposes of the correlation varied broadly from $135 \mathrm{~m}^{3} / \mathrm{hr}(600 \mathrm{gpm})$ to $255 \mathrm{~m}^{3} / \mathrm{hr}(1124 \mathrm{gpm})$, and fresh water-to-LNG flow ratios between 1.1 and 6.1, and with inlet water temperatures between $17 \mathrm{C} / 62 \mathrm{~F}$ and $29 \mathrm{C} / 85 \mathrm{~F}$. The heat transfer coefficient correlations used in the simulation on both the water $\left(h_{0}\right)$ and LNG $\left(h_{i}\right)$ sides of the exchanger are of the form recommended by Dittus and Boelter:

$$
h_{\mathrm{i}, \mathrm{o}}=\frac{k}{D_{\mathrm{i}, \mathrm{o}}}\left(f_{\mathrm{i}, \mathrm{o}}\right)(0.026)(\mathrm{Re})^{0.8}(\mathrm{Pr})^{0.33}\left(\frac{\mu}{\mu_{W}}\right)^{0.14} \quad \text { Eqn. (1) }
$$

where Re and Pr are the Reynolds and Prandtl numbers, respectively, $\mathrm{k}$ is the fluid thermal conductivity, $\mathrm{D}$ is either the inner diameter of the inside pipe (LNG) or the outer diameter of the inside pipe, and $\mu$ is the fluid viscosity in the bulk flow or at the wall. In the original simulation prior to the test, the factors, fi, 0 were set to 1.0. However, for the evaluation of the measured demonstration data, these factors were varied in an effort to fine-tune the correlation so that predictions match the measured data to an acceptable degree.

In addition, the simulation also accounts for ice formation once the water reaches the freezing point $(0 \mathrm{C} / 32 \mathrm{~F}$, or $-2 \mathrm{C} / 28 \mathrm{~F}$ for sea water) and assumes that ice is formed adjacent to the outside of the inner pipe wall, creating an additional heat transfer resistance. The data were analyzed by systematically changing the fi,o factors, and the freezing point until reasonable matches were obtained between the model predictions and the measured LNG temperature profile data. In this way, it is hoped that an improved heat transfer predictive model has been obtained; one that can be used for the design of full-scale commercial processes. The analysis was conducted by selecting representative runs over the widest range of system parameters (LNG flow rates, inlet water temperatures, heat exchanger configuration and flow ratios), and then numerically averaging the recorded data over the time periods where all parameters were stable. In addition to presenting the optimized model results, comparisons were also made to the predictions based on the optimized parameters for the actual recorded conditions in each of those runs.

Table 4 (Table 4(a) in metric units, Table 4(b) in English units) shows the measured and predicted LNG temperature data for the fourteen runs that were selected for evaluation. These particular runs covered the extremes of inlet water temperatures (shown earlier to be the most important parameter) as well as extremes 


\begin{tabular}{|l|c|l|l|}
\hline Customer: & Department of Energy - NETL & $\begin{array}{l}\text { Date of Issue: } \\
\mathbf{2 0 0 5}\end{array}$ & \\
\hline $\begin{array}{l}\text { Document } \\
\text { Title: }\end{array}$ & Heat Exchanger Field Test & $\begin{array}{l}\text { version: } \\
\mathbf{2 . 0}\end{array}$ & Page $\mathbf{1 1}$ of $\mathbf{2 8}$ \\
\hline
\end{tabular}

of flow ratios, the second most important parameter. In addition, the selected runs also cover the much of the range of LNG flow rates; viz., from $115 \mathrm{~m} 3 / \mathrm{hr}$ (498gpm) to $255 \mathrm{~m} 3 / \mathrm{hr}(1124 \mathrm{gpm})$. The table lists the measured LNG temperatures (first column) along with those predicted by the simulation using the original heat transfer coefficient correlations and assuming that ice forms on the outer wall of the inside pipe whenever that wall temperature reaches $0^{\circ} \mathrm{C} / 32 \mathrm{oF}$ (second column) and those predicted with optimized simulation parameters, as discussed below. Where available, ice measurements are also shown and compared with the revised prediction. Table 5 lists all of the available ice measurements, many of which are for runs not considered in developing the correlation.

For runs with low flow ratios, high LNG flow rates and low inlet water temperatures, the simulation with the original parameters under predicts the measured heat transfer rates in the first $152 \mathrm{~m} / 500 \mathrm{ft}$ of LNG pipe by a significant amount. On the other hand, the predicted heat transfer rates in the last $155 \mathrm{~m} / 500 \mathrm{ft}$ of pipe are somewhat higher than those measured. As a result, the heat transfer coefficient parameters (fi, fo) and the freezing points were all varied in an attempt to obtain a better match to the measured temperature data. Because the flow ratios for the 4-pass configurations were all quite low (below 2.0 in all cases), a 4-pass run, specifically the April 13th run at an LNG flow rate of $247 \mathrm{~m} 3 / \mathrm{hr} / 1088 \mathrm{gpm}$, was chosen as a representative run for the 4-pass configuration and the April 15th run at an LNG flow rate of $227 \mathrm{~m} 3 / \mathrm{hr} / 999 \mathrm{gpm}$ as representative for the 2-pass configuration. Table 2 shows the results of varying the heat transfer coefficients and the freezing point for the April 13th 4-pass run. As can be seen from Table 4, while the predictions with the original parameters give a good match to the data when inlet water temperatures are higher, they over predict heat transfer under the more severe conditions (low inlet water temperatures and low flow ratios). Consequently, since the purity of the water used as the warmant was not known, the freezing point was lowered to $-2^{\circ} \mathrm{C} / 28 \mathrm{oF}$, the value for sea water (CASE 2). As can be seen, the heat transfer is improved due to reduced ice formation, but not enough to account for the larger heat transfer in the experimental run. Cases 3-7 in Table 2 show the results of increasing the heat transfer coefficients (fi,o > 1.0), with and without changes in freezing point. Although not shown, increasing only the warmant side heat transfer coefficient actually resulted in lower heat transfer, because increased heat transfer between the bulk water and the wall actually results in increased ice formation. This is due to the fact that, at these high Reynolds numbers, the conductive resistance of the wall and ice is a significant fraction of the overall resistance. 


\begin{tabular}{|l|c|l|l|}
\hline Customer: & Department of Energy - NETL & $\begin{array}{l}\text { Date of Issue: } \\
\mathbf{2 0 0 5}\end{array}$ & \\
\hline $\begin{array}{l}\text { Document } \\
\text { Title: }\end{array}$ & Heat Exchanger Field Test & $\begin{array}{l}\text { Version: } \\
\mathbf{2 . 0}\end{array}$ & Page $\mathbf{1 2}$ of $\mathbf{2 8}$ \\
\hline
\end{tabular}

6.1. Table 2. Optimization of Simulation Parameters for April 13, 4-Pass Run

[LNG $=247 \mathrm{~m}^{3} / \mathrm{hr} / 1088 \mathrm{gpm}$, Flow Ratio $=1.22$, Twater $=24^{\circ} \mathrm{C} / 75^{\circ} \mathrm{F}$ ]

CASE 1: original parameters, $f_{i}=1.0, f_{0}=1.0, F P=0^{\circ} \mathrm{C} / 32^{\circ} \mathrm{F}$

CASE 2: $f_{i}=1.0, f_{0}=1.0, F P=-2^{\circ} \mathrm{C} / 28^{\circ} \mathrm{F}$

CASE 3: $f_{i}=1.2, f_{0}=1.2, F P=-2^{\circ} \mathrm{C} / 28{ }^{\circ} \mathrm{F}$

CASE 4: $\mathrm{f}_{\mathrm{i}}=1.3, \mathrm{f}_{\mathrm{o}}=1.3, \mathrm{FP}=0^{\circ} \mathrm{C} / 32{ }^{\circ} \mathrm{F}$

CASE 5: $f_{i}=1.0, f_{0}=1.0$, NO ICE

CASE 6: $f_{i}=1.0, f_{0}=1.0, F P=-9^{\circ} \mathrm{C} / 15^{\circ} \mathrm{F}$

CASE 7: $f_{i}=1.0, f_{0}=1.0, F P=-7^{\circ} \mathrm{C} / 20^{\circ} \mathrm{F}$

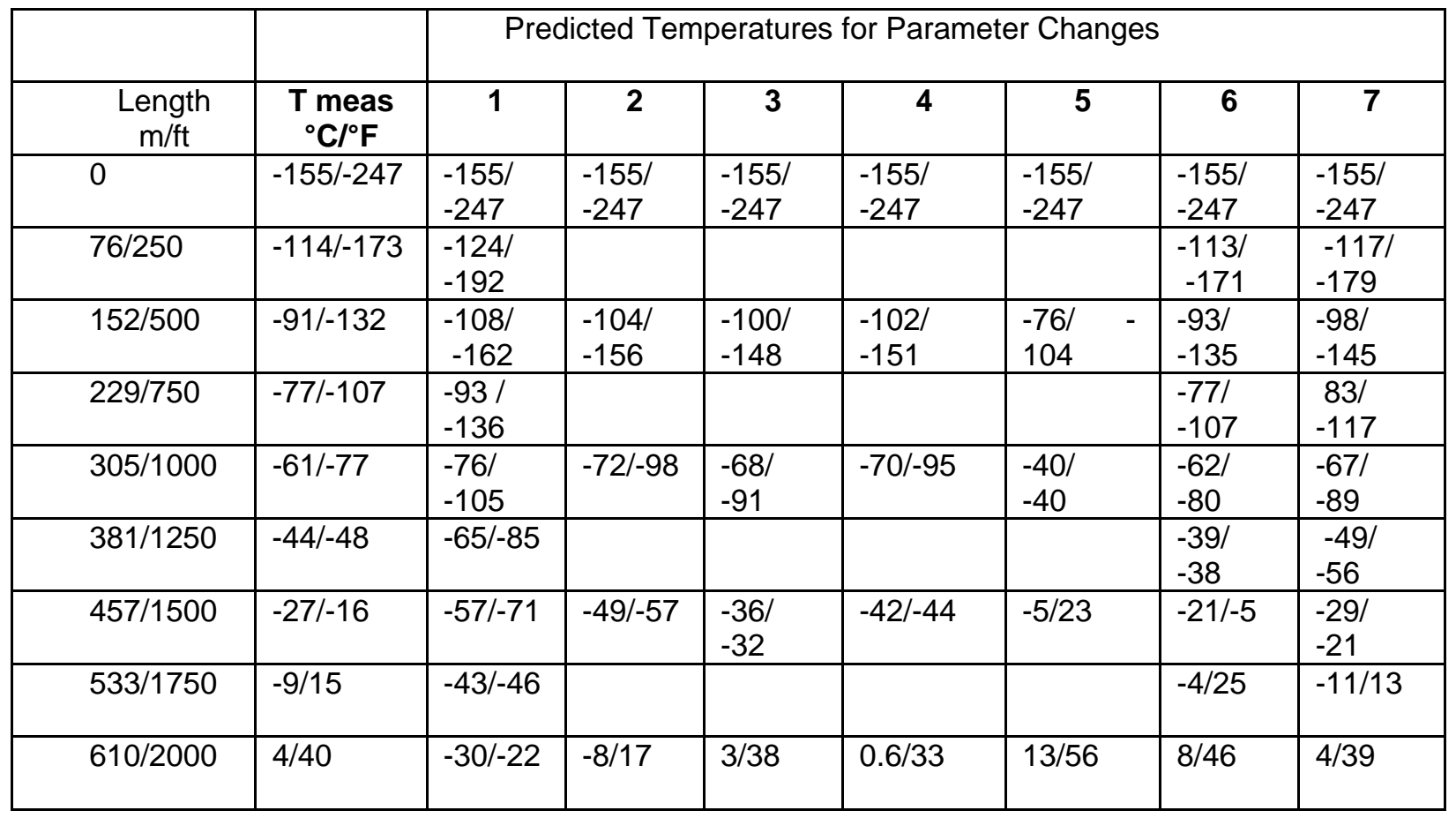

While increased heat transfer coefficients (CASES 3 and 4) do improve the heat transfer, the use of these values for other runs at higher flow ratios and higher inlet water temperatures resulted in a significant over prediction of heat transfer rates in those cases. Since lower flow ratios and lower inlet water temperatures cause increases in ice formation, it was decided instead to concentrate on changing the degree of ice formation in order to match the measured temperature profiles in both types of situations. CASE 5 is one where all ice formation was prevented (by lowering the freezing point to $-45^{\circ} \mathrm{C} /-50^{\circ} \mathrm{F}$ ) and, as can be seen, the heat transfer rates are significantly higher than those measured, leading to the conclusion that ice is definitely formed in these experiments, but not to the degree predicted by assuming that all ice formation immediately adheres to the outer wall of the inner pipe. Given the high degree 


\begin{tabular}{|l|c|l|l|}
\hline Customer: & Department of Energy - NETL & $\begin{array}{l}\text { Date of Issue: } \\
\mathbf{2 0 0 5}\end{array}$ & \\
\hline $\begin{array}{l}\text { Document } \\
\text { Title: }\end{array}$ & Heat Exchanger Field Test & $\begin{array}{l}\text { version: } \\
\mathbf{2 . 0}\end{array}$ & Page $\mathbf{1 3}$ of $\mathbf{2 8}$ \\
\hline
\end{tabular}

of wall shear in the annulus, it would not be surprising that some fraction of the ice would be sheared off the wall and become suspended in the bulk water flow. What is even more likely is that impurities in the warmant caused slush to form at the ice/water interface, and this slush was immediately swept into the bulk flow, thereby increasing the heat transfer. This effect would be magnified in sea water where slush is a common occurrence. The thickness of ice on the wall could be altered by changing the effective freezing point of the water. CASES 6 and 7 in Table 2 show two of these alterations, using freezing points of $-9^{\circ} \mathrm{C} / 15 \mathrm{oF}$ and $7^{\circ} \mathrm{C} / 20 \mathrm{oF}$, respectively.

While either of these two lower freezing points give reasonable matches to the data, it was found that when a value of $-9^{\circ} \mathrm{C} / 15 \mathrm{oF}$ (CASE 6) was used in the 2-pass runs, the predicted heat transfer rates were higher than those measured. Consequently, a separate analysis was conducted for the April 15, 2-pass run at an LNG flow rate of $227 \mathrm{~m} 3 / \mathrm{hr} / 999 \mathrm{gpm}$, and these results are shown in Table 3 . When this case was run with the original simulation parameters, the simulation failed to converge due to massive ice build-up in the first $305 \mathrm{~m} / 1000 \mathrm{ft}$ of pipe. This is designated as "ICE" in Table 3. Even when the freezing point was lowered to $2^{\circ} \mathrm{C} / 28$ oF (CASE 2 ), the simulation could not be run. The reason here is that the Reynolds number in the annulus for the two pass configuration is much higher than in the 4-pass configuration. As a result, the waterside heat transfer coefficients are much higher.

\subsection{Table 3. Optimization of Simulation Parameters for April 15, 2-Pass Run}

[LNG $=227 \mathrm{~m}^{3} / \mathrm{hr} / 999 \mathrm{gpm}$, Flow Ratio $=1.69$, Twater $\left.=19^{\circ} \mathrm{C} / 66^{\circ} \mathrm{F}\right]$

CASE 1: original parameters, $\mathrm{f}_{\mathrm{i}}=1.0, \mathrm{f}_{\mathrm{o}}=1.0, \mathrm{FP}=0^{\circ} \mathrm{C} / 32^{\circ} \mathrm{F}$

CASE 2: $\mathrm{f}_{\mathrm{i}}=1.0, \mathrm{f}_{\mathrm{o}}=1.0, \mathrm{FP}=-2^{\circ} \mathrm{C} / 28^{\circ} \mathrm{F}$

CASE 6: $\mathrm{f}_{\mathrm{i}}=1.0, \mathrm{f}_{\mathrm{o}}=1.0, \mathrm{FP}=-9^{\circ} \mathrm{C} / 15^{\circ} \mathrm{F}$

CASE 7: $f_{i}=1.0, f_{0}=1.0, F P=-7 C / 20{ }^{\circ} F$

\begin{tabular}{|l|l|l|l|l|l|}
\hline & \multicolumn{5}{|c|}{$\begin{array}{l}\text { Predicted Temperatures for } \\
\text { Parameter Changes }\end{array}$} \\
\hline Length $\mathbf{~} / \mathbf{f t}$ & Tmeas $^{\circ} \mathbf{C} /{ }^{\circ} \mathbf{F}$ & $\mathbf{1}$ & $\mathbf{2}$ & $\mathbf{6}$ & $\mathbf{7}$ \\
\hline $\mathbf{0}$ & $-155 /-247$ & $-155 /-247$ & $-155 /-247$ & $-155 /-247$ & $-155 /-247$ \\
\hline $\mathbf{7 6 / 2 5 0}$ & $-117 /-179$ & ICE & ICE & $-105 /-157$ & $-114 /-174$ \\
\hline $\mathbf{1 5 2 / 5 0 0}$ & $-97 /-143$ & ICE & ICE & $-89 /-128$ & $-93 /-136$ \\
\hline $\mathbf{2 2 9 / 7 5 0}$ & $-88 /-127$ & ICE & ICE & $-78 /-108$ & $-82 /-116$ \\
\hline $\mathbf{3 0 5 / 1 0 0 0}$ & $-85 /-121$ & ICE & ICE & $-72 /-98$ & $-76 /-105$ \\
\hline $\mathbf{3 8 1 / 1 2 5 0}$ & $-78 /-108$ & ICE & ICE & $-66 /-87$ & $-71 / /-95$ \\
\hline $\mathbf{4 5 7 / 1 5 0 0}$ & $-64 /-84$ & ICE & ICE & $-54 /-66$ & $-63 /-82$ \\
\hline $\mathbf{5 3 3 / 1 7 5 0}$ & $-62 /-79$ & ICE & ICE & $-29 /-20$ & $-47 /-53$ \\
\hline $\mathbf{6 1 0 / 2 0 0 0}$ & $-43 /-46$ & ICE & ICE & $-7 /-19$ & $-32 /-26$ \\
\hline & \multicolumn{7}{|l}{} \\
\hline
\end{tabular}




\begin{tabular}{|l|c|l|l|}
\hline Customer: & Department of Energy - NETL & $\begin{array}{l}\text { Date of Issue: } \\
\mathbf{2 0 0 5}\end{array}$ & \\
\hline $\begin{array}{l}\text { Document } \\
\text { Title: }\end{array}$ & Heat Exchanger Field Test & $\begin{array}{l}\text { Version: } \\
\mathbf{2 . 0}\end{array}$ & Page 14 of 28 \\
\hline
\end{tabular}

and, as explained earlier, this results in a prediction of additional ice formation at the pipe wall. In this case, when the freezing point was lowered to $15^{\circ} \mathrm{F}$ (CASE 6), the simulation over predicted the heat transfer. However, with the freezing point at $20^{\circ} \mathrm{F}$, a reasonable match was obtained. Since a freezing point of $20^{\circ} \mathrm{F}$ also provided a reasonable match to the 4-pass configuration data, this is the recommended value for this parameter. It should be pointed out, however, that this parameter is probably only valid for similar water-side Reynolds numbers. Unfortunately the ability to predict ice and/or slush formation and removal in the presence of high shear forces, is limited. W. Mathews of Exxon Mobil, Ref. 2, also modeled the test results. He made the ice formation temperature a function of warmant velocity and report getting an excellent correlation. If the present simulation model is to be used for design purposes, it should be upgraded to include this improvement. Note however, that this ice removal by whatever mechanism, appears to demonstrate a significant advantage for the high water velocity type of exchanger. Also there may be information in other scientific areas that explores this phenomenon.

Table 4 shows the match to the experimental LNG temperature profile data, using the parameters of CASE 7. Figure 4 shows a parity plot of the predicted values of the LNG exit temperature versus the measured values based on the new correlation (parity line) using a freezing point of $7^{\circ} \mathrm{C}\left(20^{\circ} \mathrm{F}\right)$. As can be

\section{FIGURE 4}

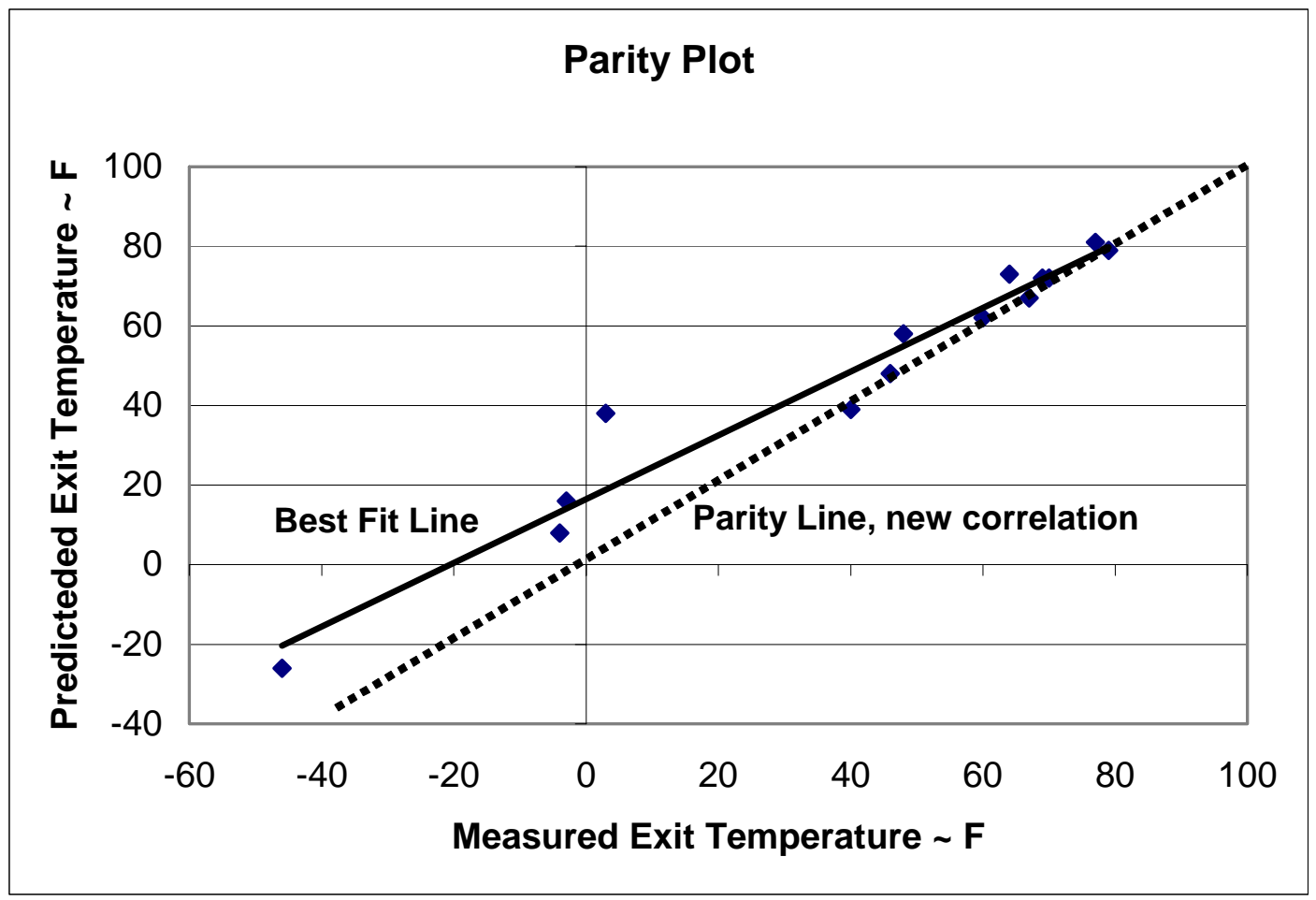

seen, the match of the predicted exit temperatures to the measured exit temperatures is reasonably good, with the actual data scattered about the best fit line, which indicates that there are no systematic errors to the comparison of predicted versus measured temperatures. In fact, in cases with the higher exit temperatures 


\begin{tabular}{|l|c|l|l|}
\hline Customer: & Department of Energy - NETL & $\begin{array}{l}\text { Date of Issue: } \\
\mathbf{2 0 0 5}\end{array}$ & \\
\hline $\begin{array}{l}\text { Document } \\
\text { Title: }\end{array}$ & Heat Exchanger Field Test & $\begin{array}{l}\text { version: } \\
\mathbf{2 . 0}\end{array}$ & Page $\mathbf{1 5}$ of $\mathbf{2 8}$ \\
\hline
\end{tabular}

(higher flow ratios, higher inlet water temperatures), the data are nearly on the parity line. However, when exit temperatures are low (lower flow ratios, lower inlet water temperatures), the model predicts higher exit temperatures than the measured values. Under those severe conditions, ice formation totally controls the heat transfer and is difficult to predict. As far as the model is concerned, the exit temperature becomes very sensitive to the inputted value of the freezing point. In some cases, changing the freezing point by only $0.6^{\circ} \mathrm{C} / 1^{\circ} \mathrm{F}$ was the difference between massive or moderate ice formation. There is one outlier experimental run in Figure 4, where the predicted exit temperature of $3^{\circ} \mathrm{C} / 38^{\circ} \mathrm{F}$ was much greater than the measured value $2^{\circ} \mathrm{C} / 3^{\circ} \mathrm{F}$. This run was conducted in a 2-pass configuration on April $14^{\text {th }}$, at an LNG flow of $255 \mathrm{~m}^{3} / \mathrm{hr} / 1125 \mathrm{gpm}$ and a flow ratio of 2.17 , with an inlet water temperature of $18^{\circ} \mathrm{C} / 65^{\circ} \mathrm{F}$. Thus, there is nothing extreme about this particular run. On the other hand, the model was able to predict the temperatures very closely up until the $380 \mathrm{~m} / 1250 \mathrm{ft}$ length, see Table 4 . Interestingly, the model predicts the cessation of ice formation at this point. So either there is an error in the experimental data, or some minor formation of ice actually occurs in that area of the pipe.

\section{TEST/MODELING CONCLUSIONS}

Consistent with the pre-test predictions, the inlet water temperature and the flow ratio are the two most important conditions for efficient heat transfer. Under conditions where the LNG is heated to desirable temperatures $\left(>4^{\circ} \mathrm{C} / 40^{\circ} \mathrm{F}\right)$, the best fit model does an excellent job of predicting the exit LNG temperatures. However, under conditions where exit gas temperatures are low $\left(<18^{\circ} \mathrm{C} / 0^{\circ} \mathrm{F}\right)$, the exit gas predictions are very dependent on the degree of ice formation. The original model assumes that once the freezing point is reached, ice is formed on the outer wall of the inner pipe. However the demonstration tests appear to indicate that this is a conservative assumption and, in fact, ice formation is significantly less than what is predicted. This is probably due to the high shear forces associated with the high Reynolds numbers in the annulus of the heat exchanger and the possible formation of slush at the ice/water interface. This phenomenon was taken into account by lowering the freezing point of the water. The optimized value of the freezing point was found to be $20^{\circ} \mathrm{F}$, providing reasonable matches to both the 2-pass and 4-pass configurations. However, under severe conditions of low inlet water temperatures and low flow ratios, ice formation is very sensitive to the selected freezing point. Consequently, the model tends to over predict the exit gas temperatures under these conditions. Note however, that these cases produce gas temperatures too low to be of practical application. If the model is to be used for design purposes without further investigation of the ice removal, it will be important that Reynolds numbers in the annulus are close to the values used in the demonstration tests and that the correlation be modified to make freezing point a function of warmant velocity. 


\begin{tabular}{|l|c|l|l|}
\hline Customer: & Department of Energy - NETL & $\begin{array}{l}\text { Date of Issue: } \\
\mathbf{2 0 0 5}\end{array}$ & \\
\hline $\begin{array}{l}\text { Document } \\
\text { Title: }\end{array}$ & Heat Exchanger Field Test & $\begin{array}{l}\text { Version: } \\
\mathbf{2 . 0}\end{array}$ & Page 16 of 28 \\
\hline
\end{tabular}

\subsection{Table 4 (a) Metric Units}

7.1.1. Measured and Predicted LNG Temperature Profiles for Selected Runs

${ }^{\text {a }}$ DATE(Pass, LNGm $3 / \mathrm{hr}$, Flow Ratio, Inlet Water Temperature)

b Original predictions based on actual measured conditions

c New match to data: $-6.67^{\circ} \mathrm{C}$ freezing point

\begin{tabular}{|c|c|c|c|c|c|c|}
\hline & & & \multirow{2}{*}{\multicolumn{2}{|c|}{ T Predicted }} & & \\
\hline & & & & & \multicolumn{2}{|c|}{ Ice } \\
\hline $\mathrm{RUN}^{\mathrm{a}}$ & $\begin{array}{l}\text { Length } \\
\text { meters }\end{array}$ & $\begin{array}{c}\text { Tmeas } \\
{ }^{\circ} \mathrm{C}\end{array}$ & $\begin{array}{c}\text { Original }^{b} \\
{ }^{\circ} \mathrm{C}\end{array}$ & $\mathrm{New}^{\mathrm{C}}{ }^{\circ} \mathrm{C}$ & $\begin{array}{c}\mathrm{New}^{\mathrm{C}} \\
\mathrm{Cm}\end{array}$ & $\begin{array}{c}\text { Meas. } \\
\mathrm{Cm}\end{array}$ \\
\hline \multirow{9}{*}{$4 / 13(4,800,1.69,86)$} & 0 & -156 & -156 & -156 & & 0 \\
\hline & 75 & -89 & -109 & & & \\
\hline & 150 & -71 & -87 & -74 & 0.15 & 0 \\
\hline & 230 & -61 & -72 & & & \\
\hline & 305 & -26 & $\begin{array}{l}-51 \\
\end{array}$ & -60 & 0 & 0 \\
\hline & 380 & 1 & -18 & & 0 & \\
\hline & 460 & 13 & 0 & 14 & 0 & 0 \\
\hline & 535 & 22 & 14 & & & \\
\hline & 610 & 26 & 22 & 22 & 0 & 0 \\
\hline \multirow[t]{9}{*}{$4 / 13(4,1088,1.22,75)$} & 0 & -155 & -155 & -155 & & 0 \\
\hline & 75 & -114 & -124 & & & 0 \\
\hline & 150 & -91 & -108 & -98 & 0.33 & 0.32 \\
\hline & 230 & -107 & $\begin{array}{l}-93 \\
\end{array}$ & & & \\
\hline & 305 & $\begin{array}{l}-61 \\
\end{array}$ & $\begin{array}{l}-76 \\
\end{array}$ & -67 & 0.005 & 0 \\
\hline & 380 & -44 & -65 & & & \\
\hline & 460 & -27 & -57 & -29 & 0 & \\
\hline & 535 & -9 & -43 & & & \\
\hline & 610 & 4 & -30 & 4 & 0 & \\
\hline \multirow[t]{9}{*}{$4 / 13(4,586,2.28,77)$} & 0 & -155 & -155 & -155 & & 0 \\
\hline & 75 & -89 & -104 & & & 0 \\
\hline & 150 & -70 & -81 & -69 & 0.165 & 0 \\
\hline & 230 & $\begin{array}{l}-59 \\
\end{array}$ & -67 & & & \\
\hline & 305 & -30 & -38 & -6 & 0 & 0 \\
\hline & 380 & -13 & -6 & & & \\
\hline & 460 & -3 & 8 & 17 & 0 & \\
\hline & 535 & 7 & 16 & & & \\
\hline & 610 & 18 & 22 & 23 & & \\
\hline \multirow[t]{6}{*}{$4 / 14(2,1033,2.92,84)$} & 0 & -155 & -155 & -155 & & 0 \\
\hline & 75 & -84 & & & & 0 \\
\hline & 150 & $\begin{array}{l}-58 \\
\end{array}$ & -64 & $\begin{array}{l}-53 \\
\end{array}$ & 0 & 0 \\
\hline & 230 & -42 & & & 0 & 0 \\
\hline & 305 & -22 & -29 & 11 & 0 & \\
\hline & 380 & 0 & & & & \\
\hline
\end{tabular}




\begin{tabular}{|l|c|l|l|}
\hline Customer: & Department of Energy - NETL & $\begin{array}{l}\text { Date of Issue: } \\
\mathbf{2 0 0 5}\end{array}$ & \\
\hline $\begin{array}{l}\text { Document } \\
\text { Title: }\end{array}$ & Heat Exchanger Field Test & $\begin{array}{l}\text { version: } \\
\mathbf{2 . 0}\end{array}$ & Page $\mathbf{1 7}$ of $\mathbf{2 8}$ \\
\hline
\end{tabular}

\begin{tabular}{|c|c|c|c|c|c|c|}
\hline & 460 & -10 & -9 & -7 & 0 & \\
\hline & 535 & 21 & & & 0 & \\
\hline & 610 & 25 & 26 & 27 & 0 & \\
\hline \multirow{9}{*}{$4 / 14(4,1046,1.59,85)$} & 0 & -155 & -155 & -155 & & \\
\hline & 75 & -94 & & & & \\
\hline & 150 & -71 & $\begin{array}{l}-93 \\
\end{array}$ & $\begin{array}{l}-79 \\
\end{array}$ & 0.127 & \\
\hline & 230 & -56 & & & & \\
\hline & 305 & -2 & -61 & -37 & 0 & \\
\hline & 380 & -9 & & & & \\
\hline & 460 & 6 & -14 & 5 & & \\
\hline & 535 & 15 & & & & \\
\hline & 610 & 21 & 15 & 22 & 0 & \\
\hline \multirow[t]{9}{*}{$4 / 14(4,1118,1.50,62)$} & 0 & -156 & -156 & -156 & & \\
\hline & 75 & -121 & & & & \\
\hline & 150 & $\begin{array}{l}-104 \\
\end{array}$ & -119 & -104 & 0.038 & \\
\hline & 230 & -89 & & & & \\
\hline & 305 & -69 & -89 & -72 & 0.025 & \\
\hline & 380 & -59 & & & & \\
\hline & 460 & -52 & -71 & -47 & 0 & \\
\hline & 535 & -39 & & & & \\
\hline & 610 & -19 & -57 & -9 & 0 & \\
\hline \multirow[t]{9}{*}{$4 / 14(2,498,6.17,67)$} & 0 & -156 & -156 & -156 & & \\
\hline & 75 & -66 & & & & \\
\hline & 150 & -34 & -38 & -48 & 0 & \\
\hline & 230 & -8 & & & & \\
\hline & 305 & 3 & 33 & 4 & 0 & \\
\hline & 380 & 14 & & & & \\
\hline & 460 & 18 & 18 & 18 & 0 & \\
\hline & 535 & 19 & & & & \\
\hline & 610 & 19 & 19 & 19 & 0 & \\
\hline \multirow[t]{9}{*}{$4 / 14(2,1125,2.17,65)$} & 0 & -155 & -155 & -155 & & \\
\hline & 75 & -108 & -118 & -108 & 0.122 & \\
\hline & 150 & -85 & -98 & -84 & 0.160 & \\
\hline & 230 & -75 & -87 & -74 & & \\
\hline & 305 & -71 & -80 & -68 & & \\
\hline & 380 & -64 & -74 & -58 & 0.051 & \\
\hline & 460 & -56 & -68 & -34 & 0 & \\
\hline & 535 & -38 & -59 & -11 & 0 & \\
\hline & 610 & -16 & -34 & 3 & 0 & \\
\hline \multirow[t]{6}{*}{$4 / 15(1124,1.30,65)$} & 0 & -155 & -155 & -155 & & \\
\hline & 75 & -122 & & & & \\
\hline & 150 & -105 & -119 & -105 & 0.41 & \\
\hline & 230 & -89 & & & & \\
\hline & 305 & -70 & -90 & -73 & 0.33 & \\
\hline & 380 & -59 & & & & \\
\hline
\end{tabular}




\begin{tabular}{|l|c|l|l|}
\hline Customer: & Department of Energy - NETL & $\begin{array}{l}\text { Date of Issue: } \\
\mathbf{2 0 0 5}\end{array}$ & \\
\hline $\begin{array}{l}\text { Document } \\
\text { Title: }\end{array}$ & Heat Exchanger Field Test & $\begin{array}{l}\text { version: } \\
\mathbf{2 . 0}\end{array}$ & Page $\mathbf{1 8}$ of $\mathbf{2 8}$ \\
\hline
\end{tabular}

\begin{tabular}{|c|c|c|c|c|c|c|}
\hline & 460 & -54 & -72 & -52 & 0.13 & \\
\hline & 535 & -40 & & & & \\
\hline & 610 & -20 & -60 & -13 & 0 & \\
\hline \multirow{9}{*}{$4 / 15(4,841,1.74,65)$} & 0 & -155 & -155 & -155 & & \\
\hline & 75 & -111 & & & & \\
\hline & 150 & -89 & -108 & -92 & 0.33 & \\
\hline & 230 & -74 & & & & \\
\hline & 305 & -59 & -77 & -61 & 0 & \\
\hline & 380 & -39 & & & & \\
\hline & 460 & -19 & -59 & -15 & 0 & \\
\hline & 535 & -3 & & & & \\
\hline & 610 & 8 & -13 & 9 & 0 & \\
\hline \multirow[t]{9}{*}{$4 / 15(4,858,1.71,81)$} & 0 & -155 & -155 & -155 & & \\
\hline & 75 & -94 & & & & \\
\hline & 150 & -72 & -91 & -78 & & \\
\hline & 230 & -59 & & & & \\
\hline & 305 & -34 & -61 & -32 & & \\
\hline & 380 & -9 & & & & \\
\hline & 460 & 4 & -9 & 7 & & \\
\hline & 535 & 14 & & & & \\
\hline & 610 & 21 & 17 & 22 & & \\
\hline \multirow[t]{9}{*}{$4 / 15(4,1040,1.40,82)$} & 0 & -156 & -156 & -156 & & \\
\hline & 75 & -102 & & & & \\
\hline & 150 & -76 & -87 & -87 & 0.20 & \\
\hline & 230 & -65 & & & & \\
\hline & 305 & -48 & -66 & -53 & 0 & \\
\hline & 380 & -24 & & & & \\
\hline & 460 & -7 & -21 & -7 & 0 & \\
\hline & 535 & 7 & & & & \\
\hline & 610 & 16 & 12 & 17 & 0 & \\
\hline \multirow[t]{9}{*}{$4 / 15(2,805,3.08,63)$} & 0 & -156 & -156 & -156 & & \\
\hline & 75 & -96 & & & & \\
\hline & 150 & -72 & -86 & -72 & 0.09 & \\
\hline & 230 & -64 & & & & \\
\hline & 305 & -61 & -68 & -50 & 0 & \\
\hline & 380 & -43 & & & & \\
\hline & 460 & -17 & -38 & 0.6 & 0 & \\
\hline & 535 & 0 & & & & \\
\hline & 610 & 9 & 6 & 14 & 0 & \\
\hline \multirow[t]{6}{*}{$4 / 15(2,9991.69,66)$} & 0 & -155 & -155 & -155 & & 0.16 \\
\hline & 75 & -117 & ICE & & & \\
\hline & 150 & -97 & ICE & -93 & & $2.54(?)$ \\
\hline & 230 & -88 & ICE & & & \\
\hline & 305 & -85 & ICE & -76 & & \\
\hline & 380 & -78 & ICE & & & \\
\hline
\end{tabular}




\begin{tabular}{|l|c|l|l|}
\hline Customer: & Department of Energy - NETL & $\begin{array}{l}\text { Date of Issue: } \\
\mathbf{2 0 0 5}\end{array}$ & \\
\hline $\begin{array}{l}\text { Document } \\
\text { Title: }\end{array}$ & Heat Exchanger Field Test & $\begin{array}{l}\text { Version: } \\
\mathbf{2 . 0}\end{array}$ & Page $\mathbf{1 9}$ of $\mathbf{2 8}$ \\
\hline
\end{tabular}

\begin{tabular}{|l|l|l|l|l|l|l|}
\hline & $\mathbf{4 6 0}$ & -64 & ICE & -63 & & \\
\hline & $\mathbf{5 3 5}$ & -62 & ICE & & & \\
\hline & $\mathbf{6 1 0}$ & -43 & ICE & -32 & & \\
\hline
\end{tabular}

\subsection{Table 4 (b) English Units}

7.2.1. Measured and Predicted LNG Temperature Profiles for Selected Runs

a DATE (Pass, LNGgpm, Flow Ratio, Inlet Water Temperature)

${ }^{b}$ Original predictions based on actual measured conditions

${ }^{\mathrm{c}}$ New match to data: $20^{\circ} \mathrm{F}$ freezing point

\begin{tabular}{|c|c|c|c|c|c|c|}
\hline & & & & redicted & & \\
\hline $\mathrm{RUN}^{\mathrm{a}}$ & $\begin{array}{l}\text { Length } \\
\text { feet }\end{array}$ & $\begin{array}{c}\text { Tmeas } \\
{ }^{\circ} \mathrm{F}\end{array}$ & $\underset{{ }^{\circ} F}{\text { Original }^{b}}$ & $\mathrm{New}^{\mathrm{c}}{ }^{\circ} \mathrm{F}$ & $\begin{array}{l}\text { New }^{\mathrm{C}} \\
\text { Inches }\end{array}$ & $\begin{array}{l}\text { Meas. } \\
\text { Inches }\end{array}$ \\
\hline $4 / 13(4,800,1.69,86)$ & $\mathbf{0}$ & -248 & -248 & -248 & & 0 \\
\hline & 250 & -129 & -164 & & & \\
\hline & 500 & -96 & -124 & -102 & 0.06 & 0 \\
\hline & 750 & -77 & -97 & & & \\
\hline & 1000 & -14 & -60 & -76 & 0 & 0 \\
\hline & 1250 & 34 & -1 & & 0 & \\
\hline & 1500 & 56 & 32 & 57 & 0 & 0 \\
\hline & 1750 & 71 & 58 & & & \\
\hline & 2000 & 79 & 72 & 79 & 0 & 0 \\
\hline $4 / 13(4,1088,1.22,75)$ & $\mathbf{0}$ & -247 & -247 & -247 & & 0 \\
\hline & 250 & -173 & -192 & & & 0 \\
\hline & 500 & -132 & -162 & -145 & 0.13 & $1 / 8$ \\
\hline & 750 & -107 & 136 & & & \\
\hline & 1000 & -77 & 105 & -89 & 0.002 & 0 \\
\hline & 1250 & -48 & -85 & & & \\
\hline & 1500 & -16 & -71 & -21 & 0 & \\
\hline & 1750 & 15 & -46 & & & \\
\hline & 2000 & 40 & -22 & 39 & 0 & \\
\hline $4 / 13(4,586,2.28,77)$ & 0 & -246 & -246 & -246 & & 0 \\
\hline & 250 & -129 & -155 & & & 0 \\
\hline & 500 & -94 & -113 & -93 & 0.065 & 0 \\
\hline & 750 & -74 & -88 & & & \\
\hline & 1000 & -22 & -36 & 21 & 0 & 0 \\
\hline & 1250 & 8 & 22 & & & \\
\hline & 1500 & 27 & 47 & 63 & 0 & \\
\hline & 1750 & 44 & 61 & & & \\
\hline & 2000 & 64 & 71 & 73 & & \\
\hline & & & & & & \\
\hline
\end{tabular}




\begin{tabular}{|l|c|l|l|}
\hline Customer: & Department of Energy - NETL & $\begin{array}{l}\text { Date of Issue: } \\
\mathbf{2 0 0 5}\end{array}$ & \\
\hline $\begin{array}{l}\text { Document } \\
\text { Title: }\end{array}$ & Heat Exchanger Field Test & $\begin{array}{l}\text { version: } \\
\mathbf{2 . 0}\end{array}$ & Page $\mathbf{2 0}$ of $\mathbf{2 8}$ \\
\hline
\end{tabular}

\begin{tabular}{|c|c|c|c|c|c|c|}
\hline $4 / 14(2,1033,2.92,84)$ & 0 & -247 & -247 & -247 & & 0 \\
\hline & 250 & -119 & & & & 0 \\
\hline & 500 & -73 & -84 & -64 & 0 & 0 \\
\hline & 750 & -43 & & & 0 & 0 \\
\hline & 1000 & -8 & -20 & 13 & 0 & \\
\hline & 1250 & 32 & & & & \\
\hline & 1500 & 57 & 59 & 68 & 0 & \\
\hline & 1750 & 70 & & & 0 & \\
\hline & 2000 & 77 & 79 & 81 & 0 & \\
\hline \multirow[t]{9}{*}{$4 / 14(4,1046,1.59,85)$} & 0 & -247 & -247 & -247 & & \\
\hline & 250 & -137 & & & & \\
\hline & 500 & -95 & -135 & -110 & 0.05 & \\
\hline & 750 & -69 & & & & \\
\hline & 1000 & -28 & -78 & -34 & 0 & \\
\hline & 1250 & 15 & & & & \\
\hline & 1500 & 42 & 7 & 41 & & \\
\hline & 1750 & 59 & & & & \\
\hline & 2000 & 70 & 59 & 72 & 0 & \\
\hline \multirow{9}{*}{$4 / 14(4,1118,1.50,62)$} & 0 & $\begin{array}{l}-248 \\
\end{array}$ & -248 & -248 & & \\
\hline & 250 & $\begin{array}{l}-186 \\
\end{array}$ & & & & \\
\hline & 500 & -156 & $\begin{array}{l}-182 \\
\end{array}$ & -155 & 0.015 & \\
\hline & 750 & -128 & & & & \\
\hline & 1000 & -92 & -128 & -97 & .01 & \\
\hline & 1250 & -74 & & & & \\
\hline & 1500 & -62 & -96 & -52 & 0 & \\
\hline & 1750 & -39 & & & & \\
\hline & 2000 & -3 & -71 & 16 & 0 & \\
\hline \multirow[t]{9}{*}{$4 / 14(2,498,6.17,67)$} & 0 & -249 & -249 & -249 & & \\
\hline & 250 & -86 & & & & \\
\hline & 500 & -29 & -37 & -55 & 0 & \\
\hline & 750 & 18 & & & & \\
\hline & 1000 & 37 & 37 & 40 & 0 & \\
\hline & 1250 & 57 & & & & \\
\hline & 1500 & 64 & 64 & 65 & 0 & \\
\hline & 1750 & 67 & & & & \\
\hline & 2000 & 67 & 67 & 67 & 0 & \\
\hline \multirow[t]{10}{*}{$4 / 14(2,1125,2.17,65)$} & 0 & -246 & -246 & -246 & & \\
\hline & 250 & -163 & -181 & -162 & 0.048 & \\
\hline & 500 & -121 & -145 & -120 & 0.063 & \\
\hline & 750 & -103 & -124 & -101 & & \\
\hline & 1000 & -96 & -112 & -91 & & \\
\hline & 1250 & -83 & -102 & -72 & 0.02 & \\
\hline & 1500 & -68 & -91 & -29 & 0 & \\
\hline & 1750 & -36 & $\begin{array}{l}-74 \\
\end{array}$ & 12 & 0 & \\
\hline & 2000 & 3 & -29 & 38 & 0 & \\
\hline & & & & & & \\
\hline
\end{tabular}




\begin{tabular}{|l|c|l|l|}
\hline Customer: & Department of Energy - NETL & $\begin{array}{l}\text { Date of Issue: } \\
\mathbf{2 0 0 5}\end{array}$ & \\
\hline $\begin{array}{l}\text { Document } \\
\text { Title: }\end{array}$ & Heat Exchanger Field Test & $\begin{array}{l}\text { version: } \\
\mathbf{2 . 0}\end{array}$ & Page $\mathbf{2 1}$ of $\mathbf{2 8}$ \\
\hline
\end{tabular}

\begin{tabular}{|c|c|c|c|c|c|c|}
\hline $4 / 15(1124,1.30,65)$ & 0 & -247 & -247 & -247 & & \\
\hline & 250 & -188 & & & & \\
\hline & 500 & -157 & -182 & -157 & 0.16 & \\
\hline & 750 & -129 & & & & \\
\hline & 1000 & $\begin{array}{l}-94 \\
\end{array}$ & -130 & -99 & 0.13 & \\
\hline & 1250 & -75 & & & & \\
\hline & 1500 & -65 & -98 & -61 & 0.05 & \\
\hline & 1750 & -40 & & & & \\
\hline & 2000 & -4 & -76 & 8 & 0 & \\
\hline \multirow[t]{9}{*}{$4 / 15(4,841,1.74,65)$} & 0 & -247 & & -247 & & \\
\hline & 250 & -168 & & & & \\
\hline & 500 & -129 & $\begin{array}{l}-163 \\
\end{array}$ & -134 & 0.13 & \\
\hline & 750 & -101 & & & & \\
\hline & 1000 & -75 & -106 & -78 & 0 & \\
\hline & 1250 & -38 & & & & \\
\hline & 1500 & -2 & -75 & 5 & 0 & \\
\hline & 1750 & 27 & & & & \\
\hline & 2000 & 46 & -8 & 48 & 0 & \\
\hline \multirow[t]{9}{*}{$4 / 15(4,858,1.71,81)$} & 0 & -247 & -247 & -247 & & \\
\hline & 250 & $\begin{array}{l}-138 \\
\end{array}$ & & & & \\
\hline & 500 & -97 & -132 & -108 & & \\
\hline & 750 & -75 & & & & \\
\hline & 1000 & -30 & -77 & -26 & & \\
\hline & 1250 & 15 & & & & \\
\hline & 1500 & 40 & 15 & 45 & & \\
\hline & 1750 & 58 & & & & \\
\hline & 2000 & 69 & 63 & 72 & & \\
\hline \multirow[t]{9}{*}{$4 / 15(4,1040,1.40,82)$} & 0 & -249 & -249 & -249 & & \\
\hline & 250 & -151 & & & & \\
\hline & 500 & -111 & -142 & -125 & 0.080 & \\
\hline & 750 & -85 & & & & \\
\hline & 1000 & -55 & -86 & -63 & 0 & \\
\hline & 1250 & -11 & & & & \\
\hline & 1500 & 19 & -5 & 19 & 0 & \\
\hline & 1750 & 45 & & & & \\
\hline & 2000 & 60 & 53 & 62 & 0 & \\
\hline \multirow[t]{10}{*}{$4 / 15(2,805,3.08,63)$} & 0 & -248 & -248 & -248 & & \\
\hline & 250 & -140 & & & & \\
\hline & 500 & -97 & -122 & -97 & 0.037 & \\
\hline & 750 & -83 & & & & \\
\hline & 1000 & -77 & -91 & -58 & 0 & \\
\hline & 1250 & -45 & & & & \\
\hline & 1500 & 2 & -36 & 33 & 0 & \\
\hline & 1750 & 32 & & & & \\
\hline & 2000 & 48 & 42 & 58 & 0 & \\
\hline & & & & & & \\
\hline
\end{tabular}




\begin{tabular}{|l|c|l|l|}
\hline Customer: & Department of Energy - NETL & $\begin{array}{l}\text { Date of Issue: } \\
\mathbf{2 0 0 5}\end{array}$ & \\
\hline $\begin{array}{l}\text { Document } \\
\text { Title: }\end{array}$ & Heat Exchanger Field Test & $\begin{array}{l}\text { version: } \\
\mathbf{2 . 0}\end{array}$ & Page $\mathbf{2 2}$ of $\mathbf{2 8}$ \\
\hline
\end{tabular}

\begin{tabular}{|l|c|c|c|c|c|c|}
\hline $\mathbf{4 / 1 5}(\mathbf{2}, \mathbf{9 9 9} \mathbf{1 . 6 9 , 6 6 )}$ & $\mathbf{0}$ & -247 & -247 & -247 & & $1 / 16$ \\
\hline & $\mathbf{2 5 0}$ & -179 & ICE & & & \\
\hline & $\mathbf{5 0 0}$ & -143 & ICE & -136 & & $1.0(?)$ \\
\hline & $\mathbf{7 5 0}$ & -127 & ICE & & & \\
\hline & $\mathbf{1 0 0 0}$ & -121 & ICE & -105 & & \\
\hline & $\mathbf{1 2 5 0}$ & -108 & ICE & & & \\
\hline & $\mathbf{1 5 0 0}$ & -84 & ICE & -82 & & \\
\hline & $\mathbf{1 7 5 0}$ & -79 & ICE & & & \\
\hline & $\mathbf{2 0 0 0}$ & -46 & ICE & -26 & & \\
\hline
\end{tabular}

Table 5: Complete Listing of Ice Measurements

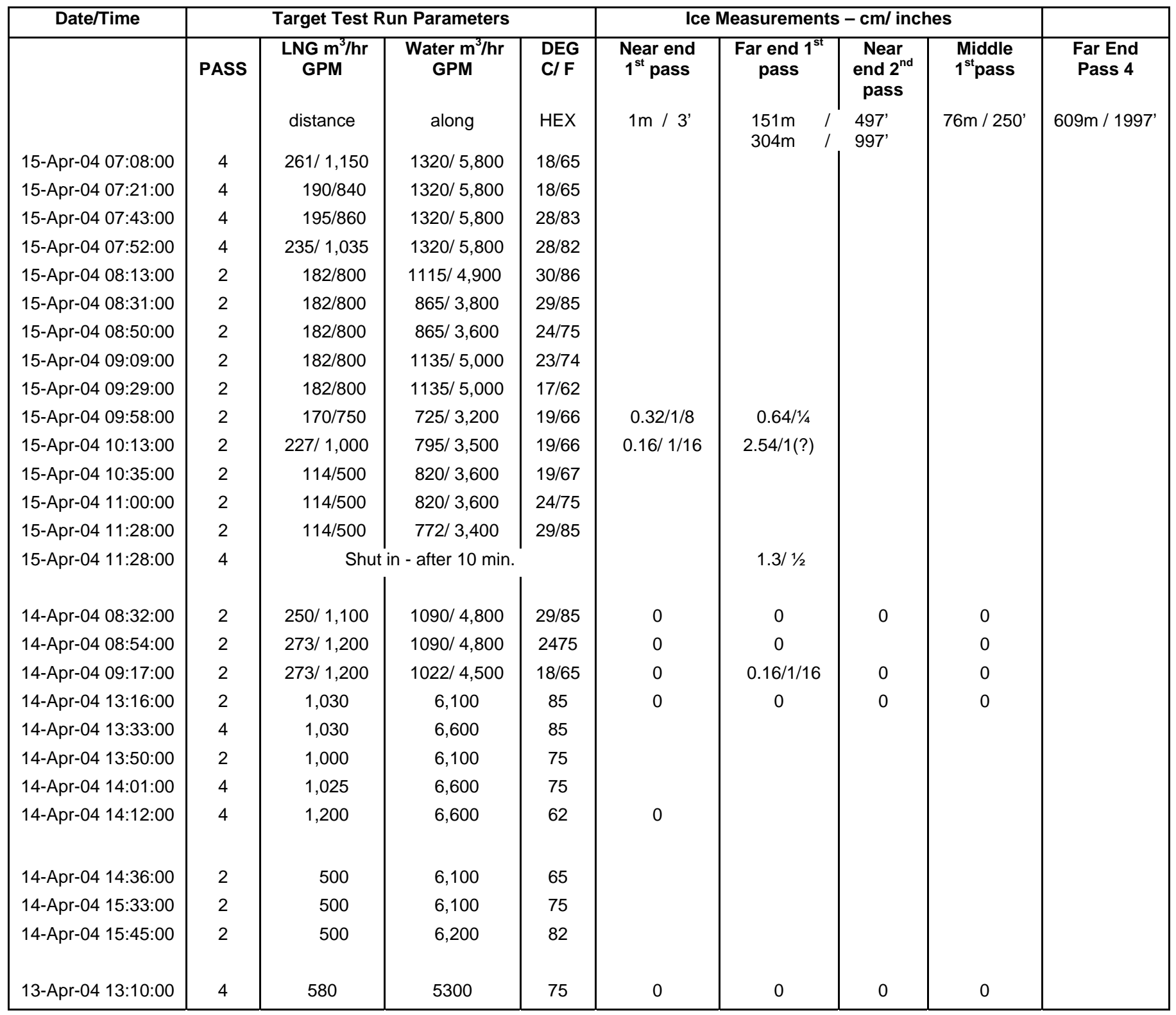




\begin{tabular}{|l|c|l|l|}
\hline Customer: & Department of Energy - NETL & $\begin{array}{l}\text { Date of Issue: } \\
\mathbf{2 0 0 5}\end{array}$ & \\
\hline $\begin{array}{l}\text { Document } \\
\text { Title: }\end{array}$ & Heat Exchanger Field Test & $\begin{array}{l}\text { Version: } \\
\mathbf{2 . 0}\end{array}$ & Page $\mathbf{2 3}$ of $\mathbf{2 8}$ \\
\hline
\end{tabular}

\begin{tabular}{|c|c|c|c|c|c|c|c|c|c|}
\hline 13-Apr-04 13:18:00 & 4 & 700 & 5300 & 75 & 0 & 0 & 0 & 0 & \\
13-Apr-04 13:44:00 & 4 & 850 & 5300 & 75 & 0 & $0.16 / 1 / 16$ & 0 & 0 \\
13-Apr-04 13:59:00 & 4 & 1090 & 5300 & 75 & 0 & $0.32 / 1 / 8$ & 0 & 0 & \\
13-Apr-04 14:20:00 & 4 & 700 & 5300 & 85 & 0 & 0 & 0 & 0 \\
13-Apr-04 14:40:00 & 4 & 700 & 5300 & 65 & $1 / 16$ & $1.11 / 0.44$ & 0 & $1 / 4$ & 0 \\
13-Apr-04 14:49:00 & 4 & 580 & 5300 & 65 & $1 / 16-1 / 8$ & $0.32 / 1 / 8$ & 0 & $1 / 8$ & 0 \\
\hline
\end{tabular}

\section{OPTIMIZATION OF THE EXCHANGER DESIGN}

As discussed earlier, the tested exchanger design evolved from the original in-the-well exchanger design. Once the numerical model and an accurate correlation became available it was possible to attempt to optimize the design to some extent. The variables subject to optimization appear to be the two liquid velocities, the two pipe diameters, and the metal forming the cryogenic pipe. Levels for the liquid velocities had already been optimized in the first study, Ref. 3. The model showed that low velocities reduced heat transfer and of course, that high velocities increased pressure drop. Based on the model calculations, optimum velocities were found to be in the range of 3-5m/s/10-15 fps. Examination of Eqn.1 shows that the wall heat transfer coefficients are only weakly dependent on diameter, approximately to the -0.2 power. However heat transfer through the metal wall is highly dependent on the wall thickness and this in turn is directly dependent on the pipe radius and inversely dependent on the metal yield strength. Separate research had led to the choice of Inconel $27-7 \mathrm{MO}$, which is discussed in more detail below. It is highly corrosion resistant, better than AL6XN, and has a yield strength of $414 \mathrm{MPa} / 60,000 \mathrm{psi}$. Since the metal is non-proprietary, it is less costly than AL6XN.

Another basic change was also made in the well-derived design. The cryo pipe was too long, resulting in high pressure drops in the LNG, thus raising operating costs. Based on this the exchanger was divided into four separate cryo runs, each one taking $75 \mathrm{~m}^{3} / \mathrm{hr}$, one quarter of the original single pipe flow of $300 \mathrm{~m}^{3} / \mathrm{hr}$. This dropped the pressure loss from over $690 \mathrm{KPa} / 100 \mathrm{psi}$ to about $70 \mathrm{KPa} / 10 \mathrm{psi}$. The optimized configuration is shown in Fig.5. Note that the exchanger is a parallel/counter flow arrangement with a nominal flow ratio of 4.5 going into each leg. This is identical to the original 4-pass usage when it was operated at a ratio of 2.5 on each leg. In either case the total water use ratio was 9.0 to 1 . Incorporating these changes the exchanger was then modeled over a range of cryo pipe diameters, using the new metal, from the original $65 / 8$ " to a low of 3". Optimum conditions, considering both heat transfer and pressure drops, were obtained for a cryo OD of 4.5", although the differences with the 5.0" and the 3.5" were small. For bigger or smaller diameters than these the performance dropped significantly. Note that all of these were based on a gas exit temperature from the exchanger of $4^{\circ} \mathrm{C} / 40^{\circ} \mathrm{F}$. Although the modeling used the flow ratio of 9 , any ratio can be used, within practical limits. If the warmant is warmer the ratio can be lowered and if it's colder it can be raised, simply by lowering the LNG rate. This latter case might be triggered by a severe cold spell, i.e. a weather delay.

Table 7 summarizes the optimized design parameters affecting the cryo pipe and Table 8, those affecting the warmant pipe. Large savings in capital costs, operating costs and weight are obtained. 


\begin{tabular}{|l|c|l|l|}
\hline Customer: & Department of Energy - NETL & $\begin{array}{l}\text { Date of Issue: } \\
\mathbf{2 0 0 5}\end{array}$ & \\
\hline $\begin{array}{l}\text { Document } \\
\text { Title: }\end{array}$ & Heat Exchanger Field Test & $\begin{array}{l}\text { Version: } \\
\mathbf{2 . 0}\end{array}$ & Page 24 of 28 \\
\hline
\end{tabular}

Table 7: Optimized Exchanger Design—Cryo Pipe

- Reduced cryo radius from 6 5/8" to 4 1/2"

- Wall thickness reduced by $47 \%$ to 0.14 "

- New metal selection Inconel 27-7MO

- Length increases from 2000' to 2160'

- Cryo weight decreased by $50 \%$

Table 8: Optimized Exchanger Design Warmant Pipe \& Water

- ID reduced from $11.5 "$ to $9.0 "$

- Weight per foot reduced from 21.0 to 12.4

- Water weight reduced by $26 \%$

- Total weight reduction per $300 \mathrm{~m}^{3} / \mathrm{hr}$ exchanger $=45,682 \mathrm{lbs}=$ $34 \%$ 


\begin{tabular}{|l|c|l|l|}
\hline Customer: & Department of Energy - NETL & $\begin{array}{l}\text { Date of Issue: } \\
\mathbf{2 0 0 5}\end{array}$ & \\
\hline $\begin{array}{l}\text { Document } \\
\text { Title: }\end{array}$ & Heat Exchanger Field Test & $\begin{array}{l}\text { Version: } \\
\mathbf{2 . 0}\end{array}$ & Page $\mathbf{2 5}$ of $\mathbf{2 8}$ \\
\hline
\end{tabular}

8.1.

Fig. 5 Optimized Exchanger Configuration

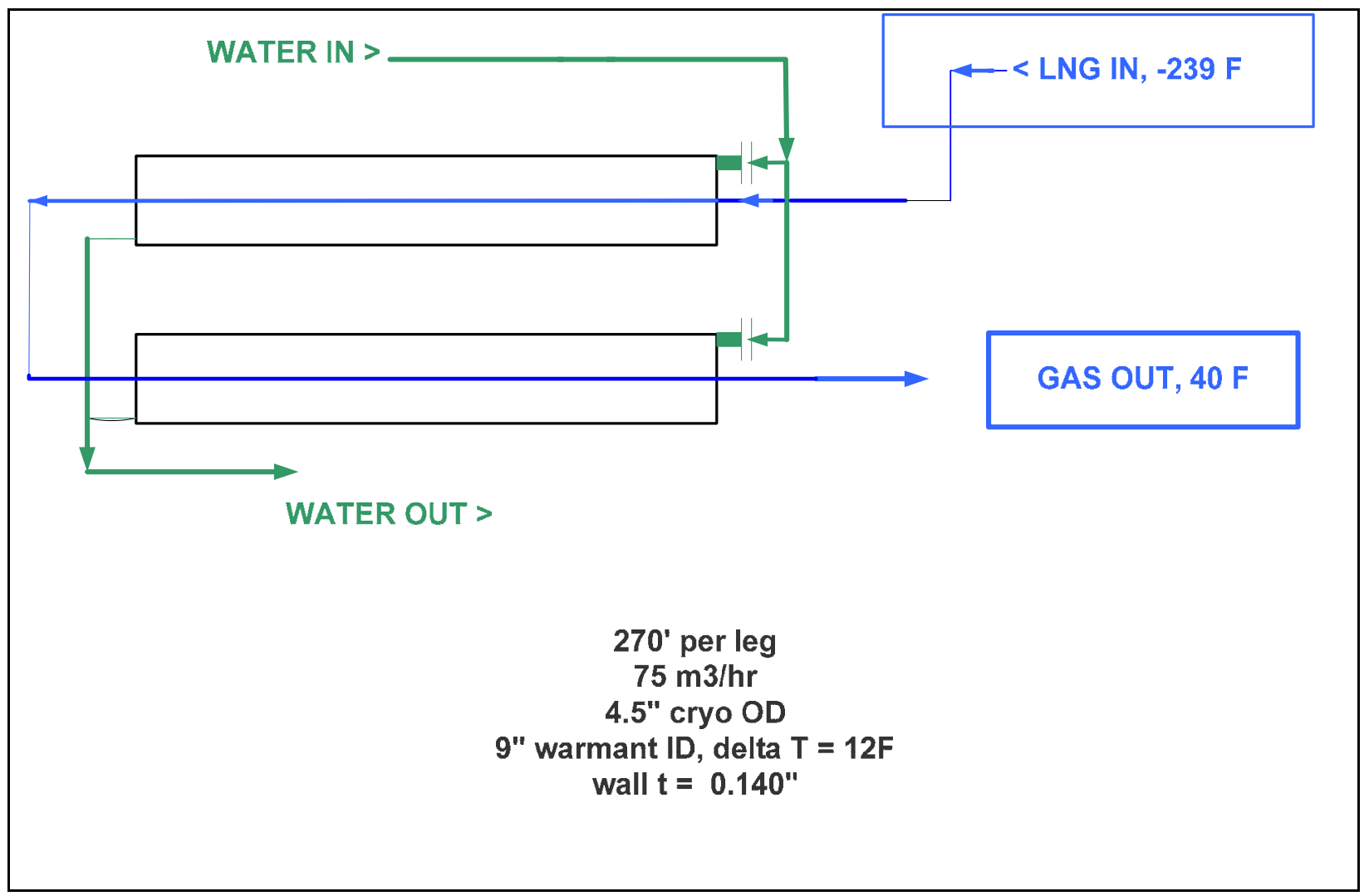

\section{COST COMPARISON WITH OTHER EXCHANGERS}

Paragon Engineering Services has performed a cost comparison between the BPE and other exchangers. The comparison is shown in Table 9. It is clear since all the exchangers are fired except the BPE and the shell and tube exchangers, that these two types have the lowest overall cost. The Table shows that the representative shell and tube at $\$ 87.8$ million is $\$ 4.4$ million lower in cost than the BPE at $\$ 92.2$ million. However this comparison was done using a thicker than design cryo wall, $5.2 \mathrm{~mm} / 0.204$ " due to the use of $12.2 \mathrm{~m} / 40$ 'pipe lengths, because of the vendor's inability to continuous weld, either spiral or seam. When continuous welding is used in the estimate with the design $3.6 \mathrm{~mm} / 0.14$ "wal; l thickness, the costs of the two exchangers are essentially equal. However the BPE has a number of advantages over shell and tube that are not evident in the cost comparison. These are:

10. ADVANTAGES OF THE BISHOP PROCESS HEAT EXCHANGER VS. SHELL AND TUBE

1. Closed loop flush system

2. Easily reparable offshore or on site. 


\begin{tabular}{|l|c|l|l|}
\hline Customer: & Department of Energy - NETL & $\begin{array}{l}\text { Date of Issue: } \\
\mathbf{2 0 0 5}\end{array}$ & \\
\hline $\begin{array}{l}\text { Document } \\
\text { Title: }\end{array}$ & Heat Exchanger Field Test & $\begin{array}{l}\text { Version: } \\
\mathbf{2 . 0}\end{array}$ & Page $\mathbf{2 6}$ of $\mathbf{2 8}$ \\
\hline
\end{tabular}

3. Fully drainable between uses. Allows exposure to air

4. Constructed on site by local labor.

5. Fully variable flow rates, turndown.

6. Lower overall costs

7. Can tolerate a high degree of turbidity, foreign matter.

8. Can handle warmant fluid very close to the warmant freezing point. Shell and tube exchangers can experience severe blockage under these conditions.

9. Can't freeze on flow stoppage or power outage. This can be a severe problem with shell and tube exchangers.

10. Overall very robust technology.

\subsection{Disadvantages}

1. Slightly higher pressure drops.

2. Possible higher weight

\section{Table 9: Excerpts from Paragon Vaporizer Cost Comparison}

\begin{tabular}{|c|c|c|c|c|c|c|c|c|}
\hline \multirow{2}{*}{\multicolumn{2}{|c|}{ Cost Summary Table }} & \multirow{2}{*}{ Units } & SCV & SCV & ORV & S/T & BPE & AAV \\
\hline & & & Sumitomo & T-Thermal $^{17}$ & Sumitomo C & C.P.P. & Butcher/Bishop & Cryoquip \\
\hline A & Gas Sendout & MMSCFD & 169 & 201 & 169 & 312 & 153 & 153 \\
\hline$B$ & Energy Required ${ }^{1}$ & kW & 336 & 597 & 559 & 839 & 559 & 0 \\
\hline D & Annual Fuel Cost for Vaporizers and Heaters ${ }^{3}$ & Million Dollars & 3.19 & 3.79 & 0 & 0 & 0 & 0 \\
\hline J & Exchanger Capital Cost ${ }^{8}$ & Million Dollars & 1.50 & 1.70 & 4.20 & 2.60 & 0.94 & 3.75 \\
\hline$S^{* *}$ & Total Installed Cost for 1.3 BCFD Sendout ${ }^{15}$ & Million Dollars & 40.3 & 47.0 & 102.9 & 44.6 & 56.2 & 115.3 \\
\hline$T^{* *}$ & Present Value Cost for 1.3 BCFD Sendout ${ }^{16}$ & Million Dollars & 283.0 & 294.9 & 177.0 & 87.8 & 92.2 & 154.9 \\
\hline
\end{tabular}

\section{ADDRESSING THE BIOTA PROBLEM}

The National Ocean and Atmospheric Administration (NOAA) has recently come out against sea water warming of LNG because they assume that all of the biota taken in by the exchangers will be destroyed. This is probably true for those exchangers that employ continuous use of biocide in warming water. The BPE employs a closed loop flush system whereby the exchangers are flushed after an LNG delivery and the flush recovered and used repeatedly until it is spent and disposed. The flush may contain anticorrosion agents and antis-scaling agents as well as the biocide. This still leaves the question of whether the biota will be affected by the $7^{\circ} \mathrm{C} / 12^{\circ} \mathrm{F}$ temperature drop expected for the 9:1 flow ratio. This is also handled in the BPE approach. Fig. 8 shows the expected turbulent velocity profile in the exchanger annulus. The biota are 


\begin{tabular}{|l|c|l|l|}
\hline Customer: & Department of Energy - NETL & $\begin{array}{l}\text { Date of Issue: } \\
\mathbf{2 0 0 5}\end{array}$ & \\
\hline $\begin{array}{l}\text { Document } \\
\text { Title: }\end{array}$ & Heat Exchanger Field Test & $\begin{array}{l}\text { version: } \\
\mathbf{2 . 0}\end{array}$ & Page $\mathbf{2 7}$ of $\mathbf{2 8}$ \\
\hline
\end{tabular}

necessarily buoyancy neutral in seawater or else they would not be entrained in the water intake. Their viscosity, however is high compared to the seawater. Because of this the biota will take the path of least resistance in the velocity profile, i.e. away from the wall. This is similar to; c particles thrown into a moving stream - they immediately are forced to the center of the flow. This means that the biota will not be exposed to the low temperatures at the cryo wall. Can they nevertheless survive a $7^{\circ} \mathrm{C} / 12^{\circ} \mathrm{F}$ temperature drop? Probably so since otherwise any sudden temperature drop at the ocean surface would produce a massive kill—which has not been observed. Of course this has to be verified by experiment, but the payoff is large. Other features of the exchanger make it advantageous: the velocity is low, around $3 \mathrm{~m} / \mathrm{sec} / 10 \mathrm{fps}$, and low impact warmant pumps can be used. These include non-kinetic types like vane, lobe or screw pumps.

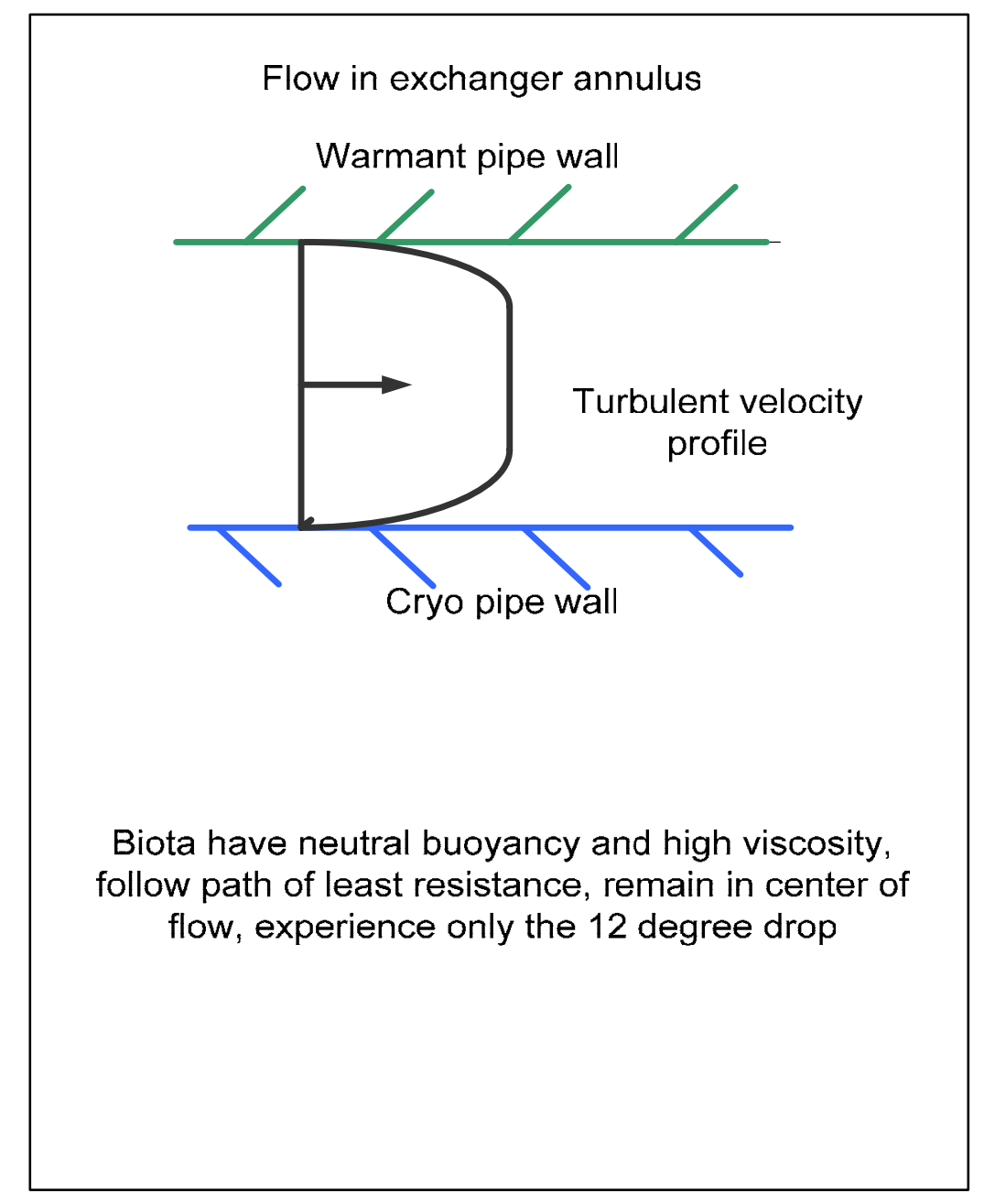

\subsection{Figure 8: Annulus Flow Velocity Profile}




\begin{tabular}{|l|c|l|l|}
\hline Customer: & Department of Energy - NETL & $\begin{array}{l}\text { Date of Issue: } \\
\mathbf{2 0 0 5}\end{array}$ & \\
\hline $\begin{array}{l}\text { Document } \\
\text { Title: }\end{array}$ & Heat Exchanger Field Test & $\begin{array}{l}\text { version: } \\
\mathbf{2 . 0}\end{array}$ & Page $\mathbf{2 8}$ of $\mathbf{2 8}$ \\
\hline
\end{tabular}

\section{References}

1. "Numerical Heat Transfer Analysis of LNG Injection into Compensated Salt Caverns", Joseph M. D'Sa, University of Houston, May. 1994.

2. Will Mathews, Exxon Mobil, Personal Communication, Mar., 2005

3. "Report 1: Critical Elements in a process to Utilize Salt Caverns in an LNG Receiving Terminal ", U.S. Dept. of Energy, National Energy Technology Laboratory, Doc. 01 r1.0, 24 April, 2003

4. Test Run Data BPE - EXCEL file available by request 


\section{Tab 5 - Attachment}

\section{Field Test Data}

The data files are in Excel format and are comprised of the information collected during each test over a four day period from April 12, 2004 through April 15, 2004. The data files are available by request. 


\begin{tabular}{|c|c|c|c|c|c|c|}
\hline \multirow[t]{3}{*}{ IMOOC0 } & $\begin{array}{l}\text { SBM-IMODCO INC. } \\
\text { MEMBER OF THE } \\
\text { IHC/CALAND GROUP } \\
\end{array}$ & \multirow{2}{*}{\multicolumn{5}{|c|}{$\begin{array}{l}\text { TAB } 6 \text {-FLOATING RE-GASIFICATION UNIT } \\
\text { FOR SALT CAVERN } \\
\text { LNG RECEIVING AND RE-GASIFICATION }\end{array}$}} \\
\hline & Now in our 5th Decade & & & & & \\
\hline & & 51059 & ССM97001 & C1 & PAGE & 3 \\
\hline
\end{tabular}

\section{TABLE OF CONTENTS}

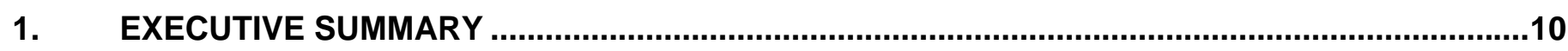

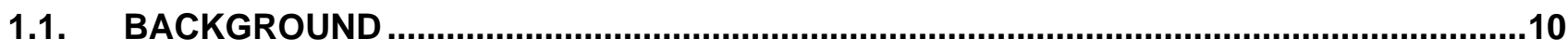

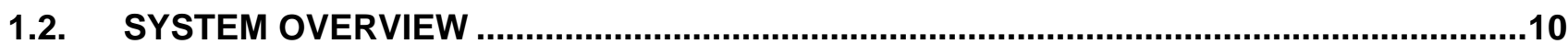

1.3. SYSTEM CONFIGURATION ............................................................................11

1.4. VESSEL SELECTION AND CONVERSION.............................................................12

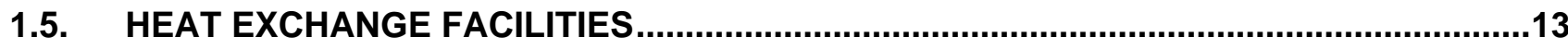

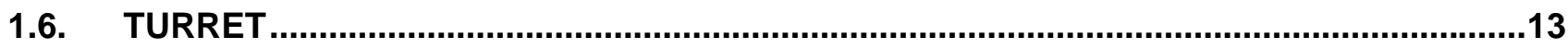

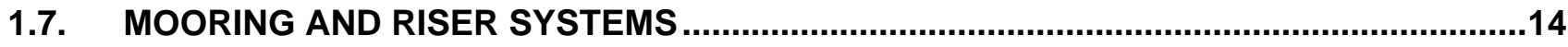

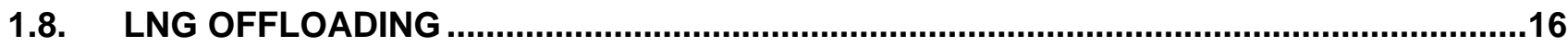

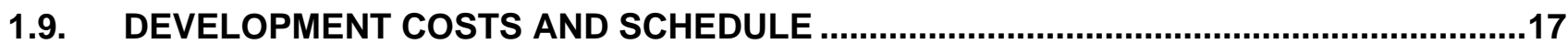

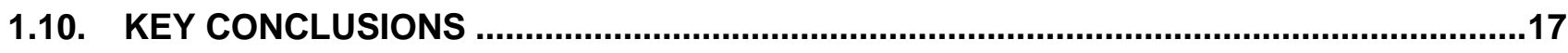

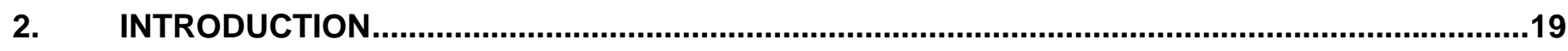

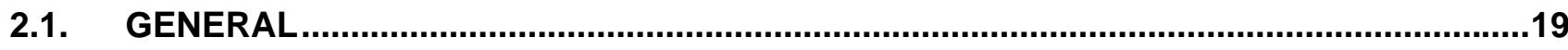

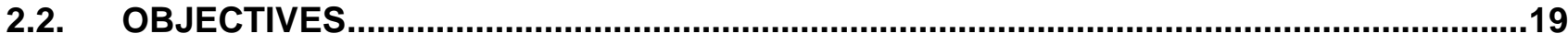

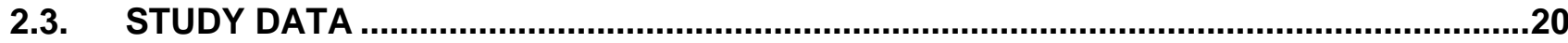

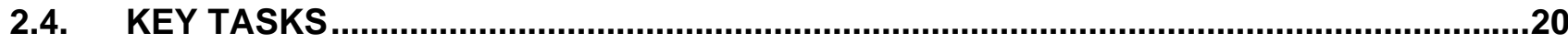

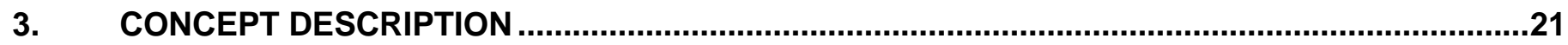

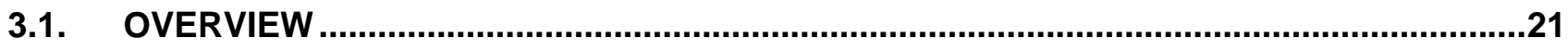

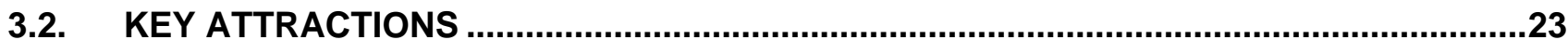

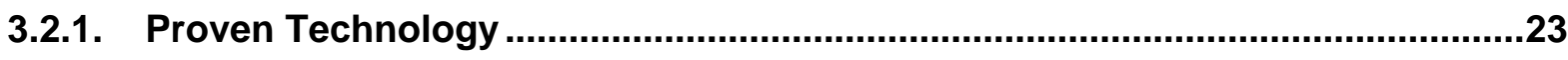

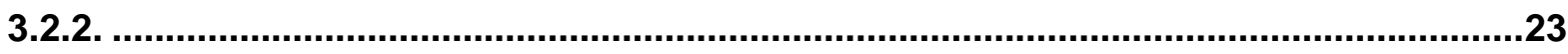

3.2.2. Wide Range of Water Depth Capability ....................................................23

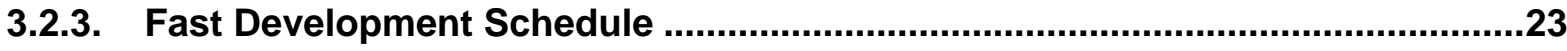

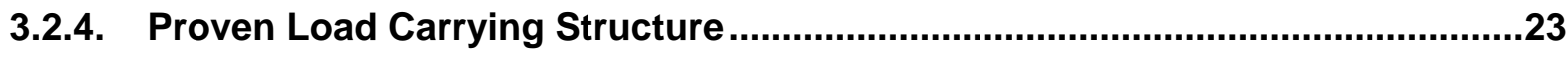

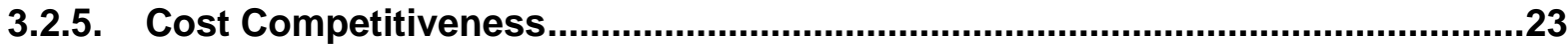

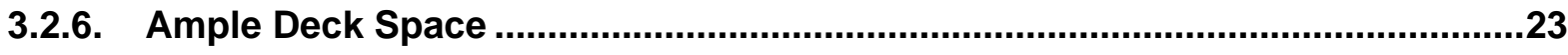

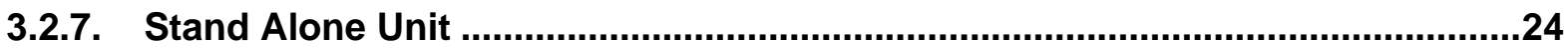

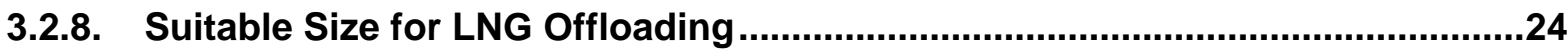




\begin{tabular}{|c|c|c|c|c|c|c|}
\hline \multirow[t]{3}{*}{ IMOOCO } & \multirow[t]{3}{*}{$\begin{array}{l}\text { SBM-IMODCO INC. } \\
\text { MEMBER OF THE } \\
\text { IHC/CALAND GROUP } \\
\text { Now in our } 5 \text { th Decade }\end{array}$} & \multirow{2}{*}{\multicolumn{5}{|c|}{$\begin{array}{l}\text { FLOATING RE-GASIFICATION UNIT } \\
\text { FOR SALT CAVERN } \\
\text { LNG RECEIVING AND RE-GASIFICATION }\end{array}$}} \\
\hline & & & & & & \\
\hline & & 51059 & CCM97001 & C1 & PAGE & 4 \\
\hline
\end{tabular}

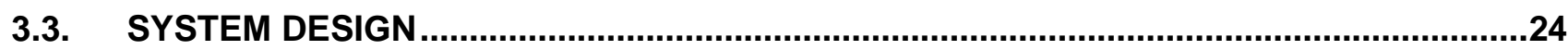

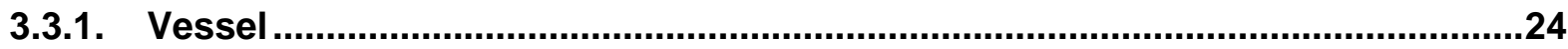

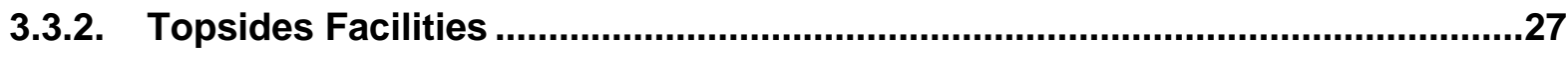

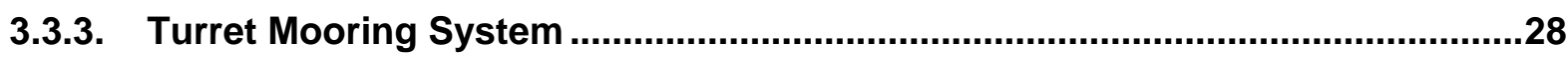

3.3.4. Riser System.............................................................................................29

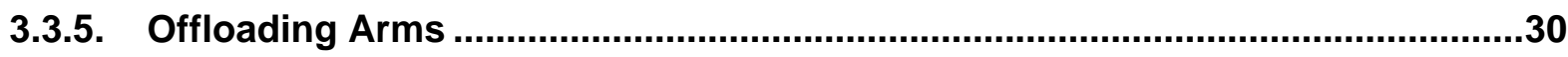

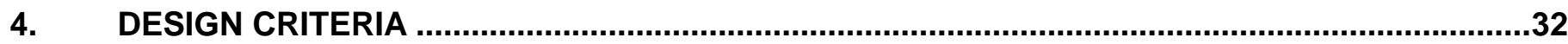

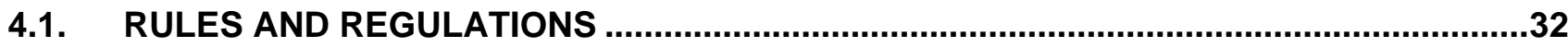

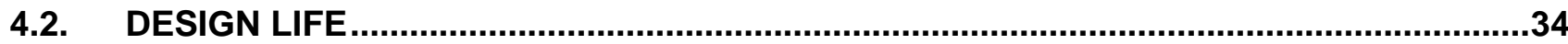

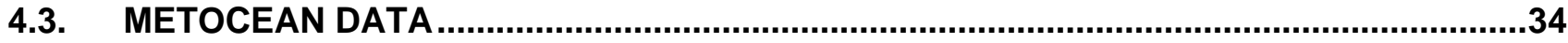

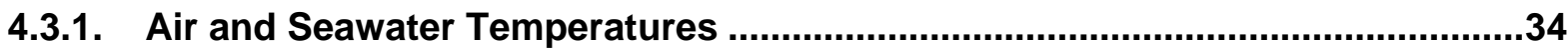

4.3.2. Prevailing Wave, Wind and Current Conditions ..........................................35

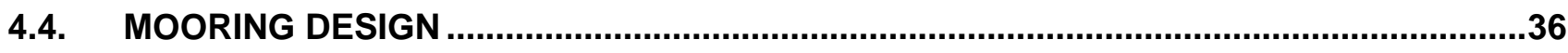

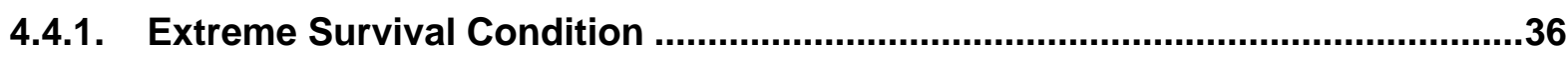

4.4.2. Offloading Condition.......................................................................................36

4.4.3. Mooring Leg Fatigue Design ........................................................................37

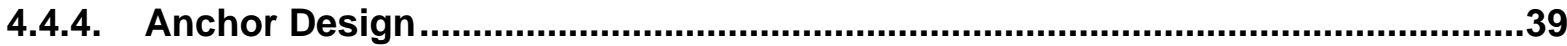

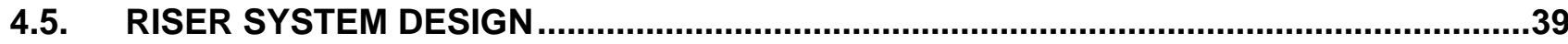

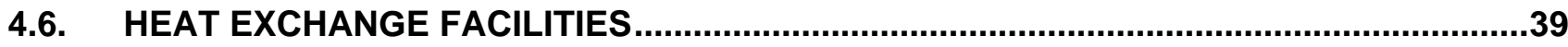

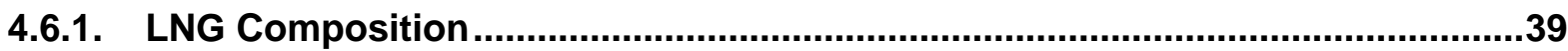

4.6.2. Processing Facilities Design Capacities....................................................40

4.7. AVAILABILITY AND RELIABILITY ....................................................................41

4.8. PASSIVE AND ACTIVE SAFETY SYSTEMS...............................................................41

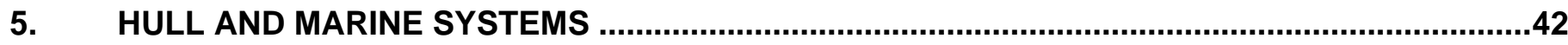

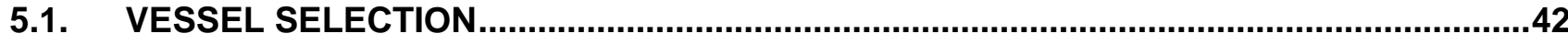

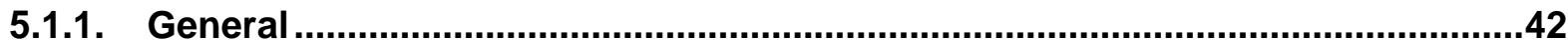

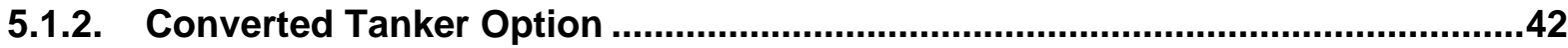

5.1.3. Intercept Option....................................................................................... 43

5.1.4. New built Option ........................................................................................44

5.1.5. Selected Option: Converted Tanker ............................................................44 


\begin{tabular}{|c|c|c|c|c|c|c|}
\hline \multirow[t]{3}{*}{ IMOOCO } & \multirow[t]{3}{*}{$\begin{array}{l}\text { SBM-IMODCO INC. } \\
\text { MEMBER OF THE } \\
\text { IHC/CALAND GROUP } \\
\text { Now in our } 5 \text { th Decade }\end{array}$} & \multirow{2}{*}{\multicolumn{5}{|c|}{$\begin{array}{l}\text { FLOATING RE-GASIFICATION UNIT } \\
\text { FOR SALT CAVERN } \\
\text { LNG RECEIVING AND RE-GASIFICATION }\end{array}$}} \\
\hline & & & & & & \\
\hline & & 51059 & ССM97001 & C1 & PAGE & 5 \\
\hline
\end{tabular}

5.1.6. Hull Structure .44

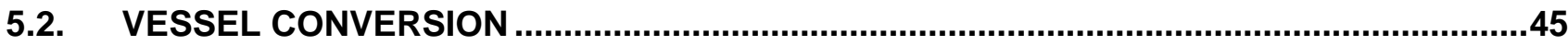

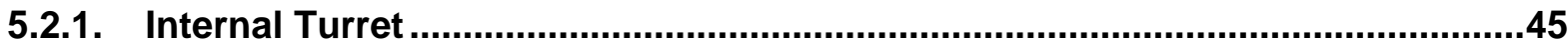

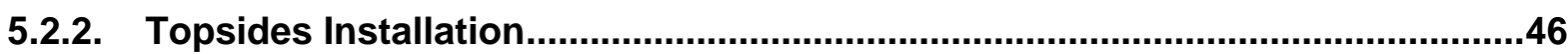

5.2.3. Tank Arrangement.......................................................................................47

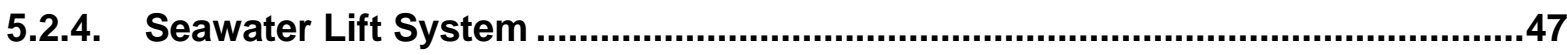

5.2.5. Hull Fendering and Mooring Facilities ..........................................................48

5.2.6. Transverse Thrusters....................................................................................48

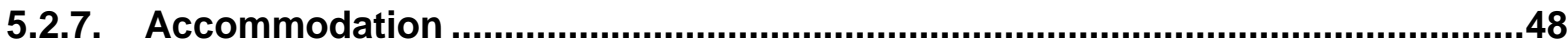

5.2.8. Corrosion Protection Systems.................................................................49

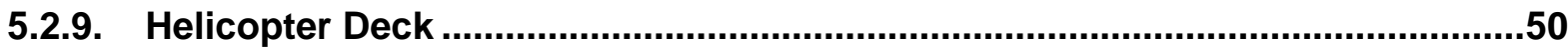

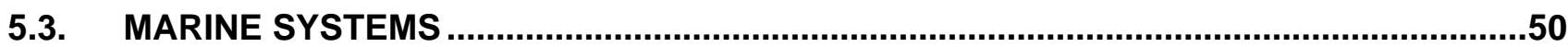

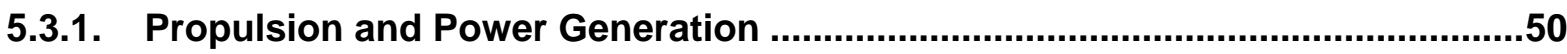

5.3.2. Heating, Ventilation and Air-conditioning System ......................................50

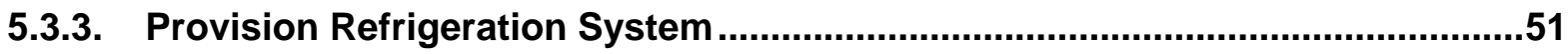

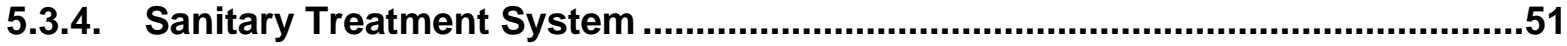

5.3.5. Fresh and Potable Water System .........................................................................51

5.3.6. Marine Seawater Service System ...................................................................51

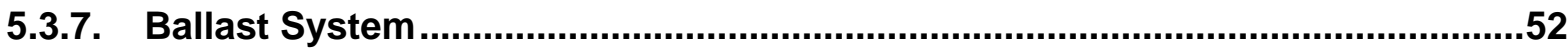

5.3.8. Tank Purging and Pressurizing System .......................................................52

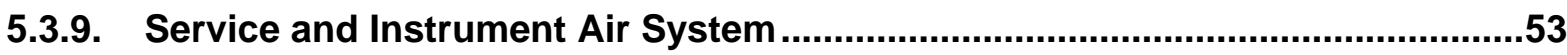

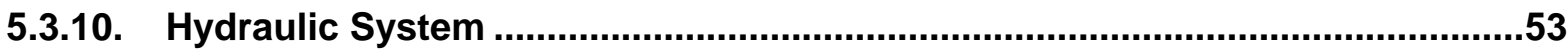

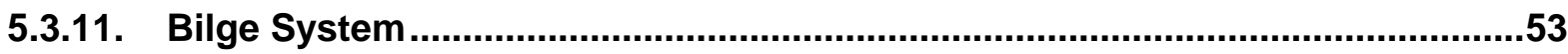

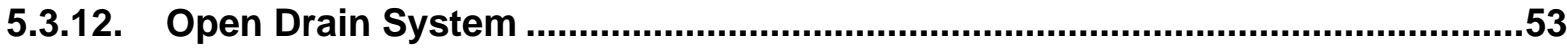

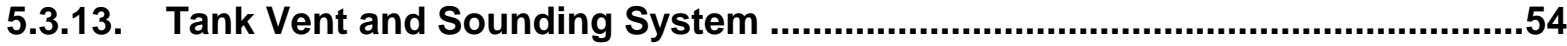

5.3.14. Fuel Oil Storage, Filling and Transfer System..............................................54

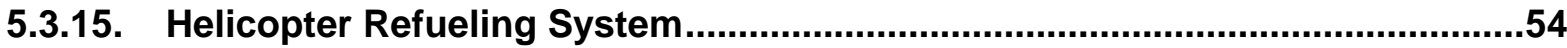

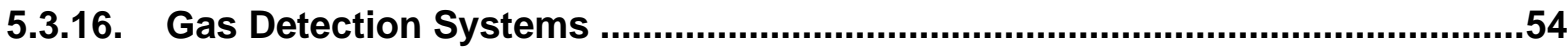

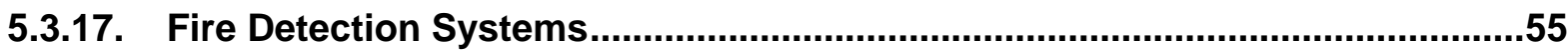

5.3.18. Fire Extinguishing and Water Deluge (Spray) System................................55 


\begin{tabular}{|c|c|c|c|c|c|c|}
\hline \multirow[t]{3}{*}{ IMODCD } & $\begin{array}{l}\text { SBM-IMODCO INC. } \\
\text { MEMBER OF THE } \\
\text { IHC/CALAND GROUP } \\
\end{array}$ & \multirow{2}{*}{\multicolumn{5}{|c|}{$\begin{array}{l}\text { FLOATING RE-GASIFICATION UNIT } \\
\text { FOR SALT CAVERN } \\
\text { LNG RECEIVING AND RE-GASIFICATION }\end{array}$}} \\
\hline & Now in our 5th Decade & & & & & \\
\hline & & 51059 & CCM97001 & C1 & PAGE & 6 \\
\hline
\end{tabular}

5.3.19. Personnel Protection and Life Saving.....................................................55

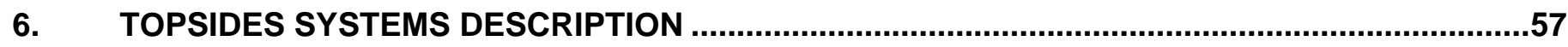

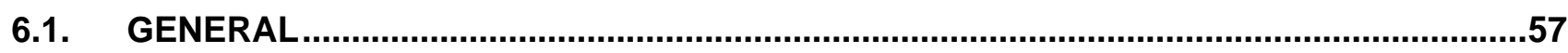

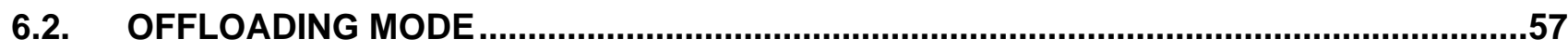

6.2.1. LNG Reception ........................................................................................57

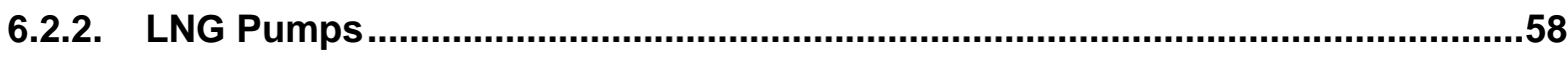

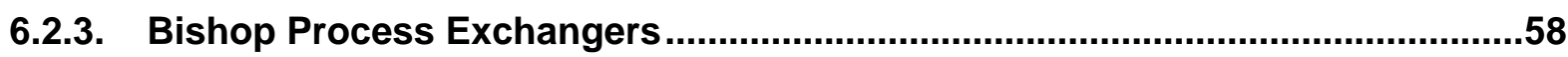

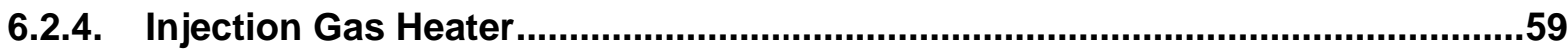

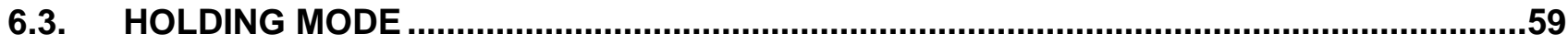

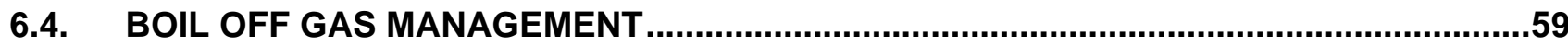

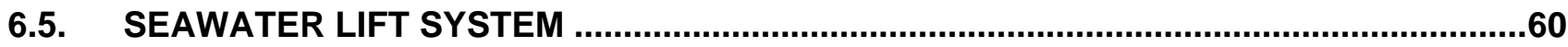

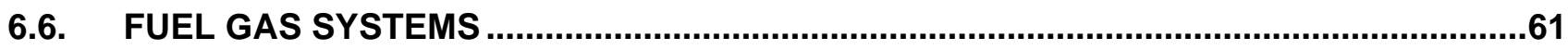

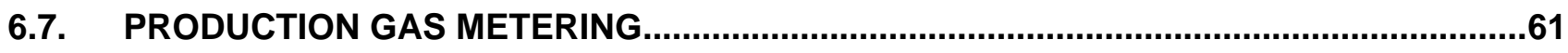

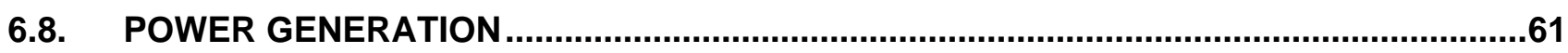

6.9. WASTE HEAT RECOVERY UNIT I HEATING MEDIUM SYSTEM ..................................62

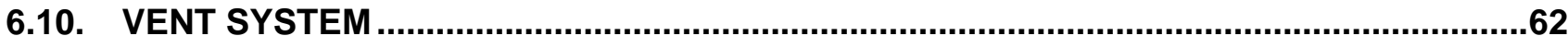

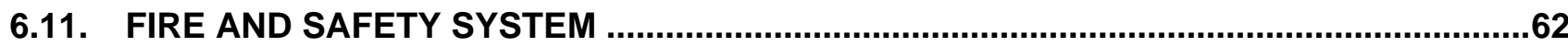

6.12. DECK LAYOUT CONSIDERATIONS ..............................................................................62

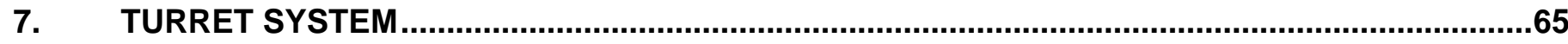

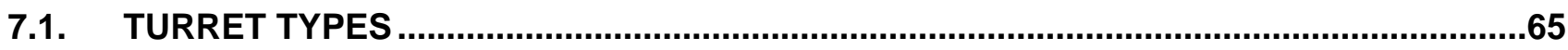

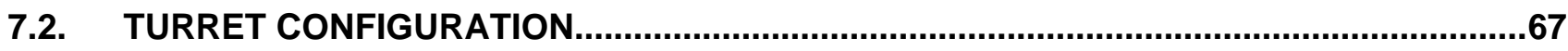

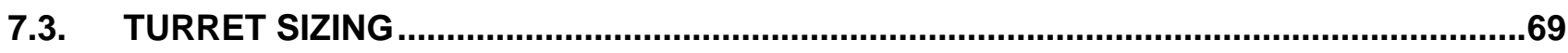

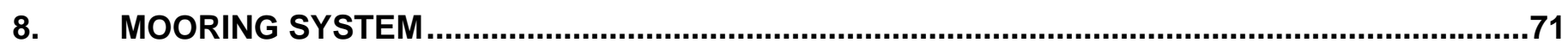

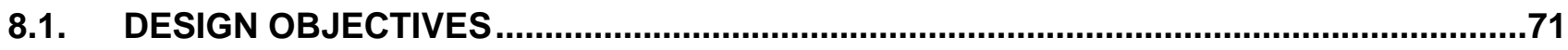

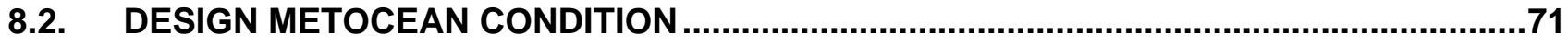

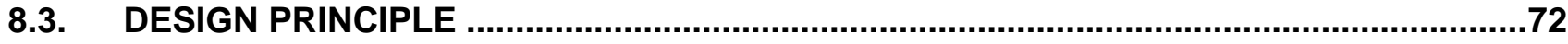

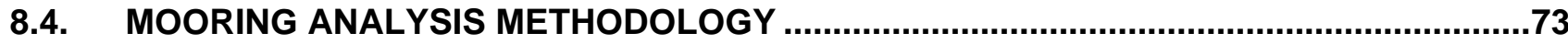

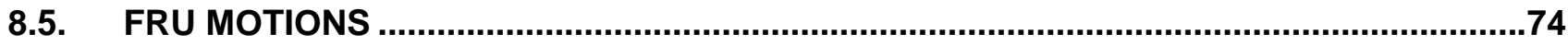

8.5.1. FRU Particulars .................................................................................. 74

8.5.2. FRU Motion Responses Analysis ............................................................ 


\begin{tabular}{|c|c|c|c|c|c|c|}
\hline \multirow[t]{3}{*}{ IMODCD } & $\begin{array}{l}\text { SBM-IMODCO INC. } \\
\text { MEMBER OF THE } \\
\text { IHC/CALAND GROUP } \\
\end{array}$ & \multirow{2}{*}{\multicolumn{5}{|c|}{$\begin{array}{l}\text { FLOATING RE-GASIFICATION UNIT } \\
\text { FOR SALT CAVERN } \\
\text { LNG RECEIVING AND RE-GASIFICATION }\end{array}$}} \\
\hline & Now in our 5th Decade & & & & & \\
\hline & & 51059 & CCM97001 & C1 & PAGE & 7 \\
\hline
\end{tabular}

8.5.3. Motion Transfer Functions ............................................................................75

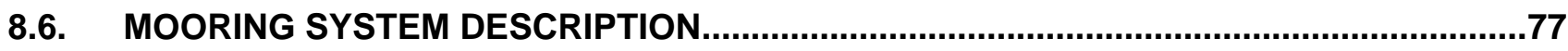

8.7. SCREENING ANALYSIS AND GOVERNING CASES ....................................................81

8.8. MOORING ANALYSIS RESULTS ...........................................................................81

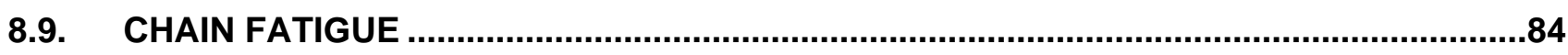

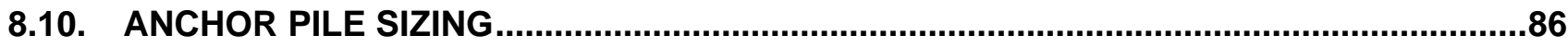

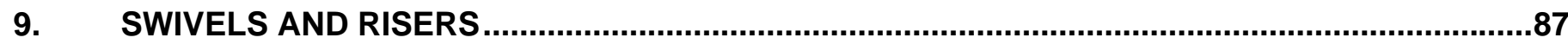

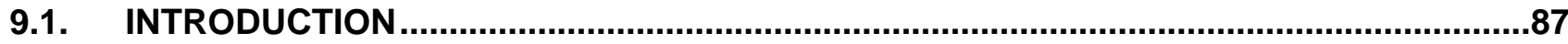

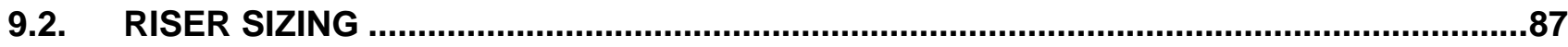

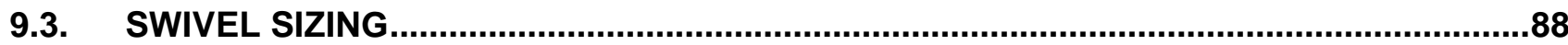

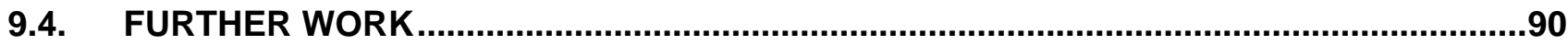

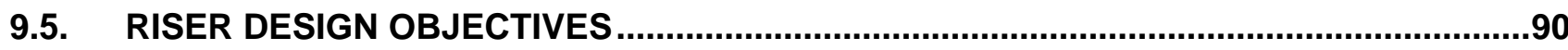

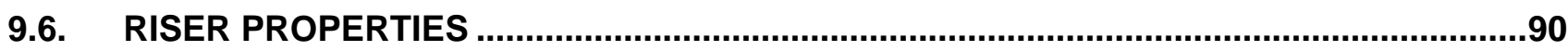

9.7. ACCEPTANCE CRITERIA AND INSTALLATION TOLERANCES....................................93

9.8. EXTREME FRU EXCURSIONS ..............................................................................93

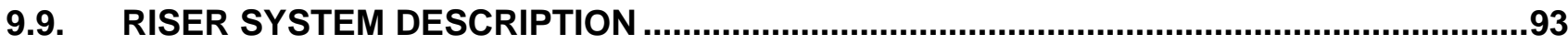

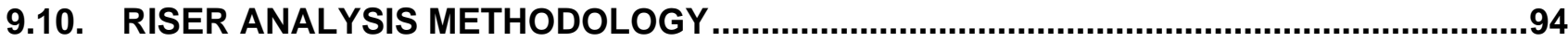

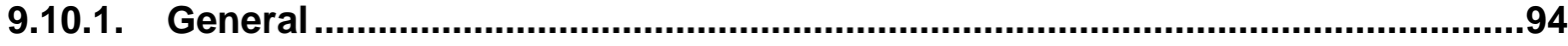

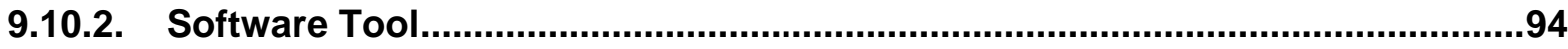

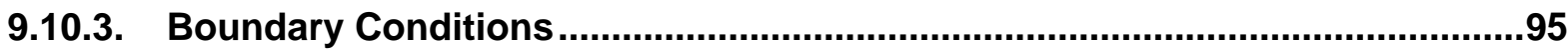

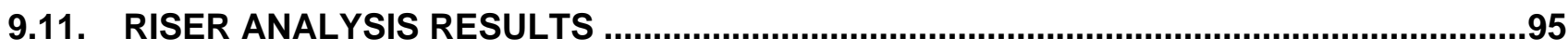

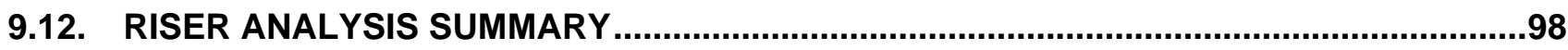

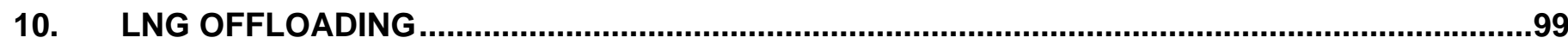

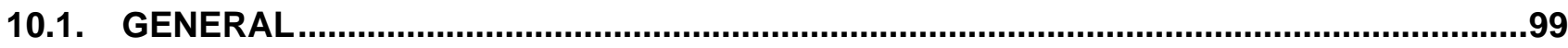

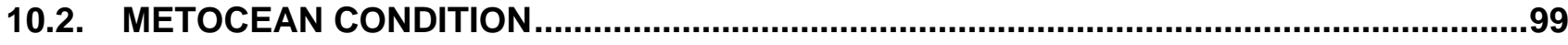

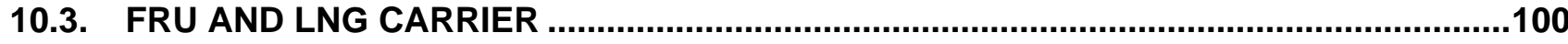

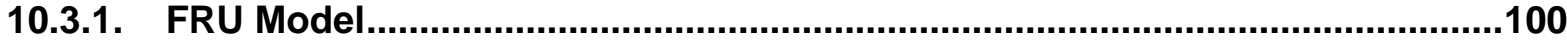

10.3.2. LNG Carrier Model.......................................................................................103

10.4. SIDE BY SIDE MOORING LINES.........................................................................104

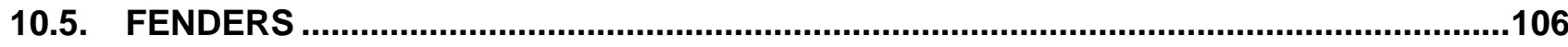




\begin{tabular}{|c|c|c|c|c|c|c|}
\hline \multirow[t]{3}{*}{ IMODCD } & $\begin{array}{l}\text { SBM-IMODCO INC. } \\
\text { MEMBER OF THE } \\
\text { IHC/CALAND GROUP } \\
\end{array}$ & \multirow{2}{*}{\multicolumn{5}{|c|}{$\begin{array}{l}\text { FLOATING RE-GASIFICATION UNIT } \\
\text { FOR SALT CAVERN } \\
\text { LNG RECEIVING AND RE-GASIFICATION }\end{array}$}} \\
\hline & Now in our 5th Decade & & & & & \\
\hline & & 51059 & CCM97001 & C1 & PAGE & 8 \\
\hline
\end{tabular}

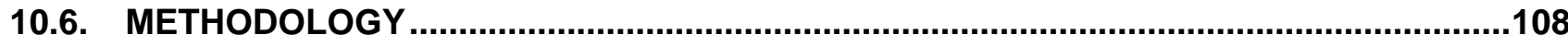

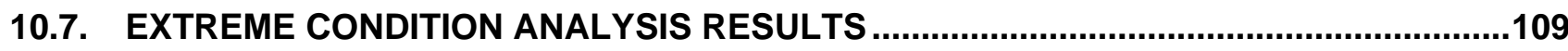

10.8. OPERATING CONDITION ANALYSIS RESULTS ......................................................109

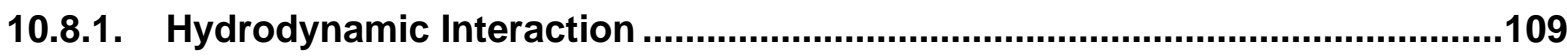

10.8.2. Side-by-Side Mooring ............................................................................112

10.8.3. Operation Envelope .................................................................................116

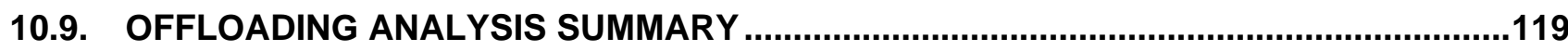

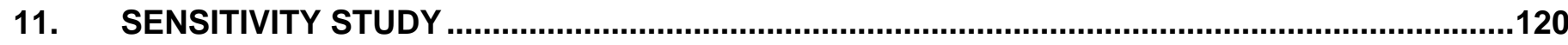

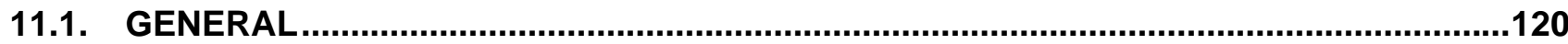

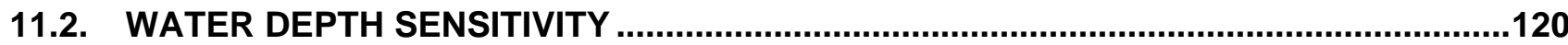

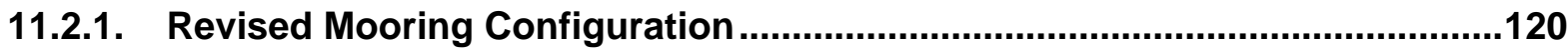

11.2.2. Mooring Analysis Results ...........................................................................123

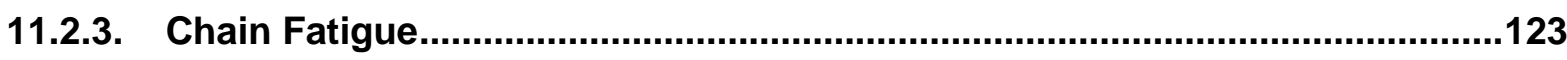

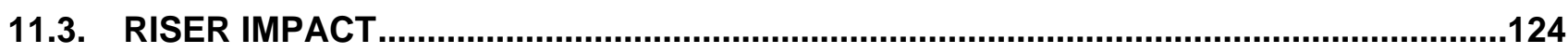

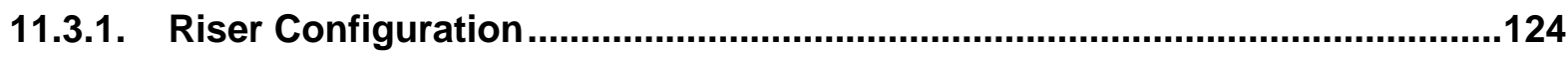

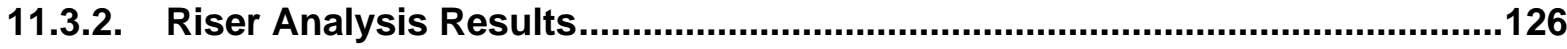

11.3.3. Riser Performance Conclusion ...................................................................127

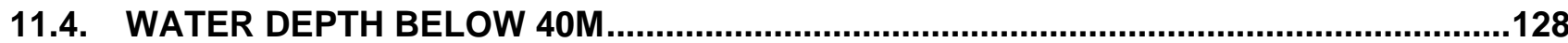

11.5. FRU TRANSIENT RESPONSE INSIDE HURRICANE EYE............................................128

12. DOWMTIME ASSESSMENT

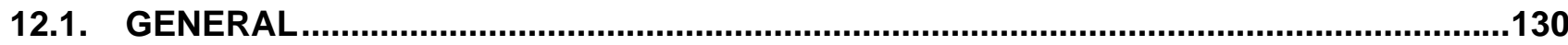

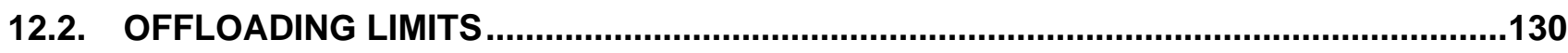

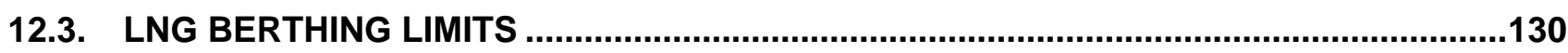

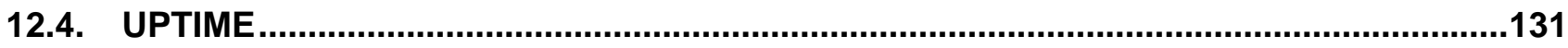

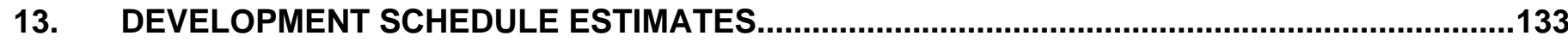

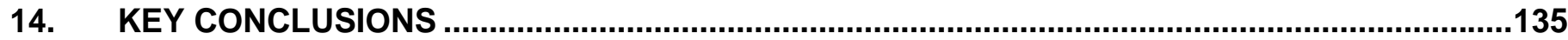

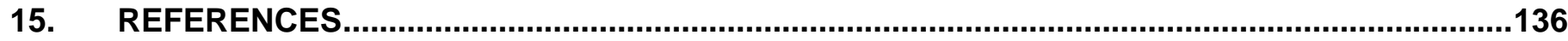




\begin{tabular}{|c|c|c|c|c|c|c|}
\hline \multirow{4}{*}{ IMOOC0 } & \multirow{2}{*}{$\begin{array}{l}\text { SBM-IMODCO INC. } \\
\text { MEMBER OF THE } \\
\text { IHC/CALAND GROUP }\end{array}$} & \multicolumn{5}{|c|}{ FLOATING RE-GASIFICATION UNIT } \\
\hline & & \multicolumn{5}{|c|}{ FOR SALT CAVERN } \\
\hline & \multirow[t]{2}{*}{ Now in our 5th Decade } & \multicolumn{5}{|c|}{ LNG RECEIVING AND RE-GASIFICATION } \\
\hline & & 51059 & CCM97001 & C1 & PAGE & 9 \\
\hline
\end{tabular}

\section{APPENDICES}

APPENDIX A - FRU GENERAL ARRANGEMENT DRAWINGS

APPENDIX B - TOPSIDES EQUIPMENT LIST

APPENDIX C - AQWA MOORING SURVIVAL ANALYSIS RESULTS

APPENDIX D - SIDE BY SIDE OPERATING ANALYSIS RESULTS

APPENDIX E - FMC OFFLOADING ARMS 


\begin{tabular}{|c|c|c|c|c|c|c|}
\hline \multirow[t]{3}{*}{ IMOOCo } & $\begin{array}{l}\text { SBM-IMODCO INC. } \\
\text { MEMBER OF THE } \\
\text { IHCICALAND GROUP }\end{array}$ & \multicolumn{4}{|c|}{ FOR SALT CAVERN } & \\
\hline & \multirow{2}{*}{ Now in our 5th Decade } & \multicolumn{5}{|c|}{ LNG RECEIVING AND RE-GASIFICATION } \\
\hline & & 51059 & CCM97001 & C1 & PAGE & 10 \\
\hline
\end{tabular}

1. EXECUTIVE SUMMARY

\subsection{BACKGROUND}

The study of using salt caverns for LNG storage is funded by the US Dept. of Energy, major operators and engineering contractors. The Floating Re-gasification Unit (FRU) is a new concept developed by SBM IMODCO (SBMI) for LNG import, re-gasification, and export to salt cavern and gas pipelines. This report summarizes the FRU feasibility study conducted by SBMI in conjunction with the development of the salt cavern concept.

The key objectives of the present study are (i) to establish the feasibility of the FRU concept for application with salt caverns for LNG storage; (ii) to develop the FRU system configuration and (iii) to assess technical and economic aspects of FRU development.

\subsection{SYSTEM OVERVIEW}

The FRU utilizes a ship shaped floating structure as the LNG receiving, re-gasification and export terminal. The FRU is turret moored via catenary anchoring legs to the sea floor to allow the vessel to weathervane to align itself with the direction of predominant environment.

The FRU receives LNG from shuttle LNG-carriers moored side-by-side. The received LNG is regasified via Bishop Heat Exchange system and then sent out to the salt caverns for storage and/or gas grid for the consumer market. Gas export is through flexible flowline risers and subsea flowlines.

The FRU has the following key features and advantages:

- Proven Technology - Although the FRU itself is a new concept, its components of vessel, turret, moorings and risers are all based on proven technologies.

- A Wide Range of Water Depth Capability - The FRU can be deployed for a wide range of water depths from $40 \mathrm{~m}$ upwards using conventional moorings, and down to $20 \mathrm{~m}$ using other types of station keeping systems such as the soft yoke system.

- Fast Development Schedule - There is a pool of existing trading tankers that can be readily converted to the FRU, and the task of conversion can be conducted by many experienced shipyards around the world.

- Proven Load Carrying Structure - Tankers that can be converted to the FRU vessel are designed to withstand the extreme environment for worldwide operations and therefore its structural members have adequate strength to withstand the large loads in the GOM hurricane condition. 


\begin{tabular}{|c|c|c|c|c|c|c|}
\hline \multirow[t]{3}{*}{ IMODCO } & \multirow[t]{3}{*}{$\begin{array}{l}\text { SBM-IMODCO INC. } \\
\text { MEMBER OF THE } \\
\text { IHC/CALAND GROUP } \\
\text { Now in our 5th Decade }\end{array}$} & \multirow{2}{*}{\multicolumn{5}{|c|}{$\begin{array}{l}\text { FLOATING RE-GASIFICATION UNIT } \\
\text { FOR SALT CAVERN } \\
\text { LNG RECEIVING AND RE-GASIFICATION }\end{array}$}} \\
\hline & & & & & & \\
\hline & & 51059 & ССМ97001 & C1 & PAGE & 11 \\
\hline
\end{tabular}

- Cost Competitiveness - The FRU vessel converted from an existing trading tanker is believed to be cost effective compared with other purpose built platforms.

- Ample Deck Space - The FRU has ample deck space for laying out topsides facilities.

- Stand Alone Unit - The FRU can remotely control the subsea trees and manifolds and therefore combine all gas processing and well control facilities on a single unit.

- Suitable Size for LNG Offloading - The ship shaped FRU vessel has a size compatible with LNG carriers and the two units can be routinely side by side moored for LNG offloading.

\subsection{SYSTEM CONFIGURATION}

The FRU configuration is developed for the northern coast of the GOM at a proven salt cavern location in a $300 \mathrm{ft}$ water depth. The FRU is proposed to be converted from a Suezmax trading tanker, and kept on station by an internal turret mooring system. The internal turret is anchored to the seabed by nine (9) anchoring legs using a chain/wire/chain combination.

The FRU receives LNG from LNG carriers through offloading arms. The Bishop Heat Exchange facilities are positioned on the deck of FRU. The vaporized gas is exported to salt cavern and gas pipelines via gas swivels and four (4) export risers. The risers pass from the vessel to the sea bottom in a steep wave configuration.

The following picture shows the artistic impression of the FRU with its mooring lines and risers. 


\begin{tabular}{|c|c|c|c|c|c|c|}
\hline \multirow[t]{3}{*}{ IMODE0 } & \multirow{3}{*}{$\begin{array}{l}\text { SBM-IMODCO INC. } \\
\text { MEMBER OF THE } \\
\text { IHC/CALAND GROUP } \\
\text { Now in our 5th Decade }\end{array}$} & \multirow{2}{*}{\multicolumn{5}{|c|}{$\begin{array}{l}\text { FLOATING RE-GASIFICATION UNIT } \\
\text { FOR SALT CAVERN } \\
\text { LNG RECEIVING AND RE-GASIFICATION }\end{array}$}} \\
\hline & & & & & & \\
\hline & & 51059 & CCM97001 & C1 & PAGE & 12 \\
\hline
\end{tabular}

FIGURE 1-1 FRU SYSTEM

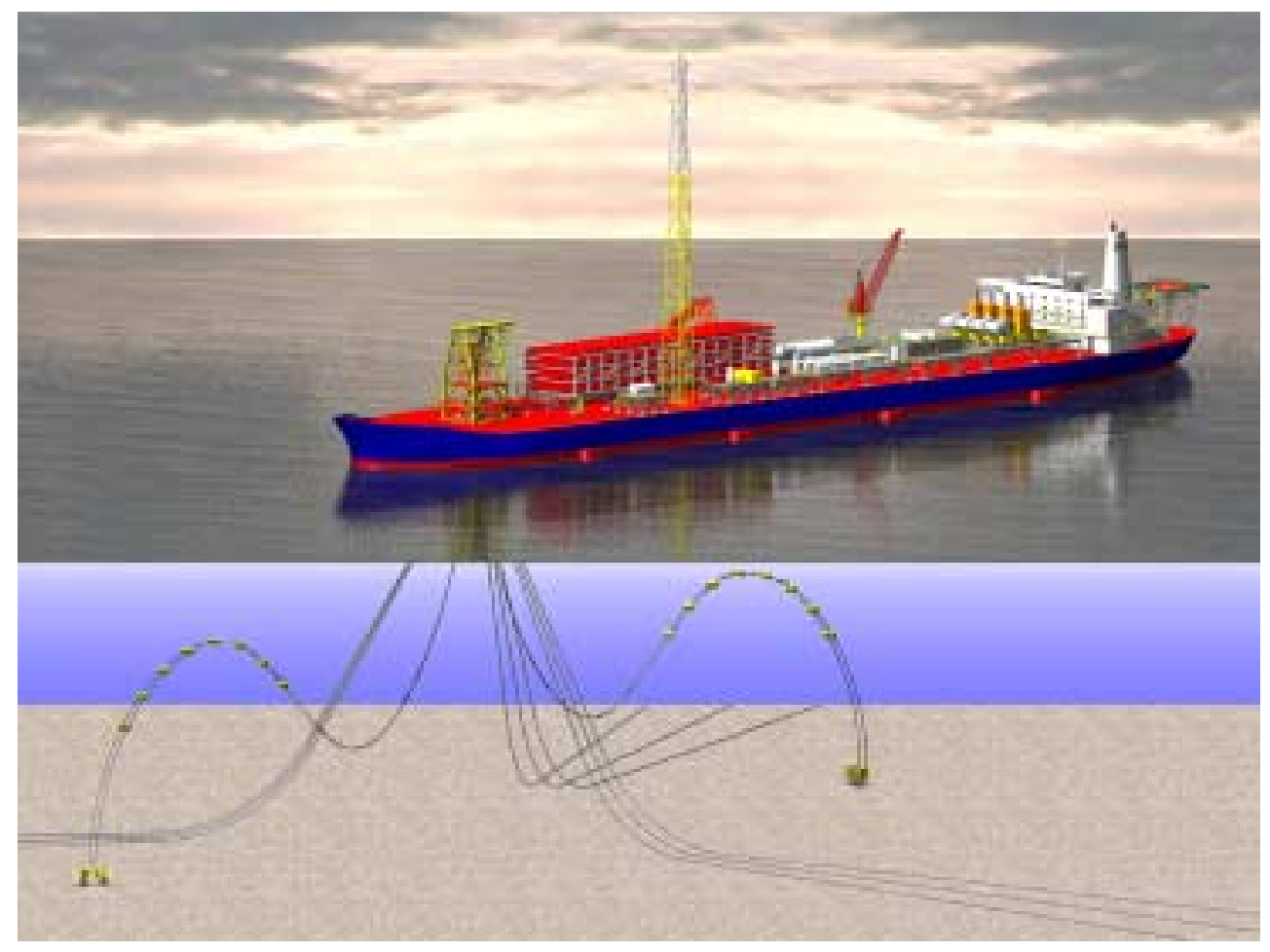

\subsection{VESSEL SELECTION AND CONVERSION}

The Suezmax tanker has been selected for conversion to an FRU giving consideration to the following:

- Amount of deck space for topside facilities

- Suitable length and width for side by side mooring of LNG carrier

- Availability of suitable vessels in the market

The selected Suezmax vessel has an overall length of $269 \mathrm{~m}$, width of $46 \mathrm{~m}$ and depth of $24 \mathrm{~m}$. A constant draft of $12 \mathrm{~m}$ has been assumed in consideration of motion, mooring load and freeboard (to be comparable with the freeboard of LNG carriers). 


\begin{tabular}{|c|c|c|c|c|c|c|}
\hline \multirow[t]{3}{*}{ IMOOED } & $\begin{array}{l}\text { SBM-IMODCO INC. } \\
\text { MEMBER OF THE } \\
\text { IHC/CALAND GROUP }\end{array}$ & \multirow{2}{*}{\multicolumn{5}{|c|}{$\begin{array}{c}\text { FOR SALT CAVERN } \\
\text { LNG RECEIVING AND RE-GASIFICATION }\end{array}$}} \\
\hline & Now in our 5th Decade & & & & & \\
\hline & & 51059 & CCM97001 & C1 & PAGE & 13 \\
\hline
\end{tabular}

\subsection{HEAT EXCHANGE FACILITIES}

The processing facilities used on the FRU are in accordance with Paragon's topsides design philosophy [Ref.1]. They mainly consist of LNG offloading arms, LNG pumping facilities, LNG vaporizers, seawater lifting pumps, and power generators.

The facilities are laid out on the FRU deck for ease of maintenance and inspection. The seawater lift pumps are located inside the cargo tanks.

\section{FIGURE 1-2 FACILITIES DECK LAYOUT}

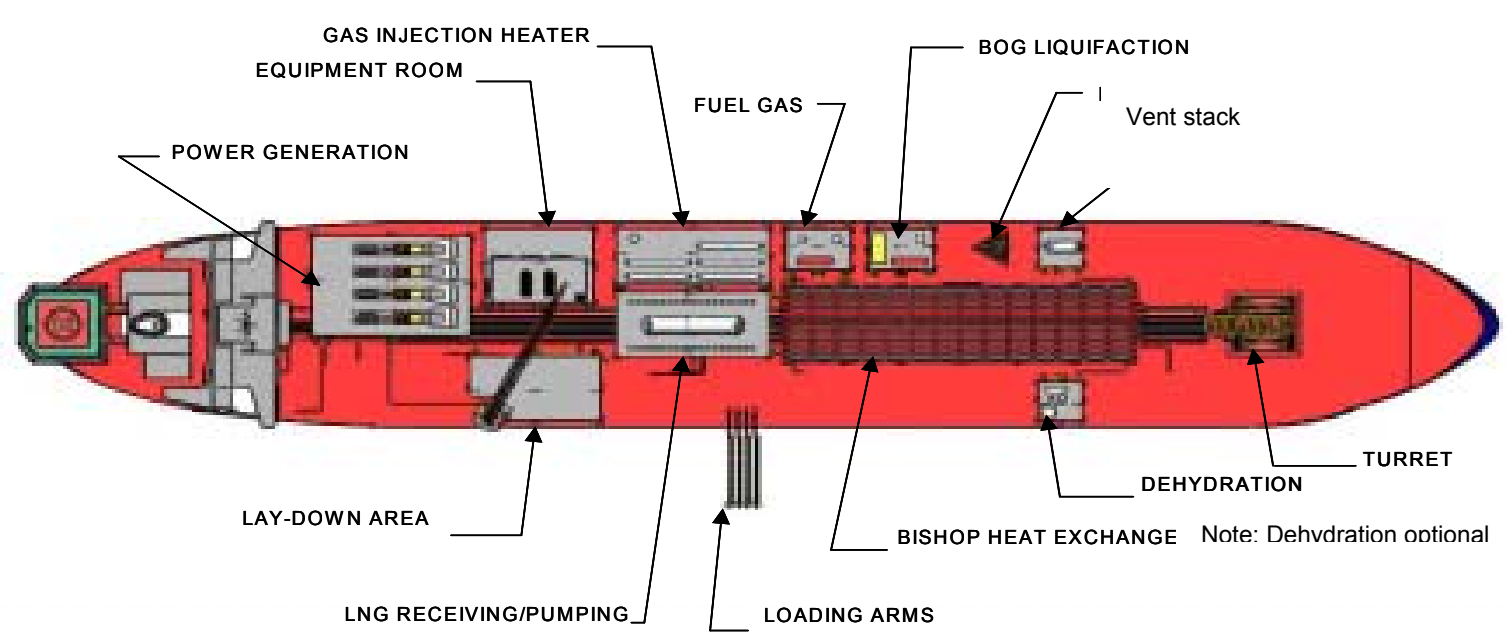

\subsection{TURRET}

An internal turret has been selected in consideration of the riser and mooring motions and loads. The turret system consists of a gantry, swivel stack, bearings, turret structure with chain table for mooring chain and riser attachment.

The turret has a chain table diameter of $9 \mathrm{~m}$ and an overall height of $51.9 \mathrm{~m}$. The FRU can rotate 


\begin{tabular}{|c|c|c|c|c|c|c|}
\hline \multirow[t]{3}{*}{ IMODE0 } & $\begin{array}{l}\text { SBM-IMODCO INC. } \\
\text { MEMBER OF THE } \\
\text { IHCICALAND GROUP }\end{array}$ & \multirow{2}{*}{\multicolumn{5}{|c|}{$\begin{array}{l}\text { FLOATING RE-GASIFICATION UNIT } \\
\text { FOR SALT CAVERN } \\
\text { LNG RECEIVING AND RE-GASIFICATION }\end{array}$}} \\
\hline & \multirow[t]{2}{*}{ Now in our 5th Decade } & & & & & \\
\hline & & 51059 & CCM97001 & C1 & PAGE & 14 \\
\hline
\end{tabular}

about this turret, which is supported on a bearing system built into the vessel's moonpool.

\section{FIGURE 1-3 TURRET SYSTEM OVERVIEW}

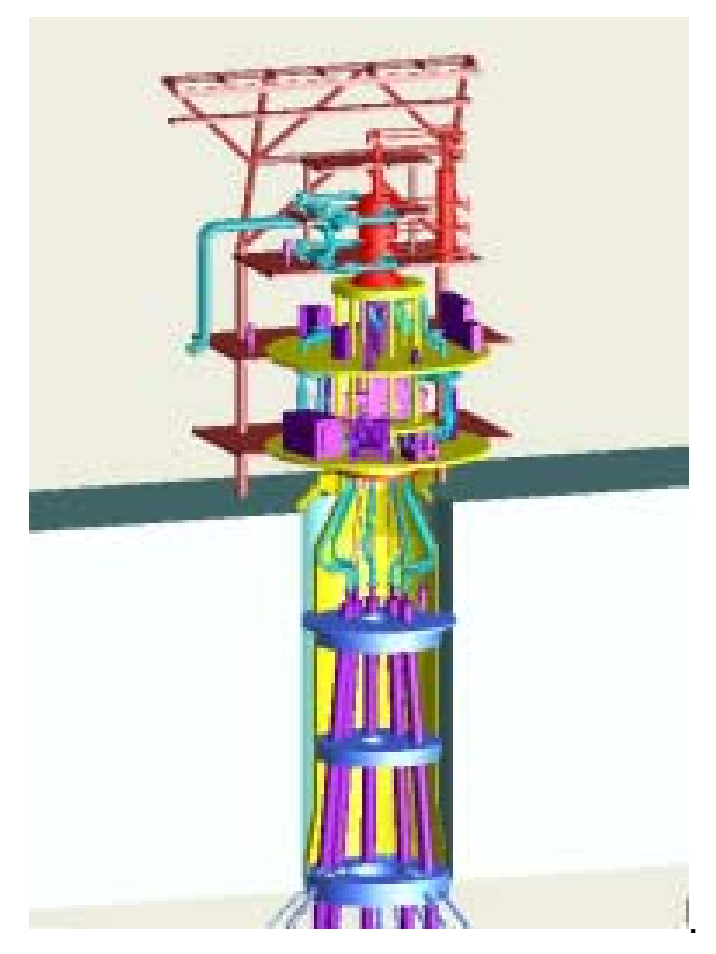

\subsection{MOORING AND RISER SYSTEMS}

The mooring system consists of three groups of three anchor legs composed of chain/wire/chain. The system is designed to withstand the GOM 100 year return hurricane condition. The mooring leg composition is presented in the following table: 


\begin{tabular}{|c|c|c|c|c|c|c|}
\hline \multirow[t]{3}{*}{ IMODCO } & \multirow[t]{3}{*}{$\begin{array}{l}\text { SBM-IMODCO INC. } \\
\text { MEMBER OF THE } \\
\text { IHC/CALAND GROUP } \\
\text { Now in our 5th Decade }\end{array}$} & \multirow{2}{*}{\multicolumn{5}{|c|}{$\begin{array}{l}\text { FLOATING RE-GASIFICATION UNIT } \\
\text { FOR SALT CAVERN } \\
\text { LNG RECEIVING AND RE-GASIFICATION }\end{array}$}} \\
\hline & & & & & & \\
\hline & & 51059 & CCM97001 & C1 & PAGE & 15 \\
\hline
\end{tabular}

TABLE 1-1 MOORING SYSTEM CONFIGURATION

\begin{tabular}{|c|c|c|}
\hline Segment & $\begin{array}{c}\text { From Anchor to } \\
\text { Chain Stopper }\end{array}$ & $\begin{array}{c}\text { Segment Characteristics } \\
\text { Lines 1-9 }\end{array}$ \\
\hline 1 & $\begin{array}{c}\text { Length } \\
\text { Diameter, Type }\end{array}$ & $\begin{array}{c}120 \mathrm{~m} \\
147 \mathrm{~mm}, \mathrm{R} 4 \text { Studless Chain }\end{array}$ \\
\hline 2 & $\begin{array}{c}\text { Length } \\
\text { Diameter, Type }\end{array}$ & $138 \mathrm{~mm}$ Sheathed Spiral Strand Wire Rope \\
\hline 3 & $\begin{array}{c}\text { Length } \\
\text { Diameter, Type }\end{array}$ & $\begin{array}{c}530 \mathrm{~m} \\
147 \mathrm{~mm}, \mathrm{R} 4 \text { Studless Chain }\end{array}$ \\
\hline & Total Leg Length & $1200 \mathrm{~m}$ \\
\hline & Pretension & $1243 \mathrm{KN}$ \\
\hline & Fairlead Angle with Horizontal & 40 degrees \\
\hline
\end{tabular}

FIGURE 1-4 MOORING SYSTEM SPREAD

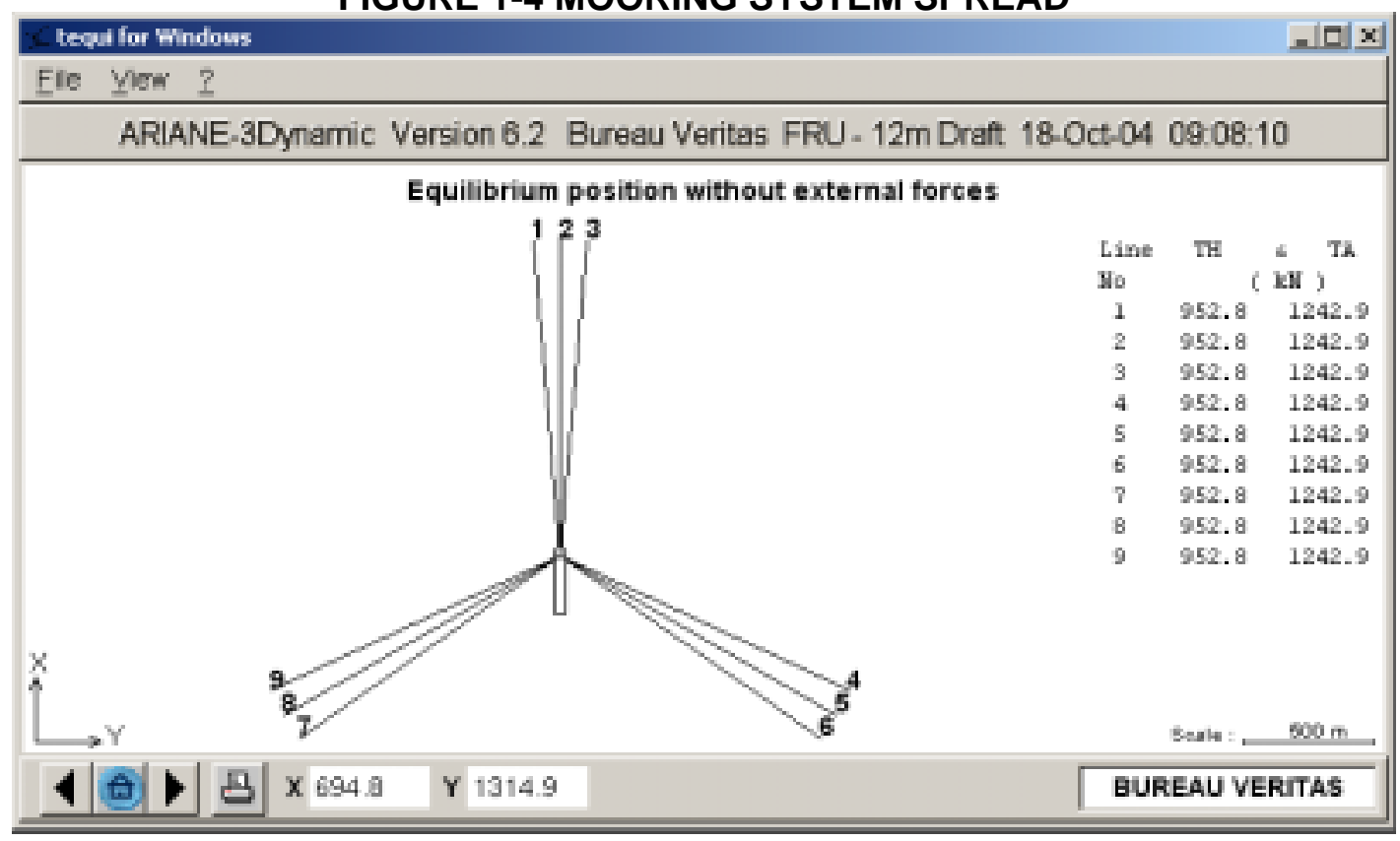




\begin{tabular}{|c|c|c|c|c|c|c|}
\hline \multirow[t]{3}{*}{ IMODE0 } & $\begin{array}{l}\text { SBM-IMODCO INC. } \\
\text { MEMBER OF THE } \\
\text { IHCICALAND GROUP }\end{array}$ & \multirow{2}{*}{\multicolumn{5}{|c|}{$\begin{array}{l}\text { FLOATING RE-GASIFICATION UNIT } \\
\text { FOR SALT CAVERN } \\
\text { LNG RECEIVING AND RE-GASIFICATION }\end{array}$}} \\
\hline & \multirow[t]{2}{*}{ Now in our 5th Decade } & & & & & \\
\hline & & 51059 & CCM97001 & C1 & PAGE & 16 \\
\hline
\end{tabular}

The mooring system analysis shows that the above mooring configuration meets the API mooring design criteria in terms of line tension safety factors, fatigue performance and offsets.

The FRU has $4 \times 16$ " flexible flowline risers. Two riser bundles are arranged for connection to salt caverns and gas pipelines (see Figure 1-1). They use a steep wave configuration to withstand the maximum offsets of the FRU. The buoyancy modules and hanging weights are attached to certain portions of the riser to achieve the desired configuration. The riser configuration is illustrated in the following plot:

\section{FIGURE 1-5 RISER CONFIGURATION}

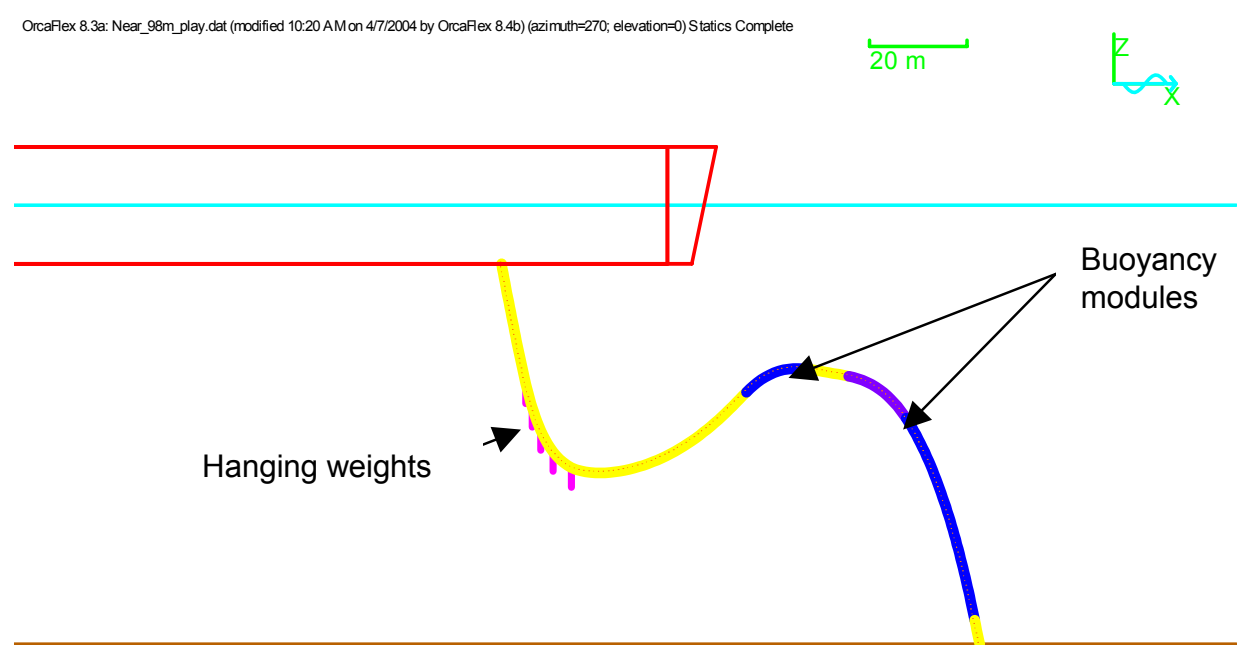

\subsection{LNG OFFLOADING}

The LNG offloading is conducted using FMC Chiksan, Double Counterweighted Marine Loading Arms. The LNG carrier is moored side by side to the FRU using sixteen (16) mooring lines. Comprehensive hydrodynamics analyses have been conducted and the results show that LNG offloading can be conducted for seastates of up to $2.5 \mathrm{~m}$ to $3.0 \mathrm{~m}$ significant wave height. The berthing operation can be conducted in similar environments. This represents an up time of over $98 \%$ in the northern GOM region. 


\begin{tabular}{|c|c|c|c|c|c|c|}
\hline \multirow[t]{3}{*}{ IMODCO } & \multirow{3}{*}{$\begin{array}{l}\text { SBM-IMODCO INC. } \\
\text { MEMBER OF THE } \\
\text { IHCICALAND GROUP } \\
\text { Now in our } 5 \text { th Decade }\end{array}$} & \multirow{2}{*}{\multicolumn{5}{|c|}{$\begin{array}{l}\text { FLOATING RE-GASIFICATION UNIT } \\
\text { FOR SALT CAVERN } \\
\text { NG RECEIVING AND RE-GASIFICATION }\end{array}$}} \\
\hline & & & & & & \\
\hline & & 51059 & CCM97001 & C1 & PAGE & 17 \\
\hline
\end{tabular}

FIGURE 1-6 SIDE BY SIDE LNG OFFLOADING

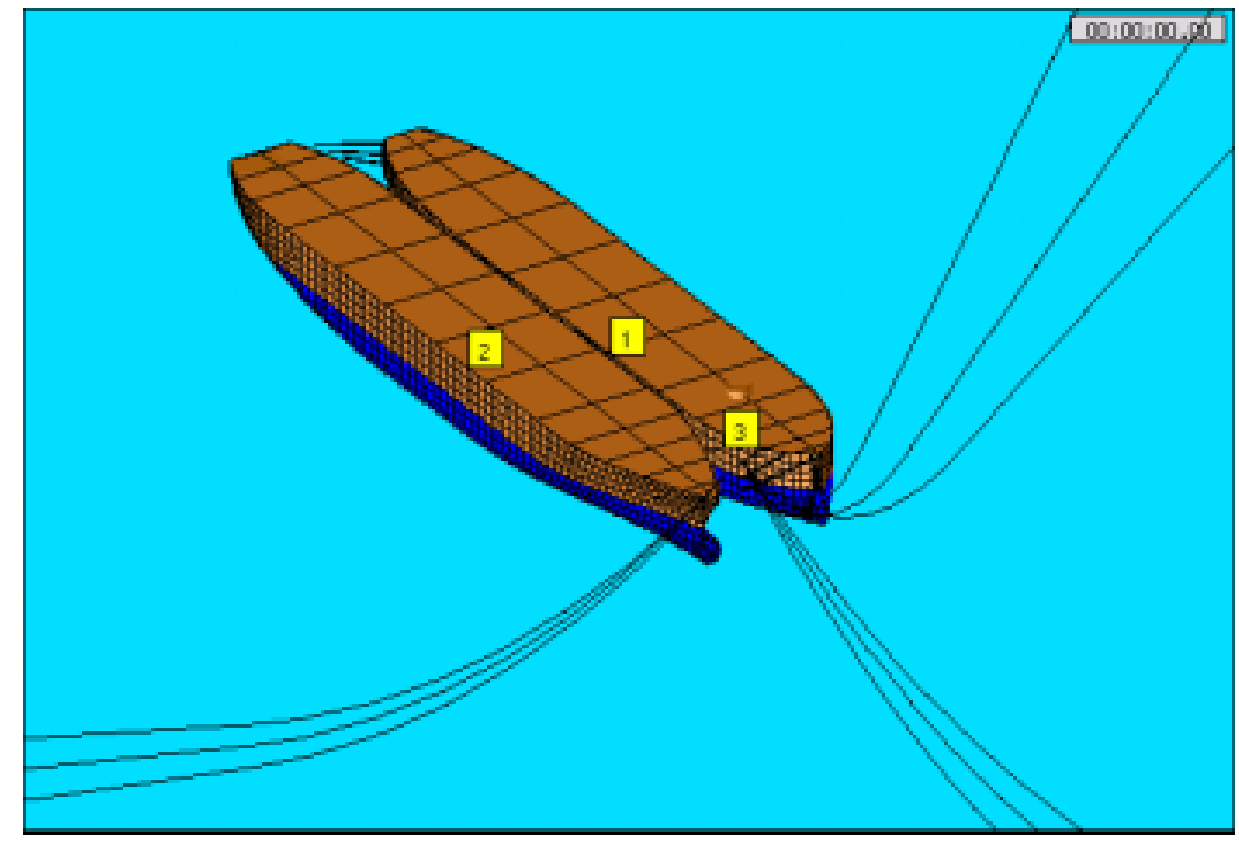

\subsection{DEVELOPMENT COSTS AND SCHEDULE}

The FRU development schedule has been estimated based on SBM's past project execution records. The system development schedule is estimated to be from eighteen (18) to twenty two (22) months.

\subsection{KEY CONCLUSIONS}

The following key conclusions can be drawn from the present study:

- $\quad$ The FRU is a feasible LNG receiving, re-gasification and export terminal concept built around proven technologies of vessel, turret, offloading, mooring and risers.

- $\quad$ The FRU offers many attractive features such as ample deck space, suitable for a wide range of water depth, proven mooring/ offloading operations, etc.

- The conventional mooring system is able to perform the stationkeeping function from water depths of $40 \mathrm{~m}$ upwards. For shallower water depths, a soft yoke concept can be applied. 


\begin{tabular}{|c|c|c|c|c|c|c|}
\hline \multirow[t]{3}{*}{ ImoOCO } & \multirow{3}{*}{$\begin{array}{l}\text { SBM-IMODCO INC. } \\
\text { MEMBER OF THE } \\
\text { IHC/CALAND GROUP } \\
\text { Now in our 5th Decade }\end{array}$} & \multirow{2}{*}{\multicolumn{5}{|c|}{$\begin{array}{l}\text { FLOATING RE-GASIFICATION UNIT } \\
\text { FOR SALT CAVERN } \\
\text {-NG RECEIVING AND RE-GASIFICATION }\end{array}$}} \\
\hline & & & & & & \\
\hline & & 51059 & CCM97001 & C1 & PAGE & 18 \\
\hline
\end{tabular}

- $\quad$ The FRU conversion from existing trading tankers is a cost effective solution.

- $\quad$ The FRU concept offers a fast development schedule of 18 months. 


\begin{tabular}{|c|c|c|c|c|c|c|}
\hline \multirow[t]{3}{*}{ IMODCO } & \multirow[t]{3}{*}{$\begin{array}{l}\text { SBM-IMODCO INC. } \\
\text { MEMBER OF THE } \\
\text { IHC/CALAND GROUP } \\
\text { Now in our 5th Decade }\end{array}$} & \multirow{2}{*}{\multicolumn{5}{|c|}{$\begin{array}{l}\text { FLOATING RE-GASIFICATION UNIT } \\
\text { FOR SALT CAVERN } \\
\text { LNG RECEIVING AND RE-GASIFICATION }\end{array}$}} \\
\hline & & & & & & \\
\hline & & 51059 & ССМ97001 & C1 & PAGE & 19 \\
\hline
\end{tabular}

\section{INTRODUCTION}

\subsection{GENERAL}

The LNG FRU project is a conceptual design study executed by SBMI on behalf of the CGI Salt Cavern LNG Joint Industry Project (JIP).

The FRU utilizes the ship shaped floating structure as the LNG receiving and re-gasification terminal. The FRU is turret moored via catenary anchor legs to the sea floor, which allows the vessel to weathervane to align itself with the direction of the predominant environment.

The FRU receives LNG via loading arms from side-by-side moored LNG carriers. The transfer of LNG from the LNG carrier to the FRU is achieved via FMC offloading arms. The received LNG will be regasified and then sent via the turret to the salt cavern for storage and/or to the gas grid for the consumer market. The vaporized gas is sent from the FRU vessel using flexible risers to fixed subsea flowlines.

This report presents the study results of the FRU concept development. The system description, design basis, engineering analysis, cost and schedule estimates, and conclusions of the study are documented herein.

\subsection{OBJECTIVES}

The main objectives of the present study can be summarized as follows:

- $\quad$ Establish FRU feasibility for application to the LNG salt cavern storage concept;

- $\quad$ Develop the system configuration;

- Assess key technical aspects of the FRU concept associated with moorings, LNG offloading and gas send out via risers;

- $\quad$ Assess concept costs for topsides equipment, vessel, moorings, risers and offloading equipment;

- $\quad$ Estimate development schedule. 


\begin{tabular}{|c|c|c|c|c|c|c|}
\hline \multirow[t]{3}{*}{ IMOOE0 } & \multirow[t]{3}{*}{$\begin{array}{l}\text { SBM-IMODCO INC. } \\
\text { MEMBER OF THE } \\
\text { IHCICALAND GROUP } \\
\text { Now in our 5th Decade }\end{array}$} & \multirow{2}{*}{\multicolumn{5}{|c|}{$\begin{array}{l}\text { FLOATING RE-GASIFICATION UNIT } \\
\text { FOR SALT CAVERN } \\
\text { LNG RECEIVING AND RE-GASIFICATION }\end{array}$}} \\
\hline & & & & & & \\
\hline & & 51059 & ССМ97001 & C1 & PAGE & 20 \\
\hline
\end{tabular}

\subsection{STUDY DATA}

The study data are derived from the following sources:

- CGI report of Salt Cavern for LNG storage;

- Paragon study of Bishop heat exchange process;

- SBMI in-house data of metocean conditions;

- SBMI in-house data of vessels, moorings and risers.

\subsection{KEY TASKS}

This FRU study address the following key tasks:

- Design Basis

- Metocean Criteria

- Tanker Selection and Conversion

- $\quad$ Process Facilities and Deck Layout

- $\quad$ FRU Hydrodynamic Motion Analysis

- $\quad$ Mooring System Sizing

- $\quad$ Sizing Of Swivels and Export Lines

- Riser Flexible Flowline Design

- $\quad$ Side-by-Side Mooring of LNG Carrier And FRU

- Motion Threshold For LNG Transfer from LNG Carrier to FRU

- $\quad$ LNG Transfer Downtime Assessment

- $\quad$ Mooring System Sensitivity To Water Depth

- $\quad$ Preliminary Development Schedule Estimate 


\begin{tabular}{|c|c|c|c|c|c|c|}
\hline \multirow[t]{3}{*}{ IMODCO } & \multirow[t]{3}{*}{$\begin{array}{l}\text { SBM-IMODCO INC. } \\
\text { MEMBER OF THE } \\
\text { IHC/CALAND GROUP } \\
\text { Now in our 5th Decade }\end{array}$} & \multirow{2}{*}{\multicolumn{5}{|c|}{$\begin{array}{l}\text { FLOATING RE-GASIFICATION UNIT } \\
\text { FOR SALT CAVERN } \\
\text { LNG RECEIVING AND RE-GASIFICATION }\end{array}$}} \\
\hline & & & & & & \\
\hline & & 51059 & ССМ97001 & C1 & PAGE & 21 \\
\hline
\end{tabular}

\section{CONCEPT DESCRIPTION}

\subsection{OVERVIEW}

The FRU utilizes a ship shaped floating structure (new built or conversion from an existing tanker) to support the LNG receiving, re-gasification and send-out facilities. The FRU is turret moored to the ocean floor which allows the vessel to weathervane and align itself with the direction of the predominant environment. The mooring system consists of three bundles of suspended catenary anchor legs. The composition of the anchor legs can be of chain or a chain/wire combination.

The FRU receives LNG via loading arms from side-by-side moored LNG carriers. The received LNG is re-gasified using the Bishop heat exchange process. The produced gas is sent out to salt caverns for storage and/or the gas grid for the consumer market.

The topsides facilities mainly consist of LNG vaporizers, cryogenic pumps, fuel gas system, seawater lift pumps, and a power generation plant. The gas flows from the weathervaning vessel to the turret by way of a fluid swivel. From the turret the gas is exported via flexible risers and subsea flowlines to salt caverns and/or existing onshore infrastructure.

The riser system consists of a number of flexible risers for the purpose of transporting the vaporized gas. The risers have a steep wave configuration and connect the geo-stationery turret to the seafloor.

Artistic illustrations of the FRU concept are presented in Figures 3-1 and 3-2. 


\begin{tabular}{|c|c|c|c|c|c|c|}
\hline \multirow[t]{3}{*}{ IMODCo } & \multirow[t]{3}{*}{$\begin{array}{l}\text { SBM-IMODCO INC. } \\
\text { MEMBER OF THE } \\
\text { IHCICALAND GROUP } \\
\text { Now in our 5th Decade }\end{array}$} & \multirow{2}{*}{\multicolumn{5}{|c|}{$\begin{array}{l}\text { FLOATING RE-GASIFICATION UNIT } \\
\text { FOR SALT CAVERN } \\
\text { LNG RECEIVING AND RE-GASIFICATION }\end{array}$}} \\
\hline & & & & & & \\
\hline & & 51059 & CCM97001 & C1 & PAGE & 22 \\
\hline
\end{tabular}

FIGURE 3-1 ARTISTIC IMPRESSION OF FRU

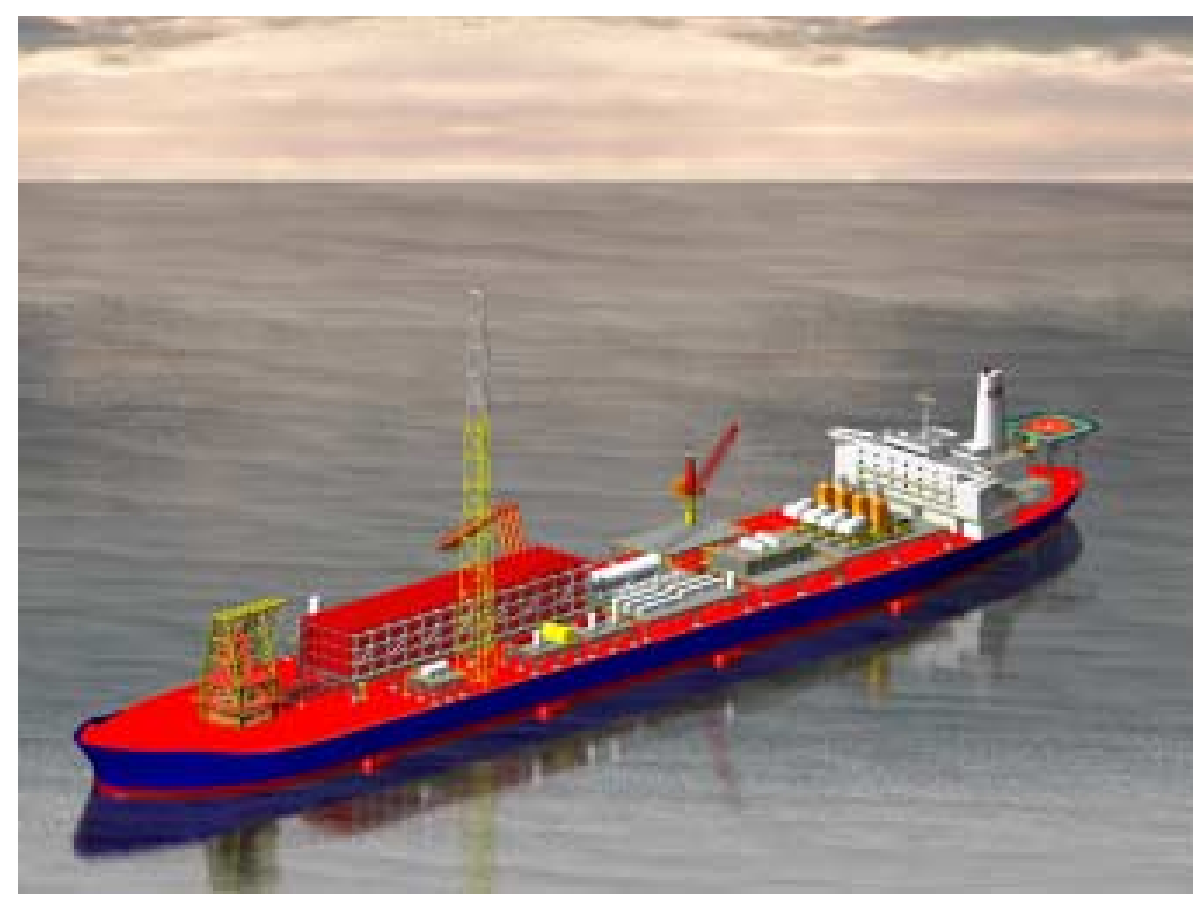

FIGURE 3-2 ARTISTIC IMPRESSION OF SIDE BY SIDE OFFLOADING

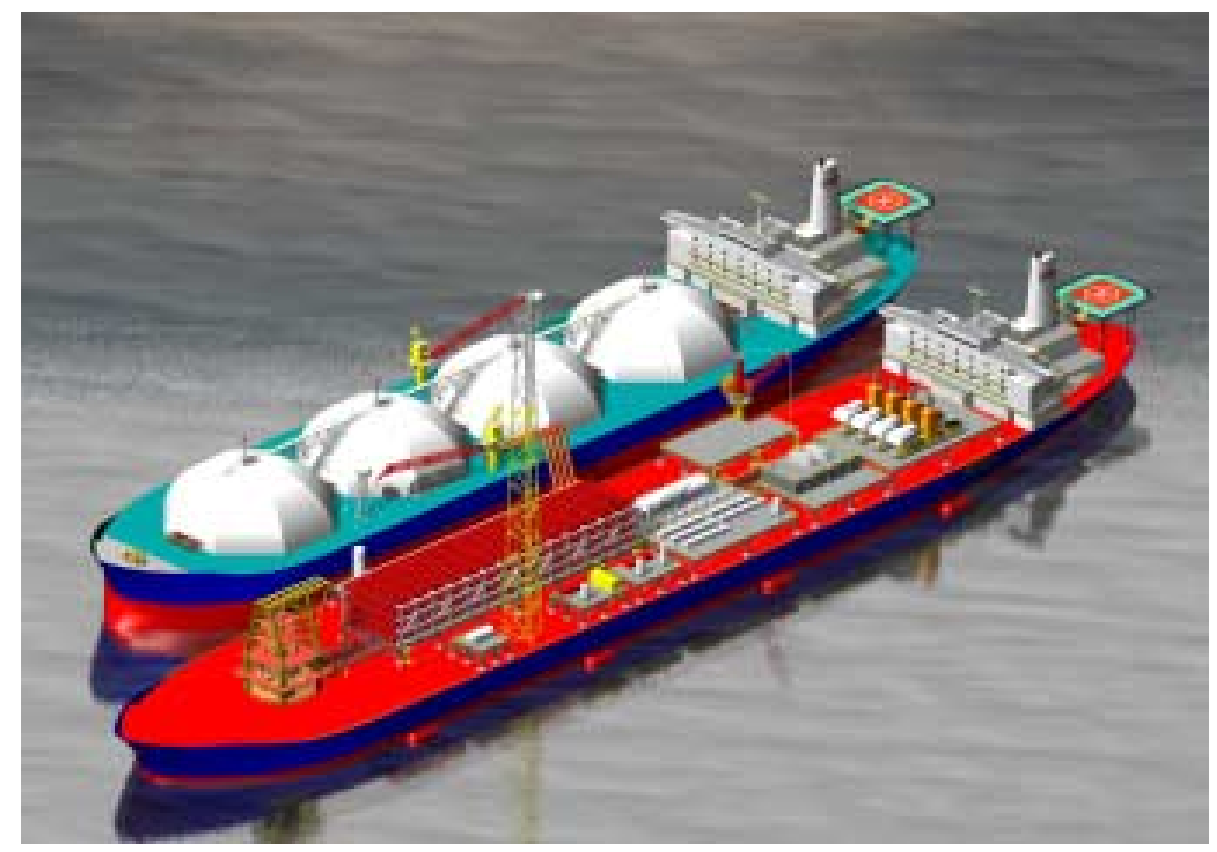




\begin{tabular}{|c|c|c|c|c|c|c|}
\hline \multirow[t]{2}{*}{ IMODED } & \multirow[t]{2}{*}{$\begin{array}{l}\text { SBM-IMODCO INC. } \\
\text { MEMBER OF THE } \\
\text { IHC/CALAND GROUP } \\
\text { Now in our 5th Decade }\end{array}$} & \multicolumn{5}{|c|}{$\begin{array}{c}\text { FOR SALT CAVERN } \\
\text { LNG RECEIVING AND RE-GASIFICATION }\end{array}$} \\
\hline & & 51059 & ССМ97001 & C1 & PAGE & 23 \\
\hline
\end{tabular}

\subsection{KEY ATTRACTIONS}

\subsubsection{Proven Technology}

Although the FRU itself is a new concept, its components are all based on proven technologies and operations. Examples of these are:

- The ship shaped floater concept is beeing used worldwide for FPSO/FSO operations; the technology of mooring and turret system design is well established in numerous applications; the flexible riser and swivel technology for high pressure gas is regularly used in turret systems;

- Side by side loading is routinely conducted with FPSO, LPG systems, etc. The cryogenic loading arm to accommodate side by side moored vessel loading is an existing technology.

\subsubsection{Wide Range of Water Depth Capability}

The FRU can be deployed over a wide range of water depth. This SBMI study has confirmed that the turret mooring system can operate from a $40 \mathrm{~m}$ water depth upwards. For water depth shallower than $40 \mathrm{~m}$, other types of station keeping system can be applied, e.g. a soft yoke system that can be disconnected for hurricane conditions.

\subsubsection{Fast Development Schedule}

There is a pool of existing trading tankers that can be readily converted to an FRU, and the task of conversion can be conducted by many experienced shipyards around the world. FPSO execution experience shows that the FRU can be completed in 18 month time.

\subsubsection{Proven Load Carrying Structure}

Tankers considered for conversion to an FRU are designed to withstand the extreme environment for worldwide operations and therefore their structures have adequate strength to withstand the large loads that the FRU will experience in the GOM hurricane environment.

\subsubsection{Cost Competitiveness}

The FRU converted from an existing trading tanker is shown to be cost effective when compared to other fixed purpose built platforms. As all equipment is located on the FRU, a separate loading system and subsea cryogenic pipeline is not required.

\subsubsection{Ample Deck Space}

The FRU has ample deck space for the arrangement of heat exchangers, utility and power generation facilities. This allows all the required facilities to be positioned on a single unit. 


\begin{tabular}{|c|c|c|c|c|c|c|}
\hline \multirow[t]{3}{*}{ IMODCO } & \multirow[t]{3}{*}{$\begin{array}{l}\text { SBM-IMODCO INC. } \\
\text { MEMBER OF THE } \\
\text { IHC/CALAND GROUP } \\
\text { Now in our 5th Decade }\end{array}$} & \multirow{2}{*}{\multicolumn{5}{|c|}{$\begin{array}{l}\text { FLOATING RE-GASIFICATION UNIT } \\
\text { FOR SALT CAVERN } \\
\text { LNG RECEIVING AND RE-GASIFICATION }\end{array}$}} \\
\hline & & & & & & \\
\hline & & 51059 & ССМ97001 & C1 & PAGE & 24 \\
\hline
\end{tabular}

\subsubsection{Stand Alone Unit}

The FRU can remotely control the subsea trees and manifolds. In addition, the FRU brings the gas from the salt cavern back through the FRU before sending it to the gas pipelines. When on-board the FRU it performs the function of metering and de-hydration if required. In this way, a separate wellhead platform can be eliminated.

\subsubsection{Suitable Size for LNG Offloading}

The ship shaped FRU vessel is sizewise compatible with an LNG carrier, which simplifies the side by side mooring for LNG loading operation. In addition, the FRU and LNG tend to move in a similar pattern, which minimizes the relative motions between the two vessels.

\subsection{SYSTEM DESIGN}

The proposed FRU concept consists of the following key building blocks:

- The ship shaped vessel

- The topsides utilities and re-gasification facilities

- The turret mooring system

- The export riser system

- The side by side LNG offloading facilities

\subsubsection{Vessel}

The FRU vessel can be a new built or a conversion from an existing trading tanker. For the purpose of this study, the conversion scenario is selected as the base case. Among existing tankers of various sizes, a Suezmax size has been selected for the following reasons:

- Amount of deck space for the Bishop heat exchange process and associated equipment;

- Suitable length and width of the vessel for side by side offloading from standard LNG carriers;

- Fit for purpose approach to optimize development economics.

The general arrangement plan of a typical Suezmax vessel is presented in Figure 3-3.

The General Arrangement of a suitable Suezmax vessel to serve as the basis for the FRU is shown below: 


\begin{tabular}{|c|c|c|c|c|c|c|}
\hline \multirow[t]{3}{*}{ IMODCO } & \multirow[t]{3}{*}{$\begin{array}{l}\text { SBM-IMODCO INC. } \\
\text { MEMBER OF THE } \\
\text { IHCICALAND GROUP } \\
\text { Now in our 5th Decade }\end{array}$} & \multirow{2}{*}{\multicolumn{5}{|c|}{$\begin{array}{l}\text { FLOATING RE-GASIFICATION UNIT } \\
\text { FOR SALT CAVERN } \\
\text { LNG RECEIVING AND RE-GASIFICATION }\end{array}$}} \\
\hline & & & & & & \\
\hline & & 51059 & CCM97001 & C1 & PAGE & 25 \\
\hline
\end{tabular}

FIGURE 3-3 GA OF A CANDIDATE VESSEL
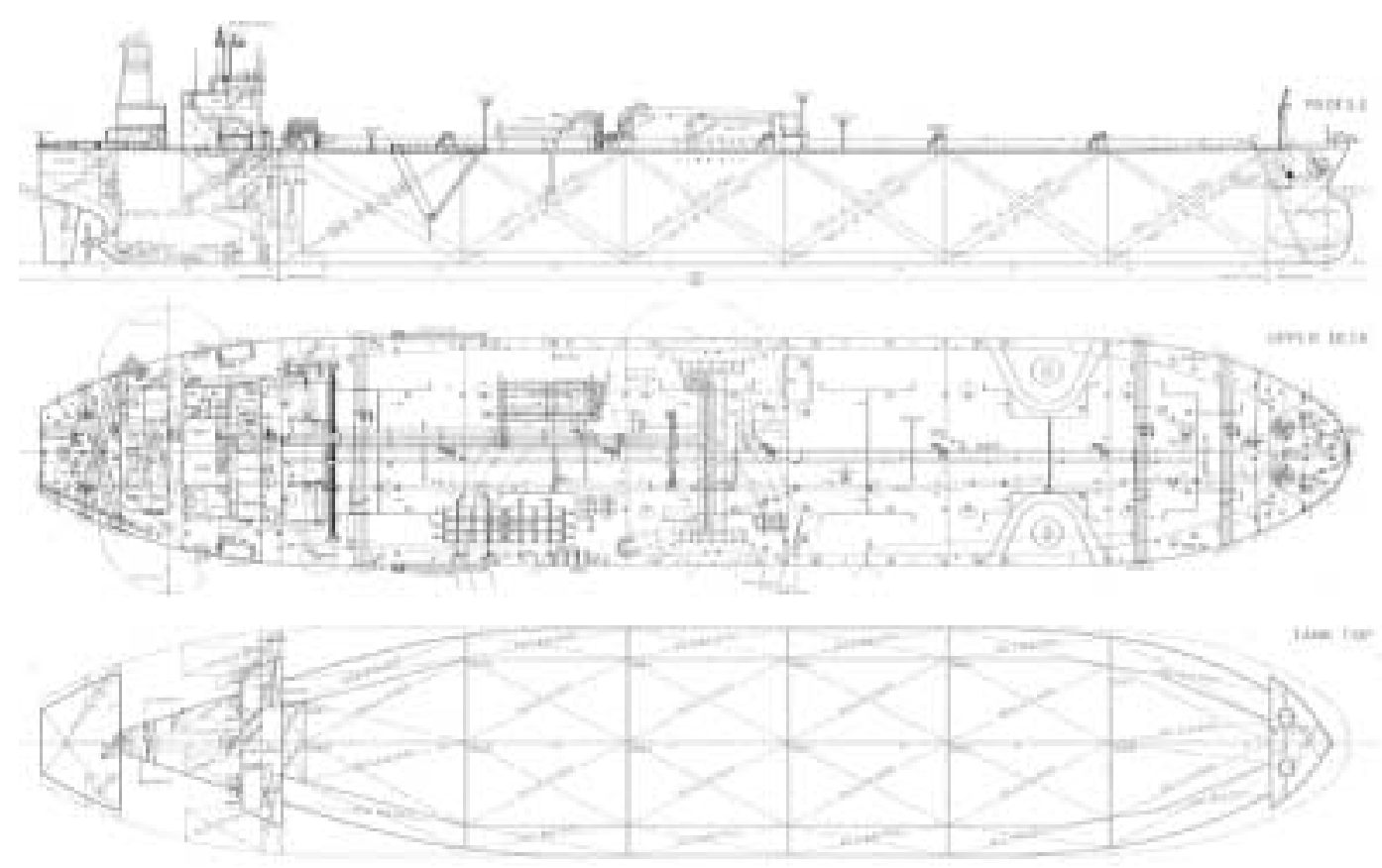

The vessel shown above and depicted in the following picture is a 1999 built Suezmax ship, that was intercepted to be converted into an FSO prior to delivery to her first owner. The size, double hull arrangement and condition make her an attractive candidate for conversion into the FRU. 


\begin{tabular}{|c|c|c|c|c|c|c|}
\hline \multirow[t]{3}{*}{ IMODCo } & $\begin{array}{l}\text { SBM-IMODCO INC. } \\
\text { MEMBER OF THE } \\
\text { IHC/CALAND GROUP }\end{array}$ & \multirow{2}{*}{\multicolumn{5}{|c|}{$\begin{array}{c}\text { FOR SALT CAVERN } \\
\text { LNG RECEIVING AND RE-GASIFICATION }\end{array}$}} \\
\hline & Now in our 5th Decade & & & & & \\
\hline & & 51059 & CCM97001 & C1 & PAGE & 26 \\
\hline
\end{tabular}

FIGURE 3-4 SUEZMAX SHIP

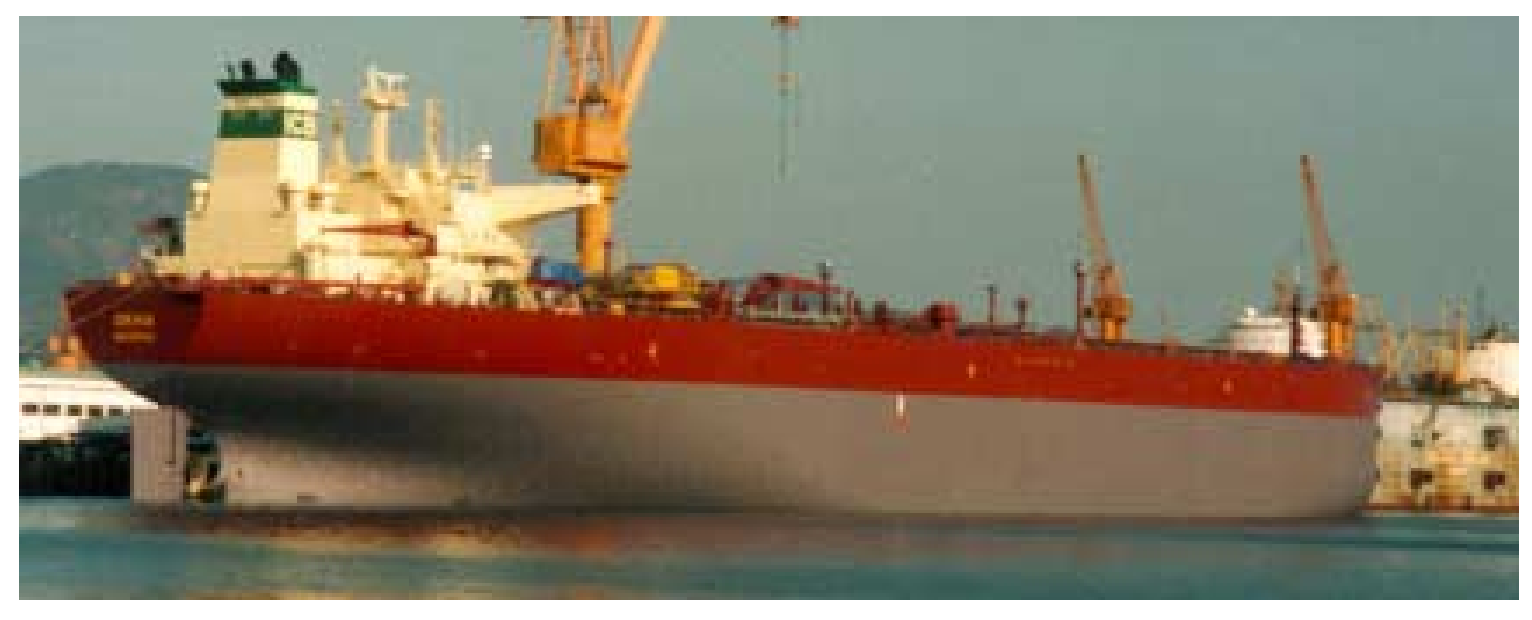

The main particulars of this vessel are listed in following table: 


\begin{tabular}{|c|c|c|c|c|c|c|}
\hline IM00B0 & $\begin{array}{l}\text { SBM-IMODCO INC. } \\
\text { MEMBER OF THE } \\
\text { IHC/CALAND GROUP } \\
\end{array}$ & \multirow{2}{*}{\multicolumn{5}{|c|}{$\begin{array}{l}\text { FLOATING RE-GASIFICATION UNIT } \\
\text { FOR SALT CAVERN } \\
\text { NG RECEIVING AND RE-GASIFICATION }\end{array}$}} \\
\hline \multirow{2}{*}{ IMODH0 } & \multirow[t]{2}{*}{ Now in our 5th Decade } & & & & & \\
\hline & & 51059 & CCM97001 & C1 & PAGE & 27 \\
\hline
\end{tabular}

\begin{tabular}{|l|c|c|}
\hline \multicolumn{3}{|c|}{ TABLE 3-1 FRU HULL MAIN PARTICULARS } \\
\hline Designation & Unit & Ballast condition \\
\hline Length overall, LOA & {$[\mathrm{m}]$} & 269.0 \\
\hline Length between perpendiculars, LBP & {$[\mathrm{m}]$} & 258 \\
\hline Breadth, B & {$[\mathrm{m}]$} & 46 \\
\hline Depth & {$[\mathrm{m}]$} & 24.0 \\
\hline Distance Turret - APP & {$[\mathrm{m}]$} & 214 \\
\hline Draught, T & {$[\mathrm{m}]$} & 12 \\
\hline Displacement, $\Delta$ & {$[\mathrm{t}]$} & 117,704 \\
\hline Waterplane Area, Aw & {$\left[\mathrm{m}^{2}\right]$} & 10330 \\
\hline LCG (ref to APP) & {$[\mathrm{m}]$} & 142.1 \\
\hline KG (ref to Keel level) & {$[\mathrm{m}]$} & 14.0 \\
\hline Roll Radius of Gyration, $\mathrm{R}_{\mathrm{xx}}$ & {$[\mathrm{m}]$} & 16.1 \\
\hline Pitch Radius of Gyration, $\mathrm{R}_{\mathrm{yy}}$ & {$[\mathrm{m}]$} & 64.5 \\
\hline Yaw Radius of Gyration, $\mathrm{R}_{\mathrm{zz}}$ & {$[\mathrm{m}]$} & 64.5 \\
\hline Wind Area (frontal) & {$\left[\mathrm{m}^{2}\right]$} & 2106 \\
\hline Wind Area (side) & {$\left[\mathrm{m}^{2}\right]$} & 7385 \\
\hline GMT & {$[\mathrm{m}]$} & 5.6 \\
\hline
\end{tabular}

It is noted that for a trading tanker, the vessel draft varies according to its loading conditions. For the FRU application, a constant draft of $12 \mathrm{~m}$ is selected.

If required, adequate greenwater protection will be provided.

\subsubsection{Topsides Facilities}

The topsides facilities consist of a number of items. These are:

- LNG vaporizers

- Cryogenic pumps

- Fuel gas system 


\begin{tabular}{|c|c|c|c|c|c|c|}
\hline \multirow[t]{3}{*}{ IMOOE0 } & \multirow[t]{3}{*}{$\begin{array}{l}\text { SBM-IMODCO INC. } \\
\text { MEMBER OF THE } \\
\text { IHCICALAND GROUP } \\
\text { Now in our 5th Decade }\end{array}$} & \multirow{2}{*}{\multicolumn{5}{|c|}{$\begin{array}{l}\text { FLOATING RE-GASIFICATION UNIT } \\
\text { FOR SALT CAVERN } \\
\text { LNG RECEIVING AND RE-GASIFICATION }\end{array}$}} \\
\hline & & & & & & \\
\hline & & 51059 & ССМ97001 & C1 & PAGE & 28 \\
\hline
\end{tabular}

- Seawater lift pumps

- Power generation plant

Careful consideration has been given to the placement of the vaporizers on or below the FRU deck. The on deck solution has the benefits of (i) easy to inspect and maintain and (ii) better preservation of the vessel structural integrity. The drawbacks include (i) an increase of topside wind load and an increase in the lift of seawater used for heat exchange. The on deck solution was selected. The seawater lift pumps are however positioned below deck to save deck space.

The layout of the topside facilities is detailed in Section 6 of this report. General arrangement drawings of the FRU are presented in Appendix A of this report.

The FRU can be self-propelled to site. Two thrusters will be provided for heading control and to aid berthing operations.

\subsubsection{Turret Mooring System}

An internal turret was selected for the mooring of the FRU. The mooring system consists of 3 groups of 3 anchor legs in a symmetric angular layout. The leg composition is of a chain/wire/chain combination.

The $3 \times 3$ mooring layout has the advantage of being able to equally distribute the mooring load among the three anchor leg groups and leave adequate space for the risers.

An illustration of the mooring configuration is presented in Figure 3-5 below. 


\begin{tabular}{|c|c|c|c|c|c|c|}
\hline \multirow[t]{3}{*}{ Imogen } & $\begin{array}{l}\text { SBM-IMODCO INC. } \\
\text { MEMBER OF THE } \\
\text { IHC/CALAND GROUP }\end{array}$ & \multicolumn{4}{|c|}{ FOR SALT CAVERN } & \\
\hline & \multirow[t]{2}{*}{ Now in our 5th Decade } & \multicolumn{5}{|c|}{ LNG RECEIVING AND RE-GASIFICATION } \\
\hline & & 51059 & CCM97001 & C1 & PAGE & 29 \\
\hline
\end{tabular}

\section{FIGURE 3-5 MOORING SYSTEM CONFIGURATION}

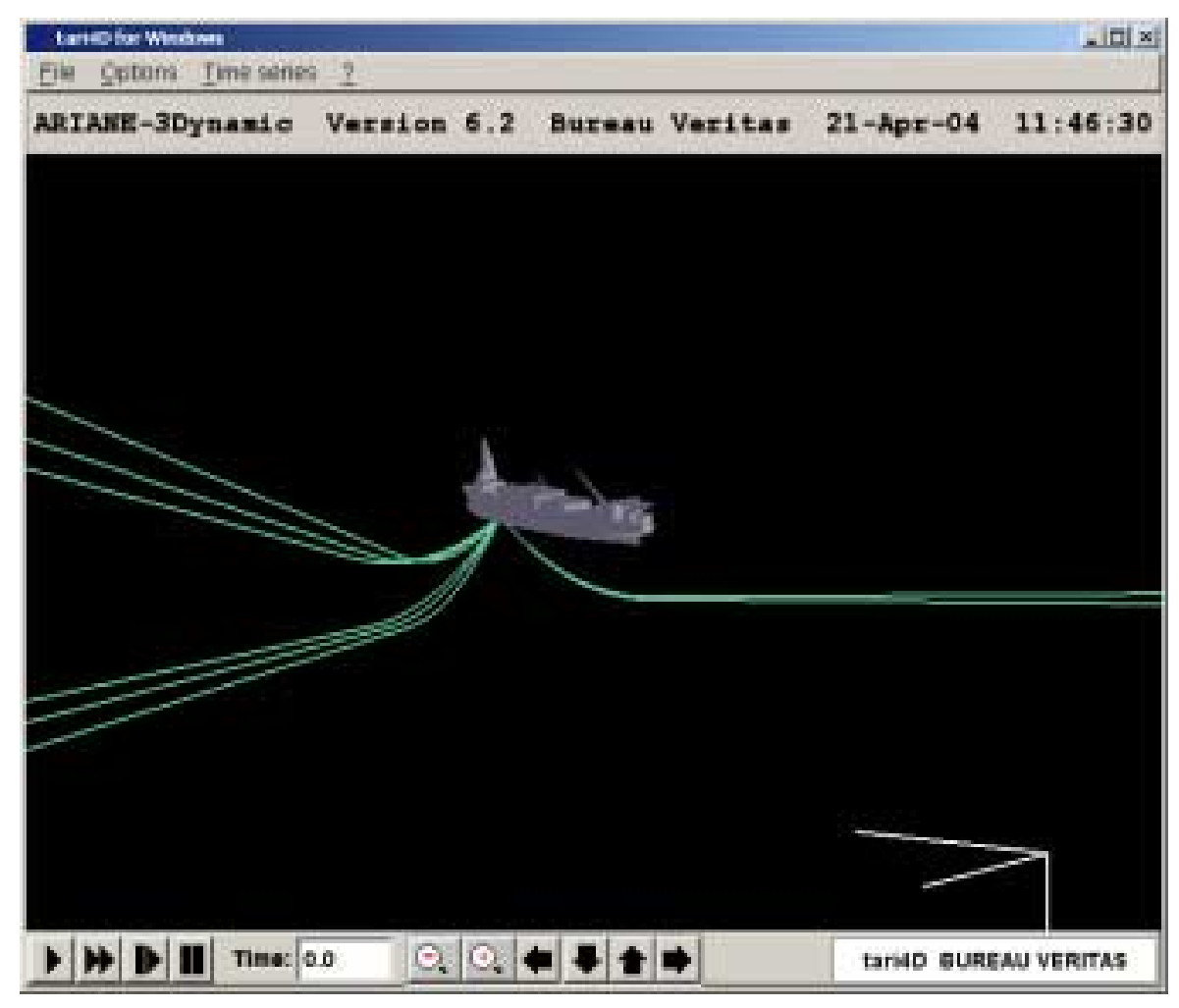

\subsubsection{Riser System}

The riser system consists of $4 \times 16$ " ID flexible risers to meet the requirement of the gas send-out without any storage onboard.

The risers have a steep wave configuration with distributed clamped weights and buoyancy modules. The risers are designed to accommodate the extreme offsets of the FRU in both the intact and damaged conditions.

An illustration of the riser configuration is presented in the plot below. 


\begin{tabular}{|c|c|c|c|c|c|c|}
\hline \multirow[t]{3}{*}{ IMODE0 } & $\begin{array}{l}\text { SBM-IMODCO INC. } \\
\text { MEMBER OF THE } \\
\text { IHCICALAND GROUP }\end{array}$ & \multirow{2}{*}{\multicolumn{5}{|c|}{$\begin{array}{l}\text { FLOATING RE-GASIFICATION UNIT } \\
\text { FOR SALT CAVERN } \\
\text { LNG RECEIVING AND RE-GASIFICATION }\end{array}$}} \\
\hline & \multirow[t]{2}{*}{ Now in our 5th Decade } & & & & & \\
\hline & & 51059 & CCM97001 & C1 & PAGE & 30 \\
\hline
\end{tabular}

FIGURE 3-6 RISER SYSTEM CONFIGURATION

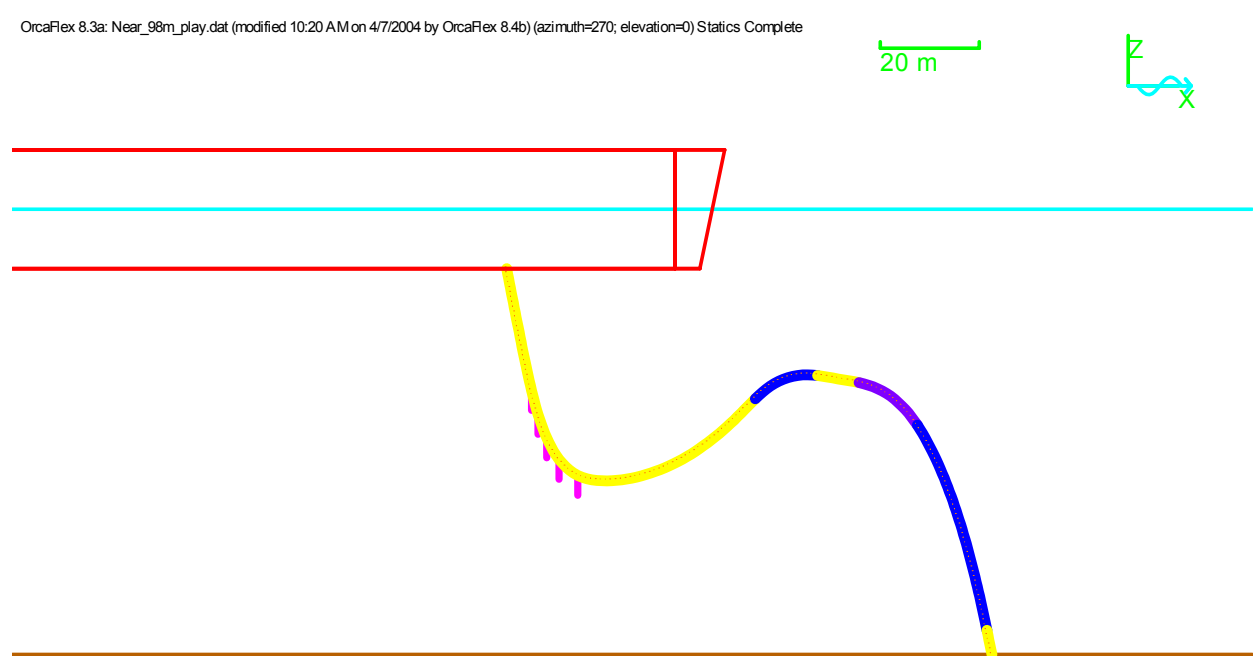

\subsubsection{Offloading Arms}

The FMC Chiksan, Double Counterweighted Marine Loading Arms are proposed for the LNG offloading. It consists of three (3) 16" x 70'-0" DCMA"S" type, fully powered marine loading arms constructed of stainless steel for LNG service and One (1) 16" x 70'-0" DCMA"S" for natural gas return. The loading arms incorporate a double counterweight assembly to balance the inboard and outboard sections of the arm.

The natural gas return arm is intended to supply LNG vapor from the FRU to the carrier as its tanks are emptied. A single loading arm is to be designated as common spare, although it may normally be used to accelerate the offloading operation.

The offloading arms have the following particulars:

- Type of Arm:

DCMA"S"

- Nominal Diameter:

$16 "$

- Length of Arm Assembly:

70

- Height of Base Riser:

$8.5 \mathrm{~m}$ 


\begin{tabular}{|c|c|c|c|c|c|c|}
\hline \multirow[t]{3}{*}{ IMODE0 } & \multirow{3}{*}{$\begin{array}{l}\text { SBM-IMODCO INC. } \\
\text { MEMBER OF THE } \\
\text { IHCICALAND GROUP } \\
\text { Now in our } 5 \text { th Decade }\end{array}$} & \multirow{2}{*}{\multicolumn{5}{|c|}{$\begin{array}{l}\text { FLOATING RE-GASIFICATION UNIT } \\
\text { FOR SALT CAVERN } \\
\text { LNG RECEIVING AND RE-GASIFICATION }\end{array}$}} \\
\hline & & & & & & \\
\hline & & 51059 & CCM97001 & C1 & PAGE & 31 \\
\hline
\end{tabular}

- Hydraulically Operated:

- 304 L Stainless steel construction.

An illustration of the offloading arm concept is presented in Figure 3-7.

\section{FIGURE 3-7 LNG OFFLOADING ARMS}

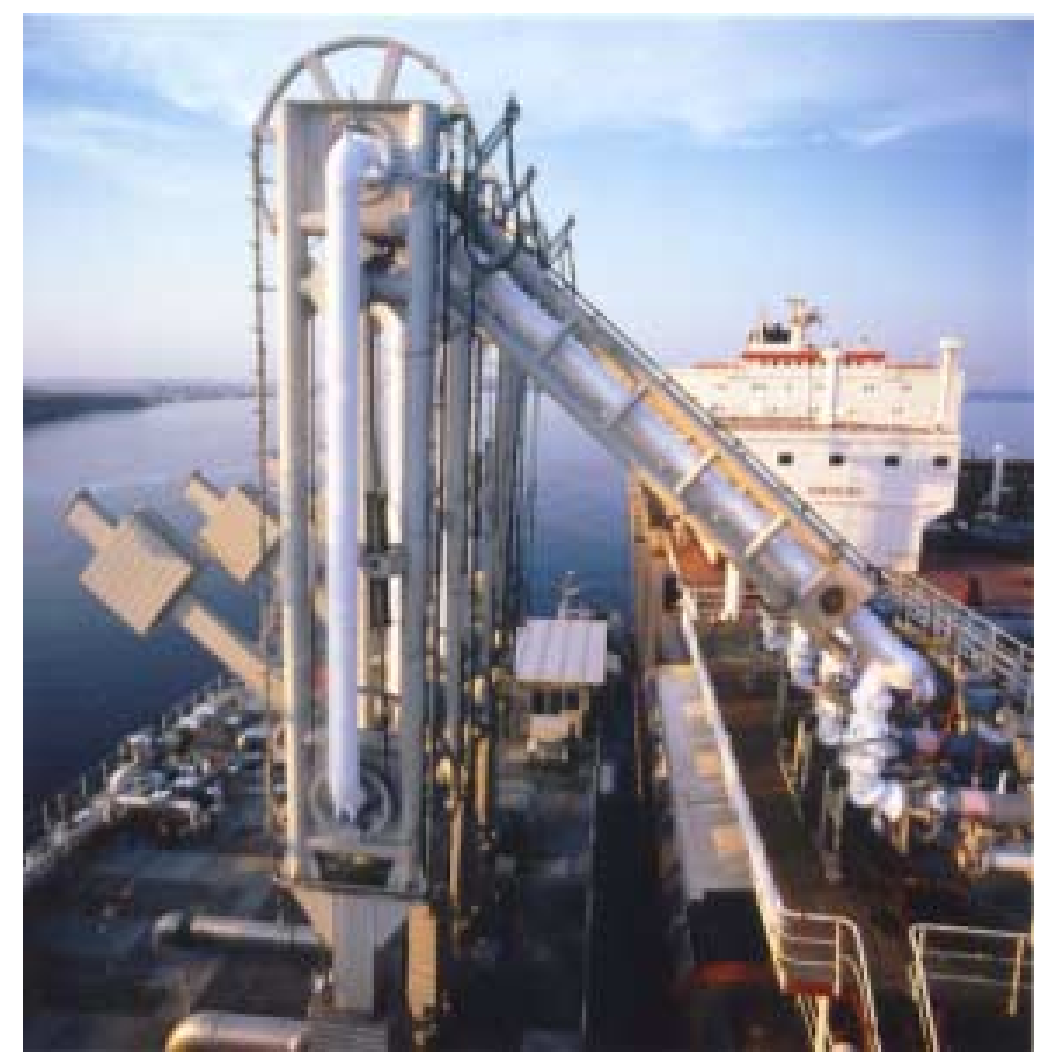




\begin{tabular}{|c|c|c|c|c|c|c|}
\hline \multirow[t]{3}{*}{ IMOOCo } & $\begin{array}{l}\text { SBM-IMODCO INC. } \\
\text { MEMBER OF THE } \\
\text { IHC/CALAND GROUP }\end{array}$ & \multicolumn{4}{|c|}{ FOR SALT CAVERN } & \\
\hline & \multirow{2}{*}{ Now in our 5th Decade } & \multicolumn{5}{|c|}{ LNG RECEIVING AND RE-GASIFICATION } \\
\hline & & 51059 & CCM97001 & C1 & PAGE & 32 \\
\hline
\end{tabular}

\section{DESIGN CRITERIA}

\subsection{RULES AND REGULATIONS}

The FRU is designed and constructed to comply with internationally recognized codes and standards, as well as applicable national codes required by the Flag State.

The FRU complies with the following rules and standards:

\section{Class Rules:}

- ABS Guide For Building and Classing Floating Production Installations, 2000 (FPI Guide);

- ABS Guide for Building and Classing Facilities on Offshore Installations, 2000 (Facilities Guide);

- ABS Rules For Building and Classing Steel Vessels, 2004

- ABS Rules for Building and Classing Mobile Offshore Drilling Units 2001(MODU Rules);

- ABS Guide Notes on the Application of Ergonomics to Marine Systems, Jan - 2003

- ABS Guide for Building and Classing Offshore LNG Terminals;

Plus the relevant sections of the following two documents:

- Code for the Construction and Equipment of Mobile Offshore Drilling Units (IMO) 1989, including 1991 amendments to the 1979 and 1989 Codes;

- International Convention for the Safety of Life at Sea Consolidated Edition, IMO, 1997

\section{American Petroleum Institute (API)}

- RP 2SK - Recommended Practices For Design and Analysis of Stationkeeping Systems for Floating Structures

- RP 17B - Recommended Practice for Flexible Risers

- RP 2G - Recommended Practices For Production Facilities On Offshore Structures

- RP 14E - Recommended Practice for Design of Offshore Production Platform Piping Systems

- RP 14J - Design and Hazard s Analysis for Offshore Production Facilities

- RP 2A - WSD, 21st Edition, Recommended Practice for Planning, Designing and Constructing Fixed Offshore Platforms - Working Stress Design, December 2000. 


\begin{tabular}{|c|c|c|c|c|c|c|}
\hline \multirow[t]{3}{*}{ IMODCO } & \multirow[t]{3}{*}{$\begin{array}{l}\text { SBM-IMODCO INC. } \\
\text { MEMBER OF THE } \\
\text { IHCICALAND GROUP } \\
\text { Now in our 5th Decade }\end{array}$} & \multirow{2}{*}{\multicolumn{5}{|c|}{$\begin{array}{l}\text { FLOATING RE-GASIFICATION UNIT } \\
\text { FOR SALT CAVERN } \\
\text { LNG RECEIVING AND RE-GASIFICATION }\end{array}$}} \\
\hline & & & & & & \\
\hline & & 51059 & CCM97001 & C1 & PAGE & 33 \\
\hline
\end{tabular}

\section{International Maritime Organization (IMO):}

- MARPOL 1973 including Protocol of 1978

- Rules for Accommodation: Conventions number 92 (Revised 1949) and 133 (1970);

- International Load Line Convention 1966 with the following resolutions:

- $\quad$ A-231 (VII) Amendments

- $\quad$ A-320 (IX) Rule equivalent to Rule 27

- International Convention On Tonnage Measurements On Ships (TONNAGE), 1969

- International Convention To Prevent Collisions At Sea (COLREG), 1972, with the following resolution: A-464 (XII)

\section{International Standards:}

- ISGOFF - International Safety Guide for Oil Tankers \& Terminals

- OCIMF

\section{National Fire Protection Association (NFPA)}

- Foam Extinguishing Systems, low Expansion and Combined Agent

- Carbon Dioxide Extinguishing Systems

- Water Spray Fixed Systems For Fire Protection

- Deluge Foam Water Sprinkler and Foam Water Spray Systems

- Centrifugal Fire Pumps

- Flammable Liquid Code

- 59A - Standard for the Production, Storage and Handling of Liquefied Natural Gas (LNG)

- National Fire Alarm Code

- 600 - Standard on Industrial Fire Brigades

American Society of Material Engineers (ASME)

ASME B31.3 Process Piping ASME Code for Pressure Piping 


\begin{tabular}{|c|c|c|c|c|c|c|}
\hline \multirow[t]{3}{*}{ IMOORO } & \multirow[t]{3}{*}{$\begin{array}{l}\text { SBM-IMODCO INC. } \\
\text { MEMBER OF THE } \\
\text { IHC/CALAND GROUP } \\
\text { Now in our 5th Decade }\end{array}$} & \multirow{2}{*}{\multicolumn{5}{|c|}{$\begin{array}{l}\text { FLOATING RE-GASIFICATION UNIT } \\
\text { FOR SALT CAVERN } \\
\text { LNG RECEIVING AND RE-GASIFICATION }\end{array}$}} \\
\hline & & & & & & \\
\hline & & 51059 & CCM97001 & C1 & PAGE & 34 \\
\hline
\end{tabular}

\subsection{DESIGN LIFE}

The FRU hull and containment system shall be designed for minimum thirty (30) year design life without drydocking.

The mooring system is to be designed for a service life of twenty (20) years.

The topsides and marine facilities (including accommodation) shall be designed for a minimum 20 year design life.

\subsection{METOCEAN DATA}

For the purpose of this study, the FRU is to be permanently moored in the US Gulf of Mexico. However, the concept shall in principle be suitable for mobilization to USA Pacific (California), US east coast and the Mediterranean, in which case it may require topside modifications for cold seawater environments and mooring modifications to accommodate different metocean conditions.

The FRU is designed for the extreme Gulf of Mexico environmental conditions. It is designed to withstand the 100-year return hurricane. The water depth for the base case design is 90 meters, which is found at the identified salt cavern location. However, the FRU can be deployed for a wide range of water depths ranging from $20 \mathrm{~m}$ to well over $1000 \mathrm{~m}$ if required.

The standard API 100 year return hurricane condition has been applied in the present study. This is considered to be conservative since the wave height reduces as they approach the coastal areas.

\subsubsection{Air and Seawater Temperatures}

Maximum air temperature $=35^{\circ} \mathrm{C}$

Minimum air temperature $=0^{\circ} \mathrm{C}$

Temperature de-rating of fired equipment is based on $35^{\circ} \mathrm{C}$ ambient temperature.

Minimum in-take sea water temperature $=20^{\circ} \mathrm{C}$

Maximum seawater temperature reduction $=12^{\circ} \mathrm{C}$ for discharge overboard. 


\begin{tabular}{|c|c|c|c|c|c|c|}
\hline \multirow[t]{3}{*}{ IMODCO } & \multirow{3}{*}{$\begin{array}{l}\text { SBM-IMODCO INC. } \\
\text { MEMBER OF THE } \\
\text { IHC/CALAND GROUP } \\
\text { Now in our 5th Decade }\end{array}$} & \multirow{2}{*}{\multicolumn{5}{|c|}{$\begin{array}{l}\text { FLOATING RE-GASIFICATION UNIT } \\
\text { FOR SALT CAVERN } \\
\text {-NG RECEIVING AND RE-GASIFICATION }\end{array}$}} \\
\hline & & & & & & \\
\hline & & 51059 & CCM97001 & C1 & $P A G E$ & 35 \\
\hline
\end{tabular}

\subsubsection{Prevailing Wave, Wind and Current Conditions}

Prevailing conditions for a possible site in the US Gulf of Mexico are tabulated below. This is based on API data. Hs and Ws are independent return values for waves and wind for a given return period. $T_{p}$ is the associated peak period with $\mathrm{H}_{\mathrm{s}}, \mathrm{TH}_{\max }$ is the associated period with $\mathrm{H}_{\max }$, and $\mathrm{V}$ is the storm current speed associated with $H_{s}$. Wind speeds $W_{s}$ is 1 minute averaged values at a 10 meter elevation.

TABLE 4-1 DESIGN METOCEAN CONDITIONS

\begin{tabular}{|c|c|c|c|c|c|c|c|}
\hline $\begin{array}{c}\text { Return } \\
\text { Period }\end{array}$ & $\begin{array}{c}\mathrm{H}_{\mathrm{s}} \\
(\mathrm{m})\end{array}$ & $\begin{array}{c}\mathrm{T}_{\mathrm{p}} \\
(\mathrm{s})\end{array}$ & $\begin{array}{c}\mathrm{H}_{\max } \\
(\mathrm{m})\end{array}$ & $\begin{array}{c}\mathrm{TH}_{\max } \\
(\mathrm{s})\end{array}$ & $\begin{array}{c}\mathrm{W}_{\mathrm{s}} \\
(\mathrm{m} / \mathrm{s})\end{array}$ & $\begin{array}{c}\mathrm{V} \\
(\mathrm{m} / \mathrm{s})\end{array}$ & $\begin{array}{c}\text { Surge \& Tide } \\
(\mathrm{m})\end{array}$ \\
\hline 100-year & 11.9 & 14.2 & 20.3 & 13.1 & 53.3 & 1.6 & 1.13 \\
\hline
\end{tabular}

The omni-directional all year wave scatter diagram with associated wind and current data is presented in the following table:

TABLE 4-2 WAVE SCATTER DIAGRAM

\begin{tabular}{|c|c|c|c|c|c|}
\hline Seastate no & Sig. Wave $\mathrm{Ht}(\mathrm{m})$ & $\mathrm{Tp}(\mathrm{sec})$ & Wind Spd $(\mathrm{m} / \mathrm{s})$ & Current Spd $(\mathrm{m} / \mathrm{s})$ & \% of Occurrence \\
\hline 1 & 1.0 & 4.4 & 4.4 & 0.2 & $5.01 \%$ \\
\hline 2 & 2.0 & 6.2 & 7.8 & 0.3 & $24.59 \%$ \\
\hline 3 & 3.0 & 7.5 & 11.1 & 0.5 & $28.36 \%$ \\
\hline 4 & 4.0 & 8.7 & 14.5 & 0.6 & $16.36 \%$ \\
\hline 5 & 5.0 & 9.5 & 17.8 & 0.7 & $10.76 \%$ \\
\hline 6 & 6.0 & 10.4 & 21.2 & 0.8 & $6.04 \%$ \\
\hline 7 & 7.0 & 11.2 & 24.5 & 1.0 & $4.39 \%$ \\
\hline 8 & 8.0 & 12.0 & 27.9 & 1.1 & $2.16 \%$ \\
\hline 9 & 9.0 & 12.4 & 31.2 & 1.2 & $1.24 \%$ \\
\hline 10 & 10.0 & 13.0 & 34.6 & 1.3 & $0.84 \%$ \\
\hline 11 & 11.0 & 13.7 & 37.9 & 1.5 & $0.22 \%$ \\
\hline 12 & 12.0 & 14.3 & 41.3 & 1.6 & $0.04 \%$ \\
\hline
\end{tabular}

Note that in the table current speed is at surface and wind speed is 1 hour averaged value. 


\begin{tabular}{|c|c|c|c|c|c|c|}
\hline \multirow[t]{3}{*}{ IMODCO } & \multirow[t]{3}{*}{$\begin{array}{l}\text { SBM-IMODCO INC. } \\
\text { MEMBER OF THE } \\
\text { IHC/CALAND GROUP } \\
\text { Now in our 5th Decade }\end{array}$} & \multirow{2}{*}{\multicolumn{5}{|c|}{$\begin{array}{l}\text { FLOATING RE-GASIFICATION UNIT } \\
\text { FOR SALT CAVERN } \\
\text { LNG RECEIVING AND RE-GASIFICATION }\end{array}$}} \\
\hline & & & & & & \\
\hline & & 51059 & ССМ97001 & C1 & PAGE & 36 \\
\hline
\end{tabular}

\subsection{MOORING DESIGN}

\subsubsection{Extreme Survival Condition}

The mooring system is designed to survive the 100-year return hurricane condition with only the FRU vessel moored (i.e. no offloading LNG carrier).

For mooring systems designed using a dynamic analysis approach, the mooring line tension safety factors, as specified by ABS and API RP 2SK [Ref.5], are as follows:

TABLE 4-3 MOORING TENSION SAFETY FACTORS

\begin{tabular}{|l|c|c|}
\hline Analysis Method & Intact & 1-Line Damaged \\
\hline Dynamic & 1.67 & 1.25 \\
\hline
\end{tabular}

The transient situation that occurs immediately after the breakage of a single leg is not a design requirement by $\mathrm{ABS}$ and $\mathrm{API}$. Based on SBM-IMODCO experience from both model tests and numerical simulations, the transient conditions are not governing compared to the damage (one line broken) case. Reference is also made to the DNV, Statoil and Marintek OMEA-98 paper "Calibration of a progressive collapse limit state for mooring lines", in which similar results were claimed: "the offset of the mooring system during the transient is unlikely to exceed the offset during the stationary conditions following the transient". Furthermore, the transient analysis using the time domain analysis lacks an objective basis. It all depends on the instant in the storm at which time the mooring line breaks.

Corrosion and wear allowances should be accounted for in the mooring system design. For chain segments, a corrosion allowance of $0.3 \mathrm{~mm}$ per year is accounted for. This results in a total reduction of $6 \mathrm{~mm}$ from the diameter based on the design life of 20 years. This $6 \mathrm{~mm}$ allowance is only assumed to reduce the breaking load of the chain.

\subsubsection{Offloading Condition}

The operating envelope for side by side LNG transfer and LNG carrier berthing operations depends on the following design limits:

- The ability of the LNG carrier to berth to the FRU

- The ability of the FRU anchoring system to withstand the environmental loads 


\begin{tabular}{|c|c|c|c|c|c|c|}
\hline \multirow[t]{3}{*}{ IMODCO } & \multirow[t]{3}{*}{$\begin{array}{l}\text { SBM-IMODCO INC. } \\
\text { MEMBER OF THE } \\
\text { IHC/CALAND GROUP } \\
\text { Now in our 5th Decade }\end{array}$} & \multirow{2}{*}{\multicolumn{5}{|c|}{$\begin{array}{l}\text { FLOATING RE-GASIFICATION UNIT } \\
\text { FOR SALT CAVERN } \\
\text { LNG RECEIVING AND RE-GASIFICATION }\end{array}$}} \\
\hline & & & & & & \\
\hline & & 51059 & ССМ97001 & C1 & PAGE & 37 \\
\hline
\end{tabular}

- The ability of the mooring lines and fenders, that connect the LNG carrier to the FRU to withstand the environmentally induced loads

- The ability of the offloading arm to handle the relative motions between the FRU and the LNG carrier

The FRU side by side offloading system operating envelope is tabulated below.

TABLE 4-4 LNG OPERATING ENVELOPE

\begin{tabular}{|l|l|c|}
\hline & & Side by Side \\
\hline LNG carrier berthing & $\mathrm{H}_{\mathrm{s}}$ & $2.5 \mathrm{~m}$ \\
\hline LNG carrier offloading & $\mathrm{H}_{\mathrm{s}}$ & $2.5 \mathrm{~m}$ \\
\hline
\end{tabular}

The LNG Loading Arms relative motion criteria are:

- Vertical Relative Motion

- Horizontal Relative Motion

- Relative Velocity

- Relative Acceleration

- Horizontal Slow Drifting

$$
\begin{aligned}
& \pm 2.0 \mathrm{~m} \\
& \pm 1.7 \mathrm{~m} \\
& \pm 1.0 \mathrm{~m} / \mathrm{s} \\
& \pm 0.5 \mathrm{~m} / \mathrm{s} 2 \\
& \pm 4.0 \mathrm{~m}
\end{aligned}
$$

\subsubsection{Mooring Leg Fatigue Design}

The chain / wire mooring legs must survive a 20 year service life. To assure this is the case a fatigue design has been carried out based on DNV POSMOOR Rules. The following equation is used to calculate the mooring leg component fatigue capacity:

$$
N c(s)=a_{D} \cdot s^{-m}
$$

where:

$\mathrm{Nc}(\mathrm{s})$ is number of stress cycles to fail under stress $\mathrm{s}$

$\mathrm{S}$ is stress cycle (double amplitude) in MPa defined as tension divided by the nominal cross section area

$a_{D}$ is the intercept parameter

$\mathrm{m}$ is the slope parameter

In calculating the nominal cross section area, $50 \%$ of the corrosion allowance has been taken into account as per DNV POSMOOR guidelines. 


\begin{tabular}{|c|c|c|c|c|c|c|}
\hline \multirow[t]{3}{*}{ IMODE0 } & $\begin{array}{l}\text { SBM-IMODCO INC. } \\
\text { MEMBER OF THE } \\
\text { IHCICALAND GROUP }\end{array}$ & \multirow{2}{*}{\multicolumn{5}{|c|}{$\begin{array}{l}\text { FLOATING RE-GASIFICATION UNIT } \\
\text { FOR SALT CAVERN } \\
\text { LNG RECEIVING AND RE-GASIFICATION }\end{array}$}} \\
\hline & \multirow[t]{2}{*}{ Now in our 5th Decade } & & & & & \\
\hline & & 51059 & CCM97001 & C1 & PAGE & 38 \\
\hline
\end{tabular}

The S-N curve parameters are presented in the following table:

TABLE 4-5 FATIGUE ANALYSIS S-N CURVES

\begin{tabular}{|l|c|c|}
\hline & $\mathbf{a}_{\mathbf{D}}$ & $\mathbf{~}$ \\
\hline Stud Chain & $1.2 \times 10^{11}$ & 3.0 \\
\hline Studless Chain & $6.0 \times 10^{10}$ & 3.0 \\
\hline Six Strand Wire & $3.4 \times 10^{14}$ & 4.0 \\
\hline Spiral Strand Wire & $1.7 \times 10^{17}$ & 4.8 \\
\hline
\end{tabular}

Based on the above parameters, it can be seen that for the same loading conditions chain fatigues much more than wire rope.

The fatigue design criteria is defined in accordance with DNV POSMOOR criteria:

$1-\mathbf{d}_{\mathrm{c}} \cdot \gamma_{\mathrm{f}}>=0$

where:

$\mathrm{dc}$ is the nominal fatigue damage

$\gamma^{f}$ is the fatigue design safety factor

The fatigue design safety factor is given by:

$\gamma=5 \quad$ when $d_{F}<=0.8$

$\gamma^{f}=5+3.0(\mathrm{dF}-0.8) / 0.2 \quad$ when $\mathrm{d}_{\mathrm{F}}>0.8$

where $d_{F}$ is the ratio between the characteristic fatigue damage $d_{c}$ in two adjacent lines.

Note: $\quad$ DNV is specified as the standard regarding studless chain fatigue, since the current editions of API and ABS have no fatigue design requirements applicable for studless chain. 


\begin{tabular}{|c|c|c|c|c|c|c|}
\hline \multirow[t]{3}{*}{ IMODCO } & \multirow[t]{3}{*}{$\begin{array}{l}\text { SBM-IMODCO INC. } \\
\text { MEMBER OF THE } \\
\text { HHCICALAND GROUP } \\
\text { Now in our 5th Decade }\end{array}$} & \multirow{2}{*}{\multicolumn{5}{|c|}{$\begin{array}{l}\text { FLOATING RE-GASIFICATION UNIT } \\
\text { FOR SALT CAVERN } \\
\text { LNG RECEIVING AND RE-GASIFICATION }\end{array}$}} \\
\hline & & & & & & \\
\hline & & 51059 & ССМ97001 & C1 & PAGE & 39 \\
\hline
\end{tabular}

\subsubsection{Anchor Design}

The anchor piles are designed to meet the following rules and regulations:

API RP 2A - WSD, 21st Edition, Recommended Practice for Planning, Designing and Constructing Fixed Offshore Platforms - Working Stress Design, December 2000.

The extreme anchor loads obtained at the seabed from the mooring analysis will be used to size the pile anchors assuming typical GOM soil conditions.

\subsection{RISER SYSTEM DESIGN}

The mooring system is designed to be passive, i.e. no adjustment of line tension is possible to maintain the vessel within a riser watch circle in the event of a line failure. Therefore, the riser system is to be designed to withstand the maximum mooring excursions.

Riser design rules require that the riser bend radius in the extreme condition should be greater than $1.5 \mathrm{x}$ storage bend radius for the mooring intact condition and $1.25 \mathrm{x}$ storage bend radius for the single mooring leg damaged condition. Also the tension in the risers should be below the riser allowable tension in all mooring design conditions.

\subsection{HEAT EXCHANGE FACILITIES}

\subsubsection{LNG Composition}

The design shall be based on the LNG composition as tabulated below: 


\begin{tabular}{|c|c|c|c|c|c|c|}
\hline \multirow[t]{3}{*}{ ImogCo } & $\begin{array}{l}\text { SBM-IMODCO INC. } \\
\text { MEMBER OF THE } \\
\text { IHC/CALAND GROUP } \\
\end{array}$ & \multirow{2}{*}{\multicolumn{5}{|c|}{$\begin{array}{l}\text { FLOATING RE-GASIFICATION UNIT } \\
\text { FOR SALT CAVERN } \\
\text { LNG RECEIVING AND RE-GASIFICATION }\end{array}$}} \\
\hline & \multirow[t]{2}{*}{ Now in our 5th Decade } & & & & & \\
\hline & & 51059 & CCM97001 & C1 & PAGE & 40 \\
\hline
\end{tabular}

TABLE 4-6 LNG COMPOSITION

\begin{tabular}{|c|c|}
\hline & $\begin{array}{c}\text { LNG Composition } \\
\text { (Paragon Data) }\end{array}$ \\
\hline $\mathrm{C} 1$ & 91.37 \\
\hline $\mathrm{C} 2$ & 4.09 \\
\hline $\mathrm{C} 3$ & 1.71 \\
\hline $\mathrm{i}-\mathrm{C} 4$ & 0.35 \\
\hline $\mathrm{n}-\mathrm{C} 4$ & 0.40 \\
\hline $\mathrm{n}-\mathrm{C} 5$ & 0.16 \\
\hline $\mathrm{n}-\mathrm{C} 6$ & 0.19 \\
\hline $\mathrm{N} 2$ & 1.55 \\
\hline
\end{tabular}

For the purposes of this study it is assumed that the given LNG composition is suitable for pipeline export. No heating value adjustments are required.

\subsubsection{Processing Facilities Design Capacities}

The design capacities of the processing facilities are basically defined in accordance with the Paragon study and are summarized as follows:

\section{LNG offloading Rate:}

$8,000 \mathrm{~m}^{3} / \mathrm{hr}$ (18 hrs offloading of $138,000-\mathrm{m}^{3}$ LNG carrier)

\section{LNG pumping:}

$24 \mathrm{LNG}$ pumps each capable of operating from $300 \mathrm{~m}^{3} / \mathrm{hr}$ at $13.5 \mathrm{MPa}$ to $600 \mathrm{~m}^{3} / \mathrm{hr}$ at $8.3 \mathrm{MPa}$.

\section{LNG vaporizing:}

32 Bishop exchangers (BPE).

Total effective length of each BPE unit: $2000 \mathrm{ft}$ ( 8 × $250 \mathrm{ft}$ ), with 6" SS inner pipe, and a 12" PE concentric outer pipe

Pressure drop:

- LNG side:

- Seawater side:
7.5 bar (110 psi)

4.5 bar (65 psi)

Minimum vaporized natural gas outlet temperature: $4.4^{\circ} \mathrm{C}$

\section{Send-out capacity / swivel sizing}

Maximum send out to salt cavern:

2.5 Bscfd

Maximum send out to pipe line to shore:

\subsection{Bscfd}




\begin{tabular}{|c|c|c|c|c|c|c|}
\hline \multirow[t]{3}{*}{ IMOOE0 } & \multirow[t]{3}{*}{$\begin{array}{l}\text { SBM-IMODCO INC. } \\
\text { MEMBER OF THE } \\
\text { IHCICALAND GROUP } \\
\text { Now in our 5th Decade }\end{array}$} & \multirow{2}{*}{\multicolumn{5}{|c|}{$\begin{array}{l}\text { FLOATING RE-GASIFICATION UNIT } \\
\text { FOR SALT CAVERN } \\
\text { LNG RECEIVING AND RE-GASIFICATION }\end{array}$}} \\
\hline & & & & & & \\
\hline & & 51059 & ССМ97001 & C1 & PAGE & 41 \\
\hline
\end{tabular}

Maximum combined send out rate: $\quad 4.0$ Bscfd

\section{Seawater Lift Pumps}

11 Seawater Lift Pumps $(11 \times 10 \%)$ with a capacity of $5,000 \mathrm{~m}^{3} / \mathrm{h}$ with a head of 80 meters.

Minimum seawater temperature: $\quad 20^{\circ} \mathrm{C}\left(68^{\circ} \mathrm{F}\right)$

\section{Power generation:}

Offloading mode: $\quad 4$ x Roll Royce RB211, 22.6 MW site rating (4 x $33 \%)$

Maximum ambient temperature for gas turbine rating: $35^{\circ} \mathrm{C}\left(95^{\circ} \mathrm{F}\right)$

Dehydration (optional)

Dehydration of gas flowing from the salt cavern to shore.

Capacity for Dehydration: 1.5 Bscfd to $7 \mathrm{lbs} /$ MMscfd.

\section{7. $\quad$ AVAILABILITY AND RELIABILITY}

Availability and reliability targets for the FRU are tentatively set for this project, and will be further refined.

The system overall reliability is targeted for $97 \%$ of the time.

The system operability, which is mostly driven by the side-by-side offloading operation, is targeted for $98 \%$.

\subsection{PASSIVE AND ACTIVE SAFETY SYSTEMS}

The FRU shall be provided with passive safety systems [passive fire protection, fire \& blast walls, cryogenic spill containment] and active safety systems [ICSS, deluge, dry powder, etc.]. The design of safety system is outside the current work scope and can be addressed in the detailed development work. 


\begin{tabular}{|c|c|c|c|c|c|c|}
\hline \multirow[t]{3}{*}{ IMODCO } & \multirow[t]{3}{*}{$\begin{array}{l}\text { SBM-IMODCO INC. } \\
\text { MEMBER OF THE } \\
\text { IHC/CALAND GROUP } \\
\text { Now in our 5th Decade }\end{array}$} & \multirow{2}{*}{\multicolumn{5}{|c|}{$\begin{array}{l}\text { FLOATING RE-GASIFICATION UNIT } \\
\text { FOR SALT CAVERN } \\
\text { LNG RECEIVING AND RE-GASIFICATION }\end{array}$}} \\
\hline & & & & & & \\
\hline & & 51059 & CCM97001 & C1 & PAGE & 42 \\
\hline
\end{tabular}

\section{HULLAND MARINE SYSTEMS}

\subsection{VESSEL SELECTION}

\subsubsection{General}

As indicated before, a conversion of an existing vessel will serve as the basis of the proposed FRU. The selection of the conversion option is discussed in the following paragraphs.

Principally, there are three alternatives with regard to the type of vessel that can be used for the FRU:

- Converted and refurbished existing tanker

- Converted intercept vessel

- New built barge

These three alternatives each have their pros and cons in terms of cost and schedule. The converted and refurbished existing tanker and intercept alternatives would have lower Capex and shorter schedules. The new built option would incur the highest Capex and the longest schedule.

Conversion of an existing tanker requires the selection and procurement of a suitable candidate vessel.

We will briefly describe the main characteristics of the alternatives.

\subsubsection{Converted Tanker Option}

Typically this would be a 10 - 15 year old or newer vessel with double hull, or double-sided, single bottom hull. Most of these vessels are motor tankers.

To accommodate the topsides arrangement and sufficient 'quay side length', potential candidates would be average size Suezmax vessels. 


\begin{tabular}{|c|c|c|c|c|c|c|}
\hline \multirow[t]{3}{*}{ IMOOR0 } & \multirow[t]{3}{*}{$\begin{array}{l}\text { SBM-IMODCO INC. } \\
\text { MEMBER OF THE } \\
\text { IHC/CALAND GROUP } \\
\text { Now in our 5th Decade }\end{array}$} & \multirow{2}{*}{\multicolumn{5}{|c|}{$\begin{array}{l}\text { FLOATING RE-GASIFICATION UNIT } \\
\text { FOR SALT CAVERN } \\
\text { LNG RECEIVING AND RE-GASIFICATION }\end{array}$}} \\
\hline & & & & & & \\
\hline & & 51059 & CCM97001 & C1 & PAGE & 43 \\
\hline
\end{tabular}

To select a suitable ship, a vessel screening is carried out to evaluate potential vessels. Screening activities would include:

- Establish vessel technical requirements,

- Technical evaluation of documentation available for proposed vessels and review of Class records,

- Prepare Vessel inspection program and inspect vessel,

- Final technical evaluation and recommendation report for Vessel selection

After selection, the vessel shall be comprehensively refurbished and a life extension scheme shall be applied to allow effective utilization of the unit for the uninterrupted service life on site.

Refurbishment work required on the vessel's existing structures, machinery and equipment shall be carried out during the conversion period according to the following criteria:

- All refurbishment work shall be credited

- Structures, machinery and equipment found in unsatisfactory condition upon the vessel's arrival to the shipyard shall be refurbished,

- Class requirements: any items due for class survey shall be surveyed during conversion in accordance with Classification Society rules,

- Any item known to be prone to deterioration through regular use or otherwise shall be overhauled,

- All equipment critical to the operation or safety of the FRU, personnel and the environment will be overhauled.

Upon completion of all survey work, there shall be no outstanding Classification Society refurbishment recommendations and the vessel will have completed the current Special Survey requirements. The vessel will start a new 5-year Special Survey period on departure from the shipyard.

The basis for the conversion is to maximize the use of existing vessel systems provided these comply with the project requirements.

\subsubsection{Intercept Option}

This would be quite similar to the above-described conversion of an existing vessel, except that due to the vessel being new any refurbishment scope would be very limited if required at all. Note that this 


\begin{tabular}{|c|c|c|c|c|c|c|}
\hline \multirow[t]{3}{*}{ IMOOR0 } & \multirow[t]{3}{*}{$\begin{array}{l}\text { SBM-IMODCO INC. } \\
\text { MEMBER OF THE } \\
\text { IHC/CALAND GROUP } \\
\text { Now in our 5th Decade }\end{array}$} & \multirow{2}{*}{\multicolumn{5}{|c|}{$\begin{array}{l}\text { FLOATING RE-GASIFICATION UNIT } \\
\text { FOR SALT CAVERN } \\
\text { LNG RECEIVING AND RE-GASIFICATION }\end{array}$}} \\
\hline & & & & & & \\
\hline & & 51059 & CCM97001 & C1 & PAGE & 44 \\
\hline
\end{tabular}

option greatly depends on the availability of a suitable vessel and the willingness of the shipowner to sell the ship.

\subsubsection{New built Option}

Typically this could be a purpose built double sided or double hull barge.

The benefit a new built vessel brings is the ability to optimize the design. Unfortunately the available yard production slots will be limited and could well influence the schedule for the project.

The vessel would be designed and supplied without propulsion and free-sailing steering systems. This implies that the new built vessel will have to be towed to site, which in turn may again influence the schedule.

\subsubsection{Selected Option: Converted Tanker}

Based on the above discussion the conversion of an existing vessel is considered most efficient for the FRU.

A critical element of a conversion project is the integrity of the hull structure. This is discussed in the following paragraph.

\subsubsection{Hull Structure}

A comprehensive steel gauging survey shall be performed. Non Destructive Examining (NDE) techniques shall be used to measure the steel thickness on all areas of the internal and external hull structures. An evaluation of further corrosion wastage of the hull corresponding to the service design life as FRU shall be carried out using average rates recommended by IACS.

A hull fatigue analysis shall be performed based on the trading history of the vessel and the steel wasteage rates obtained from the detailed hull steel survey, of the vessel on site. The analysis will identify the remaining fatigue life of the vessel for the critical hull details as analyzed by e.g. ABS Safehull A program. The required scope of steel renewals for the additional service life will then be determined and implemented.

Replacement thresholds will be set and steel renewals will be required for areas failing to exhibit sufficient scantlings after the projected service life. 


\begin{tabular}{|c|c|c|c|c|c|c|}
\hline \multirow[t]{3}{*}{ IMOOE0 } & \multirow[t]{3}{*}{$\begin{array}{l}\text { SBM-IMODCO INC. } \\
\text { MEMBER OF THE } \\
\text { IHCICALAND GROUP } \\
\text { Now in our 5th Decade }\end{array}$} & \multirow{2}{*}{\multicolumn{5}{|c|}{$\begin{array}{l}\text { FLOATING RE-GASIFICATION UNIT } \\
\text { FOR SALT CAVERN } \\
\text { LNG RECEIVING AND RE-GASIFICATION }\end{array}$}} \\
\hline & & & & & & \\
\hline & & 51059 & ССМ97001 & C1 & PAGE & 45 \\
\hline
\end{tabular}

The full scope of hull steel renewals shall be determined on completion of the findings of the hull steel condition surveys.

\subsection{VESSEL CONVERSION}

Once a vessel has been selected, the following major conversion activities will need to be performed in order to transform the tanker into the FRU:

- Internal Turret Installation

- Topsides Installation

- Tank Arrangement

- Seawater lift System

- Hull Fendering and Mooring facilities

- Transverse Thrusters

- Accommodation

- Corrosion Protection Systems

- Helicopter deck

These items are described in more details in the following paragraphs. Marine system conversion works are described in section 5.3 and subsequent paragraphs.

\subsubsection{Internal Turret}

The internal turret mooring system consists of the following major components:

- The turret assembly

- The superstructure, including the manifold decks

- The gas transfer system (incl. swivels)

- The gantry structure

A moonpool will be constructed in the forward tanks of the vessel. The turret assembly will be installed in this moonpool structure.

FIGURE 5-3 CONVERSION FOR INTERNAL TURRET 


\begin{tabular}{|c|c|c|c|c|c|c|}
\hline \multirow[t]{3}{*}{ 1М00Н4 } & $\begin{array}{l}\text { SBM-IMODCO INC. } \\
\text { MEMBER OF THE } \\
\text { IHC/CALAND GROUP } \\
\end{array}$ & \multirow{2}{*}{\multicolumn{5}{|c|}{$\begin{array}{l}\text { FLOATING RE-GASIFICATION UNIT } \\
\text { FOR SALT CAVERN } \\
\text { NG RECEIVING AND RE-GASIFICATION }\end{array}$}} \\
\hline & \multirow[t]{2}{*}{ Now in our 5th Decade } & & & & & \\
\hline & & 51059 & CCM97001 & C1 & PAGE & 46 \\
\hline
\end{tabular}

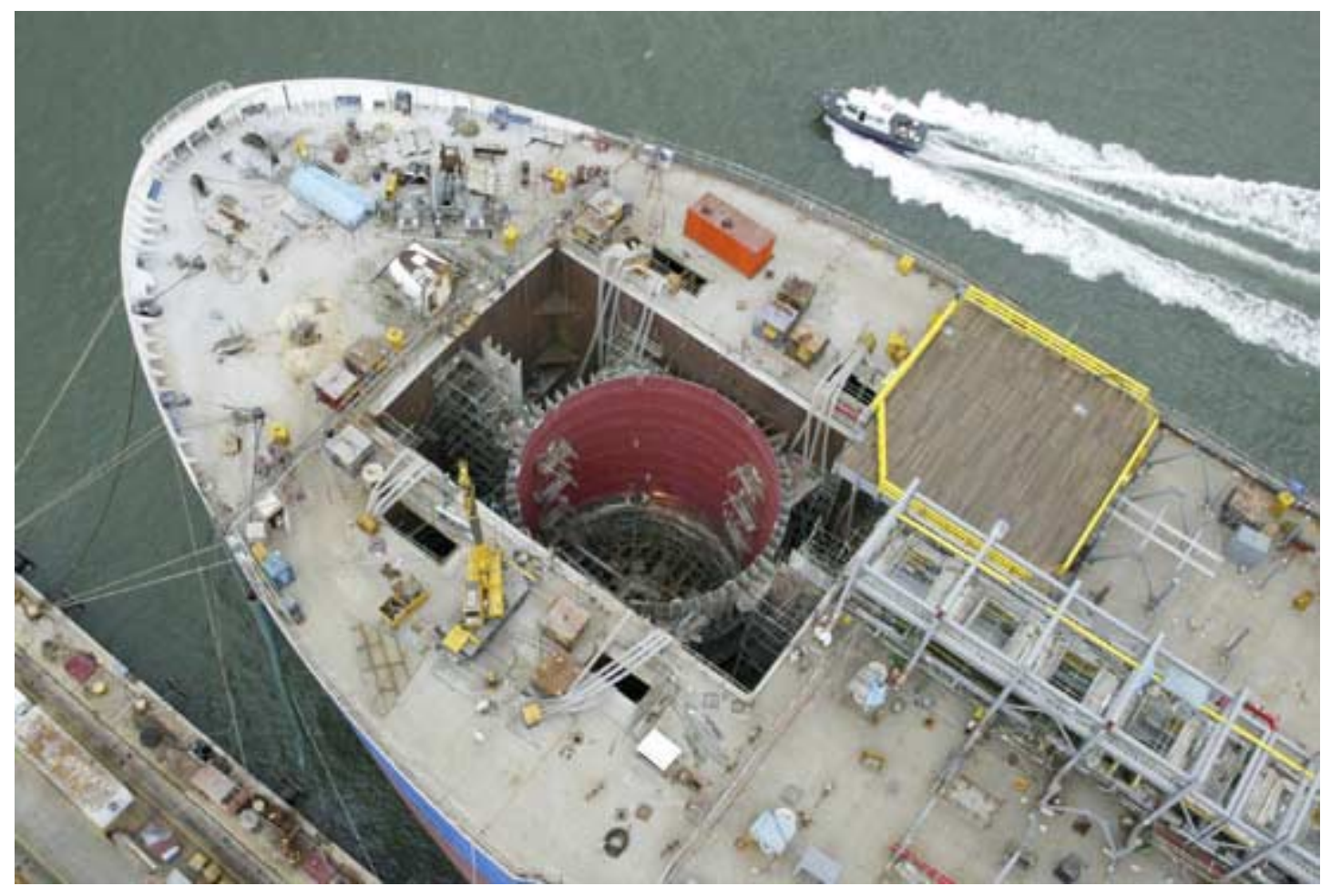

This moonpool will be constructed in a forward cargo tank of the vessel. Adjacent vessel structure shall be reinforced to adequately transfer mooring loads into the ship's hull. After positioning the turret assembly, the superstructure, gas transfer system and gantry structure can be installed.

\subsubsection{Topsides Installation}

Steel columns will be installed on support stools on the main deck above main structural members in order to support the prefabricated topsides modules. The height of these columns will be $4 \mathrm{~m}$ above the vessel deck (at centerline). This height allows access and maintenance to the underside of the modules and avoids interference with existing marine piping systems on the FRU maindeck.

An elevated flare tower having a lattice type construction will be installed in the forward area of the FRU. The foundation of this structure will be designed for ease of installation, i.e. such that no under deck stiffening is required.

For material handling on the topsides, an elevated lay down area will be provided on the main deck at the starboard side within reach of the main deck crane. The floor area will be covered with hard wood, including tie down points and sides provided with bumper bars all around. 


\begin{tabular}{|c|c|c|c|c|c|c|}
\hline \multirow[t]{3}{*}{ IMOOCo } & $\begin{array}{l}\text { SBM-IMODCO INC. } \\
\text { MEMBER OF THE } \\
\text { IHC/CALAND GROUP }\end{array}$ & \multicolumn{4}{|c|}{ FOR SALT CAVERN } & \\
\hline & \multirow{2}{*}{ Now in our 5th Decade } & \multicolumn{5}{|c|}{ LNG RECEIVING AND RE-GASIFICATION } \\
\hline & & 51059 & CCM97001 & C1 & PAGE & 47 \\
\hline
\end{tabular}

The FMC loading arms will be installed in a manner similar to topsides modules. Their supporting structure shall have an integrated spill containment system, to avoid any potential LNG spillage from falling directly onto the vessel deck.

\subsubsection{Tank Arrangement}

To maintain a draft of $12 \mathrm{~m}$, the function of several existing tanks in the former cargo area will change from cargo tanks to segregated water ballast tanks. In combination with the existing waterballast tanks in the double hull space, the individual tank loads can be optimized such that an optimum trim, bending and shear force condition is achieved.

Other cargo tanks will become void spaces.

The existing cargo pump and piping arrangement will be maintained and connected to the waterballast system to distribute water as required and to fill and empty tanks for inspection purposes.

The existing inert gas system will be retained to allow venting of the tanks.

\subsubsection{Seawater Lift System}

A tank located at a strategic location with respect to pipelines, potential recirculation, power distribution, vessel strength etc. will be transformed into pumproom.

The compartment will contain the main seawater lift pumps, piping, and associated ancillaries.

At the bottom of the vessel, new sea inlet chests will be arranged for the new seawater lift pumps. The sea chests will be of all welded steel construction, provided with gratings and anodes.

The compartment will also contain new ventilation trunks, access stairways, escape ways, hoisting beams, a hatch with cover in the vessel upper deck for material handling and all applicable steelwork for auxiliary systems. Miscellaneous platforms will be installed to allow servicing of equipment.

Furthermore, the compartment will be equipped as a workspace, i.e. with all applicable systems such as lighting, F\&G detection, firefighting systems etc.

Due to several new openings in bottom and upper deck of the vessel, compensation steel will need to 


\begin{tabular}{|c|c|c|c|c|c|c|}
\hline \multirow[t]{3}{*}{ IMOOCo } & $\begin{array}{l}\text { SBM-IMODCO INC. } \\
\text { MEMBER OF THE } \\
\text { IHCICALAND GROUP }\end{array}$ & \multicolumn{4}{|c|}{ FOR SALT CAVERN } & \\
\hline & \multirow{2}{*}{ Now in our 5th Decade } & \multicolumn{5}{|c|}{ LNG RECEIVING AND RE-GASIFICATION } \\
\hline & & 51059 & CCM97001 & C1 & PAGE & 48 \\
\hline
\end{tabular}

be installed to compensate for the loss of section modulus.

\subsubsection{Hull Fendering and Mooring Facilities}

A fendering system consisting of Yokohama type fenders will be installed on the starboard side of the FRU to allow the safe berthing of LNG carriers. This system has been analyzed in detail and will be described in a later section of this document.

The system consists of four floating fenders and one identical spare fender that will be supplied and stored in the main deck handling area. These fenders are sized in accordance with anticipated LNG carrier impact loads and will be connected to the FRU by chains.

To accommodate the mooring lines of the LNG Carriers, a system of chocks and bollards will be provided on the main deck of the FRU. Where necessary, local structural reinforcements shall be provided to withstand the loads exerted.

A suitable number of bollards and chocks will also be fitted near the landing area on the main deck to safely moor supply and bunker boats.

\subsubsection{Transverse Thrusters}

To assist in the LNG carrier berthing procedure, the FRU will have heading control capability. For this purpose, the unit will be equipped with two electric driven transverse thrusters installed at the aft end of the FRU. Anticipated required thrust capacity is $250 \mathrm{kN}$ each. Pending final vessel selection, these thrusters will be either installed in tunnels crossing the engine room, or be suspended underneath the keel of the FRU.

Given the non-docking requirement during the design life, the thrusters will be demountable whilst the FRU is afloat. Structural reinforcements shall be required in way of the openings created.

\subsubsection{Accommodation}

The existing deckhouse will be refurbished. The accommodation shall be sized to ensure that there is sufficient capacity to commission and operate the FRU from start-up through to end of design life.

Where necessary existing rooms will be rearranged into new bedrooms and offices suitable for the new FRU function. Several new store rooms, change rooms and bathrooms will be created or upgraded to fulfill the new requirements. 


\begin{tabular}{|c|c|c|c|c|c|c|}
\hline \multirow[t]{3}{*}{ IMOOCo } & $\begin{array}{l}\text { SBM-IMODCO INC. } \\
\text { MEMBER OF THE } \\
\text { IHCICALAND GROUP }\end{array}$ & \multicolumn{4}{|c|}{ FOR SALT CAVERN } & \\
\hline & \multirow{2}{*}{ Now in our 5th Decade } & \multicolumn{5}{|c|}{ LNG RECEIVING AND RE-GASIFICATION } \\
\hline & & 51059 & CCM97001 & C1 & PAGE & 49 \\
\hline
\end{tabular}

All cabins will be executed as single or double bedrooms with a dedicated wet unit, containing bathroom and toilet. Senior Staff rooms and Client cabins will be designed to be single bedrooms with a separate dayroom.

Recreation rooms, mess rooms and a helicopter reception lounge will be created and outfitted with new furniture and equipment. The galley will be completely renewed and outfitted with new equipment. All laundry equipment will be replaced by new equipment, suitable for the total persons onboard the FRU.

The existing cargo control room will be maintained, as it will be used for ballast transfer operations.

All modifications will be done in a cost effective way leaving existing structural steel, paneling and systems as much as possible in place where in good condition. It is the intent to modify the internals of the accommodation deckhouse to a minimal extent as to avoid affecting compartments that can remain as-is.

Paneling, ceilings, flooring, insulation and the run of cabling, ventilation and ducting that will be affected by the conversion will be repaired, cleaned and/or refurbished. All outfitting material shall be delivered with relevant type approval.

\subsubsection{Corrosion Protection Systems}

To protect the FRU from corrosion for the duration of the design life, a thorough corrosion protection system will be required.

A paint system will be applied to all areas that are directly exposed to the elements (outside shell, deck etc.) In areas in contact with water, a cathodic protection system will be installed as well. For the outside shell this will be a combination of an Impressed Current Cathodic Protection (ICCP) system and sacrificial anodes in seachests.

In tanks, a combination of paint and sacrificial anodes will be used. Subject to detailed design, corrosion inhibitors could be added to the ballast water as well. Void spaces not carrying any contents can either be painted or be protected by dehumidification units.

Sacrificial anodes shall be of the bolt-on type to allow for replacement on site. 


\begin{tabular}{|c|c|c|c|c|c|c|}
\hline \multirow[t]{3}{*}{ IMOOCo } & $\begin{array}{l}\text { SBM-IMODCO INC. } \\
\text { MEMBER OF THE } \\
\text { IHCICALAND GROUP }\end{array}$ & \multicolumn{4}{|c|}{ FOR SALT CAVERN } & \\
\hline & \multirow{2}{*}{ Now in our 5th Decade } & \multicolumn{5}{|c|}{ LNG RECEIVING AND RE-GASIFICATION } \\
\hline & & 51059 & CCM97001 & C1 & PAGE & 50 \\
\hline
\end{tabular}

\subsubsection{Helicopter Deck}

A helicopter deck including a dedicated fire fighting system and helicopter refueling system shall be installed at the stern end of the FRU. The helideck will be designed in accordance with CAA and ICAO requirements.

The helideck will be supported by a lattice type structure located on the main deck.

\subsection{MARINE SYSTEMS}

\subsubsection{Propulsion and Power Generation}

The existing vessel power generation and distribution system will be retained and integrated with the main power generation facility on the topsides from which the vessel systems will normally be powered.

The vessel's main engine will be used for the sail to site and be decommissioned upon arrival on site. The rudder system will be locked and no longer used once the FRU has been installed.

\subsubsection{Heating, Ventilation and Air-conditioning System}

An overpressure will be maintained inside the accommodation block, to prevent smoke and gas ingress. Airlocks will be provided on the main entrances.

The galley and laundry will be provided with local cooling and a dedicated supply and exhaust ventilation system operating at a slightly lower overpressure.

Automatic closure devices and gas detection facilities will be installed on the air intakes.

The existing HVAC system of the tanker will be refurbished and re-used. This includes both the airconditioning compressors and the air-handling units in the air conditioning unit room.

Additional capacity will be supplied by supplemental air conditioning equipment. Existing ducting will be modified where necessary to match the new accommodation layout. 


\begin{tabular}{|c|c|c|c|c|c|c|}
\hline \multirow[t]{3}{*}{ IMODCO } & \multirow[t]{3}{*}{$\begin{array}{l}\text { SBM-IMODCO INC. } \\
\text { MEMBER OF THE } \\
\text { IHC/CALAND GROUP } \\
\text { Now in our 5th Decade }\end{array}$} & \multirow{2}{*}{\multicolumn{5}{|c|}{$\begin{array}{l}\text { FLOATING RE-GASIFICATION UNIT } \\
\text { FOR SALT CAVERN } \\
\text { LNG RECEIVING AND RE-GASIFICATION }\end{array}$}} \\
\hline & & & & & & \\
\hline & & 51059 & ССМ97001 & C1 & PAGE & 51 \\
\hline
\end{tabular}

\subsubsection{Provision Refrigeration System}

The existing Provision Cold stores and Refrigeration System on the vessel will be re-used. The system arrangement and capacity will be inspected and evaluated against the new crew size. The equipment and system will be modified or upgraded as necessary to meet the new design life.

\subsubsection{Sanitary Treatment System}

The sewage treatment system and piping on the existing vessel will be retained and expanded to meet the operational requirements on the basis of the number of People on Board (POB). The sewage treatment plant and sewage system will be of an approved type by IMO and USCG.

A garbage management system including incinerator and garbage compactor will be provided.

\subsubsection{Fresh and Potable Water System}

Both existing and new fresh water systems will be utilized to support the vessel and topsides operations. Fresh water generation, storage and distribution facilities will be designed such that the new operational requirements are met.

Potable water for drinking and galley services will be disinfected by means of sterilizing equipment.

\subsubsection{Marine Seawater Service System}

The marine seawater service system will be fully segregated from the system that supplies seawater to the regasification plant.

The marine seawater service system on the existing vessel will be inspected, tested and modified or upgraded to meet the requirements for the following services:

- Fresh water generation;

- Cooling water for refrigeration system;

- Cooling water for air conditioning system;

- Cooling water for air compressors;

- Cooling water for thrusters;

- Fire water and deluge; 


\begin{tabular}{|c|c|c|c|c|c|c|}
\hline \multirow[t]{3}{*}{ IMOOF0 } & $\begin{array}{l}\text { SBM-IMODCO INC. } \\
\text { MEMBER OF THE } \\
\text { IHCICALAND GROUP }\end{array}$ & \multirow{2}{*}{\multicolumn{5}{|c|}{$\begin{array}{l}\text { FLOATING RE-GASIFICATION UNIT } \\
\text { FOR SALT CAVERN } \\
\text { LNG RECEIVING AND RE-GASIFICATION }\end{array}$}} \\
\hline & \multirow[t]{2}{*}{ Now in our 5th Decade } & & & & & \\
\hline & & 51059 & CCM97001 & C1 & PAGE & 52 \\
\hline
\end{tabular}

- General services on deck;

- Etc.

The system will be equipped with an anti-marine growth system.

\subsubsection{Ballast System}

As former cargo tanks in the FRU will be used as permanent ballast tanks, the existing ballast system will be connected to the existing cargo pipe and pump system.

This will allow the transfer of water from one water ballast tank to any other water ballast and/or void tank. This provision enables tank inspections without a need for discharging inhibited ballast water to the sea and the subsequent intake of new seawater.

New ballast and ballast stripping lines, valves, and fitting will be installed to achieve the above. The ballast control system and panels will be fully redesign for the new operational conditions, while making use of existing cargo control components.

\subsubsection{Tank Purging and Pressurizing System}

To prevent any potential gas ingress in tanks, a tank pressurization system will be provided:

Several options exist:

- Inert Gas system: this is existing on the vessel and has the advantage that oxygen is removed from the tanks

- Tank vent system: the existing inert gas system could be used for this

- Tank dehumidification system operating on a slight overpressure: this has the advantage that corrosion is retarded 


\begin{tabular}{|c|c|c|c|c|c|c|}
\hline \multirow[t]{3}{*}{ IMODCO } & \multirow[t]{3}{*}{$\begin{array}{l}\text { SBM-IMODCO INC. } \\
\text { MEMBER OF THE } \\
\text { IHC/CALAND GROUP } \\
\text { Now in our 5th Decade }\end{array}$} & \multirow{2}{*}{\multicolumn{5}{|c|}{$\begin{array}{l}\text { FLOATING RE-GASIFICATION UNIT } \\
\text { FOR SALT CAVERN } \\
\text { LNG RECEIVING AND RE-GASIFICATION }\end{array}$}} \\
\hline & & & & & & \\
\hline & & 51059 & ССМ97001 & C1 & PAGE & 53 \\
\hline
\end{tabular}

A risk assessment and selection of the most economical and operationally effective method is considered to be beyond the scope of this study.

\subsubsection{Service and Instrument Air System}

The capacity of the existing compressed air system, both for service and instrument air, will be enlarged to meet the increased air demand of FRU operations.

Instrument air will be dried, de-oiled and supplied to the topsides instrument and control systems via dedicated instrument air vessels and piping.

Service air will be supplied to consumers via dedicated service air vessels and piping.

Additional instrument and service air compressors and vessels will be installed in the engine room.

\subsubsection{Hydraulic System}

The existing hydraulic system will be retained and modified for controlling ballast valves. It will also be expanded where required to accommodate new valves such as in the seawaterlift system.

The system will be based on a common supply main and return with branch lines to the various valves. The system will be powered by a new hydraulic power unit (HPU).

\subsubsection{Bilge System}

The bilge system in the machinery spaces of the existing vessel will be retained. The seawaterlift pump compartment will be equipped with its own new dedicated bilge system.

\subsubsection{Open Drain System}

Any leakage or spillage is anticipated to come from the topsides equipment and/or loading arms and will mostly consist of LNG or of seawater containing gas.

On the maindeck, the topside equipment will therefore be provided with stainless steel drip trays with drain lines. These lines will be routed to a dedicated free standing holding tank of stainless steel with a gas separation and detection system. The gas separated from the open drain tank will be vented to the atmosphere through a vent riser. 


\begin{tabular}{|c|c|c|c|c|c|c|}
\hline \multirow[t]{3}{*}{ IMODCO } & \multirow[t]{3}{*}{$\begin{array}{l}\text { SBM-IMODCO INC. } \\
\text { MEMBER OF THE } \\
\text { IHC/CALAND GROUP } \\
\text { Now in our 5th Decade }\end{array}$} & \multirow{2}{*}{\multicolumn{5}{|c|}{$\begin{array}{l}\text { FLOATING RE-GASIFICATION UNIT } \\
\text { FOR SALT CAVERN } \\
\text { LNG RECEIVING AND RE-GASIFICATION }\end{array}$}} \\
\hline & & & & & & \\
\hline & & 51059 & CCM97001 & C1 & PAGE & 54 \\
\hline
\end{tabular}

In the event of LNG leakage, a seawater spray or deluge system will be employed to vaporize the gas in order to prevent hull damage.

The loading arm station will also be provided with stainless steel drip trays and a water deluge system to cope with possible spillage of LNG during connection and disconnection of the loading arms. The drain line from the loading station drip tray will be routed to overboard away from the loading side.

\subsubsection{Tank Vent and Sounding System}

The tank vent and sounding piping system on the existing vessel will be retained for the FRU mode of the unit. The system will be adapted in way of the turret moonpool area.

\subsubsection{Fuel Oil Storage, Filling and Transfer System}

The existing fuel oil storage tanks, filling and transfer system on the vessel will be re-used and serve the emergency diesel generator, essential diesel generator, diesel driven firewater pump and other consumers.

Fuel storage tanks outlet valves will be provided with a means of remote closure. Such means will not be cut off in the event of fire in the fuel storage and refueling area.

Bunkering stations will be provided at proper locations on the maindeck to transfer fuel from supply boats.

\subsubsection{Helicopter Refueling System}

A helicopter refueling station will be provided on the helicopter deck.

The tank and pumping area will be isolated by a safe and adequate distance from accommodation and vent openings, embarkation stations, escape routes and the helicopter landing area itself.

\subsubsection{Gas Detection Systems}

The following areas will be monitored by a fixed type gas detection system:

- LNG pumping and re-gasification area;

- LNG loading and vapor handling areas; 


\begin{tabular}{|c|c|c|c|c|c|c|}
\hline \multirow[t]{3}{*}{ IMOOE0 } & \multirow[t]{3}{*}{$\begin{array}{l}\text { SBM-IMODCO INC. } \\
\text { MEMBER OF THE } \\
\text { IHCICALAND GROUP } \\
\text { Now in our 5th Decade }\end{array}$} & \multirow{2}{*}{\multicolumn{5}{|c|}{$\begin{array}{l}\text { FLOATING RE-GASIFICATION UNIT } \\
\text { FOR SALT CAVERN } \\
\text { LNG RECEIVING AND RE-GASIFICATION }\end{array}$}} \\
\hline & & & & & & \\
\hline & & 51059 & ССМ97001 & C1 & PAGE & 55 \\
\hline
\end{tabular}

- Turret area;

- Gas control spaces;

- Entrances to accommodation area;

- Open drain tank from topside;

- Air intakes to HVAC system;

- Gas burning spaces;

- Main vent post;

The gas detection system shall comply with $A B S$ rule requirements.

\subsubsection{Fire Detection Systems}

A fixed type fire detection system will be provided. Smoke detectors will be installed in all stairways, corridors and escape routes within accommodation spaces.

\subsubsection{Fire Extinguishing and Water Deluge (Spray) System}

NFPA 59A Ch.9 is to be considered applicable to the FRU, and as is required therein, the extent of fire protection required will be determined by an evaluation based on sound fire protection engineering principles, analysis of local conditions, hazards within the facility and exposure to or from other sources of fire, such as attending LNG carriers.

The topside and turret area will be provided with a water deluge / monitor system and dry powder system by means of which a fire in any part of the unit containing equipment used for storing and regasification can be covered.

Portable fire extinguishers and loose fire fighting equipment will be part of the fire extinguishing systems.

\subsubsection{Personnel Protection and Life Saving}

All personnel protection and life saving appliances will be provided in accordance with SOLAS Facilities Guide for floating units and gravity based units.

Personnel involved in emergency response activities will be equipped with the necessary protective clothing and equipment qualified in accordance with NFPA 600 Standard on Industrial Fire Brigades. 


\begin{tabular}{|c|c|c|c|c|c|c|}
\hline \multirow[t]{3}{*}{ IMODCO } & \multirow{3}{*}{$\begin{array}{l}\text { SBM-IMODCO INC. } \\
\text { MEMBER OF THE } \\
\text { IHC/CALAND GROUP } \\
\text { Now in our 5th Decade }\end{array}$} & \multirow{2}{*}{\multicolumn{5}{|c|}{$\begin{array}{l}\text { FLOATING RE-GASIFICATION UNIT } \\
\text { FOR SALT CAVERN } \\
\text {-NG RECEIVING AND RE-GASIFICATION }\end{array}$}} \\
\hline & & & & & & \\
\hline & & 51059 & CCM97001 & C1 & $P A G E$ & 56 \\
\hline
\end{tabular}




\begin{tabular}{|c|c|c|c|c|c|c|}
\hline \multirow[t]{3}{*}{ IMODCO } & \multirow[t]{3}{*}{$\begin{array}{l}\text { SBM-IMODCO INC. } \\
\text { MEMBER OF THE } \\
\text { IHC/CALAND GROUP } \\
\text { Now in our 5th Decade }\end{array}$} & \multirow{2}{*}{\multicolumn{5}{|c|}{$\begin{array}{l}\text { FLOATING RE-GASIFICATION UNIT } \\
\text { FOR SALT CAVERN } \\
\text { LNG RECEIVING AND RE-GASIFICATION }\end{array}$}} \\
\hline & & & & & & \\
\hline & & 51059 & ССМ97001 & C1 & PAGE & 57 \\
\hline
\end{tabular}

\section{TOPSIDES SYSTEMS DESCRIPTION}

\subsection{GENERAL}

The function of the topsides of the FRU is to receive LNG from the LNG carrier, boost the pressure to either salt cavern injection pressure or pipe line pressure and vaporize the LNG before it is sent out through the turret and risers.

There is no (significant) LNG storage on the FRU and all LNG received from the carrier is directly pumped, vaporized and sent out. When there is no offloading, the regasification unit shuts down and there will be no pumping or vaporizing. This results in two different operating modes of the FRU. In the following section, both the offloading mode and holding mode will be presented.

The drawings of topside system PFD is presented in Appendix B. The equipment list is presented in Appendix C.

Drawing no. DTT92020 - Topsides LNG System PFD illustrates the process flow diagram of LNG regasification;

Drawing no. DTT92201 - Topsides Utility System (1) PFD illustrates the process flow diagrams of chemical injection, instrument air, fuel gas and vent systems;

Drawing no. DTT92202 - Topsides Utility System (2) PFD illustrates the process flow diagrams of power generation and seawater lift system;

Drawing no. DTM61001 - Turret Piping Production PFD illustrates the process flow diagrams of gas flow and exporting.

\subsection{OFFLOADING MODE}

\subsubsection{LNG Reception}

The LNG carrier pumps unload the LNG at an average rate of $8,000 \mathrm{~m}^{3} / \mathrm{hr}$ (taking 18 hours to unload a typical $138,000 \mathrm{~m}^{3}$ LNG carrier). The LNG then passes through 2 (of 3 ) $\times 16$ " unloading arms (one is spare) which hookup to the FRU pipework and into the $300 \mathrm{~m}^{3}$ surge vessel. This vessel pressure 


\begin{tabular}{|c|c|c|c|c|c|c|}
\hline \multirow[t]{3}{*}{ IMOORO } & \multirow[t]{3}{*}{$\begin{array}{l}\text { SBM-IMODCO INC. } \\
\text { MEMBER OF THE } \\
\text { IHC/CALAND GROUP } \\
\text { Now in our 5th Decade }\end{array}$} & \multirow{2}{*}{\multicolumn{5}{|c|}{$\begin{array}{l}\text { FLOATING RE-GASIFICATION UNIT } \\
\text { FOR SALT CAVERN } \\
\text { LNG RECEIVING AND RE-GASIFICATION }\end{array}$}} \\
\hline & & & & & & \\
\hline & & 51059 & CCM97001 & C1 & PAGE & 58 \\
\hline
\end{tabular}

is kept at a constant level, slightly above atmospheric pressure, to reduce the quantity of boil-off gas and to ensure flow.

The capacity of the FRU is arbitrarily set at $8000 \mathrm{~m}^{3} /$ hour. It shall be noted that there is sufficient deck space available to accommodate much larger offloading rates if so desired.

\subsubsection{LNG Pumps}

The LNG from the surge vessel will be pumped through the BPE's. The LNG pumps are submerged electric motor pumps (SEMP), designed specifically for cryogenic services.

Two operating points for the LNG pumps are identified:

In high-pressure operation, the LNG pumps pressurize the LNG from near atmospheric to a maximum of 138 barg (2000 psig) before passing to the BPEs for re-gasification. In low-pressure operation, the LP LNG pumps pressurize the LNG from near atmospheric to a maximum of 79 barg (1150 psig) before passing to the BPEs for re-gasification. This is assuming that the LNG is still above the cricondenbar at 79 barg. For higher mole-weight LNG, this may not be the case. If backpressure control is required to keep the LP BPEs above the cricondenbar, additional heating is required downstream the backpressure control valve to heat up the produced natural gas to above the minimum temperature for the production pipeline of $4^{\circ} \mathrm{C}\left(40^{\circ} \mathrm{F}\right)$

The same pumps will be used for HP and LP service. Depending on which system the pump is routed to and the operating pressure of the salt cavern, the pump will experience different backpressures. The pump will run over its curve in order to supply the discharge pressure required.

The LNG pumps are limited on power at $2050 \mathrm{~kW}$ per pump. This results in the requirement of 22 LNG pumps.

\subsubsection{Bishop Process Exchangers}

Seawater from the seawater lift pumps passes through the outer annulus of the Bishop process exchanger, and transfers the heat directly to the LNG in the inner pipe. The gas discharges from each exchanger at $4.4^{\circ} \mathrm{C}$.

HP natural gas is routed via the injection gas heater to the HP gas swivel for injection into the salt cavern. LP natural gas is sent to the Gas Metering Station and from there through the turret LP gas 


\begin{tabular}{|c|c|c|c|c|c|c|}
\hline \multirow[t]{3}{*}{ IMOORO } & \multirow[t]{3}{*}{$\begin{array}{l}\text { SBM-IMODCO INC. } \\
\text { MEMBER OF THE } \\
\text { IHC/CALAND GROUP } \\
\text { Now in our 5th Decade }\end{array}$} & \multirow{2}{*}{\multicolumn{5}{|c|}{$\begin{array}{l}\text { FLOATING RE-GASIFICATION UNIT } \\
\text { FOR SALT CAVERN } \\
\text { LNG RECEIVING AND RE-GASIFICATION }\end{array}$}} \\
\hline & & & & & & \\
\hline & & 51059 & CCM97001 & C1 & PAGE & 59 \\
\hline
\end{tabular}

swivel and risers to the pipeline to shore.

\subsubsection{Injection Gas Heater}

The gas directed to the salt cavern for injection needs to be heated further to allow injection at $15^{\circ} \mathrm{C}$ $\left(60^{\circ} \mathrm{F}\right)$.

This additional heating is required because the temperature in the salt cavern will decrease while producing from this cavern (expanding gas). Since the minimum allowable operating temperature of the salt cavern is $4^{\circ} \mathrm{C}\left(40^{\circ} \mathrm{F}\right)$, the gas needs to be injected warmer to allow for a proper operating pressure range.

Large injection gas/heating medium exchangers will be provided for this purpose. The heating medium is a closed loop system in which a glycol/water mixture is pumped around. The heating medium is heated using exhaust gas from the turbines in the waste heat recovery unit (WHRU).

\subsection{HOLDING MODE}

In holding mode, the LNG pumps and BPE's will be shut down.

While in holding mode, a portion of the LNG from the surge vessel circulates through the facilities using a small LNG circulation pump to keep the unloading equipment and piping at cryogenic temperature. This avoids excessive vapor generation at the start of offloading and speeds LNG tanker turnaround time.

In holding mode, LNG from the salt cavern can be exported to the pipeline to shore. For this purpose this gas will be produced back through the swivels to the FRU. On the FRU, the flow-rate to the pipeline will be metered. If the natural gas in the salt cavern is exposed to water in the salt cavern, hydrate formation will be a problem in the pipelines. Glycol will be injected as hydrate inhibitor at the well-head. Downstream the pressure letdown valve on the FRU, the Glycol will be recovered and regenerated.

\subsection{BOIL OFF GAS MANAGEMENT}

As part of normal operation, vapors known as Boil-Off Gas (BOG) are generated in the surge vessel, the pump reservoirs and through ambient heating of the process piping and offloading lines. 


\begin{tabular}{|c|c|c|c|c|c|c|}
\hline \multirow[t]{3}{*}{ IMOOCo } & $\begin{array}{l}\text { SBM-IMODCO INC. } \\
\text { MEMBER OF THE } \\
\text { IHCICALAND GROUP }\end{array}$ & \multicolumn{4}{|c|}{ FOR SALT CAVERN } & \\
\hline & \multirow{2}{*}{ Now in our 5th Decade } & \multicolumn{5}{|c|}{ LNG RECEIVING AND RE-GASIFICATION } \\
\hline & & 51059 & CCM97001 & C1 & PAGE & 60 \\
\hline
\end{tabular}

During offloading, a flow of vapor return gas equal to the unloading rate of $8,000 \mathrm{~m}^{3} / \mathrm{hr}$ must be returned to the LNG carrier to maintain pressure in the cargo tanks. The BOG generated during offloading is returned to the LNG carrier through a vapor return line, which uses a loading arm to connect to the carrier. A vapor return blower is used to return the gas to the carrier. It is anticipated that the BOG generated is not sufficient to supply all required vapor return. A dedicated vapor return vaporizer will be supplied to generate the additional required vapor return.

During holding mode the LNG pumps will be shut down. Therefore the BOG rate will be largely reduced. The BOG generated during holding mode will be send to a liquefaction unit that will reliquefy the BOG and send it back to the surge vessel.

\subsection{SEAWATER LIFT SYSTEM}

The LNG is re-gasified using seawater as a heat source. The seawater for the topsides is provided from lift pumps installed in one of the cargo tanks of the FRU that will be converted for use as machinery space. A total seawater flow capacity of $49,300 \mathrm{~m}^{3} / \mathrm{h}$ is required. This capacity is met by installing $11 \times 5000 \mathrm{~m}^{3} / \mathrm{h}$ pumps $(11 \times 10 \%)$. The pumps will each provide an estimated head of 80 meters. Note the head of the Seawater Lift Pumps in Paragon Vermilion Data is only 45 meters (Paragon, Vermilion 179-Mar30 Presentation). This will prove insufficient for providing the required head based on the elevation of the highest vaporizer and the pressure-drop over the seawater side of the vaporizers. This is not a specific problem for the floating regasification unit, but that the pumps are sized too small from the platform option as well.

In passing through the heat exchanger, the seawater temperature will drop from a minimum intake temperature of $20^{\circ} \mathrm{C}\left(68^{\circ} \mathrm{F}\right)$ to $8^{\circ} \mathrm{C}\left(46^{\circ} \mathrm{F}\right)$. From the heat exchanger the seawater is discharged overboard. The location of the discharge overboard shall be such that the re-circulation of cold seawater to the seawater lift pump intake will be minimal.

Solid particles shall be removed from the seawater using strainers downstream of the seawater lift pumps.

A hypo-chlorination unit will be installed in combination with shock dosing of biocide to reduce biofouling.

The main seawater users are the LNG vaporizers. During holding mode, the seawater consumption will be limited to the Liquefaction Plant and the domestic users. It is anticipated that one of the existing ship pumps can be used for this service. Otherwise one of the seawater lift pump will be kept running for the holding mode or a dedicated smaller seawater lift pump can be supplied. 


\begin{tabular}{|c|c|c|c|c|c|c|}
\hline \multirow[t]{3}{*}{ IMODCO } & \multirow[t]{3}{*}{$\begin{array}{l}\text { SBM-IMODCO INC. } \\
\text { MEMBER OF THE } \\
\text { IHC/CALAND GROUP } \\
\text { Now in our 5th Decade }\end{array}$} & \multirow{2}{*}{\multicolumn{5}{|c|}{$\begin{array}{l}\text { FLOATING RE-GASIFICATION UNIT } \\
\text { FOR SALT CAVERN } \\
\text { LNG RECEIVING AND RE-GASIFICATION }\end{array}$}} \\
\hline & & & & & & \\
\hline & & 51059 & ССМ97001 & C1 & PAGE & 61 \\
\hline
\end{tabular}

\subsection{FUEL GAS SYSTEMS}

In offloading mode, fuel gas will be taken from downstream the LP LNG vaporizers. The fuel gas will be let down to approximately 39 barg and fed to the fuel gas vessel. The fuel gas vessel is heated to at least $0{ }^{\circ} \mathrm{C}\left(32^{\circ} \mathrm{F}\right)$ in the fuel gas heater and distributed to the fuel gas consumers.

In offloading mode, the fuel gas requirement is $21 \mathrm{MMscfd}$.

In holding mode, gas produced from the salt cavern will be used as fuel-gas. When no gas from the salt cavern is available, buy-back gas from the pipeline will be used as fuel gas. The fuel gas requirement in holding mode is 2 MMscfd.

Using BOG as fuel gas will require the installation of a fuel gas compressor. In the current design all BOG will be liquefied and no BOG is lost. Using BOG as fuel gas would result in a smaller liquefaction plant at the expense of having to buy a fuel gas compressor. This is expected to be uneconomical.

\subsection{PRODUCTION GAS METERING}

Before the vaporized natural gas is sent out to the pipeline to shore it will be metered using two ultrasonic gas meters in series. A more detailed metering philosophy will be worked out during FEED.

\subsection{POWER GENERATION}

All equipment on the FRU will be electrical driven.

Power generation during offloading will be based on 4 Roll Royce RB211 generator-sets (22.6 MW each, $4 \times 33 \%$ ). The required power consumption while offloading is $57.2 \mathrm{MW}$, resulting in a loading of $84 \%$.

In holding mode, with only the LNG circulation pumps, liquefaction unit and domestic users running, the power requirement will drop to $4 \mathrm{MW}$. One RB211 will remain running to generate the power required when operating in this mode.

Power distribution shall be based on $60 \mathrm{~Hz}, 6.6 \mathrm{kV}$ and $440 \mathrm{~V}$ systems. 


\begin{tabular}{|c|c|c|c|c|c|c|}
\hline \multirow[t]{3}{*}{ IMOORO } & \multirow[t]{3}{*}{$\begin{array}{l}\text { SBM-IMODCO INC. } \\
\text { MEMBER OF THE } \\
\text { IHC/CALAND GROUP } \\
\text { Now in our 5th Decade }\end{array}$} & \multirow{2}{*}{\multicolumn{5}{|c|}{$\begin{array}{l}\text { FLOATING RE-GASIFICATION UNIT } \\
\text { FOR SALT CAVERN } \\
\text { LNG RECEIVING AND RE-GASIFICATION }\end{array}$}} \\
\hline & & & & & & \\
\hline & & 51059 & CCM97001 & C1 & PAGE & 62 \\
\hline
\end{tabular}

\subsection{WASTE HEAT RECOVERY UNIT I HEATING MEDIUM SYSTEM}

The power generator sets will be equipped with waste heat recovery units (WHRUs). The WHRUs will heat up the heating medium required for the heating of the injection gas heater. The heating medium needs to provide a maximum of $26.5 \mathrm{MW}$ to the gas flow to the salt cavern.

The heating medium system is a closed loop system consisting of a heating medium vessel and heating medium circulation pumps. From the heating medium vessel, the heating medium is pumped via the WHRU to the gas injection heaters. From the gas injection heaters, heating medium flows back to the heating medium vessel.

\subsection{VENT SYSTEM}

A vent system containing a knock-out vessel and a 50-meter high vent stack will be provided to safely release the gas from the process facility under all applicable production and upset scenarios.

\subsection{FIRE AND SAFETY SYSTEM}

The FRU shall be provided with passive safety systems (passive fire protection, fire \& blast walls, cryogenic spill containment) and active safety systems (ICSS, deluge, dry powder, etc.). The design of the safety system is outside the current work scope and can be addressed in the detailed development work.

The expected pump requirements would be in the order of:

- 1 off Firewater Pump, electric, $570 \mathrm{~m}^{3} / \mathrm{hr}(2500 \mathrm{gpm})$

- 1 off Firewater Pump, diesel, $570 \mathrm{~m}^{3} / \mathrm{hr}$ (2500 gpm)

- 2 off Firewater Jockey Pump, $45 \mathrm{~m}^{3} / \mathrm{hr}$ (200 gpm)

The design of the system will depend on which vessel is selected for the FRU, and what equipment is currently available on board.

\subsection{DECK LAYOUT CONSIDERATIONS}




\begin{tabular}{|c|c|c|c|c|c|c|}
\hline \multirow[t]{3}{*}{ IMOOR0 } & \multirow[t]{3}{*}{$\begin{array}{l}\text { SBM-IMODCO INC. } \\
\text { MEMBER OF THE } \\
\text { IHC/CALAND GROUP } \\
\text { Now in our 5th Decade }\end{array}$} & \multirow{2}{*}{\multicolumn{5}{|c|}{$\begin{array}{l}\text { FLOATING RE-GASIFICATION UNIT } \\
\text { FOR SALT CAVERN } \\
\text { LNG RECEIVING AND RE-GASIFICATION }\end{array}$}} \\
\hline & & & & & & \\
\hline & & 51059 & CCM97001 & C1 & PAGE & 63 \\
\hline
\end{tabular}

The LNG surge vessel should be located as close to the loading arms as possible. The loading arms will be located mid-ship on the starboard side of the FRU. The LNG pumps will be located directly underneath the surge vessel to avoid any unnecessary pipe routing and associated pressure drop in the suction lines.

The footprint of the BPE unit is approximately 76 meters $\times 18$ meters. The exchanger unit consists of 32 individual 4-pass exchangers; each exchanger is 76 meters long. The 32 exchangers are stacked in a configuration of 8 exchangers wide by 4 exchangers high. The resulting structure is about 10.5 meters high.

To avoid excessive pipe runs, the exchanger headers should be near the LNG pumps. The discharge lines from the BPEs run to the turret located in the bow of the ship. The exchangers should be located as close to the center of the vessel as possible. All of these factors fix the location of the Bishop exchangers as can be seen on the layout (refer to drawing RD 51059 DPT92001).

It should be noted that because of the even amount of exchanger passes, the LNG and seawater inlet and outlet of the exchanger are on the same side. Given the large sizes and amount of parallel piping and valves required, this will result in a highly congested area. It will also require large size natural gas lines to be routed underneath or past the Bishop exchanger unit to the turret at the fore end of the vessel. The same goes for the seawater overboard lines as the overboard location should be located away from the seawater intake. From this it would be more practical for the FRU design to have an odd number of exchanger passes. Whether this is possible should be investigated during FEED.

The vent stack should be located away from the accommodation. The available footprint for this is in the bow of the vessel.

The gas turbines and the LER should be located close to each other to avoid long runs of cabling. The main electrical users are the seawater lift pumps located in a converted cargo tank and the LNG pumps located underneath the surge vessel. These should also be located close by the LER to limit cable runs. The turbines should be sited in a way that they can be easily handled by the ships crane and with facilities for a lay down area. The space that is available for this is aft, near the accommodation.

The gas injection heaters are located close to the outlet of the BPEs in order to limit the length of the large size gas lines. The selected location next to the surge vessel also puts distance between these high-pressure gas exchangers and the accommodations.

The Seawater Lift Pumps will be located inside one of the cargo tanks that will be refurbished to make 


\begin{tabular}{|c|c|c|c|c|c|c|}
\hline \multirow[t]{3}{*}{ IMODCO } & \multirow[t]{3}{*}{$\begin{array}{l}\text { SBM-IMODCO INC. } \\
\text { MEMBER OF THE } \\
\text { IHC/CALAND GROUP } \\
\text { Now in our } 5 \text { th Decade }\end{array}$} & \multirow{2}{*}{\multicolumn{5}{|c|}{$\begin{array}{l}\text { FLOATING RE-GASIFICATION UNIT } \\
\text { FOR SALT CAVERN } \\
\text { LNG RECEIVING AND RE-GASIFICATION }\end{array}$}} \\
\hline & & & & & & \\
\hline & & 51059 & CCM97001 & C1 & PAGE & 64 \\
\hline
\end{tabular}

it suitable to be used as machinery space. The deck-penetration for the seawater lines to the BPEs should be as close as possible to the inlet of the BPEs.

\section{FIGURE 6-1 DECK FACILITIES LAYOUT}

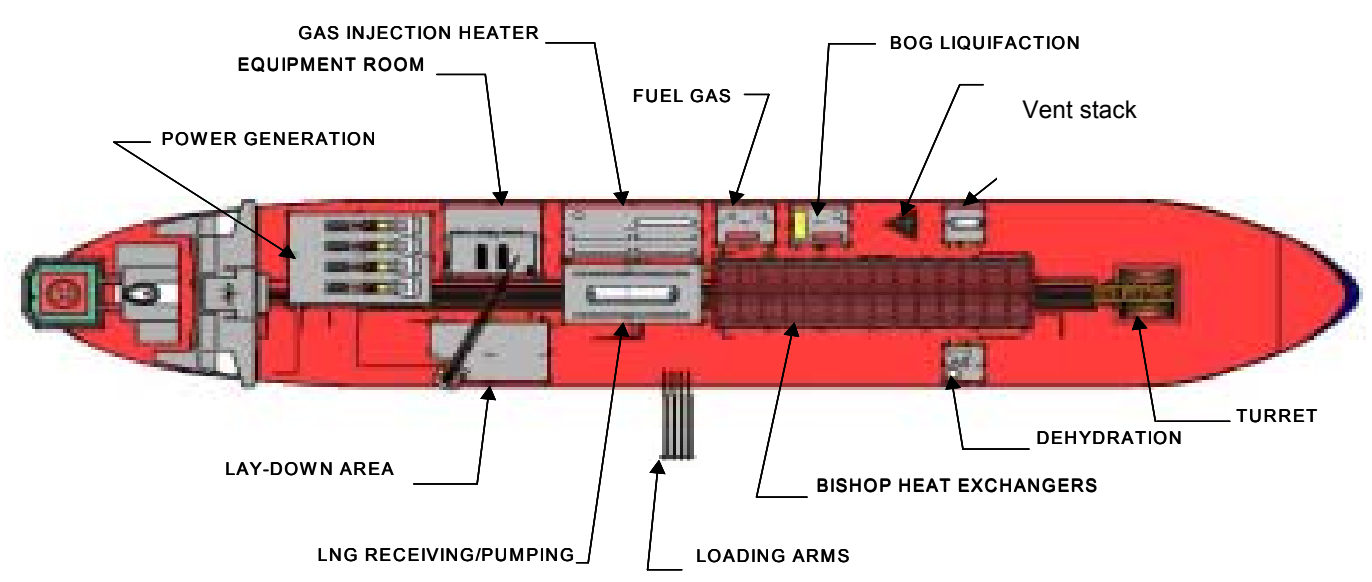




\begin{tabular}{|c|c|c|c|c|c|c|}
\hline \multirow[t]{3}{*}{ IMOOCD } & $\begin{array}{l}\text { SBM-IMODCO INC. } \\
\text { MEMBER OF THE } \\
\text { IHC/CALAND GROUP }\end{array}$ & \multirow{2}{*}{\multicolumn{5}{|c|}{$\begin{array}{c}\text { FOR SALT CAVERN } \\
\text { LNG RECEIVING AND RE-GASIFICATION }\end{array}$}} \\
\hline & Now in our 5th Decade & & & & & \\
\hline & & 51059 & CCM97001 & C1 & PAGE & 65 \\
\hline
\end{tabular}

\section{TURRET SYSTEM}

\subsection{TURRET TYPES}

The FRU is anchored to the sea floor by the turret mooring system which allows the FRU to weathervane to reduce the extreme environmental loads.

Three types of turret systems can be considered for the mooring of FRU: (i) internal turret; (ii) external raised turret and (iii) external SPT (Single Point Turret). Figures 7-1, 7-2 and 7-3 illustrate the three types of turret systems.

FIGURE 7-1 INTERNAL TURRET MOORINGS

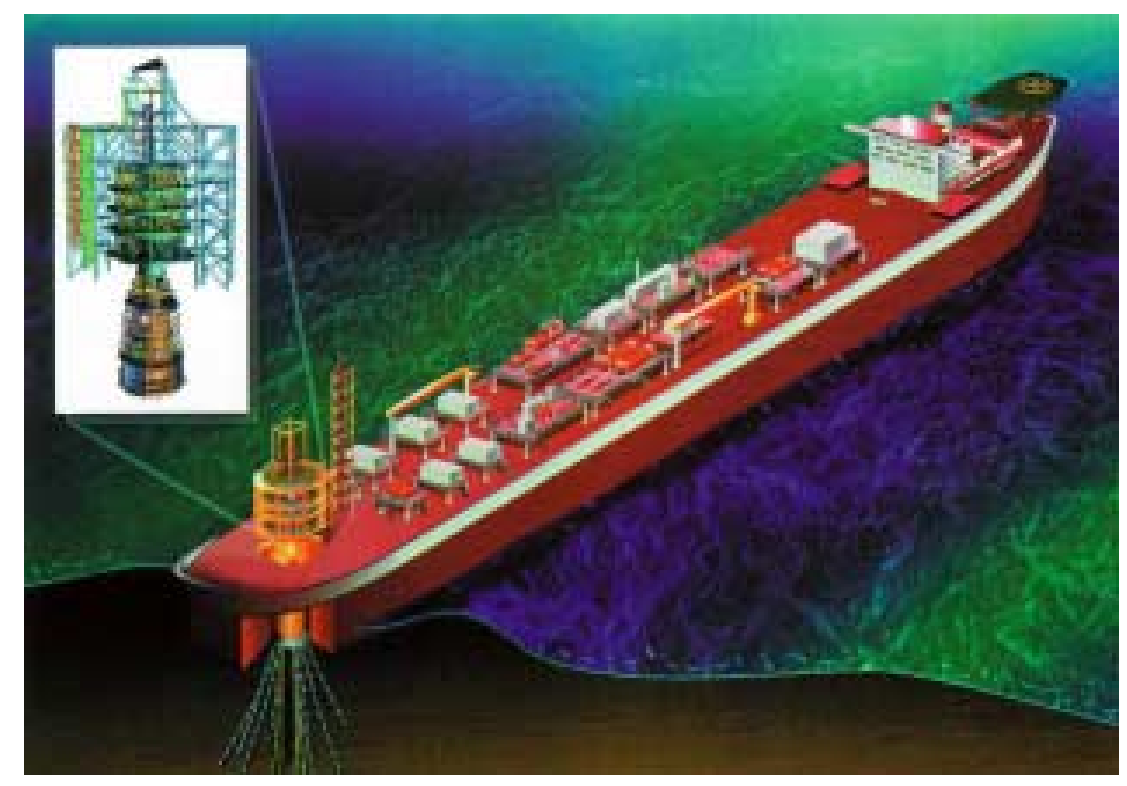




\begin{tabular}{|c|c|c|c|c|c|c|}
\hline \multirow[t]{3}{*}{ Imogen } & $\begin{array}{l}\text { SBM-IMODCO INC. } \\
\text { MEMBER OF THE } \\
\text { IHC/CALAND GROUP }\end{array}$ & \multirow{2}{*}{\multicolumn{5}{|c|}{$\begin{array}{l}\text { FLOATING RE-GASIFICATION UNIT } \\
\text { FOR SALT CAVERN } \\
\text {-NG RECEIVING AND RE-GASIFICATION }\end{array}$}} \\
\hline & \multirow[t]{2}{*}{ Now in our 5 th Decade } & & & & & \\
\hline & & 51059 & CCM97001 & C1 & PAGE & 66 \\
\hline
\end{tabular}

FIGURE 7-2 EXTERNAL RAISED TURRET MOORINGS

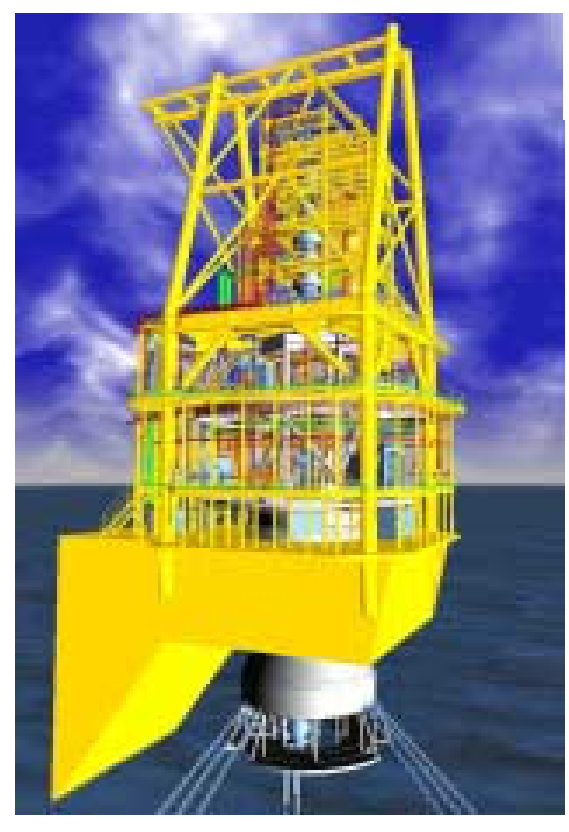

FIGURE 7-3 SINGLE POINT TURRET (SPT) MOORINGS

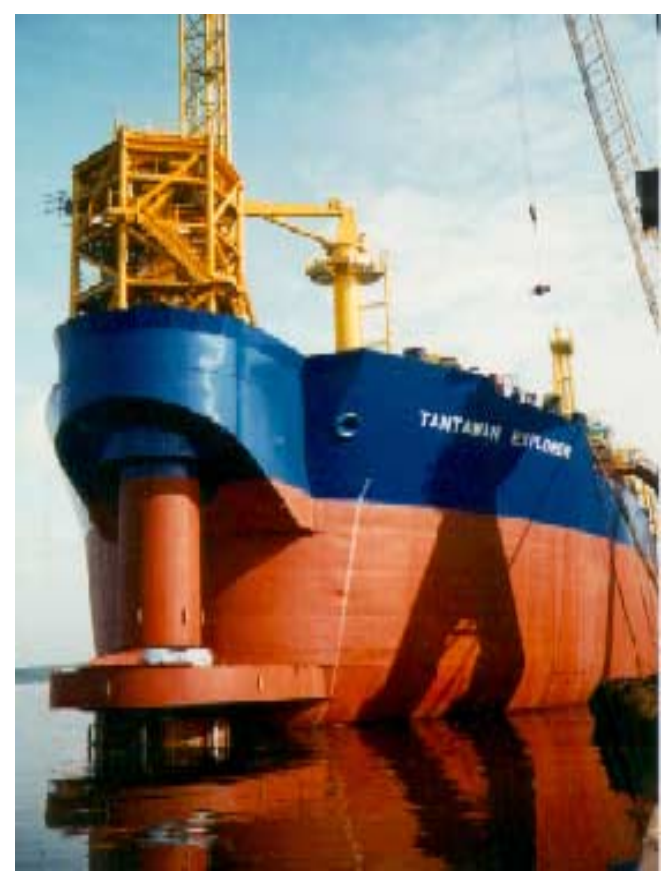




\begin{tabular}{|c|c|c|c|c|c|c|}
\hline \multirow[t]{3}{*}{ IMOOCo } & $\begin{array}{l}\text { SBM-IMODCO INC. } \\
\text { MEMBER OF THE } \\
\text { IHCICALAND GROUP }\end{array}$ & \multicolumn{4}{|c|}{ FOR SALT CAVERN } & \\
\hline & \multirow{2}{*}{ Now in our 5th Decade } & \multicolumn{5}{|c|}{ LNG RECEIVING AND RE-GASIFICATION } \\
\hline & & 51059 & CCM97001 & C1 & PAGE & 67 \\
\hline
\end{tabular}

The external SPT usually has diameter limitation and is only applied to limited number of riser situations. Given the current design of $4 \times 16$ " risers, the SPT, even though can be made to work, is not considered for this study.

Both the external raised and internal turrets are considered suitable. The internal turret option is selected because:

- The design loads are relatively large due to the harsh GOM hurricane environment;

- The cargo space loss due to the internal turret is not a design concern in this case;

- The internal turret structure is well protected from the wave slamming loads.

\subsection{TURRET CONFIGURATION}

The station-keeping solution adopted for the FRU is the internal turret type with dual bearings. The proposed solution is fully passive and designed to provide station keeping up to the 100-year return conditions without disconnection. The chaintable is located at the lower part of the turret (keel level approximately), providing chain hawse pipes and chain stoppers for attaching the anchor legs to the turret. At the other end, the anchor legs are fastened to the seabed by means of driven piles to secure the system on location.

The supports (upper and lower collars) and turret interfaces are provided by means of two bearings (a main and a lower) as well as friction pads, which allow the FRU to freely weathervane. The vessel can therefore take up the position of least resistance to the prevailing weather at all times. A stern thruster provides heading control assistance for berthing and departure operations when performing LNG transfer.

The gas transfer to salt cavern and shore is provided by four (4) 16" flexible risers and a swivel stack arrangement, as shown on Figure 7-4 below. 


\begin{tabular}{|c|c|c|c|c|c|c|}
\hline \multirow[t]{3}{*}{ IMODE0 } & $\begin{array}{l}\text { SBM-IMODCO INC. } \\
\text { MEMBER OF THE } \\
\text { IHCICALAND GROUP }\end{array}$ & \multirow{2}{*}{\multicolumn{5}{|c|}{$\begin{array}{l}\text { FLOATING RE-GASIFICATION UNIT } \\
\text { FOR SALT CAVERN } \\
\text { LNG RECEIVING AND RE-GASIFICATION }\end{array}$}} \\
\hline & \multirow[t]{2}{*}{ Now in our 5th Decade } & & & & & \\
\hline & & 51059 & CCM97001 & C1 & PAGE & 68 \\
\hline
\end{tabular}

FIGURE 7-4 INTERNAL TURRET DESIGN

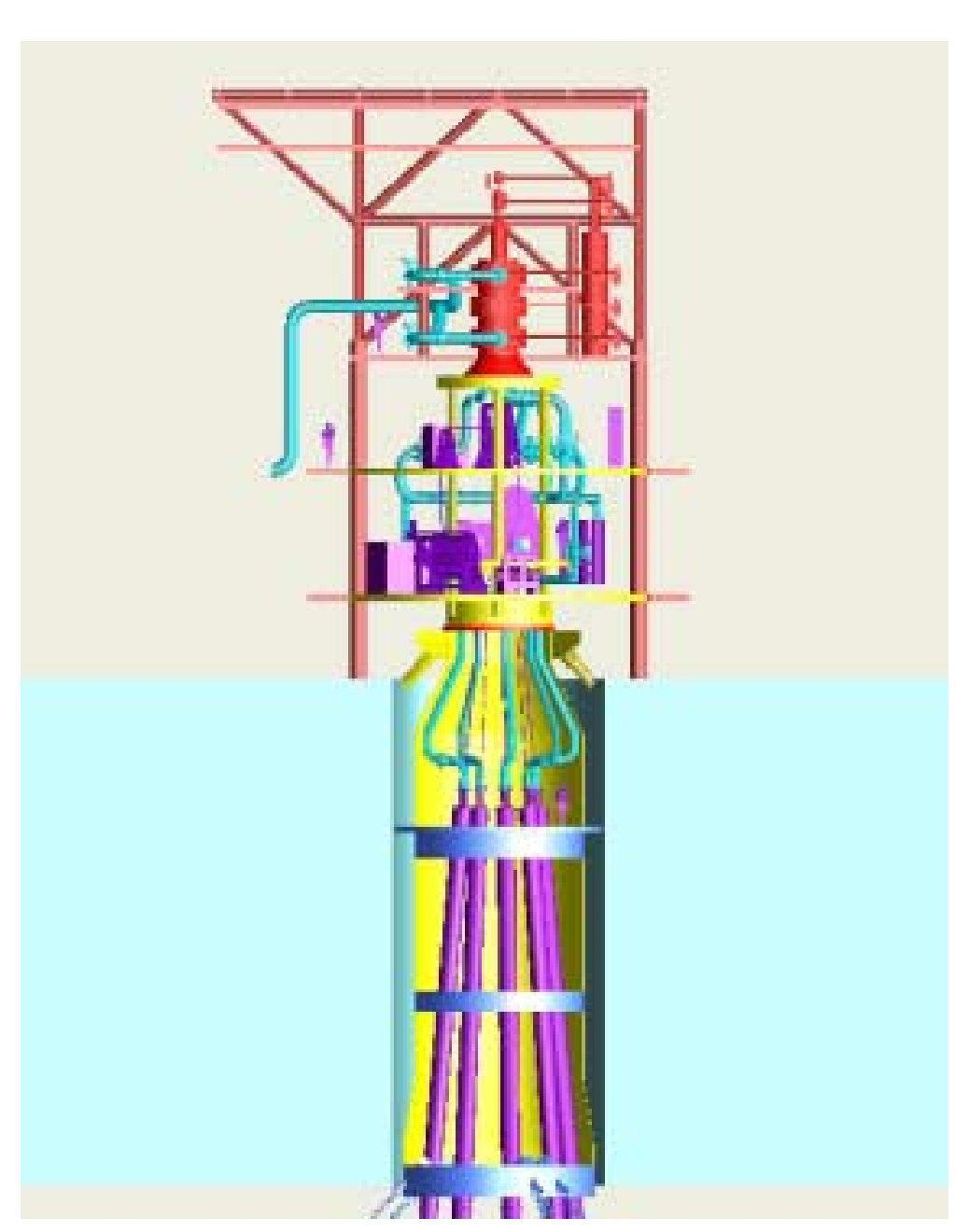

The turret main components are listed below:

- Column assembly,

- Upper collar,

- Main bearing,

- Upper support structure,

- Elastomeric pad assembly,

- Lower bearing,

- Piping system (piping, valves, flanges),

- Fluid swivel system and pedestal support structure, 


\begin{tabular}{|c|c|c|c|c|c|c|}
\hline \multirow[t]{3}{*}{ IMOOE0 } & \multirow[t]{3}{*}{$\begin{array}{l}\text { SBM-IMODCO INC. } \\
\text { MEMBER OF THE } \\
\text { IHCICALAND GROUP } \\
\text { Now in our 5th Decade }\end{array}$} & \multirow{2}{*}{\multicolumn{5}{|c|}{$\begin{array}{l}\text { FLOATING RE-GASIFICATION UNIT } \\
\text { FOR SALT CAVERN } \\
\text { LNG RECEIVING AND RE-GASIFICATION }\end{array}$}} \\
\hline & & & & & & \\
\hline & & 51059 & ССМ97001 & C1 & PAGE & 69 \\
\hline
\end{tabular}

- Handling and hoisting equipment.

\subsection{TURRET SIZING}

The turret was preliminarily sized based on the riser and mooring system dimensions and estimated equipment sizes. The chaintable diameter is $9 \mathrm{~m}$ which accommodates 6 riser slots (4 risers and 2 spare slots). The total turret height is $51.9 \mathrm{~m}$. The following assumptions have been utilized in sizing the turret structure:

- All six risers have been routed.

- The ESD valves can be used for positive isolation, so only single block valves are used immediately before the swivel.

- The main pull-in winch is situated on the lower deck. (Footprint size needs to be checked for 150t capacity)

- Auxilliary winch is also on the lower deck.(could be moved to upper deck)

- Rotating sheave for riser pull-in is located on a mezzanine deck just above the lower deck.

- $5 \mathrm{~m}$ dia main roller bearing and structural collar, mounted on 6-off elastomeric pads.

- Chainstoppers at the chaintable.

- Access to the riser deck is via the moonpool, accessed by stairwells from the ship main deck.

A general turret system GA drawing is presented in Figure 7-5. 


\begin{tabular}{|c|c|c|c|c|c|c|}
\hline \multirow[t]{3}{*}{ IMODE0 } & $\begin{array}{l}\text { SBM-IMODCO INC. } \\
\text { MEMBER OF THE } \\
\text { IHCICALAND GROUP }\end{array}$ & \multirow{2}{*}{\multicolumn{5}{|c|}{$\begin{array}{l}\text { FLOATING RE-GASIFICATION UNIT } \\
\text { FOR SALT CAVERN } \\
\text { LNG RECEIVING AND RE-GASIFICATION }\end{array}$}} \\
\hline & \multirow[t]{2}{*}{ Now in our 5th Decade } & & & & & \\
\hline & & 51059 & CCM97001 & C1 & PAGE & 70 \\
\hline
\end{tabular}

FIGURE 7-5 TURRET GA DRAWING

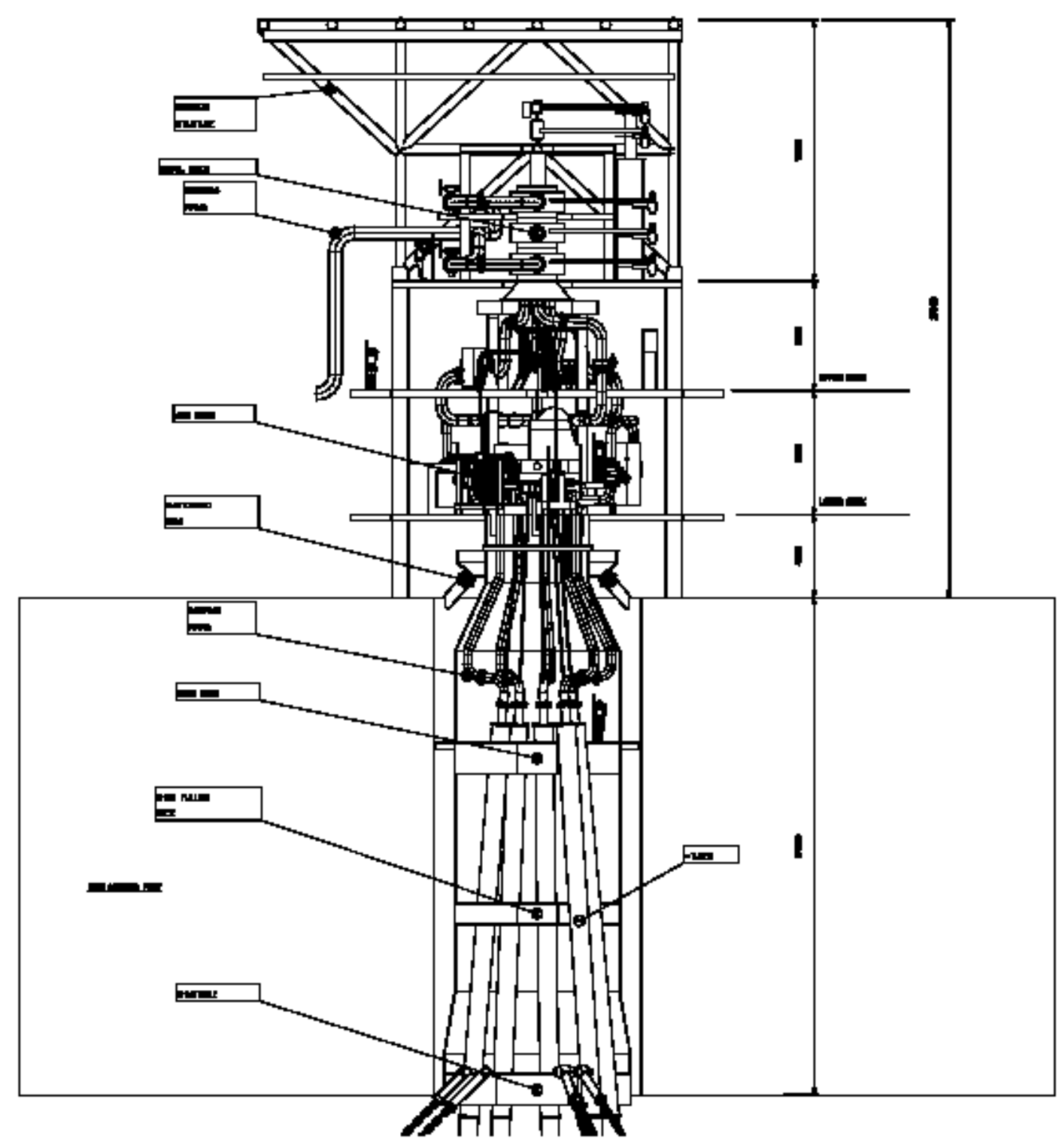




\begin{tabular}{|c|c|c|c|c|c|c|}
\hline \multirow[t]{3}{*}{ IMODCO } & \multirow[t]{3}{*}{$\begin{array}{l}\text { SBM-IMODCO INC. } \\
\text { MEMBER OF THE } \\
\text { IHC/CALAND GROUP } \\
\text { Now in our 5th Decade }\end{array}$} & \multirow{2}{*}{\multicolumn{5}{|c|}{$\begin{array}{l}\text { FLOATING RE-GASIFICATION UNIT } \\
\text { FOR SALT CAVERN } \\
\text { LNG RECEIVING AND RE-GASIFICATION }\end{array}$}} \\
\hline & & & & & & \\
\hline & & 51059 & ССМ97001 & C1 & PAGE & 71 \\
\hline
\end{tabular}

\section{MOORING SYSTEM}

\subsection{DESIGN OBJECTIVES}

The mooring system is designed to keep the FRU on station up to the survival (100-year return) condition without disconnection, according to the following criteria:

- The anchoring system must provide sufficient restoring force to keep the FRU horizontally within an offset less than or equal to the allowable excursions to ensure the integrity of the under-water riser system. For this shallow water application the allowable excursion offset is limited to $40 \%$ of the water depth.

- The maximum anchor leg tensions must be kept below specified allowable Safety factors.

The mooring system should also be capable of performing the station keeping function in the operating condition when an LNG carrier is moored side by side with the FRU.

\subsection{DESIGN METOCEAN CONDITION}

The water depth for the proposed site is $300 \mathrm{ft}(91.44 \mathrm{~m})$, which is located at a possible Salt Cavern in the GOM. A sensitivity study on water depth has also been performed to demonstrate that the FRU concept is feasible at other shallower Salt Cavern sites.

The metocean conditions are defined in section 4 of this report. The following 100-year environmental conditions were retained for the mooring system design:

\section{Waves}

Wave spectrum:

Significant Wave Height:

Spectral Peak Period:

Spectral peak period range:

Peak enhancement factor:

\section{Wind}

One hour wind speed at $10 \mathrm{~m}$ above MSL:
JONSWAP;

$\mathrm{Hs}=11.9 \mathrm{~m}$;

$\mathrm{Tp}=14.2 \mathrm{sec}$;

$12.7 \mathrm{~s}$ to $15.7 \mathrm{~s}$;

$\gamma=2.5(\sigma \mathrm{A}=0.07 ; \sigma \mathrm{B}=0.09)$. 


\begin{tabular}{|c|c|c|c|c|c|c|}
\hline \multirow[t]{3}{*}{ IMOOCo } & $\begin{array}{l}\text { SBM-IMODCO INC. } \\
\text { MEMBER OF THE } \\
\text { IHC/CALAND GROUP }\end{array}$ & \multicolumn{4}{|c|}{ FOR SALT CAVERN } & \\
\hline & \multirow{2}{*}{ Now in our 5th Decade } & \multicolumn{5}{|c|}{ LNG RECEIVING AND RE-GASIFICATION } \\
\hline & & 51059 & CCM97001 & C1 & PAGE & 72 \\
\hline
\end{tabular}

One minute wind speed at $10 \mathrm{~m}$ above MSL: Uw,10m,1 $\mathrm{min}=53.3 \mathrm{~m} / \mathrm{s}$.

\section{Current}

Depth-averaged storm current speed: $\quad U c=1.6 \mathrm{~m} / \mathrm{s}$.

\section{Storm Surge}

$+1.13 m$

\subsection{DESIGN PRINCIPLE}

The design of a station keeping system for the FRU is governed by the following criteria:

- The anchor system should provide for safe station keeping during normal operating conditions. These conditions are set either by production requirements or by offloading operations;

- The anchor system must show an acceptable level of safety with respect to fatigue failure;

- The anchor system must be capable to withstand, with an acceptable level of safety, all environmental conditions including the survival (100-year) condition.

The anchor system design, in such a harsh environment (hurricane) is usually governed by the survival condition. However, chain fatigue also should be investigated.

In the present case, the anchor system was designed by investigating various combinations of 100 year environmental conditions (waves, wind and current) and anchor system conditions (both intact and one broken leg case).

Offloading conditions will not govern the design of the anchor system as it will be shown in Section 10 since the offloading connection and disconnection limits are far smaller than the survival conditions. Typically, the offloading sea states in a GOM environment are in the following range:

- Operational waves: $\mathrm{Hs}=2.5 \mathrm{~m}$;

- Operational wind velocity: Vwind, 1 -hour $=16 \mathrm{~m} / \mathrm{s}$;

- Operational current velocity: Ucur $=0.5 \mathrm{~m} / \mathrm{s}$.

Mooring design and analyses are performed for the above sea states. Transient response analyses due to e.g. rapid changes in the hurricane wind field are also briefly discussed and would be addressed more thoroughly in the future detailed analyses. 


\begin{tabular}{|c|c|c|c|c|c|c|}
\hline \multirow[t]{3}{*}{ IMODCO } & \multirow[t]{3}{*}{$\begin{array}{l}\text { SBM-IMODCO INC. } \\
\text { MEMBER OF THE } \\
\text { IHC/CALAND GROUP } \\
\text { Now in our 5th Decade }\end{array}$} & \multirow{2}{*}{\multicolumn{5}{|c|}{$\begin{array}{l}\text { FLOATING RE-GASIFICATION UNIT } \\
\text { FOR SALT CAVERN } \\
\text { LNG RECEIVING AND RE-GASIFICATION }\end{array}$}} \\
\hline & & & & & & \\
\hline & & 51059 & ССМ97001 & C1 & PAGE & 73 \\
\hline
\end{tabular}

\subsection{MOORING ANALYSIS METHODOLOGY}

The turret anchor system provides the restoring capacity that is necessary to balance the environmental loads, hence maintaining the excursion envelope of the subsea system within acceptable limits. In the present shallow water configuration, the restoring force works on the catenary principle: when lifted off the seabed the suspended weight of the anchor lines increases hence providing more restoring force.

Under the influence of the environmental loads of the combined action of waves, wind and current, the FRU takes a mean offset from its initial position. In addition, the FRU is subjected to slowly varying wave drift motions at low frequency about the mean offset and additionally move in the wave frequency range. The magnitude of the environmental loads on the vessel therefore determines the required restoring capacity of the anchor system.

The mooring analysis, which is described in the following sections, is an iterative process aimed at defining and optimizing the anchor system and the turret structure while providing the required restoring capacity and excursion limits.

The design of the mooring system is conducted using time domain analysis.

To derive maximum line tensions and vessel excursions, the following methodology is applied:

\section{Step 1 - Tanker Hydrodynamics}

A hydrodynamic panel model of the tanker at its loading condition (12 m draft) is developed. A threedimensional diffraction/radiation analysis is performed to compute hydrodynamic coefficients, such as added mass, radiation damping, first order wave exciting forces, wave drift force coefficients, and vessel motion RAOs.

Motion RAOs and wave drift force coefficients are used for calculation of mean drift forces and slow drift motions.

\section{Step 2-Definition of anchor legs}

The anchor legs are modeled. Line composition and actual mechanical properties of the various segments, namely un-stretched lengths, linear weights in air and water, axial stiffness, etc. have been properly defined. 


\begin{tabular}{|c|c|c|c|c|c|c|}
\hline \multirow[t]{3}{*}{ IMODCO } & \multirow[t]{3}{*}{$\begin{array}{l}\text { SBM-IMODCO INC. } \\
\text { MEMBER OF THE } \\
\text { IHC/CALAND GROUP } \\
\text { Now in our 5th Decade }\end{array}$} & \multirow{2}{*}{\multicolumn{5}{|c|}{$\begin{array}{l}\text { FLOATING RE-GASIFICATION UNIT } \\
\text { FOR SALT CAVERN } \\
\text { LNG RECEIVING AND RE-GASIFICATION }\end{array}$}} \\
\hline & & & & & & \\
\hline & & 51059 & ССМ97001 & C1 & PAGE & 74 \\
\hline
\end{tabular}

\section{Step 3 - Calculation of mean environmental loads acting on the vessel}

Mean current forces and moments acting on the tanker have been calculated using coefficients from the OCIMF databases for the specified FRU loading condition.

Due to the high wind speed (48 m/s for 100-year return environment) and the topsides arrangement different from that for regular tankers, wind load corrections were applied to compute the wind forces.

Mean wave drift load is computed based on the wave drift coefficients (QTFs) obtained from the FPU wave diffraction analysis and the specified wave energy spectrum. The QTFs are corrected to account for the wave/current interaction.

\section{Step 4-Screening Analysis}

Since directional combination of wind, wave and current is not available, the following combinations have been checked:

- Collinear combination

- DNV cross condition: wind $30^{\circ}$ and current $45^{\circ}$ from wave

Both combinations have been analyzed for waves coming from $0^{\circ}, 15^{\circ}, 30^{\circ}, 45^{\circ}, 60^{\circ}, 75^{\circ}, 90^{\circ}$ and $105^{\circ}$ with respect to true North, measured clockwise.

After screening, the DNV cross condition with waves coming from $75^{\circ}$, wind coming from $105^{\circ}$ and current coming from $120^{\circ}$ were found to be the most critical. More thorough analyses were therefore performed on these cases, for both intact and damaged cases. The further analyses determined what the most probable maximum value (MPM) would be for the anchor line loads and vessel motions.

\subsection{FRU MOTIONS}

\subsubsection{FRU Particulars}

The FRU hull is assumed to be a converted Suemax tanker. Given consideration to environmental loading and the motion response characteristics of the vessel, a fixed draft of $12 \mathrm{~m}$ was selected.

The hull main particulars are presented in Table 3-1 and were used in the present analysis. 


\begin{tabular}{|c|c|c|c|c|c|c|}
\hline \multirow[t]{3}{*}{ Imogen } & $\begin{array}{l}\text { SBM-IMODCO INC. } \\
\text { MEMBER OF THE } \\
\text { IHC/CALAND GROUP }\end{array}$ & \multicolumn{4}{|c|}{ FOR SALT CAVERN } & \\
\hline & \multirow[t]{2}{*}{ Now in our 5th Decade } & \multicolumn{5}{|c|}{ LNG RECEIVING AND RE-GASIFICATION } \\
\hline & & 51059 & CCM97001 & C1 & PAGE & 75 \\
\hline
\end{tabular}

\subsubsection{FRU Motion Responses Analysis}

The motion responses of the FRU, which is part of the input to the design of mooring and riser systems, were analyzed using the wave diffraction and radiation program AQWA. AQWA is developed by Century Dynamics for advanced 3D motions analysis of floating structures.

The hydrodynamic mesh of the FRU hull, as modeled for the diffraction and radiation calculations (AQWA-LINE) is shown below.

FIGURE 8-1 HYDRODYNAMIC MESH OF THE FRU HULL

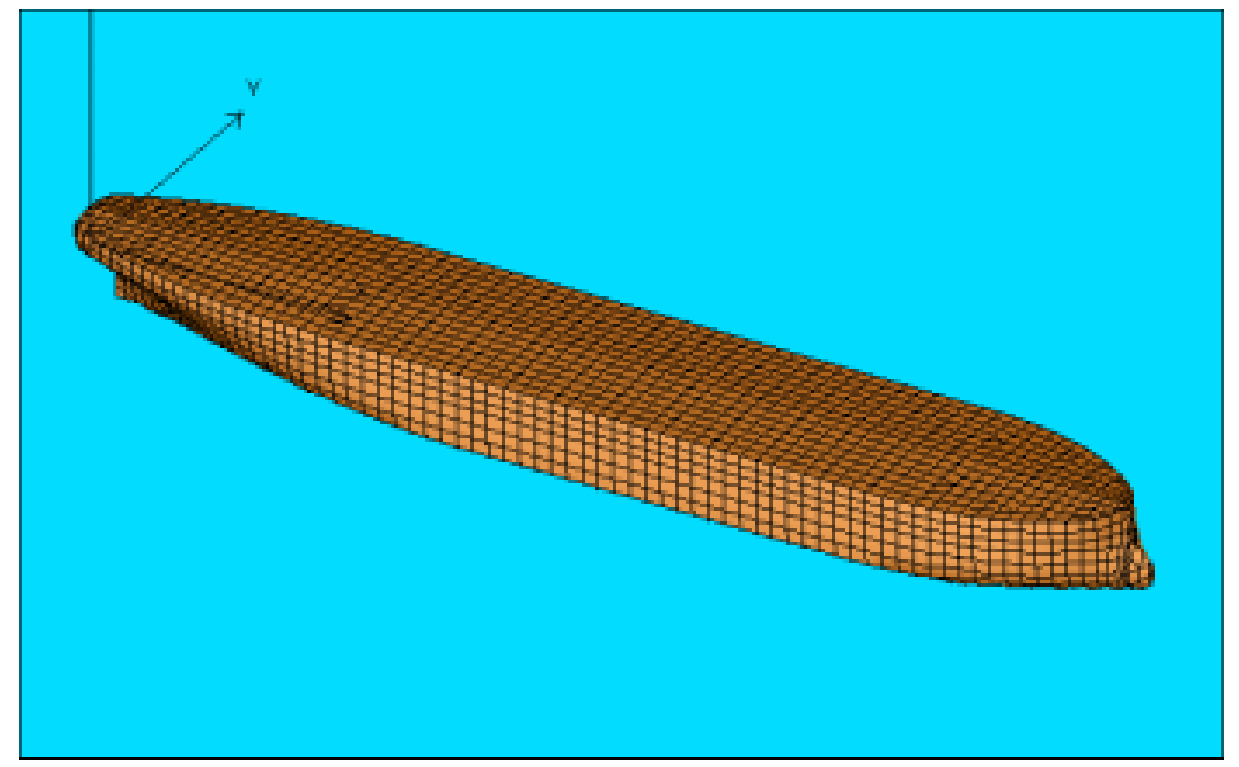

\subsubsection{Motion Transfer Functions}

The motion transfer functions of the FRU for the 6 degrees of freedom are presented in the following plot: 


\begin{tabular}{|c|c|c|c|c|c|c|}
\hline \multirow[t]{3}{*}{ 1M00Е0 } & $\begin{array}{l}\text { SBM-IMODCO INC. } \\
\text { MEMBER OF THE } \\
\text { IHC/CALAND GROUP } \\
\end{array}$ & \multirow{2}{*}{\multicolumn{5}{|c|}{$\begin{array}{l}\text { FLOATING RE-GASIFICATION UNIT } \\
\text { FOR SALT CAVERN } \\
\text { NG RECEIVING AND RE-GASIFICATION }\end{array}$}} \\
\hline & Now in our 5th Decade & & & & & \\
\hline & & 51059 & CCM97001 & C1 & PAGE & 76 \\
\hline
\end{tabular}

FIGURE 8-2 MOTION TRANFER FUNCTIONS FRU MOTION RAOS
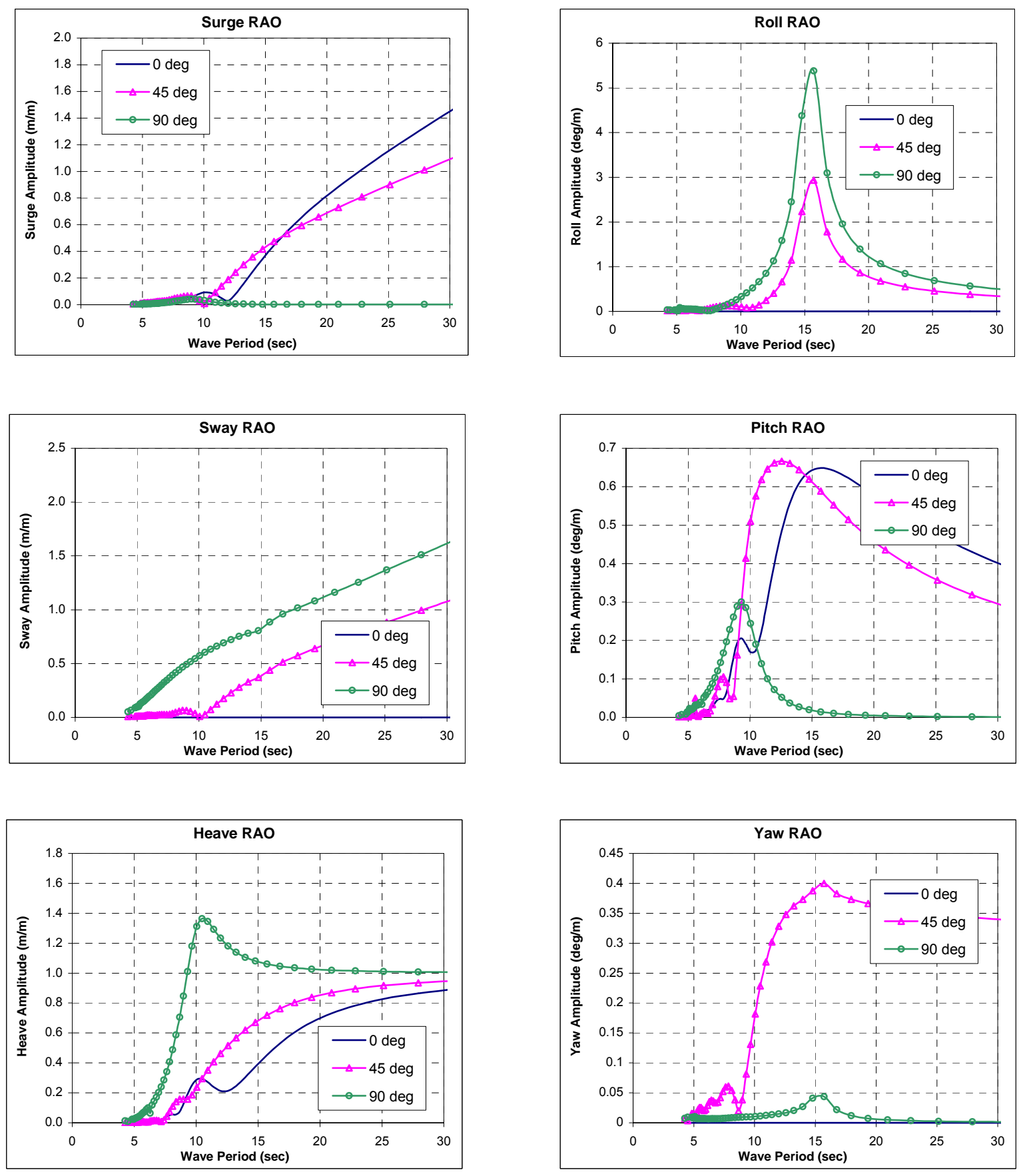


\begin{tabular}{|c|c|c|c|c|c|c|}
\hline \multirow[t]{3}{*}{ IMODCO } & \multirow[t]{3}{*}{$\begin{array}{l}\text { SBM-IMODCO INC. } \\
\text { MEMBER OF THE } \\
\text { IHCICALAND GROUP } \\
\text { Now in our 5th Decade }\end{array}$} & \multirow{2}{*}{\multicolumn{5}{|c|}{$\begin{array}{l}\text { FLOATING RE-GASIFICATION UNIT } \\
\text { FOR SALT CAVERN } \\
\text { LNG RECEIVING AND RE-GASIFICATION }\end{array}$}} \\
\hline & & & & & & \\
\hline & & 51059 & CCM97001 & C1 & PAGE & 77 \\
\hline
\end{tabular}

\subsection{MOORING SYSTEM DESCRIPTION}

The FRU is anchored to the seabed by means of an array of "chain-wire-chain" catenary anchor legs (combination of chains and wire ropes), which are connected to the vessel via a chaintable / chainstopper arrangement.

Such anchoring systems have been used successfully for permanent mooring of floating structures over the past 25 years. The chain segment characteristics are in accordance with the API RP-2SK design guideline, which has been widely used for previous permanent moorings without any major reported problem.

The wire rope segments will use sheathed spiral strand type wire rope. Such a rope construction has had trouble-free experience in permanent mooring of 25 years. It allows for a lighter mooring system, hence reducing the overall mooring loads, while also improving the load-excursions characteristics of the anchor system.

For the present base case mooring design, the wire rope segment lies on the seabed to provide some spring effect, which makes the mooring legs more compliant to the vessel's wave frequency motions. The wire rope is only lifted when the 10 year return hurricane condition is exceeded.

The composition of mooring leg is presented in the following table. 


\begin{tabular}{|c|c|c|c|c|c|c|}
\hline \multirow[t]{3}{*}{ IMODE0 } & $\begin{array}{l}\text { SBM-IMODCO INC. } \\
\text { MEMBER OF THE } \\
\text { IHCICALAND GROUP }\end{array}$ & \multirow{2}{*}{\multicolumn{5}{|c|}{$\begin{array}{l}\text { FLOATING RE-GASIFICATION UNIT } \\
\text { FOR SALT CAVERN } \\
\text { LNG RECEIVING AND RE-GASIFICATION }\end{array}$}} \\
\hline & \multirow[t]{2}{*}{ Now in our 5th Decade } & & & & & \\
\hline & & 51059 & CCM97001 & C1 & PAGE & 78 \\
\hline
\end{tabular}

TABLE 8-1 MOORING LEG COPMPOSITION

\begin{tabular}{|c|c|c|}
\hline Segment & $\begin{array}{l}\text { From Anchor to } \\
\text { Chain Stopper }\end{array}$ & $\begin{array}{c}\text { Segment Characteristics } \\
\text { Lines 1-9 }\end{array}$ \\
\hline 1 & $\begin{array}{c}\text { Length } \\
\text { Diameter, Type } \\
\text { Weight in Air (Water) } \\
\text { MBL (corroded after } 20 \text { years) }{ }^{1} \\
\text { EA }\end{array}$ & $\begin{array}{c}120 \mathrm{~m} \\
147 \mathrm{~mm}, \mathrm{R} 4 \text { Studless Chain } \\
436.5 \mathrm{~kg} / \mathrm{m}(379.5 \mathrm{~kg} / \mathrm{m}) \\
19089(17824) \mathrm{kN} \\
1229 \mathrm{MN}\end{array}$ \\
\hline 2 & $\begin{array}{l}\text { Length } \\
\text { Diameter, Type } \\
\text { Weight in Air (Water) } \\
\text { MBL } \\
\text { EA }\end{array}$ & $\begin{array}{c}550 \mathrm{~m} \\
138 \mathrm{~mm} \text { Sheathed Spiral Strand Wire Rope } \\
99.8 \mathrm{~kg} / \mathrm{m}(79.4 \mathrm{~kg} / \mathrm{m}) \\
17899 \mathrm{kN} \\
1695 \mathrm{MN}\end{array}$ \\
\hline 3 & $\begin{array}{c}\text { Length } \\
\text { Diameter, Type } \\
\text { Weight in Air (Water) } \\
\text { MBL (corroded after } 20 \text { years) }{ }^{1} \\
\text { EA }\end{array}$ & $\begin{array}{c}530 \mathrm{~m} \\
147 \mathrm{~mm}, \mathrm{R} 4 \text { Studless Chain } \\
436.5 \mathrm{~kg} / \mathrm{m}(379.5 \mathrm{~kg} / \mathrm{m}) \\
19089(17824) \mathrm{kN} \\
1229 \mathrm{MN}\end{array}$ \\
\hline & Total Leg Length $^{2}$ & $1200 \mathrm{~m}$ \\
\hline & Pretension & $1243 \mathrm{KN}$ \\
\hline & Fairlead Angle with Horizontal & 40deg \\
\hline
\end{tabular}

The following plots present the key characteristics of the designed FRU mooring systems: 


\begin{tabular}{|c|c|c|c|c|c|c|}
\hline \multirow[t]{3}{*}{ IMOOCO } & $\begin{array}{l}\text { SBM-IMODCO INC. } \\
\text { MEMBER OF THE } \\
\text { IHC/CALAND GROUP }\end{array}$ & \multicolumn{4}{|c|}{ FOR SALT CAVERN } & \\
\hline & Now in our 5th Decade & \multicolumn{5}{|c|}{ LNG RECEIVING AND RE-GASIFICATION } \\
\hline & & 51059 & CCM97001 & C1 & PAGE & 79 \\
\hline
\end{tabular}

FIGURE 8-3 MOORING SYSTEM PLAN VIEW

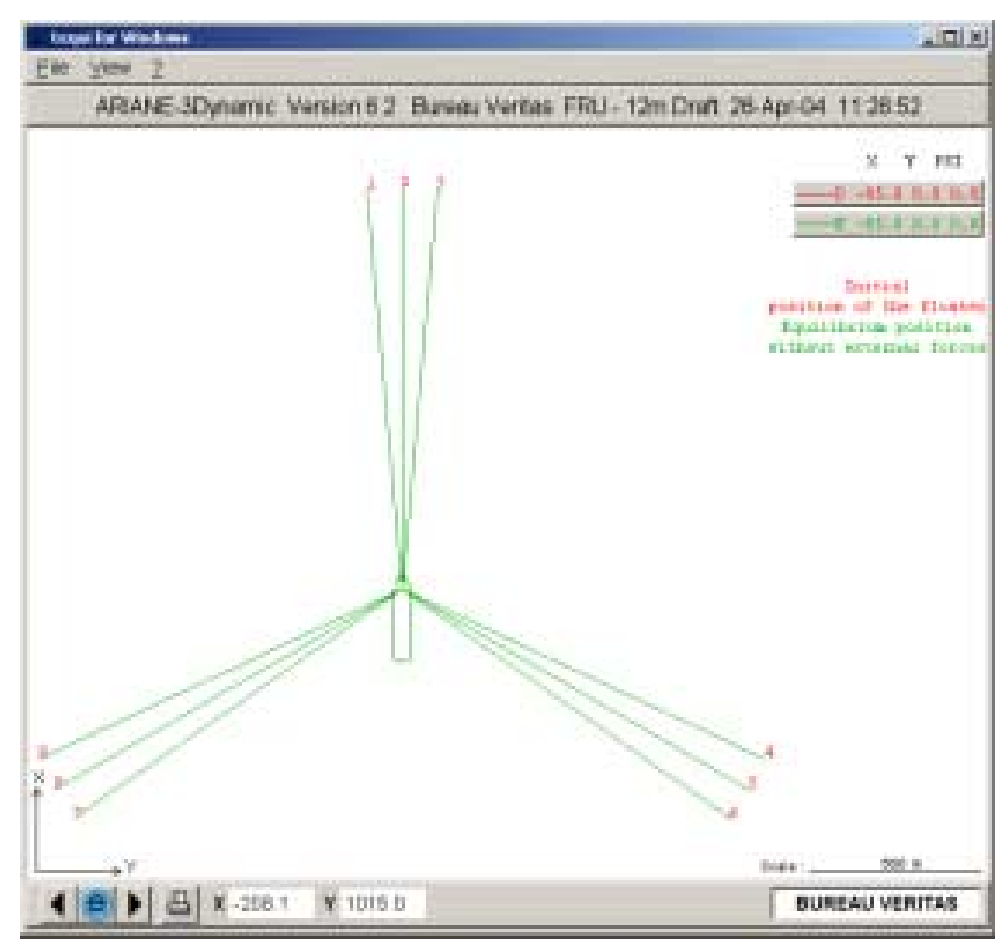

FIGURE 8-4 ANCHORING LEG CATENARY PROFILE

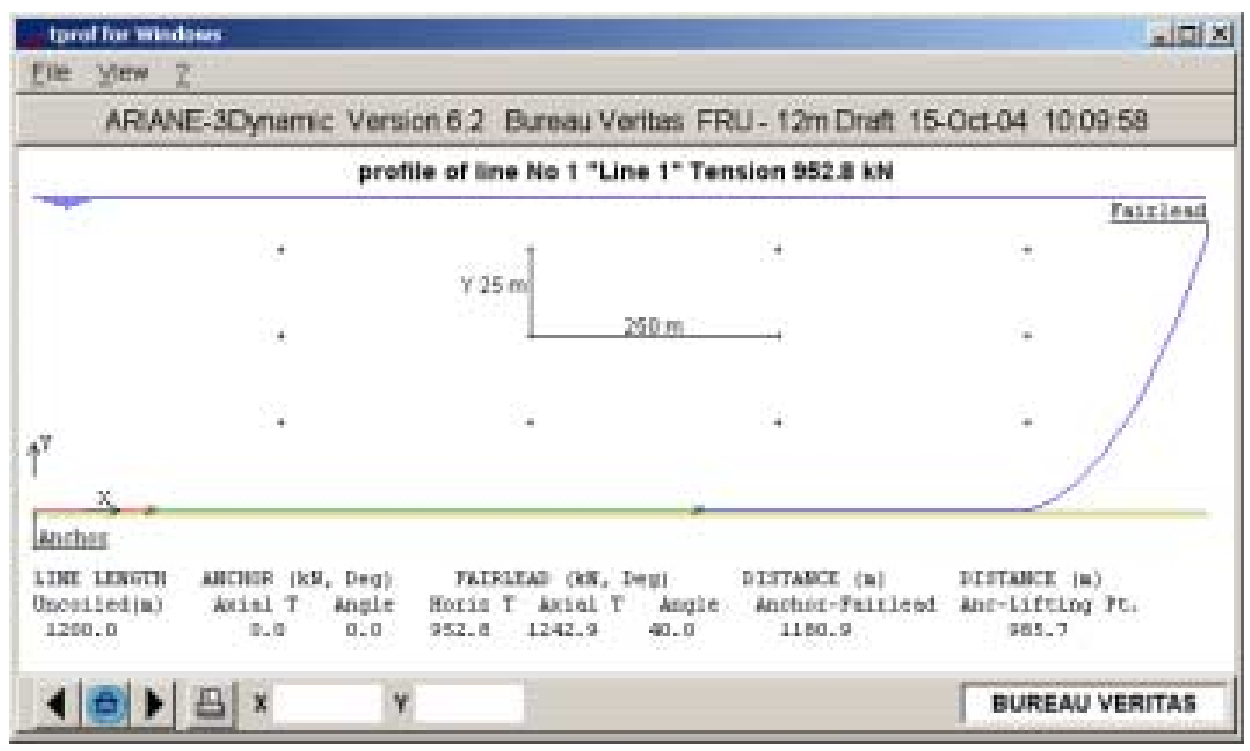




\begin{tabular}{|c|c|c|c|c|c|c|}
\hline \multirow[t]{3}{*}{ IMOOCD } & $\begin{array}{l}\text { SBM-IMODCO INC. } \\
\text { MEMBER OF THE } \\
\text { IHC/CALAND GROUP }\end{array}$ & \multirow{2}{*}{\multicolumn{5}{|c|}{$\begin{array}{c}\text { FOR SALT CAVERN } \\
\text { LNG RECEIVING AND RE-GASIFICATION }\end{array}$}} \\
\hline & Now in our 5th Decade & & & & & \\
\hline & & 51059 & CCM97001 & C1 & PAGE & 80 \\
\hline
\end{tabular}
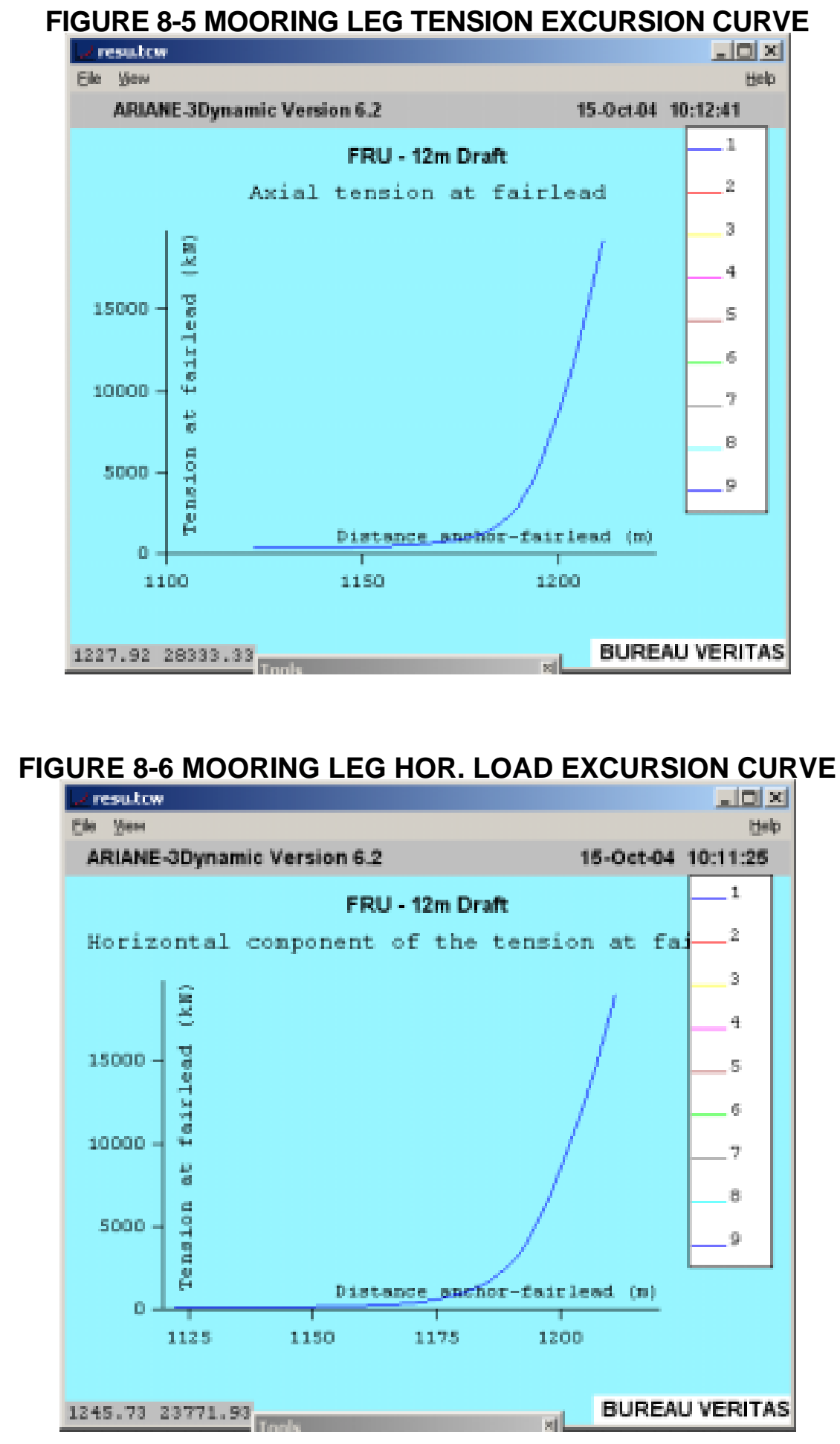


\begin{tabular}{|c|c|c|c|c|c|c|}
\hline \multirow[t]{3}{*}{ IMOORO } & \multirow[t]{3}{*}{$\begin{array}{l}\text { SBM-IMODCO INC. } \\
\text { MEMBER OF THE } \\
\text { IHC/CALAND GROUP } \\
\text { Now in our 5th Decade }\end{array}$} & \multirow{2}{*}{\multicolumn{5}{|c|}{$\begin{array}{l}\text { FLOATING RE-GASIFICATION UNIT } \\
\text { FOR SALT CAVERN } \\
\text { LNG RECEIVING AND RE-GASIFICATION }\end{array}$}} \\
\hline & & & & & & \\
\hline & & 51059 & CCM97001 & C1 & PAGE & 81 \\
\hline
\end{tabular}

\subsection{SCREENING ANALYSIS AND GOVERNING CASES}

The governing environmental conditions were found by an extensive screening analysis described below.

To achieve the design objectives, a screening of joint environmental directional conditions leading to the largest anchor leg tensions and low frequency excursions of the FRU is performed.

As stated, the anchor system is designed to withstand the 100-year (survival) environmental conditions. The joint directionality of these environmental conditions i.e. the 100-year wind, waves and current were not available. Actually, the review of the environmental data has shown that the waves, the wind and the current have predominant directions. However, the spreading is such that different directional combinations should be considered in order to find the most severe conditions.

Therefore, based on DNV POSMOOR Rules and the experience gained on previous projects, the following typical joint occurrence of environmental conditions have been considered:

- Collinear case: wind, waves and current are collinear;

- Crossed case: wind is $30^{\circ}$ and current is $45^{\circ}$ from waves.

The wind, waves and current of the above directional combinations were applied every 15 degs with reference to the mooring legs to systematically identify the most critical loadcases in terms of line tensions and offsets.

The conclusion of the screening analysis is that the governing combination for anchor leg tensions is the cross joint directionality of wind, waves and current incoming from 75 degs with reference to one bundle of anchor legs.

\subsection{MOORING ANALYSIS RESULTS}

For the most critical loadcases, time domain simulations were repeated 50 times using different random seeds, which yielded the most probable maximum values that were used for the design.

The following plots presented the wave surface profile, mooring line tension and turret excursion of a typical survival analysis case: 


\begin{tabular}{|c|c|c|c|c|c|c|}
\hline \multirow[t]{3}{*}{ IMODCO } & \multirow{3}{*}{$\begin{array}{l}\text { SBM-IMODCO INC. } \\
\text { MEMBER OF THE } \\
\text { IHCICALAND GROUP } \\
\text { Now in our } 5 \text { th Decade }\end{array}$} & \multirow{2}{*}{\multicolumn{5}{|c|}{$\begin{array}{l}\text { FLOATING RE-GASIFICATION UNIT } \\
\text { FOR SALT CAVERN } \\
\text { NG RECEIVING AND RE-GASIFICATION }\end{array}$}} \\
\hline & & & & & & \\
\hline & & 51059 & CCM97001 & C1 & PAGE & 82 \\
\hline
\end{tabular}

FIGURE 8-7 WAVE SURFACE ELEVATION

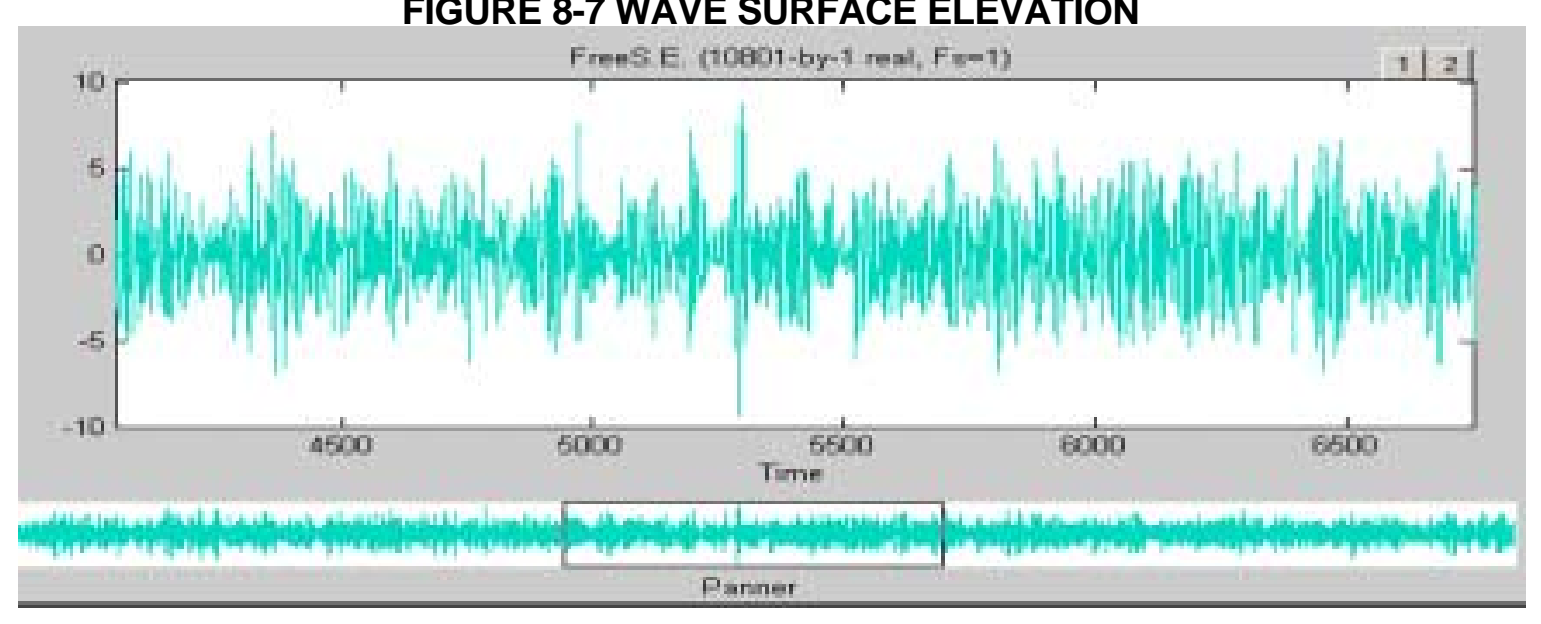

FIGURE 8-8 MOORING LINE TENSION

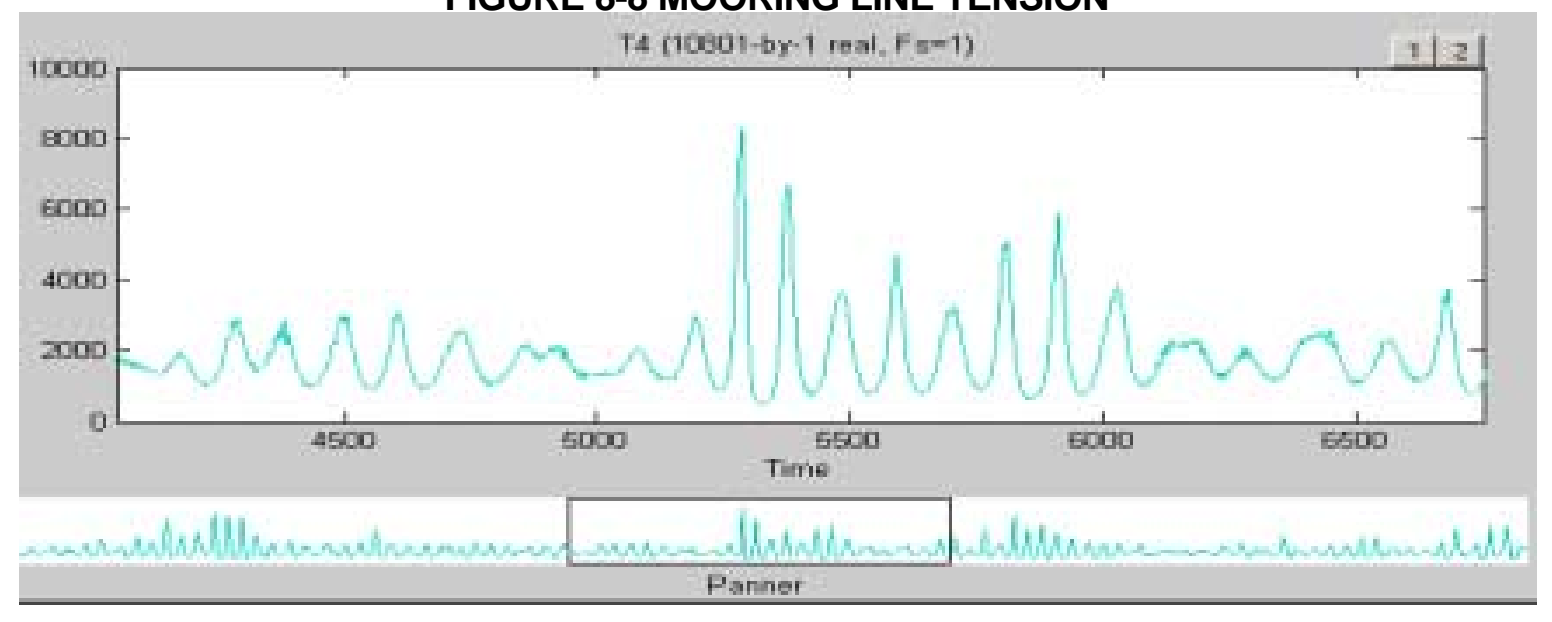

FIGURE 8-9 TURRET EXCURSION

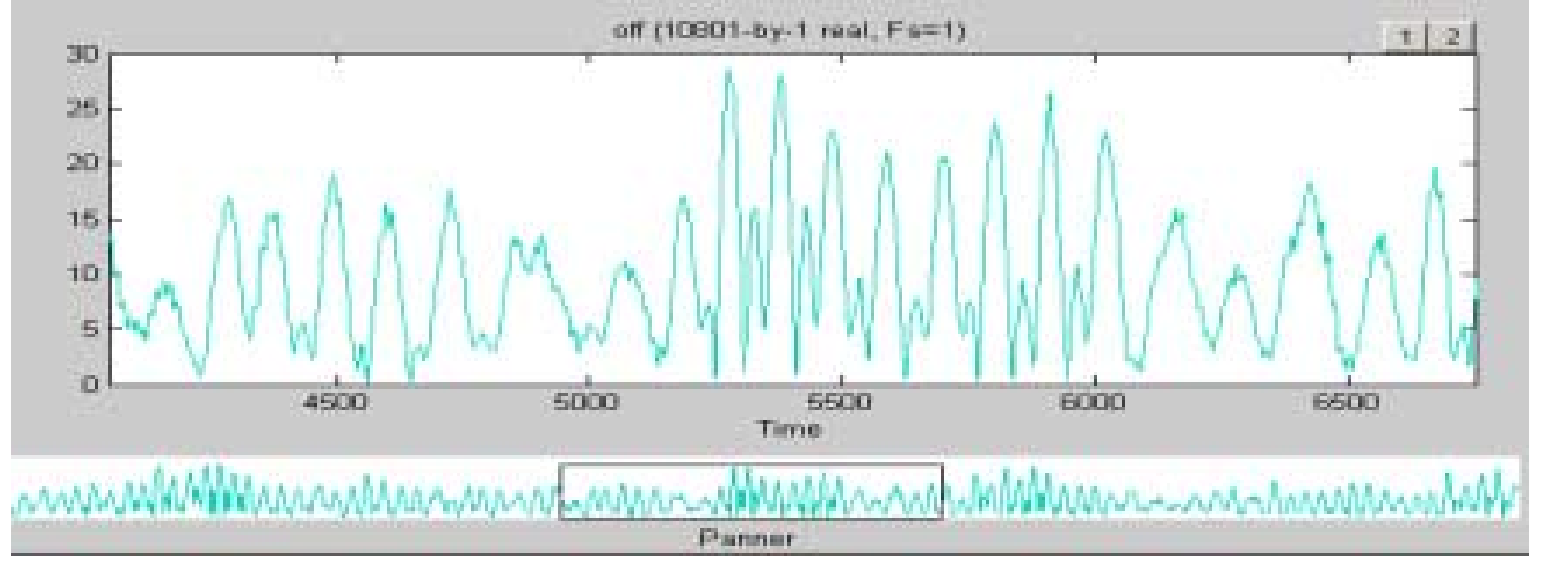




\begin{tabular}{|c|c|c|c|c|c|c|}
\hline \multirow[t]{3}{*}{ IMOOCD } & $\begin{array}{l}\text { SBM-IMODCO INC. } \\
\text { MEMBER OF THE } \\
\text { IHC/CALAND GROUP }\end{array}$ & \multirow{2}{*}{\multicolumn{5}{|c|}{$\begin{array}{c}\text { FOR SALT CAVERN } \\
\text { LNG RECEIVING AND RE-GASIFICATION }\end{array}$}} \\
\hline & Now in our 5th Decade & & & & & \\
\hline & & 51059 & CCM97001 & C1 & PAGE & 83 \\
\hline
\end{tabular}

The following table documents the design mooring line tensions and anchor loads.

TABLE 8-2 MOORING LINE TENSIONS

\begin{tabular}{|c|c|c|}
\hline Condition & Intact & Damaged \\
\hline Max Tension at Anchor [kN] & 9645 & 12750 \\
\hline Max Tension at Fairlead [kN] & 10402 & 13300 \\
\hline Safety Factor & 1.71 & 1.34 \\
\hline API Requirement & 1.67 & 1.25 \\
\hline
\end{tabular}

The mooring line configurations in the intact and damaged conditions are presented in the following two plots:

FIGURE 8-10 LINE PROFILE UNDER MAXIMUM INTACT TENSION

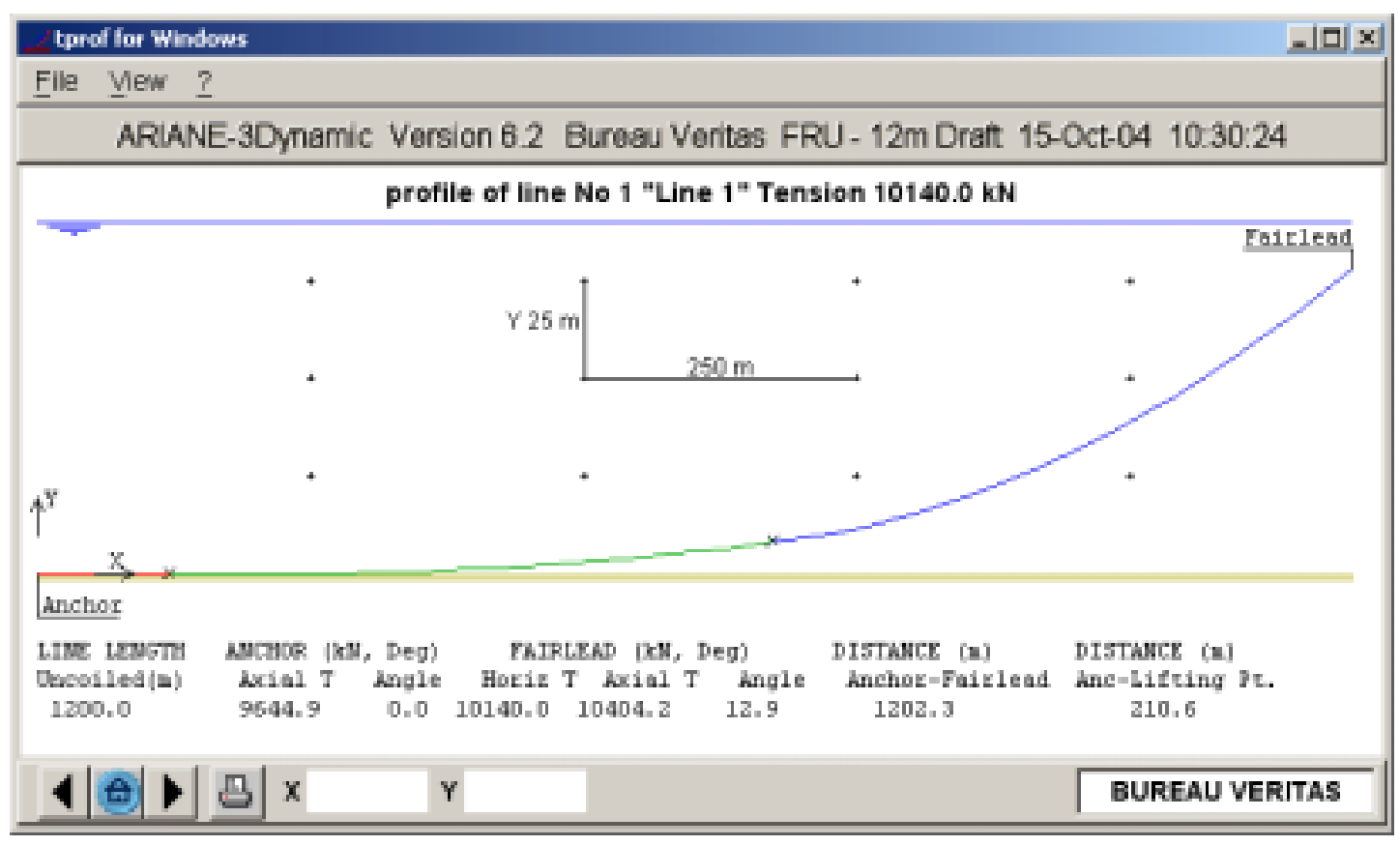




\begin{tabular}{|c|c|c|c|c|c|c|}
\hline \multirow[t]{3}{*}{ IMODCO } & \multirow[t]{3}{*}{$\begin{array}{l}\text { SBM-IMODCO INC. } \\
\text { MEMBER OF THE } \\
\text { IHC/CALAND GROUP } \\
\text { Now in our 5th Decade }\end{array}$} & \multirow{2}{*}{\multicolumn{5}{|c|}{$\begin{array}{l}\text { FLOATING RE-GASIFICATION UNIT } \\
\text { FOR SALT CAVERN } \\
\text { LNG RECEIVING AND RE-GASIFICATION }\end{array}$}} \\
\hline & & & & & & \\
\hline & & 51059 & CCM97001 & C1 & PAGE & 84 \\
\hline
\end{tabular}

FIGURE 8-11 LINE PROFILE UNDER MAXIMUM DAMAGED TENSION

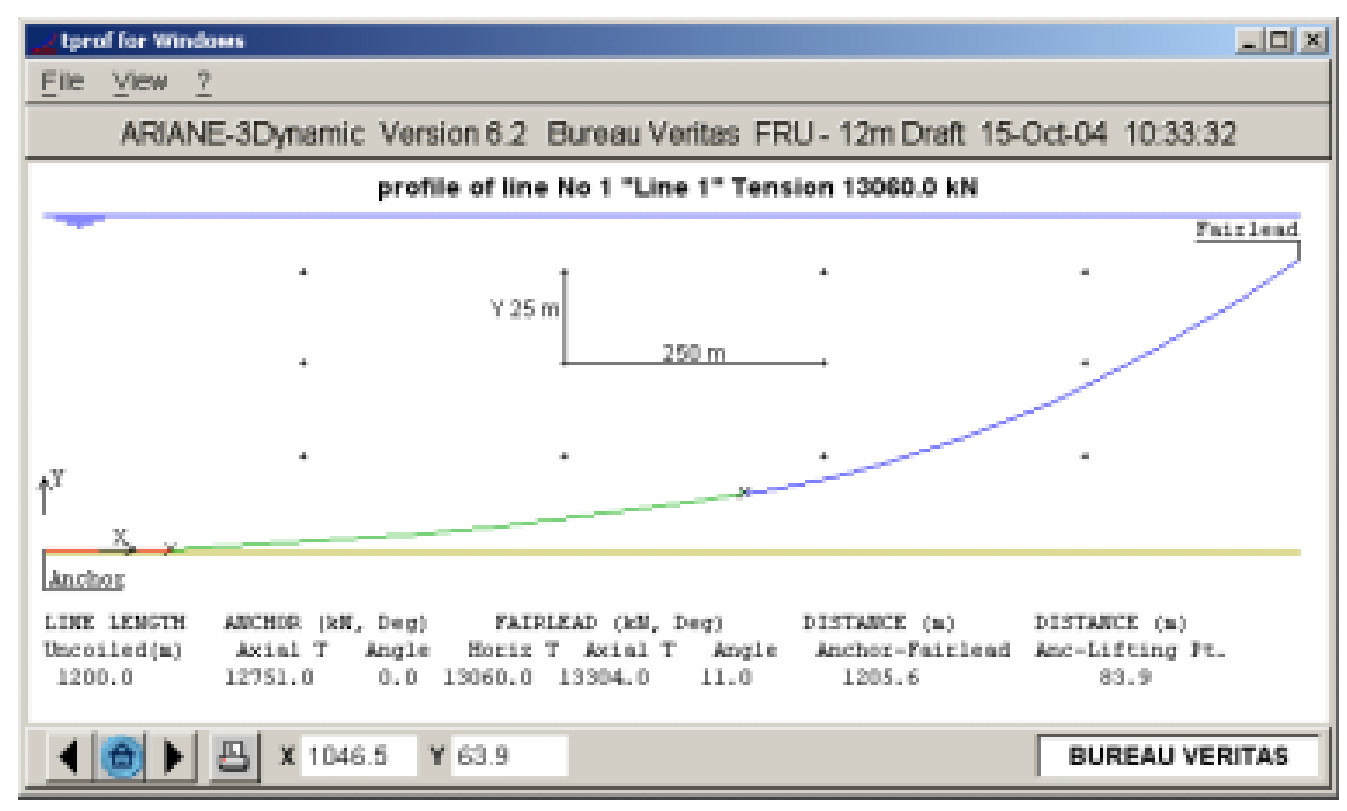

The extreme turret offsets in the mooring intact and one line damaged conditions are presented in the following table.

\section{TABLE 8-3 TURRET OFFSET}

\begin{tabular}{|c|c|c|}
\hline Condition & Intact & Damaged \\
\hline Max Offset $(\mathrm{m})$ & 30.3 & 35.0 \\
\hline$\%$ of Water Depth & $33.7 \%$ & $38.9 \%$ \\
\hline
\end{tabular}

\subsection{CHAIN FATIGUE}

In the present study, the mooring line fatigue analysis was simplistically addressed using a consolidated fatigue seastates and based on the following assumptions:

- The wave scatter diagram is omni-directional;

- All the environment (wind, waves and current) come from the most critical direction with reference to the mooring legs;

- The mooring line fatigue can be computed by Miner's linear accumulative rule. 


\begin{tabular}{|c|c|c|c|c|c|c|}
\hline \multirow[t]{3}{*}{ IMODE0 } & $\begin{array}{l}\text { SBM-IMODCO INC. } \\
\text { MEMBER OF THE } \\
\text { IHCICALAND GROUP }\end{array}$ & \multirow{2}{*}{\multicolumn{5}{|c|}{$\begin{array}{l}\text { FLOATING RE-GASIFICATION UNIT } \\
\text { FOR SALT CAVERN } \\
\text { LNG RECEIVING AND RE-GASIFICATION }\end{array}$}} \\
\hline & \multirow[t]{2}{*}{ Now in our 5th Decade } & & & & & \\
\hline & & 51059 & CCM97001 & C1 & PAGE & 85 \\
\hline
\end{tabular}

The fatigue seastates are presented in the following table:

TABLE 8-4 FATIGUE SEASTATES

\begin{tabular}{|c|c|c|c|c|c|c|c|}
\hline $\begin{array}{c}\text { Sig. } \\
\text { Wave } \\
\text { Height } \\
(\mathrm{m})\end{array}$ & $\begin{array}{c}\text { Peak } \\
\text { period } \\
(\mathrm{sec})\end{array}$ & $\begin{array}{c}\text { Wave } \\
\text { dir. from }\end{array}$ & $\begin{array}{c}\text { Wind } \\
\text { Speed } \\
(\mathrm{m} / \mathrm{s})\end{array}$ & $\begin{array}{c}\text { Wind } \\
\text { dir. from }\end{array}$ & $\begin{array}{c}\text { Current } \\
\text { Speed } \\
(\mathrm{m} / \mathrm{s})\end{array}$ & $\begin{array}{c}\text { Curr dir. } \\
\text { from }\end{array}$ & Prob. \\
\hline 1.0 & 4.4 & $75^{\circ}$ & 4.4 & $105^{\circ}$ & 0.2 & $120^{\circ}$ & $5.01 \%$ \\
\hline 2.0 & 6.2 & $75^{\circ}$ & 7.8 & $105^{\circ}$ & 0.3 & $120^{\circ}$ & $24.59 \%$ \\
\hline 3.0 & 7.5 & $75^{\circ}$ & 11.1 & $105^{\circ}$ & 0.5 & $120^{\circ}$ & $28.36 \%$ \\
\hline 4.0 & 8.7 & $75^{\circ}$ & 14.5 & $105^{\circ}$ & 0.6 & $120^{\circ}$ & $16.36 \%$ \\
\hline 5.0 & 9.5 & $75^{\circ}$ & 17.8 & $105^{\circ}$ & 0.7 & $120^{\circ}$ & $10.76 \%$ \\
\hline 6.0 & 10.4 & $75^{\circ}$ & 21.2 & $105^{\circ}$ & 0.8 & $120^{\circ}$ & $6.04 \%$ \\
\hline 7.0 & 11.2 & $75^{\circ}$ & 24.5 & $105^{\circ}$ & 1.0 & $120^{\circ}$ & $4.39 \%$ \\
\hline 8.0 & 12.0 & $75^{\circ}$ & 27.9 & $105^{\circ}$ & 1.1 & $120^{\circ}$ & $2.16 \%$ \\
\hline 9.0 & 12.4 & $75^{\circ}$ & 31.2 & $105^{\circ}$ & 1.2 & $120^{\circ}$ & $1.24 \%$ \\
\hline 10.0 & 13.0 & $75^{\circ}$ & 34.6 & $105^{\circ}$ & 1.3 & $120^{\circ}$ & $0.84 \%$ \\
\hline 11.0 & 13.7 & $75^{\circ}$ & 37.9 & $105^{\circ}$ & 1.5 & $120^{\circ}$ & $0.22 \%$ \\
\hline 12.0 & 14.3 & $75^{\circ}$ & 41.3 & $105^{\circ}$ & 1.6 & $120^{\circ}$ & $0.04 \%$ \\
\hline
\end{tabular}

For the fatigue analysis of the consolidated seastates, a time domain simulation of mooring line tensions was used and then based on the derived tension time histories, a rainflow counting method was used to compute the short term fatigue damage in each seastate. With these results the probabilities of individual seastates were used to derive the long term fatigue damage.

The computed fatigue life of the mooring chain based on the above fatigue seastates is:

- Available Fatigue Life $=557$ Years

- Service Life (assuming SF of 8 as per DNV) $=70$ Years. 


\begin{tabular}{|c|c|c|c|c|c|c|}
\hline \multirow[t]{3}{*}{ IMODCO } & \multirow[t]{3}{*}{$\begin{array}{l}\text { SBM-IMODCO INC. } \\
\text { MEMBER OF THE } \\
\text { IHCICALAND GROUP } \\
\text { Now in our 5th Decade }\end{array}$} & \multirow{2}{*}{\multicolumn{5}{|c|}{$\begin{array}{l}\text { FLOATING RE-GASIFICATION UNIT } \\
\text { FOR SALT CAVERN } \\
\text { LNG RECEIVING AND RE-GASIFICATION }\end{array}$}} \\
\hline & & & & & & \\
\hline & & 51059 & CCM97001 & C1 & PAGE & 86 \\
\hline
\end{tabular}

The above fatigue calculation shows that the service life exceeds the design life (20 years). It should be noted that the approach adopted for fatigue calculation is very conservative and actual fatigue life should be longer. Therefore it is concluded that the mooring chain fatigue design is adequate. It is noted that the mooring line wire rope will have a fatigue life far in exess of the chain.

\subsection{ANCHOR PILE SIZING}

Based on the anchor design loads derived from the mooring analysis, the anchor pile size has been estimated based on typical GOM soil conditions.

The estimated anchor size is a 54-inch diameter $\times 1.5$-inch wall thickness $\times 125$ foot $(38 \mathrm{~m})$ long. The material is $50 \mathrm{ksi}$ yield strength steel. 


\begin{tabular}{|c|c|c|c|c|c|c|}
\hline \multirow[t]{3}{*}{ IMODCO } & \multirow[t]{3}{*}{$\begin{array}{l}\text { SBM-IMODCO INC. } \\
\text { MEMBER OF THE } \\
\text { IHC/CALAND GROUP } \\
\text { Now in our 5th Decade }\end{array}$} & \multirow{2}{*}{\multicolumn{5}{|c|}{$\begin{array}{l}\text { FLOATING RE-GASIFICATION UNIT } \\
\text { FOR SALT CAVERN } \\
\text { LNG RECEIVING AND RE-GASIFICATION }\end{array}$}} \\
\hline & & & & & & \\
\hline & & 51059 & ССМ97001 & C1 & PAGE & 87 \\
\hline
\end{tabular}

\section{SWIVELS AND RISERS}

\subsection{INTRODUCTION}

Two separate riser systems can are used: the HP risers, transporting HP (2000 psi) natural gas to the salt caverns and the LP risers, transporting LP natural gas to the pipeline to shore (1000 psi).

The maximum send-out capacity to both the salt caverns and to the pipeline to shore is $2.5 \mathrm{Bscfd}$. The maximum total combined send-out rate is 4 Bscfd.

The riser system will be designed to enable gas transfer from the salt cavern to the to shore pipeline via the FRU. In order to achieve this, gas from the salt cavern will be produced through the swivel back to the FRU. The gas will pass through the metering skid, to the swivel and to the pipeline to shore.

\subsection{RISER SIZING}

There is no standard sizing philosophy for the risers, so our standard internal guidelines have been used. These require the following criteria for sizing:

- Noise

- Sonic Velocity

- Erosional Velocity

- Pressure Drop per 100 m

Of these, erosional velocity is not considered for this operation, as there will be no solids present. Since the risers will be operating sub-sea, noise considerations are also not taken into account.

The governing case for both the HP and LP risers is when 2.5 Bscfd is being handled at the minimum allowable operating pressure of 62 barg. The resulting riser selection is:

- 2 off 16 " HP (900\#) risers

- 2 off 16" LP (600\#) risers. 


\begin{tabular}{|c|c|c|c|c|c|c|}
\hline \multirow[t]{3}{*}{ IMOOE0 } & \multirow[t]{3}{*}{$\begin{array}{l}\text { SBM-IMODCO INC. } \\
\text { MEMBER OF THE } \\
\text { IHCICALAND GROUP } \\
\text { Now in our 5th Decade }\end{array}$} & \multirow{2}{*}{\multicolumn{5}{|c|}{$\begin{array}{l}\text { FLOATING RE-GASIFICATION UNIT } \\
\text { FOR SALT CAVERN } \\
\text { LNG RECEIVING AND RE-GASIFICATION }\end{array}$}} \\
\hline & & & & & & \\
\hline & & 51059 & ССМ97001 & C1 & PAGE & 88 \\
\hline
\end{tabular}

The pressure-drop at maximum flow for the HP riser is higher than suggested by our design criteria. This higher pressure drop for the maximum flow is accepted because of the high cost involved in installing an additional riser. Installing a larger size riser has not been evaluated since 16" risers were felt to be the maximum size possible for this application. It shall be noted that the upstream LNG pumps have sufficient head to overcome the higher pressure-drop and (if required) it will be cheaper to install additional pumps than an additional riser.

\subsection{SWIVEL SIZING}

Swivel sizing is based on SBM's Corporate Engineering Standards.

Since the LNG is produced, as required, to either HP or LP pressure, separate HP and LP swivels are required.

This results in the following swivel selection:

- 3 off 18" dual flow 900\# toroidal swivels

The first swivel will be used for routing the HP gas to the salt caverns. The second swivel will be used for routing the LP gas to the production pipeline. The third swivel is a common spare.

There will be a utility swivel and an electrical swivel on top of the gas swivels.

The swivel stack is illustrated by the following plot: 


\begin{tabular}{|c|c|c|c|c|c|c|}
\hline \multirow[t]{3}{*}{ IMOOCO } & \multirow{3}{*}{$\begin{array}{l}\text { SBM-IMODCO INC. } \\
\text { MEMBER OF THE } \\
\text { IHCICALAND GROUP } \\
\text { Now in our 5th Decade }\end{array}$} & \multirow{2}{*}{\multicolumn{5}{|c|}{$\begin{array}{l}\text { FLOATING RE-GASIFICATION UNIT } \\
\text { FOR SALT CAVERN } \\
\text { LNG RECEIVING AND RE-GASIFICATION }\end{array}$}} \\
\hline & & & & & & \\
\hline & & 51059 & CCM97001 & C1 & PAGE & 89 \\
\hline
\end{tabular}

FIGURE 9-1 FRU SWIVEL STACK

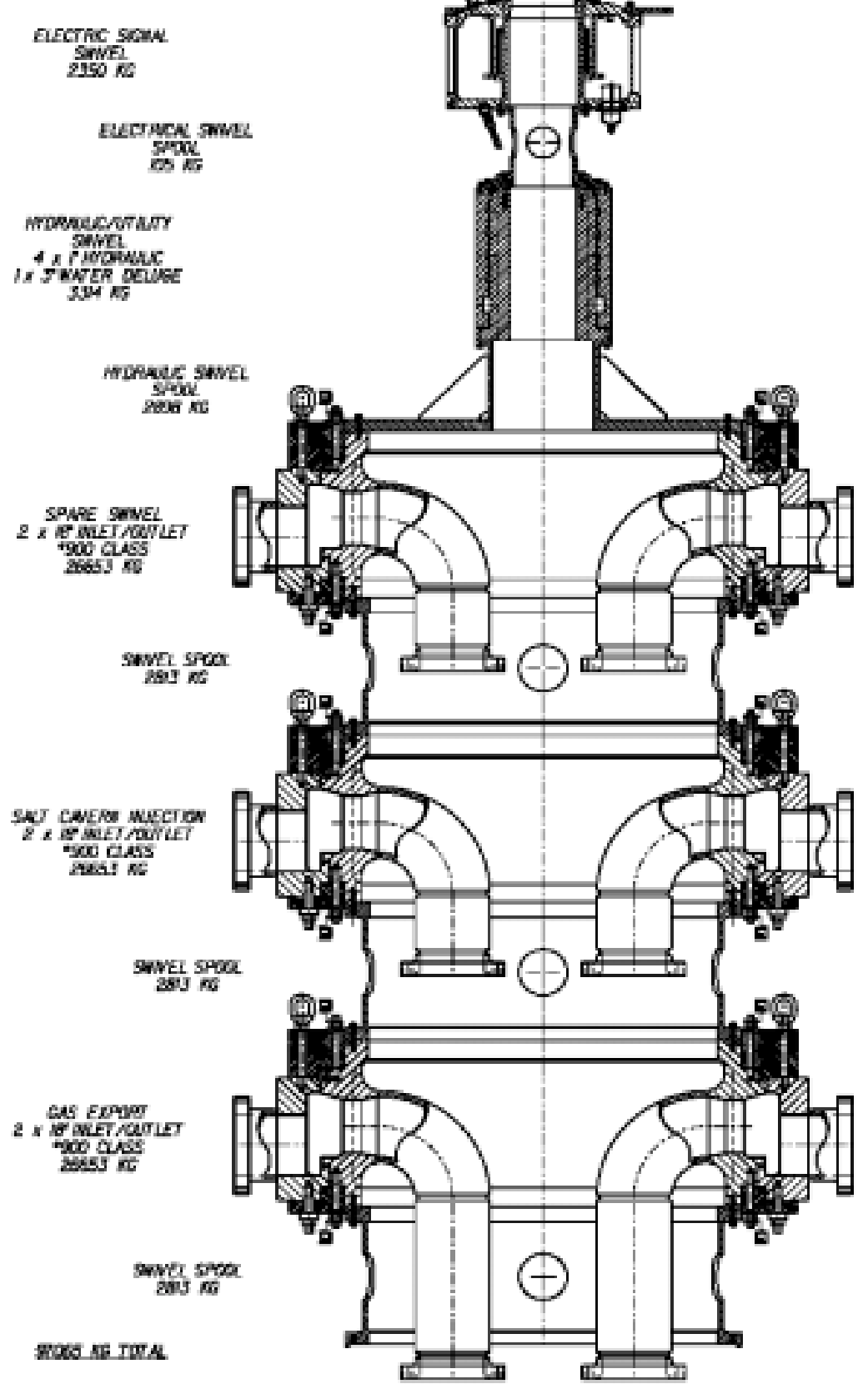




\begin{tabular}{|c|c|c|c|c|c|c|}
\hline \multirow[t]{3}{*}{ IMODCO } & \multirow[t]{3}{*}{$\begin{array}{l}\text { SBM-IMODCO INC. } \\
\text { MEMBER OF THE } \\
\text { IHC/CALAND GROUP } \\
\text { Now in our 5th Decade }\end{array}$} & \multirow{2}{*}{\multicolumn{5}{|c|}{$\begin{array}{l}\text { FLOATING RE-GASIFICATION UNIT } \\
\text { FOR SALT CAVERN } \\
\text { LNG RECEIVING AND RE-GASIFICATION }\end{array}$}} \\
\hline & & & & & & \\
\hline & & 51059 & CCM97001 & C1 & PAGE & 90 \\
\hline
\end{tabular}

\subsection{FURTHER WORK}

The sizing presented in this paragraph is preliminary. The sizing can only be finalized when more details are available on:

- Pressure drop over the Bishop exchangers

- Size and length of the new sub-sea pipelines to the salt caverns and to the pipe line to shore

In further FEED study work, the economics of more and/or larger size headers and swivels needs to be offset against additional cost for larger and/or more pumps and with a higher energy consumption. Further work must be carried out on the whole system (heat exchanger, swivel, risers and pipeline) to evaluate what pressure drop is allowable at each delivery pressures. Only then can the size of each component be finalized.

\subsection{RISER DESIGN OBJECTIVES}

The intent of this section is to describe the conceptual design of the flexible riser system, which consists of 16" gas risers for natural gas at pressures of 1000 psi and 2000 psi. The riser analysis can be summarized as follows:

- Determine the riser system configuration and confirm feasibility based on the mooring analysis outputs;

- Provide end loads from the static and dynamic analysis;

- Provide input to the design of the riser connections on the turret.

\subsection{RISER PROPERTIES}

The turret and mooring system shall be designed for the following risers:

Type: $\quad$ Flexible Pipe

Sizes: $\quad 4 \times 16$ " Natural Gas

End Terminations: $\quad$ Flange connections at both ends

Configuration: $\quad$ Steep Wave

The properties of natural gas in the riser are: 


\begin{tabular}{|c|c|c|c|c|c|c|}
\hline \multirow[t]{3}{*}{ IMODCO } & \multirow{3}{*}{$\begin{array}{l}\text { SBM-IMODCO INC. } \\
\text { MEMBER OF THE } \\
\text { IHC/CALAND GROUP } \\
\text { Now in our 5th Decade }\end{array}$} & \multirow{2}{*}{\multicolumn{5}{|c|}{$\begin{array}{l}\text { FLOATING RE-GASIFICATION UNIT } \\
\text { FOR SALT CAVERN } \\
\text {-NG RECEIVING AND RE-GASIFICATION }\end{array}$}} \\
\hline & & & & & & \\
\hline & & 51059 & CCM97001 & C1 & $P A G E$ & 91 \\
\hline
\end{tabular}

1. Pressure: $6894.76 \mathrm{kpa}(1,000 \mathrm{psi})$, density: $66.46 \mathrm{~kg} / \mathrm{m}^{3}(\min$.)

2. Pressure: $13789.52 \mathrm{kpa}(2,000 \mathrm{psi})$, density: $147.63 \mathrm{~kg} / \mathrm{m}^{3}$ (max.)

Riser design is based on natural gas in both states described above.

The following table summarizes the riser properties considered for the analysis. All information was taken from flexible pipe data sheets received from WELLSTREAM.

TABLE 9-2 RISER MECHANICAL PROPERTIES

\begin{tabular}{|l|c|c|}
\hline & & 16" Natural Gas \\
\hline Pipe O.D. & $\mathrm{mm}$ & 492.47 \\
\hline Pipe I.D. & $\mathrm{mm}$ & 406.40 \\
\hline Weight in air empty & $\mathrm{kg} / \mathrm{m}$ & 221.44 \\
\hline Failure Tension & $\mathrm{kN}$ & 6030 \\
\hline Axial Stiffness & $\mathrm{MN}$ & 674.896 \\
\hline Bending Stiffness & $\mathrm{kN}-\mathrm{m} 2$ & 95.61 \\
\hline Operating Bend Radius & $\mathrm{m}$ & 4.97 \\
\hline
\end{tabular}

Standard riser drag and inertia hydrodynamic coefficients and friction coefficients between risers and the seabed were used in the dynamic riser analysis. 


\begin{tabular}{|c|c|c|c|c|c|c|}
\hline \multirow[t]{3}{*}{ IMODCO } & \multirow[t]{3}{*}{$\begin{array}{l}\text { SBM-IMODCO INC. } \\
\text { MEMBER OF THE } \\
\text { IHC/CALAND GROUP } \\
\text { Now in our } 5 \text { th Decade }\end{array}$} & \multirow{2}{*}{\multicolumn{5}{|c|}{$\begin{array}{l}\text { FLOATING RE-GASIFICATION UNIT } \\
\text { FOR SALT CAVERN } \\
\text { LNG RECEIVING AND RE-GASIFICATION }\end{array}$}} \\
\hline & & & & & & \\
\hline & & 51059 & CCM97001 & C1 & PAGE & 92 \\
\hline
\end{tabular}

Wellstream Proprietary

\begin{tabular}{c} 
SBMIMODCO \\
DYNAMIC $406.4 \mathrm{~mm} 15.14 \mathrm{MPa} 90 \mathrm{~m}$ \\
Customer Pipe Data Sheet: A000-41-A00-040405-THL Rev 0 \\
\hline
\end{tabular}

Prepared by: Checked by: Approved by:

Inside Diameter Outside Diameter Water Depth Fluid Temperature

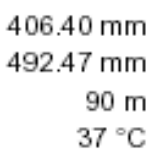

16.00 in Conveyed Fluid

19.388 in Burst/Design Ratio $295.3 \mathrm{ft}$ Collapse/Design Ratio $98.6^{\circ} \mathrm{F}$ gas

2.56

3.21

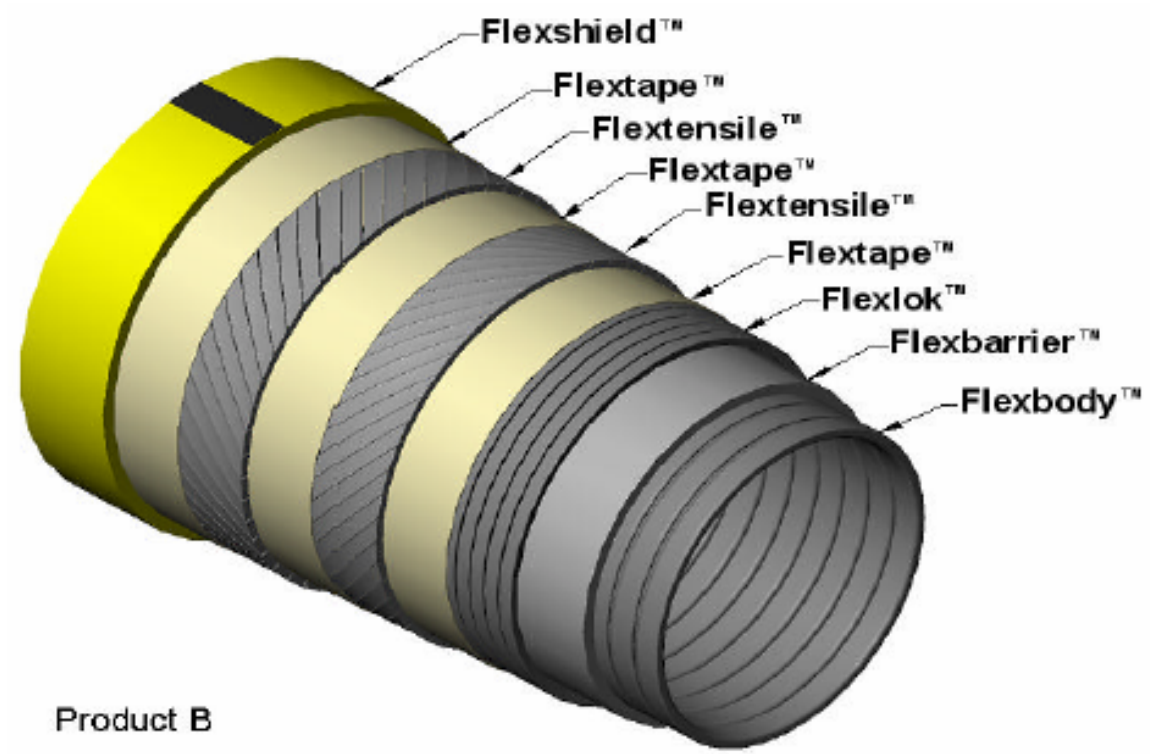

Design Pressure

Factory Test Pressure

Burst Pressure

Collapse Pressure

Collapse Depth

Failure Tension

Storage Bend Radius

Operating Bend Radius

Bending Stiffness

Weight Empty in Air

Buoyancy in seawater

Wt, Seawater in bore

Wt, S/W-filled in Annuals

Thermal Cond./Unit Length

OHTC, Uo \{based on ID\}

Pipe torsional stiffness (GJ) at $20^{\circ} \mathrm{C}$ :

Limp direction

Stiff direction

Axial Stiffness
$15.14 \mathrm{MPa}$

$22.71 \mathrm{MPa}$

$38.74 \mathrm{MPa}$

$2.91 \mathrm{MPa}$

$289 \mathrm{~m}$

$6030 \mathrm{kN}$

$3.31 \mathrm{~m}$

$4.97 \mathrm{~m}$

$95.61 \mathrm{kNm}^{2}$

$221.44 \mathrm{~kg} / \mathrm{m}$

$195.31 \mathrm{~kg} / \mathrm{m}$

$138.86 \mathrm{~kg} / \mathrm{m}$

$3.01 \mathrm{~kg} / \mathrm{m}$

$14.35 \mathrm{w} / \mathrm{m}^{\circ} \mathrm{C}$

$11.2 \mathrm{w} / \mathrm{m}^{2 \circ} \mathrm{C}$

$6626 \mathrm{kNm}^{2}$

$13998 \mathrm{kNm}^{2}$

$674896 \mathrm{kN}$
2196 psi

3294 psi

5619 psi

422 psi

$948 \mathrm{ft}$

$1355520 \mathrm{lbf}$

$10.87 \mathrm{ft}$

$16.3 \mathrm{ft}$

$231354 \mathrm{lbf} \mathrm{ft}^{2}$

$148.8 \mathrm{lb} / \mathrm{ft}$

$131.2 \mathrm{lb} / \mathrm{ft}$

$93.3 \mathrm{lb} / \mathrm{ft}$

$2 \mathrm{lb} / \mathrm{ft}$

$8.29 \mathrm{BTU}_{\mathrm{hrft}}{ }^{\circ} \mathrm{F}$ $1.98 \mathrm{BTU} / \mathrm{hrtt}^{20} \mathrm{~F}$

$16035 \mathrm{Kip} \mathrm{ft}^{2}$ $33873 \mathrm{Kip} \mathrm{ft}^{2}$ 151723 Kip 


\begin{tabular}{|c|c|c|c|c|c|c|}
\hline \multirow[t]{3}{*}{ IMODCO } & \multirow[t]{3}{*}{$\begin{array}{l}\text { SBM-IMODCO INC. } \\
\text { MEMBER OF THE } \\
\text { IHC/CALAND GROUP } \\
\text { Now in our 5th Decade }\end{array}$} & \multirow{2}{*}{\multicolumn{5}{|c|}{$\begin{array}{l}\text { FLOATING RE-GASIFICATION UNIT } \\
\text { FOR SALT CAVERN } \\
\text { LNG RECEIVING AND RE-GASIFICATION }\end{array}$}} \\
\hline & & & & & & \\
\hline & & 51059 & ССМ97001 & C1 & PAGE & 93 \\
\hline
\end{tabular}

\subsection{ACCEPTANCE CRITERIA AND INSTALLATION TOLERANCES}

The flexible riser system shall be designed such that there is sufficient clearance with the adjacent mooring lines and the FRU hull.

The following clearance acceptance criteria are to be maintained:

- Riser contact with mooring lines: Not acceptable

- Riser contact with FRU: Not acceptable

- Riser contact with seabed: Acceptable within riser design limitation and only under 100 -year extreme environmental condition.

An installation tolerance of $+/-2.5$ meters for the PLEM was assumed.

\subsection{EXTREME FRU EXCURSIONS}

Maximum vessel excursions that need to be sustained by the riser system have been obtained from the mooring analysis. Most probable maximum excursion based on 50 wave realizations was computed. Horizontal excursions are measured from the turret neutral position. They correspond to the maximum dynamic excursions and they do not include the installation tolerance. Each case is used as a "mean" position around which the riser dynamic response to wave induced vessel motion is computed.

\subsection{RISER SYSTEM DESCRIPTION}

The riser conceptual design was performed using dynamic analysis software. Details on analysis methodology are described below. The steep wave configuration is achieved by means of distributed buoyancy modules. It was analyzed and is presented in the following paragraphs.

The riser connects from a sub-sea PLEM to the bottom of the FRU turret. The termination at the FRU end is by means of a RTJ flange. A steep wave riser configuration with distributed buoyancy modules and clumped weights has been chosen:

- Total Riser Length is $173 \mathrm{~m}$, having a horizontal offset from turret attachment of $100 \mathrm{~m}$ at the equilibrium condition. Riser angle from vertical at FPU and PLEM ends are 6.6 and 29.0 degrees respectively. 


\begin{tabular}{|c|c|c|c|c|c|c|}
\hline \multirow[t]{3}{*}{ ImogCo } & $\begin{array}{l}\text { SBM-IMODCO INC. } \\
\text { MEMBER OF THE } \\
\text { IHC/CALAND GROUP } \\
\end{array}$ & \multirow{2}{*}{\multicolumn{5}{|c|}{$\begin{array}{l}\text { FLOATING RE-GASIFICATION UNIT } \\
\text { FOR SALT CAVERN } \\
\text { LNG RECEIVING AND RE-GASIFICATION }\end{array}$}} \\
\hline & \multirow[t]{2}{*}{ Now in our 5th Decade } & & & & & \\
\hline & & 51059 & CCM97001 & C1 & PAGE & 94 \\
\hline
\end{tabular}

FIGURE 9-2 RISER NOMINAL CONFIGURATION

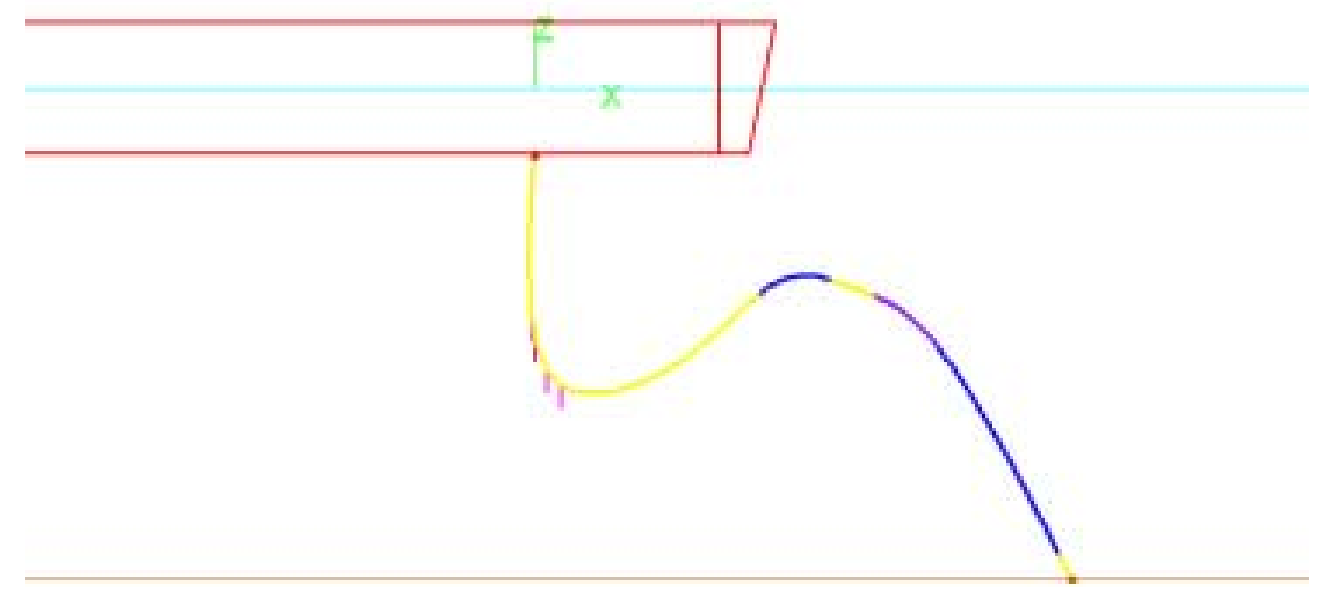

\subsection{RISER ANALYSIS METHODOLOGY}

\subsubsection{General}

This section outlines the methodology used for the riser analysis. The analysis undertaken by SBMI focuses on MBR, maximum and minimum effective tension (riser compression) and riser seabed clearance, since these factors are drivers for the selection of the riser configuration.

\subsubsection{Software Tool}

The riser static and dynamic analysis is performed using the non-linear finite element software "Orcaflex" [Ref.9]

Orcaflex is a marine dynamics program developed by Orcina for static and dynamic analysis of flexible pipeline and cable systems in an offshore / marine environment. Orcaflex is widely used in the offshore industry for analysis of flexible risers from offshore production platforms and tanker-loading buoys, cable lay, installation of subsea equipment, oceanographic moorings, pull-in analysis, etc.

The program provides fast and accurate analysis of catenary systems such as flexible risers and umbilical cables under wave and current loads and externally imposed motions. 


\begin{tabular}{|c|c|c|c|c|c|c|}
\hline \multirow[t]{3}{*}{ IMODCO } & \multirow[t]{3}{*}{$\begin{array}{l}\text { SBM-IMODCO INC. } \\
\text { MEMBER OF THE } \\
\text { IHCICALAND GROUP } \\
\text { Now in our 5th Decade }\end{array}$} & \multirow{2}{*}{\multicolumn{5}{|c|}{$\begin{array}{l}\text { FLOATING RE-GASIFICATION UNIT } \\
\text { FOR SALT CAVERN } \\
\text { LNG RECEIVING AND RE-GASIFICATION }\end{array}$}} \\
\hline & & & & & & \\
\hline & & 51059 & CCM97001 & C1 & PAGE & 95 \\
\hline
\end{tabular}

\subsubsection{Boundary Conditions}

Bend stiffeners are to be incorporated at the FRU and at the PLEM ends of each riser and are to be designed to protect the riser against excessive bending at the attachment locations.

At this stage of the analysis, riser connections are modeled as articulations, i.e. no bending stiffeners have been modeled.

\subsection{RISER ANALYSIS RESULTS}

The first analysis stage is the static analysis. Riser statics was studied for nominal (initial) vessel position, near and far vessel excursion, for both intact and damaged loading case, and for transverse direction (waves and current perpendicular to the riser plane), for intact and damaged loading case. Maximum vessel offset for intact and damaged condition is applied; with the addition of the installation tolerance of $2.5 \mathrm{~m}$. Riser is modeled without marine growth at this stage of the analysis.

The next stage is the dynamic analysis, which was performed for intact and damaged loading case, for maximum vessel offset (including $2.5 \mathrm{~m}$ installation tolerance) applied in near and far direction and for the transverse direction.

\begin{tabular}{|c|c|c|c|c|c|c|c|}
\hline \multicolumn{8}{|c|}{ TABLE 9-4 IN-PLANE RISER ANALYSIS } \\
\hline \multirow[b]{2}{*}{$\begin{array}{l}\text { Load } \\
\text { Case }\end{array}$} & \multirow[b]{2}{*}{$\begin{array}{l}\text { Hangoff } \\
\text { position }\end{array}$} & \multirow{2}{*}{$\begin{array}{c}\text { Content } \\
\text { Pressur } \\
\mathrm{e}[\mathrm{kPa}]\end{array}$} & \multicolumn{3}{|c|}{ Tension [kN] } & \multicolumn{2}{|c|}{ Curvature [rad/m] } \\
\hline & & & Min & Max & $\begin{array}{c}\text { Allowabl } \\
\mathrm{e}\end{array}$ & Max & $\begin{array}{c}\text { Allowabl } \\
\mathrm{e}\end{array}$ \\
\hline \multicolumn{8}{|c|}{ STATIC - INLINE } \\
\hline & \multirow{2}{*}{ Nominal } & 6895 & 8 & 58 & 6030 & 0.13 & 0.2012 \\
\hline & & 13789 & 8 & 67 & 6030 & 0.103 & 0.2012 \\
\hline \multirow{4}{*}{ Intact } & \multirow{2}{*}{ Far } & 6895 & 27 & 67 & 6030 & 0.067 & 0.2012 \\
\hline & & 13789 & 29 & 77 & 6030 & 0.06 & 0.2012 \\
\hline & \multirow{2}{*}{ Near } & 6895 & 4 & 58 & 6030 & 0.125 & 0.2012 \\
\hline & & 13789 & 3 & 67 & 6030 & 0.15 & 0.2012 \\
\hline \multirow{4}{*}{$\begin{array}{c}\text { Damage } \\
\mathrm{d}\end{array}$} & \multirow{2}{*}{ Far } & 6895 & 33 & 70 & 6030 & 0.058 & 0.2417 \\
\hline & & 13789 & 35 & 81 & 6030 & 0.053 & 0.2417 \\
\hline & \multirow{2}{*}{ Near } & 6895 & 3 & 57 & 6030 & 0.13 & 0.2417 \\
\hline & & 13789 & 3 & 67 & 6030 & 0.16 & 0.2417 \\
\hline \multicolumn{8}{|c|}{ DYNAMIC - INLINE } \\
\hline \multirow[t]{3}{*}{ Intact } & \multirow{2}{*}{ Far } & 6895 & 2 & 192 & 6030 & 0.145 & 0.2012 \\
\hline & & 13789 & 1 & 245 & 6030 & 0.135 & 0.2012 \\
\hline & Near & 6895 & -2 & 94 & 6030 & 0.19 & 0.2012 \\
\hline
\end{tabular}




\begin{tabular}{|c|c|c|c|c|c|c|}
\hline \multirow[t]{3}{*}{ IMOOCD } & $\begin{array}{l}\text { SBM-IMODCO INC. } \\
\text { MEMBER OF THE } \\
\text { IHC/CALAND GROUP }\end{array}$ & \multirow{2}{*}{\multicolumn{5}{|c|}{$\begin{array}{c}\text { FOR SALT CAVERN } \\
\text { LNG RECEIVING AND RE-GASIFICATION }\end{array}$}} \\
\hline & Now in our 5th Decade & & & & & \\
\hline & & 51059 & CCM97001 & C1 & PAGE & 96 \\
\hline
\end{tabular}

\begin{tabular}{|c|c|c|c|c|c|c|c|}
\hline \multicolumn{8}{|c|}{ TABLE 9-4 IN-PLANE RISER ANALYSIS } \\
\hline \multirow{2}{*}{$\begin{array}{l}\text { Load } \\
\text { Case }\end{array}$} & \multirow{2}{*}{$\begin{array}{l}\text { Hangoff } \\
\text { position }\end{array}$} & \multirow{2}{*}{$\begin{array}{l}\text { Content } \\
\text { Pressur } \\
\mathrm{e}[\mathrm{kPa}]\end{array}$} & \multicolumn{3}{|c|}{ Tension [kN] } & \multicolumn{2}{|c|}{ Curvature [rad/m] } \\
\hline & & & Min & Max & $\begin{array}{c}\text { Allowabl } \\
e\end{array}$ & Max & $\begin{array}{c}\text { Allowabl } \\
\mathrm{e}\end{array}$ \\
\hline \multicolumn{8}{|c|}{ STATIC - INLINE } \\
\hline & & 13789 & -1 & 106 & 6030 & 0.2 & 0.2012 \\
\hline \multirow{4}{*}{$\begin{array}{c}\text { Damage } \\
\mathrm{d}\end{array}$} & \multirow{2}{*}{ Far } & 6895 & 2 & 239 & 6030 & 0.135 & 0.2417 \\
\hline & & 13789 & 0 & 306 & 6030 & 0.13 & 0.2417 \\
\hline & \multirow{2}{*}{ Near } & 6895 & -4 & 94 & 6030 & 0.2 & 0.2417 \\
\hline & & 13789 & -2 & 106 & 6030 & 0.22 & 0.2417 \\
\hline
\end{tabular}

Minimum and maximum effective tension and maximum riser curvature for the transverse condition are listed in the following table:

TABLE 9-5 RISER STATIC ANALYSIS, TRANSVERSE DIRECTION

\begin{tabular}{|c|c|c|c|c|c|c|c|}
\hline \multirow{2}{*}{$\begin{array}{l}\text { Load } \\
\text { Case }\end{array}$} & \multirow{2}{*}{$\begin{array}{l}\text { Hangoff } \\
\text { position }\end{array}$} & \multirow{2}{*}{$\begin{array}{l}\text { Content } \\
\text { Pressur } \\
\mathrm{e}[\mathrm{kPa}]\end{array}$} & \multicolumn{3}{|c|}{ Tension [kN] } & \multicolumn{2}{|c|}{ Curvature [rad/m] } \\
\hline & & & Min & Max & $\begin{array}{c}\text { Allowabl } \\
\mathrm{e}\end{array}$ & Max & $\begin{array}{c}\text { Allowabl } \\
\mathrm{e}\end{array}$ \\
\hline \multicolumn{8}{|c|}{ STATIC - CROSS } \\
\hline \multirow{2}{*}{ Intact } & Trans & 6895 & 17 & 62 & 6030 & 0.082 & 0.2012 \\
\hline & Trans & 13789 & 16 & 69 & 6030 & 0.072 & 0.2012 \\
\hline \multirow{2}{*}{$\begin{array}{c}\text { Damage } \\
\text { d }\end{array}$} & Trans & 6895 & 18 & 62 & 6030 & 0.081 & 0.2417 \\
\hline & Trans & 13789 & 17 & 70 & 6030 & 0.072 & 0.2417 \\
\hline \multicolumn{8}{|c|}{ DYNAMIC - CROSS } \\
\hline \multirow{2}{*}{ Intact } & Trans & 6895 & 3 & 113 & 6030 & 0.102 & 0.2012 \\
\hline & Trans & 13789 & 4 & 125 & 6030 & 0.102 & 0.2012 \\
\hline \multirow{2}{*}{$\begin{array}{c}\text { Damage } \\
d\end{array}$} & Trans & 6895 & 4 & 115 & 6030 & 0.102 & 0.2417 \\
\hline & Trans & 13789 & 4 & 126 & 6030 & 0.101 & 0.2417 \\
\hline
\end{tabular}




\begin{tabular}{|c|c|c|c|c|c|c|}
\hline \multirow[t]{3}{*}{ IMOOCO } & \multirow{3}{*}{$\begin{array}{l}\text { SBM-IMODCO INC. } \\
\text { MEMBER OF THE } \\
\text { IHC/CALAND GROUP } \\
\text { Now in our 5th Decade }\end{array}$} & \multirow{2}{*}{\multicolumn{5}{|c|}{$\begin{array}{l}\text { FLOATING RE-GASIFICATION UNIT } \\
\text { FOR SALT CAVERN } \\
\text { LNG RECEIVING AND RE-GASIFICATION }\end{array}$}} \\
\hline & & & & & & \\
\hline & & 51059 & CCM97001 & C1 & PAGE & 97 \\
\hline
\end{tabular}

Riser effective tension and curvature are within allowable limits.

FIGURE 9-3 RISER DYNAMIC RESPONSE IN NEAR POSITION

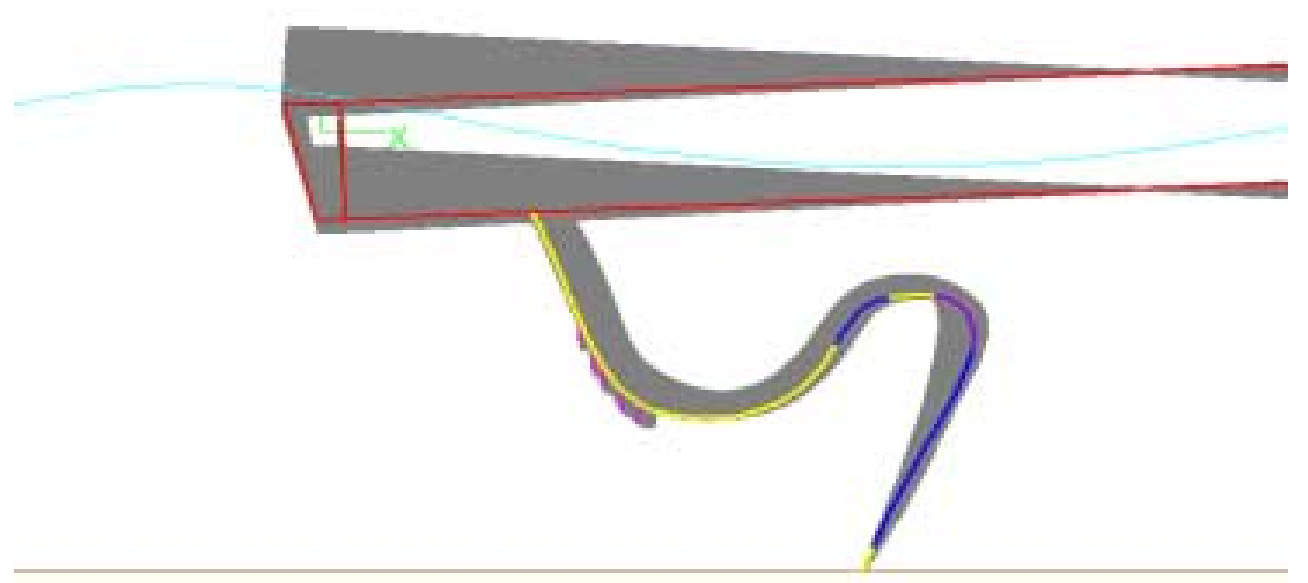

FIGURE 9-4 RISER DYNAMIC RESPONSE IN FAR POSITION

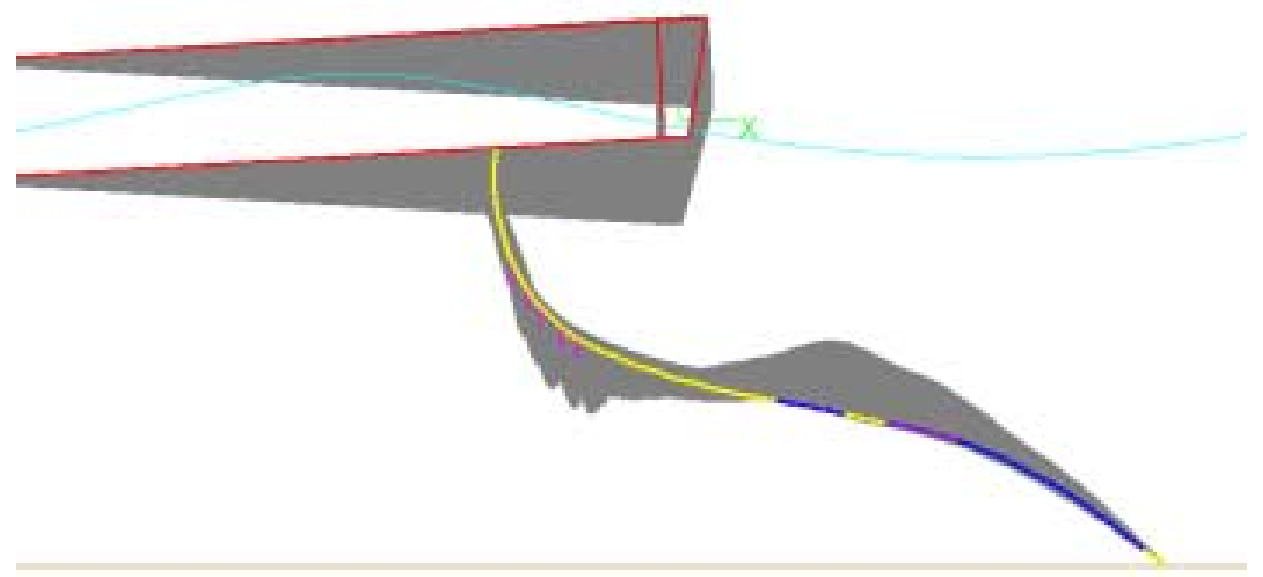




\begin{tabular}{|c|c|c|c|c|c|c|}
\hline \multirow[t]{3}{*}{ IMOOE0 } & \multirow[t]{3}{*}{$\begin{array}{l}\text { SBM-IMODCO INC. } \\
\text { MEMBER OF THE } \\
\text { IHCICALAND GROUP } \\
\text { Now in our 5th Decade }\end{array}$} & \multirow{2}{*}{\multicolumn{5}{|c|}{$\begin{array}{l}\text { FLOATING RE-GASIFICATION UNIT } \\
\text { FOR SALT CAVERN } \\
\text { LNG RECEIVING AND RE-GASIFICATION }\end{array}$}} \\
\hline & & & & & & \\
\hline & & 51059 & ССМ97001 & C1 & PAGE & 98 \\
\hline
\end{tabular}

\subsection{RISER ANALYSIS SUMMARY}

The proposed steep wave configuration meets the design requirements in terms of maximum effective tension, minimum bend radius, vessel and seabed clearance. Even with the mooring system damaged in the near position, there is adequate clearance between the lowest portion of the upper riser and the seabed. In the very far position, with the mooring system damaged, the highest axial loads are introduced into the system. There is also some minor compression observed for both risers, which could be eliminated at a detailed design stage. However, minor compression is typically acceptable. 


\begin{tabular}{|c|c|c|c|c|c|c|}
\hline \multirow[t]{3}{*}{ IMODCO } & \multirow[t]{3}{*}{$\begin{array}{l}\text { SBM-IMODCO INC. } \\
\text { MEMBER OF THE } \\
\text { IHC/CALAND GROUP } \\
\text { Now in our 5th Decade }\end{array}$} & \multirow{2}{*}{\multicolumn{5}{|c|}{$\begin{array}{l}\text { FLOATING RE-GASIFICATION UNIT } \\
\text { FOR SALT CAVERN } \\
\text { LNG RECEIVING AND RE-GASIFICATION }\end{array}$}} \\
\hline & & & & & & \\
\hline & & 51059 & ССМ97001 & C1 & PAGE & 99 \\
\hline
\end{tabular}

\section{LNG OFFLOADING}

\subsection{GENERAL}

One of the key technologies for the FRU concept is the side-by-side mooring of the terminal and the LNG Carrier. The LNG transfer can only be safely accomplished using loading arms under certain relative motion thresholds (loading arms details are presented in Appendix $F$ of this report). The vessel interconnecting mooring lines or hawsers are made up of steel wire rope with nylon a tail line. These lines and fenders between the two vessels are used to restrain the vessels and keep the relative motions between them in an envelope allowing the loading arm on the FRU to stay attached to the manifold on the LNG Carrier. At the same time, the maximum mooring line tension and fender reaction force needs to be kept below their allowable safe working limits.

This section of the report summarizes the results of the mooring and motion analysis for the FRU side by side offloading operation. The objectives of this analysis are:

- To check the system survival performance using the AQWA program;

- To determine the limiting seastates for the side by side offloading operation.

The following analysis results are documented:

- Maximum Anchor Chain Tension under the Survival Condition;

- Maximum Mooring Line Tension under the Operating Condition;

- Maximum Relative Motion, Velocity and Acceleration between LNG Loading Arm and Manifold.

- Maximum Fender Reaction under the Operating Condition;

\subsection{METOCEAN CONDITION}

The survival and operating conditions are listed below. For the operating condition, a range of wave heights and wave period are analyzed to obtain the operation envelope. 


\begin{tabular}{|c|c|c|c|c|c|c|}
\hline \multirow[t]{3}{*}{ IMOOE0 } & \multirow[t]{3}{*}{$\begin{array}{l}\text { SBM-IMODCO INC. } \\
\text { MEMBER OF THE } \\
\text { IHCICALAND GROUP } \\
\text { Now in our 5th Decade }\end{array}$} & \multirow{2}{*}{\multicolumn{5}{|c|}{$\begin{array}{l}\text { FLOATING RE-GASIFICATION UNIT } \\
\text { FOR SALT CAVERN } \\
\text { LNG RECEIVING AND RE-GASIFICATION }\end{array}$}} \\
\hline & & & & & & \\
\hline & & 51059 & ССМ97001 & C1 & PAGE & 100 \\
\hline
\end{tabular}

\section{Extreme Condition - 100-year Hurricane}

Wave Direction omni-direction

Significant Wave Height (Hs) 11.9 m

$\begin{array}{ll}\text { Peak period (Tp) } & 14.2 \mathrm{~s} \\ \text { Maximum Wave Height }(\mathrm{Hs}) & 20.9 \mathrm{~m} \\ \text { Maximum Wave Period (Tp) } & 13.1 \mathrm{~s} \\ \text { Spectrum } & \text { JONSWAP }(\gamma=2.5) \\ \text { Maximum Wind Speed (1-hr @ 10m) } & 44.1 \mathrm{~m} / \mathrm{s} \\ \text { Current } & 1.6 \mathrm{~m} / \mathrm{s}\end{array}$

\section{Operation Condition}

Wave Direction omni-direction

Significant Wave Height (Hs) 2.5 m

Peak Period (Tp)

$7.0 \mathrm{~s}$

Spectrum

JONSWAP $(\gamma=2.0)$

Associated Wind Speed

$16.0 \mathrm{~m} / \mathrm{s}$

(1 hr average, @10 m)

Wind Spectrum

API

Associated Current

$0.6 \mathrm{~m} / \mathrm{s}$

\subsection{FRU AND LNG CARRIER}

\subsubsection{FRU Model}

As stated in Section 3 of this report, a typical Suezmax tanker is selected for the conversion to the FRU. The main particulars are presented in Table 3-1. The FRU mooring leg composition is of chain and wire combination as presented in Table 8-1.

The LNG loading arm is positioned at mid-ship starboard of the FRU. Its location is defined as follows:

- Longitudinal (forward of APP)

$141.1 \mathrm{~m}$

- Transverse (starboard, from centerline)

$17.5 \mathrm{~m}$ 


\begin{tabular}{|c|c|c|c|c|c|c|}
\hline \multirow[t]{3}{*}{ IMODCO } & \multirow{3}{*}{$\begin{array}{l}\text { SBM-IMODCO INC. } \\
\text { MEMBER OF THE } \\
\text { IHCICALAND GROUP } \\
\text { Now in our } 5 \text { th Decade }\end{array}$} & \multirow{2}{*}{\multicolumn{5}{|c|}{$\begin{array}{l}\text { FLOATING RE-GASIFICATION UNIT } \\
\text { FOR SALT CAVERN } \\
\text { NG RECEIVING AND RE-GASIFICATION }\end{array}$}} \\
\hline & & & & & & \\
\hline & & 51059 & CCM97001 & C1 & PAGE & 101 \\
\hline
\end{tabular}

- Vertical (above keel)

$28.0 \mathrm{~m}$

The AQWA model of the FRU together with its mooring system is presented by the following plots. The coupled analysis of vessel and moorings has been performed.

FIGURE 10-1 AQWA MODEL OF FRU (TOP VIEW)

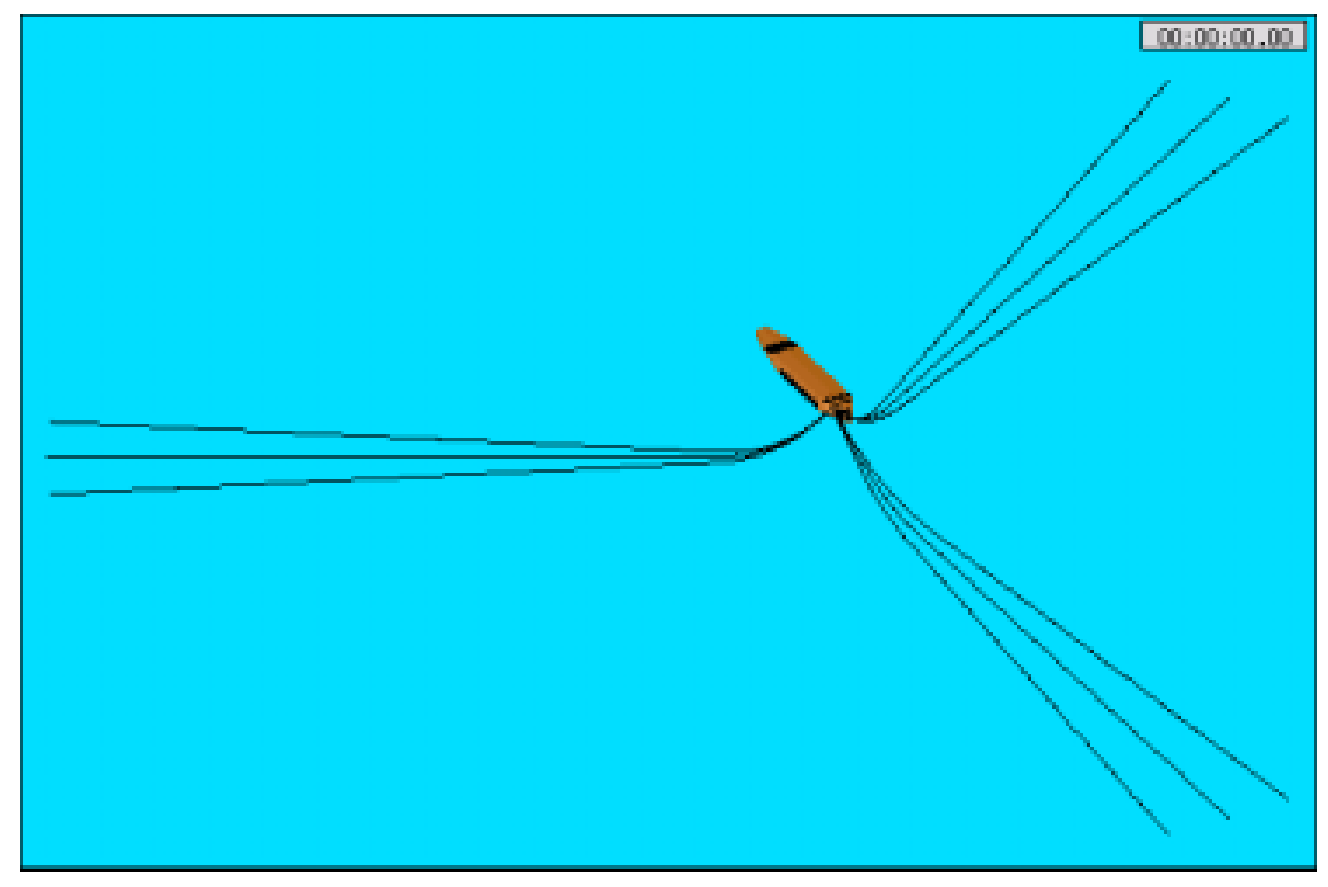




\begin{tabular}{|c|c|c|c|c|c|c|}
\hline \multirow[t]{3}{*}{ IMODCO } & \multirow{3}{*}{$\begin{array}{l}\text { SBM-IMODCO INC. } \\
\text { MEMBER OF THE } \\
\text { IHCICALAND GROUP } \\
\text { Now in our } 5 \text { th Decade }\end{array}$} & \multirow{2}{*}{\multicolumn{5}{|c|}{$\begin{array}{l}\text { FLOATING RE-GASIFICATION UNIT } \\
\text { FOR SALT CAVERN } \\
\text { NG RECEIVING AND RE-GASIFICATION }\end{array}$}} \\
\hline & & & & & & \\
\hline & & 51059 & CCM97001 & C1 & PAGE & 102 \\
\hline
\end{tabular}

FIGURE 10-2 AQWA MODEL OF FRU (NEAR VIEW)

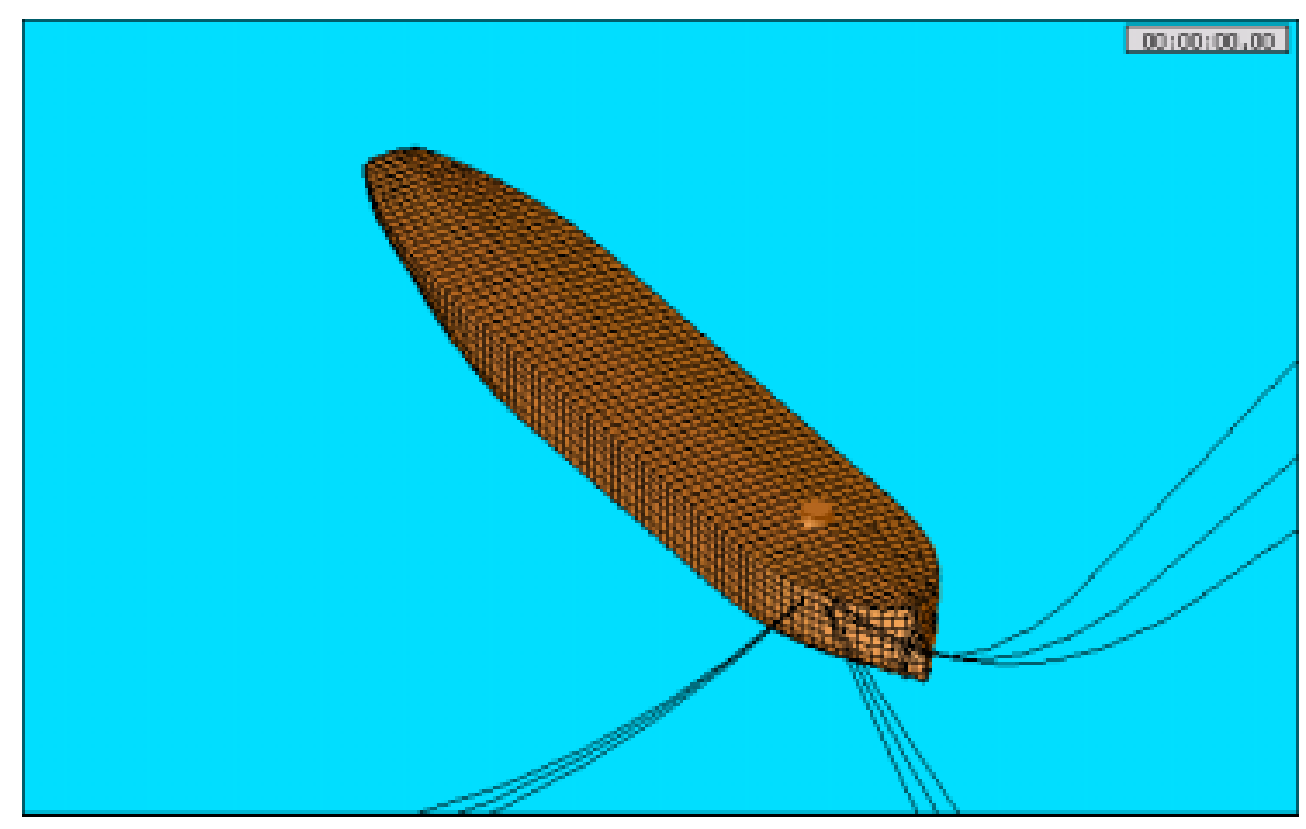

FIGURE 10-3 AQWA MODEL OF FRU (BOTTOM VIEW)

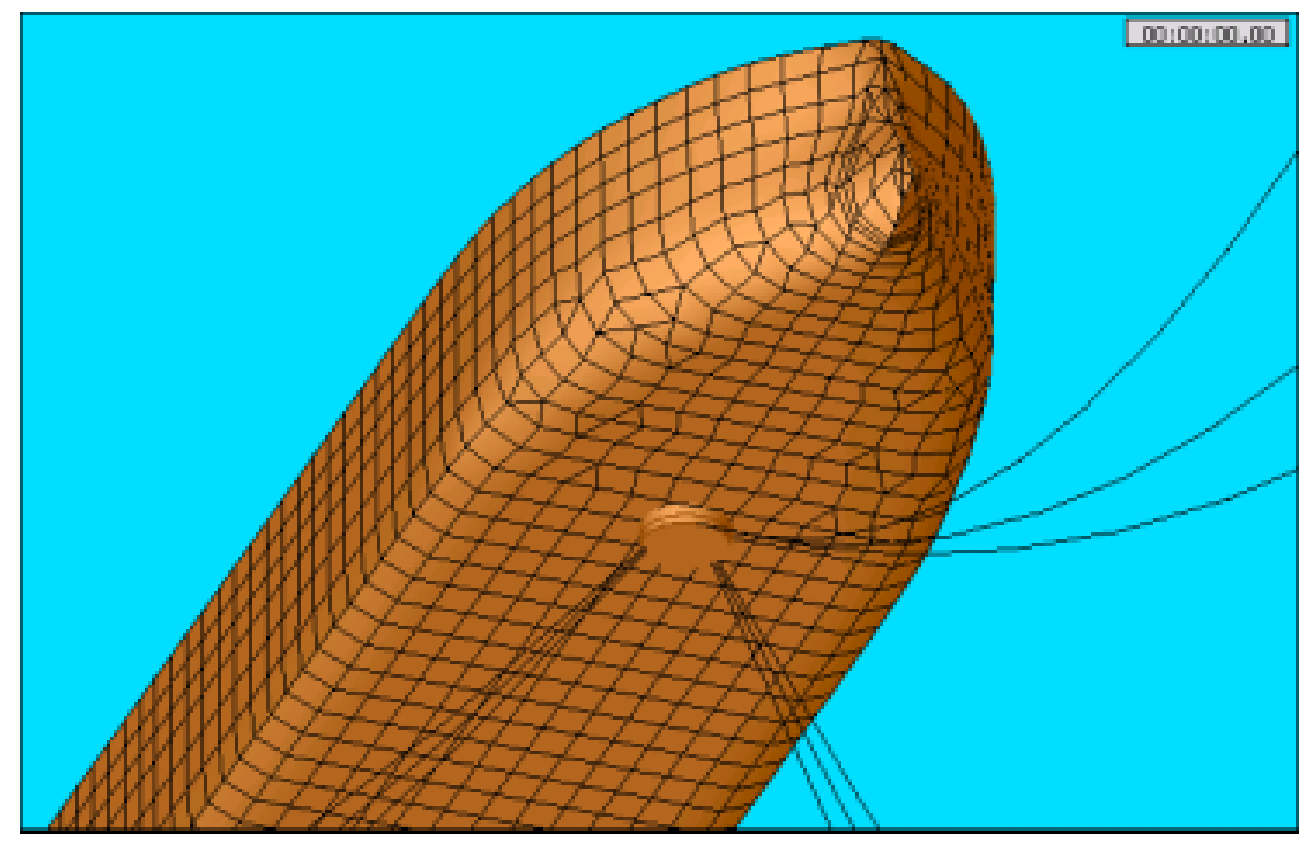




\begin{tabular}{|c|c|c|c|c|c|c|}
\hline \multirow[t]{3}{*}{ IMOOE0 } & \multirow[t]{3}{*}{$\begin{array}{l}\text { SBM-IMODCO INC. } \\
\text { MEMBER OF THE } \\
\text { IHCICALAND GROUP } \\
\text { Now in our 5th Decade }\end{array}$} & \multirow{2}{*}{\multicolumn{5}{|c|}{$\begin{array}{l}\text { FLOATING RE-GASIFICATION UNIT } \\
\text { FOR SALT CAVERN } \\
\text { LNG RECEIVING AND RE-GASIFICATION }\end{array}$}} \\
\hline & & & & & & \\
\hline & & 51059 & ССМ97001 & C1 & PAGE & 103 \\
\hline
\end{tabular}

\subsubsection{LNG Carrier Model}

A typical LNG of $138,000 \mathrm{~m}^{3}$ size is selected for this concept study. The main particulars are listed below.

\section{Main Particulars}

Length overall, LOA

Length btw perpendiculars, LBP

Breadth, B

Depth

Draught, $T$

Displacement, D

Waterplane Area, Aw

LCG (ref to APP)

KG (ref to Keel level)

Roll Radius of Gyration, Rxx

Pitch Radius of Gyration, Ryy

Yaw Radius of Gyration, Rzz

Wind Area (frontal)

Wind Area (side)

GMT
$290.0 \mathrm{~m}$

$274.0 \mathrm{~m}$

$44.2 \mathrm{~m}$

$25.0 \mathrm{~m}$

$11.0 \mathrm{~m}$

$97,641 \mathrm{~m}^{3}$

$10,130 \mathrm{~m}^{2}$

$135.4 \mathrm{~m}$

$16.3 \mathrm{~m}$

$15.1 \mathrm{~m}$

$68.5 \mathrm{~m}$

$68.5 \mathrm{~m}$

$1450 \mathrm{~m} 2$

$6065 \mathrm{~m} 2$

$4.8 \mathrm{~m}$

\section{Offloading Manifold}

Longitudinal (forward of APP) $146.4 \mathrm{~m}$

Transverse (portside, from centerline) $17.1 \mathrm{~m}$

Vertical (above keel) $27.0 \mathrm{~m}$

The AQWA model of the LNG carrier is presented in the following plot: 


\begin{tabular}{|c|c|c|c|c|c|c|}
\hline \multirow[t]{3}{*}{ IMODE0 } & $\begin{array}{l}\text { SBM-IMODCO INC. } \\
\text { MEMBER OF THE } \\
\text { IHC/CALAND GROUP } \\
\end{array}$ & \multirow{2}{*}{\multicolumn{5}{|c|}{$\begin{array}{l}\text { FLOATING RE-GASIFICATION UNIT } \\
\text { FOR SALT CAVERN } \\
\text { NG RECEIVING AND RE-GASIFICATION }\end{array}$}} \\
\hline & Now in our 5th Decade & & & & & \\
\hline & & 51059 & CCM97001 & C1 & PAGE & 104 \\
\hline
\end{tabular}

FIGURE 10-4 AQWA MODEL OF LNG CARRIER

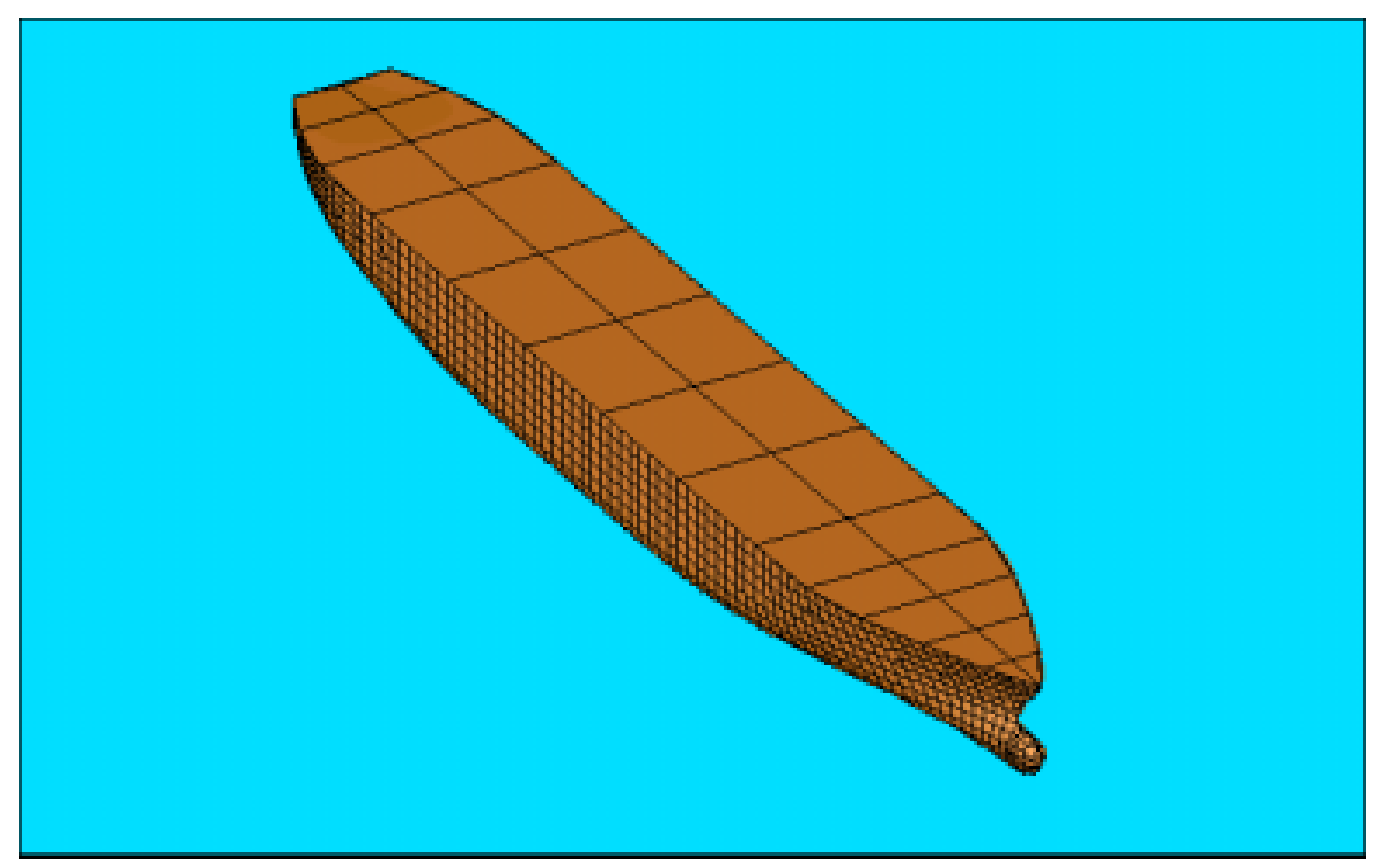

\subsection{SIDE BY SIDE MOORING LINES}

A standard sixteen (16) mooring lines arrangement is used to moor the LNG Carrier to the FRU. This line arrangement includes six (6) stern lines, four (4) spring lines and six (6) head lines.

The mooring line fairlead positions are listed below. The mooring line is made up of steel wire rope with a nylon tail line. A $20 \mathrm{~m}$ nylon tail line is used in each mooring line to achieve the desired line elasticity. A pretension of $150 \mathrm{kN}$ is adopted for each mooring line.

The properties of the steel wire rope and nylon rope are presented in the tables below. The loadextension curve of the mooring line is presented in Figure 10-6 below. Note that the steel wire rope is much stiffer than the nylon rope. Hence the elasticity of the steel wire rope is ignored when calculating the mooring line stiffness. 
SBM-IMODCO INC.

MEMBER OF THE IHC/CALAND GROUP

Now in our 5 th Decade
FLOATING RE-GASIFICATION UNIT

FOR SALT CAVERN

LNG RECEIVING AND RE-GASIFICATION

51059 ССM97001

C1

PAGE 105

FIGURE 10-5 AQWA MODEL OF FRU AND LNG CARRIER SIDE BY SIDE MOORING

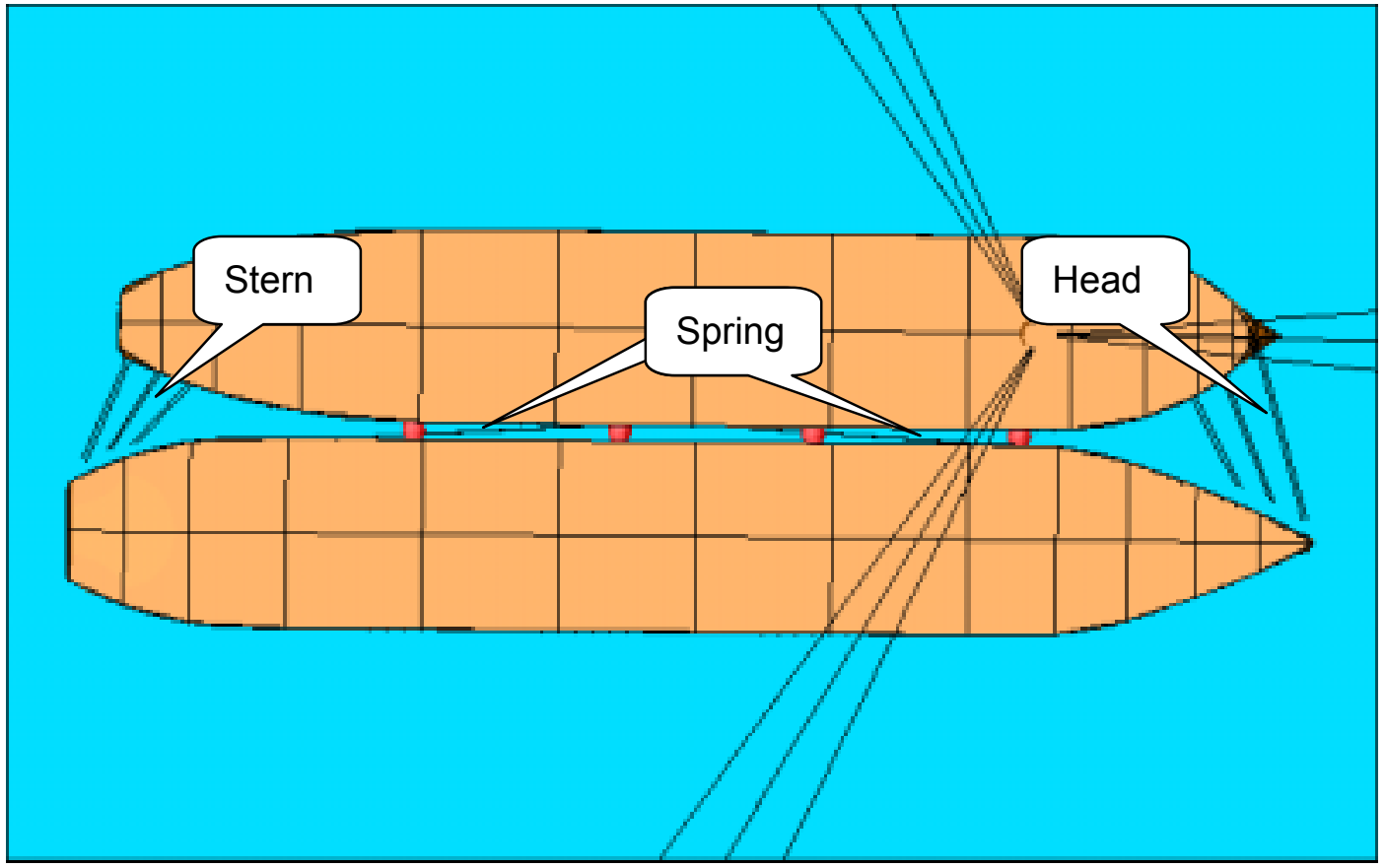

\begin{tabular}{|c|c|c|c|c|c|}
\hline \multicolumn{7}{|c|}{ TABLE 10-1 SIDE BY SIDE MOORING LINES } \\
\hline Line No. & $\begin{array}{c}\text { Type of } \\
\text { Line }\end{array}$ & $\begin{array}{c}\text { From } \\
\text { Fairlead } \\
\text { FRU }\end{array}$ & $\begin{array}{c}\text { To Fairlead } \\
\text { LNG }\end{array}$ & $\begin{array}{c}\text { Nylon Tail Line } \\
\text { Length (m) }\end{array}$ & $\begin{array}{c}\text { Pretension } \\
\text { (kN) }\end{array}$ \\
\hline 1 & stern & 1 & 1 & 20.0 & 150 \\
\hline 2 & stern & 2 & 2 & 20.0 & 150 \\
\hline 3 & stern & 3 & 3 & 20.0 & 150 \\
\hline 4 & stern & 4 & 4 & 20.0 & 150 \\
\hline 5 & stern & 5 & 5 & 20.0 & 150 \\
\hline 6 & stern & 6 & 6 & 20.0 & 150 \\
\hline 7 & spring & 7 & 7 & 20.0 & 150 \\
\hline 8 & spring & 8 & 8 & 20.0 & 150 \\
\hline 9 & spring & 9 & 9 & 20.0 & 150 \\
\hline 10 & spring & 10 & 10 & 20.0 & 150 \\
\hline 11 & head & 11 & 11 & 20.0 & 150 \\
\hline 12 & head & 12 & 12 & 20.0 & 150 \\
\hline 13 & head & 13 & 13 & 20.0 & 150 \\
\hline 14 & head & 14 & 14 & 20.0 & 150 \\
\hline 15 & head & 15 & 15 & 20.0 & 150 \\
\hline 16 & head & 16 & 16 & 20.0 & 150 \\
\hline
\end{tabular}




\begin{tabular}{|c|c|c|c|c|c|c|}
\hline \multirow[t]{3}{*}{ IMODHD } & $\begin{array}{l}\text { SBM-IMODCO INC. } \\
\text { MEMBER OF THE } \\
\text { IHC/CALAND GROUP } \\
\end{array}$ & \multirow{2}{*}{\multicolumn{5}{|c|}{$\begin{array}{l}\text { FLOATING RE-GASIFICATION UNIT } \\
\text { FOR SALT CAVERN } \\
\text { NG RECEIVING AND RE-GASIFICATION }\end{array}$}} \\
\hline & Now in our 5th Decade & & & & & \\
\hline & & 51059 & CCM97001 & C1 & PAGE & 106 \\
\hline
\end{tabular}

TABLE 10-2 MOORING LINE PROPERTIES

\begin{tabular}{|c|c|c|c|}
\hline Line Type & Standard & $\begin{array}{c}\text { Diameter } \\
(\mathbf{m m})\end{array}$ & MBL (kN) \\
\hline Steel Wire & ISO2408 & 44 & 1240 \\
\hline Tail Line & Nylon, Double & 88.9 & 1638 \\
\hline
\end{tabular}

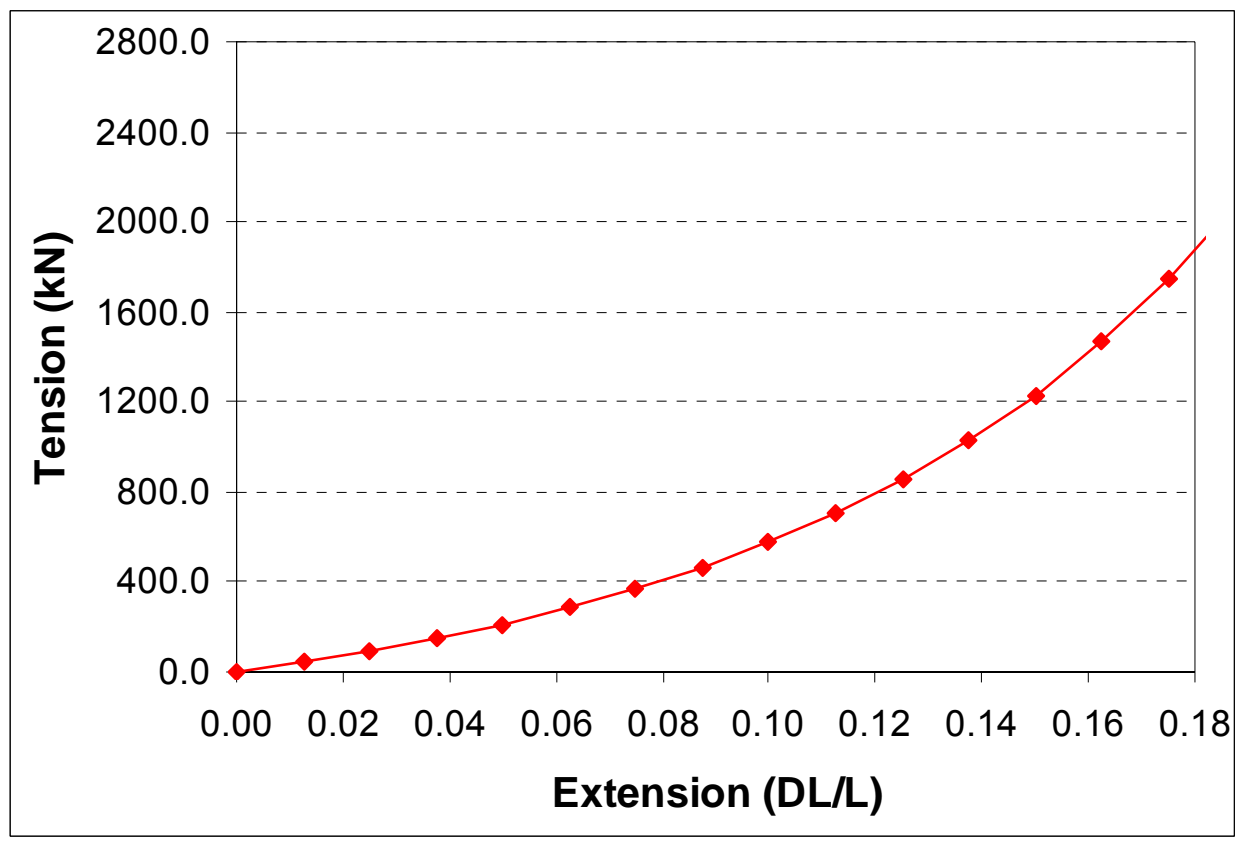

FIGURE 10-6 MOORING LINE LOAD-EXTENSION CURVE

\subsection{FENDERS}

Four (4) fenders are used for the FRU LNG carrier side by side mooring. The fender properties and arrangement are presented below.

$\begin{array}{lc}\text { Manufacture } & \text { Yokohama } \\ \text { Number } & 4 \\ \text { Height }(\mathrm{m}) & 4.5 \\ \text { Length }(\mathrm{m}) & 9.0 \\ \text { Pressure }\left(\mathrm{N} / \mathrm{cm}^{2}\right) & 5.0\end{array}$




\begin{tabular}{|c|c|c|c|c|c|c|}
\hline \multirow[t]{3}{*}{ IMODCO } & \multirow{3}{*}{$\begin{array}{l}\text { SBM-IMODCO INC. } \\
\text { MEMBER OF THE } \\
\text { IHCICALAND GROUP } \\
\text { Now in our } 5 \text { th Decade }\end{array}$} & \multirow{2}{*}{\multicolumn{5}{|c|}{$\begin{array}{l}\text { FLOATING RE-GASIFICATION UNIT } \\
\text { FOR SALT CAVERN } \\
\text { NG RECEIVING AND RE-GASIFICATION }\end{array}$}} \\
\hline & & & & & & \\
\hline & & 51059 & CCM97001 & C1 & PAGE & 107 \\
\hline
\end{tabular}

Reaction Force (kN) $\quad 4531$

At $55 \%$ deflection

FIGURE 10-7 MOORING FENDER ARRANGEMENT

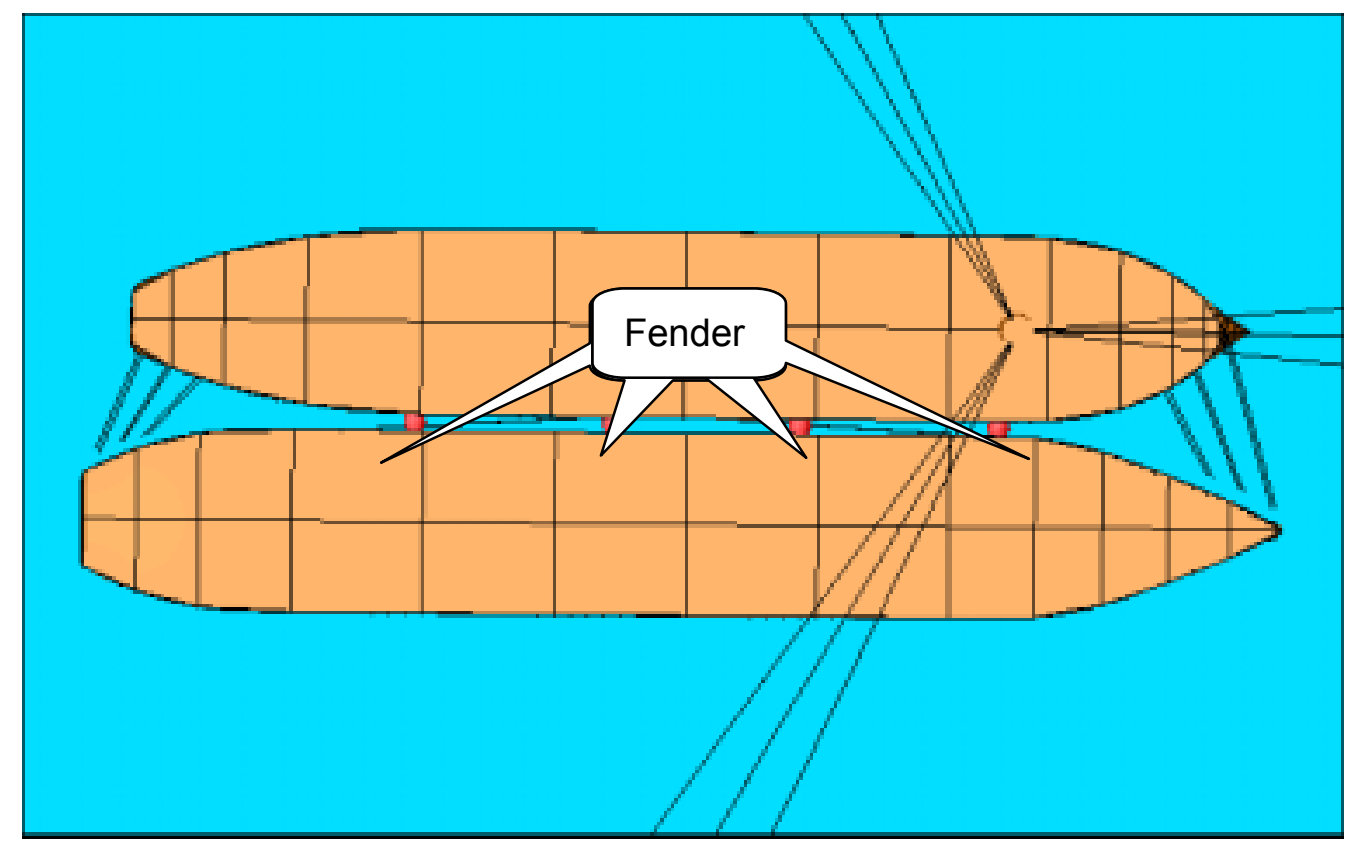




\begin{tabular}{|c|c|c|c|c|c|c|}
\hline \multirow[t]{3}{*}{ IMODG0 } & $\begin{array}{l}\text { SBM-IMODCO INC. } \\
\text { MEMBER OF THE } \\
\text { IHC/CALAND GROUP }\end{array}$ & \multirow{2}{*}{\multicolumn{5}{|c|}{$\begin{array}{c}\text { FOR SALT CAVERN } \\
\text { LNG RECEIVING AND RE-GASIFICATION }\end{array}$}} \\
\hline & Now in our 5th Decade & & & & & \\
\hline & & 51059 & CСM97001 & C1 & PAGE & 108 \\
\hline
\end{tabular}

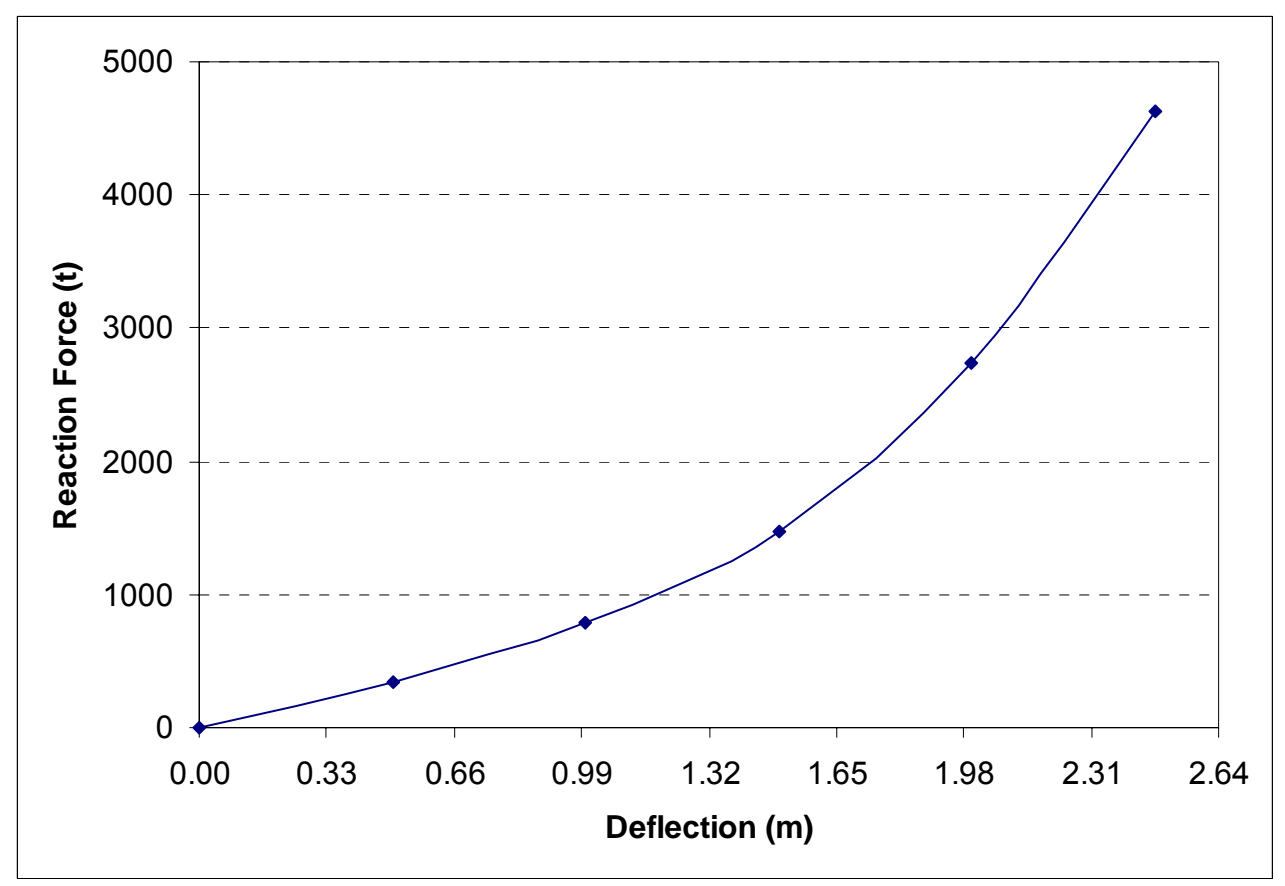

FIGURE 10-8 FENDER REACTION-DEFLECTION CURVE

\subsection{METHODOLOGY}

The AQWA program suite is used for the analysis. The analysis methodology is discussed below:

- The anchor legs are modeled as dynamic cables taking into account all hydrodynamic and inertial parameters of the chains and steel wire ropes. The vessel and mooring lines therefore represent a fully coupled dynamic system.

- The internal turret on the FRU is modeled as a swivel to allow the vessel to freely rotate about the turret axis.

- The vessel to vessel mooring lines are modeled as massless nonlinear springs based on a fiveparameter polynomial. The fenders are also modeled as nonlinear springs based using a fiveparameter polynomial. The fender element is attached to the FRU on the starboard side and its other end is free to contact the LNG vessel on its portside. The reaction force is determined by the relative distance between the FRU and LNG vessel. The friction force between the fender and the two vessels is taken into account, while the damping effect is ignored.

- The full hydrodynamic interaction between the two vessels is considered.

- Current and wind force and moment coefficients are calculated based on the OCIMF databases, and additional corrections on wind area due to the equipments on the FRU and the LNG containers on the LNG Carrier are considered. The shielding effects on the current and 


\begin{tabular}{|c|c|c|c|c|c|c|}
\hline \multirow[t]{3}{*}{ IMODCO } & \multirow[t]{3}{*}{$\begin{array}{l}\text { SBM-IMODCO INC. } \\
\text { MEMBER OF THE } \\
\text { IHC/CALAND GROUP } \\
\text { Now in our 5th Decade }\end{array}$} & \multirow{2}{*}{\multicolumn{5}{|c|}{$\begin{array}{l}\text { FLOATING RE-GASIFICATION UNIT } \\
\text { FOR SALT CAVERN } \\
\text { LNG RECEIVING AND RE-GASIFICATION }\end{array}$}} \\
\hline & & & & & & \\
\hline & & 51059 & ССМ97001 & C1 & PAGE & 109 \\
\hline
\end{tabular}

wind forces between the two vessels are ignored due to the lack of information regarding the carriers. This is considered conservative, as the shielding effects would reduce the loads on the vessels, which would lead to less relative motion and lower mooring loads. Wave drift loads are computed based on the Quadratic Transfer Functions (QTFs) obtained from the diffraction analysis.

- The current is assumed to be steady. The wind is simulated by an API wind spectrum based on the 1-hour average wind speed at $10 \mathrm{~m}$ above MSL. The 100-year return storm are assumed to be of a JONSWAP spectrum $(\gamma=3.0)$.

\subsection{EXTREME CONDITION ANALYSIS RESULTS}

This analysis confirms that the mooring system designed meets the minimum safety factor requirement of 1.67 for the survival condition.

The sensitivity analysis on the wave peak period of the 100-year return hurricane demonstrates that the wave peak period has significant effect on the maximum mooring loads.

\subsection{OPERATING CONDITION ANALYSIS RESULTS}

\subsubsection{Hydrodynamic Interaction}

With two vessels moored in such a close proximity, the hydrodynamic interaction between them is prominent. The following figures demonstrate the wave field around the two vessels and the wave interaction between them.

FIGURE 10-9 SIDE BY SIDE AQWA MODEL 


\begin{tabular}{|c|c|c|c|c|c|c|}
\hline \multirow[t]{3}{*}{ IMODL0 } & $\begin{array}{l}\text { SBM-IMODCO INC. } \\
\text { MEMBER OF THE } \\
\text { IHC/CALAND GROUP } \\
\end{array}$ & \multirow{2}{*}{\multicolumn{5}{|c|}{$\begin{array}{l}\text { FLOATING RE-GASIFICATION UNIT } \\
\text { FOR SALT CAVERN } \\
\text { NG RECEIVING AND RE-GASIFICATION }\end{array}$}} \\
\hline & Now in our 5th Decade & & & & & \\
\hline & & 51059 & CCM97001 & C1 & PAGE & 110 \\
\hline
\end{tabular}

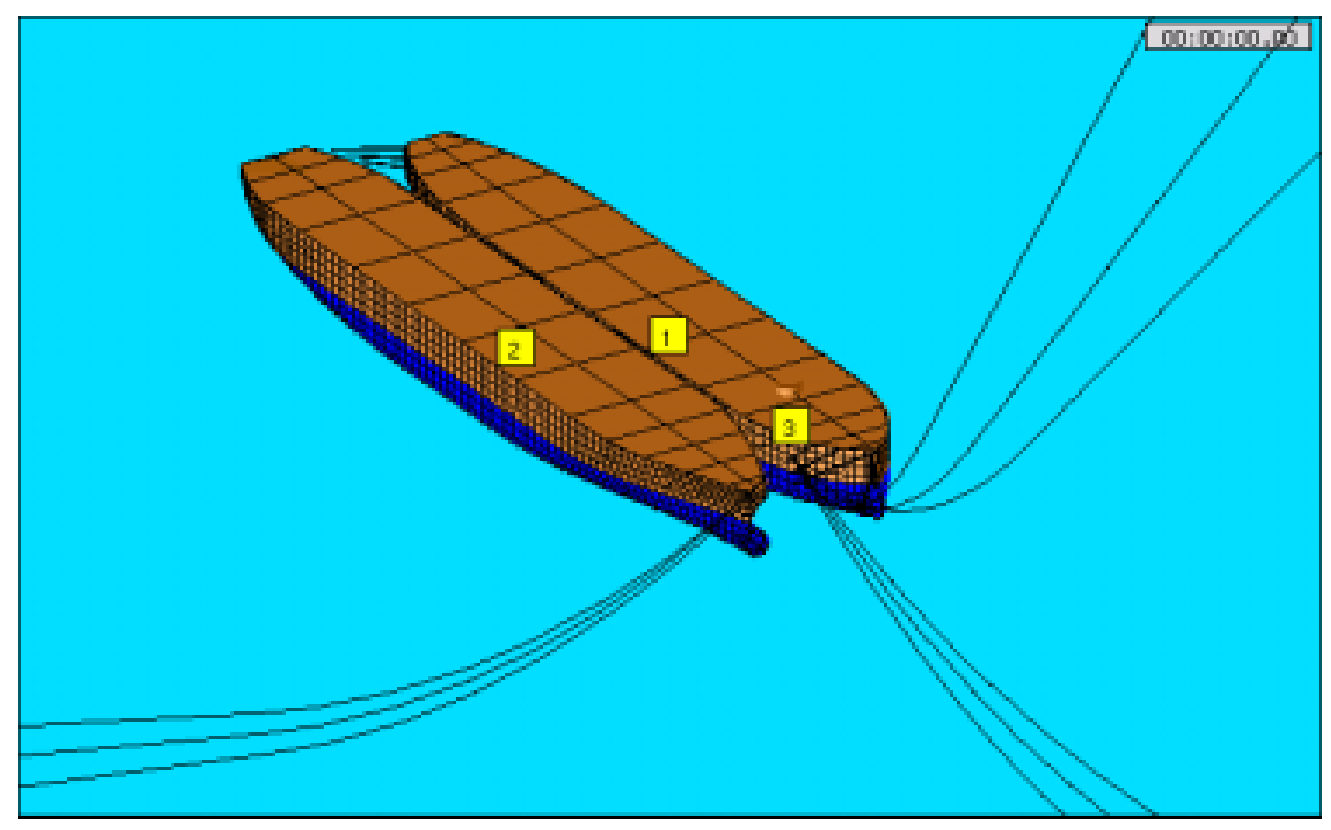




\begin{tabular}{|c|c|c|c|c|c|c|}
\hline \multirow[t]{3}{*}{ IMODED } & $\begin{array}{l}\text { SBM-IMODCO INC. } \\
\text { MEMBER OF THE } \\
\text { IHC/CALAND GROUP } \\
\end{array}$ & \multirow{2}{*}{\multicolumn{5}{|c|}{$\begin{array}{l}\text { FLOATING RE-GASIFICATION UNIT } \\
\text { FOR SALT CAVERN } \\
\text { _NG RECEIVING AND RE-GASIFICATION }\end{array}$}} \\
\hline & Now in our 5th Decade & & & & & \\
\hline & & 51059 & CCM97001 & C1 & PAGE & 111 \\
\hline
\end{tabular}

FIGURE 10-10 HYDRODYNAMIC PRESSURE DISTRIBUTION

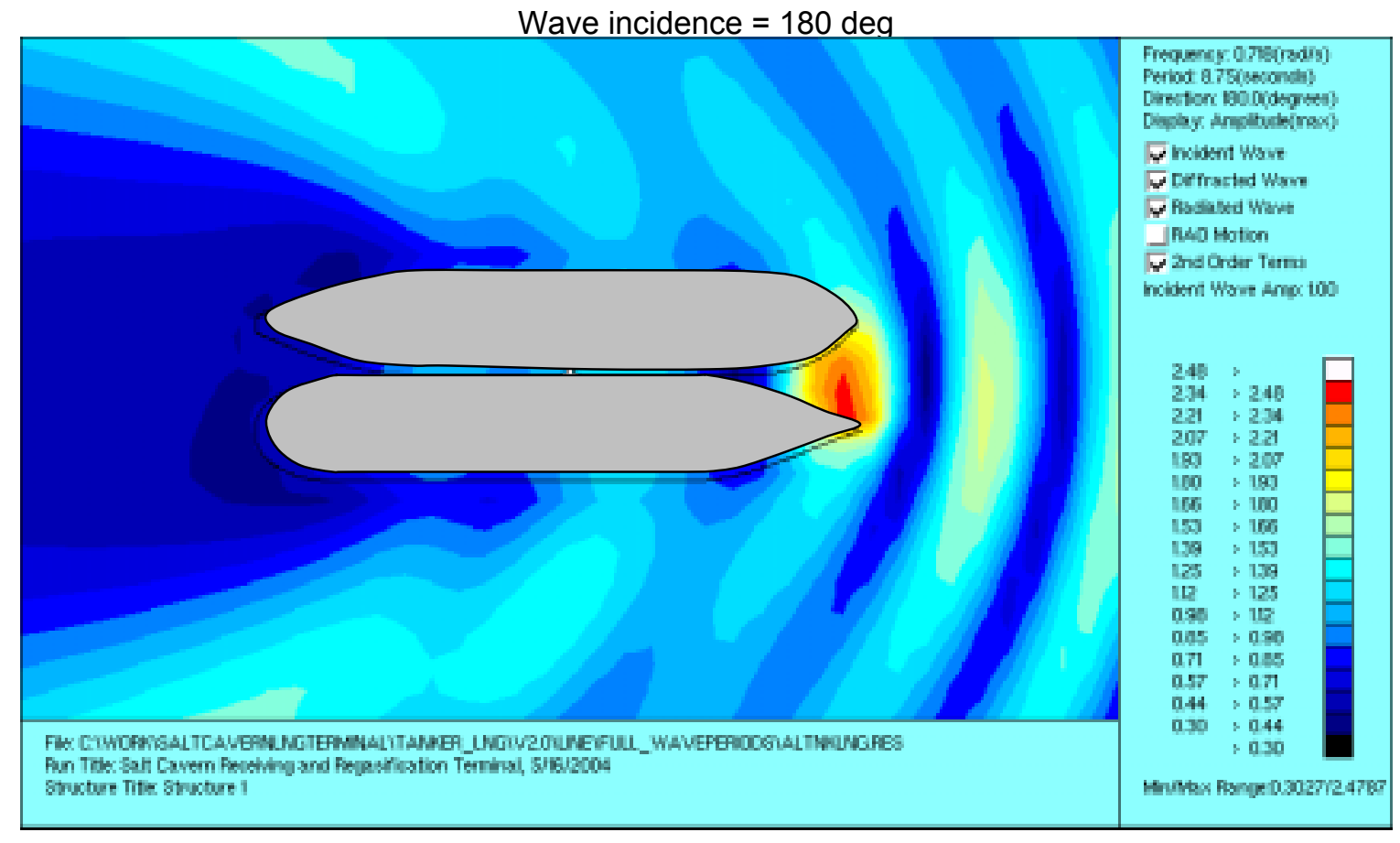

FIGURE 10-11 HYDRODYNAMIC PRESSURE DISTRIBUTION

Wave incidence $=160 \mathrm{deg}$

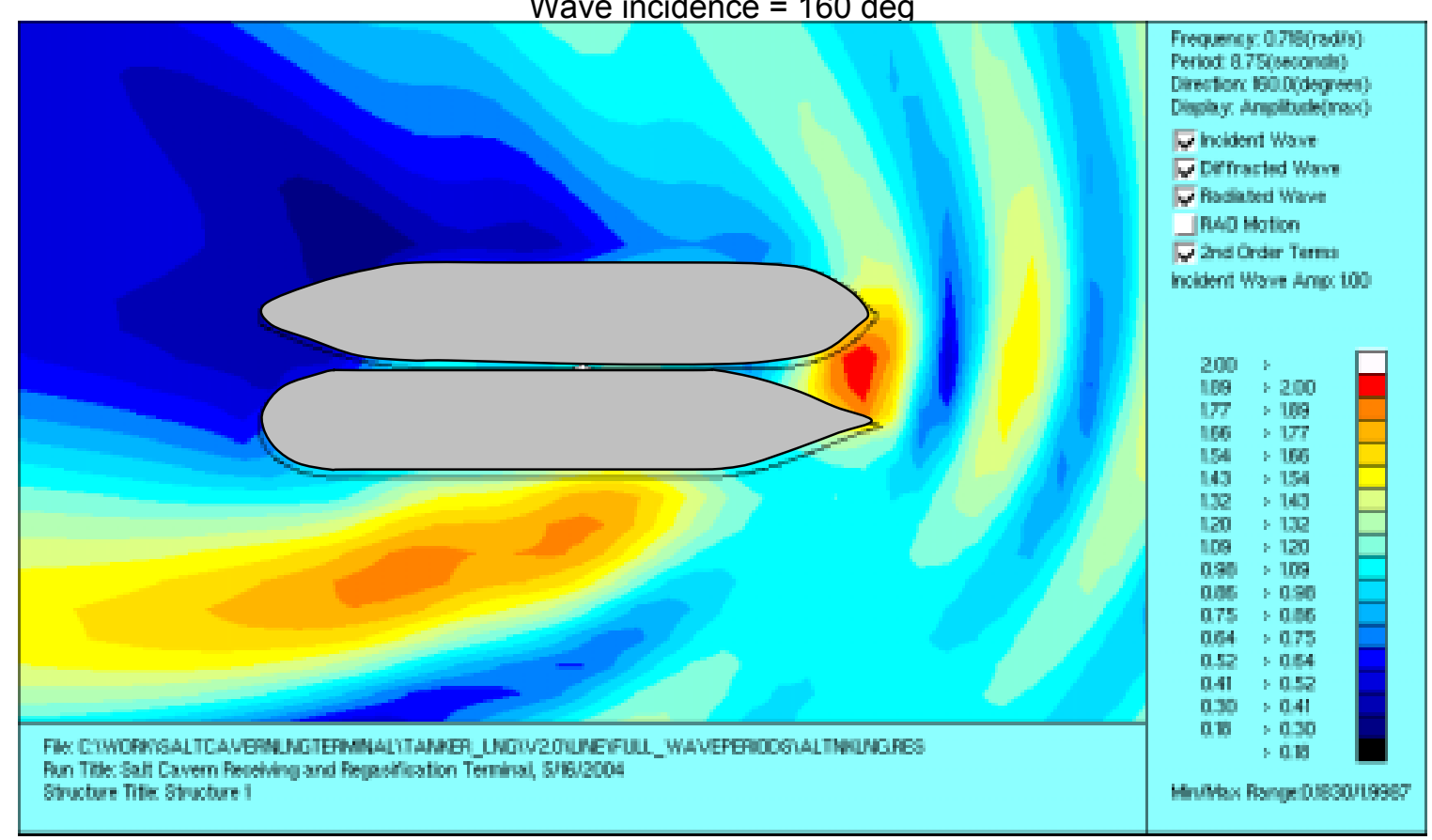




\begin{tabular}{|c|c|c|c|c|c|c|}
\hline \multirow[t]{3}{*}{ Imogen } & \multirow{3}{*}{$\begin{array}{l}\text { SBM-IMODCO INC. } \\
\text { MEMBER OF THE } \\
\text { IHCICALAND GROUP } \\
\text { Now in our } 5 \text { th Decade }\end{array}$} & \multirow{2}{*}{\multicolumn{5}{|c|}{$\begin{array}{l}\text { FLOATING RE-GASIFICATION UNIT } \\
\text { FOR SALT CAVERN } \\
\text { NG RECEIVING AND RE-GASIFICATION }\end{array}$}} \\
\hline & & & & & & \\
\hline & & 51059 & CCM97001 & C1 & PAGE & 112 \\
\hline
\end{tabular}

FIGURE 10-12 HYDRODYNAMIC PRESSURE DISTRIBUTION

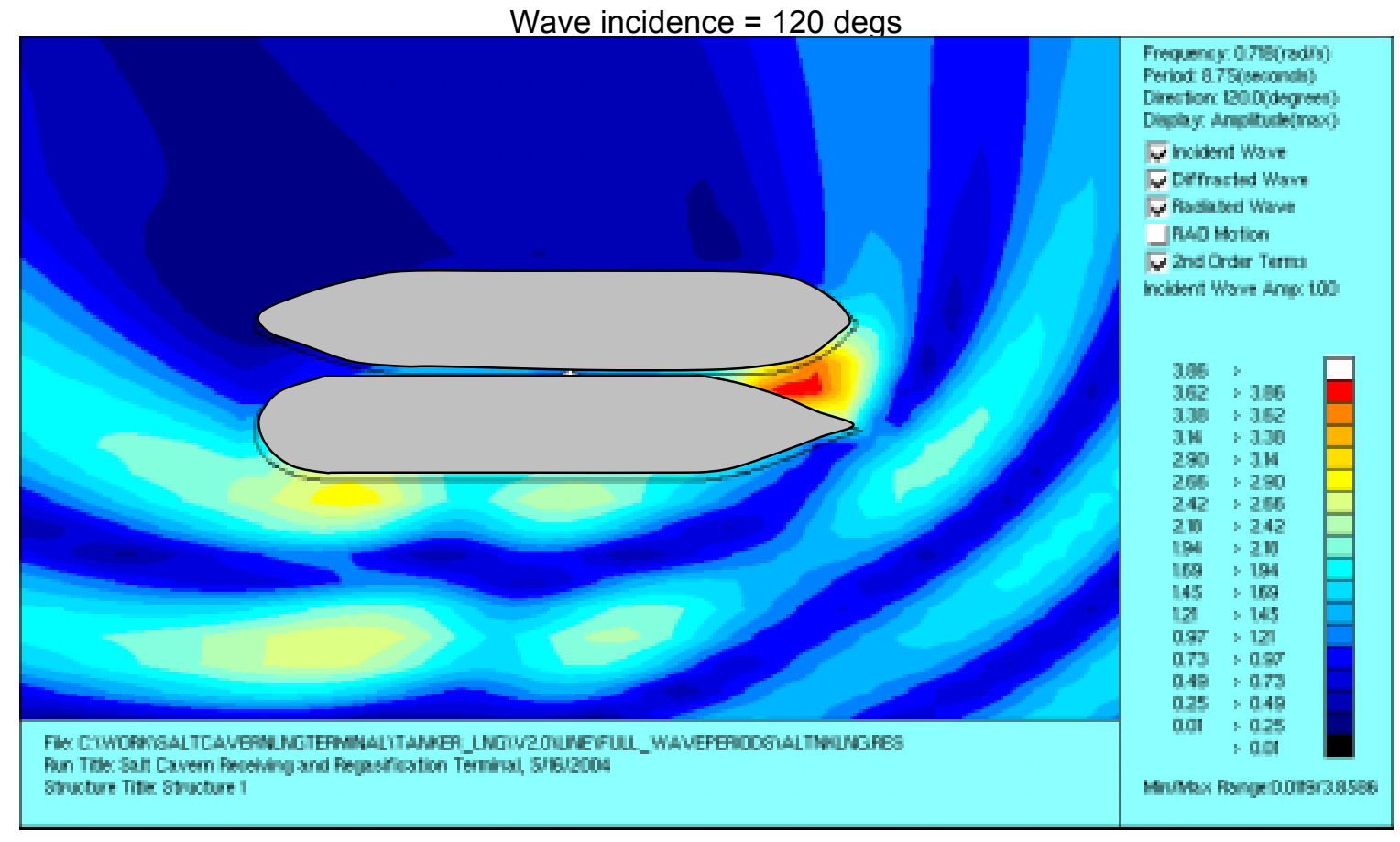

\subsubsection{Side-by-Side Mooring}

Under the operating condition, the following combinations of wind, wave and current directions are analyzed:

- Wind, wave and current collinear.

- Cross condition 1: head wave, starboard wind (150 degrees), starboard cross current (90 degrees).

- Cross condition 2: head wave, portside wind (-150 degrees), portside cross current (-90 degrees).

\section{Operating Condition}

The summary results for the side-by-side mooring and motion analysis under the target operating condition are presented below. Both mooring forces and relative motions are within the allowable.

Max. Mooring Line Tension

Max. Fender Reaction
$654 \mathrm{kN}$

$1178 \mathrm{kN}$ 


\begin{tabular}{|c|c|c|c|c|c|c|}
\hline \multirow[t]{3}{*}{ IMOOF0 } & $\begin{array}{l}\text { SBM-IMODCO INC. } \\
\text { MEMBER OF THE } \\
\text { IHC/CALAND GROUP } \\
\end{array}$ & \multirow{2}{*}{\multicolumn{5}{|c|}{$\begin{array}{l}\text { FLOATING RE-GASIFICATION UNIT } \\
\text { FOR SALT CAVERN } \\
\text { LNG RECEIVING AND RE-GASIFICATION }\end{array}$}} \\
\hline & \multirow[t]{2}{*}{ Now in our 5th Decade } & & & & & \\
\hline & & 51059 & CCM97001 & C1 & PAGE & 113 \\
\hline
\end{tabular}

Max. Anchor Leg Tension

Max. Longitudinal Relative Motion

Max. Transverse Relative Motion

Max. Vertical Relative Motion

Max. Longitudinal Relative Velocity

Max. Transverse Relative Velocity

Max. Vertical Relative Velocity

Max. Longitudinal Relative Acceleration

Max. Transverse Relative Acceleration

Max. Vertical Relative Acceleration
1579 kN

$1.91 \mathrm{~m}$ (peak-to-peak)

$1.57 \mathrm{~m}$ (peak-to-peak)

$0.28 \mathrm{~m}$ (peak-to-peak)

$0.15 \mathrm{~m} / \mathrm{s}$ (peak-to-peak)

$0.32 \mathrm{~m} / \mathrm{s}$ (peak-to-peak)

$0.11 \mathrm{~m} / \mathrm{s}$ (peak-to-peak)

$0.10 \mathrm{~m} / \mathrm{s} 2$ (peak-to-peak)

$0.21 \mathrm{~m} / \mathrm{s} 2$ (peak-to-peak)

$0.08 \mathrm{~m} / \mathrm{s} 2$ (peak-to-peak)

The time history of the mooring line tension, fender reaction force, relative motions are presented in Figure $10.13-10.17$ respectively. For the mooring line tension and fender reaction force, there are two peaks at 33 seconds and 19 seconds, which are natural periods for the horizontal shifting natural mode and transverse separating natural mode respectively. The wave frequency components are significant as well.

The longitudinal relative motion between the LNG loading arms and the manifold mainly comes from two components at periods of 179 seconds and 33 seconds. 33 seconds is the natural period of the horizontal shifting natural mode. 179 seconds is the natural period of the horizontal yaw mode. The transverse relative motion is mainly caused by the horizontal shifting natural mode at 33 seconds. For both relative motions, wave frequency components are insignificant. The relative vertical motion is mainly caused by the roll natural mode at 16 seconds and wave frequency heave motions. 
SBM-IMODCO INC.

MEMBER OF THE IHC/CALAND GROUP

Now in our 5 th Decade
FLOATING RE-GASIFICATION UNIT

FOR SALT CAVERN

LNG RECEIVING AND RE-GASIFICATION

51059 CCM97001
C1

PAGE

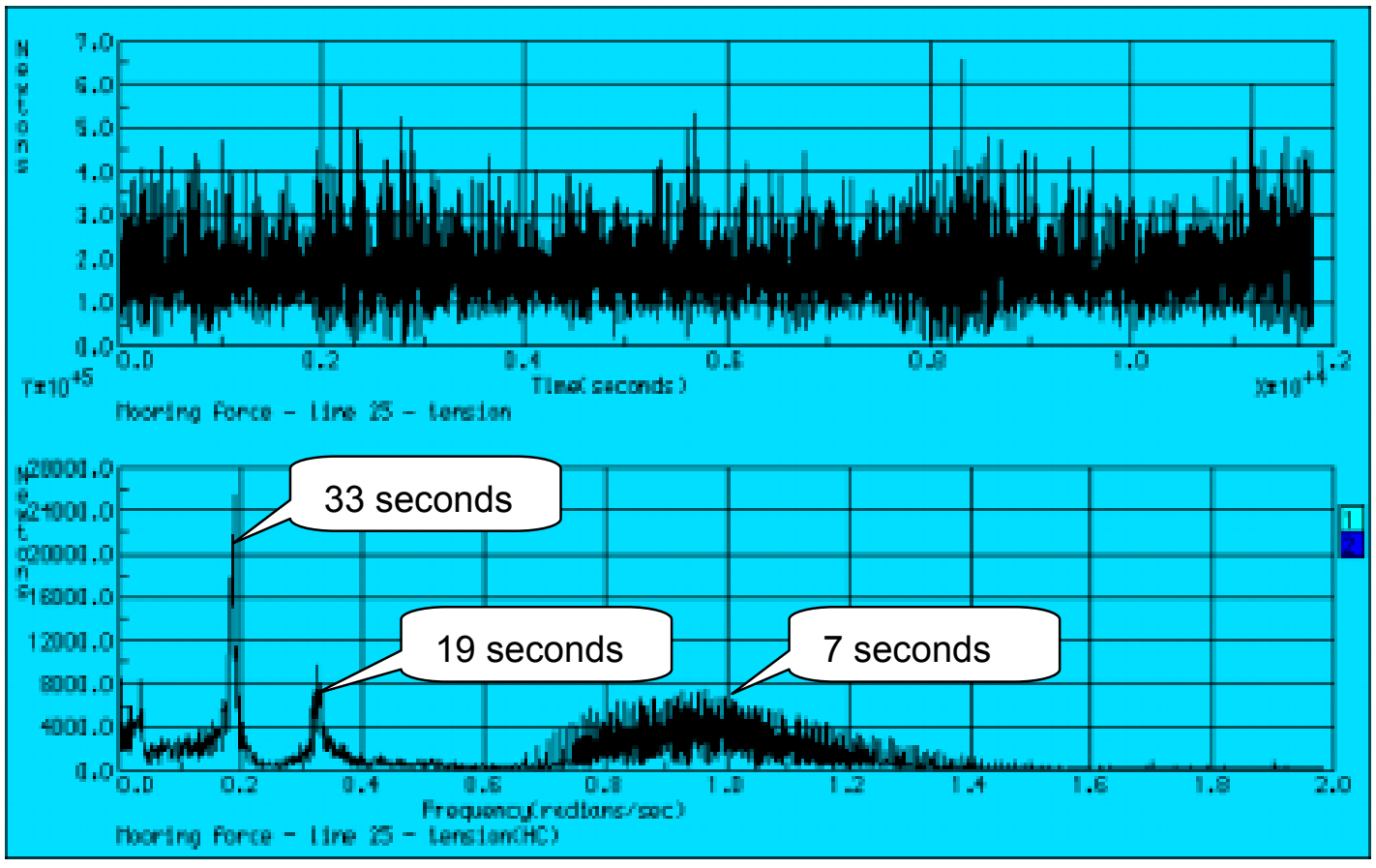

FIGURE 10-13 MOORING LINE TENSION

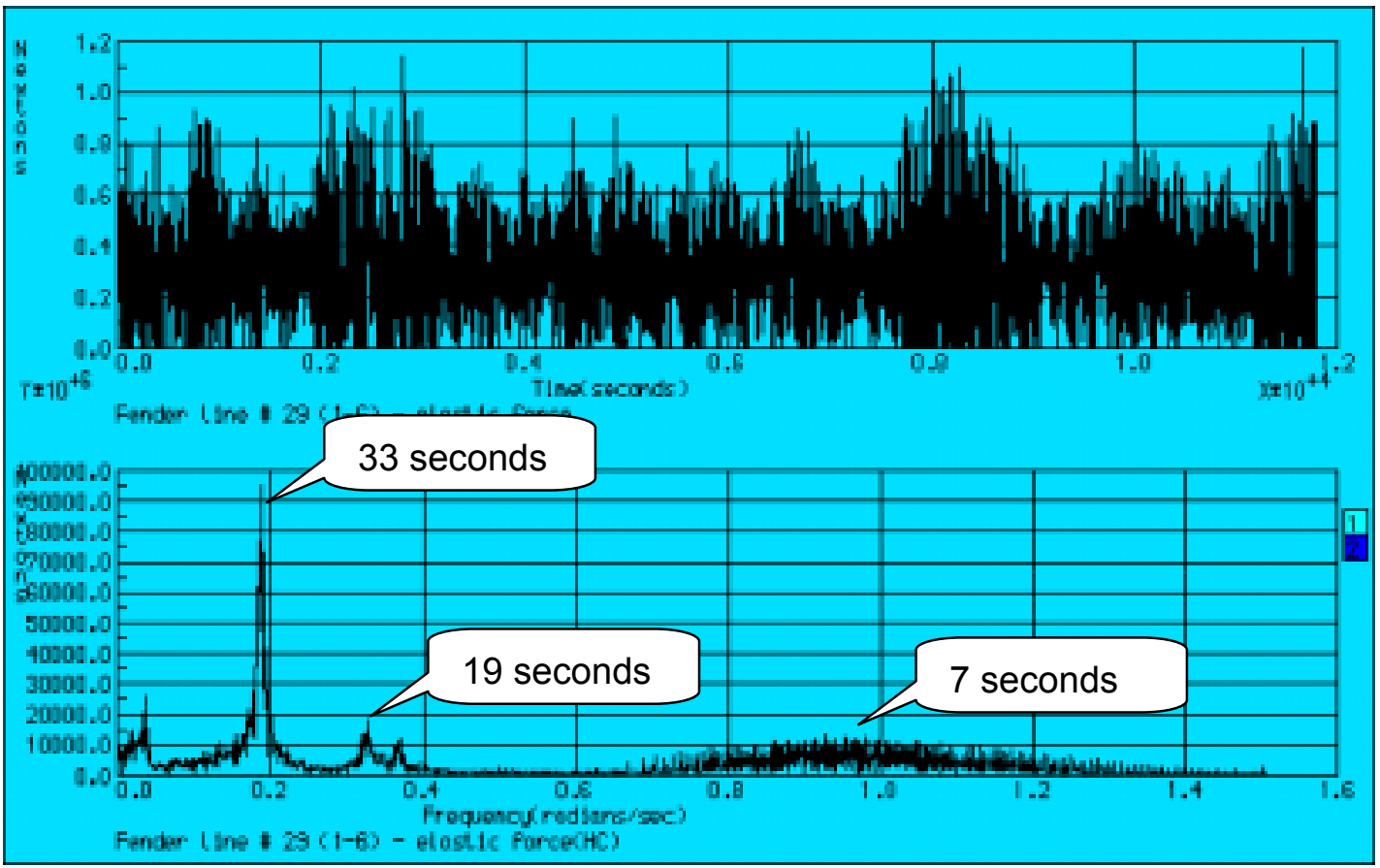

FIGURE 10-14 FENDER REACTION FORCE 


\begin{tabular}{|c|c|c|c|c|c|c|}
\hline \multirow[t]{3}{*}{ IMODE0 } & $\begin{array}{l}\text { SBM-IMODCO INC. } \\
\text { MEMBER OF THE } \\
\text { IHC/CALAND GROUP } \\
\end{array}$ & \multirow{2}{*}{\multicolumn{5}{|c|}{$\begin{array}{l}\text { FLOATING RE-GASIFICATION UNIT } \\
\text { FOR SALT CAVERN } \\
\text { NG RECEIVING AND RE-GASIFICATION }\end{array}$}} \\
\hline & Now in our 5th Decade & & & & & \\
\hline & & 51059 & ССМ97001 & C1 & PAGE & 115 \\
\hline
\end{tabular}

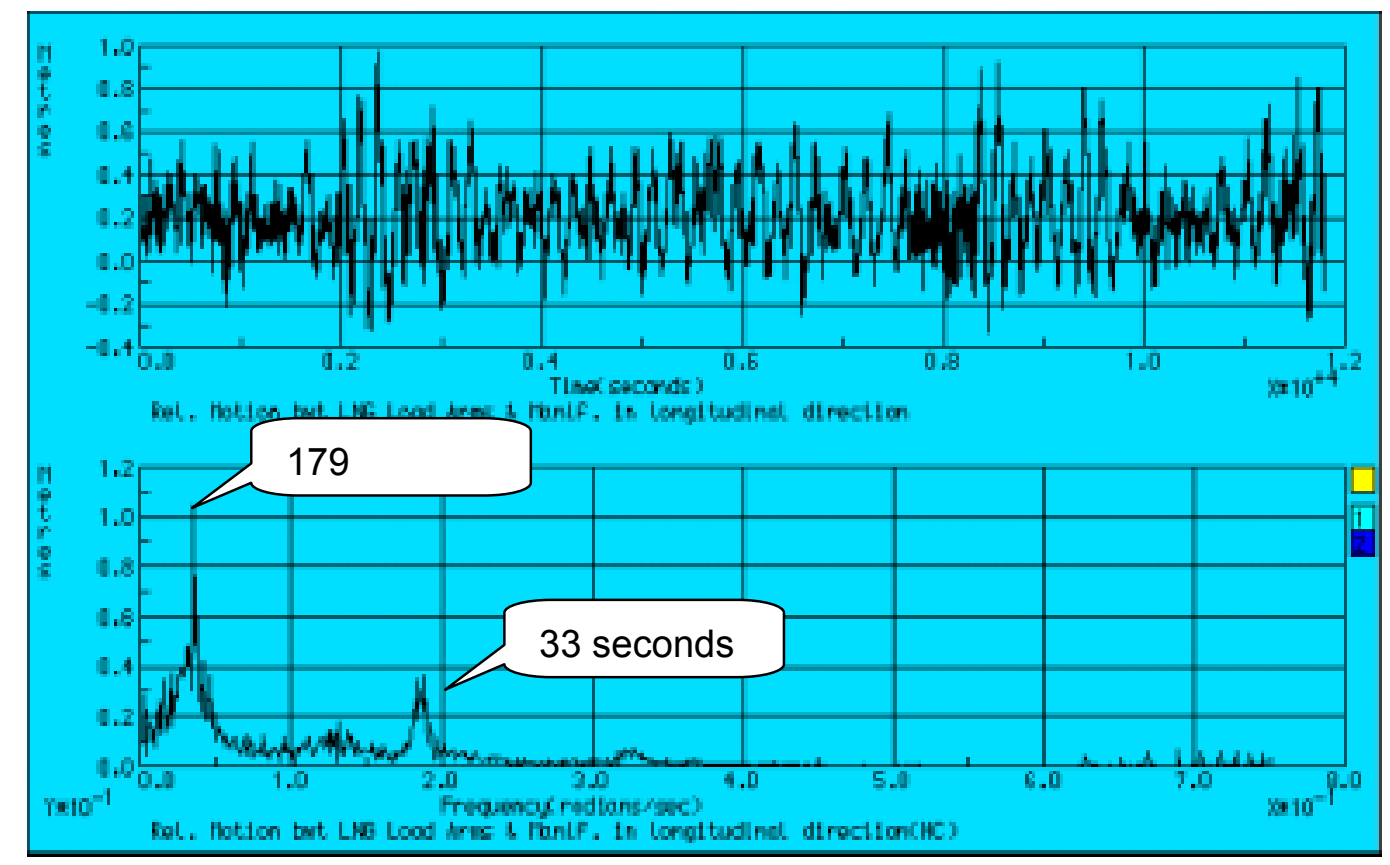

FIGURE 10-15 RELATIVE MOTION - LONGITUDINAL

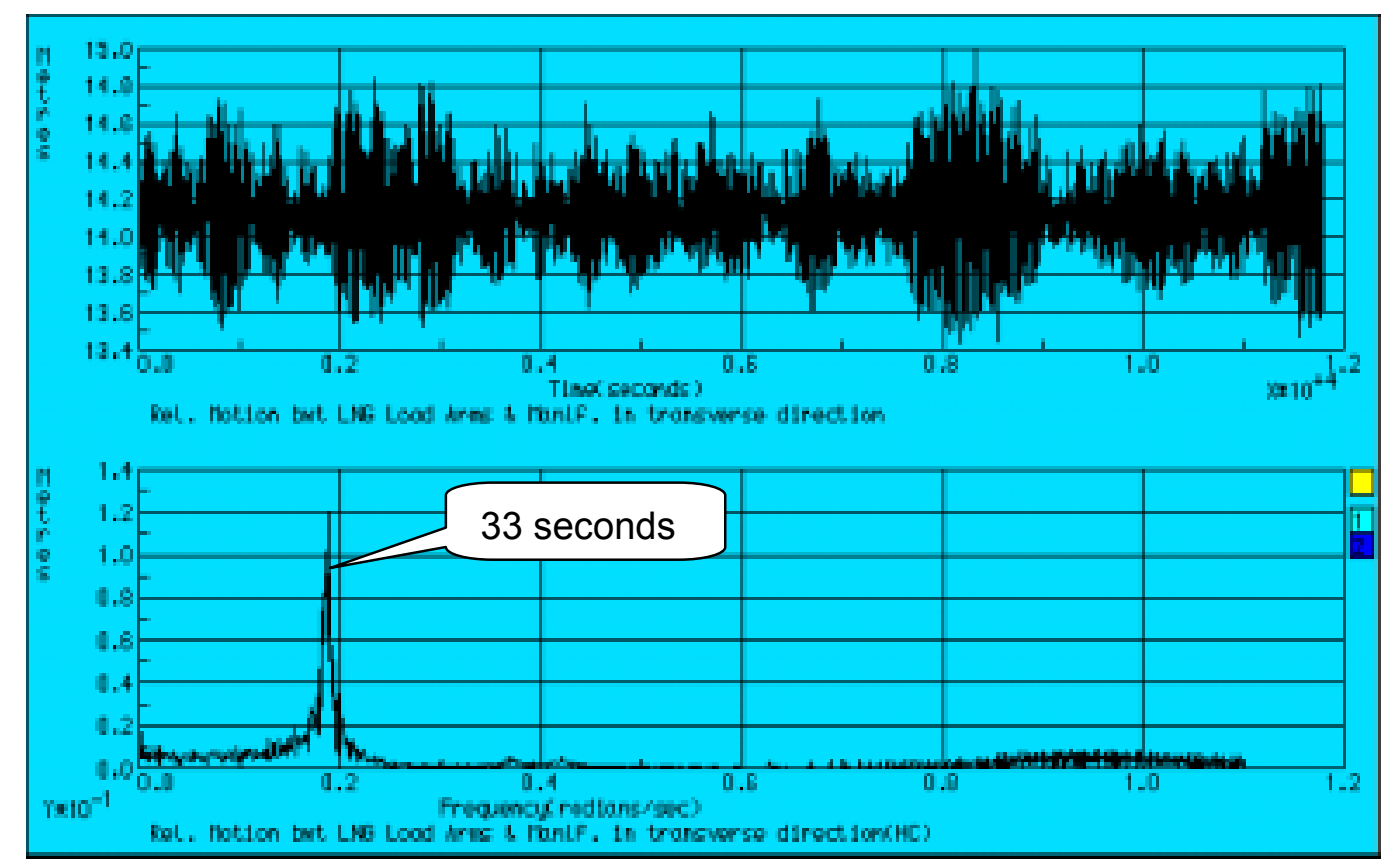

FIGURE 10-16 RELATIVE MOTION - TRANSVERSE 


\begin{tabular}{|c|c|c|c|c|c|c|}
\hline \multirow[t]{3}{*}{ IMODE0 } & $\begin{array}{l}\text { SBM-IMODCO INC. } \\
\text { MEMBER OF THE } \\
\text { IHC/CALAND GROUP } \\
\end{array}$ & \multirow{2}{*}{\multicolumn{5}{|c|}{$\begin{array}{l}\text { FLOATING RE-GASIFICATION UNIT } \\
\text { FOR SALT CAVERN } \\
\text { NG RECEIVING AND RE-GASIFICATION }\end{array}$}} \\
\hline & Now in our 5th Decade & & & & & \\
\hline & & 51059 & ССМ97001 & C1 & PAGE & 116 \\
\hline
\end{tabular}

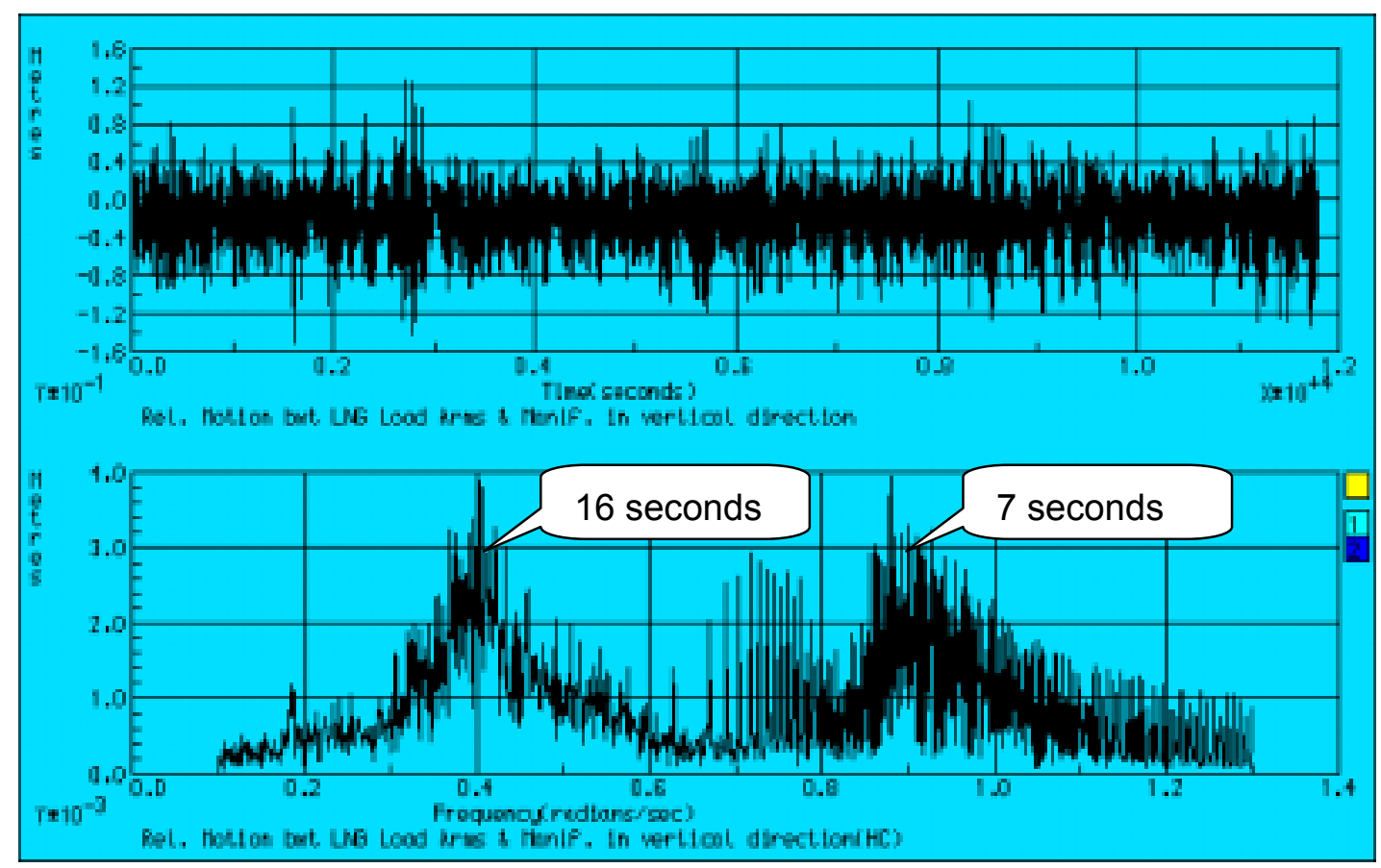

FIGURE 10-17 RELATIVE MOTION - VERTICAL

\subsubsection{Operation Envelope}

The side-by-side mooring and motion analysis is performed for a range of seastates with $\mathrm{Hs}$ from 0.5 $\mathrm{m}$ to $4.0 \mathrm{~m}$ and $\mathrm{Tp}$ from 6.0 seconds to 11.0 seconds to establish the operation envelope. The detailed analysis results are presented in Appendix D.

From the analysis results, the conclusion can be reached that the mooring line tension limit is the governing criteria in determining the operation envelope. For the different combination of wind, wave, current directions, the operation envelopes are presented in Tables 10-5 to 10-7, respectively.

It is also noted that the relative motions at the offloading arms are well below the operating limits specified in Section 4.4.2. 


\begin{tabular}{|c|c|c|c|c|c|c|}
\hline \multirow[t]{3}{*}{ IMODL0 } & $\begin{array}{l}\text { SBM-IMODCO INC. } \\
\text { MEMBER OF THE } \\
\text { IHC/CALAND GROUP } \\
\end{array}$ & \multirow{2}{*}{\multicolumn{5}{|c|}{$\begin{array}{l}\text { FLOATING RE-GASIFICATION UNIT } \\
\text { FOR SALT CAVERN } \\
\text { NG RECEIVING AND RE-GASIFICATION }\end{array}$}} \\
\hline & Now in our 5th Decade & & & & & \\
\hline & & 51059 & CCM97001 & C1 & PAGE & 117 \\
\hline
\end{tabular}

Table 10-5 Operating Envelope: Wind, wave and current collinear

\begin{tabular}{|c|c|cccccc|}
\hline \multicolumn{2}{|c|}{} & \multicolumn{6}{|c|}{ Max. Mooring Line Tension (kN) } \\
\hline \multirow{5}{*}{ Hs (m) } & 4.0 & 2577 & 3359 & 3603 & 1357 & 1215 & 1146 \\
& 3.5 & 1288 & 1593 & 1492 & 1026 & 871 & 780 \\
& 3.0 & 840 & 856 & 1027 & 700 & 664 & 648 \\
& 2.5 & 645 & 654 & 726 & 563 & 485 & 532 \\
& 2.0 & 429 & 476 & 443 & 468 & 374 & 432 \\
& 1.5 & 330 & 319 & 327 & 339 & 283 & 345 \\
& 1.0 & 234 & 251 & 253 & 250 & 229 & 268 \\
& 0.5 & 221 & 218 & 219 & 224 & 219 & 227 \\
\hline \multicolumn{2}{|c|}{} \\
\hline \multicolumn{1}{|c|}{ Tp (s) } & 6.0 & 7.0 & 8.0 & 9.0 & 10.0 & 11.0 \\
\hline
\end{tabular}

Table 10-6 Operating Envelope: Cross condition 1, head wave, starboard wind (150 degrees), starboard cross current (90 degrees)

\begin{tabular}{|c|c|cccccc|}
\hline \multicolumn{2}{|c|}{} & \multicolumn{6}{|c|}{ Max. Mooring Line Tension (kN) } \\
\hline \multirow{5}{*}{ Hs (m) } & 4.0 & 1202 & 1248 & 1451 & 1594 & 1406 & 2995 \\
& 3.5 & 847 & 849 & 1024 & 1229 & 1120 & 1457 \\
& 3.0 & 640 & 647 & 733 & 830 & 792 & 1314 \\
& 2.5 & 470 & 503 & 566 & 519 & 614 & 661 \\
& 2.0 & 345 & 378 & 421 & 392 & 479 & 516 \\
& 1.5 & 289 & 309 & 332 & 335 & 371 & 413 \\
& 1.0 & 261 & 284 & 287 & 298 & 320 & 312 \\
& 0.5 & 253 & 262 & 256 & 262 & 275 & 277 \\
\hline \multicolumn{2}{|c|}{} \\
\hline \multicolumn{1}{|c|}{ Tp (s) } & 6.0 & 7.0 & 8.0 & 9.0 & 10.0 & 11.0 \\
\hline
\end{tabular}

Table 10-7 Operating Envelope: Cross condition 2, head wave, starboard wind (-150 degrees), starboard cross current (-90 degrees)

\begin{tabular}{|c|c|cccccc|}
\hline \multicolumn{2}{|c|}{} & \multicolumn{6}{|c|}{ Max. Mooring Line Tension (kN) } \\
\hline \multirow{5}{*}{ Hs (m) } & 4.0 & 972 & 1818 & 1353 & 1067 & 882 & 1363 \\
& 3.5 & 652 & 1123 & 906 & 759 & 709 & 1017 \\
& 3.0 & 455 & 547 & 589 & 643 & 637 & 699 \\
& 2.5 & 376 & 366 & 426 & 438 & 454 & 539 \\
& 2.0 & 287 & 290 & 340 & 314 & 337 & 416 \\
& 1.5 & 243 & 246 & 289 & 250 & 274 & 330 \\
& 1.0 & 205 & 212 & 248 & 211 & 228 & 258 \\
& 0.5 & 191 & 194 & 215 & 188 & 201 & 204 \\
\hline \multicolumn{2}{|c|}{ Tp (s) } & 6.0 & 7.0 & 8.0 & 9.0 & 10.0 & 11.0 \\
\hline
\end{tabular}




\begin{tabular}{|c|c|c|c|c|c|c|}
\hline \multirow[t]{3}{*}{ Imogen } & $\begin{array}{l}\text { SBM-IMODCO INC. } \\
\text { MEMBER OF THE } \\
\text { IHC/CALAND GROUP }\end{array}$ & \multicolumn{4}{|c|}{ FOR SALT CAVERN } & \\
\hline & \multirow[t]{2}{*}{ Now in our 5th Decade } & \multicolumn{5}{|c|}{ LNG RECEIVING AND RE-GASIFICATION } \\
\hline & & 51059 & CCM97001 & C1 & PAGE & 118 \\
\hline
\end{tabular}

FIGURE 10-18 SIDE BY SIDE ANALYSIS MODEL

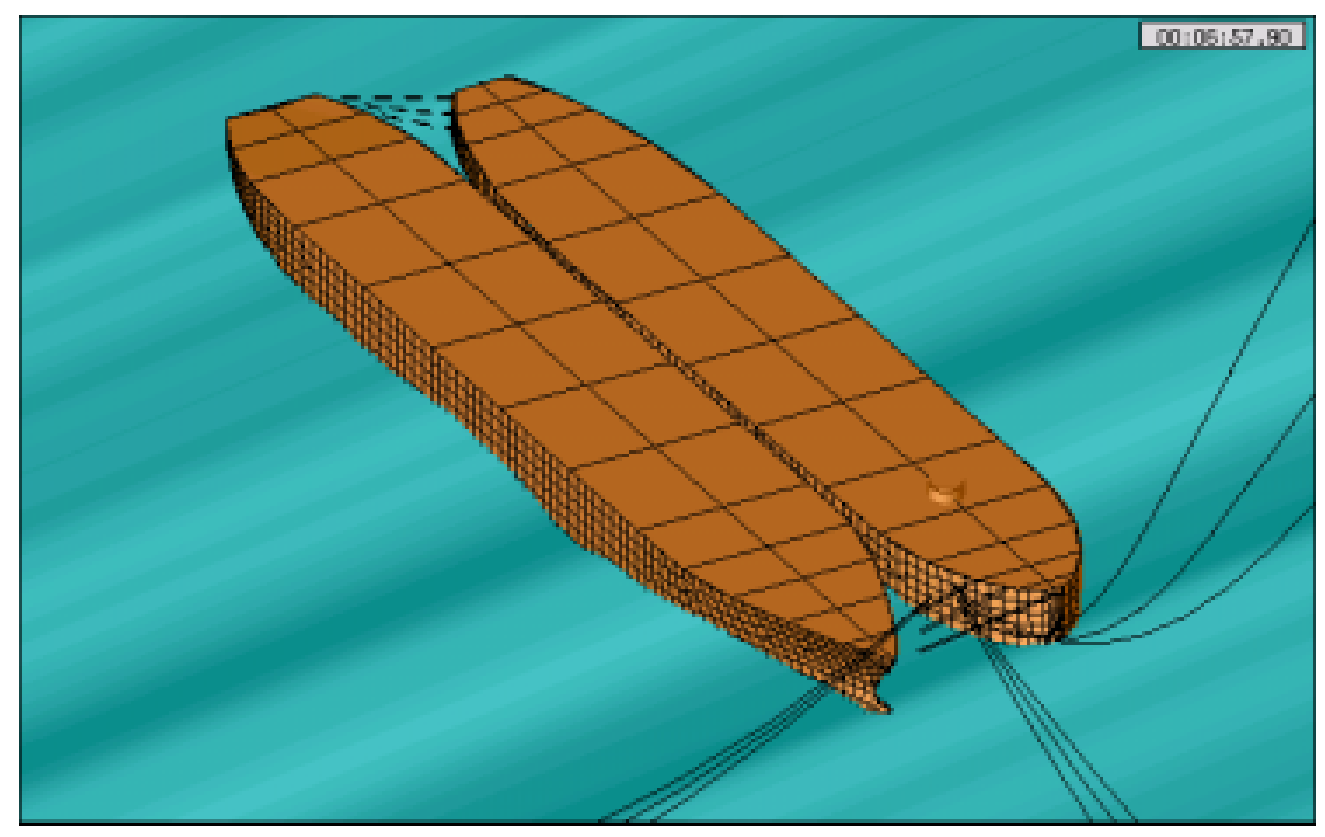

FIGURE 10-19 SIDE BY SIDE ANALYSIS MODEL

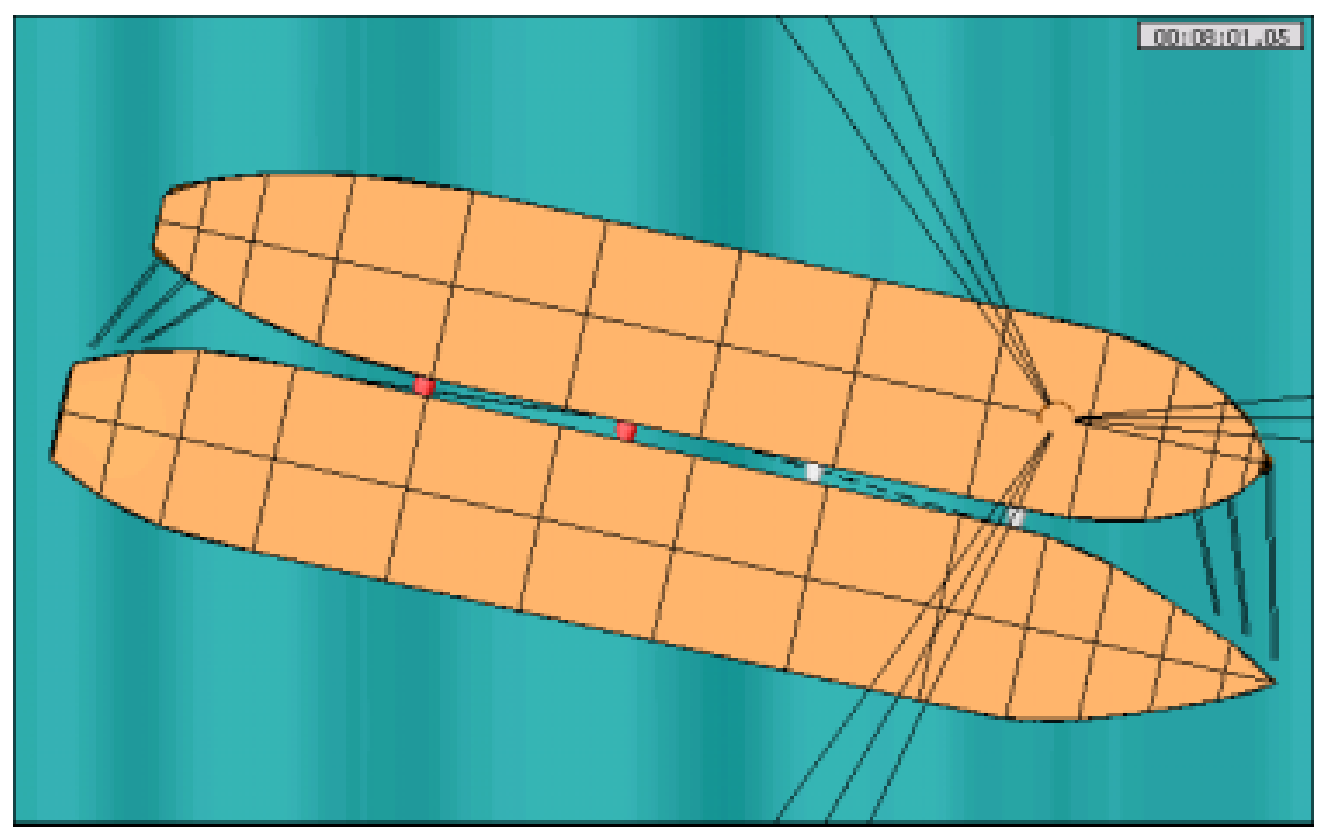




\begin{tabular}{|c|c|c|c|c|c|c|}
\hline \multirow[t]{3}{*}{ IMOOE0 } & \multirow[t]{3}{*}{$\begin{array}{l}\text { SBM-IMODCO INC. } \\
\text { MEMBER OF THE } \\
\text { IHCICALAND GROUP } \\
\text { Now in our 5th Decade }\end{array}$} & \multirow{2}{*}{\multicolumn{5}{|c|}{$\begin{array}{l}\text { FLOATING RE-GASIFICATION UNIT } \\
\text { FOR SALT CAVERN } \\
\text { LNG RECEIVING AND RE-GASIFICATION }\end{array}$}} \\
\hline & & & & & & \\
\hline & & 51059 & ССМ97001 & C1 & PAGE & 119 \\
\hline
\end{tabular}

\subsection{OFFLOADING ANALYSIS SUMMARY}

- The mooring system safely connects the LNG carrier to the FRU in the target operating environment.

- The relative motion between the FRU and the LNG carrier can be kept well below the limiting motion of the offloading arms to allow continuous offloading in the operating environment.

- The governing criteria for the offloading operating condition is the mooring line tensions.

- The design variables can be further optimized to expand the offloading environment envelope. 


\begin{tabular}{|c|c|c|c|c|c|c|}
\hline \multirow[t]{3}{*}{ IMODCO } & \multirow[t]{3}{*}{$\begin{array}{l}\text { SBM-IMODCO INC. } \\
\text { MEMBER OF THE } \\
\text { IHC/CALAND GROUP } \\
\text { Now in our 5th Decade }\end{array}$} & \multirow{2}{*}{\multicolumn{5}{|c|}{$\begin{array}{l}\text { FLOATING RE-GASIFICATION UNIT } \\
\text { FOR SALT CAVERN } \\
\text { LNG RECEIVING AND RE-GASIFICATION }\end{array}$}} \\
\hline & & & & & & \\
\hline & & 51059 & ССМ97001 & C1 & PAGE & 120 \\
\hline
\end{tabular}

\section{SENSITIVITY STUDY}

\subsection{GENERAL}

The present FRU study is based on a set of design parameters related to a Salt Cavern location in the northern coast of the GOM. The FRU concept is versatile and can be deployed in various environments and conditions. To demonstration its versatility, a number of sensitivity analyses are conducted and documented in this section.

\subsection{WATER DEPTH SENSITIVITY}

Even though the present FRU study assumes a design water depth of $90 \mathrm{~m}$, the FRU concept is capable of operating in a wide range of water depths. The stationkeeping is conducted through passive moorings. As water depth alters, the mooring system configuration can be modified to suit. For examples, wire rope can be used for suspended mooring line part in deep water depths, and in shallow waters, clamp weights can be used to limit vessel's offset for the ease of riser design.

The FRU mooring concept is capable of operating in water depths as shallow as $40 \mathrm{~m}$. To confirm this, a mooring system is designed for the same FRU in a $40 \mathrm{~m}$ water depth. The riser analysis is also conducted to establish the riser system is capable of accommodating the mooring offsets.

As water depth decreases, the mooring system design becomes more challenging. The line catenary effect that accommodates vessel's wave frequency motions is diminishing and as a result, the mooring line tension can increase significantly in shallow waters. In addition, the offset as the percentage of water depth increases which makes the riser design more difficult.

\subsubsection{Revised Mooring Configuration}

The mooring system designed for 90 m water depth has been modified in the following aspects:

- $4 \times 4$ mooring configuration instead of $3 \times 3$ configuration is adopted. This is to cope with the increased mooring line tension in shallow water;

- Clamp weights are utilized to minimize the offset;

- Mooring line pretension angle is reduced. 


\begin{tabular}{|c|c|c|c|c|c|c|}
\hline \multirow[t]{3}{*}{ IMOOF0 } & $\begin{array}{l}\text { SBM-IMODCO INC. } \\
\text { MEMBER OF THE } \\
\text { IHCICALAND GROUP }\end{array}$ & \multirow{2}{*}{\multicolumn{5}{|c|}{$\begin{array}{l}\text { FLOATING RE-GASIFICATION UNIT } \\
\text { FOR SALT CAVERN } \\
\text { LNG RECEIVING AND RE-GASIFICATION }\end{array}$}} \\
\hline & \multirow[t]{2}{*}{ Now in our 5th Decade } & & & & & \\
\hline & & 51059 & CCM97001 & C1 & PAGE & 121 \\
\hline
\end{tabular}

The composition of mooring leg is presented in the following table.

TABLE 11-1 MOORING LEG COPMPOSITION

\begin{tabular}{|c|c|c|}
\hline \multirow{2}{*}{ Segment } & From Anchor to & Segment Characteristics \\
Lines 1-16
\end{tabular}

The following plots present the key characteristics of the designed FRU mooring systems: 


\begin{tabular}{|c|c|c|c|c|c|c|}
\hline \multirow[t]{3}{*}{ IMOOCO } & \multirow{3}{*}{$\begin{array}{l}\text { SBM-IMODCO INC. } \\
\text { MEMBER OF THE } \\
\text { IHCICALAND GROUP } \\
\text { Now in our } 5 \text { th Decade }\end{array}$} & \multirow{2}{*}{\multicolumn{5}{|c|}{$\begin{array}{l}\text { FLOATING RE-GASIFICATION UNIT } \\
\text { FOR SALT CAVERN } \\
\text { LNG RECEIVING AND RE-GASIFICATION }\end{array}$}} \\
\hline & & & & & & \\
\hline & & 51059 & CCM97001 & C1 & PAGE & 122 \\
\hline
\end{tabular}

FIGURE 11-1 MOORING SYSTEM PLAN VIEW

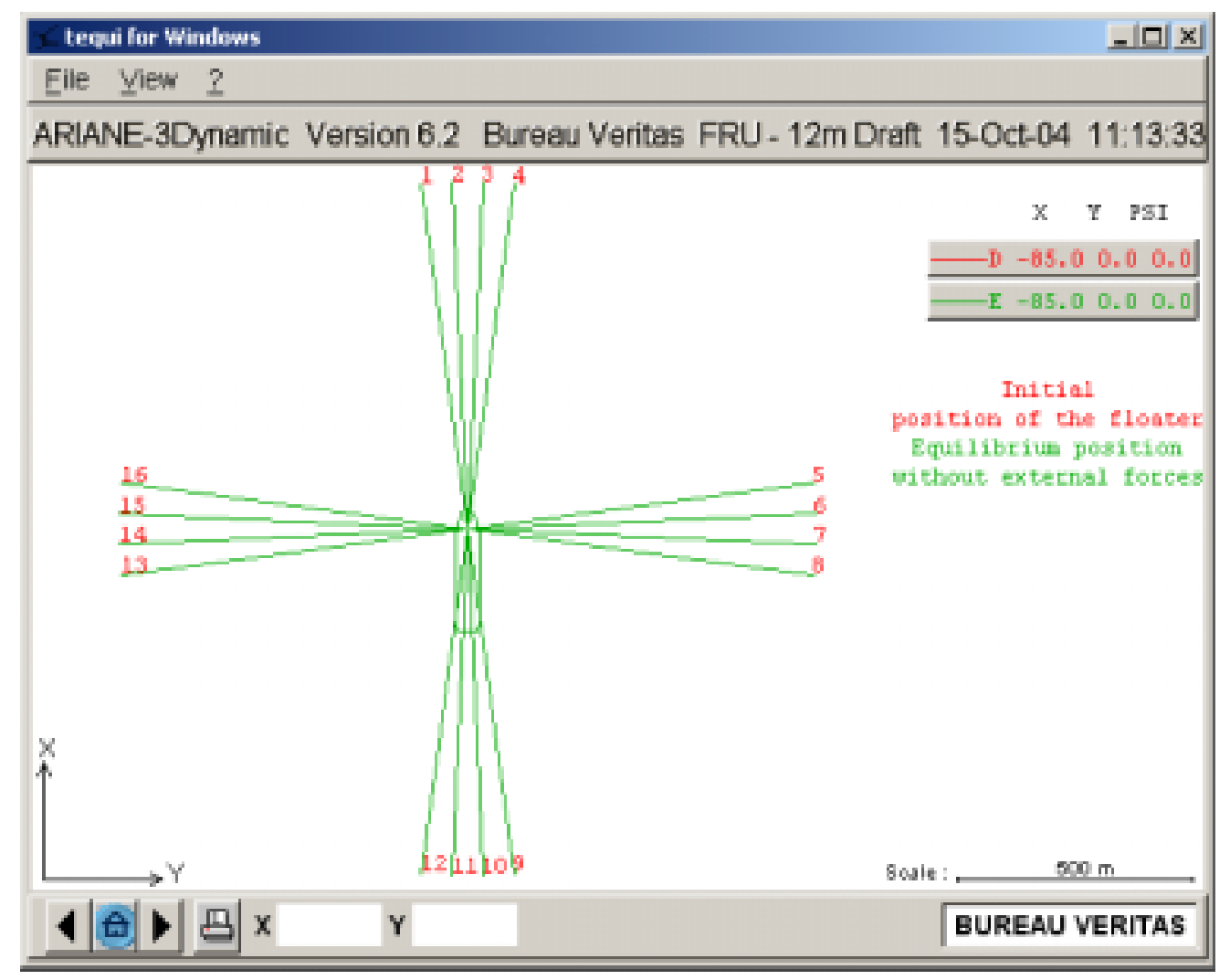

FIGURE 11-2 ANCHORING LEG CATENARY PROFILE

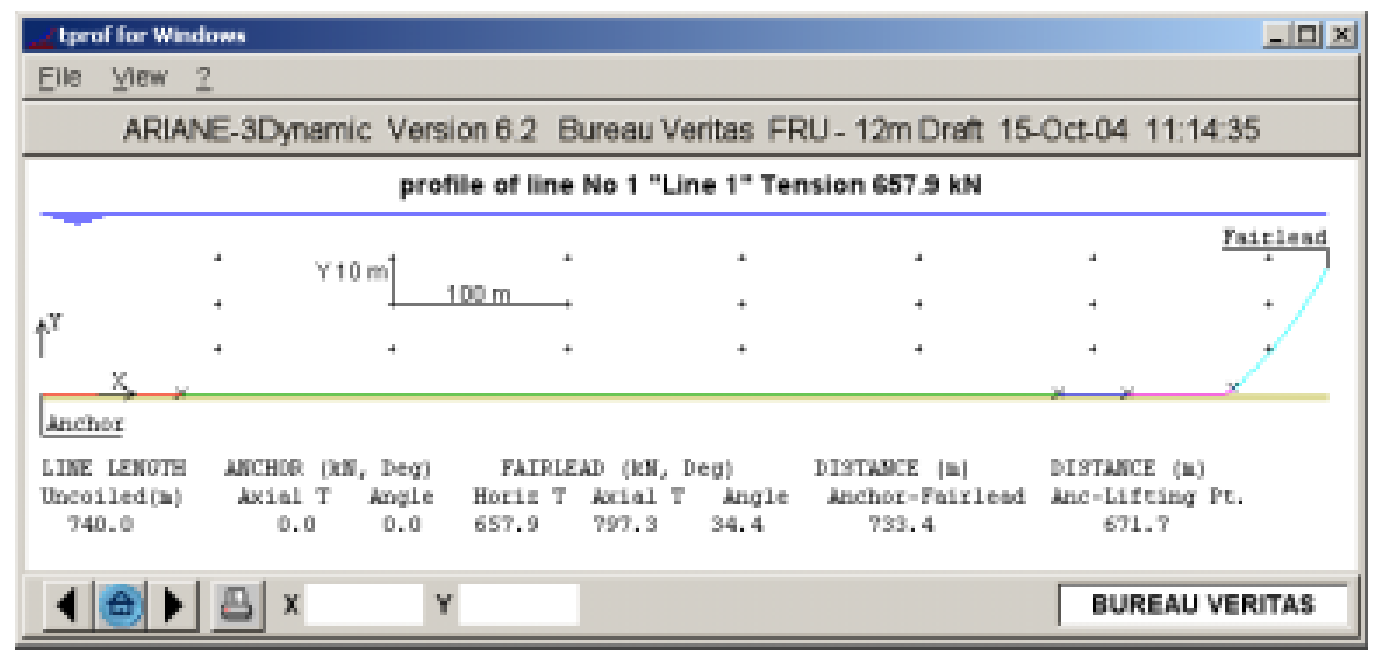




\begin{tabular}{|c|c|c|c|c|c|c|}
\hline \multirow[t]{3}{*}{ Imogen } & $\begin{array}{l}\text { SBM-IMODCO INC. } \\
\text { MEMBER OF THE } \\
\text { IHC/CALAND GROUP }\end{array}$ & \multicolumn{4}{|c|}{ FOR SALT CAVERN } & \\
\hline & \multirow[t]{2}{*}{ Now in our 5th Decade } & \multicolumn{5}{|c|}{ LNG RECEIVING AND RE-GASIFICATION } \\
\hline & & 51059 & CCM97001 & C1 & PAGE & 123 \\
\hline
\end{tabular}

\subsubsection{Mooring Analysis Results}

The same mooring analysis method has been applied. The following table documents the design mooring line tensions and anchor loads.

TABLE 11-2 MOORING LINE TENSIONS

\begin{tabular}{|c|c|c|}
\hline Condition & Intact & Damaged \\
\hline Max Tension at Fairlead $[\mathrm{kN}]$ & 11220 & 15008 \\
\hline Safety Factor & 1.68 & 1.26 \\
\hline API Requirement & 1.67 & 1.25 \\
\hline
\end{tabular}

The extreme turret offsets in the mooring intact and a single line damaged conditions are presented in the following table.

TABLE 11-3 TURRET OFFSET

\begin{tabular}{|c|c|c|}
\hline Condition & Intact & Damaged \\
\hline Max Offset $(\mathrm{m})$ & 8.9 & 10.5 \\
\hline \% of Water Depth & $22.3 \%$ & $26.3 \%$ \\
\hline
\end{tabular}

\subsubsection{Chain Fatigue}

The same approach as described in Section 8 is utilized and the computed fatigue life of mooring chain is:

Available Fatigue Life $=160$ Years

Service Life (assuming SF of 8$)=20$ Years. 


\begin{tabular}{|c|c|c|c|c|c|c|}
\hline \multirow[t]{3}{*}{ IMODCO } & \multirow[t]{3}{*}{$\begin{array}{l}\text { SBM-IMODCO INC. } \\
\text { MEMBER OF THE } \\
\text { IHC/CALAND GROUP } \\
\text { Now in our 5th Decade }\end{array}$} & \multirow{2}{*}{\multicolumn{5}{|c|}{$\begin{array}{l}\text { FLOATING RE-GASIFICATION UNIT } \\
\text { FOR SALT CAVERN } \\
\text { LNG RECEIVING AND RE-GASIFICATION }\end{array}$}} \\
\hline & & & & & & \\
\hline & & 51059 & ССМ97001 & C1 & PAGE & 124 \\
\hline
\end{tabular}

The above fatigue calculation shows that the service life meets the requirement of design life (20 years). It should be noted that the approach adopted for fatigue calculation is very conservative and actual fatigue life should be longer. Therefore it is concluded that the mooring chain fatigue design is adequate. It is noted that for the wire of the same breaking load subject to the same fatigue loading, its fatigue life is far superior to the chain.

\subsection{RISER IMPACT}

\subsubsection{Riser Configuration}

For the reduced water depth, the riser configuration is also revised and analyzed according to the offset and motions of the FRU.

The riser connects from a sub-sea PLEM to the underneath of the FRU turret column. The termination at the FRU end is byl-tube. A steep wave riser configuration with distributed buoyancy modules and clumped weights has been chosen:

- Total Length $=80 \mathrm{~m}$ comprising from hang-off at FRU:

- $40 \mathrm{~m}$ bare riser (two clumped weights are used at 12 and $17 \mathrm{~m}$ from hang-off, each of them weighing $943 \mathrm{~kg}$ )

- $8 \mathrm{~m}$ distributed buoyancy modules

- $5 \mathrm{~m}$ bare riser

- $17 \mathrm{~m}$ distributed buoyancy modules

- $10 \mathrm{~m}$ bare riser

- Horizontal Distance to PLEM flange from hang-off $=61 \mathrm{~m}$ 


\begin{tabular}{|c|c|c|c|c|c|c|}
\hline \multirow[t]{3}{*}{ IMODE0 } & $\begin{array}{l}\text { SBM-IMODCO INC. } \\
\text { MEMBER OF THE } \\
\text { IHC/CALAND GROUP }\end{array}$ & \multirow{2}{*}{\multicolumn{5}{|c|}{$\begin{array}{l}\text { FLOATING RE-GASIFICATION UNIT } \\
\text { FOR SALT CAVERN } \\
\text { NG RECEIVING AND RE-GASIFICATION }\end{array}$}} \\
\hline & \multirow[t]{2}{*}{ Now in our 5th Decade } & & & & & \\
\hline & & 51059 & CCM97001 & C1 & PAGE & 125 \\
\hline
\end{tabular}

FIGURE 11-3 RISER NOMINAL POSITION

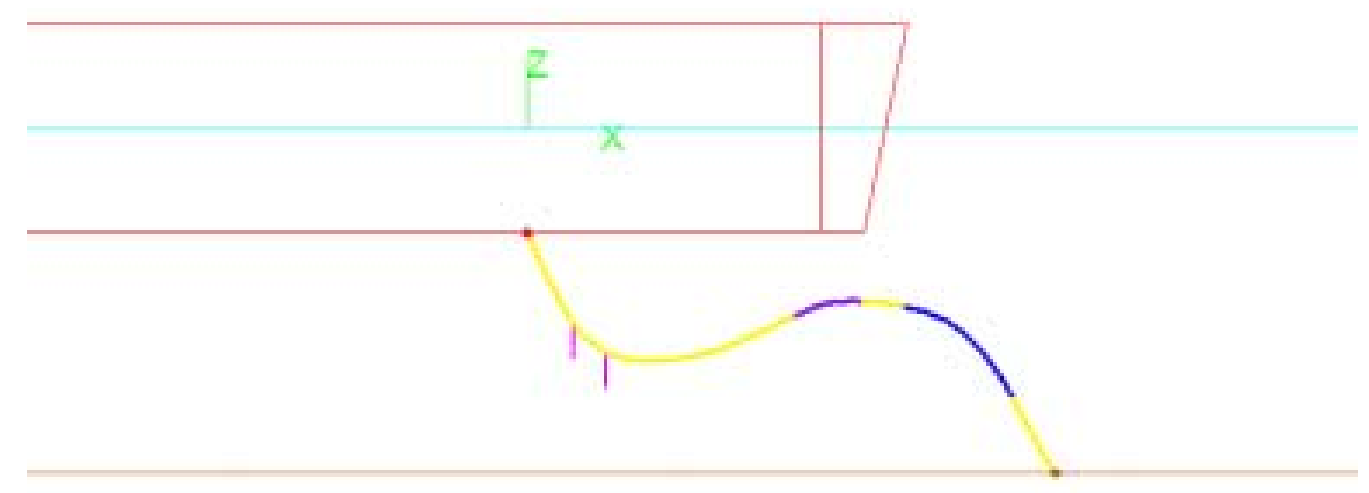

FIGURE 11-3 RISER DYNAMIC RESPONSE IN NEAR POSITION 


\begin{tabular}{|c|c|c|c|c|c|c|}
\hline \multirow[t]{3}{*}{ ImoOCO } & \multirow{3}{*}{$\begin{array}{l}\text { SBM-IMODCO INC. } \\
\text { MEMBER OF THE } \\
\text { IHC/CALAND GROUP } \\
\text { Now in our 5th Decade }\end{array}$} & \multirow{2}{*}{\multicolumn{5}{|c|}{$\begin{array}{l}\text { FLOATING RE-GASIFICATION UNIT } \\
\text { FOR SALT CAVERN } \\
\text {-NG RECEIVING AND RE-GASIFICATION }\end{array}$}} \\
\hline & & & & & & \\
\hline & & 51059 & CCM97001 & C1 & PAGE & 126 \\
\hline
\end{tabular}

FIGURE 11-4 RISER DYNAMIC RESPONSE IN FAR POSITION

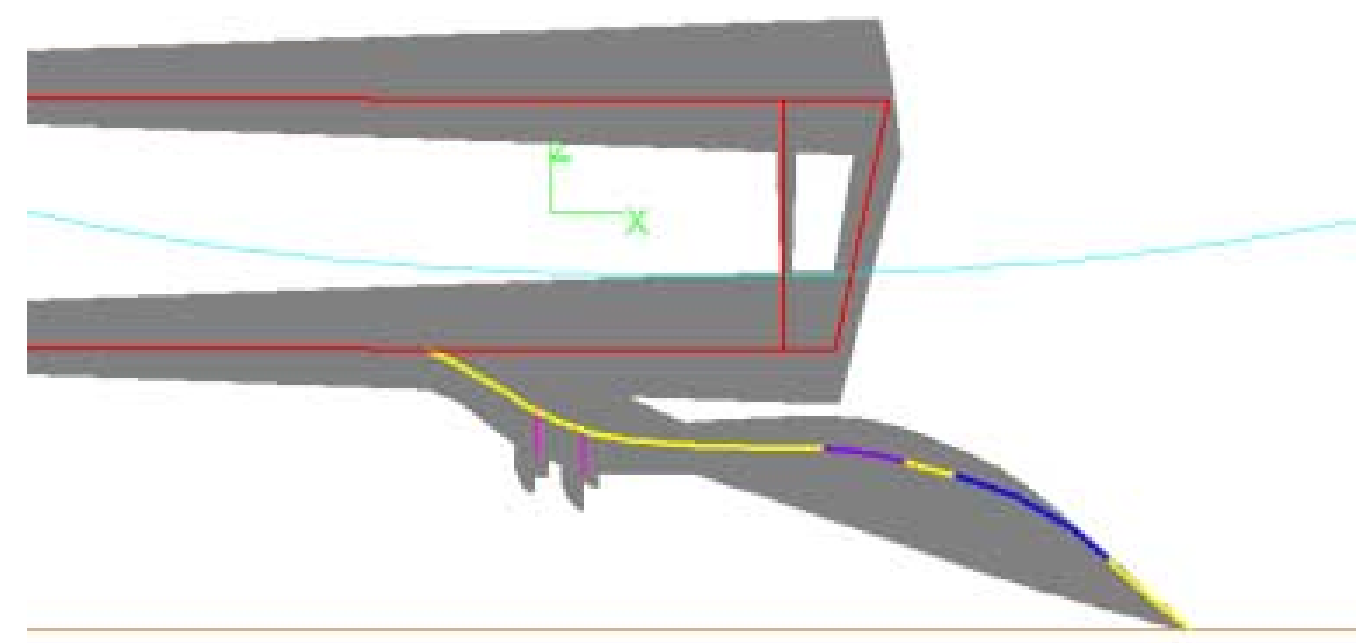

\subsubsection{Riser Analysis Results}

The same riser analysis techniques have been applied and the results are presented in the following tables:

\begin{tabular}{|c|c|c|c|c|c|c|c|}
\hline \multicolumn{8}{|c|}{ TABLE 11-4 - IN-PLANE RISER ANALYSIS } \\
\hline \multirow{2}{*}{$\begin{array}{l}\text { Load } \\
\text { Case }\end{array}$} & \multirow{2}{*}{$\begin{array}{l}\text { Hangoff } \\
\text { position }\end{array}$} & \multirow{2}{*}{$\begin{array}{l}\text { Content } \\
\text { Pressur } \\
\text { e [kPa] }\end{array}$} & \multicolumn{3}{|c|}{ Tension [kN] } & \multicolumn{2}{|c|}{ Curvature [rad/m] } \\
\hline & & & Min & Max & Allowable & Max & Allowable \\
\hline \multicolumn{8}{|c|}{ STATIC - INLINE } \\
\hline & \multirow{2}{*}{ Nominal } & 6895 & 9 & 25 & 6030 & 0.13 & 0.2012 \\
\hline & & 13789 & 9 & 29 & 6030 & 0.12 & 0.2012 \\
\hline \multirow{4}{*}{ Intact } & \multirow{2}{*}{ Far } & 6895 & 27 & 39 & 6030 & 0.072 & 0.2012 \\
\hline & & 13789 & 28 & 43 & 6030 & 0.07 & 0.2012 \\
\hline & \multirow{2}{*}{ Near } & 6895 & 5 & 24 & 6030 & 0.135 & 0.2012 \\
\hline & & 13789 & 5 & 28 & 6030 & 0.125 & 0.2012 \\
\hline \multirow{4}{*}{ Damaged } & \multirow{2}{*}{ Far } & 6895 & 34 & 45 & 6030 & 0.062 & 0.2417 \\
\hline & & 13789 & 35 & 49 & 6030 & 0.061 & 0.2417 \\
\hline & \multirow{2}{*}{ Near } & 6895 & 5 & 24 & 6030 & 0.135 & 0.2417 \\
\hline & & 13789 & 4 & 27 & 6030 & 0.13 & 0.2417 \\
\hline
\end{tabular}




\begin{tabular}{|c|c|c|c|c|c|c|}
\hline \multirow[t]{3}{*}{ IMOOF0 } & $\begin{array}{l}\text { SBM-IMODCO INC. } \\
\text { MEMBER OF THE } \\
\text { IHCICALAND GROUP }\end{array}$ & \multirow{2}{*}{\multicolumn{5}{|c|}{$\begin{array}{l}\text { FLOATING RE-GASIFICATION UNIT } \\
\text { FOR SALT CAVERN } \\
\text { LNG RECEIVING AND RE-GASIFICATION }\end{array}$}} \\
\hline & \multirow[t]{2}{*}{ Now in our 5th Decade } & & & & & \\
\hline & & 51059 & CCM97001 & C1 & PAGE & 127 \\
\hline
\end{tabular}

\begin{tabular}{|c|c|c|c|c|c|c|c|}
\hline \multicolumn{8}{|c|}{ TABLE 11-4 - IN-PLANE RISER ANALYSIS } \\
\hline \multirow{2}{*}{$\begin{array}{l}\text { Load } \\
\text { Case }\end{array}$} & \multirow{2}{*}{$\begin{array}{l}\text { Hangoff } \\
\text { position }\end{array}$} & \multirow{2}{*}{$\begin{array}{l}\text { Content } \\
\text { Pressur } \\
\mathrm{e}[\mathrm{kPa}]\end{array}$} & \multicolumn{3}{|c|}{ Tension [kN] } & \multicolumn{2}{|c|}{ Curvature [rad/m] } \\
\hline & & & Min & Max & Allowable & Max & Allowable \\
\hline \multicolumn{8}{|c|}{ DYNAMIC - INLINE } \\
\hline \multirow{4}{*}{ Intact } & \multirow{2}{*}{ Far } & 6895 & 0 & 430 & 6030 & 0.118 & 0.2012 \\
\hline & & 13789 & 0 & 560 & 6030 & 0.11 & 0.2012 \\
\hline & \multirow{2}{*}{ Near } & 6895 & -4 & 53 & 6030 & 0.19 & 0.2012 \\
\hline & & 13789 & -2 & 47 & 6030 & 0.2 & 0.2012 \\
\hline \multirow{4}{*}{ Damaged } & \multirow{2}{*}{ Far } & 6895 & -64 & 1328 & 6030 & 0.095 & 0.2417 \\
\hline & & 13789 & -50 & 1400 & 6030 & 0.09 & 0.2417 \\
\hline & \multirow{2}{*}{ Near } & 6895 & -5 & 51 & 6030 & 0.19 & 0.2417 \\
\hline & & 13789 & -3 & 45 & 6030 & 0.2 & 0.2417 \\
\hline
\end{tabular}

Minimum and maximum effective tension and maximum riser curvature for the transverse condition are listed in the following table:

TABLE 11-5 - RISER STATIC ANALYSIS, TRANSVERSE DIRECTION

\begin{tabular}{|c|c|c|c|c|c|c|c|}
\hline \multirow{2}{*}{$\begin{array}{l}\text { Load } \\
\text { Case }\end{array}$} & \multirow{2}{*}{$\begin{array}{l}\text { Hangoff } \\
\text { position }\end{array}$} & \multirow{2}{*}{$\begin{array}{l}\text { Content } \\
\text { Pressur } \\
\mathrm{e}[\mathrm{kPa}]\end{array}$} & \multicolumn{3}{|c|}{ Tension [kN] } & \multicolumn{2}{|c|}{ Curvature $[\mathrm{rad} / \mathrm{m}]$} \\
\hline & & & Min & Max & Allowable & Max & Allowable \\
\hline \multicolumn{8}{|c|}{ STATIC - CROSS } \\
\hline \multirow{2}{*}{ Intact } & Trans & 6895 & 15 & 29 & 6030 & 0.1 & 0.2012 \\
\hline & Trans & 13789 & 15 & 32 & 6030 & 0.095 & 0.2012 \\
\hline \multirow{2}{*}{ Damaged } & Trans & 6895 & 15 & 29 & 6030 & 0.1 & 0.2417 \\
\hline & Trans & 13789 & 15 & 32 & 6030 & 0.095 & 0.2417 \\
\hline \multicolumn{8}{|c|}{ DYNAMIC - CROSS } \\
\hline \multirow{2}{*}{ Intact } & Trans & 6895 & -5 & 185 & 6030 & 0.125 & 0.2012 \\
\hline & Trans & 13789 & -5 & 185 & 6030 & 0.12 & 0.2012 \\
\hline \multirow{2}{*}{ Damaged } & Trans & 6895 & -4 & 185 & 6030 & 0.125 & 0.2417 \\
\hline & Trans & 13789 & -5 & 185 & 6030 & 0.12 & 0.2417 \\
\hline
\end{tabular}

Riser effective tension and curvature are within allowable limits.

\subsubsection{Riser Performance Conclusion}

The proposed steep wave configuration meets the design requirements in terms of maximum effective tension, minimum bend radius, vessel and seabed clearance in $40 \mathrm{~m}$ water depth. 


\begin{tabular}{|c|c|c|c|c|c|c|}
\hline \multirow[t]{3}{*}{ Imogen } & $\begin{array}{l}\text { SBM-IMODCO INC. } \\
\text { MEMBER OF THE } \\
\text { IHC/CALAND GROUP }\end{array}$ & \multicolumn{4}{|c|}{ FOR SALT CAVERN } & \\
\hline & \multirow[t]{2}{*}{ Now in our 5th Decade } & \multicolumn{5}{|c|}{ LNG RECEIVING AND RE-GASIFICATION } \\
\hline & & 51059 & CCM97001 & C1 & PAGE & 128 \\
\hline
\end{tabular}

\subsection{WATER DEPTH BELOW 40M}

The above sensitivity analysis demonstartes the feasibility of the FRU in water depths as shallow as $40 \mathrm{~m}$. If the water depth is further reduced to $20 \mathrm{~m}$, it is expected that the conventional catenary mooring system will experience difficulties in performing the stationkeeping function. In such a case, the disconnectable soft yoke system can be applied. Past project experience shows that the system can remain connected up to a significant wave height of 5 or $6 \mathrm{~m}$. In the 100 year hurricane condition, the FRU will be disconnected and sail away. The soft yoke system also has the advantage of being able to support simple riser configuration and potentially serve as the wellhead platform for hosting the manifolds and metering system.

\section{FIGURE 11-5 ARTISTIC ILLUSTRATION OF SOFT YORK STATION KEEPING SYSTEM}

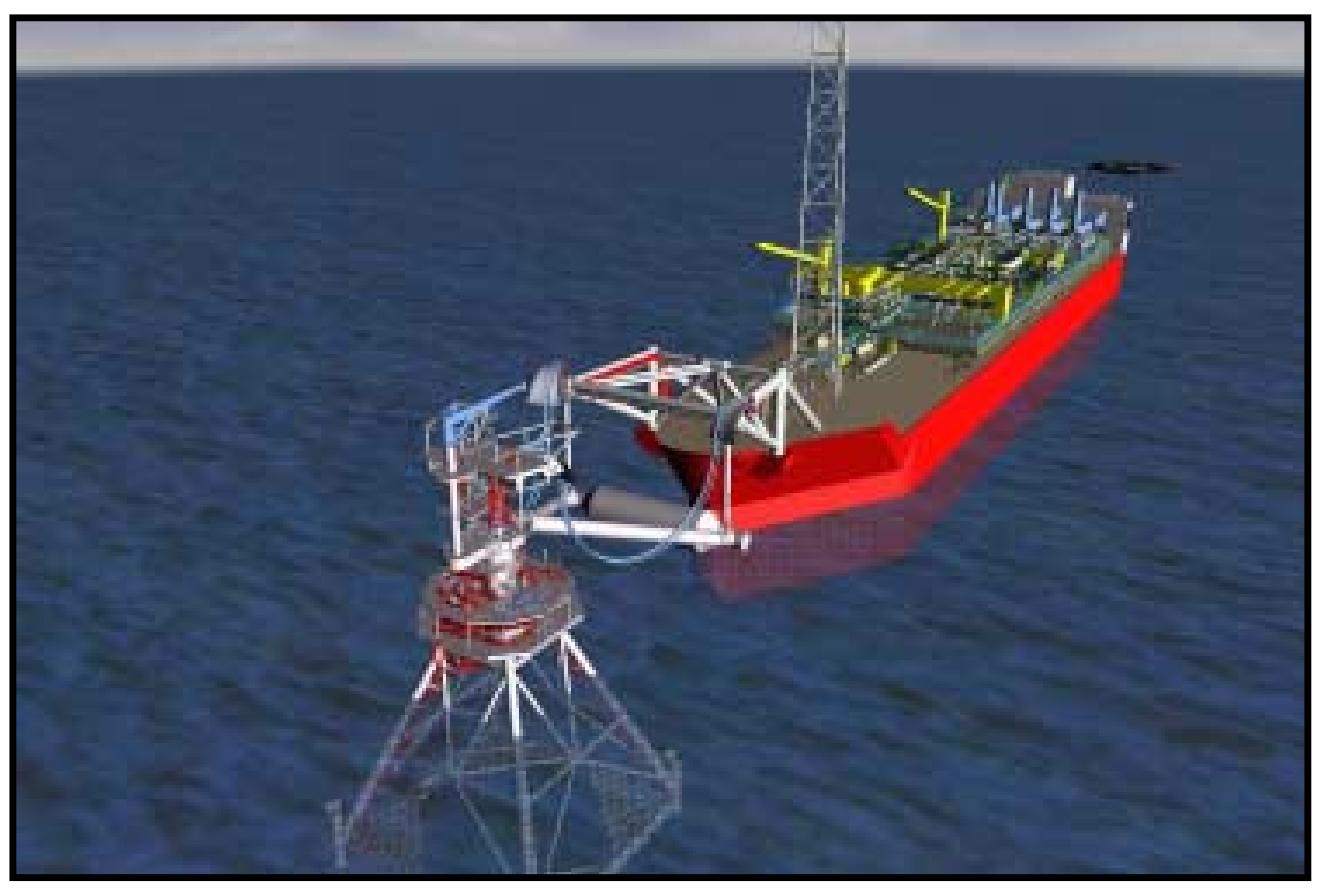

\subsection{FRU TRANSIENT RESPONSE INSIDE HURRICANE EYE}

The FRU response analyses conducted so far are based on the assumption that the seastates are stationary. The transient response of the FRU inside a hurricane eye is outside the scope of the present study. However, a separate internal study of such responses have been conducted by SBMI and the main conclusions are: 


\begin{tabular}{|c|c|c|c|c|c|c|}
\hline \multirow[t]{3}{*}{ IMODCo } & \multirow[t]{3}{*}{$\begin{array}{l}\text { SBM-IMODCO INC. } \\
\text { MEMBER OF THE } \\
\text { IHC/CALAND GROUP } \\
\text { Now in our 5th Decade }\end{array}$} & \multirow{2}{*}{\multicolumn{5}{|c|}{$\begin{array}{l}\text { FLOATING RE-GASIFICATION UNIT } \\
\text { FOR SALT CAVERN } \\
\text { LNG RECEIVING AND RE-GASIFICATION }\end{array}$}} \\
\hline & & & & & & \\
\hline & & 51059 & ССМ97001 & C1 & PAGE & 129 \\
\hline
\end{tabular}

- In the unlikely event of a category five hurricane passing over a turret moored FPSO (or FRU). Despite the fact that the wind direction changes for about $180^{\circ}$ in only two hours in the path of the hurricane, higher mooring line tension has not been observed in the eye of the hurricane, due to reduced wind speed.

- Instead, the extreme mooring line tension design is still governed by the responses caused by hurricane fringe because that location is characterized by higher wind speed and wave height than inside the eye of the hurricane.

- During the rapid change in wind direction, vessel can potentially be exposed to beam sea waves. Although this does not correspond to the highest tension in mooring legs, it can lead to the green water impact. However, the FRU has fixed draft and a constant freeboard of $12 \mathrm{~m}$. Although further study of the subject is required, the green water impact is not expected to be significant.

The study therefore concludes that the FRU mooring system can withstand the transient environment of a GOM hurricane. 


\begin{tabular}{|c|c|c|c|c|c|c|}
\hline \multirow[t]{3}{*}{ ImoOCO } & \multirow{3}{*}{$\begin{array}{l}\text { SBM-IMODCO INC. } \\
\text { MEMBER OF THE } \\
\text { IHC/CALAND GROUP } \\
\text { Now in our 5th Decade }\end{array}$} & \multirow{2}{*}{\multicolumn{5}{|c|}{$\begin{array}{l}\text { FLOATING RE-GASIFICATION UNIT } \\
\text { FOR SALT CAVERN } \\
\text {-NG RECEIVING AND RE-GASIFICATION }\end{array}$}} \\
\hline & & & & & & \\
\hline & & 51059 & CCM97001 & C1 & PAGE & 130 \\
\hline
\end{tabular}

\section{DOWMTIME ASSESSMENT}

\subsection{GENERAL}

The downtime of the FRU is determined by the limiting environments for the LNG carrier to berth to the FRU and stay connected for the offloading operation. The FRU and LNG carrier side-by-side offloading analysis has been conducted and the results reported in Section 10 in Tables 10-5 to 10-7. It can be seen that the limiting seastates are around $2.5 \mathrm{~m}$ to $3.0 \mathrm{~m}$ significant wave heights depending on wave period.

The berthing analysis has been addressed in a separate SBM internal study.

\subsection{OFFLOADING LIMITS}

Based on the results of the offloading analysis, the operable environmental conditions (significant wave heights) can be summarized in the following table:

TABLE 12-1 LIMITING ENVIRONMENTAL CONDITIONS FOR MOORING

\begin{tabular}{|c|c|c|c|c|c|c|}
\hline Wave period (s) & 6.0 & 7.0 & 8.0 & 9.0 & 10.0 & 11.0 \\
\hline Colinear & 2.5 & 2.5 & 2.5 & 3.0 & 3.0 & 3.0 \\
\hline Cross 1 & 3.0 & 3.0 & 3.0 & 2.5 & 2.5 & 2.5 \\
\hline Cross 2 & 3.5 & 3.0 & 3.0 & 3.0 & 3.5 & 3.0 \\
\hline Average & 3.0 & 3.0 & 3.0 & 3.0 & 3.0 & 3.0 \\
\hline
\end{tabular}

It can be seen that the limiting environmental conditions for side by side offloading are close for the collinear, cross 1 and cross 2 conditions. The collinear condition is used for estimating the system uptime.

\subsection{LNG BERTHING LIMITS}

LNG berthing analysis has not been conducted within the present study. However, SBM has separately commissioned a study of LNG maneuvering during berthing operation. The study assumes: 


\begin{tabular}{|c|c|c|c|c|c|c|}
\hline \multirow[t]{3}{*}{ IMOOE0 } & \multirow[t]{3}{*}{$\begin{array}{l}\text { SBM-IMODCO INC. } \\
\text { MEMBER OF THE } \\
\text { IHCICALAND GROUP } \\
\text { Now in our 5th Decade }\end{array}$} & \multirow{2}{*}{\multicolumn{5}{|c|}{$\begin{array}{l}\text { FLOATING RE-GASIFICATION UNIT } \\
\text { FOR SALT CAVERN } \\
\text { LNG RECEIVING AND RE-GASIFICATION }\end{array}$}} \\
\hline & & & & & & \\
\hline & & 51059 & ССМ97001 & C1 & PAGE & 131 \\
\hline
\end{tabular}

- The LNG carrier approaches the FRU from starboard;

- The LNG carrier uses its own propulsion;

- The FRU can use its stern thrusters to assist the berthing operation.

Based on the separate berthing analysis, the analysis has shown that the limiting environmental conditions for berthing are:

TABLE 12-2 LIMITING ENVIRONMENTAL CONDITIONS FOR BERTHING

\begin{tabular}{|l|c|c|c|c|}
\hline $\operatorname{Tp}(\mathrm{sec})$ & 6.3 & 9.2 & 12.0 & 14.8 \\
\hline Limiting Hs $(\mathrm{m})$ & 4.0 & 3.9 & 2.2 & 2.2 \\
\hline
\end{tabular}

\subsection{UPTIME}

The wave scatter diagram is presented in Table 4-2 of Section 4. Based on the limiting criteria for berthing and side by side mooring, the uptime can be computed. The following table shows the areas when the offloading operation can be safely conducted.

Combined with the wave scatter diagram, it can be computed that the uptime is $98.3 \%$, which is greater than $98 \%$. 


\begin{tabular}{|c|c|c|c|c|c|c|}
\hline \multirow[t]{2}{*}{ IMODE0 } & $\begin{array}{l}\text { SBM-IMODCO INC. } \\
\text { MEMBER OF THE } \\
\text { IHC/CALAND GROUP } \\
\text { Now in our 5th Decade }\end{array}$ & \multicolumn{5}{|c|}{$\begin{array}{l}\text { FLOATING RE-GASIFICATION UNIT } \\
\text { FOR SALT CAVERN } \\
\text { LNG RECEIVING AND RE-GASIFICATION }\end{array}$} \\
\hline & & 51059 & ССМ97001 & C1 & PAGE & 132 \\
\hline
\end{tabular}

TABLE 12-3 DOWNTIME ASSESSMENT

Red cells are non-operable for mooring and berthing

Blue cells are non-operable for mooring only

Yellow cells are non-operable for berthing only

\begin{tabular}{|c|c|c|c|c|c|c|c|c|c|c|c|c|c|c|c|c|c|c|}
\hline \multicolumn{3}{|l|}{$\mathrm{Hs}$} & \multicolumn{16}{|c|}{$\mathrm{Tp}(\mathrm{s})$} \\
\hline \multicolumn{3}{|l|}{$(\mathrm{m})$} & $0-1$ & $1-2$ & $2-3$ & $3-4$ & $4-5$ & $5-6$ & $6-7$ & $7-8$ & $8-9$ & $9-10$ & $10-11$ & $11-12$ & $12-13$ & $13-14$ & $>=14$ & SUM \\
\hline 0.0 & - & 0.5 & 0.00 & 0.00 & 0.67 & 5.77 & 5.06 & 3.51 & 0.47 & 0.28 & 0.00 & 0.00 & 0.00 & 0.00 & 0.00 & 0.00 & 0.00 & 15.77 \\
\hline 0.5 & - & 1.0 & 0.00 & 0.00 & 0.00 & 5.53 & 16.21 & 13.84 & 5.50 & 0.97 & 0.18 & 0.02 & 0.00 & 0.01 & 0.00 & 0.00 & 0.00 & 42.26 \\
\hline 1.0 & - & 1.5 & 0.00 & 0.00 & 0.00 & 0.07 & 3.83 & 12.59 & 4.71 & 2.32 & 0.32 & 0.01 & 0.02 & 0.00 & 0.00 & 0.01 & 0.00 & 23.88 \\
\hline 1.5 & - & 2.0 & 0.00 & 0.00 & 0.00 & 0.00 & 0.04 & 4.54 & 5.14 & 1.43 & 0.36 & 0.04 & 0.01 & 0.01 & 0.00 & 0.01 & 0.00 & 11.59 \\
\hline 2.0 & - & 2.5 & 0.00 & 0.00 & 0.00 & 0.00 & 0.00 & 0.08 & 2.65 & 1.45 & 0.20 & 0.06 & 0.01 & 0.00 & 0.00 & 0.01 & 0.00 & 4.45 \\
\hline 2.5 & - & 3.0 & 0.00 & 0.00 & 0.00 & 0.00 & 0.00 & 0.00 & 0.32 & 0.79 & 0.31 & 0.03 & 0.00 & 0.00 & 0.00 & 0.00 & 0.00 & 1.45 \\
\hline 3.0 & - & 3.5 & 0.00 & 0.00 & 0.00 & 0.00 & 0.00 & 0.00 & 0.02 & 0.11 & 0.24 & 0.02 & 0.00 & 0.00 & 0.00 & 0.00 & 0.00 & 0.39 \\
\hline 3.5 & - & 4.0 & 0.00 & 0.00 & 0.00 & 0.00 & 0.00 & 0.00 & 0.00 & 0.01 & 0.07 & 0.06 & 0.00 & 0.00 & 0.00 & 0.01 & 0.00 & 0.15 \\
\hline 4.0 & - & 4.5 & 0.00 & 0.00 & 0.00 & 0.00 & 0.00 & 0.00 & 0.00 & 0.01 & 0.02 & 0.00 & 0.00 & 0.00 & 0.00 & 0.00 & 0.00 & 0.03 \\
\hline 4.5 & & 5.0 & 0.00 & 0.00 & 0.00 & 0.00 & 0.00 & 0.00 & 0.00 & 0.00 & 0.01 & 0.00 & 0.00 & 0.00 & 0.00 & 0.00 & 0.00 & 0.01 \\
\hline 5.0 & & 5.5 & 0.00 & 0.00 & 0.00 & 0.00 & 0.00 & 0.00 & 0.00 & 0.00 & 0.00 & 0.00 & 0.00 & 0.00 & 0.00 & 0.00 & 0.00 & 0.00 \\
\hline \multirow[t]{2}{*}{5.5} & & 6.0 & 0.00 & 0.00 & 0.00 & 0.00 & 0.00 & 0.00 & 0.00 & 0.00 & 0.00 & 0.00 & 0.00 & 0.00 & 0.00 & 0.00 & 0.00 & 0.00 \\
\hline & & 6.0 & 0.00 & 0.00 & 0.00 & 0.00 & 0.00 & 0.00 & 0.00 & 0.00 & 0.00 & 0.00 & 0.00 & 0.00 & 0.00 & 0.00 & 0.00 & 0.00 \\
\hline \multicolumn{3}{|l|}{ SUM } & 0.00 & 0.00 & 0.67 & 11.38 & 25.14 & 34.57 & 18.81 & 7.38 & 1.71 & 0.24 & 0.05 & 0.01 & 0.00 & 0.05 & 0.00 & 100.00 \\
\hline
\end{tabular}




\begin{tabular}{|c|c|c|c|c|c|c|}
\hline \multirow[t]{3}{*}{ ImoOCo } & \multirow{3}{*}{$\begin{array}{l}\text { SBM-IMODCO INC. } \\
\text { MEMBER OF THE } \\
\text { IHC/CALAND GROUP } \\
\text { Now in our } 5 \text { th Decade }\end{array}$} & \multirow{2}{*}{\multicolumn{5}{|c|}{$\begin{array}{l}\text { FLOATING RE-GASIFICATION UNIT } \\
\text { FOR SALT CAVERN } \\
\text { LNG RECEIVING AND RE-GASIFICATION }\end{array}$}} \\
\hline & & & & & & \\
\hline & & 51059 & CCM97001 & C1 & PAGE & 133 \\
\hline
\end{tabular}

\section{DEVELOPMENT SCHEDULEESTIMATES}

The FRU development schedule from project sanction to ready for operation has also been estimated. The estimation was based on SBM's past project execution experience of FPSOs, FSOs and FGSO. Key milestones are summarized below. 


\begin{tabular}{|c|c|c|c|c|c|c|}
\hline $\begin{array}{l}\text { Hitl } \\
\text { Imoge0 }\end{array}$ & $\begin{array}{l}\text { SBM-IMODCO INC. } \\
\text { MEMBER OF THE IHC/CALAND GROUP } \\
\text { Now in our } 5 \text { th Decade }\end{array}$ & \multicolumn{5}{|c|}{$\begin{array}{l}\text { FLOATING RE-GASIFICATION UNIT } \\
\text { FOR SALT CAVERN } \\
\text { LNG RECEIVING AND RE-GASIFICATION }\end{array}$} \\
\hline & & 51059 & ССM97001 & C1 & PAGE & 134 \\
\hline
\end{tabular}

FRU DEVELOPMENT SCHEDULE MILESTONES

Preliminary Level 1 Schedule

\begin{tabular}{|c|c|c|c|c|c|c|c|c|c|c|c|c|c|c|c|c|c|c|c|c|}
\hline & ID Task Name & -1 & 1 & 2 & 3 & 4 & 5 & 6 & 7 & 8 & 9 & 10 & 11 & 12 & 13 & 14 & 15 & 16 & 17 & 18 \\
\hline 1 & Contract Award & + & & & & & & & & & & & & & & & & & & \\
\hline 2 & Field Data Available & 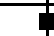 & & & & & & & & & & & & & & & & & & \\
\hline 3 & Engineering & & (a & & & & & & & & & & & & & & & & & \\
\hline 4 & Award to Fabrication Subcontract & & & & T & & & & & & & & & & & & & & & \\
\hline 5 & POs for Long Lead Equipment & & & & I & & & & & & & & & & & & & & & \\
\hline 6 & Start of Topsides Facilities Fabrication - Structural & & & & & & t & & & & & & & & & & & & & \\
\hline 7 & Award to Vessel Refurbishment / Conversion Subcontract & & & & & & & & + & & & & & & & & & & & \\
\hline 8 & Commence Equipment Testing and Commissioning & & & & & & & & & & & [ & & & & & & & & \\
\hline 9 & Complete Structural Steel Repairs & & & & & & & & & & & (a & & & & & & & & \\
\hline 10 & Modules Arrive from Module Yards & & & & & & & & & & & & $\mathbf{a}$ & & & & & & & \\
\hline 11 & First Topsides Module Lift to Vessel & & & & & & & & & & & & $\mathbf{\square}$ & & & & & & & \\
\hline 12 & Turret Loadout at Turret Yard & & & & & & & & & & & & 里 & & & & & & & \\
\hline 13 & Turret Delivered to Shipyard & & & & & & & & & & & & & + & $t$ & & & & & \\
\hline 14 & Final Topsides Module Lift to Vessel & & & & & & & & & & & & & & + & & & & & \\
\hline 15 & Complete Turret Installation into Vessel & & & & & & & & & & & & & & 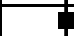 & & & & & \\
\hline 16 & Mobilize Installation Spread for Mooring Installation & & & & & & & & & & & & & & & & $t$ & 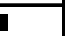 & & \\
\hline 17 & FRU Departs Shipyard for GOM & & & & & & & & & & & & & & & & & 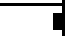 & & \\
\hline 18 & FRU Arrival and Start of Installation and Riser Hook-up & & & & & & & & & & & & & & & & & & 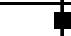 & \\
\hline 19 & FRU Ready to received First Oil & & & & & & & & & & & & & & & & & & & E \\
\hline
\end{tabular}




\begin{tabular}{|c|c|c|c|c|c|c|}
\hline \multirow[t]{3}{*}{ IMOOF0 } & $\begin{array}{l}\text { SBM-IMODCO INC. } \\
\text { MEMBER OF THE } \\
\text { IHCICALAND GROUP }\end{array}$ & \multirow{2}{*}{\multicolumn{5}{|c|}{$\begin{array}{l}\text { FLOATING RE-GASIFICATION UNIT } \\
\text { FOR SALT CAVERN } \\
\text { LNG RECEIVING AND RE-GASIFICATION }\end{array}$}} \\
\hline & \multirow[t]{2}{*}{ Now in our 5th Decade } & & & & & \\
\hline & & 51059 & CCM97001 & C1 & PAGE & 135 \\
\hline
\end{tabular}

\section{KEY CONCLUSIONS}

The following key conclusions can be drawn from the present FRU development study:

- $\quad$ The FRU is a feasible LNG receiving, re-gasification and import terminal concept built around proven technologies of vessel, turret, offloading, mooring and risers.

- $\quad$ The FRU offers many attractive features such as ample deck space, suitability for a wide range of water depth, proven mooring/ offloading operations, etc.

- The conventional mooring system is able to perform the stationkeeping function from water depths of $40 \mathrm{~m}$ upwards. For shallower water depths, a soft yoke concept can be applied.

- $\quad$ The FRU conversion from existing trading tankers is a cost effective solution.

- $\quad$ The FRU concept offers a fast development schedule of about eighteen (18) to twenty two (22) months. 


\begin{tabular}{|c|c|c|c|c|c|c|}
\hline \multirow[t]{3}{*}{ IMOOE0 } & \multirow[t]{3}{*}{$\begin{array}{l}\text { SBM-IMODCO INC. } \\
\text { MEMBER OF THE } \\
\text { IHCICALAND GROUP } \\
\text { Now in our 5th Decade }\end{array}$} & \multirow{2}{*}{\multicolumn{5}{|c|}{$\begin{array}{l}\text { FLOATING RE-GASIFICATION UNIT } \\
\text { FOR SALT CAVERN } \\
\text { LNG RECEIVING AND RE-GASIFICATION }\end{array}$}} \\
\hline & & & & & & \\
\hline & & 51059 & ССМ97001 & C1 & PAGE & 136 \\
\hline
\end{tabular}

\section{REFERENCES}

1. Michael M. Mccall, William M. Bishop, D. Braxton Scherz, "Examine And Evaluate A Process To Use Salt Caverns To Receive Ship Borne Liquefied Natural Gas", Final Report, June 10, 2003.

2. SALT CAVERNS and THE BISHOP PROCESS; Paragon presentation given on OMAE conference; June, 2004

3. Vermillion 179 Overview; Paragon presentation given at salt cavern JIP meeting; March 30, 2004

4. ABS Guide For Building and Classing Floating Production Installations, 2000 (FPI Guide).

5. RP 2SK - Recommended Practices For Design and Analysis of Stationkeeping Systems for Floating Structures.

6. RP 17B - Recommended Practice for Flexible Risers.

7. API RP 2A - WSD, 21st Edition, Recommended Practice for Planning, Designing and Constructing Fixed Offshore Platforms - Working Stress Design, December 2000.

8. Bureau Veritas, "ARIANE Theory and User Manual".

9. Ocina, "Orcaflex User Manual".

10. Century Dynamics, "AQWA User Reference Manual". 


\begin{tabular}{|c|c|c|c|c|c|c|}
\hline \multirow[t]{3}{*}{ ImoOCO } & \multirow{3}{*}{$\begin{array}{l}\text { SBM-IMODCO INC. } \\
\text { MEMBER OF THE } \\
\text { IHC/CALAND GROUP } \\
\text { Now in our 5th Decade }\end{array}$} & \multirow{2}{*}{\multicolumn{5}{|c|}{$\begin{array}{l}\text { FLOATING RE-GASIFICATION UNIT } \\
\text { FOR SALT CAVERN } \\
\text {-NG RECEIVING AND RE-GASIFICATION }\end{array}$}} \\
\hline & & & & & & \\
\hline & & 51059 & CCM97001 & C1 & PAGE & 137 \\
\hline
\end{tabular}

APPENDIX A - FRU GENERAL ARRANGEMENT DRAWINGS 

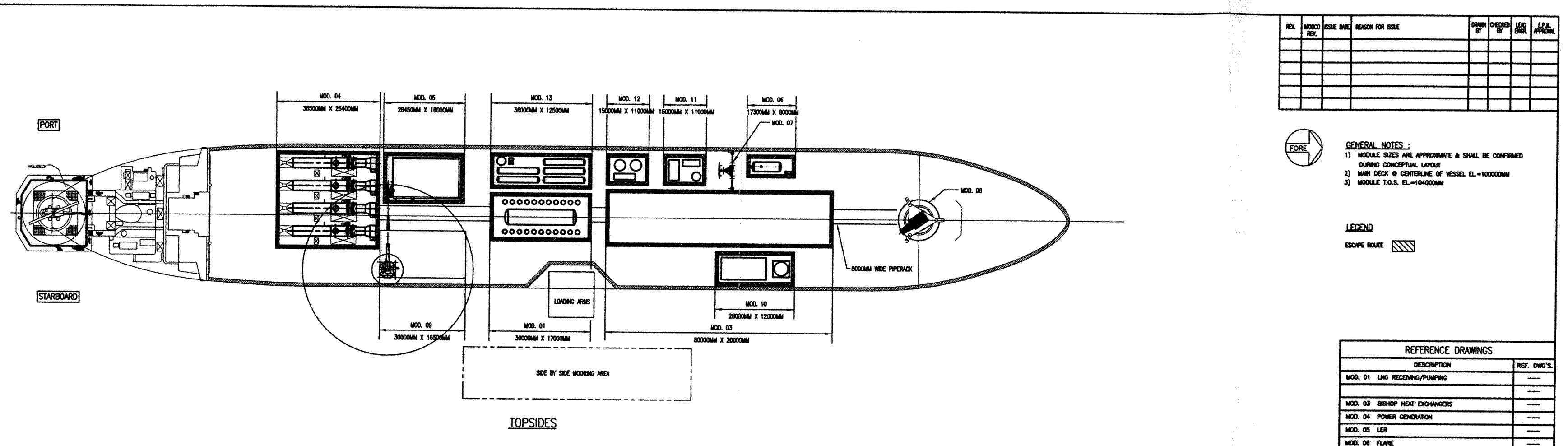

(iaid)

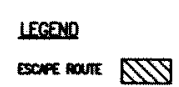
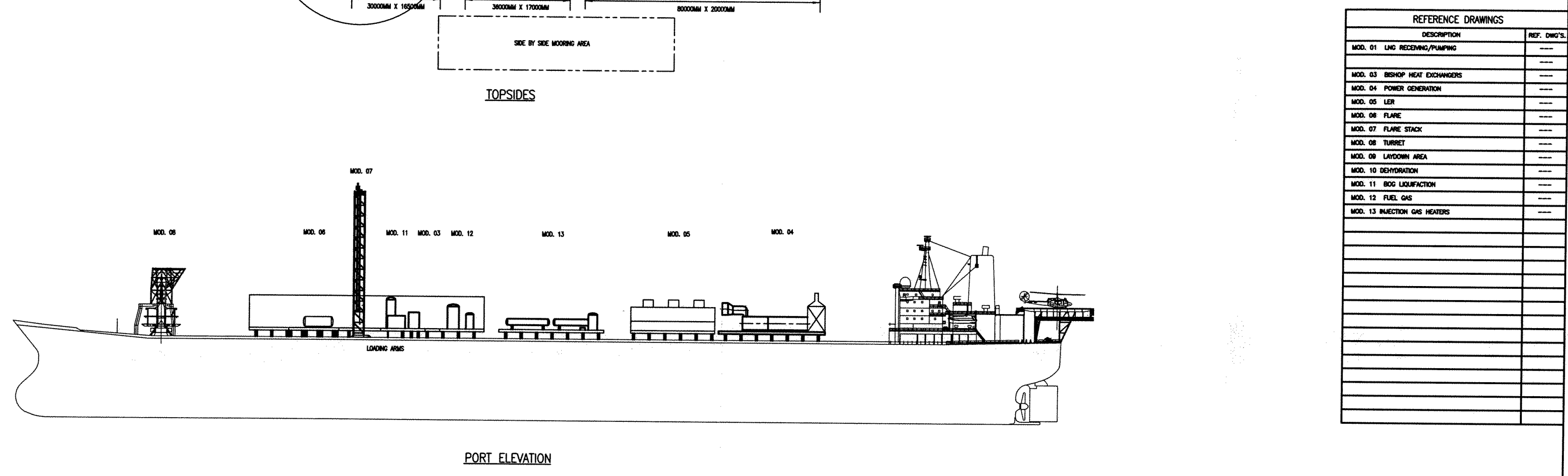

$\rightarrow 1$

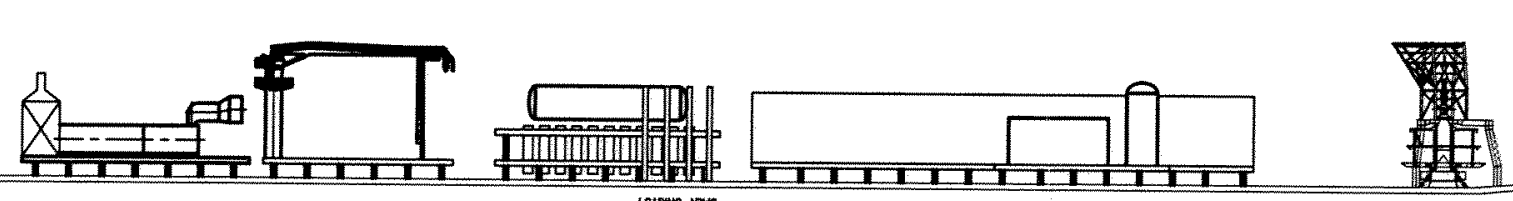
政 


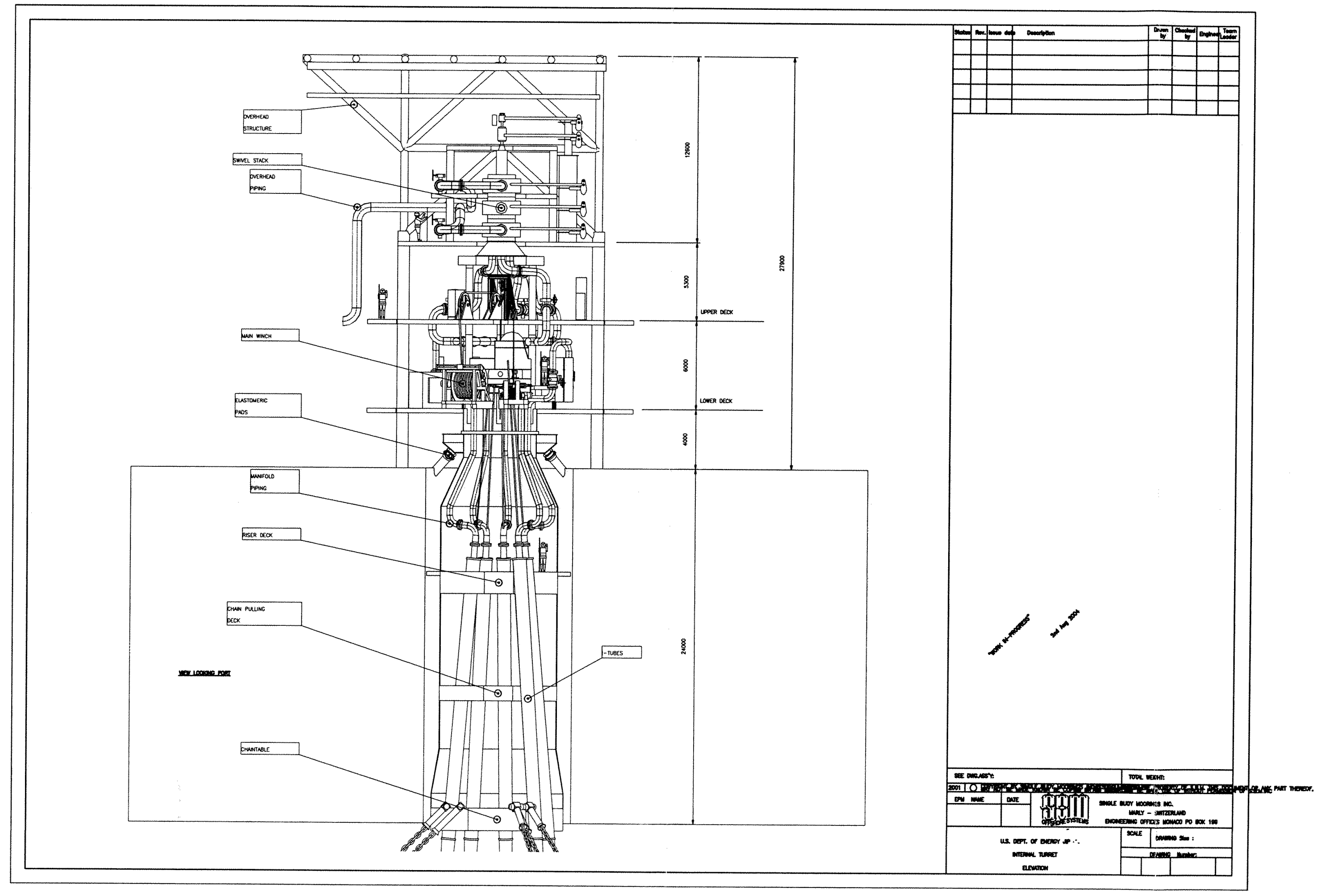




\begin{tabular}{|c|c|c|c|c|c|c|}
\hline \multirow[t]{3}{*}{ ImoOCO } & \multirow{3}{*}{$\begin{array}{l}\text { SBM-IMODCO INC. } \\
\text { MEMBER OF THE } \\
\text { IHC/CALAND GROUP } \\
\text { Now in our 5th Decade }\end{array}$} & \multirow{2}{*}{\multicolumn{5}{|c|}{$\begin{array}{l}\text { FLOATING RE-GASIFICATION UNIT } \\
\text { FOR SALT CAVERN } \\
\text {-NG RECEIVING AND RE-GASIFICATION }\end{array}$}} \\
\hline & & & & & & \\
\hline & & 51059 & CCM97001 & C1 & PAGE & 139 \\
\hline
\end{tabular}

APPENDIX B - TOPSIDES EQUIPMENT LIST 


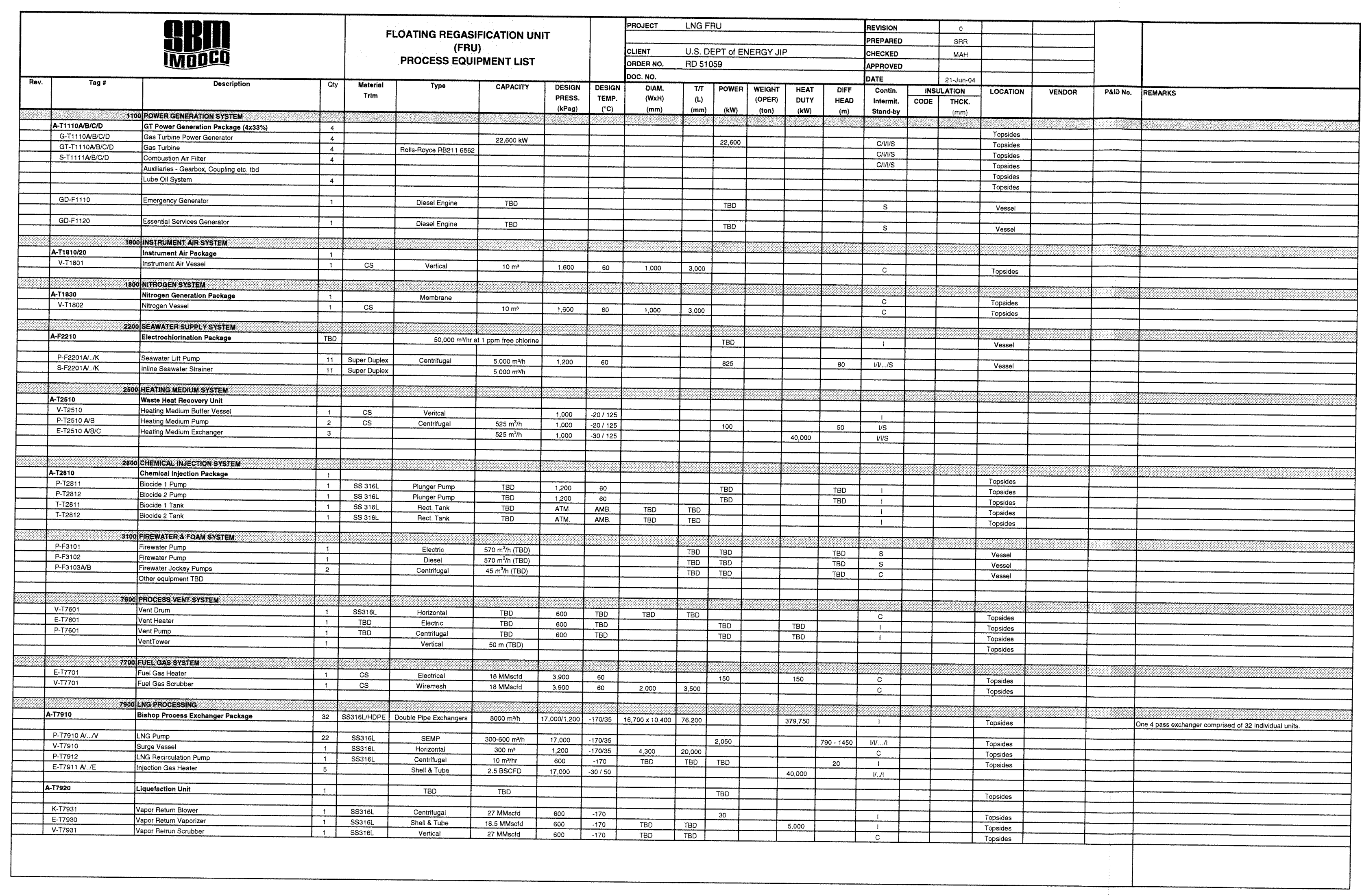




\begin{tabular}{|c|c|c|c|c|c|c|}
\hline \multirow[t]{3}{*}{ IMOOF0 } & $\begin{array}{l}\text { SBM-IMODCO INC. } \\
\text { MEMBER OF THE } \\
\text { IHCICALAND GROUP }\end{array}$ & \multirow{2}{*}{\multicolumn{5}{|c|}{$\begin{array}{l}\text { FLOATING RE-GASIFICATION UNIT } \\
\text { FOR SALT CAVERN } \\
\text { LNG RECEIVING AND RE-GASIFICATION }\end{array}$}} \\
\hline & \multirow[t]{2}{*}{ Now in our 5th Decade } & & & & & \\
\hline & & 51059 & CCM97001 & C1 & PAGE & 140 \\
\hline
\end{tabular}

APPENDIX C - AQWA MOORING SURVIVAL ANALYSIS RESULTS

(note the analyese presented in this section was conducted using a location specific environment, while in the main body of the report, the API hurricane condition was used.) 


\begin{tabular}{|c|c|c|c|c|c|c|}
\hline \multirow[t]{3}{*}{ IMODCO } & \multirow{3}{*}{$\begin{array}{l}\text { SBM-IMODCO INC. } \\
\text { MEMBER OF THE } \\
\text { IHC/CALAND GROUP } \\
\text { Now in our 5th Decade }\end{array}$} & \multirow{2}{*}{\multicolumn{5}{|c|}{$\begin{array}{l}\text { FLOATING RE-GASIFICATION UNIT } \\
\text { FOR SALT CAVERN } \\
\text {-NG RECEIVING AND RE-GASIFICATION }\end{array}$}} \\
\hline & & & & & & \\
\hline & & 51059 & CCM97001 & C1 & $P A G E$ & 141 \\
\hline
\end{tabular}

The AQWA analysis verifies that the mooring system is capable of withstanding the 100 year return hurricane environment. The maximum line tensions below those predicted conservatively predicted by Ariane.

Analysis Results Summary:

Maximum Mooring Loads, 100-year Hurricane (Hs=9.6m, Tp=13.0 s)

\begin{tabular}{|c|c|c|c|c|}
\hline \multirow[b]{2}{*}{ Random Seed } & \multicolumn{2}{|c|}{$\begin{array}{l}\text { Collinear (wind, wave, current } \\
\text { inline with mooring lines) }\end{array}$} & \multicolumn{2}{|c|}{$\begin{array}{l}\text { Oblique (wave } 75 \mathrm{deg} \text { from } \\
\text { head-on, wind } 30 \mathrm{deg} \text { from } \\
\text { wind, current } 45 \mathrm{deg} \text { from } \\
\text { wind) }\end{array}$} \\
\hline & \begin{tabular}{|c|} 
Max Mooring \\
Line Tension \\
(tonne) \\
\end{tabular} & $\begin{array}{l}\text { Max Anchor } \\
\text { Load (tonne) }\end{array}$ & $\begin{array}{c}\text { Max Mooring } \\
\text { Line Tension } \\
\text { (tonne) } \\
\end{array}$ & $\begin{array}{l}\text { Max Anchor } \\
\text { Load (tonne) }\end{array}$ \\
\hline 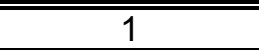 & 531.7 & 503.6 & 642.2 & 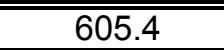 \\
\hline 2 & 572.2 & 548.4 & 644.4 & 608.8 \\
\hline 3 & 627.8 & 594.6 & 825.0 & 776.4 \\
\hline 4 & 723.0 & 703.1 & 793.1 & 775.6 \\
\hline 5 & 505.5 & 479.9 & 829.9 & 795.5 \\
\hline 6 & 641.3 & 616.9 & 660.9 & 638.8 \\
\hline 7 & 583.2 & 554.3 & 549.9 & 524.6 \\
\hline 8 & 646.7 & 623.1 & 539.2 & 507.6 \\
\hline 9 & 710.9 & 690.1 & 742.4 & 701.3 \\
\hline 10 & 762.5 & 743.5 & 565.5 & 541.0 \\
\hline $\begin{array}{l}\text { Most Probable } \\
\text { Max. }\end{array}$ & 630.5 & 605.7 & 679.2 & 647.5 \\
\hline
\end{tabular}

Note:

1) the friction force is not considered when calculating anchor loads. 


\begin{tabular}{|c|c|c|c|c|c|c|}
\hline \multirow[t]{3}{*}{ IMOOF0 } & $\begin{array}{l}\text { SBM-IMODCO INC. } \\
\text { MEMBER OF THE } \\
\text { IHCICALAND GROUP }\end{array}$ & \multirow{2}{*}{\multicolumn{5}{|c|}{$\begin{array}{l}\text { FLOATING RE-GASIFICATION UNIT } \\
\text { FOR SALT CAVERN } \\
\text { LNG RECEIVING AND RE-GASIFICATION }\end{array}$}} \\
\hline & \multirow[t]{2}{*}{ Now in our 5th Decade } & & & & & \\
\hline & & 51059 & CCM97001 & C1 & PAGE & 142 \\
\hline
\end{tabular}

Maximum Mooring Loads, 100-year Hurricane (Hs=9.6m, Tp=11.5 s)

\begin{tabular}{|c|c|c|c|c|}
\hline \multirow[b]{2}{*}{ Random Seed } & \multicolumn{2}{|c|}{$\begin{array}{l}\text { Collinear (wind, wave, current } \\
\text { inline with mooring lines) }\end{array}$} & \multicolumn{2}{|c|}{$\begin{array}{c}\text { Oblique (wave } 75 \mathrm{deg} \text { from } \\
\text { head-on, wind } 30 \mathrm{deg} \text { from } \\
\text { wind, current } 45 \mathrm{deg} \text { from } \\
\text { wind) }\end{array}$} \\
\hline & $\begin{array}{c}\text { Max Mooring } \\
\text { Line Tension } \\
\text { (tonne) } \\
\end{array}$ & $\begin{array}{l}\text { Max Anchor } \\
\text { Load (tonne) }\end{array}$ & $\begin{array}{l}\text { Max Mooring } \\
\text { Line Tension } \\
\text { (tonne) } \\
\end{array}$ & $\begin{array}{l}\text { Max Anchor } \\
\text { Load (tonne) }\end{array}$ \\
\hline $\bar{~} 1$ & 932.5 & 901.9 & 709.4 & "682.2 \\
\hline 2 & 551.5 & 521.0 & 507.5 & 481.9 \\
\hline 3 & 739.9 & 705.8 & 861.0 & 831.2 \\
\hline 4 & 684.0 & 654.1 & 665.0 & 636.1 \\
\hline 5 & 553.0 & 521.3 & 603.1 & 574.6 \\
\hline 6 & 595.0 & 564.1 & 565.9 & 537.0 \\
\hline 7 & 670.3 & 647.1 & 563.1 & 531.2 \\
\hline 8 & 577.8 & 551.0 & 623.0 & 584.9 \\
\hline 9 & 637.2 & 605.9 & 635.0 & 603.2 \\
\hline 10 & 518.1 & 488.0 & 557.6 & 525.1 \\
\hline $\begin{array}{l}\text { Most Probable } \\
\text { Max. }\end{array}$ & 645.9 & 616.0 & 629.1 & 598.7 \\
\hline
\end{tabular}

Note:

1) the friction force is not considered when calculating anchor loads. 


\begin{tabular}{|c|c|c|c|c|c|c|}
\hline \multirow[t]{3}{*}{ IMOOE0 } & \multirow[t]{3}{*}{$\begin{array}{l}\text { SBM-IMODCO INC. } \\
\text { MEMBER OF THE } \\
\text { IHCICALAND GROUP } \\
\text { Now in our 5th Decade }\end{array}$} & \multirow{2}{*}{\multicolumn{5}{|c|}{$\begin{array}{l}\text { FLOATING RE-GASIFICATION UNIT } \\
\text { FOR SALT CAVERN } \\
\text { LNG RECEIVING AND RE-GASIFICATION }\end{array}$}} \\
\hline & & & & & & \\
\hline & & 51059 & ССМ97001 & C1 & PAGE & 143 \\
\hline
\end{tabular}

Maximum Mooring Loads, 100-year Hurricane (Hs=9.6m, Tp= $14.5 \mathrm{~s})$

\begin{tabular}{|c||c|c|c|c|}
\hline \multicolumn{2}{||}{} & \multicolumn{2}{|l|}{$\begin{array}{c}\text { Collinear (wind, wave, current } \\
\text { inline with mooring lines) }\end{array}$} & $\begin{array}{c}\text { Oblique (wave 75deg from } \\
\text { head-on, wind 30deg from } \\
\text { wind, current 45 deg from } \\
\text { wind) }\end{array}$ \\
\cline { 2 - 5 } Random Seed & $\begin{array}{c}\text { Max Mooring } \\
\text { Line Tension } \\
\text { (tonne) }\end{array}$ & $\begin{array}{c}\text { Max Anchor } \\
\text { Load (tonne) }\end{array}$ & $\begin{array}{c}\text { Max Mooring } \\
\text { Line Tension } \\
\text { (tonne) }\end{array}$ & $\begin{array}{c}\text { Max Anchor } \\
\text { Load (tonne) }\end{array}$ \\
\hline \hline 1 & 938.8 & 917.7 & 752.6 & 730.4 \\
\hline 2 & 675.0 & 653.3 & 748.5 & 726.9 \\
\hline 3 & 663.6 & 641.0 & 869.1 & 847.9 \\
\hline 4 & 646.0 & 627.6 & 703.0 & 683.2 \\
\hline 5 & 565.6 & 541.7 & 666.1 & 632.1 \\
\hline 6 & 749.2 & 728.2 & 587.6 & 547.8 \\
\hline 7 & 644.0 & 620.8 & 512.7 & 491.4 \\
\hline 8 & 972.6 & 953.9 & 627.9 & 607.8 \\
\hline 9 & 677.2 & 656.3 & 645.5 & 624.0 \\
\hline 10 & 654.2 & 633.5 & 643.8 & 610.7 \\
\hline Most Probable & 718.6 & 697.4 & 675.7 & 650.2 \\
\hline Max. & & & & \\
\hline
\end{tabular}

Note:

1) the friction force is not considered when calculating anchor loads. 


\begin{tabular}{|c|c|c|c|c|c|c|}
\hline \multirow[t]{3}{*}{ Imogen } & $\begin{array}{l}\text { SBM-IMODCO INC. } \\
\text { MEMBER OF THE } \\
\text { IHC/CALAND GROUP }\end{array}$ & \multicolumn{4}{|c|}{ FOR SALT CAVERN } & \\
\hline & \multirow[t]{2}{*}{ Now in our 5th Decade } & \multicolumn{5}{|c|}{ LNG RECEIVING AND RE-GASIFICATION } \\
\hline & & 51059 & CCM97001 & C1 & PAGE & 144 \\
\hline
\end{tabular}

\section{Wind, Wave, Current Collinear}
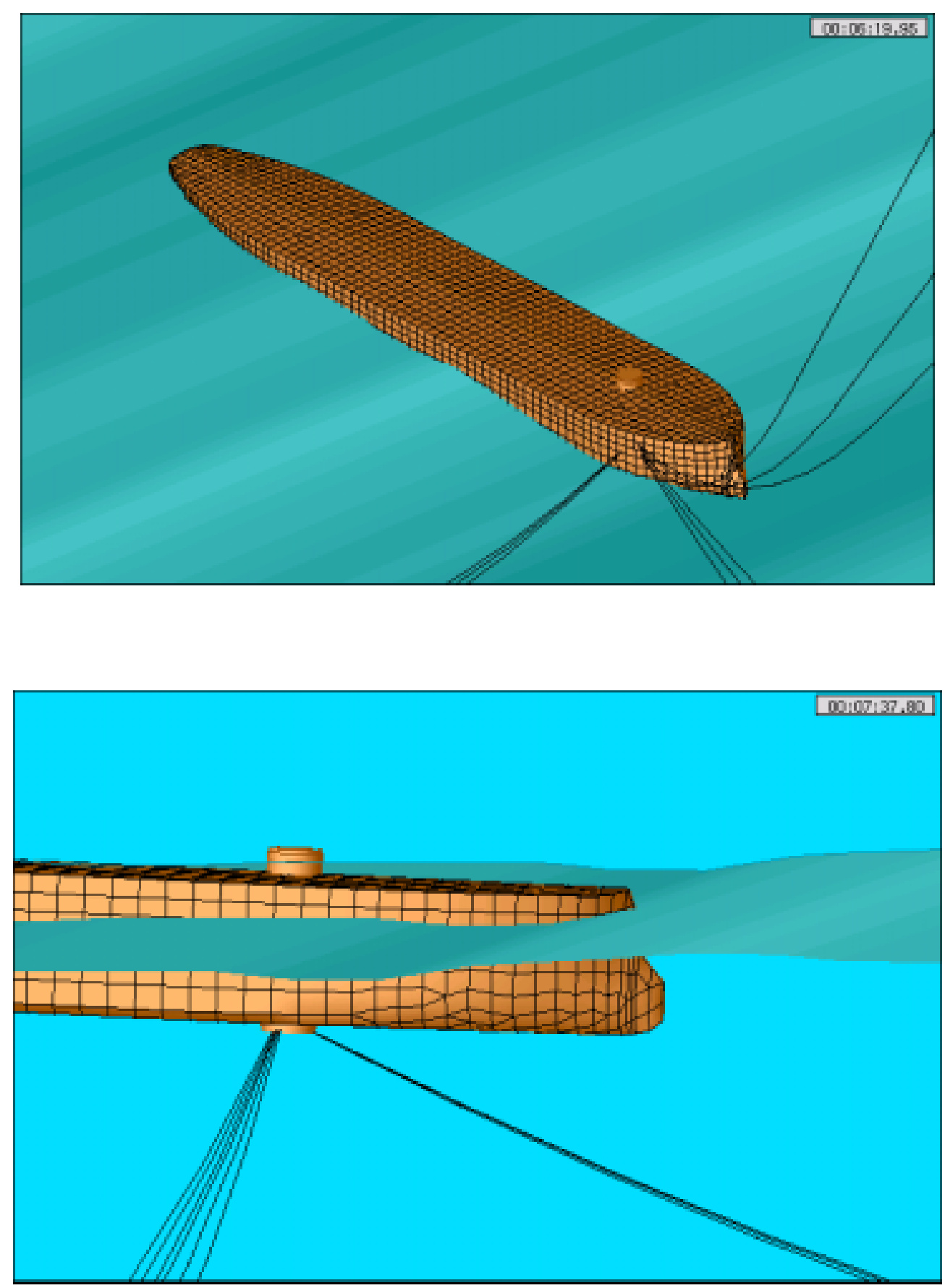


\begin{tabular}{|c|c|c|c|c|c|c|}
\hline \multirow[t]{3}{*}{ IMODCO } & \multirow{3}{*}{$\begin{array}{l}\text { SBM-IMODCO INC. } \\
\text { MEMBER OF THE } \\
\text { IHCICALAND GROUP } \\
\text { Now in our } 5 \text { th Decade }\end{array}$} & \multirow{2}{*}{\multicolumn{5}{|c|}{$\begin{array}{l}\text { FLOATING RE-GASIFICATION UNIT } \\
\text { FOR SALT CAVERN } \\
\text { NG RECEIVING AND RE-GASIFICATION }\end{array}$}} \\
\hline & & & & & & \\
\hline & & 51059 & CCM97001 & C1 & PAGE & 145 \\
\hline
\end{tabular}
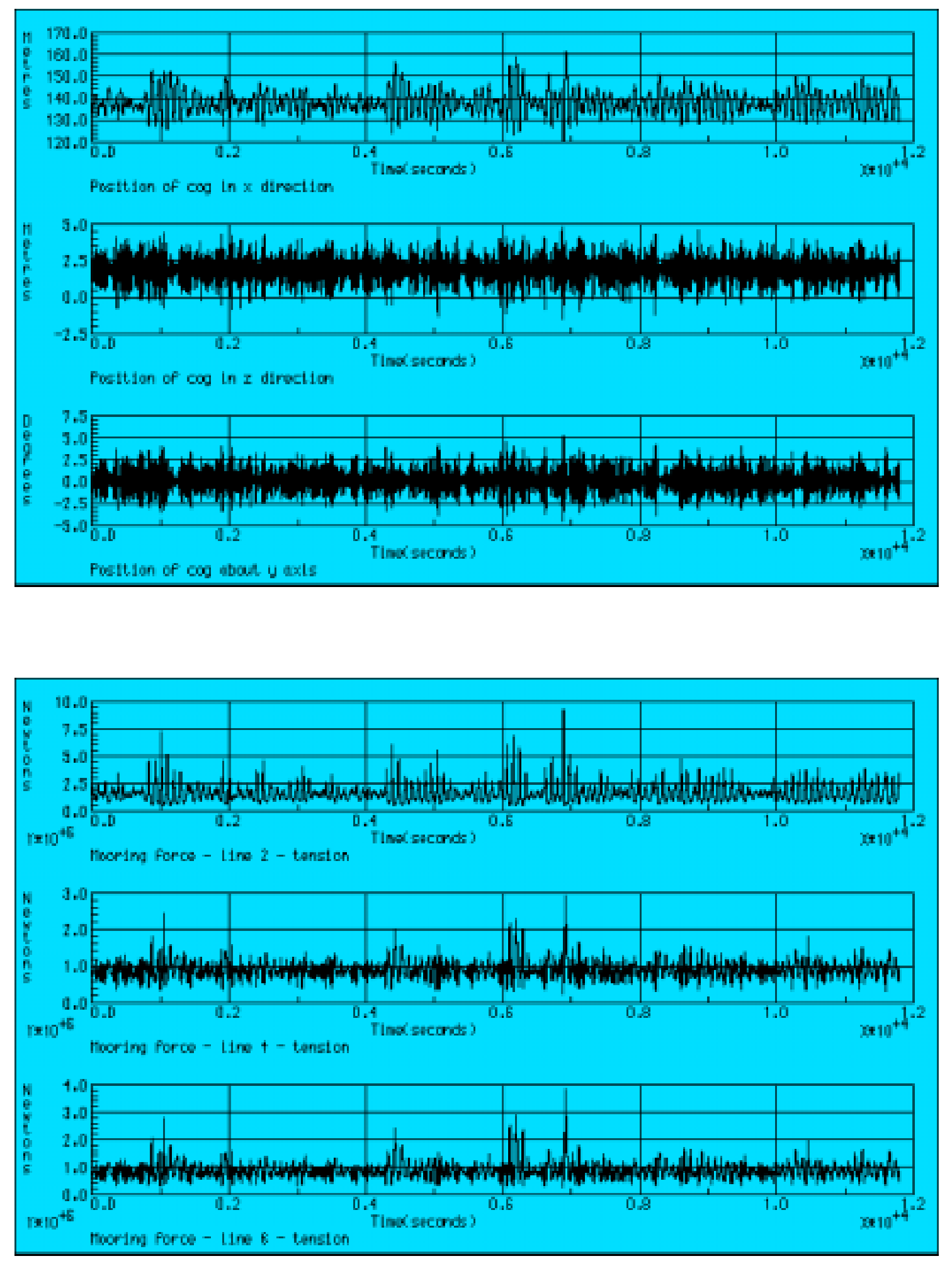


\begin{tabular}{|c|c|c|c|c|c|c|}
\hline \multirow[t]{3}{*}{ IMODCO } & \multirow{3}{*}{$\begin{array}{l}\text { SBM-IMODCO INC. } \\
\text { MEMBER OF THE } \\
\text { IHCICALAND GROUP } \\
\text { Now in our } 5 \text { th Decade }\end{array}$} & \multirow{2}{*}{\multicolumn{5}{|c|}{$\begin{array}{l}\text { FLOATING RE-GASIFICATION UNIT } \\
\text { FOR SALT CAVERN } \\
\text { NG RECEIVING AND RE-GASIFICATION }\end{array}$}} \\
\hline & & & & & & \\
\hline & & 51059 & CCM97001 & C1 & PAGE & 146 \\
\hline
\end{tabular}

Cross Condition (wave 75 degrees from head-on, wind 30 degrees from wave, current 45 degrees from wave)
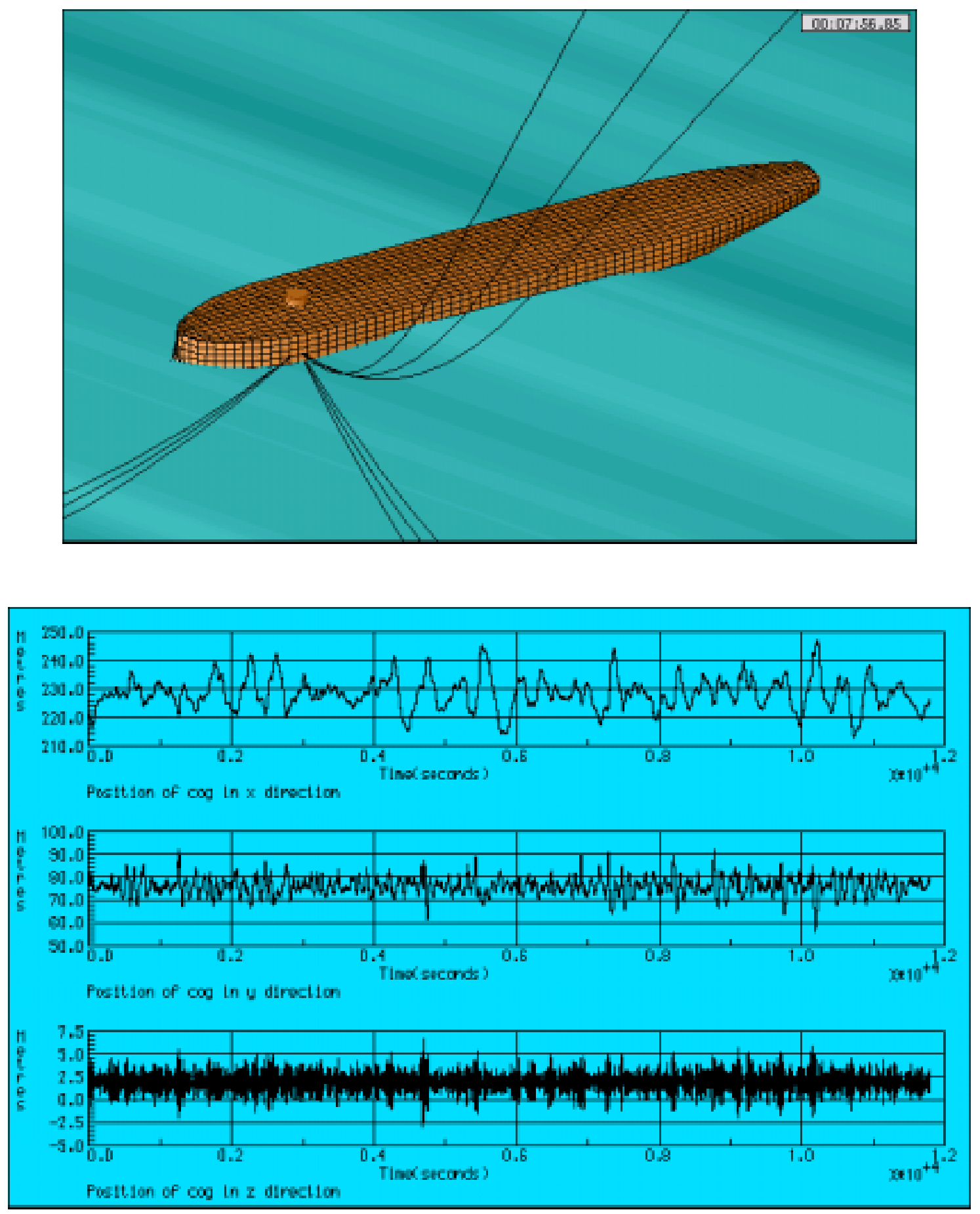


\begin{tabular}{|c|c|c|c|c|c|c|}
\hline \multirow[t]{3}{*}{ IMODCO } & \multirow{3}{*}{$\begin{array}{l}\text { SBM-IMODCO INC. } \\
\text { MEMBER OF THE } \\
\text { IHCICALAND GROUP } \\
\text { Now in our } 5 \text { th Decade }\end{array}$} & \multirow{2}{*}{\multicolumn{5}{|c|}{$\begin{array}{l}\text { FLOATING RE-GASIFICATION UNIT } \\
\text { FOR SALT CAVERN } \\
\text { NG RECEIVING AND RE-GASIFICATION }\end{array}$}} \\
\hline & & & & & & \\
\hline & & 51059 & CCM97001 & C1 & PAGE & 147 \\
\hline
\end{tabular}
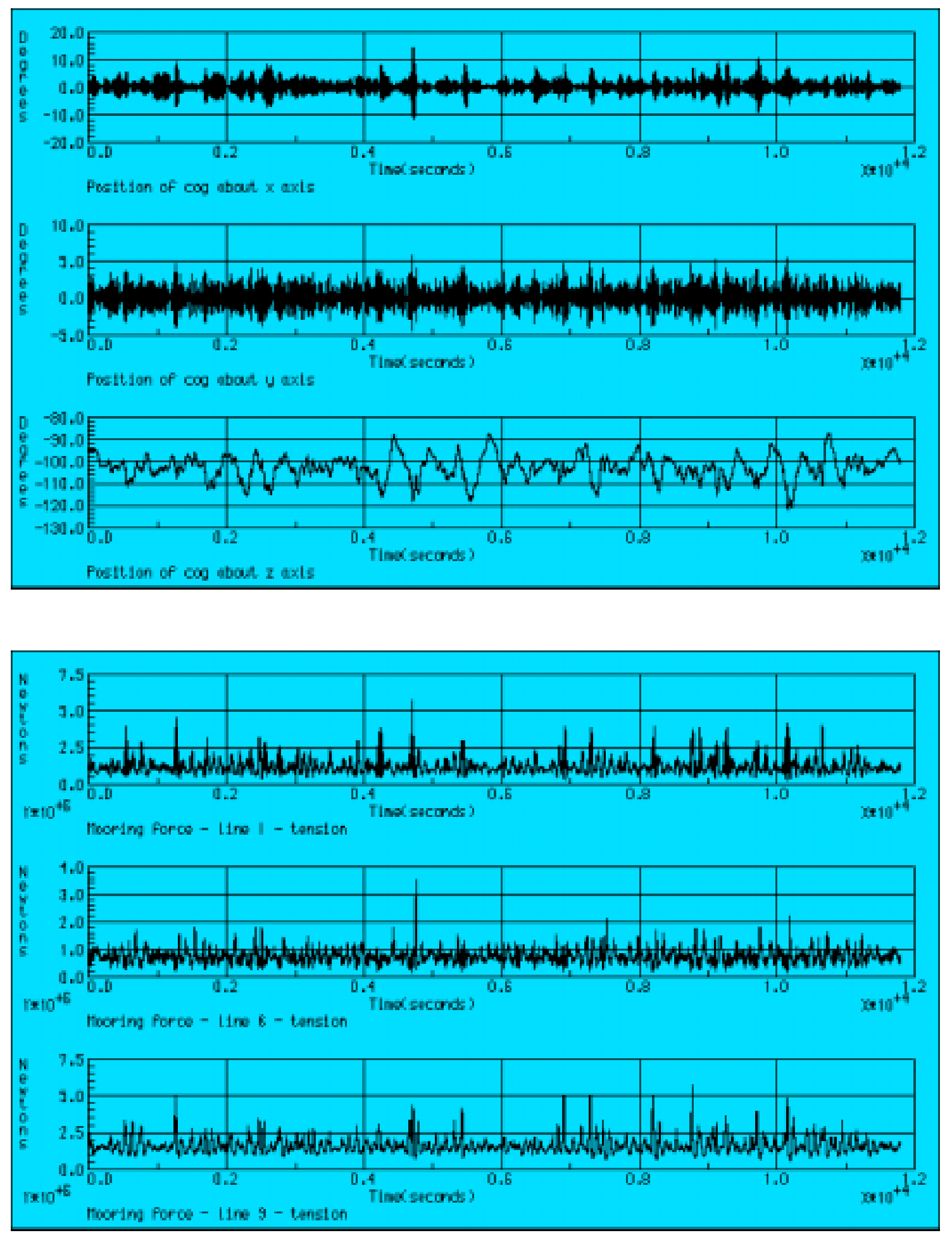


\begin{tabular}{|c|c|c|c|c|c|c|}
\hline \multirow[t]{3}{*}{ IMODCO } & \multirow{3}{*}{$\begin{array}{l}\text { SBM-IMODCO INC. } \\
\text { MEMBER OF THE } \\
\text { IHC/CALAND GROUP } \\
\text { Now in our 5th Decade }\end{array}$} & \multirow{2}{*}{\multicolumn{5}{|c|}{$\begin{array}{l}\text { FLOATING RE-GASIFICATION UNIT } \\
\text { FOR SALT CAVERN } \\
\text {-NG RECEIVING AND RE-GASIFICATION }\end{array}$}} \\
\hline & & & & & & \\
\hline & & 51059 & CCM97001 & C1 & $P A G E$ & 148 \\
\hline
\end{tabular}

APPENDIX D - SIDE BY SIDE OPERATING ANALYSIS RESULTS 


\begin{tabular}{|c|c|c|c|c|c|c|}
\hline $\begin{array}{l}\text { Hit } \\
\text { Imogen }\end{array}$ & $\begin{array}{l}\text { SBM-IMODCO INC. } \\
\text { MEMBER OF THE IHCICALAND GROUP } \\
\text { Now in our } 5 \text { th Decade }\end{array}$ & \multicolumn{5}{|c|}{$\begin{array}{l}\text { FLOATING RE-GASIFICATION UNIT } \\
\text { FOR SALT CAVERN } \\
\text { LNG RECEIVING AND RE-GASIFICATION }\end{array}$} \\
\hline & Now in our 5th Decade & 51059 & ССМ97001 & C1 & PAGE & 149 \\
\hline
\end{tabular}

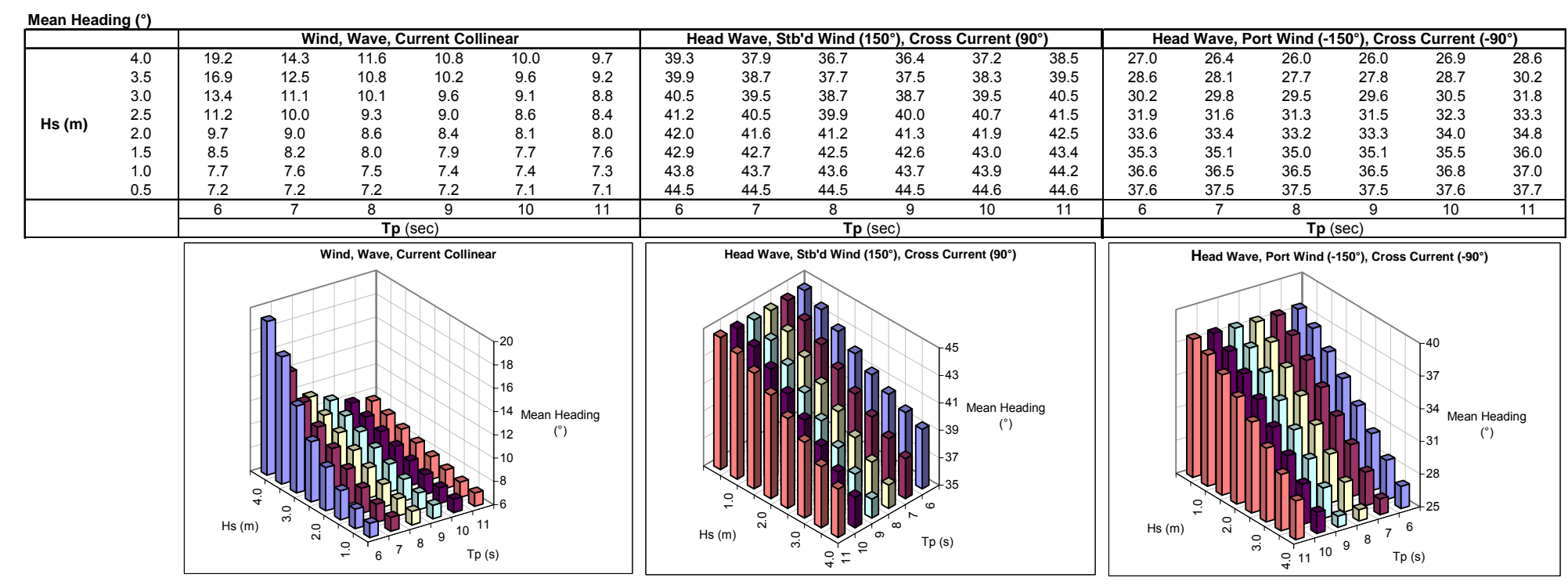




\begin{tabular}{|c|c|c|c|c|c|c|}
\hline $\begin{array}{l}\text { Hitl } \\
\text { Imoge0 }\end{array}$ & $\begin{array}{l}\text { SBM-IMODCO INC. } \\
\text { MEMBER OF THE IHC/CALAND GROUP } \\
\text { Now in our } 5 \text { th Decade }\end{array}$ & \multicolumn{5}{|c|}{$\begin{array}{l}\text { FLOATING RE-GASIFICATION UNIT } \\
\text { FOR SALT CAVERN } \\
\text { LNG RECEIVING AND RE-GASIFICATION }\end{array}$} \\
\hline & Now in our 5 th Decade & 51059 & ССM97001 & C1 & PAGE & 150 \\
\hline
\end{tabular}

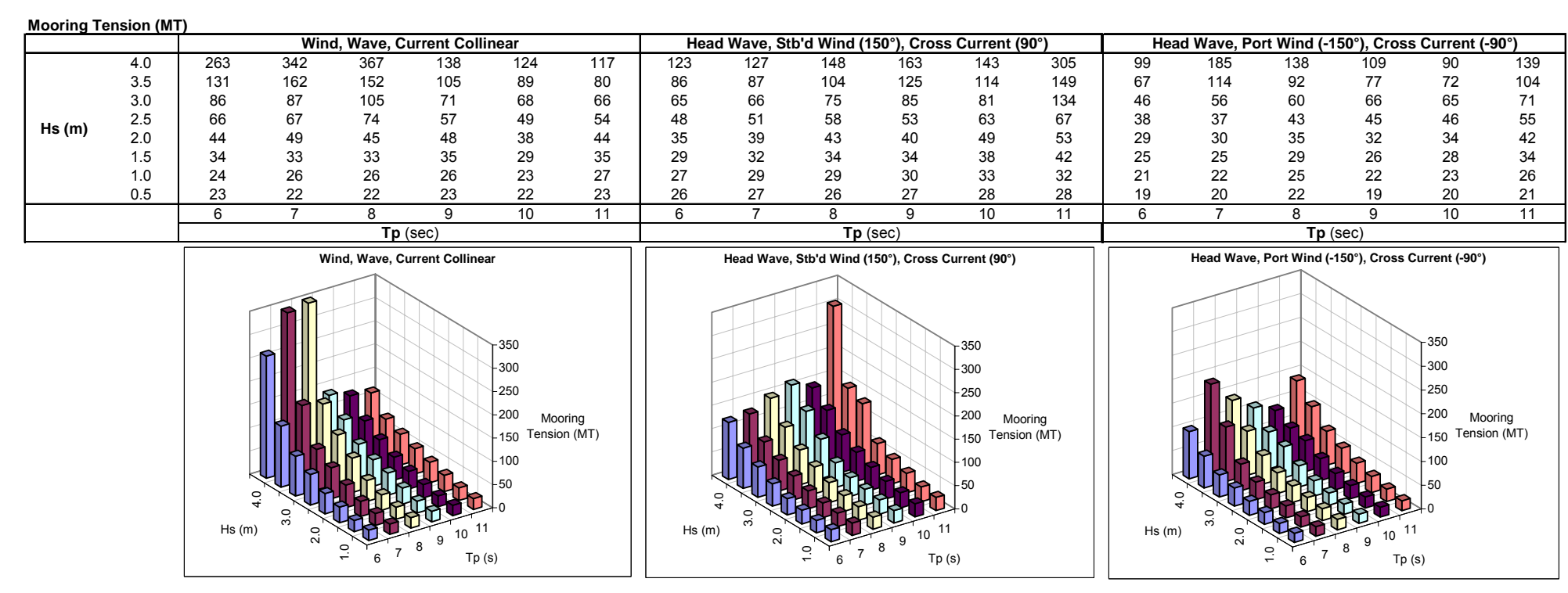




\begin{tabular}{|c|c|c|c|c|c|c|}
\hline $\begin{array}{l}\mathrm{Hi} \\
\text { IM0060 }\end{array}$ & $\begin{array}{l}\text { SBM-IMODCO INC. } \\
\text { MEMBER OF THE IHCICALAND GROUP } \\
\text { Now in our } 5 \text { th Decade }\end{array}$ & \multicolumn{5}{|c|}{$\begin{array}{l}\text { FLOATING RE-GASIFICATION UNIT } \\
\text { FOR SALT CAVERN } \\
\text { LNG RECEIVING AND RE-GASIFICATION }\end{array}$} \\
\hline & Now in our 5th Decade & 51059 & CCM97001 & C1 & PAGE & 151 \\
\hline
\end{tabular}

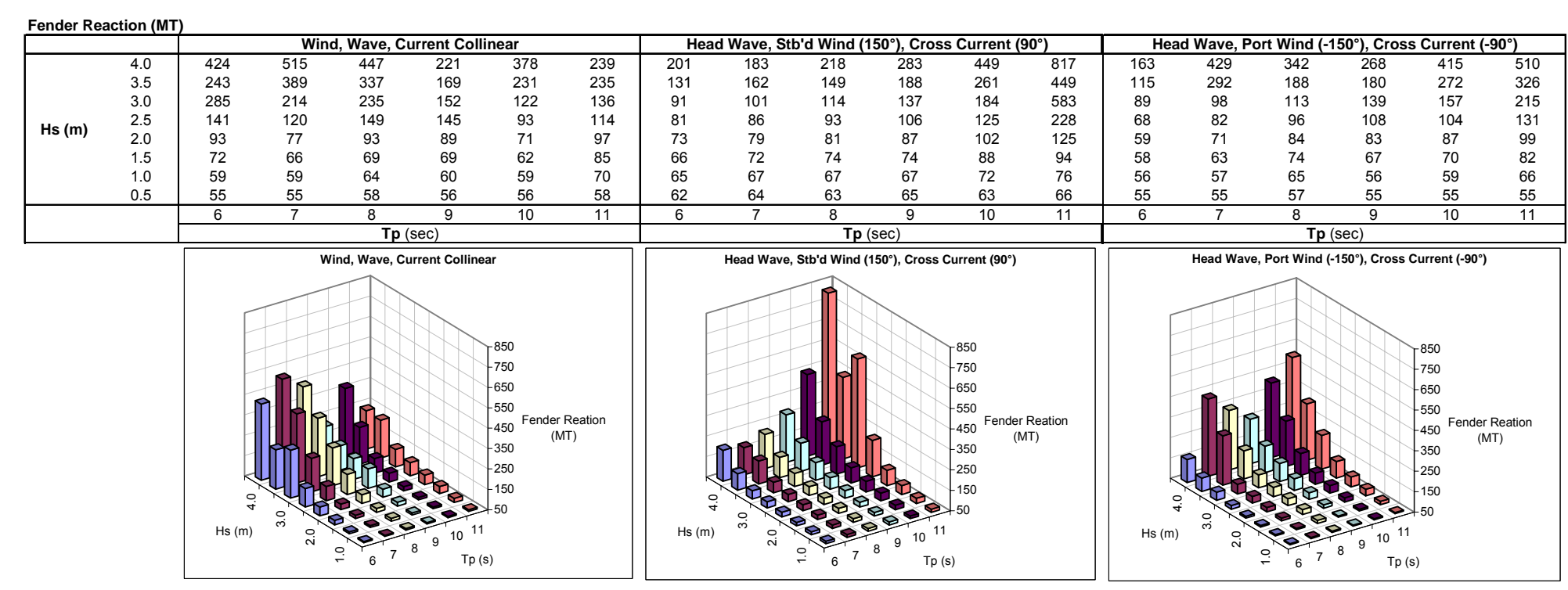




\begin{tabular}{|c|c|c|c|c|c|c|}
\hline $\begin{array}{l}\text { Hitl } \\
\text { Imoge0 }\end{array}$ & $\begin{array}{l}\text { SBM-IMODCO INC. } \\
\text { MEMBER OF THE IHC/CALAND GROUP } \\
\text { Now in our } 5 \text { th Decade }\end{array}$ & \multicolumn{5}{|c|}{$\begin{array}{l}\text { FLOATING RE-GASIFICATION UNIT } \\
\text { FOR SALT CAVERN } \\
\text { LNG RECEIVING AND RE-GASIFICATION }\end{array}$} \\
\hline & Now in our 5 th Decade & 51059 & ССM97001 & C1 & PAGE & 152 \\
\hline
\end{tabular}

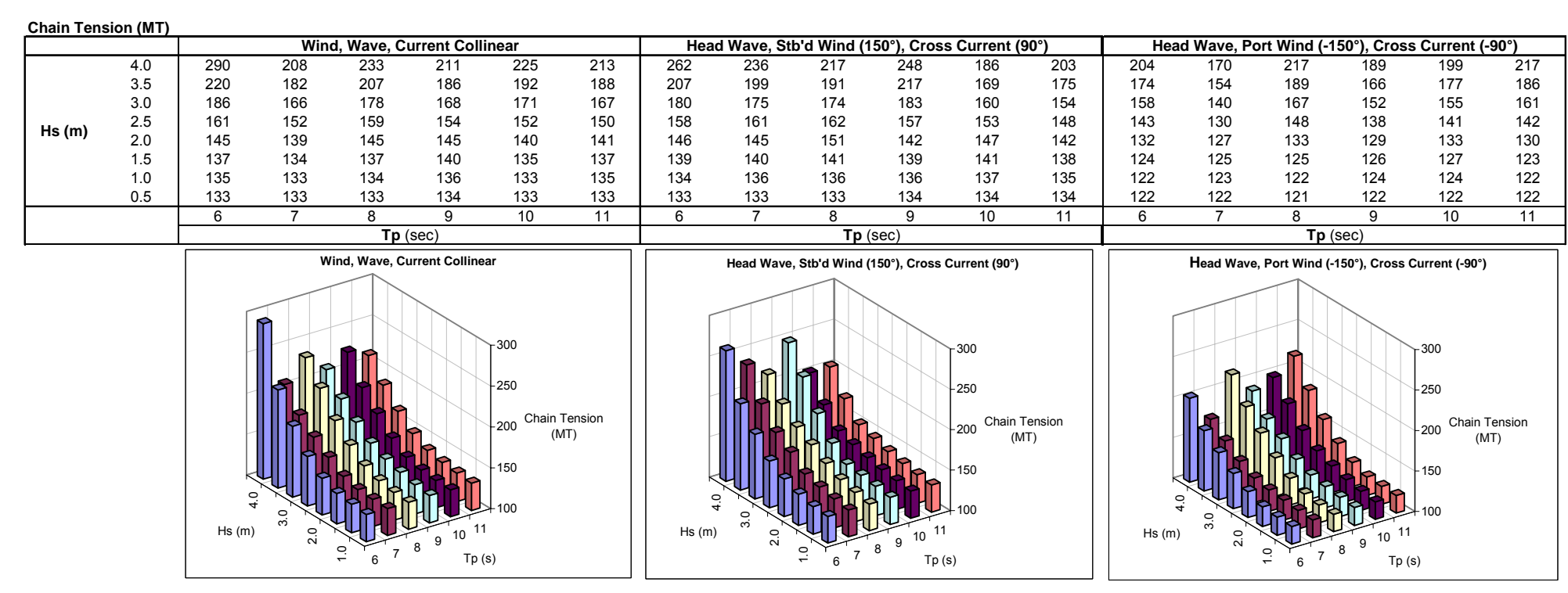




\begin{tabular}{|c|c|c|c|c|c|c|}
\hline $\begin{array}{l}\text { Hitl } \\
\text { Imoge0 }\end{array}$ & \multirow[t]{2}{*}{$\begin{array}{l}\text { MEMBER OF THE IHC/CALAND GROUP } \\
\text { Now in our } 5 \text { th Decade }\end{array}$} & \multicolumn{5}{|c|}{$\begin{array}{l}\text { FLOATING RE-GASIFICATION UNIT } \\
\text { FOR SALT CAVERN } \\
\text { LNG RECEIVING AND RE-GASIFICATION }\end{array}$} \\
\hline & & 51059 & ССM97001 & C1 & PAGE & 153 \\
\hline
\end{tabular}

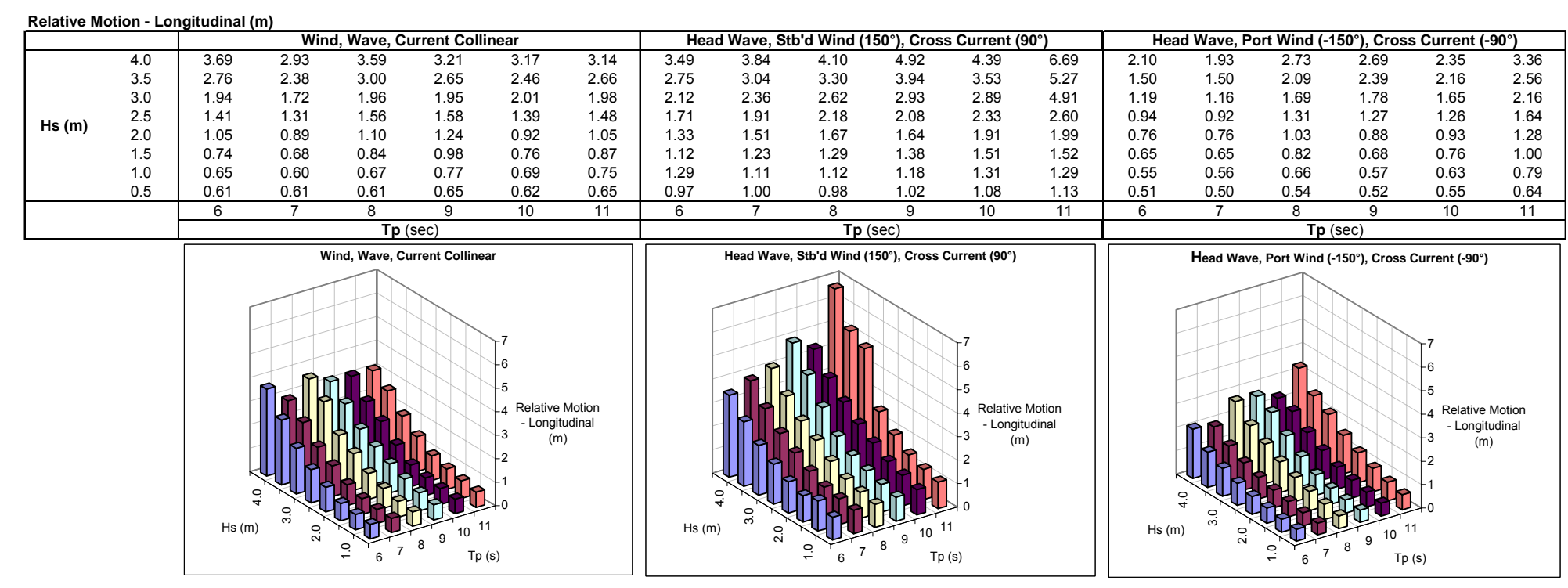




\begin{tabular}{|c|c|c|c|c|c|c|}
\hline $\begin{array}{l}\mathrm{Hi} \\
\text { IM0060 }\end{array}$ & $\begin{array}{l}\text { SBM-IMODCO INC. } \\
\text { MEMBER OF THE IHCICALAND GROUP } \\
\text { Now in our } 5 \text { th Decade }\end{array}$ & \multicolumn{5}{|c|}{$\begin{array}{l}\text { FLOATING RE-GASIFICATION UNIT } \\
\text { FOR SALT CAVERN } \\
\text { LNG RECEIVING AND RE-GASIFICATION }\end{array}$} \\
\hline & Now in our 5th Decade & 51059 & CCM97001 & C1 & PAGE & 154 \\
\hline
\end{tabular}

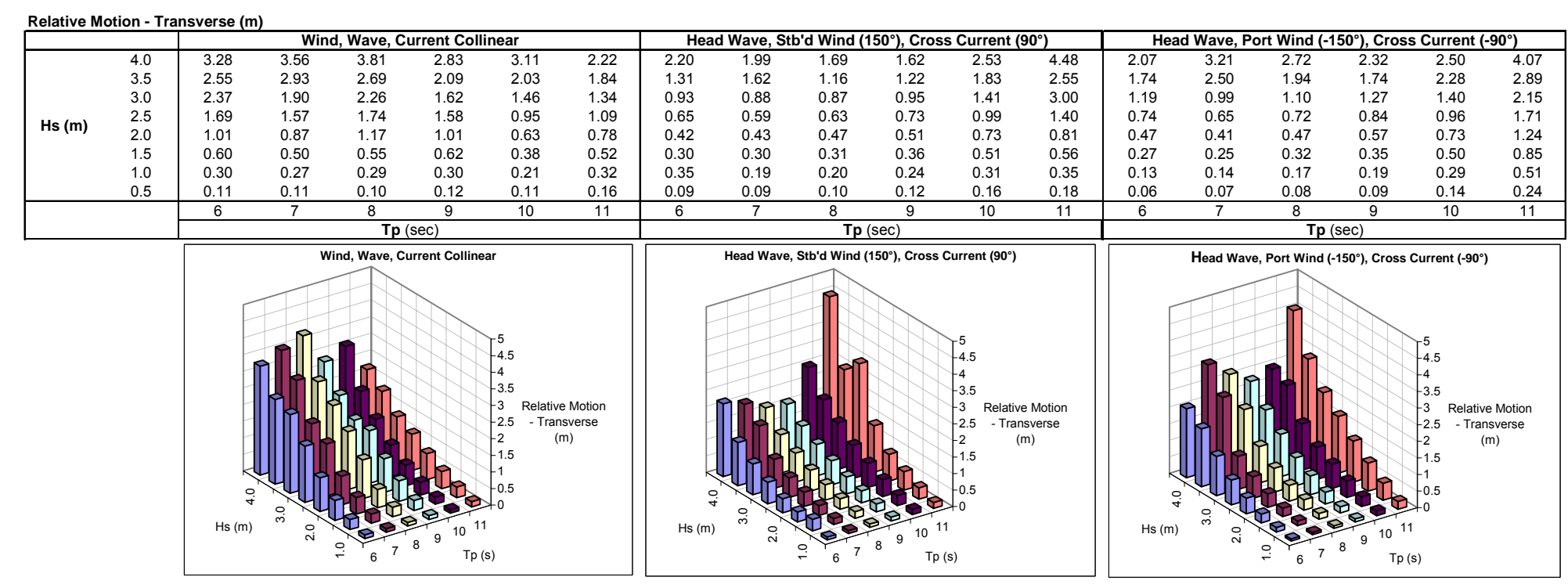




\begin{tabular}{|c|c|c|c|c|c|c|}
\hline $\begin{array}{l}\mathrm{Hi} \\
\text { IM0060 }\end{array}$ & $\begin{array}{l}\text { SBM-IMODCO INC. } \\
\text { MEMBER OF THE IHC/CALAND GROUP } \\
\text { Now in our 5th Decade }\end{array}$ & \multicolumn{5}{|c|}{$\begin{array}{l}\text { FLOATING RE-GASIFICATION UNIT } \\
\text { FOR SALT CAVERN } \\
\text { LNG RECEIVING AND RE-GASIFICATION }\end{array}$} \\
\hline & Now in our 5th Decade & 51059 & CCM97001 & C1 & PAGE & 155 \\
\hline
\end{tabular}

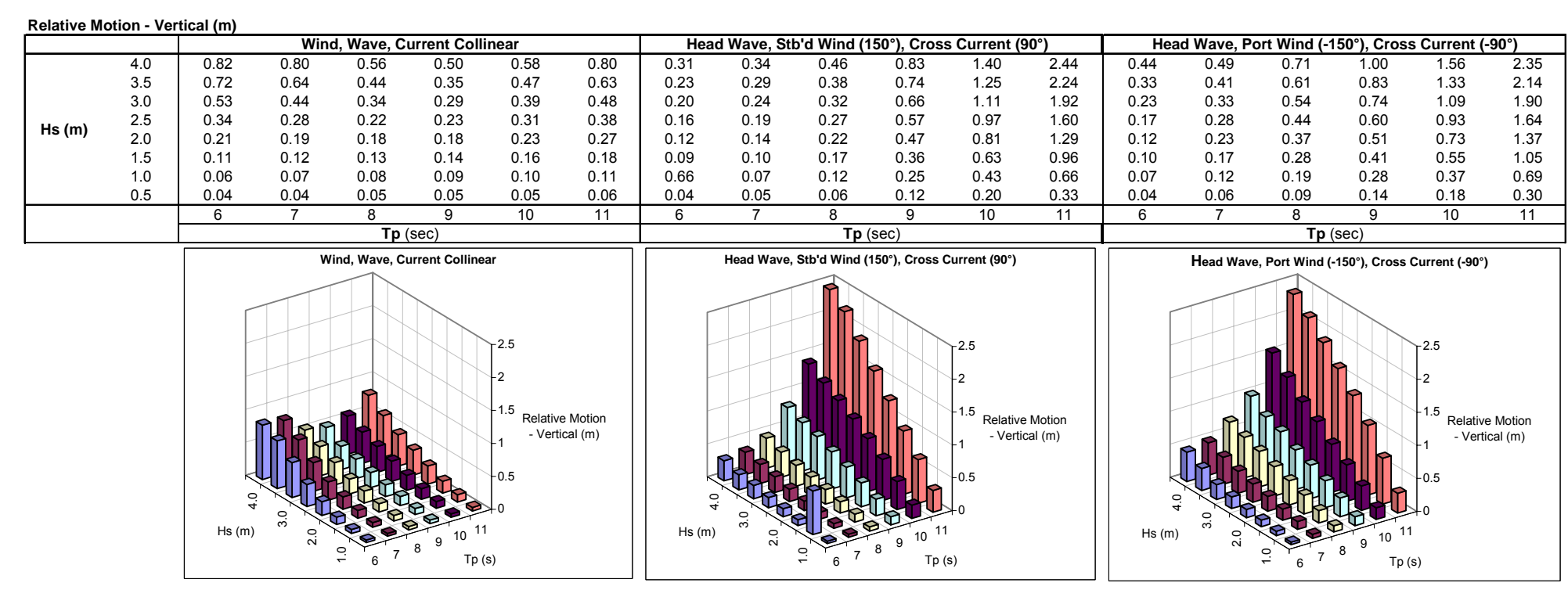




\begin{tabular}{|c|c|c|c|c|c|c|}
\hline \multirow[t]{2}{*}{ IMODCo } & \multirow{2}{*}{$\begin{array}{l}\text { SBM-IMODCO INC. } \\
\text { MEMBER OF THE IHC/CALAND GROUP } \\
\text { Now in our 5th Decade }\end{array}$} & \multicolumn{5}{|c|}{$\begin{array}{l}\text { FLOATING RE-GASIFICATION UNIT } \\
\text { FOR SALT CAVERN } \\
\text { LNG RECEIVING AND RE-GASIFICATION }\end{array}$} \\
\hline & & 51059 & CCM97001 & C1 & PAGE & 156 \\
\hline
\end{tabular}

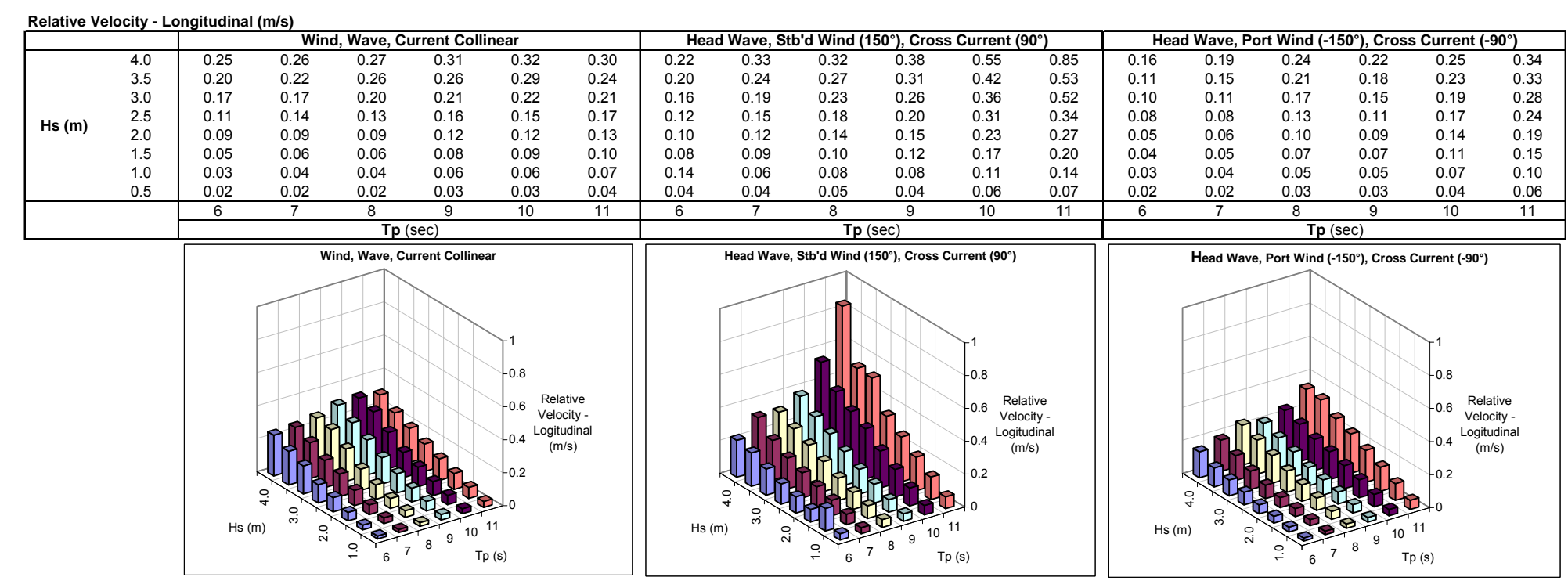




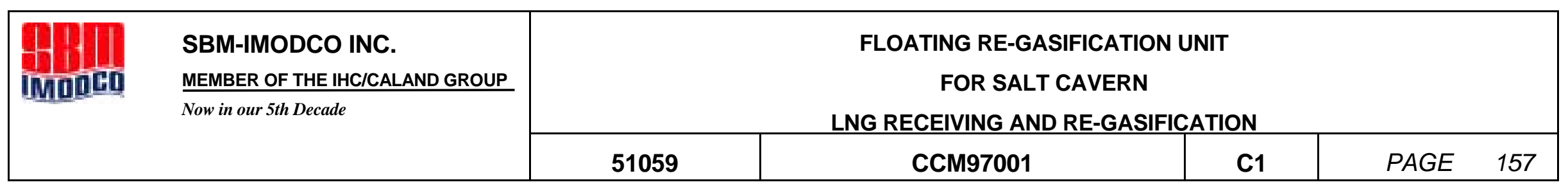

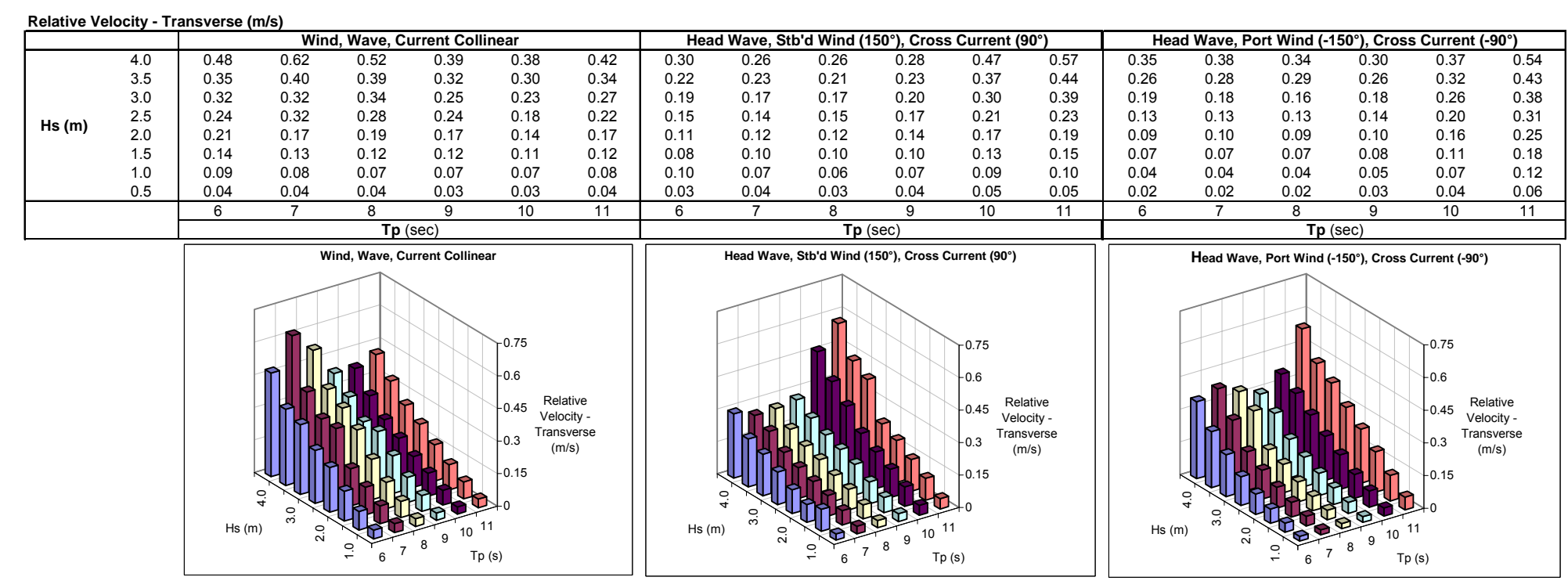




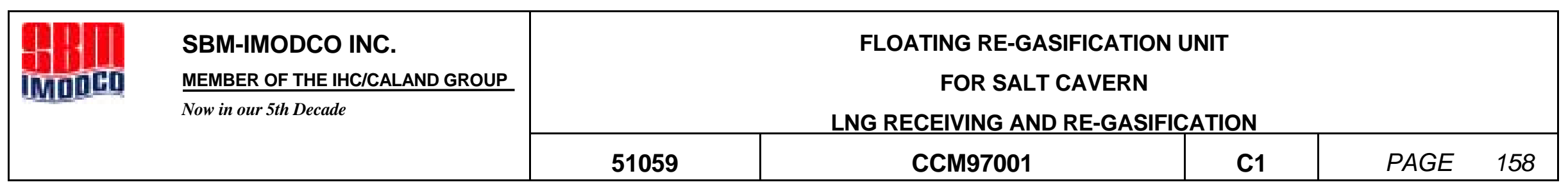

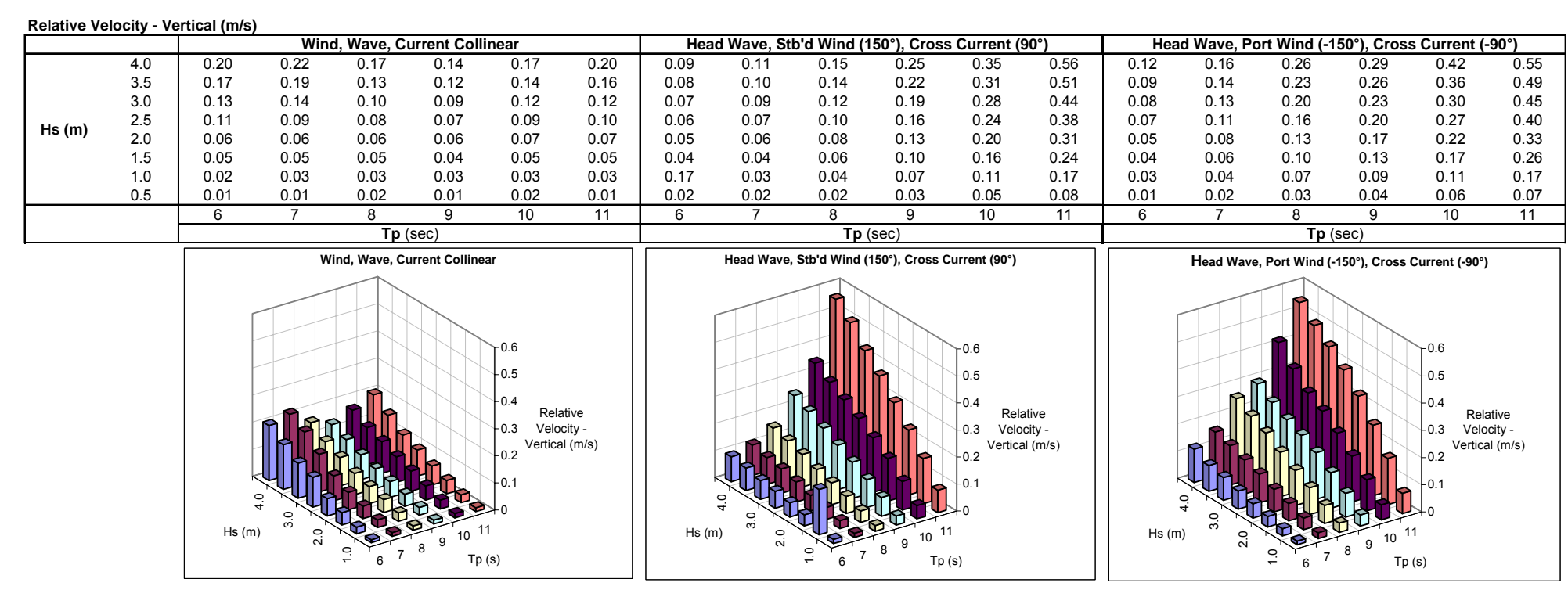




\begin{tabular}{|c|c|c|c|c|c|c|}
\hline $\begin{array}{l}\text { Hitl } \\
\text { Imoge0 }\end{array}$ & $\begin{array}{l}\text { SBM-IMODCO INC. } \\
\text { MEMBER OF THE IHC/CALAND GROUP } \\
\text { Now in our } 5 \text { th Decade }\end{array}$ & \multicolumn{5}{|c|}{$\begin{array}{l}\text { FLOATING RE-GASIFICATION UNIT } \\
\text { FOR SALT CAVERN } \\
\text { LNG RECEIVING AND RE-GASIFICATION }\end{array}$} \\
\hline & Now in our 5 th Decade & 51059 & ССM97001 & C1 & PAGE & 159 \\
\hline
\end{tabular}

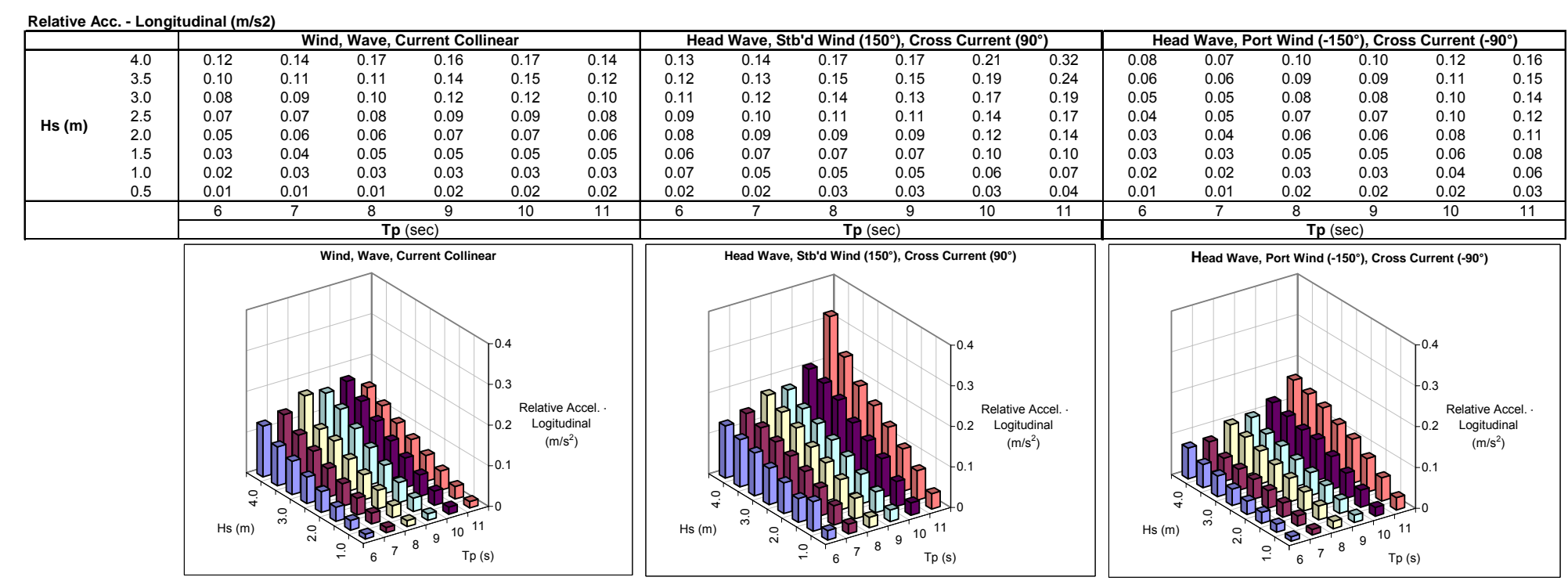




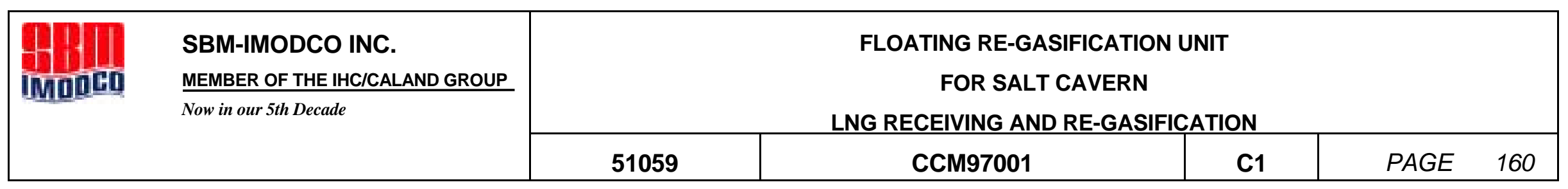

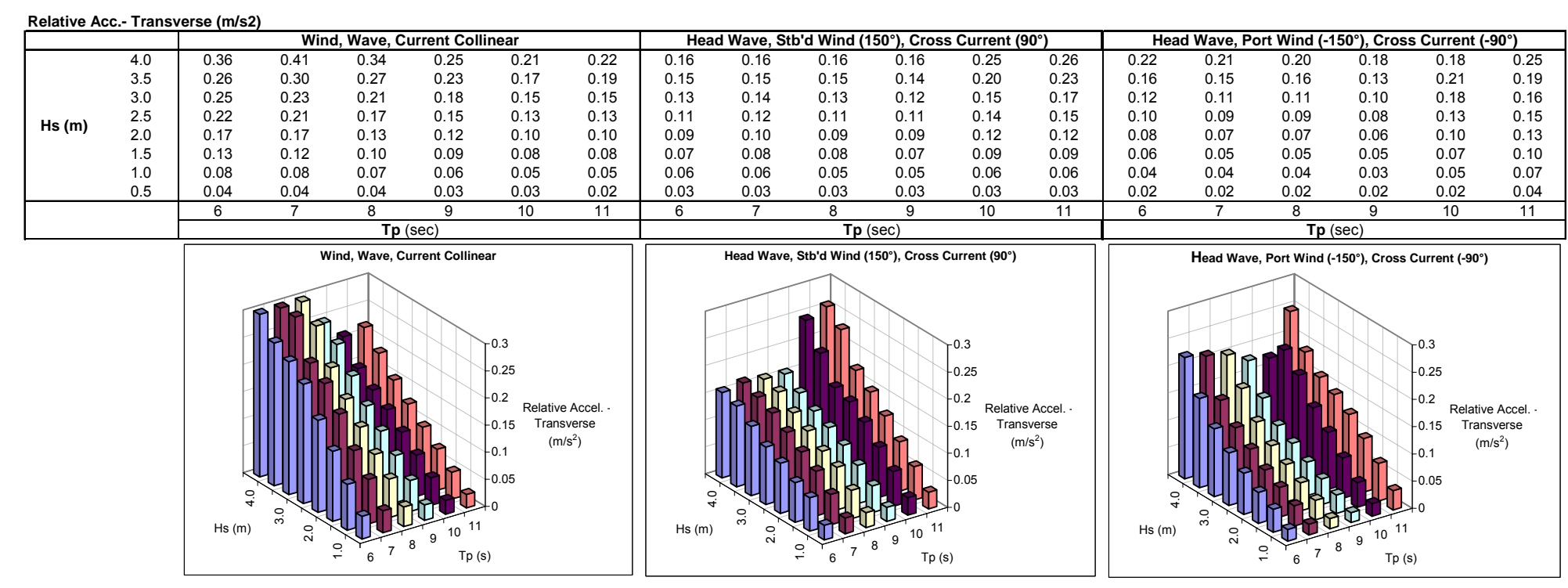




\begin{tabular}{|c|c|c|c|c|c|c|}
\hline \multirow[t]{2}{*}{ IMODE0 } & \multirow{2}{*}{$\begin{array}{l}\text { SBM-IMODCO INC. } \\
\text { MEMBER OF THE IHC/CALAND GROUP } \\
\text { Now in our 5th Decade }\end{array}$} & \multicolumn{5}{|c|}{$\begin{array}{l}\text { FLOATING RE-GASIFICATION UNIT } \\
\text { FOR SALT CAVERN } \\
\text { LNG RECEIVING AND RE-GASIFICATION }\end{array}$} \\
\hline & & 51059 & CCM97001 & C1 & PAGE & 161 \\
\hline
\end{tabular}

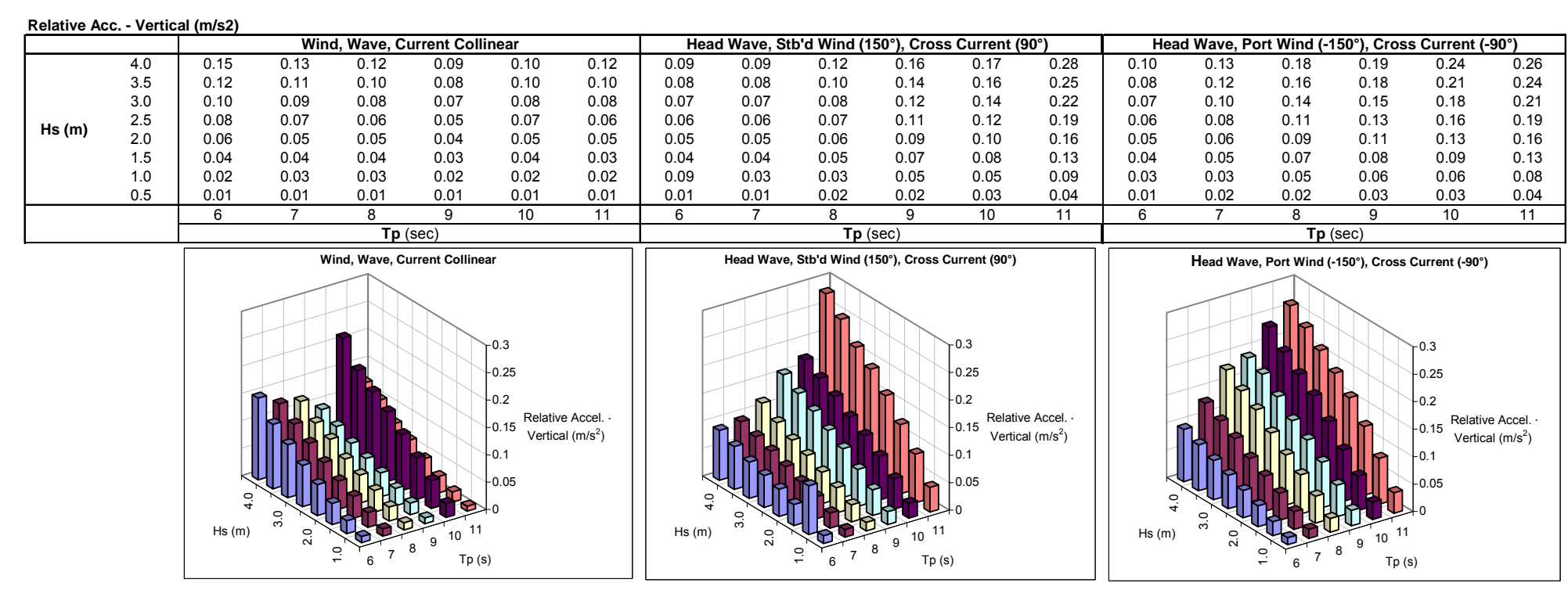




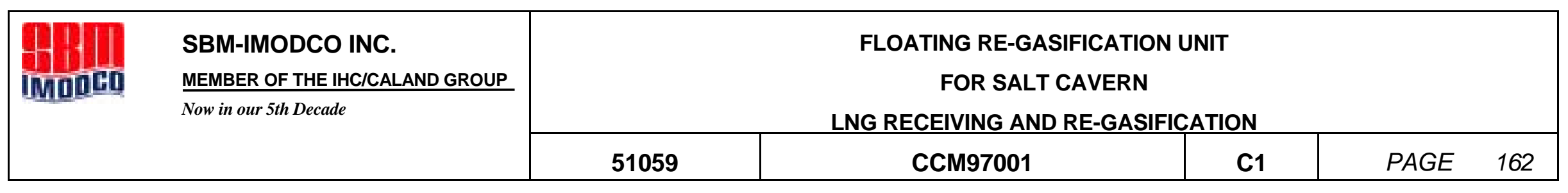

\section{Sensitivity on Random Seed:}

\begin{tabular}{|c|c|c|c|c|c|c|c|c|c|c|c|c|c|}
\hline \multicolumn{14}{|c|}{ Wind, Wave and Current Collinear } \\
\hline $\begin{array}{l}\text { Random } \\
\text { Seed }\end{array}$ & $\begin{array}{c}\text { Mean } \\
\text { Heading } \\
\left(^{\circ}\right)\end{array}$ & $\begin{array}{l}\text { Mooring } \\
\text { Tension } \\
\text { (N) }\end{array}$ & $\begin{array}{l}\text { Chain } \\
\text { Tension } \\
\text { (N) }\end{array}$ & $\begin{array}{l}\text { Fender } \\
\text { Reaction } \\
\text { (N) }\end{array}$ & $\begin{array}{c}\text { Relative } \\
\text { Motion - } \\
\text { Longitudinal } \\
\text { (m) }\end{array}$ & $\begin{array}{c}\text { Relative } \\
\text { Motion - } \\
\text { Transverse } \\
\text { (m) }\end{array}$ & $\begin{array}{c}\text { Relative } \\
\text { Motion - } \\
\text { Vertical (m) }\end{array}$ & $\begin{array}{c}\text { Relative } \\
\text { Velocity - } \\
\text { Longitudinal } \\
(\mathrm{m} / \mathrm{s})\end{array}$ & $\begin{array}{c}\text { Relative } \\
\text { Velocity - } \\
\text { Transverse } \\
(\mathrm{m} / \mathrm{s})\end{array}$ & $\begin{array}{c}\text { Relative } \\
\text { Velocity - } \\
\text { Vertical } \\
(\mathrm{m} / \mathrm{s})\end{array}$ & \begin{tabular}{|c|} 
Relative Acc. \\
- \\
Longitudinal \\
$(\mathrm{m} / \mathrm{s} 2)$
\end{tabular} & $\begin{array}{c}\text { Relative Acc. } \\
\text { Transverse } \\
(\mathrm{m} / \mathrm{s} 2)\end{array}$ & $\begin{array}{l}\text { Relative } \\
\text { Acc. - } \\
\text { Vertical } \\
(\mathrm{m} / \mathrm{s} 2)\end{array}$ \\
\hline 1 & 10.0 & 653.4 & 1487.5 & 1176.7 & 1.31 & 1.57 & 0.28 & 0.14 & 0.32 & 0.09 & 0.07 & 0.21 & 0.07 \\
\hline 2 & 10.0 & $\begin{array}{l}709.0 \\
\end{array}$ & 1448.6 & 1393.2 & 1.38 & 1.70 & 0.28 & 0.13 & 0.26 & 0.10 & 0.07 & 0.18 & 0.07 \\
\hline 3 & 10.0 & 863.3 & 1405.3 & 1454.9 & 1.45 & 1.95 & 0.29 & 0.11 & 0.30 & 0.09 & 0.07 & 0.21 & 0.07 \\
\hline 4 & 10.0 & 564.0 & 1428.2 & 1083.7 & 1.37 & 1.38 & 0.28 & 0.11 & 0.26 & 0.09 & 0.07 & 0.19 & 0.07 \\
\hline 5 & 10.0 & 583.1 & 1435.7 & 1227.4 & 1.26 & 1.72 & 0.25 & 0.12 & 0.31 & 0.08 & 0.08 & 0.21 & 0.06 \\
\hline 6 & 10.0 & 670.5 & 1390.7 & 1418.1 & 1.21 & 1.76 & 0.28 & 0.13 & 0.25 & 0.09 & 0.07 & 0.19 & 0.07 \\
\hline 7 & 10.0 & 627.4 & 1517.5 & 1327.4 & 1.53 & 1.43 & 0.26 & 0.11 & 0.28 & 0.08 & 0.06 & 0.18 & 0.06 \\
\hline 8 & 10.0 & 692.2 & 1500.4 & 1412.4 & 1.69 & 1.77 & 0.29 & 0.12 & 0.27 & 0.09 & 0.07 & 0.19 & 0.07 \\
\hline 9 & 10.0 & 651.2 & 1494.2 & 1400.7 & 1.34 & 1.62 & 0.29 & 0.11 & 0.26 & 0.09 & 0.07 & 0.19 & 0.06 \\
\hline 10 & 10.0 & 689.1 & 1437.2 & 1417.7 & 1.41 & 1.79 & 0.26 & 0.15 & 0.29 & 0.08 & 0.08 & 0.18 & 0.06 \\
\hline $\begin{array}{c}\text { Most } \\
\text { Probable } \\
\text { Max. }\end{array}$ & 10.0 & 670.3 & 1454.5 & 1331.2 & 1.40 & 1.67 & 0.27 & 0.12 & 0.28 & 0.09 & 0.07 & 0.19 & 0.07 \\
\hline
\end{tabular}

\begin{tabular}{|c|c|c|c|c|c|c|c|c|c|c|c|c|c|}
\hline \multicolumn{14}{|c|}{ Head Wave, Starboard Wind (150deg), Cross Current (90deg) } \\
\hline $\begin{array}{c}\text { Random } \\
\text { Seed }\end{array}$ & $\begin{array}{c}\text { Mean } \\
\text { Heading } \\
\left(^{\circ}\right)\end{array}$ & $\begin{array}{l}\text { Mooring } \\
\text { Tension } \\
\text { (N) }\end{array}$ & $\begin{array}{l}\text { Chain } \\
\text { Tension } \\
\text { (N) }\end{array}$ & $\begin{array}{l}\text { Fender } \\
\text { Reaction } \\
\text { (N) }\end{array}$ & $\begin{array}{c}\text { Relative } \\
\text { Motion - } \\
\text { Longitudinal } \\
\text { (m) }\end{array}$ & $\begin{array}{c}\text { Relative } \\
\text { Motion - } \\
\text { Transverse } \\
(\mathrm{m}) \\
\end{array}$ & $\begin{array}{c}\text { Relative } \\
\text { Motion - } \\
\text { Vertical (m) }\end{array}$ & \begin{tabular}{|c|} 
Relative \\
Velocity - \\
Longitudinal \\
$(\mathrm{m} / \mathrm{s})$
\end{tabular} & $\begin{array}{c}\text { Relative } \\
\text { Velocity - } \\
\text { Transverse } \\
(\mathrm{m} / \mathrm{s})\end{array}$ & $\begin{array}{l}\text { Relative } \\
\text { Velocity - } \\
\text { Vertical } \\
(\mathrm{m} / \mathrm{s})\end{array}$ & \begin{tabular}{|c} 
Relative Acc. \\
- \\
Longitudinal \\
$(\mathrm{m} / \mathrm{s} 2)$
\end{tabular} & $\begin{array}{c}\text { Relative Acc. } \\
\text { Transverse } \\
(\mathrm{m} / \mathrm{s} 2)\end{array}$ & $\begin{array}{c}\text { Relative } \\
\text { Acc. - } \\
\text { Vertical } \\
\text { (m/s2) }\end{array}$ \\
\hline 1 & 40.5 & 502.6 & 1577.6 & 838.3 & 1.91 & 0.59 & 0.19 & 0.15 & 0.14 & 0.07 & 0.10 & 0.12 & 0.06 \\
\hline 2 & 40.5 & 521.5 & 1557.0 & 963.7 & 1.99 & 0.61 & 0.16 & 0.14 & 0.13 & 0.06 & 0.09 & 0.10 & 0.05 \\
\hline 3 & 40.5 & 623.9 & 1693.9 & 884.4 & 2.11 & 0.60 & 0.18 & 0.17 & 0.16 & 0.07 & 0.12 & 0.12 & 0.06 \\
\hline 4 & 40.5 & 493.4 & 1498.1 & 1201.3 & 1.57 & 1.06 & 0.20 & 0.15 & 0.18 & 0.07 & 0.10 & 0.11 & 0.06 \\
\hline 5 & 40.5 & 435.9 & 1513.4 & 1019.6 & 1.54 & 0.80 & 0.18 & 0.14 & 0.18 & 0.07 & 0.10 & 0.13 & 0.06 \\
\hline 6 & 40.5 & 578.0 & 1570.5 & 1113.4 & 1.92 & 0.83 & 0.19 & 0.15 & 0.16 & 0.07 & 0.11 & 0.11 & 0.06 \\
\hline 7 & 40.5 & 562.7 & 1694.5 & 1215.6 & 1.86 & 0.73 & 0.19 & 0.14 & 0.17 & 0.07 & 0.10 & 0.13 & 0.06 \\
\hline 8 & 40.5 & 428.5 & 1499.6 & 964.8 & 1.56 & 0.82 & 0.20 & 0.15 & 0.16 & 0.08 & 0.11 & 0.11 & 0.06 \\
\hline 9 & 40.5 & 425.4 & 1463.4 & 908.5 & 1.61 & 0.69 & 0.19 & 0.14 & 0.17 & 0.07 & 0.10 & 0.13 & 0.06 \\
\hline 10 & 40.5 & 439.0 & 1453.8 & 931.7 & 1.49 & 0.65 & 0.19 & 0.16 & 0.17 & 0.08 & 0.12 & 0.13 & 0.07 \\
\hline $\begin{array}{c}\text { Most } \\
\text { Probable } \\
\text { Max. }\end{array}$ & 40.5 & 501.1 & 1552.2 & 1004.1 & 1.76 & 0.74 & 0.19 & 0.15 & 0.16 & 0.07 & 0.10 & 0.12 & 0.06 \\
\hline
\end{tabular}




\begin{tabular}{|c|c|c|c|c|c|c|}
\hline $\begin{array}{l}\text { Hit } \\
\text { Imogen }\end{array}$ & \multirow[t]{2}{*}{$\begin{array}{l}\text { MEMBER OF THE IHC/CALAND GROUP } \\
\text { Now in our 5th Decade }\end{array}$} & \multicolumn{5}{|c|}{$\begin{array}{l}\text { FLOATING RE-GASIFICATION UNIT } \\
\text { FOR SALT CAVERN } \\
\text { LNG RECEIVING AND RE-GASIFICATION }\end{array}$} \\
\hline & & 51059 & CCM97001 & C1 & PAGE & 163 \\
\hline
\end{tabular}

\begin{tabular}{|c|c|c|c|c|c|c|c|c|c|c|c|c|c|}
\hline \multicolumn{14}{|c|}{ Head Wave, Port Wind (-150deg), Cross Current (-90deg) } \\
\hline $\begin{array}{c}\text { Random } \\
\text { Seed }\end{array}$ & $\begin{array}{c}\text { Mean } \\
\text { Heading } \\
\left(^{\circ}\right)\end{array}$ & $\begin{array}{l}\text { Mooring } \\
\text { Tension } \\
\text { (N) }\end{array}$ & $\begin{array}{l}\text { Chain } \\
\text { Tension } \\
\text { (N) }\end{array}$ & $\begin{array}{l}\text { Fender } \\
\text { Reaction } \\
\text { (N) }\end{array}$ & \begin{tabular}{|c|} 
Relative \\
Motion - \\
Longitudinal \\
$(\mathrm{m})$
\end{tabular} & $\begin{array}{c}\text { Relative } \\
\text { Motion - } \\
\text { Transverse } \\
\text { (m) }\end{array}$ & \begin{tabular}{|c|} 
Relative \\
Motion - \\
Vertical (m)
\end{tabular} & \begin{tabular}{|c|} 
Relative \\
Velocity - \\
Longitudinal \\
$(\mathrm{m} / \mathrm{s})$
\end{tabular} & \begin{tabular}{|c|} 
Relative \\
Velocity - \\
Transverse \\
$(\mathrm{m} / \mathrm{s})$ \\
\end{tabular} & \begin{tabular}{|c|} 
Relative \\
Velocity - \\
Vertical \\
$(\mathrm{m} / \mathrm{s})$
\end{tabular} & \begin{tabular}{|c} 
Relative Acc. \\
- \\
Longitudinal \\
$(\mathrm{m} / \mathrm{s} 2)$
\end{tabular} & $\begin{array}{c}\text { Relative Acc. } \\
\text { Transverse } \\
(\mathrm{m} / \mathrm{s} 2)\end{array}$ & $\begin{array}{l}\text { Relative } \\
\text { Acc. - } \\
\text { Vertical } \\
(\mathrm{m} / \mathrm{s} 2)\end{array}$ \\
\hline 1 & 31.6 & 365.3 & 1276.3 & 803.6 & \begin{tabular}{|l|}
0.92 \\
\end{tabular} & 0.65 & 0.28 & 0.08 & 0.13 & 0.11 & 0.05 & 0.09 & 0.08 \\
\hline 2 & 31.5 & 468.0 & 1286.8 & 722.1 & 0.75 & 0.70 & 0.27 & 0.08 & 0.12 & 0.10 & 0.04 & 0.09 & 0.07 \\
\hline 3 & 31.6 & 421.0 & 1384.9 & 813.2 & 0.93 & 0.67 & 0.28 & 0.10 & 0.15 & 0.11 & 0.05 & 0.11 & 0.08 \\
\hline 4 & 31.5 & 509.0 & 1302.5 & 1000.2 & 0.93 & 1.24 & 0.32 & 0.08 & 0.16 & 0.12 & 0.05 & 0.09 & 0.09 \\
\hline 5 & 31.5 & 406.9 & 1261.1 & 890.3 & 0.83 & 0.93 & 0.28 & 0.09 & 0.13 & 0.10 & 0.05 & 0.10 & 0.08 \\
\hline 6 & 31.6 & 396.4 & 1308.7 & 858.3 & 0.97 & 0.90 & 0.28 & 0.09 & 0.14 & 0.11 & 0.05 & 0.09 & 0.09 \\
\hline 7 & 31.5 & 498.8 & 1348.0 & 1028.0 & 1.02 & 0.75 & 0.24 & 0.08 & 0.14 & 0.09 & 0.05 & 0.09 & 0.07 \\
\hline 8 & 31.5 & 479.0 & 1314.7 & 894.4 & 0.80 & 0.93 & 0.31 & 0.10 & 0.15 & 0.11 & 0.06 & 0.08 & 0.09 \\
\hline 9 & 31.5 & 477.8 & 1307.8 & 856.5 & 0.86 & 0.67 & 0.29 & 0.08 & 0.13 & 0.11 & 0.05 & 0.09 & 0.09 \\
\hline 10 & 31.5 & 447.4 & 1284.6 & 1108.9 & 0.88 & 0.72 & 0.27 & 0.10 & 0.13 & 0.10 & 0.05 & 0.09 & 0.08 \\
\hline $\begin{array}{c}\text { Most } \\
\text { Probable } \\
\text { Max. }\end{array}$ & 31.5 & 447.0 & 1307.5 & 897.5 & 0.89 & 0.82 & 0.28 & 0.09 & 0.14 & 0.11 & 0.05 & 0.09 & 0.08 \\
\hline
\end{tabular}




\begin{tabular}{|c|c|c|c|c|c|c|}
\hline \multirow[t]{3}{*}{ ImoOCO } & \multirow{3}{*}{$\begin{array}{l}\text { SBM-IMODCO INC. } \\
\text { MEMBER OF THE } \\
\text { IHC/CALAND GROUP } \\
\text { Now in our 5th Decade }\end{array}$} & \multirow{2}{*}{\multicolumn{5}{|c|}{$\begin{array}{l}\text { FLOATING RE-GASIFICATION UNIT } \\
\text { FOR SALT CAVERN } \\
\text {-NG RECEIVING AND RE-GASIFICATION }\end{array}$}} \\
\hline & & & & & & \\
\hline & & 51059 & CCM97001 & C1 & PAGE & 164 \\
\hline
\end{tabular}

APPENDIX E - LNG LOADING ARMS 


\section{FMC Loading Systems LNG Loading Technology}

\section{FMC Technologies Corporation}

- Diverse and Strong Global Supplier

- Sales of \$2.0 Billion

- 8,500 employees

- 31 Manufacturing Facilities in 14 countries

- 3 Operating Business Groups

- Business Units

- FMC Energy Systems

Energy Production Systems

Upstream Petroleum Equipment \& Services

Energy Processing Systems

Downstream Petroleum Equipment \& Services

- FMC FoodTech

Food Processing Equipment \& Services

- FMC Airport Systems

Boarding Bridges, Deicers, Loaders, etc. 


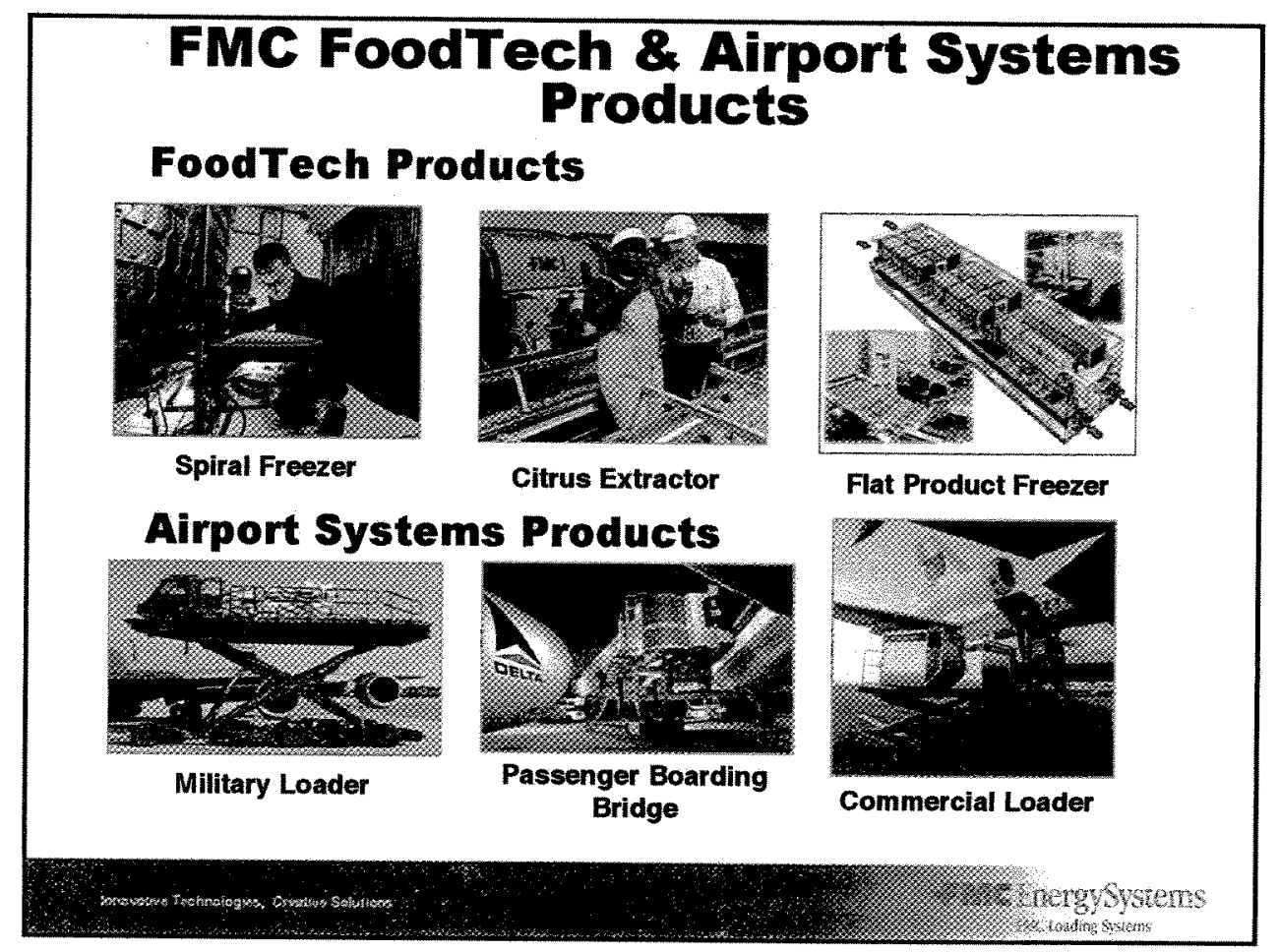

\section{Energy Production Systems}

- FMC Kongsberg Subsea

- Technology, Products, \& Systems for Full Field Subsea Development

- FMC CBV Subsea

- Brazil's Leading Energy Equipment Supplier

- FMC Surface Wellhead

- Industry Leading Surface \& Platform Wellhead Equipment

- FMC SOFEC Floating Systems, Inc.

- First in Turret Mooring Systems \& Transfer Buoys

- Modec International LLC

- Advanced Tension Leg Platform \& Production Technology

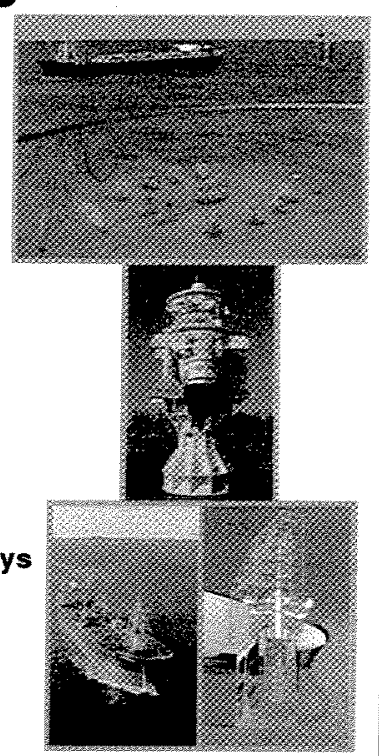




\section{Energy Processing Systems}

- FMC Fluid Control

- Industry Standard in Flowline Products \& Manifold Systems

- FMC Loading Systems

- Global Leader in Solutions for Fluid Handling

- FMC Measurement Solutions

- Industry Leader in Measurement

- FMC Material Handling Systems

- Leader in Material Handling Conveying Systems

- FMC Blending \& Transfer

- Integrated Blending Systems

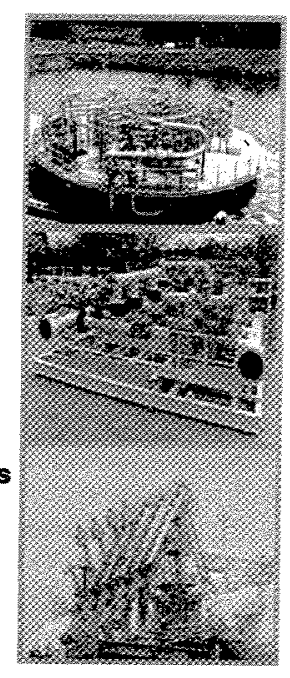

\section{FMC Loading Systems}

- Fluid Transfer Product Supplier Based in Sens, France

- USA Operation in Houston, TX

- Over 50 Years Experience in Loading Arm Business

- Approximately 150 employees

- Core technologies

- LNG Loading Arms

- Conventional Marine Loading Arms

- Truck \& Rail Loading Arms

- Piggable Systems

- Integrated Projects

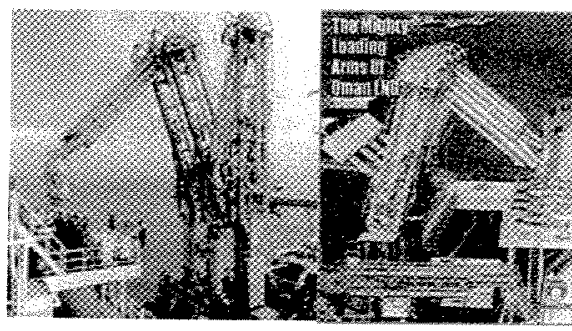

LNG Marine Loading Arms

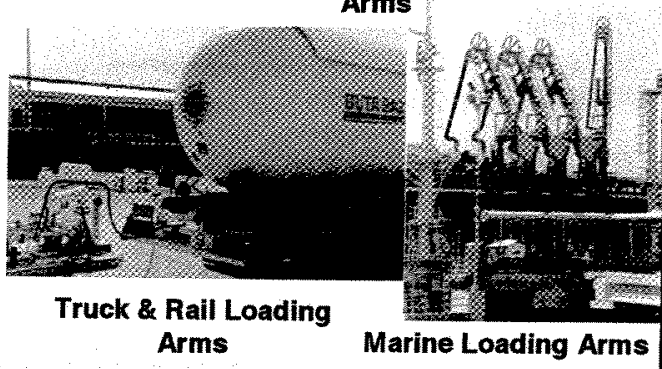



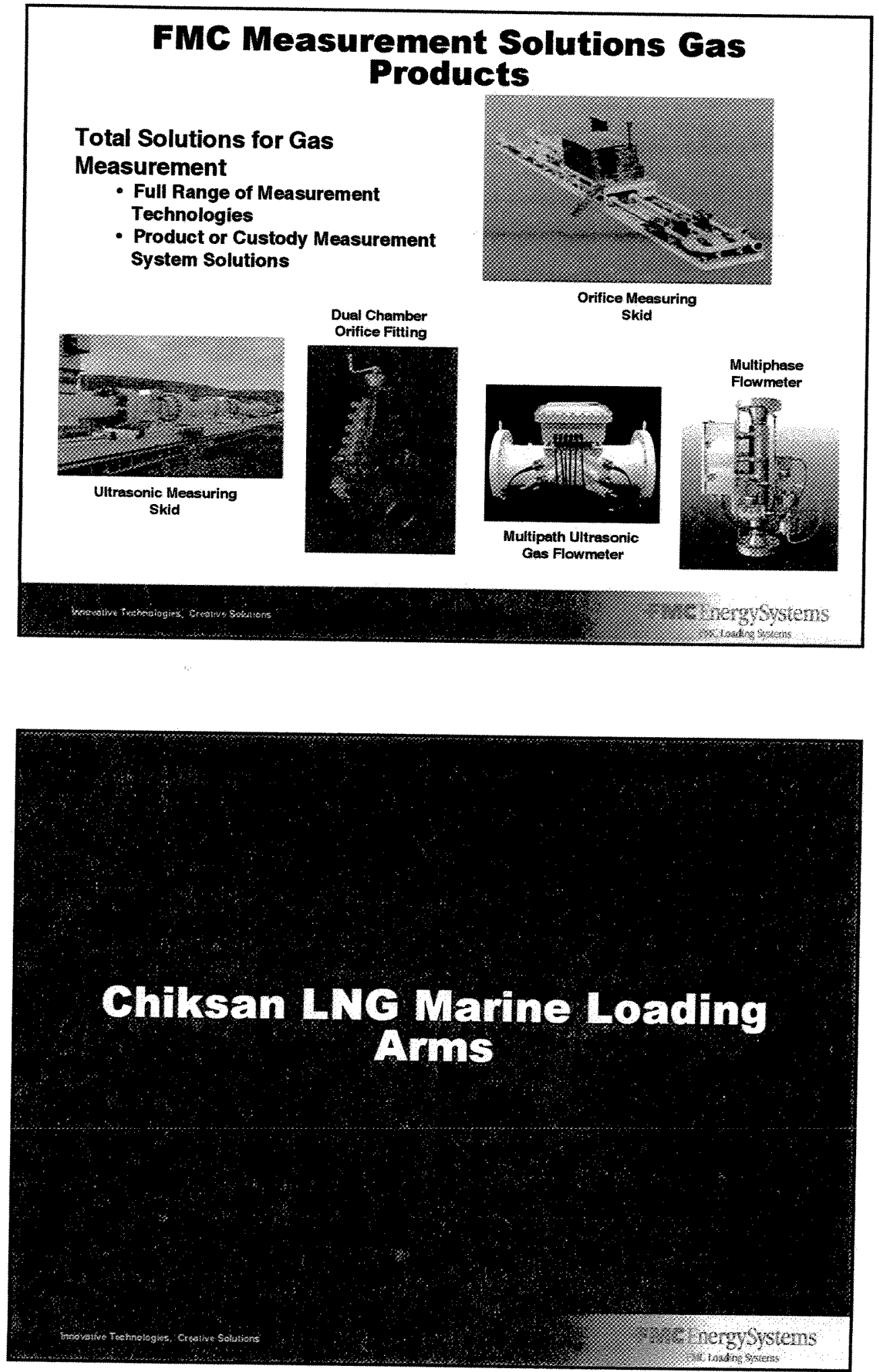


\section{Presentation Overview}

- Issues with LNG Marine Loading Arms

- Marine Loading Arm Accessories

- Couplers

- Emergency Release Systems

- Control Systems

- Onshore Locations

- Protected

- Exposed

- Offshore / Exposed Locations

- Side by Side Loading

- Tandem Loading (Ship Tethered)

- Tandem Loading (Ship Duplex Yoke Mooring)

\section{What Defines A Marine Loading} Arm?

Issues to Consider:

- Types of Ships

- Mooring Variations

- Water Level Variations

- Wave Conditions

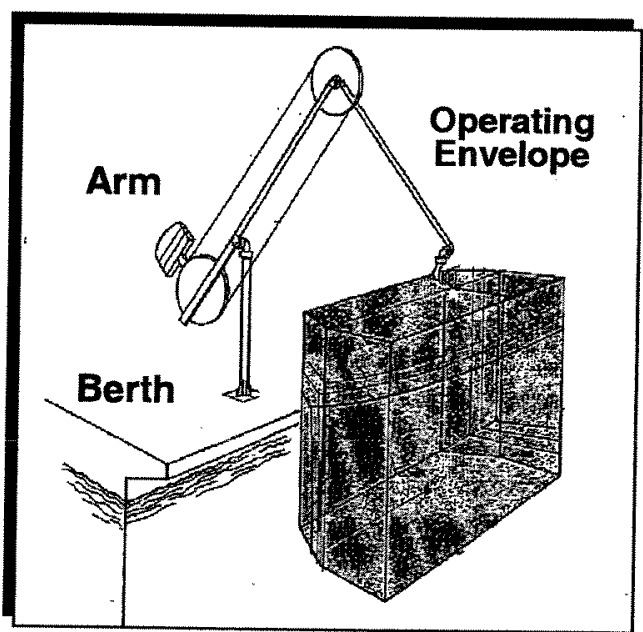




\section{Typical Operating Envelopes}

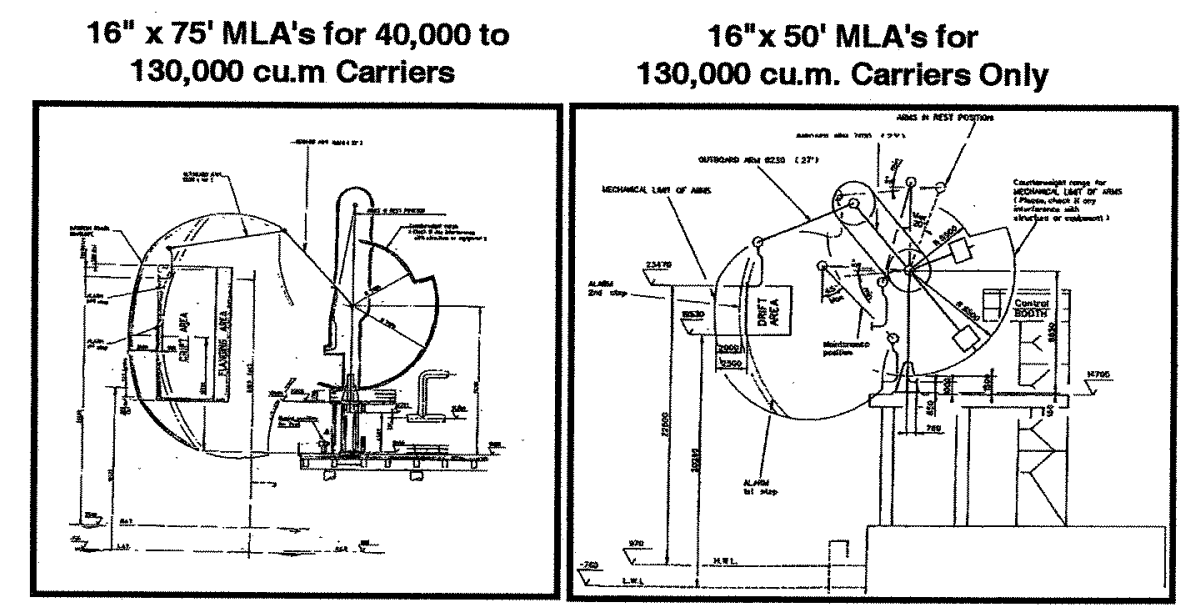

\section{Typical Marine Loading Arm Installations}

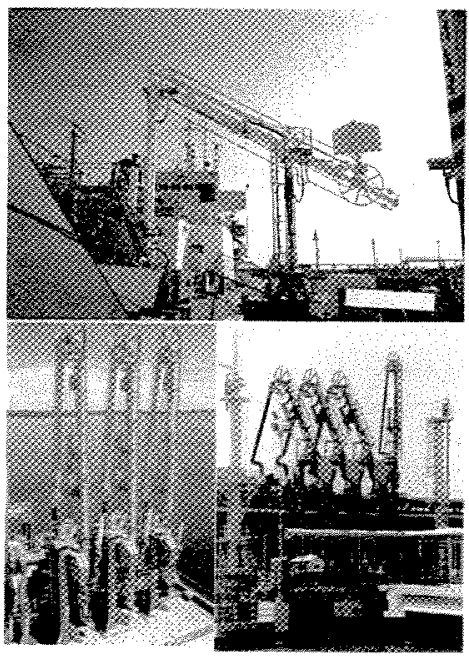

Petroleum/PetroChemical Installations

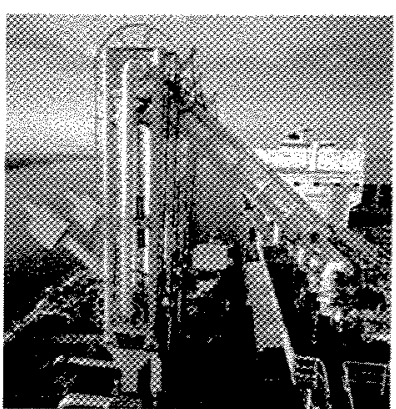

LNG Installation

- Unique to LNG

- Transported at $-162^{\circ} \mathrm{C}$

- Structured Loading Arm

- All Loading Arms Have

- ERS

- Sophisticated Control

- Systems 


\section{FMC Chiksan Marine Loading Systems}

Experience with over 300 LNG Arms Worldwide Enables FMC to Offer Different Solutions

CHIKSAN LNG MARINE LOADING ARMS

IN SERVICE SINCE 1963
20" DIAMETER: 16 UNITS
16" DIAMETER : 250 UNITS
12" DIAMETER : 62 UNITS
10" DIAMETER : 13 UNITS
8" DIAMETER : 6 UNITS

\section{LNG Marine Arm Swivel Joints}

\section{LNG Swivel Joint Technology}

- Nitrogen Purge Capability

- Seal Leak Detection Port

- Constant Motion Capability

- Snap-In Ball Races

- Isolated Ball Race Area

- Field Proven Seal Designs

- In-Situ Replacement Capability

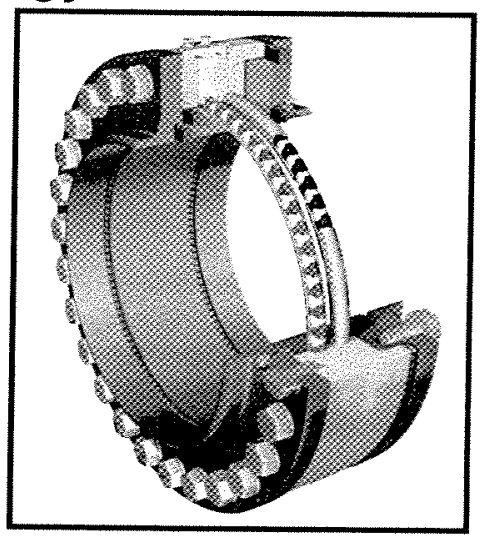

Chiksan LNG Swivel Joint 


\section{LNG Liquid ARM Pressure Drop}

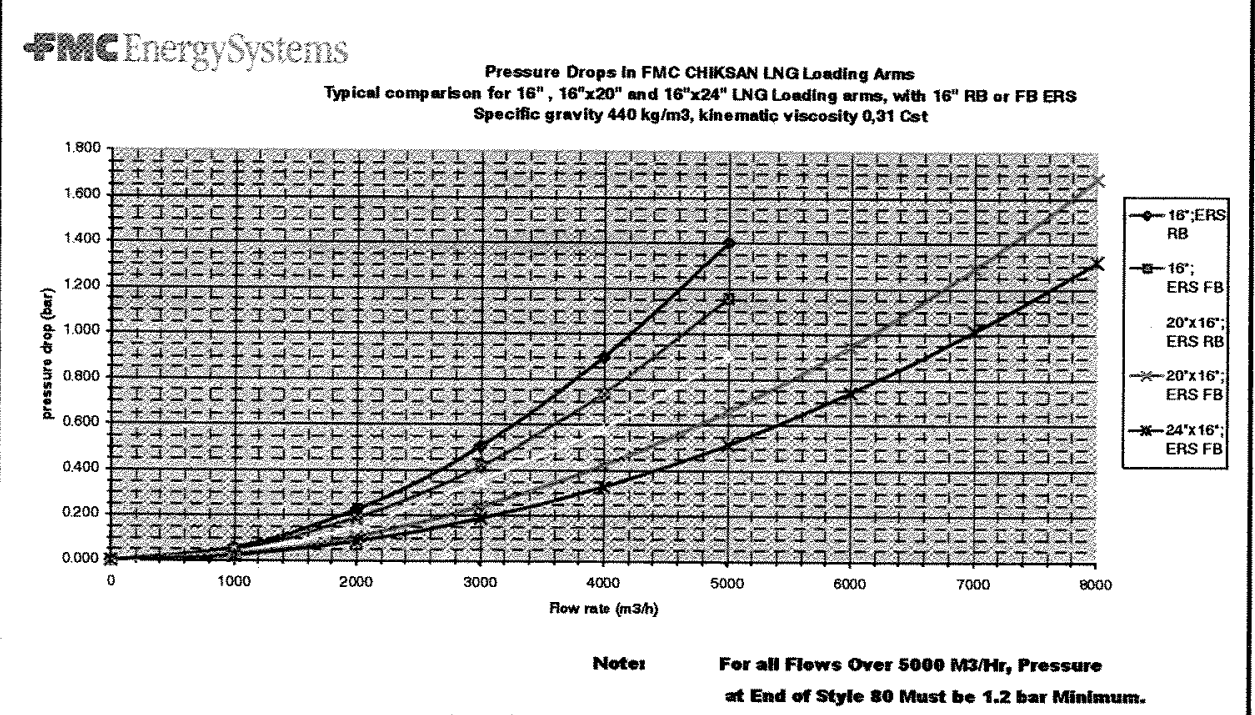

\section{Typical Vapor Arm Pressure Loss}

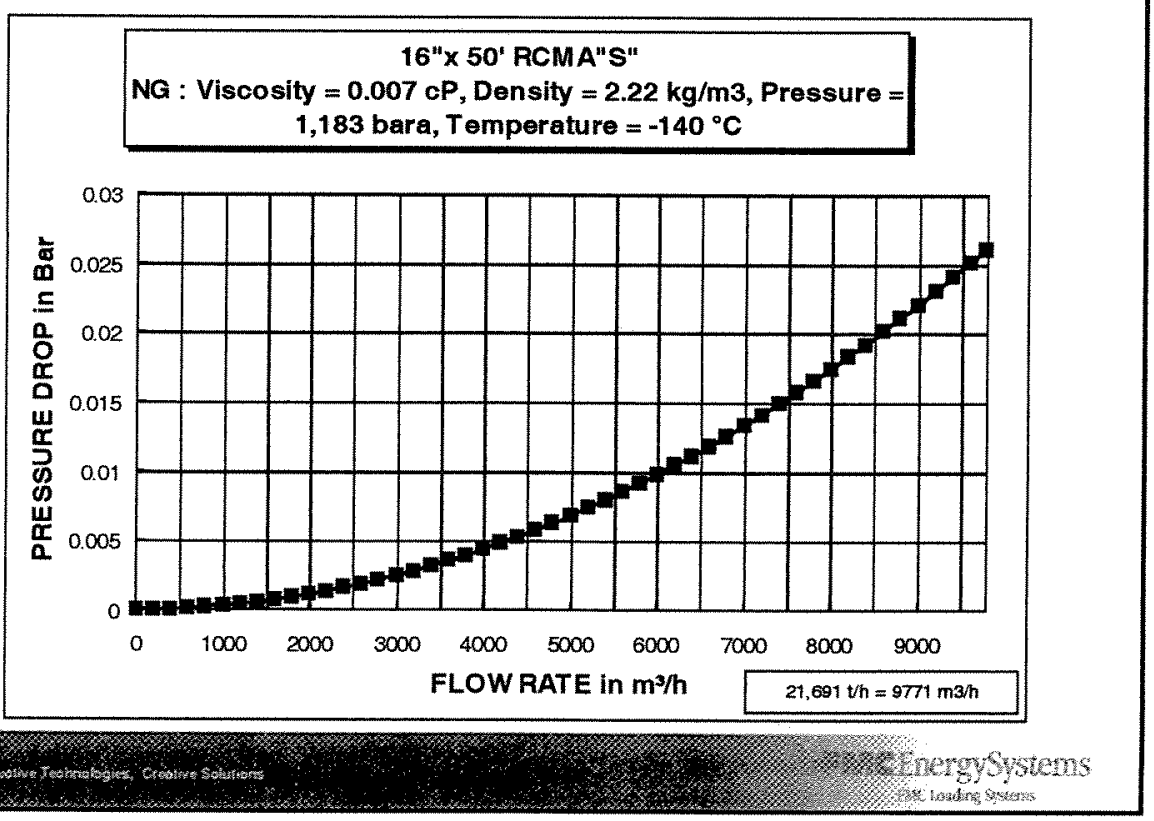




\section{Loading Times Versus Flow}

- Assumes Loading Rates Can be Achieved (NA Indicates Flows Beyond Reason for Carrier Size)

- Assumes First (Cooldown) and Last (Shutdown) Hour of Flow Average $1 / 2$ Maximum Rate.

- Assumes Flow is Divided Evenly Between Three Liquid Loading Arms

Unloading Time vs. Tanker Size $\left(\mathrm{M}^{3}\right)$

\begin{tabular}{|c|c|c|c|c|c|}
\hline Max Flow & $90,000 \mathrm{M}^{3}$ & $138,000 \mathrm{M}^{3}$ & $200,000 \mathrm{M}^{3}$ & $250,000 \mathrm{M}^{3}$ & \\
\hline $\begin{array}{c}10,000 \mathrm{M}^{3} / \mathrm{Hr} \\
3,333 \mathrm{M}^{9} \mathrm{Hr} \text { Per Arm }\end{array}$ & $10 \mathrm{Hrs}$. & 15 Hrs. & 21 Hrs. & $26 \mathrm{Hrs.}$ & \\
\hline $\begin{array}{c}12,000 \mathrm{M}^{3} / \mathrm{Hr} \\
4,000 \mathrm{M}^{3} \mathrm{Hr} \text { Per Arm } \\
\end{array}$ & 8.5 Hrs. & $12.5 \mathrm{Hrs}$. & 18 Hrs. & $22 \mathrm{Hrs}$ & \\
\hline $\begin{array}{c}15,000 \mathrm{M}^{3} / \mathrm{Hr} \\
5,000 \mathrm{M}^{5} \mathrm{Hr} \text { Per Arm }\end{array}$ & NA & 10 Hrs. & $14.5 \mathrm{Hrs}$. & 18 Hrs. & \\
\hline 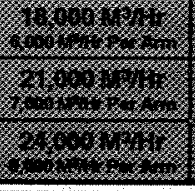 & \% & 要 & K & 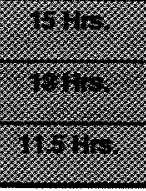 & $\begin{array}{l}\text { Red Ateas } \\
\text { Require } 20^{\circ 5} \\
\text { Loading Ams, } \\
\text { All Others } 16^{3} \\
\text { or } 20^{\circ} \text { Arms }\end{array}$ \\
\hline
\end{tabular}

\section{Typical Process Requirements}

\section{- Arm Cool Down}

- All LNG Loading Arms Must be Cooled Down Prior to Operation

- Cool Down Typically Takes 30-40 Min

- Rate Not to Exceed 8-10 Deg. C Per Minute

\section{- Arm Draining}

- LNG Loading Arms Drained with Nitrogen

- Typical Volume to Drain is $5 X$ Arm Volume

- $100 \mathrm{M}^{3}$ of Nitrogen for Four Arms 


\section{Typical Process Requirements}

- Nitrogen System Requirements

- Swivel Joint Drying System

- Pressure 0.1 - 0.5 Bar (1.5 - 7.5 PSI)

- Flow

- $\quad 0.4 \mathrm{M}^{3} /$ Hour During Operation

- $0.1 \mathrm{M}^{3} /$ Hour During Storage

- Arm Purging

- Pressure 2 Bar Min. (29.5 PSI)

- Flow $100 \mathrm{M}^{3} /$ Hour

\section{Typical LNG Marine Loading Arm}

Chiksan LNG

Structured Loading Arm Type DCMA-S

Structured Loading is Needed to:

- Ensure Product Line and Support Structure are Independent

- Mechanical loads carried by separate support structure

- Small Load Eliminates Thermal Stress

- No Thermal Stress on Support Structure Due to Isolation

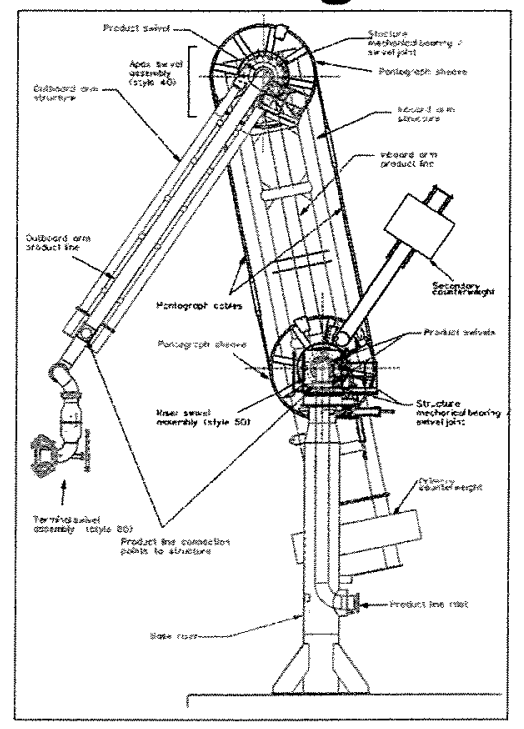




\section{Type of LNG Loading ArmsArm}

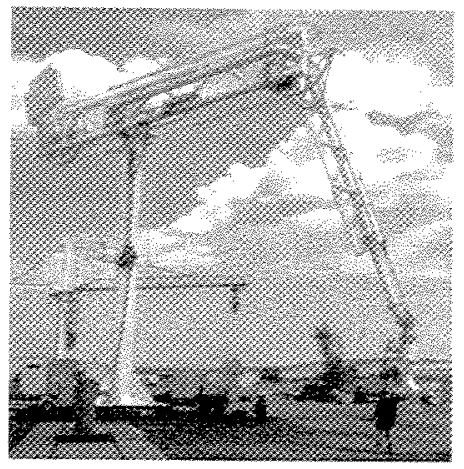

RCMA-S

Rotating Counterweight Marine Arm - Structured

- Best for Protected Shore Applications with Small/

Moderate Wave Motions

- May Require More Space on Dock

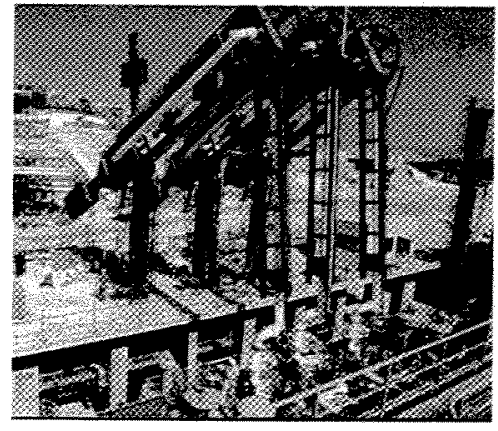

DCMA-S

Double Counterweight Marine Arm Structured

- Best for Exposed Shore I Offshore Applications with Moderate/Severe Wave Motions

- Requires Less Dock Space than RCMA-S

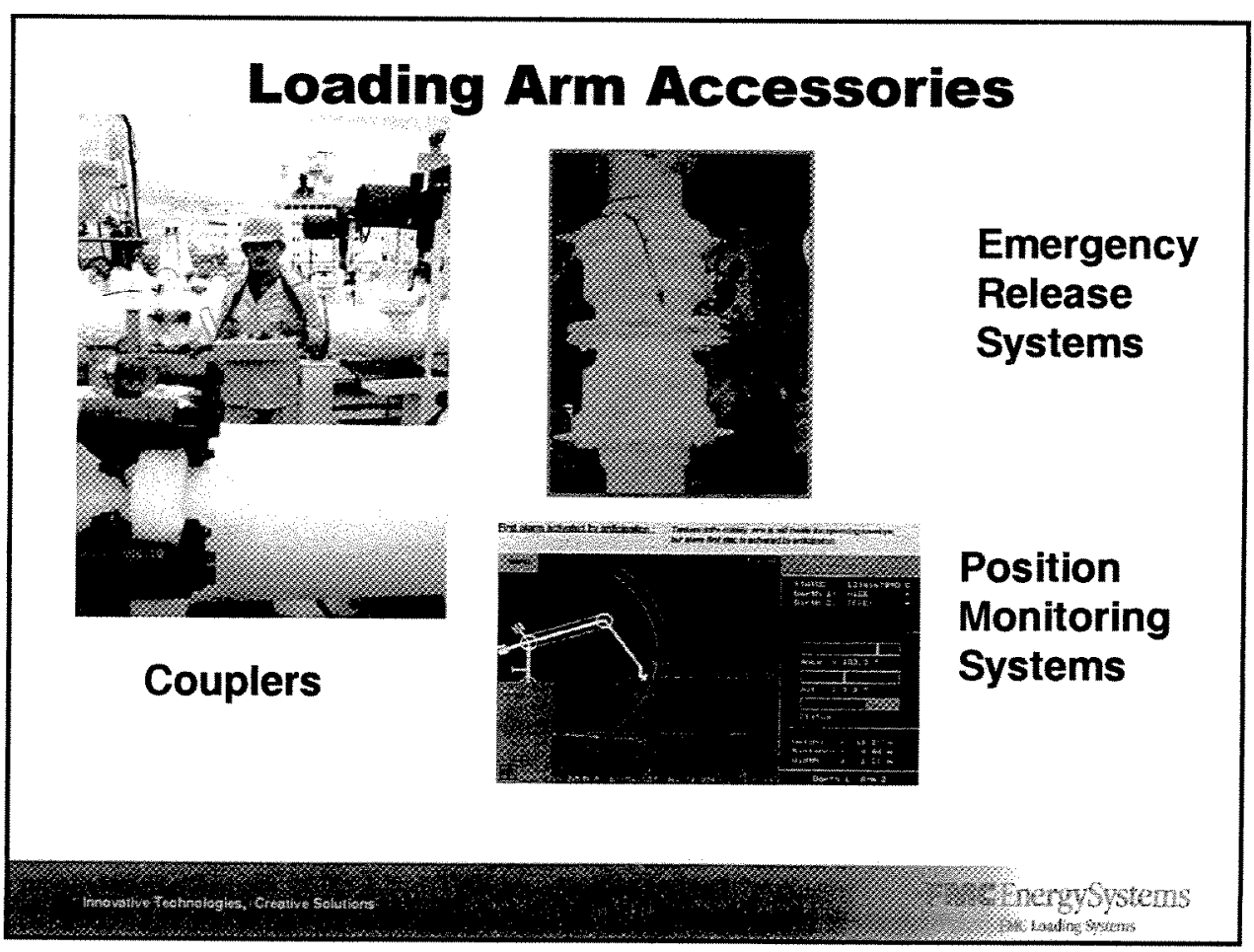




\section{Chiksan Hydraulic Quick Connect/Disconnect Coupler}

\section{Features :}

- Diameters From 6" to 16"

- Coupler Size Equal to Flange Connection

- Pressure Rating from ANSI 150 to ANSI 300

- Incorporates Seal within Coupler Flange Face

- FMC Patented Seal Protection Device

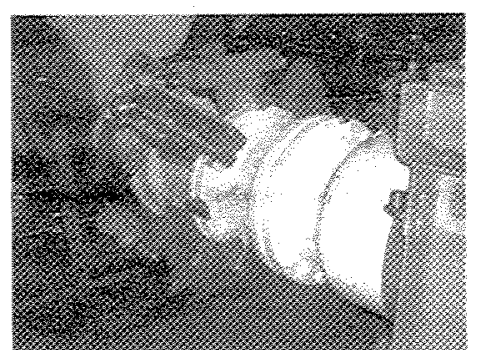

Connected to LNG Tanker
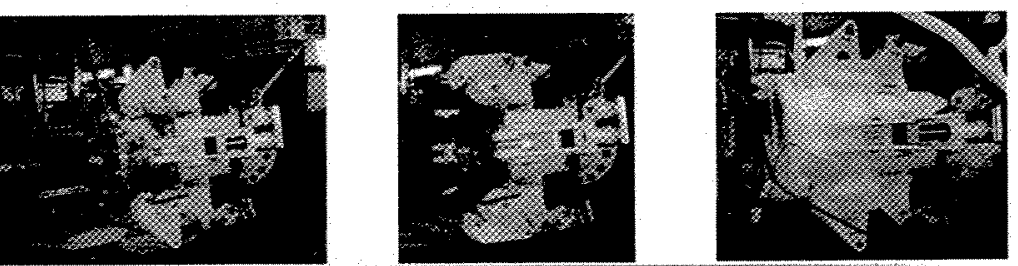

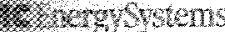

\section{Chiksan LNG Double Ball Valve Emergency Release System}

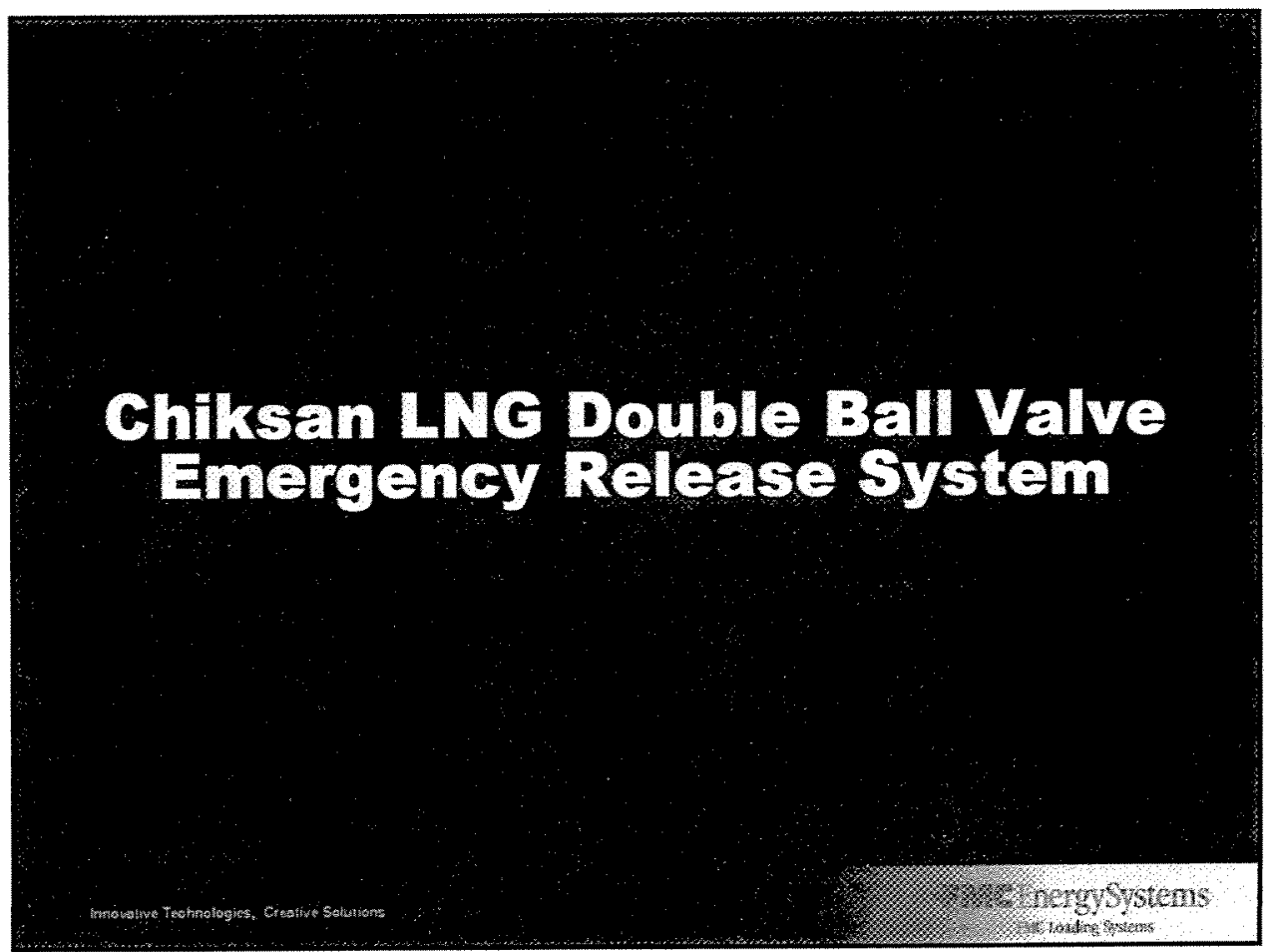




\section{FMC LNG Emergency Release System (ERS)}

\section{Design Standards}

- Meets OCIMF 1999 Edition

- Meets EN 14741997 Edition

- Meets SHELL leakage rate of $0.4 \mathrm{l} / \mathrm{hr}$

- Design pressure 30 bars (435 psi)

- Desinn Flow (16") $5000 \mathrm{M}^{3} / \mathrm{Hr}$.

- Design temperature $-165^{\circ} \mathrm{C}\left(-265^{\circ} \mathrm{F}\right)$

- Minimized volume between the valves (7.9 litres - full bore)

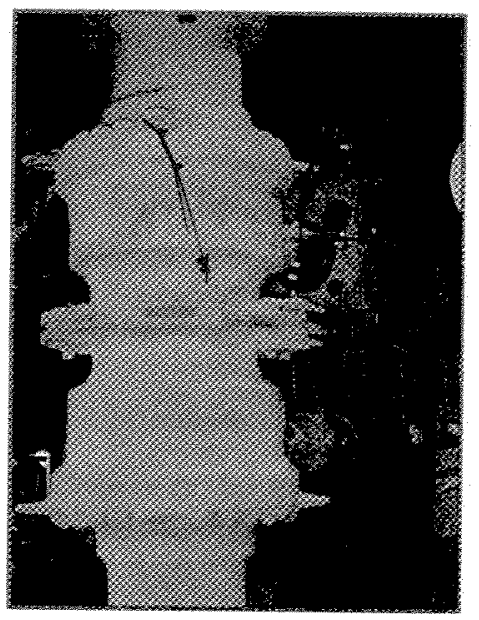

16" Full Bore LNG ERS. Cryogenic test.

\section{FMC LNG Emergency Release System (ERS)}

Cryogenic Tests According to OCIMF \& SHELL Specifications \& EN1474 (*)

\section{Available Configurations}

- Sizes: Up to $16^{\prime \prime}$

- Options: Full \& Reduced Bore

- Complete Assembly in Stainless Steel

- Spring Energized Powered Emergency Release Coupler to Ensure Proper Opening Under 25mm Ice Coating - OCIMF 1999 Requirement.

( ${ }^{*}$ EN $=$ European legislation

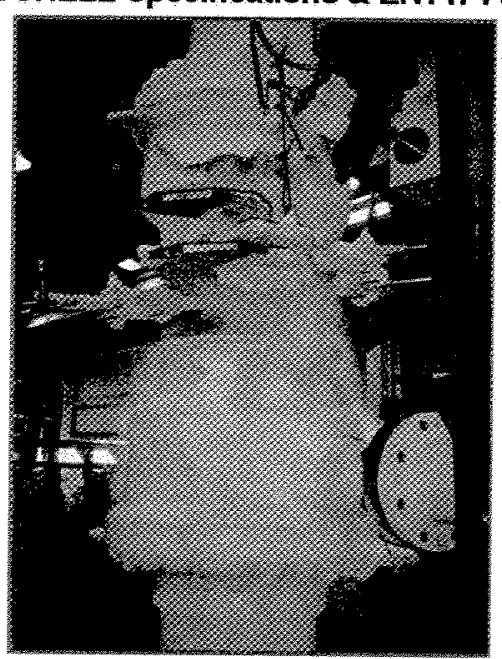




\section{Control Systems}

POSITION MONITORING SYSTEM

- Used at Most Conventional (Calm) LNG Terminals and All Exposed LNG Terminals

- Monitors Position of Arms and Signals Problems

- Pre-Alarm for Advanced Warning to Operators

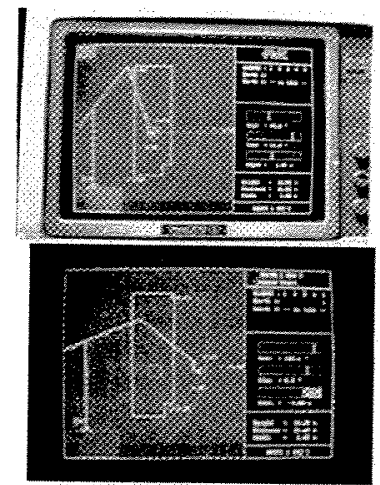

- First Stage Alarm to Shut Pumps \& Valves

- Second Stage Alarm Disconnects Arms

- Compensates for Speed of Drift

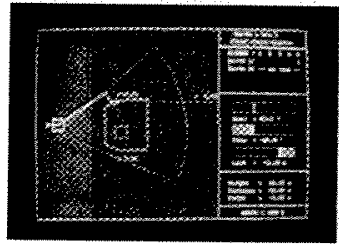

\section{Control Systems}

\section{FMC Integrated Cordless}
Remote Arm Maneuvering
- Increases Safety by Allowing
Operator Flexibility
Frequency : 433,875 to $434,650 \mathrm{MH}$
Emitting power : $10 \mathrm{~mW}$
Battery life : approx. 3 years
Protection : IP65
Weight : $3 \mathrm{~kg}$

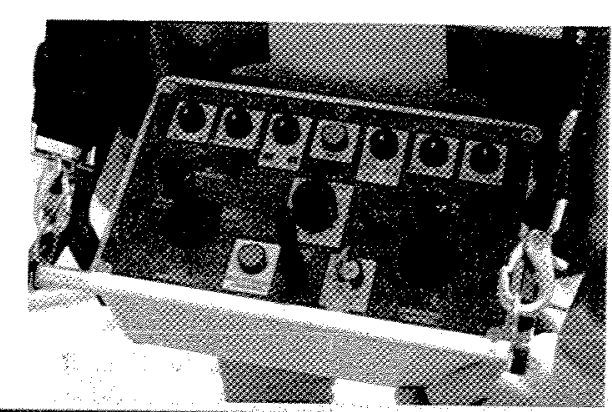




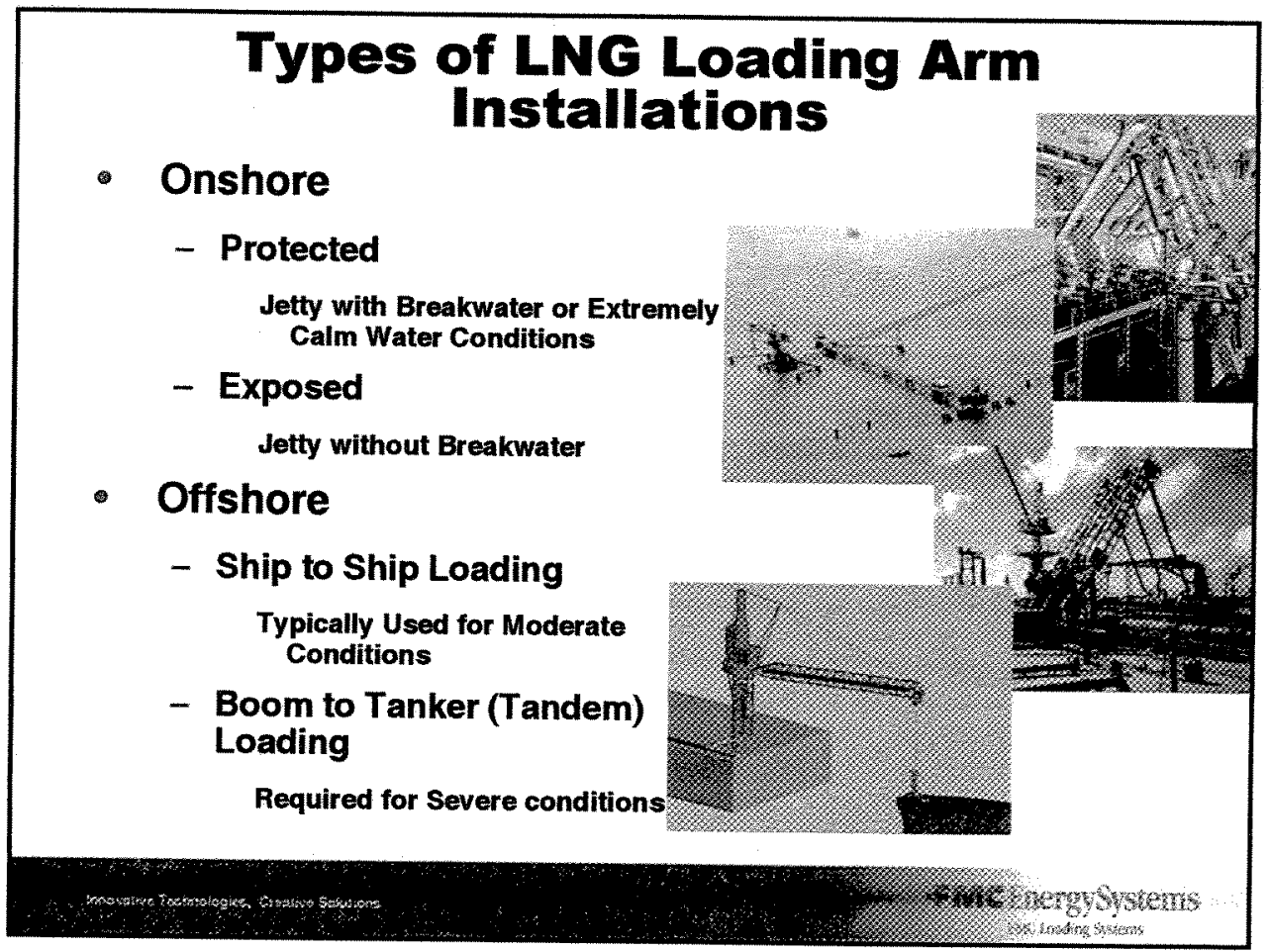

\section{Onshore - Protected (Conventional)}

- Typical Installation

- 3 Liquid / 1 Vapor Arm

- 10,000 M3/Hr Flow

- Typical Accessories

Emergency Release System Manual Coupler

Position Monitoring System

- General Flange Connection Guidelines

- Vertical Displacement +/- $0.1 \mathrm{M}$

- Horizontal Displacement +/- $0.1 \mathrm{M}$

- Velocity +/- $0.05 \mathrm{M} / \mathrm{Sec}$

- Acceleration +/- 0.025 M/Sec 2

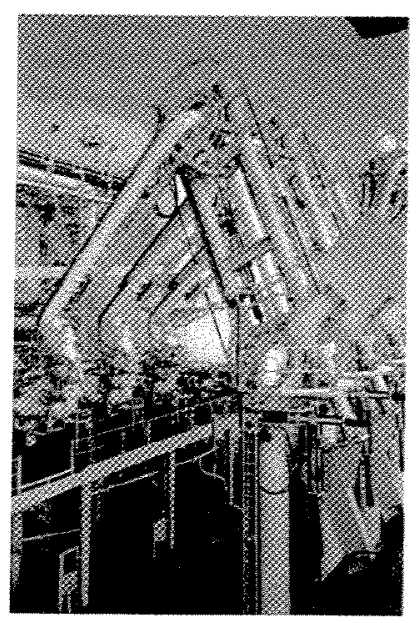




\section{Onshore - Protected (Conventional)}

- Main Considerations

- Water Level Variations

- Wave Conditions

- Range of Ships to be Loaded/Unloaded

- Allowable Flanging / Drift Areas

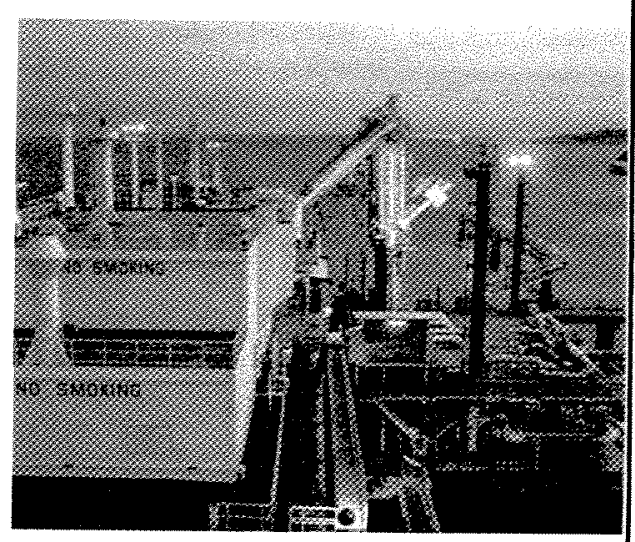

\section{Onshore - Exposed}

- Typical Installation

- 3 (2) Liquid/1 Vapor Arm

- 10,000 M3/Hr Flow

- Typical Accessories Emergency Release System Hydraulic Coupler

Constant Motion Swivel Joints Position Monitoring System

- General Flange Connection Guidelines

- Vertical Displacement $+/-0.5 \mathrm{M}$

- Horizontal Displacement $+/=0.5 \mathrm{M}$

- Velocity +1- $0.25 \mathrm{M} / \mathrm{Sec}$

- Acceleration $+/-0.125 \mathrm{M} / \mathrm{Sec} 2$

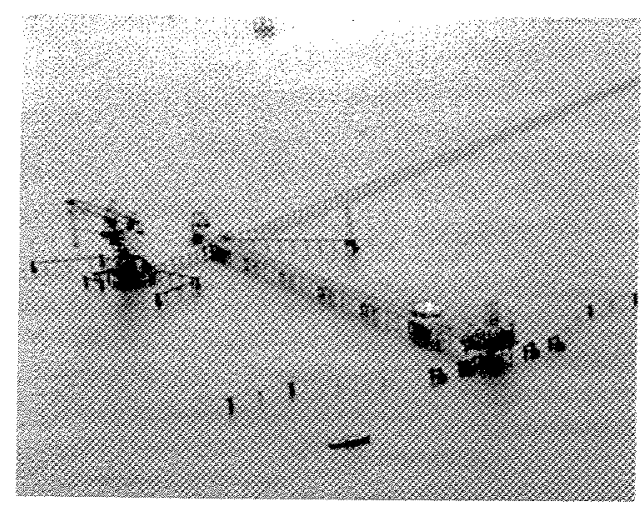




\section{Onshore - Exposed}

- Main Considerations

- Eliminates Need for Breakwater

- Water Level Variations

- Wave Conditions

- Range of Ships to be Loaded/Unloaded

- Allowable Flanging / Drift Areas

- Flange Movements During Connection

- \% Availability

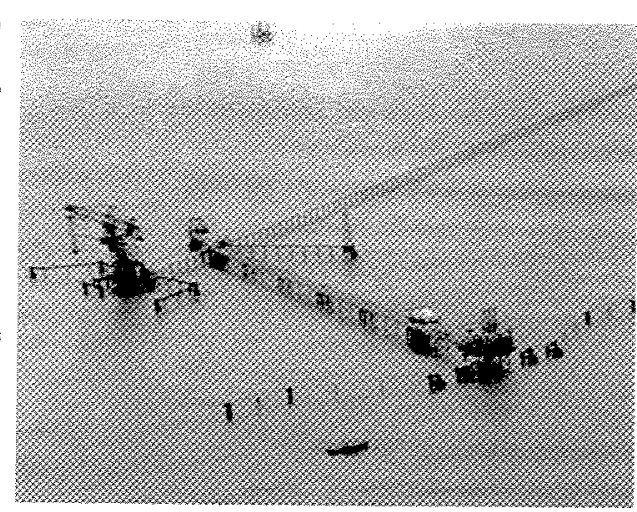

\section{Ship to Ship}

- Typical Installation

- 3 (2) Liquid / 1 Vapor Arm

- 10,000 M3/Hr Flow

- Typical Accessories

Emergency Release System Hydraulic Coupler

Constant Motion Swivel Joints Position Monitoring System May Have Targeting System

- General Flange Connection Guidelines

- Vertical Displacement $+/-2.0 \mathrm{M}$

- Horizontal Displacement $+/=1.7 \mathrm{M}$

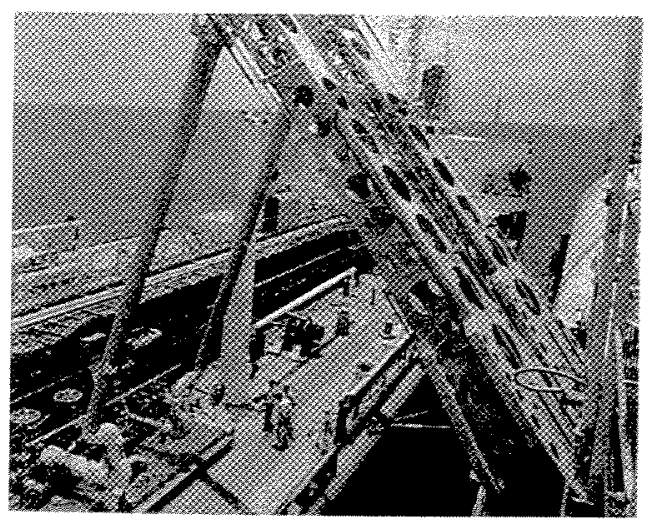

- Velocity $+/-1.0 \mathrm{M} / \mathrm{Sec}$

- Acceleration $+1-0.5 \mathrm{M} / \mathrm{Sec} 2$ 


\section{Ship to Ship}

- Main Considerations

- Wave Conditions

- Range of Ships to be Loaded/Unloaded

- Allowable Flanging / Drift Areas

- Flange Movements During Connection

- \% Availability

- When will Ship Manifold be Adapted for Connection System

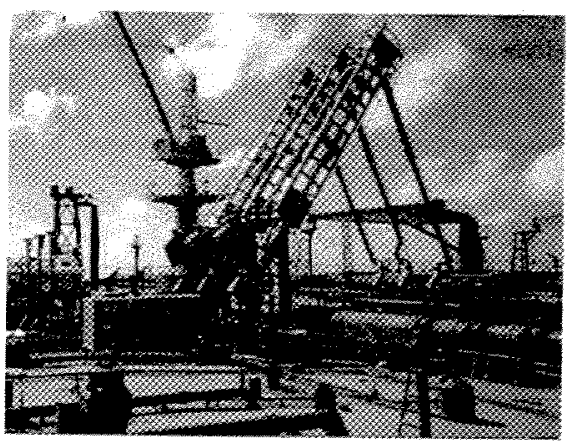

\section{Ship to Ship}

- Connection Sequence

- Maneuver Arm Over Manifold

- Drop Target Line

- Connect Target Line

- Maneuver Arm in Front of Target

- Sel "FreeWheel Mode

- Engage Winch

- Arm Pulls In

- Engage Hydraulic Coupler
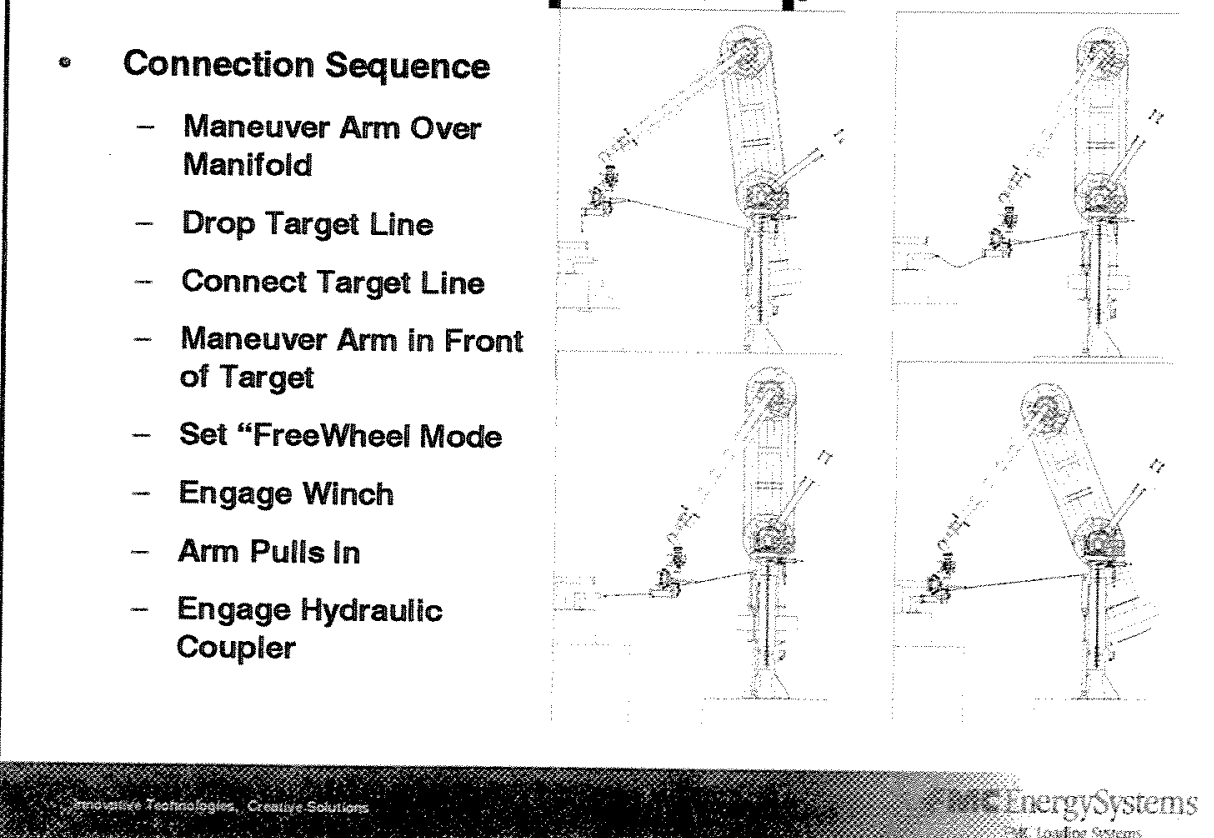


\section{Tandem Loading (Boom to Tanker)}

- Typical Installation

- 1(24 in.) Liquid / 1 (16 in.) Vapor Arm

- $10,000 \mathrm{M} 3 / \mathrm{Hr}$ Flow

- Typical Accessories

Emergency Release System

Hydraulic Coupler

Constant Motion Swivel Joints

Position Monitoring System

Targeting System

- General Connection Guidelines

- Up to $5.0 \mathrm{M}$ Significant Wave Heights

- Heave +/ $5.0 \mathrm{M}$

- Velocity +/-2.5 M/Sec

- Acceleration +/- $2.5 \mathrm{M} / \mathrm{Sec}^{2}$

- 23.0 M Diameter Operating Envelope

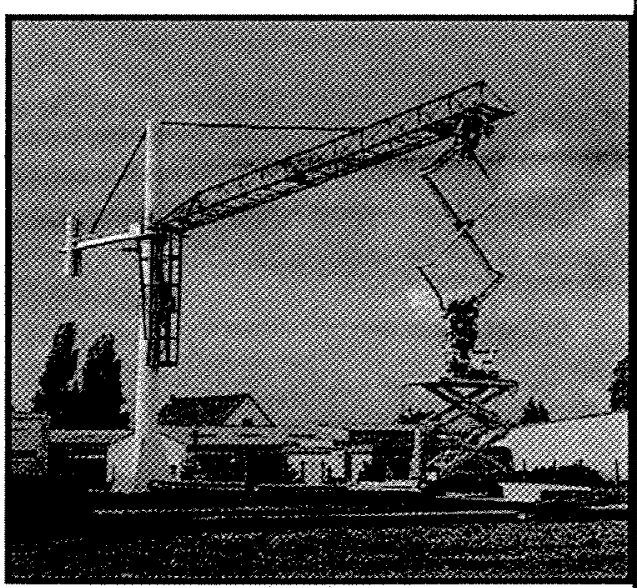

\section{Tandem Loading (Boom to Tanker)}

- Main Considerations

- Wave Conditions

- Range of Ships to be Loaded/Unloaded

- Allowable Flanging / Drift Areas

- Flange Movements During Connection

- \% Availability

- Is Spot LNG Trade a Requirement?

- Requires Modified Tankers

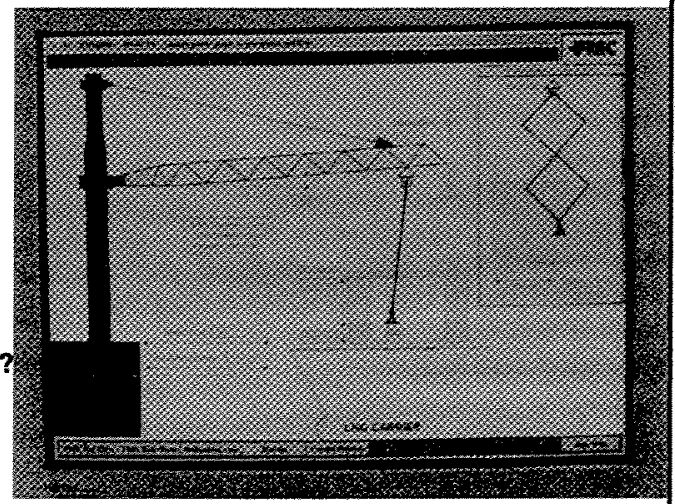



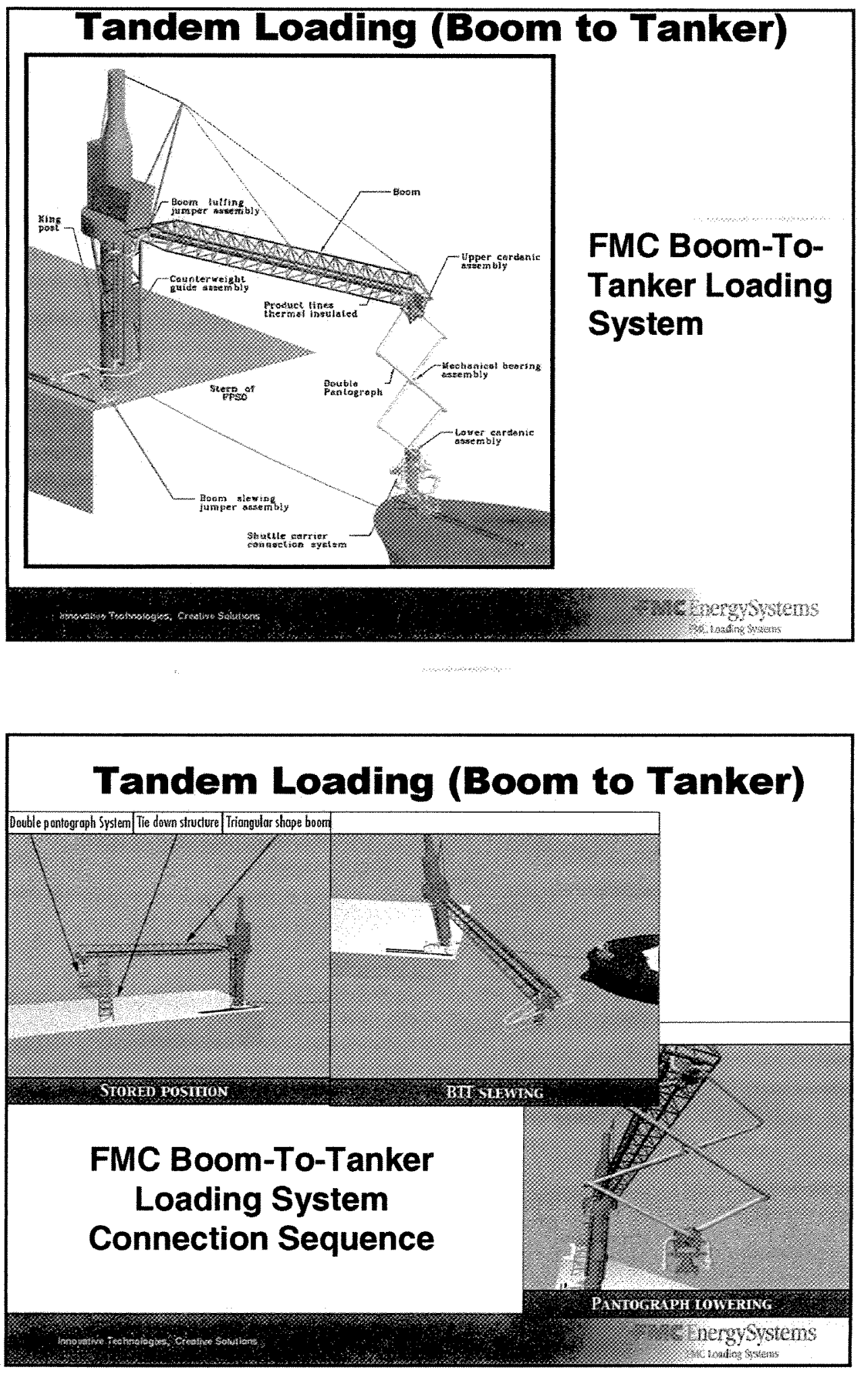


\section{Tandem Loading (Boom to Tanker)}
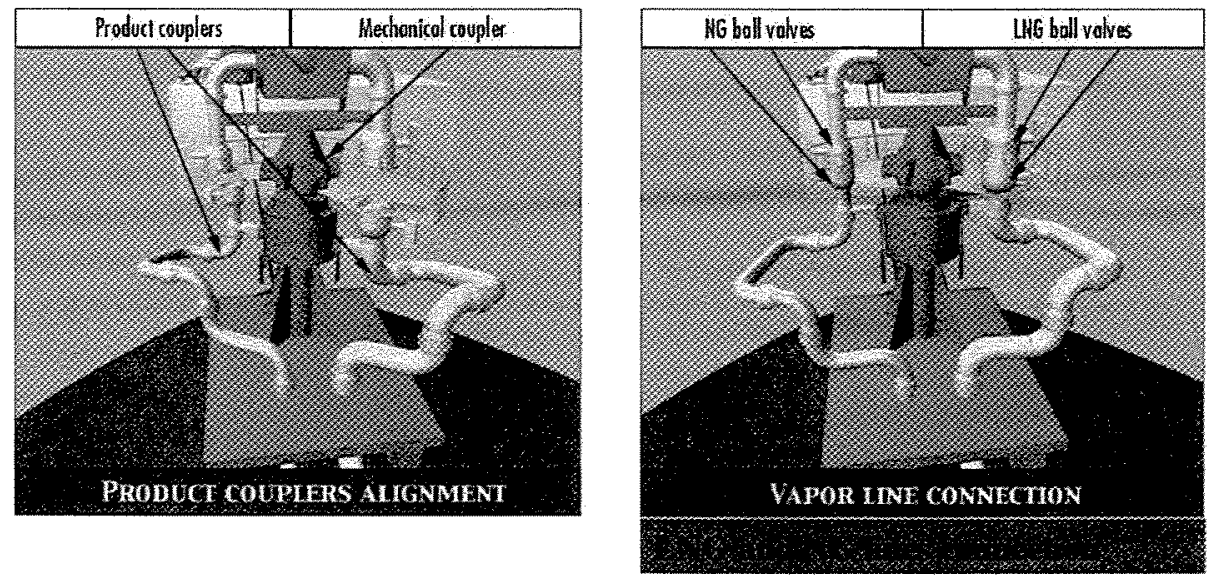

FMC Boom-To-Tanker Loading System Connection Sequence

\section{Tandem Loading (Boom to Tandem)}
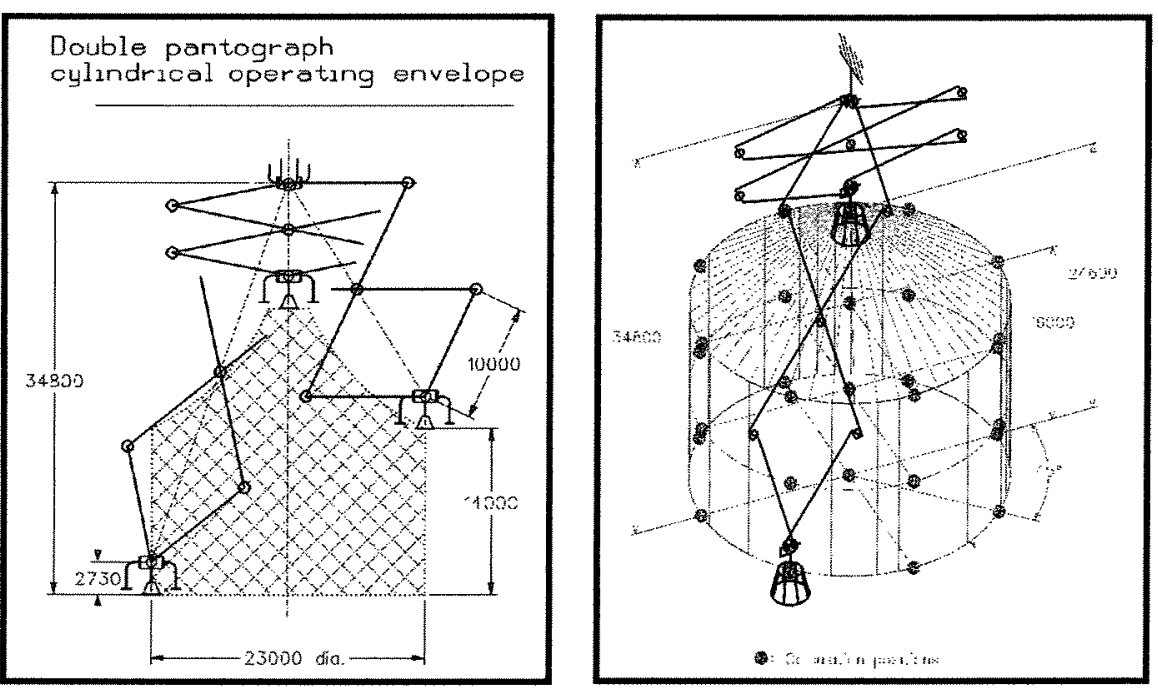

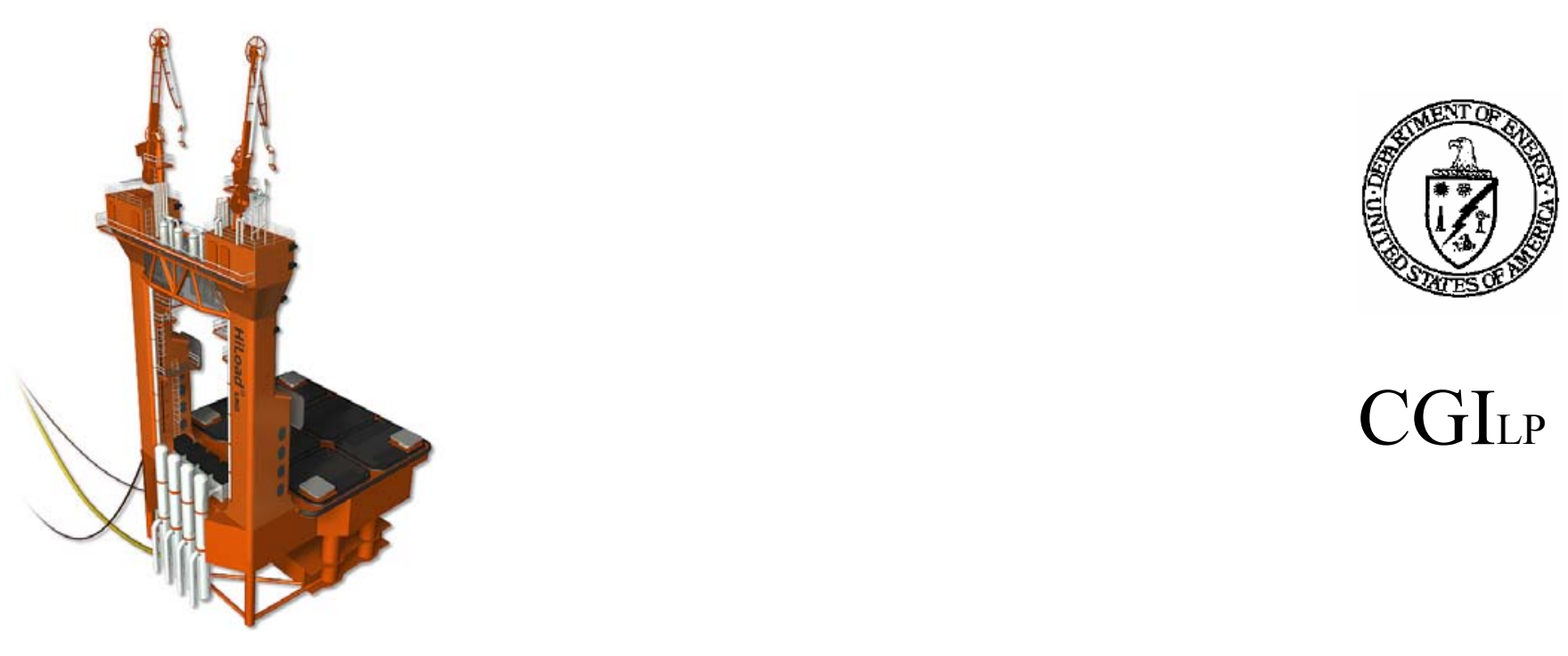

CGILP

\section{DOE Study Report}

\section{HiLoad ${ }^{\circledR} L N G$ Regasification Facility with Salt Cavern Storage}

Doc. no: RT2006-107 RE

REMORA (O) TECHNOLOGY

\begin{tabular}{|c|c|l|c|c|c|}
\hline & & & & & \\
\hline & & & & & \\
\hline 01 & $11 / 10 / 04$ & Issued for Information & PGA/SBH & CWO & LOD \\
\hline Rev. & Date & Reason for Issue: & Originated by: & Checked by: & Approved by: \\
\hline
\end{tabular}


REMORA TECHNOLOGY

\begin{tabular}{|c|c|}
\hline \multirow{3}{*}{$\begin{array}{l}\text { Document Title: } \\
\text { HiLoad }^{\circledR} \text { LNG Regas Facility with Salt Cavern Storage }\end{array}$} & Doc. no.: RT2006-107-RE \\
\hline & 2 of 48 \\
\hline & Date: $11 / 10 / 04$ \\
\hline
\end{tabular}

\section{Table of contents}

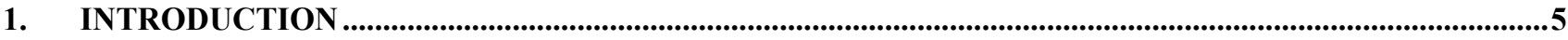

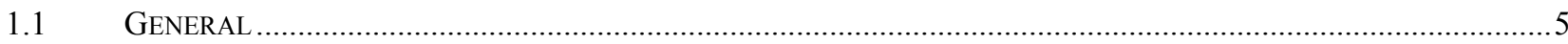

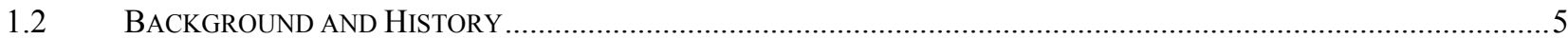

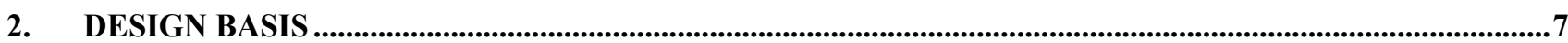

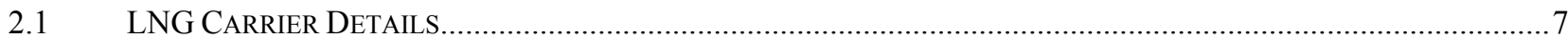

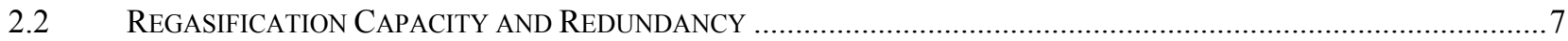

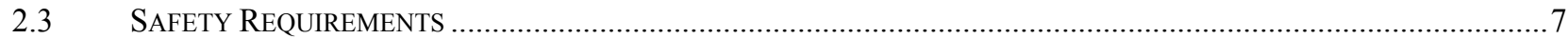

2.4 CLASS AND REGULATORY REQUIREMENTS ...............................................................................................

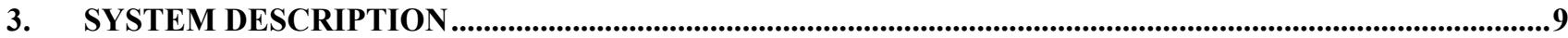

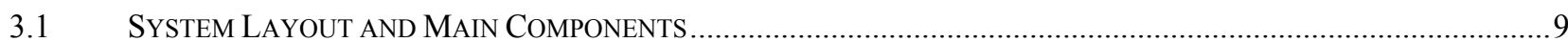

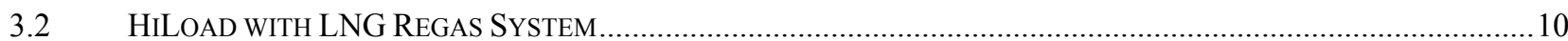

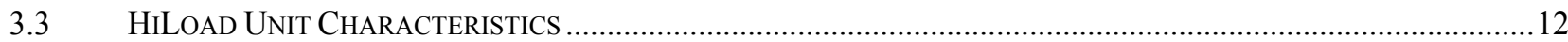

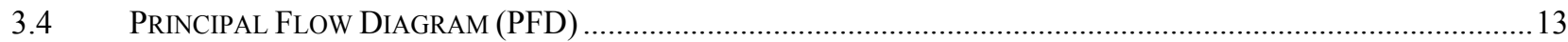

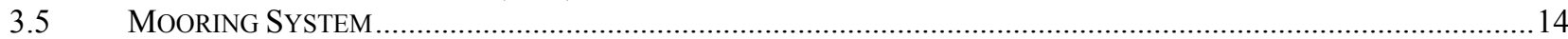

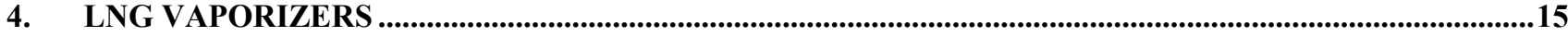

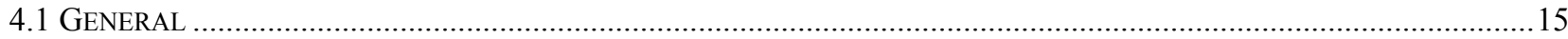

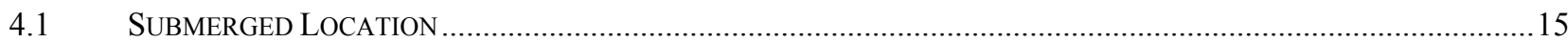

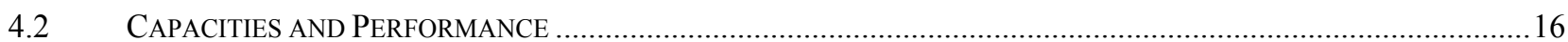

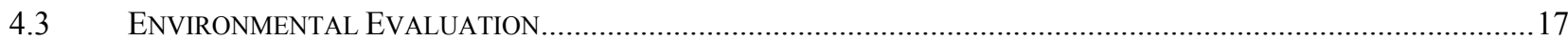

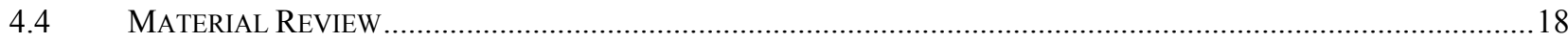

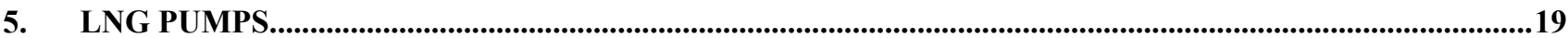

$5.1 \quad$ GENERAL

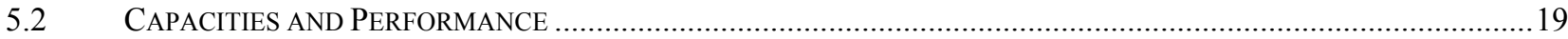

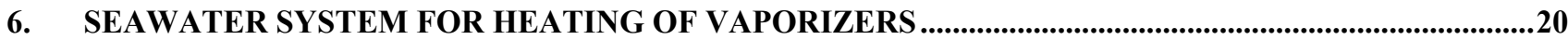

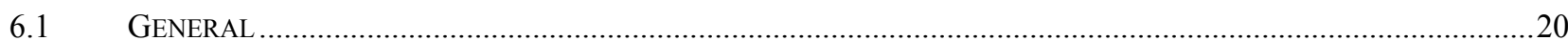

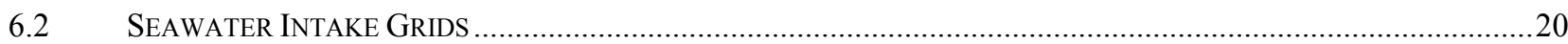

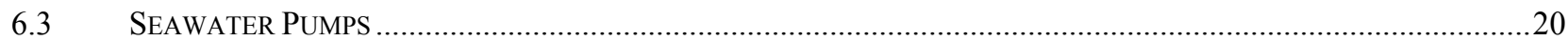

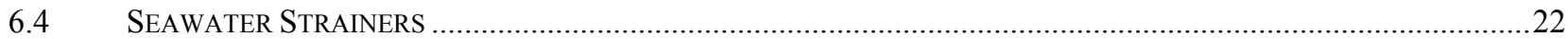

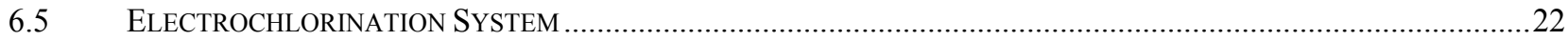

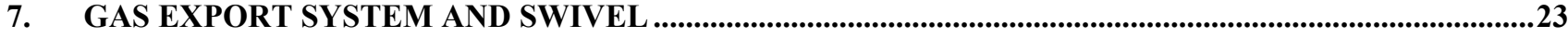

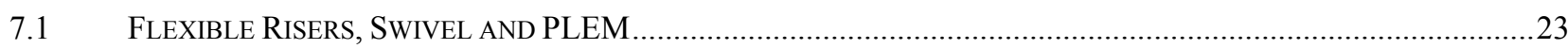

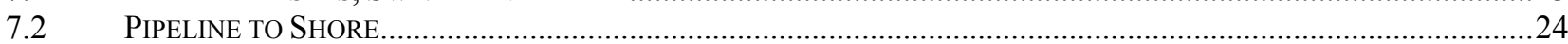

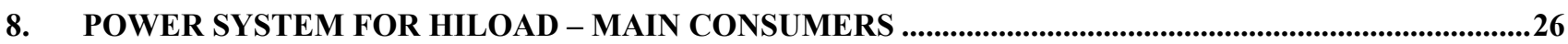

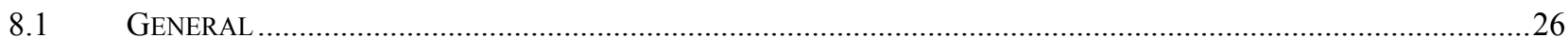

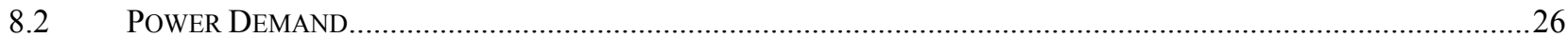

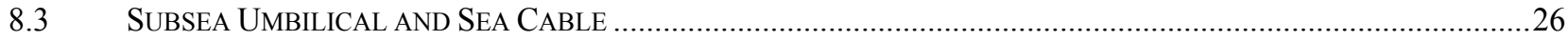

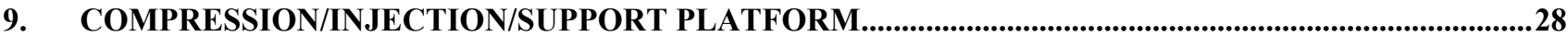

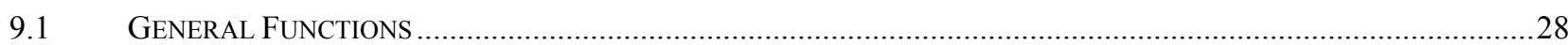

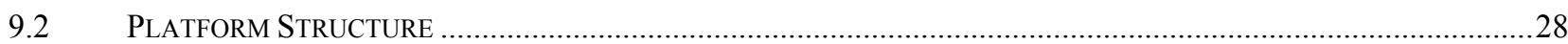


REMORA TECHNOLOGY

\begin{tabular}{|l|l|l|}
\hline DOE Study Report & \multicolumn{1}{|l|}{ Doc. no.: RT2006-107-RE } \\
\hline Document Title: & Page: & of 48 \\
\cline { 2 - 3 } HiLoad $^{\circledR}$ LNG Regas Facility with Salt Cavern Storage & Rev. no.: 01 & Date: 11/10/04 \\
\hline
\end{tabular}

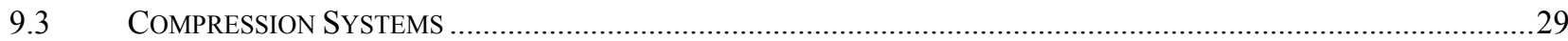

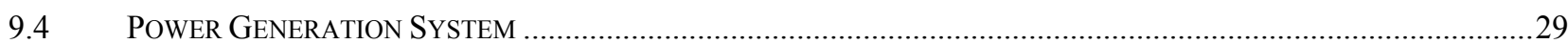

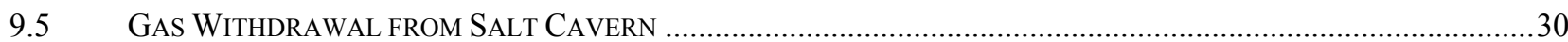

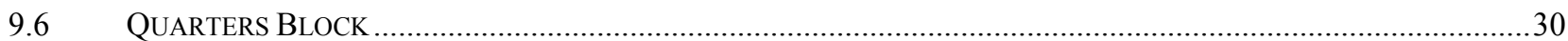

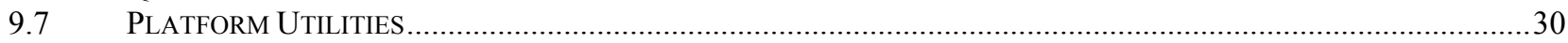

10. OUTLINE OPERATION DESCRIPTION - HILOAD ................................................................................32

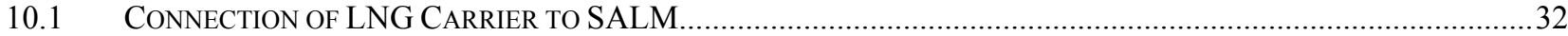

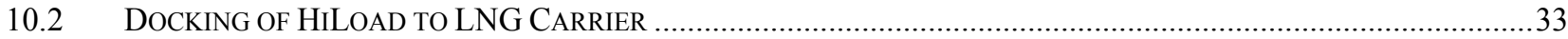

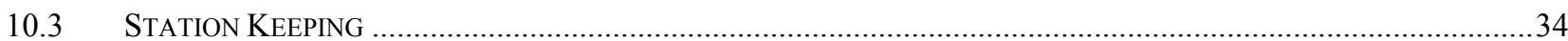

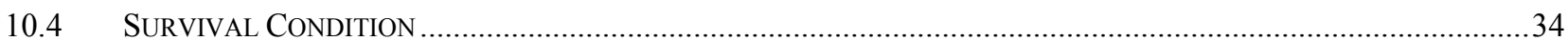

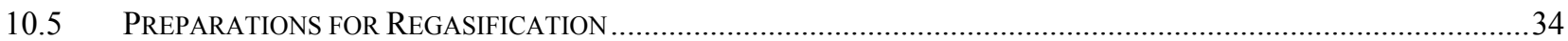

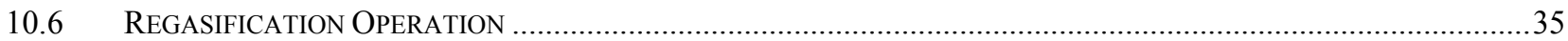

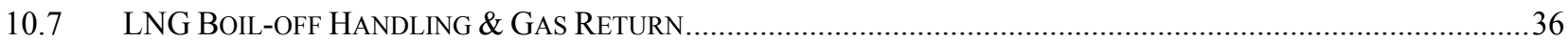

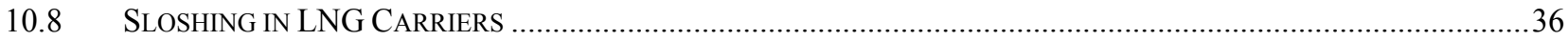

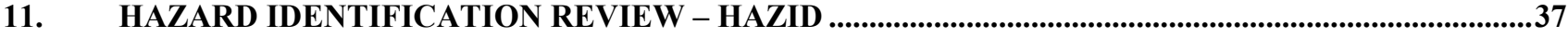

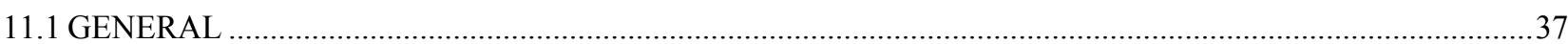

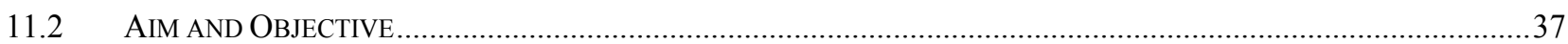

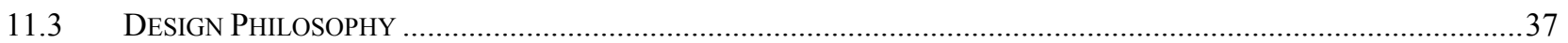

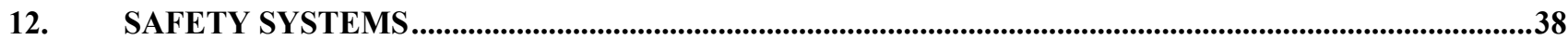

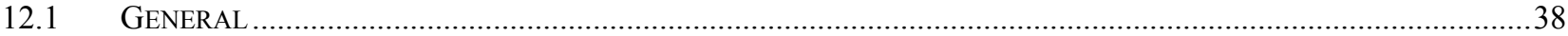

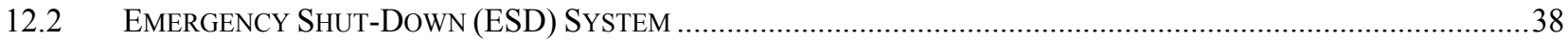

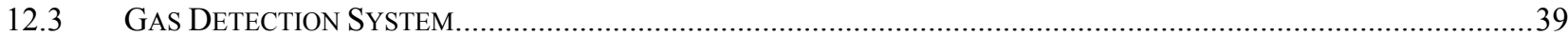

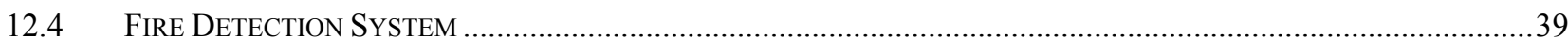

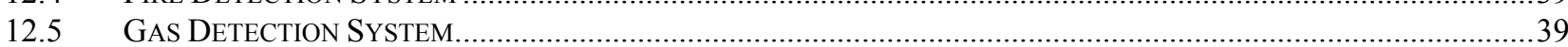

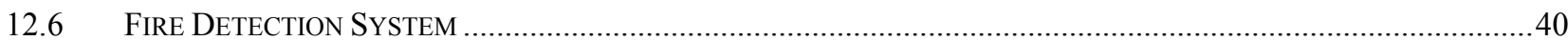

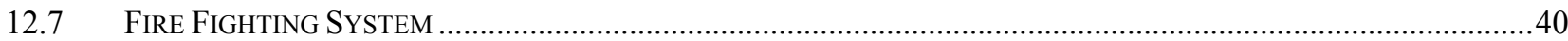

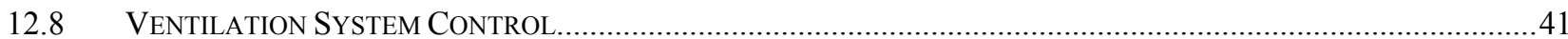

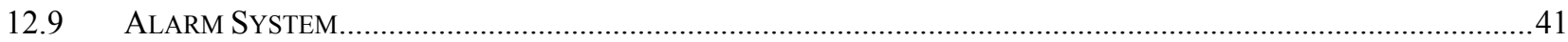

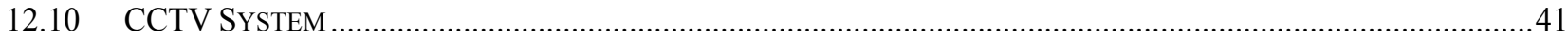

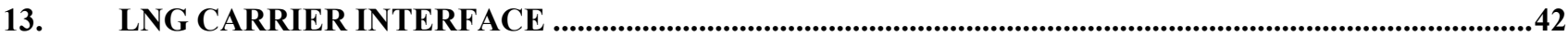

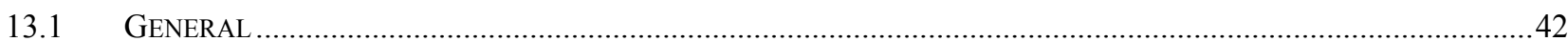

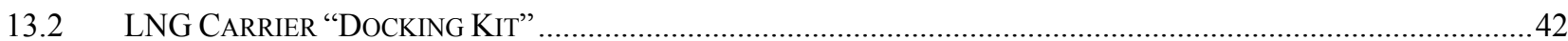

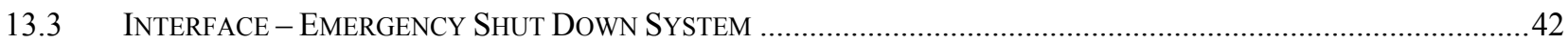

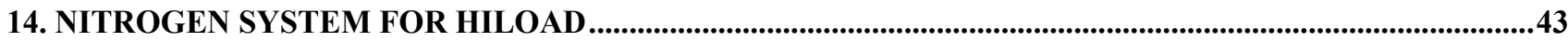

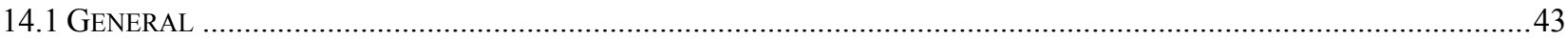

$14.2 \quad$ NitRogen GENERATION AND STORAGE SYSTEM - HILOAD .....................................................................43

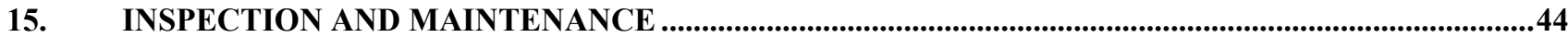

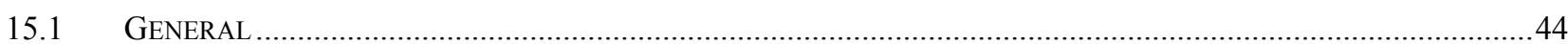

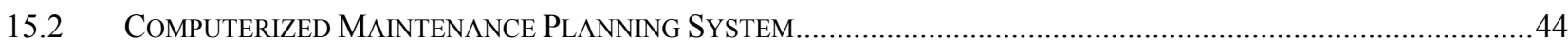

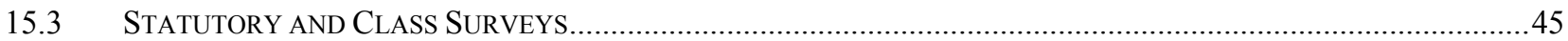

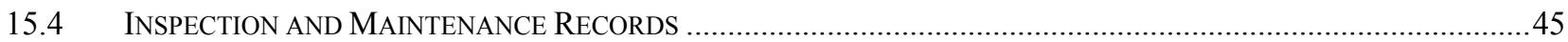

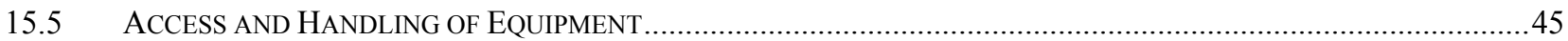

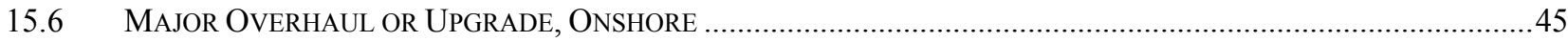




\section{REMORA TECHNOLOGY}

DOE Study Report

Doc. no.: RT2006-107-RE

Document Title:

Page: $\quad 4$ of 48

HiLoad $^{\circledR}$ LNG Regas Facility with Salt Cavern Storage

Rev. no.: 01

Date: $11 / 10 / 04$

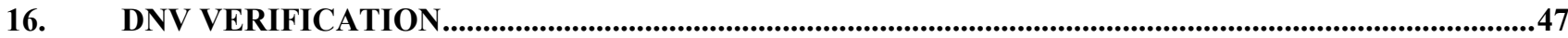

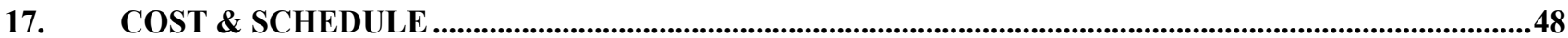

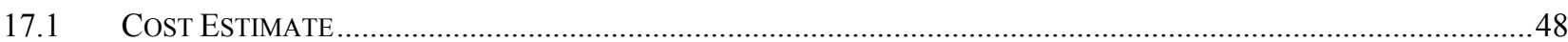

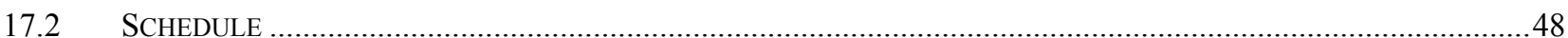




\begin{tabular}{|l|l|l|}
\hline DOE Study Report & \multicolumn{1}{|l|}{ Doc. no.: RT2006-107-RE } \\
\hline Document Title: & Page: & of 48 \\
\cline { 2 - 3 } HiLoad $^{\mathbb{R}}$ LNG Regas Facility with Salt Cavern Storage & Rev. no.: 01 & Date: 11/10/04 \\
\hline
\end{tabular}

\section{INTRODUCTION}

\subsection{GENERAL}

Remora Technology has carried out a study for Conversion Gas Imports (CGI) as part of the Salt Cavern Storage study that CGI is executing for the U.S. Department of Energy. The scope of work for the study was to carry out site specific engineering of the HiLoad ${ }^{\circledR}$ LNG Regasification Facility for use with standard LNG carriers.

\subsection{BACKGROUND AND HISTORY}

The HiLoad ${ }^{\circledR}$ Technology for offshore loading of oil has been developed during the last three years jointly by ConocoPhillips and Hitec Vision in Norway. Remora Technology was established in 2002 in order to further develop and commercialize the HiLoad ${ }^{\circledR}$ Technology.

Development of the HiLoad for offshore loading of oil has been carried out during fives phases:

- Phase 1: Feasibility Study (May 2000 - September 2000)

- Phase 2: Model Test at Marintek, Docking of HiLoad onto tanker (February 2001)

- Phase 3: Detail Engineering, 10000 man-hours (May 2001 - February 2002)

- $\quad$ Phase 4: Model Test at Marintek, Position Keeping System (April 2002)

- $\quad$ Phase 5: Wind Tunnel Test at DMI, HiLoad current drag (October 2002)

The LNG Regas version of HiLoad has been developed based on the work carried out for the oil version. The "chassis" (hull) and most of the systems onboard HiLoad will be very similar to the oil version. The LNG Regas version is also being developed in steps and the work carried out so far is described below:

- $\quad$ Phase 1: Feasibility Study (January 2003 - April 2003)

- $\quad$ Phase 2: Conceptual Design (May 2003 - November 2003)

- $\quad$ Phase 3: DOE Study (November 2003 - May 2004)

- $\quad$ Phase 4: Basic Engineering (May 2003 - ongoing)

The feasibility study and conceptual design carried out to date has verified that the solution is technically feasible with no identified showstoppers. "Approval in Principle" for the HiLoad LNG Regas Facility was granted by Det Norske Veritas 26 April 2004 (see section 16 for further information).

The system has also been found to be a very cost attractive alternative for import of LNG. 
REMORA TECHNOLOGY

\begin{tabular}{|l|l|l|}
\hline DOE Study Report & \multicolumn{2}{l|}{ Doc. no.: RT2006-107-RE } \\
\hline Document Title: & Page: & of 48 \\
\cline { 2 - 3 } HiLoad $^{\mathbb{R}}$ LNG Regas Facility with Salt Cavern Storage & Rev. no.: 01 & Date: 11/10/04 \\
\hline
\end{tabular}

The solution has been presented to several potential customers as well as on a number of LNG conferences. It has been very well received and has got significant attention in the market.

One of the latest highlights was when Remora Technology was awarded the prestigious "Woelfel Distinguished Innovation Award" for the solution at the Offshore Technology Conference (OTC) in Houston in May 2004. The award was presented by American Society of Mechanical Engineers
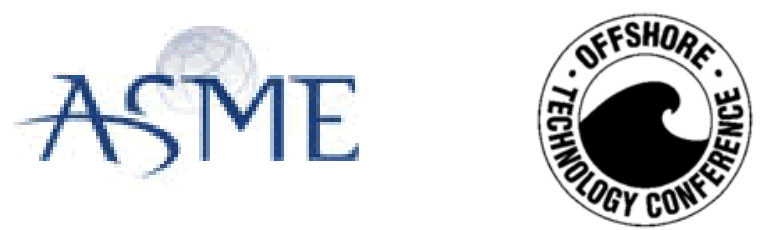

A 3D illustration of the system layout for the HiLoad LNG Regas Facility is shown below.

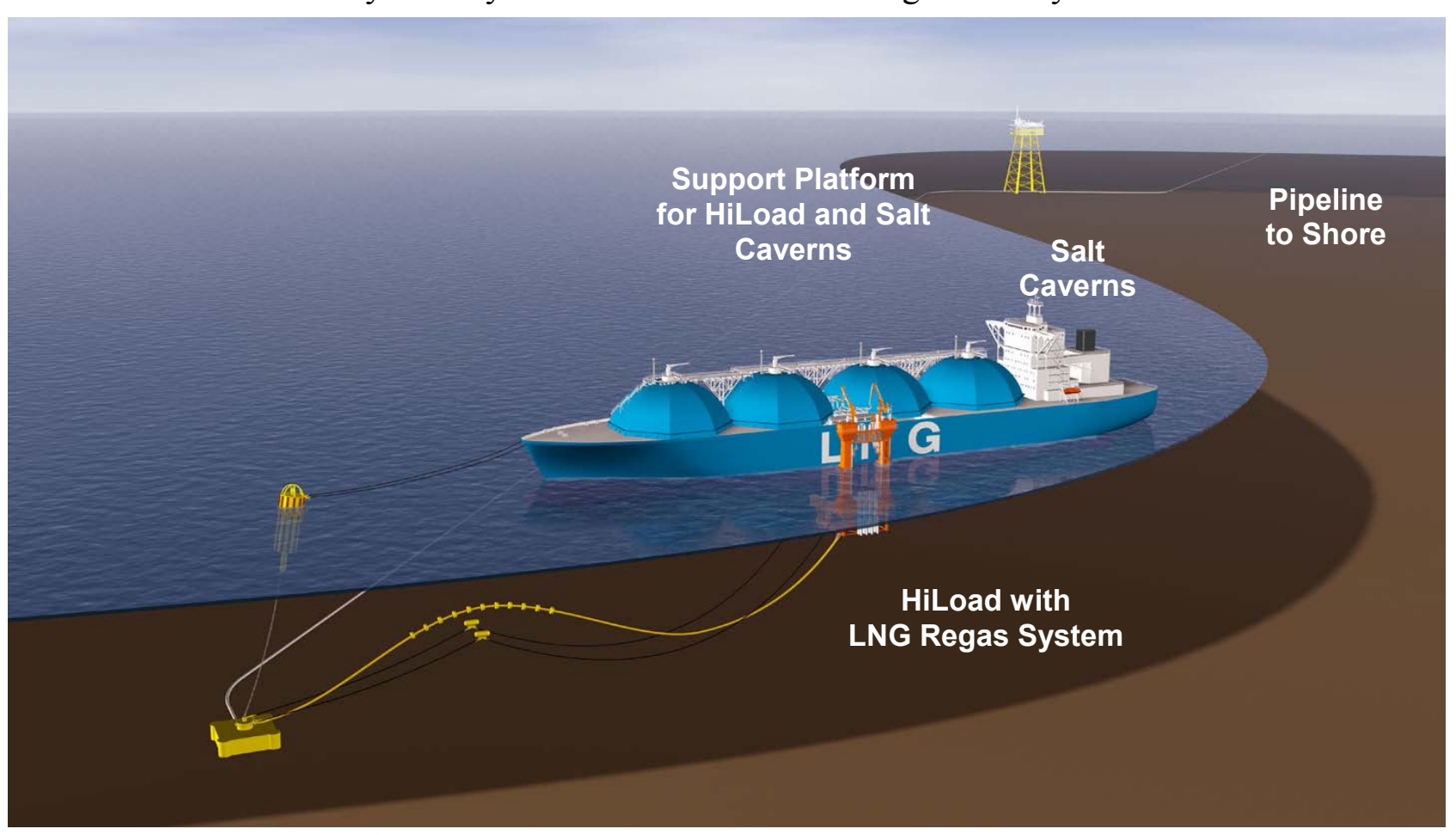

Figure 1 - HiLoad System Layout 


\begin{tabular}{|c|c|}
\hline DOE Study Report & Doc. no.: RT2006-107-RE \\
\hline Document Title: & 7 of 48 \\
\hline HiLoad $^{\circledR}$ LNG Regas Facility with Salt Cavern Storage & Date: $11 / 10 / 04$ \\
\hline
\end{tabular}

\section{DESIGN BASIS}

\subsection{LNG CARRIER DETAILS}

The HiLoad shall be able to connect and carry out the regas operation on any standard LNG carrier without any modification of the vessel. Today's standard size LNG carrier of $138000 \mathrm{~m}^{3}$ has been used when ship specific data are required.

The HiLoad shall be able to connect to LNG carriers within the size range of $80.000-220.000 \mathrm{~m}^{3}$.

\subsection{REGASIFICATION CAPACITY AND REDUNDANCY}

The HiLoad LNG Regas Facility shall be designed with a regas rate of 2 BCFD. The supply pressure for gas from HiLoad is set at 82,5 bar (1200 psi).

The seawater pumping system for the LNG Vaporizer shall be designed with redundancy in order to provide $100 \%$ capacity with one seawater pump out of operation. The systems shall also be designed to avoid freezing of the seawater in the vaporizer.

\subsection{SAFETY REQUIREMENTS}

HiLoad LNG Regasification Facility is a new concept and appropriate standards, regulations, code of practice and methods to be used when evaluating the safety requirements.

\subsection{Class AND Regulatory REQUIREMENTS}

Design and engineering of the HiLoad LNG Regasification Facility shall conform as a minimum requirement to the following applicable editions in order of precedence:

$\checkmark$ Applicable laws, rules and regulations of the relevant US authority for the selected GoM-sites (USCG, MMS)

$\checkmark$ Particular HiLoad Regasification Facility Specification developed by Remora Technology

$\checkmark \quad$ Rules and regulations from applicable Classification Society selected

$\checkmark$ Applicable Design Guidelines from SIGTTO

$\checkmark$ Applicable Guidelines from OCIMF

$\checkmark$ Applicable recognized standards and codes from NFPA and API. 
REMORA TECHNOLOGY

DOE Study Report

Doc. no.: RT2006-107-RE

Document Title:

Page:

8 of 48

HiLoad $^{\circledR}$ LNG Regas Facility with Salt Cavern Storage

\begin{tabular}{l|l} 
Rev. no.: 01 & Date: $11 / 10 / 04$
\end{tabular}

$\checkmark$ Applicable recognized standards and codes, where none of the above is adequate.

The compression/injection/support platform is designed according to the codes and standards of US Code of Federal Regulations, NFPA and API. 


\begin{tabular}{|c|c|c|}
\hline DOE Study Report & \multirow{2}{*}{\multicolumn{2}{|c|}{ Page: }} \\
\hline \multirow{2}{*}{$\begin{array}{l}\text { Document Title: } \\
\text { HiLoad }^{\circledR} \text { LNG Regas Facility with Salt Cavern Storage }\end{array}$} & & \\
\hline & Rev. no.: 01 & Date: $11 / 10 / 04$ \\
\hline
\end{tabular}

\section{SYSTEM DESCRIPTION}

\subsection{SySTEM LAYOUT AND MAIN COMPONENTS}

The proposed layout for the system is shown below.

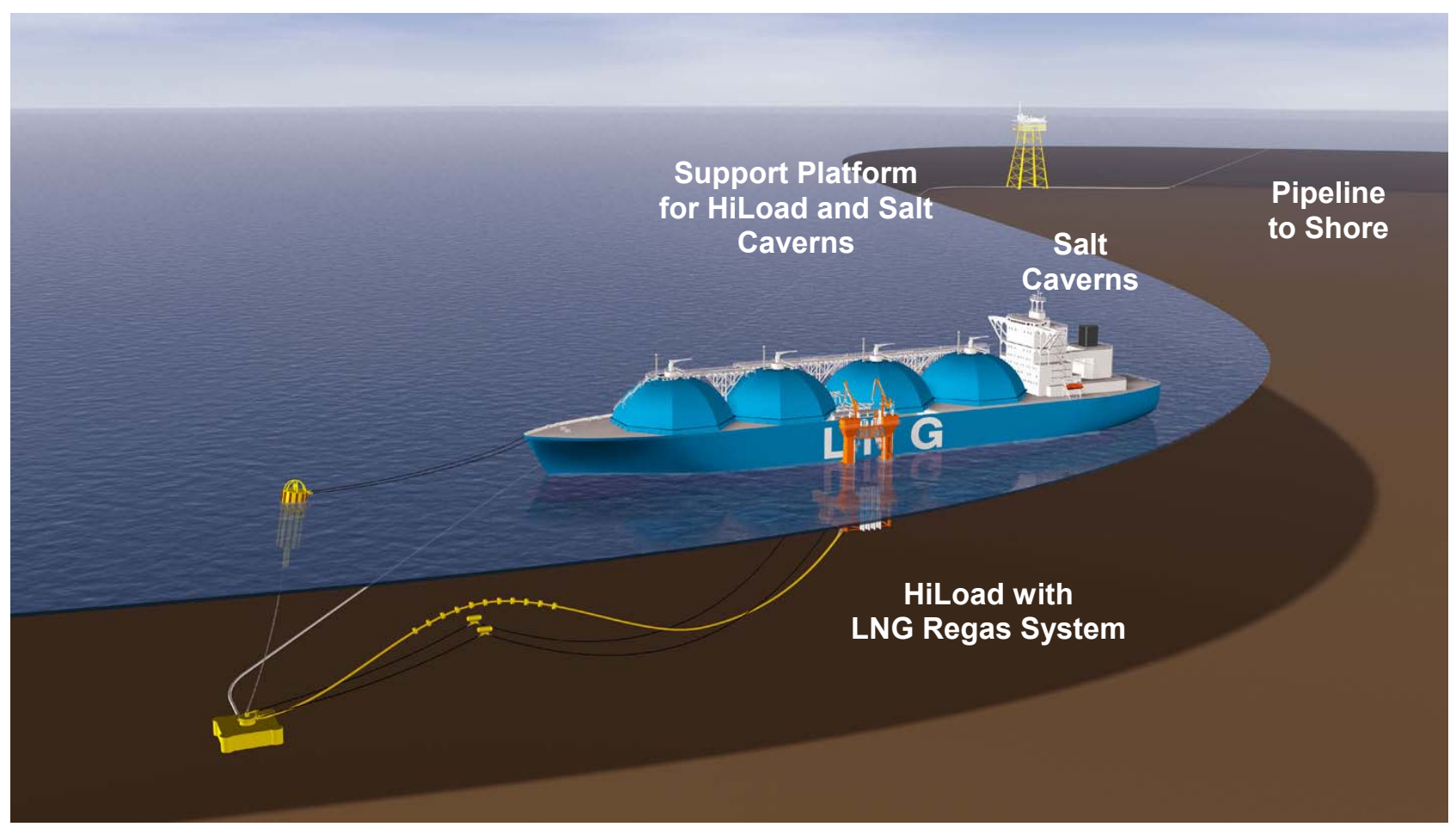

Figure 2 - HiLoad System Layout

The HiLoad Technology is built up around a semi-floating L-shaped loading terminal that can dock onto any ship in a similar way as a forklift picks up a pallet. The HiLoad is equipped with thrusters, and will be easy to manoeuvre into position on a slow-moving ship. The HiLoad will attach to the ship using buoyancy as well as the hydrostatic pressure present at the draft of the vessel's bottom.

The HiLoad is equipped with regasification equipment of 2 BCFD capacity. The gas at 82,5 bar pressure is supplied to a compression/injection platform via 2 flexible risers and a 1 nautical mile long pipeline from HiLoad. On the injection platform 1 BCFD of gas is compressed to the given salt cavern pressure ( $82,5-124$ bar) for intermediate storage. The remaining 1 BCFD is bypassed the compression system and delivered to a shore pipeline at approximately 75 bar pressure.

At periods when no ships are connected to HiLoad, gas supplies to shore is maintained at a rate of 1 BCFD by withdrawing gas from the salt dome storage. The gas is conditioned on the platform, pressure reduced to 75 bar and delivered to the shore pipeline. 
REMORA TECHNOLOGY

\section{DOE Study Report}

Document Title:

HiLoad $^{\circledR}$ LNG Regas Facility with Salt Cavern Storage
Doc. no.: RT2006-107-RE

Page: $\quad 10$ of 48

Rev. no.: 01

The pressure and flow for the system is illustrated in the below sketch.

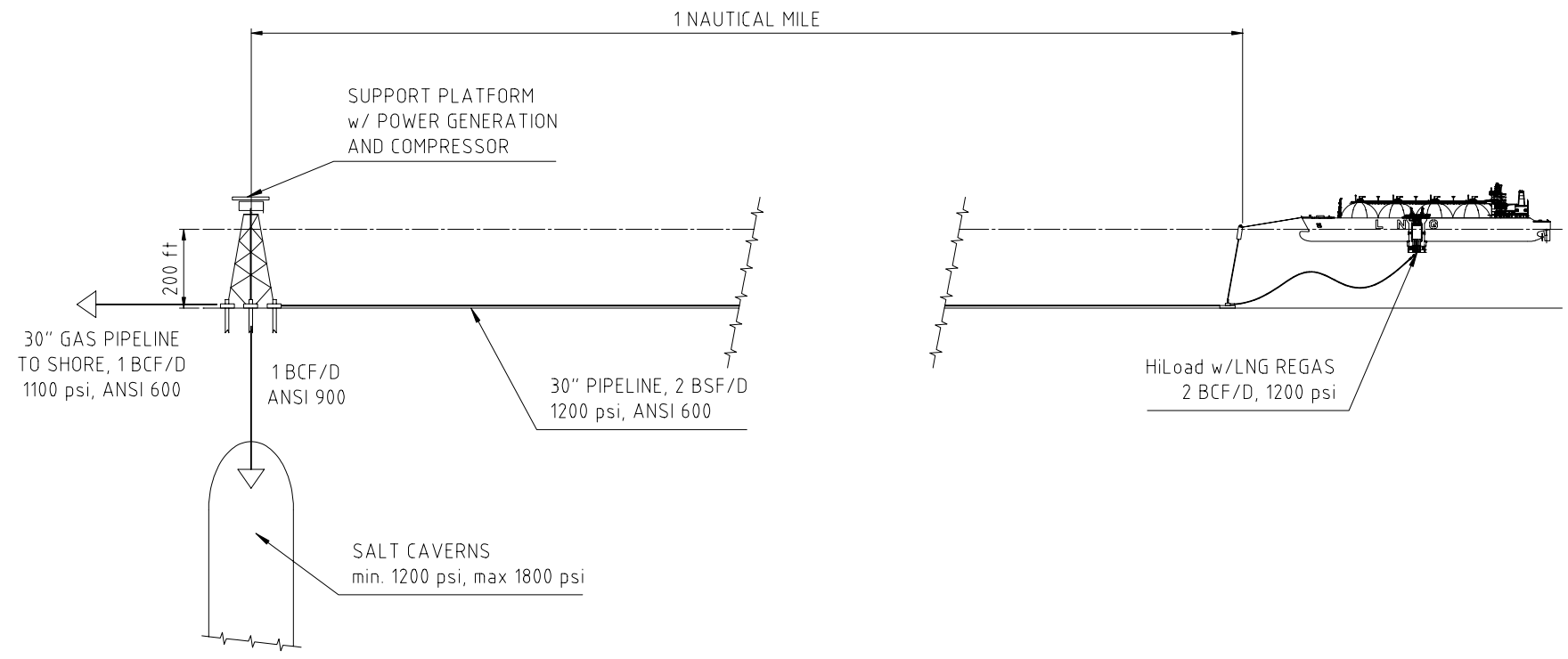

Figure 3 - Proposed System Layout

\subsection{HiLOAD WITH LNG REGAS SYSTEM}

The main components of the HiLoad System are shown in the figure below.

The main components of the LNG Regas System on the HiLoad are shown on figure below. For a description of each of these components, reference is made to separate sections of this report. 


\begin{tabular}{|l|l|l|}
\hline DOE Study Report & \multicolumn{2}{|l|}{ Doc. no.: RT2006-107-RE } \\
\hline Document Title: & Page: & 11 of 48 \\
\cline { 2 - 3 } HiLoad $^{\mathbb{R}}$ LNG Regas Facility with Salt Cavern Storage & Rev. no.: 01 & Date: 11/10/04 \\
\hline
\end{tabular}

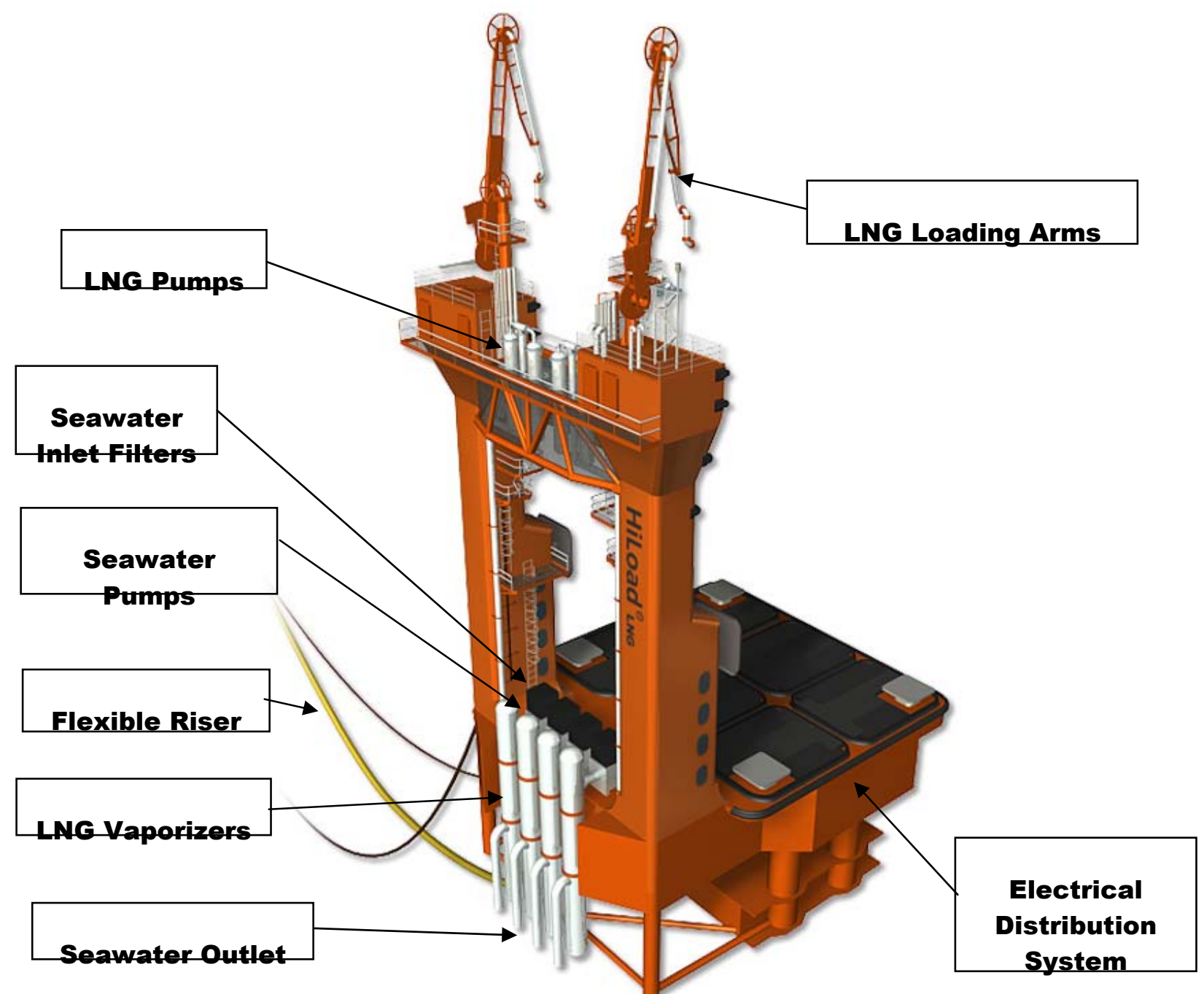

Figure 4 - HiLoad Unit, Main LNG Regas Systems

It should be noted that the above general arrangement shows only four LNG pumps and Vaporizers while it is proposed to increase the number of LNG pumps and Vaporizers to 6 each for the total capacity of 2 BCFD.

Only minor modifications need to be done to the HiLoad arrangement to include for the increased number of components. The revised General Arrangement has not been developed in this preliminary report but will be included during the later phases of the study. 


\begin{tabular}{|l|l|l|}
\hline DOE Study Report & \multicolumn{2}{|l|}{ Doc. no.: RT2006-107-RE } \\
\hline Document Title: & Page: & 12 of 48 \\
\cline { 2 - 3 } HiLoad $^{\mathbb{R}}$ LNG Regas Facility with Salt Cavern Storage & Rev. no.: 01 & Date: 11/10/04 \\
\hline
\end{tabular}

\subsection{Hiload Unit Characteristics}

The HiLoad Offshore Loading system for crude oil has been developed over a period of three years, where model testing and detailed engineering have been carried out. The LNG Regas version of HiLoad is built on the same "chassis" as the oil version, giving a considerable synergy for the two versions. Most of the LNG Regas equipment is located outside the HiLoad chassis as shown in the figure above. Compared to the basic oil version, additional buoyancy will be required due to the added weight of the LNG equipment.

The study has focused mostly on the LNG Regas equipment onboard the HiLoad, as the rest of the systems are similar to the HiLoad Offshore Loading Facility for crude oil. A large amount of documentation is available for this version of HiLoad, but is not included in this study report. However, a brief description of some of the systems and characteristics that are common for the two versions are given below.

\section{General Arrangement}

The hull is divided into three main sections: pontoon, towers and keel. It is constructed of standard carbon steel plates and profiles for simple fabrication at any yard. The room layout is designed according to the DNV Rules for Mobile Offshore Units. The General Arrangement is designed with symmetry about the centreline of the unit, which gives redundancy and simpler fabrication.

\section{Ballast System}

The unit is equipped with a high capacity ballast system in order to give a short attachment and release time (about 2-3 min.) to the carrier.

\section{Attachment System}

The top of the pontoon is equipped with a patented Friction Attachment System, which generates a strong grip onto the carrier resulting in a safety factor of 10-15 depending on the draft of the carrier. The system consists of standard and well proven equipment, which has been full-scale tested on a ship. A considerable amount of documentation is available.

\section{Fender System and LNG carrier interface}

The pontoon and towers on the HiLoad are equipped with soft shock absorbing fenders to limit the contact forces between HiLoad and the carrier during connection. It became clear at a very early stage in the development that the HiLoad and carrier interface, particularly during docking and undocking would be some of the most critical issues for a safe operation. Hence, this was carefully designed and model tested. 
REMORA TECHNOLOGY

\begin{tabular}{|l|l|l|}
\hline DOE Study Report & \multicolumn{2}{|l|}{ Doc. no.: RT2006-107-RE } \\
\hline Document Title: & Page: & 13 of 48 \\
\cline { 2 - 3 } HiLoad $^{\circledR}$ LNG Regas Facility with Salt Cavern Storage & Rev. no.: 01 & Date: 11/10/04 \\
\hline
\end{tabular}

\subsection{Principal Flow Diagram (PFD)}

The process flow diagram for the LNG Regas System on HiLoad is shown below.

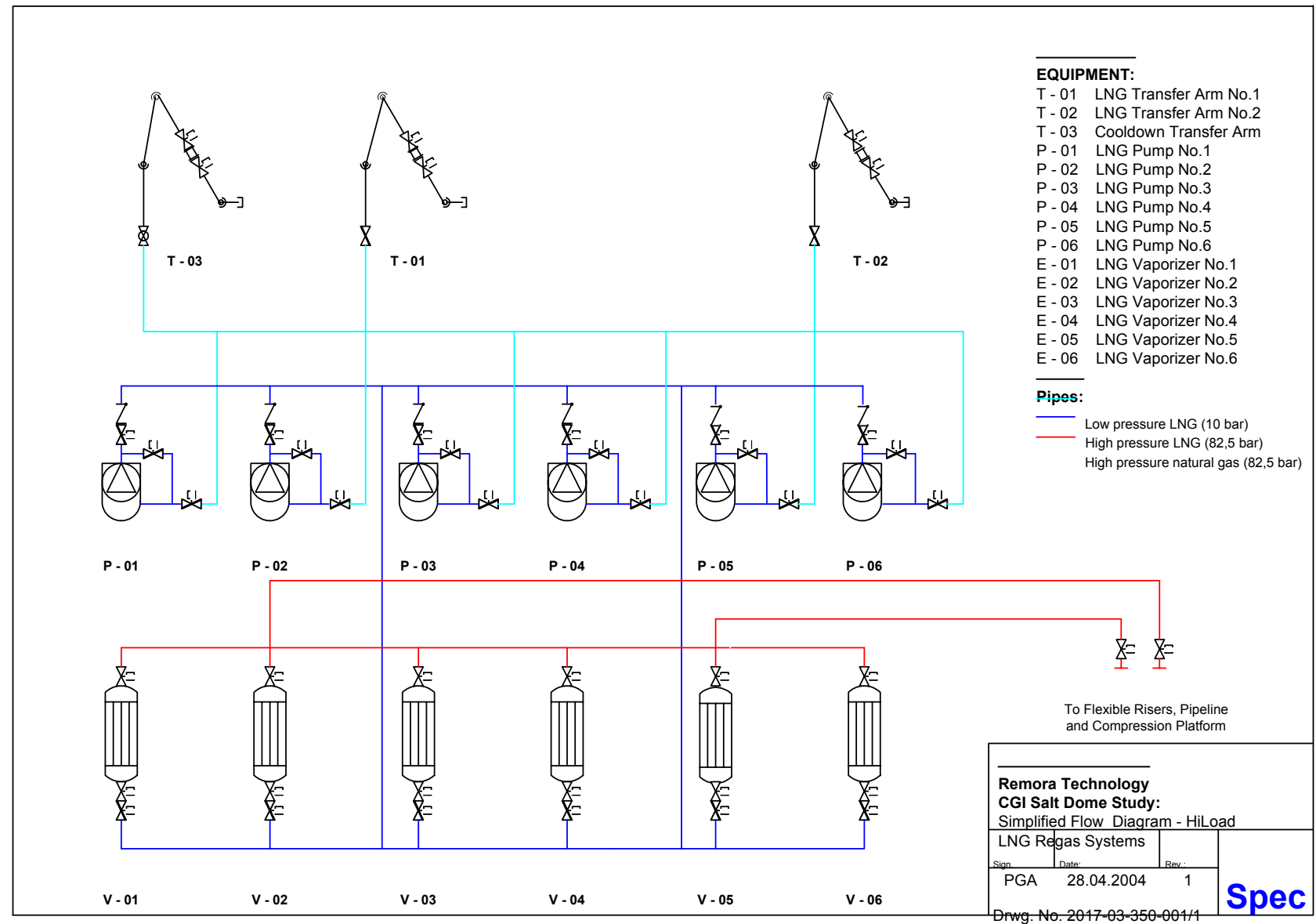

Figure 5 - Flow Diagram for Gas Systems onboard HiLoad 


\begin{tabular}{|l|l|l|}
\hline DOE Study Report & \multicolumn{2}{|l|}{ Doc. no.: RT2006-107-RE } \\
\hline Document Title: & \multicolumn{2}{|l|}{ Page: } \\
\cline { 2 - 3 } HiLoad $^{\circledR}$ LNG Regas Facility with Salt Cavern Storage & Rev. no.: 01 & Date: 11/10/04 \\
\hline
\end{tabular}

\subsection{MOORING SYSTEM}

The system layout for SALM buoy is shown on figure below.

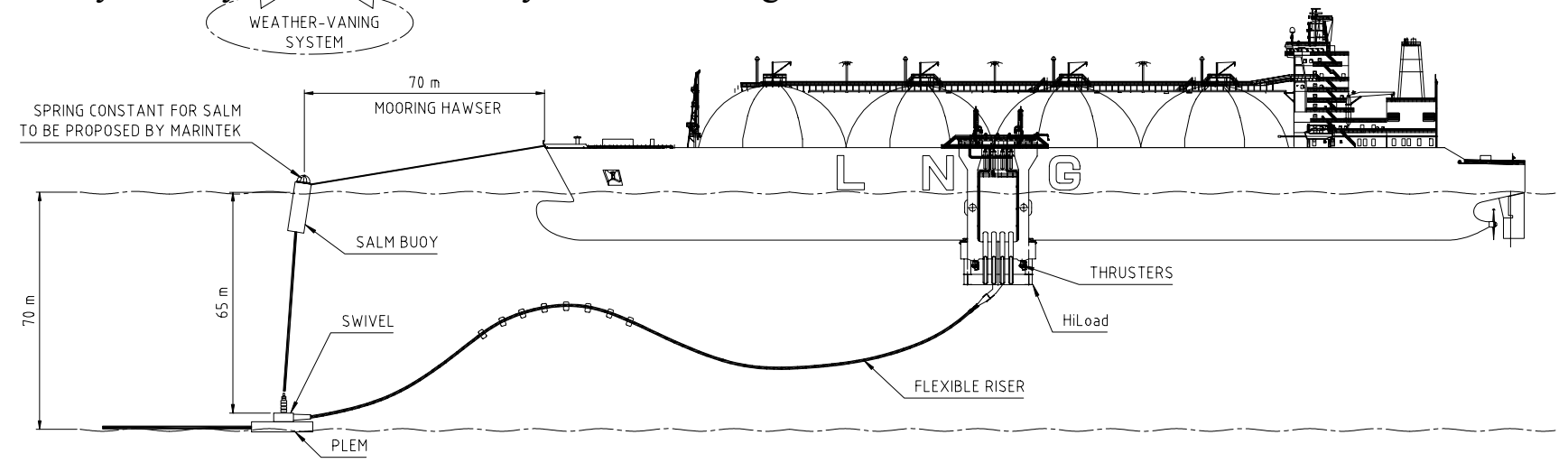

Figure 6 - System Layout, SALM mooring

The SALM is a proven single point mooring system used worldwide for 30 years for mooring of crude oil tankers. The distance between the LNG carrier and the SALM buoy will be approximately $70-80 \mathrm{~m}$. One mooring hawser will be connected to the OCIMF strong point in the bow of the LNG carrier.

The SALM system will take most of the environmental loads acting on the LNG carrier like a normal single point mooring system. However, the thrusters on HiLoad can be utilized for reduction of vessel movements and to reduce the snap loads acting on the SALM mooring system; i.e. the system will act as "thruster assisted mooring system".

A SIMO simulation of the SALM mooring HiLoad and an LNG carrier has been carried out by Marintek with very promising results. 


\begin{tabular}{|l|l|l|}
\hline DOE Study Report & \multicolumn{2}{|l|}{ Doc. no.: RT2006-107-RE } \\
\hline Document Title: & Page: & 15 of 48 \\
\cline { 2 - 3 } HiLoad $^{\mathbb{R}}$ LNG Regas Facility with Salt Cavern Storage & Rev. no.: 01 & Date: 11/10/04 \\
\hline
\end{tabular}

\section{LNG VAPORIZERS}

\subsection{GENERAL}

The HiLoad LNG Regas Facility will be equipped with direct seawater heated shell and tube LNG vaporizers. This type of vaporizers is available from a number of suppliers.

Photos of a typical shell and tube LNG vaporizer are shown below.
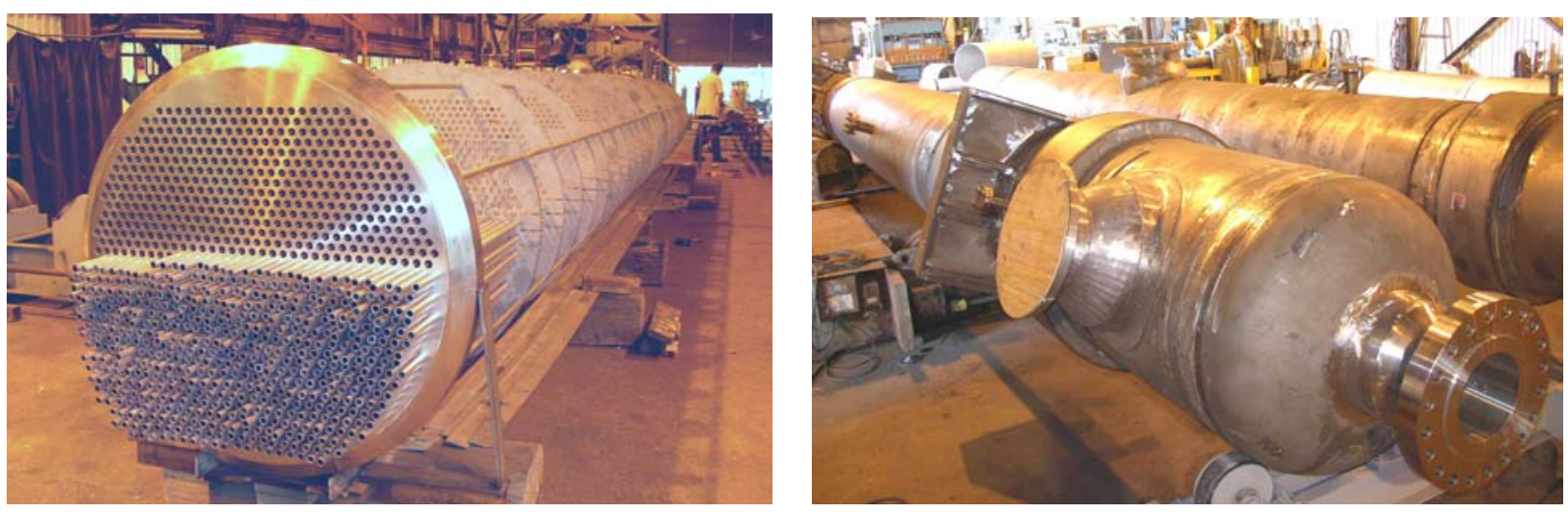

Figure 7 - Pipe Bundle, LNG Vaporizer

This type of LNG vaporizer has a unique and robust design with no movable parts. A minimum of maintenance is required which make them very suitable for the HiLoad system.

\subsection{SUBMERGED LOCATION}

The LNG vaporizers will be installed vertically (as recommended and approved by the manufacturers) and located below seawater level during normal operation. This approach has been discussed with vaporizer suppliers as well as the classification society, and statements have been received from both saying that this is believed to be a feasible and attractive solution (their statements can be provided upon request). Advantages with this location are:

- Power demand for the seawater pumps will be reduced with at least $50 \%$ due to no "lifting height"

- Increased safety, due to submergence and not close to deck on LNG carrier. The vaporizers are located on the outboard side of HiLoad, facing away from the LNG carrier.

- $\quad$ No fire exposure of the vaporizers during normal operations. 


\begin{tabular}{|l|l|l|}
\hline DOE Study Report & \multicolumn{2}{|l|}{ Doc. no.: RT2006-107-RE } \\
\hline Document Title: & Page: & 16 of 48 \\
\cline { 2 - 3 } HiLoad $^{\mathbb{R}}$ LNG Regas Facility with Salt Cavern Storage & Rev. no.: 01 & Date: 11/10/04 \\
\hline
\end{tabular}

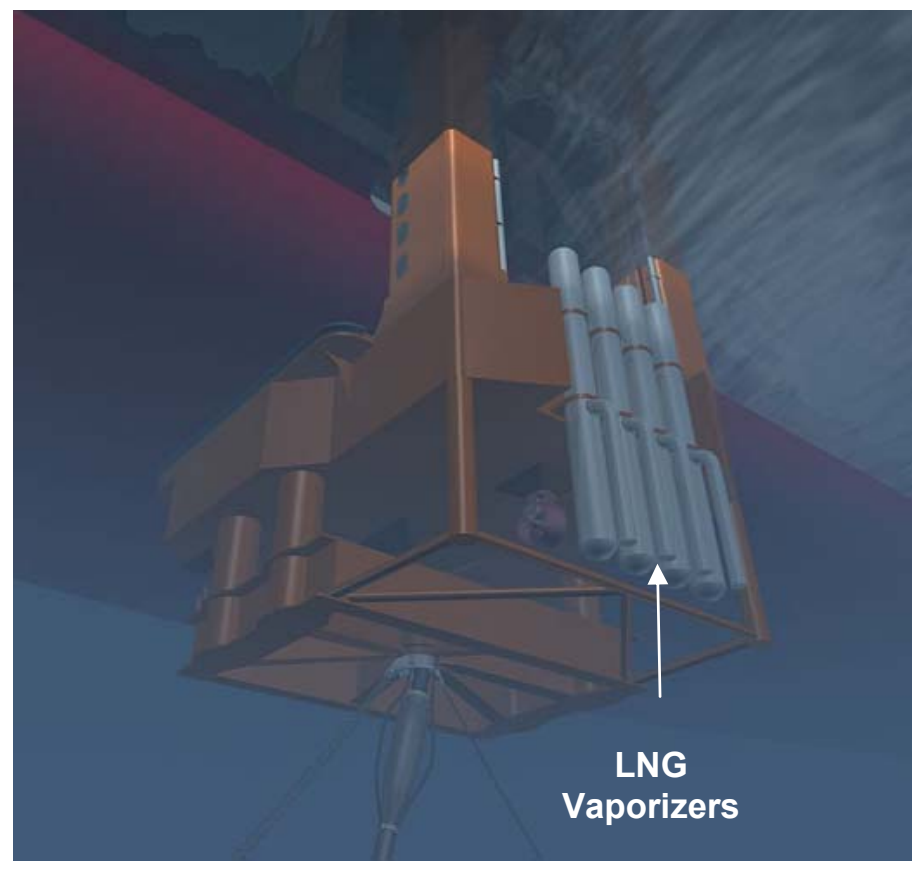

Figure 8 - Location of LNG Vaporizers

\subsection{Capacities ANd PerformanCe}

In general, the performance of seawater heated LNG vaporizers is dependent of the inlet seawater temperature, the temperature drop trough the vaporizer and the seawater flow rate.

The LNG vaporizers presently used in this study will be able to regas 2 BSCFD with an inlet seawater temperature of $20^{\circ} \mathrm{C}$. This represents the minimum seawater temperature for a US Gulf Of Mexico location.

- The seawater flow required for vaporizing the LNG at an inlet seawater temperature of $20{ }^{\circ} \mathrm{C}$ will depend on minimum seawater outlet temperature as recommended by the different suppliers in order to avoid excessive internal ice formation.

US environmental authorities have set a limit of $11^{\circ} \mathrm{C}\left(20^{\circ} \mathrm{F}\right)$ for the maximum seawater temperature drop through the vaporizers, resulting in a minimum outlet temperature of $9{ }^{\circ} \mathrm{C}$.

The total regasification capacity requires a seawater flow of approximately $29100 \mathrm{~m}^{3} / \mathrm{h}$ in total, based on a $\Delta \mathrm{T}=11^{\circ} \mathrm{C}$. 


\begin{tabular}{|l|l|l|}
\hline DOE Study Report & \multicolumn{2}{|l|}{ Doc. no.: RT2006-107-RE } \\
\hline Document Title: & Page: & 17 of 48 \\
\cline { 2 - 3 } HiLoad $^{\circledR}$ LNG Regas Facility with Salt Cavern Storage & Rev. no.: 01 & Date: 11/10/04 \\
\hline
\end{tabular}

A vaporizer size of 333 MMSCFD has been selected as a number of manufacturers have the capacity to build this size. This size will require 6 vaporizers to be installed on HiLoad to give the required regas capacity of 2 BSCFD.

Seawater requirement will be approximately $5000 \mathrm{~m}^{3} / \mathrm{h}$ for each vaporizer. The seawater flow rate may be adjusted according to the actual $\min / \max$ temperatures at the customer's site.

Compared to a previous study with lower seawater inlet temperature and corresponding lower $\Delta \mathrm{T}$ and higher seawater flow rate, the 6 vaporizers proposed in this study will in fact have a smaller diameter than the 4 vaporizers shown in figure 4.

The final selection of manufacturer and vaporizer sizes will be based on evaluation of technical, performance and commercial information.

\subsection{ENVIRONMENTAL EVALUATION}

Use of seawater as heating source for vaporizing LNG is a very environmental friendly solution because it will avoid burning gas for the heating process as is normal for most of the LNG import terminals in the United States. For the Submerged Combustion Vaporizers usually installed in the US land terminals, approx $1.5 \%$ of the imported gas is used for heating the vaporizing bath, resulting in emissions of large quantities of $\mathrm{CO}_{2}$ and $\mathrm{NO}_{\mathrm{x}}$ to the atmosphere.

An offshore LNG Terminal like HiLoad will have "unlimited" amounts of seawater available at no cost for the energy, requiring only power to drive the seawater pumps.

However, there are several environmental aspects that need to be given high attention during an approval process by the US Coast Guard and NOAA. These are:

- Max temperature drop through an LNG vaporizer

- Effect on marine life of local cooldown of seawater

- Seawater intake velocity not to exceed $0,15 \mathrm{~m} / \mathrm{s}(0,5 \mathrm{ft} / \mathrm{sec})$

- Injection of anti bio-fouling chemicals

Local cool down of the seawater needs to be studied for the given LNG terminal location. Water depth and current are two important parameters in that respect. In areas with strong current, the local cool down will be less important as "new warm seawater" will continuously flow to the terminal. With slow current and shallow water (15-25 m, typical for a GBS-terminal), the local cool down may be an issue. The HiLoad will need to be installed in deeper water for acceptable working conditions for the flexible riser. In deeper water it is expected that the effect of local cool down will not be an issue, but it has to be studied in each specific case. 
REMORA TECHNOLOGY

DOE Study Report

Document Title:

HiLoad $^{\circledR}$ LNG Regas Facility with Salt Cavern Storage
Doc. no.: RT2006-107-RE

Page: $\quad 18$ of 48

\begin{tabular}{l|l} 
Rev. no.: 01 & Date: $11 / 10 / 04$
\end{tabular}

\subsection{Material RevieW}

The LNG vaporizer will have to be made of a material with very high corrosion resistance in order to meet 20 years of successful operation. A detailed evaluation of various materials has been carried out by Remora Technology, where the conclusion is that there are several suitable materials. Final selection will mainly be a matter of weight and cost considerations. . 


\begin{tabular}{|c|c|}
\hline DOE Study Report & Doc. no.: RT2006-107-RE \\
\hline \multirow{2}{*}{$\begin{array}{l}\text { Document Title: } \\
\text { HiLoad }^{\circledR} \text { LNG Regas Facility with Salt Cavern Storage }\end{array}$} & 19 of 48 \\
\hline & Date: $11 / 10 / 04$ \\
\hline
\end{tabular}

\section{LNG PUMPS}

\subsection{GENERAL}

The HiLoad will be equipped with six vertically mounted, vessel contained, submerged motor highpressure pumps located on a deck between the two towers.

The pump and electric motor are integrally mounted on the same shaft, eliminating the need for mechanical seal or coupling. Power is supplied to the motor trough specially sheathed cables. The electrical cabling is passed trough an Ex-safe junction box. This type of pumps are cooled and lubricated by the product flow and are therefore vulnerable to loss of flow. Therefore the pump is equipped with protection devices to avoid dry running of the pump. Such devices can be undercurrent relay, low discharge pressure switch or a low vessel tank level switch.

Several leading manufactures and suppliers with a long track record are potential pump suppliers.

\subsection{Capacities and Performance}

The total regas rate of 2 BSCFD gives a required LNG flow of $\mathbf{3 5 5 0 - 3} 720 \mathbf{~ m}^{3} / \mathrm{h}$ based on LNG with specific gravity of $0,48-0,45$ respectively. The pumps selected are designed for an LNG flow of $6 \mathbf{x}$ $620 \mathrm{~m}^{3} / \mathbf{h}$ at 82,5 bar pressure at a specific gravity of 0,48 . With all the pumps in operation, the facility will have a regas capacity exceeding 2.0 BSCFD.

General characteristics for the LNG pumps are:

Liquid pumped: LNG

Operating temperature:...... $-163{ }^{\circ} \mathrm{C}$

Specific gravity:............ 0.480

Suction pressure:............min 2 Bar

Diff. head:.................. 82,5 Bar

Capacity:................... rated flow $620 \mathrm{~m}^{3} / \mathrm{h}$

Motor power required:........1950 kW

Nominal voltage:..............66 $600 \mathrm{~V}$

Frequency:.................60 Hz 


\begin{tabular}{|c|c|}
\hline DOE Study Report & Doc. no.: RT2006-107-RE \\
\hline Document Title: & 20 of 48 \\
\hline HiLoad $^{\circledR}$ LNG Regas Facility with Salt Cavern Storage & Date: $11 / 10 / 04$ \\
\hline
\end{tabular}

\section{SEAWATER SYSTEM FOR HEATING OF VAPORIZERS}

\subsection{GENERAL}

Seawater is used to heat the $\mathrm{LNG}$ from $-163^{\circ} \mathrm{C}$ to $5^{\circ} \mathrm{C}$. This require a considerable large amount of seawater for the heating process trough the LNG vaporizers. It is vital for the process that the seawater flow trough the vaporizers is maintained, to avoid freezing. In addition, to ensure high heat transfer rates in the vaporizers, the tube surfaces must no be allowed to be fouled by marine growth.

The seawater system consists of the following main components:

- Intake grids

- Seawater pumps feeding the LNG vaporizers

- Seawater strainers

- Bio-fouling protection system

\subsection{SEAWATER INTAKE GRIDS}

Coarse meshed seawater grids are installed at the intake to protect the system from being clogged by surface objects like drifting objects, plastic foil, kelp etc.

A grid with mesh size of $6 \mathrm{~mm}$ will be installed for each main seawater pump. The total area of the grids will be sufficient to maintain a low intake velocity in accordance with the requirements set by the US regulatory bodies: not exceeding 0.5 feet/second.

Cleaning of the grids will be by back-flushing. The piping system will be arranged to direct a high velocity flow of seawater backwards through the grid.

\subsection{SeaWater PUMPS}

Four submerged seawater pumps will be located on top of the pontoon on HiLoad. They are located near the LNG vaporizers in order to keep the amount of large seawater piping to a minimum. During the regas operation the pumps and strainers will be submerged. This will save significant power ( $>$ $50 \%$ ) due to no "lifting height" of seawater for the pumps. 


\begin{tabular}{|c|c|c|}
\hline \multirow{3}{*}{$\begin{array}{l}\text { DOE Study Report } \\
\text { Document Title: } \\
{\text { HiLoad }{ }^{\circledR} \text { LNG Regas Facility with Salt Cavern Storage }} \text {. }\end{array}$} & \multicolumn{2}{|c|}{ Doc. no.: RT2006-107-RE } \\
\hline & Page: & 21 of 48 \\
\hline & Rev. no.: 01 & Date: $11 / 10 / 04$ \\
\hline
\end{tabular}
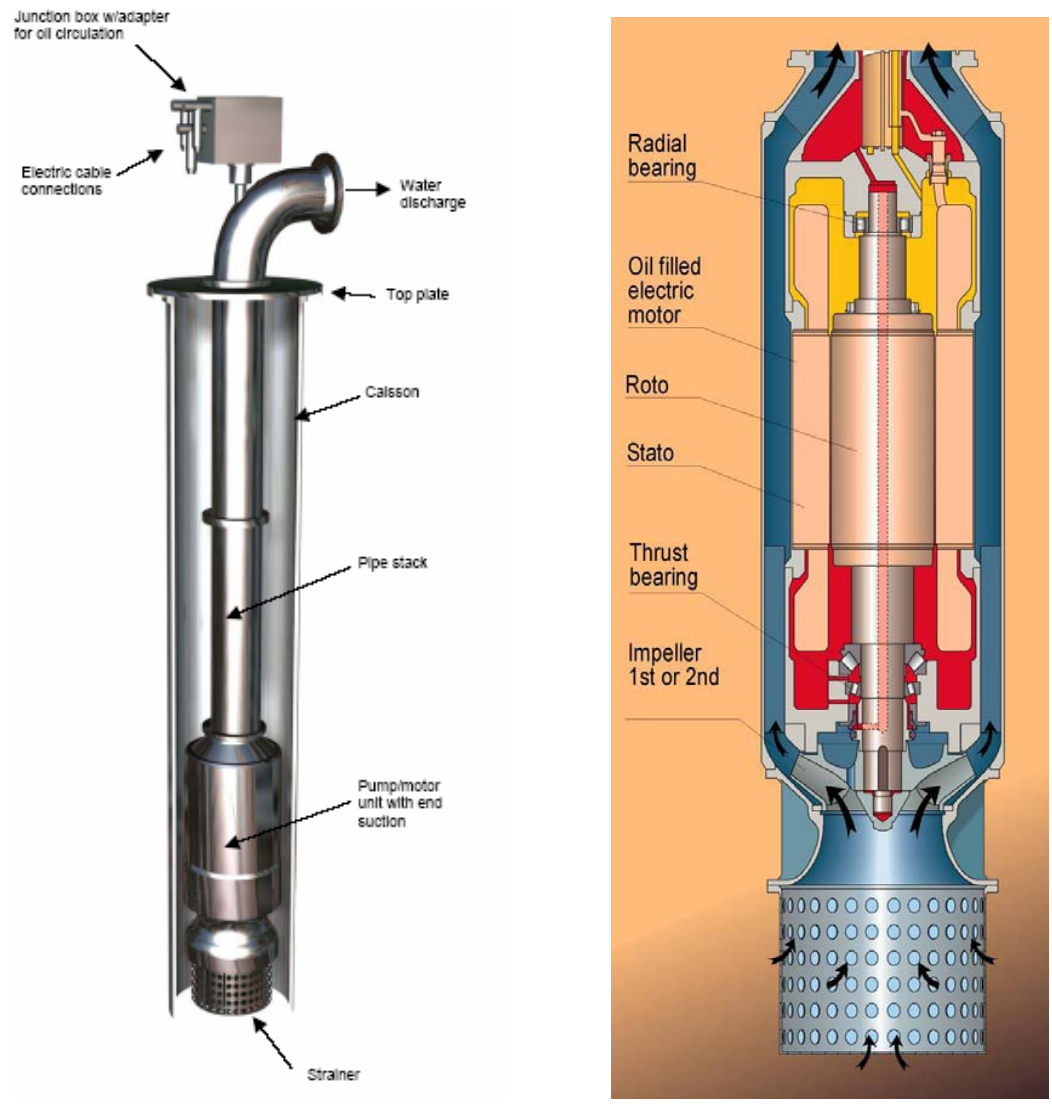

Figure 10 - Sea Water Pump and Electrical motor

The seawater pumps are designed with capacity to give sufficient seawater to sustain the full regas rate with a seawater temperature of $20^{\circ} \mathrm{C}\left(68^{\circ} \mathrm{F}\right)$. Total required seawater flow rate will be approximately $29100 \mathrm{~m}^{3} / \mathbf{h}$.

In order to prevent the possibility of freezing the seawater in the LNG vaporizer, it is important to design a robust and redundant seawater system. This has clearly been pointed out both by the potential vaporizer suppliers and the classification society.

For that reason, it has been concluded that four pumps shall be installed onboard HiLoad, with three pumps operating and one spare as stand by with each pump designed for $9700 \mathrm{~m}^{3} / \mathbf{h}$, giving a total maximum flow rate of $38800 \mathrm{~m}^{3} / \mathrm{h}$ when all 4 pumps are running. The seawater flow from all the pumps will be directed into a common manifold before the flow enters into the LNG vaporizers. Monitoring of the seawater flow and outlet temperature will also be designed will full redundancy.

The electric motors for the seawater pumps are suitable for subsea use; a typical pump/motor design for this purpose is shown in the figure 10 above. 


\begin{tabular}{|l|l|l|}
\hline DOE Study Report & \multicolumn{1}{|l|}{ Doc. no.: RT2006-107-RE } \\
\hline Document Title: & Page: & 22 of 48 \\
\cline { 2 - 3 } HiLoad $^{\mathbb{R}}$ LNG Regas Facility with Salt Cavern Storage & Rev. no.: 01 & Date: 11/10/04 \\
\hline
\end{tabular}

The pumps and strainers can be accessed for inspection and maintenance when the HiLoad is deballasted to service draft (1m freeboard for the pontoon).

\subsection{SEAWATER STRAINERS}

Each seawater pump will be equipped with an automatic self-cleaning strainer. The strainer is located downstream of the pumps and are designed for subsea operation.

The strainers can be made for the required capacity and are designed for continuously operation. Due to high filtration requirement for filter screen $(3000 \mu \mathrm{nm})$, an automatic self-cleaning strainer is used.

\subsection{ELECTROCHLORINATION SYSTEM}

The anti bio-fouling system will have to protect the LNG vaporizers from basically two kinds of marine growth:

- Macro - fouling where large objects like mussels and barnacles will grow and gradually restrict (eventually block) the seawater flow and reduce the efficiency of the cooling systems.

- Micro - fouling, where a layer of algae growth, slime, can reduce the heat transfer efficiency in the LNG vaporizers and also accelerate corrosion of the system.

From a biological point of view, a continuous base dose usually results in organisms becoming acclimated to the base dose and will continue to grow in spite of being exposed to the antibiofouling substance.

HiLoad will have a packaged electrochlorination system for production of antibiofouling substance. In the electrochlorination unit, seawater is electrolysed into sodium hypochlorite (NaOCl, "hypo") and hydrogen. Hypo is stored in a storage tank and injected into the seawater by a pumped controlled by a timer. Hydrogen, as a by-product, is diluted and ventilated by fans to a safe location outside HiLoad. 


\begin{tabular}{|l|l|l|}
\hline DOE Study Report & \multicolumn{1}{|l|}{ Doc. no.: RT2006-107-RE } \\
\hline Document Title: & Page: & 23 of 48 \\
\cline { 2 - 3 } HiLoad $^{\mathbb{R}}$ LNG Regas Facility with Salt Cavern Storage & Rev. no.: 01 & Date: 11/10/04 \\
\hline
\end{tabular}

\section{GAS EXPORT SYSTEM AND SWIVEL}

\subsection{FleXible RiSERs, SWIVEL AND PLEM}

The Flexible Risers, Swivel and PLEM are shown on the 3D illustration below.

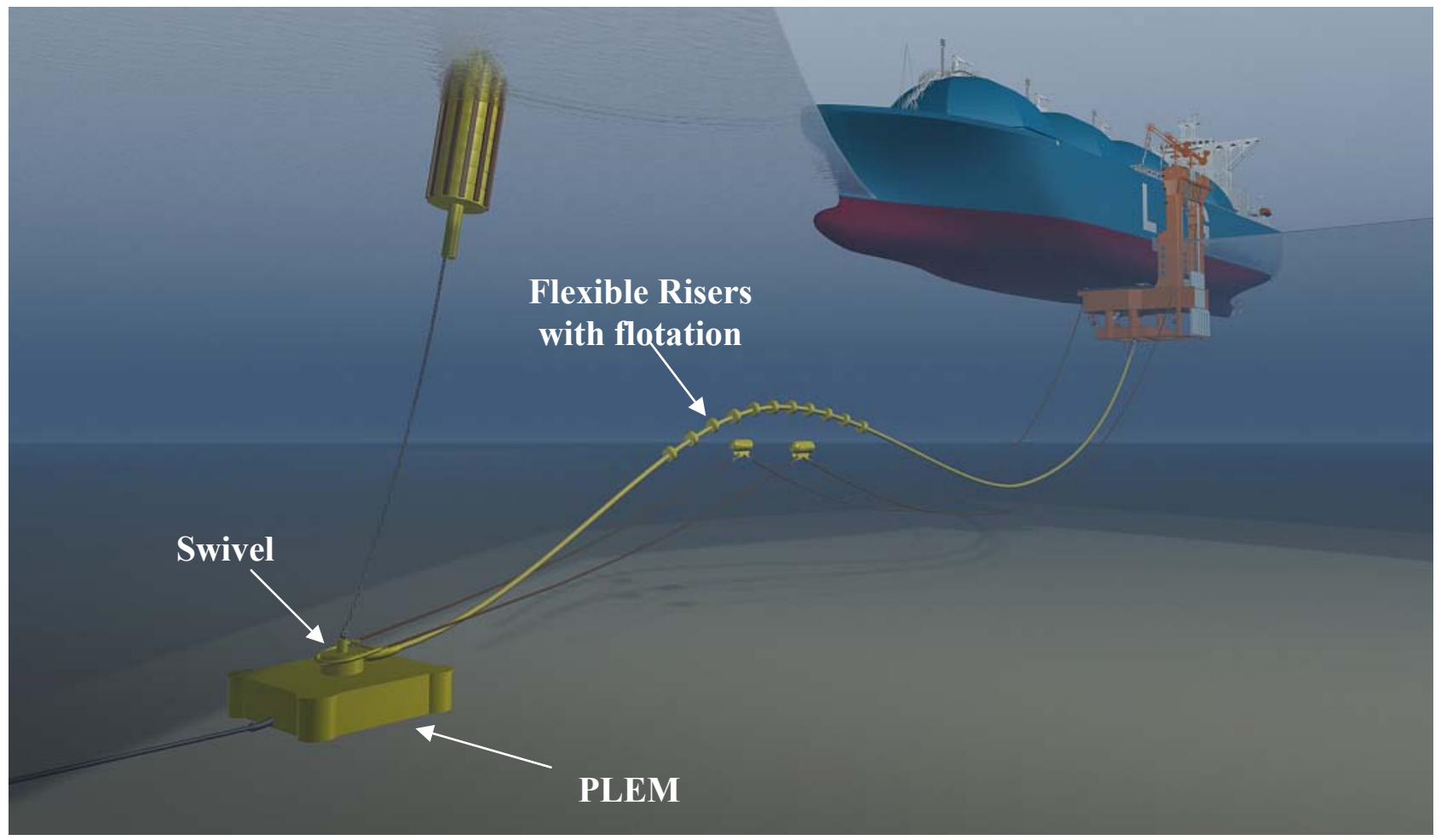

Figure 15 - Flexible Risers, Swivel and PLEM

\section{Flexible Riser}

A Flexible Gas Riser System with two flexible risers will be fitted from HiLoad and down to the PLEM on the seabed. This type of riser is a standard product and can be manufactured by different recognized suppliers.

A typical construction of the flexible riser is shown on the figure below. 


\begin{tabular}{|l|l|l|}
\hline DOE Study Report & \multicolumn{1}{|l|}{ Doc. no.: RT2006-107-RE } \\
\hline Document Title: & Page: & 24 of 48 \\
\cline { 2 - 3 } HiLoad $^{\mathbb{R}}$ LNG Regas Facility with Salt Cavern Storage & Rev. no.: 01 & Date: 11/10/04 \\
\hline
\end{tabular}

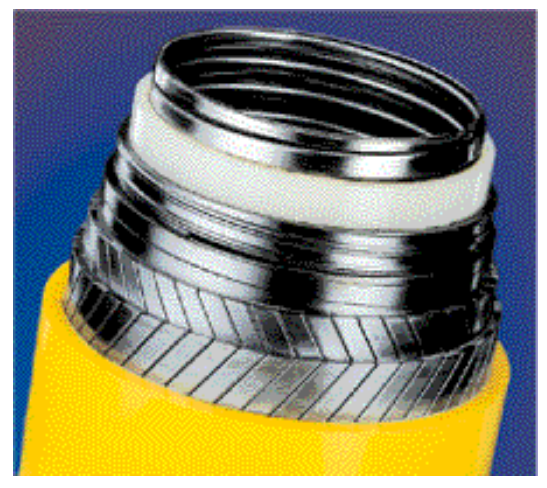

\section{Figure 16 - Typical Flexible Riser construction (NKT Design)}

Design of the flexible riser will be further addressed in detail in the latter phase of the project based on field specific data.

\section{Subsea Swivel}

A subsea swivel will be located on top of the PLEM, consisting of 2 paths for the high pressure gas, power \& signal swivels.

The electrical part of the subsea swivel will be oil filled and pressure compensated. The piston level on the compensator will be monitored to ensure that no seawater will enter the system. In case the overpressure is lost, the system will automatically shut down. Cable entry will be made in a way that no oil can escape through the umbilicals.

\section{PLEM (PipeLine End Manifold)}

The PLEM is the base for the SALM, subsea swivel and pipeline connection. The pipeline will be manifolded and the PLEM will be equipped with a non-return valve on each of the gas pipeline connections to the swivel.

The soil conditions for the selected site will determine whether the PLEM shall be of piled or suction type. Exact design of the PLEM is site specific and detailed engineering will have to be carried out when the actual site is selected and the soil conditions are known.

\subsection{Pipeline TO SHORE}

Paragon Engineering in Houston has carried out engineering of the pipeline for Remora Technology from HiLoad to platform and from platform to shore. A short summary is given below.

The gas pipeline from the HiLoad to the platform will be connected to the PLEM described above. Distance between the HiLoad and the platform will be approximately 1 nautical mile. 
REMORA TECHNOLOGY

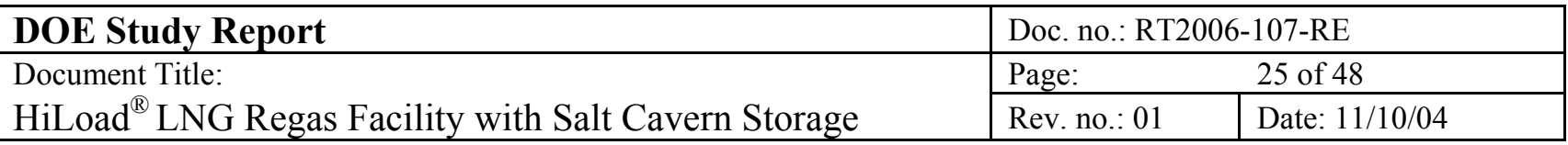

For the pipeline connecting the platform with the main distribution pipeline, the actual distance of the pipeline is not decided. Several alternatives have accordingly been studied for different pipeline lengths, ref. table 1 below. Flow rate for this pipeline is 1 BCFD for all alternative lengths. The pipeline will be corrosion protected and weight coated.

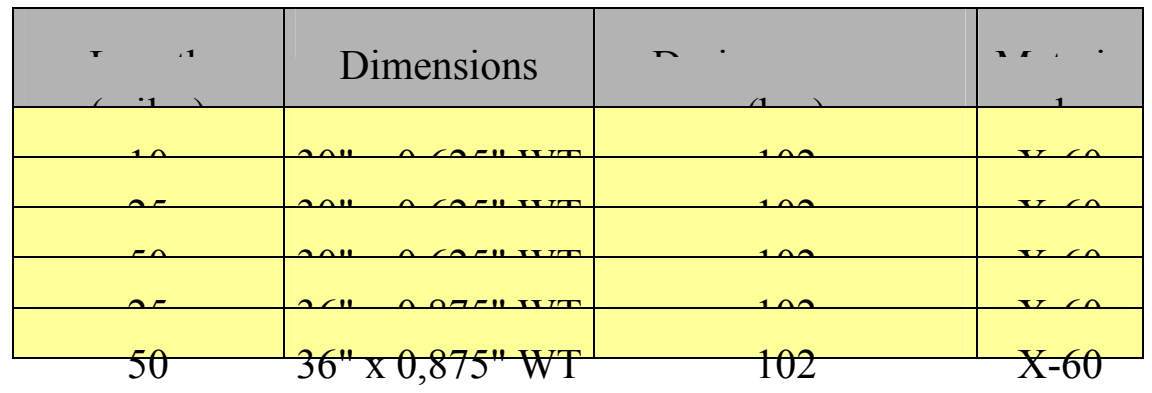

Table 1 - Pipeline Dimensions 


\begin{tabular}{|l|l|l|}
\hline DOE Study Report & \multicolumn{1}{|l|}{ Doc. no.: RT2006-107-RE } \\
\hline Document Title: & Page: & 26 of 48 \\
\cline { 2 - 3 } HiLoad $^{\mathbb{R}}$ LNG Regas Facility with Salt Cavern Storage & Rev. no.: 01 & Date: 11/10/04 \\
\hline
\end{tabular}

\section{POWER SYSTEM FOR HILOAD - MAIN CONSUMERS}

\subsection{GENERAL}

Base case in this study is to supply electric power for operation of the HiLoad from generators located on the compressor/injection platform located at the salt dome, about $2 \mathrm{~km}$ away from the HiLoad. Power requirement for the HiLoad will be about 22 MW.

Due to the high power demand, $11 \mathrm{kV} / 60 \mathrm{~Hz}$ will be used for line voltage to HiLoad. The power system is based on a 3-phase system, insulated 3-wire system for the distribution systems of $6,6 \mathrm{kV}$, $690 \mathrm{~V}$ and $230 \mathrm{~V}$.

The electrical plant will be powered through three 50\% capacity subsea cable from the platform to the PLEM and by three 50\% independent umbilicals connected to the PLEM as described in section below.

Onboard HiLoad, the $11 \mathrm{kV}$ main switchboard is divided in two switchboards, where bus-tie breakers connect the two switchboards in case one supply fails. During normal operation the bus-tie breakers will be in open position.

All the $6,6 \mathrm{kV}, 690 \mathrm{kV}$ and $230 \mathrm{kV}$ distribution switchboards are supplied from $11 \mathrm{kV}$ transformers, and are all divided in two sections for redundancy.

\subsection{PoWer Demand}

HiLoad's main electrical consumers are the 6 LNG HP send-out pumps, the 4 seawater pumps and the 3 thrusters. Together with other users in the miscellaneous utility and safety systems, the total power demand is estimated to be $18500 \mathrm{~kW}$.

A contingency factor of 1,2 is used in this design phase; this gives $22 \mathrm{MW}$ in power demand. In addition the LNG pumps will draw about 6.5 times of full load amps during start up.

\subsection{Subsea Umbilical and Sea Cable}

For supply of power, control and optical signals, static sea cables will be used from the compression/injection platform to the PLEM and dynamic umbilicals clamped to the flexible risers will be used from the PLEM and up to HiLoad. 
REMORA TECHNOLOGY

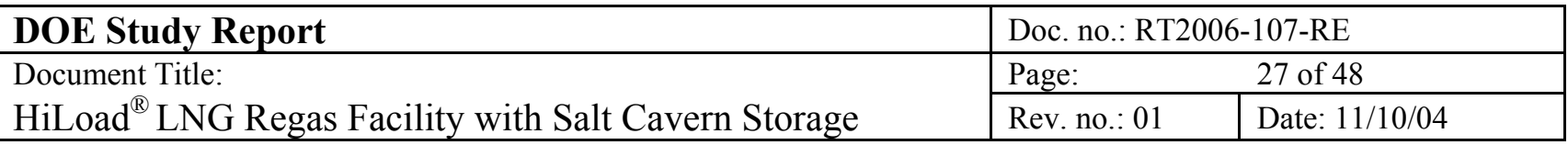

Special attention will be made for the design regarding the mechanical strains imposed on the sea cables and the dynamic umbilicals during manufacture, storage and handling, including laying, retrieval, pull-in, connection, and operational life.

The dynamic umbilicals from the PLEM to HiLoad are proposed with a redundant configuration using 3 umbilicals clamped to the flexible risers. 


\begin{tabular}{|l|l|l|}
\hline DOE Study Report & \multicolumn{1}{|l|}{ Doc. no.: RT2006-107-RE } \\
\hline Document Title: & Page: & 28 of 48 \\
\cline { 2 - 3 } HiLoad $^{\mathbb{R}}$ LNG Regas Facility with Salt Cavern Storage & Rev. no.: 01 & Date: 11/10/04 \\
\hline
\end{tabular}

\section{COMPRESSION/INJECTION/SUPPORT PLATFORM}

\subsection{General FunCTIONS}

Paragon Engineering in Houston has carried out preliminary engineering for Remora Technology of the Compression/Injection/Support Platform for the HiLoad and the Salt Cavern. The below description is a short summary of the design.

This platform will be located close to the Salt Dome location and will be the focal point for control of the LNG import, storage and send out project.

The platform will have a central control room that will be able to remotely control the regasification operations on HiLoad, compression and injection of gas to the salt dome for storage, and withdrawal, pressure control and send out of gas to the pipeline supplying gas to the customers.

The platform will receive 2 BCFD of regasified LNG from HiLoad at a pressure of approximately 80 bar. 1 BCFD of gas will be boosted to a pressure up to about 125 bar by compressors prior to injection into the salt cavern for intermediate storage. When HiLoad is in operation, the remaining 1 BCFD of gas will be routed directly into the shore pipeline from the platform at a pressure of approximately 74 bar.

When the gas supply from HiLoad is interrupted in the period between departure and arrival of LNG carriers, continuous gas supply to customers is secured by withdrawing stored gas from the salt cavern. The high pressure gas from the cavern is reduced in pressure on the platform down to the required pipeline pressure of about 74 bar. The withdrawal rate from the cavern is equal to the shore pipeline supply rate of 1 BCFD.

The main units included on the platform are:

- Gas compression

- Electrical power generators

- Centralized control room

- Crew quarters

- Utilities

- Flare and vent

\subsection{Platform Structure}

The platform will consist of a 4-legged piled structure to support the topsides and the various gas risers connecting the platform with HiLoad, the salt cavern and the export pipeline. 


\begin{tabular}{|l|l|l|}
\hline DOE Study Report & \multicolumn{1}{|l|}{ Doc. no.: RT2006-107-RE } \\
\hline Document Title: & Page: & 29 of 48 \\
\cline { 2 - 3 } HiLoad $^{\mathbb{R}}$ LNG Regas Facility with Salt Cavern Storage & Rev. no.: 01 & Date: 11/10/04 \\
\hline
\end{tabular}

The topsides will consist of a cellar deck and a main deck. The cellar deck will contain the injection compressors and the utility systems while the quarter's module and the electric power generators will be installed on the main deck.

\subsection{COMPRESSION SYSTEMS}

The platform compression system is designed to compress 1 BCFD from the incoming natural gas flow at a pressure of about 80 bar to the required salt dome injection pressure of up to 125 bar.

As a result of the preliminary studies, it is proposed to install $2 \times 50 \%$ compression trains, each of 500 MMCFD capacity. Each train is composed of electric motor, variable speed gearbox and a centrifugal turbo compressor.

Each compressor train will be mounted on a base plate with common lube oil system for motor/gearbox and compressor and a dry seal gas system for the compressor.

Nominal rating of each compressor drive motor is $15000 \mathrm{HP}(11200 \mathrm{~kW})$.

\subsection{Power Generation System}

The total electric power needed for operation of the compression plant and for the HiLoad systems will be generated by a central power generation system to be installed on the platform.

Total electric load requirement for HiLoad is estimated to about $22 \mathrm{MW}$. The gas compressors require about $24 \mathrm{MW}$ of electric power with additional power consuming utilities on the platform. Total maximum electrical load is estimated to about $49 \mathrm{MW}$.

The power plant installed on the platform will consist of 3 gas turbine driven electric generators, each of $25 \mathrm{MW}$. Thus, 3 trains, each giving $50 \%$ capacity, provide the entire electric power for both HiLoad and the injection compressors. Each train consists of a gas turbine driving the electric generator through a speed reduction gearbox, marine type inlet filters, exhaust ducting, silencers and exhaust stacks.

The gas turbines are designed for dual fuel operation. Natural gas is used for normal operation with diesel oil for start-up.

A $1000 \mathrm{~kW}$ diesel generator set is installed for emergency requirements.

Power generation will be at $11 \mathrm{kV}, 60 \mathrm{~Hz}$. Transformers will be installed for power at lower voltages. DC power requirements will be by charger and batteries. Switchgears, motor control centres and distribution boards are located in a separate compartment nearby the generators. 


\begin{tabular}{|l|l|l|}
\hline DOE Study Report & \multicolumn{1}{|l|}{ Doc. no.: RT2006-107-RE } \\
\hline Document Title: & Page: & 30 of 48 \\
\cline { 2 - 3 } HiLoad $^{\mathbb{R}}$ LNG Regas Facility with Salt Cavern Storage & Rev. no.: 01 & Date: 11/10/04 \\
\hline
\end{tabular}

\subsection{GaS WithdRAWAL From SALT CAVERN}

When high pressure gas is taken out from storage in the salt cavern, the pressure must be reduced from the storage pressure around 125 bar to pipeline pressure of about 75 bar. This will be done on the platform, either through pressure reduction valves or running the gas through turbo expanders.

Whilst the base case is to install pressure reduction valves to control the gas pressure between the salt cavern and the export pipeline pressure, the alternative use of turbo expanders have the benefit that the pressure energy available in gas stream can be recovered and the energy used to drive generators for production of electrical power.

Due to possible water absorption while the gas is stored in the salt cavern, a gas treating system may be required on the platform. The actual need for a gas drying system also depends on how the cavern will be operated. In a cavern where the pressure is maintained by varying the water level, gas will absorb water to its saturation level and a glycol based dehydration system is required for removing the water prior to export in the pipeline.

\subsection{QUARTERS BLOCK}

The quarters block will include all accommodations for 12 people with cabins, galley, dining/lounge area and offices. A central control room will be installed for the entire facility including HiLoad. The control room will cover the essential functions as HiLoad master control station, platform process control, fire and gas system, ESD system and communications.

The quarters block will be equipped with a helideck suitable for operations with Bell 412 or Sikorsky S-76 helicopters.

\subsection{Platform Utilities}

The platform will have a number of utility systems installed in order to support the main gas handling and power generation functions of the platform:

- Cooling water system

- Gas and diesel fuel system

- Emergency power system

- Fire fighting systems

- Potable, utility water and sewage system

- HVAC system

- Compressed air and nitrogen system

- Cranes, lifeboats and rafts 


\section{REMORA TECHNOLOGY}

DOE Study Report

Doc. no.: RT2006-107-RE

Document Title:

Page:

31 of 48

HiLoad $^{\circledR}$ LNG Regas Facility with Salt Cavern Storage

Rev. no.: 01

Date: $11 / 10 / 04$

- Flare stack 


\begin{tabular}{|l|l|l|}
\hline DOE Study Report & \multicolumn{1}{|l|}{ Doc. no.: RT2006-107-RE } \\
\hline Document Title: & Page: & 32 of 48 \\
\cline { 2 - 3 } HiLoad $^{\circledR}$ LNG Regas Facility with Salt Cavern Storage & Rev. no.: 01 & Date: 11/10/04 \\
\hline
\end{tabular}

\section{OUTLINE OPERATION DESCRIPTION - HILOAD}

\subsection{CONNECTION OF LNG CARRIER TO SALM}

A mooring master and an LNG Regas Supervisor who is part of the HiLoad operation team will be brought onboard the LNG carrier before it arrives at the facility. The mooring master will together with the captain on the LNG carrier lead the connection operation to the SALM.

A line handling boat will pick up the floating forerunner line and use an air gun or similar to bring the line to the LNG carrier. The forerunner will be connected to the mooring winch and the mooring hawser and the chain is pulled in through the fairlead on the LNG carrier. The chain will be connected to the OCIMF compliant strongpoint on the LNG carrier as shown on figure below.

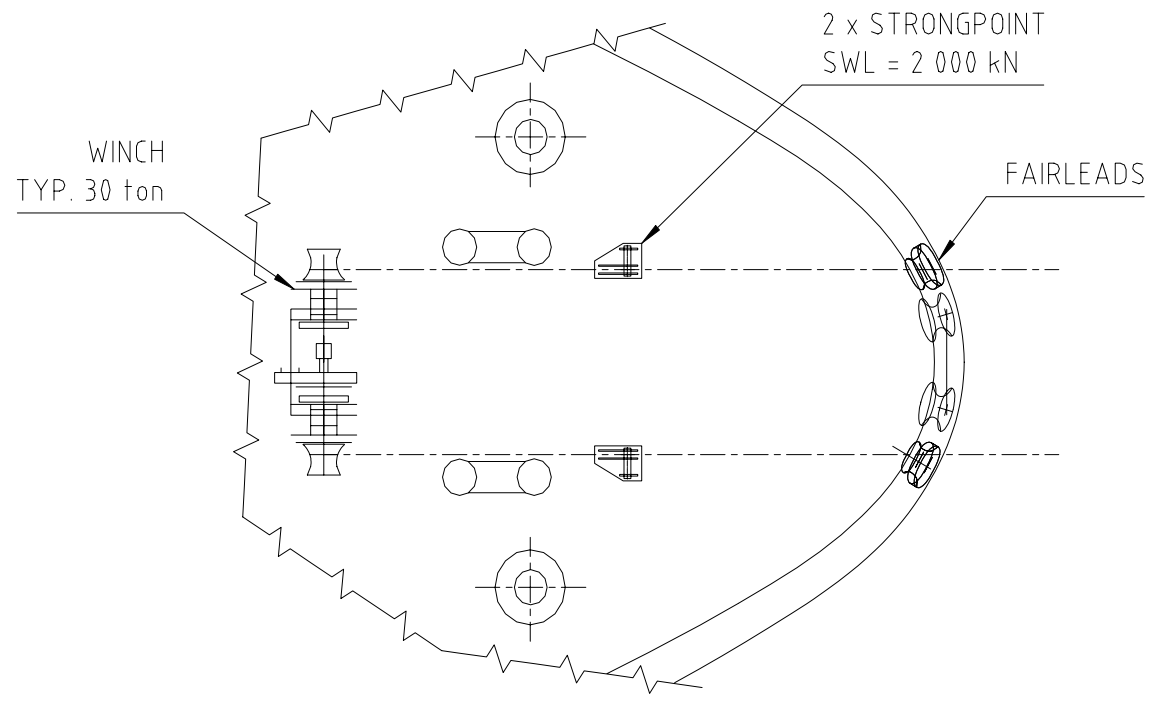

\section{Figure 22 - Typical Bow Arrangement, LNG carrier}

During connection of the LNG carrier to the SALM, the HiLoad will be positioned a safe distance away from the carrier.

Connection of a vessel to a SALM type of Single Point Mooring is a well known mooring operation used for many years for loading of oil. 


\begin{tabular}{|l|l|l|}
\hline DOE Study Report & \multicolumn{1}{|l|}{ Doc. no.: RT2006-107-RE } \\
\hline Document Title: & Page: & 33 of 48 \\
\cline { 2 - 3 } HiLoad $^{\mathbb{R}}$ LNG Regas Facility with Salt Cavern Storage & Rev. no.: 01 & Date: 11/10/04 \\
\hline
\end{tabular}

\subsection{DOCKING OF HILOAD TO LNG CARRIER}

The principles for docking HiLoad to the LNG carrier are the same as when a forklift picks up a pallet. The HiLoad will approach the LNG carrier with a $3 \mathrm{~m}$ gap between the top of the pontoon and the hull bottom.

Once the HiLoad is getting in contact with the LNG carrier's side, and the longitudinal position is confirmed to be within acceptable limits for the loading arms $(+/-3 \mathrm{~m})$, the thrusters will go into a constant thrust mode forcing the HiLoad towards the carrier side. This will make sure that the fenders on the HiLoad towers will stay in touch with the hull as the HiLoad is being de-ballasted. The tower fenders are of heavy duty type, standard fenders in daily use on berthing terminals around the World.

Due to the small waterline area and high capacity ballast pumps, the HiLoad pontoon will get in touch with the bottom of the LNG carrier within less than a minute.
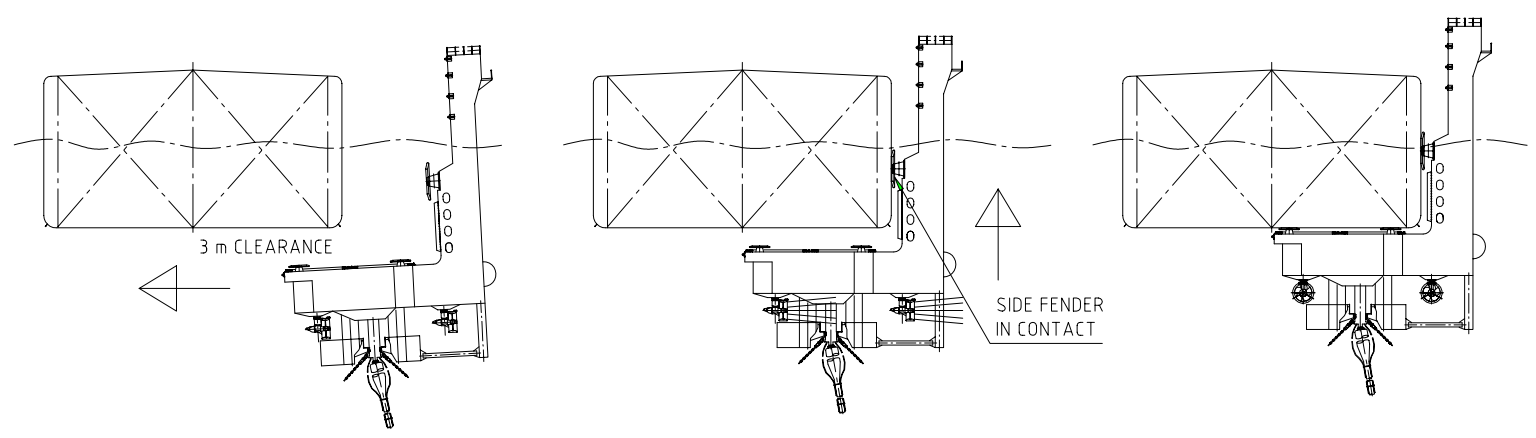

\section{Figure 23 - Typical docking sequence for HiLoad}

Impact fenders similar to the tower fenders are located in each corner of the pontoon. These fenders will effectively absorb any impact due to the relative motion between the HiLoad and the tanker.

As the HiLoad is being deballasted, the impact fenders will gradually be compressed until in line with the rest of the friction fenders covering the entire pontoon.

When a proper contact has been established between the HiLoad pontoon and the LNG carrier, the Attachment System is activated. The attachment system is making use of the hydrostatic pressure, and will make sure that the HiLoad will be clamped to the tanker with several thousand tonnes in order to not come loose. The attachment system has previously been full scale tested, with very positive results.

Model Test of docking of HiLoad to a tanker was carried out at Marintek in Trondheim, Norway. 


\begin{tabular}{|l|l|l|}
\hline DOE Study Report & \multicolumn{1}{|l|}{ Doc. no.: RT2006-107-RE } \\
\hline Document Title: & Page: & 34 of 48 \\
\cline { 2 - 3 } HiLoad $^{\mathbb{R}}$ LNG Regas Facility with Salt Cavern Storage & Rev. no.: 01 & Date: 11/10/04 \\
\hline
\end{tabular}

\subsection{STATION KEEPING}

The LNG carrier and HiLoad will weather vane around the SALM base. The HiLoad is equipped with three azimuth thrusters that can be used to provide necessary thrust in the direction required. This means that no tug will be required at the stern of the LNG carrier. The thrusters can also be used to rotate the LNG carrier to an optimal heading in order to reduce the wave motion on the carrier. Fishtailing of the carrier can also be reduced by use of the thrusters.

\subsection{Survival Condition}

The HiLoad LNG Regas Facility will be designed to survive a 100-year environmental condition. The unit will be moored by use of four mooring lines. Two lines are permanent connected from HiLoad pontoon and down to the PLEM on the seabed and two other lines are fitted on the other side of the pontoon and connected to pre-installed anchors.

The unit will be ballasted to an optimal draught minimizing the motion and loads.

\subsection{PREPARATIONS FOR REgasificATION}

The LNG systems onboard HiLoad are designed for simple operations and for remote control of the regasification process according to the overall standards and procedures established for design and operation in general for the HiLoad Facility.

Prior to arrival of an LNG carrier to the HiLoad Facility, plans will have to be developed for the actual LNG unloading and regasification operations:

- LNG unloading rate

- Sequence of tank unloading

- Envelope for max trim and draft variations

- Ballasting operations of ship

- Connection/Disconnection procedures

- Cool-down procedures of pipelines and equipment (if any)

- Safety control procedures

- Deployment and testing of fire fighting and safety equipment

The HiLoad Team, boarding the LNG carrier before docking, will do a final review of the submitted plans together with testing of the operational interface and ESD systems.

When the LNG carrier is securely docked with HiLoad, both LNG transfer arms will be connected under local control to the selected manifold connections onboard the LNG carrier. If the piping system and equipment are in cold condition after the previous docked ship, the regasification 


\begin{tabular}{|l|l|l|}
\hline DOE Study Report & \multicolumn{1}{|l|}{ Doc. no.: RT2006-107-RE } \\
\hline Document Title: & Page: & 35 of 48 \\
\cline { 2 - 3 } HiLoad $^{\mathbb{R}}$ LNG Regas Facility with Salt Cavern Storage & Rev. no.: 01 & Date: 11/10/04 \\
\hline
\end{tabular}

operations may start as soon as the systems are tested for integrity and the manifold connection between the LNG carrier and HiLoad has been cooled down.

If the HiLoad LNG system has been warmed up, the cool-down will commence as soon as the manifold connections are made up.

\subsection{REGASIFICATION OPERATION}

Before introducing LNG to the vaporizers, it is mandatory to make sure that the seawater pumps are running and supplying sufficient quantity of heating water to the vaporizers.

The cool-down and start-up operations will be performed locally with monitoring from the central control room. One vaporizer at the time will be started up. As soon as stable operations are achieved, full control of the operations will be transferred to the operator in the central control room located on the support/compression platform. Personnel onboard HiLoad may then leave for the control room.

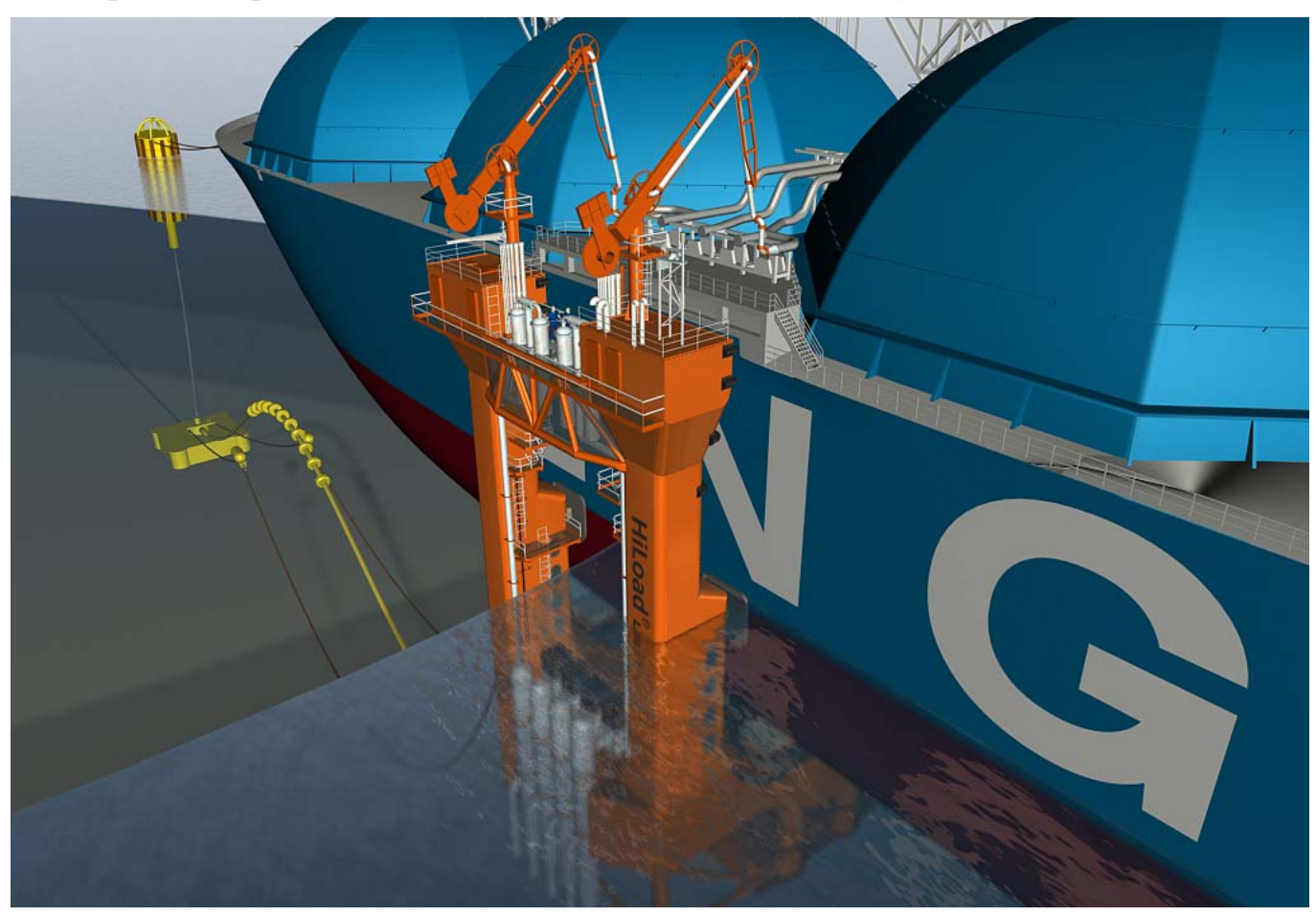

Figure 24 - LNG Regas Operation

When nearing the end of the unloading operations, the HiLoad facilities will be shut down in a controlled sequence, one by one. 


\begin{tabular}{|l|l|l|}
\hline DOE Study Report & \multicolumn{1}{|l|}{ Doc. no.: RT2006-107-RE } \\
\hline Document Title: & Page: & 36 of 48 \\
\cline { 2 - 3 } HiLoad $^{\mathbb{R}}$ LNG Regas Facility with Salt Cavern Storage & Rev. no.: 01 & Date: 11/10/04 \\
\hline
\end{tabular}

The capacity of the LNG pumps onboard the ship will be reduced accordingly, either by throttling the outlet valve, by stopping pumps, and/or by recirculation LNG onboard the LNG carrier.

In order to avoid freezing of the water side of the vaporizers, it is of utmost importance that sufficient seawater flow is maintained through the LNG vaporizers at all time until all the LNG inside the vaporizers have been evaporated.

After completion of the regas operations, the LNG transfer arms will be drained back to the LNG carrier and inerted with nitrogen before disconnection.

\subsection{LNG BOIL-OFF HANDLING \& GAS RETURN}

The regasification capacity of HiLoad is specified to 2 BCFD of gas delivered to the compression/injection platform. This capacity is equivalent to vaporizing about $3720 \mathrm{~m}^{3} / \mathrm{h}$ of LNG. Discharging a standard $138000 \mathrm{~m}^{3}$ LNG carrier will be achieved in about 36 hours.

Most LNG carriers built since 1990 are designed with a boil-off rate not exceeding $0,15 \%$ of the cargo per $24 \mathrm{hrs}$. Actual boil-off is usually less because of design margins and ambient temperatures are less than design temperatures, bringing the experienced boil-off rates as low as $0,10 \%$ per day.

For modern ships in the range of 125 - $145000 \mathrm{~m} 3$, the boil-off rate is to small to compensate for the unloading rate and additional gas needs to be supplied to the ship's cargo tanks to maintain positive tank pressure. To avoid gas supply from HiLoad, it is proposed to use the ship's vaporizers to vaporize a small amount of LNG and lead the gas to the tanks to maintain positive pressure. Required quantity will be in the range of $1000-2000 \mathrm{~m}^{3} / \mathrm{h}$, depending upon ship size and temperatures. This is well within the capacity range of the ships' LNG vaporizers.

\subsection{SLOSHING IN LNG CARRIERS}

The LNG carrier will be subject to sloshing in the partially filled LNG tanks during the offloading operation. The LNG containments system for the LNG carriers planned used for an offshore LNG terminal need to be checked for sloshing. A preliminary evaluation has been carried out for the three main LNG containment systems (Moss, SPB \& GTT Membranes). The spherical Moss design and the SPB design by IHI will not have any problems with sloshing under any loading conditions. The two different membrane designs by GTT have continuously been improved to be more robust against sloshing with reduced filling restrictions. However, any existing membrane LNG carriers need to be checked in detail by GTT in each case, using the specific local wave spectra to analyze the internal sloshing forces. 


\begin{tabular}{|l|l|l|}
\hline DOE Study Report & \multicolumn{1}{|l|}{ Doc. no.: RT2006-107-RE } \\
\hline Document Title: & Page: & 37 of 48 \\
\cline { 2 - 3 } HiLoad $^{\mathbb{R}}$ LNG Regas Facility with Salt Cavern Storage & Rev. no.: 01 & Date: 11/10/04 \\
\hline
\end{tabular}

\section{HAZARD IDENTIFICATION REVIEW - HAZID}

\subsection{GENERAL}

Remora Technology has carried out a preliminary HAZID of the LNG Regas System on HiLoad. It is planned to carry out a more detailed HAZID at a later stage together with potential customers.

A HAZID of the original oil version of HiLoad was carried out in October 2001, covering the basic HiLoad design. Accordingly, the new review covers the additional systems required for the LNG Regas operations on HiLoad.

\subsection{Aim AND OBJECTIVE}

The aim of the HAZID was to identify potential hazards associated with the LNG Regas System. The objectives have been to identify issues related to the safety of HiLoad during regas operations, to identify recommendations aimed at improving the safety of the design and operation, and/or to contribute to documenting that the safety level is acceptable.

The Hazid report deals with the consequences of external influences and equipment malfunctions onboard HiLoad, the causes, the safeguards and recommendations for reducing or eliminating the risks.

\subsection{Design Philosophy}

HiLoad's overall safety has been driving the design philosophy all the time. Potential safety issues that particularly have been focused on during the design phase are:

- Reducing fire exposure to critical components like the LNG vaporizers

- Minimizing the amount of LNG inventory in the system

- Prevent freeze-up of LNG vaporizers

- Redundant power supply and control system

- Redundancy in the LNG pumping and regasification system

- Designing a shut down system that prevents release of large amount of gas from HiLoad during all normal and ESD operations

This has to a large extent been achieved by the design described in this report. 


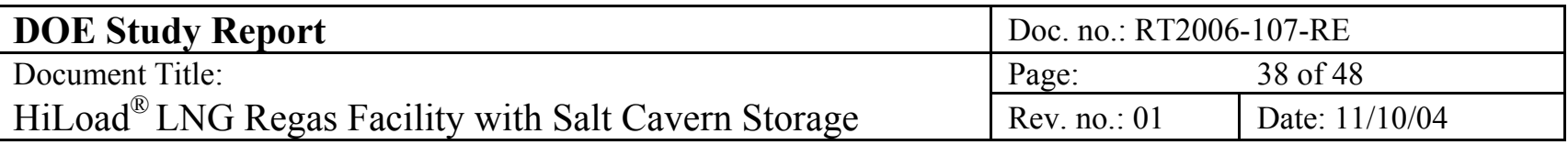

\section{SAFETY SYSTEMS}

\subsection{GeneraL}

The safety systems for the HiLoad unit comprise several systems to ensure safe and reliable offloading of LNG from the vessel to HiLoad for regas and for transportation of gas to shore. The various systems are briefly described below:

\subsection{EMERGENCY SHUT-DOWN (ESD) SYSTEM}

Emergency Shut Down and/or disconnecting functions can be carried out in case an emergency situation should occur. Such situations can be, but not limited to:

$\checkmark$ Black-out on the vessel

$\checkmark$ Black-out on HiLoad

$\checkmark$ Black-out power supply to HiLoad

$\checkmark$ Fire, explosion or gas detection

$\checkmark$ Collision danger

$\checkmark$ Gas/LNG spillage

The emergency system will be designed for 3 grades of shut down:

Automatic Shut Down (ASD) initiated by failures within essential HiLoad systems will shut down the LNG transfer system and activate safeguard equipment.

Emergency Shut Down Class I (ESDI)

ESD I shall be used if an abnormal condition occur. ESD I will stop the offloading from the vessel and the gas delivery from the regas plant.

Emergency Shut Down II (ESD II)

ESD II shall be used if an abnormal/critical situation should occur. ESD II will stop the off loading from the vessel and the gas delivery from the regas plant, disconnect the LNG transfer arms and disconnect the HiLoad from the LNG carrier.

ESD II and I can be initiated from:

$\checkmark$ Operation Command Centre.

$\checkmark$ Vessel (Telemetry system)

$\checkmark$ Vessel ESD system 


\begin{tabular}{|c|c|}
\hline DOE Study Report & Doc. no.: RT2006-107-RE \\
\hline Document Title: & 39 of 48 \\
\hline HiLoad $^{\circledR}$ LNG Regas Facility with Salt Cavern Storage & Date: $11 / 10 / 04$ \\
\hline
\end{tabular}

Local Control Panel on HiLoad.

\subsection{GAS DETECTION SYSTEM}

A gas detection system, integrated with the overall Control System, shall be installed on the HiLoad. Gas detectors shall be installed in hazardous areas, air locks and ventilation intakes.

Gas detection is to give following actions, initiated at gas content of $30 \%$ of LEL of methane in air:

$\checkmark$ Stop LNG/Gas flow.

$\checkmark$ Stop ventilation to non-hazardous areas on the HiLoad.

$\checkmark$ Stop LNG pumps on vessel.

\subsection{FiRE DETECTION SYSTEM}

A fire detection system shall be installed on the HiLoad for automatically detection of fires. There shall be installed fire detectors in all rooms.

Fire detection in two adjacent detectors in hazardous rooms will give the following action:

$\checkmark$ Stop LNG/Gas flow.

$\checkmark$ Close ventilation inlet valve and outlet valve in hazardous rooms.

$\checkmark$ Stop ventilation fans for the hazardous rooms.

Fire detection in any other area: Close ventilation inlet valve and outlet valve in the area.

\subsection{GAS DETECTION SYSTEM}

$\checkmark$ A gas detection system, integrated with the overall Control System, shall be installed on the HiLoad. Gas detectors shall be installed in hazardous areas, air locks and ventilation intakes.

Gas detection is to give following actions, initiated at gas content of $30 \%$ of LEL of methane in air:

$\checkmark$ Stop LNG/Gas flow.

$\checkmark$ Stop ventilation to non-hazardous areas on the HiLoad.

$\checkmark$ Stop LNG pumps on vessel. 
DOE Study Report

Document Title:

HiLoad $^{\circledR}$ LNG Regas Facility with Salt Cavern Storage
Doc. no.: RT2006-107-RE

Page: $\quad 40$ of 48

Rev. no.: 01

\subsection{FiRE DETECTION SYSTEM}

A fire detection system shall be installed on the HiLoad for automatically detection of fires.

Fire detection in two adjacent detectors in hazardous rooms will give the following action:

$\checkmark$ Stop LNG/Gas flow.

$\checkmark$ Close ventilation inlet valve and outlet valve and ventilation fans for hazardous rooms.

Fire detection in any other area: Close ventilation inlet valve and outlet valve.

\subsection{Fire Fighting SYSTEM}

HiLoad will be equipped with the necessary fire fighting systems required by the classification society and the regulatory authorities. The systems will include Fire Water, Water Spray, Dry Powder and Argonite Systems.

\section{Argonite System}

An Argonite system will be installed for all rooms in the pontoon. There will be no means of automatic release of the Argonite system.

Release of the Argonite shall be possible from:

$\checkmark$ HiLoad control room

$\checkmark$ Operation Control Centre for HiLoad

Release of the Argonite shuts down the ventilation system for the HiLoad.

\section{Water Spray System}

Onboard HiLoad, a water spray system will be required for the pot-mounted high pressure LNG pumps and the sides of the towers below the LNG transfer arms. The top of the towers are essential structures to support the LNG transfer arms, LNG pumps and associated piping. A water spray system is thus installed to protect the top and sides of the towers. The system will be automatically and manually released.

\section{Dry Powder}




\begin{tabular}{|c|c|}
\hline DOE Study Report & Doc. no.: RT2006-107-RE \\
\hline Document Title: & 41 of 48 \\
\hline HiLoad $^{\circledR}$ LNG Regas Facility with Salt Cavern Storage & Date: $11 / 10 / 04$ \\
\hline
\end{tabular}

Two independent systems to be installed, one on each tower, containing powder storage, powder monitor and one hand hose line.

Each monitor to cover the area of the LNG transfer arms and the LNG manifold area on board the LNG carriers.

Each system shall have sufficient powder for 45 seconds continuous operation, equivalent to a storage capacity of $1300 \mathrm{~kg}$ of dry powder.

\subsection{VENTILATION SYSTEM CONTROL}

The ventilation system control on the HiLoad shall be interfaced with the Integrated Control System and with the Fire and Gas detection system to be able to isolate the source of release when an ASD is initiated.

\subsection{AlARM SYSTEM}

An alarm system will be installed on the HiLoad. The alarm system will be a part of the Integrated Control System. Instrumentation for monitoring of critical offloading data shall be provided.

\subsection{CCTV SYSTEM}

CCTV system will be installed on the HiLoad. The CCTV system shall give good view of the LNG transfer operation and all relevant marine systems.

The CCTV system shall be integrated in the Integrated Control System. 


\begin{tabular}{|l|l|l|}
\hline DOE Study Report & \multicolumn{2}{|l|}{ Doc. no.: RT2006-107-RE } \\
\hline Document Title: & Page: & 42 of 48 \\
\cline { 2 - 3 } HiLoad $^{\mathbb{R}}$ LNG Regas Facility with Salt Cavern Storage & Rev. no.: 01 & Date: 11/10/04 \\
\hline
\end{tabular}

\section{LNG CARRIER INTERFACE}

\subsection{GENERAL}

Some consideration for the LNG Carrier Interface has been evaluated to ensure proper functions during operation. These considerations and evaluations are described in the sections below.

\subsection{LNG CARRIER "DOCKING KIT"}

Before the LNG carrier is entering the HiLoad terminal zone, about $10 \mathrm{NM}$, a mooring master is let onboard with a HiLoad docking kit. The docking kit consists of:

\section{Optical prism}

To be mounted on the rail by the cargo manifold. This will indicate the docking area for HiLoad and enables the laser reference system to lock on to the target.

\section{ESD Telemetry link}

This enables the master or mooring master to suspend or interrupt the docking operation and discharge. It will also be possible to disconnect the HiLoad form the ship by initiating an ESD from the portable ESD telemetry link.

\subsection{INTERFACE - EMERGENCY SHUT DOWN SYSTEM}

For emergency shut down of liquefied gas cargo transfer between the LNG carrier and HiLoad, a link must be established between the two units during cargo transfer. This emergency link will work in principle as when a LNG carrier is doing cargo transfer to a land terminal. The emergency shut down link between HiLoad and the LNG carrier should therefore be based on the same recommendations and guidelines.

Normally LNG carriers have an international standardized ESD connection located adjacent to its cargo manifolds. A link between HiLoad and the ship enables communication and initiation of the 2 ESD systems and when released, cause emergency shut down of cargo transfer in accordance with the overall ESD logic.

The ESD link shall follow the Recommendations and Guideline for Linked Ship/Shore Emergency Shut Down of Liquefied Gas Cargo Transfer by SIGTTO. 


\begin{tabular}{|l|l|l|}
\hline DOE Study Report & \multicolumn{1}{|l|}{ Doc. no.: RT2006-107-RE } \\
\hline Document Title: & Page: & 43 of 48 \\
\cline { 2 - 3 } HiLoad $^{\circledR}$ LNG Regas Facility with Salt Cavern Storage & Rev. no.: 01 & Date: 11/10/04 \\
\hline
\end{tabular}

\section{NITROGEN SYSTEM FOR HILOAD}

\subsection{GENERAL}

Gaseous nitrogen is required onboard HiLoad for continuous purging of certain equipment as well as for batch usage when inerting equipment and piping system prior to gas freeing.

\section{Continuous users:}

LNG transfer arms' swivels:

LNG HP send-out pumps, electrical connections.

\section{Batch users:}

These users will require larger nitrogen capacity than the continuous users, but the need for nitrogen purge is intermittent:

Pressure draining of LNG system back to ship

Inerting of a single pump vessel for pump removal

Inerting of a single LNG Vaporizer

Inerting of LNG pipe system

\subsection{Nitrogen Generation AND STORAgE SySTEM - HiLOAd}

A membrane based nitrogen generation system will be installed for provision of nitrogen to the consumers onboard HiLoad. The system will be located in HiLoad's pontoon.

The capacity of the system will cover the continuous consumption and produce sufficient nitrogen to be able to pressure drain the LNG system every $50 \mathrm{hrs}$.

$\mathrm{N}_{2}$ Production capacity: $\quad 20 \mathrm{Nm}^{3} / \mathrm{h}$

$\mathrm{N}_{2}$ Storage capacity: $\quad 500 \mathrm{Nm}^{3}$ at 7 barg 


\begin{tabular}{|c|c|c|}
\hline DOE Study Report & Doc. no.: RT & -107-RE \\
\hline Document Title: & Page: & 44 of 48 \\
\hline HiLoad $^{\circledR}$ LNG Regas Facility with Salt Cavern Storage & Rev. no.: 01 & Date: $11 / 10 / 04$ \\
\hline
\end{tabular}

\section{INSPECTION AND MAINTENANCE}

\subsection{GENERAL}

The below description gives an overview of a proposed Inspection and Maintenance program to be carried out by the Operating Company of a HiLoad LNG Regas facility.

The Operating Company shall ensure that the HiLoad, machinery and equipment within the HiLoad are inspected and maintained in accordance with all relevant rules and regulations. HiLoad shall undergo planned maintenance programs defined by Remora in accordance with recommendations from equipment suppliers, Classification Societies and the authorities. Where a manufacturer's data for maintenance is considered deficient, the Operating Company will develop procedures to ensure that the machinery or equipment is maintained to satisfactory standards.

The Operating Company has also to establish maintenance procedures for all additional machinery and equipment used.

- Hull and superstructure steel work

- Friction Attachment System

- Ballast system

- Safety, fire-fighting and anti-pollution equipment

- Navigational and communications equipment

- Azimuth Thrusters

- LNG Pumps

- LNG transfer arms

- LNG vaporizers

- Pipelines and valves

- Seawater pumps for LNG vaporizers

- Auxiliary machinery

\subsection{Computerized Maintenance Planning System}

A computer software tool designed to ease the planning, purchase and reporting related to the maintenance for the HiLoad will be integrated with the Integrated Control System (ICS). Running hours for all rotating machinery will be logged on the maintenance software automatically. 


\begin{tabular}{|l|l|l|}
\hline DOE Study Report & \multicolumn{1}{|l|}{ Doc. no.: RT2006-107-RE } \\
\hline Document Title: & Page: & 45 of 48 \\
\cline { 2 - 3 } HiLoad $^{\mathbb{R}}$ LNG Regas Facility with Salt Cavern Storage & Rev. no.: 01 & Date: 11/10/04 \\
\hline
\end{tabular}

\subsection{Statutory AND Class SuRVEYS}

Remora Technology shall establish procedures within the Computerized Maintenance Planning System, to verify that all relevant statutory surveys are carried out according to programmed schedules in accordance with national and international requirements.

All class surveys shall be carried out according to schedules agreed with the Classification Society.

\subsection{INSPECTION AND MAINTENANCE RECORDS}

Remora Technology shall establish procedures to maintain records for routine- and unscheduled inspection and maintenance carried out by the maintenance crew or third party contractors. These records are kept within the Computerized Maintenance Planning System.

\subsection{ACCESS AND HANDLING OF EQUIPMENT}

The HiLoad is equipped with one main access route in the starboard tower and one emergency escape route in the port tower. The port tower is also designed with a "lifting trunk" for handling of materials and spare parts up and down from the pontoon.

\subsection{MAJOR OVERHAUL OR UPGRADE, ONSHORE}

The only connection of HiLoad to the seabed is the flexible risers and the two parking lines. These will be designed so they will be relatively quick to connect and disconnect offshore. The HiLoad LNG Regas Facility can then be disconnected and towed to shore if a major maintenance task or upgrade of the unit should be required.

The HiLoad can be docked using a submergible barge. There are a number of such barges in operation around the world, and even more are under construction. 
REMORA TECHNOLOGY

DOE Study Report

Document Title:

HiLoad $^{\circledR}$ LNG Regas Facility with Salt Cavern Storage
Doc. no.: RT2006-107-RE

Page: $\quad 46$ of 48

Rev. no.: $01 \quad$ Date: $11 / 10 / 04$

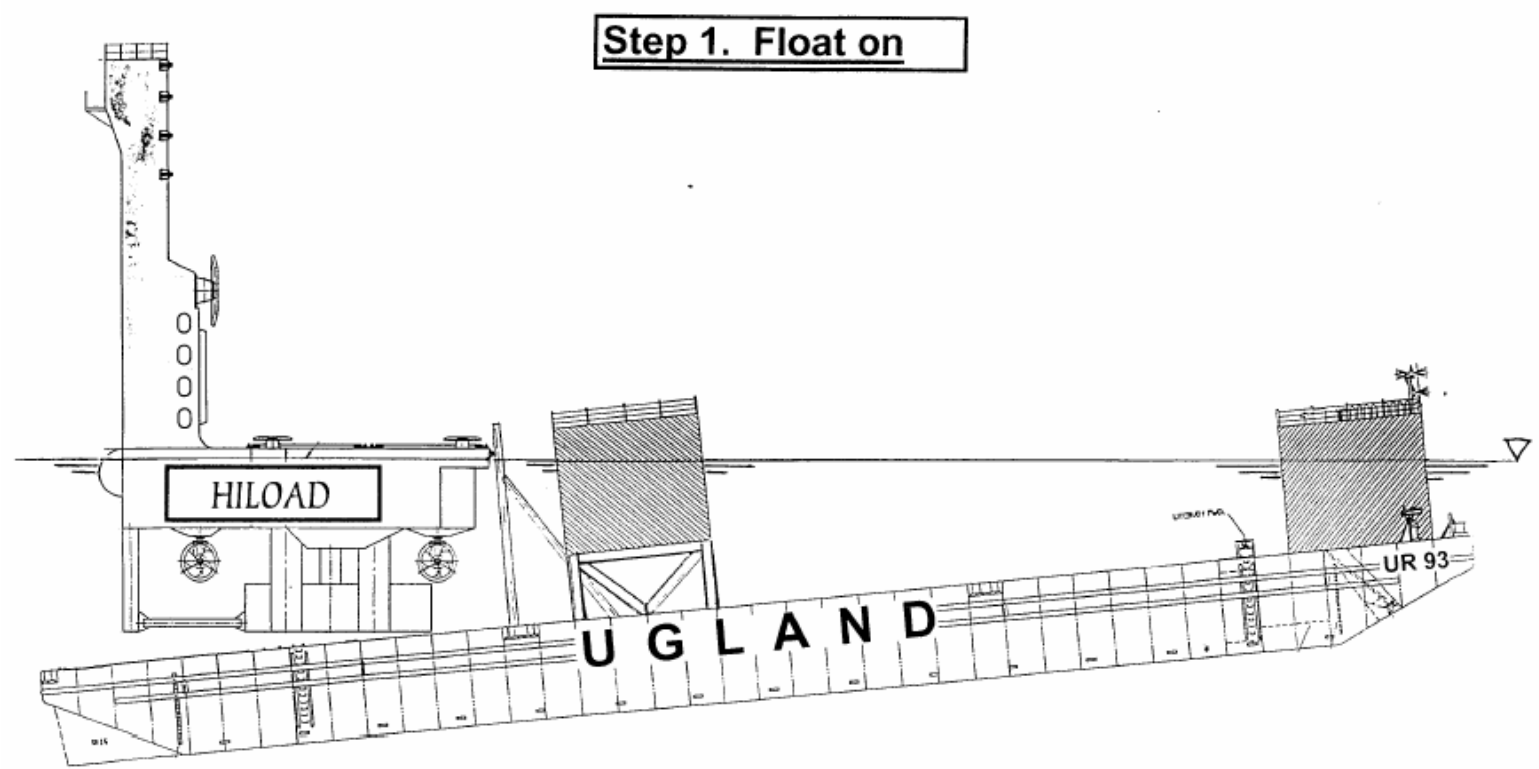

Figure 28 - HiLoad dry-docking using submersible barge 


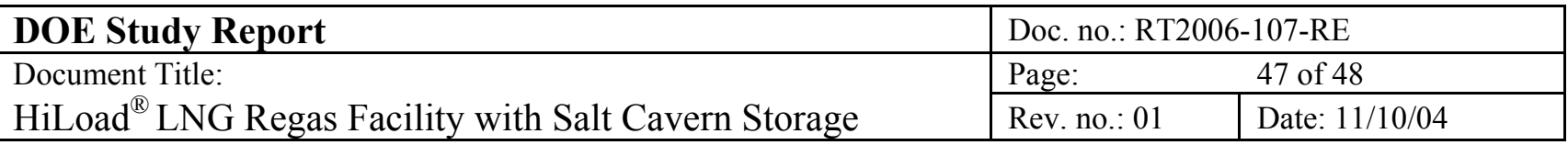

\section{DNV VERIFICATION}

\section{路}

DNT뉴

The Classification Society Det Norske Veritas (DNV) in Norway has been used as a consulting partner during the previous phases of the HiLoad development project when relevant to clarify rules, regulations and definitions for the HiLoad Facility and reviewed the proposed solutions.

In April 2004, Remora Technology received an "Approval In Principle” (AIP) from DNV for the HILoad LNG regas Terminal.

A quote from their AIP letter is given below:

"From the review conducted, DNV has no principal objections, and regards the HiLoad LNG Regas Facility concept presented as being feasible.

The approach to Approval in Principle is to focus attention on key issues, i.e. those perceived to have a need for further qualification. The concept at hand comprises components based on established and proven technology with extended applications for some of the elements.

On this basis, an "Approval In Principal" is granted, subject to the critical design issued beeing addresses and resolved in accordance with relevant Classification rules, recognised codes and standards." 


\begin{tabular}{|l|l|l|}
\hline DOE Study Report & \multicolumn{1}{|l|}{ Doc. no.: RT2006-107-RE } \\
\hline Document Title: & Page: & 48 of 48 \\
\cline { 2 - 3 } HiLoad $^{\mathbb{R}}$ LNG Regas Facility with Salt Cavern Storage & Rev. no.: 01 & Date: 11/10/04 \\
\hline
\end{tabular}

\section{COST \& SCHEDULE}

Detailed cost estimates and construction schedule has been prepared for the complete HiLoad LNG Regas Terminal including cost for the support platform and pipelines.

\subsection{COST ESTIMATE}

\begin{tabular}{|l|r|}
\hline Component & Cost (mill. USD) \\
\hline HiLoad LNG Regas w/SALM, Swivel \& Risers & 120 \\
\hline Platform & 124 \\
Salt Cavern (6,6 BCF working volume) & 92 \\
Pipelines (3x7 miles + 1x1 mile) & 40 \\
Total & $\mathbf{3 7 6}$ \\
\hline
\end{tabular}

\subsection{SCHEDULE}

A high level schedule has been established as follows:

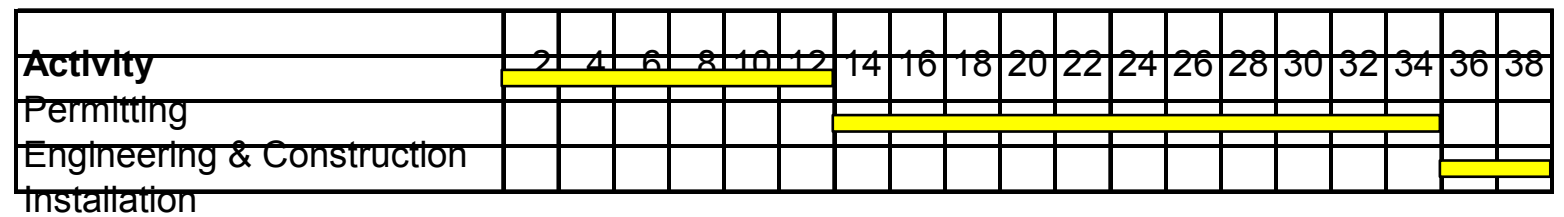




\title{
Weathervaning Platform For \\ LNG Receiving Terminal Using the Bishop Process ${ }^{\mathrm{TM}}$
}

\author{
DOE-CGI Study \\ June 28, 2004
}

L. Terry Boatman VP Product Development Dr. Allen Y. Liu, Sr. Research Engineer Wayne Herbrich, Sr. Project Mgr 


\section{Presentation Topics}

- Receiving terminal general arrangement

- Attributes of an "ideal" receiving terminal platform for salt storage of gas

- Weathervaning platform \& Column stabilized platform

- FMIC SOFEC floating terminal

- Environmental design basis

- Shallow water terminal

- Carrier berthing operations

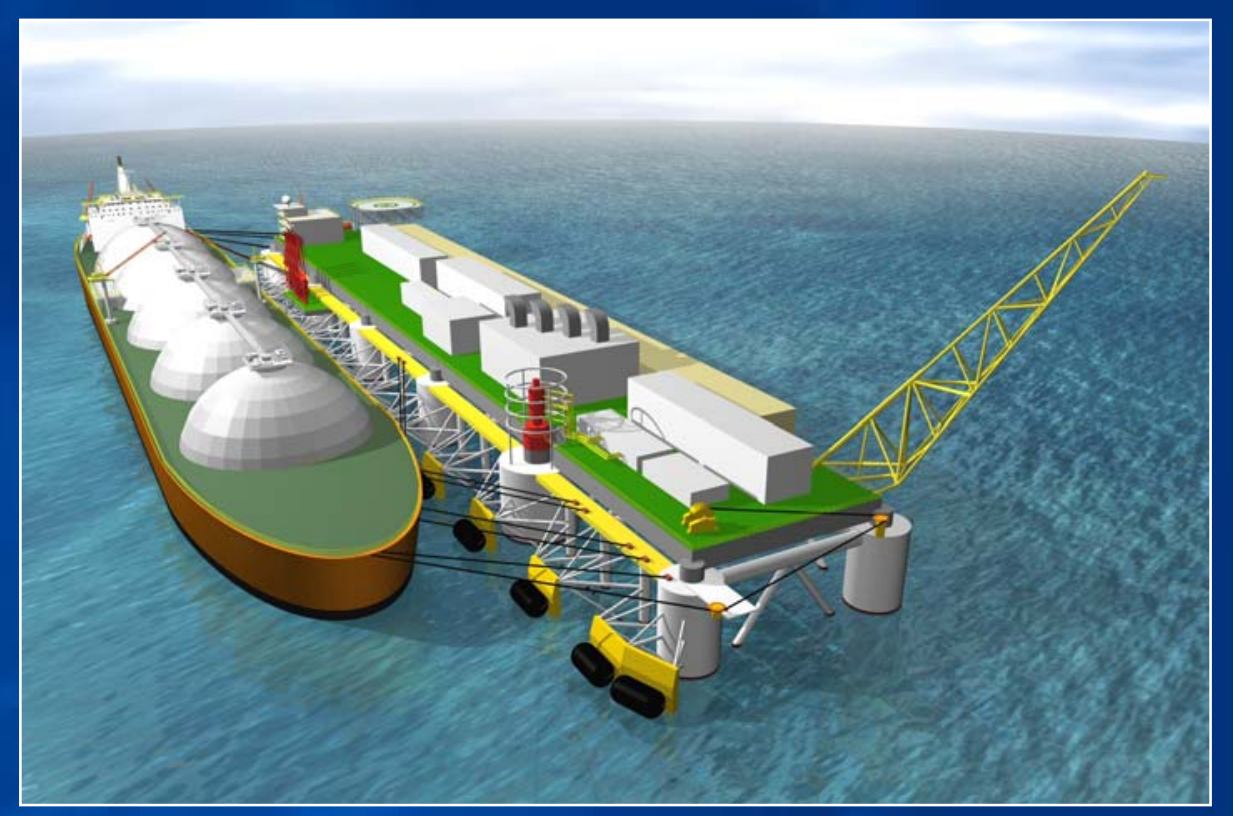

- Platform construction 


\section{Salt Cavern LNG Receiving Terminal Floating Process \& Offloading Platform}

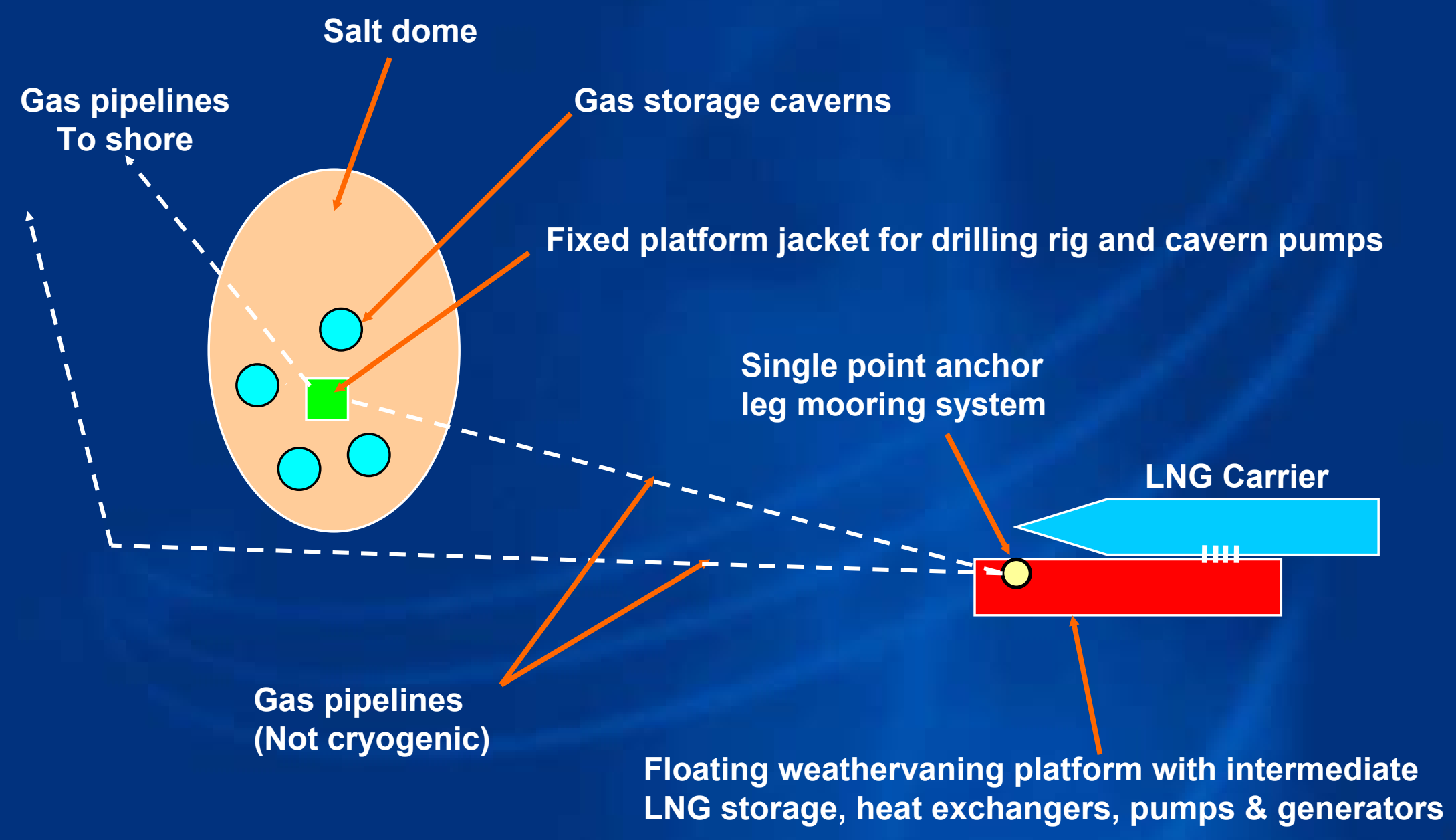




\section{Primary Attributes of an "Idea|" Terminal for the Bishop Process TM Salt Storage}

- Provide lowest overall risk by:

$>$ Least introduction of new technology

$>$ Safest berthing \& offloading operation

$>$ Safest process \& storage operation

- Maximize advantages of minimal LNG storage in terminal to provide:

$>$ Provide quickest carrier off-load turn-around time

$>$ Maximum "up-time" availability

$>$ Lowest capital and operational expenditure

$>$ Operational in shortest possible time 


\section{LNG Loading Arms - Tested for SBS}

$>$ No cryogenic hose

$>$ No new LNG manifolds on LNG carrier

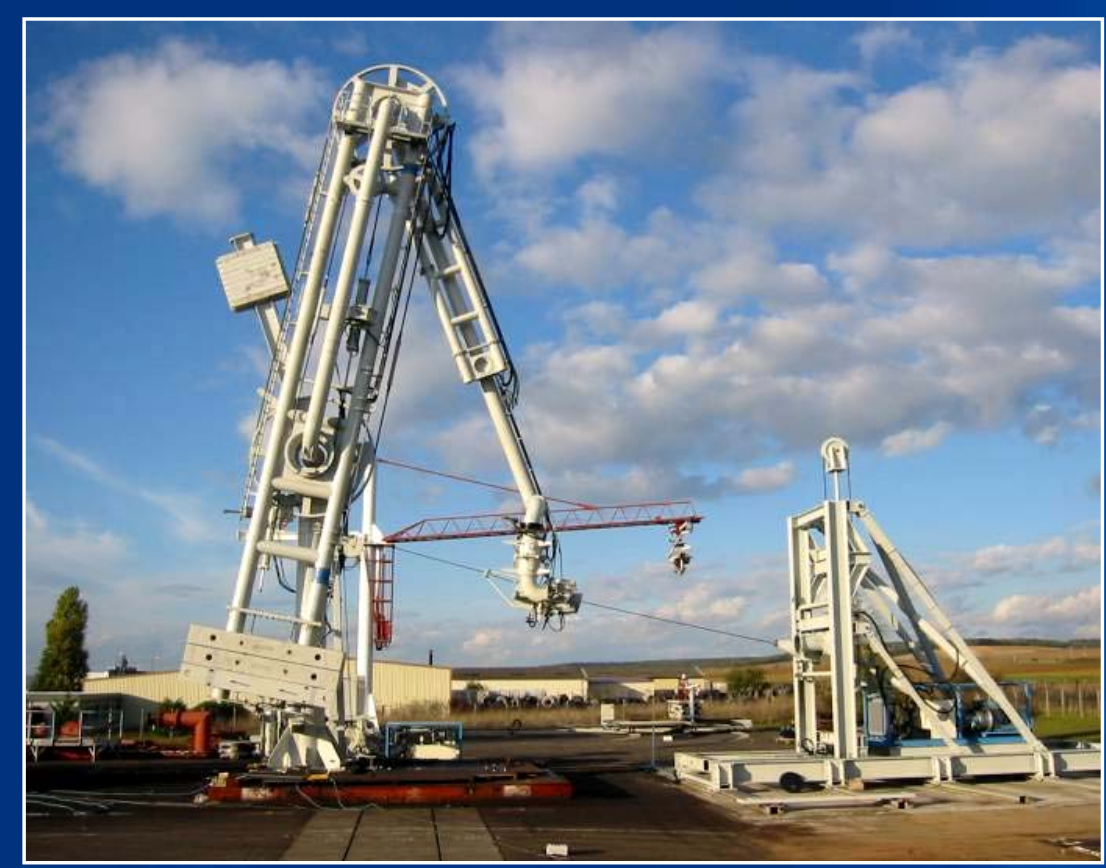

$>$ Full scale connect testing of $16^{\prime \prime}$ arm in 2003 for Shell Global Solutions by FMC

$>4 \mathrm{~m}$ vertical motion range @ $0.85 \mathrm{~m} / \mathrm{s}$

$>5 \mathrm{~m}$ horizontal motion range @ $1.15 \mathrm{~m} / \mathrm{s}$

$>10 \mathrm{~m}$ surge fore-aft (design untested)

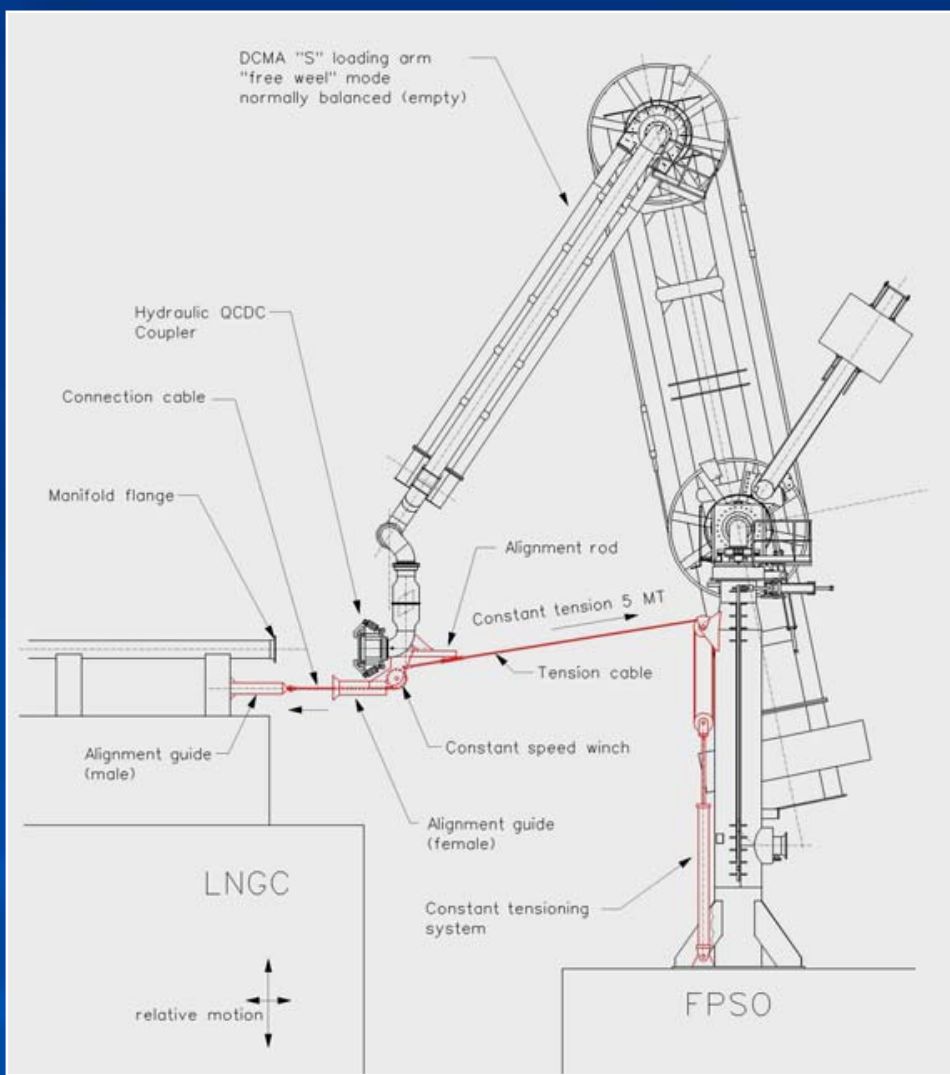

$>$ FMC Targeting system assistance for flange connection in very severe dynamic conditions.

> Simple mechanical system.

$>$ Connects to conventional midship manifolds 


\section{LNG Loading Times Vs, Flow Rate}

- Assumes Loading Rates Can be Achieved (NA Indicates Flows Beyond Reason for Carrier Size)

- Assumes First (Cool-down) and Last (Shutdown) Hour of Flow Average $1 / 2$ Maximum Rate.

- Assumes Flow is Divided Evenly Between Three Liquid Loading Arms

Unloading Time vs. Tanker Size $\left(\mathrm{m}^{3}\right)$

\begin{tabular}{|c|c|c|c|c|}
\hline Max Flow & $\begin{array}{c}90,000 \\
m^{3}\end{array}$ & $\begin{array}{c}138,000 \\
m^{3}\end{array}$ & $\begin{array}{c}200,000 \\
m^{3}\end{array}$ & $\begin{array}{c}250,000 \\
m^{3}\end{array}$ \\
\hline $\begin{array}{c}10,000 \mathrm{~m}^{3} / \mathrm{Hr} \\
3,333 \mathrm{~m}^{3} / \mathrm{Hr} \text { Per Arm }\end{array}$ & 10 Hrs. & 15 Hrs. & 21 Hrs. & 26 Hrs. \\
\hline $\begin{array}{c}12,000 \mathrm{~m}^{3} / \mathrm{Hr} \\
4,000 \mathrm{~m}^{3} / \mathrm{Hr} \text { Per Arm }\end{array}$ & 8.5 Hrs. & 12.5 Hrs. & 18 Hrs. & 22 Hrs. \\
\hline $\begin{array}{c}15,000 \mathrm{~m}^{3} / \mathrm{Hr} \\
5,000 \mathrm{~m}^{3} / \mathrm{Hr} \text { Per Arm }\end{array}$ & NA & 10 Hrs. & 14.5 Hrs. & 18 Hrs. \\
\hline $\begin{array}{c}18,000 \mathrm{~m}^{3} / \mathrm{Hr} \\
6,000 \mathrm{~m}^{3} / \mathrm{Hr} \text { Per Arm }\end{array}$ & $N A$ & $N A$ & 12 Hrs. & 15 Hrs. \\
\hline $\begin{array}{l}21,000 \mathrm{~m}^{3} / \mathrm{Hr} \\
7,000 \mathrm{~m}^{3} / \mathrm{Hr} \text { Per Arm }\end{array}$ & $N A$ & NA & 10.5 Hrs. & 13 Hrs. \\
\hline $\begin{array}{c}24,000 \mathrm{~m}^{3} / \mathrm{Hr} \\
8,000 \mathrm{~m}^{3} / \mathrm{Hr} \text { Per Arm }\end{array}$ & NA & $\mathbf{N} \mathbf{A}$ & $N A$ & 11.5 Hrs. \\
\hline
\end{tabular}

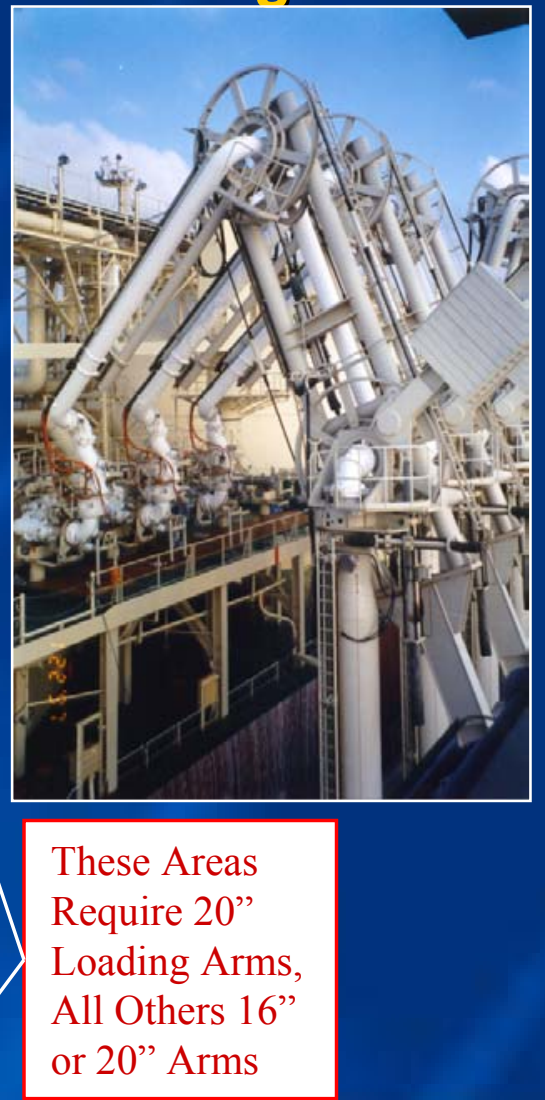




\section{Typical Floating Regas Unit Weathervaning Mono-Hull Shape}

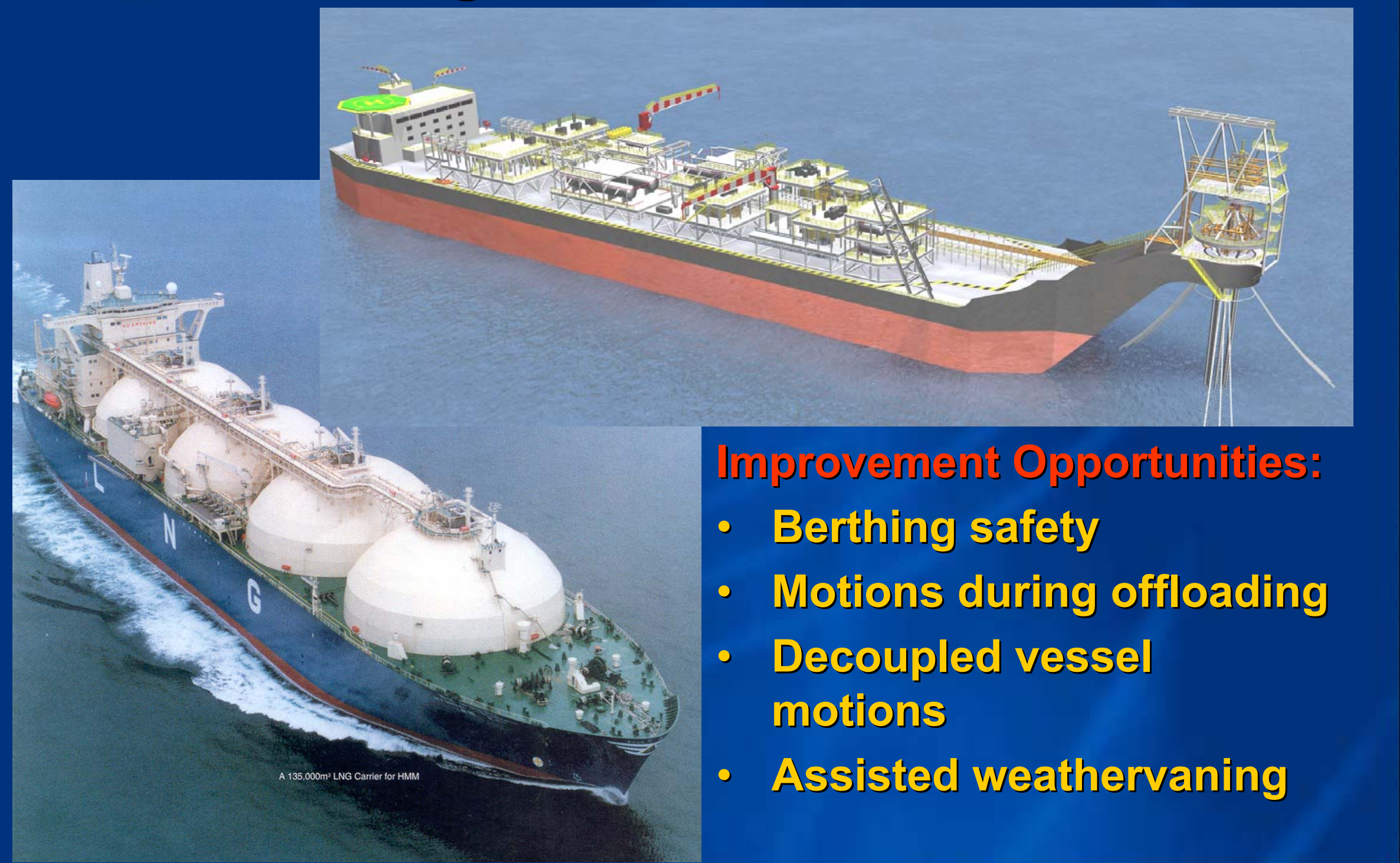




\section{Major Objective:}

Reduce Relative Motion Between Platform and LNG Carrier

- Affects berthing the LNG carrier

$>$ Safer

$>$ Quicker connection of dock lines

- Loading arm motion reduced

$>$ Easier to connect arm flanges in higher seastate

$>$ Increased offload availability $\rightarrow 90 \%$ to $97 \%$

$>$ Safer offloading operation

- Reduce carrier motion by minimizjing wave reflection from terminal structure

- Influence the heading of carrier to minimize carrier roll motion (platform thrusters) 


\section{Example of Column Stabllized Platform Semi-Submersible Grane Vessel}

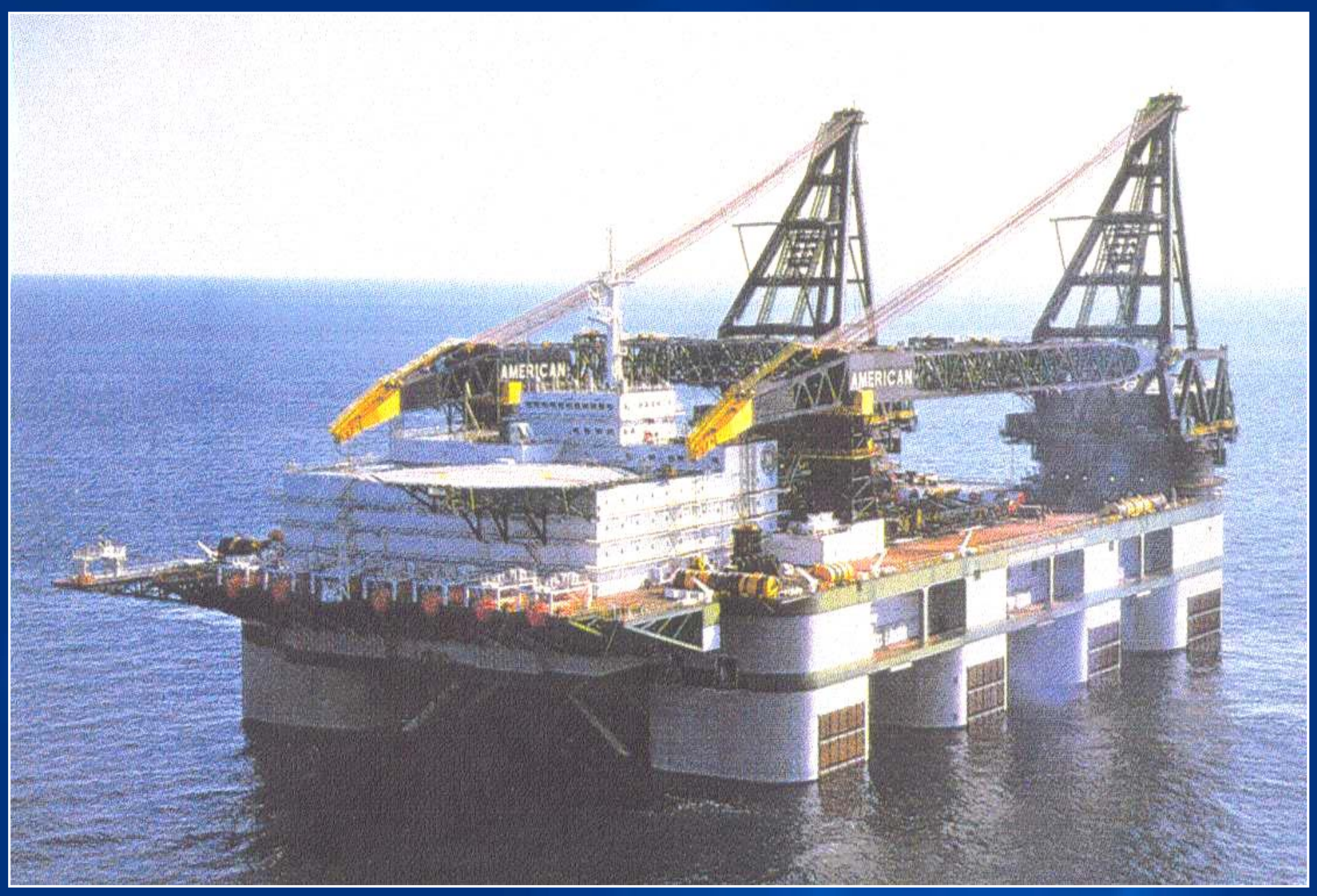

McDermott DB 102 


\section{Column Stabilized Platform Receiving Terminal Characteristics}

- Minimum relative motions

- Reduced coupled vessel motion

- Relatively low deck load, $9300 t$ process $+2500 t$ LNG $=11,800 t$

- Length - based on:

$>$ Berthing considerations, LNG carrier size \& motion optimization

$>$ Not dictated by process equipment

- Height - based on:

$>$ Air gap $(1.8 \mathrm{~m})$ above 100 year survival wave

$>16.5 \mathrm{~m}$ (54 ft) air space under deck

- Draft: $15.2 \mathrm{~m}$

$>$ As needed for displacement \& Stability, \& LNG carrier drafts
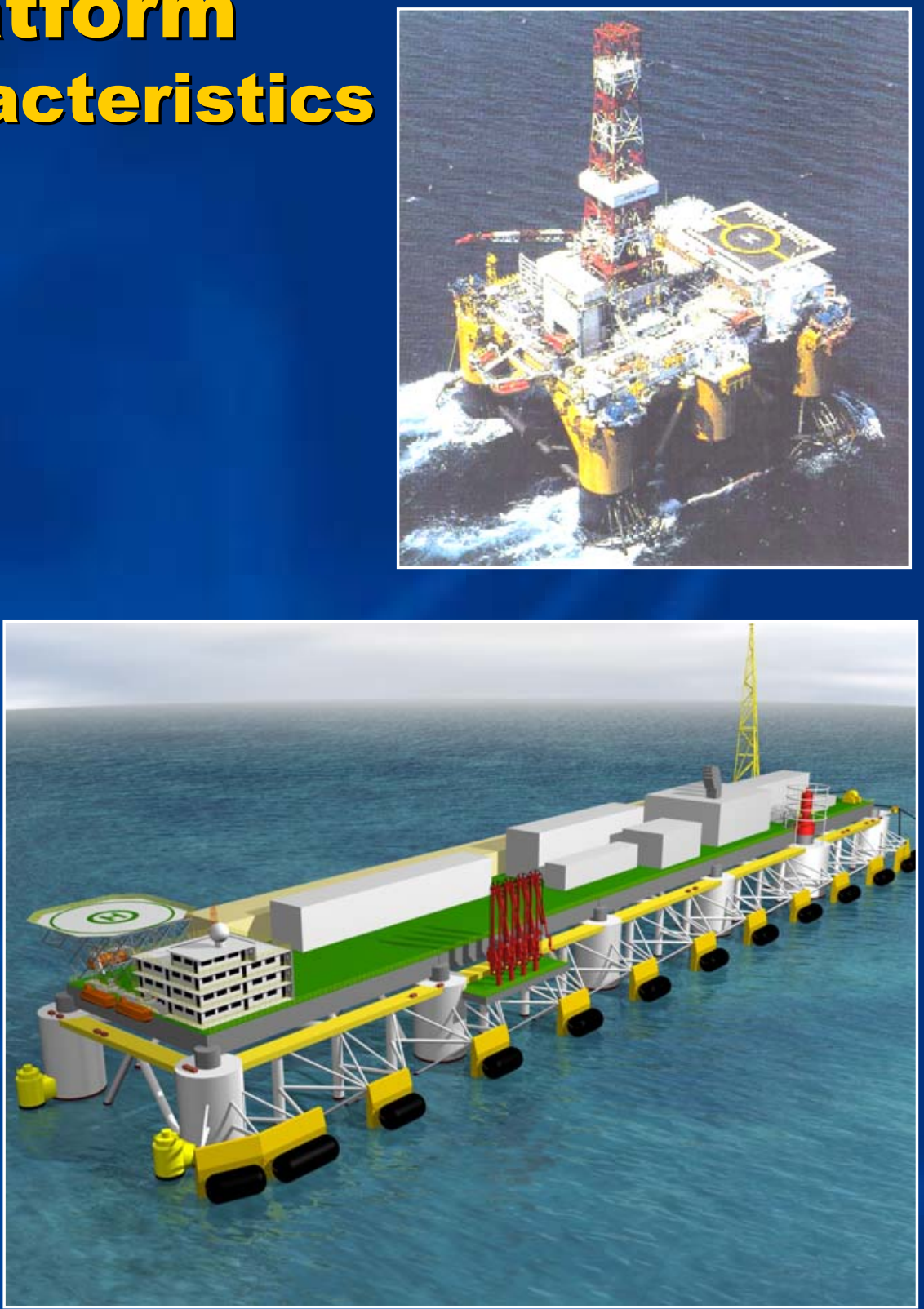


\section{Golumn Stabilized Platform vs. Hull Shape}

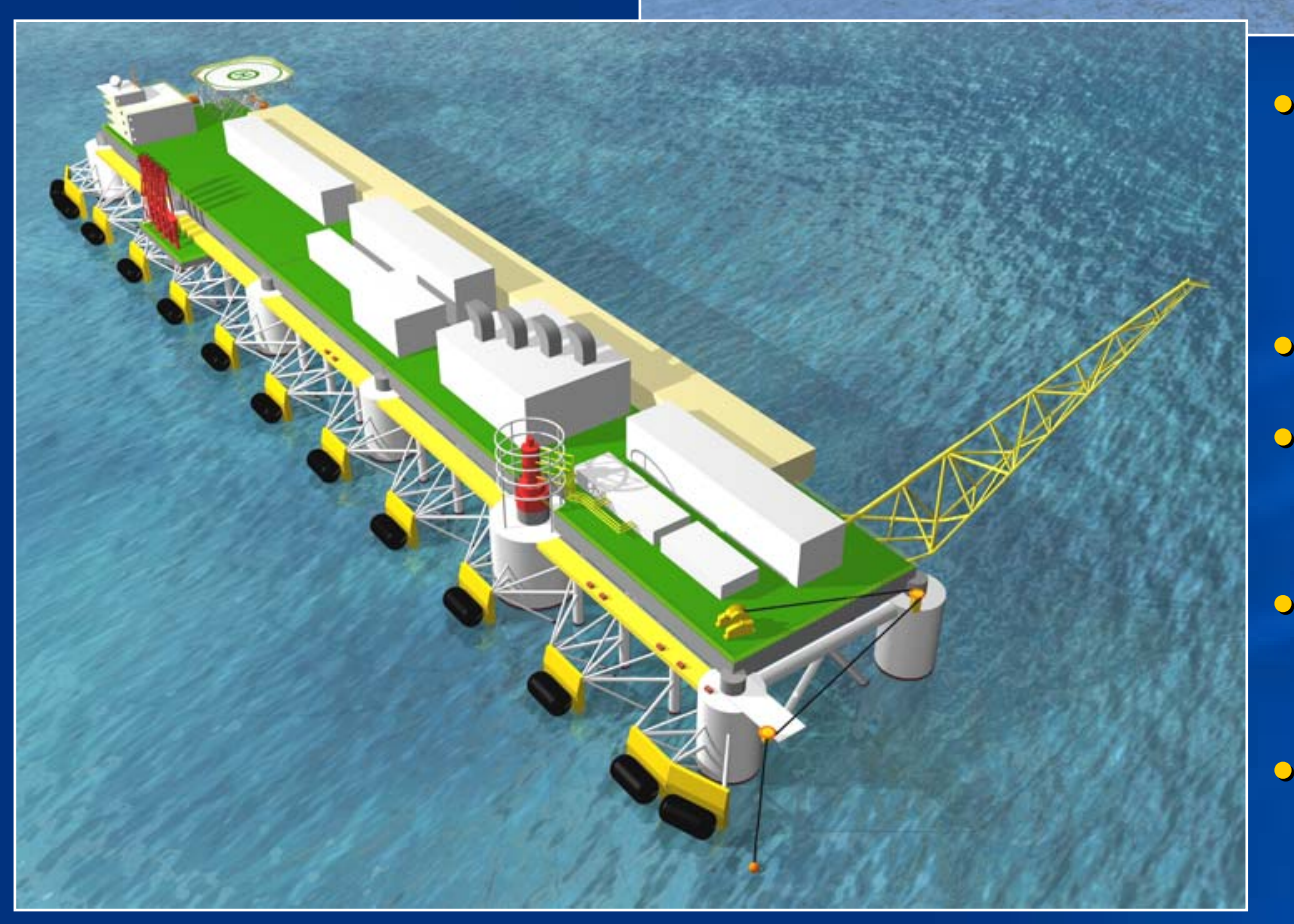

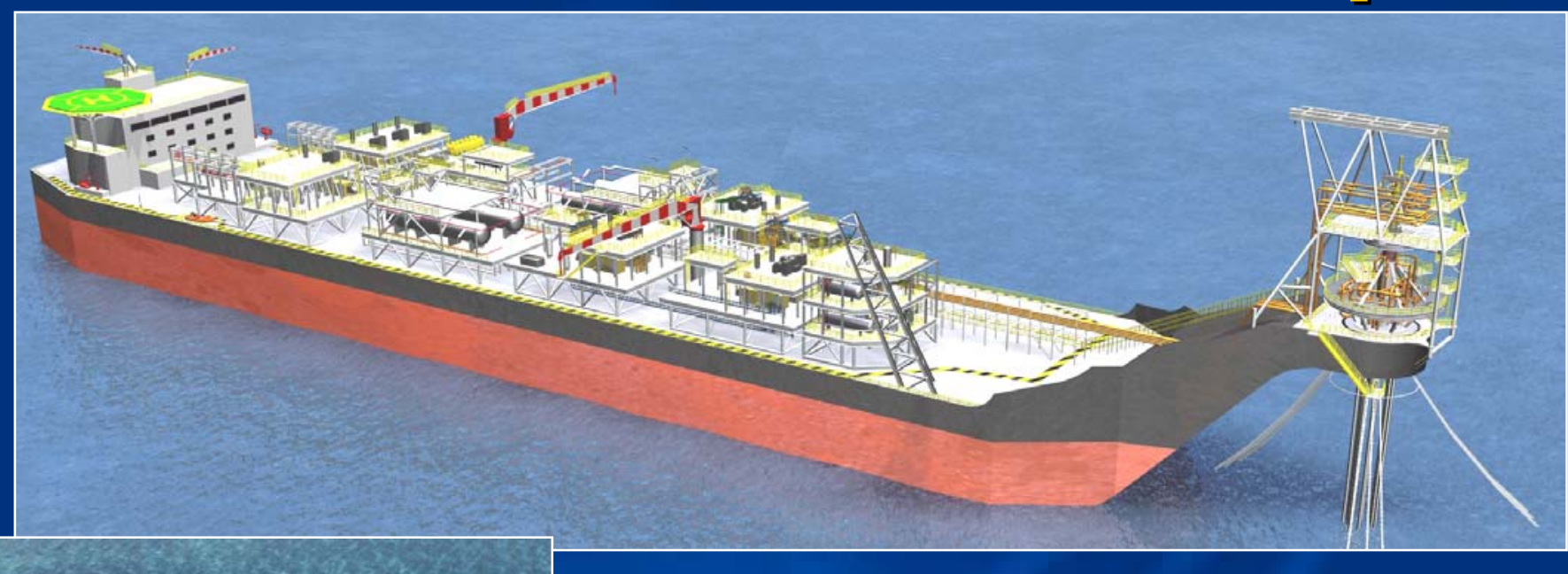

- Lower mass 25\% of monohull $(37,000 t$ vs. $150,000 t)$

- Smaller wave loading

- Transparent to wave reflection

- Low wave frequency motion response

- Smaller loads in survival storm, remains anchored in hurricane 


\section{Floating LNG Terminal For Deep Water $>40 \mathrm{~m}$ (131ft)}

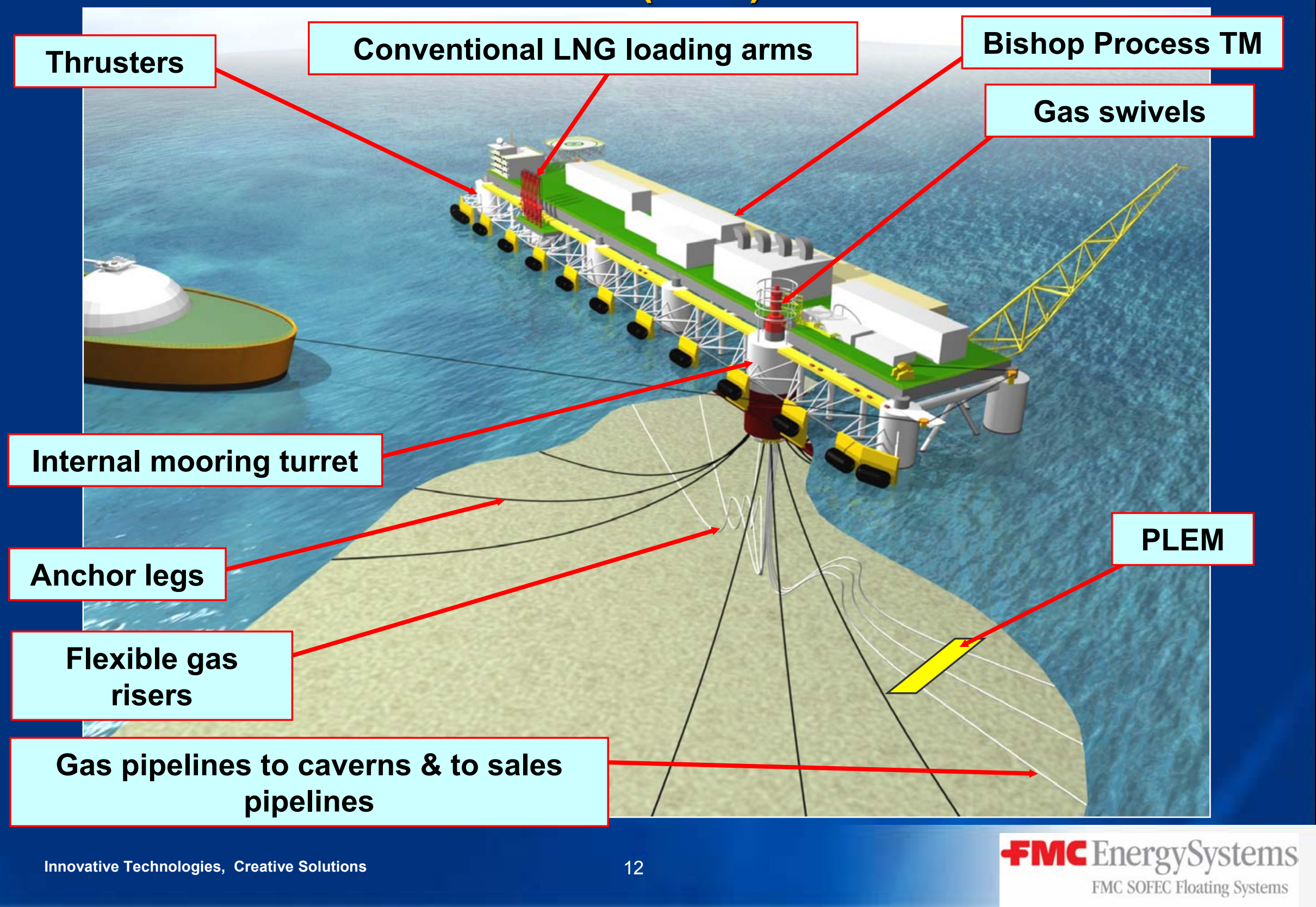


Esso Chad - Tower Yoke - Shallow Water Offshore Kibi, Cameroon, West Africa July 2003 (34m water depth)

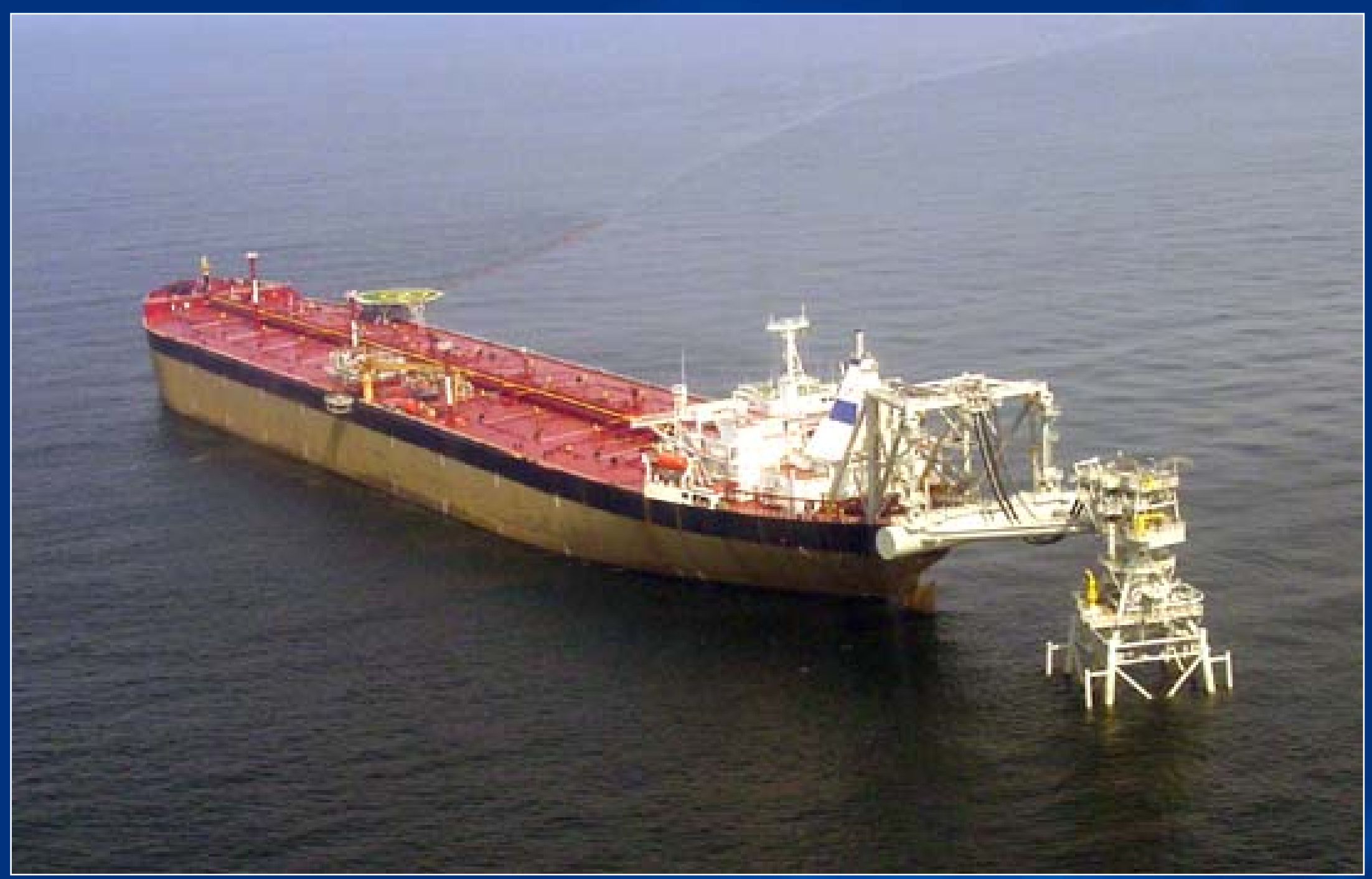




\section{CNOOC/TEXACO QHD 32-6 FPSO}

172,000 dwt FPSO Water depth $20 \mathrm{~m}$ (66ft)

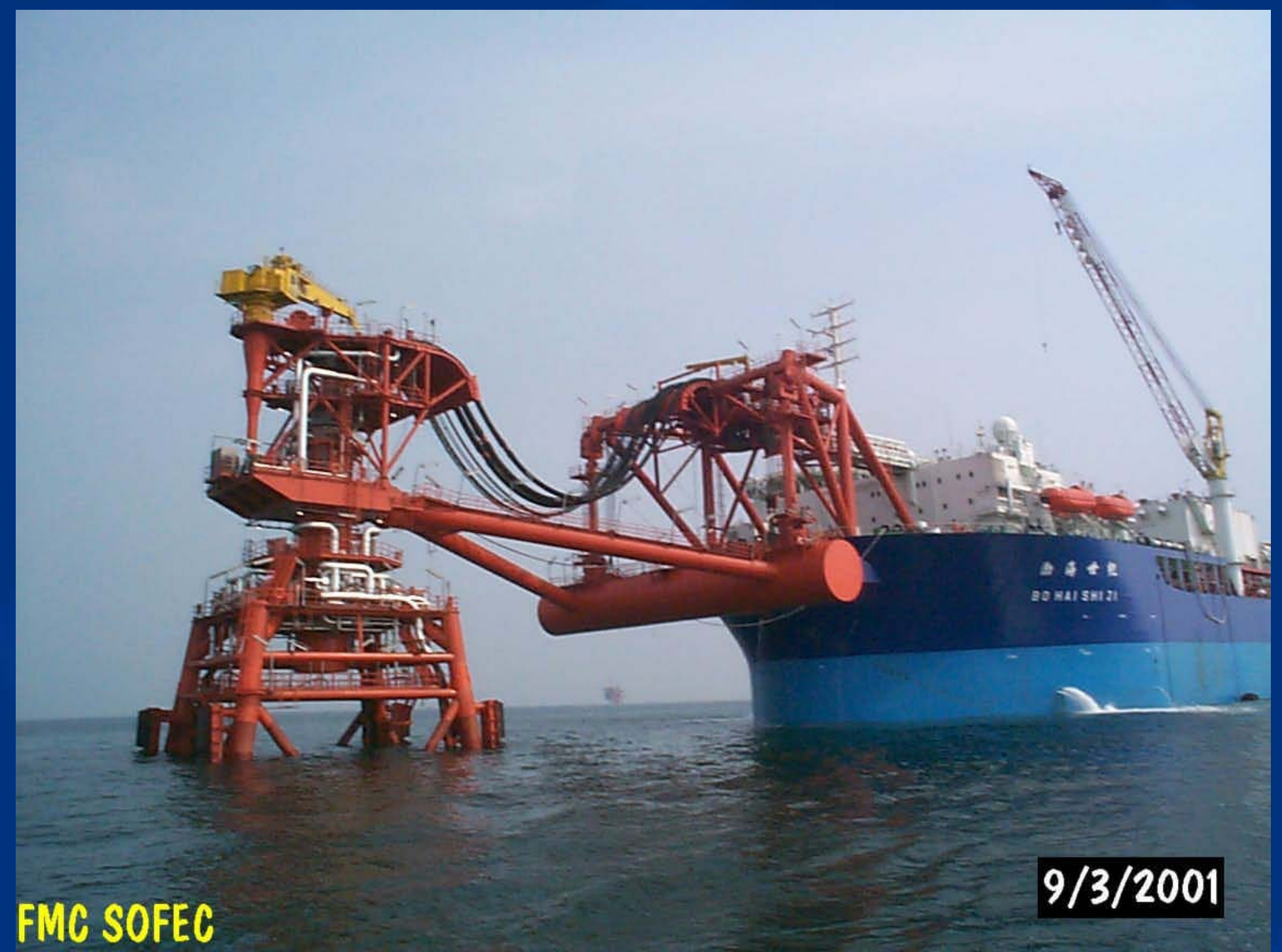




\section{LNG Terminal Loads \& Motjons - Shallow Water}

\section{Comparison of Tower-Yoke Loads \& Motions - $20 \mathrm{~m}$ Water Depth}

\begin{tabular}{|c|c|c|c|}
\hline Parameter & QHD 32-6 FPSO & LNG Terminal & Unit \\
\hline \multicolumn{4}{|l|}{ Storm Conditions } \\
\hline Significant Wave Height, Hs & 5.2 & 9.2 & meters \\
\hline Wind Speed & 26.6 & 41.2 & $\mathrm{~m} / \mathrm{s}$ \\
\hline Current Speed & 2.05 & 2.14 & $\mathrm{~m} / \mathrm{s}$ \\
\hline Vessel Displacement & 201,380 & 39,000 & m. tons \\
\hline \multicolumn{4}{|l|}{ Vessel Motions (@FP) } \\
\hline Surge, Max & 5.4 & 2.1 & meters \\
\hline Surge, Min & -9.8 & -8.8 & meters \\
\hline Sway, Max & 10.96 & 7.8 & meters \\
\hline Sway, Min & -15.42 & -3.9 & meters \\
\hline Yaw, Max & 38.5 & 29.1 & degrees \\
\hline Yaw, Min & 15.1 & 20.9 & degrees \\
\hline \multicolumn{4}{|l|}{ Tower Forces } \\
\hline Fx- Longitudinal Force & -861 & -724 & m. tons \\
\hline Fy - Transverse Force & -320 & 166 & $\mathrm{~m}$. tons \\
\hline Fz - Vertical Force & -367 & -209 & m. tons \\
\hline Fxy - Resultant Force & 871 & 724 & m. tons \\
\hline Fxyz - Resultant Force & 908 & 750 & m. tons \\
\hline Max Tension & 742 & 695 & m. ton \\
\hline
\end{tabular}




\section{FMC SOFEC LNG Floating Terminal Concept Advantages}

- Platform design suitable in any water depth (deep or shallow)

- Ample deck space for space separation of modules = safety

- Subsea cryogenic LNG pipeline is not required

- Achieves minimum relative motions between platform \& ship = improved operational availability

- Active position control using thrusters = higher operational safety for carrier mooring

- Construction efficiency, float out completely tested system

- Least introduction of new technologies

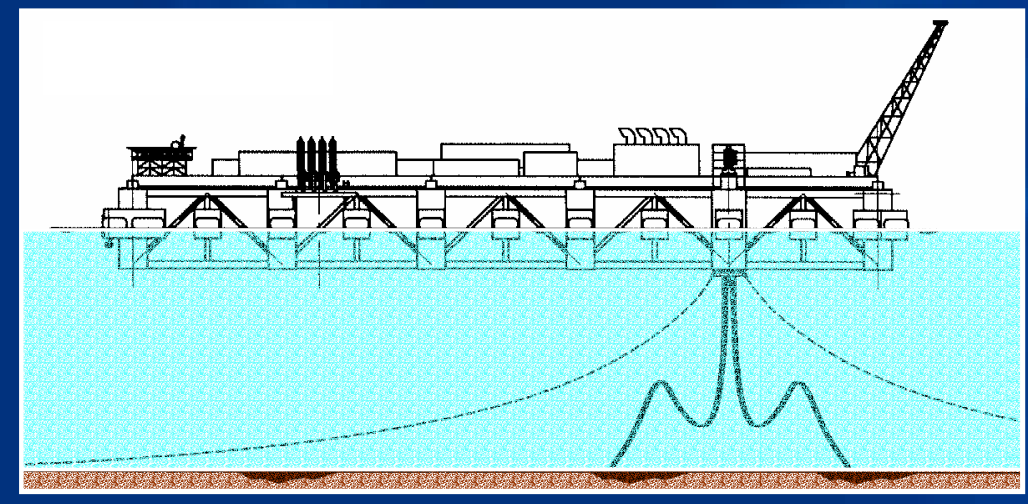

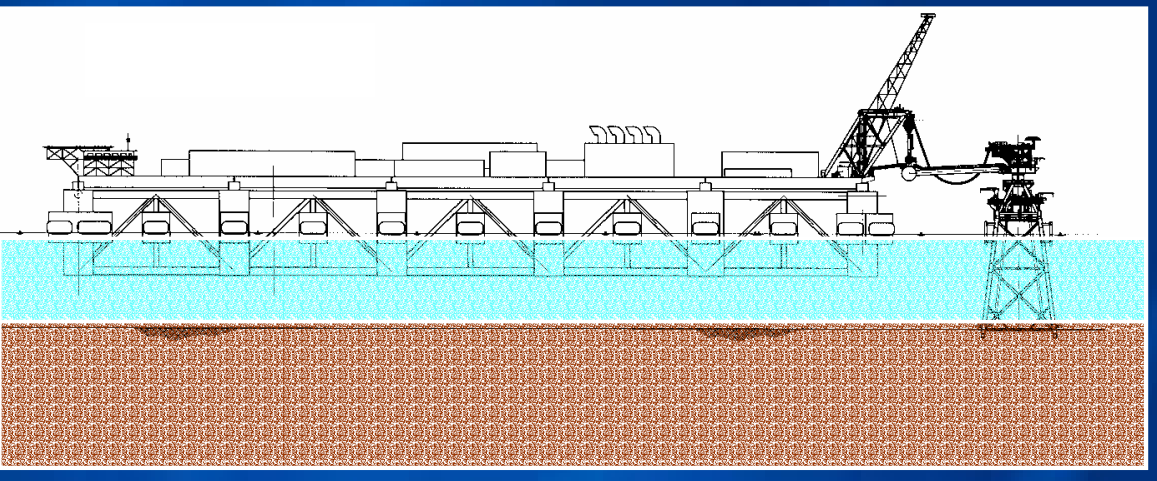

PMCEnergySystems 


\section{Column Stabilized Platform for Deep Water $>40 \mathrm{~m}$ Weight \& Dimensions}

- Deck Load 9,300 t

- LNG storage $2,500 \mathrm{t}$

- Structure 25,200 t

- Displacement $37,000 \mathrm{t}$

- Dimensions

$>\mathrm{L}=290 \mathrm{~m}$

$>\mathrm{B}=50.6 \mathrm{~m}$

$>$ Depth $=35.5$

$>$ Draft $=15.2 \mathrm{~m}(50 \mathrm{ft})$

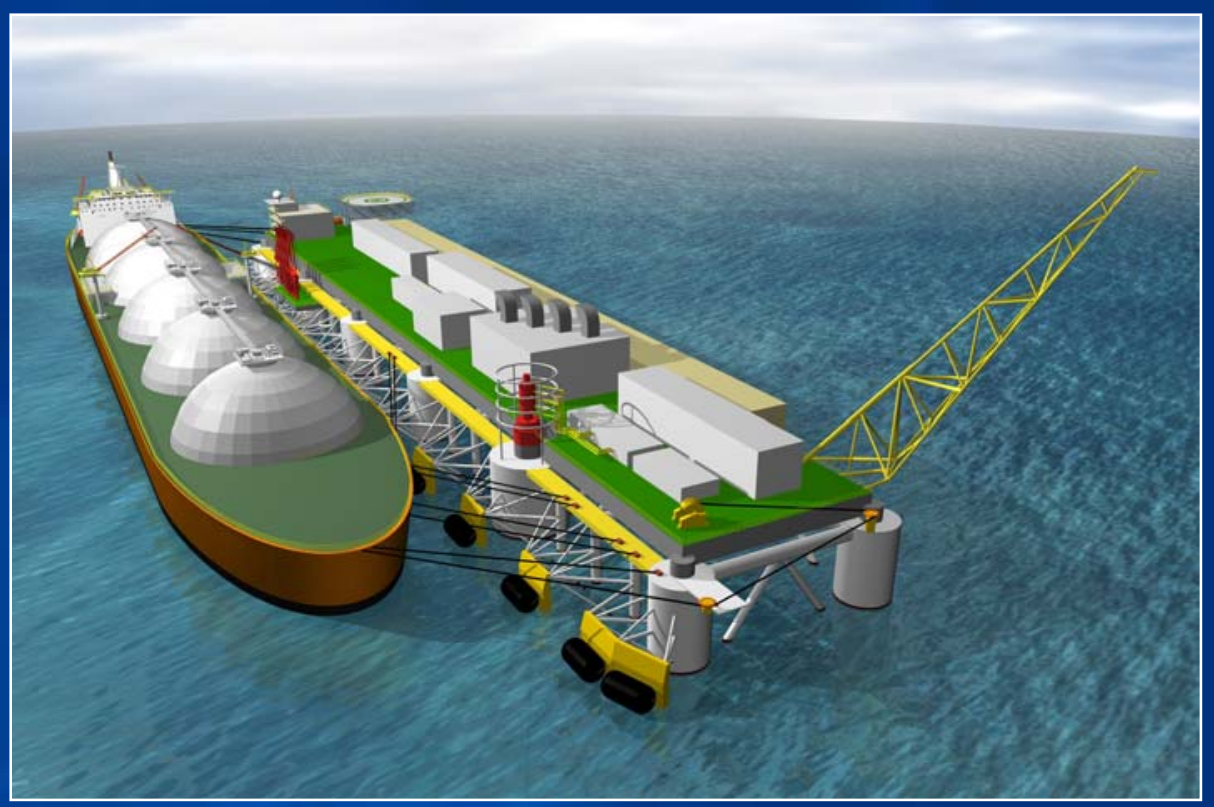

- Compare displacement with loaded $165 \mathrm{k} \mathrm{m}^{3}$ LNG carrier:

$>$ Carrier displacement $\sim 140,000$ ton ( $>3.78 \times$ mass of platform) 


\section{Design Condfitions - Deep Water}

- Carrier Berthing

2.5 meter significant wave $>90 \%$ berthing availability

- Offloading - maximum conditions

3.5 meter significant wave $>97 \%$ offload availability

-Relative motions @ Loading arms:

$<4 \mathrm{~m}$ heave, $<5 \mathrm{~m}$ sway, $<10 \mathrm{~m}$ surge

100 year storm survival load motions

-Vertical heave $\quad \pm 9.4 \mathrm{~m}(30.8 \mathrm{ft})$

-Roll motion $\quad \pm 0.8 \mathrm{deg}$

-Pitch motion $\quad \pm 3.7 \mathrm{deg}$

-Trim $1.1 \mathrm{~m}$ up at bow
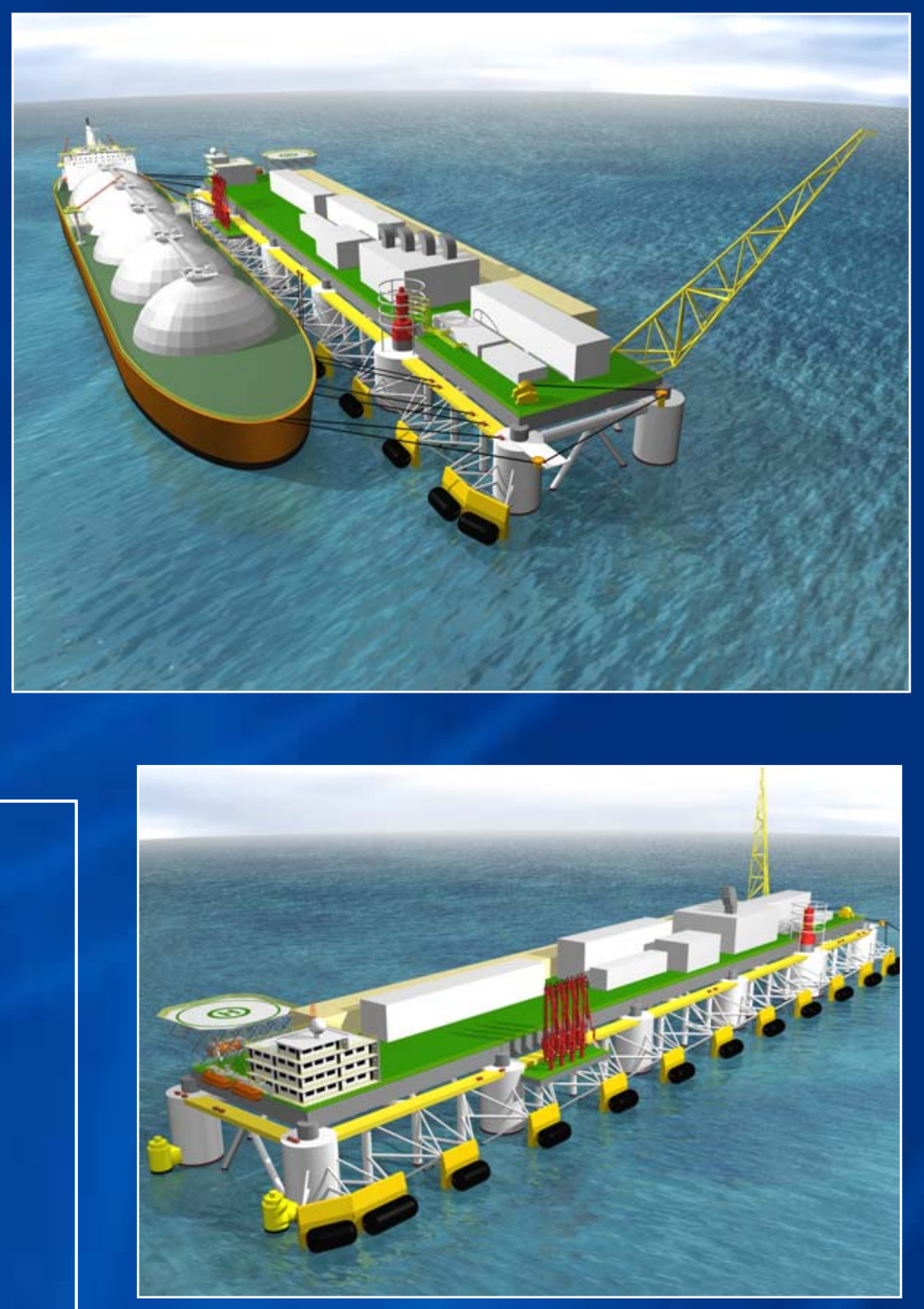


\title{
Weathervaning Platform for Shallow Water
}

\author{
Water Depth \\ $15 \mathrm{~m}$ to $40 \mathrm{~m}$ \\ (49 ft to $130 \mathrm{ft})$
}




\section{Shallow Water LNG Receiving Terminal Water depth $15 \mathrm{~m}$ to $40 \mathrm{~m}$ (49 to 130ft) \\ Tower Yoke Mooring}

Conventional LNG loading arms

Vaporizer Process Units 


\section{Shallow Water Weathervaning Platform 15 to $40 \mathrm{~m}$ (49 to $130 \mathrm{ft}$ )}

- Tower yoke mooring

- Hawser pull-in from tower

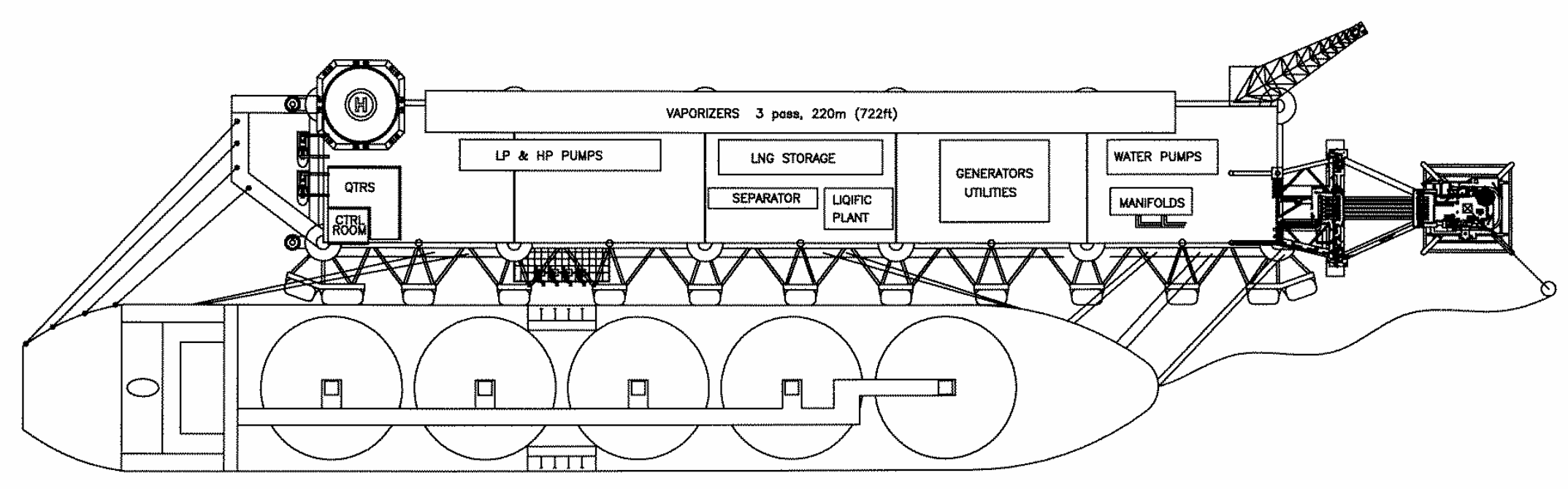




\title{
Carrier Berthing Operations Deep Water System
}

\author{
Turret Moored \\ Thruster Assisted Platform
}

Operational Premise:

Move platform to carrier, not carrier to the platform 


\section{Carrier Berthing Operations}
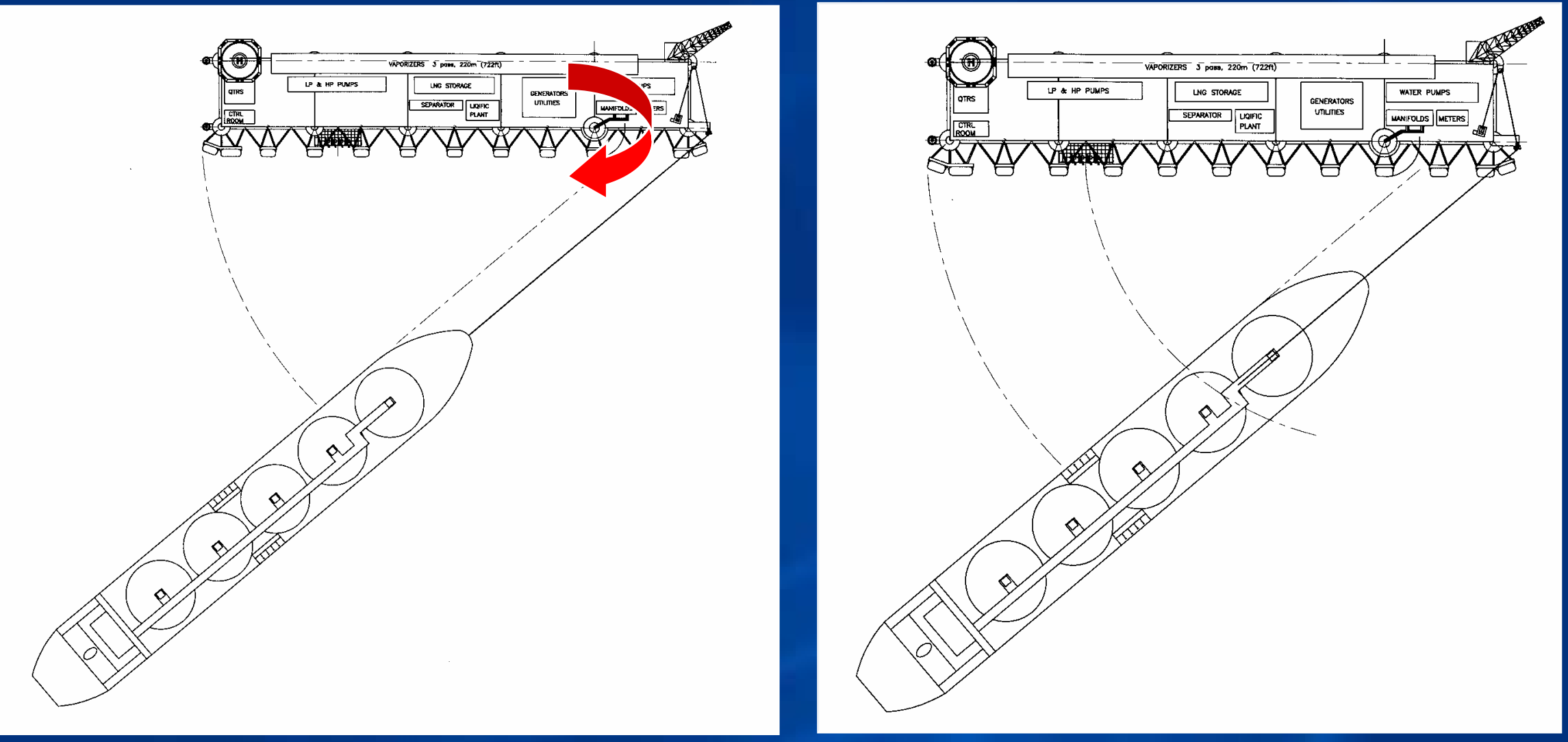

-Swing platform $30^{\circ}$ to $40^{\circ}$

- Carrier slows to dead stop

-Hawser tows carrier, aft thrust

-Engage thrusters (45t - 70t) 


\section{Carrier Berthing Operations}

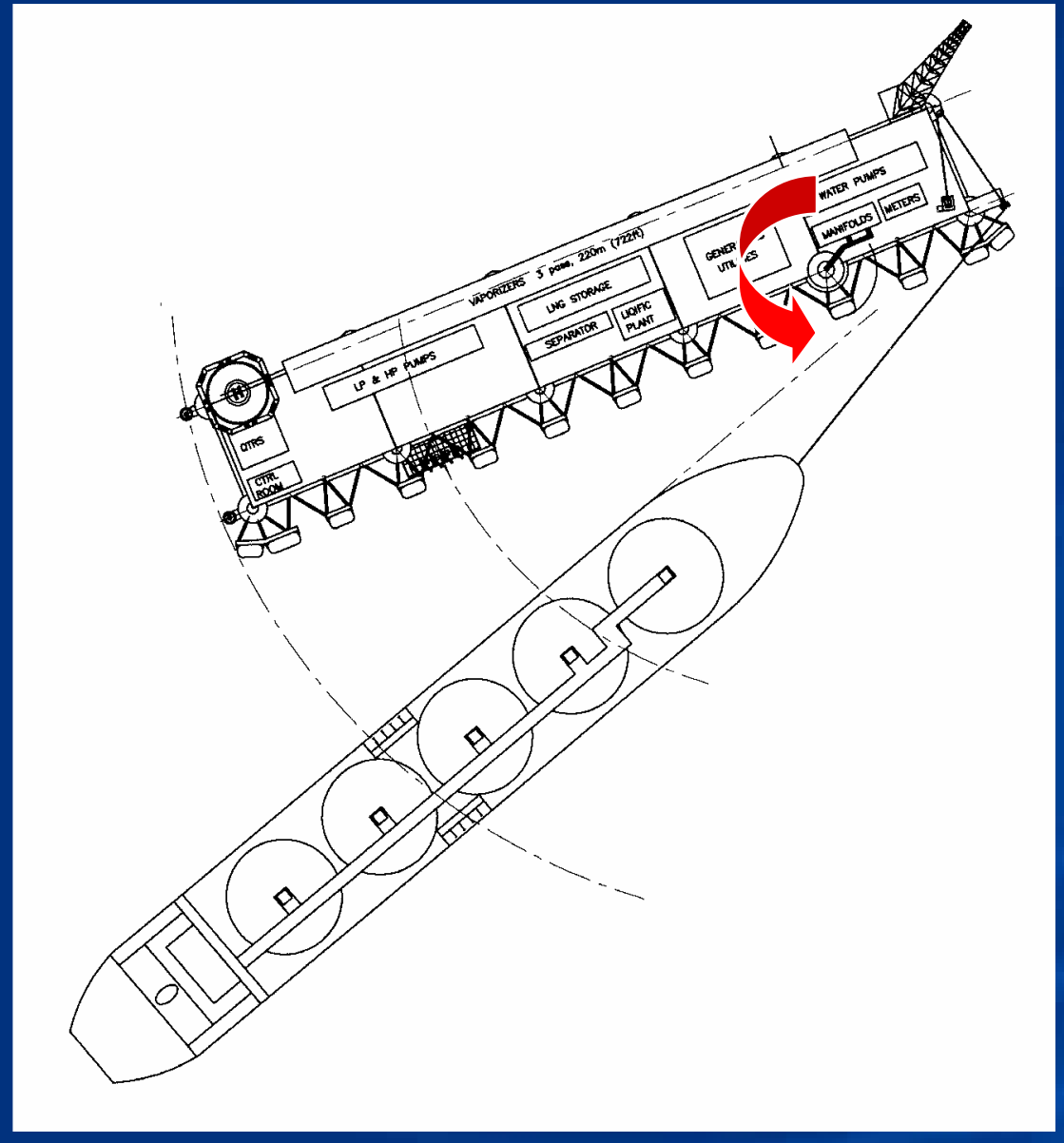

Swing platform quickly to carrier $40^{\circ}, 160 \mathrm{~m}$ arc @ $0.5 \mathrm{kt}, 11 \mathrm{~min}$

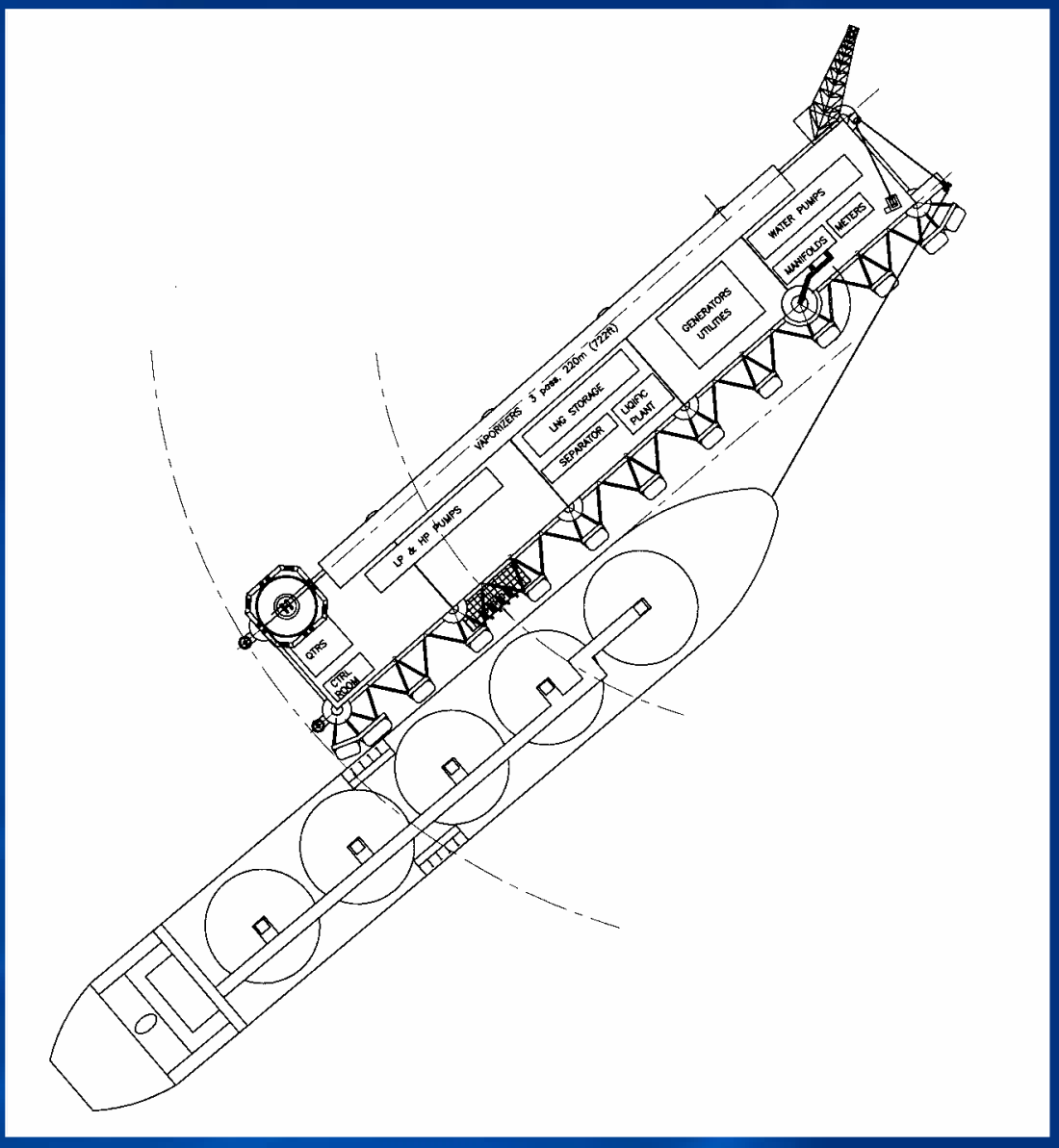

-Aft fenders contact

-Ready to align loading arms 


\section{Carrier Berthing Operations}

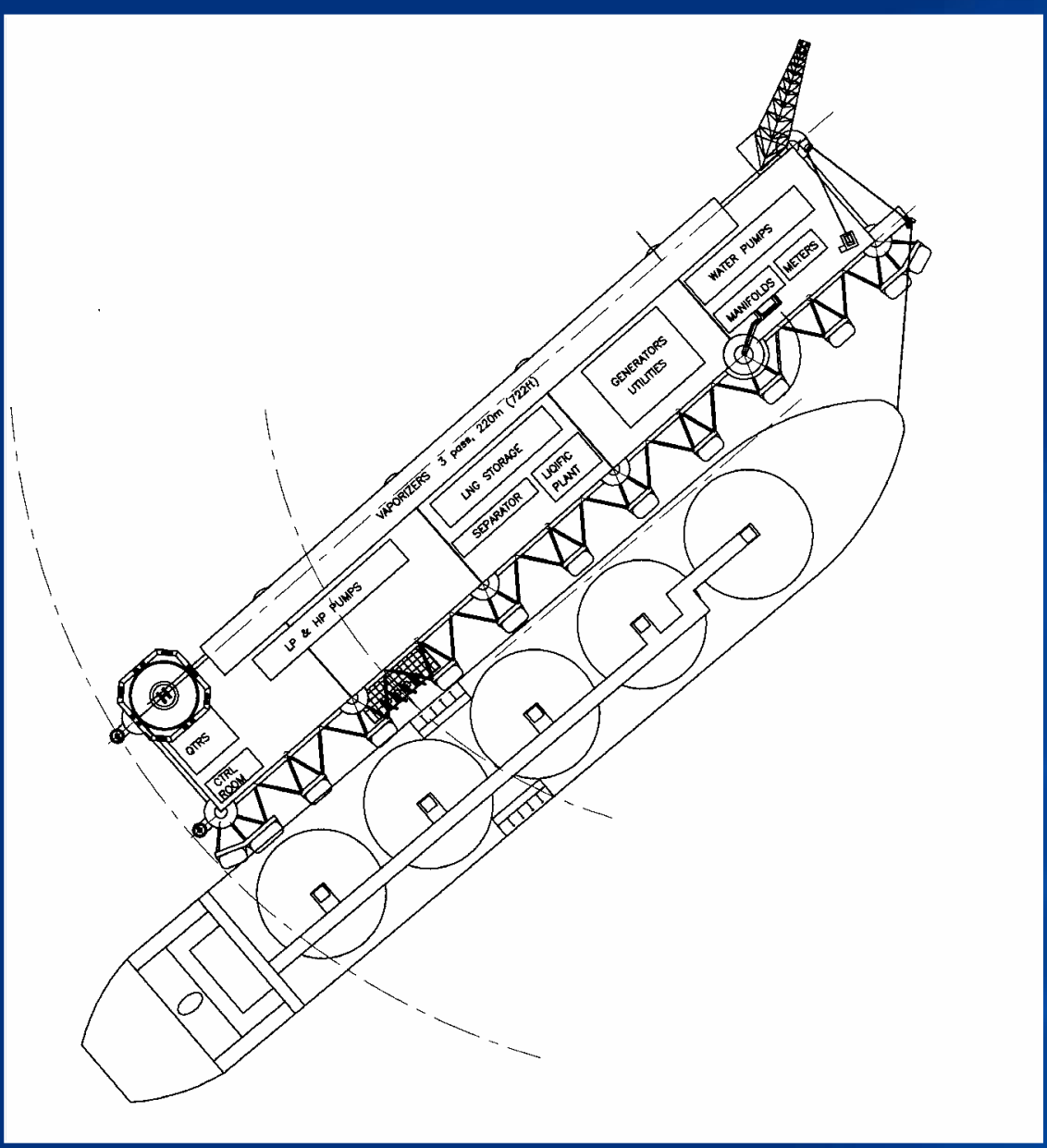

Loading arms aligned \& connected

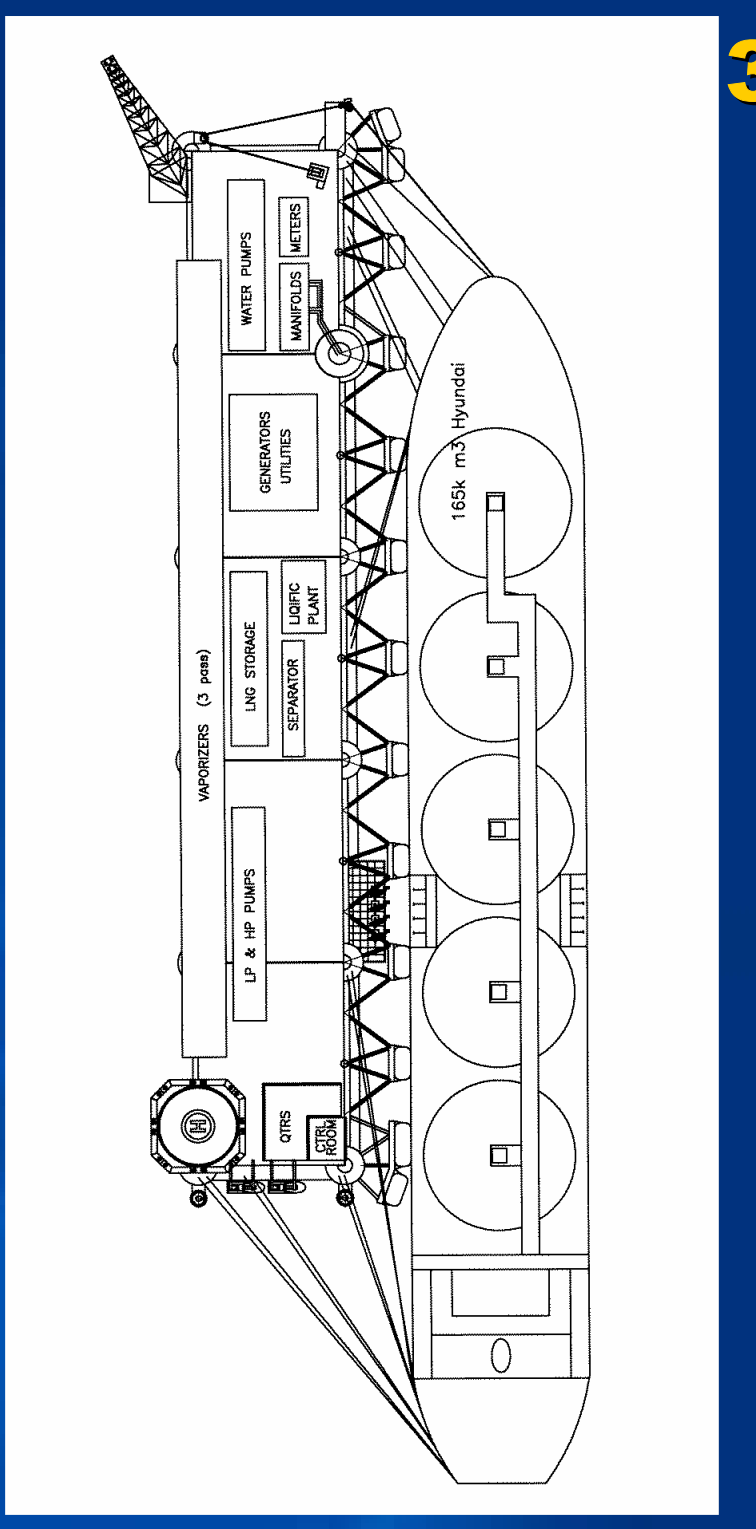

Mooring lines run to platform 


\section{Mooring \& Offloading Timeline}

\begin{tabular}{|c|c|c|c|c|c|c|c|c|c|c|c|c|c|c|c|}
\hline $\mathrm{ID}$ & Task Name & Duration & -2 & 1 & 3 & 5 & 7 & 9 & 11 & 13 & 15 & 17 & 19 & 21 & 23 \\
\hline 1 & LNG Carrier Arrives on Location & 0 days & & $5 / 6$ & & & & & & & & & & & \\
\hline 2 & Docking 3 hrs 24 min & 0.14 days & & & & & & & & & & & & & \\
\hline 3 & Mooring Master Transferred to LNG Carrier & $0.5 \mathrm{hrs}$ & & 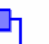 & & & & & & & & & & & \\
\hline 4 & LNG Carrier Terminal Approach & $0.75 \mathrm{hrs}$ & & & & & & & & & & & & & \\
\hline 5 & Transfer Pull-in Hawser & $0.5 \mathrm{hrs}$ & & & & & & & & & & & & & \\
\hline 6 & Pull-in Carrier & $0.75 \mathrm{hrs}$ & & & & & & & & & & & & & \\
\hline 7 & Rotate LNG Terminal to Carrier Side & $0.25 \mathrm{hrs}$ & & & if & & & & & & & & & & \\
\hline 8 & Connect Mooring Lines & $0.5 \mathrm{hrs}$ & & & ] & & & & & & & & & & \\
\hline 9 & Offloading $\quad 16 \mathrm{hrs} 48 \mathrm{~min}$ & 0.7 days & & & & & & & & & & & & & \\
\hline 10 & Deploy/Connect Loading Arms & $1 \mathrm{hr}$ & & & & & & & & & & & & & \\
\hline 11 & Pumping Ramp Up & $0.75 \mathrm{hrs}$ & & & & & & & & & & & & & \\
\hline 12 & Pumping@10,000 M3/hr & $14 \mathrm{hrs}$ & & & & & & & & & & & & & \\
\hline 13 & Pumping Ramp Down & $0.5 \mathrm{hrs}$ & & & & & & & & & & & 它 & & \\
\hline 14 & Disconnect/Retract Loading Arms & $0.5 \mathrm{hrs}$ & & & & & & & & & & & & & \\
\hline 15 & Undocking $1 \mathrm{hrs} 24 \mathrm{~min}$ & 0.06 days & & & & & & & & & & & & & \\
\hline 16 & Disconnect Mooring Lines & $0.5 \mathrm{hrs}$ & & & & & & & & & & & & & \\
\hline 17 & Rotate LNG Terminal away from Carrier & $0.25 \mathrm{hrs}$ & & & & & & & & & & & & i & \\
\hline 18 & Carrier Backs Away from LNG Terminal & $0.25 \mathrm{hrs}$ & & & & & & & & & & & & is & \\
\hline 19 & Mooring Master returns to LNG Terminal & $0.5 \mathrm{hrs}$ & & & & & & & & & & & & l & \\
\hline
\end{tabular}

\section{Total Time: $21.6 \mathrm{hr}$ for $140,000 \mathrm{~m}^{3}$ carrier}




\section{Platortosn \\ Construction Schedule}




\section{Platform Construction Advantages}

- Tubular and flat plate construction, fabricate in domestic or foreign yards

- Lends itself to modular construction

- Dockside testing of all onboard process \& power generation units

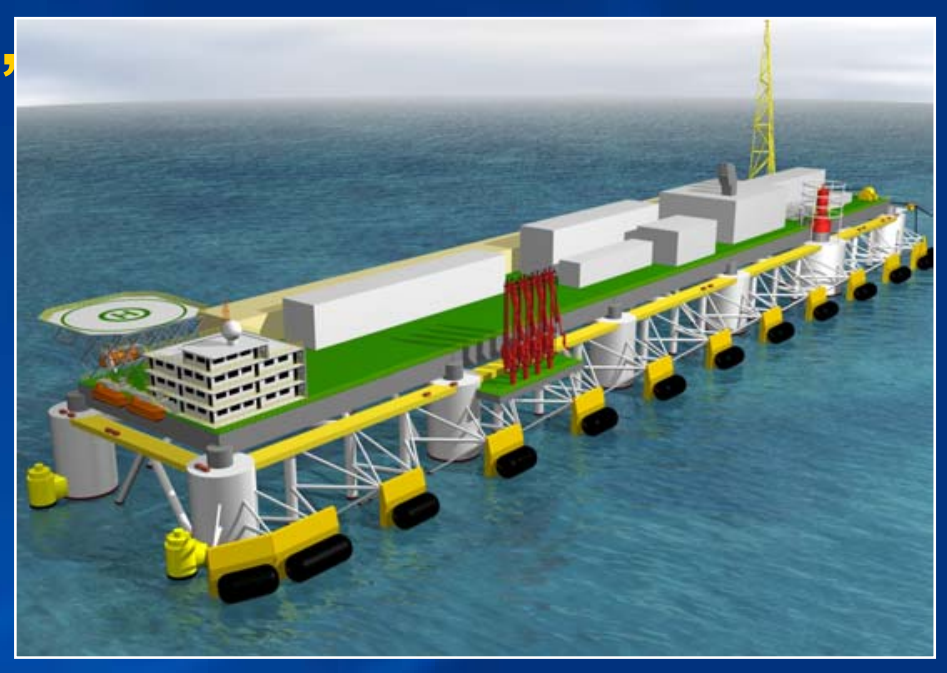

- Offshore construction spread is minimal

- Install offshore \& commission in a few weeks time 


\section{Gulf Coast Jower Fabrication - 1983 Exxon Lena Guyed Tower}

- $36.6 \mathrm{~m} \times 36.6 \mathrm{~m} \mathrm{x}$ $328 \mathrm{~m}$

- 24,000 ton trussed tower

- Brown \& Root Harbor Island Yard, 1983

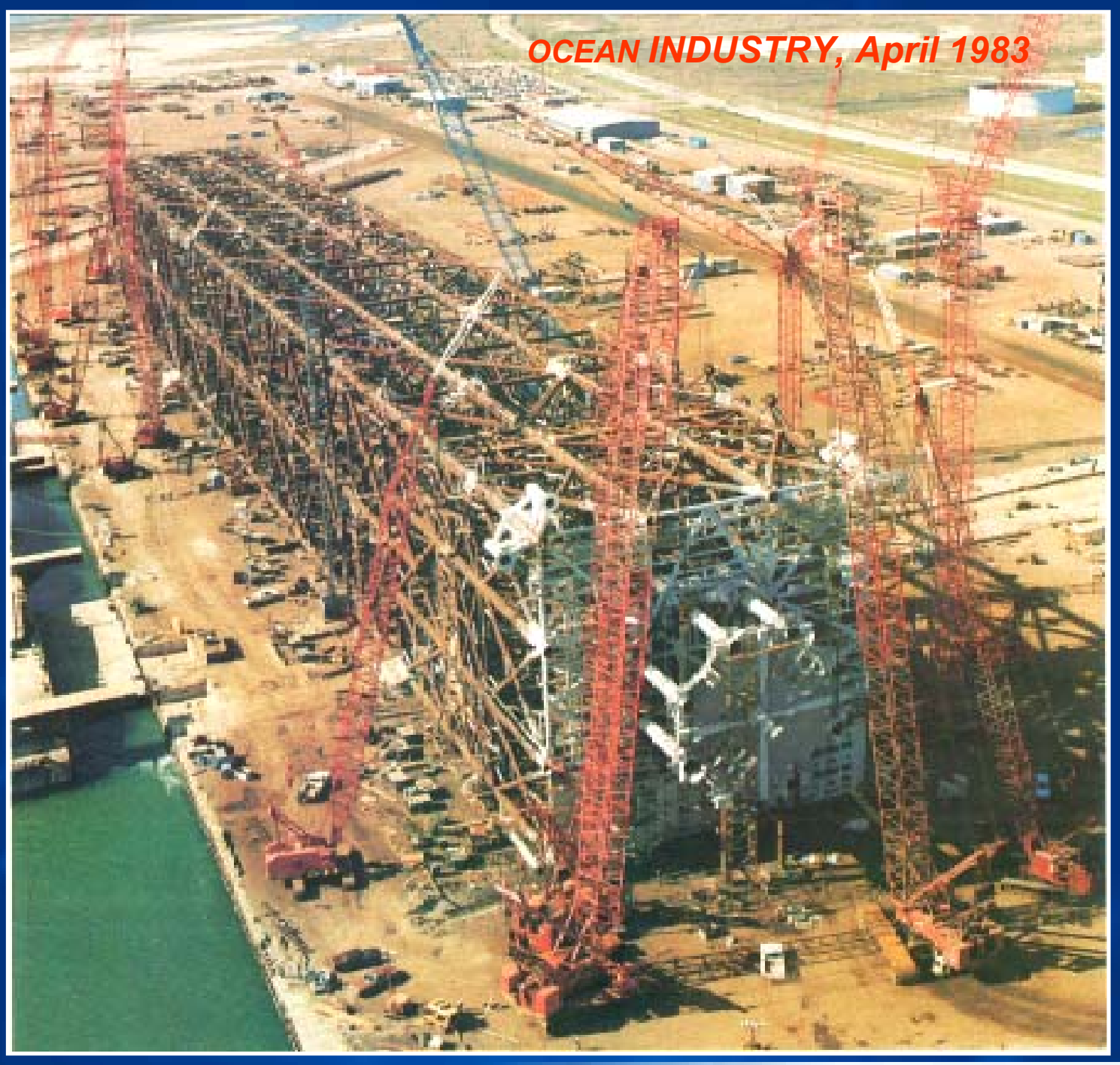




\section{Floating Platform Size}

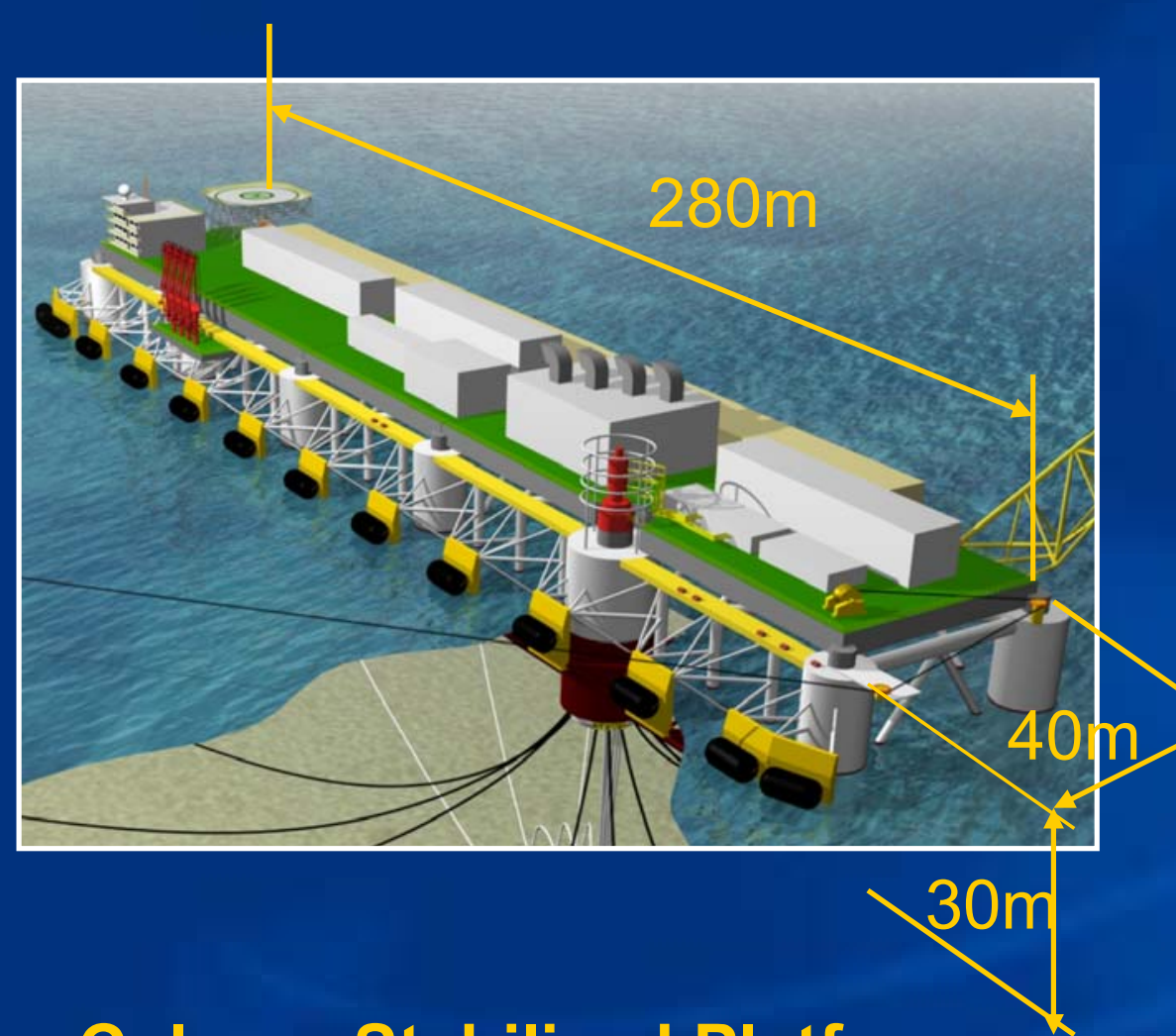

- Column Stabilized Platform

- $40 \mathrm{~m} \mathrm{~W} \times 30 \mathrm{~m} \mathrm{H} \times 280 \mathrm{~m} \mathrm{~L}$

- 21,000 ton structure (w/o deck)

- Fab yard: GoM or SE Asia

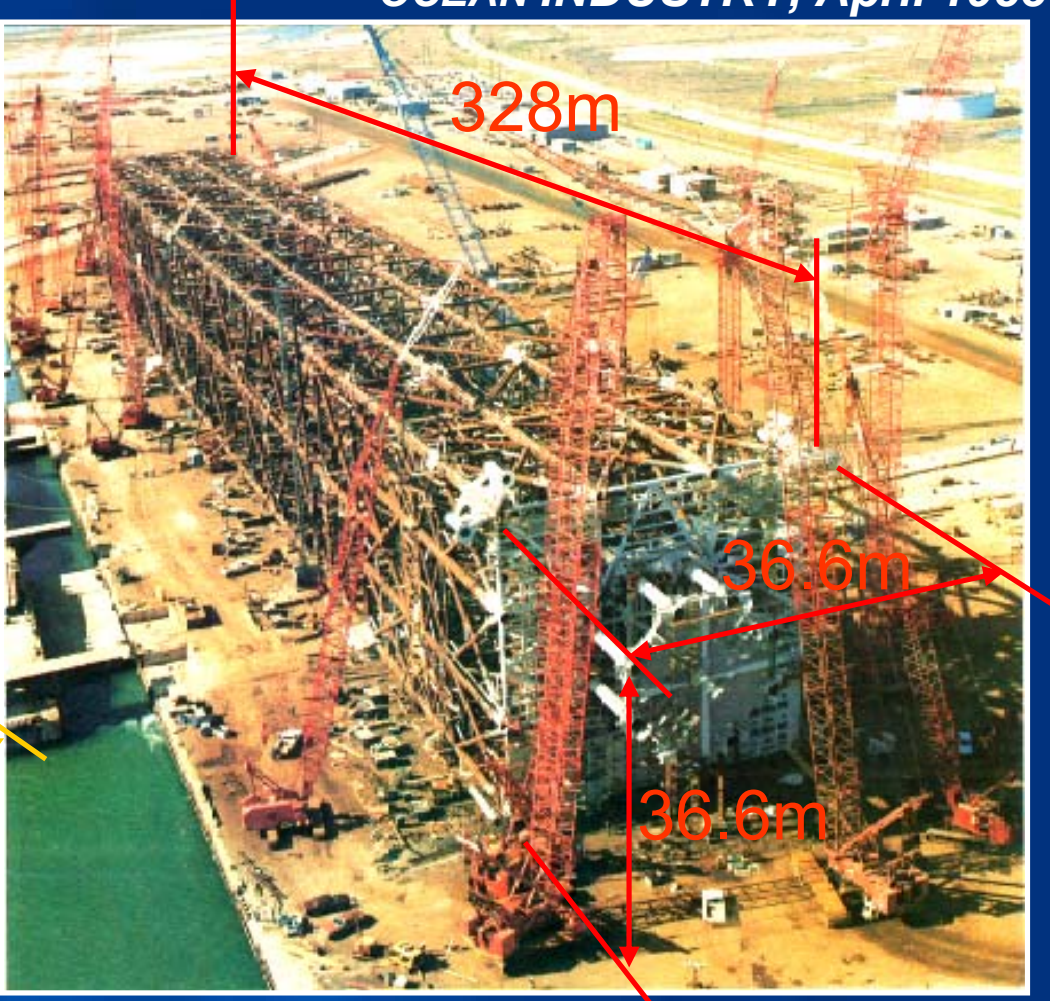

- Exxon Lena Guyed Tower

- $36.6 \mathrm{~m} \times 36.6 \mathrm{~m} \times 328 \mathrm{~m}$

- 24,000 ton trussed tower

- Brown \& Root Harbor Island Yard, 1983 


\section{Schedule for Floating Platform Design, Fabrication, Installation}

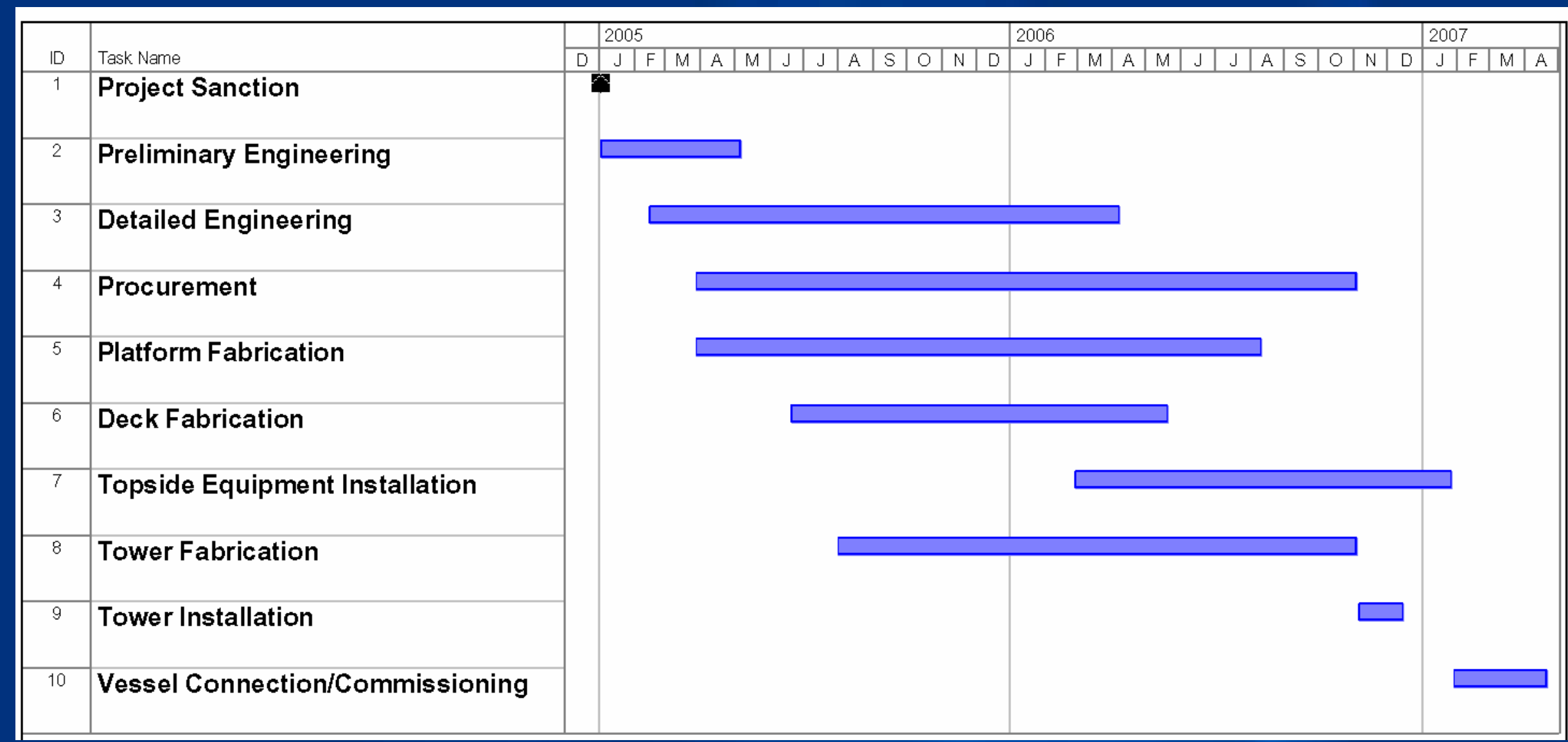

\section{Total Elapsed Time: 26 months}




\section{Gulf Coast Fabrication Plan}

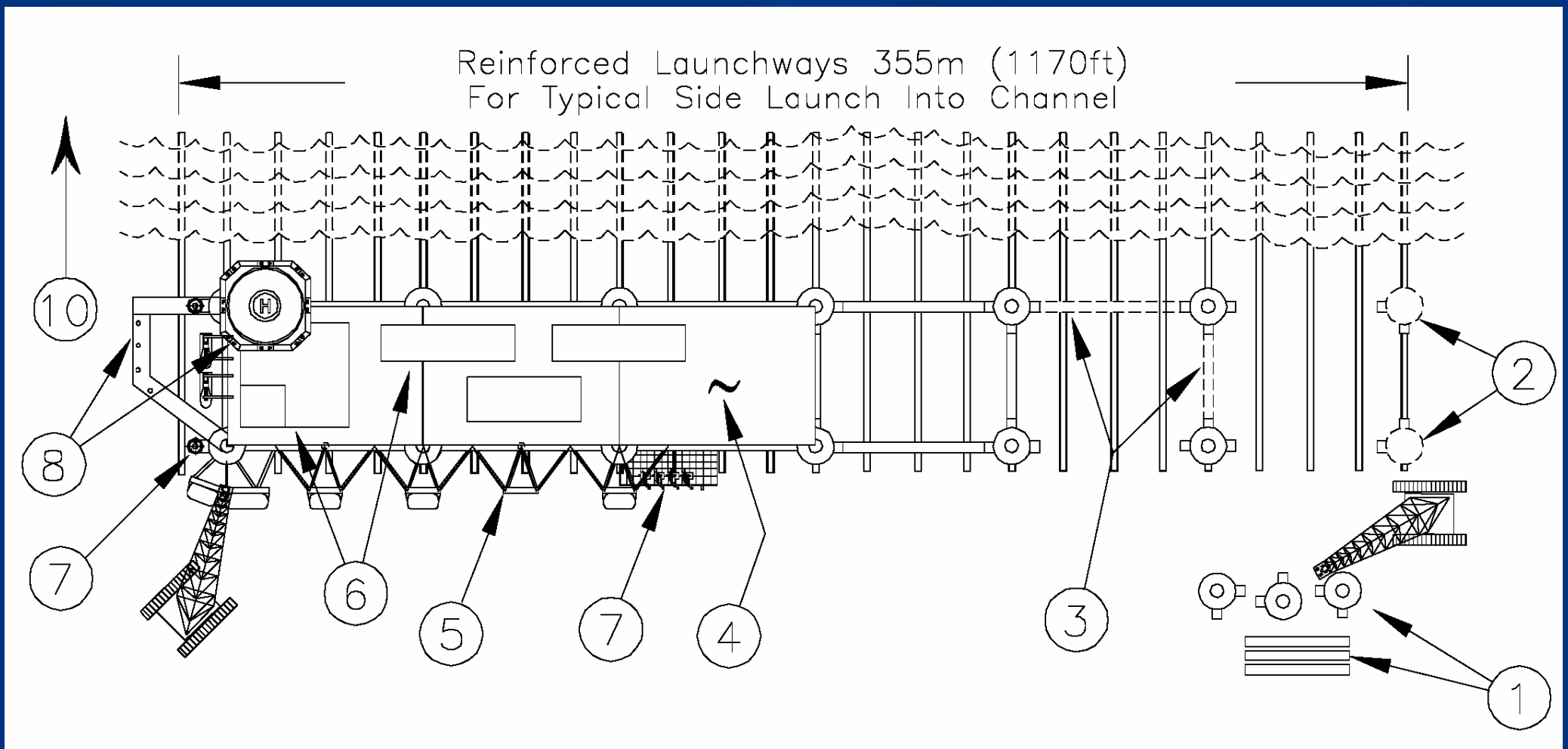

\section{GULF COAST FAB YARD}

1. FAB ALL COMPONENTS IN THE FABYARD

2. SET COLUMN SECTIONS ONTO SLIPWAY SKIDS

3. FIT/WELD CROSS BRACING SECTION BETWEEN COLUMN MODULES

4. FIT/WELD DECK SECTIONS LIFTING WITH FLOATING CRANE

5. FIT/WELD BUMPER STRUCTURES TO TERMINAL COLUMNS

6. FIT/WELD DECK NODLLES, ACCOMMODATIONS

7. FIT/WELD LOADING ARMS \& THRUSTERS

8. FIT/WELD HELIDECK \& STERN FRAME

9. FIT/WELD FLARE BOOM (NOT SHOWN)

10. LAUNCH LNG TERMINAL VESSEL 


\section{Southeast Asia Fabrication Plan - 1}

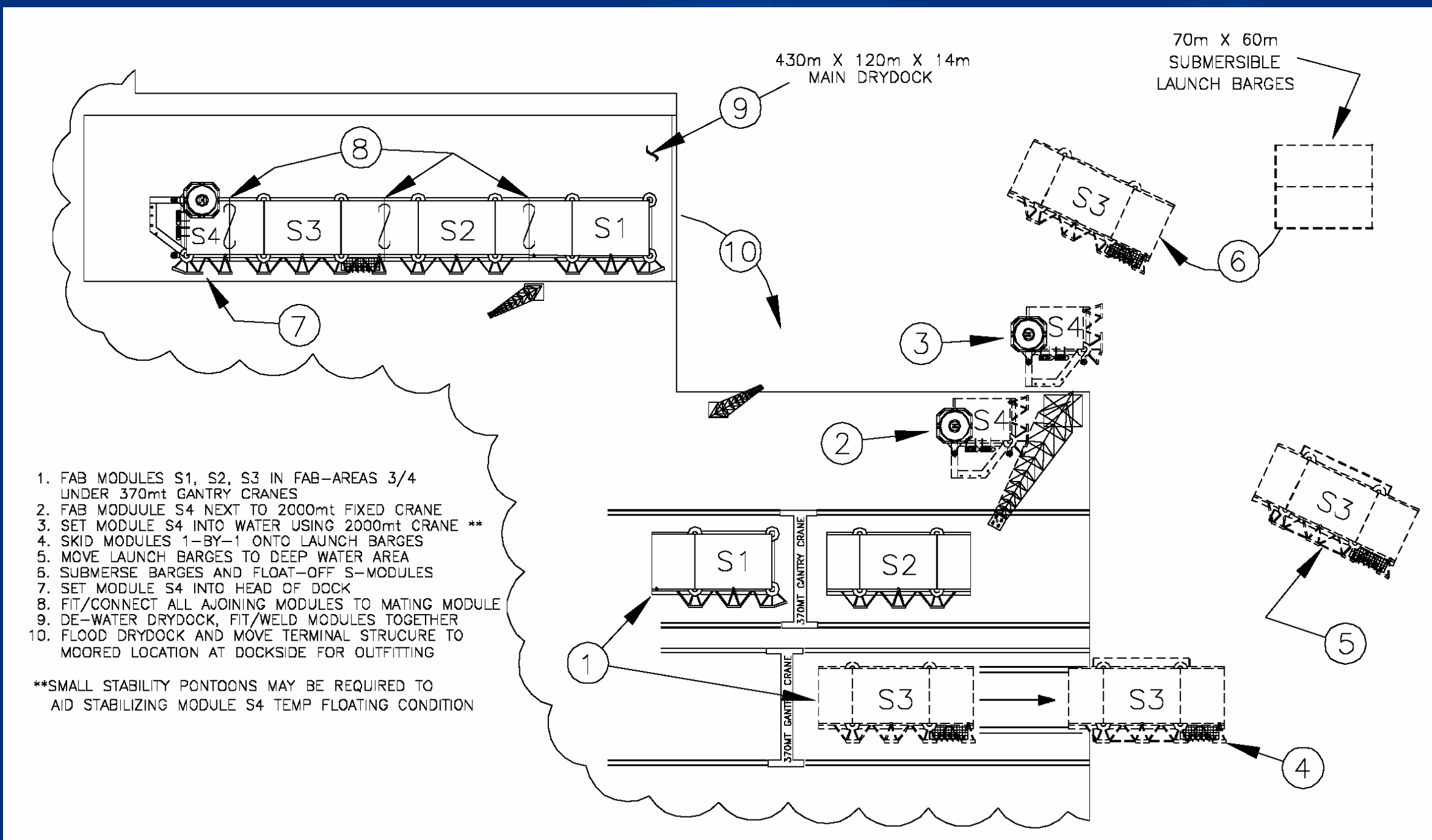




\section{Southeast Asia Fabrication Plan - 2}

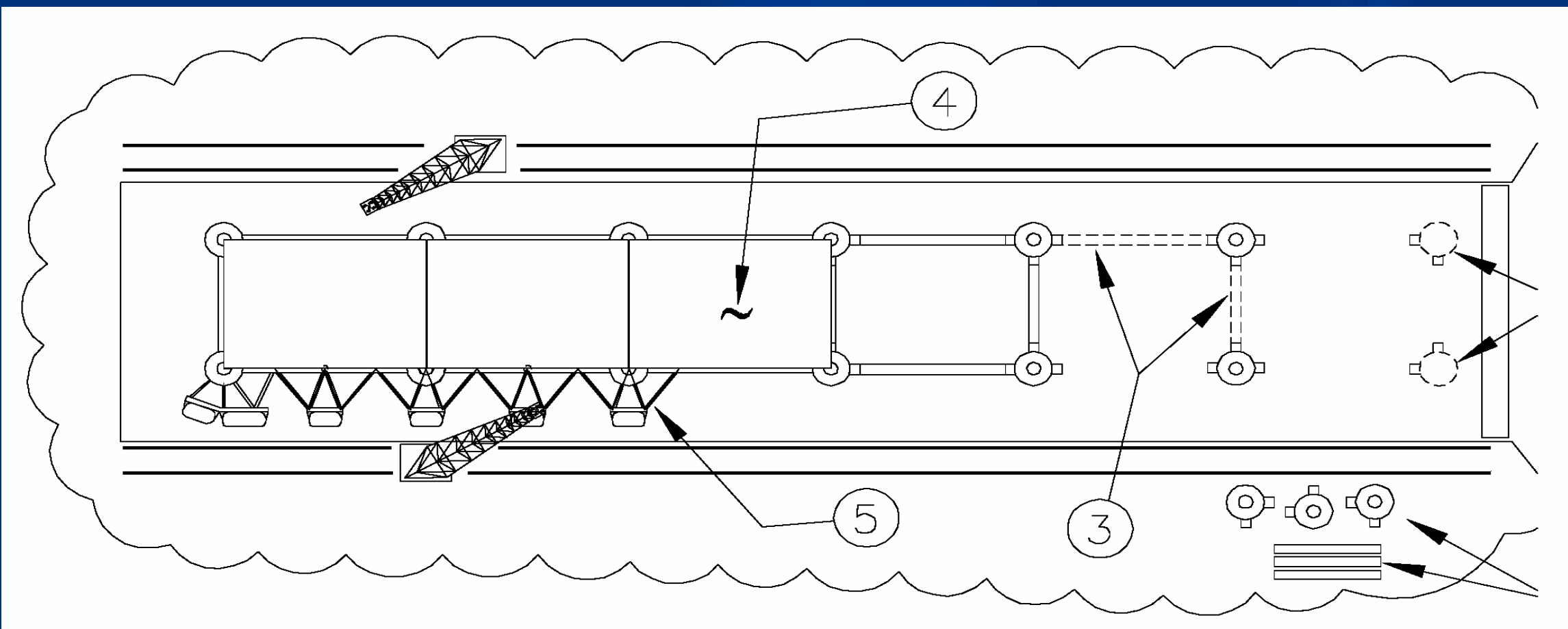




\section{Comparison of Attributes with "Ideal Terminal"}

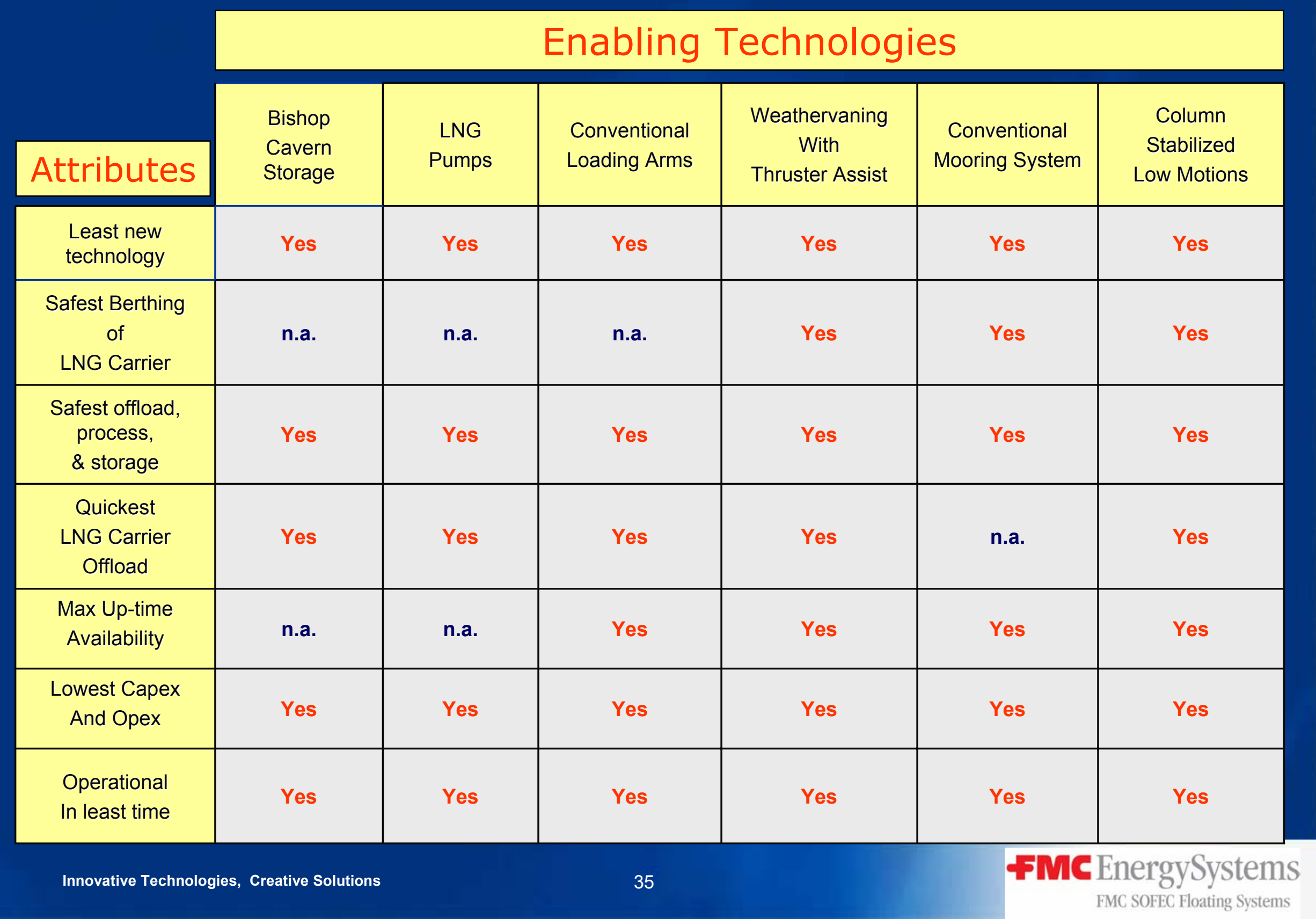




\section{Conclusions}

- There are no technology gaps to hinder design \& construction completion of a floating LNG receiving terminal within 28 months

- FMC Energy Systems can fully support the facility requirements for this project by supply of hardware systems including:

$>$ LNG loading arms

$>$ Platform, gas swivel, risers, \& mooring

$>$ Cavern wellheads, subsea or dry trees

$>$ Gas flow assurance engineering

$>$ Gas metering

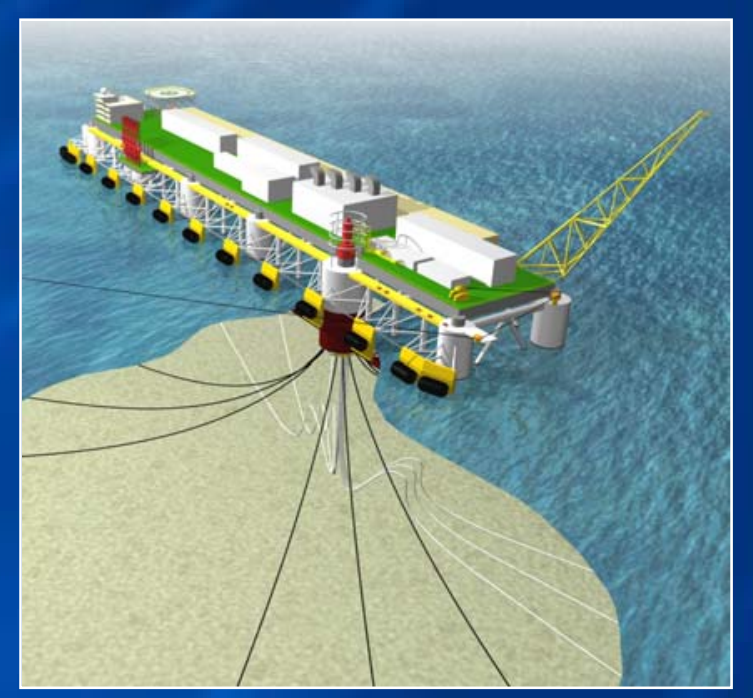




\section{SSP Floating Dock System}

The Floating Dock System consists of OPE's patented Satellite Services Platform (SSP) buoys moored to the sea floor. The Floating Dock is designed to accommodate current and the next generation LNG carrier (LNGC) sizes from 70,000 to 200,000 cubic meters in capacity. A total of six SSP's are used to berth one LNGC; four 60' SSP's are deployed along the ship and hold spring lines, and two 40' SSP's are deployed further forward and aft to hold fore and aft lines. This berthing is schematically represented in the attached sketch in Drawing I, which also shows bridges that connect the SSP's for personnel movement. The Floating Dock is designed to withstand the LNGC impact during loading operations, even during very severe weather, throughout its service life. The elimination of the requirement for rotating bearing systems during LNG unloading lowers both CAPEX and OPEX. This design has received ABS approval in principal.

The system components allow lateral impact velocities of LNGC's during docking operations of more than 5 feet per second without damage by minimizing the ship to shell reactions. This is achieved by the design of the mooring system coupled with the shell shape of the SSP. As the SSP is forced off of its equilibrium position, it exhibits a very favorable increasing spring constant whereby further displacement requires additional force. This condition serves to cushion the impact load between the LNGC and the SSP during docking operations. The attached Sketch shows an elevation of a ship at berth in contact with the SSP. Notice that the SSP has tapered sides at the water line. This feature adds to the increased spring constant as the SSP is moved off-center by contact with the LNGC.

The SSP Buoy consists of a conical-shaped hull unit and a center column assembly (see Drawing II). The internal hull and compartmental layout, along with the center column, provide maximum reserve buoyancy and excellent stability during storm conditions. The circular-shaped, double-sided hull is constructed of stiffened flat plates forming the bottom, side shell, intermediate decks and the main deck. Internal bulkheads are provided to meet strength and stability requirements.

The center column is constructed of pipes with tie-brace beams at the top end and intermediate cross members and heave plates. The center column can be raised or lowered through the center of the SSP. The center columns are ballasted, which lowers the center of gravity and helps provide for good sea keeping characteristics. The length of the center column is altered to accommodate various water depths and to optimize the SSP's motion characteristics. 
Raising or lowering the center column can be achieved by using hydraulic jacks, multi-part winches, chain jacks, or by heavy lift cranes from a service vessel. The SSP's roll and heave motions are reduced due to its low center of gravity caused by the ballasted center column, the roll damping afforded by the keel effect, and damping by the heave plates (see Sketch). At the option of the operator, the center column assembly can also serve as tanks for storage of fuel or water for servicing the LNGC.

Personnel access bridges are installed on the SSP floating dock facility to connect the SSP Buoys together. The improved SSP motions allow the use of these walkways between the buoys and existing or new LNG receiving structures, fixed or floating.

Each SSP Buoy is equipped with a chain-wire-chain spread mooring system. The semi-taut mooring system results in a small mooring footprint on the seabed. Anchor piles, suction or driven type, can be pre-installed at the offshore site, while the SSPs are under construction.

There is no requirement for mooring winches or windlasses to change the mooring tensions after the SSPS are installed on location.

A fender system is installed on each SSP Buoy, to prevent the ship and the SSP hulls from damaging each other during docking. The fenders are adjustable to match the sleek fairings of LNG vessels or ordinary tankers.

\section{Cost Estimates}

OPE was requested to provide a cost estimate for an SSP Floating Dock System to CGI as an alternate solution for CGI's base case loading system. Rather than provide a single estimate, OPE has prepared three estimates. The first estimate is for one floating dock system of six SSP's that is capable of berthing one LNGC of size from 70,000 cubic meters up to 200,000 cubic meters. The second estimate is for two docking systems. It is believed that the possibility of having two ships at berth at any given time may improve overall operations, increase efficiency, and reduce operating costs. The third estimate is for one docking system, but includes a larger SSP that can be used for accommodation and power generation, and another even larger SSP that can be used for the regassification of $L N G$, for pressuring this gas to storage pressures, and for sending gas to the sales pipelines. All estimates are installed cost estimates, and include design, project management, inspection, modeling fees, licensing fees and royalties, overheads, mooring system costs, hull costs, cost of pile installation, transportation to the Gulf of Mexico from a shipyard, and installation costs at site. These three cost estimates are attached.

The single ship docking system has an all-inclusive cost of $\$ 36.6$ million. This system could be used adjacent to a platform or a floating receiving terminal , and 
the LNG trans-shipped to another location for regassification and processing. The receiving terminal would contain the hose handling equipment necessary for moving the LNG from the ship to the terminal. A similar system is currently being designed for the BHP/Woodside project offshore Ventura County, California where the receiving terminal is a fixed platform. That platform is the Grace Platform, which is on long-term lease to the project. The Grace reservoir has been depleted, and the gas line to shore is underutilized, so this receiving scenario is able to utilize existing infrastructure. A November 17, 2003 Oil and Gas Journal article concerning that California LNG project is attached.

The dual ship docking system has a cost of $\$ 64.6$ million. This system is identical to the single ship docking system except that it contains twice as much hardware, that is, 12 total SSP's vs. 6 total SSP's. The dual ship docking system is less than twice the cost of the single ship docking system because certain engineering and overhead costs need not be duplicated.

The third cost proposal is for docking one ship, but includes one extra 190' SSP ( 7 total) that is intended to be a receiving facility. In addition, one of the 40' fore or aft buoys has been increased in size to 100'. The reason for increasing the fore or aft buoy is to provide space for personnel accommodation. The accommodation facilities would be located near to but separate from the receiving and processing facilities. Since a 100' SSP has over 10,000 square feet of deck space and can support a deck load of 1200 tons, it would be possible to also include power generation on the accommodation SSP. In addition to the above, the 100' SSP can store 1800 tons of water for personnel or ship's use. The 190' SSP has 38,000 square feet of deck space, can carry a deck load of 4600 tons, and can store 19,800 tons of liquids. The stored liquids could be water, oil, or even LNG if buffer storage was desired. If it were desired to store a ship's amount of LNG, then a larger SSP would be required, perhaps 256'. With the very large available deck load on a 190' SSP, all regassification and compression equipment could be positioned there. If the regassification and compression equipment were positioned at the ship unloading facility, then there would be no need for a sub sea LNG line, thus saving the cost of that equipment. The elimination of a sub sea LNG line would enhance project economics. A further, even larger, enhancement of project economics would be the fact that the 190' SSP would be outfitted, commissioned, and tested on-shore. When the fully complete and tested regassification facilities were taken to site offshore, they would be installed and operational in days, literally. The project would save time, be commissioned with more productive onshore hours, and would eliminate the need for large offshore installation equipment. The installed cost of this third proposal is $\$ 83.5$ million, not including the cost of accommodation, power generation, or processing equipment on the decks. 


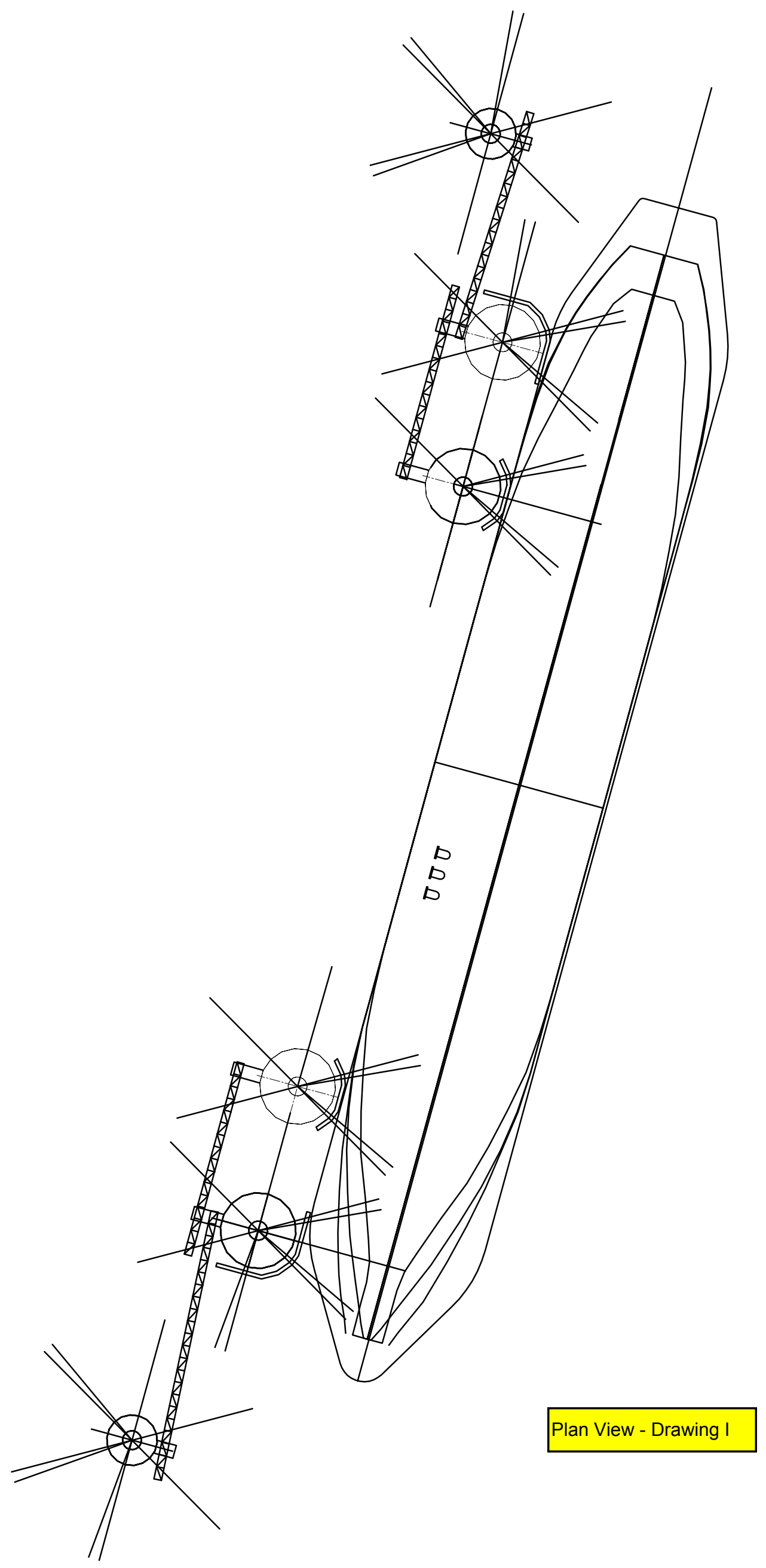




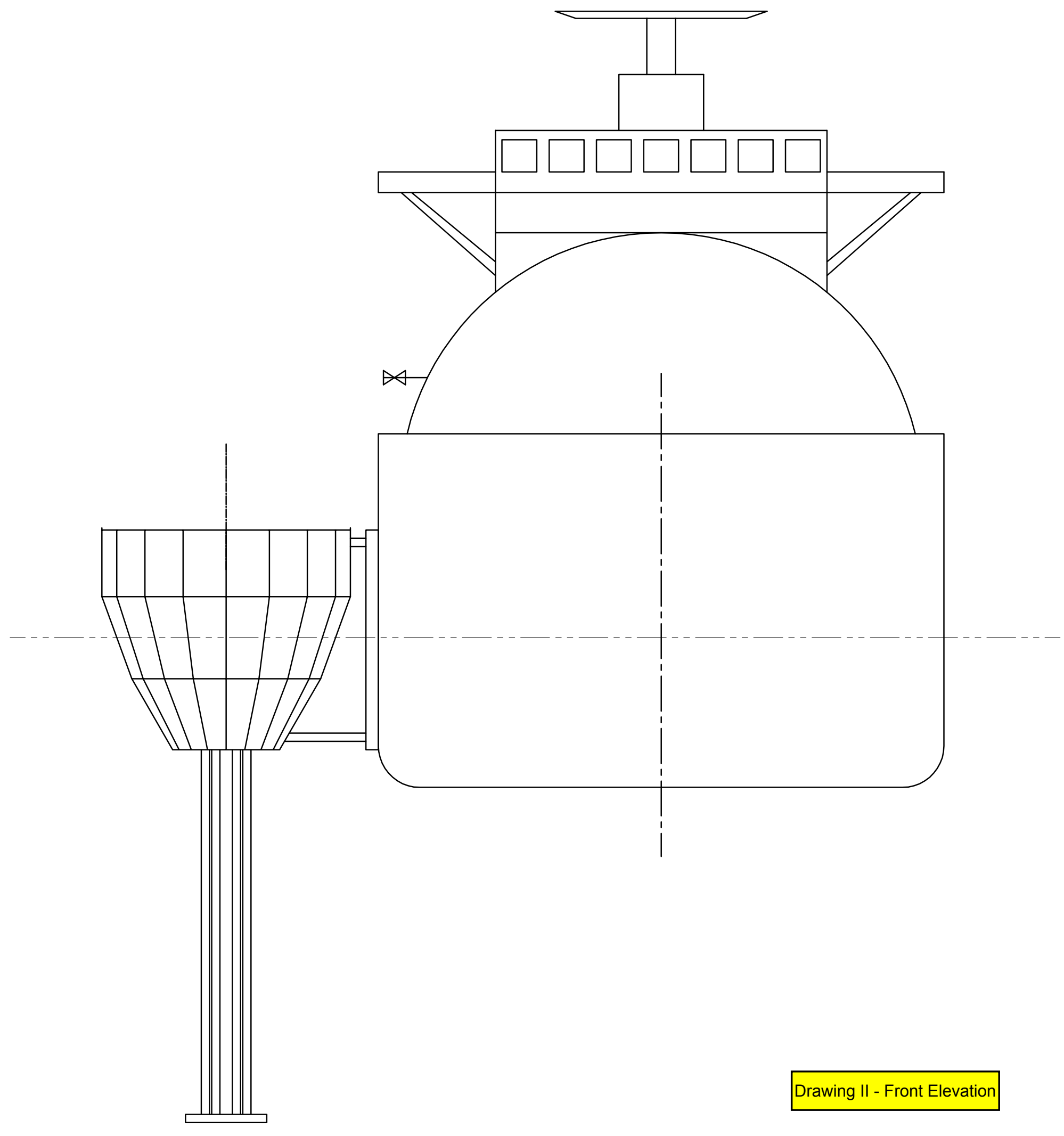




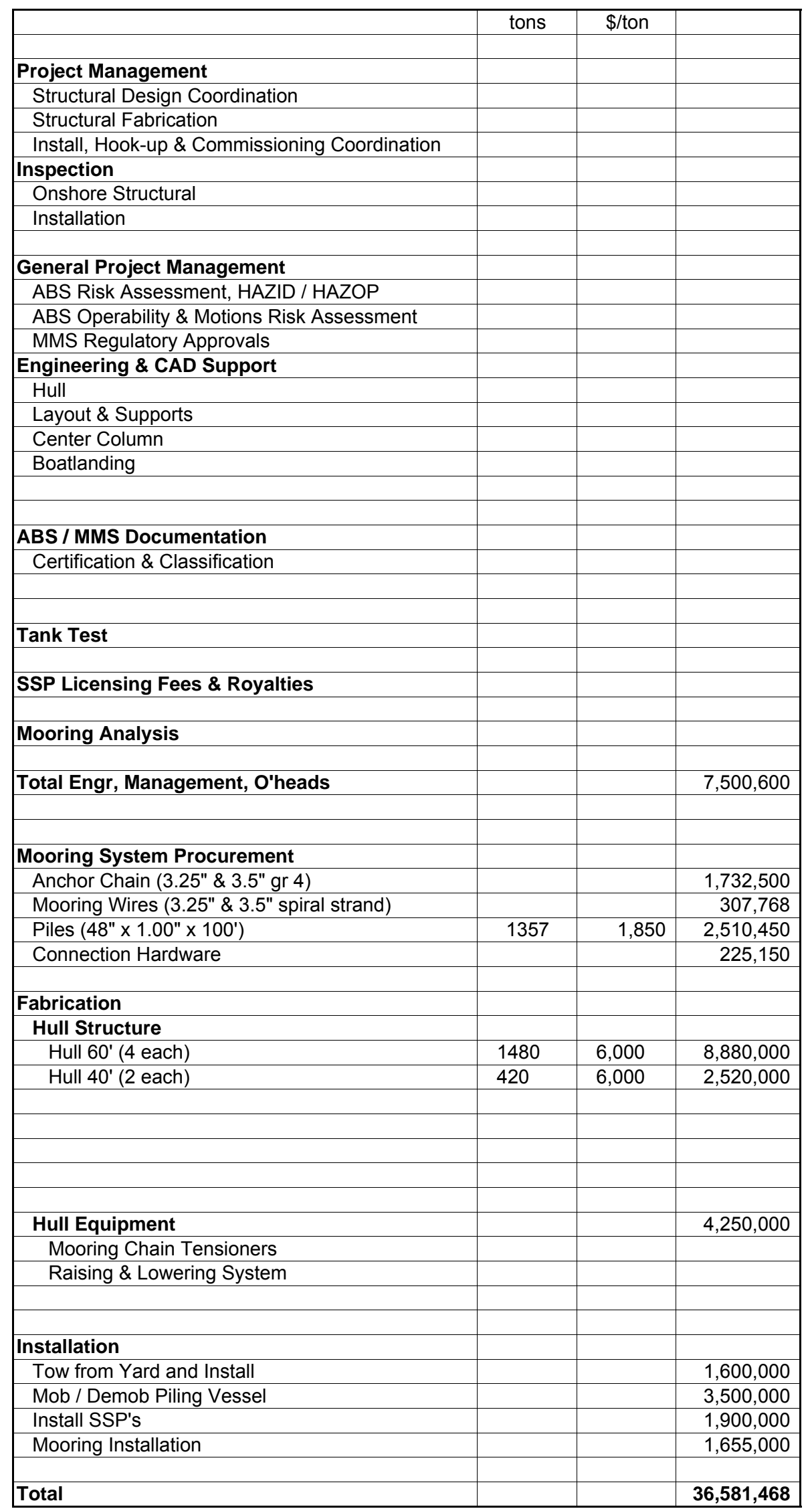




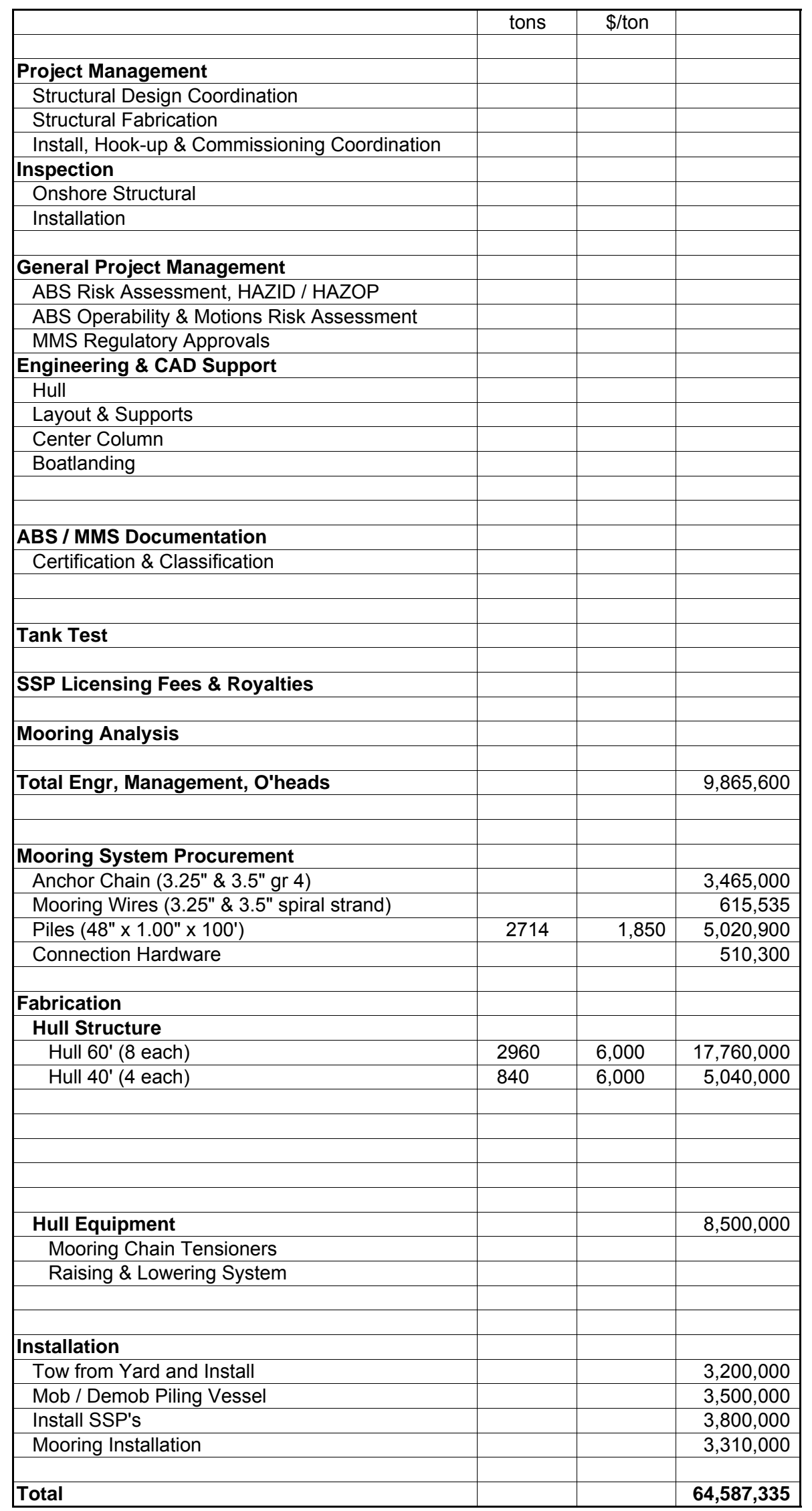


Conversion Gas Imports

Single Ship Docking, Accommodation Buoy, Receiving/Processing Buoy

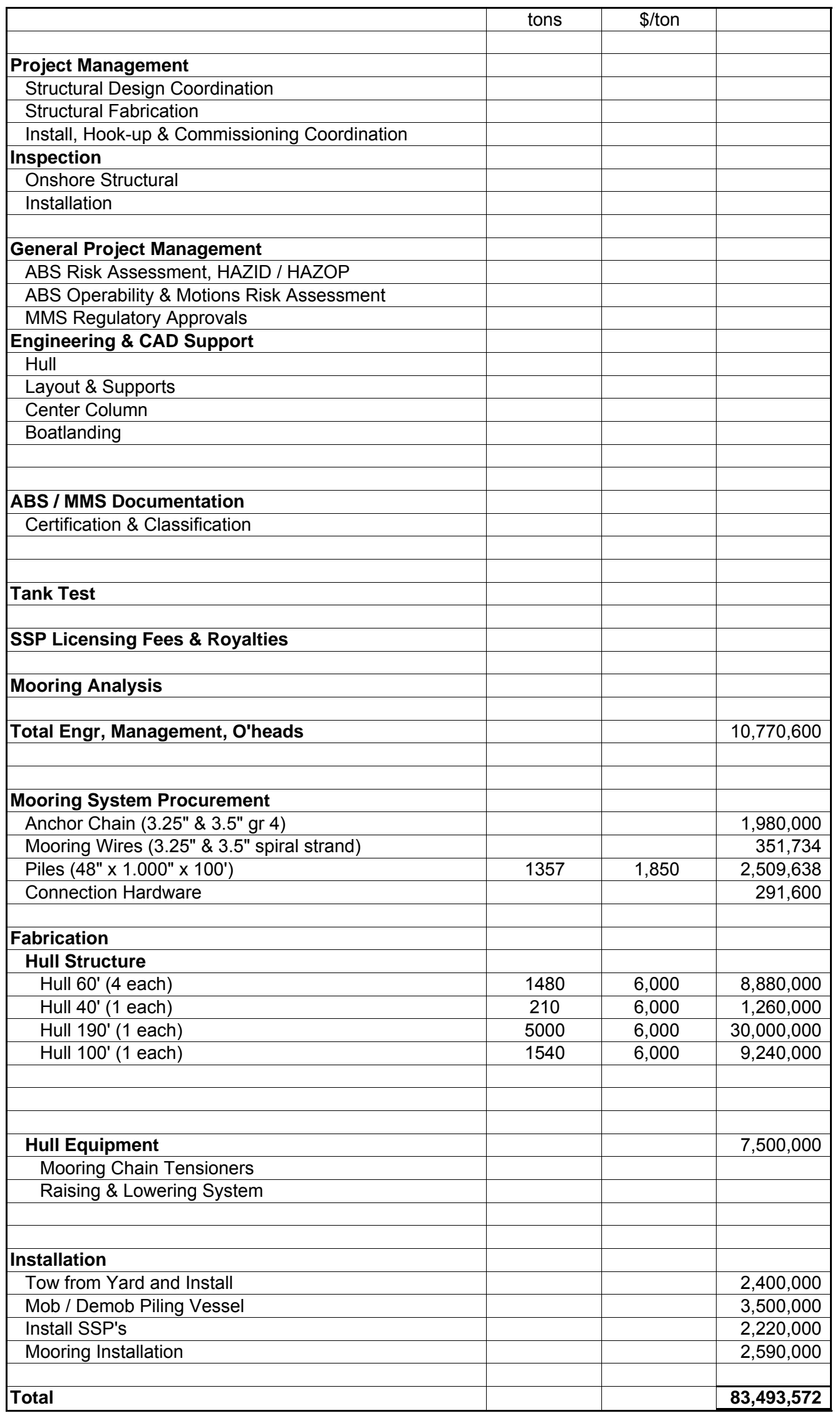




\section{System 4- Mustang Engineering Smart ${ }^{\mathrm{TM}}$ Air Vaporization Process Platform}

\section{System Overview}

The Mustang Engineering LNG Smart ${ }^{\mathrm{TM}}$ Air Vaporizer Platform receives LNG from the LNG sendout pumps at pressures from 76 barg (1100 psig) up to 138 barg (2000 psig). The platform includes air exchangers to warm intermediate fluid (Enviro Kool) which vaporizes LNG in the brazed aluminum/core exchangers. This system combines generator waste heat recovery and additional backup heating system to provide up to $75 \%$ of the total maximum required duty.(see attached Process Flow Diagram)

This system will vaporize up to 3.5 BCFD. Maximum fresh water discharge is 3.5 million gallons per day at desired temperature. Principle advantage: No seawater pumps, screens, chemical treatment or seawater discharge.

\section{Design for the DOE Study}

\section{Design Details: Basis - 3.5 BCFD maximum flow}

- Type: air exchangers, brazed aluminum/core exchangers

- Design Code: ASME

- $\quad$ Temperature of LNG: $-162^{\circ} \mathrm{C}\left(-260^{\circ} \mathrm{F}\right)$ Liquid to $4.44^{\circ} \mathrm{C}\left(40^{\circ} \mathrm{F}\right)$ gas

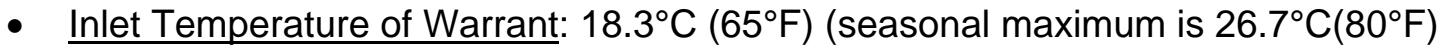

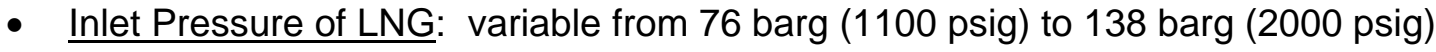

- $\quad$ Piping Material: LNG 304L ss, other pipe is CS ,HDPE 
- Layout: See attached sketch for single level platform layout.

- Unit Weight/Dimensions:

o air exchangers 90 units $(14 \times 60)$ total 120 'x600'

o Fan horsepower 10,800

o total duty $2100 \mathrm{mmBTU} / \mathrm{hr}$

o Weight - 68,000\#each total 630 tons

o Intermediate fluid Enviro Kool is $98,500 \mathrm{gpm}$,

o 6 pumps at $500 \mathrm{hp}$ with one spare, 10,000\#each

- Weight of Pumps 30 tons

o 2 tanks 90,000 gal each, $130,000 \#$ each

- Weight of tanks 130 tons dry

o 14 LNG vaporizers, 4' x 4' x 27' (vertical), 90,000\# each

- Weight 630 tons dry

o Backup heat $60 \%$ of total $1260 \mathrm{mmBTU} / \mathrm{hr}, 12$ SCVs, $100,000 \#$ each

- Weight 600 tons

- Structural Configuration: design structural framework for support of piping and for lifting assembled unit during platform fabrication.

- Piping: manifold inlet to groups of pumps with valves for isolation. Outlet of exchangers manifold into gas transfer header with valves for isolation.

- Gas Warming: must be capable of accepting HP gas from cavern for warming to pipeline pressure after $\mathrm{J}-\mathrm{T}$.

- Fabrication: Each unit will be fabricated, inspected, x-rayed, and hydrotested prior to assembly.

\section{Plant Layout}




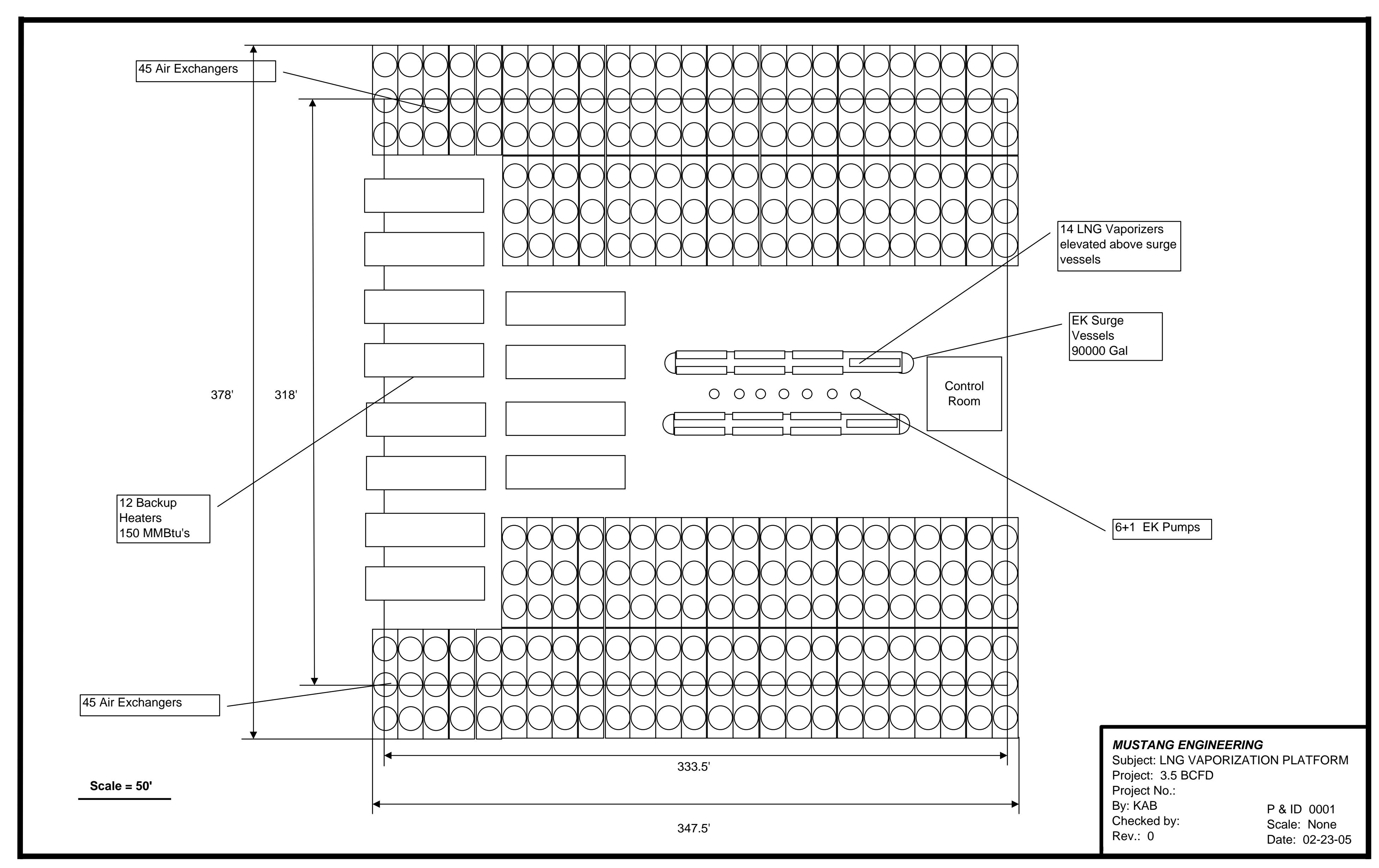




\section{LNG Smart ${ }^{\mathrm{TM}}$ Vaporization Process}

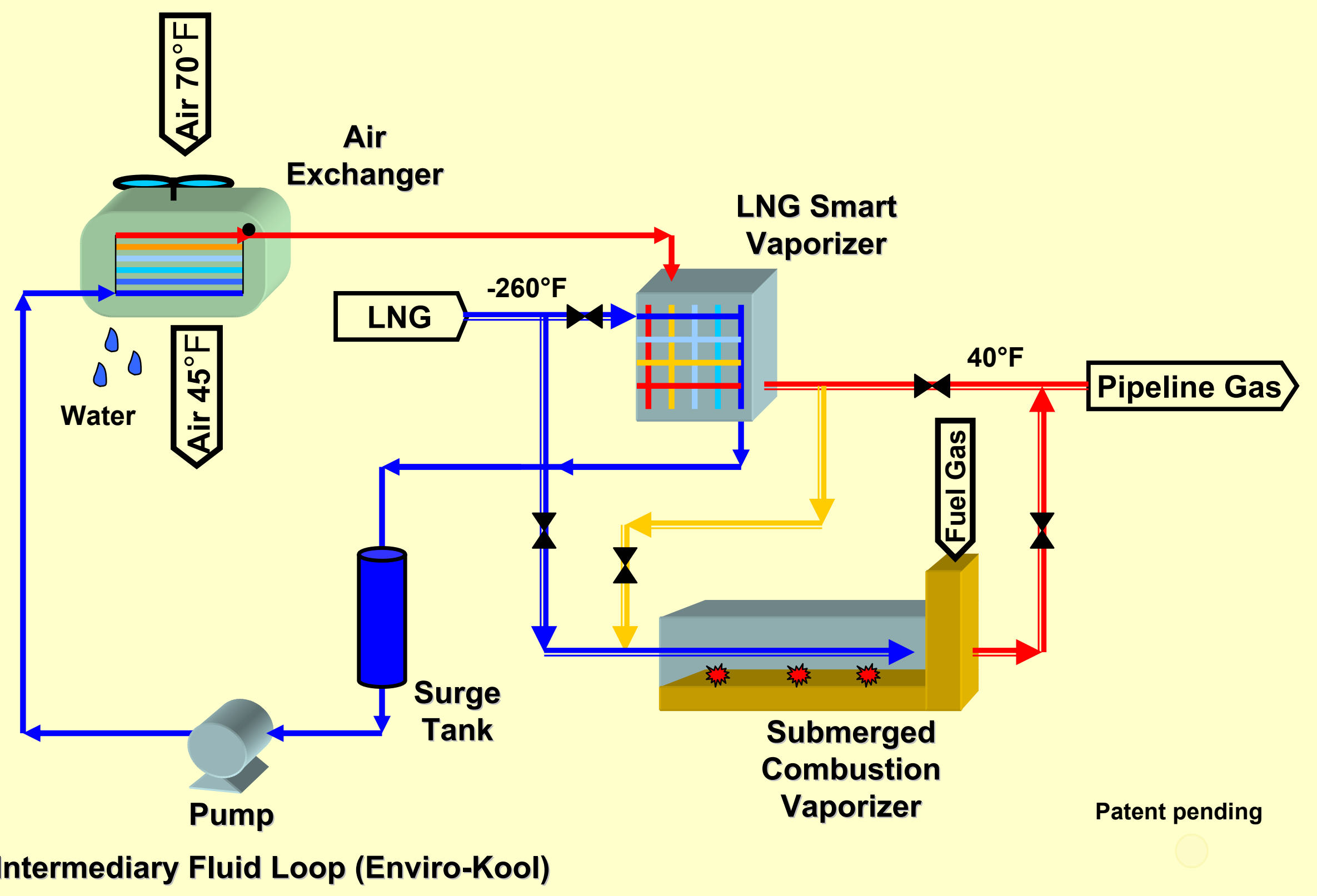




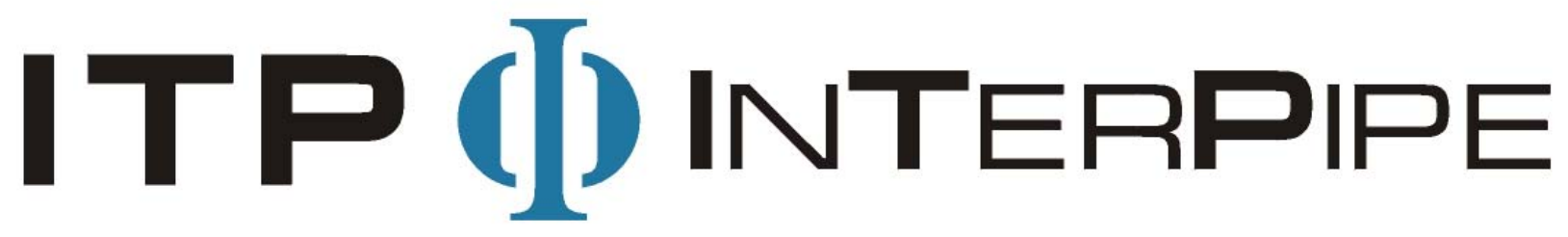

\section{ITP LNG Pipe-In-Pipe Information}

ITP\# P05.DOE.P-LNG.01.03.00

March 30, 2005

ITP (]) INTERPIPE 


\section{Table of Contents}

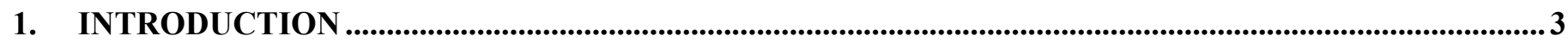

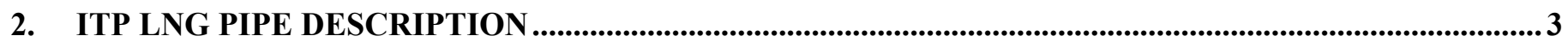

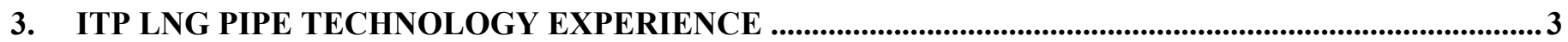

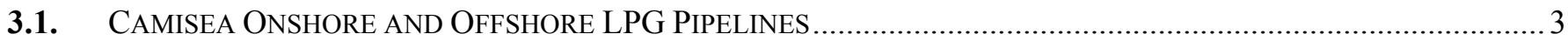

3.2. QUALIFICATION OF THE ITP SUBSEA LNG PIPELINE JOINT INDUSTRY PROJECT ....................................... 6

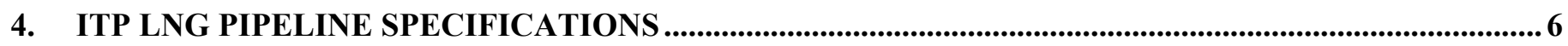

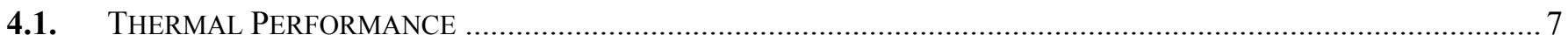

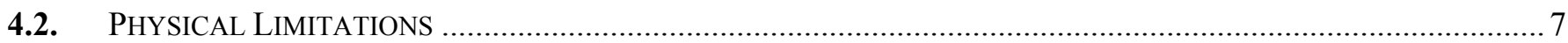

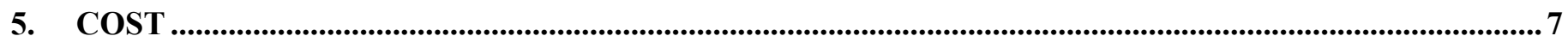

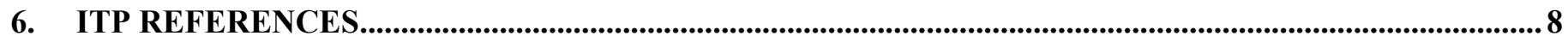

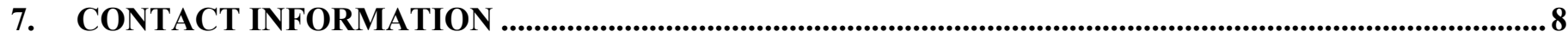




\section{Introduction}

This document gives a description of the ITP LNG Pipe-In-Pipe (PIP) including a cost estimate for a typical configuration.

\section{ITP LNG Pipe Description}

ITP began development of the LNG pipe design in 1996 and performed first full-scale tests in 1999 with LNG. In 2003, ITP was joined by four oil companies in a joint industry project with the objective of qualifying ITP's LNG pipe design for subsea transportation of LNG. The JIP successfully obtained ABS' "Approval in Principle" and DNV's "Statement of Feasibility" for the LNG pipe design for subsea service.

ITP's LNG pipe design is based upon a double or triple walled pipe-in-pipe design using a 36\% Ni steel inner pipe, a carbon steel or stainless steel outer pipe, and ITP's patented Izoflex microporous insulation. The 36\% Ni steel inner pipe has a coefficient of thermal expansion which is ten times less than the coefficient of thermal expansion of stainless steel; thus ITP's design requires no expansion loops or bellows to accommodate the expansion and contraction at cryogenic temperatures.

The pipe-in-pipe design requires no bulkheads except at either end of the pipeline. All joints between individual pipe sections are simple butt welds. The pipe-in-pipe has a continuous annulus, which is maintained at reduced pressure to enhance the thermal performance of the Izoflex insulation.

The ITP LNG pipe-in-pipe is suitable for installation subsea, on a trestle, or buried onshore.

\section{ITP LNG Pipe Technology Experience}

ITP has supplied highly insulated pipe-in-pipe oil and gas flowlines since 1993. ITP LNG pipe technology is based upon the patented Izoflex insulation, which has been in service in subsea applications since 1998. Overall, ITP has 83 miles of installed subsea pipe-in-pipe flowlines with another 67 miles to be installed in 2005.

In 2004, ITP provided the subsea pipe design for 5 miles of cryogenic LPG lines for the Camisea project, which became operational in 2004. To date, ITP has the best field-proven thermal performance $\left(0.06 \mathrm{BTU} / \mathrm{ft}^{2} \mathrm{hr}^{\circ} \mathrm{F}\right)$ for subsea flowlines.

Two projects, the Camisea LPG pipelines and the LNG joint industry project, are described below to demonstrate the maturity of the ITP LNG pipe technology.

\subsection{Camisea Onshore and Offshore LPG Pipelines}

In 2002, ITP was selected to provide the onshore and subsea propane and butane lines for the Camisea project. Figure 1 shows buried portions of the propane, butane, naphtha, and diesel pipelines. The pipelines consist of 1 $\mathrm{km}$ buried, onshore pipelines and $3 \mathrm{~km}$ of buried, offshore pipelines. The conventional trestle originally proposed generated local objections based on high visibility and concern that it would interfere with fishing boat routes. The trestle was also higher cost. 


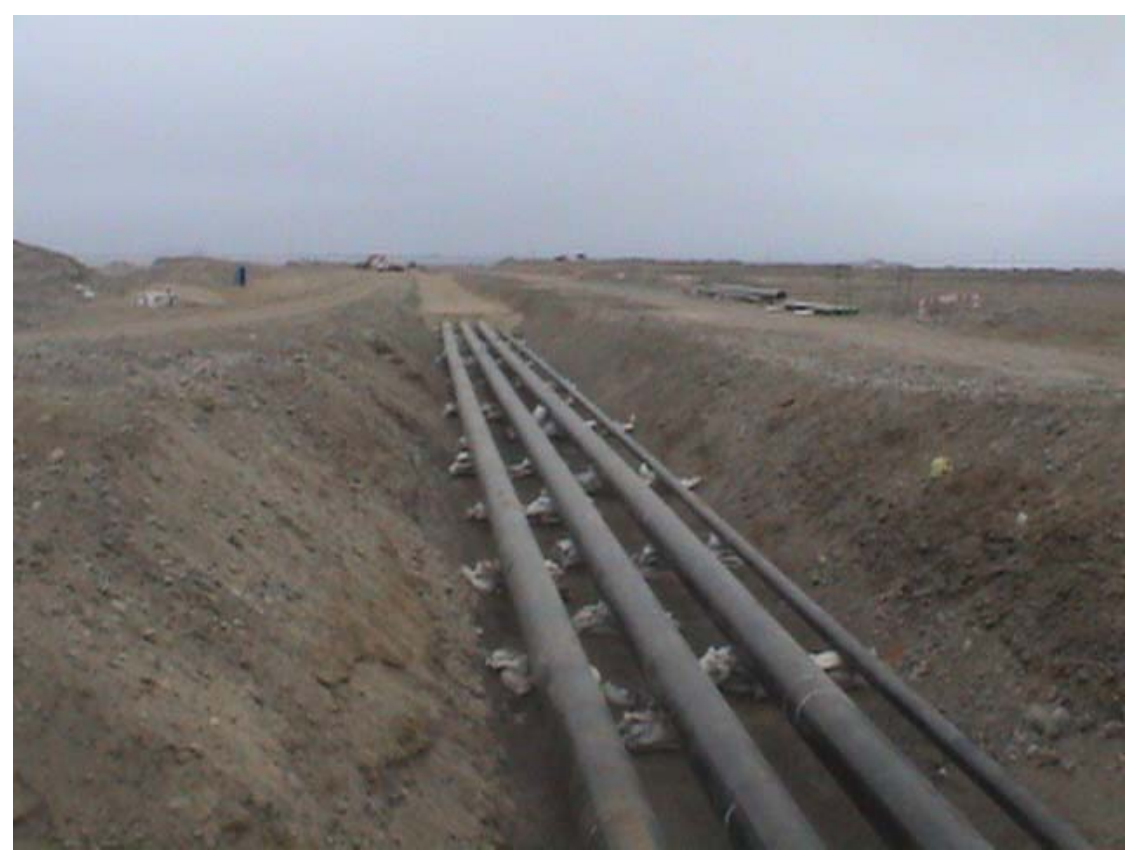

Figure 1: Buried Portion of the Camisea Pipelines

An offshore berth is connected to the Pisco fractionation plant via two 20" pipelines, which transport propane and butane at temperatures as low as $-45^{\circ} \mathrm{C}\left(-49^{\circ} \mathrm{F}\right)$. Each 20 ", carbon steel pipeline is insulated and encased in a 24", carbon steel outer pipe. In addition to the propane and butane pipelines, naphtha and diesel are also transported subsea in separate, uninsulated pipelines.

The ITP Izoflex insulation system provides a high thermal performance $\left(0.352 \mathrm{~W} / \mathrm{m}^{2}-{ }^{\circ} \mathrm{C}\right.$ or $0.062 \mathrm{BTU} / \mathrm{ft}^{2}-\mathrm{hr}^{\circ}{ }^{\circ} \mathrm{F}$ "as installed" and verified by field measurements by the operator). With the traditional insulation systems, the outer pipe diameter would be significantly larger.

There are significant construction and installation benefits, and accompanying reduced cost and risk, associated with minimizing field joints. This led to a decision to complete as much fabrication as possible onshore. Using the local labor workforce, 20 " pipe sections were insulated and inserted into the 24 " outer pipe at a temporary fabrication facility set up on-site in Peru.

With concurrence from the fractionation plant EPC contractor, space was set aside at Pisco so that the entire $3 \mathrm{~km}$ offshore pipelines were built completely onshore. These were placed on a railroad track and later pulled offshore as a unit. 


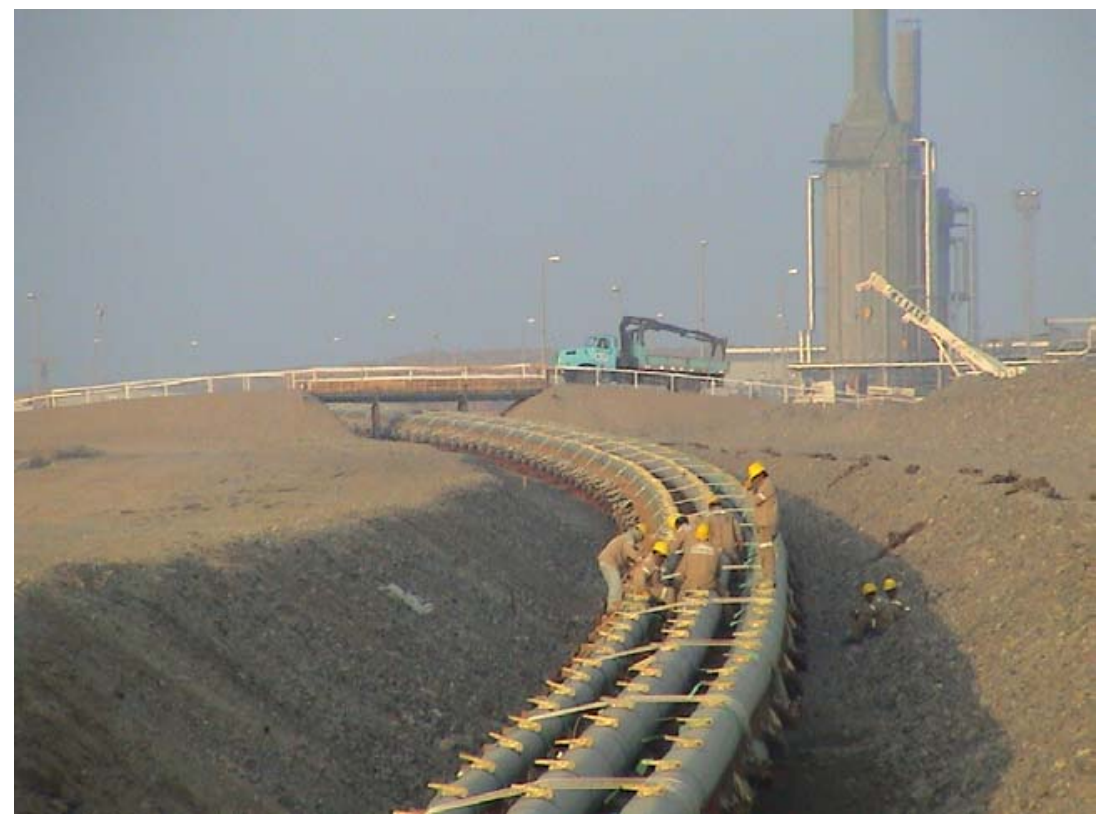

Figure 2 - Pipelines during installation

Four days after the trench was completed, the pipeline had been towed to the base of the platform (Figure 3).

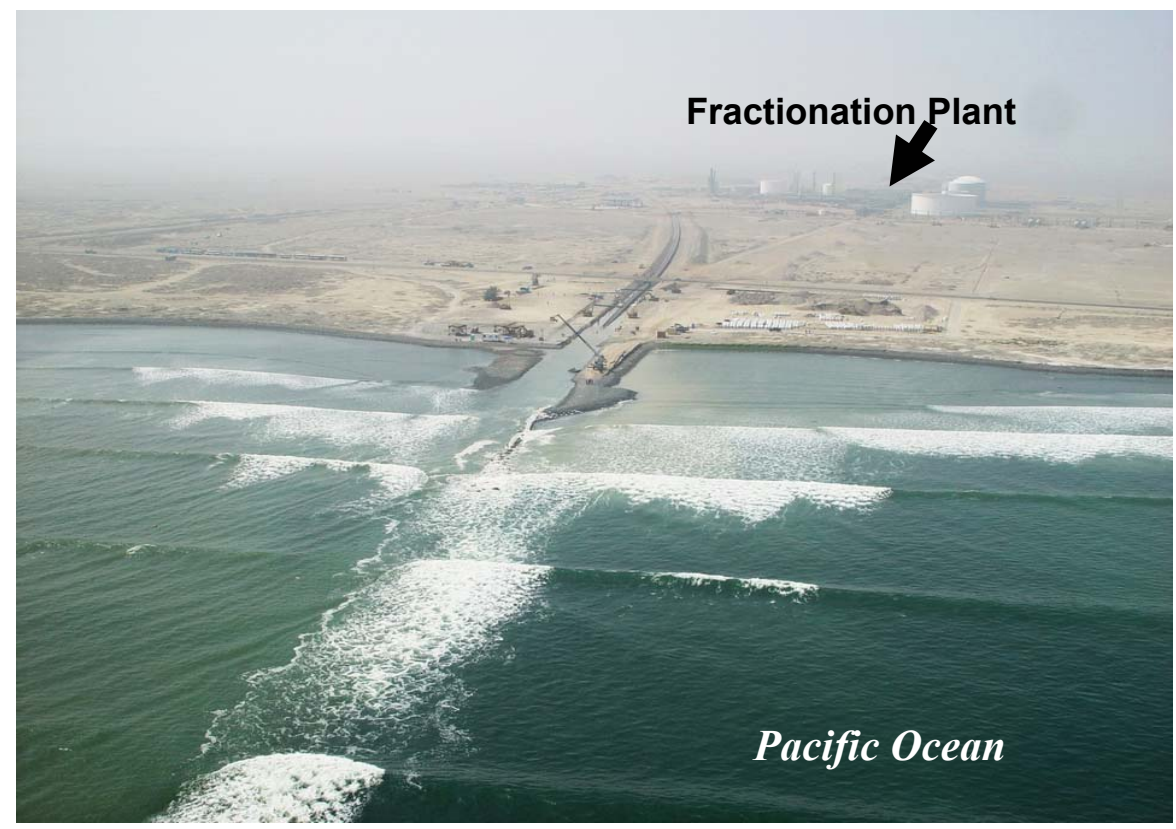

Figure 3 - Camisea site during pipe towing

The installation was completed in August 2004 and the pipelines became operational in September 2004 when the first load of butane was shipped. Field measurements of the thermal performance of the pipe-in-pipe loading system in operation confirmed that the design thermal performance was achieved.

While the system is designed to continuously circulate products through the cryogenic lines to keep the pipelines cold, the excellent thermal performance of the system results in such a low boil-off rate, that the pipelines can be 
shut-in between shipments for longer than a week, while still maintaining operating temperatures without recirculation.

The successful fabrication, installation, and operation of the Camisea cryogenic pipelines demonstrate many of the design, fabrication, and installation processes for ITP's LNG pipeline system design. In addition, the use of carbon steel pipe at $-45^{\circ} \mathrm{C}$ results in higher stresses in the carbon steel pipe than would occur at $-163^{\circ} \mathrm{C}\left(-261^{\circ} \mathrm{F}\right)$ with a $36 \%$ Ni steel pipe.

\subsection{Qualification of the ITP Subsea LNG Pipeline Joint Industry Project}

As noted above, in 2003, ITP was joined by four, major oil companies in a joint industry project with the objective of qualifying ITP's LNG pipe design for subsea transportation of LNG. In June 2004, the JIP successfully obtained ABS' "Approval in Principle" and DNV's "Statement of Feasibility" for the LNG pipe design for subsea service.

A full scale, triple wall, test section with a 24 " inner pipe was fabricated and tested. In summary, the deliverables from the JIP were:

- Demonstrated the complete fabrication process including full-scale bulkheads and $36 \%$ Ni steel inner pipe.

- Demonstrated the welding procedures required for 36\% Ni steel.

- Pressure tested the test section at 30 bar at ambient conditions.

- Fully instrumented the test section and thermally cycled the test section at liquid nitrogen temperatures to measure the mechanical stresses induced at cryogenic temperatures.

- Measured the thermal performance of the "as built" test section in boil-off tests with liquid nitrogen.

- Validated finite element modeling techniques by developing an FEA model of the test section and comparing results against actual physical measurements obtained during thermal cycling of test section.

- Provided cost and schedule estimates

The JIP has provided the ITP technology with a high degree of maturity for LNG application. The DNV and ABS certifications both state that no technological showstoppers were identified for this technology.

\section{ITP LNG Pipeline Specifications}

The advantages of the ITP LNG pipe design are:

- High thermal efficiency based upon the Izoflex insulation.

- Mechanical simplicity based upon the use of the $36 \% \mathrm{Ni}$ steel inner pipe that eliminates the need for expansion joints, internal bellows, or complicated connections.

- Simple, well-proven fabrication and installation techniques.

- Individual field-proven components $(36 \% \mathrm{Ni}$ steel for LNG tankers, Izoflex in subsea pipelines, and a standard pipe-in-pipe design).

- ITP's Izoflex insulation and the triple walled pipe design are patented. 


\subsection{Thermal Performance}

Several thermal criteria can be important in the design of an LNG pipeline. Those criteria are given below along with the performance of the ITP's standard LNG pipe-in-pipe design.

- Steady state thermal performance

$\circ$ ITP's standard design results in a U-value of $0.131 \mathrm{~W} / \mathrm{m} 2-{ }^{\circ} \mathrm{C}\left(0.023 \mathrm{BTU} / \mathrm{ft} 2-\mathrm{hr}-{ }^{\circ} \mathrm{F}\right)$ based on the I.D. of the inner pipe. This is the installed value with all manufacturing and installation tolerances included.

0 ITP's standard design gives a temperature rise of $0.1-0.2{ }^{\circ} \mathrm{C} / \mathrm{km}\left(0.3-0.6{ }^{\circ} \mathrm{F} / \mathrm{mile}\right)$ depending on the flow rate with roughly one third of this increase due to heat gained from the surroundings and two thirds of this increase due to frictional heating.

- Boil-off rate during shutdown

- ITP's standard design gives a boil off rate of less than $0.2 \% / \mathrm{hr}$.

- Warm-up time above operating temperature (time for complete boil-off)

$\circ$ The time to completely boil off the contents of the pipeline in a shut-in condition is greater than 3 weeks. During this time the pipeline will remain at LNG operating temperature without circulation.

- Cooldown time (time required to cool the pipeline from ambient to operating temperature)

- Due to the high thermal efficiency of the pipeline, the time to cool the pipeline down from ambient to LNG operating temperature is only approximately $15 \%$ longer than the residence time in the pipeline. That is, if it takes 20 minutes to flow LNG from the inlet to the outlet of the pipeline, it will take approximately 23 minutes from the start of pumping until the entire pipeline is cooled to LNG operating temperature.

- $\quad$ Surrounding soil temperature for buried pipes

$\circ$ For subea pipelines that are trenched and buried, the outer pipe is close to the seabed temperature and freezing of the soil surrounding the pipe is not an issue.

- For onshore pipelines that are buried, ITP's standard design can be buried up to approximately $1.5 \mathrm{~m}$ (4.9') without the surrounding soil temperature dropping below the freezing point of water. For greater burial depths, a greater insulation thickness can be added to maintain the soil temperature above $0{ }^{\circ} \mathrm{C}\left(32^{\circ} \mathrm{F}\right)$.

\subsection{Physical Limitations}

- Pipeline Length: There is no fundamental limit to the length of the pipeline. There may however be an economic limit to the length of a pipeline that is feasible.

- Pipeline Diameter: There is no fundamental minimum or maximum limit to the diameter of the pipeline. However, diameters greater than or equal to $\sim 38$ " will likely require that the inner pipe be welded from two plates, increasing the cost.

\section{Cost}

ITP's cost estimate for the standard design for a 24 " LNG pipeline is $\$ 3500 / \mathrm{m}(\$ 1100 / \mathrm{ft})$. The cost estimate includes all materials and labor to engineer and fabricate the pipeline. Installation of the pipeline is not included as this is highly site-specific. 


\section{ITP References}

ITP has been providing highly insulated pipe-in-pipe systems since the early 1990's with a continuous focus on reducing the overall cost of the subsea flowline (including the pipelay cost) while ensuring a high thermal performance. A summary of ITP's project experience is given in the table below.

\begin{tabular}{|c|c|c|c|c|c|c|c|c|}
\hline Project & Client & $\begin{array}{l}\text { Pipeline } \\
\text { Length }\end{array}$ & Location & $\begin{array}{l}\text { Water } \\
\text { Depth }\end{array}$ & Insulation & U-value & Application & Status \\
\hline Dunbar & Total & 15.5 miles & North Sea & $550 \mathrm{ft}$ & $\begin{array}{l}\text { Fiber } \\
\text { Glass }\end{array}$ & $\begin{array}{c}1.2 \mathrm{~W} / \mathrm{m}^{2} \mathrm{~K} \\
0.2 \mathrm{BTU} / \mathrm{ft}^{2} \mathrm{hr}{ }^{\circ} \mathrm{F}\end{array}$ & $\begin{array}{c}\text { Subsea oil \& } \\
\text { gas }\end{array}$ & In service \\
\hline ETAP & $\begin{array}{c}\text { Shell } \\
\text { ExxonMobil }\end{array}$ & $\begin{array}{c}30 \\
\text { miles }\end{array}$ & North Sea & $295 \mathrm{ft}$ & Izoflex & $\begin{array}{c}1.2 \mathrm{~W} / \mathrm{m}^{2} \mathrm{~K} \\
0.2 \mathrm{BTU} / \mathrm{ft}^{2} \mathrm{hr}^{\circ} \mathrm{F}\end{array}$ & $\begin{array}{c}\text { Subsea oil \& } \\
\text { gas }\end{array}$ & In service \\
\hline Tchibeli & $\begin{array}{l}\text { Total } \\
\text { ENi }\end{array}$ & $\begin{array}{l}15.5 \\
\text { miles }\end{array}$ & West Africa & $650 \mathrm{ft}$ & Izoflex & $\begin{array}{c}0.55 \mathrm{~W} / \mathrm{m}^{2} \mathrm{~K} \\
0.1 \mathrm{BTU} / \mathrm{ft}^{2} \mathrm{hr}{ }^{\circ} \mathrm{F}\end{array}$ & $\begin{array}{c}\text { Subsea oil \& } \\
\text { gas }\end{array}$ & In service \\
\hline JIP/GPRI & $\begin{array}{c}\text { ChevronTexaco } \\
\text { ConocoPhillips } \\
\text { ExxonMobil } \\
\text { Total, Shell } \\
\text { Marathon, BP }\end{array}$ & $240 \mathrm{ft}$ & Houston & NA & Izoflex & $\begin{array}{c}0.55 \mathrm{~W} / \mathrm{m}^{2} \mathrm{~K} \\
0.1 \mathrm{BTU} / \mathrm{ft}^{2} \mathrm{hr}{ }^{\circ} \mathrm{F}\end{array}$ & $\begin{array}{l}\text { JIP Test } \\
\text { Program }\end{array}$ & $\begin{array}{l}\text { Report } \\
\text { Available }\end{array}$ \\
\hline Bonga & $\begin{array}{l}\text { Shell, Total, ENi, } \\
\text { ExxonMobil }\end{array}$ & $\begin{array}{c}23 \\
\text { miles }\end{array}$ & West Africa & $3600 \mathrm{ft}$ & Izoflex & $\begin{array}{c}0.9 \mathrm{~W} / \mathrm{m}^{2} \mathrm{~K} \\
0.15 \mathrm{BTU} / \mathrm{ft}^{2} \mathrm{hr}^{\circ} \mathrm{F}\end{array}$ & $\begin{array}{c}\text { Subsea oil \& } \\
\text { gas }\end{array}$ & In service \\
\hline Camisea & $\begin{array}{l}\text { PlusPetrol, Hunt } \\
\text { SK, Techpetrol }\end{array}$ & $\begin{array}{c}5 \\
\text { miles }\end{array}$ & Peru & $50 \mathrm{ft}$ & Izoflex & $\begin{array}{c}0.35 \mathrm{~W} / \mathrm{m}^{2} \mathrm{~K} \\
0.06 \mathrm{BTU} / \mathrm{ft}^{2} \mathrm{hr}^{\circ} \mathrm{F}\end{array}$ & $\begin{array}{l}\text { LPG subsea } \\
\text { pipeline }\end{array}$ & In service \\
\hline LNG JIP & $\begin{array}{l}\text { ChevronTexaco } \\
\text { ConocoPhillips } \\
\text { ExxonMobil, BP }\end{array}$ & $80 \mathrm{ft}$ & France & NA & Izoflex & $\begin{array}{c}0.13 \mathrm{~W} / \mathrm{m}^{2} \mathrm{~K} \\
0.02 \mathrm{BTU} / \mathrm{ft}^{2} \mathrm{hr}{ }^{\circ} \mathrm{F}\end{array}$ & $\begin{array}{c}\text { LNG } \\
\text { qualification } \\
\text { project }\end{array}$ & $\begin{array}{l}\text { DNV \& ABS } \\
\text { approvals }\end{array}$ \\
\hline Forvie & Total & $\begin{array}{c}22 \\
\text { miles }\end{array}$ & North Sea & $460 \mathrm{ft}$ & Izoflex & $\begin{array}{c}0.8 \mathrm{~W} / \mathrm{m}^{2} \mathrm{~K} \\
0.14 \mathrm{BTU} / \mathrm{ft}^{2} \mathrm{hr}^{\circ} \mathrm{F}\end{array}$ & $\begin{array}{c}\text { Subsea oil \& } \\
\text { gas }\end{array}$ & In progress \\
\hline Rosa & Total, BP & $\begin{array}{c}41 \\
\text { miles }\end{array}$ & West Africa & $4600 \mathrm{ft}$ & Izoflex & $\begin{array}{c}0.9 \mathrm{~W} / \mathrm{m}^{2} \mathrm{~K} \\
0.15 \mathrm{BTU} / \mathrm{ft}^{2} \mathrm{hr}^{\circ} \mathrm{F}\end{array}$ & $\begin{array}{c}\text { Subsea oil \& } \\
\text { gas }\end{array}$ & In progress \\
\hline
\end{tabular}

\section{Contact Information}

Vicki G. Niesen

ITP InTerPipe, Inc.

16350 Park Ten Place

Suite 100-21

Houston, TX 77084

Ph: $\quad 281-492-2576$

Fax: 281-492-6281

Email: vicki.niesen@itp-interpipe.com 


\section{OPE, Inc.}

Cryogenic Pipeline Design 


\section{Cryogenic Pipeline Technology}

In 1996, OPE designed, procured, and installed the world's first sub sea LPG pipelines. These pipelines were used for product loading via shore to a buoy in West Africa, and the project was completed on a turnkey basis. Those pipelines were designed to operate at $46{ }^{\circ} \mathrm{F}\left(-43^{\circ} \mathrm{C}\right)$, and utilized pipe-in-pipe fabrication with insulation in the void between pipes to keep the LPG refrigerated. The pipelines have operated without maintenance from 1996 to today. When the client wished to expand their LPG loading capabilities, they returned to OPE to design a similar system with higher capacity. That second system was designed, fabricated, and installed in West Africa, and is now in operation. In addition to the LPG lines, OPE has designed, procured, and installed methanol lines for sub sea use.

As a natural extension of OPE's refrigerated sub sea pipeline experience, OPE has a patent pending for sub sea transportation of LNG. LNG transportation is similar to LPG transportation, except that the lower operation temperature of $-260 \mathrm{~F}\left(-160{ }^{\circ} \mathrm{C}\right)$ results in more severe thermal stresses. The source of the thermal stresses comes from the requirement to periodically connect the inner pipe to the outer pipe. As LNG flows through the pipeline, the inner pipe will be chilled to $-260^{\circ} \mathrm{F}\left(-160^{\circ} \mathrm{C}\right)$, while the outer pipe will be at the temperature of the seafloor, perhaps $75^{\circ} \mathrm{F}\left(24^{\circ} \mathrm{C}\right)$. This large temperature gradient causes the inner pipe to shrink while the outer pipe remains at its original length. The shrinking inner pipe therefore is placed in high tension, and the outer pipe is in compression.

There are multiple ways to accommodate the high thermal stresses that exist between the inner and outer pipes. One way is to select a material for the inner pipe that has a very low coefficient of thermal expansion. If the inner pipe has a low coefficient of thermal expansion and contracts only a small amount upon cooling to cryogenic temperature, then the thermal stresses will be quite low. LNG ships have used Invar (a 36\% iron-nickel alloy) for the inner membrane for LNG transportation for many years. Even though Invar has a very low coefficient of thermal expansion, the Invar ships have required periodic maintenance due to fatigue cracks, usually at the welds. OPE considered that periodic repair of sub sea pipeline weld cracks was unacceptable, and therefore did not pursue this approach.

An alternate material to consider for the inner pipe would be stainless steel. Type 316 Stainless is the alloy of choice for handling LNG above water aboard ships and also at plant facilities for LNG production and degasification. Unfortunately, Type 316 Stainless has a high coefficient of expansion, and also relatively low strength. Even though this stainless steel has adequate toughness for cryogenic temperatures, it is not suited for the inner pipe for handling LNG due to the very large stresses it would have to accommodate where the inner pipe connected to the outer pipe. For above water LNG 
applications, there is no need for an outer pipe, which results in thermal stresses that are low enough for the stainless steel to handle.

A third material for consideration for the inner pipe for LNG pipe-in-pipe applications is 9\% nickel steel. This is the alloy that OPE has chosen for its LNG pipelines. The addition of the nickel provides the steel with good low temperature toughness, high strength, and reasonable thermal expansion properties. This alloy has been used for LNG tanks and piping for more than 50 years, and has an excellent service history. It is weldable with conventional low temperature electrodes, and there are several suppliers of this alloy in the US, Europe, and in Japan.

There are other alloy systems that could be considered for the inner pipe, for example aluminum, titanium, and high nickel alloys such as Inconel. These alloys have been used successfully in cryogenic LNG applications, however they all have serious shortcomings when considered as candidates for the inner pipe material. Titanium and Inconel have adequate strength and toughness, but both are very expensive. Aluminum has adequate toughness and is much less expensive, but aluminum does not have adequate strength. A spreadsheet showing the advantages/disadvantages of the above materials is attached for reference.

The design of sub sea LNG pipelines must consider many different requirements, including ease of fabrication, installation, operation, long-term reliability, and of course cost. Being an offshore pipeline engineering company, OPE is well acquainted with the appropriate pipeline design codes and fabrication methods. Since most sub sea LNG lines are likely to be laid in shallow waters less than a few hundred feet deep, installation is likely to be made from conventional lay barges by the S-lay technique. However, large diameter pipe-in-pipe installation is still somewhat novel, and so the welding processes should be off-the-shelf wherever possible.

Considering that LNG ships are not likely to offload continuously into the pipeline, the pipeline will undergo continuous thermal cycling due to the pipeline warming between LNG cargos. One method to prevent the thermal cycling and thermal stress changes that occur with pipeline warming and cooling would be to continuously cycle the twin LNG lines whenever ships were not offloading. This creates an operational restriction, and so OPE designed their system so that thermal fatigue was not a limiting factor for pipeline life well in excess of 100 years.

OPE's patent pending design has several interesting features. The inner $9 \mathrm{Ni}$ pipe is high strength and carries the operational pressure. Using ASME B31.8 code for the design of the inner pipe (the pipe will not always be liquid full, so ASME B31.4 is not appropriate), the line could handle well over 1500 psi. This pressure is far above the maximum head attainable by ship's LNG pumps. The outer pipe will be low temperature carbon steel, and can easily carry the stresses from both installation and also the thermal compression stresses from operation. At locations where the inner pipe is connected to the outer pipe, the thermal stresses are transmitted across threaded connections. Threaded connections are very efficient in carrying large lateral loads, and they minimize the stresses that 
would have been seen at changes in geometry had the connections been welded. Welded closures that are required are moved away from the threaded connections to minimize stresses across welds. The threaded connections are load carrying only; they do not seal the inner pipe from the outer pipe. Seal welds to isolate the annular areas are specially designed so that stresses across seal welds are very low- perhaps $10 \%$ of the yield strength of the pipe.

The OPE design has been thoroughly tested with Finite Element Analysis (FEA). The FEA has shown that the design is robust, and has low stresses across welds. The threaded connection design was selected from commercially available threads that have been used for many decades, so there will be no limitation on the availability of suppliers of machined components that make up the LNG pipe-in-pipe system. These components have been priced from suppliers that currently supply similar items, both in the US and in Europe, so the prices that they have tendered are considered to be reasonable, but perhaps on the high side.

Having made patent application and having an advanced design proven by FEA, the next step in proving the design is to perform prototype testing. OPE is in discussion with suppliers that are interested collaborating on the test, and also in discussion with a consortium of LNG operators. It is anticipated that the prototype test will be performed late in 2005 using liquid nitrogen at $-320^{\circ} \mathrm{F}\left(-196^{\circ} \mathrm{C}\right)$. .

Using data received from suppliers and also offshore installation data from previous projects that OPE has performed we have calculated that the installed cost of 12,800 feet of LNG pipe is $\$ 19,126,800$. This price is for an inner pipe of 24 inches inside an outer pipe of 30 inches. The inner pipe is $9 \mathrm{Ni}$ steel, and the outer pipe is low temperature line pipe steel. The price includes engineering (including installation engineering), inspection and construction support during onshore and offshore fabrication, all materials, all welding consumables, and offshore installation including lay barge costs. A spreadsheet of costs that comprise the $\$ 19.1$ million total is attached for reference. 


\begin{tabular}{|c|c|c|}
\hline Material & Pros & Cons \\
\hline 1. 9Ni (OPE's choice) & $\begin{array}{l}\text { High strength } \\
\text { Long LNG service history, } \\
\text { Suppliers available in US, Europe, and } \\
\text { Japan } \\
\text { Weldable with conventional electrodes } \\
\text { Moderate Cost }\end{array}$ & $\begin{array}{l}\text { Moderate thermal } \\
\text { stresses }\end{array}$ \\
\hline 2. Invar $(36 \% \mathrm{Ni})$ & Very low thermal stress & $\begin{array}{l}\text { Fatigue cracks } \\
\text { High cost } \\
\text { Limited suppliers }\end{array}$ \\
\hline $\begin{array}{l}\text { 3. Type } 316 \text { Stainless } \\
\text { Steel }\end{array}$ & $\begin{array}{l}\text { Moderate cost } \\
\text { Readily available } \\
\text { Long LNG service history } \\
\text { Readily weldable }\end{array}$ & $\begin{array}{l}\text { Low strength } \\
\text { Very high thermal } \\
\text { stresses }\end{array}$ \\
\hline 4. Aluminum & $\begin{array}{l}\text { Moderate cost } \\
\text { Readily available } \\
\text { Long LNG service history } \\
\text { Readily weldable }\end{array}$ & $\begin{array}{l}\text { Very low strength } \\
\text { Very high thermal } \\
\text { stresses }\end{array}$ \\
\hline 5. Titanium & High Strength & $\begin{array}{l}\text { Very high cost } \\
\text { Welding is difficult } \\
\text { Limited suppliers }\end{array}$ \\
\hline $\begin{array}{l}\text { 6. High Nickel (Inconel } \\
615 \text { ) }\end{array}$ & $\begin{array}{l}\text { High strength } \\
\text { Long LNG service history, } \\
\text { Readily weldable }\end{array}$ & $\begin{array}{l}\text { Very high cost } \\
\text { Very high thermal } \\
\text { stresses } \\
\text { Limited suppliers }\end{array}$ \\
\hline
\end{tabular}




\begin{tabular}{|l|l|l|r|}
\hline \multicolumn{3}{|c|}{ Installed Cost of 12,800 Feet of LNG Pipeline } \\
\hline Materials & & & \\
\hline & & & $11,440,800$ \\
\hline Construction Support & & \\
\hline Construction Offshore & & \\
\hline Construction Onshore & & $3,576,000$ \\
\hline Weld Materials and Weld Quals & & \\
\hline & & & 58,000 \\
\hline & Including special welding equipment & & \\
\hline & & & \\
\hline & & & \\
\hline Various Special Fabrication Equipment & \\
\hline & & & \\
\hline Total & & & \\
\hline & & & \\
\hline
\end{tabular}




\title{
LNG Vaporization Technologies
}

\author{
Survey
}

For

\section{Vermilion 179}
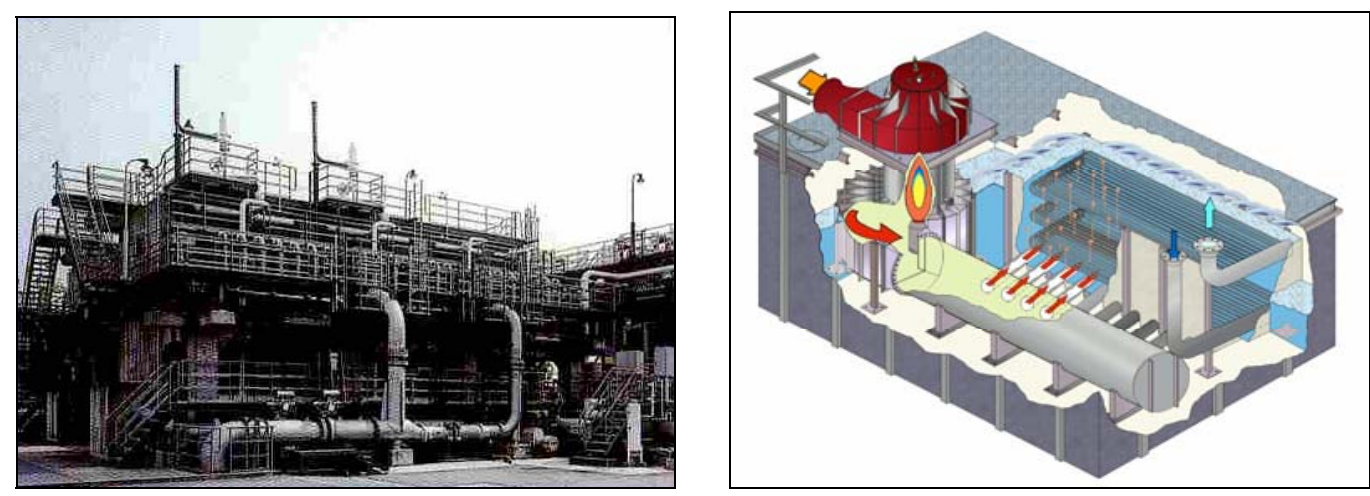

\section{amec ${ }^{\circ}$ paragon}

Prepared by

AMEC Paragon

10777 Clay Road

Houston, Texas 77041-5497 


\section{TABLE OF CONTENTS}

I. EXECUTIVE SUMMARY

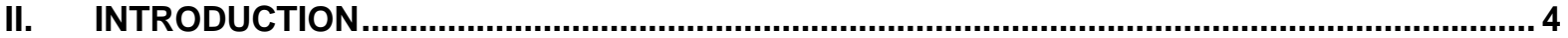

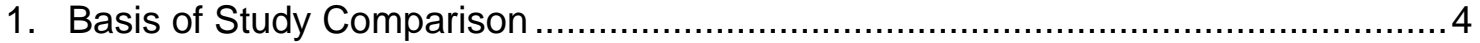

2. Cost Comparison (Based upon a 1.3 bscfd facility) ........................................ 5

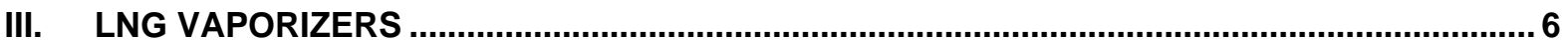

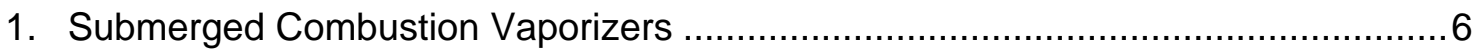

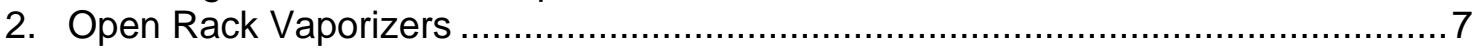

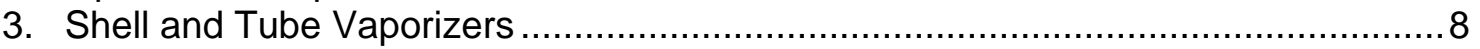

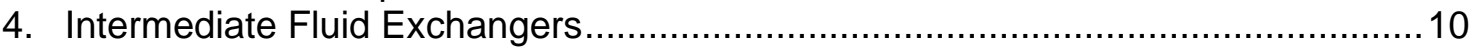

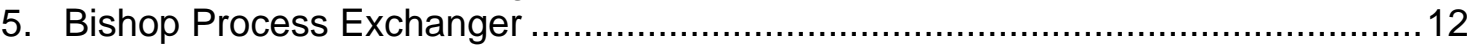

6. Forced Air (ambient) Vaporizers - Hybrid System ................................... 13

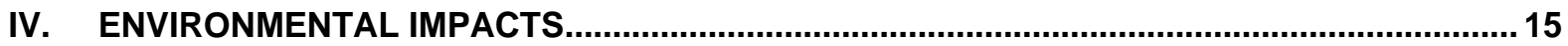

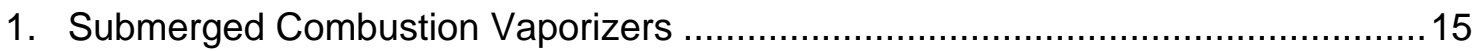

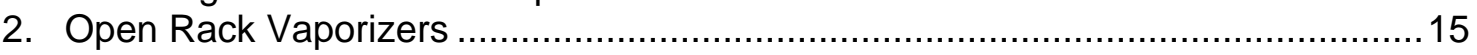

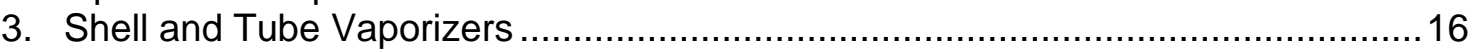

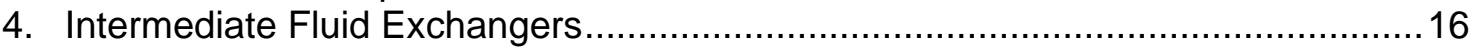

5. Bishop Process Exchanger .................................................................... 17

6. Forced Air (Ambient) Vaporizers - Hybrid System ....................................... 17

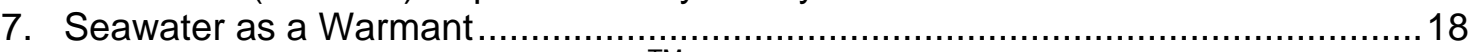

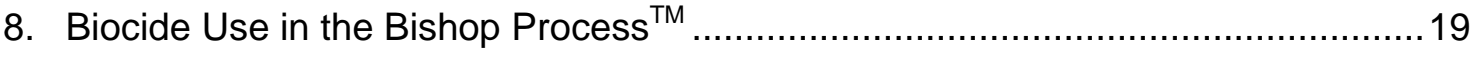

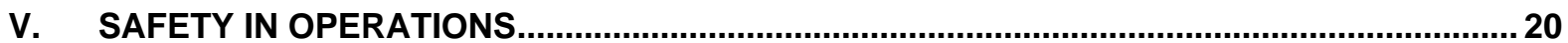

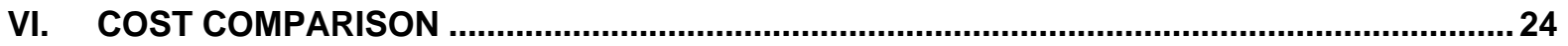

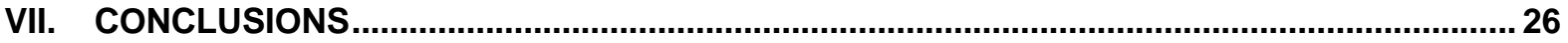

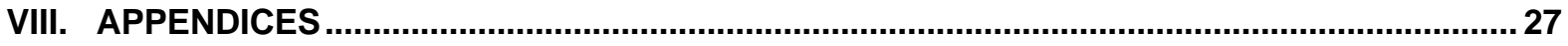

APPENDIX A: Heat Exchanger Techno-Economic Analysis .................................. 28

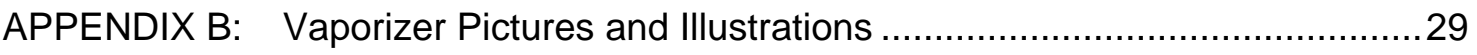

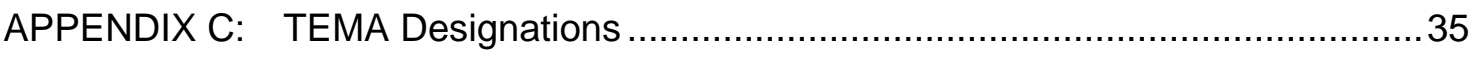

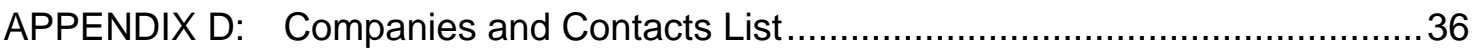

APPENDIX E: References Used by NOAA/NMFS With Regard to Impacts from Impingement/Entrainment..................................................... 38 


\section{EXECUTIVE SUMMARY}

AMEC Paragon, Inc. has prepared this report to compare and contrast the different types of technology currently available for LNG vaporization. The Study identifies each technology's strengths and weaknesses in both a qualitative and a quantitative manner, highlighting those points about each vaporizer that are deemed critical in the selection of preferred vaporizer technology.

Six different vaporization (re-gasification) technologies representing 8 vendors are evaluated. The technology and the particular vendor product used in this comparison are:

1. Submerged Combustion Vaporizers - T-Thermal, Sumitomo

2. Open Rack Vaporizers - Sumitomo

3. Shell and Tube Vaporizers - Chicago Process; E,L \& I

4. Intermediate Fluid Exchangers - Mustang Smart ${ }^{\mathrm{TM}}$

5. Bishop Process Exchanger - Butcher/Bishop

6. Forced Air Vaporizer - Cryoquip FAV

For the purposes of this Study, AMEC Paragon set forth specific design criteria common to all vaporizers to establish a suitable baseline for comparison. Each exchanger is analyzed within the following report and compared to the others. The primary factors affecting the Study's conclusions are:

- capital cost (including an assigned cost for deck space required)

- annual operating cost (power generation energy consumption, fired heater fuel cost and annual maintenance cost)

- "permit-ability".

Within the capital cost we assign an "area cost" of $\$ 600$ per square foot in recognition that some technologies require very large deck spaces to operate properly e.g. the IFE. Every comparison factor was ultimately tied to a specific cost derived within the Study. Soft issues like maintenance, whether proven technology, tendency to fouling were given a ranking, that in turn is directly tied to a cost factor included within the estimated annual operational costs.

The net present value (NPV) of each technology was calculated assuming $12 \%$ discount and a 25 year life. The annual operating cost and the total installed capital cost (including the cost for area utilized) were used in this calculation. The results are provided in Appendix A.

The best solution for any offshore terminal is the use of seawater in a basic shell and tube exchanger. This has removable, cleanable tube bundles and has the best weight, cost and energy ratings. However, there is a great deal of discussion regarding the permitting of any technology that might utilize seawater as the warmant. The issue is discussed further in Section IV and Tab 13. In summary, the issue deals with the amount of ichthyoplankton that would be destroyed and the resulting impact upon the adult fish population. There is a great deal of interagency discussion with the net result being a protracted debate with an un- foreseeable resolution that still may be challenged in the courts. This heavily impacts our recommendations, Fortunately, since alternative technology is available, the ability to permit a facility can move ahead. 
To facilitate the permitting process with minimal delay and in spite of the higher operating cost, AMEC Paragon suggests the permit be submitted assuming use of Submerged Combustion Vaporizers (SCV). This is recommended based on the belief that water-based exchangers cannot be permitted in the time allowed and that SCVs are a well-proven and accepted technology with emissions levels that will not be problematic at this site. Furthermore, if better alternative technologies emerge, the emissions impact would be less and thus a simple adjustment to the permit application would be submitted with minimal impact upon the schedule. Also, the economics would be better using an alternative as the SCV do carry a high NPV.

AMEC Paragon does strongly recommend that the FAV technology from Cryoquip be closely watched as their combination ambient air and auxiliary heater offers advantages vs. the SCV. This unit derives about $85 \%-90 \%$ of the warming from ambient air. The remainder of the heat is added via a fire-tube indirect heater unit. The key issue offshore will be the weight of the hybrid units. Cryoquip FAV unit with fans can fit within the two platform design and within the weight limitations. The use of this system would reduce the annual operating cost significantly. The full understanding of the space, weight, capital cost and energy consumption is being actively pursued by AMEC Paragon to determine the viability for an offshore location.

In addition, close watch should be maintained on any developments that would open the use of seawater. As seen in the assessment of Appendix A, the water-based shell and tube systems have the lowest overall NPV. 


\section{INTRODUCTION}

AMEC Paragon queried numerous LNG vaporizer equipment manufacturers and technology holders to obtain current information on their vaporization offerings. Each company was requested to complete and return a detailed questionnaire that was prepared by AMEC Paragon. Each manufacturer and technology holder was requested to provide specific data about their exchanger, as well as a current preliminary budgetary price estimate for the system. The list of manufacturers and technology holders contacted is attached as Appendix D.

There are several choices when it comes to choosing an LNG warming system. The most common in use globally are open rack vaporization (ORV) and submerged combustion vaporizers (SCV). These can be viewed as water based and non-water based warmant systems respectively. Alternative water based units include the shell and tube and Bishop Process ${ }^{\mathrm{TM}}$ exchangers. Alternative non-water based units include the intermediate fluid exchangers (IFE) and various ambient air vaporizers (AAV). Each of these types has been successfully tested and proven in other duties or in full-scale demonstrations, and each has potential for service in LNG vaporization.

\section{Basis of Study Comparison}

The Study requested data based upon a flow rate of $300 \mathrm{~m}^{3} / \mathrm{hr}$ (equivalent of 150 MMSCFD gas send-out) for use in the comparison. Some responses included this information and some provided data based upon a full terminal capacity of $1.3 \mathrm{bscfd}$. All of the vaporization technologies are considered to be linearly scalable and /or can be paralleled into multiple trains to achieve higher total facility flow rates. CAPEX and OPEX for larger units were determined by multiplying by the appropriate factors. AMEC Paragon Engineering specified the following:

- The LNG flow rate: 300 cubic meter per hour

- The inlet and outlet seawater temperatures: 40 deg F / 60 deg F

- The gas discharge temperature: 40 degree $\mathrm{F}$

- The maximum gas operating pressures: ANSI 1500

- The ambient air temperature: 65 degree $F$

- The LNG composition as typical of Nigeria.

Vendor responses varied widely in the amount of detail and two did not respond at all. Several vaporizer vendors did not respond to the questionnaire with data for the exact vaporizer size (duty) requested causing AMEC Paragon to normalize the Vendor data into 1.3 BCFD units for the final NPV analysis. Capital Expenditure (CAPEX) figures were taken from supplied vendor "kit" prices and, where appropriate, factored to obtain installed costs. For the Operations Costs (OPEX) the annual energy cost for fans, blowers, warmant pumps as well as for the fired heaters in some technologies was calculated using $\$ 5.00$ per million Btu, $1000 \mathrm{Btu} / \mathrm{cu} \mathrm{ft}$ and $10,000 \mathrm{BTU} / \mathrm{kW}$ as the cost factors. The cost of LNG pumping WAS NOT included as it was deemed common to all exchanger technologies.

Exchanger characteristics such as maintainability, fouling tendency, reliability, etc. were evaluated in a qualitative manner based upon communication with those who have been operating such units. Reliable maintenance cost data from the vendors was not forthcoming in their responses. In the absence of vendor data, an annual operations and maintenance cost index for these "soft" factors was developed and 
assigned based on this index. For example, a heat exchanger has a cost of $\$ 1,000,000$ and it has been given a maintenance ranking of "1" (one) based upon assumed ease / difficulty of maintenance. We would add $14 \%$ of the capital cost of the exchanger, or $\$ 140,000$, into the annual operating cost of the exchanger.

\begin{tabular}{|c|c|}
\hline INDEX & $\begin{array}{c}\text { PERCENTAGE of CAPEX for ANNUAL } \\
\text { MAINTENANCE* }\end{array}$ \\
\hline 1 & $14 \%$ \\
\hline 2 & $17 \%$ \\
\hline 3 & $21 \%$ \\
\hline
\end{tabular}

* based upon typical GOM equipment experience

In the offshore environment, there are two other factors that must be considered: 1 ) weight; 2) platform floor space. Both weight and space are precious commodities. Each of the technologies requires more or less space and the weights vary considerably. The objective is to keep the lift weights to less than 4000 tons. As an extreme example, the space for the Mustang unit will require a separate $120 \times 300$ foot platform to enable the air portion of their facility to have the unrestricted air flow required. AMEC Paragon included an "area capital cost" factor using $\$ 600$ per sq. ft. to account for this space requirement within the total capital cost amounts.

All of these factors are explained in the work sheet enclosed as Appendix A.

\section{Cost Comparison (Based upon a 1.3 bscfd facility)}

The recommendation of which exchanger to use was based principally on the net present value (NPV) of normalized CAPEX and OPEX costs. Individual component and system costs were normalized to a 1.3 billion standard cubic feet per day sendout of vaporized gas using a linear scale. An equipment installed cost (installation, piping, hookup, bulk materials, valves, instruments, controls, etc) was calculated using a factor of 3.0 times the equipment capital cost. A discount rate of $12 \%$ over a lifetime of 25 years was then used to determine present value from the total installed capital and operating costs.

Please see the notes in the Heat Exchanger Techno-Economic Analysis spreadsheet attached as Appendix A for details regarding calculations. The assumptions used in the analysis and the analysis of the "softer" issues are presented in the main page of the spreadsheet. 


\section{LNG VAPORIZERS}

\section{Submerged Combustion Vaporizers}

\section{Equipment Description}

Submerged combustion vaporizers (SCV) warm LNG inside a tube bundle within a concrete or stainless steel tank. Please see Figures 1 and 2 attached as Appendix $B$. The tank is filled with water that is continuously being warmed by injection of the exhaust of a combusted gas. Heat transfer in a submerged combustion vaporizer is very efficient. The fuel gas used for combustion is usually a side stream of the vaporized product. This side stream fuel gas typically represents 1.25 to $1.5 \%$ of the total LNG vaporized. A value of $1.3 \%$ was assumed in this analysis.

The submerged combustion vaporizers recommended by T-Thermal called for a plot area of approximately $25 \mathrm{ft}$ by $75 \mathrm{ft}$. The plot area included the actual exchanger, as well as an air blower that feeds the combustion chamber and proper equipment spacing to achieve adequate airflow and distance between exchangers. Sumitomo reported dimensions of the exchanger only. Dimensions for the Sumitomo SCVs were approximately $22 \mathrm{ft}$ by $10 \mathrm{ft}$. It is reasonable to assume that the plot area for the Sumitomo system will be very similar to that of the T-Thermal units. Plot plan areas referenced do not include plot area required for separation of fired equipment from other process equipment.

\section{Operational Issues}

Submerged combustion vaporizers have been in use for LNG service for many years, mostly in Europe, and are a well-proven technology in the US with installations at Elba Island, Lake Charles, and Cove Point. The major deficiency of these systems is that a significant portion of the vaporizer product feed must be burned to heat the water and vaporize LNG. This imposes a large annual operations fuel cost of up to $1.5 \%$ of the LNG vaporized. This is especially true for facilities designed to vaporize 1.5 to 3 Bcfd.

SCVs have a thermal cross exchange efficiency near $100 \%$. This high efficiency is obtained by exhausting the combustion products directly into the water bath. Obtaining efficiency in this manner concentrates exhaust products in the water bath, and the water inside the tank becomes very acidic. Water bath water must be monitored and treated to prevent equipment damage and to extend the life of the exchanger. In the offshore environment, it must be neutralized before discharge and then only with sufficient monitoring of temperature, $\mathrm{pH}$ and metals content. Concentration of combustion products in the water bath reduces total air emissions, but emission of $\mathrm{NOx}, \mathrm{CO}_{2}$, and $\mathrm{CO}$ is still significant and must be considered during environmental permitting. Low emission SCVs are available at a 10\% cost increase.

SCV exchangers are low maintenance and relatively simple to repair. Scheduled maintenance for these exchangers consists of surface cleaning and repainting every 2-3 years. The water bath is treated for ph level and fouling of exchangers is typically not an issue.

The SCV has very good mechanical integrity in continuous service duty. Product is circulated through stainless steel tubes submerged in the water bath the heat of which vaporizes the LNG, and each system is designed to withstand repeated 
expansions and contractions in system components due to heating and cooling from start-ups and shutdowns that normally would occur monthly. Excessive daily thermal and pressure stress, such as encountered in the cyclic Bishop Process ${ }^{\mathrm{TM}}$ could cause fatigue cracks at welded connections around the inner tubes. Usage on a floating platform, barge, FPSO would create a need to reinforce the structure for sloshing effects - not a technical barrier.

SCVs are relatively insensitive to changes in the local air temperature, water temperature, and humidity that can affect performance of other types of vaporizers. Submerged combustion vaporizers also have very rapid startup capability. The ability to readily control the supply of fuel to the combustors and therefore exhaust heat makes it easy to accommodate changes in demand for gas. Submerged combustion vaporizers have a turndown capability of approximately $10 \%$. No pumping of fluid other than LNG is necessary.

The air blower system for the exchangers requires approximately $800 \mathrm{hp}$ to force the combustion products through the water bath and into the exhaust.

An alternative SCV-type design is available from Cryoquip in which the combustion products are not fed into the water bath. The design is that of a fire-tube indirect heating unit that reduces the need for a large blower and treating of the bath water. The units are smaller and lighter than the SCV heaters. Heat recovery units capture any waste heat and are integrated into the power generation waste heat system.

\section{Open Rack Vaporizers}

\section{Equipment Description}

Open rack vaporizers (ORV) flow seawater over exposed finned tubes and vaporize the LNG inside the tubes. Please see Figure 3 attached as Appendix B. Seawater and LNG each enter separate headers, water at the top of the system and LNG at the bottom. The flows of each liquid are split into numerous streams, seawater flowing over the exterior of the finned tubes and vaporizing the LNG within. The ORV proposed by Sumitomo required 200 square feet of floor space, stands approximately 25 feet tall and can vaporize 169 MMSCFD. Each unit weighs about 8.5 tons and requires approximately $13,000 \mathrm{gpm}$ of seawater to warm the LNG to pipeline temperature.

\section{Operational Issues}

ORVs have also been in LNG vaporization service, primarily in Japan and Europe, for many years. ORVs typically are in continuous duty and use seawater as the primary heating fluid. This requires periodic replacement of the finned tubes - about every 3-5 years. The seawater must be treated with biocides to limit biological fouling of the various pumps, pipes, and heat exchangers in the system. ORVs are typically single pass systems, and the injected biocide is exhausted into the environment at the discharge point of the seawater outfall. Biocide discharge is of significant concern to the regulatory agencies responsible for maintaining fish habitat on the U.S. Gulf Coast and is the main hurdle to their use in U.S. waters.(reference Section IV)

Thermal and pressure stress encountered in the cyclic Bishop Process ${ }^{\mathrm{TM}}$, as in the SCV, may lead to cracks on welded connections of the heat exchange tubes. 
ORVs are highly susceptible to water temperature, and moderately susceptible to seasonal air temperature and humidity changes. Seawater is typically used as the warming medium and cold water reduces the efficiency of the vaporizers, as less heat is available in a given volume of water to warm the LNG. Open rack vaporizers are constructed with high surface area to liquid volume ratios and provide better heat transfer than shell and tube exchangers. The open rack vaporizer allows water to freeze at the base of the vaporizer with no danger of damaging equipment.

Regulatory permits and installed facilities pumps and piping will limit the volume of water that can be moved across the vaporizer in any given time period and ultimately the total number of BTUs that can be made available for heating LNG on any given day. The requirement for seawater inlet filters requires regular cleaning schedules that can temporarily take some units offline. Supplemental heating of the seawater feed, or a separate vaporization system, will be required for operations on cold-water days - this is typically done with SCV units.

ORVs can operate effectively at anywhere between $0 \%$ to $100 \%$ of maximum output capacity and also have a relatively quick start-up time. The 333 MMSCFD open rack vaporizer requires approximately $750 \mathrm{hp}$ to pump seawater through the system.

They are a well-proven technology and are very reliable. Maintenance requires surface cleaning, repainting, and re-spraying thermal coatings and corrosion coatings on the vaporizer tubes. This occurs every 2-3 years with the unit out of service for 3-4 weeks. Every 5-7 years major repairs and replacements are made to the exchanger surfaces.

\section{Shell and Tube Vaporizers}

\section{Equipment Description}

Shell and tube heat exchangers vaporize LNG by passing LNG through a bank of tubes that are surrounded by an external fluid, usually seawater. They differ from the ORVs primarily in the fact that the seawater in the shell and tube vaporizer is contained within the shell, as opposed to freely flowing over the finned tubes, as in the ORV and they are typically more compact. Shell and tube vaporizers come in a number of configurations. The two shell and tube exchangers examined in this study were not of the same configuration. The first exchanger, proposed by E.L. \& I., has the TEMA designation BXU (reference Figure 5 in Appendix C). It utilizes a bonnet cover head, cross flow shell, and U-tube bundle. LNG enters the tubes from the bonnet cover, travels down the exchanger, around the U-bend, and back down the exchanger to the exit at the bottom of the bonnet cover. The seawater enters the shell at the upper midpoint of the exchanger, flows across the tubes containing LNG, and exits at the lower midpoint of the exchanger.

The second exchanger, proposed by Chicago Power and Process, was of the TEMA designation NJN, but with modification. The shell and tube exchanger stands vertically and has no removable channel or head covers. The LNG enters the tubes at the lower channel cover, passes through the exchanger, and exits at the upper channel cover. The seawater enters through the side of the exchanger at an upper and lower inlet. The water flows across the LNG tubes and exits at the vertical midpoint of the shell. 


\section{Operational Issues}

Shell and tube heat exchangers have widespread use in numerous industries. Their use for LNG vaporization is still a relatively new concept. The main design issue is accounting for large thermal and pressure cyclic stresses on the tubes within the exchanger shell and at the tube sheet interface.

Maintenance and fouling are key factors in evaluating the shell and tube type exchangers. The CPP design received by the study called for fixed, welded heads. This means that the tube bundle inside cannot be removed or repaired without significant disruption to the process. The whole exchanger must be removed and sent out for repair. The E,L \& I BXU design has removable heads that allowed for onsite repairs. In this case, plugged tubes would be capped and not used again. Major repair can be done with a simple replacement of the tube bundle.

The mechanical integrity of the reviewed shell and tube heat exchangers is fairly good for continuous operation cryogenic service such as LNG. In the E.L. \& I exchanger, the U-tubes can freely contract inside the shell. In the Chicago Power and Process design, a bellows-like expansion joint in the shell will handle the thermal contractions of the interior tubes. C. P. and P. suggests that the seawater flow be started first and stopped last to minimize thermal gradient stresses. CPP utilizes AL6XN as the material of construction to satisfy the seawater corrosion effects and the cyclic cryogenic service.

Fouling is expected based on seawater quality, inlet screening systems and the amount of seawater required to warm the LNG. The shell containing the seawater has the potential to foul rather quickly and biocide treatment is a must for seawaterbased shell and tube exchangers. There is still a potential for frequent periods of down time to open the head on the exchanger to clean out the scaling on the shell. (Ideally, the fluid with the highest potential for fouling (seawater in this case) should be on the tube side for easier cleaning. This is not technically feasible in LNG applications for many reasons, including safety).

In designs with closely spaced tubes, there is a tendency for minute particles, such as seaweed that passed through the $4 \mathrm{~mm}$ water inlet screens, to "bridge" the space adding to the fouling problem. Any internal baffles used to direct the stream would form eddies and dead-zones that are likely to collect bits of material. The ability to clean these with back flushing or easy periodic access is essential. We have assigned a Maintenance Level Cost of 3 for the C.P.P. design based upon the welded heads. Based upon the likelihood of repairs and the need to clean the tube surfaces, AMEC Paragon strongly recommends the use of the BXU style shell and tube exchanger if water can be utilized.

The shell and tube exchangers using seawater have similar sensitivity to water temperature changes as were previously discussed regarding ORVs. Shell and tube exchangers using seawater are relatively insensitive to changes in air temperature and humidity.

Shell and tube exchangers also have up to a $100 \%$ turndown capability. The shell and tube exchanger from E.L. \& I. requires half the pumping power of a similarly sized open rack vaporizer. The shell and tube exchanger from Chicago Power and Process requires $50 \%$ more power than the similarly sized open rack vaporizer due to internal pressure drop due to the closely spaced tubes. 
Shell and tube vaporizers that utilize water for warming have the potential to freeze up. The water directly contacts the pipe containing the LNG at cryogenic temperatures and can rapidly freeze if sufficient water circulation is not maintained around the tubes and the temperature is allowed to locally drop below freezing. If localized eddys or areas of poor circulation are allowed to occur, layers of ice will build up, forming a layer of insulation and a barrier to heat transfer, reducing the overall efficiency of the exchanger.

Chicago Power and Process states that a minimum outlet water temperature of 43 degrees $\mathrm{F}$ and full seawater flow must be maintained at all times to prevent icing, regardless of LNG operating conditions. The relatively high outlet water temperature required by the shell and tube exchanger limits the total heat that can be transferred for any given water inlet temperature and compares unfavorably to ORVs.

It should be noted that shell and tube vaporizers do not require the use of seawater as warmant. Fluids such as propane or other hydrocarbon liquids could be used as an intermediate fluid in a closed loop system as well. Fluid use other than seawater in shell and tube vaporizers can help mitigate problems with fouling, but would require a cross exchange with another heating medium (air, combustion exhaust, or water). This would add cost and complexity but might be suitable if some external source of heat is near by.

\section{Intermediate Fluid Exchangers}

\section{Equipment Description}

Intermediate fluid exchangers (IFE) take many forms and are most associated with heat integration using heat sources such as power plant or petrochemical plant as source of heat. The intermediate fluid provides the coupling of the two sites that may be as much as several kilometers distance. The specific IFE in this Study is the one designed by Mustang Engineering, L.P. that uses forced draft ambient air heaters to warm LNG indirectly (reference Figure 5 in Appendix B). Ambient air is forced through the top of a fin-fan heater and vaporizes an intermediate fluid (propane, R22 , ammonia or other refrigerant) before exiting the bottom of the heater 10 to 25 degrees cooler, depending on ambient air temperature and humidity conditions. Heat transfer efficiency of the fin-fan heater is high, as it is designed to condense moisture from the air and work in a wet cell mode. On cold days, an auxiliary closed loop glycol heater provides supplemental heat as required. The intermediate fluid vapor is condensed and LNG vaporized in a second heat exchanger. The condensed intermediate fluid is then collected in a surge tank and pumped back to the fin-fan heaters and re-vaporized.

The fuel gas required to run the supplemental glycol heater is assumed to come as a side stream of the vaporized product. The vendor claims the Mustang's LNG Smart ${ }^{\mathrm{TM}}$ IFE yearly supplemental heating would require approximately $0.1 \%$ of total LNG vaporized for Gulf Coast locations. Mustang provided an example case studied in New Orleans, LA that saved $93 \%$ of the fuel required by an SCV, an annual fuel savings of $\$ 25.5$ million dollars. 
For a package that can vaporize 1.3 BCFD, a minimum plot area of approximately 45000 square feet is required. 34000 square feet of that plot area is devoted to the fin-fan air exchanger bays. The remaining area is required for glycol heaters, vessels, exchangers, and pumps. This area requirement and the overall weight of these units incur a significant "area cost" as we have discussed above.

\section{Operational Issues}

The LNG Smart ${ }^{\mathrm{TM}}$ system has not yet been installed at a LNG vaporization facility. The proposed regasification process essentially reverses the process used in LNG liquefaction and makes use of similar equipment and individual processes that have been used successfully in LNG facilities for years.

Maintenance for the LNG Smart ${ }^{\mathrm{TM}}$ is one area that requires further investigation. The process has more individual components than the other vaporization processes considered in the study and requires two exchangers in each fluid path to get the heat from the air or heater into the LNG - each exchanger loses efficiency. Each system will be comprised of multiple air exchangers with belt-driven fans, fan drive motors, a glycol-propane heat exchanger, glycol heater, glycol vessel, LNG-propane vaporizer, propane vessel, and pumps. Routine maintenance would be adjustment and replacement of the fan belts on the fin-fan coolers. Coatings maintenance to prevent corrosion of the aluminum wet cell fin-fan heaters may also become a longterm issue. The proposed IFE system will encounter none of the fouling issues addressed in the shell and tube vaporizers and open rack vaporizers as all of the working fluids are "clean".

The heating of the intermediate fluid in the LNG Smart ${ }^{\mathrm{TM}}$ system is done in stages; however, the LNG vaporizer still faces temperatures from -260 degrees $F$ to 40 degrees F. Stresses from thermal expansions typical of the cyclic Bishop ProcessTM are reduced by an expansion joint on the warm end of the exchanger. The expansion joint has been designed for a 25-year life. The vendor is currently investigating other heat exchanger designs (plate fin) to reduce or eliminate the potential thermal and pressure stress cracking concerns that would be more acute in the cyclic Bishop Process $^{\mathrm{TM}}$.

The LNG Smart ${ }^{\mathrm{TM}}$ exchanger is highly sensitive to air temperature and humidity changes but they are unaffected by water temperature changes. Changes in air temperature and humidity result in a larger portion of the propane being warmed by the glycol heater. Burning a side stream of the product provides the fuel gas required of this heater. Frequent use of the supplemental heater will be reduced by the heat from power generation waste heat is unlikely but would significantly increase operating costs. While the LNG Smart ${ }^{\mathrm{TM}}$ exchanger will burn more product than the ORVs fuel gas fired supplemental heat system on cold-water days, the overall energy OPEX differences between the ORV and the LNG Smart ${ }^{\mathrm{TM}}$ exchanger are likely small as there are no water pumps.

The LNG Smart ${ }^{\mathrm{TM}}$ vaporizer has a 100\% turndown capability. Pumping power for the LNG Smart ${ }^{\mathrm{TM}}$ system, which includes the glycol recirculation pumps and propane pumps, is approximately $15 \%$ of the pumping power for the open rack vaporizer. The fans for the forced draft system require approximately $4000 \mathrm{hp}$. And the supplemental heaters requires added fuel costs vs. ORV. 


\section{Bishop Process Exchanger}

\section{Equipment Description}

The Bishop Process Exchanger (BPE) is essentially a shell in tube exchanger (reference Figure 6 in Appendix B). The unique design utilizes turbulent flow of a water warmant in the annulus between an HDPE outer shell and an inner cryopipe. The unit is characterized by long U-tube runs of up to 275 feet length (essentially replacing multiple small tube surface area efficiency with single long runs of larger bore pipe). This technology was developed in 2002 as part of a U.S. Department of Energy sponsored study that was seeking to commercialize the Bishop Process ${ }^{\mathrm{TM}}$. At that time there were no LNG exchangers designed for daily cyclic duty of pressures from ambient to ANSI 900 or 1500 and ambient to cryogenic temperatures. (As a result of this D.O.E. study, many vendors have prepared designs for this duty.)

The outer pipe is a nominal 10 inches and made of HDPE or FRP. Its role is to contain and channel the low pressure water. The inner pipe is a 4.5 inch cryogenic pipe made of an alloy of $27 \%$ nickel and $7 \%$ moly. This material gives the corrosion resistance, the strength for the cyclic temperatures and pressures and can be made thin enough to assure good heat transfer. Each BPE unit consists of four (4) shell \& tube arrangements configured into a U-tube all within a structural frame. $75 \mathrm{~m} 3 / \mathrm{hr}$ of LNG passes through each of the four runs giving a overall LNG rate of $300 \mathrm{~m} 3 / \mathrm{hr}$. Water passes from one end and empties at the other end. Thus there are eight inlet sites and eight outlet sites for the water. The ratio of water to LNG is 10:1.

The individual BPE units will be fabricated, inspected, and hydro-tested in shop conditions to reduce costs and assure long service life.

The overall LNG vaporization rate will give rise to 30 of these units all rated at ANSI 1500 for the Vermilion 179 application. This will require a separate 3-level platform of at least 337 feet and about $90 \mathrm{ft}$ wide to accommodate these vaporizers. The area cost penalty is quite high but the energy cost is rather low. (a weight penalty has not been adopted but the BPE would be at the upper limit of offshore installation weight).

\section{Operational Issues}

These are very simple units and robust in design. Repair is quite simple as the outer shell can be removed to reach the inner pipe and easily replaced. The Bishop Process can accommodate some down time to individual exchanger units enabling the design of a closed loop cleaning/biocide system. The seawater side of the exchanger can be flushed with the recovery of all the fluid for proper disposal. Concentrated biocide would be stored on the platform and would be cycled through each BPE in turn with the expended biocide returned to the tank for disposal and replenishment by shore-based services. Higher concentrations will reduce the downtime required to clean.

The large numbers of pipes and valves together with the cyclic nature of the operation lends us to assign a Level 2 maintenance cost. The use of the BPE for Freedom is not recommended due to the size, weight and better water based alternatives such as shell and tube designs. Furthermore, the issues surrounding the use of any water for LNG vaporization could cause significant permitting delays. 


\section{Forced Air (ambient) Vaporizers - FAV System}

\section{Equipment Description}

Forced Air Vaporizers (FAV) use warm outside air to vaporize LNG passing through the exchangers' inner pipes. Please see Figure 4 attached as Appendix B. In the Cryoquip unit, the natural convection of the air, and consequently heat transfer rate, is enhanced by the height of the exchanger (between 45 feet and 80 feet). Fans for a forced draft are not needed because of the natural convection and height. However, their use can reduce the total numbers of units and can reduce the defrost cycle. Fans are considered essential offshore to reduce area requirements. The footprint of each exchanger is 8 feet wide by 8 feet deep, but additional spacing of approximately two (2) feet per side is required between vaporizers for access, manifolds and valves.

Cryoquip FAV units for Freedom would consist of seven (7) trains, each train consisting of nine (9) vaporizers arranged into 3 banks of 3 vaporizers. Each vaporizer unit measures $8 \times 8 \times 45$ feet (reference 7 in Appendix B). Within each train, the individual banks are being cycled into and out of operation to satisfy the defrost requirements. One bank is defrosting on standby for every two banks that are in service. The standby bank will be brought online to maintain constant vaporization as another bank is being taken offline. There is great flexibility to adjust the switching time to minimize the need for supplemental heat.

Each bank will operate for up to six hours and then defrost for one hour. The 21 banks among the 7 trains are sequenced such that a fresh bank is coming online about every 3 minutes. Fresh banks produce a much higher gas outlet temp and the vaporizer about to defrost may be 80 degree lower in outlet. The blended gas outlet is somewhere about the average of those two extremes: about -20 degree $F$ for a 65 degree design point.

In their modeling analysis, Cryoquip found that once the gas temperature starts to increase above - 60 degrees $F$, the temperature difference between the ambient air and the LNG causes the incremental surface area for each additional degree of vaporization to increase. There is a "sweet spot" at about -60 to -45 degrees $F$ that would be the lowest gas outlet temp for any given vaporizer. The switching (much like a PSA unit for gas) keeps the active banks near the sweet spot.

\section{Operational Issues}

FAVs are another recent entry into the LNG field. They have been used for many years as coolers, but not until recently have they been adapted to work with LNG. FAV have long been used in hospitals and industrial plants to vaporize cryogenic liquids such as carbon dioxide, carbon monoxide, oxygen, helium, nitrogen ,argon, etc. These typically are smaller units operating on the same principle but with a "critical mission" reliability requirement. Standard designs include operating pressures up to 15,000 psig.

The type of frost that forms is a very light powder vs hard ice one might envision. The defrost cycle naturally occurs rapidly ( $30-45$ minutes) and would be reduced if air blowers were installed. 
Maintenance for FAV exchangers is very minor. Each vaporizer has 128 finned tubes in a "once through" design with the LNG inlet at the bottom and dense-phase gas out the top. Should a tube fail, it will be plugged off and not used. No other maintenance is scheduled for the exchanger. There are considerable automated switching valves to which we have assigned a Level 2 maintenance cost. Manual isolation valves will enable the entire vaporizer to be removed from the platform during major overhaul. This helps to reduce downtime and scheduled maintenance. Also, fouling is almost non-existent as well. The vendor Cryoquip states that corrosion in salt air is not a problem for the exchangers.

These units also have great mechanical integrity. The design by Cryoquip utilizes a floating serpentine system that self-corrects for any expansions and contractions. Cryoquip states that thousands of these units that face similar cyclic duties are in use worldwide.

FAVs are sensitive to changes to air temperature and humidity. FAVs depend on air temperature, humidity, and wind speed more than the other types of LNG vaporization systems. The overall size of these systems increases significantly to allow for worst case operating conditions. The FAVs quoted by Cryoquip used an average air temperature of 65 degrees $F$ for Gulf Coast conditions (a conservative design temperature). Ambient air vaporizers also have a $100 \%$ turndown capability. No pumps or blowers are required but fans will be used.

\section{Hybrid System}

A promising solution for Freedom is a custom designed hybrid system of FAV units and supplemental heat from the turbine Waste Heat Recovery Unit (WHRU) in parallel with an auxiliary heater (Figure 7 in Appendix B). The worst-case scenario temperatures in the Gulf Coast region can reach below 30 degrees $F$ at which point there is insufficient ambient driving force to sufficiently warm the LNG. In this scenario the ambient vaporization would heat the LNG to - 40 degrees F instead of the -20 degree $F$. Supplementary heating brings the gas to the desired temperature.

The size and price of the supplementary heating system has been estimated for this report. AMEC Paragon and Cryoquip are collaborating to define the best solution with layouts, manifold piping, safety assessments, maintainability, etc. The objective is to use air for $85 \%$ - $90 \%$ of the heating and then use heater for the remainder. This should be a good tradeoff between the full SCV and full air unit. This design has fewer exchangers (better efficiency) than the IFE unit and requires much less deck space. The units are simple, robust and easily maintained. 


\section{ENVIRONMENTAL IMPACTS}

This section will review the environmental issues, advantages, and disadvantages of each vaporization technology. Economics and operational issues are covered in the other sections of this report.

\section{Submerged Combustion Vaporizers}

Submerged Combustion Vaporizers (SCV) have substantial air emissions and produce some water effluent (discharge). The air emissions are primarily NOx (nitrous oxides), $\mathrm{CO}_{2}$ and $\mathrm{CO}$. Both $\mathrm{NOx}$ and $\mathrm{CO}$ have National Ambient Air Quality Standards for the protection of human health (primary standards). That is, the emissions must be estimated and modeled to prove compliance with EPA standards. If the emissions exceed certain thresholds in the emissions estimate (e.g. $>250$ tons per year for any pollutant with a standard), the facilities qualify as a "major source" and must be permitted through a program called Prevention of Significant Deterioration (PSD) and the major equipment of the facility must then be designed with Best Available Control Technology (BACT).

The Freedom site is in open waters but still subject to some air quality requirements. Taken with the emissions from the GT units, the total emissions may alert some agency to the potential for creating an island of NOx non-compliance. This is an area of uncertainty so we have taken the conservative approach as if this were on land in Texas.

AMEC Paragon has estimated the air emissions without any controls and with TCEQ (land-based) recommended BACT controls. Without controls, the SCV equipment for a 1+ BCFD train facility using SCVs would exceed the PSD threshold for NOx, and would thus be required to use BACT. Once BACT controls are applied, the SCV would not exceed the PSD threshold for NOx or CO. The typical BACT for NOx is a Selective Catalytic reduction process utilizing liquid ammonia. - not something we want offshore. The objective is to stay well below any thresholds. However, whether the facility produces PSD level emissions or not, the facility will still be able to be permitted.

Regarding water effluents, the SCV technology produces water that must be treated before discharged. One of the air emissions controls involves injecting the exhaust gases into the bath of the heat exchanger, to recapture some of the heat, and to use the water as a "scrubber" to remove $\mathrm{NOx}, \mathrm{CO}_{2}$ and $\mathrm{CO}$. However, once these gases are dissolved in the water bath, the water becomes very acidic. The $\mathrm{pH}$, or acidity, of the water must be neutralized before it is discharged. This is a manageable problem, but one that requires some space for water treatment and adds some additional operational expense.

\section{Open Rack Vaporizers}

The ORV technology has virtually no air emissions. However, the technology requires a considerable flow of seawater. For the 1+ BCFD train vaporization case, AMEC Paragon has calculated that the seawater flow rate would be about 100,000 gpm, or about $144 \mathrm{MMgpd}$. This equates to 52.56 billion gpy. 
Once-through water use like this is known to have adverse effects on aquatic organisms through impingement and entrainment. Impingement is when animals get caught on the intake screens and are either injured or killed. This effect is well documented in the study of impingement at power plants. Modern design has reduced the impact to some extent by reducing the velocity of the water at the screen, and by designs that allow some of the organisms to be washed off the screen and returned to the water body through a return channel. Entrainment is when very small organisms (fish eggs or larvae, shrimp or crab eggs or larvae, or zooplankton [microscopic animals]) pass through the intake screens and pass through the plant equipment. There are several sources for injury or mortality for organisms that are entrained. These include:

- Temperature changes of 20 degrees $\mathrm{F}$ or more through the plant

- Pressure changes passing through the water pump

- Abrasion against the sides of the pipeline, and

- Traces of the biocide flush used to keep the plant equipment from fouling.

Most current researches assume that these four sources of injury result in $100 \%$ mortality to the organisms that are entrained. Please note the Bishop Process ${ }^{\mathrm{TM}}$ will minimize the biocide toxicity.

\section{Shell and Tube Vaporizers}

Shell and tube vaporizers will have most of the same environmental issues as ORVs. Since seawater is used to supply the heat the issues of impingement and entrainment are identical. The comment regarding biocide usage is identical to the ORV.

All of the same NOAA/NMFS objections to ORV are likely to be applied to this technology as well. This would result in the same time delays as discussed above for ORVs.

\section{Intermediate Fluid Exchangers}

The main environmental issues with Intermediate Fluid Exchangers (IFE) are the noise from the units, the production and disposal of water, and air emissions from supplemental heat sources.

AMEC Paragon does not have any data regarding the operational noise of the fans on IFE units, but the noise from this technology is likely significantly greater than any of the other technologies reviewed.

Two intermediate fluids are used in this process. The primary intermediate fluid that is used for heating the LNG will be propane, R-22, Enviro-Kool, or ammonia. All of these fluids are operating in the system at, or near, their bubble point and would evaporate quickly if spilled. The second intermediate fluid is used to provide supplementary heat to the primary intermediate fluid when necessary. This secondary intermediate fluid is likely to be glycol. The probability of small leaks or spills of glycol is moderate, but with proper design, the probability of release of this fluid outside the boundaries of the facility is small. 
The water produced (from condensing moisture from the air) is supposedly similar in quality to local rainwater but would likely have to be continuously monitored for ph, metals, oxygen content. Therefore, AMEC Paragon has assumed that the disposal or discharge of this water should not require treatment. Final judgment on this water effluent issue should await definitive data from the vendor on the quality of the water to be discharged. There is a large amount of condensation that is pure water dropping into the ocean creating a reduced salt area plume with little oxygenation. Given the size of the facility it seems logical to be able to spread the water across a huge volume of water as if it were rain water - thus the impact is deemed minor.

A supplementary heat source is required for cold ambient air temperature operations. The heat source will be a fired heater, most likely provided as additional capacity in the hot oil heater already installed as part of the process equipment. Supplemental heating is only required on a small number of days (less than 30 days per year) at this site and total emissions from this heat source should be an order of magnitude lower than of the air emission discussed for the SCVs above.

Environmentally speaking, this is a very benign vaporization technology.

\section{Bishop Process Exchanger}

The BPE carries essentially the same environmental characteristics as shell and tube vaporizers and thus will also have most of the same environmental issues as ORVs. Since seawater is used to supply the heat, the issues of impingement and entrainment are identical. The usage of biocide is identical to that of the ORV.

All of the same NOAA/NMFS objections to ORV are likely to be applied to this technology as well. This would result in the same time delays as discussed above for ORVs.

\section{Forced Air (Ambient) Vaporizers - Hybrid System}

The Cryoquip technology is essentially a passive radiator where LNG is pumped through finned tube ambient air heat exchangers. There is minimal fan noise, no intermediate fluids and no secondary exchangers making this more efficient than the IFE. There is a high potential for fog on warm days but the natural air circulation in open water is unlikely to build a fog cloud that would hamper operations. The fog would occur only when offloading a ship already at the dock. This fog will dissipate at the cool air from the exchangers and mixes with the warmer air away from the exchanger banks.

Moisture from the air will be condensed on the heat exchangers and will provide a small source of fresh water. The water produced will be similar in quality to local rainwater. AMEC Paragon assumes that the disposal or discharge of this water should not require much treatment. Final judgment on this water effluent issue should await vendor data on the water quality.

There will occasionally be a need for supplementary heating from waste heat and from fire-tube indirect heaters - similar to small SCVs. The number of days supplementary heating will be required and the total emission from supplementary heating will be similar to those described for IFEs above. The need for supplementary heating, the same as the IFE technology, means there will be some air emissions that are estimated to be $8 \%-15 \%$ of the pure SCV technology. 
In the absence of water as a warmant, this is the best alternative technology and, environmentally speaking, a very benign vaporization technology.

\section{Seawater as a Warmant}

The preferred warmant for vaporization is seawater. However, there is an overriding regulatory issue that may preclude its use for The Freedom project.

During the review of LNG applicants proposing the use of ORVs for facilities both offshore and onshore, the National Oceanic and Atmospheric Administration (NOAA) - National Marine Fisheries Service (NMFS) has objected that the ORV technology has the potential to have significant impacts to fish eggs and larvae (ichthyoplankton) and invertebrate eggs and larvae. NMFS has objected to the technology and has requested that these applicants be required to use Best Technology Available (BTA). NOAA has interpreted BTA to be one of the other available technologies such as SCV, ambient air vaporizers, or shell and tube vaporizers.

The objections and requested studies that NOAA has imposed on onshore applications have led some applicants (ExxonMobil) to withdraw the ORV technology from their onshore permit applications to FERC. According to the Galveston NMFS office personnel, ExxonMobil withdrew ORV from the Golden Pass application because of the time delay that would be required to comply with NOAA/NMFS requested studies. PES estimates that to comply with the NMFS requested studies could cause a one-year delay, and perhaps more, of the permitting process. Additionally, there is no guarantee that once the studies are complete, that NOAA would withdraw their objections to the ORV technology.

NOAA/NMFS assume that all larvae are killed if caught in the seawater intake system. The regulations require a user to estimate the overall population by species by season to arrive a population density. This is then used to calculate the numbers of larvae killed and eventually the impact on the adult population. The mitigation in the case of ChevronTexaco Port Pelican was a marine fish hatchery to replace the estimated population killed. This remedy is no longer considered viable as the perceived impact affect many species that cannot or have not been successfully farm raised.

An added concern is the lack of clear remediation if ongoing monitoring indicates the actual kill rate varies from the predicted and permitted rate. The methods and procedures for sampling are not established. If there is a discrepancy, the remediation step is not clear and the Owner risks production impact until a resolution is determined.

There may be some movement to rationalize the environmental impact as evidence by the recent February 9, 2005 USCG announcement of errors in their modeling system that grossly overstated the impact of Shell's use of seawater on the adult red drum population. The initial estimate of $8.5 \%$ has been reduced to "below $1 \%$ " but this may still be too high for some interests. It is AMEC Paragon's opinion that the issue is in the political arena vs rational scientific discussion.

FERC will continue to defer to the technical advices and requests of NOAA/NMFS when it comes to assessing the impacts of impingement/entrainment on marine fisheries. The U.S. Coast Guard is likely to follow the advice of NOAA/NMFS. Given this current permitting environment, the submission of ORV technology for offshore 
LNG facilities will result in additional pre-application studies delaying the submittal of the application, and potentially resulting in delayed action by the FERC during the NEPA review of the application, if they cannot receive concurrence from NOAA/NMFS that ORVs are acceptable. The pre-application delay could extend to as much as one year, if NOAA/NMFS requests one year pre-construction monitoring of ichthyoplankton. Or the year of monitoring could be split between pre-application and the time that the FERC is reviewing the application. Additionally, once the studies are concluded, there is the additional risk that the resource agencies (NOAA/NMFS) may not withdraw their objections to ORV technology. In any case, it is highly unlikely that the FERC would complete the Final EIS without resolving this issue with NOAA/NMFS.

\section{Biocide Use in the Bishop Process ${ }^{\mathrm{TM}}$}

One key aspect of the Bishop Process ${ }^{T M}$ technology is the ability to have a closed biocide system. The Bishop Process ${ }^{\mathrm{TM}}$ is by nature cyclic with periods of idle time between ship offloading activities. During this downtime one or more exchangers, seawater pumps and portions of the inlet and outlet piping can be isolated and flushed with concentrated biocide served from a storage tank on the platform. The flush process is rotated through all units over the period of a week. The biocide inventory is maintained by a shore-based service provider. Minimal biocide is released into the environment.

While developed for the Bishop Process exchanger, the concept works as well with ORV and shell and tube designs as long as the Bishop Process ${ }^{\mathrm{TM}}$ is utilized. 


\section{SAFETY IN OPERATIONS}

\section{LNG HAZARDS RESULT FROM THREE (3) MAIN FACTORS:}

- Its cryogenic temperature

- Its flammability characteristics

- Its dispersion characteristics

\section{LNG HAZARDS:}

LNG is a cryogenic liquid, with a temperature of approximately $-162^{\circ} \mathrm{C}\left(-260^{\circ} \mathrm{F}\right)$. By itself LNG will neither burn nor explode. However, like other cryogenic liquids LNG can cause freeze burns, and upon prolonged exposure, it can cause more serious injury.

Another hazard of LNG stems from the flammability of vaporized LNG. Each volume of LNG, when vaporized and warmed to ambient temperature, will produce a vapor volume more than 600 times the volume of the LNG. Initially, the vapor will be close to the liquid temperature, and hence heavier than air. As more heat is absorbed from the ambient, and the vapor becomes lighter than air, it will rise and can be carried away by the wind. This results in the so called "vapor cloud". LNG vapors in a 5\% to 15\% (by volume) mixture with air are highly flammable. If a source of ignition is found there is high risk that the flame will propagate towards the evaporating liquid pool and ignite the pool. The ignition of the vapor cloud can cause extensive damage to life and property. Hence, prevention of spills, and provisions to deal with spills in case they were to occur, are major factors in designing safety systems.

\section{SAFETY PROTECTION SYSTEMS}

Protection systems to counter the LNG Hazards can be divided into two categories:

- Passive systems: built-in design features that prevent or minimize the effect of hazardous situations. A good example is the dispersed asset of the multiple trains for the Freedom site.

- Active systems: measures to detect hazardous situations in a timely manner and provide ways to avoid or minimize damage from these situations.

\section{SAFETY FEATURE INSTALLATION}

A centralized spill, fire, and combustible gas alarm, and control system will provide input to an information management system. The primary purpose is to provide plant operators with a central facility for monitoring the conditions of accidental spills, fires, and the release of combustible gases. It will also provide the operators with information and a means of responding to emergencies involving these conditions.

The main distributed control system, DCS console, is the physical operator/alarm and control system interface and will be located in the central control room, which is manned 24 hours a day. Various lighted push buttons, digital read outs and annunciates provide the operator with complete monitoring and control capabilities.

Automatic detection devices, manual alarms and audible and visual signaling devices will be strategically located throughout the terminal. Hazard detection and alarm signaling devices will report to the central control room and tie- in to the DCS. 
Automatic detection devices will include flame, fire and heat, smoke, low temperature and combustible gas detectors. The hazard detection system will be designed to minimize the time a spill, leak or fire might go undetected by installing multiple and redundant different detectors within the terminal to detect gas, fire, low temperatures and low and/or high operating pressures outside normal operating levels. The detectors will be located to provide warning as quickly as possible. The detector signals are continuously monitored by an online computer in the control room that identifies a hazardous condition within the terminal to alarm and locate the situation for operating personnel.

The following safety and firefighting features will be installed:

a. Spill-collection system will be designed to deflect and prevent LNG spills. The LNG leak detection system is typically designed to detect spills and to shutdown the plant less than two minutes after a spill, and the LNG spill can be contained in the drainage basin area. The LNG spill sump will be designed for removing water and keeping debris free.

b. Fixed high expansion foam protect will be provided in accordance with NFPA-11A.

C. Hydrants approximately 90 meters apart and firewater monitors approximately 60 meters apart to be installed on the firewater main. Isolation valves in the fire water main will be provided.

d. Automatic actuation for the firefighting system will be automatic, actuated by combustible gas detectors and low temperature detectors.

\section{EMERGENCY SHUTDOWN (ESD) AND EMERGENCY DEPRESSURIZATION (EDP) SYSTEM}

The isolation systems will be located in different areas along with equipment with fire, explosion and toxicity potential risks. An emergency shutdown (ESD) and emergency depressurization (EDP) system will be provided to protect plant personnel, plant equipment and the environment in case of an emergency such as a fire, potential dangerous process upset, or LNG leak. The ESD system will isolate the unit/system where an incident is occurring from the adjacent units/system. The EDP system will reduce the hydrocarbon inventory of the system and it's pressure. Equipment and piping are divided into sections called ESD zones, considering the plot plan and process flow.

The EDP system shall be fail- safe and include a fire sensitive element on the actuator supply for immediate depressuring. The primary design guide is API 521 and the requirements as highlighted in its Performance Standard. EDP valving shall be a fail open, actuated ball or gate valve. LNG process temperature $(-160 \mathrm{C})$ discharges from relief valves shall receive a full review for appropriate materials of construction and possible inclusion in the positive material identification program. Results shall be documented in the subsequent HAZID/HAZOP findings.

\section{OVERPRESSURE PROTECTION}

The relief system will be to provide overpressure protection on all pressure vessels and piping systems. ASME pressure vessel code, API RP 520, API RP 521 and API RP14C provide the principal consensus engineering recommended practice that will be followed. However, these recommended practices allow options that are sometimes conflicting and were developed for onshore plant systems. To reduce PSV and Flare design capacity, a HIPPS (High Integrity Pressure Protection System) concept is utilized. 


\section{LNG PUMP DISCHARGE DEADHEAD PROTECTION}

The combined 1st Stage and 2nd Stage LNG pumps take the LNG from the suction header at 70 psig and pressure up to 3000 psig (MAOP) for salt cavern storage or to 1100 psig for send out to the pipelines. The 1st Stage (Low-pressure) LNG pump discharge pressure is 1100 psig with shut off pressure at 1245 psig, and the discharge header is ANSI 900 with a MAWP of 2220 psig. Therefore, no deadhead over-pressure protection for the low-pressure LNG pumps is provided.

The 2nd Stage (High-pressure) LNG pump discharge pressure is up to 3000 psig (MAOP) with shut off pressure at 3100 psig. These 2nd Stage LNG pumps are connected to a $1500 \mathrm{lb}$ ANSI header with a MAWP of $3660 \mathrm{psig}$. Therefore a pressure relief is located at the discharge of the 2nd Stage LNG pumps set at 3220 psig, discharging back into the suction header of the 2nd Stage LNG pumps.

\section{HIGH INTEGRITY PRESSURE PROTECTION SYSTEM (HIPPS)}

Primary overpressure protection for each of the terminal's systems is provided by an emergency shutdown system (ESD) that isolates the system from continued flow upon sensing a high pressure (HP) condition. This essentially isolates each system from another enabling an over-pressure system to be designed specifically for that system.

Secondary overpressure protection is provided by pressure safety valves (CSVs) designed to prevent overpressure within each system. This approach works well for the Marine LNG Pipeline, the combined LNG pumps, storage caverns themselves (each can be isolated) and piping and equipment on the Cavern Support Platform.

For over pressure protection of the vaporizer and header down stream of the LNG pumps the Basis of Design calls for a HIPPS system to be installed. When HIPPS is applied as a pressure protection system, an appropriate Safety Integrity Level (SIL) for each specific HIPPS needs to be developed during the detail-engineering phase of this project. These HIPPS systems are an independent, instrumented shutdown system designed for high reliability, which will provide the secondary level of overpressure protection usually provided by a pressure safety valve (PSV) system. HIPPS uses redundant pressure sensors and control logic to close shutdown valves (SDVs) when the pressure exceeds the normal emergency shutdown pressure. With a HIPPS system PSV, the corresponding relief piping and flare sizing will be significantly reduced in size since they now only needed to size to accommodate SDV leakage / fire relief requirements.

A high integrity pressure protection system, HIPPS, will be used for emergency shutdown of high-pressure LNG pumps and the seawater supply system for effective depressurizing of the Bishop Exchangers.

The Freedom Terminal blow-down criteria is to provide depressurizing on all equipment that processes LNG to achieve 100 psig or $50 \%$ of the vessel design pressure, which ever is lower, within 15 minutes.

\section{FLARE DESIGN CRITERIA}

A high-pressure flare system, including a high-pressure flare stack, high-pressure flare knockout drum, and collection system, will be provided. This system will collect relief valve and emergency blow-down discharges from throughout facility. A separate platform will be provided for the flare stack. 
The flare will be sized to fit the actual inventory of the LNG and the gas that is not sequestered in the caverns or in the pipeline. In the Bishop Process ${ }^{T M}$ we have no inventory of LNG other than what is in the pipes and vaporizers. The LNG delivered to the vaporizer can be isolated at the ship and within the pipeline from the dock to the pumps.

API RP 521 Section 3.15 contains extensive guidance relative to relief requirements for external fire. To paraphrase, a pressure relief device adequate for the external fire scenario should be installed for all vessels, heat exchangers, and filters with a liquid inventory that is located with in a potential fire zone. The guidelines are less clear on the treatment of vapor filled equipment that may be subject to thermal failure prior to overpressure. In these cases, other preventive measures such as depressurizing systems may be more appropriate.

Based on the work performed on the Vermilion 179 site and the dispersion of assets due to the multiple trains, the estimated relief requirement in term of heat input from a fire is based upon one train being affected. This is approximately $1 / 3$ the requirement of the Vermilion site.

The flare system is designed with a disposal capacity of 150 MMSCFD capacities. All equipment and vessels with design pressures higher than 285 psig and equipped with pressure relief and blow-down valves are connected to this system. The design of the flare boom and flare tip is selected so that the maximum radiation level at the base of the boom does not exceed 1500 Btu/hr.-ft. ${ }^{2}$ with a 60 mph wind speed directed toward the platform.

The $190 \mathrm{ft}$. long flare boom and flare tip will be installed on a separate flare platform.

\section{FLARE SCRUBBER:}

The high-pressure flare system includes a flare scrubber. It is a cryogenic pressure vessel designed to entrain liquids from the gas stream in accordance with API 521, based on a liquid droplet size no larger than 400 microns. The vessel design pressure will be at least 1.5 times the expected backpressure or 150 psig, whichever is greater. The flare scrubber is sized for one (1) minute based on design inlet rate of the vaporizer train i.e. $166 \mathrm{~m}^{3} / \mathrm{min}$. 


\section{COST COMPARISON}

Manufacturers and technology holders of each type of vaporizer were contacted and requested to design an LNG vaporizer that could vaporize 300 cubic meters per hour of LNG (approximately 150 MMSCFD of gas). A current budgetary price estimate for the system was reported by each manufacturer or technology holder and was incorporated into the comparison. A list of assumptions made by AMEC Paragon to perform this comparison is attached as Appendix A and may be found on the "General" tab. Table 1 shows a summary of vaporizers and costs.

The total capital cost of all required equipment was calculated and normalized to 1.3 BCFD, a suitable size for a single Freedom LNG train. This was done to normalize the data since the designs submitted by the vendors each varied in production ability. The installation cost of the system was calculated by applying a factor of 2.5 to the bare equipment costs ( a typical Gulf of Mexico factor). An "area cost" was calculated to reflect the variable plot space required by the different technologies. - Note the heavy area cost for the IFE and BPE units. The sum of the total capital cost, the area cost and installation cost yields the total installed cost.

Annual operating cost was determined by considering three factors:

Energy - $\quad$ based on the total power generation required @ the stated heat rate for GT power @ a fuel price of $\$ 5 / \mathrm{mm}$ Btu

Fuel - $\quad$ annual cost of product burned for fired heat at $\$ 5 / \mathrm{mm}$ Btu

Maintenance - maintenance cost based on percentage of capital cost.

The three annual operations cost factors were calculated, totaled, and normalized to 1.3 BCFD using a linear scale. Again, this was done to normalize the data for a better comparison.

The net present value (NPV) cost of each system, which includes CAPEX and OPEX, was determined using a discount factor of $12 \%$ and a project lifetime of 25 years.

\section{Results of NPV Comparison}

The vaporization system that had the highest NPV e.g. the submerged combustion vaporizer systems from: 1) T-Thermal, 2) Sumitomo with the NPV of \$302 million and $\$ 290$ million, respectively. The LNG Smart ${ }^{\mathrm{TM}}$ intermediate fluid vaporizer had an NPV at $\$ 301$ million. The ORV system follows the IFE with a NPV of \$197 million. The FAV unit is almost the same at $\$ 183$ million. The BPE systems from Butcher / Bishop had present value cost of $\$ 104$ million. The shell and tube exchanger from Chicago Power and Process had the lowest cost of $\$ 97$ million. The NPV amounts for ORV and Shell and Tube exchangers do not include CAPEX or OPEX for supplemental heaters. Notes on the calculations of the costs may be found in the table below and on the "Summary" and "CASE 1" tabs of Appendix A.

NOTE - the data supplied by E.L. \& I was considered to be incorrect to the point we did not make any final comparisons - the data is included for information only. 


\section{Scaleability}

There was concern, initially, about cost and capacity scale-up from the study's design specifications. However, after talking with T-Thermal and Sumitomo, scale-up does not seem to be an issue. T-Thermal indicated a cost increase of approximately $15 \%$ for a capacity increase of $25 \%$. After examining several of Mustang's different designs, it was determined that the LNG Smart ${ }^{\mathrm{TM}}$ system is also scaleable. The Bishop Process Exchanger is directly scaleable as determined in the D.O.E. study. The FAV units are directly scaleable to the vaporization rate specified. 


\section{CONCLUSIONS}

The D.O.E. Study was based upon a specific design basis that incorporated the Bishop Process Exchanger. That design was used because at the time there was no alternative for the required cyclic duty. Since the project has evolved and been completed, there have been many vendors step forward with designs to meet the cyclic duty in both temperature and pressure required for the Bishop Process ${ }^{\mathrm{TM}}$.

If water-based solutions can be permitted, AMEC paragon would recommend the shell and tube design. If there is an immediate requirement to permit a facility, AMEC Paragon recommends Vermilion 179 Freedom consider filing the Deepwater Port Permit application utilizing SCV units. This is based upon the following strategy.

1. Water based vaporizers will be subject to considerable technical, legal and legislative delays.

2. SCV are a well-proven and accepted technology with emissions levels that will not be problematic at this site.

3. The economics of alternative technologies promise to be superior to the SCV.

4. Any other technology would have less air emissions and thus would fall under the level being sought.

5. Continued examination of the Cryoquip hybrid system that should offer operating cost advantages.

6. Monitor the regulatory activity related to water usage to determine whether its use could be considered.

AMEC Paragon recommends that continued monitoring of the FAV system and plans to work with Cryoquip to get good capital cost and operating cost numbers. If this technology appears sound at some point into the permitting process, a revision to the permit would be requested. Obtaining a revision should be relatively easy, as we would be decreasing the air emissions without significantly degrading any other environmental factor. AMEC Paragon will continue to work with Cryoquip to define the best solution for Vermilion 179.

Though it shows great promise, we do not recommend forwarding the Mustang LNG Smart $^{\mathrm{TM}}$ process technology as the recommended vaporizer technology to FERC at this time. The reasons for this are twofold. The first is that while promising, it is still an unproven technology and we should await further testing of the units prior to committing to this vendor. Second, the air emissions for this technology are significantly less than the only other viable vaporizer technology (SCVs). If we were permitted for the LNG Smart ${ }^{\mathrm{TM}}$ process and then for any reason had to revert to SCVs we would then be faced with justifying to regulators the tenfold increase in emissions. 


\section{APPENDICES}

Appendix A - Heat Exchanger Techno-Economic Analysis

Appendix B - Vaporizer Pictures and Illustrations

Appendix C - TEMA Designations

Appendix D - Companies and Contacts List

Appendix E - References Used by NOAA/NMFS 


\section{APPENDIX A: Heat Exchanger Techno-Economic Analysis}




\section{Heat Exchanger Techno-Economic Analysis}

This spreadsheet is to aid in the comparison of different types of heat exchangers. The comparison will be done assuming cyclic temperatures and pressures for each exchanger, all located in an offshore environment for the cases of $300 \mathrm{~m} 3 / \mathrm{h}$ and $10000 \mathrm{~m} 3 / \mathrm{h}$ of LNG. These exchangers must be capable of going from ambient temperatures and pressures to $-260{ }^{\circ} \mathrm{F}$ and up to ANSI 900 pressures, with the possibility of going to ANSI 1500 in future designs. Heat exchangers to be examined will include Submerged Combustion Vaporizers (SCV), Open Rack Vaporizers (ORV), Shell and Tube Vaporizers (S/T), the Bishop Process Exchanger (BPE), and Intermediate Fluid Exchangers (IFE) like Mustang's LNG Smart ${ }^{\mathrm{TM}}$.

The following will be the basis for the cost comparison:

\begin{tabular}{|c|c|c|}
\hline Estimated Heat Rate & 10,000 Btu/kWhr & (estimated using average heat rates for gas turbines) \\
\hline $\begin{array}{l}\text { Gas Pricing } \\
\text { Offshore "Area" Cost }\end{array}$ & $\begin{array}{l}\$ 5.00 / \mathrm{MM} \mathrm{Btu} \\
\$ 600.00 / \mathrm{sqft}\end{array}$ & $\begin{array}{l}\text { (projected E.I.A. long term pricing) } \\
\text { (platform space cost estimated from recent / current GOM projects) }\end{array}$ \\
\hline Annual Operating Time & $6,960 \mathrm{hr}$ & $24 \mathrm{hr} / \mathrm{day}, 7$ days/wk, $52 \mathrm{wks} / \mathrm{yr}$ \\
\hline
\end{tabular}

The section below describes the rating system for maintenance and reliability:

$\begin{array}{llll}\text { Maintenance: } & 1 & \text { Good } & \text { Repairs are easily performed in the field by maintenance personnel (14\%). } \\ & 2 & \text { Average } & \text { Field repairs can be done but may often require work from a specialist (17\%). } \\ & 3 & \text { Poor } & \text { Little ability to field repair. Most repairs will require shop work (21\%). }\end{array}$

(Note: Typical annual maintenance costs may be as much as $7-11 \%$ of the capital investment for a complex system in a relatively extreme environment. It is believed that these numbers may easily be doubled to more accurately reflect the costs for this facility. Factors of $14 \%$, $17 \%$, and $21 \%$ were used in this analysis.

\begin{tabular}{|c|c|c|c|}
\hline \multirow[t]{3}{*}{ Fouling Tendency: } & 1 & Good & Very little fouling \\
\hline & 2 & Average & Moderate fouling \\
\hline & 3 & Poor & High fouling tendency \\
\hline \multirow[t]{3}{*}{ Mechanical Integrity: } & 1 & Good & High resistance to cyclic duty problems \\
\hline & 2 & Average & Moderate resistance \\
\hline & 3 & Poor & Low resistance \\
\hline \multirow{3}{*}{$\begin{array}{l}\text { Operational Issues: } \\
\text { (Availability) }\end{array}$} & 1 & Good & Insensitive to weather or other environmental factors \\
\hline & 2 & Average & Moderate sensitivity \\
\hline & 3 & Poor & Very sensitive \\
\hline \multirow[t]{3}{*}{ "Permitability" } & 1 & Good & Insensitive to air and water quality/use permits \\
\hline & 2 & Average & Moderate sensitivity \\
\hline & 3 & Poor & Very sensitive \\
\hline \multirow[t]{3}{*}{ Installed Base History } & 1 & Good & $>5$ successful installations \\
\hline & 2 & Average & 1 to 4 \\
\hline & 3 & Poor & No installations \\
\hline
\end{tabular}

SPECIAL NOTE: The data provided by E.L. \& I did not seem to be accurate. AMEC Pargon relies entirely upon the data provided by the vendors. This data was deemed inaccurate. The column is highlighted in yellow 


\section{Heat Exchanger Comparison for 1.3 BCFD Sendout Basis}

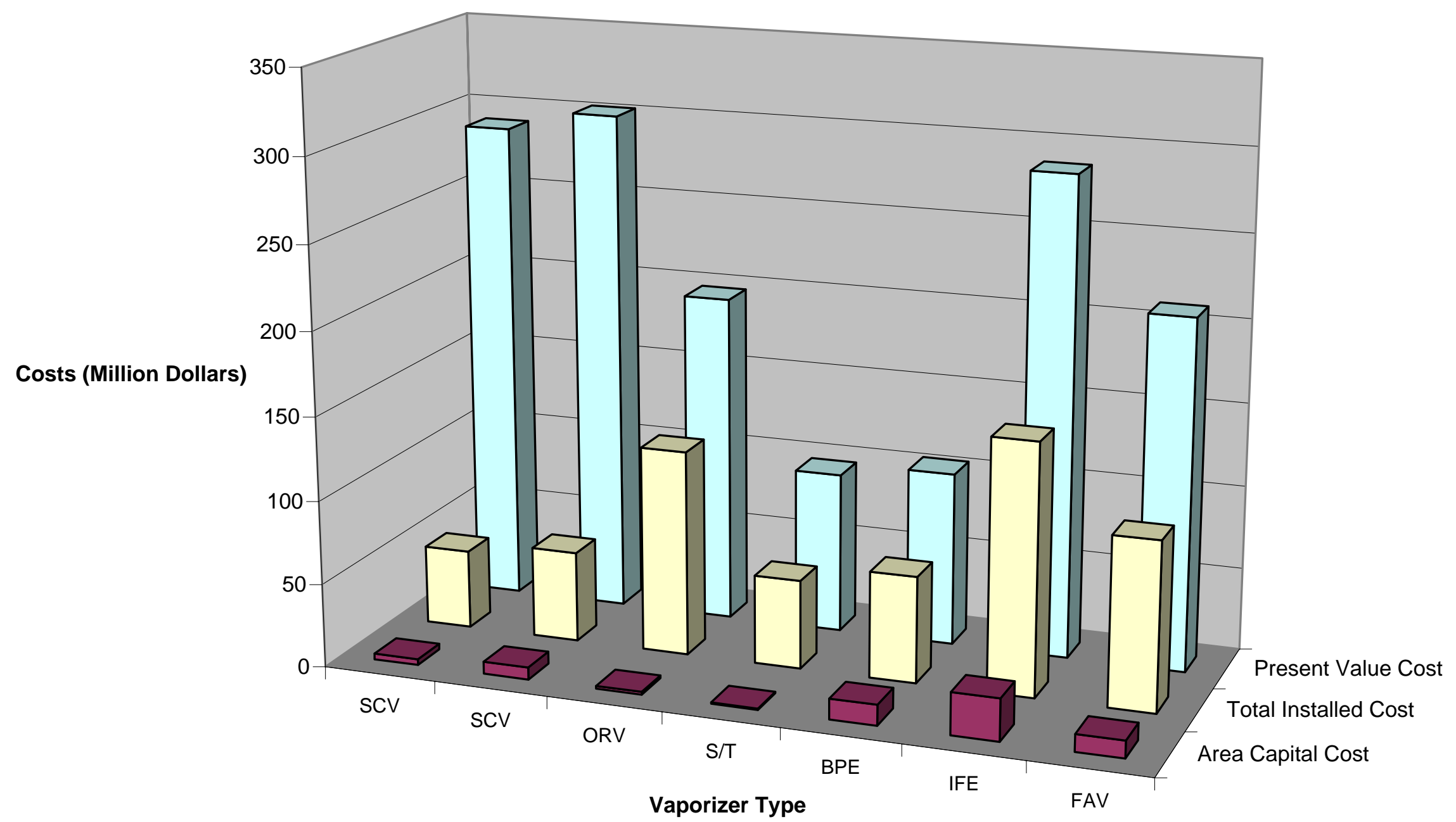


Heat Exchanger OPEX Comparison for 1.3 BCFD Sendout Basis

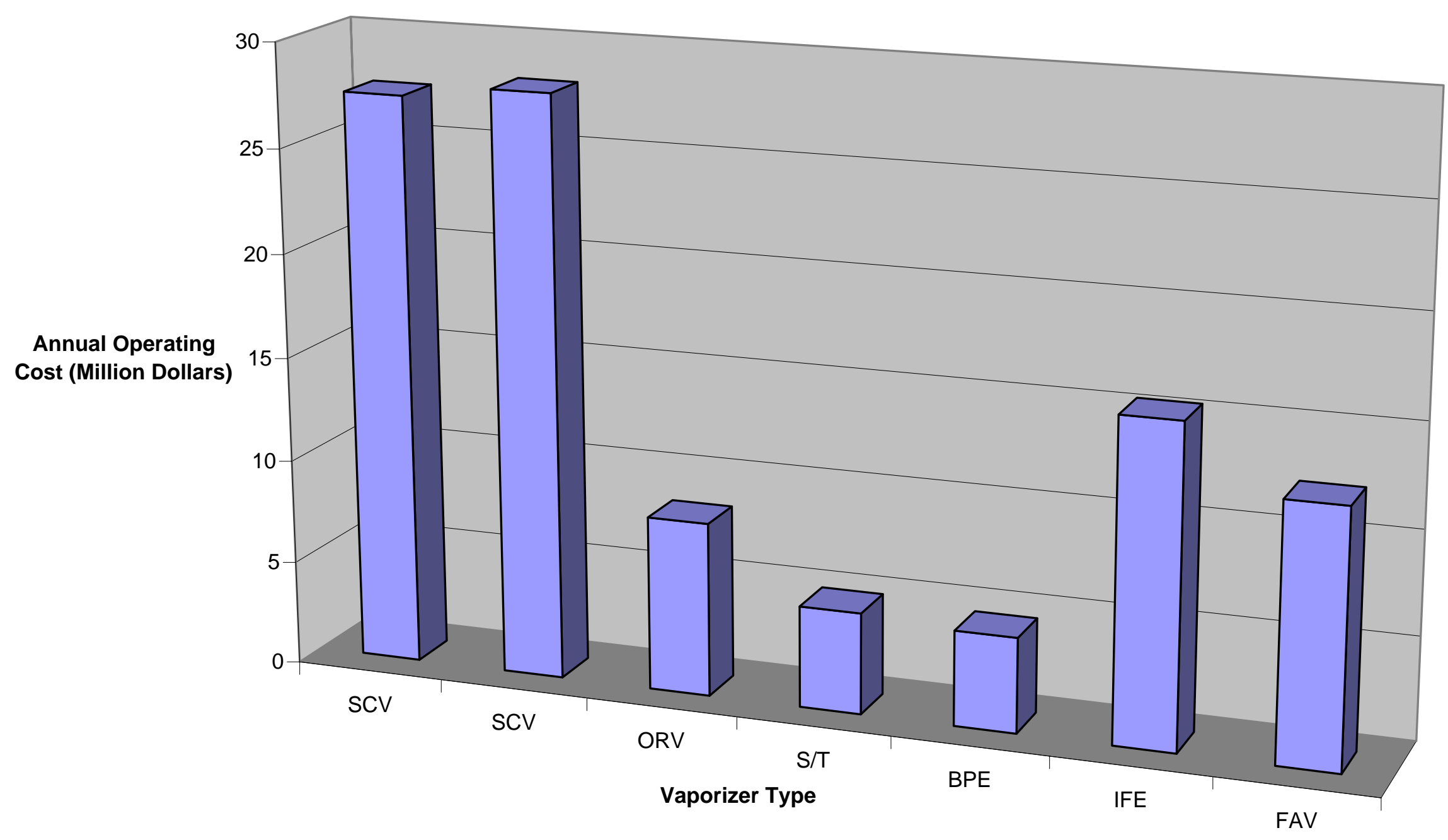




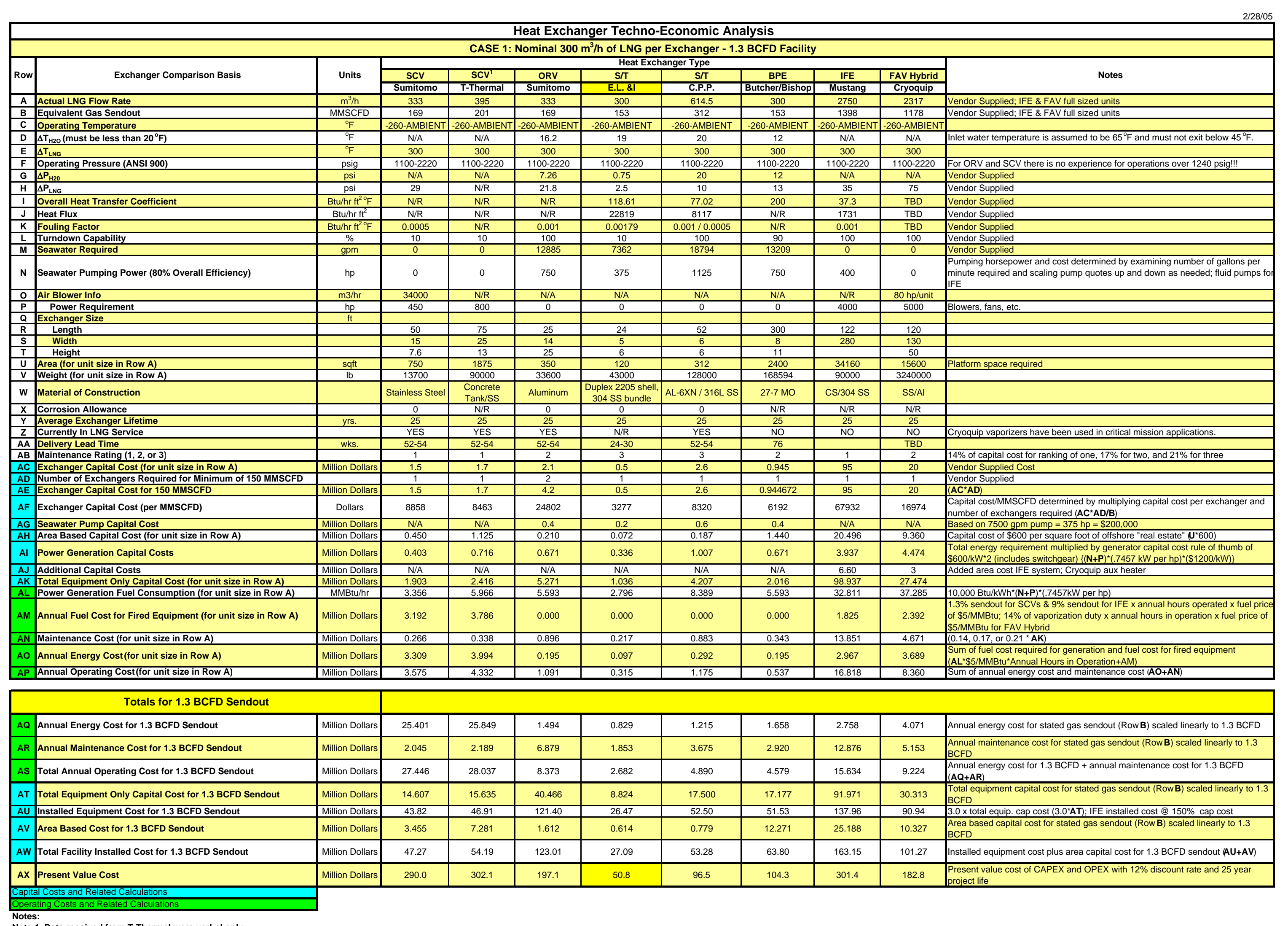

Notes:
Note 1. Data received from T-Thermal were verbal only 


\begin{tabular}{|c|c|c|c|c|c|c|c|}
\hline \multirow{3}{*}{ cash flow.xls } & \multirow{4}{*}{$\begin{array}{c}\text { Year } \\
n\end{array}$} & \multirow{3}{*}{$\begin{array}{c}\text { PVF } \\
\mathrm{i}\end{array}$} & \multirow{3}{*}{$\begin{array}{c}\text { Inputs } \\
\text { Annual } \\
\text { capital invested }\end{array}$} & \multirow{3}{*}{$\begin{array}{l}\text { Inputs } \\
\text { Annual } \\
\text { Expense }\end{array}$} & \multirow{3}{*}{$\begin{array}{l}\text { Calcs } \\
\text { PV } \\
\text { Capital }\end{array}$} & Calcs & \multirow{3}{*}{$\begin{array}{l}\text { 2/28/05 } \\
\text { tax effect neglected } \\
\text { (totals at bottom) }\end{array}$} \\
\hline & & & & & & \multirow{3}{*}{$\begin{array}{l}\text { PV } \\
\text { Expense }\end{array}$} & \\
\hline & & & & & & & \\
\hline & & 0.12000 & & & & & \\
\hline & 0 & 1.00000 & 47.27 & 27.45 & 47.274 & 27.446 & \\
\hline & 1 & 0.89286 & 0 & 27.45 & 0.000 & 24.506 & \\
\hline & 2 & 0.79719 & 0 & 27.45 & 0.000 & 21.880 & \\
\hline & 3 & 0.71178 & 0 & 27.45 & 0.000 & 19.536 & \\
\hline & 4 & 0.63552 & 0 & 27.45 & 0.000 & 17.443 & \\
\hline & 5 & 0.56743 & 0 & 27.45 & 0.000 & 15.574 & \\
\hline & 6 & 0.50663 & 0 & 27.45 & 0.000 & 13.905 & \\
\hline & 7 & 0.45235 & 0 & 27.45 & 0.000 & 12.415 & \\
\hline & 8 & 0.40388 & 0 & 27.45 & 0.000 & 11.085 & \\
\hline & 9 & 0.36061 & 0 & 27.45 & 0.000 & 9.897 & \\
\hline & 10 & 0.32197 & 0 & 27.45 & 0.000 & 8.837 & \\
\hline & 11 & 0.28748 & 0 & 27.45 & 0.000 & 7.890 & \\
\hline & 12 & 0.25668 & 0 & 27.45 & 0.000 & 7.045 & \\
\hline & 13 & 0.22917 & 0 & 27.45 & 0.000 & 6.290 & \\
\hline & 14 & 0.20462 & 0 & 27.45 & 0.000 & 5.616 & \\
\hline & 15 & 0.18270 & 0 & 27.45 & 0.000 & 5.014 & \\
\hline & 16 & 0.16312 & 0 & 27.45 & 0.000 & 4.477 & \\
\hline & 17 & 0.14564 & 0 & 27.45 & 0.000 & 3.997 & \\
\hline & 18 & 0.13004 & 0 & 27.45 & 0.000 & 3.569 & \\
\hline & 19 & 0.11611 & 0 & 27.45 & 0.000 & 3.187 & \\
\hline & 20 & 0.10367 & 0 & 27.45 & 0.000 & 2.845 & \\
\hline & 21 & 0.09256 & 0 & 27.45 & 0.000 & 2.540 & \\
\hline & 22 & 0.08264 & 0 & 27.45 & 0.000 & 2.268 & \\
\hline & 23 & 0.07379 & 0 & 27.45 & 0.000 & 2.025 & \\
\hline & 24 & 0.06588 & 0 & 27.45 & 0.000 & 1.808 & \\
\hline & 25 & 0.05882 & 0 & 27.45 & 0.000 & 1.614 & \\
\hline Totals & & & 47.27413404 & & 47.274 & 242.712 & PV Cost $=$ \\
\hline & & & Total capital & & PV cap & Pvexp & \\
\hline
\end{tabular}




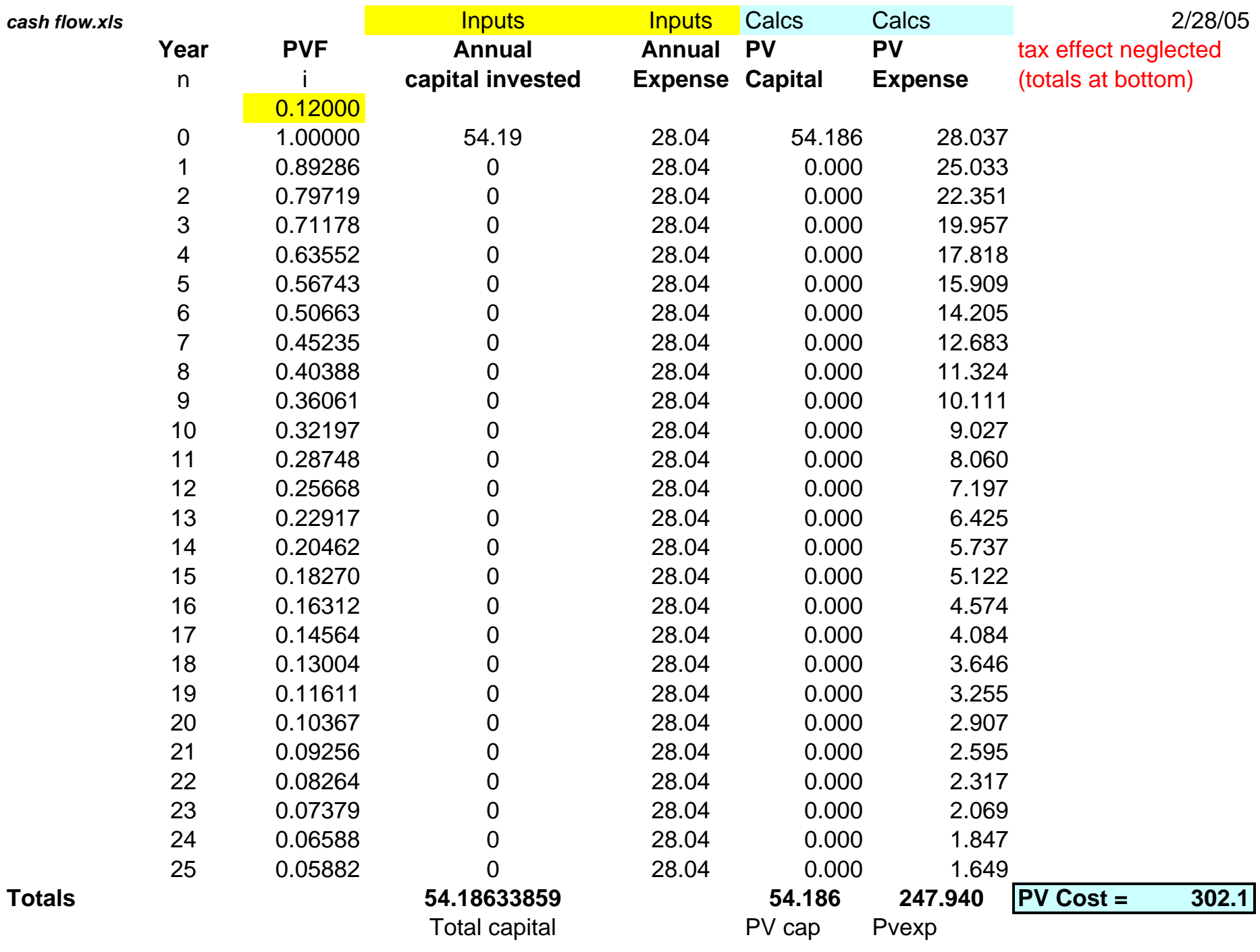




\begin{tabular}{|c|c|c|c|}
\hline \multicolumn{3}{|l|}{ cash flow.xls } & Inputs \\
\hline & Year & PVF & Annual \\
\hline & $\mathrm{n}$ & $\mathrm{i}$ & capital invested \\
\hline & & 0.12000 & \\
\hline & 0 & 1.00000 & 123.01 \\
\hline & 1 & 0.89286 & 0 \\
\hline & 2 & 0.79719 & 0 \\
\hline & 3 & 0.71178 & 0 \\
\hline & 4 & 0.63552 & 0 \\
\hline & 5 & 0.56743 & 0 \\
\hline & 6 & 0.50663 & 0 \\
\hline & 7 & 0.45235 & 0 \\
\hline & 8 & 0.40388 & 0 \\
\hline & 9 & 0.36061 & 0 \\
\hline & 10 & 0.32197 & 0 \\
\hline & 11 & 0.28748 & 0 \\
\hline & 12 & 0.25668 & 0 \\
\hline & 13 & 0.22917 & 0 \\
\hline & 14 & 0.20462 & 0 \\
\hline & 15 & 0.18270 & 0 \\
\hline & 16 & 0.16312 & 0 \\
\hline & 17 & 0.14564 & 0 \\
\hline & 18 & 0.13004 & 0 \\
\hline & 19 & 0.11611 & 0 \\
\hline & 20 & 0.10367 & 0 \\
\hline & 21 & 0.09256 & 0 \\
\hline & 22 & 0.08264 & 0 \\
\hline & 23 & 0.07379 & 0 \\
\hline & 24 & 0.06588 & 0 \\
\hline & 25 & 0.05882 & 0 \\
\hline Totals & & & $\begin{array}{c}123.0087226 \\
\text { Total capital }\end{array}$ \\
\hline
\end{tabular}

Inputs Calcs

Annual PV

Expense Capital

8.37

8.37

8.37

8.37

8.37

8.37

8.37

8.37

8.37

8.37

8.37

8.37

8.37

8.37

8.37

8.37

8.37

8.37

8.37

8.37

8.37

8.37

8.37

8.37

8.37

8.37

Total capital
Calcs

PV 2/28/05

Expense (to

$\begin{array}{rr}123.009 & 8.373 \\ 0.000 & 7.476 \\ 0.000 & 6.675 \\ 0.000 & 5.960 \\ 0.000 & 5.321 \\ 0.000 & 4.751 \\ 0.000 & 4.242 \\ 0.000 & 3.788 \\ 0.000 & 3.382 \\ 0.000 & 3.019 \\ 0.000 & 2.696 \\ 0.000 & 2.407 \\ 0.000 & 2.149 \\ 0.000 & 1.919 \\ 0.000 & 1.713 \\ 0.000 & 1.530 \\ 0.000 & 1.366 \\ 0.000 & 1.220 \\ 0.000 & 1.089 \\ 0.000 & 0.972 \\ 0.000 & 0.868 \\ 0.000 & 0.775 \\ 0.000 & 0.692 \\ 0.000 & 0.618 \\ 0.000 & 0.552 \\ 0.000 & 0.493\end{array}$

$\begin{array}{llll}123.009 & 74.046 \quad \text { PV Cost }= & 197.1 \\ \end{array}$

PV cap Pvexp 


\begin{tabular}{|c|c|c|c|c|c|c|c|}
\hline \multirow{4}{*}{ cash flow.xls } & & & & & & \multirow[b]{2}{*}{ Calcs } & \multirow{4}{*}{$\begin{array}{l}\text { 2/28/05 } \\
\text { tax effect neglected } \\
\text { (totals at bottom) }\end{array}$} \\
\hline & & & Inputs & Inputs & Calcs & & \\
\hline & Year & PVF & Annual & Annual & & \multirow{3}{*}{$\begin{array}{l}\text { PV } \\
\text { Expense }\end{array}$} & \\
\hline & $n$ & $\mathrm{i}$ & capital invested & Expense & Capital & & \\
\hline & & 0.12000 & & & & & \\
\hline & 0 & 1.00000 & 27.09 & 2.68 & 27.087 & 2.682 & \\
\hline & 1 & 0.89286 & 0 & 2.68 & 0.000 & 2.395 & \\
\hline & 2 & 0.79719 & 0 & 2.68 & 0.000 & 2.138 & \\
\hline & 3 & 0.71178 & 0 & 2.68 & 0.000 & 1.909 & \\
\hline & 4 & 0.63552 & 0 & 2.68 & 0.000 & 1.705 & \\
\hline & 5 & 0.56743 & 0 & 2.68 & 0.000 & 1.522 & \\
\hline & 6 & 0.50663 & 0 & 2.68 & 0.000 & 1.359 & \\
\hline & 7 & 0.45235 & 0 & 2.68 & 0.000 & 1.213 & \\
\hline & 8 & 0.40388 & 0 & 2.68 & 0.000 & 1.083 & \\
\hline & 9 & 0.36061 & 0 & 2.68 & 0.000 & 0.967 & \\
\hline & 10 & 0.32197 & 0 & 2.68 & 0.000 & 0.864 & \\
\hline & 11 & 0.28748 & 0 & 2.68 & 0.000 & 0.771 & \\
\hline & 12 & 0.25668 & 0 & 2.68 & 0.000 & 0.688 & \\
\hline & 13 & 0.22917 & 0 & 2.68 & 0.000 & 0.615 & \\
\hline & 14 & 0.20462 & 0 & 2.68 & 0.000 & 0.549 & \\
\hline & 15 & 0.18270 & 0 & 2.68 & 0.000 & 0.490 & \\
\hline & 16 & 0.16312 & 0 & 2.68 & 0.000 & 0.438 & \\
\hline & 17 & 0.14564 & 0 & 2.68 & 0.000 & 0.391 & \\
\hline & 18 & 0.13004 & 0 & 2.68 & 0.000 & 0.349 & \\
\hline & 19 & 0.11611 & 0 & 2.68 & 0.000 & 0.311 & \\
\hline & 20 & 0.10367 & 0 & 2.68 & 0.000 & 0.278 & \\
\hline & 21 & 0.09256 & 0 & 2.68 & 0.000 & 0.248 & \\
\hline & 22 & 0.08264 & 0 & 2.68 & 0.000 & 0.222 & \\
\hline & 23 & 0.07379 & 0 & 2.68 & 0.000 & 0.198 & \\
\hline & 24 & 0.06588 & 0 & 2.68 & 0.000 & 0.177 & \\
\hline & 25 & 0.05882 & 0 & 2.68 & 0.000 & 0.158 & \\
\hline Totals & & & 27.08652727 & & 27.087 & 23.720 & PV Cost = \\
\hline & & & Total capital & & PV cap & Pvexp & \\
\hline
\end{tabular}




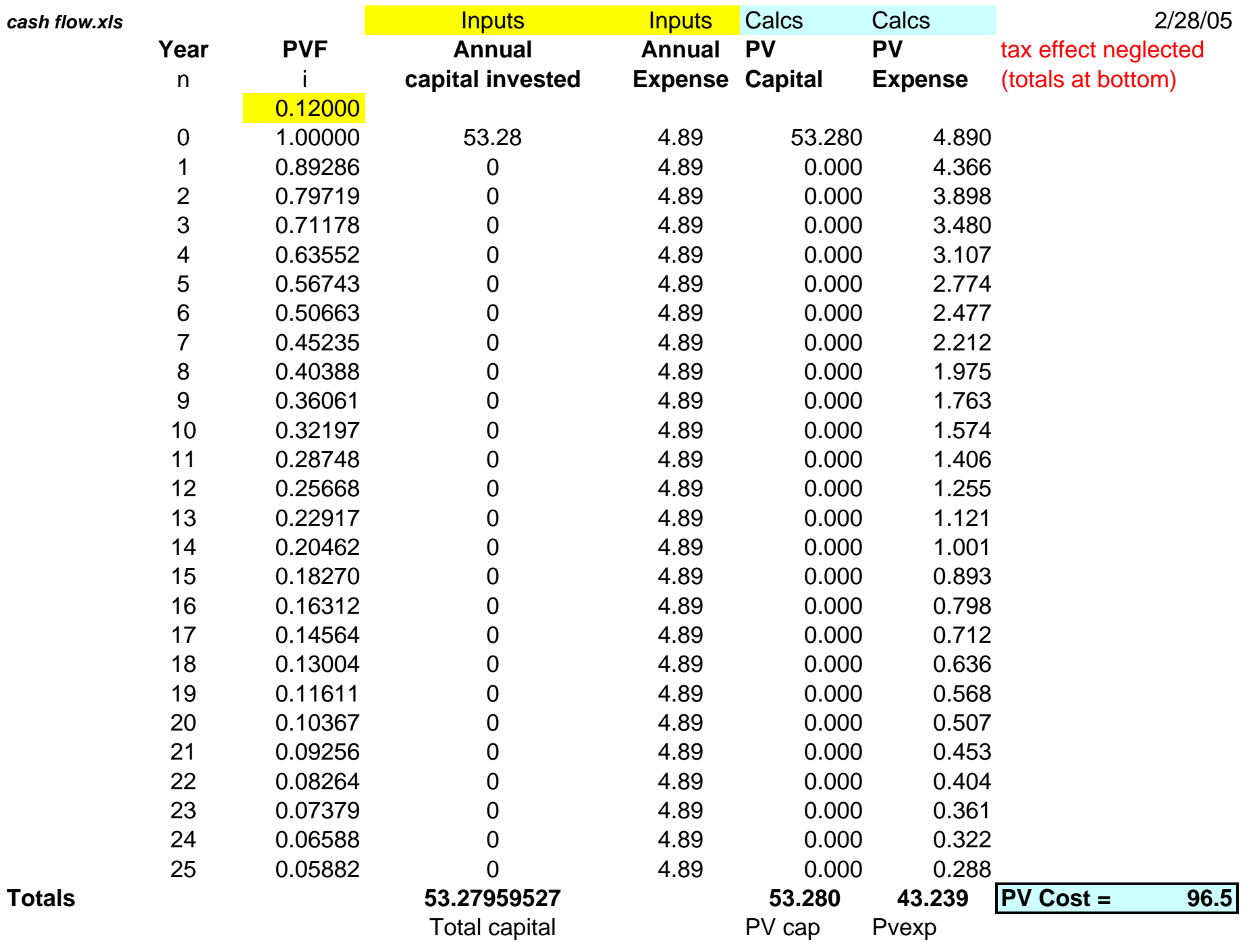




\begin{tabular}{|c|c|c|c|c|c|c|c|}
\hline \multirow{2}{*}{ cash flow.xls } & & & Inputs & Inputs & Calcs & Calcs & \multirow{3}{*}{$\begin{array}{l}\text { 2/28/05 } \\
\text { tax effect neglected } \\
\text { (totals at bottom) }\end{array}$} \\
\hline & $\begin{array}{c}\text { Year } \\
\mathrm{n}\end{array}$ & $\begin{array}{l}\text { PVF } \\
\mathrm{i}\end{array}$ & $\begin{array}{c}\text { Annual } \\
\text { capital invested }\end{array}$ & $\begin{array}{l}\text { Annual } \\
\text { Expense }\end{array}$ & $\begin{array}{l}\text { PV } \\
\text { Capital }\end{array}$ & $\begin{array}{l}\text { PV } \\
\text { Expense }\end{array}$ & \\
\hline & & 0.12000 & & & & & \\
\hline & 0 & 1.00000 & 63.80 & 4.58 & 63.802 & 4.579 & \\
\hline & 1 & 0.89286 & 0 & 4.58 & 0.000 & 4.088 & \\
\hline & 2 & 0.79719 & 0 & 4.58 & 0.000 & 3.650 & \\
\hline & 3 & 0.71178 & 0 & 4.58 & 0.000 & 3.259 & \\
\hline & 4 & 0.63552 & 0 & 4.58 & 0.000 & 2.910 & \\
\hline & 5 & 0.56743 & 0 & 4.58 & 0.000 & 2.598 & \\
\hline & 6 & 0.50663 & 0 & 4.58 & 0.000 & 2.320 & \\
\hline & 7 & 0.45235 & 0 & 4.58 & 0.000 & 2.071 & \\
\hline & 8 & 0.40388 & 0 & 4.58 & 0.000 & 1.849 & \\
\hline & 9 & 0.36061 & 0 & 4.58 & 0.000 & 1.651 & \\
\hline & 10 & 0.32197 & 0 & 4.58 & 0.000 & 1.474 & \\
\hline & 11 & 0.28748 & 0 & 4.58 & 0.000 & 1.316 & \\
\hline & 12 & 0.25668 & 0 & 4.58 & 0.000 & 1.175 & \\
\hline & 13 & 0.22917 & 0 & 4.58 & 0.000 & 1.049 & \\
\hline & 14 & 0.20462 & 0 & 4.58 & 0.000 & 0.937 & \\
\hline & 15 & 0.18270 & 0 & 4.58 & 0.000 & 0.836 & \\
\hline & 16 & 0.16312 & 0 & 4.58 & 0.000 & 0.747 & \\
\hline & 17 & 0.14564 & 0 & 4.58 & 0.000 & 0.667 & \\
\hline & 18 & 0.13004 & 0 & 4.58 & 0.000 & 0.595 & \\
\hline & 19 & 0.11611 & 0 & 4.58 & 0.000 & 0.532 & \\
\hline & 20 & 0.10367 & 0 & 4.58 & 0.000 & 0.475 & \\
\hline & 21 & 0.09256 & 0 & 4.58 & 0.000 & 0.424 & \\
\hline & 22 & 0.08264 & 0 & 4.58 & 0.000 & 0.378 & \\
\hline & 23 & 0.07379 & 0 & 4.58 & 0.000 & 0.338 & \\
\hline & 24 & 0.06588 & 0 & 4.58 & 0.000 & 0.302 & \\
\hline & 25 & 0.05882 & 0 & 4.58 & 0.000 & 0.269 & \\
\hline Totals & & & 63.80222969 & & 63.802 & 40.489 & PV Cost = \\
\hline & & & Total capital & & PV cap & Pvexp & \\
\hline
\end{tabular}




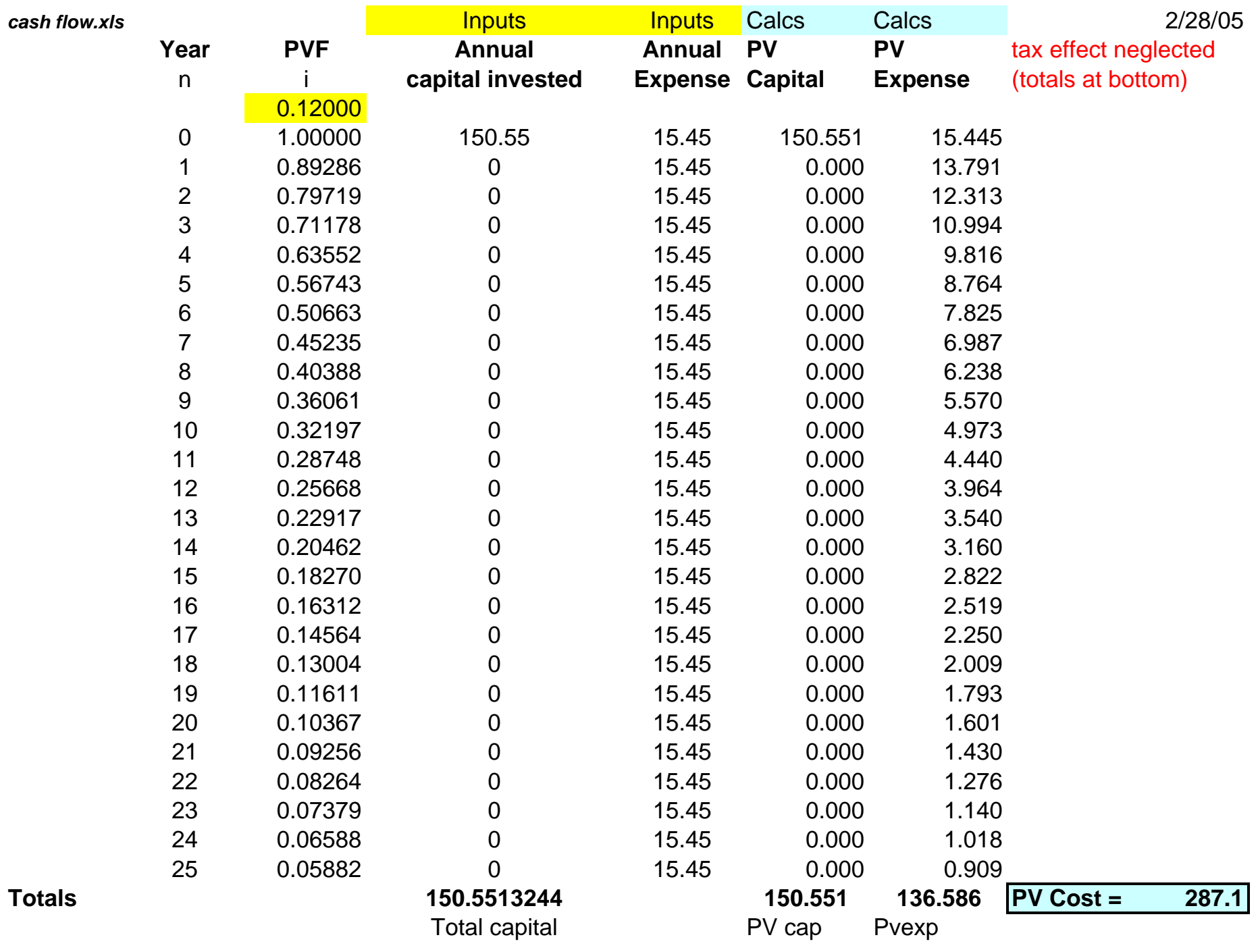




\begin{tabular}{|c|c|c|c|c|c|c|c|}
\hline \multirow{4}{*}{ cash flow.xls } & & & & & & \multirow[b]{2}{*}{ Calcs } & \multirow{4}{*}{$\begin{array}{l}\text { 2/28/05 } \\
\text { tax effect neglected } \\
\text { (totals at bottom) }\end{array}$} \\
\hline & & & Inputs & Inputs & Calcs & & \\
\hline & Year & PVF & Annual & Annual & & \multirow{3}{*}{$\begin{array}{l}\text { PV } \\
\text { Expense }\end{array}$} & \\
\hline & $n$ & $\mathrm{i}$ & capital invested & Expense & Capital & & \\
\hline & & 0.12000 & & & & & \\
\hline & 0 & 1.00000 & 27.09 & 2.68 & 27.087 & 2.682 & \\
\hline & 1 & 0.89286 & 0 & 2.68 & 0.000 & 2.395 & \\
\hline & 2 & 0.79719 & 0 & 2.68 & 0.000 & 2.138 & \\
\hline & 3 & 0.71178 & 0 & 2.68 & 0.000 & 1.909 & \\
\hline & 4 & 0.63552 & 0 & 2.68 & 0.000 & 1.705 & \\
\hline & 5 & 0.56743 & 0 & 2.68 & 0.000 & 1.522 & \\
\hline & 6 & 0.50663 & 0 & 2.68 & 0.000 & 1.359 & \\
\hline & 7 & 0.45235 & 0 & 2.68 & 0.000 & 1.213 & \\
\hline & 8 & 0.40388 & 0 & 2.68 & 0.000 & 1.083 & \\
\hline & 9 & 0.36061 & 0 & 2.68 & 0.000 & 0.967 & \\
\hline & 10 & 0.32197 & 0 & 2.68 & 0.000 & 0.864 & \\
\hline & 11 & 0.28748 & 0 & 2.68 & 0.000 & 0.771 & \\
\hline & 12 & 0.25668 & 0 & 2.68 & 0.000 & 0.688 & \\
\hline & 13 & 0.22917 & 0 & 2.68 & 0.000 & 0.615 & \\
\hline & 14 & 0.20462 & 0 & 2.68 & 0.000 & 0.549 & \\
\hline & 15 & 0.18270 & 0 & 2.68 & 0.000 & 0.490 & \\
\hline & 16 & 0.16312 & 0 & 2.68 & 0.000 & 0.438 & \\
\hline & 17 & 0.14564 & 0 & 2.68 & 0.000 & 0.391 & \\
\hline & 18 & 0.13004 & 0 & 2.68 & 0.000 & 0.349 & \\
\hline & 19 & 0.11611 & 0 & 2.68 & 0.000 & 0.311 & \\
\hline & 20 & 0.10367 & 0 & 2.68 & 0.000 & 0.278 & \\
\hline & 21 & 0.09256 & 0 & 2.68 & 0.000 & 0.248 & \\
\hline & 22 & 0.08264 & 0 & 2.68 & 0.000 & 0.222 & \\
\hline & 23 & 0.07379 & 0 & 2.68 & 0.000 & 0.198 & \\
\hline & 24 & 0.06588 & 0 & 2.68 & 0.000 & 0.177 & \\
\hline & 25 & 0.05882 & 0 & 2.68 & 0.000 & 0.158 & \\
\hline Totals & & & 27.08652877 & & 27.087 & 23.720 & PV Cost = \\
\hline & & & Total capital & & PV cap & Pvexp & \\
\hline
\end{tabular}




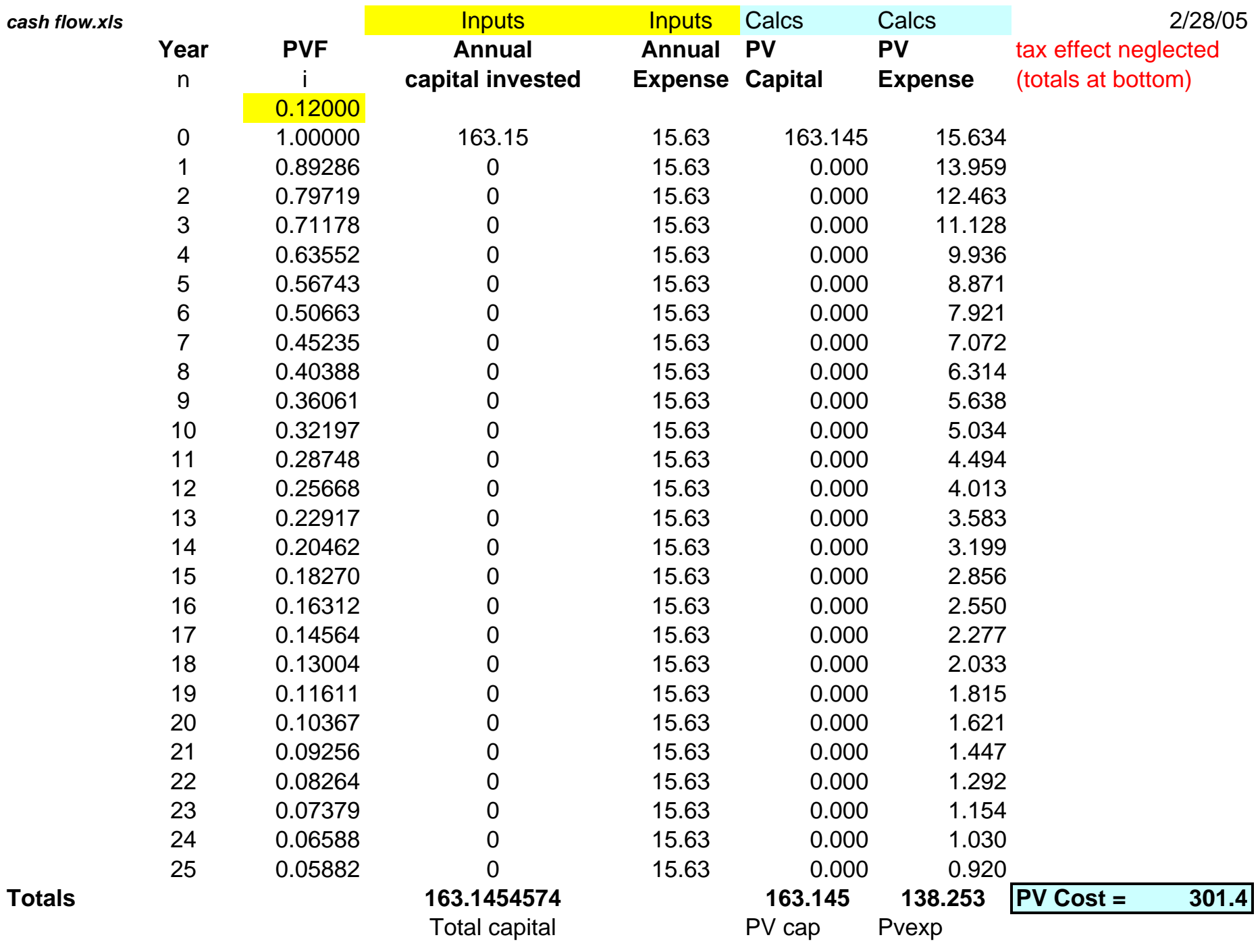




\begin{tabular}{|c|c|c|c|c|c|c|c|}
\hline \multirow{2}{*}{ cash flow.xls } & & & Inputs & Inputs & Calcs & Calcs & $2 / 28 / 05$ \\
\hline & $\begin{array}{c}\text { Year } \\
\mathrm{n}\end{array}$ & $\begin{array}{c}\text { PVF } \\
\mathrm{i}\end{array}$ & $\begin{array}{c}\text { Annual } \\
\text { capital invested }\end{array}$ & $\begin{array}{l}\text { Annual } \\
\text { Expense }\end{array}$ & $\begin{array}{l}\text { PV } \\
\text { Capital }\end{array}$ & \multirow[t]{2}{*}{$\begin{array}{l}\text { PV } \\
\text { Expense }\end{array}$} & \multirow[t]{2}{*}{$\begin{array}{l}\text { tax effect neglected } \\
\text { (totals at bottom) }\end{array}$} \\
\hline & & 0.12000 & & & & & \\
\hline & 0 & 1.00000 & 101.27 & 9.22 & 101.265 & 9.224 & \\
\hline & 1 & 0.89286 & 0 & 9.22 & 0.000 & 8.235 & \\
\hline & 2 & 0.79719 & 0 & 9.22 & 0.000 & 7.353 & \\
\hline & 3 & 0.71178 & 0 & 9.22 & 0.000 & 6.565 & \\
\hline & 4 & 0.63552 & 0 & 9.22 & 0.000 & 5.862 & \\
\hline & 5 & 0.56743 & 0 & 9.22 & 0.000 & 5.234 & \\
\hline & 6 & 0.50663 & 0 & 9.22 & 0.000 & 4.673 & \\
\hline & 7 & 0.45235 & 0 & 9.22 & 0.000 & 4.172 & \\
\hline & 8 & 0.40388 & 0 & 9.22 & 0.000 & 3.725 & \\
\hline & 9 & 0.36061 & 0 & 9.22 & 0.000 & 3.326 & \\
\hline & 10 & 0.32197 & 0 & 9.22 & 0.000 & 2.970 & \\
\hline & 11 & 0.28748 & 0 & 9.22 & 0.000 & 2.652 & \\
\hline & 12 & 0.25668 & 0 & 9.22 & 0.000 & 2.368 & \\
\hline & 13 & 0.22917 & 0 & 9.22 & 0.000 & 2.114 & \\
\hline & 14 & 0.20462 & 0 & 9.22 & 0.000 & 1.887 & \\
\hline & 15 & 0.18270 & 0 & 9.22 & 0.000 & 1.685 & \\
\hline & 16 & 0.16312 & 0 & 9.22 & 0.000 & 1.505 & \\
\hline & 17 & 0.14564 & 0 & 9.22 & 0.000 & 1.343 & \\
\hline & 18 & 0.13004 & 0 & 9.22 & 0.000 & 1.199 & \\
\hline & 19 & 0.11611 & 0 & 9.22 & 0.000 & 1.071 & \\
\hline & 20 & 0.10367 & 0 & 9.22 & 0.000 & 0.956 & \\
\hline & 21 & 0.09256 & 0 & 9.22 & 0.000 & 0.854 & \\
\hline & 22 & 0.08264 & 0 & 9.22 & 0.000 & 0.762 & \\
\hline & 23 & 0.07379 & 0 & 9.22 & 0.000 & 0.681 & \\
\hline & 24 & 0.06588 & 0 & 9.22 & 0.000 & 0.608 & \\
\hline & 25 & 0.05882 & 0 & 9.22 & 0.000 & 0.543 & \\
\hline Totals & & & 101.265164 & & 101.265 & 81.567 & PV Cost = \\
\hline & & & Total capital & & PV cap & Pvexp & \\
\hline
\end{tabular}




\begin{tabular}{|c|c|c|c|c|c|c|c|c|c|}
\hline \multirow{2}{*}{\multicolumn{2}{|c|}{ Cost Summary Table }} & \multirow{2}{*}{ Units } & SCV & SCV & $\mathrm{S} / \mathrm{T}$ & $\mathrm{S} / \mathrm{T}$ & BPE & IFE & FAV \\
\hline & & & Sumitomo & T-Thermal17 & E.L., \& I. & C.P.P. & Butcher/Bishop & Mustang & Cryoquip \\
\hline A & Gas Sendout & MMSCFD & 169 & 201 & 153 & 312 & 153 & 1398 & 1178 \\
\hline B & Energy Required1 & $\mathrm{kW}$ & 336 & 597 & 280 & 839 & 559 & 3281 & 3728 \\
\hline C & Annual Energy Cost for Power Generation2 & Million Dollars & 0.117 & 0.208 & 0.097 & 0.292 & 0.195 & 1.142 & 1.298 \\
\hline D & Annual Fuel Cost for Vaporizers and Heaters3 & Million Dollars & 3.19 & 3.79 & 0 & 0 & 0 & 1.62 & 5.22 \\
\hline$E$ & Total Annual Energy Cost4 & Million Dollars & 3.31 & 3.99 & 0.10 & 0.29 & 0.19 & 2.76 & 6.52 \\
\hline $\mathbf{F}$ & Annual Maintenance Cost5 & Million Dollars & 0.27 & 0.34 & 0.22 & 0.88 & 0.34 & 13.85 & 4.67 \\
\hline G & Annual Operating Cost6 & Million Dollars & 3.58 & 4.33 & 0.31 & 1.18 & 0.54 & 16.62 & 11.19 \\
\hline $\mathrm{H}$ & Annual Operating Cost per MMSCFD & Million Dollars & 0.021 & 0.022 & 0.002 & 0.004 & 0.004 & 0.012 & 0.009 \\
\hline |** & Annual Operating Cost for 1.3 BCFD Sendout7 & Million Dollars & 27.45 & 28.04 & 2.68 & 4.89 & 4.58 & 15.45 & 12.34 \\
\hline $\mathbf{J}$ & Exchanger Capital Cost8 & Million Dollars & 1.50 & 1.70 & 0.50 & 2.60 & 0.94 & 95.00 & 20.00 \\
\hline K & Pump Capital Cost & Million Dollars & N/A & N/A & 0.20 & 0.60 & 0.40 & N/A & N/A \\
\hline L & Generation Capital Cost9 & Million Dollars & 0.403 & 0.716 & 0.336 & 1.007 & 0.671 & 3.937 & 4.474 \\
\hline M & Area Capital Cost & Million Dollars & 0.45 & 1.13 & 0.07 & 0.19 & 1.44 & 27.10 & 9.36 \\
\hline $\mathrm{N}^{* \star}$ & Area Capital Cost for 1.3 BCFD Sendout10 & Million Dollars & 3.45 & 7.28 & 0.61 & 0.78 & 12.27 & 25.19 & 10.33 \\
\hline 0 & Total Capital Cost11 & Million Dollars & 2.35 & 3.54 & 1.11 & 4.39 & 3.46 & 98.94 & 36.83 \\
\hline $\mathbf{P}$ & Total Capital Cost per MMSCFD & Million Dollars & 0.01 & 0.02 & 0.01 & 0.01 & 0.02 & 0.07 & 0.03 \\
\hline $\mathrm{Q}^{\star *}$ & Total Capital Cost for 1.3 BCFD Sendout12 & Million Dollars & 18.06 & 22.92 & 9.44 & 18.28 & 29.45 & 91.97 & 40.64 \\
\hline$R^{* \star}$ & Installation Cost for 1.3 BCFD Sendout13,14 & Million Dollars & 29.21 & 31.27 & 17.65 & 35.00 & 34.35 & 33.39 & 60.63 \\
\hline $\mathbf{S}^{* *}$ & Total Installed Cost for 1.3 BCFD Sendout15 & Million Dollars & 47.3 & 54.2 & 27.1 & 53.3 & 63.8 & 150.6 & 101.3 \\
\hline$T^{* \star}$ & Present Value Cost for 1.3 BCFD Sendout16 & Million Dollars & 290.0 & 302.1 & 50.8 & 96.5 & 104.3 & 287.1 & 210.4 \\
\hline
\end{tabular}

Present Value Cost for 1.3 BCFD Sendout16 Notes:

Note 1. Sum of all required energy inputs except LNG pumps (pumps, blowers, etc.)

Note 2. Total energy required multiplied by required generator heat (fuel) input of $10000 \mathrm{Btu} / \mathrm{kW} \mathrm{hr}$ and fuel cost of $\$ 5 / \mathrm{MM}$ Btu

Note 3. Annual cost of product burned for heat/generation at $\$ 5 / M M$ Btu

Note 4. Sum of annual fuel cost for power generation and vaporizers and heaters

Note 5. Annual maintenance cost based on percentage of capital cost

Note 6. Annual energy cost plus annual maintenance cost

We 7. Annual operalng cost for stated gas sendour (ROW $A$ ) scaled linearly to 1.3 BCFD

ote 8. Exchanger capilal cost for

Note 9. Total energy requirement multiplied by generator capital cost rule of thumb of $\$ 600 / \mathrm{kW} * 2$ (includes switchgear)

Note 10. Area capital cost for stated gas sendout (Row A) scaled linearly to 1.3 BCFD

Note 11. Sum of all capital costs

Note 12. Total capital cost for stated gas sendout (Row A) scaled linearly to $1.3 \mathrm{BCFD}$

Note 13. 2.0 times total capital cost for $1.3 \mathrm{BCFD}$ sendout

Note 14. Installation cost for IFE given by Mustang (already included in exchanger capital cost)

Note 15. Installation cost plus total capital cost for 1.3 BCFD sendout

Note 16. Present value cost over 25 year witetime using $12 \%$ discount factor

Note 17. Data received from T-Thermal were verbal only. 


\section{APPENDIX B: Vaporizer Pictures and Illustrations}

Figure 1. Submerged Combustion Vaporizer Illustration

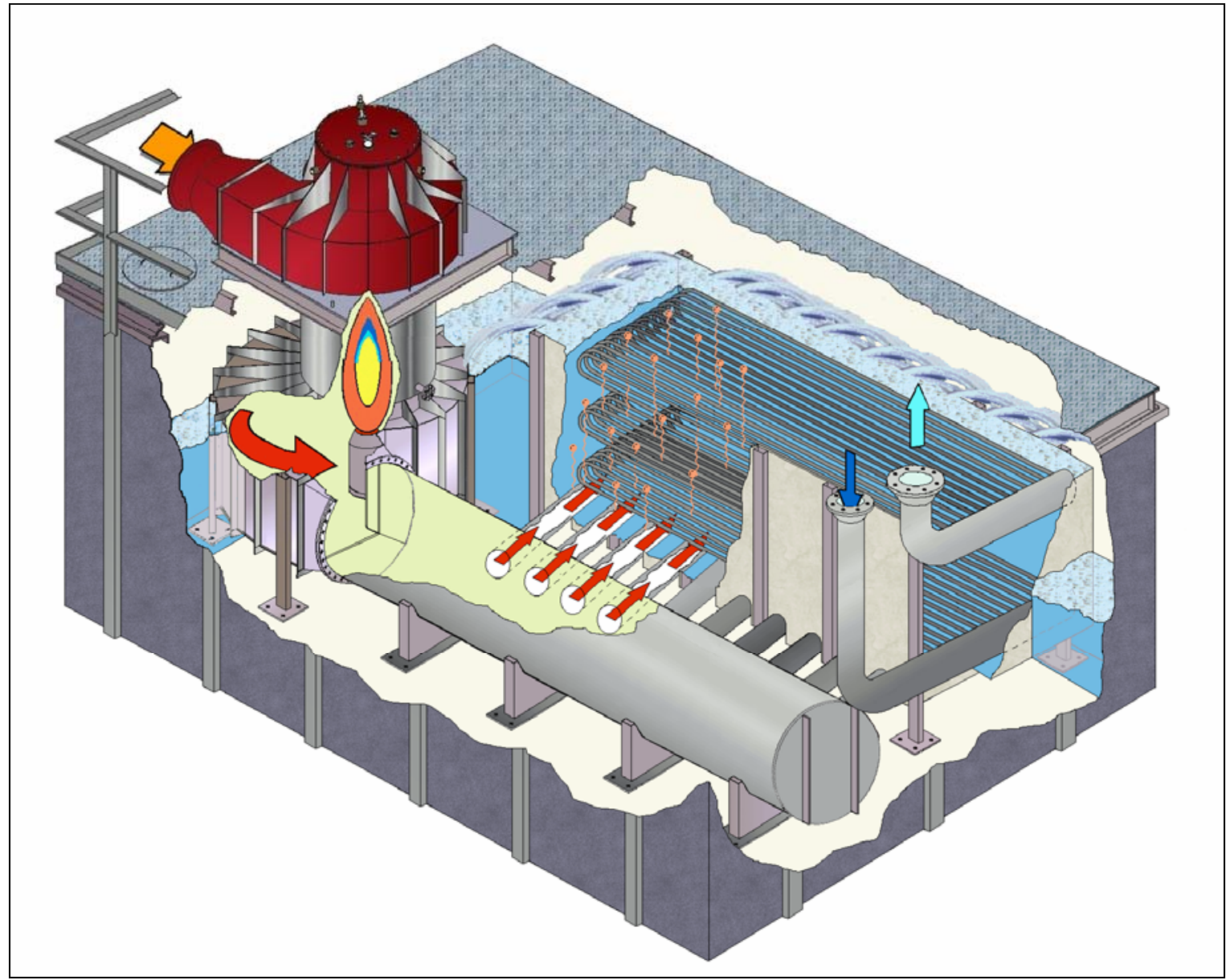

Courtesy of T-Thermal Company 


\section{Figure 2. Submerged Combustion Picture}

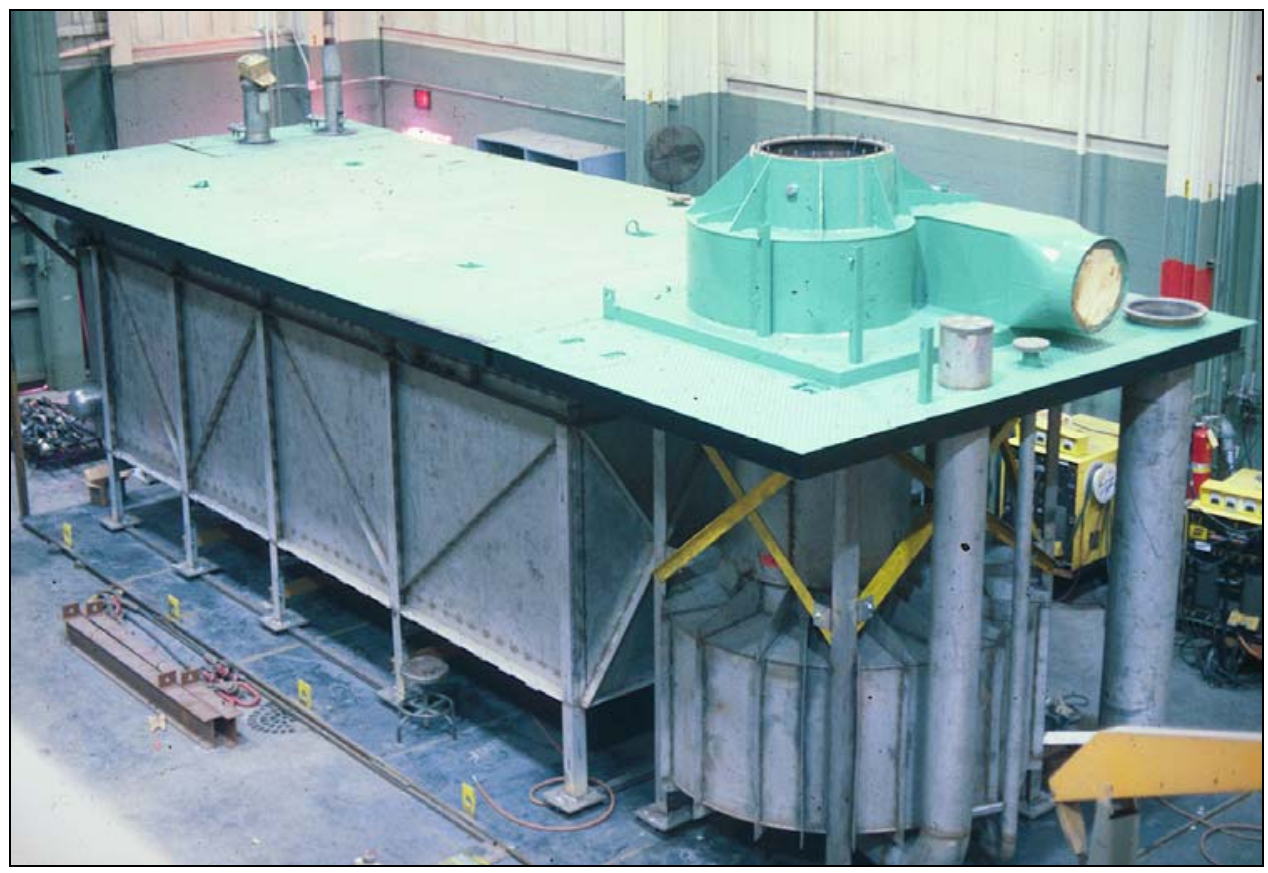

Courtesy of T-Thermal Company

Figure 3. Open Rack Vaporizer Picture

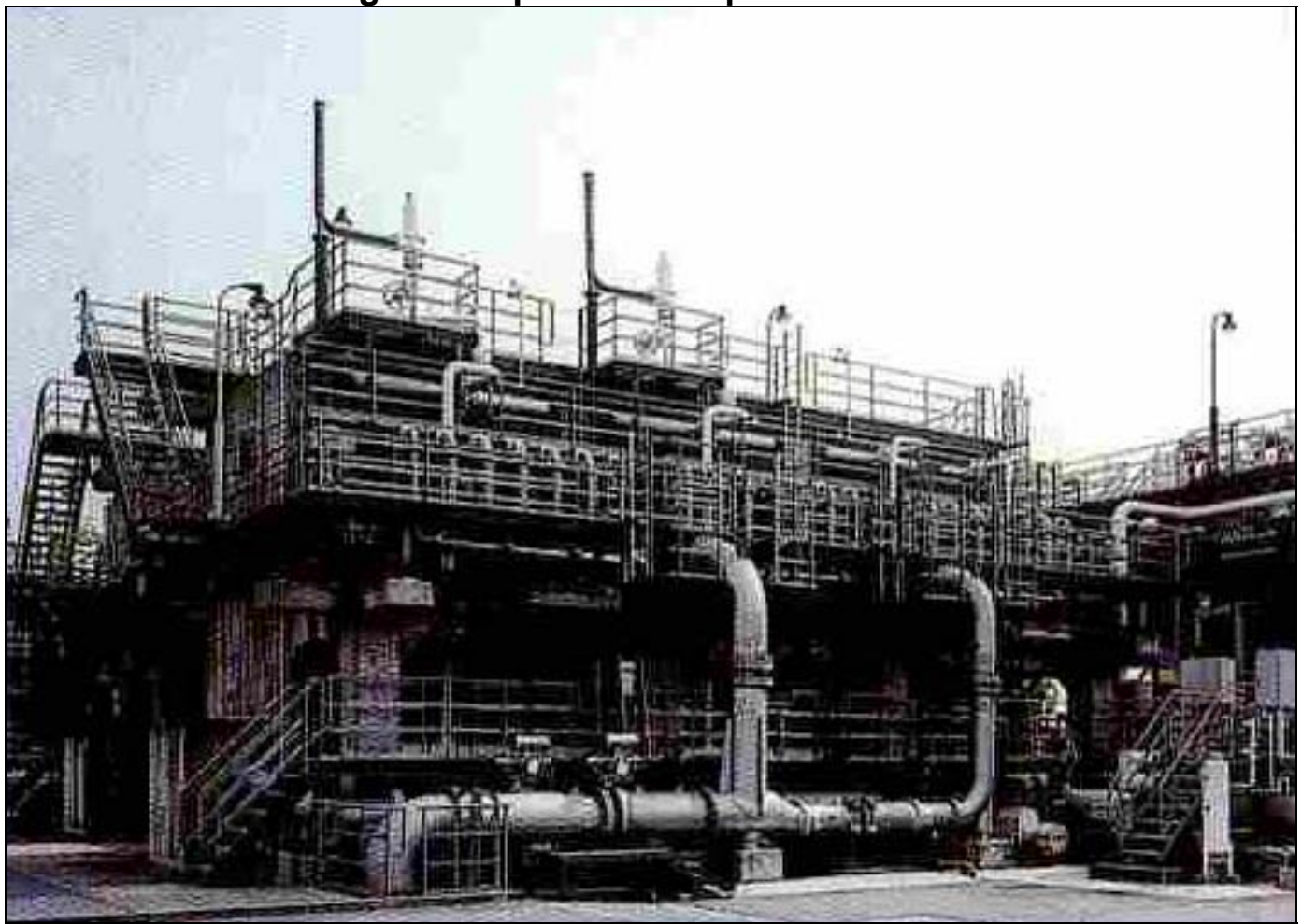

Courtesy of Sojitz Corporation of America 
Figure 4. Ambient Air Vaporizer Picture

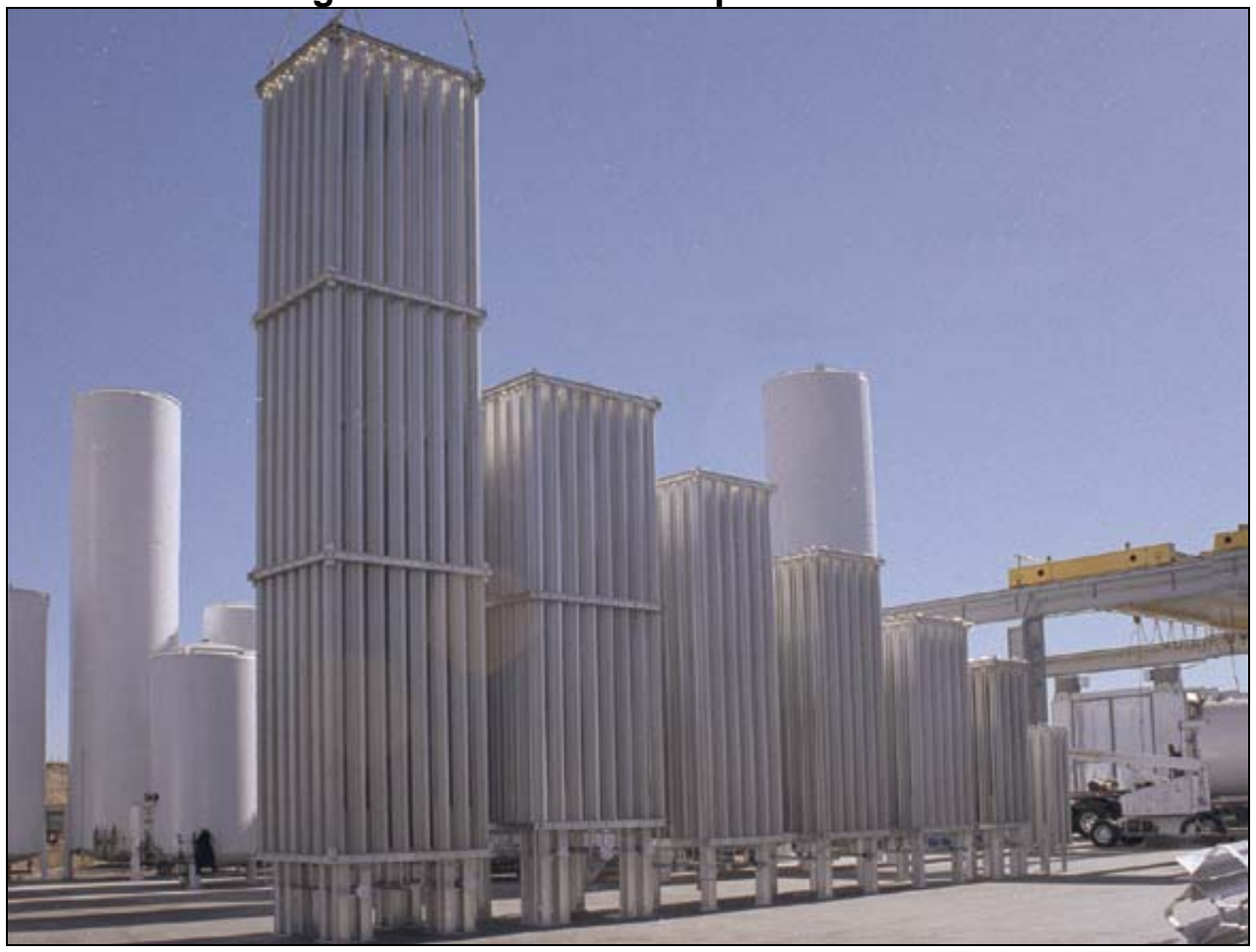

Courtesy of Cryoquip

Figure 5. Mustang IFE System

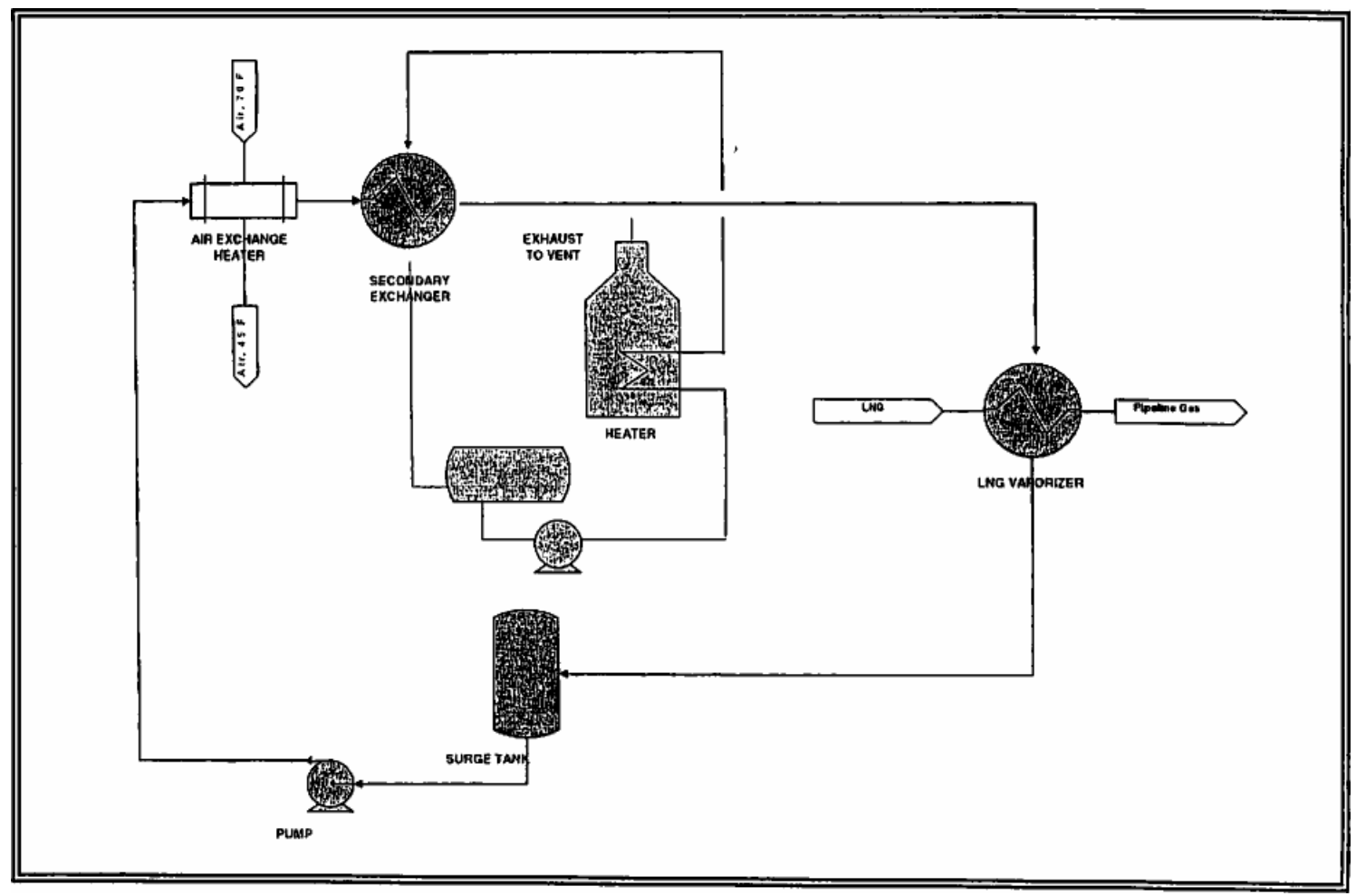


FIGURE 6a. Bishop Exchanger General Layout

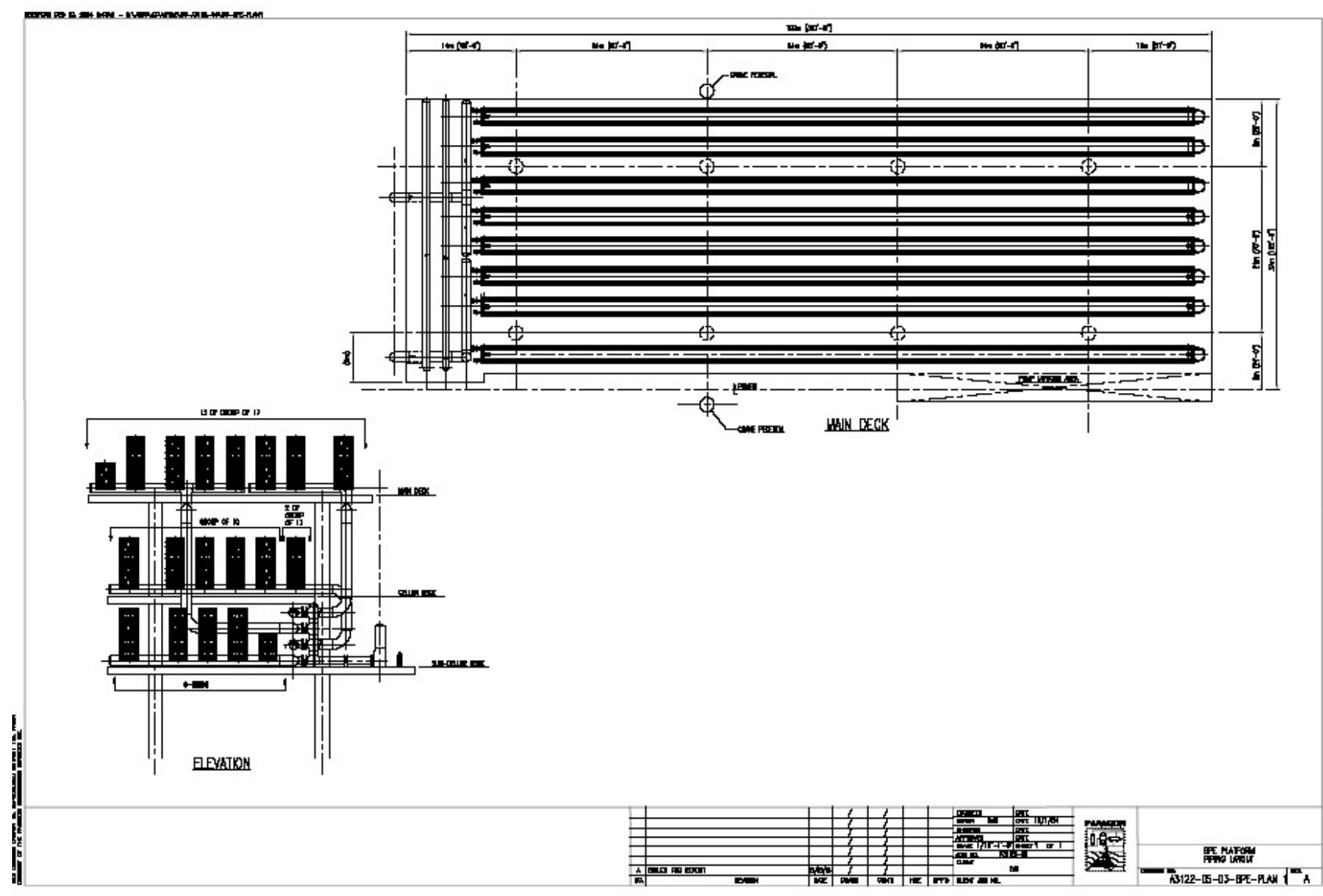


FIGURE 6b. Bishop Exchanger Piping Detail

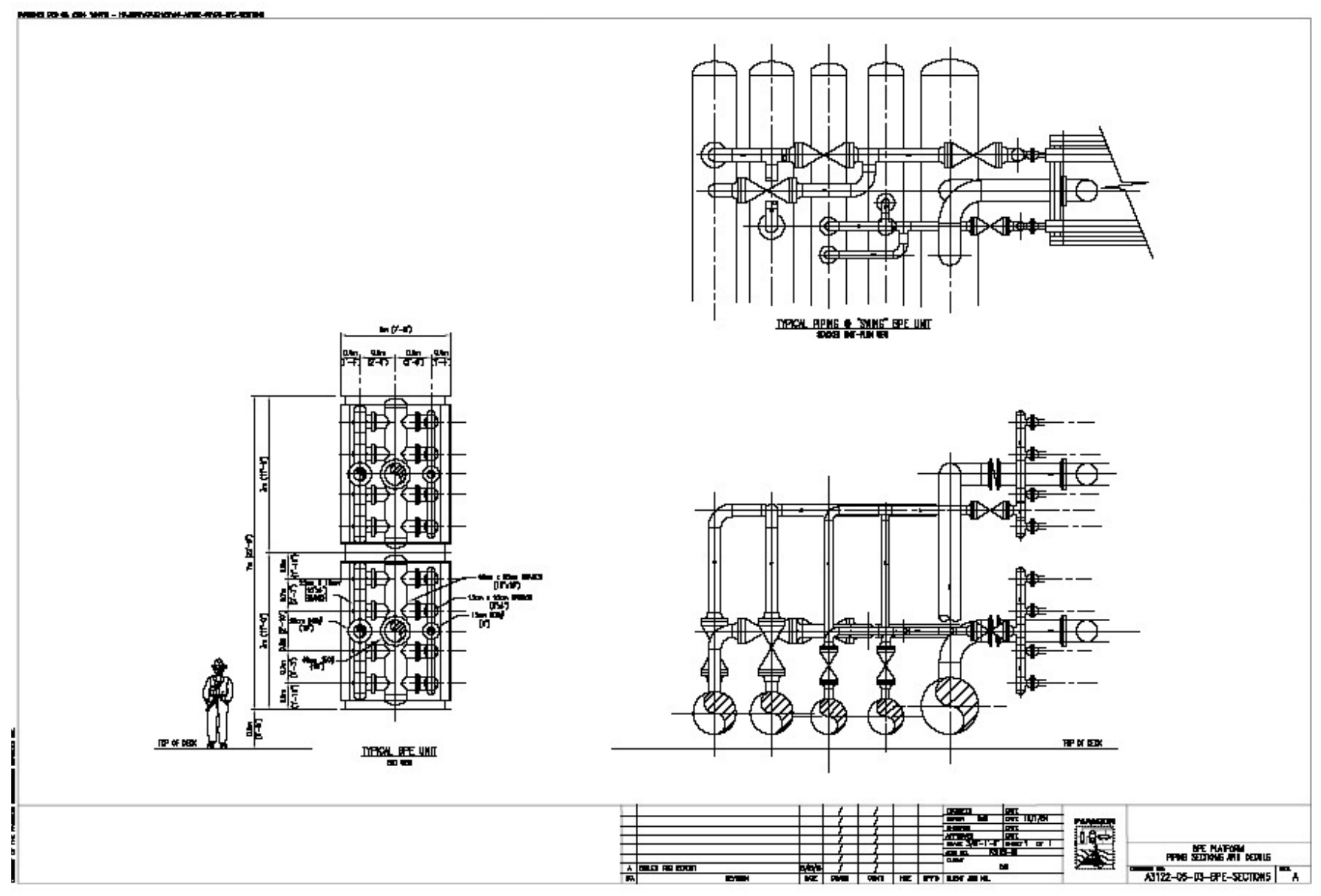


FIGURE 7. FAV Schematic

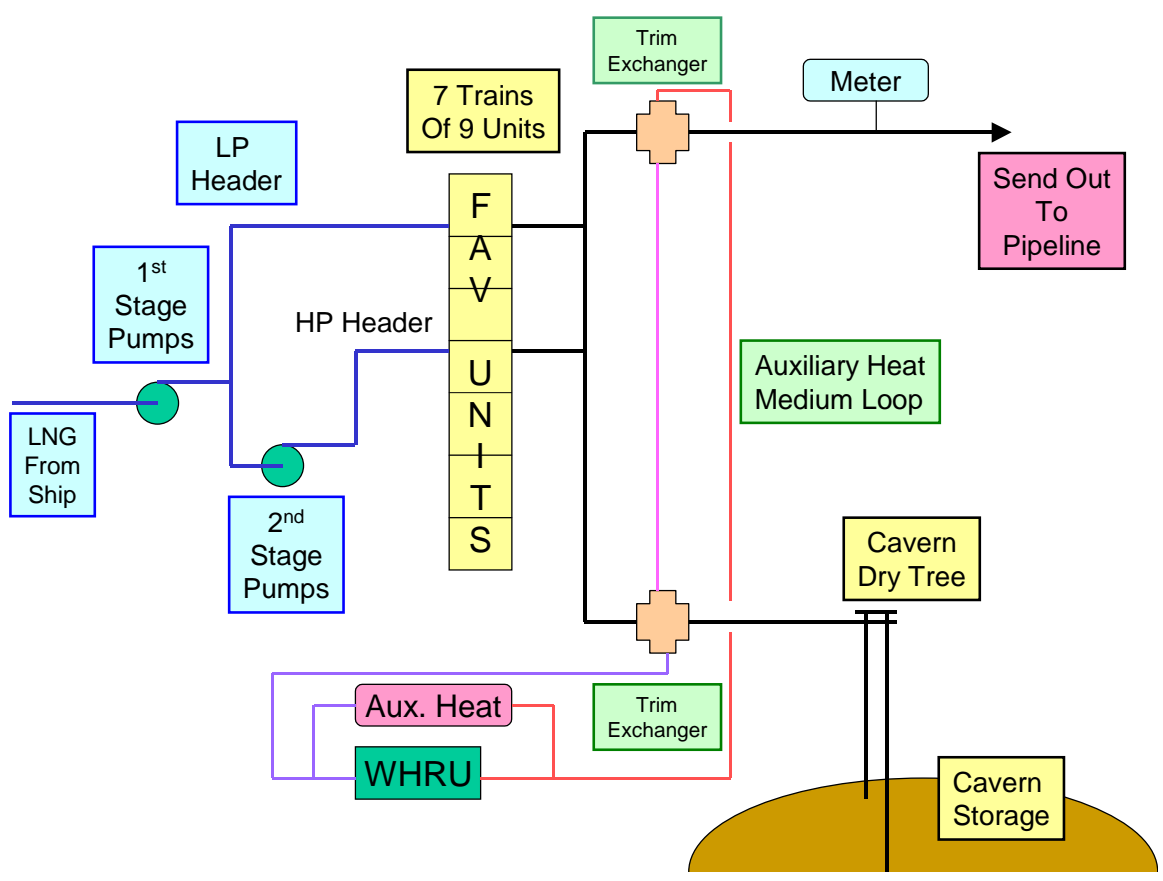


APPENDIX C: TEMA Designations
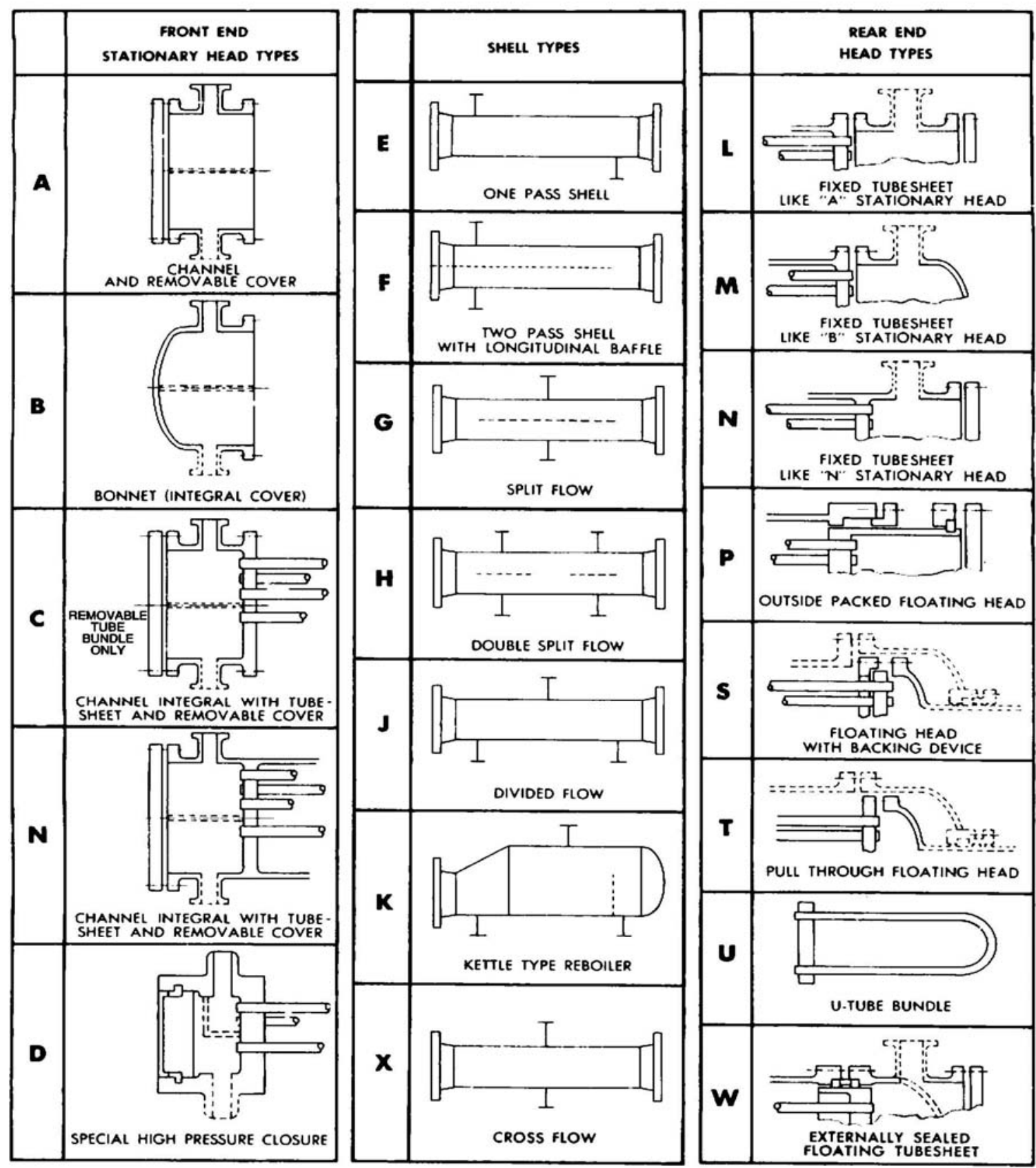

Courtesy of TEMA 


\title{
APPENDIX D: Companies and Contacts List
}

\section{Open Rack Vaporizers:}

\section{SOJITZ CORPORATION OF AMERICA (SUMITOMO)}

Three Riverway, Suite 800

Houston, TX 77056

Contact: Robert J. (Bob) Wilde

Ph 713/966-5741

Fax 713/961-0723

E-mail: wilde.Robert@sky.sojitz.com

\section{Shell and Tube Vaporizers:}

E.L.I., Inc.

P.O. Box 23768

Harahan, LA 70183-0768

Contact: Tim Irwin

Ph 504/739-2470

Fax 504/739-2484

CHICAGO POWER \& PROCESS

$625 \mathrm{~W}$. University Drive

Arlington Hts., IL 60004

Contact: Mike Cahill

Ph 847/870-7900

Fax 847/870-7905

E-mail:

info@chicagopowerandprocess.com

MANNING \& LEWIS ENGINEERING COMPANY - NO RESPONSE

675 Rahway Avenue

Union, NJ 07083

Contact: Kevin Elwood

Ph 908/687-2400

Fax 908/687-2404

E-mail: kevin.elwood@manninglewis.com

\section{Bishop Process Exchanger:}

\author{
BUTCHER'S WELDING \& FABRICATING SERVICE \\ 5637 Etheline \\ Houston, Texas 77039 \\ Ph 281/590-9391 \\ Fax 281/449-8563 \\ E-mail: jbutcher@butcherweldfab.com
}




\section{Submerged Combustion Vaporizers:}

\section{SOJITZ CORPORATION OF AMERICA (SUMITOMO)}

Three Riverway, Suite 800

Houston, TX 77056

Contact: Robert J. (Bob) Wilde

$\mathrm{Ph} 713 / 966-5741$

Fax 713/961-0723

E-mail: wilde.Robert@sky.sojitz.com

\section{T-THERMAL COMPANY}

Five Sentry Parkway East

Blue Bell, PA 19422

Contact: Edward R. Vogel, Jr. Marc Rost

$\mathrm{Ph}$ 610/832-8717 8713

Fax 610/834-0473

E-mail: evogel@selasfluid.com

mrost@selasfluid.com

\section{Ambient Air Vaporizers:}

\section{CRYOQUIP}

1259 S. Cedar Crest Blvd., 336

Allentown, PA 18103

Contact: Lyn Himmelberger

Ph 610/437-1867

Fax 610/770-0766

E-mail: Ihimmie@aol.com

\section{Intermediate Fluid Vaporizers:}

\section{MUSTANG ENGINEERING}

16001 Park Ten Place

Houston, TX 77084

Contact: Milos Soudek

$\mathrm{Ph} 713 / 215-8000$

Fax 713/ 215-8506

E-mail: Milos.Soudek@mustangeng.com 


\section{APPENDIX E: References Used by NOAA/NMFS With Regard to Impacts from Impingement/Entrainment}

Boreman, J., Goodyear, C.P., Christensen, S.W. An Empirical Methodology for Estimating Entrainment Losses at Power Plants Sited on Estuaries. Trans. Amer. Fish. Soc. $1981 ; 110: 253-60$.

Camp Dresser \& McKee, Inc. Sediment Sampling: Point Comfort Turning Basin. Project No. 3161. Aug. 1980.

Cook, R.L. The Texas Shrimp Fishery: A Report to the Governor and the $77^{\text {th }}$ Legislature of Texas. Texas Department of Parks and Wildlife. Sept. 2002.

Ditty, J.G. Ichthyoplankton in Neritic Waters of the Northern Gulf of Mexico Off Louisiana: Composition, Relative Abundance, and Seasonality. Fish. Bull. 1986; 84(4): 935-946.

Ditty, J.G. Seasonality and Depth Distribution of Larval Fishes in the Northern Gulf of Mexico Above Latitude 2600'N. Fish. Bull.1988; 86(4): 811-22.

Duronslet, M.J., Lyon, J.M., Marullo, F. Vertical Distribution of Postlarval Brown, Penaeus aztecus, and White P. setiferus, Shrimp During Immigration Through a Tidal Pass. Trans. Amer. Fish. Soc. 1972; 101:748-52.

Environmental Protection Agency (US). The Ecological Condition of Estuaries in the Gulf of Mexico. EPA 620-R-98-004. U.S. Environmental Protection Agency, Office of Research and Development. National Health and Environmental Effects Research Laboratory, Gulf Ecology Division, Gulf Breeze, FL. 1999.

Environmental Protection Agency (US). Case Study Analysis for the Proposed Section 316(b) Phase II Existing Facilities Rule. EPA-821-R-02-002. U.S. Environmental Protection Agency. Office of Water.

Goodwin Procter. Between Scylla \& Charybdis: EPA and Second Circuit Raise New Challenges for Electricity-Generating Facilities Under Clean Water Act 316(b). Environmental Law Advisory. 2004.

Holt, S.A., Holt, G.J., Arnold, C.R. Distribution of Eggs and Larvae of Red Drum (Sciaenops ocellatus) in Texas Coastal Waters. Cont. Mar. Sci. 1988; 30:196.

Houde, E.D. Fish Early Life Dynamics and Recruitment Variability. P.17-29. In Hoyt, R.D. (ed.). Proceedings of the $10^{\text {th }}$ Annual Larval Fish Conference held in Miami, FL May 18-23, 1986. American Fisheries Society Symposium 2. 1987. American Fisheries Society, Bethesda, MD.

Houde, E.D. Subtleties and Episodes in the Early Life of Fishes. J. Fish Biol. 1989; 35 Supplement A: 29-38. 
Lochmann, S.E., Darnell, R.M., McEachran, J.D. Temporal and Vertical Distribution of Crab Larvae in a Tidal Pass. Estuaries 1995; 18:255-63.

Marley, R.D. Spatial Distribution Patterns of Planktonic Fish Eggs in Lower Mobile Bay, Alabama. Trans. Amer. Fish. Soc. 1983; 112:257-66.

Minello, T.J. The Neritic Zooplankton of the Northwestern Gulf of Mexico. College Station: Texas A\&M University; 1980. 240p.

Moffett, A.W. The Shrimp Fishery in Texas. Texas Parks and Wildlife Department. Coastal Fisheries Branch. Jan. 1990.

Palafox, S.D., Wolford, E.D. Non-Fishing Human Induced Mortality of Fisheries Resources in Galveston Bay. Galveston Bay National Estuary Program Publication. GBNEP-29. Webster, TX. 1993.

Riverkeeper, Inc. Comprehensive Survey and Investigation of Dry Cooling Systems to Reduce Impingement and Entrainment. 2003.

(http://riverkeeper.org/document.php/227/1_Riverkeepers_.pdf).

Temple, R.F., Fischer, C.C. Vertical Distribution of the Planktonic Stages of Penaeid Shrimp. Publ. Inst. Mar. Sci. Univ. Texas. 1965; 10:59-67.

Temple, R.F., Fischer, C.C. Seasonal Distribution and Relative Abundance of PlanktonicStage Shrimp (Penaeus spp.) in the Northwestern Gulf of Mexico, 1961. Fish. Bull. 1967; 66(2): 323-34.

Tetra Tech. Evaluation of Cooling System Alternatives: Proposed Morro Bay Power Plant. 2002. (http://www.swrcb.ca.gov/rwqcb3/MorroBayDNA/Reports/TetraTechMBPP.pdf) 
December 15, 2004

Mr. Mike McCall

Conversion Gas Imports, LLC

2929 Briarpark Suite 220

Houston, TX 77042

Dear Mike;

E \& E has been tasked with conducting a preliminary study of the potential effects of the Bishop Process heat exchanger on species managed by the Gulf of Mexico Fishery Management Council in Vermillion Block 179 (VR 179), offshore Louisiana. The Bishop Process ${ }^{\mathrm{TM}}$ is a vaporizer technology utilizing a simple, modular pipe-in-pipe design comprised of an inner 6-inch cryogenic pipe containing LNG and an outer 12-inch coated polymer pipe. Each heat exchanger will have the capacity to heat up to 300 cubic meters $\left(\mathrm{m}^{3}\right)$ of $\mathrm{LNG}$ per hour at pressures up to 2200 pounds per square inch resulting in a regasification rate of about 6.5 million standard cubic feet per hour. For the purposes of this analysis, we were provided with water throughput of $100,000 \mathrm{~m}^{3}$ /hour.

\section{Summary}

As a first step in determining potential effects, the density of both eggs and larvae were determined utilizing NOAA (National Oceanic and Atmospheric Administration) data (SEAMAP 1982-2002). Following instructions from NOAA fisheries specialists, survey data was manipulated to determine the number of eggs that may be present per million gallons of seawater. A similar process was used for determining ichthyoplankton larvae present. Additional adjustments were made to comply with information presented in a memo from Nancy Thompson of NOAA to Roy Crabtree, the Regional Administrator. ${ }^{1}$

Generally, managed species constituted a very small percentage of the total number of larvae identified in the database. Only the taxonomic group for sciaenids (red drum and others) was above one percent. Percentages for trigger fish, snapper and sea basses, which represent reef fish species, totaled less than one percent of the overall larvae found within the VR179 Block. Finally, for Coastal Migratory Pelagic Fishes, mackerels and bluefish were the only species found, and composed less than one percent of the total larvae. These results suggest that ichthyoplankton larvae near the facility do not contain significantly high numbers of species managed within the Gulf of Mexico, and thus impacts to these groups from entrainment and impingement will be low.

1 See Attachment 1. 
During maximum Bishop Process flow periods (634 mgd), and assuming 100\% mortality when eggs and larvae are entrained, the daily mortality for eggs will represent approximately 0.00427 $\%$ of the eggs found within the VR179 Block. Similarly, the daily mortality for larvae will represent $0.00427 \%$ of the larvae found within the block. Although seasonal and daily fluctuations will occur, these values are less than significant, especially when water volumes for the entire eastern Gulf of Mexico are considered.

\section{Analysis}

Original SEAMAP data (1982-2002) for 42 ichthyoplankton sampling stations located within a 30 nautical mile (NM) by 30 NM block surrounding VR179 (see Figure 1 and Table 1) were downloaded from NOAA's database [http://www.gsmfc.org/sm_surveys.html]. It was felt that sampling data within this locale would be relative for potential operational impacts to ichthyoplankton. Data included both egg and larval information. Egg data were not taxaspecific, but only listed by number per volume. Larval data included several taxonomic levels; primarily family, genus and/or species.

Data were originally downloaded in 'text' format from the SEAMAP database and then copied into an Access ${ }^{\circledR}$ database for manipulation purposes. For egg information, the database (inclusive of 34 of the 42 sampling stations where eggs were collected) was then sorted by station-sample number. Per instructions from NOAA Fisheries Specialist David Hanisko (NMFS Pascagoula Laboratory), numbers of eggs per cubic meter of water for each station were determined by considering the total number of eggs counted, divided by the volume of water filtered per sample (see Table 2). These numbers were then summed and averaged (i.e., per 34 stations) to determine the total number of eggs that would occur in a cubic meter of water. This number was then converted to eggs per gallon of water and subsequently adjusted for a million gallons of seawater.

A similar approach was taken for ichthyoplankton larvae, except larval data were available from all 42 SEAMAP stations. Data were first sorted by cruise, vessel, station, and sample, next the measured and not measured numbers of larvae were added (i.e., = total larvae collected), and then this result was divided by the volume of water filtered for each sample. If an aliquot was required prior to sorting, then the sample was multiplied by the required factor for assuring that the sample results were equitable to a whole sample (i.e, for $1 / 2$ aliquots - larval values were multiplied by 2). This resulted in determination of the total number of larvae per cubic meter of water per station-sample. Then all station-samples were summed to determine an average across the VR179 block (i.e., concentration normalized to station). This value represented the average number of larvae that would be found (considering all 42 stations) in a cubic meter of water across the block associated with VR179. This number was then converted to larvae per gallon of water and subsequently adjusted for a million gallons of seawater (see Table 3 ). 


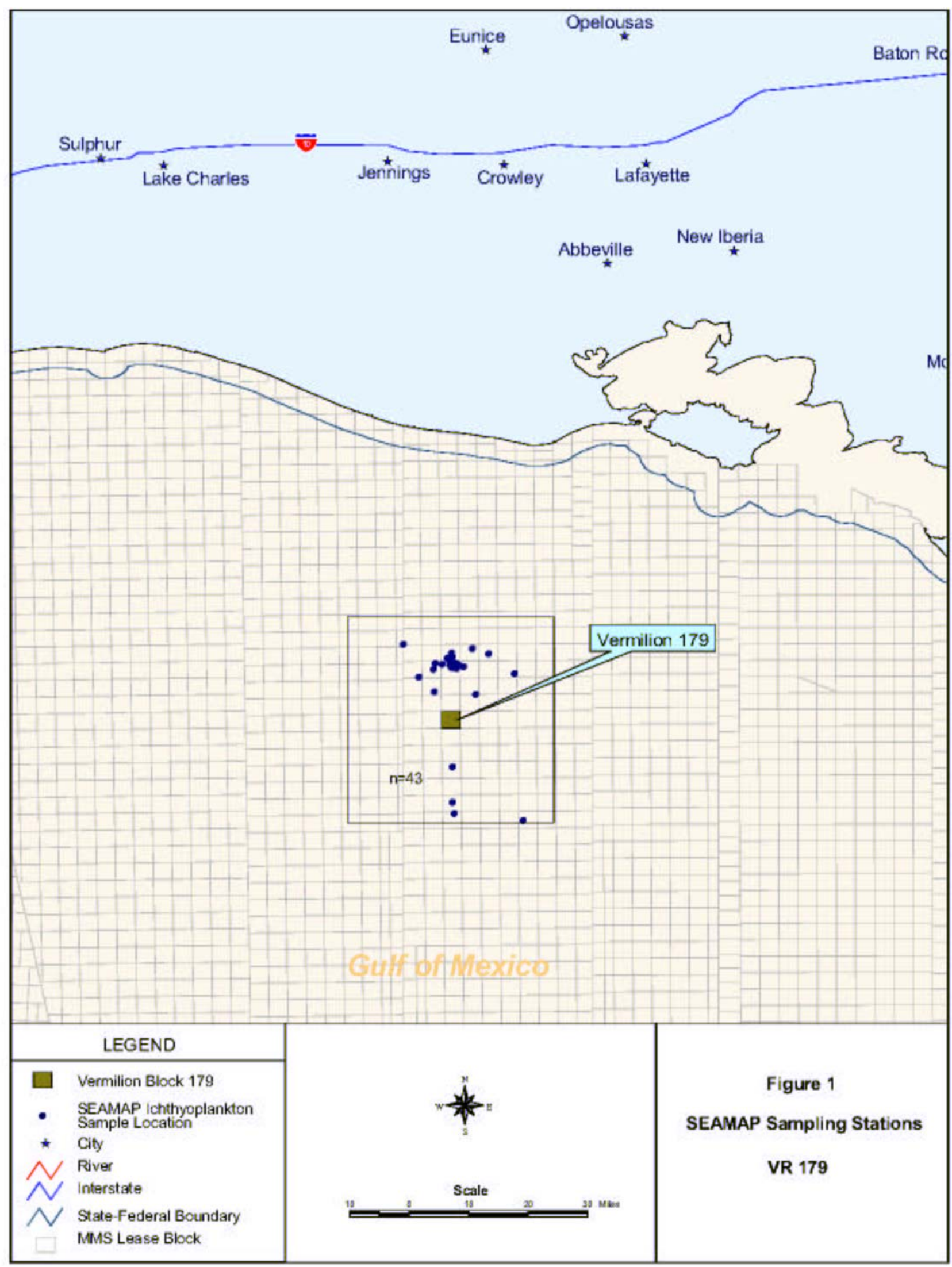


Table 1 - SEAMAP Stations Within a 30 x 30 NM Block near VR179

\begin{tabular}{|c|c|c|c|c|c|c|c|}
\hline LAT & LONG & CRUISE & VESSEL & STATION & SAMPLE & GEAR & MESH \\
\hline 29.00117 & -92.50233 & 013 & 17 & 00061 & 27927 & 01 & 03 \\
\hline 28.99900 & -92.48433 & 016 & 63 & 00156 & 28606 & 01 & 03 \\
\hline 29.00200 & -92.54250 & 025 & 63 & 00089 & 29645 & 01 & 03 \\
\hline 29.00000 & -92.50000 & 145 & 04 & 41072 & 03114 & 01 & 03 \\
\hline 29.00000 & -92.50000 & 146 & 04 & 41358 & 02670 & 01 & 03 \\
\hline 28.75000 & -92.50000 & 146 & 04 & 41359 & 02673 & 01 & 03 \\
\hline 29.00000 & -92.50000 & 153 & 04 & 42847 & 04062 & 01 & 03 \\
\hline 28.99500 & -92.47333 & 160 & 04 & 44167 & 05440 & 01 & 03 \\
\hline 28.93333 & -92.54500 & 163 & 04 & 44720 & 06274 & 01 & 03 \\
\hline 28.92667 & -92.44333 & 167 & 04 & 45841 & 07017 & 01 & 03 \\
\hline 29.00033 & -92.52517 & 169 & 04 & 46245 & 07559 & 01 & 03 \\
\hline 28.63833 & -92.49667 & 180 & 04 & 50024 & 09810 & 01 & 03 \\
\hline 29.03833 & -92.45167 & 184 & 04 & 50714 & 10046 & 01 & 03 \\
\hline 28.62167 & -92.32833 & 184 & 04 & 50728 & 10049 & 01 & 03 \\
\hline 29.02500 & -92.41167 & 189 & 04 & 51681 & 11907 & 01 & 03 \\
\hline 28.96833 & -92.58167 & 191 & 04 & 52172 & 12286 & 01 & 03 \\
\hline 29.00167 & -92.50667 & 195 & 04 & 53241 & 13042 & 01 & 03 \\
\hline 29.01500 & -92.51167 & 200 & 04 & 54190 & 14755 & 01 & 03 \\
\hline 29.00217 & -92.50117 & 202 & 04 & 54532 & 15178 & 01 & 03 \\
\hline 28.99733 & -92.50383 & 205 & 04 & 55268 & 16649 & 01 & 03 \\
\hline 28.66633 & -92.49917 & 208 & 04 & 55287 & 17267 & 01 & 03 \\
\hline 29.04933 & -92.61933 & 210 & 04 & 00195 & 18475 & 01 & 03 \\
\hline 28.99917 & -92.50667 & 214 & 04 & 00177 & 19035 & 01 & 03 \\
\hline 28.98933 & -92.48933 & 217 & 04 & 04157 & 20300 & 01 & 03 \\
\hline 28.99967 & -92.50017 & 219 & 04 & 00135 & 20636 & 01 & 03 \\
\hline 29.00017 & -92.49767 & 221 & 04 & 00197 & 21434 & 01 & 03 \\
\hline 28.99900 & -92.49867 & 226 & 04 & 00203 & 23068 & 01 & 03 \\
\hline 29.00133 & -92.49733 & 232 & 04 & 00004 & 24549 & 01 & 03 \\
\hline 29.00000 & -92.50000 & 237 & 04 & 00191 & 26008 & 01 & 03 \\
\hline 29.00267 & -92.49217 & 240 & 04 & 00190 & 26681 & 01 & 03 \\
\hline 28.99217 & -92.49483 & 242 & 04 & 04044 & 26882 & 01 & 03 \\
\hline 28.99900 & -92.50183 & 246 & 04 & 00074 & 28002 & 01 & 03 \\
\hline 28.98800 & -92.54733 & 250 & 04 & 00171 & 29325 & 01 & 03 \\
\hline 28.97667 & -92.35000 & 823 & 20 & 20075 & 00437 & 01 & 03 \\
\hline 29.01683 & -92.50050 & 865 & 28 & 00019 & 06001 & 01 & 03 \\
\hline 29.02667 & -92.50167 & 925 & 28 & 00046 & 14935 & 01 & 03 \\
\hline 29.00317 & -92.49933 & 936 & 28 & 28090 & 17083 & 01 & 03 \\
\hline 29.00167 & -92.50000 & 946 & 28 & 28037 & 18669 & 01 & 03 \\
\hline 29.00100 & -92.50067 & 955 & 28 & 28049 & 20408 & 01 & 03 \\
\hline 28.99783 & -92.50183 & 965 & 28 & 28035 & 21626 & 01 & 03 \\
\hline 28.99133 & -92.50133 & 975 & 28 & 28038 & 23220 & 01 & 03 \\
\hline
\end{tabular}


Table 2 - Determination of the Number of Ichthyoplankton Eggs from SEAMAP Data near VR179

\begin{tabular}{|c|c|c|c|c|c|c|c|c|c|}
\hline P_STA_NO & SAMPLE_NO & GEAR_CODE & MESH_CODE & VOL_FILT & MAX_DEPTH & NO_EGGS & MULTIPLIER1 & Total Eggs & Eggs/M3 \\
\hline 41072 & 03114 & 01 & 03 & 69 & 24 & 157 & 1 & 157 & 2.275362319 \\
\hline 41358 & 02670 & 01 & 03 & 59 & 21 & 10 & 1 & 10 & 0.169491525 \\
\hline 41359 & 02673 & 01 & 03 & 80 & 35 & 450 & 1 & 450 & 5.625 \\
\hline 45841 & 07017 & 01 & 03 & 76 & 22 & 200 & 1 & 200 & 2.631578947 \\
\hline 46245 & 07559 & 01 & 03 & 58 & 19 & 200 & 1 & 200 & 3.448275862 \\
\hline 50024 & 09810 & 01 & 03 & 76 & 26 & 81 & 1 & 81 & 1.065789474 \\
\hline 50714 & 10046 & 01 & 03 & 65 & 20 & 161 & 1 & 161 & 2.476923077 \\
\hline 50728 & 10049 & 01 & 03 & 77 & 30 & 47 & 1 & 47 & 0.61038961 \\
\hline 51681 & 11907 & 01 & 03 & 46 & 17 & 200 & 1 & 200 & 4.347826087 \\
\hline 52172 & 12286 & 01 & 03 & 65 & 28 & 200 & 1 & 200 & 3.076923077 \\
\hline 53241 & 13042 & 01 & 03 & 61 & 20 & 200 & 1 & 200 & 3.278688525 \\
\hline 54190 & 14755 & 01 & 03 & 61 & 20 & 577 & 2 & 1154 & 18.91803279 \\
\hline 54532 & 15179 & 01 & 03 & 64 & 26 & 0 & 1 & 0 & 0 \\
\hline 55268 & 16649 & 01 & 03 & 56 & 16 & 15 & 1 & 15 & 0.267857143 \\
\hline 55287 & 17267 & 01 & 03 & 64 & 25 & 121 & 1 & 121 & 1.890625 \\
\hline 00195 & 18475 & 01 & 03 & 55 & 25 & 20 & 1 & 20 & 0.363636364 \\
\hline 00177 & 19035 & 01 & 03 & 52 & 23 & 19 & 1 & 19 & 0.365384615 \\
\hline 04157 & 20300 & 01 & 03 & 68 & 24 & 2936 & 1 & 2936 & 43.17647059 \\
\hline 00135 & 20636 & 01 & 03 & 46 & 23 & 20 & 1 & 20 & 0.434782609 \\
\hline 00197 & 21434 & 01 & 03 & 45 & 18 & 19 & 1 & 19 & 0.422222222 \\
\hline 00004 & 24549 & 01 & 03 & 53 & 21 & 19 & 1 & 19 & 0.358490566 \\
\hline 00191 & 26008 & 01 & 03 & 61 & 22 & 540 & 1 & 540 & 8.852459016 \\
\hline 00190 & 26681 & 01 & 03 & 56 & 21 & 308 & 1 & 308 & 5.5 \\
\hline 04044 & 26882 & 01 & 03 & 60 & 21 & 190 & 1 & 190 & 3.166666667 \\
\hline 04044 & 26883 & 01 & 03 & 58 & 21 & 200 & 1 & 200 & 3.448275862 \\
\hline 00074 & 28002 & 01 & 03 & 60 & 24 & 171 & 1 & 171 & 2.85 \\
\hline 00171 & 29325 & 01 & 03 & 52 & 24 & 818 & 1 & 818 & 15.73076923 \\
\hline 20075 & 00437 & 01 & 03 & 372 & 17 & 401 & 1 & 401 & 1.077956989 \\
\hline 00046 & 14935 & 01 & 03 & 95 & 19 & 328 & 1 & 328 & 3.452631579 \\
\hline 28090 & 17083 & 01 & 03 & 56 & 20 & 124 & 1 & 124 & 2.214285714 \\
\hline
\end{tabular}




\begin{tabular}{|c|c|c|c|c|c|c|c|c|c|}
\hline P_STA_NO & SAMPLE_NO & GEAR_CODE & MESH_CODE & VOL_FILT & MAX_DEPTH & NO_EGGS & MULTIPLIER1 & Total Eggs & Eggs/M3 \\
\hline 28037 & 18669 & 01 & 03 & 46 & 32 & 117 & 1 & 117 & 2.543478261 \\
\hline 28049 & 20408 & 01 & 03 & 45 & 21 & 24 & 1 & 24 & 0.533333333 \\
\hline 28038 & 23220 & 01 & 03 & 80 & 25 & 941 & 1 & 941 & 11.7625 \\
\hline 63042 & 25664 & 01 & 03 & 94 & 23 & 451 & 1 & 451 & 4.79787234 \\
\hline \multicolumn{9}{|c|}{ Sum for all Stations-samples } & 161.1339794 \\
\hline \multicolumn{9}{|c|}{ Mean eggs per cubic meter of seawater for all Stations-samples } & 4.73923 \\
\hline \multicolumn{9}{|c|}{ Eggs per gallon of seawater [based on 1 cubic meter $=264.1720512$ gallons] } & 0.017940 \\
\hline \multicolumn{9}{|c|}{ Eggs per Million gallons of seawater } & 17,939 \\
\hline
\end{tabular}


Table 3 - Determination of the Number of Ichthyoplankton Larvae from SEAMAP data near VR 179

\begin{tabular}{|l|r|r|r|r|}
\hline Station & Sample & \multicolumn{1}{c}{ LatD } & \multicolumn{1}{c}{ LonD } & LARVAE/M \\
\hline 00061 & 27927 & 29.00117 & -92.5023 & 13.71739 \\
\hline 00156 & 28606 & 28.999 & -92.4843 & 1.607843 \\
\hline 00089 & 29645 & 29.002 & -92.5425 & 1.151515 \\
\hline 41072 & 03114 & 29 & -92.5 & 1.811594 \\
\hline 41358 & 02670 & 29 & -92.5 & 8.372881 \\
\hline 41359 & 02673 & 28.75 & -92.5 & 3.125 \\
\hline 42847 & 04062 & 29 & -92.5 & 1.752577 \\
\hline 44167 & 05440 & 28.995 & -92.4733 & 3.075 \\
\hline 44720 & 06274 & 28.93333 & -92.545 & 3.830189 \\
\hline 45841 & 07017 & 28.92667 & -92.4433 & 4.289474 \\
\hline 46245 & 07559 & 29.00033 & -92.5252 & 15.68966 \\
\hline 50024 & 09810 & 28.63833 & -92.4967 & 0.184211 \\
\hline 50714 & 10046 & 29.03833 & -92.4517 & 5.815385 \\
\hline 50728 & 10049 & 28.62167 & -92.3283 & 0.597403 \\
\hline 51681 & 11907 & 29.025 & -92.4117 & 4.804348 \\
\hline 52172 & 12286 & 28.96833 & -92.5817 & 7.046154 \\
\hline 53241 & 13042 & 29.00167 & -92.5067 & 2.491803 \\
\hline 54190 & 14755 & 29.015 & -92.5117 & 32.57377 \\
\hline 54532 & 15178 & 29.00217 & -92.5012 & 4.825397 \\
\hline 55268 & 16649 & 28.99733 & -92.5038 & 0.553571 \\
\hline 55287 & 17267 & 28.66633 & -92.4992 & 1.59357 \\
\hline 00195 & 18475 & 29.04933 & -92.6193 & 1.639394 \\
\hline 00177 & 19035 & 28.99917 & -92.5067 & 2.307692 \\
\hline 04157 & 20300 & 28.98933 & -92.4893 & 19.48529 \\
\hline 00135 & 20636 & 28.99967 & -92.5002 & 0.173913 \\
\hline 00197 & 21434 & 29.00017 & -92.4977 & 2.5777 \\
\hline 00203 & 23068 & 28.999 & -92.4987 & 1.563636 \\
\hline 00004 & 24549 & 29.00133 & -92.4973 & 4.792453 \\
\hline 00191 & 26008 & 29 & -92.5 & 9.803279 \\
\hline 00190 & 26681 & 29.00267 & -92.4922 & 5.035714 \\
\hline 04044 & 26882 & 28.99217 & -92.4948 & 4.58333 \\
\hline 00074 & 28002 & 28.999 & -92.5018 & 4.516667 \\
\hline 00171 & 29325 & 28.988 & -92.5473 & 8.903846 \\
\hline 20075 & 00437 & 28.97667 & -92.35 & 6.016129 \\
\hline 00019 & 06001 & 29.01683 & -92.5005 & 14.22917 \\
\hline 00046 & 14935 & 29.02667 & -92.5017 & 3.315789 \\
\hline 28090 & 17083 & 29.00317 & -92.4993 & 2.7857 \\
\hline 28037 & 18669 & 29.00167 & -92.5 & 5.86965 \\
\hline 28049 & 20408 & 29.001 & -92.5007 & 19.35556 \\
\hline 28035 & 21626 & 28.99783 & -92.5018 & 3.580645 \\
\hline 28038 & 23220 & 28.99133 & -92.5013 & \\
\hline 63042 & 25664 & 28.99833 & -92.5007 & 9.074468 \\
\hline & & & & \\
\hline & & & & \\
\hline
\end{tabular}




\begin{tabular}{|l|c|}
\hline Station Sample $\quad$ LatD LonD & LARVAE/M $^{3}$ \\
\hline Sum for all Stations-samples & 254.71876 \\
\hline $\begin{array}{l}\text { Mean larvae per cubic meter of seawater for all } \\
\text { Stations-samples }\end{array}$ & 6.06473 \\
\hline $\begin{array}{l}\text { Larvae per gallon of seawater [based on 1 cubic } \\
\text { meter = 264.1720512 gallons] }\end{array}$ & 0.022957 \\
\hline Larvae per Million gallons of seawater & 22,957 \\
\hline
\end{tabular}

To provide a more realistic density estimate for eggs and larvae entrained, an adjustment to the derived mean densities was applied based on information provided in Nancy B. Thompson's (NOAA, NMFS, SEFSC) memo to Roy Crabtree, dated February 18, 2004 (see Attachment 1). The memo proposed use of a multiplier of 3 applied to SEAMAP data to account for extrusion of specimens from the $0.333 \mathrm{~mm}$ mesh net that is used for standard SEAMAP sampling. The results of this adjustment are presented in Table 4. It must be understood that this adjustment is theoretical and at present no technical basis has yet been presented for use of a multiplier near VR179.

Table 4 - Density and Entrainment Estimates for Ichthyoplankton near VR179

\begin{tabular}{|c|c|c|c|}
\hline Data Source & Average No./gallon & $\begin{array}{l}\text { Average No./1 million } \\
\text { gallons seawater }\end{array}$ & $\begin{array}{l}\text { Million entrained per } \\
\text { day at normal ( } 634 \\
\left.\text { MGD }{ }^{2}\right) \text { flow }\end{array}$ \\
\hline \multicolumn{4}{|c|}{ SEAMAP Data (May-November); 1982- 1999} \\
\hline Fish Eggs (34 samples) & 0.017940 & 17,939 & 11.3733 \\
\hline Fish Larvae (42 samples) & 0.022957 & 22,957 & 14.5547 \\
\hline Combined (eggs + larvae) & 0.040897 & 40,896 & 25.9280 \\
\hline \multicolumn{4}{|c|}{ SEAMAP Annual Estimate Adjusted ${ }^{1}$ for mesh size (per NOAA Memo - N. Thompson; 2-18-04) } \\
\hline Fish Eggs (34 samples) & 0.05382 & 53,820 & 34.1199 \\
\hline Fish Larvae (42 samples) & 0.06887 & 68,870 & 43.6641 \\
\hline Combined (eggs + larvae) & 0.12269 & 122,690 & 77.7840 \\
\hline
\end{tabular}

$1=$ Represents use of a multiplier of 3 as provided by NOAA Memo; N. Thompson - February 18, 2004.

$2=$ Represents maximum flow rate for facility - would only be applicable to 15 days per month.

The database was sorted similar to the method described in above, for each station by taxonomic grouping (see Table 5). As would be expected, forage species (Engraulidae, i.e., anchovy species) were found in highest numbers within the VR179 Block, as were the common carangid species Chloroscombrus chrysurus (Atlantic bumper). Other significant groups included gobies, croaker, and sand trout that are common species within brown shrimp fishing grounds in the central and western Gulf of Mexico. 
Table 5 - Larvae per cubic meter of Seawater Based on Taxonomic Groupings for SEAMAP data from Block VR179

\begin{tabular}{|l|r|r|}
\hline \multicolumn{1}{|c|}{ Taxonomic Group } & Sum of Stations & \% of Total \\
\hline ENGRAULIDAE & 37.9801215 & 14.91170848 \\
\hline CHLOROSCHRYSU & 33.69695852 & 13.23005831 \\
\hline UNID.FISH & 28.79153942 & 11.30409871 \\
\hline SYMPHURUS & 22.14444653 & 8.694325297 \\
\hline GOBIIDAE & 21.65940823 & 8.503890155 \\
\hline CLUPEIFORMES & 21.17485337 & 8.313644826 \\
\hline MICROPOUNDULA & 9.470059176 & 3.718122959 \\
\hline OPISTHOOGLINU & 8.907057375 & 3.497077886 \\
\hline BREVOORTIA & 8.814466117 & 3.46072482 \\
\hline CYNOSCIARENAR & 7.254838121 & 2.848385599 \\
\hline BOTHIDAE & 4.396774305 & 1.726256107 \\
\hline SYACIUM & 4.300329131 & 1.688389922 \\
\hline OPHIDIIDAE & 3.361129164 & 1.319642389 \\
\hline SYACIUMPAPILL & 3.260186761 & 1.280010507 \\
\hline BREGMACEROS & 2.970736813 & 1.166367025 \\
\hline ETROPUS & 2.808958359 & 1.102849768 \\
\hline SCIAENIDAE & 2.724177169 & 1.069563082 \\
\hline ETROPUSCROSSO & 2.593813638 & 1.018379913 \\
\hline PLEURONECTIFO & 2.088553266 & 0.820005208 \\
\hline CYNOGLOSSIDAE & 1.869565217 & 0.734026391 \\
\hline HARENGUJAGUAN & 1.700193454 & 0.667527858 \\
\hline SERRANIDAE & 1.280776424 & 0.502856861 \\
\hline CLUPEIDAE & 1.081921983 & 0.424782875 \\
\hline MICRODESMIDAE & 1.068138833 & 0.419371352 \\
\hline CYNOSCION & 1.053289385 & 0.41354118 \\
\hline DIPLECTRUM & 1.029418577 & 0.404169053 \\
\hline EUTHYNNALLETT & 1.023327956 & 0.401777761 \\
\hline SCOMBRIDAE & 0.996922609 & 0.391410526 \\
\hline PERCIFORMES & 0.985847528 & 0.387062241 \\
\hline CITHARICHTHYS & 0.817271266 & 0.320876037 \\
\hline MENTICIRRHUS & 0.67168314 & 0.263715406 \\
\hline SCOMBERMACULA & 0.669376074 & 0.262809609 \\
\hline PEPRILUPARU & 0.639355146 & 0.251022829 \\
\hline CYNOSCINOTHUS & 0.61645557 & 0.242032026 \\
\hline SCOMBERCAVALL & 0.5400808 & 0.212045858 \\
\hline LEIOSTOXANTHU & 0.206183215 \\
\hline BROTULA & 0.203859744 \\
\hline PRIONOTUS & 0.188060261 \\
\hline SYNODONTIDAE & 0.169978559 \\
\hline SPHYRAENA & 0.1450237995 \\
\hline LUTJANIDAE & 0.45352358 \\
\hline
\end{tabular}




\begin{tabular}{|c|c|c|}
\hline Taxonomic Group & Sum of Stations & $\%$ of Total \\
\hline PEPRILUBURTI & 0.31673564 & 0.124356356 \\
\hline OPHICHTHIDAE & 0.308449027 & 0.121102877 \\
\hline SELENE VOMER & 0.306872294 & 0.120483822 \\
\hline CARANX & 0.304193215 & 0.119431965 \\
\hline TRICHIULEPTUR & 0.299245133 & 0.117489255 \\
\hline PEPRILUS & 0.290618258 & 0.114102182 \\
\hline CENTROPRISTIS & 0.284494 & 0.111697684 \\
\hline MICROPOGONIAS & 0.276923077 & 0.108725197 \\
\hline MURAENIDAE & 0.273634053 & 0.107433865 \\
\hline LUTJANUS & 0.239060837 & 0.093859771 \\
\hline POMATOMSALTAT & 0.238961039 & 0.093820589 \\
\hline LARIMUSFASCIA & 0.21702131 & 0.085206639 \\
\hline ENGYOPHSENTA & 0.216949031 & 0.085178261 \\
\hline CARANGIDAE & 0.211947748 & 0.083214664 \\
\hline SYMPHURPLAGIU & 0.196236559 & 0.077046156 \\
\hline BLENNIIDAE & 0.191779639 & 0.075296285 \\
\hline ICHTHYAOPHION & 0.188679245 & 0.074079013 \\
\hline OPHICHTGOMESI & 0.184421118 & 0.072407192 \\
\hline AUXIS & 0.173581706 & 0.068151435 \\
\hline LABRIDAE & 0.147736519 & 0.05800413 \\
\hline LUTJANUCAMPEC & 0.142553602 & 0.055969219 \\
\hline CONGRIDAE & 0.137560009 & 0.054008641 \\
\hline BOTHUS & 0.136620298 & 0.053639693 \\
\hline TRIGLIDAE & 0.129026969 & 0.05065841 \\
\hline CERATIOIDEI & 0.126278697 & 0.049579386 \\
\hline MYROPHIPUNCTA & 0.107326636 & 0.042138452 \\
\hline CYCLOPSETTA & 0.098260834 & 0.038579048 \\
\hline SPHOEROIDES & 0.088950914 & 0.034923798 \\
\hline SERRANIPUMILI & 0.087822014 & 0.034480571 \\
\hline TETRAODONTIDA & 0.075582437 & 0.029675083 \\
\hline CALLIONYMIDAE & 0.071653689 & 0.028132583 \\
\hline HYPSOBLHENTZI & 0.070414317 & 0.027645982 \\
\hline BALISTIDAE & 0.063111791 & 0.024778874 \\
\hline ANGUILLIFORME & 0.062735849 & 0.024631272 \\
\hline SPARIDAE & 0.058239472 & 0.02286591 \\
\hline PEPRILUALEPID & 0.057971014 & 0.022760508 \\
\hline SCORPAENIDAE & 0.052359103 & 0.020557166 \\
\hline RHOMBOPAURORU & 0.052198853 & 0.020494249 \\
\hline BASCANIBASCAN & 0.05094086 & 0.020000338 \\
\hline CITHARISPILOP & 0.050613957 & 0.019871989 \\
\hline SYNGNATHUS & 0.049180328 & 0.01930912 \\
\hline CHAETODFABER & 0.046829335 & 0.018386076 \\
\hline SCIAENOOCELLA & 0.044444444 & 0.017449723 \\
\hline DECAPTEPUNCTA & 0.043778802 & 0.017188379 \\
\hline
\end{tabular}




\begin{tabular}{|c|c|c|}
\hline Taxonomic Group & Sum of Stations & $\%$ of Total \\
\hline CYNOSCIREGALI & 0.043478261 & 0.017070381 \\
\hline SYACIUMGUNTER & 0.043010753 & 0.016886829 \\
\hline MORINGUIDAE & 0.037735849 & 0.014815803 \\
\hline SOLEIDAE & 0.036714976 & 0.014414989 \\
\hline GRAMMISTIDAE & 0.033370411 & 0.01310185 \\
\hline OPHICHTREX & 0.031367925 & 0.012315636 \\
\hline APOGON & 0.025974026 & 0.01019789 \\
\hline SCOMBEROMORUS & 0.025 & 0.009815469 \\
\hline SELENE & 0.025 & 0.009815469 \\
\hline STROMATEIDAE & 0.025 & 0.009815469 \\
\hline TRICHIURIDAE & 0.024427302 & 0.009590617 \\
\hline BRAMIDAE & 0.024193548 & 0.009498841 \\
\hline SCARIDAE & 0.023138298 & 0.00908453 \\
\hline BLENNIOIDEI & 0.02173913 & 0.00853519 \\
\hline ELOPIDAE & 0.018867925 & 0.007407901 \\
\hline MYCTOPHIDAE & 0.018867925 & 0.007407901 \\
\hline GERREIDAE & 0.018181818 & 0.007138523 \\
\hline CYCLOPTERIDAE & 0.016949153 & 0.006654556 \\
\hline OLIGOPLSAURUS & 0.016949153 & 0.006654556 \\
\hline ALUTERUS & 0.016393443 & 0.006436373 \\
\hline PARALICHTHYIN & 0.016393443 & 0.006436373 \\
\hline AHLIA EGMONT & 0.016393443 & 0.006436373 \\
\hline URANOSCOPIDAE & 0.015873016 & 0.006232044 \\
\hline PSEUDOMFUGESA & 0.015188172 & 0.005963161 \\
\hline STELLIFLANCEO & 0.015151515 & 0.005948769 \\
\hline THUNNUSTHYNNU & 0.015151515 & 0.005948769 \\
\hline EPHIPPIDAE & 0.014492754 & 0.005690127 \\
\hline SERRANUS & 0.01344086 & 0.005277134 \\
\hline APLATOPCHAULI & 0.013214488 & 0.005188256 \\
\hline UROPHYCREGIA & 0.012987013 & 0.005098945 \\
\hline MUGIL & 0.012987013 & 0.005098945 \\
\hline POMACENTRIDAE & 0.012987013 & 0.005098945 \\
\hline OPHICHTMELANO & 0.0125 & 0.004907735 \\
\hline PHAENOMLONGIS & 0.0125 & 0.004907735 \\
\hline TRACHURLATHAM & 0.0125 & 0.004907735 \\
\hline CARANX CRYSOS & 0.010309278 & 0.004047616 \\
\hline CERATIOIDEA & 0.008064516 & 0.00316628 \\
\hline LUTJANUSYNAGR & 0.005376344 & 0.002110854 \\
\hline BREGMACEROTID & 0.002688172 & 0.001055427 \\
\hline RYPTICUS & 0.002688172 & 0.001055427 \\
\hline Total & 254.7159 & 100.00 \\
\hline
\end{tabular}




\section{Potential Effects to Managed Species}

Several species designated as 'managed' by the Gulf of Mexico Fishery Management Council (GMFMC) were identified in SEAMAP larvae data (Table 6). To evaluate the potential impacts to these species (and groups), all taxonomic groups that were likely to include managed species were summed and their total volumetric values compared to the total number of larvae by taxa per cubic meter of seawater presented in Table 5. This provided an estimate of the percent occurrence of these managed species/groups found at stations within the VR179 Block.

Generally, managed species constituted a very small percentage of the total number of larvae identified in the database. Only the taxonomic group for sciaenids (red drum and others) was above one percent. Percentages for trigger fish (Balistidae), snapper (Lutjanidae) and sea basses (i.e., grouper - Serranidae), which represent reef fish species, totaled less than one percent of the overall larvae found within the VR179 Block. Finally, for Coastal Migratory Pelagics, mackerels (Scombridae) and bluefish (Pomatomus saltatrix) were the only species found, and composed less than one percent of the total larvae. These results suggest that ichthyoplankton larvae near the facility do not contain significantly high numbers of species managed within the Gulf of Mexico, and thus impacts to these groups from entrainment and impingement will be low.

It must be reiterated that this analysis is very conservative. Other species, which are not managed species but occur within designated managed 'families', will be included in the number of fish counted. This occurs because morphological characteristics common at the family level are used by taxonomists during counting and sorting, thus non-managed species cannot be distinguished from managed species.

Table 6 - Summary of Larvae of GMFMC Managed Species from SEAMAP data for VR179

\begin{tabular}{|c|c|c|}
\hline Taxonomic Group & $\begin{array}{l}\text { Sum of Stations } \\
\left(\text { (larvae } / \mathrm{m}^{3}\right)\end{array}$ & Percent of Total \\
\hline SCIAENIDAE & 2.724177169 & \\
\hline SCIAENOOCELLA & 0.044444444 & \\
\hline Total & 2.768621613 & 1.09 \\
\hline BALISTIDAE & 0.063111791 & \\
\hline Total & 0.063111791 & 0.025 \\
\hline LUTJANIDAE & 0.370212456 & \\
\hline LUTJANUCAMPEC & 0.142553602 & \\
\hline LUTJANUS & 0.239060837 & \\
\hline LUTJANUSYNAGR & 0.005376344 & \\
\hline Total & 0.757203239 & 0.29 \\
\hline SERRANIDAE & 1.280776424 & \\
\hline Total & 1.280776424 & 0.50 \\
\hline
\end{tabular}




\begin{tabular}{|r|r|} 
Taxonomic Group & $\begin{array}{c}\text { Sum of Stations } \\
\text { (larvae } / \mathbf{~ m}^{\mathbf{3}} \text { ) }\end{array}$ \\
\hline SCOMBERCAVALL & 0.5400808
\end{tabular}

\section{Ichthyoplankton Biomass Calculations and Relative Impact Assessment}

Determination of ichthyoplankton biomass for relative impact assessment of Bishop Process impingement and entrainment was based on water volume within the $30 \times 30 \mathrm{NM}(55.5 \mathrm{~km} \times$ $55.5 \mathrm{~km}$ ) VR179 Block. The following provides detailed discussions on the methods used to determine relative mortality for ichthyoplankton occurring within the block:

\section{Determination of water volume within the VR179 Block}

Generally, based on NOAA bathymetric charts, 2 depth profiles (A and B; see Figure 2) occur within the Block. Average depth, percent of block and areal extent and volume for these 2 depth profiles are shown in Table 7.

Figure 2 - Bathymetry for VR 179 Block

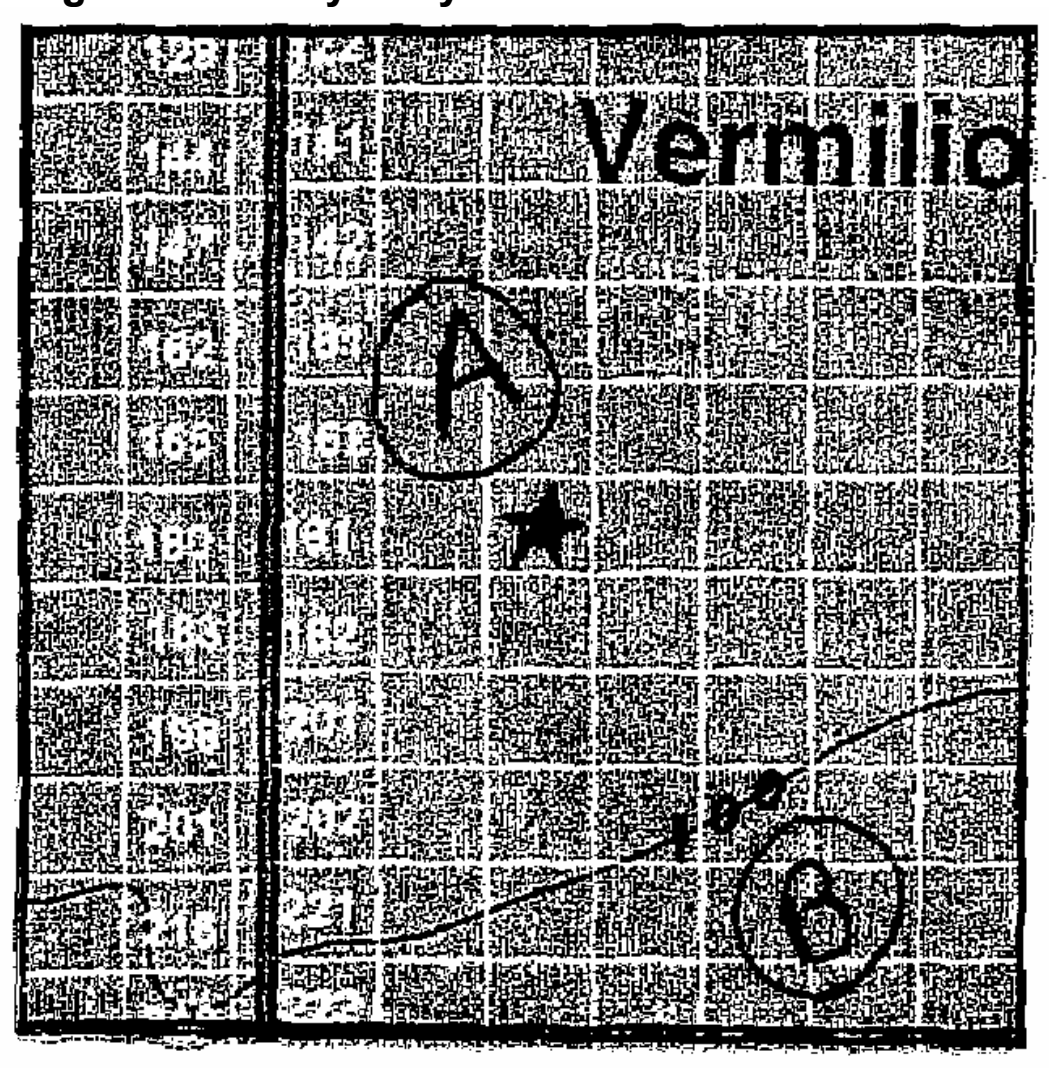


Table 7 - Determination of Volume of Water for VR179 Block

\begin{tabular}{|c|c|c|c|c|}
\hline $\begin{array}{l}\text { Depth Profile } \\
\text { Designation }\end{array}$ & $\begin{array}{l}\text { Average } \\
\text { Depth }^{1} \text { in } \\
\text { Profile (m) }\end{array}$ & $\begin{array}{l}\text { Portion of } \\
\text { Block }\end{array}$ & $\begin{array}{l}\text { Areal Extent }{ }^{2} \text { of } \\
\text { Depth Profile } \\
\text { (square meter) }\end{array}$ & $\begin{array}{c}\text { Volume }{ }^{3} \text { of Depth } \\
\text { Profile (cubic } \\
\text { meter) }\end{array}$ \\
\hline A & 15.24 & 0.804 & $2,476,521,000$ & $3.7742 E+10$ \\
\hline$B$ & 30.5 & 0.196 & $603,729,000$ & $1.8414 \mathrm{E}+10$ \\
\hline
\end{tabular}

Notes:

1 Average depth relatively assumed based on depth isopleths noted for each profile.

2 Based on $30 \times 30 \mathrm{NM}(55.5 \mathrm{~km} \times 55.5 \mathrm{~km}=3,080,250,000$ square meters $)$ Block.

3 Based on Areal Extent of Depth Profile (sq. meter) X Average Depth of Profile (meter).

Based on these calculations, over 56 billion cubic meters of water exist within the designated VR179 Block. This equals approximately 14,834,800,000,000 gallons.

\section{Determination of egg and larval densities per water volume within the VR179 Block}

Based on NOAA SEAMAP data for the 42 stations located within the VR179 Block, an average of 17,939 eggs and 22,957 larvae exists in a million gallons of seawater. With extrapolation for the volume of water existing within the VR179 Block (see Table 7), an average of 266,121,477,200 eggs and 340,562,503,600 larvae occur within the Block.

\section{Determination of relative egg and larval mortalities during Bishop Process operations compared to VR179 Block densities}

During maximum Bishop Process flow periods (634 mgd), approximately $11.3733 \mathrm{M}$ eggs and 14.5547M larvae per day will be entrained (*does not address extrusion multiplier as previously presented in Table 4).

\section{Conclusion}

Based on these values, and assuming 100\% mortality when eggs and larvae are entrained, the daily mortality for eggs will represent approximately $0.00427 \%$ of the eggs found within the VR179 Block. Similarly, the daily mortality for larvae will represent $0.00427 \%$ of the larvae found within the block. Although seasonal and daily fluctuations will occur, these values are less than significant, especially when water volumes for the entire eastern Gulf of Mexico are considered.

Sincerely,

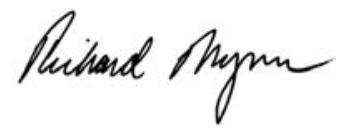

Richard R. Myers, J.D.

Principal 


\section{ATTACHMENT 1}

\section{NOAA TECHNICAL MEMORANDUM - 2/18/04}




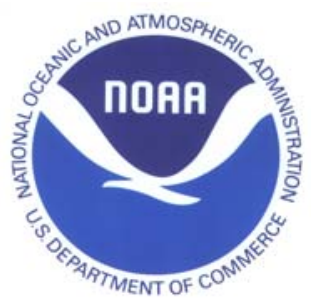

United States Department of Commerce

National Oceanic and Atmospheric Administration NATIONAL MARINE FISHERIES SERVICE SOUTHEAST FISHERIES SCIENCE CENTER 75 Virginia Beach Drive

Miami, Florida 33149

February 18, 2004

\section{MEMORANDUM}

FOR: $\quad$ F/SER Roy Crabtree, Regional Administrator

FROM: $\quad$ F/SEC4 Nancy B. Thompson, Science Administrator

SUBJECT: Potential Impacts of Liquid Natural Gas Processing Facilities on Fishery Organisms in the Gulf of Mexico

This memorandum provides additional information on potential impacts of proposed Liquid Natural Gas (LNG) processing facilities in waters of the Gulf of Mexico. In a memo to you dated July 11, 2003, I provided some preliminary comments on Chevron's Draft EIS for the Port Pelican Deepwater Liquefied Natural Gas facility. Herein, the scientific staff of the Southeast Fisheries Science Center and the NOAA Center for Coastal Fisheries and Habitat Research provide a review of the Port Pelican Final Environmental Impact Statement (PPFEIS) and a broader and more comprehensive review of the potential impacts of developing other facilities that use flow through systems to warm LNG in the Gulf of Mexico. Our conclusion and recommendation is that these flow through systems should be avoided in favor of closed loop systems. The negative impacts to fishery species and living marine resources in the Gulf from a single flow-through facility are potentially severe, and cumulative impacts from multiple facilities must be considered a threat to fishery resources.

There is a special concern regarding the siting of flow through facilities in or near estuarine passes. Most fishery organisms in the Gulf of Mexico use estuaries as nursery grounds, and eggs and larvae recruit into these areas through tidal passes. Locating facilities in or near these tidal passes will be especially damaging to fishery resources, since eggs and larvae of fishery species are often concentrated in these areas. Locating LNG facilities in shallow water also increases the proportional area of impact. The area filtered per year can be calculated by combining average water depth with the expected intake volume of a facility. The sites farthest offshore only filter an area of about $2 \mathrm{~km}^{2}$ per year, because of the water column depth (Table 1). In contrast, Sabine Lake, TX has an average depth of about $2 \mathrm{~m}$, and the Golden Pass LNG site proposed for Sabine Pass will filter $69 \mathrm{~km}^{2}$ each year. Sabine Lake has a surface area of $226 \mathrm{~km}^{2}$, a volume of about $0.45 \mathrm{~km}^{3}$, and an average annual input of freshwater of $14.9 \mathrm{~km}^{3}$ (Bianchi et al. 1999). The proposed facility in Sabine Pass will filter about $0.14 \mathrm{~km}^{3}$ of water each year, or over $30 \%$ of the estuary's volume and about $1 \%$ of the inflow every year. Corpus Christi Bay (Nueces Estuary) has a surface area of $444 \mathrm{~km}^{2}$, a volume of about $1.33 \mathrm{~km}^{3}$, 
and an average annual input of freshwater of only $0.77 \mathrm{~km}^{3}$ (Bianchi et al. 1999). The proposed facility in the La Quinta Channel, filtering the same $0.14 \mathrm{~km}^{3}$ of water each year, will filter $10 \%$ of the estuary's volume and about $18 \%$ of the inflow every year. In addition, the number of facilities being proposed should be considered, because cumulative impacts may be important. The locations of 13 LNG facilities in the Gulf of Mexico are shown in Figure 1 (not included); seven of these are flow through systems and six are closed loop systems (Table 1). Two additional LNG facilities have been identified, but we have limited information for them.

Table 1. Proposed Liquified Natural Gas processing facilities in the Gulf of Mexico

\begin{tabular}{|c|c|c|c|c|c|c|c|}
\hline Name & Location & $\begin{array}{c}\text { Expected } \\
\text { Flow Rate } \\
\text { Million } \\
\text { Gal/day } \\
\end{array}$ & $\begin{array}{c}\text { Expected } \\
\text { Flow Rate } \\
\text { Million } \\
\text { Gal/year } \\
\end{array}$ & $\begin{array}{c}\text { Water } \\
\text { depth } \\
(\mathrm{m})\end{array}$ & $\begin{array}{c}\text { Area } \\
\text { filtered } \\
\text { per year } \\
\left(\mathbf{k m}^{2}\right) \\
\end{array}$ & $\begin{array}{c}\begin{array}{c}\text { Intake } \\
\text { screen Size } \\
(\mathrm{mm})\end{array} \\
\end{array}$ & $\begin{array}{c}\text { Intake } \\
\text { Flow Rate } \\
\text { (ft/sec) }\end{array}$ \\
\hline $\begin{array}{l}\text { Vista del Sol LNG } \\
\text { (ExxonMobil) }\end{array}$ & & 100 & 36,500 & 3 & 46.1 & GunderBoom & 0.2 \\
\hline $\begin{array}{l}\text { Golden Pass LNG } \\
\text { (ExxonMobil) }\end{array}$ & & 100 & 36,500 & 2 & 69.1 & GunderBoom & 0.2 \\
\hline El Paso Energy Bridge & ${ }^{\circ}$ & 133 & 48,545 & 87 & 2.1 & 21 & 1 \\
\hline Shell Gulf Landing & & 136 & 49,640 & 16.8 & 11.2 & 6.35 & 0.5 \\
\hline Port Pelican & $\begin{array}{l}36 \text { miles S-SW of Freshwater City, LA } \\
29^{\circ} 01^{\prime} 33.41^{\prime \prime} \mathrm{N}, 92^{\circ} 32^{\prime} 11.85^{\prime \prime} \mathrm{W} \\
\end{array}$ & 176 & 64,240 & 25 & 9.7 & 6.35 & 0.5 \\
\hline Main Pass & & 100 & 36,500 & 64 & 2.2 & 6.35 & 0.5 \\
\hline ConocoPhillips ICE-T & & 200 & 73,000 & 22 & 12.6 & 6.35 & 0.5 \\
\hline \multicolumn{8}{|l|}{ ExxonMobil Offshore } \\
\hline \multicolumn{8}{|l|}{ ExxonMobil } \\
\hline $\begin{array}{l}\text { Lake Charles (Trunkline) } \\
\text { existing }\end{array}$ & & Closed loop & $n / a$ & $n / a$ & $\mathrm{n} / \mathrm{a}$ & $\mathrm{n} / \mathrm{a}$ & $\mathrm{n} / \mathrm{a}$ \\
\hline Oxy-Chem & & Closed loop & $n / a$ & $n / a$ & $\mathrm{n} / \mathrm{a}$ & $\mathrm{n} / \mathrm{a}$ & $\mathrm{n} / \mathrm{a}$ \\
\hline Freeport & & Closed loop & $n / a$ & $n / a$ & $\mathrm{n} / \mathrm{a}$ & $n / a$ & $\mathrm{n} / \mathrm{a}$ \\
\hline Corpus Christi (Cheniere) & & Closed loop & $\mathrm{n} / \mathrm{a}$ & $\mathrm{n} / \mathrm{a}$ & $\mathrm{n} / \mathrm{a}$ & $\mathrm{n} / \mathrm{a}$ & $\mathrm{n} / \mathrm{a}$ \\
\hline Cameron (Hackberry) & LA & Closed loop & $n / a$ & $n / a$ & $\mathrm{n} / \mathrm{a}$ & $n / a$ & $\mathrm{n} / \mathrm{a}$ \\
\hline Sabine Pass (Cheniere) & LA & Closed loop & $n / a$ & $n / a$ & $n / a$ & $n / a$ & $n / a$ \\
\hline
\end{tabular}

One approach taken in examining the impact of these facilities on fishery species is to estimate the density of fish eggs and larvae in the water column near the facility and calculate the average number of planktonic organisms that are likely to pass through the facility and die based on seawater intake rates. Although we have attempted some of these calculations below, such calculations of egg and larvae density near facilities are

based on average values collected over relatively long time periods and integrated over the entire water column. The temporal and spatial distributions of these organisms, however, are extremely patchy. Thus, we should be aware and concerned about the 
possibility of a LNG facility being located just downstream from a spawning aggregation, because under these conditions a large portion of an entire cohort may be killed.

\section{Port Pelican LNG Facility}

The Port Pelican Liquid Natural Gas (LNG) processing facility is proposed for coastal Louisiana in $25 \mathrm{~m}(83 \mathrm{ft})$ of water. During Phase II of its operation, it is projected to take in 176.4 million gallons of seawater per day or 64.4 billion gallons per year. The water will be used to warm the LNG and will undergo a temperature decrease of $11^{\circ} \mathrm{C}$ $\left(20^{\circ} \mathrm{F}\right)$. The intake rate will be around $15 \mathrm{~cm} / \mathrm{sec}(0.5 \mathrm{ft} / \mathrm{sec})$, allowing most larger organisms to avoid impingement at the intake structures, but water passing through the facility will undergo mechanical, pressure, temperature, and chemical $(\mathrm{NaOCl})$ shock. Some entrained eggs and larvae may survive any one of these adverse conditions (Cada et al. 1981, Muessig et al. 1988), but the combination of these stresses will be lethal to almost all organisms passing through the facility. There is a long litany of research, supported by the electrical power industry, indicating that the mechanical damage associated with agitation and impact with impeller blades results in death to fish eggs and larvae. Although estimates of potential pressure flux are not given in the PPFEIS, rapid fluctuations in pressure are known to inflict, sub-lethal, antemortem, and lethal trauma on young fishes (Govoni et al. 2004). A temperature flux of $10^{\circ} \mathrm{C}$ would result in death of fish eggs and larvae (reviewed in Kamler, 1992), and the LD-50's listed for $\mathrm{NaOCl}$ in the PPFEIS for fishes are appropriate values. Until shown otherwise, we must assume that all fish and invertebrates will die after entrainment and simultaneous exposure to these four environment stress factors.

\section{Impacts of Entrainment Mortality at Port Pelican on Fishery Stocks}

Many questions need to be addressed about potential impacts of such a facility on the coastal ecosystem, and one of the most important is whether the entrainment and mortality of fish eggs and larvae at the facility will have significant population effects on fishery stocks. A stock assessment approach to this problem requires information on:

a) Numbers of eggs, larvae, and juveniles that are expected to be entrained (and killed) by species.

b) Daily natural mortality estimates by life stage during the first year of life by species, including hatching success. This allows an estimation of survival from viable egg to age of entrainment.

c) Age-structured population model (e.g., VPA or forward-projection model) estimates of recruits to age- 1 and population fecundity (need maturity schedule and fecundity relationship). This allows stock-level estimates of egg production (viable eggs) and overall survival from viable egg to recruitment at age-1.

The specific data needed for such an in depth analysis are generally not available; stock assessments have been done for relatively few species,. In addition, such an effort would require a great amount of time from stock analysts, and when underlying density dependence is considered, the results may still not be clear cut. An alternative analysis could be based on the "near field" approach described by Boreman et al. (1981), Barnthouse and Van Winkle (1988), and Boreman and Goodyear (1988). This approach sidesteps some issues in (a) and (b) and develops direct estimates of relative loss. The approach does not attempt to make the final step of incorporating this loss into a population-level model. One problem would be how to characterize and assess the "near 
field".

We can make simplified calculations of the number of eggs and larvae entrained and killed in a LNG processing facility, but these estimates are based on many assumptions. For example at Port Pelican, SEAMAP data collected with oblique bongo net $(0.333-\mathrm{mm}$ mesh) tows were used to estimate fish egg and larvae densities. Average densities of 3.06 eggs per $\mathrm{m}^{3}$ (14 samples) and 6.21 larvae per $\mathrm{m}^{3}$ (32 samples) were obtained from cruises in June through November between 1984 and 1999 in a 30 nautical mile block around the proposed LNG facility site. These densities can be used to calculate that 1.13 billion eggs and larvae (Table 2 ) would pass through the facility under

Table 2. Density and entrainment estimates for plankton near the Port Pelican LNG facility in coastal Louisiana waters.

\begin{tabular}{|c|c|c|c|}
\hline Data Source & $\mathrm{No} / \mathrm{m}^{3}$ & $\begin{array}{l}\text { No/1million } \\
\text { gallons water }\end{array}$ & $\begin{array}{c}\text { Millions entrained } \\
\text { during Phase II } \\
\text { (176.4 MGD) }\end{array}$ \\
\hline \multicolumn{4}{|l|}{$\begin{array}{l}\text { A. Original SEAMAP Data } \\
\text { (June-November) }\end{array}$} \\
\hline Fish Eggs (14 samples) & 3.06 & 11,583 & 373 \\
\hline Fish Larvae (32 samples) & 6.21 & 23,507 & 757 \\
\hline Sum (Fish eggs+larvae) & 9.27 & 35,091 & 1,130 \\
\hline \multicolumn{4}{|l|}{$\begin{array}{l}\text { B. SEAMAP estimate for } \\
\text { (December-May) }\end{array}$} \\
\hline Fish Eggs & 1.38 & 5,225 & 168 \\
\hline Fish Larvae & 2.80 & 10,603 & 341 \\
\hline Sum (Fish eggs+larvae) & 4.18 & 15,828 & 510 \\
\hline \multicolumn{4}{|c|}{ SEAMAP annual estimate $(A+B)$} \\
\hline Fish Eggs & & & 541 \\
\hline Fish Larvae & & & 1,098 \\
\hline Sum (Fish eggs+larvae) & & & 1,639 \\
\hline \multicolumn{4}{|c|}{$\begin{array}{l}\text { SEAMAP annual estimate adjusted } \\
\text { for mesh selection, } 3^{*}(A+B)\end{array}$} \\
\hline Fish Eggs & & & 1,623 \\
\hline Fish Larvae & & & 3,294 \\
\hline Sum (Fish eggs+larvae) & & & 4,918 \\
\hline $\begin{array}{l}\text { Shrimp larvae, annual estime } \\
\text { (Temple and Fischer 1967) }\end{array}$ & 0.25 & 927 & 60 \\
\hline $\begin{array}{l}\text { Zooplankton, annual estimat } \\
\text { (Minello 1980) }\end{array}$ & 2000 & $7,570,824$ & 487,455 \\
\hline
\end{tabular}

peak operating conditions (Phase II) during the summer and fall. Winter and spring densities, however, are lower (Ditty et al. 1988). At a station in coastal Louisiana waters closer to shore (10-12 m bottom depth), Ditty (1986) recorded average fish larvae densities to be 2.86 per $^{3}$ in summer and fall and 1.29 per $^{3}$ in winter and spring. Using this ratio of winter-spring : summer-fall densities, we can estimate densities and 
entrainment mortality (510 million eggs and larvae) during winter and spring at the Port Pelican site based on the SEAMAP data. Combining these data gives an annual mortality estimate of 1.6 billion eggs and larvae (Table 2). The density estimates for fish larvae from the SEAMAP samples (6.21 per $\mathrm{m}^{3}$ in summer and fall) appear relatively high in comparison with other estimates in this general area of the northern Gulf of Mexico (Ditty, 1986, Sogard et al. 1987, Hernandez 2001), although differences in mesh size, distance from shore, season, and taxa examined exist among these studies. In contrast, however, concentrations of fish larvae as high as $10-90$ per $\mathrm{m}^{3}$ have been found in this area (Govoni, et al. 1989; Govoni and Grimes 1992; Govoni 1993) and in the northeastern Gulf (Govoni et al. 1985) associated with frontal zones or with the presence of petroleum drilling platforms (Hernandez 2001).

In addition to corrections needed for seasonality, there also is evidence that many small eggs and larvae can pass through the 0.333-mm mesh nets used in the SEAMAP collections. Comyns (1997) reported that catches of small red drum larvae were 5-8 times larger in a $0.202-\mathrm{mm}$ mesh net compared with a 0.333 -mesh net. Similarly, Houde and Lovdal (1984) found that larval fish densities in Biscayne Bay, FL collected in a $0.035-\mathrm{mm}$ mesh net were 8.45 times larger than catches in a $0.333-\mathrm{mm}$ mesh net towed simultaneously; this high extrusion rate was partly the result of active spawning in a coastal embayment, especially of bay anchovy and of the presence of soft bodied, recently hatched, and very small larvae (smaller than $2.5 \mathrm{~mm}$ in length). Despite the lack of specific data on net catch efficiency for SEAMAP estimates, some correction factor would appear necessary to adjust the mean densities at Port Pelican for eggs and larvae passing through the $0.333-\mathrm{mm}$ mesh net. To provide a more realistic density estimate for eggs and larvae entrained, a multiplier of 3 was used in Table 2. These calculations convert to a best estimate of entrainment and mortality of 4.9 billion fish eggs and larvae each year. Evidence for determining this multiplier is relatively weak, however, and multipliers from 1 to 8 could also be justified under different assumptions, resulting in estimates of entrainment between 1.6 and 13.1 billion eggs and larvae each year.

The larval fish taxonomic composition from the SEAMAP collections is shown in Table 3 and was used to estimate annual mortality of eggs and larvae for different fish taxa during Phase II, assuming that all entrained organisms at the Port Pelican LNG facility would die. Highest mortalities are estimated at 730 million eggs and larvae of carangids (jacks) each year, 693 million Engraulidae (anchovies), 496 million clupeids (herrings), and 495 million sciaenids (drum).

The PPFEIS concludes that mortality on the order of billions of eggs and larvae would have a minimal impact on fish populations based on the fecundity of individual fish. According to this approach, if the facility kills 13 million snapper eggs and larvae per year, and an adult snapper spawns 1 million eggs in a year, the facility only is harvesting the equivalent of 13 spawning females each year. This rationale is flawed and misleading. A single fish larva present in the water column is the product of many spawned eggs (hundreds to potentially thousands) depending upon larvae age and early life stage mortality rates. 
Table 3. Entrainment estimates of eggs and larvae (in millions per year) for different Families and Orders of fishes based on the taxonomic composition of fish larvae collected in SEAMAP samples, annual mean densities adjusted for mesh selection in Table 2, and Phase II flow rate of 176.4 million gallons of seawater per day.

\begin{tabular}{|c|c|c|c|c|}
\hline TAXON & $\begin{array}{l}\text { Percent of } \\
\text { larvae } \\
\text { collected }\end{array}$ & $\begin{array}{l}\text { Millions of } \\
\text { eggs/year }\end{array}$ & $\begin{array}{l}\text { Millions of } \\
\text { larvae/year }\end{array}$ & $\begin{array}{l}\text { Total eggs } \\
\text { and larvae }\end{array}$ \\
\hline Carangidae & $14.84 \%$ & 240.8 & 488.7 & 729.5 \\
\hline Engraulidae & $14.09 \%$ & 228.6 & 464.0 & 692.7 \\
\hline Unidentified Fish & $13.94 \%$ & 226.2 & 459.2 & 685.4 \\
\hline Clupeiformes & $10.09 \%$ & 163.7 & 332.3 & 496.0 \\
\hline Sciaenidae & $10.07 \%$ & 163.4 & 331.6 & 495.0 \\
\hline Cynoglossidae & $8.32 \%$ & 135.1 & 274.2 & 409.3 \\
\hline Gobiidae & $8.05 \%$ & 130.7 & 265.2 & 395.9 \\
\hline Clupeidae & $6.32 \%$ & 102.5 & 208.0 & 310.6 \\
\hline Paralichthyidae & $4.69 \%$ & 76.2 & 154.6 & 230.7 \\
\hline Scombridae & $1.35 \%$ & 22.0 & 44.6 & 66.6 \\
\hline Bregmacerotidae & $1.32 \%$ & 21.4 & 43.4 & 64.8 \\
\hline Ophidiidae & $1.31 \%$ & 21.2 & 43.1 & 64.3 \\
\hline Bothidae & $1.20 \%$ & 19.5 & 39.6 & 59.1 \\
\hline Serranidae & $0.90 \%$ & 14.7 & 29.7 & 44.4 \\
\hline Stromateidae & $0.57 \%$ & 9.2 & 18.6 & 27.8 \\
\hline Pleuronectiformes & $0.56 \%$ & 9.2 & 18.6 & 27.8 \\
\hline Ophichthidae & $0.34 \%$ & 5.5 & 11.1 & 16.6 \\
\hline Lutjanidae & $0.27 \%$ & 4.3 & 8.8 & 13.1 \\
\hline Triglidae & $0.26 \%$ & 4.2 & 8.5 & 12.6 \\
\hline Microdesmidae & $0.23 \%$ & 3.7 & 7.6 & 11.3 \\
\hline Perciformes & $0.21 \%$ & 3.5 & 7.0 & 10.5 \\
\hline Blenniidae & $0.15 \%$ & 2.4 & 4.8 & 7.2 \\
\hline Sphyraenidae & $0.13 \%$ & 2.1 & 4.3 & 6.4 \\
\hline Synodontidae & $0.13 \%$ & 2.1 & 4.2 & 6.3 \\
\hline Trichiuridae & $0.13 \%$ & 2.0 & 4.1 & 6.2 \\
\hline Pomatomidae & $0.10 \%$ & 1.6 & 3.3 & 4.9 \\
\hline Tetraodontidae & $0.06 \%$ & 1.0 & 2.0 & 3.1 \\
\hline Muraenidae & $0.05 \%$ & 0.9 & 1.8 & 2.7 \\
\hline Labridae & $0.05 \%$ & 0.8 & 1.7 & 2.5 \\
\hline Moringuidae & $0.04 \%$ & 0.6 & 1.2 & 1.8 \\
\hline Callionymidae & $0.03 \%$ & 0.6 & 1.1 & 1.7 \\
\hline Congridae & $0.03 \%$ & 0.5 & 0.9 & 1.4 \\
\hline Balistidae & $0.02 \%$ & 0.4 & 0.8 & 1.2 \\
\hline Anguilliformes & $0.02 \%$ & 0.3 & 0.6 & 0.9 \\
\hline Ephippidae & $0.02 \%$ & 0.3 & 0.6 & 0.9 \\
\hline Soleidae & $0.02 \%$ & 0.3 & 0.6 & 0.9 \\
\hline Scorpaenidae & $0.02 \%$ & 0.3 & 0.6 & 0.9 \\
\hline Syngnathidae & $0.02 \%$ & 0.3 & 0.5 & 0.8 \\
\hline Sparidae & $0.02 \%$ & 0.3 & 0.5 & 0.8 \\
\hline Scaridae & $0.01 \%$ & 0.2 & 0.4 & 0.6 \\
\hline Myctophidae & $0.01 \%$ & 0.2 & 0.3 & 0.5 \\
\hline Gerreidae & $0.01 \%$ & 0.1 & 0.3 & 0.4 \\
\hline Monacanthidae & $0.01 \%$ & 0.1 & 0.3 & 0.4 \\
\hline Uranoscopidae & $0.01 \%$ & 0.1 & 0.3 & 0.4 \\
\hline
\end{tabular}

The problem of building a facility that increases fish egg and larvae mortality also can be viewed in a more general context. Mortality of fish eggs and larvae is already high, and stock success can depend on survival and transport of recruits to appropriate nursery

habitats (Houde 1987, 1989). Many potential recruits are already lost because of environmental conditions, starvation, predation, or transport (current) variability. Mortality caused by LNG facilities is an additional mortality factor. If the facility kills 
the few recruits destined for survival, it may have a dramatic effect on a fish stock. Because the natural conditions that affect survival vary in time and space, it is highly unlikely that we will be able to determine the survival potential of eggs and larvae killed by entrainment. The variability in natural mortality, the uneven or patchy distribution of eggs and larvae, and the unknown effects of density dependent compensation in survival all contribute to uncertainty in estimating mortality or potential impacts of mortality from LNG facilities. The limited amount of information available on animal densities, distributions, and processes that influence survival does not support a conclusion that LNG facilities will have only minimal impacts on fishery stocks.

\section{Entrainment of other Plankton at Port Pelican}

Temple and Fischer (1967) estimated the distribution and abundance of shrimp larvae in the coastal waters off Galveston and western Louisiana; they examined monthly plankton data (oblique tows; $0.200-\mathrm{mm}$ mesh) from 11 stations located from $14 \mathrm{~m}$ to 82 $\mathrm{m}$ in bottom depth. The total average catch of all stages of penaeid shrimp larvae from their samples over the entire study area provides an estimate of larval shrimp density in waters near the Port Pelican facility. This annual estimate of 0.245 larvae per $\mathrm{m}^{3}$ converts to 59.7 million shrimp larvae entrained per year during Phase II (Table 2). There is substantial seasonal variability in the abundance of shrimp larvae, and $90 \%$ of the larvae were caught in the 4 months from August through November. Rogers et al. (1993) also sampled in coastal waters off Calcasieu Lake and obtained a mean density in nighttime tows of 0.05 brown shrimp postlarvae per $\mathrm{m}^{3}$ from January through April.

In addition to decapod larvae, all zooplankton passing through the LNG facility are likely to be killed. A rough estimate from Minello (1980) indicates that average annual mesozooplankton densities (mostly copepods) are around 2000 per $\mathrm{m}^{3}(0.200 \mathrm{~mm}$ mesh) in coastal waters off Texas and Louisiana. Zooplankton provide food for fish larvae, and at this density, 487 billion zooplankton per year would be entrained. From another perspective, each year the facility would "sterilize" the entire water column for an area of $9.7 \mathrm{~km}^{2}$ (2.7 square nautical miles) around the site (Table 1).

\section{Potential for Entrainment Mortality at Inshore Locations}

Estuaries are important nurseries for many fishery species such as penaeid shrimps, blue crabs, gulf menhaden, Atlantic croaker, spot, southern flounder, spotted seatrout, and red drum. Many species spawn offshore or near estuarine passes, and larvae are seasonally concentrated in these passes. There is a large amount of literature on the migration of estuarine dependent species through tidal passes, but different sampling techniques, experimental designs, and project goals make comparisons among studies difficult. In Cedar Bayou, a tidal pass into Mesquite Bay, Texas, King (1971) found weekly average densities of penaeid shrimp postlarvae in March to reach as high as 300 per $\mathrm{m}^{3}$ with an average density at his 5 stations of 16.3 per $^{3}$ from January through April. Weekly mean densities of blue crab megalopae were recorded as high as 1000 per $\mathrm{m}^{3}$ with an average density of 58.7 per $\mathrm{m}^{3}$ from January through April. Lochman et al. (1995) reported average densities of crab larvae (mainly blue crab) in Matagorda Bay Ship Channel ( a pass through Matagorda Island into Matagorda Bay, Texas) to be 2.5 per $\mathrm{m}^{3}$ from April through August. Copeland and Truit (1966) reported highest densities of brown shrimp postlarvae in April at 0.75 per $^{3}$ in Aransas Pass, Texas. Within one mile of Aransas Pass in the Gulf of Mexico, Holt et al. (1988) reported densities of red 
drum eggs from early September through mid-October as high as 20 per $\mathrm{m}^{3}$ (more typically between 2-3 per $\mathrm{m}^{3}$ ). Duronslet et al. (1972) collected penaeid shrimp postlarvae at different locations in the water column in Bolivar Roads, the pass into Galveston Bay, Texas, from November through April and reported a mean density of 0.37 brown shrimp postlarvae per $\mathrm{m}^{3}$ from all nets. Hartman et al. (1987) identified 71 fish and 11 crustacean taxa from zooplankton samples taken in Keith Lake Pass near Sabine Lake, Texas using 0.505-mm mesh nets. Overall mean densities (number per $\mathrm{m}^{3}$ ) for gulf menhaden, blue crab, white shrimp, and brown shrimp reported from their study were $1.0,0.34,0.20$, and 0.08 , respectively; but seasonal and interannual variation in the densities for most species was high. Highest densities occurred for gulf menhaden in spring $1986\left(2.75\right.$ per $\left.\mathrm{m}^{3}\right)$, in fall 1984 for blue crab $\left(1.03\right.$ per $\left.\mathrm{m}^{3}\right)$, in summer 1985 for white shrimp $\left(0.73\right.$ per $\left.\mathrm{m}^{3}\right)$, and in spring 1985 for brown shrimp $\left(0.19\right.$ per $\left.\mathrm{m}^{3}\right)$. Using seasonal densities and flow data, they estimated that Keith Lake Pass served as an immigration route for approximately 40 million brown shrimp, 116 million white shrimp, 314 million blue crab, 900 million gulf menhaden and 27 million Atlantic croaker annually. Densities of fish larvae in Oyster Bayou Pass into Fourleague Bay, Louisiana have been reported as high as 10-49 per $^{3}$ (Raynie and Shaw 1994). Sampling monthly throughout the year, Ruple (1984) recorded average densities of fish larvae to be 308 per $\mathrm{m}^{3}$ in the outer surf zone and 86 per $^{3}$ in the inner surf zone off Horn Island, Mississippi. In Dog Keys Pass into Mississippi Sound between Horn Island and Ship Island, Lyczkowski-Shultz et al. (1990) collected fish larvae in January and May and reported an overall mean density around $1.5 \mathrm{per}^{3}$. In Main Pass and Lower Mobile Bay, Marley (1983) reported mean densities of fish eggs to be over 100 per $\mathrm{m}^{3}$. An obvious conclusion from these studies is that densities of crustacean and fish larvae (and fish eggs) in estuarine passes can be extremely high during some periods of the year. Variability is great both spatially and temporally. These density patterns indicate an enormous potential for extensive entrainment mortality in and near estuarine passes.

Ecosystem effects of filtering large volumes of water in estuarine passes also should be considered. In addition to the mortality of fish eggs and larval fish and crustaceans, most phytoplankton and zooplankton are likely to be killed in water passing through the facility. Densities of these organisms at inshore sites and in estuaries are generally much higher than in offshore waters (Minello 1980). These organisms are the base of the food web for many species in estuarine systems, and negative impacts on the estuarine food webs should be expected. Dissolved oxygen also may be reduced by a concomitant increase in detrital material in the system. 


\section{Entrainment versus Impingement}

The swimming speeds of larval fishes vary greatly but are on average far less than the $15 \mathrm{~cm} / \mathrm{sec}$ estimated as the velocity of water at the Port Pelican intake (see Hunter 1981, Johnston and Hall 2004, Osse and van den Boogaart 2004). Webb and Weihs (1986) reported swimming speeds as low as $0.03 \mathrm{~cm} / \mathrm{sec}$ for early stage larvae. Even for settlement stage larvae, swimming speeds range between 7 to $21 \mathrm{~cm} / \mathrm{sec}$ (Leis and Carson-Ewart 1997, 1999, Stobutzki and Bellwood 1997). Thus, most fish larvae and all eggs in the water column should truly be considered plankton and be expected to flow through facilities that take in seawater.

At least two of the proposed nearshore facilities plan to use Gunderboom's Marine Life Exclusion System, a "water-permeable barrier that keeps fish eggs, larvae and other aquatic organisms a safe distance away from an industrial intake structure" (Gunderboom, Inc. ; http://www.gunderboom.com/mls/mles.html). From internet searches, it appears that this technology has been used mainly in riverine systems and is unproven in eutrophic and often turbid estuarine systems such as those found on the Gulf coast. Seaby et al. (2002) reported fouling of Gunderboom material by bacteria, plants, and animals (including tube dwelling crustaceans) in Bowline Pond of the Hudson River Estuary where salinities range between 0.1 and $10 \mathrm{ppt}$. The loss of permeability was measured as a reduction in water flow through the fabric, and in panels of material not exposed to air-burst cleaning, permeability declined nonlinearly over time. After 20 days in Bowline Pond, flow across the fabric was reduced by 49\%. After 29 days exposure, average flow was reduced by $62 \%$. Air-burst cleaning increased fouling; and over a 30day exposure period, the highest loss of permeability was $97 \%$ in a panel exposed to flowing water and air-burst cleaning. Seaby et al. (2002) concluded that fouling was likely to cause a failure of the system and result in entrainment of organisms. Fouling may be even greater in eutrophic estuarine systems. Cooling water in flow-through LNG facilities will have many similar impacts as warming water in electrical power generating facilities. Various cooling system alternatives and an assessment of entrainment problems for these facilities are reported by Tetra Tech (2002) and Riverkeeper (2003).

Planktonic fish eggs and small larvae not entrained will be impinged on permeable barriers regardless of the reduction of effective intake water velocity. As noted above in reference to net efficiencies, a mesh size of $0.333 \mathrm{~mm}$ can be expected to retain only a fraction of the eggs and larvae suspended in the water column. The estimate of Houde and Lovdal (1984) from Biscayne Bay, indicates that inshore, only about 10\% of fish larvae may be retained by $0.333-\mathrm{mm}$ mesh. Gunderboom aperture size, therefore, would have to be much smaller than $0.333 \mathrm{~mm}$ to prevent the entry of eggs and larvae. In the fouling experiment conducted by Seaby et al. (2002), Gunderboom fabric had an aperture size of $1 \mathrm{~mm}$. In eutrophic and sediment laden water, fabric with an aperture size less than $0.333 \mathrm{~mm}$ would clog much more rapidly. Even if a small mesh size was used, and filtration efficiency could be maintained (i.e., no clogging), planktonic eggs and larvae would be impinged on the mesh surface and likely suffer mortality due to predation, starvation, or physical agitation. Aggregating predators are likely to feed upon impinged organisms, and air burst cleaning may damage any survivors.

\section{Vertical Distribution of Larvae and Eggs near Port Pelican}


Information on the vertical distribution of fish eggs and larvae in coastal waters of the northern Gulf of Mexico is limited, but patterns appear related to time of day, water column depth, and vertical stratification or stability. In deeper water, 100 to $200 \mathrm{~m}$, fish eggs and larvae are more abundant in the upper $100 \mathrm{~m}$. The shallower $(25 \mathrm{~m})$ water column of the proposed Port Pelican processing plant is likely to be hydrographically well mixed (at least in winter), and fish eggs and larvae should be more evenly dispersed in the water column. Govoni et al. (1985, 1989) and Sogard et al. (1987) sampled during winter, and fish larvae were well dispersed vertically $(<100 \mathrm{~m})$, unless the presence or passage of a frontal zone stratified the water column. Lyczkowski-Shultz and Steen (1991) sampled in September-October at three depths in coastal waters off Mississippi Sound (bottom depth was 18-25 m) and found red drum larvae concentrated in deeper waters at night and in the upper $5 \mathrm{~m}$ during the day. Temple and Fischer (1965) examined the vertical distribution of penaeid shrimp larvae at one station off Galveston, TX; when the water column was stable, they showed that larvae were more abundant at 18 and $34 \mathrm{~m}$ depths than at the surface $(2 \mathrm{~m})$. These data emphasize the inherent variability in distributions of marine organisms, the uncertainty involved in selecting a vertical strata to sterilize in the coastal ocean, and the need to avoid flow-through systems and entrainment mortality.

\section{Potential Impacts of Discharge Water}

A $0.5^{\circ} \mathrm{C}$ decrease in water temperature $100 \mathrm{~m}$ from the discharge may still influence essential fish habitat by additively cooling the water where fish spawn and where fish eggs and larvae develop. This decrease in temperature will not be static, but cooled water will mix, the discharge will be continuous, and the water in the area as a whole will cool. Gonad maturation and spawning of fishes is controlled, in large part, by temperature. The rate of development of fish embryos and larvae is also controlled by temperature; cooler temperatures slow the rate of development and alter the mechanism of muscle development (e.g., Johnston and Hall, 2004). As development rate slows and larvae remain longer in early developmental stages, mortality increases (Houde 1987). Chlorination of the discharged water may also have detrimental effects on surrounding waters. The formation of many disinfectant by-products in addition to bromoform is likely (see WHO 2000), and fishery impacts of chronic exposure to these chemicals is unknown. The effects of discharging cooled and chlorinated water also may increase in relatively restricted tidal pass areas, as compared to offshore locations.

\section{Literature Cited}

Barnthouse, L. W. and W. Van Winkle 1988. Analysis of impingement impacts on Hudson River fish populations. p. 182-190 In Barnhouse, L. W., R. J. Klauda, D. S. Vaughan and R. L. Kendall (ed.). Science, law, and Hudson River power: a case study in environmental impact assessment. American Fisheries Society, Monograph 4 , Bethesda.

Bianchi, T. S., J. R. Pennock and R. R. Twilley 1999. Biogeochemistry of Gulf of Mexico estuaries. New York, John Wiley and Sons, Inc.

Boreman, J., C. P. Goodyear and S. W. Christensen 1981. An empirical methodology for estimating entrainment losses at power plants sited on estuaries. Transactions of the American Fisheries Society 110: 253-260.

Boreman, J. and C. P. Goodyear 1988. Estimates of entrainment mortality for striped bass 
and other fish species inhabiting the Hudson River Estuary. p. 152-160 In Barnhouse, L. W., R. J. Klauda, D. S. Vaughan and R. L. Kendall (ed.). Science, law, and Hudson River power: a case study in environmental impact assessment. American Fisheries Society, Monograph 4, Bethesda.

Cada et al. 1981. p. 111-122 In Jensen, L. D. (ed.). Issues associated with impact assessments: Proceedings of the 5th national Workshop on Entrainment and Impingement.

Comyns, B. H. 1997. Growth and Mortality of Fish Larvae in the Northcentral Gulf of Mexico and Implications To Recruitment. Dissertation, Louisiana State University, $200 \mathrm{p}$.

Copeland, B. and Truitt 1966. Fauna of the Aransas Pass Inlet, Texas. II. Penaeid shrimp postlarvae. Tex. J. Sci. 18: 65-74.

Ditty, J. G. 1986. Ichthyoplankton in neritic waters of the northern Gulf of Mexico off Louisiana: Composition, relative abundance, and seasonality. Fish. Bull., U.S. 84: 935-46.

Ditty, J. G., G. G. Zieske and R. F. Shaw 1988. Seasonality and depth distribution of larval fishes in the northern Gulf of Mexico above latitude 26 degrees N. Fish. Bull., U.S. 86: 811-23.

Duronslet, M. J., J. M. Lyon and F. Marullo 1972. Vertical distribution of postlarval brown, Penaeus aztecus, and white, P. setiferus, shrimp during immigration through a tidal pass. Trans. Am. Fish. Soc. 101: 748-52.

Govoni, J. J., A. J. Chester, D. E. Hoss and P. B. Ortner 1985. An observation of episodic feeding and growth of larval Leiostomus xanthurus in the northern Gulf of Mexico. Journal of Plankton Research 7: 137-146.

Govoni, J. J., D. E. Hoss and D. R. Colby 1989. The spatial distribution of larval fishes about the Mississippi River plume. Limnol. Oceanogr. 34(1): 178-187.

Govoni, F. and C. Grimes 1992. The surface accumulation of larval fishes by hydrodynamic convergence within the Mississippi River plume front. Cont. Shelf Res.12: 1265-1276.

Govoni, J. J. 1993. Flux of larval fishes across frontal boundaries - examples from the Mississippi river plume front and the western gulf stream front in winter. Bull Mar Sci 53: 538-566.

Govoni, J. J. 2004. The development of form and function in fishes, and the question of larval adaptation. Bethesda, MD, American Fisheries Society. Amer. Fish. Soc. Symp 40:

Hartman, R. D., C. F. Bryan and J. W. Korth 1987. Community structure and dynamics of fishes in a Southeast Texas estuary. U.S. Fish and Wildlife Service, Albuquerque. $116 \mathrm{p}$.

Hernandez, F. J., Jr. 2001. The across-shelf distribution of larval, postlarval, and juvenile fishes collected at oil and gas platforms and a coastal jetty off Louisiana west of the Mississippi River delta. Ph.D. Dissertation, Louisiana State University,

Holt, S. A., G. J. Holt and C. R. Arnold 1988. Distribution of eggs and larvae of red drum (Sciaenops ocellatus ) in Texas coastal waters. Cont. Mar Sci. 30: 196.

Houde, E. D. and J. A. Lovdal 1984. Seasonality of occurrence, foods and food preferences of ichthyoplankton in Biscayne Bay, Florida. Estuarine, Coastal and Shelf Science 18: 403-419.

Houde, E. D. 1987. Fish early life dynamics and recruitment variability. p. 17-29 In Hoyt, 
R. D. (ed.). Proceedings of the10th Annul Larval Fish Conference held in Miami, FL May 18-23, 1986. American Fisheries Society Symposium 2. American Fisheries Society, Bethesda, MD.

Houde, E. 1989. Subtleties and episodes in the early life of fishes. J. Fish. Biol. 35 Supplement A: 29-38.

Hunter, J. R. 1981. Feeding ecology and predation of marine fish larvae. p. 33-79 In Lasker, R. (ed.). Marine fish larvae: morphology, ecology, and relation to fisheries. University of Washington Press,

Johnston, I. A. and Hall 2004. Mechanisms of muscle development and responses to temperature changes.. ,. p. 85-116 In Govoni, J. J. (ed.). The development of form and function in fishes, and the question of larval adaptation. American Fisheries Society, Bethesda, MD.

Kamler, E. 1992. Early life history of fish: an energetics approach. Chapman and Hall Fish and Fisheries Series 4.

King, B. D. 1971. Study of migratory patterns of fish and shellfish through a natural pass. TPWD, Tech. Ser. No. 9: 1-54.

Leis, J. M. and B. M. Carson-Ewart 1997. In situ swimming speeds of the late pelagic larvae of some Indo-Pacific coral-reef fishes. Mar. Ecol. Prog. Ser. 159: 165-174.

Leis, J. M. and B. M. Carson-Ewart 1999. In situ swimming and settlement behaviour of larvae of an Indo-Pacific coral-reef fish, the coral trout Plectropomus leopardus (Pisces: Serranidae). Mar. Biol. 134: 51-64.

Lochmann, S. E., R. M. Darnell and J. D. Mceachran 1995. Temporal and vertical distribution of crab larvae in a tidal pass. Estuaries 18: 255-263.

Lyczkowski-Shultz, J., D. L. Ruple, S. L. Richardson and J. H. Cowan, Jr 1990. Distribution of fish larvae relative to time and tide in a Gulf of Mexico barrier island pass. Bull. Mar. Sci. 46: 563-577.

Lyczkowski-Shultz, J. and J. Steen, Jr 1991. Diel vertical distribution of red drum Sciaenops ocellatus larvae in the north central Gulf of Mexico. Fishery Bulletin 89: 631-641.

Marley, R. D. 1983. Spatial distribution patterns of planktonic fish eggs in lower Mobile Bay, Alabama. Trans. Amer. Fish. Soc. 112: 257-266.

Minello, T. J. 1980. The neritic zooplankton of the northwestern Gulf of Mexico. Texas A\&M University, College Station, 240 p.

Muessig, P. H., J. R. Younf, D. S. Vaughan and B. A. Smith 1988. Advances in field and analytical methods for estimating entrainment mortality factors. p. 124-132 In Barnhouse, L. W., R. J. Klauda, D. S. Vaughan and R. L. Kendall (ed.). Science, law, and Hudson River power: a case study in environmental impact assessment. American Fisheries Society, Monograph 4, Bethesda.

Osse, J. W. M. and J. G. M. van den Boogart 2004. Allometric growth in fish larvae: timing and function. p. 167-194 In Govoni, J. J. (ed.). The development of form and function in fishes, and the question of larval adaptation. American Fisheries Society, Bethesda, MD.

Raynie, R. C. and R. F. Shaw 1994. A comparison of larval and postlarval gulf menhaden, Brevoortia patronus, growth rates between an offshore spawning ground and an estuarine nursery. Fish Bull 92: 890-894.

Riverkeeper, I. 2003. Comprehensive survey and investigation of dry cooling systems to reduce impingement and entrainment. Riverkeeper, Inc. (http://riverkeeper.org/campaign.php/fishkills/we_are_doing/622), 
Rogers, B. D., R. F. Shaw, W. H. Herke and R. H. Blanchet 1993. Recruitment of postlarval and juvenile brown shrimp (Penaeus aztecus Ives) from offshore to estuarine waters of the northwestern Gulf of Mexico. Estuarine, Coastal and Shelf Science 36: 377-394.

Ruple, D. L. 1984. Occurrence of larval fishes in the surf zone of a northern Gulf of Mexico barrier island. Estuarine, Coastal and Shelf Science 18: 191-208.

Seaby, R. M., P. A. Henderson, C. Cailes and J. R. Somes 2002. Gunderboom fouling studies. (http://riverkeeper.org/document.php/138/Appendix_C_Pis.pdf). Pices Conservation Ltd (www.irchouse.demon.co.uk), England.

Sogard, S. M., D. E. Hoss and J. J. Govoni 1987. Density and depth distribution of larval gulf menhaden, Brevoortia patronus, Atlantic croaker, Micropogonias undulatus, and spot, Leiostomus xanthurus , in the northern Gulf of Mexico. Fishery Bulletin 85: 601-609.

Stobutzki, I. and D. R. Bellwood 1997. Sustained swimming abilities of the late pelagic stages of coral reef fishes. Mar. Ecol. Prog. Ser. 149: 1-3.

Temple, R. F. and C. C. Fischer 1965. Vertical distribution of planktonic stages of penaeid shrimp. Publ. Inst. Mar. Sci. Univ. Texas 10: 59-67.

Temple, R. F. and C. C. Fischer 1967. Seasonal distribution and relative abundance of planktonic-stage shrimp (Penaeus spp.) in the northwestern Gulf of Mexico, 1961. Fish. Bull., U.S. 66: 323-334.

Tetra Tech 2002. Evaluation of cooling system alternatives - proposed Morro Bay power plant. Tetra Tech, Inc. (http://www.swrcb.ca.gov/rwqcb3/MorroBayDNA/Reports/TetraTechMBPP.pdf),

Webb, P. W. and D. Weihs 1986 . Functional locomotor morphology of early life history stages of fishes. Transactions of the American Fisheries Society 115: 115-127.

WHO 2000. United Nations Environment Programme, International Labour Organisation, World Health Organization, International Programme On Chemical Safety. Environmental Health Criteria 216. Disinfectants And Disinfectant ByProducts. http://www.inchem.org/documents/ehc/ehc/ehc216.htm: 


\section{A Novel Process to use Salt Caverns TO RECEIVE SHIP BORNE LNG}

DE-FC26-02NT41653

PhASE I:
EXAMINE AND EVALUATE A PROCESS TO USE SALT CAVERNS IN THE RECEIPT OF SHIP BORNE LNG

OBJ ECTIVES, SCOPE OF WORK \& TASKS

PHASE II:

FIELD TEST AND FULL SCALE DESIGN OF CRITICAL COMPONENTS OF A SALT CAVERN BASED LNG RECEIVING TERMINAL

OBJ ECTIVES, SCOPE OF WORK \& TASKS 


\section{PHASE 1 \\ DE-FC26-02NT41653 \\ "Examine and Evaluate a Process to Use Salt Caverns to Receive Ship Borne Liquefied Natural Gas (LNG)"}

\section{A. OBJECTIVES}

The objective of this project is to examine the critical elements of an innovative process to pressurize and warm LNG, used together with traditional salt cavern storage technologies, to receive and store LNG.

\section{B. SCOPE OF WORK}

The project team shall identify and examine critical elements that must be operationally viable in order to use salt caverns to directly receive LNG. Each critical element shall be studied using, as appropriate, mathematical modeling, engineering practices, literature searches, and industry queries. Solutions shall be described or alternative approaches suggested for each critical element. Two potential sites, one with the salt formation onshore and a receiving facility at a dock on navigable inland waters, and one with the salt formation below the Gulf of Mexico with a receiving facility on an offshore platform, shall be selected. Conceptual designs for both locations shall be developed. Based on the sites selected and conceptual designs developed, cost estimates for construction of the two sites shall be developed. Operating characteristics and cost comparisons shall be made between the two salt cavern based LNG receiving facilities and (a) conventional liquid tank storage shore based LNG receiving facility and (b) the El Paso Energy Bridge tankers.

\section{TASKS TO BE PERFORMED}

\section{Task 1. Identify Critical Elements}

Subtask 1.1 Identify Potential Salt Formations which could be used for LNG Receiving The project team shall examine public and purchasable data compiled by the Bureau of Economic Geology, University of Texas, and the New Orleans Geological Society for geophysical and oil and gas well information regarding salt formation located in the Gulf of Mexico and on shore near navigable waters. The project team shall review and cross reference pipeline locations, water depths, and navigable fairways to potential salt locations. A variety of source documents from the Mineral Management Service, U.S. Coast Guard, and industry sources shall be consulted.

\section{Subtask 1.2 Identify Marine Mooring and Offloading Initiatives for LNG Vessels}

The project team shall catalogue the various techniques, facility designs, and enabling technologies under development for the mooring and offloading of LNG vessels at sea. The project team shall review the many technologies developed by the international oil industry to accommodate offshore cargo transfers, and an array of designs for at-sea facilities that are being developed by individual companies and consortiums of companies both in the U.S. and abroad that can be applied to the LNG industry.

\section{Subtask 1.3 Determine Major Equipment Requirements}

The project team shall perform a conceptual design to identify major equipment components and their operating requirements. Particular attention shall be paid to the pumps and heat exchangers necessary to offload a cargo of LNG and warm and inject it into salt caverns. The project team shall also visit LNG pump and heat exchanger manufacturers to discuss the operation characteristics of components of the El Paso Energy Bridge system. An innovative high-pressure, high capacity heat exchanger (pipe in pipe coaxial design, using seawater as the warmant) shall be mathematically modeled to confirm heat transfer rates 
and to confirm that icing is controlled. The design parameters shall be examined through mathematical modeling by expert and industry sources using the commercially available computer code, HYSIS.

\section{Subtask 1.4 Determine Salt Cavern Requirements}

The project team shall evaluate salt cavern sizes, well bore requirements, development plans and time required to be utilized for LNG receiving service. Particular attention shall be placed on optimizing design features to better receive the warmed LNG at high rates and the temperature requirements compatible with salt formations. These requirements shall be mathematically modeled by expert and industry sources, including a rock mechanical analysis to determine minimum allowable cavern temperatures.

\section{Task 2. Develop Conceptual Design of a Salt Cavern-Based LNG Receiving Terminal}

Two cases shall be developed by the project team, (1) one onshore with the ship unloading from a conventional dock, sending vaporized LNG to existing caverns and, (2) offshore, with the caverns and the ship unloading facilities at sea. The project team shall prepare construction time and cost estimates utilizing expert and industry sources and applying generally accepted estimating techniques.

\section{Task 3. Comparison to Existing Conventional Liquid Storage Terminals and El Paso Energy Bridge System}

Prepare rubrics to compare conventional terminals and the El Paso Energy Bridge system to salt cavern terminals based on costs, throughput, terminal and cavern operating characteristics, security concerns, safety issues, community acceptance, and flexibility.

\section{DELIVERABLES}

Deliverables shall be submitted in accordance with Attachment B, "Federal Assistance Reporting Checklist" and the instructions accompanying the checklist. In addition, reports shall be prepared and presented as follows:

Final Report shall include at a minimum "Critical Elements in a Process to Utilize Salt Caverns in a LNG Receiving Terminal," "Conceptual Design of a Salt Cavern Based LNG Receiving Terminal," and "Comparisons Between a Conventional LNG Terminal and a Salt Cavern Based Receiving Terminal."

Electronic monthly Informal Exceptions Reports. This report allows Recipients to communicate developments, achievements, changes and problems. The Recipient enters a brief narrative discussion of the following topics: approach changes; performance variances, accomplishments, or problems; open items; and status assessment and forecast. Each of these topics is addressed, as appropriate, for a given reporting period and the report is submitted to the DOE COR periodically via e-mail, as required, during the life of the project. The report shall be submitted in either MS Word or WordPerfect and in accordance with the following format:

Award No.

Reporting Period - Identify month and year of the reporting period.

Completed Tasks - Identify project tasks that were completed during the reporting period. Identify tasks by both the descriptive name and number.

Key Milestone Update - Identify completion of key project milestones and modifications being considered or required down to at least work breakdown structure Level 2 . Discuss lower WBS tasks when appropriate to communicate impacts to critical path and medium to high-risk project tasks.

Discussion Topics - Identify issues that require DOE COR attention or action. 
Significant Accomplishments - In a short paragraph per accomplishment, identify achievement of noteworthy advancements in research, design, manufacture or commercialization activities of the project, and important breakthroughs that resolve critical science and technology risks or development barriers.

Presentations \& Publications - Identify briefing packages, press releases, articles, and papers planned and given that discuss the project.

Site Visits - Identify site visits planned and given with high level corporate or government officials.

Travel - Identify travel planned or completed to accomplish/manage project tasks.

\section{E. BRIEFINGS}

\section{Kickoff Meeting}

A project kickoff meeting shall be held at the Department of Energy's National Energy Technology Laboratory's Morgantown office. A presentation shall be given by the project team to discuss the plans for the project, details on all tasks, costs and budgets, and deliverables.

\section{Close-Out Meeting}

A project close-out meeting shall be held at the Department of Energy's National Energy Technology Laboratory's Morgantown office to discuss the findings and results of the project.

\section{Technical Presentations}

Technical paper(s) shall be presented at meetings as mutually agreed upon by the project team and the DOE COR. 
PHASE 2

DE-FC26-02NT41653

\section{“Field Test and Full Scale Design of Critical Components of a Salt Cavern based LNG Receiving Terminal”}

\section{A. OBJECTIVES}

The objective of this project is to design, construct, field test, and evaluate the performance of critical components of a salt cavern based LNG receiving facility and to describe their application in LNG receiving facilities in the Gulf coast. The critical components to be tested are a high capacity, energy efficient LNG heat exchanger, a high pressure LNG pump, and offshore LNG ship mooring and product transfer systems.

\section{B. SCOPE OF WORK}

The project team shall design, construct and field test a scaled version of a high capacity and energy efficient LNG heat exchanger, a high pressure LNG pump, and offshore LNG ship mooring and product transfer systems, and describe these elements in applications in the Gulf coast and Northeast U.S. The design, construction, testing, and evaluation shall be conducted using industry accepted design, engineering, construction and operating practices. Field test performance results shall be integrated into design, engineering, construction and operating cost estimates for applications in onshore and offshore applications. Optimizing solutions for materials and methods of construction, throughput capacities, energy consumption, capital and operating costs and environmental impacts of operation shall be developed. Conceptual designs of full-scale applications of the heat exchanger in an onshore and an offshore LNG receiving terminal shall be developed and compared to an array of alternative LNG heat exchanger/vaporizers in current use.

\section{TASKS TO BE PERFORMED}

\section{Task 1. Heat Exchanger Field Test and Application}

\section{Subtask 1.1 Identify Scaled Design}

The project team shall review the results of earlier research on the heat exchanger (pipe in pipe coaxial design, using water or seawater as warmant) to determine a scaled size and configuration that would represent full-scale operation and performance. Mathematical modeling and engineering judgment shall be used to define the scaled version, its operating requirements, and predictive results.

\section{Subtask 1.2 Identify Field Test Protocol and Field Test Requirements}

The project team shall develop an appropriate test protocol, and define the requirements for the field test including number of tests, operating conditions, equipment, instrumentation and recording of results. As a minimum, critical measurements of temperatures, pressures, and flow volumes of both LNG and warmant shall be captured. Key control parameters are expected to be the temperature of the warmant and the ratio of warmant injection volume to LNG flow, Key variables shall be temperatures and pressures of the warmant and the dense phase natural gas (warmed LNG) along the length of the exchanger, flow rates of both fluids, and the extent of icing in the system. Duration of individual tests shall be long enough to achieve steady state operation and the number of tests conducted shall be sufficient to simulate a wide range of expected actual operating conditions. A minimum of 32 tests are anticipated, 4 tests per day for a total of 8 working days. 
Subtask 1.3 Identify Potential Field Test Sites and Obtain Access Rights for conduct of Test

The project team shall research possible test sites and negotiate contractual access to the selected site for purposes of the test.

\section{Subtask 1.4 Design and Engineer Test Equipment}

The project team shall design the scaled heat exchanger, and equipment necessary to integrate it into the test site's equipment and operation. A hazard identification and an operations analysis for safety and other considerations shall be made on the final design.

\section{Subtask 1.5 Presentation to COR for Acceptance of Scaled Design and Field Test Requirements}

The project team shall present for review and approval of COR the test plan including recommended scale, design, site, test protocol, and other matters pertinent to the fieldwork and conduct of the test.

\section{Subtask 1.6 Construct and Conduct Field Test}

The project team shall construct the heat exchanger, integrate it into the test site facilities and conduct the field test according to the test protocol as approved in Subtask 1.5.

\section{Subtask 1.7 Integrate Test Results With Predictive Model}

Test data shall be evaluated and incorporated into the predictive model. The modified predictive model shall be used to optimize full-scale designs and performance characteristics of the field-tested heat exchanger.

\section{Subtask 1.8 Full-Scale Conceptual Design of Onshore and Offshore Applications}

The project team shall develop conceptual designs of the heat exchanger and describe its operating performance, and economical considerations in an onshore and an offshore terminal application.

\section{Subtask 1.9 Evaluate Environmental Impacts}

The project team shall conduct a preliminary environmental analysis to evaluate the environmental impacts of the cold-water discharge of the full-scale heat exchanger and identify any mitigating modifications, if necessary. This shall be done for both fresh water and offshore types of installation.

\section{Subtask 1.10 Comparison to Existing LNG Heat Exchangers and LNG Terminal Operations \\ The project team shall compare conventional heat exchangers and LNG tank based terminal operations to the high capacity heat exchanger and its application to a salt cavern based LNG terminal with respect to costs, throughput, energy consumption, metallurgy and temperature cycling, environmental impacts, terminal operating characteristics, security concerns, safety issues, community acceptance, and flexibility.}

\section{Subtask 1.11 Topical Report}

The project team shall prepare a topical report on Subtasks $1.1-1.10$.

\section{Task 2. Field Test High Pressure LNG Pump}




\section{Subtask 2.1 LNG Pump Design, Construction and Test Protocol}

A pump manufacturer shall be selected to design, construct, and test a full scale pump operating at discharge pressures in excess of 2,000psi. Test protocols common to the industry for conduct of the test shall be developed.

\section{Subtask 2.2 LNG Pump Test}

The pump manufacturer shall conduct the pump test in accordance to the test protocols established in Subtask 2.2. The test pump shall be instrumented in accordance with the manufacturer's recommendations to determine all pertinent operating parameters including power consumption, the pump operating envelop, various temperature responses including fluid warming, etc. Strain gages shall be used to determine the pump's structural response. Results shall be compared with standard pumps.

Subtask 2.3 Pump Application in Onshore and Offshore Salt Cavern Based LNG Receiving Terminal

The design of the pump tested shall be evaluated for use in onshore and offshore applications in the U.S. Gulf and Northeast coastal areas.

\section{Subtask 2.4 Topical Report}

The project team shall prepare a topical report on Subtasks $2.1-2.3$.

Task 3. Conceptual Design, Engineering, Evaluation, and Model Test of an Offshore LNG Receiving and Product Transfer System.

\section{Subtask 3.1 Conceptual Design and Engineering of an Offshore LNG Import and Gas Storage Terminal}

The project team shall develop an overall system design, expanding the work done in the previous research, using Vermilion block 179 as the site basis. This shall include the basis of design, field lay out, health, safety, security, and environmental (HSSE) assessments, and a system cost estimate.

\section{Subtask 3.2 LNG Ship Mooring Terminal Design and Model Basin Test}

A lay-out of the ship mooring terminal shall be developed, a mooring analysis including verification tests in a model test basin shall be performed, and the LNG transfer systems, and utility systems shall be incorporated into the design. A hydrostatic and structural analysis shall be conducted on the completed design.

\section{Subtask 3.3 LNG Regasification, Cavern/Pipeline Injection and Send-Out Platform Design}

The project team shall develop the platform lay-out, LNG and vapor return systems, Regasification systems, platform utility systems, injection, conditioning and send out systems, and the structural design of the platform necessary to contain them.

\section{Subtask 3.4 Topical Report}

The project team shall prepare a topical report on Subtasks 3.1-3.3. 


\section{DELIVERABLES}

Deliverables shall be submitted in accordance with Attachment B, "Federal Assistance Reporting Checklist" and the instructions accompanying the checklist. In addition, reports shall be prepared and presented as follows:

Electronic monthly Informal Exceptions Reports. This report allows Recipients to communicate developments, achievements, changes and problems. The Recipient enters a brief narrative discussion of the following topics: approach changes; performance variances, accomplishments, or problems; open items; and status assessment and forecast. Each of these topics is addressed, as appropriate, for a given reporting period and the report is submitted to the DOE COR periodically via e-mail, as required, during the life of the project. The report shall be submitted in either MS Word or WordPerfect and in accordance with the following format:

Award No.

Reporting Period - Identify month and year of the reporting period.

Completed Tasks - Identify project tasks that were completed during the reporting period. Identify tasks by both the descriptive name and number.

Key Milestone Update - Identify completion of key project milestones and modifications being considered or required down to at least work breakdown structure Level 2. Discuss lower WBS tasks when appropriate to communicate impacts to critical path and medium to high-risk project tasks.

Discussion Topics - Identify issues that require DOE COR attention or action.

Significant Accomplishments - In a short paragraph per accomplishment, identify achievement of noteworthy advancements in research, design, manufacture or commercialization activities of the project, and important breakthroughs that resolve critical science and technology risks or development barriers.

Presentations \& Publications - Identify briefing packages, press releases, articles, and papers planned and given that discuss the project.

Site Visits - Identify site visits planned and given with high level corporate or government officials.

Travel - Identify travel planned or completed to accomplish/manage project tasks.

\section{E. BRIEFINGS}

\section{Subtask 1.5 Test Approval Meeting}

\section{Closeout Meeting}

A project closeout meeting shall be held at the Department of Energy's National Energy Technology Laboratory's Morgantown office to discuss the findings and results of the project.

\section{Technical Presentations}

Technical paper(s) shall be presented at meetings as mutually agreed upon by the project team and the DOE COR. 


\section{ENTERGY-TULANE ENERGY INSTITUTE}

LIQUEFIED NATURAL GAS (LNG) IMPORTS AND THEIR IMPACT ON THE STATE, REGIONAL, AND NATIONAL ECONOMIES

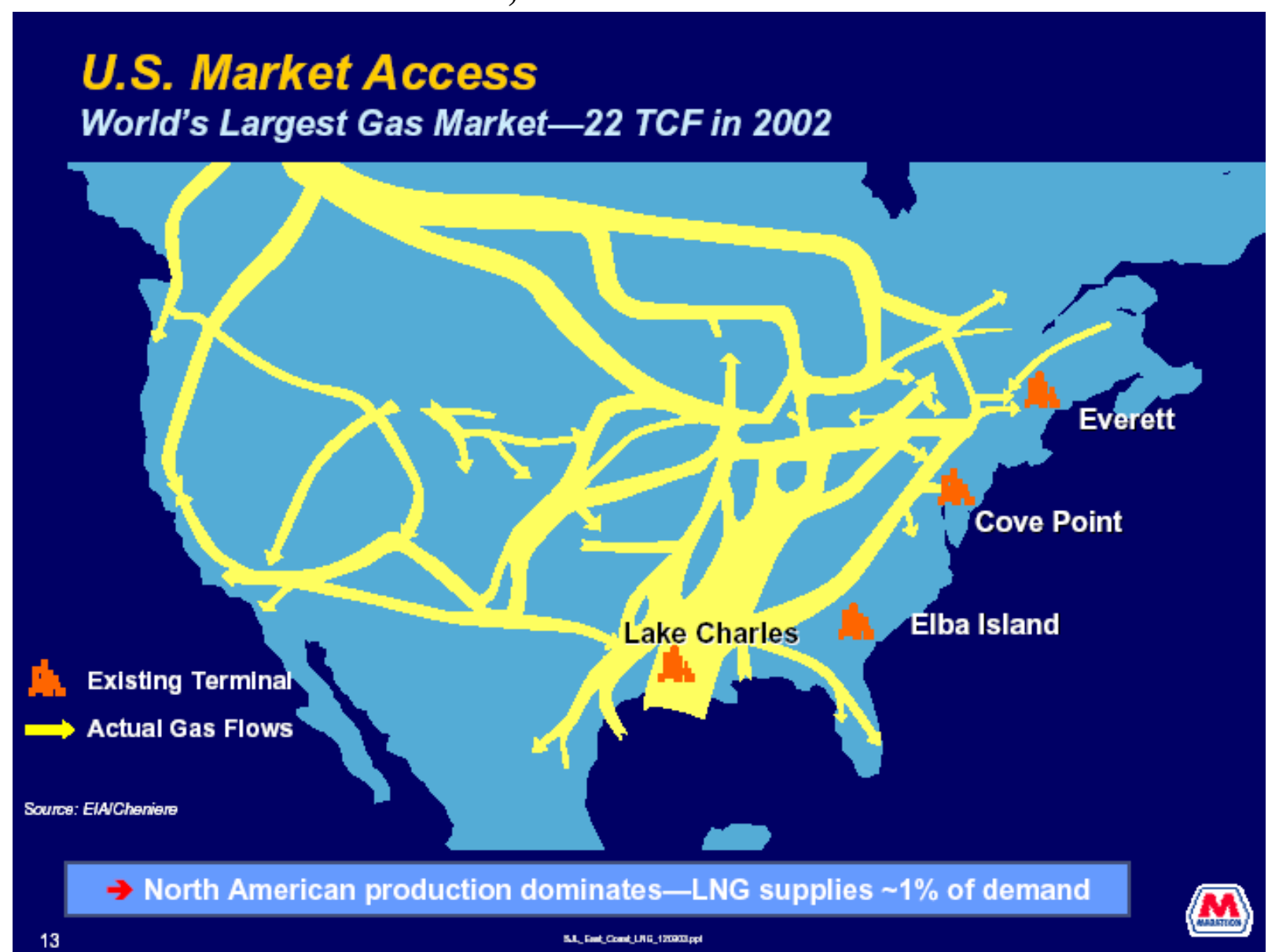

PRePared BY

ERIC N. SMith, James W. MCFARLAND, John M. Trapani III

Stathis E. Michaelides, John R. MORONEy, AND ChaRLES W. NELSON

APRIL 2, 2004 


\section{TABLE OF CONTENTS}

1. Executive Summary 1

2. Objectives 3

3. Background, History and Market Environment 6

4. LNG Technology and Capacity 14

5. Businesses Affected by LNG Growth 21

6. $\quad$ Proposed LNG Projects in North America 28

7. Proposed LNG Projects on the Gulf Coast 30

8. Estimated Investment and Operating Costs for Louisiana LNG Projects 33

9. Impact of LNG Projects on the State and Region 41

Industrial Markets for Gas 54

Impact on Chemical Industry 55

International Substitution - Trinidad $\quad 61$

Pipeline Issues $\quad 63$

Storage Considerations $\quad 69$

10. Environmental Considerations 75

11. Impact of LNG Projects on Gas Supplies and Prices 78

12. Recommendations and Policy Implications 90

13. Future Research Options 92

13. Bibliography 93 


\section{ACKNOWLEDGEMENTS}

This report includes contributions from a number of people besides those listed on the title page. Significant assistance was provided by the Energy Information Agency and by the National Petroleum Council, both of whom published in late 2003 comprehensive reports analyzing supply options for natural gas in North America.

In addition, both Bob Nimocks and Mark Voss of Zeus Development Corp., a consulting firm specializing in LNG analysis, were invaluable contributors, not only through their published reports, but also by generously providing access to presentations prepared by various participants in their recent LNG conferences.

We separately acknowledge recent presentations made by Marathon, Shell, and Banc of America on the general subjects of LNG production, transportation, re-gasification and consumption.

In terms of understanding non-conventional offshore LNG delivery systems we also appreciated the contributions of Jens Kaalstad of APL, of Mike McCall at CGI, Inc., and of Bill Bennett representing the Main Pass Energy Hub development of Freeport-McMoRan, Inc.

Finally, we appreciate the efforts of Craig Taylor of HNG Storage Company who provided information on salt cavern storage of natural gas.

\section{The Authors}

The views expressed herein are exclusively those of Entergy-Tulane Energy Institute, a Tulane University research entity. The views expressed herein are not necessarily those of Entergy Corporation or any of its affiliates. 


\section{List of Figures}

Figure 1: Overall Demand Growth Will Moderate, While the Power Sector Drives GrowthIndustrial Demand Declines. (pg. 6)

Figure 2: Future Supplies Come from Traditional and New Sources (pg. 7)

Figure 3: The Rate of Production Decline is Increasing (pg. 8)

Figure 4: Production Response from Increased Drilling Has Been Modest (pg. 8)

Figure 5: Indigenous Resources Are Not Fully Utilized (pg. 9)

Figure 6: LNG Fleet Has 55 New Ships on Order (pg. 16)

Figure 7: Hoegh LNG's SRVTM Shuttle and Regas Vessel (pg. 20)

Figure 8: North Dayton Gas Storage Facility (pg. 25)

Figure 9: Salt Cavern Gas Storage Facilities (pg. 26)

Figure 10: Potential Salt Cavern Storage Sites (pg. 27)

Figure 11: Existing and Proposed North American LNG Import Terminals (pg. 28)

Figure 12: Proposed Gulf Coast LNG Terminals (pg. 30)

Figure 13: STL ${ }^{\mathrm{TM}} \&$ STP ${ }^{\mathrm{TM}}$ - Submerged Turret Loading \& Production (pg. 32)

Figure 14: Integrated Gas Value Chain (pg. 33)

Figure 15: Integrated Gas Value Chain (pg. 34)

Figure 16: Lake Charles Facility (pg. 35)

Figure 17: LNG Receiving Terminal (pg. 36)

Figure 18: Main Pass 299 (pg. 37)

Figure 19: Three New Salt Dome Caverns (pg. 37)

Figure 20: Deepwater Port \& LNG Regas Vessel (pg. 38)

Figure 21: LNG Regas Vessel (pg. 39)

Figure 22: Absolute Level of Gas Consumption (pg. 42)

Figure 23: Relative Level of Gas Consumption (pg. 43)

Figure 24: Industrial Markets for Natural Gas (pg. 54)

Figure 25: Industrial Markets for Natural Gas: Chemicals (pg. 55)

Figure 26: U.S. Market Demand (pg. 56)

Figure 27: Natural Gas Focus (pg. 57)

Figure 28: Industrial Market News (pg. 57)

Figure 29: Petrochemical Involvement in Trinidad and Tobago (pg. 63)

Figure 30: The Gas Pipeline Grid (pg. 64)

Figure 31: Impact of 2004 Cove Point LNG Imports on Pipeline Flows-Winter Flows (pg. 65)

Figure 32: Impact of 2004 Cove Point LNG Imports on Pipeline Flows (pg. 66)

Figure 33: LNG Imports To The North East Will Have A Major Effect On Pipeline Owners And Shippers Holding Firm Transport (pg. 67)

Figure 34: LNG Could Be Both A Threat And Opportunity To Gulf Coast and Northeast Pipelines (pg. 68)

Figure 35: LNG Suppliers and Power Generators See Natural Gas Market Differently (pg. 69)

Figure 36: Simplified Natural Gas Supply Network (pg. 71)

Figure 37: Major LNG Tanks in New England (pg. 74)

Figure 38: Growing Net Imports of LNG in TCF/year (pg. 78)

Figure 39: Everett Marine Terminal (pg. 79)

Figure 40: Lake Charles Terminal (pg. 80) 
Figure 41: Elba Island Terminal (pg. 80)

Figure 42: Cove Point Terminal (pg. 81)

Figure 43: Supply to Existing U.S. LNG Terminals (pg. 83)

Figure 44: Gas Price Volatility is Linked to Capacity Utilization (pg. 85)

Figure 45: LNG Imports Are Needed, But Face Obstacles (pg. 86)

Figure 46: LNG Imports Can Lower Costs to Consumers (pg. 87)

Figure 47: A Balanced Fuel Portfolio is Essential (pg. 87)

Figure 48: Increased Access Lowers Costs to Consumers (pg. 88)

Figure 49: Higher Prices Impact Domestic Industrial Growth (pg. 88) 


\section{LIST OF TABLES}

Table 1: Production and Effective Capacity Utilization by Area (pg. 10)

Table 2: Comparison of Costs: Offshore Buoy vs. Onshore Terminal (pg. 19)

Table 3: LNG Storage and Send Out Capacity 2005 (pg. 23)

Table 4: Active LNG Receiving Terminal Projects in North America (pg. 29)

Table 5: Active LNG Receiving Terminals in Louisiana (pg. 31)

Table 6: Comparison of Costs: Offshore Buoy vs. Onshore Terminal (pg. 40)

Table 7: Historical Gas Thruput and Disposition for Louisiana (pg. 41)

Table 8: Generic Estimates for the Direct Capex Associated with New LNG Receiving Terminals and the Cumulative Spend Associated with Select Projects Constructed in Louisiana (pg. 45)

Table 9: Projected Capital Expenditures for Expanded Capacity in Louisiana 2004-2009 (pg. 46)

Table 10: Direct and Total Jobs (Man Years) Created in Louisiana by New CAPEX on LNG Terminals 2004-2009 (pg. 48)

Table 11: Projected Additional Operational Expenditures (OPEX) for Expanded LNG Capacity in Louisiana 2004-2009 (pg. 49)

Table 12: Direct and total Jobs (Man Years) Created in Louisiana by Additional LNG Operating Expenses 2004-2009 (pg. 50)

Table 13: Estimates for Direct Capex and Man Years Associated with Regional LNG Receiving Terminal Projects Constructed along the Gulf Coast (pg. 51)

Table 14: Chapter 11 Statement Referencing Natural Gas (pg. 58)

Table 15: Petrochemical Development in Trinidad and Tobago (pg. 62)

Table 16: Distances between LNG Sources and Receiving Terminals (pg. 65)

Table 17: LNG Storage and Send Out Capacity (pg. 73)

Table 18: Capacity at Existing Terminals Before \& After Expansion (pg. 82) 


\section{ENTERGY-TULANE ENERGY INSTITUTE}

\section{LIQUEFIED NATURAL GAS IMPORTS AND THEIR IMPACT ON THE STATE, REGIONAL, AND NATIONAL ECONOMIES}

\section{EXECUTIVE SUMMARY}

This phase I report surveys the intermediate-term prospects for Louisiana as a host for LNG terminal facilities and the impact on natural gas pricing and price volatility of this fundamental change in the supply mix. It also discusses the longer-term impact, on Louisiana companies in particular, of a transition to LNG as the primary source of long-term gas supply. As part of this analysis, we identify and profile existing Louisiana import terminal capacity and examine several proposals for expanding Louisiana's capability including proposals for offshore unloading of LNG. We also examine the impact on gas consumers, in particular the petrochemical industry. A major objective is to quantify the near-term effects on Louisiana associated with developing and constructing LNG terminals, both onshore and offshore, including estimating temporary and permanent jobs associated with building and manning the new terminals. In order to complete this estimate, we review the status of the 4 existing terminals, all of which are undergoing expansions as well as review the 40 odd proposals for new terminals, in light of the NPC and EIA reports, to determine those that will actually be built ( between 10 and 14 for all of North America) . In particular, we allocate terminals between the Gulf Coast, which rely on existing pipeline infrastructure for gas distribution, and those that will be located on the Atlantic Seaboard, closer to consuming population centers.

Based on our assumptions, we expect nine terminals to be built along the Gulf Coast with six of those in Louisiana or immediately offshore Louisiana. We also assume one plant in Alabama and two units in Texas. The Louisiana plants will generate direct capital spending of $\$ 2.3$ billion over a six year period and generate an average of 1,625 jobs per year during the six year building program. Longer term, the plants will add 618 direct permanent jobs at the conclusion of the build out period. Applying multipliers to account for indirect spending and job increases the total capital expenditure increases to $\$ 4.9$ billion, the construction jobs to 3,980 and the permanent jobs to 1,513 . 
A second finding is the need to develop a new commercial contract structure which will allow for the purchase, by the petrochemical industry, of re-gasified LNG on a long term basis, on the order of 20 years. The goal of this effort is to minimize the gas price volatility associated with our existing gas marketing system, thereby mitigating the loss of productive capacity and jobs in the petrochemical sector seen over the last few years. There is precedent, as this is the model for virtually all of the world trade in LNG. Long term non-recourse project financing requires long term gas sales contracts and will likely require the same for increases in exports to North America.

A third result is a need to reduce the BTU content of imported LNG. The US market requires a lean gas which contains 1000 to 1050 BTU/cubic foot. The bulk of the world's LNG has values exceeding $1100 \mathrm{BTU}$. To meet the US standard, the imported gas will either need to be diluted or the NGLs, the C2s through C4s, will need to be removed. We believe the best location to effect the removal is at or near to the receiving terminal. Once removed, the NGLs can then be transferred through existing pipelines for use as chemical feedstock. Alternatively, they can be used as fuel in combined cycle power plants equipped to burn this high BTU fuel.

A final finding is that in relying on imported LNG for a greater share of gas consumption the US will require an expansion of gas storage along the pipeline system. The Gulf Coast is blessed with the presence of numerous salt domes which can be solution mined to provide large volume, in ground storage with high deliverability which is ideal for meeting peak demands for gas. Such storage is analogous to the liquid storage used by the Strategic Petroleum Reserve and much superior to the use of low deliverability depleted reservoir storage which represents the bulk of existing ground storage in North America.

We believe this report should be of interest to providers of natural gas, to regulators, to consumers, particularly the power sector and the petrochemical sector which together represent 93\% of the gas consumed in Louisiana, and to the major pipeline companies transporting gas out of State, most of which emanates from Henry Hub, located in Erath, Louisiana. Henry Hub is directly North of Lake Charles, and is the focal point of existing North American gas distribution and new LNG receiving terminal infrastructure. 


\section{OBJECTIVES}

During this first phase of the project, we utilize secondary sources to identify and quantify the scale and the impacts, both positive and negative, on Louisiana, the Region, and the Nation. Core sources are the National Petroleum Council's study, the preliminary conclusions of which were published September 25, 2003, and the recently issued Energy Outlook 2004 by the Energy Information Agency of the U. S. Department of Energy. Two published reports prepared by Zeus Development Corporation were also used as sources of information, figures and diagrams. In addition, Zeus' recent LNG conference, in Boston this past December, 2003 was a major source of the graphic materials which we have used, with permission to illustrate this paper.

Primary and secondary economic impacts are identified and examined. For example, a primary effect already underway is a rise in engineering and construction jobs associated with the expansion of existing terminals and the garnering of permits for new terminals. Similar benefits will occur later in the process associated with equipment and material suppliers as well as with specialty service providers such as onshore and marine construction firms, diving companies, dredging contractors etc. We identify domestic and international suppliers of technology, products, and services that are impacted by terminal and vessel construction.

One step removed are industries affected by the new gas supply, for instance, new combined cycle power generation units located in close proximity to LNG receiving terminals, new power plants designed to utilize NGLs (Natural Gas Liquids), and new investments associated with efficiently storing re-gasified LNG.

We investigate the long-term impact on existing infrastructure resulting from a changeover to LNG. Here, we include storage sites, interstate pipelines, power plants, and petrochemical plants in Louisiana that use natural gas and natural gas liquids (NGLs) both as sources of energy and as feed stock for the production of chemical intermediates. Several market participants are profiled at all levels of the gas supply, distribution, and consumption network.

Secondary effects include effects associated with the potential for closing existing conventional power plants and commodity petrochemical plants which find the current pricing regime for natural gas, be it domestic or imported, to be economically untenable. Similar issues surface with the operation of existing interstate pipeline systems at lower volumes, a result of new LNG 
terminals being built along the Atlantic Seaboard. The development of these terminals will result in lower throughput for the trunk lines, not just to the terminal locations, but to a multistate area around each facility.

Another secondary effect is the impact on new offshore exploration and production programs for domestic natural gas. Specifically, will the price for landed LNG establish a cap on finding and development costs for new domestic production? This possibility occurs when LNG volume reaches a point where it effectively sets the price. At present, LNG is barely $2 \%$ of consumption. By the end of the decade, it is projected to surpass $10 \%$. Today, LNG can be landed and re-gasified for prices starting as low as $\$ 3.25 /$ mcf. Relatively few Independents focused on U.S. production can match those prices, and the major oil companies are not even in the game.

We examine the likely impact of an increase in LNG import volumes on price volatility. There is an argument that increasing the share of market held by LNG, particularly LNG imported under long-term contracts will dampen gas price volatility. Historically, gas supplies arriving in the U.S. in the form of LNG have been priced on a short-term basis. Until fairly recently, all LNG arriving here came in the form of spot cargoes as none of the existing terminals were tied to specific LNG sources. This situation differs markedly from Japan, Taiwan, and Korea, who together represent 70\% of world wide LNG receipts, where long-term LNG supplies support base load power generation rather than serve as a marginal supply source to cover seasonal peaking requirements. As long-term importation of dedicated supplies becomes the rule in the U.S., can we expect to see a lessening of gas price volatility? We believe that will be the case.

We quantify the effects of growth in combined cycle power generation, the ultimate driver for growth in natural gas demand in the U.S. We examine the loss of flexibility inherent in the decline of older fossil fuel, steam cycle units capable of burning both oil and gas. Some of this decline is just aging of the installed generating fleet, but a part also reflects an environmental regulatory bias against generating plants fired with oil. In either case, the loss of flexibility has had, and will continue to have, a negative impact on the volatility of gas prices, regardless of the level of LNG import volume. 
In developing our scenario, we provide an up-to-date survey of the technologies for LNG transportation and re-gasification. Our analysis includes a discussion of a proposed ChevronTexaco facility, offshore Louisiana, Freeport - McMorRan's plans for redeveloping its offshore sulfur mine as a receiving terminal, three proposed plants in the Bahamas designed to feed gas into Florida, and the El Paso-Excelerate project that uses re-gasification units onboard turret moored LNG tankers. Such tankers only require a buoy and a pipeline connection to deliver gas into currently existing sub-sea pipeline infrastructure. FERC has now approved both the ChevronTexaco facility and the first Energy Bridge installation, in addition to three onshore terminals. 


\section{BACKGROUND, History AND MARKET ENVIRONMENT}

The North American Natural Gas market is in a period of transition resulting from an increase in demand for gas along with a concomitant decline in supply, particularly from the U.S. outer continental shelf.

Overall Demand Growth Will Moderate, While the Power Sector Drives Growth-Industrial Demand Declines

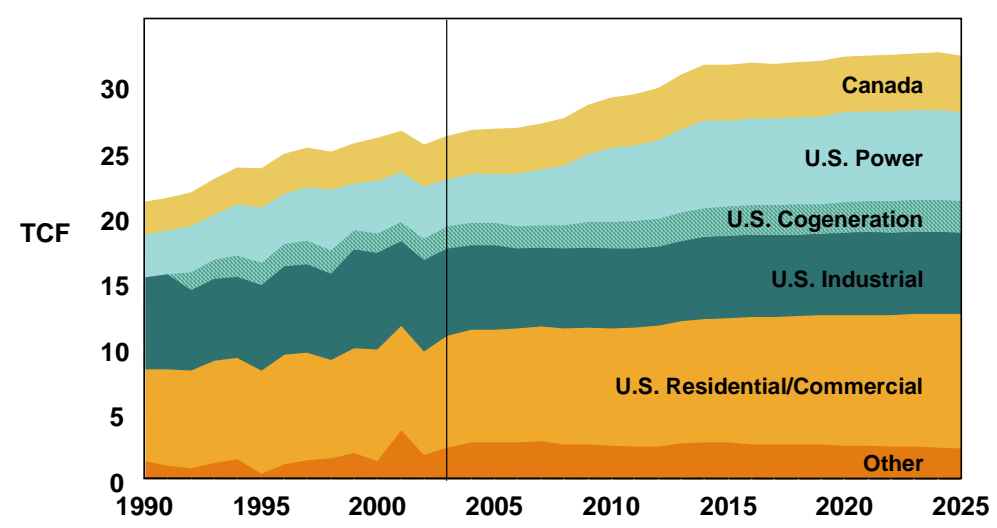

Figure 1 Source: NPC/NOIA Meeting, September, 2003

The anticipated increase in demand from 23 TCF today to 31 TCF in 2025 results from increasing reliance on natural gas as the fossil fuel of choice for power generation. Growth results from environmental benefits associated with its use in new combined-cycle power plants vs. conventional steam cycle plants. The newer units are cost effective, and more efficient than traditional units. Over 230,000 megawatts of this new capacity have been added in the last ten years.

Traditional power plants burn coal, oil or gas to boil water, which is then fed through a steam turbine that drives an electrical generator. In contrast, combined cycle units burn gas directly in a combustion turbine, using the mechanical energy released to power a generator. Then, in a second step, the hot exhaust gases from the combustion turbine are used to boil water, creating steam, which is then used to power a conventional steam turbine, generating additional 
electricity. The two stages of "combined" generation extract up to 30\% more usable power, from the same amount of fuel used in a traditional steam cycle plant.

Were it not for the higher efficiency, the gas supply problem could be much worse than it is. In fact, "gas on gas" displacement of older gas-fired, steam cycle plants has freed up significant amounts of gas for use in meeting additional electrical demand growth. Unfortunately, this has come at a "cost" of the loss of flexibility associated with the dual fuel capacity of the older plants to burn either gas or liquid hydrocarbon fuels. This dual fuel capability helped to keep gas prices in line with oil prices based on a BTU balance. That relationship has been de-coupled by the emergence of the combined cycle plants.

In total, the U.S. in 2003 supplied 23 TCF of gas. Of that amount, 19 TCF was produced onshore, in the lower 48 states; and offshore, from the Gulf of Mexico. Of the 19 TCF, about 25 $\%$ comes from the Gulf. The following chart from the National Petroleum Council's 2003 report illustrates sources of gas going forward. As one can see, since at least 1995, production from the shelf offshore and the lower 48 has been in decline.

\section{Future Supplies Come from Traditional and New Sources}

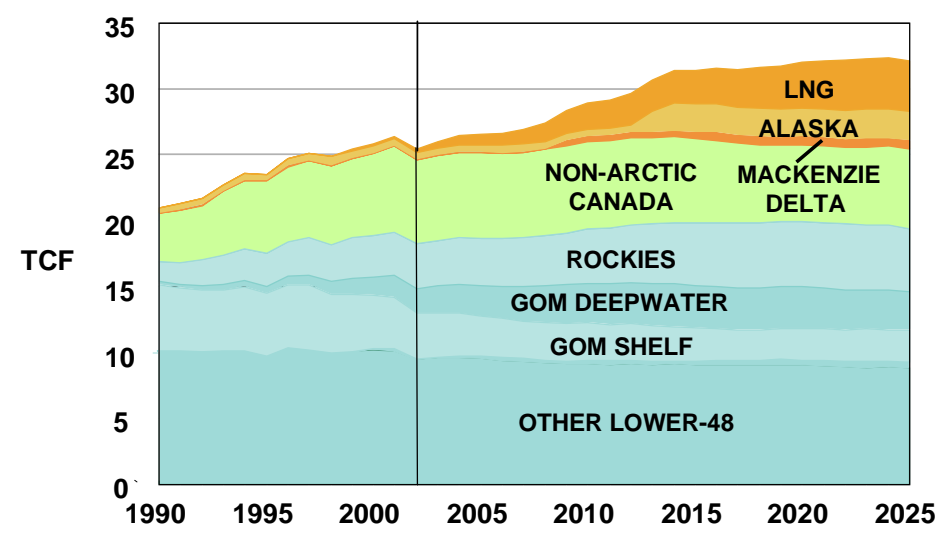

Figure 2

Source: NPC/NOIA Meeting, September, 2003 
The continuing decline in supply, results from a decline in gas production, from mature lower 48 onshore sources as well as from offshore Gulf of Mexico "Shelf" production. The result going forward is increasing reliance on deepwater associated gas, non-conventional gas such as coal bed methane (Rockies gas) and LNG, even assuming pipelines from Alaska and Canada are completed within the planning horizon.

As the two following NPC charts illustrate, we are drilling new discoveries faster, but we are

The Rate of Production Decline is Increasing

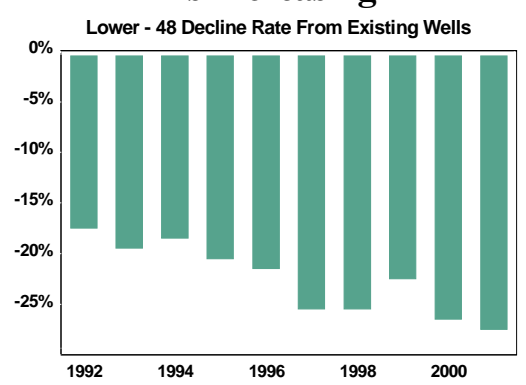

Production Response from Increased Drilling Has Been Modest

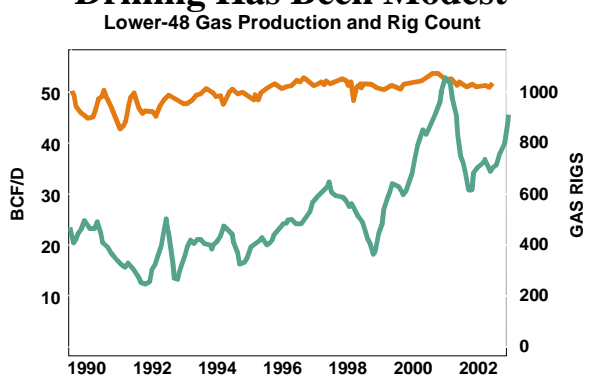

Figure 3

Figure 4

finding less in the way of new reserves with each well, even given the higher numbers of wells being drilled. :

Beyond the areas where gas development is allowed, there are significant quantities of gas that are unavailable for U.S. consumption. Proscribed supplies totaling 148 TCF include the east and west coasts of the U.S. as well as the eastern Gulf of Mexico and sections of the Rockies. Not shown are Alaskan Reserves on the North Slope, also currently off limits to development and approximately equal in total to the amounts shown for the lower 48 . 


\section{Indigenous Resources Are Not Fully Utilized}

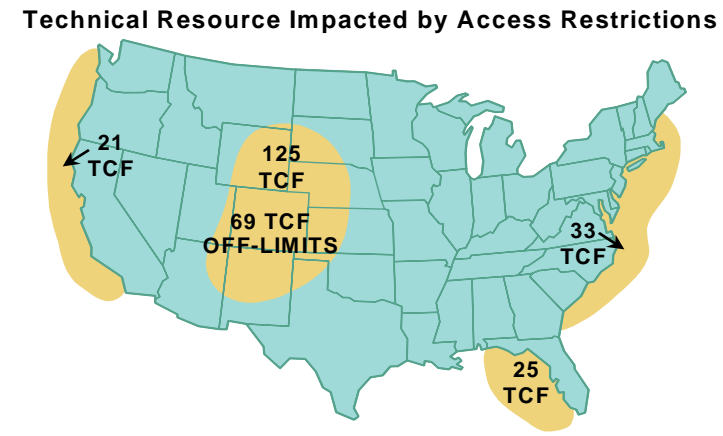

Figure 5

Source: NPC/NOIA Meeting, September, 2003

\section{$\underline{\text { Domestic Capacity Assumptions }}$}

Any discussion of U.S. import requirements needs capacity assumptions. We use a capacity model developed by the EIA, and updated annually. The model defines effective productive capacity as the maximum production available from natural gas wells considering constraints associated with production, gas gathering, processing, and transportation. This benchmark is then used to measure effective utilization.

In their recently published 2003 report on capacity, the EIA assumes capacity of 57.005 bcf/day or 20.8 tcf/year including the lower 48 states and the Gulf of Mexico. Actual production of dry gas in 2003 is estimated to be 51.406 bcf/day or 18.8 tcf/year. This leaves nominal surplus capacity of 5.6 bcf/day or 2 tcf/year. In fact, regional utilization rates vary significantly and gas is not perfectly fungible because of logistical limits. A good example of this effect is the Rocky Mountain region where pipelines limit deliverability and give rise to a price discount vs. gas available at Henry Hub where 15 pipelines meet.

Looking at production in the lower 48, non-traditional gas sources onshore, in particular coal bed methane, have been able to stabilize onshore gas production. According to the EIA, New Mexico, the Rocky Mountains and the southeast states generated about 2.3 TCF of Coal bed Methane in 2003. The major source is New Mexico with .9 TCF. 
The following table summarizes information for the regions.

Table 1: Production and Effective Capacity Utilization by Area

\begin{tabular}{|c|c|c|c|c|c|c|c|}
\hline & \multicolumn{2}{|c|}{ Expected } & \multicolumn{2}{|c|}{ Effective } & \multicolumn{3}{|l|}{ Surplus } \\
\hline Region & \multicolumn{2}{|c|}{ Production } & \multicolumn{2}{|c|}{ Capacity } & Capacity & \multicolumn{2}{|c|}{ ty Utilization \% } \\
\hline Fed. Gulf of Mexico & 13.807 & 5.0 & 13.851 & 5.1 & .244 & .1 & 99.7 \\
\hline Texas & 13.231 & 4.8 & 14.563 & 5.2 & 1.322 & .4 & 90.9 \\
\hline Rocky Mountain* & 5.655 & 2.1 & 7.070 & 2.6 & 1.415 & .5 & 80.0 \\
\hline Oklahoma & 4.331 & 1.6 & 4.734 & 1.7 & .403 & .1 & 91.5 \\
\hline New Mexico & 4.190 & 1.5 & 4.656 & 1.7 & .466 & .2 & 90.0 \\
\hline Louisiana & 3.996 & 1.5 & 4.152 & 1.5 & .156 & .1 & 96.2 \\
\hline South East & 1.761 & .6 & 2.121 & .8 & .360 & .1 & 83.0 \\
\hline Kansas & 1.373 & .5 & 1.554 & .6 & .181 & .1 & 88.4 \\
\hline California & 1.009 & .4 & 1.067 & .4 & .058 & & 94.6 \\
\hline Other & 2.253 & .8 & 3.248 & 1.2 & .995 & .4 & 69.4 \\
\hline Total bcf/day & 51.406 & 18.8 & 57.005 & 20.8 & 5.599 & 2.0 & 90.2 \\
\hline Total TCF/yr & eline lim & atiol & estrict e & ffective & pacity to & $1 / 3^{\mathrm{rd}}$ & of potential \\
\hline
\end{tabular}

Source: EIA Natural Gas Productive Capacity for the lower 48 States, Table ES-1 Year 2003

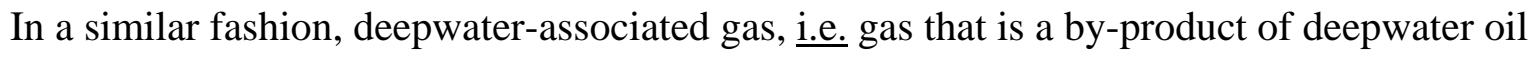
production, continues to grow along with deepwater oil production, even while Shelf production is declining, so that deepwater associated gas has acted to mitigate a relatively steep decline in Shelf gas production. Of the roughly 5 TCF (trillion cubic feet of gas /year) coming from the Gulf of Mexico, 75\% has traditionally come from the Shelf which we define as that area of the U.S. Gulf extending out to a water depth of 1,000 feet. Beyond 1,000 feet, in the "Deepwater" region, reservoirs are biased towards oil production with some associated gas. Deepwater associated gas contributes about a quarter of total natural gas produced from the Gulf of Mexico, while the entire Gulf contributes about 25\% of total lower 48 supply.

Because of a lack of attractive prospects, Major oil companies have virtually stopped Shelf exploration and development. Independent oil and gas companies in the aggregate have been 
unsuccessful in replacing produced reserves on the Shelf. The result is a drop in current production and more ominously, a decline in the reserves to production ratio (R/P).

That is, a decline in the ratio of proved reserves to annual production expressed as the number of years of inventory remaining, assuming level production. When gas reserves are "proved up” more rapidly than gas is produced, inventory in terms of the number of years of stable production available, increases. Conversely, when gas is produced faster than reserves are replaced, inventories are reduced, and the ratio declines. It is this latter case which exists on the Shelf.

While individual exceptions exist, the average new Shelf discovery continues to get smaller and to be produced more quickly. Aggregate production continues to drop, despite increased levels of drilling. As might be expected, most of the drilling activity in shallow water over the last few years has been development drilling designed to extract marginal reserves through existing infrastructure, not exploration drilling focused on finding new reserves. One relevant result has been a continuing decline in offshore construction activity in the shallow water gulf.

Frontier exploration potential does exist, but it tends to be "Deep Shelf” gas reservoirs in shallow water. We define these reservoirs as high pressure, high temperature, possibly sour, gas accumulations located in shallow water, but at depths of at least 15,000 feet below the sea floor. The Minerals Management Service, the government’s offshore landlord, has been offering royalty relief in hopes of coaxing more aggressive development of this potential.

Exploration of these fields is still in its infancy. Drilling wells below 15,000 feet TD, the point where federal royalty relief kicks in, is very expensive, despite the positive effects of a shallow water environment, the availability of existing infrastructure in the form of platforms and export pipeline systems, and the beneficial cash flow effects of royalty relief.

On the negative side, these wells require drilling equipment that exceeds the capabilities of normal shallow Shelf equipment. Perhaps 30 of the 125 operating jack ups in the Gulf would be able to handle the derrick loads and mud pumping requirements of these drilling programs. As you might expect, these are not the least expensive units to charter. Typical estimates for drilling a new deep shelf gas well are in the $\$ 20 \mathrm{~mm}$ range with another $\$ 20 \mathrm{~mm}$ in completion costs if the well is a success. 
Then there is the immediate $\$ 20 \mathrm{~mm}$ cost if the well is a dry hole, a more than distinct possibility given the difficulty in generating accurate seismic information in this regime. These are the levels of cost one expects to see for major oil wells in deep water, not the "rule of thumb" for gas wells. While there have been successes, including wells drilled by El Paso and Freeport McMoRan, the high costs of failure seem to have dampened enthusiasm for exploitation of the shallow water, deep gas, frontier.

The reasons are structural. A Major can shrug off a \$20 million dry hole, once a quarter. However, only the largest Independents have balance sheets that can take that sort of abuse. The "Catch 22" is that the Majors are now so large that finding a deep gas field of 25 to $250 \mathrm{bcf}$ is simply not material to them. While that size discovery is definitely material to an Independent, so is the reporting problem created by a $\$ 20 \mathrm{~mm}$ dry hole. We believe that A large part of the anemic response to the MMS royalty incentives for deep shelf gas drilling can be attributed to 1) the inability of the only interested parties to manage the risk of failure, and 2) of the only financially qualified parties to see any material benefit from the effort.

Another frontier is deepwater gas, usually found in association with oil accumulations in waters beyond 1,000 feet in water depth. There are a few deepwater gas only, developments. However, the costs of drilling and developing deepwater wells are also high, a result of the need for higher priced drilling and completion functions. In addition, the need for expensive deepwater sub-sea wellhead and pipelines to get the gas to market generally acts to reduce enthusiasm for deliberately exploring for gas only reservoirs in deep water.

Much more likely, is the development of coordinated gas transportation networks designed to get deepwater, associated gas to market from multiple sources, a pre-requisite for producing deepwater oil reservoirs. While the gas is needed, it is a by-product of oil exploration and development and only exists because of the attractiveness of deepwater oil drivers.

In summary, both deep shelf and deep water gas resources have some potential. However, both are expensive to find and develop. Incremental deepwater gas has the allure of new oil production to drive the economics. Deep shelf gas does not. Deep shelf gas appears to result in finding and development costs that exceed landed costs of gas imported as LNG, increasingly, a much more predictable source of supply. 


\section{Gas Imports}

Besides lower 48 production, the U.S. imports via pipeline, significant quantities of gas from both western and, more recently eastern, Canada. Gross supplies are about 4.6 TCF/yr. Since we also export about 1 TCF of gas, net imports are approximately 3.6 TCF/year.

In addition to pipeline imports and exports, during 2003, about .540 TCF of LNG was imported, which arrives through four terminals located in Massachusetts, Maryland, Georgia and Louisiana. Of that total, about $40 \%$ arrived in Louisiana and Massachusetts with $60 \%$ arriving at Elba Island. Georgia. Although Alaska contains large quantities of gas, it has no outlets, to the lower 48 states. It does use some gas locally and it also exports limited quantities, abut 66 BCF/year to Japan as LNG. 


\section{LNG TECHNOLOGY AND CAPACITY}

There are presently about 150 million metric tons per annum (MMTA) of LNG, or 7.1 TCF of gas under standard conditions, created and distributed worldwide. Over the next 20 years that total is expected to grow dramatically, with a large portion of the growth, a result of supplying the North American market.

\section{$\underline{\text { Onshore Facilities-Liquefaction }}$}

Today, production is concentrated in 20 liquefaction plants, which include a total of 78 LNG liquefaction trains. In addition, 15 new plants are on the drawing boards, each with multiple trains and each requiring at least 5 TCF of dedicated, proven gas reserves in order to justify nonrecourse financing and multi-year gas supply and consumption contracts that are core features of these developments. Three units are actually in construction. These units are in Egypt (Damietta), Norway (Snohvit) and Eastern Russia (Sakhalin Island).

The liquefaction portion of LNG facilities cost in the $\$ 800 \mathrm{~mm}$ to $\$ 1$ billion range, including an allowance for cryogenic storage, but excluding the costs of producing and processing the gas feedstock for the LNG train.

In terms of design, five liquefaction technologies are in use. Air Products and Chemicals supplied 57 plants using a mixed-refrigerant-with-propane pre-cooling process. Six use the Black and Veatch (Prico) model, two use Linde technology, seven are using the ConocoPhillips Cascade process, and six use the TEAL process. 


\section{Onshore Facilities Re-gasification}

After transport to the receiving location by specialized vessels, the next step in the process is regasification. World wide, there are over 40 receiving terminals in operation today and upwards of 50 units are being proposed with at least 40 being suggested to supply LNG to the North American market. Of this latter total, the EIA assumes that no more than 14 will be built, with ten in the lower 48 or the Bahamas and up to four in Mexico. New plants are on top of expansions, already underway, at the four existing terminals.

Three major items comprise a typical re-gasification terminal. The first is a pier with adequate water depth, on the order of 35 feet, sufficiently isolated from other industrial operations. The berth includes multiple unloading arms and associated piping capable of withstanding cryogenic temperatures. Typically four articulated loading arms and one gas recycle arm are used. Immediate access to a ship’s berth is a given. Here, the issue is marine travel time and shipping capacity. Most piers are designed to service ships arriving on a 7 to 10 day cycle with no more than $30 \%$ of the nominal berth time utilized. Ships typically offload at onshore terminals in 1214 hours.

Second, are heat exchangers or "vaporizers" which add enough heat to the LNG to convert it back into the gas phase. Adding heat is usually accomplished by one of two methods. When on a coast, seawater exchange is common. This option presupposes and endless supply of seawater which can be discharged with a temperature drop of $10-15^{\circ} \mathrm{F}$.

When up a river or estuary without an endless supply of sea water, fresh water baths with submerged combustion heat exchangers, typically fueled by natural gas, are more common. Approximately 95\% of the existing terminals use one of these two methods.

The remaining system is integrated where waste heat from adjacent power generation is the source of re-gasification heat. In all cases, re-gasification capacity aka "send out" capacity, is a design constraint separate and apart from gross storage capacity.

A third consideration in the design of receiving terminals is the volume and number of tanks available for storage. Most terminals have settled on 5 days of storage assuming a send out capacity of $\$ 1$ bcf/day or 5 to 6 bcf in total. This equates to the combined cargoes of two ships. 
The cost of a typical terminal with one berth, a send out capacity of $1 \mathrm{bcf} /$ day and storage of 5 bcf would be in the range of $\$ 400-600 \mathrm{~mm}$.

\section{Conventional Offshore LNG Transportation}

Today, there are currently 151 LNG ships in operation with 55 new ships on order. Existing ships range in size from 55,000 cubic meters to 140,000 cubic meters with the most common size being 125,000 to 138,000 cubic meters. Today, the price for one 140,000 cubic meter ship is in the $\$ 175 \mathrm{~mm}$ range. Larger ships have been designed with capacities of up to 250,000 cubic meters. Most of the existing ships are equipped with dual fuel propulsion plants based on boilers and steam turbines. However, the newest ships utilize dual fuel diesel reciprocating engines. These engines generate electrical power which is fed to multiple electric thrusters. In both cases, the power plants are designed to be fired with either conventional diesel fuel or with natural gas, resulting from the boil off of gas that occurs during the course of a voyage. This boil off is a result of the auto-refrigeration phenomena, a cooling effect whereby the bulk of the LNG is maintained in liquid form. The following chart provides information on historical size and the growth of the LNG fleet:

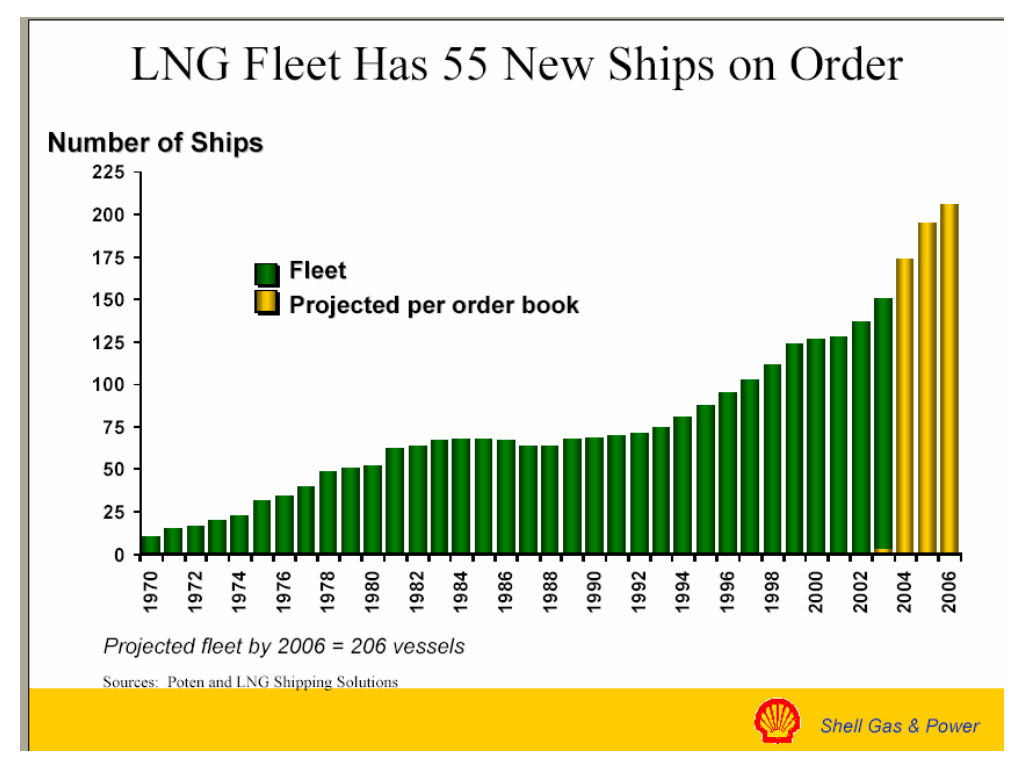

Figure $6 \quad$ Source Shell Gas and Power GPA Conference 12/03 
Perhaps the most critical item on any LNG ship is the cryogenic containment system. LNG exists at atmospheric pressure, but at a temperature of $-262^{\circ} \mathrm{F}$. In order to minimize heat leakage into the liquid, highly efficient insulation methods are required. There are three main suppliers of the marine tanks with two basic configurations. The most common units use the "independent" system that consists of a series of self-supporting aluminum spherical tanks designed by Moss or Ishikawa Heavy Industries (IHI), Norwegian and Japanese suppliers. The containment units are typically insulated with polyurethane. A second approach utilizes tanks which conform to the ship's interior structure. In these tanks a thin metal membrane utilizing low temperature tolerant stainless steel alloys serves as an impermeable barrier to the liquid. The membrane is supported by a structural grid which is insulated then protected with a conventional exterior steel shell.

One version of this “membrane” technology is supplied by the French firm Gaz Transport and consists of a thin invar (stainless steel) membrane supported structurally and then insulated by plywood boxes filled with Perlite, a mineral which acts as a natural insulator, followed by an outer shell of steel. A second French firm, Technigaz supplies a similar system utilizing a stainless steel membrane insulated by polyurethane. All containment systems have both primary and secondary containment barriers, all are designed on the principle of "leak before failure" and all are designed to contain any leak for at least 15 days.

Both Technigaz and Moss are controlled by Saipem, an Italian construction firm linked to Agip through ENI, the Italian energy company. ENI also controls Snamprogetti, an engineering firm with experience in the construction of LNG liquefaction plants.

\section{Offshore Re-gasification}

A new technique for offloading LNG is just now reaching the commercial stage. This technique uses new LNG tankers that side load in a conventional fashion but have the capability for onboard re-gasification upon arriving at an offshore terminal buoy. The vessel discharges pressurized gas to the buoy rather than LNG. Sub-sea pipelines then move the gas onshore or to offshore storage. We believe that the storage function will be provided by salt dome caverns, located either onshore or offshore, at sites along the Texas-Louisiana Gulf Coast. One disadvantage of this approach is the cost associated with converting a 12-24 hour port call into a 
five day discharge visit. A major advantage is the elimination of the capital cost of a conventional receiving terminal as well as the time and costs associated with an onshore port call. The following chart compares the tolling fees generated by each approach. 
Table 2

\section{Comparison of Costs: Offshore Buoy vs. Onshore terminal}

\begin{tabular}{|c|c|c|c|c|}
\hline & \multicolumn{2}{|c|}{ Onboard Regas } & \multicolumn{2}{|c|}{ Conventional } \\
\hline & & & Terminal & \\
\hline Required \# of Vessels & 5 & & 4 & \\
\hline Distance & 4,500 & nmiles & 4,500 & nmiles \\
\hline Speed & 19 & knots & 19 & knots \\
\hline Vessel Cargo Capacity & 140,000 & cubic meters & 140,000 & cubic meters \\
\hline \# of Buoys & 2 & & & \\
\hline Distance to Shore & 30 & kilometers & & \\
\hline Waterdepth & 100 & meters & & \\
\hline Roundtrip time & 26.8 & days & 21.7 & days \\
\hline Regas Capacity & 460 & t/hr & 460 & t/hr \\
\hline Cost per vessel & 201 & million USD & 175 & million USD \\
\hline Total vessel investment & 1,005 & million USD & 700 & million USD \\
\hline \multicolumn{2}{|c|}{ Total buoy-pipeline investm } & million USD & & \\
\hline Operational costs & 495,000 & \$/day & 353,000 & \$/day \\
\hline LNG delivered & 4,030 & Mt/yr & 4,030 & Mt/yr \\
\hline Gas delivered & 584 & Mcubic ft/d & 584 & Mcubic ft/d \\
\hline transport cost at beach & 0.86 & USD/MMBtu & 0.64 & USD/MMBtu \\
\hline Terminal service cost & & no charge & 0.40 & USD/MMBtu \\
\hline Gas in pipeline cost & 0.86 & USD/MMBtu & 1.04 & USD/MMBtu \\
\hline \multicolumn{3}{|c|}{ Source: APL/Zeus Jens Karlstad 12/10/03 } & & \\
\hline
\end{tabular}

In terms of status, the first vessel is now afloat, and plans are to have it operational by the end of 2004/early 2005. It will offload its cargo at a buoy located at West Cameron 603, south of Lake Charles, La. The buoy and mating system are being provided by APL, a Norwegian supplier of similar loading buoys for the transfer of oil cargoes to shuttle tankers.

As the above chart illustrates, the cost for each vessel is estimated at $\$ 201 \mathrm{~mm}$ or $15 \%$ more than a conventional LNG tanker of the same capacity. For a 4,500 nautical mile journey, one needs 25\% more ship capacity to account for the extra time spent in discharging gas. Ergo, five of the more expensive ships are needed, costing $\$ 1.005$ billion. vs. the $\$ 700 \mathrm{~mm}$ needed to acquire four of the less expensive ships without the turret mooring capability. In addition, a buoy system costs approximately $\$ 50 \mathrm{~mm}$ per buoy and two buoys are needed at a receiving location in order to have a continuous gas supply. Adding salt cavern storage could increase the total by an 
additional \$50-100 mm.

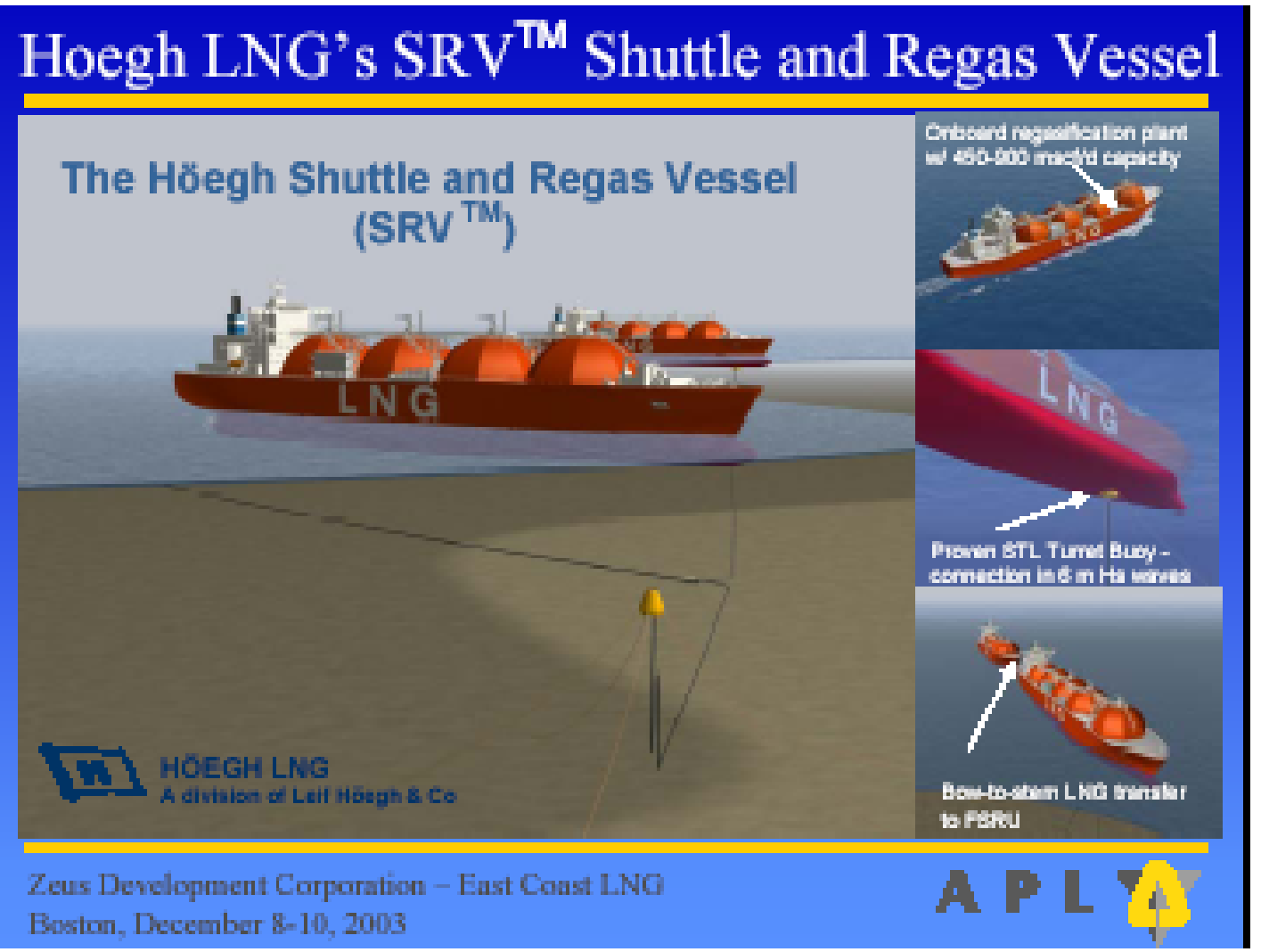

Figure 7 Courtesy of Zeus Development, Hoegh LNG and APL

All in, the offshore buoy case, including ships and local storage, costs about $\$ 1.2$ billion, or about the cost of four conventional ships plus a conventional onshore receiving terminal. However, the time delays and costs associated with entering and leaving an inshore port are eliminated as are many of the regulatory restrictions governing perceived dangers to local onshore populations. 


\section{BuSINESSES AFFECTED By LNG GROWTH}

Besides the direct positive impact of LNG on the Gulf Coast, there are a host of secondary effects that need to be addressed.

\section{Natural Gas Liquids}

For example, the market for Natural Gas Liquids, the c2s through c4s, will be impacted as imported LNG contains significant percentages of these materials. With domestic production, these materials are normally stripped and used for chemical feedstock. In the rest of the world, these components are left in the gas stream to enhance the heating value of the gas. It is improbable that international LNG suppliers will have an interest in supplying two different grades of LNG in order to meet U.S. pipeline specifications, at least as long as the U.S. is a minority customer for LNG.

The result will be a Hobson's choice. Will the NGLs be left in the gas stream requiring a change in the specification for pipeline gas and a subsequent change in operating conditions for gas-fired power plants and other consumers? Or, will the existing standard be maintained by adding a new scope of activity at the receiving terminal, a requirement for removal of NGLs.

Another option involves diluting the imported gas with nitrogen or air in order to produce a $1,000 \mathrm{btu} / \mathrm{cubic} \mathrm{ft}$. gas stream acceptable to the pipeline industry. The disadvantage of this route is that the btu carrying capacity of the pipeline system is reduced, and, if you add air, you are on the way to producing a combustible mixture. If you add nitrogen, there is the possibility that you will increase NOX emissions when the diluted gas is burned.

\section{Peaking Demand Storage}

Beyond the issue of btu content, will significant quantities of LNG be reserved for peaking demand during winter, as is now the case with remote LNG storage facilities?

In addition to the marine terminal at Everett, Mass., there are multiple satellite terminals with storage capacity for approximately 14 BCF scattered through out a four state region. The remote terminals exist to cover peak demand during the most extreme winter weather. All have relatively high send out capacity. Their normal operating mode is to receive gas in small 
quantities over a seven month fill cycle, then to stand by for possible use during perhaps 3-7 days during the five month winter portion of the cycle. This contrasts with marine terminals which must distribute the bulk of their inventory during the period between ship callings, every 7-10 days throughout the year. In Everett, the remote terminals are partially supplied by the marine terminal which has additional send out capability of $100 \mathrm{~mm}$ cubic ft./d via truck transport. This equates to approximately $36.5 \mathrm{BCF} /$ year.

In the whole country, there are 113 facilities that handle LNG of which 55 are owned by local utilities and 18 are owned by pipeline companies. If we ignore the marine import terminals (4), the Alaskan export terminal (1), and Alaska’s stranded utilities with no pipeline connection (2), we are left with 108 remote units in the lower 48 states which exist to cover peak demand.

Of these sites, 57 can produce and store LNG by liquefying pipeline gas. Another 39 can receive LNG, store it and then re-gasify it on site. In addition, there are three stranded utilities in the lower 48, two vehicular fueling facilities, one each in California and in Texas, and five other miscellaneous small generators of LNG.

While the absolute storage capacity of these 108 facilities is modest, say 85 BCF in total, they have much higher deliverability than other forms of storage. This makes them significant players during peak demand periods. The EIA estimates that these remote LNG locations are able to re-gasify roughly $11.7 \mathrm{BCF} /$ day and represent $14 \%$ of the comparable deliverability of underground storage, $23 \%$ of peak deliverability in the consuming Eastern region of the U.S. They also provide $10 \%$ of peak deliverability in the western region, but only $1.8 \%$ in the producing region. This data is summarized in the following table. 
Table 3: LNG Storage and Send Out Capacity 2005

\begin{tabular}{|c|c|c|c|c|c|c|c|c|c|c|c|}
\hline \multicolumn{12}{|c|}{ LNG Storage and Send Out Capacity cc 2005} \\
\hline \multicolumn{12}{|l|}{ 04-Feb-04 } \\
\hline & Alaska & West & Producing & Other East & SASB & New England & New Jersey & Oth NASB & NASB & Consuming East & Total \\
\hline \multirow{3}{*}{$\begin{array}{l}\text { Marine Terminals-Export } \\
\text { Marine Terminals-Import }\end{array}$} & 1 & & & & & & & & & 0 & 1 \\
\hline & & & 1 & & 2 & 1 & & & 1 & 3 & 4 \\
\hline & & & $25 \%$ & & $50 \%$ & $25 \%$ & & & $25 \%$ & $75 \%$ & $100 \%$ \\
\hline \multirow{2}{*}{\begin{tabular}{|l|} 
Storage Capacity/terminal \\
Total Storage Capacity
\end{tabular}} & & & 9.3 & & 7.55 & 4.35 & & & 4.35 & 11.9 & 21.2 \\
\hline & & & 9.3 & & 15.1 & 4.35 & & & 4.35 & 19.5 & 28.75 \\
\hline \multirow[t]{2}{*}{ Share of storage Capacity } & & & $32 \%$ & & $53 \%$ & $15 \%$ & & & $15 \%$ & $68 \%$ & $100 \%$ \\
\hline & & & & & & & & & & & \\
\hline Reg Send out & & & 1.70 & & 1.81 & 0.92 & & & 0.915 & 2.7 & 4.421 \\
\hline \multirow[t]{2}{*}{ Peak Send out } & & & 1.80 & & 2.54 & 1.15 & & & 1.15 & 3.7 & 5.485 \\
\hline & & & & & & & & & & & \\
\hline \multicolumn{12}{|l|}{ Non-marine Terminals } \\
\hline \multirow{3}{*}{$\begin{array}{l}\text { Storage with liquefaction } \\
\text { Storage without liquefaction } \\
\text { Stranded Utilities }\end{array}$} & & 8 & 3 & 18 & 12 & & & 16 & 16 & 46 & 57 \\
\hline & & 0 & 3 & 2 & 6 & 14 & 4 & 10 & 28 & 36 & 39 \\
\hline & 2 & 3 & & & & & & & 0 & 0 & 5 \\
\hline Vehicular fueling & & 1 & 1 & & & & & & 0 & 0 & 2 \\
\hline \multirow{2}{*}{$\begin{array}{l}\text { N2 rejection units and other } \\
\text { Total }\end{array}$} & & 4 & 1 & & & & & & 0 & 0 & 5 \\
\hline & 2 & 16 & 8 & 20 & 18 & 14 & 4 & 26 & 44 & 82 & 108 \\
\hline Total & $2 \%$ & $15 \%$ & $7 \%$ & $19 \%$ & $17 \%$ & $13 \%$ & $4 \%$ & $24 \%$ & $41 \%$ & $76 \%$ & $100 \%$ \\
\hline BCF of Storage/facility & 0.66 & 0.66 & 0.44 & 0.50 & 0.96 & 1.00 & 1.00 & 0.96 & 0.97 & 0.85 & 0.79 \\
\hline Storage Capacity & 1.3 & 10.5 & 3.5 & 10.0 & 17.2 & 14.0 & 4.0 & 24.8 & 42.8 & 70.0 & 85.3 \\
\hline \multirow{2}{*}{ Percentage of Storage } & $2 \%$ & $12 \%$ & $4 \%$ & $12 \%$ & $20 \%$ & $16 \%$ & $5 \%$ & $29 \%$ & $50 \%$ & $82 \%$ & $100 \%$ \\
\hline & days & & & & & & & & & & \\
\hline \multirow[t]{3}{*}{ Remote Send Out } & 10.0 & 1.050 & & & & & & & & 0.000 & 1.1 \\
\hline & 6.3 & & 0.556 & 1.587 & 2.729 & 2.222 & 0.635 & 3.941 & 6.798 & 11.114 & 11.7 \\
\hline & & & & & & & & & & & \\
\hline \multicolumn{2}{|c|}{ Comparable in ground send out } & 10.5 & 30.0 & & & & & & & 48.0 & 88.5 \\
\hline Relative capability & & $10.0 \%$ & $1.9 \%$ & & & & & & & $23.2 \%$ & $14.4 \%$ \\
\hline Combined lower 48 count & & 16 & 9 & 20 & 20 & 15 & 4 & 26 & 45 & 85 & 110 \\
\hline BCF of Storage/facility & & 0.66 & 1.42 & 0.50 & 1.61 & 1.22 & 1.00 & 0.96 & 1.05 & 1.05 & 1.03 \\
\hline Storage Capacity & & 10.5 & 12.8 & 10.0 & 32.3 & 18.4 & 4.0 & 24.8 & \begin{tabular}{l|l}
3 & 47.2 \\
\end{tabular} & 89.5 & 113 \\
\hline Percentage of Storage & & $9 \%$ & $11 \%$ & $9 \%$ & $29 \%$ & $16 \%$ & $4 \%$ & $22 \%$ & $42 \%$ & $79 \%$ & $100 \%$ \\
\hline Peak Send Out & & 1.1 & 2.4 & 1.6 & 5.3 & 3.4 & 0.6 & 3.9 & 7.9 & 14.8 & 18.2 \\
\hline \multirow{2}{*}{\multicolumn{2}{|c|}{$\begin{array}{l}\text { Comparable in ground send out } \\
\text { Peak send out Relative capability }\end{array}$}} & 10.5 & 30.0 & & & & & & & 48.0 & 88.5 \\
\hline & & $10.0 \%$ & $7.9 \%$ & & & & & & & $30.8 \%$ & $20.6 \%$ \\
\hline
\end{tabular}

\section{Underground Storage}

Comparable figures for below ground storage capacity are an absolute total of 8.4 TCF including 4.3 TCF of base gas, and 3.9 TCF of working gas, of which 2.8 TCF was actually in storage at the end of September, 2003. At the end of the heating season we anticipate available unused working gas in storage of approximately 1 TCF. This storage is spread among 418 locations with a maximum deliverability of about 88.5 BCF/day.

Within the underground segment there are three sub-segments, depleted reservoir storage, aquifers, and salt caverns. Depleted reservoirs total 351 fields, aquifers represent 39 locations 
and salt caverns are the balance of 28. In terms of absolute storage volume, depleted reservoirs total 7.0 TCF, aquifers account for 1.2 TCF, and salt caverns total 218.5 BCF. In terms of base gas, non-salt storage requires $4.3 \mathrm{TCF}$ and salt caverns require $75.2 \mathrm{BCF}$.

Non-salt underground storage, the depleted reservoirs and aquifers, work in much the same way. They are typically cycled once a year, with injection during seven months of mild weather, followed by withdrawal during the following five months of winter. The EIA estimates that lines and compressors are sized to handle about $87.5 \mathrm{BCF} /$ day so full working storage of 3.9 TCF could theoretically be exhausted in 45 days of peak send out.

Gross salt cavern storage capacity, at 218.5 BCF is much smaller than reservoir and aquifer underground storage techniques and is concentrated along the Gulf Coast. About one third or 75.2 $\mathrm{BCF}$ is base gas, leaving working capacity at $143.3 \mathrm{BCF}$. Base gas needs to remain in a salt cavern to maintain the structural integrity of a cavern, but is proportionately less than with depleted reservoirs, on the order of $34 \%$ vs. non salt in ground requirements of $52 \%$. Of the working capacity, 122.7 BCF was actually in storage as of the end of September 2003. It takes less than a month to deliver all working gas from a salt dome meaning that delivery, in extremis, is in excess of $1 \mathrm{BCF} /$ day, roughly the same deliverability as one modern LNG receiving terminal. The following Figure illustrates facilities associated with two underground salt caverns located in Texas. 


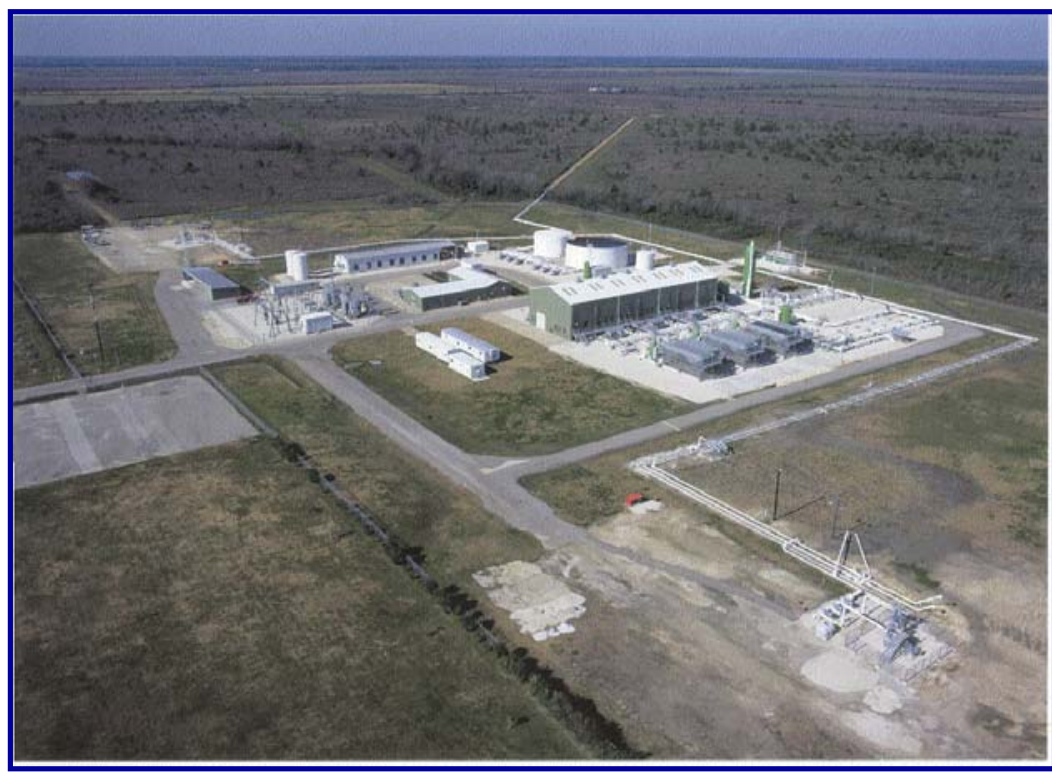

\section{Figure 8}

North Dayton Gas Storage Facility

Will additional salt cavern storage capability be developed along the Gulf Coast to store regasified LNG? There are reportedly ten new salt caverns and 52 new non-salt reservoirs slated for development over the next three years. There are also over 1,000 small salt caverns either idle or currently storing various liquid petrochemical feed stocks. In terms of maximum size, Freeport-McMorRan is talking about 28 billion cubic feet salt cavern storage offshore at Main Pass 299 split between three caverns. Deliverability would exceed the sum of all existing gas salt cavern storage to date.

On a less dramatic scale, HNG, a Texas company, has proposed four sites for additional capacity while Conversion Technology Inc. has received government funding to run full scale tests on direct conversion of LNG to a chilled high pressure gas, based on their patented salt cavern gas injection process. 


\section{Salt Cavern Gas Storage Facilities}

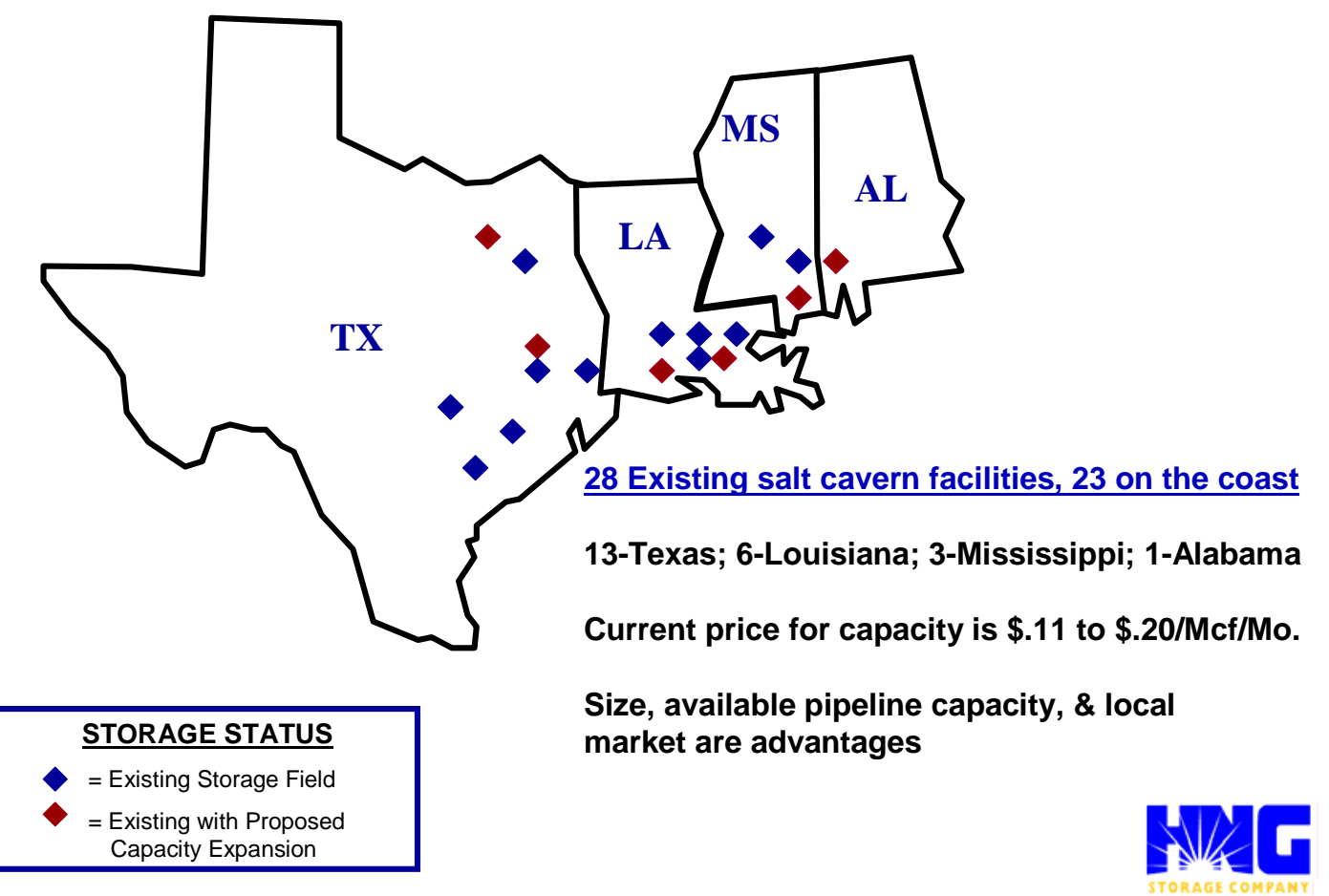

Figure 9 Courtesy of Zeus Development Corp. and HNG Storage Systems

The following chart illustrates new target salt dome locations, both onshore and offshore that could be developed as additional storage sites. 


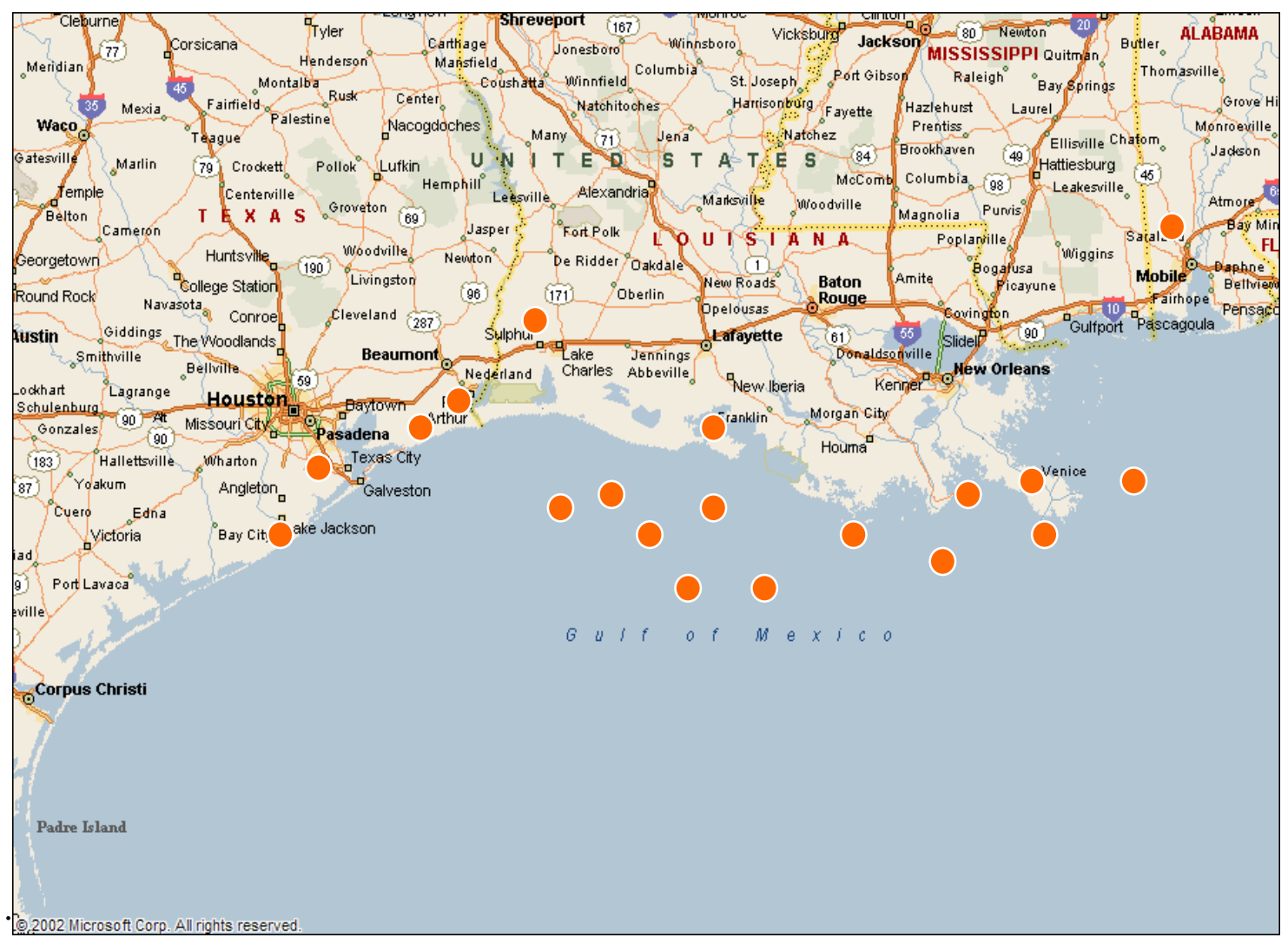

Figure 10 Potential Salt Cavern Storage Sites $\quad$ Source: HMR Invest and CGI Inc.

Salt cavern storage is a segment where the Gulf Coast states including Louisiana and Texas have the natural assets to play a significant role in the North American transition to LNG base load usage.

\section{Utilization and Profitability of the Interstate Pipeline System}

Lastly, what happens to our interstate pipeline system, designed to move gas from the Gulf and Canada to major population centers, if strategically placed Atlantic Seaboard LNG terminals set up direct axial distribution around new receiving terminals? One consulting firm, McKinsey and Company has concluded that five, 1 Billion/day LNG terminals on the East Coast will cut the revenues on trunk lines initiating in Louisiana by $\$ 4.8$ billion/year. 


\section{Proposed LNG Projects in North America}

The attached figure generated by Shell Gas and Power for a recent Gas Producers Association meeting summarizes the status of existing and proposed LNG receiving terminals in the U.S. We count a total of 41 projects, including expansions at existing facilities. Perhaps, over the next 10 to 20 years, 14 of the new units will be built, with concentrations on the Gulf Coast and along the Atlantic Seaboard, including plants in the Bahamas, with pipelines to Florida, and plants in Baja California, with pipelines into Southern California.

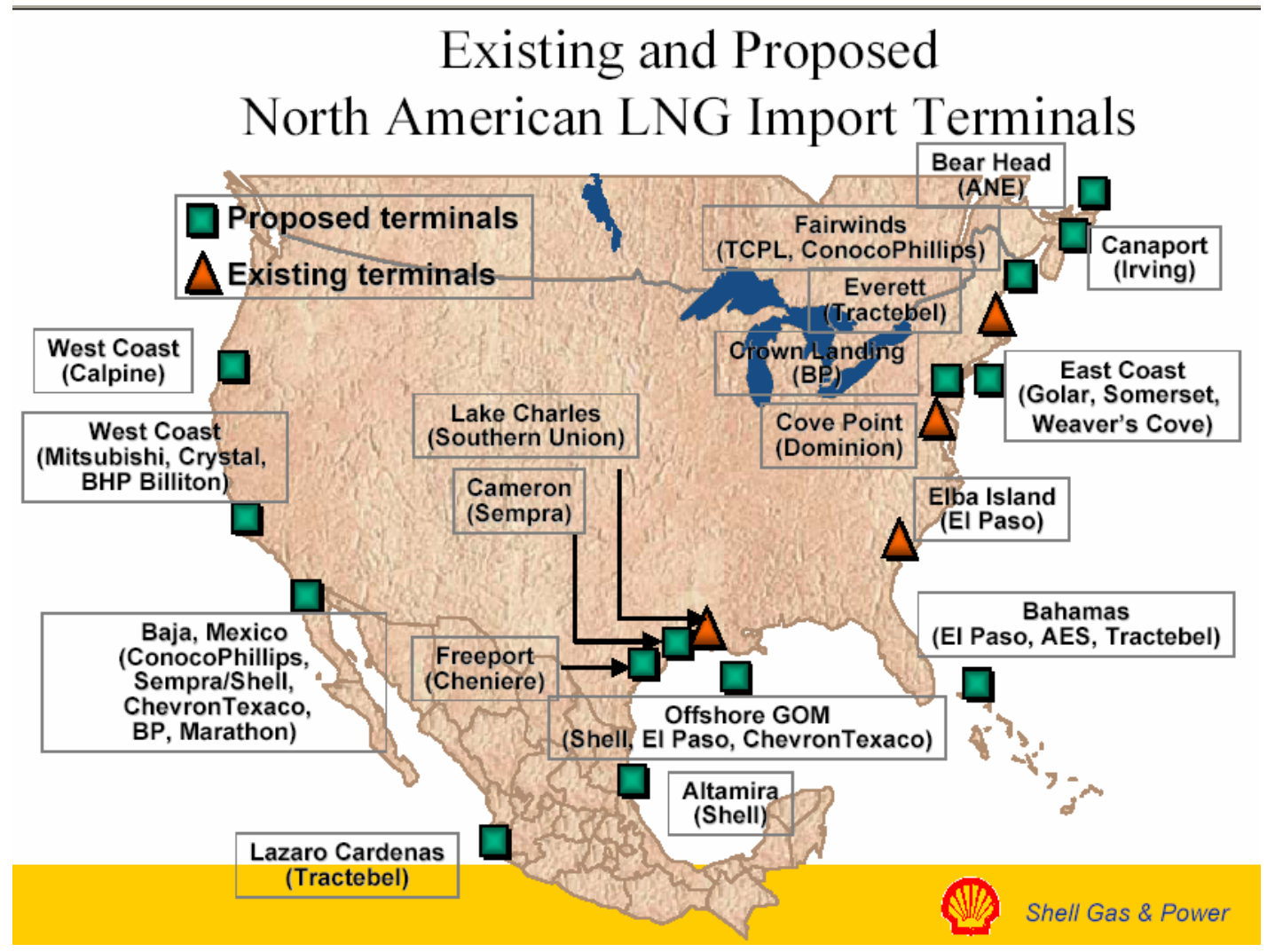

\section{Figure 11}

There are multiple projects proposed at several locations, including the Bahamas, Mobile, Alabama, Sabine Pass, Texas and Baja California. Many of these projects will end up falling by the wayside or will be combined into single projects. This recently happened to two of the projects in Baja, California, when Shell and Sempra combined their projects into a single facility. 
Certainly the projects on Grand Bahama championed by El Paso and Tractebel will also be candidates, along with a third project in the Bahamas, Ocean Key, sponsored by AES.

The following table provides details and the current status of each of the announced facilities in North America. These facilities are estimated to cost from $\$ 300$ for expansion of an average onshore facility to \$800 million for a new major offshore location. Forty-one facilities of both types have been proposed with approximately eight to be located along the Louisiana Gulf Coast.

Table 4: Active LNG Receiving Terminal Projects in North America

\begin{tabular}{|c|c|c|c|c|c|c|c|c|}
\hline$\#$ & Company & City & State & Capex & Status & Storage & Send out & Onstream \\
\hline 1 & ExxonMobil & Mobile & Alabama & 600 & Stalled & & 1.000 & 2007 \\
\hline 2 & Cheniere Energy & Mobile & Alabama & 300 & Announced & & 1.500 & 2007 \\
\hline 3 & Crystal/Venoco & Los Angeles & California & 118.7 & Proceeding & 0.00 & 0.800 & 2007 \\
\hline 4 & BHP Billiton & Cabrillo Pt. & California & 350 & Proceeding & & 0.800 & 2008 \\
\hline 5 & Mitsubichi & Los Angeles & California & 350 & Proceeding & & 2.000 & 2007 \\
\hline 6 & Calpine & Humboldt Bay & California & & & & 1.000 & 2007 \\
\hline 7 & Irving Oil Ltd. & New Brunswick & Canada & 350 & Proceeding & & 1.000 & n/a \\
\hline 8 & Access NE Energy & Nova Scotia & Canada & & & & 1.000 & 2007 \\
\hline 9 & AES Oceans LNG & Ocean Cay,Bimini & FBahamas & 500 & Proceeding & & 0.800 & n/a \\
\hline 10 & Tractebel & Freeport, Grand B & FBahamas & 450 & Proceeding & 7.63 & 0.800 & 2005 \\
\hline 11 & $\mathrm{BP}$ & Tampa & Florida & 350 & Proceeding & & 1.000 & 2007 \\
\hline 12 & Shell,BG & Elba Island & Georgia & 0 & Active & 4.00 & 0.446 & 1978-2001 \\
\hline 13 & Shell,BG & Elba Island & Georgia & 145 & Active & 3.50 & 0.364 & 2006 \\
\hline 14 & ChevronTexaco & Port Pelican & Louisiana & 800 & Permit & 6.99 & 0.800 & 2007 \\
\hline 15 & ChevronTexaco & Port Pelican & Louisiana & 800 & Permit & & 0.800 & $2009 ?$ \\
\hline 16 & Sempra Energy Res. & Cameron & Louisiana & 700 & Proceeding & & 1.500 & 2006 \\
\hline 17 & Southern Union Phase I & Lake Charles & Louisiana & 177 & Active & 6.30 & 0.630 & $1981-1990$ \\
\hline 18 & Southern Union Phase II & Lake Charles & Louisiana & 80 & Active & 3.00 & 0.570 & 2006 \\
\hline 19 & Freeport McMoran I & Venice & Louisiana & 300 & Engineering & 1.30 & 3.100 & 2006 \\
\hline 20 & Freeport McMoran II & Venice & Louisiana & 300 & Engineering & 28.00 & & $2008 ?$ \\
\hline 21 & Shell & GOM & Louisiana & 700 & Announced & & 1.000 & $2008 / 9$ \\
\hline 22 & Energy Bridge & GOM & Louisiana & 200 & Permit & 0.00 & 0.584 & 2005 \\
\hline 24 & Conoco/TransCanada & | Harpswell & Maine & 350 & |Proceeding & & 0.500 & 2009 \\
\hline 25 & Dominion & Cove Point & Maryland & 225 & Active & 5.00 & 0.750 & $1978-2003$ \\
\hline 26 & Dominion & Cove Point & Maryland & 100 & Active & 2.50 & 0.250 & 2005 \\
\hline 27 & Tractebel & Everett & Mass. & & Active & 3.30 & 0.435 & 1971 \\
\hline 28 & Tractebel & Everett & Mass. & 100 & Active & 0.00 & 0.265 & 2002 \\
\hline 29 & Weaver's Cove Energy & Falls River & Mass. & 225 & Proceeding & 4.24 & 0.400 & \\
\hline 30 & Shell,Total & Altamira & Mexico & 400 & Partnering & & 0.500 & 2006 \\
\hline 31 & ConocoPhillips & Rosarito & Mexico & 400 & Partnering & & 0.800 & 2007 \\
\hline 32 & Marathon & Tijuana & Mexico & 350 & Proceeding & & 0.750 & 2007 \\
\hline 33 & Sempra and Shell & Costa Azul-Baja & Mexico & 300 & Proceeding & & 1.000 & 2006,7 \\
\hline 34 & ChevronTexaco & Baja & Mexico & & & & 0.700 & 2007 \\
\hline 35 & Tractebel & Lazaro Cardenas & Mexico & & & & 0.500 & $n / a$ \\
\hline 36 & & Manzanillo & Mexico & & & & 1.000 & $n / a$ \\
\hline 37 & $\mathrm{BP}$ & Philadelphia & New Jersey & 500 & Proceeding & & & n/a \\
\hline 38 & Cheniere Energy & Corpus Cristi & Texas & 500 & Proceeding & & 1.500 & 2007 \\
\hline 39 & Cheniere Energy & Sabine Pass & Texas & 500 & Proceeding & & 1.500 & 2007 \\
\hline 40 & Cheniere Energy & Freeport & Texas & 400 & Proceeding & & 1.500 & 2007 \\
\hline 41 & Cheniere Energy & Brownsville & Texas & 300 & Proceeding & & 1.500 & 2007 \\
\hline 23 & ExxonMobil & Sabine Pass & Texas & 600 & Proceeding & & 1.000 & 2007 \\
\hline \multirow[t]{2}{*}{42} & ExxonMobil & Corpus Cristi & Texas & 600 & Proceeding & & 1.000 & 2007 \\
\hline & & & & 13421 & & 75.76 & 37.344 & \\
\hline
\end{tabular}




\section{Proposed LNG Projects on the Gulf Coast}

Gulf Coast facilities have location-specific benefits, beyond their proximity to population centers needing seasonal gas for heating and power. As the following figure points out, many of these facilities will interconnect with existing gas processing plants onshore which in turn are connected to trunk lines and to chemical intermediate lines feeding the petrochemical corridor between Mobile, Alabama and Corpus Christi, Texas.

\section{Proposed Gulf Coast LNG Terminals}

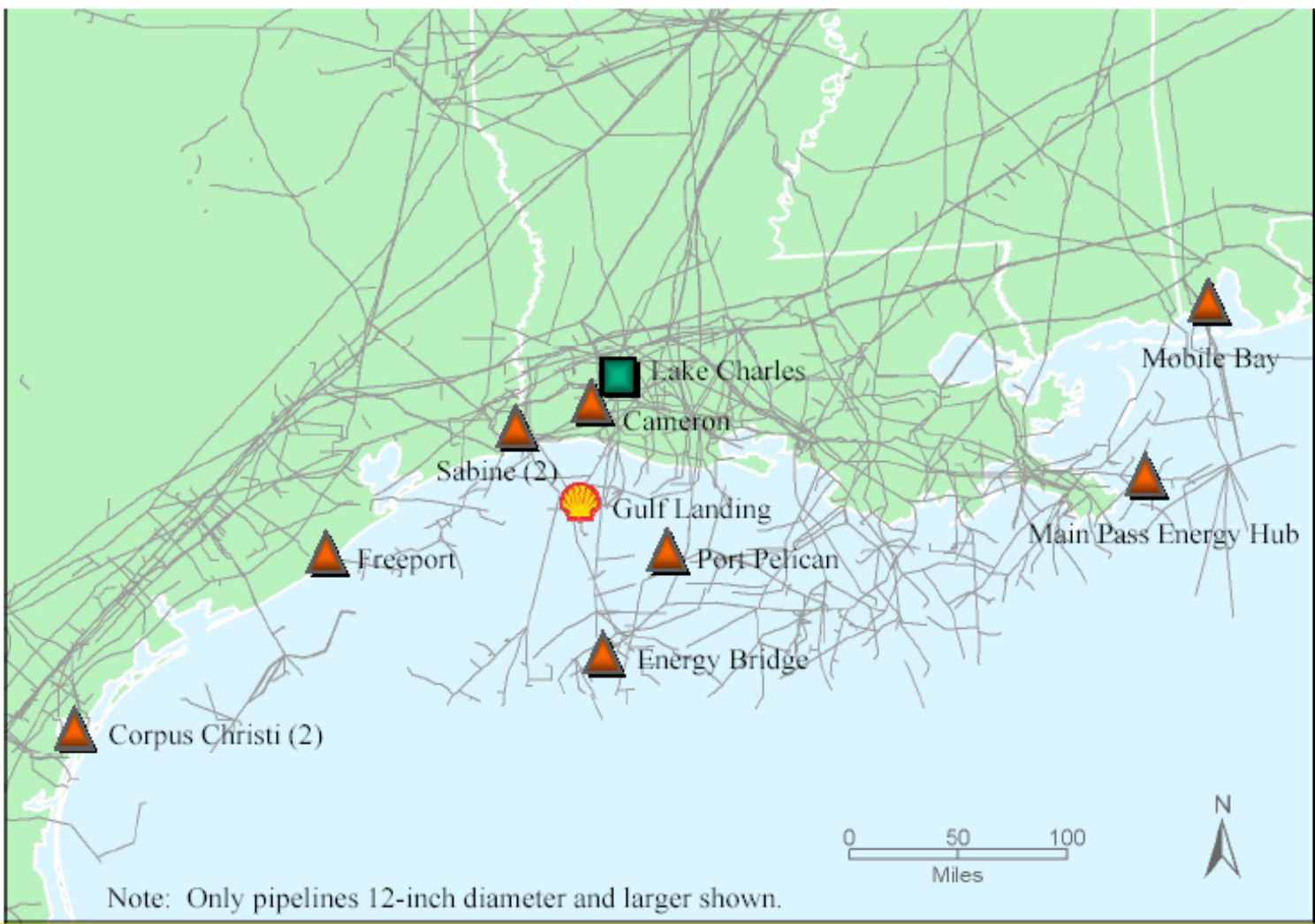

Figure 12 Courtesy Waldemar Nelson and Company and Shell Gas and Power

Louisiana and Texas both have existing infrastructure, including pipelines, compression, gas processing plants, and other facilities associated with the conversion of large amounts of raw natural gas into pipeline quality gas. This includes the ability to extract and monetize C-2s 
through C-4s. It is logical to assume that these units will be looking for additional throughput, given the long term decline of shelf production.

Gulf Coast gas clients include a high percentage of petrochemical manufacturers and power generators in the customer mix. These customers are subject to fewer seasonal effects than are customers of Atlantic Seaboard terminals. The latter customer base includes a high percentage of residential and commercial customers who use the gas and electricity for heating and cooling.

Louisiana and Texas both have access to solution mined Salt Dome storage which is more efficient for filling and removal of natural gas than the much more common depleted gas field storage. While the initial cost of establishing storage is higher, the amount of gas that must remain in depleted reservoirs is lower, approximately 34\% versus reservoir storage where 50$60 \%$ is the norm.

Finally, there is the crucial location of Henry Hub, the major dispatch point for U.S. wholesale gas deliveries. The bulk of the gas destined for the eastern third of the country passes through Henry Hub’s 15 pipelines.

Typical receiving facilities are estimated to cost from $\$ 500 \mathrm{~mm}$ for a "green fields” onshore facility to $\$ 700$ million for a major offshore terminal. Approximately 41 options of both types have been proposed with approximately 15 located along the Gulf Coast. Nine of these, including incremental expansions at existing terminals are associated within Louisiana. The following table adds additional detail on Louisiana locations and the current announced status of these units.

\section{Table 5: Active LNG Receiving Terminals in Louisiana}

\begin{tabular}{|c|c|c|c|c|c|c|c|c|}
\hline \# & Company & City & State & Capex & Status & Storage & Send out & Onstream \\
\hline 1 & ChevronTexaco & Port Pelican & Louisiana & 800 & Permit & \multirow[t]{2}{*}{6.99} & 0.800 & 2007 \\
\hline 2 & ChevronTexaco & Port Pelican & Louisiana & 800 & Permit & & 0.800 & $2009 ?$ \\
\hline 3 & |Sempra Energy Res. & Cameron & |Louisiana & 700 & Proceeding & & 1.500 & 2006 \\
\hline 4 & Southern Union Phase I & Lake Charles & Louisiana & 177 & Active & 6.30 & \multicolumn{2}{|c|}{$0.6301981-1990$} \\
\hline 5 & Southern Uniont Phase II & Lake Charles & Louisiana & 80 & Active & 3.00 & 0.570 & 2006 \\
\hline 6 & Freeport McMoran I & Venice & Louisiana & 300 & Engineering & 1.30 & 3.100 & 2006 \\
\hline 7 & Freeport McMoran II & Venice & Louisiana & 300 & Engineering & 28.00 & & $2008 ?$ \\
\hline 9 & Energy Bridge & GOM & Louisiana & 200 & Permit & 0.00 & $\begin{array}{l}1.000 \\
0.584\end{array}$ & 2005 \\
\hline & & & & 4057 & & 45.59 & 8.984 & \\
\hline
\end{tabular}


The first of these to come on-stream, other than the expansion at Lake Charles, will be the offshore buoy system known as the Energy Bridge located at West Cameron 603. This buoy and turret system should be up and running by early 2005. An illustration follows:

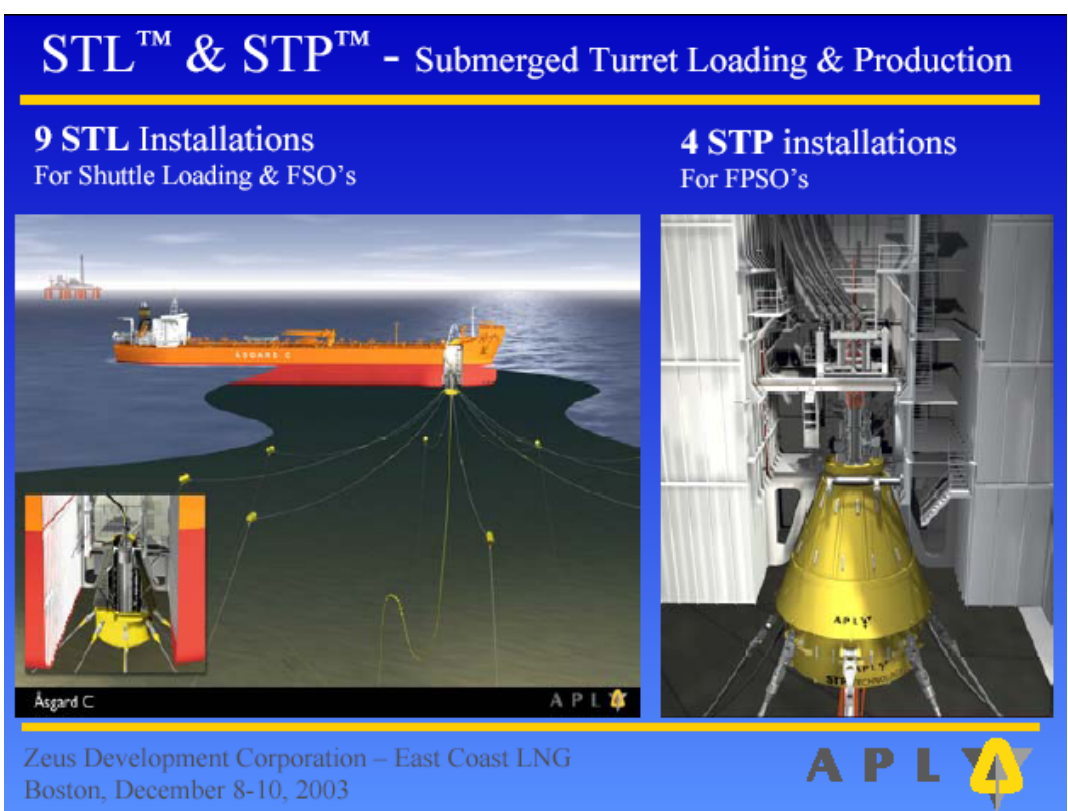

Figure 13 Courtesy of APL, and Zeus Development Corp. 


\section{ESTIMATED INVESTMENT COSTS AND OPERATING COSTS FOR LOUISIANA LNG PRojects}

The costs of building LNG re-gasification terminals are significant, on the order of \$500 million per location. In the prior tables, we estimated a total of $\$ 4.1$ billion for Louisiana, $\$ 13$ billion overall, if everything proposed were to be built. However, the balance of the value chain upstream from each terminal can be five times that sum.

The steps involved and the approximate contribution each makes to the value stream were estimated by Marathon Oil at a recent LNG conference sponsored by Zeus Development Corporation and illustrate the buildup in the price of gas between its discovery and its' final delivery.

\section{Figure 14}

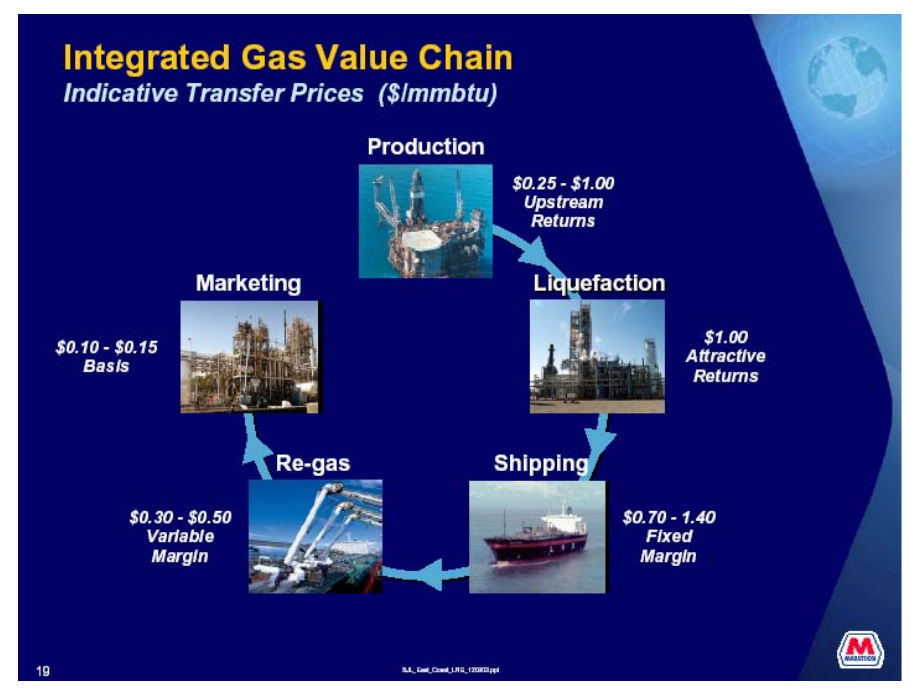

In terms of competitive sources of LNG, numerous locations exist. The following chart, also from Marathon and Zeus, gives details on a number of export locations. As you will note, Trinidad and Tobago have the lowest aggregate cost, a function of gas quality and proximity to the U.S. market. However, there are at least eight other sources, all with costs below $\$ 3.25 / \mathrm{mcf}$. 


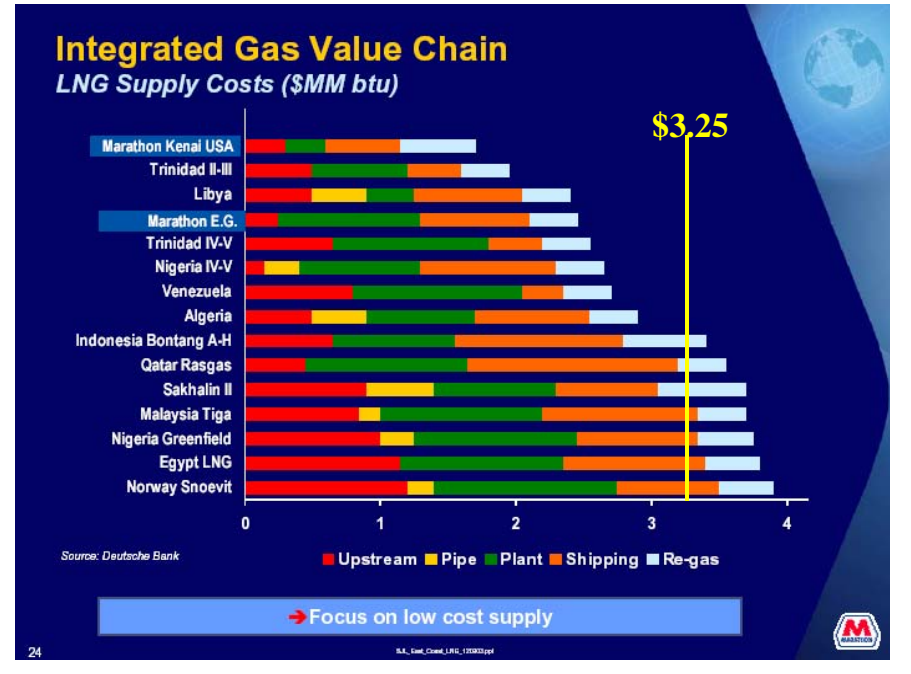

Figure 15 Courtesy of Zeus Development Corp and Marathon Oil Company

At least 15 separate receiving projects have been announced for LNG import projects along the coasts of Texas, Louisiana and Alabama. These projects would have significant construction activity that could improve near-term employment in Louisiana. Once built, a plant would have continued positive employment impact for 20 to 30 years. Any Texas or Alabama site will marginally affect Louisiana employment as regional service companies and contractors will certainly gain employment from these locations, as well.

At a secondary level, the impact of any Gulf LNG receiving terminal on the future operation of the significant pipeline industry spanning our state is a topic deserving mention. Louisiana actually uses about 1.5 TCF of gas a year. However, Louisiana processes and exports a total of over 5 TCF per year. In fact, Louisiana is the largest gas exporter in the nation.

In addition, the potential for additional salt cavern gas storage in the state should not be underestimated. There is one estimate that 700 BCF of new gas storage will be required in order to meet deliverability demands. At the moment ten salt dome caverns are being proposed along the Gulf Coast and Louisiana should be a major beneficiary of this effort.

Four types of Central Gulf LNG receiving terminals are covered in this document. 
The first, is expansion and new builds of onshore facilities, such as the Lake Charles Trunk line Terminal owned by Southern Union. Technical challenges onshore are minimal, although regulatory issues are under heated debate between industry and the communities where expansion or new construction is being undertaken. This is a view of the Lake Charles facility.

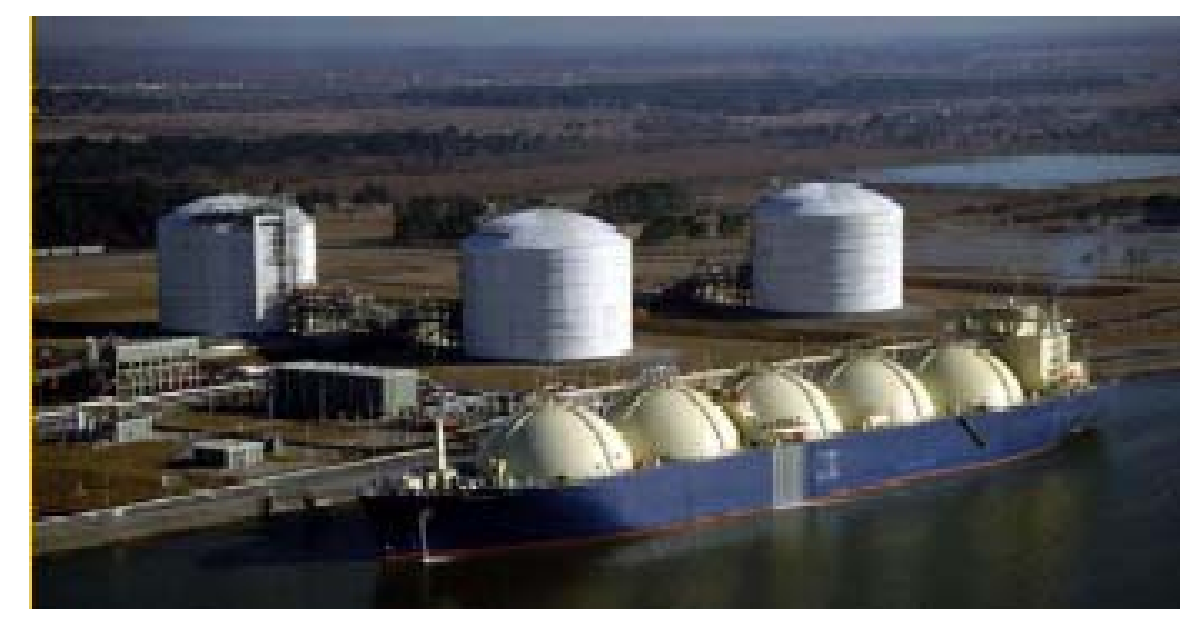

Figure 16 Photo Courtesy of Zeus Development and Panhandle Energy

The second project type, are Gravity Based Structures (GBS), large concrete structures in 50 to 80 feet of water, supported on the seabed in a manner similar to many North Sea oil and gas platforms dating back to the 1970's. Ship berthing and LNG storage are accomplished with the same concrete structure, which would be pre-fabricated onshore, floated to location, and submerged to the Gulf floor. Operators proposing this type of terminal include ChevronTexaco and Shell. Although small concrete, steel or hybrid concrete/steel GBS units have been deployed in Louisiana coastal waters since the 1960's, the large structures envisioned (roughly equivalent in volume to the new Reliant Center in Houston) for the GBS receiving terminals will draw heavily from European experience for their design and operating philosophies as nothing of this sort has been installed in Gulf waters to date. The soft Gulf soils contrast significantly from firmer North Sea ocean bottoms, and this will affect Gulf of Mexico designs for proposed GBS systems. 


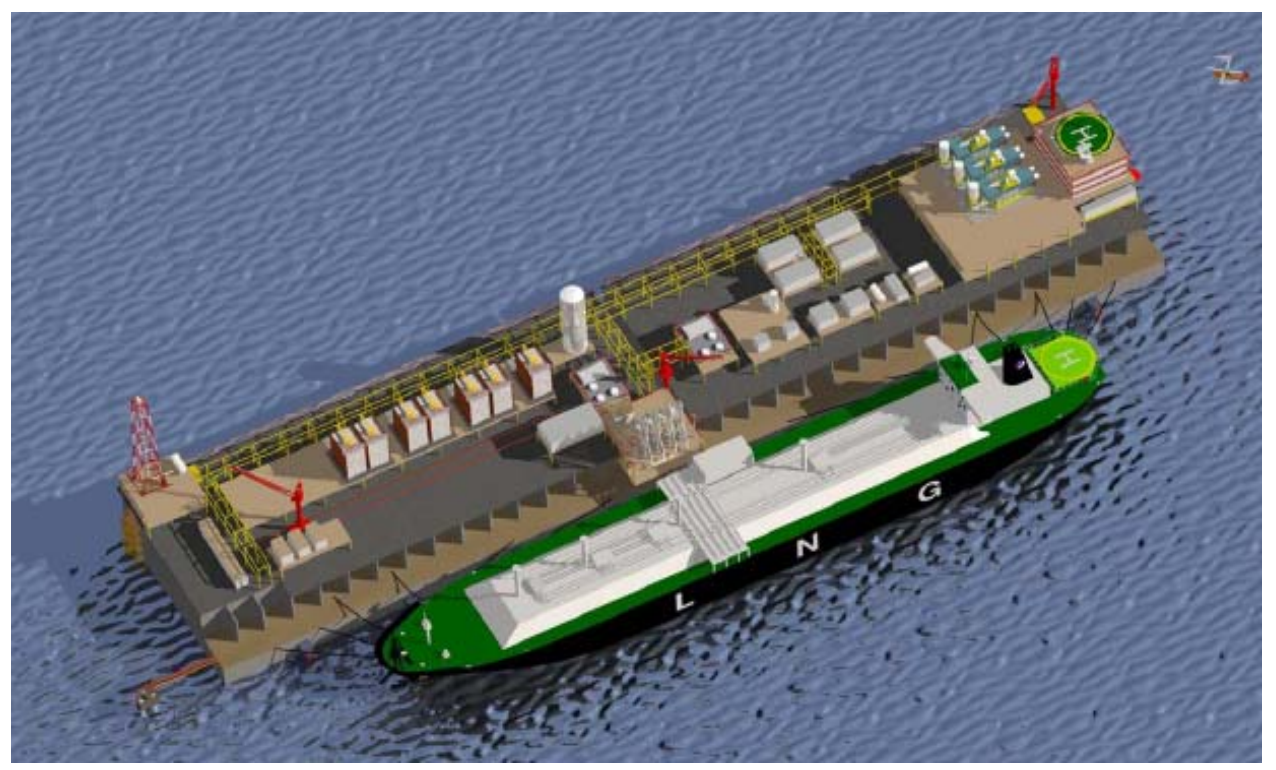

Figure 17

Photo Courtesy of Zeus Development Corp, GPA and Shell Gas and Power

A third type of LNG receiving terminal now being proposed uses existing or new offshore steel platforms held in place by deep piles in a manner analogous to the thousands of offshore structures built in the Gulf over the past 60 years. Ship berthing could be at such a modified structure, or at unloading buoys offset some distance from the structure. Storage of LNG could be at platform level or, after re-gasification of the LNG, in purpose-built caverns leached from salt domes. Salt dome storage of CNG is a common practice at onshore locations throughout the Gulf States. Technical issues surrounding the use of conventional piled offshore structures for a Louisiana offshore LNG receiving terminal are minimal, and the use of salt dome storage offshore has promise as a cost-effective system for receiving, storing and delivering imported natural gas. The major proponent of this approach is Freeport-McMoRan which intends to redevelop its’ Main Pass 299 Sulfur Mine as an Energy Hub focused on LNG.

The original facility cost over $\$ 1$ billion and successfully mined sulfur for a number of years before being shut down, a victim of the cost of the natural gas consumed as part of the Frasch sulfur mining process. 
Following is the current configuration of Main Pass 299.

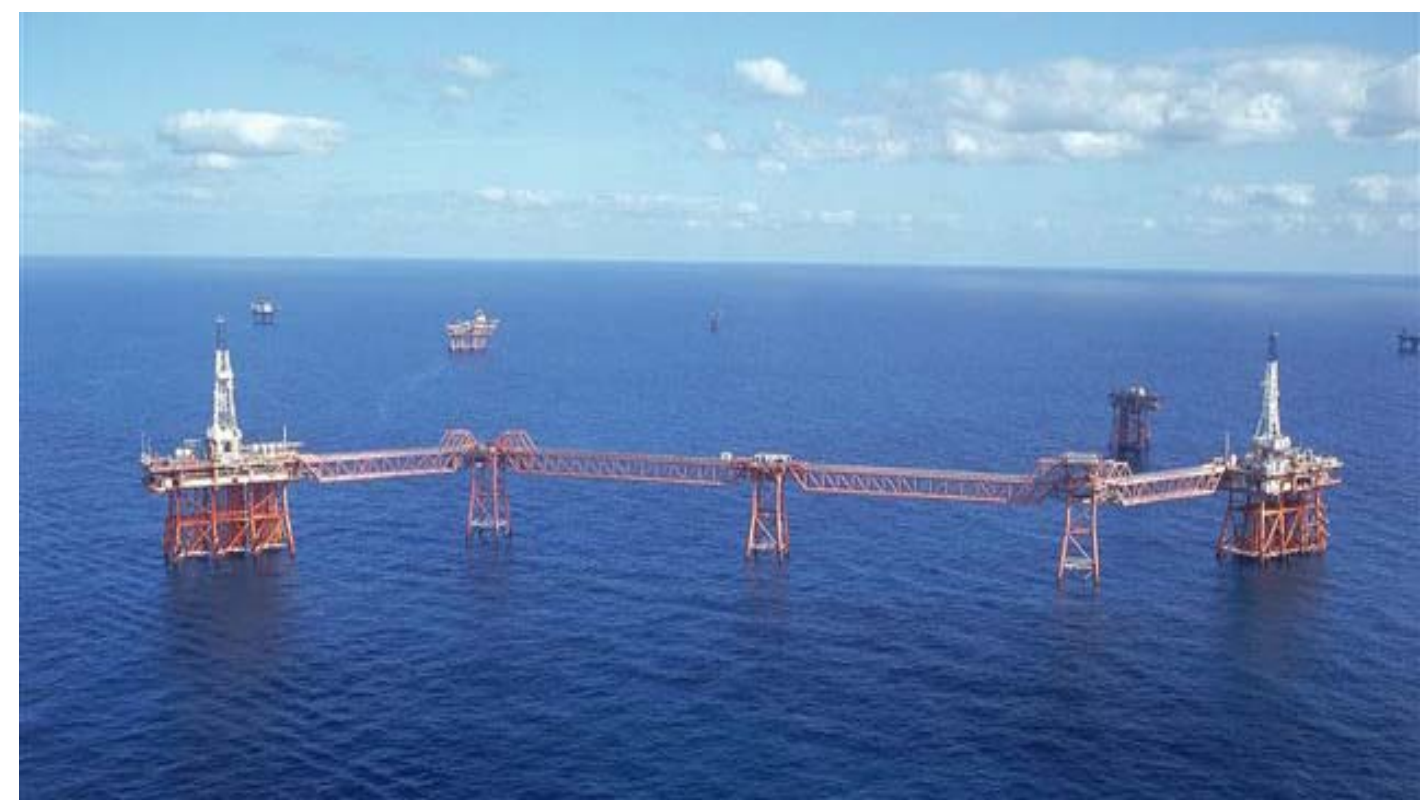

Figure 18 Photo Courtesy of W. Bennett and Associates and Freeport

This following rendering illustrates the changes necessary to convert the mine to an energy port. Note the three new salt dome storage caverns in the right foreground.

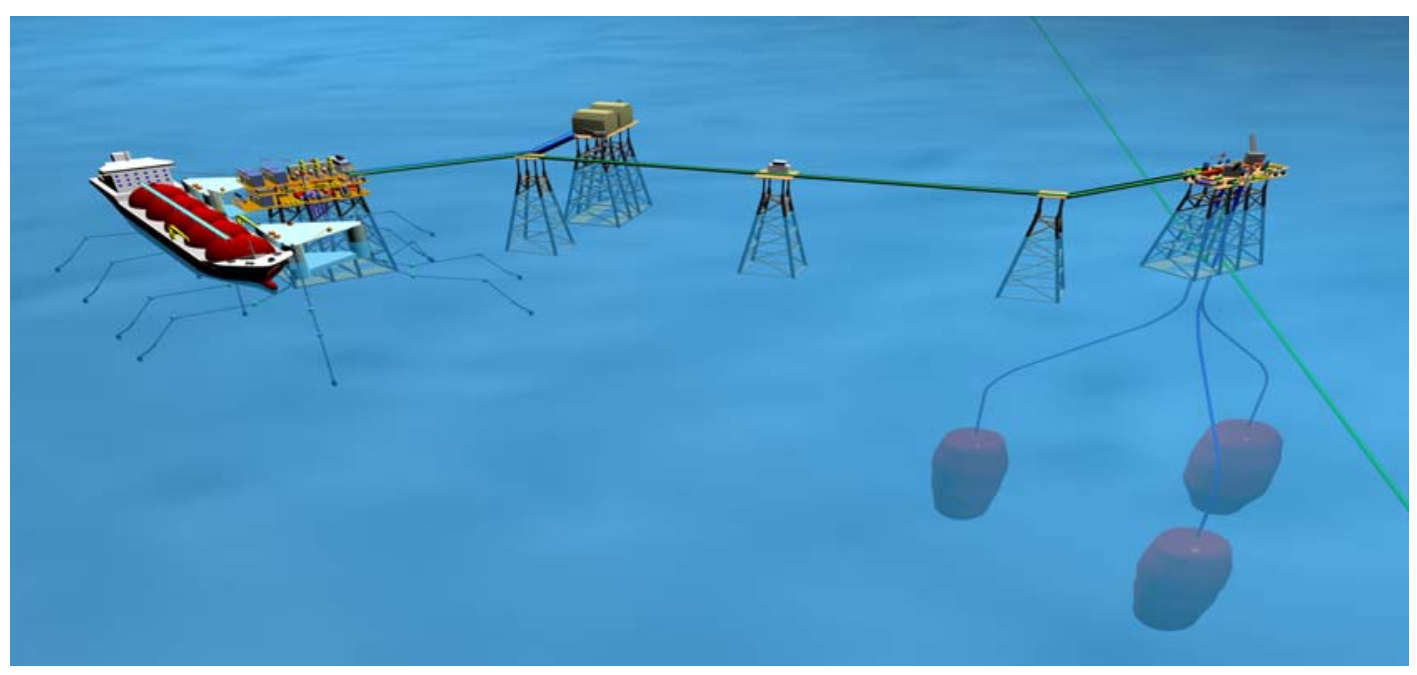

Figure 19 Photo Courtesy of W. Bennett and Associates and Freeport 
Freeport is in the detailed engineering stage and hopes to submit FERC applications by the end of 2004 and to be receiving gas by 2006.

Finally, a fourth option involves the use of a modified LNG ship as an unloading terminal. In this case the LNG ship arrives at an offshore location and connects to a submerged buoy that includes a connection to a sub-sea gas trunk line. The LNG is then re-gasified onboard the ship and delivered to shore by pipeline. A similar system is used extensively in the North Sea for loading and delivering crude oil from offshore platforms to shuttle tankers.

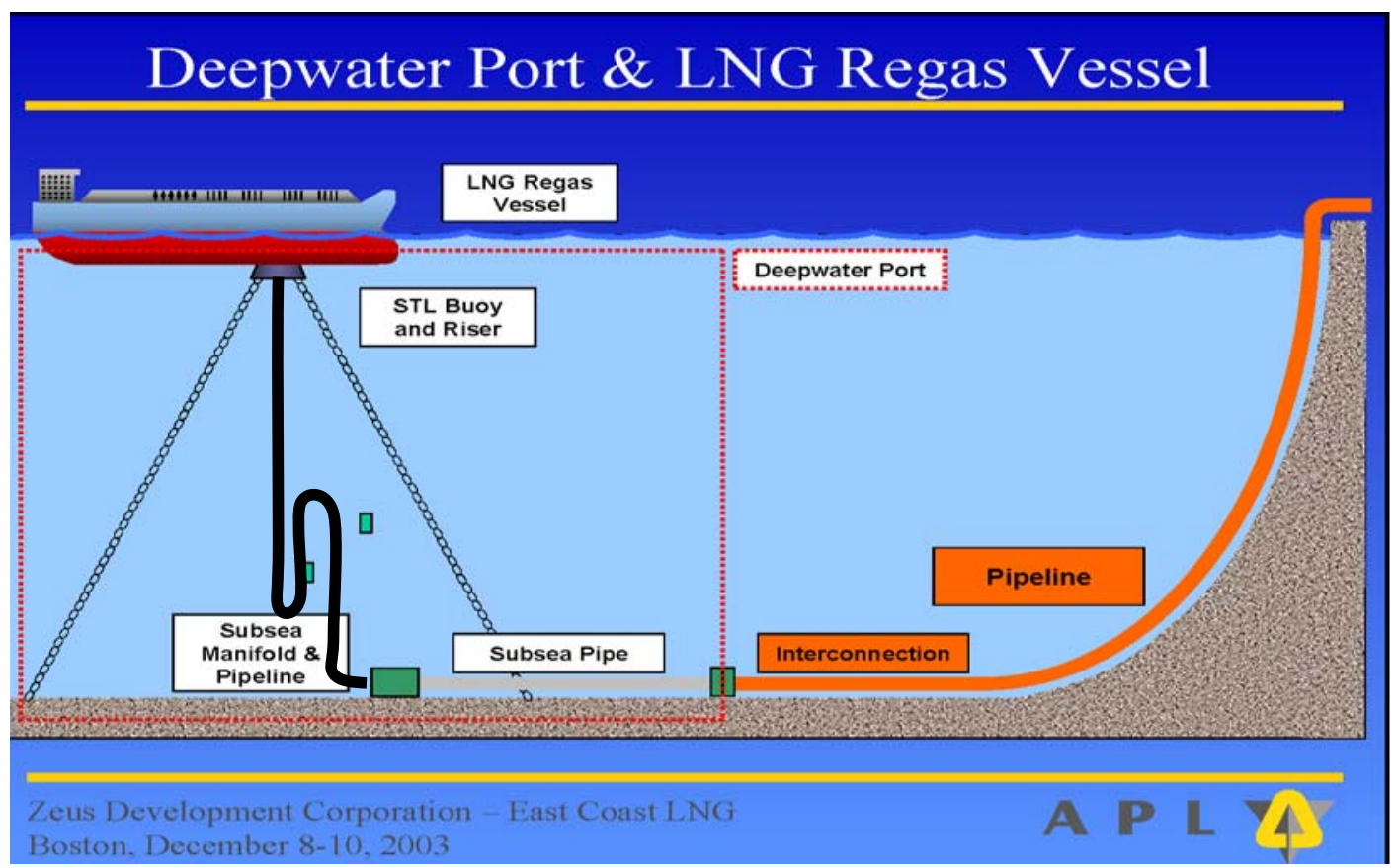

Figure 20

Slides Courtesy of Zeus Development and APL 


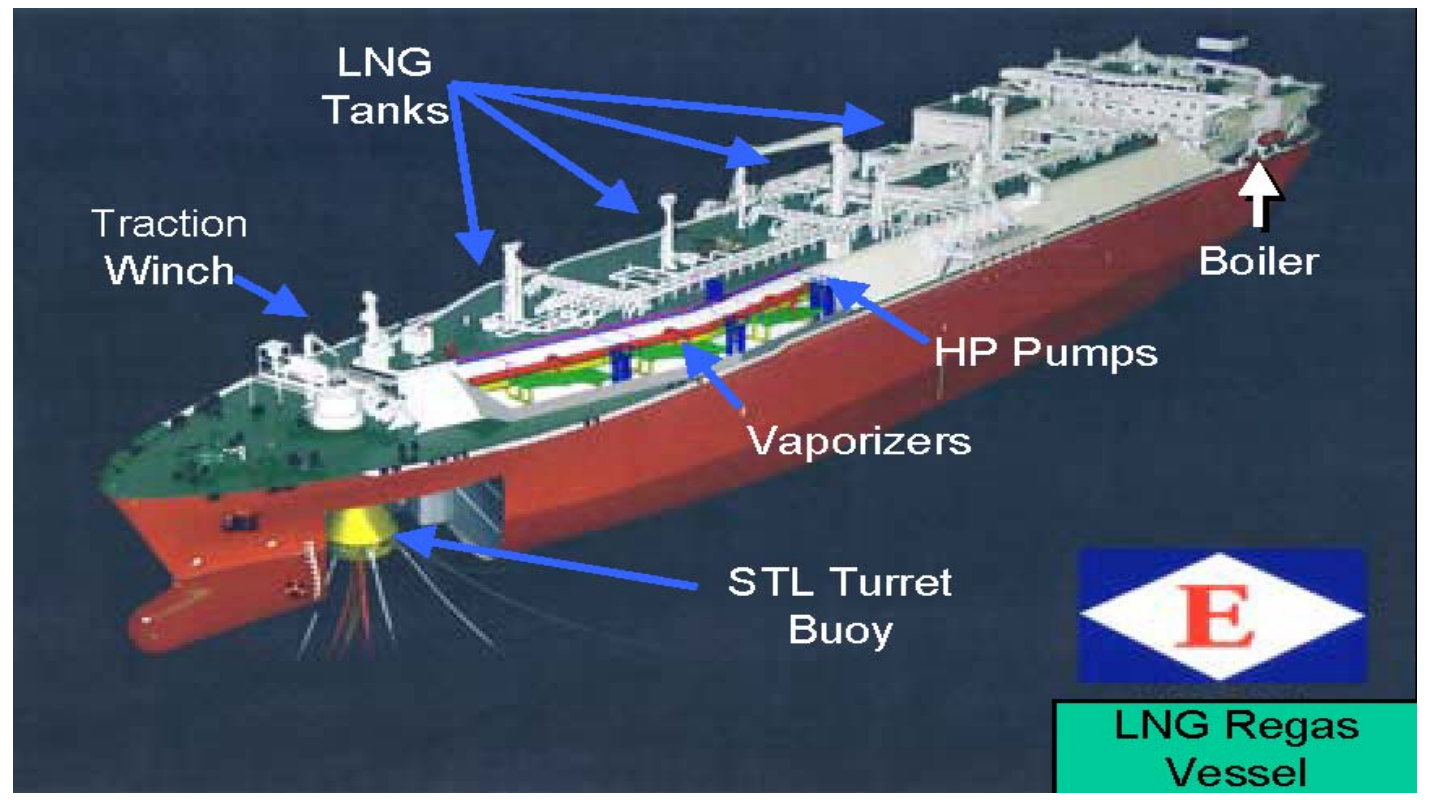

Figure 21 Slide Courtesy of Zeus Development, APL, and Exmar

This technique is being championed by El Paso and Excelerate, a Tulsa partnership. One of these ships is afloat and nearing completion in Korea. FERC has granted a permit to proceed with installation of the offshore buoy. The first test of this approach will occur at the end of 2004/beginning 2005 when gas will be unloaded at El Paso’s West Cameron 603 site. A comparison of the costs of direct offshore unloading vs. those of a generic inshore facility follows: 
Table 6:

Comparison of Costs: Offshore Buoy vs. Onshore Terminal

\begin{tabular}{|c|c|c|c|c|}
\hline & \multicolumn{2}{|c|}{ Onboard Regas } & \multicolumn{2}{|c|}{ Conventional } \\
\hline & & & Terminal & \\
\hline Required \# of Vessels & 5 & & 4 & \\
\hline Distance & 4,500 & nmiles & 4,500 & nmiles \\
\hline Speed & 19 & knots & 19 & knots \\
\hline Vessel Cargo Capacity & 140,000 & cubic meters & 140,000 & cubic meters \\
\hline \# of Buoys & 2 & & & \\
\hline Distance to Shore & 30 & kilometers & & \\
\hline Waterdepth & 100 & meters & & \\
\hline Roundtrip time & 26.8 & days & 21.7 & days \\
\hline Regas Capacity & 460 & t/hr & 460 & t/hr \\
\hline Cost per vessel & 201 & million USD & 175 & million USD \\
\hline Total vessel investment & 1,005 & million USD & 700 & million USD \\
\hline \multicolumn{2}{|c|}{ Total buoy-pipeline investm } & million USD & & \\
\hline Operational costs & 495,000 & \$/day & 353,000 & \$/day \\
\hline LNG delivered & 4,030 & Mt/yr & 4,030 & Mt/yr \\
\hline Gas delivered & 584 & Mcubic ft/d & 584 & Mcubic ft/d \\
\hline transport cost at beach & 0.86 & USD/MMBtu & 0.64 & USD/MMBtu \\
\hline Terminal service cost & & no charge & 0.40 & USD/MMBtu \\
\hline Gas in pipeline cost & 0.86 & USD/MMBtu & 1.04 & USD/MMBtu \\
\hline \multicolumn{3}{|c|}{ Source: APL/Zeus Jens Karlstad 12/10/03 } & & \\
\hline
\end{tabular}

The trade off is between a larger fleet (5) of more expensive (\$202 mm each) vessels plus two buoys and pipe line tie in ( $\$ 100 \mathrm{~mm}$ ) vs. fewer (4), less expensive (\$175 mm each) vessels plus an onshore terminal (capex not shown) costing on the order of $\$ 500 \mathrm{~mm}$. A major advantage of offshore unloading is the relative ease of obtaining permits for that facility, a result of fewer jurisdictions.

This project has just been approved by FERC. It and ChevronTexaco's Port Pelican are the only two offshore projects on the Gulf Coast to have reached this stage of development. 


\section{IMPACt OF LNG Projects ON THE STATE AND REgion}

Louisiana handles on the order of 7.1 TCF of gas annually, of which roughly 5.1 TCF is produced locally. The balance is imported, either through interstate pipelines or as LNG from international sources. Supporting this throughput, we have about .6 TCF of gas storage capacity with the bulk of that capacity represented by eight depleted gas fields. We also have six salt cavern storage sites.

Table 7: Historical Gas Thruput and Disposition for Louisiana

\begin{tabular}{|c|c|c|c|c|c|c|c|}
\hline \multicolumn{8}{|l|}{ LOUISIANA- (TCF) } \\
\hline Supply and Disposition (TCF) & 1997 & 1998 & 1999 & 2000 & 2001 & 2002 & 2003 \\
\hline Dry Production & 5.080 & 5.133 & 5.111 & 4.928 & 5.097 & & \\
\hline Interstate Receipts & 2.106 & 1.672 & 1.584 & 1.621 & 1.627 & & \\
\hline International Receipts & 0.031 & 0.043 & 0.065 & 0.127 & 0.145 & & \\
\hline Withdrawals from Storage & $\underline{0.293}$ & $\underline{0.239}$ & $\underline{0.271}$ & $\underline{0.339}$ & $\underline{0.202}$ & & \\
\hline Supply & 7.510 & 7.087 & 7.031 & 7.015 & 7.071 & & \\
\hline Consumption & 1.661 & 1.569 & 1.495 & 1.537 & 1.304 & & \\
\hline Interstate Deliveries & 5.787 & 5.215 & 5.284 & 5.284 & 5.561 & & \\
\hline Injections to Storage & 0.302 & 0.322 & 0.262 & 0.243 & 0.352 & & \\
\hline Balancing Item & $\underline{-0.243}$ & $\underline{-0.019}$ & $\underline{-0.010}$ & $\underline{-0.049}$ & $\underline{-0.147}$ & & \\
\hline Disposition & 7.507 & 7.087 & 7.031 & 7.015 & 7.070 & & \\
\hline Marketed Production & & 1.569 & 1.495 & 1.537 & 1.304 & & \\
\hline Field and Pipeline Consumption & & 0.255 & 0.228 & 0.250 & 0.236 & & \\
\hline Used by consumers & & 1.314 & 1.268 & 1.286 & 1.068 & 1.194 & $100 \%$ \\
\hline Residential & & 0.048 & 0.045 & 0.050 & 0.049 & 0.049 & $4 \%$ \\
\hline Commercial & & 0.024 & 0.025 & 0.026 & 0.029 & 0.025 & $2 \%$ \\
\hline Industrial & & 0.922 & 0.876 & 0.906 & 0.747 & 0.796 & $67 \%$ \\
\hline Electric Power & & 0.320 & 0.322 & 0.305 & 0.243 & 0.324 & $27 \%$ \\
\hline Storage Capacity & 0.559 & 0.564 & 0.564 & 0.569 & 0.580 & & $100 \%$ \\
\hline Salt Caverns & 0.000 & 0.000 & 0.034 & 0.039 & 0.046 & & $8 \%$ \\
\hline Aquifers & 0.029 & 0.033 & & & & & \\
\hline Depleted Fields & 0.530 & 0.530 & 0.530 & 0.530 & 0.530 & & $92 \%$ \\
\hline
\end{tabular}


Of the total production, about 1.5 TCF is used locally and 5.6 TCF is transferred out of state. Netting out 1.6 TCF of interstate receipts, mainly from Texas, we are exporting a net 4 TCF through the interstate pipeline system. That is double the net exports of the next largest interstate exporter, Texas, at 1.9 TCF, and on a par with net imports into the U.S. from Canada, which totaled 3.6 TCF in 2002.

Looking at marketed production, we first net out gas used in the production and transmission process (about .3 TCF) to arrive at gas actually delivered to consumers of about 1.2 TCF annually. Of this total, industrial customers are responsible for $67 \%$ of consumption while power generators use $27 \%$. The $6 \%$ balance of the gas or .08 TCF is used for local residential and commercial applications.

This is quite a different profile from Texas and for the U.S. as a whole. In the US, 4.8 TCF is used by residences, 3 TCF is used by commercial establishments, 7.4 TCF is used by industry and 5.3 TCF is converted to electrical power.

The following two charts illustrate the magnitude of the various segments as well their relative importance in each state. New York is also included as a sample of a gas consuming state.

\section{Absolute Level of Gas Consumption}

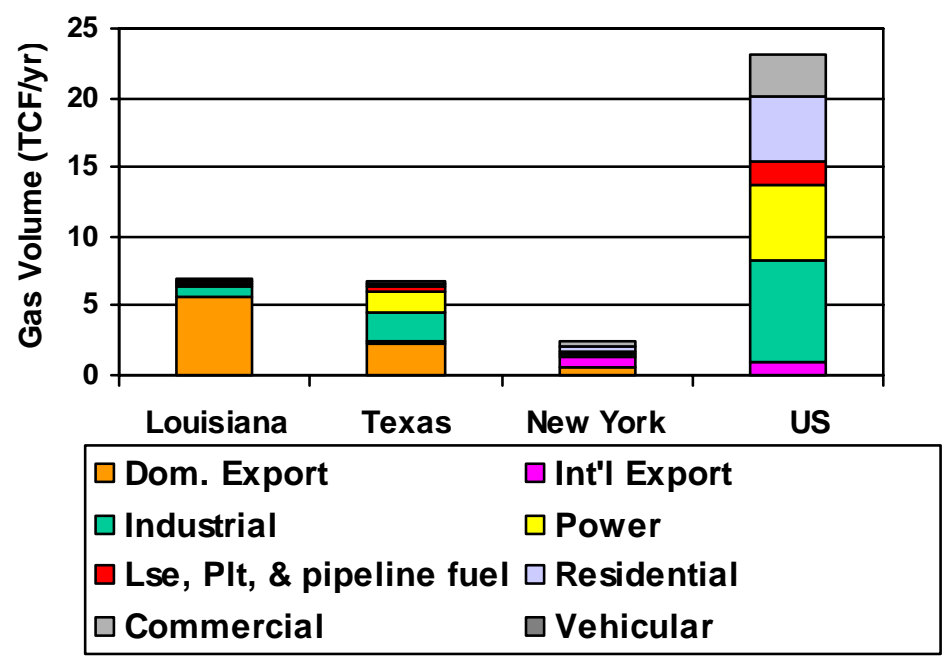

Figure 22 ETEI \& EIA 
On a relative basis, Louisiana exports almost $80 \%$ of the gas that is available to the state. This is much higher than in Texas where over $60 \%$ remains in the state. In Texas, a higher percentage of available gas is used for industrial purposes and for power generation. New York also uses over $60 \%$ of its gas, but for power, commercial and residential applications. New York has minimal industrial consumption but exports almost $40 \%$ of available gas. This suggests a higher degree of seasonality in New York than in Texas or Louisiana.

Relative Level of Gas Consumption

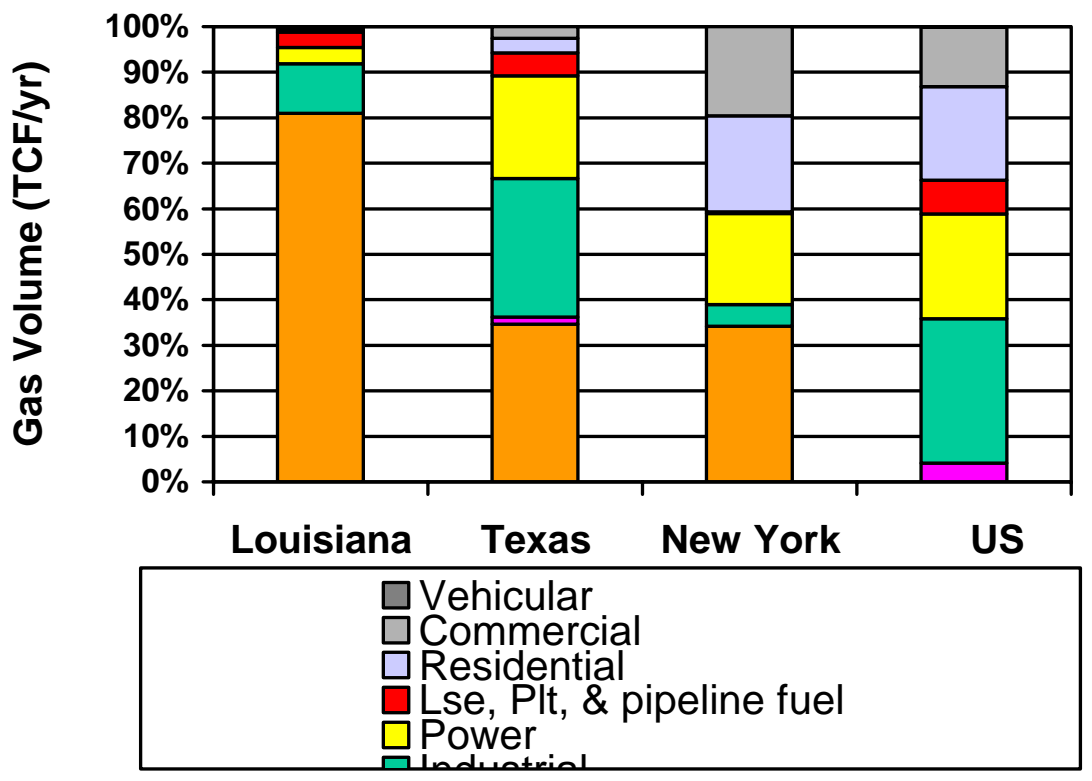

Figure 23

ETEI \& EIA

\section{Direct and Indirect Economic Effects of Capacity Growth}

The United States currently has four LNG import terminals. Distrigas in Massachusetts, Cove Point in Maryland, Elba Island in Georgia and Lake Charles in Louisiana. The four terminals collectively have the capacity to import about 1 TCF of gas per year, but actually only imported about .5 TCF in 2003 which amounted to $2 \%$ of total consumption during that year. However, this did represent a more than doubling of imports from the prior year. Once current expansions are complete the capacity of these four terminals will be doubled to 2 TCF/year. After that phase 
is complete, the only way for growth to continue is through the commissioning of new receiving terminals.

Various energy firms have announced plans to substantially expand import capacity during the next six years. The increased capacity planned for Louisiana will entail continued expansion of the Lake Charles plant plus construction of at least one new onshore terminal and up to five new offshore facilities. Cumulative direct expenditures, 2004-2009, for engineering, site preparation, construction costs, and pipeline installation will be some $\$ 2.32$ billion. This expenditure plan assumes that approximately 37\% of each plant will be sourced outside of the state.

We propose to employ direct and indirect GSP multipliers to analyze a most likely case scenario. To do this we use GSP and employment multipliers developed by for Louisiana by the Bureau of Economic Analysis in Baton Rouge.

\section{Methodology}

To begin the process, we estimate the total value of two generic receiving terminals, one onshore and a second offshore. In each case, we estimate the total spending for each of nine expenditure categories in the onshore case and of seven categories in the offshore case.

Next, we estimate the percentage of the capital expenditures that will represent the domestic scope of work. We then further subdivide the domestic share of work between labor and material. Using assumed all in labor costs, we then derive a head count for each type of project. To complete this portion of the analysis, we then distribute the total domestic spend over a four year period, for each category of work scope. We then add the annual spending and derive percentages that represent the distribution of spending on each type of project.

In a second phase of the analysis, we list specifically identified projects which have been announced and for which we have estimated to capital expenditure estimates. Each of the project totals is split, based on project category (onshore vs. offshore), first into domestic scope of work vs. imported scope, then the domestic scope is split into labor and materials. The labor portion is then used to derive head count totals. The domestic total spend is then spread over four years based on the target completion date and the characteristic spending pattern derived earlier. 
At this point we have the starting point for the third phase of the analysis which involves attaching the characteristic multipliers mentioned at the beginning of this discussion of the methodology. In the case of Louisiana, we used a multiplier of 2.1166 for capital expenditures and a multiplier of 2.4479 is used in connection with the head count forecast.

The following table summarizes the first two phases of the analysis.

First we have the results of the generic onshore and offshore analyses in terms of direct capex and of direct head count. This is followed by the application of the derived patterns to the actual projects we expect will take place in Louisiana. Finally, the yellow highlighted area covers the expenditure multiplier while the blue section covers the man year multiplier.

Table 8: Generic Estimates for the Direct Capex Associated with New LNG Receiving Terminals and the Cumulative Spend associated with Selected Projects Constructed in LA

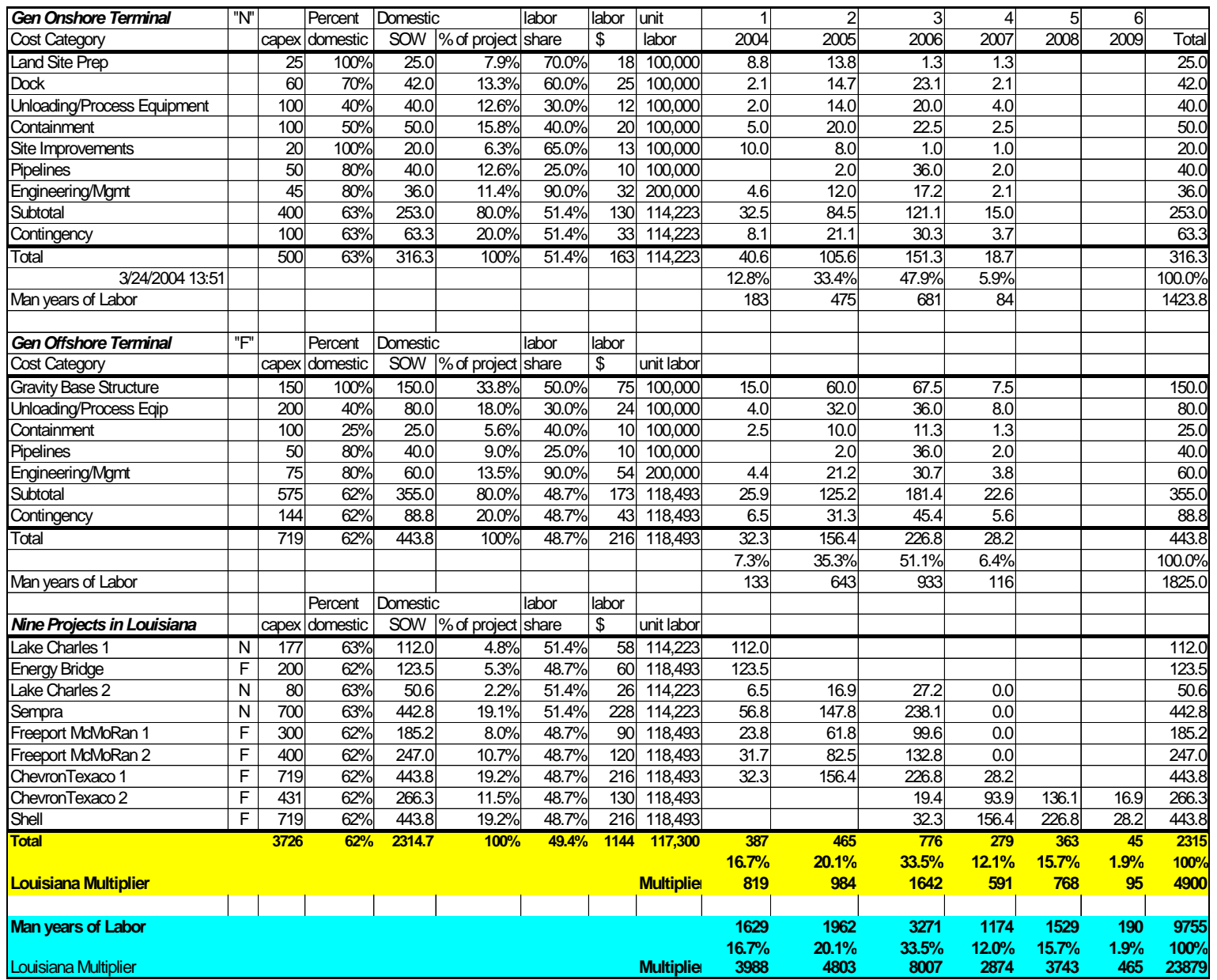

ETEI and ION \& Co. 
The $\$ 2.32$ billion of direct on-site capital expenditures (CAPEX) will increase the demand for materials and services in industries that are major suppliers for this type of petrochemical plant construction. We employ a coefficient of 2.1166, obtained from the most recent Louisiana inputoutput model, to project that each \$ 1 million of direct CAPEX will increase Louisiana Gross State Product (GSP) by $\$ 2.1166$ million. Thus, the cumulative spend of $\$ 2.32$ billion in direct CAPEX would generate a cumulative increase of $\$ 4.9$ billion in Louisiana GSP ( $\$ 2.32$ billion times $2.1166=\$ 4.9$ billion $)$.

The direct capital expenditures create new construction and manufacturing jobs along Louisiana's Gulf Coast. We project a cumulative six year total of 9,755 direct man years of work, with an average of 1,626 jobs on an annual basis over the six year program.

The increased economic activity generating these 9,755 direct man years of work would of course generate new indirect jobs in industries supplying raw materials and services supporting the on-site construction. The Louisiana job multiplier is 2.4479, meaning that each direct full time job in the construction phase generates 1.4479 full time jobs elsewhere in the Louisiana economy. Accordingly the 9,755 cumulative direct man years will add 14,124 indirect man years for a total of 23,879 total man years of activity. Looked at on an average annual basis, these numbers translate into 1,626 annual direct jobs and 2,354 indirect jobs over the six year period.

The following table highlights the direct and total capex generated by the new building program and provides explanatory footnotes covering the application of the multipliers and the final magnitude of the effect. After the multipliers, we are looking at a $\$ 4.9$ billion infusion into the state's economy over five years, or an average of a \$ 1 billion addition to a $\$ 149$ billion base case for Louisiana GSP. 


\section{Table 9}

Projected Capital Expenditures for Expanded LNG Capacity in Louisiana 2004-2009

\begin{tabular}{|l|r|r|r|r|r|r|r|}
\hline Year & $\mathbf{2 0 0 4}$ & $\mathbf{2 0 0 5}$ & $\mathbf{2 0 0 6}$ & $\mathbf{2 0 0 7}$ & $\mathbf{2 0 0 8}$ & $\mathbf{2 0 0 9}$ & \\
\hline $\begin{array}{l}\text { CAPEX } \\
\text { (\$ millions) }\end{array}$ & 387 & 465 & 776 & 279 & 363 & 45 & 2315 \\
\hline $\begin{array}{l}\text { Total GSP } \\
\text { multiplier }\end{array}$ & 2.1166 & 2.1166 & 2.1166 & 2.1166 & 2.1166 & 2.1166 & \\
\hline $\begin{array}{l}\text { Increase in } \\
\begin{array}{l}\text { LA GSP } \\
\text { (\$ millions) }\end{array}\end{array}$ & 819 & 984 & 1642 & 591 & 768 & 95 & 4900 \\
\hline
\end{tabular}

(i) Table 9 Shows the time path of projected capital expenditures (CAPEX) on 8 LNG projects from 2004-2009. These projected capital investments cover only the domestic share of these investments, and exclude overseas investments in unloading and processing equipment, docking equipment, containment vessels, and engineering/management. As shown in Row 1, cumulative CAPEX would be about $\$ 2.32$ billion.

(ii) The domestic share of CAPEX in Louisiana onshore terminals is assumed to be $63 \%$, and in offshore terminals $62 \%$. We assume that three onshore terminals (Lake Charles 1, Lake Charles 2, and Sempra) will be completed by year-end 2006, and that five offshore terminals (Energy Bridge, Freeport McMoRan 1 and 2, Chevron/Texaco 1 and 2, and Shell) will be finished by year-end 2009.

(iii) The direct capital investments shown in the first row would generate expansion elsewhere in the Louisiana economy, particularly in those sectors that supply materials and services for the new LNG plants during their construction phase. Growth in these other sectors is usually termed the "ripple effect." Row 2 shows the total Gross State Product (GSP) multiplier of 2.1166. This GSP multiplier simply means that $\$ 1$ million of CAPEX in constructing new LNG capacity would generate a contemporaneous overall growth of $\$ 2.1166$ million in GSP. Projections of each year's overall growth in GSP attributable to direct CAPEX are shown in line 3. The cumulative six-year addition to Louisiana's GSP would be nearly $\$ 5$ billion. This cumulative addition can be compared with Louisiana Gross State Product of \$149 billion in year 2001 (Bureau of Economic Analysis, www.bea.gov/bea/regional/gsp/).

(iv) The numbers shown in the first row of Table 9 are not forecasts of capital expenditures. Instead, they are projections based on information at February 6, 2004. If capital expenditures were to be accelerated or delayed, the time path in Table 9 would be modified. However, the cumulative six-year expenditure of roughly $\$ 2.32$ billion would probably not change appreciably. Nor would the cumulative increase of some $\$ 5$ billion in Louisiana Gross State Product. 
Comparable information on direct and indirect head count and on cumulative Louisiana employment is detailed in the third table. The addition of almost 24,000 man years of work over a six year period should be a welcome goal to anyone interested in improving the state's economy.

Table 10: Direct and Total Jobs (Man Years) Created in Louisiana by New CAPEX on LNG Terminals 2004-2009

\begin{tabular}{|l|r|r|r|r|r|r|r|}
\hline Year & $\mathbf{2 0 0 4}$ & $\mathbf{2 0 0 5}$ & $\mathbf{2 0 0 6}$ & $\mathbf{2 0 0 7}$ & $\mathbf{2 0 0 8}$ & $\mathbf{2 0 0 9}$ & \\
\hline $\begin{array}{l}\text { Direct Jobs } \\
\text { (Manyears) }\end{array}$ & 1629 & 1962 & 3271 & 1174 & 1529 & 190 & 9755 \\
\hline $\begin{array}{l}\text { Jobs } \\
\text { Multiplier }\end{array}$ & 2.4479 & 2.4479 & 2.4479 & 2.4479 & 2.4479 & 2.4479 & \\
\hline $\begin{array}{l}\text { Total Jobs } \\
\text { (Manyears) }\end{array}$ & 3988 & 4803 & 8007 & 2874 & 3743 & 465 & 23879 \\
\hline
\end{tabular}

(i) Construction of 8 new LNG terminals could create 1629 additional direct manyears of employment in 2004, 1962 additional direct manyears in 2005, and so on. We project the cumulative six-year increase in direct employment to be 9755 manyears. As one would expect, the time path of employment closely follows that of CAPEX.

(ii) Just as direct CAPEX creates a ripple effect throughout the Louisiana economy, so does direct employment in LNG construction. The jobs multiplier of 2.4479 shown on the second line means that each additional direct manyear of employment creates about 1.45 new jobs elsewhere in Louisiana. Thus 1629 additional direct jobs in 2004 would create a total of 3988 new jobs that year. Adding total jobs across the third row, we project that 23,879 additional manyears of full-time employment would be created in Louisiana.

(iii) It is useful to compare the total GSP multiplier 2.1166 with the total jobs multiplier 2.4479. The jobs multiplier is slightly larger than the GSP multiplier because the industries providing materials and services to new LNG construction are themselves relatively labor intensive. One may correctly view these multipliers as practically constant during a period as brief as six years.

Once the new capacity additions are complete, the terminals will require additional operations expenditures (OPEX) for personnel, maintenance, and fuel gas. We estimate that annual operating expenses will be $\$ 20$ million/year for the average onshore terminal and \$25 million for the offshore terminals. We project cumulative additional direct OPEX of \$238 million and cumulative OPEX after the multiplier effect of $\$ 504$ million. Annual steady state effects would be $\$ 84$ million direct and $\$ 178 \mathrm{~mm}$ including indirect effects, beginning in 2008.

These numbers are detailed in the following table. 
Table 11: Projected Additional Operational Expenditures (OPEX) for Expanded LNG Capacity in Louisiana, 2004-2009

\begin{tabular}{|l|r|r|r|r|r|r|r|}
\hline Year & $\mathbf{2 0 0 4}$ & $\mathbf{2 0 0 5}$ & $\mathbf{2 0 0 6}$ & $\mathbf{2 0 0 7}$ & $\mathbf{2 0 0 8}$ & $\mathbf{2 0 0 9}$ & \\
\hline $\begin{array}{l}\text { Direct OPEX } \\
\text { (\$ millions) }\end{array}$ & 0 & 5 & 5 & 59.3 & 84.3 & 84.3 & 237.9 \\
\hline $\begin{array}{l}\text { Total GSP } \\
\text { multiplier }\end{array}$ & 2.1166 & 2.1166 & 2.1166 & 2.1166 & 2.1166 & 2.1166 & \\
\hline $\begin{array}{l}\text { Increase in LA } \\
\text { GSP } \\
\text { (\$ millions) }\end{array}$ & 0 & 11 & 11 & 126 & 178 & 178 & 504 \\
\hline
\end{tabular}

(i) Annual operational expenditures are assumed to be $\$ 20$ million for the three onshore terminals (Lake Charles 1, Lake Charles 2, and Sempra), and \$25 million for the five offshore terminals (Freeport McMoRan 1 and 2, Chevron/Texaco 1 and 2, and Shell).

(ii) Some instances, (for example, Lake Charles 1 and Lake Charles 2), entail expansion of LNG capacities for terminals already in place. In these instances, projections of additional operational expenditures (OPEX) include only incremental OPEX attributable to expanded capacities, and do not include OPEX for capacity already in place in 2004.

For example, the 25 percent additional capacity at Lake Charles 1 is projected to come on line in 2005 and is the source of $\$ 5$ million incremental OPEX in 2005, 2006, and each year thereafter. In 2007 , $\$ 54.3$ million in new OPEX occurs in other terminals, thus leading to total incremental OPEX of $\$ 59.4$ million in 2007 and each year thereafter.

(iii) Increases in both the scale of LNG imports and direct operational expenditures stimulate permanently greater demand for services such as plant maintenance, fuel gas, and marine operations. Increases in demand for these inputs drive expansion in these other sectors of Louisiana's economy. Hence each year's overall increase in Louisiana Gross State Product is shown in the last row of Table 11 The cumulative six-year increase is about $\$ 504$ million.

Similarly, in terms of man years of work, the cumulative direct operating census should grow by 618 man years or by 1,513 man years after applying the relevant multiplier to account for indirect additions. On an annual basis, the census should average 219 direct jobs and 536 total 
jobs once a steady state condition is achieved. While much smaller than the temporary effects, these operating jobs will have longevity going for them, remaining in place over the 25 to 30 year operating life of the facilities.

Table 12: Direct and Total Jobs (Man Years) Created in Louisiana by Additional LNG Operating Expenses, 2004-2009

\begin{tabular}{|l|r|r|r|r|r|r|r|}
\hline Year & 2004 & 2005 & 2006 & 2007 & 2008 & 2009 & \\
\hline $\begin{array}{l}\text { New Direct } \\
\text { Jobs } \\
\text { (manyears) }\end{array}$ & 0 & 13 & 13 & 154 & 219 & 219 & 618 \\
\hline $\begin{array}{l}\text { Jobs } \\
\text { Multiplier }\end{array}$ & 2.4479 & 2.4479 & 2.4479 & 2.4479 & 2.4479 & 2.4479 & \\
\hline $\begin{array}{l}\text { Total New } \\
\text { Jobs } \\
\text { (manyears) }\end{array}$ & & & & & & & \\
\hline
\end{tabular}

(i) We assume that the direct and total jobs created by larger operating expenditures would come after the additional LNG capacity is in place.

(ii) New jobs created by larger capital expenditures are distinct from new jobs attributable to greater operating expenses. Jobs created during the construction phase would dwindle as new construction is completed. By contrast, permanently larger operating expenditures would create new jobs that remain permanently.

In view of the currently high unemployment rate in Louisiana of approximately $6 \%$, these additions, of both temporary construction jobs and permanent operating staff, should be a welcome boost to Louisiana's labor market.

Beyond the direct and indirect economic effects of Louisiana based terminals on Louisiana, we also examined the effects on Louisiana of building three additional units in Texas and one new terminal in Alabama. While we did not perform the full analysis, we did identify the aggregate direct capex and direct man years of effort. Our algorithm assumed that Louisiana and Texas companies would each garner $75 \%$ of the domestic work to be performed in their home states and that they would also pick up $25 \%$ of the work in the adjacent state. Work in Alabama was split amongst all three states into equal thirds. The effect of including the Alabama project and redistributing the Texas-Louisiana workload is to increase the Texas share of direct spending and census totals at the expense of the Louisiana share. Those calculations follow. 


\section{Table 13: Estimates for Direct Capex and Man Years Associated with Regional LNG Receiving Terminal Projects Constructed along the Gulf Coast}

\begin{tabular}{|c|c|c|c|c|c|c|c|c|c|c|c|c|c|c|c|c|c|}
\hline & & & Percent & Domestic & & labor & & & & year & 1 & 2 & 3 & 4 & 5 & 6 & \\
\hline Nine Projects in Louisiana & & capex & domestic & sow & $\%$ of project & share & labor $\$$ & unit labor & hd count & finished & 2004 & 2005 & 2006 & 2007 & 2008 & 2009 & Total \\
\hline \multirow[t]{2}{*}{ Total } & & 3726 & $62 \%$ & 2314.7 & $100.0 \%$ & $49.4 \%$ & $\$ 1,144$ & \begin{tabular}{l|l|}
4 & 117,300 \\
\end{tabular} & & & 386.6 & 465.4 & 776.2 & 278.5 & 362.8 & 45.1 & 2314.7 \\
\hline & & & & & & & & & & & \begin{tabular}{|l|l|}
$16.7 \%$ \\
\end{tabular} & $20.1 \%$ & $33.5 \%$ & $12.0 \%$ & $15.7 \%$ & $1.9 \%$ & $100.0 \%$ \\
\hline Man years of Labor & & & & & & & & & 9755 & & 1629 & 1962 & 3271 & 1174 & 1529 & 190 & 9755 \\
\hline \multicolumn{18}{|l|}{3 Projects in Texas } \\
\hline Freeport-Cheniere & $\mathrm{N}$ & 500 & $63 \%$ & 316.3 & $33.3 \%$ & $51.4 \%$ & $\$ 163$ & \begin{tabular}{|l|l|}
3114223.0 \\
\end{tabular} & 1424 & 2007 & 40.6 & 105.6 & 151.3 & 18.7 & & & 316.3 \\
\hline Sabine Pass-ExxonMobil & $\mathrm{N}$ & 500 & $63 \%$ & 316.3 & $33.3 \%$ & $51.4 \%$ & $\$ 163$ & \begin{tabular}{|l|l|}
3 & 114223.0 \\
\end{tabular} & 1424 & 2008 & & 40.6 & 105.6 & 151.3 & 18.7 & & 316.3 \\
\hline Corpus Christi-Cheniere & $\mathrm{N}$ & 500 & $63 \%$ & 316.3 & $33.3 \%$ & $51.4 \%$ & $\$ 163$ & \begin{tabular}{|l|l|}
3114223.0 \\
\end{tabular} & 1424 & 2009 & & & 40.6 & 105.6 & 151.3 & 18.7 & 316.3 \\
\hline \multirow[t]{2}{*}{ Total } & & 1500 & $63 \%$ & 948.8 & $100.0 \%$ & $51.4 \%$ & $\$ 488$ & & & & 40.6 & 146.2 & 297.5 & 275.7 & 170.1 & 18.7 & 948.8 \\
\hline & & & & & & & & & & & $4.3 \%$ & $15.4 \%$ & $31.4 \%$ & $29.1 \%$ & $17.9 \%$ & $2.0 \%$ & $100.0 \%$ \\
\hline \multirow[t]{2}{*}{ Manyears of Labor } & & & & & & & & & 4271 & & 183 & 658 & 1339 & 1241 & 766 & 84 & 4271 \\
\hline & & & & & & & & & & & & & & & & & \\
\hline \multicolumn{18}{|l|}{1 Project in Alabama } \\
\hline \multirow[t]{2}{*}{ Mobile - Cheniere } & $\mathrm{N}$ & 500 & $63 \%$ & 316 & $100.0 \%$ & $51.4 \%$ & $\$ 163$ & \begin{tabular}{|l|l|}
314223.0 \\
\end{tabular} & 1424 & 2007 & 40.6 & 105.6 & 151.3 & 18.7 & & & 316.3 \\
\hline & & & & & & & & & & & $12.8 \%$ & $33.4 \%$ & $47.9 \%$ & $5.9 \%$ & $0.0 \%$ & $0.0 \%$ & $100.0 \%$ \\
\hline \multirow[t]{2}{*}{ Man years of Labor } & & & & & & & & & 1424 & & 183 & 475 & 681 & 84 & 0 & 0 & 1424 \\
\hline & & & & & & & & & & & & & & & & & \\
\hline Grand Total Spend for GC & 13 & 5726 & $62.5 \%$ & 3580 & $100.0 \%$ & & & & & & 467.7 & 717.2 & 1225.1 & 572.9 & 532.9 & 63.9 & 3579.7 \\
\hline 13 projects at 10 locations & & & & & & & & & & & $13.1 \%$ & $20.0 \%$ & $34.2 \%$ & $16.0 \%$ & $14.9 \%$ & $1.8 \%$ & $100.0 \%$ \\
\hline Project Labor Cost & & & & & & $50.1 \%$ & $\$ 1,795$ & & & & 234.5 & 359.6 & 614.3 & 287.2 & 267.2 & 32.0 & 1794.8 \\
\hline \multirow[t]{2}{*}{ Man years of Labor } & & & & & & & & & 15450 & & 1995 & 3095 & 5292 & 2499 & 2295 & 274 & 15450 \\
\hline & & & & & & & & & & & & & & & & & \\
\hline \multirow{2}{*}{\multicolumn{18}{|c|}{\begin{tabular}{|r|} 
For Louisiana and Texas, assume loca \\
$2 / 4 / 0417: 38$
\end{tabular}}} \\
\hline & & & & & & & & & & & & & & & & & \\
\hline \multirow{2}{*}{\begin{tabular}{|l} 
Geographic Split \\
State \\
\end{tabular}} & & & Percent & Domestic & & labor & & annual & & year & 1 & 2 & 3 & 4 & 5 & 6 & \\
\hline & & capex & domestic & Sow & $\%$ of spend & share & labor \$ & pay & hd count & finished & 2004 & 2005 & 2006 & 2007 & 2008 & 2009 & Total \\
\hline \multicolumn{2}{|l|}{ Louisiana Spend } & 3336 & $62.3 \%$ & 2079 & $58.1 \%$ & $57.6 \%$ & $\$ 1,034$ & & & & 314 & 421 & 707 & 284 & 315 & 39 & 2078.6 \\
\hline \multirow{3}{*}{\begin{tabular}{|l} 
average pay rate \\
La. Census \\
\end{tabular}} & & & & & & & & $\$ 115,298$ & & & \begin{tabular}{|l|}
$15.1 \%$ \\
\end{tabular} & $20.2 \%$ & \begin{tabular}{|l|}
$54.0 \%$ \\
\end{tabular} & $13.7 \%$ & $15.1 \%$ & $1.9 \%$ & $100.0 \%$ \\
\hline & & & & & & & & & 8971 & $58 \%$ & 1353 & 1816 & 3052 & 1226 & 1358 & 166 & 8971 \\
\hline & & & & & & & & & & & & & & & & & \\
\hline \multirow{3}{*}{\begin{tabular}{|l|} 
Texas Spend \\
average pay rate \\
Tx. Census \\
\end{tabular}} & & 2223 & $62.8 \%$ & 1396 & $39.0 \%$ & $39.3 \%$ & $\$ 706$ & & & & 141 & 261 & 468 & 283 & 218 & 25 & 1395.6 \\
\hline & & & & & & & & $\$ 117,234$ & & & \begin{tabular}{|l|}
$10.1 \%$ \\
\end{tabular} & $18.7 \%$ & \begin{tabular}{|l|}
$33.5 \%$ \\
\end{tabular} & $20.2 \%$ & $15.6 \%$ & $1.8 \%$ & $100.0 \%$ \\
\hline & & & & & & & & & 6024 & $39 \%$ & 607 & 1127 & 2018 & 1220 & 942 & 109 & 6024 \\
\hline |x. Census & & & & & & & & & & & & & & & & & \\
\hline \multirow{2}{*}{\begin{tabular}{|l|} 
Alabama Spend \\
average pay rate \\
\end{tabular}} & & 167 & $63.3 \%$ & 105 & $2.9 \%$ & $3.0 \%$ & $\$ 54$ & & & & 14 & 35 & 50 & 6 & 0 & 0 & 105.4 \\
\hline & & & & & & & & $\$ 119,143$ & & & \begin{tabular}{|l|}
$12.8 \%$ \\
\end{tabular} & $33.4 \%$ & \begin{tabular}{|l|}
$67.9 \%$ \\
\end{tabular} & $5.9 \%$ & $0.0 \%$ & $0.0 \%$ & $100.0 \%$ \\
\hline Ala. Census & & & & & & & & & 455 & $3 \%$ & 58 & 152 & 218 & 27 & 0 & 0 & 455 \\
\hline \multirow[t]{2}{*}{\begin{tabular}{|l} 
Total Spend(in millions) \\
\end{tabular}} & & 5726 & $62.5 \%$ & 3580 & & $100.0 \%$ & $\$ 1,795$ & & & & 467.7 & 717.2 & 1225.1 & 572.9 & 532.9 & 63.9 & 3579.7 \\
\hline & & & & & & & & $\$ 116,166$ & & & $13.1 \%$ & $20.0 \%$ & $34.2 \%$ & $16.0 \%$ & $14.9 \%$ & $1.8 \%$ & $100.0 \%$ \\
\hline Total Census & & & & & & & & & 15450 & & 2019 & 3095 & 5288 & 2473 & 2300 & 276 & 15450 \\
\hline
\end{tabular}

ETEI \& Waldemar Nelson \& Company

As you will note the total direct spend increases from $\$ 2.3$ billion in Louisiana to $\$ 3.6$ billion for all three states. Similarly, the direct man years increase from 9,755 for just Louisiana to a total of 15,450 for the region.

\section{$\underline{\text { Strategic Arquments for a Louisiana Location }}$}

Louisiana has the newest and largest of the four existing U.S. LNG terminals, at Lake Charles; unmatched access, through Henry Hub, to the country’s interstate pipeline network; and a number of salt dome formations, both onshore and offshore, with potential for use as future storage caverns. These should be strong arguments in favor of Louisiana as the primary location for new LNG re-gasification terminals, particularly of offshore receiving terminals.

Given the dominant role of interstate pipeline exports to Louisiana, followed by petrochemical consumption and power generation; it is strategically important that an adequate gas supply be 
maintained if these segments of Louisiana's economy are to remain viable. Such metrics are equally valid for Texas. Long term, Louisiana and Texas should also foster the petrochemical and power segments as they have less intrinsic volatility than the pipeline segment. Interstate pipeline exports are much more heavily weighted towards heating and cooling loads.

Petrochemical loads show little seasonality. Regional power loads are certainly seasonal, but regional generation should lie between petrochemicals and interstate pipeline demand in terms of volume volatility. Moreover the seasonal loads peak in the summer vs. winter peaks in most gas consuming areas.

With continuing declines in local production, particularly from the shallow water shelf of the Gulf of Mexico, we are experiencing increasing imports of gas in the form of LNG, some 540 BCF in 2003, double the imports in 2002. We should consider the potential for dedicating new LNG imports on a priority basis to petrochemical users and then to power customers. In practice, this will likely be the outcome in any case, as chemical customers will be more likely to sign up for long term, non-interruptible, gas supply contracts. Moreover, if supplies are on a dedicated basis, then arguments about btu content are minimized. Power customers will have to contend with local regulatory restraints in signing up for longer duration supply contacts. However, their unregulated business should be free to sign such agreements. Then too, they could adjust to high btu gas if plants were proximate to receiving terminals and if consumption was based on long term contracts.

\section{The Offshore Production Environment}

The following discussion outlines the major factors that will enter into the choice of terminal locations and the potential negative economic impact of those choices on the Louisiana economy.

The U.S. Gulf historically has produced $25 \%$ of U.S. domestic gas supply, most of which is landed in Louisiana and Texas. U.S. onshore production, from both conventional and unconventional sources, supplies 55\% of our needs. Onshore gas from Western Canada supplies another 18\% of demand and LNG, the swing source, provided 2\% in 2003.

Until recently, analysts felt a decline in Gulf production was temporary. However, it has become apparent that there is a paucity of exploration prospects in the shallow waters south of Louisiana 
and Texas, despite prices that are more than double historical levels. It appears that shallow water operators preferentially drilled development wells over the last few years. These wells exploited existing "proved" reserves and used existing installed infrastructure resulting in minimum Finding and Development costs. Such low risk projects met capital deployment hurdle rates, but resulted in a steady reduction in aggregate production. In effect we have been living off of existing inventory.

Significant new gas supplies based on exploration drilling have not been discovered or developed. Indeed gas exploration drilling has been confined by and large to the search for deep gas on the Shelf and to exploitation of associated gas, a by-product of deepwater oil exploration efforts. Associated gas is now approximately $25 \%$ of total Gulf gas production.

Deep gas wells on the shelf are expensive to drill, on the order of $\$ 20,000,000 /$ well vs. shallow gas wells at $\$ 3-5 \mathrm{~mm}$. and have not been pursued by major companies. Majors actually have a positive driver to avoid deep gas on the Shelf and to instead promote imports of their considerable proved reserves of international gas. Domestically, Majors maximize profits by selling deepwater, associated gas and by importing relatively low cost stranded gas into the U.S.

The reason for enthusiasm on the part of Majors for LNG is that it solves two problems. It serves as a life extension project for installed infrastructure along the Gulf Coast and it also provides access for international stranded reserves to the largest gas market in the world. Why exactly would Majors worry about finding immaterial quantities of risky, and expensive domestic offshore deep gas reserves?

Large Independents could be potential developers of deep gas on the shelf. So far, the twin inducements of royalty relief and existing infrastructure have not been adequate to entice larger Independents to look for deep Shelf reserves. Smaller Independents simply cannot afford the consequences of \$20 million dry holes. They are consigned to searching for constantly shrinking shallow reservoirs on the shelf, on the order of 1-5 BCF per well, while continuing to make maximum use of existing platform and pipeline infrastructure. 


\section{$\underline{\text { Industrial Markets for Gas }}$}

The largest U.S. market in volume, if not in political clout, for gas is the industrial market. As the following chart illustrates, consumption is spread out among a number of segments, most of which are under economic pressure as a result of volatile gas prices and short term delivery contracts. The magnitude of the segment is roughly equivalent to the size of all existing and planned LNG terminals, while the chemicals sub-segment is roughly the size of the existing four terminals after expansion.

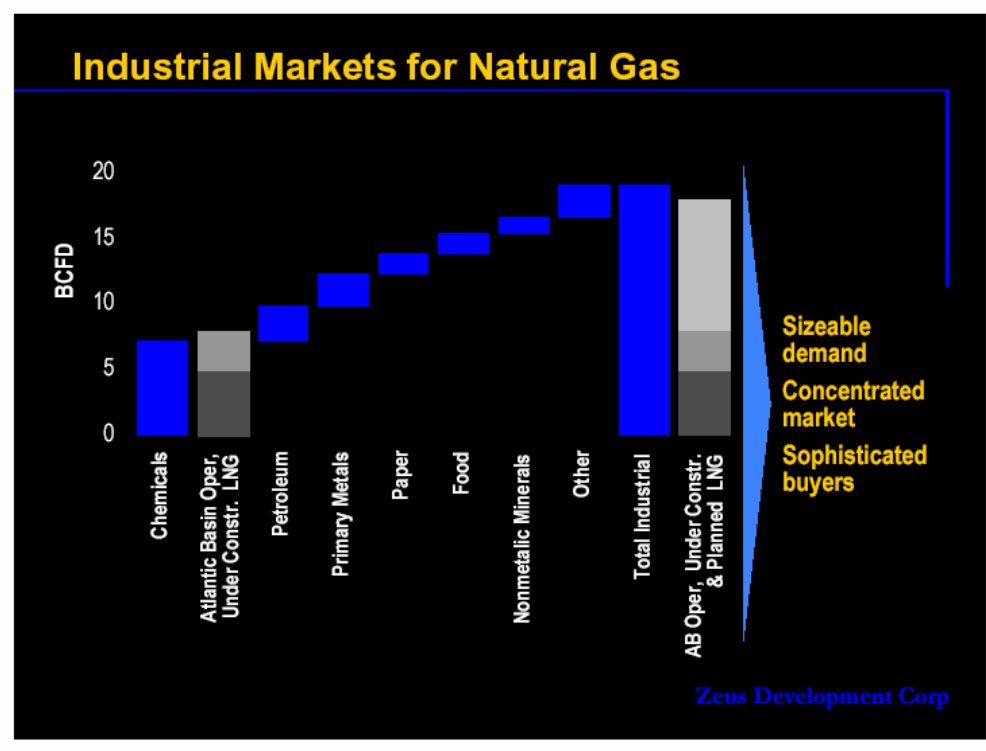

Figure 24 Zeus Development Corp., Presentation of 12/03

In the case of Louisiana, there is precedent available. Aluminum production was very much a part of the industrial corridor, through the 1980s, with two Alcoa smelters located in Chalmette and in Baton Rouge, La. According to Dan Borne', the President of the Louisiana chemical Association, long term gas supply contracts, initially at $\$ .19 / \mathrm{mcf}$, provided the economic rationale for locating these plants in Louisiana. Unfortunately, those gas contracts expired and subsequent new contracts of shorter duration were priced ever closer to market rates. Both units were closed. Recently, one of the few remaining aluminum smelters in the U.S., located in the Northwest ceased production during the California energy crisis. Even though the hydropower contract was still in force, the electricity needed to support aluminum production was worth more to commercial power customers than as a component of domestic aluminum production. 
Getting back to the petrochemicals, we have further broken out the chemicals sub-segment into the various product markets that utilize gas. That is the subject of the following slide.

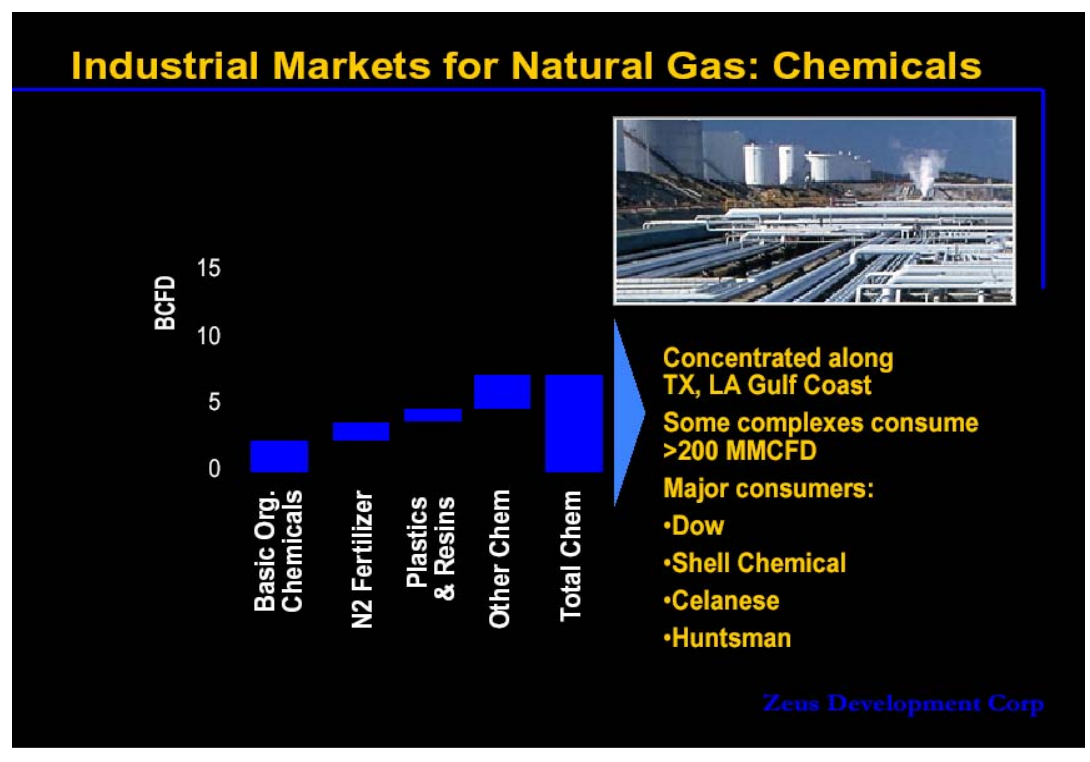

Figure 25 Zeus Development Corp, Presentation of 12/03

Even the coming hydrogen economy depends on ready access to natural gas as virtually all U.S. hydrogen production depends on steam reforming natural gas.

\section{The Impact on the local Petrochemical Industry}

The following chart gives meaning to the term "demand destruction". In it Marathon attempts to outline the posture of participants on both the Demand and the Supply side of the equation. 


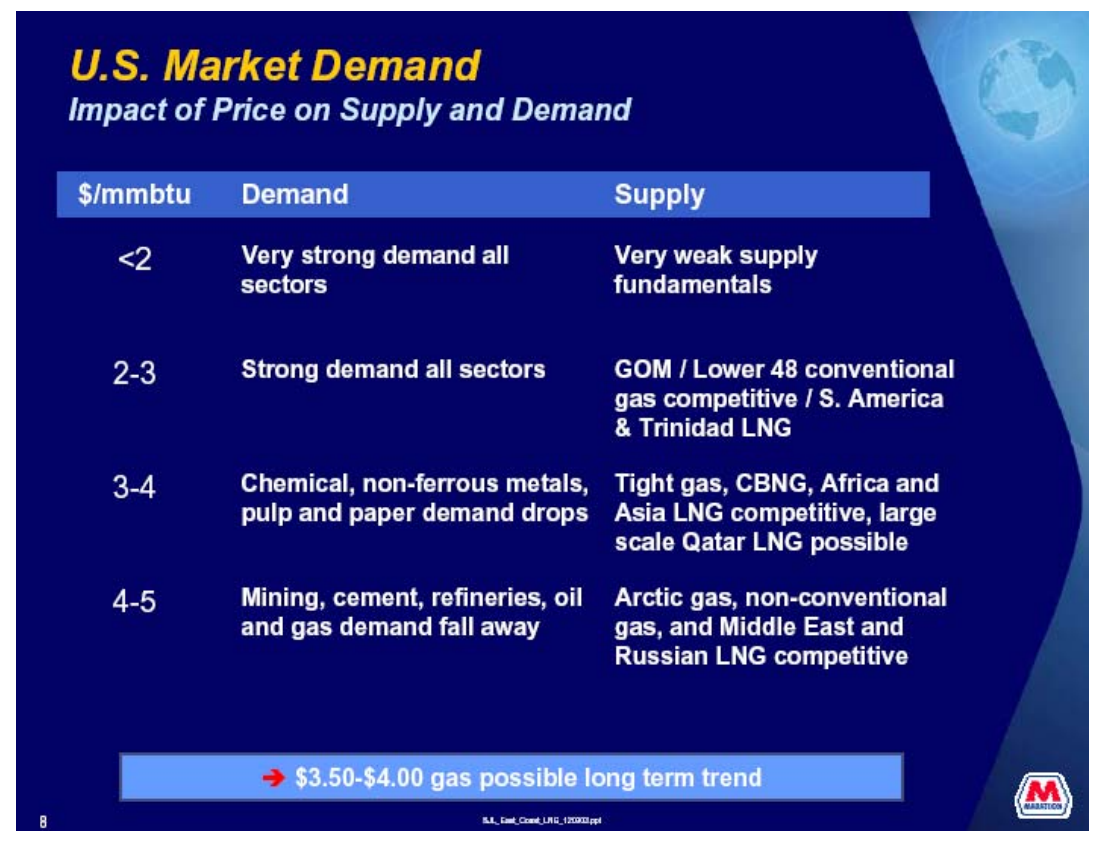

Figure 26

Source: Marathon Oil, Presentation at Zeus Development Corp., 12/03

The effects of higher gas prices, and gas price volatility, coupled with the decline in local domestic gas production; is having dire consequences for commodity petrochemical production situated along the Gulf Coast. These plants exist because of the historical availability of low cost fuel and feed stock, primarily methane but also the higher molecular weight hydrocarbons such as the C-2s through C-4s usually found in associated gas. The production of ammonia based fertilizers, methanol, ethylene, styrene, propylene, butyl rubber and a whole gamut of monomers intended for ultimate conversion into plastics are at risk. A number of fertilizer units are already in bankruptcy, and more are to follow. 


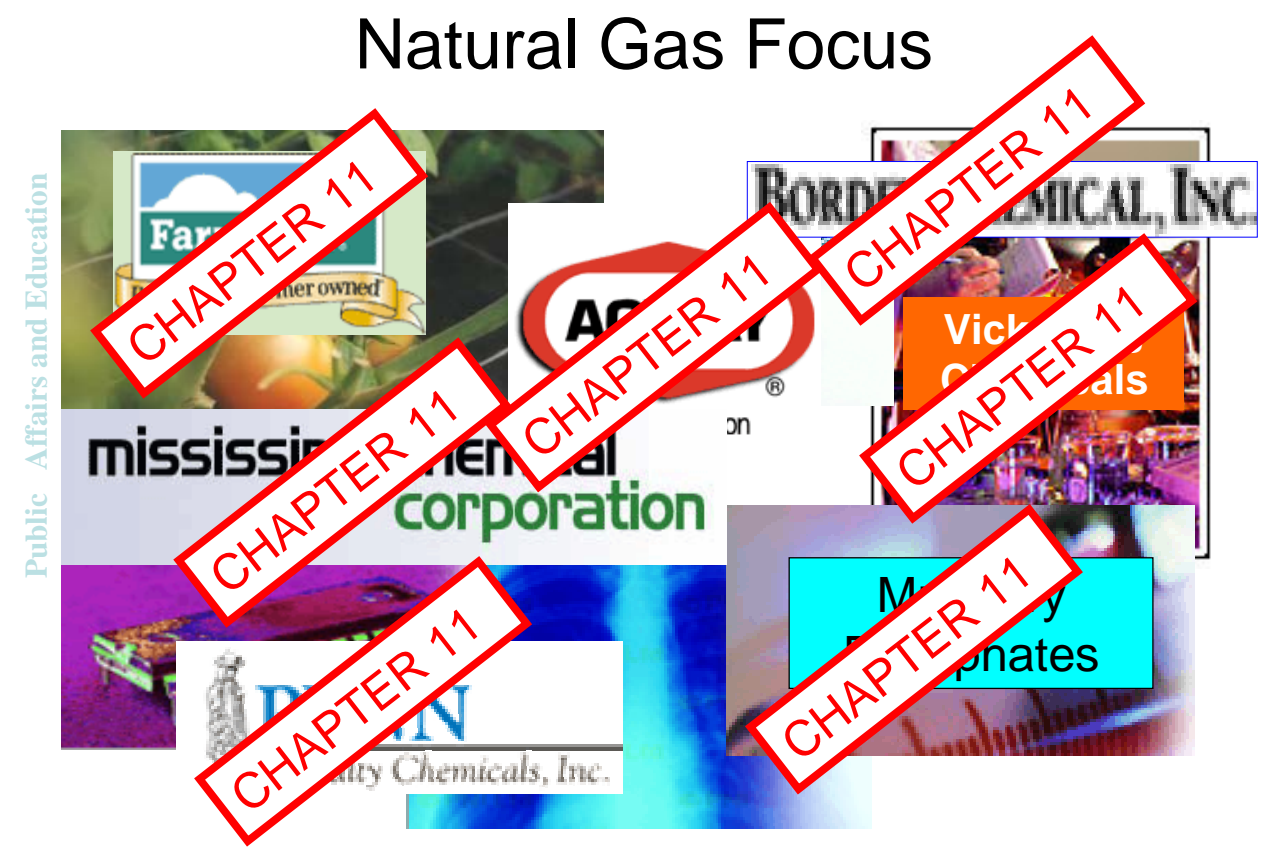

Figure 27 Source: T. Michaels, The National Ocean Industries Association and The American Chemical Council,

The next chart illustrates recent industry news concerning the relocation of commodity chemical intermediates from U.S. to foreign locations

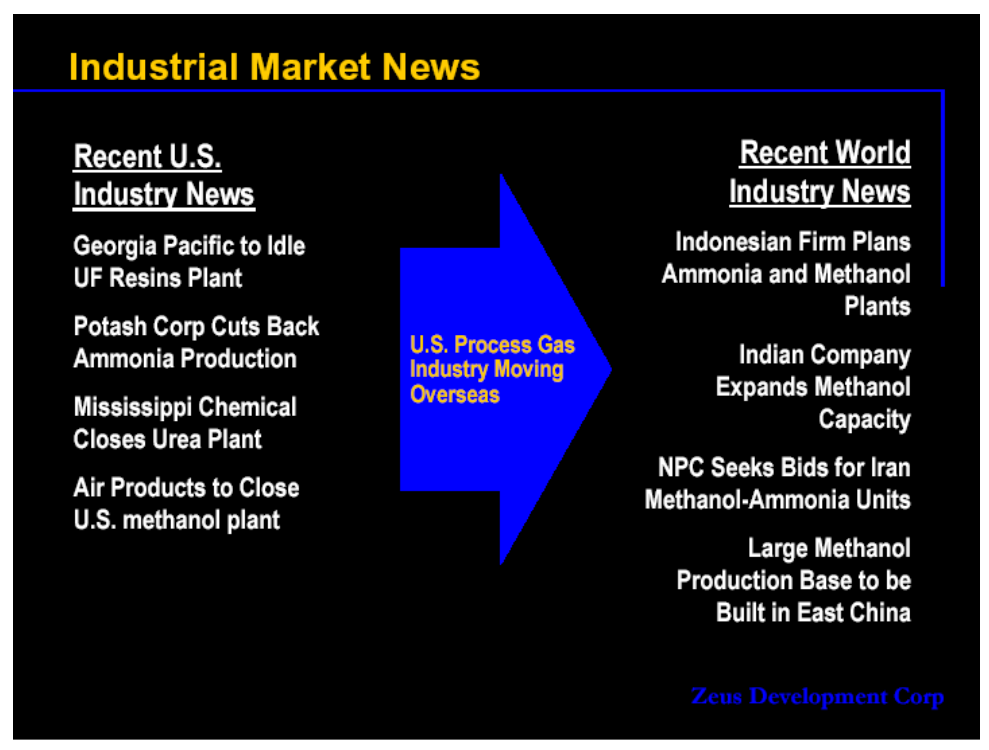

Figure 28

Source: Zeus Development Corp., Presentation of 12/03 
Ultimately, plants will have no choice but to move nearer to international gas sources. This movement, and the linked requirement for the import of synthetic fertilizers into the U.S., could have a deleterious effect, not only on the domestic gas supply chain and ammonia producers, but also on the competitiveness of North America's agricultural businesses, including Louisiana's corn, sugarcane, soybean and cattle production. The following, is a list of casualties in energy intensive chemical production.

Table 14:

\section{CHAPTER 11 STATEMENTS REFERENCING NATURAL GAS}

\begin{tabular}{|c|c|c|}
\hline Company & Location & $\underline{\text { Details }}$ \\
\hline Agrifos & Texas & Bankrupt fertilizer company \\
\hline Agway & Syracuse, NY & Bankrupt fertilizer company \\
\hline Borden Chemicals \& Plastics & Geismar, LA & $\begin{array}{l}\text { Constitutes 9\% of U.S. PVC } \\
\text { market }\end{array}$ \\
\hline Farmland & Midwest \& Louisiana & Bankrupt fertilizer company \\
\hline Mississippi Chemical & Yazoo City, MS & Bankrupt fertilizer company \\
\hline Mulberry Phosphates & Florida & Bankrupt fertilizer company \\
\hline Penn Specialty Chemical & Conshohocken, PA & $\begin{array}{l}\text { Only "significant global } \\
\text { supplier" of many specialty } \\
\text { chemicals based on high } \\
\text { purity furfural and furan }\end{array}$ \\
\hline Vicksburg Chemical & Mississippi & Bankrupt fertilizer company \\
\hline
\end{tabular}

PLANT / PRODUCTION SHUTDOWNS OR RELOCATIONS MENTIONING NATURAL GAS

Company Location Details

\begin{tabular}{|l|l|l|}
\hline Air Products & Pace, FL & Ceased production at plant \\
\hline Alcan & West Virginia & Plant idled \\
\hline Alcoa & $\begin{array}{l}\text { Troutdale, OR } \\
\text { Rockdale, TX } \\
\text { Longview, WA } \\
\text { Goldendale, WA }\end{array}$ & Plants idled \\
\hline Cytec & Fortier, LA & $\begin{array}{l}\text { Suspends operations at Fortier } \\
\text { ammonia plant; 400 metric } \\
\text { ton/year capacity }\end{array}$ \\
\hline
\end{tabular}




\begin{tabular}{|c|c|c|}
\hline Dow-Chemical & Plaquemine, LA & $\begin{array}{l}\text { Permanently moved } 1.2 \text { billion } \\
\text { pounds of chlor-alkali } \\
\text { production to Europe in part } \\
\text { due to high U.S. natural gas } \\
\text { prices }\end{array}$ \\
\hline Dow Chemical & Texas & $\begin{array}{l}\text { Accelerated shutdown of } 2 \\
\text { ethylene crackers in Texas } \\
\text { City and Seadrift, due in part } \\
\text { to high feedstock costs. }\end{array}$ \\
\hline Farmland Industries & Pollack, LA & $\begin{array}{l}\text { Permanent closure of Pollack } \\
\text { ammonia plant; 500K metric } \\
\text { ton/year capacity }\end{array}$ \\
\hline Formosa Plastics & Baton Rouge, LA & $\begin{array}{l}\text { Shutdown } 2 \text { units at Scenic } \\
\text { Highway plant making } \\
\text { plastics and ethylene } \\
\text { dichloride; loss of at least } 89 \\
\text { jobs }\end{array}$ \\
\hline Glencore & Kalispell, MT & $\begin{array}{l}\text { Columbia Falls plant } \\
\text { operating at } 20 \% \\
\text { (Alcoa's Ferndale plant in } \\
\text { Bellingham, WA is the only } \\
\text { other aluminum plant } \\
\text { operating in the Northwest) }\end{array}$ \\
\hline Kaiser & Washington State & $\begin{array}{l}\text { Mead, Tacoma, Trentwood } \\
\text { plants idled }\end{array}$ \\
\hline Mississippi Chemical & $\begin{array}{l}\text { Yazoo City, MS } \\
\text { Donaldsonville, LA }\end{array}$ & $\begin{array}{l}\text { Permanent shutdown of } \\
\text { Donaldsonville plant }\end{array}$ \\
\hline Ormet & Baton Rouge, LA & $\begin{array}{l}\text { Shutdown Burnside alumina } \\
\text { plant } 18 \text { months ago; loss of } \\
260 \text { jobs }\end{array}$ \\
\hline Terra Industries & Blytheville, AR & $\begin{array}{l}\text { Suspend ammonia \& urea } \\
\text { production (respectively } 14 \% \\
\text { and } 73 \% \text { of total North } \\
\text { America production); loss of } \\
60 \text { jobs }\end{array}$ \\
\hline Texas Nitrogen & $\begin{array}{l}\text { Blytheville, AR } \\
\text { Verdigrio, OK }\end{array}$ & $\begin{array}{l}\text { Curtailed } 2003 \text { production } \\
\text { with shutdown of Blytheville } \\
\text { plant and one of two ammonia } \\
\text { plants at Verdigio }\end{array}$ \\
\hline Texas Petrochemicals & Texas & $\begin{array}{l}\text { Shutdown of one dehydro unit } \\
\text { for January and February } 2003\end{array}$ \\
\hline U.S. Global Octane & Deer Park, TX & $\begin{array}{l}\text { Shutdown } 660,000 \text { ton/year } \\
\text { methyl tertiary butyl ether }\end{array}$ \\
\hline
\end{tabular}




\section{LAYOFFS MENTIONING NATURAL GAS}

Company

Location

Details

\begin{tabular}{|l|l|l|}
\hline ExxonMobil & Baton Rouge, LA & $\begin{array}{l}\text { Layoff of 30 laboratory } \\
\text { workers and 44 early } \\
\text { retirements }\end{array}$ \\
\hline
\end{tabular}

T. Michaels, NOIA, American Chemical Council 
In order to detail the positive benefit of low gas prices on commodity chemicals production, the following table, taken from a recent presentation by the government of Trinidad and Tobago, is useful. Trinidad has nine new world class ammonia plants, none of which pay more than $\$ 1.00 /$ mcf for gas. 
Table 15

\begin{tabular}{|c|c|c|c|c|}
\hline \multicolumn{5}{|c|}{ Petrochemical Development in Trinidad and Tobago } \\
\hline Company & Year & Capex & Product & Comments \\
\hline Atlantic LNG I & 1999 & 930 & LNG & \\
\hline Atlantic LNG II & 2002 & 550 & LNG & \\
\hline Atlantic LNG III & 2003 & 550 & LNG & \\
\hline Atlantic LNG IV & 2005 & 1200 & LNG & Under Construction \\
\hline Hydo Agri Trinidad & 1959 & na & Ammonia & \\
\hline Trinidad Nitrogen (Tringen I) & 1977 & 125 & Ammonia & \\
\hline PCS Nitrogen I & 1981 & 333 & Ammonia & Formerly Arcadian \\
\hline PCS Nitrogen II & 1984 & 173 & Granular Urea & \\
\hline Tringen II & 1988 & 350 & Ammonia & \\
\hline PCS Nitrogen III & 1996 & 75 & Ammonia & \\
\hline Farmland/Miss. Chemical & 1998 & 300 & Ammonia & \\
\hline PCS Nitrogen IV & 1998 & 252 & Ammonia & \\
\hline Caribbean Nitrogen Company & 2002 & 300 & Ammonia & \\
\hline N 2000 & 2004 & 315 & Ammonia & Under Construction \\
\hline \multicolumn{5}{|l|}{$\begin{array}{l}\text { Development in Trinidad } \\
\text { and Tobago continued }\end{array}$} \\
\hline T\&T Methanol Co. (ITMC) & 1984 & 183 & Methanol & \\
\hline Caribbean Methanol Co. & 1993 & 200 & Methanol & \\
\hline T\&T Methanol Co. (ITMC) & 1996 & 235 & Methanol & \\
\hline Methanol IV & 1998 & 265 & Methanol & \\
\hline Titan Methanol & 1999 & 261 & Methanol & \\
\hline Atlas Methanol & 2004 & 400 & Methanol & Under Construction \\
\hline N 5000 & 2004 & 520 & Methanol & Under Construction \\
\hline Caribbean Ispat Ltd. & 1980 & 468 & Direct Reduced Iron & \\
\hline Ispat DRI & 1999 & 200 & Direct Reduced Iron & \\
\hline Phoenix Park Gas Processors Ltd. & 1991 & 99 & NGLS & \\
\hline Petrotrin & 1997 & 12 & MTBE & \\
\hline
\end{tabular}

Source: The Macroeconomics of Widening Natural Gas Utilization

1975-1997 Sandra Racha, Zeus 12/03 
In a relatively short time, Trinidad has not only become the supplier of choice for LNG into the U.S., but has also become a world class supplier of ammonia and methanol, products that have seen a series of plant closings in the U.S. over the last five years.

The following pie charts provide a sense of the magnitude of the results.

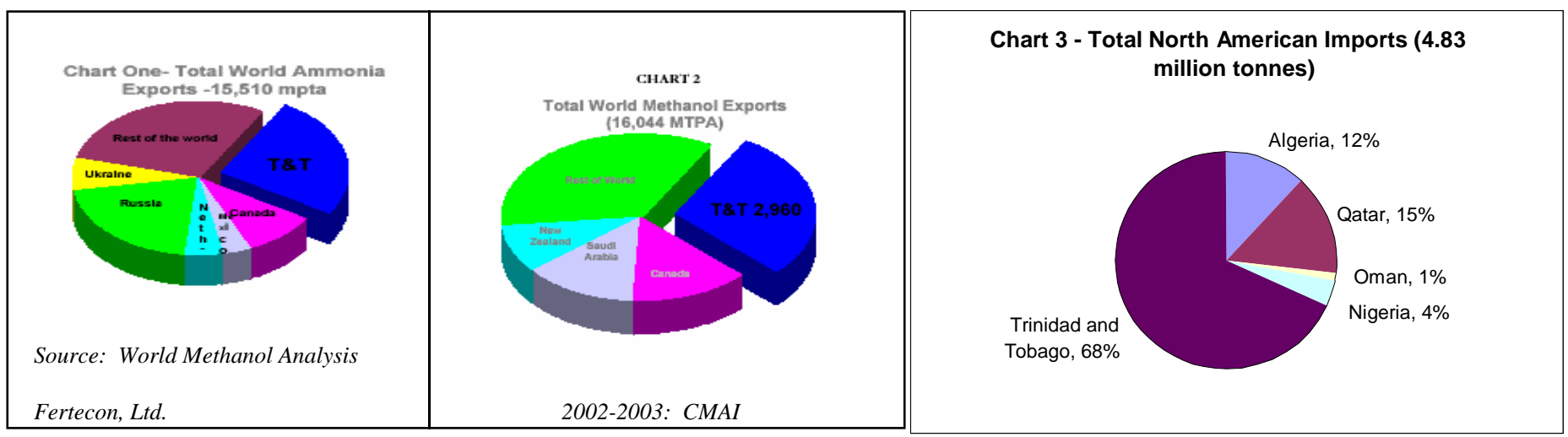

\section{Figure 29}

\section{Source: The Macroeconomics of Widening Natural Gas Utilization}

1975-1997 Sandra Racha, Zeus 12/03

\section{Pipeline Issues}

The pipeline infrastructure of Louisiana, the Gulf Coast and the balance of North America is an asset that needs to be maintained in order to support the needs of all gas consumers. Decisions affecting the placement of new LNG receiving facilities should support the goal of a healthy interstate pipeline system, rather than create disruptions that result in a loss of system reliability or availability. New LNG terminals will generate a negative impact on existing trunk line deliveries of domestic gas within a 400 mile radius of an LNG terminal. The gas pipeline grid can be reset to cover gas demand at alternate destinations, but only at an incremental capital cost, spread over a declining volume base. 
The following slide illustrates the complexity of the existing grid.

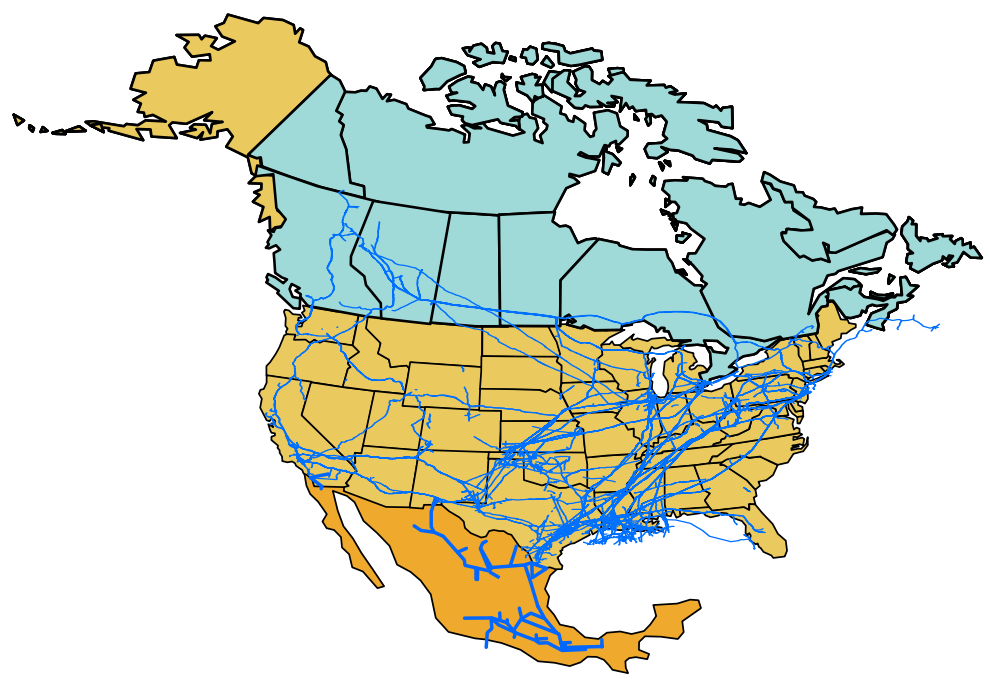

Figure 30 Source: National Petroleum Council 2003 outlook

The financial health of the North American pipeline system will be an issue. Atlantic Seaboard and West Coast buyers will not be anxious to pay dual tariffs. The initial cost associated with landing LNG in Louisiana will be approximately $\$ .40$ /mcf. That will be additive to existing pipeline tolls for moving gas up through the U.S. trunk line network, of approximately $\$ .60 / \mathrm{mcf}$, or a total of $\$ 1.00 / \mathrm{mmcf}$.

East Coast consumers will prefer the option of importing LNG directly and re-gasifying on location. The net savings of $\$ .60 / \mathrm{mcf}$ is not insignificant. As the following chart illustrates, incremental shipping costs will not narrow the gap. Travel distances from international LNG sources to coastal Louisiana can exceed travel distances to relevant population centers such as Boston, New York, Philadelphia, Chesapeake Bay, Georgia, and the Bahamas locations being considered for re-gas plants to feed Florida. 
Table 16: Distances between LNG Sources and Receiving Terminals

\begin{tabular}{|lccc|}
\hline Distances in Nautical Miles & Algeria & Qatar & Trinidad \\
\hline Boston or Fall River Mass. & 3,300 & 8,000 & 2,000 \\
Cove Point, Maryland & 3,700 & 8,400 & 1,900 \\
Lake Charles, Louisiana & 5,000 & 9,700 & 2,200 \\
\hline
\end{tabular}

Source: Weaver's Cove Energy 12/10/03 \& Zeus Development Corp.

Cambridge Energy Research Associates (CERA) generated the following analysis in connection with their review of the impact on interstate pipeline volumes and margins of re-activating the Cove Point facility in Maryland. As can be seen, the addition of 243 million cubic feet of gas/day at Cove Point, during the winter, reduces interstate pipeline deliveries into Virginia, North Carolina, Kentucky, and West Virginia. In addition, gas imported into New York, from Ontario, Canada drops, displaced by re-routed domestic gas from the Gulf.

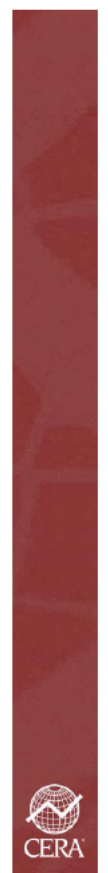

\section{Impact of 2004 Cove Point LNG Imports on Pipeline Flows-Winter Flows \\ (MMcf per day)}

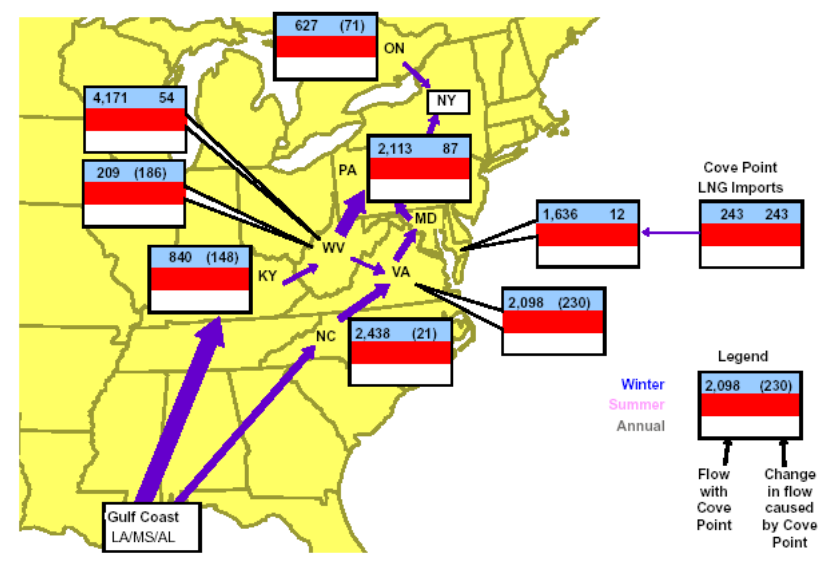

Source: Cambridge Energy Research Asscoites
31002-12

Figure 31 Source: CERA \& Zeus Development Corp., Presentation of 12/03 
The following analysis shows winter, summer and annual impacts of Cove Point receipts.

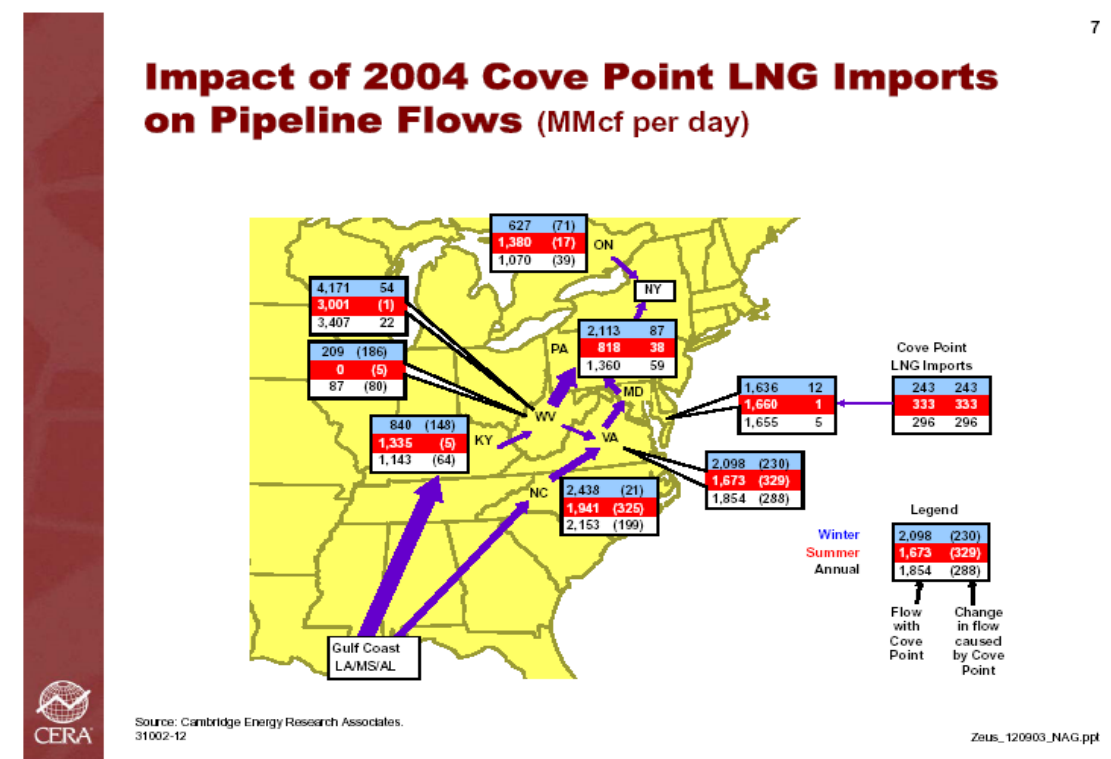

Figure 32 Source: CERA \& Zeus Development Corp., Presentation of 12/03

In another recent study, by McKinsey and Co. the estimated effects of the introduction of 5 BCF/d (roughly 5 terminals the size of Cove Point) would be a reduction from $90 \%$ to $79 \%$ in trunk line utilization with an accompanying drop in average tolling fees from $\$ .60 / \mathrm{mmBTU}$ to $\$ .36 / \mathrm{mmBTU}$. This translates into a $\$ 4.8$ billion "haircut" for the owners of interstate pipelines currently supplying the Atlantic Seaboard market from Maine to Florida. 


\section{LNG IMPORTS TO THE NORTH EAST WILL HAVE A MAJOR EFFECT ON PIPELINE OWNERS AND SHIPPERS HOLDING FIRM TRANSPORT}

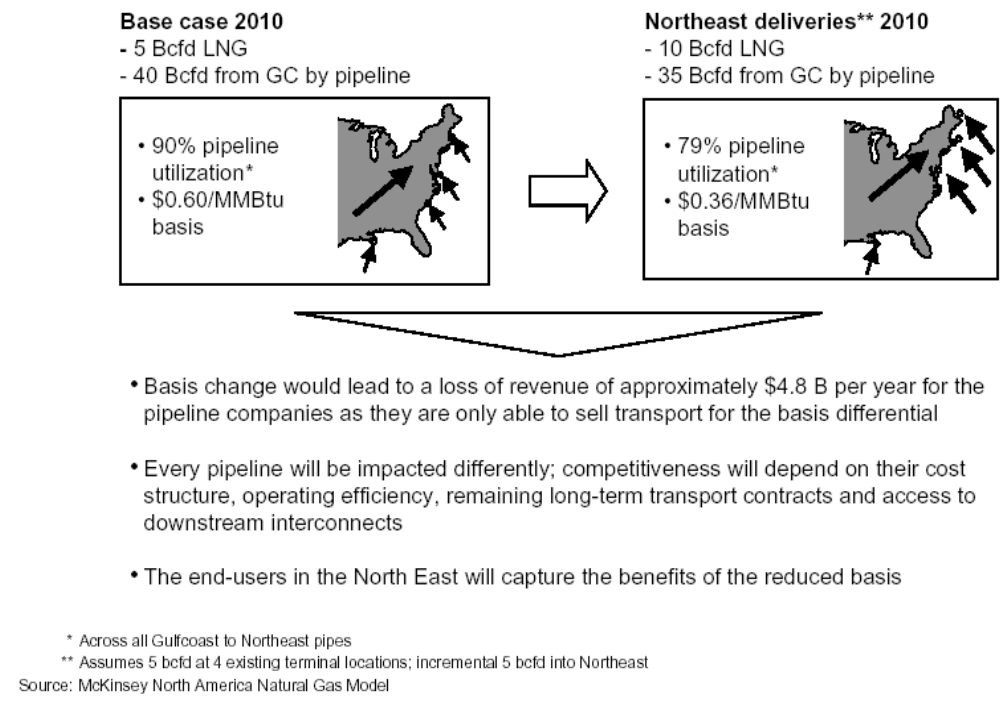

Figure 33 Courtesy of Zeus and McKinsey and Co., 12/03

Once operational, terminals unavoidably generate a negative impact on existing trunk lines, not just at the receiving location, but within an estimated 400 mile radius of the terminals. With time and capital for additional pipeline infrastructure, the interstate gas pipelines can be reset to cover gas demand at alternate destinations, but only at an incremental capital cost, spread over a declining volume base.

The states of New England provide a ready example of what to expect. Although supplied by pipelines from the Gulf and from both eastern and western Canada, they rely for up to 25\% of their total gas demand on LNG imported into the Everett Terminal in Boston. LNG is used locally, it also feeds the Mystic \#1 and \#2 power plants, and it is fed into the regional pipeline grid. In addition, it is also supplied via tank trucks to approximately fifteen satellite locations throughout New England used for surge storage. Additional New England regional LNG marine terminals are under consideration, one in Fall River, just south of Boston, two in Maine and one, just announced by BP, on the New Jersey-Pennsylvania border. 
If we assume a send out capacity of $1 \mathrm{bcf} /$ day for each plant, this equates to up to $4 \mathrm{BCF} / \mathrm{day}$ or 1.5 TCF/year of gas that will not be traveling up from the Gulf Coast or down from Canada.

The following chart, also generated by McKinsey and Company, highlights those areas which are likely to bear the brunt of the negative impact from the creation of additional LNG import capacity. It also illustrates the point that LNG importing locations in the Canadian Maritimes and in the Gulf will likely add throughput to the pipeline system.

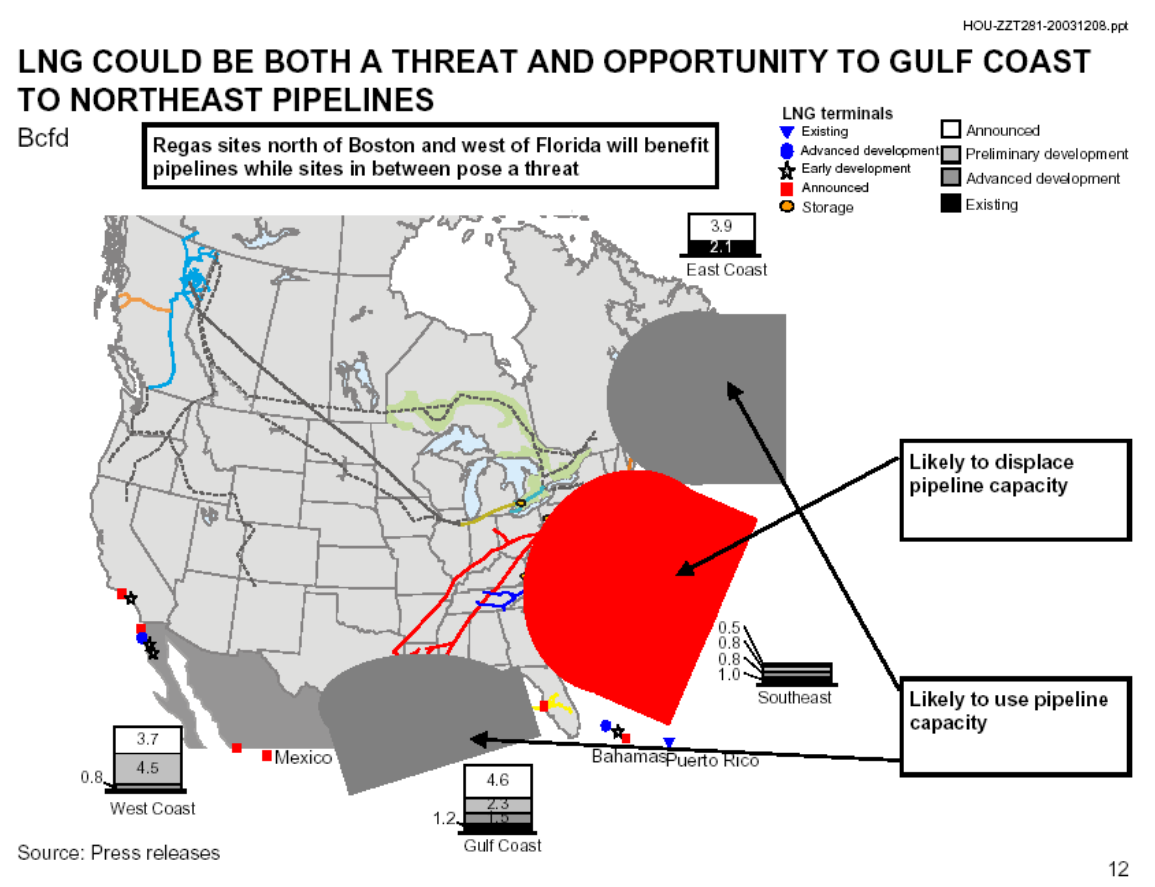

Figure 34 Source: Zeus Development Corp. and McKinsey \& Co., 12/03

The negative situation holds for facilities located in Massachusetts, New York and New Jersey, Maryland, the Carolinas, and in Georgia. It will also hold true for imports into the Atlantic coast of Florida from the Bahamas. In each case, volumes will be displaced from pipelines originating in Louisiana and Texas. While some of that throughput will be replaced by receiving facilities in the Gulf and by deliveries to population centers farther from the coast, the transition will require additional pipeline permitting and investment in order to hold throughput volumes and tolling fees constant. 


\section{$\underline{\text { Storage Considerations }}$}

Given seasonal and volatile demand for natural gas and gas generated power, significant amounts of storage are required in order to guarantee deliverability during the coldest five months of the year. The following chart illustrates the differences in perception between LNG suppliers and LDCs/power generators.

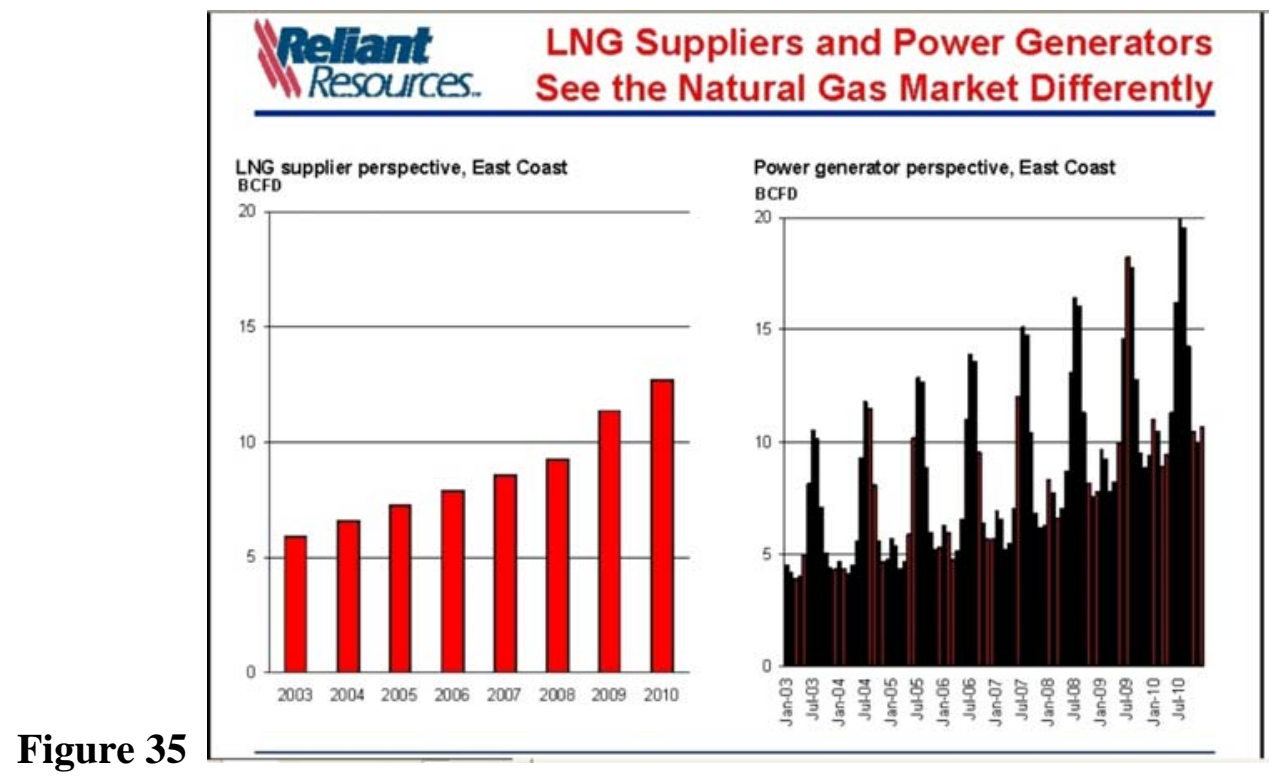

Reliant \& ZDC, 12/03

LNG suppliers have a long supply chain that is highly capital-intensive, typically $\$ 3$ billion from the gas field to the receiving location for send out capacity of $1 \mathrm{bcf} /$ day. They and their funding sources require a uniform off-take that maximizes the utilization of the liquefaction trains and the LNG transportation system. They like the left hand chart.

Historically, U.S. LNG users have been using LNG to meet peak demand situations which occur on a few days within a five month period running from the end of September until the end of February. For them, base demand is perhaps $40 \%$ of peak requirements. They see the chart on the right. The result of these conflicting perceptions is a peak delivery system which is based on above ground LNG storage with very rapid delivery capabilities, since no one would install pipeline capacity to cover these intermittent requirements. Hence, the advent of storage systems.

According to EIA data, for 2001, the U.S. had available inground gross natural gas storage of 8.4 TCF to support consumption of 22.7 TCF in 2002. Conventional inground storage capacity is split between Depleted fields (7 TCF), Aquifers (1.2 TCF), and Salt Caverns (.2 TCF). There are 
a total of 418 storage sites of which 351 are depleted fields, 39 are aquifers and 28 are salt caverns.

Natural Gas suppliers face a long and involved supply network that starts at the gas field, extends through the processing of the raw gas, and includes temporary storage at three points along the major interstate gas trunk lines which span the continent; in the U.S., South central to Northeast, in Canada, West to East. 
The following schematic from HNG Storage, a salt cavern storage company, illustrates this path to market.

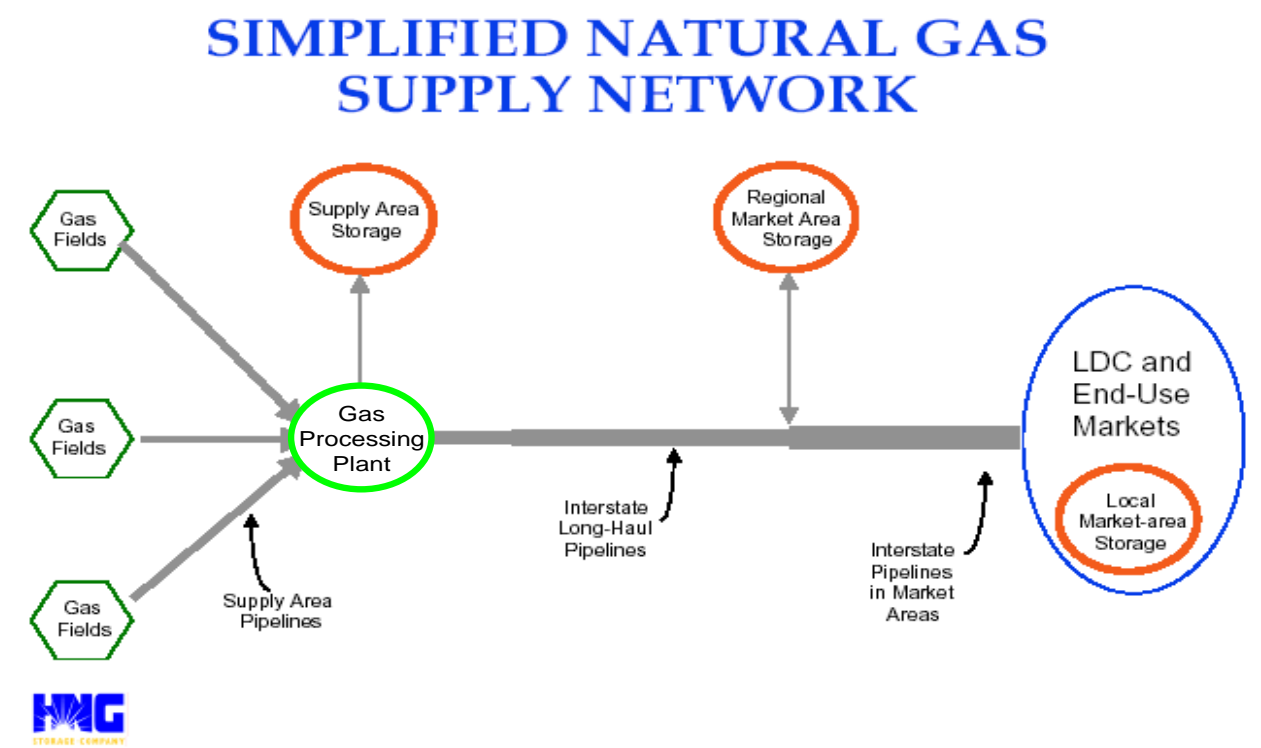

Figure $36 \quad H N G$, Zeus Development Corp., 12/03, ETEI

According to the EIA, of total storage capacity, Louisiana had 14 facilities with storage for .580 TCF. Of these eight are depleted reservoir facilities capable of storing .530 TCF and six are salt caverns able to hold .05 TCF.

Texas by comparison, has a total of 35 storage facilities with storage capacity of .686 TCF of which .605 TCF is in 22 depleted fields and .117 TCF is associated with 13 salt caverns. Texas' capacity for salt dome storage is currently more than double that of Louisiana.

Mississippi had capacity for .134 TCF at seven sites of which .042 TCF were in three salt caverns while Alabama had two locations which can store a total of 5 BCF of which $60 \%$ was in a single salt cavern.

In terms of actual gas volumes stored at September, 2003, the U.S. held 7 TCF in depleted reservoirs and aquifers. Of that subset more than half, or 4.3 TCF was base gas and unavailable for use. The balance of 2.7 TCF represented “working” gas available to handle winter peak 
demand. A characteristic feature of depleted reservoir storage is the relatively slow rate of injection or withdrawal of gas. Basically gas is added at a steady rate for seven months then retrieved during a five month period beginning in October and ending the following February. In effect the inventory turn is once a year and the ability to increase the flow, in either direction, is quite limited. Underground working gas storage will end up the winter season at approximately 1 TCF.

Gas volumes stored in salt caverns are much smaller, at 198 BCF, of which 123 BCF was available and the balance of 75 BCF was considered base gas. As is the case with reservoirs, the 75 BCF of cushion gas, acts to prevent physical damage to the cavern. Salt caverns need relatively less cushion gas and can be filled or drained more quickly, within a four week time frame, vs. the two months required for reservoir storage. Deliverability from salt caverns in order to meet a peak load could be at a rate of $123 \mathrm{BCF} / \mathrm{month}$ or $4.1 \mathrm{BCF} /$ day (albeit only for one month).

The same logic that applies to salt cavern storage also applies to LNG storage. After terminal expansions are complete in 2005, gross storage at the four existing sites will be 28.8 BCF with a maximum send out of $5.5 \mathrm{BCF} /$ day resulting in a time to exhaustion of 5.24 days.

In addition, remote, non-marine LNG terminals have storage capacity of 85.3 BCF and peak delivery of $12.8 \mathrm{BCF}$, so, total LNG peak send out will be $18.2 \mathrm{BCF} / \mathrm{day}$. That equates to $20.6 \%$ of total send out capability of all in-ground storage, $23.2 \%$ of in-ground storage in the Eastern region, $10 \%$ of the West and $1.9 \%$ of the Producing region.* 
Table 17: LNG Storage and Send Out Capacity

\begin{tabular}{|c|c|c|c|c|c|c|c|c|c|c|c|}
\hline \multicolumn{5}{|c|}{ LNG Storage and Send Out Capacity cc 2005} & & & & & & & \\
\hline \multirow[t]{2}{*}{$05-A p r-04$} & & & & \multicolumn{8}{|c|}{ Eastern Region is location of the bulk of LNG StorageCap. } \\
\hline & Alaska & West & Producing & Other East & SASB & New England & New Jersey & Oth NASB & NASB & Consuming East & Total \\
\hline Marine Terminals-Export & 1 & & & & & & & & & 0 & 1 \\
\hline \multirow[t]{2}{*}{ Marine Terminals-Import } & & & 1 & & 2 & 1 & & & 1 & 3 & 4 \\
\hline & & & $25 \%$ & & $50 \%$ & $25 \%$ & & & $25 \%$ & $75 \%$ & $100 \%$ \\
\hline Storage Capacity/terminal & & & 9.3 & & 7.55 & 4.35 & & & 4.35 & 11.9 & 21.2 \\
\hline Total Storage Capacity & & & 9.3 & & 15.1 & 4.35 & & & 4.35 & 19.5 & 28.75 \\
\hline Share of storage Capacity & & & $32 \%$ & & $53 \%$ & $15 \%$ & & & $15 \%$ & $68 \%$ & $100 \%$ \\
\hline Reg Send out & & & 1.70 & & 1.81 & 0.92 & & & 0.915 & 2.7 & 4.4 \\
\hline Peak Send out & & & 1.80 & & 2.54 & 1.15 & & & 1.15 & 3.7 & 5.5 \\
\hline \multicolumn{12}{|l|}{ Non-marine Terminals } \\
\hline Storage with liquefaction & & 8 & 3 & 18 & 12 & & & 16 & 16 & 46 & 57 \\
\hline Storage without liquefaction & & 0 & 3 & 2 & 6 & 14 & 4 & 10 & 28 & 36 & 39 \\
\hline \multirow{2}{*}{$\begin{array}{l}\text { Vehicular fueling } \\
\text { N2 rejection units and other }\end{array}$} & & 1 & 1 & & & & & & 0 & 0 & 2 \\
\hline & & 4 & 1 & & & & & & 0 & 0 & 5 \\
\hline \multirow[t]{2}{*}{ Total } & 2 & 16 & 8 & 20 & 18 & 14 & 4 & 26 & 44 & 82 & 108 \\
\hline & $2 \%$ & $15 \%$ & $7 \%$ & $19 \%$ & $17 \%$ & $13 \%$ & $4 \%$ & $24 \%$ & $41 \%$ & $76 \%$ & $100 \%$ \\
\hline BCF of Storage/facility & 0.66 & 0.66 & 0.44 & 0.50 & 0.96 & 1.00 & 1.00 & 0.96 & 0.97 & 0.85 & 0.79 \\
\hline Storage Capacity & 1.3 & 10.5 & 3.5 & 10.0 & 17.2 & 14.0 & 4.0 & 24.8 & 42.8 & 70.0 & 85.3 \\
\hline \multirow[t]{2}{*}{ Percentage of Storage } & $2 \%$ & $12 \%$ & $4 \%$ & $12 \%$ & $20 \%$ & $16 \%$ & $5 \%$ & $29 \%$ & $50 \%$ & $82 \%$ & $100 \%$ \\
\hline & days & & & & & & & & & & \\
\hline \multirow[t]{2}{*}{ Remote Send Out } & 10.0 & 1.050 & & & & & & & & 0.000 & 1.1 \\
\hline & 6.3 & & 0.556 & 1.587 & 2.729 & 2.222 & 0.635 & 3.941 & 6.798 & 11.114 & 11.7 \\
\hline \multicolumn{2}{|c|}{ Comparable in ground send out } & 10.5 & 30.0 & & & & & & & 48.0 & 88.5 \\
\hline Relative capability & & $10.0 \%$ & $1.9 \%$ & & & & & & & $23.2 \%$ & $14.4 \%$ \\
\hline Combined lower 48 count & & 16 & 9 & 20 & 20 & 15 & 4 & 26 & 45 & 85 & 110 \\
\hline Percentage of Storage & & $9 \%$ & $11 \%$ & $9 \%$ & $29 \%$ & $16 \%$ & $4 \%$ & $22 \%$ & $42 \%$ & $79 \%$ & $100 \%$ \\
\hline Peak Send Out & & 1.1 & 2.4 & 1.6 & 5.3 & 3.4 & 0.6 & 3.9 & 7.9 & 14.8 & 18.2 \\
\hline & & & & & & & & & & & \\
\hline \multicolumn{2}{|c|}{ Comparable in ground send out } & 10.5 & 30.0 & & & & & & & 48.0 & 88.5 \\
\hline \multicolumn{3}{|c|}{ Peak send out Relative capability $\mathbf{1 0 . 0 \%}$} & $7.9 \%$ & & & & & & & $30.8 \%$ & $20.6 \%$ \\
\hline
\end{tabular}

*EIA data, ETEI Format 
Details on the geographic distribution, just in New England, follow in this chart presented by Weaver's Cove Energy, the developer of a proposed receiving terminal in Falls River, Mass. south of Boston:

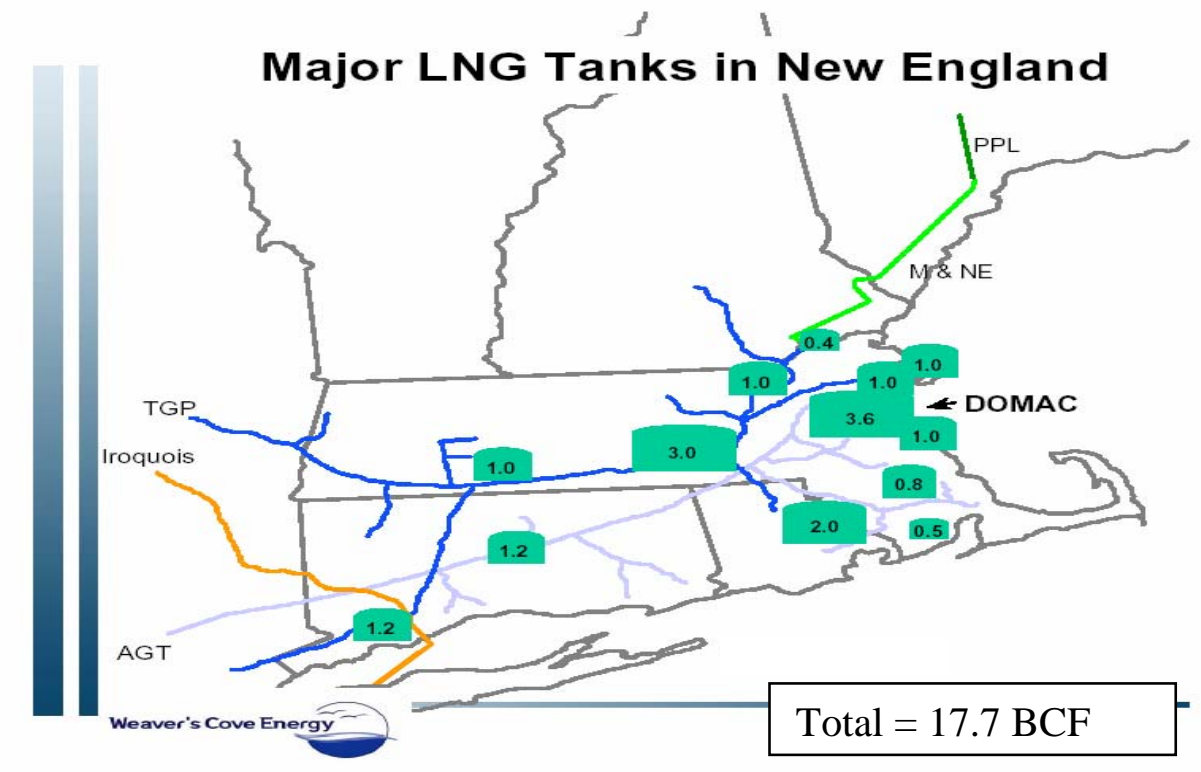

Figure 37

Source: Weaver's Cove Energy \& Zeus Development Corp., 12/03

During 2001, Massachusetts actually received 6.3 BCF and withdrew 6.0 BCF. A year earlier, the state added 4.5 BCF and withdrew 12.0 BCF. Peak flows were in 1981 when 15.2 BCF of gas was received with 12.6 BCF in withdrawals.

In terms of activity at other existing terminals, Maryland brought in 2.9 BCF in 2001 and withdrew 3.7 BCF. While that state's additions peaked in 1996 with 4.9 BCF, the 2001 withdrawal was a record. Georgia added 6.8 TCF in 2001 with withdrawals of only .6 BCF, or a build of 6.2 BCF. Louisiana records are incomplete. 


\section{ENVIRONMENTAL CONSIDERATIONS:}

The following are some of the environmental considerations pertinent to the operation of LNG plants inshore or offshore:

A. In the process of re-gasification of LNG, using submerged combustion heaters, there is a progressive shift in the $\mathrm{pH}$ of the water, which is used as the heat transfer medium. This water may be easily treated before it is returned in the local aquatic environment by one of the following two ways:

1. By mixing this water with significantly larger volumes of ambient water.

2. By chemically treating the water.

Neither of these methods presents any technical challenges and costs to the plant operation will be minimal.

B. Water at ambient temperature must be withdrawn and circulated in heat exchangers throughout the plant. Typically, the water is returned to the environment at temperatures approximately $10^{\circ} \mathrm{F}$ lower than ambient. Because such a temperature difference will have an adverse impact on aquatic life, the following two methods may be used to limit the temperature drop:

1. Designing the heat exchangers and the processes for higher mass of the water to pass through the plant.

2. Mixing the water with ambient water before it is pumped to the environment.

3. A third method is the combination of the facility with a power generation system. The power generation system disposes of a significant amount of waste heat that may be used to restore the water to ambient conditions or to replace the heat added during submerged combustion vaporization. 
C. The use of ambient water in the plant as well as the solutions proposed in parts A and B above, necessitates the use of larger pumps. These pumps will typically be of high volume and low head, similar to the pumps used in fossil fuel power plants for their cooling systems. The pump suction will inevitably cause disturbance to aquatic life. This effect may be minimized by using moving screens at the inlet of the pumps. The technology is well known and the effect of the addition of screens will be minimal to the cost of equipment.

D. Any dredging operations in the channel leading to the plant may disturb the ecosystem. In the case of "brown field" locations the disturbance of the sediment will bring to the surface toxic substances and heavy metals that are attached to sedimentary particles. We have accumulated considerable technical experience with dredging operations and chemical fixing of sedimentary matter to minimize the adverse effects of dredging.

E. An environmental benefit to Louisiana of the increased use of natural gas for power production is in the area of global warming: For a given amount of heat produced, natural gas emits a significantly lower amount of $\mathrm{CO}_{2}$ and other gases that contribute to global warming. Since global warming will eventually cause a sea-level rise and, as a consequence, considerable loss of the Louisiana coastal environment, including vast ecosystem areas, the proposed facility will have a long-term beneficial impact to the coastal environment of Louisiana assuming that imported gas is used preferentially for power generation.

F. A second group of environmental concerns are related to the aesthetic and security issues of the facility: the building of any industrial facility is considered by some to have an adverse effect on the aesthetics of its surroundings. Also, any facility for the processing of flammable or explosive chemicals poses potential safety problems to the surrounding communities as well as security concerns from terrorist attacks. In this case, these concerns are minimized by establishing facilities offshore. In such an offshore location the aesthetic impact to the surroundings is minimal if not absent. Also, the potential risk from a malfunction, fire, explosion or even terrorist attack on the facility would be limited to the facility itself and to its immediate vicinity and will not have any impact on nearby communities. 
Existing onshore LNG plants have been re-activated, expanded and several new terminals, both onshore and offshore, have successfully navigated at least the FERC regulatory process. Given a track record that includes one Alaskan plant operating since 1969, one "lower 48" plant operating since 1971 and a second since 1990, we believe that the environmental issues are well understood. In addition to the two plants in operation since 1990, both Cove Point, in Maryland and Elba Island in an estuary between Georgia and South Carolina have been re-started after long periods of mothballing with no apparent ill effects. 


\section{ImPaCt of LNG Projects on Gas SuPPlies ANd Prices}

According to the EIA, LNG is currently 2\% of domestic consumption, approximately 540 billion cubic feet per year in 2003, and is far outweighed by natural gas imported from Canada, currently up to $20 \%$ of “lower 48 ” U.S. domestic supply. However, we have a declining domestic production base, now at 19 TCF/year including both offshore and onshore. And, Canada's ability to export to the US shortfall is stagnating at around 4 TCF/year.

Given limitations on alternate sources, forecasters assume that imported LNG will be the primary source of marginal supply in the near future. They expect LNG gross imports to climb to 2.2 TCF/year and to garner as much as an $8 \%$ market share by 2010 . That growth will continue through 2025 when demand will reach 31 TCF/year. At that point gross imports will be 4.8 TCF/year and represent 15\% of supply. The following chart gives some idea of the EIA's forecasted increase in net LNG imports.

\section{Growing Net Imports of LNG in TCF/year}

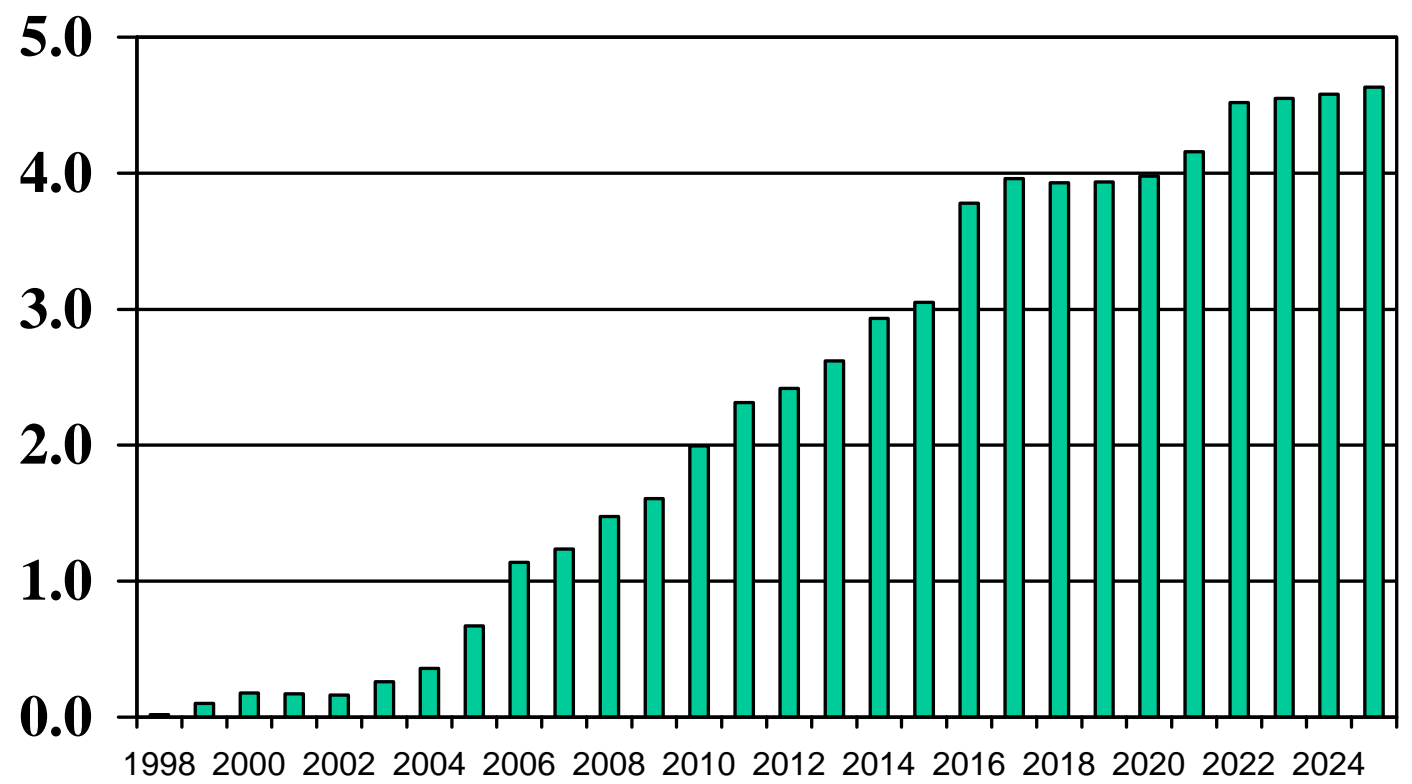

Figure 38

Sources: EIA AEO-2004 
The quadrupling of market share in seven years (2003-2010) requires immediate expansion of existing import terminals. In addition, up to 10 new units are needed in the U.S., along with two to three units in Mexico, and one or two in Canada, if North American demand is to be met. LNG imports now arrive through four re-gasification terminals constructed from the early 70s through the early 1980s. Three of these plants are on the Atlantic Seaboard and one is on the Gulf Coast.

During the last 20 years, two of the Atlantic seaboard units were mothballed and the remaining two plants, one in Boston and the other in Louisiana, operated well below rated capacity, more as static storage and peak shaving units than to satisfy base load demand.

The existing terminals are located in Everett, Massachusetts, Cove Point, Maryland, Elba Island, Georgia, and Lake Charles, Louisiana. Illustrations of these plants, their ownership and supply details follow: Everett is the oldest terminal and the only unit to remain in continuous operation since its construction in 1971.

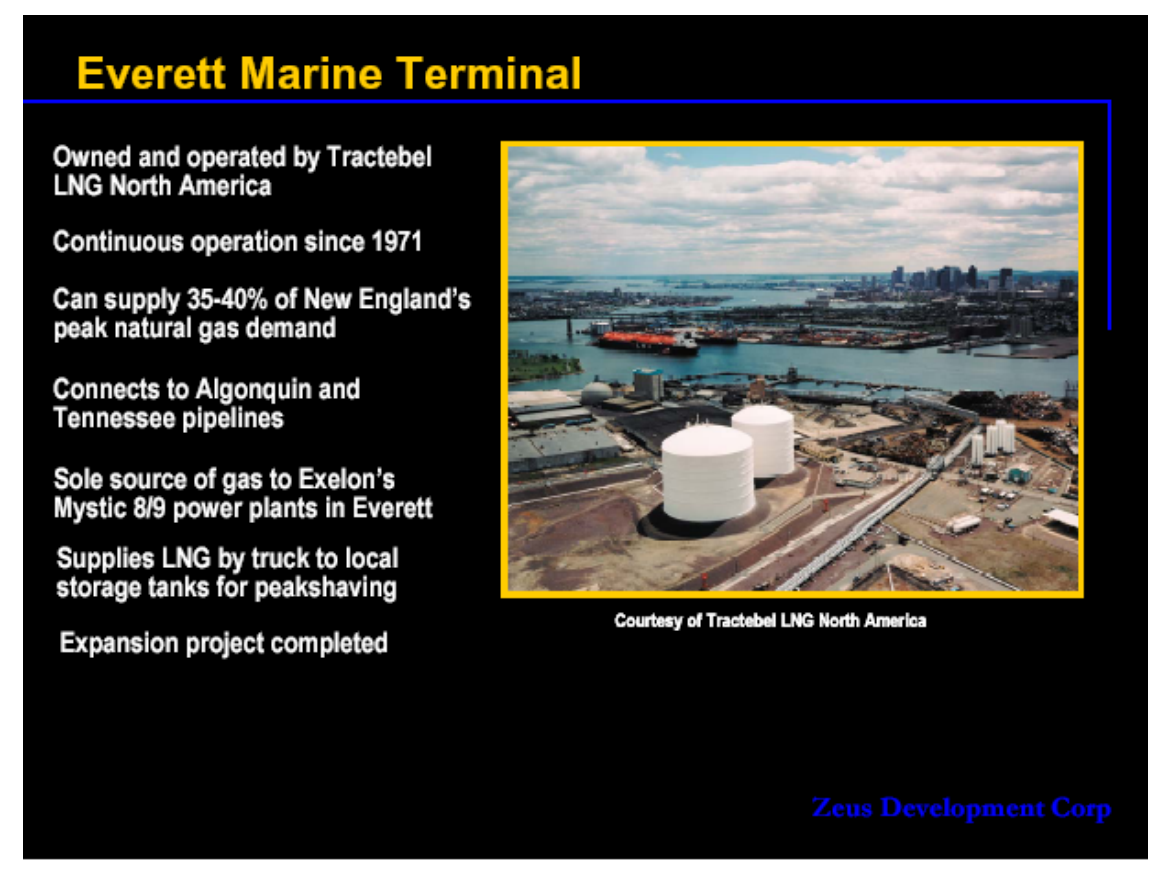

Figure 39

Source: Zeus Development Corp. \& Tractabel, 12/03 
Lake Charles is the newest terminal. It was mothballed and then was re-commissioned in 1990 and has been in operation continuously since 1990 .

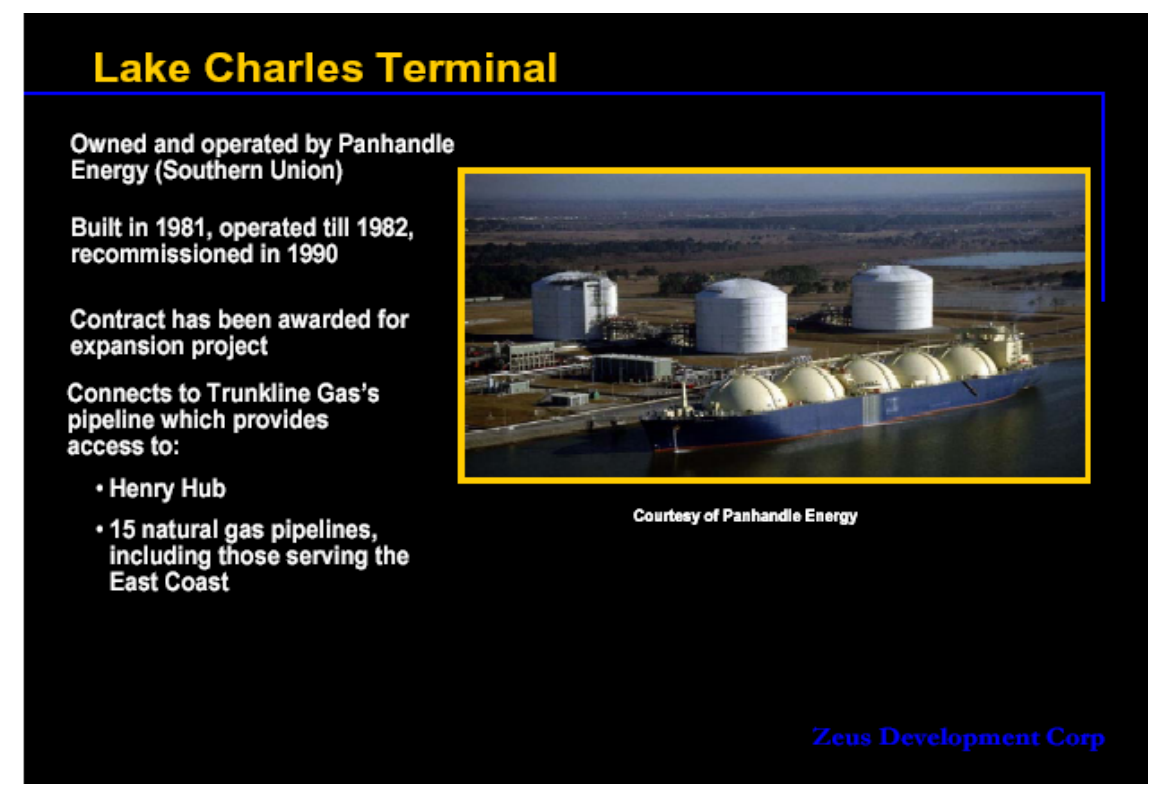

Figure 40

Source: Zeus Development Corp. \& Panhandle Energy (now Southern Union), 12/03

Elba Island, located near Savannah, Ga. On the border with South Carolina, was commissioned in 1978, operated until 1982, and was then mothballed until 2001. Just recently, El Paso has ceded its remaining claims on capacity to Shell. Details follow:

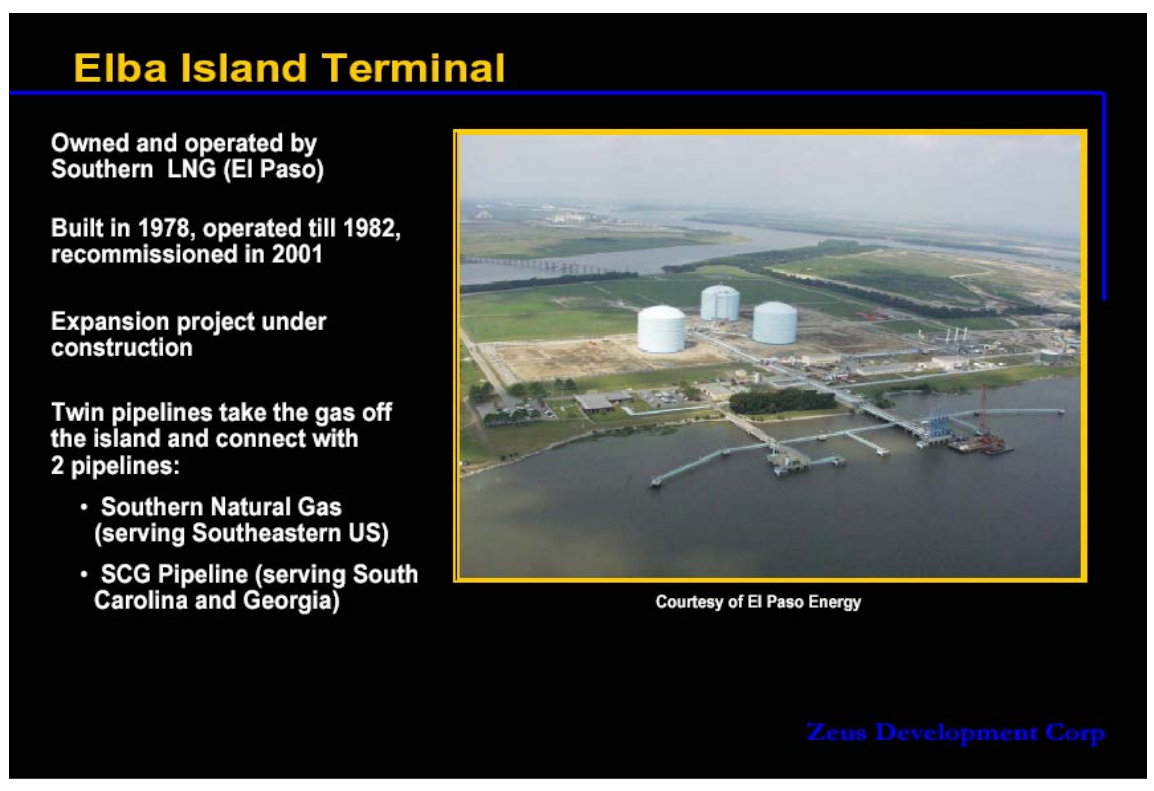

Figure 41

Source: Zeus Development Corp. \& El Paso, 12/03 
Finally Cove Point is the last of the mothballed terminals to come back on stream. This facility originally brought on stream in 1978 has undergone an expedited re-commissioning and is now back on line after a 23 year hiatus.

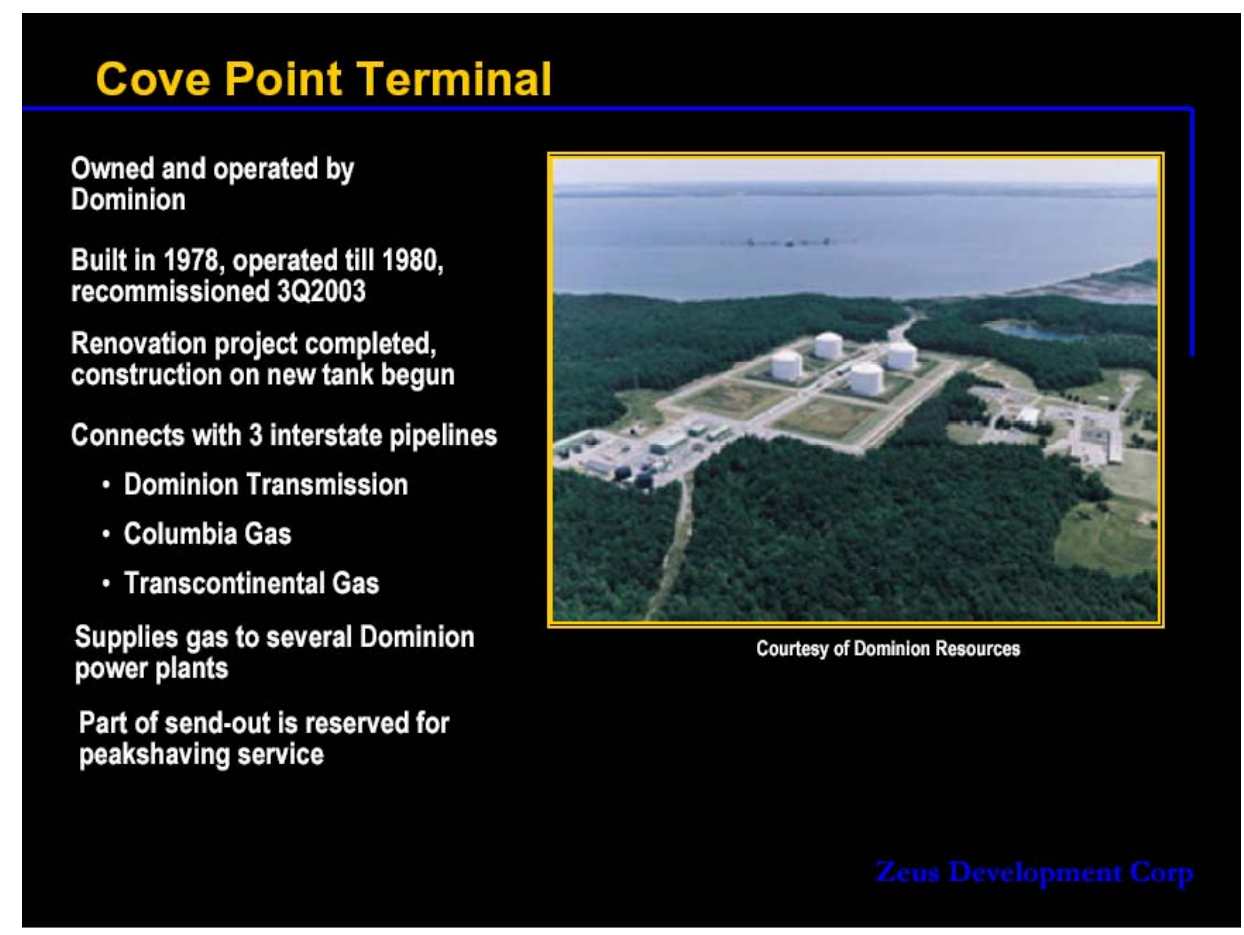

Figure 42 Source: Zeus Development Corp. \& Dominion, 12/03

LNG terminals are rated on both their absolute storage capacity as well as their "send out" capacity, a measure of how quickly they can vaporize LNG and send it out through the pipeline system. Send out capacity is further defined in terms of peak capacity vs. steady state capabilities. Details on the existing plants, both before and after expansion follow. 
Table 18: Capacity at Existing Terminals Before \& After Expansion

\begin{tabular}{|c|c|c|c|c|c|c|c|c|}
\hline & online & Storage & $\begin{array}{c}\text { Send } \\
\text { out }\end{array}$ & Peak & $\begin{array}{c}\text { Peak } \\
\text { Turnover }\end{array}$ & Capex & Berths & Pipelines \\
\hline $\begin{array}{l}\text { Existing } \\
\text { Facilities }\end{array}$ & & $\mathrm{Bcf} / \mathrm{d}$ & Bcf/d & Bcf/d & Days & $\mathrm{mm} \$$ & & \\
\hline Everett Mass. & 1971 & 3.5 & .435 & .550 & 6.4 & & 1 & Algonquin, Tennessee \\
\hline $\begin{array}{l}\text { Cove Point, } \\
\text { Maryland }\end{array}$ & 1978 & 5.0 & .750 & 1.00 & 5.0 & & 2 & $\begin{array}{l}\text { Dominion, Columbia, } \\
\text { \& Transcontinental }\end{array}$ \\
\hline $\begin{array}{l}\text { Elba Island, Ga. } \\
\text { Lake Charles. }\end{array}$ & 1978 & 4.0 & .446 & .675 & 5.9 & & 1 & Southern NG, SCG \\
\hline La. & 1982 & 6.3 & 0.63 & 1.00 & 6.3 & $80+$ & 1 & Henry Hub=15 lines \\
\hline $\begin{array}{l}\text { Existing } \\
\text { Facilities }\end{array}$ & & & & & & & & \\
\hline Expanded & & & & & & & & Gas sources \\
\hline $\begin{array}{l}\text { Everett Mass. } \\
\text { Cove Point, }\end{array}$ & 2002 & 4.35 & 0.92 & 1.15 & 3.8 & 100 & 1 & Trinidad \\
\hline $\begin{array}{l}\text { Maryland } \\
\text { Elba Island, Ga. }\end{array}$ & 2005 & 7.8 & 1.00 & 1.32 & 5.9 & 225 & 2 & Trinidad, WA, Norway \\
\hline (pipeline & & & & & & 145 & $1+2$ & \\
\hline limited) & 2006 & 7.3 & .806 & 1.22 & 6.0 & & & Trinidad and Shell \\
\hline $\begin{array}{l}\text { Lake Charles, } \\
\text { La. }\end{array}$ & 2006 & 9.3 & 1.20 & 1.30 & 7.2 & 477 & $1+1$ & Trinidad \& WA \\
\hline
\end{tabular}

Data courtesy of Zeus Development Corp.and EIA Jan, 2003 report

\section{$\underline{\text { LNG Supplies }}$}

LNG is imported from several sources with Trinidad and Tobago dominating, followed by Algeria. Trinidad supplied approximately $77 \%$ of North American LNG demand in 2003. In the $3^{\text {rd }}$ quarter of 2003 it supplied 90\%, with other sources dividing the balance. In order to penetrate the U.S. market LNG's delivered price needs to equal the near term, existing market price for domestically produced gas delivered at Henry Hub under relatively short term contracts (less than 3 years) plus the toll to move that gas to particular geographic markets.. 


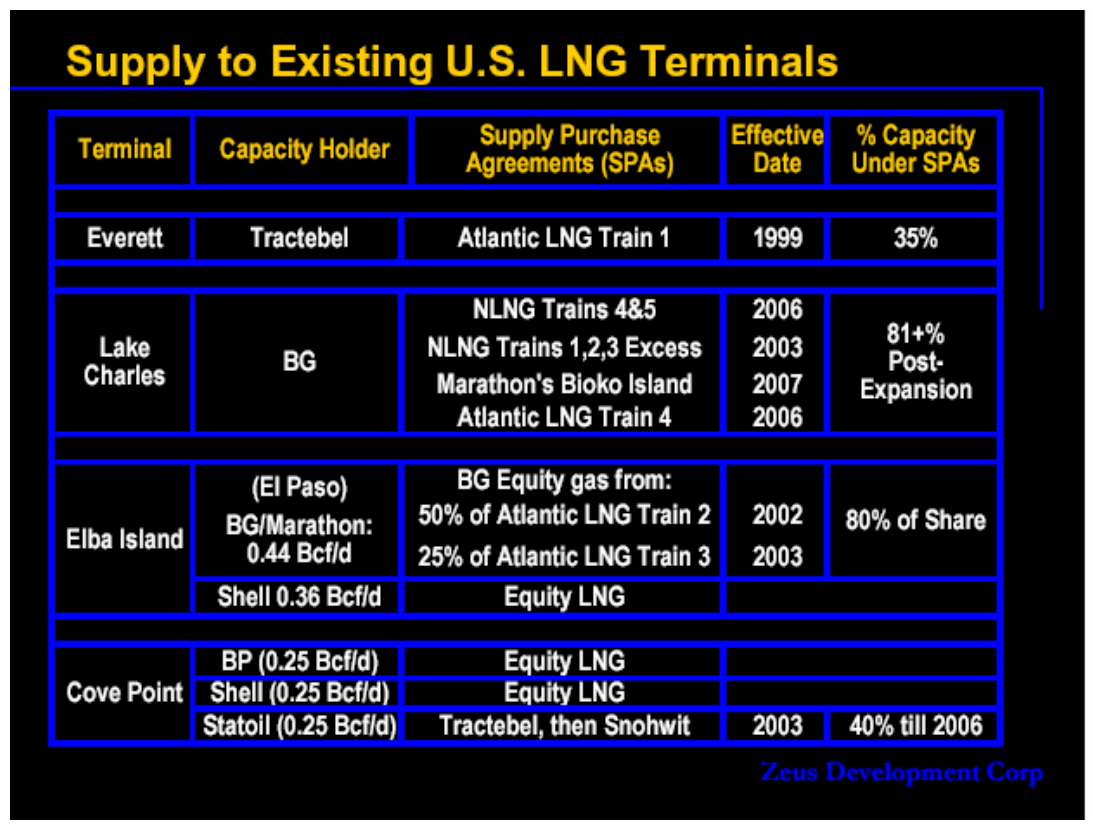

Figure 43

Source: Zeus Development Corp., 12/03

Other than Trinidad, available LNG has to travel farther to reach the U.S. than it does to reach other international receiving locations. Secondly, virtually all international LNG transportation facilities have been built using non-recourse project financing based on long term "back-to-back" supply and purchase contracts with terms on the order of 25 years. The result is that, absent Tractabel, the U.S. Atlantic and Gulf Coast terminals are typically “markets of last resort” attracting only occasional spot deliveries of non-committed or surplus LNG supplies. This explains the variety of sources supplying the U.S., despite its historically small consumption of LNG.

Trinidad is our current major source, having supplied 77\% of imports in 2003. Venezuela could well become a major supplier, if politics stabilize and its offshore gas fields, such as Deltana, are developed. In the meantime, West Africa and the Middle East are slated to become major suppliers because of large volumes of stranded gas available there that are linked to Major oil companies with existing infrastructure along the Gulf Coast.

These companies have acquired or are building liquefaction capacity at the source, gaining access to ship capacity and acquiring terminal capacity in the U.S. As far as the U.S. is concerned, the four existing terminals will be base loaded on LNG from Trinidad, Nigeria, and 
eventually Norway. Algeria will continue as an opportunistic supplier, although its major clients will remain European, because of proximity.

By 2010, each of the four existing terminals will have been expanded and new terminals will either be functioning or in the final stages of construction so that LNG will then represent approximately $8 \%-10 \%$ of national supply, and we will be importing approximately 2.2 tcf/year of natural gas. That figure is projected grow to $4.8 \mathrm{TCF} /$ year by 2025 at which point it will represent over $15 \%$ of supply, roughly the role held by Canada today and slightly smaller than the volume provided by Louisiana in 2003.

During the latter half of 2003, Mexico imported gas from the U.S. at rates peaking at close to one TCF/year, using ten onshore pipelines between Baja California and Matamoros. In the future, imported LNG will be landed in Mexico, on both coasts, and will be utilized primarily to generate electrical power, which will be used on both sides of the border.

In addition, Mexico could eventually be capable of supplying the southwestern U.S. with incremental gas and power using domestically produced gas. Mexico has plans to develop its onshore gas reserves that parallel the US border (the Burgos Basin). These resources can mitigate the increasing north-south exports of gas that take place as a result of growth rates in Mexico which exceed 6\%/year. Unfortunately, Pemex does not have the capital to develop these reserves while also attempting to maintain oil output.

As many as four LNG re-gasification terminals could operate in Mexico by the end of the decade. One or two will be located in Baja, Mexico, with a third further south. They will serve the West Coast of North America. One of the Baja terminals will be owned jointly by Sempra, a large gas consumer, and Shell a major supplier, and will use LNG imported from Indonesia. Other gas will be provided from Australia. A fourth plant is slated to supply gas to Mexico’s northeast coast. 
New LNG receiving stations need to be approved and brought on stream with alacrity. As the following graph illustrates, the closer to full utilization one gets, the more volatile is the resultant gas pricing.

\section{Figure 44 High Utilization is Linked to Gas Price Volatility}

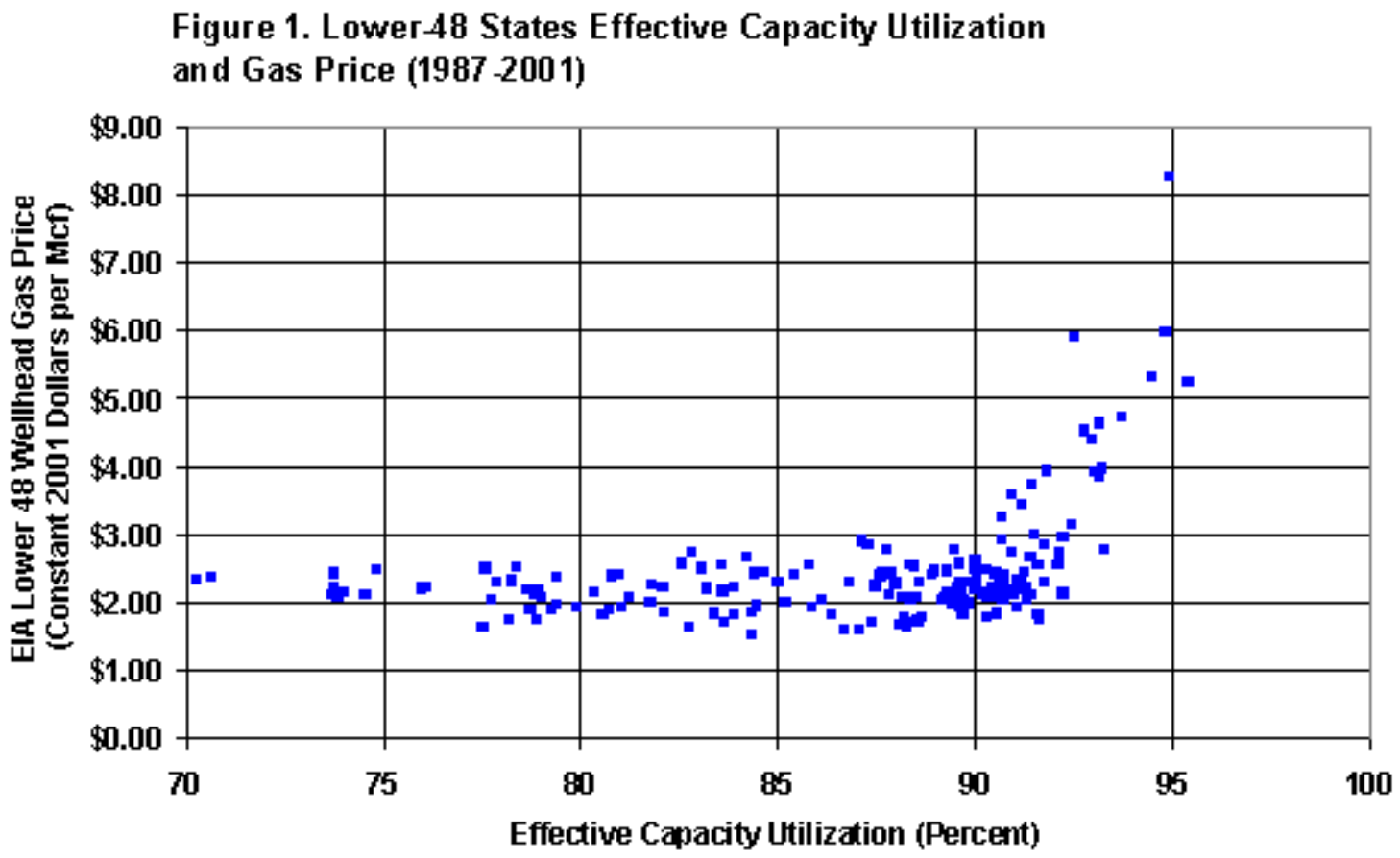

Source: Energy hformation Administration, Office of Dil and Gas, Reserves and Production Division.

Source: EIA 2003

Below 90\% utilization, wellhead gas prices have ranged between $\$ 1.50$ and \$3.00/mcf. However pricing becomes extremely volatile once effective utilization reaches $90 \%$. Beyond $90 \%$ historical prices have quickly escalated into the \$6-9.00 range. 
The following chart, illustrates locations and capacity additions needed to prevent shortages. The left hand chart shows existing North American locations in red while the right hand chart details existing capacity in red, expansion potential in pink, and capacity to be added with new locations, in tan. We've assumed that over half of the new terminals actually built will be located in the Gulf region.

\section{NG Imports A re Needed, But Face Obstacles}

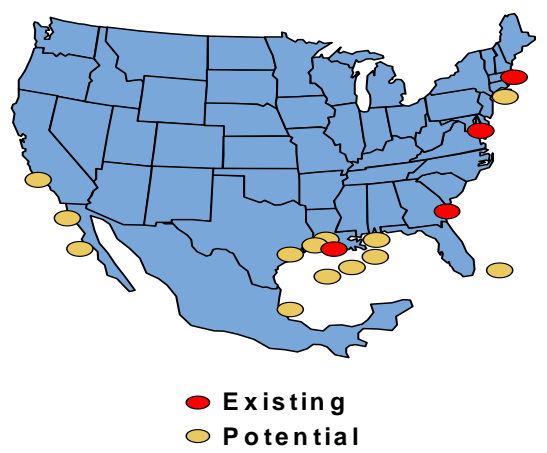

Potential

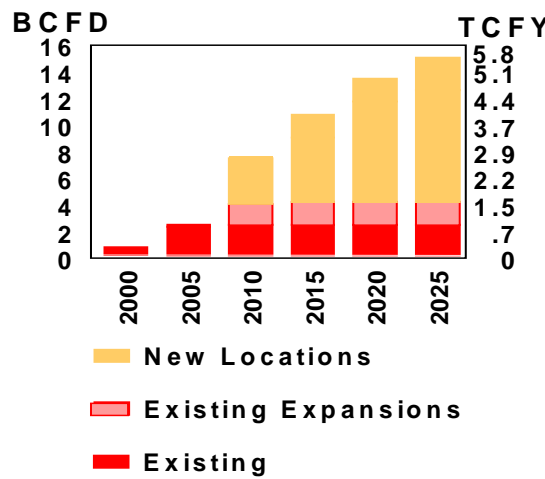

Figure $45 \quad$ Source: National Petroleum Council 2003Outlook and Tulane

The results of delays in approving new LNG receiving terminals will negatively impact gas pricing going forward. Conversely, a policy of streamlining permits and limiting appeals can produce significant reductions in aggregate gas prices and price volatility borne by consumers.

Even if LNG terminals receive permits without delays, there is also a need to support a balanced portfolio of fuel types, particularly in power and industrial applications. This would act to dampen demand for gas. Right now, coal, fuel oil, and nuclear power face serious regulatory hurdles because of perceived issues of safety and pollution. The estimate is that a price swing of approximately $\$ 3.00$ is possible (high to low) with a more enlightened policy towards the use of alternate fuels in power generation. 


\section{LNG Imports Can Lower Costs to Consumers}

Process LNG project permits within one year.

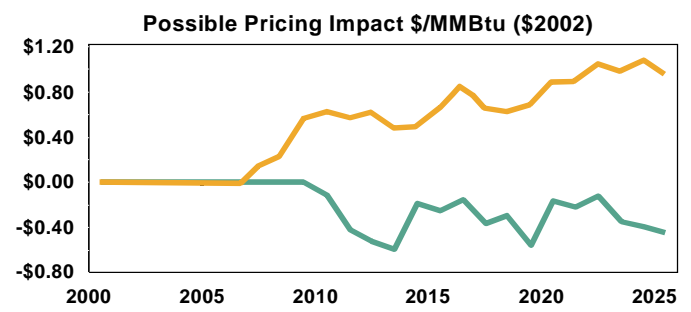

Figure 46

Source: National Petroleum Council, 2003, Outlook and ETEI

A Balanced Fuel Portfolio is

Essential

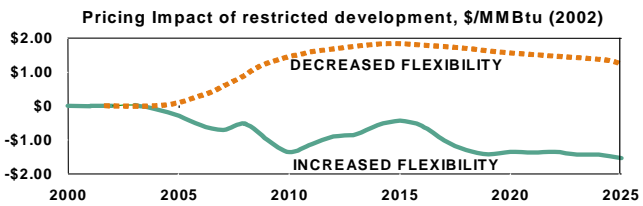

Figure 47

Source: National Petroleum Council 2003 Outlook

A corollary issue is the loss of flexibility resulting from the widespread use of combined cycle power generation. The older steam cycle plants were equipped with dual fuel capability which led to a natural arbitrage between oil and gas prices. The new plants can only burn natural gas, disrupting the linkage between oil and gas pricing. As gas-on-gas competition has shut down older, less efficient plants, flexibility needed to moderate price volatility has been lost. 


\section{Increased Access Lowers Costs to Consumers}

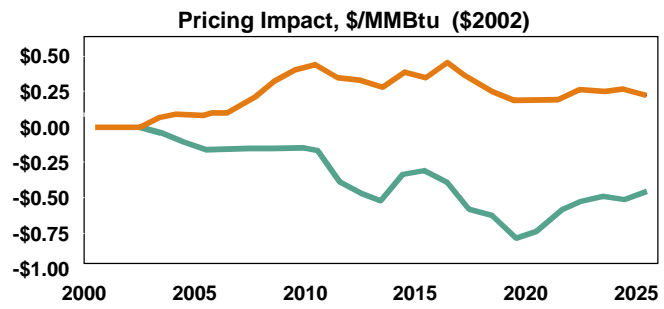

Figure 48

Source: National Petroleum Council, 2003, Outlook

Similarly, increasing access to existing gas resources in the lower 48 states, now subject to moratoria, can lower gas prices by increasing supply that is accessible through existing infrastructure. Here a decline in the use of natural gas by industrial consumers is already apparent.

Demand Destruction in North America has made Trinidad a world leader in methanol and ammonia production, in addition to being our lead supplier of LNG. The following chart

\section{Higher Prices Impact Domestic Industrial}

\section{Growth}

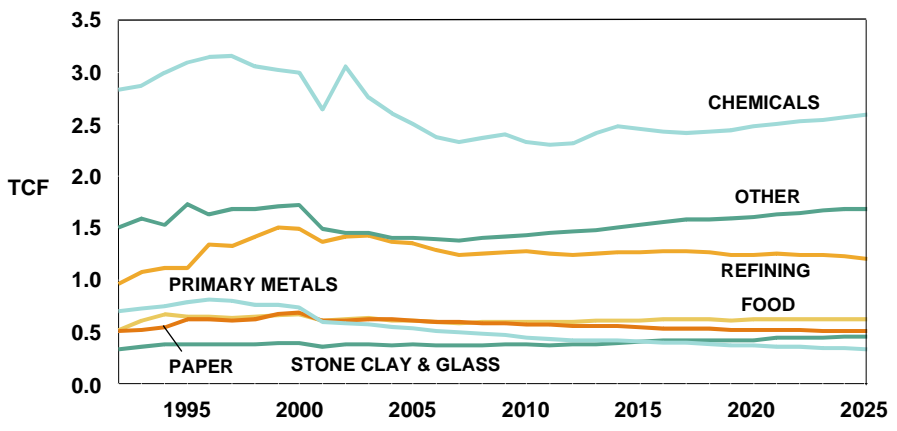

Figure 49

Source: National Petroleum Council, 2003, Outlook 
outlines the historical and anticipated decline in industrial gas consumption as a result of higher gas prices and continued gas price volatility. Generally, the high the share of product cost associated with natural gas, the greater the impact.

Non-proprietary, energy intensive products other than chemicals, show the same pattern, including primary metals production, refining, and various refractory products. 


\section{Recommendations and Policy Implications}

Re-tooling the U.S. to operate on imported LNG will be a massive, multi-year effort requiring a concerted effort by government, gas providers, gas transporters, gas storage companies, and gas users. The sooner we get started, the less disruptive will be the transition.

Unfortunately, there is a fundamental conflict between users of gas on the Atlantic Seaboard, who prefer the lower tolling costs of axial distribution patterns emanating from local LNG receiving terminals to the more costly option of landing gas on the Gulf Coast and shipping it through existing pipelines to the East Coast of the US.

Partially offsetting this effect is the certainty of conflict in the regulatory regime associated with site selection at any onshore location, with the Atlantic Seaboard and California being the most problematic areas.

While there will be construction benefits associated with constructing new terminals, the beneficial impact will be diluted due to limits on our ability to supply key components of these facilities. In the case of Louisiana plants, only $60+\%$ of the work scope can be handled locally.

However, Louisiana and the other Gulf Coast states should actively encourage the location of unloading facilities in their areas. Each of these plants will cost $\$ 500-700 \mathrm{~mm}$ and will require up to 1,600 construction workers over a period of 5-6 years to bring on line. Each new unit will also generate 50-100 permanent jobs.

Assuming standard multiplier effects, we expect to see spending on new plants in Louisiana on the order of $\$ 2.3$ billion over a 6 year period with multiplier effects increasing that impact to $\$ 4.9$ billion.

We should also actively encourage the development of new, salt cavern storage. According to the NPC and the EIA studies, up to 700 billion cubic feet of new storage will be needed. These facilities are low profile, and they will help to diminish the volatility associated with natural gas when supplies are short. 
Louisiana and Texas should work cooperatively to maintain the presence of the petrochemical industry by providing priority access to imported LNG as a feed stock for these plants.

Louisiana should consider applying traditional business development techniques to maintaining the presence of process plants that are highly dependent on stable, affordable natural gas supplies. The 30,000 jobs involved generate wages that exceed the state average by $64 \%$.

Louisiana and Texas should also work to support the power generation industry by providing priority access to imported LNG as a fuel for power generation.

Louisiana should consider supporting the development of onshore receiving terminals, integrated gas separation units and combined cycle power plants capable of utilizing C-2s through C-4s in the imported gas stream. The technical synergies are significant. 


\section{Future Research Options}

Multiple options exist for a more detailed review of the economic effects associated with the transition to LNG as a base energy source for North America, the U.S. and Louisiana. Each of the areas touched on in this report is deserving of additional study. However, on a priority basis, the following studies need to be undertaken sooner rather than later.

Funding sources for the following studies is the first priority. Then we need to organize to undertake the following studies:

What are the relative economics of onshore vs. offshore unloading?

What are economically quantifiable benefits of salt cavern storage vs. LNG above ground storage?

What are the options, including power generation, for integrating LNG, with its higher btu content, into the existing pipeline and power grids.

What options exist for renovating existing, idle steam reforming capacity associated with defunct ammonia production?

What is the impact on the agricultural community from using imported fertilizer vs. the domestically produced variety?

What are the opportunities for shipping, receiving and storing products, such as methanol and ammonia, as they shift to offshore sourcing?

What are the options for reuse of interstate pipeline capacity and onshore gas processing plants made redundant by Atlantic Seaboard LNG receiving facilities? 


\section{Bibliography}

1. American Energy Solutions, Inc., North American Natural Gas, Are We Running Out? 2003.

2. Baltimore Sun, $7 / 26 / 03$, Cove Point Start Up, 12/19/03, Sempra Inks deal for Indonesian LNG from BP to Supply Planned Mexican Terminal.

3. Bloomberg, 6/16/03, Norwegian Shipper Bergesen Aims for Top Spot in Natural Gas, with 9 vessels will be in top three outside of oil company fleets; 1/15/04, Exxon Mobil plans second Gulf Coast LNG Terminal near Corpus Christi; 1/27/04, Unocal, El Paso Stow Natural Gas in Reef, Caverns. 62 new facilities planned for next 3 years, of which 10 involve salt domes where gas can be withdrawn 8 times faster than with reservoir storage.

4. Boston Herald, 1/17 /04, Reliance on gas comes with risks; Cold snaps, low supplies drain plants.

5. Catell, Robert, CEO, KeySpan is likely to retool and expand Providence RI LNG storage site into a full-service LNG regasification facility.

6. Cospolich, Jim, Waldemar S. Nelson and Company, Salt Caverns add Spice to Storage Government funded full scale trial of Bishop Process to take place in April at Cherokee Peak Shaving Plant north of Atlanta.

7. Dallas Morning News, Sudeep Reddy, 2/12/04, Liquefied Gas Slowly Catches Fire in US. Houston Experts Say.

8. EIA Energy Picture, 8/22/02.

9. $\quad$ EIA US LNG Markets and Uses, 1/03.

10. EIA International Energy Outlook 2003, Key Issues to 2025.

11. EIA Natural Gas Productive Capacity for the lower 48 States 1985-2003. 
12. EIA Natural Gas Annual Dry Production, by State, Export Volumes by Point of Exit.

13. EIA North America, The Energy Picture, Prepared by North American Energy Working Group June, 2002.

14. EIA The Global Liquefied Natural Gas Market Status and Outlook 12/03.

15. EIA Louisiana Natural Gas Annual Supply and Disposition Balance, US and La. Salt Cavern Storage, Natural Gas Net Imports and Receipts, Import Volumes by Point of Entry, Details on Mexican and Canadian exports to US, Natural Gas Production and Use by Louisiana, monthly data 1998-9/2003.

16. EIA Annual Outlook 2003, EIA Annual Outlook 2004.

17. Electric Light and Power, 12/22/03, Shell and Sempra plan to form 50-50 JV to Build, Own and Operate a $\$ 600 \mathrm{~mm}$ LNG receiving terminal in Mexico.

18. Energy Central Professional , 7/22/02, Mexican Natural Gas Imports increase by 138\% in June; 1/16/04, EIA Says Long Term Gas Supply Picture Not So Rosy, Quotes from Annual Energy Outlook 2004.

19. Excelerate Energy LLC announces Energy Bridge status.

20. Farrell, S., Presentation of PFC Energy to NOIA Washington Meeting, March, 2003.

21. Fort Worth Star-Telegram, Dan Miller, 2/2/04, US Looking at Liquefied Natural Gas to Supply Energy Needs.

22. Greater Baton Rouge Business Report, 3/16/04, Liquefied Natural Gas could stabilize prices for Louisiana Industry.

23. Houston Chronicle, Michael Davis, 11/10/02, Pipedreams-Plans to build 4 gas plants may be first wave or end up all wet. Dow Chemical reserves thruput at Cheniere Energy’s proposed LNG terminal in Freeport Texas; 11/23/03 LNG is Available but Access the Issue. 
24. Houston Business Journal, Monica Perin, 2/20/04, Shell Energy venture proposes to ship Russian LNG to the West Coast.

25. IMA Associates - LNG Ships 1994.

26. Industrial Information Resources, Inc., Lists of LNG Projects 8/3, 9/9, 10/15/03; 10/15/03, Enbridge and Gaz Metropolitain to Develop new LNG Receiving Terminal in Quebec; 4/10/02, Aquila Merchant Services Group Plan New 12 bcf Natural Gas Complex in Liberty, Texas; 7/23/02, BP Moss Point \$40 mm Natural Gas Processing Plant Expansion Nears Construction; 7/30/02, Dynegy Completes Expansion at its Chico, Texas Natural Gas Processing Facility.

27. Marquez, James, HMRI, 12/15/03, List of over 50 publicly traded companies involved with LNG, worldwide.

28. National Gas Intelligence Power Market Today, 9/26/03, NPC Study recommends Removal of Offshore Drilling Bans starting in 2005; 10/15/03, FERC Warned to Tread Lightly in Adjusting Quality Specs (btu content) to Accommodate LNG;1/14/04, Energy and Environmental Analysis, Inc., EEA: Gas Market Could remain at full throttle over next two years; 1/19/04, ExxonMobil, Eyeing 4 US LNG Terminals, Inks \$12 billion supply deal with Qatar; 1/19/04, Shell Plans Offshore LNG Terminal Offshore Louisiana; 1/21/04, Higher Distillate Oil Prices, ,Less Gas from Canada Boost US Gas Prices;1/25/04, Mitsubichi to file for LNG Terminal in Long Beach, Ca., Crystal Energy LLC LNG Receiving Site seeks Federal, Local Approvals to deliver Alaskan LNG to Santa Barbara Channel; 1/26/04, AES Bahamas LNG Project gets FERC Authorization, Canada Needs LNG Too; 1/28/04, Second Bahamas-to-Florida Pipeline Closes in on FERC Certificate; 2/2/04, BG, Trunkline Plan Pipeline, Phase II Expansion for Lake Charles LNG Terminal; 2/2/04, Petal Gas Announces Open Season for Storage Services Starting 4/1/04 at Petal Miss 9.5 bcf salt cavern storage facility; 2/5/04, Report by Credit Sights forecasts more international expansion for domestic producers with further declines in domestic production. 
29. National Petroleum Council Preliminary Report September, 2003, National Petroleum Council Presentation at NOIA Fall Meeting September, 2003.

30. Offshore Engineer Marshall Deluca, 12-03, Details on Port Pelican at WC 213. Details on CGI direct storage of LNG in salt domes Terminals Set for Takeoff, Making the Concrete Case, Brian Raine and Gordon Jackson, Arup Energy.

31. Offshore Magazine A. Kaplan, VP of Major Projects for Marathon and G. Marshall, November, 2003. “Worldwide LNG Trade to Expand with Gas Demand”.

32. Offshore Source, 1/2004, ExxonMobil plans $\$ 600$ mm LNG Terminal near Sabine Pass.

33. Oil and Gas Journal, 4/22/02, Andy Flower - Market Access Remains Key for LNG Producers; 2/22/03, IEA says world will need to invest \$ 16 trillion over next 30 years to maintain present level of energy production; 7/31/03, Tideland unit approved for Texas Mexico Crossing for both liquids and gas; 8/6/03, SG Resources Louisiana LLC is moving forward with new salt cavern storage facility in Evangeline Parish with capacity for 16 bcf of gas, ChevronTexaco-8/6/03; Crystal Energy LLC, 11/12/03, Future bodes better for Methanol Consumers than for producers according to CMAI in its 2003 World Methanol Cost Study; 11/5/03, Crystal Energy selects OPE to perform conceptual engineering for LNG offloading hub in Santa Barbara Channel; 11/18/03, Chevron Texaco reports that Port Pelican LLC has received approval from Marad and DOT to construct own and operate and LNG Receiving and Regas terminal; 1/14/04, per API US inventories of natural gas fell to record low levels in 2003 as a result gas liquids production fell 9\% from 2002 levels; 2/6/04, IEA forecasts gas consumption to grow at $2.8 \%$ per year to 2025 vs $1.8 \%$ /year for oil and1.5\% for Coal. In 2025, gas will account for $28 \%$ of global energy use. Douglas Westwood sees LNG facilities expanding rapidly through 2007 with total capex of \$39 billion liquefaction, \$20.5 billion, tankers \$11 billion, regas $\$ 7.5$ billion, 1/15/04 DOE and industry ask regulators to coordinate LNG's role.

34. Peterson, R.W., Giants on the River A story of Chemistry and the Industrial Development on the Lower Mississippi River Corridor. 
35. Philadelphia Inquirer, Adam Fifield, 2/18/04, Planned BP \$500 mm Liquefied Natural Gas Terminal in Logan Township Is Called Possible Terror Hazard.

36. Pritchard Capital Products, 12/17/03, Excelerate Energy LLC announced funding and tolling agreements with El Paso's Louisiana Energy Bridge program related to delivery of LNG to WC 603 in late 2004-early 2005, Tender for 8 LNG Ships put out by ExxonMobil to transport Qatar LNG; 12/17/03, US LNG imports projected at 2.2 TCF in 2010 vs 540 BCF in 2003 according to EIA; 12/17/03, EIA announcement of 540 bcf of LNG in 2003, 2/9/04 Mexico Imports $19.820 \mathrm{bcf} / \mathrm{d}$ or . $7 \mathrm{tcf}$ of gas from US according to Mexican Energy Minister Luis Felipe Calderon; 2/5/04, Rick Cape, President of Atlantic LNG says Trinidad and Tobago to double LNG production to $18 \mathrm{~mm}$ tones per annum in next two years with train IV and streamlining on trains I-III. Shell finds deep gas (26,000 $\mathrm{ft}$ TD) at Shark Prospect at South Tembalier 174, Statoil acquires Norsk Hydro’s 10\% share of Snohvit liquefaction plant, David Manning CEO of Keyspan, states that in January on certain very cold days, LNG was 50\% of its supply in the Boston Area, Sempra Chief Executive warns of demand destruction and high gas prices until new LNG terminals come on stream.

37. Reuters News Service/Houston Chronicle, 6/13/03, Marcel Kramer, Statoil-Venezuela President, Speed essential for Venezuela LNG Project based on Deltana Platform; 11/11/03, Details on Mexican terminals; 11/23/03, ExxonMobil to import LNG from Qatar for Sabine Pass plant; 12/18/03, Spencer Abraham states US needs 13 LNG Import Terminals; 1/7/04, U.S. Seen adding 8 new LNG receiving terminals over next 10 years; 2/20/04, Thierry Demarest, President of Total is looking at two LNG regas projects, one in Asia and a second in the US Gulf; 2/17/0, Mexican Regulatory OK for ChevronTexaco \$650 mm LNG terminal offshore Baja California; 2/17/04, BG raises LNG Output Target for 2006 by $10 \%$ to $6.6 \mathrm{~mm}$ tones, imported more than 100 cargoes into US in 2003; 2/25/04, Total confirms Iran LNG Production Deal.

38. Rigzone, 8/24/03, ChevronTexaco to supply LNG from Gorgon Field in Australia to West Coast of North America; 1/26/04, Algerian Blast raises Concerns about Proposed Mexican Costa Azul (Shell-Sempra) Natural Gas Facility. 
39. Upstream, Dann Rogers, 8/8/03, LNG Quenches US Thirst Falling Reserves and increasing consumption see imports rise 67\%; 11/14/03, Tide Turns and Onshore LNG opposition grows; 11/14/03, Greenspan puts focus on gas crisis and LNG as possible solution. An economic recovery will boost demand quicker, than terminals can be built; 11/14/03, Shell looks into China's LNG Future; 1/16/04, McMoRan to turn up heat on deep gas hunt; 1/16/04, Cheniere set to build LNG Foundations in Mobile Bay; 11/28/03, ExxonMobil announces Sabine Pass Terminal; 12/12/03, Alaska LNG group eyes silver lining-Development group plans to present LNG liquefaction proposal to state legislature.

40. USB Warburg, 11/19/03, Sakhalin 2 looks to supply LNG to US; 11/25/03, Repsol to supply gas to Shell's Cove Point Facility; 11/28/03, Statoil to buy LNG from Algeria to Supply US 11/19/03, Shell hoping to supply Sakhalin Island LNG to U.S.; 11/28/03, Nigerian LNG signs second deal with Shell, Gazprom opts for LNG for Shtokman field in the Arctic Barents Sea; 12/17/03, Sempra plants in Mexico and in Cameron La. won’t be onstream until 2007; 12/19/03, Sempra to buy LNG from BP in Indonesia to supply Mexican LNG terminal; 1/5/04, LNG Japan (50-50 Sumitomo and Nissho Iwai) preempts BG rights to Tangguh stake sale; 2/19/04, Repsol awarded site to build $\$ 350 \mathrm{~mm}$ Mexican regas plant at Lazaro Cardenas.

41. Weil, Howard, 12/23/03, El Paso Assigns LNG Rights at Elba Island to British Gas, Sempra and Shell Propose Terminal in Baja, Mexico

42. Wolfe, John, Operations Consultant for Regas Plants, 12/10/04.

43. Zeus Development Corp, Boston Conference, "East Coast LNG a Most Valuable but Challenging Market” 12/8-10/03; Tim Bleakley, Principle, McKinsey \& Company, East Coast Powerball: The Gas Industry’s largest wager; Kenneth L. Yeasting, Director, Cambridge Energy Research Associates, East Coast LNG and the impact on North American Transmission; Gordon Shearer, CEO, Weaver's Cove Energy-Opportunities, Challenges for Supplying New England with LNG; Mark Sudbury, President, New York and Southeast Regions, Reliant Energy Wholesale Group-electric Power to the East Coast, the Shock of High Gas Prices, and opportunities for LNG; Craig Taylor, President, HNG Storage-The Challenge for LNG to Serve Weather sensitive Commercial and Residential Markets as Gas displaces 
heating Oil; Sandra Racha, Economist, Central Bank of Trinidad and Tobago-Lessons Learned from Trinidad and Tobago's Policy Initiatives; Richard Grant, President, Tractebel LNG North--Global LNG Integration from a Base of Gas and Power Distribution: Tractebel's Perspective; Steve Lowden, Sr. VP Business Development and Integrated Gas, Marathon Oil Company--Global LNG Integration by an Oil Major, Marathon’s Perspective; Chuck Bayens, Chairman, Zeus Development Corp. A Review of Shipping and Existing Terminal Activities and Issues; Paul Cavicchi, President and CEO Tractebel Project Development, Inc. Case Study: Tractebel's Proposed Bahamian Terminal; Jens Kaalstad, Managing Director, APL Inc. Offshore East Coast Terminals: The Latest on Regas Ships.

44. Zeus Development Corp. - LNG Receiving and Regasification Terminals, An Overview of Design, Operation and Project Development Considerations, Rev. 1

45. Zeus Development Corp. - LNG Non-Traditional Concepts for Receiving and Regasification, Examining how new terminal designs may expand LNG's access to high value markets, Conclusions from the 2003 Conference. 


\begin{tabular}{|l|l|l|l|}
\hline Customer: & $\begin{array}{l}\text { The United States Department of Energy } \\
\text { National Energy Technology Laboratory }\end{array}$ & $\begin{array}{l}\text { Date of Issue: } \\
\text { 24 April 2003 }\end{array}$ & \\
\hline $\begin{array}{l}\text { Document } \\
\text { Title: }\end{array}$ & Master Document Register & $\begin{array}{l}\text { Version: } \\
\text { R2.0 }\end{array}$ & Page 1 of 7 \\
\hline
\end{tabular}

\title{
Examine and Evaluate a Process to use Salt Caverns to RECEIVE SHIP BORNe LIQUEFIEd NATURAL GAS
}

\author{
FinAL REPORT \\ StART DATE: OCTOBER 10, 2002 \\ END DATE: JUNE 10, 2003 \\ BY \\ Michael M. MCCALL \\ WILLIAM M. BISHOP \\ D. BRAXTON SCHERZ
}

ISSUE DATE: APRIL 24, 2003

DOE AWARD NUMBER:

DE-FC26-02NT41653

\section{SubMitTINg Organizations}

D. BRAXTON \& ASSOCIATES

2123 FM 1960 W \#108

Houston, TX 77090
CONVERSION GAS IMPORTS, L.L.C. 2929 BRIARPARK, STE 220

HOUSTON, TX 77042

RESPEC, INC

P.O. Box 725

RaPID CITY, SOUTH DaKOTA 57709
PROF. WILLIAM THOMPSON WASHINGTON STATE UNIVERSITY

Pullman, WAshington 


\begin{tabular}{|l|l|l|l|}
\hline Customer: & $\begin{array}{l}\text { The United States Department of Energy } \\
\text { National Energy Technology Laboratory }\end{array}$ & $\begin{array}{l}\text { Date of Issue: } \\
\mathbf{2 4} \text { April } 2003\end{array}$ & \\
\hline $\begin{array}{l}\text { Document } \\
\text { Title: }\end{array}$ & Master Document Register & $\begin{array}{l}\text { Version: } \\
\text { R2.0 }\end{array}$ & Page 2 of 7 \\
\hline
\end{tabular}

\section{DISCLAIMER}

"This report was prepared as an account of work sponsored by an agency of the United States Government. Neither the United States Government nor any agency thereof, nor any of their employees, makes any warranty, express or implied, or assumes any legal liability or responsibility for the accuracy, completeness, or usefulness of any information, apparatus, product, or process disclosed, or represents that its use would not infringe privately owned rights. Reference herein to any specific commercial product, process, or service by trade name, trademark, manufacturer, or otherwise does not necessarily constitute or imply its endorsement, recommendation, or favoring by the United States government or any agency thereof. The views and opinions of authors expressed herein do not necessarily state or reflect those of the United States Government or any agency thereof." 


\begin{tabular}{|l|l|l|l|}
\hline Customer: & $\begin{array}{l}\text { The United States Department of Energy } \\
\text { National Energy Technology Laboratory }\end{array}$ & $\begin{array}{l}\text { Date of Issue: } \\
\mathbf{2 4} \text { April 2003 }\end{array}$ & \\
\hline $\begin{array}{l}\text { Document } \\
\text { Title: }\end{array}$ & Master Document Register & $\begin{array}{l}\text { Version: } \\
\text { R2.0 }\end{array}$ & Page 3 of 7 \\
\hline
\end{tabular}

\begin{abstract}
The goal of the U.S. Department of Energy cooperative research project is to define, describe, and validate, a process to utilize salt caverns to receive and store the cargoes of LNG ships. The project defines the process as receiving LNG from a ship, pumping the LNG up to cavern injection pressures, warming it to cavern compatible temperatures, injecting the warmed vapor directly into salt caverns for storage, and distribution to the pipeline network. The performance of work under this agreement is based on U.S. Patent 5,511,905, and other U.S. and Foreign pending patent applications. The cost sharing participants in the research are The National Energy Technology Laboratory (U.S. Department of Energy), BP America Production Company, Bluewater Offshore Production Systems (U.S.A.), Inc., and HNG Storage, L.P.

Initial results indicate that a salt cavern based receiving terminal could be built at about half the capital cost, less than half the operating costs and would have significantly higher delivery capacity, shorter construction time, and be much more secure than a conventional liquid tank based terminal. There is a significant body of knowledge and practice concerning natural gas storage in salt caverns, and there is a considerable body of knowledge and practice in handling LNG, but there has never been any attempt to develop a process whereby the two technologies can be combined. Salt cavern storage is infinitely more secure than surface storage tanks, far less susceptible to accidents or terrorist acts, and much more acceptable to the community.

The project team developed conceptual designs of two salt cavern based LNG terminals, one with caverns located in Calcasieu Parish Louisiana, and the second in Vermilion block 179 about 50 miles offshore Louisiana. These conceptual designs were compared to conventional tank based LNG terminals and demonstrate superior security, economy and capacity. The potential for the development of LNG receiving terminals, utilizing salt caverns for storage and the existing comprehensive pipeline system has profound implications for the next generation of LNG terminals. LNG imports are expected to become an increasingly more important part of the U.S. energy supply and the capacities to receive LNG securely, safely, and economically must be expanded. Salt cavern LNG receiving terminals both in onshore and offshore locations can be quickly built and provide additional import capacity into the U.S. exceeding 6-10 Bcf/day in the aggregate.
\end{abstract}




\begin{tabular}{|l|l|l|l|}
\hline Customer: & $\begin{array}{l}\text { The United States Department of Energy } \\
\text { National Energy Technology Laboratory }\end{array}$ & $\begin{array}{l}\text { Date of Issue: } \\
\mathbf{2 4} \text { April } 2003\end{array}$ & \\
\hline $\begin{array}{l}\text { Document } \\
\text { Title: }\end{array}$ & Master Document Register & $\begin{array}{l}\text { Version: } \\
\text { R2.0 }\end{array}$ & Page 4 of 7 \\
\hline
\end{tabular}

\section{TABLE OF CONTENTS}

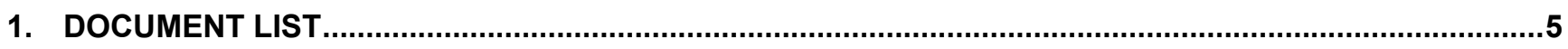

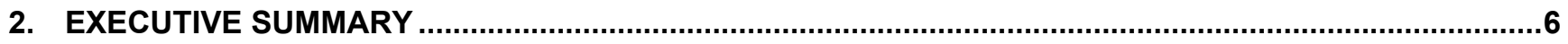




\begin{tabular}{|l|l|l|l|}
\hline Customer: & $\begin{array}{l}\text { The United States Department of Energy } \\
\text { National Energy Technology Laboratory }\end{array}$ & $\begin{array}{l}\text { Date of Issue: } \\
\mathbf{2 4} \text { April } 2003\end{array}$ & \\
\hline $\begin{array}{l}\text { Document } \\
\text { Title: }\end{array}$ & Master Document Register & $\begin{array}{l}\text { Version: } \\
\text { R2.0 }\end{array}$ & Page 5 of 7 \\
\hline
\end{tabular}

\section{DOCUMENT LIST}

\begin{tabular}{|c|c|}
\hline \multicolumn{2}{|c|}{ Task 1.0 Identify Critical Elements } \\
\hline CGI/DOE_Doc 01 & $\begin{array}{l}\text { Final Report I "Critical Elements in a Process to Utilize Salt Caverns in a } \\
\text { LNG Receiving Terminal" }\end{array}$ \\
\hline CGI/DOE_Doc 02 & $\begin{array}{l}\text { Subtask } 1.1 \text { Identify Potential Salt Formations Which Could be Used for } \\
\text { LNG Receiving }\end{array}$ \\
\hline CGI/DOE_Doc 03 & $\begin{array}{l}\text { Subtask } 1.2 \text { Identify Marine Mooring and Offloading Initiatives for LNG } \\
\text { Vessels }\end{array}$ \\
\hline CGI/DOE_Doc 04 & Subtask 1.3 Determine Major Equipment Requirements \\
\hline CGI/DOE_Doc 05 & Subtask 1.4 Determine Salt Cavern Requirements \\
\hline \multicolumn{2}{|c|}{ Task 2.0 Develop Conceptual Design of a Salt Cavern LNG Receiving Terminal } \\
\hline CGI/DOE_Doc 06 & $\begin{array}{l}\text { Final Report II "Conceptual Design of a Salt Cavern Based LNG } \\
\text { Receiving Terminal" } \\
\text { Design basis A: The LNG Onshore Terminal } \\
\text { Design Basis B: The Offshore Terminal }\end{array}$ \\
\hline \multicolumn{2}{|c|}{$\begin{array}{l}\text { Task 3.0 Comparison of LNG Terminals Conceptual Designs with Traditional LNG Receiving Terminals } \\
\text { and EI Paso's Energy Bridge }{ }^{\circledR}\end{array}$} \\
\hline CGI/DOE_Doc 07 & $\begin{array}{l}\text { Final Report III “Comparisons Between LNG Receiving Terminals: } \\
\text { Conventional, Salt Cavern Based, Offshore, and 'Energy Bridge'®”" }\end{array}$ \\
\hline CGI/DOE_Doc 08 & Matrix for Comparison \\
\hline
\end{tabular}




\begin{tabular}{|l|l|l|l|}
\hline Customer: & $\begin{array}{l}\text { The United States Department of Energy } \\
\text { National Energy Technology Laboratory }\end{array}$ & $\begin{array}{l}\text { Date of Issue: } \\
\mathbf{2 4} \text { April } 2003\end{array}$ & \\
\hline $\begin{array}{l}\text { Document } \\
\text { Title: }\end{array}$ & Master Document Register & $\begin{array}{l}\text { Version: } \\
\text { R2.0 }\end{array}$ & Page 6 of 7 \\
\hline
\end{tabular}

\section{EXECUTIVE SUMMARY}

The goal of the U.S. Department of Energy cooperative research project is to define, describe, and validate, a process to utilize salt caverns to receive and store the cargoes of LNG ships. The project defines the process as receiving LNG from a ship, pumping the LNG up to cavern injection pressures, warming it to cavern compatible temperatures, injecting the warmed vapor directly into salt caverns for storage, and distribution to the pipeline network. The performance of work under this agreement is based on U.S. Patent $5,511,905$, and other U.S. and Foreign pending patent applications. The cost sharing participants in the research are The National Energy Technology Laboratory (U.S. Department of Energy), BP America Production Company, Bluewater Offshore Production Systems (U.S.A.), Inc., and HNG Storage, L.P.

Research reveals that LNG ship mooring and unloading at an onshore terminal could be done using conventional docks, jetties, loading arms, and other equipment used in LNG transfer service currently. There is no need for modifications to LNG ships currently in service and the unloading rates could approximate those achieved in conventional LNG tank based terminals. The offshore version of the conceptual design would need further development of loading techniques and equipment for LNG transfer at sea. There are multiple industry initiatives underway to develop offshore mooring and unloading equipment drawing on the significant experience of the oil and LPG industries where offshore product transfer operations take place in much of the world today. It is believed by those in the industry that within a year several solutions to offshore LNG transfer will be certified by the agencies that deal in marine technologies.

The major pump manufacturers have designed LNG pumps capable of developing cavern injection pressures, and the project team is advised that there are no technical difficulties in building and operating such pumps.

A high capacity, high efficiency, seawater warmed, pipe in pipe heat exchanger was studied in the research and conclusions have been drawn that the heat exchange at high rates is feasible. It is expected that a field test of the heat exchanger studied will be conducted to demonstrate its performance. This field test is expected to be the subject of a related cooperative research project

A salt cavern rock mechanics study was performed as a part of the project which confirmed that salt caverns can accept and discharge gas at high rates and at temperatures varying from 0 Degrees $F$ to 110 Degrees $F$. This enables unloading of ships at normal rates and provides very high deliverability into the natural gas pipeline grid. The conceptual design terminals have pipeline deliverability in excess of $3 \mathrm{Bcf} / \mathrm{Day}$, a rate that is as much as 6 times the rate of delivery that most tank based LNG terminals can achieve.

There are more than 1000 salt caverns in the U.S. and Canada in which hydrocarbon products are stored. All of the Strategic Petroleum Reserve's 600+ million barrels of crude oil are stored in salt caverns. In addition there are more than 600 million barrels of other products stored in salt caverns, including hydrogen, natural gas, ethylene, propylene, ethane, propane, butane, natural gasoline and refined products. Salt cavern storage facilities provide a logistical link between the natural gas, petrochemical and refining industries and are an integral part of the most comprehensive energy and processing industry infrastructure in the world found along the Gulf coast. Salt cavern operations occur largely unseen and unnoticed by the public because of their underground nature and trouble free operation.

More than two dozen potential sites were identified in the project combining salt formations suitable for storage, proximate multiple pipelines for large take away capacity and navigable water. The sites are about evenly split between onshore salt formation locations and offshore salt formation locations. Research reveals that because of the convergence of pipeline capacities and salt formations that a few very large capacity salt cavern based receiving terminals could provide all of the U.S.'s future LNG import needs. 


\begin{tabular}{|l|l|l|l|}
\hline Customer: & $\begin{array}{l}\text { The United States Department of Energy } \\
\text { National Energy Technology Laboratory }\end{array}$ & $\begin{array}{l}\text { Date of Issue: } \\
\mathbf{2 4} \text { April } 2003\end{array}$ & \\
\hline $\begin{array}{l}\text { Document } \\
\text { Title: }\end{array}$ & Master Document Register & $\begin{array}{l}\text { Version: } \\
\text { R2.0 }\end{array}$ & Page 7 of 7 \\
\hline
\end{tabular}

Initial results indicate that a salt cavern based receiving terminal could be built at about half the capital cost, less than half the operating costs and would have significantly higher delivery capacity, shorter construction time, and be much more secure than a conventional liquid tank based terminal. There is a significant body of knowledge and practice concerning natural gas storage in salt caverns, and there is a considerable body of knowledge and practice in handling LNG, but there has never been any attempt to develop a process whereby the two technologies can be combined. Salt cavern storage is infinitely more secure than surface storage tanks, far less susceptible to accidents or terrorist acts, and much more acceptable to the community.

The project team developed conceptual designs of two salt cavern based LNG terminals, one with caverns located in Calcasieu Parish Louisiana, and the second in Vermilion block 179 about 50 miles offshore Louisiana. These conceptual designs were compared to conventional tank based LNG terminals and demonstrate superior security, economy and capacity. The potential for the development of LNG receiving terminals, utilizing salt caverns for storage and the existing comprehensive pipeline system has profound implications for the next generation of LNG terminals. LNG imports are expected to become an increasingly more important part of the U.S. energy supply and the capacities to receive LNG securely, safely, and economically must be expanded. Salt cavern LNG receiving terminals both in onshore and offshore locations can be quickly built and provide additional import capacity into the U.S. exceeding 6-10 Bcf/day in the aggregate. 


\begin{tabular}{|l|l|l|l|}
\hline Customer: & $\begin{array}{l}\text { The United States Department of Energy } \\
\text { National Energy Technology Laboratory }\end{array}$ & $\begin{array}{l}\text { Date of Issue: } \\
24 \text { April } 2003\end{array}$ & \\
\hline $\begin{array}{l}\text { Document } \\
\text { Title: }\end{array}$ & $\begin{array}{l}\text { Report I: Critical Elements in a process to Utilize Salt Caverns in an LNG } \\
\text { Receiving Terminal }\end{array}$ & $\begin{array}{l}\text { Doc \# \& Version: } \\
\text { Doc } 01 \text { r1.0 }\end{array}$ & Page 1 of 11 \\
\hline
\end{tabular}

\title{
Critical Elements in a process to Utilize Salt Caverns IN AN LNG RECEIVING TERMINAL
}

\author{
BY \\ Michael M. McCaLl \\ WILLIAM M. BISHOP \\ D. BRAXTON SCHERZ
}

\begin{tabular}{||c|c||c|c|c|c|c|c|c||}
\hline \hline r 1.0 & For client review & $04 / 24 / 03$ & вS & мm & & & \\
\hline Version & Reason for Issue & $\begin{array}{c}\text { Issue } \\
\text { Date }\end{array}$ & $\begin{array}{c}\text { Orig. } \\
\text { Chk. Appr. } \\
\text { CGI }\end{array}$ & $\begin{array}{c}\text { Chk. } \\
\text { NETL }\end{array}$ & Appr. & Review \\
\hline \hline $\begin{array}{l}\text { Document Title: } \\
\text { Critical Elements in a process to Utilize Salt Caverns } \\
\text { in an LNG Receiving Terminal }\end{array}$ & \multicolumn{2}{|c||}{$\begin{array}{c}\text { Document No: } \\
\text { DE-FC26-02NT41653 }\end{array}$} \\
\hline
\end{tabular}


2. GLOSSARY OF TERMS

3. LNG FUNDAMENTALS.

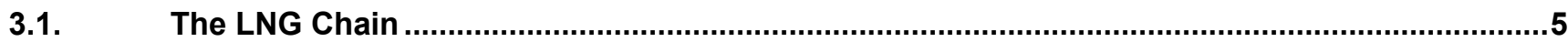

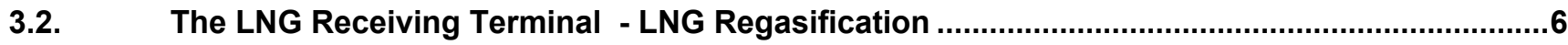

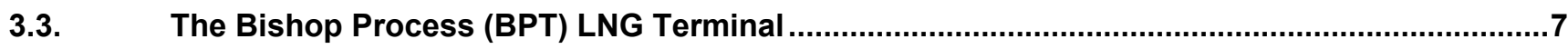

3.4. Fundamental Differences - Conventional and BPT LNG Terminal .........................................

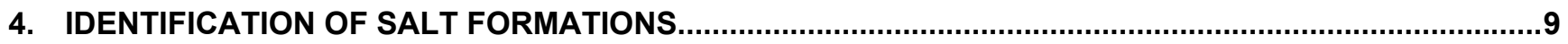

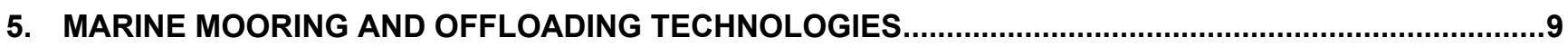

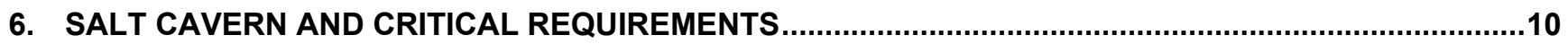

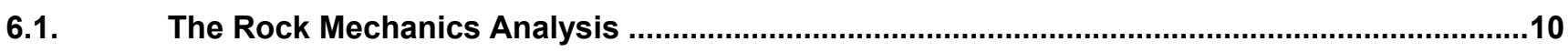

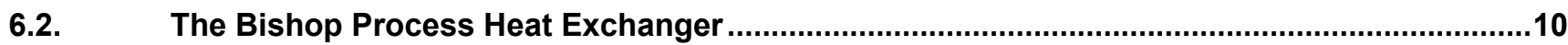

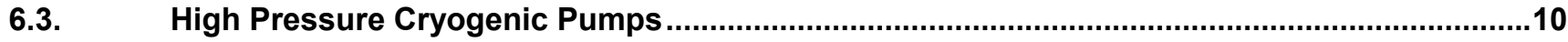




\begin{tabular}{|l|l|l|l|}
\hline Customer: & $\begin{array}{l}\text { The United States Department of Energy } \\
\text { National Energy Technology Laboratory }\end{array}$ & $\begin{array}{l}\text { Date of Issue: } \\
\mathbf{2 4} \text { April 2003 }\end{array}$ & \\
\hline $\begin{array}{l}\text { Document } \\
\text { Title: }\end{array}$ & $\begin{array}{l}\text { Report I: Critical Elements in a process to Utilize Salt Caverns in an LNG } \\
\text { Receiving Terminal }\end{array}$ & $\begin{array}{l}\text { Doc \# \& Version: } \\
\text { Doc 01 r1.0 }\end{array}$ & Page $\mathbf{3}$ of 11 \\
\hline
\end{tabular}

\section{EXECUTIVE SUMMARY}

Each element critical to the process of using salt caverns in the receipt of LNG has been identified and confirmed as feasible in the course of this research. Key elements examined were potential sites, salt cavern tolerances for gas injections at varying temperatures, LNG pumps capable of developing cavern injection pressures, predicted performance of a unique, high capacity, high efficiency heat exchanger, and offshore LNG ship mooring and unloading systems.

As a whole, the concept of using salt caverns in the receipt of ship borne LNG is foreign to the LNG industry and incorporates salt cavern storage technology with which most participants in the LNG industry have little familiarity. In the course of the research each element was examined in turn confirming the feasibility of the system as a whole. The major challenge for the implementation of a salt cavern alternative to the traditional tank based LNG receiving terminals lie in the perceived risks associated the technologies required to implement the projects, onshore somewhat, but offshore more so. A field test of the heat exchanger will most likely be necessary to provide confirmation to industry that that element is proven.

\section{GLOSSARY OF TERMS}

\section{AIR DRAFT}

The distance between the surface of navigable water, such as a channel, and the lowest point on some obstruction above it, a bridge for instance. A ship cannot use a waterway if it needs more vertical clearance than available. This consideration prevents certain tankers from reaching some terminals.

\section{ASSOCIATED AND NON-ASSOCIATED NATURAL GAS}

Natural gas is found in underground structures similar to those containing crude oil. There are three types of natural gas reservoir:

1. Structures from which only gas can be produced economically-called NON-ASSOCIATED GAS (or unassociated gas).

2. Condensate reservoirs which yield relatively large amounts of gas per barrel of light liquid hydro- carbons. Although many condensate reservoirs are produced primarily for gas, there are cases where gas is reinjected or "re-cycled" to improve liquid recovery, particularly if no gas market is yet available. This gas also is termed NON- ASSOCIATED.

3. Reservoirs where gas is found dissolved in crude oil (SO LUTION GAS) and in some cases also in contact with underlying gas saturated crude (GAS- CAP GAS). Both are called ASSOCIATED GAS. (Gas-cap gas is almost never produced until most of the economically recoverable oil has been yielded). In such fields, gas production rates will depend on oil output with the oil usually representing the major part in terms of energy equivalents.

\section{BACKHAUL}

A tanker's revenue-producing return voyage. Some ships shuttle between two tankers ports. They travel in one direction as dictated by normal oil flow patterns or refining system's needs. Often, they have no natural employment from when they discharge to their port of origin where another load awaits. They would like to find a cargo to pay their costs on this return trip. This is possible because oil tankers are capable of carrying many different products, e.g. a tanker carrying refined gasoline to a receiving terminal may have the opportunity to move to a nearby terminal to load "charge stock" and carry it back along a similar route to the refining terminal. Otherwise, the tanker must return in ballast. Charters often relet ships at bargain back haul rates for these voyages. They prefer some income to none.

While backhauls in the oil transportation industry are common, there are not yet enough LNG terminals worldwide to make backhauling feasible. However, LNG backhauls will be employed as the trade grows. 


\begin{tabular}{|l|l|l|l|}
\hline Customer: & $\begin{array}{l}\text { The United States Department of Energy } \\
\text { National Energy Technology Laboratory }\end{array}$ & $\begin{array}{l}\text { Date of Issue: } \\
24 \text { April 2003 }\end{array}$ & \\
\hline $\begin{array}{l}\text { Document } \\
\text { Title: }\end{array}$ & $\begin{array}{l}\text { Report I: Critical Elements in a process to Utilize Salt Caverns in an LNG } \\
\text { Receiving Terminal }\end{array}$ & $\begin{array}{l}\text { Doc \# \& Version: } \\
\text { Doc 01 r1.0 }\end{array}$ & Page 4 of 11 \\
\hline
\end{tabular}

\section{BOIL OFF GAS (BOG)}

During storage and transport, the vapor (almost pure methane) that escapes as LNG "boils" at atmospheric pressure and $-160^{\circ} \mathrm{C}$. This vapor boil off can be quite large and is captured and used as fuel for the facility or the LNG ship, or is compressed and sent out in the natural gas supply stream at the receiving terminal.

\section{CITY GATE}

A measuring station, which may also include pressure regulation, at which a distributing gas utility receives gas from a natural gas pipeline company or the transmission System.

\section{DAILY AVERAGE SEND-OUT}

The total volume of gas delivered during a period of time divided by number of days in the period.

\section{DAILY PEAK}

The maximum volume of gas delivered in any one day during a given period, usually a calendar year

\section{DISTRIBUTION COMPANY or GAS UTILITY}

A company which obtains the major portion of its gas operating revenues from the operation of a retail gas distribution system and which operates no transportation system other than incidental connections to a transportation system of another company. For purposes of American Gas Association (A.G.A.) statistics, a distribution company obtains at least 95 per cent of its gas operating revenue from the operation of its retail gas distribution system. (See also Transmission Company.)

\section{DISTRIBUTION SYSTEM}

Feeders, mains, services and equipment which carry or control the supply of gas from the point or points of local supply (usually the city gate station) to and including the consumer meters.

\section{FIXED MOORING}

An offshore facility (usually adjacent but not connected to shore) capable of safely securing an ocean going vessel through a system of anchors, chains, and buoys. The ship maintains a fixed heading after it is secured. An inexpensive offshore mooring solution but typically reserved for benign location or locations where wind and wave are unidirectional.

\section{INTERRUPTIBLE GAS}

Gas made available under agreements, which permit curtailment or cessation of delivery by the supplier.

\section{LINE PACK}

A method of peak-shaving by withdrawing gas from a section of a pipeline system in excess of the input into that section, i.e. normally the difference between the actual volume of gas in the pipeline at low flow (increased pressure) and that at normal flow.

\section{LIQUEFIED NATURAL GAS (LNG)}

Natural gas that has been liquefied by cooling to minus $258^{\circ} \mathrm{F}\left(-161^{\circ} \mathrm{C}\right)$ at atmospheric pressure.

\section{LIQUEFIED PETROLEUM GAS (LPG)}

Any hydrocarbon mixture in either the liquid or gaseous state the chief components of which consist of propane, propylene, butane, iso-butane, butylene or mixtures there- of in any ratio.

\section{LOAD FACTOR}

The ratio of the average load over a designated period to the peak load occurring in that period. Usually expressed as a percentage. 


\begin{tabular}{|l|l|l|l|}
\hline Customer: & $\begin{array}{l}\text { The United States Department of Energy } \\
\text { National Energy Technology Laboratory }\end{array}$ & $\begin{array}{l}\text { Date of Issue: } \\
24 \text { April } 2003\end{array}$ \\
\hline $\begin{array}{l}\text { Document } \\
\text { Title: }\end{array}$ & $\begin{array}{l}\text { Report I: Critical Elements in a process to Utilize Salt Caverns in an LNG } \\
\text { Receiving Terminal }\end{array}$ & $\begin{array}{l}\text { Doc \# \& Version: } \\
\text { Doc } 01 \text { r1.0 }\end{array}$ \\
\hline
\end{tabular}

\section{OFF-PEAK}

The period during a day, week, month or year when the load being delivered by a gas system is not at or near the maximum volume deliverable by that system.

\section{MOORING - ONSHORE}

Any facility connected to dry land providing a means to secure a ship

\section{MOORING - OFFSHORE}

A system of anchors, chains, and a buoy whereby a ship can securely fasten itself and remain on station in most weather conditions

\section{PEAK or PEAK LOAD}

The maximum load consumed or produced by a unit or group of units in a stated period of time.

\section{PEAK SHAVING}

The practice of augmenting the normal supply of gas during peak or emergency periods from another source where gas may have either been stored during periods of low demand, or manufactured specifically to meet the peak demand.

\section{SALT CAVERN}

A void within a salt formation solution mined usually for the purpose of hydrocarbon storage

\section{SALT FORMATION}

An underground geologic structure consisting of a highly monolithic substance consisting mainly of sodium chloride There are mainly tow types of formations embedded salt, and salt domes. Salt domes are highly pure and are well suited for cavern creation.

\section{SEND-OUT}

The quantity of gas delivered by a plant or system during a specified period of time.

\section{WEATHERVANE}

A ocean going vessel's reaction to the direction of the winds, waves and currents while berthed in an offshore mooring capable of $360^{\circ}$ rotation about its fixed mooring. Weathervaning moorings are robust and rather expensive but provide a safe offshore mooring in a variety of sea conditions.

\section{LNG FUNDAMENTALS}

\subsection{The LNG Chain}

The following Figure 3.1 is a graphical indication of the LNG Chain. In summary, natural gas is produced and transported to a liquefaction facility. The front end of the liquefaction facility dehydrates and removes mercury and $\mathrm{CO} 2$ from the gas stream. The gas stream is usually routed through a fractionation process where much of the Liquid Petroleum Gases (LPG's) are removed. However some liquefaction facilities remove very little LPGs. The lean gas stream, containing mainly methane and some ethane, is routed through a high capacity heat exchanger where it gives up its latent heat of vaporization and becomes a liquid at atmospheric pressures. At this point the Liquefied Natural Gas (LNG) is minus $160^{\circ} \mathrm{C}\left(-258^{\circ} \mathrm{F}\right)$ and must be kept cold throughout the storage and transportation process.

LNG is stored in large cryogenic tanks at pressures very slightly above atmospheric. To transport LNG to the buyer's receiving terminals, special liquid gas carriers are used. The ships are very large and are constructed with highly insulated tanks of varying designs and materials able to withstand cryogenic temperatures. 


\begin{tabular}{|l|l|l|l|}
\hline Customer: & $\begin{array}{l}\text { The United States Department of Energy } \\
\text { National Energy Technology Laboratory }\end{array}$ & $\begin{array}{l}\text { Date of Issue: } \\
\mathbf{2 4} \text { April } 2003\end{array}$ & \\
\hline $\begin{array}{l}\text { Document } \\
\text { Title: }\end{array}$ & $\begin{array}{l}\text { Report I: Critical Elements in a process to Utilize Salt Caverns in an LNG } \\
\text { Receiving Terminal }\end{array}$ & $\begin{array}{l}\text { Doc \# \& Version: } \\
\text { Doc } 01 \text { r1.0 }\end{array}$ & Page 6 of 11 \\
\hline
\end{tabular}

Upon arrival at the receiving terminal the LNG vessel pumps its cargo to cryogenic storage tanks of similar design and volume to those at the liquefaction terminal. The receiving terminal moves the LNG through a high pressure pumping system and into a vaporizer where the liquid is warmed and returned to natural gas. After vaporization, the gasified LNG flows into the existing pipeline infrastructure where it is delivered to the customer.

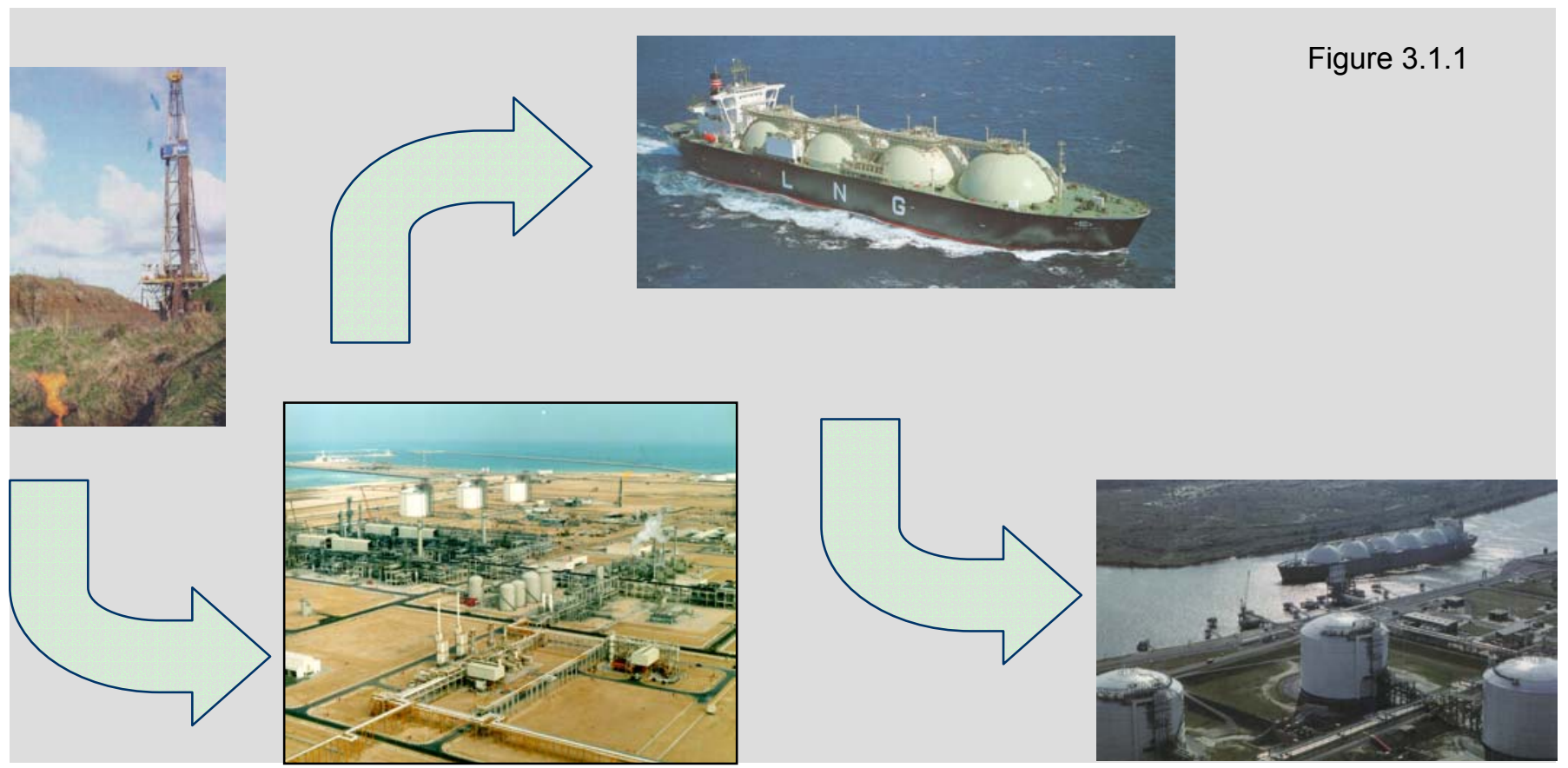

3.2. The LNG Receiving Terminal - LNG Regasification

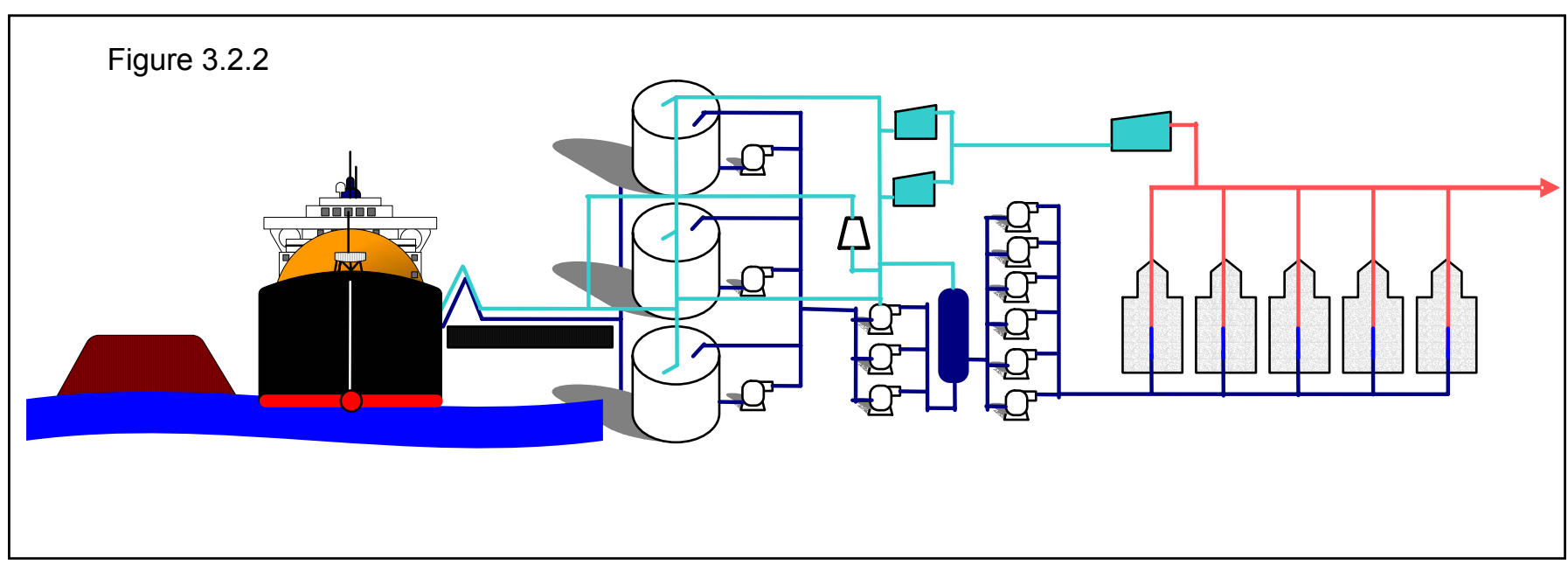

Figure 3.2.2 is a diagram showing the typical components of and LNG receiving terminal. The LNG carrier is moored along side a typical berth classified for gas carrier service. The ships pumps move the LNG off the 


\begin{tabular}{|l|l|l|l|}
\hline Customer: & $\begin{array}{l}\text { The United States Department of Energy } \\
\text { National Energy Technology Laboratory }\end{array}$ & $\begin{array}{l}\text { Date of Issue: } \\
24 \text { April 2003 }\end{array}$ & \\
\hline $\begin{array}{l}\text { Document } \\
\text { Title: }\end{array}$ & $\begin{array}{l}\text { Report I: Critical Elements in a process to Utilize Salt Caverns in an LNG } \\
\text { Receiving Terminal }\end{array}$ & $\begin{array}{l}\text { Doc \# \& Version: } \\
\text { Doc 01 r1.0 }\end{array}$ & Page 7 of 11 \\
\hline
\end{tabular}

vessel and into the storage tanks. The high pressure pumps pass LNG through the vaporizers and out to the pipeline infrastructure to market. The machinery required to recover Boil Off Gas (BOG) is clearly marked. During discharge, BOG is essential as it must be used to fill the evacuated volume of the ships tanks at rates equal to or slightly exceeding LNG pumping rates.

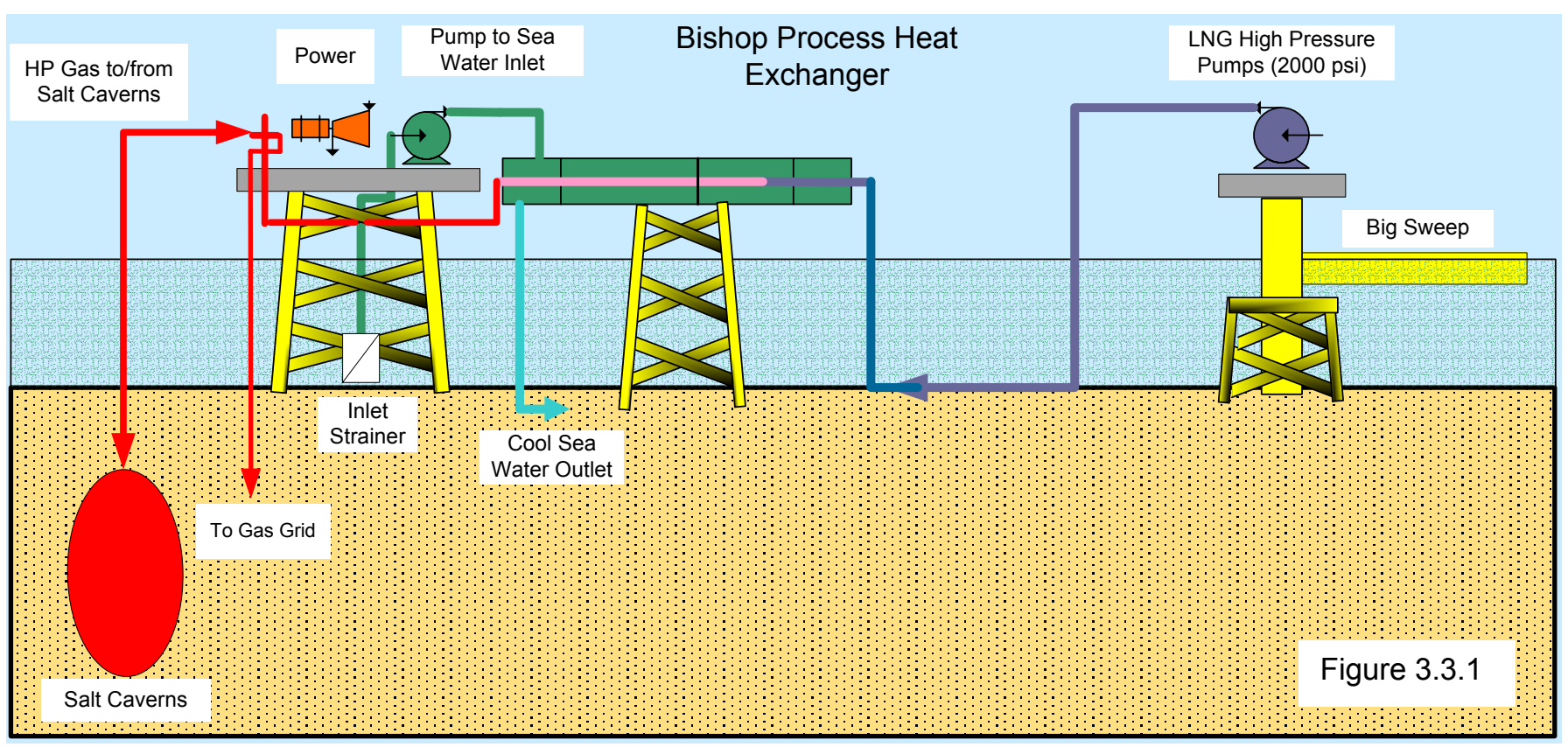

\subsection{The Bishop Process (BPT) LNG Terminal}

Figure 3.3.1 shows the major components of an offshore BPT LNG terminal. The operating principles are very similar between the onshore and offshore terminal. To summarize, the LNG carrier moors with the "Big Sweep" arm, a weathervaning structure that contains the offloading equipment. The high pressure pumps are located on the mooring platform. LNG is moved across the sea floor through cryogenic piping where it is warmed in the Bishop Process heat exchanger. The warmed gas flows through a well head located on the platform housing power generation, sea water circulating pumps, and the cavern solution mining/service equipment. The gasified LNG is directed to either the salt cavern or the existing pipeline infrastructure. A conceptual design with greater detail appears in Task 2.0.

\subsection{Fundamental Differences - Conventional and BPT LNG Terminal}

Although the two terminal designs share many common equipment items, there are some fundamental differences that are better illustrated in Figure 3.4.1 below. Existing terminals receive LNG at approximately $160 \mathrm{C}$ or $-250 \mathrm{~F}$. The LNG is pumped to a cryogenic storage tank until it is required for sendout. At that point the LNG is pumped to approximately 70 barg (1000 psi ) and warmed in vaporizers of various designs and capacities. Most U.S. receiving terminals have a send out capacity of 0.5 (existing) to 1.5 (projected) billion cubic feet per day Bcfd. 


\begin{tabular}{|l|l|l|l|}
\hline Customer: & $\begin{array}{l}\text { The United States Department of Energy } \\
\text { National Energy Technology Laboratory }\end{array}$ & $\begin{array}{l}\text { Date of Issue: } \\
\mathbf{2 4} \text { April } 2003\end{array}$ & \\
\hline $\begin{array}{l}\text { Document } \\
\text { Title: }\end{array}$ & $\begin{array}{l}\text { Report I: Critical Elements in a process to Utilize Salt Caverns in an LNG } \\
\text { Receiving Terminal }\end{array}$ & $\begin{array}{l}\text { Doc \# \& Version: } \\
\text { Doc 01 r1.0 }\end{array}$ & Page 8 of 11 \\
\hline
\end{tabular}

The terminal using salt caverns for storage and the BPT exchanger to warm LNG varies in its processing model only. For example, the BPT terminal receives cargoes from a standard LNG carrier in the conventional manner. However, the ships pumps supply LNG to the suction side of the high pressure pumps in the BPT terminal rather than passing the liquid directly to an LNG storage tank. The LNG is immediately pumped to 2000 psig, warmed in the BPT heat exchanger, and routed either to the natural gas grid, or to salt caverns for storage. The major fundamental difference between the two LNG terminals is the method for LNG storage. Conventional terminals store LNG in cryogenic tanks as a liquid, the BPT LNG terminal warms LNG for immediate storage as natural gas in salt caverns. Otherwise, the technologies, components, and principles vary little.

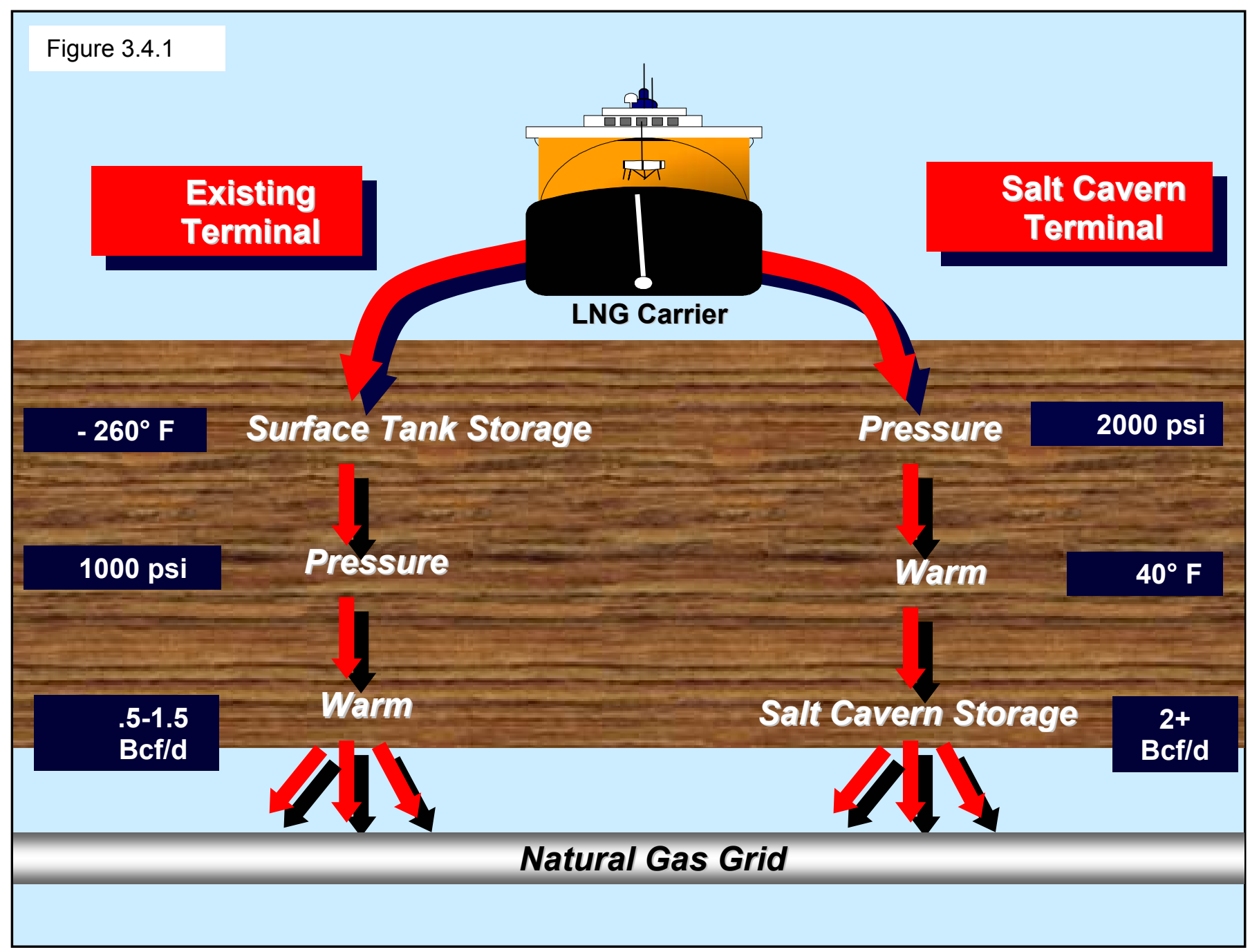




\begin{tabular}{|l|l|l|l|}
\hline Customer: & $\begin{array}{l}\text { The United States Department of Energy } \\
\text { National Energy Technology Laboratory }\end{array}$ & $\begin{array}{l}\text { Date of Issue: } \\
\mathbf{2 4} \text { April 2003 }\end{array}$ & \\
\hline $\begin{array}{l}\text { Document } \\
\text { Title: }\end{array}$ & $\begin{array}{l}\text { Report I: Critical Elements in a process to Utilize Salt Caverns in an LNG } \\
\text { Receiving Terminal }\end{array}$ & $\begin{array}{l}\text { Doc \# \& Version: } \\
\text { Doc 01 r1.0 }\end{array}$ & Page 9 of 11 \\
\hline
\end{tabular}

\section{IDENTIFICATION OF SALT FORMATIONS}

Subtask 1.1 of this document defines several sites suited for a Salt Storage LNG terminal both onshore and offshore. Dozens of potential locations have been identified in Texas, Louisiana, Mississippi and offshore areas adjacent to these states that have similar potential. Because of the close proximity of the existing natural gas grid, a series of LNG receiving facilities using the existing infrastructure in the Gulf of Mexico coastal area and contiguous salt caverns within the region could meet virtually any growth necessary in LNG imports required to replace declining production or meet growing natural gas demand.

There are salt formations suitable for the creation of salt caverns for storage purposes in most areas of the world except the Pacific Rim. Several contour maps describing the salt formations (salt domes in this case) are included as attachments. It is interesting to note that the Gulf of Mexico contains perhaps the most ideal salt formations anywhere in the world. That, coupled with approximately 10 Bcfd pipeline capacity in the GOM and coastal areas offer a unique opportunity to work with an underutilized natural resource to help meet the Nation's energy needs.

\section{MARINE MOORING AND OFFLOADING TECHNOLOGIES}

The solution to LNG transfer offshore lies in the technology and operational procedures that have been used in the offshore oil industry for over 30 years. Task 1.2 identifying marine mooring and offloading initiatives compares the existing and proposed LNG offshore transfer technologies, identifies the commonalities, and recognizes industry requirements and transfer preferences. Reduced NIMBY (not in my backyard) concerns and permitting requirements, siting flexibility, quicker construction times, and comparable CAPEX/OPEX are among the many advantages of transferring and handling LNG offshore.

Several offshore transfer challenges have been identified including the need to minimize the relative motion between LNG vessel and transfer facility, and the requirement to improve linking systems (transfer arms, hoses, subsea pipelines, etc.) for high availability.

Every major vendor with designs promoting the transfer of LNG offshore contributed to this study. Task 1.2 includes a matrix summarizing promising existing and conceptual designs. As of this writing, the only design nearing implementation is termed "Energy Bridge" developed by EI Paso Global LNG. Energy Bridge combines LNG shipping and regasification on a single ocean-going vessel and is technically quite feasible. The remaining designs are approximately 24 to 48 months away from fabrication.

The matrix indicates that oiil and natural gas producers considering LNG offshore transfer schemes prefer moorings that provide high availability. Weathervaning moorings (a mooring allows LNG vessel rotation around a vertical axis to assume a heading of minimum motion), facilitate maximum stability and good availability. Side by side cargo transfer is also essential (at least in the near term) as there are no existing or planned LNG carriers employing any other loading/unloading techniques.

Linking technologies (the apparatus and equipment required to safely interface between ship and shore) have improved rapidly over the last ten years, and there are plans to introduce an LNG hose capable of cryogenic liquid transfer sometime during 2004. The use of a hose in water without icing of the exterior surface could allow for tandem (e.g. vessel stern to vessel bow) LNG transfer similar to the standard procedure for transferring oil for ship to ship.

Currently all the technologies required for safe LNG transfer at sea exist, although not within the same company. There might be a possibility to consolidate LNG offshore engineering and design under the coordination of a recognized E\&C firm. The design firm would be tasked with conceiving and fabricating (with 


\begin{tabular}{|l|l|l|l|}
\hline Customer: & $\begin{array}{l}\text { The United States Department of Energy } \\
\text { National Energy Technology Laboratory }\end{array}$ & $\begin{array}{l}\text { Date of Issue: } \\
24 \text { April 2003 }\end{array}$ & \\
\hline $\begin{array}{l}\text { Document } \\
\text { Title: }\end{array}$ & $\begin{array}{l}\text { Report I: Critical Elements in a process to Utilize Salt Caverns in an LNG } \\
\text { Receiving Terminal }\end{array}$ & $\begin{array}{l}\text { Doc \# \& Version: } \\
\text { Doc } 01 \text { r1.0 }\end{array}$ & Page 10 of 11 \\
\hline
\end{tabular}

vendor support), a system capable of combining the heretofore proven LNG technologies into one universal package acceptable to the LNG industry.

\section{SALT CAVERN AND CRITICAL REQUIREMENTS}

\subsection{The Rock Mechanics Analysis}

The results of RESPEC's rock mechanic analysis confirm that salt caverns can be used in LNG receiving terminal applications. Gasified LNG at temperatures from $43.3^{\circ}\left(110^{\circ} \mathrm{F}\right)$ down to $-17.8^{\circ} \mathrm{C}\left(0^{\circ} \mathrm{F}\right)$ can be safely and reliably injected, stored, and withdrawn. Limits on cavern cycling and withdrawal rates are no different in LNG service than for conventional gas storage facilities, and are widely known in the industry. The report indicates that salt caverns can tolerate low temperatures. The results of the study also confirm that the use of salt caverns in LNG receiving is fundamentally no different than the widespread use of salt caverns for the natural gas pipeline industry.

\subsection{The Bishop Process Heat Exchanger}

The Bishop Process heat Exchanger (BPT), a critical component of the subject technology is a high capacity, pipe in pipe heat exchanger. These exchangers allow an LNG tanker to be offloaded at rates consistent with conventional LNG terminals but with resulting pressures suitable for injection of the gas directly into salt caverns without the use of compressors. Thus no significant amount of LNG is ever stored on the surface. In addition, because the exchangers use seawater or other waters as a warmant, the fuel operating costs are approximately $25 \%$ of gas fired exchangers.

Through numerical modeling performed under the present contract, proposed exchanger configurations, process design, and operational considerations have been successfully verified. HYSYS and MATLAB the process software used to design the exchanger, documented the location and thickness of the icing condition (a predicted consequence of using water to warm LNG). The warm water flow systems have been integrated into exchanger design to optimize BPT efficiencies and increase operational flexibility. The BPT exchanger inner annulus will be fabricated from stainless steel, a resilient material known to be resistant to cryogenic temperatures. The outer pipe can be fabricated with HDPE or coated carbon steel depending upon site conditions and specific application. The inner annulus will be centralized with a device designed to incorporate the effects of thermal expansion and contraction.

\subsection{High Pressure Cryogenic Pumps}

The major process differences in the BPT LNG receiving terminal and the traditional terminal are defined by the configuration of the High Pressure Pumping units called a "4-Pack" and the pipe-in-pipe configuration of the BPT. Each "4-Pack" is designed to pump 6,480 m3/day at 152 barg (2,200 psig) of LNG discharging immediately into the pipe-in-pipe Bishop Process heat Exchanger. Each pump with its own exchanger will gasify about $135 \mathrm{mmcfd}$. Each 4-pack and its associated BPT exchanger has the capacity of gasifying approximately $540 \mathrm{mmscfd}$. There are three major pump manufacturers in the world. Each manufacturer indicated that the pump and motor could be successfully fabricated using the technologies and processes currently available. The pump manufacturers advise that the pumps are not flow rate or pressure limited but rather horsepower limited. Therefore any pressure or pumping rate desired can be achieved with multiple units.

The major equipment items required for the BPT terminal have been identified. The pump manufactures confirm that the high pressure pumps required for the BPT process can be fabricated and pre-tested using 


\begin{tabular}{|l|l|l|l|}
\hline Customer: & $\begin{array}{l}\text { The United States Department of Energy } \\
\text { National Energy Technology Laboratory }\end{array}$ & $\begin{array}{l}\text { Date of Issue: } \\
\mathbf{2 4} \text { April } 2003\end{array}$ \\
\hline $\begin{array}{l}\text { Document } \\
\text { Title: }\end{array}$ & $\begin{array}{l}\text { Report I: Critical Elements in a process to Utilize Salt Caverns in an LNG } \\
\text { Receiving Terminal }\end{array}$ & $\begin{array}{l}\text { Doc \# \& Version: } \\
\text { Doc } 01 \text { r1.0 }\end{array}$ & Page 11 of 11 \\
\hline
\end{tabular}

existing materials, technology, and know-how. The BPT exchanger has been conceptually designed and a working model should be field tested to demonstrate its operating characteristics. 


\begin{tabular}{|l|l|l|l|}
\hline Customer: & $\begin{array}{l}\text { The United States Department of Energy } \\
\text { National Energy Technology Laboratory }\end{array}$ & $\begin{array}{l}\text { Date of Issue: } \\
\mathbf{2 4} \text { April } 2003\end{array}$ & \\
\hline $\begin{array}{l}\text { Document } \\
\text { Title: }\end{array}$ & $\begin{array}{l}\text { Subtask 1.1 Identify Potential Salt Formations Which Could be used for } \\
\text { LNG Receiving }\end{array}$ & $\begin{array}{l}\text { Doc \# \& Version: } \\
\text { Doc 02 r1.0 }\end{array}$ & Page 1 of 5 \\
\hline
\end{tabular}

\title{
Identify Potential Salt Formations Which Could be Used for LNG Receiving
}

\author{
BY \\ MichaEL M. MCCALL \\ WILLIAM M. BISHOP \\ D. BRAXTON SCHERZ
}

\begin{tabular}{|c|c||c|c|c|c|c|c|c||}
\hline r 1.0 & For client review & $04 / 15 / 03$ & вS & мм & & & \\
\hline Version & Reason for Issue & $\begin{array}{c}\text { Issue } \\
\text { Date }\end{array}$ & $\begin{array}{c}\text { Orig. } \\
\text { Chk. Appr. } \\
\text { CGI }\end{array}$ & $\begin{array}{c}\text { Chk. } \\
\text { NETL }\end{array}$ & Appr. & Review \\
\hline \hline $\begin{array}{l}\text { Document Title: } \\
\text { Identify Potential Salt Formations Which Could be } \\
\text { used for LNG Receiving }\end{array}$ & \multicolumn{7}{|c||}{$\begin{array}{c}\text { Document No: } \\
\text { DE-FC26-02NT41653 }\end{array}$} \\
\hline
\end{tabular}




\section{TABLE OF CONTENTS}

1. EXECUTIVE SUMMARY

2. TABLE OF SALT FORMATIONS SUITABLE (PARTIAL LIST) FOR DEVELOPMENT OF LNG RECEIVING FACILITIES.

3. CONTOUR MAPS 


\begin{tabular}{|l|l|l|l|}
\hline Customer: & $\begin{array}{l}\text { The United States Department of Energy } \\
\text { National Energy Technology Laboratory }\end{array}$ & $\begin{array}{l}\text { Date of Issue: } \\
24 \text { April } 2003\end{array}$ & \\
\hline $\begin{array}{l}\text { Document } \\
\text { Title: }\end{array}$ & $\begin{array}{l}\text { Subtask 1.1 Identify Potential Salt Formations Which Could be used for } \\
\text { LNG Receiving }\end{array}$ & $\begin{array}{l}\text { Doc \# \& Version: } \\
\text { Doc } 02 \text { r1.0 }\end{array}$ & Page 3 of 5 \\
\hline
\end{tabular}

\section{EXECUTIVE SUMMARY}

The U.S. coastal areas of the Gulf of Mexico have a convergence of multiple salt formations suitable for natural gas storage, major shipping fairways and harbor approaches capable of accommodating the largest LNG ships, and the most comprehensive natural gas pipeline infrastructure in the world. This section of the study defines several sites suited for a Salt Storage LNG terminal both onshore and offshore. A detailed conceptual design appearing later in this study describes two ideal locations that best exemplify this convergence, an onshore location in Calcasieu Parish, Louisiana, and an offshore site in Vermilion block 179. At these two sites LNG ships can easily access nearby salt formations, and nearby natural gas pipelines with take away capacity exceeding 2 Bcf/day are in close proximity.

Dozens of other potential locations have been identified in Texas, Louisiana, Mississippi and offshore areas adjacent to these states that have similar potential. A series of LNG receiving facilities using the existing infrastructure in the Gulf of Mexico coastal area and contiguous salt caverns within the region could meet virtually any growth necessary in LNG imports required to replace declining production or meet growing natural gas demand.

\section{TABLE OF SALT FORMATIONS SUITABLE (PARTIAL LIST) FOR DEVELOPMENT OF LNG RECEIVING FACILITIES}

\begin{tabular}{|l|l|l|}
\hline \multicolumn{1}{|c|}{ Site } & \multicolumn{1}{|c|}{ Location } & \multicolumn{1}{c|}{ County } \\
\hline \multicolumn{1}{|c|}{ Onshore Texas } & \multicolumn{1}{|c|}{ Pefferson } & DOE SPR Site \\
\hline Big Hill & Jefferson & \\
\hline Spindletop & Brazoria & DOE SPR Site \\
\hline Bryan Mound & Brazoria & \\
\hline Hoskins Mound & Brazoria & \\
\hline Stratton Ridge & \multicolumn{1}{|c|}{ Parish } \\
\hline \multicolumn{1}{|c|}{ Onshore Louisiana } & Cameron & \\
\hline Black Bayou & Cameron & DOE SPR Site \\
\hline West Hackberry & Calcasieu & This site was chosen for the conceptual facility \\
\hline Sulphur Mines & St. Mary & \\
\hline Cote Blanche Island & Iberia & \\
\hline Jefferson Island & Iberia & \\
\hline Vermilion Bay & Plaquemines & \\
\hline Venice & & Please reference the following contour maps \\
\hline & & \\
\hline \multicolumn{1}{|c|}{ Offshore Louisiana } & 115 & This site was chosen for the conceptual facility \\
\hline East Cameron & 73 & \\
\hline South Marsh Island & 179 & \\
\hline Vermilion & 16 & \\
\hline Grand Isle & 175 & \\
\hline Eugene Island & 178 & \\
\hline Eugene Island & 188 & \\
\hline Eugene Island & 205 & \\
\hline Eugene Island & 128 & \\
\hline Eugene Island & & \\
\hline
\end{tabular}




\begin{tabular}{|l|l|l|l|}
\hline Customer: & $\begin{array}{l}\text { The United States Department of Energy } \\
\text { National Energy Technology Laboratory }\end{array}$ & $\begin{array}{l}\text { Date of Issue: } \\
24 \text { April } 2003\end{array}$ & \\
\hline $\begin{array}{l}\text { Document } \\
\text { Title: }\end{array}$ & $\begin{array}{l}\text { Subtask 1.1 Identify Potential Salt Formations Which Could be used for } \\
\text { LNG Receiving }\end{array}$ & $\begin{array}{l}\text { Doc \# \& Version: } \\
\text { Doc } 02 \text { r1.0 }\end{array}$ & Page 4 of 5 \\
\hline
\end{tabular}

\begin{tabular}{|l|l|l|}
\hline Eugene Island & 126 & \\
\hline West Delta & 133 & \\
\hline Main Pass & 290 & \\
\hline Main Pass & 299 & \\
\hline & & \\
\hline
\end{tabular}

\section{SALT FORMATION LOCATIONS}

The red designations on the map below indicate the location of the formations mentioned above. Each of these locations are in close proximity with the GOM natural gas gathering systems capable of up to 10 Bcfd takeaway.

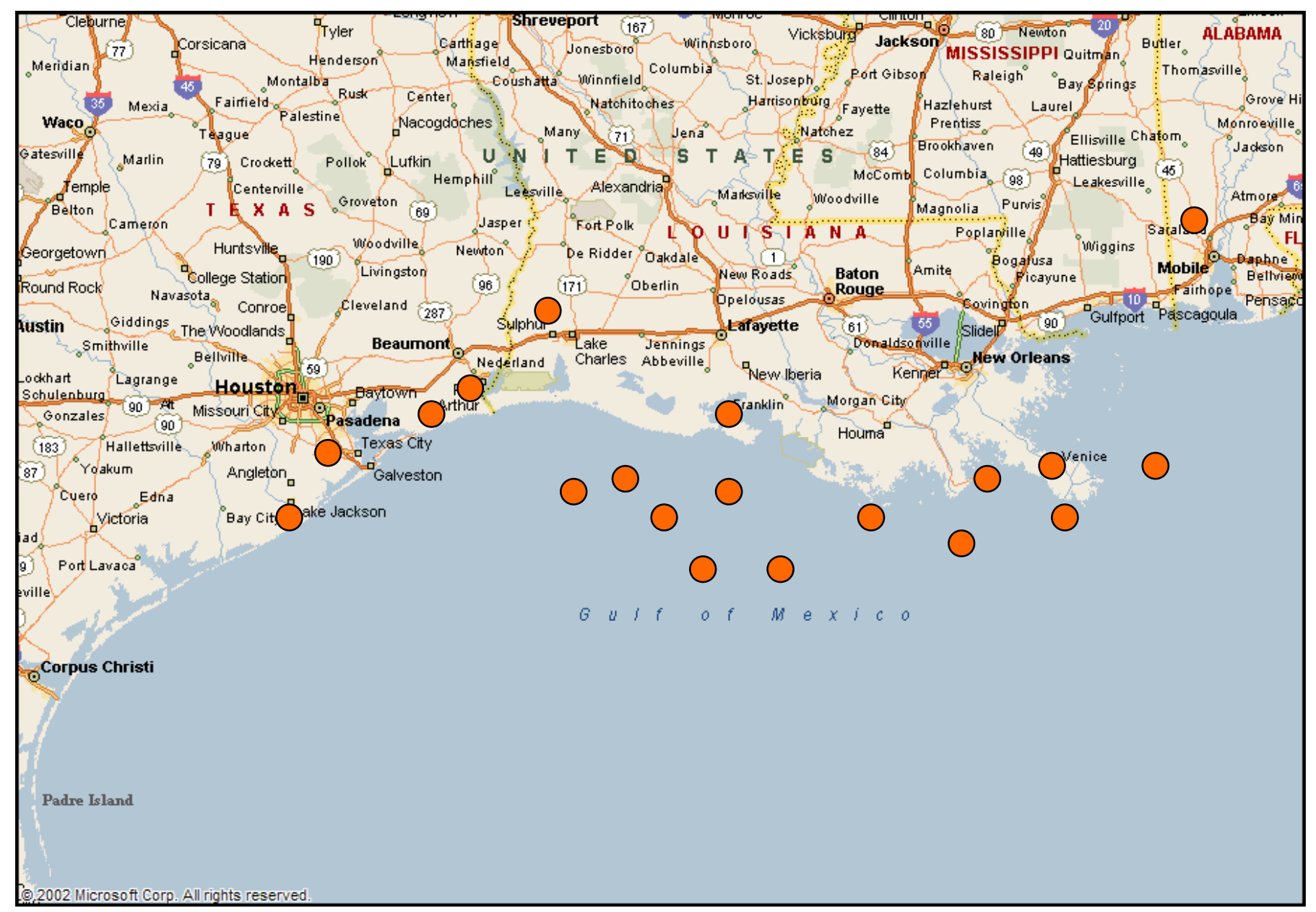

While $10 \mathrm{Bcf}$ or even greater of storage is a large amount of natural gas stored in one location, the actual size of the cavern compared to the salt formation is quite small, on the order of $1 / 100$ th to $1 / 1000$ th of the overall size of the domal formation. The attached contour maps indicate dome formations of sizes ranging from one to about four miles apart. The top of salt is ideally located about 1000 feet below the surface allowing for economical cavern creation at design pressures. The salt dome itself extends far below the surface, eventually joining with the basal 


\begin{tabular}{|l|l|l|l|}
\hline Customer: & $\begin{array}{l}\text { The United States Department of Energy } \\
\text { National Energy Technology Laboratory }\end{array}$ & $\begin{array}{l}\text { Date of Issue: } \\
\mathbf{2 4} \text { April } 2003\end{array}$ \\
\hline $\begin{array}{l}\text { Document } \\
\text { Title: }\end{array}$ & $\begin{array}{l}\text { Subtask 1.1 Identify Potential Salt Formations Which Could be used for } \\
\text { LNG Receiving }\end{array}$ & $\begin{array}{l}\text { Doc \# \& Version: } \\
\text { Doc } \mathbf{0 2} \text { r1.0 }\end{array}$ & Page 5 of 5 \\
\hline
\end{tabular}

formation. The salt caverns are washed in areas of the dome at prescribed distances from the edge and the top of salt formation to ensure the integrity of the storage cavity.

\section{CONTOUR MAPS}

The locations mapped on the following pages were selected because the salt formations are appropriately close to the seabed and in the midst of the extensive GOM gathering systems. Currently there is no hydrocarbon storage in any of these but each is ideal for development of cavern storage. 


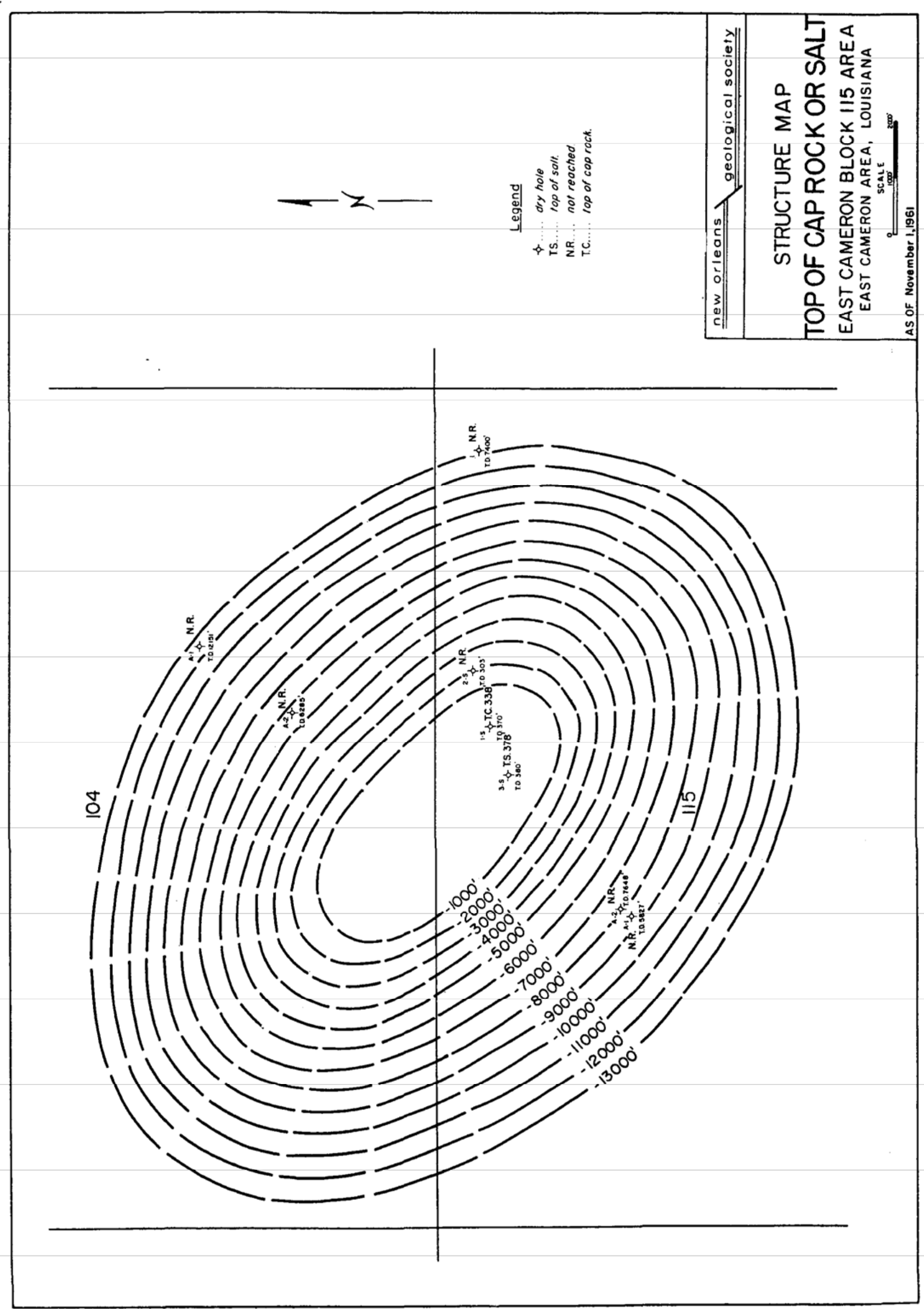




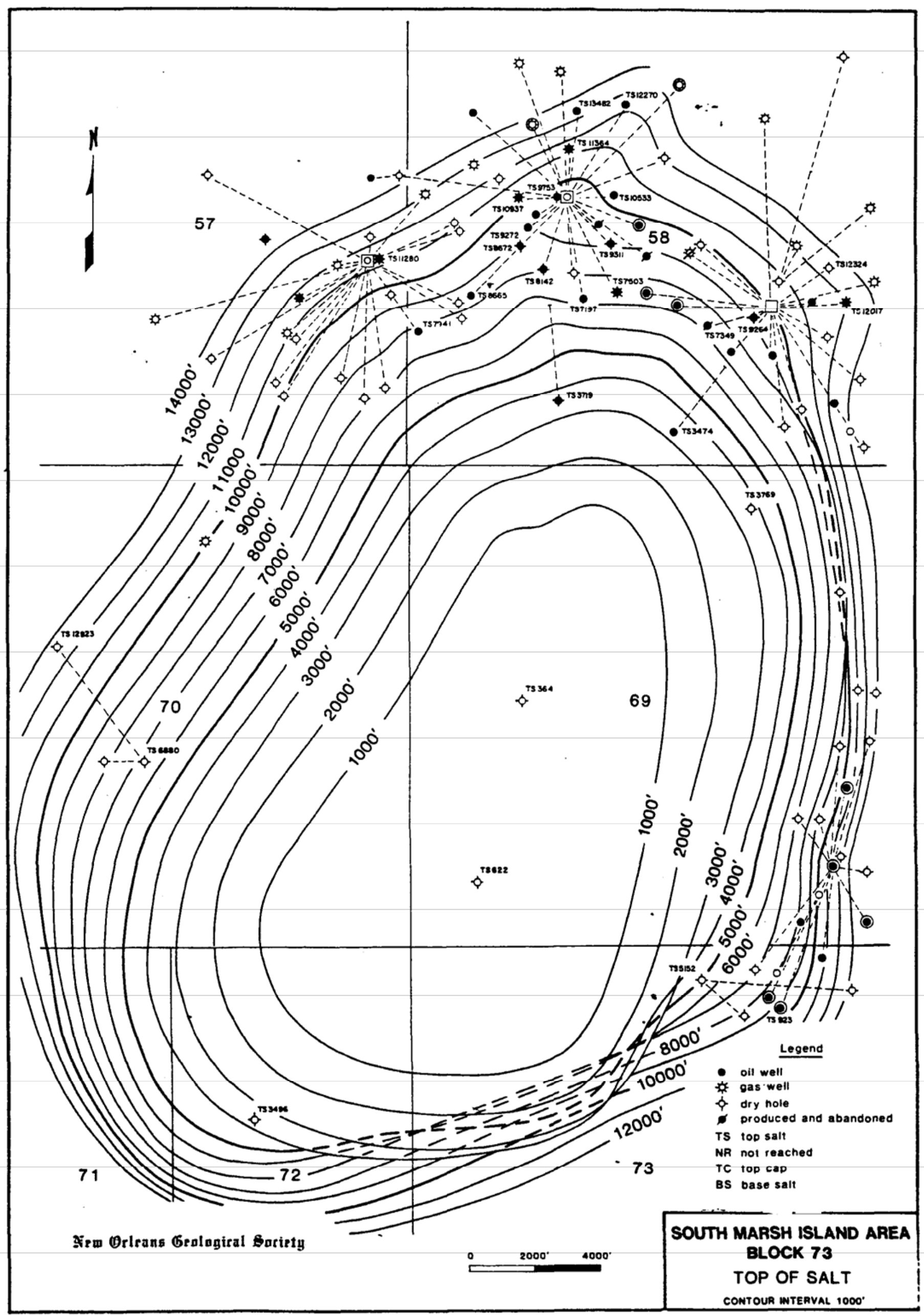




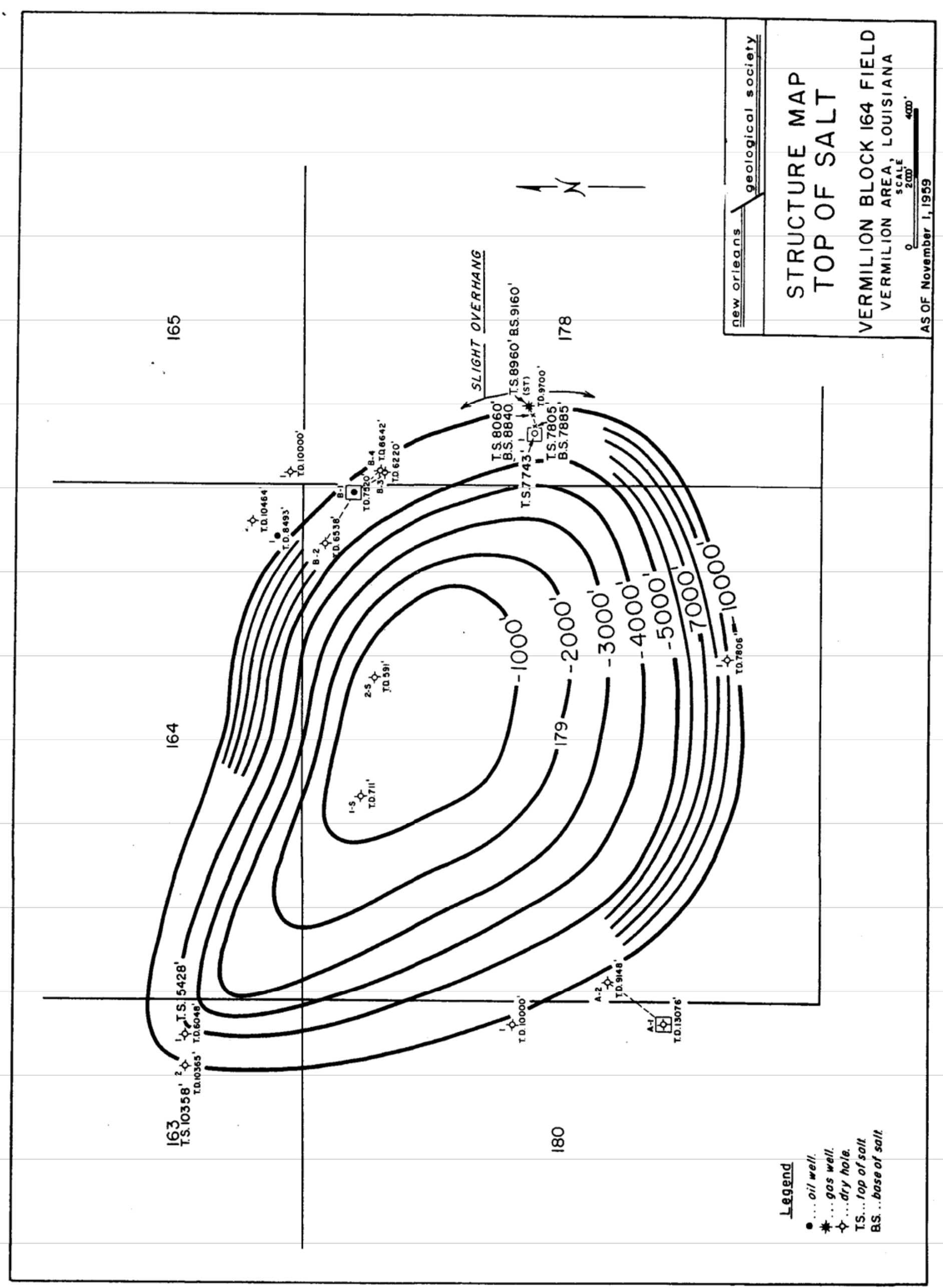




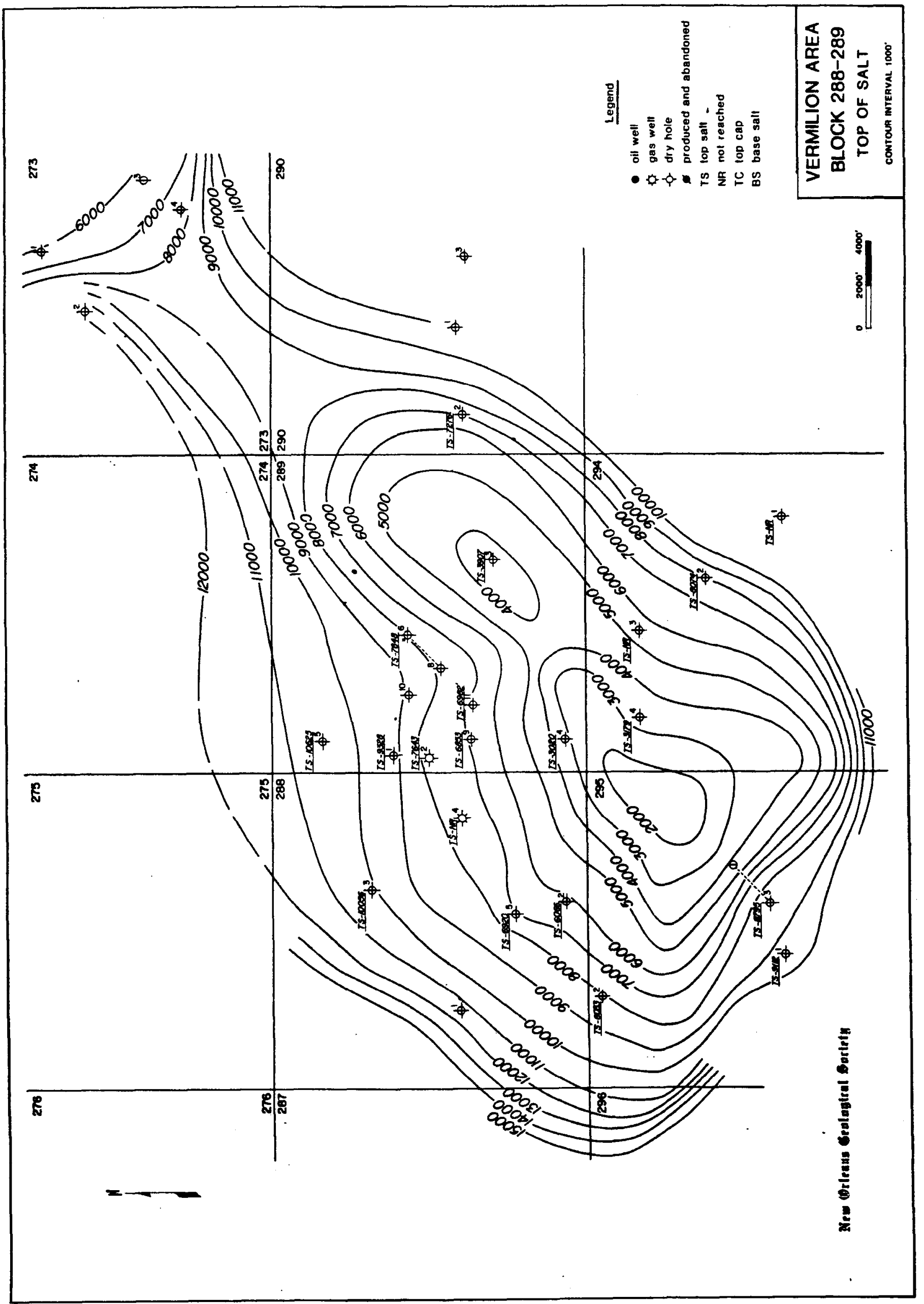




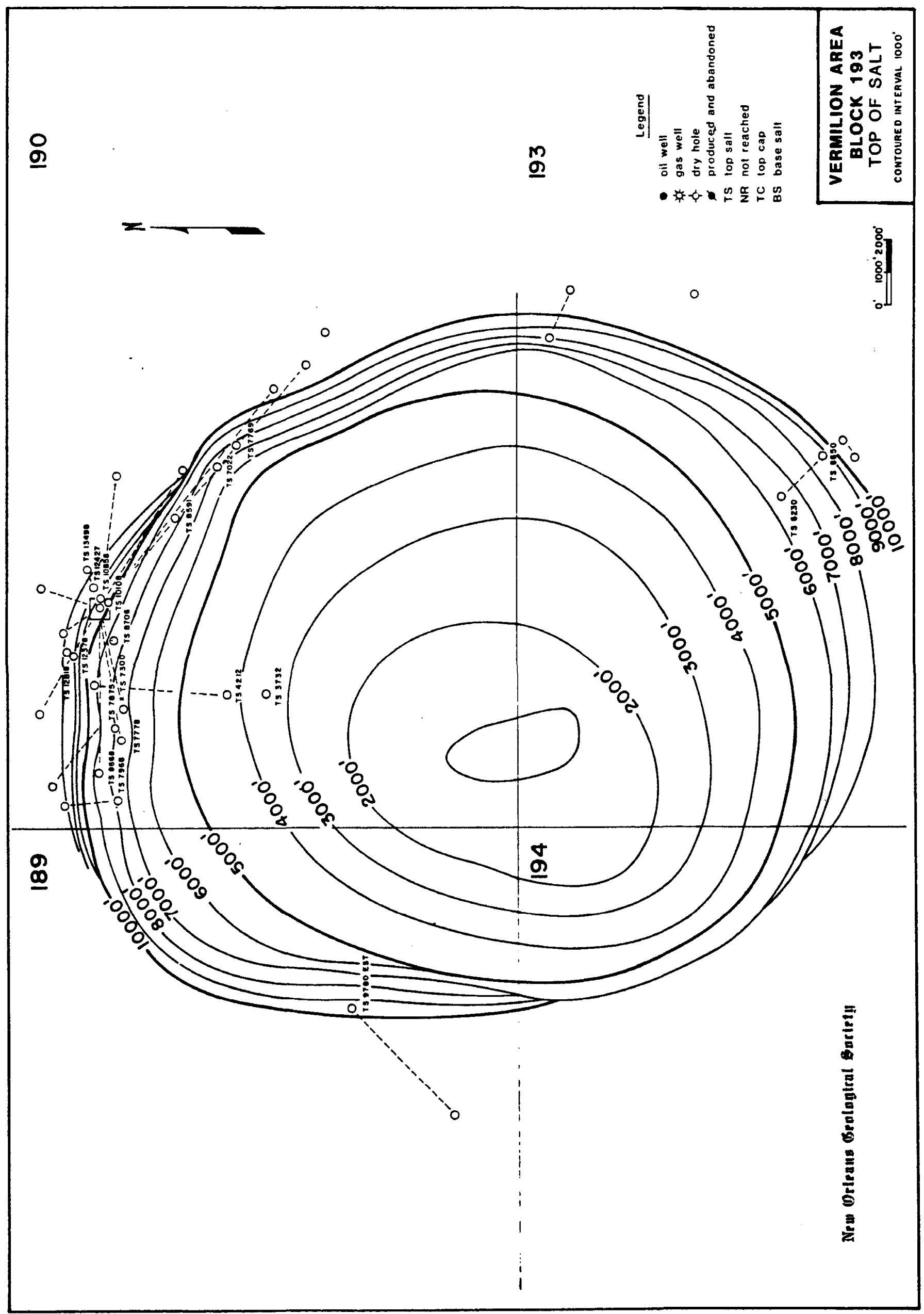




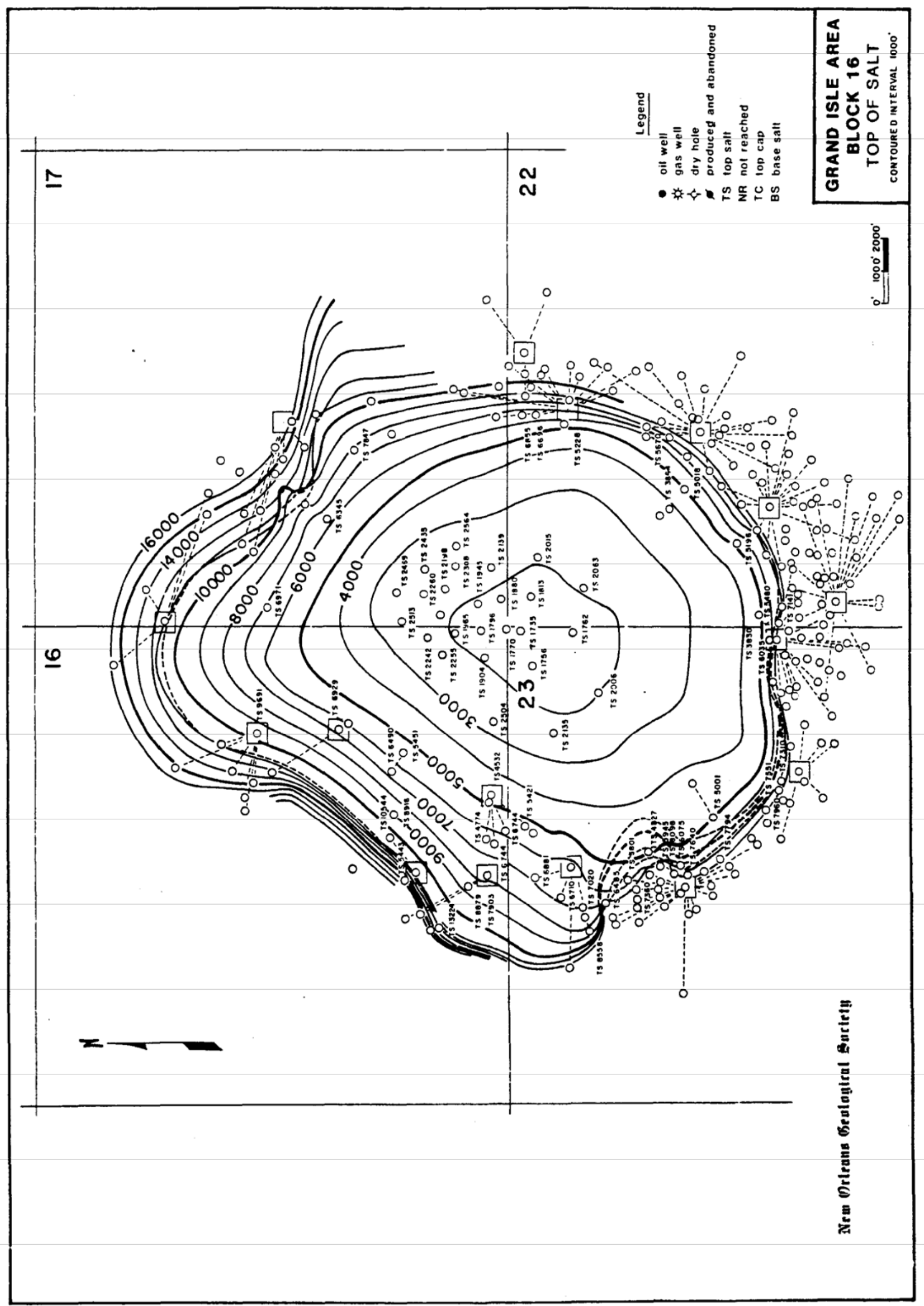




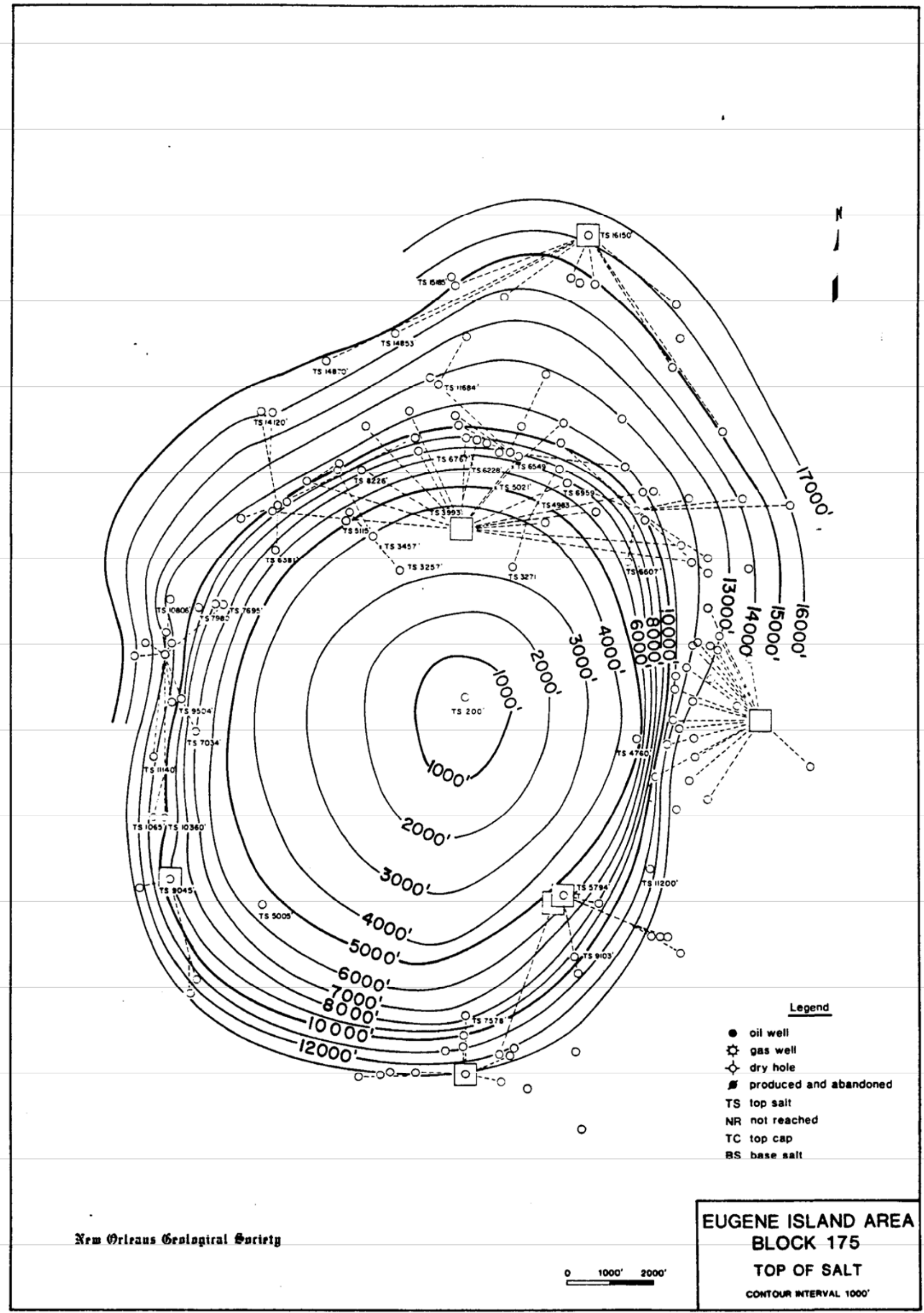




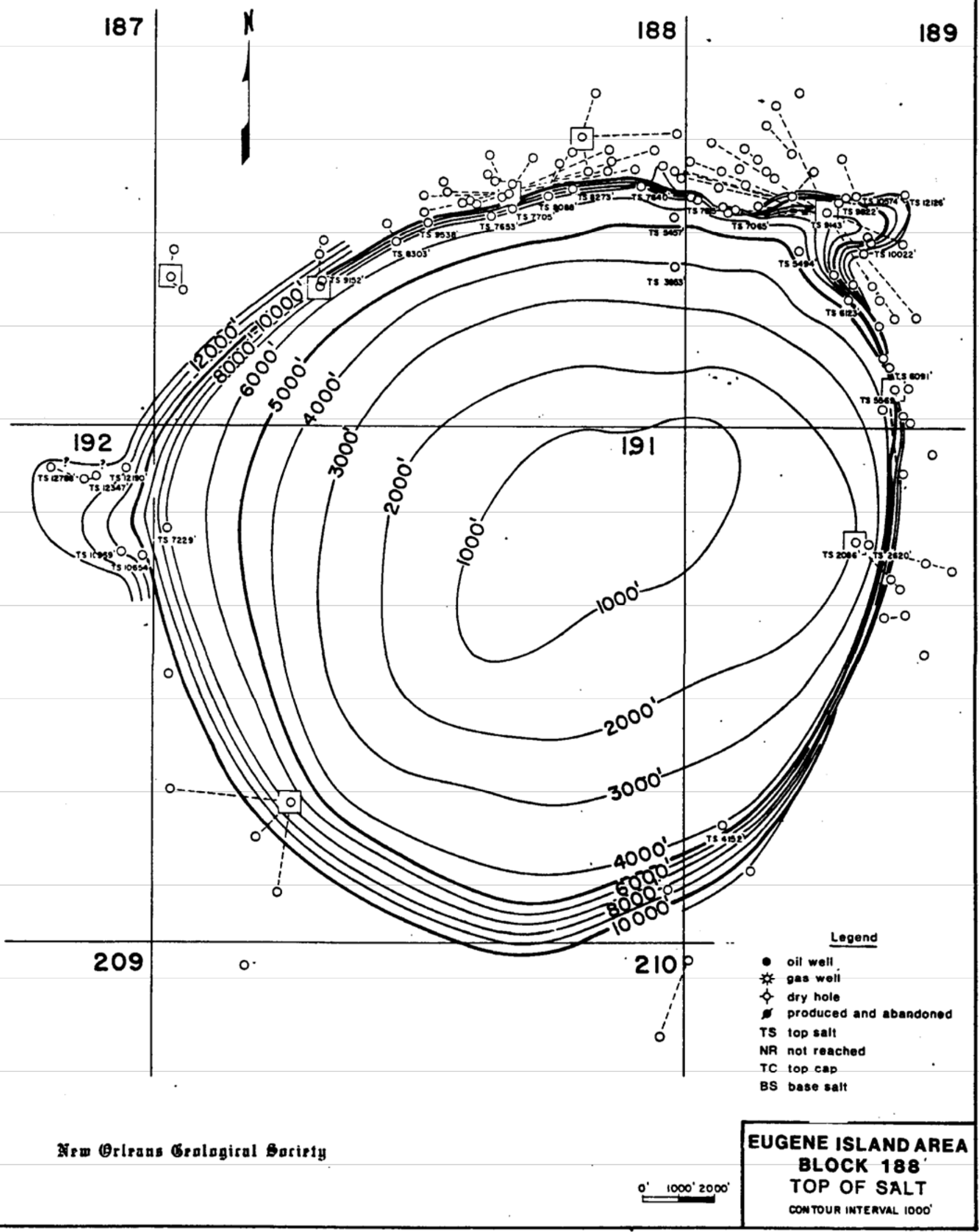




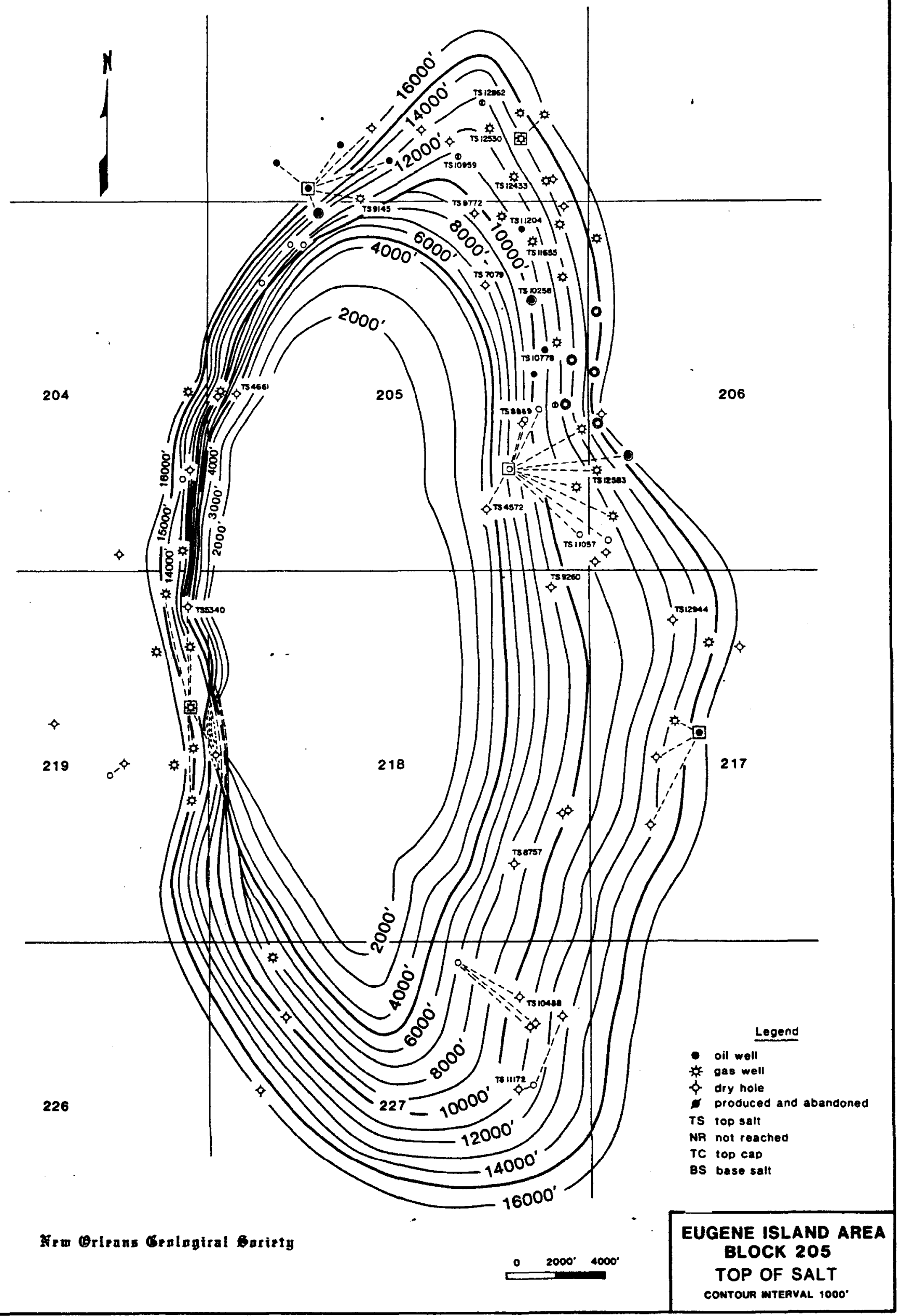




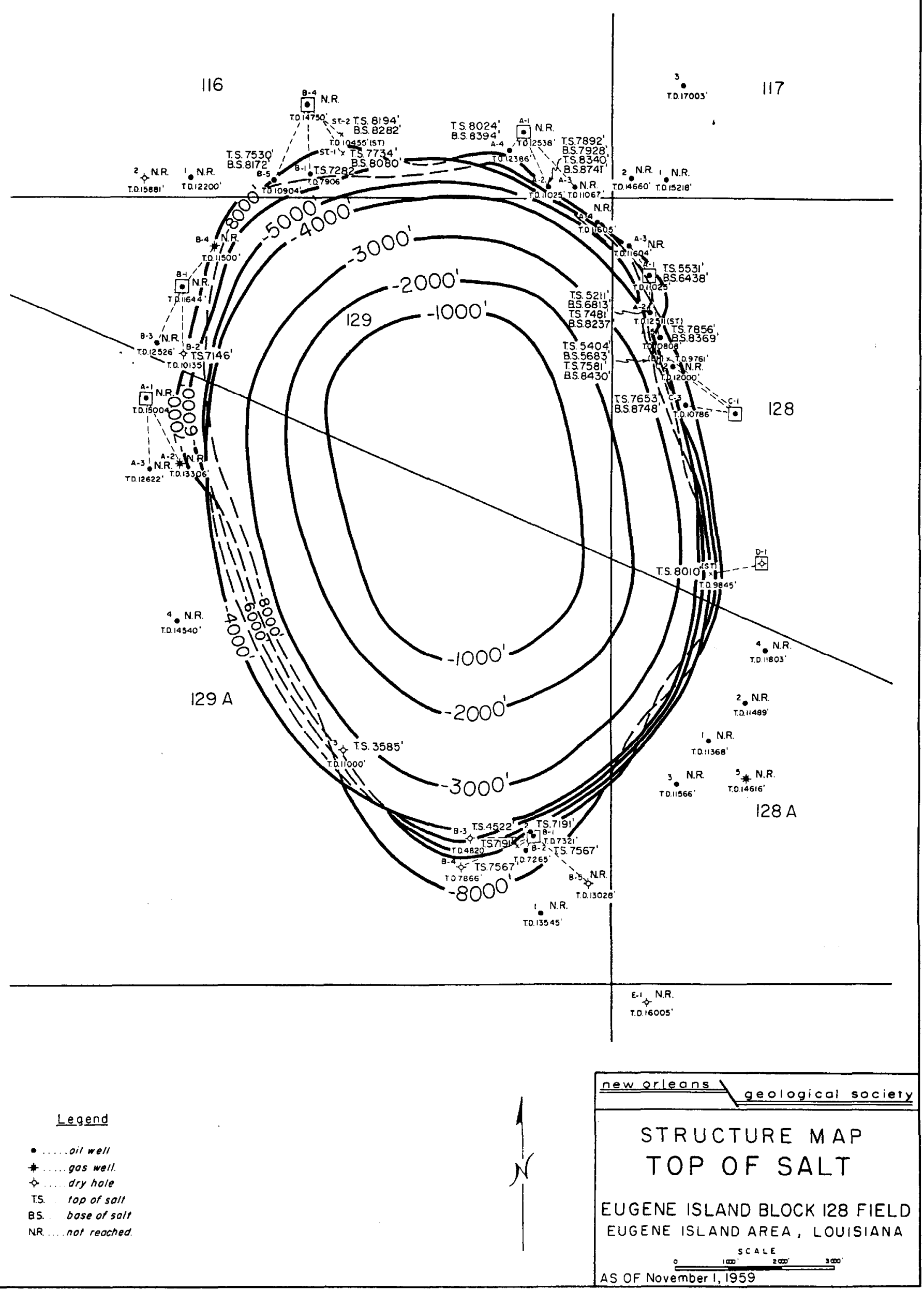




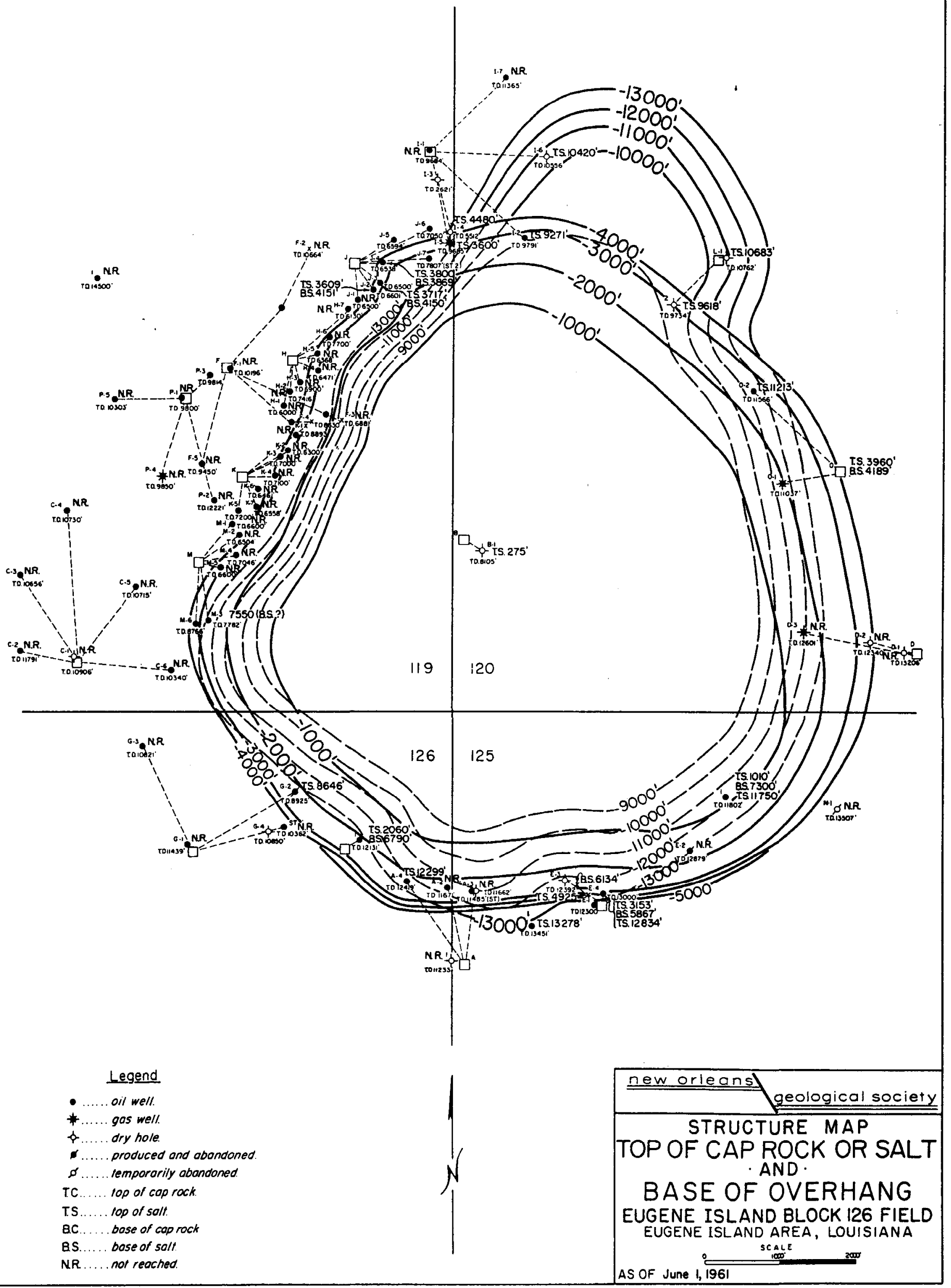




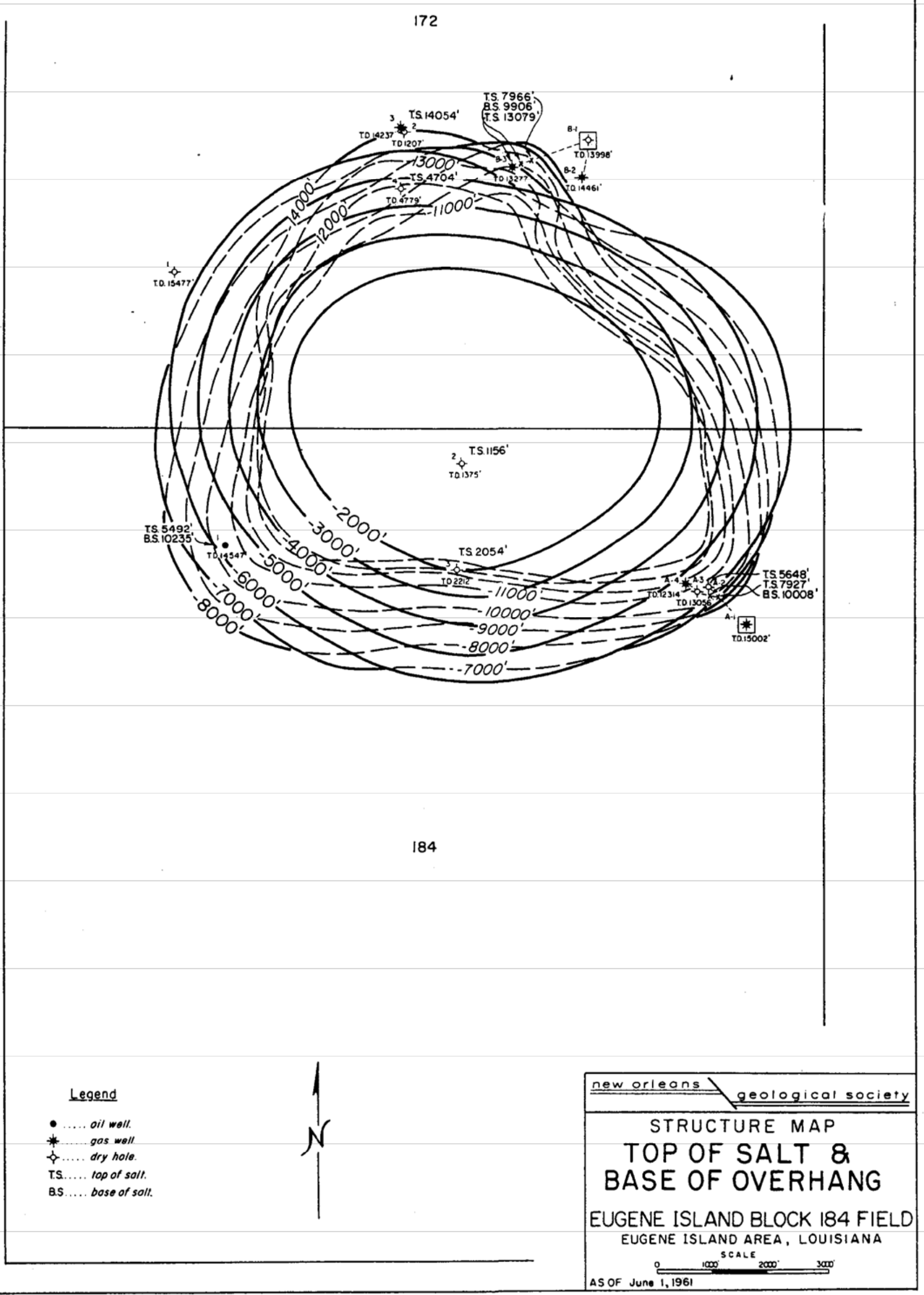




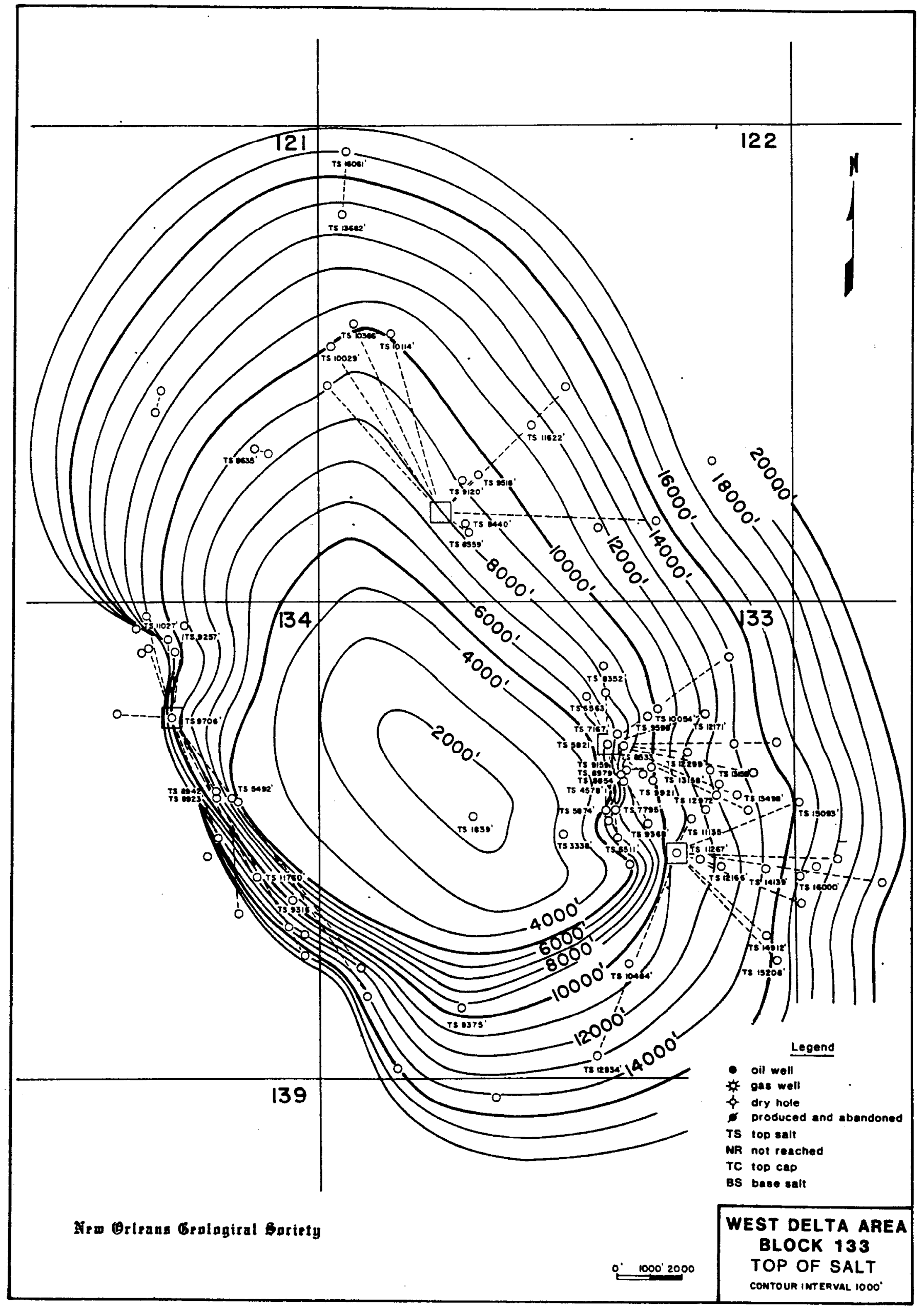




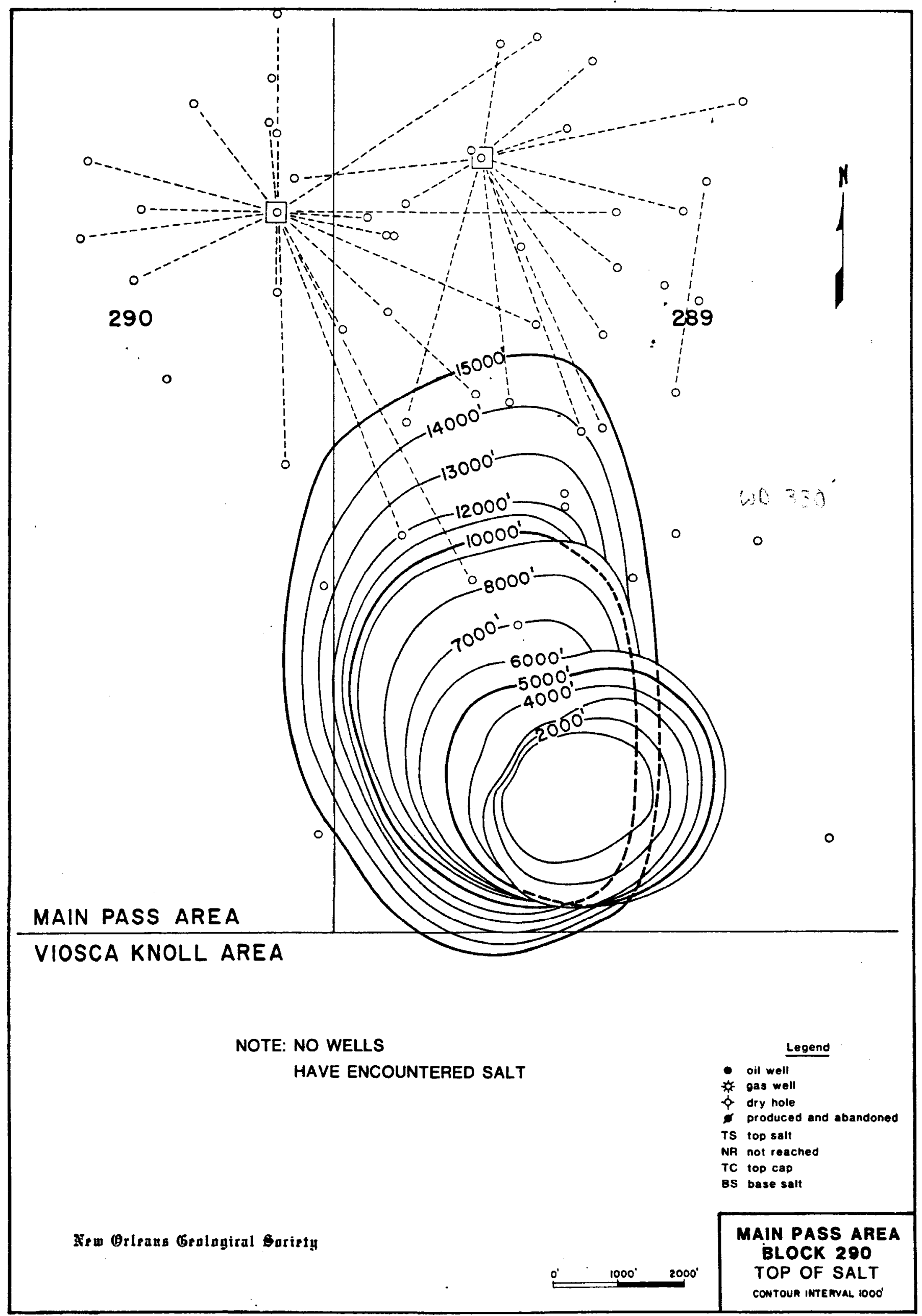




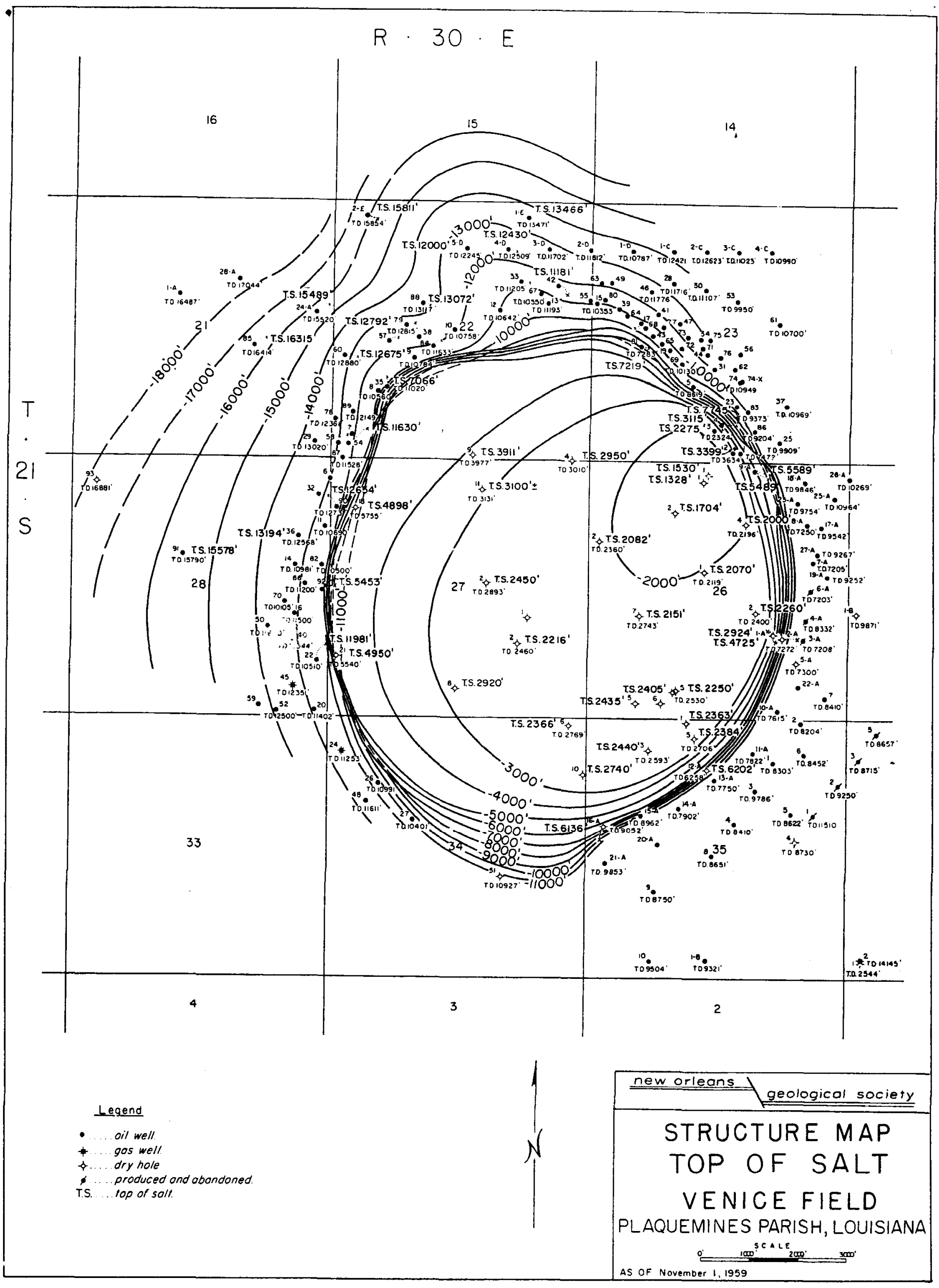




\begin{tabular}{|l|l|l|l|}
\hline Customer: & $\begin{array}{l}\text { The United States Department of Energy } \\
\text { National Energy Technology Laboratory }\end{array}$ & $\begin{array}{l}\text { Date of Issue: } \\
29 \text { April } 2003\end{array}$ & \\
\hline $\begin{array}{l}\text { Document } \\
\text { Title: }\end{array}$ & $\begin{array}{l}\text { Subtask 1.2 } \\
\text { Identify Marine Mooring and Offloading Initiatives for LNG Vessels }\end{array}$ & $\begin{array}{l}\text { Doc \# \& Version: } \\
\text { Doc } 003 \text { r4.0 }\end{array}$ & Page 1 of $\mathbf{4 0}$ \\
\hline
\end{tabular}

\section{Examine and Evaluate a Process to use Salt Caverns to Receive SHIP BORNE LIQUEFIED NATURAL GAS}

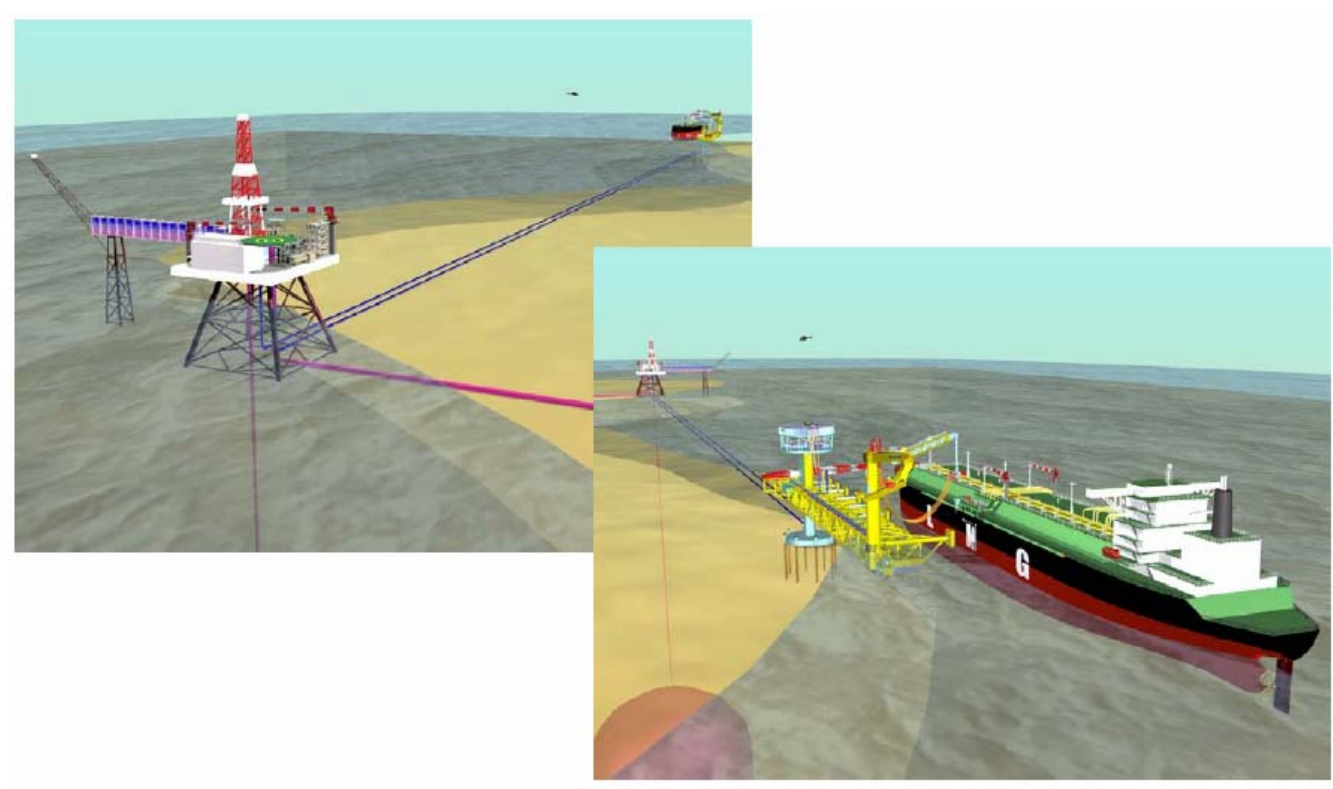

\section{BY}

MichaEL M. MCCALL

WILLIAM M. BISHOP

D. BRAXTON SCHERZ

\begin{tabular}{|c|c|c|c|c|c|c|c|c|}
\hline r 4.0 & For client review & $04 / 24 / 03$ & BS & мM & & & & \\
\hline Version & Reason for Issue & $\begin{array}{l}\text { Issue } \\
\text { Date }\end{array}$ & Orig. & $\begin{array}{l}\text { Chk. } \\
\text { CGI }\end{array}$ & Appr. & $\begin{array}{c}\text { Chk. } \\
\text { NE }\end{array}$ & $\begin{array}{l}\text { Appr. } \\
\text { TL }\end{array}$ & Review \\
\hline \multicolumn{2}{|c|}{$\begin{array}{l}\text { Document Title: } \\
\text { Subtask 1.2 Identify Marine Mooring and } \\
\text { Offloading Initiatives for LNG Vessels }\end{array}$} & \multicolumn{7}{|c|}{ Document No: } \\
\hline
\end{tabular}




\begin{tabular}{|l|l|l|l|}
\hline Customer: & $\begin{array}{l}\text { The United States Department of Energy } \\
\text { National Energy Technology Laboratory }\end{array}$ & $\begin{array}{l}\text { Date of Issue: } \\
29 \text { April } 2003\end{array}$ & \\
\hline $\begin{array}{l}\text { Document } \\
\text { Title: }\end{array}$ & $\begin{array}{l}\text { Subtask 1.2 } \\
\text { Identify Marine Mooring and Offloading Initiatives for LNG Vessels }\end{array}$ & $\begin{array}{l}\text { Doc\# \& Version: } \\
\text { Doc } 003 \text { r4.0 }\end{array}$ & Page 2 of $\mathbf{4 0}$ \\
\hline
\end{tabular}

\section{TABLE OF CONTENTS}

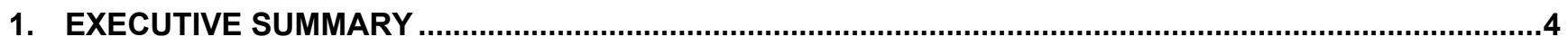

2. MOORING AND TRANSFER TECHNOLOGIES - THE OFFSHORE OIL INDUSTRY ..............................4

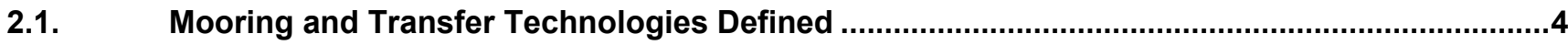

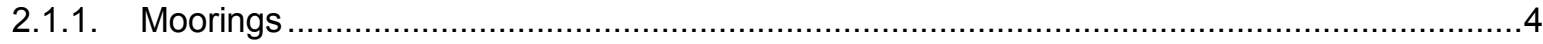

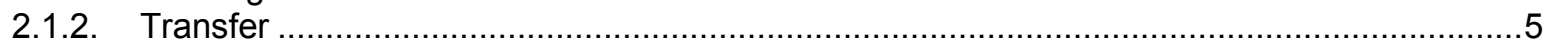

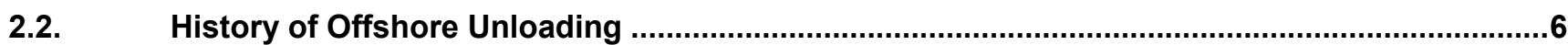

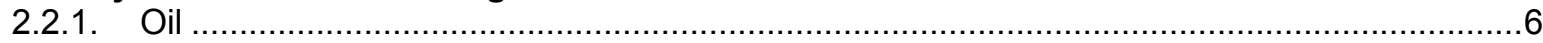

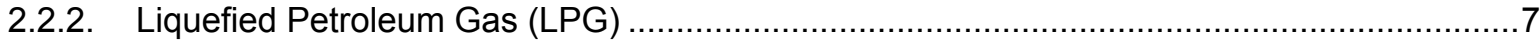

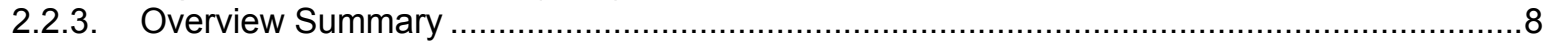

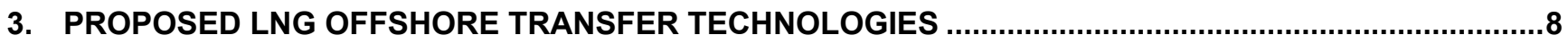

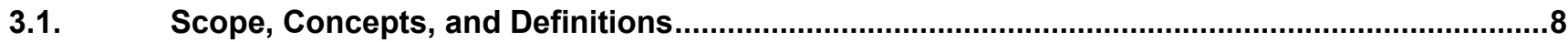

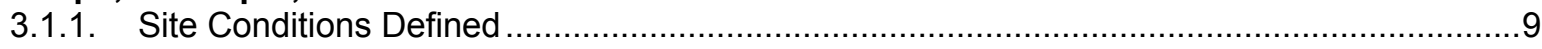

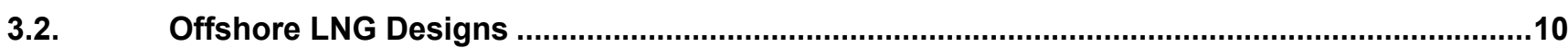

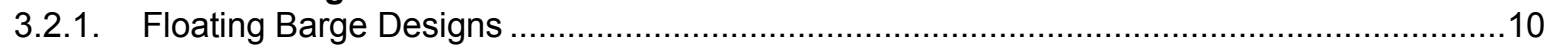

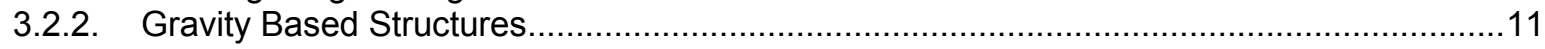

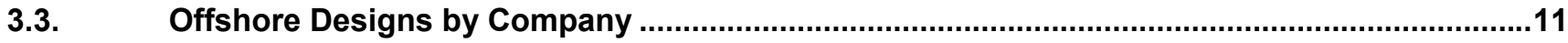

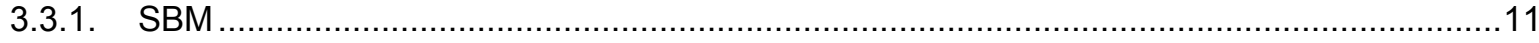

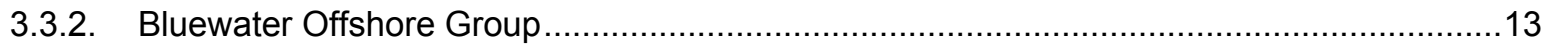

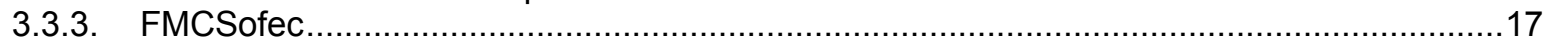

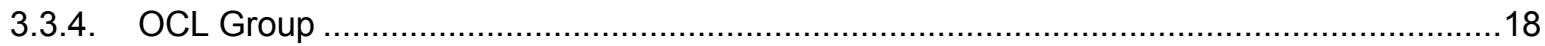

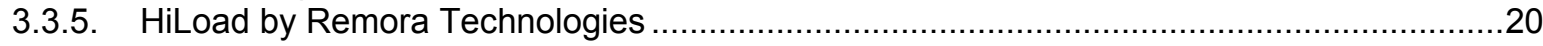

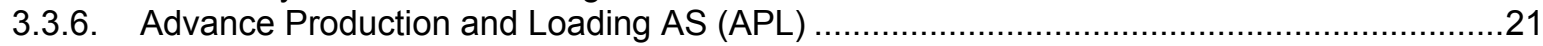

3.3.7. New Architectures of LNG Transfer by TFE, GdF, Eurodim, and ITP ..........................22

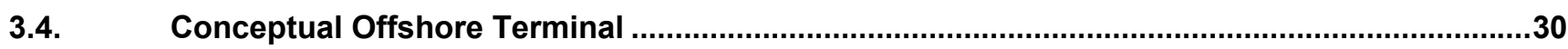

4. LINK TECHNOLOGIES TO FACILITATE LNG OFFSHORE TRANSFER ...........................................31

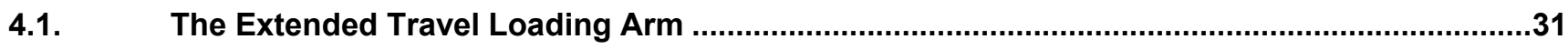

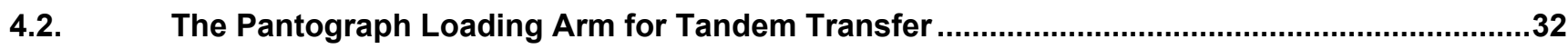

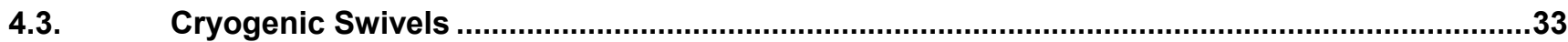

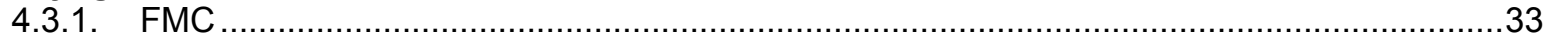

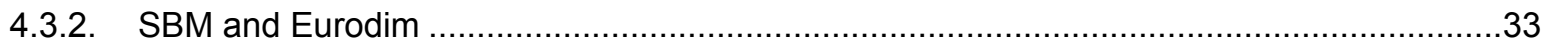

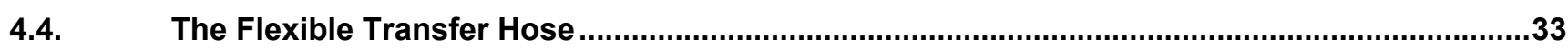

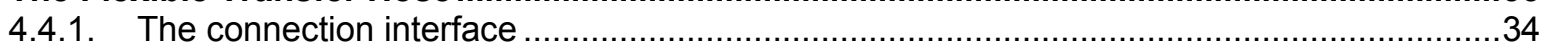




\begin{tabular}{|l|l|l|l|}
\hline Customer: & $\begin{array}{l}\text { The United States Department of Energy } \\
\text { National Energy Technology Laboratory }\end{array}$ & $\begin{array}{l}\text { Date of Issue: } \\
29 \text { April } 2003\end{array}$ \\
\hline $\begin{array}{l}\text { Document } \\
\text { Title: }\end{array}$ & $\begin{array}{l}\text { Subtask 1.2 } \\
\text { Identify Marine Mooring and Offloading Initiatives for LNG Vessels }\end{array}$ & $\begin{array}{l}\text { Doc \# \& Version: } \\
\text { Doc } 003 \text { r4.0 }\end{array}$ & Page 3 of 40 \\
\hline
\end{tabular}

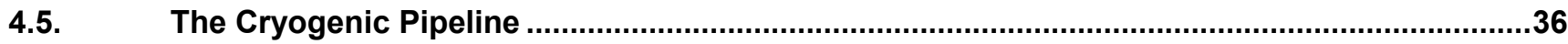

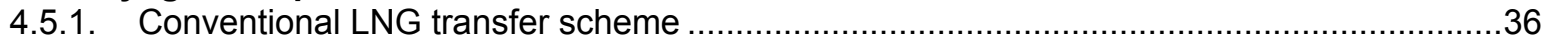

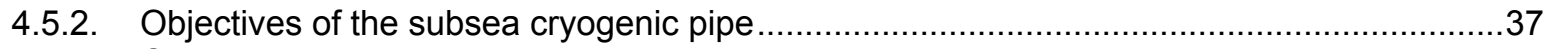

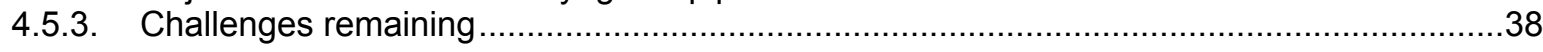

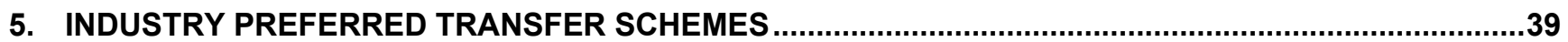

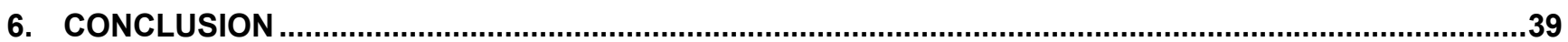




\begin{tabular}{|l|l|l|l|}
\hline Customer: & $\begin{array}{l}\text { The United States Department of Energy } \\
\text { National Energy Technology Laboratory }\end{array}$ & $\begin{array}{l}\text { Date of Issue: } \\
29 \text { April } 2003\end{array}$ & \\
\hline $\begin{array}{l}\text { Document } \\
\text { Title: }\end{array}$ & $\begin{array}{l}\text { Subtask 1.2 } \\
\text { Identify Marine Mooring and Offloading Initiatives for LNG Vessels }\end{array}$ & $\begin{array}{l}\text { Doc \# \& Version: } \\
\text { Doc } 003 \text { r4.0 }\end{array}$ & Page $\mathbf{4}$ of $\mathbf{4 0}$ \\
\hline
\end{tabular}

\section{EXECUTIVE SUMMARY}

This research confirms the feasibility of using offshore mooring facilities in a salt cavern based LNG receiving terminal. Task 1.2 identifying marine mooring and offloading initiatives compares the existing and proposed LNG offshore transfer technologies, identifies the commonalities, and recognizes industry requirements and transfer preferences. Reduced NIMBY (not in my backyard) concerns and permitting requirements, siting flexibility, quicker construction times, and lesser CAPEX/OPEX are among the many advantages of transferring and handling LNG offshore.

Producers considering LNG offshore transfer schemes prefer moorings that provide high availability. Weathervaning moorings (a mooring allows LNG vessel rotation around a vertical axis to assume a heading of minimum motion), facilitate maximum stability and good availability. Some producers have gone to gravity based structures that provide high availability in rough seas as they securely rest on the ocean floor. Also preferred are side by side cargo transfer schemes to accommodate current LNG ship cargo piping arrangements.

Several offshore transfer challenges have been identified including the need to minimize the relative motion between LNG vessel and transfer facility, and the requirement to improve linking systems (transfer arms, hoses, subsea pipelines, etc.) for high availability. Well designed marine berths capable of using the vessel's existing cargo manifolds could bring about the transfer LNG at sea in the very near future.

All the technologies required for safe LNG transfer at sea currently exist, although not within the same company. There is a possibility to consolidate LNG offshore engineering and design under the coordination of a recognized E\&C firm capable of combining the heretofore proven systems into one universal package acceptable to the LNG industry. This effort, coupled with the design work and testing necessary to complete the system is expected to take between 12 and 18 months to complete. The realization of an offshore LNG terminal using salt cavern storage is expected to take about 12 additional months for regulatory approval, and about 20 to 30 months to construct.

\section{MOORING AND TRANSFER TECHNOLOGIES - THE OFFSHORE OIL INDUSTRY}

The LNG trade offshore will follow in the footsteps of the proven technologies used in today's successful offshore oil industry. To appreciate the methods and systems to be employed by LNG offshore applications we must review the methodologies used to transfer oil at sea.

\subsection{Mooring and Transfer Technologies Defined}

\subsubsection{Moorings}

fig .2.1.1-1

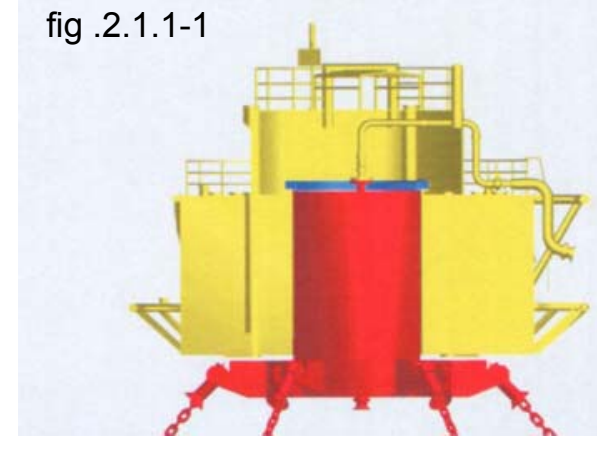




\begin{tabular}{|l|l|l|l|}
\hline Customer: & $\begin{array}{l}\text { The United States Department of Energy } \\
\text { National Energy Technology Laboratory }\end{array}$ & $\begin{array}{l}\text { Date of Issue: } \\
29 \text { April } 2003\end{array}$ & \\
\hline $\begin{array}{l}\text { Document } \\
\text { Title: }\end{array}$ & $\begin{array}{l}\text { Subtask 1.2 } \\
\text { Identify Marine Mooring and Offloading Initiatives for LNG Vessels }\end{array}$ & $\begin{array}{l}\text { Doc \# \& Version: } \\
\text { Doc } \mathbf{0 0 3} \mathbf{4 . 0}\end{array}$ & Page $\mathbf{5}$ of $\mathbf{4 0}$ \\
\hline
\end{tabular}

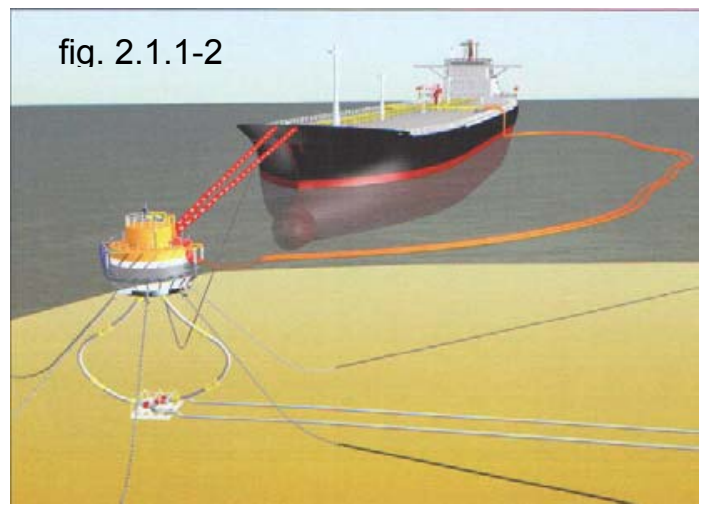

Vessels capable of transferring large quantities of oil at sea are classified as either Floating Storage Offshore (FSO) vessels used solely for storage and transfer, or Floating Storage and Production Offshore (FPSO) facilities which have the capability of processing the hydrocarbon stream into various petroleum products. These facilities whether spread moored, in a single, fixed orientation, or weathervaning (freely rotating with wind and current in a 360 degree motion around a fixed point) provide safe moorings for offshore oil transfer. Weathervaning moorings are used in more severe site conditions and provide greater availability in rough weather.

The Cantenary Anchored Leg Mooring (CALM) system (fig 2.1.1-1) also provides a popular, inexpensive option for product transfer. The CALM buoy consists of two main structural components; a turret structure (red) moored to the ocean floor, and a buoy body (yellow) that rotates with the ship. The product lines attach to the stationary structure and mate with rotating discharge piping through a fluid swivel. The ship approaches the CALM buoy, extends its hawser (large diameter polyester or nylon mooring line) through the bow, and connects to the rotating portion of the buoy. A floating cargo transfer hose is attached to the loading manifold of the receiving tanker, and the tanker weathervanes freely during the transfer operation. There are several weathervaning designs employing CALM buoys of many configurations. Some are fitted to the bow (fig. 2.1.1-2), or to the underside of the moored vessel. FPSO's and FSO's usually employ attached buoys for more permanent operation.

\subsubsection{Transfer}

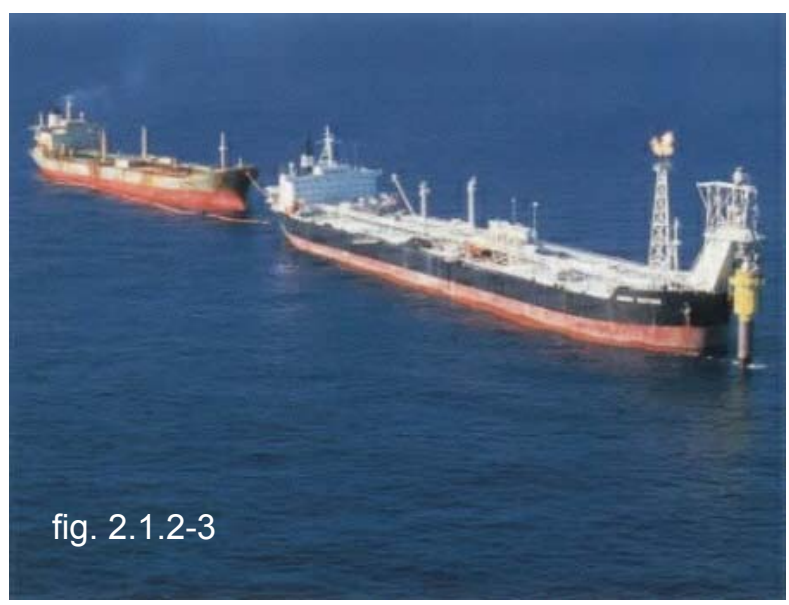

The transfer of oil from an offshore field and production facility employs several safe, reliable technologies that will be described in this section of the report. Understanding the methodologies used to transfer oil offshore is tantamount to the understanding of transferring LNG offshore. Many of the concepts and technology used to offload oil at sea could be applied to the transfer of LNG offshore. The following pictures and explanations will define the methods in current use beginning with the most popular option, tandem transfer (fig. 2.1.2-3).

Using the tandem transfer method, the receiving vessel approaches the stern of a moored storage vessel. A very strong hawser is attached to the stern of the moored tanker or storage facility while the approaching ship is still a safe distance away. A tugboat is then tied to the stern of the approaching vessel as the ships engines reverse thrust, pulling the two vessels apart. The hawser absorbs the strain and the vessels assume a relatively stable position in relation to each other. The ship's engine continuously pulling astern, maintains this relative position throughout the transfer operation.

The transfer of product from the mid-ship manifold of the offloading vessel to the mid-ship product manifold of the receiving tanker takes place through a large diameter floating hose capable of high oil transfer rates. After the receiving vessel is filled, air is used to blow back and purge the hose to the offloading tanker. The hose can then be disconnected and capped to prevent spillage.

The tug pulls the receiving vessel away for the offloading tanker as the hawser is loosened. The hawser is removed from the receiving vessel and the offloading vessel is made ready for the next receiving tanker. 


\begin{tabular}{|l|l|l|l|}
\hline Customer: & $\begin{array}{l}\text { The United States Department of Energy } \\
\text { National Energy Technology Laboratory }\end{array}$ & $\begin{array}{l}\text { Date of Issue: } \\
29 \text { April } 2003\end{array}$ & \\
\hline $\begin{array}{l}\text { Document } \\
\text { Title: }\end{array}$ & $\begin{array}{l}\text { Subtask 1.2 } \\
\text { Identify Marine Mooring and Offloading Initiatives for LNG Vessels }\end{array}$ & $\begin{array}{l}\text { Doc \# \& Version: } \\
\text { Doc } 003 \text { r4.0 }\end{array}$ & Page $\mathbf{6}$ of $\mathbf{4 0}$ \\
\hline
\end{tabular}

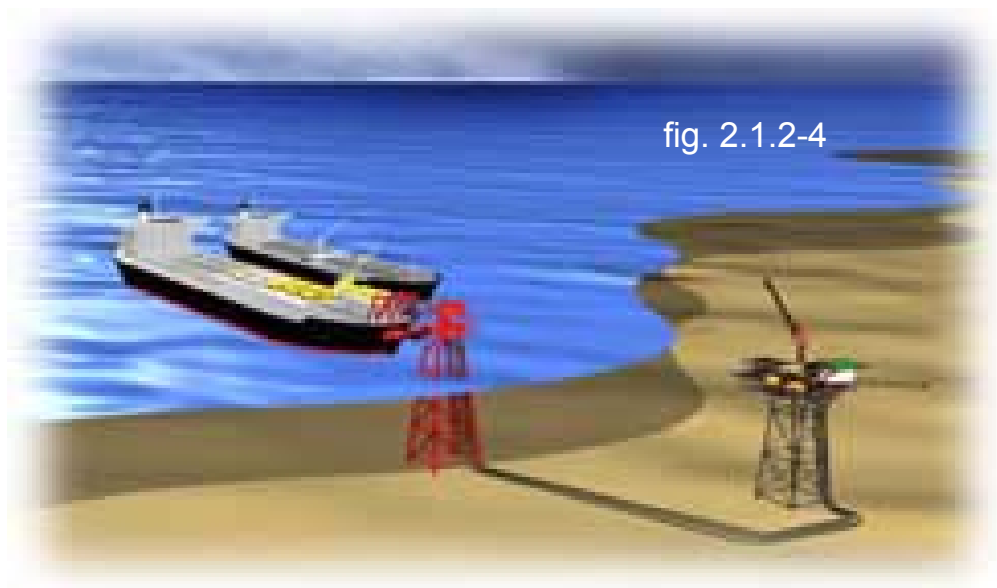

Its main advantages when compared to side-by-side offloading are: (1) Easier and safer berthing and mooring operation, (2) Higher availability, (3) Safer operation due to larger separation distance, (4) Quicker disconnection and sail-away, and (5) Robust mooring: no inadvertent breakaway risk

The side by side method of offloading is used from time to time in the offshore oil industry and is pictured in fig. 2.1.2-4. In this configuration, the receiving vessel approaches the side of the offloading tanker and is secured via polyester or nylon lines. A Yokohama fender, fig. 2.1.2-5, can be used to safely separate the two vessels. Cargo transfer takes place via loading arms, or more typically through flexible rubber hoses connecting the ships manifolds.

fig. 2.1.1-5

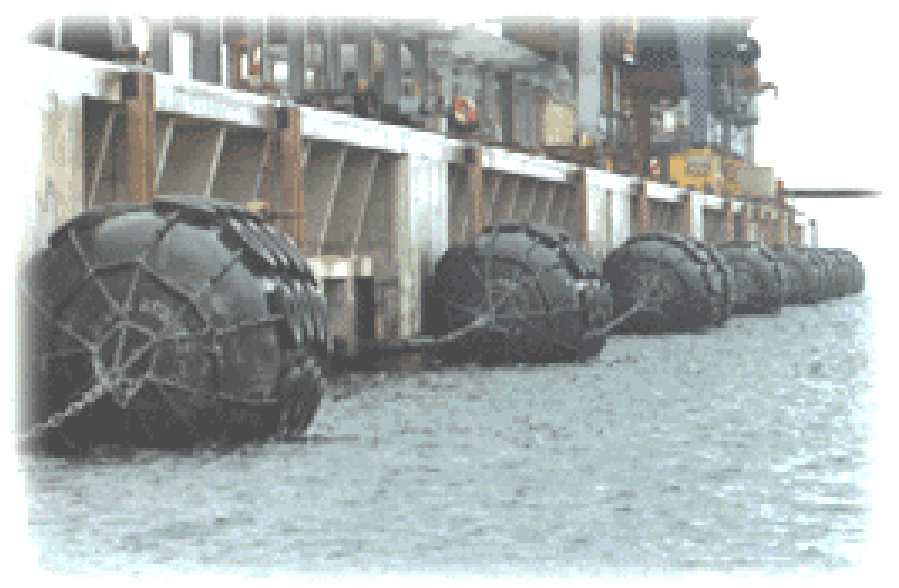

\subsection{History of Offshore Unloading}

\subsubsection{Oil}

FPSOs have been an integral part of the offshore oil industry since the late 1970's and have been used mainly in the North Sea, Brazil, Southeast Asia, and the China Sea. There are over 75 FPSO in current operation. Many are conversions (fig. 2.2.16 ) but, more and more, large scale offshore oil projects (e.g. Shell's Bonga Project with capacities of 200 thousand barrels of liquid per day) are specifying new-build FPSOs (fig. 2.2.1-7) for production at sea. The safety and reliability have been acceptable, and the technologies have been well proven over the years.

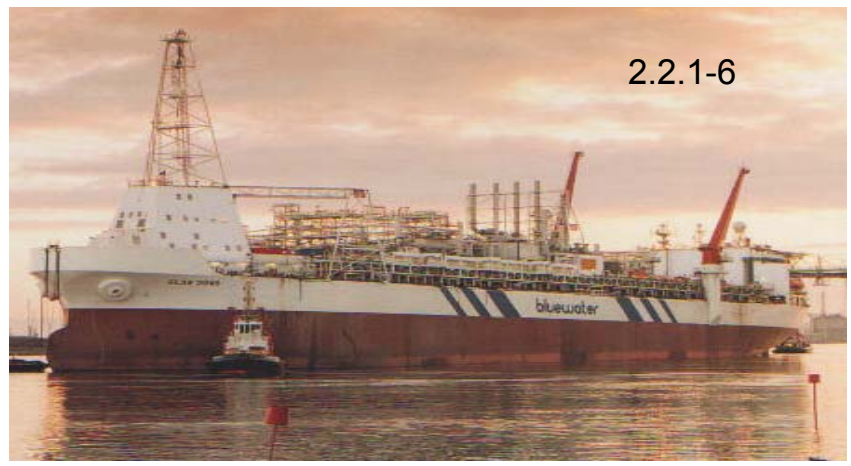




\begin{tabular}{|l|l|l|l|}
\hline Customer: & $\begin{array}{l}\text { The United States Department of Energy } \\
\text { National Energy Technology Laboratory }\end{array}$ & $\begin{array}{l}\text { Date of Issue: } \\
29 \text { April } 2003\end{array}$ & \\
\hline $\begin{array}{l}\text { Document } \\
\text { Title: }\end{array}$ & $\begin{array}{l}\text { Subtask 1.2 } \\
\text { Identify Marine Mooring and Offloading Initiatives for LNG Vessels }\end{array}$ & $\begin{array}{l}\text { Doc \# \& Version: } \\
\text { Doc } 003 \text { r4.0 }\end{array}$ & Page $\mathbf{7}$ of $\mathbf{4 0}$ \\
\hline
\end{tabular}

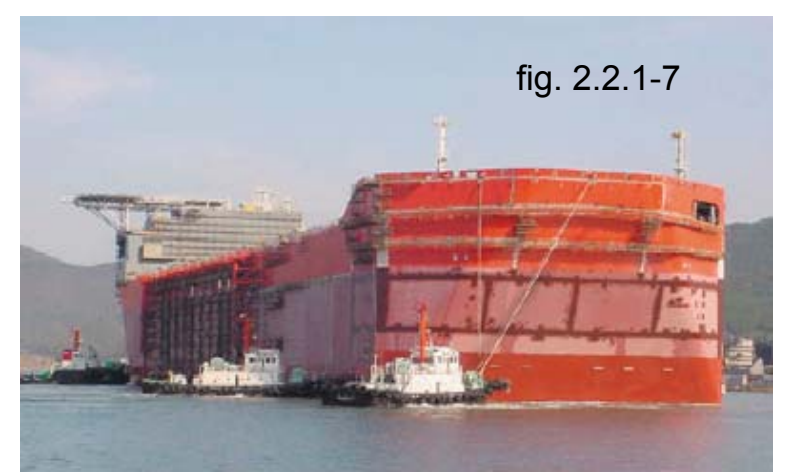

According to an INTEC Engineering study commissioned by DeepStar (a multiphase deepwater technology study currently funded by 16 oil companies and more than 40 contributing manufacturers, vendors, consulting organizations, classification organizations, and contractors), the largest spill from an FPSO occurred in the late 1990's approximately 3,900 barrels of oil were spilled from the Texaco Captain FPSO during startup at its field location.

The spill was attributed to human error during the start-up procedure; an overboard dump valve was inadvertently left open and hydrocarbons were released. Oil spills from all other FPSO operations have reportedly spilled less than 500 barrels of oil combined. FPSO's have been successfully operating for a cumulative 460 plus FPSOyears, processing an estimated 6.4 billion barrels of crude oil.

\subsubsection{Liquefied Petroleum Gas (LPG)}

Liquefied Petroleum Gases (e.g. propane and butane) are also transferred offshore. As of this time three dedicated LPG FSOs have been placed into service and another three are on order. Chevron Corporation built the first dedicated LPG FSO and placed it into service off the Nigerian coast in July of 1997. The Escravos (fig. 2.2.2-8) held 54,000 cubic meters of liquid and is 172 meters long. Quoting Mr. Dick Matzke of Chevron Overseas Petroleum, "The Escravos Gas Project is the boldest initiative to end gas flaring in Nigeria, and the NNPC embarked on this project because of its positive environmental ramifications as well as its economic benefits to Nigeria." (Author's note: the Nigerian Government has decided to end gas flaring by

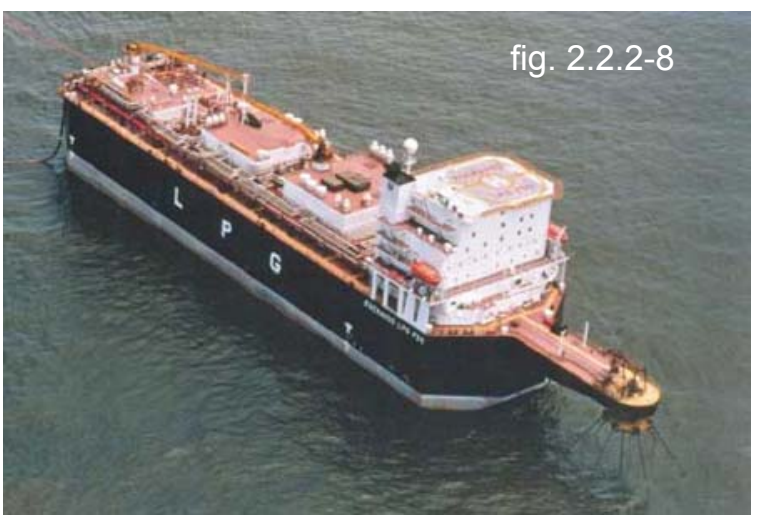
2005. This requirement will bring about an Atlantic Basin LNG supply "push." If the United States is ready with a sufficient number of LNG terminals and adequate storage, approximately 2 to 3 BCFD of the predicted 3 to 5 BCFD shortfall could be filled by this supply source.)

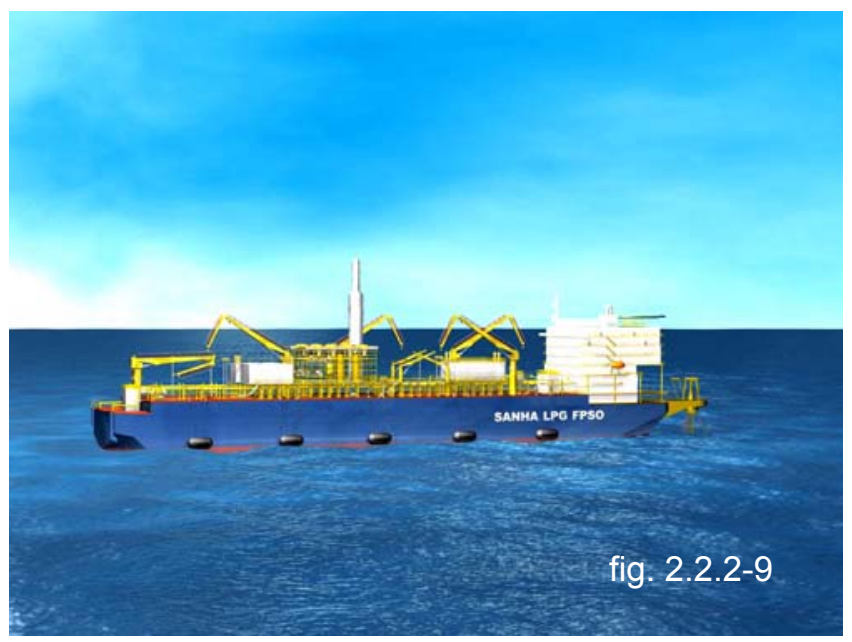

The American Bureau of Shipping (ABS) has played an active role in the qualification of LPG FSOs and the newly conceived LPG FPSO, the "Sanha." The "Sanha," slated for operation on the Sanha Field in Angola's Block 0 , is the world's first new-build LPG FPSO. The vessel, will have the largest hull of any LPG FPSO ever built and will have a production capacity of $211,880 \mathrm{cf} / \mathrm{d}$ and storage capacity of 4.7 million cf. The Sanha (fig. 2.2.2-9) will include LPG storage tanks and LPG production plants such as gas separators, gas refrigerators, and boil-off gas reliquefaction units on the upper deck or topsides.

Unlike LNG, which is primarily methane that must be stored at extremely low temperatures $\left(-260^{\circ} \mathrm{F}\right)$, LPG is primarily propane, which can be stored at a much 


\begin{tabular}{|l|l|l|l|}
\hline Customer: & $\begin{array}{l}\text { The United States Department of Energy } \\
\text { National Energy Technology Laboratory }\end{array}$ & $\begin{array}{l}\text { Date of Issue: } \\
29 \text { April } 2003\end{array}$ & \\
\hline $\begin{array}{l}\text { Document } \\
\text { Title: }\end{array}$ & $\begin{array}{l}\text { Subtask 1.2 } \\
\text { Identify Marine Mooring and Offloading Initiatives for LNG Vessels }\end{array}$ & $\begin{array}{l}\text { Doc \# \& Version: } \\
\text { Doc } 003 \text { r4.0 }\end{array}$ & Page $\mathbf{8}$ of $\mathbf{4 0}$ \\
\hline
\end{tabular}

higher or warmer temperature $\left(-56^{\circ} \mathrm{F}\right)$. Although the main gas compound is different, the key issues for safe storage and transportation for both gases in the liquefied form are storage temperature and the gas containment system. The ABS has been selected as the classification society of record, and no doubt plans to use the experience gained with the LPG FPSO to qualify offshore LNG units in the future.

In addition to the efforts of the classification societies to promote the safe transfer of liquefied gases from ship to ship, the International Chamber of Shipping (ICS), the Oil Companies International Marine Forum (OCIMF), and the Society of International Gas Tanker and Terminal Operators (SIGTTO) published the first "Ship to Ship Transfer Guide (Liquefied Gases)" in 1980. The guide covers ship to ship (STS) transfer operations of liquefied petroleum gases (LPG). Primarily, it is intended to familiarize masters and ship operators with the general principles involved.

Updated in 1995, the guide has become a reference for industry standard practice. Quoting from the opening section of the 1995 edition, "The STS (ship to ship) transfer of LPG cargoes has become a common practice. Experience gained from these regular operations has proved that STS transfer operations can be safe, given compliance with satisfactory procedures and suitable weather and sea conditions." The LNG industry is sure to follow.

\subsubsection{Overview Summary}

The above brief review of the storage and loading history of the offshore oil industry indicates that the technologies are successful, reliable, safe, and well understood. While LPG temperatures don't approach the process temperatures of LNG, the classification societies realize that the key issues involving safety and containment have already been solved by the tank and shipping vendors. The industry has reason to believe that the experience gained over the last 25 years can be applied to the offloading of LNG offshore described in the next section.

\section{PROPOSED LNG OFFSHORE TRANSFER TECHNOLOGIES}

\subsection{Scope, Concepts, and Definitions}

There are numerous offshore LNG transfer and receiving facility designs in various stages of development. This section will identify all known candidates as of the first quarter of 2003 . The designs will be categorized according to type, either weathervaning or fixed; side or tandem loading, and applicable operational sea states will be assigned. Each design will be pictured and briefly described in this section of the document. There will be no attempt to qualify the LNG transfer design based on LNG process (e.g. liquefaction or regasification) as the overriding emphasis of this study is concerned with the development of the transfer technology only. The attachment to this document will summarize all designs in a matrix lending itself to evaluation and quick reference.

Tandem and side by side cargo transfer have been discussed. The concept of spread mooring and weathervaning must now be addressed. The spread moored vessel (graphical representation fig. 3.3.1-18) is attached via its onboard mooring lines to a system of buoys securely buried in the sea floor in patterned arrangements designed to fit the ship. A massive chain (or chains) attached to each buoy is raised to the surface and connected to a large buoyant device for easy handling. As the vessel approaches the mooring location, the ships crew passes a mooing line to the line handlers who (in a small boat) attach the mooring line to each mooring chain. All mooring lines are attached in turn, each line winched aboard, and the vessel assumes its secure location in the middle of the mooring arrangement. 


\begin{tabular}{|l|l|l|l|}
\hline Customer: & $\begin{array}{l}\text { The United States Department of Energy } \\
\text { National Energy Technology Laboratory }\end{array}$ & $\begin{array}{l}\text { Date of Issue: } \\
29 \text { April } 2003\end{array}$ & \\
\hline $\begin{array}{l}\text { Document } \\
\text { Title: }\end{array}$ & $\begin{array}{l}\text { Subtask 1.2 } \\
\text { Identify Marine Mooring and Offloading Initiatives for LNG Vessels }\end{array}$ & $\begin{array}{l}\text { Doc \# \& Version: } \\
\text { Doc } 003 \text { r..0 }\end{array}$ & Page $\mathbf{9}$ of $\mathbf{4 0}$ \\
\hline
\end{tabular}

In principle, the ship's motions and the size of the mooring infrastructure will be minimized when the mooring allows the vessel to face into the environmental conditions, bow first, or "head-up" In calm or benign site conditions the vessel can be maintained head-up moored to a conventional loading dock, or spread moored as described above. Mooring the ship to a weathervaning offshore mooring sometimes known as a single point mooring or (SPM) as described in section 2.1.1 ensures that no matter what wind and current conditions exist, the ship always seeks a point of minimum motion. The following diagrams depict the various mooring motions that a weathervaning tanker might experience depending of course on the design of the mooring facility. In fig. 3.1-10, the ship rotates around a vertical axis ahead of the bow which tends to optimize mooring design.

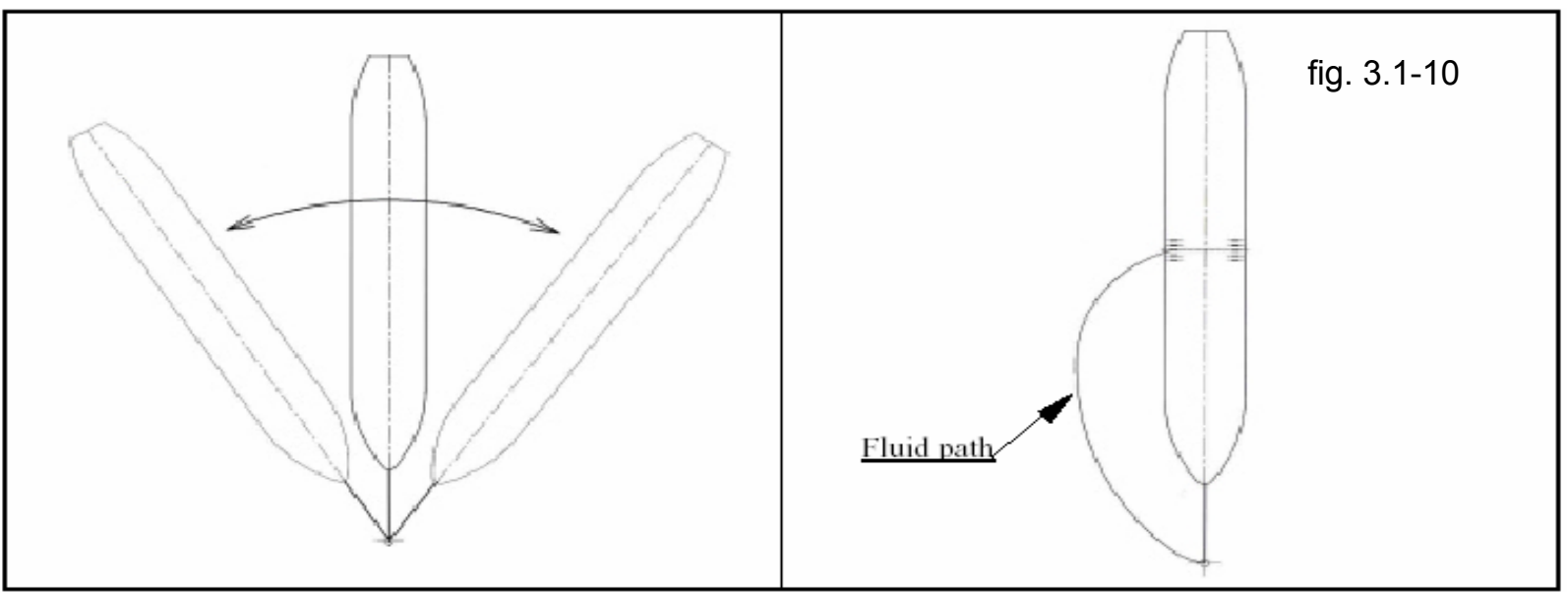

In figure 3.1-11, the rotation is close to the manifold which tends to optimize the transfer system piping and better accommodate side by side transfer.

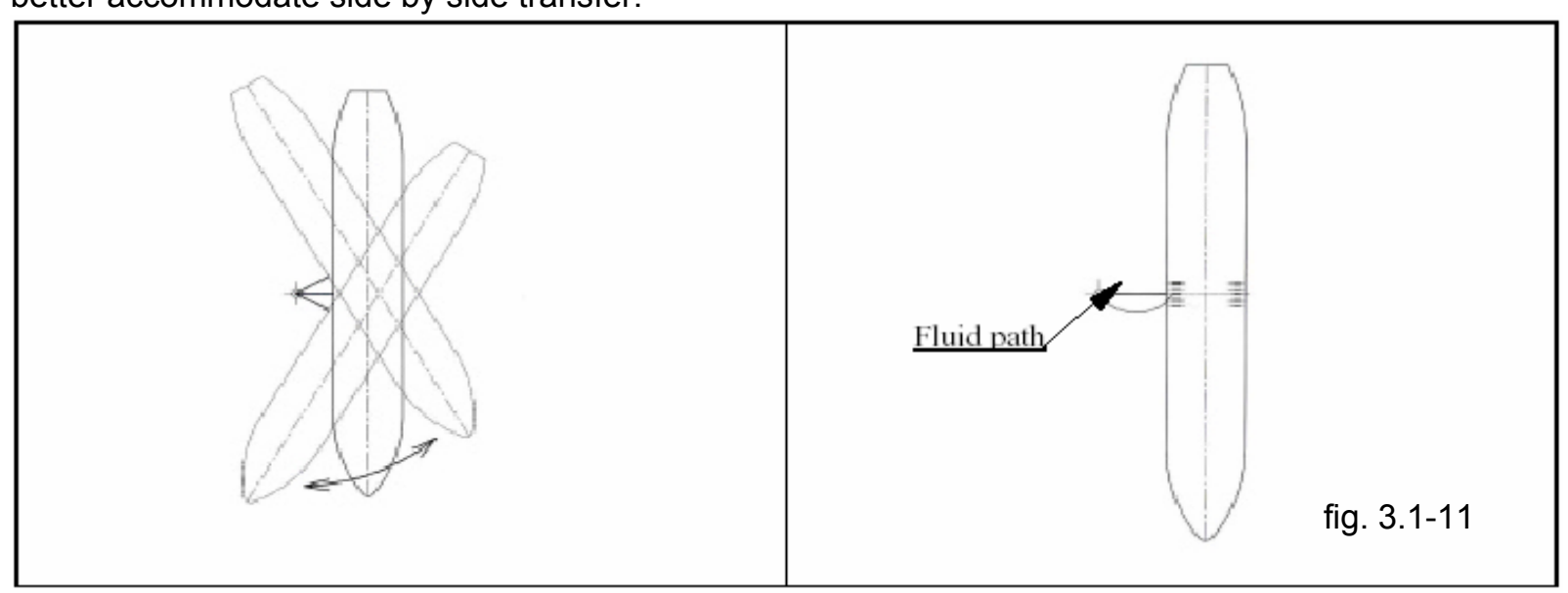

\subsubsection{Site Conditions Defined}

The following table defines site conditions in terms of severity and will be used throughout this report to quantify and rate the offshore mooring designs. 


\begin{tabular}{|l|l|l|l|}
\hline Customer: & $\begin{array}{l}\text { The United States Department of Energy } \\
\text { National Energy Technology Laboratory }\end{array}$ & $\begin{array}{l}\text { Date of Issue: } \\
29 \text { April } 2003\end{array}$ & \\
\hline $\begin{array}{l}\text { Document } \\
\text { Title: }\end{array}$ & $\begin{array}{l}\text { Subtask 1.2 } \\
\text { Identify Marine Mooring and Offloading Initiatives for LNG Vessels }\end{array}$ & $\begin{array}{l}\text { Doc \# \& Version: } \\
\text { Doc } 003 \text { r4.0 }\end{array}$ & Page $\mathbf{1 0}$ of $\mathbf{4 0}$ \\
\hline
\end{tabular}

\begin{tabular}{|c|c|c|c|}
\hline Design Description & $\begin{array}{c}\text { Wave } \\
\text { Hs }\end{array}$ & $\begin{array}{c}\text { Wind } \\
\text { Avg. speed / Peak speed }\end{array}$ & Current \\
\hline Benign & 1.5 to $2.0 \mathrm{~m}$ & $20 \mathrm{~m} / \mathrm{s} \mathrm{to} 30 \mathrm{~m} / \mathrm{s}$ & 0.5 to $1.5 \mathrm{knot}$ \\
\hline Moderate & 2.0 to $4.0 \mathrm{~m}$ & $30 \mathrm{~m} / \mathrm{s} / 36.5 \mathrm{~m} / \mathrm{s}$ & 1.5 to 2.0 \\
\hline Severe & over 4.0 & $30 \mathrm{~m} / \mathrm{s} 36.5 \mathrm{~m} / \mathrm{s}$ & 2.0 or over \\
\hline
\end{tabular}

Note: At approximately 2.0 to 2.5 meters $\mathrm{Hs}$, the mooring tug boats start to lose thrust and control as the propeller "breaks" the water during heavy swell.

\subsection{Offshore LNG Designs}

Traditional LNG import terminals all have a protected berthing environment for the LNG carriers, to enable them to berth and moor safely, and to minimize the motions during LNG offloading. The standard jetty LNG offloading arms have a limited reach, and are equipped with quick disconnect and emergency release couplers, to prevent damage of the ship's manifold or to the loading arms in case of an unexpected drifting of the LNG carrier, e.g. due to a broken mooring line. Depending on the local environmental conditions, the offloading jetties may require protection from rough seas by a breakwater. Sometimes dredging is necessary to allow the ships to berth and adds additional expense.

More and more, the industry is looking for alternative solutions, to keep the LNG carriers away from the shoreline, for various reasons: port authority concerns, permitting issues, public opposition, environmental and safety concerns, and recently also security concerns. Equally attractive is the possibility of an offshore LNG import terminal potentially saving money, if a long trestle, breakwater, and dredging could be avoided. These arguments also apply to LNG export terminals, although those locations are generally in more benign areas.

\subsubsection{Floating Barge Designs}

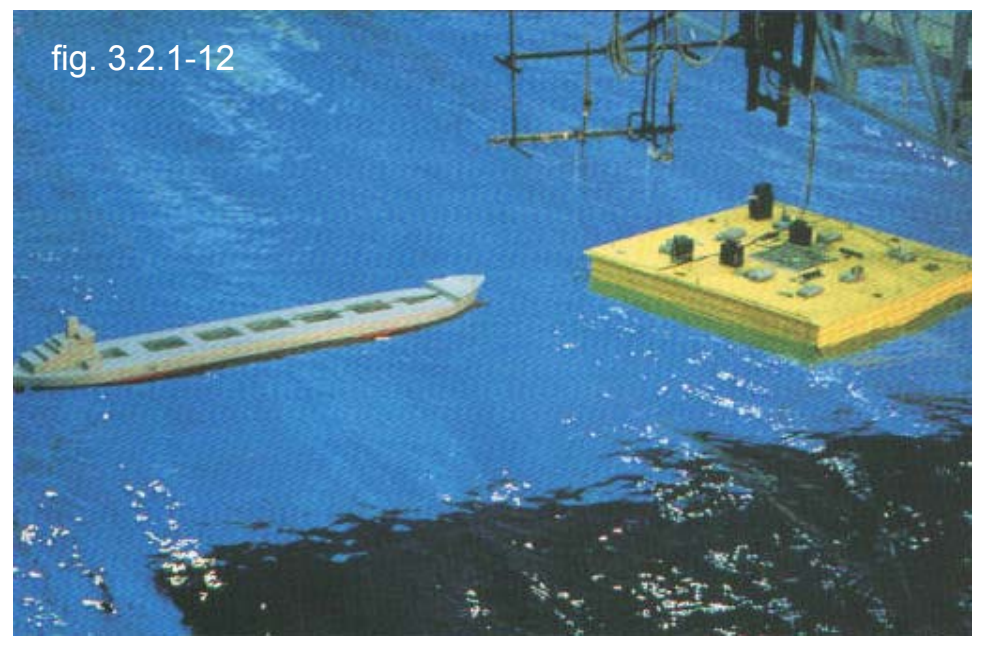

Several iterations of the floating barge have been conceptually designed over the years. The fig. 3.2.1-12 represents the former Mobil Oil venture into the LNG offshore liquefaction market. Most of the current designs are based on barges of ship shape design. These floating designs are capable of liquefaction or regasification and share the same mooring and transfer concerns with their counterparts mentioned later in this section. 


\begin{tabular}{|l|l|l|l|}
\hline Customer: & $\begin{array}{l}\text { The United States Department of Energy } \\
\text { National Energy Technology Laboratory }\end{array}$ & $\begin{array}{l}\text { Date of Issue: } \\
29 \text { April } 2003\end{array}$ & \\
\hline $\begin{array}{l}\text { Document } \\
\text { Title: }\end{array}$ & $\begin{array}{l}\text { Subtask 1.2 } \\
\text { Identify Marine Mooring and Offloading Initiatives for LNG Vessels }\end{array}$ & $\begin{array}{l}\text { Doc \# \& Version: } \\
\text { Doc } 003 \text { r. }\end{array}$ & Page 11 of 40 \\
\hline
\end{tabular}

\subsubsection{Gravity Based Structures}

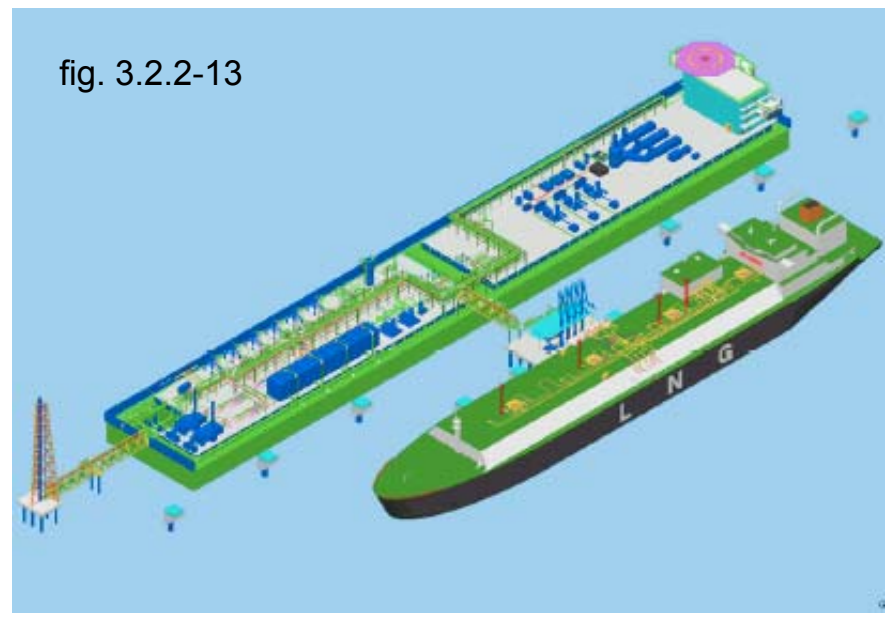

Gravity Based Structures (GBS) fig. 3.2.2-13 are gaining popularity due to storage capacity, space, ability to withstand wind/wave conditions, and protection for the moored LNG tanker. Gravity based structures differ from all other offshore designs in that they are not floating hulls. Rather the gravity based structure is an extremely large prestressed concrete hull that rests on the ocean floor. The bottom soil conditions and bathymetry must be

well known and suited to support the weight of the large structure without settling. Gravity based structures like their large floating counterparts include the LNG containment system in the lower hull, but due to costs and structural limits are restricted to water depths of about 75 meters or under. The process machinery is

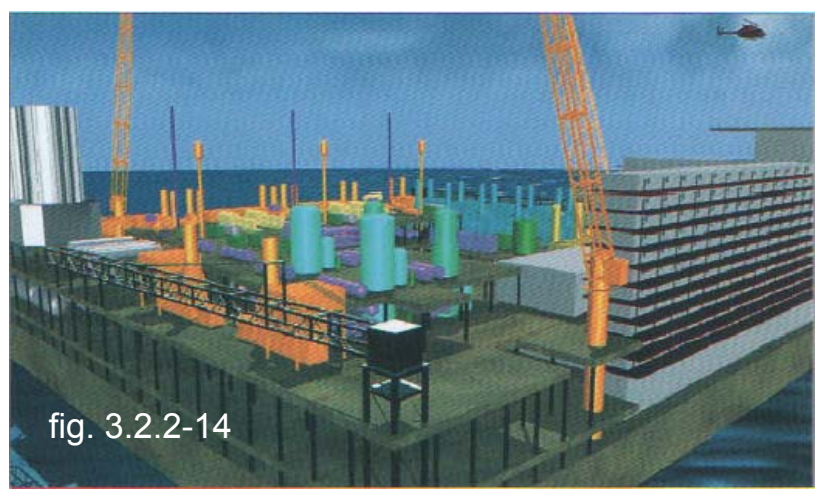
located on the upper deck as seen in figure 3.2.2-14.

\subsection{Offshore Designs by Company}

\subsubsection{SBM}

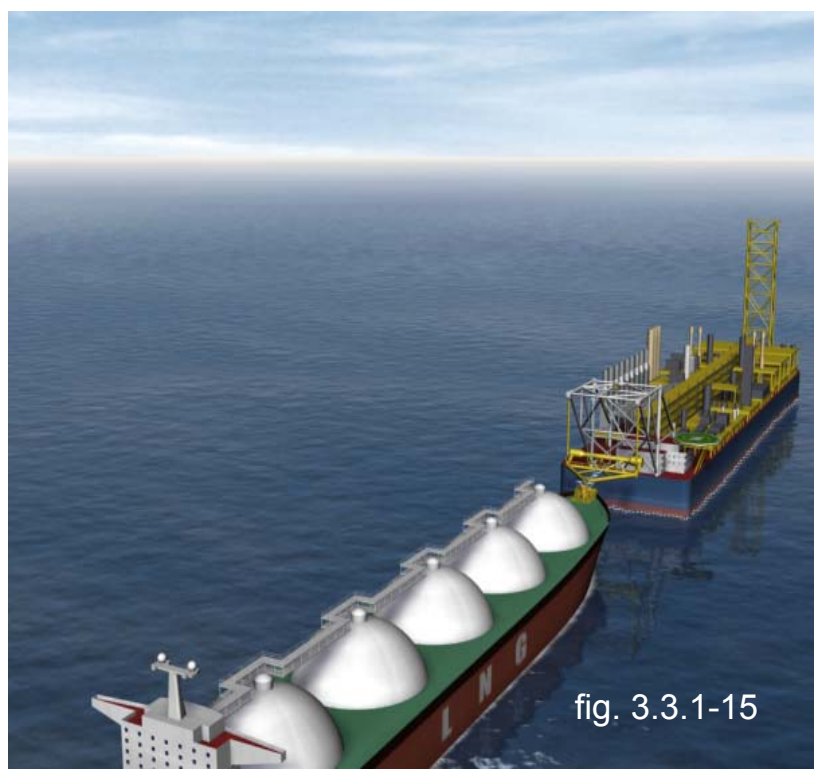

SBM, a leader for more than 40 years in the supply of offshore oil terminals, has more than 360 units installed worldwide as of today. In the more recent past SBM has developed several components namely a cryogenic swivel and offloading arm critical for the implementation of LNG transfer. Under the increasing demand from major oil companies involved in the "LNG Chain", such developments have been further advanced in the last few years in the form of engineering studies and proof of concept testing. The concepts submitted herewith integrate the result of these developments and engineering studies.

Industry requests prompted SBM to develop a singlepoint mooring (SPM) LNG Import/Export Terminal, that allows the transfer of LNG from/to LNG Carriers (LNGCs) in severe environmental conditions, i.e. in open sea, well away from the coast line fig. 3.3.1-15. The LNG can either be transferred to/from shore directly using a cryogenic LNG Subsea Pipeline, or in case of an Import terminal, it could be regasified on the 


\begin{tabular}{|l|l|l|l|}
\hline Customer: & $\begin{array}{l}\text { The United States Department of Energy } \\
\text { National Energy Technology Laboratory }\end{array}$ & $\begin{array}{l}\text { Date of Issue: } \\
29 \text { April } 2003\end{array}$ & \\
\hline $\begin{array}{l}\text { Document } \\
\text { Title: }\end{array}$ & $\begin{array}{l}\text { Subtask 1.2 } \\
\text { Identify Marine Mooring and Offloading Initiatives for LNG Vessels }\end{array}$ & $\begin{array}{l}\text { Doc \# \& Version: } \\
\text { Doc } 003 \text { r4.0 }\end{array}$ & Page $\mathbf{1 2}$ of $\mathbf{4 0}$ \\
\hline
\end{tabular}

SPM tower, and piped directly to a subsea gas pipeline network fig 3.3.1-16. SBM has also model tested a disconnectable RTM (riser turret moored) LNG vessel capable of 1.0 BCFD regasification onboard.

The SPM LNG Import/Export Terminal concept relies on the combination of conventional technologies, (1) mooring an LNGC to a fixed Jacket structure through a Soft Yoke. This station keeping concept has been applied successfully on six previous SBM installations, and (2) transferring the LNG fluid through hard piped LNG offloading arms with swivels and fluid connectors. Similar technology is used on conventional jetties for LNG offloading.

Figures 3.3.1-15 and 16 illustrate SBM's conceptual design. The vessel is moored using a special connection affixed to the bow, and the LNG transfer takes place in piping and swivels independent of the mooring loads. The system is design for rapid connection and disconnection in case an emergency departure is required. SBM states that the offshore

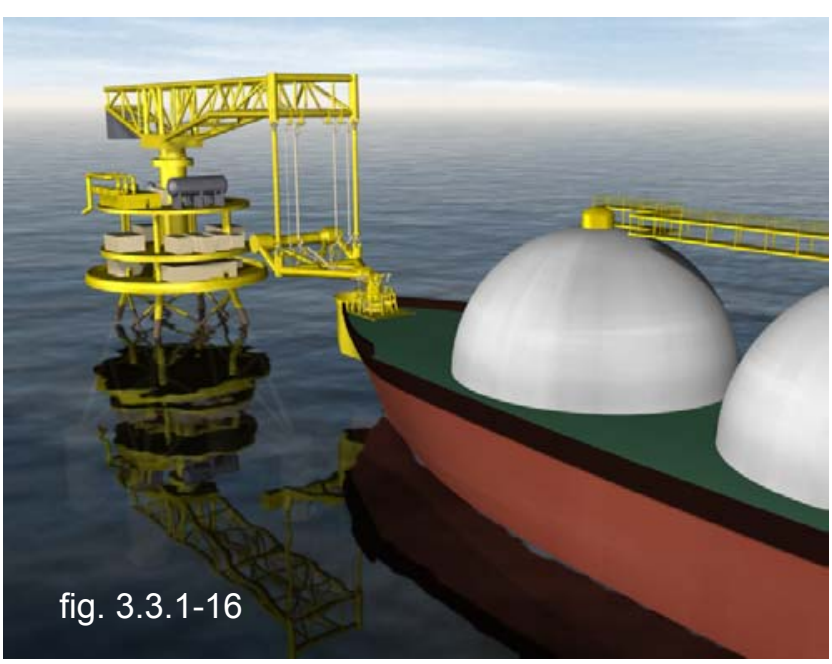
mooring system pictured can accommodate vessel connection in seas of 2.5 meters Hs with disconnection required in seas of 3.0 meters Hs or above. However, a more robust system can be designed for severe weather sites. The tandem connected, weathervaning system is capable of LNG transfer in severe weather conditions with seas exceeding 5 meters.

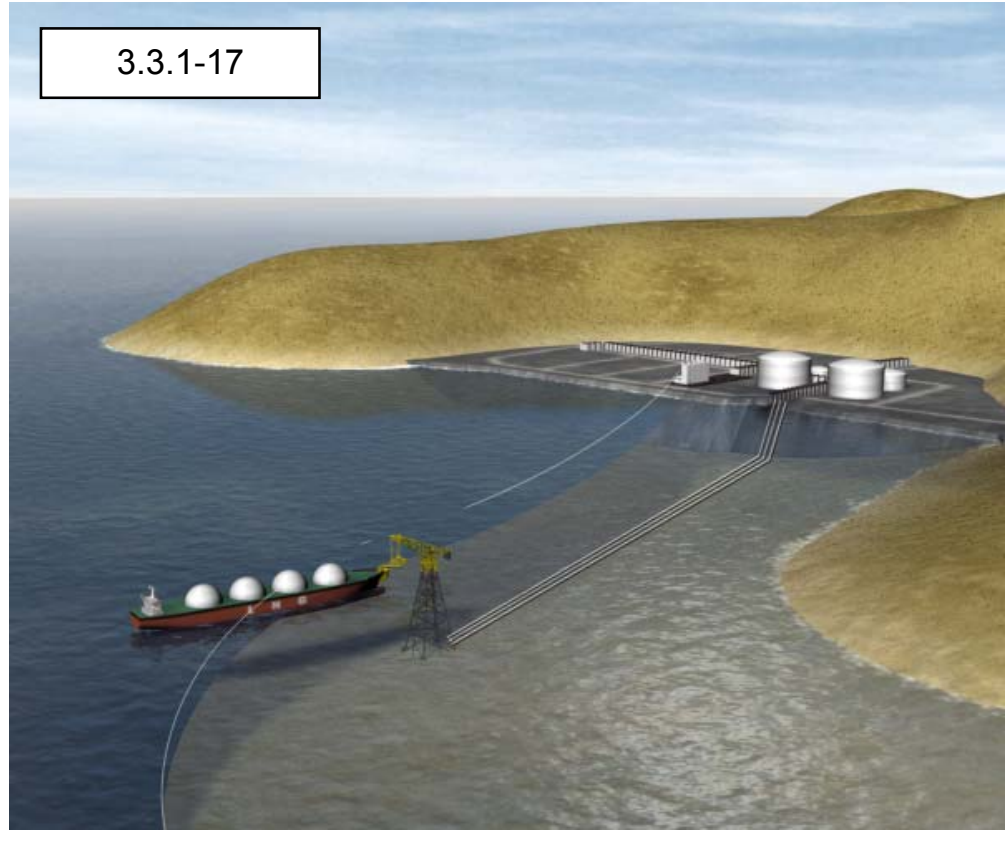

LNG Import/Export Terminal with Onshore LNG Storage

Awaiting the commercialization of cryogenic subsea pipelines, the offshore LNG loading terminal using the Single Yoke Mooring Offshore (SYMO) (fig. 3.3.117) could revolutionize LNG terminal operations the same way the Single Point Mooring (SPM) revolutionized crude oil loading operations. With a weathervaning LNG carrier moored to an SPM tower, LNG import or export terminals no longer need high-cost (port, breakwater) and maintenance intensive (dredging) marine facilities.

Conventional Buoy Mooring (CBM) with midship Loading Tower

In relatively benign conditions bow offloading may not be necessary, making it possible to use standard carriers. 


\begin{tabular}{|l|l|l|l|}
\hline Customer: & $\begin{array}{l}\text { The United States Department of Energy } \\
\text { National Energy Technology Laboratory }\end{array}$ & $\begin{array}{l}\text { Date of Issue: } \\
29 \text { April } 2003\end{array}$ & \\
\hline $\begin{array}{l}\text { Document } \\
\text { Title: }\end{array}$ & $\begin{array}{l}\text { Subtask 1.2 } \\
\text { Identify Marine Mooring and Offloading Initiatives for LNG Vessels }\end{array}$ & $\begin{array}{l}\text { Doc \# \& Version: } \\
\text { Doc } 003 \text { r4.0 }\end{array}$ & Page 13 of $\mathbf{4 0}$ \\
\hline
\end{tabular}

A solution is the use of a fixed tower with a rotating boom, which connects to a spread-moored carrier via the midship manifold, below.

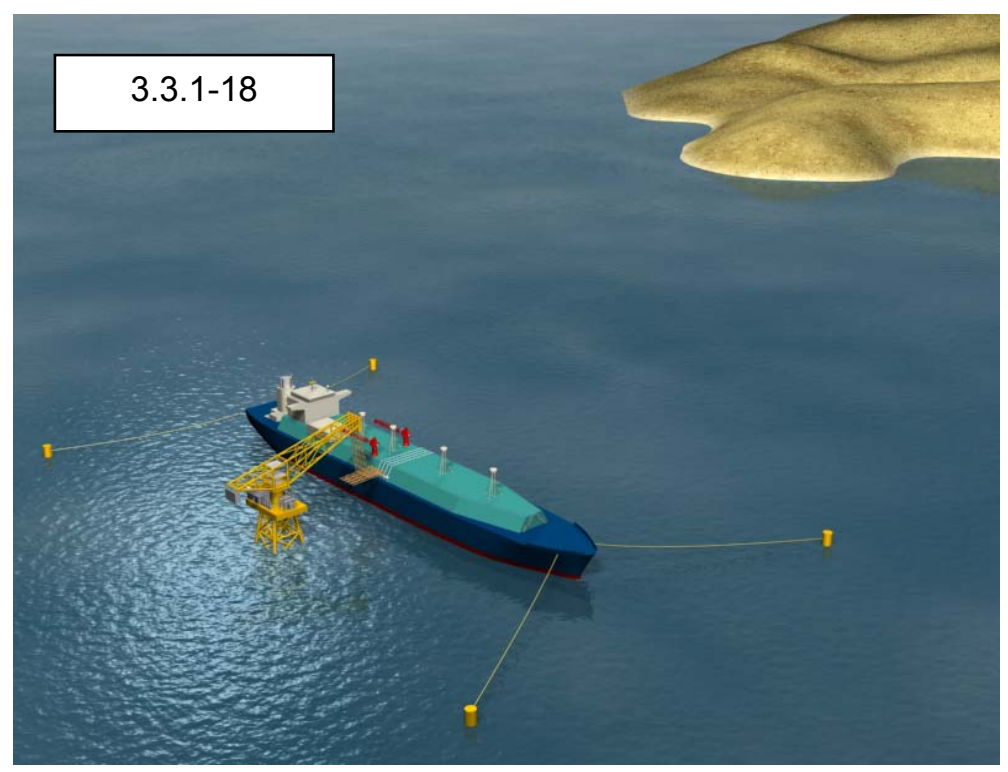

In benign environmental conditions, a Conventional Buoy Mooring (CBM) can be used to hold the carrier in position during the offloading operations.

\subsubsection{Bluewater Offshore Group}

Given that both production and import of LNG will move more and more offshore, Bluewater recognized a need for a safe, efficient and reliable transfer system. Since there is a wide variance in water depth and environmental conditions between the potential sites, a whole suite of concepts has been developed to serve each application's specifics (fig 3.3.2-19) on the following page.

All concepts share a common philosophy:

1. High System Availability. The investments made in the LNG production and transport chain are large, and so are the costs associated with downtime of LNG production and / or demurrage of the carriers. High system availability is achieved by using weathervaning mooring systems, and a robust flow path and a minimum number of cryogenic mechanical components. All concepts are based upon proven components.

2. Suitability for Non-Dedicated Vessels. The current market trend indicates that a spot market for LNG is developing. To allow flexible and efficient operation of the terminal facilities, it is essential that vessels of opportunity can be handled. Transfer of LNG in all systems takes place at the midship manifold and minimum adaptation of the LNG carrier is required.

The advantages of an LNG offshore terminal include:

- the lower costs for construction and operation

- the possibility to locate the terminal in deeper water thereby eliminating the need for dredging

- increased availability, safety and reduced voyage time as LNG carriers need not enter and maneuver in congested waters. 


\begin{tabular}{|l|l|l|l|}
\hline Customer: & $\begin{array}{l}\text { The United States Department of Energy } \\
\text { National Energy Technology Laboratory }\end{array}$ & $\begin{array}{l}\text { Date of Issue: } \\
29 \text { April } 2003\end{array}$ & \\
\hline $\begin{array}{l}\text { Document } \\
\text { Title: }\end{array}$ & $\begin{array}{l}\text { Subtask 1.2 } \\
\text { Identify Marine Mooring and Offloading Initiatives for LNG Vessels }\end{array}$ & $\begin{array}{l}\text { Doc \# \& Version: } \\
\text { Doc } 003 \text { r4.0 }\end{array}$ & Page 14 of 40 \\
\hline
\end{tabular}

fig. 3.3.2-19 LNG Transfer Offshore

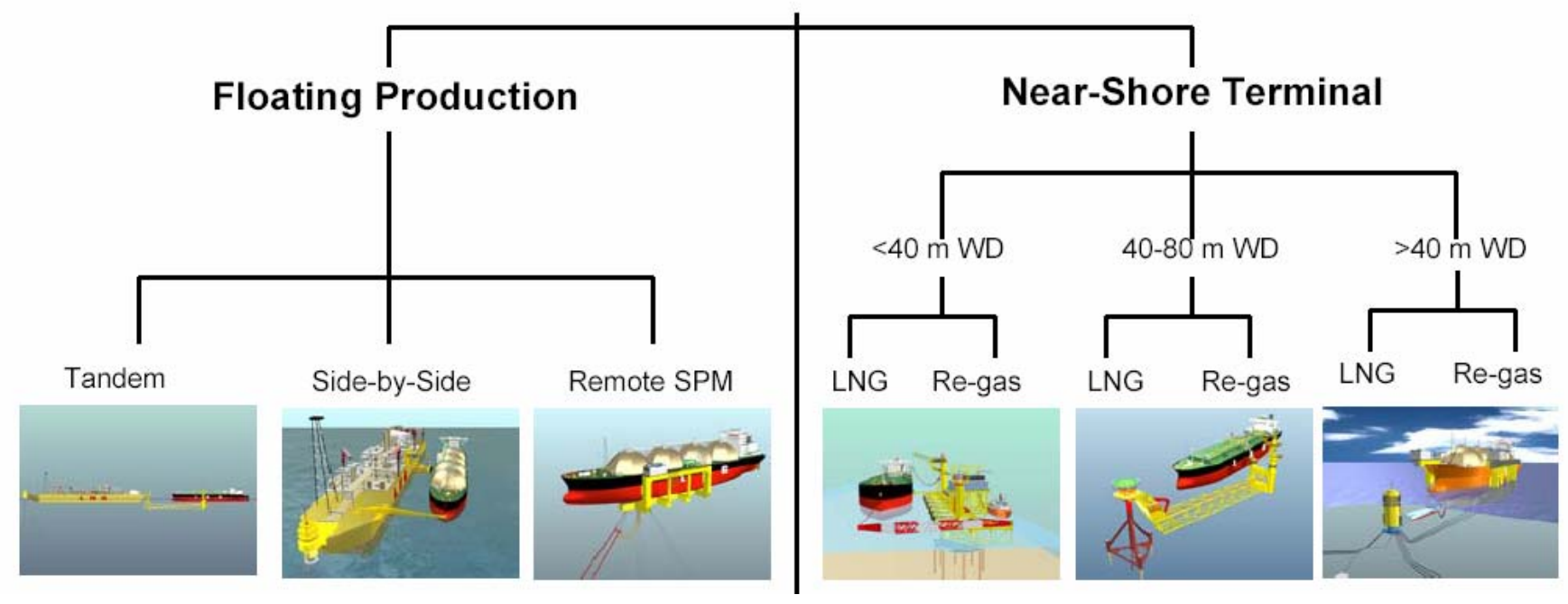

Bluewater Offshore Group has developed a series of concepts for LNG terminals based on the premise of safe transfer of LNG offshore to and from non-dedicated tankers in wave heights of up to $\mathrm{H}_{\mathrm{s}}=5.0 \mathrm{~m}$ and flow rates of up to $10,000 \mathrm{~m}_{3} / \mathrm{hr}$. Three near shore concepts were developed. The term near shore does not necessarily indicate a distance from the shore line, rather it refers to the shallower water depths closer to land. These near shore designs can be located in water depths from 15 up to 100 meters

Medium Waterdepth Terminal. This concept, dubbed 'Big Sweep' consists of three basic elements; see figure 3.3.2-20 on the following page.

- A jacket structure with turntable, anchored to the seabed

- A submerged rigid arm, hinged at one end to the jacket turntable and terminating at its other end with a buoyant column, and

- The LNG loading and transfer structure, located on top of the buoyant column.

To allow the vessel and arm to passively 'weathervane' into the most favourable direction with respect to the environment, the turntable is connected to the jacket structure by means of a bearing. This allows the turntable to rotate $360^{\circ}$ with respect to the jacket. The turntable supports the rigid arm hinges, the cryogenic fluid swivels and the hawser attachment point. 


\begin{tabular}{|l|l|l|l|}
\hline Customer: & $\begin{array}{l}\text { The United States Department of Energy } \\
\text { National Energy Technology Laboratory }\end{array}$ & $\begin{array}{l}\text { Date of Issue: } \\
29 \text { April } 2003\end{array}$ & \\
\hline $\begin{array}{l}\text { Document } \\
\text { Title: }\end{array}$ & $\begin{array}{l}\text { Subtask 1.2 } \\
\text { Identify Marine Mooring and Offloading Initiatives for LNG Vessels }\end{array}$ & $\begin{array}{l}\text { Doc \# \& Version: } \\
\text { Doc } 003 \text { r4.0 }\end{array}$ & Page 15 of 40 \\
\hline
\end{tabular}
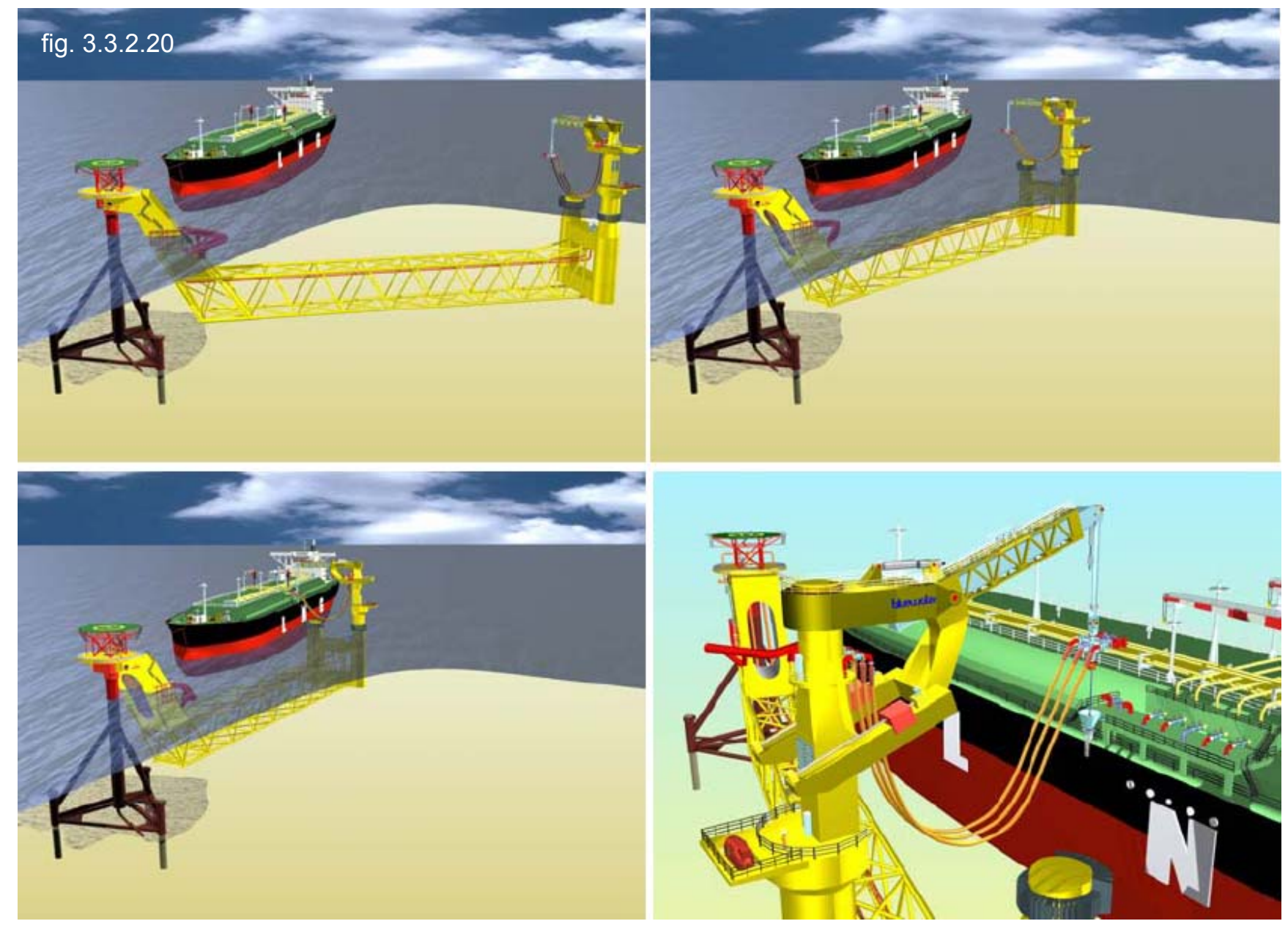

The overall length of the rigid arm is such that the buoyant column is positioned nominally near the midship cargo manifold of the LNG carrier. By adjusting the length of the mooring hawser the carrier's cargo manifold can be lined up to the offloading station for vessel sizes ranging from large to very large gas carriers.

The buoyant hull is equipped with a thruster system to swing the arm in a safe position during approach of the vessel and in-line with the vessel in the operational mode. A water ballast tank allows draft adjustment of the loading arm to match tanker size and / or drafts. The standard fluid transfer system consists essentially of 3 Pipe-in-Pipe (PIP) lines. Two lines are dedicated to LNG; either in full flow mode or re-circulation mode. The third line is dedicated for vapour return. The flow paths cross the weathervaning and pitch hinges between the jacket and the rigid arm. This is achieved with swivels and full metal jumpers which can be easily inspected and serviced.

The loading arm is normally trailing the jacket but can be temporarily 'parked' away from the LNG carrier line of approach, with its own propulsion. In this position the entire loading arm assembly cannot be damaged by a failed mooring approach of the export carrier tanker. Note that offshore tanker mooring to SPM systems is standard marine practice and that a failed approach run very rarely happens. Should the carrier 'brush' against the terminal, this will be a 'low energy' collision which can be accommodated by the cushioning fender system. 


\begin{tabular}{|l|l|l|l|}
\hline Customer: & $\begin{array}{l}\text { The United States Department of Energy } \\
\text { National Energy Technology Laboratory }\end{array}$ & $\begin{array}{l}\text { Date of Issue: } \\
29 \text { April } 2003\end{array}$ & \\
\hline $\begin{array}{l}\text { Document } \\
\text { Title: }\end{array}$ & $\begin{array}{l}\text { Subtask 1.2 } \\
\text { Identify Marine Mooring and Offloading Initiatives for LNG Vessels }\end{array}$ & $\begin{array}{l}\text { Doc \# \& Version: } \\
\text { Doc } 003 \text { r4.0 }\end{array}$ & Page 16 of 40 \\
\hline
\end{tabular}

The LNG carrier moors in tandem with the turntable and once it has secured itself safely and the overall alignment is stable, the loading arm will be deployed from its parked position toward the vessel's manifold. The hose deployment and loading operation may now be initiated. After completion of the transfer operations all of the steps discussed above are done in reverse order.

Shallow Water depth Terminal. Developed from the 'Big Sweep' system, this unit shown in fig. 3.3.2-21 is designed to operate in water depths below $40 \mathrm{~m}$. It allows direct offshore-to-shore transfer of LNG, at rates up to $10,000 \mathrm{~m} 3 / \mathrm{hr}$ from non-dedicated vessels.

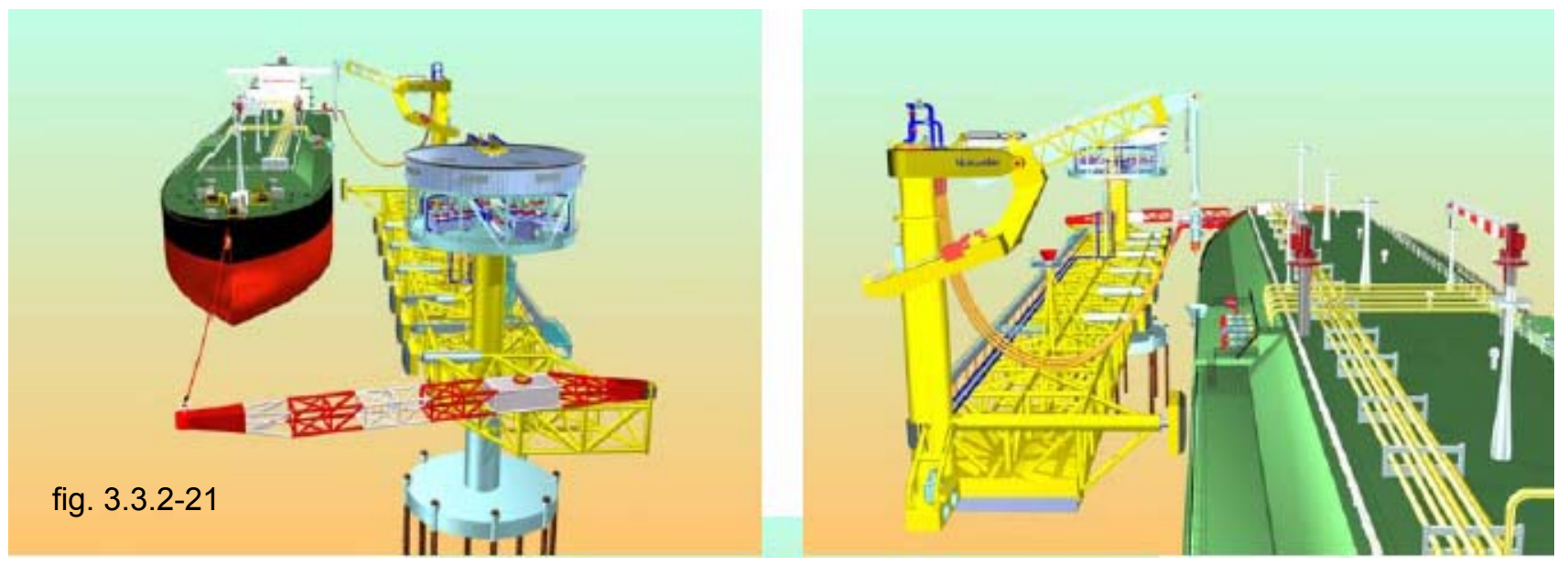

Motion characteristics are such that offloading can proceed up to significant wave heights of $3 \mathrm{~m}$, depending on the water depth, which may be as little as 15 metres. For extreme survival conditions such as in the Gulf of Mexico, the free-end of the unit is water-ballasted and set temporarily on the seabed. With dynamic positioning (DP) capability the unit would track the movement of the LNG carrier manifold when loading or unloading LNG. DP would also allow the unit to move out of the way when the LNG carrier is mooring itself to the turntable on the jacket, thereby avoiding marine hazards. Re-gasification equipment may be located on the unit for applications without LNG storage e.g. where gas is stored in salt caverns or delivered directly to the shore gas grid.

Offshore Re-Gasification Dock. The concept of a floating dock is not new, however in combination with a reduced displacement and connected to a Single Point Mooring (SPM) system, and also fitted with a simple but redundant Dynamic Positioning (DP) system, it becomes a powerful tool to:

- Berth standard LNG vessels offshore

- Enable unloading LNG through standard marine loading arms

- Allow transfer operation to continue in conditions up to $4 \mathrm{~m}$ significant wave height

- Provide a stable platform for a re-gasification plant

- Allow disconnection from its anchor legs for dry docking for campaign maintenance

The Offshore Regasification Dock also lends itself to remote deepwater locations where floating production and storage facilities may be required.

In essence the concept is based on mooring permanently a partly submerged dock, through an articulated rigid arm to a catenary anchor leg buoy, see figure 3.3.2-22. The articulated rigid arm has been selected because it allows the dock to take up a position of sway and yaw relative to the buoy, when seen from above. Since the concept is based on having transverse propulsion means integrated in the dock, it is quite clear that 


\begin{tabular}{|l|l|l|l|}
\hline Customer: & $\begin{array}{l}\text { The United States Department of Energy } \\
\text { National Energy Technology Laboratory }\end{array}$ & $\begin{array}{l}\text { Date of Issue: } \\
29 \text { April } 2003\end{array}$ & \\
\hline $\begin{array}{l}\text { Document } \\
\text { Title: }\end{array}$ & $\begin{array}{l}\text { Subtask 1.2 } \\
\text { Identify Marine Mooring and Offloading Initiatives for LNG Vessels }\end{array}$ & $\begin{array}{l}\text { Doc \# \& Version: } \\
\text { Doc } 003 \text { r4.0 }\end{array}$ & Page $\mathbf{1 7}$ of $\mathbf{4 0}$ \\
\hline
\end{tabular}

with an LNG vessel mooring on the hawser messenger wire of the SPM and inching itself up to the buoy, the dock is now able to fully track the path the LNG vessel will follow, including yaw and sway.
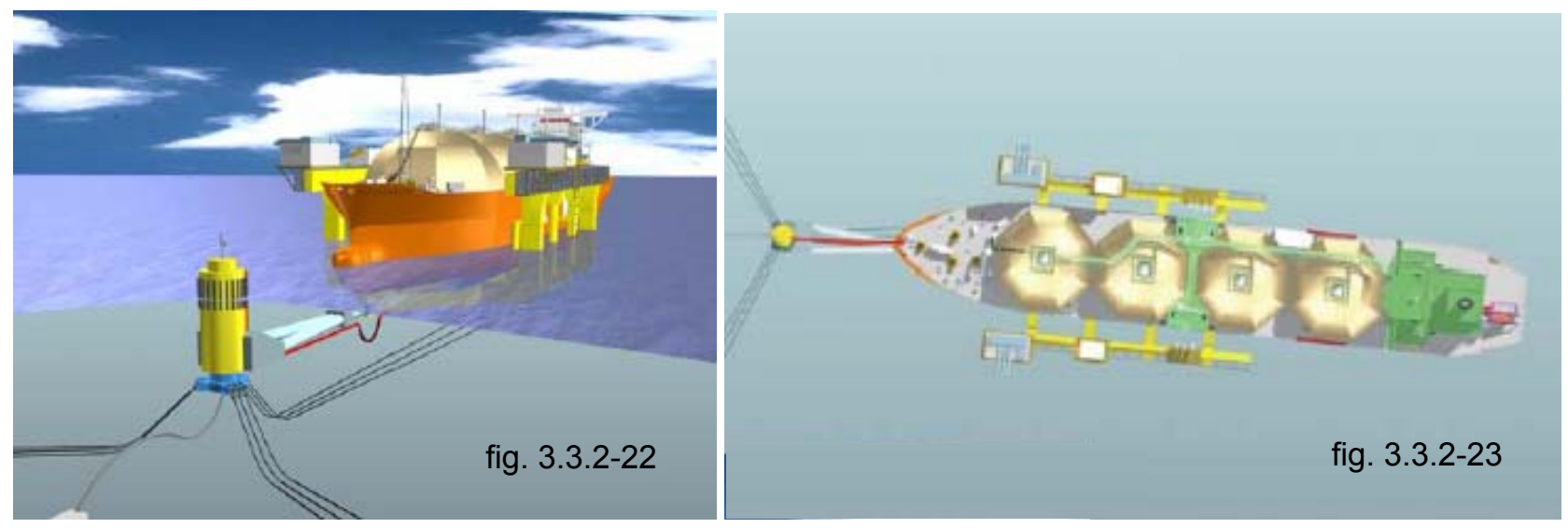

Hence the dock can simply maintain sideway clearance with the LNG vessel until it surfaces to contact the underside of the hull once it has completed its approach, see fig. 3.3.2-23.

The amount of contact force is a function of operating environmental parameters and will be of such

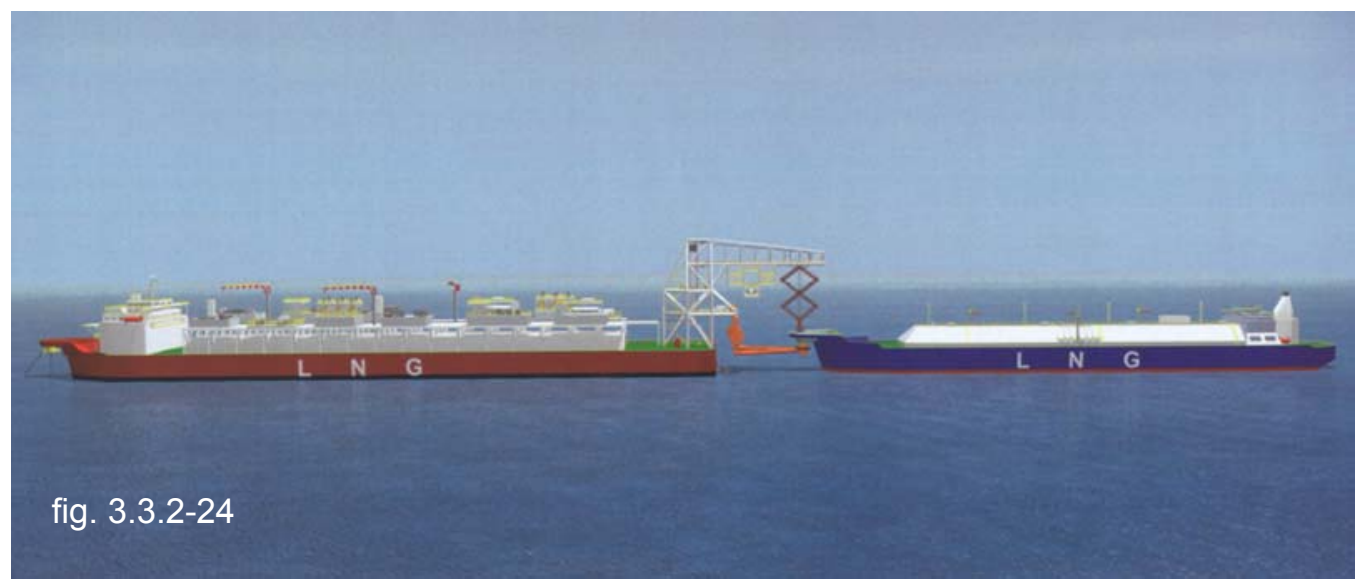
magnitude that no relative motions occur between vessel and dock. At all times contact forces are modest and can be easily accepted by the vessel. Effectively, the vessel is now fixed to the SPM through friction only. This design has major

the use of traditional loading arms is feasible over a wide range of weather conditions. advantages in that

\subsubsection{FMCSofec}

FMC the industry leader in the development and sales of cryogenic loading arms and swivels has established a new technology company with Sofec a manufacture of offshore terminal systems, to develop a generation of tandem LNG offshore offloading facilities. FMC Energy Systems has combined these two industry proven technologies to create a safe, reliable, tandem LNG loading/offloading system. The LNG Tandem Offloading System, which is capable of transferring LNG at a rate of $15,000 \mathrm{~m} 3 / \mathrm{hr}$, is comprised of two totally independent systems, the LNG transfer system and the mechanical mooring system (fig.3.3.3-24). 


\begin{tabular}{|l|l|l|l|}
\hline Customer: & $\begin{array}{l}\text { The United States Department of Energy } \\
\text { National Energy Technology Laboratory }\end{array}$ & $\begin{array}{l}\text { Date of Issue: } \\
29 \text { April } 2003\end{array}$ & \\
\hline $\begin{array}{l}\text { Document } \\
\text { Title: }\end{array}$ & $\begin{array}{l}\text { Subtask 1.2 } \\
\text { Identify Marine Mooring and Offloading Initiatives for LNG Vessels }\end{array}$ & $\begin{array}{l}\text { Doc \# \& Version: } \\
\text { Doc } 003 \text { r4.0 }\end{array}$ & Page 18 of 40 \\
\hline
\end{tabular}

The LNG transfer system utilizes industry proven LNG transfer technology from FMC Loading Systems in France. It provides simple LNG connection by vertically suspending the LNG Chiksan loading arms system, a double pantograph comprised of four sixteen-inch product lines, from a fixed outboard boom.

The mechanical mooring system uses a robust duplex yoke that minimizes the sway motions between vessels to maximize the FPSO's ability to offload in harsh weather conditions (fig. 3.3.3-25). This new concept in mooring yoke technology decouples lateral stiffness from fore and aft stiffness resulting in a dual or duplex action. This duplex yoke, made by FMC SOFEC Floating Systems,

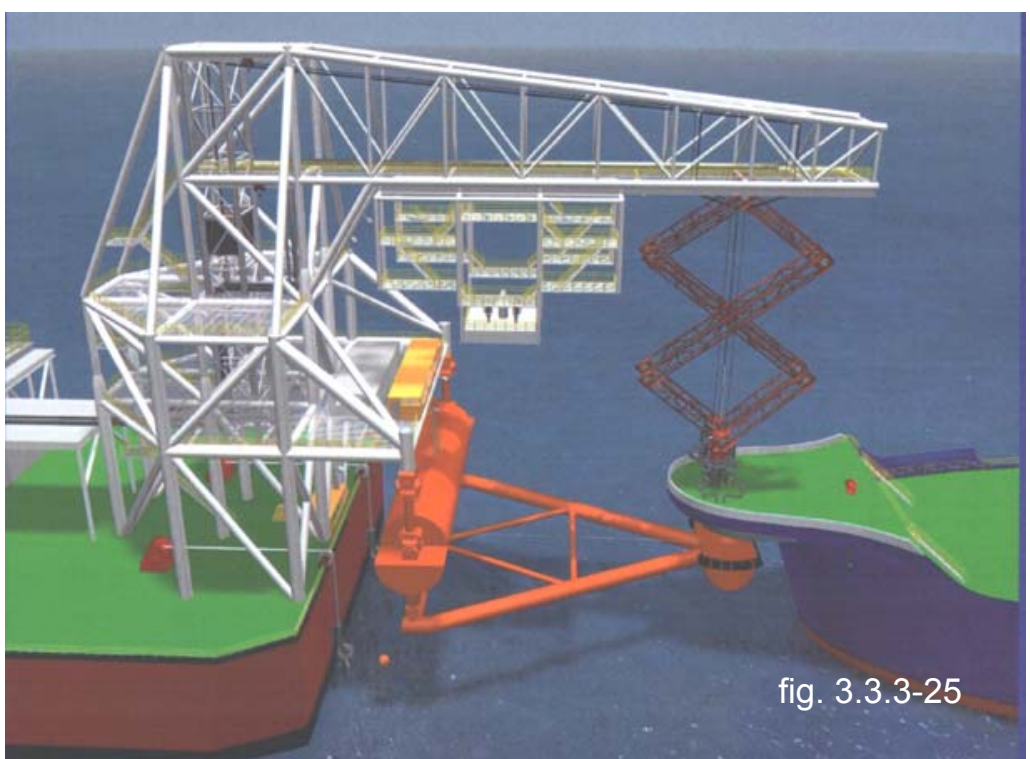
moors the vessels using a combination of industry proven yoke and high load connector technology. The mechanical mooring system is connected using a simple and safe procedure that minimizes assistance from auxiliary vessels. The duplex yoke has been very successful in wave basin model testing as well as extensive computer simulation. Fully integrated, these two systems have resulted in an excellent combination of proven technologies. The above figures illustrate the robust character of the Sofec yoke type mooring system coupled with the vertical, "Pantograph" LNG loading arm.

\subsubsection{OCL Group}

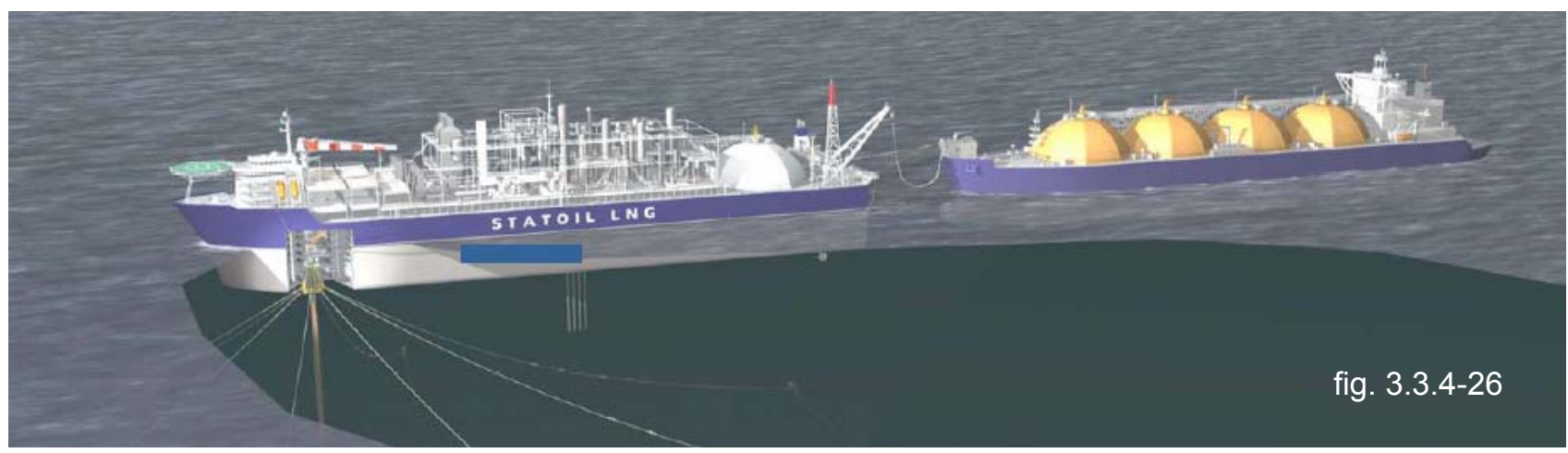

OCL Group a consortium of Statoil, Navion, APL, and Framo developed a novel system for offshore transfer of Liquefied natural gas based on a concept using a crane to suspend an array of flexible piping, from the tip of the crane to the LNG tanker (fig. 3.3.4-26. Although the system is based on the use of standard, proven components and procedures whenever possible, the actual transfer between the two vessels has not been performed. The project thru its step by step approach verified that the offshore loading system was technically feasible, but specific items such as loading regularity, connect/disconnect procedures, and safety were evaluated in general terms only. To fully develop the project, a computer model of the loading procedure and model test must be made. OCL in now in the process of verifying three important aspects in the current phase of development: 


\begin{tabular}{|l|l|l|l|}
\hline Customer: & $\begin{array}{l}\text { The United States Department of Energy } \\
\text { National Energy Technology Laboratory }\end{array}$ & $\begin{array}{l}\text { Date of Issue: } \\
29 \text { April } 2003\end{array}$ & \\
\hline $\begin{array}{l}\text { Document } \\
\text { Title: }\end{array}$ & $\begin{array}{l}\text { Subtask 1.2 } \\
\text { Identify Marine Mooring and Offloading Initiatives for LNG Vessels }\end{array}$ & $\begin{array}{l}\text { Doc \# \& Version: } \\
\text { Doc } 003 \text { r4.0 }\end{array}$ & Page 19 of $\mathbf{4 0}$ \\
\hline
\end{tabular}

- Behavior of the two tandemly moored vessels, especially the motions in the offloading area through scaled model testing

- Transfer of the flexible pipe and connection to the shuttle tanker

- Full scale testing of the actual flexible pipe configuration at actual temperature. The mechanical tension/compression and hydraulic testing have proven that transfer can be unproblematic with correct procedures.

The diagram below In fig 3.3.4-27 outlines the design conditions and distances between the offloading vessels.

- Relative movements +/- 6 meter (Design Maximum +/- 15 meter)

- Relative yaw +/- 15 degrees

(Design Maximum +/- 35 degrees)

- Relative roll +/- 10 degrees

(Design Maximum +/- 10 degrees)

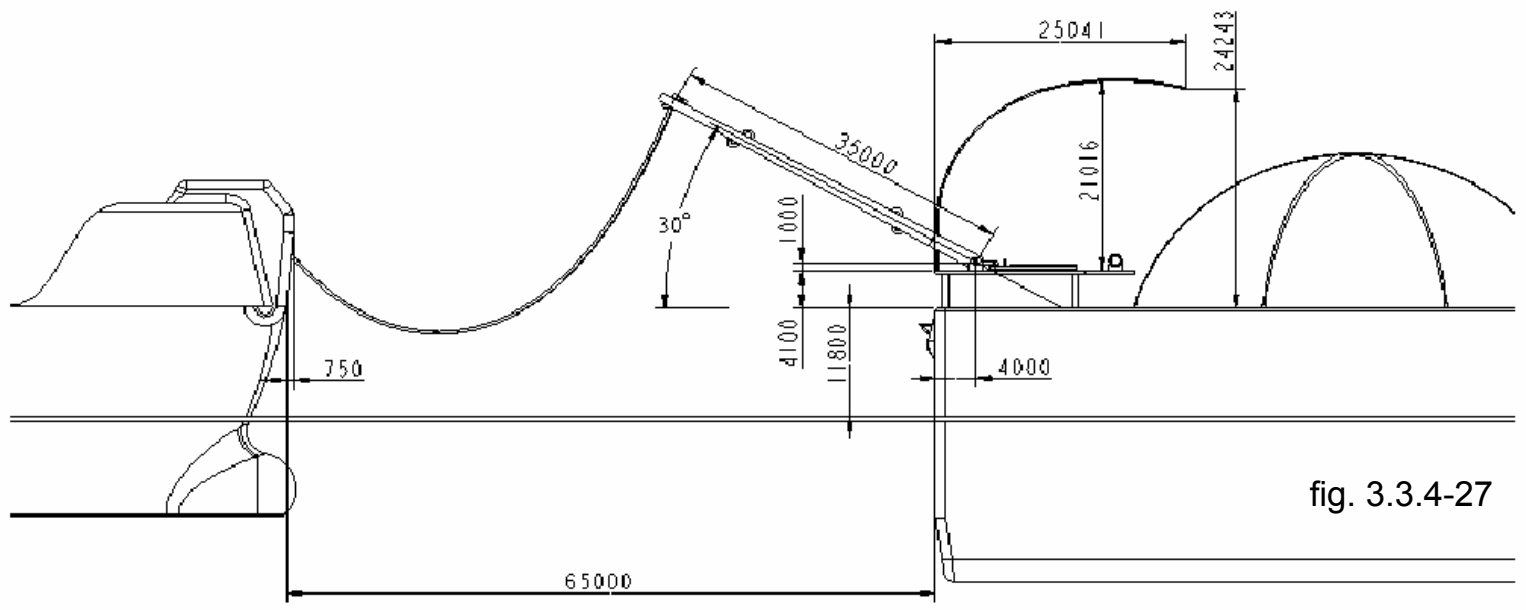




\begin{tabular}{|l|l|l|l|}
\hline Customer: & $\begin{array}{l}\text { The United States Department of Energy } \\
\text { National Energy Technology Laboratory }\end{array}$ & $\begin{array}{l}\text { Date of Issue: } \\
29 \text { April } 2003\end{array}$ & \\
\hline $\begin{array}{l}\text { Document } \\
\text { Title: }\end{array}$ & $\begin{array}{l}\text { Subtask 1.2 } \\
\text { Identify Marine Mooring and Offloading Initiatives for LNG Vessels }\end{array}$ & $\begin{array}{l}\text { Doc \# \& Version: } \\
\text { Doc } 003 \text { r. } 4\end{array}$ & Page $\mathbf{2 0}$ of $\mathbf{4 0}$ \\
\hline
\end{tabular}

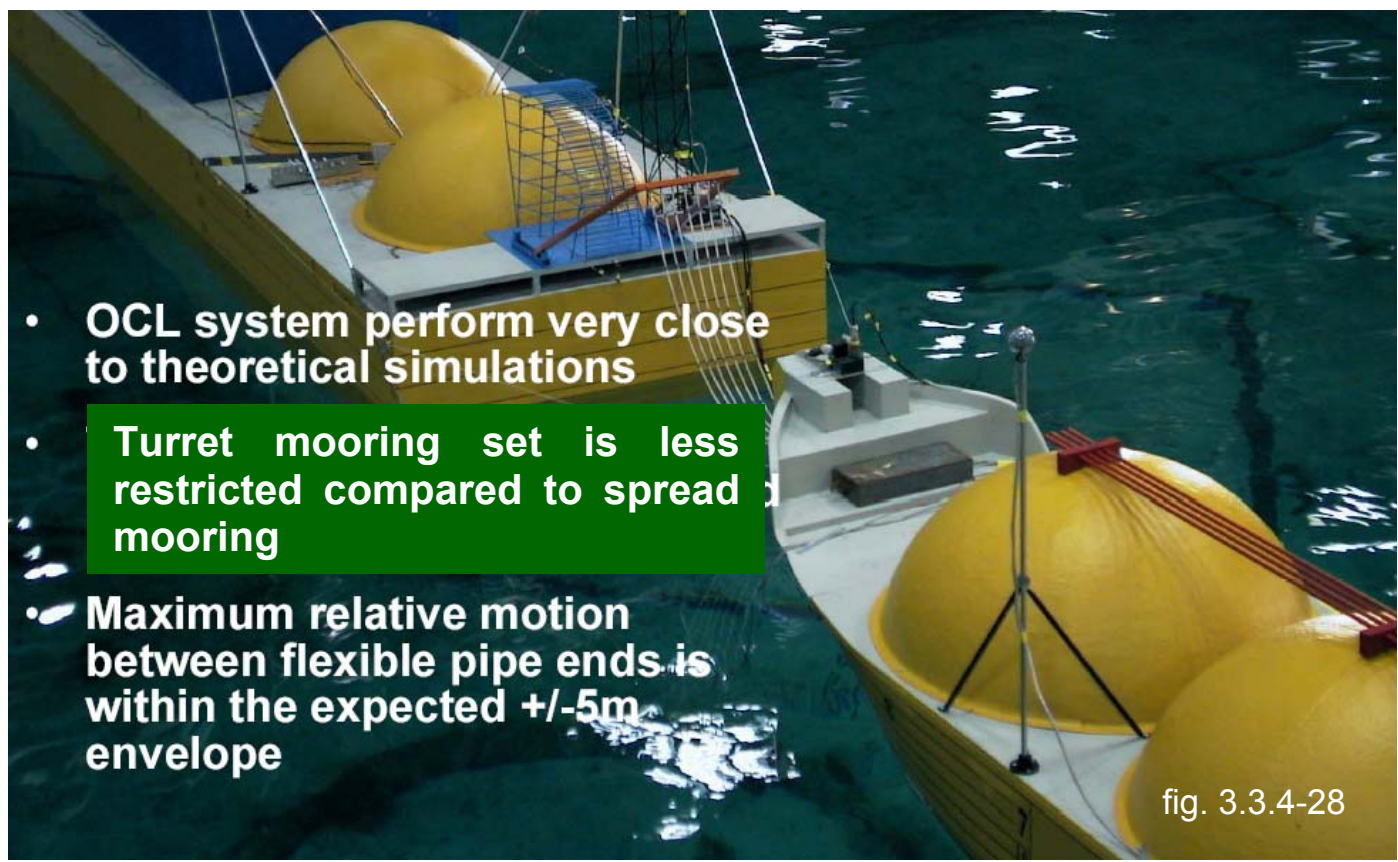

Figure 3.3.4-28 above summarizes the test results of the modeled offloading system. The hardware and the arrangement of the flexible piping connection can be readily seen in this photograph of the model.

\subsubsection{HiLoad by Remora Technologies}

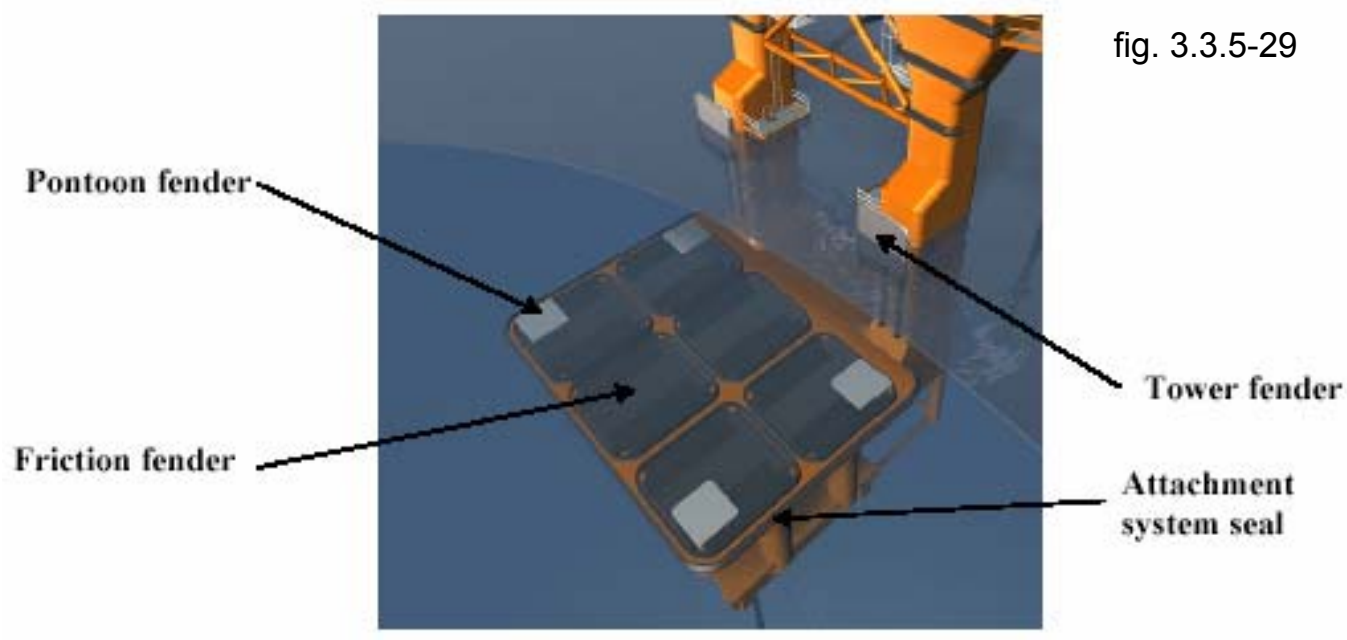

The HiLoad concept (fig 3.3.5-29) has been developed, engineered and model tested in cooperation with ConocoPhillips, and the application developed for the offshore oil industry is now ready for fabrication. The main purpose of the HiLoad development project has been to develop a mooring-less offshore loading system for deepwater fields in the US Gulf of Mexico. The remotely operated 


\begin{tabular}{|l|l|l|l|}
\hline Customer: & $\begin{array}{l}\text { The United States Department of Energy } \\
\text { National Energy Technology Laboratory }\end{array}$ & $\begin{array}{l}\text { Date of Issue: } \\
29 \text { April } 2003\end{array}$ & \\
\hline $\begin{array}{l}\text { Document } \\
\text { Title: }\end{array}$ & $\begin{array}{l}\text { Subtask 1.2 } \\
\text { Identify Marine Mooring and Offloading Initiatives for LNG Vessels }\end{array}$ & $\begin{array}{l}\text { Doc \# \& Version: } \\
\text { Doc } 003 \text { r. }\end{array}$ & Page 21 of 40 \\
\hline
\end{tabular}

HiLoad unit will dock onto any tanker in a similar way as a forklift picks up a pallet (fig 3.3.5-30) The HiLoad unit will connect to the forward part of the tanker, allowing the tanker to weathervane during operation kept in position by the HiLoad thrusters controlled by a Dynamic Positioning System. The tanker loading hose is stored onboard the HiLoad, and can simply be pulled along the tanker deck towards the midship manifold using one of the tanker's mooring winches.

During the development study it became clear that the HiLoad would have a number of other possible applications. It was therefore decided to also look at an LNG application whereby the device moors with the LNG tanker and safely positions the vessel for smooth operation with respect to tides and currents. Rather

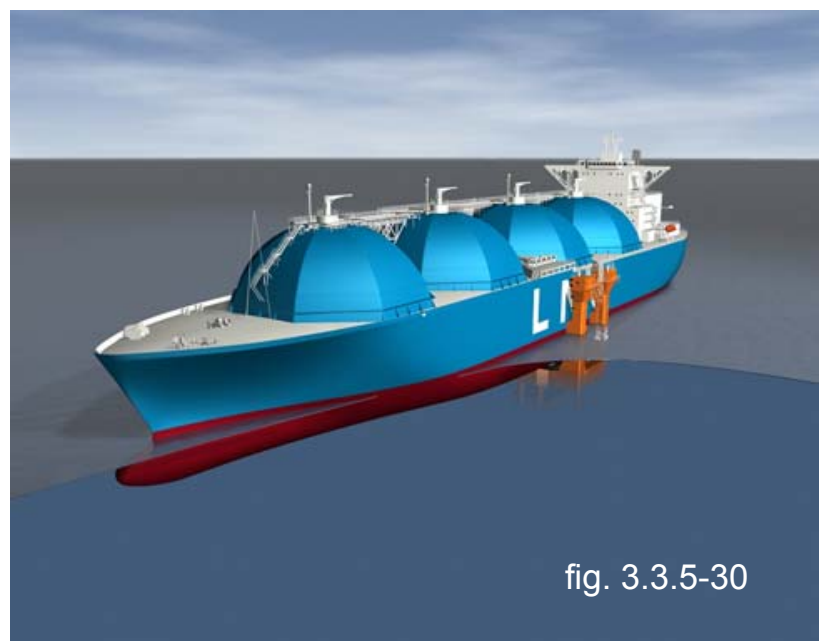
than employ a hose and reel device for the transfer of cargo, a cryogenic hose and boom arrangement could be used. In addition, Remora Technologies has proposed to construct a series of heat exchangers aboard the HiLoad unit to allow the vessel to discharge vaporized LNG through flexible risers and into an existing subsea gas gathering system. Although the LNG modifications have been conceptually designed, the actual HiLoad mooring system has been full scale tested and is ready for use.

\subsubsection{Advance Production and Loading AS (APL)}

fig. 3.3.6-31

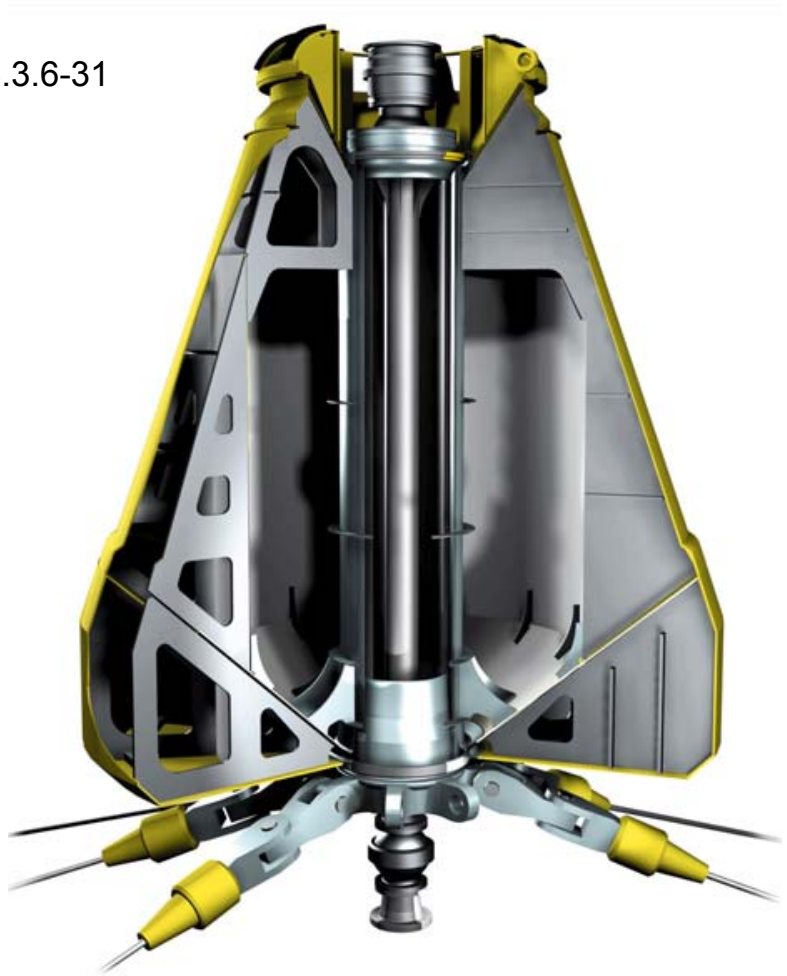

The submerged turret loading (STL) technology offers a flexible, safe and cost-effective solution for offshore loading of crude oil. First introduced in 1993, it is now recognised as the new standard in offshore loading. Per April 2000, 24 ships incorporated or were being fitted with the STL/STP mating cone which is an "internal" CALM buy of sorts (fig. 3.3.6-31).

STL systems currently in operation are installed in water depths from 85 to 350 metres, and have been designed for significant wave heights up to 16.4 metres. Tests in ocean basins have verified the feasibility of the STL/STP mooring systems for water depths from 40 to 900 metres. And mooring system analyses have demonstrated the suitability of these systems for water depths from 20 to more than 2000 metres. APL provides the mooring system and design for the offshore LNG regasification ("Energy Bridge") vessels built in Daewoo's shipyards by El Paso, Inc.

STL equipment is installed in a dedicated compartment (fig. 3.3.7-32) with an access trunk. Vessel modifications are restricted to standard steelwork, since all complicated bearing structures form part of the STL buoy. A buoy-locking mechanism, loading manifold and 


\begin{tabular}{|l|l|l|l|}
\hline Customer: & $\begin{array}{l}\text { The United States Department of Energy } \\
\text { National Energy Technology Laboratory }\end{array}$ & $\begin{array}{l}\text { Date of Issue: } \\
29 \text { April } 2003\end{array}$ & \\
\hline $\begin{array}{l}\text { Document } \\
\text { Title: }\end{array}$ & $\begin{array}{l}\text { Subtask 1.2 } \\
\text { Identify Marine Mooring and Offloading Initiatives for LNG Vessels }\end{array}$ & $\begin{array}{l}\text { Doc \# \& Version: } \\
\text { Doc } 003 \text { r. } 4\end{array}$ & Page 22 of $\mathbf{4 0}$ \\
\hline
\end{tabular}

guidance system are key components placed in the STL compartment. The pull-in winch and hydraulic power packs will be located on deck. A buoy moored to the seabed forms the basis for the STL system. Pulled into and secured in a mating cone, this unit connects the vessel to the mooring system.

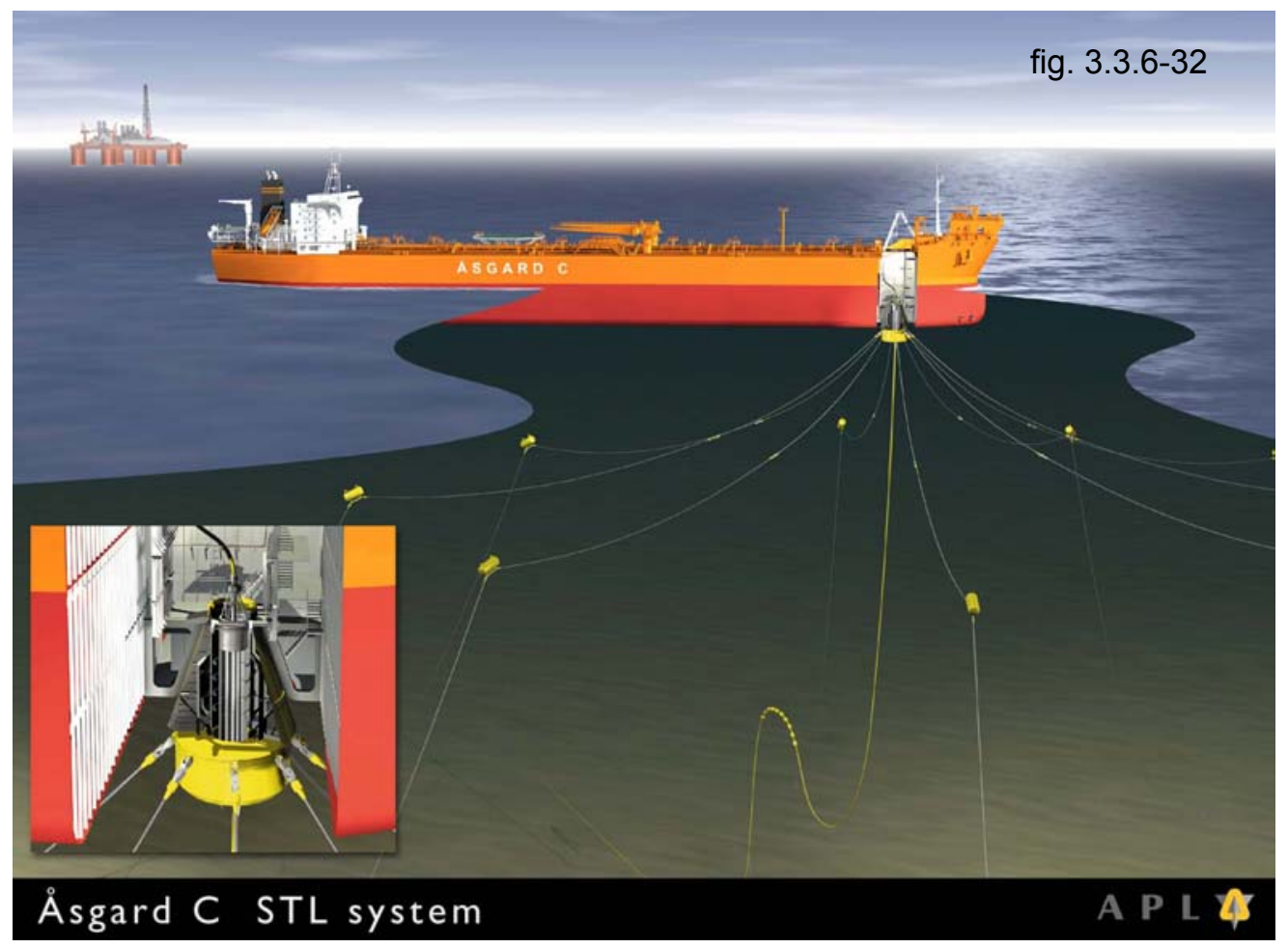

The buoy structure incorporates a turret connected to the mooring and a flexible riser. The outer hull rotates freely around the turret with the weathervaning vessel by means of internal bearings. The hydrocarbon stream is transferred through an in-line swivel and via the loading manifold to the vessel piping system. Or, in the case of Energy Bridge, the flow is reversed as the vaporized LNG moves through the in-line swivel and turret section, through the riser to the (pipeline end manifold) PLEM, and existing subsea gas grid. Figure 3.3.6-32 is an arrangement of a typical buoy and offshore production field. The riser through which the hydrocarbons flow is represented in yellow, and drops out of the center of the STL buoy.

APL's technology is the only offshore LNG mooring system certified and in the fabrication phase. Delivery of the first tanker and the sub sea infrastructure required for cargo transfer should be completed by late 2004 . El Paso has announced that the Gulf of Mexico will be the first site for an Energy Bridge application. Task 3.0 of this study includes a detailed review of El Paso's Energy Bridge concept using APL's technology.

\subsubsection{New Architectures of LNG Transfer by TFE, GdF, Eurodim, and ITP}

Eurodim, s.a. has over the last three years coordinated a consortium of the above the French companies to develop new architectures and components for the transfer of LNG offshore. The designs originating from this group are applicable to both the loading and receiving terminal. The first goal of the R\&D effort was to propose alternatives to traditional jetties (the dock and approach trestle), and to define the critical components of the designs that needed further study or testing. The consortium decided that the following conditions were to be met:

- To locate the mooring facility some distance from the coast to minimize navigational and siting problems

- To be able to load and unload non-dedicated vessels at $10,000 \mathrm{~m} 3 / \mathrm{hr}$ 


\begin{tabular}{|l|l|l|l|}
\hline Customer: & $\begin{array}{l}\text { The United States Department of Energy } \\
\text { National Energy Technology Laboratory }\end{array}$ & $\begin{array}{l}\text { Date of Issue: } \\
29 \text { April } 2003\end{array}$ & \\
\hline $\begin{array}{l}\text { Document } \\
\text { Title: }\end{array}$ & $\begin{array}{l}\text { Subtask 1.2 } \\
\text { Identify Marine Mooring and Offloading Initiatives for LNG Vessels }\end{array}$ & $\begin{array}{l}\text { Doc \# \& Version: } \\
\text { Doc } 003 \text { r4.0 }\end{array}$ & Page 23 of 40 \\
\hline
\end{tabular}

- To realize a significant CAPEX reduction by replacing the costly approach trestle and breakwater with subsea cryogenic pipelines and cryogenic hoses for cargo transfer

- To ensure a level of safety equal or above that which is realized for traditional jetties.

The following designs are weathervaning and are suited to severe weather sites.

\section{Rotating quay}

The consortium developed a system, which combined the advantages of:

- A traditional jetty noted for safety, reliability, with components using a proven technology, and able to accommodate non-dedicated ships.

- A single point mooring (SPM) that could be sited far from the coast, with cheaper cost, weathervaning capability to accommodate higher operating thresholds

This rotating quay, designed to replace the traditional jetty, was patented by TotalFinaElf in January 2000 (3.3.7-33). This revolving quay, which is mounted around a vertical axis on a fixed supporting structure, allows the moored vessel to weathervane with wind and current. The fixed structure is connected to the shore by subsea cryogenic lines.

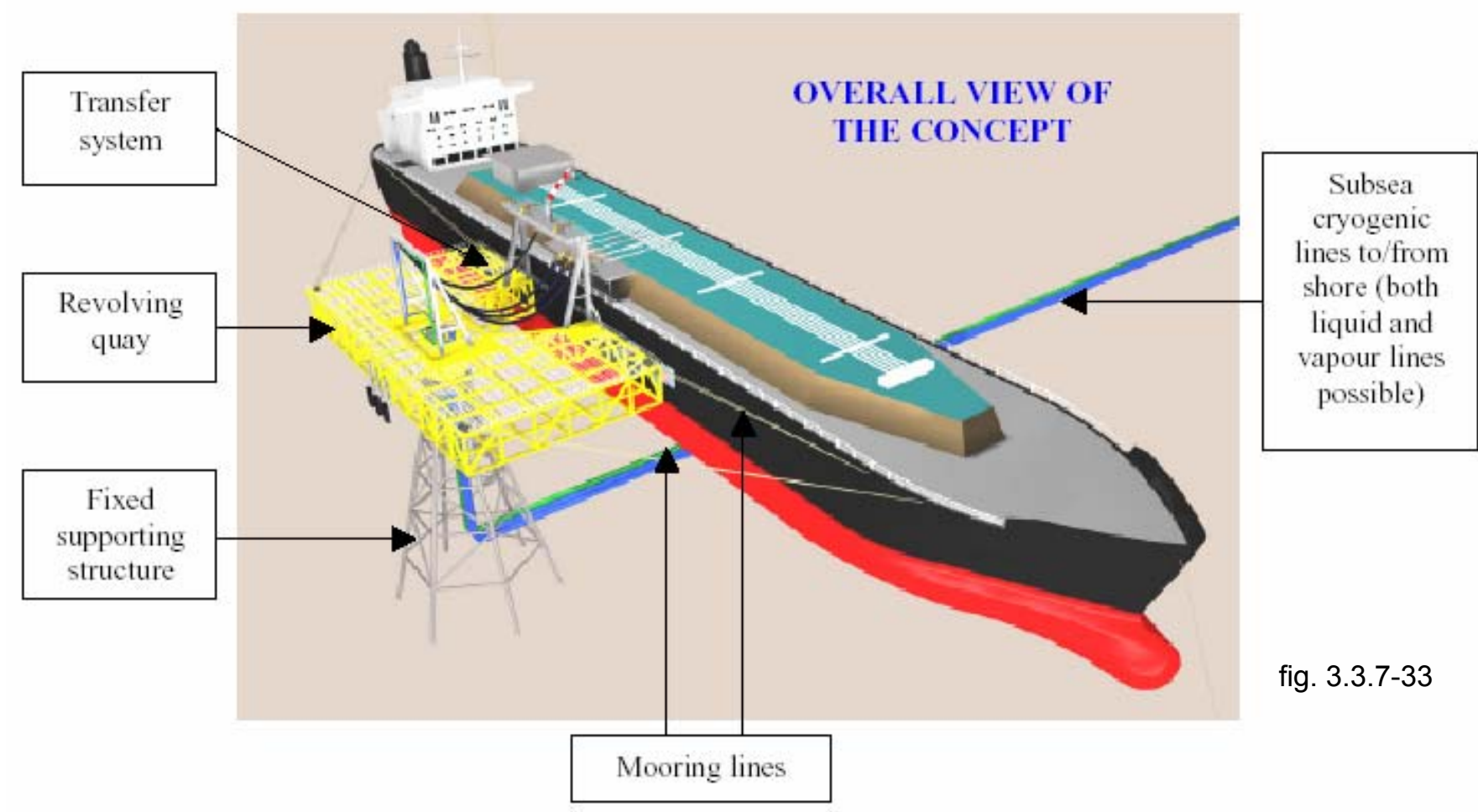

As the ship approaches the dock, the system allows a tug to position the quay parallel to the vessels parallel body for safe mooring. Soft hawsers, a simple and reliable system used in the offshore oil industry are used to provide the required flexibility fore and aft. After securing the vessel to the rotating quay, the movable structure maintains the optimum heading of the ship with reference to wind and waves. In case of emergency, 


\begin{tabular}{|l|l|l|l|}
\hline Customer: & $\begin{array}{l}\text { The United States Department of Energy } \\
\text { National Energy Technology Laboratory }\end{array}$ & $\begin{array}{l}\text { Date of Issue: } \\
29 \text { April } 2003\end{array}$ & \\
\hline $\begin{array}{l}\text { Document } \\
\text { Title: }\end{array}$ & $\begin{array}{l}\text { Subtask 1.2 } \\
\text { Identify Marine Mooring and Offloading Initiatives for LNG Vessels }\end{array}$ & $\begin{array}{l}\text { Doc \# \& Version: } \\
\text { Doc } 003 \text { r4.0 }\end{array}$ & Page 24 of 40 \\
\hline
\end{tabular}

a quick departure can be achieved with a very high level of safety and reliability. An illustration of the system is given on Figures 3.3.7-33 and 34 .

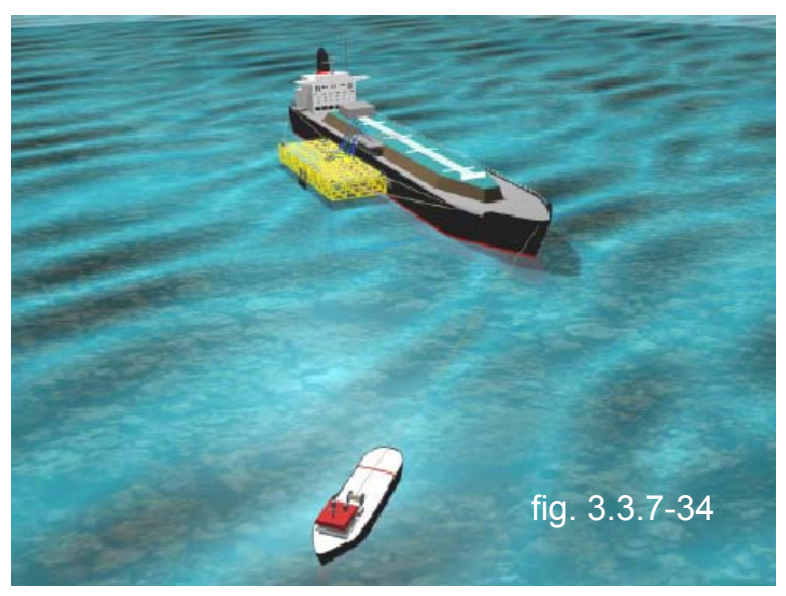

This concept meets the objectives set for all of the liquefied gas transfer architectures:

- Serving non-dedicated ships

- Applicable for both loading and discharging terminals

- Able to handle any type of liquefied gas.

- Flexibility with regard to depth.

- More compliant than a traditional berth with regard to weather operating thresholds.

- Reducing significantly the overall cost compared to traditional jetty design

- Eliminating the navigational, traffic and neighboring constraints by allowing the system to be at some distance from the coast.

In addition it presents several remarkable advantages:

- All components are standard and similar to the ones used on traditional jetties: mooring hooks, fenders, arms, gangway, etc.

- The system uses the same rules, standards and guidelines for design as used for traditional jetties e.g. OCIMF guidelines for mooring, PIANC (Permanent International Association of Navigation Congresses) or BSRA (British Ship Research Association) standards for fender selection, OCIMF specification for loading arms, all SIGTTO guidelines, etc.

- The rotating quay can support either hard arms or flexible hoses for the product transfer; the shape of the rotating quay can be adapted accordingly

Also, the supporting structure and the rotating quay have similar lattice structures (jacket and lattice beam) allowing a yard to build both structures at the same time. Transportation to the site can be made on two barges and installation is straightforward. Although this has not been estimated in detail, there is obviously an important reduction of the construction and installation time compared to a traditional jetty, which requires extensive civil work and piling.

Berthing and station keeping are also unique to this design in that the mooring facility actually tracks the parallel body of the ship while berthing. Traditional facilities require two to three $6,500 \mathrm{HP}$ tugboats to turn the vessel before docking. Once the ship is parallel to the berthing line tugs push the vessel toward the breasting dolphins at speeds no greater than 15 to $20 \mathrm{~cm} / \mathrm{sec}$. Berthing thresholds are limited to waves of 1.2 to 1.5 meters $\mathrm{Hs}$, and wind from 12 to $15 \mathrm{~m} / \mathrm{sec}$. Because the ship seldom if ever contacts the breasting dolphin fenders exactly parallel, each breasting dolphin must be

fig. 3.3.7-35

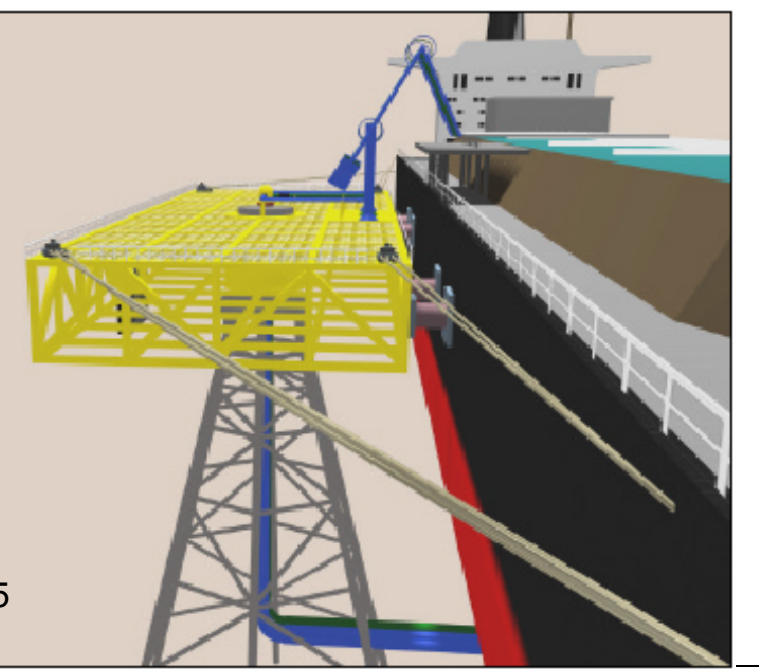

Filename: 41653R01 


\begin{tabular}{|l|l|l|l|}
\hline Customer: & $\begin{array}{l}\text { The United States Department of Energy } \\
\text { National Energy Technology Laboratory }\end{array}$ & $\begin{array}{l}\text { Date of Issue: } \\
29 \text { April } 2003\end{array}$ & \\
\hline $\begin{array}{l}\text { Document } \\
\text { Title: }\end{array}$ & $\begin{array}{l}\text { Subtask 1.2 } \\
\text { Identify Marine Mooring and Offloading Initiatives for LNG Vessels }\end{array}$ & $\begin{array}{l}\text { Doc \# \& Version: } \\
\text { Doc } 003 \text { r. } 4\end{array}$ & Page $\mathbf{2 5}$ of $\mathbf{4 0}$ \\
\hline
\end{tabular}

able to absorb all the berthing energy. Consequently, these structures are robust and expensive.

The rotating quay "self aligns" as its system of fenders come in contact with the vessel, fig. 3.3.7-35. For example as soon as the parallel body of the ship contacts the first breasting fender, the quay turns naturally to contact the remaining fenders immediately, thus sharing the berthing energy equally. Because the facility weathervanes and the ship rides the path of least resistance at the dock, mooring line stresses are reduced. Eight mooring lines rather than 12 to 16 are required to keep the ship secure, even in rough conditions

The cost savings are evident as the breasting dolphins can be made lighter, the mooring dolphins and accompanying catwalks eliminated, and the number of mooring hooks and lines reduced.

\section{Ariel Fluid Path SPM}

The Aerial Fluid Path (AFP) by TotalFinaElf and engineering by Eurodim is a side transfer weathervaning structure supporting a boom approximately 220 meters long. The boom is designed to rotate around the
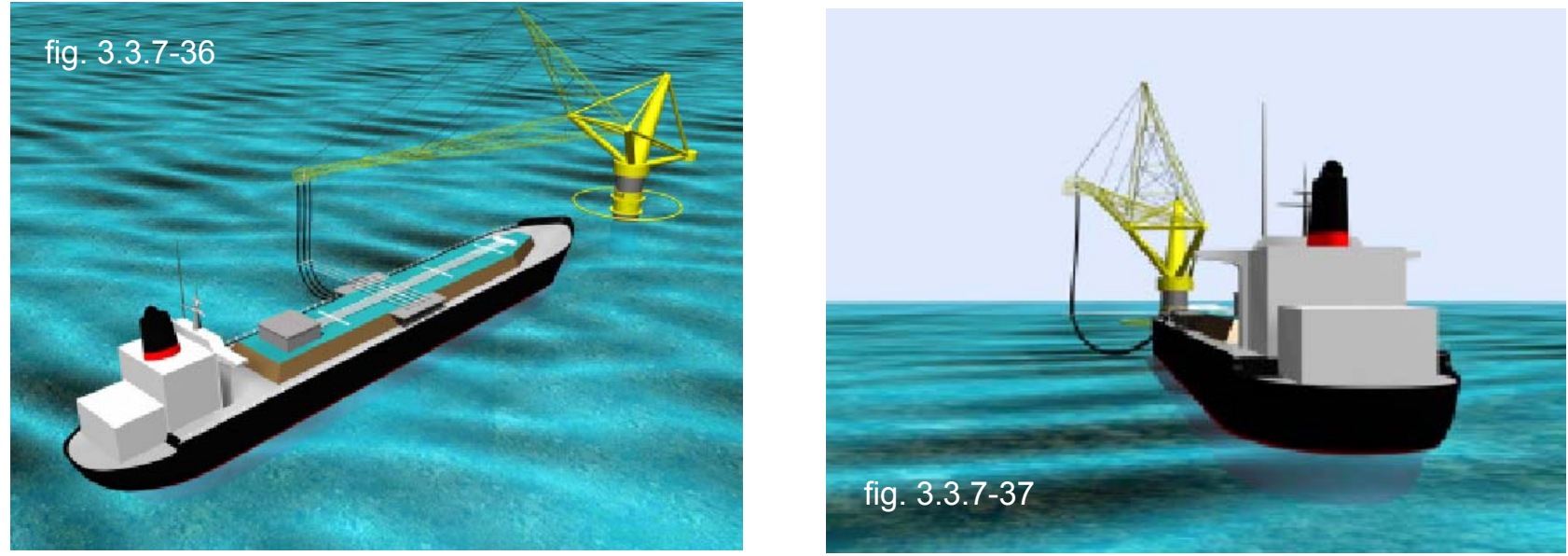

vertical axis of a fixed tower type single point mooring

(SPM). The boom is suspended about 50 meters above the water's surface to accommodate the largest LNG carriers, and the length is designed to reach the midship manifold as pictured above (figs. 3.3.7-36 \& 37)

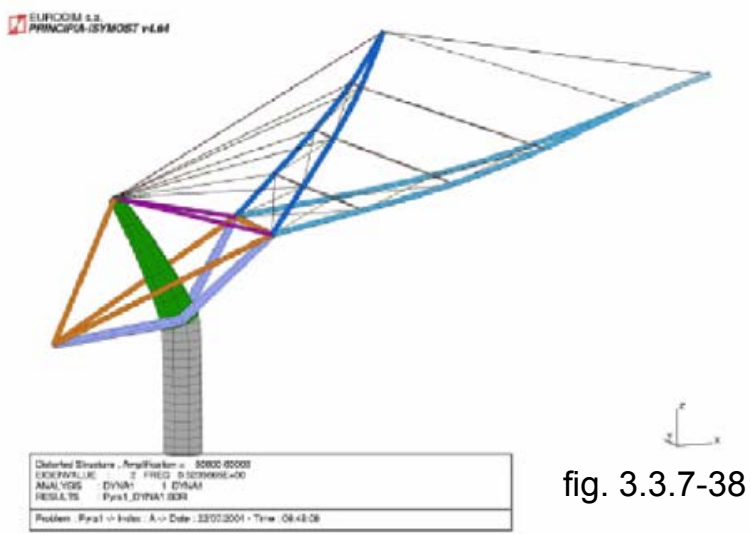

The boom carries the weight of the large diameter

flexible LNG hoses connected to the LNG tanker's manifold and is free to rotate with the ship. A patented beam and cable arrangement ensure that the hoses never exceed their designed bending radius. 


\begin{tabular}{|l|l|l|l|}
\hline Customer: & $\begin{array}{l}\text { The United States Department of Energy } \\
\text { National Energy Technology Laboratory }\end{array}$ & $\begin{array}{l}\text { Date of Issue: } \\
29 \text { April } 2003\end{array}$ & \\
\hline $\begin{array}{l}\text { Document } \\
\text { Title: }\end{array}$ & $\begin{array}{l}\text { Subtask 1.2 } \\
\text { Identify Marine Mooring and Offloading Initiatives for LNG Vessels }\end{array}$ & $\begin{array}{l}\text { Doc \# \& Version: } \\
\text { Doc } 003 \text { r. }\end{array}$ & Page 26 of $\mathbf{4 0}$ \\
\hline
\end{tabular}

The structure is self supporting and the boom and SPM structure has been modeled and designed to operate outside the natural frequencies that the waves and environment might impose. For this reason the standard industrial crane and boom proved unacceptable and the alternative (pictured) was employed. The diagram below is a graphical representation of the boom operating in its first (fig. 3.3.7-38) and second (fig. 3.3.7-39) natural frequency vibration modes without adverse effects. This AFP concept appears to provide good operating thresholds with maximum safety, minimum cost and construction times and reduction of underwater infrastructure and mooring equipment.

\section{Light Reel Tandem Offloading System}

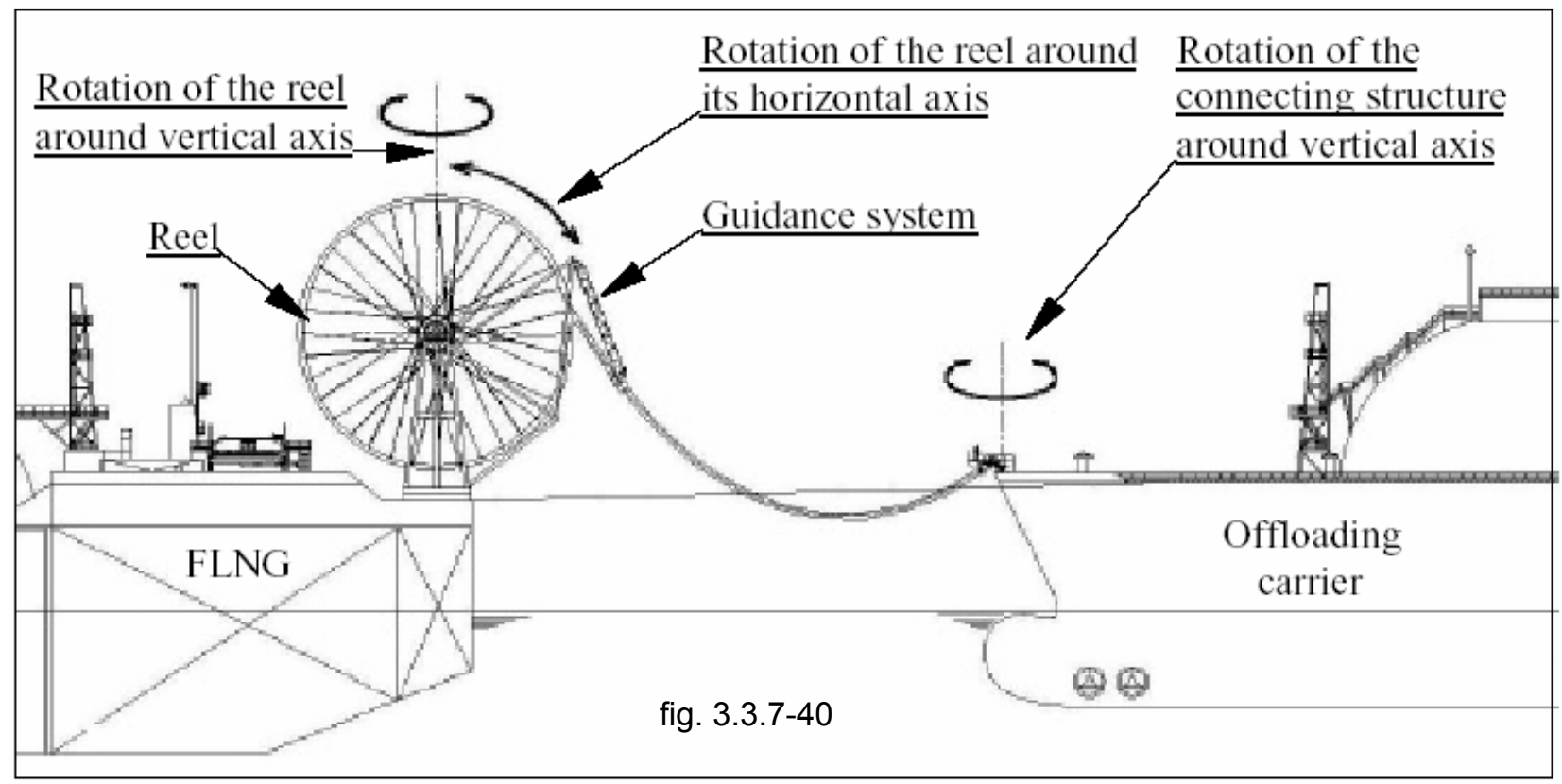

As previously established, the use of tandem transfer, weathervaning offshore units are required for safe use in the most severe siting conditions. The Light Reel system (fig. 3.3.7-40 \& 41) developed by Bluewater and Eurodim is an unusual departure from the designs listed above, but uses many familiar design concepts.

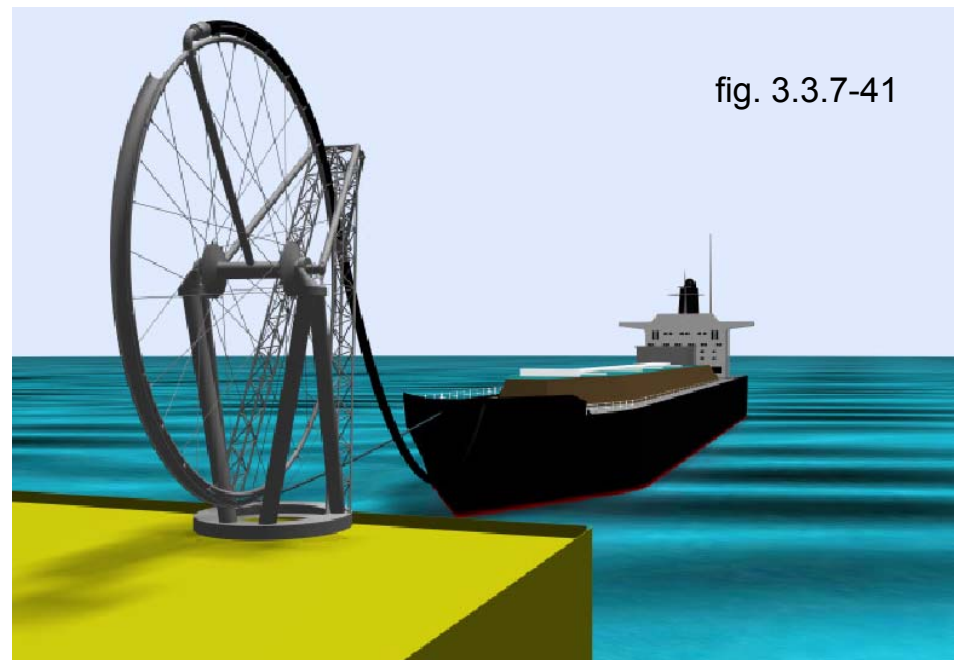

The Light Reel unit requires further study to evaluate the mechanical requirements for routine coupling with the offloading LNG vessel, and uncoupling under emergency conditions, however a brief description is provided below.

To summarize, a 16 meter reel containing the flexible LNG transfer hose is wound around the outside diameter for storage and use. One rotation of the reel can store about 100 meters of cryogenic hose. During LNG transfer the hose is connected to a structure on the bow of an LNG carrier, and clamped 


\begin{tabular}{|l|l|l|l|}
\hline Customer: & $\begin{array}{l}\text { The United States Department of Energy } \\
\text { National Energy Technology Laboratory }\end{array}$ & $\begin{array}{l}\text { Date of Issue: } \\
\mathbf{2 9} \text { April } 2003\end{array}$ & \\
\hline $\begin{array}{l}\text { Document } \\
\text { Title: }\end{array}$ & $\begin{array}{l}\text { Subtask 1.2 } \\
\text { Identify Marine Mooring and Offloading Initiatives for LNG Vessels }\end{array}$ & $\begin{array}{l}\text { Doc \# \& Version: } \\
\text { Doc } 003 \text { r4.0 }\end{array}$ & Page 27 of $\mathbf{4 0}$ \\
\hline
\end{tabular}

with a hydraulic connecting device. The swivels also serve to reduce the torque on the hoses ensuring reliability and long life. Two vertical swivels allow the joints to cope with large relative angles of motion between the two vessels, and the vessels are free to move as seen in fig. 3.3.7-42.

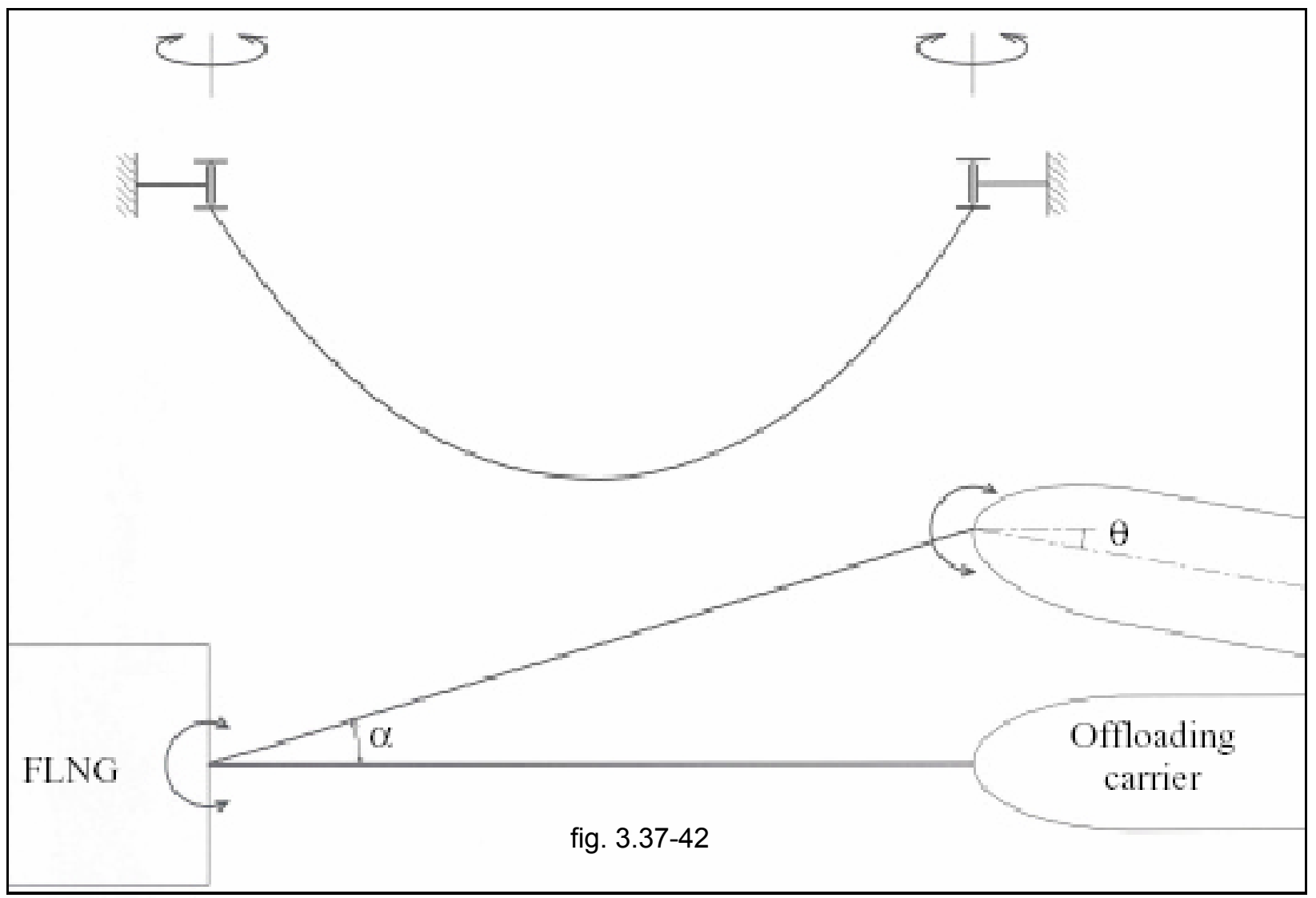

\section{Conventional Buoy Moorings}

Less severe sties with prevailing environmental conditions orientating the LNG carrier in one predominant direction can be served with a Conventional Buoy Mooring (CBM) system, sometimes called a "multi-buoy

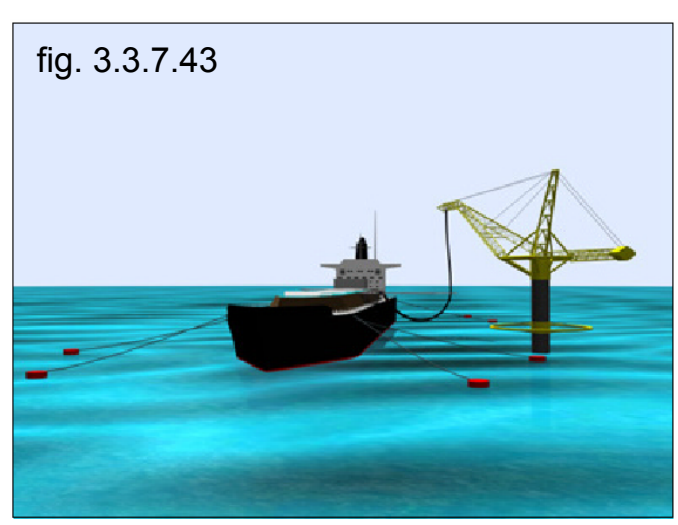
mooring." The mooring forces of the ship, instead of being transmitted to the jetty structure via the piles of the mooring and breasting dolphins, are transmitted by the ship mooring lines to the

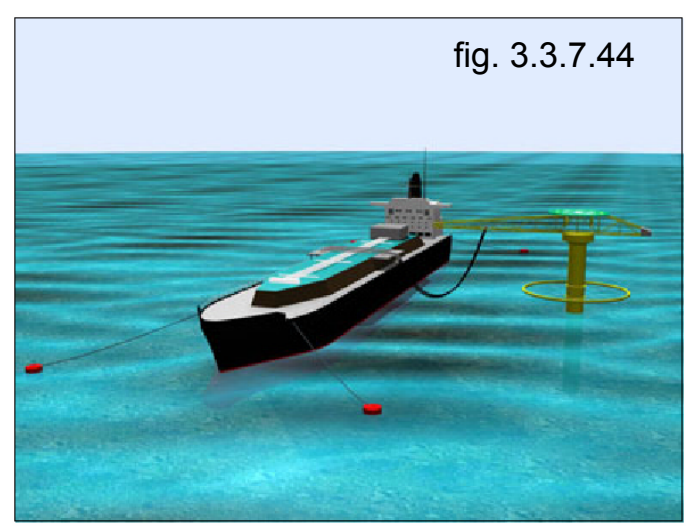




\begin{tabular}{|l|l|l|l|}
\hline Customer: & $\begin{array}{l}\text { The United States Department of Energy } \\
\text { National Energy Technology Laboratory }\end{array}$ & $\begin{array}{l}\text { Date of Issue: } \\
29 \text { April } 2003\end{array}$ & \\
\hline $\begin{array}{l}\text { Document } \\
\text { Title: }\end{array}$ & $\begin{array}{l}\text { Subtask 1.2 } \\
\text { Identify Marine Mooring and Offloading Initiatives for LNG Vessels }\end{array}$ & $\begin{array}{l}\text { Doc \# \& Version: } \\
\text { Doc } 003 \text { r. }\end{array}$ & Page 28 of $\mathbf{4 0}$ \\
\hline
\end{tabular}

chains of the multiple mooring buoys that are securely anchored to the seabed. From a structural stand point, this system carries the mooring loads in an optimised manner as no bending moment is generated in the structural link. This catenary structural link is in simple terms a massive "spring" that can be "tuned" during the engineering phase for the site conditions (wind, wave, and current) and calling vessels fig 3.3.7-43 $\& 44$.

A fixed tower riser (or support) linking sea bed/subsea cryogenic lines for LNG and vapor return line (or a trestle with aerial lines) could be used to transfer the cryogenic liquids. If flexible hoses were to be used with the CBM mooring concept, they could be supported in a catenary configuration between a cantilevered boom and a fixed tower. The boom would provide the overhead support required to position the transfer hose at the LNG carrier midship manifold.

Depending on the environmental conditions and the effect of wind and/or current, mooring stiffness, the location of the fixed tower, and boom orientation would be optimized. Optimized moorings range from that seen in (3.3.7-43) where the boom is perpendicular to the longitudinal axis of the moored LNG carrier, to an arrangement (3.3.7-44) where the boom is quite parallel to the longitudinal axis of the ship. This mooring arrangement would allow pivoting around a vertical axis with the hoses linking the boom tip to the midship manifold similar to the Aerial Fluid Path SPM concept. Anticipating the development of the required link technologies this mooring system could be used to transfer cryogenic liquids to the storage or processing

fig. 3.3.7.45
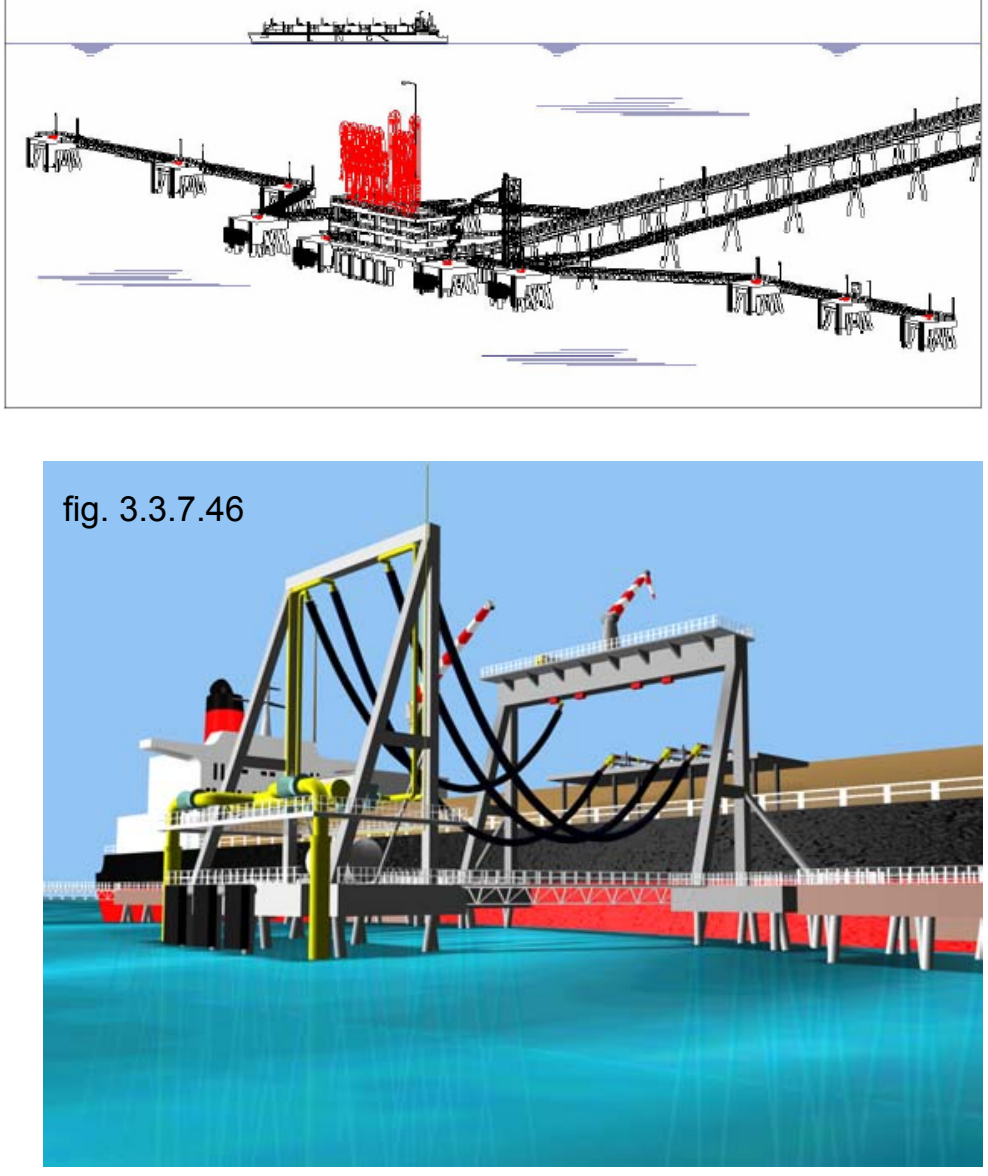
facility.

\section{Conventional Mooring Arrangements and} the "Gerris"

For benign site conditions, e.g. site with Hs ranging from 0.5 to 1.5 meters a conventional mooring jetty without a protective breakwater could be used to secure the LNG vessel. Cargoes could be transferred to shore via subsea cryogenic pipelines or conventional approach trestles. TFE and Eurodim have attempted to reduce conventional jetty cost with the following alternative to the standard OCIMFG/SIGTTO mooring jetty consisting of four breasting and four mooring dolphins fig 3.3.7.45.

The "Gerris," (fig. 3.3.7-46 \& 47) another concept by TFE and Eurodim was devised to determine the feasibility of offloading a nondedicated LNG ship at sea. À cost estimate for the "Gerris" jetty and an approach trestle of 2,500 and 5,000 meters comprised the based case of the project. TFE wanted to be able to, locate the facility some distance from the coast, load and unload dedicated tankers, and take advantage of the cryogenic hose for a more compliant and motion forgiving transfer system. 


\begin{tabular}{|l|l|l|l|}
\hline Customer: & $\begin{array}{l}\text { The United States Department of Energy } \\
\text { National Energy Technology Laboratory }\end{array}$ & $\begin{array}{l}\text { Date of Issue: } \\
29 \text { April } 2003\end{array}$ & \\
\hline $\begin{array}{l}\text { Document } \\
\text { Title: }\end{array}$ & $\begin{array}{l}\text { Subtask 1.2 } \\
\text { Identify Marine Mooring and Offloading Initiatives for LNG Vessels }\end{array}$ & $\begin{array}{l}\text { Doc \# \& Version: } \\
\text { Doc } 003 \text { r. }\end{array}$ & Page 29 of $\mathbf{4 0}$ \\
\hline
\end{tabular}

The hydrodynamic behavior and operating thresholds were assumed to be equal to a traditional jetty.

The study proved the feasibility of the "Gerrris" as an alternative to traditional designs subject to development of the linking technologies to be discussed in the next section.

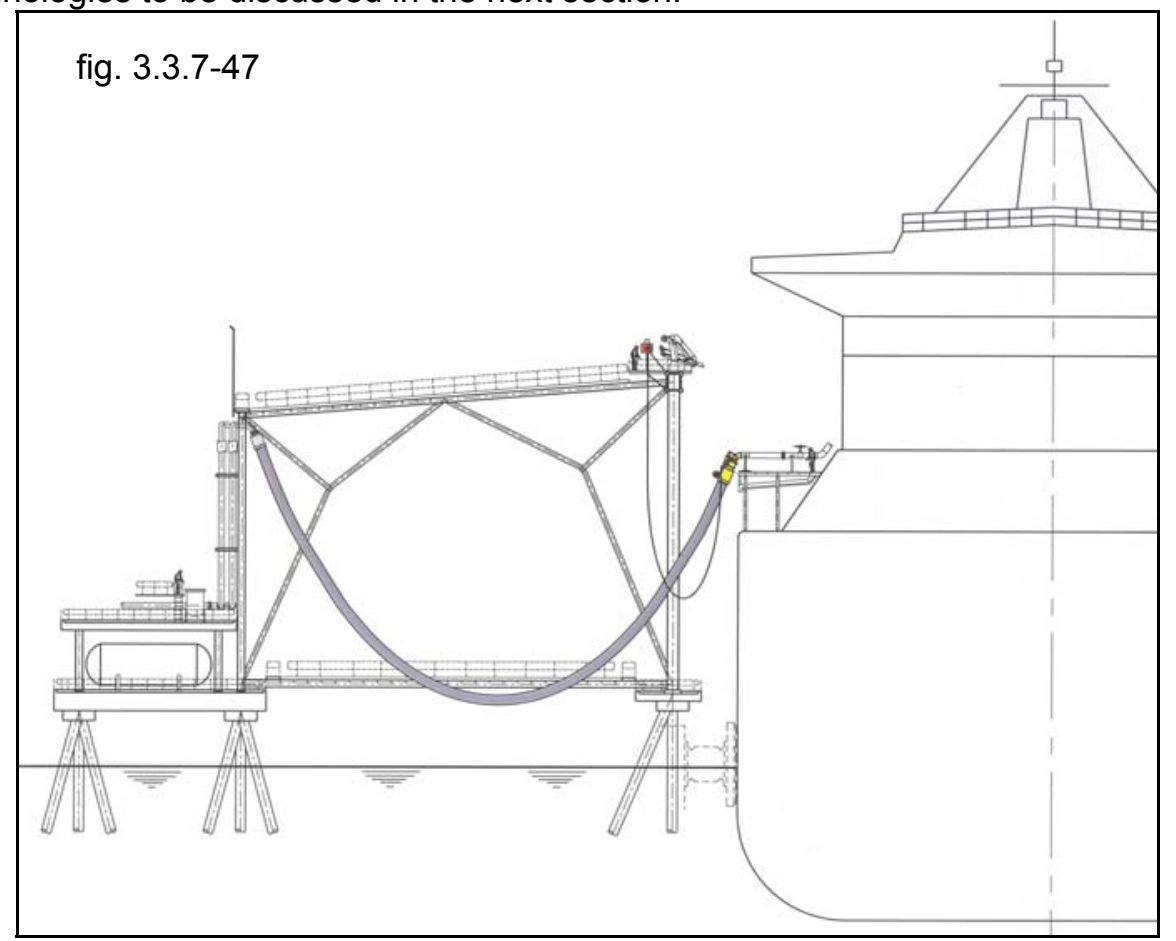




\begin{tabular}{|l|l|l|l|}
\hline Customer: & $\begin{array}{l}\text { The United States Department of Energy } \\
\text { National Energy Technology Laboratory }\end{array}$ & $\begin{array}{l}\text { Date of Issue: } \\
29 \text { April } 2003\end{array}$ & \\
\hline $\begin{array}{l}\text { Document } \\
\text { Title: }\end{array}$ & $\begin{array}{l}\text { Subtask 1.2 } \\
\text { Identify Marine Mooring and Offloading Initiatives for LNG Vessels }\end{array}$ & $\begin{array}{l}\text { Doc \# \& Version: } \\
\text { Doc } 003 \text { r4.0 }\end{array}$ & Page $\mathbf{3 0}$ of $\mathbf{4 0}$ \\
\hline
\end{tabular}

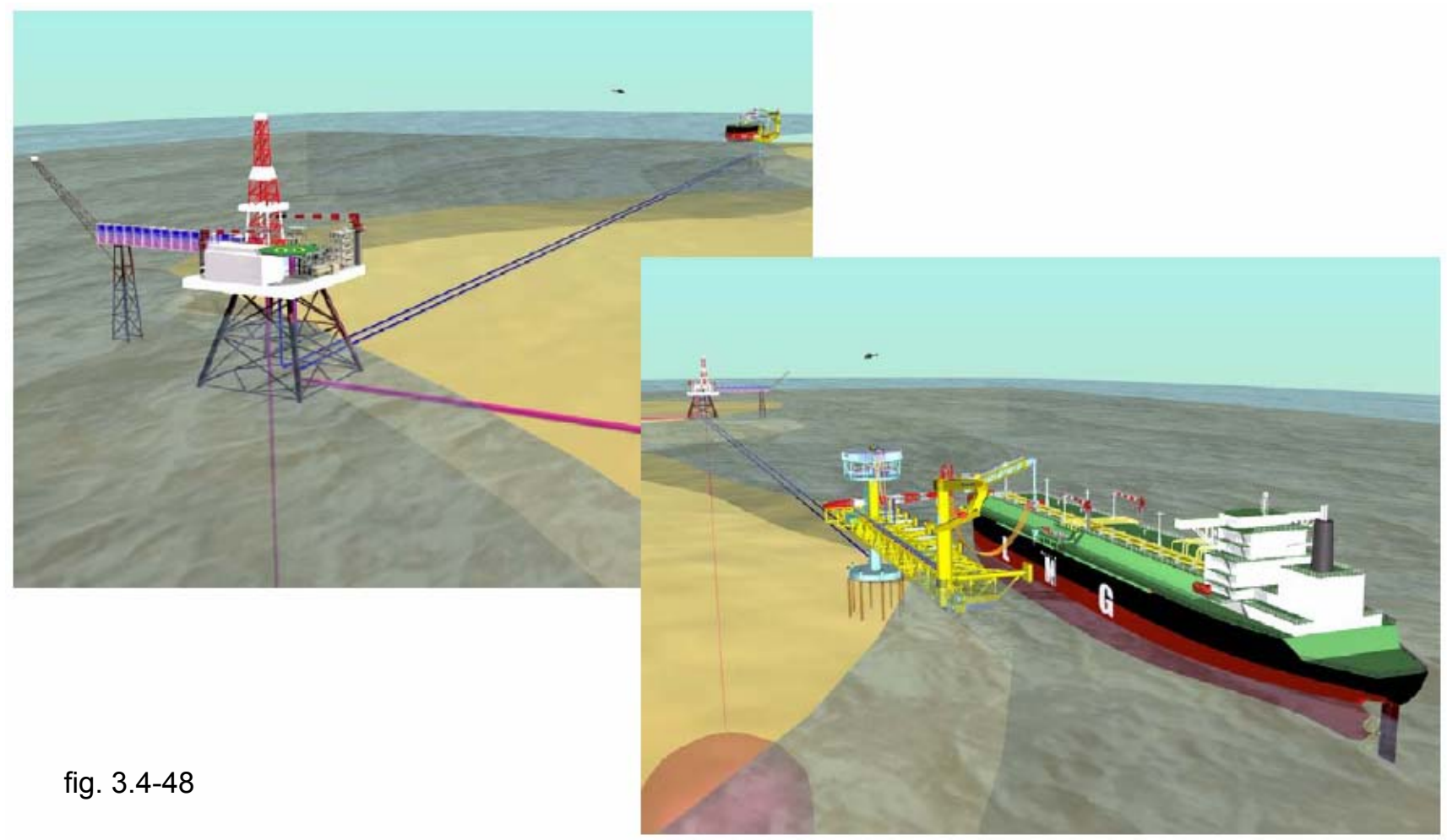

\subsection{Conceptual Offshore Terminal}

Bluewater Offshore Group, a contributor to this study, has proposed the below facility as an option for the receiving of LNG offshore for salt cavern storage (fig 3.4-48). This conceptual design could be located in water of from 60 to 200 feet, and addresses many of the offshore transfer concerns of the LNG producers. For additional details, please refer to Task 2.0 to further review the conceptual design of this offshore terminal concept. 


\begin{tabular}{|l|l|l|l|}
\hline Customer: & $\begin{array}{l}\text { The United States Department of Energy } \\
\text { National Energy Technology Laboratory }\end{array}$ & $\begin{array}{l}\text { Date of Issue: } \\
29 \text { April } 2003\end{array}$ & \\
\hline $\begin{array}{l}\text { Document } \\
\text { Title: }\end{array}$ & $\begin{array}{l}\text { Subtask 1.2 } \\
\text { Identify Marine Mooring and Offloading Initiatives for LNG Vessels }\end{array}$ & $\begin{array}{l}\text { Doc \# \& Version: } \\
\text { Doc } 003 \text { r4.0 }\end{array}$ & Page $\mathbf{3 1}$ of $\mathbf{4 0}$ \\
\hline
\end{tabular}

\section{LINK TECHNOLOGIES TO FACILITATE LNG OFFSHORE TRANSFER}

\subsection{The Extended Travel Loading Arm}

Offshore Ship to Ship LNG Arms with Hydraulic Coupler and Optional Targeting System

Application

Calm to Moderate Motion Offshore Ship to Ship Transfer

Guidelines for Motion Between Ships During Connection

- Max. Vertical Flange Displacement for Connection:

- Max. Horizontal Flange Displacement for Connection:

$+/-2.0 \mathrm{M}$

- Max. Flange Velocity for Connection:

- Max. Flange Acceleration for Connection

$+/-1.7 \mathrm{M}$

$+/-1.0 \mathrm{M} / \mathrm{Sec}$

$+/-0.5 \mathrm{M} / \mathrm{Sec} 2$

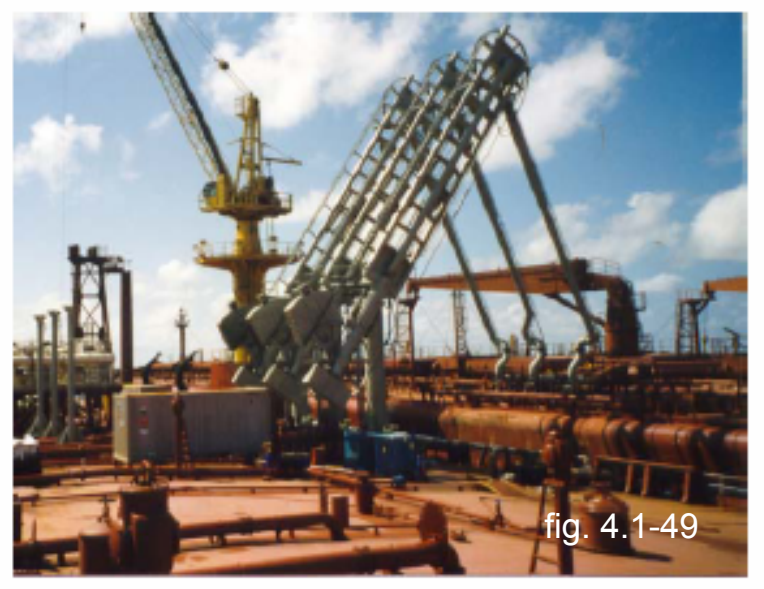

\section{Ship to Ship Offshore Chiksan LNG Loading Arms}

Key Advantages:

- Chiksan Proven LNG Constant Motion Swivel Joints to Eliminate

Excessive Wear Caused by Wave Action

- Removable Elbows \& Cartridge Swivel Joints for In Situ Maintenance

- Chiksan Emergency Release System (Meets OCIMF 1999)

- Position Monitoring System for Ultimate Loading Safety

- Chiksan LNG Hydraulic Coupler for Safe, Reliable Connection in an

Unstable (Moving) Environment with Patented Seal Protection System

(Meets OCIMF 1999)

- Optional Targeting System to Ensure Connection in Roughest

Environments 


\begin{tabular}{|l|l|l|l|}
\hline Customer: & $\begin{array}{l}\text { The United States Department of Energy } \\
\text { National Energy Technology Laboratory }\end{array}$ & $\begin{array}{l}\text { Date of Issue: } \\
29 \text { April } 2003\end{array}$ & \\
\hline $\begin{array}{l}\text { Document } \\
\text { Title: }\end{array}$ & $\begin{array}{l}\text { Subtask 1.2 } \\
\text { Identify Marine Mooring and Offloading Initiatives for LNG Vessels }\end{array}$ & $\begin{array}{l}\text { Doc \# \& Version: } \\
\text { Doc } 003 \text { r4.0 }\end{array}$ & Page $\mathbf{3 2}$ of $\mathbf{4 0}$ \\
\hline
\end{tabular}

The extended travel arms in figure 4.1-49 could be employed in benign environments for side by side LNG transfer with high availability. However, availability in moderate environments would suffer.

\subsection{The Pantograph Loading Arm for Tandem Transfer}

Application

Moderate to Severe Motion Offshore With Large Distance between Vessels

Guidelines for Motion between Vessels during Connection:

- Up to 5.0 M Significant Wave Heights

- Max. Heave

- Max. Flange Velocity for Connection

- Max. Flange Acceleration for Connection

$$
\begin{aligned}
& \text { +/- } 5.0 \mathrm{M} \\
& +/-2.5 \mathrm{M} / \mathrm{Sec} \\
& +/-2.5 \mathrm{M} / \mathrm{Sec} 2
\end{aligned}
$$

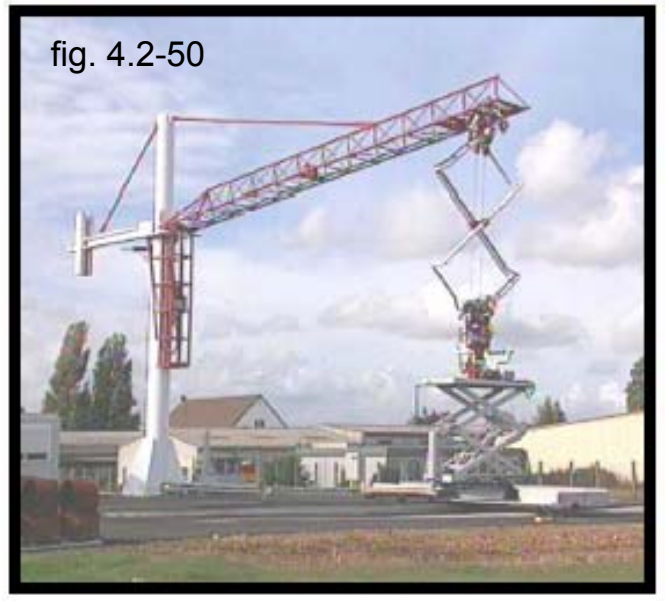

Key LNG Transfer Advantages:

- Chiksan Proven LNG Constant Motion Swivel Joints to Eliminate Excessive Wear Caused by Wave Action

- Removable Elbows \& Cartridge Swivel Joints for In Situ Maintenance

- Chiksan Emergency Release System (Meets OCIMF 1999)

- Position Monitoring System for Ultimate Loading Safety

- Chiksan LNG Hydraulic Coupler for Safe, Reliable Connection in an Unstable (Moving) Environment with Patented Seal Protection System (Meets OCIMF 1999)

- Targeting System to Ensure Connection in Roughest Environments

- Available with Double Pantograph System (1-24 "Liquid Line and 116"Vapor) or Twin type Double Pantograph System (3-16" Liquid Lines and 1-16" Vapor Line)

- 10,000 M3 Loading Rate with Double Pantograph System

FMC's Pantograph loading arm (fig. 4.2-50) is an important link technology that is currently being tested at FMC's facilities in France. With million of cycles and many more planned, the Pantograph loading arm is now ready for commercial use.

The Boom to Tanker Tethered Tandem Loading System (fig. 4.2-51) right uses FMC's pantograph loading shown in a tethered arrangement with a built for purpose crane and boom to facilitate hook-up. The industry has requested a more robust system for mooring purposes and the technology by FMCSofec in Section 3.3.3 is the result. Its articulated technology and proven swivel arrangement reduces transfer risk, but the tandem loading arrangement precludes all existing LNG tankers

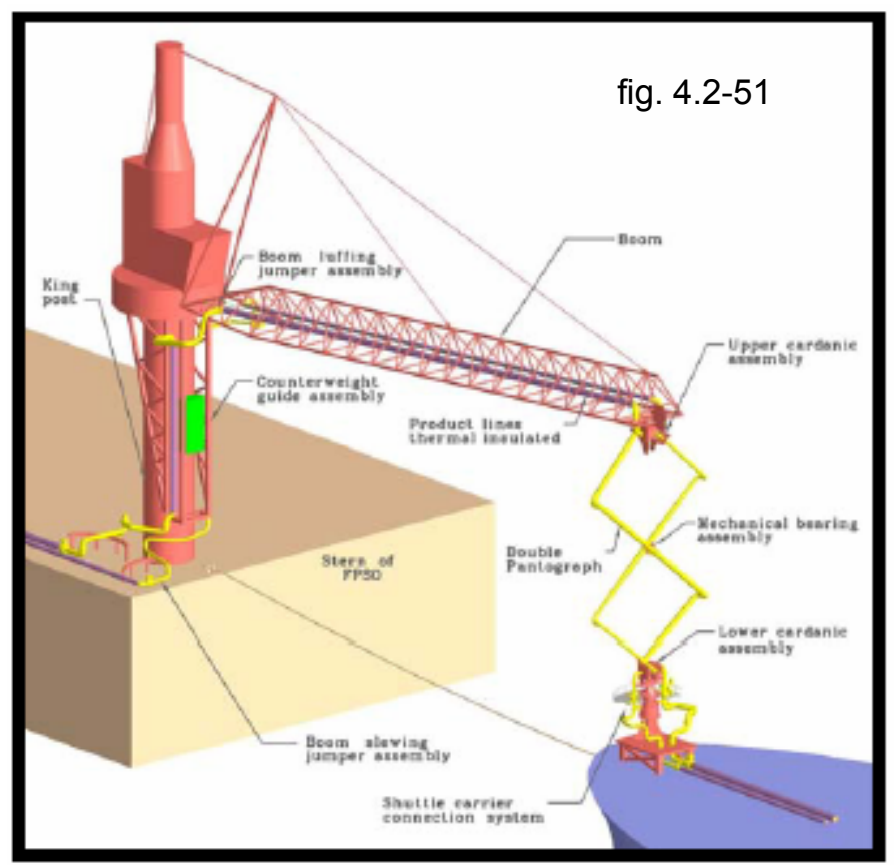




\begin{tabular}{|l|l|l|l|}
\hline Customer: & $\begin{array}{l}\text { The United States Department of Energy } \\
\text { National Energy Technology Laboratory }\end{array}$ & $\begin{array}{l}\text { Date of Issue: } \\
29 \text { April } 2003\end{array}$ & \\
\hline $\begin{array}{l}\text { Document } \\
\text { Title: }\end{array}$ & $\begin{array}{l}\text { Subtask 1.2 } \\
\text { Identify Marine Mooring and Offloading Initiatives for LNG Vessels }\end{array}$ & $\begin{array}{l}\text { Doc \# \& Version: } \\
\text { Doc } 003 \text { r..0 }\end{array}$ & Page $\mathbf{3 3}$ of $\mathbf{4 0}$ \\
\hline
\end{tabular}

\subsection{Cryogenic Swivels}

The cryogenic swivel is a key linking technology that must be employed in almost any offshore LNG terminal design. The liquid swivels must meet the following conditions:

Flow rate from 5,000 to $10,000 \mathrm{~m} 3 / \mathrm{hr}$

Diameters from 16 " to 24 "

Service temperature $-163^{\circ} \mathrm{C}$

Design Pressure 20 bar

The vapor swivels must meet the following conditions:

Service temperature $-120^{\circ} \mathrm{C}$

Design Pressure 6 bar absolute

\subsubsection{FMC}

FMC is the recognized leader in the manufacture and worldwide use of the cryogenic swivel. While several companies have swivel applications in LPG transfer systems, FMC has over 30 years of LNG swivel design, operation, and maintenance. The

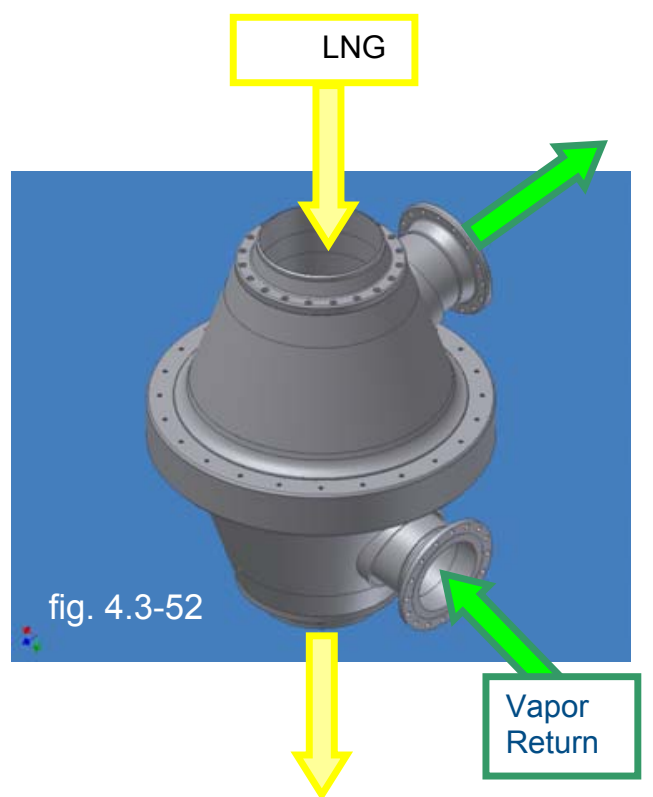
LNG industry maintains a strong confidence in the cryogenic swivels designed and built by FMC.

\subsubsection{SBM and Eurodim}

On a parallel path with FMC, SBM and Eurodim are also developing cryogenic swivels. SBM is currently testing a full scale model of its LNG swivel, and has operated the unit through many cycles. Neither company has certified its LNG swivels, but design is well past the conceptual phase.

\subsection{The Flexible Transfer Hose}

The flexible cryogenic transfer hose developed by Technip-Coflexip has already been built and tested for over 1.5 million cycles under cryogenic and warm conditions. Technip-Coflexip promoted the JIP for the development of the 16" cryogenic hose (description fig. 4.4-53 \& 54) to be used for LNG transfer offshore. Participants in this JIP were BP, BHP, Chevron, Gaz de France and Shell. The hose tested met all criteria, and Technip-Coflexip proved that lengths of up to $100 \mathrm{~m}$ of identical composition could be manufactured in their facilities in La Trait. However, production of the $100 \mathrm{~m}$ hose is approximately 12 months from realization.

Others not pictured yet very much involved in the design and fabrication of LNG cryogenic hoses

fig. $4.4-53$

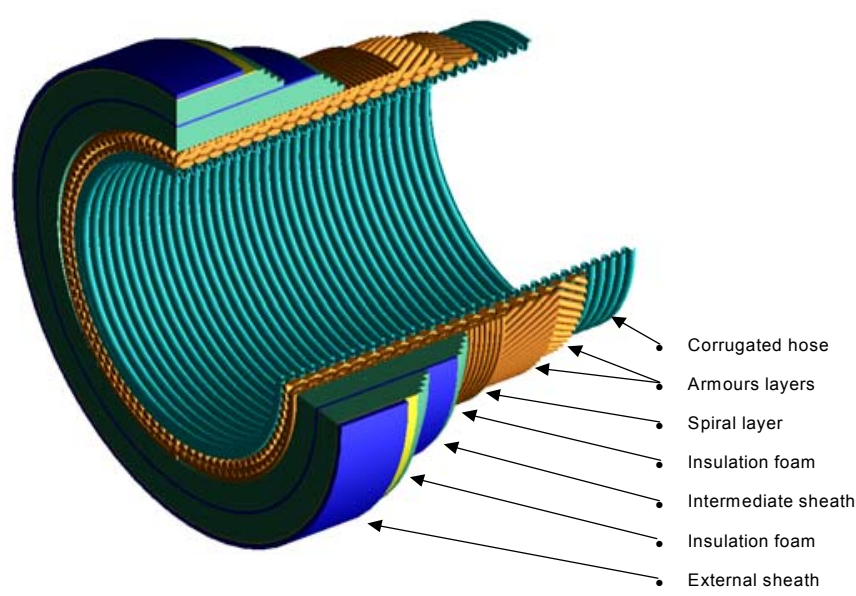




\begin{tabular}{|l|l|l|l|}
\hline Customer: & $\begin{array}{l}\text { The United States Department of Energy } \\
\text { National Energy Technology Laboratory }\end{array}$ & $\begin{array}{l}\text { Date of Issue: } \\
29 \text { April } 2003\end{array}$ & \\
\hline $\begin{array}{l}\text { Document } \\
\text { Title: }\end{array}$ & $\begin{array}{l}\text { Subtask 1.2 } \\
\text { Identify Marine Mooring and Offloading Initiatives for LNG Vessels }\end{array}$ & $\begin{array}{l}\text { Doc \# \& Version: } \\
\text { Doc } 003 \text { r4.0 }\end{array}$ & Page $\mathbf{3 4}$ of $\mathbf{4 0}$ \\
\hline
\end{tabular}

include the joint venture sponsored by ExxonMobil with SeriorFlexonics, and Alcatel Cryoflex ${ }^{\mathrm{TM}}$ Flexible Pipe a division of Nexans, A.S.

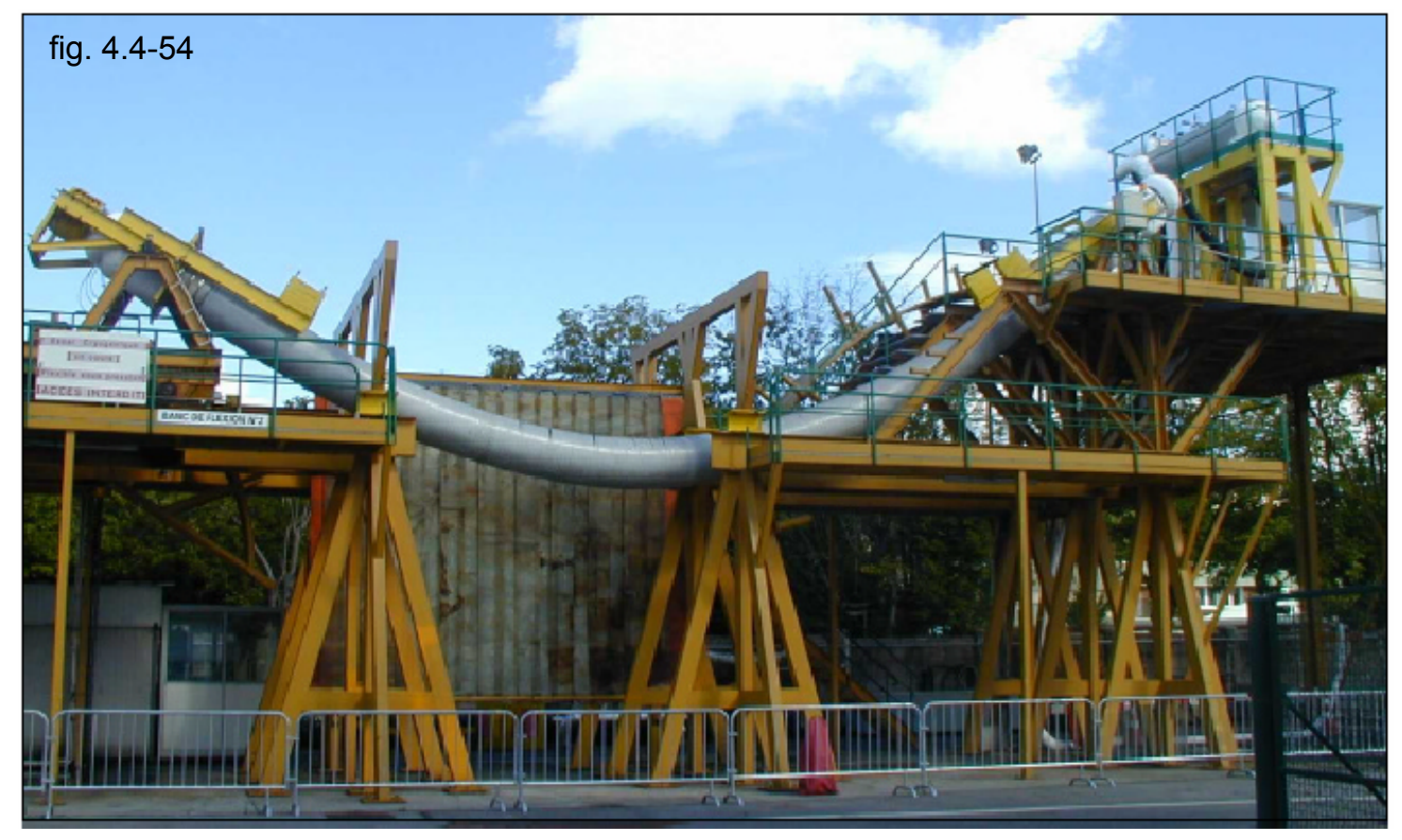

\subsubsection{The connection interface}

In conjunction with the hose test, Amri-KSB, Technip-Coflexip, and Eurodim formed a consortium to develop and test a connecting system compatible with a typical LNG ship manifold. The connection system was to have the means for automatic connection a t sea, and integrate all the necessary components including emergency shutdown and quick connect/disconnect couplers.

The connecting system has been developed with the following design philosophy:

- Safety is priority.

- Reliability is priority - avoid complexity and sophistication

- Respect of flexible hose integrity and behaviour predictability under all circumstances

- "Blind" connection and disconnection in dynamic conditions

- Safe and reliable emergency disconnection with very minimal spillage: "no spill"

- Minimal weight to maximize dynamic connection performances

- Outboard connection to avoid compatibility issues (fig. 4.4.1-55)

- Connection handling along the main acceleration axis (fig. 4.4.1-56) so that the mobile mass is simply hanging on the lifting cable which also serves also as a guiding cable ensuring that the pin and receiver cleanly mate. 


\begin{tabular}{|l|l|l|l|}
\hline Customer: & $\begin{array}{l}\text { The United States Department of Energy } \\
\text { National Energy Technology Laboratory }\end{array}$ & $\begin{array}{l}\text { Date of Issue: } \\
29 \text { April } 2003\end{array}$ & \\
\hline $\begin{array}{l}\text { Document } \\
\text { Title: }\end{array}$ & $\begin{array}{l}\text { Subtask 1.2 } \\
\text { Identify Marine Mooring and Offloading Initiatives for LNG Vessels }\end{array}$ & $\begin{array}{l}\text { Doc \# \& Version: } \\
\text { Doc } 003 \text { r4.0 }\end{array}$ & Page $\mathbf{3 5}$ of $\mathbf{4 0}$ \\
\hline
\end{tabular}

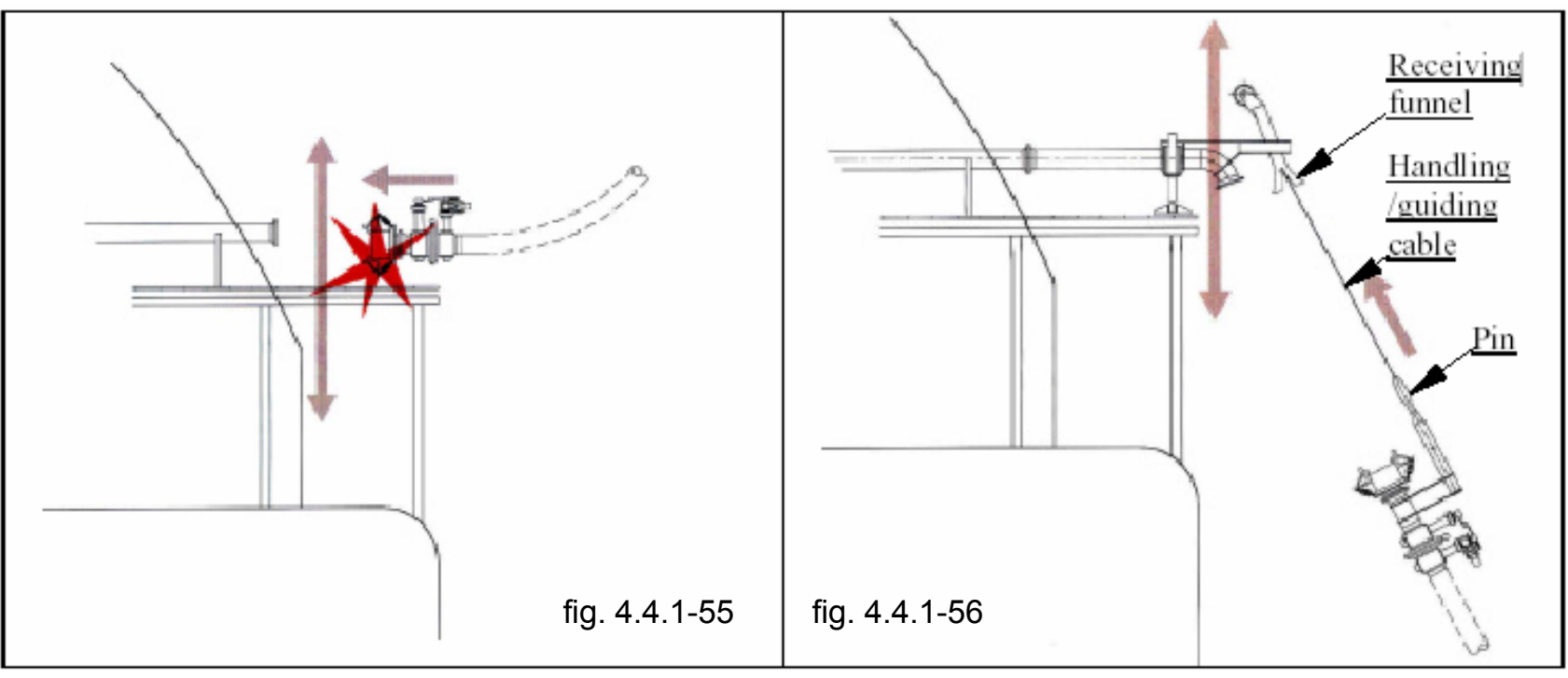

Figures 4.4.1-57 and 58 show the connecting system developed by the consortium this year.

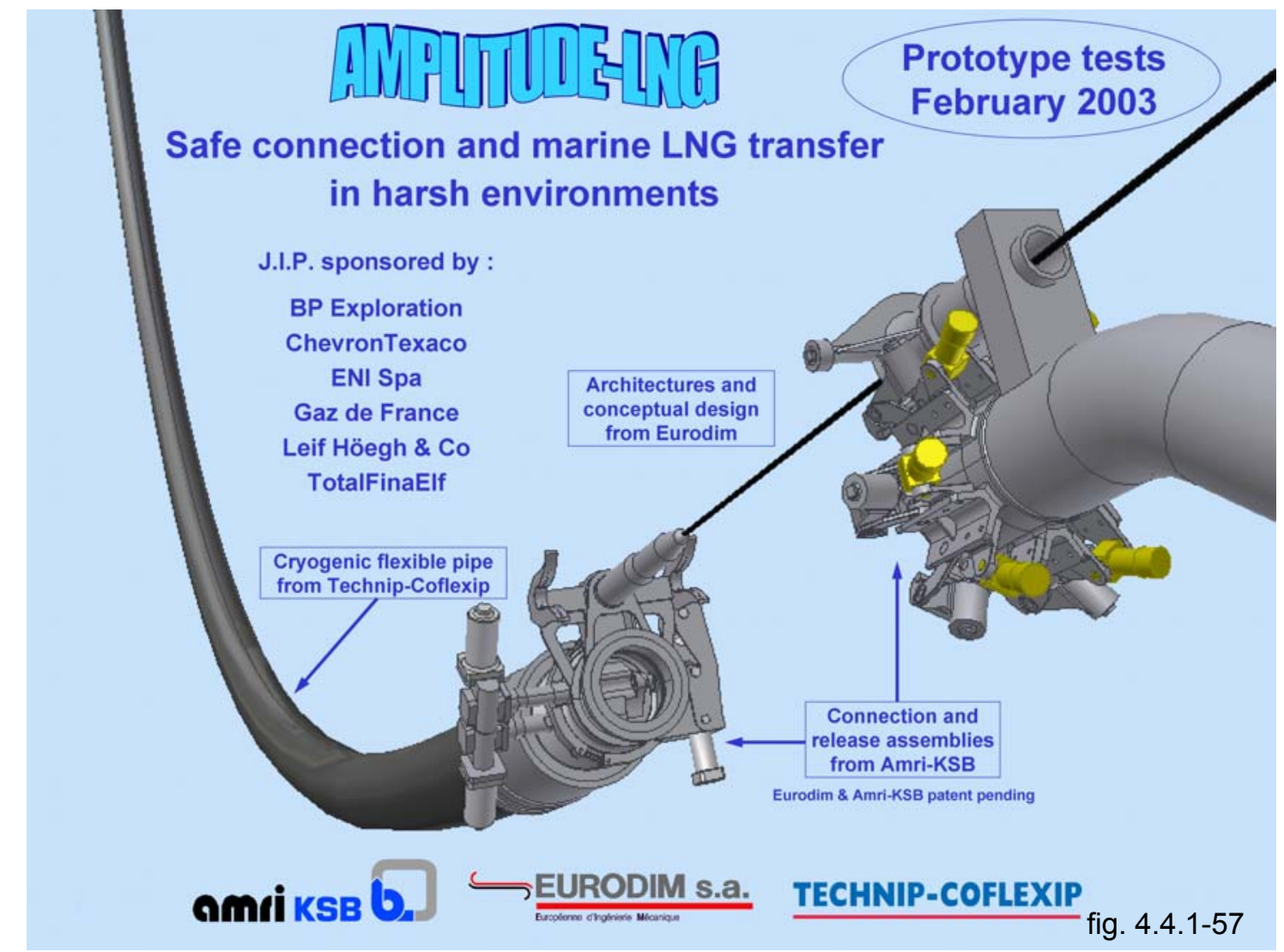




\begin{tabular}{|l|l|l|l|}
\hline Customer: & $\begin{array}{l}\text { The United States Department of Energy } \\
\text { National Energy Technology Laboratory }\end{array}$ & $\begin{array}{l}\text { Date of Issue: } \\
29 \text { April } 2003\end{array}$ & \\
\hline $\begin{array}{l}\text { Document } \\
\text { Title: }\end{array}$ & $\begin{array}{l}\text { Subtask 1.2 } \\
\text { Identify Marine Mooring and Offloading Initiatives for LNG Vessels }\end{array}$ & $\begin{array}{l}\text { Doc \# \& Version: } \\
\text { Doc } 003 \text { r. } 4\end{array}$ & Page $\mathbf{3 6}$ of $\mathbf{4 0}$ \\
\hline
\end{tabular}

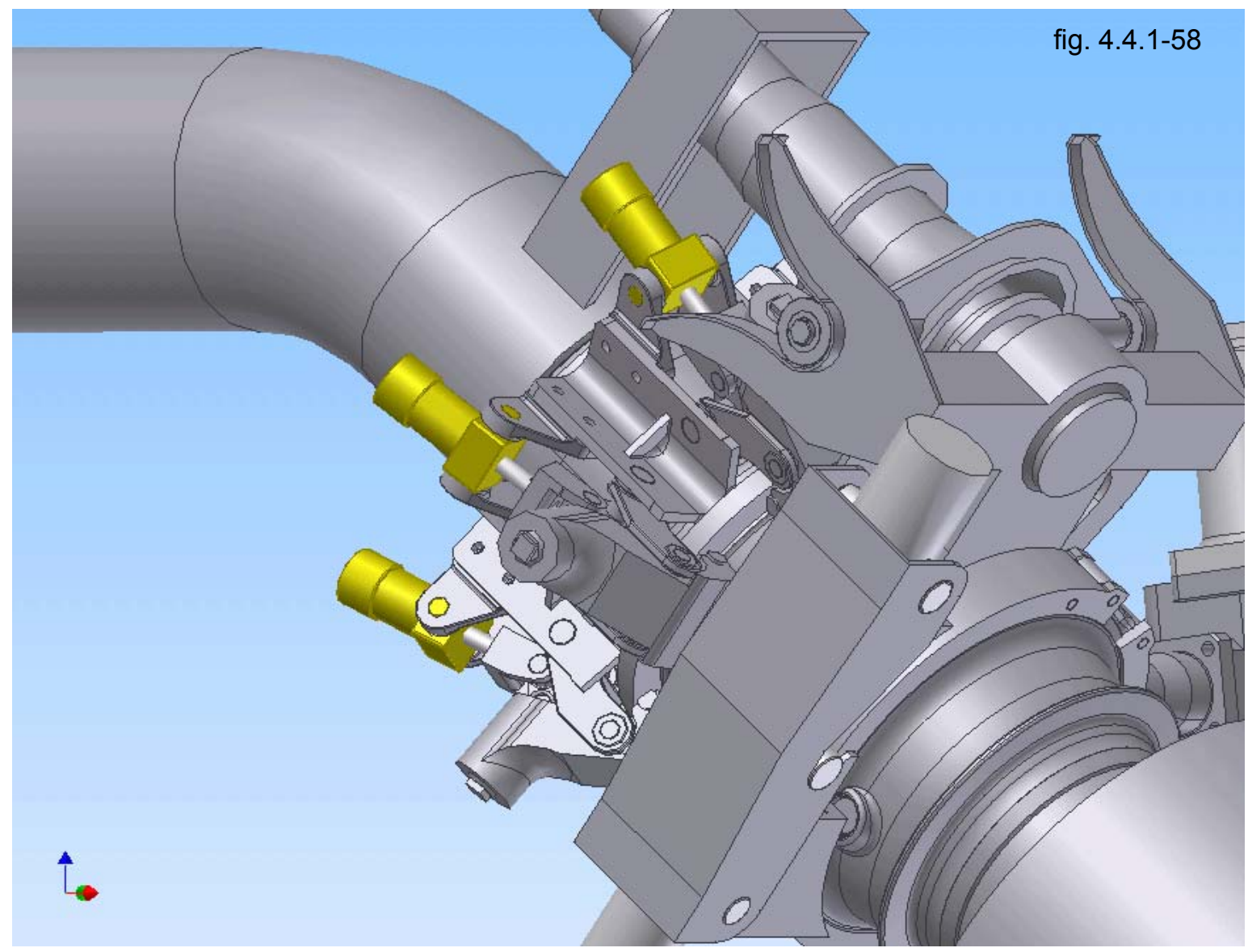

\subsection{The Cryogenic Pipeline}

\subsubsection{Conventional LNG transfer scheme}

The link between an LNG carrier and the onshore terminal storage area is defined by the transfer facilities, which typically feature:

a. A marine jetty head with berthing and mooring dolphins, connected to a platform, fitted with a gangway, loading arms, and some process related equipment

b. An approach trestle (or causeway), which supports the cryogenic pipelines. Typically two LNG pipelines in the diameter range of 20 to 40 inches, used in parallel during cargo transfer, and in series to keep the piping cold in stand-by mode. Utility piping, wiring and fiber optics for electrical and telecommunication, and a maintenance road atop the trestle for equipment access complete the design. The cold vapor return piping to and from the LNG storage tanks also services the dock via the approach trestle.

ITP's proposed subsea cryogenic pipeline could replace the expensive approach trestle (fig. 4.5.1-59) and reduce the construction and operation costs of LNG transfer facilities, as seen in the following photograph. 


\begin{tabular}{|l|l|l|l|}
\hline Customer: & $\begin{array}{l}\text { The United States Department of Energy } \\
\text { National Energy Technology Laboratory }\end{array}$ & $\begin{array}{l}\text { Date of Issue: } \\
29 \text { April } 2003\end{array}$ & \\
\hline $\begin{array}{l}\text { Document } \\
\text { Title: }\end{array}$ & $\begin{array}{l}\text { Subtask 1.2 } \\
\text { Identify Marine Mooring and Offloading Initiatives for LNG Vessels }\end{array}$ & $\begin{array}{l}\text { Doc \# \& Version: } \\
\text { Doc } 003 \text { r4.0 }\end{array}$ & Page $\mathbf{3 7}$ of $\mathbf{4 0}$ \\
\hline
\end{tabular}

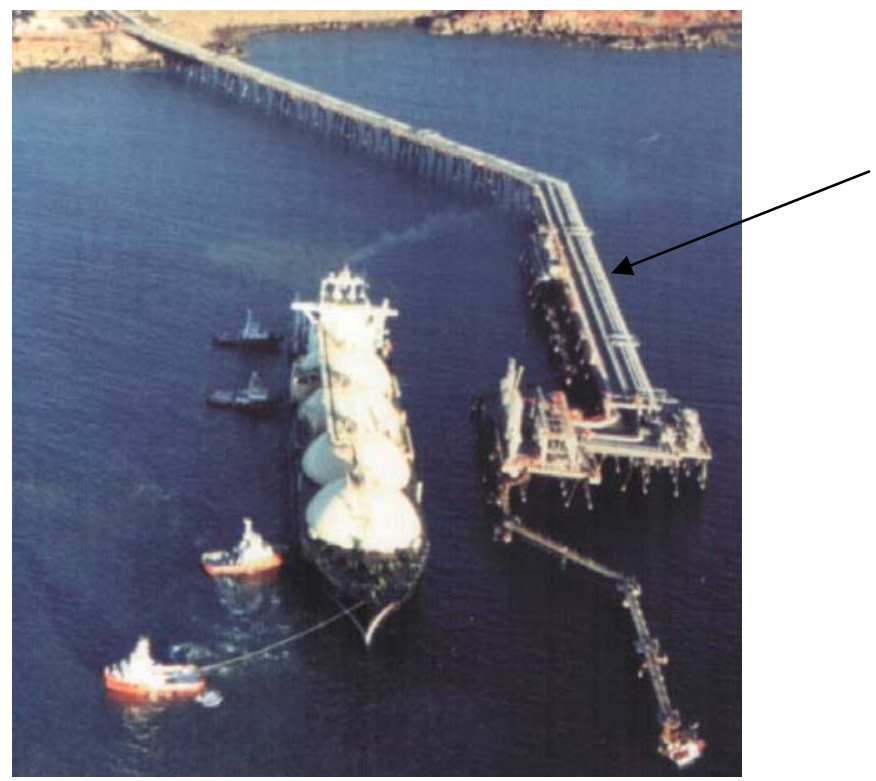

Typical LNG Jetty

Approach Trestle supporting $L N G$ pipelines, utilities, vapor return, and roadway

fig. 4.5.1-59

\subsubsection{Objectives of the subsea cryogenic pipe}

The subsea cryogenic pipeline provides the fluid connection between the offloading platform and the onshore storage facility.

The main criteria that led to the final design of the ITP subsea LNG pipe system are the following:

a. Cost reduction. Use of a cryogenic subsea pipeline is a major part of a larger industry focus to reduce the costs of the LNG chain. However, gas operators will consider purchasing this new architecture only if significant cost savings are achieved in comparison to conventional offloading technologies. By avoiding the civil work associated with the trestle, the cryogenic subsea pipeline can be built in less time and offers significant construction cost savings. TotalFinaElf estimated that overall costs could be reduced by 20 to 40 million USD, including the jetty head. Marine facility savings are further increased if the use of ITP's subsea pipeline technology precludes the construction of a large marine breakwater.

b. Environment: Two main environmental objectives are targeted :

- Visual impact. The near shore and shore side view is no longer impacted by a long artificial trestle, a source of great satisfaction to the local population.

- Normal local marine traffic can continue on course without being hindered by the trestle

c. Wider range of LNG terminal locations. The subsea cryogenic pipeline is capable of handling challenging marine conditions yet still allows erection of offshore LNG terminals in environments that heretofore were ill suited for LNG terminal use. By proposing a technique that offers the flexibility of locating the LNG transfer point far away from the coast, ITP gives the gas operators more choices for siting their LNG terminals (e.g. industrial area, coastal areas with shallow draught, etc.). 


\begin{tabular}{|l|l|l|l|}
\hline Customer: & $\begin{array}{l}\text { The United States Department of Energy } \\
\text { National Energy Technology Laboratory }\end{array}$ & $\begin{array}{l}\text { Date of Issue: } \\
29 \text { April } 2003\end{array}$ & \\
\hline $\begin{array}{l}\text { Document } \\
\text { Title: }\end{array}$ & $\begin{array}{l}\text { Subtask 1.2 } \\
\text { Identify Marine Mooring and Offloading Initiatives for LNG Vessels }\end{array}$ & $\begin{array}{l}\text { Doc \# \& Version: } \\
\text { Doc } 003 \text { r..0 }\end{array}$ & Page $\mathbf{3 8}$ of $\mathbf{4 0}$ \\
\hline
\end{tabular}

\subsubsection{Challenges remaining}

The main challenges associated with the subsea LNG pipeline are:

a. Cryogenic environment

- The materials of construction have to be resistant to low temperature.

- The shrinkage of the pipe has to be accommodated.

b. Simple and robust design The Operators participating in the ongoing development of the subsea cryogenic pipeline generally require that the selected design has to avoid the use of complex devices or high technology components which typically increase OPEX (maintenance cost) CAPEX, and the risk of system failure. On this basis, concepts such as those described previously (underwater tunnels or subsea expansion loops / expansion joints) could not be considered.

c. High thermal performance Due to the length of line envisioned (typically more than $1 \mathrm{~km}$ ), heat transfer between the LNG pipe and the sea environment has to be reduced as much as possible. Therefore the insulation system has to be highly thermally effective, water tight, and strong enough to permit handling and installation.

d. Reliability and safety The proposed system (fig. 4.5.3-60) has to be long lived and able to withstand the various stress/strain conditions both during installation and LNG transfer operations. If possible, the system should to be fail-safe, i.e. the pipeline should remain operational in case of local damage.

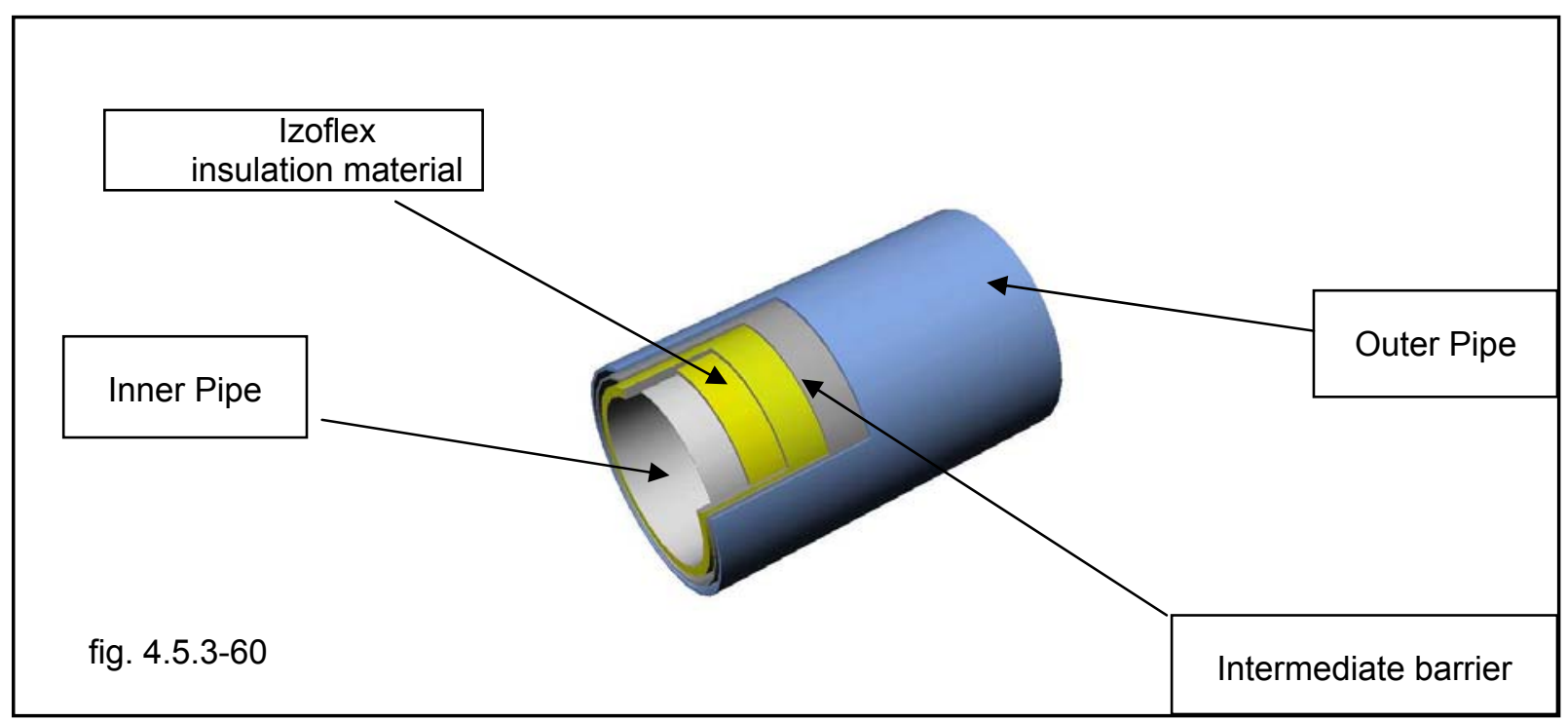




\begin{tabular}{|l|l|l|l|}
\hline Customer: & $\begin{array}{l}\text { The United States Department of Energy } \\
\text { National Energy Technology Laboratory }\end{array}$ & $\begin{array}{l}\text { Date of Issue: } \\
29 \text { April } 2003\end{array}$ & \\
\hline $\begin{array}{l}\text { Document } \\
\text { Title: }\end{array}$ & $\begin{array}{l}\text { Subtask 1.2 } \\
\text { Identify Marine Mooring and Offloading Initiatives for LNG Vessels }\end{array}$ & $\begin{array}{l}\text { Doc \# \& Version: } \\
\text { Doc } 003 \text { r4.0 }\end{array}$ & Page $\mathbf{3 9}$ of $\mathbf{4 0}$ \\
\hline
\end{tabular}

\section{INDUSTRY PREFERRED TRANSFER SCHEMES}

The most significant LNG offshore terminal designs have been presented in this section. The all important LNG links connecting the shore or process facility also have been outlined above. Many of these units already exist and are waiting for additional development, or the development of complimentary/enabling technologies.

Interviews over the course of this study with the major producers and potential importers of LNG indicated that the industry wants an offshore terminal capable of the following:

- High availability at $98 \%$ or above

- A site specific fit for purpose design with high reliability

- Side by side LNG transfer

- Rapid transfer rates at $10,000 \mathrm{~m} 3$ or above

- Risk's judged to be equivalent with traditional terminals

- Lower CAPEX and OPEX

\section{CONCLUSION}

The results of this industry survey are included in the attached matrix, however, for the convenieince of the reader, a summary of findings follows.

A thorough review of the technologies that are currently used in the transfer of hydrocarbons offshore indicate that many of the technologies and operational procedures can be employed by the LNG industry. For example, ship to ship transfer of oil and LPG has become a time tested, proven and reliable technology. The use of tugs, hawsers, and floating hoses, facilitates both side by side and tandem arrangements. Transferring petroleum products via Single Point Moorings (SPM's) and Catenary Anchored Leg Mooring (CALM) Buoys have provided additional savings and reliability. Floating Production Storage Offshore (FPSO's) have also grown in size and complexity and have been safely operated world wide.

Running in parallel with the technological advancements pursuant to the offshore oil industry, the LNG trade has accumulated extensive operational experience over the last 30 years. LNG on-shore facilities employ process technologies similar to the oil industry howbeit with upgraded metallurgies to accommodate the cryogenic temperatures (LNG is $-160^{\circ} \mathrm{C}$ ). The LNG trade has taken advantage of process modeling, FEA, CAD, and CAM resulting in rapid growth and excellent safety records for LNG manufacturing, storage, transportation, and regasification. Economies of scale, and lower equipment cost now make offshore LNG transfer possible. Among the many advantages:

- Reduced NIMBY concerns

- Reduced permitting requirements

- Quicker regulatory approval process

- $\quad$ Siting flexibility

- Reduced construction times

- Possibility for substantial reduction in CAPEX and OPEX

The study was awarded to CGI to prove the feasibility of developing a new LNG receiving and storage process. Task 1.2 identifying marine mooring and offloading initiatives compares the existing and proposed LNG offshore transfer technologies, identifies the commonalities, and recognizes industry requirements and transfer preferences. 


\begin{tabular}{|l|l|l|l|}
\hline Customer: & $\begin{array}{l}\text { The United States Department of Energy } \\
\text { National Energy Technology Laboratory }\end{array}$ & $\begin{array}{l}\text { Date of Issue: } \\
29 \text { April } 2003\end{array}$ & \\
\hline $\begin{array}{l}\text { Document } \\
\text { Title: }\end{array}$ & $\begin{array}{l}\text { Subtask 1.2 } \\
\text { Identify Marine Mooring and Offloading Initiatives for LNG Vessels }\end{array}$ & $\begin{array}{l}\text { Doc \# \& Version: } \\
\text { Doc } 003 \text { r..0 }\end{array}$ & Page $\mathbf{4 0}$ of $\mathbf{4 0}$ \\
\hline
\end{tabular}

Several offshore transfer challenges were identified including:

- The need for a secure mooring arrangement sufficient for cargo transfer

- The need to minimize the relative motion between LNG vessel and transfer facility

- The requirement to develop materials and technologies to safely facilitate LNG transfer and handling

- The ability to transfer LNG at sea using the LNG carrier's existing manifolds

- Reduced cost: New technology must be cheaper to mitigate risk weighting

In addition to the actual facility used to move the LNG between the terminal and the LNG vessel, specific links to offloading vessels and shore side facilities have to be employed to accommodate the siting of future offshore LNG terminals. These "link technologies" use clever adaptations of current technologies with upgraded materials and designs to accommodate the rigors of cryogenic service. There is a world wide effort to conceive, design, and test these link technologies with many new and innovative designs coming out of Europe, namely France and the Netherlands. These link technologies include:

- LNG subsea cryogenic pipelines to connect the land based facility with the offshore marine terminal

- Extended travel loading arms to accommodate relatively large ship to ship excursions along three axes

- Flexible loading lines to connect the transfer mechanism to the floating vessel

- Counter weighted yokes and cryogenic swivels to allow tandem ship to ship cargo transfer

- Extended ultra long floating cryogenic hoses and submersible flexible risers to facilitate LNG cargo movement through water without fractures due to freezing

The matrix attached to the end of Task 1.2 summarizes the offshore unloading initiatives included in this document. The matrix provides a convenient format to highlight trends, requirements, and technologies most desired by the LNG industry. Referencing the attached matrix, the LNG offshore industry seems to be moving in the direction described below:

- The offshore mooring should weathervane (rotation of the vessel around a vertical axis), to provide maximum availability, and facilitate maximum stability and minimum motion during LNG transfer operations (Note: Gravity Based Structures by design and installation provide protection from the elements without weathervaning and are exceptions),

- Offshore mooring facilities are expected to have high availability and remain operational, even in rough weather

- Side by side cargo transfer is preferred

- Ship/Shore link technologies are site specific, and development is crucial

- Decreased CAPEX and OPEX over conventional LNG terminals are expected 
Attachment I 


\begin{tabular}{|c|c|c|c|c|c|c|c|c|c|c|c|c|}
\hline Description & $\begin{array}{l}\text { Company \& } \\
\text { Application }\end{array}$ & $\begin{array}{c}\text { Contact } \\
\text { Information }\end{array}$ & $\begin{array}{l}\text { Mooring } \\
\text { Design }\end{array}$ & $\begin{array}{c}\text { Transfer } \\
\text { Method \& } \\
\text { Flow Rate } \\
(\mathbf{m} 3 / \mathrm{hr}) \\
\end{array}$ & $\begin{array}{l}\text { Water } \\
\text { Depth } \\
\text { Max/Min }\end{array}$ & $\begin{array}{c}\text { Sea (Hs) } \\
\text { Condition } \\
\text { Docking }\end{array}$ & $\begin{array}{l}\text { Sea }(H s) \\
\text { Condition } \\
\text { Operating }\end{array}$ & $\begin{array}{c}\text { Site } \\
\text { Condition } \\
\text { Rating }\end{array}$ & Shore Link & $\begin{array}{c}\text { Stage of } \\
\text { Development }\end{array}$ & $\begin{array}{l}\text { Completion } \\
\text { Schedule }\end{array}$ & $\begin{array}{c}\text { Facility } \\
\text { Cost } \\
\text { mmUSD }\end{array}$ \\
\hline $\begin{array}{l}\text { SBM Offshore } \\
\text { Terminal }\end{array}$ & $\begin{array}{c}\text { Single Buoy } \\
\text { Moorings, Inc. } \\
\text { Soft Yoke Mooring } \\
\text { Tower } \\
\text { Loading/Unloading }\end{array}$ & \begin{tabular}{|l} 
5 Route de Fribourg \\
P. O. Box 152 \\
Marly, Switzerland, \\
CH-1723 \\
Tel. - 37792051434
\end{tabular} & Weathervaning & $\begin{array}{c}\text { Tandem } \\
\text { Bow Manifold } \\
\text { Liq. 12,000 }\end{array}$ & $\begin{array}{c}\text { No limit } \\
25 \mathrm{~m}\end{array}$ & 3.0 & $5.5 \mathrm{~m}$ & Severe & $\begin{array}{l}\text { Rec. Terminal: } \\
\text { Tandem un- } \\
\text { loading arm with } \\
\text { cryogenic swivel. } \\
\text { Transfer to shore } \\
\text { through cryogenic } \\
\text { subsea pipeline. }\end{array}$ & $\begin{array}{l}\text { Transfer system: } \\
\text { Arms and swivels } \\
\text { tested. } \\
\text { Class: Approved } \\
\text { in Principle. }\end{array}$ & \begin{tabular}{|l}
$\begin{array}{l}\text { Final design } \\
\text { phase to } \\
\text { completion }\end{array}$ \\
$30 \mathrm{mo}$.
\end{tabular} & \\
\hline & $\begin{array}{c}\text { Single Buoy } \\
\text { Moorings, Inc. } \\
\text { STMO Transfer } \\
\text { Loading/Unloading }\end{array}$ & \begin{tabular}{|l|} 
5 Route de Fribourg \\
P. O. Box 152 \\
Marly, Switzerland, \\
CH-1723 \\
Tel. - 37792051434
\end{tabular} & Weathervaning & $\begin{array}{c}\text { Tandem } \\
\text { Bow Manifold } \\
\text { Liq. 12,000 }\end{array}$ & $\begin{array}{c}\text { No limit } \\
40 \mathrm{~m}\end{array}$ & 3.0 & $5.0 \mathrm{~m}$ & Severe & $\begin{array}{l}\text { Liq. Terminal: } \\
\text { Tandem un- } \\
\text { loading arm with } \\
\text { cryogenic swivel. } \\
\text { No shore link } \\
\text { required. }\end{array}$ & $\begin{array}{l}\text { Transfer system: } \\
\text { Arms and swivels } \\
\text { tested. } \\
\text { Class: Approved } \\
\text { in Principle. }\end{array}$ & $\begin{array}{l}\begin{array}{l}\text { Final design } \\
\text { phase to } \\
\text { completion }\end{array} \\
30 \text { mo. }\end{array}$ & \\
\hline Riser Turret Mooring & $\begin{array}{c}\text { Single Buoy } \\
\text { Moorings, Inc. } \\
\text { Riser Turret } \\
\text { Mooring } \\
\text { Unloading }\end{array}$ & $\begin{array}{l}\text { 5 Route de Fribourg } \\
\text { P. O. Box 152 } \\
\text { Marly, Switzerland, } \\
\text { CH-1723 } \\
\text { Tel. - } 37792051434\end{array}$ & Weathervaning & $\begin{array}{c}\text { Bow Turret } \\
\text { Disconnectable } \\
1 \text { BCFD }\end{array}$ & $\begin{array}{c}\text { No Limit } \\
50 \mathrm{~m}\end{array}$ & 4.5 & 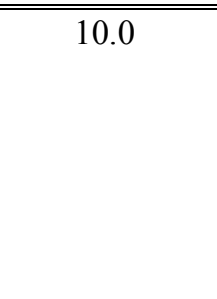 & Severe & $\begin{array}{l}\text { Rec. Terminal } \\
\\
\text { Standard HP riser } \\
\text { and carbon steel } \\
\text { to existing gas } \\
\text { infrastructure }\end{array}$ & $\begin{array}{l}\text { Preliminary } \\
\text { Deign } \\
\text { Model tested }\end{array}$ & $\begin{array}{l}\text { Final design to } \\
\text { completion: } \\
24 \text { months }\end{array}$ & \\
\hline $\begin{array}{l}\text { Bluewater } \\
\text { "Big Sweep" } \\
\text { Liq. Terminal }\end{array}$ & $\begin{array}{l}\text { Bluewater Offshore } \\
\text { Production } \\
\text { Systems, Inc. } \\
\text { Loading only }\end{array}$ & $\begin{array}{l}8554 \text { Katy Freeway, } \\
\text { Suite } 327 \\
\text { Houston, TX 77024 } \\
\text { Tel } 7137228131\end{array}$ & Weathervaning & $\begin{array}{l}\text { Tandem } \\
\text { Liq. 12,000 }\end{array}$ & $\begin{array}{c}\text { No limit } \\
100 \mathrm{~m}\end{array}$ & $3.0 \mathrm{~m}$ & 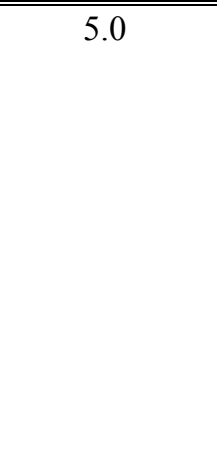 & Severe & $\begin{array}{l}\text { Liq. Terminal: } \\
\text { Tandem un- } \\
\text { loading thru } \\
\text { cryogenic swivel, } \\
\text { subsea cryogenic } \\
\text { pipeline to } \\
\text { "Manipulator" for } \\
\text { LNG vessel } \\
\text { loading }\end{array}$ & $\begin{array}{l}\text { Liq. Terminal: } \\
\text { Conceptual } \\
\text { design for LNG } \\
\text { delivery. "Big } \\
\text { Sweep" scaled } \\
\text { and physically } \\
\text { tested at Marin } \\
\text { "Manipulator" } \\
\text { scaled and } \\
\text { physically tested. }\end{array}$ & $\begin{array}{l}\text { Testing to } \\
\text { Construction } 30 \\
\text { mo. }\end{array}$ & \\
\hline $\begin{array}{c}\text { Bluewater } \\
\text { Deepwater Remote } \\
\text { SPM Dock }\end{array}$ & $\begin{array}{l}\text { Bluewater Offshore } \\
\text { Production } \\
\text { Systems, Inc. } \\
\text { Loading only }\end{array}$ & $\begin{array}{l}8554 \text { Katy Freeway, } \\
\text { Suite } 327 \\
\text { Houston, TX } 77024 \\
\text { Tel } 7137228131\end{array}$ & "Weathervaning & $\begin{array}{c}\text { Tandem } \\
\text { Liq. } 12,000\end{array}$ & $\begin{array}{c}\text { No limit } \\
100 \mathrm{~m}\end{array}$ & 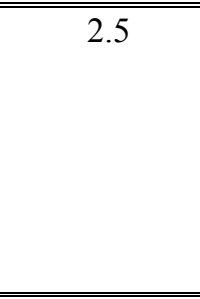 & $4.5 \mathrm{~m}$ & Severe & None & Conceptual & $\begin{array}{l}\text { Concept to } \\
\text { construction } 48 \\
\text { mo }\end{array}$ & \\
\hline
\end{tabular}




\begin{tabular}{|c|c|c|c|c|c|c|c|c|c|c|c|c|}
\hline Description & $\begin{array}{l}\text { Company \& } \\
\text { Application }\end{array}$ & $\begin{array}{c}\text { Contact } \\
\text { Information }\end{array}$ & $\begin{array}{c}\text { Mooring } \\
\text { Design }\end{array}$ & $\begin{array}{c}\text { Transfer } \\
\text { Method \& } \\
\text { Flow Rate } \\
\text { (m3/hr) }\end{array}$ & $\begin{array}{c}\text { Water } \\
\text { Depth } \\
\text { Max/Min }\end{array}$ & $\begin{array}{c}\text { Sea }(\mathrm{Hs}) \\
\text { Condition } \\
\text { Docking }\end{array}$ & $\begin{array}{c}\text { Sea }(\mathrm{Hs}) \\
\text { Condition } \\
\text { Operating }\end{array}$ & $\begin{array}{c}\text { Site } \\
\text { Condition } \\
\text { Rating }\end{array}$ & Shore Link & $\begin{array}{c}\text { Stage of } \\
\text { Development }\end{array}$ & $\begin{array}{l}\text { Completion } \\
\text { Schedule }\end{array}$ & $\begin{array}{c}\text { Facility } \\
\text { Cost } \\
\text { mmUSD }\end{array}$ \\
\hline
\end{tabular}

\begin{tabular}{|c|c|c|c|c|c|c|c|c|c|c|c|c|}
\hline $\begin{array}{l}\text { Bluewater } \\
\text { "Big Sweep" } \\
\text { Rec. Terminal }\end{array}$ & $\begin{array}{l}\text { Bluewater Offshore } \\
\text { Production } \\
\text { Systems, Inc. } \\
\text { Near Shore } \\
\text { Unloading }\end{array}$ & $\begin{array}{l}8554 \text { Katy Freeway, } \\
\text { Suite } 327 \\
\text { Houston, TX } 77024 \\
\text { Tel } 7137228131\end{array}$ & Weathervaning & $\begin{array}{l}\text { Side x Side } \\
\text { Liq } 12,000 \\
\text { Gas. } 8,000\end{array}$ & $\begin{array}{l}100 \mathrm{~m} \\
30 \mathrm{~m}\end{array}$ & $3.0 \mathrm{~m}$ & $9.0 \mathrm{~m}$ & Severe & $\begin{array}{l}\text { Rec Terminal: Liq } \\
\text { - "Manipulator" } \\
\text { LNG flexible via } \\
\text { cryogenic subsea } \\
\text { pipelines to shore } \\
\text { terminal } \\
\text { Gas: } \\
\text { "Manipulator" } \\
\text { LNG flexible } \\
\text { system to } \\
\text { vaporizers, } \\
\text { flexible riser to } \\
\text { gas grid or cavern } \\
\text { storage } \\
\end{array}$ & $\begin{array}{l}\text { Rec. Terminal: } \\
\text { Conceptual } \\
\text { design for gas } \\
\text { delivery. "Big } \\
\text { Sweep" scaled } \\
\text { and physically } \\
\text { tested at Marin } \\
\text { "Manipulator" } \\
\text { scaled and } \\
\text { physically tested. }\end{array}$ & $\begin{array}{l}\text { Testing to } \\
\text { Construction } 30 \\
\text { mo. }\end{array}$ & \\
\hline $\begin{array}{c}\text { Binder } \\
\text { Bluewater } \\
\text { Shig Sweep" } \\
\text { Shallow Design }\end{array}$ & $\begin{array}{l}\text { Bluewater Offshore } \\
\text { Production } \\
\text { Systems, Inc. } \\
\text { Near Shore } \\
\text { Unloading }\end{array}$ & $\begin{array}{l}8554 \text { Katy Freeway, } \\
\text { Suite } 327 \\
\text { Houston, TX } 77024 \\
\text { Tel } 7137228131\end{array}$ & Weathervaning & $\begin{array}{l}\text { Side } x \text { Side } \\
\text { Liq. } 12,000 \\
\text { Gas. } 8,000\end{array}$ & $\begin{array}{l}40 \mathrm{~m} \\
15 \mathrm{~m}\end{array}$ & $2.5 \mathrm{~m}$ & $3.0 \mathrm{~m}$ & Moderate & $\begin{array}{l}\text { Rec Terminal: Liq } \\
\text { - "Manipulator" } \\
\text { LNG flexible via } \\
\text { cryogenic subsea } \\
\text { pipelines to shore } \\
\text { terminal } \\
\text { Gas: } \\
\text { "Manipulator" } \\
\text { LNG flexible } \\
\text { system to } \\
\text { vaporizers, } \\
\text { flexible riser to } \\
\text { gas grid or cavern } \\
\text { storage }\end{array}$ & $\begin{array}{l}\text { Rec. Terminal: } \\
\text { Conceptual } \\
\text { design for gas } \\
\text { delivery. "Big } \\
\text { Sweep" scaled } \\
\text { and physically } \\
\text { tested at Marin } \\
\text { "Manipulator" } \\
\text { scaled and } \\
\text { physically tested. }\end{array}$ & $\begin{array}{l}\text { Testing to } \\
\text { Construction } 30 \\
\text { mo. }\end{array}$ & \\
\hline $\begin{array}{c}\text { Bluewater } \\
\text { Regasification } \\
\text { Dock }\end{array}$ & $\begin{array}{l}\text { Bluewater Offshore } \\
\text { Production } \\
\text { Systems, Inc. } \\
\text { Unloading or } \\
\text { Regasification }\end{array}$ & $\begin{array}{l}8554 \text { Katy Freeway, } \\
\text { Suite } 327 \\
\text { Houston, TX 77024 } \\
\text { Tel } 7137228131\end{array}$ & Weathervaning & $\begin{array}{l}\text { Side x Side } \\
\text { Liq } 12,000 \\
\text { Gas } \\
\text { 3.0 BCFD }\end{array}$ & $\begin{array}{c}\text { No limit } \\
40 \mathrm{~m}\end{array}$ & $2.5 \mathrm{~m}$ & $4.0 \mathrm{~m}$ & Moderate & $\begin{array}{l}\text { Rec Terminal: } \\
\text { Fixed LNG } \\
\text { unloading arm to } \\
\text { either subsea } \\
\text { cryogenic pipe or } \\
\text { directly to on- } \\
\text { board vaporizers }\end{array}$ & Conceptual & $\begin{array}{l}\text { Concept to } \\
\text { construction } 36 \\
\text { months }\end{array}$ & \\
\hline $1+1, \sqrt{3}$ & $\begin{array}{l}\text { Bluewater Offshore } \\
\text { Production } \\
\text { Systems, Inc. } \\
\text { Loading only }\end{array}$ & $\begin{array}{l}8554 \text { Katy Freeway, } \\
\text { Suite } 327 \\
\text { Houston, TX 77024 } \\
\text { Tel } 7137228131\end{array}$ & Weathervaning & $\begin{array}{l}\text { Side } x \text { Side } \\
\text { Liq. 12,000 }\end{array}$ & $\begin{array}{c}\text { No limit } \\
40 \mathrm{~m}\end{array}$ & $2.0 \mathrm{~m}$ & $3.5 \mathrm{~m}$ & Moderate & $\begin{array}{l}\text { Rec Terminal: } \\
\text { Fixed LNG } \\
\text { unloading arm to } \\
\text { either subsea } \\
\text { cryogenic pipe or } \\
\text { directly to on- } \\
\text { board vaporizers }\end{array}$ & Conceptual & $\begin{array}{l}\text { Concept to } \\
\text { construction } 24 \\
\text { months }\end{array}$ & \\
\hline conit & $\begin{array}{c}\text { Remora } \\
\text { Technology } \\
\text { Unloading only }\end{array}$ & $\begin{array}{l}1400 \text { West Belt } \\
\text { North, Buildding B, } \\
\text { Houston, Texas, } \\
77043 \\
\text { tel. } 7134685550 \\
\text { cwo }\end{array}$ & Weathervaning & $\begin{array}{l}\text { Side } \mathrm{x} \text { side } \\
\text { Liq. } 12,000 \\
\text { Gas } 8,000\end{array}$ & $\begin{array}{c}\text { No limit } \\
40 \mathrm{~m}\end{array}$ & $2.5 \mathrm{~m}$ & $4.5 \mathrm{~m}$ & Severe & $\begin{array}{l}\text { Rec Terminal: } \\
\text { Liq: LNG } \\
\text { cryogenic flexible } \\
\text { riser } \\
\text { Gas: HiLoad }\end{array}$ & $\begin{array}{l}\text { Ready for } \\
\text { Manufacture: } \\
\text { HiLoad } \\
\text { mechanism. } \\
\text { Class: Approved } \\
\text { in Principle. }\end{array}$ & $\begin{array}{l}\text { Concept to } \\
\text { FEED } 4 \text { mo } \\
\text { FEED to proof } \\
\text { of concept } 16 \\
\text { mo }\end{array}$ & 50 \\
\hline
\end{tabular}




\begin{tabular}{|c|c|c|c|c|c|c|c|c|c|c|c|c|}
\hline Description & $\begin{array}{l}\text { Company \& } \\
\text { Application }\end{array}$ & $\begin{array}{c}\text { Contact } \\
\text { Information }\end{array}$ & $\begin{array}{l}\text { Mooring } \\
\text { Design }\end{array}$ & $\begin{array}{c}\text { Transfer } \\
\text { Method \& } \\
\text { Flow Rate } \\
\text { (m3/hr) }\end{array}$ & $\begin{array}{c}\text { Water } \\
\text { Depth } \\
\text { Max/Min }\end{array}$ & $\begin{array}{c}\text { Sea (Hs) } \\
\text { Condition } \\
\text { Docking }\end{array}$ & $\begin{array}{c}\text { Sea }(\mathrm{Hs}) \\
\text { Condition } \\
\text { Operating }\end{array}$ & $\begin{array}{c}\text { Site } \\
\text { Condition } \\
\text { Rating }\end{array}$ & Shore Link & $\begin{array}{c}\text { Stage of } \\
\text { Development }\end{array}$ & $\begin{array}{l}\text { Completion } \\
\text { Schedule }\end{array}$ & $\begin{array}{c}\text { Facility } \\
\text { Cost } \\
\text { mmUSD }\end{array}$ \\
\hline
\end{tabular}

\begin{tabular}{|c|c|c|c|c|c|c|c|c|c|c|c|c|}
\hline $\begin{array}{l}\text { Remora Technologies } \\
\text { HiLoad }\end{array}$ & & @remoratech.com & & & & & & & $\begin{array}{l}\text { onboard } \\
\text { vaporizers via } \\
\text { high pressure } \\
\text { flexible riser }\end{array}$ & $\begin{array}{l}\text { Conceptual: } \\
\text { Transfer system: } \\
\text { Liq: long cryo } \\
\text { flexible hose } \\
\text { under } \\
\text { development. } \\
\text { Gas: proven HP } \\
\text { flexible riser from } \\
\text { vaporizer. }\end{array}$ & $\begin{array}{l}\text { Ready to build } 6 \\
\text { mo } \\
\text { Construction for } \\
\text { first cargo } 18 \\
\text { mo }\end{array}$ & \\
\hline FMCSofec & $\begin{array}{l}\text { FMCSofec } \\
\text { Loading }\end{array}$ & $\begin{array}{l}\text { FMC Loading } \\
\text { Systems } \\
\text { FMC Technologies } \\
\text { Inc } \\
11997 \text { FM } 529 \\
\text { Houston TX } 77041 \\
\text { Phone } 2814053030\end{array}$ & Weathervaning & $\begin{array}{c}\text { Tandem } \\
10-12,000 \mathrm{M} / \mathrm{hr}\end{array}$ & $\begin{array}{l}\text { No Limit } \\
20 \text { meters }\end{array}$ & $5.0 \mathrm{~m}$ & $10.0 \mathrm{~m}$ & Severe & $\begin{array}{l}\text { Tandem Link by } \\
\text { FMC Pantograph } \\
\text { single or duplex } \\
\text { loading arm. } \\
\text { No shore link } \\
\text { required }\end{array}$ & $\begin{array}{l}\text { Design Phase } \\
\text { Class approved } \\
\text { swivels and } \\
\text { Pantograph } \\
\text { loading arm full } \\
\text { scale tested }\end{array}$ & $\begin{array}{l}\text { Detail design } \\
\text { Engineering to } \\
\text { completion } 24 \\
\text { mo }\end{array}$ & \\
\hline $\begin{array}{l}\text { Shell FC } \\
\text { S }\end{array}$ & $\begin{array}{l}\text { Shell Global } \\
\text { Solutions, Inc. } \\
\text { Loading only }\end{array}$ & $\begin{array}{l}\text { Westhollow } \\
\text { Technology Center, } \\
3333 \text { Highway } 6 \\
\text { South, Houston, TX } \\
\text { 77082-3101, USA } \\
\end{array}$ & Weathervaning & $\begin{array}{l}\text { Side } \mathrm{x} \text { side } \\
\text { Liq. } 12,000\end{array}$ & $\begin{array}{c}\text { No Limit } \\
30 \mathrm{~m}\end{array}$ & $2.0 \mathrm{~m}$ & $3.0 \mathrm{~m}$ & Moderate & $\begin{array}{l}\text { Liq Terminal: } \\
\text { Loading Arms }\end{array}$ & $\begin{array}{l}\text { Design modeled. } \\
\text { Class: Approved } \\
\text { in principle }\end{array}$ & $\begin{array}{l}\text { FEED through } \\
\text { construction } 48 \\
\text { mo }\end{array}$ & 750 \\
\hline MOSS Maritime & $\begin{array}{l}\text { Moss Maritime a.s } \\
\text { Unloading only }\end{array}$ & $\begin{array}{l}\text { P.O. Box } 120 \\
\text { N-1325 } \\
\text { Lysker, Norway } \\
4767526250\end{array}$ & Weathervaning & $\begin{array}{l}\text { Side x Side } \\
\text { Liq } 12,000\end{array}$ & $\begin{array}{l}\text { No limit } \\
30 \mathrm{~m}\end{array}$ & $2.5 \mathrm{~m}$ & $3.0 \mathrm{~m}$ & Moderate & $\begin{array}{l}\text { Rec Terminal } \\
\text { Liq Loading } \\
\text { Arms. } \\
\text { Vaporization to } \\
\text { Flexible riser }\end{array}$ & $\begin{array}{l}\text { Conceptual } \\
\text { Class: Approved } \\
\text { in principle }\end{array}$ & $\begin{array}{l}\text { FEED through } \\
\text { construction } 48 \\
\text { mo }\end{array}$ & 550 \\
\hline $\begin{array}{c}\text { EurodimTFE } \\
\text { Boom \& Hose } \\
\end{array}$ & $\begin{array}{l}\text { EURODIM, s.a. } \\
\text { Loading \& } \\
\text { Unloading }\end{array}$ & $\begin{array}{l}21 \text { avenue Edouard } \\
\text { Belin } \\
\text { 92566 RUEIL } \\
\text { MALMAISON } \\
\text { CEDEX } \\
\text { France } \\
+33 \text { (47) } 160586\end{array}$ & Weathervaning & $\begin{array}{l}\text { Side manifold } \\
\text { Liq } 12,000\end{array}$ & $\begin{array}{l}150 \mathrm{~m} \\
25 \mathrm{~m}\end{array}$ & $2.5 \mathrm{~m}$ & $4.5 \mathrm{~m}$ & Severe & $\begin{array}{l}\text { Cryogenic subsea } \\
\text { pipeline }\end{array}$ & Conceptual & $\begin{array}{l}\text { Concept to } \\
\text { construction } 36 \\
\text { mo }\end{array}$ & \\
\hline $\begin{array}{l}\text { EurodimTFE } \\
\text { Rotating Quay }\end{array}$ & $\begin{array}{l}\text { EURODIM, s.a. } \\
\text { Loading \& } \\
\text { Unloading }\end{array}$ & $\begin{array}{l}21 \text { avenue Edouard } \\
\text { Belin } \\
\text { 92566 RUEIL } \\
\text { MALMAISON } \\
\text { CEDEX } \\
\text { France } \\
+33(47) 160586 \\
\end{array}$ & Weathervaning & $\begin{array}{c}\text { Side manifold } \\
\text { Liq } 12,000\end{array}$ & $\begin{array}{l}150 \mathrm{~m} \\
25 \mathrm{~m}\end{array}$ & $2.5 \mathrm{~m}$ & $4.5 \mathrm{~m}$ & Severe & $\begin{array}{l}\begin{array}{l}\text { Cryogenic subsea } \\
\text { pipeline }\end{array} \\
\end{array}$ & Conceptual & $\begin{array}{l}\text { Concept to } \\
\text { construction } 36 \\
\text { months }\end{array}$ & \\
\hline 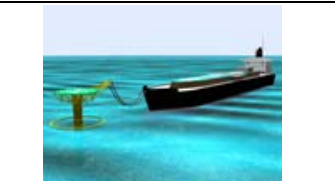 & $\begin{array}{l}\text { EURODIM, s.a. } \\
\text { Loading \& } \\
\text { Unloading }\end{array}$ & $\begin{array}{l}21 \text { avenue Edouard } \\
\text { Belin } \\
\text { 92566 RUEIL } \\
\text { MALMAISON }\end{array}$ & Weathervaning & $\begin{array}{l}\text { Side manifold } \\
\text { Liq } 12,000\end{array}$ & $\begin{array}{l}150 \mathrm{~m} \\
25 \mathrm{~m}\end{array}$ & $2.5 \mathrm{~m}$ & $4.5 \mathrm{~m}$ & Severe & $\begin{array}{l}\text { Cryogenic subsea } \\
\text { pipeline }\end{array}$ & Conceptual & $\begin{array}{l}\text { Concept to } \\
\text { construction } 36 \\
\text { mo. }\end{array}$ & \\
\hline
\end{tabular}




\begin{tabular}{|c|c|c|c|c|c|c|c|c|c|c|c|c|}
\hline Description & $\begin{array}{l}\text { Company \& } \\
\text { Application }\end{array}$ & $\begin{array}{c}\text { Contact } \\
\text { Information }\end{array}$ & $\begin{array}{l}\text { Mooring } \\
\text { Design }\end{array}$ & $\begin{array}{c}\text { Transfer } \\
\text { Method \& } \\
\text { Flow Rate } \\
(\mathrm{m} 3 / \mathrm{hr})\end{array}$ & $\begin{array}{c}\text { Water } \\
\text { Depth } \\
\text { Max/Min }\end{array}$ & $\begin{array}{c}\text { Sea }(H s) \\
\text { Condition } \\
\text { Docking }\end{array}$ & $\begin{array}{l}\text { Sea }(\mathrm{Hs}) \\
\text { Condition } \\
\text { Operating }\end{array}$ & $\begin{array}{c}\text { Site } \\
\text { Condition } \\
\text { Rating }\end{array}$ & Shore Link & $\begin{array}{c}\text { Stage of } \\
\text { Development }\end{array}$ & $\begin{array}{l}\text { Completion } \\
\text { Schedule }\end{array}$ & $\begin{array}{c}\text { Facility } \\
\text { Cost } \\
\text { mmUSD }\end{array}$ \\
\hline
\end{tabular}

\begin{tabular}{|c|c|c|c|c|c|c|c|c|c|c|c|c|}
\hline $\begin{array}{l}\text { EurodimTFE } \\
\text { Turret Moored }\end{array}$ & & $\begin{array}{l}\text { CEDEX } \\
\text { France } \\
+33(47) 160586 \\
\end{array}$ & & & & & & & & & & \\
\hline $\begin{array}{c}\text { El Paso } \\
\text { Energy Bridge }\end{array}$ & $\begin{array}{l}\text { El Paso Global } \\
\text { LNG } \\
\text { Unloading only }\end{array}$ & $\begin{array}{l}\text { P.O. Box } 2511 \\
\text { Houston, Texas } \\
\text { 77252-2511 } \\
\text { (713) 420-5161 }\end{array}$ & Weathervaning & $\begin{array}{c}\text { Bottom Turret } \\
\text { Gas } 1050 \\
\text { Side Manifold } \\
\text { Liq 12,000 }\end{array}$ & $\begin{array}{l}\text { No limit } \\
100 \mathrm{~m}\end{array}$ & $4.0 \mathrm{~m}$ & $12.0 \mathrm{~m}$ & Severe & $\begin{array}{l}\text { Regas Facility } \\
\text { Flexible riser } \\
\text { Can also } \\
\text { discharge LNG } \\
\text { thru side manifold }\end{array}$ & $\begin{array}{l}\text { Tested and in } \\
\text { Fabrication at } \\
\text { Daewoo shipyard } \\
\text { Korea } \\
\text { Class: Approved } \\
\text { in Principle. }\end{array}$ & $\begin{array}{l}\text { In fabrication to } \\
\text { construction } 24 \\
\text { mo. }\end{array}$ & 245 \\
\hline $\begin{array}{l}\text { ChevronTexaco } \\
\text { (ExxonMobil) } \\
\text { Gravity Based } \\
\text { Structure } \\
\end{array}$ & $\begin{array}{l}\text { ChevronTexaco } \\
\text { Loading \& } \\
\text { Unloading }\end{array}$ & $\begin{array}{l}\text { 6001 Bollinger } \\
\text { Canyon Rd., Room } \\
\text { L4032 } \\
\text { P.O. Box } 6045 \\
\text { San Ramon, CA } \\
\text { 94583-2324 }\end{array}$ & Fixed & $\begin{array}{c}\text { Side manifold } \\
\text { Liq } 12,000\end{array}$ & $\begin{array}{l}75 \mathrm{~m} \\
50 \mathrm{~m}\end{array}$ & 1.5 & 3.0 & Moderate & $\begin{array}{l}\text { Liq Terminal } \\
\text { Loading Arms } \\
\text { Rec. Terminal } \\
\text { Loading arms to } \\
\text { pipeline to gas } \\
\text { grid }\end{array}$ & $\begin{array}{l}\text { Several in Service } \\
\text { Class Approved } \\
\text { in Principle }\end{array}$ & $\begin{array}{l}\text { FEED to } \\
\text { construction } 48 \\
\text { mo. }\end{array}$ & 750 \\
\hline Spread Moored & $\begin{array}{l}\text { EURODIM, s.a. } \\
\text { Loading \& } \\
\text { Unloading }\end{array}$ & $\begin{array}{l}21 \text { avenue Edouard } \\
\text { Belin } \\
\text { 92566 RUEIL } \\
\text { MALMAISON } \\
\text { CEDEX } \\
\text { France } \\
+33(47) 160586 \\
+\end{array}$ & Fixed & $\begin{array}{c}\text { Side manifold } \\
\text { Side x side } \\
\text { Tandem } \\
\text { Liq } 12,000 \\
\end{array}$ & $\begin{array}{c}\text { No Limit } \\
40 \mathrm{~m}\end{array}$ & $1.5 \mathrm{~m}$ & $2.5 \mathrm{~m}$ & Benign & $\begin{array}{l}\text { Cryogenic subsea } \\
\text { pipeline }\end{array}$ & $\begin{array}{l}\text { Many used on oil } \\
\text { offshore transfer } \\
\text { Class Approved } \\
\text { in Principle }\end{array}$ & $\begin{array}{l}\text { FEED to } \\
\text { Construction } 18 \\
\text { mo }\end{array}$ & $10-25$ \\
\hline Spread Moored & $\begin{array}{c}\text { Single Buoy } \\
\text { Moorings, Inc. } \\
\text { STMO Transfer } \\
\text { Loading/Unloading }\end{array}$ & $\begin{array}{l}5 \text { Route de Fribourg } \\
\text { P. O. Box 152 } \\
\text { Marly, Switzerland, } \\
\text { CH-1723 } \\
\text { Tel. - } 37792051434\end{array}$ & Fixed & $\begin{array}{l}\text { Side Manifold } \\
\text { Liq. 12,000 }\end{array}$ & $\begin{array}{l}150 \mathrm{~m} / \\
20 \mathrm{~m}\end{array}$ & $1.5 \mathrm{~m}$ & $2.5 \mathrm{~m}$ & Benign & $\begin{array}{l}\text { Cryogenic } \\
\text { subsea pipeline }\end{array}$ & $\begin{array}{l}\text { Conceptual } \\
\text { design and } \\
\text { analysis }\end{array}$ & $\begin{array}{l}\text { Final design to } \\
\text { completion: } 30 \\
\text { months }\end{array}$ & \\
\hline$\underset{\text { Gerris }}{2+2}$ & $\begin{array}{l}\text { EURODIM, s.a. } \\
\text { Loading \& } \\
\text { Unloading }\end{array}$ & $\begin{array}{l}21 \text { avenue Edouard } \\
\text { Belin } \\
\text { 92566 RUEIL } \\
\text { MALMAISON } \\
\text { CEDEX } \\
\text { France } \\
+33(47) 160586 \\
\end{array}$ & Fixed & $\begin{array}{l}\text { Side manifold } \\
\text { Liq 12,000 }\end{array}$ & $\begin{array}{c}\text { No Limit } \\
40 \mathrm{~m}\end{array}$ & $1.0 \mathrm{~m}$ & $2.5 \mathrm{~m}$ & Benign & $\begin{array}{l}\text { Cryogenic subsea } \\
\text { pipeline }\end{array}$ & Conceptual & $\begin{array}{l}\text { Concept to } \\
\text { construction } 30 \\
\text { mo }\end{array}$ & $20-40$ \\
\hline $\begin{array}{c}\text { Conventional } \\
\text { Jetty }\end{array}$ & $\begin{array}{l}\text { EURODIM, s.a. } \\
\text { Loading \& } \\
\text { Unloading }\end{array}$ & $\begin{array}{l}21 \text { avenue Edouard } \\
\text { Belin } \\
\text { 92566 RUEIL } \\
\text { MALMAISON } \\
\text { CEDEX } \\
\text { France } \\
+33 \text { (47) } 160586\end{array}$ & Fixed & $\begin{array}{c}\text { Side manifold } \\
\text { Liq 12,000 }\end{array}$ & $\begin{array}{c}\text { No Limit } \\
40 \mathrm{~m}\end{array}$ & $1.0 \mathrm{~m}$ & $2.5 \mathrm{~m}$ & Benign & $\begin{array}{l}\text { Cryogenic subsea } \\
\text { pipeline }\end{array}$ & Conceptual & $\begin{array}{l}\text { Concept to } \\
\text { construction } 30 \\
\text { mo }\end{array}$ & $25-40$ \\
\hline
\end{tabular}




\begin{tabular}{|l|l|l|l|}
\hline Customer: & $\begin{array}{l}\text { The United States Department of Energy } \\
\text { National Energy Technology Laboratory }\end{array}$ & $\begin{array}{l}\text { Date of Issue: } \\
\text { 24 April 2003 }\end{array}$ & \\
\hline $\begin{array}{l}\text { Document } \\
\text { Title: }\end{array}$ & $\begin{array}{l}\text { Subtask 1.3 } \\
\text { Determine Major Equipment Requirements }\end{array}$ & $\begin{array}{l}\text { Doc \# \& Version: } \\
\text { Doc 04 r2.0 }\end{array}$ & Page 1 of 20 \\
\hline
\end{tabular}

\section{Examine and Evaluate a Process to use Salt Caverns to Receive SHIP BORNE LIQUEFIED NATURAL GAS}

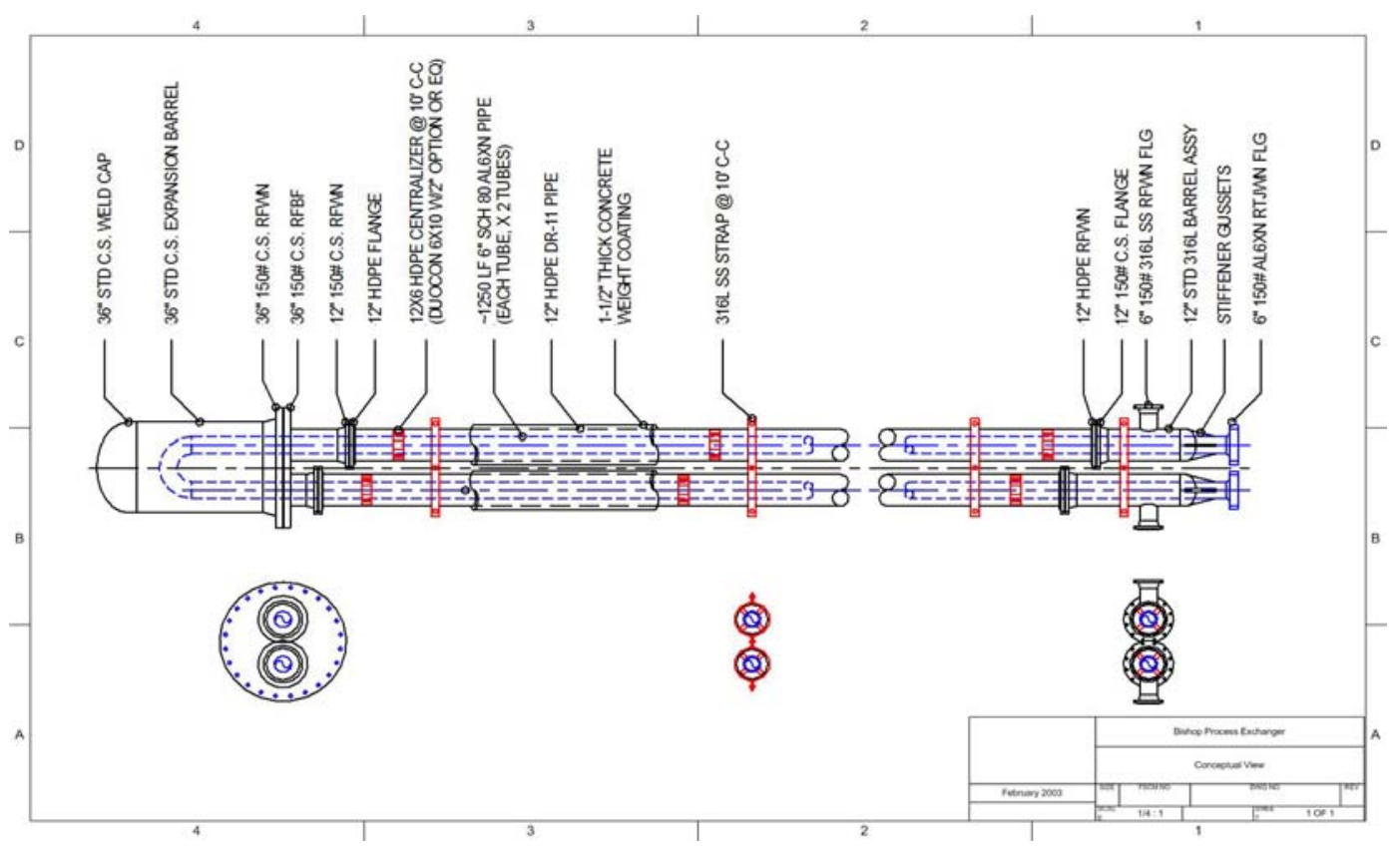

\section{BY \\ MiCHAEL M. MCCALL \\ WILLIAM M. BISHOP \\ D. BRAXTON SCHERZ}

\begin{tabular}{|c|c||c|c|c|c|c|c|c||}
\hline r 2.0 & For client review & O4/24/03 & вs & мм & & & \\
\hline Version & Reason for Issue & $\begin{array}{c}\text { Issue } \\
\text { Date }\end{array}$ & $\begin{array}{c}\text { Orig. } \\
\text { Chk. } \\
\text { CGI }\end{array}$ & $\begin{array}{c}\text { Appr. } \\
\text { Chk. } \\
\text { NETL Appr. }\end{array}$ & Review \\
\hline \hline $\begin{array}{l}\text { Document Title: } \\
\text { Subtask 1.3 Determine Major Equipment } \\
\text { Requirements }\end{array}$ & \multicolumn{7}{|c||}{$\begin{array}{c}\text { Document No: } \\
\text { DE-FC26-02NT41653 }\end{array}$} \\
\hline \hline
\end{tabular}




\begin{tabular}{|l|l|l|l|}
\hline Customer: & $\begin{array}{l}\text { The United States Department of Energy } \\
\text { National Energy Technology Laboratory }\end{array}$ & $\begin{array}{l}\text { Date of Issue: } \\
\text { 24 April 2003 }\end{array}$ & \\
\hline $\begin{array}{l}\text { Document } \\
\text { Title: }\end{array}$ & $\begin{array}{l}\text { Subtask 1.3 } \\
\text { Determine Major Equipment Requirements }\end{array}$ & $\begin{array}{l}\text { Doc \# \& Version: } \\
\text { Doc 04 r2.0 }\end{array}$ & Page 2 of 20 \\
\hline
\end{tabular}

\section{TABLE OF CONTENTS}

1. EXECUTIVE SUMMARY

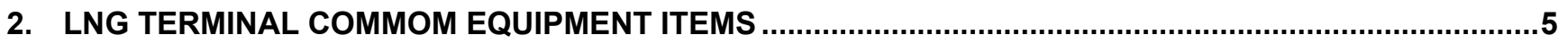

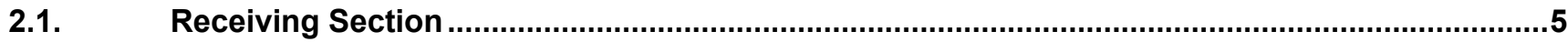

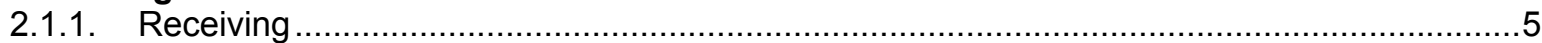

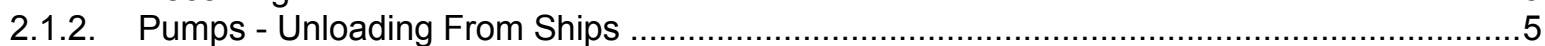

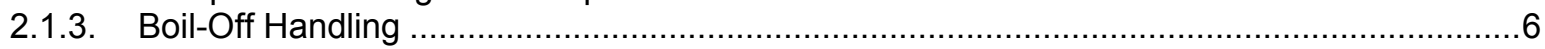

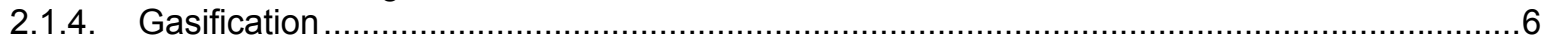

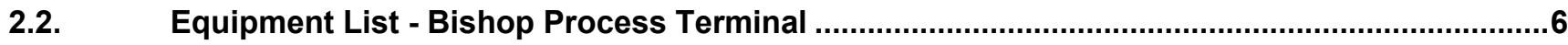

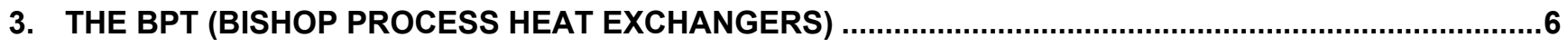

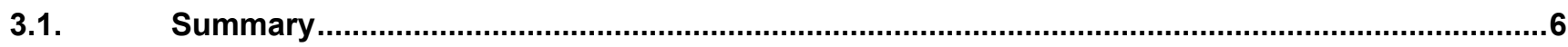

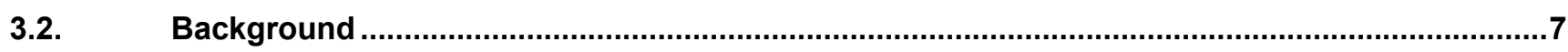

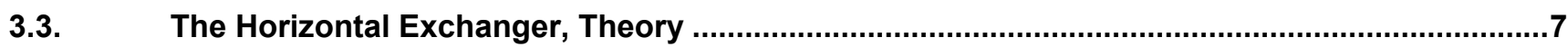

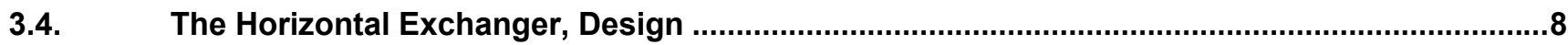

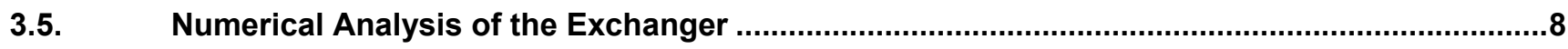

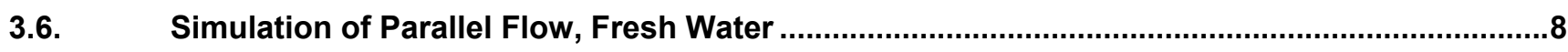

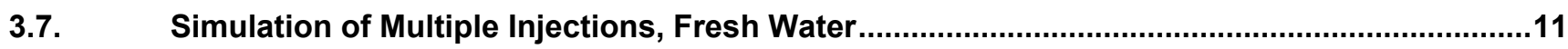

3.8. Simulation of a Counter-Flow Exchanger, Using Seawater ..............................................12

3.9. Simulation of a Combined Parallel and Counter-Flow Exchanger, with Two Warmant Injections (Mixed Injection). ...........................................................................................13

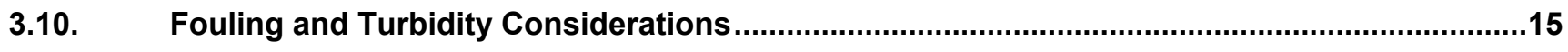

3.11. Simulation Using Finite Element Analysis ....................................................................16

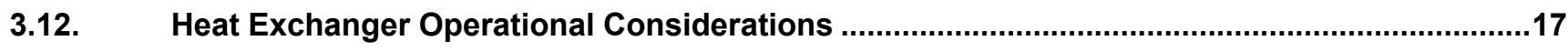

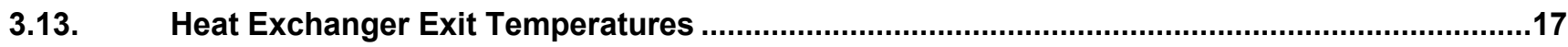

3.14. Using the Available Low Temperature to Process High Heating Value Gas ........................18

3.15. Bypassing Full Cavern Pressure to Feed a Base Load ......................................................18

3.16. Use of the Waste Heat from Power Generation ..................................................................18

3.17. Estimating Warmant Temperature Operational Range, Required Flow Ratio .........................19

3.18. Emergency Shut-in of the Exchangers, Shut-in Conditions ................................................19

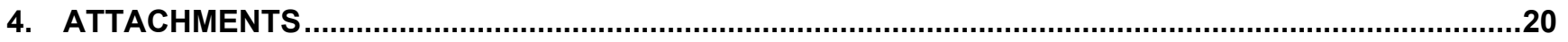




\begin{tabular}{|l|l|l|l|}
\hline Customer: & $\begin{array}{l}\text { The United States Department of Energy } \\
\text { National Energy Technology Laboratory }\end{array}$ & $\begin{array}{l}\text { Date of Issue: } \\
24 \text { April } 2003\end{array}$ \\
\hline $\begin{array}{l}\text { Document } \\
\text { Title: }\end{array}$ & $\begin{array}{l}\text { Subtask 1.3 } \\
\text { Determine Major Equipment Requirements }\end{array}$ & $\begin{array}{l}\text { Doc \# \& Version: } \\
\text { Doc 04 r2.0 }\end{array}$ & Page 3 of 20 \\
\hline
\end{tabular}

4.1. Attachment 1 - "4-Pack" - High Pressure LNG Pumping Unit .............................................20

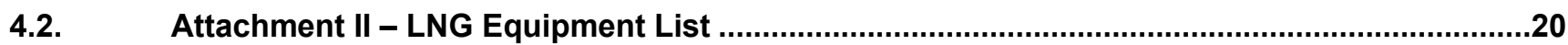

4.3. Attachment III - Numerical Analysis of BPT - Full Report ..................................................20 


\begin{tabular}{|l|l|l|l|}
\hline Customer: & $\begin{array}{l}\text { The United States Department of Energy } \\
\text { National Energy Technology Laboratory }\end{array}$ & $\begin{array}{l}\text { Date of Issue: } \\
\text { 24 April 2003 }\end{array}$ & \\
\hline $\begin{array}{l}\text { Document } \\
\text { Title: }\end{array}$ & $\begin{array}{l}\text { Subtask 1.3 } \\
\text { Determine Major Equipment Requirements }\end{array}$ & $\begin{array}{l}\text { Doc \# \& Version: } \\
\text { Doc 04 r2.0 }\end{array}$ & Page 4 of 20 \\
\hline
\end{tabular}

\section{EXECUTIVE SUMMARY}

The research confirms that a ships cargo can be unloaded and warmed to salt cavern compatible temperatures at normal ship discharge rates through the use of a high capacity, high efficiency heat exchanger. All large scaled LNG receiving terminals offload liquefied natural gas, pump it to pipeline pressures, and warm the high pressure liquid stream in heat exchangers of various designs. As the LNG approaches its pipeline compatible discharge temperature (about $5^{\circ} \mathrm{C}(40 \mathrm{~F})$ ) the density decreases and the stream enters the pipeline as a dense phase gas. A terminal using the Bishop Process heat Exchanger (BPT) employs all of the basic design parameters of the typical LNG receiving terminal

The entire LNG receiving terminal consists of three functional areas, LNG receiving, LNG regasification, and LNG storage. The regasification area includes the Bishop Process Heat (BPT) Exchangers and the warmant circulation equipment. LNG is unloaded by the ship's pumps at an average rate of about $7600 \mathrm{~m} 3 / \mathrm{hr}$. During ship unloading mode of operation, LNG is transferred from an LNG tanker into the salt caverns for storage and delivery. Because of the very small volumes of the surge vessel and the cylinders housing the LNG high pressure pumps, LNG boil-off is quite small compared to conventional terminals.

The major process differences in the BPT LNG receiving terminal and the traditional terminal are defined by the configuration of the High Pressure Pumping units called a "4-Pack" and the pipe-in-pipe configuration of the BPT. Each "4-Pack" is designed to pump 6,480 m3/day at 152 barg (2,200 psig) of LNG discharging immediately into the pipe-in-pipe Bishop Process heat Exchanger. Each pump with its own exchanger will gasify about $135 \mathrm{mmcfd}$. Each 4-pack and its associated BPT exchanger has the capacity of gasifying approximately $540 \mathrm{mmscfd}$. For the purposes of this study, a nominal 2,000 psi discharge pressure has been used.

The BPT, a critical component of the subject technology is a high capacity, pipe in pipe heat exchanger. These exchangers allow an LNG tanker to be offloaded at rates consistent with conventional LNG terminals but with resulting pressures suitable for injection of the gas directly into salt caverns without the use of compressors. Thus no significant amount of LNG is ever stored on the surface. In addition, because the exchangers use seawater or other waters as a warmant, the fuel operating costs are approximately $25 \%$ of gas fired exchangers.

Through numerical modeling performed under the present contract, proposed exchanger configurations, process design, and operational considerations have been successfully verified. HYSYS and MATLAB the process software used to design the exchanger, documented the location and thickness of the icing condition (a predicted consequence of using water to warm LNG). The warm water flow systems have been integrated into exchanger design to optimize BPT efficiencies and increase operational flexibility. The BPT exchanger inner annulus will be fabricated from stainless steel, a resilient material known to be resistant to cryogenic temperatures. The outer pipe can be fabricated with HDPE or coated carbon steel depending upon site conditions and specific application. The inner annulus will be centralized with a device designed to incorporate the effects of thermal expansion and contraction.

The major equipment items required for the BPT terminal have been identified. The pump manufactures confirm that the high pressure pumps required for the BPT process can be fabricated and pre-tested using existing materials, technology, and know-how. The BPT exchanger has been conceptually designed and a working model will be built to prove its operating characteristics. 


\begin{tabular}{|l|l|l|l|}
\hline Customer: & $\begin{array}{l}\text { The United States Department of Energy } \\
\text { National Energy Technology Laboratory }\end{array}$ & $\begin{array}{l}\text { Date of Issue: } \\
\text { 24 April 2003 }\end{array}$ & \\
\hline $\begin{array}{l}\text { Document } \\
\text { Title: }\end{array}$ & $\begin{array}{l}\text { Subtask 1.3 } \\
\text { Determine Major Equipment Requirements }\end{array}$ & $\begin{array}{l}\text { Doc \# \& Version: } \\
\text { Doc 04 r2.0 }\end{array}$ & Page 5 of 20 \\
\hline
\end{tabular}

\section{LNG TERMINAL COMMOM EQUIPMENT ITEMS}

The entire LNG receiving terminal consists of three functional areas, LNG receiving, LNG regasification, and LNG storage. The receiving area includes the marine facilities, surge vessel, high pressure pumps, and vapor handling system. The regasification area includes the Bishop Process Heat (BPT) Exchangers and the warmant circulation equipment. The storage area consists of the solution mined salt caverns either existing or created on or in conjunction with the unloading site.

\subsection{Receiving Section}

\subsubsection{Receiving}

LNG will be transported to the receiving terminal via tankers. LNG is unloaded by the ship's pumps at an average rate of about $7600 \mathrm{~m} 3 / \mathrm{hr}$. The high pressure pumping units are designed to unload the entire contents of a $138,000 \mathrm{~m} 3$ tanker within 18 hours. Because the entire contents of the LNG vessel are gasified and sent immediately to the caverns, the BPT LNG terminal is not limited by the send-out capacity of the vaporizer. Rather, the delivery from the salt caverns (at $3.0 \mathrm{Bcf}$ or more per day) and the number of ships capable of discharging over a given period of time determine terminal sendout capacity.

There are two distinct operating modes of the terminal: Ship Unloading and Stand-by. During ship unloading mode of operation, LNG is transferred from an LNG tanker into the salt caverns for storage and delivery. During the stand-by mode of operation (while no ship is unloading LNG), a portion of LNG is circulated around the unloading facilities in order to maintain cold temperatures. Because of the very small volumes of the surge vessel and the cylinders housing the LNG high pressure pumps, LNG boil-off is quite small compared to conventional terminals.

\subsubsection{Pumps - Unloading From Ships}

LNG is unloaded by the ship's pumps and passes through three 16" LNG Unloading Arms which are manifolded together. From the unloading arm manifold, LNG is delivered via two unloading pipelines to a single surge vessel with a working capacity of $520 \mathrm{~m} 3$. The surge vessel is kept at a constant level, slightly above atmospheric pressure to suppress boil-off and ensure flow. The LNG leaving the surge vessel is piped to the High Pressure Pump Reservoirs that house 4 large LNG pumps. These high pressure receiving units are called "4-packs" (Attachment 1). The pumps, a proven technology, will be among the largest capacity LNG send-out pumps manufactured, with an integral in-line motor rated at 2,600 horsepower. Built from aluminum to the latest codes and standards, each pump in the 4-pack has a capacity of $270 \mathrm{~m} 3 / \mathrm{hr}$, or $6480 \mathrm{~m} 3 /$ day. The 4-pack cylinder and pump arrangement will be skid mounted, and delivered from the factory ready for field installation.

The LNG is pressurized to 2,200 psig and passes out the discharge of the pump immediately into the pipe-inpipe Bishop Process Heat Exchanger. Each pump with its own exchanger will gasify about $135 \mathrm{mmcfd}$. Each 4pack has the capacity of gasifying approximately $540 \mathrm{mmscfd}$. Seven 4-packs have been specified for the Base Case with a total capacity of approximately $3.8 \mathrm{Bcfd}$. The discharge of each exchanger connects to a common header which forms the beginning of the pipeline routing the gasified LNG to the salt cavern storage facility.

During the standby mode, a portion of LNG from the surge vessel and each 4-pack is circulated through the unloading piping at the ship berthing area. It is returned by the recirculation line in order to keep the unloading equipment and piping at cryogenic temperature. This avoids excessive vapor generation at the initiation of ship unloading and speeds LNG tanker turnaround times. 


\begin{tabular}{|l|l|l|l|}
\hline Customer: & $\begin{array}{l}\text { The United States Department of Energy } \\
\text { National Energy Technology Laboratory }\end{array}$ & $\begin{array}{l}\text { Date of Issue: } \\
\text { 24 April 2003 }\end{array}$ & \\
\hline $\begin{array}{l}\text { Document } \\
\text { Title: }\end{array}$ & $\begin{array}{l}\text { Subtask 1.3 } \\
\text { Determine Major Equipment Requirements }\end{array}$ & $\begin{array}{l}\text { Doc \# \& Version: } \\
\text { Doc 04 r2.0 }\end{array}$ & Page 6 of 20 \\
\hline
\end{tabular}

\subsubsection{Boil-Off Handling}

During normal operation, vapors know as Boil-Off Gas (BOG) will be generated in the surge vessel, in the High Pressure Pump Reservoirs and through ambient heat leakage in the unloading line. A portion of the generated BOG equivalent to the unloading rate $(7600 \mathrm{~m} 3)$ must be returned to the ship via the vapor return line, the Ship Vapor Return Blower, and the LNG Vapor Return Arm to maintain pressure in the ship tanks. Additional requirements for BOG will be supplied from a low pressure reducing station supplied by the send-out stream.

During standby mode while no liquid is passing through the heat exchangers, the amount of BOG generated by heat leaks and pumping energy is reduced. However, the unloading BOG compressor will be sized to compress the entire content of BOG during standby also. If required, a small amount of LNG can be sprayed into a desuperheater installed at the suction of the Boil-Off Gas Suction Knock-Out Drum to maintain suitable low vapor temperature at the compressor suction.

\subsubsection{Gasification}

There are 28 pipe-in-pipe BPT vaporizers at 152 bar $(2,200$ psi) specified for the Base Case because the cavern operator requested a 200 psi discharge pressure increase to better suit the site described in Task 2.0. To accomplish this, 4 additional pumps were required. The heat exchanger calculations for this study are based on a nominal 138 bar $(2,000 \mathrm{psi}), 24$ pumps case. For the nominal case, all vaporizers are to operate at 138 barg. The slight increase in operating pressure is well within the capability of the equipment specified for the nominal case. The BPTs are sufficient for the entire regasification requirement without supplemental heat; however, waste heat from the gas turbines used for power generation during unloading could provide warmer water to the exchanger thus increasing efficiency.

The seawater loop consists of a Seawater Lift Pumping structure complete with pumps and rotary screen type strainer. The water circulates through multiple pass flow loops integral with the BPT exchanger. The seawater, flowing through the outer annulus of the pipe-in-pipe exchanger transfers the seawater heat content directly to the LNG stream within the inner pipe. The re-gasified LNG is sent to the Gas Metering Station for pipeline delivery. The temperature and pressure of the send-out gas from these units will be approximately $4^{\circ} \mathrm{C}$ and 151.5 barg, respectively. Part of the send-out gas may be used as fuel gas or vapor return to the tanks of the unloading vessel. A detailed review of the Bishop Process heat Exchanger follows this section.

\subsection{Equipment List - Bishop Process Terminal}

Attachment II references the equipment list required for a Bishop Process LNG terminal.

\section{THE BPT (BISHOP PROCESS HEAT EXCHANGERS)}

\subsection{Summary}

A critical component of the subject technology is the use of high capacity, pipe in pipe heat exchangers. These exchangers allow a LNG tanker to be offloaded at rates consistent with conventional LNG terminals but with resulting pressures suitable for injection of the gas directly into salt caverns without the use of compressors. Thus no significant amount of LNG is ever stored on the surface. In addition, because the exchangers use seawater or other waters as a warmant, the fuel operating costs are approximately $25 \%$ of gas fired 


\begin{tabular}{|l|l|l|l|}
\hline Customer: & $\begin{array}{l}\text { The United States Department of Energy } \\
\text { National Energy Technology Laboratory }\end{array}$ & $\begin{array}{l}\text { Date of Issue: } \\
\text { 24 April 2003 }\end{array}$ & \\
\hline $\begin{array}{l}\text { Document } \\
\text { Title: }\end{array}$ & $\begin{array}{l}\text { Subtask 1.3 } \\
\text { Determine Major Equipment Requirements }\end{array}$ & $\begin{array}{l}\text { Doc \# \& Version: } \\
\text { Doc 04 r2.0 }\end{array}$ & Page 7 of 20 \\
\hline
\end{tabular}

exchangers. The following sections discuss the development of these exchangers, the theory involved, the numerical modeling performed under the present contract, proposed exchanger configurations, and operational considerations.

\subsection{Background}

The original pipe in pipe heat exchangers were developed for salt cavern use when it was recognized that two hanging strings in a cavern well could form a counter flow heat exchanger. That is, the outer annulus would carry LNG into the cavern, forcing warm brine out of the cavern through the center tubing and warming the LNG in the process. Preliminary calculations showed the LNG would be warmed to temperatures compatible with the salt rock mechanics. This was followed by a finite element analysis (Ref. 1) that confirmed the preliminary results. The technology was then patented, U.S. Patent No. 5,511,905.

This in-cavern heat exchanger technology is expected to work well but it requires that the caverns in use be operated in a compensated manner, that is, brine is used as an operating medium, forcing it out when LNG is injected and pumping it back in when gas is withdrawn. This requires use of a surface brine pond, or some other brine storage medium, which is usually expensive. Because of this, no natural gas storage caverns are in compensated operation in this country at this time. This may change as the cost of gas rises for the necessary gas cushion that must be left in the cavern after drawdown. Higher value gaseous hydrocarbon products are stored using compensation. To allow uncompensated gas cavern operation to include LNG warming, the horizontal (surface) pipe in pipe exchanger was then developed.

\subsection{The Horizontal Exchanger, Theory}

The surface heat exchanger is freed from the use of cavern brine storage in that any warmant available on the surface may be used, such as seawater, process water, fresh water, etc. This warmant is not dependent on cavern brine return flow rates and thus may be pumped at any rate to achieve the desired LNG warming rate. Further, exchanger diameters can be chosen without affecting well size and number, which becomes very expensive as size is increased.

In designing a horizontal pipe in pipe heat exchanger of this type, it is important that no phase change be allowed to take place during the process. Phase change can disrupt the heat exchange mechanism as well as causing vapor lock, cavitation and other problems. Thus the exchanger is designed to operate above the cricondenbar of the fluid in question. This ensures that the fluid is always in the dense phase, that is, outside of the two-phase dome on a pressure-enthalpy chart. For methane this occurs at pressures above about 700 psi. For higher molecular weight natural gases, the cricondenbar is somewhat higher but usually well below the pressure required for injection into most salt caverns. A second concern is that density stratification be minimized. This can occur in single phase flow when density varies across the flow due to temperature or other changes and can degrade the exchanger performance. This type of stratification is governed by the Densimetric Froude Number given by:

$$
F=V\left(g D \frac{\Delta \gamma}{\gamma}\right)^{-\left(\frac{1}{2}\right)}
$$

Here $\mathrm{V}$ is fluid velocity, $\mathrm{g}$ is acceleration due to gravity, $\mathrm{D}$ is the pipe diameter, $\gamma$ is the fluid density and $\Delta \gamma$ is the change in fluid density. If $\gamma$ is large, the terms involving stratification in the governing equation of fluid motion drop out of the equation. As a practical example, two-phase flows in enclosed systems generally lose 


\begin{tabular}{|l|l|l|l|}
\hline Customer: & $\begin{array}{l}\text { The United States Department of Energy } \\
\text { National Energy Technology Laboratory }\end{array}$ & $\begin{array}{l}\text { Date of Issue: } \\
\text { 24 April 2003 }\end{array}$ & \\
\hline $\begin{array}{l}\text { Document } \\
\text { Title: }\end{array}$ & $\begin{array}{l}\text { Subtask 1.3 } \\
\text { Determine Major Equipment Requirements }\end{array}$ & $\begin{array}{l}\text { Doc \# \& Version: } \\
\text { Doc 04 r2.0 }\end{array}$ & Page 8 of 20 \\
\hline
\end{tabular}

all stratification when the Froude Number rises to a range of from 1 to 2 . In the present application, the value of the Froude Number ranges in the hundreds, which assures complete mixing of any density variations. These high values are determined by the fact that in dense phase flow, the term $\Delta \gamma / \gamma$ in the equation above is small. This is necessarily so since the change in density occurs over the length of the heat exchanger.

\subsection{The Horizontal Exchanger, Design}

In choosing diameters for the suspended strings in a cavern-installed heat exchanger, the outer diameter was constrained by the proposed well size which was limited by cost. At some point additional wells are cheaper than going with larger wells. From that point it was desirable to balance the pressure drop in the two paths while obtaining the desired heat transfer. In a surface exchanger, the diameters can be almost any size, so the selection was based on availability and workability of the cryogenic (inner) pipe. This resulted in the selection of $65 / 8$ " stainless, although other sizes are certainly feasible. Once the diameter is chosen, a limit on the flow velocity of the LNG is determined so as to limit pressure drop, and eventually determine the number of exchangers required to achieve a desired tanker offload rate. For the 6 5/8" pipe a maximum flow rate of 333 $\mathrm{m} 3 / \mathrm{hr}$ (velocity $=15.6 \mathrm{fps}, 4.75 \mathrm{~m} / \mathrm{sec}$ ) through 24 parallel exchangers will offload a 135,000metric ton tanker in $17 \mathrm{hrs}$ of constant rate $(8000 \mathrm{~m} 3 / \mathrm{hr})$ pumping. This is the nominal design point. Exchangers can be added or subtracted as needed to vary the rate. The stainless wall thickness has to be designed to accommodate the pressure required to reach and inject into the target salt cavern. In the nominal case, a 2000 psi pressure has been assumed, requiring a wall thickness of 0.432 " $(.011 \mathrm{~m})$ for the 316 stainless and 0.219 " $(0.0056 \mathrm{~m})$ for AL6XN. In the simulations which follow, only one was made using this latter thickness. Other materials may be suitable. For the warmant pipe, HDPE has been tentatively selected for its low roughness and resistance to corrosion. Other materials like coated steel are feasible, depending on the application. The cryogenic pipe is held in place inside the warmant pipe by centralizers. The numerical analysis, discussed below, was then used to approximately optimize the warmant pipe inside diameter and warmant flow rates.

\subsection{Numerical Analysis of the Exchanger}

The numerical analysis was performed by Prof. William Thomson, Chemical Engineering Department, Washington State University. The analysis took the natural gas properties for the specified gas and the heat transfer correlations from HYSYS and coupled this with MATLAB which is a computational code. The correlation used is the Dittus-Boelter equation. HYSYS is not set up to handle long pipe in pipe exchangers, nor can it calculate ice formation. This latter was done by iterating the solutions in MATLAB and making the wall surface conform to the warmant freeze point in the flow. The full report by Prof. Thomson is included in Attachment III. A range of variables was investigated. These included warmant pipe ID, warmant flow direction-parallel or counter flow, ratio of warmant flow to LNG flow, degree of fouling, cryo pipe wall thickness, warmant type-fresh or seawater, LNG and warmant inlet temperatures and the affect of sequential warmant injections. Note that the lowest temperature used for the LNG is $-250^{\circ} \mathrm{F}\left(117^{\circ} \mathrm{K}\right)$ since the high pressure cryogenic pumps add $10^{\circ} \mathrm{F}$ for the given flow rate, Ref 2 . The natural gas used in all calculations has a specific gravity of 0.62 and the composition in mole percent is: N2 1.55, C1 91.37, and C2 4.09. , C3 1.71, i-C4 0.35, n-C4 0.40, i-C5 0.16, n-C5 0.18, C6 0.19 . The thermal conductivity used for the 316 stainless was 6.8 Thermal conductivity for the AL6XN (one case) was $7.9 \mathrm{btu} / \mathrm{hr}-\mathrm{ft}-{ }^{\circ} \mathrm{F}$.

\subsection{Simulation of Parallel Flow, Fresh Water}




\begin{tabular}{|l|l|l|l|}
\hline Customer: & $\begin{array}{l}\text { The United States Department of Energy } \\
\text { National Energy Technology Laboratory }\end{array}$ & $\begin{array}{l}\text { Date of Issue: } \\
\text { 24 April 2003 }\end{array}$ & \\
\hline $\begin{array}{l}\text { Document } \\
\text { Title: }\end{array}$ & $\begin{array}{l}\text { Subtask 1.3 } \\
\text { Determine Major Equipment Requirements }\end{array}$ & $\begin{array}{l}\text { Doc \# \& Version: } \\
\text { Doc 04 r2.0 }\end{array}$ & Page 9 of 20 \\
\hline
\end{tabular}

In an attempt to minimize icing, the initial simulations were done for the parallel flow case, the rationale being that the higher warmant temperature at the inlet would inhibit icing. This is in fact the case, but at the downstream end of the exchanger, the warmant and LNG temperatures approached each other and thus extended the required exchanger length. Table 2.1 lists all of the parallel flow simulations.

Table 2.1 Simulation Results for Parallel Flow Heat Exchanger

CONDITIONS

RESULTS

\begin{tabular}{|c|c|c|c|c|c|c|c|c|c|c|c|c|c|c|c|}
\hline & Ratio & TH2O & TLNG & Tube & & nnulus & Fouling & Delta $P$ & Delta $P$ & T out & L(OF) & $L(40 F)$ & Qdot & ICE & Ice \\
\hline Case & H2O/LNG & INLET & INLET & D & Sch & D & & $\mathrm{H} 2 \mathrm{O}$ & LNG & $\mathrm{H} 2 \mathrm{O}$ & & $T @ 2500$ & BTU/s & $\begin{array}{l}\text { Max } \\
\text { Thick }\end{array}$ & Length \\
\hline 1 & 2.25 & 80 & -250 & 6" & 80 & $11 "$ & 0.0000 & 277 & 106 & 32 & 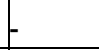 & -4 & 21570 & $0.23 "$ & $200-2500$ \\
\hline 2 & 2.25 & 80 & -250 & 6" & 80 & 14 & 0.0000 & 37 & 86 & 37 & - & -3 & 19494 & 0.15 & $0-2500$ \\
\hline 3 & 3.75 & 80 & -250 & 6" & 80 & 11 & 0.0000 & 667 & 128 & 48 & 1275 & 2500 & 25076 & & \\
\hline 4 & 3.75 & 80 & -200 & 6" & 80 & 11 & 0.0000 & 523 & 85 & 55 & 1025 & 1975 & 20629 & & \\
\hline 5 & 2.5 & 80 & -250 & 6" & 80 & 11 & 0.0000 & 304 & 117 & 34 & 1575 & 19 & 23414 & 0.025 & $900-2500$ \\
\hline 6 & 2.5 & 80 & -200 & 6" & 80 & 11 & 0.0000 & 300 & 110 & 41 & 1175 & 34 & 19611 & & \\
\hline 7 & 3.75 & 80 & -250 & 6" & 80 & 11 & 0.0035 & 670 & 97 & 51 & 2400 & 3 & 21861 & & \\
\hline 8 & 3.75 & 80 & -200 & 6" & 80 & 11 & 0.0035 & 672 & 92 & 57 & 1925 & 19 & 18338 & & \\
\hline 9 & 2.5 & 80 & -250 & 6" & 80 & 11 & 0.0035 & 300 & 93 & 39 & - & -7 & 20794 & & \\
\hline 10 & 2.5 & 80 & -200 & 6" & 80 & 11 & 0.0035 & 300 & 88 & 46 & 2150 & 9 & 17498 & & \\
\hline 11 & 3.75 & 80 & -250 & 6" & 80 & 14 & 0.0000 & 94 & 111 & 47 & 1450 & 33 & 24611 & 0.01 & $0-350$ \\
\hline 12 & 3.75 & 80 & -200 & 6" & 80 & 14 & 0.0000 & 84 & 98 & 53 & 1150 & 2250 & 20342 & & \\
\hline 13 & 2.5 & 80 & -250 & 6" & 80 & 14 & 0.0000 & 44 & 93 & 39 & - & -11 & 20415 & 0.07 & $0-2500$ \\
\hline 14 & 2.5 & 80 & -200 & 6" & 80 & 14 & 0.0000 & 43 & 100 & 42 & 1525 & 28 & 10093 & 0.023 & $0-1175$ \\
\hline 15 & 3.75 & 80 & -250 & 6" & 80 & 14 & 0.0035 & 93 & 94 & 52 & - & -2 & 21350 & & \\
\hline 16 & 3.75 & 80 & -200 & 6" & 80 & 14 & 0.0035 & 93 & 109 & 56 & 2050 & 14 & 17943 & & \\
\hline 17 & 2.5 & 80 & -250 & 6" & 80 & 14 & 0.0035 & 43 & 90 & 40 & - & -15 & 20003 & & \\
\hline 18 & 2.5 & 80 & -200 & 6" & 80 & 14 & 0.0035 & 42 & 86 & 46 & 2350 & 4 & 17033 & & \\
\hline 19 & 3.75 & 80 & -250 & 6" & 80 & $11 "$ & 0.0017 & $891 / 3360 \mathrm{ft}$ & 169 & 49 & 1820 & 22 & 21848 & & \\
\hline 20 & 3.75 & 80 & -200 & 6" & 80 & $11 "$ & 0.0017 & 742 & 121 & 55 & 1470 & 2800 & 20104 & & \\
\hline $7^{\prime}$ & 3.75 & 80 & -250 & 6" & 80 & 11 & 0.0035 & $900 / 3395$ & 153 & 50 & 2400 & $24 / 3395$ & 23947 & & \\
\hline $8^{\prime}$ & 3.75 & 80 & -200 & 6" & 80 & 11 & 0.0035 & $900 / 3395$ & 143 & 56 & 1925 & $37 / 3395$ & 19897 & & \\
\hline $10^{\prime}$ & 2.5 & 80 & -200 & 6" & 80 & 11 & 0.0035 & $420 / 3500$ & 143 & 43 & 2170 & $26 / 3500$ & 19050 & & \\
\hline $11^{\prime}$ & 3.75 & 80 & -250 & 6" & 80 & 14 & 0.0000 & 123 & 177 & 46 & 1470 & 3255 & 25398 & 0.014 & $0-350$ \\
\hline $15^{\prime}$ & 3.75 & 80 & -250 & 6" & 80 & 14 & 0.0035 & $130 / 3500$ & 155 & 48 & 2555 & $21 / 3500$ & 23691 & & \\
\hline $16^{\prime}$ & 3.75 & 80 & -200 & 6" & 80 & 14 & 0.0035 & $130 / 3500$ & 146 & 54 & 2065 & $34 / 3500$ & 19700 & & \\
\hline $18^{\prime}$ & 2.5 & 80 & -200 & 6" & 80 & 14 & 0.0035 & $60 / 3500$ & 138 & 42 & 2345 & $22 / 3500$ & 18710 & & \\
\hline 21 & 2.5 & 80 & -200 & 6" & 80 & 12 & 0.0035 & $197 / 3500$ & 141 & 42 & 2205 & $24.5 / 3500$ & 018934 & & \\
\hline 22 & 3 & 80 & -250 & 6" & 80 & 12 & 0.0017 & $281 / 3500$ & 171 & 40 & 2030 & $28 / 3500$ & 24342 & & \\
\hline
\end{tabular}




\begin{tabular}{|l|l|l|l|}
\hline Customer: & $\begin{array}{l}\text { The United States Department of Energy } \\
\text { National Energy Technology Laboratory }\end{array}$ & $\begin{array}{l}\text { Date of Issue: } \\
\text { 24 April 2003 }\end{array}$ & \\
\hline $\begin{array}{l}\text { Document } \\
\text { Title: }\end{array}$ & $\begin{array}{l}\text { Subtask 1.3 } \\
\text { Determine Major Equipment Requirements }\end{array}$ & $\begin{array}{l}\text { Doc \# \& Version: } \\
\text { Doc 04 r2.0 }\end{array}$ & Page 10 of 20 \\
\hline
\end{tabular}

\begin{tabular}{|l|l|l|l|l|l|l|l|l|l|l|l|l|l|l|l|}
\hline 23 & 2.5 & 80 & -250 & $6^{\prime \prime}$ & 80 & 12 & 0.0035 & $197 / 3500$ & 149 & 35 & 2905 & $10 / 3500$ & 22692 & 0.0004 & $@ 3500$ \\
\hline 24 & 3 & 80 & -250 & $6^{\prime \prime}$ & 80 & 12 & 0.0035 & $280 / 3500$ & 154 & 42 & 2660 & $17 / 3500$ & 23304 & & \\
\hline 25 & 3.5 & 80 & -250 & $6^{\prime \prime}$ & 80 & 12 & 0.0035 & $378 / 3500$ & 157 & 47 & 2485 & $22 / 3500$ & 23760 & & \\
\hline 26 & 4 & 80 & -250 & $6^{\prime \prime}$ & 80 & 12 & 0.0035 & $491 / 3500$ & 159 & 51 & 2415 & $26 / 3500$ & 24114 & & \\
\hline 27 & 3.5 & 80 & -250 & $6^{\prime \prime}$ & 80 & 12 & 0.0017 & $378 / 3500$ & 176 & 45 & 1925 & $33 / 3500$ & 24828 & & \\
\hline 28 & 4 & 80 & -250 & $6^{\prime \prime}$ & 80 & 12 & 0.0017 & $491 / 3500$ & 179 & 38 & 1820 & $38 / 3500$ & 25206 & & \\
\hline 29 & 2.5 & 80 & -250 & $6 "$ & 80 & 12 & 0.0017 & $200 / 3500$ & 164 & 34 & 2240 & $34 / 3500$ & 23388 & 0.059 & $>3500$ \\
\hline 30 & 3 & 80 & -250 & $6 "$ & 80 & 13 & 0.0017 & $148 / 3500$ & 169 & 40 & 2100 & $27 / 3500$ & 24226 & & \\
\hline 31 & 3.5 & 80 & -250 & $6^{\prime \prime}$ & 80 & 13 & 0.0017 & $199 / 3500$ & 173 & 45 & 1960 & $32 / 3500$ & 24716 & & \\
\hline 32 & 4 & 80 & -250 & $6^{\prime \prime}$ & 80 & 13 & 0.0017 & $258 / 3500$ & 177 & 49 & 1890 & $36 / 3500$ & 25094 & & \\
\hline 33 & 3 & 80 & -250 & $6^{\prime \prime}$ & 80 & 13 & 0.0035 & $148 / 3500$ & 152 & 42 & 2730 & $15 / 3500$ & 23165 & & \\
\hline 34 & 3.5 & 80 & -250 & $6^{\prime \prime}$ & 80 & 13 & 0.0035 & $199 / 3500$ & 155 & 47 & 2555 & $20 / 3500$ & 23626 & & \\
\hline 35 & 4 & 80 & -250 & $6 "$ & 80 & 13 & 0.0035 & $258 / 3500$ & 158 & 51 & 2450 & $24 / 3500$ & 23983 & & \\
\hline 36 & 2.5 & 80 & -250 & $6 \prime$ & 80 & 13 & 0.0017 & $106 / 3500$ & 159 & 34 & 2555 & $12 / 3500$ & 22872 & 0.076 & $>3500$ \\
\hline
\end{tabular}

A study of the parallel flow results provides some immediate observations:

Warming is a strong function of the warmant flow velocity more so than the volumetric flow rate. Compare runs 5 and 13 which have the same flow rate but different warmant velocities due to different warmant diameters (11" vs. 14 "), where the final gas temperature is lower by 30 degrees for the smaller diameter pipe.

Very high flow rates in the same warmant diameter increase velocities and thus warming, but at the expense of high pressure drops. Compare cases 3 and 1. With a flow ratio of 3.75 and a pressure drop of 667 psi, case 3 reaches an LNG temperature of $40^{\circ} \mathrm{F}$ at $2500^{\prime}$, which was the original target length based on hand calculations. Preheating the LNG results in much less than a one for one improvement in the gas exit temperature.

Comparing case 5 with 6 and case 7 with 8 . In each case a 50 degree $F\left(28^{\circ} \mathrm{K}\right)$ warming of the LNG resulted in only about a 15 degree $\left(8^{\circ} \mathrm{K}\right)$ increase in the exit gas temperature at $2500^{\prime \prime}(762 \mathrm{~m})$.

High fouling factors make a significant difference, compare cases 5 and 9 . However these factors are probably too high, discussed below.

In the case of parallel flow, the formation of ice is pushed downstream from the entry point by the high heat rate delivered by the entering warmant. The ice starting point can be pushed downstream by increasing this rate, and can be eliminated entirely in this manner, see cases 3, 4, 7 and 8. Increasing the warmant diameter will lower the velocity and offset this effect, see case 11.

The effect of icing is to increase the pressure drop and local velocities, but it is difficult to separate these effects from other factors. Ice formation is self limiting, as expected, i. e. the thicknesses shown are stable. The increased velocities increase the heat transfer to the ice, while the increased insulating effect decreases heat transfer to the cryo wall. The simulation shows that the warmant bulk temperatures can approach the freezing point within at least $2^{\circ} \mathrm{F}\left(1^{\circ} \mathrm{K}\right)$ without causing excessive icing. This increases the delta $\mathrm{T}$ available from the warmant beyond what was assumed in early calculations. 


\begin{tabular}{|l|l|l|l|}
\hline Customer: & $\begin{array}{l}\text { The United States Department of Energy } \\
\text { National Energy Technology Laboratory }\end{array}$ & $\begin{array}{l}\text { Date of Issue: } \\
\text { 24 April 2003 }\end{array}$ & \\
\hline $\begin{array}{l}\text { Document } \\
\text { Title: }\end{array}$ & $\begin{array}{l}\text { Subtask 1.3 } \\
\text { Determine Major Equipment Requirements }\end{array}$ & $\begin{array}{l}\text { Doc \# \& Version: } \\
\text { Doc 04 r2.0 }\end{array}$ & Page 11 of 20 \\
\hline
\end{tabular}

Comparing the exit warmant temperatures with the exit LNG temperatures shows that the temperature difference between the two flows is becoming very small, thus extending the exchanger length. This dictated that the counter flow configuration should be examined.

\subsection{Simulation of Multiple Injections, Fresh Water}

Multiple injections of warmant can multiply the heat available as well as increasing the available temperature potential. Fig. 2.1 is an energy balance showing the flow ratio of warmant to LNG required to reach a given

Figure 2.1 Ratio of Warmant to LNG Flow Rate for Various LNG Exit Temperatures

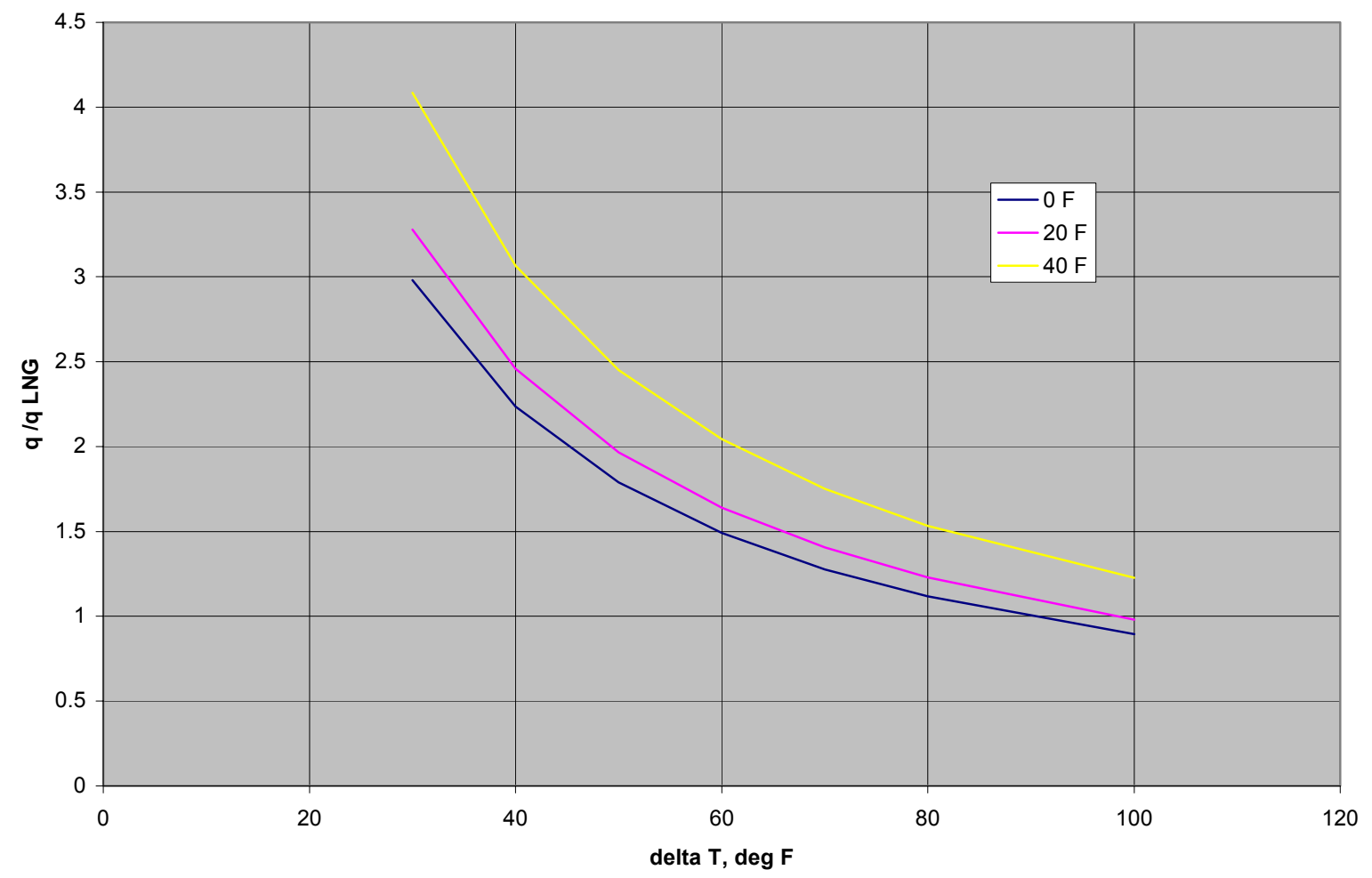

LNG exit temperature as a function of delta $\mathrm{T}$, the temperature available in the warmant above its freezing point. For instance, if the fresh water is at $72^{\circ} \mathrm{F}$ it has an available delta $\mathrm{T}$ of 40 degrees. Entering the figure at this temperature and requiring an exit temperature of $0^{\circ} \mathrm{F}$, shows that a flow ratio of about 2.25 is needed. If a second injection is used the energy available is doubled and the figure must be entered at a delta of 80 degrees. This produces a required flow ratio of only about 1.1. Again this is strictly an energy balance and says nothing about the length of the heat exchanger. However since the driving temperature difference is increased, the length will be shortened. This is illustrated in Table 2.2, where the base case for comparison is Case 1 in Table 2.1. There are two main issues investigated in this table. The first is without a 2 nd injection. It shows that a $20^{\circ} \mathrm{F}\left(11^{\circ} \mathrm{K}\right)$ rise in the warmant injection temperature to $100^{\circ} \mathrm{F}$ causes a $44^{\circ} \mathrm{F}\left(24^{\circ} \mathrm{K}\right)$ rise in the LNG at $2500^{\prime}$ as compared to the case where the warmant is injected at $80^{\circ} \mathrm{F}\left(44^{\circ} \mathrm{K}\right)$. Compare case 1 with case 2 in the table. This reflects the larger amount of energy stored in the warmant per degree of temperature increase as compared to warming the LNG. The second point, obtained from comparing cases 1 and 6 , shows that the intermediate injection allows the LNG to reach $40^{\circ} \mathrm{F}$ in just 2117 ', while without this injection, the LNG 


\begin{tabular}{|l|l|l|l|}
\hline Customer: & $\begin{array}{l}\text { The United States Department of Energy } \\
\text { National Energy Technology Laboratory }\end{array}$ & $\begin{array}{l}\text { Date of Issue: } \\
\text { 24 April 2003 }\end{array}$ & \\
\hline $\begin{array}{l}\text { Document } \\
\text { Title: }\end{array}$ & $\begin{array}{l}\text { Subtask 1.3 } \\
\text { Determine Major Equipment Requirements }\end{array}$ & $\begin{array}{l}\text { Doc \# \& Version: } \\
\text { Doc 04 r2.0 }\end{array}$ & Page 12 of 20 \\
\hline
\end{tabular}

is at only $-4^{\circ} \mathrm{F}$ at $2500^{\prime}$. This result has driven the optimization process to use of a second injection, but with some modification beyond this case.

TABLE 2.2 Effect of Inlet Warmant Temperature and 2nd Warmant Injection for the Base Case (No Fouling)

\begin{tabular}{|c|c|c|c|c|c|c|c|c|}
\hline & $\%$ Warmant & Warmant & Tout H2O & L@ & L@ @ 40 F) & $\begin{array}{c}\text { Warmant } \\
\text { Delta } P\end{array}$ & ICE & Ice \\
\hline Case & Replaced1 & INLET & @2500ft & $O F$ & T @ 2500 & Psi & Max Thick & Length \\
\hline 1 & 0 & $80 \mathrm{~F}$ & $33 \mathrm{~F}$ & - & $-4 F$ & - & $0.2301 "$ & 150-> \\
\hline 2 & 0 & 100 & 44 & $1281 \mathrm{ft}$ & 40 & - & None & - \\
\hline 3 & $30 \%$ & 80 & 44 & 1500 & 30 & 135 & 0.009 & $750->1250$ \\
\hline 4 & $40 \%$ & 80 & 50 & 1477 & 36 & 145 & 0.009 & $750->1250$ \\
\hline 5 & $50 \%$ & 80 & 55 & 1463 & 2500 & 155 & 0.009 & $750->1250$ \\
\hline 6 & $100 \%$ & 80 & 66 & 1435 & 2117 & 244 & 0.009 & $750->1250$ \\
\hline
\end{tabular}

1 Warmant totally replaced at midpoint with various quantities of fresh warmant at $80 \mathrm{~F}$

2 For SI units: 80 OF $=300 \mathrm{~K}, 33 \mathrm{OF}=274 \mathrm{~K}, 135 \mathrm{psi}=0.93 \mathrm{Mpa}, 106 \mathrm{psi}=0.71 \mathrm{Mpa},,-40 \mathrm{~F}=253 \mathrm{~K}, 0.2301 \mathrm{in}=5.84$ $\mathrm{E}-03 \mathrm{~m}, 150 \mathrm{ft}=45.7 \mathrm{~m}$

\subsection{Simulation of a Counter-Flow Exchanger, Using Seawater}

Because of the long exchanger lengths required by the parallel flow approach, counter-flow exchangers were studied. In addition, seawater was incorporated into the model, partly to offset the increased icing that was expected and because seawater is a prime warmant candidate. The previous modeling had indicated that it was possible for the bulk temperature of the warmant to approach the freezing point without unduly increasing the icing problem. This increases the delta $T$ available, and needs to be checked with further detailed modeling and a physical test. Thus seawater should be good down to about $28^{\circ} \mathrm{F}$ as an exit temperature. The results of the counter-flow simulations are presented in Table 2.3. Of primary interest in this table is Case 8 , where $40^{\circ} \mathrm{F}$ is reached in approximately 2590'. Icing is somewhat of a problem in that it grows to $0.409 "$. This case, plus the previous parallel flow case with a second injection, Table 2.2, Case 6, indicated what should form the final and best configuration resulting from this series of simulations, namely a combined parallel and counter-flow exchanger. It will be discussed next. 


\begin{tabular}{|l|l|l|l|}
\hline Customer: & $\begin{array}{l}\text { The United States Department of Energy } \\
\text { National Energy Technology Laboratory }\end{array}$ & $\begin{array}{l}\text { Date of Issue: } \\
\text { 24 April 2003 }\end{array}$ & \\
\hline $\begin{array}{l}\text { Document } \\
\text { Title: }\end{array}$ & $\begin{array}{l}\text { Subtask 1.3 } \\
\text { Determine Major Equipment Requirements }\end{array}$ & $\begin{array}{l}\text { Doc \# \& Version: } \\
\text { Doc 04 r2.0 }\end{array}$ & Page 13 of 20 \\
\hline
\end{tabular}

Table 2.3 Counter-Flow Heat Exchanger: Effect of Parameters1 [Seawater, No Fouling]

\begin{tabular}{|c|c|c|c|c|c|c|c|c|c|c|}
\hline & Equiv. & Warmant & Warmant & LNG & L@ @ $40 \mathrm{~F}$ & L@0F & LNG2 & $\mathrm{H} 2 \mathrm{O2}$ & ice $\max$ & icing \\
\hline Case & Flow ratio & Diameter & $T$ & Inlet T & $(\mathrm{ft})$ & (ft) & $\Delta \mathrm{P}(\mathrm{psi})$ & $\Delta \mathrm{P}$ (psi) & thick (in) & $\begin{array}{c}\text { Interval } \\
\text { (ft) }\end{array}$ \\
\hline 1 & 2.25 & 11 in & $80 \mathrm{~F}$ & $-250 \mathrm{~F}$ & - & 2285 & 71 & 325 & 0.911 & $0->1435$ \\
\hline 2 & 2.25 & 12 & 80 & -250 & - & 2716 & 82 & 186 & 1.159 & $0->1925$ \\
\hline 3 & 2.25 & 12 & 70 & -250 & NOT Feasible & - & - & - & - & - \\
\hline 4 & 2.25 & 12 & 80 & -250 & - & 2716 & 82 & 186 & 1.159 & $0->1925$ \\
\hline 5 & 2.25 & 12 & 90 & -250 & 2681 & 2178 & 101 & 139 & 0.569 & $0->1365$ \\
\hline 6 & 2.25 & 12 & 80 & -250 & NOT Feasible & - & - & - & - & - \\
\hline 7 & 2.5 & 12 & 80 & -250 & 3317 & 2736 & 121 & 258 & 1.102 & $0->1925$ \\
\hline 8 & 2.75 & 12 & 80 & -250 & $\sim 2590$ & 2035 & 100 & 190 & 0.409 & $0->1190$ \\
\hline 9 & 2.25 & 12 & 80 & -250 & NOT Feasible & - & - & - & - & - \\
\hline 10 & 2.25 & 12 & 80 & -200 & 2328 & 1770 & 79 & 113 & 0.347 & $0->1050$ \\
\hline 11 & 2.75 & 12 & 80 & -250 & $\sim 2590$ & 2035 & 100 & 190 & 0.409 & $0->1190$ \\
\hline 12 & 2.75 & 13 & 80 & -250 & 2992 & 2395 & 114 & 118 & 0.539 & $0->1610$ \\
\hline 13 & 2.25 & 11 & 70 & -250 & NOT Feasible & - & - & - & - & - \\
\hline 14 & 2.25 & 11 & 90 & -250 & 2797 & 2285 & 104 & 371 & 0.913 & $0->1435$ \\
\hline
\end{tabular}

1 For SI units: $11 "=(0.028 \mathrm{~m}),-250 \mathrm{OF}=116 \mathrm{~K}, 33 \mathrm{OF}=274 \mathrm{~K}, 71 \mathrm{psi}=0.49 \mathrm{Mpa}, 325 \mathrm{psi}=2.24 \mathrm{Mpa}$, , 0.991 in $=0.025 \mathrm{~m}, 1435 \mathrm{ft}=437 \mathrm{~m}$

2 At the length required for the LNG to reach $40 \mathrm{OF}$, or $0 \mathrm{OF}$

\subsection{Simulation of a Combined Parallel and Counter-Flow Exchanger, with Two Warmant Injections (Mixed Injection).}

Based on the ability of the parallel flow configuration to minimize icing, the counter-flow configuration increased efficiency and the ability of a second injection to double the energy available, it was decided to combine these effects. The result is an exchanger which starts with parallel flow at the inlet, doubles back to the warmant source where it receives a second warmant injection, both flows being expelled at the midpoint, now the farthest end of the exchanger. A preliminary design of such an exchanger is shown in Figure 2.2. All pipes of the exchanger are fixed at the fluid injection end and the cryo pipe is free to expand into the capsule at the opposite end. Approximately 4.5' of expansion space has been allowed. 


\begin{tabular}{|l|l|l|l|}
\hline Customer: & $\begin{array}{l}\text { The United States Department of Energy } \\
\text { National Energy Technology Laboratory }\end{array}$ & $\begin{array}{l}\text { Date of Issue: } \\
\text { 24 April 2003 }\end{array}$ & \\
\hline $\begin{array}{l}\text { Document } \\
\text { Title: }\end{array}$ & $\begin{array}{l}\text { Subtask 1.3 } \\
\text { Determine Major Equipment Requirements }\end{array}$ & $\begin{array}{l}\text { Doc \# \& Version: } \\
\text { Doc 04 r2.0 }\end{array}$ & Page 14 of 20 \\
\hline
\end{tabular}

Figure 2.2 Prototype Bishop Process Heat Exchanger
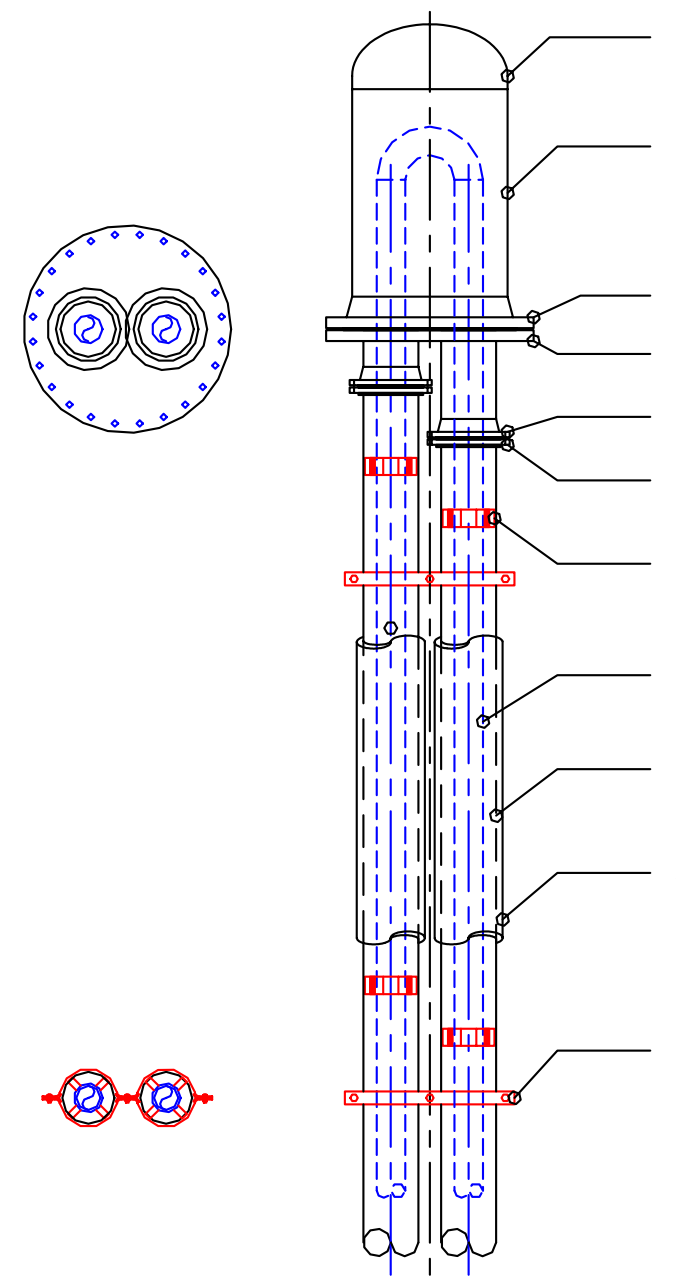

36" STD C.S. WELD CAP

36" STD C.S. EXPANSION BARREL

36" 150\# C.S. RFWN

36" 150\# C.S. RFBF

12" 150\# C.S. RFWN

12" HDPE FLANGE

12X6 HDPE CENTRALIZER @ 10' C-C (DUOCON 6X10 W/2" OPTION OR EQ)

1250 LF 6" SCH 80 AL6XN PIPE

(EACH TUBE, X 2 TUBES)

12" HDPE DR-11 PIPE

1-1/2" THICK CONCRETE

WEIGHT COATING
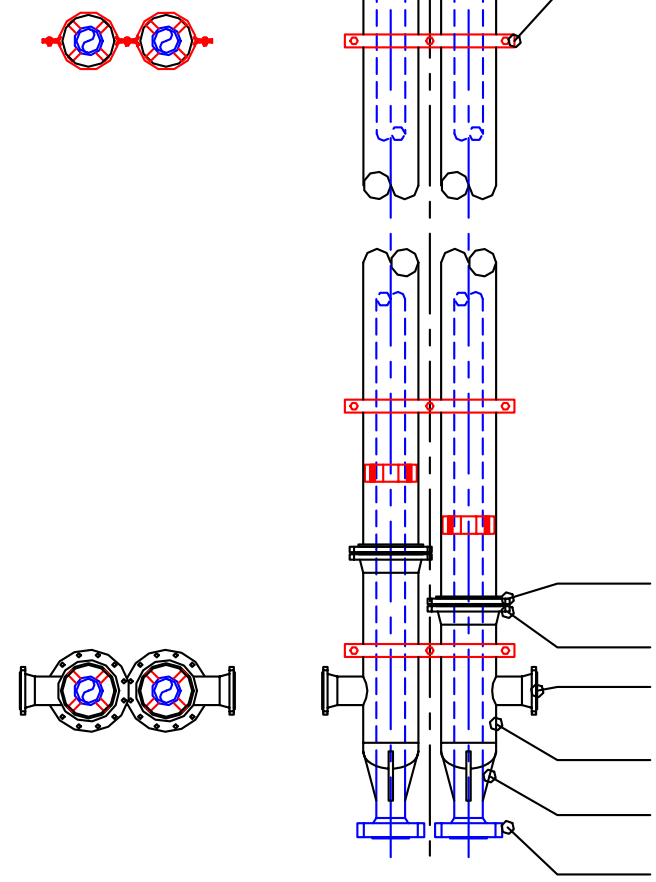

12" HDPE RFWN

12" 150\# C.S. FLANGE

6" 150\# 316L SS RFWN FLG

12" STD 316L BARREL ASSY

STIFFENER GUSSETS

6" 150\# AL6XN RTJWN FLG 


\begin{tabular}{|l|l|l|l|}
\hline Customer: & $\begin{array}{l}\text { The United States Department of Energy } \\
\text { National Energy Technology Laboratory }\end{array}$ & $\begin{array}{l}\text { Date of Issue: } \\
\text { 24 April 2003 }\end{array}$ & \\
\hline $\begin{array}{l}\text { Document } \\
\text { Title: }\end{array}$ & $\begin{array}{l}\text { Subtask 1.3 } \\
\text { Determine Major Equipment Requirements }\end{array}$ & $\begin{array}{l}\text { Doc \# \& Version: } \\
\text { Doc 04 r2.0 }\end{array}$ & Page 15 of 20 \\
\hline
\end{tabular}

This will vary depending on the cryo material. Simulation results for this exchanger are shown in Table 2.4.

TABLE 2.4 Effect of Mixed Injection Heat Transfer1

[Seawater, Flow ratio $=2.5,12 "(0.305 \mathrm{~m})$ Warmant Diameter]

\begin{tabular}{|c|c|c|c|c|c|c|c|}
\hline Case & Configuration & $\mathrm{L}\left(@ 0^{\circ} \mathrm{F}\right)$ & $\begin{array}{c}\mathrm{L} @ 40^{\circ} \mathrm{F} \\
\mathrm{T} @ 3500 \mathrm{ft}\end{array}$ & $\begin{array}{c}\Delta \mathrm{P} H 2 \mathrm{O} \\
(\mathrm{psi})\end{array}$ & $\begin{array}{c}\Delta \mathrm{P} \text { LNG } \\
(\mathrm{psi})\end{array}$ & $\begin{array}{c}\text { ICE } \\
\text { Max Thick } \\
\text { (in) }\end{array}$ & $\begin{array}{l}\text { ICE } \\
\text { Length } \\
(\mathrm{ft})\end{array}$ \\
\hline 1 & $\begin{array}{l}\text { Mixed } \\
\text { Parallel }\end{array}$ & $1433 \mathrm{ft}$ & $2033 \mathrm{ft}$ & 1142 & 912 & None & - \\
\hline 2 & $\begin{array}{l}\text { Flow } \\
\text { Counter- }\end{array}$ & 2900 & $10 \mathrm{~F}$ & 2053 & 1723 & None & - \\
\hline 3 & Flow & 2736 & 3317 & 2584 & 1214 & 1.102 & $0->1925$ \\
\hline
\end{tabular}

1 For SI units: $0^{\circ} \mathrm{F}=255^{\circ} \mathrm{K}, 1433 \mathrm{ft}=437 \mathrm{~m}, 2033 \mathrm{ft}=620 \mathrm{~m}, 114 \mathrm{psi}=0.76 \mathrm{MPa}, 91 \mathrm{psi}=0.63 \mathrm{Mpa}$,

$1.102 \mathrm{in}=0.028 \mathrm{~m}, 1925 \mathrm{ft}=587 \mathrm{~m}$

2 At $2033 \mathrm{ft} \quad 3$ At $3500 \mathrm{ft} \quad 4$ At $3317 \mathrm{ft}$

This table compares pure parallel flow and counter-flow cases with the mixed configuration case. Each of the cases has a 2.5 warmant to LNG ratio with a thick walled cryo pipe, 0.432 " $(.0110 \mathrm{~m})$ and a 12 " $(0.305 \mathrm{~m})$ warmant pipe. The warmant is seawater at $80^{\circ} \mathrm{F}$. Parallel flow was maintained in the mixed exchanger up to 1250 ', where it met the counter-flow and both were expelled. The mixed flow case reaches $40^{\circ} \mathrm{F}\left(278^{\circ} \mathrm{K}\right)$ in 2033' $(620 \mathrm{~m})$. This is by far the best result of all of the simulations. It is not yet fully optimized, that is thin wall pipe could be used, flow ratio could be varied, the warmant or LNG could be preheated, etc. However it appears that the final design will be close to this configuration. Note that at $1250^{\prime}(381 \mathrm{~m})$, where the flow changes from parallel to counter, the temperature has reached $-16^{\circ} \mathrm{F}\left(246^{\circ} \mathrm{K}\right)$ and the pressure drop was $70 \mathrm{psi}(0.48 \mathrm{Mpa})$. As shown in the table, total pressure drop for both fluids was significantly lower than for the comparison cases. This is due both to the shorter length and to the lower viscosities in the warmer fluids. The lower pressure requirements represent a significant operational savings. In cases where it is feasible to warm the gas just to $0^{\circ} \mathrm{F}$, for instance, the required total length is reduced to less than 1433'. Note that this is far from being optimized since the first 1250' is the parallel flow heat exchanger, followed by a short counter-flow exchanger. Making the sections of equal length will reduce overall length even more. The option of going to $0^{\circ} \mathrm{F}$ is discussed in a following section.

\subsection{Fouling and Turbidity Considerations}

A comparison of simulations for fouling factors of 0.0017 and $0.0035 \mathrm{hr}-{ }^{\circ} \mathrm{F}-\mathrm{ft} 2 / \mathrm{btu}$ is shown in Figure 2.3. For the fouling factors considered, length of exchanger increases about $40 \%$ over the zero fouling case. Unfortunately, the factors simulated are large for seawater exchangers, which are typically in the range of $0.0005 \mathrm{hr}-{ }^{\circ} \mathrm{F}-\mathrm{ft} 2 / \mathrm{btu}$ at ambient temperatures. For the colder environment of the present exchangers and for the metals used, actual factors may be lower. Also, fouling factor effect will be combined with wall thickness and the pipe thermal conductivity effects, which will all combine to affect exchanger length and have not been optimized in this study.

The fouling factor of $0.0005 \mathrm{hr}-\mathrm{F}$-ft2/btu quoted in this report is for long term operating conditions and thus represents true operating conditions. This effect will to a great extent be masked in the exchanger by variation in wall thickness and the steel conductivity which have not yet been optimized. It is anticipated that with higher water velocities and colder temperatures in the Bishop Process exchangers (as compared to overhead rack types for instance) less fouling will be developed. 


\begin{tabular}{|l|l|l|l|}
\hline Customer: & $\begin{array}{l}\text { The United States Department of Energy } \\
\text { National Energy Technology Laboratory }\end{array}$ & $\begin{array}{l}\text { Date of Issue: } \\
\text { 24 April 2003 }\end{array}$ & \\
\hline $\begin{array}{l}\text { Document } \\
\text { Title: }\end{array}$ & $\begin{array}{l}\text { Subtask 1.3 } \\
\text { Determine Major Equipment Requirements }\end{array}$ & $\begin{array}{l}\text { Doc \# \& Version: } \\
\text { Doc 04 r2.0 }\end{array}$ & Page 16 of 20 \\
\hline
\end{tabular}

However, in the event that fouling becomes a bigger problem than indicated by the 0.0005 value, there are at least two remedies. 1) Because of the configuration of the exchangers and their intermittent operation, it is possible to drain and flush each exchanger between tanker arrivals. This flush could be for chemical fouling as well as a biocide. The flush liquid could be recovered after each use and finally disposed of when spent. 2) In the extreme case the warmant pipe is designed as a sleeve over the cryo pipe and its centralizers. This sleeve could be removed from each exchanger and then both the cryo and warmant pipes cleaned as needed. This could be done one exchanger at a time so as to minimize disruption.

All ambient exchangers have some problem with fouling. It is believed that the Bishop Process exchanger would be least effected. These will be investigated in detail before performing a field test. Fouling data from existing LNG/seawater exchangers should be incorporated.

In addition, turbidity in the warmant is considered to be a problem in some exchangers. However, in the present case, the velocities in the warmant pipe are much higher than they would be in any source body, and thus settling of particles in this pipe should not be a problem. Typical turbidity is primarily composed of soft clay particles which do not present an erosion problem. Harder minerals like quartz, if incorporated into the flow could cause erosion, but this effect should be confined to the bottom center-line of the warmant pipe.

Figure 2.3 Exchanger Length vs. Flow Ratio for Various Fouling Factors

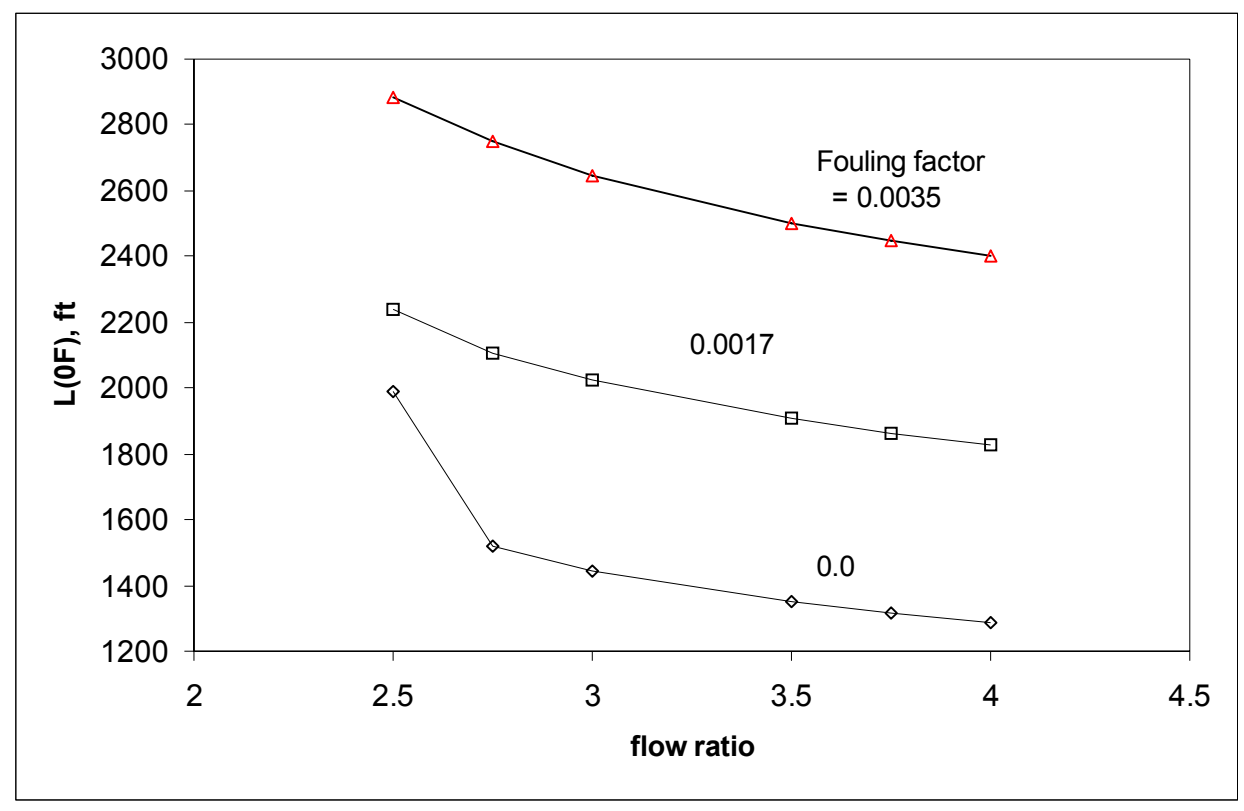

\subsection{Simulation Using Finite Element Analysis}

A computational fluid dynamics code, CFD-ACE, was used to attempt a preliminary confirmation of the foregoing simulations, which are based on correlations. Remaining funding permitted only a coarse grid modeling. The results of this modeling predicted a $2^{\circ} \mathrm{F}\left(1^{\circ} \mathrm{K}\right)$ less of a drop in the warmant temperature over the first $165^{\prime}(50 \mathrm{~m})$ of the parallel flow. Since this is the region where the gradients are steepest, this may not represent a significant discrepancy. Additionally, the higher warmant temperature would cause higher heat 


\begin{tabular}{|l|l|l|l|}
\hline Customer: & $\begin{array}{l}\text { The United States Department of Energy } \\
\text { National Energy Technology Laboratory }\end{array}$ & $\begin{array}{l}\text { Date of Issue: } \\
\text { 24 April 2003 }\end{array}$ & \\
\hline $\begin{array}{l}\text { Document } \\
\text { Title: }\end{array}$ & $\begin{array}{l}\text { Subtask 1.3 } \\
\text { Determine Major Equipment Requirements }\end{array}$ & $\begin{array}{l}\text { Doc \# \& Version: } \\
\text { Doc 04 r2.0 }\end{array}$ & Page 17 of 20 \\
\hline
\end{tabular}

transfer downstream. This degree of agreement appears to be sufficient for this stage of the technology. Ultimate refining of the prediction capability will await the field test results.

\subsection{Heat Exchanger Operational Considerations}

Fig. 3.12-1 is a schematic of an LNG receiving terminal (offshore version) using a Bishop heat exchanger. The tanker pumps offload the LNG to the terminal high pressure pumps. These raise the LNG pressure such that it matches the pipeline and cavern requirements. This will normally put the pressure well above the cricondenbar of the LNG being pumped, which assures that the gas stays in the dense phase. Referencing the nominal design case for this study, LNG moves from the high pressure pumps, and will pass directly to the heat exchangers at $8000 \mathrm{~m} 3 / \mathrm{hr}$ and 2000psi. Nominally, twenty-four pumps are required to meet these process conditions. The cryogenic pumps are restricted to about 2,600 horsepower but not in pressure within reasonable limits. Higher discharge pressures (e.g. the 2,200 psi 28 pump case) require more pumps at lower flow rates per pump to maintain horsepower restraints.

Figure 3.12-1

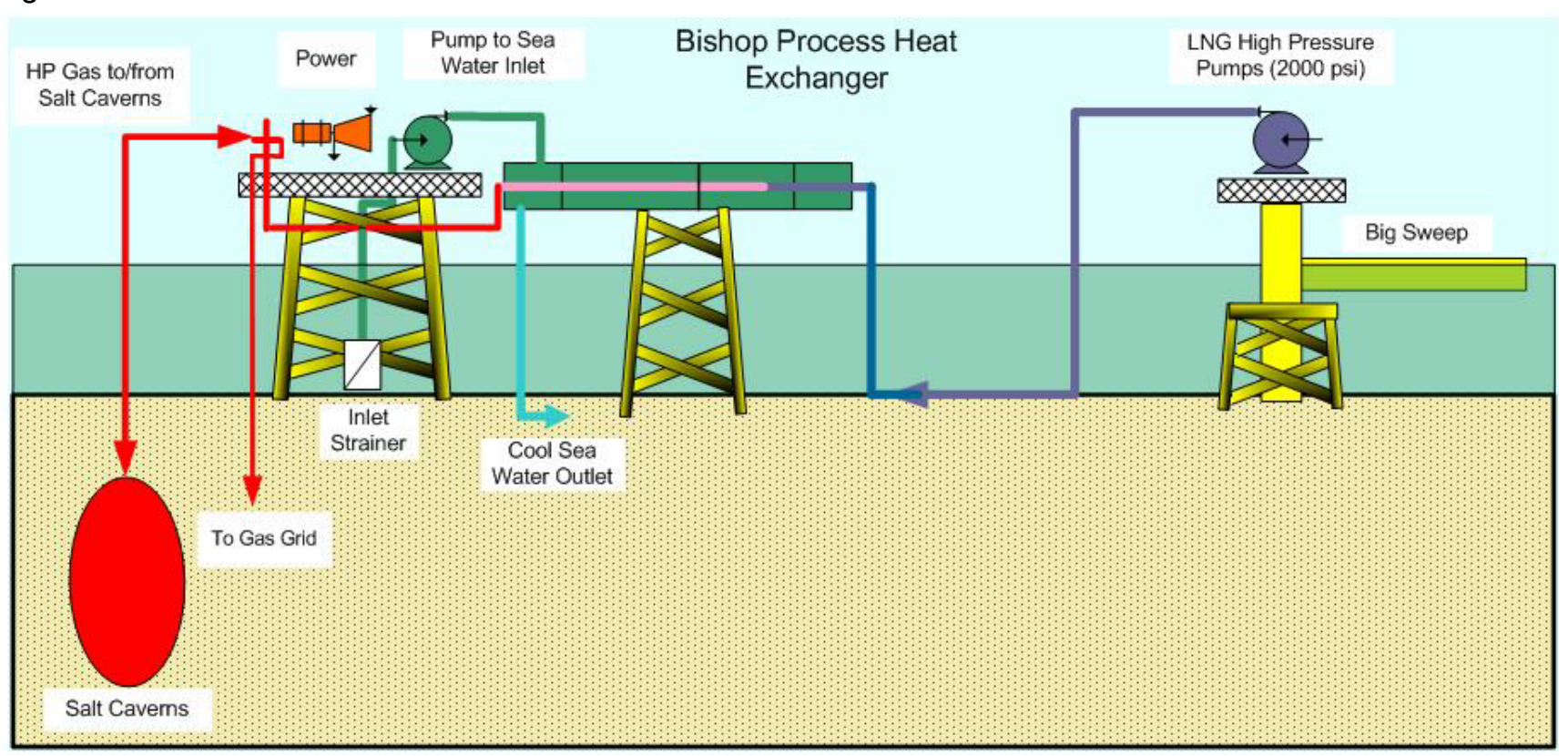

\subsection{Heat Exchanger Exit Temperatures}

The first pass through the exchangers will take the dense phase gas to the temperature desired for the cavern. The RESPEC rock mechanics study, discussed in a later section, shows that at least down to $0^{\circ} \mathrm{F}$, and probably lower, the temperature does not have a negative effect on the cavern. This provides some leeway in determining the exchanger exit temperature. To make the exchangers shorter and less expensive, gas could be allowed to enter the cavern at $0^{\circ} \mathrm{F}$ and then make a return pass through the exchangers on the way out. This final pass could also be used to offset cooling caused by the pressure drop down to pipeline conditions. Final desired temperature would depend on the specific pipeline and the amount of mixing expected. Generally speaking moderately low temperatures are desirable in a pipeline to increase throughput. If the cavern is 


\begin{tabular}{|l|l|l|l|}
\hline Customer: & $\begin{array}{l}\text { The United States Department of Energy } \\
\text { National Energy Technology Laboratory }\end{array}$ & $\begin{array}{l}\text { Date of Issue: } \\
\text { 24 April 2003 }\end{array}$ & \\
\hline $\begin{array}{l}\text { Document } \\
\text { Title: }\end{array}$ & $\begin{array}{l}\text { Subtask 1.3 } \\
\text { Determine Major Equipment Requirements }\end{array}$ & $\begin{array}{l}\text { Doc \# \& Version: } \\
\text { Doc 04 r2.0 }\end{array}$ & Page 18 of 20 \\
\hline
\end{tabular}

distant from the storage caverns, a second, exit pass through the exchangers is not possible. This is the case for the Liberty Project, discussed later, where the caverns are 35 miles from the proposed terminals. Here the exchangers are limited to whatever the connecting pipeline can be reasonably designed for. A benefit of a remotely located cavern, such as for Liberty, is that the gas will warm to ambient temperature during the trip.

Making use of the cavern tolerance for low temperatures does not mean that the well casing can tolerate the same temperatures. It is important that this casing be protected. The temperature range over which a cemented casing can operate can be improved by using some of the advanced cements now available. However a failsafe technique is to provide a hanging string and to shunt a warm stream of gas down the annulus. Calculations would have to be performed to determine the rate and temperature required. The same operation would be performed for both entry and exit of the cooled gas.

\subsection{Using the Available Low Temperature to Process High Heating Value Gas}

Much of the LNG available world wide has heating values above that which is allowable in the domestic pipelines that transport it. This often requires consideration of removal of liquid petroleum gasses at or near the receiving terminal or mixing with other gas if that is possible. It would appear to this writer that it would be much preferable to remove the heavier gases at the source and ship them separately if necessary, rather than ship them in the relatively high cost LNG mode. Nevertheless, it is possible to remove a portion of these by using the temperature and pressure drop as the gas exits the cavern. Assuming a typical gas with a gravity of 0.705 and a heating value of $1250 \mathrm{btu} / \mathrm{mcf}$ is injected at $40^{\circ} \mathrm{F}$, dropping it from $2000 \mathrm{psi}$ in the cavern to $1000 \mathrm{psi}$ for the pipeline drops the gas gravity to 0.625 and the heating value to $1140 \mathrm{btu} / \mathrm{mcf}$. Dropping the same gas from $0^{\circ} \mathrm{F}$ and $2000 \mathrm{psi}$ to $1000 \mathrm{psi}$ drops the gravity to 0.61 and the heating value to $1100 \mathrm{btu} / \mathrm{mcf}$. These are much more acceptable heating values. Of course the liquids have to be separated and collected. The cavern will drop in pressure as it is drawn down and the pressure drop at the valve will be reduced. However at the same time the temperature in the cavern will be dropping, offsetting the reduced temperature drop at the valve. Whether this type of operation is worth doing will of course depend on the project specifics and marketing considerations.

\subsection{Bypassing Full Cavern Pressure to Feed a Base Load}

If, as might be expected, a proposed LNG terminal is feeding a fairly constant base load, it is not necessary to bring all of the delivered LNG to cavern pressure. The cavern can be bypassed with pipeline pressure only. For instance, the Liberty project analyzed in this study, proposes as one option to bring in 1.7 BCFD on average. This is done with a terminal that operates at approximately $4.1 \mathrm{BCFD}$ when offloading. If the true base load is 1.7 BCFD, 1.7 of the 4.1 BCFD only needs to be pumped to pipeline pressure, say 900 psi. This requires two smaller pipelines, one high pressure, one low pressure, rather than one high pressure. In the Liberty case these would be 35 miles long. However $41 \%$ of the gas would only go to 900 psi rather than 2,200 psi that the caverns require. This would be a significant energy saving as well as reducing the number of required pumps. For projects where the dock, exchangers and caverns are co-located, the main receiving pipeline would only be taking low pressure gas downstream of the cavern and the shunt pipeline would be a simple cavern bypass.

\subsection{Use of the Waste Heat from Power Generation}




\begin{tabular}{|l|l|l|l|}
\hline Customer: & $\begin{array}{l}\text { The United States Department of Energy } \\
\text { National Energy Technology Laboratory }\end{array}$ & $\begin{array}{l}\text { Date of Issue: } \\
\text { 24 April 2003 }\end{array}$ & \\
\hline $\begin{array}{l}\text { Document } \\
\text { Title: }\end{array}$ & $\begin{array}{l}\text { Subtask 1.3 } \\
\text { Determine Major Equipment Requirements }\end{array}$ & $\begin{array}{l}\text { Doc \# \& Version: } \\
\text { Doc 04 r2.0 }\end{array}$ & Page 19 of 20 \\
\hline
\end{tabular}

Referencing the nominal case in this study, a terminal processing $8000 \mathrm{~m} 3 / \mathrm{hr}$ of LNG to 2000psi, approximately $80,000 \mathrm{hp}(60,000 \mathrm{kw})$ of power is required for the LNG and warmant pumps together. Assuming a warmant to LNG flow ratio of 2.5 , and a power generation efficiency of 0.37 , approximately $15^{\circ} \mathrm{F}$ $\left(8^{\circ} \mathrm{K}\right)$ can be added to the ambient warmant temperature by installing suitable heat exchangers. Conversely, if the heat is added to the LNG, which may be more efficient, the inlet temperature of the LNG can be raised by about $45^{\circ} \mathrm{F}\left(25^{\circ} \mathrm{K}\right)$. In cases where the available warmant temperature is low, use of the waste heat should be considered in order to reduce heat exchanger length. For U.S. Gulf of Mexico coastal waters, summer surface temperatures average around $85^{\circ} \mathrm{F}\left(29^{\circ} \mathrm{C}\right)$ and winter temperatures around $65^{\circ} \mathrm{F}\left(18^{\circ} \mathrm{C}\right)$. Addition of the $15^{\circ} \mathrm{F}$ $\left(8^{\circ} \mathrm{K}\right)$ to the winter warmant temperature would bring it to $85^{\circ} \mathrm{F}\left(29^{\circ} \mathrm{C}\right)$. In cases where the warmant drops to unusually low temperatures not contemplated in the exchanger design, this can be overcome by offloading at a lower rate, thus increasing the warmant to LNG flow ratio. Obviously warmant temperature histories need to be studied to determine final design operating ranges. If relatively extreme temperature lows are anticipated, it may be necessary to provide supplementary gas-fired heating of either the warmant or the LNG. Another option is simply to lower the target exchanger exit temperature. Most of these considerations go away if multiple injections are used as was discussed under the simulation in section 2.4.4. A discussion of the feasible range of ambient warmant temperatures follows in the next section.

In addition to using the waste heat as a pre heater for the LNG or the warmant, the LNG can be used to precool the air intake for the power generation turbines. This will pre-warm the LNG by some small amount.

\subsection{Estimating Warmant Temperature Operational Range, Required Flow Ratio}

Using a simple energy balance as was done in preparing Figure 2.1 it is possible to write an equation for the required flow ratio for a given available warmant temperature:

$$
\Delta \mathrm{T} \text { qw/qlng }=132
$$

Here $\Delta T$ refers to the warmant temperature less the warmant minimum temperature. For seawater this minimum would be about $30^{\circ} \mathrm{F}$. This equation is valid for bringing the gas to $40^{\circ} \mathrm{F}$. If we assume seawater at $50^{\circ} \mathrm{F}$, available delta $\mathrm{T}$ becomes 20 degrees. Using the equation this would require a flow ratio of 6.6, which is unacceptably high. However if a second injection is made to double the energy available, delta T becomes 40 and the resultant flow ratio is 3.3 , which is not too bad. If additionally the LNG is preheated by waste heat from the power source, delta T remains at 40 but the right hand side of the above equation becomes 115 instead of 132. Then with two warmant injections the required flow ratio becomes 2.9. This is an acceptable flow ratio. It can be reduced even further by lowering the gas exit temperature if downstream conditions permit. Of course the above calculation says nothing about the heat exchanger specifications. Referring back to the discussion on "mixed" flow exchangers in section 2.4.4, it is probable that the exchanger length even in this example can be held to acceptable dimensions. It would even be feasible to double the exchanger back to the warmant source twice rather than once and obtain four injections of the lower temperature warmant, two parallel and two counter-flows. Note that above calculations are for pure methane. Results for typical natural gases would vary.

\subsection{Emergency Shut-in of the Exchangers, Shut-in Conditions}

If in the case of an emergency, loss of power for instance, both the warmant flow and the LNG flow are stopped, the warmant, seawater or fresh water, will not freeze. This is due to the high volume of warmant contained in a section of exchanger compared to that for the LNG. If both flows are stopped the approximate 


\begin{tabular}{|l|l|l|l|}
\hline Customer: & The United States Department of Energy & Date of Issue: \\
& National Energy Technology Laboratory & 24 April 2003 \\
\hline $\begin{array}{l}\text { Document } \\
\text { Title: }\end{array}$ & Subtask 1.3 & Doc \# \& Version: & Doc 04 r2.0 \\
& Determine Major Equipment Requirements & Page 20 of 20 \\
\hline
\end{tabular}

equilibrium temperature is $35^{\circ} \mathrm{F}\left(1.5^{\circ} \mathrm{C}\right)$. This is far removed from freezing since the heat of fusion of the warmant is extremely high, $143 \mathrm{btu} / \mathrm{lb}$ for water. If the LNG is stopped and the warmant flow continues, there is of course no problem. If the LNG is stopped and the warmant is drained, say from a pipe failure, the LNG will simply warm over time at cavern or pipeline pressure, depending on the destination to which it is connected. The small amount of LNG in the exchangers is not capable of changing these pressures.

When the exchangers are not in use it is proposed that they "ride" on cavern or pipeline pressure. That is that they remain open to their destination. This minimizes pressure cycling of the exchanger pipe and provides a back pressure for the cryogenic pumps at startup.

\section{ATTACHMENTS}

\subsection{Attachment 1 - "4-Pack" - High Pressure LNG Pumping Unit}

\subsection{Attachment II - LNG Equipment List}

\subsection{Attachment III - Numerical Analysis of BPT - Full Report}


Attachment I 


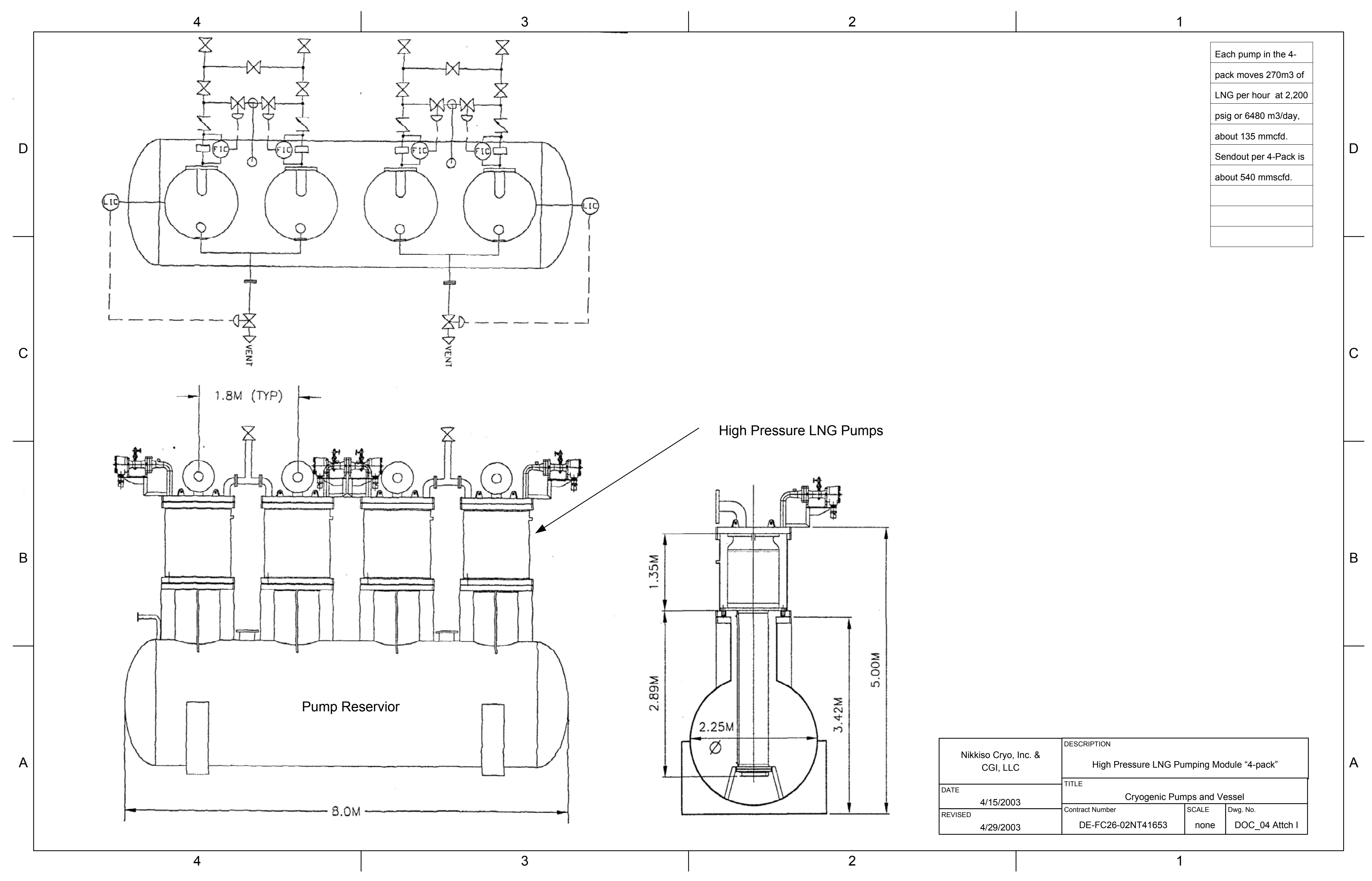


Attachment II 


\begin{tabular}{|c|c|}
\hline \multicolumn{2}{|c|}{ Attachment II Major Equipment List } \\
\hline Description & Details \\
\hline $\begin{array}{l}\text { STORAGE TANKS/PROCESS VESSELS } \\
\text { Salt Storage Caverns } \\
\text { Recondenser } \\
\text { BOG Compressor Knock Out Drum } \\
\text { HP Fuel Gas Knock Out Drum } \\
\text { HP Flare Knock Out Drum, } \\
\text { Service Water Storage Tank } \\
\text { Diesel Storage Tank } \\
\text { Surge Vessel } \\
\text { Foam Tank }\end{array}$ & $\begin{array}{l}6 \text { ea total 18BCF } \\
9 ' I D \times 45^{\prime}, 304 \text { SS } \\
70 \mathrm{m3} \\
3 \mathrm{~m} 3 \\
50 \mathrm{~m} 3 \\
20 \mathrm{~m} 3 \\
50 \mathrm{~m} 3 \\
540 \mathrm{~m} 3 \\
4 \mathrm{~m} 3 \\
\end{array}$ \\
\hline $\begin{array}{l}\text { VAPORIZERS/HEAT EXCHANGERS } \\
\text { Bishop Process heat exchanger } \\
\text { HP knockout drum heater } 20 \mathrm{~kW} \\
\text { Gaseous N2 Vaporizer } 35 \mathrm{~kW} \\
\text { Gaseous N2 Vaporizer (Spare) } 35 \mathrm{~kW} \\
\text { Liquid N2 Pressurization vaporizer } 35 \mathrm{~kW} \\
\text { Turbogenerator Heat Recovery LNG Exchanger } \\
\text { Turbogenerator Inlet Air Chiller } \\
\text { Liquid N2 Vaporizer } 35 \mathrm{~kW}\end{array}$ & $\begin{array}{l}28 @ 270 \text { tons } / \mathrm{hr} .(7,560 \mathrm{~m} 3 / \mathrm{hr}) \\
20 \mathrm{~kW} \\
35 \mathrm{~kW} \\
35 \mathrm{~kW} \\
35 \mathrm{~kW} \\
\\
35 \mathrm{~kW} \\
\end{array}$ \\
\hline $\begin{array}{l}\text { PUMPS } \\
\text { Second stage sendout pump } \\
\text { Seawater pump } \\
\text { Process Area Sump Pump } \\
\text { Service Water Pump }\end{array}$ & $\begin{array}{l}28 @ 270 \mathrm{~m} 3 / \mathrm{hr} \\
2187 \mathrm{~m} 3 / \mathrm{hr} \\
10 \mathrm{hp}, 5 \mathrm{~m} 3 / \mathrm{hr} \\
5 \mathrm{hp}, 57 \mathrm{~m} 3 / \mathrm{hr}\end{array}$ \\
\hline $\begin{array}{l}\text { COMPRESSORS } \\
\text { Ship unloading compressor, 59 MMSCFD } \\
\text { Ship vapor return blower } \\
\text { Instrument air compressor and drier }\end{array}$ & $\begin{array}{l}59 \mathrm{MMSCFD} \\
4.0 \mathrm{mmMm} 3 / \mathrm{hr} \\
100 \mathrm{scfm}\end{array}$ \\
\hline $\begin{array}{l}\text { SEAWATER STRUCTURE } \\
\text { Seawater Intake Structure } \\
\text { Seawater Outfall Structure } \\
\text { Seawater Intake Screens } \\
\text { Seawater Rotary Screens }\end{array}$ & $\begin{array}{l}12,000 \mathrm{~m} 3 / \mathrm{hr} \text { each } \\
12,000 \mathrm{~m} 3 / \mathrm{hr} \text { each } \\
12,000 \mathrm{~m} 3 / \mathrm{hr} \text { each } \\
12,000 \mathrm{~m} 3 / \mathrm{hr} \text { each }\end{array}$ \\
\hline $\begin{array}{l}\text { UTILITIES } \\
\text { Flares } \\
\text { HP Flare } \\
\\
\text { N2 Dewar for Terminal, Vac. insul. tank, } 42 \mathrm{~m} 3 \\
\text { Electrochlorination Unit, } 12,000 \mathrm{~m} 3 / \mathrm{hr}\end{array}$ & $415,000 \mathrm{~kg} / \mathrm{hr}$ \\
\hline $\begin{array}{l}\text { Firewater Protection } \\
\text { Firewater Protection System } \\
\text { includes distribution piping, hydrant system, AFFF foam system } \\
\text { and water tanks for fire fighting systems, incl. dry powder (jetty) } \\
\text { Electric Firewater Pump } \\
\text { Diesel Driven Firewater Pump } \\
\text { Firewater Jockey Pump }\end{array}$ & $\begin{array}{l}2500 \mathrm{gpm} \\
2500 \mathrm{gpm} \\
200 \mathrm{gpm}\end{array}$ \\
\hline $\begin{array}{l}\text { Emergency Generator } \\
\text { Gas Turbine Generator } \\
\end{array}$ & $\begin{array}{l}\text { Diesel Driven, } 1050 \mathrm{~kW} \\
2 \text { ea., 32MW, GE LM 2500+ }\end{array}$ \\
\hline $\begin{array}{l}\text { BUILDINGS } \\
\text { Administration Office/Control Center } \\
\text { Compressor Building } \\
\text { Warehouse/Maintenance Building }\end{array}$ & $10,000 \mathrm{ft} 2$ \\
\hline $\begin{array}{l}\text { MARINE FACILITY } \\
\text { Traditional Jetty } \\
\text { Platform and Topworks } \\
\text { Berth, walkways and dolphins } \\
\text { LNG Unloading Arms } \\
\text { Vapor Ret. Unloading Arm }\end{array}$ & $\begin{array}{l}320 \text { meter ship accommodation } \\
3 \text { ea. } 16 " \text { Dia } \\
10,500 \mathrm{~m} 3 / \mathrm{hr}, 16 " \mathrm{D}\end{array}$ \\
\hline
\end{tabular}


Attachment III 


\title{
FINAL REPORT
}

\section{Thermal Analyses of LNG Heat Exchangers}

\author{
Report submitted to CGI
}

By

William J. Thomson

Chemical Engineering Consultant

February 28, 2003

\section{SUMMARY}

The operation of a double pipe heat exchanger to heat high pressure LNG prior to storage in a salt dome, has been simulated using an "in-house computer code in combination with the Peng-Robinson Equation of State for prediction of the dense gas LNG properties. The robustness of the code was compared to the predictions of a Computational Fluid Dynamics code (CFD-ACE) and it was found to adequately corroborate the in-house simulation code. However, the question of the uncertainty in the heat transfer coefficient correlation still remains. The simulation was used to conduct a parametric study of the effects of various system parameters; specifically,

Flow ratio of Warmant/LNG: $2.25-3.75, \mathrm{~m}^{3} / \mathrm{m}^{3}$

Warmant inside pipe diameter: [0.279-0.356 m (11"-14")]

Fouling factor: $0-6.17 \mathrm{E}-4 \mathrm{~m}^{2}-\mathrm{K} / \mathrm{W}\left(0.0035 \mathrm{ft}^{2}-\mathrm{h}-\mathrm{F} / \mathrm{BTU}\right)$

Inlet LNG temperature: $116 \mathrm{~K}-172 \mathrm{~K}\left(-250{ }^{0} \mathrm{~F},-150{ }^{0} \mathrm{~F}\right)$

Warmant inlet temperature: $294 \mathrm{~K}-311 \mathrm{~K}\left(70^{\circ} \mathrm{F}-100\right)$

The parametric study assumed a stainless steel pipe with an inside diameter of $0.168 \mathrm{~m}$ (6"schedule 80 pipe). In addition to the parametric study, a separate evaluation was also conducted for the effects of pipe wall thickness, co-current versus counter current flow, seawater versus fresh water and multiple injections.

While the design of the heat exchange system has not been optimized, the results of the parametric study have succeeded in narrowing the design parameters. For example, it was found that: (1) flow ratios between 2.5 and 3.0 are necessary to be able to heat the LNG to $255 \mathrm{~K}\left(0^{\circ} \mathrm{F}\right)$ or above, in a pipe length of $762 \mathrm{~m}(2500 \mathrm{ft}),(2)$ a thinner walled pipe halves the length of pipe necessary to reach $255 \mathrm{~K}$, (3) due to increased ice formation, counter-current flow has only a small advantage over co-current flow, (4) multiple injections of fresh warmant are advantageous, with $50 \%$ replacement at mid-length resulting in the heating of the LNG to $277 \mathrm{~K}$ in a pipe length of $762 \mathrm{~m}(2500 \mathrm{ft})$, and (5) a mixed, co-current/counter current midpoint injection is able to heat the LNG to $277 \mathrm{~K}$ in a pipe length of $50.9 \mathrm{~m}(2003 \mathrm{ft})$. 
Under these flow conditions it has been determined that conduction through the pipe wall and/or through a fouling deposit or ice layer is the controlling heat transfer resistance. Thus, maximum heat transfer efficiency will be obtained by employing clean pipes, avoiding significant ice formation and utilizing the thinnest pipe walls that are compatible with the expected fluid pressures. Consequently, seawater as the warmant has an advantage over fresh water in that it is less prone to ice formation. Because of the need for flow ratios of 2.5 or greater, the avoidance of excessive pressure drops on the warmant side of the exchanger, will require warmant pipe diameters of at least $0.305 \mathrm{~m}$ (12").

\section{RESULTS}

\section{$\underline{\text { Simulation Approach }}$}

Because the HYSYS simulation code is not set up for double pipe heat exchanger configurations of the type employed in this application, we have developed a "stand alone" computer code, running on MatLab, in order to calculate the heat transfer and pressure losses in a co-current or counter-current, double pipe heat exchanger. The code employs LNG properties derived from the HYSYS software package, which are based on the Peng-Robinson equation of state. The code is iterative, since it accounts for ice formation, variable fluid properties and counter-current flow. While the energy balances predicted by this code can be closed to within $99.9 \%$, the calculations are based on the Dittus-Boelter heat transfer coefficient correlation, which is the same correlation used in HYSYS. However, the Reynolds numbers of the flows used here extend beyond those upon which the original correlation was based. Consequently, we have compared the heat transfer predictions of our code with that predicted by the CFD-ACE computational fluid dynamics code. In a preliminary simulation, using a very coarse finite volume grid, it was found that the CFD code consistently under-predicted the heat transfer rates calculated by the in-house code. For example, the warmant temperature drop over the first $50 \mathrm{~m}$ of the pipe was calculated to be about $1 \mathrm{~K}$, less than that predicted by the in-house code. Unfortunately, there was not sufficient time in this phase of the project to do a complete CFD simulation, which would require a much finer grid in order to obtain an accurate simulation. Figure 1 shows the radial temperature profile predicted by the CFD code at a point 10 meters downstream of the exit. In this figure, the y-axis values up to $0.0841 \mathrm{~m}$ are in the LNG and the values above $0.0951 \mathrm{~m}$ are in the warmant. As can be seen, the profile is very flat across the two fluids, as would be expected for turbulent flow, and there is a large gradient across the pipe wall.

\section{$\underline{\text { Parametric Study }}$}

Figures 2 and 3 show selective properties (bulk temperatures, pressures, and ice thickness) as a function of the exchanger length for the "base case" run, which is defined as: 


\section{Base Case}

Inlet LNG temperature $=116 \mathrm{k}(-250 \mathrm{~F})$, Inlet water temperature $=300 \mathrm{k}(80 \mathrm{~F})$, volumetric flow ratio $=2.25$, fouling $=0.0000$ Warmant inside diameter $=11 \mathrm{in}(0.279 \mathrm{~m})$, LNG inside pipe diameter $=0.168 \mathrm{~m}$ ( 6 " schedule 80 ) stainless with wall thickness $=.011 \mathrm{~m}(0.432$ in)

As can be seen, the LNG temperature barely reaches $0{ }^{\circ} \mathrm{F}(255 \mathrm{~K})$ at a length of $3000 \mathrm{ft}$. (914 $\mathrm{m})$. This is due to the continuous build-up of ice on the outer diameter of the inner tube. In addition, with the inlet pressure arbitrarily fixed at $1000 \mathrm{psi}(6.89 \mathrm{Mpa})$, the pressure drop on the water-side of the exchanger is about 340 psi ( $2.34 \mathrm{MPa})$.

Figures 3-7 show the results of the parametric study, providing the length required for the LNG to reach $0{ }^{\circ} \mathrm{F}(255 \mathrm{~K})$ and the warmant side pressure drop as a function of flow ratio and fouling factor. Of course the pressure drop is independent of fouling, since the fouling thickness would be much less than the pipe diameter. For purposes of presenting the parametric results, the exit LNG temperature was chosen to be $0{ }^{\circ} \mathrm{F}(255 \mathrm{~K})$, since it was not possible to reach $40{ }^{\circ} \mathrm{F}(277 \mathrm{~K})$ in many of the cases. As noted above, the warmant pressure drops are large for a warmant pipe diameter of $11 "(0.279 \mathrm{~m})$ and it appears that a $12 "(0.305 \mathrm{~m})$ diameter may provide a trade-off between heat transfer (pipe length required) and pressure drop. Another factor of interest in these plots is the influence of the resistance to heat transfer exerted by the inner pipe wall in combination with fouling. This can be seen in the dependence of length on flow ratio as the warmant pipe diameter and fouling factor increases. For example, at low flow ratios in the 14" $(0.356 \mathrm{~m})$ warmant pipe diameter, there is little difference in the dependence of length required to reach $0{ }^{\circ} \mathrm{F}(255 \mathrm{~K})$ on the fouling factor. This is because the convective resistance to heat transfer becomes the dominant resistance under these conditions.

The effect of flow ratio and warmant pipe diameter on length (to reach $0{ }^{\circ} \mathrm{F}$ ) and warmant pressure drop, can be more clearly seen in the cross-plots of Figures 8 and 9. These plots can be used to determine the optimum trade-off between heat transfer (length required) and pressure drop.

\section{Effect of Inlet LNG Temperature}

Table 1 shows the effect of the inlet LNG temperature for the base case. As can be seen, the length to reach $0{ }^{\circ} \mathrm{F}(255 \mathrm{~K})$ is a strong function of the inlet LNG temperature. In fact, $0{ }^{\circ} \mathrm{F}$ cannot be reached for the base case (inlet LNG temperature $=-250{ }^{\circ} \mathrm{F}, 116 \mathrm{~K}$ ), but the required length drops by a factor of two, if the inlet LNG temperature is increased by $50{ }^{\circ} \mathrm{F}(27.8 \mathrm{~K})$. In addition, an increase of $90{ }^{\circ} \mathrm{F}(50 \mathrm{~K})$ in the inlet temperature, allows the $\mathrm{LNG}$ to reach $40^{\circ} \mathrm{F}(274 \mathrm{~K})$ in a $2500 \mathrm{ft}(762 \mathrm{~m})$ long pipe.

\section{Effect of Warmant Freezing Temperature}

Figure 10 shows the effect of using seawater (freezing point $=271 \mathrm{~K}, 28{ }^{\circ} \mathrm{F}$ ) versus fresh water (freezing point $=273 \mathrm{~K}, 32{ }^{\circ} \mathrm{F}$ ) on the LNG temperature and ice thickness versus pipe length. As can be seen, the LNG temperature at a $2500 \mathrm{ft}$ (762 m) length reaches -4 ${ }^{\circ} \mathrm{F}(253 \mathrm{~K})$ when using fresh water, but reaches $13{ }^{\circ} \mathrm{F}(262 \mathrm{~K})$ when seawater is used as 
the warmant. The primary reason for this is that ice formation in the case of seawater occurs $500 \mathrm{ft}(152 \mathrm{~m})$ further down the pipe and reaches a thickness of only 0.05 " $(0.0013 \mathrm{~m})$, whereas it reaches a thickness of $0.225 "(0.0057 \mathrm{~m})$ in the case of fresh water.

TABLE 1

Effect of Inlet LNG Temperature for Base Case ${ }^{1}$ [Fresh water, no fouling]

\begin{tabular}{|c|c|c|c|c|c|c|c|c|}
\hline Case & $\begin{array}{c}\text { TLNG } \\
\text { INLET } \\
\left({ }^{0} \mathrm{~F}\right) \\
\end{array}$ & $\begin{array}{c}\triangle \mathrm{P} H 2 \mathrm{O} \\
@ 2500 \mathrm{ft} \\
(\mathrm{psi})\end{array}$ & $\begin{array}{c}\triangle P \text { LNG } \\
@ 2500 f t \\
(p s i)\end{array}$ & $\begin{array}{c}\text { Tout H2O } \\
@ 2500 \mathrm{ft} \\
\left({ }^{0} \mathrm{~F}\right)\end{array}$ & $\left(\begin{array}{c}\mathrm{L} \\
\left(0^{0} \mathrm{~F}\right)\end{array}\right.$ & $\begin{array}{c}\mathrm{L} \\
\left(@ 40{ }^{0} \mathrm{~F}\right) \\
T @ 2500\end{array}$ & $\begin{array}{c}\text { ICE } \\
\text { Max Thick } \\
\text { (in) }\end{array}$ & $\begin{array}{c}\text { Ice } \\
\text { Length } @ \\
(\mathrm{ft})\end{array}$ \\
\hline 1 & -250 & 268 & 106 & 33 & - & -4 & 0.2301 & $150->$ \\
\hline 2 & -240 & 259 & 108 & 33 & 1988 & 6 & 0.1499 & $425->$ \\
\hline 3 & -235 & 255 & 109 & 34 & 1750 & 11 & 0.1084 & $500->$ \\
\hline 4 & -230 & 251 & 110 & 34 & 1581 & 16 & 0.0644 & 625-> \\
\hline 5 & -225 & 248 & 111 & 34 & 1455 & 21 & 0.0241 & $800->$ \\
\hline 6 & -220 & 245 & 112 & 34 & 1379 & 25 & & \\
\hline 7 & -200 & 245 & 108 & 38 & 1234 & 30 & & \\
\hline 8 & -180 & 245 & 105 & 41 & 1099 & 35 & & \\
\hline 9 & -160 & 244 & 100 & 45 & 972 & 40 & & \\
\hline 10 & -150 & 244 & 98 & 47 & 911 & 42 & & \\
\hline
\end{tabular}

${ }^{1}$ For SI units: $-250^{\circ} \mathrm{F}=116 \mathrm{~K}, 260 \mathrm{psi}=1.79 \mathrm{Mpa}, 106 \mathrm{psi}=0.71 \mathrm{Mpa}, 33^{\circ} \mathrm{F}=274 \mathrm{~K},-4^{0} \mathrm{~F}=$ $253 \mathrm{~K}, 0.2301 \mathrm{in}=5.84 \mathrm{E}-03 \mathrm{~m}, 150 \mathrm{ft}=45.7 \mathrm{~m}$

\section{The Effect of Multiple Injections - Co-Current Flow}

The effect of warmant inlet temperature and one additional warmant injection (at the midpoint) is shown in Table 2, using seawater as the warmant. The table lists the results in the co-current heat exchanger, showing the effect of warmant inlet temperature (100 ${ }^{\circ} \mathrm{F}, 311 \mathrm{~K}$ vs. $80{ }^{\circ} \mathrm{F}, 300 \mathrm{~K}$ ) and of a second injection at the mid-point. Four separate cases are shown for the latter; with the injected quantity of warmant expressed as a percentage of the inlet warmant flow, with values from $30-100 \%$. Case 1 is the seawater base case run and, as can be seen, preheating the warmant to $100{ }^{\circ} \mathrm{F}$, allows the LNG to reach $40{ }^{\circ} \mathrm{F}(277 \mathrm{~K})$ at a length of $2500 \mathrm{ft}(762 \mathrm{~m})$. This seems like a very advantageous way to go, since it is a big improvement over the case with freshwater inlet at $80^{\circ} \mathrm{F}$. Notice that there is no ice formation when the warmant is preheated. In the case of a second injection, replacing the warmant with $50 \%$ of the original flow allows the LNG to reach $40{ }^{\circ} \mathrm{F}$ at a length of $2500 \mathrm{ft}$. It also reduces the warmant pressure drop from $244 \mathrm{psi}$ (1.68 Mpa), for $100 \%$ injection to $155 \mathrm{psi}(1.07 \mathrm{Mpa})$.

TABLE 2 


\section{Effect of Inlet Warmant Temperature and Warmant Injection for Base Case}

[Sea Water, No Fouling] ${ }^{2}$

\begin{tabular}{|c|c|c|c|c|c|c|c|c|}
\hline Case & $\begin{array}{l}\% \text { Warmant } \\
\text { Replaced }^{1}\end{array}$ & $\begin{array}{c}\text { Warmant } \\
\text { INLET }\end{array}$ & $\begin{array}{l}\text { Tout H2O } \\
@ 2500 f t\end{array}$ & $\begin{array}{l}\mathrm{L} @ \\
0{ }^{\circ} \mathrm{F}\end{array}$ & $\begin{array}{c}\left.\mathrm{L} @ 40^{\circ} \mathrm{F}\right) \\
T @ 2500\end{array}$ & $\begin{array}{c}\text { Warman } \\
\text { Delta P } \\
\text { Psi }\end{array}$ & $\begin{array}{c}\text { ICE } \\
\text { Max Thick }\end{array}$ & $\begin{array}{c}\text { Ice } \\
\text { Length }\end{array}$ \\
\hline 1 & 0 & $80^{\circ} \mathrm{F}$ & $33^{\circ} \mathrm{F}$ & - & $-4^{\circ} \mathrm{F}$ & - & $0.2301 "$ & $150->$ \\
\hline 2 & 0 & 100 & 44 & $1281 \mathrm{ft}$ & 40 & - & None & - \\
\hline 3 & $30 \%$ & 80 & 44 & 1500 & 30 & 135 & 0.009 & $750->1250$ \\
\hline 4 & $40 \%$ & 80 & 50 & 1477 & 36 & 145 & 0.009 & $750->1250$ \\
\hline 5 & $50 \%$ & 80 & 55 & 1463 & 2500 & 155 & 0.009 & $750->1250$ \\
\hline 6 & $100 \%$ & 80 & 66 & 1435 & 2117 & 244 & 0.009 & $750->1250$ \\
\hline
\end{tabular}

1 Warmant totally replaced at midpoint with various quantities of fresh warmant at $80 \mathrm{~F}$

2 For SI units: $80^{\circ} \mathrm{F}=300 \mathrm{~K}, 33^{\circ} \mathrm{F}=274 \mathrm{~K}, 135 \mathrm{psi}=0.93 \mathrm{Mpa}, 106 \mathrm{psi}=0.71 \mathrm{Mpa},,-4{ }^{0} \mathrm{~F}=$ $253 \mathrm{~K}, 0.2301 \mathrm{in}=5.84 \mathrm{E}-03 \mathrm{~m}, 150 \mathrm{ft}=45.7 \mathrm{~m}$

\section{Counter-Current Heat Exchange}

A separate analysis was also conducted for counter-current heat exchange, using seawater as the warmant. Since the simulation program for the counter-current case employs an explicit algorithm, it is first necessary to estimate the warmant exit temperature (cold end of the exchanger). This is done by assuming the exit LNG temperature reaches $40{ }^{\circ} \mathrm{F}(274$ $\mathrm{K})$, and then calculating an overall energy balance to estimate the exit warmant temperature. The calculations then start at that end and proceed until the specified inlet warmant temperature is reached. Because enthalpies are also a function of pressure, and a particular set of input parameters may not lead to a feasible solution, this process is iterative. At that point, the exit warmant temperature is reset and the calculations are repeated.

The results of the simulation for 10 separate cases are shown below in Table 3 . The cases where a particular input parameter was varied, are identified in color. In a number of cases, it is not possible to reach even $0^{0} \mathrm{~F}(255 \mathrm{~K})$, within $3500 \mathrm{ft}(1,069 \mathrm{~m})$, and these are listed in the table as being "not feasible". The pressure drops are listed for the length required to attain either $40{ }^{\circ} \mathrm{F}$ or $0{ }^{0} \mathrm{~F}(274 \mathrm{~K}$ or $255 \mathrm{~K})$. The only available direct comparison between the co-current and counter-current exchanger with seawater is for the base case. In the case of the base case for the co-current exchanger, the LNG could only reach $-4{ }^{0} \mathrm{~F}(253 \mathrm{~K})$ at a length of $2500 \mathrm{ft}(762 \mathrm{~m})$. However, as can be seen from the first case in Table $1,0{ }^{0} \mathrm{~F}$ can be reached at a length of $2285 \mathrm{ft}(696 \mathrm{~m})$ in the countercurrent configuration. It should be noted, that in comparison to the co-current operation, ice formation is present in every counter-current run, persisting over most of the exchanger and reaching thicknesses as large as $1.1 "(0.00279 \mathrm{~m})$. This is a consequence of low warmant temperatures at the cold end of the exchanger. It should also be kept in mind that all the calculations in Table 3, assume no fouling on the warmant side of the inner pipe. Whereas the inlet warmant temperature has a very large effect in co-current operation, preheating the LNG to $-200{ }^{\circ} \mathrm{F}(144 \mathrm{~K})$ had the biggest advantage in the 
counter-current operation, requiring only $2328 \mathrm{ft}(71 \mathrm{~m})$ to reach $\left.40{ }^{0} \mathrm{~F} 274 \mathrm{~K}\right)$. Note that this run resulted in the least ice formation of all the runs listed in Table 3.

TABLE 3

\section{Counter-current Heat Exchanger: Effect of Parameters ${ }^{1}$ [Seawater, No Fouling]}

\begin{tabular}{|c|c|c|c|c|c|c|c|c|c|}
\hline \multicolumn{4}{|c|}{ INPUT } & \multicolumn{6}{|c|}{ RESULTS } \\
\hline $\begin{array}{c}\text { Equiv. } \\
\text { Flowratio } \\
\end{array}$ & $\begin{array}{l}\text { Warmant } \\
\text { Diameter }\end{array}$ & $\begin{array}{c}\text { Warmant } \\
\mathbf{T} \\
\end{array}$ & $\begin{array}{c}\text { LNG } \\
\text { Inlet T } \\
\end{array}$ & $\begin{array}{c}\mathrm{L} @ 40^{\circ} \mathrm{F} \\
(\mathrm{ft})\end{array}$ & $\begin{array}{c}\mathbf{L} @ 0^{\circ} \mathrm{F} \\
(\mathrm{ft})\end{array}$ & $\begin{array}{c}\text { LNG }^{2} \\
\Delta \mathbf{P}(\mathrm{psi})\end{array}$ & $\begin{array}{c}\mathrm{H}^{2} \mathrm{O}^{2} \\
\Delta \mathrm{P}(\mathrm{psi})\end{array}$ & $\begin{array}{c}\text { ice max } \\
\text { thick (in) }\end{array}$ & $\begin{array}{c}\text { icing } \\
\text { Interval (ft) }\end{array}$ \\
\hline 2.25 & 11 in & $80^{\circ} \mathrm{F}$ & $-250^{\circ} \mathrm{F}$ & - & 2285 & 71 & 325 & 0.911 & $0->1435$ \\
\hline 2.25 & 12 & 80 & -250 & - & 2716 & 82 & 186 & 1.159 & $0->1925$ \\
\hline 2.25 & 12 & 70 & -250 & NOT Feasible & - & - & - & - & - \\
\hline 2.25 & 12 & 80 & -250 & - & 2716 & 82 & 186 & 1.159 & $0->1925$ \\
\hline 2.25 & 12 & 90 & -250 & 2681 & 2178 & 101 & 139 & 0.569 & $0->1365$ \\
\hline 2.25 & 12 & 80 & -250 & NOT Feasible & - & - & - & - & - \\
\hline 2.5 & 12 & 80 & -250 & 3317 & 2736 & 121 & 258 & 1.102 & $0->1925$ \\
\hline 2.75 & 12 & 80 & -250 & $\sim 2590$ & 2035 & 100 & 190 & 0.409 & $0->1190$ \\
\hline 2.25 & 12 & 80 & -250 & NOT Feasible & - & - & - & - & - \\
\hline 2.25 & 12 & 80 & -200 & 2328 & 1770 & 79 & 113 & 0.347 & $0->1050$ \\
\hline 2.75 & 12 & 80 & -250 & $\sim 2590$ & 2035 & 100 & 190 & 0.409 & $0->1190$ \\
\hline 2.75 & 13 & 80 & -250 & 2992 & 2395 & 114 & 118 & 0.539 & $0->1610$ \\
\hline 2.25 & 11 & 70 & -250 & NOT Feasible & - & - & - & - & - \\
\hline 2.25 & 11 & 90 & -250 & 2797 & 2285 & 104 & 371 & 0.913 & $0->1435$ \\
\hline
\end{tabular}

1 For SI units: $11^{\prime \prime}=(0.028 \mathrm{~m}),-250^{\circ} \mathrm{F}=116 \mathrm{~K}, 33^{\circ} \mathrm{F}=274 \mathrm{~K}, 71 \mathrm{psi}=0.49 \mathrm{Mpa}, 325 \mathrm{psi}$ $=2.24 \mathrm{Mpa}, 0.991 \mathrm{in}=0.025 \mathrm{~m}, 1435 \mathrm{ft}=437 \mathrm{~m}$

${ }^{2}$ At the length required for the LNG to reach $40{ }^{0} \mathrm{~F}$, or $0{ }^{0} \mathrm{~F}$

Thus, on the basis of these calculations, it appears that while counter-current operation is advantageous due to the higher overall temperature driving force for heat transfer, the low temperatures for both warmant and LNG at the cold end of a counter-current exchanger is a distinct disadvantage, due to the relatively large formation of ice over much of the exchanger length. The net trade-off between these two factors appears to be positive. That is, counter-current lengths are somewhat less than co-current lengths, but the effect is not very large. However, ice would be less of a problem if the warmant side of the inner pipe became fouled.

Effect of Pipe Wall Thickness 
The effect of the pipe wall thickness was evaluated by comparing the results for a AL6XN pipe, with a wall thickness of $0.0056 \mathrm{~m}(0.219$ ") versus the 6 " schedule 80 stainless steel pipe with a thickness of $0.011 \mathrm{~m}(0.432$ "), utilizing seawater under base case conditions, but with a flow ratio of 2.5 and a warmant pipe diameter of 12 ". These results are shown below in Table 4 along with a comparison of the same conditions with the thicker walled pipe. As can be seen, the thinner pipe wall reaches $0{ }^{\circ} \mathrm{F}(255 \mathrm{~K})$ in about half the distance required for the thicker pipe wall, although neither pipe is able to reach $40{ }^{\circ} \mathrm{F}(277 \mathrm{~K})$ in a length of $3500 \mathrm{ft}(1067 \mathrm{~m})$.

TABLE 4

Effect of Pipe Wall Thickness ${ }^{1}$

[Base Case with Seawater, Flow ratio $=2.5,12$ " $(0.305 \mathrm{~m})$ Warmant Diameter]

\begin{tabular}{|c|c|c|c|c|c|c|c|c|}
\hline Case & $\begin{array}{l}\text { Pipe Wall } \\
\text { Thickness } \\
\text { (in) }\end{array}$ & $\left(\stackrel{\mathrm{L}}{\left.0^{0} \mathrm{~F}\right)}\right.$ & $T @ 3500 \mathrm{ft}$ & $\begin{array}{c}\Delta \mathrm{P} \mathrm{H} 2 \mathrm{O} \\
@ 0^{\circ} \\
(\mathrm{psi})\end{array}$ & $\begin{array}{c}\Delta \mathrm{P} \mathrm{H} 2 \mathrm{O} \\
@ 3500 \mathrm{ft} \\
(\mathrm{psi})\end{array}$ & $\begin{array}{c}\text { Tout } \mathrm{H} 2 \mathrm{O} \\
@ 3500 \mathrm{ft} \\
\left({ }^{0} \mathrm{~F}\right)\end{array}$ & $\begin{array}{c}\text { ICE } \\
\text { Max Thick } \\
\text { (in) }\end{array}$ & $\begin{array}{c}\text { Ice } \\
\text { Length } @ \\
\text { (ft) }\end{array}$ \\
\hline 1 & 0.432 & $2900 \mathrm{ft}$ & $10^{\circ} \mathrm{F}$ & 112 & 205 & 33.2 & 0.02 & $0->1500$ \\
\hline 2 & 0.219 & 1505 & $30^{\circ} \mathrm{F}$ & 98 & 200 & 31.6 & None & - \\
\hline
\end{tabular}

$1^{1}$ For SI units: $0.432 "=(0.011 \mathrm{~m}), 2900 \mathrm{ft}=884 \mathrm{~m}, 10^{\circ} \mathrm{F}=261 \mathrm{~K}, 112 \mathrm{psi}=0.77 \mathrm{MPa}, 205 \mathrm{psi}$ $=1.41 \mathrm{Mpa}, 33.2^{\circ} \mathrm{F}=273.7 \mathrm{~K}, 0.02 \mathrm{in}=5.1 \mathrm{E}-4 \mathrm{~m}, 1500 \mathrm{ft}=457 \mathrm{~m}$

\section{Effect of Mixed Injection}

Given the fact that relatively large quantities of ice tend to form at the cold end of a counter-current exchanger but not in the co-current exchanger, a "mixed" injection scheme was evaluated. In this configuration, co-current flow was maintained up to a pipe length of $1250 \mathrm{ft}(38.1 \mathrm{~m})$ at which point, the configuration was changed to a countercurrent flow with fresh warmant. Table 5 compares these results for the thick walled pipe under base case conditions but at a flow ratio of 2.5 and a 12 " $(0.305 \mathrm{~m})$ warmant pipe diameter, with both co-current flow and counter-current flow. At the point where the configuration was changed from co-current flow to counter current flow (1250 ft, $381 \mathrm{~m})$, the LNG temperature had reached $-16^{\circ} \mathrm{F}(246 \mathrm{~K})$ and the warmant pressure drop was 70 psi $(0.48 \mathrm{Mpa})$. As can be seen from Table 5 , the mixed injection case is far superior; the LNG is heated to $40{ }^{\circ} \mathrm{F}(274 \mathrm{~K})$ in a length of $2033 \mathrm{ft}(620 \mathrm{~m})$, whereas the countercurrent case requires a length of $3317 \mathrm{ft}(1011 \mathrm{~m})$ and the co-current case is not able to reach $40{ }^{\circ} \mathrm{F}(274 \mathrm{~K})$ in a length of $3500 \mathrm{ft} .(1218 \mathrm{~m})$ In addition, the total warmant pressure drop is significantly lower in the mixed injection configuration, at $114 \mathrm{psi}(0.76$ $\mathrm{MPa})$, versus $258 \mathrm{psi}(1.78 \mathrm{MPa})$ in the counter-current configuration.

TABLE 5 


\section{Effect of Mixed Injection Heat Transfer ${ }^{1}$ \\ [Base Case with Seawater, Flow ratio $=2.5,12$ " $(0.305 \mathrm{~m})$ Warmant Diameter]}

\begin{tabular}{cccccccc} 
Case & Configuration & $\left(\begin{array}{c}\mathrm{L} \\
\left(0^{0} \mathrm{~F}\right)\end{array}\right.$ & $\begin{array}{c}\mathrm{T} @ 3500 \mathrm{ft} \\
4{ }^{\circ} \mathrm{F}\end{array}$ & $\begin{array}{c}\Delta \mathrm{P} H 2 \mathrm{H} \\
(\mathrm{psi})\end{array}$ & $\begin{array}{c}\Delta \mathrm{P} \text { LNG } \\
(\mathrm{psi})\end{array}$ & $\begin{array}{c}\text { Max Thick } \\
(\mathrm{in})\end{array}$ & $\begin{array}{c}\text { Icength } @ \\
(\mathrm{ft})\end{array}$ \\
\hline 1 & Mixed & $1433 \mathrm{ft}$ & $2033 \mathrm{ft}$ & $114^{2}$ & $91^{2}$ & None & - \\
2 & Co-current & 2900 & $10^{\circ} \mathrm{F}$ & $205^{3}$ & $172^{3}$ & None & - \\
3 & Counter-Current & 2736 & 3317 & $258^{4}$ & $121^{4}$ & 1.102 & $0->1925$
\end{tabular}

1 For SI units: $0{ }^{0} \mathrm{~F}=255 \mathrm{~K}, 1433 \mathrm{ft}=437 \mathrm{~m}, 2033 \mathrm{ft}=620 \mathrm{~m}, 114 \mathrm{psi}=0.76 \mathrm{MPa}, 91 \mathrm{psi}=$ $0.63 \mathrm{Mpa}$, , $1.102 \mathrm{in}=0.028 \mathrm{~m}, 1925 \mathrm{ft}=587 \mathrm{~m}$

2 At $2033 \mathrm{ft}$

3

At $3500 \mathrm{ft}$

4 At $3317 \mathrm{ft}$

\section{Conclusions and Recommendations}

No attempt was made in this study to optimize the heat exchanger design for heating the LNG to $0{ }^{\circ} \mathrm{F}$ or $40{ }^{\circ} \mathrm{F}$. Nevertheless, a number of preliminary design guidelines have emerged.

- Counter-current heat exchange, while providing for a larger temperature driving force over the total length of the exchanger, is prone to large ice depositions, which somewhat mitigates the effect of the larger temperature driving force.

- A inlet volumetric flow ratio (warmant/LNG) of at least 2.5 will be necessary to achieve the desired goals of heating the LNG to $40{ }^{\circ} \mathrm{F}$.

- The heat transfer resistance of the pipe wall is dominant, therefore the utilization of the thinnest pipe wall which is compatible with pressure considerations is advantageous.

- In order to avoid unacceptable pressure drops on the warmant-side of the exchanger, the warmant pipe diameter will have to be at least $12 "(0.305 \mathrm{~m})$.

- A mixed co/counter - current exchanger with warmant replacement at the switch point, appears to be desirable, avoiding ice formation at the cold end and providing for larger temperature driving forces at the hot end.

Once the economics have been clearly defined, the heat exchanger design should be optimized, allowing for uncertainties in the input parameters (fouling, heat transfer coefficients). The accuracy of the heat transfer coefficients should be ascertained, by 
optimizing the finite volume element grid in the CFD code so that it more accurately calculates transport conditions in the vicinity of the wall. 


\section{FIGURES}

FIGURE 1

Temperature profile predicted by CFD across a radial section of the exchanger at $10 \mathrm{~m}$ downstream from pipe entrance entrance.

(Temperature in $\mathrm{K}$; Y-Axis coordinate in $\mathrm{m}$; wall between 0.0841 and $0.0951 \mathrm{~m}$ )

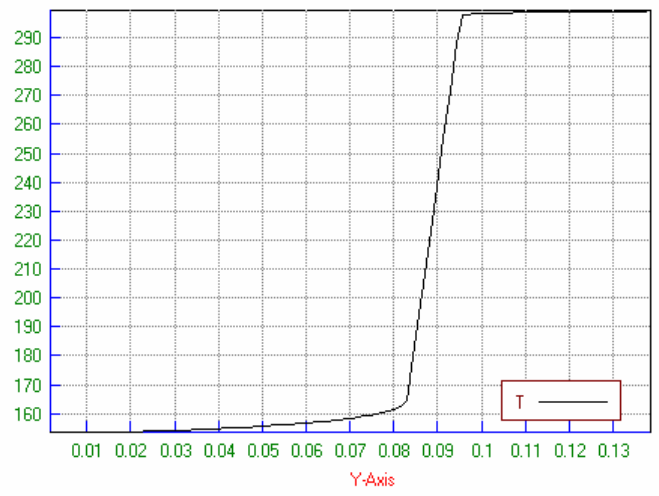

FIGURE 2

Axial Temperature and Pressure Gradients for "Base" Case
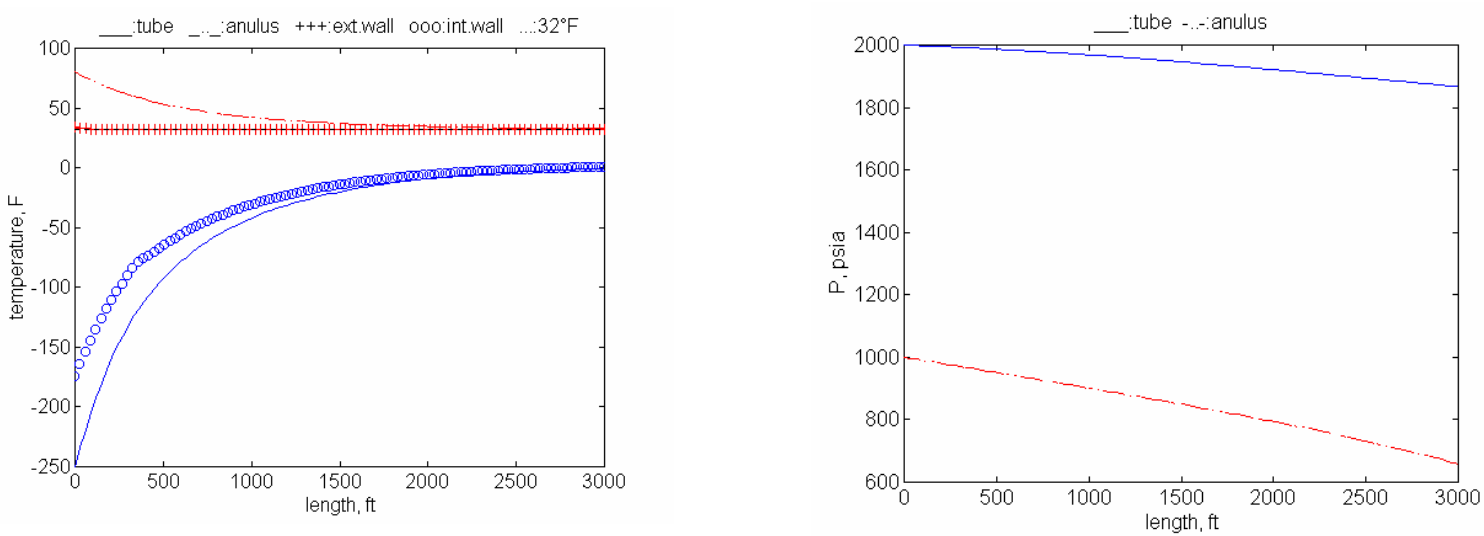

FIGURE 3

Ice Thickness versus Pipe Length for "Base" Case

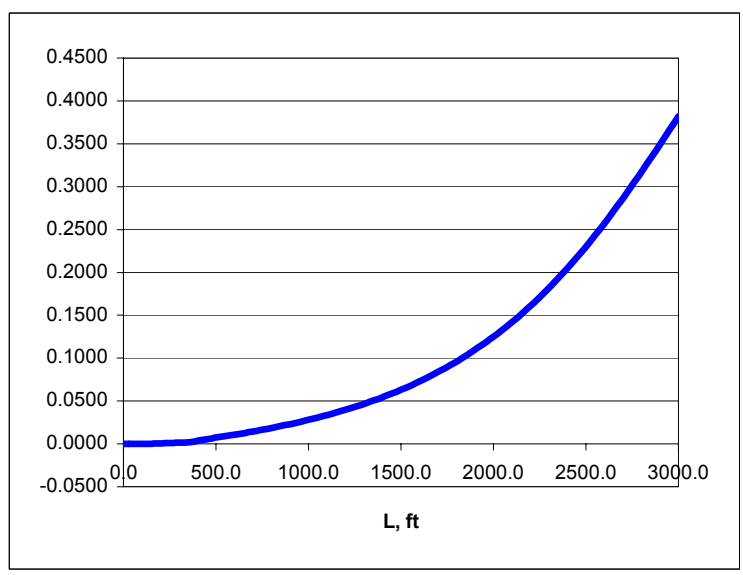


FIGURE 4

Length (to reach $0{ }^{\circ} \mathrm{F}$ ) and Warmant Pressure Drop vs, Flow Ratio

[Warmant Pipe Diameter $=11$ "]
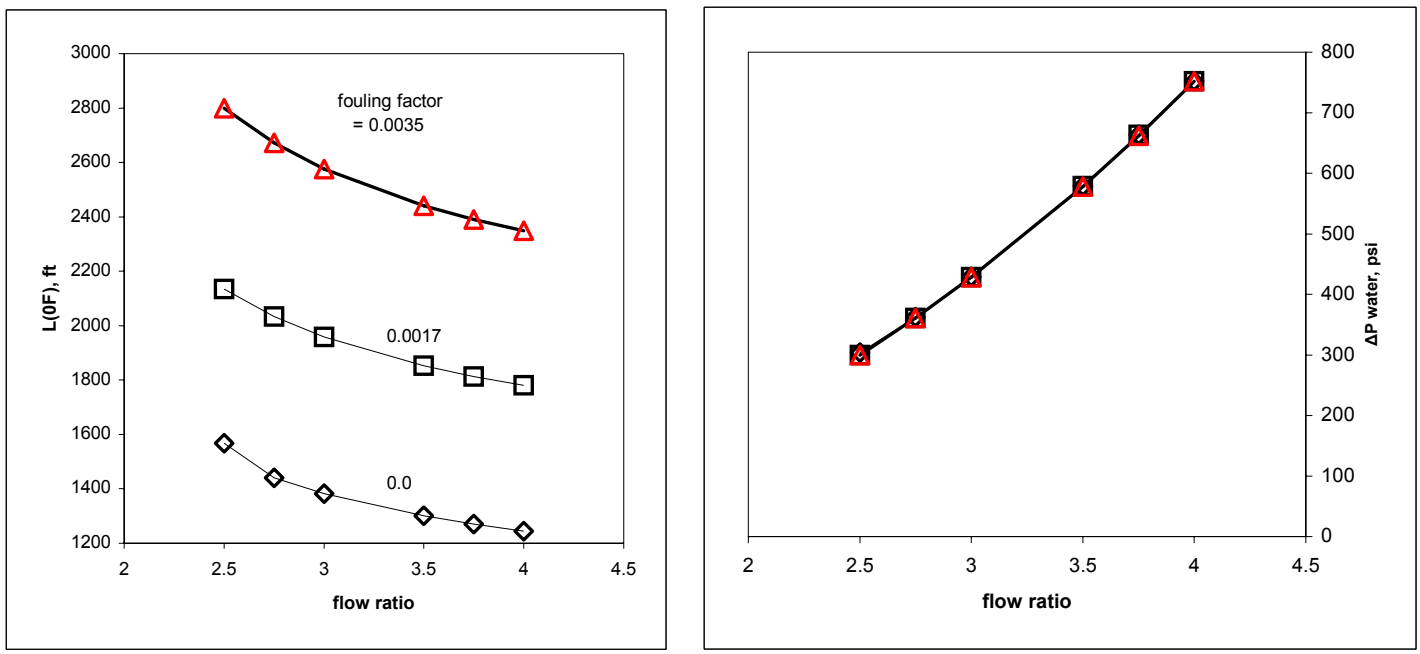

FIGURE 5

Length (to reach $0{ }^{\circ} \mathrm{F}$ ) and Warmant Pressure Drop vs, Flow Ratio

[Warmant Pipe Diameter = 12"]
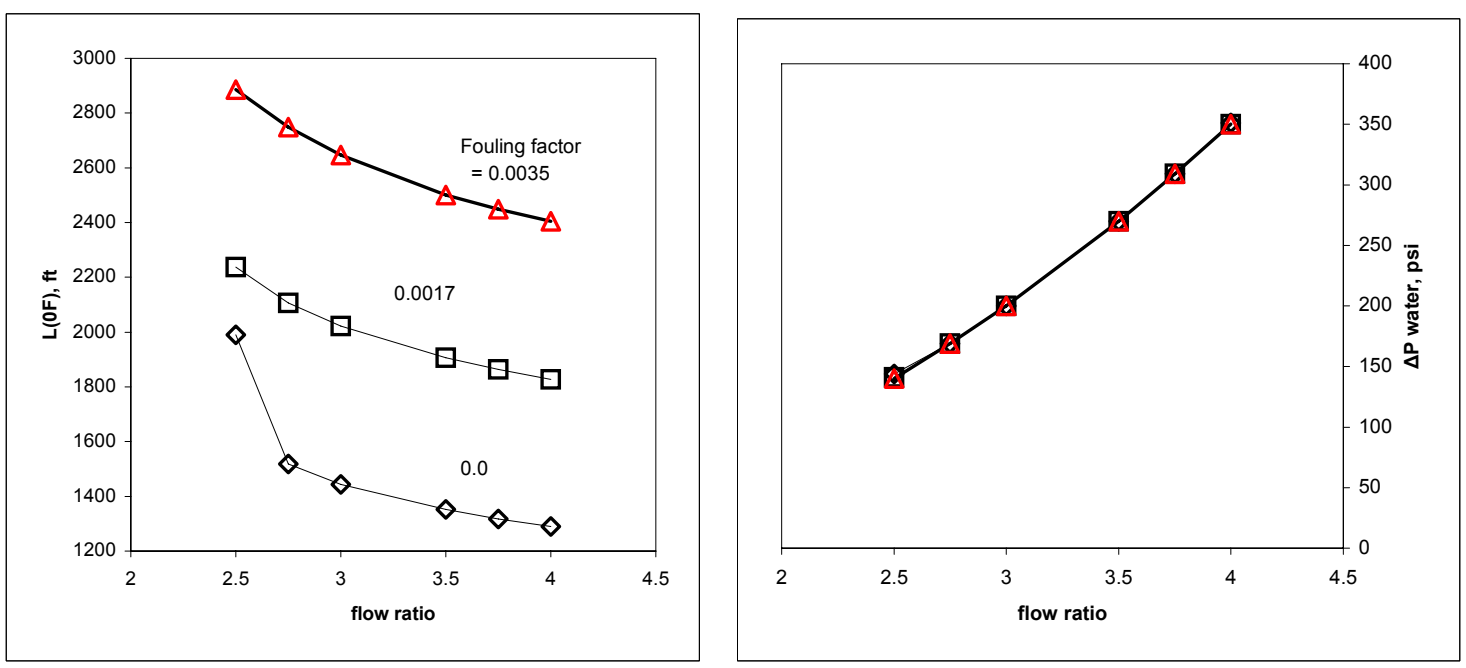
FIGURE 6

Length (to reach $0{ }^{\circ} \mathrm{F}$ ) and Warmant Pressure Drop vs, Flow Ratio

[Warmant Pipe Diameter $=13$ "]
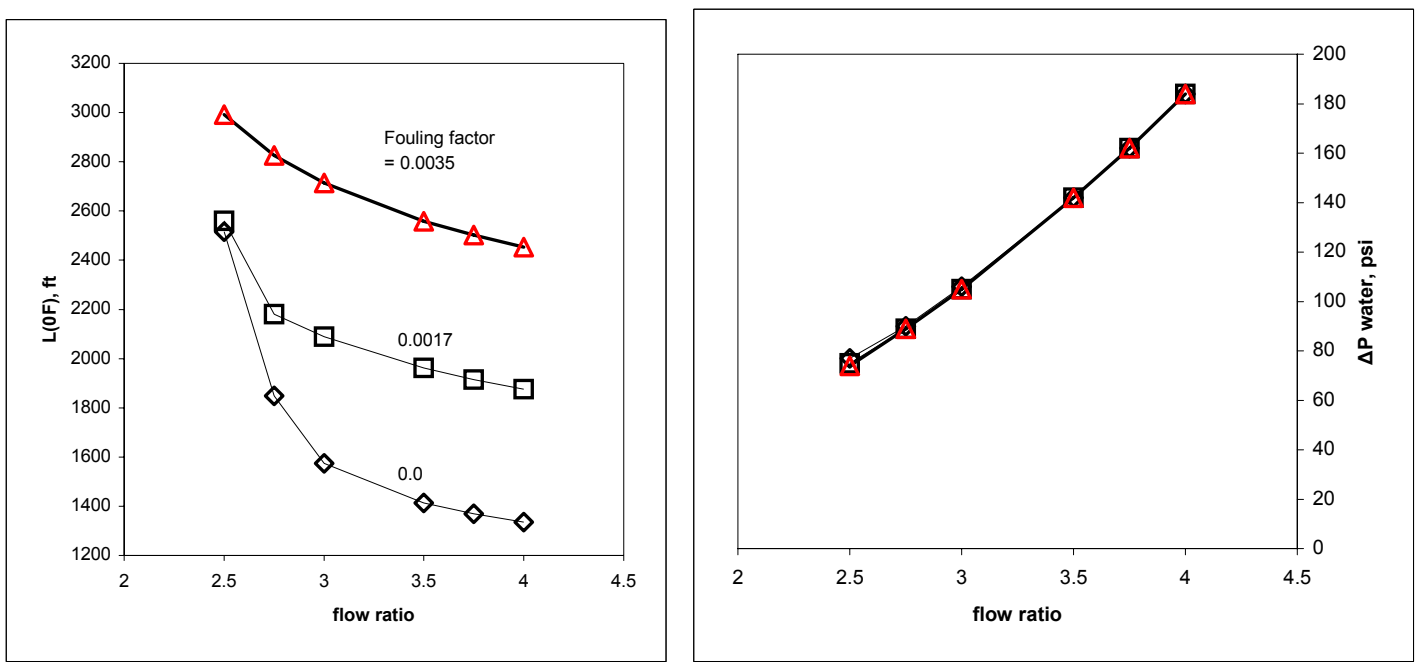

FIGURE 7

Length (to reach $0{ }^{\circ} \mathrm{F}$ ) and Warmant Pressure Drop vs, Flow Ratio

[Warmant Pipe Diameter $=14$ "]
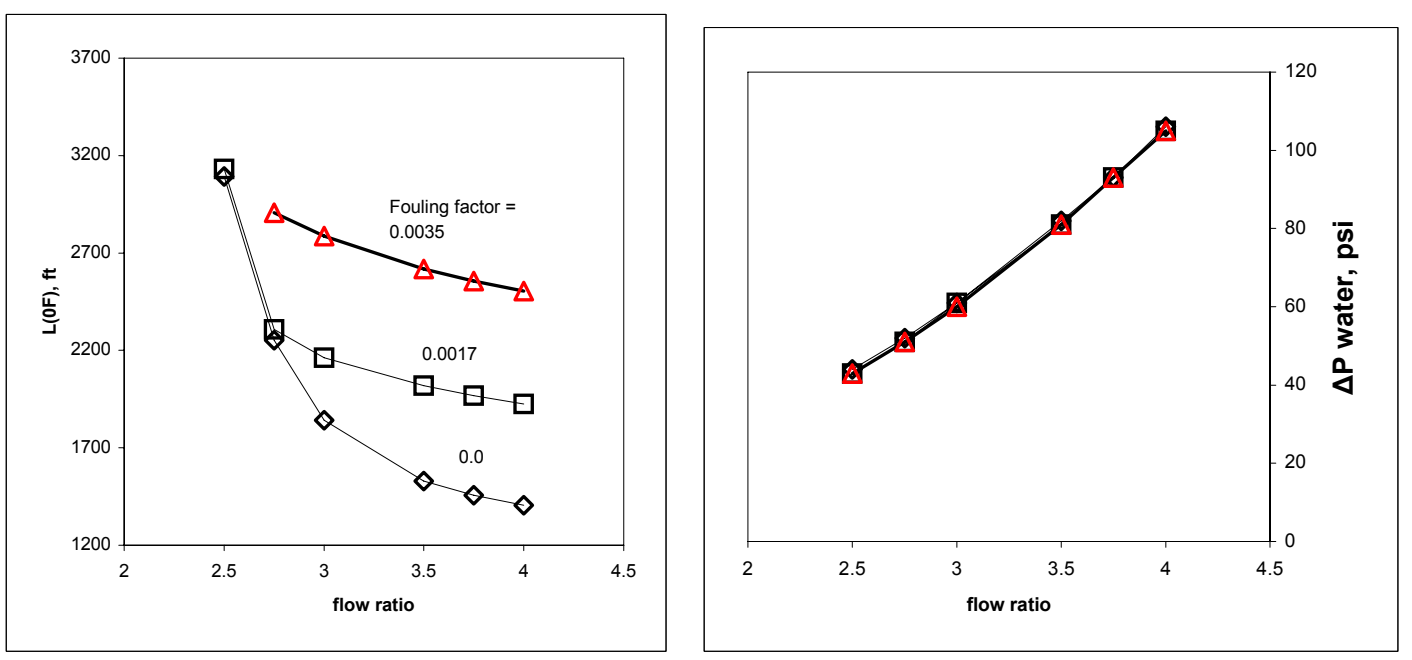
FIGURE 8

Effect of Warmant Diameter and Flow Ratio on Length

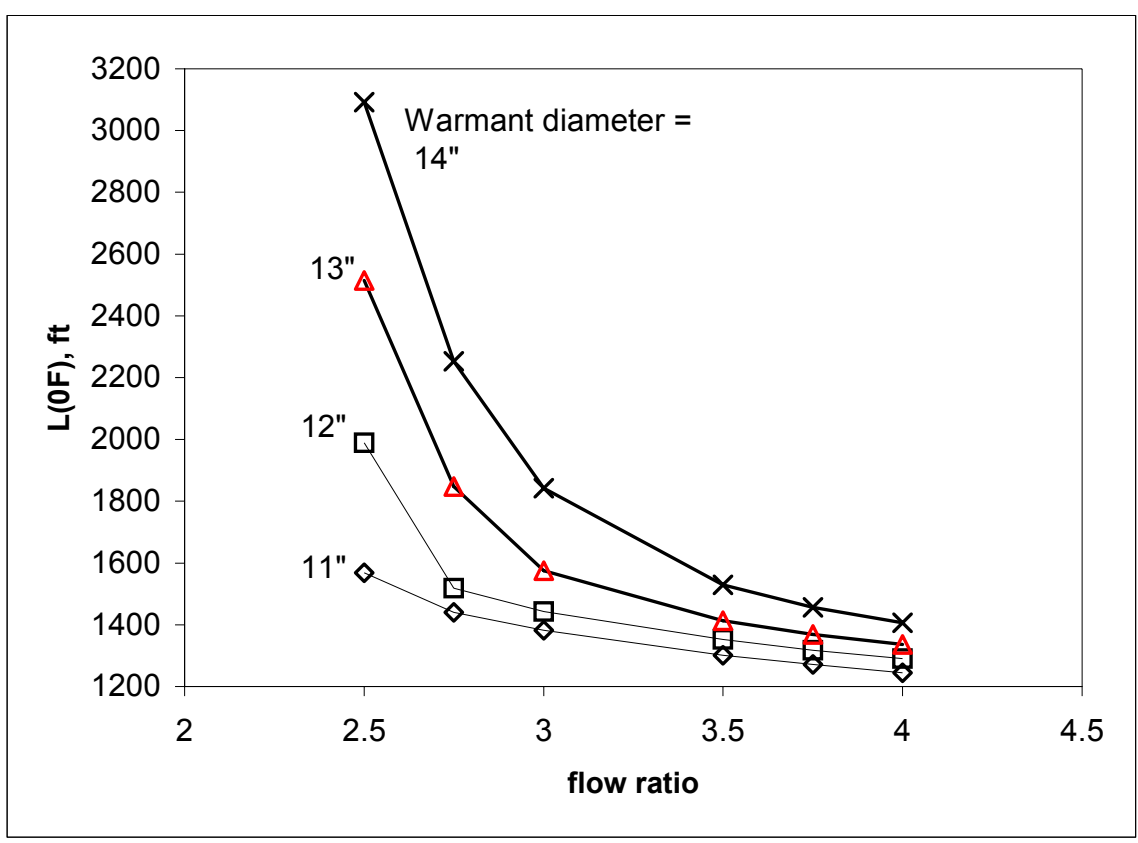

FIGURE 9

Effect of Warmant Diameter and Flow Ratio on Pressure Drop

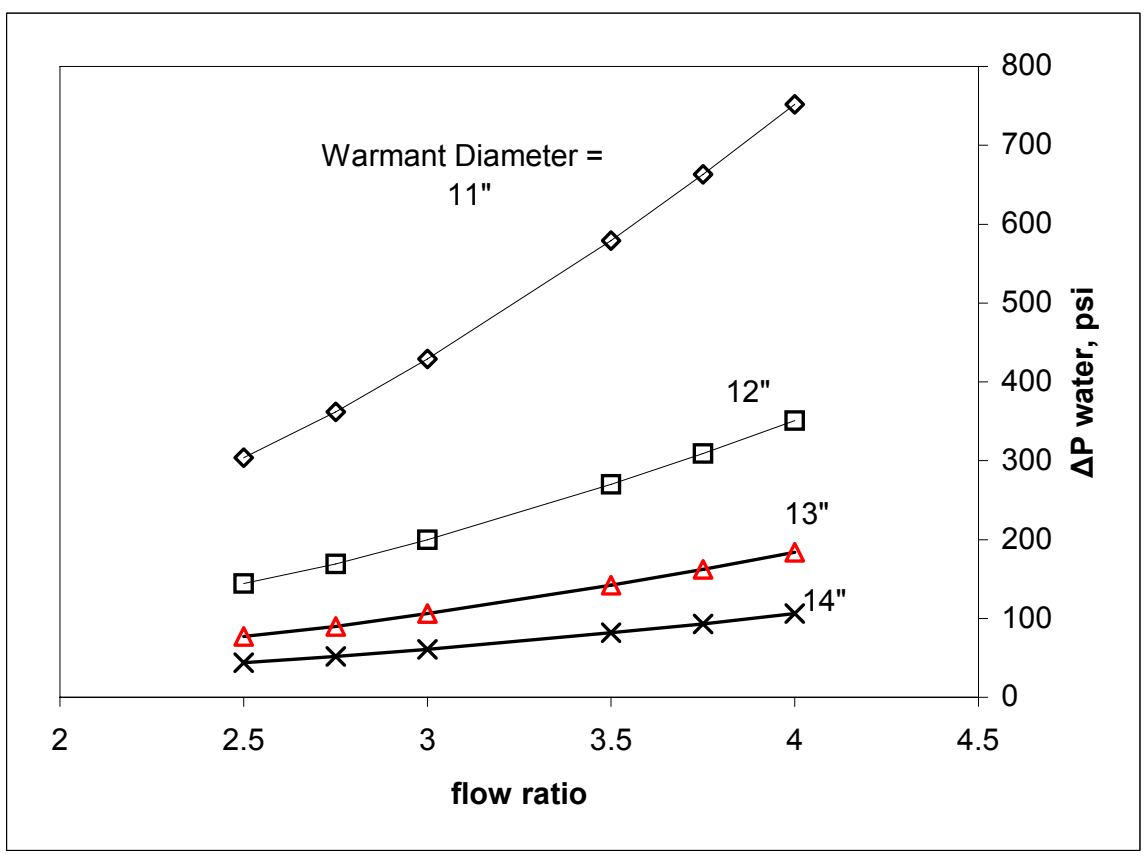


FIGURE 10

Effect of Sea Water on LNG Temperature and Ice Thickness

[Base Case Conditions]
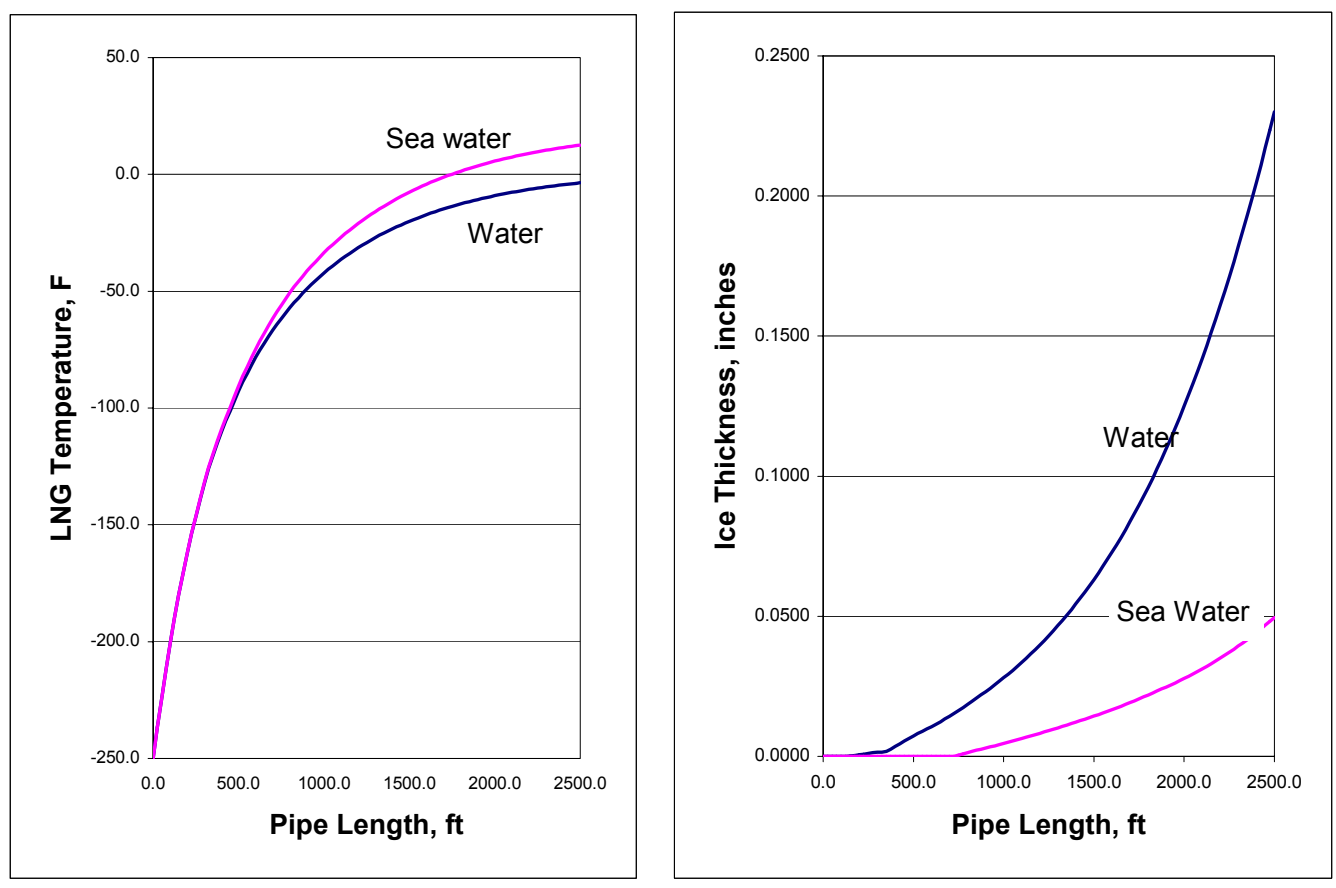


\begin{tabular}{|l|l|l|l|}
\hline Customer: & $\begin{array}{l}\text { The United States Department of Energy } \\
\text { National Energy Technology Laboratory }\end{array}$ & $\begin{array}{l}\text { Date of Issue: } \\
24 \text { April } 2003\end{array}$ & \\
\hline $\begin{array}{l}\text { Document } \\
\text { Title: }\end{array}$ & Subtask 1.4 Determine Salt Cavern Requirements & $\begin{array}{l}\text { Doc \# \& Version: } \\
\text { Doc } 05 \mathrm{r} 1.0\end{array}$ & Page 1 of 4 \\
\hline
\end{tabular}

\title{
Determine Salt Cavern Requirements
}

\author{
BY \\ MiChAEL M. MCCALL \\ WILLIAM M. BISHOP \\ D. BRAXTON SCHERZ
}

\begin{tabular}{|c|c||c|c|c|c|c|c|c||}
\hline r 1.0 & For client review & $02 / 09 / 03$ & вs & мм & & & \\
\hline Version & Reason for Issue & $\begin{array}{c}\text { Issue } \\
\text { Date }\end{array}$ & $\begin{array}{c}\text { Orig. } \\
\text { Chk. Appr. } \\
\text { CGI }\end{array}$ & $\begin{array}{c}\text { Chk. } \\
\text { NETL }\end{array}$ & Appr. & Review \\
\hline Document Title: & \multicolumn{2}{|c||}{$\begin{array}{c}\text { Document No: } \\
\text { CGI/DOE_DOC 05 } \\
\text { DE-FC26-02NT41653 }\end{array}$} \\
\hline
\end{tabular}




\begin{tabular}{|l|l|l|l|}
\hline Customer: & $\begin{array}{l}\text { The United States Department of Energy } \\
\text { National Energy Technology Laboratory }\end{array}$ & $\begin{array}{l}\text { Date of Issue: } \\
24 \text { April } 2003\end{array}$ & \\
\hline $\begin{array}{l}\text { Document } \\
\text { Title: }\end{array}$ & Subtask 1.4 Determine Salt Cavern Requirements & $\begin{array}{l}\text { Doc \# \& Version: } \\
\text { Doc } 05 \text { r1.0 }\end{array}$ & Page 2 of 4 \\
\hline
\end{tabular}

\section{TABLE OF CONTENTS}

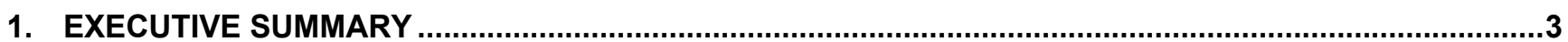

2. THE EFFECT OF LOW TEMPERATURE GAS INJECTION ON SALT CAVERN STABILITY .....................3

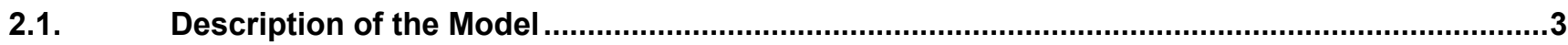

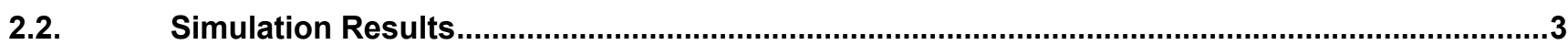




\begin{tabular}{|l|l|l|l|}
\hline Customer: & $\begin{array}{l}\text { The United States Department of Energy } \\
\text { National Energy Technology Laboratory }\end{array}$ & $\begin{array}{l}\text { Date of Issue: } \\
24 \text { April } 2003\end{array}$ & \\
\hline $\begin{array}{l}\text { Document } \\
\text { Title: }\end{array}$ & Subtask 1.4 Determine Salt Cavern Requirements & $\begin{array}{l}\text { Doc \# \& Version: } \\
\text { Doc } 05 \text { r1.0 }\end{array}$ & Page 3 of 4 \\
\hline
\end{tabular}

\section{EXECUTIVE SUMMARY}

The results of RESPEC's rock mechanic analysis confirm that salt caverns can be used in LNG receiving terminal applications. Gasified LNG at temperatures from $43.3^{\circ} \mathrm{C}\left(110^{\circ} \mathrm{F}\right)$ down to $-17.8^{\circ} \mathrm{C}\left(0^{\circ} \mathrm{F}\right)$ can safely and reliably be injected, stored, and withdrawn. Limits on cavern cycling and withdrawal rates are no different in LNG service than for conventional gas storage facilities, and are widely known in the industry. The report indicates that salt caverns can tolerate low temperatures. The results of the study also confirm that the use of salt caverns in LNG receiving is fundamentally no different than the widespread use of salt caverns for the natural gas pipeline industry..

\section{THE EFFECT OF LOW TEMPERATURE GAS INJECTION ON SALT CAVERN STABILITY}

This analysis was performed by Joel D. Nieland of RESPEC, Rapid City, South Dakota. RESPEC is a firm that specializes in rock mechanics including testing and modeling. They have extensive experience with salt. Their complete report is included as Attachment I. The purpose of the study was to determine what effect, if any, the injection of colder than normal gas would have on cavern stability. Since any lowering of the allowable injection temperature could decrease heat exchanger requirements, it was also desired to explore the lower limits on injection temperature. The injection temperatures studied were

- $0^{\circ} \mathrm{F}\left(-18^{\circ} \mathrm{K}\right)$

- $40^{\circ} \mathrm{F}\left(4.4^{\circ} \mathrm{K}\right)$

- $110^{\circ} \mathrm{F}\left(44^{\circ} \mathrm{K}\right)$ for comparison temperatures more typical of normal cavern operations.

\subsection{Description of the Model}

The salt cavern modeled was based on a conceptual offshore Gulf of Mexico receiving terminal consisting of six identical caverns at what would be their initial service volumes, i.e. a relatively small volume of $2.2 \mathrm{MMB}$ $(350,000 \mathrm{~m} 3)$. The intent would be to expand these as time and demand allowed. The fill and drawdown rates were made high so as to assess what the cavern limits might be as well as to examine a maximum terminal use. The facility was assumed to receive and deliver gas in two scenarios:

1. Receive one tanker of 3BCF ( $140,000 \mathrm{~m} 3 \mathrm{LNG})$ in 18 hours ( 0.75 days) and discharge it in 3 days. Pressure at the casing seat fluctuates between 2000psi and 1350 psi. Injected gas temperatures were $0^{\circ} \mathrm{F}$ and $40^{\circ} \mathrm{F}$. Simulation continued for five years in each case.

2. Receive two tankers of 6 BCF total over 36 hours ( 1.5 days) and discharge it also in 3 days. The pressure fluctuates at the casing seat between 2000psi and 705psi. Injected gas temperatures were $0^{\circ} \mathrm{F}, 40^{\circ} \mathrm{F}$ and $110^{\circ} \mathrm{F}$. Simulation continued for five years in each case.

\subsection{Simulation Results}

The most significant unknown before the completion of this study was the effect that wide ranges of temperatures would have upon cavern structure. Modeling for temperature ranges from $-17.8^{\circ} \mathrm{C}\left(0^{\circ} \mathrm{F}\right)$ to $43.3^{\circ}$ $\left(110^{\circ} \mathrm{F}\right)$, the simulations showed that the temperature effect is virtually neutral. Some of the reasons for this are: 


\begin{tabular}{|l|l|l|l|}
\hline Customer: & $\begin{array}{l}\text { The United States Department of Energy } \\
\text { National Energy Technology Laboratory }\end{array}$ & $\begin{array}{l}\text { Date of Issue: } \\
24 \text { April } 2003\end{array}$ & \\
\hline $\begin{array}{l}\text { Document } \\
\text { Title: }\end{array}$ & Subtask 1.4 Determine Salt Cavern Requirements & $\begin{array}{l}\text { Doc \# \& Version: } \\
\text { Doc } 05 \mathrm{r} 1.0\end{array}$ & Page 4 of 4 \\
\hline
\end{tabular}

1. The salt properties of importance remain constant or improve with decreasing temperature. The coefficient of thermal expansion is approximately constant over the temperature range covered, and thermal conductivity increases at low temperatures thus decreasing thermal stresses. Also the thermal contraction at lower temperatures reduces the stress in the tangential and vertical directions. This is a plus. However creep rate is slowed, slowing the response to these lowered stresses and thus stresses are slower to be relieved. This is a negative. The net effect is very small.

2. The temperature change for a given change in pressure is less when the compression or expansion starts at a lower temperature. This can be seen from a pressure-enthalpy chart. It is also seen in Fig 4.8 of the RESPEC report where the temperature swings for the $110^{\circ} \mathrm{F}$ injections are larger than those for the $0^{\circ} \mathrm{F}$ injections.

3. As time passes, the cavern wall temperature cycling takes place about a fairly steady average temperature. This also can be seen from Fig 4.8. For the $110^{\circ}$ injections, wall temperature cycles about an average of about $104^{\circ}$, the $40^{\circ}$ injections about $44^{\circ}$ and the $0^{\circ}$ injections about $3^{\circ} \mathrm{F}$. Thus in the vicinity of the wall, a new temperature base is established to which the salt has adapted structurally over time, except for the variations about the mean.

The RESPEC report does point out that over long periods of continuous and intense cycling as simulated in these cases, tensile fracturing is predicted to occur on the cavern periphery. These are fractures perpendicular to the wall and could eventually cause sloughing off of the wall and roof and reduce the life of the cavern. This concern would be the same for any cavern under this type of pressure cycling. This type of failure would not be catastrophic and indeed the failure anticipated by the simulation has not, according to RESPEC, been corroborated by observation of actual caverns.

Nevertheless, several guidelines exist that proscribe against rapid cyclic depressurization, and operators need to be aware of a potential problem. The high pressure fluctuations observed in the present model can of course be overcome by simply making the cavern larger so that the pressure drop with withdrawal of one or two cargoes is not of concern.

As was discussed earlier in this section, these studies do not include the effect of temperature on the last cemented casing. Depending on the gas injection temperature, this casing may need to be protected by using a suitable cement or by slipstreaming warm gas in an outer annulus provided by a hanging string. A temperature of $40^{\circ} \mathrm{F}$ should not pose a problem since many brine wells are operated at this temperature. The literature may reveal data on operating at colder temperatures. 
Attachment I 


\section{FEASIBILITY OF OFF-LOADING CHILLED NATURAL GAS IN SALT CAVERNS: GEOMECHANICAL ASSESSMENT}

Topical Report RSI-1712

prepared for

Conversion Gas Imports

2929 Briarpark, Suite 220

Houston, Texas 77042

April 2003 


\title{
FEASIBILITY OF OFF-LOADING CHILLED NATURAL GAS IN SALT CAVERNS: GEOMECHANICAL ASSESSMENT
}

Topical Report RSI-1712

\author{
by \\ Joel D. Nieland \\ RESPEC \\ P.O. Box 725 \\ Rapid City, South Dakota 57709
}

prepared for

Conversion Gas Imports

2929 Briarpark, Suite 220

Houston, Texas 77042

April 2003 


\section{TABLE OF CONTENTS}

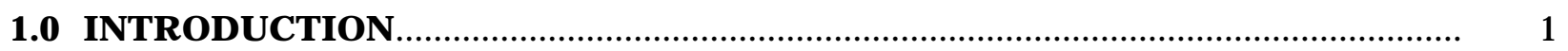

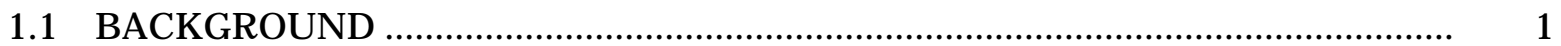

1.2 OBJ ECTIVE OF THE GEOMECHANICAL EVALUATION ................................ 1

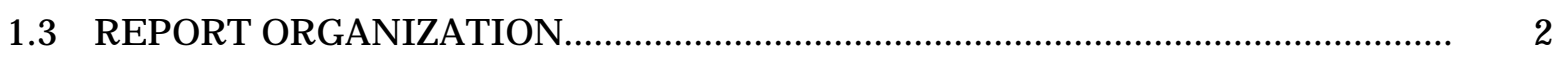

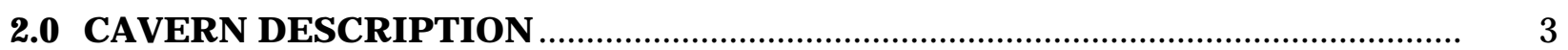

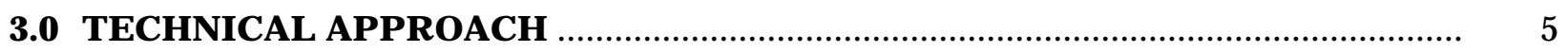

3.1 NUMERICAL MODELING .......................................................................... 5

3.1.1 Cavern Thermodynamics Program ...................................................... 5

3.1.2 Heat Transfer Finite Element Program ................................................. 5

3.1.3 Thermomechanical Finite Element Program............................................. 6

3.1.4 Constitutive Model for Salt.................................................................. 6

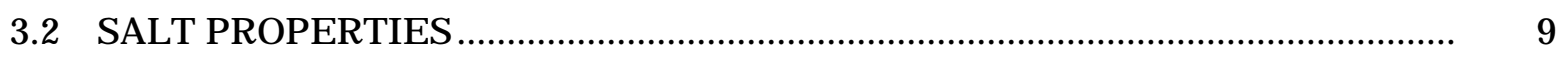

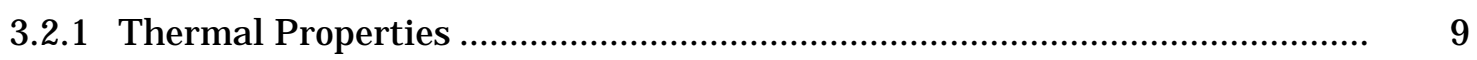

3.2.2 Elastic Properties ............................................................................ 9

3.2.3 Creep Properties.................................................................................... 10

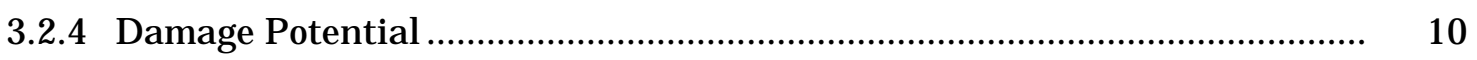

3.2.5 Tensile Strength ................................................................................. 11

3.3 PROPERTIES OF CAVERN FLUIDS ........................................................... 11

3.3.1 Natural Gas Characteristics............................................................. 12

3.3.2 Brine Characteristics .................................................................... 12

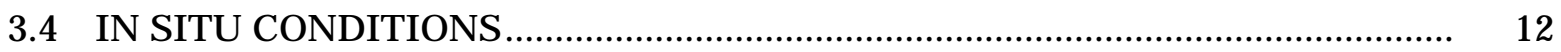

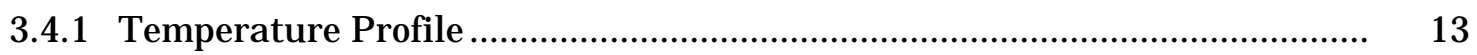

3.4.2 Stress Distribution ............................................................................. 13

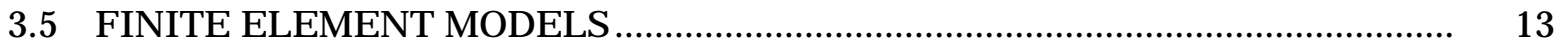

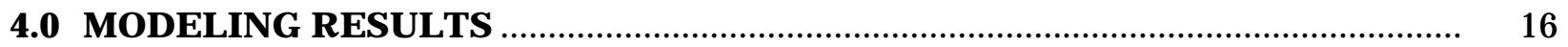

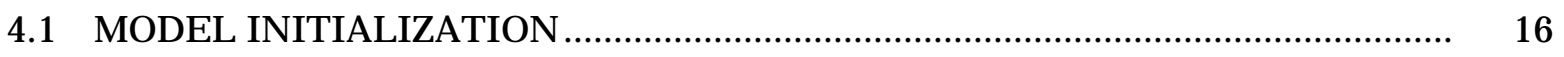

4.2 TEMPERATURE CHANGES DURING GAS STORAGE .................................. 18

4.3 CAVERN STABILITY DURING GAS STORAGE SCENARIOS ......................... 18

4.4 EVALUATION OF GAS WITHDRAWAL RATE ............................................... 35

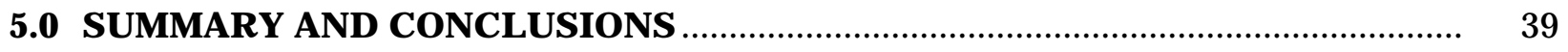

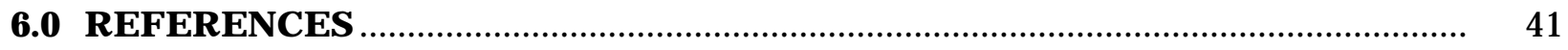




\section{LIST OF TABLES}

TABLE

PAGE

3-1 Estimates of Munson-Dawson Creep Parameters for Avery I sland Salt ................ 11

3-2 Gas Composition................................................................................... 12 


\section{LIST OF FIGURES}

FIGURE

PAGE

2-1 Schematic of Modeled Cavern ........................................................................ 4

3-1 Axisymmetric Finite Element Model Used to Represent LNG Receiving Terminal Caverns.

4-1 Model ed Gas Storage Cycles.

4-2 Temperature Distributions in Salt for Single-Tanker Scenario With $-17.8^{\circ} \mathrm{C}\left(0^{\circ} \mathrm{F}\right)$ Gas I njection Temperature .

4-3 Temperature Distributions in Salt for Single-Tanker Scenario With $4.4^{\circ} \mathrm{C}\left(40^{\circ} \mathrm{F}\right)$ Gas Injection Temperature......

4-4 Temperature Distributions in Salt for Double-Tanker Scenario With $-17.8^{\circ} \mathrm{C}$ $\left(0^{\circ} \mathrm{F}\right)$ Gas I njection Temperature.

4-5 Temperature Distributions in Salt for Double-Tanker Scenario With $4.4^{\circ} \mathrm{C}\left(40^{\circ} \mathrm{F}\right)$ Gas Injection Temperature....

4-6 Temperature Distributions in Salt for Double-Tanker Scenario With $43.3^{\circ} \mathrm{C}$ $\left(110^{\circ} \mathrm{F}\right)$ Gas I njection Temperature.

4-7 Temperature Distributions Around Top of Cavern During First Withdrawal in Double-Tanker Scenarios

4-8 Cavern Wall Temperature Versus Time for Various Gas Storage Scenarios 25

4-9 Damage Potential Contours Around Top of Cavern During First Withdrawal for Double-Tanker Scenarios

4-10 Maximum Principal Stress Contours Around Top of Cavern During First 3-Day Withdrawal of Single-Tanker Simulations

4-11 Maximum Principal Stress Contours Around Top of Cavern During First 3-Day Withdrawal of Double-Tanker Simulations.

4-12 Maximum Principal Stress Contours Around Top of Cavern During 3-Day Withdrawal of Single-Tanker Simulation With $-17.8^{\circ} \mathrm{C}\left(0^{\circ} \mathrm{F}\right)$ Injection Temperature After Cycling for 5 Years......

4-13 Maximum Principal Stress Contours Around Top of Cavern During 3-Day Withdrawal of Single-Tanker Simulation With $4.4^{\circ} \mathrm{C}\left(40^{\circ} \mathrm{F}\right)$ Injection Temperature After Cycling for 5 Years.

4-14 Maximum Principal Stress Contours Around Top of Cavern During 3-Day Withdrawal of Double-Tanker Simulations With $-17.8^{\circ} \mathrm{C}\left(0^{\circ} \mathrm{F}\right)$ Injection Temperature After Cycling for 5 Years

4-15 Maximum Principal Stress Contours Around Top of Cavern During 3-Day Withdrawal of Double-Tanker Simulation With $4.4^{\circ} \mathrm{C}\left(40^{\circ} \mathrm{F}\right)$ Injection Temperature After Cycling for 5 Years 


\section{LIST OF FIGURES \\ (Continued)}

4-16 Maximum Principal Stress Contours Around Top of Cavern During 3-Day Withdrawal of Double-Tanker Simulation With $43.3^{\circ} \mathrm{C}\left(110^{\circ} \mathrm{F}\right)$ Injection Temperature After Cycling for 5 Y ears.....

4-17 Maximum Principal Stress Contours Around Top of Cavern During 10-Day Double-Tanker Withdrawal

4-18 Maximum Principal Stress Contours Around Top of Cavern During 20-Day Double-Tanker Withdrawal

4-19 Maximum Principal Stress Contours Around Top of Cavern During 30-Day Double-Tanker Withdrawal 


\subsection{INTRODUCTION}

\subsection{BACKGROUND}

Conversion Gas Imports, LLC (CGI) was awarded a contract in September 2002 by the National Energy Technology Laboratory to examine an innovative process to off-load natural gas from liquefied natural gas (LNG) tankers directly into an offshore salt storage cavern or into a pipeline for injection into an onshore cavern. The process involves warming and pressurizing the gas by means of a heat exchanger to temperatures that can be safely accepted by salt storage caverns. RESPEC was engaged by CGI to evaluate salt cavern stability for such a facility.

Salt cavern storage of natural gas is a proven technology. The gas injected into conventional salt storage caverns is generally injected at temperatures greater than $37.8^{\circ} \mathrm{C}\left(100^{\circ} \mathrm{F}\right)$. However, LNG tankers store LNG at a temperature of about $-157^{\circ} \mathrm{C}\left(-250^{\circ} \mathrm{F}\right)$. Thus in order to off-load directly into a salt storage cavern, the LNG must be converted from a liquid to a gas and be heated to a temperature that can be safely accepted by salt storage caverns. The economic viability of this process is dependent on the minimum gas temperature that can be safely accepted by a salt storage cavern.

The structural integrity of a solution-mined cavern in a salt dome is dependent upon the state of stress in the salt surrounding the cavern. The stress state around a cavern is used to determine the structural stability of the cavern roof and walls and to evaluate the potential for connectivity with other caverns or connectivity with geologic strata outside of the salt dome. The stress state in the salt around the cavern is dependent on (1) the original in situ state of stress, (2) the gas pressure in the cavern, (3) cavern geometry, (4) salt creep, and (5) temperature changes in the salt. Because salt has a relatively high coefficient of thermal expansion, temperature changes from the original in situ temperature can have a significant effect on stresses surrounding the cavern.

\subsection{OBJECTIVE OF THE GEOMECHANICAL EVALUATION}

The objective of this geomechanics evaluation is to evaluate the stability of a generic cavern for various gas injection temperatures. The cavern stability will be evaluated in terms of the stability of the cavern roof and walls. This objective is addressed in this evaluation using (1) salt properties available in the open literature and (2) numerical modeling of the generic cavern design using software developed by RESPEC specifically for modeling excavations in salt. The assumptions associated with in situ conditions, geometric approximations, and salt characterization are described throughout the report. 


\subsection{REPORT ORGANIZATION}

A description of the generic cavern and its setting is given in Chapter 2.0, and the technical approach to the geomechanics modeling is described in Chapter 3.0. Chapter 4.0 presents the geomechanics modeling results, and Chapter 5.0 gives a summary of the modeling results and the study condusions. Cited references are provided at the end of the report. 


\subsection{CAVERN DESCRIPTION}

The cavern model used in this investigation is a cylindrically shaped cavern typical of those used for conventional natural gas storage in the Gulf Coast region. The cavern is assumed to be in located in a salt dome and an all-salt stratigraphy is assumed. The modeled cavern has a roof depth of 730 meters (2,400 feet), a total depth of 960 meters (3,150 feet), and a radius of 22 meters ( 72 feet). The total volume of the cavern is $350,000 \mathrm{~m}^{3}$ ( 2.2 million barrels ( $M$ M bbls)). The casing seat is at a depth of 716 meters (2,350 feet). The maximum casing seat pressure is assumed to be $13.8 \mathrm{MPa}(2,000 \mathrm{psi})$ or $0.019 \mathrm{MPa}$ per meter of depth $(0.85 \mathrm{psi} / \mathrm{foot})$. The minimum pressure evaluated at the casing seat is $4.9 \mathrm{MPa}$ (700 psi) or $0.0067 \mathrm{MPa}$ per meter of depth ( $0.30 \mathrm{psi} / \mathrm{foot})$. The cavern size is based on a facility with six caverns having the working gas capacity of two LNG tankers (about $1.9 \times 10^{8} \mathrm{Nm}^{3}$ (7 billion cubic feet (Bcf))). ${ }^{1}$ Figure 2shows a schematic of the cavern modeled in this study. The model assumes an in situ temperature in situ temperature of $33^{\circ} \mathrm{C}\left(92^{\circ} \mathrm{F}\right)$ at the cavern midheight.

${ }^{1}$ Natural gas quantities are expressed in terms of normal cubic meters $\left(\mathrm{Nm}^{3}\right)$ with reference conditions of $0^{\circ} \mathrm{C}$ and $0.101325 \mathrm{MPa}$ and in terms of standard cubic feet (scf) with reference conditions of $60^{\circ} \mathrm{F}$ and $14.696 \mathrm{psi}$. 
RSI-1399-03-001

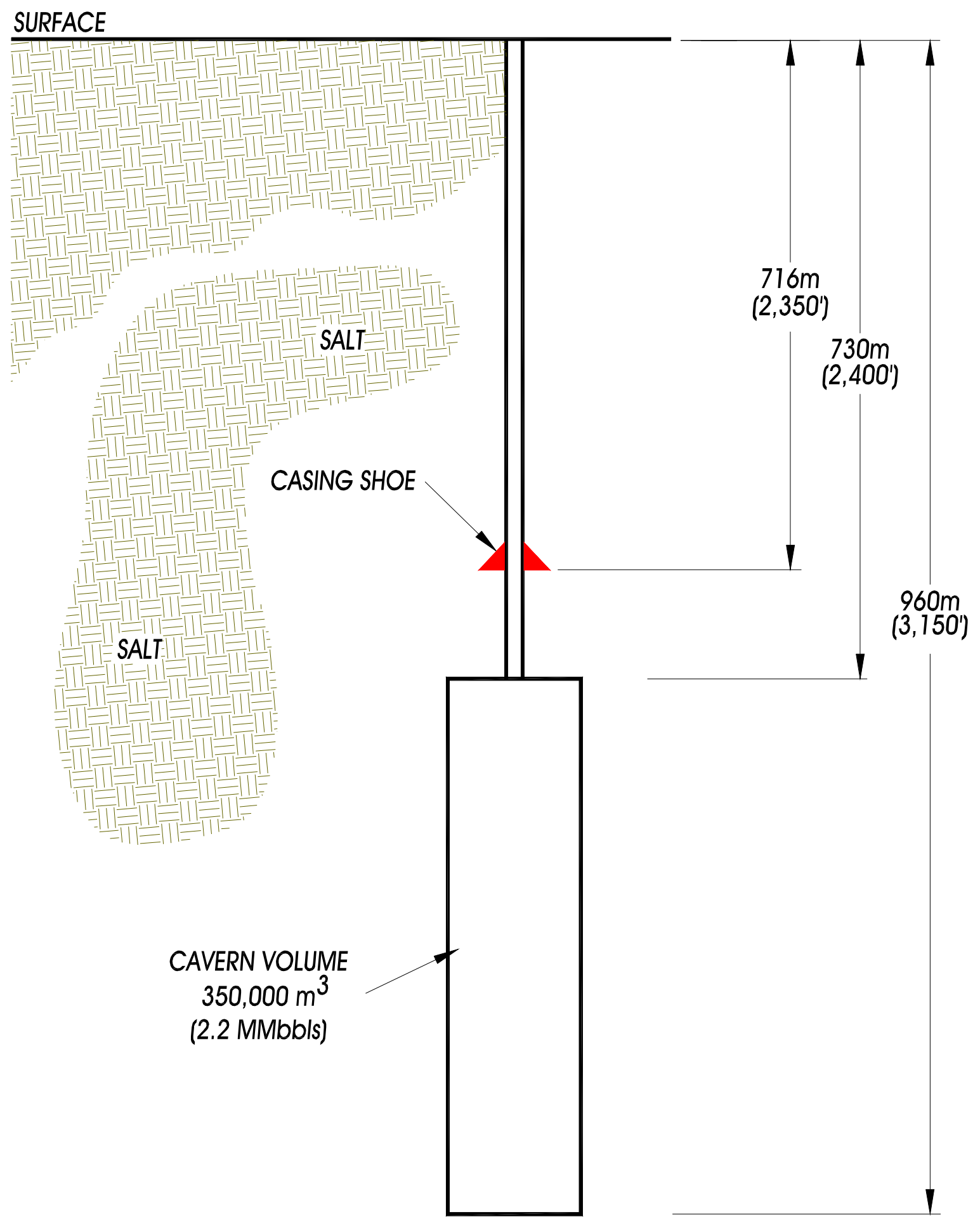

Figure 2-1. Schematic of Modeled Cavern. 


\subsection{TECHNICAL APPROACH}

Cavern stability for the LNG receiving terminal was based on the following performance criterion: the injection of chilled gas must not result in extensive areas of tensile stress or salt damage (microfracturing). Extensive areas of tensile stress or salt damage could lead to spalling of the roof and/or walls of the cavern and subsequent damage to the casing seat, well, and/or hanging string. This criterion was evaluated using numerical models of the cavern described in Chapter 2.0. The following sections describe the numerical modeling methods, material and cavern fluids properties, in situ conditions, and the finite el ement model used.

\subsection{NUMERICAL MODELING}

Numerical modeling software was used to model the thermodynamics in the caverns, the heat transfer in the salt surrounding the caverns, and the mechanical behavior of the salt surrounding the caverns. These specialized computer programs and the constitutive model used to define the viscoplastic deformation of the salt are described in the following subsections.

\subsubsection{Cavern Thermodynamics Program}

The Salt Cavern Thermal Simulator (SCTS) [Nieland, 2002] is a program for simulating the thermodynamics and heat transfer related to the storage of natural gas in underground salt caverns. It accounts for the thermal effects associated with gas compression and expansion; the mass transfer during injection and withdrawal; and the heat transfer between the gas and its surroundings, both in the wellbore and in the cavern.

SCTS was used to determine cavern wall temperatures throughout the simulated LNG receiving terminal gas cycle. SCTS calculates a single bulk cavern temperature and a single cavern wall temperature. The cavern wall temperature as a function of time, determined from SCTS, was applied as a boundary condition to the thermal finite element model to estimate the temperature of the salt surrounding the cavern as a function of time.

\subsubsection{Heat Transfer Finite Element Program}

SPECTROM-41 [Svalstad, 1989] is a finite element heat transfer analysis program that has been developed by RESPEC to analyze thermal problems in geologic formations. The primary transport process modeled by SPECTROM-41 is conductive heat transfer. SPECTROM-41 has the capability to model complex material properties (including temperature-dependent thermal conductivity) and boundary conditions. SPECTROM-41 was used in this study to simulate the heat transfer between the cavern and the surrounding salt. The results of these calculations were 
then integrated into the thermomechanical analyses to account for the thermal stresses and strains that are a result of the temperature changes in the salt surrounding the cavern.

\subsubsection{Thermomechanical Finite Element Program}

SPECTROM-32 [Callahan et al., 1989] is a thermomechanical, finite element program that has been developed by RESPEC for the solution of rock mechanics problems. It was designed specifically for the simulation of underground openings and structures. SPECTROM-32 not only has the capability to model the elastic-plastic response that is commonly associated with brittle rock types, but it also has the capability to simulate the viscoplastic behavior that is observed in rock salt. The features and capabilities of SPECTROM-32 that were required specifically for this investigation include:

- Option for axisymmetric geometries

- Kinematic and traction boundary conditions

- Munson-Dawson multimechanism constitutive model for viscoplastic behavior of salt

- Capability to represent arbitrary in situ stress and temperature fields

- Capability to simulate excavation operations.

\subsubsection{Constitutive Model for Salt}

The deformation rate of salt can be decomposed into thermal expansion, elastic deformation, and inelastic deformation. The inelastic deformation is stress-, temperature, and ratedependent. It is comprised of both viscoplastic and brittle components, with the viscoplastic component usually dominating in the range of stress and temperature expected in the salt surrounding natural gas storage caverns. Considerable research has been performed to determine a satisfactory constitutive law that characterizes the viscoplastic behavior of rock salt. The Munson-Dawson multimechanism constitutive model has been found to perform reasonably well in fitting data from laboratory constant-stress tests and in predicting the response of laboratory, field, and bench-scale tests performed on salt from Avery Island [DeVries, 1988]. Two differential rate equations comprise the Munson-Dawson model: (1) the strain-rate equations which give the viscoplastic strain rates (Equation 3-1) and (2) the evolutionary equation which gives the rate of change of an internal variable (Equation 3-2). The three-dimensional form of the Munson-Dawson model is given bel ow.

$$
\begin{gathered}
\dot{\varepsilon}_{\mathrm{ij}}^{\mathrm{vp}}=\frac{\partial \sigma_{\mathrm{e}}}{\partial \sigma_{\mathrm{ij}}} \mathrm{F} \dot{\varepsilon}_{\mathrm{s}} \\
\dot{\zeta}=(\mathrm{F}-1) \dot{\varepsilon}_{\mathrm{s}}
\end{gathered}
$$


where:

$$
\begin{aligned}
& \dot{\varepsilon}_{\mathrm{s}}=\sum_{\mathrm{i}=1}^{3} \dot{\varepsilon}_{\mathrm{s}} \\
& \dot{\varepsilon}_{\mathrm{s}_{1}}=\text { steady-state strain rate for mechanism i } \\
& \dot{\varepsilon}_{\mathrm{s}_{1}}=\mathrm{A}_{1} \exp \left(-\mathrm{Q}_{1} / \mathrm{RT}\right)\left(\sigma_{\mathrm{e}} / \mu\right)^{\mathrm{n}_{1}} \\
& \dot{\varepsilon}_{\mathrm{s}_{2}}=\mathrm{A}_{2} \exp \left(-\mathrm{Q}_{2} / \mathrm{RT}\right)\left(\sigma_{\mathrm{e}} / \mu\right)^{\mathrm{n}_{2}} \\
& \dot{\varepsilon}_{\mathrm{s}_{3}}=\left[\mathrm{B}_{1} \exp \left(-\mathrm{Q}_{1} / \mathrm{RT}\right)+\mathrm{B}_{2} \exp \left(-\mathrm{Q}_{2} / \mathrm{RT}\right)\right] \cdot \sinh \left[\mathrm{q}\left(\sigma_{\mathrm{e}}-\sigma_{\mathrm{o}}\right) / \mu\right] \mathrm{H}\left(\sigma_{\mathrm{e}}-\sigma_{\mathrm{o}}\right) \\
& F= \begin{cases}\exp \left[\Delta\left(1-\frac{\varsigma}{\varepsilon_{t}^{*}}\right)^{2}\right] & \text { for } \varsigma<\varepsilon_{t}^{*} \\
1 & \text { for } \varsigma=\varepsilon_{t}^{*} \\
\exp \left[-\delta\left(1-\frac{\varsigma}{\varepsilon_{t}^{*}}\right)^{2}\right] & \text { for } \varsigma>\varepsilon_{t}^{*}\end{cases} \\
& \varepsilon_{\mathrm{t}}^{*}=\mathrm{K}_{\mathrm{o}} \exp (\mathrm{cT})\left(\sigma_{\mathrm{e}} / \mu\right)^{\mathrm{m}} \\
& \Delta=\alpha+\beta \log \left(\sigma_{\mathrm{e}} / \mu\right)
\end{aligned}
$$

and

$$
\begin{aligned}
\dot{\mathrm{e}}_{\mathrm{ij}}^{\mathrm{vp}} & =\text { viscoplastic strain-rate tensor } \\
\sigma_{\mathrm{e}} & =\sqrt{3 \mathrm{~J}_{2}} \text { (effective stress) } \\
\mathrm{J}_{2} & =\frac{1}{2} \mathrm{~s}_{\mathrm{ij}} \mathrm{s}_{\mathrm{ji}} \\
\mathrm{s}_{\mathrm{ij}} & =\sigma_{\mathrm{ij}}-\delta_{\mathrm{ij}} \sigma_{\mathrm{m}} \text { (deviatoric stress tensor) } \\
\sigma_{\mathrm{m}} & =\frac{1}{3} \sigma_{\mathrm{kk}} \text { (mean stress) }
\end{aligned}
$$




$$
\begin{aligned}
\sigma_{\mathrm{ij}} & =\text { stress tensor } \\
\delta_{\mathrm{ij}} & =\text { Kronecker delta } \\
\varsigma & =\text { internal variable } \\
\mathrm{T} & =\text { absolute temperature } \\
\mathrm{H}(\mathrm{x}) & =\text { Heaviside function } \\
\mu & =1.395\left(10^{6}\right) \text { psi (a constant) } \\
\mathrm{Q}_{1} / \mathrm{R} & =22,732 \mathrm{R} \text { (a constant) } \\
\mathrm{n}_{1} & =5.5 \text { (a constant) }
\end{aligned}
$$

$A_{1}, A_{2}, B_{1}, B_{2}, Q_{2}, n_{2}$, $q, \sigma_{0}, \delta, K_{0}, c, m, \alpha, \beta=$ experimentally determined parameters.

As indicated by Equation 3-3, the steady-state creep rate $\left(\dot{\varepsilon}_{\mathrm{s}}\right)$ based on the Munson-Dawson model is composed of three terms. Each term is associated with a different creep mechanism. The first and third mechanisms $\left(\dot{\varepsilon}_{s_{1}}\right.$ and $\left.\dot{\varepsilon}_{s_{3}}\right)$ are dislocation climb and dislocation glide, respectively, and the second mechanism $\left(\dot{\varepsilon}_{s_{2}}\right)$ is referred to as the undefined mechanism. The relative contribution of each mechanism to the steady-state creep rate strongly depends on the effective stress and temperature.

When pressure conditions in a storage cavern are changed, the transient nature of the Munson-Dawson model can be an important factor in the response of the cavern. According to Equation 3-1, the steady-state creep rate is multiplied by a transient factor (F) to obtain the viscoplastic strain rate. The value of the transient factor depends on whether the internal variable $(\varsigma)$ is less than, equal to, or greater than the transient strain limit $\left(\varepsilon_{\mathrm{t}}^{*}\right)$, which is a function of the effective stress and temperature. When $\varsigma<\varepsilon_{\mathrm{t}}^{*}$, the viscoplastic strain rate is greater than the steady-state creep rate $(F>1)$. This is the work-hardening branch of the Munson-Dawson model. The work-hardening branch is commonly associated with an increase in loading, such as when a cavern is excavated or when the cavern pressure is decreased. When $\varsigma>\varepsilon_{t}^{*}$, the viscoplastic strain rate is less than the steady-state creep rate $(F<1)$. This is the recovery branch of the Munson-Dawson law. This branch is commonly associated with a decrease in loading, such as when the cavern pressure is increased. Through the evolutionary equation, the value of the internal variable is al ways approaching the transient strain limit. In turn, the viscoplastic strain rate is always approaching the steady-state creep rate (i.e., $F$ approaches unity as $\varsigma$ approaches $\varepsilon_{\mathrm{t}}^{*}$ ). 
The Munson-Dawson model has 14 parameters that must be determined experimentally or estimated empirically. The parameter values used to represent the salt are presented in Section 3.2.3.

\subsection{SALT PROPERTIES}

The following sections describe the material properties that were used to simulate the salt surrounding the LNG receiving terminal cavern in this analysis.

\subsubsection{Thermal Properties}

The specific heat of salt was assumed to be $840 \mathrm{~J} / \mathrm{kg}-\mathrm{K}(0.20 \mathrm{Btu} / \mathrm{lbm})$, based on measurements by Dahlstrom [1988], and the density of salt was assigned a typical value of $2,160 \mathrm{~kg} / \mathrm{m}^{3}\left(135 \mathrm{lbm} / \mathrm{ft}^{3}\right)$. The thermal conductivity of salt changes significantly with temperature. In the SPECTROM-41 simulations, the thermal conductivity of salt as a function of temperature is based on recent measurements made on rock salt from the Michigan Basin [Nieland et al., 2001] and is described by:

$$
K=a\left(\frac{T}{T_{0}}\right)^{b}
$$

where:

$$
\begin{aligned}
\mathrm{K}= & \text { thermal conductivity } \\
\mathrm{a}= & 6.678 \mathrm{~W} / \mathrm{m}-\mathrm{K} \\
\mathrm{T}= & \text { absolute temperature }(\mathrm{K}) \\
\mathrm{T}_{0}= & \text { absolute temperature which water freezes } \\
& \text { at } 1 \text { atm pressure }(\text { e.g., } 273.15 \mathrm{~K}) \\
\mathrm{b}= & -1.793 .
\end{aligned}
$$

A constant value of $5.4 \mathrm{~W} / \mathrm{m}-\mathrm{K}$ (3.1 Btu/hr-ft- $\left.{ }^{\circ} \mathrm{F}\right)$ was used in scTs to make the thermodynamic calculations to estimate the cavern wall temperature as a function of time. This value was determined using Equation 3-11 and the assumed original in situ temperature of $33^{\circ} \mathrm{C}\left(92^{\circ} \mathrm{F}\right)$ at the cavern midheight.

\subsubsection{Elastic Properties}

The Young's modulus (E) and Poisson's ratio ( $v$ ) used for the salt in this study are based on laboratory testing of Avery Island salt [Hansen and Carter, 1984]. The average values of Young's modulus and Poisson's reported are $30.6 \mathrm{GPa}\left(4.44 \times 10^{6} \mathrm{psi}\right)$ and 0.38 , respectively. 
The coefficient of linear thermal expansion for salt only varies slightly throughout the temperature range expected around the caverns. A constant value of $3.9 \times 10^{-5} \mathrm{~K}^{-1}\left(2.2 \times 10^{-5}\right.$

$\mathrm{R}^{-1}$ ) was used to model the salt in this study and is calculated from a temperature-dependent equation given by Senseny et al. [1992] at the assumed cavern midheight temperature of $33^{\circ} \mathrm{C}$ $\left(92^{\circ} \mathrm{F}\right)$.

\subsubsection{Creep Properties}

Because Avery Island salt was extensively tested for the nuclear waste program, its creep properties are available in the open literature. Avery Island salt creep properties were used to represent the salt hosting the caverns of the LNG receiving terminal evaluated here. The Munson-Dawson creep parameters for Avery Island salt are shown in Table 3-1 [DeVries, 1988].

\subsubsection{Damage Potential}

The criterion used to evaluate whether or not damage (micro- or macrofracturing that causes porosity and permeability increases) occurs in the salt is based on the stress state. Two stress measures are used in defining the damage criteria: the first invariant of the stress tensor, $I_{1}$, and the second invariant of the deviatoric stress tensor, $\mathrm{J}_{2}$. These two stress measures are defined as follows:

$$
\begin{gathered}
\mathrm{I}_{1}=\sigma_{1}+\sigma_{2}+\sigma_{3} \\
\mathrm{~J}_{2}=\frac{1}{6}\left[\left(\sigma_{1}-\sigma_{2}\right)^{2}+\left(\sigma_{1}-\sigma_{3}\right)^{2}+\left(\sigma_{2}-\sigma_{3}\right)^{2}\right]
\end{gathered}
$$

where:

$$
\sigma_{1}, \sigma_{2}, \sigma_{3}=\text { principal stresses. }
$$

A damage limit has been established that is based on dilation observed in an extensive database of creep tests of WIPP and Avery I sland salt [Van Sambeek et al., 1993]. The dilation limit can be expressed mathematically in terms of the stress invariants as:

$$
\sqrt{J_{2}} \leq 0.27 I_{1}
$$

The term "damage potential" is defined as the ratio of $\sqrt{I_{2}}$ to $I_{1}$. Thus regions of salt exhibiting a damage potential value of 0.27 or larger are expected to experience damage. Damage is expected to increase with increasing damage potential values. 
Table 3-1. Estimates of Munson-Dawson Creep Parameters for Avery Island Salt (After DeVries [1988])

\begin{tabular}{|c|c|c||}
\hline Parameters & Units & Estimators \\
\hline \hline $\mathrm{A}_{1}$ & day $^{-1}$ & $2.09\left(10^{26}\right)$ \\
\hline $\mathrm{A}_{2}$ & day $^{-1}$ & $1.13\left(10^{14}\right)$ \\
\hline $\mathrm{B}_{1}$ & day $^{-1}$ & $5.94\left(10^{10}\right)$ \\
\hline $\mathrm{B}_{2}$ & day $^{-1}$ & $1.89\left(10^{3}\right)$ \\
\hline $\mathrm{K}_{\circ}$ & - & $2.52\left(10^{4}\right)$ \\
\hline $\mathrm{m}$ & - & 2.54 \\
\hline$\alpha$ & - & -8.83 \\
\hline$\beta$ & - & -5.05 \\
\hline $\mathrm{q}$ & - & 3,330 \\
\hline $\mathrm{Q}_{2} / \mathrm{R}$ & $\mathrm{K}$ & 6,520 \\
\hline $\mathrm{n}_{2}$ & - & 3.14 \\
\hline$\sigma_{0}$ & $\mathrm{MPa}$ & 8.82 \\
\hline $\mathrm{C}$ & $\mathrm{K}^{-1}$ & $9.20\left(10^{-3}\right)$ \\
\hline$\delta$ & - & 0.242 \\
\hline
\end{tabular}

\subsubsection{Tensile Strength}

The tensile strength of Gulf Coast dome salts, based on indirect tensile tests on salt from 11 Gulf Coast salt domes [Pfeifle et al., 1995], is generally less than $2 \mathrm{MPa}$ (300 psi). However, as a conservative measure in this study, we assume a tensile strength of zero.

\subsection{PROPERTIES OF CAVERN FLUIDS}

The mechanical response of a storage cavern depends not only on the material properties of the salt surrounding the cavern but also on the material properties of the fluids inside the cavern. In the simulations, cavern fluids were represented by their pressures applied as normal tractions to the surfaces of the cavern walls. The fluids were assumed to be essentially stagnant, and at a given depth, the vertical pressure gradient was assumed to be equal to the fluid's density at that depth. The following two subsections describe how the vertical pressure gradients for natural gas and saturated brine were derived. 


\subsubsection{Natural Gas Characteristics}

Natural gas is modeled in SCTS as a real gas using the American Gas Association's Detail Characterization Method as described by Starling and Savidge [1994]. The gas composition used to model the gas off-loaded from tankers is described in Table 3-2 [Bishop, 2002].

Table 3-2. Gas Composition

\begin{tabular}{||c|c||}
\hline Gas Component & Mole Percent \\
\hline \hline Methane & 91.37 \\
\hline Nitrogen & 1.55 \\
\hline Ethane & 4.09 \\
\hline Propane & 1.71 \\
\hline i-Butane & 0.35 \\
\hline n-Butane & 0.40 \\
\hline i-Pentane & 0.16 \\
\hline n-Pentane & 0.18 \\
\hline n-Hexane & 0.19 \\
\hline
\end{tabular}

Gas pressure is applied in the finite element model with tractions on the cavern surface. A linear pressure gradient was assumed for the gas in the cavern and is based on the bulk cavern gas density estimated by SCTS.

\subsubsection{Brine Characteristics}

Brine was represented in the cavern model during simulation of the leaching and dewatering processes. Because of the very small compressibility of brine (approximately $2.8 \times$ $\left.10^{-4} / \mathrm{MPa}\left(1.9 \times 10^{-6} / \mathrm{psi}\right)\right)$, the increase in brine density associated with the hydrostatic pressure increase over the height of a cavern is negligible (about 0.1 percent change per 305 meters (1,000 feet)). Consequently, the brine density was assumed to remain a constant $1,201 \mathrm{~kg} / \mathrm{m}^{3}$ $\left(75 \mathrm{lb} / \mathrm{foot}^{3}\right)$, resulting in a vertical pressure gradient of $0.0011 \mathrm{MPa} / \mathrm{meter}(0.52 \mathrm{psi} / \mathrm{foot})$.

\subsection{IN SITU CONDITIONS}

Since the creep rate of salt is dependent on temperature and stress, it is important to model temperatures and stresses which are representative of those in the vicinity of the cavern. The following two subsections describe the in situ temperature and stress distributions assumed in this analysis. 


\subsubsection{Temperature Profile}

The undisturbed temperature profile in the salt dome was chosen to be representative of an offshore facility and is described by:

$$
\mathrm{T}=10+0.00254 \mathrm{z}
$$

where $\mathrm{T}$ is the temperature in degrees Centigrade and $\mathrm{z}$ is the depth in meters. This results in an undisturbed in situ temperature of $33^{\circ} \mathrm{C}\left(92^{\circ} \mathrm{F}\right)$ at the cavern midheight.

\subsubsection{Stress Distribution}

The undisturbed in situ stress distribution was assumed to be isotropic and equal to the weight of the overburden. The weight of the overburden is based on the typical rock salt density of $2,160 \mathrm{~kg} / \mathrm{m}^{3}\left(135 \mathrm{lbm} / \mathrm{ft}^{3}\right)$. At the cavern midheight depth, the vertical stress is estimated to be about $18.0 \mathrm{MPa}(2,610 \mathrm{psi})$.

\subsection{FINITE ELEMENT MODELS}

Because of axial symmetry, the LNG receiving terminal caverns are modeled using an axisymmetric model. It is assumed that the caverns for such a facility would be sufficiently separated (e.g. web-to-diameter ratios greater than 3) that cavern interactions can be neglected.

Figure 3-1 shows the axisymmetric cavern model used. The region immediately outside the walls of the caverns is very finely subdivided. This extremely fine subdivision was used to accurately represent the high stress and temperature gradients that were anticipated near the cavern periphery. The extents of the models were sel ected to isol ate the response of the caverns from the influences of the radial and bottom boundaries which are artificial truncations of the actual horizontal and vertical extents of the salt.

The kinematic boundary conditions specified along the sides of the axisymmetric models were:

- No radial displacement along the centerline

- No radial displacement along the outer radius

- No vertical displacement al ong the bottom surface.

The upper surface of the models is free to move in the vertical direction. 
RSI-1399-03-002

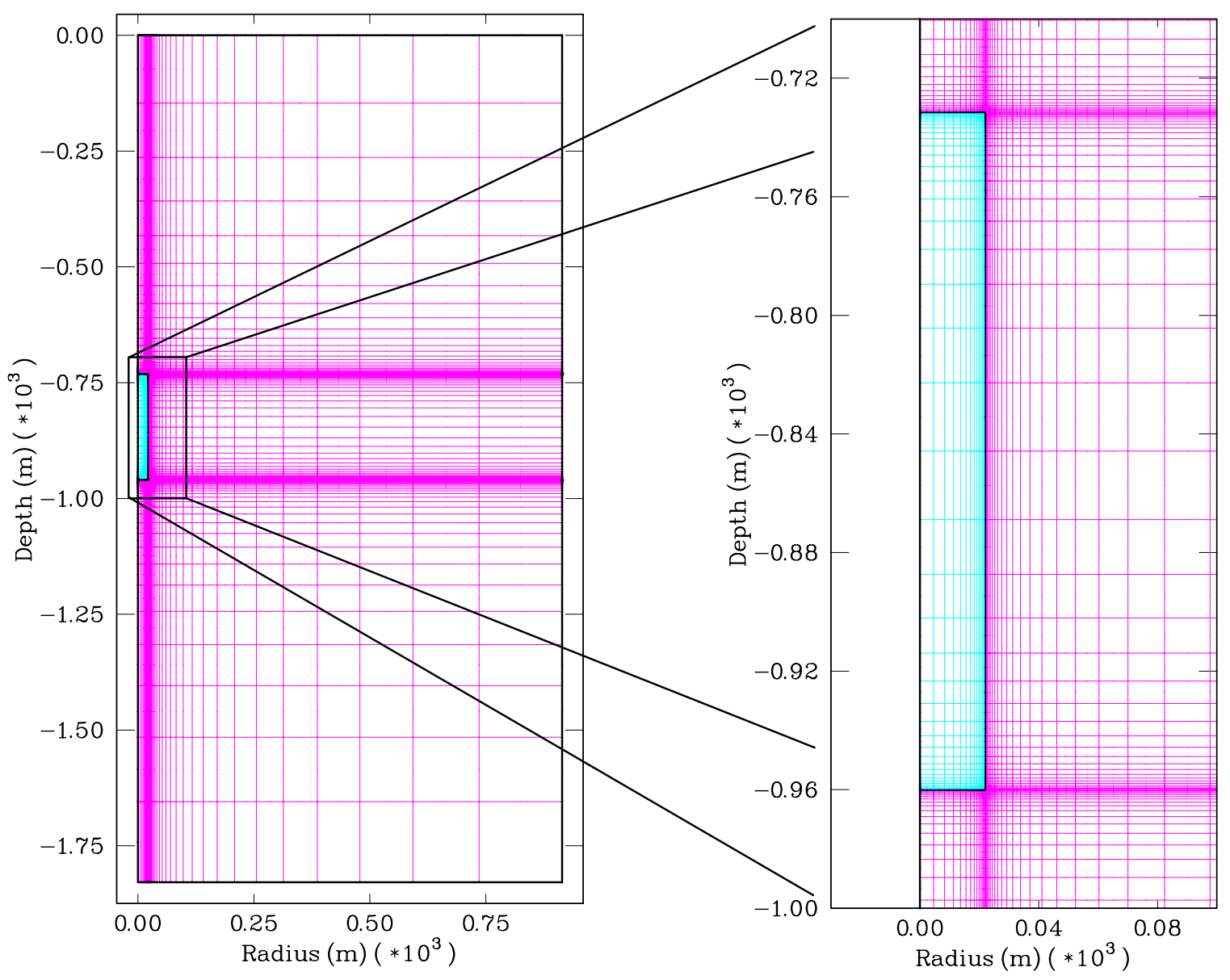

Figure 3-1. Axisymmetric Finite Element Model Used to Represent LNG Receiving Terminal Caverns. 
After excavation of the salt, normal tractions are specified al ong the surfaces of the cavern to simulate the fluid pressure inside the cavern. The magnitudes of these tractions are equal to the hydrostatic pressure based on the density of brine during the solution mining portion of the simulation and based on the respective wellhead pressure and gas density during the natural gas storage portion of the simulated history. The cavern is modeled between the depths of 730 meters and 960 meters (2,400 feet and 3,150 feet). There are 13,623 nodes and 4,444 8-noded finite elements in this model. 


\subsection{MODELING RESULTS}

Cavern stability is evaluated in terms of damage potential and the development of tensile stresses. Salt that has a damage potential greater than the 0.27 limit does not indicate immediate failure of the salt, only that the salt is in a stress state that will result in microfracturing of the salt that could eventually lead to spalling. Tensile failure, however, will occur immediately if the tensile strength of the salt is exceeded. The tensile strength of salt is low (1-2 MPa (150-300 psi)) and we conservatively assume no tensile strength in this study. The maximum principal stresses are examined to determine tensile regions in the salt. The sign convention used here assumes compression is negative and thus the maximum principal stress is the least compressive (or most tensile) of the three principal stresses.

CGI proposed two 5-year gas storage scenarios to be used in the evaluation of the LNG receiving terminal. As described in Chapter 2.0, the hypothetical terminal was designed to have a working gas capacity approximately equal to that contained in two LNG tankers. The first scenario consists of continuous cycles of withdrawing and injecting a single LNG tanker load of gas. In this scenario, the casing seat pressure is reduced from $13.8 \mathrm{MPa}(2,000 \mathrm{psi})$ to 9.3 $\mathrm{MPa}(1,350 \mathrm{psi})$ to represent the removal of a single LNG tanker load of gas (about 50 percent of the working gas) over a 3-day period, followed by repressurization to $13.8 \mathrm{MPa}$ (2,000 psi) over a 0.75 -day period to represent the gas injection from a single LNG tanker. The second storage scenario consists of withdrawing and injecting the gas from two LNG tankers. In this scenario, the casing seat pressure is reduced from 13.8 $\mathrm{MPa}(2,000 \mathrm{psi})$ to $4.9 \mathrm{MPa}$ (705 psi) to represent the removal of the double-tanker load of gas (the entire working gas) over a 3-day period, followed by repressurization to $13.8 \mathrm{MPa}(2,000 \mathrm{psi})$ over a 1.5-day period to represent the gas injection from two LNG tankers. The pressure cycles for the two gas-storage scenarios are shown in Figure 4-1. The single-tanker scenario was evaluated for gas injection temperatures of $-17.8^{\circ} \mathrm{C}\left(0^{\circ} \mathrm{F}\right)$ and $4.4^{\circ} \mathrm{C}\left(40^{\circ} \mathrm{F}\right)$. The double-tanker scenario was evaluated for gas temperatures of $-17.8^{\circ} \mathrm{C}\left(0^{\circ} \mathrm{F}\right), 4.4^{\circ} \mathrm{C}\left(40^{\circ} \mathrm{F}\right)$, and $43.3^{\circ} \mathrm{C}\left(110^{\circ} \mathrm{F}\right)$.

\subsection{MODEL INITIALIZATION}

The stress and temperature history of the salt surrounding the caverns prior to gas storage was estimated by modeling the leaching and dewatering of the cavern. In the leaching simulation, the cavern was leached for a period of 500 days, assuming a $21^{\circ} \mathrm{C}\left(70^{\circ} \mathrm{F}\right)$ freshwater injection temperature. This was followed by dewatering of the cavern over a period of 100 days using $4.4^{\circ} \mathrm{C}\left(40^{\circ} \mathrm{F}\right)$ gas at a pressure of $10.3 \mathrm{MPa}(1,500 \mathrm{psi})$. The cavern was then filled with $4.4^{\circ} \mathrm{C}\left(40^{\circ} \mathrm{F}\right)$ gas to a pressure of $13.8 \mathrm{MPa}(2,000 \mathrm{psi})$ over a 10 -day period. The stress and temperature distribution at this point was then used as the starting point for all of the modeled storage scenarios. 


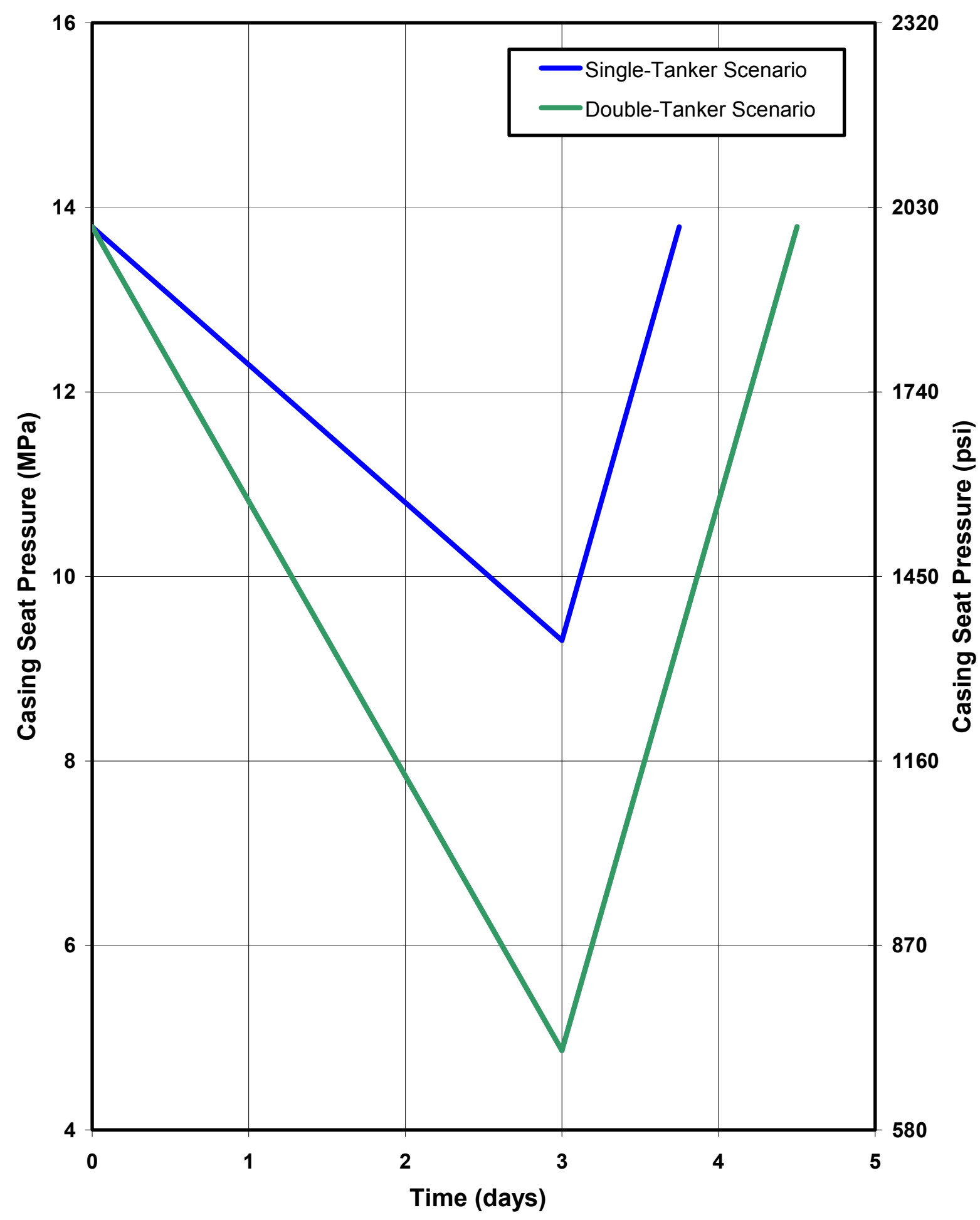

Figure 4-1. M Modeled Gas Storage Cycles. 


\subsection{TEMPERATURE CHANGES DURING GAS STORAGE}

The temperature changes that occur in the salt can have a significant effect on cavern stability. Salt has a very high coefficient of thermal expansion (5-10 times higher than most rock) and thus temperature changes result in stress changes due to the thermal expansion or contraction that occurs. The creep rate of salt is also highly temperature dependent. Since the stress state in the salt is redistributed as it creeps, temperature changes in the salt will affect this stress redistribution process. Because the gas temperature in a cavern changes significantly as it is compressed and decompressed, the simulated gas storage cycles result in both short-term and long-term temperature changes in the salt. The short-term temperature changes in the salt that are the result of gas injection and withdrawal only affect the first couple of meters of salt surrounding the cavern. The long-term temperature changes, that affect a much larger region, are much more gradual.

Figures 4-2 through 4-6 show the predicted temperature distribution in the salt surrounding the cavern at various times for each of the simulated cycles. These figures indicate the longterm temperature changes that occur gradually. For the $-17.8^{\circ} \mathrm{C}$ and $4.4^{\circ} \mathrm{C}\left(0^{\circ} \mathrm{F}\right.$ and $\left.40^{\circ} \mathrm{F}\right)$ gas injection temperatures (both the single-tanker and double-tanker simulations), the salt around the cavern is cooled during the 5-year simulations. In the simulations with a $-17.8^{\circ} \mathrm{C}\left(0^{\circ} \mathrm{F}\right)$ injection temperature, the salt is cooled significantly more than in the simulations with the $4.4^{\circ} \mathrm{C}\left(40^{\circ} \mathrm{F}\right)$ injection temperature. The double-tanker scenario cools the salt only slightly more than the singletanker scenario with the same injection temperature. In the doubletanker simulation with a gas injection temperature of $43.3^{\circ} \mathrm{C}\left(110^{\circ} \mathrm{F}\right)$, the salt around the cavern is heated during the 5-year simulation.

Figure 4-7 shows the temperature distribution around the upper portion of the cavern during the first gas withdrawal in the double-tanker scenarios. This figure indicates the shortterm temperature changes that occur during gas withdrawal. The temperature change at the cavern surface is about $50^{\circ} \mathrm{C}\left(90^{\circ} \mathrm{F}\right)$. Note that the over this 3-day withdrawal period, only a couple of meters of salt around the cavern have a significant change in temperature. Figure 4-8 shows the cavern wall temperature predicted by SCTS for the first 90 days for each of the 5-year simulations. The temperature changes during injection and withdrawal for the singletanker simulations are less than half of those for the double-tanker simulations.

\subsection{CAVERN STABILITY DURING GAS STORAGE SCENARIOS}

In all of the simulations, the least stable conditions occur at the end of gas withdrawal. Thus only results during gas withdrawal are presented in this section. Because the initial stress and temperature conditions are the same for all of the simulations, the results for first withdrawal are exactly the same for both of the single-tanker simulations. Likewise, the results for the first withdrawal of all the double-tanker simulations are exactly the same. 


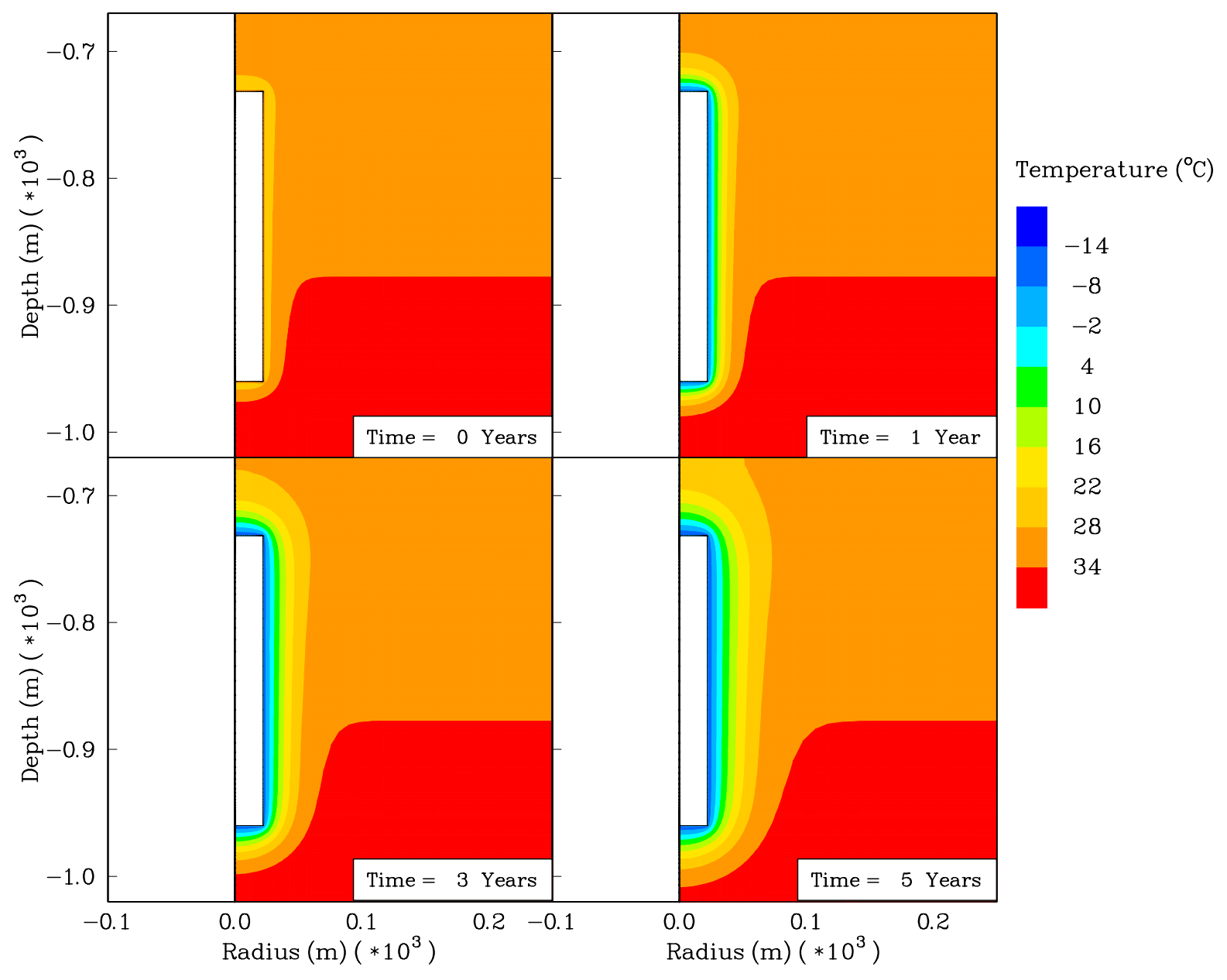

Figure 4-2. Temperature Distributions in Salt for Single-Tanker Scenario With $-17.8^{\circ} \mathrm{C}\left(0^{\circ} \mathrm{F}\right)$ Gas Injection Temperature. 


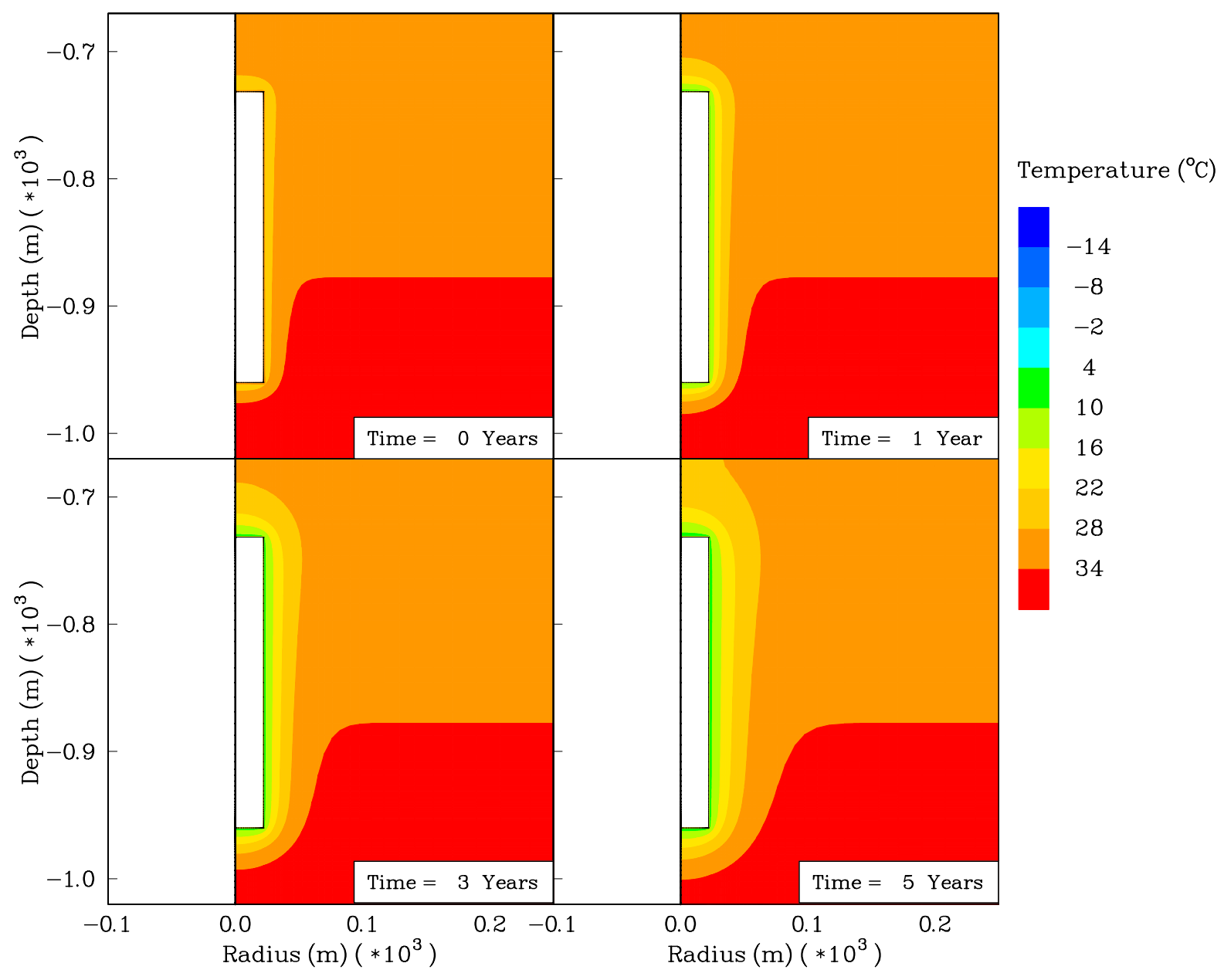

Figure 4-3. Temperature Distributions in Salt for Single-Tanker Scenario With $4.4^{\circ} \mathrm{C}\left(40^{\circ} \mathrm{F}\right)$ Gas Injection Temperature. 


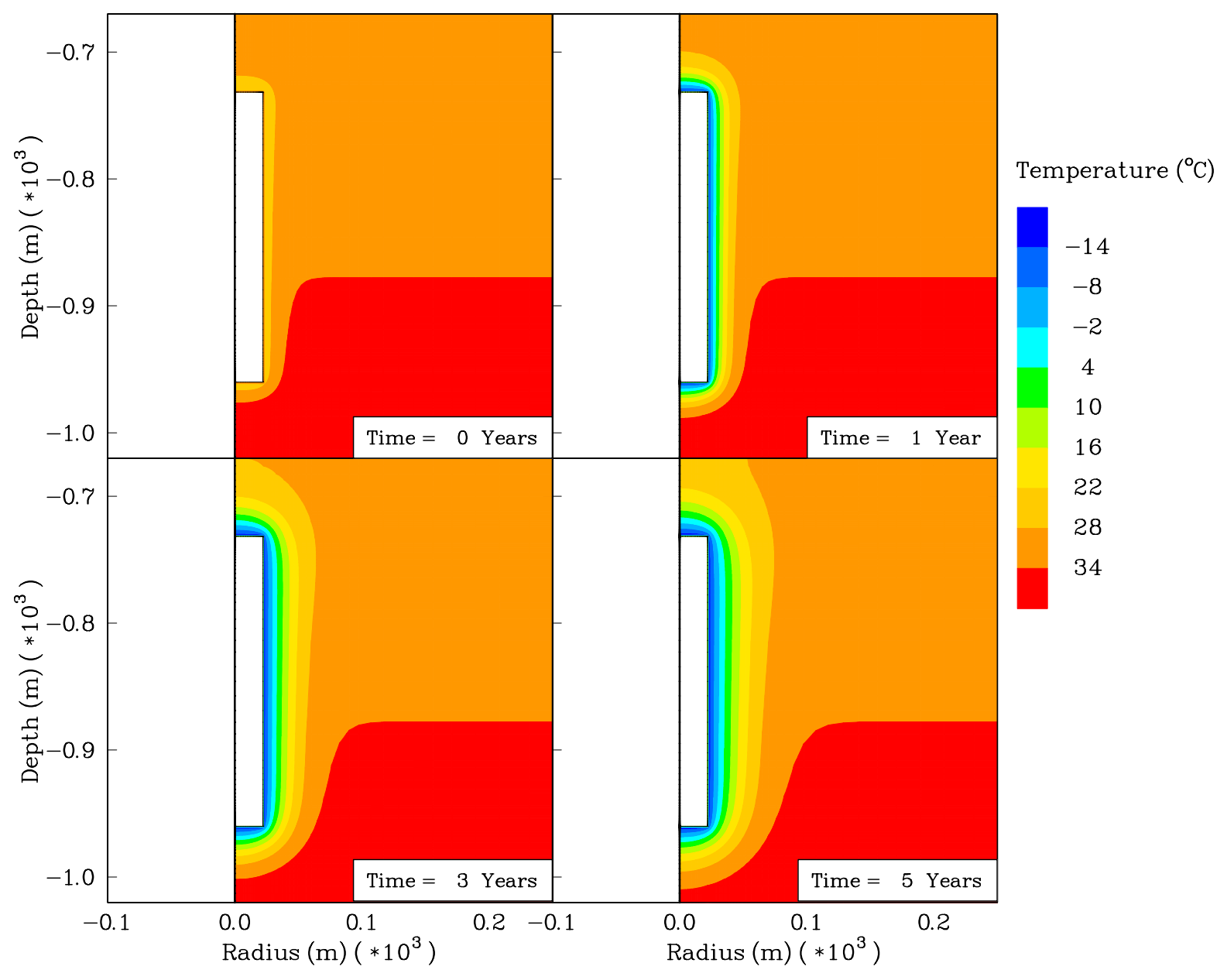

Figure 4-4. Temperature Distributions in Salt for Double-Tanker Scenario With $-17.8^{\circ} \mathrm{C}\left(0^{\circ} \mathrm{F}\right)$ Gas Injection Temperature. 


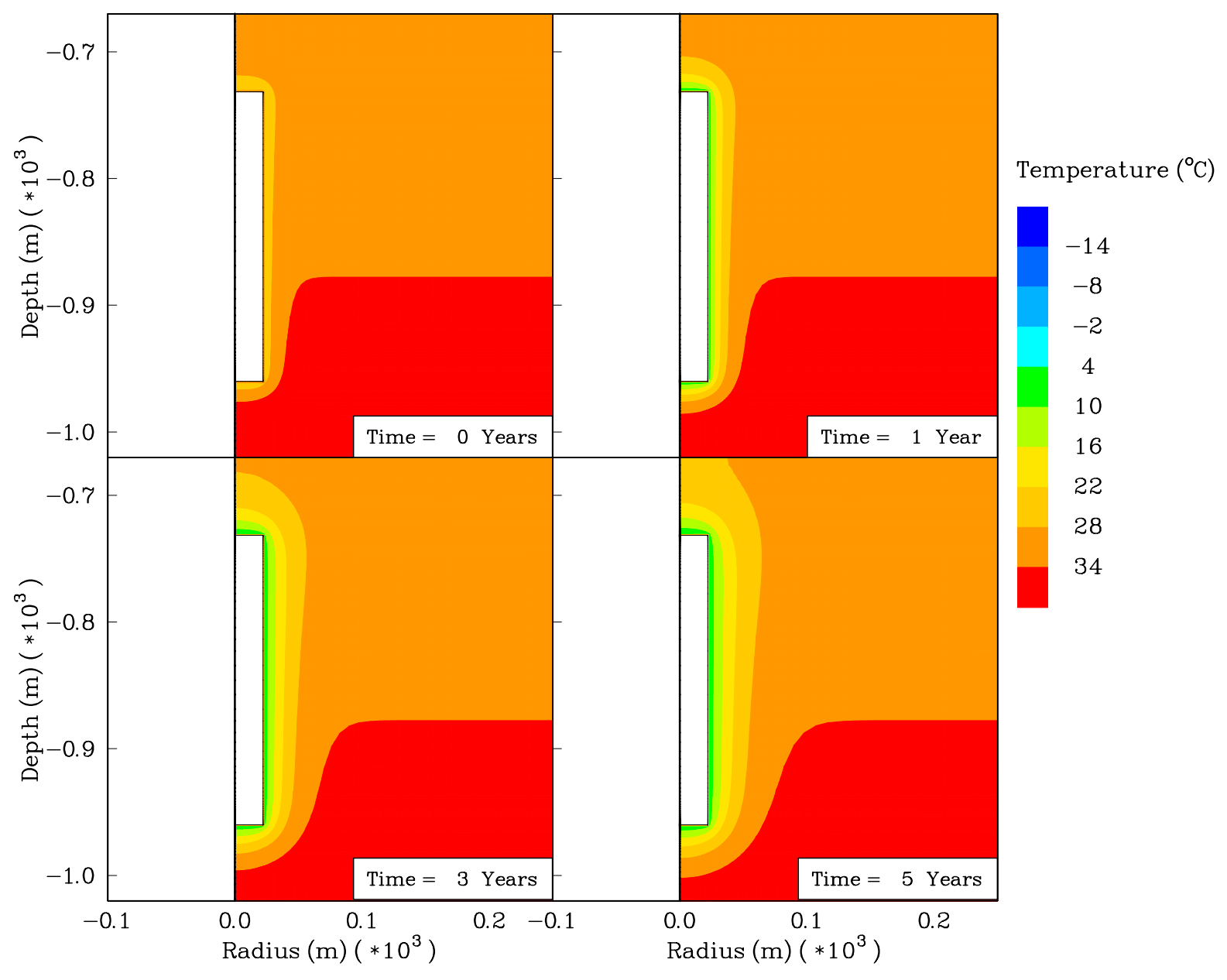

Figure 4-5. Temperature Distributions in Salt for Double-Tanker Scenario With $4.4^{\circ} \mathrm{C}\left(40^{\circ} \mathrm{F}\right)$ Gas Injection Temperature. 


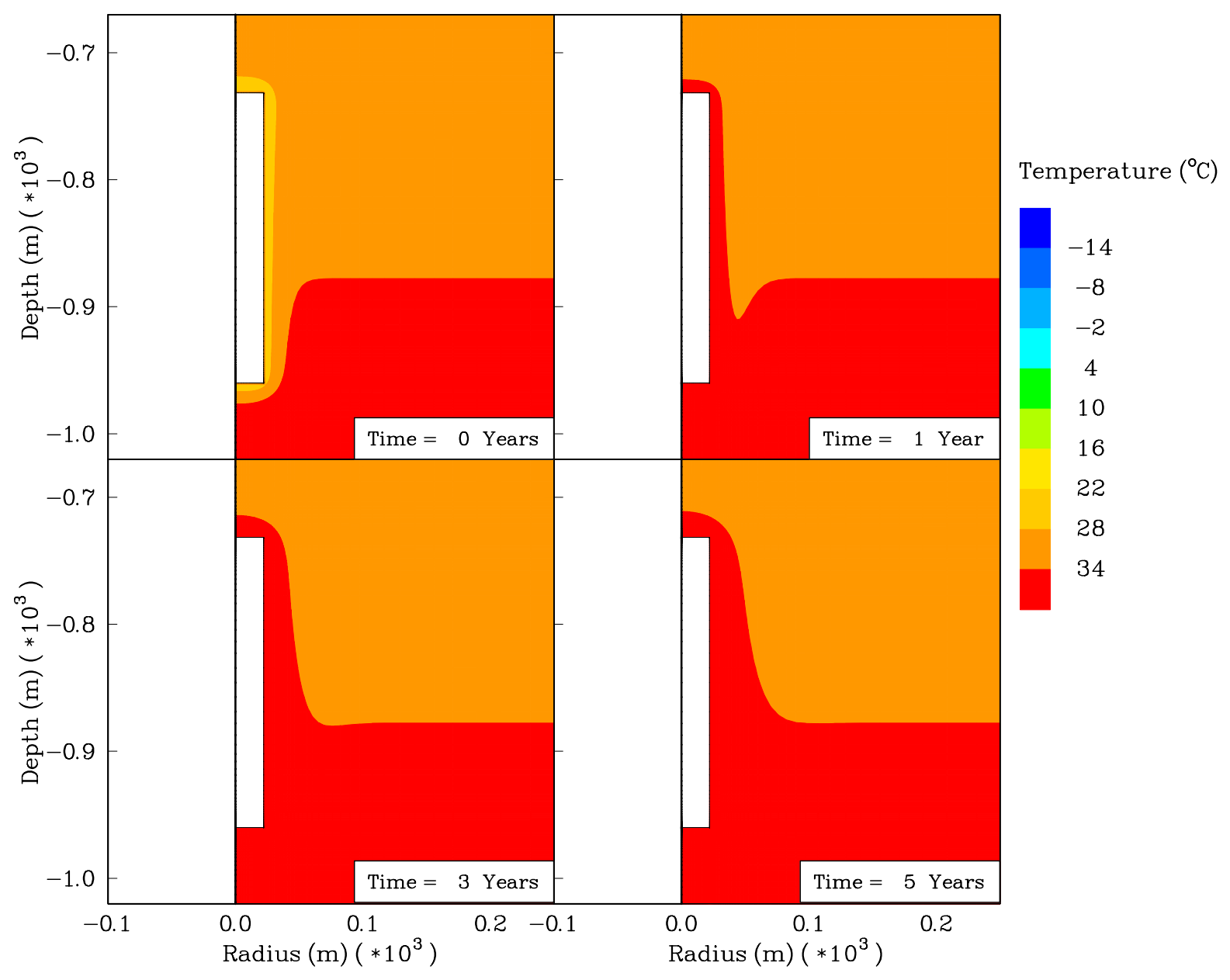

Figure 4-6. Temperature Distributions in Salt for Double-Tanker Scenario With $43.3^{\circ} \mathrm{C}$ $\left(110^{\circ} \mathrm{F}\right)$ Gas Injection Temperature. 
RSI-1399-03-009

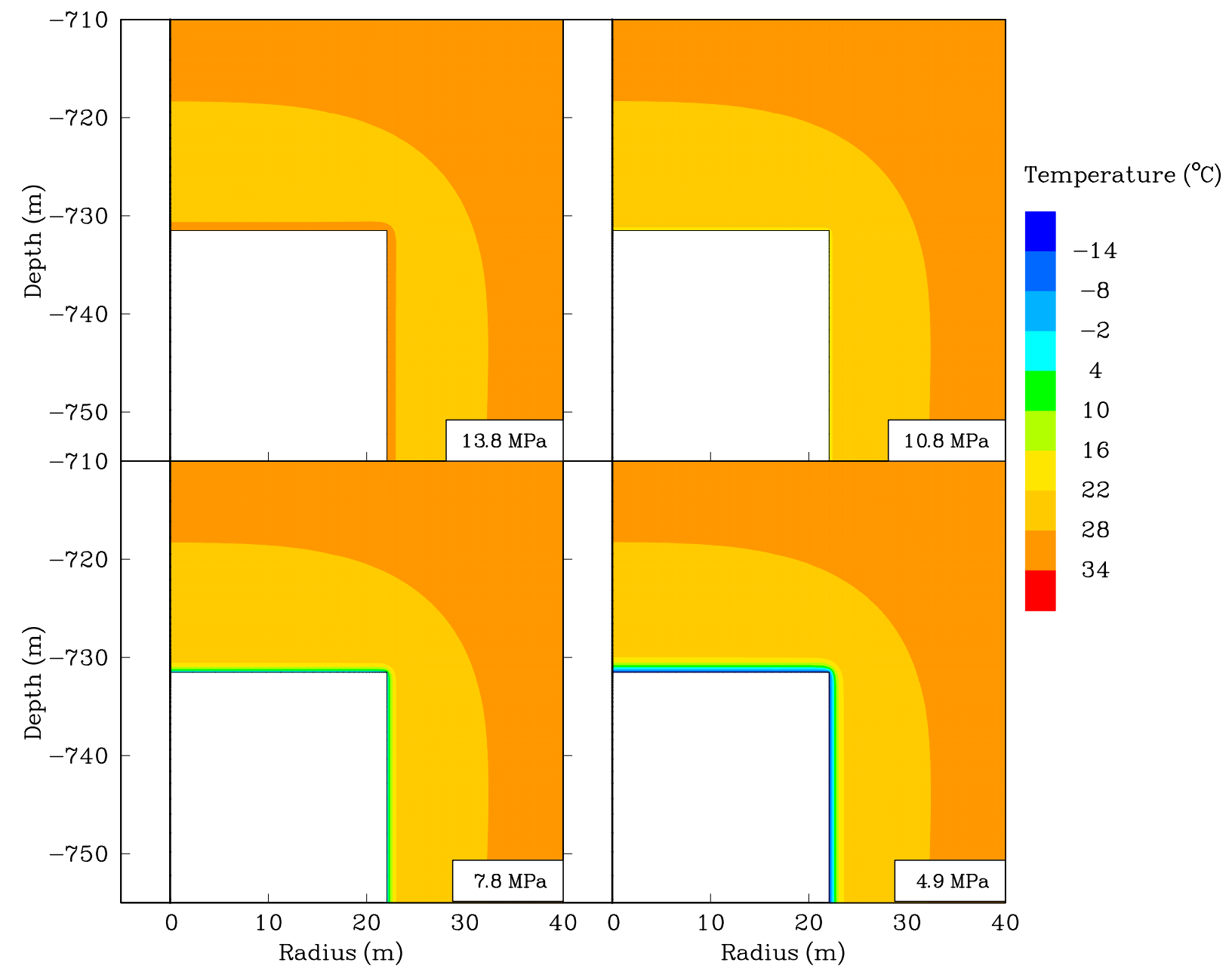

Figure 4-7. Temperature Distributions Around Top of Cavern During First Withdrawal in Double-Tanker Scenarios. 


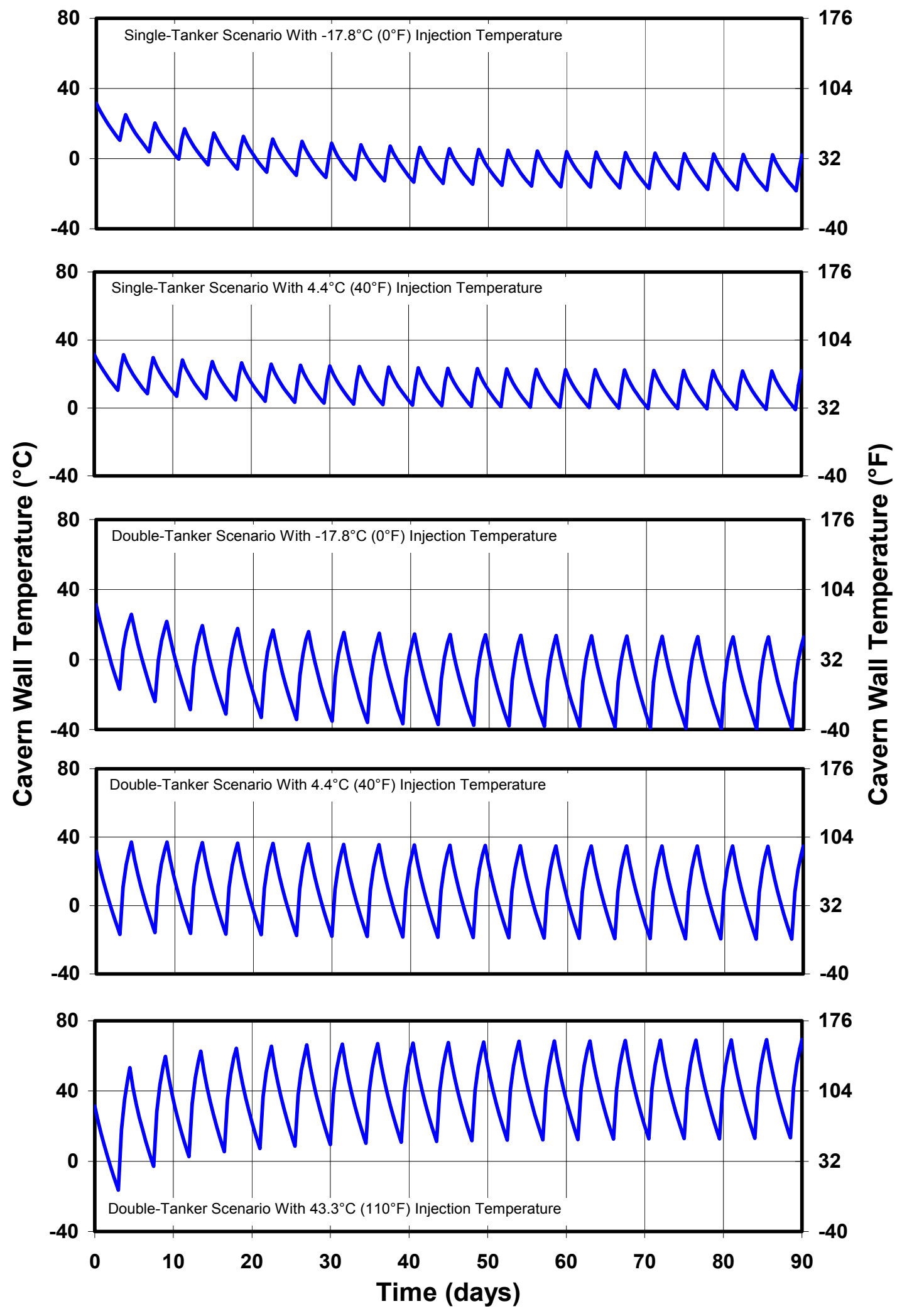

Figure 4-8. Cavern Wall Temperature Versus Time for Various Gas Storage Scenarios. 
Figure 4-9 shows damage potential contours in the salt around the upper portion of the cavern during the first withdrawal for the doubletanker simulations. As shown in this figure, the values of damage potential in the salt increase as the cavern pressure decreases. However, with the exception of the sharp corner between the roof and walls (which is an artifact of the simplified cavern geometry), damage potential values remain significantly below the 0.27 limit. Damage potential contours are not shown in regions that are in tension (note the "uncontoured" region around the cavern periphery at lower pressures) because the damage potential is not meaningful in tensile regions. Throughout all of the 5-year simulations, the damage potential values in the salt remain low.

Figure 4-10 shows maximum principal stress contours in the salt during the first withdrawal for the singletanker simulations. In this case, tensile stresses just start to develop near the end of the 3-day withdrawal. At the end of the 3-day withdrawal, the tensile zone extends about 0.3 meter ( 1 foot) into the salt. Figure 4-11 shows maximum principal stress contours in the salt during the first withdrawal for the double-tanker simulations. In this case, tensile stresses start to devel op in the first day of the 3-day withdrawal period, and by the end of the withdrawal period, the tensile zone extends about 1.5 meters ( 5 feet) into the salt.

Figures 4-12 and 4-13 show maximum principal stress contours in the salt around the top of the cavern during withdrawal after 5 years of cycling for single-tanker simulations with injection temperatures of $-17.8^{\circ} \mathrm{C}\left(0^{\circ} \mathrm{F}\right)$ and $4.4^{\circ} \mathrm{C}\left(40^{\circ} \mathrm{F}\right)$, respectively. Small regions of tensile stresses develop by the end of withdrawal in both cases. Thus the results for both cases after 5 years are very similar to those during the first gas withdrawal.

Figures 4-14, 4-15, and 4-16 show maximum principal stress contours in the salt around the top of the cavern during withdrawal after 5 years of cycling for double-tanker simulations with injection temperatures of $-17.8^{\circ} \mathrm{C}\left(0^{\circ} \mathrm{F}\right), 4.4^{\circ} \mathrm{C}\left(40^{\circ} \mathrm{F}\right)$, and $43.3^{\circ} \mathrm{C}\left(110^{\circ} \mathrm{F}\right)$, respectively. Again, very little difference is seen between the initial withdrawal results (Figure 4-11) and the results after 5 years. Also, the results for the three different injection temperatures are very similar.

All of the simulations indicate that tensile fractures will develop around the cavern periphery. The orientation of the tensile stresses is tangential to the cavern surface and will result in fractures oriented perpendicular to the cavern surface. Since these tensile zones occur only near the cavern surface and are surrounded by highly compressive zones, it is unlikely that fractures would result in catastrophic failure of the cavern nor are they likely to form connections to other caverns or the edge of the salt dome. However, repeated fracturing of the cavern periphery by continuously cycling the gas will result in salt on the roof and sidewalls progressively sloughing off, reducing the life of the cavern. 
RSI-1399-03-011

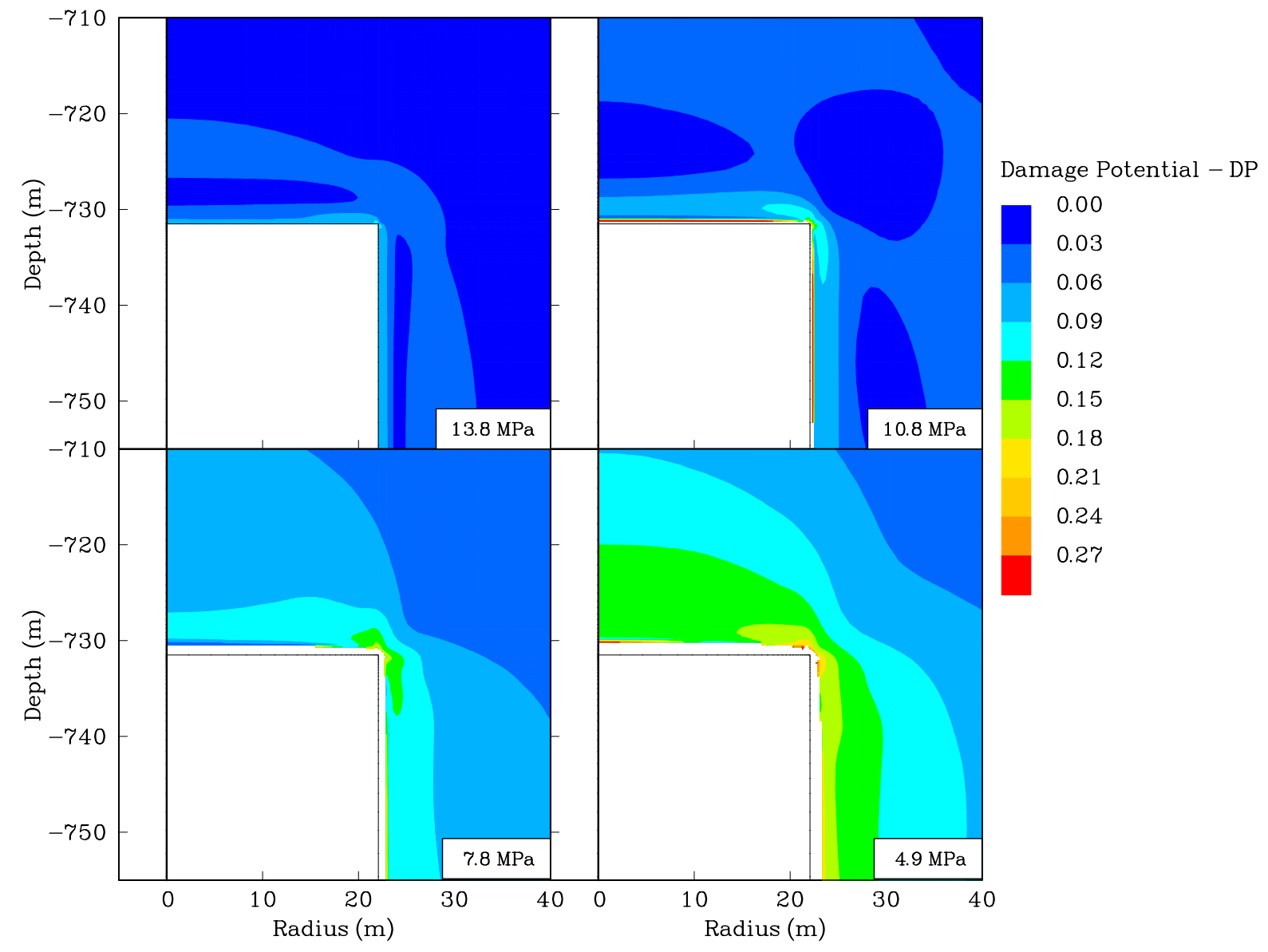

Figure 4-9. Damage Potential Contours Around Top of Cavern During First Withdrawal for Double-Tanker Scenarios. 
RSI-1399-03-012

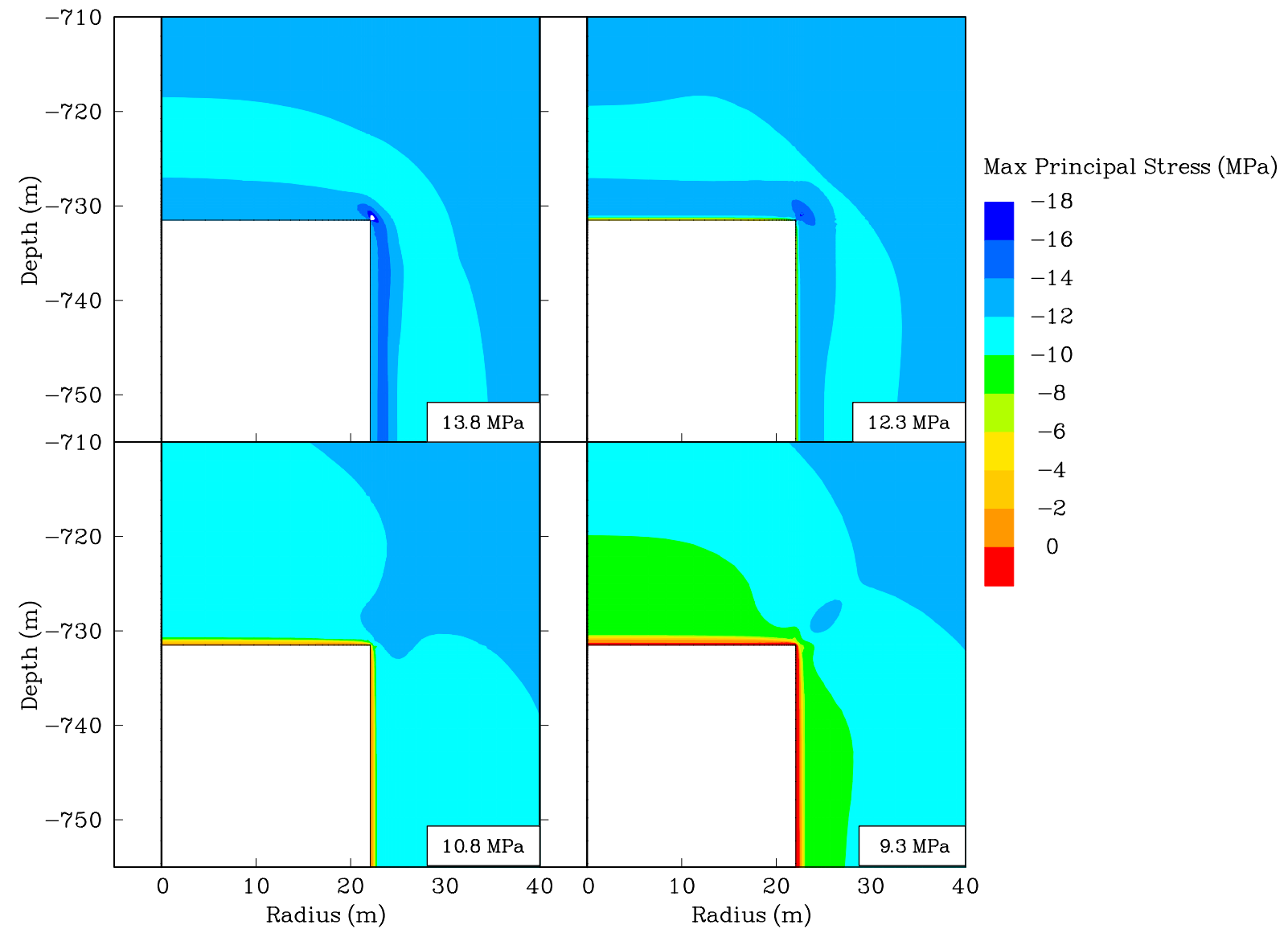

Figure 4-10. Maximum Principal Stress Contours Around Top of Cavern During First 3-Day Withdrawal of Single-Tanker Simulations. 
RSI-1399-03-013

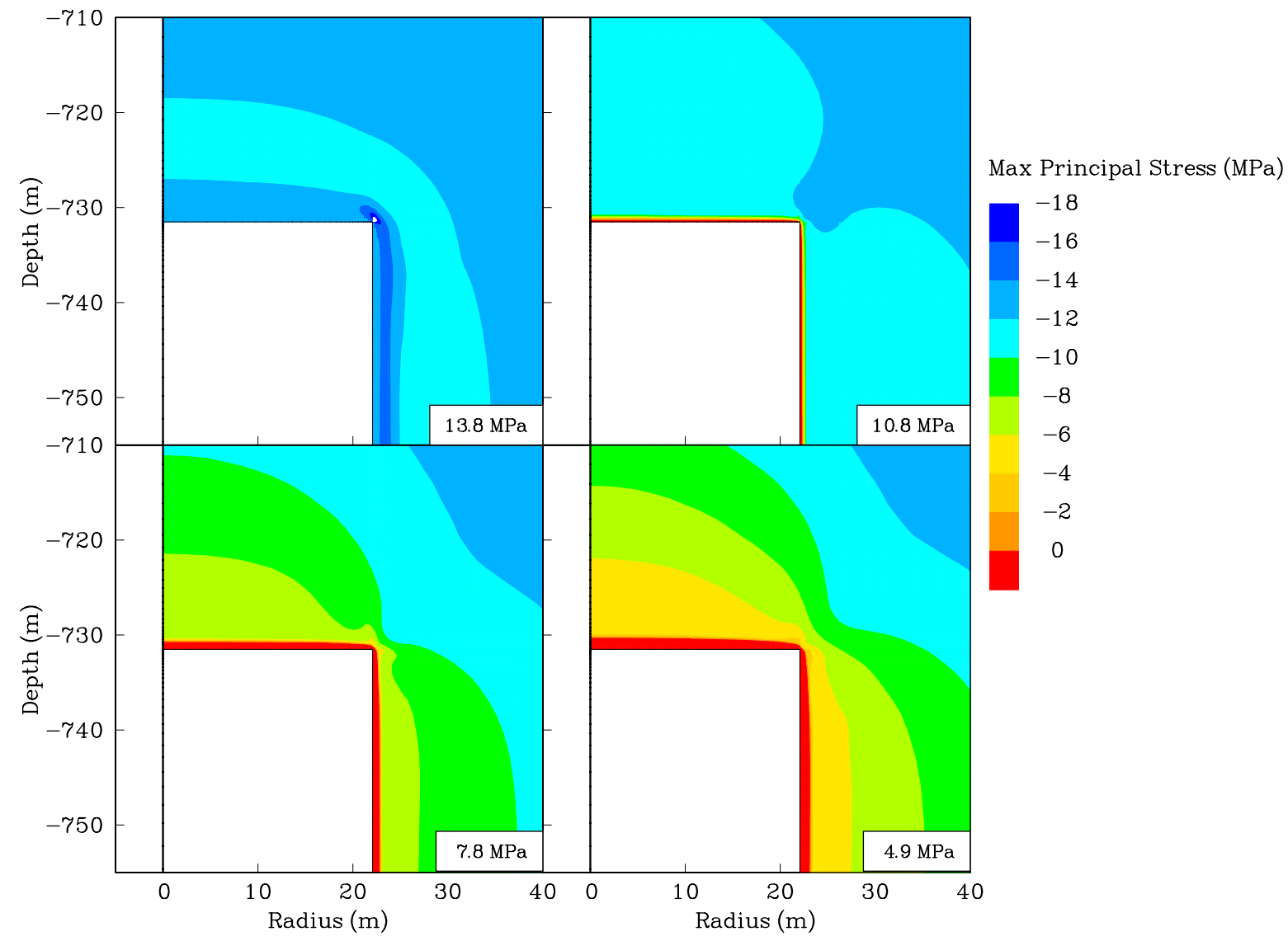

Figure 4-11. Maximum Principal Stress Contours Around Top of Cavern During First 3-Day Withdrawal of Double-Tanker Simulations. 
RSI-1399-03-014

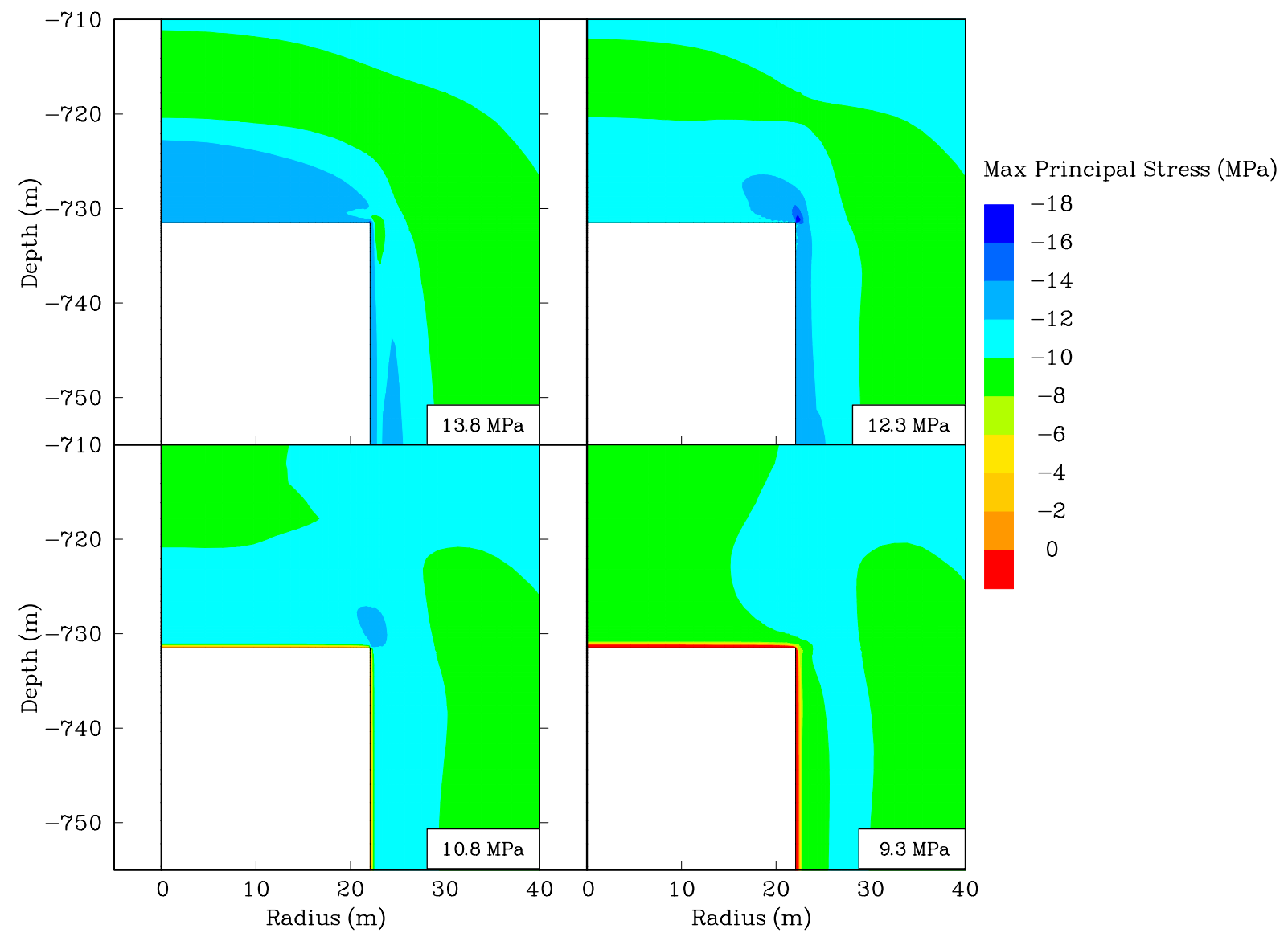

Figure 4-12. Maximum Principal Stress Contours Around Top of Cavern During 3-Day Withdrawal of Single-Tanker Simulation With $-17.8^{\circ} \mathrm{C}\left(0^{\circ} \mathrm{F}\right)$ Injection Temperature After Cycling for 5 Years. 
RSI-1399-03-015

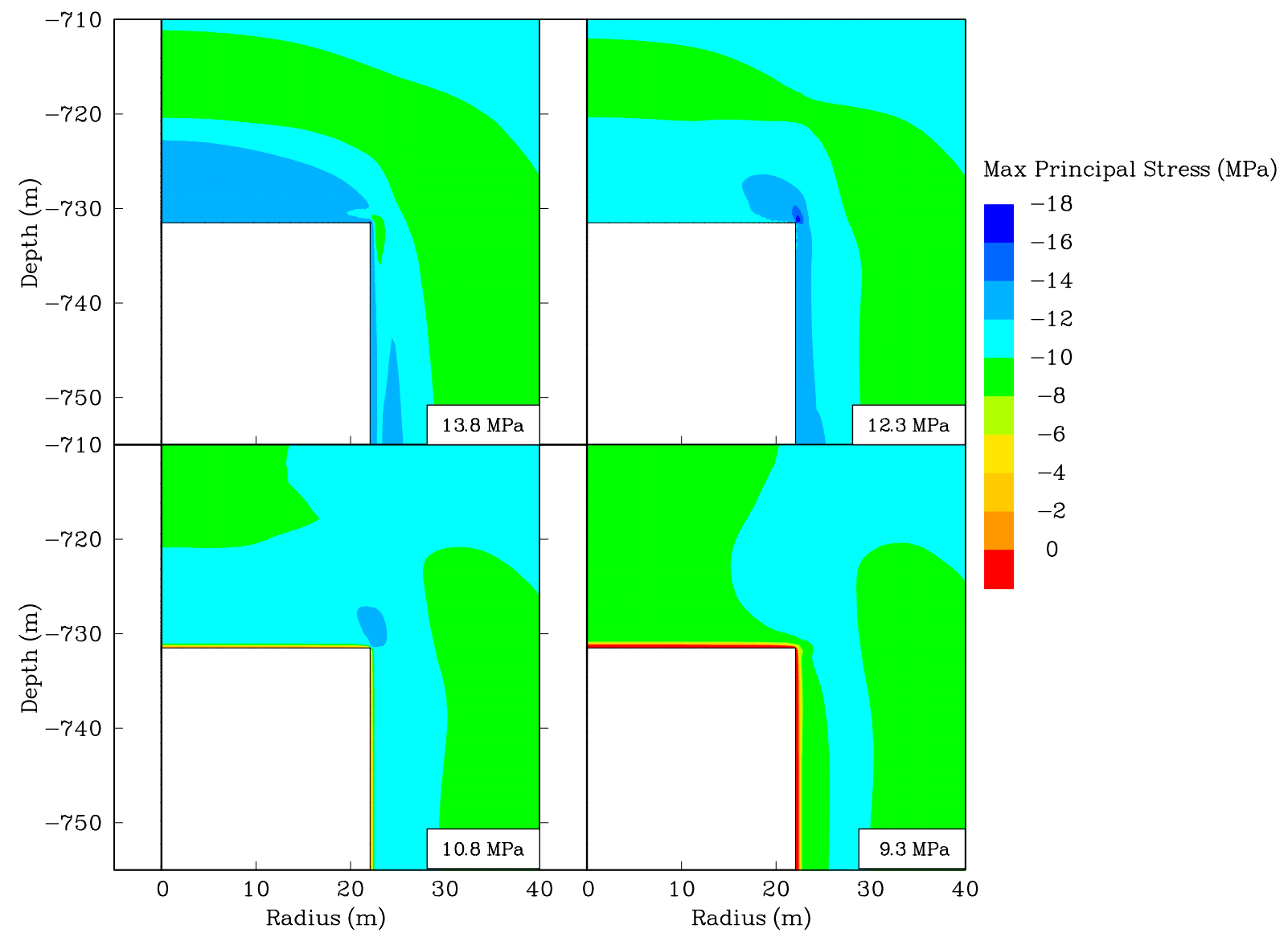

Figure 4-13. Maximum Principal Stress Contours Around Top of Cavern During 3-Day Withdrawal of Single-Tanker Simulation With $4.4^{\circ} \mathrm{C}\left(40^{\circ} \mathrm{F}\right)$ Injection Temperature After Cycling for 5 Years. 


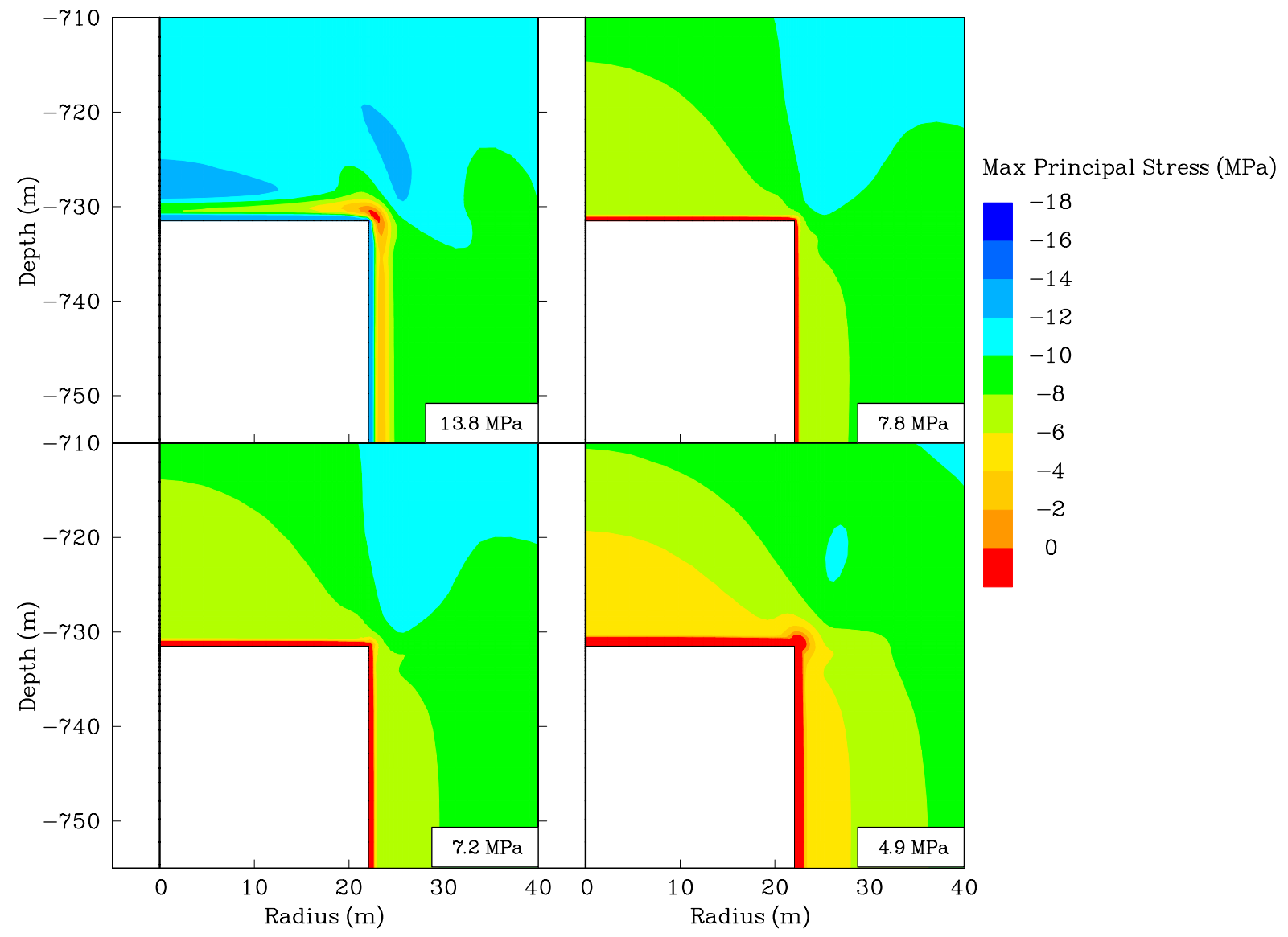

Figure 4-14. Maximum Principal Stress Contours Around Top of Cavern During 3-Day Withdrawal of Double-Tanker Simulations With $-17.8^{\circ} \mathrm{C}\left(0^{\circ} \mathrm{F}\right)$ I njection Temperature After Cycling for 5 Years. 


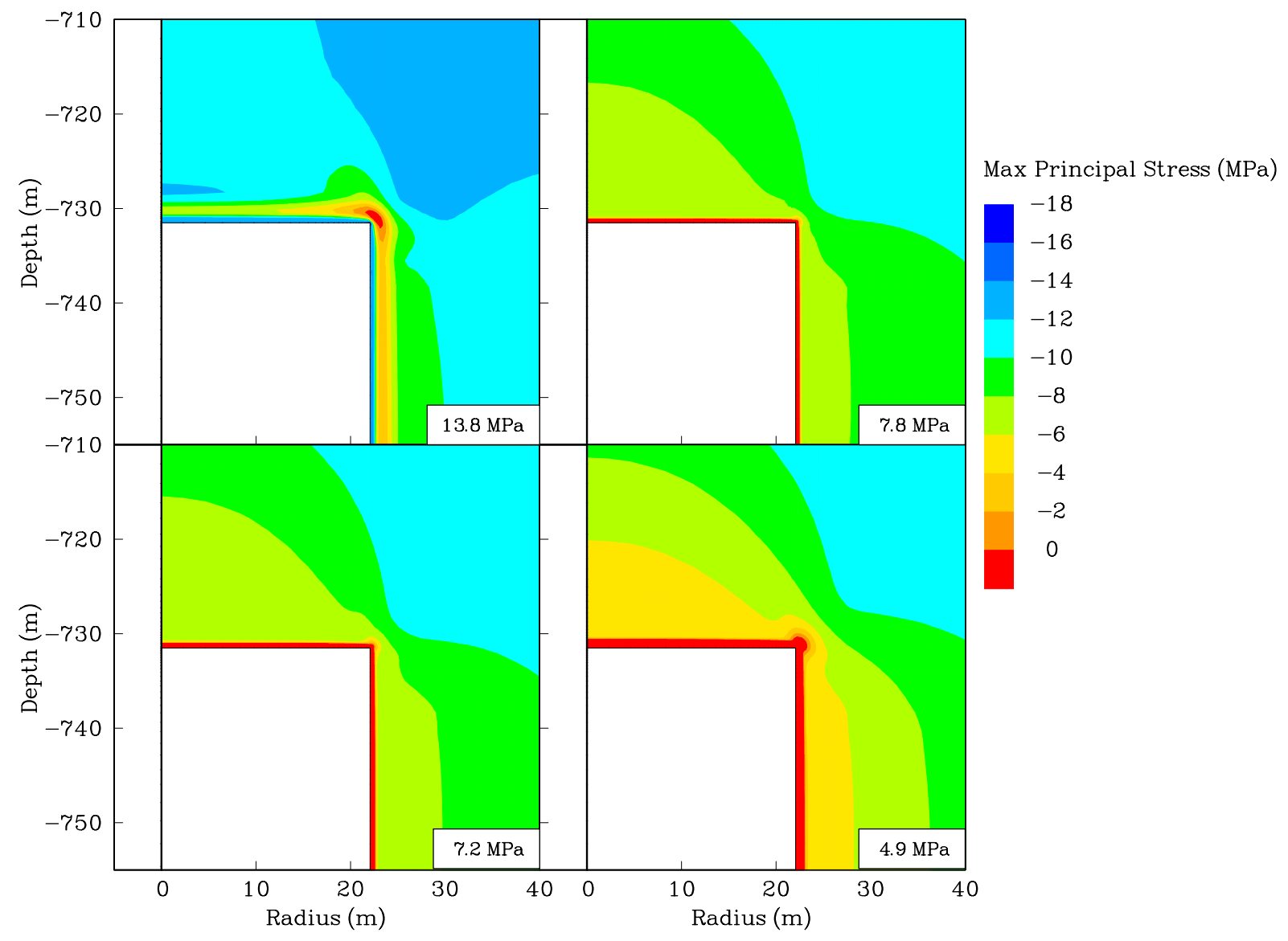

Figure 4-15. Maximum Principal Stress Contours Around Top of Cavern During 3-Day Withdrawal of Double-Tanker Simulation With $4.4^{\circ} \mathrm{C}\left(40^{\circ} \mathrm{F}\right)$ Injection Temperature After Cycling for 5 Years. 


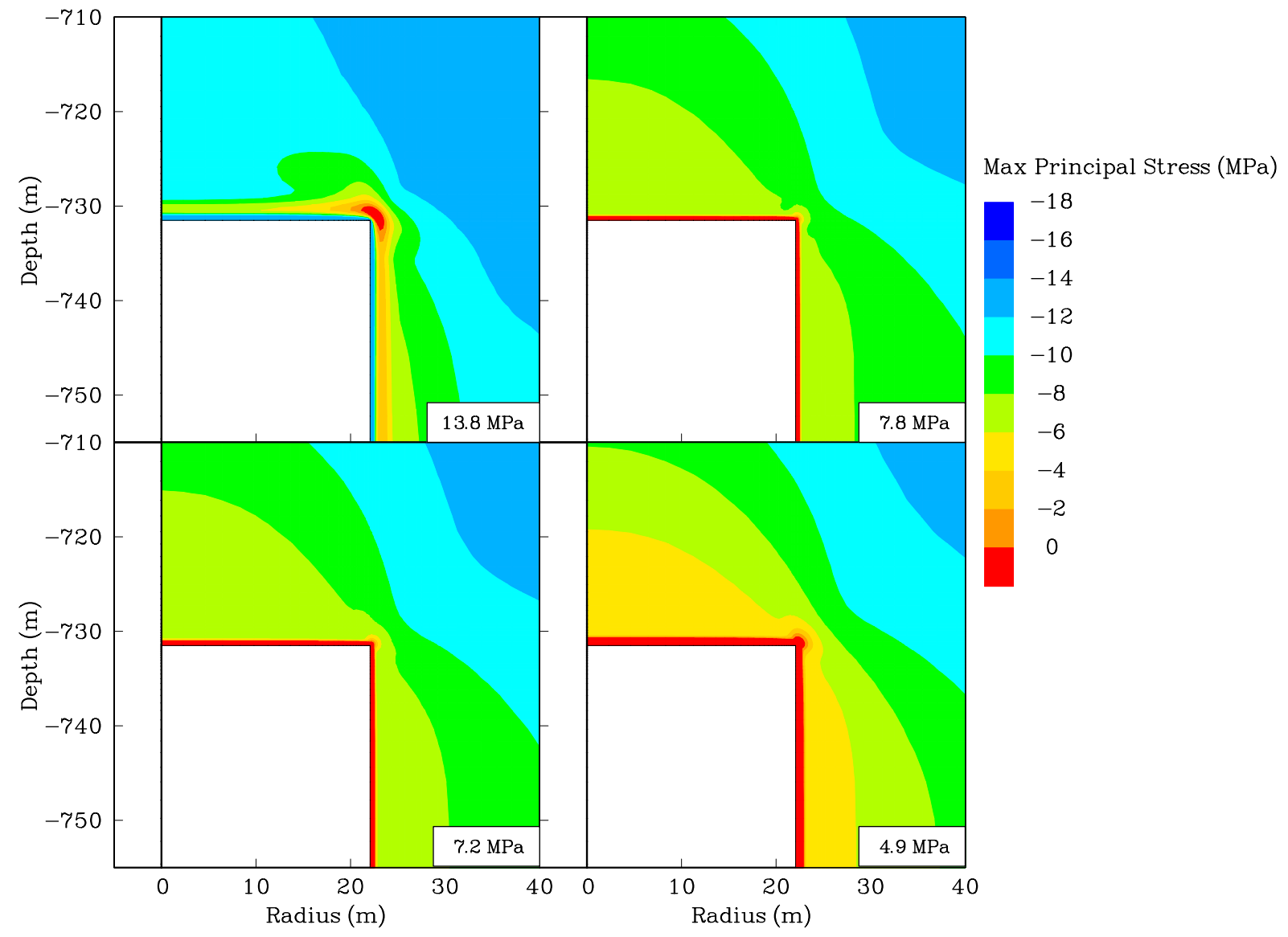

Figure 4-16. Maximum Principal Stress Contours Around Top of Cavern During 3-Day Withdrawal of Double-Tanker Simulation With $43.3^{\circ} \mathrm{C}\left(110^{\circ} \mathrm{F}\right)$ Injection Temperature After Cycling for 5 Years. 


\subsection{EVALUATION OF GAS WITHDRAWAL RATE}

Three simulations were made to investigate the effect of the withdrawal rate on cavern stability. Similar to the double-tanker scenarios, the entire working gas was withdrawn from the cavern. Rather than withdrawing the gas in a 3-day period, 10-day, 20-day, and 30-day withdrawals were simulated. These simulations used the same initial conditions as the previous simulations. Contours of the maximum principal stress around the top of the cavern for these three simulations are shown in Figures 4-17 through 4-19. There is not much difference between the results of the 10-day withdrawal and the original 3-day withdrawal (Figure 4-11). However, during the 20-day withdrawal, the region of tensile stresses that develops is somewhat smaller. Increasing the withdrawal time to 30 days reduces the size of the tensile zone even more. Reducing the withdrawal rate allows more time for heat transfer to take place between the gas and the salt, reducing the thermal gradients that result in thermal contraction in the salt. Also, salt creep has more time to redistribute the stresses in the salt to counteract the thermal contraction that occurs. 
RSI-1399-03-019

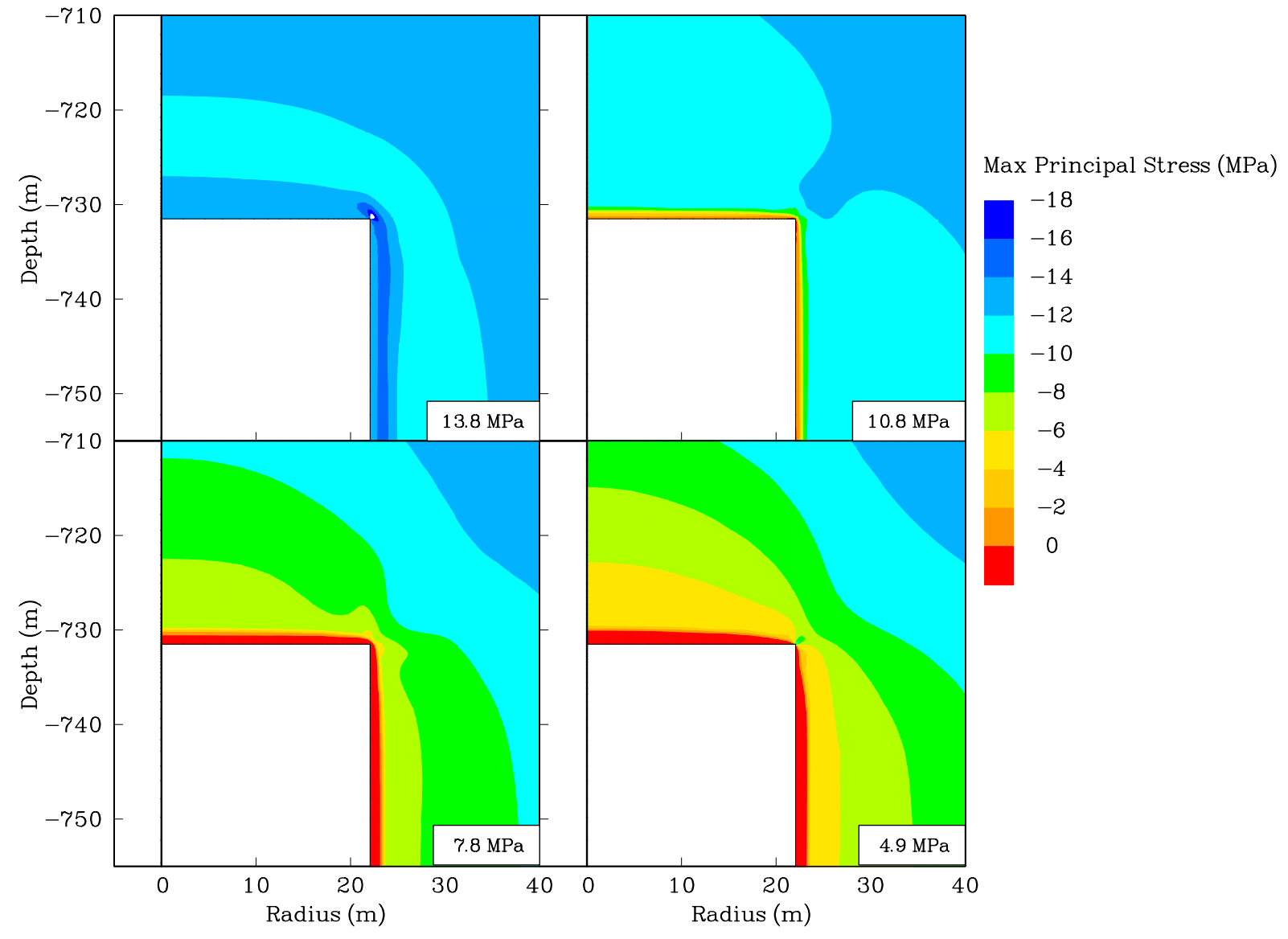

Figure 4-17. Maximum Principal Stress Contours Around Top of Cavern During 10-Day Double-Tanker Withdrawal. 
RSI-1399-03-020

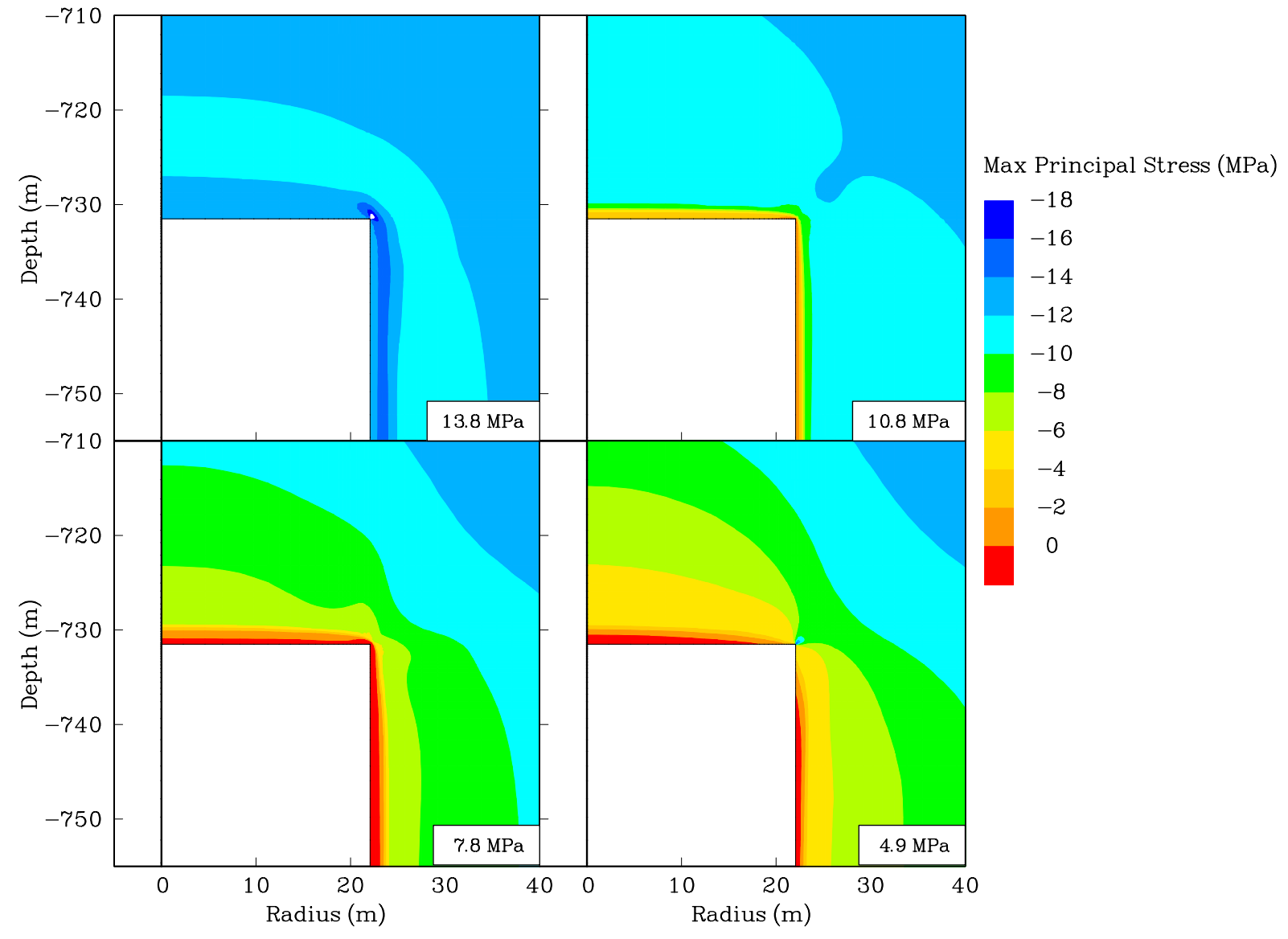

Figure 4-18. Maximum Principal Stress Contours Around Top of Cavern During 20-Day Double-Tanker Withdrawal. 
RSI-1399-03-021

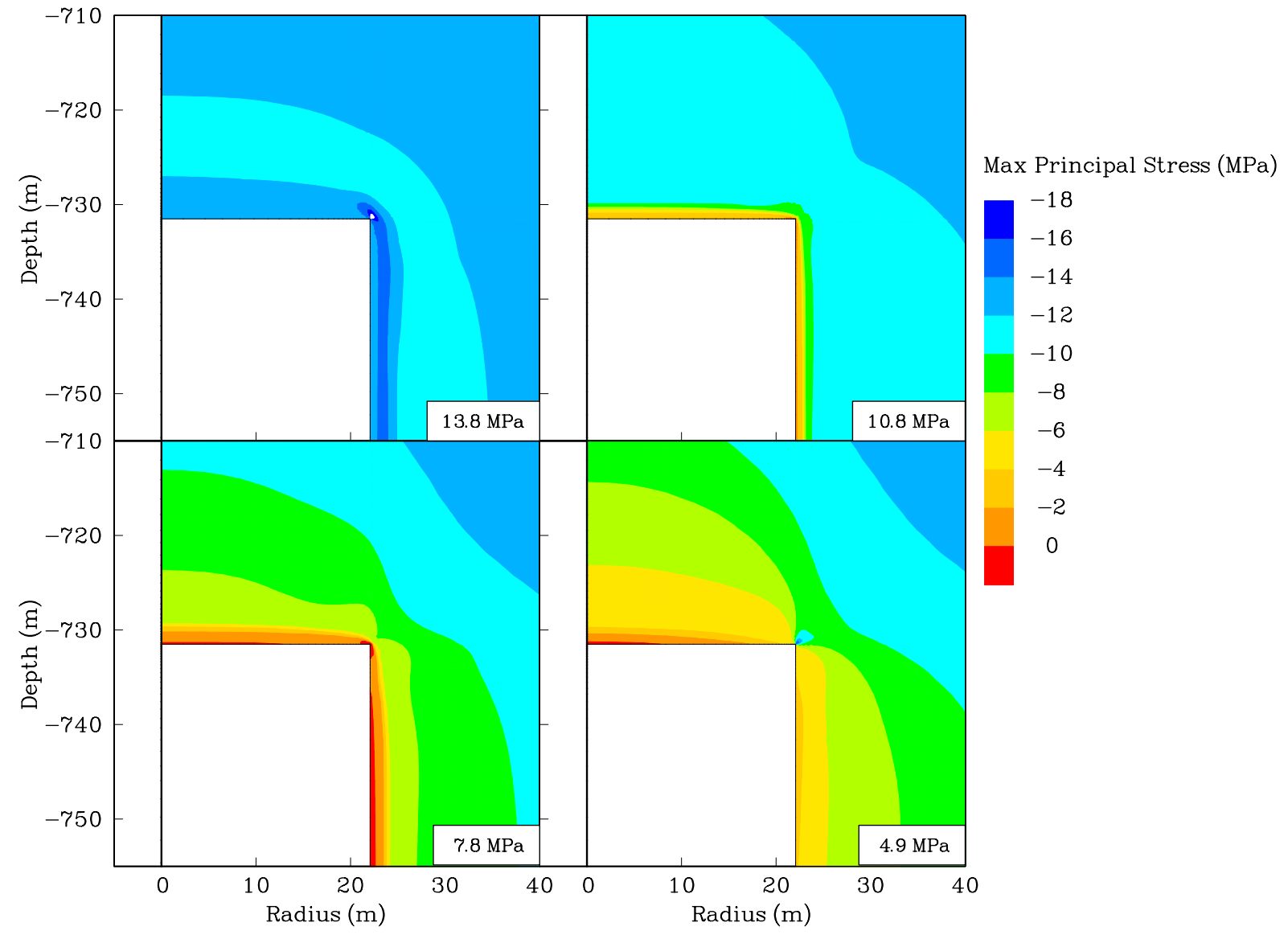

Figure 4-19. Maximum Principal Stress Contours Around Top of Cavern During 30-Day Double-Tanker Withdrawal. 


\subsection{SUMMARY AND CONCLUSIONS}

A geomechanical study was performed to investigate the feasibility of off-loading natural gas from liquefied natural gas (LNG) tankers directly into a salt storage cavern. Because the economics of this process depend on the temperature to which the natural gas must be heated to be safely injected into a storage cavern, several cavern injection temperatures were investigated. The study investigated chilled gas injection temperatures of $-17.8^{\circ} \mathrm{C}\left(0^{\circ} \mathrm{F}\right)$ and $4.4^{\circ} \mathrm{C}\left(40^{\circ} \mathrm{F}\right)$ and also a more conventional gas injection temperature of $43.3^{\circ} \mathrm{C}\left(110^{\circ} \mathrm{F}\right)$.

The six-cavern facility that was investigated was sized to accommodate approximately two LNG tankers of working gas (about $1.9 \times 10^{8} \mathrm{Nm}^{3}$ (7 B ff)). Only one cavern in the facility was modeled. It was assumed that the caverns at the facility would be sufficiently separated so that cavern interactions can be neglected. The study considered a cylindrical cavern located in a salt dome which is typical of conventional natural gas storage caverns. The cavern had a typical working gas pressure range, with a minimum pressure of $0.007 \mathrm{MPa}$ per meter of depth $(0.30$ psi/foot) at the casing shoe and a maximum pressure of $0.019 \mathrm{MPa}$ per meter of depth $(0.85$ psi/foot) at the casing shoe. A casing shoe depth of 716 meters (2,350 feet) was assumed, resulting in a minimum pressure of about $4.9 \mathrm{MPa}$ (705 psi) at the casing shoe and a maximum pressure of about $13.8 \mathrm{MPa}(2,000 \mathrm{psi})$ at the casing shoe. All of the gas storage simulations started at the end of a 20-month cavern development simulation.

The gas storage scenarios evaluated for the LNG off-loading facility cycle the working gas more rapidly than conventional natural gas storage caverns. The single-tanker scenario consists of continuous 3.75-day cycles of approximately 50 percent of the working gas. In each cycle, 50 percent of the working gas was withdrawn over a 3-day period followed by reinjection over a 0.75-day period. This storage scenario was evaluated for gas injection temperatures of $-17.8^{\circ} \mathrm{C}$ $\left(0^{\circ} \mathrm{F}\right)$ and $4.4^{\circ} \mathrm{C}\left(40^{\circ} \mathrm{F}\right)$. The double-tanker scenario consists of continuous 4.5-day cycles of the entire working gas. In each of these cycles, the complete working gas was withdrawn over a 3-day period, followed by reinjection over a period of 1.5 days. This storage scenario was evaluated for gas injection temperatures of $-17.8^{\circ} \mathrm{C}\left(0^{\circ} \mathrm{F}\right), 4.4^{\circ} \mathrm{C}\left(40^{\circ} \mathrm{F}\right)$, and $43.3^{\circ} \mathrm{C}\left(110^{\circ} \mathrm{F}\right)$.

The simulations indicate that the gas injection temperature has very little impact on cavern stability. Over the 5-year storage simulations, the salt around the cavern was cool ed significantly below the initial midheight temperature of $33.1^{\circ} \mathrm{C}\left(91.6^{\circ} \mathrm{F}\right)$ for injection temperatures of $-17.8^{\circ} \mathrm{C}$ $\left(0^{\circ} \mathrm{F}\right)$ and $4.4^{\circ} \mathrm{C}\left(40^{\circ} \mathrm{F}\right)$ and heated slightly above the initial temperature with an injection temperature of $43.3^{\circ} \mathrm{C}\left(110^{\circ} \mathrm{F}\right)$. However, cavern stability after 5 years of storage was similar for all three injection temperatures. This demonstrates the ability of the creep of salt to effectively counteract the thermal stresses that are generated due to the gradual cooling (or heating) of the salt surrounding the cavern. 
High withdrawal rates will result in tensilefracturing of thecavern periphery. Although this is not likely to result in catastrophic failure of the cavern, it will result in salt on the roof and sidewalls progressively sloughing off, reducing the life of the cavern. Tensile zones developed during withdrawal for the simulations with chilled gas injection temperatures, as well as the simulation with the more conventional gas injection temperature of $43.3^{\circ} \mathrm{C}\left(110^{\circ} \mathrm{F}\right)$, because of the large temperature drop that occurs during gas withdrawal. For the single-tanker scenario where 50 percent of the working gas is cycled, the temperature drop in the cavern during 3-day withdrawal was predicted to be about $21^{\circ} \mathrm{C}\left(38^{\circ} \mathrm{F}\right)$. For the doubletanker scenario where 100 percent of the working gas is cycled, the temperature drop in the cavern during 3-day withdrawal was predicted to be about $48^{\circ} \mathrm{C}\left(87^{\circ} \mathrm{F}\right)$.

The extent of tensile fracturing can be alleviated by two methods. First, decreasing the ratio of gas withdrawn to the total working gas was shown to significantly reduce the amount of salt around the cavern that experiences tensile stresses. Secondly, decreasing the withdrawal rate reduces the temperature swings by all owing more time for heat transfer to take place between the cavern and surrounding salt and also allows more time for salt creep to counteract the thermal stresses that do occur. This was demonstrated by the 10-, 20-, and 30-day withdrawal simulations.

The off-loading of chilled natural gas directly into salt cavern appears to be feasible. However, the development of tensile fracturing is generally not permitted in the design of conventional storage caverns. If tensile fracturing is to be permitted, its implications with respect to cavern life must be investigated further. Also, the evaluated storage scenarios repeatedly cycle the cavern over its operating pressure range at a very high frequency (81 times per year for the double-tanker storage scenario). This cycling frequency also is not typical in conventional natural gas storage caverns and warrants an investigation of salt fatigue.

Although this study indicates that the off-loading of chilled natural gas is feasible, the study is generic and actual gas storage facilities would require site and design-specific analyses. Salt properties, including creep, damage, and in situ temperatures, are known to vary significantly from site to site. Cavern design parameters, such as geometry and depth, also vary significantly among storage facilities. 


\subsection{REFERENCES}

Bishop W., 2002. Personal electronic communication between J . D. Nieland, RESPEC, Rapid City, SD, and W. Bishop, Conversion Gas I mports, Houston, TX, November 7.

Callahan, G. D., A. F. Fossum, and D. K. Svalstad, 1989. Documentation of SPECTROM32: A Finite Element Thermomechanical Stress Analysis Program, DOE/CH/10378-2, prepared by RE/SPEC Inc., Rapid City, SD, for the U. S. Department of Energy, Chicago Operations Office, Argonne, IL, Vol. I and II.

Dahlstrom, D. J ., 1988. Thermal Properties Measurements of Avery I sland Salt Core, RSI-0334, prepared by RE/SPEC Inc., Rapid City, SD, for Stone \& Webster Engineering Corporation, Boston, MA.

DeVries, K. L., 1988. Viscoplastic Laws for Avery I sland Salt, RSI-0333, prepared by RE/SPEC Inc., Rapid City, SD, for Stone \& Webster Engineering Corporation, Boston, MA.

Hansen, F. D. and N. L. Carter, 1984. "Creep of Avery I sland Rock Salt," Proceedings of the First Conference on the Mechanical Behavior of Salt, University Park, Pennsylvania, November 1981, pp. 71-83.

Nieland, J . D., 2002. Salt Cavern Thermal Simulator Version 1.5 User's Manual, Revision 1, RSI-1650, prepared by RESPEC, Rapid City, SD, for Gas Technology Institute, Chicago, IL.

Nieland, J . D., K. D. Mellegard, R. S. Schalge, and H. D. Kaiser, 2001. Storage of Chilled Natural Gas in Bedded Salt Storage Caverns, Revision I, RSI-1354, prepared by RESPEC, Rapid City, SD; Sofregaz US Inc., Houston, TX; and IDS Engineering, Houston, TX; for the United States Department of Energy, National Energy Technology Laboratory, Morgantown, WV.

Pfeifle, T. W., T. J . Vogt, and G. A. Brekken, 1995. Correlation of Chemical, Mineralogic, and Physical Characteristics of Gulf Coast Dome Salt to Deformation and Strength Properties, Research Project Report No. 94-0004-S, prepared by RE/SPEC Inc., Rapid City, SD, for the Solution Mining Research Institute Inc., Woodstock, I L.

Senseny, P. E., F. D. Hansen, J . E. Russell, N. L. Carter, and J . W. Handin, 1992. "Mechanical Behaviour of Rock Salt: Phenomenology and Micromechanisms," International J ournal of Rock Mechanics and Mining Sciences \& Geomechanics Abstracts, Vol. 29, No. 4, pp. 363-378. 
Starling, K. E. and J . L. Savidge, 1994. Compressibility of Natural Gas and Other Related Hydrocarbon Gases, Report No. 8, $2^{\text {nd }}$ Edition, Catalog No. XQ9212, prepared for American Gas Association.

Svalstad, D. K., 1989. Documentation of SPECTROM-41: A Finite Element Heat Transfer Analysis Program, DOE/CH/10378-1, prepared by RE/SPEC Inc., Rapid City, SD, for the U.S. Department of Energy, Chicago Operations Office, Argonne, IL.

Van Sambeek, L. L., J . L. Ratigan, and F. D. Hansen, 1993. "Dilatancy of Rock Salt in Laboratory Tests," Proceedings, 34th U.S. Symposium on Rock Mechanics, University of Wisconsin-Madison, Madison, WI, J une 27-30, B. C. Haimson (ed.), International J ournal of Rock Mechanics and Mining Sciences \& Geomechanics Abstracts, Pergamon Press, Vol. 30, No. 7, pp. 735-738. 


\begin{tabular}{|l|l|l|l|}
\hline Customer: & $\begin{array}{l}\text { The United States Department of Energy } \\
\text { National Energy Technology Laboratory }\end{array}$ & $\begin{array}{l}\text { Date of Issue: } \\
24 \text { April } 2003\end{array}$ & \\
\hline $\begin{array}{l}\text { Document } \\
\text { Title: }\end{array}$ & Report II: “Conceptual Design of a Salt Cavern Based LNG Terminal” & $\begin{array}{l}\text { Doc \# \& Version: } \\
\text { Doc } 06 \text { r1.0 }\end{array}$ & Page 1 of 13 \\
\hline
\end{tabular}

\title{
Conceptual Design of a Salt Cavern Based lng Terminal
}

\author{
BY \\ Michael M. McCaLl \\ WiLliam M. BISHOP \\ D. BRAXTON SCHERZ
}

\begin{tabular}{|c|c|c|c|c|c|c|c|c|}
\hline r 1.0 & For client review & $24 / 04 / 03$ & BS & MM & & & & \\
\hline Version & Reason for Issue & $\begin{array}{l}\text { Issue } \\
\text { Date }\end{array}$ & Orig. & $\begin{array}{l}\text { Chk. } \\
\text { CGI }\end{array}$ & Appr. & $\begin{array}{l}\text { Chk. } \\
\text { NE }\end{array}$ & $\begin{array}{l}\text { Appr. } \\
\text { TL }\end{array}$ & Review \\
\hline \multicolumn{2}{|c|}{$\begin{array}{l}\text { Document Title: } \\
\text { Conceptual Design of a Salt Cavern LNG } \\
\text { Terminal }\end{array}$} & \multicolumn{7}{|c|}{ Document No: } \\
\hline
\end{tabular}




\begin{tabular}{|l|l|l|l|}
\hline Customer: & $\begin{array}{l}\text { The United States Department of Energy } \\
\text { National Energy Technology Laboratory }\end{array}$ & $\begin{array}{l}\text { Date of Issue: } \\
24 \text { April } 2003\end{array}$ & \\
\hline $\begin{array}{l}\text { Document } \\
\text { Title: }\end{array}$ & Report II: “Conceptual Design of a Salt Cavern Based LNG Terminal” & $\begin{array}{l}\text { Doc \# \& Version: } \\
\text { Doc 06 r1.0 }\end{array}$ & Page 2 of 13 \\
\hline
\end{tabular}

\section{TABLE OF CONTENTS}

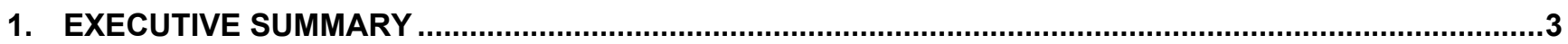

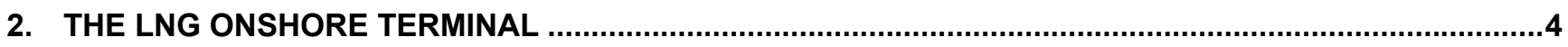

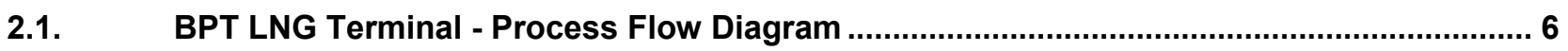

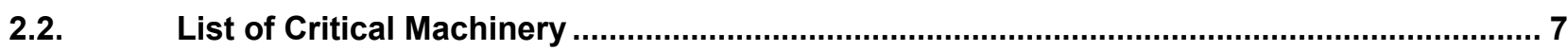

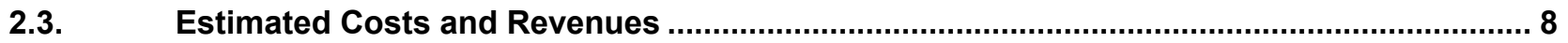

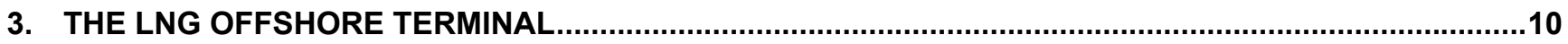

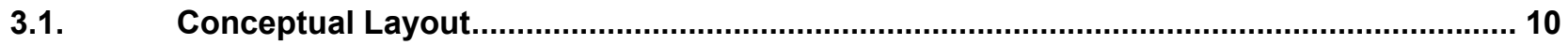

3.2. Offshore Terminal - Estimated Cost and Revenue ......................................................... 12 


\begin{tabular}{|l|l|l|l|}
\hline Customer: & $\begin{array}{l}\text { The United States Department of Energy } \\
\text { National Energy Technology Laboratory }\end{array}$ & $\begin{array}{l}\text { Date of Issue: } \\
\mathbf{2 4} \text { April } 2003\end{array}$ & \\
\hline $\begin{array}{l}\text { Document } \\
\text { Title: }\end{array}$ & Report II: “Conceptual Design of a Salt Cavern Based LNG Terminal” & $\begin{array}{l}\text { Doc \# \& Version: } \\
\text { Doc 06 r1.0 }\end{array}$ & Page 3 of 13 \\
\hline
\end{tabular}

\section{EXECUTIVE SUMMARY}

Numerical modeling, finite element analysis, and reviews by experts specialized in pipe-in-pipe technology confirmed the feasibility of the using salt cavern in the receipt of LNG. The study team used the critical elements referenced in Task 1.0 to conceptually design two LNG receiving terminals, (1) an onshore terminal capable of economic, safe, and reliable LNG transfer and regasification, and (2) an offshore terminal using the identified elements required to transfer and regasify LNG safely, reliably, and economically.

A specific site was identified for both terminals. The onshore terminal is located at the mouth of the Calcasieu River, in Cameron Parrish, Louisiana. The offshore terminal is located in the Gulf of Mexico over Vermillion Block 179, about 50 miles south of Interstate City, Louisiana. Each of the following conceptual LNG receiving terminal are designed according to the known environmental surroundings of the sites. Both terminals employ the BPT exchanger, associated pumping equipment, and utilize salt caverns for storage. All cost estimates are site specific and are accurate to within $\pm 35 \%$.

The Onshore Terminal uses proven technology. Other than the pumping and regasification process already discussed, the marine unloading facility represents little departure from typical LNG receiving terminal. The marine berth and Ship to Shore interface are quite familiar to the industry, and docking/undocking methods are accepted world wide. Because the LNG industry is familiar with the critical components, the BPT onshore terminal will most likely be the first terminal constructed.

Based on a throughput cost of service of $\$ 0.096$ per mmBtu, the conceptual "Liberty" land based terminal has an internal rate of return of $15.0 \%$.

LNG offshore is coming, and coming quickly. The concept of moving LNG offshore is at least 30 years old, and the methodologies of LNG at-sea transfer will be almost identical to the procedures developed for the offshore oil industry. Design firms, E\&C companies, and experts having a thorough insight of the transfer of oil and LPG offshore, realize that the technologies to handle cryogenic materials will have to be further developed and refined. All imminently workable LNG offshore solutions in various stages of testing or fabrication are based on this understanding.

This section of the study reveals that the proposed conceptual offshore terminal is competitive in terms of total installed cost, operation and maintenance. The throughput fee and rate of return are similar to the onshore design, and both are advantageous compared to conventional LNG terminals with similar capacities. Based on the same pro forma economic evaluation, the conceptual offshore terminal generates a $15 \%$ internal rate of return on a throughput cost of service of $\$ 0.095 \mathrm{mmBtu}$.

Additional study and development of the key components (cryogenic swivels, flexible transfer systems, and cryogenic subsea piping), further wave tank modeling, and industry willingness to "risk" moving LNG offshore are required before an LNG at-sea can become a reality. However, if the total install cost for the terminal can be kept within the reasonable estimates of this study, an LNG offshore terminal could be built by 2006. 


\begin{tabular}{|l|l|l|l|}
\hline Customer: & $\begin{array}{l}\text { The United States Department of Energy } \\
\text { National Energy Technology Laboratory }\end{array}$ & $\begin{array}{l}\text { Date of Issue: } \\
24 \text { April } 2003\end{array}$ & \\
\hline $\begin{array}{l}\text { Document } \\
\text { Title: }\end{array}$ & Report II: “Conceptual Design of a Salt Cavern Based LNG Terminal” & $\begin{array}{l}\text { Doc \# \& Version: } \\
\text { Doc } 06 \text { r1.0 }\end{array}$ & Page 4 of 13 \\
\hline
\end{tabular}

\section{THE LNG ONSHORE TERMINAL}

By design the BPT LNG receiving terminal is capable of sending out as much as 3.0 Bcfd from the salt storage caverns. The process itself is capable of regasifying as much as $3.8 \mathrm{Bcfd}$. To provide the large volumes of LNG necessary to help mitigate the natural gas shortfall projected by the EIA, CERA, and others, the LNG terminal must be located near a pipeline infrastructure capable of sufficient capacity to take advantage of the BPT terminal's substantial send-out capability. Knowing that some of the nation's largest pipelines pass through an area in South Louisiana known as "Henry Hub," the Study Team assembled various maps and charts of the Louisiana Gulf
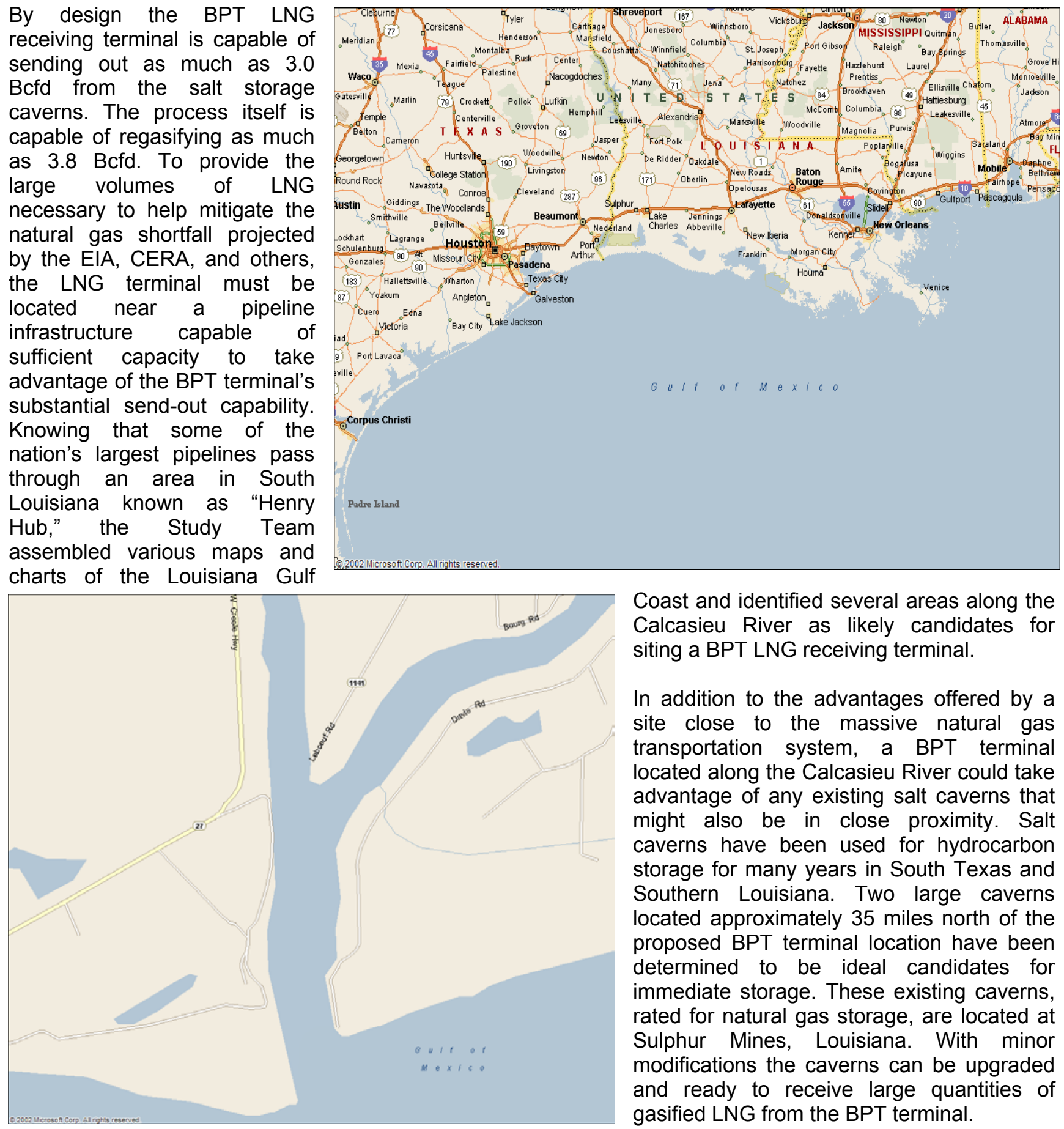

Coast and identified several areas along the Calcasieu River as likely candidates for siting a BPT LNG receiving terminal.

In addition to the advantages offered by a site close to the massive natural gas transportation system, a BPT terminal located along the Calcasieu River could take advantage of any existing salt caverns that might also be in close proximity. Salt caverns have been used for hydrocarbon storage for many years in South Texas and Southern Louisiana. Two large caverns located approximately 35 miles north of the proposed BPT terminal location have been determined to be ideal candidates for immediate storage. These existing caverns, rated for natural gas storage, are located at Sulphur Mines, Louisiana. With minor modifications the caverns can be upgraded and ready to receive large quantities of gasified LNG from the BPT terminal. 


\begin{tabular}{|l|l|l|l|}
\hline Customer: & $\begin{array}{l}\text { The United States Department of Energy } \\
\text { National Energy Technology Laboratory }\end{array}$ & $\begin{array}{l}\text { Date of Issue: } \\
24 \text { April } 2003\end{array}$ & \\
\hline $\begin{array}{l}\text { Document } \\
\text { Title: }\end{array}$ & Report II: “Conceptual Design of a Salt Cavern Based LNG Terminal” & $\begin{array}{l}\text { Doc \# \& Version: } \\
\text { Doc } 06 \text { r1.0 }\end{array}$ & Page 5 of 13 \\
\hline
\end{tabular}

A visit to the Cameron Chamber of commerce and local courthouse yielded several very detailed maps indicating that an area west of the river, and at the mouth of the river just past the channel entrance could provide an ideal location for the marine facility, high pressure LNG pumps, and BPT exchangers (see Attachment I). An investigation of the site revealed that the land was marshy, uninhabited, and fairly remote. The Sabine National Wildlife Area lies well to the north of the proposed location.

While no natural harbor exists along the Calcasieu River capable of berthing a large ocean going vessel, there appears to be ample space to dredge a slip on the western bank, and expand a small area just inside the mouth of the river. To facilitate

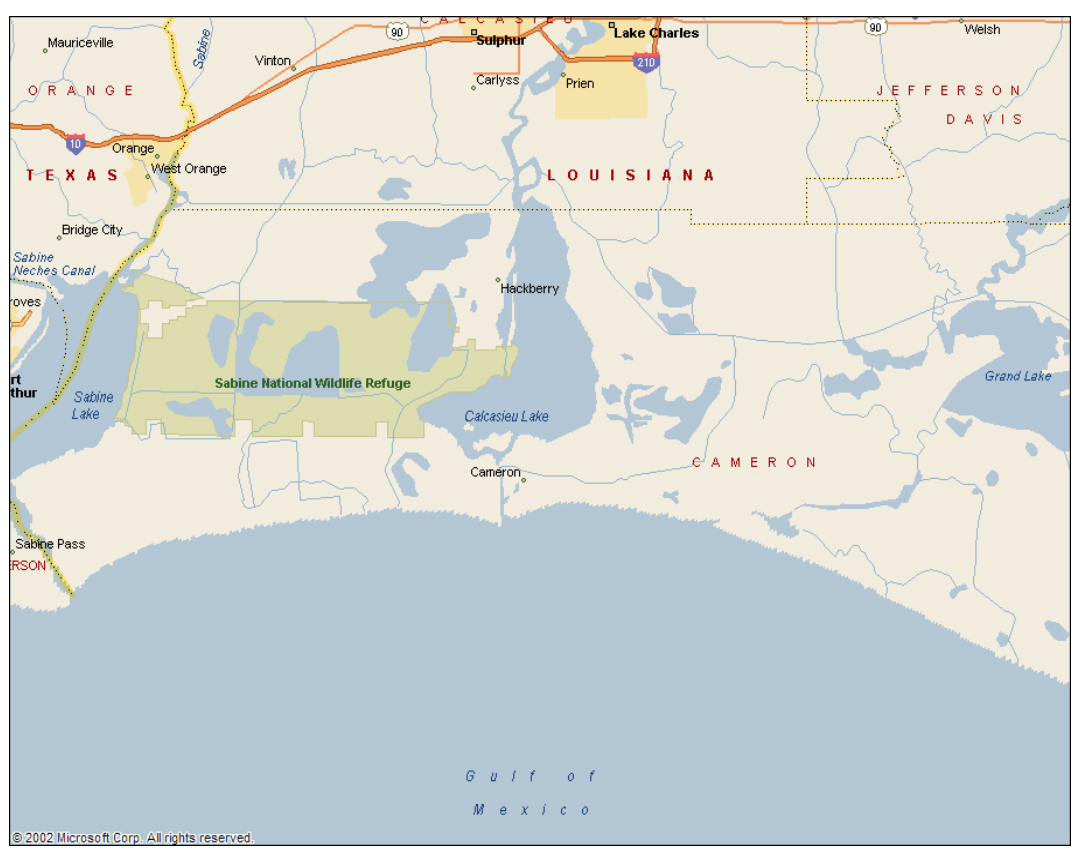
LNG tanker maneuvering a turning basin will also have to be created at the mouth of the river (Attachment II Plan View - Onshore LNG Terminal).

The turning basin located at the mouth of the river offers no additional restrictions to navigation or vessel traffic. The USCG requires that all vessels in the vicinity of an LNG tanker entering a navigable waterway observe a Restricted Navigational Area (RNA). The RNA is defined as a clear space two miles ahead and one mile behind the LNG vessel until it is safely berthed. The turning basin at the mouth of the river will actually decrease traffic delays, as the LNG tanker will be quickly docked and off the river almost immediately after entering the river channel. Attachment II indicates the location of the proposed slip and turning basin.

Also identified in Attachment II are:

1. The loading and transfer arms

2. Surge cylinder

3. LNG pump house

4. Vapor generator (required for forced vaporization)

5. Water warmant intake and pumping structure

6. Water warmant outfall structure

7. Bishop Process Heat Exchangers

8. Office, control room, and machine shop

9. Power generation station

All components in the Plan View are drawn to scale and the dock reflects the capability of the BPT terminal to accept LNG carriers up to $250,000 \mathrm{~m} 3$. Although tankers of this size may never be built, the BPT LNG terminal with its massive sendout capability would be a likely offloading destination for LNG carriers of this size.

The gasified LNG discharged from the terminal via the proposed 42" diameter high pressure pipeline is clearly marked. The pipeline connects the marine receiving terminal to the salt cavern storage facility located 35 miles away at Sulphur, Louisiana. The BPT LNG process does not require that LNG storage be located at or near the marine terminal, a major siting and security advantage. 


\begin{tabular}{|l|l|l|l|}
\hline Customer: & $\begin{array}{l}\text { The United States Department of Energy } \\
\text { National Energy Technology Laboratory }\end{array}$ & $\begin{array}{l}\text { Date of Issue: } \\
24 \text { April } 2003\end{array}$ & \\
\hline $\begin{array}{l}\text { Document } \\
\text { Title: }\end{array}$ & Report II: “Conceptual Design of a Salt Cavern Based LNG Terminal” & $\begin{array}{l}\text { Doc \# \& Version: } \\
\text { Doc } 06 \text { r1.0 }\end{array}$ & Page 6 of 13 \\
\hline
\end{tabular}

\subsection{BPT LNG Terminal - Process Flow Diagram}

A Process Flow Diagram (PFD) of the BPT LNG terminal is illustrated in Attachment III. Although the mechanical elements differ between the BPT onshore and offshore terminal, the same basic process principles apply. Much of the machinery required to receive, regasify, and sendout out LNG to salt storage is identical. Therefore, the PFD depicted in Attachment III will be conceptually applicable to both terminals.

Referencing Attachment III, the LNG vessel arrives and is secured at the berth. The four High Pressure Pumps (G-1 through G-4) housed in Pump Reservoir (C-2) are kept cold via recirculation of LNG with the Standby Mode Circulating Pump (G5) discharging into the LNG unloading line, through the surge vessel, and returning to the High Pressure Pump Reservoir(C-1). Recirculating LNG is allowed to flood the pump and motor housing and reenter the suction side of Circulating Pump G5. The vapor generated by the recirculation process is reliquefied in a Reliquefaction Packaged Compressor Unit K-2.

Just prior to discharge, one pump from a single 4-pack, is placed in the recirculation mode with its discharge valve to the BPT exchanger cracked. The loading and vapor arms are connected and the LNG tanker begins to discharge its cargo. The LNG from the ship's cargo pumps, pressurized at about 45 to 60 psig, begins to fill the surge vessel. The suction and discharge valves from the 4-pack are opened in increasing fashion to accommodate increasing volumes of LNG received from the ship's cargo pumps until an equilibrium is achieved. As the ship brings more and more cargo pumps online, the 4-packs are started accordingly until full pumping rates are achieved.

During the full rate pumping mode, all LNG is circulated through the Bishop Process Heat Exchangers (BPT) shown in the drawing as E-1 through E-4. Warming water is provided from a source with pump G6. The exchangers are designed with two separate inlets that circulate the warming water in opposite directions and provide a way to "refresh" the heat transfer capability. Multiple circulation modes ensure that the proper heat transfer takes place even with colder warmant temperatures.

After leaving the exchanger, the regasified LNG now in the dense phase (for a detailed discussion, reference Subtask 1.3), passes through the 42" diameter pipeline and into the salt cavern storage facility.

Boil Off Gas (BOG), is required to fill the ships tanks during discharge, and must be returned to the ship at the equivalent unloading rate. BOG is usually supplied via vapor generated by agitation in the LNG storage tanks during unloading. While discharging at the BPT LNG terminal, a reducing station supplied from the outlet of the BPT exchanger, and a blower (K-3) will provide the prescribed amount of vapor.

Rate down and return to standby mode is accomplished by reversing the above procedure. 


\begin{tabular}{|l|l|l|l|}
\hline Customer: & $\begin{array}{l}\text { The United States Department of Energy } \\
\text { National Energy Technology Laboratory }\end{array}$ & $\begin{array}{l}\text { Date of Issue: } \\
\mathbf{2 4} \text { April } 2003\end{array}$ & \\
\hline $\begin{array}{l}\text { Document } \\
\text { Title: }\end{array}$ & Report II: “Conceptual Design of a Salt Cavern Based LNG Terminal” & $\begin{array}{l}\text { Doc \# \& Version: } \\
\text { Doc 06 r1.0 }\end{array}$ & Page 7 of 13 \\
\hline
\end{tabular}

2.2. List of Critical Machinery

\title{
Liberty LNG Terminal to Existing Salt Cavern Storage
}

\author{
Description \\ UPGRADES TO EXISTING STORAGE CAVERNS (Sulphur Mines, La) \\ PROCESS VESSELS \\ Recondenser, 9'ID x 45', 304 SS \\ BOG Compressor Knock Out Drum 35 m3 \\ HP Fuel Gas Knock Out Drum, 3 m3 \\ HP Flare Knock Out Drum, $50 \mathrm{~m} 3$ \\ Service Water Storage Tank, $20 \mathrm{~m} 3$ \\ Diesel Storage Tank, $50 \mathrm{~m} 3$ \\ Foam Tank, $4 \mathrm{~m} 3$ \\ Surge Vessels \\ VAPORIZERS \\ Submerged Combustion Vap., $205 \mathrm{mmcfd} / 433 \mathrm{~m} 3 / \mathrm{hr}$ \\ CPP Shell and Tube $150 \mathrm{mmcfd} / 317 \mathrm{m3} / \mathrm{hr}$ \\ Bishop Process $128 \mathrm{mmcfd} / 270 \mathrm{~m} 3 / \mathrm{hr}$ \\ HEAT EXCHANGERS \\ Standby glycol/fuel gas heater $127 \mathrm{~kW}$ \\ HP knockout drum heater $20 \mathrm{~kW}$ \\ Gaseous N2 Vaporizer 35 kW \\ Gaseous N2 Vaporizer (Spare) $35 \mathrm{~kW}$ \\ Liquid N2 Pressurization vaporizer $35 \mathrm{~kW}$ \\ Liquid N2 Vaporizer $35 \mathrm{~kW}$ \\ Waste Heat recovery from turbo-generator exhaust \\ PUMPS \\ High Pressure sendout pump, 2,200 psi @ 270 m3/hr \\ Process Area Sump Pump, 10 hp, 5 m3/hr \\ Service Water Pump, 5 hp, 57 m3/hr \\ Firewater Pumps \\ COMPRESSORS \\ BOG compressor, 0.5 MMSCFD \\ Ship Vapor Return Blower \\ Ship Unloading Compressor \\ SEAWATER INTAKE/OUTFALL (Incl Electrochlorination) \\ Seawater pump (warmant), $3150 \mathrm{~m} 3 / \mathrm{hr}$ \\ Electrochlorination Unit, $19,000 \mathrm{~m} 3 / \mathrm{hr}$ \\ Seawater Intake Structure $(19,000 \mathrm{~m} 3 / \mathrm{hr}$ each) \\ Seawater Outfall Structure $(19,000 \mathrm{~m} 3 / \mathrm{hr}$ each)
}




\begin{tabular}{|l|l|l|l|}
\hline Customer: & $\begin{array}{l}\text { The United States Department of Energy } \\
\text { National Energy Technology Laboratory }\end{array}$ & $\begin{array}{l}\text { Date of Issue: } \\
24 \text { April } 2003\end{array}$ & \\
\hline $\begin{array}{l}\text { Document } \\
\text { Title: }\end{array}$ & Report II: “Conceptual Design of a Salt Cavern Based LNG Terminal” & $\begin{array}{l}\text { Doc \# \& Version: } \\
\text { Doc } 06 \text { r1.0 }\end{array}$ & Page 8 of 13 \\
\hline
\end{tabular}

Seawater Intake Screens $(20,000 \mathrm{~m} 3 / \mathrm{hr}$ each)

Seawater Rotary Screens $(20,000 \mathrm{~m} 3 / \mathrm{hr}$ each)

\title{
UTILITIES
}

HP Flare, $415,000 \mathrm{~kg} / \mathrm{hr}$

Electrical Switchgear \& Power Distrib (5\% of FC)

Emergency Generator - Diesel Driven, $500 \mathrm{~kW}$

Lighting Generator - Diesel Driven, $750 \mathrm{~kW}$

GE LM 2500+ with chiller and DLE low emissions package

Instrument air compressor and drier, $100 \mathrm{scfm}$

N2 Dewar for Terminal, Vac. insul. tank, $42 \mathrm{~m} 3$

Firewater Protection System (Foam Sys, dry powder, tanks)

MARINE FACILITIES - JETTY

Platforms and walkways

Cryogenic Piping (I/E, piping w/ insulation)

Berth (Mooring, Breasting Dolphins)

Dredging

MARINE FACILITIES - UNLOADING

Unloading Arms

\section{NAVIGATIONAL AIDS (lighting and buoys)}

BUILDINGS

Administration Office/Control Center

Building for Sendout Pumps

Warehouse/Maintenance Building, 10,000 sf

\author{
SITE PREPARATION \\ BULKS \\ Piping (exclud. trestle) \\ Piling \\ Insulation and Paint \\ Instrumentation and metering skids
}

\section{REAL ESTATE}

PIPELINE TO SULPHUR MINES

TIE IN TO MAJOR FOUR PIPELINES

\subsection{Estimated Costs and Revenues}

There are three major elements contributing to the overall total installed cost (TIC) of the LNG onshore terminal, the LNG terminal at the mouth of the Calcasieu River, the upgrades and pipeline interconnects required for the existing salt cavern facilities, and the 35 mile pipeline required to connect the offloading terminal to the storage caverns. The cost estimates for the financial model (Attachment IV) were developed using a factored cost estimating program specific to the industry. Budget estimates for upgrading the existing salt cavern facilities are based on actual operating experience and direct quotations. Pipeline estimates were sourced from the contractors. 


\begin{tabular}{|l|l|l|l|}
\hline Customer: & $\begin{array}{l}\text { The United States Department of Energy } \\
\text { National Energy Technology Laboratory }\end{array}$ & $\begin{array}{l}\text { Date of Issue: } \\
24 \text { April } 2003\end{array}$ & \\
\hline $\begin{array}{l}\text { Document } \\
\text { Title: }\end{array}$ & Report II: “Conceptual Design of a Salt Cavern Based LNG Terminal” & $\begin{array}{l}\text { Doc \# \& Version: } \\
\text { Doc } 06 \text { r1.0 }\end{array}$ & Page $\mathbf{9}$ of 13 \\
\hline
\end{tabular}

The financial model applied is based on a long-established standard model for gas storage. Necessary modifications were made to reflect the key economic and financial aspects of the onshore LNG Terminal modeled after the actual project mentioned throughout the above sections, especially in the area of terminal energy use fees and actual terminal energy use requirements.

The major elements of the terminal TIC and $O \& M$ budget are included on the second and third page of Attachment IV. The major elements of the economic/financial model and its results are shown on the "Summary" page, e.g. Attachment IV pg. 1.

Most of the items on the "Summary Facility Assumptions" page are self explanatory. Notable items, parameters, and assumptions for the Onshore LNG terminal are described below.

The facility sizing basis is shown in the section of the "Summary" page labeled "Facility Basis" and "LNG Terminal Project Metrics." The reference assumption is 225 cargos per year and this corresponds to 1.7 Bcf per day average daily import and grid dispatch quantity. Note that 16 Bcf figure for "Storage Working Gas Volume" is an off-line technical result regarding total storage capacity of the salt caverns and the economic model makes no assumptions regarding the amount of storage capacity required for the LNG terminal operations.

"Pricing" is the next section of the "Summary" page. The "Throughput Fee" is assumed as a \$ amount per mmBtu. This assumption can be varied to determine the IRR associated with the assumed fee to satisfy a certain IRR target or "hurdle rate." The "Other Revenue" line allows for other revenue that might be generated as a percentage of LNG throughput. In fact, the storage terminal with multiple connections may be able to realize fees from services in addition to LNG import terminal operations (such as gas storage or hub services). These fees may or may not relate to the percentage of revenue from LNG terminal throughput fees. For a reference case focused on only LNG terminal operations, both of the "other revenue" assumptions have been set to zero. The "Pricing" section also includes pricing parameters for the "Terminal Energy Use Charge" expressed as a percentage of throughput retained by the terminal as a fuel charge. In the financial projections, this amount is inflated with the general inflation rate and the amount is modeled as a Henry Hub index price.

The "Other Assumptions" section of the "Summary" page includes a number of important parameters that affect the economics/financial results. The section labeled "Others" is reflects fees for "Technology Rights" and is intentionally left blank to better compare the onshore and offshore options.

The next major section of the "Summary Facility Assumptions" block of the "Summary" page shows the capital cost for various major components of the terminal. These are largely self-explanatory. The "Project Metrics" summarizes some commonly applied quantity references for the LNG terminal business.

The "Tax Rates" section shows the assumptions for tax rates applicable for a Louisiana project. The calculation of "terminal value" for cash flow purposes assumes sale of the facility on an EBITDA multiple basis with the resulting proceeds realizing capital gains treatment for federal tax purposes and ordinary rates for state tax purposes.

The "Depreciation" section allows different assumptions to be made that affect primarily the after-tax cash flows to the ownership. In order to provide for a more conservative (i.e. higher required fee or reduced IRR depiction) assessment, the reference assumption is for straight-line depreciation over 20 years.

"Financial Assumptions" are shown in the block on the upper right hand side. A 50-50 debt equity structure is assumed with debt costs at prime plus $2 \%$ which corresponds to $6.75 \%$ for a reference case. The time period for repaying debt has a strong effect on equity cash flows, debt service coverages, and equity returns. Given the long term nature of the related investments for LNG production and transport, a 20 year amortization period is assumed.

The "Financial Results" block shows model outputs generally from the cash flow calculation. The cost of capital is a straightforward calculation based on the input assumptions for costs and amounts of debt and equity. The "Project Economics" section reflect results for the project without any debt. This is essentially an "all equity" approach to project NPV and IRR. Estimated EBTIDA amounts are expressed in thousands of 


\begin{tabular}{|l|l|l|l|}
\hline Customer: & $\begin{array}{l}\text { The United States Department of Energy } \\
\text { National Energy Technology Laboratory }\end{array}$ & $\begin{array}{l}\text { Date of Issue: } \\
24 \text { April } 2003\end{array}$ & \\
\hline $\begin{array}{l}\text { Document } \\
\text { Title: }\end{array}$ & Report II: “Conceptual Design of a Salt Cavern Based LNG Terminal” & $\begin{array}{l}\text { Doc \# \& Version: } \\
\text { Doc 06 r1.0 }\end{array}$ & Page 10 of 13 \\
\hline
\end{tabular}

dollars per year. Equity returns as NPV and IRR are shown on an after tax basis for cash-on-cash expected flows. Minimum debt service coverages are demonstrated on a pre-tax basis as shown. Based on a throughput fee of $\$ 0.096 \mathrm{mmBtu}$, the conceptual land based terminal in years one through five averaged an EBITDA of $\$ 45,129,000$ USD based on a through-put of 225 cargoes per year. On a $16.4 \%$ after tax equity IRR the projected equity return was $\$ 21,377,000$ USD.

The same financial model is used for the offshore terminal with modifications to Project Budget and $O$ \& $M$ expenses only.

\section{THE LNG OFFSHORE TERMINAL}

\subsection{Conceptual Layout}

The offshore LNG terminal using the BPT exchangers and salt caverns as storage is pictured in Attachment V. The Process Flow Diagram varies little from the onshore terminal, therefore more attention will be focused on offshore layout. The illustration clearly shows the swing arm mechanism "Big Sweep" designed to safely berth the LNG carrier and an adjacent platform with the major process machinery. The mooring platform houses the high pressure LNG pumps that pressurize the LNG to 2,200 psig. The pressurized liquid is routed to the regasification platform via a subsea pipeline rated for cryogenic service. LNG passes through the BPT exchanger and moves directly into the offshore gas gathering system, or to the salt caverns for storage. The following explanation is excerpted from section 1.2 for the reader's convenience.

The 'Big Sweep' concept consists of three basic elements, see figure 3.1-1 on the following page.

- A jacket structure with turntable, anchored to the seabed

- A submerged rigid arm, hinged at one end to the jacket turntable and terminating at its other end with a buoyant column, and

- The LNG loading and transfer structure, located on top of the buoyant column.

To allow the vessel and arm to passively 'weathervane' into the most favourable direction with respect to the environment, the turntable is connected to the jacket structure by means of a bearing. This allows the turntable to rotate $360^{\circ}$ with respect to the jacket. The turntable supports the rigid arm hinges, the cryogenic fluid swivels and the hawser attachment point.

The overall length of the rigid arm is such that the buoyant column is positioned nominally near the midship cargo manifold of the LNG carrier. By adjusting the length of the mooring hawser the carrier's cargo manifold can be lined up to the offloading station for vessel sizes ranging from large to very large gas carriers.

The buoyant hull is equipped with a thruster system to swing the arm in a safe position during approach of the vessel and in-line with the vessel in the operational mode. A water ballast tank allows draft adjustment of the loading arm to match tanker size and / or drafts. The standard fluid transfer system consists essentially of 3 Pipe-in-Pipe (PIP) lines. Two lines are dedicated to LNG; either in full flow mode or re-circulation mode. The third line is dedicated for vapour return. The flow paths cross the weathervaning and pitch hinges between the jacket and the rigid arm. This is achieved with swivels and full metal jumpers which can be easily inspected and serviced.

The loading arm is normally trailing the jacket but can be temporarily 'parked' away from the LNG carrier line of approach, with its own propulsion. In this position the entire loading arm assembly cannot be damaged by a failed mooring approach of the export carrier tanker. Note that offshore tanker mooring to SPM systems is standard marine practice and that a failed approach run very rarely happens. Should the carrier 'brush' against the terminal, this will be a 'low energy' collision which can be accommodated by the cushioning fender system. 


\begin{tabular}{|l|l|l|l|}
\hline Customer: & $\begin{array}{l}\text { The United States Department of Energy } \\
\text { National Energy Technology Laboratory }\end{array}$ & $\begin{array}{l}\text { Date of Issue: } \\
24 \text { April } 2003\end{array}$ & \\
\hline $\begin{array}{l}\text { Document } \\
\text { Title: }\end{array}$ & Report II: “Conceptual Design of a Salt Cavern Based LNG Terminal” & $\begin{array}{l}\text { Doc \# \& Version: } \\
\text { Doc } 06 \text { r1.0 }\end{array}$ & Page 11 of 13 \\
\hline
\end{tabular}

The LNG carrier moors in tandem with the turntable and once it has secured itself safely and the overall alignment is stable, the loading arm will be deployed from its parked position toward the vessel's manifold. The hose deployment and loading operation may now be initiated. After completion of the transfer operations all of the steps discussed above are done in reverse order.
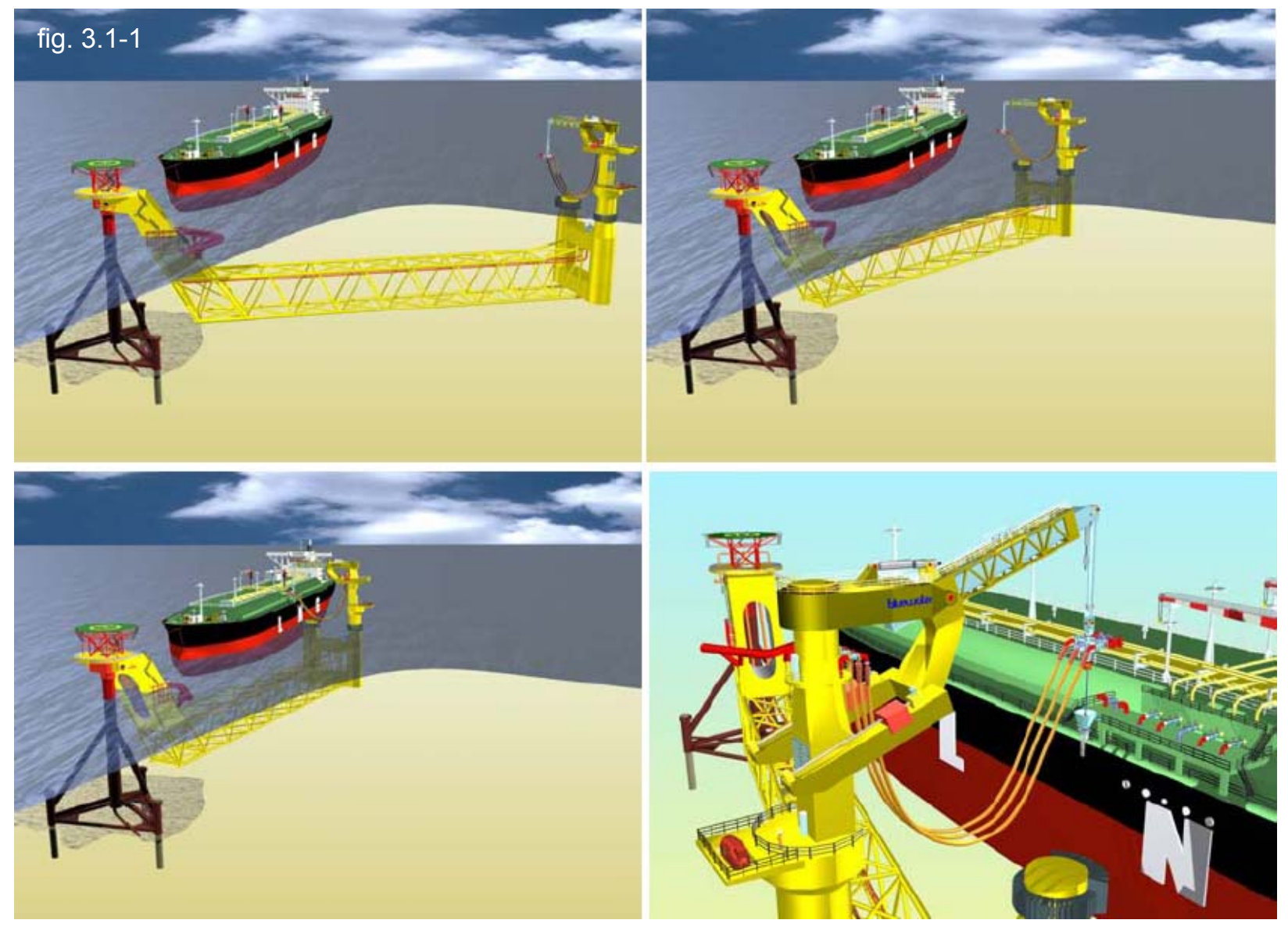

Shallow Water depth Terminal. Developed from the 'Big Sweep' system, this unit shown in fig. 3.1-2 is designed to operate in water depths below $40 \mathrm{~m}$, It allows direct offshore-to-shore transfer of LNG, at rates up to $10,000 \mathrm{~m} 3 / \mathrm{hr}$ from non-dedicated vessels.

Motion characteristics are such that offloading can proceed up to significant wave heights of $3 \mathrm{~m}$, depending on the water depth, which may be as little as 15 meters. With dynamic positioning (DP) capability the unit would track the movement of the LNG carrier manifold when loading or unloading LNG. DP would also allow the unit to move out of the way when the LNG carrier is mooring itself to the turntable on the jacket, thereby avoiding marine hazards. For extreme survival conditions e.g. the Gulf of Mexico, the free-end of the unit is waterballasted and set temporarily on the seabed. 


\begin{tabular}{|l|l|l|l|}
\hline Customer: & $\begin{array}{l}\text { The United States Department of Energy } \\
\text { National Energy Technology Laboratory }\end{array}$ & $\begin{array}{l}\text { Date of Issue: } \\
24 \text { April } 2003\end{array}$ & \\
\hline $\begin{array}{l}\text { Document } \\
\text { Title: }\end{array}$ & Report II: “Conceptual Design of a Salt Cavern Based LNG Terminal” & $\begin{array}{l}\text { Doc \# \& Version: } \\
\text { Doc } 06 \text { r1.0 }\end{array}$ & Page 12 of 13 \\
\hline
\end{tabular}

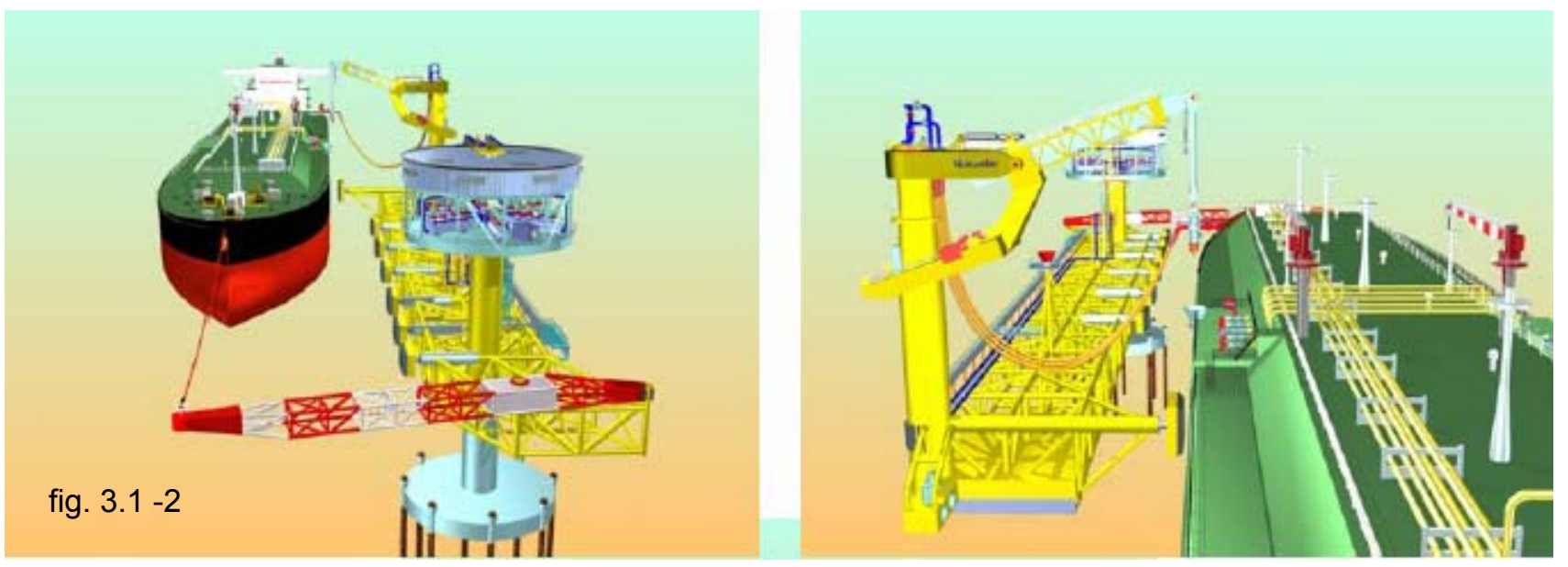

Re-gasification equipment may be located on the unit for applications without LNG storage e.g. where gas is stored in salt caverns or delivered directly to the shore gas grid.

Attachment $\mathrm{VI}$ is a plan view if the facility to scale. The platforms are approximately 1800 meters apart to allow for ample maneuvering distance. Although the plan view indicates that four caverns will be used for storage, the number and size of the caverns are for the most part subject to customer requirements as most salt formations can accommodate any number of caverns. Attachment VII has been included to better illustrate the major components of the offshore LNG terminal.

\subsection{Offshore Terminal - Estimated Cost and Revenue}

There are three major elements contributing to the overall total installed cost (TIC) of the LNG offshore terminal, (1) platforms and weathervaning mooring facilities, (2) the cryogenic pipeline required to connect the mooring facility to the cavern platform, and (3) the newly designed solution mined salt storage caverns. The cost estimates for the financial model (Attachment VIII) were developed using a factored cost estimating program specific to the industry. Budget estimates for the offshore mooring facilities are based on actual operating experience and direct quotations. Cryogenic pipeline estimates were sourced from the contractors.

The financial model applied is based on a long-established standard model for gas storage. Necessary modifications were made to reflect the key economic and financial aspects of the offshore LNG Terminal based on the designers best estimates, especially in the area of terminal energy use fees and actual terminal energy use requirements.

The major elements of the terminal TIC and $O \& M$ budget are included on the second and third page of Attachment VIII. The major elements of the economic/financial model and its results are shown on the "Summary" page, e.g. Attachment VIII pg. 1.

Most of the items on the "Summary Facility Assumptions" page are self explanatory. Please refer to section 2.3 of this report for additional details of notable items, parameters, and assumptions for the Offshore LNG terminal.

The "Financial Results" block shows model outputs generally from the cash flow calculation. The cost of capital is a straightforward calculation based on the input assumptions for costs and amounts of debt and equity. The 


\begin{tabular}{|l|l|l|l|}
\hline Customer: & $\begin{array}{l}\text { The United States Department of Energy } \\
\text { National Energy Technology Laboratory }\end{array}$ & $\begin{array}{l}\text { Date of Issue: } \\
24 \text { April } 2003\end{array}$ & \\
\hline $\begin{array}{l}\text { Document } \\
\text { Title: }\end{array}$ & Report II: “Conceptual Design of a Salt Cavern Based LNG Terminal” & $\begin{array}{l}\text { Doc \# \& Version: } \\
\text { Doc } 06 \text { r1.0 }\end{array}$ & Page 13 of 13 \\
\hline
\end{tabular}

"Project Economics" section reflects results for the project without any debt. This is essentially an "all equity" approach to project NPV and IRR. Estimated EBTIDA amounts are expressed in thousands of dollars per year. Equity returns as NPV and IRR are shown on an after tax basis for cash-on-cash expected flows. Minimum debt service coverages are shown on a pre-tax basis as shown. Based on a throughput fee of $\$ 0.095 \mathrm{mmBtu}$, the conceptual offshore terminal in years one through five averaged an EBITDA of $\$ 42,698,000$ USD based on a through-put of 230 cargoes per year. On a $16.4 \%$ after tax equity IRR the projected equity return was $\$ 20,493,000$ USD. 
Attachment I 


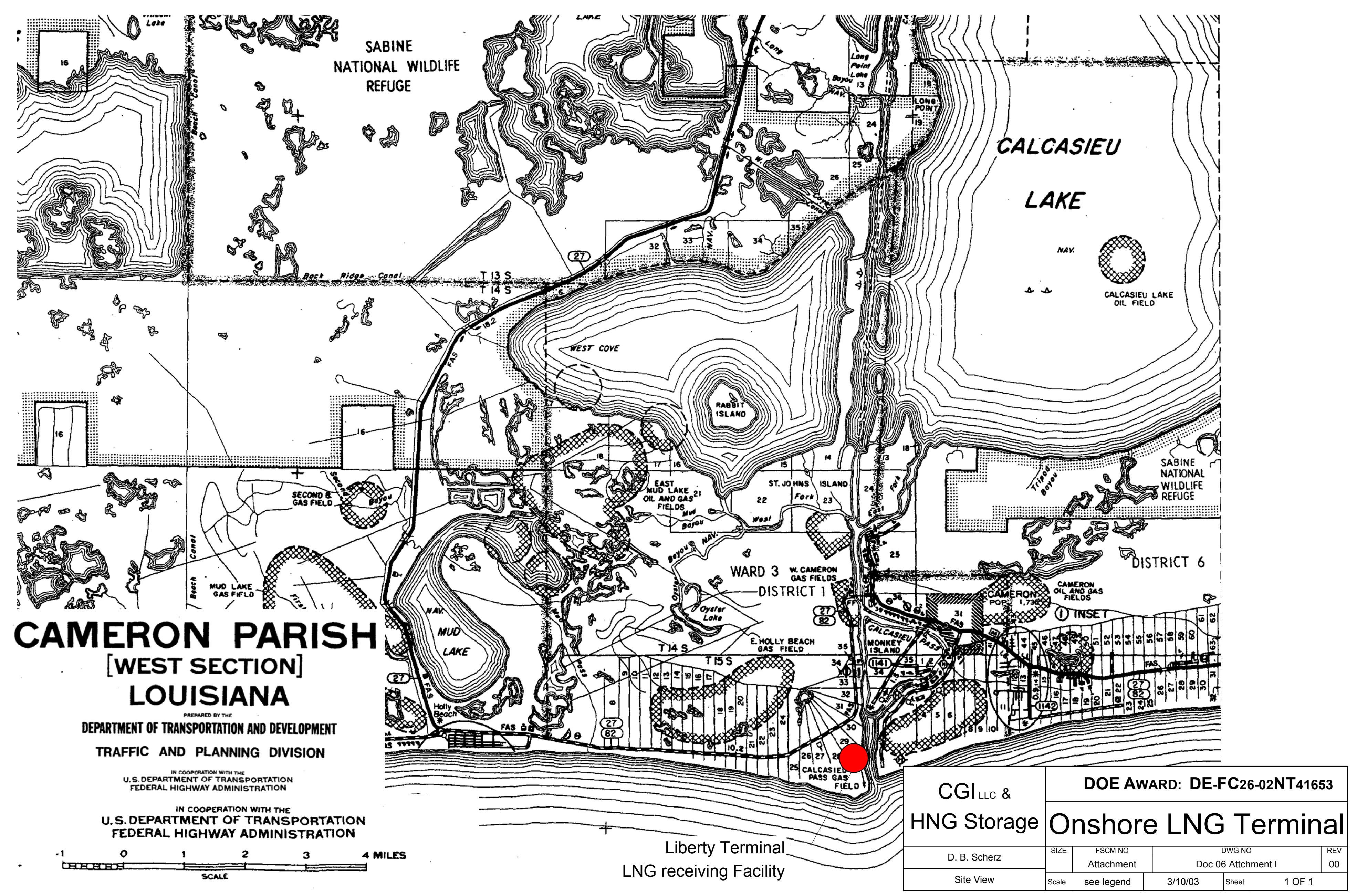


Attachment II 


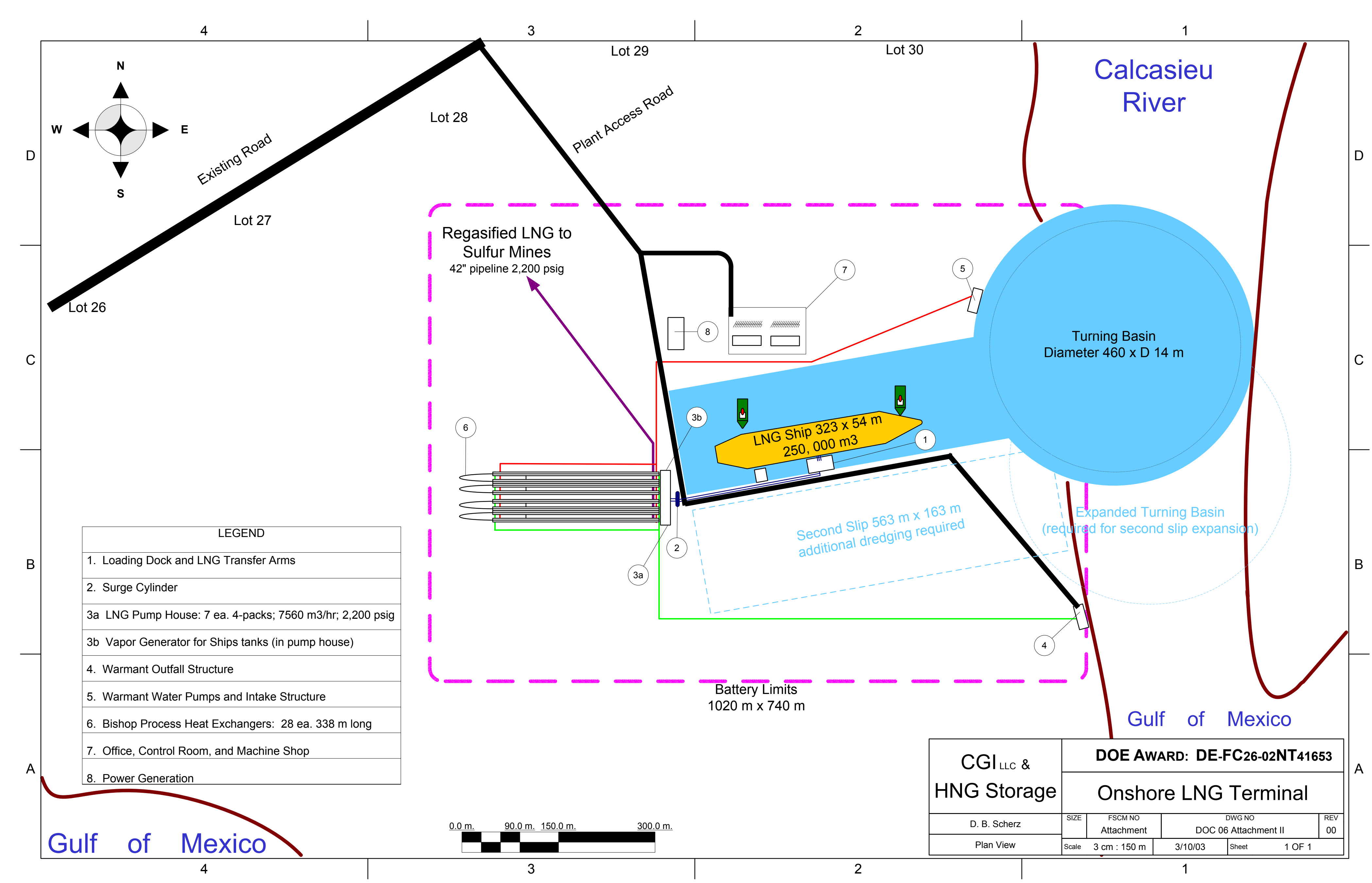


Attachment III 


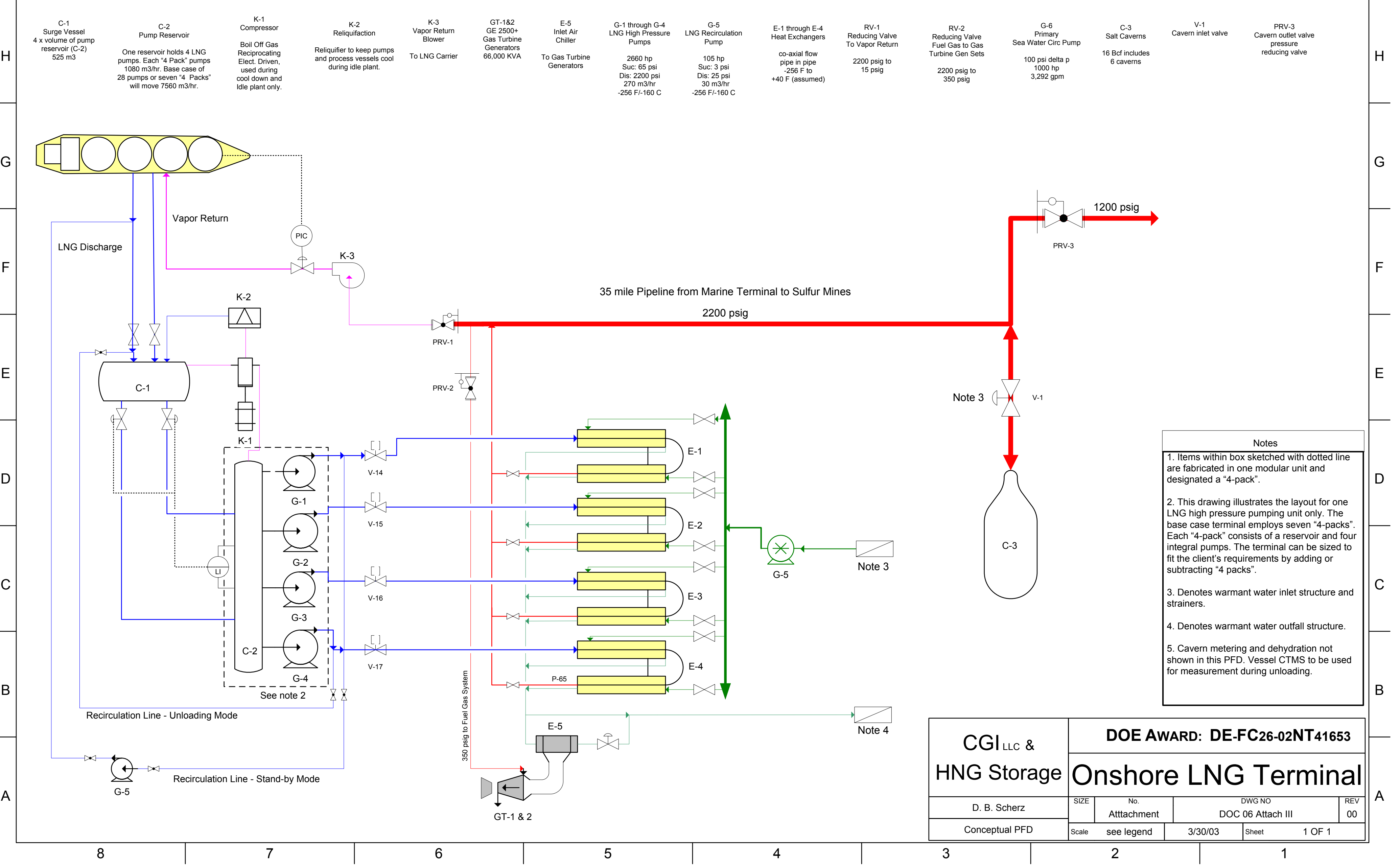


Attachment IV 


\section{LIBERTY LNG TERMINAL \\ PROFORMA ECONOMICS \\ Doc 06 Attachment IV pg 1}

\section{SUMMARY FACILITY ASSUMPTIONS}

\section{FINANCIAL ASSUMPTIONS}

\section{Facility Basis - Firm Service}

Cargos per Year

LNG Discharge per Ship, cubic meters LNG

LNG Btu content, Btu/scf

Storage Working Gas Volume, Bcf

Storage Base Gas Volume, Bcf

Pricing

Throughput Fee, $\$ / \mathrm{MmBtu}$

Facility Costs, $\$$

\begin{tabular}{rlr} 
& Facility Costs, $\$$ & \\
\cline { 2 - 3 } 225 & Marine Port Facilities & $56,733,600$ \\
138,000 & LNG Process \& HP Pipeline & $136,310,776$ \\
1067 & Terminal Utility System & $28,188,700$ \\
16.00 & Storage Surface Facility & $17,363,650$ \\
7.30 & Storage Construction & $18,358,100$ \\
& Header Pipeline & $14,397,250$ \\
& Engineering \& Const. Mgmt. & $14,925,225$ \\
& Project Acquisition \& Tech. Rights & $1,920,000$ \\
0.096 & Owner Costs, Permits, Misc. & $7,361,958$ \\
$0.0 \%$ & Financing Fees & $16,281,125$ \\
$0.00 \%$ & Contingency & $43,784,595$ \\
$\$ 3.50$ & Total Facility Cost & $\mathbf{3 5 5 , 6 2 4 , 9 7 9}$
\end{tabular}

Assumed Henry Hub Index for initial year

Gas Storage Net Revenue Realized \$MM/year

$\$ 0.0$

\section{Other Assumptions}

(Delivered), $\$ / \mathrm{Mcf}$

Base Gas Source ("Lease" or "Buy")

Total Operations Cost, \$M/Year

- Labor \& Maintenance, $\$ \mathrm{M} / \mathrm{Yr}$

- Electrical Demand Charge, \$M/Yr

Management Overhead, \$M/Year

Property Taxes (assumed amount), \$M/Yr

Storage Site Lease Fee, \$M/yr

$\%$ Revenue Stream to Inflation Protect, \%/yr

General Inflation Rate

Inflation applied to certain annual costs, $\% / \mathrm{yr}$

Energy Use for Terminal ops., \% of throughput

Full storage cavern compression charge rate

$\%$ of throughput requiring compression at cavern

Project \& Technology Rights

Running Royalty, as \% of Henry Hub index

Project \& License Upfront Payment, \$MM

\section{LNG Terminal Project Metrics}

Load Factor (based on 240 cargos/yr max)

Reference Annual throughput, mcf/yr

Annual LNG Offloaded, BCF/yr

Reference throughput, million mmBtu/yr $\quad 653,086,4$

Daily equivalent amount (mcf/day)

\section{Tax Rates}

Federal, $\% / \mathrm{YR}$

State, \%/YR

Blended Rate, \%/Yr

Property, \%/YR, initial year/capital cost

Capital Gain Rate for Terminal Value

Depreciation

Depreciation (Straight-Line or Accel) Straight-Line

Depreciable Life, Years

Project Life, Years
Financial Structure

Sr. Debt Percent of Capital

Jr. Debt Percent of Capital

Equity Percent of Capital

Senior Debt Term

Junior Debt Term

Base Gas Lease Carrying Cost, \%/YR

FINANCIAL RESULTS

\begin{tabular}{|lr|}
\hline & \\
Cost of Capital & $\mathbf{1 0 . 8 8 \%}$ \\
\hline Pretax WACC & $\mathbf{9 . 6 0 \%}$ \\
WACC & $\mathbf{1 5 . 0 \%}$ \\
Equity Return (assumed from above) & \\
& \\
Project Economics & $\mathbf{1 4 7 , 5 7 9}$ \\
\hline Project NPV@Pretax WACC, \$M & $\mathbf{1 5 . 1 \%}$ \\
Project Pretax IRR & $\mathbf{9 3 , 8 3 5}$ \\
NPV @ WACC (tax-effected), \$M & $\mathbf{1 2 . 1 \%}$ \\
Project IRR (tax-effected) & $\mathbf{\$ 4 2 , 1 3 9}$ \\
Yr. 1 EBITDA \$M/year & $\mathbf{\$ 4 5 , 1 2 9}$ \\
Avg. EBITDA, Yrs 1-5, \$M/year & \\
Equity Returns, AFTER-Tax & $\mathbf{2 1 , 3 7 7}$ \\
\hline Equity NPV@ Assumed Equity Return, \$M & $\mathbf{1 6 . 4 \%}$ \\
Equity IRR (calculated) & \\
& Pre-tax \\
Debt Coverage & $\mathbf{3 . 5}$ \\
\hline Minimum EBITDA/Interest Coverage & $\mathbf{2 . 6}$ \\
\hline Minimum EBITDA/Debt Service &
\end{tabular}

$0.00 \%$ based on mmBtu throughput
Rate

$50.0 \% \quad 6.75 \%$

$0.0 \%$

$15.0 \%$ 
LIBERTY LNG TERMINAL

PROFORMA ECONOMICS

Doc 06 Attachment IV pg 2

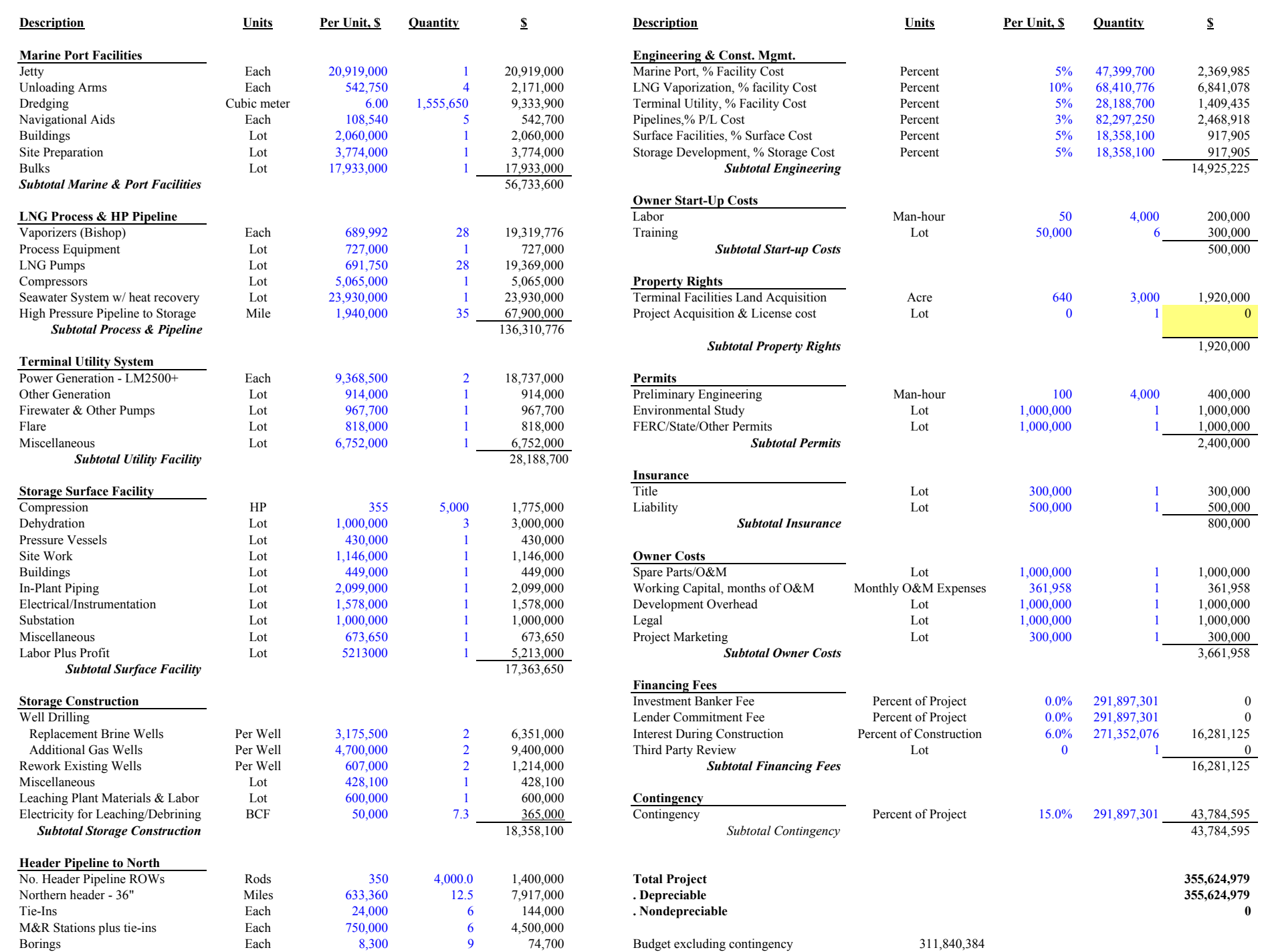


LIBERTY LNG TERMINAL

PROFORMA ECONOMICS

Doc 06 Attachment IV pg 3

Operations \& Maintenance Expenses - Year 1

\begin{tabular}{|c|c|c|c|c|}
\hline Description & $\underline{\text { Units }}$ & $\underline{\text { Per Unit }}$ & Quantity & $\underline{\text { Total Cost }}$ \\
\hline Managers & Each & 100,000 & 3 & 300,000 \\
\hline Administrative & Each & 40,000 & 2 & 80,000 \\
\hline Field Operators \& Technicians & Each & 45,000 & 14 & 630,000 \\
\hline Benefits & $\%$ of Payroll & $35 \%$ & $1,010,000$ & 353,500 \\
\hline Subtotal Labor & & & & $1,363,500$ \\
\hline Subcontractor Services & & & & \\
\hline Contract Repairs & Lot & 240,000 & 1 & 240,000 \\
\hline Contract Services & Lot & 600,000 & 1 & 600,000 \\
\hline Equipment Rental & Lot & 120,000 & 1 & 120,000 \\
\hline Computer Services & Lot & 10,000 & 1 & 10,000 \\
\hline Subtotal Subcontractor Services & & & & 970,000 \\
\hline Material \& Supplies & & & & \\
\hline Spare Parts & Lot & 160,000 & 1 & 160,000 \\
\hline Chemicals & Lot & 100,000 & 1 & 100,000 \\
\hline Plant Supplies & Lot & 140,000 & 1 & 260,000 \\
\hline Subtotal Material \& Supplies & & & & 260,000 \\
\hline
\end{tabular}

Direct Operating \& Maintenance

\begin{tabular}{ll} 
Expenses & \\
\hline Major item replacement & Lot \\
Recruiting \& Training & Lot \\
Insurance & Lot \\
Auto \& Truck Rental & Lot \\
Tools \& Equipment & Lot \\
Travel & Lot \\
Miscellaneous & Lot \\
\multicolumn{1}{c}{ Subtotal Direct Opereration \& Misc. Exp. } &
\end{tabular}

200,000
20,000
$1,300,000$
40,000
80,000
10,000
100,000

Project O\&M Total

\begin{tabular}{lr}
1 & 200,000 \\
1 & 20,000 \\
1 & $1,300,000$ \\
1 & 40,000 \\
1 & 80,000 \\
1 & 10,000 \\
1 & 100,000 \\
\cline { 2 - 2 } & $1,750,000$ \\
& \\
& $\mathbf{4 , 3 4 3 , 5 0 0}$
\end{tabular}


Attachment V 


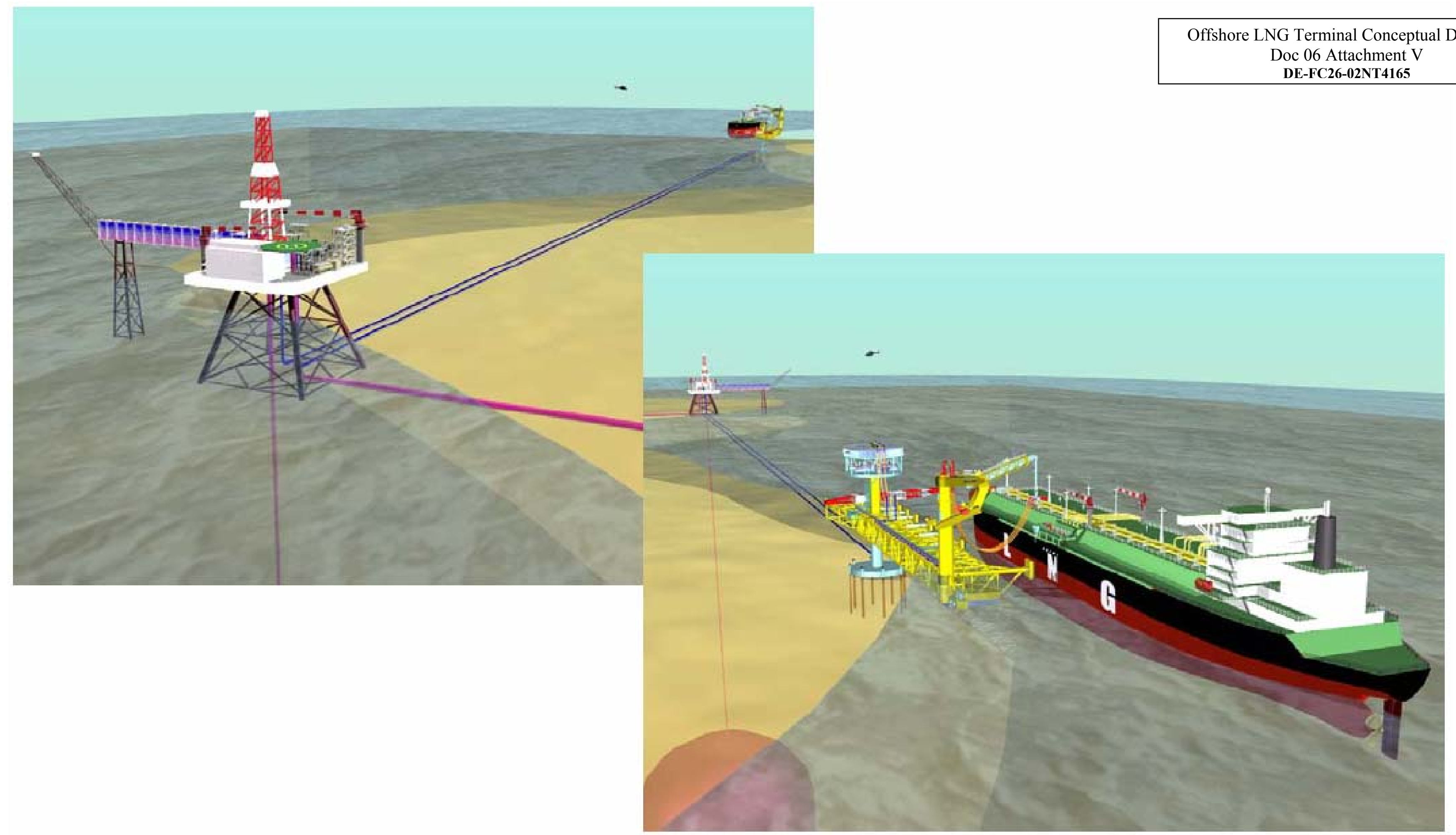

Field Lay-out for LNG Import Terminal with Salt Cavern Storage 
Attachment VI 


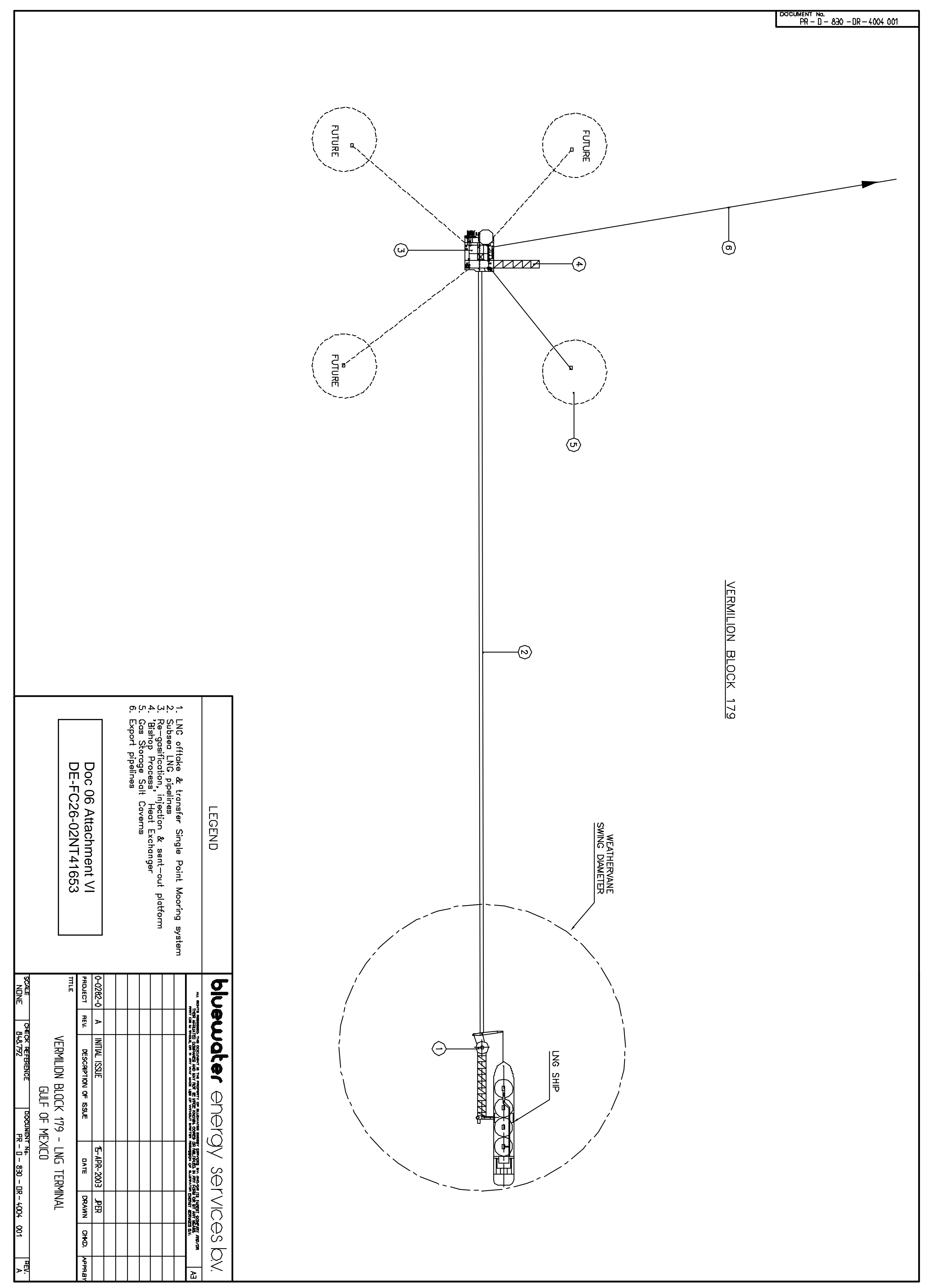


Attachment VII 


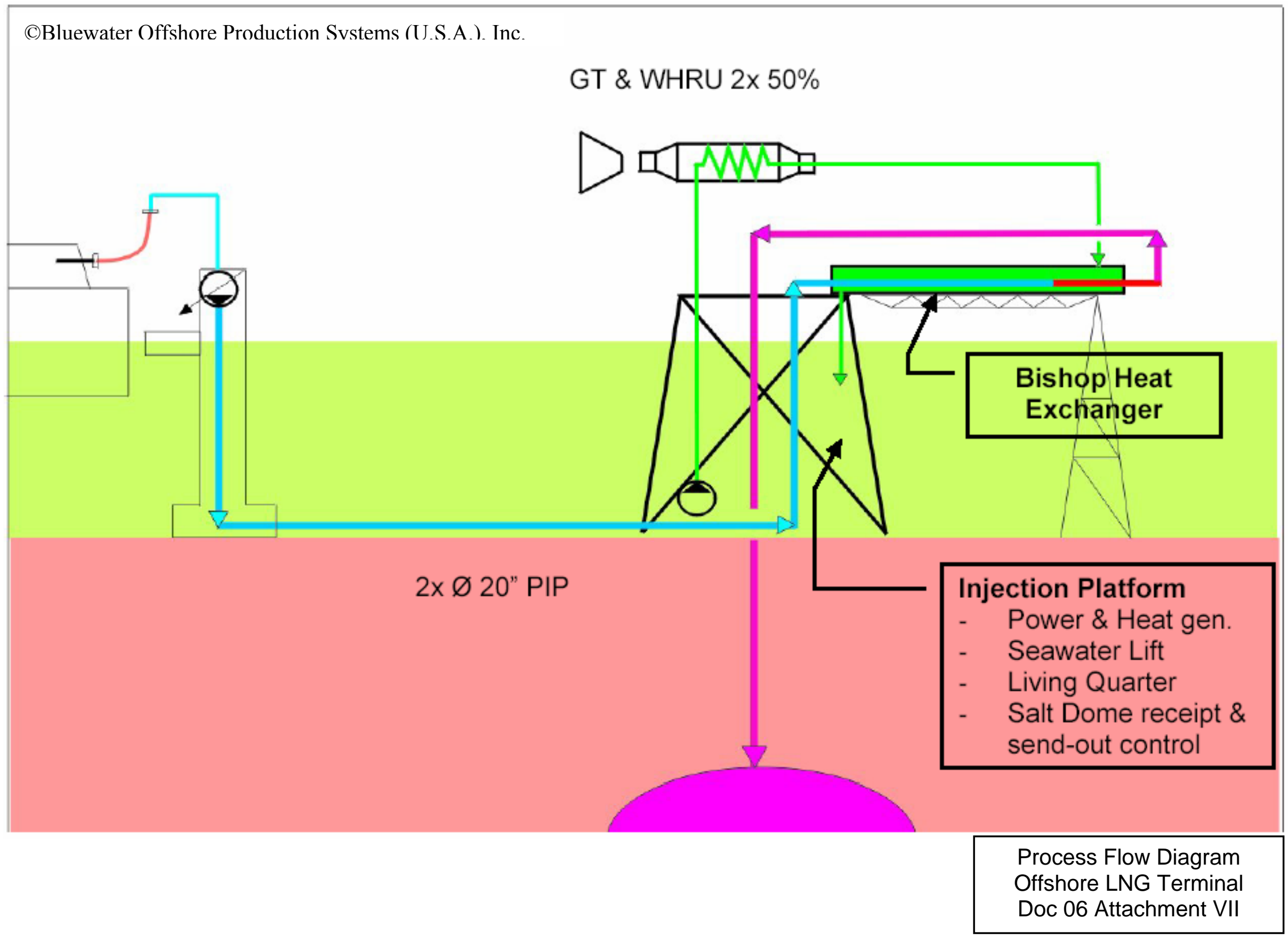


Attachment VIII 


\section{BLUEWATER LNG TERMINAL \\ PROJECT SUMMARY}

Doc 06 Attachment VIII pg 1

\section{SUMMARY FACILITY ASSUMPTIONS}

\section{Facility Basis - Firm Service}

Cargos per Year

LNG Discharge per Ship, cubic meters LNG

LNG Btu content, Btu/scf

Storage Working Gas Volume, Bcf

Storage Base Gas Volume, Bcf

\section{Pricing}

\section{Throughput Fee, \$/MmBtu}

Other Revenue - \% of Terminal Throughput Rev. Terminal Energy Use Charge, \% of throughput

Assumed Henry Hub Index for initial year

Gas Storage Net Revenue Realized \$MM/year

\section{Other Assumptions}

Base Gas Price (Delivered), \$/Mcf

Base Gas Source ("Lease" or "Buy")

Total Operations Cost, \$M/Year

- Labor \& Maintenance, $\$ M / Y r$

- Electrical Demand Charge, $\$ M / Y r$

Management Overhead, \$M/Year

Property Taxes (assumed amount), \$M/Yr

Storage Site Lease Fee, $\$ M / y r$

$\%$ Revenue Stream to Inflation Protect, \%/yr

General Inflation Rate

Inflation applied to certain annual costs, \%/yr

Energy Use for Terminal ops., \% of throughput

Full storage cavern compression charge rate

$\%$ of throughput requiring compression at cavern

Project \& Technology Rights

Running Royalty, as \% of Henry Hub index

Project \& License Upfront Payment, \$MM

$0.00 \%$ based on mmBtu throughput

\section{Facility Costs, \$}

Marine Port Facilities

Terminal Utility System $\quad 28,188,700$

Storage Surface Facility $\quad 25,055,650$

Storage Construction $\quad 43,996,100$

Header Pipeline

Engineering \& Const. Mgmt.

Project Acquisition \& Tech. Rights

Owner Costs, Permits, Misc.
Financing Fees

$0.0 \%$

$0.00 \%$

$\$ 3.50$

$\$ 0.0$

Contingency

Total Facility Cost

$18,698,900$

$15,433,327$

10,000

$8,595,792$

$15,341,511$

$41,375,277$

$\mathbf{3 3 6 , 4 4 7 , 7 5 6}$

LNG Terminal Project Metrics

Load Factor (based on 240 cargos/yr max)

Reference Annual throughput, $\mathrm{mcf} / \mathrm{yr}$

Annual LNG Offloaded, BCF/yr

$96 \%$

3.50

lease

7,350

7,150

200

360

4,000

500

$100 \%$

$3.0 \%$

$1.5 \%$

$0.35 \%$

$1.25 \%$

$5 \%$

626

Daily equivalent amount (mcf/day) $\quad 1,737,997$

Tax Rates

Federal, \%/YR

$35.0 \%$

State, $\% / Y R \quad 4.50 \%$

Blended Rate, \%/Yr. $\quad 37.93 \%$

Property, \%/YR, initial year/capital cost $\quad 1.19 \%$

Capital Gain Rate for Terminal Value $\quad 20 \%$

Depreciation

Depreciation (Straight-Line or Accel) Straight-Line

Depreciable Life, Years

Project Life, Years

20
20

\section{FINANCIAL ASSUMPTIONS}

Financial Structure \% Capital

Sr. Debt Percent of Capital

$50.0 \%$

$\underline{\text { Rate }}$

Jr. Debt Percent of Capital

Equity Percent of Capital

$50.0 \%$

$0.0 \%$

Senior Debt Term

Junior Debt Term

Base Gas Lease Carrying Cost, \%/YR

FINANCIAL RESULTS

Cost of Capital

Pretax WACC

WACC

Equity Return (assumed from above)

$9.60 \%$

$15.0 \%$

Project Economics

Project NPV@Pretax WACC, \$M

140,265

Project Pretax IRR

NPV@ WACC (tax-effected), \$M

$15.1 \%$

Project IRR (tax-effected)

Yr. 1 EBITDA \$M/year

Avg. EBITDA, Yrs 1-5, \$M/year

$\$ 39,849$

$\$ 42,698$

Equity Returns, AFTER-Tax

Equity NPV@ Assumed Equity Return, \$M

Equity IRR (calculated)

Debt Coverage

Minimum EBITD

Pre-tax 
BLUEWATER LNG TERMINAL

PROJECT BUDGET

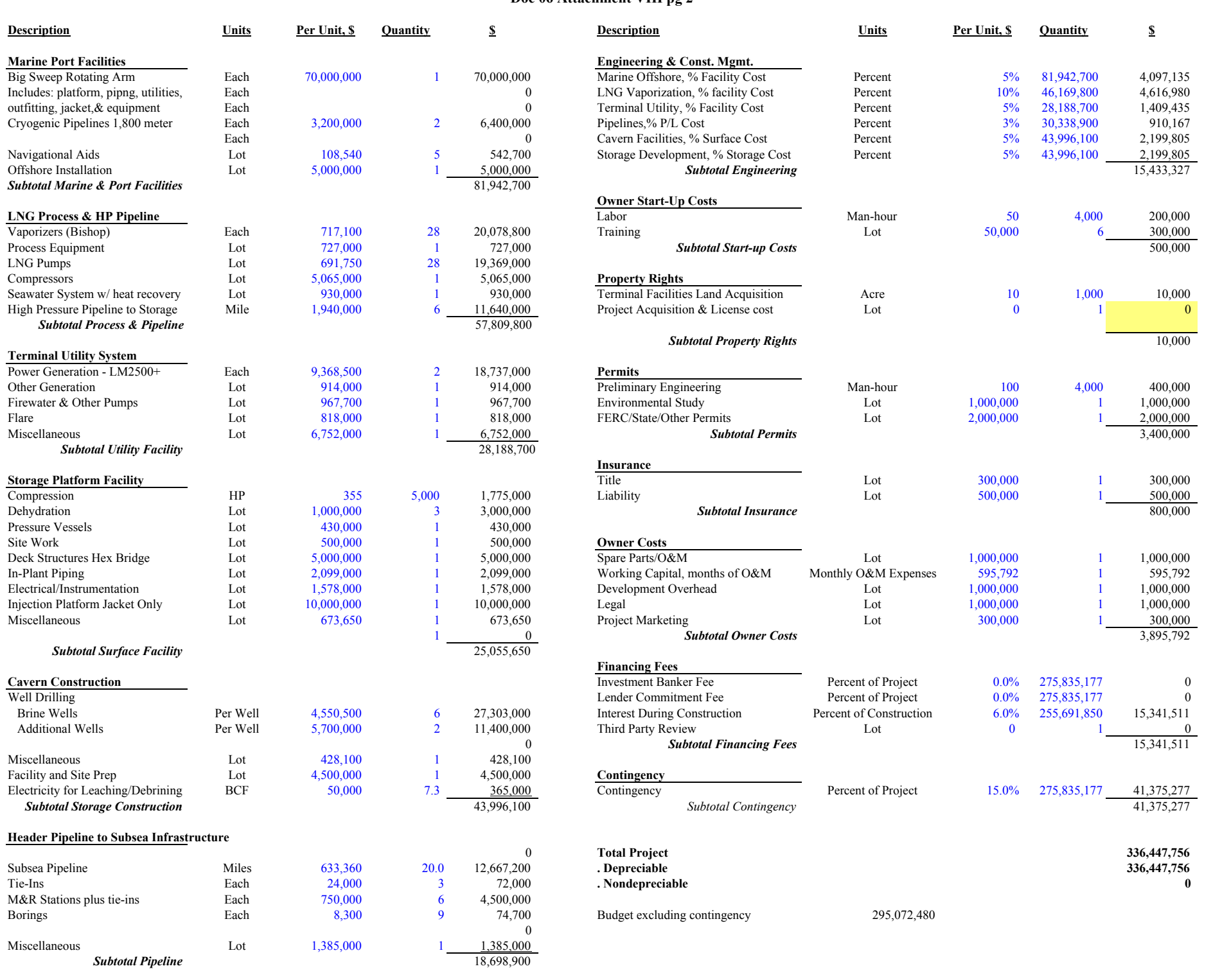




\section{BLUEWATER LNG TERMINAL \\ OPERATIONS AND MAINTENANCE EXPENSES \\ Doc 06 Attachment VIII pg 3 \\ Operations \& Maintenance Expenses - Year 1}

\begin{tabular}{|c|c|c|c|c|}
\hline Description & $\underline{\text { Units }}$ & Per Unit & Quantity & $\underline{\text { Total Cost }}$ \\
\hline Managers & Each & 100,000 & 6 & 600,000 \\
\hline Administrative & Each & 40,000 & 4 & 160,000 \\
\hline Field Operators \& Technicians & Each & 45,000 & 18 & 810,000 \\
\hline Benefits & $\%$ of Payroll & $35 \%$ & $1,570,000$ & 549,500 \\
\hline
\end{tabular}

Subcontractor Services

\begin{tabular}{ll}
\hline Contract Repairs & Lot \\
Contract Services & Lot \\
Equipment Rental & Lot \\
Computer Services & Lot
\end{tabular}

Subtotal Subcontractor Services

10,000

Material \& Supplies

\begin{tabular}{ll}
\hline Spare Parts & Lot \\
Chemicals & Lot \\
Plant Supplies & Lot
\end{tabular}

Direct Operating \& Maintenance Expenses

$\begin{array}{ll}\text { Major item replacement } & \text { Lot } \\ \text { Recruiting \& Training } & \text { Lot } \\ \text { Insurance } & \text { Lot } \\ \text { Transport Rental } & \text { Lot } \\ \text { Tools \& Equipment } & \text { Lot } \\ \text { Travel } & \text { Lot } \\ \text { Miscellaneous } & \text { Lot }\end{array}$

Miscellaneous

$\begin{array}{lc}\text { Lot } & 200,000 \\ \text { Lot } & 50,000 \\ \text { Lot } & 1,300,000 \\ \text { Lot } & 500,000 \\ \text { Lot } & 80,000 \\ \text { Lot } & 250,000 \\ \text { Lot } & 100,000\end{array}$

Subtotal Direct Opereration \& Misc. Exp.

Project O\&M Total

\section{.}




\begin{tabular}{|l|l|l|l|}
\hline Customer: & $\begin{array}{l}\text { The United States Department of Energy } \\
\text { National Energy Technology Laboratory }\end{array}$ & $\begin{array}{l}\text { Date of Issue: } \\
\text { 24 April 2003 }\end{array}$ & \\
\hline $\begin{array}{l}\text { Document } \\
\text { Title: }\end{array}$ & $\begin{array}{l}\text { Report III: Comparisons Between LNG Receiving Terminals: } \\
\text { Conventional, Salt cavern Based, and "Energy Bridge®” }\end{array}$ & $\begin{array}{l}\text { Doc \# \& Version: } \\
\text { Doc 07 r2.0 }\end{array}$ & Page 1 of 7 \\
\hline
\end{tabular}

\title{
Comparisons between LNG Receiving Terminals: Conventional, Salt cavern Based, and "Energy Bridge ${ }^{\circledR}$ "
}

\author{
BY \\ MiCHAEL M. MCCALL \\ WILLIAM M. BISHOP \\ D. BRAXTON SCHERZ
}

\begin{tabular}{|c|c|c|c|c|c|c|c|c|}
\hline r 1.0 & For client review & 02/09/03 & BS & мм & & & & \\
\hline Version & Reason for Issue & $\begin{array}{l}\text { Issue } \\
\text { Date }\end{array}$ & Orig. & $\begin{array}{l}\text { Chk. } \\
\text { CGI }\end{array}$ & Appr. & $\begin{array}{l}\text { Chk. } \\
\text { NE }\end{array}$ & $\begin{array}{l}\text { Appr. } \\
\text { TL }\end{array}$ & Review \\
\hline \multicolumn{2}{|c|}{$\begin{array}{l}\text { Document Title: } \\
\text { Comparisons Between LNG Receiving Terminals: } \\
\text { Conventional, Salt cavern Based, and "Energy } \\
\text { Bridge }{ }^{\circledR} \text { " }\end{array}$} & \multicolumn{7}{|c|}{ Document No: } \\
\hline
\end{tabular}




\section{TABLE OF CONTENTS}

1. EXECUTIVE SUMMARY ......

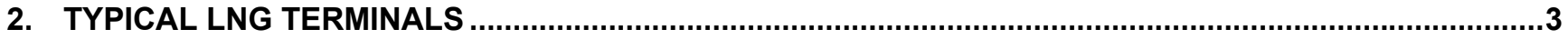

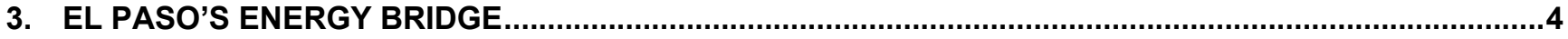

4. SUMMARY OF ESTIMATED CAPITAL, OPERATION, AND FUEL COSTS .........................................6 


\begin{tabular}{|l|l|l|l|}
\hline Customer: & $\begin{array}{l}\text { The United States Department of Energy } \\
\text { National Energy Technology Laboratory }\end{array}$ & $\begin{array}{l}\text { Date of Issue: } \\
24 \text { April 2003 }\end{array}$ & \\
\hline $\begin{array}{l}\text { Document } \\
\text { Title: }\end{array}$ & $\begin{array}{l}\text { Report III: Comparisons Between LNG Receiving Terminals: } \\
\text { Conventional, Salt cavern Based, and “Energy Bridge®” }\end{array}$ & $\begin{array}{l}\text { Doc \# \& Version: } \\
\text { Doc } 07 \text { r2.0 }\end{array}$ & Page 3 of 7 \\
\hline
\end{tabular}

\section{EXECUTIVE SUMMARY}

The technologies in the LNG industry have remained essentially unchanged over the years. "Energy Bridge," a notable exception developed by El Paso Global LNG Co., combines LNG shipping and regasification on a single ocean-going vessel. Energy Bridge because of its mobility, "zero footprint", and offloading flexibility may have advantages in markets where spot trades command higher prices. The LNG spot market continues to grow, but long term baseload LNG sales contracts have yet to be eclipsed. Whether or not Energy Bridge realizes its true competitive advantage has yet to be confirmed.

Five representative LNG terminals were evaluated to determine an indicative cost of service required to achieve a $15 \%$ IRR on each project. A summary review of the findings (Table 4.1) prepared for this Document 07, indicates that the Bishop Process Exchanger LNG terminals generate the lowest terminal fees required to achieve the $15 \%$ IRR condition. This is attributable to competitive CAPEX costs, very high sendout rates, excellent fuel efficiencies, and lower operating costs.

\section{LNG TERMINALS - FIVE CASES}

Five generally defined LNG terminals were selected for the basis of this study. There were no attempts to "equalize" the terminals by establishing a base line capacity, or any other common element that might skew the results of the matrix. Rather, each terminal is based upon an actual or proposed LNG project. The Bishop Process Onshore and Offshore terminals in this section are representative also and are not to be confused with the onshore and offshore terminals in Task 2.0. Terminals in Task 2.0 are site specific and estimated costs reflect each terminal location. Terminal send-out is a product of design, and the results of the comparisons have been based on a $100 \%$ load factor for each project and unitized on a BTU basis. Regarding El Paso's Energy Bridge ${ }^{\circledR}$, there are no provisions for a land based receiving terminal. For cost comparison purposes the estimate for an LNG vessel of $138,000 \mathrm{~m} 3$ of membrane tank design was used.

An LNG specific cost estimating model using factored analysis was chosen as a basis of the calculated results. LNG receiving terminals have many machinery items in common and the costs for these items remain common throughout the comparison. There are of course major differences in the methods used to store LNG, the design of the marine facility, and the methods used to vaporize LNG. These major differences are reflected in capital costs, fuel cost, and personnel required to staff the terminals.

For the first case, an LNG terminal located on the Pacific Coast of the Americas (North or South) was selected. Pacific coast LNG sites typically share several major design similarities including, (1) the requirement for a breakwater and a long approach trestle to protect and access the LNG berth, and (2) large LNG storage tanks to allow for adequate reserve due to the long distances from LNG supplier (Asia in most cases) to the receiving terminal. These requirements generally increase the cost of the terminal as indicated in the following tables.

An estimate of an LNG terminal located on the Atlantic coast of North America forms the basis of the second case. This terminal will serve as a baseload LNG receiving facility, and benefits from a good location directly adjacent to deep water. For this reason a short approach trestle connects the dock with the shore facility, and no breakwater is required. Storage can be optimized because there are several LNG supply terminals located within reasonable shipping distances from the receiving facility.

Cases three and four reflect LNG receiving terminals based on the use of the Bishop Process Heat Exchanger (BPT) and use salt caverns for storage. A detailed discussion of the Onshore and Offshore BPT terminal is included in Task 2.0 of this study. El Paso's Energy Bridge ${ }^{\circledR}$ concept represents the fifth case. 


\begin{tabular}{|l|l|l|l|}
\hline Customer: & $\begin{array}{l}\text { The United States Department of Energy } \\
\text { National Energy Technology Laboratory }\end{array}$ & $\begin{array}{l}\text { Date of Issue: } \\
\text { 24 April 2003 }\end{array}$ & \\
\hline $\begin{array}{l}\text { Document } \\
\text { Title: }\end{array}$ & $\begin{array}{l}\text { Report III: Comparisons Between LNG Receiving Terminals: } \\
\text { Conventional, Salt cavern Based, and "Energy Bridge }{ }^{\circledR} \text { ” }\end{array}$ & $\begin{array}{l}\text { Doc \# \& Version: } \\
\text { Doc 07 r2.0 }\end{array}$ & Page 4 of 7 \\
\hline
\end{tabular}

\section{EL PASO - ENERGY BRIDGE®}

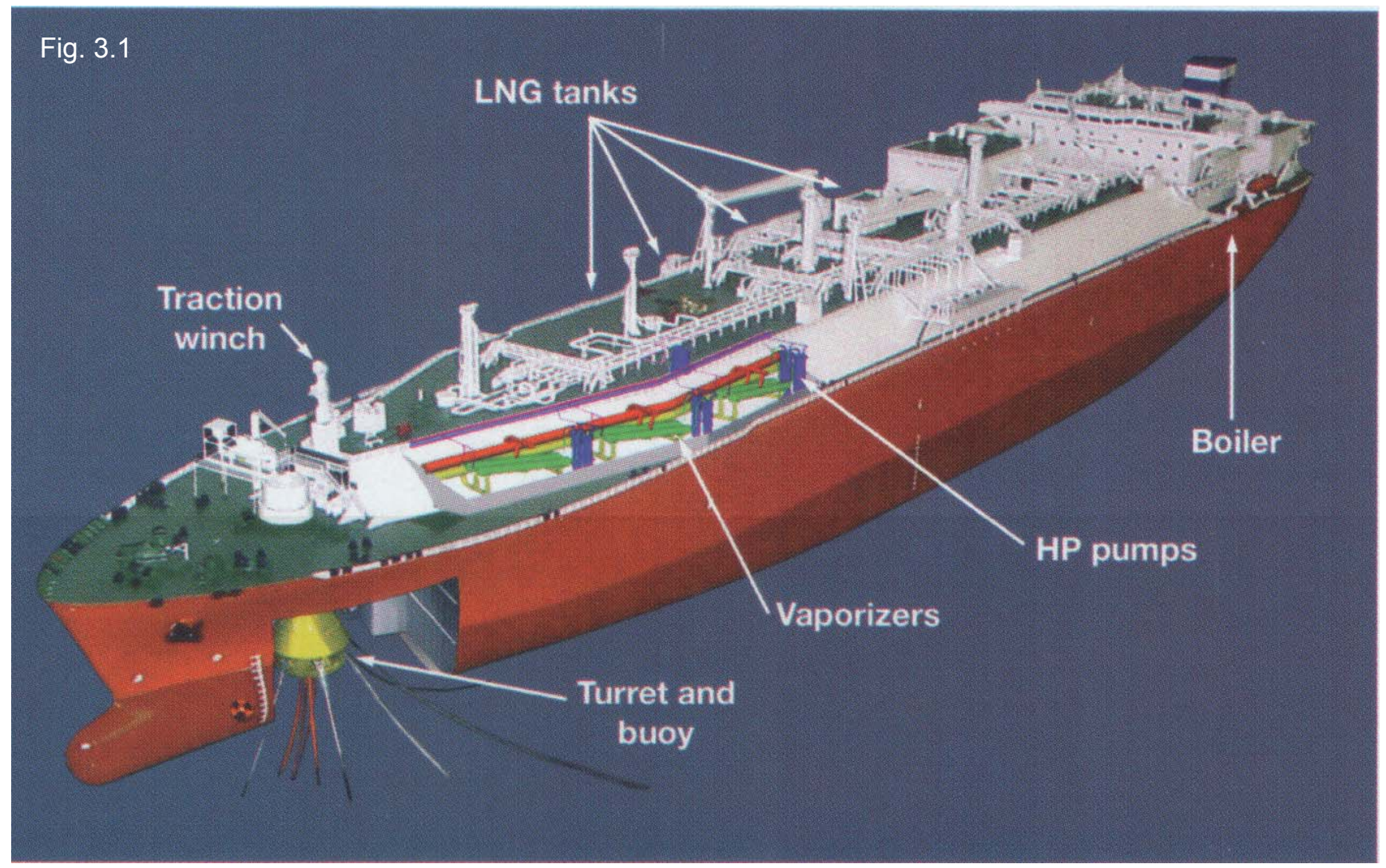

The fifth LNG terminal used in the comparison is based on El Paso's Energy Bridge concept. EL PASO'S ENERGY BRIDGE developed by EI Paso Global LNG Co., combines LNG shipping and regasification on a single ocean-going vessel. Proven technologies are employed by Energy Bridge allowing natural gas to be delivered directly to coastal markets. With this new system, scheduled gas delivery from remote regions could take place on a baseload or seasonal basis, using highly reliable offshore moorings and subsea pipelines to shore.

Figure 3.1 above is an artist's rendering of what an EPEB vessel might look like. A new ship design is not required, simply modification of an existing LNG carrier. Shown are some of the major components, such as onboard vaporizers and a view of the turret with the docking buoy attached to the receiving housing.

The EPEB inter-connection design uses the APL Submerged Turret Loading (APL) system, with a docking buoy that provides a single-point mooring system with high reliability for offshore LNG-vessel unloading. The APL system has been proven in actual conditions and under very severe conditions in the North Sea off the coast of Norway.

Connections with the APL buoy have been made in seastates over 5 meters and operational loading has taken place on seastates over 13 meters. There are currently 19 APL buoys in service, used for traditional oil and gas 


\begin{tabular}{|l|l|l|l|}
\hline Customer: & $\begin{array}{l}\text { The United States Department of Energy } \\
\text { National Energy Technology Laboratory }\end{array}$ & $\begin{array}{l}\text { Date of Issue: } \\
\text { 24 April 2003 }\end{array}$ & \\
\hline $\begin{array}{l}\text { Document } \\
\text { Title: }\end{array}$ & $\begin{array}{l}\text { Report III: Comparisons Between LNG Receiving Terminals: } \\
\text { Conventional, Salt cavern Based, and "Energy Bridge®” }\end{array}$ & $\begin{array}{l}\text { Doc \# \& Version: } \\
\text { Doc 07 r2.0 }\end{array}$ & Page 5 of 7 \\
\hline
\end{tabular}

production operation. Over 1,000 connections have been made to date in the North Sea with a $100 \%$ success rate.

EI Paso envisions a fleet of specially equipped EPEB vessels bringing LNG to market. Figure 3.2 shows the general system layout. Upon arrival in the terminal area, the EPEB ship connects to a submerged offloading system which moors the vessel and connects it to an offload pipeline. This takes place well offshore and

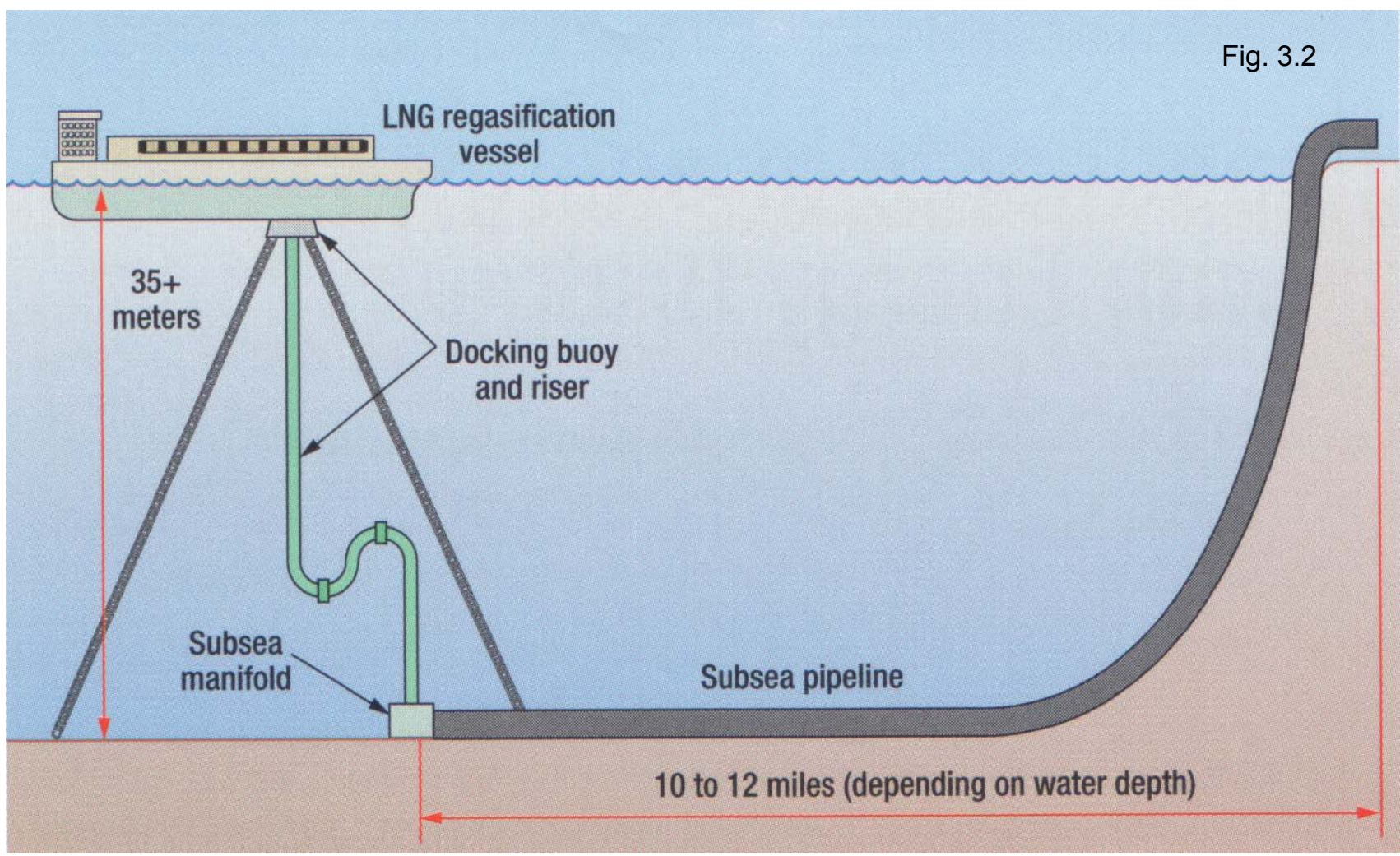

typically over the horizon. Once connected to the offload pipeline, the ship begins onboard regasification to provide safe LNG conversion to vaporous natural gas at pressures up to 1,400 psi.

Referring to Figure 3.2, the gas is sent through the offloading system and riser to a seabed pipeline that leads to an onshore customer's facility, or a nearby as transmission pipeline. At conclusion of the transfer the ship releases the offloading system to its idle position safely beneath the ocean's surface where it remains until the next ship arrives. Each 138,000 m3 tanker carries about 3 Bcf of gas and will typically off load in 7 to 10 days. At $100 \%$ load factor the vessel can discharge its cargo in about 5.5 days.

Figure 3.3 shows how the system will look when gas is being offloaded. The APL system is suitable for water depths of 35 meters to well over 100 meters. Once the ship is connected to the mooring buoy, it freely weathervanes with the wind and the current, thus mitigating much of the stress on the mooring lines and anchors. Once connected send-out to shore can occur in seas of 10 to $11 \mathrm{~m}$, providing for high reliability. The typical offshore gas installation have two offloading buoys and risers to accommodate simultaneous docking and undocking assuring continuous flow. 


\begin{tabular}{|l|l|l|l|}
\hline Customer: & $\begin{array}{l}\text { The United States Department of Energy } \\
\text { National Energy Technology Laboratory }\end{array}$ & $\begin{array}{l}\text { Date of Issue: } \\
\text { 24 April 2003 }\end{array}$ & \\
\hline $\begin{array}{l}\text { Document } \\
\text { Title: }\end{array}$ & $\begin{array}{l}\text { Report III: Comparisons Between LNG Receiving Terminals: } \\
\text { Conventional, Salt cavern Based, and "Energy Bridge }{ }^{\circledR} \text { ” }\end{array}$ & $\begin{array}{l}\text { Doc \# \& Version: } \\
\text { Doc 07 r2.0 }\end{array}$ & Page 6 of 7 \\
\hline
\end{tabular}

A detailed review of the marketing aspects of this innovative design is beyond the scope of this study. However, general reactions to Energy Bridge and its comparison to the other four LNG terminal options will be assessed in the matrix of Doc 08 of this study Task.

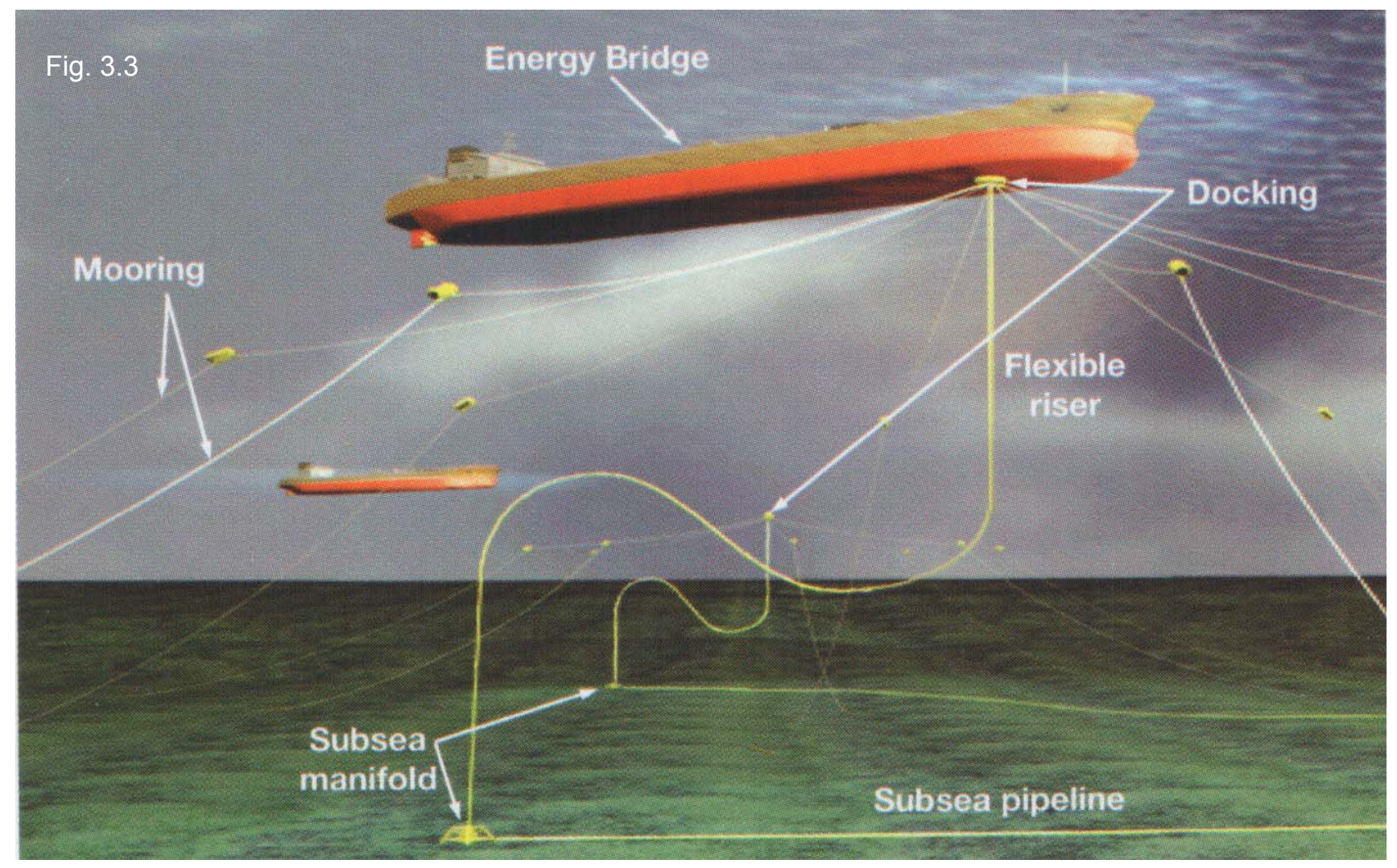

\section{SUMMARY OF LNG TERMINAL ESTIMATED CAPITAL, OPERATION, AND FUEL COSTS}

LNG terminal estimated Operating and Maintenance costs are based on historical LNG operation and maintenance data. The major engineering firms estimate OPEX costs at $1.5 \%$ of the TIC capital cost of the terminal for the first year of operation and $1 \%$ thereafter. For the purposes of this study, CGI will use that assumption for all five terminal examples and average costs over a 20 year period. The O\&M costs do not include fuel gas or imported power. The estimated fuel consumption of each terminal and fuel efficiencies have been derived from engineering studies listing the power requirements, or from fuel requirements published in existing tariffs. Table 4.1 includes a summary of all critical elements involved in the analysis, and it is understood that the results are indicative rather than actual.

As the table indicates, the BPT LNG terminals due to competitive CAPEX costs, excellent fuel efficiencies, and lower operating costs generate the lowest terminal fees required to achieve the $15 \%$ IRR condition. The equipment list used to generate the factored analysis and the summary sheet of the financial model for each terminal is included in Doc 07 Attachment I. The following document (Doc 08) includes the matrix used to summarize the advantages and disadvantages of each LNG terminal design. 


\begin{tabular}{|l|l|l|l|}
\hline Customer: & $\begin{array}{l}\text { The United States Department of Energy } \\
\text { National Energy Technology Laboratory }\end{array}$ & $\begin{array}{l}\text { Date of Issue: } \\
\text { 24 April 2003 }\end{array}$ & \\
\hline $\begin{array}{l}\text { Document } \\
\text { Title: }\end{array}$ & $\begin{array}{l}\text { Report III: Comparisons Between LNG Receiving Terminals: } \\
\text { Conventional, Salt cavern Based, and "Energy Bridge®” }\end{array}$ & $\begin{array}{l}\text { Doc \# \& Version: } \\
\text { Doc 07 r2.0 }\end{array}$ & Page 7 of 7 \\
\hline
\end{tabular}

Table 4.1 - LNG Terminal Cost Comparison

\begin{tabular}{|c|c|c|c|c|c|c|c|c|c|c|}
\hline 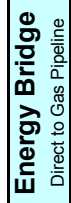 & 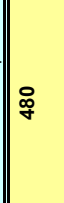 & 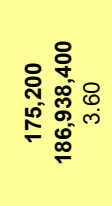 & $\stackrel{\square}{0}$ & 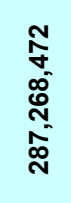 & $\stackrel{\text { th }}{\leftarrow}$ & 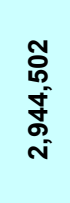 & $\begin{array}{l}8 \\
0 \\
8 \\
0 \\
0 \\
\text { in }\end{array}$ & \begin{tabular}{l}
0 \\
\multirow{0}{0}{} \\
0
\end{tabular} & ஓे & ঙั \\
\hline 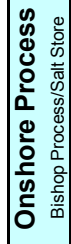 & | & 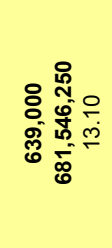 & $\stackrel{\llcorner}{\sim}$ & 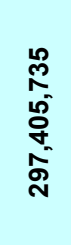 & $\underset{0}{J}$ & $\begin{array}{l}8 \\
o \\
+ \\
o \\
0 \\
0 \\
\text { j. }\end{array}$ & $\begin{array}{l}8 \\
0 \\
0 \\
0 \\
\infty \\
\infty\end{array}$ & $\frac{0}{0}$ & 今े & 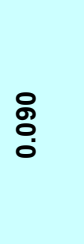 \\
\hline 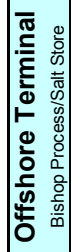 & 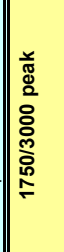 & 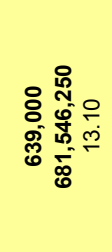 & $\stackrel{\mathscr{\nu}}{N}$ & 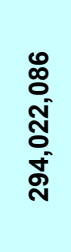 & $\stackrel{?}{0}$ & $\begin{array}{l}\stackrel{0}{N} \\
\text { m } \\
\stackrel{-}{0} \\
\text { m. }\end{array}$ & 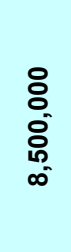 & $\stackrel{\hat{o}}{0}$ & 㥐 & $\begin{array}{l}\text { Oे } \\
\text { Oे }\end{array}$ \\
\hline 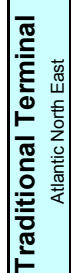 & | & 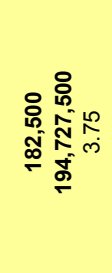 & $\hat{\sigma}$ & 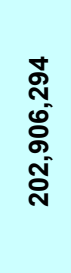 & $\stackrel{\text { S }}{\leftarrow}$ & $\begin{array}{l}8 \\
\stackrel{0}{1} \\
0 \\
0 \\
0 \\
i\end{array}$ & $\begin{array}{l}0 \\
0 \\
0 \\
0 \\
0 \\
0\end{array}$ & $\begin{array}{l}\text { I } \\
\text { S }\end{array}$ & $\begin{array}{l}\text { ๖े } \\
\text { ळ. } \\
0\end{array}$ & స్ ָ̊ \\
\hline 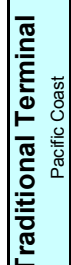 & 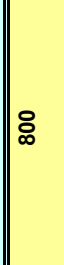 & 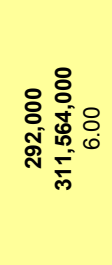 & $\stackrel{0}{\circ}$ & 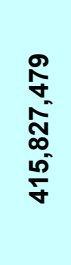 & $\stackrel{m}{\longrightarrow}$ & 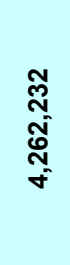 & 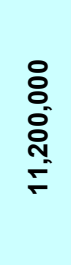 & $\begin{array}{l}\text { గ్ర } \\
\text { O̊ }\end{array}$ & 今े & 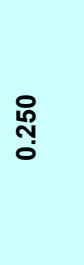 \\
\hline 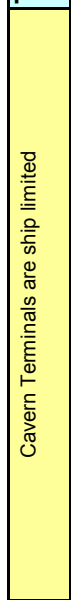 & 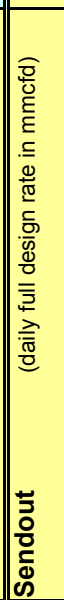 & 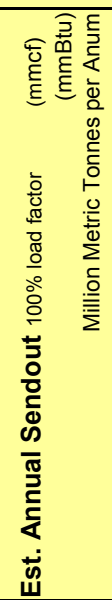 & 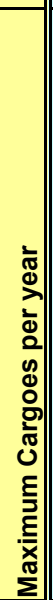 & 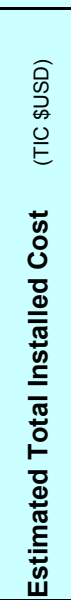 & 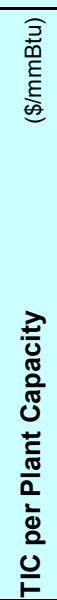 & 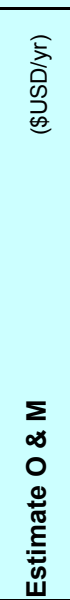 & 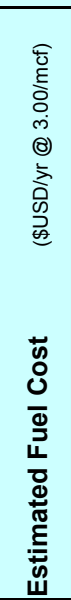 & 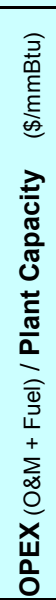 & 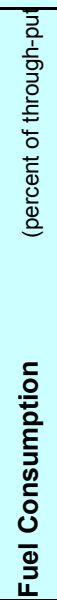 & 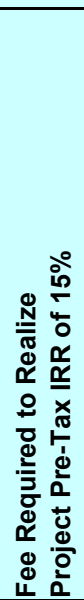 \\
\hline
\end{tabular}

Note: Table 4.1 references LNG terminals representative of geographic locations and as such do not refer specifically to the Pro-Forma estimates for the LNG Onshore and Offshore terminals presented in Task 2.0 


\section{PACIFIC COAST LNG TERMINAL \\ PROFORMA ECONOMICS}

Project Summary

\section{SUMMARY FACILITY ASSUMPTIONS}

\section{FINANCIAL ASSUMPTIONS}

\section{Facility Basis - Firm Service}

Cargos per Year

LNG Btu content, Btu/scf

Storage Working Gas Volume, Bcf

Storage Base Gas Volume, Bcf

Pricing

Throughput Fee, $\$ / \mathrm{MmBtu}$

Other Revenue - \% of Terminal Throughput Rev Terminal Energy Use Charge, \% of throughput Assumed Henry Hub Index for initial year

Gas Storage Net Revenue Realized \$MM/year

Other Assumptions

Base Gas Price (Delivered), \$/Mc

Base Gas Source ("Lease" or "Buy")

Total Operations Cost, \$M/Year

- Labor \& Maintenance, $\$ M / Y r$

- Electrical Demand Charge, $\$ \mathrm{M} / \mathrm{Yr}$

Management Overhead, \$M/Year

Property Taxes (assumed amount), \$M/Yr

Storage Site Lease Fee, \$M/yr

$\%$ Revenue Stream to Inflation Protect, \%/yr

General Inflation Rate

Inflation applied to certain annual costs, $\% / y r$

Energy Use for Terminal ops., \% of throughput

Full storage cavern compression charge rate

$\%$ of throughput requiring compression at cavern

Project \& Technology Rights

Running Royalty, as \% of Henry Hub index

Project \& License Upfront Payment, \$MM

\section{Facility Costs, $\$$}

$50,910,255$

LNG Vaporization \& Process

$74,108,000$

Terminal Utility System

Storage Surface Facility

Site Specific Misc

Header Pipeline

Engineering \& Const. Mgmt.

Project Acquisition \& Tech. Rights

Owner Costs, Permits, Misc.

Financing Fees

Contingency

Total Facility Cost

$28,288,700$

$166,070,000$

$31,423,797$

$19,674,248$

50,000

$7,191,583$

$21,048,045$

$\begin{array}{rlr}0.0 \% & \text { Financing } & 21,048,045 \\ 0.00 \% & \text { Contingency } & 56,133,750\end{array}$

$\$ 3.50$

$\$ 0.0$

\section{LNG Terminal Project Metrics}

Load Factor (based on 240 cargos/yr max) $\quad 100 \%$

Reference Annual throughput, mcf/yr 291,076,745

Annual LNG Offloaded, BCF/yr 291

Reference throughput, million mmBtu/yr $\quad 310,578,887$

Daily equivalent amount (mcf/day) 808,547

Tax Rates

Federal, \%/YR $\quad 35.0 \%$

State, $\% / Y R \quad 4.50 \%$

Blended Rate, \%/Yr. $\quad 37.93 \%$

Property, \%/YR, initial year/capital cost $\quad 0.88 \%$

Capital Gain Rate for Terminal Value $\quad 20 \%$

Depreciation

Depreciation (Straight-Line or Accel) Straight-Line

Depreciable Life, Years

Project Life, Years

20

$0.00 \%$

$00 \%$ based on mmBtu throughput 0
Financial Structure

Sr. Debt Percent of Capital

Jr. Debt Percent of Capital

Equity Percent of Capital

\% Capita

$\underline{\text { Rate }}$

Senior Debt Term

Junior Debt Term

Base Gas Lease Carrying Cost, \%/YR

$6.75 \%$
$0.0 \%$

$50.0 \% \quad 15.0 \%$

FINANCIAL RESULTS

\begin{tabular}{|lr|}
\hline & \\
Cost of Capital & \\
\hline Pretax WACC & $\mathbf{1 0 . 8 8 \%}$ \\
WACC & $\mathbf{9 . 6 0 \%}$ \\
Equity Return (assumed from above) & $\mathbf{1 5 . 0 \%}$ \\
& \\
Project Economics & $\mathbf{2 1 8 , 6 6 0}$ \\
\hline Project NPV@Pretax WACC, \$M & $\mathbf{1 5 . 7 \%}$ \\
Project Pretax IRR & $\mathbf{1 4 2 , 1 7 4}$ \\
NPV @ WACC (tax-effected), \$M & $\mathbf{1 2 . 5 \%}$ \\
Project IRR (tax-effected) & \\
& $\mathbf{\$ 5 7 , 2 4 1}$ \\
Yr. 1 EBITDA \$M/year & $\mathbf{\$ 6 1 , 0 5 9}$ \\
Avg. EBITDA, Yrs 1-5, \$M/year & \\
Equity Returns, AFTER-Tax & $\mathbf{4 1 , 8 1 6}$ \\
\hline Equity NPV@ Assumed Equity Return, \$M & $\mathbf{1 7 . 1 \%}$ \\
Equity IRR (calculated) & \\
\hline & Pre-tax \\
Debt Coverage & $\mathbf{3 . 7}$ \\
\hline Minimum EBITDA/Interest Coverage & $\mathbf{2 . 7}$ \\
\hline Minimum EBITDA/Debt Service &
\end{tabular}




\begin{tabular}{|c|c|c|c|c|c|c|c|}
\hline \multicolumn{8}{|c|}{ LNG Terminals Cost Comparison Equipment Summary Sheet } \\
\hline $\begin{array}{l}\text { Traditional Land Based Terminal } \\
\text { West Coast w/Breakwater } \\
\text { Capacity - } 0.8 \text { Bcfd } \quad \text { Description }\end{array}$ & $\begin{array}{c}\text { Bare } \\
\text { Equipment } \\
\text { Cost }(\$ M)\end{array}$ & $\begin{array}{l}\text { Steel } \\
\text { Concrete } \\
\text { I/E \& Piping } \\
\text { Cost }(\$ M)\end{array}$ & $\begin{array}{l}\text { Installed } \\
\text { Direct \& } \\
\text { Indirect } \\
\text { Cost (\$M) }\end{array}$ & $\begin{array}{l}\text { Freight } \\
\text { Spares } \\
\text { Other } \\
\text { Cost }(\$ M)\end{array}$ & $\begin{array}{l}\text { Taxes } \\
\text { Duties } \\
\text { Insurance } \\
\text { Cost }(\$ M)\end{array}$ & $\begin{array}{c}\text { Contract } \\
\text { Engineering } \\
(12 \%) \\
\text { Cost }(\$ M)\end{array}$ & $\begin{array}{l}\text { Total } \\
\text { Cost } \\
\text { Cost (\$M) }\end{array}$ \\
\hline $\begin{array}{l}\text { LNG STORAGE TANK } 2 \times(160,000 \mathrm{~m} 3) 6.4 \text { Bcf } \\
\text { LNG Storage Tank Subtotal }\end{array}$ & $62,000.0$ & $\begin{array}{r}27,280.0 \\
27280\end{array}$ & $\begin{array}{r}54,684.0 \\
54684\end{array}$ & $\begin{array}{r}1,364.0 \\
1364\end{array}$ & $\begin{array}{r}1639.3 \\
1639.28\end{array}$ & $\begin{array}{r}9835.7 \\
9835.68\end{array}$ & $\begin{array}{l}94,803 \\
94,803\end{array}$ \\
\hline \multicolumn{8}{|l|}{ PROCESS VESSELS } \\
\hline Recondenser, 9'ID x 45', 304 SS & 142.0 & 85.9 & 172.2 & 15.7 & 8.1 & 48.0 & 472 \\
\hline BOG Compressor Knock Out Drum 70 m3 & 35.6 & 25.5 & 51.0 & 4.1 & 2.3 & 13.4 & 132 \\
\hline HP Fuel Gas Knock Out Drum, 3 m3 & 10.5 & 7.5 & 15.0 & 1.2 & 0.7 & 4.0 & 39 \\
\hline HP Flare Knock Out Drum, 50 m3 & 28.8 & 20.6 & 41.3 & 3.3 & 1.8 & 10.9 & 107 \\
\hline Service Water Storage Tank, $20 \mathrm{~m} 3$ & 12.2 & 8.1 & 16.1 & 1.4 & 0.7 & 4.4 & 43 \\
\hline Diesel Storage Tank, $50 \mathrm{~m} 3$ & 16.8 & 11.1 & 22.2 & 1.9 & 1.0 & 6.0 & 59 \\
\hline Foam Tank, $4 \mathrm{~m} 3$ & 6.5 & 4.3 & 8.6 & 0.7 & 0.4 & 2.3 & 23 \\
\hline Process Vessels Subtotal & 252.4 & 162.9 & 326.5 & 28.3 & 15.0 & 89.0 & 874.2 \\
\hline \multicolumn{8}{|l|}{ VAPORIZERS } \\
\hline Open Rack Vaporizers, 170 ton/hr ( 3 each) & 5,940 & 4,574 & 9,168 & 703.9 & 397.2 & 2361.9 & 23,145 \\
\hline Submerged Combustion Vaporizers, 170 Tons/hr (2 each) & 1,736 & 1,337 & 2,680 & 205.7 & 116.1 & 690.3 & 6,764 \\
\hline Shell \& Tube & 0 & 0 & 0 & 0.0 & 0.0 & 0.0 & 0 \\
\hline Vaporizers Subtotal & 7,676 & 5,911 & 11,848 & 910 & 513 & 3,052 & 29,909 \\
\hline \multicolumn{8}{|l|}{ HEAT EXCHANGERS } \\
\hline Standby glycol/fuel gas heater $127 \mathrm{~kW}$ & 6.1 & 4.03 & 8.07 & 0.7 & 0.4 & 2.2 & 21 \\
\hline HP knockout drum heater $20 \mathrm{~kW}$ & 0.8 & 0.53 & 1.06 & 0.1 & 0.0 & 0.3 & 3 \\
\hline Gaseous N2 Vaporizer 35 kW & 0.66 & 0.74 & 1.48 & 0.1 & 0.1 & 0.3 & 3 \\
\hline Gaseous N2 Vaporizer (Spare) 35 kW & 0.66 & 0.74 & 1.48 & 0.1 & 0.1 & 0.3 & 3 \\
\hline Liquid N2 Pressurization vaporizer 35 kW & 0.66 & 0.74 & 1.48 & 0.1 & 0.1 & 0.3 & 3 \\
\hline Liquid N2 Vaporizer $35 \mathrm{~kW}$ & 0.66 & 0.74 & 1.48 & 0.1 & 0.1 & 0.3 & 3 \\
\hline Heat Exchangers Subtotal & 9.5 & 7.5 & 15.0 & 1.1 & 0.6 & 3.8 & 37.7 \\
\hline \multicolumn{8}{|l|}{ WASTE HEAT RECOVERY } \\
\hline Waste Heat Recovery Subtotal & 0 & 0 & 0 & 0 & 0 & 0 & 0 \\
\hline \multicolumn{8}{|l|}{ PUMPS } \\
\hline First stage sendout pump, 416 m3/hr (intank) & $\$ 640$ & 668.8 & 1340.6 & 84.6 & 53.4 & 317.9 & 3,105 \\
\hline Second stage sendout pump, $325 \mathrm{~m} 3 / \mathrm{hr}$ & $\$ 825$ & 862.1 & 1728.2 & 109.1 & 68.8 & 409.8 & 4,003 \\
\hline Seawater pump, $2187 \mathrm{~m} 3 / \mathrm{hr}$ & $\$ 452$ & 472.3 & 946.8 & 59.8 & 37.7 & 224.5 & 2,193 \\
\hline Sub combustion Vap. Overflow pump, $5 \mathrm{hp}$ & 15.00 & 21.5 & 43.0 & 2.3 & 1.6 & 9.5 & 93 \\
\hline Process Area Sump Pump, $10 \mathrm{hp}, 5 \mathrm{~m} 3 / \mathrm{hr}$ & 7.10 & 10.2 & 20.4 & 1.1 & 0.8 & 4.5 & 44 \\
\hline Service Water Pump, 5 hp, $57 \mathrm{m3} / \mathrm{hr}$ & 17.40 & 24.9 & 49.9 & 2.6 & 1.9 & 11.1 & 108 \\
\hline Firewater Pumps & 203.70 & 213 & 426.7 & 26.9 & 17.0 & 101.2 & 988 \\
\hline Pumps Subtotal & $2,160.20$ & 2,273 & 4,556 & 286 & 181 & 1,079 & 10,534 \\
\hline \multicolumn{8}{|l|}{ COMPRESSORS } \\
\hline BOG Compressors & 800.00 & 440 & 882 & 86.0 & 42.9 & 254.6 & 2,506 \\
\hline Ship Vapor Return Blower & $1,000.00$ & 550 & 1102.5 & 107.5 & 53.7 & 318.3 & 3,132 \\
\hline Ship Unloading Compressor & $2,200.00$ & 1155 & 2315.3 & 233.8 & 114.7 & 680.4 & 6,699 \\
\hline Compressors Subtotal & $4,000.00$ & 2,145 & 4,300 & 427 & 211 & 1,253 & 12,337 \\
\hline \multicolumn{8}{|l|}{ SEAWATER INTAKE SYSTEM (Incl Electrochlorination) } \\
\hline Electrochlorination Unit, $12,000 \mathrm{~m} 3 / \mathrm{hr}$ & 20 & 29 & 57.33 & 3.0 & 2.1 & 12.7 & 124 \\
\hline Seawater Intake Structure $(12,000 \mathrm{~m} 3 / \mathrm{hr}$ each $)$ & 1,100 & 1150 & 2304 & 145.5 & 91.7 & 546.4 & 5,337 \\
\hline Seawater Outfall Structure $(12,000 \mathrm{~m} 3 / \mathrm{hr}$ each) & 1,100 & 1755 & 3517 & 175.7 & 128.1 & 764.6 & 7,440 \\
\hline Seawater Intake Screens $(13,200 \mathrm{~m} 3 / \mathrm{hr}$ each $)$ & 400 & 858 & 1720 & 74.9 & 59.8 & 357.3 & 3,470 \\
\hline Seawater Rotary Screens $(13,200 \mathrm{~m} 3 / \mathrm{hr}$ each $)$ & 400 & 1078 & 882 & 85.9 & 47.4 & 283.2 & 2,777 \\
\hline Seawater Intake System Subtotal & 3,020 & 4,869 & 8,480 & 485 & 329 & 1,964 & 19,148 \\
\hline \multicolumn{8}{|l|}{ UTILITIES } \\
\hline HP Flare, $415,000 \mathrm{~kg} / \mathrm{hr}$ & 507 & 84 & 167.6 & 44.7 & 15.5 & 90.9 & 909 \\
\hline Electrical Switchgear \& Power Distrib ( $5 \%$ of FC) & & 2,850 & & 142.5 & 57.0 & 342.1 & 3,392 \\
\hline Emergency Generator - Diesel Driven, 500 kW & 230.0 & 63.3 & 126.8 & 21.6 & 8.5 & 50.4 & 501 \\
\hline Gas Turbine Generator, 4 MW, Centaur 50 & $4,500.0$ & 990.0 & $1,984.5$ & 409.5 & 152.2 & 896.9 & 8,933 \\
\hline Instrument air compressor and drier, $100 \mathrm{scfm}$ & 299.8 & 165.1 & 331.0 & 32.2 & 16.1 & 95.5 & 940 \\
\hline N2 Dewar for Terminal, Vac. insul. tank, $42 \mathrm{~m} 3$ & 78.0 & 60.1 & 120.4 & 9.2 & 5.2 & 31.0 & 304 \\
\hline Firewater Protection System (Foam Sys, dry powder, tanks) & 300.0 & 198.0 & 396.9 & 33.9 & 18.1 & 107.4 & 1,054 \\
\hline Utilities Subtotal & $5,914.4$ & $4,410.5$ & $3,127.1$ & 693.7 & 272.6 & $1,614.2$ & $16,032.5$ \\
\hline \multicolumn{8}{|l|}{ MARINE FACILITIES - JETTY } \\
\hline Topworks (Road/750 meter Trestle/Pipeway) & & 9,000 & 0 & 450.0 & 180.0 & 1080.0 & 10,710 \\
\hline Cryogenic Piping (I/E, piping w/ insulation) & & 17,050 & 0 & 0.0 & 341.0 & 2046.0 & 19,437 \\
\hline Berth (Mooring, Breasting Dolphins) & & 24,000 & 0 & $1,200.0$ & 480.0 & 2880.0 & 28,560 \\
\hline Dredging & & - & 0 & 0.0 & 0.0 & 0.0 & 0 \\
\hline Marine Facilities - Jetty Subtotal & & 50,050 & 0 & 1650 & 1001 & 6006 & 58707 \\
\hline
\end{tabular}




\begin{tabular}{|c|c|c|c|c|c|c|c|}
\hline \multicolumn{8}{|l|}{ |MARINE FACILITIES - UNLOADING } \\
\hline Unloading Arms & 8,650 & 963 & 1930.6 & 740.2 & 236.1 & 1385.2 & 13,905 \\
\hline Marine Facilities - Unloading Subtotal & 8,650 & 963 & 1,931 & 740 & 236 & 1,385 & 13,905 \\
\hline BREAKWATER & 0 & 60,000 & 0 & 3,000 & 1,200 & 7,200 & 71,400 \\
\hline Breakwater Subtotal & 0 & 60,000 & 0 & 3,000 & 1,200 & 7,200 & 71,400 \\
\hline \multicolumn{8}{|l|}{ NAVIGATIONAL AIDS (lighting and buoys) } \\
\hline \multicolumn{8}{|l|}{ Navigational Aids Subtotal } \\
\hline \multicolumn{8}{|l|}{ BUILDINGS } \\
\hline Administration Office/Control Center & & 1400 & & 70.0 & 28.0 & 168.0 & 1,666 \\
\hline Compressor Building (Included in cost of compressors) & & 350 & & 17.5 & 7.0 & 42.0 & 417 \\
\hline Warehouse/Maintenance Building, 10,000 ft2 & & 525 & & 26.3 & 10.5 & 63.0 & 625 \\
\hline Buildings Subtotal & & 2275 & & 113.75 & 45.5 & 273 & 2707.25 \\
\hline SITE PREPARATION & & 2,850 & & 142.5 & 57.0 & 342.1 & 3,392 \\
\hline Site Preparation Subtotal & & 2,850 & & 143 & 57 & 342 & 3,392 \\
\hline \multicolumn{8}{|l|}{ BULKS } \\
\hline Piping (exclud. trestle) & & 12,000 & & 600.0 & 240.0 & 1440.0 & 14,280 \\
\hline Piling & & 0 & & 0.0 & 0.0 & 0.0 & 0 \\
\hline Insulation and Paint & & $\$ 7,981$ & & 399.1 & 159.6 & 957.8 & 9,498 \\
\hline Electrical/Instrumentation & & 9000 & & 450.0 & 180.0 & 1080.0 & 10,710 \\
\hline Bulks Subtotal & & 28,981 & & 1,449 & 580 & 3,478 & 34,488 \\
\hline REAL ESTATE & & 3,000 & & & & & 3,000 \\
\hline Real Estate Subtotal & & 3,000 & & & & & 3,000 \\
\hline \multicolumn{8}{|l|}{ OSBL INFRASTRUCTURE } \\
\hline \multicolumn{8}{|l|}{ Includes access roads, bldgs, hospitals, stores, bridges } \\
\hline OSBL Infrastructure Subtotal & & 0 & & & & & 0 \\
\hline UNADJUSTED GRAND TOTAL & 62,683 & 195,177 & 89,267 & 11,291 & 6,282 & 37,575 & 371,275 \\
\hline CONTINGENCY $12 \%$ OF THE TOTAL & & & & & & & 44,553 \\
\hline ADJUSTED GRAND TOTAL & & & & & & & 415,827 \\
\hline
\end{tabular}


ATLANTIC COAST LNG TERMINAL

PROFORMA ECONOMICS

Project Summary

\section{SUMMARY FACILITY ASSUMPTIONS}

\section{FINANCIAL ASSUMPTIONS}

\section{Facility Basis - Firm Service}

Cargos per Year

LNG Discharge per Ship, cubic meters LNG

LNG Btu content, Btu/scf

Storage Working Gas Volume, Bcf

Storage Base Gas Volume, Bcf

Pricing

Throughput Fee, \$/MmBtu

Other Revenue - \% of Terminal Throughput Rev.

Terminal Energy Use Charge, \% of throughput

Assumed Henry Hub Index for initial year

Gas Storage Net Revenue Realized \$MM/year

\section{Other Assumptions}

Base Gas Price (Delivered), \$/M

Base Gas Source ("Lease" or "Buy")

Total Operations Cost, \$M/Year

- Labor \& Maintenance, $\$ M / Y r$

- Electrical Demand Charge, \$M/Yr

Management Overhead, \$M/Year

Property Taxes (assumed amount), \$M/Yr

Storage Site Lease Fee, \$M/yr

$\%$ Revenue Stream to Inflation Protect, \%/yr

General Inflation Rate

Inflation applied to certain annual costs, $\% / y r$

Energy Use for Terminal ops., \% of throughput

Full storage cavern compression charge rate

$\%$ of throughput requiring compression at cavern

Project \& Technology Rights

Running Royalty, as \% of Henry Hub index

Project \& License Upfront Payment, \$MM
Facility Costs, \$

Marine Port Facilities

Terminal Utility System $\quad 28,288,700$

Storage Surface Facility $\quad 57,000,000$

Site Specific Misc $\quad 1,116,097$

Header Pipeline

Engineering \& Const. Mgmt.

Project Acquisition \& Tech. Rights $\quad 50,000$

50,000
$7,191,583$

$11,133,903$

$30,142,500$

$\begin{array}{rlr}0.0 \% & \text { Financing Fees } & 11,133,903 \\ 0.00 \% & \text { Contingency } & 30,142,500\end{array}$

$0.00 \%$

$\$ 3.50$

$\$ 0.0$

Total Facility Cost

$\mathbf{2 4 5 , 7 1 7 , 9 8 6}$

LNG Terminal Project Metrics

Load Factor (based on 240 cargos/yr max) $\quad 100 \%$

$\begin{array}{rlr}3.50 & \text { Reference Annual throughput, mcf/yr } & 182,263,008 \\ \text { buy } & \text { Annual LNG Offloaded, BCF/yr } & 182 \\ 2,499 & \text { Reference throughput, million mmBtu/yr } & 194,474,630\end{array}$

$\begin{array}{rlr}3.50 & \text { Reference Annual throughput, mcf/yr } & 182,263,008 \\ \text { buy } & \text { Annual LNG Offloaded, BCF/yr } & 182 \\ 2,499 & \text { Reference throughput, million mmBtu/yr } & 194,474,630\end{array}$

$\begin{array}{llr}2,499 & \text { Reference throughput, million mmBtu/yr } & 194,474,630 \\ 2,299 & \text { Daily equivalent amount (mcf/day) } & 506,286\end{array}$

200

Federal, \%/YR $\quad 35.0 \%$

State, $\% / Y R \quad 4.50 \%$

Blended Rate, \%/Yr. $\quad 37.93 \%$

Property, \%/YR, initial year/capital cost $\quad 1.63 \%$

Capital Gain Rate for Terminal Value $20 \%$

Depreciation

Depreciation (Straight-Line or Accel) Straight-Line

Depreciable Life, Years

20

Project Life, Years

20

$.00 \%$ based on mmBtu throughput
Financial Structure

Sr. Debt Percent of Capital

\% Capital

Jr. Debt Percent of Capital

$50.0 \%$

Equity Percent of Capital

Rate

Senior Debt Term

Junior Debt Term

Base Gas Lease Carrying Cost, \%/YR

FINANCIAL RESULTS

\begin{tabular}{|lr|}
\hline \multicolumn{1}{|l|}{ Cost of Capital } & \\
\hline Pretax WACC & $\mathbf{1 0 . 8 8 \%}$ \\
WACC & $\mathbf{9 . 6 0 \%}$ \\
Equity Return (assumed from above) & $\mathbf{1 5 . 0 \%}$ \\
& \\
Project Economics & $\mathbf{1 0 8 , 5 3 1}$ \\
Project NPV@Pretax WACC, \$M & $\mathbf{1 5 . 3 \%}$ \\
Project Pretax IRR & $\mathbf{6 9 , 9 5 9}$ \\
NPV @ WACC (tax-effected), \$M & $\mathbf{1 2 . 2 \%}$ \\
Project IRR (tax-effected) & \\
& $\mathbf{\$ 2 9 , 6 4 0}$ \\
Yr. 1 EBITDA \$M/year & $\mathbf{\$ 3 1 , 7 5 1}$ \\
Avg. EBITDA, Yrs 1-5, \$M/year & \\
Equity Returns, AFTER-Tax & $\mathbf{1 7 , 8 4 6}$ \\
\hline Equity NPV@ Assumed Equity Return, \$M & $\mathbf{1 6 . 7 \%}$ \\
Equity IRR (calculated) & \\
& Pre-tax \\
Debt Coverage & $\mathbf{3 . 6}$ \\
\hline Minimum EBITDA/Interest Coverage \\
Minimum EBITDA/Debt Service
\end{tabular}




\begin{tabular}{|c|c|c|c|c|c|c|c|}
\hline \multicolumn{8}{|c|}{ LNG Terminals Cost Comparison Equipment Summary Sheet } \\
\hline $\begin{array}{l}\text { Traditional Land Based Terminal } \\
\text { East Coast no Breakwater reqd. } \\
\text { Capacity - } 0.5 \text { Bcfd } \\
\qquad \text { Description }\end{array}$ & $\begin{array}{c}\text { Bare } \\
\text { Equipment } \\
\text { Cost }(\$ M) \\
\end{array}$ & $\begin{array}{l}\text { Steel } \\
\text { Concrete } \\
\text { I/E \& Piping } \\
\text { Cost }(\$ M) \\
\end{array}$ & $\begin{array}{l}\text { Installed } \\
\text { Direct \& } \\
\text { Indirect } \\
\text { Cost }(\$ M) \\
\end{array}$ & $\begin{array}{l}\text { Freight } \\
\text { Spares } \\
\text { Other } \\
\text { Cost }(\$ M) \\
\end{array}$ & $\begin{array}{c}\text { Taxes } \\
\text { Duties } \\
\text { Insurance } \\
\text { Cost }(\$ M) \\
\end{array}$ & $\begin{array}{l}\text { Contract } \\
\text { Engineering } \\
(12 \%) \\
\text { Cost }(\$ M) \\
\end{array}$ & $\begin{array}{c}\text { Total } \\
\text { Cost } \\
\text { Cost }(\$ M) \\
\end{array}$ \\
\hline LNG STORAGE TANK $2 \times(125,000 \mathrm{~m} 3) 5.0 \mathrm{Bcf}$ & $45,000.0$ & $19,800.0$ & $22,500.0$ & 990.0 & 846.0 & 5076.0 & 49,212 \\
\hline LNG Storage Tank Subtotal & & 19800 & 22500 & 990 & 846 & 5076 & 49,212 \\
\hline \multicolumn{8}{|l|}{ PROCESS VESSELS } \\
\hline Recondenser, 9'ID x 45', 304 SS & 142.0 & 85.9 & 172.2 & 15.7 & 8.1 & 48.0 & 472 \\
\hline BOG Compressor Knock Out Drum 70 m3 & 35.6 & 25.5 & 51.0 & 4.1 & 2.3 & 13.4 & 132 \\
\hline HP Fuel Gas Knock Out Drum, 3 m3 & 10.5 & 7.5 & 15.0 & 1.2 & 0.7 & 4.0 & 39 \\
\hline HP Flare Knock Out Drum, $50 \mathrm{~m} 3$ & 28.8 & 20.6 & 41.3 & 3.3 & 1.8 & 10.9 & 107 \\
\hline Service Water Storage Tank, $20 \mathrm{~m} 3$ & 12.2 & 8.1 & 16.1 & 1.4 & 0.7 & 4.4 & 43 \\
\hline Diesel Storage Tank, $50 \mathrm{~m} 3$ & 16.8 & 11.1 & 22.2 & 1.9 & 1.0 & 6.0 & 59 \\
\hline Foam Tank, $4 \mathrm{~m} 3$ & 6.5 & 4.3 & 8.6 & 0.7 & 0.4 & 2.3 & 23 \\
\hline Process Vessels Subtotal & 252.4 & 162.9 & 326.5 & 28.3 & 15.0 & 89.0 & 874.2 \\
\hline \multicolumn{8}{|l|}{ VAPORIZERS } \\
\hline Open Rack Vaporizers, 168 ton/hr ( 3 each) & 0.0 & 0.0 & 0.0 & 0.0 & 0.0 & 0.0 & 0 \\
\hline Submerged Combustion Vaporizers, 170 ton/hr ( 1 each) & 898.0 & 691.5 & $1,386.1$ & 106.4 & 60.0 & 357.1 & 3,499 \\
\hline Shell \& Tube & $1,100.0$ & 847.0 & $1,697.9$ & 130.4 & 73.6 & 437.4 & 4,286 \\
\hline Vaporizers Subtotal & 1,998 & 1,538 & 3,084 & 237 & 134 & 794 & 7,785 \\
\hline \multicolumn{8}{|l|}{ HEAT EXCHANGERS } \\
\hline Standby glycol/fuel gas heater $127 \mathrm{~kW}$ & $\$ 6$ & 4.03 & 8.07 & 0.7 & 0.4 & 2.2 & 21 \\
\hline HP knockout drum heater $20 \mathrm{~kW}$ & $\$ 1$ & 0.53 & 1.06 & 0.1 & 0.0 & 0.3 & 3 \\
\hline Gaseous N2 Vaporizer 35 kW & $\$ 1$ & 0.74 & 1.48 & 0.1 & 0.1 & 0.3 & 3 \\
\hline Gaseous N2 Vaporizer (Spare) 35 kW & $\$ 1$ & 0.74 & 1.48 & 0.1 & 0.1 & 0.3 & 3 \\
\hline Liquid N2 Pressurization vaporizer $35 \mathrm{~kW}$ & $\$ 1$ & 0.74 & 1.48 & 0.1 & 0.1 & 0.3 & 3 \\
\hline Liquid N2 Vaporizer $35 \mathrm{~kW}$ & $\$ 1$ & 0.74 & 1.48 & 0.1 & 0.1 & 0.3 & 3 \\
\hline Heat Exchangers Subtotal & 9.5 & 7.5 & 15.0 & 1.1 & 0.6 & 3.8 & 37.7 \\
\hline \multicolumn{8}{|l|}{ WASTE HEAT RECOVERY } \\
\hline Waste Heat Recovery Subtotal & 0 & 0 & 0 & 0 & 0 & 0 & 0 \\
\hline \multicolumn{8}{|l|}{ PUMPS } \\
\hline First stage sendout pump, 416 m3/hr (intank) & $\$ 640$ & 668.8 & 1340.6 & 84.6 & 53.4 & 317.9 & 3,105 \\
\hline Second stage sendout pump, $325 \mathrm{~m} 3 / \mathrm{hr}$ & $\$ 825$ & 862.1 & 1728.2 & 109.1 & 68.8 & 409.8 & 4,003 \\
\hline Seawater pump, $2187 \mathrm{~m} 3 / \mathrm{hr}$ & $\$ 452$ & 472.3 & 946.8 & 59.8 & 37.7 & 224.5 & 2,193 \\
\hline Sub combustion Vap. Overflow pump, 5hp & $\$ 15$ & 21.5 & 43.0 & 2.3 & 1.6 & 9.5 & 93 \\
\hline Process Area Sump Pump, $10 \mathrm{hp}, 5 \mathrm{m3} / \mathrm{hr}$ & $\$ 7$ & 10.2 & 20.4 & 1.1 & 0.8 & 4.5 & 44 \\
\hline Service Water Pump, 5 hp, $57 \mathrm{m3} / \mathrm{hr}$ & $\$ 17$ & 24.9 & 49.9 & 2.6 & 1.9 & 11.1 & 108 \\
\hline Firewater Pumps & 203.70 & 213 & 426.7 & 26.9 & 17.0 & 101.2 & 988 \\
\hline Pumps Subtotal & $2,160.20$ & 2,273 & 4,556 & 286 & 181 & 1,079 & 10,534 \\
\hline \multicolumn{8}{|l|}{ COMPRESSORS } \\
\hline BOG Compressors & 800.00 & 440 & 882 & 86.0 & 42.9 & 254.6 & 2,506 \\
\hline Ship Vapor Return Blower & $1,000.00$ & 550 & 1102.5 & 107.5 & 53.7 & 318.3 & 3,132 \\
\hline Ship Unloading Compressor & $2,200.00$ & 440 & 2315.3 & 198.0 & 100.4 & 594.6 & 5,848 \\
\hline Compressors Subtotal & $4,000.00$ & 1,430 & 4,300 & 392 & 197 & 1,168 & 11,486 \\
\hline \multicolumn{8}{|l|}{ SEAWATER INTAKE SYSTEM (Incl Electrochlorination) } \\
\hline Electrochlorination Unit, $12,000 \mathrm{~m} 3 / \mathrm{hr}$ & 20 & 29 & 57.33 & 3.0 & 2.1 & 12.7 & 124 \\
\hline Seawater Intake Structure $(12,000 \mathrm{~m} 3 / \mathrm{hr}$ each $)$ & 1,100 & 1150 & 2304 & 145.5 & 91.7 & 546.4 & 5,337 \\
\hline Seawater Outfall Structure $(12,000 \mathrm{~m} 3 / \mathrm{hr}$ each) & 1,100 & 1755 & 3517 & 175.7 & 128.1 & 764.6 & 7,440 \\
\hline Seawater Intake Screens $(13,200 \mathrm{~m} 3 / \mathrm{hr}$ each $)$ & 500 & 1073 & 2150 & 93.6 & 74.7 & 446.7 & 4,337 \\
\hline Seawater Rotary Screens $(13,200 \mathrm{~m} 3 / \mathrm{hr}$ each $)$ & 500 & 1348 & 2701 & 107.4 & 91.3 & 545.8 & 5,293 \\
\hline Seawater Intake System Subtotal & 3,220 & 5,353 & 10,730 & 525 & 388 & 2,316 & 22,532 \\
\hline \multicolumn{8}{|l|}{ UTILITIES } \\
\hline HP Flare, $415,000 \mathrm{~kg} / \mathrm{hr}$ & 506.6 & 83.6 & 167.6 & 44.7 & 15.5 & 90.9 & 908.8 \\
\hline Electrical Switchgear \& Power Distrib ( $5 \%$ of FC) & & $1,908.1$ & & 95.4 & 38.2 & 229.0 & $2,270.6$ \\
\hline Emergency Generator - Diesel Driven, 500 kW & 230.0 & 63.3 & 126.8 & 21.6 & 8.5 & 50.4 & 500.5 \\
\hline Gas Turbine Generator & 0.0 & 0.0 & 0.0 & 0.0 & 0.0 & 0.0 & 0.0 \\
\hline Instrument air compressor and drier, $100 \mathrm{scfm}$ & 299.8 & 165.1 & 331.0 & 32.2 & 16.1 & 95.5 & 939.7 \\
\hline N2 Dewar for Terminal, Vac. insul. tank, $42 \mathrm{~m} 3$ & 78.0 & 60.1 & 120.4 & 9.2 & 5.2 & 31.0 & 303.9 \\
\hline Firewater Protection System (Foam Sys, dry powder, tanks) & 300.0 & 165.1 & 331.0 & 32.3 & 16.1 & 95.5 & 940.0 \\
\hline Utilities Subtotal & $1,414.4$ & $2,445.2$ & $1,076.7$ & 235.4 & 99.6 & 592.4 & $5,863.6$ \\
\hline \multicolumn{8}{|l|}{ MARINE FACILITIES - JETTY } \\
\hline Topworks (Road/150 meter Trestle/Pipeway) & & $9,000.0$ & 0.0 & 450.0 & 180.0 & $1,080.0$ & $10,710.0$ \\
\hline Cryogenic Piping (I/E, piping w/ insulation) & & $1,915.0$ & 0.0 & 95.8 & 38.3 & 229.8 & $2,278.9$ \\
\hline Berth (Mooring, Breasting Dolphins) & & $17,000.0$ & 0.0 & 850.0 & 340.0 & $2,040.0$ & $20,230.0$ \\
\hline Dredging & & 0.0 & 0.0 & 0.0 & 0.0 & 0.0 & 0.0 \\
\hline Marine Facilities - Jetty Subtotal & & $27,915.0$ & 0.0 & $1,395.8$ & 558.3 & $3,349.8$ & $33,218.9$ \\
\hline
\end{tabular}




\begin{tabular}{|c|c|c|c|c|c|c|c|}
\hline \multicolumn{8}{|l|}{ |MARINE FACILITIES - UNLOADING } \\
\hline Unloading Arms & 0.0 & 0.0 & $1,470.0$ & 0.0 & 29.4 & 176.4 & $1,675.8$ \\
\hline Marine Facilities - Unloading Subtotal & 0.0 & 0.0 & $1,470.0$ & 0.0 & 29.4 & 176.4 & $1,675.8$ \\
\hline BREAKWATER & 0.0 & 0.0 & 0.0 & 0.0 & 0.0 & 0.0 & 0.0 \\
\hline Breakwater Subtotal & 0.0 & 0.0 & 0.0 & 0.0 & 0.0 & 0.0 & 0.0 \\
\hline \multicolumn{8}{|l|}{ NAVIGATIONAL AIDS (lighting and buoys) } \\
\hline \multicolumn{8}{|l|}{ Navigational Aids Subtotal } \\
\hline \multicolumn{8}{|l|}{ BUILDINGS } \\
\hline Administration Office/Control Center & & $1,400.0$ & & 70.0 & 28.0 & 168.0 & $1,666.0$ \\
\hline Compressor Building (Included in cost of compressors) & & 350.0 & & 17.5 & 7.0 & 42.0 & 416.5 \\
\hline Warehouse/Maintenance Building, $10,000 \mathrm{ft} 2$ & & 525.0 & & 26.3 & 10.5 & 63.0 & 624.8 \\
\hline Buildings Subtotal & & $2,275.0$ & & 113.8 & 45.5 & 273.0 & $2,707.3$ \\
\hline SITE PREPARATION & & $2,850.5$ & & 142.5 & 57.0 & 342.1 & $3,392.0$ \\
\hline Site Preparation Subtotal & & $2,850.5$ & & 142.5 & 57.0 & 342.1 & $3,392.0$ \\
\hline \multicolumn{8}{|l|}{ BULKS } \\
\hline Piping (exclud. trestle) & & $12,000.0$ & & 600.0 & 240.0 & $1,440.0$ & $14,280.0$ \\
\hline Piling & & 0.0 & & 0.0 & 0.0 & 0.0 & 0.0 \\
\hline Insulation and Paint & & $5,342.7$ & & 267.1 & 106.9 & 641.1 & $6,357.8$ \\
\hline Electrical/Instrumentation & & $9,000.0$ & & 450.0 & 180.0 & $1,080.0$ & $10,710.0$ \\
\hline Bulks Subtotal & & $26,342.7$ & & $1,317.1$ & 526.9 & $3,161.1$ & $31,347.8$ \\
\hline REAL ESTATE & & 500.0 & & & & & 500.0 \\
\hline Real Estate Subtotal & & 500.0 & & & & & 500.0 \\
\hline \multicolumn{8}{|l|}{ OSBL INFRASTRUCTURE } \\
\hline \multicolumn{8}{|l|}{ Includes access roads, bldgs, hospitals, stores, bridges } \\
\hline OSBL Infrastructure Subtotal & & 0.0 & & & & & 0.0 \\
\hline UNADJUSTED GRAND TOTAL & 35,555 & 92,892 & 48,057 & 5,664 & 3,078 & 18,420 & 181,166 \\
\hline CONTINGENCY $12 \%$ OF THE TOTAL & & & & & & & 21,740 \\
\hline ADJUSTED GRAND TOTAL & & & & & & & 202,906 \\
\hline
\end{tabular}




\section{LNG ONSHORE TERMINAL WITH CAVERN STORAGE \\ PROFORMA ECONOMICS}

Project Summary

\section{SUMMARY FACILITY ASSUMPTIONS}

\section{FINANCIAL ASSUMPTIONS}

\section{Facility Basis - Firm Service}

Cargos per Year

LNG Discharge per Ship, cubic meters LNG

LNG Btu content, Btu/scf

Storage Working Gas Volume, Bcf

Storage Base Gas Volume, Bcf

Pricing

Throughput Fee, \$/MmBtu

Other Revenue - \% of Terminal Throughput Rev.

Terminal Energy Use Charge, \% of throughput

Assumed Henry Hub Index for initial year

Gas Storage Net Revenue Realized \$MM/year

\section{Other Assumptions}

Base Gas Price (Delivered), \$/Mcf

Base Gas Source ("Lease" or "Buy")

Total Operations Cost, \$M/Year

- Labor \& Maintenance, $\$ \mathrm{M} / \mathrm{Yr}$

- Electrical Demand Charge, \$M/Yr

Management Overhead, \$M/Year

Property Taxes (assumed amount), $\$ \mathrm{M} / \mathrm{Yr}$

Storage Site Lease Fee, $\$ M / y r$

$\%$ Revenue Stream to Inflation Protect, \%/yr

General Inflation Rate

Inflation applied to certain annual costs, $\% / \mathrm{yr}$

Energy Use for Terminal ops., \% of throughput

Full storage cavern compression charge rate

$\%$ of throughput requiring compression at cavern

Project \& Technology Rights

Running Royalty, as \% of Henry Hub index

Project \& License Upfront Payment, \$MM
Facility Costs, $\$$

LNG Process \& HP PIpeline

$47,118,345$

$51,374,800$

$28,288,700$

$\begin{array}{lr}\text { Terminal Utility System } & 108,000,000\end{array}$

$\begin{array}{lr}\text { Storage Surface Facility } & 108,00,000 \\ \text { Site Specific Misc } & 17,788,105\end{array}$

Header Pipeline

Engineering \& Const. Mgmt.

Project Acquisition \& Tech. Rights $\quad 50,000$

Owner Costs, Permits, Misc. 7,385,958

Financing Fees $\quad 15,154,197$
Contingency
Total Facility Cost
$\mathbf{3 1 , 2 4 2 , 5 0 0}$

LNG Terminal Project Metrics

Load Factor (based on 240 cargos/yr max) $\quad 98 \%$

Reference Annual throughput, mcf/yr $\quad 639,280,701$

Annual LNG Offloaded, BCF/yr 639

Reference throughput, million $\mathrm{mmBtu} / \mathrm{yr} \quad 682,112,508$

Daily equivalent amount (mcf/day) $\quad 1,775,780$

Tax Rates

Federal, \%/YR

$35.0 \%$

State, $\% / Y R$

Blended Rate, \%/Yr. $\quad 37.93 \%$

Property, \%/YR, initial year/capital cost $\quad 1.19 \%$

Capital Gain Rate for Terminal Value $\quad 20 \%$

Depreciation

Depreciation (Straight-Line or Accel) Straight-Line

Depreciable Life, Years

20

Project Life, Years

20

$0.00 \%$ based on mmBtu throughput
Financial Structure

Sr. Debt Percent of Capital

\% Capital

Jr. Debt Percent of Capital

$50.0 \%$

$0.0 \%$

$50.0 \%$

Rate

Equity Percent of Capital

$0.0 \%$

Senior Debt Term

Junior Debt Term

Base Gas Lease Carrying Cost, \%/YR

FINANCIAL RESULTS

\begin{tabular}{|lr|}
\hline & \\
Cost of Capital & \\
\hline Pretax WACC & $\mathbf{1 0 . 8 8 \%}$ \\
WACC & $\mathbf{9 . 6 0 \%}$ \\
Equity Return (assumed from above) & $\mathbf{1 5 . 0 \%}$ \\
& \\
Project Economics & $\mathbf{1 6 2 , 1 4 2}$ \\
\hline Project NPV@Pretax WACC, \$M & $\mathbf{1 5 . 7 \%}$ \\
Project Pretax IRR & $\mathbf{1 0 6 , 3 5 2}$ \\
NPV @ WACC (tax-effected), \$M & $\mathbf{1 2 . 5 \%}$ \\
Project IRR (tax-effected) & \\
& $\mathbf{\$ 4 1 , 6 1 8}$ \\
Yr. 1 EBITDA \$M/year & $\mathbf{\$ 4 4 , 5 7 6}$ \\
Avg. EBITDA, Yrs 1-5, \$M/year & \\
Equity Returns, AFTER-Tax & $\mathbf{3 1 , 0 0 6}$ \\
\hline Equity NPV@ Assumed Equity Return, \$M & $\mathbf{1 7 . 1 \%}$ \\
Equity IRR (calculated) & \\
\hline & Pre-tax \\
Debt Coverage & $\mathbf{3 . 7}$ \\
\hline Minimum EBITDA/Interest Coverage & $\mathbf{2 . 7}$ \\
\hline Minimum EBITDA/Debt Service &
\end{tabular}




\begin{tabular}{|c|c|c|c|c|c|c|c|}
\hline \multicolumn{8}{|c|}{ LNG Terminals Cost Comparison Equipment Summary Sheet } \\
\hline \multirow{3}{*}{$\begin{array}{l}\text { BIShop ProcesS } \\
\text { Average capacity } 1.75 \text { Bcfd }\end{array}$} & & & Installed & Freight & Taxes & Contract & Total \\
\hline & Equipment & $\begin{array}{l}\text { Concrete } \\
\text { I/E \& Piping }\end{array}$ & $\begin{array}{l}\text { Direct \& } \\
\text { Indirect }\end{array}$ & $\begin{array}{l}\text { Spares } \\
\text { Other }\end{array}$ & $\begin{array}{l}\text { Duties } \\
\text { Insurance }\end{array}$ & $\begin{array}{l}\text { Engineering } \\
\qquad(12 \%)\end{array}$ & Cost \\
\hline & Cost (\$M) & Cost (\$M) & Cost (\$M) & Cost (\$M) & Cost (\$M) & Cost (\$M) & Cost $(\$ M)$ \\
\hline \multicolumn{2}{|l|}{ GLNG Storage Caverns: 6 ea $\times 2$ BCF $=12$ BCF $(608,000 \mathrm{~m} 3)$} & 60,000 & & 3,000 & 1,200 & 3,600 & 67,800 \\
\hline \multicolumn{2}{|l|}{ Salt Cavern Storage 2 each at $15 \mathrm{BCF}$ total $30 \mathrm{BCF}$} & 60,000 & - & 3,000 & 1,200 & 3,600 & 67,800 \\
\hline \multicolumn{8}{|l|}{ PROCESS VESSELS } \\
\hline Recondenser, 9'ID x 45', 304 SS & 142.0 & 85.9 & 172.2 & 15.7 & 8.1 & 48 & 472 \\
\hline BOG Compressor Knock Out Drum 70 m3 & 35.6 & 25.5 & 51.0 & 4.1 & 2.3 & 13 & 132 \\
\hline HP Fuel Gas Knock Out Drum, 3 m3 & 10.5 & 7.5 & 15.0 & 1.2 & 0.7 & 4 & 39 \\
\hline HP Flare Knock Out Drum, 50 m3 & 28.8 & 20.6 & 41.3 & 3.3 & 1.8 & 11 & 107 \\
\hline Service Water Storage Tank, $20 \mathrm{~m} 3$ & 12.2 & 8.1 & 16.1 & 1.4 & 0.7 & 4 & 43 \\
\hline Diesel Storage Tank, $50 \mathrm{~m} 3$ & 16.8 & 11.1 & 22.2 & 1.9 & 1.0 & 6 & 59 \\
\hline Foam Tank, 4 m3 & 3.3 & 2.1 & 4.3 & 0.4 & 0.2 & 1 & 11 \\
\hline Process Vessels Subtotal & 249.2 & 160.7 & 322.2 & 28.0 & 14.8 & 87.9 & 862.7 \\
\hline VAPORIZERS & & & & & & & \\
\hline Open Rack Vaporizers, 168 ton/hr & 0 & 0 & 0 & 0.0 & 0.0 & - & 0 \\
\hline Submerged Combustion Vaporizers, 168 ton/hr & 0 & 0 & 0 & 0.0 & 0.0 & - & 0 \\
\hline Bishop Process & 6,020 & 3,973 & 7,964 & 680.3 & 362.8 & $1,077.5$ & 20,078 \\
\hline Vaporizers Subtotal & 6,020 & 3,973 & 7,964 & 680 & 363 & 1,077 & 20,078 \\
\hline HEAT EXCHANGERS & & & & & & & \\
\hline Standby glycol/fuel gas heater $127 \mathrm{~kW}$ & 6.1 & 4.03 & 8.1 & 0.7 & 0.4 & 2.2 & 21 \\
\hline HP knockout drum heater 20 kW & 0.8 & 0.53 & 1.1 & 0.1 & 0.0 & 0.3 & 3 \\
\hline Gaseous N2 Vaporizer 35 kW & 0.66 & 0.74 & 1.5 & 0.1 & 0.1 & 0.3 & 3 \\
\hline Gaseous N2 Vaporizer (Spare) 35 kW & 0.66 & 0.74 & 1.5 & 0.1 & 0.1 & 0.3 & 3 \\
\hline Liquid N2 Pressurization vaporizer $35 \mathrm{~kW}$ & 0.66 & 0.74 & 1.5 & 0.1 & 0.1 & 0.3 & 3 \\
\hline Liquid N2 Vaporizer 35 kW & 0.66 & 0.74 & 1.5 & 0.1 & 0.1 & 0.3 & 3 \\
\hline Heat Exchangers Subtotal & 9.5 & 7.5 & 15.0 & 1.1 & 0.6 & 3.8 & 37.7 \\
\hline WASTE HEAT RECOVERY & & & & & & & \\
\hline Waste Heat Recovery Subtotal & 0 & 0 & 0 & 0 & 0 & 0 & 0 \\
\hline PUMPS & & & & & & & \\
\hline First stage sendout pump, 416 m3/hr (intank) & 0.0 & 0.0 & 0.0 & 0.0 & 0.0 & 0.0 & 0 \\
\hline Second stage sendout pump, 28 each @270 m3/hr & 225.0 & 5386.5 & 1583.6 & 287.3 & 144.0 & 431.7 & 8,058 \\
\hline Seawater pump, $3160 \mathrm{~m} 3 / \mathrm{hr}$ & $2,100.0$ & 2194.5 & 527.9 & 277.7 & 97.7 & 289.3 & 5,487 \\
\hline Sub combustion Vap. Overflow pump, $5 \mathrm{hp}$ & 0.0 & 0.0 & 0.0 & 0.0 & 0.0 & 0.0 & 0 \\
\hline Process Area Sump Pump, $10 \mathrm{hp}, 5 \mathrm{~m} 3 / \mathrm{hr}$ & 0.0 & 0.0 & 0.0 & 0.0 & 0.0 & 0.0 & 0 \\
\hline Service Water Pump, 5 hp, 57 m3/hr & 3.6 & 0.0 & 17.4 & 0.3 & 0.4 & 2.5 & 24 \\
\hline Firewater Pumps & 203.7 & 213 & 426.7 & 26.9 & 17.0 & 101.2 & 988 \\
\hline Pumps Subtotal & $2,532.3$ & 7,794 & 2,556 & 592 & 259 & 825 & 14,558 \\
\hline COMPRESSORS & & & & & & & \\
\hline BOG Compressors & 800.0 & 264 & 529.2 & 77.2 & 32.3 & 191.2 & 1,894 \\
\hline Ship Vapor Return Unit w/Blower & $1,000.0$ & 330 & 661.5 & 96.5 & 40.4 & 239.0 & 2,367 \\
\hline Ship Unloading Compressor & 0.0 & 0 & 0.0 & 0.0 & 0.0 & 0.0 & 0 \\
\hline Compressors Subtotal & $1,800.0$ & 594 & 1,191 & 174 & 73 & 430 & 4,261 \\
\hline SEAWATER INTAKE SYSTEM (Incl Electrochlorination) & & & & & & & \\
\hline Electrochlorination Unit, $12,000 \mathrm{~m} 3 / \mathrm{hr}$ & 20 & 29 & 57.33 & 3.0 & 2.1 & 12.7 & 124 \\
\hline Seawater Intake Structure $(12,000 \mathrm{~m} 3 / \mathrm{hr}$ each) & 1,100 & 1150 & 2304 & 145.5 & 91.7 & 546.4 & 5,337 \\
\hline Seawater Outfall Structure $(12,000 \mathrm{~m} 3 / \mathrm{hr}$ each) & 1,100 & 1755 & 3517 & 175.7 & 128.1 & 764.6 & 7,440 \\
\hline Seawater Intake Screens $(13,200 \mathrm{~m} 3 / \mathrm{hr}$ each $)$ & 500 & 1073 & 2150 & 93.6 & 74.7 & 446.7 & 4,337 \\
\hline Seawater Rotary Screens $(13,200$ m3/hr each) & 500 & 1348 & 2701 & 107.4 & 91.3 & 545.8 & 5,293 \\
\hline Seawater Intake System Subtotal & 3,220 & 5,353 & 57.33 & 525 & 388 & 2,316 & 22,532 \\
\hline$\underline{\text { UTILITIES }}$ & & & & & & & \\
\hline HP Flare, $415,000 \mathrm{~kg} / \mathrm{hr}$ & 507 & 84 & 167.6 & 44.7 & 15.5 & 90.9 & 909 \\
\hline Electrical Switchgear \& Power Distrib ( $5 \%$ of FC) & & 3,618 & & 180.9 & 72.4 & 434.1 & 4,305 \\
\hline Emergency Generator - Diesel Driven, 500 kW & 230.0 & 63.3 & 126.8 & 21.6 & 8.5 & 50.4 & 501 \\
\hline Gas Turbine Generator, 22MW, GE LM2500 (back-up) & $11,000.0$ & $2,420.0$ & $4,851.0$ & $1,001.0$ & 372.0 & 2192.5 & 21,837 \\
\hline Instrument air compressor and drier, $100 \mathrm{scfm}$ & 299.8 & 82.4 & 165.3 & 28.1 & 11.1 & 65.7 & 652 \\
\hline N2 Dewar for Terminal, Vac. insul. tank, $42 \mathrm{~m} 3$ & 78.0 & 60.1 & 120.4 & 9.2 & 5.2 & 31.0 & 304 \\
\hline Firewater Protection System (Foam Sys, dry powder, tanks) & 300.0 & 198.0 & 396.9 & 33.9 & 18.1 & 107.4 & 1,054 \\
\hline Utilities Subtotal & $12,414.4$ & $6,525.1$ & $5,827.9$ & $1,319.4$ & 502.8 & $2,972.1$ & $29,561.7$ \\
\hline MARINE FACILITY - TRADITIONAL WHARF & & & & & & & \\
\hline Platform and topworks & & $4,500.0$ & 0.0 & 225.0 & 90.0 & 540.0 & $5,355.0$ \\
\hline Berth, walkways and dolphins & & $17,000.0$ & 0.0 & 850.0 & 340.0 & $2,040.0$ & $20,230.0$ \\
\hline & & 0.0 & 0.0 & 0.0 & 0.0 & 0.0 & 0.0 \\
\hline Dredging & & $1,400.0$ & 0.0 & 70.0 & 28.0 & 168.0 & $1,666.0$ \\
\hline Marine Facilities - Jetty Subtotal & & $22,900.0$ & 0.0 & $1,145.0$ & 458.0 & $2,748.0$ & $27,251.0$ \\
\hline
\end{tabular}




\begin{tabular}{|c|c|c|c|c|c|c|c|}
\hline \multicolumn{8}{|l|}{ UNLOADING ARMS } \\
\hline Arms: Unloading and Vapor Return & $1,960.0$ & 788.0 & $1,930.6$ & 196.2 & 94.7 & 561.4 & $5,531.0$ \\
\hline Marine Facilities - Unloading Subtotal & $1,960.0$ & 788.0 & $1,930.6$ & 196.2 & 94.7 & 561.4 & $5,531.0$ \\
\hline Piepline to Caverns 15 miles @ 1.5 mmUSD/mile & & 22,500 & & & & & 22,500 \\
\hline Pipeline Subtotal & & 22,500 & & & & & 22,500 \\
\hline \multicolumn{8}{|l|}{ NAVIGATIONAL AIDS (lighting and buoys) } \\
\hline \multicolumn{8}{|l|}{ Navigational Aids Subtotal } \\
\hline \multicolumn{8}{|l|}{ BUILDINGS } \\
\hline Administration Office/Control Center & & 850 & & 42.5 & 17.0 & 102.0 & 1,012 \\
\hline Compressor Building (Included in cost of compressors) & & 200 & & 10.0 & 4.0 & 24.0 & 238 \\
\hline Warehouse/Maintenance Building, 10,000 ft2 & & 525 & & 26.3 & 10.5 & 63.0 & 625 \\
\hline Buildings Subtotal & & 1,575 & & 78.75 & 31.5 & 189 & 1874.25 \\
\hline \multirow[t]{2}{*}{ SITE PREPARATION } & & 2,171 & & 108.5 & 43.4 & 260.5 & 2,583 \\
\hline & & 2,171 & & 109 & 43 & 260 & 2,583 \\
\hline \multicolumn{8}{|l|}{ BULKS } \\
\hline Piping (exclud. trestle) & & 19,853 & & 992.7 & 397.1 & 2382.4 & 23,625 \\
\hline Piling & & 0 & & 0.0 & 0.0 & 0.0 & 0 \\
\hline Insulation and Paint & & 9264.8 & & 463.2 & 185.3 & 1111.8 & 11,025 \\
\hline Electrical/Instrumentation & & 9000 & & 450.0 & 180.0 & 1080.0 & 10,710 \\
\hline Bulks Subtotal & & 38,118 & & 1,906 & 762 & 4,574 & 45,360 \\
\hline REAL ESTATE & & 750 & & & & & 750 \\
\hline Real Estate Subtotal & & 750 & & & & & 750 \\
\hline \multicolumn{8}{|l|}{ OSBL INFRASTRUCTURE } \\
\hline \multicolumn{8}{|l|}{ Includes access roads, bldgs, hospitals, stores, bridges } \\
\hline OSBL Infrastructure Subtotal & & 0 & & & & & 0 \\
\hline UNADJUSTED GRAND TOTAL & 28,205 & 173,209 & 25,200 & 9,754 & 4,191 & 19,645 & 265,541 \\
\hline CONTINGENCY $12 \%$ OF THE TOTAL & & & & & & & 31,865 \\
\hline ADJUSTED GRAND TOTAL & & & & & & & 297,406 \\
\hline
\end{tabular}




\section{LNG OFFSHORE TERMINAL WITH CAVERN STORAGE}

PROFORMA ECONOMICS

Project Summary

\section{SUMMARY FACILITY ASSUMPTIONS}

\section{Facility Basis - Firm Service}

Cargos per Year

LNG Discharge per Ship, cubic meters LNG

LNG Btu content, Btu/scf

Storage Working Gas Volume, Bcf

Storage Base Gas Volume, Bcf

Pricing

Throughput Fee, \$/MmBtu

Other Revenue - \% of Terminal Throughput Rev.

Terminal Energy Use Charge, \% of throughput

Assumed Henry Hub Index for initial year

Gas Storage Net Revenue Realized \$MM/year

\section{Other Assumptions}

Base Gas Price (Delivered), \$/Mcf

Base Gas Source ("Lease" or "Buy")

Total Operations Cost, \$M/Year

- Labor \& Maintenance, $\$ \mathrm{M} / \mathrm{Yr}$

- Electrical Demand Charge, \$M/Yr

Management Overhead, \$M/Year

Property Taxes (assumed amount), $\$ M / Y r$

Storage Site Lease Fee, $\$ M / y r$

$\%$ Revenue Stream to Inflation Protect, \%/yr

General Inflation Rate

Inflation applied to certain annual costs, $\% / \mathrm{yr}$

Energy Use for Terminal ops., \% of throughput

Full storage cavern compression charge rate

$\%$ of throughput requiring compression at cavern

Project \& Technology Rights

Running Royalty, as \% of Henry Hub index

Project \& License Upfront Payment, \$MM
Facility Costs, $\$$

$\begin{array}{lr}\text { Terminal Utility System } & 51,374,800\end{array}$

Storage Surface Facility $\quad 55,900,000$

Site Specific Misc $\quad-10,670,245$

Header Pipeline

Engineering \& Const. Mgmt.

Project Acquisition \& Tech. Rights $\quad 50,000$

Owner Costs, Permits, Misc. $\quad 7,653,250$

Financing Fees $\quad 15,156,957$

Contingency

Total Facility Cost $\quad 332,024,057$

LNG Terminal Project Metrics

Load Factor (based on 240 cargos/yr max) $\quad 98 \%$

Reference Annual throughput, mcf/yr $\quad 639,280,701$

Annual LNG Offloaded, BCF/yr 639

Reference throughput, million $\mathrm{mmBtu} / \mathrm{yr} \quad 682,112,508$

Daily equivalent amount (mcf/day) $\quad 1,775,780$

Tax Rates

200

360

4,000

500

$100 \%$

$3.0 \%$

$1.5 \%$

$0.35 \%$

$0.00 \%$

$0 \%$

$35.0 \%$

State, \%/YR $\quad 4.50 \%$

Blended Rate, $\% / Y r$. $\quad 37.93 \%$

Property, \%/YR, initial year/capital cost $\quad 1.20 \%$

Capital Gain Rate for Terminal Value $\quad 20 \%$

Depreciation

Depreciation (Straight-Line or Accel) Straight-Line

Depreciable Life, Years

Project Life, Years

20
20

$0.00 \%$ based on mmBtu throughput
FINANCIAL ASSUMPTIONS

Financial Structure

Sr. Debt Percent of Capital

\% Capital

Jr. Debt Percent of Capita

$50.0 \%$

Equity Percent of Capital

Rate

Senior Debt Term

Junior Debt Term

Base Gas Lease Carrying Cost, \%/YR

FINANCIAL RESULTS

\begin{tabular}{|lr|}
\hline & \\
Cost of Capital & $\mathbf{1 0 . 8 8 \%}$ \\
\hline Pretax WACC & $\mathbf{9 . 6 0 \%}$ \\
WACC & $\mathbf{1 5 . 0 \%}$ \\
Equity Return (assumed from above) & \\
& \\
Project Economics & $\mathbf{1 6 7 , 5 0 0}$ \\
\hline Project NPV@Pretax WACC, \$M & $\mathbf{1 5 . 9 \%}$ \\
Project Pretax IRR & $\mathbf{1 1 0 , 6 7 6}$ \\
NPV @ WACC (tax-effected), \$M & $\mathbf{1 2 . 7 \%}$ \\
Project IRR (tax-effected) & \\
& $\mathbf{\$ 4 1 , 8 2 1}$ \\
Yr. 1 EBITDA \$M/year & $\mathbf{\$ 4 4 , 7 9 2}$ \\
Avg. EBITDA, Yrs 1-5, \$M/year & \\
& $\mathbf{3 3 , 9 3 7}$ \\
Equity Returns, AFTER-Tax & $\mathbf{1 7 . 4 \%}$ \\
\hline Equity NPV@ Assumed Equity Return, \$M & \\
Equity IRR (calculated) & Pre-tax \\
Debt Coverage & $\mathbf{3 . 7}$ \\
\hline Minimum EBITDA/Interest Coverage & $\mathbf{2 . 7}$ \\
\hline Minimum EBITDA/Debt Service &
\end{tabular}




\begin{tabular}{|c|c|c|c|c|c|c|c|}
\hline $\begin{array}{l}\text { LNG Terminals Cost Comparison Equi } \\
\text { LNG Offshore Terminal with Salt Cavern Storage } \\
\text { Bishop Process } \\
\text { Average capacity } 1.75 \text { Bcfd }\end{array}$ & $\begin{array}{c}\text { pment S } \\
\text { Bare } \\
\text { Equipment } \\
\text { Cost (\$M) }\end{array}$ & $\begin{array}{c}\text { ammary S } \\
\text { Steel } \\
\text { Concrete } \\
\text { I/E \& Piping } \\
\text { Cost (\$M) } \\
\end{array}$ & $\begin{array}{l}\text { heet } \\
\text { Installed } \\
\text { Direct \& } \\
\text { Indirect } \\
\text { Cost (\$M) } \\
\end{array}$ & $\begin{array}{c}\text { Freight } \\
\text { Spares } \\
\text { Other } \\
\text { Cost }(\$ \mathrm{M}) \\
\end{array}$ & $\begin{array}{c}\text { Taxes } \\
\text { Duties } \\
\text { Insurance } \\
\text { Cost }(\$ \mathrm{M}) \\
\end{array}$ & $\begin{array}{c}\text { Contract } \\
\text { Engineering } \\
(12 \%) \\
\text { Cost }(\$ M) \\
\end{array}$ & $\begin{array}{c}\text { Total } \\
\text { Cost } \\
\text { Cost }(\$ M)\end{array}$ \\
\hline $\begin{array}{r}\text { Salt Storage Caverns: } 6 \times 3.5 \text { BCF }=21 \text { BCF }(1,065,000 \mathrm{~m} 3) \\
\text { Salt Cavern Storage } 6 \text { each at } 3.5 \text { Bcf total } 21 \text { bcf }\end{array}$ & & $\begin{array}{l}20,000 \\
20,000\end{array}$ & $\begin{array}{l}30,000 \\
30,000\end{array}$ & $\begin{array}{l}1,000 \\
1,000\end{array}$ & $\begin{array}{l}1,000 \\
1,000\end{array}$ & $\begin{array}{l}6,000 \\
6,000\end{array}$ & $\begin{array}{l}58,000 \\
58,000\end{array}$ \\
\hline \multicolumn{8}{|l|}{ PROCESS VESSELS } \\
\hline Recondenser, 9'ID x 45', 304 SS & 142.0 & 85.9 & 172.2 & 15.7 & 8.1 & 48 & 472 \\
\hline BOG Compressor Knock Out Drum 70 m3 & 35.6 & 25.5 & 51.0 & 4.1 & 2.3 & 13 & 132 \\
\hline HP Fuel Gas Knock Out Drum, 3 m3 & 10.5 & 7.5 & 15.0 & 1.2 & 0.7 & 4 & 39 \\
\hline HP Flare Knock Out Drum, 50 m3 & 28.8 & 20.6 & 41.3 & 3.3 & 1.8 & 11 & 107 \\
\hline Service Water Storage Tank, $20 \mathrm{~m} 3$ & 12.2 & 8.1 & 16.1 & 1.4 & 0.7 & 4 & 43 \\
\hline Diesel Storage Tank, $50 \mathrm{~m} 3$ & 16.8 & 11.1 & 22.2 & 1.9 & 1.0 & 6 & 59 \\
\hline Foam Tank, $4 \mathrm{~m} 3$ & 3.3 & 2.1 & 4.3 & 0.4 & 0.2 & 1 & 11 \\
\hline Process Vessels Subtotal & 249.2 & 160.7 & 322.2 & 28.0 & 14.8 & 87.9 & 862.7 \\
\hline \multicolumn{8}{|l|}{ VAPORIZERS } \\
\hline Open Rack Vaporizers, 168 ton/hr & 0 & 0 & 0 & 0.0 & 0.0 & - & 0 \\
\hline Submerged Combustion Vaporizers, 168 ton/hr & 0 & 0 & 0 & 0.0 & 0.0 & - & 0 \\
\hline Bishop Process & 6,020 & 3,973 & 7,964 & 680.3 & 362.8 & $1,077.5$ & 20,078 \\
\hline Vaporizers Subtotal & 6,020 & 3,973 & 7,964 & 680 & 363 & 1,077 & 20,078 \\
\hline \multicolumn{8}{|l|}{ HEAT EXCHANGERS } \\
\hline Standby glycol/fuel gas heater $127 \mathrm{~kW}$ & 6.1 & 4.03 & 8.1 & 0.7 & 0.4 & 2.2 & 21 \\
\hline HP knockout drum heater 20 kW & 0.8 & 0.53 & 1.1 & 0.1 & 0.0 & 0.3 & 3 \\
\hline Gaseous N2 Vaporizer 35 kW & 0.66 & 0.74 & 1.5 & 0.1 & 0.1 & 0.3 & 3 \\
\hline Gaseous N2 Vaporizer (Spare) 35 kW & 0.66 & 0.74 & 1.5 & 0.1 & 0.1 & 0.3 & 3 \\
\hline Liquid N2 Pressurization vaporizer $35 \mathrm{~kW}$ & 0.66 & 0.74 & 1.5 & 0.1 & 0.1 & 0.3 & 3 \\
\hline Liquid N2 Vaporizer $35 \mathrm{~kW}$ & 0.66 & 0.74 & 1.5 & 0.1 & 0.1 & 0.3 & 3 \\
\hline Heat Exchangers Subtotal & 9.5 & 7.5 & 15.0 & 1.1 & 0.6 & 3.8 & 37.7 \\
\hline \multicolumn{8}{|l|}{ WASTE HEAT RECOVERY } \\
\hline Waste Heat Recovery Subtotal & 0 & 0 & 0 & 0 & 0 & 0 & 0 \\
\hline \multicolumn{8}{|l|}{ PUMPS } \\
\hline First stage sendout pump, $416 \mathrm{~m} 3 / \mathrm{hr}$ (intank) & 0.0 & 0.0 & 0.0 & 0.0 & 0.0 & 0.0 & 0 \\
\hline Second stage sendout pump, 28 ea @ 270 m3/hr & $6,300.0$ & 6583.5 & 13196.9 & 833.2 & 525.4 & 1564.8 & 29,004 \\
\hline Seawater pump, $3160 \mathrm{~m} 3 / \mathrm{hr}$ & $2,100.0$ & 2194.5 & 4399.0 & 277.7 & 175.1 & 1043.2 & 10,190 \\
\hline Sub combustion Vap. Overflow pump, 5hp & 0.0 & 0.0 & 0.0 & 0.0 & 0.0 & 0.0 & 0 \\
\hline Process Area Sump Pump, $10 \mathrm{hp}, 5 \mathrm{~m} 3 / \mathrm{hr}$ & 0.0 & 0.0 & 0.0 & 0.0 & 0.0 & 0.0 & 0 \\
\hline Service Water Pump, 5 hp, $57 \mathrm{~m} 3 / \mathrm{hr}$ & 17.4 & 24.9 & 49.9 & 2.6 & 1.9 & 11.1 & 108 \\
\hline Firewater Pumps & 192.5 & 201 & 403.2 & 25.5 & 16.1 & 95.6 & 934 \\
\hline Pumps Subtotal & $8,609.9$ & 9,004 & 18,049 & 1,139 & 718 & 2,715 & 40,235 \\
\hline \multicolumn{8}{|l|}{ COMPRESSORS } \\
\hline$\overline{\text { BOG Compressors }}$ & 800.0 & 264 & 529.2 & 77.2 & 32.3 & 191.2 & 1,894 \\
\hline Ship Vapor Return Unit w/Blower & $1,000.0$ & 330 & 661.5 & 96.5 & 40.4 & 239.0 & 2,367 \\
\hline Ship Unloading Compressor & 0.0 & 0 & 0.0 & 0.0 & 0.0 & 0.0 & 0 \\
\hline Compressors Subtotal & $1,800.0$ & 594 & 1,191 & 174 & 73 & 430 & 4,261 \\
\hline \multicolumn{8}{|l|}{ SEAWATER INTAKE SYSTEM (Incl Electrochlorination) } \\
\hline Electrochlorination Unit, $12,000 \mathrm{~m} 3 / \mathrm{hr}$ & 20 & 29 & 57.33 & 3.0 & 2.1 & 6.4 & 117 \\
\hline Seawater Intake Structure $(12,000 \mathrm{~m} 3 / \mathrm{hr}$ each) & 0 & 0 & 0 & 0.0 & 0.0 & 0.0 & 0 \\
\hline Seawater Outfall Structure $(12,000 \mathrm{~m} 3 / \mathrm{hr}$ each) & 0 & 0 & 0 & 0.0 & 0.0 & 0.0 & 0 \\
\hline Seawater Intake Screens $(13,200 \mathrm{~m} 3 / \mathrm{hr}$ each) & 250 & 69 & 56 & 23.4 & 7.7 & 22.5 & 429 \\
\hline Seawater Rotary Screens $(13,200 \mathrm{~m} 3 / \mathrm{hr}$ each) & 250 & 69 & 56 & 23.4 & 7.7 & 22.5 & 429 \\
\hline Seawater Intake System Subtotal & 520 & 166 & 170 & 50 & 17 & 51 & 975 \\
\hline \multicolumn{8}{|l|}{ UTILITIES } \\
\hline HP Flare, $415,000 \mathrm{~kg} / \mathrm{hr}$ & 507 & 84 & 167.6 & 44.7 & 15.5 & 90.9 & 909 \\
\hline Electrical Switchgear \& Power Distrib ( $5 \%$ of FC) & & 3,001 & & 150.0 & 60.0 & 360.1 & 3,571 \\
\hline Emergency Generator - Diesel Driven, 500 kW & 115.0 & 31.6 & 63.4 & 10.8 & 4.3 & 25.2 & 250 \\
\hline Gas Turbine Generator, 32MW, GE LM2500+ & $11,000.0$ & $2,420.0$ & $4,851.0$ & $1,001.0$ & 372.0 & 2192.5 & 21,837 \\
\hline Instrument air compressor and drier, $100 \mathrm{scfm}$ & 299.8 & 82.4 & 165.3 & 28.1 & 11.1 & 65.7 & 652 \\
\hline N2 Dewar for Terminal, Vac. insul. tank, $42 \mathrm{~m} 3$ & 78.0 & 60.1 & 120.4 & 9.2 & 5.2 & 31.0 & 304 \\
\hline Firewater Protection System (Foam Sys, dry powder, tanks) & 300.0 & 198.0 & 396.9 & 33.9 & 18.1 & 107.4 & 1,054 \\
\hline Utilities Subtotal & $12,299.4$ & $5,876.7$ & $5,764.5$ & $1,277.8$ & 486.2 & $2,872.9$ & $28,577.5$ \\
\hline \multicolumn{8}{|l|}{ MARINE UNLOADING STRUCTURE } \\
\hline Platforms and Hex Bridge & & $50,000.0$ & 0.0 & $2,500.0$ & $1,000.0$ & $6,000.0$ & $59,500.0$ \\
\hline Cryogenic Piping (2 each 32" dia x L 1800 meters @ 1800 \$/m)) & & $6,480.0$ & 0.0 & 324.0 & 129.6 & 777.6 & $7,711.2$ \\
\hline Big Sweep Arm & & $5,000.0$ & 0.0 & 250.0 & 100.0 & 600.0 & $5,950.0$ \\
\hline & & 0.0 & 0.0 & 0.0 & 0.0 & 0.0 & 0.0 \\
\hline Marine Facilities - Subtotal & & $61,480.0$ & 0.0 & $3,074.0$ & $1,229.6$ & $7,377.6$ & $73,161.2$ \\
\hline
\end{tabular}




\begin{tabular}{|c|c|c|c|c|c|c|c|}
\hline \multicolumn{8}{|l|}{ MARINE UNLOADING ARMS } \\
\hline Arms: Unloading and Vapor Return & $1,500.0$ & 963.0 & $1,930.6$ & 168.2 & 88.8 & 527.2 & $5,177.8$ \\
\hline Marine Facilities - Unloading Subtotal & $1,500.0$ & 963.0 & $1,930.6$ & 168.2 & 88.8 & 527.2 & $5,177.8$ \\
\hline SUBSEA PIPELINE To Cavern (total 6 = I mile long) & & $1,120.0$ & 0.0 & 56.0 & 22.4 & 134.4 & $1,332.8$ \\
\hline To existing subsea infrastructure ( 5 miles to tie in & & $3,500.0$ & 0.0 & 175.0 & 70.0 & 420.0 & $4,165.0$ \\
\hline Pipeline Subtotal & & $4,620.0$ & 0.0 & 231.0 & 92.4 & 554.4 & $5,497.8$ \\
\hline \multicolumn{8}{|l|}{ NAVIGATIONAL AIDS (lighting and buoys) } \\
\hline \multicolumn{8}{|l|}{ MODULAR STRUCTURES } \\
\hline Administration Office/Control Center & & 500.0 & & 25.0 & 10.0 & 30.0 & 565.0 \\
\hline Compressor Building (Included in cost of compressors) & & 0.0 & & 0.0 & 0.0 & 0.0 & 0.0 \\
\hline Warehouse/Maintenance Building, 10,000 ft2 & & 0.0 & & 0.0 & 0.0 & 0.0 & 0.0 \\
\hline Buildings Subtotal & & 500.0 & & 25.0 & 10.0 & 30.0 & 565.0 \\
\hline SITE PREPARATION & & 0.0 & & 0.0 & 0.0 & 0.0 & 0.0 \\
\hline Site Preparation Subtotal & & 0.0 & & 0.0 & 0.0 & 0.0 & 0.0 \\
\hline \multicolumn{8}{|l|}{ BULKS } \\
\hline Piling & & 0 & & 0.0 & 0.0 & 0.0 & 0 \\
\hline Insulation and Paint & & 4201.4 & & 210.1 & 84.0 & 252.1 & 4,748 \\
\hline Electrical/Instrumentation & & 9000 & & 450.0 & 180.0 & 540.0 & 10,170 \\
\hline Bulks Subtotal & & 22,204 & & 1,110 & 444 & 1,332 & 25,091 \\
\hline REAL ESTATE & & 0 & & & & & 0 \\
\hline Real Estate Subtotal & & 0 & & & & & 0 \\
\hline \\
\hline OSBL Infrastructure Subtotal & & 0 & & & & & 0 \\
\hline UNADJUSTED GRAND TOTAL & 31,008 & 129,550 & 65,406 & 8,958 & 4,538 & 23,060 & 262,520 \\
\hline CONTINGENCY $12 \%$ OF THE TOTAL & & & & & & & 31,502 \\
\hline ADJUSTED GRAND TOTAL & & & & & & & 294,022 \\
\hline
\end{tabular}


Energy Bridge ${ }^{\circledR}$ LNG TERMINAL

PROFORMA ECONOMICS

Project Summary

\section{SUMMARY FACILITY ASSUMPTIONS}

\section{FINANCIAL ASSUMPTIONS}

\section{Facility Basis - Firm Service}

Cargos per Year

LNG Discharge per Ship, cubic meters LNG

LNG Btu content, Btu/scf

Storage Working Gas Volume, Bcf

Storage Base Gas Volume, Bcf

Pricing

Throughput Fee, \$/MmBtu

Other Revenue - \% of Terminal Throughput Rev.

Terminal Energy Use Charge, \% of throughput

Assumed Henry Hub Index for initial year

Gas Storage Net Revenue Realized \$MM/year

65
138,000
1067
16.00
7.30

\section{Other Assumptions}

Base Gas Price (Delivered), \$/Mcf

Base Gas Source ("Lease" or "Buy")

Total Operations Cost, $\$ M / Y e a r$

- Labor \& Maintenance, $\$ M / Y r$

- Electrical Demand Charge, \$M/Yr

Management Overhead, \$M/Year

Property Taxes (assumed amount), \$M/Yr

Storage Site Lease Fee, $\$ M / y r$

$\%$ Revenue Stream to Inflation Protect, \%/yr

General Inflation Rate

Inflation applied to certain annual costs, $\% / \mathrm{yr}$

Energy Use for Terminal ops., \% of throughput

Full storage cavern compression charge rate

$\%$ of throughput requiring compression at cavern

Project \& Technology Rights

Running Royalty, as \% of Henry Hub index

Project \& License Upfront Payment, \$MM

200

360

4,000

500

$100 \%$

$3.0 \%$

$1.5 \%$

$1.00 \%$

$0.00 \%$

$0 \%$
Facility Costs, $\$$

Marine Port Facilities

\begin{tabular}{ll}
$19,981,000$ \\
\hline
\end{tabular}

Storage Surfe

$175,000,000$

Site Specific Misc $\quad 3,640,466$

Header Pipeline

Engineering \& Const. Mgmt.

Project Acquisition \& Tech. Rights $\quad 50,000$

Owner Costs, Permits, Misc. 7,653,250

Financing Fees $\quad 13,421,313$

Total Facility Cost 292,730,563

LNG Terminal Project Metrics

Load Factor (based on 65 cargos/yr max) $\quad 100 \%$

Reference Annual throughput, mcf/yr 176,822,322

Annual LNG Offloaded, BCF/yr 177

Reference throughput, million mmBtu/yr $\quad 188,669,417$

Daily equivalent amount (mcf/day) 491,173

Tax Rates

$35.0 \%$

$4.50 \%$

Blended Rate, \%/Yr. $\quad 37.93 \%$

Property, \%/YR, initial year/capital cost $\quad 1.37 \%$

Capital Gain Rate for Terminal Value $20 \%$

Depreciation

Depreciation (Straight-Line or Accel) Straight-Line

Depreciable Life, Years

Project Life, Years

20
20

$0.00 \%$ based on mmBtu throughput
Financial Structure

Sr. Debt Percent of Capital

\% Capital

$50.0 \%$

Jr. Debt Percent of Capital

$0.0 \%$

$50.0 \%$

Rate

Equity Percent of Capital

20

Senior Debt Term

Junior Debt Term

Base Gas Lease Carrying Cost, \%/YR

FINANCIAL RESULTS

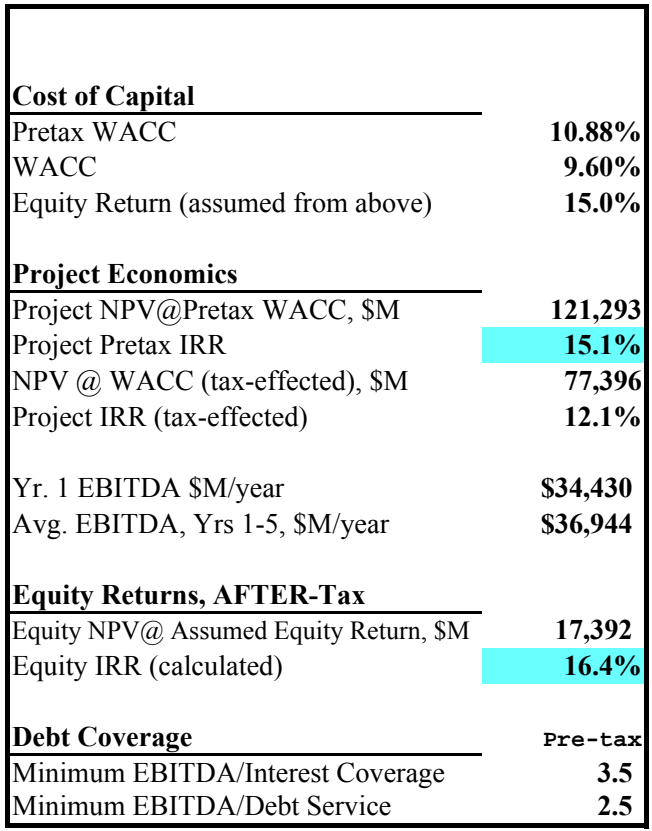




\begin{tabular}{|c|c|c|c|c|c|c|c|}
\hline \multicolumn{8}{|c|}{ LNG Terminals Cost Comparison Equipment Summary Sheet } \\
\hline \multirow{3}{*}{$\begin{array}{l}\text { Shipboard Regasification } \\
\text { Capacity } 0.48 \text { Bcfd }\end{array}$} & \multirow{3}{*}{$\begin{array}{c}\text { Bare } \\
\text { Equipment } \\
\text { Cost (\$M) }\end{array}$} & \multirow{3}{*}{$\begin{array}{l}\text { Steel } \\
\text { Concrete } \\
\text { I/E \& Piping } \\
\text { Cost (\$M) }\end{array}$} & \multirow{3}{*}{$\begin{array}{l}\text { Installed } \\
\text { Direct \& } \\
\text { Indirect } \\
\text { Cost (\$M) }\end{array}$} & \multirow{3}{*}{$\begin{array}{l}\text { Freight } \\
\text { Spares } \\
\text { Other } \\
\text { Cost }(\$ M)\end{array}$} & \multirow{3}{*}{$\begin{array}{c}\text { Taxes } \\
\text { Duties } \\
\text { Insurance } \\
\text { Cost }(\$ M)\end{array}$} & \multirow{3}{*}{$\begin{array}{c}\text { Contract } \\
\text { Engineering } \\
(12 \%) \\
\text { Cost }(\$ M)\end{array}$} & \multirow{3}{*}{$\begin{array}{c}\text { Total } \\
\text { Cost } \\
\text { Cost (\$M) }\end{array}$} \\
\hline & & & & & & & \\
\hline & & & & & & & \\
\hline GLNG Storage Caverns: 2 ea $\times 3$ BCF $=6$ BCF $(304,400$ m3) & & - & - & - & - & - & - \\
\hline LNG Storage Tank Subtotal - NA - & & - & - & NA & - & - & - \\
\hline \multicolumn{8}{|l|}{ PROCESS VESSELS } \\
\hline Recondenser, $9^{\prime}$ ID x 45', 304 SS & 0.0 & 0.0 & 0.0 & 0.0 & 0.0 & - & 0 \\
\hline BOG Compressor Knock Out Drum 70 m3 & 0.0 & 0.0 & 0.0 & 0.0 & 0.0 & - & 0 \\
\hline HP Fuel Gas Knock Out Drum, 3 m3 & 0.0 & 0.0 & 0.0 & 0.0 & 0.0 & - & 0 \\
\hline HP Flare Knock Out Drum, $50 \mathrm{~m} 3$ & 0.0 & 0.0 & 0.0 & 0.0 & 0.0 & - & 0 \\
\hline Service Water Storage Tank, $20 \mathrm{~m} 3$ & 0.0 & 0.0 & 0.0 & 0.0 & 0.0 & - & 0 \\
\hline Diesel Storage Tank, $50 \mathrm{~m} 3$ & 0.0 & 0.0 & 0.0 & 0.0 & 0.0 & - & 0 \\
\hline Foam Tank, $4 \mathrm{~m} 3$ & 0.0 & 0.0 & 0.0 & 0.0 & 0.0 & - & 0 \\
\hline Process Vessels Subtotal & 0.0 & 0.0 & 0.0 & 0.0 & 0.0 & 0.0 & 0.0 \\
\hline \multicolumn{8}{|l|}{ VAPORIZERS } \\
\hline Shell and TubeVaporizers, $168 \mathrm{ton} / \mathrm{hr}$ & 1,200 & 924 & 1,852 & 142.2 & 80.2 & 477 & 4,676 \\
\hline Submerged Combustion Vaporizers, $168 \mathrm{ton} / \mathrm{hr}$ & 0 & 0 & 0 & 0.0 & 0.0 & - & 0 \\
\hline Bishop Process & 0 & 0 & 0 & 0.0 & 0.0 & - & 0 \\
\hline Vaporizers Subtotal & 1,200 & 924 & 1,852 & 142 & 80 & 477 & 4,676 \\
\hline HEAT EXCHANGERS & & & & & & & \\
\hline Standby glycol/fuel gas heater $127 \mathrm{~kW}$ & 0 & 0.00 & 0.0 & 0.0 & 0.0 & - & 0 \\
\hline HP knockout drum heater $20 \mathrm{~kW}$ & 0 & 0.00 & 0.0 & 0.0 & 0.0 & - & 0 \\
\hline Gaseous N2 Vaporizer 35 kW & 0 & 0.00 & 0.0 & 0.0 & 0.0 & - & 0 \\
\hline Gaseous N2 Vaporizer (Spare) $35 \mathrm{~kW}$ & 0 & 0.00 & 0.0 & 0.0 & 0.0 & - & 0 \\
\hline Liquid N2 Pressurization vaporizer $35 \mathrm{~kW}$ & 0 & 0.00 & 0.0 & 0.0 & 0.0 & - & 0 \\
\hline Liquid N2 Vaporizer $35 \mathrm{~kW}$ & 0 & 0.00 & 0.0 & 0.0 & 0.0 & - & 0 \\
\hline Heat Exchangers Subtotal & 0.0 & 0.0 & 0.0 & 0.0 & 0.0 & 0.0 & 0.0 \\
\hline WASTE HEAT RECOVERY & & & & & & & \\
\hline Waste Heat Recovery Subtotal & 0 & 0 & 0 & 0 & 0 & 0 & $\mathrm{c}$ \\
\hline PUMPS & & & & & & & \\
\hline First stage sendout pump, $416 \mathrm{~m} 3 / \mathrm{hr}$ (intank) & 0.0 & 0.0 & 0.0 & 0.0 & 0.0 & - & 0 \\
\hline Second stage sendout pump, $325 \mathrm{~m} 3 / \mathrm{hr}$ & $1,800.0$ & 1881.0 & 3770.6 & 238.1 & 150.1 & 894.2 & 8,734 \\
\hline Seawater pump, $2187 \mathrm{~m} 3 / \mathrm{hr}$ & 0.0 & 0.0 & 0.0 & 0.0 & 0.0 & - & 0 \\
\hline Sub combustion Vap. Overflow pump, 5hp & 0.0 & 0.0 & 0.0 & 0.0 & 0.0 & - & 0 \\
\hline Process Area Sump Pump, $10 \mathrm{hp}, 5 \mathrm{~m} 3 / \mathrm{hr}$ & 0.0 & 0.0 & 0.0 & 0.0 & 0.0 & - & 0 \\
\hline Service Water Pump, $5 \mathrm{hp}, 57 \mathrm{~m} 3 / \mathrm{hr}$ & 17.4 & 24.9 & 49.9 & 2.6 & 1.9 & 11.1 & 108 \\
\hline Firewater Pumps & 0.0 & 0 & 0.0 & 0.0 & 0.0 & - & 0 \\
\hline Pumps Subtotal & $1,817.4$ & 1,906 & 3,820 & 241 & 152 & 905 & 8,842 \\
\hline COMPRESSORS & & & & & & & \\
\hline BOG Compressors & 0.0 & 0 & 0 & 0.0 & 0.0 & - & 0 \\
\hline Ship Vapor Return Unit w/Blower & 0.0 & 0 & 0 & 0.0 & 0.0 & - & 0 \\
\hline Ship Unloading Compressor & 0.0 & 0 & 0.0 & 0.0 & 0.0 & - & 0 \\
\hline Compressors Subtotal & 0.0 & 0 & 0 & 0 & 0 & 0 & 0 \\
\hline SEAWATER INTAKE SYSTEM (Incl Electrochlorination) & & & & & & & \\
\hline Electrochlorination Unit, $12,000 \mathrm{~m} 3 / \mathrm{hr}$ & 0 & 0 & 0 & 0.0 & 0.0 & - & 0 \\
\hline Seawater Intake Structure $(12,000 \mathrm{~m} 3 / \mathrm{hr}$ each) & 0 & 0 & 0 & 0.0 & 0.0 & - & 0 \\
\hline Seawater Outfall Structure $(12,000 \mathrm{~m} 3 / \mathrm{hr}$ each) & 0 & 0 & 0 & 0.0 & 0.0 & - & 0 \\
\hline Seawater Intake Screens $(13,200 \mathrm{~m} 3 / \mathrm{hr}$ each $)$ & 0 & 0 & 0 & 0.0 & 0.0 & - & 0 \\
\hline Seawater Rotary Screens $(13,200 \mathrm{~m} 3 / \mathrm{hr}$ each) & 0 & 0 & 0 & 0.0 & 0.0 & - & 0 \\
\hline Seawater Intake System Subtotal & 0 & 0 & 57.33 & 0 & 0 & 0 & $\mathrm{c}$ \\
\hline UTILITIES & & & & & & & \\
\hline HP Flare, $415,000 \mathrm{~kg} / \mathrm{hr}$ & 0 & 0 & 0.0 & 0.0 & 0.0 & - & 0 \\
\hline Electrical Switchgear \& Power Distrib ( $5 \%$ of FC) & & 429 & & 21.4 & 8.6 & 51.4 & 510 \\
\hline Emergency Generator - Diesel Driven, 500 kW & 0.0 & 0.0 & 0.0 & 0.0 & 0.0 & - & 0 \\
\hline Gas Turbine Generator, $22 \mathrm{MW}, \mathrm{GE}$ LM2500 & 0.0 & 0.0 & 0.0 & 0.0 & 0.0 & - & 0 \\
\hline Instrument air compressor and drier, $100 \mathrm{scfm}$ & 149.9 & 41.2 & 82.6 & 14.1 & 5.6 & 32.9 & 326 \\
\hline N2 Dewar for Terminal, Vac. insul. tank, $42 \mathrm{~m} 3$ & 78.0 & 60.1 & 120.4 & 9.2 & 5.2 & 31.0 & 304 \\
\hline Firewater Protection System (Foam Sys, dry powder, tanks) & 0.0 & 0.0 & 0.0 & 0.0 & 0.0 & - & 0 \\
\hline Utilities Subtotal & 227.9 & 530.0 & 203.0 & 44.7 & 19.4 & 115.3 & $1,140.3$ \\
\hline Offshore Platform and APL Subsea Installation & & & & & & & \\
\hline APL Buoy & & 12000 & & 600.0 & 240.0 & $1,440.0$ & 14,280 \\
\hline Pipeline to Plem 1 mile @ 2.3 mmUSD & & 2300 & & 115.0 & 46.0 & 276.0 & 2,737 \\
\hline Plem & & 0 & & 0.0 & 0.0 & - & 0 \\
\hline Turret, riser, moorings, and installation (EP supplied) & & 9000.0 & & 450.0 & 180.0 & $1,080.0$ & 10,710 \\
\hline Marine Facilities - Platform Subtotal & & 23300 & & 1165 & 466 & 2796 & 27727.0 \\
\hline
\end{tabular}




\begin{tabular}{|c|c|c|c|c|c|c|c|}
\hline \multicolumn{8}{|l|}{ MARINE FACILITIES - UNLOADING } \\
\hline Arms: Unloading and Vapor Return & $175,000.0$ & 0.0 & 0.0 & $14,000.0$ & $3,605.0$ & $10,500.0$ & $203,105.0$ \\
\hline Marine Facilities - Unloading Subtotal & $175,000.0$ & 0.0 & 0.0 & $14,000.0$ & $3,605.0$ & $10,500.0$ & $203,105.0$ \\
\hline SUBSEA PIPELINE To Cavern Platform (2 pipes 1 mile) & & 0.0 & & 0.0 & 0.0 & 0.0 & 0.0 \\
\hline To existing subsea infrastructure (11 miles) & & $2,000.0$ & & 100.0 & 40.0 & 240.0 & $2,380.0$ \\
\hline Pipeline Subtotal & & $2,000.0$ & & 100.0 & 40.0 & 240.0 & $2,380.0$ \\
\hline \multicolumn{8}{|l|}{ NAVIGATIONAL AIDS (lighting and buoys) } \\
\hline \multicolumn{8}{|l|}{ MODULAR STRUCTURES } \\
\hline Administration Office/Control Center & & 100 & & 5.0 & 2.0 & 12.0 & 119 \\
\hline Compressor Building (Included in cost of compressors) & & - & & 0.0 & 0.0 & - & 0 \\
\hline Warehouse/Maintenance Building, 10,000 ft2 & & - & & 0.0 & 0.0 & - & 0 \\
\hline Buildings Subtotal & & 100 & & 5 & 2 & 12 & 119 \\
\hline SITE PREPARATION & & 257 & & 12.9 & 5.1 & 30.9 & 306 \\
\hline Site Preparation Subtotal & & 257 & & 13 & 5 & 31 & 306 \\
\hline \multicolumn{8}{|l|}{ BULKS } \\
\hline Piping (exclud. trestle) & & 1,286 & & 64.3 & 25.7 & 154.3 & 1,531 \\
\hline Piling & & 0 & & 0.0 & 0.0 & 0.0 & 0 \\
\hline Insulation and Paint & & 600.2 & & 30.0 & 12.0 & 72.0 & 714 \\
\hline Electrical/Instrumentation & & 5000 & & 250.0 & 100.0 & 600.0 & 5,950 \\
\hline Bulks Subtotal & & 6,886 & & 344 & 138 & 826 & 8,195 \\
\hline REAL ESTATE & & 0.0 & & & & & 0 \\
\hline Real Estate Subtotal & & 0 & & & & & 0 \\
\hline \multicolumn{8}{|l|}{ OSBL INFRASTRUCTURE } \\
\hline \multicolumn{8}{|l|}{ Includes access roads, bldgs, hospitals, stores, bridges } \\
\hline OSBL Infrastructure Subtotal & & 0 & & & & & 0 \\
\hline UNADJUSTED GRAND TOTAL & 178,245 & 35,904 & 5,904 & 16,055 & 4,507 & 15,903 & 256,490 \\
\hline CONTINGENCY $12 \%$ OF THE TOTAL & & & & & & & 30,779 \\
\hline ADJUSTED GRAND TOTAL & & & & & & & 287,268 \\
\hline
\end{tabular}




\begin{tabular}{|l|l|l|l|}
\hline Customer: & $\begin{array}{l}\text { The United States Department of Energy } \\
\text { National Energy Technology Laboratory }\end{array}$ & $\begin{array}{l}\text { Date of Issue: } \\
24 / 04 / 2003\end{array}$ & \\
\hline $\begin{array}{l}\text { Document } \\
\text { Title: }\end{array}$ & Task 3 Doc 08: Matrix for Comparison of Five LNG Terminal Designs & $\begin{array}{l}\text { Doc \# \& Version: } \\
\text { Doc } 08 \text { r1.0 }\end{array}$ & Page 1 of 4 \\
\hline
\end{tabular}

\title{
Matrix for Comparison of Five LNG Terminal Designs
}

\author{
BY \\ Michael M. MCCALL \\ WILLIAM M. BISHOP \\ D. BRAXTON SCHERZ
}

\begin{tabular}{|c|c|c|c|c|c|c|c|c|}
\hline r 1.0 & For client review & $02 / 09 / 03$ & BS & MM & & & & \\
\hline Version & Reason for Issue & $\begin{array}{l}\text { Issue } \\
\text { Date }\end{array}$ & Orig. & $\begin{array}{l}\text { Chk. } \\
\text { CGI }\end{array}$ & Appr. & $\begin{array}{l}\text { Chk. } \\
\text { NE }\end{array}$ & $\begin{array}{l}\text { Appr. } \\
\text { TLL }\end{array}$ & Review \\
\hline \multicolumn{2}{|c|}{$\begin{array}{l}\text { Document Title: } \\
\text { Matrix for Comparison of Five LNG Terminal } \\
\text { Designs }\end{array}$} & \multicolumn{7}{|c|}{ Document No: } \\
\hline
\end{tabular}




\begin{tabular}{|l|l|l|l|}
\hline Customer: & $\begin{array}{l}\text { The United States Department of Energy } \\
\text { National Energy Technology Laboratory }\end{array}$ & $\begin{array}{l}\text { Date of Issue: } \\
24 / 04 / 2003\end{array}$ & \\
\hline $\begin{array}{l}\text { Document } \\
\text { Title: }\end{array}$ & Task 3 Doc 08: Matrix for Comparison of Five LNG Terminal Designs & $\begin{array}{l}\text { Doc \# \& Version: } \\
\text { Doc } 08 \text { r1.0 }\end{array}$ & Page 2 of 4 \\
\hline
\end{tabular}

\section{TABLE OF CONTENTS}

1. MATRIX FOR COMPARISON PURPOSES... 


\begin{tabular}{|l|l|l|l|}
\hline Customer: & $\begin{array}{l}\text { The United States Department of Energy } \\
\text { National Energy Technology Laboratory }\end{array}$ & $\begin{array}{l}\text { Date of Issue: } \\
\mathbf{2 4 / 0 4 / 2 0 0 3}\end{array}$ \\
\hline $\begin{array}{l}\text { Document } \\
\text { Title: }\end{array}$ & Task 3 Doc 08: Matrix for Comparison of Five LNG Terminal Designs & $\begin{array}{l}\text { Doc \# \& Version: } \\
\text { Doc 08 r1.0 }\end{array}$ & Page 3 of 4 \\
\hline
\end{tabular}

\section{MATRIX FOR COMPARISON PURPOSES}

This matrix is based on a five tiered rating system with indicators depicting "Excellent to Acceptable" as follows:

$$
\begin{aligned}
& \Theta=\text { Excellent } \\
& =\text { = Very Good } \\
& =\text { Good } \\
& \bigoplus=\text { Fair } \\
& =\text { Acceptable }
\end{aligned}
$$

The first section of the matrix is based on the quantitative results of the factored analysis (see Doc 07 for Summary Table) discussed in prior sections and other calculated parameters. The quantitative analysis for the five terminals lends itself to a ranking whereby each terminal is uniquely rated "Acceptable through Excellent" unless the numerical results were equivalent. To better interpret the quantitative results of the matrix below, the

\begin{tabular}{|c|c|c|c|c|c|}
\hline Parameter & $\begin{array}{l}\text { Pacific } \\
\text { Coast }\end{array}$ & $\begin{array}{c}\text { Atlantic } \\
\text { Coast }\end{array}$ & $\begin{array}{c}\text { BPT } \\
\text { Onshore }\end{array}$ & $\begin{array}{c}\text { BPT } \\
\text { Offshore }\end{array}$ & $\begin{array}{l}\text { Energy } \\
\text { Bridge }\end{array}$ \\
\hline \multicolumn{6}{|l|}{ Quantitative } \\
\hline Annual Sendout & & $\bigoplus$ & 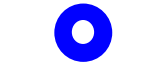 & 0 & \\
\hline TIC per Capacity & $\oplus$ & ) & c & (0) & \\
\hline \multicolumn{6}{|l|}{ OPEX per Capacity } \\
\hline \multicolumn{6}{|l|}{ Fuel Consumption } \\
\hline Service Fee & $\oplus$ & O & c & (2) & \\
\hline \multicolumn{6}{|l|}{ Qualitative } \\
\hline Security & $\oplus$ & $\bigoplus$ & 0 & 0 & ) \\
\hline \multicolumn{6}{|l|}{ Capacity } \\
\hline Economy & & (2) & $c$ & 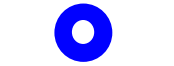 & ) \\
\hline Buyer Response & (-) & 0 & 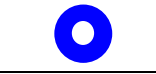 & (2) & ) \\
\hline
\end{tabular}
reader should refer to Table 4.3 in Doc 07 "LNG Terminal Cost Comparison."

All subjective parameters are based on a qualitative analysis and represent the experience of the Study Team and industry polling. Because the rankings in each parameter under the qualitative analysis are subjective, the five terminals may share a common ranking from time to time. 


\begin{tabular}{|l|l|l|l|}
\hline Customer: & $\begin{array}{l}\text { The United States Department of Energy } \\
\text { National Energy Technology Laboratory }\end{array}$ & $\begin{array}{l}\text { Date of Issue: } \\
24 / 04 / 2003\end{array}$ & \\
\hline $\begin{array}{l}\text { Document } \\
\text { Title: }\end{array}$ & Task 3 Doc 08: Matrix for Comparison of Five LNG Terminal Designs & $\begin{array}{l}\text { Doc \# \& Version: } \\
\text { Doc } 08 \text { r1.0 }\end{array}$ & Page 4 of 4 \\
\hline
\end{tabular}

\begin{tabular}{|c|c|c|c|c|c|}
\hline Netback to Seller & $\bigoplus$ & 0 & 0 & 0 & 0 \\
\hline Construction Time & 0 & 0 & 0 & 0 & 0 \\
\hline Permitting Complexity & 0 & 0 & 0 & 0 & 0 \\
\hline
\end{tabular}

